
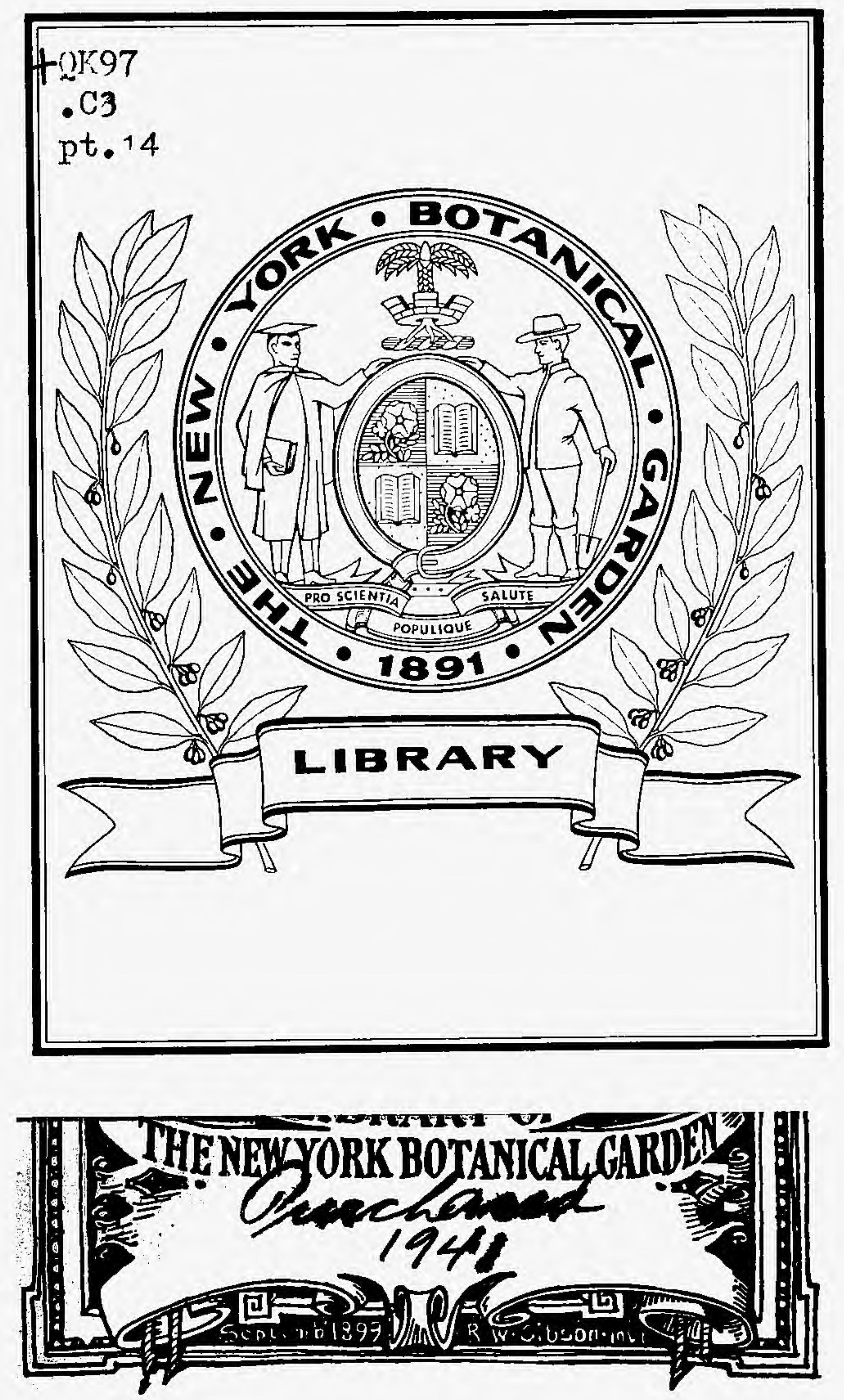


\section{DE CANDOLLE \\ PRODROMUS}

SYSTE II TIS UNIVERS A LIS

REGNI VEGETABILIS.

PARS XIV 
PARISIIS. - TUPIS L. MARTINET VIA DICTA MIGNON, 2 


\title{
DE GAVDOLLE
}

\section{PRODROMUS}

\section{SYSTEMATIS NATURALIS}

REGNI VEGETABILIS

\author{
ENUIIERATIO CONTRACTA \\ ORDINLIM, GENERUM, SPECIERUMQUE PLANTARUM \\ HUCUSQUE COGNITARUM, JUXTA METHODI NATURALIS NORMAS DIGESTA \\ EDITORE ET PRO PARTE \\ AUCTORE \\ ALPHONSO DE CANDOLLE \\ pars decima quarta
}

Sistens Polygonaceas, Proteaceas, Thymelaaceas, Santalaceas, aliosque minores ordines Monochlamydearum.

\section{PARISIIS}

\section{SUMPTIBUS VICTORIS MASSON}

FORO DICTO DE L'ÉCOLE-DE-MÉDECINE, No 17

TENITRUE APUD EUMDEM LIPSIE, PROCURANTE F, WAGNER

OCTOR. M DCCC LYT CL NOVEMR. M DCCC LVII 


\section{SIGNORUM PRODROMI EXPLICATIO.}

$\odot$ Planta monocarpica duratione ignotâ.

(1) Planta monocarpica annua.

(2) Planta monocarpica biennis.

F Planta rhizocarpica, seu perennis herbacea.

b Planta lignosa, cujus magnitudo est ignota.

$\hbar$ Suffrutex, nempe planta lignosa cujus altitudo ad summum bipedalis.

Э Frutex, nempe planta lignosa, a basi ramosa, plus quam bipedalís.

5 Arbuscula, nempe planta lignosa, trunco donata et infra 25 ped. altitudinis.

5 Arbor, nempe planta lignosa, trunco donata et 25 ped. superans.

$\checkmark$ Scandens.

ơ Planta seu flos masculus.

OQ Planta seu flos femineus.

భ Planta seu flos hermaphroditus.

$\infty$ Numerus indefinitus, sic ovula $\infty$, id est plurima non numero definito.

? Signum dubitationis.

I In synonymiâ aut loco natali indicat specimen ab auctore ipso aut viatore inscriptum.

v. s. c. Visa sicca culta.

v. s. sp. aut v. s. Visa sicca spontanea.

v. v. sp. aut $v$. v. Visa viva spontamea.

v. v. c. Visa viva culta.

$\mathrm{v}$. in h. Visa in herbario. 


\title{
PRODROMUS
}

\section{SYSTEMATIS UNIVERSALIS}

\author{
REGNIVEGETABILIS.
}

Ordo CIXXI. POLYGONACE (1).

Persicariæ Adans. fam. 2, p. 273. - Vaginales Linn. plitos. bot. ed. 2, p. 34 (ex parte). - Holoraceæ, sect. 5, Linn. pralect. ed. Giseke, p. 306. - Polygoneæ Juss. gen. p. 82, DC. fl. fr. 3, p. 363, Brown prodr. Al. Nov.-Holl. p. 418, Meisn. monogr. Polyg. p. 2, Bartl. ord. nat. p. 1.07, Endl. gen. p. 304 et 1377, suppl. IV, 2, p. 44, Encheir. p. 187, Schnitzl. iconogr. fam. fusc. 8, t. 103.Polygonaceæ Lindl. introd. nat. syst. ed. 2 (1832), p. 211, Veget. kingd. ed. 3, p. 502, C.-A. Meyer in Mém. Acad. S.-Pétersb. $6^{\text {e }}$ sér., sc. math. et phy.s. 6, p. 135, Meisn. gen. p. 316 (227), et in Mart. $f$ brasil. fasc. XIV,p. 1.

Flores hermaphroditi vel abortu unisexuales, polygamo-monoici v. dioici. Calyx (aut, si mavis, perigonium) herbaceus vel corollinus, 3.6-sepalus partitusve, persistens et cum fructu plus minus increscens; sepalis laciniisve nunc ternis uniserialibus, nunc quinis quincunciatim imbricatis, nunc quaternis senisve biseriatim imbricatis vel subvalvatis, æqualibus vel inæqualibus, exterioribus tunc 2 vel3, herbaceis (rarius subpetaloideis), minoribus vel majoribus, sæepius Concavis vel carinatis, interdum alatis rel spinoso-armatis, interioribus 2 vel 3 , petaloideis (rarius herbaceis), planis vel plicatoconcavis, integerrimis vel margine dentatis, fimbriatis spinulosisve, demum sæpius scarioso-membranaceis, reticulato-venosis, nervo medio nonnunquain in callum tumente. Stamina perigyna, definita, $1-15$, sæpissime 6 vel 8 vel 9 , vel rarissime indefinite numerosa, annulo calycis fundo adnato obsoleto vel in glandulas squamulasve incrassato inserta, si sepalis isomera vel pauciora tunc 1 -serialia iisdem alterna, si plura tunc bi-(vel pluri?) serialia, seriei inte-

(1) Exceptis Eriogoneis, auctore C.-F. Meisuer.

xIv. 
rioris 2 vel 3 sepalis interioribus achæniique faciebus anteposita, stigmatibus alterna ; filamenta capillạria vêl subalata, persistentia, libera vel interdum basi dilatata brevissine connata; antheræ biloculares, rimis longitudinalibus dehiscentes, ovales vel oblongæ, medio dorso affixæ versatiles vel rarius basifixæ erectæ immobiles, connectivo angusto (appendicibus nullis), omnes introrsæ vel rarius 5 exteriores introrsæ et 3 interiores extrorsæ vel omnes latere dehiscentes: Pollen sphæroideum. Germen unicum. et carpophyllis 2 vel 3 vel rarissime (in Calligoneis) 4 conflatum, liberum vel rarius calyci adnitum, ovatum vel ellipticum, compressum vel trigonum, 1-loculire vel raro septis spuriis semi-triloculare, ovulo unico basilari sessili vel funiculo brevi suffulto erecto (micropyle apicem loculi spectante), vel rarius ex apice funiculi basilaris lungiusculi pendulo (micropyle basin loculi spectante), demum erecto. Styli 2-4, angulos ovarii spectantes, liberi vel plus minus connati, rarissime angulis adnati (cfr. Rumex). Stigmata capillața vel depresso-discoidea vel renifornia, integerrima, lævia, rarius attenuato-filiformia, papillosa vel penicillato-fimbriata. Achænium 1-loculare, 1-spermum, indehiscens, calyce plus minus aucto sicco vel rarius baccato interdum alato arete tectum, inclusum yel rarius exsertum, liberum vel rarissime plus minus adnatum, 2-3-1-gonuin (raro inferne teres vel subglobosum), angalis acutis obtusisve interdum aleformibus integris vel dentatis echinatisve, pericarpio tenui crustaceo vei membranaceo vel subspongioso extus lævissimo nitido vel minute punctato vel granulato-striato vel rarissime echinato, intus lævi vel septula 3 vel 6 membranacea longitudinalia imperfecta formante. Semen loculo conforme, erectum, liberum vel cum pericarpio concrescens, 2-34-gonum vel teres, interduri s.lcis longitudinalibus 3 vel 6 (yuorum 3 alterni profundiores) 3-vel 6-lobumm, testâ membranaceâ, umbilico basilari latiusculo nudo (arillo nullo). Albumen copiosum, farinosum (album), rarius carnoşo-corneum (virescens), nonnunquam in ambitu sulcato-ruminatum. Embryo antitropus, nunc lateralis, albuminis angulo vel rariıs lateri accumbens vel semi-immersus et tunc plus minus arcuatus, nunc axilis, albumine inclus112, rectus; radiculâ superậ, albumen plerumque superante (exsertâ); cotyledonibus sịbi accumbentibus, foliaceis, linearibus planis vel latis anfractuosis, interdum albumen hipartientibus, per germinationem epigæis viridibus; plụmulà inconspicuâ.-Herbæ vel frutices vel rarius arbores, per totum orbem diffusæ, aliæ in arenosis aridis vel salsis, aliæ in solo humido vel pingui crescentes, aliæ ripariæ vel aquaticæ, pleræque incomptæ, insipidæ vel adstringentes vel acres vel oxalico-acetose; radicibus ramosofibrosis quandaque tuberculosis; caulibus nunc subterraneis peren- 
nibus (rhizomatibus) lignosị sæe tuberiformibus, nune plerumque epigæis decumbentibus erectis vel volubilibus, teretibus sulcatis angulatisve haud raro fistulosis, nodis sæpe tumentibus, ramis interdum articulatis vel spinescentibus vel in cirrhum excrescentibus; foliis sparsis (disposit. spirali $\frac{2}{5}$ vel rarius $\frac{3}{8}$ ), herbaceis vel coriaceis, deciduis vel rarius perennibus, simplicibus, integerrimis planis, rarius undulatis vel crispato-crenulatis, rarissime palmatịm vel pinnatim laciniatis, sæpius glandulis superficialibus vel immersis plerumque pellpcidis punctatis, nervis pinnatis vel rarissime palmatis, vernatione marginibus revolutâ,; petiolis imân hasi plus minus dilatatâ amplexicaulibus vel in vaginam (ochream) expansis herhaceam vel sæpius membranaceam decoloriem, cylindrico-tubuloșam, truncatam, integram vel bifidam, margine vel basi sæpe ciliatam, demum plerumque laceram, persistentem vel deciduam, nunc subnullam, ochreis summis plerumque aphyllis bractearum locum tenentibus; floribus axillaribus, fasciculatis aut pseudo-verticillatis, raro salitariis, aut in racemos vel spicas vel capitula collectis, spicis capitulisve solitariis vel sæpe geminatis vel racemosis corymbosis paniculatịsve, bracteis ochreiformihus, sæpius turbinato-cyathiformibus ciliatis nudisve, 1-plurifloris vel pluribus in involucrum dentatum 1-pluriflorum connatis; pedicellis eapillaribus (interdum subnullis) plerumque articulatis, fructiferis sæpe nutantibus deflexisve nonnunquam indurato-incrassatis, parte infranodali sæpissime breviore persistente, supranodali cum calyce continuâ et deciduâ nonnunquam alatâ vel clavatâ; calycibus parvis viridibus vel flavescẹntibus vel sæpius albis vel roseis vel sanguineis (runquam cœruleis nec vere luteis), fructiferis sæpe fuscescentibus.

\section{CONSPECTUS DIAGNOSTICUS DIVISIONUM.}

\section{Subardo I. ERIOGONE E.}

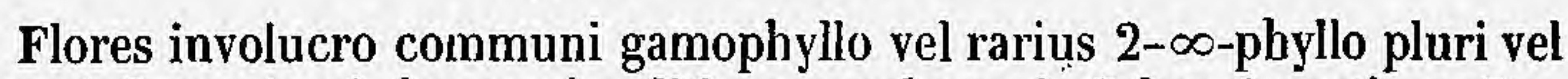
raro 1-floro cincti, hermaphroditi, raro polygami. Galyx 6-partitus. Stamina 9. Ovarium liberum, ovulo basilari orthotropo. Embryo in albumine parco inclusum. Ochreæ veræ nullæ vel obsoletæ.

\section{Subarda II. POLYGQOAEE.}

Flores involucro destituti. Stamina 1-9, sæpissime 6 vel 8, rarissime 12-17. Ovarium liberum yel rararius inferna ça çaci adnatum, ovulo basilari erecto. Folia varie ochreata.

Tribus I. P-terygogarpe. - Achænium 2-4-gonum, angulis in alam vel cristam expansis. Embryo axilis. Flores hermaphroditi (excepto. Oxygono). 
Subtribus I. Calligonece.- Ovarium 4-gonum. Stigmata 4, capitata. Achænii tetraquetri anguli alati vel dentato-cristati vel echinati vel in membranam vesicæformem expansi. Calyx 5-partitus, marcescens, haud accrescens. Stamina 12-17.

Subtribus II. Rhabarbarece. - Ovarium 2-3-gonum. Stigmata 2 vel 3. Achænium lenticulare, alâ cinctum vel triquetrum 3 -alatum, alis integerrimis nudis. Calyx 4-6-partitus. Stamina 6 vel 8 vel 9 .

Tribus II. APTEROCARPE. - Achænii anguli apteri (rarissime alati, cfr. Fagopyrum). Embryo lateralis (rarius axilis). Stamina definita, 6-9, rarissime 1-5.

Subtribus I. Ceratogonece. - Flores monoici. Calyx femineus 6-fidus, sepalis 3 exterioribus connatis in tubum fructum includentem triquetrum apice 3-dentatum, angulis apice vel ex mediâ carinâ in spinam excrescentibus, interioribus multo minoribus erectis.

Subtribus II. Rumicece. - Flores hermaphroditi vel polygamodioici. Calyx 4-6-partitus, marcescens, lobis interioribus 2 vel 3 accrescentibus erecto-conniventibus fructum includentibus, exterioribus ix auctis patulis vel reflexis. Achænium triquetrum, rarius ares.

Subtribus III. Eupolygonece. - Flores hermaphroditi. Calyx 3-5partitus, lobis subæqualibus super fructum conniventibus conformibus vel exterioribus 3 interdum carinatis vel alatis. Achænium liberum, lenticulare vel triquetrum, 1-loculare, calyce sicco inclusum, rarius exsertum.

Subtribus IV. Coccolobece. - Flores hermaphroditi vel polygamodioici. Calyx 5-partitus, demum clausus carnosus vel tarde marcescens. Achænium calyce inclusum eique basi sæpe adnatum, trigonum vel subglobosum, semi-triloculare. Semen sulcato-3-6-lobum. Albumen sæpius ruminatum.

Subtribus V. Triplaride - Flores dioici, rarius hermaphroditi. Calyx fructifer siccus, 6-vel rarius 3-partitus, lobis 3 exterioribus auctis erectis alæformibus membranaceis, interioribus minoribus subinclusis vel rarius nullis. Achænium liberum, inclusum vel subexsertum triquetrum vel sulcato-trilobum, 1- vel semi-3-loculare. Albumen (semper?) ruminatum.

\section{Subordo III. BRUNNICHIEE.}

Flores exinvolucrati, hermaphroditi. Calyx 5-partitus, fructifer siccus. Stamina 8. Ovarium liberum, triquetrum. Ovulum e funiculo basilari libero longiusculo pendulum, demum erectum. - Ochreæ nullæ vel obsoletæ. Stirpes pleræque fruticosæ scandentes cirrhigeræ.

Subordo IV. SYMIMERIEA.

Flores dioici, polyandri. Calyx femineus 6-partitus, lobis interioribus in tubum triquetro-pyramidatum ovario incluso adhærentem connatis. Ochreæ veræ nullæ. 


\section{Subordo I. ERIOGONEÆ (1).}

Eriogoneæ (tribus Chenopodiac.) Dumort. Anal. fam. p. 17. - Eriogoneæ (trib. Polygon.) Bentham in Linn. Trans. 17, p. 405. - Eriogoneæ (ordo) Meisn. gen. p. 317 (229).

\section{Characteres in conspectu, p. 3 , jam enuntiati.}

I. ERIOGONUM Mich. fl. bor. Am. 1, p. 246, t, 24, Lam. ill. t. 947, Nutt. gen. 1, p. 260, et in Journ. Acad. Philad. 7, p. 50, t. 8, Hook. fl. bor. Am. 2, p. 133,t. 175-177, Benth. in Linn. Trans. 17, p. 405, Endl. gen. n. 1992. - Encycla et Stenogonum Nutt. in Journ. Acad. nat. sc. Philad. v. 1. - Espinosa Lagasca, ex Endl. gen. suppl. $4,2, p .44$.

Involucrum multiflorum (raritus 1-florum), gamophyllum, 5-rarius 6-8-dentatum vel lobatum, rarissime irregulariter 3-5-fidum. Perigonium profunde 6-fidum. Stamina 9. Ovarium triquetrum, stylis 3 apice capitato-stigmatosis. Achænium triquetrum vel trialatum. Embiyo intra albumen haud copiosum rectus, axilis vel sæpius plus minus incurvo-excentricus; radiculâ accumbentiadscendente, cotyledonibus crassiuscule foliaceis breviore vel sæpius longiore. - Herbæ vel suffrutices, sæpius cæspitosi et plus minus lanâ densâ brevi subfloccosâ præsertim in paginâ inferiore foliorum et ad basin caulis vestiti. Folia caulina ad basin caulis approximata et subradicalia vel secus ramos alterna, basi attenuata in petiolum imâ basi dilatato-amplexicaulem vel vaginantem, exstipulata. Pedunculi vel rami floriferi, scapiformes, axillares vel terminales, sub ramificatione nudi vel rarius verticillo foliorum instructi, nunc apice involucrum unicum ferentes, sæpius in ramos 2-3-plures, semel vel repetite 2-3-chotome umbellatimve divisi. Bracteæ sub inflorescentiæ ramificationibus tot quot rami vel (radiis abortientibus) numerosiores, basi vulgo connatæ, nunc brevissimæ adpressæ vel patentes, nunc in folia expansæ, nunc membranaceæ stipulæformes, et interdum folia foventes intra bracteas sub involucro sessili oriunda. Umbellæ generales vel partiales, radiis abortientibus, interdum in capitula mutatæ. Involucra solitaria vel complura capitata, intra bracteas 2 sessilia vel pedicellata, alaria, terminalia, vel (ramo altero dichotomiæ repetite abortiente) secus ramos paniculæ unilateraliter disposita. Pedicelli intra involucrum uniflori, liberi vel basi pedunculo brevissimo impositi. Bracteolæ (filamenta sterilia Nutt.) inter pedicellos numerosæ (ubi magis evolutæ ternæ, exteriore subtendente, interioribus ad basin pedicelli oppositis, sed sæpius pauciores), nunc setaceæ plus minus ciliato-plumosæ, nunc præsertim exteriores latiores, dorso plumoso lanatæ, rarius brevissimæ vix conspicuæ, interdum dense plumosæ ex involucro exsertæ. Flores hermaphroditi vel subdioico-polygami. Perigonium ad apicem pedicelli articulatum, ex involucro exsertum, usque ad basin 6-partitum vel rarius fere ad medium turbinato-gamophyllum; laciniæ petaloideæ vel rarius herbaceæ, æquilatæ vel exteriores latiores, per anthesin vulgo æquilongæ, interiores rarissime breviores, circa fructum sæpe auctæ et exterioribus longiores. Stamina exserta vel inclusa, in $\mathbf{f l}$. subfemineis brevissima et effoeta ; filamenta basi plus minus pilosa, rarissime omnino glabra. Ovarium apice sæpe pilosum, rarius undique vestitum. Styli longitudine (etiam in eadem specie) variabiles. Embryo in $\$$ prioribus fere rectus, radiculâ brevi, cotyledonibus latis albumen fere in duas partes dividentibus ; in $\S$ tertio plus minus incurvo-excentricus, radiculâ ad insertionem accumbenti-inflexâ, adscendente, plus minus elongatâ ; in $\S$ ultimis valde curvatus, cotyledonibus brevibus porrectis, radiculâ e basi fructus accumbenli-erectà, cotyledonibus sæpe triplo longiore. In his achænium sæpe rostratum, in cæteris ovato- vel oblongo-pyramidatum. Genus hic præsertim ex inflorescentiâ in $§ 9$ divisum, nempe :

(1) Auctore G. Bentham. 


\section{A. Embryo subrectiis.}

$\$$ 1. Alata. Perennia. Inflorescentiæ 2-3-chotome vel umbellatim divisæ. Involucrá pedunculata. Acliænia alata ......... (Species 1-3).

$\$$ 2. Ekiantha. Perennia. Inflorescentiæ 2-3-chotome divisæ. Perigonium villosum. Achænia exalata. ................. (4-9).

\section{B. Embryo plus minus incurvo-excentricus.}

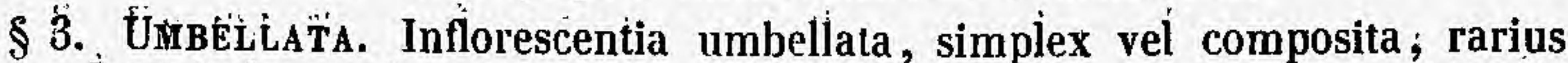
ad capitulum reducta ........................ (1028).

\$ 4. Desmocephala. Pérennia: Inflorescentiæ simplices vel parcè ramosæ. Involucra in capitulis alaribus terminalibusve sessilia . . . . (29-37).

$\$ 5$. Virgata: Pẻrennia vèl anintua: Inflorrescentiæ dichotởme vel fásciculatim ramosæ; ramis aphyllis. Involucra solitaria, oninia sessifolia. . (38-55).

$\S 6$. Corymbosa. Perennia vel àntitta. Inflorescentiæ umbellatæ, ramulis aphyllis brevibus 2-3-chotomis fasciculatisve in cyinam corymbosam dispositis: Involucra solitaria, inferiora pedicellatá, sùperiora subìsessilia (56-65).

$\$ 7$. Pedunculatá. Perennia vel annua. Inflorescentiæ laxe 2-3-chotomæ ratioulis aphylilis. Involucra omnia longiuscule pedicellata. . . (66-76).

$\$$ 8. FoliosA. Ánnua. Inflorescentiæ 2-3-chotome ramosissimæ, ad ramificationes foliatæ. ................ 77-80).

$\$ 9$. Subștipulata. Annua. Inflorescentiæe 2-3-chotome ramosæ, bracteis stipuliformibus folia foventibus . ............ (81).

\section{\$. ALATA.}

Caulis basi perennis. Indumentum subsericeum. Folia subradicalia. Rami fớriferi seu pedunculi scapiformes apice umbellatim vel 2 -3-chotome divisi. Iñuolitcrà pedunculata alaria, vel terminalia, multiflora. Perigonia glabra vel puberula. Achænia matura perigonio longiona, trialata. Embryo axilis, fere rectús vel leviter incuirvo-excentricus. - Inflorescentiấ Corymbosis accedentia, sed habitu et præsertim seminibus Erianthis affiniora, achæniis ab omnibus distincta.

1. E. H I ER A C I F o I I U , herbaceum, elatum; subsericeo-villosum, foliis subradicalibus petiolatis oblongis lanceolatisve elongatis, caulinis paucis linearibus, paniculâ Q.3-chotome corythbosâ, involucris pedicellatis campanulatis $\mathbf{5}$-dentatis, perigo-

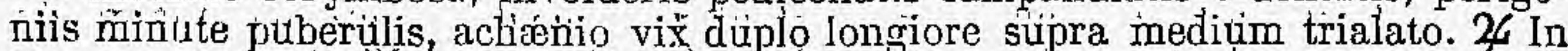
Texas occidentali (Wright $\mid \mathrm{n}$. 616). Folia 3-4-pollicaria, semi-pollicem lata, basi in petiolum longe angùstata; trinquè viridia; piliśs loǹ guiusciulís rèstita. Ramus florifer $1 \frac{1}{3}$ pedalis, folio uno alterove instructis. Bractere ad ramificattiones inflorescentias parvce, acutce. Pedicelli ultimi involucro ter quaterve loñgiores. Involucra $1 \frac{1}{1}$ linearia, dentibus brevibus obtusis inærualibus. Perigonii flavi laciniæ subæequales, sub anthesi $1 \frac{1}{2}$ lin., fructifer:e 2 lin. longæ. Achæniam 3 lin. longam, oblongum, obtusum, basi obluse trigonum, a medio ad apicem acute et latiuscule trialatum. Embryo albumen fère dividens, cotyledonibus amplis ovalibus, radi-

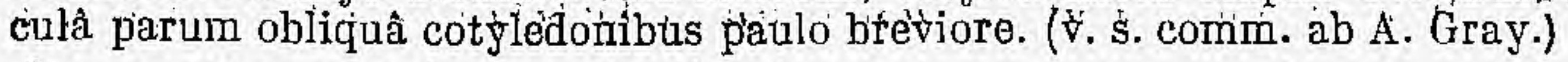

2. E. Al a tu (Torr.! in Frémorit Rep.), herbaceum, elatum, subsericeo-villosum, foliis subradicalibus petiolatis oblongis lanceolatisve elongatis, caulinis paucis, pedunculis axillaribus terminalibusque abice 2 -3-chotomis umbellatisve, involucris pedicellatis campantatis 5-dentatis, perigoniis parvis glabris, ach:niơ 3-4-plo longiore a basi trialato. $\Psi$ In montibus Scopulosis in régione superiore fl. Platte meridionalis et Bahia Salada (Fremont!), in Novo-Mexico (Abert! Fendler! n. 763, Wright!). Habitus fere $E$. hieracifolii, sed præter corymbum terminalem adsunt etiam pedunculi breves laterales. Perigonia multo minora, sub anthesi vix lineam longa, néc miniltum sứt fructu aucta. Achæniưm 3-4 lin. longum, a bàsi àd àpicem laté triálatum. (v. s.) 
$\beta$. elatum, caule sub-3-pedali, foliis radicalibus 6-8 poll. Iongis. In montibus Scopulosis inter fl. Platte et Sweetwater (Geyer / ñ. 145). - Hook. Journ. 1853, p. 263.

3. E. A T R ORUBEN (Engelm.I pl. Wisliz. p. 24), herbaceum, elatum; foliis subradicalibus petiolatis lanceolatis elongatis villosis, caulis glaberrimi glauci (aplyylli?) ramis 2-3-chotomis, involücris long̈issime pedicellatis cumpảnulatis 5-denlatis, aclicenio superie anguste trialato perigonium glabrum jaulo sujerante. 24 In Novo-Mexico ad Cosiliuiriachi (Wislizenus!). Folia fere pritecedentium. Rani floriferi 1-2-pedales, sub ramificátioniibius inferioribuls more $E$. inflat turgidi. Pedicelli viltimi 1-4 póllicares. Involucrà linedin longa et láta, 25-30-flora. Perigonii atrorubentis lacini:e subequales. Aclixerlium superne ängustatum, àthguste et obtudse trialatum. Embryo levitcr incurvus, cotyledoriès tnagnè, radicilla lotigiuscula léviter obliqua. (v. s. in h. A. Gray.)

\section{\$ 2. Eriantha.}

Gdulis basi perennis. Ranti floriferi sedu pedünculi 2-3-chotome ramosi. Involucra solitaria (vel in $E$. cinereo capitata). Perigonium extus villosum. Villamenta basi pilosa. Embryo (ubi observalus) reclus, axilis.

- Perigonii fructiferi lacinia suboquales herbdcea. - Tracliytheca ìutt.

4. E. Lóng If olì um (Nutt.! in Trats. Amer. Phil soc. v. 5 , p. 164) caulé érectó liasi folioso, foliis oblongo-linearibus basi lotige ängustatis subtus aljo-tometitosis, sujperioribus sparsis, paniculfâ amplà 2-3-clotóme ramoșâ, bracteis minutis intolucris solitariis jedicellatis campanulätis multifloris perighoniisque extus lanatis. భ In Arkansas (Nutt.!), Texas (Drummond! Lindheim. t1. 167 ! Wrighlt; Ii. 615!), Floridà (Ledvenworth!). E. texanum Scheele; Linntiła, r. 22, p. 150. Caules elati, striati, plüs rnititius tomientosi. Foliä sup̣ra molliter villosia vel glabứá; viridia vel siccitale nigricantia, inferiora cespitosa 3-4-pollicaria, superiora temota, solitaria vel subfasciculata, ramorum paniculæ minuta bracteeformia. Involucrum obtuse 5-dentatum. Bracteolæ lineares extus pilosic. Perigonium sub anthesi $1 \frac{1}{4}$ lin. longum, fructiferum 3 lin. vèl ètiam longius, laciniis vix inæequalibus angustis herbdceis villosis. Embryo rectus; incualis. Radichla brevis, 'otýledonies amplæ ovatæ. (v. s.)

* Perigonium coloratum subpetaloideum, iaciniis interiortbus demum scepius longlaribüs.

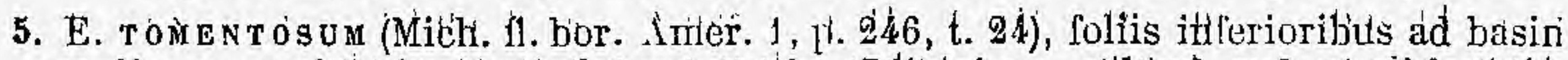
caulis approximatis spathulatu-obotatis oblongisve sullitus rufescenti-lanatis; ramis floriferis 2-3-chotome ramosis ternatim yerticillatimve foliatis, involucris solitariis sessilibus canijpânulatatis rufo-laliätis 5-dentalis laxe multilloris, perigonii extus lanati lacihiis intorioribus sul, anthesi longiotibus. $\&$ In Carolin merid. (Michaux, Fraser! Eiliutt!); (teorgià (Mich.), Floridâ (Croom! Ghàjuntan! Rugel I). Herba 1-3-pedalis. Latha foliorum paniculierque brevis densa siepius ruféscerls. Folia inferiora lotige petiulata, 1-3-pollicaria. ramorum floralium sessilia, ovata, obovata rel bblonga. Involucra alia in dichotomiis vel secus ramos sessilia, alia termitralia; obtuse 5 -deritata. Perigonii fructiferi lacinies interiores ovatés, fere 4 lin. longæe, ext. vix 2 lin. longiores. Embryo rectus. Madicula brevis. (v. s.)

6. E. unDี lanatis; ramis floriferis brevibús dichotomis opposite verticillatinne foliatis, involucris sèssilíbus solilarits carijpanulatis 5 -dentatis multifioris extus peri-

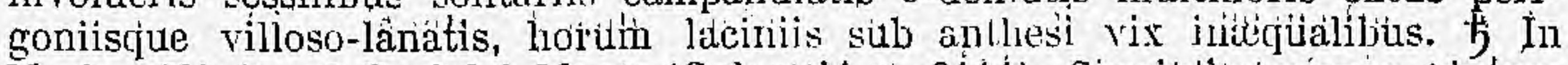
IIexico (Nće!), ad Real del Monte (Galeotti! ri. 3i1i). Sjeciniinta manca tdntum vidi. Fruticulum exhíbent humilem rảmosissimitum dense foliatum subcáspititosum. Folia 1-1-pollicaria, cŕassiusculá; supra dernùì huda, màrgine revoluta et undulatb-crišpa; subtus more E. toméntosi lanata, tamorumi floralium paica, similia at minora. trvolucra iis $\mathrm{E}$. tomentosi subsimiliá at. mithius villusa. Flotes multo miuores. G'enitalia pilosa. (v: s. in h. DC. et Hook.)

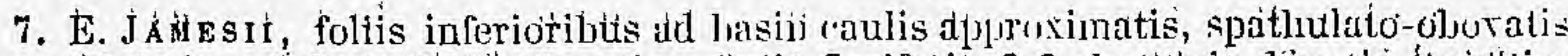
oblononglsve subtứs albido-lanatis, räniis floriferis 2-3-chutónis länatis torindtim

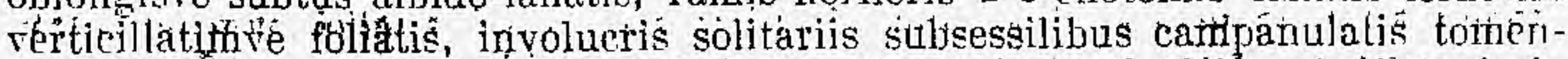

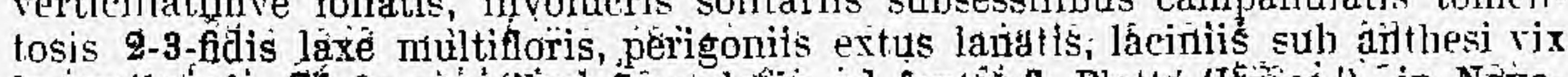

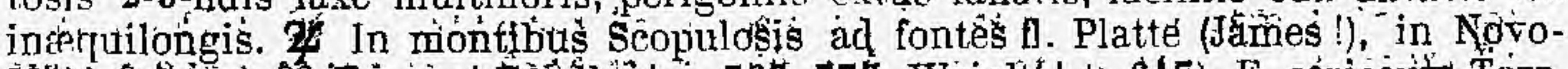

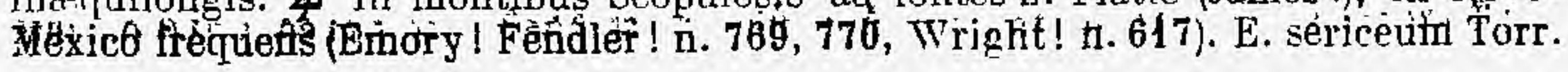


pl. Rocky M. 1. 241, excl. syn. Pursh et Nutt. - Valde affinis E. tomentoso. Statura minor. Lana canescens nec rufescens. Folia vulgo angustiora, acutiora. Involucra submembranacea, sæpius biloba. Flores minores; laciniæ interiores demum accrescentes, vix 3 lin. longæ. Embryo rectus, radiculâ vix cotyledonibus breviore. (v. s.)

8.? E. CINER EUM (Benth. bot. Sulph. p, 45), foliis in parte inferiore caulis ramosi subfasciculatis ovatis vel ovato-oblongis subtus albido-cinereis cauleque tomentosis, pedunculis nudis elongatis apice dichotome ramosis, involucris 3-6-capilatis lateralibus terminalibusque sessilibus campanulatis multifloris villosis, perigoniis extus villosulis sub anthesi subæqualibus. $\not 4$ vel $ち$ Ad San Pedro in Californiả inferiore (Hinds!). Suffrutex habitu $E$. oblongifolio affinis, perigonio villoso facile distinctus. Caules 1-2-pedales (decumbentes?), ad medium foliati. Tomentum brere, in paginà superiore siccitate fuscescens. Folia majora pollicaria, margine undulato-crispa et revoluta, petiolo 2-4 lin. longo. Pedunculus jedalis. Bracteæ parvæ, lanceolatic. Involucra 2 lin. longa, breviter 5-6-dentata. Bracteolæ plumosæ, demum exsertæ. Perigonium fere 2 lin. longum. Filamenta basi pilosula. Ovarium glabrum. Species forte Desmocephalis consocianda. Embryon ignotus. (v. s.)

9. Е. LAGHNoGXNum (Torr.! in pl. Fendl. mss.), foliis ad basin caulis cæspitosis oblongis lanceolatisve acutis subtus albo-lanatis, ramis floriferis subnudis dichotonis lanatis, involucris solitariis campanulatis 5 -dentatis multifloris perigoniisque extus tomentosis, laciniis horum sub anthesi vix inæequalibus, ovario dense lanato. \% In Novo-Mexico (Fendler! n. 765), in montibus Scopulosis (Gordon!). Caules brevissimi, dense cæspitosi, foliis vix pollicaribus, basi in petiolum longiusculum angustatis, supra canescentibus vel demum glabratis. Ramus florifer tenuis, pedalis. Involucra pauca, 2 lin. longa. Flores vix $1 \frac{1}{2}$ lin. longi, laciniis intus glabris luteís. Ovarium lanâ albâ dense obtectum. Styli glabri. Filamenta imà basi longe pilosa. Embryo (ex sched. Torr.) rectus, radiculâ cotyledonibus æquilongâ. (v. s. in h. A. Gray et Hook.)

\section{\$3. UMBELlata.}

Caulis basi perennis. Ramus florifer seu pedunculus simplex vel umbellifer, infra umbellam nudus vel verticillo foliorum instructus. Umbella simplex vel composita, laxa, radiis uninvolucriferis vel in capitulum involucris sessilibus contracta. Perigonium extus villosum vel glabrum. Filamenta basi pilosa. Embryo (ubi observatus) plus minus incurvo-excentricus.

\section{* Perigonium extus villosum vel pilosum.}

10. E. FLAv U (Nutt.! in Fras. catal.), foliis ad basin caulis crespitosis spathulatoobovatis ollongisve subtus vel utrinque albo-lanatis, pedunculo nudo vel unifoliato, umbellà breviradiatâ simplici vel in capitulum contractâ, involucris canpanulatis lanatis multilloris 5-dentatis, perigoniis sericeo-villosis. $\mathscr{F}$ In montibus Scopulosis regionis sup. 11.Platte (Nutt.! Geyer! n.15), in montibus Cœruleis (Gairdner! Dougl.!). E. sericeum Pursh! fl. Amer. sept. 1, p. 277. Radix crassa, rubens. Caules brevissimi, ciespitosi, petiolorum basibus dense obtecti, ramis sterilibus brevissimis vel nullis. Pedunculus semi-pedalis vel paulo altior. Umbella 4-8-radiata, bracteis oblongis petiolatis foliaceis involucrata, radiis inæquilongis plerisque semipollicaribus. Involucra vix 3 lin. longa, dentibus latis obtusis erectis. Perigonia longiusćula, exserta, flava, laciniis interioribus demum paulo longioribus. Embryo (cx Nutl.) excentricus. (v. s.)

$\beta$. crassifolium, caule brevissimo vaginis densius obtecto, foliis crassioribus, lanả densiore lreviore. In montibus Scopulosis ad regionem super. fl. Platte (Nutt.! Geyer! n. 15, Gordon!). E. crassifolium Benth. Trans. soc. linn. Lond. 17, p. 408, Hook. 1. bor. Amer. t. 176. E. aureum Nutt.! mss. (v. s.)

11. E. SPH ER OCEPHAL U (Dougl.! - Benth. Trans. soc. linn. Lond. v. 17, p. 407), caule humili ramoso folioso, foliis subverticillato-fasciculatis oblongis basi angustatis subtus albo-lanatis, pedunculis subsimplicibus, involucro subsolitario late campanulato tomen toso multifloro 6-7-fido, perigoniis extus sericeo-pilosis. $\mathscr{F}$ vel $\hbar$ Ad fl. Oregon superiorem (Douglas! Nutt.! exped. Wilkes! etc.). Fruticulus? (vel herba dura) irrcgulariter ramosus. Folia ad ramificationes sæpius fasciculata, petiolis basi dilatatis imbricatis, in ramis verlicillata vel pauca remota, sub- 
ertogondm. POLYGONAC. ERIOGON. (auctor bentham).

opposita. Inwolucra 1-2, rarius plura, laciniis angustis demum patentibus vel reflexis. Flores in involucro numerosissimi, capitulum globosum formantes. Perigonia flava, minus villosa ac in E. flavo, $1 \frac{1}{2}$ lin. longa, laciniis interioribus paulo longioribus. Semen haud vidi. - E. geniculatum Nutt.! in Journ. Acad. nat. sc, Philad. n. ser. v. 1, p. 162, ex eadem regione, fide specim. vetusti in herb. Hook. videtur huc referendum esse. (v. s.)

12. E. D o U G A SII, caulibus cæspitoso-ramosissimis, foliis inferioribus confertis ovatis obovatisve in petiolum angustatis utrinque dense albo-lanatis, pedunculis medio verticillo foliorum instructis, involucris ad apicem pedunculi paucis solitariisve capitatis 6-8-fidis lanatis multifloris, perigoniis extus pilosulis. $\mathcal{Y}$ In montibus Coruleis (Gairdner! Douglas!). E. ovalifolium Benth. in Trans. soc. linn. Lond. 17, p. 409, non Nutt.- Simile E. ovalifolio, at distinctum pedunculis omnibus medio foliatis et perigonio extus pilis sericeis plus minus vestito. Ovarium hirsutum. (v.s.)

13. E. C E SP I T o S M (Nutt.! in Journ. Acad. nat. sc. Philad. v. 7, p. 50, t. 8, f. 2, non Benth. in Trans.), caulibus brevibus cæspitoso-ramosissimis, foliis confertis oblongospathulatis cuneatisve basi in petiolum angustatis utrinque dense lanatis, involucris ad apicem pedunculi solitariis vel paucis capitatis 6-8-partitis linatis, perigoniis extus basi pilosulis. $\mathscr{F}$ vel $\hbar$ In montibus Scopulosis ad flumen Colorado occidental. (Nuttall I), ad Walwaleh (exped. Wilkes!). Suffrutex vel herba rerennis. E. ovalifolio minor. Folia cum petiolo subsemipollicaria, 1-1 $\frac{1}{2}$ lin. lata. Pedunculi 1-3-pollicares. Invol. laciniæ anguste oblongæe, patentes vel reflexæe. Flores pauciores quam in E. ovalifolio, minores. Perigonii laciniæe orbiculate, interiores vix angustiores, intus pilosissime. Filamenta pilosa. Ovarium glabrum. Conf. ad n. 17. (v. s. comm, a cl. Torrey.)

14. Е. ТнY мог DES, caule suffruticoso cæspitoso-ramosissimo, foliis parvis confertis brevissime petiolatis oblongo-linearibus margine revolutis incanis, involucro ad apicem pedunculi nudi vel medio floriferi solitario multifloro 6-8-tido, perigoniis extus basi reflexo-pilosis. $\$$ Ad fl. Spokan in regione Oregon superioris (exped. Wilkes!). Habitus ferc Thymi vulgaris. Folia 2-3 lin. longa, petiolis breviter vaginantibus. Pedunculi plerique bipollicares, medio verticillo foliorum sæpius instructi. Involucra 2 lin. longa, in specimine (an constanter?) solitaria. Perigonia $1 \frac{1}{2}$ lin. longa, laciniis orbiculatis subæqualibus margine crispulis. Pluribus notis convenit descr. E. Andini Nutt., vix tamen omnino idem. Ovarium ad angulos pilosum. (v. s. in h. Torr.)

15. E. A n d r u m (Nutt. in Journ. Acad. nat. sc. Philad. n. ser. 1, p. 160), caule cæspitoso-ramosissimo, foliis parvis spathulatis undique tomentoso-lanatis margine rellexis, involucro ad apicem pedunculi nudi solitario fere ad basin sub-8-partito, floribus parvis luteis extus pubescentibus. 5 In summis montibus Scopulosis juxta 1. Colorado occidental. (Nutt.). Valde affine ex Nutt. E. crspitoso ; folia subdimidio minora, multo angustiora; flores lutei nec ochroleuci et vix dimidium magnitudinis eorum E. cæspitosi. Pedunculi 2-3-pollicares. Involucri laciniæ reflexæ. Ovarium glabrum.

16. E. AG A ULE (Nutt.! in Journ. Acad, nat. sc. Philad.n. ser.1, p. 160), caule brevissimo crespitoso ramosissimo, foliis parvis confertis brevissime petiolatis oblongolinearibus margine revolutis incanis, involucris intra folia sessilibus paucifloris, perigoniis extus lanatis. $\%$ In summis montibus Scopulosis juxta fl. Colorado occidentalem (Nutt.1). Habitus Aretice. Caules densissime cæespitosi, demum bipollieares. Nomen acaulis verosim. imposuit auctor ob invol. sessile absque pedunculo vel ramo florifero. Folia 2 lin. longa, petiolis membranaceo-dilatatis vaginantibus imbricatis ramos obtegentibus. Involucra intra vaginas superiores fere occulta, membranacea, tomentosa, iniequaliter et breviter 3-5-dentata. Perigonia flava, sub anthesi vix semilineâ longiora, laciniis fere æqualibus. Ovarium dense tomentosum. (v. s. in h. Hook.)

17. E. ANDROSACEUM, caule brevissimo cxspitoso, foliis confertis oblongis basi in petiolum angustatis utrinque albo-lanatis vel supra denudatis, involucris ad apicem pedunculi scapiformis umbellatis subcapitatisve multifloris sublanatis 5 -dentatis, perigoniis extus basi pilosulis laciniis subæqualibus. 2 In locis alpinis montium Scopulosorum (Drummond !). E. cæspitosum Benth. in Trans. soc. linn. Lond. v. 17, p. 408, non Nutt. Herba parva, dense cæspitosa. Radix ut in affinibus crassa, rubens. Folia subradicalia $\frac{1}{2}-\frac{3}{4}$ poll. longa, 1-2 lin. lata, supra sæpe viridia. subtus nivea. Pedunculus scapiformis, sæpius 2-3-pollicaris, umbellæ radiis bre- 
vissimis; nunc 4-6-pol caris, umbelle radiis subpollicaribus. Bractexe sub̉ ümbellâ oblongæ, floribus breviores. Perigonia flava videntur, lineâ paulo longiora, laciniis vix inæqualibus. Stamina subexserta. Ovarium glabrum. (v. s.)

18. E. P YR OL E FOLIUM (Murray riss. Hook. journ. bot. 1853, p. 395, t. 10; ubi errore E. staticifolium vocatur), radice longe fusiformi ramosâ, caulibus brevissimis; foliis rosulatis rotundato-spathulatis obovatisve in petiolum requilongum attenuatis integerrimis coriaceis, scapis glabris digitalibus et ultra nudis, umbellarum bracteis sub umbellầ 2 spathulatis, involucris 6-9 jrevi-campanulatis 6-dentätis, perigonii lobis obovatis extus bási centroque pilosis, ovario superne pilosoọ. $\mathcal{Z}$ In Californiâ sejpt. ad Shastey bute (Edinb. exped. Oregon. n. 643). Radix 3-5-pollic. àpice multiceps. Cábiles 1-2 pollice. foliis tecti. Folia 6-9-lin. Ionga, 3-5-lin. lata, ex auct. cit. gläberrima, ex specim. meis basi ciliata et pilosa, limbo glájiriủšculo. Involucrum pilosiusculum. (Ex descr., ic. et specim. authent. adjúnxit Älph. DC.)

19. E. GNAPHAL ODES (Benth. in Hook. journ. bot. 1853 , p. 265), undique dense albolanatum, caulibus brevibús laxe ramosis subcæespitosis, foliis oblongis in petiolum longe angustatis, involucris ad apicem pedunculi simplicis subeapitatis umbellatisve tubulosis 5 -deritatis albo-lanatis, perigoniis minimis, extus basi pilosis, laciniis interioribus sub anthesi minoribus oblongis. $\mathscr{F}$ vel 5 In montibus nigris flum. Platte superioris (Gordon! Geyer! n. 158). Caules basi sublignosi, ramis 3-4-pollicaribus, foliatis, undique uti folia pedunculi et involucra lanâ denssâ molli niveâ obtectís. Folia subpollicaria, petiolo pariter pollicari. Pedunculi 2-4-pollicares. Bracteæe sub capitulo vel umbellâ paucæe, foliaceæ, flores superantes. Involucra 8-10, angusta, dentibus aculiusculis. Perigonia vix : lin. longa. (v. s.)

\section{* Perigonium extus glabrum:}

20. E. PAU C If L o U M (Pursh fl. Amer. sept. v. 2, p. 735), foliis ad basin caulis approximatis oblongo-linearibus subtus vel utrinque albo-lanatis; pedunculis apice capituliferis, involucris plurimis sessilibus tubulosis tomentosis paucifloris, perigoniis glabris. $\not{F}$ In Louisianâ superiore (Bradbury). E. parviflorüm Nutt. gen. v. 1, p. 161. Statura pusilla. Caulis basi cespitosus sublignosus. Pedunculus 2-4-poljicaris. Capitulum parvưm, densum, involueris circiter 8. (v. olim in herb. Lambert.)

21. E. oval i f o Lru m (Nutt. in Journ. Acad. nat. sc. Philad. v. 7, p. 50, t. 8, f. 1, non Benth. in Trans.), caulibus brevibus cespitoso-ramosissimis, foliis confertis petiolatis subrotundo-ovalibus utrincrue dense albo-lanatis, involucris ad apicem pedunculi scapiformis paucis solitariisque globoso-capitatis multifloris 6-8-fidis lanatis, perigoniis extus glabris, taciniis interioribus obovatis vix emarginatis. $\mathcal{F}$ vel $\hbar$ In montibus Scopulosis ad fontes f1. diissouri (Nutt. Burke !), circa lacum Great Sält (Stansbury !). Encycla oralifolia Nutt.l in Journ. Acad. nat. sc. Philad. n. ser. v. 1, p. 166. Foliorum lamina 3-7 lin. longa et lata, petiolo sæpius longiore interdüm pollicari. Pedunculi semipedales nudi. Capitulum per anthesin 6-8 lin. diametro, demum fere pollicare. Perigonii lacinise exteriores orbiculatæ, $1 \frac{1}{2}$ lin. longæe, post dnthesin aucted, interiores angustiores et paulo longiores (nec breviores), obtusissimæ vel subretusa. Stamina in floribus fertilibus brevia (ari interdum longiora?), basi villosa. Ovarium glabrum vel apice parce pilosum. Hæ species cum binis sequentibus quodammodo accedunt formis monocephalis Desmocephalorum, floribus etiam verosimiliter subpolygamis of laciniis perigonii exterioribus post anthesin late orbiculatis approximantur. Conf. ad n. 12. (v. s.)

22. E. PUR PURE U in (Nutt.! mss. in Jerb. Hook.), caulibus brevibus cespitoso-ramosissimis, foliis confertis petiolatis subrotundo-ovalibus utrinque dense albojanatis, involucris ad anicem perlunculi stapiformis paucis capitatis nultifloris laniatis, 5-7-fidis, perigoniis extus glabris laciniis interioribus cuneato-oblongis emarginatis. $\mathcal{F}$ rel $\mathrm{b}$ In montibus Scopulosis (Nuttall! Burke! Frémont!). Ericycla purpurea Nutt.! ini Journ. Acad. nat. sc. Philad. n. ser. r. 1, p. 166. - Ab E. ovalifolio vix differt flotibus paulo minoribus, intensius coloratis, laciniis interioribus angustioribus. An ejus var.? (v. s.)

ß. tenuius, floribus paulo minotibus purntireis vel pallidis. In mont. Scopulosis (Nutt. ! Gordon l), âd fl. Clamet (exped. Wilkes !). E. elọgatum Nutt. ! in herb. Hook. ! non Benth., nomen verosimiliter ab auct. mutatum in E. tenellum et

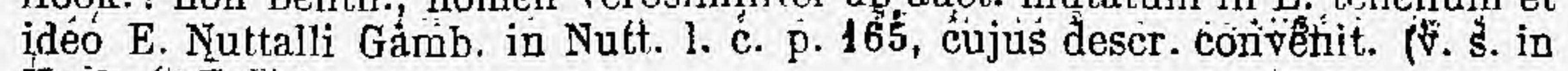
Hooks. ét Torrí.) 
23. E. ToLM I ANUM (Hooli. I fl. bor. Amer. 2, 1. 134), cáulibús laxe cæspitoso-ramosissimis; foliis approxitnatis ovatis in jetiolum angustatis supra glabriusculis sublus albo-lomentosis, involucris ad apicem pedunculi nudi perfaucis globoso-capiiatis profunde 5-7-fidis multifloris, perigoniis extus glabris laciniis late oblongis subxqualibus, staminibus subexsertis. 24 Ad flum. Wallawalah (Tolmie 1). Cæspes multở laxior quiam in prícedentibus, ramis interdum elongatis. Foliá màgríitudine E. ovalifolii, std teneriori, suprd sæépius denudata. Pedunculit graciles, 3-4 poll. longi. Capitula vix semipollicem diametro. Flores (havi?) lineam longi: Ovarium apice pilosulum. (v. s. in h. Hook.)

24. E. U⿳̆⿴囗十 BELLAT Ư (Torr.! in Ann. Lyc. nát. hist. v. 2, p. 241, non Benth. in Trans.), caule basi laxe ramoso subcespitoso, foliis approximatis ovalibus in petiolum angustatis albo-tomentosis, supra demum glabratis, . pedunculo apice simpliciter vel bis umbellato, involucris villosulis profunde 6-8-fidis, laciniis lanceolatis tưbo longioribus réflexo-pátentibus, perigoniis glabris. \& In mont. Gœrul'eis (Doudgl. !); in mon̈t. Sćopulosis ad fl. Platte super. (James! Frémont!), circa Great, Salt lake (Stansbury!). E. stellatum Benth. in Trans. soc. linn. Lond. v. 17, j. 409 , Hook. 1. bor. Amur. 2, p. 134, t. 177. Rami steriles decumbentes subfasciculatim foliosi. Folia $\frac{1}{2}-1$ poll. lonwa, petiolo sspe pollicari. Pẹdunculi spithamæi, infra umbellain nudi vel medio terticilln foliorum instructi. Bracteæ sub umbiellâ umbellulisve oblơtige; glabriuscule. Purigonia (flava?) laciniis interibrihus post anthesin accretis. Ovariumi apjice pilosulum. Embryo curvulus; radiculâ óbliquâ. (v. s.)

$\beta$. majus. Caulis basi laxius ramosus, Pedunculi sulppedales, Lana uberior, etiam

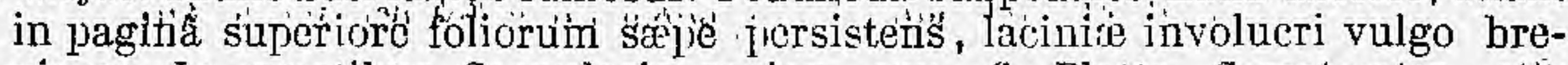
viores. In ، montibus Scopulosis region. sup. 11. Platte, Sweetwater, etć. (Gordon! Frémont! Burke! Geyèr! n. 241 et 403). E. ellipticưn Nutt. Journ. Acad. nat. sc. Philad. n. ser. v. 1, p. 161, huc referendum videtur. Deser. omhino convenit excepto " embryone concentrico is forte in semine immaturo observato. (v. s.)

25. E. ANG tos t i foliis ad básin caulis apjproximatis oblongo-linearibus subtus vel utrinque ảlho-lanatis, pedunculo nudo vel medio foliifero upice simpliciter umbellato, involucris solitarís late campañulatis lúnâtis multilloriș, laciniis tủbo sübbrevioribùs, perigoniis tobris. $\mathscr{Z}$ Ad fl. Oŕcgon juxta Kettle Fálls (Dougl. !), in mont. Scopulosorum versurấ occidentali (Nutt.!), ibìden vèrsus fl. Oregoin (exped. Wilkes I). E. umbellatum Benth. in Trans. soc. linn. Lond. 17, p. 410, t. 18, f. 2, non Torr. Affine hinc E. umbellato, hine E. heracloidi; ab illo foliis angustis it peduncalis scepius verticillum foliorum gerentibưs, $a b$ hoć staturà minoré fóliisqưe. Umbella coństanter simplex videtur, radiis $4-8$, singulis involuctum unictim ferentibus. Folia caulina 1-1 $\frac{1}{-}$ poll. longa, $1-2$ lin. lata. Bractese sub umbellâ oblonge. Perigonia (flava?) illis E. umbellati minora, lacinits inter se ferc requalibus. Stamina basi pilosa. Ovatium apice pilosulum. An forte E. heracleoidis var.? (v. s.)

26. E. HER A CLE oI Des (Null. in Journ. Lmor. Acad. nat. sc. Philad. 1. 7, p. 49), foliis ad basin caulis approximatis spathulato-oblongis subtus albo-lanatis, pedunculo elöngató medio foliifero apice bis umbellato, involucris in umbellựa pedicellatis campantulatis lanatis multifloris, perigoniis glabris. $\mathcal{H}$ Ad fontes fl. Missouri (Nutt.), ad fl. Oregon supra Kettle Falls (Dougl. !), in vaile Kooskoosky (Gejer! n. 396). Ab E. angustifolio differt staturầ elatiore (ultràpedaldi), foliis majoribus latioribus et umbellis compositis. (v. s.)

$\dot{\beta}$. minus, foliis brcvioribus, pedunculis intcrdum nudis. In regione Oregon superiore ad fi. Cleär Water (Spaldin r !).

27. Е. cơ póst т и (Dougl.! in Benth. Trans. sớc. lints. Lotid. 17, p. 410, t. 17, f. 10), foliis ad basin caulis approximatis longe petiolatis ovatis basi rotundatis cordatisve supra demum glabratis subtus dense albo-lanatis, pedunculo longissimo sub-

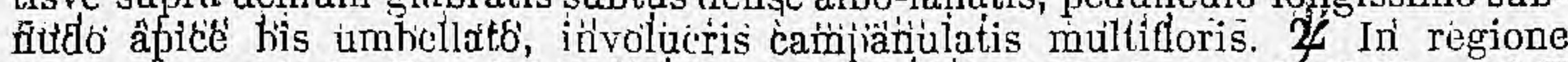
Oregon superioris (Dougl.! Nutt.! Gerón! in. 425). Folia fere E. latifolii, petioli basi vacrinantés, 24-pollicares, làminâ $1-1 \frac{1}{2}$-pollicari. Pedunculus scapiforhits, validus, ultrapedalis; rudus vel rarius (in specim. cultis) folio solitario

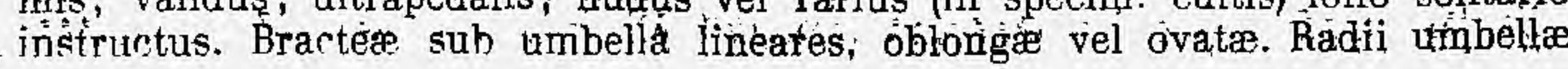




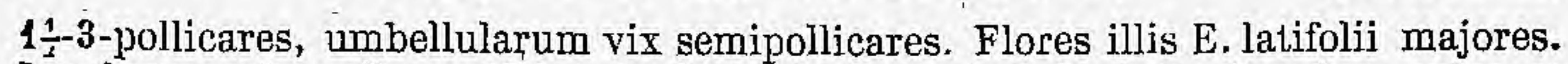
Involucra vulgo pilosa vel lanata, irregulariter sub-5-dentata. Ovarium apice et filamenta basi pilosula, at minus quam in præcedentibus. Perigonia post anthesin aucta, laciniæ interiores elongatæ obovatæ, exteriores breviores latiores marginibus membranaceo-crispis. (v. s.)

B. leianthum, involucris glaberrimis. In regione Oregon superioris ad Clear Water (Spalding!), ad 11. Spokan et Kooskoosky (Geyer! n. 470).

28. E. P OLYANTHUM, caule ramoso folioso, foliis subverticillato-fasciculatis oblongis ovatisve acutis basi angustatis subtus albo-lanatis, pedunculis subsimplicibus, involucro subsolitario late campanulato tomentoso multifloro 6-8-fido, perigoniis glaberrimis. $\not{\zeta}$ vel $ち$ In Californiâ (Frémont!), ad flum. Sacramento super. (exped. Willes!). Affine E. sphærocephalo sed majus, folia latiora crassiora. Involucri laciniæ oblongæ sæpius reflexie. Flores majores. Perigonium extus semper glaberrimum videtur, fructiferum fere 3 lin. longum, laciniis interioribus paulo longioribus. Styli et filamenta basi pilis brevibus hispida. Embryo incurvus (v. s. in herb. Torr. et Hook.)

\section{$\S$ 4. Desmocephala.}

Caulis basi perennis. Rami floriferi seu pedunculi simplices vel irregulariter subumbellatim parce ramosi. Involucra in capitulis alaribus terminalibusve plura sessilia. Perigonia extus villosa vel glabra. Embryo plus minus incurvoexcentricus. - Eriogona fasciculata et latifolia Benth. $l$. $c$.

\section{* Rami foliati. Capitula globosa densiflora, involucris multifloris.}

29. E. FAscraulat um (Benth. in Trans. soc. linn. Lond.17, p. 411), suffruticosum, foliis secus ramos fasciculatis oblongo-linearibus basi angustatis margine revolutis rigidulis glabris vel subtus tenuiter albo-tomentosis, umbellà ad apicem pedunculi nudi inæequaliter 3-5-radiatâ rarius capitatâ, involucris pluribus sessilibus 5-dentatis perigoniisque pubescentibus rarius glabratis. 5 In Californiâ (Menzies! Dougl.!), ad San Pedro (Hinds!), Santa Barbara (Nutt.!), San Felippe (Parry !). E. rosmarinifolium Nutt.! in Journ. Acad. nat. sc. Philad. n. ser. 1. p. 16k. Rami foliati sublignosi, semipedales vel longiores. Folia $\frac{1}{2}-\frac{3}{4}$-pollicaria. Pedunculi 3-8-poll., terminales, umbellæ radiis 2-3 juzequaliter elongatis divaricatis, 1-2 brevissimis. Bracteæ sub capitulis numerosæ, oblongo-lineares. Involucra 5-gona, tubuloso-campanulata, dentibus brevibus. Perigonia lineam longa, laciniís subæqualibus. (v. s.)

30. E. POL YF OLYUM, suffruticosum, foliis secus ramos subfasciculatis oblongis cuneatisve basi in petiolum angustatis margine revolutis supra cinereo- subtus albidotomentosis, umbellâ ad apicem pedunculi nudi inæuualiter 3-5-radiatâ rárius capitatâ, involucris pluribus sessilibus truncatis sulb-5-dentatis pubescentibus, perigoniis extus pilosis. $\hbar$. In Sierrâ Nevadâ Californiæe (Frémont!), ad San Diego (Parry!). Valde affine E. fasciculato. Folia latiora, molliora, utrinque tomentosa. Flores villosiores. Involucri dentes brevissimi, lati, obtusi. (v. s. in h. Torr. et Hook.)

31. E. Parvif oli um (Sm.l in Rees Cycl.), fruticulosum, foliis secus ramos fasciculatis brevissime petiolatis ovatis margine revolutis undulatis sultus lanatis, pedunculis dichotome vel subumbellatim parce ramosis, involucris sessilibus ad ramificationes vel apices ramorum capitatis anguste campanulatis angulatis 5-dentatis multifloris sublanatis, perigoniis glabris. 5 In maritimis Californiæ (Menzies! Dougl.! Beechey! Nutt.! Hartw.! n. 1940 et 1941). Folia 3-6 lin. Ionga, basi truncata vel subcordata. Pedunculi interdum simplices. Capitula pauca dense globosa, bracteis paucis parvis ovatis subtensa. Bracteolæ plumosæ, subexsertæ. Perigonii laciniæ sub anthesi inter se subæquales, interiores demum longiores. Ovarium glabrum. (v. s.)

* Folia ad basin caulis approximata (ramis foliatis abbreviatis). Capitula globosa densiflora, involucris multifloris.

32. E. o BLONGIF olium (Benth. in Trans. soc. linn. Lond. v. 17, p. 412), foliis ad basin caulis approximatis oblongo-ovatis basi angustato-rotundatis subtus vel utrinque albo-lanatis, pedunculis elongatis simplicibus monocephalis vel ramosis oligo- 
cephalis, involucris in capitulo 3-6 sessilibus campanulatis glabris sublanatisve 5-7-dentatis multifloris. $\mathcal{F}$ In Californià (Dougl.!). Ab E. latifolio diversum videtur foliorum formâ, involucris minoribus interdum lanâ fere destitutis. Pedunculi nunc simplices sæepius apice umbellati. Bracteolæ quam in $\mathrm{E}$. latifolio breviores et minus plumosæ. (v. s.)

ß? minus, involucris lanatis. Ad 11. Spokan in regione Oregon superioris (exped.

Wilkes (). Cfr. etiam affine E. cinereum n, 8.

33. E. L A TIF OLXUM (Sm.! in Rees Cycl.), foliis ad basin caulis approximatis ovatis basi late rotundatis vel cordatis supra arachnoideo-subtus dense lanatis, pedunculis elongatis simplicibus monocephalis vel ramosis oligocephalis, involucris in capitulo 2-6 sessilibus campanulatis lanatis brevissime 5-dentatis multilloris, perigonii glabri laciniis subrequalibus. 24 In maritimis Californiæ (Menzies! Eschscholtz! Chamisso! Hinds! Hartw.! n. 1939, exped. Wilkes!). E. arachnoideum Eschsch.! in Mem. Acad. Petrop. v. 10. Habitus ut in aflinibus valde variabilis.

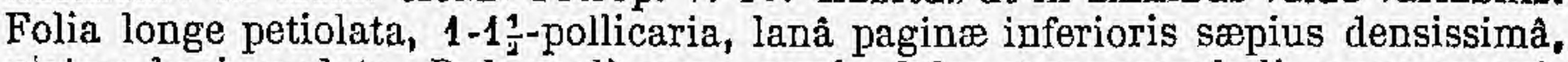
majora basi cordata. Pedunculi nunc semipedales et monocephali, nunc sesquipedales pleiocephali ad ramificationes sæpe bracteis foliaceis instructi. Capitula globosa, dernum pollicem fere diametro. Bracteolæ exsertæ, dense plumosæ, sæpe rufescentes. Perigonia lineâ paulo longiora. Filamenta fere glabra vel imâ basi leviter pilosa. (v. s.)

* * Folia ad basin caulis approximata. Involucra in capitulis pauca, tubuloso-campanulata, Roribus paucioribus.

34. E. AFFINE, foliis ovatis margine undulatis basi rotundatis,crassiusculis supra demum glabris subtus allo vel rufo-lanatis, petiolis longis basi exappendiculatis, pedunculis elongatis rigidis nudis ramosis arachnoideo-lanatis, involucris in capitulo 1-3 anguste campanulatis truncatis glabris vel margine lanatis, perigoniis glabris. భ In Californiâ superiore (exped. Wilkes!). Aff. E. nudo et E. auriculato, a priore differt imprimis paniculâ tomentosà, sæpius ramosiore. Folia majora at non auriculata ut in sequente. (v. s. in h. Torrey.)

35. E A URICULATUM (Benth. in Trans. soc. linn. Lond. v. 17, p. 412), foliis ovatis margine undulatis basi rotundatis vel subcordatis crassiusculis supra demum glabris subtus albo-lanatis, petiolis longis basi sæepius auriculato-dentatis, pedunculis elongatis rigidis nudis ramosis glabris, involucris in capitulo 3-4 anguste campanulatis truncatis glabris vel margine lanatis, perigoniis glabris. $\mathscr{F}$ In Californiâ superiore (Douglas!). Folia fere E. latifolii a quo differt imprimis pedunculo elatiore ramosiore glaucescente nec ad ramificationes lánato, ramis rigidioribus nonnunquam subinflatis, capitulis minoribus lanâ fere omnino destitutis. His notis E. nudo simile et, forte cjus varietas, folia tamen multo majora, longius petiolata, etc. (v. s.)

36: E. NUDum (Dougl.! in Benth. 1. c. p. 413), foliis ovatis margine undulatis basi rotundatis vel subcordatis supra demum glabris subtus albo-lanatis, petiolis basi nudis, pedunculo elongato rigidulo nudo paniculato glabro; involucris in capitulo 1-3 anguste campanulatis truncatis sub-5-dentatis glabris vel margine lanatis, perigoniis glabris vel extus parce puberis. $\not$ In planitiebus distr. Oregon (Dougl.! Nutt.!), in Californiâ (Beechey! exped. Wilkes!). E. arachnoideum Hook. et Arn.! Bot. Beech. p. 158, non Eschsch. Ab E. latifolio differt glabritie et inflorescentiâ. Folia tempore antheseos raro pollicaria, primordialia majora longe petiolata. Pedunculus seu ramus florifor, 1-3-pedalis. Bractex ad ramificationes el sub inrolucris breves, ovatæ, interdum subtomentosæ. Involucri $1 \frac{1}{2}$ lin. longi, dentibus brevissimis obtusis. Bracteolæ vix exsertæ, parce plumosæ. Perigonii laciniæ subæquales (v. s.).

f. pubiflorum, involucris 2 lin. longis, perigoniis pubescentibus. An species propria? In Galiforniâ (Frémont!). (v. s. in h. Torr.)

37. E. Elatu M (Dougl.! in Benth. Trans. soc. linn. Lond. v. 17, p. 413), foliis amplis subcordato-oblongis viridibus supra villosulis subtus velutinis, pedunculo elongato rigido nudo, involucris capitatis vel pedicellatis glomeratis tubulosocampanulatis, perigoniisque glabris. 2 In planitie Multnomak regionis Oregon super. (Dougl. !), ad Wallawallah (exped. Wilkes!), in Californiâ (Coulter! n. 693). Folia inferiora subradicalia multo majora quam in cæateris speciebus (4-6-polli- 
caria, petiolo 4 -pollicari) et vix subtus canescentia. Pedunculus sesquipedalis, ut in affinibus 2-3-chotome ramosus vel irregulariter umbellątus, involuera glomeratim pedicellata, rạius stricte capitata. Perigonii laciniæ spḷ anthesi subæquales, interiores post anthesin auctæ. Embryo incurvo-excentricus, fadiculà longâ. (v. s.)

\section{§5. VIRGATA.}

Caules basi perennes vel annui. Rami floriferi dichotome vel fasciculatịm ramosi. Involucra solitaria (sæpius angusta vel parva), omnia sessilia, terminalia et secus ramos rigidos paniculæ unilateraliter dispoșitạ.

* Perennia vel suffruticosa (1).

38. E. DE C UM B ENS (Benth. in Trans. spc. linn. Lond. v. 17, p. 415), rampllis sterilibus foliatis laxe decumbentibus, foliis ovatis longe petiolatis utrinque albo-lanatis, pedunculi ramis elongatis flexuosis floccoso-lanatis, bracteis involucrum requantibus patentibus, involucris secus ramos remotis crassiusculis dense lanatis, dentibus 3 recurvo-patentibus alternis minutis vel nullis. $\psi$ vel $\hbar$ ad $1 \mathrm{l}$. Ôregon (Dougl.!). Rami foliati, semipedales longioresque. Folia pollicaria, petiqlo 1-2-pollicari. Panicula pedalis, repetite ramosa. Bractese inferiores foliacea qltrapollicares, superiores lineares. Involucra in dichotomiis et secus ramos sessilia, fere 3 lin. longa, formâ fere E. nivei, magnitudine E. dichotomi, dentibus tubo paulo previoribus. Perigonii laciniæe demum fere 2 lin. longæ, exteriores orbículatær, interiores angustiores erectæ. Filamenta basi pilosula. Embryo valde incurvus, radiculà longậ. (v. s.)

39. E. NI VEU (Dougl. ! in Benth. 1. c. 1. 414), famulis foliatis brevibus subcespitosis, foliis oblongis basi angustatis pedunculoque albo-lanatis, bracteis patentibus, involucris tenuibus niveis paucifloris secus ramos sessilibus paucis remotis, dentibus 3 cæteris longioribus subpatentibus. 26 In vallibus mont. Corruleorum (Dougl.!), in valle fl. Oregon (Geyer! n. 590). Folia vix pollicaria, petiolo 1-2-pollicari. Pedunculi (cum paniculà) pedales, basi simplices aphylli vel rarius verticillo foliorum instructi, superne ramosi, ramis paucis numerosisve gracilibus. Bracteæ inferiores foliacea, summre sub involucris floribus vix breviores, recurvo-patentes. Involucra $1 \frac{1}{2}-2$ lin. longa dentibus 2 minutis, 3 longioribus patentibụs. Bracteolæe intra involucrum párce pilose. Perigonii laciniè exteriores $1 \frac{1}{2}$ lin. longie fere orbiculatæ, interiores angustiores. (v, s.)

40. E. ріснот то чм (Dougl.! in Benth. 1. c. p. 415), ramulis foliatis brevibus subcæsipitosis, foliis oblongis basi angustatis pedunculoque albo-lanatis, bracteis brevibus appressis, involucris crassiusculis dense lanatis pluritloris secus ramos sessilibus paucis remotis, dentibus 5 brevibus subrequalibus. $\mathcal{F}$ Ad fl. Oregon (Nutt. 1 et in montibus Coruleis (Dougl,!). Affine E. niveo sed rigidius, strictius. Bractem involucra dimidio breviores, appressæ. Involucrą tubulosa is E. nivei majora. Flores fere E. decumbentis. Filamenta parce pilosa. Ovarium glaberrimum. Embryo E. decumbentis. (v. s.)

ß. humile, densius pireo-lanatum. In mont. Scopulosis ad fl. Oregon (Nutt.). E. album (Nutt.l in Journ. Acad. nat. sc. Philad. n. ser. v. 1, p. 164. (1. s. in herb. Höol.)

41. E. EL ONG A UM (Benth. bot. Sulph. p. 45), foliis prope basin caulis paucis ovatooblongis lanceolatísve petiolatís undulatís supra arachnoideo-subtus alho-lanatis, pedunculo albo-lanato vel demum glabrato, involucris secus ramos longos rigidus sessilibus remotís tubulosis lánatis truncatis, bracteis brevibus appressis, perigonii glabri laciniis parum incequalibus. \% In Californiâ (Frémont! Coultêr!), prope San Pedro (Hinds!). Affine E. dichotomo. Folia ad basin rami floriferi et ad ramificationes inferiores bipollicaria, in petiolum brevem angustata. Rami floriferi 1-2-pedales, prope basin fasciculato-ranısi, ramulis paucis semel vel bis furcatis. Involucra in quoque ramo 5-9, extus tomentosa, obsolete 5-6-dentata, 3 lin. longa. Bracteolit parce plumosæ. Perigonium 1 lin. longum, lạciniis exterioribus ovalibus, interioribus late oblongis. Ovarium glaberimum. Embryo curvatus. (v. s.)

(1) Gfr.etiam g. 50 . 
42. E. TRA CHY G ON UM (Torr. Imss.), perenue, ramis foliatis, foliis oblongo-lanceolatis basi angustatis utrinque pedunculoque albo-lanatis, involucris secus pedupculi ramos rigidos strictos sessilibus summis approximatis tubuloso-campanulatis glabris vel margine lanatis obtuse 5 -dentatis, bracteis brevibus subappressis, perigonii glabri laciniis parum inæequalibus. $\mathcal{Z}$ In Californiâ (exped. Wilkes!). Rami foliati fere semipedales. Pedunculi parce rámosi, 6-9-pollicares. Folia majora pollicaria. Involucra inferiora valde remota, superiora conferta, omnia lineấ panlo longiora, extus glabra 5-costata, ad os lanata. Flores quam in E. elongato paulo majores. Qvarium ad angulos pubescens. (v. s. in h. Torr.)

43. E. W RI G H TI (Torr.! mss.), perenne, ramis foliatis, foliis ovatis basi in petiolum angustatis utrinque v. subtus albo-lanatis, pedunculo subfloccoso irregulariter dichotomo, bractẹis brevibus acuminatis subpatentibus, involucris secus ramos rigidọs sessilibus paucis remotis vel summis confertis tubuloso-campanulatis lanatis breviter 5-dentatis, perigonii glabri laciniis exterioribus orbiculatis interioribus oblongis. 3 In Texas occidentali (Wright i n. 623) (1). Caules basi sublignosi, ramis foliatis 3-6-pollicaribus. Folia $\div-1$ poll. longa, petiolo 2-4-lineari, supra demum sæepe denudata. Pedunculi 6-10-pollicares, ramis valde inæqualibus, ultimis involucra $1-4$ gerentibus. Involucra $1 \frac{1}{2}$ lin. longa. Bracteolæ parce pilosa. Perigonii laciniæ sub anthesi $1 \frac{1}{-}$ lin. longæ, albæ. Filamenta basi et ovarium apice pilis minutissimis exasperata. (v. s. coppm. a cl. A. Gray.)

ß. floccoşum, undique tọmento vel lanâ densiore vestitum. In Novo-Mexico (Wright!).

44. E. HELIANTH E M F o L U U, perenne, ramis foliatis, foliis parvis oblongo-ovatis basi angustatis utrinque albo-lanatis, pedunculis subfloccosis 2-3-chotome ramosissimis, bracteis brevibus subpatentibus, involucris secus ramos rigidulos tenues sessilibus superioribus confertis parvis tubuloso-campanulatis tomentellis 5-dentatis, perigonii glabri laciniis exterioribus orbiculatis interioribus ovalibus. $\mathcal{\zeta}$ In Texas occidentali (Wright! n. 624), prope Chihuahua (herb. Scheer!). Alfipo E. Wrightii, sed hụmilius, inflorescentiấ ramosiore tenuiore, folia sæpius minora confertiora, tamen interdum pollicaria. Involucra vix lincam longa, ad apices ramulorum conferta. Flores albi $\mathrm{E}$. Wrightii, sed multo minores, laciniis (saltem in floribus submasculis) minus inæequalibus (v. s. comm. a cl. 1 . Gray.)

45.? E. ORTH OCL A O ON (Torr.! mss.), perenne? foliis subradicalibus paucis petiolatis ovatis subcordatis obtusis crassis utrinque albo-lanatis, pedunculo albo-lanato, bracteis brevibus appressis involucris secus ramos paucos longos strictos numerosis subremotis tubulosis truncatis lanatis multifloris, perigonii glabri laciniis obovatis parum inequalibus. $\angle$ ? In Novo-Mexico (Fendler! n. 764), ad Sierra de Tunecha (Simpson !). Folia 1-1 $\frac{1}{2}$-pollicaria, petiolo pollicari. Pedunculus scapiformis, $1-1 \frac{1}{2}$-pedalis, ramis perpaucis. Involucra in quoque ramo 8-20, axi adpressa, 2 lin. Ionga', bracteis latis subconnatis fulta. Perigonia alba vel rosea, 2 lin. longa. Filamenta imà basi pilosa. Ovarium glaberrimum. (v. s. in h. Torr. et A. Gray.)

463 E. в A с в м os u м (Nutt. in Journ. Acad. nat. sc. Philad.n. ser. v. 1, p. 161), perenne? foliis subradicalibus longe petiolatis elliptico-ovatis subtus albo-lanatis, pedunculo albo-lanato, bracteis appressis hrevibus, involucris secus ramos paucos breves sessilibus lanatis obsolete dentatis, perigoniis glabris oblongis basi attenuatis. $\mathcal{Y}$ ? In montibus Scopulosis ad fl. Colorado occident. (Nuttall). Scapi ex Nutt. sesquipedales, ramis 5-6 breviusculis. Flores numerosi, majusculi. Ex schedulà cum icone rudi in herb. Torr. a specimine Nuttalliawo sumptà valde affine videtur E. orthoclado et E. obtuso, Habilus prioris, flores E. obtusi, ab utroque differre videtiur foliis subacutis.

47. E. oв USUM, perenne, foliis ad basin caulis approximatis longe petiolatis late ovatis bạsi et apice obtusis crassis utrinque albo-lanatis, pedunculo albo-lanato, bracteis brevibus appressis, involucris secus ramos breves floribundos sessilibus tubuloso-campanulatis 5-dentatis lanatis multifloris, perigonii glabri laciniis obovalibus parum inæqualibus. $\not{\nvdash}$ In montibus Scopulosis ád Décharge du lac (Fré-

(1) De E. Wrightii et numeris itin. vide in Addendis præs. vol. (Alph. DC.) 
mont 1). Folia pollicaria, petiolo sesquipollicari. Pedunculus scapiformis pedalis, dichotome et stricte paniculatus, ramis multo brevioribus et crebrioribus quam in E. orthoclado. Involucra longiora, evidentius dentata, dentibus obtusiș. Flores ejusdem magnitudinis, laciniis tamen angustioribus. Ovarium apice pilis minutis exasperatum. Embryo valde curvatus, radiculâ longâ erectâ. An var. E. racemosi ? (v. s. in h. Torr.)

48. E. S T R с т u M (Benth. in Trans. soc. linn. Lond. v. 17, p. 414), perenne, basi cæespitoso-ramosissimum, foliis confer tis oblongo-ovatís basi longe angustatis subtus vel utrinque albo-lanatis, pedunculis glabris vel inferne arachnoideo-lanatis, involucris parvis secus ramos graciles paucis sessilibus remotis glabris sublanatisve 5-dentatis paucifloris, perigonii glabri laciniis exterioribus ovalibus. 4 In montibus Gœruleis (Dougl.! Frémont1). Pedunculi scapiformes pedales et ultra, ramis erectis strictis. Bracteæ parvæ adpressæ. Involucra panca, vix lineâ longiora. Perigonia fructifera valde aucta, laciniis exterioribus 2 lin. longis ovalibús interioribus angustioribus. (v. s.)

B. lachnostegia, involucris fere 2 lin. longis albo-lanatis. In collibus ad Snake river (Frémontl). (v. s. in h. Torr.)

\section{* Annua (1).}

49. E. ViR G A UM, annuum, foliis ad basin caulis confertis, petiolatis obovatis oblongisve basi angustatis utrinque pedunculoque albo-lanatis, bracteis brevibus appressis, involucris secus ramos longos rigidos sessilibus remotis tubulosis lanatis breviter 5-dentatis, perigonii glabri laciniis parum inæqualibus. (1) In Galifornià (Frémont!). Afline E. elongato sed annuum et tenuius, involucra et flores minora, illa vix 2 lin. longa, dentibus manífestís, perigonia vix $\frac{3}{4}$ lin. longa. Ovarium apice minute puberulum. (v.s. in h. Torr. et Hooks.)

50. ? E. POLXCLADON, annuUM? foliis secus caulem obovali-oblongis in petiolum angustatis utrinque pedunculoque ramosissimo albo-lanatis, bracteis brevibus appressis, involucris secus ramos tenues erectos strictos sessilibus remotis parvis vix lanatis 5-dentatis paucifloris, perigonii glabri laciniis exterioribus obovaliorbiculatis. (1)? In Texas occidentali (Wright!). Specimen unicum vidi herbee duræ, bipedalis, lanâ laxâ súbfloccosâ vestitæ. Folia caulina semipoll. ad poll. longa, radicalia jam detrita. Involucra lineam longa, dentibus obtusis. Perigonia fructifera lineâ breviora, laciniis interioribus quam exteriores dimidio angustioribus. Stamina in floribus subfemineis brevia, glabra. Achænium longe rostratum. Embryo valde incurvus, cotyledonibus brevibus latis subadscendentibus, radiculà longissimâ, accumbenti-erectâ. (v. s. in h. Á. Gray.)

51. E. AGET OSEL L oIDES (Torr.! mss.), annuum, foliis secus caulem obovali-oblongis in petiolum angustatis utrinque pedunculoque gracili albo-lanatis, bracteis brevibus appressis, involucris secus ramos paucos tenues rigidulos sessilibus remotis brevibus campanulatis tomentellis obtuse 5 -dentatis multifloris, perigonii parvi glabri laciniis parum inæqualibus. (1) In Californiâ (exped. Wilkes!). Herba gracilis, pedalis vel paulo altior, ad medium vel usque ad inflorescentiæ ramificatjonen laxe foliata. Folia maxima subsesquipollicaria. Involuccra vix lineâ longiora, floribus numerosis in sicco pulchre rubentibus. Ovarium apice ad angulos tenuissime puberulum. Embryo præcedentium. (v. s. in h. Torrey.)

52. E. LEUCOCLADON (Benth. pl. Hartw: p. 333), annuum, foliis ad basiu caulis approximatis longe petiolatis oblongis utrinque albo-tomentosis, pedunculo subfasciculatim ramoso albo-lanato, bracteis hrevibus appressis, involucris secus ramos tenues strictos sessilibus remotis parvis glabriusculis paucifloris breviter 5-dentatis, perigonis juarvis glabris, laciniis exterioribus late obovatis. (1) In Californiâ ad fl. Carmel (Hartweg| n. 1942). Afline hine E. acotoselloidi, illinc E. stricto, a priore differt caulis parte foliatà vix pollice longiore, foliis longius petiolatis, inflorescentiâ et floribus. Panicula multo ramosior, 4-6-pollicaris. Flores minores, flavescentes, laciniis exterioribus basi longe angustalis dorso fuscis. Involucra vix lineâ longiora. (v. s.)

(1) Cfr. etiam n. 45 et 46 . 
erlogondu. POLYGONAC. ERIOGON. (atcton BENTHAM). 17

53. E. G R A C IL E (Benth. bot. Sulph. p. 46), annuum, usque ad inflorescentiam foliatum, foliis petiolatis ovatis oblongisve cauleque albo-lanatis, pedunculis subfasdivergentes parvis gessilibus superne glabris, involucris sccus ramos virgatos vel perigoniis pexigoniis parvis glabris, laciniis exterioribus late obovatis interioribus oblongis emarginatis. (1) In Californiâ (Frémont !), ad San Pedro (Hinds!). Herba $\frac{1}{4}-1$-pedalis, glabrior et tenuior quam sjecies procedentes, aflinior E. vimineo, sed multo gracilior, involucris floribusque multo minoribus et lanà copiosiore. Folia inferiora semipollicaria vel longiora, longe petiolala. Fmbryo valde incurvus, radiculà longầ (v. s.)

54. E. vi m I e U M (Dougl.! in Benth. Tranśs. soc. linn. Lond. r. 17, p. 416); aunumm, foliis radicalibus vel sub inflorescentiâ petiolatis ovatis orbiculatis vesubtus tomentosis, pedunculis divaricato-ramosissimis superne glabris, involucris secus ramos tenues paucis sessilibus remotis glabris breviter 5 -dentatis paucifloris, perigonii glabri laciniis exterioribus late obovatis, interioribus oblongis. (1) In Amcricâ boreali occidentali, ad radices montium Corvlcorum (Dougl.!), in terrâ Snake (Tolmie), Californiâ (Frémont), ad Kooskoosky et Oregon (exped. Wilkes I). Pedunculi (cum paniculâ) erecti, 6-8-pollicares, basi sublanati. Involucra 1: lin. longa, dentibus obtusis. Perigonia lineam longa. (v. s.)

$\beta$. eriocladon, paniculæ ramis involucrisque laxe lanatis (lanâ facile derasâ). Ad fl. Sacramento prope Sutters-Fort (exped. Wilkes !).

55. E. IN T R I c A т U в (1) (Benth. bot. Sulph. p. 44, t. 22), annuum, foliis subradicalibus rosulatis longe petiolatis suborbiculatis viscoso-pubescentibus, pedunculo divaricato-ramosissimo glaberrimo, involucris secus ramulos dense fasciculatos sessilibus remotis paucis minimis multifloris, perigonii glabri laciniis cuneato-oblongis vix inæqualibus. (1) In Californiâ ad San Bartholomè (Hinds!). Herba $\frac{1}{2}-2$-pedalis, siccitate nigricans. Folia semipollicaria. Rami ad quemque nodum inflorescentiæ densissime fasciculati. Bractere ninutæ , atentes. Involucra vix $\frac{1}{4}$ lin. longa. Brac:teolse exteriores intra involucrum late spathulatce, interiorcs anguste. Perigonia vix $\div$ lin. longa. (v. s. comm. a cl. Hinds.)

\section{§6. CORYMBOSA.}

Caules basi fruticosi vel annui, foliati. Pedunculi vel rami floriferi apice umbellatim divisi, ramulis breviter et repetite 2-3-cholome vel umbellatim subdivisis in cymam corymbiformem dispositis. Involucra solitaria, alaria vel terminalia, inferiora pedicellata, superiora subsessilia.

\section{* Caulibus basi fruticuloso-ramosissimis.}

56. E. CONFERTIFLORUM, caule-fruticuloso virgato-ramosissimo, foliis anguste oblongis supra demum nudis subtus albo-lanatis, pedunculis brevibus, cymâ compactâ, bracteis omnibus minutis, involucris breviter pedicellatis tubuloso-campanulatis glabriusculis 5 -dentatis, perigonii glabri laciniis interioribus minoribus. 5 In Californià ad Shaste river (exped. Wilkes!). Fruticulus pedalis. Folia 1-1-pollicaria, breviter petiolata, margine recurva. Pedunculi sub cymâ 1-2-polljcares. Cyma $1 \frac{1}{2}$-poll. lata. Involucra lineam longa. Perigonia fructifera 1 lin. longa, laciniis basi angustato-incrassatis, exterioribus late ovatis, interioribus oblongo: ovalibus. Embryo valde incurvus, radiculâ longissimâ, cotyledonibus parvis suborbiculatis. (v. s. in h. Torr.)

$\beta$. Stansburyi, cymâ majore trichotomâ præter axillas bractearum glaberrimá, involucris numcrosissimis. - Prope Great Salt Lake (Stansbury !)

57. Е. соRум во SUM , caule fruticuloso, foliis oblongo-lanceolatis crassiusculis subplanis (laxe lanatis?), pedunculis brevibus, cymis corymbiformibus compactis subumbellatis, bracteis sub radiis foliaceis, involucris tubuloso-campanulatis glabriusculis 5-dentatis, perigonii glabri laciniis interioribus minoribus emargi-

(1) Planta a Nuttallio primum (PJ. Gamb. in Proceed. Acad. nat. sc. Philad.) sub nomine E. denudati designata, dein (Journ. Acad. nat. sc. Philad. n. ser. v. 1, p. 161) ad $\mathrm{E}$. intricatum meum relata, videtur ex descr. species longe diversa, sed mihi omnino ignota. 
nalis. 5 In itinere Californico prope Grand-Rijer (Frémontl). Affine E. confertifloro. Folia scepe sesquipollicaria. Inflorescentia multo ramosior, 2-3 poll. diametro. Bracteæ foliaceæ 3-6 lin. longæ, sub ramis primariis secundariisve verticillatæ. Involucra et flores quam in E. confertifloro paulo majora. Perigonia basi carnoso-crassiuscula. (vं. s. comm. a cl. Torr. specim. a mucore semides. tructo.).

58. E. Sim p SoNi, caule fruticuloso, foliis linearibus supra viridibus subtus niveolanatis margine valde revolutis, umbellis compositis cymæformibus laxc paucifloris, bracteis minutis, involucris tubuloso-campanulatis 5-dentatis inflores. centiàcque albo-lanatis demum glabratis, perigoniis glabris... 5 In Sierra de Tunecha (Novi-Mexici?) (Simuson!). Specimen unicum vidi mancum. Inflorescentia fere E. confertiflori sed flores, multo pauciores. Involucra pleraque sessilia (primarium tantum in specimine pedicellatim), viridia, dentibus rubentibus. Perigonia lineam longa, alba, nervis rubentibus. (v. s. in h. Torr.)

ß. Noccoso-lanata, cyıâ ampliore multiflorâ. In planitiebus Chugwater prope Great Salt Lake (Stansbury!) (v.s. spec. manc. in h. Torr.)

59. E. м с с о т н E CA (Nuft.! in Journ. Acad. nat. sc. Philad: n. ser. v. 1, p. 162), caule fruticuloso, foliis oblongis sublinearibusve subplanis supra arachnoideo-subtug albo-lanatis, pedunculis hrevibus, umbellis pluries ramosis laxe cymæformibus, bracteis parvis vel perpaucis sub umbellâ foliaceis, involucris turbinatis tubulosisve 5-dentatis inflorescentiåque pubescentibus glabratisve, perigonii glabri laciniis exterioribus late interioribus anguste ovalibus. 5 in montibus -Scopulosis Oregon superioris (Nutt.! Dougl.l Burke! Geyer I n. 253). Fruticulus pedalis, basi ramosissimus. Folia breviter petiolata, subpollicaria, 11-3 lin. lata, margine siccitate leviter recurva, supra demum glabrata. Pedunculi sub ramificatione 1-3 poll. longi, uti inflorescentia lana brevi parcâ pubescentes vel glabrati. Cymæ floribundæ, qúam in præcedentibus multo laxiores, $1 \frac{1}{2}-2 \frac{1}{2}$ poll. latse, 2-3-chotome vel umbellatim pluries ramosæ. Involucra pleraque breviter, inferiora longiuscule pedicellata, vix $1 \frac{1}{2}$ lin. longa, dentibus obtusis margine membranaceis. Perigonia (ex Nutt. flava, ex Geyer alba), sub anthesi lineam longa, laciniis vix basi incrassatis. Species valde varíabilis nec forte a duabus sequentibus rite distincta. (v. s.)

$\beta$ ? laxiflorum, major, inflorescentiâ tomentosiore lanâ subfloccosâ, involucris $1 \frac{1}{2}$ lin. Longis. Ad Oregon (Nutt. I' in herb. Hook. sub nom. E. laxiflori).

$\gamma$ ? Fendlerianum, foliis planis sesquipollicaribus 3-5 lin. latis, inflorescentiå laxiore, indumento subfloccoso, involucris-fere 2 lin. longis. In Novo-Mexico (Fendler I n. 767, in herb. A. Gray).

60. E. EFFU SU (Nutt.! in Journ. Acad. nat. sc. Philad. n. ser. v. 1, p. 163), caule fruticuloso, foliis oblongo-linearibus subplanis supra arachnoideo- subtus albolanatis, pedunculis brevibus in paniculam ramosissimam strictam vel laxiuscu: lam divisis, bracteis parvis, involucris turbinato-campanulatis 5-dentatis inflorescentiàque laxe tomentosis, perigonii glabri laciniis exterioribus late interioribus angustius ovalibus. b In montibus Scopulosis (Gordon l), in planitiebus n. Platte superioris (Nutt.! Frémont!), in Californià (Frémont! Coulter ! n. 693) et in Novo-Mexico? (Fendler, n. 768, specimen valde mancum). Valde affine :E. microthece ct E. brevicauli, el forte omnia unius speciei varietates. A priore differt foliis vulgo angustioribus, paniculă ramosiore strictiore fere semper lanatê, involucris brevioribus (sub anthesi lineam vix superantibus), ab E: brevicauli ramis foliatis laxioribus minus dense lanatis, inflorescentia vero fere semper lanatâ. Perigonia lineam longa, basi crassiuscula attenuata et rubentia. (v. s. in h. Hook. et Torr.)

$\beta$ ? rosmarinoides, elatius, foliis sesquipollicaribus lineam latis margine magis revolutis. In California (Frémont!). (v. s. in h. Torr. et Hook.)

61. E. BREvi Caule (Nutt. ! in Journ. Acad. nat. sc. Philad, n. ser, v. 1, p. 163), caule fruticuloso, ramis foliatis brevibus, foliis oblongo-linearibus lanceolatisve in petiolum longe angustatis utrinque dense niveo-lanatis, pedunculis longiusculis umbellisque pluries ramosis laxe cymæformibus glaberrimis lævibus, bracteis parvis, involucris parvis tubuloso-campaunulatis breviter 5 -dentatis perigoniisque glabris. 5 In mont. Scopulosorum regione Oregon (Nutt.!) et fl. Platte superioris (Gordon I Geyer I n. 139, Frémont, l). E. Fremonti Torr. I in Frém. report. Fruti- 
culus liabitu fere Phagnali. Rami foliati 2-3-pollicares laxi, vel breviores in cœspitem contracti, vaginis petiolorum niveo-lanatis obtecti. Folia 1-2 poll. longa, 1-2 lin. lata, petiolis sæupe pollicaribus. P'edtnculi 3-5-pollicares, vulgo uti tota inflorescentia levissimi flavicantes vel aurei. Bracter connate, acuminatæ, intus lanatæ. Involucra lineam longa. (v. s.).

$\beta$. aupeum, lanâ laxiore, involucris sesquilinearibus. In regione fl. Colorado superioris ad Black Fork (Geyer! n. 210).

62. E. M I C R A r r U M (Nutt.! in Journ. Acad. nat. sc. Philad. n. ser. v. 1, p. 164), caule fruticuloso, ramis foliatis ablbreviatis, foliis oblongó-linearibus lanceolatisve in petiolum longe ongustatis utrinque dense niveo-lanatis, pedunculis longiusculis umbellisque pluries ramosis cymæformibus laxe foccoso-lanatis, bracteis parvis, involueris campanulatis multifloris 5 -dentatis floccoso-lanatis, perigoniis glabris. 5 Ad fl. Oregon a Wallawallah versus Orientern (Nutt. 1), ad fl. Platte (Gordon!). Valde affine E. brevicauli, differt inflorescentiâ minore lanatà, involucris lạtius campanulatis. (v. s. in h. Hooker.)

\section{* Herba annua, elata.}

63. E. M U L T I L L OR U M (Benth. in Trans. soc. linn. Lond.v. 17, p. 413), caule erecto elato, foliis caulinis sessilibus oblongo-lanceolatis undulatis supra arachnoideo subtus albo-lanatis, pedunculo apice corymboso 2-3-chotome ramosissimo, involucris glabriusculis sublanatisve campanulatis 5 -dentatis, perigonii fructiferi glabri laciniis exterioribus basi condatis. (1) In Texas (Drumm. I Riddell I Hale I Lindh.I

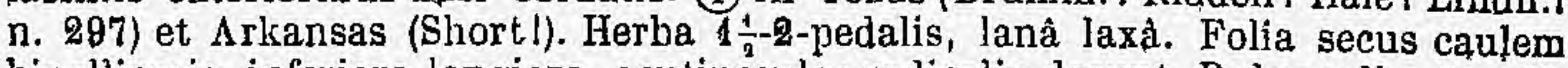
bipollicaria, inferiora longiora, acutiuscula ; radicalia desunt. Pedunculí subnudi, semipedales longioresque. Inflorescentiæ rami divaricati. Involucra parva, numerosa, pedieellata. Perigonia parva, laciniæ exteriores sub fructu orbiculatæ, basi sinu angusto cordatæ, interiores oblongo-lineares. Ovarium glabrum. (v. s.)

64. E. CYMOS U M, caule erecto elato, foliis petiolatis oblongis supra arachnoideo- subtus albo-lanatis, pedunculis axillaribus terminalibusque 2-3-chotome corymbosoramosissimis, involucris campanulatis 5-dentatis inflorescentiâque subfloccosolamatís, perigonii glabri basi angulati laciniis exterioribus late, interioribus anguste ovalibus. (1) In Texas occidentali (Wrighti! n. 619). Statura E. annui. Gymz numerosæ, multa ramosiores. Involucra brevissime pedicellata, demum vix 2 lin. longa. Perigonia longiuscule exserta, lineâ breviora. (v. s. comm. a cl. A. Gray.)

65. E. A N U U M (Nutt. in Trans. Amcr. Flill. soc. 1. 5, p. 164), caule erecto elato, foliis petiolatis oblongis subtus vel utrinque albo-lanatis, pedunculo albo-lanato apice Q-3-chotome ramosó, involucris late campanulatis niveo-lanatis 5-dentatis multifloris, perigonii glabri vix ungulati laciniis exterioribus oralibus, interioribus oblorgis. (1) In Arkiansas nsque ad mont. Scopulosos (Nutt. I James ! Frémont I Gordon ! Geyer! n. 661), Texas (Berland.! 2003, Lindh. ! n. 516), et Novo-Mexico (Wislizenus ! Fendl.! n. 771). E. Lindheimerianum Scheele in Linnæâ, v. 22, p. 149. Caules simplices vel parum ramosi, pedales et ultra. Folía 1-2-pollicaria, ad axillas sæpe fasciculata, radicalia longiora. Pedunculi semipedales, terminales, aphylli. Bracteæ minutæ. Involucra pedicellata, 2 lin. longa. Perigonia parva. (v. s.)

\section{$\$ 7$. Pedunculata.}

Caules nunc basi perennes vel suffruticosi nunc annui. Pedunculi sæpius scapiformes, laxe 2-3-chotomi. Involucra solitaria terminalia et alaria, omnia longiuscula pedicellata. Perigonia glabra vel rarius pilosula.

\section{* Caules basi perennes vel syffrutescentes.}

66. Е. TENELL U (Torr.! Ann. Lyc. nat. hist. New-York, r, 2, p. 241), suffruticosum, basi dense cespitosum, foliis confertis parvis petiolatis ovatis utrinque albotomentosis, pedunculis glaberrimis glaucis laxe 2-3-chotomis, involueris omnibus longe pedicellatis erectis campanulatis 5-dentatis, perigonii glabri laciniis exterioribus orbiculatis interioribus oblongis. $\%$ b. Ad radices mont. Scopulosorum (James!), in Novo-Hexico (Abert! Fendler! n. 766). Folia in cæspitem densissimum conferta, 3-4 lin. longa, petiolo 2-3-lineari. Pedunculus nunc 2-3-pollicaris, valde ramosus, nun ultra semipedalis jam infra medium laxe ramosus. Bracleæ 
parvu. Pedicelli ultimi tenucs et rigiduli, erecti, $\frac{1}{2}-1 \frac{1}{2}$ poll. longi. Involucra $1 \frac{1}{2}-2$ lin. longa. Perigonia 1 lin., laciniis inter. leviter emarginatis. (v. s.)

$\beta$. ramosissimum, ramis foliatis densis lignosis 2-6-pollicaribus, foliis paulı majoribus. In Texas (Riddell! Lindheimer ! n. 683). (v. s.)

\%. leptocladon, foliis crespitosis semipollicaribus, petiolo 6-9 lin. longo, pedunculis sesquipedalibus a medio laxe ramosis oligocephalis. In Texas occiderttali (Wright! n. 619).

67. E. PLATY P Y L L M (Torr.! mss.), caule suffuticoso ramis foliatis elongatis, foliis longe petiolatis orbiculatis utrinque albo-lanatis, pedunculis glabris glaucis laxe 2-3-chotomis, involucris omnibus longe pedicellatis erectis campanulatis 5-dentatis, perigonii glabri laciniis exterioribus obovato-orbiculatis interioribus anguste oblongis. 5 In Texas occidentali (Wright! n. 618). Hoc etiam præecedenti affine est sed elatius, ramis foliatis $\frac{1}{2}-1$-pedalibus. Folia fere latiora' quam longa, basi truncata nec angustata, pleraque semipollicaria, petiolo subpollicari. Panicula amplior. Perigonia fructifera $1 \frac{1}{2}$ lin. longa, laciniis minus dilatatis apice sæepe emarginatis. An inter varietates E. tenelli recensenda? (v. s.)

68? E. CIL IA T U M (Torr.! mss.), perenne? foliis subradicalibus late obovato-spathulatis in petiolum longe angustatis margine ciliatis utrinque glabris viridibus, pedunculis glabris parce dichotomis, involucris paucis longe pedicellatis late campanulatis multifloris 5-6-dentatis glabris, perigonii glabri tubo turbinato laciniis subæequalibus. 24? In Mexico septentr. prope Monterey (Gregg!), ad Buenavista (Edwardes). Folia $\frac{1}{2}-1$-pollicaria, petiolo æquilongo vel longiore basi valde dilatato margine pilis longis ciliato. Pedunculi scapiformes, pedales. Pedicelli rígidi, 2-4-pollicares. Bractere parvæ vel subfoliaceæ. Involucra 2 lin. longa. Flores numerossimi, atro-rubentes. Bracteolæ interiores dense plumosæ, exsertæ. (v. s. in h. Torr.) (1).

\section{** Herba annua.}

69.? E. TAICH O P OD U M (Torr. I in Emory report), pedunculo elato glaberrimo glaico haud inflato, ramis oppositis vel verticillato-fasciculatis ramosissimis, pedicellis secus ramos ultimos alternis divaricatis capillaribus, involucris minutis 5 -dentatis, perigonii extus pilosuli laciniis subæqualibus oblongis. (1) In declivitate orientali Andium Californise (Emory). Folia mihi desunt, sed planta E. inflato affinis videtur, panicula ampla multo ramosior, pedicelli ultimi semipollicares, omnium tenuissimi, Involucra pauciflora, vix semilineam longa. Bracteolæ paucæ; obovali- vel lineari-ublongæ. Perigonia minuta. (v. s. comm. a cl. Torrey).

$\beta$. minor, foliis subradicalibus longe petiolatis orbiculatis cordatis viridibus pubeseentibus, paniculâ humili divaricato-ramosissimâ. In Novo-Mexico (Wright ! coll. 1851). Folia E. glandulosi, sed panicula glaberrima. (v. s.)

70. E. INFLAтU (Torr.! in Frém. 2, rep.), annuum foliis radicalibus longe petiolatis late ovatis pilosis viridibus, pedunculo elato glaberrimo glauco sub : nodis sæpe inflato 2-3-chotome ramoso, pedicellis cajillaribus, involucris parvis late campanulatis 5-fidis glabris pancifloris, perigonii minuti laciniis subæqualibus extus pilosulis. (1) In montibus Scopulosis (Frémont!). Folium unieum vidi 10 lin. longum, 6 lin. Jatum, petiolo ultra pollicari piloso. Pedunculus cum paniculà parce ramosà sesquipedalis, sub ramificationibus inferioribus sæepius (nec semper?) singulariter inflatus. Pedicelli alares semipollicares. Involucra semilineam longa, multo latiora quam in $\mathrm{E}$. trichopodo, bracteolæ intra invol. exteriores ohovate, interiores lineares. Perigonia vix semilineam longa. (v. s. in l. Torrey.)

71. E. GORD ONI, annuum, glabcrrimum, foliis radicalibus longiuscule petiolatis late ovatis orbiculatisve, pedunculis 2-3-chotome-ramosissimis gracilibus haud inflatis, pedicellis longis subcapillaribus erectis, involucris latiuscule campanulatis breviter 5-dentatis, perigonii glabri laciniis subrequalibus. (1) In montibus Scopulosis ad fl. Platte super. (Gordon l). Affine E. cordato, sed majus el ramosius.

(1) Speciem vidi in herb. Torr. ad San Juan de la Vaquerie a cl. Gregg lectam, huic affinem, pedunculis ramosioribus superne puberulis, bracteis sæpe foliaceis, involncris minoribus, sed ob flores mancos haud rite definire potui. 
Folia paulo majora, crassiora, non ciliata. Panicule $\frac{1}{2}-1$-pedales. Pedicelli plerique pollice longiores. Perigonia lineam longa glaberrima. (v. s. in h. Hook.)

72. E. COR D A T M (Torr. ! mss.), annuum, humile, foliis radicalibus longe petiolatis late ovatis subcordatis ciliatis villosisve viridibus, pedunculis divaricato-2-3-chotomis gracilibus glaberrimis haud inflatis, pedicellis capillaribus erectis, involueris late campanulatis glabris 5-dentatis, perigonii extus hispidi laciniis subiequalibus. (1) In Californià (Frémont !), prope San Felippe ad margines deserti (Parry !). Herha 3-5-pollicaris. Folia semipollicaria, petiolo longiore, crassiuscula, nunc præter cilias marginales glabra, nunc undique villosa at non albicantia. Bractea, ut in affinibus, minutæ. Pedicelli et involncra E. inflati, sed perigonia hispidiora. (v. s. in h. Torr.)

73. E. RENIF ORM (Torr. ! mss.), annuum, hunile, foliis subradicalibus longe petiolatis orbiculato-cordatis subreniformibus utrinque dense albo-lanatis, pedunculis divaricato-2-3-chotomis glaberrimis, pedicellis gracilibus, involucris late campanulatis 5-dentatis, perigoniis glabris, (1) In itinere californico leg. Frémont 1 Statura E. cordati. Folia subsemipollicaria, sxepe latiora quam longa, petiolo fere pollicari. Pedunculus infra ramos 2-3-pollicaris, parce ramosus. Bractea intus sweje lanatr. Involucra fere lineam lata. (v. s. in h. Torrey.)

74. E. GLANDUL oS UM (Nutt. ! in herb. Hook.), annuum, humile, foliis subradicalibus longe petiolatis orbiculatis parce pilosis viridibus, pedunculo divaricato-2-3-chotome ramosissimo glanduloso-pilosulo, pedicellis ultimis capillaribus divaricatis, involucris minutis late campanulatis $\mathbf{5}$-dentatis, perigonii minimi laciniis exterioribus parce hispidulis. (1) In montibus Scopulosis Californix superioris (Gambel1). Oxytheca glandulosa Nult. Journ. Acad. nat. sc. Philad. n. ser. v. 1, p. 170. Statura E. cordati. Panicula ramosior, undique glandulis pedicellatis instructa. Bractese parvæe. Pedicelli ultimi 2-3 lin. lnngi. Involucra el flores semilineam longa. (v. s. in h. Hook.)

75. E. RоTUNDIF OLIUM, annuum, humile, foliis subradicalilsus longe petiolatis orbiculatis subcordatis supra glabris subtus cano-tomentosis, pedunculo divaricato 2-3-chotome ramosissimo glabro, pedicellis rigidulis suberectis, involucris latc campanulatis 5-dentatis, perigonii glabri laciniis exterioribus transverse oblongis, interioribus angustis. (1) In Texas occidentali (Wright! n. 625). Herba 3-6-pollicaris, paniculxe ramis pedicellisque multo rigidioribus quam in procedentibus. Folia 3-4 lin. diametro, crassiuscula, petiolo semipollicari vel longiore. Bractere sub ramis breves, intus lanater. Involucra $\frac{1}{4}$ lin. Iata. Perigonia semilinearia, paulo ultra medium divisa, laciniis exterioribus duplo latioribus quam longis. Achænium ut in affinibus rostratum. Embryo ad radiculæe insertionem valde curvatus, cotyledonibus brevibus suborbiculatis adscendentibus, radiculà longâ, accumbenti-erectà. (v. s. comm. a cl. A. Gray.)

76. E. G E r v u m (Nutt. ! in Journ. Acad. nat. sc. Philad.n. ser. r. 1, p. 162), annuum, caule basi breviter foliato, foliis longe petiolatis late ovatis orbiculatisve supra arachnoideo-subtus albo-lanatis, paniculả pedunculatâ 2-3-chotome ramosissimâ glabrâ, pedicellis rigidulis deflcxis, involucris campanulatis 5-dentatis, perigonii glabri laciniis exterioribus quadratis, interioribus dimidio angustioribus. (1) In montibus Scopulosis in regione fl. Platte super. (Nuttall! Frémont! Gordon: Geyer ! n. 151, Burke !), in Sierra de Tunecha (Simpson !), ad Green River (Stansbury !), et in planitiebus fl. Oregon (Nuttall!). Herba semipedalis pedalisve, pedicellis reflexis facile distinguenda. Folia semipollicaria. Pedunculus et panicula sæpius glancescunt. Bracteæ parvæ, intus lanatr. Pedicelli ultimi 2-3 lin. long1, Involuera raro lineam longa, dentibus brevibus latis intus lanatis. Perigonia parva, paulo ultra medium divisa. Embryo præecedentium. Variat caule nano, pedunculo scapiformi paucifloro, vel fere a basi ramosissimo, involucris numerosissimis multifloris. (v. s.)

\section{\$ 8. FOLIOSA.}

Herbæ annuæ, 2-3-chotome ramosissimæ, ad ramificationes foliatæ. Involucra solitaria, terminalia et alaria, sessilia vel pedicellata, profunde 5-8-fida. Perigonia glabra vel hirtella.

77. E. ABERTIANUM (Torr. in Emory rep.), annuum, durum, pubescens vel villosum 2-3-chotome ramosissimum, foliis inferioribus alternis longe petiolatis, ovatis 
subcordatisve ad ramificationes oppositis verticillatisve linearibus vel inferioribus ovatis, involucris alaribus pedicellatis profunde 5-8-fidis, perigonii glabri laciniis exterioribus orbiculatis basi cordatis. (1) In Novo-Mexico (Abert! Emory! Édwardes!), circa Chihuahua frequens (Wislizenus!). Herba semipedalis vel rarius subpedalis, interdum nana, sequentibus ramosior et magis foliata, perigoniis diu persistentibus coloratís conspicua. Pubes laxa, mollis. Involucra numerosa, pedicello nune 2-3 lin., nune 1-2-poll. longo fulta, ipsa 2 lin. longa, tubo breví campanulato, laciniis lineari-oblongis subuqualibus foliaceis. Pcrigonia per antliesin lineam longa, ad maturitatem dimidio aucta, laciniæe exteriores ut in E. multifloro basi profunde cordate sinu clauso, interiores angusta, medio contractæe, apice retusí. Achæenium acutangulum. Radicula longa. Variat staturâ, pube copjíosiore vel tenuiore, foliis inferioribus obtusis yel aculis, undulatis vel planis, pedułtculorum longitudine, etc. (v.s.).

78. E. PHARNACE IDES (Torr-! mss.), annuum, elatum, pubescens, 2-3-chotome ramosum, foliis linearibus subtus cano-tomentosis inferioribus paucis alternis subpetiolatis ad ramificationes sessilibus verticillatis, involucris alaribus longe pedi-. cellatis profunde 5-8-fidis, perigonïi glabri laciuiis exterioribus latis subcordatis. (1) In Novo-Mexico (Wright!). Herba erecta, ultra pedalis, pube molli parcâ. Folia $\frac{1}{3}-1 \frac{1}{2}$-pollicaria, marginc subrevoluta, supra glabra, subtus tomento laxo albida. Involucra pedicello capillari 1-2 poll. longo fulta, ipsa 2 lin. longa, late campaun lata, paulo ultra medium in lacinias sæpius 5 lanceolatas divisa. Perigonia per anthesin vix semilineâ longiora, alba. Antheræ in sicco nigricantes. Fructus non vidi. (v. s.)

79. E. SALs U g INosum (Hook. journ. 1843, p. 264), annuum, durum, glabrum, dichotome fasciculatimve ramosissimum, foliis imis paucis oblongis spathulatisve, ad ramificationes oppositis verticillatisve linearibus, involucris sessilibus alarilfus vel ramulos piliformes terminantibus incequaliter 5 -partitis, perigonii lyirtelli laciniis subequalibus obtusis. (1) In mont. Scopulosis ad fl. Colorado super. (Gambel! Geyer, n. 100). Stenogonum salsuginosum Nutt. I in Journ. Acad, nat. sc. Philad. n. ser. v. 1, p. 170. Herba nunc semipedalis, nunc nana vix pollicaris ; sapius glaucescens. Folia crassiuscula, radicalia subpollicaria longe petiolata, caulina bracleas Eriogonorum plurimorum referunt, jaucis interdum intra

bracteas adjectis. Involucra circa lineam longa, foliolis aliis omnino solutis, aliis basi plus minus connatis. Perigonia lin. longa, extus pilis brevibus crassis hispida, laciniis summo apice glabrisfnitidulis. Achæenium acute trigonum, fere trialatum. Semen et embryo omnino Pedunculatorum. (v. s.)

80. E. DIVARICATUM (Hook. journ. 1853, p. 265), annuum, humile, pubescens, ramis divaricatis dichotomis, foliis petiolatis ovalis crassiusculis, radicalibus rosulatis, ramealibus ad dichotomias intra bracteas geminis fasciculatisve, involucris alaribus sessilibus ramulosve, breves terminantibus minutis hemisphrericis profunde 5-fidis, perigonii hirtelli laciniis oblongis subrequalibus. (1) In mont. Scopulosis ad (1um. Colorado super (Geyer !n. 92). Herba 3-4-pollicaris, a basi sæpe multicaulis. Folia radicalia 3-5 lin. longa, obtusa, basi angustata, petiolo subsemipollicari. Bracteæ ad ramificationes breviter connate, oblongæ, inferiores interdum in folia expansæ, superiores minimre. Folia intra bractcas radicalibus similia, gradatim minora. Involucra vix lineam longa. Perigonia semilinearia vel paulo longiora. species quoad foliationem transitum præbet inter priecedentes et sequentem. (v.s.)

\section{$\$ 9$. Substipulata.}

Herba annua, inflorescentiâ et involucris Pedunculatorum, bracteis ad ramificationes brunneo-scariosis stipuliformibus, folits intra bracteas geminis fasciculatisve. Species Foliosis affinis.

81. E. ANGUL O SU M (Benth. in Trans. soc. lim. Lond. v. 17, p. 406, t. 18, f.1), annuum, erectum, 2-3-chotome verticillatimve ramosum, foliis ad basin caulis approximatis alternis petiolatis ad ramificationes intra bracteas stijulioformes geminis faseiculatisve, omnibus -oblongo-linearibus subtus vel utrinque lanuginosis demum ramisque glabratis, involucris pedicellatis parvis hemisphæricis 5-dentatis glabriusculis. (1) In Californiâ (Douglas! Coulter! n. 193). Herba fere a basi

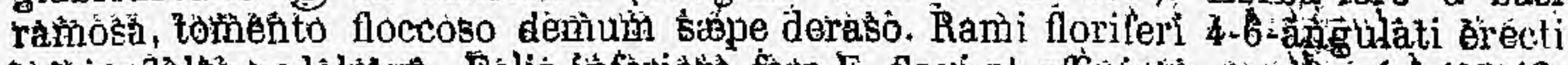

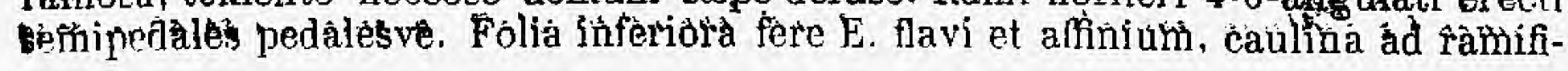


cationes angustiora gradatim minora. Bractern stipuleformes tot quot folia vel rami vel interdum duplicatæ, fusco-scariosæ, longitudine valde variabiles, interlum fere evanidx. Pedunculi alares et terminales, capillares, 6-12 lin. longi, inferiores sæpe storiles vel ad spinulam reducti. Involucra multiflora, 2-3 lin. diametro, dentibus tubo vix brevioribus. Bractcolie interiores spathulata. Perigonia parva, extus minute puberula, laciniis iequilongis exterioribus ovali-oblon$\mathrm{g} \mathrm{s}$, interioribus lineari-oblongis. (v. s.)

II. QXYTHECA Nutt. in Journ. Acad. nat. sc. Philad. $n$. ser. $v .1, p .169$, excl. sect. Gomphotheca. - Brisegnoa Remy in Cl. Gay. Hist. Chil. v. 5. p. 291. - Tetraraphis Miers mss. in diss. lect. in Soc. Linn. Lond. hov. 1852, Id. in Linn. Trans. $21,2$. p. $141, t .17$.

Involucrum pauciflorum 4 -fidum (rarius ex Remy 5-fidum), laciniis spinuloso-aristalis. Perigonium 6-fidum (v. ex Miers 4 -fidum). Stamina 9 v. ex Miers 8). Achænium compressiusculum. Embryo leviter incurvo-excentricus, radiculâ longissimâ, cotyledonibus breviter ovatis. - Herba annua, BorealiAmericana et Chilensis, habitu Eriogonorum Pedunculatorum, sed involucris primo intuitu distinguenda. An revera tamen ab illis separanda?

O. DENDROIDEA (Nutt. ! l. c.). (1) In montibus Scopulosis juxta flumen Lewis (Auttall!), in Andibus Mendozæ ad La Punta de los Vacas (Gillies!), in descensu Orientali inter Mendoza et Aconcagua alt. 8000 ped. (Niers), in prov. Corquimbo montibus arenosis in Cordilleras de Ovalle et Hurtado (CI. Gay). - 0. foliosa. Nutt.1 l.c. 0. apiculata Miers in Tayl. Ann. nat. hist. 1852, v. 2, p. 292. Brise-

- gnoa chilensis Remy in Cl. Gay, l. c., p. 292, 1. 58, f. 2. Tetraraphis apiculata Miers in litt. Herba 3-6-pollicaris, basi simplex et breviter foliata. Folia ad basin caulis conferta, subrosulata, linearia vel lineari-lanceolata, semipollicaria vel vix pollicaria, basi in petiolum brevem angustata, margine recurva, sulstus costata, utrinque viridia, pilis brevibus eglandulosis hirtella. Pedunculus scapiformis infra ramos pollicem altus, dein 2-3-chotome divaricato-ramosissimus, pilis minutis sæpins glanduliferis hirtellus. Bractere inferiores lineam longue vel interdum in folia 9-5 lin. longa angusta vel latiora expansie. Pediculli alares, capjllares, inferiores 1-3 lin. longi, superiores et terminales brevissimi. Involucra lineâ breviora, laciniis inscqualihus; arisțe albe involucro sape longiores, sed valde inæquales. Perigonium minimum extus pubescens, laciniis subæqualibus ovali-oblongis tenuibus ad medium connatis. Styli 3. Achenium perigonio paulo aucto inclusum. 0 . foliosa. Nutt. est cadem ex specim. vegetioribus descripta. Planta Chilensis ut ut alumbratio Gayana onnino cum illả Nuttallii convenit. Cl. Miers in speciminilus suis Chilensibus tlores vidit tetrameros 8-andros, ego in speciminibus tam Chilensibus quam borcali-Americanis fores constanter vidi hexameros 9-andros ut in genere Eriogono. ( 1 . s. in h. Hooker.)

\section{Species exclusa.}

OXYTHECA GLANDULOSA Nüt. = Eriogonum glandulusum.

III. NEMAC.IULIS Nutt. in Journ. Acad. nat. sc. Philad. n. ser. v. 1, p. 168.

Bracteolæ ommes liberæ; exteriores involucrum constituentes, minores, subsessiles, vacuæ. Perigonium 6-fidum Eriogoni. Stamina (an semper ?) 3 . Ovarium et fructus Eriogoni. Embryo valde curvatus, radiculâ lonyissimâ. llerba annua, Californica, bracleolis ovatis stipitatis intus lanatis insignis.

N. Nutralzir. (1) Ad San Diego in California Nuttall!) X. de'nulata et $\mathrm{X}$. foliosa Yutf. !1. c. Herba prostrata vel divaricata. Folia subradicalia, cuneato-oblongi, basi in petiolum longe augustata, utrintue mollissime et dense albo-lanata, nunc ix pollicaria nune 3 poll. longa. Rani Ruriferi e collo orti, scicie plures, tenues et rigiduli, divaricati, remote dichotomi stmipadales ad pedales, glabrati. Bracterc ad ramificationes parve, vel inferiores plus minus foliacce el folia nonmulla intra bracteas orta sicjc foventes. Fasciculi florum globosi, 2-3 lin. diametro, multiflori, arcte sessiles, alares, terminales, vel secus ramos ultimos disposilı. Bractcolie lineá breviores, exteriores $\mathbf{3 - 4}$ orato-oblouga et vacur involuerum Friogonorum referentes, interióres paulo longiores et tradatim iecrescentes, 
ovato-orbiculate, stipitatæ; omnes crassiusculse, concavie, extus glaberrimæ intus lanâ longâ implexả albà vestitæ. Flores parvi, intra bracteolas solitarii vel ís breviores, in pedicello articulati. Perigonii glabri lacinixe exteriores late obovate, interiores oblongæ, omnes medio crassiusculie, margine membranaceæ. Achænium nitidum, breviter ovoideum, apice triquetrum. (v.s. in h. Hook.)

IV. CHORIZANTHE $R$. Br. mss. ex Benth. in Trans. soc. linn. Lond. v. 17, p. 416, $t .17$, f. 11, t. 19, Endl. gen. n. 1981. - Trigonocarpus Bertero mss. in herb. n. 713.

Involucrum uniflorum, tubulosum, triangulare, dentibus 6 , rarius 5 . Perigonium 6-fidum. Stamina 9. Styli 3. Achænium triangulare. Embryo intra albumen haud copiosum, nunc rectus axilis, nunc incurvo-excentricus. Suffrulices.Chilenses vel herbæ annuæ Californicæ, Foliatio et inflorescentiæ ratio fere Eriogonorum; paniculæ tamen magis cymæformes vel corymbiformes, et ramuli ultimi sæpe capitati. Involucra sessilia, bracteata, dentibus sæpe uncinato-aristatis et inæqualibus, illis angulorum majoribus, extimo maximo, nunc vero omnibus subæqualibus muticisque. Blacteolæ interiores minutæ vel sæpius nullæ. Perigonium in pedicello brevi articulatum, inclusum vel breviter exsertum, sæpius petaloideum et glabrum. Semen in speciebus perpaucis observatum.

\section{- Suffrutices (Chilenses).}

1. C. v IR GA $\mathrm{xA}$ (Benth. in Trans. soc. linn. Lond., v. 17, p. 416, t. 19, f.1), suffruticosa, cæspitosa, foliis-ad basin caulis confertis linearibus utrinque sericeo-villosis, pedunculis elongatis subnudis subsimplicibus tomentosis, cymis in capitula terminalia pauca condensatis, involucris scriceis, dentibus inequalibus bracteisque subulato-aristatis. 5 In Andibus Chilensium (Cuming! n. 205), ad Cuesta de Zapala (Bridges! n. 519, Gillies!), secus flum. Cachogual (Bertero! n. 713), ad Rio Claro Rancaguce, etc., frequens (GI. Gay). Folia ad basin caulis numerosa, superiora 3-4-natim verticillata, basi caulem vaginantia, 6-10 lin. longa. Pedunculi (vel rami floriferi) pedales, foliorum verticillis 1-2 instructi. Involucri dentes exteriores recurvi. Perigonium infundibuliforme, 2 lin. longum, apice 6-fidum; laciniæe subæquales, breves, latie, patentes, margine crenulato-crispæ. Achænium oblongum, triquetrum. Semen conforme. Albumen parcum. Embryo rectus, axilis; cotyledones oblongæe, radiculà paulo longiores. (v. s.)

$\beta$. tomentosa, indumento foliorum breviore appresso, involucris minoribus, brevius aristatis. Ad Santiago de Chile (exped. Wilkes!).

2. C. PEDUNCULARIS (Benth. 1. c. p. 416), suffruticosa, subcrespitosa, foliis ad basin caulis approximatis oblongo-linearibus utrinque sericeo-villosis, pedunculis elongatis, nudis tomentosis, cymis in capitulum terminale solitarium condensatis, involucris tomentosis dentibus valde inæqualibus bracteisque lanceolatis muticis. 5 In Andibus Ghilensium (Cuming! n. 288). Indumentum canescens vel rubescens. Folia minus conferta et parum longiora quam in G. virgato, plerumque alterna, basi dilatato-amplexicaulia. Pedunculi demum fere pedales. Involucra 3-4 lin. longa, dentibus erectis, interioribus minimis. Flos brevissime pedicellatus. Perigonii lacinićc subæquales. (v. s.)

3. C. MACRAEI (Benth. l. c. p. 417), caule suffruticoso ramoso folioso, foliis linearibus ramisque sericeo-pubescentibus, involucris sericeis, dentibus brevibus parum iusequalibus bracteisque acutis muticis. 5 Prope Coquimbo(Macrae!). Suffrutex liumilis. Folia alterna, basi pilosa. Pedunculi 2-3-pollicares, aphylli exceptis bracteis sub cymà foliaceis vorticillatis. Involucra minora et minus tomentosa quam in C. pedunculari. Perigonium longe pedicellatum at non exsertum, breve. Lacinice interiores exterioribus duplo majores. (v.s.)

B. humilis, ramis brevibus cæspitosis, pedunculis 1-2 poll. longis. Ad Cocquimbo (Cl. Gay !). (v. s. in h. DC.)

4. C. Ramosissima (Benth. l. c. p. 147), caule suffruticoso ramosissimo folioso, foliis linearibus ramisque sericco-pubescentibus, pedunculis trichotomis, cymis laxis, involucris sericeis, dentibus brevibus inæqnalibus acutis muticis. 5 In Andibus Chilensium ad balneas Collina (Macrae l), in prov. Coquimbo (Cl. Gay l). Media inter 
chorizanthe. POLYGONAC. ERIOGON. (auctor bentham). 25

C. Macræi et C. paniculatam, et forte hujus varictas. Habitus prioris a quà differt cymis laxe trichotomis ad tricholomias foliatis. A C. paniculatâ differt involucris longioribus et inflorescentià multo breviore. Perigonium subvillosum. (v. s.)

5. C. pan I U L A t A (Benth. l. c. p. 417), caule suffruticoso ramoso folioso, foliis linearibus utrinque ramisque tomentoso-pubescentibus paniculà laxe 2-3-chotomà divaricatâ, cymis paucilloris, involucris sericeo-tomentỏsis dentibus brevibus inæqualibus acutis muticis. 5 In Andibus Chilensibus (Cuming! n. 249, Bridges! n. 515, Pœppig $\lceil\mathrm{n} .34$ ), ad Rancagua (Bertero! n. 714), in prov. Coquimbo (Gl. Gay! n. 898). Caules basi tortuoso-ramosi, foliis alternis semi-amplexicaulibus. Paniculse numerose semipedales, foliis sub ramificationibus verticillatis basi connatis. Involucra alia alaria sessilia, alia ad apices ramorum in cymas 6-12-floras conferta. Dentes crassi, subpatentes. Perigonium fere glabrum, laciniis subæqualibus. (v. s.)

6. C. vaginata (Bentlı. 1. c. p. 417), caule suffruticoso ramoso folioso, foliis lanceolatis aristatis basi dilatato-vaginantibus ramisque sericeo-pilosis, janiculà dichotomâ, cymis corymbosis, involucris sericeo-pilosis, dentibus vix inisrualibus breviter subulato-aristatis. tj Ad Valparaiso (Cuming! n. 479, Bridges! n. 514), Quintero (Bertero! n. 1364), Colchagua (Cl. Gay!). Caules basi vaginis foliorum alternorum omnino obtecti, Rami floriferi dichotomi, foliis sæpius oppositis connatis vaginantibus. Perigonium intra involucrum breviter pedicellatum, extus sericeum, laciniis subæqualibus. Folia floralia, bracteæe et involacrorum dentes rariant longius breviusve subulato-aristata vel rarius submutica. (v. s.)

7. C. F R ANK EN I I DES (Remy in Cl. Gay Hist. Chil. v. 5, p. 288), caule fruticoso ramoso folioso, foliis lanceolatis mucronatis glaberrimis basi vaginantibus, vaginis margine tantum ciliatis, foliis superioribus oppositis connatis, paniculà diehotomâ subdensâ, involucris nigricantibus glaberrimis extus reticulatim nervatis, dentibus subulato-aristatis. 5 In arenosis maritimis la Serena Chilensium frequens (Cl. Gay). Species milii ignota affinis dicitur C. vaginata et forte ejus varietas erit glabrata nigrescens.

8. C. GLABRESCENS (Benth. 1. c. p. 418), caule sulfruticoso ramoso folioso, foliis linearibus ramisque parce pilosis vel demum glabratis, cymis subcorymbosis, involucris glabris dentibus subrequalibus subulato-aristatis. 5 Ad Coquimbo (lord Colchester! Cuming! n. 904, Cl. Gay!) Affinis C. Macrei, differt staturâ humiliore, glabrilie et dentibus involucri longius aristatis. Perigonii laciniæ fere iequales. (v. s.)

$$
\text { + Herba annua (Californica). }
$$

9. C. st a T I C o IDEs (Benth. in Trans. soc. linn. Lond. $x$. 17, p. 418), annua, foliis radicalibus petiolatis spathulatis hirsutis subtus tomentosis, caulibus subnudis erectis 2-3- chotome ramosis, cymis laxe corymbusu-paniculatis, involucris glabriusculis, dentibus iner(pualijous subulato-aristatis, perigonii laciniis integris crenulatisve. (1) In Californià (Douglas! Coulter! n. 574 ct 5'76), ad San Diego et Sta Barbara (Nuttall !). C. nudicaule Nutt. ! in Journ. Acad. sc. Pliil. n. ser. v. 1, p. 166. G. discolor Nutt. 11 c. p. 167. Folia radicalia rosulata. Caules semipedales ad dichotomias 'articulati, bracteas' $2-3$ breves verticillatas gerentes. Involucra fructifera aucta, dentibus valde inæqualibus, majoribus seppe 2 lin. longis corniformibus, basi non membranaceis, apice rarius uncinatis. Perigonium brevissime pedicellatum, laciniœ exteriores lanceolatæ, interiores majores, obovatæ, apice integræ vel varie emarginate vel crenulatæ. (v.s.)

10. C. Fim B I A t A (Nutt.! in Journ. Acad: nat. sc. Philad. n. ser. v. 1, p. 168), annua, foliis radicalibus petiolatis spathulatis hirsutis subtus fomentosis, caulibus subnudis erectis 2-3-chotome ramosis, cymis laxe corymboso-paniculatis, involucris glabris villosisve dentibus inæqualibus subulato-aristatis, perigonii laciniis laccro-fimbriatis. (1) In Californiâ (Coulter! n. 574*), ad San Diego (Nuttall !). Valde affinis C. staticoidi, nec diversa videtur nisi perigonii laciniis, saltem 3 majoribus, lateraliter longe fimbriatis. (r. s. in h. Hooker et Torr.)

11. C. D o v G AsII (Bentlı. in Trans. soc. linn. Lond. v. 17, p. 188), annua, caule erecto 2-3-chotome ramoso, foliis radicalibus petiolatis spathulatis, caulinis oblongo-linearibus ramisque subsericeo-pilosis, cymis multifloris in capitula terminalia paniculata condensatis, involucris pilosis dentibus patantihus basi membranaceo- 
dilatatis apice inæqualiter subulato-aristatis plerisque uncinatis. (1) In Cảliforniâ (Douglas 1). Herba semipedalis. Capitula florum circa 4 lin. diametro. Bracteæ subulatæ dentesque involucri purpnrascentes, majores apice uncinatæ. Perigonium subsessile, lacinia omnes uquales, oblongo-cunentic, apice truncatæ, mucronulatre. (v. s.)

B. Hartwegi, foliis paucis sublatioribus, capitulis densioribus - ad Santa Cruz

(Hartweg ! n. 1935). C. nudicaulis Benth. pl. Hartw. p. 332, non Nutt. (v.s.).

12. C. ANGUSTIFoliA (Nutt.I1.c. p. 167), annua, humilis, crecta, foliis omnibus lineari-spathulatis molliter pilosis, cymis multifloris in capitula terminalia vel sublateralia confertis, involucris pilosis, dentibus patentibus basi vix dilatatis, apice inæqualiter subulato-aristatis plerisque uncinatis. (1) In Californià superiore ad Pueblo de los Angeles (Nuttall!), prope San Francisco (exped. Wilkes! Parry!). Vix non forma nana C. Douglasii (v. s.).

13. G. membranagea (Benth. Trans. soc. linn. Lond. v. 17, p. 419, tab. 17. f. 11), annua, caule erecto subdichotome ramoso, foliis linearibus ramisque laxe lanatis, cymis multifloris in capitula terminalia subpaniculata condensatis, involucris tomentosis infundibuliformibus, limbo membranaceo-dilatato, dentibus æqualibus breviter subulato-aristatis. (1) In Californiâ (Dougl.! Frém:!) Herba subpedalis. Lana caulis et foliorum nivea, tenuis, subdecidua. Capitula florum globosa, fructifera is Scabiosarum nonnullarum similia. Pedicelli perigonio æquilongi. Embryo incurvo-excentricus, cotyledonibus ovatis, radiculầ accumbenti-erectâ. (v. s.)

14. G. PUNGENS (Benth, in Trans. soc. linn. Lond. v. 17, p. 419, t. 19, f, 2), annua ? dura, ramis elongatis diffusis subdichotomis foliis petiolatis spathulatis ramisque pilosis, cymis multifloris laxe capitatis, capitulis irregulariter paniculatis, involucris pubescentibus, dentibus inæqualibus, bracteisque longe subulato-aristatis. (1)? In Californiâ (Dougl. !), ad Montercy (Nuttall ! Hartweg! n. 1936, exped. Wilkes!). Herba dura, sed verosimiliter uti præcedentes annua. Rami sesquipedales, pilis mollibus patentibus villosi. Capitula secus ramos numerosa, multiflora, breviter pedunculata. Involucri dent's exteriores 11 t bracteæe pungentes. Perigonium subsessile, laciniis æqualibus. ( $r$. s.)

15. C. S teluUla ta (Benth. pl. Hartw., p. 333), annua, piloso-pubescens, caule erecto 2-3-chotome subramoso fastigiato, foliis paucis oblongo-linearibus radicalibus spathulatis, cymis parvis capitatis multifloris, involucri inter costas transversim venosi dentibus brevibus membranaceo-marginatis breviter recurvoaristatis, perigonii laciniis bifidis. (1) In Califoruia valle Sacramento (Hartw.: n. 1937). Caules vix semipedales. Folia pollicaria vel superiora breviora, 1-2 lin. lata, utrinque viridia. Gymæe in capitula 9-15 lin. lata confertæ. Involucra florida 2 lin. longa, fructifera parum aucta, rugis transversis et costis elevatis insignia. (v.s.)

16. C. DiF U S A (Benth. pl. Hartw., 333), annua, pilosula, pusilla, ramulis diffusis a basi dichotomis aphyllis, foliis radicalibus longe petiolatis oblongis spathulatisve, cymis parvis subcapitatis, involucri dentibus insequalibus basi mẹmbranaceo-marginatis apice uncinato-aristatis. (1) Prope Monterey (Hartw.! n. 1938), ad littus maris (Parry!). Foliorum petioles 2-3 lin. longus, lamina nunc vix longior, nunc fere pollicaris. Involucri tubus vix lineam longus, pilosulus, dentes majores tubo æquilongi, alterni multo bréviores, omnes usque ad medium marginati. Sequenti affinis et forte mera varietas, dentibus calycinis evidentins marginatis. (v.s.)

17. C. p в o с U m в ens (Nutt. in Journ. Acad. nat. sc. Plilad. n. ser. v. 1, p. 167), annua, molliter pilosa, ramulis diffusis divaricato-dithotomis subaphyllis, foliis radicalibus petiolatis spatllulatis, cymis parvis subcapitatis involucri dentibus insequalibus, a basi subulatis uncinato-aristatis. (1) Ad San Diego (Nuttall !). C. uncinata Nutt. I l. c. Herba pusilla, nunc fere acaulis, nunc rimosissima fragilis. Deñtes involucri semper uncinati. (v. s. in h. Hook. et Torr.)

\section{$\dagger$ Species non satis nota, annua (Chilensis).}

18. C. commissuralis (Romy in Cl. Gay, Hist. Chil. v. 5, p. 287), herbacea, annua, neano-pubescens vel subglabrata, ramis sub dichotomiis inflato-articulosis fragili bus, foliis oblongis oppositis inferioribus basi attenuatis, involucris solitariis in dichotomiis insidentibus sessilibus. (1) In Chili locis siceis ad Guanta, Copiapo, Cha- 
niarcillo, etc. (Cl. Gay). Planta -6-pullicaris, ramis fragilibus. Folia radicalia pollicaria vel longiora, 2-4 lin. lata ; caulina minora. Involucra íncavo-tomentosa, rarius glabrata, maturitate basi indurata, dentibus inter se suberqualibus, extus recurvis subulato mucronatis. Flos in involucro sessilis. An IIucronew species?

V. MLCRONEA Benth. in Trans. soc.linn. Lond. v.17, p. 419, t. 20, Endl. gen. $\pi .1980$. Involuerum uniflorum, lubulosum, compressum, 2-dentatum, rarius 3-4-dentatum. Perigonium et genitalia Chorizainthis. - Herba Californica, habitu peculiari, sed vix characteribus a Chorizanthis distinguenda. An cum C. commissurali mera sectio illius generis?

M. calrforntca (Benth. 1. c. t. 20). (1) In Californiả (Dougl.!) prope San Díego (Parry !). Herba annua, spithamwa, erecta? , pilosiuscula, ramis dichotomis divaricatis. Folia ad basin caulis petiolata, oblonga, linearia, obtusa. Bractese foliaceie ad dichotumias et sub floribus stellato-trilolæe (Lernic basi connatæe?), amplexicaules, lobís late ovatis apice aristulatis. Involucra alaria, sessilia, superiora ad apices ramorum terminalia approximata; dentes subulato-aristati, subpungentes, exteriore longiore, sub fructu indurati, spinosi. Perigonium involucro inclusum, pedicello ebracteato sequilongum, laciniis subæqualibus. (v. s.)

\section{CWNTROSTEGIA A. Gray mss.}

Involucrum papyraceum, 1 - florum, rarius 2 -florum, tubulosum, venosum, apice inæqualiter 5 -dentatum ! dentibus mucronato-aristulatis), basin juxta 3-calcalum, calcaribus magnis divaricatis breviter subulalo-aristatis. Flores inclusi, pedicellati. Perigonium 6-parlitum, petaloideum; laciniis tenuibus lineari-spathulatis, ungue hirsutulo. Stamina 9. Ovarium 3-gonum. Styli 3, graciles; stigmata capitata. Achænium triquetrum. Embryo incurvo-excentricus, radiculâ longâ. - Ilerba annua, denissa, glabra, a basí ramosa ; ramis diffusis, floriferis flextosis; foliis radicalibus ignotis, ramealibus bracteisve minimis oppositis et alternis, sæpius 2-3-fidis, segmentis subulatis; involucris ad nodos solitariis subsessilibus.

C. THUR BERI. (1) In collibus arenosis arl San Felipe Laljfornix legil G. Thurber, maio 1853. Herba 2-3-pollicaris, rigidula. Calcaria involucro artullonga, grossa, superne haud raro processu vel calcare minimo iucta. (A. Gray mss.)

VII. PTLROSTEGIA Fisch. et Mey. Ind. 2. sem. hort. Petrop. p. 48, Endl. gen. n. 1979, suppl. IV, 2, p. 44 .

Involucrum diphyllum, uniflorum, fructiferum ampliatum dor'so bialatum. Perigonium 6-fjdum Eriogoni. Stamina (an semper ?) 6. Ovarium et styli Eriogoni. Achænium triquetrum, involucro inclusum. Embryo intra albumen haud copiosum excentricus, cotyledonibus suborbiculatis planis, radiculâ superâ. - Herbæ Californicæ ramosissimæ. Folia radicalia rosulata? caulina opposita exstipulata. Involucra in axillis solitaria subsessilia; foliola singula composita videntur e foliolis tribus, quorum margines connati in alas dorsales dilatantur.

1. P. DRYmaRIoIDEs (Fisch. et Mey: 1. c.), annua, prostrata, gracilis, foliis obovatospathulatis obcordatis vel reniformi-bifidis, involucro fructifero margine membranaceo cristato-dentato. (1) In Californix arenosis maritimis (Hook. et Arn. bot. Beech. t. 90). P. micropliylla Nutt.! in Journ. Acad. nat. sc. Philad. n. ser. v. 1. Herba paria, tenera, habitu Drymariæe similis, glabra vel tenuiter pubescens, viridis. Folia variant 2-3-linearia vel semipollicaria, latiora et emarginata vel etiam profunde bifida vel angustiora et integra, basi in petiolum angustata. Flores minuti. Involucri fructifera vix $1 \div$ lin. longa, late dilatata et eirca fruetum complicata, alis viridibus crassiusculis marginem hyalinum dentatum æquantibus.

2. P. MACROPTERA (Benth.! bot. Sulph. p. 44), ramis divaricatis junioribus canotomentosis, foliis obovatis spathulatisve integerrimis, id volucro fructifero maximo hyalino reticulato apice obselete triloho. $\not{4}$ ? In California thefidionali ad sigum 
Magdalenæ (Hinds!). Caules rigiduli, ad nodos tumiduli, demum glabrescentes. Folia subcarnosa, 4-6 lin. longa, involucra florida vix lineam longa, fructifera 4-5 lin. longa, 6-7 lin. lata, tenuiter hyalino-membranacea, reticulato-rubrovenia, margine obscure sinuato-triloba, cseterum integerrima, alis dorsalibus inequalibus foliolo inso texturâ consimilibus.

\section{Subordo II. POLYGONEE (1), Juss, gen. p. 82. - Polygonaceæ Meisn. gen. p. 316 (227).}

Characteres in conspectu, p. 3 , enuntiati.

Tribus I. PTER YGOCARPAE, Meisn. in Mart. fl. bras. fasc. 14, Polyg.p. 5.

Achænium lenticulare vel 2-4-quetrum, angulis in alam vel cristam (sæpius echinatam) expansis. Embryo in axi albuminis farinosi rectus. Calyx subcorollinus, demum vix accrescens fructuque multo minor, rarius eum includens. Antheræ versatiles.

Subtribus I. CALLIGONEE, C. A. Meyer in Mém. Acad. Saint-Pétersb. $6^{\mathrm{e}}$ sér. sc. math. et phys. 6, p. 142.

Flores hermaphroditi. Calyx corollinus, 5-partitus, haud accrescens, marcescens, sub fructu reflexus, laciniis subæqualibus. Stamina 12-17, filamentis subulatis. Stigmata 4, subsessilia, capitata. Achænium 4-sulcum vel 4-gonum, angulis cristato-alatis dentatis vel echinatis vel in membranam vesicæformem coeuntibus. Semen 4-lobum. - Frutices Asiæ mediæ et occidentalis et $A$ fricæ borealis, virgati, subaphylli, glauci, ramulis articulatis, ochreis hyalinis, floribus in axillâ ochrearum fasciculatis, pedicellis articulatis.

VIII. CALLIGONUM Linn. gen. $n .600$, Gartn. fil. fr. 3, p. 200, t. 215, f. 9, Endl. gen. n. 1989 (sectio Eucalligonum, excl. sect. b. et c.), Ledeb. fl. ross. 3, p. 495.-Polygonoides Tourn. it. $2, p .356$.

Flores hermaphroditi. Calyx coloratus, subcorollinus, vix increscens, lobis planis subæqualibus patentibus demum reflexis. Stamina 12-17, subhypogyna, filamentis subulatis basi connatis, antheris ovatis versalilibus. Ovarium 4-gonum, 4-sulcum. Styli 4, liberi, filiformes, stigmatibus capitatis. Achænium subgloboso-letragonum, apterum, selis 8-16-seriatis (ex angulis præcipue ortis) ramosis cancellato-intertextis echinatum, pericarpio sublignoso. Semen 4-gonum vel 4-lobum. Embryo in axi albuminis farinosi rectus, cotyledonibus linęaribus. - Frutices Africæ borealis Asiæque mediæ et occidentalis ramosissimi, glauci, fere aphylli; ramis validis, sæpe dichotomis, annotinis debilibus articulatis teretibus filiformibus, internodiis elongatis, ochreis membranaceis brevibus bilobis enerviis, foliis semitereti-filiformibus internodio brevioribus caducis floribus lateralibus in ochrearum axillâ fasciculatis parvis albis vel roseis, pedicellis articulatis.

1. C. comosum (L'Hérit. in Trans. soc. linn. Lund. 1, p. 180), achienio ovali vel subgloboso, setis 12-16-seriatis densissimis longis basi dilatalâ contiguis ramosissimis, laciniis elongatis tenuibus vix rigidis, ramis validis tortuosis vel flexuosis, annotinis sepe fasciculatis. 5 In Aegypto (Olivier ! Sieber! Schimper! n. $\mathbf{5 4 2}$ et 651), in deserto prope El Tor, Arabice Petreæe (Boissier! Boré! n. 37), Syriâ, Persià (Aucher Eloy l), Algeriả (Desf. Balansa, n. 752 !), ins. Canar. (Webb? fide Decaisne). Arabice : Artas, Rassii (Acerbi, Ehrenberg). Internodia ramulorum 1-2-pollicaria. Achænii (cum setis) diameter fere pollicaris. ( $\nabla$. s.)

(1) Auctore G.-F. Meisner. 
2. C. POLYG ONOIDES (Linn. sp. p. 478), achenio ovato, setis 12-16-seriatis basi dilatatâ contiguis vel in cristam confluentibus densissime intertextis fragilibus, laciniis elongatis vix rigidulis, ramis validlis flexuosis vel tortuosis. I In arenosis subsalsis, circa mont. Ararat (Tourn.), in Armenià et Syrià (Aucher Eloy! n. $\mathbf{5 2 7 8}$ et 2561, Szowitz!).--L'Hérit. 1. c. p. 179, Lam. dict. 1. p. $563^{*}$. Polygonoides orientalis, Ephedrse facie Tourn. coroll. 47, iter 2, p. 356, cum ic. Ramulorum annotinorum internodia pollicaria, dimiclio tenuiora et fructus paulo minor quam G. comosi. (v. s.)

3. C. M on G o I C M (Turcz.! pl. Mongol.-Chín. n. 27), achænio oblongo, setis 16-seriatis basi distinctis laxiusculis tenuibus apice vix rigidis. $\hbar$ In arenosis Mongolire chinensis (Turcz.1). Rami lignosi, teretes, albidi, levissime striati, subflexuosi, ad nodos parum incrassati, ramulis herbaceis filiformibus glaucis alternis vel plerumque iterato-dichotomis aphyllis, internodiis subpollicaribus, pedicellis calyce paulo brevioribus. (v. s. fructu semimaturo in herb. DC. et Ledeb.)

$\beta$. Gobicum, achenii setulis paulo longioribus vix rigirlis. In Mongoliâ. C. Goljicum Bunge! mss. (v. s. fructu jun. in h. Ledeb.)

4. C. CAPU T-Medus a (Schrenk enum. pl. nov.1, p.9), achrnio subgloboso-ovali, setis 8-seriatis rigidis tenacibus basi validis distinctis, apice ramosissimis spinescentibus. 5 In deserto Soongoro-Kirghisico (Karelin et Kiriloff ! n. 1932).-Ledeb.! fl. ross. 3 , p. 495 . Rami virgati, graciles, elongati, substricti, cinerei, ramulis anno-

- tinis subfasciculatis secundis strictis glaucis, internodiis 1-2-jollicaribus, ochreis brevibus truncatis 2-4-floris. Pedicelli vix flore longiores, infra medium articulati. Fructus (cum setis) diam. 10 lin., setarmu ramulis brevibus. (v. s. in h. Ledeb. DC. Mart.)

5. C. MuREx (Bunge! mss. in reliq. Lehmann.), achenio subgloboso-ovali, setis 8-seriatis semibifidis basi validis discretis, cruribus partem basilarem requantibus apice palmatim 3-5-spinulosis, spinulis patentibus rigidis crure brevioribus. 5 In deserto Mongolico? (Alex. Lehmann l). Achænii (cum setis) diam. 5-6 lin., setularum crura rufa circ. 1 lin., spinula $\div$ lin. longa pallidæ. (v. s. absque loci nat. indic. in $\mathrm{h}$. Reg. Berolin.)

IX. PTEROCOCGUS Pallas iter 2, append. p. 738, t. 5, Meisn. gen. p. 317 (228), Ledeb. fl. 1'oss. 3, p. 494. - Pallasia Linn. fil. suppl. p. 252, Gortn. fil. fr. 3, p. 28, t. 184, f. 2. - Calligonum Lam. ill. t. 410, Ledeb. fl. alt. 2, p. 206. - Sect. c. Cialligoni, Pterococcus Endl. gen. n. 1989.

Achænium tetragono-ellipticum, angulis expansis in alam duplicem coriaceo vel scarioso-membranaceam serratam vel iniegram, faciebus lævibus nudis. - Cæt. omnia habitusque Calligoni.

1. P. A P II Y L U (Pallas iter, 2, p. 332; append. p. 738), ramis adultis fuscis, achrenii faciebus suborbicularibus, alis chartaceis planis denticulatis apice rotundatis, dentibus brevissimis stepe obtusiusculis obsoletisve. ந In arenâ mobili ad Wolgam, Urenburg, deserti Caspici et Soóngorice. - Ledeb.! fl. ross. 3, p. 494. Calligonum polygonoides Pall. iter 3, p. 356 (non Linn.). Pallasia Pterococcus Pall. fl. ross. p. 70 (quoad plant. Wolgensem, sed excl. ic.). Pallasia Caspica Linn. fil. suppl. p. 252. Calligonum Pallasia L'Hérit. in Trans. soc. linn. Lond. 1, p. 180, Willd. sp. 2, p. 927. Achrnium 8-9 lin. longum, alarum dentibus vix $\frac{1}{5}$ lin. longis. Pedicelli calyce longiores. (v. s.)

2. P. TETRAPTERUS, ramis adultis cinereis, achænii faciebus ovatis vel subrotundatis, alis coriaceis margine cristato-spinulosis apice-acutis conniventibus, dentibus subdistichis patulis. 5 Calligonum tetrapterum Jaub. et. Sp. Ill. pl. or. t. 471. Inter Bagdad et Alep (Olivier et Brug.). Rami stricti, graciles. Articuli apice in raginulam cupuliformem aphyllam vel foliiferam dilatati. Folia minima, subulata rel dentiformia. Fasciculi 2-5-flori, distichi, remoti. Pedicelli 2 lin. longi. Flos 2 lin. latus. Achænium 4-5 lin. longum, 3-4 latum, stipitulatum, dentibus polymorphis rigidis brevibus.

3. P. So NGoricus (C.-A. Meyer in Bullet. Acad. S. Petersb. 8, p. 340), ramis adultis fuscis, achæenii faciebus ellipticis, alis chartaceis vel coriaceis utrinque acutis inciso-serratis subundulatis. $\hbar$ In deserto Soongoro-Kirghisico ad lacum Saisang 
Nor.-Ledeb.! fl. russ. 3, p. 494. Pallasia Pterococcus Pall. 11. ross. p. 70, t. 77, 78 (excl. planta Wolgensi). Calligonum songaricum Endl. gen. suppl. IV, 2, p. 50 (excl. syn. Led.). Ramuli elongati, irregulariter flexuosi, cinerei, demum atropurpurei, annotini fasciculati, 1 lin. crassi, internodiis $1-2$ poll. Folia 6-8 lin. longa, acutiuscula. Flos diam. 3 lin. Achrenia 7-9 lin. longa et parum angustiora, alarum dentibus $\frac{1}{2}$ lin. longis acutis vel obtusis.

a. Ravidus (Ledeb.! 1. c.), achænii alis chartaccis flavescentibus. Galligonum flavidum Bunge! delect. sem. h. Dorpat, 1839 , p. 8. (v. s.)

B. mibicundus (Led. 1. c.), achsenii alis coriaceis rubicundlis. Calligonum rubicundum Bunge! l. c. (v. s.)

4. P. crispus (G. A. Meyer in Bullct. Acad. S. Petersb. 8, p. 340), ramis adultis fuscis, achanii faciebus ellipticis, alis coriaceis undulatis utrinque acutis, margine bicristatis spinuloso-inciso-dentatis. Ij In Sibirik̂. Altaicâ ad flum. Irtysch, deserto Soongoro-Kirghisico--Ledeb.! fl. ross. 3, 1 . 495. Calligonum Pallasia Ledeb.! fl. alt. 2, p. 206 (excl. synon.). C. crispum Bunge delect. sem. h. Dorp. 1839. Rami graciliores et strictiores quam P. Soongorici; achconium paulo inajus, dentibus 1 lin. longis rigidioribus; caly $\mathrm{x}$ major, expansus diam. 4 lin. (v. s.)

5. P. LEUCOCLADOS (Schrenk in Bullet. phys. math. Icad. S. Peters. 3, p. 211), ramis omnibus albidis, achænii faciebus suhorbiculatis, alis chartaceis planis subintegerrimis apice rotundatis 5 .In littore orientali maris Caspii; deserto SoongoroKirghisico Sibiriæ Altaice (Schrenli) et Uralensis (Karelin et Kiriloff, n. 1931 !): -Ledeb.1 f1. ross. 3, p. 494. Forsan mera var. P. aphylli, attamen characteres indicati constantes esse videntur et achrenia paulo minora, circ. semipollicaria. (v. s. in h. Ledeb.)

a. strictus (Ledeb. $11 \%$ ), ramis strictis.

B. flexuosus (Led. 1. c.), ramis flexuosis. P. aphyltus Karelin et Kirilof? enum. pl. Soongor. n. 738 (excl. synon.).

X. CALLIPHYSA Fischer et G.-A. Meyer index sem. h. Petropol. 1835, p. 24, Meisn. gen. p. 317 (228).-Calligoni sect. b. Calliphysa Endl. gen. p. 308, suppl. 4, 2, p. 50:

Achanium profunde 4-sulcatum, jugis rotundatis apteris, dense obtectum setis apice in membranan fructum yesica instar includentem expansis. Cæt. et habitus Culligoni.

C. JUNCEA (Fisclı. et Hej. 1. c.). 5 In litture orientali maris Casjii (Karelin), in Sibiriâ Uralensi et deserto Soongoro-Kirghisico ad lacum Saișang Tor.-Ledeb! fl. yoss. 3, p. 495. Cálligonum Calliphysa Bunge, deleet. sem, h. Dorp. 1839, p. 8. Rami validi, teretes, laves, cinereo-vel flavo-fusci, sape valde flexuosi, annotini filiformes, dense fasciculati vix semilineam crassi, internodiis plerumque semipollicaribus. Flores hermaphroditi. Calyx coloratus, marcescens. Ovarium 4-sulcatum. Achænium vesicreforme, ellipticum, 4-5 lin. longum, 3 lin. latum, membranâ tenerầ evenià rugulosâ pallide rufâ. (v. s.)

B. flexuosa (Bong. et C.-A. Mey. fl. alt. suppl. n. 248, Ledeb. I. c.), ramis lignosis flexuosis, foliis tenuioribus angustioribus.

\section{Subtribus II. RHABARBAREA.}

Flores hermaphroditi. Calyx herbaceus vel corollinus, 4-6-partitus. Stamina 6 vel 8 vel 9 . Achænium nudum vel rarius calyce inclusum, inerme, lenticulare vel triquetrum, angulis in alam membranaceam edentatam productis. - Herbæ vel rarius frutices, floribus in racemos vel paniculas terminales congestis, rarius lateralibus fasciculatis.

XI. PTEROPYRUM Jaubert et Spach, Plant. orient. 2, p. 7, t. 107-109, Endl. gen. suppl. $4,2, p .54, \mathrm{n} .1993 \mid 3$.

Flores hermaphroditi. Culyx rotatus, 5-partitus, subcorollinus, marcescens, parum accrescens, lobis 2 exterioribus demum reflexis, interioribus 3 pauló minoribus achænio adpressis. Stamina 8 , quorum 3 calycis lobis interjoribus 
anteposita longiora ; filamenta persistentia, bași subdilatata et barbulâ cincta ; antheræ versatiles. Ovarium ovoideo-triquetrum. Styli 3 breves, subdivergentes; stigmata capitata. Achænium coriaceum, cordato-ovoideum, 3-alatum, rostrato-acuminatum, alis membranaceis rotundatis sinu profundo transverso bipartitis transverse striatulis nervuloque intramarginali percursis. Semen loculo conforme, longe rostratum. Fmbryo in axi albuminis farinosi rectus, cotyledonibus semiteretibus, radiculâ exsertâ brevioribus. - Frutices Orientales ramosissimi, erecti, inermes, ramulis alternis, junioribus striatis, foliis coriaceis subpersistentibus alternis vel subfasciculatis angustis, ochreisbrevissimis menibranaceis truncatis vel bipartitis, floribus lateralibus fasciculatis, pedicellis capillaribus infia medium arliculatis singulis basi ochreolâ vaginatis, fructiferis pendulis.

\section{Secl. I. Streptocarya, Jaub. et Spach, l. c.}

Achænium quavis facic ad sinum alarum in plicam transversam hippocrepidoideam distortum, unde alarum, lobi terminales respectu inferiorum quasi alterni; achænium velut 6 -alatum et semen infra rostrum transverse sinuosum. Folia ramea plana vel planiuscula, plerumque margine revoluta et nervo medio instructa, fascicularia enervia ex parte teretiuscula.

1. P. A U c II ER II (Jaub. et Spach, l. c. p. $8^{*}$, t. 107), foliis fascioularibus spathutatovel lanceolato-linearibus vel subfiliformibus teretiusculis, alarum aclıenii lobis terminalibus ab inferioribus remotiusculis. 5 In collibus aridis Persiæ borealis (Aucher Eloy, n. 5269 !). (v. s. in h. Shuttleworth.)

2. P. O LIVERII (Jaub. et Spach, l. c. p. 9 *,t. 108), foliis fascicularibus obovatis vel oblongis vel spathulatis vel sublinearibus teretiusculis planisve, alarum achænii lobis inferioribus terminales fere obtegentibus. $\hbar$ In Persia boreali prope Teheran (Olivier ! et Bruguière) et Scinde (Stocks). - Wight ic. t. 1809. (v. s. in h. DC.)

3. P. Gracile (Boiss. in Kotsqly pl. I'ers. bor. 1840, diagn. pl. ur. n. 12, p. $102 \%$ foliis solitariis carnosulis glaucis elliptico-vel lineari-obovatis obtusis eveniis, achænii lobis utrinque emarginatis, terminalíbus cum inferioribus (fere triplo majoribus) basi imbricatis. $\hbar$ In nuonte Elbro Persiæ boreal. (Kotschy, n. 664!). Verisimiliter mere forma P. Oliverii, a quo nonnisi ramis fructiferis simplicissimis

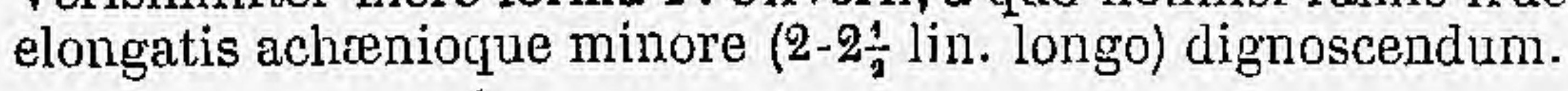

\section{Sectio 11. Orthocarya, Jaub. et Spach, l. c. p. 9.}

Achænium non distortum, alis subriandurieformibus. Semen non sinuosum.

4. P. scoparIUM (Jaub. el Spacli, 1. c. p. $9^{*}$, t. 109), foliis omnibus subfiliformibus terstibus vel subteretibus enervis, alarum achænii sinu aperto. 5 In Arabiæ ditione Mascat (Aucher Eloy, n. 5270 l) Habitus Ericæ scopariæ. Rami ramulique graciles, erecti, albi, vix striati. Folia 3-5 lin. longa, $\frac{1}{2}$ lin. crassa, obtusissima, mutica. Pedicelli 2 lin. longi, sepalis duplo longiores. (v. s. sine fr.)

5. P. Griffit hi (Meisn. mss. in I. Lemann. 1851), foliis solitariis spathulatis oblusiusculis enerviis rel subtus obsolete 1-nerviis, alarum achænii sinu-lobis terminali et basilari contiguis obtecto. 5 In collibus circa Sharkabad, Affghanistan (Griffith | journ. 721). Ramuli graciles, patuli, stricti, subspinescentes, juniores albi sulcato-striati. Ochrese brevissimæ, fuscescenles. Folia carnosula, 3-6 lin. longa, 1-2 lin. lata, atlenuato-subpetiolata, lavia, margine recurva. Fasciculi pauciflori, pedicellis infra medium articulatis calycem æquantibus. Acheenium calycem dimidio superans, rectum, faciebus profunde cordatis late ovatis. (v. s. in herb. Lemann, nunc a Benth. et Univ. Cautabrigiens. div.)

6. P. Nozanum (Boiss.! in Schlech1. bot. Zeit. 1853, p. 734 , solum nomen), foliis 2.4 fnsciculatis subcarnosis viridibus linearibus lanceolatisque obtusis obsolete 1 -nerviis, alarum achænii sinu lobis terminali et basilari contiguis tecto. $\zeta$ Ad ripam Dialæe et Tigridis, prope Mossul (Noë, n. 1002 !). Ramuli patentes, inermes. Ochreæ deciduæ. Fasciculi 2-4-flori, pedicellis folia floralia equantibus supra basin articulatis. Achænium roseum. Cæet. P. Griffithii. (v. s.) 
XII. RHEUM Linn. gen. n. 401, amœn. acad. 3, p. 211, t. 4, Schkuhr Handb. 1, p. 349, t. 110, Gaertn. fr. 2, p. 177, t. 119, Lam. ill. t. 324, Meisn. Polyg. prodr. t. 1, f. 2, 3, t. 2 , f. D; gen. p. 316 (228), Endl. gen. n. 1984, suppl. 4, 2, p. 15. - Rhabarbarum Tourn. inst. p. 89, t. 18, Adans. fam. $2 ;$ p. 277.

Flores hermaphroditi (rarius passim abortu unisexuales). Galyx semicorollinus, 6-partitus, persistens, haud increscens, laciniis æqualibus vel alternis paullo minoribus. Glandulæ vel squamæ perigynæ nullæ. Stamina 9 (rarissime 6 ) imo calyci inserta, filamentis subulatis, antheris versatilibus ovalibus introrsis. Ovarium trigonum. Styli 3 (raro 2-4), brevissimi, patuli, stigmatibus depresso-capitatis cuneiformi-reniformibus-indivisis lævibus. Achænium samaroideum, alato-triquetrum (raro compressum vel 4-alatum), calycem sibi adpressum longe superans, pericarpio tenui subcrustaceo, alis coriaceis vel membranaceis integris. Semen erectum, triquetrum. Embryo in axi albuminis farinosi rectus, radiculâ brevi superâ, cotyledonibus foliaceis planis marginibus samaræ facies spectantibus. - IJerbæ perennes, Asiæ occidentalis; mediæ et borealis Rossiæque australis; rhizomate crasso lignescente; caulibus epigæis, annuis, erectis, crassis, fislulosis vel nullis ; foliis latis, sæpe amplissimis, palminerviis, integris vel laciniatis, ochreis membianaceis vaginantibus laxis marcescentibus haud ciliatis; floribus paniculatis vel spiciformi-racemosis, albidis roseis vel sanguineis; pedicellis fasciculatis, capillaribus, infra medium articulatis, raro crassiusculis continuis, fruclibus junioribus sæpius sanguineis, maturis fuscis. - Folia et petioli oxalico-aciduli usui culinario vario inserviunt. Rhizoma plurium nec salis certarum specierum, sub nomine "Radix Rhei et Rhabarbari s. Rhapontici " officinale, præler amylum, saccharum, tanninam et calcem oxalicam, varia ratione, continet materiam propriam $R$ habarbarina vocatam, amaram, nauseoso-aromaticam, resinosam, flavo-colorantem, et jam sæculo $X$ a Sinis acceptum Arabum commercio Europæis allatum, serius inter medicamina præstantissima in universalem admissum est. Cfr. Nees et Ebermayer Handb. d. Med. Pharm. J3ot. I, p. 455, Journ. de pharm. 13, p. 344. Bischoff Med. Bot. p. 551, Edinb. med. et surg. Journ. 1823, p. 168, Royle Ill. Himal. p. 314, Endl. Encheir. p. 189.

\section{§1. Racemi paniculati. Folia dentata vel laciniata.}

1. R. PAL M т U M (Linn. fasc. 7 , t. 4 ; sp. pl. p. 531), caule elato folioso, petiolis subcylindricis, foliis herbaceis ambitu suborbicularibus cordatis palmatilobis scabriusculis, paniculâ foliatâ, pedicellis flore vix longioribus, achæeniis oblongo-ovalibus subcordatis apice rotundatis vel emarginatis, alis latitudine seminis. $\hbar$ In insulis oræ orientalis Asiæ borealis (Pallas ct Georgi) et in jugo montium aridorum Tatarix Sinice (fide Endl.) - Houtt. pl. syst. 6. p. 475*, 1. 50, f. 2, Blackw. herb. t. 600, $a, b$, Hayne Arzn. gew. 12, t. 10, Ledeb. 11. ross. 3, p. 496. Petioli supra obsolete sulcali, margine rotundati. Folia 3 -vel 5 -nervia, papilloso-scabriuscula vel supra glahra, lobis ovatis-ollongis lanceolatisve acutis indivisis vel inciso-dentatis vel pinnatifidis. Paniculæ rami puberuli, demum patuli, pedicellis fasciculatis. (v. v. c.)

2. R. HY B RI DUM (Murr. comment. Goetting. 2, 1780, p. 2. t. 1, comm. nov. soc. reg. Goett. 5 , p. 50, t. 12), caule elato folioso, petiolis longis supra canaliculatis subtus sulcatis, foliis herbaceis ovatis basi emarginatis vel breve cuneatis inciso-dentatis (raro passim subintegris), paniculâ foliatâ fastigiatâ laxiusculà, pelicellịs fructu plus dimidio brevioribus, achenio magno ovato emarginato basi rotundato, alis semine latioribus. $\mathcal{F}$ Hab...? Verisimiliter jorogenies hylorida ex R. palmato et undulato vel Rhapontico. - Ait. Kew, 2, p. 42, Willd. sp. 2, p. 490, Yoir. dict. 6, p. $195^{\star}$, Nees pl. off. suppl. 2, t. 1. Folia 3-5-nervia, subtus puberula, dentibus indivisis sinubusque brevibus obtusis, raro lanceolatis acutis. (v. s. c.)

3. glabrum, foliis demum glaberrimis, siepius prolunde corclatis, aohænio basi cordato apice rotundato leviter emarginato, alis semine parvo longioribus sæepiusque latioribus. $\mathrm{R}$. dentatum Mart. ind. sem. b. Monac. 1839, Linnæa, 44, litt. 4,135 . Planta spectahilis, staturà humana altior; folia margine 
minute denticulato-ciliolata, plana vel rugosa, infima excluso petiolo pedalia et ultra, juniora subtus puberula. Panicula serius evoluta quam R, undulati, floribus numerosissimis lacteis, plerisque haud fructificantibus (abortu mas. culis): Fructus tarde maturescentes. (v. v. c.)

\section{Racemi paniculati. Folia indivisa, integra.}

3. R. MACROPTERUM (Mart. ind. sem. lr. Monac. 1848), caule elato folioso, petiolis semiteretibus supra subconcavis, foliis herbaceis ovatis acuminatis obsolete undulatis e basi rotundatâ vel leviter cordatã breve cuneatis $\mathbf{5}$-nerviis, nervis lateralibus confluentibus bași marginalibus, paniculà fastigiatâ densiflorâ, pedicellis prope basin articulatis fructu dimidio brevioribus, achænio magno late ovato-elliptico utrinque profunde cordato, sinu apicis lato, alis semine sublatioribus. $\mathcal{H}$ Patria ignota. R. sanguineum ind. hort. Halens. 1851 ? (ex fructu tantum nobis notum). Folia ampla, longiora quam lata, ciliolata, subtus in nervis minute puberula, cœeterum glabra. Achæenium pro genere maximum, usque ad 6 lin. longum, 4-5.lin. latum, ovale vel ovatum vel subquadrangulum, angulis rotundatis, alis basi 1 lin., apice 2 lin. latis faciem seminis aquantibus vel latioribus. (v. s.. c.)

4. R. UNDUL A T U (Linn. sp. p. 531 ; amcen. 3, p. $212, \mathrm{t} .4$ ), caule elato folioso, petiolis semiteretibus supra leviter eanaliculatis margine-rotundatis dorso exsulcis, foliis herbaceis ovatis cordatis undulatis 5-7-nerviis supra glabris subtus puberulis, paniculâ fastigiatá densiflorâ inferne foliosâ, pedicellis prope basin articulatis fructum subrquantibus, achænio mediocri ovato vel ovali utrinque emarginato vel apice subtruncato-rotundato, alis semine convexo subangustioribus apice parum dilatatis. $\%$ In Síbiriâ Transbaicalensi ęt Dàhurià. - Poir. dict. 6, p. ${ }^{193^{*}}$. Ledeb. ! fl. ross. 3, p. 496, Nees pl. offic. t. 116,117 , Reichenb. ic. exot. 2, p. 6 , t. 117 ? (recedens folio subrotundo et fructu apice exciso). R. Rhabarbarum Linn. syst. p. 385, Houttuyn Pfl. syst. 6 , p. $473^{*}$, t. 50, f. 1, Schkuhr Handb. 1, p. 350 , t. 110. R. muricatum Blanco fl. de Filipinas, ed. 1, p. 327.? Caulis 4-5-pedalis, lævis, glaber, viridis. Ochreæ cito deciduæ. Petioli parce puberuli, paissim rubentes, supra plani, apicem versus plus minus elevato-marginati (scil. folii nervis marginalibus in petiolnm decurrentibus), superiores fere 4-goni. Folia ovata, semper longiora quam Iata, fortiter undulata, dense ciliolata, subtus ad venas vel undique pilosiuscula, basi sinu haud profundo cordata nec unquam cuneata, 5-7-nervia, nervis exterioribus sæpius basi confluentibus; folia summa subsessilia 2-3-plo longiora quam lata. Paniculæe rami erecti. Flores plerique fertiles. Calycis fructiferi lobi obovato-oblongi. Achenia parum longiora quam lata, juniora sanguinea. (v. s. sp. jun. Turcz. 1 in herb. DC. et v. c.)

5. R. R н a P on t i u m (Linn. mat. med. p. 169, sp. pl. p. 531), caule elato folioso, petiolis semicylindricis supra planis subtus sulcatis, foliis suborbicularibus profunde cordatis undulatis 5-nerviis supra-glabris subtus ad venas puberulis, snperioribus ovatis vel acưminatis, paniculấ fastigiatâ foliatâ densiflorấ, pedicellis fructu brevioribus infra medium articulatis, achæniis oblongo-ovalibus utrinque emarginatis, alis seminis fere latitudine infra medium dimidio angustioribus, seminis faciebus ovato-ellipticis subplanis nitidis transverse rugulosis minute granulatostriatis. $\mathcal{Z}$ In desertis et subalpinis Sibiriæ Altaicæe et Baicalensis et in Davuriâ.Poir. dict. 6, p. 192 * Hayne Arzneigew. 12, t. 7 ? Nees pl. offic. t. 113-115, Ledeb. 1 fl. alt. 2 , p. $90^{*}$, FI. ross. 3, p. 496 . R. undulatum Pall. it. 2, p. 531, 551; 3, p. 317, 322. R. sibiricum Pall. ex Sievers in Pall. Neu. nord. Beitr. 7, p. 182. R. compactum Kar. et Kiril. enum. pl. Soongor. n. 733 (fide Ledeb.). A R. undulato, cui nimis affine; distinguitur petiolis subtus sulcatis, foliis (saltem inferioribus) latioribus quam longis, superioribus minus attenuato-elongatis, omnibus minus undulatis, sinu baseos profundiore angustiore, paniculæ ramis semierectis, et præsertim achænio paulo majore apice basique æquilato et profundius emarginato, alis apice latioribus, seminis faciebus paulo majoribus planis vel vix convexis. (t. v. c.)

6. R. M I CROCARPUM, caule elato folioso, petiolis depresso-semicylindricis supra planis vel subconcavis margine obtusiusculis subtus subexsulcis, foliis ovatis subacuminatis subplanis sinu lato leviter cordatis 5 -nerviis, venis subtus puberulis, paniculâ fastigiatâ densiflorả, pedicellis fructu sublongioribus infra medium articu. latis, achænio parvo ovato urinque rotundato vel apice leviter emarginato, alis 
Sémine triplu angustiortbus basi evanescentibus. $\%$ Patria ignota. Caulis tenuiter

sulcatus. Folia remoté leviterque undulata, vix crispa. Achæním 3 lin. lungum

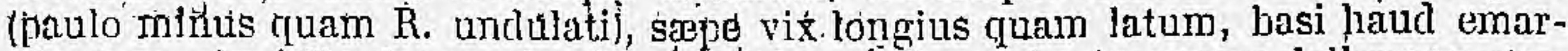
ginatum, alæ $\frac{1}{2}$ lin. latic vel apice paululum latiores, lasin versus deliquescentes, seminis facies subplanse fusce nitidœ late : ovato-elliptice vix ncuminatæ minute rugulosa . Cætera R, undulati. (vi. r. c. in horto Bdsil. ubi scmina jam m. jun. maturat, reliquis spec. præcocius.)

7. R. compa c т u (Linn. sp. p. 531), caule elato, petiolls, súlcatis supra planis, foliis subcoriaceis late oratis undulato-sublobatis cordatis obtusissimis glaberrimis licicilis rmargine subcartilagineo arguto denticnlatis renis grosse prorninentitibus, panicula ramis nutantibus, achreniis (ex Nees) magnis acutis atrofuscis. $\%$ In

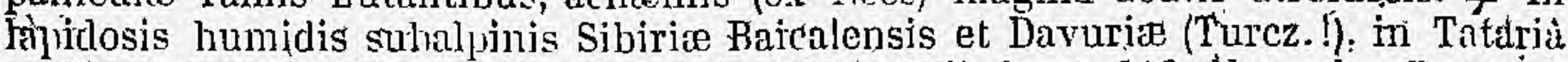
ot Chint (ex Willd.).-Poir. dicl. 6, p. 194*, Mill. ic. t. 218, Tees pl. off. surpi)l. t. 106, Hayne Arzneigew. 12, t. 9? Ledeb. fl. ross. 3, p. 497. R. nutans Pall. ex Georgi Beschrr. d. russ. Reiclis, 3 , 4, p. 948.? Caulis sulcatus. Folia crassiuscula, obsolete undutata rel jlana, 7-nerviá, norris crassis subtus parce pilosinsculis, esterioriłuzis basi confluentijus et a' limbo Jreviter denudatis marginalibus. Panirulir fructiferie rami erecti, pedicellorum articulo inferiore vix 1 lin. superiore 3. lin. longo fructum subrequante. Achænium sųborbiculare, basi cordatım, apice rotundatum yel leviter cmarginatum, alis semine plus dimidio angustioribus apice paruni dilatatis. (v. s. sp. iu li. DC. et Leded. et y. c.)

8. R. T ^ тA R I G u (Linn. fil. suppl. p. 229), caule humili aphyllo, petiolis abbreviatis semicrlindricis (ex Poir. angulato-sulcatis), foliis herbaceis orbicularibus levissime cordatis planis glaberrimis cartilagineo-dentieulatis crasse 3-nerriis, paniculie remis sulcatis demum divaricatis, pedicellis geminis supra medium articu-

- latis, achénio ovato-elliptico cortlató apice rotundato vel emarginato, alis seminc angustióribus sulsereniis. $\mathscr{Y}$ In Tatariâ minori (Willa.), in hossiâ australi ad Wolgam, cleserto Casılico et Soongoro-Kirghisico, Turcomanià, Sibirià Uralensi? èt Altaich.-Poir. dict. 6, p. 193, Ledeb.! fl. ross. 3, p. 497. R. Caspicum Pall. in nov. act. Icad. Pefropol. 10, p. 382. R. Rhejonticun Gmel. it. 2, p. 13; t: 198 . Folia suborbidularia, nònnunquam latiora quam longa, tenue herbacea, leviter undulata vel plana, utrinipue glaberrima vel margine et subtus in nervis veñisque grosse mominentibus-minute papilloso-scabriuscula, sinu baseos parum profundo. Pedicelli fructu longiores vel breviores. (v. s. sp. et c.)

9. R. TETRA ON OPUS (Mart. ind, sem. h. Monac. 1839), caule elato folioso, petiolis longiş subquadrangulis sulcatis supra plano-concavis, foliis deltoideo-ovatis basi subcucullatà breviter cuneatis 5-nerviis glabris vel subtus tenuiter puberulis superioribus, sessilibus, paniculis latiusculis, achænio orato-elliptico utrinque cordato vel apice enarginato, alis semine dimidio angustioribas apice vix dilatatis. \%. Yálria ignota. - Linnara 14, litt. p. 135. Speries petiolorum formá bene- distineta. (r. r. c.)

10. R. GRASSINERVIU (Fischer, ex Lindl. med..R. p. 950), caule elato folioso, petiolis subteretibus supra conravis subtus sulcatis, foliis late subdeltoideo-ovatis suberispatis subtus puberulis basi cucullal i breviter e'uneatis, nervis 5-7 crassissimis sulcatis lateralibus confluentibus marginantibus, paniculis densifloris, achenio ivato-elliptico cordato apice late emaryinato sublruncato, alis latitudinem semi-

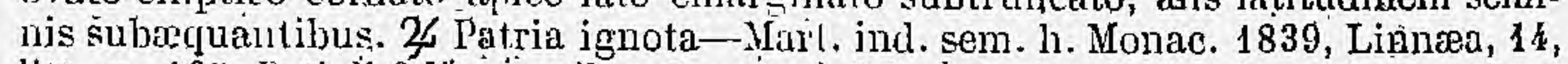
liı. p. 135. Pitioli folio inquilongi, suliquadrangulo-teretes, supra ajicem versus concavi, angulis obtusis, scetione tronsrersali sublunato-orbiculares. Folia summa l,reviter potiolata. ( $\mathrm{v}, \mathrm{r} \cdot \mathrm{r}$ )

11. R. So oN G OR I ti ฯ (Schrenk in Bullet. plyys.-math. Acad. Petersb. 2, p. 114), caule fere allhyllo ramosissimn, lutiolis subcylindricis, foliis reniformibus profunde eordalis a a ice rolumdatis levilus glabris, lobis baseos dilatatis petiolo contiguis, lurlicellis geminis florem salir puantibus supra medium articulatis; achronio alıguste alat.o. Z In salsuginosis versus $\mathrm{m}$. Alatau deserti Soongoro-Kirghisici Sibiria Nhaice (Schrenli). - Letel, n, ross. 3, p. 497.

19. R. . E U cor h z u м (Pall. in nov. act. Acud. Petrop. 10, p. 381), glabrum, caule humili aphyllo, petiolis abbrevialis depressis supra canaliculatis, foliis rigide coriaceis transverse ovalibus subrenj formibus vel suborbicularibus planis margine denticulatis passim papillnso-asperulis nervis 3 crassis prominentibut, paniculæ corym- 
biformis ramis suleatis demum divaricatis, pedicellis fructu multo breviopibus crassiusculis subcontinuis, sepalis 3 , interioribus demum auctis fruetu parum brevioribus, aclinnio suborbiculari cordato apice rotuudato, alis semine fatioribus. $\%$ In lapidosis et schistosis montium $\Lambda$ ltaicorum deserti Chinensis (Pallas l) et Soongoro-Kirghisici (Karelin ot Kiriloff, n. 1927l)-Poir. dict. 6, p. 196 *, Ledeb.! fl. alt. 2. p. $91^{\star}$, ic. fl. ross. alt. t. 491 , fl. ross. 3, p. 497. R. nanum sievers in Pall.Nou. nord. Beitr. 7, p. 264, 337. Radix longa, ramosa, allon (Pall: in sched.). Folia 5-14 poll. lata, 3-10 poll. longa, plerumque latiora quam longa. Panicula 1-2 poll. longa, racemis singulis $\frac{4}{2}$-vix 1 poll. longis compactis, fasciculis paucifloris, pedicellis imã ljasi obscurc articulatis, per anthesin brevissimis. Calyx herbaceus, sepalis 3 interioribus achunii facicbus adpressis et parum brevioribus ovalibus obtusis. Achæenii alke rosee, voni intramarginali percurste. (v. s. sp.)

13. R. Ri B es (Gronov. fl. orient. p. 130), caule elato folioso superne aphyllo, pètiolis semiteretibus supra subconcavis, foliis coriaceis subcordato-orbicnlaribus rèniformibusre subjplanis glabris vel subtus in neryis scabriusculis crassiuscule 5-nerviis margine minute denticulatis, paniculâ fastigiatâ̆, pedicellis infra medium articulátis flore majusculo multo longioribus fruotum subæquantibus, achænio magno ovato-oblongo cordato apice obtuso subintegro, alis semine dimidio angustioribus apjice rix dilatatis. $\%$ In Persia australi; ubi Rivas vocatur (Aucher Eloy 1 Kotschy, 11. 252, 586 !), m. Carmelo, Libano, prov. Aderbeidschan, Hindoo-Khoósh, (Labill.! Szovits !). - Ait. hort. Kew. 2, p. 42. Poir. dict. 6, p. $185^{*}$, Desf in Ann. Mus, 2, t. 94, Dill. Eltlı. 1. 191, t. 158, f. 199, Pocook Orient. p. 189, t. 84. Gaüles subsimplices sulcati. Petioli mediocres, margine obtusi, dorso sulcati. Folia $\frac{1}{2}-2$ ped. lata, 4-12 poll. longa, plana vel liviter crisjato-undulata, verruculoso-asjera, nervis subtus pajilloso-scabridis. Pedicclli fasciculati. Calyx $1 \frac{1}{2} \mathrm{lin}$. longus. Achæaia semipolicaria, 4-5 lin. lafa, sanguinea, carnoso-succulenta (arlstíngentia fide Polr.)., ajpice interdum émarginata, alæe ajjice basirue $1 \frac{1}{2}$ lin. Latr, medio paulo angustiores seminis facies planse. (v. s. sp.)

14. R. A USt RALE (D. Don prodr. 11. 'nepal. p. 75), caule humili verruculoso-scabro, petiolis gracilibus teretiusculis angulato-sulcatis scabris, folís suborbicularíbus sinu lato cordatis obtusis planis subtus margineque scabris, calycis lobis ovalioblongis apice cremulatis, achonio ovali cordato, apjice rotundato vel vix omarginato, alis coriaceis semine angustioribus tenerrime transverse striatis. $\mathcal{Z}$ In Nepdliả ad Gossainthan (Wall.) - Sweet Brit. fl. Gard. t. 269. R. Emodi Wall: list n. 1727 (ex partt), Proyle Ill. Himal, p. 317, Bot: mag. t. 3508 ? Radix fusiformis, ramosa, intus aumantiaca. Caulis aplyyllus, $1 \frac{1}{2}-2$-pedalis, petiolis 4 poll., folís 3-4 poll. longis, fore 3 poll. latis. Tota planta verrucis minutissimis cartilagineis scalorosa (Don): Caulis 6-10-ped. foliosus (Hook.). Caljx (ex pl. cultâ) purpureus, lobis integerrimis. - Paniculro racemiformes, stricta, longæ, fructiferse deñsæ. Achania juniora sanguinea, ovata, obtusa, basi vix cordata, alis angustis apicem versus haud dilatatis. - - Planta Doniana ohsi.ura, Sweetiana et Hookcriana forsan potius ad sccuenten referenda, sed hac verisimiliter non specifice distincta, (v. V. C.)

15. 11. Em ODt (Wall. I list n. 1727, ex parte), caule elato folioso, petiolis semitèretibus 'supra stlbconcatis margine obtusis, foliis herbaceis amplis ovatis obtusis cordatis subundulatis 5-7-nerviis subtus margineque minute pilosiusculis, smmmis sessilibus orato-oblongis; paniculd fastigiatà densiflorâ, jeticellis infra medium articulafis fructı plus dimidio hrevioribus, achrenio magne ovato-vel oblongo-ovali cordato ápice suboinarginato, alis semine longe acuminato diritidio angustioribus ajjice parum dilatatis. $\%$ In Emodo ad Gossáinthan et Kamaon (Wall. 1), Neetee (Webh), Tatariù usque ad Ladak, alt. 10,000=16,000 ped. (Ḿ̉oorcroft), Garwhal (Strachey et Winterbottom!) - Meisn. in Wall. pl. As. rar. 3, p. 65 (excl.? syn. Don). H. Emodium Wall. ex Nees et Ebermayer med-pharm. Bot. 1. p. 455. 11. Wobbianum Royle Ill. himal. p. 318, t. $78, a$. R. australe Hạyne Atrzn. gew. 12, t. 6 ? Nees pl: off: suppl. $5, t, 5,6$ ? Hec verisimiditer vera planta officinalis; rhizoma enim specininum a cl. Stracliey et Winterbottom lectorum egregie radicem Rhei oflicinarum redolet. Flores albidi, plante culta parvi, skjontanoe majusculi, pedicellos requantos. Achenla semipgllicaria. (v.s. sp. et. v. c.)

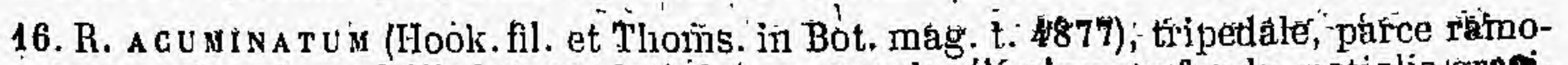
surn, puberulum, foliis late cordatis longe acuminatis sinu jurqundo, petiolis igraglibus pupra conosís subtus ramisque panieule sulcatis, granulatis, zpanicule;om- 
positæ ramis strictis erectis basi folio ovato parvo fultis, ealyce pedicellum gra cilem zequante majusculo sanguineo, lobis subæqualibus late oblongis, samarâ lóngiusculâ cordato-oblongâ apice, subemarginatâ, alis seminis latitudinem subæquantibus apice paulo latioribus. $\mathscr{\nvdash}$ In rupestribus et fruticosis subalpinis alpinisque Sikkim Himalayæ et Nepalixe orient., alt. 9-13,000 p. Radix gracilis seepe pluripedalis, intus aurantiaca spongiosa, parum odora et usui medico vix commendanda. Cáulis $2-3$ pedes nec ultra altus, sulcatus, purpurens, cum ramis petiolisque punctis crystallinis granulatus. Ochreæ longæ acuminatæ. Folia spithamæa, supra opaca, subtus puberula, crystallino-puneticulata. Panicula parce ramosa. Flores patentes diametro 3 lin., luride purpurei, sanguinei vel fusco-purpurei. Stamina ex ic. (procul dubio errore) sex. Stigmata depresso-capitata, obtusa, integra. Samara ut in R. Emodi, cui proxime affine, sed per sex annos in h. Kew. culta, characteribus indicatis, quamvis levibus, constanter distinctam se pro.. bavit.

17. R. Nов1LE (Hook. fil. et Thoms. Ill. Himal. pl. t. 19), caule simplici foliis bracteisque reflexis deorsum imbricatis dense tecto, foliis breve crasseque petiolatis integerrimis, radicalibus rosulatis ovato-oblongis obtusis basi cuneatis, caulinis orbicularibus repente transientibus in bracteas diaphano-mernbranaceas stramineas bullatas, paniculis brevibus ochreis magnis roseis inclusis, floribus 6-andris 2-4-gynis, achænio compresso vel 3-4-gono, 2-4-alato, lateribus tuberculatis. భ In rupibus abruptis regionis Sikkim, mont. Himalayæ orient., ailt. 13-15000 ped. Species pulchra, habitu maxime insignis. Radix elongato-fusiformis; rhizoma crassum breve, juxta caulem emortuum anni proteriti caulem emittens récentem erectum 3-5-pedalem, foliis bracteisque omnino velatum et columnam conicam - referentem. Folia radicalia magna, viridia, nitida. Ochrex foliis bracteisque deflexis omnino absconditæ, maximæ, roseæ, demum laceræ fuscescentes.'Bracteæ foliis caulinis conformes membranaceæe stramineæ nitidæ supra convexæ, superiores rubro-marginatæ. Paniculæ basi flabellato-ramosæe, Flores virides, pedicellati, sepalis 6 æqualibus oblongis obtusis. Ovarium breviter stipitatum. Styli 2-4, stigmatibùs eapitatis. Achænia pendula, atrofusca. Caules aciduli ab incolis Chuka voeantur et comeduntur.

\section{\$3. Racemi spiciformes, indivisi. Folia indivisa. Pedicelli fasciculati, infra medium articulati.}

18. R. Rнizos TAG Y U (Schrenk in Bull. Acad. S.-Petersb. 10, p. 254, et ej. enum. pl. nov. 2, p. 17), caule humili ? simplici aphyllo, foliis coriaceis suborbicularibus obtusis cordatis 5-9-nerviis subundulatis rugosis subtus, in venis cum petiolo caulo pedunculoque minute puberulis, racemo stricţo, pedicellis fructu brevioribus, achænio parvo suborbiculari utrinque rotundato vel basi emarginato, alis semine dimidio angustioribus basi èvanescentibus. $\%$ In Sibiriæ Altaicæ deserto Soongoro-Kirghisico (Schrenk) et in summis alpibus ad fl. Lepsa (Karel., et Kiril. n. 1929 !).- Ledeb.! fl. ross., p. 498. R. aplostachyum Karelin et Kíriloff enum. pl. Soong. in Bull. soc. imper. nat. Mosqu. 1842, p. 442. Folia circ. semipedalia et parum angustiora, valde rigida, petiolo limbum æquante subtereti supra plano? Racemus terminalis circ. semipedalis, interdum basi ramis paucis brevibus auctus, superne densiflorus, bracteis inferioribus remotis sterilibus. Flores rosei? Achænia (submatura) $2 \frac{1}{7}$ lin. longa et vix angustiora. (v. s. sp.).

19. R. Moorcroftianum (Wall. list sub n. 1727), subacaule, glabrum, petiolis bre vibus crassis supra planis subtus convexis lævibus, foliis rigide cormaceis late ovatis subrotundisque cordatis obtusis planis 7-nerviis dense reticulatis margine repando-subcrenatis, racemis folia subæquantibus densifloris, bracteis obsoletis, - pedicellis fructu multo brevioribus, achænio mediocri subrotundo-ovali vix emarginato, alis eveniis semine demum paulo latioribus. \& In m. Himalaya (Wall.), Tibet, alt. 14000 ped. (Strachey et Winterbottom 1).-Royle Inl. Himal. p. 318, sine diagn. Simillimum sequenti, sed ubique glabrum. Folia supra læete viridia, subtus inter venas sanguinea, nervo venisque supra immersis (nec insculptis), subtus leviter prominulis viridibus pulchre denseque reticulatis ; racemi simplices, pedunculati, aphylli, continui, pedicellis calycem æquantibus; achænia cruenta, utrinque rotundata vel vix emarginata. (v. s. sp. in herb..soc. linn. Lond.)

90. R. SpICIF on me (Royle Ill. Himal. p. 318, t. 78), caule subnullo, petiolis folio brevioribus canaliculatis dorso exsulcis pedunculisque glabris, foliis crasse coria- 
ceis late ovatis obtusis cordatis 5-nerviis utrinque stellato-pulescentibus subtus reticulatis, racemis folia æquantibus cylindricis compactis, pedicellis fructum subæquantibus, achænio mediocri ovato-elliptieo utrinque rotundato vel apice emarginato; alis semine lanceolato-oblongo latioribus. $\mathscr{Z}$ In Himalayæ borealis faucibus (Royle), in Garwhal, alt. 11,000 ped. (Strach. et Winterbottom!), Rhizoma crassum, luteo-fuscum. Petioli 1-2-pollicares, crassi, sectione transversali semiIunares. Folia 6-8 poll. longa, 5-6 poll. lata, plana, subtus rubra, nervis crassis, lateralibus basi confluentibus, venularum reticulo latiusculo subtus levissine prominulo supra, cum venis primariis insculpto. Racemi pedunculati, continui. Flores virescenti-albidi. Achænia magnit. et formâ fere R. undulati, 3-4 lin. longa, 3 lin. lata, rosea, sed alæs (eruentæ) látiores. (v. s. sp. in herb. soc. linn. Lond.)

\section{Species abscura.}

R. CR U E T U M (Sievers in Pall. Neu. Mord. Beitr. 7, p. 294). In Sibiriæ Altaicæ deserto Soongoro-Kirghisico (Sievers). Forsan idem ac R. leucorhizum, monente Lejob. fl. ross. 3, p. 498 .

\section{Species exclusce.}

R. DIGXNUM Wahl,$=$ Oxyria reniformis Hook.

R. Rhapontrcum Delarbr. = Rumex alpinus Linn.

XIII. OXYRIA Hill veget. syst: 10, p. 24, Campdera Rum. p. 153, t. 3, f. 3, Hook. $九$. scot. p.99, R. Brown in Ross voy. 'ed. 2, p. 192, Chlor. Melvill. p. 23, Meisn. in Wall. pl. As. rar. 3, p. 64, gen. p. 316 (228), Endl. gen. n. 1983, Nees jun. gen. R. germ. fasc. $8, t$. 10. - Donia $R$. Br. (non alior). - Acetosæ sp. Mill. - Lapathi sp. Lam. Rumicis sp. Linn. Gartn. fr. 2, p. 180, t.119, f. 2, Lam. ill. t. 271, f. 6. - Rhei sp. Wahlenb.

Flores hermaphroditi. Calyx herbaceus, 4-sepalus, sepalis 2 interioribus majoribus erectis demum achænio adpressis non auctis, exterioribus 2 reflexis. Stamina 6, æqualia, quorum 4 sepalis alterna et 2 interioribus anteposita, filamentis capillaribus, antheris versatilibus oblongis. Ovarium compressum, marginatum, ovulo basilari orthotropo. Stigmata 2, subsessifolia, penicillata. Achænium lenticulare, membranaceum, alâ latâ diaphanâ cinclum. Semen crectum compressum. Embryo in axi albuminis farinosi rectus, cotyledonibus ellipticis planis faciebus achænii angulos spectantibus, radiculâ superầ elongatâ. - Herbæ perennes humiles regionum alpinarum et arclicarum hemisphærii borealis, caule erecto subramoso paucifolio vel aphyllo, foliis subcarnosis reniformibus vel cordato-ovatis, omnibus petiolatis, ochreis parvis membranaceis oblique truncatis nudis, racemis laxiusculis, verticillis dimidiatis basi 1-bracteatis, pedicellis capillaribus infra medium articulatis, floribus virescentibus, achæniis demum sæpe sanguineis.

1. O. RENIFORM IS (Hook. fl. scot. p. 111), achænio basi cordato vel integro, alâ apice integrâ vel levissime incisâ. $\mathcal{Y}$ In Europæe Alpibus, Pyrenæis, Apennino, Carpatho, Gaucaso, Tauro (Kotschy !, n. $20 a, 151 b, 231 a$ ), Sibiriâ, Scandinaviâ, Scotiâ, Spitzberg, Groenlendià, Americâ aretiçâ usque ad White mountains New Hampshire, ins. Aleut., in Kamtschatkâ- Nert. et Koch Deutschl. fl. 2, p. 606, Cham. et Schl. in Linnæa, 3, 58, Ledeb.! fl. ross. 3, p. 498. Rumex digynus Linn. sp. ed. 2, p. 480 , fl. lapp. n. 132 , obs. $\beta$. Grertn. fr. 2 , t. 119 , Fl. dan. t. 14, Engl. bot. t. 910 , Svensk Bot. t. 692. Acetosa digyna Mill. dict. n. 4. Lapathum digynum Lam.fl. fr. 3, p. 6, Ill.t. 271, fig. 6. Oxyria digyna Campd. Rum. p. 155, t. 3, f. 3 . Schult. syst. 7, p. 1383 $^{\star}$. Rheum digynum Wahlenb. fl. lapp. p. 101, t. 9, f. 2. Donia sapida et digyna $\mathrm{R}$. Br. in Ross voy. ed. 1, p. 42. Oxyria acida $\mathrm{R}$. Br. ex Hook. et Arn. Brit. fl. ed. 6, p. 360. Variat staturâ digitali usque ad sesquipedalem, caule aphyllo vel basi paucifolio, racemis subsimplicibus vel paniculatis. (v. v.)

2. O. ELATIOR (R. Brown!. in Wall. list n. 1726), achenio utrinque cordato, ala apice basique usque ad semen incisà transverse venosâ. $\Varangle$ In Emodo Kamaonensi (Blinkworth !), in Himalaya et Kunawur (Royle) et Alp. Elamont. Persico ? (fide . specim. mane. Aucher Eloy, n. 5979). - Meisn. in Wall. pl. As, rar. 3 p. 64, Royle 
ع. Ill. Hìnfat p. 31\%, Hook. ic. t. 483. Caules nune 1-2-pollicares (Royle); nune (in [" hortis präecipue) 1-3-pedales paucifolii. Omnes partes paulo majores quam præ1. cedentis. Folia radicalia suborbicularia profunde cordata, usque ad 3-4 poll. longa, a. nervis gradiantibus, petiolo gracili usque ad pedem longo. Panicula $\left.\frac{1}{2}-1-1\right)$ edalis, zrracemis erectis subadpressis continuis, fructiferis densis. Pedicelli achanio sublongiores. Achænium 2-2 $\div$ lin. longum, alis obsolete venusis. (v. s. sp. et v. c.)

XIV. OXYGONUM, Burchell travels 1, p. 548, Lindl. nat. syst. Bd. 2, p. 443, Endl. gen. n. 1988, suppl. 4, 2, p. 50, Meisn. in Linnoxd, 14, p. 487, gen. p. 317 (229).

Flores hermaphroditi (ex Burch. monoicí, or $4-f i d i)$. Calyx infundibuliformis, tubo brevi ovoideo supra ovarium constricio, limbo corollino 5-parlito patulo, lobis æqualibus oblingis acutis marcescentibus. Stamina 8 , fauci inserta, æqualia, exserta, 5 calycis lobis alterna, 3 eorum in terioribus anteposita ; filamenta filiformia, basi dilatatà contigua : antheræ versatiles, ovales, utringue emarginatæ. Ovarium triquetrum, liberum, ovulo erecto. Styli : $:$, breves, filiformes, exserii. basi connati ; stigmala capitata integra. Achænium calyce inclusum, oblongum. angulis membranaceis 3 -alatum (Burch.) vel suborbiculare, utrinque emarginatum, faciebus planis vel dente lineâ transversali in alam excurrente præditis, alis semine fatioribus integerrimis vel medio apicalatis (Sonder). Semen ereclum, turbinato-tricjuetrum, funiculo brevissimo. Embryo in albumine farinososubaxilis, rectus, colyledonibus foliaceis obovatis planis, radiculâ superâ conicâ. - Herbæa annuæ? vel pereunes Africæ austıalis interioris, habitu Polygoni, ochreis membranaceis cylindrico-tubulosis ore horizontaliter truncato selaceo-ciliatis, foliis leebaceis pinnatifidis integirisve. racemis terminalibus et ? axillaribus spiciformibus solitariis simplicibus aphyllis, bracteis ochreiformibus distantibus 1-plurifloris, pedicellis apice articulalis.

1. O. GAL G A R A T U (Burch. !.1. c. et pl. Afr. austr. extratrop. n, 2459 !), glabrum, glaucescens?, foliis linearibus acufis integris vel passim dente brevi infra'medium - auctis, pediçellis fasciculatis bracteam vix superantibus. (1)? In Africà àustrali

- interiori. Rami subangulato-sulcati. Ochreæe breves (2-3 lin. longæx, minute glanduloso-punctátse, demum imberbes. Folia $\frac{1}{2}-1$ poll. longa, $\frac{1}{2}-1$ lin- lata Flores vix majores quam Polygoni avicularis. (v. s. sp. mancum in h. DC.)

9. O. DR E G I, glaberrimum, caulc érecto vel adscendente liaud nodesó, folìis lanceo$\because$ lato-oblongis acutiusculis integerrimis attenualo-petiolatis, junioribus mucronu-

$\therefore$ latis, racemis elongatis interruptis, bracteis non ciliatis eglandulosis. (1) In gra-

$\therefore$ minosis et arenosis Caffraria (Drège!) et Sandrivier (Z@yher n. 1451), Port Natal.

- (Krauss, n. 283 !). 0. Dregeanum Meisn. in Linnaci 14, p. $487^{*}$, et in Hook. Lond.

journ. 2, p. 45 L. 0, alatum $\beta$ Dregenum, Sonder in Linnuxed 23, p. 98 (v. s.).

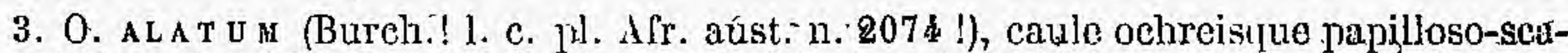
briusculis, foliis lanceolatis dentatis vel inciso-pinnatifidis, racemis elongatis apice continuis, pedicellis fasciculatis glandulosis bracteá subduplo longioribus. (1) In Caffrarlà.-Lindl. nat. syst. edit. 2, p. 4.43, Sonder in Linnoca 23, p. 98* lex́cl. var. a): A præcedente proter folia differt pédicellis longioríbus, 3-5 lin. longis: Folia

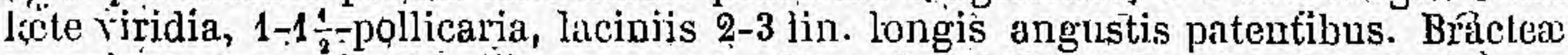
superiores approximate. Flores patentes diam. fere 3 lin. Achsenium late 3-alatum, alis međio apiculatis, fariębus inęlio dente anctis. ( $\mathrm{s}$ s. sp. mancum in li. DC.)

4. O. ZE Х E R I (Sonder in Linneà 23, p. 100*), glabrum, caule basi suffruticoso$\therefore$ erecto tereti, ramis angulatis, foliis 3 -fidis vel pinnatifidis, laciniis linearibus mucro-

- nadis-integerrimis vel subdenlatis, racemis interrup tis, pedicellis solitariis eglandulosis. 26 In Caffrariæe monte Makalisberg (Zeýlıer n. 1451.b.). Ochrese 3-4 lín., cíliis $1 \frac{1}{2}-2$ lin. longis. Folia jollicaria, pleraque 3-fida, lacinís rhachique $\frac{1}{2}-1$ lin. latis. Racemi 2-4 poll. pedicelli 2-3 lin. tongi, glabri vel puberuli. Flores.lutescentes. Achienium ignotum.

5. O. OAN ESCENS (Sonder l. c. p. 100*), pilis brevissimis reversis canescens, caule basi suffrutescente erecto teretiusculo, ramis angulatis, foliis pinnatifidis vel sub-

- $\because$ jipinnotifidis, laciniis subdentatis setâ terminatis, racomís interruptis, pedicollis

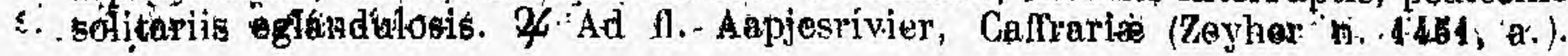


Ochrearum dentes virides, setâ disculóri terminati. Racemi 2-3-pull. Ciustera, exceptâ pubescentiâ, 0 . Zeylịeri, cujus forsan mera varietaș.

Tribus II. APTERQCARPAL, Meisn. in Mart. fl. bras, fasc. 14 , Polyg. p. 5.

Achænium calyce sicco et plus minus aucto vel mutato inclasum (rarius exsertum, cfr. Polygoni sp. et Fagopyrum), liberum, lenticulare vel triquetrum, angulis obtusis acutisve apteris (rarissime in alam coriaceain, nec membranaceam, productis, cfr. Fagopyrum). Embryo lateralis vel rarịus axilis. Stamina definita.

\section{Suburibus I, OERATOGONEAE.}

Flores polygamo-monoici Masc. Calyx herbaceus vel corollinus, 5-6-partitus, lobis subæqualibus. Stanina -4-6-8. Fem. Calyx alte gamo'sepalus, sepaliș 3 exterioribus in tubumm triquetrum apice 3 -dentatum connatis, apice vel ex medio angulo in cornu vel spinam productis, interioribus 2 ? vel 3 minoribus fauci insertis petaloideis marcescentibus patulis vel 3 herbaceis conniventibus. A chænium calycis tubo indurato inclusum. - Herbæ hạbitu Polygoni vel Rumicis.

XV. GERATOGONUN Meisn. in Wallich pl. As. rar. $3, p .63$, gen. p. 317 (220), Endi. gen n. 1991. - Oweñia Hilsenb. mss. - Tulygun sp. Wall., Bojer..

Hores polygamo-monoici, ơ et $ᄋ$ ? vel $\gamma$ ex eadem bracten̂. Mase. Calyx corollinus, profunde 5-partilus, lobis æqualibus oblusis planis. Stamina 8, filamentís subulatis, antheris ovalibus medio dorso affixis versatilibus. Fem. Calyx biseriatim 5 ?-vel 6-sepalus, sepalis 3 exteriovibus coriaceo-berbaceis connatis in tubum triquetrum utrinque attenualum apice 3 -dentatum demum açcrescéntem, angulis carinatis medio processu spiniformi recto patentissimo armatis; sepalis 3 vel 2 ? interioribus fanci angusiæ insertis, dentíbus alternis, petaloideis oblongis abtusis marcescentibus (sepalis fl. masc. similibus). Stamina 8 vel-6.? Qvarium trigonum, ovulo erecto. Styli.... Achænium calycis tubo inclusum et conforme, paulo brevius. Semen basilare, ereclum, achænio conforme, angulorim dente brevi obtuso, integumento membranaceo. Embryo in axi albuminis farinosi rectus, colyledonibus foliaceis ovalibus planis 3-nerviis álbumen in duas partes secantibuss, radiculà clongatâ superâ. - IJcỉbæ annuæ Africæ orientalis tropicæ, caulibus ramosis erectis vel adscendentibtis, ochreis membranaceis cylindrico-tubulosis infra apicem folitgeris ore horjzonValiter truncalo setaceo-cilialis, foliis herbaceis petiolatis pinnatifidis integrisve, racemis spiciformibus terminalibus solitariis indivisis aphyllis, bracteis ochreiformibus plurifloris, pedicellis exsertis apice cum Gore articulatis, floribus nutantibus, fructibus pendulis.

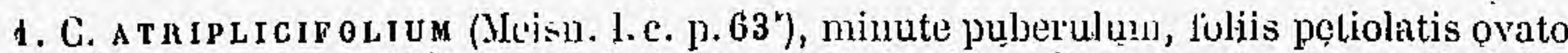
vel angulato-deltoidéis lanceolatisque acutis luasi breviter cınoatı-attenuatis integerrimis vel minute tindulato erenulatis, ochrearum sctis lubum dequantibus, raeemis clongatis, bracteis longe distantibus 3-2-ftoris ciliatis pelicellos dimidios iequántibus. $\mathcal{F}$ ? In Africie tropicie ora australi-orientali. Polygonum atriphicifolium Wall.! list-n. 1719. P. Ofienii Bojer in Ann. sc. nat. 2o sér. 4, p. 267, t. 9, Meisi. ibid. 7, p. 288, Boj. in $7^{\circ}$ rapport soc: île Maurice, p. 37. (r. s. เ. ex fiorto Calcutt.)

2. C. Condof anu , glabrum, foliis subsessilibus uratis acutis bási longe ciuneatoattenuatis sinuato-lobatis passinque integris margine planis, ochrearum setis debilibus tủbo triplo brevioribus, racemis elongatis, bracteis longe distantibus 3-6-fioris demum pedicellos dimidios cequantibus. (1) In umbroșis humidis montis Arasch Cool, Cordofan (Kotschy I). C. atriplicifolium Hochstett! ! in Katsschy 
pi. Nub. exsicc. n. 117). Præter notas jam indicatas a præcédente differt pedicellis fructiferis crassioríbus, calyce demum paulo májore, limbi lobis longioribus omnibusque petaloideis erectis, tubi faciebus supra el infra medium foveolâ impressis. Folía $1-2 \frac{1}{2}$ poll. longa, $\frac{1}{2}-1$ poll. lata, utrinque sinu unico lato vel rarius duobus excisa, lobis sünubusque 3 lin. latis rọtundatis, petiolo ad basin usque limba de. currente alato. Oehrearum cilia tenerrima 1-1 $\frac{1}{2}$ lin. longa, basi dilatata. Calycis fructiferi tubus 4 lin., limbus $1 \frac{1}{2}$ lin. longus. Forsan var.-sequentis. (v. s.)

3. G. sinu a T M (Hochstett. et Steudel in Schimp. pl. Abyss. exsicc. sect. 1, n. 264!) humile, puberulum, foliis' attenuato-subpetiolatis ovatis acutis profunde pinnatifidis, hobis sinubusque obtusís, ochrearum ciliis debilibus tubo triplo brevioribus, racemis abbreviatis, bracteis contiguis vel infimis distantibus pedicellos fructiferos subæquantibus. (1) In Abyssinixe regione Mernsach, ubi Chachito vocatur. (Schimper !). G. atriplicifolium A. Richard, voy: Abyssin. 5, p. 231. Foliorum lobi ovati vel oblique triangulares, margine subundulati. Folia, monente Rich, l, c., variabilia, interdum in eodem specimine passim indivisa. (v. s.)

XVI. EMEX Necker elem. 2. p. 214, Campdera Rum.p. 56, t. 1, fig. 1, Endl. gen. n. 1992, suppl. 4, 2, p. 51, Meisn. gen. p. 317 (228). - Vibo Monch Meth. p. 318. - Centropodium Burchell trav. 1, p. 340, Lindl. nat. syst. ed. 2, p. 442. - Podocentrum Burchell mss. in herb. DC. - Rumex spinosus Linn. sp. p. 481, Gartn. fr. 2, $p .180$, t. 119, Mirb. in Ann, Mus. 13, t. 4, f. 44.

Flores polygamo-monoici. Masc. Calyx herbaceus, 5-6-partitus, lobis æqualibus patentibus. Stamina $4-6$, sepalis alterna, filamentis brevilus, antheris basifixis oblongis utrinque emarginatis. Fem. Calyx herbaceús trigonoinfundibuliformis, 6-fidus, demum auclus et induratus, dentibus 3 exterioribus tubi angulos terminantibus spinescentibus subrecurvo-patentibus, interioribus 3 minoribus planis erecto-conniventibus, tubo turbinato-triquetro lacunoso-vel foveato-nérvoso incrassato. Ovarium subtriquetrum, ovilo basilari erecto.. Styli 3 breves erectiusculi, stigmatibus penicillatis. Achæníum calycis tubo inclusum, liberum, subtriquetrum. Semen erectum turbinatotriquetrum. Embryo albumini farinoso circumpositus, cotyledonibus foliaceis elliptico-oblongis, radículâ. superâ exsertâ. Herbæ Europæ Africæque australis et Australiæ, humiles, flexuoso et subdichotomo-ramosæ, ochreis membranaceis truncatis eciliatis mox laceris, foliis sparsis herbaceis petiolatis deltoideo-ovatis integerrimis, floribus virescentibus axillaribus aggregatis pseudoverticillatis vel sæpe in racemos axillares breves aphyllos basi femineos superne masculos dispositis.

1. E. Spinosi (Campd.! Rum. p. 58, excl. $\beta$ t. 1 , fig. 1), calycis fructiferi dentibus interioribus lanceolatis acutis muticis, exterioribus spinescentibus sæpe arcuato-subrecurvis, foliis ovato-deltoideis hasi truncatis - vel subcordatis: (1) In totâ Europâ australiớri, præesertim in arenosis littoris mediterranei, in ins. Canariensibus, Barbariâ, Aggypto, Syriâ, Persiâ, Asiâ minore, jam quoque (immigrata) in Brasiliâ. - Schult. fil. syst. veg. 7, p. 1476, excl. $\beta$. Rumex spinosus Linn. sp. p. 481, DC. Lam. ill. t. 271, fig. 4, Gærtn. fr. 2, t. 119, Sibth. et Smith fl. Græc. t. 347. R. glaber Forsk. fl. AEg. Arab. p. 75). Vibo spinosa Mcench Meth. p. 318. Caules sæepe pedales et ultra, demum defóliati et spicam longe ínterruptam simulantes, verticillis $2-3$ poll. distantibus. Fructus infimi demum valde incrassati, calyce quasi suberoso-costato. (v. s. sp. et v. c.)

2. E. GENTn Op OD IUM (Meisn. in Linnæâ, 14, p.490) calycis fructiferi dentibus interioribus late ovato-triangularibus mucronato-acuminatis, exterioribus spiniformibus rectis patulis, foliis ovatis basi plus minus cuneato-attenuatis. (1) In Africâ australi (Thuób., Drège I Krauss n. 784 ! etc.), Novâ-Hollandiá occid.-merid. (Drumm. n. 290 ! Preiss n. 1895), Melbourne (Mull. mss.) et introdùcta ? in Indiâ orient. (teste Steinheil), Rumex spinosus Thunb, prodr. p. 67, Fl. cap, p. 341. Emex spinosa 3 Capensis Campd.1.c. p. 59; Schult. syst. 7, p. 1476. Centropodium Burchell! trav.1, p. 340. Podocentrum Rurch.pl. exs. Afr. n. 2877! Emex australis Steinheil in Ann. sc: nat., 2. sér. 9, p. 195, t. 7, fig. 16, Niquel in pli. Preiss, 1, p. 625. conf. Mẹisu. ib. \&, p. 273. Folia plerumque minora quan precedentis. (v. s.) 
Subtribus II. RUMICEAE C.-A. Meyer in Mém. Acad. S.-Pétersb. 6, p. 143, excl. gen. Emex, Oxyria et Rheum.

Calyx herbaceus vel corollinus, profunde 4-5-6-partitus, lobis interioribus erectis demum plus minus auctis et mutatis conniventibus fructum includentibus (valvae vocatis) coriaceis vel scarioso-membranaceis reticulatis margine sæe dentatis vel spinulosis, exterioribus minoribus plerumque vix auctis reflexis. Stamina 6 vel-8. Styli $2-3$ breves vel subnulli, stigmatibus penicillatis vel capitatis. Achænium lenticulare vel triquetrum, apterum. Embryo lateralis vel rarius axilis. - Herbæ vel frutices, habitu vario. Flores hermaphroditi vel diclines, sæpius polygami, plerumque fasciculati vel pseudo-verticillati, pedicellis articulatis.

XVII. RUMEX Linn.gen. 357, Schkuhr Handb. 1, p. 310, t. 100, Gartn.fr. 2, p. 178, t.119, Lam.ill.t. 271 (excl: fig. \& et 6), Campdera Monogr. du genre Rumex, Paris, 1819, A. Saint-Hilaire in Mém. Mus. 2, $t$. 4, Mirbel in Ann.Mus. 13, t. 4, Wall. sched. crit. 1, p. 154, Meisn. Polyg. prodr. t. 1, fig. 1, t. 2, f. E., gen. pl. vasc. 317 (228) et in Mart. f. bras. fasc. 14, Polyg. 7, Endl. gen. n. 1993, suppl. 4. 2, p. 51, Nees jun. gen. Al. Germ. fasc. 2, p. 2, t. 54.- - Acetosa et Lapathum Tourn. inst. p. 502, 504, t. 287.— Lapathum Adans. fam. 2, p. 277.

Flores hermaphrodili vel abortu diclines polygami vel dioici. Calyx herbáceus, profunde 6-partitus (ralissime 4-partitus; cfr. R. comosus), lobis biserialibus imbricatis, cujusque seriei inter se æqualibus (vel demum subæqualibus), exterioribus tribus in flore femineo saltem minoribus patentibus vel reflexis haud accrescentibus, interioribus (petalis auct. nonnull.) tribus (vel rarissime 2) patulis vel ereclis accrescentibus vel marcescentibus super fructum conniventibus etunque sæpius samaræformem reddentibus vel sibi invicem applicatis demum vel coriaceis induratis vel subdiaphano-membranaceis (valva dictis) plus minus venoso-reticulatis margine integerrimis vel dentatis vel spinulosis, unius vel plurium nervo medio inferne sæpius plus minus incrassato tuberculum subgtobosum vel oblongum (callum vel granum vel glandulam atict.) formante. Stamina 6 , imo calyci inserta ejusque lobis alterna (quasi lobis exterioribus geminatim opposita), filamentis brevissimis, antheris basifixis erectis oblongis. Ovarium trigonum, ovulo basilari orthotropo. Styli 3 capillares, brevissimi, liberi, decidui vel ovarii angulis adnati, stigmatibus penicillato-multifidis. Achænium calycis lobis interioribus auctis (valvis) reclusum, liberum, ovato-pyramidale, triquetrum, crustaceum, 1-loculare, læve, nitidum, fuscum. Semen achænio conforme, erectum, subsessile, testâ tenui membranaceâ. Embryo lateralis, albuminis angulo accumbens vel semi-immersus, arcualıs, antitropus, colyledonibus foliaceis, radiculâ superâ elongatâ. - Herbæ, rarius frútices, rarissime arbores, totius orbis præcipue regionum temperatarum incolæ, sæpe succulentæ, succo oxalico-acido rarius subinsipido scatentes, radicibus fibrosis vel rarius tuberosis, caulibus sæpe fistulosis sulcatis, ochreis tenue membranaceis diaphanis cylindraceis oblique truncatis nunquam ciliatis infra medium foliigeris cito laceris vel deciduis, foliis sparsis herbaceis vel subcarnosis (nunquam coriaceis) subrotundo-ovatis vel ovalibus oblongis lanceolatisve nonnunquam cordatis vel hastatis rarissime pinnatifidis, infimis petiolatis, summis sæpius sessilibus, floribus parvis virescentibus vel flavescentibus fasciculatis verticillos spurios vel dimidiatos formantibus, vertícillis ochreâ communi folioque fultis vel aphyllis in racemos continuos vel interruptos dispositis, racemis simplicibus vel paniculato-ramosis, lateralibus sæpe fasciculatis, pedicellis singulis ochrea minuta fultis capillaribus prope basin (carius medio vel supra) nodulosoarticulatis nonnunquam demum incrassatis indaratisque, calycibus fructiferis caulibusque (rarius etiam foliorum venis) nonnunquam sanguineis. 


\section{Sectio I. Lapa'THum.}

Flores hermaphroditi vel passim unisexualibus mixli. sipala interiora (valvæ) demum plus minus aucta et coriaceo-membranacea, haud vel vix diaphana plus minus elevato-reticulata, nervo medio-ad medium usque vel uịtra in callum ovalemm vel subglobosum (nutnquam deflexum) tumente vel rarius hudo, marginibus integris vel dentatis vel spinulosis. - Herba annwe vel biennes vel perennes, insípidx vel adstringentes, parius acfdæe, foliis-indivisis,-intimis basi rotundatis vel cordatis (nee unquan hastatis) vel rarius attenuatis, summis lnceolațis linearibusve, norvis pinnatis.

\section{1. Valve integerrima, rarius basin versus obsolete eroso- vel undulato-dentatce.}

A. Valva omnes callo destituta, raro obsoletissime calliferce (sp. 8, 9, 11).

1. h. LATrPoliós (Humb.! mss, in h. Willd. n. 7028), caule crasso fistulosó; ochreis maximis, folís (caulinis) breve petiolatis ovatis subacuminatis planis Dasi rotundatis margine recurro undulato-crenatis, supra glabris, subtus ininute puberulis conferte penniveniis, racemis paniculatis aphyllis folio brevioribus, yerticillis subeonfluentibus dense multifloris, pedicellis calyce 2-3-plo Iongioribus, calycis magni lobís ovatis obtusis, interioribus duplo majorlbus penniveniis integerrimis ecallosis. $\angle$ Circe Santa Fé de Bogota. - Cham. et Sclil. in Linnoxâ 3, p. 61, Scbult. fil. sist. 7, p: 1474. R. olatior flor. dioicis, Bonpl. mss. in herb. Kunth 1 Species a Kinnthio in Nov. gen. ef Synopsi neglecta, non satis nota, certe distinctissima. Caulis diam. pollicaris. Folia fi-8 poll. longa, 4-6 poll. lata, petiolo subpollicari, Raceni terminales et axillares, subsessiles, simplices, verticillis indiștinctis, pedicellis capillaribus proje basin articulatis. Flores fide Schult: l, c. hermaphrqditi et valvæ graniferæ, sed ex pistillo minuto potius diclines ( (quales in sched. dicuntur) et valvice penitus egallosie nobis videntur. Sepala interiora 2 lin. longa,-penninervia, nee reticulata. (v. s. jun. in h. reg. Berolín.)

2. R. T o L IMENSiś (Weddell in Ann. sc. nat. $3^{\circ}$ sér. 13, p. 262) caúte ereclo crassu striato glahro, follis radicalibus petiolatis oblongo-lanceolatis cordatis acutiusculis margine subrevolutó undulatis supra glabris subtus puberulis, caulinis ovatis acutis basi rotundatis vel subcórdatis margine undulato- denticulatis, ochreis petiolo multo longioribus, racemis paniculatis, pedicellis superne incrassatis, valvis olovatis integerrimis nudis. Z In monte Tolima reipub. Novo-Granatensis (Goudot in h. Mus. paris.). Folia radicalia $\frac{4}{2}$-pedem longa. Racemi axilJares et terminales.

3. R. MAR I C OA (Remy in Gay, Hist. de Cliile, 5, p. 281 ), glaberrimus, caule adseendente, foliis petiolatis oblongo-obovalilus rel spathulatis margine crispatulis oblusis vel rarius subacutis, ochreis internodia suhæequantibus magnis, racemis 1-3 terminalibus spiciformibus compactis aphyllis. $\%$ In humidis et maritimis prov. Chilensium San Carlos et Chiloe. Radix repens. Caulis subflexuosus, 2-12-pollicaris vel ultra, ochreis amplis fere tectus. Folia subcrassa, excluso petiolo $1-3$ poll. longa, 4-18 lik. lata, integra, demum margine chispa: Flor. dioici. Calycis lobi rubescentes, ovali-oblongi, integri, ecallosi. Stigmata 3, crassa, penicillata.

4. R. AL PINUS (Lim. sp. 1, p. 480), foliis ovališ coratis obtusis vel breve acuminatis planis vel subundulatis, infimis nıximis suborbiculari-ovatís, petiolo canaliculato, paniculâ subaphyllâ, racemis fasciculatis sessilibus laxifforis basi interruptis fructiferis densis, pedicellis calyce longioribus, floribus polygamis, valvis majusculis tenue membranaceis late triangulari-ovatis cordatis obtuse acuminatis subintegerrimis tenuiter reticulatis ecallosis. $\not 4$. In solo pingui circa casas pastorum in alpinis et subal pinis Europis a Lapponiâ ad Calabriam.-Campd. Rum., p. 66 et $105^{\star}$, t. 2, Blackwell her], t. 262, LKorner t. 203, Hajne Arzneigew. 13, t. 7, Mert. et Koch Deutschl. fl. 2, p. $617^{*}$, Schult. fil. syst. 7, p. $1440^{*}$. Lapathum aljpinum Lam. fl. fr. 3, p. 7. Acetosa alpina Mœench Meth. p. 357. Rheum Rhàponticum Delarbr. f]. Auvergn. ed. 2, p. 527 (non Linn.). (v. v.)

5. R. AQU a t ICUS (Linn. Sp. 1, p. 479), foliis acutis planis, infimis late ovalis yel ovatob́longis basi latâ leviter cordatis, superioribus oblongis basi obtusisis vel subatte- 
nuatis, summis lanccolatis, potiolo supris contracto-canaliculato, janiculà laxiusculâ, vorticillis domurn indistinctis, valvis mediocribus late triangulari-ovatis obtusis leviter cordatis tenuitur reticulatis subintegerrimis ecallosis. 26 Ad fossas ripasque Europé medir: et horealis passim, in Inerià articà (Beechey) et Syria (Ehronberg), Sibirià. - Wallr, sched, crit. p. 176, Mert. el Koch! Deutschl. fl. 2, j. 617*, Ledeh. 11. ross. 3, 1'. 508, Ductiartre, Revuc bot. 1846 , p. 350 , Blackwell

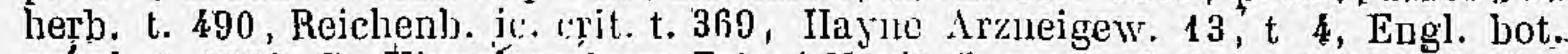
suppl. t. 2698. R. Hippolapallum Fries! Novit. 11. suec. ed. 2, p. 106 . R. latifolius G. F. W. Mey. Chlor. Hanuor. p. 478 (erel. syn. PoIl.). R. Heleolapathum Drejer I mss. in h. reg. Berol. Fl. duj. t.'2288, De Bruyn in Nederl, Kruydl. Arch, 1, p. 555. R. Caldejrurum Watson! in T. C. Hunt! pl. Azor. exsice. n. 216 , R, undulatus Besser mss.? (fide sp. jum. in h. DC.). Sub nom. R. aquatici L., Campdera 1. c. p. 100 cvidenler commiscuit R. HJarolapallsum Huds., R. aquaticum L. et verisimiliter etiam R. maximum Schreb. Gfr. Schult, fil. syst. 7, p. 1428, obs. 8 . (v. x. et, s.)

6. R. GM ELIN (Turcz.! cat. Baieal. n. 986), foliis glaucis scabriusculis obtusis sulyundulatis, inferioribus subtriangulari-ovatis profunde cordatis lobis rotundatis, superioribus ovatis ohlongisfuo hasi ol,tusis rel corlatis, summis sublanceolatis, paniculâ sul)apliflat, racemis latiusculis, jedicollis fore longioxibus, valvis majusculis ovalo-ellipticis utrinque rotumdatis integerrimis ecallosis. 24 In humidis et subalpinis Sibirice Baicalensis et Datruriæe. - Gńnel. Sil. 3, p. 112, n. 90, fide Tur'ez, Lerleb, t]. ross. 3, j.“508, sjuecies non satis nota, R. acquatico et alpino nimis aflinis, ab utraque lu'ircipue loliis glaucis distincta. (r. sp. jun. in h. DC.).

7. R. A r trieus (Trautv. in Mittendorfi Reise 1, 2, p. 8, 14, 29, 446, 155), caule simplici, foliis oblongis breviter crispis, radicalibus obtusiusculis basi rotundatis vel subcordatis, caulinis acutiusculis in petiolum angustalis, racemo terminali simplici vol basi semel composito apshyllo aut basi 1-2-folio, verticillis remotissimis, pedicellis apjec incrassatis, floriljus polygamis pendulis, valvis integerrimis oblongis demum ovatis obtusis ecallosis. 24 . In Sibiria arctica ad fl. Taimyr et Boganida. - Walp. Ann. Jot. 1, p. 552, Ledeb. A. ross. 3, p. 506. Radix repentis. Calycis infundibuliformis lobi interiores subaquales, primo ellípticooblongi apice rotundali, demum ovati obtüsiusculi.

8. R. ANGUStrolivs (Campd. Rum. p. 63 et $73^{*}$, t. 1, f. 2), glaberrimus, caule simplici, folis lanceolatis acutis sulwevuiis, summis linearibus, racemo terminali simplici, verticillis diseretis 5-8-[loris summis aphy]lis, inferioribus remotis, pedicullis demum crassiusculis nutantibus caljec fructifero magno duplo brevioribus, valvis inxifualibus obtusis integerrimis ecallosis, unà late ovata subcordatâ laxe reticulatâ nervo losi tumiclulo, relitpuis dimidio angustioribus. $\mathcal{H}$ In Oriente. (Tourn.), Armeniâ, (Koch, in Linnìa, 22, p. 212), in Caucasi monte Arekligeduk prov. Karabagh (Szovits !) - Schutt. fil. syst. 7, 1). 1385*, Ledeb.! fl. ross. 3 , p. 499. Species insignis. Caulis $6-10$-pollicaris, simplicissimus, gracilis, læcvis, paucifolius, a medio norifer: Ochreir deciduce. Folia plam, utrinque attenuata, infima cum petiolo $1 \div$ pollicari 3 poll. longa, 2-6 lin. lata, summa semi-polticaria vix lineam lata, internodia Doralia inguantia. Pedicelli $9-2 \frac{1}{3}$ lin. longi, infra medium articulati. Cal $\times \mathrm{x}$ junior sanguineus, fructifer pallidior subcoriaceus, yalvâ majore 5 lin. lọngà et basi í cquilatâ, sæepius obsolele obtuserue acuminatâ, nervo inferne callum tenucm linearem mentiente. (v. s.)

9. R. venosus (Pursh fl. bor. Am. 2, p. 732), caule ramoso, foliis petiolatis, íufimis...., caulinis ovato-lanceolalis oblongisve acutis basi attenuatis, paniculâ apliyllà, racemis solitariis simplicibus pedunculatis potulis, fasciculis $\mathbf{3 - 8}$-floris, floribus hermaphroditis, pelicellis capillaribus valvam æquantibus, valvis aqualibus maximis orbicularibus profunde corratis integerrimis dense nervoso-reticulatis ccallosis. $\mathcal{Y}$ In Louisianà superiore ad 11 . Missouri et in Amer. bor. occidentali ad 11. Colombiam, etc. - Canpd. Rum. p. 131, t. 2, f. 7, Nutt: gen. 1, p. 240, Schult. fil.syst. 7, p. 1\$63**, Hool. 11. bor. Am. 2, p. 130, t. 174. Caulis vix pedalie. Folia crassa, plana, glabra, parva (ex Pursh), 3-4-potlicaria (ex ic. Hook.). Pedicelli prope hasin articulatí. Varve 8-10 lin. longæ lateque; apice scepiús subtruncate vel leviter emarginatce, rigidulo-nembranace $e$, nervo basi jassim tumidulo, rotioulo jrominulo, sepalis exferigribus dellexis sinu valvar.um angusto dimidio hrevipribus. (v. s. in h. Mart. lact. a sereniss. prind. Neuwied!) 
10. R. oxysepal, Us (Meisn. in pi. Preiss. 1, p. $625^{*}$ ), caule ramoso, foliis radicalibus....., caulinis lanceolatis undulato-crenulatis basi obtu'sis, inferioribus longe petiolatis, summis linearibus, racemis terminalibus et axillaribus simplicibus, verticillis distantibus 2-4-floris, superioribus aphyllis, pedicellis calycem parvum subaquantibus, sepalis (junioribus) anguste lanceolatis apice uncinato-incurvoacutis, interioribus ab exterioribus superatis integerrimis ecallosis. $\mathcal{F}$ ? In Australiâ meridionali-occidentali (Preiss n. $1357 !$ ). Species non satís nota, forsan nil nisi status junior Rumicis Drummondî, cfr. p. 61. (v. s.).

11. R. LONGIFOLIUS (DC.! fl. fr. 0 , p. $368^{*}$ ), foliis elongatis acutis undulatis, infimis e basi subcordatâ vel obtusâ oblongis, superioribus lanceolatis utrinque attenuatis, summis linearibus, petiolis supra planis lineâ tenui marginatis, paniculâ simplici superne aphyllâ, racemis sessilibus, valvis mediocribus late ovatis leviter cordatis obtusis tenuiter reticulatis subirıtegerrimis ecallosis vel obsolete calliferis. భ In Europâ, Asià et Americà boreali et areticâ passim, nec non in Caucaso, Guadeloupe (Bertero ex Balbis) et Chili (Bert. n. 594). R. crispus $\beta$ domesticus Weinm. fl. Petropol. p. 37. R. acquaticus $\beta$ crisjatus Wahlenls. fl. lappon. p. 31. R. domesticus Hartm. fl. scandin. p. 148, Cham.! in Línneá, 3, p. 59, il. 6, p. 591, Schult. fil. syst. 7, p. 1424 , Reiclien]. ic. crit. 4, p. 35, t. 345, Hook. et Arn. Bot Beech. p. 129, Ledeb. fl. ross. 3, j. 506. R. Hippolapathum et domesticus Fries Novit. fl.'suec. ed. 2, p. 106. R: alpinus Eugl. bot. t. 2694 (non Linn.). R. distans Dumort. fl. belg. prodr.p. 17 ? R. chilensis herb. reg. Berolin.! R. hippiatricus Remy in Gay Hist. de Chile,? p. $281^{*}$, (recedens foliis fere omnibus radicalibus et basi attenuatis). Species

- simillima R. crispo, sed distincta foliis minus crispis vel passim planis, radicalibus basi haud attenuatis, valvis $\frac{1}{3}$ majoribus (minoribus quam R. Patientise) ecallosis vel obsolete calliferis (fide Koch syn. ed. 2, p. 706). Valvce integérrimæ vol rarius basi obsolete denticulatie. (v. s.)

B. nanus (R. domesticus Hook. fl. bor. Am. 2, p. 129), jurpurascens, caule palmari vel semipedali paucifolio racemo simplici terminato. - Ledeb. fl. ross. 3, p. 506. In Americâ occid, arcticâ (Chamisso !). (v. s. in h. Berolin.)

12. R. ELBURSExsis (Boiss. in Kotscliy pl. Pers. bor. exścicc. 1846, Diagn. pl. or.n. 12, p. $100 \%$, foliis inferioribus petiolo supra plano paulo longioribus teneris oblongolanceolatis acutiusculis basi incequalibus breve, cupeatis vel rotundato-subtruncatis, summis lanceolato-linearibưs, paniculà elongatâ spiciformi depauperatâ laxiusculà superne aphyllà, pedicellis fructiferis deflexis capillaribus calyce subb. duplo longioribus, valvis amplis orbicularibus acutiusculis basi truncatis nudis reticulatis obsolete eroso-denticulatis. $\zeta$ ? In monte Elbrus v. Elburs Persiæ bor. (Kotschy, 1. 294). Planta bipedalis et ultra, caule erecto inferne simplici ; folia radicalia 8-10-pollicaria, $2 \frac{4}{2}$ poll. lata, petiolo $4-5$ poll. longo, basisubcanalicalato, dorso convexo striato; panicula angusta, fere pedalis; valvæ 4 liı. latie. A proximo R. longifolio differt foliis non undulato-crispis, valvis majoribus lıaud cordatis, etc.

B. Valve omnes vel ex parte calliferce, raro subcallosa (n: $10 \beta, 16,37,38 \beta$ ).

13. R. FIS C HE I (Reichenl. ic. pl. rar. 4, p. 58 , sine ic.), foliis ovato-oblongis obtusis undulatis, radicalibus elongatis profunde cordatis, caulinis basi subtruncatorotundatis, summis lanceolatis basi breve attenuatis, paniculà subaphyllâ, racemis sessilibus subsolitariis, verticillis distantibus, pedicellis calycem fructiferum mediocrem subecpuantibus, valvis late ovatis obtuse subacuminatis basi subtruncatis leviter reticulatis, unà callo ovato crasso, reliquarúm nervo plus minus tumidulo. $2 \mathrm{In}$ Sibiria et deserto Soongoro-Kirghisico--Schult. fil. syst. 7, p. 1431, Ledeb. 11. ross. 3, p. 505. Folia rigidiuscula, petiolo subcanaliculato. Paniculse rami solitarii vel fasciculati. Calyx fructifer, 2 lin. longus, valvis subintegerrimis basi truncato-rotundatis. Species foliis ad $R$. aquaticum accedens, sed ralvis multo minoribus callosis distincta iisque cum R. crispo conveniens a quo pracipue foliis differt. (v. v. c.)

14. R. CRISPUS (Linn: sj. 1, p. 476), foliis elongatis undulato-crispis utrinque attenuato-acutis, infimis elongato-oblongis, caulinis lanceolatis, summis linearibus, paniculis basi foliosis demum densis subapliyllis, verticillis approximatis, valvis mediocribus late ovatis subcordatis obtusis elevato-reticulatis integerrimis vel basi obsolete denticulatis omnibus calliferis. $\mathcal{H}$ In incultis et pratis Europæe totius, Sibiriâl Tauriâ, Caucaso Syriẩ (Ehrenberg), Americả bor. (ex Hook.), Mexico 
(Mart. et Galeotti), Montevideo (Chamisso), ins. Falkland (Hook. fil.), Ghili (Cl. Gay), Nov.-Zelandiâ (A. Cunn., d'Urville, Haoul), China, Japonjả (Thunlı.), Javà (Junghuhnn). - Campd. Rum. p. 95 ", Wallr. sched. 1, p. $170^{*}$, Mert. et Koch Deutschl. fl. 2, p. 608 , Schult. fil. syst. 7, p. 1421, Ledeb. fl. ross. 3, p. 505, Curt. fl. Lond. t. 18 , Fl. dan. t. 1334, Engl. bot. t. 1990, Lam. ill. t. 271, fig. H, Hayne Arzneigew. 13, t. 3. Lapathum crispum Lam. fl. fr. 3, p. 3. (v. v.)

B. nudivalvis, valvis omnibuss nudis vel unicâ callơ parvo vel obsoleto præditâ.Mert. et Koch l. c., Ledeb. 1. c., Fries ! herb. norm. fascic. 7. In Europâ paśsim. Forma R. longifolium nimis appropinquans. ( $r$. s.)

15. R. EL ONGAT US (Guss. pl. rar. napol. 1826 , p. $150^{*}$, t. 28), caule erecto simplici, foliis subundulatis, radicalibus oblongo-lanceolatis longe petiolatis caulinisque sublinearibus strictis non crispis, verticillis omnibus distantibus 5 -8-floris inferioribus foliosis, pedicellis calyce demum longioribus, valvis mediocribus cordato-ovatis acutis reticulatís integerrimis, unicâ callifurâ. $\%$ In stagnis Calabriæe orientalis. Pedicelli fructiferi 3-5 lin. longi, gracikes. Valva 2 lin. longe, $1 \frac{1}{2}$ lin. latæ. Folia haud crispa, sed leviter vel obsolete repando-vel crenato-undulata. Cæt. omnia R. crispi, cujus forsan var.

16. R. Kunjт hianus (Schult. fil. syst. 7, p. $1423 \%$, foliis lanceolatis utrinque angustatis margine undulato-crispis, radicalibus elongatis, racemis axillaribus, verticillis approximatis , pedicellis calyce fructifero longioribus, valvis mediocribus ovato-oblongis obtusis subintegerrimis reticulatis unicâ vel omnibus (nervo basi tumidulo) obsolete calliferis nudisve. $\mathcal{F}$ In humidis editiorilsus Mexici prov. de los Pastos, alt. 500-1000 hexapod. R. longifolius Kuntlı! in H. et B. nov. gen. 2, p. $180^{\text {* }}$ (non DC.). R. Kunthii Campd. Rum.p. 97*. R. crispus Cham. et Schl.! in Linnæâ; 3, p. 59. Caulis 3-4 ped., simplex vel ramosus. Folja radicalia subpedalia $1 \frac{1}{2}$ poll. lata, petiolo fere 5-pollicari, caulina dimidio minora, petiolo subpollicari. Paniculæ rami 2-5, fasciculati (rarius passim solitarii), valde inrequales, $1-10$ poll. longi, hasi folio fulti, verticillis demum contiguis, pedicellis fructiferis $\mathbf{2 - 4}$ lin. longis prope medium articulatis. Valvæ tenuiter membranacew, 2 lin. longæ, basi fere 2 lin. latæ, interdum subcordatæe et prope basin obsolete undulato-crenulatæe, callo unius parvo oblongo, reliquarum multo minore vel subnullo. (v. s. in h. Willd. n. 7029 !)

17. R. MEXI c^NUs, foliis omnibus petiolatis lanceolatis utrinque attenuatis acutius. culis planis vel margine obsolete crenulato-undulatis, summis linearibus, panicula simplici basi foliatâ, racemis solitariis sessilibus patulis densifloris basi subinterruptis, pedicellis calyce fructifero mediocri subbrevioribus, valvis demum late ovatis laxe reticulatis omnibus callo oblongo ipsis multo angustiore preditis. 4 In Mexico circa Leon (Mendez, n. 1 !), alibique (Schiede, n. 90 ! C. Ehrenberg!). Caulis subsimplex, gracilis. Oclirce longe, angusta, deciduce. Petioli supra concavi. Folia radicalia nondum observata, caulina (incluso petiolo 6-18 lin. longo) 5-8 poll. longa, 5-9 lin. lata, perfecte plana vel passim (exsiccatione?) minute undulato-crenulata. Panicula 4-6-pollicaris, racemís $1-2 \frac{1}{2}$ poll. longis, verticillis inferioribus distantibus, superioribus subconfluentibus, pedicellis vix 2 lin. Iongis. Valvæ fere 2 lin. longæ et sæpe vix angustiores, basi truncatæ vel subrotundatæ (nec cordatæ), integerrimæ, achænio majores, venis paucis elevatis remotiusculis intra marginem arcuatim coeuntibus, callo unius sæe obsoleto. Proxime affinis R. Kunthiano differt preceipue racemis haud verticillatis et pedicellis dimidio brevioribus. (v. s.)

18. R. BERLANDIER I, foliis elongato-lanceolatis utrinque attenuatis obtusiusculis planis vel undulato-crispis subsinuosis, paniculà simplici aphyllâ, racemis solitariis sessilibus erectis, verticillis dense multifloris discrutis inferioribus distantibus, pedicellis calycem fructiferum mediocrem subæcquantibus, valvis ovalis obtusis tenuiter reticulatis, omnibus crasse calliferis. $\psi$ In Mexicd circa Tampico, Bejar et Matamoros (Berlandier, n. 115!1699? sp. jun. et 2315 !), Louisianâ (Drummond! n. 279,281 et 282 , sp. jun.), et in Chili I circa Coquimbo, Valdivia, etc. (Cl. Gay). R. Romassa Remy in CI. Gay ! Hist. de Chile 5, p. $280^{*}$. Procedentibus simillimus quidem, sed distinctus verticillis discretis (vix summis contiguis), achænio valvas subæquante, valvarum callis crassioribus ovato-oblongis subæqualibus vel tertio obsoleto. A R. crispo differt pedicellis brevioribus ot valvis minoribus apicem versus magis attemuatis, etc. (v. s.) 
18. R. c U e e r o tús (Campd.Rum. p. 66 et $95^{*}$, excl. syn. Thunb.), foliis onnibus petiolatis obovatis vel cuneato-oblorigis utrinque obtusis undulato-crenulatis vel demum planis, racemo terminali indiviso r'cl pauciramoso subapinyLlo, verticillis densifloris inferìoribus remotiusculis, pedicèlis flore brevioribus demum ${ }_{j}$ crassiuscuilis, valvis mediocribus ovato-oljlongis acutis omnibus' callo grosso oblóngó munitis. \& Circa Buenos-A yres (Commerson), Montevideo-(Sellow), in Brasiliłe provi. S.-Pául, Ghili (Bertero, n. 1234! Pćpp.! d'Urville! Ghamisso! Gi. Gay, Lechler, n-172, al etc.), America antaretica (Hook. fil.) - Schult. fil. syst. 7, p. 1416. , Hook. fil. antarct. voy. 1 , p. 67 , et 2 , p. 341 , Remy in Cl. Gay Hist. de Chite, p. 276, Meisn. in. Mart. fl. bras. fasc. 14, Polyg. p. 9. R. Mtuntevidensis Spreng. Cur. post. p. 144, fide Cham. et Schleeht. in Linnæầ 3, 1. 58. R. arenarius Poeppig! diar. n. 298. R. Peruantis Meyen mss. fide Endl. R. Chilensis Moris.... Caulis adscendens; subsimplex,

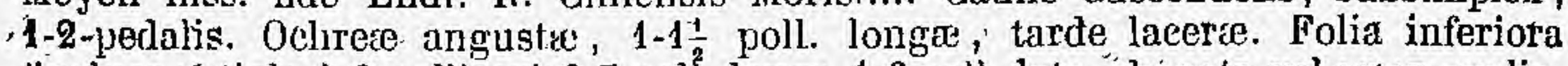
(incluso pétiolo 1-2-pollicari) 3-7 poll. longa, $\frac{1}{2}-3$ poll. lata, obovata vel sæpe ovalia, basi sicpius insequalia et subcordata, superiora sensim minora et plus mitius cuneato-angustata, ajice olstusa vel rotundata, nonmurquam margịne fờtiter crispa (sp. Pœppig), summn lanceolata, utrincuc acutíscula. Racemus terminalis, interruptus, simplex vel sepius basi ramis $1-3$ alternis folio fultis auctus, 2 -4-pollicaris. Flores ex Bert. disici. Calyx (jun.) fere 2 lin. longus, jedicello paulo lont gior, lobis sanguineis oblongis obtusis, interioribus dimidio longioribus. Valve callo crassissimo gibljoso-elevalto predite. (v. s.)

$\beta . ?$ alismafolius (Hook. fil. antaret. roy. 1, p. 67, et 2, p. 341), foliis ovatovel lineari-oblongis rarius basi attenuatis. In ins. antaret. Aukland. An distincta sp.?

20. R. MAGEL L A I C US (Griseb.! in Leechler pl. Inagell. exsiecc. n. 1175), folijs subcarnosis? omnibus petiolatis lanceolatis undulato-crispis attenuato-acutis basi rotundàtis vel vix attentuatis, painiculà subsimplici elongatâ supra àphyllâ, racemis sessilibus patulis, verticillis dense multifloris contiguis vel infimis discretis, calycibus subsessilibus mediocribus, valvis ellipticis obtusìusculis integerrimis tenuiter: venosis omnibus subsecqualiter calliferis, callo oblongo læevi minute púnctato. \% In littore ád Sandy-Point, ins. Maclor. s. FalkIand (Lechler, n. 1175 !). R. Patientia Gaudick., fide Griscb. Folia fortiter undulato-criș!a, infimá 5-8-pollicaria, 6-8 lin. lata, ommia acuta. Pedicelli basi articulati, tenues, fructiferi vix $\frac{1}{2}$ lin. longi. Valvae 2 lin. longæe, magis ovales quam ovatse, callum crassum oblongum margine angusto tenuiter subreticulato cingentes. A R. cuneifolio (cujus var. $\beta$ forsan huc spectat) et R. chrysucarpo foliis longioribus acutisque et floribus subsessilibus facile distinguenda'. (v. s.).

21. R. chr ysocar pos (Moris ! enum. sem. 1). taurin.1831, Mém. Acad. Taur: 38, p.46, t. 2), foliis elongato-lanceolatis utrinque attenuatis obtusis planis subundulatisque, caulinis petiolatis basi rotundatis, summis subsessilibus angustațis, jániculà simplici subaphyllâ, racemis solitariis basi longe intertuptis sujura subcontinuis, pedicellis calycce fructifero mediocrí sublongioribus, valvis delloideo-ovatis obtusiusculis olssolete reticulatis omnibus subrequaliter callo oblongo crassiusculo proditis. \& Patria ignota, verisimiliter Mexico aut Chili. Valde accesssit ad B. Nexicanum et Berlandieri, sed distinctus podicellis longioribus, valvis majoribus, callis grosssioribus, etc. 1 R. Britannicà et salicifolio differt foliis infrá medium haud latioribus, sapissime undulatis et valvis omnibus aqualiter càlliferis. (v. s. in h. DC.)

22. R. FLORIDANU , foliis petiulatis olongalo-lanceolatis utrinque sequaliter angustatis acutis planis, panicula simplici superne aphyllâ, racemis solitâinis sessilibus continuis vel basi breve interruptis rlemum densis, pedicellis catyce fiuctilero medíocri subjdujjo longioribus, valvis late ovato-deltoideis demun latioribus quam Jongis, breviter obtuseque aruuninatis denso reticulatis omnibus subrqualiter grosse calliferis. $\not$ ? In Flurila ad flum. Manattee (Rugel!). Folia infima ignota.

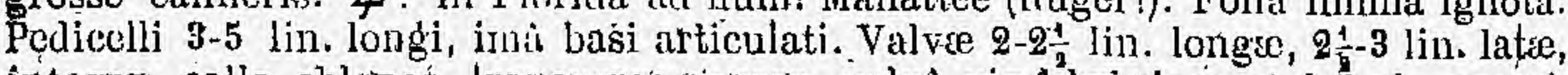
integra, callo oblongo, transverse rugoso, valvà vix $\frac{1}{3}$ brèviore et $4-5$-plu angustiore. Cæxt. fere $\mathrm{R}$. chrysoearpi et verticilhati, a juriure recedens precipue foliis acutis, pedicellis longioribus ct validioribus, racemis minus interruptis; a posteriore pedicellis brevioribus; ab utroqué valvis demum reniformi-delteiddeis basi truncatis (ñec attenuatis nec cordatis) distinctius reticulatis. (v. $s$. in h. Shiúttleworth.) 
23. R. BR1TANNICA (1) (Linn. sp. 1, p. 476); foliis ovato-oblongis lanceolatisque acutis planis o basí rotiundatâ bruviter attenúatis omnibus petiolatis, summis sublinearibus, panicula simplici sulbaphyllà, racemis subsolítariis sessilibus basi interruptis supra densifloris, verticillis approximatis, pelicellis calyce fructifero mediocrí brevioribus, valvis oratis obtasiusculis tenuiter ruticulatis, una callo teniui lineari, reliquis sıbnudis. Ұ I In inundatis stagnisque a Pensylvaniâ et Garolina ad Missouri et Texas (Frank, h. Un. itin. 1837! Rièhl, n. 397! Wrightt! etc.). - Schult. fil. syst. 7, p. $1420^{*}$. R. Clay tonit Campd. Rum. p. 66 ot 99. R. xanthorhizus Hoffmansegg Naclitr. p. 239, ex Scliult. Folia 4-7 poll. longa, ihfra medium semper latiora ot usque ad 2 joll. lata. Panicula jun. basi paucilolia. Valve 2 lin. longie, integerrime, haud cordatie. (v: s.)

$\beta$. polygonifolius (Loudon......L panicula ramis inferioribus seepe fasciculatis et passim ramosis, valvis unnibus' calliferis, callo uno gróssiore. Patria? R. verticillatus $\beta$. R. polygonifolius hort. Vindobon. et ind. sem. h. Petropol. 9, suppl. p. 18 ? (v. v. c.)

24. R. SA LICIF OL IUS (Wuinm. in flord, 1821, p. 28), foliis clongatis subplanis utrintue attenuato-acutis, inflmis oblongis, superioribus lanceolatis, omnibus petiólatis, petioln canaliculato, panicula simplici inferne fuliosâ, racemis solitariis sessilibus basi - interruptis supra densifloris, vertieillis indistirctis, pedicellis calyco fructifero mediocri subbrevioribus, valvis ovatis vol orato-olblongis ol, tusiusculis tenıi ter reticulatis, unả vel duobus inßequaliter calliferis, tertia nurlà. $\psi$ In Sibiriâ arcticả (ox Led.), ad portum \$.-Francisci Caljfornico (Cliamisso!), in Americâ boreali.-Cham. et Schlecht.! in Linuasi; 3, p. 60, Scliult. fll. syst. 7, p. 1418', Hook. et Arn, Bot. Booch. p. 157, Hook. 11. bor. Am. 2, p. 129 ? Leilub. I 11. ross. 3, p. 504. R. verticillatus Richardson, apjend. pr. 11. R. pallidus Bigel. mss. (fide Hook.). Forsan mera var. R. Britannicæ, attamen constanter dillerre videtur foliis longioribus (6-9 poll. longis, 8-14 lin. latis) jró longitudine angustioribus, infra medium haud latioribus, utrinque subrequaliter angustatis et valvarum callo crassiore (Jvato vel oblongo, majorem vălrio partem tegente, altero, dum adest, minore). Flores non dioici, sed mase et fern. mixti. Valvöe integerrime, haud cordatie. Planta Hookeri (ficle sp. in h. reg. Berolin.) recedens pedicellis calyce longioribis et valvis subnudis, potius ad R. crispum vel longifolium pertinere videtur. (v.s. sp. et c.)

B. -angustifolius (Ledeb, ? 1. c.), foliis angastioribus lineari-oblongis, valvis demum omnibus calliferis. - In ins. Sitcha. - Hook. l. c. R. salicifolius Bongard! Veg. ins. Sitcha, p. 161. (v.-s.)

25. R. VERT IGILLATUS (Linn. sp. 1, p. 476), glaberrimus, foliis elongatis, infimis cordato-elliplicis obtusis subundulatis, superioribus lanceolatis utrinque attenuatis acutis planis, paniculâ inferne foliosâ, racemis solitariis aphyllis, verticillis rlistantibus multifloris, pediccllis fructiferis deflexis calyce meediocri pluries longioribus, valvis nvatis oblusis ruguloso-renosis omnibus grosse calliferis. $\%$ In aquis et paludibus a Canadà ad Floridam et Louisianam.-Pluck. Amalth. t. 354, fig. 1, Campd. Rum. p. 98*, Schult. fil. ss st. 7, p. 1419* A simillimo R. Hydrolapathum fncile distinguitur foliis radicalibus basi oblique subcordatis subundulatis et pedicellis fructiferis longioribus (5-8 lin. longis) nec non paniculà juniore basi tạttum foliigerâ. Char. ex ochreis vero a Linnico, Campderâ aliisque ad dístin. guendam hanc speciem a R. Britannicà adhibitus nil valet, nam in utrâque specie ochrere penitus similes, juniores internodia longe vaginantes, mox laceræe et domum decidurs. Racemi scssiles. Valvè integerrimse, laud cơrdaté nec vérê reticulate, omnium callo crasso oblongo. (v. s. sp. et v. c.)

26. R. HYDROLAPATHUM (Huds. fl. angl, p. 154), folis utrinque attenuatis acutis, infimis longissimis lanceolato-oblongis płanis, superioribus lanceolatis minute undulato-crenulatis, summis linearibus, petiolis supra plauis, pauiculà latíusculà superne demum aphyllâ, verticillis discretis demum contiguis densissimis, valvis mediocribus triangulari-ovatis oblongisic basi subtruncato-rotundatis ruguInso-venósis, omnibus inịualitèr crasse calliferis vel tertià subnudà. భ̧ In paludi-

(1) Britannica, tomen apud veteres plantie officinalis ex insulis occidentalibus Europe, quad botanici siec. XVI et XXVII Rumicibus diversis tribuerunt (confer ad Munting. de verấ antiq. herbâ-Britannicâ, 1 vol. $4^{\circ}$, Amstel., 1681, cim figuris non despiciendis) Linnieusque arbitrarie ad plantam americanam veteribus ignotam tráñ̂́tulit. (Alph. DC.) 
bus et aquis Europæ mediæ et borealis et regni Neapolitani. - Smith! Engl. fl. 2; p. 195, Wallioth! sohed. crit. p. 172, Schult. fil. syst. 7, p. $1429^{*}$, Ledeh. 1 . ross. 3 , p. 507 , Lobel. ic. t. 285 , f. 2, Reichenb. ic. crit. t. 370 , Hayne Arzneigew. 13 , t. 4. R. Britannicâ Huds. fl. angl. ed. 1, p. 135, Hoflim. Germ. ed. 1, p. 128 (non-Linn.). R. aquaticus Smith, fl. brit. 1, p. 394 , Poll. Palat. 1, p. 361, DG.!f. fr. 3, p. 373, Fries! Novit. fl. suec. 2, p. 109 , herb. norm: fasc. 6 ! (non Linn.). R. acutus Wah́lenb. fl. suec. p. 223 (excl. $\beta$ ). R. maximus Gmel. fl. bad. 2 , j. 99 (non - Schreb.). Folia radicalia erecta, 1-3-pedalia, 2-7 poll. lata, longe petiolata, nervo dorsali vadido. Panicula florifera fere ad apicem usque foliosa (a $\mathrm{R}$ aquatico tegre distinguenda, fructifera vero facillime). Pedicelli fructiferi 2-4 lin. (passim 5-6 lin.) longi ; calyx fructifer basi turbinato-attenuatus 2-2 $\frac{1}{2}$ lin. lorigus, semper longior quam latus, valvis haud cordatis, nee vere reticulatis subintegerrimis, callo oblongo grosso, 1-1 $\frac{1}{2}$ lin. longo sursum attenuato; in tertiâ nonnunquam minore vel deficiente. (r. v.)

27. R. M A I mus (Schreb. in Schweigg. et Kortefl. Erlang. 1, p. 152, non Gmel. nec Campd.), folits elongatis acutis planis minute undulato-crenulatis, infimis pralongis oblongo-lanceolatis basi rotundatâ vel cordatâ inøqualibus, superioribus lanceolatis basi attenuatis, petiolis supra planis nervoso-marginatis, panicula subaphyllâ latiusculà, verticillis discretis, valvis majusculis triangulari-ovatis basi latâ subemarginatis reticulatis omnibus grosse calliferis. $\psi$ Ad fossas et paludes Europæ mediæ et borealis, in provinciis Caucasicis et? ins. promont. Virid. (cfr. A. Schmidt 11. cap Vert, 1852, p. 178). - Wallr. sched. crit. p. $174^{*}$, Mert. et Koch. Deuschl. fl. 2, p. 616, Schult. fil. syst. 7, p. 1428, Ledeb. fl. ross. 3, p. 507, Fries! herb. norm. fasc. 6. R. aquaticus Campd. Rum. p.100 (excl. syn. plur.), $\alpha$ heterophyllus G.-F.-W. Mey, Chlor. hanov. p. 477. R. acutus Schultz Fl. Starg. p. 92, Hartm. Seand. fl. p. 147, Swensli Bot. t, 161 (fide Fries), $\beta$. latifolius Wahlenb. fl. suec. p. 223. R. heterophyllus Schultz, Fl. Starg. suppl. p. 21. A simillimo R. Hydrolapa-thum facile distinguitur foliis infimis (æque longis) basi inæqualibus rotundatis cordatisve nec attenuatis et valvis majoribus (usque ad 3 lin. longis), sæpius vix longioribus quam latis, basi truncatis vel subemarginatis, distinctius reticulatis sæpiusque (nec semper; ut Koclı voluit) denticulatis, unius callo plerumque multo minore. (v. s.)

B.? propinquus, ramis contraotis, verticillis confertis, valvis late cordatis, unius callo reliquis majore. In Suecià cirea Gothenburg. R. propinquus Areschoug in Lindblom Bot. Notiser, 1841, p. 17, ex Mohl et Schlecht. Bot. Zeit. 1846, p. 345, Walp. Annal. 1, p. 552. Forsan propria sp.

28. R. WALL I GH I, divaricato-ramosus, foliis acutis, inferioribus oblongis subundulatis subcordatis, superioribus planis utrinque angustatis, summis linearibus patentibus, paniculâ simplici, verticillis folio fultis densifloris superioribus confluentibus, pedicellis calyce fructifero parvo longioribus apice turbinato-incrassatis, valvis ovatis lanceolato-acuminatis acutis omnibus æqualiter calliferis. $\psi$ ? In Bengalià, Sylhet, Oude. R. acutus Roxb. fide Wall. R. Roxburghianus Wallich, list n. 1731! (ex parte, non Schult. syst.). F. comosus Hamilt. I mss. (non Forsk.). R. Wallichianus Meisn. in Wall. pl, As. rar. 3, p. 64. Caulis crassus, flexuosus, sulcatus. Valve integerrimæ, grauulo oblongo adeo tectæ, ut nil nisi margo angustús et acumen remaneant et reticulatio nulla appareat. (v. s.)

29. R. So ONG On icus (Físch. et C.-A.Mey. ind. 9, sem. h. Petrop. p. 85), foliis oblongis ovatisve obtusis vel acutiusculis, verticillis folio fultis, pedicellis tenuibus calyce fructifero parvo longioribus apice obovato-vel subgloboso-incrassatis, valvis ovatis triangulari-acuminatis acutis reticulatis, callo uno majore, tertio sæepe obsoleto vel nullo. $\odot$ In montanis deserti Soongoro-Kirghisici Sibirice Altaica.-Ledeb. fl. ross. $3, p .50 k$. Preter notas indicatas el valvas paulo minores ofnnia fere $R$. Wallichii. (v. s.)

30. R. LIт T ORALis (Kunth in H. et B.! nov. gen. 2, p. 181 *), foliis petiolatis, caulinis lanceolato-oblongis utrinque acutis margine crispis, verticillis folio fultis remotis multifloris, pedicellis pendulis, calyce fructifero longioribus, valvis parvis ovato-oblongis acutiusculis omnibus calliferis. $\mathcal{F}$ In littore Oceani Pacifici Peruvia. - Campd. Rurn. p. 92, Sćlault. fil. syst. 7, p. 1417. R. parvifolius Willd.! mss. in herb, n. 7030 (specim. Humboldt. mancum, fr. semimaturis). Caulis erectus, 2-3ped., ramis sulcatis patulis. Folia infima ignota, caulina sesquipollicaria, 6-8 lin. 
lata; petioli 4 lin., pedicelli 3 lin. Iongi. A R. conglomerato vix satis distinctus. (v. s. in herb. Willd, et Kunth.)

31. R. G ONGLOMERA TUS (Murr. prodr. 11. Goett. p. 52), foliis infimis ovatis oblongisve obtusis vel acutis basi cordatis vel rotundato-angustatis, superioribus lanceolatis utrinque attenuato-acutis sæpius margine crispulis, summis linearibus internodio subæqualibus, paniculæ ramis divaricato-patentibus adscendentibus, verticillis distantibus folio fultis summis tantum aphyllis, pedicellis calyce fructifero parvo subbrevioribus, valvis ovato-oblongis subacuminatis obtusis omnibus grosse calliferis. $\mathcal{Z}$ Ad fossas et vias Europæ totius, region. Taurico-Cáucas., Syriæe (Ehrenb.!), Daghestan (C. Koch !), Tenerifre (Webb !), cap B.-Sp. (Linnæâ 14, p, 492) et Americæ borealis. - Wallr. I sched. p. 156 *, Ledeb. fl. ross, 3, p. 503, Morison, sect. 5, t. 27, f. 9, Sturm. Abbild. fasc. 73, n. 4. R. Hydrolapathum Scop. Carn. 1, p. 262 (non Huds.). R, glomeratus Schreb. Spicil. fl. Lips. ed. 2, p. 64, Reichénb. ic. crit. fig. 552. R. dubius Retz. prodr. n. 387. R. paludosus With. p. 354, Ait. Kew. ed. 1, p. 482. R. Nemolapathum Ehrh. Beitr: 1,"p. 181 (fide Koch. Cfr. R. sanguineum $\beta$ ). M. Bieb. Taur.-Gauc. 1, p. 289, Campd. Rum. p. 92. R. undulatus Schrank Bair. 1l. 1, p. 625. R. crispus $\beta$ Poll. 1 . palat. p. 358. R. acutus Smith! fl. Brit. 1. p. 391, Engl. Bot. t. 724, DC. fl. fr. 3, p. 375, Campd. Rum. p. 145, Schult. fil.syst. 7, p. 1408, Hook. fl. bor. Amer. 2, p. 130. R. virgatus Hænke, fl. Ind. p. 39. Lapathum virgatum Moench Metl. p. 355. (v. v.)

B. pycnocarpus (Wallroth Sched. p. 157), foliis undulato-crispis, valvis callo crasso fere omnino tectis. In Eưopâ passim. R. Winterlii Zuccagni Spicil. fl. florent. p. 45, Campd. Rum. p. 149. R. campestris Savi fl. pis. 1, p. 372. R. pusillus Delarbr. fl. Auvergn. ed. 2, p. 523. R. divaricatus Thuill. fl. Paris, 2, 1, p. 182, excl. syn. (v. s.)

32. R. LAGhanus (Forsk. fl. \&g. Arab. p. 209), foliis petiolatis, radicalibus spathulatis obtusis, caulinis late lanceolatis, valvis integris granulatis. In Natoliâ. Campd. Rum. p. 143. Species vix nota, a præcedente forsan haud distíncta.

33. R. SANGUINEUS (Linn. sp، 1, p. 476), foliis infimis ovato-oblongis vel subpanduriformibus cordatis obtusis vel acutis, superioribus lanceolatis acutis basi cordatis obtusisve margine sæpius crispulis, summis linearibus, paniculæe ramis erectopatentibus rectis aphyllis vel basi tantum foliosis, verticillis distantibus superioribus subconfluentibus, pedicellis calyce fructifero parvo subbrevioribus, valvis oblongis subacuminatis obtusis, unicâ vel passim duobus calliferis. $\mathcal{\digamma}$ In umbrosis et ad vias Europæ totius, region. Taur.-Caucas., Syriæ (Ehrenberg l), Africæ australis (Linnæâ, 14, p. 402, Ecklon et Zeyh. herb. n. 9), Americæ borealis (Pursh, Ell. Torr. etc.) et Chili (Cl. Gay, Hist. Chil. 5, p. 277).--Smith! fl. Brit. 1, p. 390, Gaudin fl. helv. 2, p. 579, Hook. fl. bor. Am. 2, p. 130, Koch syn. fl. Germ. ed. 2, p. 705. R. Nemolapathum Wallr. sched. p. 158*, Mert. et Koch Deutschl. fl. 2, p.611. R. nemorosus G. F.-W. Mey. Chlor. hanov. p. 479. Simillimus R. conglomerato et in herbariis sæpissime cum eo confusus commixtusque, satis tute tamen ab eo dignoscendus racemis exceptâ. basi aphyllis et valvis angustioribus, unà callo globoso-ovato grosso, reliquis nudis vel alterâ rarius callò minore præditâ. (v.s.)

a. genuimus (Smith l. c.), caule et foliorum venis sanguineis. R. sanguineus Linn. et auct. plurim. Campd. Rum. p. 93, Schult. fil. syst. 7, p. 1415*, Blackw. herb. t. 492, Engl. Bot. t. 1533, Sturm Abbild. fasc. 73, n. 6. Lapathum sanguineum Lam. fl. fr. 3, p. 2. (v. s.)

ß. viridis (Smith! l. c.), caule venisque foliorum viridibus. - Sturm 1. c. n. 5. R. acutus Curt. fl. Lond. 3, p. 21. $\beta$ Hudson fl. angl. p. 155. R. viridis Sibth. fl. oxon. p. 118. R. Nemolapathum Ehrh.I Beitr. 1, p. 181 (fide ej. specim. in herb. Smith l), DC. ff. fr. 3, p. 373, Reichenb. ic. crit. fig. 551, Ledeb. fl. ross. 3, p. 503. $\alpha$ exsanguis Wallr. sched. p. 158. R. nemorosus Schrad. in Willd. enum. 1, p. 397, DG.! fl. fr. 6, p. 367, Campd. Rum. p. 92, Schult. fil. syst. 7, p. 1413. R. condylorles M. Bieb. Il. Taur.-Cauc. 1, p. $288_{i}$ 3, p. 278, Gampd. Rum. p. 94, Schult. fil, syst. 7, p: 1415. R. rupestris Legall in Cơngrès scientif. de France, 1849, 1, p. 143. (v.v.)

$\gamma$ : Reynieri, floribus dioicis ? sepalis interioribus nullis. R. auratus. Smith in Rees Cycl. n. 30, Campd. Rum. p. 90, t. 1, f. 5, Schult. 1.c. p. 1407. Favrodine dorée Reynier in Mém. soc. Lausanne, 2, p. 261. R. aureus Gmel. in Linn. syst. 2, 1, p. 585 (non alior.). Planta obscura, verisimiliter monstrosa, perperam pro var. R. pulchri habita, procul dubio ad R. sanguineum spectans. 
84. H. ECKL ONI , caule erecto subsimplici, foliis caulinis breve petiolatís lanceolatis utrinque attenuatis acutis, paniculâ aphyllâ, racemis sessilibus densifloris basi interruptis, verticillis multifloris superioribus contiguis, pedicellis supra modium articulatis calycem fructiferum parvum subsequantibus, valvis ovatis subacutis margine angusto tenue reticulatis grosse calliferis vel tertiá passim nudâ. $\nLeftarrow$ ? In Africà Capensi ad flam. Garip et Zwartkop (EckIon! Drègel). R. Ecklonianus Meisn. in Linnæâ 14, p. $493^{*}$. Habitus R. sanguinei et lancoolati, sed racemi subcantinui, fructiferi densi subcompacti, calyx fructifer paulo major ( $1 \frac{1}{2}$ lin. longus), valvæ haud acuminatoe et plerumque omnes eallifers. Fol. radicalia ignota. (v. s.)

35. R. MEY ERTANUS , caule erecto subramoso, foliis caulinis petiolatis oblongo-lanceolatis utrinque attenuatis, supcrioribus lanceolatis vel subspathulạtis, paniculâ subaphyllat, racemis gracilibus basi interruptis, verticillis approximatis discretis superne contiguis donse multifloris, pedicellis supra medium articulatis calyce fruclifero parvo sublongioribus, valvis ovatís obtusis subvenoșis, unicât minute calliferâ, reliquarum nervo basi tumidulo. $\mathcal{F}$ ? In Africâ Capensi (Drège T K̇rauss!). 1. Meyeri Meisn. in Linne 14, p. $494^{*}$, et in Hook. Lond. Jaurn. 2, p. 451. A proximo R. Ecklonii differt racemis fructiferis patentibus gracilioribus, minus densifioris, valvis majoribjus subnudis. Folia acuta vel obtusiuscula nonnụncluam pollicem lata, radicalia ignota. $\Delta \mathrm{n}$ a $\mathrm{R}$. spathulato Thunb. satis distinctus? (v. s.)

36. R. S PAт H L A T U (Thunb. jrodr. p, 67, f. cap. 1, p. 340), caule pedali ercetiusculo, foliis petiolatis oloovatis bhtusis, superioribins lanceolatis, floribus verticillatis, pedicellis erectis, valvis calliferis. $\mathscr{Y}$ ? Ad cap. B.-Spei.-Campd. p. 145, Schult. fil. systt, 7, p. 1417. Species vix nota, forsaf priecedentem includens.

37. R, LANGE OLATUS (Thunb. prodr. p. 67, fl. cap. p. 340), caule erecto ramoso sub1lexuoso, ramis adscendentibus, foliis caulinis breve petiolatis elongato-lanceolatịs attenuato-acutiusculis basi rotundatis icll breve attenuatis, racemis terminglipus axillarihusque solitariis indivisis sessilibus basi interruptis gracilibus, verticillis 3-8-floris, pedicellis calyce parvo 2-30-plo longioribus supra medium articulätis, valvis ovato-oblongis a medio in actmen ligulæeforme subito angustatis (eca?losis?). $\&$ Ad Gaput B.-Spei (Thumb. Drège !). - Campd. Rum. p. 148, Schult. fil, syst. 7, p. 1476, Meisn. in Linn'eâ 14, p. 493. Species non satis nota, calyee fructifero nondum observate, dubii igitur loci; accedens ad R. sangnineum, sed jam pedieellis longioribus tenuioribus et medio vel paulo supra (घec prope båsin) articulatis satis distincta (v. s.)

38. R. L IN EA R Is (Campd. Rum. p. 90), caule ramoso, foliis breve petiolatis oblongolinearibus acuminatis " serratis " (?), racemis terminalibus et axillaribus supprioribus aplyyllis, verticillis distantibus, pedicellis brevibus basi articulatis, valvis deltoideo-ovatis obtısiusculis omniḷus calliferís. $\%$ Ad caput B.-Spei - Schult. fil. syst, 7, p. 1407. Folia 3-4 poll. longa, 5-6 lin. lata. Ochrex longæ acutæ. Species non so,tis nota.

[5? affinis, humilis, caule adscendente ramoso, foliis anguste lanceolatis utrinrue attenuatis subacutis breve petiolatis, naniculà brevi aphyllấ, racemis paucis sessillibus indivisis continuis deusifloris, verticillis canfluentihus, pedicellis calyco fructifero parro brevioribus apice articulatis, valvis deltoideoovatis obtusiusculis reticulatis, omplium vel duarun nervg fumidulo. $\%$ Ad capat B.-Spei (Drège I). R. linearis Meisn. in Linnæd 14, p. 495*; Forsan distincta specics. (v. s.)

39. R. SYLVESTRIS (Wallr.! sched. critic. p. $161^{*}$ ot in Linnâa 14, p. 567 , non? Campd.), fohịs infinis oyato-oblongis obtusis cordatis, superioribus ovato-lanceolatis lyasi fotphndatis val breve attenuatis summisroue lanceolatis utpinque atteruatịs margine crispulis, paniculæ ramis semierectis simplicibus vel divisis foliosis jnferioribus verticillato-fasciculatis inferne interruptis supra gontinuis dense multifforis, pedicellis calyce fructífero mediacri demum longioribus, valvis ovatoplilongis acuminatis obtusis obsolete reticulatis integris vel uṇâ alterấve dente brevi tcuui munitis, callo unius crasso reliquarum passim minore vel absoleto. $\mathscr{F}$ In umhrosis Europre jlassim, Germaniag (Walli.!), Suecie (Fries! herl), nopm. fasc. 5 el 10), Volliynix (Besser! in h. DC.), regni Neapolit. (Ten. Syll. p. 182) et? ins. promonl. Virid. (Brumer, n. 133 at 235, in lierb. Slutttew. sp. imperfect.). Schult. fil. sj:s1. 7, p. 1406, Ratzoburg in Hayne Arzneigew. 13, p. 1, t. 1. R. acutus Limn. in herb. Upsa]. teste Fríes l.c. R. obtusịfolịus Frịies! et Bess.! ll.cc, var. $\gamma$ Mert. et Koch Deutsclil. fl. 2, p. 611, Sturm Abbild. fasc. 73, n.11. Stirps adhuc dubiis 
vexata, hine ad R. obtusifolium, inde (et propius quiden ex nostrâ sententiâ)ạd R. conglomeratum accedens, forsan eorumdem hybrida progenies ; a priore, cui staturâ altiore, robustiore, panicula compositâ, racemis crectis nec divaricatis, verticillis magis approximatis pedicellisque longioribus similis, constanter differt præcipue calyce fructifero dimidio minore, valvis angustioribus integris vel obsolete dentatis et unius (rarius plurium) callo multo majore crasso ovato; a R. conglomerato vero, cui ealyce fructifero multo similior, recedit racemis haud divaricatis, basi tantum foliosis, superne continuis densiforis, pedicellis longioribus, vaktis fere duplo majoribus passim denticulo munitis, callis crassioribus sæpius inæqualibus. Multis formis intermediis in R. obtısifolium transire dicitur apud Koch l. c., quod vero nostrâ observatione non comprobatur. (v. s.)

40. R. DAGHESTANi U,S (G. Kach $!$ in Linnæâ 22,p.209), stricte erectus, glaberrimus, folips infumis cordato-oblongis, summis lanceolatis, paniculæ longæ ramis folio fultis simplicibus somipatulis aphyllis, verticillis approximatis densissimis, pedi. cellis calyce mediacri paulo longioribus basi articulatis, valvis ovato-oblongis dente uno alterove brevịssimo instructis integrisve reticulatis, callis parvis, uno majore. Z In salo calcareo et limoso Daghestaniæ (C. Koch!). A simillimo R. sylvestri differt racemis aphyllis et valvarum callis minoribus vel obsoletis. (v. sp. jun. in h. reg. Berolin.)

41. R. BRASILIENS Is (tink l enum. h.Berol. p. 349), foliis petiolatis utrinque attenuatis acutis, radicalibus oblongis, caulinis lanceplatis, summis subsessilibus linearibus, paniculâ simplici, racemis solitarịis, vertícillis onnibus folio fultịs inferioribus distantibus superioribus contiguis, pedicellis calyce fructifero parvo paulo longioribus, valvis ovato-oblongis acuminatis acutis obsoletc reticulatis integerrimis vel passim dente subulato patenti munitis omnihus subæqualiter calliferis. $\%$ In Brasillâ, in fossis circa Rio-Janeiro frèquens (Lund, n. 589 !).--Schult.l fil. syst. 7, p. $1417^{\circ}$, Steinheil in. Ann. sc. nat. $2^{\circ}$ sér. 9 , p. 194, Meisn. in Mart. fl. bras. fasc. 14, Polyg. p.9. R. incomplus Weinm. in Florả 1821, p. 28. Folia radicalia semipedalia, fere 2 poll. lata, subacuta, plana vel basi leviter undulata, sụperiora acutả plana. Racemí ad apicem usque foliis linearibus circ. pollicaribus prææditi, calyce fructifero demum fere $1 \frac{1}{2}$ lin. longo, valvis in ácumen acutiusculum attenuatis unâ vel duabus passim infra medium dente solitario $\frac{1}{2}$ lin. longo patenti munitis, callis oblongis crassiusculis subæqualibus. (v. sp. e. in herb. reg. Berolin.)

42. R. Patientia (Linn. sj. 1, p. 476), foliis jtanis vel subundulatis acuminatis infimis magnjs caulinisque ovato-ablongis basi rotundatis vel breve attenuatis, summis lanceolatis, petiolis canaliculatis, paniculă superne aphyllâ, racemis solitariis sessilibus densis, verticillis approximatis, valvis majusculis late ovatis obtusis subcopdatis tenuiter reticulatis subintegerrimis, unius callo parvo reliquarum nervo basi subincrassato. $\mathcal{\zeta}$ Ad fossas Europæ mediæe et australis, Tauriæ, Sibirine Altaice, Ghili ( Gl, Gay), ins. Maclov. (d'Urville), S.-Helenæ, et colitur ad usum chlinarium in hartis oleraceis, unde verisimiliter aufuga passim spontanea invenitur - Gampd. Rum. p. 102, Mert. et Koch Deutschl. fl. 2, p. 607 *, Schult. fil. syst. 7, A. 1432, Ledeb. fl. foss. 3, p. 507. Lapathum hortense Lam. fl. fr. 3, p. 3, Blackw. herb. t. 489, Schkuhr Handb. t. 100. Radix amara adstringens, olim inter stomachica et antiherpetica officinalis. Valvæ circ. 2 lin. longæ, haud acuminatæ, leviter cardata, unius callo parro ovato-oblongo, reliquis subnudis, nervo basi vix tumidula. (v. v. c.)

43. R. 0 L X M P I C U (Boiss. diagn. pl. orient. 5, p. 45 *), caule elato angịloso, follis infimis longe petiolatis ovato-oblongis acutiuseulis subundulatis rigidiusculis basi breve attenuatis, superioribus oblongo-lanceolatis abbreviatis, panịculâ subaphyllâ strictissima; ramis abbreviatis adpressis, verticillis approximatis, valyis cordatoovatis reticulatis obtuse denticulatis, unicâ calliferâ. $\mathcal{F}$ ? In pratis et ad rivulos Olympi Bithynici (Boiss.). Folia infima $\frac{1}{2}-1$ ped. Ionga, media 4 poll. lată, petiolo basi canaliculato. Panicula 1-2 pedalis. Valviæe 2 lin. longæ.: An a R. Pạtientiấ satis distincta?

44. R. ORIENTAL is (Bernhardi in Schult. fil. syst. 7, p.1433*), foliis undulatis acutis, infimis elongato-oblongis basi vix angustatâ subcordatis, superioribus oblongis lanccolatisque basi rotundatis vel summis attenuatis, pauiculầ aphyl'ấ, racemis subsolitariis sessilibus densis, verticillis subindistinctis, valvis majusculis late ovatis vel suborbicularibus obtusis profunde cordatis tenuiter reticulatis mi- 
nute denticulatis subintegrisve, unius callo crasso reliquarum subnullo. $\mathscr{\nvdash}$. In Oriente (Tourn. Cor. 38 ?), circa Ephesum (Boiss. diagn. 5, p. 46), Afghanistan (Griffith! herb. n. 1700) R. Dioscoridis Hayne Arzneigew̌. 13, p. 5, t. 5. R. mácrophyllus Wallr.mss, fide Hayne. Fólia radicalia pedalia et ultra, 4 poll. lata. Valva pedicello gracili subpreviores, 3-4 lin. longæ, unius callo crasso ovatoreliquarum nervo basi tumidulo. Planta hortensis e seminilus opio venali adhærentibus educata, a simillimo R. Patientia recedens foliis infimis plus minus cordatis, valvis paulo majoribus profundius cordatis distinctius denticulatis et callo majore munitis. (v. s. sp. et c.)

45. R. coNFERTUS (Willd.! enum. p. 397), foliis ovatis et ovato-oblongis obtusis uṇdùlatis, infimis basi latâ profunde cordatis, superioribus basi rotundatis v. brevissime attenuatis, summis lanceolatis, petiolis subcanaliculatis, paniculâ subaphyllâ, racemis densis basi interruptis, pedicellis calyce fructifero magno sublongioribus medio articulatis, valvis suborbicularibus breve obtuseque acumínatis profunde cordatis laxiuscule reticulatis minute crenato-dentatis, unicâ callo parvo, reliquís subnudis. $\mathcal{H}$ In Rossiâ mediâ et australi, Caucaso, Davuriâ, Sibiriâ. - Campd. Rum. p. 107, t. 2, f. 2, Hornem. H. Hafn. 1, p. 349, Poir. dict. suppl. 4, p. 324. (exel. $\beta$ ), Schult. fil. syst. 7, p. 1434*, Ledeb. I fl. ross. 3 , p. 509. R. alpinus M. Bieb. Taur. Cauc. 1, p. 291 (non Linn). R: undulatus Desf. Cat. h. Paris. ed. 3, p. 389 , Hornem. I. c. p. 351. R. pauciflorus Campd.! Rum. p. $104^{*}$ : R. retroflexus Lag., fide Link! herb. R. Candollii Mart. hort. Berolin. 1840 (fide herb. reg. Berol.). Folia inferiora fere 'R. aquatici L., pedalia, 6-7. poll. lata, obtusissima, superiora breve pefiolata et minus profunde cordata, supra basin latam haud contracto-angustata. Paniculæ racemi sessiles, solitarii $\dot{v}$. fascienlati, verticillis aphyllis, pedicellis capillaribus. Calyx fructifer fere R. orientalis, sed valvæ latiores (sæpe vix longiores quam latæ) constanter acumine brevi triangulari obtuso integro terminatæ, venarum reticulo magis prominulo et laxiore, margine distinctius repando-denticulato, unius callo minore ovato, reliquarum nervo sæpius basi tumidulo. K. pauciflorus Campd.! , fide specim. autographi imperfecti in herb. DC., non differt nisi paniculà subsessili coutractâ brevissimâ; valvæ minime omnes calliferæ. nec grosse serratæ; ut ab auct. perperam descriptæe sunt. (v. s. sp. et v. c.)

46. R. CORDIFOLIU (Hornem. Ind. sem. h. Hafn.), foliis planis obtusissimis, ovatis v. ovato-oblongis infimis profunde cordatis, superioribus basi subtruncato-rotundatis, summis lanceolatis, petiolis anguste canaliculatis obtusangulis, paniculâ aphyllâ, racemis densis basi interruptis, pedicellis calycem fructiferum magnum subæquantibus infra medium articulatis, valvis reniformi-ovatis levissime cordatis breve acuminatis laxiuscule reticulatis eroso-denticulatis, unâ crasse calliferâ, reliquis nudỉs., $\mathcal{Y}$. - In Rossiầ mediâ et Sibiriâ Altaicâ. - Reichenb. ic. crit. 5 , p. 52 , t. 487 , Schult. fil. syst. 7 , p. $1436^{*}$, Led. fl. ross. 3, p. 509. Forsan R. conferti var., differt tamen foliis planis v. passim obsolete undulatis et præcipue valvis paulo majoribus, plerumque latioribus quam longis (4-5 lin.), acumine integro majore sapiusque acuto, margine distinctius denticulato (passim tameu integro), unius callo fortiore, reliquarum nervo vix tumidulo. Paniculæ racemi fasciculati. (v. v. c.)

4. R. CoNSPERSUs (Hartm. Scand., fl. p. 147), foliis elongatis subundulatis basi obtusis $v$. brevissime et sæpius inæqualiter attenuatis, infmis oblongis obtusis basi rotundatis emarginatisve, summis lanceolatis, paniculà laxâ, ramís patulis, verticillis discretis, valvis mediocribus late ovatis v. suborbicularibus sæpius obsolete obtuseque acuminatis tenuiter reticulatis basi denticulatis, unicâ calliferâ. $\mathcal{Y}$ In Europâ boreali, Sueciâl (Friès! herb. norm. fasc. 7 ). R. aquaticus $\beta$ conspersus Mert. et Koch Deutschl. 11. 2, p. 617, Schult. fil. syst. 7, p. 1427 obs. et 1728. R. cristatus Fries ! nov. fl. Suec. (non DC. nec Wallr.). R. acutus Fries $\lfloor$ herb. norm. fasc. 9. R. Hippolapathum Fries? ibid. 5. (fide sp. jun. in herb. Shuttlew., forsan ad R. aquaticum referendi). R. nemorosus Steven! mss, in herb. DC. (non Schrad.). R. HJdrolajathum Campd. Rum. p. 145? (non Huds.). - Speciés cum duabus præcedentibus $R$. acjuatico sane valde affinis, at diversa foliis infimis oblongis nec ovatis nec profunde cordatis nec basi latioribus

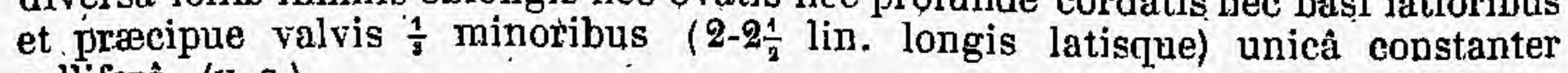
callifierâ. (v. s.) 


\section{\$2. Valva distinete serrulatoe $v$. inciso-dentatce, dentibus planis $v$. subulatis rectis $v$. uncinatis, calliferce $v$. rarius nudoe. - Sp. (primâ exceptâ) omnes herbaceo:}

48. R. G IGAN TE tis (Ait. h. Kew. ed. 2, 2, p. 323), fruticosus vel arboreus, foliis herbaceis petiolatis ovato-oblongis subcordatis longe acuminatis acutissimis subtus in nervis scabrido-puberulis, summis lanceolatis utrinque attenuatis, paniculâ terminali diffusâ laxiuseulâ basi foliosâ, pedicellis calycem fructiferum requantibus, valvis majusculis suborbicularibus cordatis acutiusculis tenuiter reticulatis eroso-denticulatis subecallosis. 5 . In nemoribus montium ins. Sandwich, 0-Wahu (Menzies, Gham.! Gaudich. n. 233 !). Frutex 40-ped. (ex Menz.). Folia ramea usque ad 9 poll. longa, $2 \frac{1}{3}$ poll. lata, petiolo bipollicari. Panicula magna, apice apliylla, ramis sùbsimplictbus patulis subsolitariis puberulis, pedicellis fasciculatis capillaribus prope basin articulatis apice obovato-incrassatis. Flores monoici. Valvæ $2 \frac{1}{2}-3$ lin. longæ, subacuminatre, venis tenuibus arcte reticulatæ; interstitiis sub lente pulchre cellulosis, ecallosæ v. passim nervo basi tumidulo. Achænii facies subrotundo-rhombere punctículatæ. (v. s. in h. DC., Kunth et Berolin.)

49. R. c RIst a t Us (DG.! cat. h. Monspel. $1813, j$. 139 , non Wallr.), foliis ovatis oblongisque, infimis amplis nbtusis basi rotundatis subundulatis, caulinis attenuato-acutis, summis lanceolatis, paniculâ subaphyllâ, racemis continuis brevibus densissimis, valvis magnis subrotundo-ovatis cordatis obtusis tenuiter denseque reticulatis infra medium eroso-serratis inæqualiter calliferis. $\mathcal{4}$ Patria ? - Campd. Rum. p. 66 et 104 , Schult. fil. syst. 7, p. $1436^{*}$. Folia infima elongatoovata vel oblonga, basi haud cordata. Panicula densa, racemis subsolitariis sessilibus indivisis, pedicellis, calyce fructifero magno longioribus. Valvse magnit. R. Patientiæ vel conferti, vix longiores quam- latæ, grossiuscule et insequaliter eroso-serratix, unius callo grosso subgloboso-ovato, reliquarum minoribus. Similis R. conferto et cordifolio, sed follis non cordatis valvisque distinctissimus. (v. s. c. ex horto Monspel. in h. DG.)

50. R. SYRIACUS, foliis petiolatis acutis, superioribus oblongis crenulato-crispulis basi rotundatis, summis lanceolato-linearibus brevibus, racemis indivisis apice apbyllis, verticillis approximatis dense multifloris infimis distantibus, valvis magnis suborbiculari-ovatis subacuminatis dense reticulatis subequaliter grosse graniferis, utrinsecus 5-7-dentatis, dentibus e basi latiusculâ subulatis rectis patentibus brevibus. $\%$ ? In Syriâa ad Giss El Hajar (G. Ehrenberg!). R. macropterus G. Ehrenb.! mss. (ex parte). Caulis superne ramosus, ramis simplicibus semierectis. Folia infima ignota. Verticilli summi contigui, pedicellis valvas æequantibus vel passim-longioribus, 3-5 lin. longis, demum vix incrassatis, medio vel paulo infra articulatis. Valvæ 3 lin. longæ et vix angustiores, callis subrqualibus grossis, dentibus dimidiam valva latitudinem requantibus vel.brevioribus $\frac{1}{2}-1$ lin. longis. Procedenti proxime affinis. (v. s. in h. reg. Berol.)

51.R. PEREGRINUS (Schult. fil. syst. 7, p. 1437*, non Boiss.), foliis radicalibus amplis ovatis profunde cordatis, caulinis ovato-lanceolatis acuminatis, racemis terminalibus et axillaribus patentibus, verticillis laxis superioribus aphyllis valvie majusculis cartilagineis cordato-reniformibus breve acuminatis grosse reticulatis dentibus utrinsecus pluribus subulatis rectis brevibus patentibus, unica callo parvo munitis. $\%$ Patria? Colebatur olim in h. Monacensi. Caúlis erectus, superne ramosus. Folia radicalia usque ad 14 poll. longa, 7 poll. lata. Racemi solitarii vel gemini, pedicellis gracilibus calyce fructifero longioribus, 2-4 lin. longis, infra medium articulatis. Flores ex magnâ parte steriles, decidui. Valva 2-3 lin. longæ, $2 \frac{1}{2}-3 \frac{1}{2}$ lin. latæe, dentibus dimidià earum latitudine brevioribus. Affinis dicitur $\mathrm{R}$. cristato $\mathrm{DC}$. et pulchro L., sed ab utroque satis distinctus.

52. R. овтUSIFOLIUS (Linn. sp. 1, p. 478), foliis infimis ovato-oblongis obtusis vel acuminatis cordatis, caulinis ovatis sublanceolatisque acutis basi rotundatis vel obtusis, summis sublinearibus utrinque attenuatis, paniculâ apice aphyllâ verticillis inferioribus distantibus, pedicellis, calyce fructifero mediocri subrequalibus, valvis $\theta$ basi ovatâ utrinsecus 2-4-dentatà in acumen deltoideum integerrimum acutiusculum attenuatis tenuiter reticulatis inæqualiter calliferis, dentibus lineari-subulatis patulis. $\mathcal{H}$. In ruderatis et humidis Europæ totius, 
reg. Taurico-Caucasicæ, Sibiriæe, Afghanistan (Griffith n. 1698?), ins. Canariens., Americe borealis, Brasiliæe (Widgren n. $\mathbf{7 0 5}$ ! in h. Sonder). - Campd. Rum. p. 86, Wallr. ! sched. p. 166 ! Mert. et Koch Deutschl. 11. 2, p. 610 (excl. $\gamma$ ), Schult. fil. syst. 7, p. 1404 , Ledeb. fl. ross. 3, p. 502 (excl. syn. Wallr.), Curt. fl. Lond. 3 , t. 22, Engl. Bot. t. 1999, Fl. Dan. t. 1834, Hayne Arzneigew. 13, t. 1. Lapathum sylvestre Lam. fl. f. 3, p. 4. L. obtusifolium Moench Meth. p. 356. Rumex lævigatus Willd.! herb. Spreng. syst. 2, p. 159, Schult. 1. c. p. 1402 et 1728. Ledeb. 1. c. p. 502. R. sylvestris Campd. Rum. p. 146 ? (non Wallr.). R. sepium M. Bieb. fide Steudel. R. patens Ind. sem. h. Berol. 1851, 1852 ? Variat staturâ, foliorum magnitudine, pedicellis 2-6 lin. longis crassiusculis et tenuibus gracilibus calyce demum passim longioribus, valvarum acumino brevi triangulari aut oblongo linguæformi; dentibus sæpe tarde excrescentibus abbreviatisque (valvæ latítudine semper brevioribus), callo uno majore ovato crassiusculo, reliquis sæpius obsoletis. - R. levigatus Willd. ! herb. $\mathrm{n}, 7043$, jnsignis est foliis radical. subpedalibus 7 poll. latis, obtusissimis, çeterum a plantî̀ vulgari nullo modo diserepat.

a. concolor (Wallr. sched. p. 167), foliorum venis cauleque viridibus. R. obtusifolius Linn. 1. c., Willd. sp. 2, p. 254, DG. f1. fr. 3, p. 575. R. Rugelii Meisn. in Pl. Rugel. exsicc. 1843 (forma foliis caulinis elongatis). (v. v.)

$\beta$. discolor (Wallr. 1. c. p. 168), foliorum venis cauleque parpureis. R. divaricatus Linn. fide Iries ! herb. norm. fasc. 7. (cfr. R. pulcher.) R. sanguineus Poir. dict. 5, p. 63, Campd. Rum. p. 85, t. 1, f. 4, Schult. fil. syst. 7, p. 1403 * R. sanguineus $\beta$ latifolius hort. Paris. Trevir. cat. h. Vratislav. (v. v.)

"R. CÁISPO-OBTUSIFOLIUS, caulis summitate ramisque gracilibús, foliis caulinis oblongis acutis planis e basi rotundatâ breve cuneato-attenuatis, summis lanceolatis, racemis laxis, verticillis remotis, pedicellis cápillaribus infra medium articulatis, valvis (juniorib.) parvis late ovatis obtusis prope basin brevissime serratodenticulatis vel subintegris, unâ calliferâ. - Circa S. Louis, Missouri. R. crișpoobtusus G. Engelm.! mss. in herb. reg. Bcrolin. Omnino hybrida videtur, valvarum dentíbus foliisque ad R. obtusifolium, ralvarum formâ et magnitudine ad $R$. crispum spectans, in juniore statu a R. pratensi vix dignoscenda. (v. s.).

53. R. PRATENSIS (Mert. et Koch! Deutschl. fl. 2, p. $609^{\circ}$ ), foliis elongatis, infimis cartlato-oblongis acutis, summis lanceolatis, paniculæ ramis aphyllis, verticillis approximatis, pedicellis calyce fruetifero mediocri longioribus, valvis late triangulari-ovatis subcordatis obtusis apice integerrimis inferne utrinsecus dentibus 8-6 brevibus triangularihus acuminatis subulatisque munitis inæqualiter calliferis vel duabus subnudis. $\mathscr{F}$ - In pratis Europæe passim et in region. Gaucasicis. Schult. fil. syst. 7, p. 1438, Engl. Bot. suppl. t. 2757, Koch syn. ed. 2, p. 706, Hook. et Arn.! Brit. Il. ed. 6, p. 359, Ledeb. fl. ross. 3, p. 503. R. acutus et oljtusifolius auct. plur. (ex parte). R. acutus M. Bieb. Taur.-Cauc. 1, p. 289, (teste Ledeb.). R. cristatus Wallr.! sched: p. $163^{\text {* }}$ (non DC.). R. adulterinus Wallr. mss., ex Linniseâ 14, p. 567. R. Oxylajathum Waltr.! miss. Hayne Arzneigew. 13, t. 2. R. ambiguus Gay mss. ex Gaudin Helv. 2, p. 589. Monente ipso Koch 1. c: forsan hybrida progenies ex R. obtusifolie et crisjo, luuic accedens foliis elongatis, illi tamen multo similior et vix tute distinguenda, preter folia infima magis elongata et pro longitudine angustiora, recedens priecipue pedicellis longioribus tenuioribusque et valvis plerumque minoribus basi subcordatâ latiore longitudinem æquantibus, acumine breviore et latiore, dentibus numerosioribus sed brevioribus rarius subulato-acuminatis, callo uno ovato mediocri, reliquis minoribus vel nullis. Fructus nunquam perfecti, teste Wallroth in Linnæeà 14, p. 82. (v. v.)

54. R. S U т т I o Bus (Boiss. diagn. pl. or. 5, p. 46*), caule elato sulcato, folij inferioribus amplis ovato-oblongis acutis basi rotundatis vel subcordatis undulatosubrepandis, superioríbus subsessilibus ovato-lanceolatis acutissimis, onrî̉bus ad nervos subtus asjero-puberulis, paniculæ ramis elongatis, verticillis subdistinetis, valvis mediocribus_subtrilobo-orbicularibus reticulatis, lobo terminali integro, lateralibus latioribus obtusioribus acute brevidentatis, unicà calliferâ. $\psi$ ? In pratis alpinis Tmoli Lydiæe (Boiss). Monente ipso auctore forsan hybrida ex $R$. crispo et hamaio (peregrino Boiss. nec Schult.) in quorum consortio inventa est. Caulis 4-5-ped. Fol. inferiora pedalia 4-5 poll. lata. Racemi aphylli? Vaive $2 \frac{1}{6}$ lin. longe lateeque, dentibus dimidiâ earum latitudine mul to brevioribus rectis. 
55. R. ST ENOPHYLLUS (Ledeb.! fl. All. 2, p. 58*, Icon. 1. 399, fl. ross. 3, p. 505), foliis lanceolato-oblongis utrinque attenuatis acutiuseulis planis vel subundulatis, superioribus lanceolatis linearibusque, janiculâ simplici foliosâ, racemis Juasi interruptis supra continuis, verticillis dense multifloris, pedicellis calyce fiructifero mediocri duplo longioribus tenuibus, valvis coriaceis late triangularibus olstusiusculis basi truneatis tenuiter dense reticulatis ineiso-serrulatis subrequaliter calliferis. $\%$ In hunidis Rossige australis prope Sareptam (Becker 1. 35!), Astraklran! et deserti Soongoro-Kirghisici Sibiriæe Altaicco (Karel. et Kiril. in h. Soc. imp. N. C. Mosqu. n. 1921 !), Cat. sem. h. Petropol. 1851, 1852. Racemí solitarii, sessiles, pedicellis capillaribus. Valvat haud cordatee, apice interdum integrce, dentibus triangularibus brevibus passim breviter subulatis, callis mediocribus ovatis, uno plerumque majore. A proximo affini R. pratensi differt foliis inferioribus non cordatis, valvis paulo minoribus (1-1: lin. longis latistue) acumine breviore obsoleto vel nullo interdum subdentato, etc. (v. s. in h. Ledeb. DC. etc.)

56. R. BREVIPES, foliis obtusis, caulinis inferioriluus ovato-oblongis subcoídatis, summis lanceolatis utrinque vix attenuatis brevissime petiolatis patentibus, racemis indivisis patenthus elongatis apiee aphyllis, verticillis reihutis paucilloris, pedicellis calyce fructifero mediocri brevioribus crassis, valvis ovatis obtusis reticulatis insequaliter calliferis utrinque 4-7-dentatis, dentibus subulatis tenuibus rectis vel passim subhamatis dimidiam valve latitudinem subrequantibus. W ? In Mexico inter Tampico et Real del Monte (Berlandier n. 243! C. Elırenberg n. 40 !). R. pulcher? C. Elırenb.! in herb. reg. Berolin. Caulis erectus, gracilis, superne ramosus. Folia radicalia ignota, caulina inferiora circ. 3 poll. louga, 1 poll. lata, petiolo semipollicari. Verticilli 3-6-vel infimi 8-12-1lori. Pedicelli $1 \frac{1}{2}-2$ lin. longi, medio vel paulo infra articulati. Valvis coriaceo-herbacce,

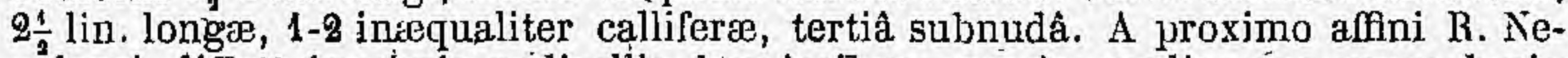
palensi differt inprimis pedicellis-brevioribus rassis, medio nec prope basin articulatis et callis parvis sépe obsoletis; a $R$. obtusifolio discrepat valvarum dentibus subulatis basi vix dilatatis, etc. (v.s.)

57. R. Nepalens is (Spreng. syst. 2, p. 159), divaricato-ramosus, toliis petiolatis acutis, radicalibus oblongis basi angustatâ subcordatis, caulinis ovato-oblongis basi rotundato-subcordatis, summis Innceolatis, verticillis remotis densifloris sumnis subaphyllis, pedicellis calyce fructilero majusculo sublongiorilous deflexis, valvis ovato-oblongis obtusis reticnlatis subulato-fimbriatis, unicâ obsolete calliferâ, subulis uncinatis dimidiâ valva latitudine vix longiơribus. $\mathcal{F}$ In Nepaliâ, Kamaun (Wall. list n. 17981), mont. Neilgherry peninsulid Ind. or. ult. 7000-8000 ped. (Wight! Leschénault n. 317! Metz n. 970!), Java (Zollinger 11. 2959 1), Il'ricà Capensi (Drège! Krauss!). R. Napalensis Meisn. in Wall. pl. Ls. far. 3, p. 64 et Linnal 14, p. 492, Wight ic. t. 1810. R. ramulossus E. Mey.! mss. in h. Drige. IR. uncinulatus Schrad.? Ind. sem. h. Goett. 1823, p. 5. Ilabitus et folia caulina R. obtusifolii. Caulis crussus, sulcatus. Fol. inflma usque ad jedem -longa, 2-3 poll. lata, sursum attenuata, basi lata rel paulo angustuta rotundata vel leviten sapiusque inarualiter cordata. Valve $2 \frac{1}{2}$ lin. longæ, $1 \frac{1}{3}-2$ lin. latic, apice integra, subulis utrinsecus $5-8$ vix unquam 1 lin. longis. (v. s.)

58. R. RAMULOSUS, patenti-ramosus, foliis petiolatis acutis e basi rotundatà sensim attenuatis, infimis elongato-oblongis, superiorilous lanceolatis, summis linearibus, racemis indivisis gracilibus sulıerne aphyllis, verticillis distantibus multifloris, pedicellis caljece fructifero najusculo sublongioribus, valvis ovatis obtusiusculis penninerviis utritisecus 5-8-dentatis, unicà calliferâ, dentibus patenitibus sủbülatis uncinatis valvise latitudinem subequantibus. $\psi$ ? In Syriâ circa Giss El Hajar, (G. Ehreuberg !). R. macropterus G. Ehrenb. ! mss. in herb. reg. Berolin. (ex parte). Caulis superne ramosus, ramis simplicibus patentibus vel adsceadentibtis. Folia crispulo-crenata, in venis subtus puberula, infinta 5-6-poll. longa, 12-16 lin. lata; petiolo 4-5-pollicari. Racemi elongati, basi tantum foligeri, jedicellis infra medium articulatis yalvas demum inquantibus vel longiuribus jurum incrassatis. Valvze $2 \frac{1}{2}-3$ lin. longa, subulis $1 \frac{1}{2}$-fere 2 lin. longis, nervis furtiter prominulis parallelis pateintibus prope marginem tantum anastomosanlibus (nec vere reticulatis) unius callo consjicuo miediocri, reliquarum nervo sirpius crássiusculo. Cet. R. Nepalensis. (v. s. in h. reg. Berol.) 
59. R. H A M t U (Trevir. in Nov. Act. Acad. Leop. Carol. 13, p. 174), foliis acutis inferioribus petiolatis ovatis et ovato-oblongis cordatis, summis subsessiflibus lanceolatis basi attenuatis, racemis indivisis strictis elongatis, verticillis distantibus densifloris summis subaphyllis, pedicellis calyce fructifero majusculo brevioribus crassiusculis; valvis suborbicularibus breve obtuseque triangulari-acuminatis basi subtruncatis dense reticulatis incequaliter calliferis subulato-dentatis, subulis utrinsecus 6-9 hamatis valvæ latitudinem subrequantibus. $\mathscr{Z}$ In Nepalià, Kamaon, ult. 7000 ped. (Strachey et. Winterbottom!), reg. alpinà Tmoli Asiæ min. (Boissier Balansa n. 352!). - Schult. fil. syst. 7, p. $1401^{*}$ 'R. tuberosa Roxb.! in h. Willd. m. 7044 (sp. jun. sed ex folis sine dubio huc spectans). R. Roxburghianus Schult. fil. l. c. p. $1402^{*}$ (non Wall.). R. jèregrinus Boiss. Diagn. 5, p. 46 (non Schult.), R. uncatus et uncinatus hort. R. Nejalensis hort. nonnull. Forsan R. Nepalensis var. vegetior, attamen notis indicatis satis distincta. Caulis erectus, validus, superne semipatenti-ramosus; folia minute undulato-crenulata, infima minus elongata et angustata; verticilli densiores; valvæ latiores (vix longiores quam latæ), subulis longioribus crassioribusque, callo uno magno avato, reliquis minoribus conspicuis vel tertio interdum obsoleto. (v. v. c. et s. sp.)

60. R. STEUDELIANUS, foliis lanceolatis obtusiusculis utrinque attenuatis, radicalibus petiolatis elongatis vel passim ovatis subcordatiscue, summis subsessilibus, racemis elongatis strictis subaphyllis, verticillis remotis, pedicellis calyce fructifero majusculo sublongioribus erassiusculis, valvis ovatis breviter et obtusiuscule acuminatis reticulatis subecallosis, subulis utrinsecus 4-6 tenuibus hamatis dimidià valvæe latitudine subbrevioribus. $\mathscr{H}$ In Abyssiniâ (Schimper n. 380 ) et 933 !). R. Steudelii Hochst.! in Schimp. pl. Abyss. exsicc. 1840 et 42 . A. Rich. tent. fl Abyss. 2, p. 229, Walp. Ann. 3, p. 292. Omnia R. Nepalensis, exceptis \& fol: adicalibus minoribus (cum petiolo 6-9 poll. longis, 1-1 $\frac{1}{2}$ poll. latis) et valvis herbaceis ccallosis, unius nervo tantum basi paulo incrasśato. Caulis erectus, simplex vel ramosus, ramis semierectis. (v. s.)

ß. cordifolius (A. Rich. in Voy. Abyss. 5, p. $229^{*}$ ), foliis infimis cordatis. In Abyssinia prov. Onodgerate. (A. Petit.)

61. R. EHRENBERGI , foliis petiolatis lanceolatis undulatis, infimis olstusis basi rotundatis vel breve attenuatis, superioribus utrinque attenuatis, summis linearibus, racemo indiviso stricto folioso, verticillis dense multifloris summis contiguis, pedicellis calyce fructifero mediocri brevioribus, valvis deltoideis longiuscule acuteque acuminatis reticulatis iniequaliter calliferis, dentibus utrinsecus $\mathbf{4 - 5}$ setaceo-subulatis rectis patentissinis valvæe latitudine demum, longioribus. $\mathscr{H}$ ? In Egyptō ad lacum Nenzaleh (G. Ehrenberg!): R. pectinatus G. Ehrenb.! mss. Caulis simplex vel basi ramosus et a basi florifer. Verticilli inferiores remoti pedicellis infra medium articulatis demum incrassatis passimque calyce sublongioribus, valva unius callo crasso ovato lovi, reliquarum minore. Species quasi ambigua. R. Nepalensem inter et R. dentatum, ab illo recedens valvis paulo minoribus et angustioribus, dentibus paucioribus haud uncinatis, 'callis majoribus; a posteriore valvis $\frac{1}{3}$ majoribus, dentibus numerosioribus $2 \cdot 3$-plo longioribus et callo, non minore quidem, sed non ad valvæ marginem usque extenso, margine igitur magis conspicuo et manifeste reticulato. (v. s. in h. reg. Berolin.)

62. R. DEN T A U U (Campd. Rum. p. 64 et $81^{*}$ ), foliis petiolatis subobtusis, inferioribus oblongis subcordatis, superioribus lanceolatis sublinearibusve basi subito cuneatis, verticillis discretis densifloris omnibus folio fultis, pedicellis calycem fructiferum mediocrem subrequantibus, valvis ovato-lanceolatis acuminatis acutis grosse calliferis utrinsecus 1-3-dentatis vel passim inermibus, dentibus subulatis rectis patentibus valve latitudinem subæquantibus. $\mathscr{H}$ ? In $\mathbb{E g y p t o}$ (Schimp. herb. Un. itin. n. 47 ! Bové n. 288 ! Ehrenb.?! Boissier ! etc.), Penins. Ind. or. (Heyne!). Kamaon (Strachey et Winterbottom !) Khasya (Griffith!). - Schult. fil. syst. 7, p. 1395 (descr. bona), Wallich list n. 1730 ! Meisn. in Wall. pl. As. rar. 3, p. 64. Caulis erectus, pelalis et ultra, simplex vel ramosus. Folia glabra, interdum supra basin rotundatam angustata subpanduræformia, sæpe crispato-undulata. Valvarum calli subequales, puncticulati. - R, dentatus Linn. Mant. p. 926, eujus diagn. et ic. citata (Dill. Elth. t. 158, f. 191) inter se dissentiunt, et R. dentatus Murr, in Comment. Goetting. 1774, p. 46, t. 10, et Houttuyn PH. Syst. t. 47, 
f. 2, cujus descr. et ic. etiam a stirpe nostrâ recedit, synonyma sunt valde dubia. (v. s.)

63. R. CALLOSIS'InUs, foliis infimis lanceolato-oblongis supra basin rotundatam angustatis superioribus lanceolatis basi obtusis, summis sublinearibus utrinque attenuato-acutis, racemo stricto simplici vel basi ramoso folioso, verticillis densissime multifloris superioribus contiguis, pedicellis caljce fructifero mediocri brevioribus crassiusculis, valvis coriaceis ovatis breve acuteque acuminatis æequaliter crasse calliferis, dentibus utrinsecus 2-3 subulatis rectís patentibus valvæ latitudinem sub'equantibus. $\mathcal{H}$ ? In Egypto circa Damiette et in insulis lacus Menzaleh (G. Ehrenberg (). R. Menzalensis et? quadridentatus (sp. jun.). G. Ehrenberg! mss. Caulis subsimplex. Folia infima longe petiolata, subpanduræformia, obtusiuscula, subundulata. Racemi laterales, dum adsunt, semierecti. Verticilli inferiores distantès, pedicellis prope basin articulatis. Valvæ omnes callo evato crassissimo totam fere valve faciem occupante $1 \frac{1}{2}$ lin. longo 11 . crasso sæpe rugoso-tuberculoso munitæ, dentibus tenuibus $1-1 \frac{1}{3}$ lin. longis. Forsan $\mathrm{R}$. dentati var.? attamen valvis $\frac{1}{3}$ majoribus ete. insigniter recedens. (v. s. in h. reg. Berolin.)

64. R. KцотzsGranus, foliis petiolatis, superioribus lanceolatis acutiusculis basi breve cuneato-attenuatis, panicula simplici, racemis indivisis elongatis semicrectis strictis ad apicem usque foliosis, verticillis dense multifloris superioribus contiguis, pedicellis calyce mediocri subbrevioribus, valvis ovato-deltoideis cum acumine medioeri subacuto tenuiter reticulatis subsequaliter calliferis, dentibus utrinsecus $2-3$ e basi latà subulatis rectis dimidià valvæ latitudine subbrevioribus. $\%$ ? In Nepaliâ (fide herb. Berolin.), Afghanistan (Griffith, n. 1697!-1699? sp. jun. et Journ. $\mathrm{n}_{*}$ 726). Caulis ramosus. Folia inferiora ignota. Pedicelli infra medium articulati. Calyx fructifer $1 \frac{1}{2}-2$ lin. longus, valvis sæpius obtusiuscu., oblongo valvâ dimidià angustiore, unius s’epius reliquis majore. Omña fere $\mathrm{R}$. dentati, sed valvarum dentes minus subulati, basi dilatati (marginem potius serratum reddentes) et calli faciem valvæ haud abscondentes, sed earum margine reticulato $\frac{1}{2}$ lin. la to cincti. (v. s. in h. reg. Berol. et Griffith.)

65. R. S тrictus (Link enum. 1. Berol. p. $350 \%$ ), caule erecto subsimplici, foliis petiolatis acutiusculis, infimis ovato-oblongis lanceolatisve basi rotundatis, summis lineari-lanccolatis utrinque attenuatis, verticillis omnibus folio fultis discretis demum remotis, pedicellis calyce mediocri brevioribus erassiusculis, valvis deltoideo-ovatis acutis fortiter reticulatis inæqualiter calliferis, dentibus utrinsecus infra medium 3-4 patentibus subulatis rectis vel hamatis valvæ latitudinem xquantibus. $\mathcal{F}$ In Syriæe montibus Cassii (Boissier!), Grusià et circa Constantinopolim (C. Koch), regno Mascato (Auclier-Eloy, n. 5281 !). - Schult. fil. syst. 7, p. $1397^{\circ}$, C. Koclı in Limnæà 22, p. 208. Caulis 1-2-pedalis, strictus, simplex vel basi pauciramosus. Folia sæpe subundulata, infima 2-3 poll, longa, petiolum æquantia, summa 1-1 $\frac{1}{2}$ poll. longa, patentia. Verticilli 8-12-flori, juniores subcontigui, fructiferi $\frac{1}{2} 1$ poll. distantes, pedicellis vix. 2 lin. longis deflexis. Valvæ $2-2 \div$ lin. longe, $1 \frac{1}{2}$ lin. latæ, coriace:e, dimidio superiore triangulari acutiusculo integerrimo, venarum reticulo denso grosse jrominulo, dentibus satis validis, callis ovato-oblongis, uno majore crasso. Differt a $R$. dentato valvis dimidio majoribus reticulatis, dentibus longioribus, callis inæqualibus; a R. pulchro iisdem notis et caule stricto subsimplici; a R. obtusifolio foliis minoribus, radicalibus non cordatis, valvis crassioribus, dentibus magis spinescentibus. (v. v. c. et s. sp.)

66. R. CHA LEPENS IS (Mill. dict. n. 11), caule ramoso, foliis cordato-oblongis acutis basi dentatis infimis amplis, floribus longe pedicellatis, valvis profunde subspinoso-dontatis. (2) In Aleppo. - Morison Hist. 2, p. 580, Campd. Rum. p. 142, Schult. fil. syst. 7 , p. 1473 . Folia infima $9-10$ poll. longa, 3 poll. lata. Flores verticillati, hermaphroditi, valvis nudis? Species vix nota.

67. R. R E T I U L A TUS (Bess. Ind. sem. l. Cremen. 1820), caule suberecto subsimplici, foliis petiolatis, infimis oblongis cordatis obtusiusculis, superioribus lanceolatis basi subangustatis, summis linearibus, verticillis omnibus folio fultis discretis, fructiferis remotis., pedicellis calyce sublongioribus, valvis subcoriaceis ovato-

- deltoideis subcordatis angustato-acutiusculis, inæqualiter grosse calliferis, dentibus utrinsecus 4-5 subulatis rectis patentibus valvæe latitudine longioribus. $\mathscr{Z}$ In Græciâ (Sartori! in herb. Zuccar.), prov. Caucasicis circa Tiflin (h. Ledeb. I), 
Bagdad (Nö̈, n. 1096!), - Spreng. Neue Entdeck. 3, p. 18, excl. syn. R. Ucranici. Schult. fil. syst. 7, p. $1398^{\circ}$, G. Koch in Linnæeâ 22, p. 207, Ledeb.! fl. ross. p. 501. Inter R. strictum et pulchrum medius, priori similior caule subsimplici, valvis callisque majoribus, sed discrepans foliis infimis cordatis et jedicellis subulisque longioribus, calýcis reticulatione tenuiore; a posteriore caule subsimplici, valvarum dentibus paucioribus duplo longioribus, etc., distinctus. (v. s.)

68. R. FOVEOLA'T US (Hochstett: in Lorent Wanderungen im Orient, 1845, ex Florâ $1845, p .26$ ), caule erecto, ramis adscendentibus, foliis petiolatis lanceolatis subundulatis, racemis foliosis, verticillis multifloris, pedicellis calyce paulo longioribus curvatis, valyis foveato-reticulatis omnibus calliferis utrinque acute 2-3-dentatis. 24? Circa Diarbekir.-Duchartre, Revue bot. 1, p. 223. A R. reticulato vix satis distinetus videtur valvarum dentibus paucioribus, pedicellis longioribus ; a R. pulchro differt issdem notis et ramis haud divaricatis.

69. Ћ. P U L H E R (Linn. sp. 1, p. 477), ramis divaricatis rigidis, foliis infimis cordatoolilongis sæpius panduræformibus, superioribus' lanceolatis acutis basi obtusis, summis linearibus, verticillis remotis superioribus aphyllis, pedicellis calyce brevioribus demum crassis, valvis cartilagineis mediocribus ovato-oblongís obtusiusculis reticulatis inæqualiter calliferis, dentibus utrinsecus $4-6$ validis rectis valyæe dimidiâ latitudine vix longioribus. $\mathcal{Z}$ In incultis siccis Europæ mediæ et austzalis, prov. Caucasicis-(Hohen.! Szovits! etc.), Syrix (G. Ehrenberg!), Africa borealis, ins. Ganar.! Maderse (Chamisso), cap. B.-Sp. (Ecklon et Zeph.! n. 5, 111), Brasilice (Saint.Hil.).-Morison Hist. sect. 5, t. 27, f. 13, Campd. Rum. p. 82*, Engl. bot. t. 1576; Reichenb. ic. crit. t. 486, Schult. fil. syst: 7, p. 1399 , Ledeb.! fl. ross. 3 , p. 501. R. divaricatus Linn. sp. 1, p. 477 (cfr. R. obtusifolius (3), M. Bieb. Taur.Cauc. 3, p. 279. R. uncinatus G. Ehrenb.! mss. in herb. reg. Berol. R. tuberculatus C. Koclı? in Linnæâ 22, p. 208. Lapathum sinuatum Lam. fl. fr. 3, p. 5. Valvæ ommes calliferæ, callo verruculoso, uno crassiore, 1-2 sape obsoletis. Variat præterea valvis ovato-oblongis, acumine integro longiore vel breviore, rarius ovatis, acumine breviore latiore vel obsoleto. (v. v. et s. sp.)

$\beta$ ! echinatus, valvis jassim dimidio majoribus, spinis fortioribus, callis crussis sæpe lævibus. In ins. Sardiniâ (Phil. Thomas !), ad pedem m. Libani (Meryon! in h. DC.). R. Agyptiacus Balbis! mss. in h. DC. R. spinosus Thomas! pl. Sardin. exsicc. B. sulfocatus Moris, teste Balbis ! in h. DC. Planta naua, digitalis, quasi acaulis, primo vultu a typo valde discrepans et ad R. Aggytiacum accedens, sed procul dubio statum abnormem sistens, evidenter mutilatione caulis primarii et evolntione ramorum brevium ex ejus basi productâ. Valvæ ex parte haud minores quam R. Nepalensis. (v.s.)

70. R. R A U L IN I (Boiss.! diagn. -pl. or. n. 12, p. $100^{*}$ ), catule erecto validorangulatosulcato dichotomo, foliis radicalibus longe petiolatis parvis oblongo-ovatis bbtusis basi breve attenuatis minute undulatis, verticillis remotis omnibus folio lizearilanceolato fultis, pedicellis fructiferis deflexis crassis induratis apice incrassatis calyce sublongioribus, valvís triangularibus reticulatís inequàliter callileris utrinsecus spinulis $4-6$ rectis validis sepe bicuspidatis valvæ latitudine longioribus

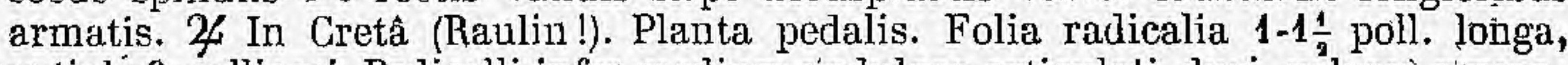
petiolo 3-pollicari. Pedicelli infra medium noduloso-articulati, duri, valvam æequantes vel paulo longiores. Valvæ $2 \frac{1}{2}$ lin. longæ, acumine oblongo acutiusculo subdenticulato, callis oblongis ruguloso-tuberculatis, mo majore, spinulis subulatis compressisve, unâ alterave in plerisque valvis apice breviter bifidis nuvquam hamatis. Species insignis, R. pulcluro, precijue $\beta$ echinato, proxime accedens, sed valvis bene distincta. (v. s. in h. Boiss.)

11. R. DeN t I G L a t U S (C. Koch! in Linnæê, 22, p. 208, non Campd.), glaberrimus, erectus, ramis divaricatis, foliis petiolatis oblongis margine crispulis, verticillis distantibus foliosis summis aplryllis, valvis orato-oblongis reticulatis dentieulatis calliferis, callis duobus obliteratis. $\Varangle$ ? In planitie prope Araxen (C. Koch !). Sjaecies obscura, ex specimine juniore insufficienter descriptâ, monente cl. auctore forsen mera var. R. obtusifolii, nobis potius R. pulchri statum juniorem exhibere videtur, a quo vix differt nisi pedicellis calyce longioribus 5-6 lin. longis. (v. s.)

72. R. LA p p U L A, ramis semipatentibus strictis, foliis caulinis breve petiolatis ovatooblongis acutis basi rotundatis, summis subsessilibus lanceolatis utrinque attenuatis, paniculâ simplici basi pauciloliă, verticillis distantíbùs densifloris, pedi- 
cellis calycem fructiferum parvum subrequantibus crassiusculis, valvis coriaceis ovatis breviter obtuseque subacuminatis nervosis, duabus grosșe calliferis tertia subriuda, dentibus utrinsecus 5-6 subulatis hamatis dimidia valve latitudine brevioribus. $\mathcal{F}$ Patria? Cadulis crectus. Folia undukato-crenulata, radicalia ignota. Racemi terminales et axillares solitarii, indivisi, fere aphylli, pedicellis infra medium articulatis. A proximo R. pulchro discrepat valvis paulo brevioribus (vix 2 lin. longis), acumine precipue dimidio breviore et magis triangulari, callis haud verruculosis, dentilous brevioribus et distinctius uncinatis. (v. v. c. in lorto Genev.)

73. R. UCRÁNI G US (Fisch. Cat. h. Gorenki, 1812, p. 16), caule hưmili patulo-ramoso, foliis omnibus petiolatis acutis basi obtusis, caulinis oblongo-lanceolatis linearibusque undulato-crispulis basi sulttruacatis vel panduriformi-auriculatis, verticillis remotis folio fultis, pedicellis calyce fructifero parvo sublongioribus, valvis ovatis subulato-acuminatis omnibus grosse calliferis, dentibus utrinsecus 2-4 setaceis patentibus valvâ brevioribus. (- In Rossiâ mediâ et australi (Becker, n. 36 I), Sibirịâ Uralensi et orientali._Campd. Rum. p. 64 et $80^{*}$, Besser in Florâ 1832, 2. Bcilll. p. 15, Schult. fil. syst. 7, p. $1393^{*}$, Ledel. fl. ross. 3, p. 501. R. maritimus Gcorgi! (fide Ledeb.). R. persicarioides, crispatulus et pulcherrimus hort. et herb. plur. Lapathum rubellum Moench. Accedit ad R. palustrem, sed vegetatione annuâ, foliorum formâ et omnibus partibus minoribus tenuioribus distincta. Valvarum dentes subulati, tenues, recti, ipsarum latitudinem requantes. (v. v. c. et s. sp.)

74. R. PERS I A R I O IDES (Linn. sp. 1, p. 477, non Thunb.), caule humili ramosissimo, foliis infimis ovato-lanceolatis, ,summis lincaribus, verticillis remotis folio fultis, pedicellis gracilibus, valvis parvis ovato-oblongis subacuminatis omnibus grosse calliferis, dentibus utrinsecus 3 valvam æquantibus. $\odot$ In liumidis, fossis sylvisque Americæ lor. et Putagoniæe.-Pursh f1. bor. Am., 1, p. 248, Campd. Rum. p. 64 et $79^{*}$, Schull. 1, c. p. 1392, Hook. et Arn. bot. Beech. p. 158 ? Hook. fl. bor. Am. 2, p. 130? (cfr. R. maritimus). Præter foliorum formam a priecedente vix differre videtur,

75. R. GRISPATULUS (Michaux f1. lor. Imer. 1, p. 217), foliis crispato-undulàtis, infimis ovalibus, superioribus lanceolatis, verticillis superioribus aphyllis, valvis obtuse cordatis utrinque cristato-tridèntalis, 2 inæqualiter calliferis, tertiâ nudâ. OIn Kentucky.-Pursh 11. bor. Am.1, p. 248, Campd. Rum. p. 65 et 88. R. crispatus Pers. ench. 1, p. 1395 ? Species non satis nota, præecedenti nimis affinis, sed præter notas indicatas floribus majoribus differre dicitur.

76. R. MARITIMUS (Linn. sp. 1, y. 478), foliis lanceolatis acutiusculis utrinque attenuatis vel infimis oblongis basi obtusis, verticillis densifloris omnibus folio lineari patenti fultis superioribus confluentibus, pedicellis tenuibus calyce fructifero parum longioribus, valvis rhombeo-ovatis cum acumine lanceolato acuto integerrimo omnibus calliferis deutibus utrinsecus 2 setaceis patentibus rectis valvam æquantibus vel longioribus. (2) In paludosis et fossis jriereipue salinis Europæe! Taurix, Sibicix! et? Amer. bor.- Engl. bot. t. 725, F]. dan. t. 1208, DC. fl. fr. $\mathrm{s}$, p. 375 , excl. $\beta$. Camp. Rum: p. 63 et $76^{*}$, Wallroth sched. 1, p. $169^{*}$, Seliult. fil. syst. 7, p. 1390, Ledeb. f1. ross. 3, p. 500. R. Anthoxanthum Murr. prodr. p. 52. R. aureus Wither. 1. 356. R. acutus Poll. palat. 1, p. 359 (non Linn.). R. persicárioides Hook: fl. bor. Am. 2, p. 130 ? Lapathum minus Lam. fl. fr. 3, p. 4. Variat staturâ digitali et 1-3-pedali, caule subsimplici et patulo-ramoso, foliis inferioribus 3-10 poll. longis, 1-1 $\frac{1}{2}$ poll. latis planis vel subundulatis, floribus in singulis verticillis confertissimis vel puucioribus, calyce fructifero majore vel minore, dentibus longioribus vel brevibus (nunquam tamen valvâ brevioribus). Inflorescentia demum flavida, sepe densissima, verticillis haud raro omnibus contiguis. (v. v. et s. sp.)

77. R. Palustris (Smith ! fl. Brit, 1, p. 394*, Engl. fl. 2, p. 194), foliis lanceolatis utrinque attenuatis acutiusculis, verticillis remotiusculis densifloris omnibus folio lineari patenti fultis, pedicellis fructiferis calyce vix longioribus, valvis ovatooblongis cum acumine lanceolato acuto integerrimo ommibus calliferis, dentibus utrinsecus 2-3 setaceis patentibus rectis valvâ brevioribus. (2) In paludosis Europæ passim, in Sibiriâ et Davuriâ.-Campd. Rum. p. 63 et 78, Mert. et Koch Deutschl. fj. 2, p. 614*, Sclurlt. fil. syst. 7, p. 1388, Engl. bot. t. 1392, Fl. dan. t. 1873, Ledeh.! fl. ross. 3, p. 500. R. maritimus Wither. Arrangem. p. 356, Hoffm. D. fl. 1, p. 172, Schkuhr, t: 100 ? $\beta$ Éuds. Añgl. p. 155, DC. fl. fr. 3, p. 375. R. limosus Thuill. ! fl. 
Paris, ed. 2, p. 182. Species nonnisi in statu fructifero a R. maritimo tute dignoscenda, nempe verticillis tunc semper distantilus, valvis panlo majoribus, callis grossioribus et dentibus brevioribus (latitudinem valvæ vix superantibus), fortioribus, rigidioribus sæpiusque basi dilatatis. (v. s.)

78. R. S т в IN I (Becker! fl. francof. p. 165), foliis radicalibus late oblongis cordatis, caulinis e basi rotundatâ lanceolatis, summis linearibus, verticillis remotis, superioribus approximatis aphyllis, pedicellis calyce fructifero longioribus, valvis ovatis apice protracto integerrimis omnibus calliferis, dentibus utrinsecus 2 seta-

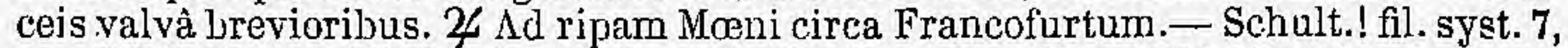
p. 1390*, Sturm Abbild. fasc. 73, n. 3, Koch syn. ed. 2, p. 704. Species insignis, a præcedentibus notis indicatis et a R. conglomerato, cui etiam similis, valvis dentatis facile dignoscenda. Cfr. Babington in Henfrey Bot. Gazette, nov. 1849, n. 11, Schlecht. Bot. Zcit. 1850 , p. 274. (r. s.)

79. R. ULIGINos us (Guss. pl. rar. Neap. 1826, p. $151^{*}$, t 29), foliis utrinque attenuatis acutis, radicalibus breve petiolatis lineari-oblongis margine eroso-crispis, caulinis subsessilibus angustissimis, verticillis distantibus dense multifloris omnibus folio fultis, pedicellis calycem fructiferum parvum æquantibus, valvis ovatolanceolatis acutis omnibus grosse calliferis, dentibus utrinsecus $2-4$ subulatis rigidis patentibus valvæ latitudinem subæquantibus. $\odot$ In humidis et uliginosis Aprutii prope lacum Fucinum.-Boccone Mus. t. 104. Radix comoso-fibrosa. Caulis a basi patenti-ramosus et florifer, ramis simplicibus strictis. Folia radicalia 6-7 poll. longa, 6-8 lin. lata, acutiuscula, caulina 1-2 poll. longa, 1-1\% lin. lata. Verticilli vix summi contigui. Valvis $1 \frac{1}{2}$ lin. longæ, ex ic. hand reticulatæe, callis oblongis, dentibus ex ic. utrinsecus 4, ex diagn. 2-3. Forsan a R. Steinii aut palustri haud distincta.

80. R. Chinensis (Campd.! Rum. p. 63 et $76^{\circ}$ ), foliis petiolatis lanceolatis acutis utrinque attenuatis, radicalibus elongatis subundulatis, verticillis densifloris discretis omnibus folio lineari fultis inferioribus remotis, pediccllis calycem fructiferum mediocrem sequantibus, valvis ovatis acuminatis omnibus grosse calliferis, dentibus utrinsecus infra medium 1-2 subulatis rectis patentissimis valvâ sublongioribus. \& In Chinâ (G. Stauton! typus, Millet, Beechey), Bengaliâ (Hamilt.!), sillet (Wallich!), Assam (Wall.! et Griffith!!), Cochinchinâ (Lour.), Japoniâ ? (Thunb.). Schult. fil.syst. 7, p. $1388^{*}$, Hook. et $\Lambda$ rn. bot. Beech. p. 208. R. setaceus Hamilt. mss. Meisn. in Wall. pl. As. rar. 3, p. 64. R. Roxburghianus Wall list n. 1731, 1 et 2 partim. R. persicarioides Thuub. 11. jap. p. 148 ? (non Linn.). R. crispus Lour. Coch. p. 269 ? (non Linn.). R. Loureirii Campd. Rum. p. 142? R. Loureirianus Schult. l. c. p. 1474. R. denticulatus Campd. p. 143? Schult. l. c. (non G. Koch). A simillimo R. maritimo differt valvis majoribus ( $1 \frac{4}{2}$ lin. longis), dentibus pancioribus, etc., a $R$. palustri dentibus valvam seqnantibus vel longioribus, etc. (v. s. in h. DG., soc. linn. Lond, et comm. a cl. Wall.)

81. R. GARIPENSIs (Meisn. in Linnæà 14, p. 491*), fuliis petiolatis acutis undulatis, infimis oblongis basi sulucordato-rotundatis, superioribıs lanceolatis, verticillis remotis vel superioribus contiguis omnibus folio lincari fultis, valvis parvis ovatis breve acuminatis reticulatis, unâ grosse calliferâ, reliquis subnudis, dentibus utrinsecus 2-3 setaceis rectis valrà sublongioribus. $\odot$ ? In umbrosis ad fl. Garip Africæ Capensis (Drège!) R. maritimus E. Moy.! en. pl. Drège exsicc. A proximo R. Marshalliano distinguendus caule ramoso, foliis, valvarum dentibus tenuioribus, etc.

o. elatus (Meisn. l.c.), caule gracili ramisque erectis, verticillis romotis. (v.s.)

$\beta$. humilis (Meisn. l. c.), caule brevi basi depresse ramoso, vertjcillis subconfluentibus. (v. s.)

82. R. Marschallianus (Reichenb. ic. pl. rar. 4, p. $56 ; 6$, p. 13, t. 516), caule sub simplicissimo gracili, foliis petiolatis oblongis lanceolatisque obtusis vel summis acutis basi attenuatis, verticillis remotis omnibus folio fultis, calyce parvo 6-partito, valvis ovatis longe acuminatis reticulatis, unâ (rarius 2) grosse calliferâ, dentibus utrinsecus 2-4 sotaceo-subulatis patentibus valvam subsequantibus vel longioribus. $\odot$ In Rossia australi secus Wolgam (Becker, n. 34, al) et mare Caspium! Tauriâ, Sibiriấ Uralensi et Altaicâ! deserto Soongoro-Kirghisico! Ledẻ.! I1. alt. 2, p. 59, Fl. ross. 3, p. 499. h. Egyptiacus Linn. sp. 1, p. 477, Pall. M. Bieb. Taur.Cauc. 1, p. 290 (éxcl. syn. præter Pall.), Campd. Rum. p. $74^{\circ}$; Schult. fil. syst. 7, 
p. 1385. Caulis erectus. Valvæ 2 vel plerumque unica callo grosso præeditæ. Simillimus quidem sequenti, sed notis jam indicatis et præcipue flore 6-partíto,6-andro 3-gyno bene distinctus. A R. Ucranico jam caule subsimplici, foliorum formâ, valvís majoribus et duobus plerumque nudis differt. Species etiam in \&gypto et Sardiniâ crescere dicitur. ajud Schult. et Spreng., sed procul dubio ex errore vel confusione cum R. comoso et pulchro. (v. s.)

$\alpha$. longidens, valvarum dentibus ipsis longioribns.

$\beta$. brevidens (Ledeb. f1. ross. 3, p. 500), valvarum dentibus ipsas non superantibus vel brevioribus.

83. R. comosus (Forsk: fl. ægypt. arab. p. $76^{*}$ ), caule humili vel subnullo, foliis petiolatis oblongo- yel lineari-lanceolatis undulatis utrinque attenuatis vel basi obtusis, verticillis densissimis omnibus folio fultis, calyce parvo 4-vel rarius 6-partito, valvis ovatis acuminatis reticulatis, unâ grosse calliferâ, dentibus utrinque 2-4 setaceo-subulatis valvà multo longioribus, superioribus suberecto-porrectis. $\odot$ In Egypto circa Girghe (Sieber! Bové, n. 287!), Benisnef, Cahiram, Pyramid. (Ehrenberg !), ad ripas Nìli (Boissier !), -Campd. Rum. p. 149. Schult. fil. syst. 7, p. 1387 *. R. Aggyptiacus Reichenb. ic. pl. rar. 4, p. 58, Sieber! h. Egypt. R. Egyptius Boiss. 1 mss. pl. Ag. exsicc. Caulis simplex vel patenti-ramosus vel subabortivus. Verticilli subconfluentes raro distantes. Valva major 1-i lin. longa, altera minore nuda vel rarissime callo minore prædita, dentibus inferioribus 3-5 lin. longis patentissimis rectis.

a. subacaulis, caule ramisque abbreviatis ( $\frac{1}{2}-1$ poll. longis), verticillis in spicam basilarem densissimam cylindricam vel subglobosam capituliformem congestis, floribus plerumque 4-partitis, 4-andris, 2-gynis, achanio lenticulari. Forma vulgaris. (v. s.)

B. caulescens, caule conspicuo $\left(\frac{1}{2}-1 \frac{1}{2}-\right.$ pedali), verticillis discretis demum distantibus, floribus plerumque 6-partitis, 6-andris, 3-gynis, achænio triquetro. (v, s.)

84. R. BRownir (Campd.;! Rum. p. 64 et 81 "), caule ramoso, internodiis elongatis, foliis caulinis petiolatis e basi latiore truncato- vel subhastato-rotundatâ elongatolanceolatis acuminatis acutis subundulatis, racemis indivisis elongatis aphyllis, verticillis remotis 5-8-floris, pedicellis calyce fructifero parvo sublongioribus crassiusculis, valvis ellipticis subulato-acuminatis reticulatis ecallosis fimbriato-dentatis, dentibus utrinsecus 3-5 subulatis hamatis valve latitudinem subæquantibus. 24 Circa Port-Jackson et in montibus cœruleis Novæ-Holl. orient. (Lesson l), Adélaide (Ferd, Mïller !). R. fimbriatus R. Br. prodr. p. 421 (non Poir.). R. Brownianus Schult. fil. syst. 7, p. $1395^{*}$. Folia radicalia ignota. Pedicelli infra medium articulati. Accedit ad R. pulchrum, sed differt caule gracili, ramis haud divaricatis valvis nudis, dentibus hamatis. (v. s. in h. DG. et Kunth.)

85. R. D R U M ONDIt (Meisn. in Enum. pl. Preiss. 2, p. 272 \%), caille ereeto ramisque simplicibus strictis, foliis oblongo-lanceolatis acutis minute undulato-crispulis basi obtusis, inferioribus longe petiolatis, summis linearibus, racemis longis aphyllis, verticillis remotis 8-12-floris, pedicellis fructiferis deflexis calyce longioribuis incrassatis apice turbinatis, valvis ovatis lineari-acuminatis reticulatis ralliferis vel tertiâ nudâ, dentibus utrinsecus $1-3$ subulatis rectis vel subhamatis valvæe latitudine brevioribus. $\mathscr{\Psi}$ ? In Novâ-Hollandiâ austro-occid. ad fl. Cygnorum (Drummond, 11. 207! 703 ! et? 291, Mangles!). R. Brownii Schlecht.? in Linneit $20, p .576$, cujus valvie dicuntur subulis rectis armatæe et sepala exteriora " in carinà muricù:ı unicà serie instructâ., " Forsan R. Brownii var., attamen constanter recedens pedicellis longioribus, valvis distincte calliferis, acumine lineari-subulato nec setacen, marginibus 1-3,dentatis nec fimbriatis. (v. s.)

86. R. MULLERI, raule erecto simplici, foliis elongato-lanceolatis obtusiusculis basi subito attenuatis margine integerrimo planis, summis linearibus, vertícillis axillaribus longe remotis, summis approximatis aplryllis, pedicellis fructiferis nutantibus circa medium articulatis calyce longioribus rigidis apice turbinato-incrassatis, valvis majusculis triangulari-ovatis obtusiusculis obsolete reticulatis calliferisque prope basin utrinque spinulis 1-2 crassiusculis rectis patulis valwæ latitudine brevioribus armatis. భ ? Circa Melbourne Anstralice Felicis (Dr Ferd. Müller!). R. Drummondii Nüll. (non Meisn.). Proxime quidem præcedenti affinis, sed distinctus foliis egregie attenuatorelongatis, usque ad 10 poll. longis, 6-8 lin. latis, 
margine haud crispulis, racemo foliaso, calyce plus dimidio majore, valvis haud

- acuminatìs dentibusque fortioribus rectis. (v. s. comm. a cl. Sander.)

87. R. GUNNINGAмI , caule diffuso-ramosissimo, foliis superioribus subsessilibus lanceolatis linearibusque utrinque attenuatis acutis, verticillis remotis $\mathbf{3}$-8-floris summis demum aphyllis, pedicellis calyce fructifero parvo sublongioribus vix incrassatis, valvis rhombeis cum acumine lineari acuto ipsis sublongiore venosis ecallosis prope basin utrinque dente hrevi subulato recto patente armatis. $\Varangle$ ? Circa Wangaroa, Nov.-Zelandiæe (A. Cunningham !). R. fimhriatus A. Cunn.! in Ann. of nat. hist. 1, p. 455 (non R. Br.). R. Brownianus Raoul Choix p, 42, A. Rich. in d'Urville, Voy. Astrolab. p. 177. R. flexuosus Forst. ? ex Spreng. syst. 2, p. 162, mant. 1 , fl. hal. p. 38 . Forsan stirjis nostræe status junior, valvarum dente parvulo facile præterviso. Species distinctissima, a præcedentibus facile dignoscenda. hami patentes vel adscendentos, subsimplices. Folia infima ignota. Vạlvarum dentes ipsarum latitudine subbreviores. (v. s. comm. a cl. Heward.)

$\beta$. Hookeri, foliis angustc lipearibus, pedicellis fruetiferis incrassațis, valvarum acumine recụrvo marginibus utrinsecus longiuscule 3-4-spinulosis, nervo carinato interdum spinifero. In Novâ-Zelandiâ. R. flexuosus Hook. fị. fl. Nav.-Zel. 2, p. 211 (non? Forst. et excl. syn. Campd.)

88. R. Dumosus (A. Cumningh. $1 \mathrm{mss}$,), diffuso-ramosissimus, ramis divaricatis filiformibus, foliis subsessilibus lanceolatis utrinque attenuatis acutis undulatocrenulatis, fascičulis axillaribus 2-5-floris, pedicellis rigidis crassiusculis calycem fructiferum mediocrem suberquantibus, valvis triangulari-ovatis acuminatís dense reticulatis ecallosis, acumine linoapi-subulato plano, dentibus utrinsecus infra medium 1-3 subulatis rectis brevibus. $\mathcal{F}$ In Nov.-Holl. orient. subtrop. (A. Cunningham 1), Liverpool Plains et mant. Coeruleis (Lesson 1). Planta insignis, caule suffruticoso, ramis longis intricatis ad apicem usque foliosis massas amplas, rotundas (more Mï̈llenbeckiæ complexæ) formans, pedicellorum medio articulatorum basibus persistentibus recurvis spinulas axillares mentientibus. Felia infịna ignota. Valva fere 2 lin. -longæe, $1 \frac{1}{2}$ lin. late, infra medium utrinque dentibus 1-2 (raro 3) basi latioribus dimidiam earum latitudinem rix æquantibus armatse, acumine triangulari-lineari njice-subulato dimidiam valvam sistente. $(\nabla . s$. in $h$. Gunningh., DG., Kunth, soc. linn. Lond. et comm. a cl. Heward.)

89. R. BUGEPHAL OPH OR US (Linn. sp. 1, p. 479), caule humili subsimplici.erecto vel adscendente, foliis petiolatis ellipticis vel lanceolatis acutiusculis vel infimis spathplatis subrotundisve, summis linearibus, racemo indiviso apice aphyllo, verticillis remotis 2-5-floris, pedicellis inarticulatis arcuato-deflexis demum clavatoincrassatis induratis calyce longioribus, valvis parvis deltoideis subecallosis, dentibus utrinsecus $2^{x}-4$ subulatis patentibus. $\odot$ In arenosis, præsertim maritimis circa mare Mediterraneum, Europee australis totius, Africæ borealis (Poir. Desf, Bové! etc.), Syriæ (G. Ehrenb!), ins. Azoric. (T.-C. Hunt.!), Canariens. (Brouss.! Webb I Blauner !), Mauritii (Sonneral).-Campd. Rum. p. 139, t. 3, f. 2, Schult. fil. syst. 7 , p. $1472^{*}$, Cav. ie. p. 456 , t. 41 , f. 1, Gaertn. fr. 2 , p. 180, t. 119, f. 2, Lam. ill. t. 271, f. 5, Sibth. et Sm. fl. græe. t. 345. R. aculeatus Linn. sp. 1, p. 481, Gampd. p. 141, Schult. l. c. p: 1473 (ex cit. Baul. et ic.). Lapathum bucephalophorum Lam. A. fr. 3, p. 7. R. membranaceus Poir. Voy. en Barb. 2, p. 155. R. Creticus Campd. p. 149 ? Radix fibrosa. Caulis 1 poll. usque ad 2 ped. altus, simplex vel basi pauciramosus. Variat præterea foliis latioribus angustioribusque et præcipue (secundum maturitatis gradum) pedicellis calyce fructifero parum vel demum duplo longioribus plus minus incrassatis, nonnunquam (v: g. in specim. Algeriens. Bové) 4-5 lin. longis apicem versus fere $1 \frac{1}{2}$ lin. latis valde arcuatis supra fortiter convexis subtus profunde concavis fere cochleariformibus, et valvarum spinulis brevioribus vel longioribus plus minus rigidis rectis vel uncinatis interdum (v. g. in specim. Syriacis Elirenherg) valde incrassalis. Cfr. Steinheil in Ann. sc. mat. 2. sér. 9, p. 193, 199, t. 7, fig. 1-15. (v. v. et s. sp.)

90. ?R. FI M B I I T U S (Poir. dicl. 5, p. $65^{*}$, non R. Br'), radice tuberosấ, cạle herbaceo sarmentoso ramoso, foliis carnosis petiolatis subcordatis subrepandis, racemo terminali, vorticillis 3-k-4loris, pedicellis brevibus tenuibus medio articulatis, valvis (precipue apicem versus) tenuiter laciniato-fimbriatis subplumpsis. - Ad caput B.-Sp. - Campd. Rum. p. 138, Schult. fil syst. 7, p. 1471. Species valde ohscura, radiče tuberosâ et foliis carnosis ad sect. Acetosam accedens, floribus hermaphro- 
ditis vero et reliquis notís potius $R$. Nepalensi et pulchro, ex auctore R. Lunariœ affinis. Caules ex Poiret nodosi, perduli, ex Bosc decumbentes.

\section{Sectio i. Acetosella.}

Flores dioici. Calyx fructifer clausus, non auctus, achæenio arcte adpressus et vix major, valvis herbaceis immutatis integerrimis valvatim contiguis. Herbæ acidæ, folits sagittato- vel hastato-laciniatis integrisve, floribus paniculatis parvis.

01. A. A oet osel a (Linn. sp. 1, p. 481), caule erecto símplici vel ramoso, foliis omnibus petiolatis lanceolatis vel linearibus hastato-trilobis integerrimisve, paniculâ aphyllâ, pedicellis brevibus apice articulatis, valvis ovatis obsolete venosis ecallosis, sepalis exterioribus vix minoribus adpressis. 24 In pratis siccis, ericetis, arenosis totius fere orbis, sed in plurimis, nisi omnibus, regionibus extra Europam et Sibiriam verisimiliter haud indigena, in Europá a Laponià ád Mediteṛranoum, in region. Caucasicis! Asià australi, occidentali, boreali et arcticâ $!$ ins. Canar. (Webb ! Bourgeau, n. 546), Africâ boreali (Bové!) et australi (Thunb. Drège! 8036, ex parte, Krauss, n. 793 I), Novâ-Hollandiâ (Verreaux, n. 48!), ins. Philippinis (Cuming, n. 2461 I), Maclovianis (Gaudich.I d'Urville! Hook. fil.), Chili (Philippi I Gl. Gay), Amer. hor. a Floridâ (Rugel I) ad Canadam. - Curt. fl. Lond, 5, t. 29, Engl. Bot. t. 1674 , Campd. Rum. p. 120, t. 2, f. 4. Wallr. sched. 1, p. 185*, Mert. et Koch, Deutschl. 11. 2, p. 620, Schult. fil. syst. 7, p. 1455, Hook. fl. bor. Amer. 2, p. 129, Boiss. Yoy. en Fisı. p. 551. C. Koch in Linneê 22, p. 211, Ledeb. fl. ross. 3, p. 511, Hook. fil. antaret. Voy. 2, p. $3 \$ 1$. Acetosa Acetosella Mill. dict. n. 2. A. hastata Moench Meth. p. 357. Lapatlium Acetosella Scop. Carn. ed. 2, p. 439. Lapathum arvense Lam. I. Ir. 3, p. 8. Varietates sequentes, etiainsi per formas intermedias subconfluentes, distingui possunt:

$\alpha$. latifolia (Wallr.! sched. 1, p. 186), foliis hastatis, lanceolatis vel radicalibus ovato-oblongis, auriculis divergentibus patentibus vel retrorsis interduns dente auctis, caule subsolitario elatiore subsimplici. Tabern. ic. t. 429, fig. dextra. (v. v.)

ß. integrifolia (Wallr. 1 1. c.), foliis oblongo-vel lineari- lanceolatis basi attenuatis integerrimis vel passin auriculâ unầ vel duabus obsoletis præditis, caule elatiore subsimplici. (v. v.)

y.? Adscensionis, foliis longisșime petiolatis (petiolo laminam 2-3-plo superante), lanceolata-trilobis vel basi breviter patenti-auriculatis vel passim suhiptegris, bracteis ovato-lanceolatis caudato-acuminatis diaphanis flores longe superantibus. Ex ins. Adscensionis (Ecklon $!$ in h. Mart.) $\$$ ignota. (v.s.)

\&. vulgaris, foliis hastatis vol satittatis, lobis anguste lanceolatis vel linearibus integris, caulibus subcæspitosis erectis ramosis humilioribus. Tabern. ic. t. 440 , Fl. dan. t. 1161 . R. Acetosella $\beta$ minor Wallr.! in h. DG. R multifidus $\beta$ Szovits I mss. in h. DG. (v. v.)

s. gracilis, foliis hastatis vel sagittatis, lobis linearibus elongatis vel lateralibus subfliformibus integris, caulibus subsolitariis gracilibus. Tabern. ic. t. 441, fig. sinistra. (v. v.)

9. procurrens (Wallr. l. c. p. 187); caulibus diffusis, basi radicantibus, ramulis florentibus adscendentibus, foliis hastatis lobis integris. R. Acetosella $\beta$ repens DC.I fl. fr. 3, p. 378, Blackw. herb. t. 307. (v. v.)

n. minima (Wallr. 1. c.), nana, foliis plerumque omnibus integerrimis, radicalibus subrotundis, caulinis lineari-filiformibus. In Alpibus Helvetiæ ! Pyrenæis ! Tabern. ic. t. 441, fig. dextra. R. Pyrenaicus Pour. Chlor. Hispan. n. 1417, Lapeyr. A br. suppl. p. $49_{\imath}$ Schult. I. c. p. 1456, in notâ.

0. multifida (DC. I fl. fr. 3, p. 378), foliis palmàto-multifidis, scil. hastatis vel sagittatis, lobis anguste linearibus vel filiformibus, lateralibus (sæpius falcatis) 2- $\infty$-fidis, caule solitario elatiore subsimplici. In Europà australi, Smy yrnâ, m. Tmolo (Balansa, n. 351!). - Wallr. sched. 1, p. 186, Sturm Abbild. fasc. 74. R. multifidus Linn. sp. 1, p. 482, Sibth. et Sm. fl. grcec. t. 349, Campd. Rum. p. 123, Schult. 1. c. p. 1457 . Acetosa multifida Mill. dict. suppl. 1, p. 8. R. supinus Campal.? Rum. p. 147, Boccone Mus. p. 164. R. acetoselloides Belansa! pl. exsicc. orient. n. 351; Bull. soc. bot. Fr. 1, p. 282. (v. v.) 


\section{Sectio III. ACETOSA.}

Flores dioici vel polygamo-monoici, paniculati. Valvæ increscentes, demum orbiculares vel reniformes diaphano-membranaceæ tenuiter venosæ, venis vix vel haud prominulis, callo minuto squamulæformi a basi valvæ deflexo, rarius oblongo, sed valvâ multo breviore et angustiore, vel nullo, marginibus integerrimis vel rarissime obsolete denticulatis.-Herbæ vel rarius frutices vel arbusculæ, acidæ, sæpe glaucæ, foliis hastatis sagittatisve interdum sinuato-pinnatifidis, summis plerumque amplexicaulibus, infimis palminerviis et nonnunquam integerrimis vel cordato-orbicularibus.

\section{$\S 1$. Herba annuce vel perennes.}

92. R. GRAMINIFolius (Georgi Beschr. d. Russ. Reichs 3, 4 , p. 921), caule humili folioso ochreis hyalinis arcte vaginato, foliis filiformi-linearibus elongatis integerrimis vel passim dente vel lobo laterali uno alterove auctis, panieulâ simplici aphyllâ, fasciculis paucifloris remotis, valvis parvis ovato-subrotundis venosorugulosis nudis. $\mathcal{Y}$ In Asiâ arcticà secus mare Glaciale (Tilesius I), Kamtschatka, ins. Curilis.-Lambert in Trans. linn. soc. Lond. 10, p. 264, t. 10, Campd. Rum. p. 124 , Schult. fil. syst. 7, p. 1458 , Ledeb. 11. ross. 3, p. 512 . R. angustissimus Ledeb.! in Mém. Acad. S.-Pétersb. 5, p. 536. R. graminens Pall fide herb. Ac. Petropol. Radix simplex. Caules sæpe subcespitosi, plerumque simplices, ochreis conspicuis nitentibus oblique truncatis diu integris. Folia glauca? 2-5 poll. longa, 13-1 lin. lata. Panicula folia superans, ramis erectis, infimis interdum divisis, floribus dioicis? pedicellis capillaribus calyce brevioribus apice articulatis. Valvæ 1 lin. longæe, integræ, haud cordatæ, ecallosæ, sepalis exterioribus valvarum margini adpressis. (v. s. in h. Ledeb, Mart. DC. etc.)

93. R. ENGELMANNI (Ledebour! mss. in herb.), caule erecto simplici gracili, foliis omnibus petiolatis vel summis subsessilibus hastatis, auriculis patentissimis indivisis, lobo mediolanceo lato vel lineari acuto, radicalibus ovali- vel ovato-oblongis lanceolatisve obtusis cordatis vel cuneato-attenuatis auriculis latioribus sæpe abbreviatis vel passim nullis, summis linearibus indivisis, paniculà simplicissimâ aphyllâ, perlicellis basi articulatis, valvis parvis subcordato-orbicularibus tenerrime reticulatis ecallosis. 4 ? In Americæ bor. Red River (Nutt. !) Texas (Drummond I Wright!), Missouri (Engelm.!), Floridâ orientali (Rugel, n. 36 !). R. hastulatus Baldwin apud Elliott, teste Nuttall mss. in herb. DC. (non Campd.). R. angustifolius Engelm.! mss. in h. Ledeb. et Berol. Planta verisimititer perennis,

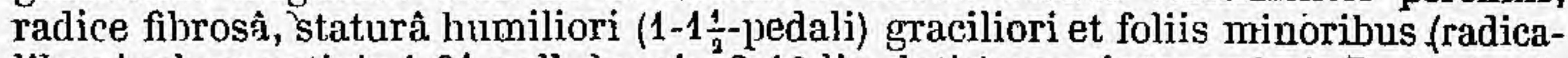
libus incluso petiolo 1-2 $\frac{1}{2}$ poll. longis, 2-10 lin. latis) sæpe integerrimis R. Acetosellam referens, calyce yero fructifero samaroideo longe ahborrens, a R. Acetosâ et affinibus apprime dignoscenda paniculâ elongatâ gracili, racemis solitariis subfiliformibus laxiusculis, fruetiferis densiusculis, valvis vix ultra 1 lin. longis, squamulâ ad basin vix conspicuâ deflexâ haud tumescenti. Ochreæ hyalinæ, longiusculæ, laceræ. Flores dioici, pedicellis capillaribus calyce subbrevioribus. Achænium castaneum, læve, nitinissimmm. Variat foliorum lobis omnibus anguste linearibixs. (v. s.)

$\hat{\beta} . ?$ Geyeri, vegetior, foliis omnibus lanceolatis acutis integerrimis utrinque æqualiter attenuatis 1-nerviis subeveniis, paniculâ simplici süpra aphýllâ, racemis junioribus densifloris continuis vel basi interruptis, pedicellis flore longioribus infra medium articulatis. In Rocky mountains (Geyer, n. 488!). Forsan n. sp. in specim. fructif. maturis denuo examinanda. Folia infma 2-4 poll. longa, 5-8 lin. lata, petiolo limbum æequante. (v. s. in. h. Shuttleworth.)

94. R. A cetos A (Linn. sp. 1, p. 481, excl. $\delta$ et $\varepsilon$ ), glaber vel inferne puberulus ochreis laciniato-dentatis, foliis infimis longe petiolatis venosis cordato- vel hastato- vel sagittato-ellipticis ovatisve obtusis, auriculis vix divergentibus, superioribus sensim angustioribus acutis, paniculâ elongatâ subsimplici aphyllâ, valvís mediocribus demum subrotundis leviter cordatis,' squamulâ deflexâ ad basin obsoletâ, achrenio atrofusco lívi nitidissimo. $\boldsymbol{\Psi}$ In pratis Europre totius, Asiæe et Amer. bor., et arct. (Beechey), capit. B.-Sp. (Drège 1), ins. Maclovian. (Gaudich.), Chili (Cl. Gay.) et colitur in ussum culinarium (cfr. R. Hispanícum). - Blackw. herb. t. 230, Plenk off. t. 280, Engl. Bot. t. 127, Campd. Rum. p. 117, Wallr. sched. 1, p. 377 * excl. $\beta$. Schult. fil. syst. 7, p. 1450, Hook. fl. bor. Am. 2, 
p. 129, Ledeb.! fi. ross. 3, p, 510. R. haplorhizus Czern. Turcz. in Bull. Soc. imp. nat. Mosc. 1852, p. $445^{*}$. Lapathum Acetosa Scop. Carn. ed. 2, 1, p. 260. Lajathum pratense Lam. fl. fr. 3, p. 8, Acetosa pratensis Mill. dict, n. 1. Rumex acuminatus et Commersonii Campd. Rum. p. 116 et 148 ?. R. Pseudo-Acetosa Bertol. fl. Ital. 4, p. 252 (fide Koch). R. thyrsiflorus Fingerh. in Linnæâ 4 , p. 380. - Admodum variat statura et foliorum dimensione. Formæ sequentes præsertim distingui, nec tamen pro varietatibus stabilibus haberi possunt.

a. vulgaris (Koch Synops. ed. 2, p. 709), foliis inferioribus hastato- vel sagittatoellipticis oblongisve obtusis, superioribus parum angustioribus, auriculis integris.-Fi.Dan. t. 2534, Sturm Abbild. fasc. 74, n. 7, Hayne Arzneigew. 13, 1. 6. Hujus mere status abnormis submonstrosus viddetur R. micranthus Campd.! mss. in h. DC. (ex pomario horti Monspel.) recedens tantum calyce (jun.) minuto, stigmatibus valvas superantibus. (v. v.)

ß. angustatus, foliis caulinis basi hastatâ valde angustatis sæpius elongatis crispis tortisque, auriculis integris. - Sturm Ább. fasc. 74, n. 8. R. Acetosa $\beta$ auriculatus Wallr.! l. c. p. 182, Koch l. e. R. oblongus Campd. Rum. p. 115? Schult. 1. e. p. 1447. (v. v.)

$\gamma$. fissus (KKoch 1. c.), foliorum auriculis passim 2-3-fidis dentatisve. R. inter, medius Sturm Abb. fasc. 74, n. 7 fig. $\beta$ (non DC.). (v. v.)

$\delta$. latifolius, foliis infimis vel etiam caulinis sueto majoribus (limbo 3-6 poll. longo $1 \frac{1}{2}-2 \frac{1}{2}$ poll.-lato petiolum subrequante), sinu augusto, lobis subparallelis obtusis (R. mutabilis Campd.! mss, in herb. DC.), vel sinu lato, lobis patentibus acutis (R. oxyotus Campd.!1. c. Rum. p. 114, Schult. 1. c. p. 1447), vel foliis obovatis obtusissimis lobis brevibus patentibus parallelisve (R. rugosus Campd,11. c. p.113, Schult. l. c.p. 1446). (v. s.)

95. R. T MoL Eu (Boiss.! diagn. pl. Or. n. 12, p. 101 \%), ochreis integris, foliis crassiusculis frmis glaucis oblongo-triangularibus hastatis auriculisque divergentibus acutis superioribus sessilibus, paniculâa thyrsoideâ densâ, valvis parvis ovatís integris basi rotundatis callo disciformi minuto deflexo. $\mathcal{\nvdash}$ ? In subalpinis humidis montis Tmoli-Lydiæ (Boiss. !). - Habitus et statura R. Acetose et montani, sed recedens glaucescentiâ̂, foliis crassioribus, paniculâ densâ, valvis minoribus basique haud cordatis. Radix ignota. Caulis rigidus, valde sulcatostriatus. Panicula 5-10-pollicaris. (v. s. in h. Boiss.)

96. R. montanus (Desf. Tabl. ed. 2 ; p. 48), ochreis integris, foliis ovato-oblongis acuminatis sinu lato hastato-cordatis, auriculis patentibus brevibus nüllisve, radicalium petiolo mediocri, summis subsessilibus anguste lanceolatis amplexicaulibus, paniculâ subaphyllâ, racemis inferioribus fasciculatis ramosisve, valvis mediocribus subrotundo-ovatis subcordatis squamulâ ad basin minutâ, achænio olivaceo-fusco nitido sub lente minute striato. $\angle$ In pratis montanis alpinisque Europæ, Caucasi et Sibiriæ Altaicæ! - Schult. fil. syst. 7, p. 1443* Ledeb.l fl. ross. 3, p. 510 . R. Acetosa $<$ Linn. sp. 1, p. 481 , $\beta$ Smith Engl. fl.' p. 196, Spenner fl. Frib. p. 1064. R. Acetosa alpina Fries! Herb. norm. fasc. 11. Acetosa alpina Mill. dict. n. 6. R. arifolius All. Pedem. 2, p. 204, DC.l fl. fr. 3 , p. 37.7, Niert. et Koch Deutschl, fl. 2, p. 620 (non Linn. nec Ait). R. amplexicaulis Lapeyr.1 hist. abr. Pyren. p. $200^{*}$, DC. fl. fr. 6, p. 369; Campd. Rum. p. 112. Schult. fil. syst. 7, p. 1466, Boccone Mus. t. 125. R. Hispanicus Gmel. fl. Bad. 2, p.112 (nec 3, p. 255). R. horizontalis C. Koch 1 in Linnsea 22, p. 211 (fide sp. autogr. in h. reg. Berol.). R. Italicus hort. Paris! olim (fide h. DC.). - Folia caulina inferiora petiolo duplo longiora et semper latiora quam R. Acetose $\left(\frac{3}{4}-2\right.$ poll. lata) sinu baseos semper latiore auriculisque patentibus (nunquam, ut in illâ, deorsum spectantibus), valvæe paulo minores (vix unquam ultra 2 lin. longæe) semperque paulo longiores quam latæ. (v. v. et s. sp.)

97. R. His p a i a U s (Koch Synops. fl. Germ. ed. 2, p. 709), foliis sagitlatis hastatisque venosis, paniculâ subsimplici aphyllâ, ralvis ovatis callo oblongo ultra medium valve excurrente. $\mathcal{F}$ In Hispania? Golitur in usum culinarium. Acetosa Hispanica màxima Munting diss. de vera Herba Britann. p. 225 cum ic. bonà. Gmel. fl. Bad. 3, p. 255 in adnot. (non ib. 2, p. 112). R. Acetosa $\beta$ Linn. fl. Suec. p. 118. Bertol. fl. Ital. 4, p. 255 in notà (ex lioch) - Planta nobis nondum visa,valvarum callo bene distincta.

98. R, I × т E M E d U S (DC. ! fl. fr. 6, p. $369 \%$, radice fusiformi-cylindricû, caule simXIV. 
plici, foliis anguste hastato- vel sagittato-lanceolatis linearibusve acutis, auriculis divaricatis bifidis inciso-dentatis integrisve, infimis longe petiolatis passim hastatooblongis obtusis, summis, sessilibus amplexicaulibus, paniculâ abbireviątâ pyramidatả aphyllâ fructiferâ densâ, racemis subsimplicibus patulís, valvis majusculis reniformi-orbicularibus cớdatis imâ basi conspicue granuliferis. $\not{F}$ In Pedemontio! (All. Ræper!), Galliầ australi! Hispaniâ, Liguriâ, Siciliâ, verisimil. totà regione-Mediterraneâ.-Zanoni, Rar. stírp. hist. t. 4, Campd. Rum. p. 119, t. 2, f. 3, Schult. 1. c. p. 1453 ' (excl. syn. nonnull.), Boiss. voy. Esp. p. 550. R. multifidus All. Pedem. 2, p. 505 (excl. syn.). R. triangularis Guss. fl. sicul. (non DC., ex Boiss.). Sjecies simillima quidem R. Acetosæ $\hat{\beta}$ et $\gamma$, at notís indicatis constanter, ut videtur, distineta. Valvæ demum majores (2-3 lin. latæ) sub'quadrato-vel reniformi-orbiculares, paulo latiores quam longæ, distinctius cordat:e, granulo convexo evidentiore. Caulís raro pede altior. Folia 1-3 lin. (infima rarius 4-5 lin.) lata. Panicula 2-5.pollicaris, ramís semipatentibus vel adscendentibus, infimo solo šepius pauciramoso. (v. s.).

99. R. papilla is (Boiss. et Reuter! Pugill. pl. nov. Afr. bor. et Hisp. 1852, p. 107*), radice cylindricâ simplici, foliis carnosulis venosis utrinque minute papillosopuberulis subviscidis, radicalibus oblongo-lanceolatis hastato-sagittatis iacutis, auriculis brevibus sæpe bifidis, paniculâ elongatâ ramosissimâ densiflorâ, valvis mediocribus subcordato-ovatis, callo minuto subrotundo-disciformi. $\%$ Circa Matritum et in Sierrâ de Avila (Reuter). Species, etiam cultura ab auctoribus probata, a R. Acetosã constanter discrepans : naturâ indumenti, caule rigidiore, foliis pro longitudine angustioribus magisque carnosiś, paniculâ ramosiore, densiore et valvarum callo disciformi nec squamiformi deflexo. Præterea mense serius quam illa floret. Folia radicalia longiuscule petiolata; auriculis angustis acutis, summa sessilia lanceolato-linearia. (v. s. in h. Boiss.)

100. R. TнYRS OIDES (Desf. fl: atlant. p. 321), canle erecto simplici, foliis sagittatooblongis, infimis petiolatis obtusis undulatis, superioribus subsessilibus amplexicaulibus acụtis, paniculâ pyramidatâ abbreviatâ aphyllâ fructiferâ densâ, pedicellis valvâ longioribus, valvis mediocribus late reniformi-obcordatis imầ basi granuliferis. ' $\mathcal{F}$ In incultis Barbariæ (Desf.), Oran (Balansa, n. 424!), Sỉciliæ (Guss. Splitgerber 1), Sardiniæ (Moris), monte d'Aseo Corsicæ (Phil. Thomas l), Gibraltar et San Roque (Boiss.).-Poir. dict. 5, p. 69, Campd. Rưm. p. 119*, Schult. fil. syst. 7, p. 1453, Boiss. ! voy. Esp. p. 550. R. intermedius Guss. prodr. fl. sicul. 1, p. 449 (fide Schultz. non DC.). Habitus et folia R. Acetosæ et tuberosi, sed radix videtur simplex, fusiformis, panicula brevis (3-5-pollicaris) demum densa, et præcipue valvæ distinctissimæ, semper latiores quạm longæ $\left(1 \frac{1}{2}\right.$ lin. longæ, $2 \frac{1}{2}-3$ lin.) latre, basi truncatæ vel vix ac ne vix emarginatæ, apice plus minus manifeste emarginatæ, granulo ad basin magis cónspicuo ovali crassiusculo pallido, sepala exteriora obovata obtusissima reflexa valvâ parum breviora, majora quam specierum affinium. Pedicelli capillares, supra basin articulati. Valvæ subintegerrimæ, tenerrime retículatæ. Achænium castaneum, læve, nitidum. (v, s.)

101. R. TUBE R os U S (Linn. sp. 1, p. 481), radice fasciculato-tuberosâ, tuberculis elliptico-fusiformibus, foliis hastato-oblongis sinu aperto auriculis divergentibus acutis integris vel inciso-dentatis, infimis longe petiolatis obtusis, caulinis acutis, paniculâ brevi aphyllâ laxiusculâ, valvis pedicellum æequantibus, mediocribus ovatoorbicularibus basi truncatis vel emarginatis apice rotundatis, unâ basi graniferá. భ In Europâ australi mediterraneâ, Asiâ minore, Smyrnæ (Balansa, n. 353!), prov. Gaucasie. (Hohenack.). Zanoni, Rar. stirp. hist. t. 3, Smith in Rees Gycl. n. 34, Sibth. et Sm. fl. graec. t. 348, DC. fl. fr. 3, t. $376^{*}$, Campd. Rum. p. 115, Schult. 1. c. p. 1448 , C. Koch in Linnæâ 22 , p. 210 , Ledeb.! fl. ross. 3 , p. 511. Acețosa tuberosa Mill. dict. suppl. 1, p. 8. R. retroflexus Lagasca? Elench. fl. matrit. p. 13. Campd. p. 148, Schult. l. c. p. $1449^{*}$ (Planta obscura, ex descr. l. e. nullo modo recedens, nisi radicis tuberculis subsessilibus nec fibris plus minus elongatis stipitatis). Gaulis erectus, simplex, paucifolius, foliis summis subsessilibus sublinearibus amplexicaulibus. Flores dioici, pedicellis capillaribus supra basin articulatis, valvis tenerrime reticulatis integerrimis, achænio atro-castaneo haud junctato. Omnia fere R. Acetosæe, exceptâ radice quæ exacte illam Spirese Filipendulæ imitat. Planta junior sæpe multicaulis, foliis radicalibus passim orbiculari-cordatis, caulibus spithamæis simplicibus paucifoliis, racemo simplici brevi densifloro. (v. s.) 
102. R. Tingrt an us (Linn. sp. 1, p. 479), radice fibrosâ subsimplici, caule folioso erecto vel diffuso patulo-ramoso, foliis ornnibus petiolatís ovato-vel oblongo-hastatis eroso-vel sinuoso-crenatis lobatisve vel passim integris; caulinís acutis auriculis brevibus divergentibus, infimis, sæpius cordatis integris obtusis, paniculâ simplici, racemis elongatis aphyllis laxís, verticillis paucifloris, flor. polygamis, valvis magnis cordato-subrotundis integris ecallosis. $\%$ In arenosis reg. Mediterranearum, præcipue secus mare, Galliæ austr.! Italiæ, Hispaniæ (Dufour !), archipèlagi Græci, Algeriæ (Bové !), Tanger (Salzm.!).-Morison híst. 2, p. 583, sect. 5, t. 28 , f. 8, Zanoni hist. j. 9 , t. 6 , DC.I fl. fr. 6, p. $570^{*}$, Campd. Rum. p. $126^{*}$. Schult. fil. syst. 7, p. 1459 , Boiss. voy. Esp. p. 550. R. sinuatus Nathhorst, fide Steudel. Caules 1-2-pedales, ramis patulis vel adscendentibus. Folia subcarnosa, viridia vel vix glaucescentia, limbo petiolum æequante vel longiore 1-2 poll. longo 4-8 lin. (raro 12-18 lin.) lato, auriculis obtusiusculis, dentibus lacinulisve sinubusque plerumque rotundato-obtusissimis $\frac{1}{2}-2$ lin. longis apicem versus evanescentibus. Racemi paniculati (rarius solitarii) indivisi, 3-8-pollicares; basi interdum folio lanceolato-hastato muniti, floribus masc. et hermaphr. mixtis. Bracteæ hyalinæ, oblongæ, acuminatæ, 4-5 lin. longæ, subintegræ, deciduæ. Valvæ demum 4-5 lin. longæ, profunde cordatæ. (v. s.)

103. R. S сни нев , caule erecto subsimplici folioso sulcato, foliís omnibus petiolatis deltoideis integris basi truncatis ver hastato-cordatis auriculis brevibus apiceque acutis, panicullâ subsimplici elongatâ aphyllâ, fruetiferâ densâ, floribus polygamis, valvis magnis orbiculari-ovalibus leviter cordatis integerrimis basi squamuligéris. $\%$ In Abyssiniá (Schimper, n. 514!). Species foliorum formâ et magnitudine conveniens cum $R$. Maderensi, cæteris vero notis, præsertim colore viridi nec glauco, paniculæ formâ valvisque distinctissimâ. A R. Tingitano recedit foliis majoribus, acutis, nunquam sinuatis, integerrimis vel minute undulatis, valvis angustioribus, sinu baseos angustiore squamulâque manifestâ, nec. non sepalis exterioribus duplo minoribus. A R. Abyssinico, cui valvis convenit, fóliis longe discrepat. (v. s.)

104. R. MaDERensis (Lowe mss. (Webb Phyt. Canar. 3, p. 287 ), caule erecto ramoso folioso, foliis herbaceis glaucis omnibus petiolatis ovato-vel oblongo-deltoideis subhastatisve integerrimis basi truncatis vel cordatis apice lobisque obtusis, paniculâ subcorymbosấ aphyllâ, racemis ramosis filiformibus patentibus latiusculis, floribus polygamis, valvis magnis ovali-orbicularibus sinu angusto profunde cordatis eroso-denticulatis ecallosis. భ Ins. Maderâ (Lowe), Teneriffâ (Webbl), Hierro (Bourgeau, n. 89 !). R. Tingitanus Webb et Bourgeau pl. Canar. exsicc. n. 89 (non Linn.). Radix ignota. Caules vel rami pedales subvirgati, graciles, sanguinei, juniores cum foliis glauci. Petioli tenues $\frac{1}{2}-2 \frac{1}{2}$ poll. longi. Folia $1-2 \frac{1}{2}$ poll. longa, 6-20 lin. lata, rarius 3 poll. longa, $2 \frac{1}{2}$ poll. lata, multo tenuiora quam R. Tingitani, nervis 5 e basi radiantibus tenuissimis evanescentibus, lobis baseos rotundatis obsoletis vel breviter in angulum productis. Panicula semipedalis, patens, irregulariter dichotoma, ramulis gracillimis subflexuosis, bracteis parvis remotiusculis 2 -4-floris pedicellis brevioribus obtusiusenlis, pedicellis capillaribus valvam aquantibus infra medinm articulatis, valvis 3 lin. longis (paululum longioribus quam latis) tenue membranaceis venosisque, lobis basilaribus prope sinum angustissimum continuis. (v. s.)

105. R. L A T I Y A V Is (Meisn. in Linnæấ 14, 497 ), radice pyriformi-taberosâ solidâ, caule erecto ramoso, foliis omnibus petiolatis, caulinis hastato-trilobis, laciniis lineari-lanceolatis indivisis lateralibus patentibus terminali brevioribus, infmis subcordato-ovalibus obtusissimis, summis linearibus indivisis, paniculâ simplici aphyllâ laxiusculà, floribus monoicis, pedicellis infra medium articulatis, valvis mediocribus reniformi-subrotundis tenue reticulatis basi truncatis vel leviter cordatis subecallosis. $\%$ Cap. Bonæ-Spei (Mundt et_Maire ! Drège! Krauss ! n. 794 l). - Meisn. in Hook. Lond. Journ. 2, p. 451 ! Affinis R. Acetosæ, intermedio et tuberoso, sed vel foliorum et valvarum formà, vel radice bene distincta. Valvæe demum semper latiores quam longæe, integerrimæ, squamulâ ad basin nullâ vel obsoletâ .

a. acetosoides (Meisn. l. c.), foliorum radicalium lobo terminali oblongo lanceo. lato, lateralibus ovatis oblongisve 3-4-plo majore. R. tuberosus Sieb. pl. Cap. n. 134 ! (fide sp. masc. in herb. Mart. - Gfr. R. cordatus).

ß. decipiens (Meisn. 1. c.), foliorum radicalium lobis linearibus vel anguste lan- 
ceolatis, lateralibus terminali dimidio brevioribus interdum latioribus rectis vel sursum falcatis. (v.s.)

106. R. DREGEX, radice....., caule erecto simplici, foliis summis hastato-lanceolatis acutiusculis in petiolum cuneato-attemuatis supra auriculas breves sæpe denticulo auctis, paniculâ aphyllâ, racemis simplicibus, verticillis multifloris remotis, pedicellis medio articulatis, floribus dioicis, valvis magnis subrotundo-ovalibus cordatis apice rotundatis dense nervoso-reticulatis ecallosis. $\nvdash$ ? Port-Natal (Drège, ก. 4694 !). R. Dregeanus Meisn: in Linnæấ 14, p. $496^{*}$. (v. s.).

107. R. s A I т т A тus (Thunb. prodr. p. 76, Fl. cap. 1, p. 341), caule erecto flexuosorameso folioso, foliis omnibus petiolatis profunde cordato-vel hastato-triangula. ribus acuminatis, auriculis divergentibus integris, paniculis áphyllis flexuosis, racemis patentissimis ramosis, pedicellis prope basin articulatis, valvis magnis profundle cordato-orbicularibus laxiuscule reticulatis ecallosis: $2 \zeta$ In rupestribus et fruticosis ad cap. Bonse-Spei (Thunb. Drège! etc.), Port-Natal (Krauss!). - Meisn. in Linneea 14, p. 498, et in Hook. Lond. Journ. 2, p. 451. R. luxurians Linn. fil. suppl. p. 212, Schult. fil. syst. 7, p. 1467 ? (non ? Linn. mant. p. 64, nec? Gampd. Rum. p. 132, cfr. R. scutatus). Acetosa luxurians Mill. dict. suppl. 1, p. 8. R. túberosus DG. ! cat. Poir. dict. 5, p. 67 (excl. syn. et deser. radicis), pl. cap. Un. itin. n. 710, fide Sthult. 1. c. p. 1450 (non Linn.).-R. Burchellii Campd.! Rum. p. 135 *, Schult. 1. c. p. 1468. Frutex scandens, ex- Krauss. Radix ignota. Folia petiolum æequantia vel brevicra, 1-1 $\frac{1}{2}$ poll. longa, sxe haud longiora quam lata. Paniculæ terminales et axillares compositæe, fructiferce denswe, floribus dioicis rarius monoicis, pedicellis, capillaribus valvà sublongioribus. Valvæ 3 lin. lọngæ, integerrim̧æ, purpurascentes.'Achænium majuscrlum, castaneum, nitidum,' sub lente minute striatum.

a. angustilobus (Meisn. l. c.), foliis petiolum subrquantibus hastato-vel sagittatotriangularibus, lobis lariceolatis vel triangulari-oblongis attenuato-acutis, lateralibus patentibus terminali brevioribus. (v. s.)

ß. megalotys (Meisn. 1. c. p. 499), foliis petiolo brevioribus hastato-triangularibus, lobis lanceolatis vel oblongo-triangularibus, lateralibus divaricatis terminali plerumrue longioribus et angustioribus. (v. s.)

$\gamma$. latilobus (Meisn. 1. c.), foliis petiolum subæquantibus, inferioribus cordato-vel triangulari-hastatis, superioribus hastatis, lobo terminali late ovato vel deltoideo-acuminato acuto vel obtuso basi ín auriculas ipso dimidio breviores et angustiores parum divergentes defluente (Burchell, n. 2890 !). R. triangularis DC.! fi. fr. 6, p. 368 (non Guss.), Campd. Rum. p. 131, Schult. fil. syst. 7, 1. $1464^{\circ}$, excl. syn. Bertol. et Guss. (v. s. sp. ef c.)

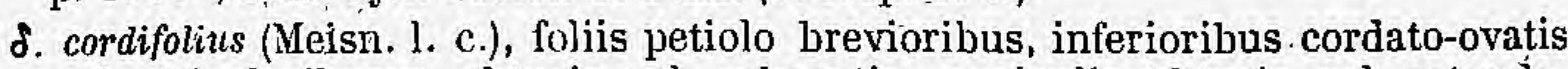
suborbicularibusve obtusis vel subacutis, auriculis obtusis vel rotundatis. (v. s.)

108. R. C ORDA T U S (Desf. (cat. h. paris. od. 2, p. 40), radice pyriformi-tuberosâ, caule subsimplici erecto basi paucifolio, foliis petiolatis cordato-ovatis subrotundisve obtusis, caulinis subhastatis, summis lanceolatis acutis, paniculà simplici, racemis erectis aphyllis, fasciculis remotis paucinoris, pedicellis medio articulatis, valvis mediocribus cordato-ovatis subrotundisve obtusis tenue reticulatis squamulâ ad basin minutà deflexâ. Ұ Cap. Bonæ-Spei (Thunb.? Drège! Krauss, n. 799 ! Ecklon et Zeyh. n. 13 et 61 !).-Poir. dict. suppt. 4, p. $324^{\circ}$, Campd. Rum. p. 136, Schult. fil. syst. 7, p. 1469, Meisn. in Linnæâ 14, p. $500^{*}$, et in Hook. Lond. Journ. 2, p. 451. R. tuberosus Thunb. prodr. p. 67, Fl. cap. 1, p. 341, Sieber pl. cap. n. 134 ? (fide sp. jun. in h. DG.). R. sarcorhizus Link! enum. p. 351, Schult. $1 . c$. j.1469: Caules annui. Paniculæ rami solitarii, simplices, pedicellis.capillaribus valvâ demum brevioribus. Flores polygamo-monoici, valvis integris. (v. $s$. in h. DC., Link, Drège, etc.)

109. R. A Bxssinicús (Jacq. $h$. Vindob. 3, p. $48^{*}, t .93$ ), foliis petiolatis acuminatis acutis, infimis late ovatis vel subtrilobo-triangularibus hastato-cordatis, superioribus hastatis sagittatisve lobis lateralibus patentibus intermedio elongato-lanceolato 2-3-plo breviorihus, summis lanceolatis integerrimis, paniculá apice aphylla, racemis patulis laxiusculis fructiferis densis, pedicellis prope basin articulatis, valvis majusculis ovali-subrotundis cordatis tenuiter reticulatis imá basi 
minute calliferis. $\%$ In Abyssiniả, ad rivos montis Selnoloda (Schimper, n, 398 ! ins. Borbon. (Boivin, n. 1118!).-Campd. Rum. p. 67, et 108, t. 3, f. 7, Mirb. in Ann. Mus. 13, t. 4, f. 46 , Schult. fil: syst. 7, p. 1441, A. Rich. voy. en Abyss. 5, p. $229^{*}$. R. arifolius Ait. 11 kew. ed. 1, p. 487, ed. 2, I1, p. 324, excl. syn. Willd non Linn. fil., nec All. R. sagittifolius Plenk elem. term: (fide Campd.).'Habitus $R$. Acetosæ, sed omnibus partibus major. Radix fusiformi-fasciculata. Caulis (ex Jacq.) 4-9-pedalis. Folia caulina cum jetiolo 3-7 poll. longa, $\frac{1}{3}-1$ poll. lata, basi passim cuneatoattenuata, lobis lateralibus 3.4 lin. usque ad 1 poll. longis. Panicule rami ramosi, sæepe fasciculati. Pedicelli valvas æequantes. Flores polygami (ex Jacq. hermaphroditi). Valvwe 2-3 lin. longse, margine subintegerrimæ, apice rotundate. (v. s.)

110. R. A RI Fo L i U s (Linn. fil. suppl. p. 212, non Jacq. nec All.), caule suffrutescente? foliis longe petiolatis cordato-orbicularibus vel triangularibus subacuminatis 5-7-nerviis, paniculà terminali...., valvis ovato-orbicularibus integris nudis. $\mathcal{H} \mathrm{Pa}$ tria? - Willd. sp. 2, p. 262 (exci. syn. Jacq.), Poir. dict. 6, p. 69, Schult. fil. syst. 7, p. 1442. R. Abyssinicus Desf. tabl. p. 48 ? R. macrophyllus Campd.I Rum. p. 67 et 109 (fide h. DC.). Folia 3-7-nervia, infima, excluso jetiolo, laminam aquante usque ad 7 poll. longa lataque, lobis lateralibus brevibus late triangularibus vel obsoletis rotundatis, superiora petiolo 2-3-plo longiora, 2-5-pollicaria, lobis lateralibus rectis triangularibus vel antrorsum subfalcatis $\frac{1}{2}-1 \frac{1}{2}$ joll. longis, $4-10 \mathrm{lin}$. latís, terminali vix latiore, sinu lato patente jarum profundo. Species non satis nota, a precedente tamen, quacum a plerisque conjungitur, distinguenda. (v. $\mathrm{v}$. et s. c.)

111. R. L A GER US (Balbis ! misc. j. 19), multicaulis, decumbens, radice fibrosà, ramis adscendentibus loliosis, foliis jetiolatis pinnatifidis, infimis latioribus basi cuneatoattenuatis lobis utrinque 2-3 linearibus ovatisve sinubusque obtusis, summis lanceblato-linearibus indivisis, racemis terminalibus axillaribusque subaphyllis, valvis magnis cordato-reniformibus callo lanceolato munitis. (In Agypto (Delile, Oliv., Sieber ! Ehrenberg 1), Syrił (Labill.), Arabiâ desertâ, versus Palæestinam (Boiss. !):- Campd. Rum. p. 127, Schult. fil. syst. 7, p. 1460 *. R. pictus Forsle.? 11. Ag. Arab. p. 77, Campd. p. 147, R. roseus Poir. dict. 5, p. 65? Desf. fl. atl. 1, p. 320 ? Caules digitales-spithamæi; patenti-decumbentes vel adscendentes, interdum procumbentes. Folia subearnosa, glaucescentia, omnia petiolatá, petiolum rquantia vel longiora, $\frac{1}{2}-1 \frac{1}{2}$ poll. longa, lyrata vel protunue pinnatifida, sinubus rotundatis, lobis patentibus 2-6 lin. longis, 1-3 lin. latis, interdum passim paucidentatis incisisve. Verticilli remoti, 2-5-flori, jedicellis tenuibus prope medium articulatis, vạlvâ, subbrevioribus, bractệ hyalinâ obtusâ longioribus. Flores masculi et hermaphroditi (vel passim feminei fertiles) in eodem racemo. Valvre tenue membrana cex, laxe rubro-reticulat:, integerrimæ vel obsolete crenulatæ, juniores suborbiculatæ, adultæ reniformes, 3 lin. longæe, 4-5 lin. latæe (quasi transverse ovales), callo pallido oblongo $1 \frac{1}{2}$ lin. longo crassiusculo lavi preditc. Achanium rufum, læve, nitidum, faciebus elliptico-lanceolatis. (v. s. sp. et c.)

$\beta$ ? lucidus, foliis haștato-rhombeis sinuato-pinnatifidis, valvis (jun.?) lanceolatis nudis. $\mathcal{F}$ In Africâ boreali. R, lucidus Campd. Rum. p. 150, Schult. 1. c. p. $1460 *$. R. atriplicifolius Reichenb. apud Schult. l. c. Planta valde obscura, ex speciminibus verisimiliter junioribus tantum cognita. Folia atroviridia.

$\gamma$ ? bipinnatus, foliis cor latis profunde bipinnatifidis, floribus dioicis. $\not{\xi}$ ? In Marocco et Mogador (Brouss.!). R. bipinnatus Linn. fil. suppl. p. 211, Campd. p. 127, Schult. l. c. p. 1461 *. Acetosa bipinnata Mill. dict. suppl. n. 9. Planta dubia, fructifera ignota. "R. bipinnatus Schousb." in Teneriffạ vel Mogador a Broussonnet! lecta in herb. DG. est mere R. Acetosella $\alpha$ mas!

112. R. CRE Trcus (Boiss. 1 diagn. pl. or. D. 12, p. $102^{*}$, radice sublignosà multicipiti, caulibus adscendentibus herbaceis, foliis viridibus parvis longiuscule petiolatis hastato-triangularibus obtusis, basi truncato-subcordatis, auriculis brevibus obtusis, panicula brevi confertì, pedicellis capillaribus infra medium nodoso-articulatis, floribus...... calyce fructifero magno, lobis exterioribus deflexis, interioribus subaquilongis apice dilatatis, valvis rotundis vel reniformibus basi truncatis vel emarginatis, callo. squamiformi yarvo deorsum adpresso. $\mathcal{\psi}$ In Cretà (Raulin !). Facies fere R. scutati, sed inflorescentiâ et valvis distinctus. (v. s. in h. Boíss.)

113. R. s c u t a r us (Linn. sp. 1, p. 480), radice sublignosâ multicipiti, caule decumbente vel adscendente ramoso basi suffruticoso, foliis omnihus petiolatis, late 
ovatis triangularibus vel subpanduriformibus cordatis hastatisve acuminatoacutis vel infimis obfusissimis, racemis solitariis vel paniculatis elongatis, fascieulis 2-4-floris remotis, floribus polygamo-monoicis, valvis magnis late ovalibus vel demum orbicularibus basi emarginatis nudis. $\%$ In ruderatis, lapidosis, rup̣ibus et muris Europæ fere totius, práecipue montium unde torrentes è flumina in planitiem sequitur, ín Helvetià ! Germaniâ ! Scandinavià,. Belgio I Galliâ I (Bourgeau pl. Pyren. n. 188 !), Lusitaniâ (Welwitșeh, ñ. 621 !), Hispaniâ ! Italiâ ! Siciliâ ! Græciâ, Rumeliâ ! Áfricâ boreali ! Caucaso ! Asiâ minore !-Morison hist. sect. 2, t. 28, f. 9, Campd. Rum. p. 132, t. 2, f. 6, Schult. fil. syst. 7, p. 1464, Wallr. sched. 1, p. 181, Ledeb.! fl. ross. 3, p. 509. Acetosa scutata Mill. dict. n. 3, Wapathum alpestre Scop. Carn. ed. 2, p. 261. L. scutatum Lam. fl. fr. 3, p. 6, Moench meth. p. 357. Rumex alpestris Jaca. enum. p. 62, Campd. Rum. p. 147. R. hastrefolius Campd. p. 148 ? R. hastatus Link! mss. in herb. (hand Don.). Racemi láxiflori, terminales et axillares, simplices vel hasi pauciramosi, pèdicellis capillaribus valvas aquantibus infra medium articulatis. Valvæ tenue membranaceæ et venoฐæ, basi emarginatæ vel cordatæ, integercimæ, callo vel squamulâ ad hasin pullâ. Achænium pallide fuscum, nitidum, sub lente obsolete striatum.

๙. vulgaris, viridis vel parum glaucus, foliis hastato-triangularibus lobis acutis obtusisve sinubus lateralibus latis vel obsoletis, caule et paniculâ elongatis, valvis leviter cordatis. - Zanoni. hist. t. 7, Blackw. herb. t. 306, Sturm Abbild. fasc. 74, n. 3, 4. R. luxurians hort. (non Linn.)'. R. scutatus $\beta$ hàstilis Koch!syn. ed. 2, p. 708, est hujus forma foliis elongatis lobisque angustis. (v. v.) ,

" monstrosus, sepalis interioribus sæpiusque etiam ovario valde elongatis linguæformibus. Occurrit etiam in var. $\beta$ et $\gamma$. (v. v. spont.)

$\beta$. glaucus, totus casio-glaucus, foliis inferioribus omnibusve deltoideis, sinubus lateralibus subnullis, racemis elongatis sæpe simplicibus, valvis leviter cordatis. - Zanoni hist. t. 8, Sturm Abbild. fasc. 74, n. 5. R. glaucus Jaeq. misc. 3, p. 64, ic. rar. t. 67. (v. v. c. et s. sp. e Siciliâ, Moricand! Splitgerb. l).

$\gamma$. hastifolius, viridis vel glaucus, foliis hastato-panduriformibus trilobisve, sinubus lateralibus profundis angustatis, caule racemisque elongatis, valvis profundius cordatis. In Caucaso (Bieb. Steven! Szovits ! Hohenack.! etc.), in monte Tauro (Kotschy, n. 419! Aucher-Eloy, n. 1951 ! Balansa, n. 354 !), Gonstantinopoli! R. hastifolius Bieb. fl. taur.-cauc. 1, p. 290. R. pubeseens G. Koch? in Linnæâ 22, p. 211. (v. s.)

d. Astnensis, viridis, puberulus, foliis infimis vel omnibus cordato-vel reniformiorbicularibus obtusissimis, sinubus lateralibus nulliș, racemo subsimplici, herbâ sæpe nanâ (digitali vel spithamæâ). In scoriis vulcanis montis સૈtna. (Jari n. 53 ! Heldreich l) R. Etnensis Presl delic. Prag. p. 68. (v. s.)

114. R. induratus (Boiss. et Reut. ! pugill. pl. nov. Afr. bor. et Hisp. p. 107), glaucus, dichotomo-ramosissimus, foliis subrotundo-cordatis hastatis trilobisve, racemis elongatis laxis persistentibus demum rigidis induratis subspinosis intricatis, valvis orbiculatis sinu angusto profunde cordatis. $\mathcal{F}$ Ad sepes, vineảs, rupes Hispaniæ centralis et australis (Boiss.l Reuter, Willkom, n. 212! 478 !). R. scutatus var. glaucus Boiss. I voy. Esp. p. 549. Proter notes indicatas omnia R. scutati precipue $\beta$ glauci (cujus forsan mere var.), attamen babitum peculiarem præ se ferre et culturâ non mutari ab auctoribus dicitur. (v. s.)

115. R. NIVALis. (Hegetschw. et Heer fl. d. Schweiz, p. 345, Neue Denkschr. d. Schweiz. Nat: Gesellsch. 3. t. 1), nanus, glaucescens, glaber, foliis crassiusculis, radicalibus longe petiolatis subratundo-ovatis obtusis hastato-subcordatis, auriculis obtusis vel obsoletis, caulinis subsagittatis paucis vel multis, racemo, subsimplići aphyllo inferne. interrupto, loribus dioicis, valvis parvulis ovalibus obtusis vel demum cordato-orbicularibus obsolete venosis achænium parum superantibus, squamulâ ab basin exiguâ deflexâ. $\psi$ In glareosis Alpium altissimarum Helvetiæ ! Bavariæ, Carnioliæ ! Il ýriæ ! - Koch syn. ed. 2, p. 708. Rhizoma multiceps,-lignescens. Caules 1-6-pollicares, foliis paucis parvisque.Verticilli 5-15-flori, infimi disereti, pedicellis tlore longioribus medio vel paulo infra articulatis, floribus rubellis. Forśan R. Acetosíe forma glacialis, depauperata ? (v. s.)

116. R. VESICARIUS (Linn. sp. 1, p. 479), caule humili ramoso, foliis subcarnosis petiolatis ovatis vel deltoideis obtusis vel acutiusculis e basi cordatâ vel subhastatâ sæuius cuneato-attenuatis, summis angustioribus, racemis simplicibus 
vel paniculatis aphyllis, fasciculis 2 -5-floris remotis, pedicellis 1 -floris vel apice plerumque flores 2 dorso connatos gerentibus, valvis maximis tenue reticulatis suborbicularibus utrinque sinu angusto cordatis replicatis margine integris valde inæqualibus calliferis vel subnudis. (1) In regionibus Mediterraneis passim (Siciliâ, ex Bertol., Græciâ !), Syriâ ! EEgypto ! (Acerbi ! Ehrenb.! otc.), Arabiâ petræâ! (Delile, Bové !), Persiâ austr.!. (Kotschy!), Afglianistan (Griff.!), penins. Ind. or, (Wall.!), Javâ ! ins. Sanctâ-Helenâ (ex Schult.), Canariis! Cubâ ! (Humbolddt! in h. Willd.). - Barrel. ic. 1112, Hort. Eystett. vern. ord. 6, t. 15, f. 3, Campd. Rum. p.129, t. 3, f. 1 et 8 , in Ann. Mus. 13, t. 4, f. 45, Schult. fil. syst. 7, p. $1462^{\star}$. Lapathum vesicarium Moench meth. p. 356. Flores hermaphroditi paucis masculis mixti, in singulis pedicellis plerumque gemini dorso longitudinaliter vel oblique connati. Valvæ haud nervoso-marginatæe.

a. articulatus; pedicellis medio vel paulo infra articulatis valvas subæquantibus, floribus omnibus vel plerisque duplicatis; valvis plerumque longioribus quam latis (5-7 lin. longis), venis purpureis vel concoloribus, callo nullo vel obsoleto.-R. vesicarius Webb! phytogr. Canar. 3, p. 216 (Bourgeau, n. 548 !), Boiss. in Kotschy pl. Pers. austr. n. 33 ! R. roseus Delile? fl. Arab. petr. 8, ex Decaisne in Ann. sc. nat. $2^{\circ}$ sér. 2, p. 243 , Bové, n. $40^{\prime}$ ! (v. s. sp. et v. v. c.)

B! singuliforus, pedicellis articulatis 1 -floris, flore simplici, valvis basi callo brevi præeditis. R.' roseus Kotschy pl. Eg. exsić. n. 95. Multicaulis, caulibus digitalibus, valvis vix ültra 3 lin. longis, apice subintegris, venis paucis prominulis roseis vel concoloribus laxe reticulatis. An nova sp.? (ฬ. s.)

$\boldsymbol{\gamma}$. inarticulatus, pedicellis valvas æquantibus continuis (rarissime passim prope medium articulatis), floribus duplicatis vel rarius simplicibus, callo nullo vel obsoleto. R. vesicarius Wall, list, fol. 47 et $215, \mathrm{n} .1732$ l' Wight herb. propr. n. 14 ! Meisn. in Wall.pl. As. rar. 3, p. 64, Hoffmans. pl. Jav. n. 58 ! Zolling. n. 2694 ! (v. s, et v. v. c.)

f? Auroheri, pedicellis articulatis valvâ brevioribus, floribus duplicatis vel simplicibus, valvis maximis (6-7 lin. longis) iequalibus ovatis apice obtuso integerrimis vel emarginatís, basi grosse calliferis tenuiter reticulatis, lateribus extrorsum replicatis super callum per plicam conniventibus. In Syrià et Algeriấ (Balańsa, n. 1029!). R. roseus Aucher-Eloy! (sine numero in h. DC.). Planta Aucheri forsan propria sp., sed specim. unicum suppetens insufficiens. Herba vix spithamsea, a basi dichotome ramosissima, caulibus adscendentibus, foliis hastato-lanceolatis subundulato-sinuosis integrisve cum petiolo circ. pollicaribus, infimis duplo latioribus ovato-deltoideis; flores omnes (?) simplices, valvis apice haud emarginatis. Specimina Balansana nonniși valvarum callo magno a var. $\alpha$ recedunt. (v. s.)

117. R. T RIFIDUS (Campd. Rum. p: 129), caule herbaceo, ramis passim exasperatis, foliis obovatis trifidis in petiolum longum subdecurrentibus subdenticulatis vel summis integris, racemis oppositifoliis subpaniculatis folio subbrevioribus: Patria? - Tourn. inst. 1 ; p. 503, Schult. p. 1462. Species nimis obscura, potius penitus omittenda.

118. R, R oSEU S (Linn. sp. 1 , p. 480, excl. syn. Shaw), caule humili a basi ramoso folioso, foliis subcarnosis petiolatis subcordato-ovatis vel deltoideis acutiuseulis integerrimis basi truncatis vel cuneato-attenuatis, summis lanceolatis, racemis subsimplicibus aphyllis, fasciculis 2-4-floris remotis, floribus simplicibus vel 2 dorso connatis, valvis magnis orbicularibus vel transverse ovalibus apice basique profunde lateque emarginatis tenuiter laxeque reticulatis, nervulo tenui marginali continuo passim spinuloso-ciliato cinctis, basi callo deflexo munitis, 1-2 expansis planís, reliquis minoribus longitudinaliter plicatis. (1) In Agypto (Linn.), Algeriâ (Balansa, n. 1028, ex parte), ins. Cypro (Sibth.), Arajbiâ pẹţææâ (AucherEloy, n. 69! Schimper, n. 179! Schubert! Boissier!)-Sibth. et Sm. fl. græc. t. 346 , Campd.'Rum. p. 128, Schult. fil. syst. 7, p. 1462 *. Acetosa rosea Mill.? dict. n. 16. Præeter calycem fructiferum, pedicellos breviores infra medium articulatos et staturam semper himiliorem multicaulem omnia ut in R. vesicario L. (v. s.)

119. R. m A CRANThus (Boiss. ! in Kotschy pl. exsicc. it. Cilicic. n. 69 f. 109, 233 d.), glaberrimus, caule erecto, foliis lanceolatis utrinque attenuatis acutis integerrimis 1 -nerviis eveniis, summis linearibus, paniculà simplici apice áphyllâ, valvis coriaceis magnis pedicello crassiusculo extra medium articulato longioribus late ovatis 
acutis vel suborbicularibus breve acuminatis basi truncatis ecallosis. $\mathcal{Y}$ In alpibus Taúr, prope Güllek Magara et in m. Gisyl Deppe (Kotschy !). Caulis 'basi lignescens, ochreis longis fuscis tectus, spithamæus. Folia infima $2 \frac{1}{2}$ poll. longa, 4-5 lin. lata, in petiolum brevem attenuata, viridia (nec glatuca). Pedicelli fructiferi 3 -5 lin. longi, recurvi, parte supranodali 1 lin. longâ. Valvæe 5-6 lin. longæ basique reque late elevato-reticulatæ, pallide virides, sæpe passim rosex, modice diaplianic. (v. s. in li. DC.).

\section{§ 2. Suffrutices, frutices vel arbusculce.}

120. R. FRUtescens (Petit-Thouars fl. Tristan 'd'Acunha, in Mélang. de bot. p. 38), glaber, humilis, caulibus suffruticosis fasciculatis adscendentibus, foliis obovatooblongis retusis, lloribus glomeratis masc. et fem. intermixtis, valvis calliferis. $\zeta$ In ins. Tristan d'Acunha.- Carmichael, in Trans. Soc. Linn. Lond. 12, p. 506, Campd. Rum. p. 138, Schult. fil. syst. 7, p. 1471. Caules sesquipedales, sulcati. Species valde obscura.

121. R. SUFFRUTicosus (Gay ! ined.), caule decumbente? basi suffruticoso, ramis humilibus crectis vel adscendentibus, foliis hastatis lobo medio auriculisque patentissimis linearibus acutis indivisis, petiolo; apice cuneato-dilatalo, paniculâ * simplici brevi aphyllà, floribus dioicis? valvis mediocribus subrotundo-ovatis obtusissimis tenerrime reticulatis subecallosis. $\mathcal{F}$ ? In rupestribus mont. Pico de Canellas Asturiæe (Duriéu! pl. select. Hisp. Lusitan. sect. 1, n. 236 !). R. Acelosella Holl! pl. Lusit. exsicc. (fide 'herb. Mart). Rami semipedales, foliosi. Folia omnia petiolata, incluso petiolo $\frac{1}{2}-2$ poll. longa, $\frac{1}{2}-1 \frac{1}{2}$ lin. lata, auriculis horizontalibus rectis vel falcatis 2-4. lin. longis, summa haud amplexicaulia. Panicula 2-3-pollicaris, racemis erectis, fructfferis densiusculis, perieellis capillaribus basi articulatis valvâ brevioribus. Valvæ 2 lin. longæe, integerrimæe, semper plus minus ovatæe (nec fere orbiculares) basi subtruncatæe vel vix emarginatæ, squamulà ad luasin minutà deflexà obsoletâ, nec tumescente. Sepala exteriora patula et multo minora quam R. Acetosce. Achænium castaneum, læve, nitidum. (x. s.)

122. R. н А s t a T u s (D. Don prodr. fl. nepal. p. 74), caule lignoso decumbente ramosissimo, ramis erectis dense sulcatis, foliis glaucis omnibus longe petiolatis liastatotrilobis, lobis linearibus indivisis lateralibus patentibus longis sursum falcatoinflexis obtusis intermedio acutó, racemis paniculatis laxifloris, valvis mediocribus subreniformibus rotundisve inciso-cordatis apice subemarginatis, unicà plicatà, squamulà ad basin deflexà obsoletc̀. 5 In Nepalià (Wall.), Dheyra Dhoon et Kamaon (Blinkworth! Strachey et Winterbottom!), Afghanistan (Griffith! n. 1716, journ. 53). - Wall. list n. 1729 ! Schult. fil. syst. 7; p.1467, Meisn. in Wall. pl. As. rar. 3, p. 64. Caules vere lignosi, validi. Rami florentes $1-1 \frac{1}{2}-$ pedales. Foliorum lobi $\frac{1}{2}-1$ lin.lati. Verticilli discreti, 2-10-flori, pedicellis capillaribus basi articulatis valvam sequantibus, valvis pellucido-membranaceis reticulato-venosis magnit. R. Acetose. Flores dioici (ex Don polygami). Descr. apud Don verisimiliter ad ramulos tantum mancos facta, quum planta " herba palmaris " dicatur. (v. s.)

123. R. NERvosus (Vahl symb. p. 27 *), suffrúticosus, diffuso-ramosus, glaberrimus, foliis crassis glaucis petiolatis lanceolatis acutis 3 -nerviis eveniis integerrimis, paniculis terminalibus, jedicellis ternis capillaribus calyce fructiferō longioribus apice incrassatis, valvis orbicularibus integris basi squamulà patente albâ palmatà auctis. † In montibus Hadiensibus Arabiæe, ubi Ohrob vocatur (Forsk.).-Campd. Rum. p. 110, Schult. l. c. p. 1443*, Jauh. et Spach ill. t. 452. R. persicarioides Forsk. fl. Ag. Arab. p. 76 (non alior.). Petioli internodiis foliisque rquales, pollicares. Species non satis nota.

124. R. A I S F FOL IUS (Fresen. in Flora 1828, 2, p. 602, et Mus. Senkenberg. 3, p. 63), fruticosus, diffuso-ramosus, glaberrimus, foliis petiolatis carnosis glaucis lanceolatis acutis integerrimis basi attenuatâ vel obtusâ tenuiter 3 -nerviis eveniis, paniculis aphyllis laxis, racemis subsimplicibus patulis, fasciculis 2 -5-floris, floribus dioicis? valvis majusculis orbicularibus sinu angusto profunde cordatis, callo basilari minuto integro. F In collibus, vallibus, paludibus, ad rivos Abyssinie, ubi Hachot vocatur (Ruppel, Schimper, B. 152 ! 1067 ! et 1484 !). — $\Lambda$. Rich. voy. Abyss. 5, p. $230^{*}$. Petioli plerumque pollice breviores, lamina $1-1 \frac{1}{2}$ poll. longa, 4-6 lin. lata. Pelicclli capillares, valva sublbreviores, infra medium articu- 
lati. Valvæe 3-4 lin. longæ latæque, tenuiter reticulatæ, marginè integerrimæ, imâ basi granulo minutó obluso integro (nec palmato) munite. An a $R$. nervoso satis distincta? (v. s. in herb. DC. et sluttlew.)

125. R. Limoniastrum (Jaubert et Spach! pl. orient. 2, p. 6 *, t. 106), fruticosus, glaberrimus, ramis suberectis, foliis carnosis glaucis petiolatis oblongo-spathulatis lanceolatisve obtusiusculis basi attenuatis obsolete 1 -vel-3-nerviis eveniis, paniculâ subsimplici aphyllâ, racemis adscendentibus laxiusculis, faściculis 2-5-floris, floribus hermaphroditis', valvis majusculis reniformibus duplo latioribus quam longis apice emarginatis basi minute calliferis. 5 In monte Diebbel Akadar ditionis Mascate Arabic (Aucher-Eloy, n. 5280 !). Species insignis, præcedenti umnibus fere notis conveniens, sed floribus hermaphroditis et valvis $(3-4$ lin. latis, vix $1-\frac{1}{2}$ lin. longis) distinctissima. (v. s. in h. Sluttlew.)

126. R. LUNARI (Linn.sp. 1, p. 479), frutex arborescens, sempervirens, glabẹrrimus, foliis petiolatis subcarnosis glaucis ovatis vel ellipticis obtusis basi cuneatis vel subcordatis 3-7-nerviis, paniculis compositis aphyllis, racemis laxifloris fructiferis densis, valvis magnis cordato-orbicularibus reticulatis basi minute calliferis. J In ins. Canariens., Tenerifià (Brouss. Chr. Smith! Webb), Palmá (Blauṇer !). - Campd. Rum. p. $136^{*}$, t. 2, f. 5, Schult. fil. syst. 7, p. 1470, Webb et Bertl. phytogr. Canar. 3, p. 387. Acctosa Lunaria Mill. dict. n. 6. Lapathum arborescens Mocnch meth. p. 355, Pluk. phyt. t. 252, f. 3. Rumex polygamus Cavı ic.1, p. 14, t. 22. Folia integerrima, inferiora obsolete venosa. Pedicelli capillares, valvas uquantes, prope basin articulati. Flores ex Campdera, hermaphroditi, ex aliis monoici vel polygami, ex nostrà observatione dioici, rarius masculis paucis femineis intermixtis, masculi primo vultu 3-sepali, sepalis enim interioribus minimis exterioribus staminibuisque quadruplo brevioribus, antheris 6 (nec 12 ut Smith tradit), sed profunde bilobís. Valvæe 3-4 lin. longæ latæeque, integerrimæ, densiuscule reticulatx, callo ad imam basin parvulo obtuso. (v. v. c. et sp.)

\section{Rumicis species obscurce et vix notce.}

127. R. An nE N C. Koch! ! in Linneà 22, p. 209), caule erecto simplici, foliis sulbcoriaceis acutis planis, radicalibus longe petiolatis cordatis oblongis, caulinis breve petiolatis ovali-oblongis vel lanceolatis cordatis tenuiter crispulo-crenatis, summis sublincaribus, paniculâ fästigiatâ superne aphyllà, racemis ramosis aphyllis, verticillis paucifloris approximatis infimis remotis, pedicellis capillaribus calyce parvulo subduplo longioribus basi articulatis, sepalis ovalibus obtusis, valvis..... 2 In planitic editiore Armeniæ (C. Koch !). Caulis 3-pedalis. Folia infima pedalia, $2 \frac{1}{2}-3$ poll. lata. Panicula pedalis, racemis subsolitariis pedunculatis adscendentibus. Calyx magnit. R. Acetosellw. Species fide auct. R. longifolio DC. proxima, nobis potius ad R. Fischeri ct orientalem accedere videtur. (v. s. jun. in lierb. reg. Berolin.)

128. R. BIDENS (R. Brown prodr. f1. Nov.-Holl:p. 421), foliis lineari-lanceolatis basi attenuatis, floribus diclinibus, valvis hastatis nudis. - In ins. Van Diemen.

129. R. BonaRIENSIS (Canip. Rum. p. 144), caule erecto, foliis petiolatis oblongoellipticis breve, obtuseque acuminatis, paniculà inferne foliosâ, verticillis circ. 10-floris, lloribus hermaphroditis, pedicellis brevibus, valvis..... In paludosis Bonariæ (Commerson). - Schult. fil. syst. 7, p. 1475, Meisn. in Mart. fl. Bras. fasc. 14. Polyg. p. 11.

130. R. н о т I I IS (Lour. fl. cochinch, 1, p. 269), caule erecto ( 3 pedali) tereti aculeato; foliis lanceolatis planis integerrimis patentibus, floribus dioicis spicatis, valvis integerrimis inermibus nudis. In Coehinchinâ.-Campd. Rum. p. 147, Schult. fil. syst. 7, p. 1475. Species plane obscura, forsan non generis, an Polygoni species e sect. Echinocaulon?

131. R. FLEXU os US (Forst. ex Spreng. syst. 2, p. 162, mant. 1, fl. hal. p. 38), caulo lierbaceo dichotomo angulato, ramis flexuosis, foliis oblongo-lanceolatis acutiusculis hasi attenuatis venosis glabris margine crispis floribus subverticillatis polygamo?-monoicis, verticillis falio fultis remotis, valvis lanceolatis integerrimis. In Novâ-Zeelandiâ (Forst.). - Scluult. l. c. p. 1459. Cfr. R. Cunninghamii.

132. R. Ludovicranus (Rafin. Il. ludov, p. 30), caule erecto (2-3-pedali) striato, 
foliis petiolatis crassis lanceolatis acutis integris subundulatis, racemis paniculatis, floribus verticillatis hermaphroditis, valvis demum granulatis.... In umbro . sis et palustrihus Americæ borealis. - Gampd. p. 145, 'Schult. p. 1475. Forsan mere R. conglomeratus.

133. L. MAgELLANi GuS. (Campd. Rum. p. 144), caule erecto, foliis petiólatis oblongolinearibus elongatis acuminatis glabris margine runcinato-crispis, paniculâ inferne foliosâ, floribus confertis..... In terrâ Magellanicá.-Schult. 1. c. p. 1475, Cl. Gay, hist. de Chile, p. 280 (desc. ex Campd. depromta).

134. R. MIGROGARPUS (Campd: Rum: p. 143)....., valvis demum ovato-lanceolatis integris vel leviter dentatis..... In Chinâ. Schult. li c. p. 1474.

\section{Species indescripta.}

R. AFE R (Savi in Atti di storia nat. di Bologna, 1830, 3, p. 90, ex Oken Isis, 1833, p. 1100). In Aggypto.

R. A me Ricanus (Gampd. Rum. p. 151), ex ic. citata Barrel, t. 539, aut ad R. vesicarium, aut ad R.'scutatium spectat.

R. Sinua tus (Nathihorst, in Linn. amœn. 4, p. 481, Campd. p. 148). - MonspeliiCfr. R. Tingitahus.

R. Lenit a T U (Gouah herbor. Monsp. p. 268, Campd. Rum. p. 148).

R. м А I м U S (Campd. Rum. p. 149). Cfr. R. alpinus L.

R. mont ANus (Campd. p. 149, non Desf. ?). R. monticola Schult. fil. syst. 7, p.1476.

R. SYL VAT I A (Rafin. Ann, nat. 1820, p. 12):

R. Schultzil et R. SPURIUS (Rafin. in New-York med. Repos. t. 5, exSchult. 1.c. p. 1476.

R. TOURNEF ORTIY, NEBRIODES, SAGITTIFOLIUS, CALTHAFOLIUS, LANUGInosus, auritus, bulbosus, orientalis, subrotundus, Campd. Rúm. p. 149 et seq.

R. erosus, hexagyus, Alexandinus, Ochotensis, hort. (ex Schult. l. G. p. 1476), STREPENS, TAURicus, hort. (ex Steudel).

\section{Species exclusie.}

R. DIGYNUS Linn. = Oxyria reniformis Hook:

R. HAStul a tus Sm. = Mühlenbeckia Chilensis Meisn.

$\left.\begin{array}{l}\text { R. GLABER Forsk.? } \\ \text { R. SPINosus Linn. }\end{array}\right\}=$ Emex spinosa-Campd.

R. sprosus Thunb. = Emex Centropodium Meisn.

R. UMBELLAT US Hoụttuyn. = Polygonum Chinense Linn.

XVIII. ATRAPHAXIS Linn. gen. $\pi .356$, Juss. gen. p. 82, Lam. ill. t. 265, Jaubert et Spach pl. arient. 2, p. 11. - Tragopyrum M. Bieb. R. taur.cauc. suppl. p. 284, Endl. l. c. n. 1994, Presl bot. Bemerk. p. 109.

Flores hermaphroditi. Calyx corollinus, acerescens, 4-vel 5-partitus, pa tens, lobis biseriatis imbricatis, exterioribus 2 minoribus concavis demun reflexis, interioribus 2 vel 3 demum erectis scariosis reticalatis achænio adpressis el majoribus. Stamina 6 vel 8 (rarissime 7 vel 9) imo calyci inseria eoque breviora, 4 vel 5 ejus lobis alterna, 2 vel 3 lobis interioribus anteposira majora, filamentis subulatis persistentibus basi dilatata in annulum brevissimum calyci adnatum confluentibus, antheris dorso affixis versatilibus ovalibus introrsis. Ovarium lenticulare vel triquetrum, ovulo fundo loculi affixo atropo. Styli 2 vel 3 , breves, subliberi, decidui, stigmatibus capitatis integris. Achænium lenticulare vel triquetrum, apterum, sepalis interioribus auctis(valvis) inclusuın, lave, pericarpio crustaceo tenui. Semen liberum, testâ membranaceâ tenui. Embryo curvatus, albuminis farinacei angulo accumbens, cotyledonibus linearibus, radiculâ superâ elongatâ rectâ. - Frutices vel fruticuli Orientales 
et Sibirici, ramosisșimi, ramis sæpe spinescentibus, junioribus striatis vel angulatis, foliis sparsis coriaceis vel carnosis sæpe glaucis subsessilibus cum pulvillo persistente 3 -costato articulatis, ochreis subdiaphano-scariosis basi vaginantibus plerumque 2 -nerviis apiceque bifidis, floralibus (bracteis) aphyllis turbinato-cynthiformibus 1 -3-floris, racemis laxis, pedicellis capillaribus articulatis fructiferis nutantibus.

Sectio I. Euatraphaxis Jaub. et Spach, l. c. 2, p. 12. - Atraphaxis Linn. gen. n. 356, M. Bieb. fl.taur.-cauc. 1, p. 288, Gcertn. fr. 2, p. 182, t. 119, Endl. gen. n. 1995, suppl. 1v, 2, p. 64, Meisn. gen. p. 317 (228), prodr. Polyg. t. 2, fig. F., Ledeb. fl. ross: 3, p. 513.

Flores omnes 4-partiti, 6-andri, ovario lenticulari-compresso, stylo brevissimo indiviso vel bifurco, stigmatibus 2 . Valvæ 2 planæ, achænio adpressæ. Racemuli abbreviati e ramillulis novellis ramulisve brevissimis lateralibus orti.

\section{§.1. Pedicelli juxta vel infra.medium articulati, parte supranodali sepalis exterioribus longiore.}

1. A. SPINOSA (Linn. sp. 1, p. 475), ramis gracilibus elongatis ramulisque patulis strictis spinescentibus vel inermibus, ochreis brevibus fuscis, foliis parvis glaucis reticulatis glabris ellipticis lanceolatisve acutis attenuato-subpetiolatis, rarius subrotundis obovatisve, raçemis lateralibus brevibus foliosis, sepalis interioribus primo patentibus lateribus replicatis, deinde erectis planis suborbicularibus achænio late ovato accumbentibus. $t$ In Asia occid. temper--Buxb. cent. 1, p. 19, t. 30 ? G. Koch in Linn. 22, p. 212, Ledeb. ! fl. ross. 3, p. 514. Tragopyrum spinosum Presl bot. Bemerk. p. 109. Folia 3-6 lin. longa, $1-4$ lin. lata, margine integra plana vel subrecurva undulato-crenulata. Florum fasciculi axillares in apice ramulorum lateralium approximati racemum brevem foliosum formantes, pedicellorum articulo superiore sepalis extérioribus subduplo longiore. Notas quibüs var. sequentes distinguuntur haud stabiliores invenimus quam foliorum formam; rami secundum fruticis ætatem et (fide Ledeb.) soli indolem mutici vel spinosi evadunt, quare præeunte Ledebour illas speeies in unam contrahimus.

๙, Linnezana, ramulis spinescentibus, pedicellis medio articulatis, valvis cordatovel reniformi-orbicularibus achænio parum longioribus subtriplo latioribus. In region. Caucasicis (Hohenack.I etc.), Armeniâ (Chesney exped. Euphrat.? n. 115 !). A. spinosa Linn. I.L'Hérit. stirp. 1, p. 27, t. 14, Lam. ill. t. 265 , Ledeb. fl. alt. 2, j. 56, Schult. fil. syst. 7, p. 1380 *, Jaub. et Spach, 1. c. p. 12. A. replicata Lam. dict. 1, p. 329, ill. t. 265, f. 2, Schult. 1. c. p. 1381. A. densiflora' C. Koch, in Linneấ 22, p. 212 ? (v. v. c. et s. sp.)

$\beta$. Fischeri, ramulis muticis, pedicellis infra medium articulatis, valvis subreniformibus basi truncatis achenio dimidio longioribus subtriplo latioribus. In Rossiẩ australi et Sibiriâ. A. Fischeri Jaủb. et Spach, l. c. p. 12, Bunge! mss. reliq. Lehmann. in hb. reg. Berol. A. Laxmanni Agardh, in Schult. fil. syst. 7, p. 1382 ? Jaub, ot Spach, l. c. p. 13. A. crassifolia Agardh, l. c. p, 1381? Jaub. et Sp. l. c. p. 13. (v. v. c. et s. sp.)

$\gamma$. Karelini, ramulis muticis, foliis crassiusculis, floralibus obtusissimimis vel retusis cordato-vel obovato-subrotundis, ramulorum sterilium acutis, pedicellis juxta vel infra medium articulatis, valvis cordato-subrotundis achænio vix longioribus duplo latioribus. In montosis littoris orientalis maris Caspii (Karelin !).'A. Karelini Jaub. et Spach, 1. c. p. 12. A réplicata Fisch. (fide Spach). A. crassifolia $\beta$ Fisch.! in herb. Mart. (v. s.)

2. A. SINA I A (Jaub. et Spach, 1. c. p. 12), ramulis sterilibus spinescentibus, foliis glaucis rhombeo-vel cuneato-orbicularibus obtusissimis retusisve planis vel mar-1 gine recurvis vix undulatis passim acutis, pedicellis medio articulatis, parte supranodali sepalis exterioribus vix longiore, valvis cordato-vel reniformi-orbicularibus achænio subdimidio longioribus subduplo latioribus. $\hbar$ In montibus Arabiæ petrex iRuppell! Botta! Ehrenb.! Aucher-Eloyl n. 2563 ex parte, Schimper, n. $450 !$ Bové, n. 36 I). A. spinosa Fresen. in Mus. Senkenberg. p. 74; Decsne! fl. Sin. in Ann. sc. nat. 2" sér. p. 243 (non Linn.). Tragopyrum rotundifolium Presl bot. Bemerls, p. 109. Folia pleraque obtusissima, sæpius subrotundo-obovata, 
ramulorum sterilium superiora acuta vel acuminulata. Achænium ovato-rhombeum vél elliptico-subrotundum. (v.s.)

3. A. APGHANICA, ramulis patentibus spinescentibus, oclireis brevibus fascescen tibus, folits parvis crassiusculis glabris'subenerviis ovatis acutis vel obovatís obtusissimis integerrimis, pedicellis valvis subbrevioribus infra medium articulatis, parte supranodali sepalis exterioribus dimidio longiore, valvis mediocribus reniformi-subrotundis, tenuiter venosis vix reticulatis, achænio ovato hinc plano inde subcarinato-convexo subdimidio longioribus. $\hbar$ In collibus lapidosis Afghaniæ et Kulloo-Pass (Griffith!). Ramosissima, ramis nunc gracilibus elongatis sulcatis, aunc abbreviatis. Folia subsessilia; 3-4 lin. longa, 2-3 lin. lata, plana vel margine subrecurva. Florum fasciculi axillares vel ramulos brevissimos terminantes. Sepala exteriora reflexa, valvæ 4 lin. longæ latieque. Achænium ovato-acutum, læve, nitidum. Difiert ab A. Sinaicâ et spinosâ foliis eveniis vel obsoletissime venosis et pedicellorum parte supranodali breviore, ab A. compactâ pedicellis infra medium articulatis. (v. s. in herb. Lcmann, nunc Univ. Cantabrig.)

\section{§ 2. Pedicelli juxta vel paulo infra apicem articulati, parte supranodali sepalis exterioribus breviore.}

4. A. сомраст А (Ledeb.! fl, Altaic. 2, p. 55; ic. fl. Alt. t. 411), ramulis sterilibus spinescentibus, foliis glaucis glabris planis vel margine recurvis plerisque ovalibus obovatisve obtusis vel mucronulatis, valvis cordato-orbicularibus achænio subdimidio longioribus et triplo latioribus. $\$$ In Sibiriâ Uralensi, Altaica et deserto Soongoro-Kirghisíco (Karelin et Kiril.! h. Soc, imp. Mosq. 11. 1919 ! Jaub. et Spach 1. c. p. 13, Led. fl. ross. 3, p. 513. A. spinosa Eicliw. Casp. Cauc. p. 7 (non alior.). Tragopyrum compactum Presl bot. Bemcrk. p. 109. Folia pleraque 3-4 lin. longa, 2-3 lin: lata basi cuneato-attenuata subsessilia, nervis parum prominulis. Ochrese albæe, laceræ, internodia ramorum juniorum brevia subæquantes. Valvæ $4-4 \frac{1}{2}$ lin. latic, paulo breviores quam latæ, pedicello toto sublongiores. Achænium ellipticum vel sulbrotundum, obtusissimum. (v. s.)

5. A. CANESCENS (Bunge! ind. sem. h. Dórpat. 1839, p. 3), ramulis sterilibus spinescentibus, foliis minute canescenti-puberulis ovatis obovatis vel ovali-subrotundis obtusis acutisve margine recurvis, valvis cordato-subrotundis achænio vix - longioribus et parum latioribus. $\$$ Ad lacum Noor-Saisan deserti Soongoro-Kirghisici Sibirix Altaicæ (Bunge !).- Bunge in Bong. et C.-A. Mey. suppl. fl. Alt. p. 62, t. 14, Jaub. et Spach, 1. c. p. 13, Ledeb:! fl. ross. 3, 513. Tragopyrum canescens Presl bot. Bemerk. p. 109. Rami stricti, juniores albi glabri, ochreis albis inter-

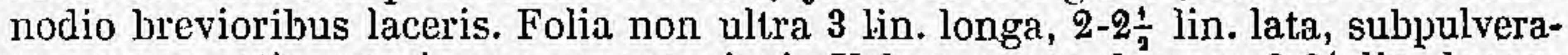

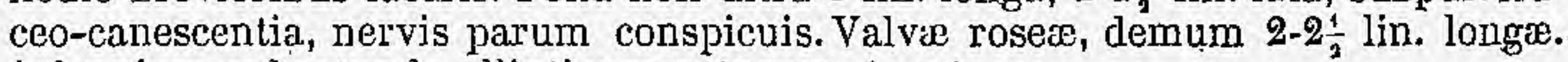
Acliænium subrotundo-ellipticum retusum. (v.s.)

\section{Sectio II. Tragatraphaxis Jaubert et Spach pl. or. 2, p. 13.}

Fiores dimorphi, alii-4-partiti, 6-9-andri, achænio lenticulari, valvis planis, vel 3-4-gono; alii 5-partiti, 8-andri, achænio triquetro, valvis concavis (lateribus extrorsum recurvis silbi invicem contiguis vel adpressis). Stylus brevissimus, indivisus, stigmatibus 2-3 basi subconfluentibus.

6. A. vartabizis (Jaub. et Spach, I. c. p. 13 et 16, t. 110), ramulis sterilibus spinescentibus, foliis viridibus glabris subrotundis rhombeis ovatis obovatis spathulatis vel sublanceolatis obtusis retusis acutisque, racemulis abbreviatis, pedicellis solitariis approximatis juxta vel infra medium articulatis, valvis cordato-vel reniformi-subrotundis achænio majoribus. ந In Syriâ, prope Halep, ct in Cappadociâ (Coquebert, Aucher-Eloy! 11. 2563, ex parte). Glaberrima, ramis tortugsis vel gracilibus cinereis, fertilibus muticis. Folia 3 lin. longa, crassa, reticulato-venosa, passim apiculata. Oolreæe albidæ vel pallide fuscæe, campanulatæ 2-nerviæ, 2-vel pluridentatæe, summæ aphyllæe subintegræ subimbricatæ. Racemuli terminales 5-9-flori, basi foliati, pedicellis solitariis ochreolà proprià destitutis. Calyx roseus, valvæ 3 lin. longæ, 4-5 lin. latæ, levissime cordatæ. Achæenium valvis subdimidio brevius, subtriplo angustius, faciebus ovato-vel rhombeo-subrotundis. (v. s.) 
Sectio iil. Tragopyrum Jaubert et Spach pl. or, 2, p. 13. - Genus Tragopyrum $M$. Bieb. fl. taur.-cauc. 3, p. 284, Endl. gen. n. 1994, suppl. 1v, 2, p. 64. - Polygonellæ sect. b. Meisn. gen. 2, p. 228. - Polygoni sp. Linn. Willd. Lam. Gartn. fr., t. 119.

Flores omnes 5-partiti, 8-andri, trigyni, achænio triquetro, valvis concavis, late. ribus extrorsum recurvis sibi invicem contiguis. Racemi interrupti, plerumque elongati, fasciculis 2-5-floris, pedicellis singulis basi ochıeolâ proprià præeditis.

\section{$\S 1$. Folia reticulato-nervosa vel pennivenia.}

- Pedicelli juxta vel infra medium articulati, parte supranodali sepalis exterioribus longiore. Sepala exteriora reflexa, valyis subrotundis minora. Styli basi connati.

7. A. Billardieri (Jaub. et Spach, l.c. p. 14 ct $17, t$. 111), ramulis substrictis, sterilibus spinescentilus, novellis puberulis, foliis viridibus glabris reticulatovenosis basi abrupte angustatis ovalibus oboratisve obtusis vel acutis vel passim sublanccolatis acuminulatis ${ }_{2}$ pedicellis juxta medium articulatis, parte supranodali sepalis exterioribus subduplo longiore, valvis cordato-vel reniformi-rotundis achæenio ovato-acuto subduplo longioribus. 5 In Syrià (Labill. 1), Antilibano (Boiss !), Gretà (Heldreich l). Tragopyrum Billardieri Endl. gen. suppl. 4, 2, p. 54. Frutex humilis? tortuosus ramosissimus, ramis senioribus aphyllis. Ochrese plerumque intermedio breviorés. Folia erassa, plana vel margine subundulato revoluta, non ultra 5 lin. longa, $1 \frac{1}{2}-2 \frac{1}{2}$ lin. lata, brevissime petiolata. Racemi densiusculi, $\frac{1}{2}-1 \frac{1}{2}-$ pollicares, ramulos subpollicares basi foliatos terminantes. Calyx roseus, sepalis exteriorilus medio viridibus, valvis circ. 3 lin. latis. (v. s.)

$\beta$. Graca, ramulis floriferis gracilibus foliosis, racemo terminali subpollicari aphyllo laxe multifloro, pedicellis subsolitariis, foliis omnibus lanceolatis utrinque attenuatis acutis. In altissimis Tymphrysti, etc., in Eubæâ (Zuccarini, n. 419!). A. Græca Meisn. mss. in herb. Zucc. Folia 4-6 lin: longa, 2 lin. lata. Cietera omnia ut in pl. Boiss. et Heldr. Calyx fructifer nondum observatus. (v. s.)

8. A. T OUR NEF ORT II (Jaub. et Sp. 1. c. p. 14 et 18, t. 112), ramulis omnibus muticis', novellis puberulis, foliis viridibus elliptico-oblongis nervosis cuspidulatis margine crispis puberulisque basi cuneato-angustatis, pedicellis juxta medium articulatis, parte supranodali sepalis exterioribus majusculis vix longiore, valris reniformi-orbicularibus achænio ovato-acuto subduplo longioribus. İ In Armeniâ (Tourn.). Tragopyrum Tournefortii Endl. gen. suppl. 4, 2, p. 54. Frutex erectus, ochreis albidis longe cuspidatis internodia subrequantibas. Folia 5-10 lin. longa, dense penninervia subreticulata. Racemi terminales pollicares aphylli, densiusculi, bracteis contiguis 2-3-floris, pedicellis exsertis 2-3 lin. longis, calyce rubro, demum fusco.

9. A. LATEVIRENS (Jaub. et Sp. l. c. p. 14), ramulis flexucsis muticis, novellis puberulis, foliis viridibus obovatis subrotundis ovalibusve obtusis vel apiculatis reticulatis margine crispis basi truncatis vel breve angustatis, pedicellis infra medium articulatis, parte supranodali sepalis exterioribus subduplo longiore, ralvis ovato-subrotundis achæenio ovato acutiusculo dimidio longioribus. $\$$ In deserto Soongoro-Kirghisico Sibirise Altaicæ (Bong. et Mey. Karel. et Kiril. n. 429 I). Tragopyrum lætevirens Ledeb.! fl. Alt. 2, p. 75 ", ic. fl. Alt. t. 122, fl. Ross. 3, p. 516, Endl. l.c. Trag. buxifolium Karel. et Kiril. enum. pl. Alt. n. 794. Polygonella læetevirens Meisn. gen. 2, p. 228. Ochreæe albidie, longe cuspidatæ, plerumque internodio breviores. Folia usque ad pollicem longa et 8-10 lin. lata, sed plerumque 3-4-plo minora basi rotundata vel passin (superiora præcipue) brevissime angustata, subsessilia. Pedicelli pars supranodalis infranodali subtriplo longior. (v. s.)

10. A. BUXIFolia (Jaub. et Sp. 1. c. p. 14), ramulis flexuosis muticis, foliis viridibus reticulatis obovatis subrotundis ovalibusve obtusis vel apiculatis basi cuneatoattenuatis margine crispis, pedicellis juxta medium articulatis, parte supranodali sepalis exterioribus subduplo longioribus, valvis subrotundis basi truncatis rel rotundatis achænio ovato subduplo longioribus. நIn Iberiâ, Georgiâ Caueasicâ, Mingrelià (M. Bieb. Wilhelms! Szovits!). Polygonum buxifolium M. Bieb. fl. taur.cauc. 1, p. 300. P. frutescens Güldenst. Reise 1, p. 924 (non alior). P. Caucasicum Hofm. in Comm. Soc. phys. med. Mosq. I, 1, p. 10. 1. crispulum Sims Bot. Mag. 
t. 1065 (excl. $\beta$ ). Tragopyrum buxifolium M. Bieb. 1. c. 3, p. 284, Endl. 1. c. Ledeb. ! fl. ross. 3 , p. 516. Polýgonella brevifolia Meisn. gen. 2, p. 228. Ramuli tenues, cum foliis mox glabri, internodiis $\frac{1}{2}-1$ poll. longis. Ochreæ fuscæ, internodio breviores, breviter 2 -dentata. Folia usque ad 1, poll. longá, 6-7 lin. lata, șubpetiolata, utrinque elevato-réticulata, basi semper cuneato-angustatá. Flores roseí, sejpala exteriora pro gẹnere xnagna late ovalia fere 2 lin. longa, valvæ demum paulo latiores quam longæ $3 \frac{1}{2}-4 \frac{1}{2}$ lin. latæ. (v. s.)

11. A. LANGEOLATA, subǵlauca, ramis muticis elongatis, fóliis lanceolatis vel oblongo-lanceolatis acutis vel mucronulatis basi attenuatis penninerviis margine recurvis, racemìs terminalibus laxis supra aphyllis, bracteis acuminatis semipatentibus basi fuscis pedicellorum parte supranodali sepalis exterioribus longiore, valvis subrotundis basi subtruncatis achænitim ovato-oblongum superantibus. † In Rossiâ mediâ et australi, deserto Caspio, Davuriâ, Sibiriâ. Uralensi, Altaicâ et Baicalensi. Polygonum frutescens Linn. fl. Upsal. p. 95, Willd. sp. 2, p. 440, Lam. ili. t. $315, \hat{\ell}, 2$. Polygonum fruticosum Gmel. Sib̆. 3, p. 60, t. 12, f. 2. Tragopyrum lanceolatû́m M. Bieb. fl. taur.-cauc. 3, p. 285, Ledeb. fl. Alt. 2, p. 73; Fl. ross. 3, p. 515. Tragop. glaucum Lessing in Linnæâ 9, p. 204 (ide Ledeb.). Polygonella lanceolata Meisn. gen. 2, p. 228. Atrophaxis micrantha Jaub. et Spach l. c. p. 15? Pedicelli nunc medio, nuic paulo supra vel infra articulati. Valyæ haud cordatæ. Achænium valvas subæquans.

$\alpha$, divaricata (Ledeb. 1 fl, ross. p. 515), ramis varie flexis (valde elongatis abbreviatisve), foliis angustis vel latioribus, nonnunquam subobovatis. T. buxifolium var. Karel. et Kiril. enuta. pl. Soongor. n. 724. (v. s. sp. et c.)

ß. stricta, (Ledeb. 1. c.), ramis valde elongatis strictis, inferioribus sæepe subfasciculatis. Polygonurn frutescens Bot. reg. t. 254 (Karel, et Kïril. in h., Soc. imp. Mosq. n. 430 !).

y.. subspinosa (Bong. et Mey. suppl. fl. Alt. n. 253, Led. 1. c.), divaricato-ramosissima, ramis apice nudis subspinescentib us, foliis vix glaucis. (v. s.)

* Pedicelli supra medium articulati, parte supranodabi sepalis exterioribus breviore vel subaquali (nec longiore).

12. A. pecrpiens (Jaul) et Spach, 1. c. p. 15), inermis, glabra, foliis glaucescentibus reticulato-venosis lanceolatis oblongisve basi attenulatis vix undulatis, infimis subspathulato-obtusis, summis subulato-acuminatis, pedicellorum parte, supranodali infranodali 2 -3-pló breviore sepala exteriora subæquante, valvis ovato-subrotundis 'basi truncatis vel subcordatis achænium' elliptico-oblongum parum superantibus. $ち$ Patria?... Polygonum frutescens hort. paris. olim. Forsan mere forma A. Janceolatæ, sed pedicellis supra medium, articulatis discrepans. Styli brevissimi pltra medium vel fere toti connati.

13. A. PUNGENS (Jaub. et Spach, 1. c. p. 14), ramis divaricatissimis spinescentibus vel subinermibus, foliis glaucis vel flavo-viridibus late ellipticis obovatis vel sublanceolatis acuminato-subcuspidatis planis reticulato-venosis e basi truncalâ vel cuneatâ in petiolum brevem attenuatis, racemis lateralibus abbreviatis, pedicellorum parte supranodali sepalis exterioribus subbreviore, valvis suborbicularibus achæenio ovato acuto dimidio longioribus. † In Davuriâ (Turcz.!) et Sibiriâ Altaicâ et Transibaicalensi (Bunge! Turcz., etc.), Polygonum fruticosum Gmel. Sib. 3, p. 59, t. 12, f. 1 (fide Ledeb., nobis vero potius ad A. lanceolatam referendum videtur). Tragopyrum pungens $M$. Bíeb. I. c. 3, p. 285, Ledeb.! 1 : ross. 3, p. 515 . Polygonella pungens Meisn. gen. 2, p. 228.

a. latifolia (Led.11. c. p. 516), caule ramusissimo ramisque brevioribus confèrtis spinescentibus, foliis late ellipticis obovatisve mucronatis plus minus glaucis, pedicellis brevioribus. T. pungens Spreng. syst. 2; p. 251, Led. fl. Alt. 2, p. 76, ic. fl. Alt. t. 426. A pungens Jaub. et Spach, l. c. (v. s.) /

$\beta$. angustifolia (Led.! l. c. p. 516 ), caule elongato ramisque brevioribus patentiscimis subspinescentibus, foliis anguste oblongis acuminato-subcuspidatis glaucis, pedicellis brevioribus. T. glaucum Spreng. l. c. p. 251. T. lanceolatum Turcz.! cat. Baical. n. 983. A. Davurica Jaub. et Spach, l. c. p. 15 ? (v. s.)

v. irbermis (Led.! 1. c.), caule ramisque elongatis patentissimis inermibus, foliis anguste oblongis acunuinatis llavo-viridibus, pedicellis longioribus: (v. s.)

14. A. GRANDIFl ORA (Jaub. et Spach, l. c. p, 15 et $19^{*}$, t. 113), inermis, foliis glau- 
cis subscabro-puberulis lanceolatis oblongisve acutis subpénninerviis, pedicellis apice articulatis, sepalis erecto-patulis subequálibus omnibus rhombeo-subrotundis, exterioribus valvis vix $\frac{1}{3}$ brevioribus. 5 In Armeniâ (Tourn, Coquebert! AucherEloy, n. 2565, ex Spach,.n. 2599 ! ex h. DG.). Polygonum grandiflorum Willd. sp. 2, p. 440, ex. syn. Tourn. cor. p. 39. Tragopyrum grandiflarum M. Bieb.l. c. 3,p. 285. Ramuli jun. puberuli, plerumque fere toti ochreis tecti, plerique racemo brevi denso terminati, pedicellis 2 lin. longis, calycibus carneis viridi-venosis, valvis demum 4 lin. longis. Styli basi connati. (v. s.)

15. A. A U CHERII (Jaub. et Spach, 1. c. p. 15 et 20*, t. 114), inermis, subglabra, foliis viridibus lanceolatis linearibusque utrinque attenuatis acutis obsolete penninerviis planis, racemis terminalibus interruptis foliosis vel apice aphyllis, pedicellis prope apicem artículatis, sepalis valvisque erecto-patulis subæqualibus ovalibus obtusis achænium parum superantibus. $\hbar$ In Persia boreali (Aucher-Eloy 1 n. 5271, ex Spach, n. 2571 । ex herb. Shuttlew.). Frntex 1-2-pedalis, ochreis albidis 2-nerviis, foliis coriaceis usque ad 2 poll. longis, 1-3 lin. latis, racemis 1-3 poll. longis, fasciculis 2-5-floris, calyce viridi et carneo variegato, valvis demum sepalis exterioribus vix longioribus subdimidio latioribus. Stýli basi connati. (v. s.)

\section{\$. 2. Folia evenia, angusta, 1-nervia vel subenervia.}

16. A. ANGUSTIFOLIA (Jaub. et Spach, 1. c. p. 15 et $21^{\circ}$, t. 115), inermis, foliis viridibus linearibus vel subspathulato-linearibus ácutis basi attenuatis 1 -nerviis, racemis terminalibus aphyllis densis, pedicellis infra medium articulatis, parte supranodali sepalis exterioribus reflexís subduplo longiore, valvis subrotundis achænio subduplo longioribus. † In Armeniâ (Aucher-Eloy, n. 2564! Coquebert). Tragopyrum linearifolium Aucher-Eloy; n. 2391 I in herb. DC. Rami erecti, graciles, albidi, internodiis 8-10 lin. longis. Folia coriacea 6-18 lin. longa, $\frac{1}{2} 1 \frac{1}{2}$ lin. lata, margine interdum revoluto obsolete scabriuscula, summa duplo minora. Racemi 1-3-pollicares, pedicellis demum 3-4 lin. longis, calyce carneo. (v.'s. in h. DG. et Shuttlewi)

17. A. SU A. DAFOLIA (Jaub. et Spach; 1. c. p. 15), glabérrima, ramulis sterilibus spinescentibus, foliis glaucis anguste linearibus acutis basi non angustatis obsolete 1-nerviis margine plerumque revoluto, jedicellis juxta medium articulatis, valvis ovato-subrotundis sepalis roflexis parum majoribus achænio ovato subduplo longioribus. † In Mediâ, prope hodiernam urbem Taurim. (Aucher-Eloy, n. 5272. in Mus. Paris.)

\section{Species exclusce.}

A. cungifolia Poir., ob fructum 3-locularem, etc. sine dubio ordinis alieni.

A. Diorca Bosc! mss. et
TRAGOPYRUM POLYGAMUM Spreng. $\{=$ Polygonella parvifolia Mx.

A. Unduata Willd. (A, inermis Mill.) = Polygonum Atraphaxis Thunb.

XIX. POLYGONELLA Michx h. bor. Amer. 2, p. 240, Meisn. gen. 317(228, excl. sect. Atraphaxi et Tragopyro), G.-A. Meyer, in Mém. Acad. Petersb. 6* sér. sc. math. et phys. 6, 2, p. 145, fig. 2, A. Gray pl. Lindheimer. in Boston journ. of nat. hist. 5, p. 23, Endl. gen. suppl. 4, 2, p. 53, n. 19931/1. - Lyonia Rafin. in New-York med. Repos, 2, hex. 5 (non alior.).- Stopinaca Rafin. ex Endl. gen. p. 1377.-Gonopyrum C.-A. Mey. l.c.p. 144, ic. f. 1, Meisn. gen. 2, p. 368. - Polygoni sp. Linn. Willd. Lam. etc. - Polygoni sectio Nutt. gen. 1, p. 255, Endl. gen. p. 307 et 1377, sub n. 1986. - Tragopyri sp. Spreng. syst. 2, p. 251.

Flores hermaphroditi vel polygamo-dioici. Calyx corollinus, profunde 5-partitus marcescens, lobis subæqualibus demum vixauctis vel interioribus 3 demum ampliatis erecto-conniventibus achænio adpressis (valvis) subscariosis 1-nerviis subeveniis. Stamina 8 imo calyci inserta inclusa, filamentis 5 calycis lobis alternis subulatis, interioribus 3 lobis et achænii faciebus antepositis basi plus minus dilatatis vel auriculatis, antheris globoso-ovalibus dorso affixis versatilibus. Ovarium trigonum, ovulo basilari erecto. Styli 3 breves liberi vel subnulli, stigmatibus subcapitatis integris. Achænium liberum, triquetrum, 
læve, angulis acutis apteris integerrimis. Semen erectum, liberum, testâ membranaceâ tenui. Embryo axilis vel ad angulum albuminis cornei lateralis, rectus, cotyledonibus angustis, radiculâ superâ subexsertâ. - Herhæ vel fruticuli Americæ borealis, erecti, glabri, sæpius glaucescentes et demum aphylli, caulibus simplicibus' gracilibus ramosisve, ochreis herbaceis cylindricis truncatis margine foliigeris ciliatis nudisve, foliis angustis interdum in axiltis fasciculatis, racemis spiciformibus paniculatis, rhachi ochrcis parvis turbinatis (bracteis) subimbricatis dense teclâ et quasi articulatâ, pedicellis subsolitariis cum calycis basi altenuatâ nodoso-articulatis, calycibus fructiferis pendulis.

Sectio 1. Eupolygonelba, Endl. gen. suppl. iv, 2, p. 54. - Polygonella $C$. A. Mey. l. c. p. 145, ic. fig. 2.

Filamenta omnia fliformia, vix basi dilatata. Styli brevissimi. Ochrese ciliatæ yel nudæ nervoso-striatæ. Caules vel rami lerbacei elongati, graciles, superne paniculati, racemis filiformibus, bracteis 1-1loris. Sepala subæqualia.

1. P. PARVIFOLIA (Mich. fl. bor. Amer. 2, p. 241), suffruticosa, ramis ștrictiusculis inferne simplicibus foliosis superne aphyllis, ochreis arctissimis eciliatis, foliis cuneato-linearibus obtusis, paniculæ compositæ ramis distantibus ramulisque patulis, spicis subsessilibus brevibus, bracteis subimbricatis muticis 1 -floris, floribus subsessilibus, sepalis' interioribus ovalibus paulo auctis achænium æquantíbus, embryone, axili: in in pinetis arenosis Carolinæ ! Georgiæ! Floridæ! Arlsansas! - Meisn. gen. 2, p. 228, Nutt. gen. 1, p. 256 (sub Polygono). Polygonum polygamum Vent. Cels. t. 65, Ell. sketch 1, p. 458. Polygonella polygama A. Gray in pl. Lindheim. p. 23 (excl. syn. P. gracile). Atraphaxis dioica Bosc! mss. in h. DC. Rami 1-2-pedales. Folia viridia? 10-15 lin. longa, extra medium 1-3 lin. lata, apice rotundatâ mutica, basin versus sensim attenuafa nec vere petiolata, plus minus distincle sed tenuiter nervoso-striolata. Paniculæ rami basi nec folio nec ochreâ fulti. Spiculee $\frac{1}{3}$ raro 1 poll. longæ, bracteis $\frac{1}{2}$ lin., floribus vix 1 lin. longis. Flores polygamo-dioici, albi, filamentis basi omnibus (interioribus 3 distinctius) paulo dilatatis, Achænium calycem æquans, haud acuminatum, faciebus ellipticis. (v. s.)

B. subenervis, foliis suljenerviis (vel basi obscure 3 -nerviis) glaucis? ochreisque brevioribus (10 lin. longis, 2 lin. latis), paniculæ ramis ramulisque basi folio, fultis. In ripà fl. Manattee Floridæe (Rugel, n. 455 ! sp. flor. jun. sine fr.). Forsan n. sp.

2. P. в RАCHY STACHYA, suffruticosa, ramis supraaxillaribus, ochreis eciliatis, foliis filiformi-linearibus brevibus obtusis planis subenerviis basi attenuatis, paniculæ compositæ inferne foliosæ ramis ramulisque patulis, spicis brevibus subsessilibus, bracteis imbricatis muticis, pedicellis demum breve exsertis, sepalis ovalibus. $ち$ In Floridâ, circa Miami (Rugel! sine numero). Rami graciles, erecti vel adscendentes, a basi ramosi. Folia $3-5$ lin. louga, apice latiora $\frac{1}{2}$ lin. lata, in ramulis sæe fasciculata. Spicæ 3-5 lin. longæe. Flores hermaphroditi. Sepala subæqualia. Fílamenta basi leyiter dilatafa. Stigmata subsessilia. (v. s. in herb. Shuttlew. specim. pauca, sine fr.)

3. P. Gra Gil is (Nutt. gen.1, p. 256, sub Polygono), glaucescens, ramis supraaxillaribus filiformibus paniculatis, ochreis imberbibus, foliis spathulatis obtusis subparallele 3-5-nerviis, spicis subcapillaribus, bracteis subcontiguis muticis, pedicellis brevissimis, sepalis ovato-oblongis demum vix auctis semipatentibus achænio acuminato superatis, embryone axili. $\odot$ (ex Torr. in herb. Meisn.). In arenosis aridis Garolinæ (Fraser!), in Georgiâ (Nutt.), Louisianà (Short!), Floridâ, circa IItami, Aspalagâ, S.-Marks (Rugel, n. 561 !). Pol ygonum setaceum Nutt. Short! in lierb. Mleisn. (non alior.). Caules 2-pedales et ultra, stricti, sulcato-lineati, superne paniculati, ramis plus minus remote supra ochream nascentibus, basi nudis, ultimis fere capillaribus. Ochreæ 5-6 lin. longæe, integerrimæ, margine angustissime subscariosæ, summæe aphyllæ. Folia ochreæ margini inserta, 1-1 $\frac{1}{2}$ poll. longa, $1 \frac{1}{2}-3$ lin. lata, attenuato-subpetiolata, plus minus glauca. Spicæ tenuissimæ. Flores díoici vel sæpius jolygamo-dioici, albi vel carnei, demum 1 lin. longị penduli. Sejala ovato-oblonga, exteriora non reflexa, interiora 1-nervia evenia, inferne sæpius (saltem in fl. fem.) glandulis rufis pellucidis exiguis punctata. Filamenta 3 interiora basi leviter thombeo-dilatala. Stigmata subsessilia. Achænium fere 
$1 \frac{1}{2}$ lin. longum, acuminatum, semiexsertum, faciebus ellipticis lævibus nitidis. (v. s.)

4. P. cIliAta, caule herbaceo subsimplici, ramis axillaribus vel nudis, ochreis setis paucis erectis tubo sublongioribus ciliatis, foliis viridibus subulatis acutissimis striatis supra canaliculatis, paniculà simplici brevi basi foliosà, spicis subsessilibus tenuibus filiformibus continuis, bracteis minutis contiguis cuspidato-acutis cciliatis, pedicellis brevissimis, sepalis oblongis obtusis patulis achænio superatis. $\odot$ ? Ad flum. Manattee Floridæ australis (Rugel, n. 429 l). Caulis erectus, 2-pedalis, gracilis, tenuiter striatus, ramis, dum adsunt, ex ochrea nec supra provenientiJus, ochreis viridibus striatis, ore setis 3-5 lin. longis flavescentibus cfliato. Folia

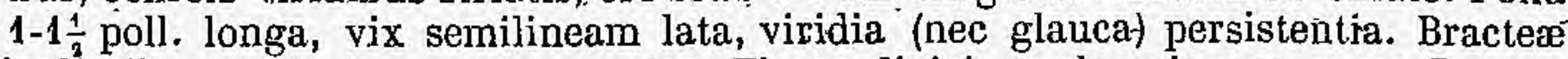
pedicellos brexissimos subrequantes. Flores dioici, paulo minores quam P. gracilis; albi vel rubelli, demum penduli. Sepala subæqualia, obsolete 1 -nervia, eglandulosa, demum vix ac ne vix aucta, exteriora non reflexa. Stamina inclusa, filamentis basi vix dilatatís. Styli 3 brovissimi, exserti. Achæinium acuminatum (matirum ignotum), faciebus oblongo-ellipticis. (v. s.)

Sectio 11. Gonopyrum Fisch et C. A. Mey. l. c. 'p. 144, ic. f. 1, Meisn. gen. 2, p. 288, Endl. gen. suppl. Iv, 2, p. 54.

Filamenta interiora (quæ sepalis interioribus et achænii facicbus anteposita) basi manifeste dilatata vel auriculata. Styli breves liberi. Crules erecti, apice paniculati. Ochreæ eciliatæe. Folia subfiliformia. Bracteæ 1-floræ. Flores hèrmaphroditi.

5. P. ER I coIDEs (A. Gray, in plant. Lindheimer. l. c. p. 22), frutescens? caule sulcato, foliis filiformi-linearibus vel angustissime spathulato-linearibus obtusis acutisve fugacibús, racemis densifloris, bracteis contiguis breve cuspidato-acuminatis obsolete 1-nerviis margine angustissime scariosis, sepalis extérioribus reflexis, interiuribus erecto-conniventibus, staminum interiorum basi obcordatâ auriculis obtusis, embryone axili. $\$$ ? In planitiebus aridis, ad $\mathrm{n}$. Rio Brazos, Texas (Drummond n. 3\$8! Lindheimor, Wright). Gonopyrum Americanum Fisch. et Mey.l.c. p. 14k *. Fructum maturum non vidimus. Si embryo revera axilis, ut ab auctoribus traditur, tune species a sequente, cui cæterum simillima, certe distincta. (v.s.)

6. P. Meisneriana (Shuttlew. 1 in Rugel pl. exsicc. 1843), frutescens, caule superne obsolete sulcato, foliis lineari-filiformibus obtusis diu persistentibus, racemis confertifloris, bracteis subimbricatis setaceo-acuminatis obsolete plurinerviis margine albo-membranaceis, sepalis exterioribus reflexis, interioribus creclo-conniventitibus auctis cordato-subrotundis tenerrime venosis, staminibus 3 interioribus acutiuscule lateque auriculatis, embryone laterali. 5 Ad Blackwarrior River, Blount County, Alabama (Rugel I). Glaberrima; caules pedales et ultra, crecti, graciles, ramis infimis filiformibus sterilibus, superioribus corymboso-paniculatis racemo terminatis. Ochrex 2-3 lin. longx, oblique truncate, neriosæ, arcte adpressæ, margine foliigeræ. Folia 5-10 lin. longa, subteretia, rarius subplana, apicem versus vix dilatata, $\frac{1}{\pi}$ lin. lata, enervia, livide viridia (nec glauca), juniora prope apicem plus minus decoloria sæepiusque fasciculata. Kacemi $\frac{1}{2}-1 \frac{1}{2}$ poll. longi, subsessiles vel breve pedunculati, continui, aplyylli, rhachi bracteis dense tectà, quasi spicam filiformem articulatam referente. Bractex 1 lin. longæ, ochreis similes, amplectenti-infundibuliformes, hinc constanter-folio abortivo sululato erecto ilsis vix breviore cuspidatæe, inferne virides, secus marginem albæ teneræ. Pedicelli solitarii, capillares, 2 lin. longi, florem suboequantes, exserti, patuli, demum recurvi, infra medium articulati, parte infranodali paula breviore bracteam subæquante. Flores rosei vel albidi, omnes? hermaphroditi. Embryo certe! non axilis, sed in angulo vel prope angulum seminis lateralis. (v. s.)

7. P. AR T I U l A T A (Meisn. gen. 2, p. 228), cáule gracili basi lignescente, foliis filiformibus deciduis, paniculâ fastigialâ, racemis filiformibus, bracteis turbinatis subcontiguis truncatis acutiusculis vel cuspidulatis, pedicellis longe exsertis, sepalis subæqualibus omnibus semierectis, filamentorum interiorum basi subrlıomboideâ, embryone laterali. $\mathcal{F}$ ln arenosis siccis Americæe bor.-orientalis, Georgia ! New-Jersey! Massachusetts ! Canadâ! (Hook.). Polygonum articulatum Linn. sp. 1, p. 520, Willd. sp. 2, p. $450^{\circ}$ (non R. Br. nec Perrottet), Nutt. gen. 1, p. 255, Hook. fl. Jor. Amer. 2, p. 133, A. Gray, in pl. Lindheim. p. 23. Caules

XIv. 
$\frac{1}{3}-1 \frac{1}{2}$-pedales, erecti, superne rel rarius a basi paniculatö-ramosi. Folia $\frac{1}{2}-1$ poll. longa, fugacissima. Racemorum rhachis quasi articulata. Flores hermaphroditi, parvi, pulchelli, albi vel carnei, sepalis demum 1 lin. longis, exterioribus obovatis, interioribus ovalibus paulo majoribus, apice plerumque nervo incrassato subcarihatis sæe peque mucronulatis. Stigmata subśessilia. Achænium calyoem æequañs, faciebus elliptico-lanceolatis. (v. s.)

XX. THYS.LNELLA Asa Gráy pl. Lindheimer, in Boston Journ. of nat. hist. 5, p. 24*, in notd, Endl: gen. suppl. IV, 2, p. 5.4, n. 1993/2.

Flores polygamo-dioici. Calyx corollinus; 5 -partitus, lobis omnibus erectis margine scarioso eroso-fimbriatis, exterioribus 2 cordato-sagittatis demum auctis (in flore fertili integris, fide 'Torr.), interioribus minoribus o,vato-lanceolalis pectinato-fimibrialis. Stamina 8 , calycem æquantia, filamentis subulatis basi non dilatatis, antheris dorso affixis ovalibus. Ovarium 3-gonum. Styli 3 filiformes breves, stigmatibus simplicibus. Fruct..... Embbryo (fide Torrey mss. in h. Meisn.) ad latus albuminis reclus. - Herba Ámericæ borealis calidioris, glabra, caule crecto ramoso tereti striato, ochreis herbaceis arcte cylindricis striatis integris apice foliigeris ore truncato setis longis tenerrimis albis ciliato, foliis sparsis linearibus parallele nervoso-lineatis, spicis racemoso-paniculatis pedunculatis cylindrico-filiformibus, bracteis adpressoimbricatis amplectentibus ovatis oblique truncatis margine subscariosis setulâ atbidâ acuminatis 1-flotis, pedicellis medio articulatis.

F. Fin briata (A.Gray, 1. c.). $\bigcirc$ ? In Georgià (Ell, A. Gray), Floridà (Short l Torrey! Rugel!). Polygonum fimbriatum Ell. sketch, 1, j. 588. Planta insignis, pulchra, facie fere Persicariarum, bipedalis et ultra, caule virgato, infra paniculain sæpe simplici, internodiis 1-2-pollicaribus, ochreis circ. 5 lin. longis fuscis, ciliis mol-

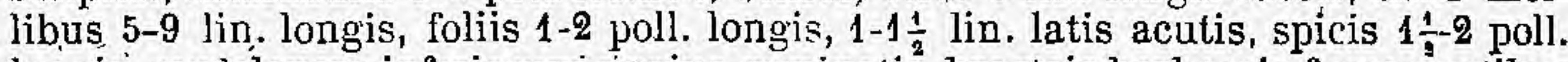
longis, ramulorum inferiorum siepius geminatis, bracteis herbaceis fuscescentibus 1 lin, longis flore dimidio hrevioribus, alabastris ovatis acutis, calyce albo vel incarnato. (v. s.)

\section{Subtribus III EUPOLYGONEAE C. A. Meyer in Mém. Ac.} Pétersb. $6^{\mathrm{c}}$ sér. $6, p .145$.

Flores hermaphroditi. Calyx corollinus, rarius herbaceus, 3-6-partitus, lobis subæqualibus super fruccum conniventibus (exterioribus nunquam reflexis) conformibus vel exterioribus carinatis vel demum alatis. Stamina 5-8 (rarissime 3-1, filamentis subulatis sæpius basi cum squamulis glandulisve perigynis alternantibus, antheris versatilibus omnibus introrsis aut tribus seriei interioris extrorsis. Styli 2-3 filiformès, sæpe connati vel brevissimi, stigmatibus capitatis integris. Achænium lentieulare vel triquetrum, liberum, calyce adpresso sicco parum aucto inclusum vel rarius exsertum. Atbumen farinosum vel corneum. Embibryo lateralis vel centralis. - Herbæ vel rarius suffrutices, habitu et inflorescentiâ variis.

XXI. KOENIGIA Linn. gen. 1241, Juss. gen. p. 83, Lam. Ill. t. 51, Gartn. fr. 2, p. 212, t. 128, Endl. gen. n. 1985, Meisn. gen. 317 (228).

Flores hermaphroditi. Calyx herbaceus, infundibularis, 3-4-partitus, lobis subæquálibus. Stamina $3 \cdot 1$, lobis alterna, médio tubo inserta, inclusa, filamentis filiformibus, antheris ovatis incumbentibus. Ovarium compressúm, oyulo basilari orthotropo. 'Stigmata $2-3$ subcapitata vel 1 sessile bilobum. Achænium calyce immutato inclusum, lenticulare, semine erecta. Embryo intra albumen farinosum lateralis, arcuatus, cotyledonibus planis ovalibus vèl orbicularibus, radiculâ superâ elongatâ. - Herbæ regionum arcțicarum 
et mont. Himalayæ; pusillæ, tenellæ, ramosæ vel cæspitoso-multicaules, foliis alternis vel passim oppositis integerrimis, ochreis membranaceis brevibus laxis, capitulis paucifloris terminalibus axillaribusve pedunculatis foliis summis 3-5 subverticillato-approximatis cinctis, floribus exiguis albido-virescentibus bracteolis membranaceis interstinctis.

1. K. Islandia (Linn. mant. p. 35), glaberrima, foliis obovatis subcarnosis, floribus 3-fidis, 3-andris, stigmatibus $2-3$ subcapitatis. $\odot$ In uliginosis maritimis et alpinis Norwegiæ! Laponiæ! Islandiæe! Groenlandiæe / sinus Eschscholtzii, ins. Aleuticarum ! et Kuriliúm ! Kamtschatkæ! Sibiriæ Altaicæ et Baicalensis! - Lam. IIl. t. 51, Flor. dan. t. 418, Gærtn. fr. 2, t. 128, Wahlenb. fl. lap.. p. 45, Roem. et Schuit. syst. 2, p. 873 , mant. p. 672, Cham. I et Schl. in Linnæê 3 , p. 36, Hook. fl. bor. Am. 2; p. 129, Ledeb. I l. ross. 3, p. 534. (v. s.)

2. Kr. MoNANDRA (Decsne, in Jaquemont voy. bot. p. $142 *$ t. 147), glaberrima, foliis óvalibus vel subrotundis crassiusculis (rarissime passim subrepandis), floribus 4 -fidis 1- (rarissime 2-) andris, stigmate subsessili bilobo. $\mathcal{Y}$ In humidis Cashmere (Jaquemont), Kamaoon, alt. 12,000 ped. (Strachey et Winterbottom, n. 38, ex parte .). Caules erecti, circ. pollicares. Folia inferiora petiolo vix longiora, 2-3 lin. longa, summa conformia subsessilia. Ochrese hyalinie, fuscescentes, enervise, petiolo breviores, demum lacers. (v. s. in herb. soc. linn. Lond.)

3. K.? NEPALENSIS (D. Don fl. Nep. p. 74), hispide (in caule retrorsum) pilosa, foliis ovatis acutis petiolatis, floribus 3-partitis, 3 ?-andris, 3-gynis, achænio triquetro. $\bigodot$ ? In Gossain Thaai Nepaliæ. Planta obscura, forsan ítentica cum Polygono (Cephalophilont) fiticauli Meisn. sed tune descr. Donii quoad char. genericoș valde inaccurata.

XXII. POLYGONUM Linn. syst. nat. ed. $1, n .640$ (excl. sp. pl.), Schreb. gen. n. 677, Lam. IIl. t. 315 (excl. f. 2), Schkuhr Handb. t. 108 (excl.f. 2 et 5), Gartn. fr. 2, p. 182, t. 119, Meisn. monogr. gen. Polyǵ. prodr. Geneva 1826 (excl. Fagopyro), ejusd. synops. Polyg. Ind. or. in Wall. pl. As. rar. $3, p$. 53, ejuisd. gen. 317 (228), Nees jun. gen. A. Germ. fasc. 8, t. 7, Endl. gen: n. 1986, suppl. 4, 2, p. 45, Babingt. in Trans. soc. linn. Lond. 18, p. 93. - Bistorta, Persicaria, Polygoni et Fagopyri sp. Tourn. inst. p. 509 sq. Tovara Adans. fam. 2, p. 276. - Helxine Linn. gen. ed. 1, $n .330$ (non Req.). .-. Laigunea Lour. f. Coch. 1, p. 271. - Antenoron Rafin. fl. Ludov. p. 28. - Ampelygonum Lindl. in Bot. reg. 1838, misc. 118. - Echinocaulos Hassk. H. Bogor. p. 85, - Cilylocalyx Hassk mss (ex eod. ibid.).

Flores hermaphroditi. Calyx corollinus vel semiherbaceus, 5-partitus (rarissime-4-3-part.), lobis subæqualibus integerrimis quincunciatim imbricatis, omnibus conformibus planis vel exterioribus 2-3-carinatis concavis vel dorso alatis, patentibus vel conniventibus demum fructui adpressis parum auctis marcescentibus. Stamina 8, rarius 7-4, libera, imo calyci inserta sæpius cum squamulis annuli perigyni (sæpe obsoletis) alternantia, calycis lobis alterna et, si iisdem plura adsunt, 2 vel 3 (seriei interioris) lobis interioribus et ovarii faciebus anieposita, filamentis subulatis persistentibus, antheris medio dorso affixis versatilibus ovalibus introrsis (vel seriei interioris extrorsis) polline sphæroideo. Ovarium liberum, compressum vel trigonum, ovulo basilari erecto. Styli 2 vel 3 liberi filiformes vel plus minus connati, plerumque deciduj basin relinquentes, sæpe brevissimi vel subnulli. Stigmata capitata, rarius agariciformia, integra. Achænium calyce sicco inclusum ('iarissime semi-exsertum) lenticulare' aut pyramidato-triquetrum, 'sæpius stylorum basi acuminatum, angulis obtusis acutisve apteris integerrimis, pericarpio tenui crustaceo. Semen sessile, achænio conforme, hilo basilari latiusculo, lestâ tenui membranaceâ. Embryo lateraliș, angulo albumínis cornei vel rarius farinosi accumbens vel semiimmersus, arcuatus, colyledonibus foliaceis angustis, radiculâ superâ brevi. - Stirpes totius orbis omniumque regionum et locorum incolæ, multiformes, herbaceæ vel pereintes, raro suffruticosæ, prostratæ, erec1æ vel volubiles; ecirrhosæ, caulibus sæpe nodosis vel fistulosis; ochreis membranaceis decoloribus vel-rarius herbaceis cylindricis ciliatis nudisve vel bipartitis vel demum lacero-multifidis, floralibus (bracteis) plerųmque aphyllis; 
foliis heibaceis (raro subcoriaceis vel subcarnosis), sparsis (dispositione spirali $\frac{2}{5}$ vel rarius $\frac{5}{8}$ ), penninerviis, nonnunquam cordat is vel sagittatis, rarissime pinnatisectis, rarissime glaucis, sæpe glanduloso-punctalis quandoque maculatis; floribus axillaribus solitåriis vel aggregatis vel racemosis spicatis capitatis paniculatisve, parvis, albis-vel rubris; pedicellis articulatis plerumque fasciculatis.

\section{CONSPECTUS SECTIONUM.}

I. Tepuis. Flores axillares. Calyx 4-partitus. Stamina 6 , filamentis basi dilatatis. Achænium lenticulare. . . . . . . . . (Species 4).

II. Avigularia. lilores axillares v. spicas foliosas rarius aphyllas formantes. Calyx 5-partitus. Stam. 8, rarissime 5-6. Achænium triquetrum. Cotyledones incumbentes. Ochreæ nembranaceæ, bipartitæ vel lacero-multifidæ, nec setoso-ciliatæ ................. (9-72).

III. Persicaria. Racemi spiciformes gemini vel racemoso-paniculati, rarissime solitarii. Calyx 5-3-part. Stam. 8-4. Achænium lenticulare vel triquetrum. Cotyledones accumbentes. Ochreæ cylindricæ, truncatæ, setosocilialæ v. ratius imberbes ............... (73-151).

IV. Amblygonon. Racemi spiciformes paniculati. Calyx 5-part. Stam. 5-8, sæpius 7. Achæn. lenticulare angulis obtusis. Cotyledones incumbentes. Óchreæ cylindricæ truncatæ. . . . . . . . . . (152-156).

V. Bistorta. Racemi spiciformes v. subglobosi solitarii. Cal. 5-part. Stam. $6-8$. Ach. triquetrum. Cotyled. accumbentes. Ochreæ membranaceæ, oblique truncatæ, imberbes. ................. (157-166).

VI. Cephalophilon. Capitula globosa solitaria vel geminata vel corymbosopaniculata. Cal. 5-4-part. Stam. 8 vel 6 . Ach. lenticulare v. triquetrum. Cotyl. accumbentes. Ochreæ cylindricæ, oblique truncatæ, eciliatæ, interdum basi herbaceo-auriculatæ .... ........ (167-179).

VII. Echinocaulon. Flor. spicati v. subcapitati. Cal. 5-part. Stam. 8. Ach. triquetrum vel raro lenticulare. Caules ad nodos vel ubique vel etiam petioli et foliorum nervi plus minus retrorsum aculeolati vel strigillosi. Ochrex eciliatæ. Folia sæpius hastata vel sagitlata. ........ (180-193).

VIII. Tiniaria. Flores axillares vel racemosi vel paniculati. Cal. 5-part., laciniis exterioribus carinato-concavis vel dorso alatis. Stam. 8. Ach. thiquetrum. Caules (unicâ sp. exceptâ) volubiles. Ochreæ apice imberbes. Folia cordata vel hastata. ................. (194-201).

IX. Aconogonon. Flores racemoso-paniculati. Cal. 5-part. Stam. 8. Achæn: triquetrum . Cotyl.accumbentes. Ochreæ oblique truncatæ, eciliatæ (202-215).

Sectio I. TephIs. - Genus Tephis Adans. fam. 2, p. 276.

Calyx herbaceus, 4-partitus, lobis exterioribus (ovarii arigulos spectantibus) carinato-concavis, jnterioribus planis, achænii faciebus adpressis. Stamina 6 , inclusa, filamentis basi dilatatà contiguis. Glandulæe vel squamulæ perigyna nullæ. Ovarium ovatum compressum, stylis 2 brevissimis erectis subcontiguis, stigmatibus capitatis exignis. Achænium calyce sicco immutato parum aucto inclusum, lenticulare, obtusangulum, facicbus ellipticis convexis lævibus nitidis. Embryo angulo albuminis farinosi accumbens, cotyledonibus accumbentibus ( $\$(0)$ angustis. - Fruticuli humiles, ramosi, foliosi, ochreis semibifidis aeutis demum laceris diu persistentibus, floribus axillaribus. - Sectio ad Atraphaxin (Euatraphaxin) accedens quidem calyce k-partito, filamentis basi dilatatis et fructu compresso, cæteris notis vero abhorrens et omnino Polygono accensenda, habitu sectioni Aviculariæ (præcipue P. maritimo), nec non Mühlenbeckiis nonnullis (v, g. M. vulcanic $x$ ) similis.

1. P. A TRAPHAX oIdes (Thunb. prodr. p. 77), ramosissima, glaberrima, ramis rigidis ad apicem usque foliosis, ochreis semilyyalinis inferne fuscis 6-8-nerviis inter- 
nodia brevia œcluantibus, foliis sessilibus subcarnoso-coriaceis ovalibus ublongisve acutis 1-nerviis eveniis margine recurvo-crispulis, floribus in summis axillis subsolitariis subsessilibus spicam densam foliosam formantibus. $\hbar$ In collibus lapidosis el graminosis cap. Bonæ-Spei (Berg. Thunb. Drège! Krauss n. 1265 ! etc.) -Dill. Elth. t. 32, f. 36. P. undulaturn Berg. pl. Cap. p. 135 * (non Murr.). P. Atraphaxis Thunl. 11. cap. p. 385. Atraphaxis undulata Linn. sp. 1, p. 475, Schult. fil. syst. 7, p. 1382, Meisn. in Linnæâ 14, p. 489. (v. s.)

Sectio 11. Avicularia Meisn. Polyg. prodr., p. 43 et 85, t. 1, f. 36, t. 4, f. $0^{\prime}$; synops. ap. Wall., l. c., p. 61. - Genus Centinodia J. Bauh. hist. 3, p. 374. - Genus Polygonum Tourn. inst., p. 510, t. 290, Adans. fam. 2, p. 276.

Calyx semi-corollinus, lobis exterioribus (sæpe carinatis) rel omnibus medio herbaceis. Stamina 8 , rarissime $5-6$, squamulis glandulisve perigynis nullis vel obsoletis. Styli 3 (rarissime 2) brevissimi vel subnulli, stigmatibus capitatis. Aclisnium oalyce sicco parum aucto ap tero inclusum (raro apice exsertum), 3-cluetrum (rarissime compressum). Albumen corneum. Cotyledones incumbentes, oll angustæ. Herbae (sæpe nanæ) rarius suffrutescentes, decumbentes vel erectæo nunquam volubiles, nec aquaticx); ochreis tenere membranaceis decoloribus (hyalinis) tenuiter nervosis vel subenerviis, integris vel bipartitis vel demum tacero-multifidis, margine nunquam setigeris; foliis indjvisis; floribus axillaribus fasciculatis vel foliorum summorum abortu racemoso-spicatis; bracteis ochreiformibus.

\section{§1. Suffruticosa, caulibus ramisque elongatis basi saltem lignosis.}

* Caules ramique apice aphylli, racemo nudo vel basi tantum folioso terminali.

2. P. Cunninghimir, elalum, glaucum? ramis patentibus dense sulcatis apice adultisque aphyllis, ochreis arete cylindricis parallele nervosis deciduis, , foliis linearibus obtusiusculis 1 -nerviis margine recurvis, racemis terminalibus interruptis aphyllis, bracteis turbinatis aeutis plurifloris, achæenio lævi nitidissimo. 5 In Novâ-Hollandiâ orientali et australi, ad flum. Lachlan et Darling (A.Cunningh. n. 153!), prope Adelaïde (Behr ! in h. Sonder.), Swan River (Drimmond coll. 6, n. 218 !). P. junceum A. Cunn. mss. (non Ledeb.), Mitchell exp. trop. austr. p. 85 . Frutex 5-7 pedalis. Rami rigidissini, acute sulcati, sæpe fasciculati, internodiis demum 1-1 $\frac{1}{2}$ poll. longis. Ochreæ hyalinæ, fuscescentes, semipollicares, 8-10-nerviæ. Folia 8-12 lin. longa, $\frac{1}{3}-\frac{3}{3}$ lin. lata, caduca. Galyx magnit: P. avicularis, viridis, margine albidus, lobis 3 exterioribus subcarinato-concavis. Stamina' 8 , caljce paulo breviora, filamentis basi dilatatâ contiguis. Styli brevissimi. Aclrænium triquetrum licvissimum, nitidissimum, angulis obtusiusculis, faciebus ovatooblongi's concavis. (v. s. in h. Cunningh. DC. etc. et comm. a cl. Heward et Sonder.)

3. P. DIGLINUM (Ferd. Müller! in Transact. plilos. soc. of Victoria, 1, p. 23), glabrum, glaucum, caule suffruticoso ramisque erectis sulcatis apice aphyllis, ochreis brevibus lnxiusculis fusco-liyalinis integris binerviis caducis, foliis raris linearibus utrinque attenuatis eveniis, fasciculis paucifloris distantiljus, floribus dioicis octandris trigynisque, pedicellis calyce 5-partito-lævi brevioribus, achænio subgloboso triquetro nitido vix anguloso. 5 In arenosis, ad flum. Murray et Murrumbidgee, Australiæ felicis. Folia et habitus fere P. Cunninghamii, sed flores rariores, minores et unisexuales. (v. s. masc. in $\mathrm{lr}$. Sonder.)

4. P. EQUISETIF onME (Silth. et Smith prodr. 1l. græc 1, p. 266, ic. t. 364), caule suffruticoso adscendente, ochreis multinerviis lacero-capillaceis, foliis oblongis, floribus axillaribus 6 -andris digynis. 5 In sepibus ins. Cretie. An correcte descripta?

B., trigynum (Boiss.! voy. en Esp. 2, p. 554, excl. syn. Bert. et Guss.), caule basi suffruticoso erecto ramoso sulcato-striato demum aphyllo, ochreis tenuiter multinerviis internodio elongato multo brevioribus, foliis lanceolatis vel sublinearibus acutis venosis, racemis subaphyllis basi interruptis, bracteis 2-4-floris pedicellos apice articulatos inquantibus folium lineare minutum gerentibus vel summis apliyllis, calyce subenervi, achænio triquetro nitidulo

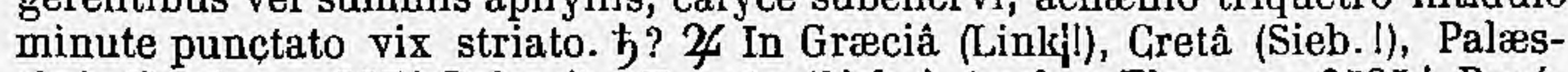
tinâ (Bové, n. 397! Boìss. l), AEgypto (Sieb.! Aucher-Eloy, n. 2585 ! Bové, 
11. 38 ! 328 ! Ehrenb.! Acerbi! etc.), Barbariâ (Desf.), Tanger (Salzm.!), Hispaniâ austr. (Boiss.!), Afğhanistan (Griff.! n. 1720, ex parte):-Bory, Chauub. éxéd. Morée, p. 113, Link! in Linnæeà 9, p. 570. P. equisetiforme $\alpha^{-}$Græcum Meisn. Pol. prodr. p. 86. P. suffruticosim Salzm.! mss. P. crenatum et Mareoticum Ehrenb.! mss..P. tumidum Auch.-El.! mss. (an Delile?). Rami (fide tink) late decumbentes. Internodia elongata. Ochrea infra medium subcoriacer fusce, supra hyalinæ lacero-multifidæ. Folia subsessilia, margine crispula. Valde accedit ad P. Bellardi, sed differt caule suffruticoso, ochreis, spicis densioribus, pedicellis brevioribus. (v. s.)

5. P. scoparium (Requien! in Lois. fl. gall. ed. 2, 1, p. 284), caule e basi lígnosâ ramosissimo, ramis erectis gracillimis subsimplicibus dense sulcatis aphyllis, ochreis remotis brevibus fuscis multinerviis margine truncato denticulato-fissis, spicis longis interruptis, bracteis 1-2-floris, calyce enervi, achæenio subnitido minutissime punctato haud striato. 5 In Corsicà et Sardiniâ. (Phíl. Thomas !. Requiẹn ! Moris! etc.) - Bocc. Mus. rar. p. 49 , t. 41 . P. equisetiforme $\beta$ Corsicanum Meisn. Polyg. prodr. p. 86. P. Bocconi DC. mss. 1 A præecedente certe distincta species multo ramosior, rarnis tenuioribus subfiliformibus aphyllis plerumque simplicibus, ochreis brevioribus margine vix hyalino brevius inciso-laceris, bracteis remotioribus omnibus aphyllis 2-1-floris pedicellos superantibus. Achænium calyce demum (constanter?) paulo longius. (v. s.)

6. P. EHRENBERGI , caule e basi suffruticosâ diffuso-ramosissimo foliosó, ramis graeillimis laxis tenerrime striatis, ochreis semihyalinis 8-10-nerviis basi tumidulis, foliis lineari-lanceolatis obtusiusculis planis enerviis, summis abbreviätis evanescentibus, racemis denum aphyllis subcontinuis, bracteis fuscis laxiusculis 2-4-floris, pedicellis exsertis medio articulatis, caljce basi valde attenuato, achænio nitido minute punctato. 5 ? 26 In Egypto, circa Fanah et Rosette (Ehrenberg !). $\Lambda$ præcedentibus differt caulibus-laxissimis obsolete striatis, foliis evienis $\left(\frac{1}{2}-1\right.$ poll. longis, 1-2 lin. latis), pedicellis paulo longioribus pröpe medium (nec apice) articulatis, etc. Rami adscendentes. Ochrearum basis fusca persistens. Calyx semicorollinus, patens, fere P. elegantis, sed fere dimidio minores. Stam. 8. Achænium inclusum. (v. s. in h. reg. Berolin.)

7. P. s в тоSU (Jacq. obs. 3, p. 8, t. 57), caule suffruticoso a basi ramoso, ramis adscendentibus gracilibus tenuiler striatis, ochreis hyalinis angustis 6-nerviis fimbriato-laceris; foliis lineari-lanceolatis subulatisve margine revolutis tenuiter pinnato-venosis, racemis interruptis apice aphyllis, pedicellis bracteà floreque brevioribus, achænio ovato subnitido. bIn Armeniâ (Tourn., Aucher-Eloy, n. 2588, ex Spach, n. 2530 ! ex h. DC.).-Willd. sp. 2, p. 450, Meisn. Pol. prodr. p. 86; Jaubert et Spach pl. or. 2, t. 125. Rami subsimplices, ochreis internodio dimídio brevioribus. Folia internodia æquantia vel superantia. Bracteæ 3-1-floræ. Stam. 8. Ichanii facies ovato-oblongie. (v. s.)

8. P: LUZULOIDES (Jaub. et Spach pl. Or. t. 126), suffruticosum, radice repente, caulibus herbaceis adscendentibus gracilibus tenuiter striatis , $_{2}$ ochreis hyalinis Jongis laxiusculis tenuiter multinerviis, foliis lineari-lanceolatis elongatis utrinque attenuatis acutis tenuiter venoso-striatis, racemis filiformibus inferne interruptis apice vel totis aphyllis, pedicellis bracteà denticulato-lacerâ calyceque brevioribus. 5 In Persire montibus Elwind (Aucher-Eloy! n. 2589, Noë, ĩ. 604! 1115 !) F. dracunculifolium Boiss. I mss. P. setoso simillimum, sed jam foliis multo longioribus ( $1 \frac{1}{2}-2 \frac{1}{2}$ poll. longis, internodia elongata aquantibus vel superantibus) facile distinguendum. Achenium maturum ignotum. (v. s.)

\section{* * Caules ramique ad apicem usque foliosi, floribus igilur omnibus axillaribus.}

9. P. Ro longis graciJibus subsimplicibus sulcatis, ochreis brevibus semihyalinis 12-nerviis lacero-multifidis, foliis linearibus utrinque attenuato acutis dense nervoso-siriatis, lloribus in summis axillis subsolitariis, achenio parvulo opaco minute punctatostriato. 5 In campis arenosis collibusque aridis mari finitimis Campaniæ (Ten.!), virca Romam et in terrâ vulcanicâ vetustâ (pozzolana) circa Neapolim. - Bocc. MLus. 2 , p. 66, t. 58; Guss. cál. pl. 1821 , p. 79. P. flagellare Bertol. in Seh. et Maur. 4l. rom. prodr. p. 142 ; ej. lucubr. 1822 , n. 4, p. 33, Ten.! fl. neap: app. 4, p. 17, sylloge, 1. 195. P. aviculare y Romanum Meisn. Pol. prodr. p. 88. P. controversum 
Guss, ex Tineo cat: h. Panormit. 1827, p. 284. Species a $P$. aviculari, quocum promiscue provenit, jam habitu distinctissima nec unquam in hoc transiens. Rami sæepe 2-3-pedales, ramulis brevibus secundis. Folia sæepe ex ramulis brevissimis nascentia false fasciculata, internodia sequantia vel paulo superantia, 6-10 lin. longa, 1-1 $\frac{1}{2}$ lin. lata, plana vel margine leviter revoluta. Flores in apice caulium ramulorumque rari, parvuli, pedicellis ochreâ brevioribus. (v. s.)

10. P. Brasiliense (C. Koch ! in Linnæâ, p. 206), caule suffruticoso? erëcto ramisque gracilibus subsimplicibus sulcatis, ochreis brevibus laxis semihyalinis 12-16-nerviis multifido-lacerìs, foliis crassiusculis glaueescentibus lineari-lanceolatis obtusiusculis margine revolutis eveniis subtus 1-nerriis, axillis 2-1-floris, pedicellis ochreả floreque brevioribus, achænio incluso nitido, faciebus ovatís minute punctatis haud striatis. $\%$ In littore, prope Montevideo (Sellow!) et circa Mendozam (Gíllies ! in herb. Arnolt).-Meisn. in Mart. fl. bras. fasc. 14, Polyg. p. 21. P. aviculare var. Montevidense, Cham. et Schl. 1 in Linnæâ 3, p. 50. Caules inferne demum aphylli, internodís pollicaribis ochreas longe superantibus. Folia 4-6 lin. longa, 1 lin. lala. Calyx subherbaceus. Achrenium fuscum, triquetrum vel angulo tertio siepe obsoleto lenticulare. Differt a P. aviculari achænio non striato et a proximo P. striato foliis eveniis, etc. (v. s.)

11. P. с A м P o R य (Meísn. in Mart. fl. hras. fasc -14, Polyg. p. 21 "), caule suffruticnso? adscendente ramisque filiformibus subsimplicibus elongatis tenuiter sulcatis glabris apice angulatis levibus, ochreis brevibus semihyalinis demum laceris subdeciduis, foliis herbaceis linearibus sublanceolatisve subvenosis, summis abbreviatis, spicis elongatis interruptis foliosis, pedicellis bracteam floremque æquantibus, calycis lobis obtusis exterioribus 3 obsolete carinato-uninerviis, achænio mediocri incluso faciebus late ovatis nitidis minutissime punctatis haud striatis. $\mathcal{F}$.

«. boreale (Meisn. 1. c.), foliis omnibus planis vol margine leviter recurvis , inferioribus venosis, floribus paulo majoribus (1-1 $\frac{1}{4}$ lin. longis). In Tézas (Drummond coli. 1, n. 274 ! 2, n.254!), circa Bejar (Berlandier, n. 1770!). Caules erecti? (v.s.)

B. australe (Meisn. l. c.), foliis superioribus subulato-linearibus margine revolutis supra sulcato-lineatis, subtus 1 -nerviis, calyce vix 1 lin. longo. Circa

- Buenos-Ayres (Tweedie lin herb. Arnott). Caules procumbentes? ramis adscendentibus. Proxime affine P. Brasiliensi et striato, sed diversum ramis laxioribus filiformibus, ochreis brevioribus nervis paucioribus, internodiis floralibus longioribus folia superantibus, etc. An a P. flagelliformi. Wedd. satis distinctum? (v. s.)

12. P、 FLAGELLIFORME (Weddell, in Ann. sc. nat. $3^{\circ}$ sér. 13, p. 80), caule basi lignescente elongato procumberte striato minutissime puberulo, ochreis brevibus mox laceris longe ciliatis, foliis lineari-setaceis internodia longe superantibus margine revolutis, axillis 2-3-floris, pedicellis brevissimis... 5 In Brasiliæ meridionalis prov. Rio Grande (Gaudich. 1.. imp. Bras. n. 349).-Meisn. in Mart. 11. bras. fasc. 14, Polyg. p. 22. Valde accedere videtur ad P. Brasiliense ef $P$. camporum $\beta$.

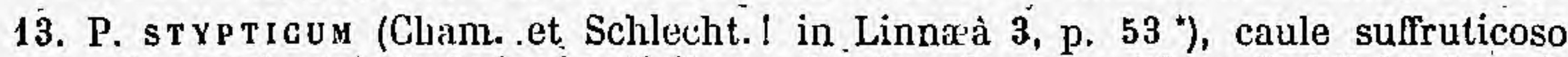
erecto, ramis strictissimis simplicibus sulcatis, ochreis mullinerviis bilobis laceris tarde deciduis, nervis validis fuscis persistentibus, foliis anguste linearibus acutissimis nervoso-striatis margine revolutis, junioribus subacerosis, floribus subsolitariis brevissime pedicellatis, achienio... $\psi_{\%}$ v. $\hbar$ Ad flum. Rio Negro Brasiliz meridionalis (Sellow 1),-Meisn. in Mart. fl.bras. fasc. 14, Polyg.p. 21. Radix lignosa, crassiuscula, valde adstringens, cum herbâ inter remediạ styptica adhibita et valde laudata. Rami juncei, inferne demum aphylli. Ochreæ 4-5 lin. longæ, internodio breviores vel summis longiores. Folia internodio pluries longiora, usque ad 2 poll. longa, 1 lin. lata, supra nervoso-striata, subtus venosa. Flores in summis axillis semicorollini, albi, basi virescentes, ochream subæruantes, 8-andri, 3-gyni. Proxime accedit ad P. striatum et setosum, sed foliis longioribus angustissimis et ochreis evanescentibus nil nisi nervos relinquentibus; etc., bene distincta. (v. s. in l. reg. Berol.)

14. P. STRIATUM (C. Koch! in Linnæé 22, p. 206), caule a basi lignosâ ramoso et norifero, ramis gracilibus patentibus tenuiter striatis, ochreis internodio multo brevioribus semihyalinis lacero multifidis, nervis 10-12 tenuibus lævibus, foliis subcarnosis lineari-oblongis obtusiusculis dense ruguloso-striatis margine revo- 
lutis, axillis $2-4$-floris, pedicellis exsertis, achænio incluso mediocri faciebus ovatis lævibus nitidis. $ち$ In Chili prov. Coquimbo (Cl. Gay! in h. DC:), Valdivià (Lechler, n. 712 !). P. maritimum Remy in Gay, hist. de Chile, p. 269 (ex deser. procul dubio). Rami elongati, cubitales, subsimplices. Ochreæ summæ tantum integræ. Folia internodia æquantia, 6-8 lin. longa, 1.2 lin lata, exsiccata sæe nigricantia, supra dense ruguloso-striatd, subtus basi 3 -nervia, axillis fere omnibus, imo inferioribus, floriferis. Calyx semicorollinus, magnit. P. avicularis. A proximo sequente differt ochreis brevibus, nervis tenuioribus, foliis minoribus. Facies fere P. Bellardi, sed caules ad apicem usque foliosi, foliis summis decrescentibus quidem, at non-abortientibus nanisve, ochreæ magis nervósæ et achænium læve. (v. s.)

15. P. Ghil eNse (C. Koch ! in Linnæâ 22, p. 206), glaucum, caulibus basi lignosis tenuiter striatis, ochreis internodio dimidio brevioribus semihyalinis dense nervoso-striatis demum laceris, nervis tenuibus lævibus, foliis subcarnosis linearioblongis dense sulcato-lineatis margine revolutis, axillis 3-7-floris, pedicellis calyce mediocri longioribus apice articulatis, achænio inclaso faciebus ovatis lævibus. nitidis. † In arenâ mobili Jittorali Chili, ubi Sanguinaria dicitur. (Chamisso! Bertero, n. 1244! Cuming! etc.), et in Magellanicâ (Hook. fil., Lechler, n. 1128 !). P. aviculare? Bert.! mss. in h. DC. et in atti di storia nat. Bologna, 3, fasc. 12, p. 403. P. maritimum Cham. et Schl. in Linneâ 3, p. 51 (quoad pl. Chilens.); Hook. et Arn. Bot. Beech. p. 43 ? Hook. fil. antarct. voy. p. 340. P. Sanguinaria Remy in Gay, hist. de Chile, 5, p. $270^{*}$. Caules elongati (ex Remy lignosi). Ochrea minus candicantes, juniores internodia sequantes, ultra medium fuscæ, nervis $20-30$ tenuihus parallelis plerisque bifidis lævibus vel vix basi scabriusculis dense lineatæ. Folia 6-12 lin. longa, 1-4-lin. lata, internodiis sæpe longiora, exsiccatione? utrinque dense ruguloso-striata. Cæt. fere omnia $\mathrm{P}$. maritimi, sed calyx per florescentiam minor et pedicelli longiores. (v.s.)

16. P. MAR IтIM Uм (Linn. sp. 1, p. 519), multicaule prostratum glaucum, caulibus basi-lignosis sulcato-striatis parce ramosis, ochreis magnis adpressis hyalinis basi fuscis 12-nerviis bipartitis demum laceris, foliis subcarnosis ovali-vel linearioblongis eveniis vel subtus penniveniis, axillis 3 -1-floris, achænio calycem (pro genere) magnum æquante vel breviter superante acutangulo, faciebus ovatis lævibus nitidissimis. $\mathcal{\zeta}$ In Europæ littoribns Atlanticis fab Hiberniâ, Angliâ australi et Hollandiâ ad Gibraltar) et Mediterraneis ubique, ad mare Nigrım (Odessa, Tauria), in Syrîa (Ehrenb.! Kotschy, n. 423 !), Egypto (Bové), Barbariâ (Desf. h. DC.!), ins. Azoricis (Guthnik I Hunt. !), Canariis (Webb! Bourgeau, n. 160 !), Amer. bor. Pensylvaniẩ (Pursh), Novâ-Cæesareâ (A. Gray!), Garolinấ merid. (Ell.! Green!). Barrel. obs. p. 104 , t. 560 , f. 1, Camerar. epit. t. 691 , DC. I fl. fr. 3 , p. $368^{\circ}$, Meisn. Polyg. prodr. p. 89 (excl. syn. Ray, Thunb. et Link.), Fl. græc. t. 363, Engl. Bot. suppl. t. 2804 , Ledeb. 1 . ross. 3 , p. 534, Hook. et Arn. I brit. fl. ed. 6, p. 354. P. parvifolium Schott, in Oken Isis, 1818, p. 821 ? P. glaucum Nutt. geñ. 1, p. 254 (fide Ell.! et A. Gray! in h. Meisn.). P. argenteum Ehrenb.! mss. Varial caulibus digitalibus el pedalibus, simplicibus et parce ramosis, ochreis ovato-oblongis (jun. lobis integris obtusis), nunc omnibus internodia superantibus caulemque omnino occultantibus, nunc iisdem demum brevioribus, foliis 5-10 lin. longis, 1-5 lin. latis obtusis acutisve planis vel margine revolutis patentibus vel subadpressis, pedicellis brevissimis vel florem subæquantibus. Flores pro genere magni, Fagopyro submajores, patuli, albi vel pallide rosei basi extus virescentes. Achænium calyce (nunquam arete clausa) æquale vel parum longius. (v, v. et s. sp.)

17. P. Ray1 (Babingt. Man. of brit. bot. ed. 2, p. 275), multicaule prostratum subglaucum, caulibus ramosissimis sulcatis ab imâ 'basi floriferis, ochreis internodio brevioribus hyalinis basi fuscis remote 6-8-nervis ovato-oblongis acutis adpressis, demum bipartitis lacerisque, fuliis lanceolato-oblongis acutis, subtus 1-nerviis venosis, achænio calycem magnum dimidio superante acutangulo faciebus ovatis lievibus nitidissimis. \& In littoribus Scotiæ, Angliæe occidentalis, Cambriæ, Hiberniæe, Galliøe australis, et in Guriâ, ad mare Nigrum (G. Koch 1), - Watson! in Hook. Lond. Journ. 3, p. 604 et Phy tolog. 1846, p. 615, Engl. Bot. suppl. 2805, C. Koch! in Linnéa 22, p. 202. P. marinum Ray synops. ed. 2, p. 59; ed. 3, p. 147. P. Roberti Loisel.! fl. gall. ed. 2 v. 1, p. 283 (ex parte), Hook et Arn.! brit. fl. ed. 6, p. 354. Species P. maritimo valde quidem accedens, sed distincta, caulibus gracilioribus 2-3-pedalibus plerumque ramosissimis diffusis, internodiis $\frac{1}{9}-1 \frac{1}{2}$ poll. longis, summis exceptis, nunquam ochreis occultatis foliisque viridibus vel leviter 
tantum glaucis, ochreis brevioribus parce nervosis minus caudicantibus, et imprimis achænio, calycem constanter dimidio superante. A P. littorali Link, quocum promiscue in Scotià crescit iisdem notis et flore fructuque triplo majore discrepat. P. Roberti Lois. (fide specim. ab ipso auct. comm.) est species mixta ex P. aviculari (quocum conjungitur a Petit, in Féruss. Bullet. 1828, p. 111), littorali et Rayi, idcoque omnino delenda. (v. v. et s. sp.)

18. P. Ṕ A о о у С ні (Chram. et Schlecht. ! in Linnæà 3, p. 51 *), caulibus suffruticosis prostratis pauciramosis exsulcis junioribus ochreis penitus occultatis, oclireis magnis hyalinis semifuscis laxiusculis 5-nerviis bipartitis, lobis margine interiore 2-nerviis demum lacero-fimbriatis, foliis carnosulis lineari-lanceolatis acutiusculis 1-nerviis cveniis margine revolutis, axillis superioribus approximatis 1-3-floris, pedicellis calyce magno infundibuliformi multo brevioribus, achænio incluso acutangulo, faciebus ovato-lanceolatis levibus nitidis. 5 In arenoso littore porti S. Francisci Californiæe (Chamisso! Eschscholtz!) usque ad isthmum de Fuca (Menzies, Douglas) et? in Floridâ occidentali (Drummond, fide Hook.).- Hook. et Arn. - Bot. Beech. p. 158, Hook. fl. bor. Am. 2, p. 132. P. confertiflorum Dougl. mss. (ex Hook.). Ochreæ caules juniores omnino abscondentes, nervis ulrinque 2 ex petioli insertione excurrentibus margini lobi hyalini interiori (folio proximo) approximatis sulpparallelis, nervo quinto e basi ochrexe ad ejus fissuram dorsalem (folio

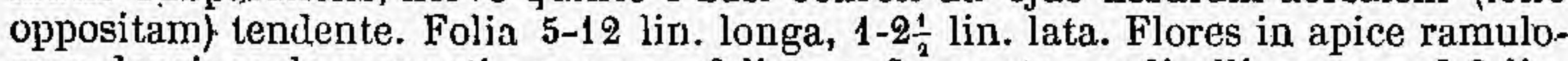
rum densiuscule congesti, racemum foliosum formantes, pedicellis usque ad 3 lin. lóngis. Calyx corollinus basi attemuatus. Styli fere ovarii longitudine. (v. s. sp. et cult. in hort. spc: hortic. Londin.)

19. P. L ACERU M (Kunth ! in H. et B. nov. gen. 2 , p. $179{ }^{*}$ ), caulibus diffusis procumbentibus, oclireis laceris, foliis subcarnosis linearibus eveniis, axillis bifloris.... F In montibus Peruviæe, in aquis thermalibus, prope Caxamarca (Humb.).-Meisn. Polyg. prodr, p. 90. Species obscura, e fragmentis Humboldtianis in $h$, Kunth haud certe ab affinibus dignoscenda, simillima P. striato, sed foliis eveniis et ochreis longioribus magis laceris recedens. (v. s.)

\section{§ 2. Suffruticulosa, caulibus brevibus (digitalibus v. subspithamceis) basi lignosis $v$. e rhizomate lignoso nascentibus herbaceis, ad apicem usque foliosis.}

20. P. Libani (Boiss.! diagn. pl.0r.12, p. $99^{*}$ ), multicaule nanum glabrum, caulibus brevibus dense ochreatis foliosisque, ochreis argenteo-hyalinis internodia-superantibus laxiusculis ovatis acutis, subenerviis demum breviter parceque lacerociliosis, foliis crassiusculis viridibus linearibus obtusis, mox muticis, lævilus subtus basi 1-nerviis apicem versus margine revolutis supra enerviis, floribus solitariis sessilibus ochreà inclusis, calyce parto semiherbaceo, fructifero clauso trigono, achænio incluso levissimo nitido. I In mont. Hermon et Libano Syrio (E. Boissier!). Proximum P. paronychoidi, sed præter staturam nanam recedens foliis brevioribus mucronulo albido fugacissimo cito muticis, etc. Ochrea prope marginem nervorum vestigia obsoleta ostendunt. (v. s.)

21. P. paronychioides (C.-A. Mey.! en. pl. Talusch, p. 20, ex C. Koch, in Linnæà 22, p. 202), caulibus e rhizomate lignoso crasso numerosis duris cxspitosis brevibus adsçendentibus dense foliosis ochreisque hyalinis 3-nerviis laceris undique tectis, foliis patulis anguste linearibus subulatisque mucronatis margine revolutis punctato-scabriusculis, floribus stibsolitariis ochrêa inclusis sessilibus parvulis, achænio minuto lenticulari vel obsolete trigono lævi nitido, faciebus valde convexis. 5 In provinc. Caucasicis (C.-A. Mey.! Hohenack. 1), Aderbeidschan (Szovits!), circa Cabul alibique in Afghanià (Grifr.! n: 1733, journ. 853 et n. 1730). P. Paronychia C.-A. Mey.! enum. pl. Cauc. p. 158, n. 1898, Ledeb. fl. rass. 3, p. 534 (non Cham. et Schl.). P. Meyeri Steudel nomencl. ed. 2, II, p. 376. P. pauciflorum Endl. gen. suppl. IV, 2, p. 49. Ochreæ internodia brevissima superantes et penitus occultantes, lanceolaté, acuminatæ, candicantes, ciliato-laceræ. Folia subcarnosa, glaucescentia, subtus 1-nervia. Achronium ovatum. (v. s.)

22. P. Dum osum (Boiss. ! in Kotschy pl. Pers. austr. 1845, n. 242 ; diagn. p. $83{ }^{*}$ ), a basi ramosissimum, ramis erectis strictis exsulcis mox subaphyllis junioribus canescentibus, ochreis internodio dimidio brevioribus hyalinis everviis-bifidis 
lacerisve, Loliis linearibus margine revolutis punctato-scabriusculis subtus 1-nerviis, axillis 2-lloris, pedicellis calycem majusculum æquantibus... 5 Circa Perse. polin, Persiæ austr. (Kotsch5, n. 242). Fruticulus semipedalis.cæspites hémisphæricos formans, ramis teretibus haud striatis, foliis deciduis. Proxime affine P. paronychioidi et salicornioidi, ab illo internodiis longioribưs et floribus triplo majoribus, ab utroque caule non striato, ochreis, etc., facile dignoscendum. Achænium ignotum. (v. s.)

23. P. SALICORNIOIDES (Jaub. et Spach pl. Or. t. 123, cum descr.), caulibus e basi lignosâ numerosis digitalibus erectis rigidis sulcatis ramisque patentibus apice subspinescentibus mox subaphyllis, ochreis internodio multo brevioribus hyahinis cylindricis truncatis binervits bifidis vel demum bipartitis, folis carnosis brevibus caducis ovato-lanceolatis margine revolutis, summis subulatis vel subnullis, axillis 2-1-lloris, floribus subsessilibus ex oclıruà exsertis demum cernuis, achænii trigoni facielus ovatis minute punctatis. 5 In alpe Kuh-Delu Persiæ australis (Kotschy, n. 468 !). P. oligophyllum Boiss.! in pl. Kotsehy l. c. cfr. ejusd. diagn:-7, p. 84. Rhizoma lignosum, crassitie penne anserinæ, multiceps, ramị digitalibus vel subspithameis strictis vel subflexuosis albidis, junioribus ad apicem usque foliosis, foliis rix 3 lin. longis, summis multu minoribus. Flores campanulati, magnit. P. maritimi. (v. s.)

24. P. M U G ONAT U M (Royle mss. Babingt. in Transact. linn. soc. Lond, 18, p. 115 \%) cauke lignoso prostrato ramoso pubescente, ochreis internodia brevissima superantibus hyalinis albis ovatis acutis enerviis lobatis, foliis lineari-lanceolatis longo subulato-mucronatis 1 -nerviis margine recurvis, floribus sessilibus papvis, achænio triquetro lævi. ち In liunawur (Royle). Affine videtur P. Afghanico et dumoso, sed notis indicatis satis distinctum.

25. P. A F G H A Ni U M, suffruticosum, multicaule, caulibus herbaceis erectis filiformibus subangulatis pulvereo-puberulis, ochreis internodio brevioribus longis lyyalinis oblongis obsolete 3-nerviis ciliato-laceris, foliis linearibus setaceo-mucronatis obsolete 1-nerviis eveniis glabris internodio longioribus, floribus solitariis subsessilibus semi-5-fidis... b In Afghanistan (Griffith, n. 1724!). Rhizoma lignosum 4-pollicare, digiti fere crassitie, caulibus annuis numerosissimis spithamæis subsimplicibus basi lignescentibus ibique pauciramosis, jnternodiis 8-10 lin, longis papilloso-punctatis vel cinereo-puberulis obsolete angulatis vel superioribus sæpe

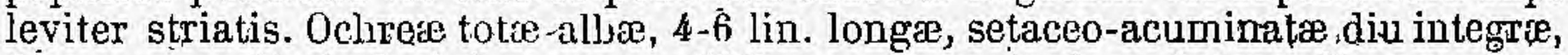
demum margine in lacinias paucas ciliiformes fissæx, juniores internodia æquantes, reliquæ iisdem $\frac{1}{5}-\frac{1}{2}$ breviores. Folia 8-12 lin. longa, $\frac{1}{2}-1$ lin. lata, plana vel margine subrevoluta. Flores pauci, magnit. fere P. avicularis. Achænium ignotum. A P. dumoso certe differt foliis glabris, floribus multo minoribus, etc. A P. mucronato differe videtur caulibus annuis subsimplicibus, internodiis longioribus ochreas superantibus. (v. s. in herb. Lemann., nunc Univ. Cantabrig.)

26. P. тнуміғ ости (Jäb. et Spach pl. Or. t. 116, cum descr.), humite, ramis lignosis brevibus crassiusculis, ramulis herbaceis erectis strictis tennibis angulatis substriatis, ochreis brevibus laxis hyalinis obsolete binerviis fimbriatolaceris, foliis coriaceis ovali-lanceolatis margine revolutis eveniis dortso 1 -nerviis internodia æquantibus, axillis 3-1-floris, floribus subsessilibus, achænio incluso faeichus ovatis minute punetatis nitidis. 5 In Persià austŗali (Aucher; n. 5276, Kotschy, n. 719 !) P. Kotschyanum Boiss. ! in Kotschy pl. Pers. austr. i. 719, fide Boiss. diagn. 7, p. 84. Fruticulus digitalis vel spithameus, liabitu P. salicornioidis et dumosi, sed ab utroque distinctus ramulis angulatis obsolete sulcatis, foliis latioribus læte viridibus, thore minore, etc. Partes herbacee, punctato-scabriusculic vel (in specim. Kotschy passim) glabræ. (v.s.)

27. P. RADicosum Boiss. I in Kolschy pl. Pers. austr. 1845, et Pers. bor. 1846; diagn. n. 7 , p. 84), glabrum, caulibus e rhizornate lignóso crasso pluribus herbaceis nanis adscendentibus, ochreis brevibus hyalinis enerviis obtusis diu integris, foliis subcarnosis patulis obovato-oblongis attenuato-petiolatis obtusis eveniis subtus 1 -nerviis internodio longioribus, axillis $2-4$-floris, pedicellis brevissimis apice articulatis, calyce mediocri infundibuliformi semi-5-fido, achæenio incluso obsolete puncticulato nitidissimo. I In alpibus Persiæe australis (Kंotschy, in. 779 !) et borealis (id. n, 499, Aucher-Eloy, n. 5274!, et Afghaniæ (Griffith, n. 1723! journ. 1094). P. serpyllaceum Jaub. et Spach pl, Or. t. 117, cum descr. Fruticulus cæespi- 
POLYGondm. POLYGONACE $A$ (AUCTOR MEISNER).

tosus facie Serpylli, inferne ochreis fuscis dense squamatus, caulibus herbaceis 1-4-pollicaribus angulatis substriatis, foliis 3-5 lin. longis, 1-2 $\frac{1}{2}$ lin. latis, planis vel margine subrevolutis. Calyx herbaceus, margine rubëllus, fructifer séśquilineam longus. (v. s. in h. DG. et Giriff.)

28. P. LemaNNIANUM, glalurum, caulibus e rlizomate lignoso brevi pluribus subdigitalibus filiformibris, ochreis internodia brevissima superantibus hyalinis albis enerviis inoiso-paucidentatis inferioribus oblongis acutis, summis duplo latioribus ovatis obtusiusculis imbricatis diu integris, foliis ochreas subæquantibus subulato-linearibus mucronulatis vel demum muticis obtusis margine revolutis, floribus solitariis sessilibus parvis infundibuliformibus semi-5-fidis... $\quad$ In alpinis Indise, ad Kohi-Baba et Youurt, alt. 10,000-15,000 ped. (Griffith, n. 1726!). Caules

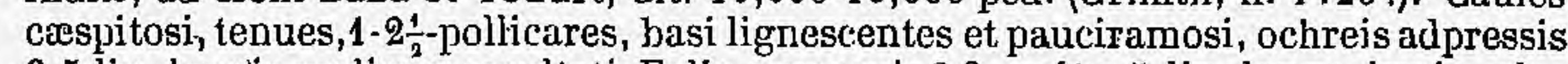
3-5 lin: longis undique occultati. Folia carnosula? 3-rarius 5 lin. longa, lævia, glabra, patula. Calyx corollinus, magnit. P. herniarioidis, semipatens. Achæenium non vidimus. Habitu accedit ad P. tubulosum, ochreis ad P. molliæforme, at foliis, floribus, ete., ab utrorque longe diversum. (v. s. in h. Lemann.; nunc Univ. Cantabrig.)

29.? P. S T YLIGERU ar (de Bruy11, in pl. Junghuln. p. 311 *), glabrum, caulibus suffruticosis (?) prostratis ramosis lineis scabris striatis, ochreis tripartitis lacerofimbriatis albidis striatis binerviis, foliis anguste lanceolatis acutiusculis basi angustatis internodio duplo longioribus, axillis 2-3-floris, pedicellis ochreà inclusis, calyee dorso scabro, stylo brevi 3-vel raro 2-partito, achænio 3-gono, (raro compresso) incluso ditido tenerrime striatulo styli basi rostellato. $\$$ ? In Javâ (Jungh.). Nisi suffruticosa diceretur, plantam cum sequentc potius Polygono Roxburghii proxime affinem crediderim.

30.? P. A N O M a u m (de Bruyn, in pl. Junghuhn. p. 311 \%), glabrum, caulibus suffruticosis (?) prostratis scabriusculo-striatis, achreis bilobis lutescentibus binerviis fibrilloso-laceris, foliis anguste linearibus acutis basi attenuatis internodia sequantibus, axillis 3-4-floris, pedicellis ochream superantibus, calycis lobis 3 dorso alato marginatis scabris, stylo 2-vel rarissime 3 -partito, achænio calycem :equante compresso (raro 3-gono) nitido tenuissime punctato-striato curvato, faciebus inæqualiter convexis. 5 In montibus Javæ (Jungh.). Cum præcedente R. Roxburghii et cilioso affine videtur.

\section{§ 3. Herbacea, annua $v$. perennia.}

- Caules ad apicem usque foliosi, floribus igitur omnibus axillaribus, interdum in racemos terininales foliosos congestis.

31. P. M OLLIAE F OR M (Boiss. I in Kolschy pl. Pers. austr. 1845; diagn. n. 7, p. 84 ), caule nano debili filiformi dichotomo-ramoso, ramulis apicibusque ochreis hyalinis acuminatis enerviis subintegris dense imbricatis, foliis setaceo-linearibas internodia cequantibus patulis, floribus intra ochreas occultis solitariis parvulis... $\odot$ In glareosis montis Kuli-Drëna Persice australis (Kotsclyy, n. 778 !) et borealis, prope Teleran (id. n. 573 !), alp. Kkoh i Baba (Afghaniæe? Griff. n. 1732 l). Plantula tota vix sesquipollicaris, ochreis niveis nitentibus ramulos dense tegentibus, foliis 3-5 lin. longis, caúlinis planis angustissime linearibus subtrinerviis, cæteris brevioribus filiformilsus. Flores non vidimus. (v. s. in h. DG. et Griflth.)

32. P. TUBULOSUM (Boiss. $!$ in Kotschy pl. Pers. austr. et bor. 1845, 1846; diagn. n. 7, p. 83 \%, nanum, pluricaule, glabrum, oclireis internodia śuperantibus adpressis hyalinis enerviis, ovatts acuminatis diu integris, foliis carnosulis planis obtusiusculis 1-nerviis eveniis, inferioribus obovato-oblongis, summis linearibus, floribus geminis ochreà brevioribus sessilibus, calycis lobis acutiusculis tubo angusto triplo brevioribus, achenii inclnsi triquetri faciebus lanceolatis nitidis obsolete paniculatis. $\odot$ In montibus Persice australis, prope Schiraz (Kotschy, 11. 432 ! 5000!). et prope Teheran (id. n. 48!). Canles 1-3-pollicares, erecti vel patuloadscendentes, pauciramosi, angulati, haud striati, toti ochreis foliisque dense tecti, ochreis demum parce ciliato-laceris, foliis $k$-10 lin. longis, 1-3 lin. latis, superioribus sensim angustioribus. Species calycis achseniique formâ insignis et soli P. rottboellioidi proprius accedens. foliis junioribus ia utrâque mucronulo albo exigro deciduo terminatis, sed caulibus laxiusculis nee strictis, ochreis enerviis. foliis majoribus patulis, etc., bene distincta. (v. s.) 
33. P. потт вовLLI IDES (Jaub. et Spach pl. Or. t. 122, cum deser.), caule filiformi rigidulo e basi patenti-ramoso, ramis adscendentibus subangulatis non striatis, ochreis adpressis hyalinis biparfitis basi utrinque obsolete 1-nerviis lobis subintegris, foliis carnosulis subadpressis linearibus planis 1-nerviis internodio longioribus ramulisque papilloso-scabriusculis, axillis 3-1-floris, floribus subsessilibus, calyce anguste tubuloso limbo brevi 5 -fido patulo demum clauso, achænio lævi faciebus ranceolatis. $\odot$ In arenosis Persiæ, inter Teheran et Ispahan (Olivier! et Bruguière, Aucher-Eloy,; in. 2590 biș). Caulis subpedalis. Calycis tubus limbo longior. (v. s. in h. DC.)

34. P. A G ER OS U M (Ledeb.! mss. in herb.), caule digitali a basi ramoso, ramis patentibus vel adscendentibus subsimplicibus leviter striatis foliisque punctatoscabriusculis, ochreis argenteis enerviis internodia superantibus mox lacerociliatis, foliis lanceolatis acutis margine revolutis subtus 1 -nerviis eveniis patulis summis parvulis, floribus solitarijs sessilibus, achænio parvulo acute trigono faciebus ovatis lævibus nitidissimis. $\odot$ In Surgessa (Schrenk, n. 1.06!). Ochreær tenerrimæ, internodio demum paulo breviores. Folia 2-5 lin. longa, usque ad 1 lin. lata, sub lente papillosa, viridia nec glauca, summa parvula, sel non evanescentia. Flores demum vix ochream æquantes. Stamina 8? Achæenium inclusum. Habitus omnino præcedentis, sed calycis achænique forma valde diversa. (v. $s$. in h. Ledeb.)

35. P. POLYCNEMOIDES (Jaub. et Spach pl. Or. t. 120, cum desci), caule prostrato e basi ramoso, ramis filiformilous flaccidis subangulatis estriatis internodiic ochreas foliaque superantibus, ochreis brevibus hyalinis subenerviis demum inciso-fimbriatis, foliis subcarnosis patulis subulato-linearibus ramulisque 'fere lævibus, axillis-1-2-floris, calyce subsessili parvo infundibulari lobis tubum æequantibus, achænii inclusi faciebus ovatis nitidis minute punctatis. $\bigcirc$ In Persiâ, prope Bagdad (Aucher-Eloy, n. 2590, ex Spach, 3085! ex h. DC.), circa Acrobat et Youurl Afghaniæ? (Griffith, n. 1729! 1725! journ. 989, 115k). Caules vix spithamæi, ramulis, foliisque vix ac ne vix punctato-scabriusculis. Stamina 8. Accedit ad P. roltboellioides, sed caulibus debilibus, internodiis longioribus, oclireis hrevibus, calyce, etc., facile distinguendum. (v. s. in h. DC. et Griff.)

36. P. Olivieri (Jaub. et Spach, l. c. t. 121, cum desur.), glabrum, caulibus prostratis gracilibus flexuosis angulatis estriatis, ochreis internodia (brevia) subsequantibus hyalinis subenerviis inciso-dentatis, foliis carnosulis internodia supcrantibus patulis lineari-subulatis planis eveniis subtus 1 -nerviis, floribus subsolitariis subsessilibus parvulis, calycis lobis tubo brevioribus, achænio incluso nitido faciebus ovato-oblongis elevato-purıcticulatis. $\odot$ In Mesopotamià (oliv. et Bruguière), in Syrià (Ehrenb.!), Afghanístan (Griff. n. 1727? journ. 862), Kamaon, alt. 11,500 ped. (Strachey et Winterbottom herb. Himal. n. 49!). Forsan P. polyenemoirtis var. vel forma vegetior, caulibus e basi ramosis spithamá nonnunquam longioribus, ochreis foliis internodiisque quam in illâ longioribus, calyce distinctius 5-nervi. (v. s. in h. Griff. soc. linn. Lond. et reg. Berolin.)

37. P. coRRIGI OLOIDES (Jaub. et Spach, l. c. t. 124, cum descr.), multicaule procumbens glaberrimum glaucescens, caulibus laxís ramosis triquetris striatulis levibus, ochreis parvis laxis hyalinis enerviis inciso-dentatis, foliis spathulatolinearibus 1-nerviis eveniis, axillis 3-6-floris, pedicellis ochreâ calyceque parvo longioribus prope basin articulatis, achrenii parvi calyce brevioris faciebus ovatis lavibus nitidis. $\odot$ In Persiâ, inter Teheran et Ispahan (Olivier I et Bruguière). P. myriantlıum Boiss, et Noë $!$ mss. Herba diffusa, glauca, Corrigiolæ facie; foliis internodia æquantibus vel superantibus obtusis acutisve margine subrevolutis, pedicellis $1 \frac{1}{2}-2$ lin. longis calyce subduplo longioribus, parte supranodali infranodali ochream vix superante ferc triplo longiore qquâ notâ species a P. herniarioide et effuso proxime affinibus facile distinguenda). Stamina 8. Achænium circ. $\frac{2}{8}$ lin. longum. (v. s. in h. DG. et Boiss.)

38. P. M I Q U L I ANum (Meisn. mss. in herb. Hohenack.), multicaule, glabrum, caulibus prostratis elongatis pauciramosis teretibus striatis, ochreis brevibus subhyalinis 6-nerviis inciso-fimbriatis deciduis, foliis subcarnosis? spathulato-linearibus obtusis margine revolutis eveniis subtus 1-nerviis, axillis 1-3-floris, pedicellis tenuibus exsertis basi articulatis calyce clauso carinato-trigono basi attenuato sublongioribus, stigmatibus exsertis, achænio majusculo calycem æquante facie-. 
bus ovatis sublævibus -nitidis. $\mathscr{F}$ ? In campis circa Mangalore, penins. Ind. or. or. (Metz pl. exsicc. territ. Canara, -n. 19 al et 1613 ! P. elegans Roxb. var.? Miquel! in pl. Metz, 1. c. Omnia fere P. corrigioloidis, sed planta videtur perennis caulibus duris pedalibus et ultra, gracilibus, leviter striatis, foliis internodia brevia æquantibus, ochreis distincte nervosis. Stamina 8. Achænii facies prope marginem obsolete striatæ. (v. s.)

39. P. EFFUSUM, multicaule procumbens glabrum, caulibus ramosis elongatís filiformi-tenellis tenuiter striatis levibus, ochreis parvis liyalinis enerviis dentatolaceris foliisque internodiis elongatis brevioribus, foliis anguste limearibus subenerviis eveniis, axillis 3-5-floris, pedicellis demum florem subæquantibus medio vel supra articulatis, achænio calycem parvum æquante faciebus ovatis nitidis apice obsolete striatis. $\odot$ In Ind. or. regno Oude (Wall.! list n. 1691/3), Kamaon (Strachey et Winterbott. lierb. Hímal. n. 22 !), Afghanistan (Griff.! Journ. 53). P. Dryandri Wall. l. c. (ex parte). P. herniarioides o Meisn. in Wall. pl. As. rar. 3, p. 62 (ex parte). P. Indicum Roth nov. pl. sp. p. 208 ? Simillimum P. corrjgioloidi, sed constanter distinctum pedicellis brevioribus medio vel supra (nec própe basin) articulatis, calyce minore, aclıænio incluso. A P. herniarioide jam habitu recedit. Caules valde debiles. Folia obtusa vel acutiuscula. Calyx corollinus. Stamina 8. ( $\nabla$. s.)

40. P. RoxвURнHi, multicaule, prostratum, ramis tenuissime striatis, minute papilloso-scabriusculis, ochreis hyalinis ciliato-laceris prope marginem 1-nerviis, foliis 'internodio longioribus patulis linearibus acutis vel lineari-oblongis apiculatis margine scabriusculis, axillis $\mathbf{3}-\mathbf{5}$-floris, pedicellis infra medium articulatis brevibus, calyce mediocri carinato-trigono basi attenuato, achænio nitido, faciebus ovato-rhombeis apice margineque obsolete punctatis. $\odot$ In totâ Indiâ orientali, Afghanistan (Griđ. n. 1721!), ins. Philippinis (Cuming, n. 1289 !), Nova-Zeelandiâ ? Chinâ? et Africâ australi (Drège!). P. elegans Roxb. h. Bengal. p. 29, fl. Ind. 2, p. 291 ! P. Dryandri Spreng. syst.' 2, p. 25.5 ? Meisn. Polyg. prodr. p. 88, Hook. fil. f1. Nov.-Zealand. 2, p. 210 ? P. aviculare Walp. in act. Leop. 19 suppl. 1, p. 407. P. Meyeni C. Koch, in Linnæa 22, p. 205 ? P. herniarioides Benth. in Hook. Journ. 1853, p. 194. $\Lambda$ vicularia Indica Didrichsen, in Anderson Nya Bot. Notiser for 1850, ex Bot. Zeit. 1855, p. 592. Species variabilis. Caules sub lente papilloso-seabriusculi. Dchrewe superiores internodia æquantes, albæ, basi fuscæe, dense brevi-ciliatæ. Folia 5-12 lin. Ionga, 1-2 lin. lata, sessilia, plana vel margine subrecurva, omnia conformia linearia ant summa ex apice obtuso minute apiculata. Flores magnit. 1'. avicularis, pedicellis brevibus scabriusculis vel subnullis. Stam. 8. Achænium calycem rquans vel demum brevissime exsertum, faciebus medio lævibus apice marginecque suls lente puncticulatis. Differt a P. herniarioide præecipue folis haud spatlualatis et floribus majoribus, a $P$. effuse et corrigioloide pedicellis brevioribus, cl.c. Virrietates sequentes primo vultu satis discrepantes, tamen limitibus firmis distingui non possunt. (v. s.)

a. longifolium, foliis internodio multo longioribus linearibus acutis planis, ochreis majusculis, pedicellis calyce brevioribus vel subnullis.-Wall. list n. 1691, F. ux parte, H I L! Wight! n. 12 ! Drège!. P. prostratum Roxb.! mss. in herb. DC. (non K. Br.). P. Indicum (Roth ? nov. pl. sp. p. 208), Meisn. ap. Wall. l. e. p. 62 (ex partc). P. herniarioides $\beta$ prostratum Meisn. 1.c.p.62, et in Linnæâ 14 , p. 486, Babingt. in Linn. Trans. 18, p. 113 ? P. elegans Miquel! in Metz pl. exsicc. Canara, n. 19 ! P. aviculare Lour.? Coch. 1, p. 276, Roxb.? h. Beng. p. 29, Don fl: Nepal. p. 72.

B. brevifolium, foliis internodia parum vel vix superantibus anguste linearibus aculiusculis margine recurvis, oclireis abbreviatis parvis, pedicellis calyce brevioribus (Wall. list n. 1691, F et K, ex parte, aliique). P. elegans Soland.! mss. in herb. DC., Hornem. ! in herb. reg. Berol. P. linifolium Roth ? nov. pl. sp.p. 207 (non alior).

$\gamma$. spathulatum, foliis internodio requalibus vel parım longioribus spathulatooblongis subplanis acutiusculis vel ex apice rotundato minute apiculatis, ochreis parvulis, pedicellis calyce brevioribus (Wall. list n. 1691/5 ! 6! et ex parte, 1, Cuming Philipp. n. 1289 ! etc.).

d. pelicellare, foliis internodia subæquantibus linearibus acutiusculis, ochreis parvis, pedicellis calycem subæquantibus (Wall. n. 1691/K, ex parte, Griffith, n. 1721 ! elc.). 
41. P. PLEBEJUM (R. Brown prodr. ft. N.-Holl. p. 420), caule decumbente gracili ramosissimo leviter striato et scabriusculo, internodiis brevibus, ochreis minutis hyalinis subenerviis lacero-ciliatis, foliis lineari-spathulatis internodia subæquantibus obtusis 1-nerviis margine sulincrassato recurvis, axillis 1-3-floris, pedicellis ochream. æquantibus supra medium articulatis, calyee parvo subcarinato-trigono basi attenuato, achænio incluso acutangulo nitido faciebus ovatis lævibus. $\odot$ ? In Novà-Hollandiâ orientali, tropicâ et extratrop. (R. Br., A. Gunningh.!-n. 13):-Meisn. mon. p. 90. Preccedenti simillimum, sed omnes partes minores, ochre:e parvulæ prope marginem obliquum utrinque obsoletissime 1-nerviæe, pedicelli apice ar culati, etc. Folia summa internodiís longiora. Calyx-subcorollinus. Stam. 8 (ex R. Br. 5). Achæniự calycem cequans. (v. s. comm. a cl. Heward.)

42. P. HE R I A R I I DES (Delile AEgypt. p. 13), prostratum multicaule ramosissimnm, ramis leviter striatis scabriuseulisque, ochreis brevibus laxis semihyalinis prope marginem obsolete 1-nerviis breviter dentato-ciliatis, foliis spathulato-oblongis linearibusve obtusis muticis 1-nerviis eveniis internodia æquantibus vel superantibus, axillis 3-6-floris, pedicellis calyce parvo brevioribus vel sulbnullis, achænio acutangulo acumine brevi exserto-faciebus ovato-rhombeis nitidissimis levibus apice obsolete punctato-striatis. (-) In arenosis \&gypti (Del., Sieber I Schimper, Boiss.! Bové, n. 370! etc.), Abyssiniæ (Schimper, n. 142! 1581 h, Senegaliæ (ex C. Koch), Mozambique (Peters, n. 8! in lierb. reg. Berol.), Syriæ (herb. Ledeb.!), Siciliæ (Jan n. 53 l). - Meisn. Polyg. prodr. p. 89, Fresen.! in Mus. Senkenberg. 3, p. 64, Ledeb. fl. ross. 3 , p. 533. P. tropicum G. Koch? in Limnæa 22, p. 205 et 398. P. coronulatum Steudel. Facies omnino P. ávicularis var. prostrates, sed omnibus parlibus mifor et praterea foliis eveniis; achænio nitido, etc., bene distincta. A'P: corrigioloide et effuso differt caulibus rigidioribus, junioribus in angulis punctato-scabriusculis, pedicellis brevioribus, etc. Formæ duæe distingui possunt. (v. s.)

a. foribundum, foliis internodiisque abbrevialis (3-7 lin. longis), axillis, pluri. floris, floribus in apice ramorum quasi spicam continuam foliosam formantibus (Raddi ! Acerbi! Boissier! Schimper, n. 142 ! et 1581 ! etc.).

$\beta$. foliosum, foliis internodiisque elongatis (7-14 lin. longis), axillis 1-2-floris (Sieber! Ehrenberg! Bové, n. 370 !).

43. P. ILLECEBROIDES, multicaule procumbens, caulibus filiformibus ramosis striato-angulatis lævibus, ochreis brevissimis albis subenerviis dense lacero-ciliatis, foliis linearibus obtusis vel submucronulatis internodia brevia suḅquantibus summis nanis margine revolutis, floribus in summis axillis 1-2 subsessilibus parvulis, achænio incluso acutangulo lævi nitido. భ ? In Bengaliâ (Wall.'list fol. 214, n. 1691/K, ex parte), Kiamaon (Strachey et Winterbottom herb. Himal. n. 23), Afghanistan (Griffith!). T. 'herniarioides y Meisn. in Wall. pl. As. rar. 3, p. 62. A præcedente differt habitu multo graciliore, ochreis remotioribus minoribus den sius longiusque ciliatis basi utrinqúe obsolete 1 -nervîs, foliis summis ninutis vix ochream superantibus. (v. s.)

44. P. CLIFF ORTIOIDES (Meisn. in Wall. pl. As. rar. 3; p. 62*), eaule erecto tel adscendente patulo-ramoso lævi striato apice acutangulo, ochreis semihyalinis internodio brevioribus prope marginem 1-nerviis demum ciliatis, foliis internadio longioribus linearibus acutis rigidis punctato-scabriusculis margine revolutis supra canaliculatis, subtus 1-nerviis, axillis summis 2-4-floris, pedicellis calyce carinato-trigono mediocri ochreisque brevioribus, achenio incluso acutangulo lævi nitido. $\odot$ ? In Nepalià (Wall. list n. 1691, B ! ex parte, et G). P. Dryandri Wall. 1.c. Herba palmaris, rarius subpedalis, rigidula, in ternodiis raro semipollice longioribus, summis brevissimis, ochreis fuscescenti-albidis diu integris floribusque congestis absconditis. Folia usque ad 1 poll. longa, $\frac{1}{2}-1 \frac{1}{2}$ lin. Jata, nervo supra sulciformi, subtus acute prominulo. Flores racemos terminales foliosos densiusculos formantes, magnit. P. avicularis. Stamina 8 , raro 6 rel 5. (v., s.)

45. P. Perrottetir, caule humili subadscendente filiformi a basi ramoso minute scabriusculo, ochreis internodio multo brevioribus hyalinis subenerviis bifidis laceris; foliis linearibus rel spathulatis flaccidis planis eveniis internolio multo longioribus, axillis 1-5-floris, pedicellis calycem demum carinatum ærquintibus infra medium articulatis, achænio incluso acutangulo lævi nitidissimo. $\odot$ In Senegaliâ (Perrottet ! in h. DG.; Lelièvrel in h. Kunth.). P. linifolium Perrott.! mss. 
l. c. P. exiguum Meisn. Polyg. prodr. p. $90^{*}$. Caules $\frac{1}{2}-1 \frac{1}{2}$-pedales, valde debiles. Ochreæ argenteæ, basi fuscie, immo juniores dense ciliatæo, nervis 2-3 obsoletis. Folia tenuia, læevia, 6-18 lin. longa, 1-4 lin. lata, obtusa vel subacuta. Flores fere P. avicularis, sed achæenium minus et læevissimum. Stamina 5-8. Nomen P. exiguum mutavimus, quia ineptum et olim species 2 diversas conjunxit. (v.s.)

46. P. crirosum, caule hiumili a basi ramóso erecto decumbente striato scabriusculo, ochreis hyalinis fúvis subenerviis dense ciliatis, foliis internodio longioribus anguste linearibus acutis 1-nerviis eveniis scabriusculis, axillís 1-3-floris, pedicellis ochreâ calyceque brevioribus basi articulatis, calyce parvulo carinato-trigono, achænio jụcluso minuto lievi nitido. $\odot$ In Kamaon et Silhet (Wall. list n. 1691/2 ! et 4 !), A'ssamiâ sujeriore (Wall. I). P. Dryandri Wall. 1. c. (ex parte). P. exiguum Meisn. in Wall. pl: As. rar. 3, p. 62 (non Polyg. prodr.). Differt a præcedente catle foliisque magis scabriusculis, oclireis minoribus fulvisque nec argenteis, foliis vix unquam pollice longioribus nee ultra 1 lin. latis nunquam sjathulatis et jræsertin floribas minoribus et sessilibus. (v'. s.)

47. P. iumifusum (Merk! mśs. in lierb. reg. Berol.), caule prostrato a basi ramosissimo et florifero, ramís filiformibus laribus, oclireis brevibus dilatatis hyalinis subenerviis subincisis deciduis, foliis lineari-oblongis obtusis in petiolum attenuatis planis eveniis, axillis 4-10-10ris, pedicellis apice articulatis, achænio calycem paulo superante acutangulo léevi. $\odot$ In Sibiriâ Altaìcà et orientali $D^{r}$ Merk 1 1788). - Sievers, in Pall. neu. nord. Beitr. 7, p. 289 ? Ledob. I1. ross. 3, p. 351, G. Koch, in Linnseâ 22 , p.-205. Caules 4-6-pollicares, debiles, haud striati, inter-

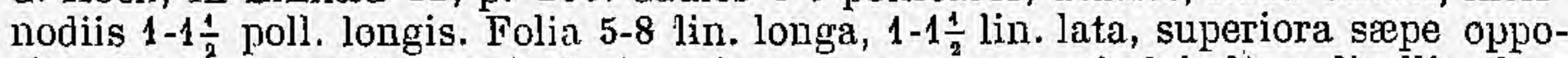
sita: Flores magnit. P. avicularis, primo dense glomerati, deindè pedicellis elongatis- (calyce demum longioribus) laxiusculi. Achænium trigonum, calyce virïdi margine corollino demum fere $\frac{1}{4}$ longius. (v. s. in h. reg. Berolin.)

48. P. PROPINQUUM (Ledeb. fl. ross. 3, p. 532), caule a basi ramoso decumbente ramisque striatis, ochreis fissis, lobis ovato-linceolatis, foliis sessilibus oblongis acutiusculis obtusisvo basi attenuafis glabris, axillis 2-3-floris, pedicellis flore lorevioribus, achrenio calycem-superante levi. $\odot$ In Rossià australi, circa Astrachan (Blume pl. exsice.). Teste auctore A. nviculari proximum, sed ochreis brevioribus et achsenio exserto levi distinctum.

49. P. GRAMNIF OLIUM (Wierzbicky, fide Heuffel! mss. in herb. DC.), multicaule, glâbrum, caulibus debilibus subsimplicibus diffusis gracilibus obsolete lineatis levibus, ochreis lrevibus scmiliyalinis obsolete 6-nerviis demum laceris, foliis linearibus muticis 1-nerviis cvenifis planis, axillis 2-3-floris, pedicellis ochreâ inclusis calycem parvum enervium demum 3 -gonum iequantibus, achænio breviter exserto lævi nitidissimo. ( In rijpis arenosis Danubii, ad monasterium Bazias, in Banatu (Heuffel!). Habittus P. avicularis var. diffusi et P. arenarii; ab illo discrepans foliis ereniis, achænio lsevi, etc., ab hoc caule apice haud aphyllo. A p. oxyspermo et salsugineo "quibus achænio cxserto accedit, foliis ochreis calyce achrinión que minoribus differt. ( $\mathrm{r}$. s.)

50. P. OXXSPERM gracili creclo ramisque strictissimis striatis, ochreis semihyalinis 6-nerviis margine fissis, foliis lineari-oblongis planis subeveniis summis parvulis, axillis 2-4-floris, pedicullis calyce longioribus, achænio semiexserto faciebus ovato-lanceolatis levibus nitidis. $\odot$ In ins. Abro maris Baltici, in Sibirià Baicailensi (Turcz.I), ad flum. Jenisean (Gmel.! in herb. Mus. Stuttgart), in Agypto? (Aeerbi l in lierb. DC.). - Ledeb.! I1. ross. 3, p. 530. Species achænia exserto sursum attenuàto lævi facile distinguenda. Racemi terminales interrupti foliosi. (v. s.)

51. P. SAl SUGINeum (M. Bieb: Casp. p. 169, fl. Taur. Cauc. p. 304), caule humili a basi patenti-ramoso, ramis adscendentibuś filiformibus striatis, ochreis internodio multo brevioribus semihyalinis lacéro-bipartitis basi nervosis, floralibus incisis, foliis internodia subæequantipus subulato-linearibus margine revolutis summis nanis, floribus solitáriis su],sessilibus (5-andris, ex Bieb.), achænio calycem anguste infundibularcin superante faciebus lancèlatis opacis minute punictatis substriafis. $\odot$ In Rossiñ australi, circa Sareptam (Bunge! in herb. DG., Becker, n. 34!) et prov. Caucasi orient. (Biel3. I).- Meisn. Polyg. prodr. p. 91, Ledeb.! fl. ross. 3, p. 530 . Hinc præcedenti, inde P. arenario simile, ab utroque jam achænio distinetum. (v. s.) 
52. P. А с т t os u (M. Bieb. I fl. Tour. Cauc. 1, p. 304, 3, p. 286), glaucum procumbens a basi ramosum, ramis striatis, ochreis albis subenerviis bipartitis lobis diu subintegris, foliis subcarnosis eveniis oblongo-linearibus obtusiusculis, axillis 1-4-floris, pedicellis calyce ochreâque brevioribus, achsenio incluso parvo faciebus ovatis subnitidis obsolete punctatis. ( In Rossiâ australi, deserto Caspio, Caucaso (M.Bieb. in herb. Willd.), Sibirià Altaicâ (Ledeb.!) et Uralensi (Karelin !), Armeniâ (G. Koch), Afghanistan (Griff.! Journ. 471).-Meisn. Polyg. prodr. p. 89, C. Koch, in Linuæâ 22, p. 200, Ledeb. ! fl. ross: 3, p. 533. P. aviculare Karel. et Kiril, en. jl. Soongor. n. 721, ex parte, leerb. soc.imp. N. C. Mosq. n. 1913, $1916 !$ P. acidum Willd.! herb. n. 7659 (non. Pall.). Caules digitales-palmares, fere a basi floriferi, foliis semipollicaribus $1-2$ lin. latis, flores magnit. P. avicularis, cujus formæ pro*. strate accedit, colore glauco tamen et foliis carnosulis eveniis, etc., facile distinguenda. (v. s.)

$\beta$ ? elatius, caulibus erectis elatioribus ( $1-1 \frac{1}{2}$ pedalibus), internodiis elongatis ( $1 \frac{1}{3}-2 \frac{1}{2}$ poll. longis) folia superantibus, ochreis inferioribus temuiter 6 -nerviis superioribus enerviis, pedicellis demum calyce longioribus. In Afghanistan (Griffith! u. 1720, ex parte). Facies P. avicuJaris erecti, sed characteres $P$. acetosi. Vix propria sp. (v. s. in herb. Lemann., nunc Univ: Cantabrig.)

53. P. coGNA t u (Meisn. Polyg. prodr. p. 91), glaberrimum, multicaule, prostratum, ramis subangulatis levibus, oclireis internodia subæquantibus hyalinis bipartitis lobis 1-nerviis diu integris, foliis internodio longioribus oblongis vel subovatis lanceolatisve acutis vel apiculatis 1-nerviis eveniis planis margine scabriusculis, axillis 3-8-floris, calyce demum aueto majusculo carinato-trigono nervoso basi indurato, achænif inclusi faciebus nitidis ovatis minute punctato-striatis. $\mathcal{F}$ In provinciis Caucasicis, a littore maris usque ad alt. 6,500 ped., in Syriâ, Persiâ, Afghanistan, Himalayà, Sibirid. - Ledeb. fl. ross. 3, p. 533. P. alfine Stephan, in herb. Willd. n. 7654, Spreng. syst. 2, p. 256 (haud Don.)

a. alpestre, pedicellis calyce brevioribus, caulibus elongatis (pedalibus et ultra), foliis plerumque majoribus. In Iberiâ (Hohenack.! Wilhelms I), m. Ararat (\$zo. vits!), Syriâ (Ehrenb!! Ausher-Eloy, n. 1345! 2582! Heldreich!), Tauro (Kotschy, n. 422! Libano (Boiss.!), Garwhal, alt. 14,500 ped. (Strachey et WVinterbott. herb. Himal. n. 46 !). P. alpestre C.-A. Mey.! ind. Cauc - p. 157, Jaubert et Spach p1. Or. 2, p. 26, t. 118, G. Koch, in Linnæå 22, p. 337. P. acetosum et maritimum Eichw. Casp. Cauc. p. 23 et 30 . P. acetosi var. latifolia M. Bieb. Taur. Cauc. 3, p. 286. P. pluriflorum C. Koch! in'Linnæâ 22, p. 202 et 337. P. Libanoticum Ehrenb.! mss. P. monticolum Steud. nomencl. ed. 2, p. 376. (v. v. c. et. s. sp.)

$\beta$. rupestre (Fish. et Mey. ind. sem. h. Petrop. 8, p. 19), pedicellis calycem requantibus vel superantibus, caulibus brevibus (digitalibus) foliis plerumque minoribus. In Iberia (Fischer ! Wilhelms!), prope Damascum (h. DG.!), in Sibiriâ Altaicá (Ledeb.). P. rupestre Karel. et Kiril. en. pl. Alt. n. 789, et Soongor. n. 722. (r. s.)

$\%$ ammannioides, pedicellis calycem subæquantibus, caulibus elongatis, foliis minoribus sæpius anguste lanceolatis acutis, brevius petiolatis. In Persiæ prov. Aderbidjan (Aucher-Eloy, n. 5273 I). P. ammannioides Jaub. et Spach 1. c. t. 119 , cum descr. (v. s.)

54. P. RECUMBENS (Royle mss. Babingt. in linn. Trans. 18, p. $116^{*}$ ), caule prostrato ramoso sulcato scabro, ochreis internodia subequantibus semihyalinis 3-5-nerviis laceris, foliis subsessilibus ellipticis acutis internodio 2-3-plo longioribus planis subtus venosis margine venisque scabris, axillis 3-6-floris, pedicellis ochreâ calyceque brevioribus apice articulatis, caljce parro carinato-trigono, achænio incluso obtusangulo lavi nitido. $\mathcal{Y}$ 'In Mnssooree (Royle), Kamaon (Wall. ! in herb. Meisn., Strachey et Winterbott. n. 41), Simla (lady Dalhousie ! in herb. Arnott, Hügell in herb. Mart.). Suffruticosum (ex Babingt.), foliis ad $P$. avicularis formas latifolias et $P$. cognatum accedens, cæterum vero bene distinctum. Ochreæ juniores internodio longiores, demum parum breviores. Flores in superioribus axillis approximato-congesti, corollini. (v. s.)

55. P. G ONF E R T U (Royle mss. Babingt. 1. c. p. $116^{*}$ ), caule prostrato ramoso scabro, ochreis internodia brevia superantibus hyalinis lanceolatis acutis demum laceris nervis paucis extra medium evanidis, foliis loreve petiolatis oblongis obtusiusculis 
1-nerviis margine nervoque subtus scabris, pedicellis calycem parvum suljglobosum demum patentem subæquartibus apice articulatis, achænio calyce aucto breviore compresso vel trigono obtusangulo lævi nitido. $\mathcal{F}^{\prime}$ ? In Kamaon. (Royle.)

56. P. RAM osis Simum (Michx. 11. bor. Am. 1, p. 237), erectum, ramis erecto-patentibus tenuiter striatis, ochreis internodio multo brevioribus semihyalinis 6-nerviis demum laceris, foliis petiolatis ovali-oblongis acutiusculis planis obsolete penninerviis margine scabriusculis, pedicellis subsolitariis calycem majusculum lierbaceum æquantibus, achænio incluso faciebus ovatis opacis granulato-striatis. $\odot$ In Americâ boreali. - Meisn. Polyg. prodr. p. 91. P. erectum Linn: sp. 1, p. 520? Mühlenb. catt. p. 40.0mnia fere $\mathrm{P}$. avicularis var. vegeti, sed folia majora (1.2 poli. longa, 5-10 lin. lata), summa vix minora, semper petiolo 1-3 lin. longo tenui prope basin ochrea inserto priedita et venis paucioribus semipatentibus obsolete notata, juniora subevenia. Calyx viridis, fructifer, $1 \frac{1}{2}$ lin. longus (magnit. P. Convolvuli), lobis medio obsolete 1 -nerviis eveniis margine anguste albido-petaloideis. (v. s.)

57. P. FLORIBUNDUM (Schlecht. in herb. Willd. n. 7639), caule erecto paniculatoramosissimo ramisque gracilibus sulcatis, ochreis semilhyalinis 6 -nerviis lacerofimbrialis, foliis sessilibus oblongis subovatisque 1 -nerviis subeveniis summis flores vix superantibus, axillis summis approximatis 3 -5-floris, pedicellis capillaribus calycem corollinum rquantibus apice articulatis, achænio incluso subnitido, faciebus ovatis obsolete punctato-striatis. $\odot$ Circa Astrachan (Tauscher! in herb. Mart.), in Sibiriâ Uralensi (Pall.), ad lacum Indersk! (herb. Acarl. Petrop., Ledeb.). - Spreng. syst. 2, p. 257, Meisn. Polyg. prodr. p. 92, Ledeb.I n. ross. 2, p. 529. Species insignis floribus (magnit. P. avicularis, sed basi tantum herbaceis) in ramorum apice racemum continuum densum formantibus, foliis floralibus parvis fere occultatis. Fructum nonnisi immaturum observavimus. (v. s.)

58. P. AVIC ULARE (Linn. sp. 1, p. 519), caule procumbente adscendente vel erecto a basi ramoso sulcato, ochreis internodio brevioribus albis $6-8$-nerviis bifidis demum laceris, foliis ellipticis lanceolatis linearibusve planis venosis, axillis 3-5-floris, pedicellis calyce semiherbaceo trigono subnervoso brevioribus apice articulatis, achænio incluso subopaco faciebus ovatis granulato-striatis. $\odot$ In cultis et incultis Europæ totius, Asiæ borealis et occidentalis (Saharunpore; fide Royle; Cabul, Griffith, n. 1718 et'1718 a!), Africæ bor. et austral. (Desf., Thunb.? Lalamde ! in h. Kunth.), in Abyssiníă (Schimper, n. 869 !), Americà bor. a Tenesseo (Rugel, n. 193!) et Carolinâ ad Labrador et ins. Sitcha, Mcxico (G. Ėhrenberg! in herb. Berol.), Chili (Gl. Gay), Nova-Zealandiâ (Colenso! Huok. fil.), Nov.-Holl. austro-occid. (Drummond !).-Blackwell Herb. t. 31 5, Fl.dan. t. 803, Hayne getr.Darst. 5, t. 33, Engl. bot. t. 1252, Meisn. Polyg. prodr. p. 87 (excl. syn. plur), Mert. et Koch D. fl. 3, p. $58^{*}$, Hook. fl. bor. Am. 2, p 132, Ledeb. fl. ross. 3, p. 531, C. Koch ín Linnæâ 22, p. 203, Watson in Hook, Lond. Journ. 3, p. 604, Physiologist 1846, p. 615. P. Centinodium Lam. A. fr. 3, p. 237. P. geniculatum Poir. dict. 6, p. 147. P. provinciale $\mathrm{C}$. Koch in Linnæâ 22, p. 204. Planta tristissima, secundum stationis naturam innumeras induens formas, quarum sequentes priecipue :

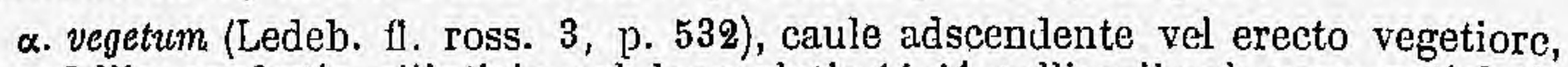

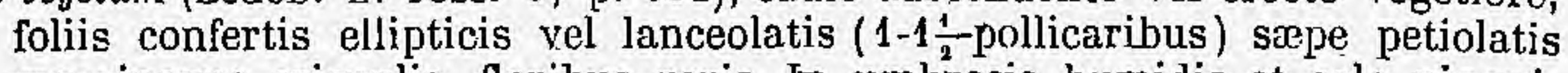
margineque crispulis, floribus raris. In umbrosis humidis et solo pingui. P. latifolium Tourn. inst. p. 510. P. Monspeliense Thieb.! (Gide h. DC.), Pers. enchir. 1, p. 439. P. Roberti Lois.! fl. gall. ed. 2, v. 1, p. 283 (ex parte, cfr. P. Rayi). (v. v.) K

B. erectum (Ledeb. 1. เ. excl. syn. Linn.), caule elatiore erecto vel suberecto gracili, minus ramoso, internodiis elongatis, foliis lanceolatis, floribus versus extremitates crebrioribus. In solo glareoso subumbroso, inter segetes. P. erec. tum Roth Tent. fl. Germ. 1, p. 455 , C. Koch? in Linneeâ 22 , p. 109 . Accedit ad P. Bellardi et olim cum eo confusum, sed ramis floriferis ad apicem usque foliosis et achænio distincte granulato-striato bene distincta. (v. v.)

$\gamma$. diffusum, caule procumbente ramosissimo gracili laxo internodiis elongatis, foliis subsessilibus lanceolatis spathulatis vel linearibus sæpe obtusis, axillis fere omnibus fertilibus plerumque multifloris. In incultis siccis capens. (Drège! Burke! Colenso!), Cabul. (Griff. n. 1718!), Kamaon (Strachey et Winterbott. n. 21!), Swan-Rivór (Drumm. u. 231! etc.). P. aviculare Babingt. in Linn. 
Trans. 18, p. 114). $\gamma$ laxum Ledeb. fl. ross. 3, p. 532 (excl. syn.). P. nervosum Wallr.? in Linnæế 14, p. 568, P. arenarium Rafin.! mss. in herb. DG. (non W. et Kit.) (v. T.).

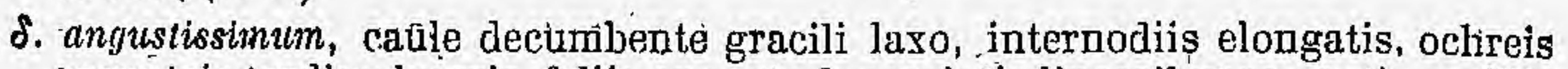
argenteis tardius laceris, foliis anguste lanceolatis linearibusve acutis, axillis plerisque fertihibus paucifloris, achenii apice subexserto. In arenosis. $P$. neglectum Besser! enum. pl. Volhyn. p. 45 (ex parte), Eichw. Skizze, p. 132. P. aviculare arvense Gerhard! pl. exsicc. var. oxyphylla Wallr.! mss. in h. DC. (v. v.)

. depressum, caulibus abbreviatis radiatim terræ adpressis ramosis conferto foliosis florigerisque, internodiis brevibus, foliis parvis ovalibus lanceblatis linearibusve acutis obtusisve. In solo sicco duro lapidoso vel arenoso; viis tritis, plateis urbium, ete. R. microphyllum Ruiz! in herb. Berolin. forma floribus sueto minoribus ad P. herniarioides accedens, sed achrenio striato. (v.v.)

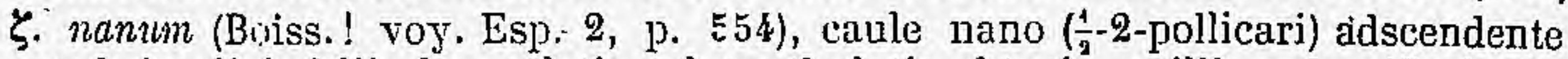
subsimplici, foliis lanceolatis vel spathulatis olutusis, axillis subunifloris. In arenosis inundatis el exsiccatis summarum Alpium Helvetiæ! Pedemontii! Galloprovinciæe! Sierræ Nevadıe! alt. 9,500 ped. P. nanum BorJ Saint-Vinc. fl. Sierra Nev. n. 115, teste Boiss. 1. c. (v. v.)

59. P. Lit torale (Link in Schrad. Journ. 1, p. 54), diffuse laxeque decunibens, ramis elongatis gracilibus, internodiis mediacribus, ochreis brevibus tenuinerviis, foliis crassiusculis unguicularibus ovalī-vel lineari-lanceolatis plerumque obtusis subenerviis, axillis 3-6-floris, caljce subenervi, achrenio incluso parvo faciebus orato-oblongis convexis minute punctatis obsolete striatis. $\odot$ In littoribus maris Baltici, Scotiæe, Angliæ, Galloprovinciæ (Loisel!), Græcice (Zuccarini, n. 418! Marget!), Sibiriæ (Gmel. ! in herb. Mus. Stutfgart), Amer. bor. (Short) nec non in solo gypsaceo et salino -Hercynixe (Wallr.). - Link enum. 1, p. 385, C. Koch in Linnzéa 22, p. 204. P. salsuginosum Wallr. mss. ex Linnceâ 14, p. 568. P. aviculare var. littorale Mort. et Koch D. fl. 3, p. 59, Koch synops. ed 2, p. 712. R. crassinerve Cesati stirp. Ital. fasc. 2, cum ic. Excepto achənio omnia feie P. avicularis diffusi et depressi, sed vix mere ejusdem var., a P. maritimo distinctissimum. Stamina 5, ex Nutt. et Ledę. (v. v. et s. sp.)

B. Buxifolium (Ledeb. I f. ross. 3, p. 532, sub P. aviculari); caulibus abbreviatis, foliis lineari-oblongis obtusis attenuato-subpetiolatis subeveniis, axjllis 1-2-floris, achænió calycem paulo superante suljnitido mirnte punctato obsolete striato. In ins. Sitcha (Eschscholtz!). P. buxifolimm Nutt., ex Bongard veg.ins. Sitcha, p. 161. P. aviculare \& latifolium Mich. fl. bor. Am.1, p. 237. (v.s.)

60. P. DREGEI, caule e basi suffrutescente? ramosissimo, ramis gracillimis subsimplicibus leviter striatis angulatisve, ochreis laxis semilhyalinis 6-nerviis laceris, foliis unguicularibus internodio brevioribus oblongis acutiusculis planis 1 -nerviis eveniis, axillis 1-3-floris, pedicellis ochreâ calyceque oblongo brevioribus, achænio breviter exserto faciebus oblongo-lanceolatis obsolete puncticnlatís nilidulis. 4 Cap. Bons -Spei (Drège!). P. aviculare var.? Dregeanum Meisn. in Linnæea 14, p. 486 (excl. specim. a). Omnia fere P. avicularis (ad quod certe -specim. Drege $a$ pertinent), sed achænium constanter elongatum (fere 2 lin. longum), faciebus lanceolatis haud strictis, et folia evenia. (v. s.)

61. P. R o y er (Babingt. in Linn. Trans. 18, p.115*), caule prostrato ramoso 3-4-gono, angulis scabris, ochreis brevibus acutis lobatis obsolete binerviis, foliis linearilanceolatis acutis utrinque dense glanduloso-punctatis, floribus ill summis axillis approximatis parvis, pedicellis brevissimis apice articulatis, achæeio calycem rquante acutangulo faciebus granulato-striatis. $\% \mathrm{Ad}$ Theog et Phagoo Indix borealis (Royle). A P. aviculare vix differre videtur nisi ochreis obsolete binerviis ct foliis "glanduloso-punctatis", an potius papilloso-scabriusculis?

* Caules ramique floriferi apice aphylli (rarius foliis nanis muniti, cfr. P. tenue, Galifornicum), racemo nudo vel basi tantum folioso terminati.

62. P. BELLA RDI (All. fl. Pedem. 2, p. 205 , t. 90, f. 2), caule erecto gracili ramoso, internodiis elongatis sulcatis summis angulatis, ochreis semihyalinis 6-8-nerviis laceris, floralibus inferioribus folio nano angusto acuminatis summis aphyllis, foliis lanceolatis vel- jinearibus planis venosis, racemis interruptis, fasciculis 2-5-floris, pedicellis calyce demum clauso longioribus, achænio incluso faciebus 
ovatis subnitidis minute punctatis obsolete vel vix striolalis. $\odot$ In tota Eurojâ australı, Barbarià, AEgypto, Arabiâ, Syrî̀, prov. Caucasicis, Rossiâ mediâ, australi et Asiaticâ, Indià loureali.-Willd. sp. 2, p. 450 , DC. fl. fr. 3, p. $369^{\star}$, Ledeb.! fl. ross. 3, p. 530. P. rectum Barrel. obs. 1143, p. 104, t. 560 , .. 2 ? P. aviculare $\beta$ erectum Mcisn. Polyg. prodr. p. 88 et auct. plur. (ex parte). Speciés variabilis, I'. avicularis formæ erecte similis et olim cum cà confusa, sed distincta spicis apice aphyllis et aclisenio subnitido sub lente minute punctato olssolete vel haud striato. Fornise sequentes insuper variant caule $\frac{1}{2}-3-4$-pedali, ochreis longioribus vel brevioribus plus minus hyalinis, floribus magnit. P. avicularis vel dimidio majoribus, achænio plus minus nitidulo (rarius fere opaco), nunc obsolete striolato, nurie (et quidem plerumque) subtilissime punctato, sed numruam eodem modo granilato-striato ac P. avicularis.

๙. virgatum, caule stricte erecto modice ramoso, ramis semicrectis subsimplicibus, racemis elongatis lexis pluries interruptis. In Eurojł austr. ef Syrià. P. virgatum Lois. I nouv. not. 18 ; fl. Gall. ed. 2,1, p. 284. P. Ruizianum C. Koch! in Linnæe 22, p. 207. P. chlorocoleon Steudel! in pl. Kolschy, n. 231 (in $\beta$ transiens). P. Kilaiłelianum Sadler! 11. com. Pestlı. cd. 1, I, 1.. 287. P. Gmeliní hort. Paris., ex herb. Loís.! (v. s. el v. v. c.)

B. patulum, caule erceto virgato modice ramoso, ramis divaricato-patentibus striclis, spicis basi interruptis apice densiusculis, bracteis subunifloris pedicello brevioribus. In Oriente. P. patulum A. Bieb. Taur.-Cauc. 1, p. 304, C. Koch in Linnæca 22, p. 198. P. laxiflorum Pall. mss. in herb. Willd. n. 7653 (non Weihe). P. Bellardi Karelin el Kíril. a.1028 1 Aucher-Eloy, n. 5275 ! Sclimper, Sinai, n. 388 ! ctc. I. spectahile Lehm. ind. sem. h. Hamb. 1820 el 1825 fexcl. syn. Ten.), fide Linnot 3, p. 50. P. reticulatum G. Koch! l. c. p. 200. (v. s.)

$\gamma$. gracilius (Ledeb.! fl. róss. 3, p. 530 ), caule gracili crecto párum ramosó, ramis subfiliformibus erecto-patentibus subsimplicibus strictis, racemis pluries interruptis, pedicellis subsolitariis (raro ternis)" flore longioribus. In Sibiriâ. P. strictum Ledeb.! fl. Alt. 2, y. 86, ic. t. 444 (non All.), Turcz. cat. Baical. n. 978, Karel. et Kiril. enum. pl. 17t. n. 792 ! 1030 ! C. Kooch ! l. c. p' 199. (v. s.)

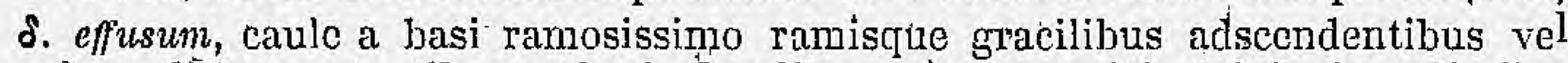
laxe diffuso-patentibus, ochreis floralibus minus remotis 1-2-floris pedicellos superantiluus. In Europâ austr. et Caucaso. P. flagelliforme et arenarium Lois.! nouv. not. 17, 18, fl. Gall. ed. 2, 1, p. 283, 281 (ex parte). P. pulchellum Loisel. 1. c. p. 19 ; fl. Gall. 1, p. 284 , t. 26 . P. rubriflorum Friv.! mss. (v. s.)

63. P. DE I IDU M (Boiss, et Noë $l$ in Schlecht. Bot. Zeit. 1853, p. 734), glabrum, a basi ramosum, caule erecto gracili ramisque patulis strictis teretibus acute sulcatis levibus, ochreis semilyyalinis brevibus 6-8-nerviis laceris, foliis caducis..., racemis longis interruptis, bracteis 2 -4-floris pedicellos sulserfuantibus, calyce corollino mediocri, fruetifero 3-gono nervoso, achænio incluso lævi nitidissimo. $\odot$ In Persix alpibus Kirrind. (Noë, n. 485! 1025 !). Admodum simile P. Bellardi (præecipue P. stricto Ledels. et patulo Bieb.), sed dirersum habitu magis junceo, lolíis, ut videtur, caducissimis (plane niulla vidimus), racemis 4-7-pollicaribus apiccm usque valde remotifloris el achenio nitidissimo nec punctato nec striato. (v. s. in h. Boiss.)

64. P. No EANUM (Boiss.! 1. c. p. 734), multicaule glabrum, caulibus erectis pauciramosis teretibus lineatis levibus demum junceis subapliyllis, ochreis scmiliyalinis laxiusculis laceris basi 6 -nerviis, foliis lanceolatis utrinque attenuato-acutis subeveniis junioribus glaucis, summis linearibus, racemis interruplis, hracteis 2-3-floris pedicellos subsuperantibus diu integris, inferioribus folio ipsis vir longiore deciduo munitis, summis subcuntiguis, calsce semilierbaceo mediocri cnervi, fructifero trigono, achœnio incluso łæevi nitidissimo. $\odot$ ? In Persiâ circa Mlohammera et Bassora (Nö̈, n. 61! et 92!). Planta junior ralde accedit ad P. acctosum, adulta ad P. Bellardi, ab illo dlffert racemis apice aphyllis, ab hoc achirnio minore levi nitidissimo. (v. s. in. h. Boiss.)

65. P. ARGY R OC OLE ON (Steudel! in Liotsclyy pl. Aleph. n. 440), caule crecto paniculato-ramoso striato, internodiis longis, oclireis lirevibus scmihyalinis tenuiter 6-8-nerriis laceris, ncrris scabriusculis, foliis lanccolate-lincaribus planis subvenosis floralibus nanis, raccmis subcontinuis laxis apice ajlly-llis demum filiformiluus interruptis, bracteis liyalinis stibintegris 1-3-fluris ledicillos surerantilus, 
calyce mediocri subherbaceo subevenio patulo, achænii inclusi parvi faciebus ovatis nitidissimis lwvibus. (In arenâ insularum Tigridis prope Mossul (Kotschy !), et circa Julalabad (Griffith!), Bagdad (Noë, n. 345!). - Kunze! in Linnzeâ 20, p. 17*. Achænio lævi a P. Bellardi cæeterum simillimo facile distinguendum. Racemi demum elongati 2-4-pollicares. (v. v. c. ct s. sp.)

66. P. J U N E U M (Ledeb. fl. ross. 3, p. $529^{*}$, non Cunn.), caule erecto gracili paniculato-ramosissimo paucifolio ramisque striatis, internodiis longissimis, ocbreis laceris, foliis petiolatis oblongis linearibusve utrinque attenuatis acutis, racemis subcontinuis laxiusculis aphyllis, fasciculis 1-paucifloris, pedicellis flore brevioribus, achænio calycem subexcedente... $\odot$ In Sibiriâ Uralensi. P. divaricatum Lessing in Linnæâ 9, p. 204 (non Willd.). An a procedente aut P. Bellardj satis distinctum?

67. P. E L EGAN (Ten.! fl. Ncap. prodr. suppl. 2, p. 66; fl. Neap. 2, p. 207, t. 35, non alior.), caule erecto gracili paniculato-ramoso ramisque palulis tenuiter striatis, internodiis elongatis, ochreis multinerviis lacero-fimbriatis floralibus hyalinis diu integris, foliis lineari-lanceolatis acutis subeveniis, racëmis elongatis laxis aphyllis, fasciculis 2-4-floris, pedicellis bracteam scquantibus calyce corollino majusculo patente brevioribus, acliænii faciebus ovato-ellipticis lævibus? Ұ In Italiầ meridionali et florâ Tergestinà (Ten.). - Link enum. p. 385, Mcisn. Polyg. prodr. p. 86. $\mathrm{P}$. equisetiforme Mayer mss. fide Ten. (non alior). Facies $\Gamma$. Bellardi et equisetiformis, sed facile dignoscendum spicis penitus aphyllis, calyce fere triplo majore (ḿagnit. P. orientalis), laciniis orbiculari-obovatis, etc. Caulis suffruticosus, fide Ten. Sylloge, p. 194. (v. s. c.)

68. P. ARENARIU M (Waldst. et Kitaib. ! pl. rar. Hungar. p. 69, t. 67), caulibus decli-

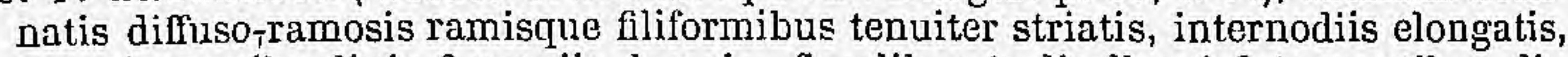
ochreis semihyalinis 6-nerviis lacoris, floralibus pedicellos 1-3 xquantibus diu integris, foliis lineari-lanceolatis subvenosis plawis, spicis tenellis interruptis aphyllis, calyec corollino parvo, achenio incluso nitidissimo faciebus ovatis concavis lavissimis. $\odot$ In Europà orientali, alı Hungariâ et Rossiâ medià (Lithuaniâ l) ad australem, Georgiam Gaucasicam et Sibiriam Uralensem usque. - M. Bieb. fl. Taur.-Cauc. p. 303, Meisn, Polyg. prodr. p. 87, Ledeb.! fl. ross. 3, p. 531.P. neglectum Bess. enum. Vollıyn. p. 45 (ex parte, fide Ledeb.). P. patulum Karelin! in herb. DG. (non Bicb.). Simillimum P. Bellardi var. effuse, sed facile dignoscendum spicis penitus aphyllis et achænio minore lævissimoque. Variat staturâ spithamæầ ad bipedalem, caule siepe a basi ramosissimo, spicis 1-3-jollicaribus rectis rel flexuosis, junioribus basi foliosis. (r. s.)

69. P. CALIF ORNICUM, caule erecto debili ramisque patulis tereti-filiformibus apice angulatis, ochreis hyalinis brevibus enerviis lacero-ciliatis, foliis filiformibus mucronulato-acutis eciliatis subtus sulcatis, floralibus subulatis nanis, floribus axillaribus solitariis in spicam subtenellam continuam approximatis, calyce corollino parro enervi, achienió... $\odot$ In Galifớniâ (Hartweg, n. 1944!). Herba tenella 3-6-pollicaris, glaberrima, internodiis demum 5-7 lin. longis teretibus vel superioribus acute angulatis. Folia patula, inferiora 6-8 lin. longa, vix $\frac{1}{3}$ lin. lata, haud rigida, summa vix 2 lin. longa. Spica filiformis, floribus subsessilibus roseis? Calyx 1 lin. longus, ecurinatus, laciniis acutis stamina 8 basi dilatata superantibus. Adhathium non vidimus. Species proxime affinis $P$. arenario et tenui, sed ab utroque jam ochreis enerviis et foliis filiformibus, a posteriore præterea habitu haud stricto, caulibus minus angulatis, foliis nec rigidis nec scabriusculis, et a P. coarctato jam lloribus duplo minoribus distincta. (v's. in h. DC.)

70. P. TEXUE (Nichx. fl. bor. Am. 1, p. 238), caule erecto stricto ramisque gracillimis superne angulatis, ochreis semilhyalinis 3 -nerviis fimbriato-laceris, foliis lincaribus acutis 3-nerviis margine minute ciliato-scabriusculis, floralibus subulahis nanis, floribus remote axillaribus solitariis, achenio mediocri incluso faciebus ovatis medio lacribus nitídis seeus margines punctatis subopacis. (In Americâ. bo. reili a Canada ad Carolinam et Xissouri asraue.- Meisul. Polyg. yrodr. 1. 91, Hook. fl. hon. An. 2, p.132. P. linifoli um Mülllenb. ! cat. p. 40 (fide herb. Willd. n. 7666 !), Spreng. syst. 2, p. 256 (non lioth nec P'crrott.). P. filiforme Barton comp. fi. Philad. 1, p. 186 (non Thunb.). Variat caule digitali ad pedalem, a basi ramosissimo vel rarius subsimplici. Dchrese jne mrnodio mult $n$ breviores. Folia inferiora $6-1 /$ lin. 
longa, $1 \frac{1}{2}$ lin. lata, summa nana et subabortiva. Spica elongata interrupta foliosa vel apice aphylla, pediccllis ochrea calyceque brevioribus. Calyx fere $\mathrm{P}$. avicularis virescenti-albus vel rubellus, fructifer arcte clausus. (v. s.)

71. P. с OAR C т A тu (Douglas! mss. non Willd.), caule erecto dichotomo tereti lievi, ramis. filiformibus erectis, ochreis semihyalinis 2-nerviis demum bipartitis laccris, foliis linearibus acutis 1 -nervi is eveniis nargine rovolutis, spicis filiformibus laxis basi interruptis apice aplryllis, bracteis 1-2-floris, ealyce patente demum clauso deflexo obsolete carinato-trigono, achænio incluso lævissimo nitido, faciebus ovato-oblongis. $\odot$ In Americâ boreali-occidentali et arctica. L-Hook. 11. bor, Am. 2, p. 133. Rami haud sulcati, ramuli subangulati, suls lente punctato-scabriusculi. Ochreæ diu adpressæ integræeque, infra medium fuscœ, nervis 2 submarginalibus tenuibus. in parte hyalinâ evanescentibus haud excurrentibus. Bracteæe hyalinæe subenerviæ, pedicellis subsolitariis longiores, inferiores folio subulato $2-4$ lin. longo in superioribus decrescente munitæ, summæ aphyllæ muticæ. Flores primo erecti, demum refracto-penduli. Cxct. fere omnia P. tenuis. Achænium, ex Hook., " minutissime punctatum," nobis in specim. Franklin. et Dougl. omnino live risum est.

a. majus, palmari-pedale, dichotomum, foliis inferioribus laniccolatis (1-1 $\frac{1}{2}$ poll. longis, 1-1: lin. latis) punctato-scabriusculis margine leviler recurvis, spicis filiformibus 2-3-pollicaribus, calyce 2 lin longo, lobis oblongis. Ad flum. Columbia (Dougl.!), in mont. Scopulosis (Geyer, n. 355 l) (v. s.)

3. minus, digitale, pauciranosum, foliis angustioribus (6-9 lin. longis, $\frac{1}{2}$ lin. latis)-lævibus margine revolutis, spicis brevibus ( $\frac{1}{2}$ poll.) densifforis, calyce 1 lin. longo, lobis obovatis. In Amer. arcticâ? (Franklin! in herb. Arnott), Oregon (Spalding.) (v. s.)

72. P. POLYGALOIDES, nanum, glabrum, caule erceto tenui pauciramoso, ochreis hyalinis bipartitis laceris 3 -nerviis, foliis anguste linearibus acutis 1 -nerviis planis, spicis terminalibus densifforis ovato-oblongis basi folio fultis, bracteis imbricatoadpressis floro majoribus prominulo-1-nerviis medio circumscripte viridibus margine albido-membranaceis, calyce parvo 5-partito carinato-trigono, achsenio incluso triquetro, faciebus ovato-oblongis granulato-striatis opacis. $\odot$ In ClearWater, Oregon (Spalding !). Plantula insignis, facie Polygalarum quarumdam, v. g. P. Monspeliensis, caule digitali tereti lævi, infra nodos angulato, ochreis basi fuscescentibus 2-3 lin., foliis 6-12 lin. longís, $\frac{1}{3}$ lin. lalis, margine subtus obsolete nerviformi. Spicæe 5-7 lin., bracteæ demum 2 lin. longæ, 1 lin. latæ, maculâ viridi lineari-lanceolatầ utrinque acutâ. Flores semilherbacei, 8-andri. Bracteæ bujus speciei revera. folia sunt, margine scarioso aucta, et basi ochrcam genuinam (caulinis omnino similem) gerunt. (v. s. in h. DC.)

Sectio ili. Persicaria Meisn. Polyg. prodr. p. 66 (excl. § 2), t. 1, fig. 18, 27-29, t. 3, fig. L. M. N.; synops. in Wall. pl. Asiat. rar. 3, p. 55 ; et in Mart., Fl. Bras. Polyg. p. 12, Endl. gen. p. 307 (1). - Genus Persicaria Tourn. Inst. p. 509, t. 290. - Tovara, Adans. fam. 2, p. 276. - Antenoron, Rafin. Fl. Ludov. p. 28.

Calyx coloratus, raro viridis, nonnunquam glanduloso-punct interjectis squamulis perigynis minutis (interdum obsoletis). Styli 2-3 plus minus connati, raro liberi, stigmatibus capitatis. Achænium calyce aptero parum aucto inclusum, lenticulare vel trigonum. Albumen corneum. Cotyledones accumbentes $0=$. Herbæ decumbentes vel erectæ, pleræque hydrophytæ, interdum natantes (nunquam volubiles), caulibus inermibus, ochreis membranaceis vel rarius herbaceis cylindricis nervosis ore horizontaliter truncato setaceo-ciliato vel rarius nudo, foliis herbaceis indivisis plerumque lanceolatis vel oblongis margine fere semper ciliolato-scabriusculis, sepius glanduloso-punctatis, racemis spiciformibus densis laxisve geminatis vel racemosis (raro solitariis), bracteis ochreiformibus turbinatis vel oblique truncatis sæpe ciliatis plerumque plurifloris, calycibus rubris vel rarius albis.

(1) Quoad species Europicas hujus sectionis cfr. Alex. Braun, in Florâ 1824, et de Bruyn, in Nederland. Kruidkund. Arch. 1, p. 487-510. 


\section{Súbsectio I. Trigyna.}

Styli 3 (nuncruam? 2) scmiconnati. Achænium triquetrum. Calyx 5-(rarissine 4-) partitus. Stamina 8 (raro pauciora, cfr. sp. $73,83,84,87-80,94$ ). Folia prope basin, rarius circa medium ochrex inserta. Bracter turljinate, truncat:e.

\section{Series I. Spicce cylindracece, lineares vel oblongce, densiflorce, continuce (raro subfiliformes vel interrupta, cfr. sp. 78-80). \\ * Ochrea pilis tenuibus sapiusque brevibus ciliata.}

73. P. тINCTORIUM (Lqur. fl. Coclı. 1, p. 297 *), caule subsimplici, ochreis mediocribus angustis glabriusculis breve ciliatis prope basin foligeris, foliis ovalibus ovatisve obtusiusculis attenuato-petiolatis ciliolatis glabris pellucido-punctatis, spricis racemosis oratis oblongisve obtusis densifloris, bracteis pedicellos æquantibus inferioribus ciliolatis, staminibus 6-8 stỳloque inclusis, achænio lævi nitido faciebus ovatis. $\mathcal{F}$ ex Lour.; in lortis Europ. $\odot$. In Chinâ.-Willd. sp. 2, p. 445, Ait. Kew. 2, p. 31, Meisn. Polyg. prodr. p. 81. Herba erecta 1-3-pedalis. Folia materiem indigo succedaneam continentia, exsiccatione corrulescentia, in arte.tinctoriâ adhibita. Spicœ pulchræe, floribus magnitudine et calore fere P. orientalis, subeveniis eglanduḷsis. Stamina semper 8 numeravi. Stylus ipteṛdım breviter exsertus. (v. v. c.)

74.? P. G ilia t u (Lour. fl. Coch. 1, p. 299 *, haud Don), caule tetragono tenui erecto, oclireis ciliatis, foliis subsessilibus ovato-lanceolatis glabris, rspicis brevissimis, calycel 5 -fido, staminibus 8, stylis 3 , achæenio triquetro. In Chinâ. - Ileisn. Polyg. prodr. p. 71. P. Loureiri Poị. dict. suppl. 4, p. 667, Spreng. susst. 2, p. 2̨53. Species ominino obscura.

75. P. BISHIR E (Hamilt.! mss.), eglandulosum, caule infra glabro, ramis pedunculis ochreisque dense adpresso-pilosis spicigeris bis dichotomis, ochreis longiusculis angustis breviciliatis infra medium foliigeris, foliis subsessilibus oblongo-lanceolatis acuminatis basi acutis brevissime pilosiusculis, spicis lineari-oblongis contipuis strictis densilloris, bracteis imbricatis puboscentibus ciliolatis, pedicellis exsertis, staminibus 8 styloque exsertis, achænio lavi nitido faciebus late ellipticis angulis obtusiusculis. $\mathscr{\not}$ ? In Sukanagur, penins. ? Ind. or. (Hamilt. !)--Meisn. in Wall. pl. As. rar. 3, p. 56 . (v. s. in h. Wall. soc. limn. Lond.)

76. P. cons Pe R s u (Meisn. in Wall. pl. As. rar. 3, p. $56^{*}$ ), caule eglandıloso superne cum ochrcis pedunculisque adpresse piloso, ochreis longis angustis glandulosoconspersis Jongiuscule ciliatis prope medium foliigeris, foliis lanceolatis acuminatis attenuato-petiolatis molliter adpresso-puherulis supra glabrescentibus subtus dense fusco-punetatis, spicis geminatis linearibus gracilibus basi lạxiusculis, bracteis subimbricatis ciliolatis calycibusque glandulosis, staminilops 8 styloque exsertis, achænio lævi. \& ? Ad flum. Irawaddi, circa Pegu (Wall.! list n. 1709, D., ex parie), et circa Goalpara, in penins. Ind. or. (Hamilt.! Wall. list n. 1708, F. !). P. Goyalpare Hamilt. ! mss. Afline P. Bishiræe et barbato, sed jam foliis glanduloso-conspersis dignoscendum. (r. s.)

77. P. viscosusi (Elamilt. mss. Don prodr. f. Nepal. p. 71), caule ramoso glanduloso patenti-lirsuto, ochrcis brevilus laxis hirsutis ciliatis, foliis ovatis vel lanceolatis adpresse hirsutis glabralisve, spicis brevibus oblongis continuis, pedunculis dense glandulosis hirsutjs vel glabriuscplis, bracteis subimbricatis lirsutis ciliatis pedicellos suberfuantibus, calyco eglanduloso, staminibus 8 styloque inclusis, achinnio ovato-trigano obsolete puncticulato. 24 ? In Nepaljà superiore (Hamilt.), Sịllet (Wall. list n. 1713 I), Lssanià superiore (Wall.I).-Mleisn. Polıg. prodr. p. 73; apud Wall. 1. c. p. $55{ }^{*}$. A simili P. hirsuto Walt. jam foliis pedunculisque glandụlosis facile dịstinguitur. Flores purpurei, fide Don.

$\alpha$, ramosissimum (Meisn. I. c. p. 55), caule adscendente divaricato-ramosissimo, foliis ovatis vel oblongis obtusis basi subcuneatis, utrinque parce glandulosis hị̂sutisque, sæpe crispato-undulatis, spicis subsolitariis. (v. s.)

B. vernicosum (Mcisn. 1. c.), caulibus erectis subsimplicibus, foliis lanceolatis subacutis ljasi sensim attenualis, densius strigoso-hirsutis punctisque resi- 
noso-glandulosis fuscis conspersis et quasi vernice obductis, spicis paupis racemosis. P. hirsutum Hamilt.! mss. (non Walt.). - Wall. n. 1713, sub litt. A. (v. s.)

78. P. h I R S т и (Walt. fl. Carol. p. 132 ), eglandulosum, ochreis longiuscule ciliatis cauleque patenti-fulvo-hirsutis, foliis lanceolatis e basi rotundatâ sensim attenuatis pilosis glabrisve, spicis geminatis ternisve anguste linearibus continuis vel interruptis, pedunculis apice glabris, bracteis subimbricatis ciliolatis nudisve pedicellos subærquantibus, calyce staminibus 8 styloque inclusis, achænio læri nitido angulis obtusiusculis. $\odot$ In Amer, hor. calidiore. - Mich. fl. bor. Am. 1, p. 239, Meísn. Polyg. prodr. p. 79. Caules 3-4-pedales, graciles, adscendentes, basi radicantes ibique sepe glabri. Folia $2-3$ poll. longa, $4+10$ lin. lata, pubescentiâ brevigre raripre vel nụllẩ. Ochrearum cilia debilią 1-2 lin. longa. Bractełc plerum. que imberbes. (v. s.)

๙. dasyphyllum, foliis utrinque dense hirsutis tarde glabrescentibus, bracteis inferioribus pilosiusculiș. In Carolinâ (Bosc! Frạs.! iṇ h. DG.)., Georgiâ et Floridâ (Torr. I Short! in h.: Meișn.).

ß. glabrescens, caule, foliis (excepto nervo medio) bracteisque glabris. In Flofidà (Rugel, 1843 et $1845, \mathrm{n}, 86$ !).

\section{** Ochrea setis pilisve rigidis longiusculis ciliate.}

79. P. HYDROPIPEROIDES (Mich. fl. har. Am. 1, p. 239, non Pursli) ${ }_{3}$ caule glabro, ochreis longis angustis aduresse pilosiusculis setis mediocribus dense ciliatis, foliis lineari-lanceolatís utringue attenuatis adpresse pilosiusculis vel demum excepto margine nervoque glabratis, spicis geminis yel subracemosis linearibus vel subfiliformibus laxiusculis basi interruptis, bracteis subimbricatis breviciliatis, calyce eglanduloso, staminibus 8 stylaque inclusis, achinnia lævissimo nitido faciebus late avatis. $\odot$ In humidis fossisque Americæ bor. a Canadâ agd flóridam (Rugel! n. 85), Texas (Drumm. n. 140 I), Missouri (Engelm. 1), Mexico, Surinam (Wüllschlœgel, n. 448! in herh. Mart.), Brasil. merid. (Sellow l), Ghili (Bridges ! n. 356, ex parte), Novâ-Hollandiâ (Thieb. !). - Bigelow 11. Bost. 1, p. 156. P. mite Pers. Ench. 1, p. 440, Meisn. monogt. p. 75, et in Mart. fl. Bras. fase. 14, Polyg. p. 17 (non Schrank). P. australe Thieb. ! in Pers. Ench. 1, p. 440 (ide herb. DC.) P. punctatum Schweinitz! mss. (non Ell.) et I'. Persoonii Engelm.l mss. in herb. Le deb. Admodum accedit ad P. minus Ait., sed præter flores constanter 8-andros hemitrigynos dilfert caule firmiore, ochrearum ciliis longioribus, foliis puberulis basi haud contractis, pedicellis longioribus, etc. (v. s.)

$\beta$. virgatum, ochrearum bractearumque ciliis longioribus (illis 3.4 lin., his 1-2 lin. longis), foliis utrinque dintịus pubescentibus. In Louisianà (Short!), Floridà ocientali (Mitchell! in herb. DG., Rugel, n. 297 ! 298 !), Mexica (Berland. n. 334 ! Mart. el Galeotti, 11. 457, 458, 460), Brasiliâ (Sellow ! Gardner, n. 5991), Chili (Gham.I d'Urville!). P. virgatum Clram. et Schlecht. I in Linnnæâ 3, p. 45*, Remy in Gay hist. de Chile, j. 268. Forma P. persicarioide et setaceo valde similis, sed ab illo discrepans ciliis longioribus, spicis tenuiopịbus et achronio, etc.; ab hoc spicis tenuioribus, ochrearụm setis brevioribus, foliorum pilis tenerioribus nec setiformibus. (y. s.)

80. P. SETACEUM (Baldw. in Ell. sketch, 1, p. 455), caule glabro, ochreis adpresse pilosis setis rigidis longis dense piliatis, folis lanceolatis longe attenuatis basi breviter angustatis adpresse strigillosis demum excepto margine nervoque glabrescentibus, spicis geminatis anguste linearibus continuis laxiusculis, pedunculis apice adpresse strigillosis, bracteis contiguis longiuseule setoso-ciliatis plurifloris, pedicellis exsertis, calyce eglanduloso, staminibus 8 styloque inclusis, achænio lævi nitido obtusangulo. $\odot$ In Georgiâ (Balḍw.), Loụisiąpậ (Drummond !).-Meisn. mon. p. 79. Prsecedenti valde affine. (v. s.)

81. P. Jucundu (Meisn. mon. p. 71 *), glabrum, caule gracili, ochreis brevibus laxiusculis setis tenuibus longiuscule ciliatis, folitis oblongo-lanceolatis utrinque attenuatis margine scabriusculis, spicis paucis oblongis .cylindrieis continuis densifloris, hracteis imbricațis ciliplatis, pedicellis longiusculle exsertịs, calyce eglanduloso, staminibus 8 stylaque subexsertis, achænio obtusangulo faciebus ovatis lævibus nitidíssimis. $\odot$ ? In Chinâ (Staunton I). P. barbatum Thunb.? Jap. p. 165, Houttuyn Pfl. syst. 6, p, 446, t. 49, f. 2 ? Ab affinibus (proxime præceden[: tịbus et P. minori, persicarioide, etc.) jam spicarụm formâ facile distinguitur (v. s.) 
82. P. STAGNINUM (Hamilt.! mss.), caule glabro, ochreis longis dense pilosis longe setaceo-ciliatis, foliis oblongo-lanceolatis utrinque aticnuatis dense adpresso-villosis, junioribus sericeis, spicis geminatis, rel subpaniculatis oblongis densifloris, Jracteis imbricatis longe ciliatis pedicellos superantibus pedunculisque adpresse jilosis, calyce subeglanduloso extus pubescente, stam. 8 -styloque subexserlis, ảchenio lævi. $\mathcal{H}$ In Bengaliâ (Wall.! lisı n. 1709 , A. ex parte, et G. !). - Meisn. in Wall. pl. As. rar. 3, p. 56. Afline P. Bischira et consperso, sed pube ciliisque brevioribus, foliis eglandulosis, etc., bene distinctum. (v. s.)

83. P. RIVULARE (Roth nov. pl. sp. p. 206), ochreis laxis adpressis strigosis rigide longeque setoso-ciliatis, fðliis oblongo-lanceolatis margine " setoso-scariosis et setis adpressis ciliatis ", spicis oblongis, floribus 6 -andris hemitrigynis... In Indiâ orientali.-Meisn. mon. p. 69 , Roxb.? cat. h. Beng. p. 29 ; fl. ind. ed. 1832, p. 290 (cfr. F. Hornemanni). Planta obscura, forsan à P. barbato haud distincta, ap. Mert. et Koch Deutschl. Flora 3, p. 55, synonymis P. Persicaria adscripta.

84. P. в а в в а т и (Linn. sp. 1, p. 518 , non Walt. nec? Thunb.), caule firmo glabro, ochreis pilosis longe setoso-ciliatis, foliis elongato-lanceolatis utrinque attenuatis margine nervoque strigilloso-scabriusculis, spicis geminatis vel racemo-paniculatis linearibus densifloris, bracteis imbricatis brevibus dense setuloso-ciliatis pedicellos 1-2 subsuperantibus, calyce eglanduloso, staminibus 5-8 inclusis, stylo demum exserto, achænio lævi nitido. $\mathscr{\psi}$ In humidis Indiæ orient. totius, Ghinæ, Japonia?-Roxb. fl. ind. ed. 1832, 2, p. 289, Neisn. mon. p. 80 (excl. syn. plur.), ot in Wall. pl. As. rar: 3, j. 56, Hook. et Arn. Bot. Beech. p. 208 et 2rig, Wight ic. t. 1798, Babingt. in Lihn. Trans. 18, p. 100, Blume? Bijdr. p. 533. Variat caule gracili sæpius crasso nodoso nec non basi radicante, ochreis 6-10 lin. longis sæpe internodia dequantibus, setis 3-8 lin. longis validis vel tenuioribus, foliis 2-3 poll. longis, $\frac{1}{2}-1$ poll. latis, acutis vel rarius obtusis. (v.s.)

a. vulgare (Meisn. ap. Wall. 1.ac.), foliis utrinque pube brevissimâ scabriusculis vel supra glabrescentibus, nervo subtus ochreiscjue adpresse pilosis vel' substrigosis. In Indiâ or. (Wallich! list n. 1708, C. D. G. et 1709, E. G., Strachey et Winderbottom herb. Himal. n. 20 !), Java (Zollinger, n. 96 !), ins. Philipp. (Cuming, n. 642 !), Ceylan (Thwaites, n. 3000), Abyssinià (Schimp. n. 1993 !).

3. hirtellum (Meisn. 1. c.), foliis utrinque pube densiore brevi adpresså pilosiusculis, pedunculis adpresse strigillosis. (Wall. n. 1708, E.! I!)

$\gamma$. glabratum (Meisn. 1. c.), foliis glabris rix margine scabriusculis, bracteis obsolete ciliatis cum peduneulis ochreisque glaberrimis. (Wall. n. 1708, B. et ex parte A.)

85. P. Ham rL t ONir (Spreng. syst. cur. post. p. 155), caule firmo cum ochreis pedunculisque dense adpresso-hirsuto, ochreis langis laxilusculis dense longeque setosociliatis, foliis lanceolatis utrinque attenuatis supra dense scabriusculis subtus molliter puberulis, spicis ramoso-paniculatis anguste cylindricis continuis strictis densifloris, bracteis imbricatis obtusis, pedicellis demum breviter exsertís, calyco eglanduloso, stam. 8 inclusis, stylo demum exserto, achrenio obtusangulo lævi nitido. $\mathcal{Y}$ ! In Nepaliê (Hamilt.), circa Julalabad (Griffith ${ }_{r}$.n. 1711 1), Kamaou (Strach. et Winterbott.. n. 19 !), P. hispidum Hamilt. in Don prodr. fl. Nep. p. 71 (non H. B. K.). P. Babingtonii Endl.gen. suppl. 4, 2, p. 47. Bractea breves, obtusæ, pilosiusculæ, dense ciliolatæe vel subimberbes: Cætera fere omnia P. barbati, cujus forsan mera varietas pubescentiá densiore magisque scabrà recedcns. (v. s. in herb. Griff. et linn. soc. Lond.)

86. P. РACIIX тA CHY Uи (Rafin. fl. Ludov, p. 29), caulibus ramosis, folis petiolatis lanceolatis scabriusculis, spicis densis abbreviatis, staminibus 8 stylos 3 superantibus. In Louisianâ. Spicæe circ. $1 \frac{1}{2}$ poll. longæe, flor. albis. Species obscura:

\section{Series II. Spica filiformes vel anguste lineares laxiuscula vel interruptce (raro crassiuscula vel striclae) (cfr. sp. 89, 91, 92, 97).}

* Glandula in calyce bracteis pedunculisque nullo (rarius pauca obsolete, in calyce nonnisi luce transparente visibiles (cfr. 88, 89, 92).

87. P. DECIPIENS (R. Br. prodr. f1. N.-Holl. p. 420), caule erecto, ochreis ciliatis, foliis lanceolatis acuminatis margine lævibus ramisque glabris, spicis subfiliformibus, 
bracteis nudis, floribus eglandulosis glaloris 6 -andris hemitrigynis. Circa PortJackson. - Meisn. mon. p. 74. Species obscura.

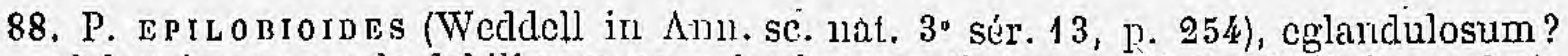
glaberrimum, caulc debili ramoso, welnreis angustis longe ciliatis, foliis lanceolatis acuminatis in petiolum Jreven attenuatis, spicis 2-3 filifurmilus laxissimis. bracteis 2-7-floris, staminijus 6, achacnio triquetro... In Brasilia: pror. MattoGrosso. - Meisn. in Mlart. 1l. bras. fasc. 14, Polyg. p. 18. Species insufficienter descripta, forsan a P. acri liadd distincta.

89. ? P. Paraguayense (Wedd. 1. c. p. 253), caule erecto crasso simplici hirsuto, ochreis magnis laxis dense pilosis cilialis, foliis lanceolatis vel ovato-lanceolatis acuminatis basi abrupte attenuatis utrincuo pubescentibus, costâ jotiolouue hirsutis, spicis subternis erectis subcylindricis exilibus, bracteis setoso-pilosis 2-3-floris pedicellos subsquantibus, slaminibus 5 subexsertis, achænio nitidissimo, facicbus rotundato-ovatis acuminatis concavis. $\odot$ ? In Brasilia prov. Matto-Grosso, ad 11. Paraguay. - Meisn. in Mart. fl. bras. fasc. 14, Polyg. p. 15. Pedale, ochreis superioribus internodia æequantibus, foliis palmaribus, pedicellis incequalibus, uno bracteam superante, floribus albidis.

90. P. PU BESCENS (Blume bijdr. p. 532), caule adscendente, ochreis internodia subpquantibus strigosis setaceo-ciliatis, foliis lanccolatis acuminatis basi attenuatis supra scabris subtus villosis, spicis solitariis filiformibus, floribus 8-andris hemitrigynis. $\mathcal{Y}$ In Javâ. - Meisn. mon. 1). 97.

$\beta$. Hasskarlii, foliis petiolatis oblongo-lanccolatis longe acurninatis in nervo strigosis supra glabris subtus minute pubcrulis subglaucis, spicis 6-8-pollicaribus, bracteis setoso-ciliatis. P. pubescens Hassk. pl. Jav. rar. p. $218^{*}$, an Blume?

91. P. FISSU M (Blume bijdr. p. 532), caule adscendente, ochreis internodia subæquantibus strigosis setaceo-ciliatis, foliis lineari-lanceolatis ciliolatis supra scabriusculis subtus pubescentibus, spicis filiformibus virgatis densifloris, floribus 8-andris hemitrigynis. $\mathscr{F}$ In Javâ.-Meisn. mon.p. 97, de Bruyn in pl. Junghulın. p. 306 * P. gramineum Nor. fide Hassk. in Tijdsclir. voor Nat. en Phys. 8, p. 18. An a P. barbato satis distinctum ? Bractes truncatæ, ciliatæ; achænium fuscum, nitidum, faciebus ovatis apice subsulcato-jmpressis, ex de Bruyn l.c.

ß. latifolium (Hassk. pl. Jav. rar. p. $218 \%$ ), ochreis internodio brevioribus, foliis oblongo-lanceolatis, costâ strigosâ vel glabrê., spicis paniculatis demum crassis, bracteis brovibus ciliatis glabris.

\%. glabrescens (de Bruyn l. c.), foliis in nervis setosis, cæterum glabrescentibus.

92. P. Donir (Meisn. mon. p. 72, excl. syn. Don, nec Meisn. in Wall. pl. As. rar.), caule gracili glabro, ochreis angustis pilosiusculis setis validis ipsas æequantibus dense ciliatis supra basin foliigeris, foliis lanceolatis utrinque æequaliter attenuatis adpresse puberulis vel supra glabratis dense subpellucido-punctatis, spicis racemosis filiformibus continuis densifloris, bracteis contiguis angustis dense longeque setoso-ciliatis 1-2-floris pedicellos superantibus, calyce subeglanduloso, genitalibus inclusis. ()? In Nepaliâ (Wall.! 1821).-Wight ic. t. 1801? A sinjillimo P. Posumbu differt ochrearum setis longioribus fortioribusque (5-6 lin. longis), foliis angistioribus (vix ultra 6 lin. latis) utrinque æqualiter attenuatis, et precipue spicis continuis strictis. Bracteæ glabræ, eglandulosæ. Folia subtus tenuiter pubescentia, supra versus marginem parce minuleque scabriuscula. Rami pedunculique glabri. (v. s. in h. DC.).

93. P. L ONGISETUM (de Bruyn in pl. Junghuhn, p. 307 "), caule adscendente striato glabro, ramis strictis, ochreis arctis internodio brevioribus parce adpresso-setosis, oris ciliis vagina longioribus validis, foliis lanceolatis acuminatis breve petiolatis subtus punctis elevatis pellucidis dense conspersis margine venisque parce setosis, spicis geminatis filiformibus strictis basi interruptis, bracteis multifloris glabris longe rigideque ciliatis pedicellos stubæquantibus demum divaricatissimis, floribus..., achænio trigono nitido lævi, faciebus ovatis sulcato-excavalis. $\odot$ ? In monte Gedé Javie (Jungh.). Habitus P. mitis Schrank, spicæ P. minoris, ex auctore. An a P. Donii sat distinctum?

94. P. Posum вu (Hamilt. in Don prodr. fl. Nepal. p. 71, non Wall. list, n. 1722), caule adscendente gracili glabro vel cum ochreis longiuscule piloso-ciliatis infra 
medium foliigeris pilosiusculo, foliis lanceolatis acuminatis attenuato-petiolatis ciliolatis utrinque vel in solo margine venisque pilosiusculis vel supra glabris, spicis solitariis vel subracemosis interruptis laxis, bracteis contiguis angustis dense ciliatis subunifloris, pedicellis demum exsertis, calyce subeglanduloso, geniLalibus inclusis, achænio (ex Babingt.) opaco levi. $\odot$ ? In Nepaliâ et Avâ (Wall.), IIussooree (Royle), Kamaon (Strachey et Winterbottọm, ni. 17!), Javâ (Blume, Zolling. 1). - Meisn. mon. p. 73. P. Donii Meisn. in Wall. pl. As. rar. 3, p. 57 (nec ej. monogr.), Babingt. in Linn. Trans. 18, p.'103. Facies P. flaccidi, sed distinctum omnibus partibus obsolete glandulosis vel (lloribus præcipue) penitus eglandulosis, spicis latioribus semper debillimis, bracteis semper eiliatis demum plus minus remotis et uni-(raro 2-3) floris. Achænium maturum non vidi. (v. s.)

$\alpha$. tenerum (Meisn. in Wall. pl. As. rar. 3, p. 58, sub P. Donii), caule decumbente radicante flaccido eglanduloso glabro, ochreis breviljus (3-4 lin.), ciliis tenpioribus (2-3 lin, longis), foliis exceptis nervis glabriusculis molliter ciliatis, sjicis raris. P. Posumbu Meisn. mon. p. 73 (non Wall. list, n. 1722). P. gracile et Biscaticlium Hamilt.! mss. (Wall. list, fol. 215, n. 1723, B.! C.!).

B. firmum (Meisn. l. c.), caule firmiore adscendente vel erecto (sæpe ramosissimo) obscure glanduloso-punctato sæpe adpresse puberulo, ochreis denșịns piloșis, spicis subpaniculatis. (Wall. list, n. 1721, B.! et 1723, A.! G.!)

\%. macrophyllum (Meisn. 1. c.), caule erecto subsimplici, ochrearum ciliis fortioribus, foliis oblongo-lanceolatis pellucide punctatis glabriusculis, spicis racemosis minus interruptis (Wall. list, n. 1723, A.l). Ochrearum tụbus 4-6 lin:, ciliis 4-6 lin. longis. Folia subduplo majora quam in var. $\alpha$ et $\beta$ :

d. ? caspitosum, ochreis brevibus, foliis utrinque hirtis, florihus 7-8-andris. In Javâ. P. eæespilosum Blume Bijdr. p. 532? Meisn. mon. p. 98, Zollinger, pl. exsicc. n. 1959 ! ? P. procumbens de Bruyn (1) in pl. Jungh. p. 307. Habitus varietatis $\alpha$, sed folia utrinque pilis adpressis longiusculis jarce strigillosolirsuta.

เ. ? ovatum, foliis petiolatis ovatis acutis minute ciliolatis glabris basi cuneatoangustatis (Wall. list, n. 1719, in h. DC.). Folia circ. pollicaria vel breviora, 6-9 lin. lata, petiolo 6-8 lin. longo. Get. ut in var. $\alpha$. An n. sp.?

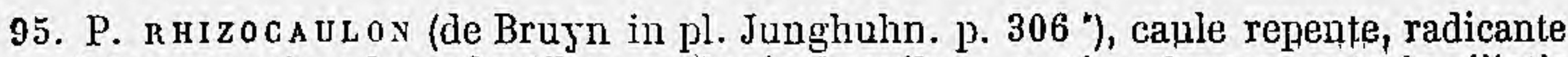
glabro, ramis adscendentibus, ochreis brevibus arctis adpresse setosis ciliatis supra basin foliigeris, foliis lanceolatis longe acuminatis breve petiolatis margine nervisque setulosis, spicis solitariis geminisve filiformibus interruptịs rectis, bracleis turbinatis oblique truncatis ciliatis, floribus 7-8-andris hemitrigynis, achænio trigono lævi nitido faciebus ellipticis. $\odot$ ? In sylvis montium Javæ (Jungh.). Caulis interdum 4-pedalis, ad spicas usque e nodis radicans (de Bruyn). Forsan mera var. P. Posumbu.

96. P. oR Y z т о RUM, caule adscendente, oclureis internodia subrecuantibus setaceociliatis, foliis lineari-lanceolatis subtus in renis supra ad marginem costamque strigosis, spicis axillaribus et terminalibus subsolitariis filiformibus pendulis, floribus 7-8-andris hemitrigynis. $\odot$ ? In oryzetis Javæ. P. oryzetum (sphalmate?) Blume Bijdr. p. 532, Meisn. mon. p. 97. P. spirale Nor. (fide Hassk. in Tidj. voor Nat. 8 p. 18), Forsan mera var. præcedentis aut P. flaccidi.

f. attenuatum (Blume 1. c.), caule procumbente, ochreis internodio triplo brevioribus.

97. P. о D O R а т U (Lour. Goch. 1, p. $299^{*}$ ), caule adscendente geniculato basi repente, ochreis ciliatis, foliis subsessilibus lanceolatis glabris, spicis terminalibus longis strictis, staminibus 8 inclusis, stylis 3 , achænio trigono utrinque acuminato. $\odot$ ? Colitur in Cochinchinâ. - Meisn. mon. p. 76. Planta valde obscura, pedalis, piperato-acris, condimentaria.

(1) "P. mrocumbens Bl. Bijdr. p. 532, " ut a cl. de Bruyn I. c. scribitur, apud Blume 1. c. non cxstat. Numen igitur lapsu calami ortum videtur sive pro P. pubescente, sive potius pro P.'crespitoso Blume l. c. 
* Calyces (scepius cum bracteis pedunculis ochreisque) glanduloso-punctati. Stamina 8 inclusa. Stylus 3-partitus vel semitrifidus. Herba erecta vel adscendentes, caule gracili glabro, foliis subsessilibus utrinque attenuatis plus minus pellucido-punctatis, bracteis 1-3 raro multifloris.

98. P. м А С R N т I U M, ochreis brevibus setuloso-pilosiusculis pervis in setas ralidas semipollicares excurrentibus; folís oblongo-lanccolatis longe acuminatis basi obtusis ciliatis parce adpresso-pilosiusculis vel supra glabrescontibus, pediccllis demum brevo exsertis, calyce magno minute punctato, stylo demum exserto, achænio olstusangulo faciebus late ovatis levijus nitidissimis. $\odot$ ? In paludosis jugi Klnasyani, lnd. or. (Wall.! Griff.!). Caulis erectus, patulo-ramosus. Ochrex 5-7 lin. longe, demum laxiuscula, marginem versus glabrate el fortiter nervosæ, nervis in setas valídas 5-7 lin. longas productis. Folia prope basin ochrece inserta, brevissime petiolata, 5-7 poll. longa, 10-18 lin. lata, caudató-acuminata, basi angustato-oljtusa. Spica terminales solitaria vel gemina, filiformes, continuse, 2-3 pull. longe, strictiusculo, bracteis subimbricatís turbinatis oblique truncatis subenerviis glabris inferioribus setis $\frac{1}{2}-3 \mathrm{lin}$. longis cilialis superioribus nudis 1-3-floris, pedicollis demum breviter exsertis. Calyx pro genere magnus, 2-2 $\frac{1}{2}$ lin. longus, 5-partitus, fructifer clausus ovatus. Stamina 8, caljee fere dimidio breviora. Stylus semitrifidus. Achomium nigrum, calyce brevius, faciebus subplanis. $\mathrm{Ab}$ aflinibus $\mathrm{P}$. acri, flaccirlo et Donii jam floribus duplo majoribus, etc., discrepat. (v. s. comm. a cel. Wallich.)

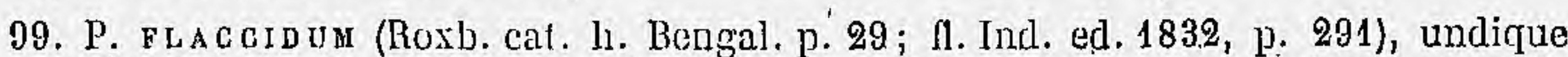
glandulis fuscis sessilibus pellucidis plus minus conspersum, ochreis angustis setaceo-ciliatis, foliis lanceolatis acuminatis ciliolatis utrincue glabris vel in nervo pilosiusculis, spicis $1-3$ erectis basi interruptis, lpactcis subcontiguis angustis horizontaliter truncatis ciliatis, pedicellis demum exsertis, genitalibus inclusis, achsenio grauulato striato subnitido. 24 ? In humidis Indirs orientalis totius, Cabul (Grifl.! Journ. 912), ins. Marian. (Gaudich.!), Jovà-Hollandià trop. (Milchell l). P. acre Meisu, in Wall. $\mu l$. As. rar. 3 , p. 57 (excl. syn. H. B. IK), Mitch. exped. trop. austr. P. 148 ? P. Hydropiper Lour. Coch. 1, 1. 295 ? (non Linn.). P. glabrum Roxb.? Don Nepal. p. 71 (non Willd.). A I'. acri H. B. K., qnocum olim conjunximus, unico charactere, serl constanter, differt, achæmio scil. egregie, quamvis minute, granulato-striato et minus nitido, granulatione simili ac $\mathrm{P}$. Hydropiperis, sed tenuiore. Cieterum, seque ac illud, satis variabile. (v. s.)

u. vchreis foliorumque nerro pilosiusculis, ciliis 1-2 lin. longis, bracteis ciliatis vel summis subimlerbibus. Ad Cabul, Julalabad, Khasya, ete. (Griff. n. 117 l), Kamaon (Strachey et WVinterbottom, n. 161). P. rivulare Helfer, pl. exsicc. 17. 35 !

$\beta$. ochreis foliorumque nervo glabris, cilis 1-2 lin. longis. $P$. mite Wall. list, n. 1721/1, 3. ex parte, et F.! H. ! P. flaccidum Hamilt.! mss. P. tonellum Roxb. ex Wall.! in h. Puerari, nune DG.

$\gamma$. oclireis foliorumque nervo vel etiam venis pilosiusculis, ciliis $3-4$ lin. longis, bracteis angustis vix contiguis longiuscule ciliatis. (Wall. n. 1721/3, ex parte).

100. P. HoRXEmAXXI, undique glanduloso-puncticulatum, ochreis glabriusculis modice (eiliis 1-2 lin. longis) piloso-ciliatis infra medium loliigeris, foliis lanceolatis utrinque attenuatis glabris obsolete ciliolatis, spicis geminis vel racemosis elongato-filiformibus basi interruptis, bracteis anguste turbinatis 3-6-floris subimberbibụs, pedicellis longe exsertis calyce basi valde attenuato longioribus, achænio nitido obsolete puncticulato apice exserto. $\odot$ ? Circa Calcuttam, fide Hornem. P. rivulare Konig. Hornem.! (non? Roth, cujus descr. saltem non convenit, cli. supra, n. 83). Exceptà inflorescentià et achanio, omnia P. laccidi. (v. s. in h. Ledeb. et liunth.)

101. P. A C RE (H. B.. K. nov, gen. 2, p. 179, uan Lam.), ubicue glandulis fuscis sessilibus pellucidis puncticulatum, caule adscendente gracili glabro, ochreis tenuiter venoso-striatis glabriusculis setis tenuibus mediocribus ciliatis supra basin foliigeris, foliis lanceolatis acuminatis ciliolatis nervo subtus seal,riusculis vel glabris, spicis 1-3 erectis filiformibus basi interruptis, bracteis turbinatis truncatis brcyiciliatis vel imberbibus 1-4-floris, pedicellis demum exsertis, genitalibus inclusis, achenio nitido obsolete punctieulato. $\mathcal{H}$ ? In humidis fossisque Americæ 
fere totius, a Pensylvanià et Missouri ad Floridam, Mexico (Berland. n. 344! Mart. et Galeotti, etc.), Californiâ et Guayaquil (Beechey, Chamisso!, Voy. Sulphur), Quito (Jameson, n. 493!), Chili (Pơpp. n. 125, Meyen!), Buenos-Ayres (Bacle, n. 25!), Brasilia (Polıl! Sollow, Mart. herb. fl. bras. n. 249! Blanchet, n. 297! 638 ! 1020 ! Gardner, n. 599 ! etc.), Surinam (Wullschlægel, n. 447! etc.), Columbiâ Vargas, 1. 51 !), ins. Antill. (Bertero! Badier! etc.). - Meisn. monogr. p. 77, Cham, et. Schl. in Linnæâ 3, p. 45, Nees et Schauer ilj. 19, p. 710 ? P. liydropiperoides Pursh 11. Am. sept. 1, p. 270 (non Michx.). P. Hydropiper Miehx. fl: bor Am. 1, p. 238, Bigel. fl. Bost. 1, p. 155 (non Linn.). P. punctatum Ell. sketch. 1, p. 455*, Torrcy 11 . North and Middle etc., 1, p. 402. Planta valde variabilis staturâ, caule ramoso vel subsimplici gracili laxo vel strictiore, foliorum magnitudine et præcipue inflorescentiâ et ochrearum bractearumque ciliis. Sequentes formæ (potius quam varietates stabiles) præcipue distinguendæe. (v. s.)

$\alpha$. confertiforum, spicis linearibus (1-2 poll. longis) confertifloris, bracteis 3-5-floris angustis horizontaliter truncatis brevissime ciliatis, ochrearum ciliis 1-2 lin. longis, achænio sæpe lenticulari. In Pennsylvaniâ (Moser! in herb. Un. itin. 1832, sub nom. P. mitis Pers.), Missouri (Drumm. n. 3! Engelm.!), Aspalagâ, Floridâ (Ruge)), Mexico (Schiede, n. 88 !).

3. leptostachyum, spicis gracillimis (3-5-poll.) magis interruptis, bracteis 1-3-floris vix summis contigais angustis horizontaliter truncatis, varie ciliatis (ciliis 1-3 lin. longis) vel imberbibus, ochrearum ciliis 1-2 lin. longis. In Amer. bor. (Riehl, n, 311 ! Rugel, pl. Florid. «. 198 !). et australi, præcipue tropicâ. P. acre $\alpha$ aquatile Mart. fl. bras. fasc. 14, Polyg. p. 18, t. 5, fig. 1. P. antihæcmorrhoidale Mart.! Reise 2, p. 550, Linniea, 1830, Litt. p. 41. P. distachyum et P. gracilescens Mart. 1 mss.

\%. brachystachyum, foliis summis approximatis parvis, spicis paucifloris pedunculisque brevibus ( $\frac{1}{2}-1$-poll. longis!. Cæt. omnia ut in $\alpha$ et $\beta$, sed facies satis aliena. Ad Aspalaga, Floridie (Rugel!).

\&. majus, ochreis imberbibus vel rarius parce ciliolatis, foliis petiolatis sueto majoribus (4-5 poll. longis, 10-14 lin. latis), spicis subsolitariis basi tantum semel interruptis, bracteis contiguis solito majoribus ( 2 lin. longis, 1 lin. latis) nudis vel infimis obsolete ciliolatis subbifloris pedicellos subæquantibus. Ad fl. S. Marks, Floridxe (Rugel, n. 615!). Forsan n. sp., sed specim. nostra nimis juvenilia. Glaberrima, caule subsimplici sueto fortiore inferne nodoso et radicante.

-. riparium (Mart. fl. bras. fasc. 14, Polyg. p. 18, t. 5, f. 2), spicis solitariis vel geminatis elongatis laxissimis pluries interruptis, bracteis remotis brevibus oblique truncatis imberbibus. $\%$ In inundatis prov. Bahiensis, Brasil. (Mart.!), Venezuelà ? (0tto, n. 796, in herb. reg. Berol. sp. jun.). P. riparium Mart. I mss. in herls. Ac. Monac. P. maritimum Fl. flum. 4, t. 39? (non Linn.). Forsan dis. tincta sp. Exceptâ inflorescentiâ omnia fere P. acris, sed bracteæ demum valde diversæ, latiores ct magis patulæ, potius cucullato-ovatæ quam turbinata, formâ et magnitudine illis P. spectabilis et densiflori similes.

\section{Subsectio II. DIgYNA.}

Styli 2 (rarius passim 3, c.fr. P. Hydropiper, mite, serrulatum, minus, lanigerum, persicarioides). Achæenium compressum vel biconvexum, lenticulare, raro passim trigonum. Stamina 4-8, sæpissime 5-7.

Series I. Spica filiformes vel anguste lineares, scepius elongata vel laxiflorce vel interruptce, bracteis nonnisi junioribus subimbricatis demum contiguis vel plus minus distantibus, 3-1-raro multifloris.

\section{\$1. Pedunculi cum bracteis vel saltem calyces glanduloso-punctati. Styli 2 vel rarius 3 , plus minus connati.}

102. P. LEPTOSTACHYU (De Bruyn in Pl. Junghuhn p. $307^{*}$ ), caule adscendente glabro, ochreis laxis internodis 2-3-plo brevioribus glandulosis ciliatis ad nervos setosis infra medium foligeris, foliis petiolatis oblongo-lanceolatis longe acuminatis basi attenuatis glandulosisque supra ad renas strigosis subtus adpresse pilosis, spicis solitariis geminisve filiformibus Iongissimis interruptis pendulis (basi 
genuflexis) loracteis remotis elongato-infundibuliformilus glandulosis submuticis sulstrifloris, pedicellis longe exsertis, calyce glanduloso, floribus 8-andris hemidigynis, aclituio.... $\%$ ? In montibus Javac (Jungl). Sujeir 9-pollicares, bracter: inferiores 1-2 poll. distantes (De Br.). Flores pauci tantum ab auctore observati, forsan liaud constanter cligyni et tune planta potius $\mathrm{P}$. flaccido approximanda, nisi forte ipsius var.

103. P. H Y D O P P R R (Linn. sp. 1, p. 517, non Mich.), ochreis brevibus breve pilosociliatis, foliis lanccolatis utrinque attenuatis ciliolatis glabris vel in nervo scabriusculis, spicâ gracili nutaute interruptâ inferne foliosâ, bracteis subimberbibus, pedicellis exsertis, calyce 4- (rarius 3- vel 5-) partito dense glanduloso-junctato fructifero majusculo ovato-elliptico, staminibus 6 (raro 8) styloque semi-2-3-fido inclusis, achornio ovato hinc parum inde valde convexo (rarius obtuse trigono granulato-striato opaco. $\odot$ ln fossis et inundatis Europæe totius, et passim in Amer. bor. - Blackwell Herb. t. 119, Sclikuhr Handlb. t. 108, Engl. Bot. t: 989, Hayne Abb. 5, t. 20, Fl. Dan. t. 1376, Reichenb. ic. crit. 5, t. 494, Meisn. Mon. p. 76 (excl. syn. plur.), t. 3, M., Mert. et Koch D. Fl. 3, p. 57, Hook. Fl. Bor. Am. 2, j. 132, Ledeb. Fl. Ross. 3, p. 523. P. acre Lan. FI. Fr. 3, p. 234 (non herb.). P. glandulosum Poir.I dict. 6, p. 149 (non R. Br.) Variat prister formas sequentes, caule decumbente, adscendente et erecto, sæe cum oclireis glandulis consperso, spicis. plus minus laxis, nunc fere filiformibus paucifloris, stylo sæpe demum exserto, achænio minus fortiter granulato, Folia semper minute-glanduloso-punctata siepe quasi perforata, punctis decoloribus vel fuscis, tenuioribus quam P. acris. Totius plantæe sapor acris, urens.

$\alpha$. vulgare, caule crecto vel adscendente, ochrearum ciliis remotiusculis $\frac{1}{2}-1$ raro 2 lin. longis, foliis lanceolatis oblusiusculis vel rarius acutis ( $1-4$ poll. longis, 4-10 lin. latis) medio sæpe maculà nigrâ notatis, spicis solitariis vel subra-

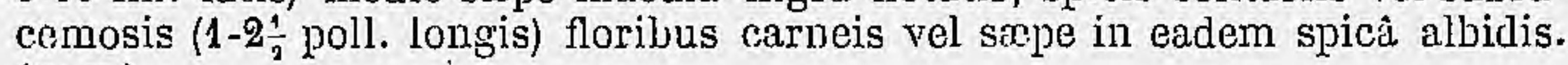
(v. v.)

B. angustifolium (Alex. Braun ! in Flora 1824, p. 356), pusillum, caule depresso, loliis lineari-lance olatis parvis (pollicariljus vel brevioribus), spicis paucifloris. (r. s.)

$\gamma$. obtusifolium (1. Braun! 1. c.) caule humili ramoso basi repente, foliis parvis (subpollicaribus) oblongis ovalibus vel subcuneiformibus obtusis, axillis omnibus floriferis spica terminali brevi pauciftorà. (v. s.)

10k. P. GRAGILE (R. Br. Prodr. Fl. Nov. Holl. p. 419, non Nult.), caule erecto, foliis lanceolatis acuminatis glabris pelluctdo-punetatis margine scabris, spicà filiformi nutante rara, bracteis 1-2-lloris ochreisque ciliatis, floribus 4 - andris hemidigynis glandulosis. $\bigcirc$ ? Circa Port Jaekson (Br.) et Adelaide (Behr).-Meisn. Mon. p. 73, Schlecht. in Linuiea 20, p. 576. P. graeile A. Cunningham! mss. Ford. Mítller ! P. acre Nitchell Exped. Trop. Austr. p. 148 ? Varial staminibus 5 et 6. Ochreæ 8-10 lin. longe, glanduloso-punctate, glabriusculæ, ciliis vix $1 \frac{1}{2}$ lin., in planta Behrii fero 3 lin. longis. Spica filiformes, debiles, interrupte, bracteis sepe imberbibus. Galyx 4-partitus, lobis rotundatis subenerviis pellucido-punctatis, vel 2 interioribus eglandulosis. Genitalia inclusa. Stylus bipartitus. Achænium lentículare, suborbiculare, acuminatum, minute puncticulatum. (v. s. comm. a. cl. Hervard et Sonder.)

\section{§ 2. Pedunculi cum bracteis floribusque eglandulosi (raro obsolete glandulosi, cfr. n.107 et 112). Styli 2 vel rarius 3 , plus minus connati.}

105. ? P. A вyssinicum (A. Rich. Tent. Fl. Abyss. 2, p. $225 \%$, caule repente seminatante, ramis emersis erectis glabris, ochreis subpollicaribus internodio multo brevioribus setoso-ciliatis sericeis, foliis sessilibus anguste lanceolatis acutis sulbglaucis subtus punctatis in nervis hirtellis margine ciliatis; spicis subpaniculatis gracilibus, bracteis remotiusculis cucullatis setoso-ciliatis 2-floris pedicellos iequantibus, staminibus 5 inclusis, stylo profunde bipartito, achænio tumido apiculato nitido. $\mathscr{Y}$ ? In aquis Abjssinix prope $\Lambda$ doam, ubi Lequareba vocatur. Walpers Ann. 3, p. 283. Calyx pallide roseus, glaber, lobis 5 ovalibus obtusissimis. - Aflinitas, ut etiam sequentis, nobis omnino dubia. 
106. ? P. S E T OS UUM (A. Rich. 1. c. p. $227^{\star}$ ), caule erecto, ochreis internodia subæquantibus longe adpresso-hirsutis setoso-ciliatis, foliis breve petiolatis oralioblongis longe acuminatis basi angustatis setusu-ciliatis pilis setosis subtus longiusculis supra brevibus raris rel subnullis conspersis, spicis subpaniculatis......, bracteis cucullatis obtusissimis brere setoso-ciliatis 2-3-floris, staminibus......, stylo bipartito longo, achænio turgido lævi nitido. $\psi$ ? Ad rivulos prov. Chire Abyssinixc. - Walp. Ann. 3, p. 283: Folia superne siepius glabriuscula, subtus ad nervos præcipue pilosa. Sepala oblonga, obtusiuscula. - An potius P. nodoso approximandum?

107. P. M I t (Schrank Bair. Flora 1, p. 668. - non Pers.), ochreis adpresse pilosiusculis setulis tenuibus bteviter ciliatis prope basin foliigeris, foliis subsessilibus lanceolatis utrinque subæqualiter attenuatis glabris riervo margineque pilosiusculis, spicis subsolitariis gracilibus nutantibus interruptis laxifloris, bracteis remotiusculis breve turbinatis ciliolatis, pedicellis demum exsertis, calyce 5-partito, staminibus 6-8 styloque 2-3-partito iuclusis, achenio ovato hinc plano indo gibbo-convexo vel obtuse trigono subnitido obsolete puncticulato. $\odot$. In humidis et fossis passim per totam Europam, in Rossiâ mediâ et prov. Cancasicis. - Engl. Bot. suppl. t. 2867, Ledeb. fl. Ross. 3, p. 522, Fries herb. norm. fasc. 4 ! et 7 ? P. hybridum Chaubard! in St. $\Lambda$ mans fl. Aginens. p. 163. P. Hydropjperi-Fersicaria Meisn. mon : p. 94. P. dubium Stein. A. Braun! in Flora 1824, p. 357, Schiede de pl. hybr. p. 27. P. laxiflorum Weihe in Flora 1826, p. 746, Reichenb. fl. excurs. p. 571, Nert. et Koch D. Fl. 3, p. 55. P. Braunii Bluff et Fingerl. Comp. fl. Germ. 1, p. 509, Spenner fl. Frib. p. 3(18. P. minus Reichenb. ic. crit. 5, p. 57 (excl. syn. plerisque) t. 493 ? Planta forsan hybrida, medium tenens $P$. minus inter et Hydropiper ; a priore distincta staturâ elatiore magis erectâ, foliis inajoribus basique semper attenuatis, spicis nutantibus semper et plerumque pluries interruptis, bracteis angustioribus brevius ciliatis summis imberbibus, pedicellis longioribus, floribus majoribus nec uncuam 5-andris, achsenio duplo-majore minus uitido faciebus sub lente medio obsolete striato-puncticulatis ; a P. Hydropipere: gustu non acri, ochreis bracteisque longius ciliatis, achæniis minoribus minus opacis calycibusque eglandulosis vel rarius obsolete glandulosis. (v. v.)

108. P. S A L I C I F O L I U (Delile EgJpt. p. 12, non Brouss.), ochreis glabriusculis breve piloso-ciliatis supra basin foliigeris, foliis subsessilibus elongato-lanceolatis longe attenuatis basi contracto-angustatis ciliolatis glabris, spicis racemosis erectis continuis laxiusculis, bracteis contiguis turbinatis subimberbibus, pedicellis brevc exsertis, staminibus 6 styloque bipartito inclusis, achænio biconvexo ovato lievissimo nitido. $\odot$ ? In AEgypto (Del., Sieber !, Ehrenb. l etc.), Tanger (Salzm. !), Siciliâ (Splitgerber 1), Gréciâ (Zuccarini ! - Meisn. mon. p. 77, Boiss. Yoj. Esp. 2, p. 551, adnot. sub P. serrulato. P. pseudo-hydropiper Salzm.! pl. exs. Tanger. - Forsan sequentis var., recedeus foliis basi subito angustatis, ochrearum ciliis tenuioribus brevioribusque et jroccipue bractcis aut omnibus nudis aut rarissime passim obsolete ciliolatis et achænio nunquam (?) trigono: Folia usque ad 7 poll. longa, 5-7 lin. lata, acutissima, raro obtusa. (v. s.)

109. P. SERRULA T M (Lagasca ! nov. gen. et sp. 14, n. 181), ochreis pilosiusculis longe sctoso-ciliatis supra basin foliigeris, foliis brevissime petiolatis lanceolatis vel linearibus attenuato-elongatis basi vix angustatâ obtusis subcordatisve glabris margine nervoque scabriusculis, spicis subracemosis continuis laxiusculis, bracteis contiguis anguste turbinatis ciliolatis, podicellis longiuscule exsertis, staminibus 6-8 (raro 5) styloque 2-3-partito inclusis, achronio lowi nitidissimo hine plano inde convero vel strpius obtusangulo-trigono. $\odot$ ? In Europá australi, Hispanià (Lag.), Sicilià (Jan! Guss. 1), Toscanâ (Bertol.), Galloprovinciâ (A. DC.! Boiss.), Græciầ, Cretâ (Heldreich !) Georgiâ Caucasicà (Hohenack.!), Syriâ (Ehrenb.!) Mesopotamiâ (Noé n. 1000 !), As gjpto (Cocpuebert !), ins. Canar. (Brouss.! Clur. Smith!) Cap. B. Sp. (Ecklon n. 649 ! Burch. n. 383! Drège! Krauss n. 801 !), Muzambiquc (Peters! in herb. reg. Berol.), Abyssiniâ (Scluimper n. 182!), Javâ (Zolling. n. 893 !), Novâ Holl. (herb. DC. ! Preiss n. 1354!), Tovî Zeeland. (1. Cumn. n. 33 !), Surinam? (Focke). - Meisn. mon. p. 77 (cxcl. syn. Roxb.), Boiss. Vuy. Es11. 2. p. 551. P. barbatum Thunh. Jap. p. 385 ? non Linn. P. salicifolium Brouss. Willd. enum. p. 428 (non Lag.). P. scalirum Poir. dict. 6. p. 148 ? P. minus Ten, syll. 凡. Neap. p. 196 ? Meisn. in pl. Preiss. 1, 1). 623. P. strictum Meisn. in Linnæâ 14, p. 485, Chan. et Schl. ib. 3, p. 44 (quoad specim. Capens.). P. macrochroum Mic. in 
Linnxà 18, p. 242*? (non Fresen. cfr. P. acre). P. rubicundum Soland. mss. (fide herb. Cunningh.). P. ciliatum Ehrenb. I mss. P. prostratum Hook. fil. fl. N. Zealarid. p. 209 ? (non R. Br.). - Ab affinibus simillimisque P. minori, salicifolio et miti jam oclırearum cilliis multo lóngioribus et validioribus ( $\$-5$ lin. Iongis), a P. Hydropipere glatıdularum defectu ete. distinguitur. (v. s.)

B. Azoricum, ochrearum setis abbreviatis, $2-3$ lin. longis. - Ins. S. Xichael, Azor. - P. Azoricum Watson! in Hunt, jil. Azor. exsicc: 1. 233! - Flores in nonnullis specim. Uredine tumefacti et plus minus deformati. (v. s.)

110. P. MiNus (Huds. fl. Angl. 1, p: 148), caule procumbente vel erecto gracili glabro, ochreis pilosiusculis setis tenuibus longiusculis dense ciliatis prope basin foliigeris, foliis linearibus vel lanceolatis basi rotundatis vel rarius breve attenuatis glabris margine nervoque scabriusculis, spicis subracemosis erectis laxiusculis, bracteis breve turbinatis truncatis dense piloso-ciliatis- pedicellos superantibus, staminibus 5 (raro 8) styloque 2-3-partito inclusis, achrenio parvo biconvexo (raro trigono) nitidissimo lævi. $\odot$ In sterilibus siccis Europæe fere tolius, Caucasi, Sibiriæe, Indiæ orient. (Wall.! Wight ! Griff ! etc.), Javie (Blume), Chinæ (Staunt. !), Novie Hollandise (h. Mart. 1), Chili (Philippi! in h. Kunth.), ins. Cap. virid. (fide l3runner in Flora 1840, Beibl. 1, p. 8). Var. $\beta$ ubique rarior.- $\Lambda$ it. hort. Kew. ed. 2 , p. 418, Engl. Bot. t. 1043, A. Braun in Flora 1824, p. 356, Mert. et Koch D. Fl. 3, p. 58, Ludeb. fl. Ross. 3, p. 523. P. strietum All. fl. Pedem. n. 2051, t. 68, f. 2, Mísn. mon. p. 74 (excl. syn. Schrank) et in Wall. pl. As. rar. 3, p. 57. P. angustifolium Roth tent. fi. Germ. II, 1, p. 453 (non Poir). P. pitusillum Lam.! fl: Fr. 3, p. 235. DC. I1. Fr. 3, p. 366 (excl. syn. Schrank). P. intermedium Ehrh. Herb. 94. P. Persicaria $\beta$ Linn. sp. 1, N. 518.

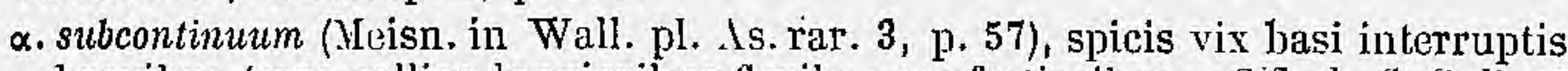
brevibus (raro pollice longioribus floribus confertioribıs.- Schulz fl. Gilll. et. Germ. exs. cent. 4, n. 34! P. Banka et Posumbu Hamilt. mss. Wall. list n. 1722 ! P. daplnnophyllum Andrz. (fide Besser ! in leerb, Acisn.). P. mite strictum Fries herb. norm. fasc. 11! P. hypostictum Mici. in Metz. pi. Nilagir. exs. n. 971 ! P. tenellum Blume Bijdr. p. 530 ? non? Roxb. (v. v.)

$\beta$ : interruptum (Meisn. 1. c.), spicis filiformibus laxioribus pluries interruptis, caule plerumque elatiore foliis latioribus. P. minus Fries licrls. norm. fasc. 4 ! P. scrrulatum Guss. mss. non Lag. (v. s.)

111. P. interruptum (Bunge ! en. pl. Chin. bor. p. 58, n. 323), glabrum, caule humili erecto simplici debili, ochreis brevibus hyalinis breviciliatis, foliis lantcolatis acutis attenuato-subpetiolatis ciliolatis, spicà solitarià brevi interruptit, Jracteis hyalinis turbinatis obtusis ciliolatis pedicellos 1-3 æquantibus, floribus 5 -fidis 5 ? -andris semidigynis. $\odot$ In Ghinâ. Herbula tenella digitalis vel palmaris. Forsan P. minoris forma depauperata. (v. s. in li. Ledeb., DG., Mart.)

112. P. C A R E Y (Olney, Rhode Island plants p. 29), caule erecto laxe hirsuto, ochreis breviciliatis, foliis lanceolatis utrinque attenuatis parce adpresso-pilosiusculis, spicis racemosis linearibus continuis, pedunculis pilis capitatis parce hispidulis, bracteis subimbricatis ciliatis, pedicellis exsertis, calyce minute pellucido-punctato, staminibus 5-8 styloque semibifido inclusis, achænio ovali lenticulari nitidissimo faciebus valde convexis lævibus. $\bigcirc$ ? In Amer. bor., Vermont, Rhode Island, Massachusetts, Now Hampshire.- -. Gray man. Bot. Nortlı Un. Stat.p. 386. Walp. Annal. 3, p. 920. Caulis ramosissimus, gracilis, 3-5-pedalis, glanduloso. sotosus; ochree mediecres, laxiusculæe, setoso-ciliatic; folia. obscure pellucidopunctata, margine nervoque setulosa; spica longe pedınculatie, elongatie, lutantes, dense; calyx 5-partitus; stamina 5 (fide A. Gray 6-8). Hirsutie, quamvis rariore, simile P. hirsuto Walt., sed achenio lenticulari etc. abforrens; a P. minori et affinibus vero jam hirsutie distinctum. (v. s. comm. a cl. Torrey),

113. P. Roet T ER (Roth nov. pl. sp. p. 205), caule erecto simplici gracili stricto, ochreis setaceo-ciliatis, foliis ovato-lanceolatis acuminatis pubescentibus, spicis filiformibus.raris, bracteis remotis 1 - floris, floribus 0 - andris " monogynis ", achænio compresso.... $\odot$ ? In Indià orient. (Heyne)- Neisn. mon. p. 80.-Species valde obscura.

114. P. A sSA I I U r, caule erecto glabro, ochreis brevibus angustis adpresse setulosis setis tenuibus longiusculis denise ciliatis infra medium foliigerı, foliis oblongo- 
lanceolatis utrinque attenuatis ciliolatis glabris nervo reniscrue subtus dense adpresso-pilosiusculis, spicis geminatis vel subracemosis filiformibus erectis strictis basi-interruptis, bracteis contiguis turbinatis oblique truncatis glabris dense setosociliatis vel summis subnudis 1-2-floris pedicellos aquantibus, calyce parvo eglanduloso, staminibus 5-6 styloque semibifido inclusis, achænio elliptico-lenticulari biconvexo nitidissimo làvi. $\odot$ ? In Assamià (Vallich !). - Simillimum P. Posumbu, sed flore minore, genitalium numero, achænio parvulo lenticulari bene distinctun. Caulis gracilis, simplex ? Ochrex arcte cylindrice, 5-6 lin. longæe, albida, tenuiter venosæ, ciliis 3 lin. longis. Folia 2-3-pollicaria, 8-12 lin. lata, brere petiolata, minute denseque pellucido-punctata, exsiccatione (more P. tinctorii) colore indigocyaneo tincta. Bractearum cilia fere 1 lin. longa. Galyx fructifer ovatus, vix 1 lin. longus. (v. s. comm. ab ill. Wallich.)

115. P. JAP ONI U M, caule erecto glabro, ochreis longis laxiusculis adpresse setulosis setis longiusculis rigidulis ciliatis basi foliigeris, foliis elongato-lanceolatis acuminatis margine nervoque setuloso-scabriusculis, spicis subracemosis filiformibus continuis laxiusculis, bracteis subcontiguis anguste lurbinatis ciliatis, pedicellis 1-2 demum exsertis, staminibus 7-8 styloque semi-2-3-fido subexsertis, ar hienio suborbiculari biconvexo (rarius trigono) lavi nitido. $\odot$ ? In Japoniâ (Zollinger pl. Jap. exsicc. n. 205 !). P. barbatum Thunb. fl. Jap. p. 165 ? (non alior.). Caulis subsimplex nodosus, satis validus. Ochrese pollicares, superiores internodia requantes, ciliis setaceis 3-4 lin. longis. Folia 4-6-pollicaria, 6-10 lin. lata attenuato-petiolata, subtus obsolete glanduloso-punctata. Spicse 1-3-pollicares, pedunculis bracteis calycibusque eglandulosis, pedicellis demum longiuscule exsertis. Calyx 5- partitus, fructifer ovatus vix 1 lin. longus subenervis. Stam. 7 vel rarius 8. Vilde accedit ad P. barbatum et Posumbu, sed acha'nio etc., satis distinctum. (v.s. in h. DC.)

\section{\$3. Pedunculi cum bracteis Roribusque eglandulosi. Styli 2 ad basin} usque liberi subulati rigiduli subparalleli, demum exserti deflexi. Achcenium acutangulo-lenticulare faciebus valde convexis lavibus nitidis. - Spicce axillares et terminales, longa, angustissima, interruptce, bracteis remotis 1-3-floribus turbinatis truncatis ciliolatis summis subnudis. Calyx 4-partitus. Stamina 5 inclusa, glandulis perigynis alterna.

116. P. Virginianum (Linn. sp. 1, p. 516), caule crecto ramoso stricto, juniore cum ochreis angustis breviciliatis foliisque adpresse pubescentibus, petiolis ochream subequantibus, foliis ovatis vel ovali-oblongis basi rotundatis vel breve attenuatis pedicellis demum exsertis, calyce nutante fructifero majusculo, achænii faciebus ellipticis. $\mathcal{Y}$. In Amer. bor. temperatà et calidiore. - Mich. fl. Bor. Am.1, p. 238, Pursh fl. Am. sept. 1, p. 270 , Neisn. mon. p. 81, t. I, f. 27-29, t. III, N. IIook. fl. Bor. Am. 2, p. 132. Torara, Adans. Fam. 2, p. 976. Polygonum muticum Nœnch suppl. p. 266. Persicaria Virginiana Gartn. fr. 2, p. 180, t. 119, f. 3. Antenoron racemosum Rafin. fl. Ludov. p. 28? (cui tribuuntur stamina 4 et ach:en. striatum) - reliqua bene congruunt. - Caules annui 2-4-pedales, spicis 6-12-poll. longis, planta culta demum constanter rigidis, spontaneæ debilibus. Flores albidi. (v. v. c. et. s. sp.)

117. P. FILIFORM E (Thunb. 11. Jap. p. $163^{\mathrm{k}}$ ), caule erecto ramoso, cum ochreis laxis dense piloso-ciliatis foliisçue adpresse pubescente, petiolis superioribus ochreâ brevioribus, foliis ovatis vel ovalibus subacuminatis, pedicellis subinclusis, calyce parro patente, achrenii faciebus late ovatis. $\mathcal{F}$ ? In Japonia. (Thunb., Zollinger jl. Japon. exs. n. 203 !)-Willd. sp. 2, p. 444, Meisu. mon. p. 75. Species habitu, foliis latis, inflorescentia (spicis 5-8 poll. longis tenuissinis) et achænio simillima P. Virginiano, sed distincta foliis constanter? minus acuminatis, jube rariore, bractearum ciliis brevioribus et precipue flore fructurfuc dimidio minoribus (v. s. in herb. DC.) 
Senies II. Spioce cylindrica, ouato, oblonga vel lineares (nec foliformes), continuce, densiflorce (rara laxiusculce vel interruptee, cf $r$. $s p .118$, $146,149,250)$.

\section{A. Ochrece tota-membranacece cylindraceo-tubulose, limbo truncato erécto (sp. 118-150).}

\$ 1. Stamina 5-8, (plerumque 6-7). Pedunculi eglandulosi, laves, glubri vel pubescentes (raro obsolete ǵlandulosi, cfr. P. nodosum).

- Ochreà setis rigidulis basi incrassatis (scil. nèrvis excurreñitibis, nec pilis debilibus)

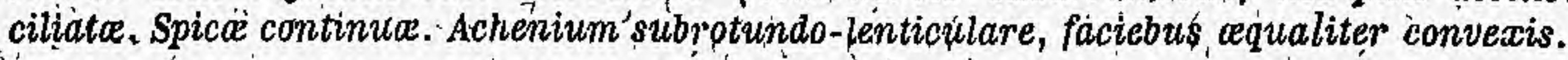

118. P. PoIR E r I I (Meisn. monogr. p. 79, excl. $\beta$ et cit. Rheede), cąulé erecto gtabro, ochreis longis laxiusculis parce adpresso-strigillosis breve setoso-ciliatis basi foliigeris, folíis attenuato-petiolatis elongato-lanceolatis acuminatis glabris margine nervoque rigide setulosis, spicis elongato-linearibus laxiusculis, bracteis turbinatis truncatis nudis, staminibus 6 styloque apice bifido inclusis. $\nvdash ?$ In Indiâ or. et Molaccis '(fide. Poir. sel verisim. ex errore), ìns: Mascärenh. (Commerson, Bory St. Vinc.! Sięber h. Maurit., n. 142 ! Telfuir! Bojer !) - Wall. list n. 1712 ! Meisn. in Wall. pl. As, rar. 3 ; p. 56. P. serratum Poir.l dict. 6 , p. 144 excl. $\beta$ (non Linn.). P. acre Sieber 1 l. c. (aun Ikuntl..). P. spinulosum Rojer! mss. in h. Ledeb. et Sonder. Ochreæ longæ, sæpe internodia superantes, ciliis $1 \frac{1}{2}-2 \frac{2}{2}$ lin. longis. Fodiá 6-8-pollicaria, medio vix pollicem lata, pellucido-punetata, margine egregie setulis pallidis antrorsum spinulosa. Spicæ racemosæ vel subsolitariæ, 2-3-pollicares, strictæ, bracteis subcontiguis 3-5-floris, pedicellis demtum exsertis. Calyx 5-partitus, pellucidu-punctatus, lruetifer clausus ovalis basi attenuatus $1 \frac{1}{2}$ lin. longus. Achenium breve ácuminaturn, liuve, nitichum, angulis obtasiusculis, faciebus modixe convexis: (v. s.)

119. P. MADAGASCARIENSE, calle apice cúm podunculis ochreis folisque adpresse puberulo, ochreis longis angustis breve denseque ciliatis prope basin foliigeris, foliis sessilibus elongato-Iineari-lanceolatis acuminatis basi obtusis margine tenuiter pilosiusculis nnędiơ demum gldbratis, spicis linearibus densifloris, bracteis subimbricatis oblique truncatis dense ciliatis, staminibus 7 inclusis; stylo blpartito exserto. $Z$ ? ln Madagascar. (Commerson, ex Poir.) P. surratum $\beta$ Poir. dict. 6; p. 144. P. I'viretii $\beta$ Meisn. mon. p. 79 . - Prsecedenti proxime quidem affine, sed nolis indicatis specitice distinctum. Folia haud pellucido-punctata. Achænium obtısangulum, longiuscule mucronatum, faciebus subconvexis.) (v. s. in h. DG.).

120. P. SUBSESSILE (R. Br. prodr. fl. Nov,-Holl. p. 419), ochreis pilosis strigosoeiliatis, foliis subsessilibus elongatto-lanceolațis utrinque pubescentibus scabriusculis basi obtusiusculis, spïicis cylindraceis pedunculatis, bracteis ciliatis, floribus 5-andris-hemidigynis glabris. $\bigcirc$ ? Circa Port-Jackson (R. Br., Lesson!), in Australiâ felici (Ferd. Müller !) et in ins. Diemen. (R. Br.). - Meisn. mon. p, 73. Species accédens ad P. hydropiperoidis Mich. $\beta$ virgatum, sed pricter genitalium numerum distincta ochreis longioribus, internodia juniora subæquantibus, spicis continuis, densioribus, bracteis brevioribus, oblique trupcatis, parce breviciliatis, superioribus nudis. Caulis juvior et pedunculí adpresse pilosiúsculi. Bractex pedicellos subrequantes. Calyx eglandulosus. Achænium subrotundo-lentículare, nitidissimum, leve; faciebus valde convexis. (v. s'.in h. Kunth. DG. Meisn.)

121. P. ADENOPHYLLUM (Cham. et Schl. I in Linneà 3, p. $48 \%$ ). caule apice cum pedunculis, bracteis ochreisque tenuiter strigoso, ochreis longis laxis longe setosociliatis infra medium folitgeris, foliis subsessilibus elongato-lanceolatis utrinque sparse strigillosis-subtus glanduloso-punctatis, spicis 1-3 elongatis cylindricis densifloris, bracteis turbinatis setose-ciliatis, staminibus 6-8 inclusis, stylo semibifido subexserto, achænio biconvexo lævi bitido. $\%$ ? Cap. Bonæ-Spei (Mundt et Maire 1), Mozambique (D' Peters !). P. barbatum Thunb, A. cap. p. 385 ? (non alibi, nec alior.). P. tomentosum Eckl. el Zeyh. pl. Cap. exs. n. 2. Præcedenti (saltem specim. Lesson) nimis affine. (v. s. in h., reg. Berolin.)

xIv. 


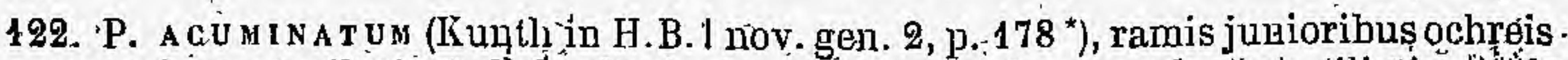
que adpresse pitosiusculis; ochreis angustis longe denseque setoso-ciliatís juốpe , basin foligeris, foliis lankeolatis acuminatis basi attenuatis pilosiusculis vel exépto margine nervoque glabris, spicis geninatis vel-rácemosig lineăribus dènsifloris, bracleis subimbiricatis ovatis obtusis glabris ciliatis vel subimberbibus, pedicellis demum exsertis, calyce 4-5-partito eglanduiloso; stylo semibifido exserto, achénio late elliptico biçonvexo nitido angulis acutiusculis. $\mathcal{F}$ In Colombiâ (Hưmb.), Guianâ anglicâ, gallicâ et batavâ, totâ Brasiliâ, Montevídeo; Peruviâ (Rựiz H et Africâ australi. - Meisn. mon. n. 78. (ex parte), et in Mart. fl. bras. fasc. 14, Polyg p. 14, t: 4, Cham. et Schl: in Linmeâ 3, j. 46 . P. cuspidatum Willd. herb: ex Spreng. syst. 2, p. 256 . P. eréctum Fl. flum. 4 , t. 42 ? Species polymorpha, toliónum magnitudine et formâ, pubescentia quantitate et indole, spicis densis vel laxiusculis nec nod florum frequeintỉa et mágnîtúdine mîre varians. Formà sequentes faicile 'pro tot speciebus haberi possunt, sed intermediĺs connexde vi⿱亠乂 vajietates stabiles sistere videntur. (v. s.)

a. Humboldtii (Meisn. in Fl. brasil. 14, a 14, t. 4, fig. 1), foliis subtus adpressopubescentibus, supra ramisque junioribus strigillosis $\left(6-8\right.$ poll.:longis, $1-1: \frac{1}{g}$ póll. Iatis), ochrearum setis subsemipolliearibus, spicis- $3-4-$ pollicaribus, bracteis glabris setoso-ciliatis sub-7-floris, staminibus 5-8 inclusis. P. acuminatum Kunth! ! , e. (v. s. in h. Willd. et Kunth.)

B. glábrescens, foliis elongatis supra vel rarius tringue (exeepto tamen margine nervuque) glabris vel minute scabriúsculis, caưle-glabro vel-finfra nodos pilosiusculo, ochrearum setis subsemipolivaribus, bracteis glabris, staminibuts 6 , caljcem subaquantibus, stylo semibifido.-Benth. $t$ in. Hook. Lond: Jotírn. 4, p. 624. P. graminifolium Hoflmannsegg! nss. in herb. Mart P. ciliatum Raiz! mss. in herb. Berolin. (Sehomburgh, n. 102! 370! Wullsehlægel; n. 449! Martios! etc:)

y. subcordatum, catle glabriusculo, folifs oblongis basì rotundato-subcordatis (4-5 poll. longis, 1-2 poll. latis) adpresse strígillosis, pube 'subtus densiore molliore, ochrearum setis debilibus 3-6 lin. longis, spicis densiftóris, bracteis pilosis setulis 1-2 lin. longis dense ciliatis, stam. 6 calycem subæquantihus, stylo semibifido.-Cham. et Schl. 1. c.-Brasil. merid. (Sellow! in h.,Berolin.)

¿? setigerim, caule glabro vel infra nodos pilosiusculo, ochreis fongíssime setosociliatis, foliis elongatis utrinque scabris, et-breve pllosis, bracteis sub-5-floris, calyce 4-rarius 5-partito, stam. 6 exsertis. Ad fl. Parąguay; prov: MattoGrosso. P. setigerum Wíd.dell in Anñ. se: nat. $3^{\circ}$ sér. 13, p. 253. Vix própria sp.

c. brachystemon, caule glabro, ochrearum setis 6-10 lin. longis, foliis elongatis utrinque minute scabriusculo-puberulis, junioribus subtus subsericeis, spicis 2-3 poll. longis laxiuseulis, bracteis glabris vix imbricatis, stam. 6 calyce dimidio brevioribus, stylo ultra medium bipartito. Ad Surinam (Hostmann, n. 473 !), Pernambưco (Gardn. n: 1123 !)

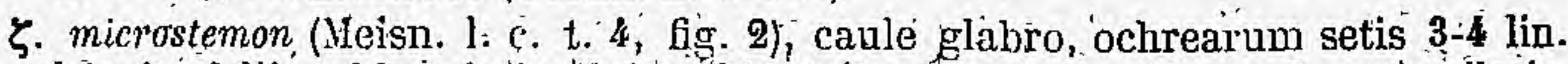
longis, foliis ablreviatis (3-4 poll.) utrinque subæqualiter adpresso-pilosis, spicis 1-3-pollicaribus densifloris, bracteis imbricatis pubescentibus 5-7-floris, calyce minore stámina 6 a chariium que dimidio superante, stylo ultra medium bipartito. İn Brasiliâ (Sellow! Mart.! n. 2324, 2344, in herb. Ac. Monac.)

n. ? Weddellii, caule glabro vel ad nodos piloso, ochreis longe seteso-ciliatis, foliis elongatis utrinquie pilosiusculis vel supra strigosis, junioribus subtus sericeis, bracteis 8-10-1joris pilosis longe ciliatis, stam. 6 exisertis. In Brasília merid. (Wedd., Sellow! Lund, n. 488 ! in herb. DC. P. floribundum Wedd. I. c. p. 253 (noi alior.). An cum $\zeta$ projsiam sp. sistens?

9. Capense, foliis basi obtusis excepto margine nervo veniscue glabritusculis (3-5 poll. longis, 6-9 lin: latis), spicis ramosis densifloris, bracteis imberbibus rel infinis obsolete ciliatis, stam: 7 calyce fere dinnidio brevioribus, stylo semibifido. In distr. Uitenlıage, Zejher, n. 141 in herb. Arnott.

- Ochrea glabra, nuda, ciliis nullis (raro brevissimis, cfr. P. amphibium) Spice cylindrica, contimua, densiflore. Calyx 5-partitus. Achonium subrotundo-lenticulare, faciebus aqualiter convexis.

123. P. GL A B RU M (Willd. I sṕ, 2, p. 447), glaberrimum, ochreis longis infra medium 


\section{POLYGONUM. POLYGONACE E (AUCTOR MEISNER):}

foliigeris bracteisque éciliatis, fulijs elongato-lanecolulis aeuminatis actenuatopetiolatis glanduluso-puncficulatis etiam in margine nervoque glaberrimis, spir is geminatis vel peniculatis anguste 'eylindricis, bracteis' subimbricatis breve turbiuatis oblique truncatis subaculis 2-4-1loris, calyee eglanduloso fructífero ovator stannínibus 6 (raro 7-8) inclusis, stylo semibifido subexsertó, achir nio biconvexú (taro trigono)-nitido. 24 In aquosis Intliæ orient. totius (Wall. lisl, n. 1711! excl. $\mathrm{F}$ : et partim. B., Wight, etc.), Afghanistan (Gruff.! Journ. 29), ins. Sandwic. (Gaudich.I in herb. DG., Chann. fide Linnees 3, p. 40); Brasil. merid. (Clian. I), Banda oriental ('Tweedie in herłs. Ar̃n.?). - Rheede Malab, 12, t. 7T, Meisn. mon. p." 78 , ef in Mirt. fl. bras. lasc. 14, Poljg. p. 14, Roxb. Iort. Beng. p, 29 ? Al. Ind. ed. 1832, p, 287, Babingt. iu Linn. Trans. 18, p. 102, Wight ic. t. 1799). Species omnium partium glabritiè perfectâ, ochreis prælongis bracteisque omni ciliorum vestigito carentilius ab ornnibús facile distinguenda. Folic 6-10 poll. longa, raro dimidio minora. Pedícelli demum exserti. (v. s.).

'¿. obscilrum (Meisn. in Wall. pi. As. rar. 3, p. 57), foliis obsolete glandulosopunctatis vel inpuinctatis (Wallich! n. 1711,1,2,3, 4, 1720! etc.). P. tenellum Roxb. ? cat. hort. Beng. 1. 29, fl. Ind. 289 (fide Wall. in herb. DC. non Blume.)

3. glandulosissimum (Neisn. 1. c.), foliis; presertim subtus, densissime fuscopunctatis, pedunceulis interduni apice obsolete glandulosis. - Wall. n. 1711, E. I Wight I Sellow! in hérb. Berol.).P. fluviatile Hamilt. ! mss. P. nutans Roxb. Miquel iń Mètz pl. és. Cunara, n. 265!

124. P. і в в R BE (Soland. ex Forst) yrodr. n. 517), glabrum; ochreis elongatis angustis bracteisque nudis infra medium foliigeris, foliis lanceolatis acurninatis attenuato-petiolatis głanduloso-puinetatis nervo subtus márgineque minute scabriusculis, spicis paniculatis linearilns gracilibus, Joracteis subjimftrcatis lreve turbinatis horizontaliter truncatis 1-6-floris, pedicellis exsertis, staniuibus 6 (ex Guillem. 3-5) inclusis, stylo semibilido rlenum exserto, achanio subrotundo-lentieulari biconvcxo nitirhissimb. $\not \psi$ ? In paludosis ius. Taïti, ułi Tamoré vocatur̃ (Forst., Cơmmerson? Bertero, Mơrenhout! Becelioy! etc.) - Guillernin in Ann. se. nat. 2. sér. 7, p. 188. 1'. Jarbatum Commers.? ex Guillem. (non aliox). P. glabrum Gham. et Sclil: in Linnsad 3, y. 46 ? (iunoad sp. ex Polynesiâ). P. Persicaria Hook: et Arn.! Boł. Beech. p. 68. Proecedenti nimis affine, sed ochrex caulinæ scmper internodio breviores, folia margine nèrvoque scalriuscula, spice tenuiorés et minus rigida, bractore haud oblifpere truncatse floresque panlo minortes. (v. s. in h. DC. et Arvott.)

125. P. S U м т r ANu (De Bruyn in pl. Junghuhn, p. $308^{*}$ ), caule adscendente glabro, ochreis internodio plus duplo brevioribus ghabris basi foliigeris, foltis petiolatís ovato-lanceolatis basi inferioribus subtruncatis superiorilous attenuatis parce setuliferis glabrisve margine ciliato-scaluis, spicis gerninatis strictis breve oblongoeonicis densis, bracteis cucullato-ovatis striatis nudis, floribus-5-andris lremidigynis, achænio orbiculari compresso nitido, faciebus teruíssime puncticulatis eonvexis medio gibbosis. $\mathscr{\nvdash}$ ? In Sumatrâ (Jungli.). Planta circiter pedem alta, folits 2 poll.-longis, 9 lin, latis, spicis 5 - 11 lin. longis. (De Br.)

126. ए. А рйів и (Límn. sp. 1 ; p.' 517), caule natante repente vel erecto, óchreis - pubescentijus tenuiter-ciliațis nudisve cỉrca medium foliigerịs, folîs ovali-oblon. gis vel lanceolatis, sjpicâ terminalị 'subsolitarià oblongầ obtusâ, bracteis ovatis acutís pedicellos subrequantibus, calyce cglandulośo, staminibus 5 , stylo semibificlo, achrnnio obovato-subrotundo mucrouato biconvexo angulis acutiusculis. Y In aquitis stagnantibus înundatisquue Europe totius a mare glacialí ad Caucasum, Sibiriâ, China (Staunton!), Ind. or. (Grifith! Journ. 771, Strachey ct Winterbottbm I), Cap. Bone Spèi (Drège!), Amer. bor., Mexico. - Engl. bot. t. 436, Meịn. mohs. p. 67, Mert. et Koch D. f.. 2, p. 51 *, Hook. fl. bor. Ap. 2, p. 131, Ledéb. fl. ross. A, p. 520. P. caccineum Mühlemb. cat p. 40, Willd, enum. p. 428. Variat, præter formas seq., folior um magnitudine, spicis 1-21 poll. Iongis, quandoque geminis vel paucis axillaribus, foliorum impressionibus longitúdinalibùs plus minus conspicuis vel nullis.

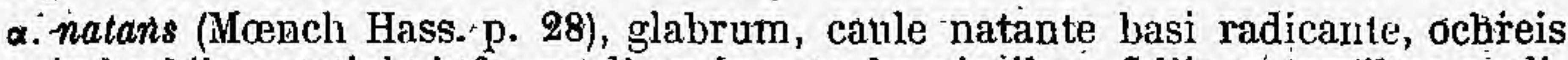
imberbibus petiolo infra medium inserto breviorihus, foliis natanfibus ovalioblơngis obtuisis vel acutiusculis basi rotandatis vel subcordatis margine èliolatis glaberínimisve, spicis emersis abbreviatis, getitalibus exsertis. - 
FI. dan. t. 282. $\alpha$ aquaticum Willd, sp. 2, p. 443. P. coccineum $\alpha$ aqpaticum Mühlenb. cat. p. 40, Willd. enum. p. 428, Pursh fl. Am. sept. 1, p. 271 fGrîfith, 1. 1706 ! Strachey et Winterbott: herb. Himal. n. 26 ! etc.). (v. v.)

B. coinosum (Koch syn. fl. Germ. p. 617), eaule repente adscendente apice cum ochreis folitisque scabrinsenlo-pubescente, petiolis abbreviatis, foliis lanceolatis acutis. Ad stagnorum margines. P. amphibium $\beta$ aquaticum Wallr. sched. crit. p. 190 (Karelin et Kiril. in 'herb. sod. imp.'Mosq. n. 1029 !). (v, v.)

$\gamma$. terrestre (Leers fl. Herborp. p. 99), caule erecto, ochreis pilosiusculis breviciliatis petiolo brevi supra medium inserto longioribus, foliis elongato-lanceolatis acuminatís basi subcordatis adpresse scabro-pilosiusculis lineis longitudinalibus impressis notatis, bracteis ciliolatis pedunculisque piloso-scabris, genitalibus' exsertis inclusisve. In fossis hand profundis. - Willd. sp. 2 p. 443. (v. v.)

d. maritimum (Dethard. compend. fl. Megapolit. p. 33), caule prostrato foliis - breve petiolatis lanceolatis scabris undulatis. In paludosis littoris Baltici. Mert. et Koch I. c.

c. Mühlenbergii, caule erecto apice puberulo, ochreis pilosiusculis imberbibus infra medium folingeris petiolo longioribus, foliis oblongis acuminatis :basi angustatâ obtusis vel breve attenuatis minute puberulis sape subtus subsericeis vel supra demum glabris,'spicis sæpius geminiș (alterâ majore bipollicari), floribus magnis pulehré rubris, genitalibus exsertis. In Americâ bor. arcticâ (Eranklin!) et temperatâ (Mühlenberg, A. Gray! Mosér l étc.), Mexico (G. Ehrenberg! in herb. Berolin.). P. coccineum terrestre Mühleṇb. cat. p. 40, Willd. enum. p. 428. P. Bistorta Walt. fl. Carol. p. 131 (non Linn.). P. amphibium emersum Mich. fl. bor. Am. 1, p. 240. P. aquaticum A. Grayl mss. in herb. DG. Forsan distincta sp. Folia nunquam impressionibus illis longitudimalibus lineata observavimus. (v.s.),

127. P. GLANDULosum (R. 'Br. prodr. fl. Nov.-Holl.' p, 419)', ochreis bracteisque nudis, foliis elongato-lanceolatis acuminatis subtus glandulosis margine scabris pedunculisque glabris; spicis alternis cylindraceis, floribus 6-andris digynis glabris. Circa Portt-Jackson et in Nov.-Holl. austro-occid,? (Preiss). - Meisn. jn pl. Preiss. 1, p. 623? Videtur aff. P. glabro, imberbï et scabrinervio, forsan a P. nodoso haud distinctia. Specim. Preissiana quæ vidimus pessima ideoque valde incerta.

$\because *$. Ochrea pilis tenuibus brevibus (nec setis rigidis) ciliata, plus minus adpresso-pubescentes. Folia utrinque attenuata, margine nervoque adpresso-pilosiuscula. Spica continuce, densiftora.

128. P. PR OSTRATUM (R. Br. prodr. fl. Nov.-Holl. p. 419), caule prostrato tenuiter piloso, ochreis brevibus laxiusculis brevi-ciliatis, foliis subpetiolatis lanceolatis subeglandulosis excepto margine nervoque glabris, spicis breve pedunculatis axillaribus terminalibusque subsolitariis lrevibus oblongis, bracteis imbricatis breve turbinatis glabris pedicellos superantibus inferioribus ciliolatis, staminibus 5 styloque semibifido inclusis, aclrænio ovali-lenticulari alterâ facie convexiore. \% Circa Port-Jaclsson, ad fi. Murray, et in Tasmanniâ (R. Br., A. Gunn-n. 21 l), ad Victoriam (Ferd. Müll, in lit.), Swan-River (Drumm, n., 230 !), et in Novâ-Zealąndià, ubi Putunaoué vócatur (d'Urville, Raoul I in h. DC.).-A. Cunnningh. in Aun. of. nat. hist. 1, p. 455, A. Rich. in Voy. Astrolab. p. 177, Raoul Ghoix, p. 42, Hook. f.- fl. Nov.Zel. p: 209. Planta humilis e Dasi lignescente, multicaulis, caulibus subadscendentibus spithamæis vel subpedalibus, ochreis $4-5$ lin., ciliis vix 1 lin.

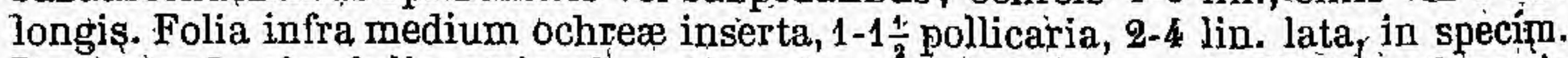
Drummond. glandulis atris plus ninus punctata. Spica semipollicares, bracteis 2-3-floris. Calyx 5-partitus eglandulosus, fructifer ovato-oblongus $1 \frac{1}{2}$ lin. Jongus. Planta Novæ-Zealandiæ forsan distincta, sed nobis e specim. imperfectis tantum (quibus caules glabri) cognita, Cfr. supra P. serrulatum. (v. s. in herb. DC., Shuttl. et comm. a cl. Heward et Sonder.)

129. P. Ludovicranum, caule glabro, ochreis petiolum æequantibus glabriusculis brevissime ciliolatis, foliis lanceolatis minute adpresso-puberulis demum excepto margine nervoque glabris, spicis geminatis vel subracemosis lineari-oblongis obtusis, pedunculis setuloso-scabris eglandulosis, bracteis ovatis acutis clliolatis, pedicellis demum exsertis, staminibus 7 inclusis, stylo semibifido breviter exserto, achænio subrotundo-lenticulari hiconvexa nitidissimo. \%? In Louisianạ (Drum- 


\section{POTYGONOM. POLYGONACEA (AUCTOR MEISNER).}

mond $\lfloor$ n. 10, 22, 32, 300, Tainturier! in h. DG.) A P. segetum, cui tota facie et char. plerisque convenit, constanter differt pedunculis eglandulosis pube brevi adscendente tenui vel fortiore hispidulis, ochreis bracteisque ciliolatis et achrenio haud punctato, facie utràque convexâ.' (v. s.)

130. P. A'T TENUA T UM (R. Br. prodr. Fl. Nov. Holl.p. 420), ochreis petiolos subæquantibus ciliatis, fóliiss elongato-lanceolatis utrínque attenuatis tenuissime pubescentibus, spicis pedunculatis eylindraceis strictis, bracteis ciliatis, floribus 8 -andris hemidigynis glabris, $\mathcal{F}$ ? In Novâ Holl. intratropicâ. - Meisn. mon. p. 72.

131. P. AR T I U UA A U M (R. Br. l, c. p. 420 , non alior.), caule glabro, ochreis glabris ciliatís, foliis elongato-lancéolatis acuminatis attenuatis utrinque pubescentibus subtus subsericeis, pedunculis pilosis, spicis cylindráceis, bracteis subciliatis, floribus 5-6-andris hemidigynis glabris. $\nvdash$ ? In Nov. Holl. intratrop. - Meisn. mon. . p. 71. P. australerspreng. syst. 2, p, 258 ?

132. P. L ANI GERUM (R. Br. l. c. p. 419), totum incanum, ochreis longis breviciliatis vel demum imberbibus, folits lanceolatis acuminatis subtus densius albo-lanatis, spicis geminis vel tacemosis linearibus, bracteis subimbricatis ovatis ciliolatis nưdisve pedicellos sabsequantibus, staminibus 6 (raro 7-8), styloque semi- 2-3-fido sưbexsertis, achæenio subrotundo-lenticulari (raro trigono) faciebus convexis. భ - In Indiạ or., Nova Hollandiâ et Af́ricâ australi. - Meisn. mon. p. 70. Flores oarnei vel rarius albi.

a. Australasicum; bracteis ochreisque imberbibus.-Circa Port Jackson. (Br. 1. c)

$\beta$. Indicum, caulibus gracilihùs ramosis, ochreis internodio multo brevioribus, foliis digitalibus, spicis paniculatis gracilibus, bracteis plus minus canescentibus imberloibus vel infimis ciliolatis, calyce minorc, fructifero magis ovato $1 \frac{1}{2}$ lin. longo. $\rightarrow$ In Bengaliâ, Nepaliâ (Wall. lịst, n. 1714!), Kamaon (Strachey et Winterbotton li. Himal: n. 15 !), Peninsulâ (Wight l), Javấ (Hoffm'anns. n. 134!), nns. Philippin (Guming n. 1377!). P. lanatum Roxb. cat. H. Beng. p. 29; -fl. Ind. ed. 1832, 2, p. 285.* P. lanigerum Meisn: in Wall: pl. As. rar. 3, p. 55. P. arachnoideum kllotzsch! mss. in h. Berolin. (v.s.)

$\gamma$ Africanum, caule subsimplici crasso toto fere ochreis occultato, foliis palmaribus (5-8 poll. longis, 1-1 $\frac{1}{2}$ poll. latis), spicis geminatis vel subracemosis crassioribus, bracteis glabratis ciliolatis floribusque majorilus, ealyce fructifero suborbiculari fere 2 lin. longo. - In Africê australi-orientali subtropicâ (Burchell cat. geogr. n. 2281 ! Drège !). P. lanigerum Meisn. in Linnseà 14; p.485. (v. s.)

133. P. PERSICAR IOIDES (Kunth in H. et B. nov. gen. 2, p. 179), caule glabro, ochreis ciliolatis; foliis subsessilibus lanceolatis parce minuteque adpresso-puberulis demum excepto margine nervọuie glabris, spicis racemoso-paniculatis lineari-oblongis attenuatis, pedunctilis glabris calycibusque eglandulosis, bracteis subimbricatis turbinatis brevibus inferioribus ciliolatis, pedicellis demum exsertis, staminibus 7-8 styloque semi 2-3-fido subinclusis, achænio parvülo biconvexo vel trigono. $\mathcal{Y}$. In Mexieo (Humb., Berland. n. 2342!' Schiede n. 62! Mart. et Galeotti, etc.), Peruviâ (Ruiz !), GuayaquiI (ex Bentl. Bot. Sulphur 1. 159), Surinam (Kegel n. 892 !), Nendoza (Gîllies!), Chili (Bert. n. 1245! Cl. Gay !), - Meisn. mon. p. 69, id. in Linnæa 21, p. 263, in Mart. fl. Bras. fasc. 14, Polyg., p. 16, Cham. et Schl. in Linnæȧ 3, p. 44, Mart. et Galeotti in Bull. Ac. Brux. 10, n. 4, p. 12. P. Tarmense Ruiz. l. mss. in h. Berolin. P. scabridum Willd. li. fide Cham. el Schl. J. c. Ochrearum cilia haud ultra 1 lin. longa. Spicæ 1-1 $\frac{1}{2}$-pollicares, densiflorie, bracteis summis nudis. Calyx 5- (ex Kunth 4-) partitus, enervis, albus ex Berland. fruetifer ovatus vix lineam longus. Achænium magnit. P. ninoris, lævissimum nitidum. Proximum P. Ludoviciano et nodọso, ab illo præcipue pedunculis glabris, ab hoc bractèis truncatis ciliolatis etc, dignoscendum. (v. s.)

$\beta$. pediunculis parce adpresso-pilosiusculis. - In Mexico (Schiede'n. 1149 l). Cham. in Línnæà $6, p$. 368. Forma, ad P. Ludovicianum proxime accedens, exceptis pedunculis tamen cum $P$. persicarioidi congrua. (v. s.)

134. P. Persica Ria (Linn. sp. ed. 1, p. 361); ochreis arcte cylindricis breviciliatis, foliis lancéolatis, spicis subracemosis ovatis oblongisve obtusis densifloris, pedunculis glabris calycibusque eglandulosis bracteis oblique trunétis eiliolatis pedi.: cellos superantibus, stanininibus 6 (raro 8 ) styloque semíbifido subinclnsis, achænio 
lenticulari (raro 3-gono) faciehus planis vel alterâ convoxxâ vel subgibbâ. $\odot$ In ạgrís et incuitis Enuropæe et Sibirile totius, Davuriâ, prov. Caucasicis, Indiẩ or. passim (Grillith 1), Chină? (Béecliey p. 208, Aleyen), Manillả ?, ins. Sandlvic? (Meyen), Cochinchinà? (Lour.), Amer. bor., Californiâ , (Beechey -p. 158), Chili ubi Buraznillo dicitur (Cl. Gay). - Blackwell Herb. t. 118, Gurt. Fl. Lond. t. 23, Engl. Bot. t. 756, Meisn. mon. p. fí (excl. $\beta$ et j). A. Braun in Florâ 1824, p. 361, Rẹichẹnb. ic, crit. 5 , p. 55, t. 491, Hoók. fl. Bor. Am,-2, p. 131, Ledeb, fl. Ross. 3, p. 522. P. biforme Wahlenb. I-Suec. 1; p, 242. P.tomentosum Schrank Bav. 1, p. $\mathbf{6 6 9}$.

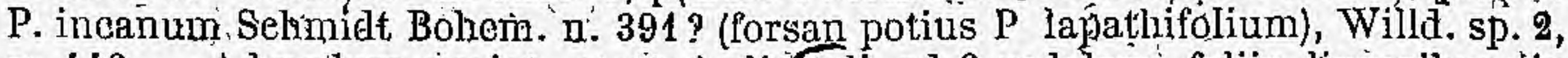
p, 446. - Admodum variat, staturâ digitáli ad. 3-pedalem, foliis linearibus vix jollicaribus 2-3 lin. latis usque ad 4 polli. longis $1 \frac{1}{2}$ poli. lațis, utrinque puberulis vel excepto margine nervoque glabris, subtus concoloribus vel rarius incanis, sum yel-absque maculâ uigrâ semilunari in modio limbo, spicis subsolitarìis vel pảniculatis $\frac{1}{2}-1 \frac{1}{2}$ poll. longis, quandoque basi interruptis, Ochrearum cilia crebria tenera, in caule nunquam lìneâ unâ breviora. Calyx carneus vel albuş, frụctifer ére. 1 lin. longus ovatus.

$\alpha$. agreste, caule lrumili ( $\frac{1}{2}-1 \frac{1}{2}-$ pedali) erecto vol adscendente paruin ramoso, foliis mediocribus ( $1-2$ poll. longis) gtabriusculis, spicis axillaribus terminalibusque subsolitariis oblongis obtusis-( $\frac{1}{2}-1$ poll. longis), floribus plerumque albis.-

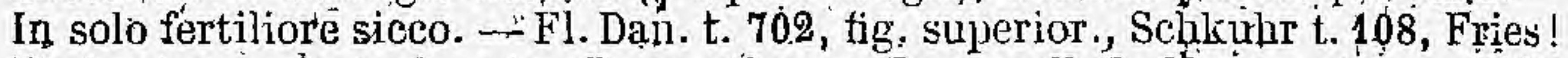
Herb. norm. fasc. 4 , etc. P. serotinum Ten. syll \$l. Neaps app. p. 566 ? (v. v.)

B. elatius, caule erecto (1-3-ped.) parum ramoso, folis majoribus (4-6 poll. longis

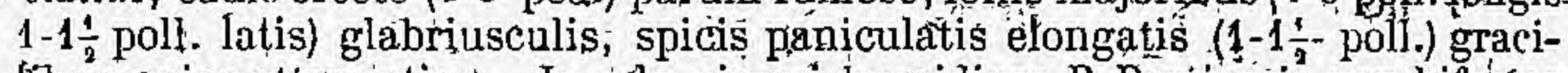
fibus apice attenuatis. - In solo pingui humidiore. P. Perșicaria var. biforme Frîes! Novit. fnant. II. Herb. norm. fasc. 10. (v. v.)

7 ruderale, prostratum, a basi diffuse ramosum, foliis minoribus lanceolatis vel

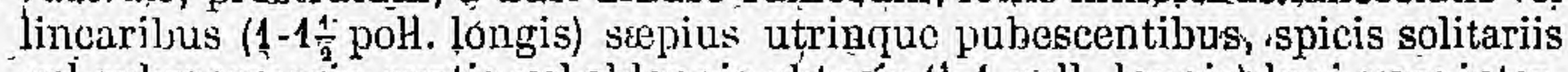
vel subracemosis ovatis vel oblongis ohtusís ( $\frac{1}{2}-1$ poll. longist basi sæepe interruptis, floribus plerumque roseis. - In stèrilibus siccis, lapidosis. (v. v.)

o. depauperatum, caule digitali erecta subsimplici, foliis parvis angustis, spicâ solitarià subglobosâ yelovatà (vix semi-pollicari) plerumque rósea. - In sterilibus arenusis, pracipue in editioribus Alpium etc. - P. miñus Lagasca Hort. sicc, Lond. n. 107 ! non alior. (v..v.)

135. P. Nodosu (Pers.! enchir. 1, p. 440). caule nollosw, ochreis laxiusculis mox glabrátis minute ciliolatis, foliis oblongis lanceolatisve subtus glandulqaso-punçtafis infimis aJjhreviato-oyalibus ovatisve suminis linearibus, spicis racemosis linearibus sursum attenuatis laxiusculis nutantibus pedunculis glabris, bracteis ovatis acutis nudis pedicellos supèrantibus, calyce eglandulaso tenuiter nervoso, staminibus 6 stylogue Jipartito inclusis, achæuii lenticúlaris (raríssime trigonil faciebus rubrotundis concavis. $\odot$ Ad rivulos et paludes Europæ totius, Sibirix, Caucasi, Syriw, Persiæ (Kotschy n. 437 !), Indiæe orieul. (Grifith n. 1708! 1709!), Ca1) sp. (Drège 1), Mozambique (B. Peters 11.8 ! in 1. Berolin.), America bor. !, JCexici (Berlandięr!), Ghili (Bridges n. 356 ! Cl. Gay.), Nove Holland orient et austral. (A. Cumingh. n. $22 !$ Ferd. Müller 1 - Mor. Hist. sect. $5, t_{t} 29$, .2 , Reichenb. ic. erit. 5, p. 59, t. 496 , Ledeb. fi. Ross. 3, p. 521 . Specius a plerisque auctoribus (aud Persoon usque fere omnibus) vel cum P. Persicaria, velcum $P$. lapathifollio confusa vel commixta. F. Injathifolimin Mert. et Koch D. Fl. 3, p. 52 (ex parte) $\alpha$ ovatum A. Braun! in Spenn. f1. Frib, p. 307, B minus Ten. syll. fl. Neap, p. 195? p. paniculatum Alidr. (Gide 1. DC, $i$ ). P. incanum Willd. en. p. 429. P, tenuiflorum Prosl (Guss.! in l. DC.), Ten. syll. 11. Neap. p. 196 ct 566, Tinéo cat. H. Panormit. 1827, p. 284, P. laxum Reichenb. ic. crit. 5, p. $56, t$, 492, Engl. Bot. t. 2822. P.Persicaria var. vernicosum Glıam et Schl. in Linnaâ 3, p. 43 ? P. qua-

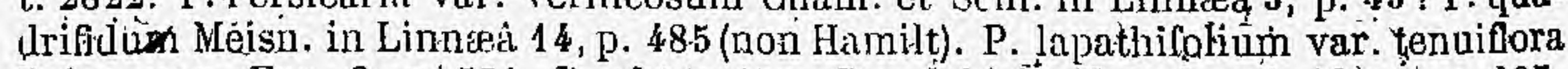
Boiss. vor. Esp. 2, p. 551. I' obtusatum Steudel! in Kotschy pl. Alepp. n. 137. P. glandulosum Heward I mss. in h. Cunn. Sonder I mss. in pl. Müller (nơn alior.). P ptriculatum, Remy in Gay hist. de Ghile ${ }^{1} .267$ ? - Omnes fere easdem formas induit a: I'. Persigaria, sód distinguitur caule plermmene altiore (2-6-pedali) sae-

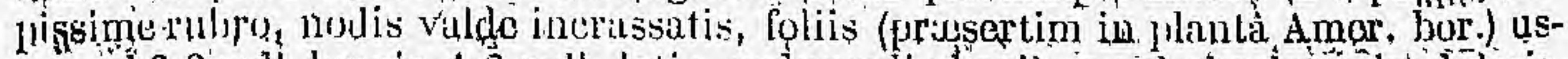

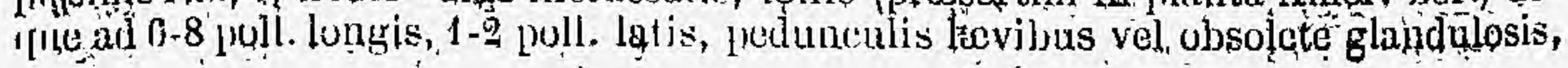


spicis usque ad $2 \frac{1}{2}$ poll. longis, bracteis inferioribus ssepe acuminatis yel-absolete ciliolatis. Flores carnei vel albi: Styli crura recurvo=divaricata. (v. v.)

136. P. Nr Lо т г U M, arulibus adscendentibus nodosis glabris, ochreis arete tubu - İosis pilosiusculiś densiuscule brevfciliatis, folifsoblongo-lanceolatîs basiattenuatis eglandinlosis margine nervơque subtus pilosiusculis, spicis racemosis torevibus linearibus continuis densifloris summis ajproximatis subsessilibus, pedunculo communi ,elongato eglandiloso glabro; bracteis contiguis brevibus turhinatis truncatis nudis 1-2, floris pedicellos superantibus, staminibus 6-7 - styloque semibifido inclisis, achænii-compressi faciebus ovato-ellipticis modice convexis levibus nitidis. $\mathcal{F}$ ? In Agyjto, ad fossas circa Damiate (G. Ehrenberg l). Forsan mere var. P. nodosi, sed ochrearum ciliis longiaribus (1-2 lin. longis), foliis constanter apicem verșus minus quam basi attenuatis stepiys obtusis, inflorescentià peciulịari quasi spicam compositám referente; nec non bractearum et acliœnii formâ satis discrepáns. (v. s. in h. Rég. Berolin.)

\$ 2. Stamina 5-8.(plerumque 6-7). Pedunculi glandiloso-scabridi, glandulis sessilibus vel stipitatis vel pilis simplicibus intermixtis plus minus tecti. Herboe erectovel adscendentes; ochrea bracteoque pilis brevissimis tenuibus ciliato; ; spicá cylindrica, oblongae; continuce, plerumquie densifloro.

137. P. L AP A T H IF O LXU (Ait. H. Kew 2, p. 30, non? Linn.), ochreis laxis parce pilogiúsculis glabrisve júbioribus brevissime ciliolatis, folis lanceolatis vel elliptico vel línoari-lunceolatîs utrinque attenuatis subtus glanduloso-punctatis, spicis oblongis obtusis densifloris, bracteis ovatis nudis plurifloris pedicellos superañtibus cum pedunculis ealycibusque glanduloso-scabriusculis, calyce 4-5-partito demum fortiter nervoso, stáminibus .6 inclusis, stylo divaricato-semibifido srépe exsèrto, achénii compressi (rarissime trigoni) faciebus subrotuudis concavis. ( In agris et incultis Europæe totius, Sibiriæe; Caucasi, Indiæe orientalis (Roxb.), Africæ australis (Burké ! in h! Arnott), Peruviie (Dombey! in h. Kunth.), Chili (Cl., Gay.)Willd.! sp. 2, î. 442 ; hierb. n. 7634 ! Engl. brit. t. 1382, Mert. et Koch D. Fl. 3, p. 52 (excl. syn. plur.), Reichenb. ic. crit. 5 , I. 58 , t. 495 , Ledeb.' fl. ross. 3 , p. 521. P. Pennsylvanicum Curt. 11. Lond. t. 73 (non Linn.). P. scabrum Moench meth p. 6.29" (non suppl.). P. Iapathifolium pallens Pers. ench. 1, p. 439. P. nutans Moxb. $I$ in Willd. herb. n. 7640, cfr. Linnea 3, p. 44, H. Beng. p. 29 ? Fl. Ind. ed. 1832,2, p. $285^{*}$ ? P. pallidum Wither. (ex Steud.).P. turgidum Thuill, 1. fl. Paris. ed. 2,1, p. 199 forma incana (fide herb. DC.). P. vernum hafin. hl Ludov. p. 302 ? P. somplocarpum De Bruyn in Nederl. Krüidkund. Arch, 1, p. 506." ? P, visco- sum Bastard.I mss. in herb. DC. P. Donii, orienţale,patulum hort. quorundam. P. lapathifolium auct. complur., v. g. Smith fl. brit. 1, p. 425, Mert. et Kuch 1. c. etc.. etiam P. nodosum includit quod ilto multo, vulgarius. - Iisdem formis ludit ac $\mathrm{P}$, nodosum et Persicaria, foliis margine nervoque scabriusculis vel penitus glabris, interdum subtus incanis, haud raro maculà atrả notatis, ochreis bracteisque nunc distinctius.ciliolatis yel denticulatis nuncinudis, spicis $\frac{-1}{2}-1$ poll. longis solitariis racemosis vel paniculatis, pedunculorum glandulis raris vel crebrioribus sessilibus vel stipitatis, etc. Bractere infimæ sepius cuspidato-acuminate. Flores nrajores quam precedentium, virescenti-albidi (nunquam? rübri). Calyx frucțfér semper conspicue nervosus. (v. v.)

138, P. SP E T TABLE (Mart.! mss, in herl. Ac. Nomac. n. 234.4), glabrum, ochreis ampilis caulem crassum abscondentibuis cilís, minutis deciduis, fqliis petiolatis lanceolato-oblongis glanduloso-punctatis margine nervoque scabriuseulis, spicis geminis vel subracemosis linearibus strictis densiflloris, pedunculis glabris dense glanduloso'-scabrinsculis, bracteis ovatis qbtusis nudis $1-\infty$-floris pedicellos subæquantibus, calyce 5-parti to, staminibus 6-7 styloque bipartito- inclusis, achæenio suborbiculari faciebus subplanis. $\mathcal{F}$ ? In Brasiliie jurov. Bahiensi (Mart.), Pernambuco (Gardner, n. 1124!), Matto Grosso et Minas Geraës (Wedd., Clatissen, n. 282), Rio Janeiro (Schüch !), Havanà (Ramon de la Sagra, n. 12, in herb. DG.), - Neisn. in Mart. Al. bras. fase. 14 , Polyg. p. $13^{\star}$, t. 3 . P. collare Niart.! mss. 1. c. P. ferrugincum Weddell in Anm, sc. nat. $3^{\circ}$ sér. 13, p. 252 (ex cit. Gardn.).P. gumamiferum Wedp. ? ihid. F. glabrum Gluan. et Seltt. ? in Linneà 3, p. 46 (quoad specim. Brusil.). Gaules 4-6-pedales, crassissimi, superne ramosi. Oclirea glabre, infri mcilium 
foliigerse, nervosæe, diu integræ, ciliis vix $\frac{1}{2}$ lin. longis Folia $6-10$ poll. Yonga, $1 \frac{1}{-2}-2$ poll. lata, rarius minora, utrinque attenuata, minute ciliolata, margine nervoque punctato-puberula, cæterum glaberrima. Spic $æ 1-k$-pollicares, pedunculorum glandulis creberrimis minutis sessilibus, bracteis subeglandulosis infimis minutissime ciliolatis acutis. Calyx obsolete pellucido-punctatus, albus vel roseus, fruetifer subrotundo-ovatus $1 \frac{1}{2}$ lin. longus, lobis obtusis tenuiter plurinerviis. Achænii anguli rotundati, facieș subplanæ nitiaæ minutissime pu.ncticulatæ. (v.s.)

$\beta$. incanum, adpresse incano-tomentosum, foliorum paginâ superiore cưm ochreis internodiisque demúm glabratis, jedunculis bracteisque fere glabris. Prope Santarem, prov: Para, Spruce, n. 640! (v. s, in h. Acad. Monac.)

139. P. GLUTYNos UM (Wallich! liśt, (n. 1717), caule subincapo vel glabno, ochreis medíocribus laxis glabriusculis, junioribus brevissime ciliatis, foliis lanceolatis attenuato-petiolatis, subtus incano-tomentosis, supra glabratis in nervis scabriusculis, spicis axillaribus terminalibusque subsessilibus, densifloris, peduneulis minute glandulosis, bracteis subimbricatis ovatis: obtusiusculis nudis glabris 1-2-floris pedicellos superantibus demum patulis, calyce 4-partito parce glandaloso tenuiter nervoso, staminibus 6 styloque semibifido inclusis, achænio brbiculari, faeiebus concavis. $\%$ ?.Ad ripam fl. Irawaddi et Bramaputræ (Wall. 1).--Meisn, in Wall. pl. As, rar. 3, p. 55. Galyx fructifer. vix lineam longus. A proxime affininibus P. lanigero, jam pedunculis glandulosis, P. lapathifolio calyce minore tenuinervio, etc., facile dignoscitur. (v. s.)

$\beta$. Capense, caule firmiore nodoso; superne fere toto ochreis abscondito; foliis utrinque incanis, nervo dense adpresso hirsùto. Ad Gàp. Bonæ-Spei (Drègel), P. glutinosưn Meisn. in Linnæâ 14, p. 484. Folia usque ad 4-5 poll. longa. 1 poll. lata.-(v. s.)

140. P. BungeANum (Turcz. iń Bull. suc. imp. Mosc. 1840, p. 77), caule erecto inferne aculeolato, ochreis adpresse pilosiusculis, foliis oxato-lanceolatis basi hand attenuatis, supre ad nervos; subtus undique adpresso-pilosiusculís; spicis paniculatis peduueulisque glandulis stipitatis radspersis, floribus 8-andris digynis, achænio... Z2? In Clinà boreali (Bunge). P. Pensylivanicum Bunge pl. Chin. p. 131 (non alior.). Species nton satis nota. Aculeoli in inferiori-caulis parte rari minutique.

141. P. Pensyluan a di (Linn. sp. 1 , p. 519 , non Curt.), caule subdïchotomo, ramis glabris vel cum pedunculis glandulóso-hispidulis, ochreis glabris eciliatis, foliis petiolatis lanceolätis glabris margine nervoque scabriusculis; spicis solitariis oblongis'obtusis, bracteis ovatis obtusis imberbibus plurifloris, pedicellis demum exsertis, calyce 5-partito subeglanduIoso tenuinervio, sțamínibus 7 exsertis inclusisve; stylo longiusculo semibifido, exserto, achærii suborbicularis faciebus concavis. $\odot$ In humidis pinguibusque Americæ bor. temperatæ totius, et in Mexico (C. Ehrenberg.!). - Willa. sp, 2. p. 448; Mich. fl. bor. Amer. 1, p. 240, 'Meisn. mon. j. 69. P. scabrum Moencl suppl. p. 267 (non ejusd. Meth.). P. bicorne Rafin. fl. Ludov. p. 29 ? Variat pedunculis interdum fere glabris lævibusque (Ríęhl n. 289 l), glandulis tantum rarissimis sessilibus conspersis, bracteis obtusis vel acutis integerrimis vel infimis (subinde glandulosis) obsolete dentato-ciliolatis. Facieș P. Persicariæ, sed notis indicatis bene distinctum. (v. s.)

142. P. INGARNATUM (Elliott ketch 1, p. 456), ochreis glabris, foliis lanceolatis supra pubcscentibus, pedunculis punictatis, floribins subconfertis 6-andris hemidigynis. () In fossis Americe borealis. Planta 'nobis obscura, ex auctore P. Pensylvanico quïdein proxima, sed distincta staminum numero, floribùs minoribus confertioribus, pedunculis nunquam hispidis folisque majoribus.

143. P. SEGE T U M (Kunth l in H. et B. nov. gen. 2, p. $177^{*}$ ), glabrum, ramis junioribus pedunculisque glanduloso-puberulis, oclireis bracteisque eciliatis, foliis lanceolatis utrinque attenuatis subtus glanduloso-punctatis margine pervoque 'minute scabriusculis glaberrimisve, spicis solitariis' vel subracemosis oblongis gracilibus, bracteis ovatis acutiusculis plurifloris calyceque '5-partito eglandulosis, pedicellis demum exsertis, staminibus 7, stylo semibifido exserto, achænio suborbiculari, facie âlterâ vel utrâque gíbbo-couvexâ. Ž In Americâ tropicâ et subtrop. - Meisn. mon. p. 67. P. acuminatum Mart. et Galeotti in Bull. Ac. Brux. 10, n. 4, p. 12 ? (non Kunth?). Nímis alline P. Pennsylvanico, recedens tantum spicis gracilioribus et calyce eglanduloso, fructifero dimidio minore et magís ovato. (v. s.) 
a. genuinum, staminibus, inclusis, calycem requátibus. In Nova Granatâ inter segetes (Humb. herls. Kunth! Schlim, n. 351! Tunke, n. 250!), Mexico (C. Ehren. berg! in herb. reg. Berolin:)

B. stamineum;-staminibu's exsertís, stylos æquantibus vel superantibus. In Texas (Lindl. in herb. Berol.), Mexico (Hartweg, n. 105 l), Cubâ (Ramon de la Sagra, n. 187 ! in h, DG.). P. Persicaria var. Benth. ! pl. Hartw. p. 16.

\%. Lindenii, staminibus calyce brevioribus, bracteis subacuminatis. In Mexico (Linden; n. 107!).

144. P. EuAtrus (R. Br. prodr. fl. Nov-Holl. p. 419), caule scabriusculo, ochreis ciliatis, foliis oblongo-lanceolatis acuminatis in petiolum decurrentíbus, spicis cylindraceis atternis, bracteis imberbibus pedunculisque glanduloso-pubescentibus, floribus 5-andris hemidigynis. $\odot$ Circa Port-Jąckson. Meisn. monogr. p. 70.

145. P. DeNs irl or u M (Meisn. ill Mart, fl. bras., fasc. 14, Polyg. p. 13 *), caule gracili glabro, ochrcis longis angustis glabris ciliolatis nudisve prope medium foliigeris, foliis lanceolatis acuminatis attenuato-subpetiolatis margine nervoque scabriuscilis vel 'glabratis, spicis racemosis linearibus strictis, pedunculis glanduloso-punctatis, bracteis contiguis breve turbinatis oblique truncatis obtusis glabrís eciliatis 3-6-tloris calycibusque 4-52partitis obsolete glandulosis, pedicellis exsertis, staninibus 6-7 (raro 8) styloque seni-2-3-fido inclusis, tachenio lenticulari ovali biconvexo. $భ$ In Americâ tropicà et subtropicâ, Limà (Gaudich. n. 75), VaIparaiso (herb. Berolin.). P. acuminatum Meisu.,mon. p. 78, ex parte (non h. Kunth). P. Portoricense Bert. in h. Balbis. A proxime affini P. spectabili differt oanle tenuiore, interqodiis longioribus oclureas plus minus superantibus, bracteis omnibus eciljatis, pedicellis exsertis, et priccipue calyce fructifero semper dimidio longiore quam lato ovato-oblongo $1 \frac{1}{2}$ lin. longo, achænịo dimidio minore minusque orbiculari faciébus valde convexis demum lavissimis, angulis haud rotundatis, styli, basi,persistente lóngiore. Folia 3-5 polli, longa, 5-1.0 lin. lata. Spicæ 1-2-pollicarcs. A. P. segetum dilfert pedicellis exsertis, bracteis obtusis, stylo incluso, etc. (V. s.)

a. imberbe, ochreis peñitus eciliatís. In Lơuisianâ (Drummond, n. 12! Tainturíer l), Floriclä orientali (Rugél, n. 199 !), fortorico (Wydler, n. 329 !), Guianâ Gallicâ (Martín! etc.), Limả (Gaudich.! n. 75 !). Valparaiso (fide herb. Berol.).

$\beta$. ciliolatum, ochreis brovissime ciliolatis demum sæe mutticis. In Brasil. merid. Banda oriental. (Bacle! in h. BC.)

146. P. S C A BR INER Rium (Royle, mss.), caule glabro-superne cum pelunculis glandulis subsèssilibus ' tecto, ochreis mediocribus eciliatis glabris, foliis, lanceolatis utrinque dense glanduloso-punctatis margine nervoque puberulo-scabriusculis, - spicis geminatis vel subracemosis laxis, dracteis acutis glabris pedicellos $\mathbf{3 - 4}$ subaquantibus calycibusque 4 -partitis eglandulosis, staminibus 6 inclusis, stylo semibifida, achrenio... $\mathcal{F}$ In Himalayæe reg. Mussooree (Royle). - Babingt. iń Lìnn. Traus. 18, p. 101 *.

$\beta$. ciliolatum, ochreis junioribus internodia superantibus bracteisque inferioribus brevissime ciliolatis, pedunculis parce glandulosis vel subnudis, spicis strictis linearibus continuis densifloris (1.2 poll. longis), bracteis subimbricatis eglandulosis. Ad ripas fl. Irawaddi (Wall.! list, ' $n, 1711 / 2$, ex parte) et in Assam (Wall.). Valde accedit ad P. quadrifidum $\beta$ et P. glabrum, ap jllo distinctum spicis longioribus magisque cylindricis (nec sursim attenuatis) et bracteis majoribus, ab hoc ochreis ciliolatis, foliis haud glaberrimis. (vi.s.)

147. P. HIP роротамI' (G. Ehrenberg! Inss. in herb. reg. Berol.), ochreis Iongís glabris parce glandulosis margine. imberbi remote glanduloso-denticulatis, foliis lanceolatis oblongisque subtus lense fusco-punctatis margine nervoque pilososcabriusculis vel demüm glabris, 'spicis racemosis anguste cylindricis dehsifloris, pedunculis parce gkanduloso-scabriusculis, bracteis subobliquẹ truncatis nudis pedicellos superantibus, calyce 5-jartito eglanduloso, staminibus 6-8 inclusís, stylo 2-3-partito subexeerto, achænio compresso vel rarius trigono obtusangulo, faciebus late ovalibus lévibus nitidissimis. $\mathcal{W}$ In Dongolâ (Ehrenb.!). Caules crassi, modosi, radicantes ramique adscendentes, sanguinei. Ochrex circ. pollicares, juniores internodia æquantes vel superantes, venis tenuibus striatæ, apice laxiusculle, diu integré, infra medium foliggeræ. Folia 3-4 poll. longa, 8-12 lin. lata, 
subàcuminata, in petiolum Jrevom decurrentia, interdum undulata. Spices 1-2 pollicares, continuæ, strictæ, erectio, bracteis contiguis breve turlinatis sanguineis enervís plưrifloris. Calyx carneus (magnit. fere $\mathrm{P}$. orientalis), lobis 3-nerviis. Stamina 6-7 (rarius 8). Achonium magnit. P. Persicariae. A P. scabrinervio proxime affini differt bracteis nunquamaeatis ochreisque eciliatis. (v, s.)

148. P. QUADRIFIDU M (Hamilt. !'mss.) caule glabro superne, cum pednnculis glandutis şessilibus dense tecto, oclróis longis glabris ciliolalis, folịs elongato-laneeoIatis utrinque attenuatis glanduloso-punctatis nargine nervoque adpresso-strigillosis, spicis paniculatis oblongis attenuatis densifloris, bracteis breve turbinatis acutiusculis nudis pedicellos 1-3 sequantíbus, calyce 4 -partito parce glanduloso, staminibus 6 styloque bipartite inclusis, açhsenio orbiculari faciebuśs subeoneavis. 24 ? In Indiâ. boreali, Chimbada (Hamilt. ! Wall. list, n. 1711; F. I sub P. glabro), Kamaon (Strachey et Winterbottom herd, Himal. n. 24). - Meisn. in Wall. pl. As. rar.: 3, p. 56 (nón Linnxâ 14 , p. 485 , quod P. nodosum). Gaulis èrectuis. 0chres brévissime ciliate, prope medium foliigeræ. Folia subséssilia, acuminata. Spicæe $\frac{3}{4}-1 \frac{1}{2}$ póli. Iongæ, continu⿰d, apicem versus aftenuata. Calyx parce glaridulis conspersus, fructifer late ovatus, 1 lin. longus, levitér nervosus. Açhænịum subnitidum, minutissime puncliculatum, angulis rotundatis. (v. s.)

B. Simlense, oçhireis muticis. P. Simlense Royle mss. Babingt. in Linn. Trans. 18, p. $102^{*}$. Exceptis ochreis haud ciliatis nullo modo a spec. Hamilt differre videtur.

\section{\$ 3. Stamina 4. Calyx 4-partitus, eglandulosuss. Genitalia inclüsa.} Achenium lenticulare. Caules erecti, juniores cum ramis glandulosohispidi vel hirsuti.

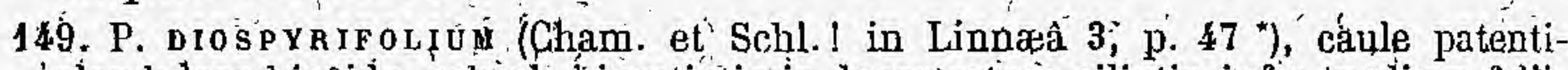
glanduloso-hisppido, ochrels hirsutissimis dense setoso-ciliatis infra medium folìgeris, foliis élliptico-oblongis acuminatis basi subcordàto-rotundatis eglandülosis adpresse strígillósis vel subtus glabriusculis, spicis paniculatì̀ linearibus latiusculis, bracteis contiguis ovatis dense ciliolatis $3 \rightarrow 10$-floris pedunculiscrue glabriusculis eglandulosis, pedicellis exsertis, calyce parro; stylis 2 subliberís, achæuio subrotundo biconvero. $\%$ In paludosis Brasilize, prov. Río Janeiro (Beyrich, Sellow, ete.) et-Minas Geraës (Martius !). - Meisn. in Mart. fl. bras. fasc. 14, Polyg. p. 12, t. 1, fig. 1. Faeie valde accedif ad P. acuminati var. microstemon; sed floribus parvis 4 -andris, stylis ad basin usque discretis, etc., facile dignoscitur. ( $v$, $s$. in h. reg. Berolin., Mart., Arnott.)

150. P. PER YIAN UM, caule infra nodơs cam ramis pedunculisque glanduloso-hispido demum glabrąto, ochress adpresșe pilosis prope basin foliigeris, cilíis proprins nullis, foliis lancealáto-oblongis acuminatis basi rotundatis utrinque aelpressopilosis eglandulosis, spicis geminatis oblongis brevibus interruptis, bracteis'ovatis. derse adpresso-pilosis 2-4-floris pedicellos æquantibus, calyce magno, stylo breviter bifido, achienio lenticulari... \& In Peruviâ (Mathews, n. 3120!). Gaulis . erectus, gracilis, ramorum et pedunculorum pube densiore breviore glgndulisque mixtạ. Oclureie pollicares, interuodiu breviores, laxæ, ore erecto'membranaceo ciliis propriis destriuto. Folia subsessilia, 3-4 poll. longa, 10-14 lin. latạ, basi vix anguștąta. Spicai axillarés et terminales, $1-1 \frac{1}{2}$ poll. longæe. Calyx carneus vel albus, magnit. P. orientalis, infundibuiliformis, subevenius. Species insignís, liirsutie et floribus magnis P. hirsulo, foliis $\mathrm{P}$. diospyrifolio similis, cæeterum vero distinctissima. (v. s. in herb. Shuttlew.)

\section{B. Ochrece hypocraterimorpha, tubo membranaceo cylindrico, limibo foliaceo recurvo patente.}

15i. P. HispIDUM (Kunth in H. et B, nov. gen. 2, p.178 *, haud Don), saulerecto superno ochreis alscondito et cum jisdem petiolis foliorum nervo pedunculisqae seloso-hirsuto, ochreis laxis limbo crenato hirsuto-ciliato, foliis ovatis vel.ohlongofanceolatis acuminatis in petiolum decurrentibus glanduloso-punctatis adpresso pilosiuscalis rel glabrescentibus, spicis cylindricis eontinuis densifloris, bracteis ovalis ylahriusculis ciliolalis, calyie 5 -partito, staminibus 5 , stylo bipartito, achieniq suborbiculari faciobús subplanịs vel altera convexâ. \& Ln Amer trop., Colom-

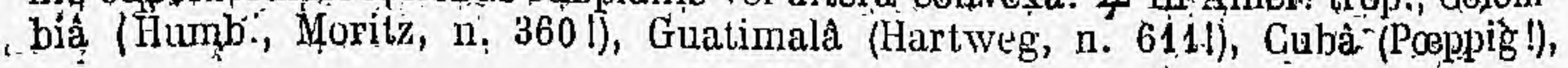


Perqvia (Ruiz!), Brasil. prov. Bahiens. (Mart.!), Pernambuco (Gardner, n. 1122!). Meisp. mon. p. 80, et in Mart. fl. bras. fasc. 14, Polyg. p. 12, t. 2, Benth. I pl. Hartweg, p. 90. P. hirtum Willd.! mss. in leerl. n. 7647. P. pilosum Ruiz! mss. in lierb. reg. Berolín (non Roxb.). P. inundatum Mart.! mss. in herb.-Ac. Monac. n. 2227. Flores rubri et albi. (v. s.).

Seetía Iv. AmBLygonon Meisin: mon. $p .43$ et $53, t .3, \mathrm{~K}$, el in Wall. pl. As. rar. 3, p. 54, Endl, gen. p. 307. - Genus Lagunea Lour. fl. Coch. $1, p, 271$.

- Calyx corolliuus. Stamina 7 , rarius 5 vel 6 , rarissime 8 , cuin squamulis perigynis alternantia. Stylus staminibus brevior, e medio divaricato-bifidus, stigmatibus eapitatis Achænium calyce aucto immutato inclusum, lenticulare, obtusangulum, acuminatum ${ }_{3}$ faciebus orbicularibus licviluus nitidis. Colyledones incumbentes, lineares oll. Herbæ liabitu Persicariarum, radicibus fibrusis, foliis integerrimis, spicis geminatis vel racemosis cyliñdricis canfertíforis, bractẹis turbinatis.

152. P. ORIENTALE (Linn. sp. 1, p. 519), totún mollitér pilosum, caule elato ramoso, ochreis hypocraterimorphis limbo foliaceo patente ciliolato deciduo, foliis ovatis oblongisque acuminatis in petiolum decurrentibus, spicis paniculatis oblongis mutantibus, bracteis ovatis acutis pubessentibus $\mathbf{8 - 5}$-floris, floribus majusculis patentibus; stigmatibus pileifformibus, achænio basi obtuso faciebus depressis. O In Inḍiâ orientali, Novâ-Holłandiâ (R. Br.), Africicâ aústrali, et colitun ornàmenti - gratià in Europâ, Amer. bor, et Japonià.

a. yrandiflorum (Meisn. apud Wall.1. e. p. 54), spicis-nutantibus; floribus mägnis, ächæenii angulis linế $\cdot$ notatis, pube omnium partium breviore. $\mathrm{P}$. orientale Linn.- Mill. ic. t. 201, Gurt. Bot. mag. t. 213, Willd.sp. 2, p. 448, Gærtn. fr. 2, p, 182 , t. 119, f: 5, R. Br. prodr. Nov.-Holl. p. 420, Meisn. mon. p. 53, t. 1, fig. 30-35 et t. 3, K., Benth. in Hook. Lond. Journ. 1, p. 4,91. P. altissimum Moench meth. p. 630. Variat floribus roseis domum sanguineis et albis. (v. v. c.)

B. pilosum (Meisn, apud Wall. $l_{\text {a }}$ c.), spicis interdum erẹctis strictiusculis, floribus mediocríbus, liveâ in achæenii angulo obsoletâ vel nullâ, omnium partium pube copiosiore longiore sejpe fere aureo-soriceâ. In India or. (Wall. list, n. 1710 ! 1709, B. ! Royle, Grífith | Helfer, n. 34! etç.), Javâ (Blume, Hoffmannsegg, n. 50 ! Zolling. n. 186,5 h, Chinà, (Staunton! Beechey, Fortune, A., n. 4l), - Babbingt. in Linn. Trans. 18, p. 99 *, Benth. in Hook. Journ. 1853, p. 193. P. pilosum Roxb. h. Beng. n. 29, 0 . ind. ed. 1832, $2^{\prime}$, p. 286, Meisn. mon. p. 54, Wall.! list, n. 1718 . P. urientale Indicum Hamilt. mss. P. amœnum Blume bijdr. p. 532. P. Cochinẹhinense Meisn. man. p. 55. P. torquatum de Bruyn in pl. Jungls. j. 303 ${ }^{\mathrm{k}}$. Lagunea Cochinchinensís Lour. 1l. coch. 1, p. 271 . (v. s.)

153. P. L п ват и , pilosum, demum glabrescens, oclireis petiolo brevi longioribus arcte cylindricis, limbo lreriaceo patente rejuando-crenato piloso-ciliato diu persistente, foliis lancęolatis utrinque attenuatis superioribus sessilibus, spicis solitarils erectis cylindrico-linearibus densifloris strictis hasi interruptis, bracteis ovatis ciliolatis, staminíbus 7 breve exsertis, achænio bíconyexo lineâ marginis obsoletâ. $\odot$ ? Ad fl. Senegal (Lelièvre l in herb. Kunth) et ostia Nili (G. Elırenberg !). Caules ramique adscendentes, cum ochreis pilosi, demum glabrati. Ochrę medio vel paulo infra foliigerse, tubo membranaceo striato, limbo stubreflexo. Folia- $3-4$ poll longa, 5-10 lin. lata, inferiora petiolo vix 3 lin. longo fulta, pilosiuscula yel adpresse hirsuta demum glahrescentia, infima non observata. Spiese 1-2-pollicares, bracteâ infima $\frac{1}{2}-\hat{i}$ poli distante 1 -florà, reliquís contiguis pluriflorís cucullato-ovatis acutiuseulis pubescentibus, pedicellis exsèrtis. Calyx magnit. P. orientalis, patulus, albus vel carñcus. (v. s. in h. reg. Berolin.)

154. P. SENGGALESE (Meisp., mon. p. $54{ }^{*}$ ), glabrum, achreis intẹrnodia superantibus limbo erecto membranaceo tenuissime breviciliato mox nudo, foliis petiolatis elongato-lancelatis acuminatis margine seabriusculis; spicis racemosis vel subsolitariis dinearibus, hracteis junioribus 2 -4-1loris achænii faciebus depressis angulo hawd lineato. () Ad flumina Xgypti (G. Ehrenh.lh-Abyssiniæ (Ruppell ! Schimper, 11. 163!), in Senegal.(Perrottet!), ius. Borljonia (Boivin !). P. articulatum

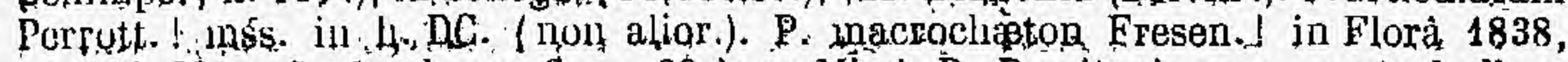
1. 601; Mlus. Senkenberg. 3, p, 63 (non Miq.). P. Persicaria var. Inegaphyllum 
G. Ehrenbérg! miss. in herb. reg. Berol. Càules elati, nodósi. Folia sæe dense glanduloso-punctata et subtus vernicosa, summa longe acuminata. Flores albidi. (v. v. e; et s. sp.)

155. P. Javan I cu of (De Bruyn in pl. Junghuhn, p. $303^{*}$ ), ochreis muticis, mediis internodia æequantibus infra medium foligeris petiolo brevioribus cauleque glabris, foliis elongaţo-lanceolatis longe acuminatis basi attenuatis minutissime setosis, pedunculis divaricato-dichotomis adpresse-setosis,' spicis cylindraceis densis tlexis, bracteis acutiusculis pedieellos vequantibus subglabris inferioribus parce ciliolatis, achænii faciebus inæqualiter convexis lævibus nitidis. $\odot$ ? In Javâ

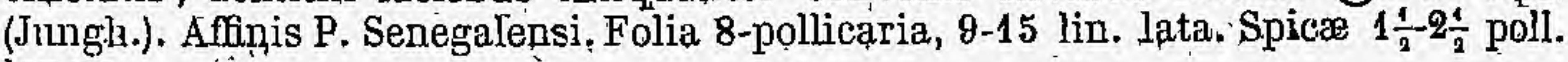
longe.

156. P. то MEN т os UM (Willd. sp. 2, p. 447), totum adpresse pilosum, canle erécto sulcato crasso inferme glabrescente, ochreis longis limbo membranaced erdcto longe setoso-ciliato, foliis oblongo-lanceolatis utrinque attenuatis, spicis paniculatis linearibus strictis denșifloris, bracteis obtusis ciliatis, achænii angulis haud lineatis faciebus convexis. $\mathcal{H}$ In totâ Indià orientali (Wall.! list, n. 1709 , excl. B., G., H., ex parte), Javâ -(Blume), ins. Philippìn. (Cuming, n. 627!), Geylan (Thwaites, n. 2248 !), Africà austr. (Drège d etc.). - Roxb. fl. Beng. p. 29, fl. Ind. ed 1832; 2, p. $287^{*}$, Meisn: mon. p. 81, ap. Wall: 1. c. p. 55. P. ochreatum Houttuyn, ph. syst. 6 , p. 442 , t. 49, f. 1. P. pulchrum Blume bijdr. p. 530, Hassk. pl. Jav.rar ; p. $218^{*}$, De Bruyn in Pl. Jungh. p. $302^{*}$. Flores rarissime 6-andri. (v. s.)

$\alpha$. sericeo-velutinum (Meisn. in Wall. pl.As. rar. 3, p. 55), foliis vel omnibusutrinqụe vel senioribus nonnisi subbtus densissime velutinis serieeo-splendentibus, pedunculis bracteísque plis minus pilosis (Wall. list, n. 1708, A.! 1709, C.! E.! F.! et ex parte A. ct D.).

B. denudatum (Meisn. 1. c.), foliis vix novellis sericeo-velutinis, adultis pube rariore brevissimâ (in paginà superiore sæepe ad puncta prominula reducta) scabriusculis, bracteis brevius ciliatis" pedunculisque glabris, (Wall. list, n. 1708, G.! I., 1709, D., ex parte).

\%. strigillosum. (Meisn. in Linnceâ, 14, p. 483), foliis pube hrevi rigidiısculà scabriusculis -rarius subsericeis. In Áfricâ australî-orien'tali- (Drège, Krauss, n. 800 ! 802 !). - Hook. Lond. Journ. 2, p. 450.

ઈ. glandulosum (Meisn. in Lin̄næễ 14, p. 484), foliis subtus glanduloso-punctatis, subtus pilis brevibus adpressis molliter pubescentibus, calyce pellucido-punctato. In Africâ australi (Drège !).

Sectio V. Bistorta Tourn. inst. p. 511, Linn, syst. nat, p. 137, Adans. fam. '2, p. 277, Meisn. monogr. p. 43 et $50, t .3$, H et J, et in Wall. pl. As. rar. 3, p. 53, Endl. gen. p. 307.

Calyx corollinus, profunde 5 -fidus, 'nunquarn glandulosus, fructifer immutatus vix auctus: Stamina 8 (rarissime 9). Styli 3 (rárissime 2) Iòngi. Stigmata minuta, Achænium triquetrum (raro lenticulare, cfr. P. hulbiferum). Cotyledones acumbentes $\circ=$ Herbæ perennes vel suffruticuli cululibus ramisve plerumque monostachyis, spicà densiflorà, contiuuâ, bracteis paleaceis ovatis vel lanceolatis ochreisque tenere membranaceis cylindricis oblique truncatis nunquam ciliatis. Folia nunquam pellucido-punetata, margine plerumque anguste revoluta et undulato-vel crispulo: crenulata.

\section{\$1. Herbae rhizomate lignoso crasso simplici abbreviato vel tortuaso, caulibus annuis simplicissimis erectis monostachyis (raro pleiosta- chyis, cfr. P. viviparum, Bistorta). - Meisn. ap. Wall. 1. c.}

157. P. 'VIVIPA RUM (Linn. sp. 1, p. 516), rhizomate timberiformi, caule annuo simplicissimo monostachyo erecto, ochreis mediocribus, foliis glabris infumis ovatis vel oblongispetiolis apteris, superioribus lanceolatis vel linearibus margine revoluto dense nervoso-crenulatis, spicá elongato-lineari graçili laxiusculấbasi sæjius bulbilliferà et vivipàrâ, floribus inferioribus subsessilibus súperioribus pedicellatis, staminibus exsertis. $\mathcal{F}$ In Europe totius pascuis precipue alpinis, et in Asià et Amer. borealị et arcticâ, ins. Spitzberg (Martins !), Melville, Groenlandiá l ins. Aleut. ! Kamtschatka! Sibiriâ! Tibet et Kamaon, alt. 15,000 ped. (Wallich !n. 1633, 
ex parte, Strachey et Winterbottom, herb. Hímal. n. 4! 5!), Caucaso. - Tóurn. inst. t. 291, fig . g. k., Gmel. Sibir. 3, p. 44, t. 7, f. 2, Fl. Dan. t. 13, Schkuhr, t. 108, Eng!. bot. t. 669, Pursh. fl. Am. sept. 1, p. 271, Meisn. mon. p. 52, t. 3, H., t. 5, fig. 1-11, Cham, et Schl, in Linnæấ 3, p.' \$8, Hook. Il. bor. Am. 2, n. 130, Led'eb. fl. ross. 3, p. 519. De bulbillis cfr. Meisn. monogr. p. 20, Dickie, in Ann. et Mag. of nat. hist. $1840, \mathrm{n} .34$, p. 55 . Variat statưa dígitali ad pedalem. caulibus e rhizomate contracto solitariis vel rarius $2-3$, foliis basi obtusis vel breviter attenuatis, infimis sæpe minoribus ovatis et phus minus cordatis, spict 1-4-pollicari, sæpius basi interrúptà (rarissime casu fortuíto ramosà, herb. Ledebour !), bulbilliferâ vel rarius fructiferâ. Flores albi, raro pallide rosei, dimidio minores quam P. Bistorts. (v.v.)

158. P. BULBIFERUM (Róle InsS), rhizomate crasso lignoso, caulibus annuis simplicissimis 1-stachyis, ochreis longis, foliis margine revoluto costato-crenulatis subtus puberulis lanceolatis vel inferioribus ellipticis petiolatis, superioribus-subsessilibus, petioló aptero, spịcâ compactâ elongato-ciblongạa, bași laxiụsçulâ vel interruptâ bulbilliferâ, bracteis pvatis acuminatis, staminibus calyce parvo brèvioribus demum elongatis, stylis 2-3 longe exsertis, achænlo lenticulari vel globoso-trigono faciebus convexis minute granulato-striatis subopacis. $\&$ In Kunawur (Royle) et Nepaliâ. (Wallich! list, sub n. 1683). - Babingt. in Liñ. Trans. 18, p. $94^{*}$. P. viviparum Meisn. in Wall. pl. As. rar. 3, p. 53: Forsan mere præcedentis var. (v. S.)

159. P. S PH A R OS TA A Y U (Meish., mon. p. 53, et apud Wall. 1. c. p. 52), foliis margine costato-crenulatis glabris vel subtus puberulis, inferioribus lanceolatis obtusis basi attenuatis petiolo aptero, supremis sẹssilibus linearibus, spicầ compactâ brevi oblongâ vel subglobosâ basi truncatà, bracteis ovatis pédicellos brevissimos superantibus, staminibus exsertis vel inclusis. $\&$ In alpibus Nepalia, Sirmore, Kamaon, Garwhal, Assarn, Pundua (Wallich list, n.1683 | 1.684 ! Griffitli ! Royle, Stracley et Winterbottom herb. Himal.n.1!).P. macropbyllum Don fl. Nepal, p. 70, Babingt. in Linn. Trans. 18, p. $95^{*}$ (nomen omnino ineptum), P. tente Don l. c. (non Michx.). P. gracillimum Spreng.. syst. eùr. post. p. 154. P. affine var. angùstifolium Wall. ! list, n. 1683. Spiç carnex, núnquam bulbilliferæ. Species P. Bistortam inter et vî̀iparum exacte'media, illí spicâ brevi densấ et foliis subtus sepe pubescentìbus, huic foliis minoribus lyasi attenuatis et petiolo aptero conveniens. ( $v \cdot s)$.

160. P. ST E N OPY YLUM (Meisn. mon: p. 52), foliis linearibus obtusis margine revolutis subtus niveo-tomentosis; ochreis integris apice rotundatis, spieâ 'oblongâ floribus cernuis pedicellatis, bracteis longe cuspidatis, calycis lobis lineari-oblongis obtusis, stylo trifido. $\mathcal{F}$ In alpibus Nepalix́. P. angustifolium Don prodr. fl. Nepal. p. 70 (non aliorum). P. bracteatum Spreng. syst. cur. post. p. 154. Verisimiliter mera var. P. sphærostachyi.

161. P. Bis torta (Linn. sp. 1, p. 516), chizomate crasso torto, caulibus anmuis simplicissimis, ochreis longis nervoso-striatis, foliis glabris vel subtus puberulis, foliis infimis cordatis oblusis petiolo longo-superne alato, superioribus prope ochreæ apicem subsessilibus cordato-lanceolatis, summis línearibus vel abortivis, spicâ densâ oblongà obtusâ, pedicellis flore longioribus, staminibus exsertis. $\mathcal{Y}$ In pascuis pinguibus et subpaludosis, precipue montanis Europe totius, Sibiriæ! in Kamtschatka ! Caucaso ! Syriâ ! (Aucher-Eloy, n.1345 !), Hímalayâa (Hoffmeister \’ in herb., reg. Berol.), Americâ bor., præsertỉm acticâ. - Toúrn. inst. t. 291, fig. A-F et L, Meísn. mon: j. 51, L. 3, J. Cham. et Schl, in Linnæâ 3, p. 37, Haok. fli.. bor. Am. 2, p. 130, Ledeb. fl. ross. 3, p. 518. P. bistortoides Pursh 1 l. Am. sept. 1, p. 271 (non? Walt.). P. ellipticum Willd. herb, n. 7626, Spreng. syst. 2, p. 253. Spica nunquam bulbillifera. Flores carnei, raro albi.

a vulgare, caulibus simplicibus, foliis inferioribus ovato-oblongis, superioribus oblongo-lanceolatis, spicâ oblongâ cylindricâ.- Mill. ic. t. 160, Blackwell Herb. t, 254, Fl. Dan. t. 421, Engl. Bot. t. 509, Bull. Herb; t. 314, Hayne Darst. 5, t. 19. (v. v.)

$\beta$ angustifolium, caule simplici vel apico 2-3-ramoso, ramis 1-stachyis, foliis inferioribus oblongo-lanceolatis, superioribus elongato-lanceolatis linearibusve, spicâ sæpius abbreviatâ oxatơ-oblongâ. P. Bistorta $\beta$ alpinum Turcz.1 mss, in h. DG: (Karek. et Kiril. n. 428 !). P. confusum Meisn. in Wall. pl. As. rar. 3, p. 53. P. bistortoides Boíss.! diagn. 5, p. 46, Kotschy pl. Gilic. 
n. 38, 47d, 48a, 218, 331b. P. carneum G: Koch! ’n Linnæa 22, p. 197, P. splendens Klotzsch $!$ in plant. princ. Waldemar t. 88 , ined. (v.' s..)

$\gamma$. minus, caule palmari vel subpedali simplici, foliis parvis (radicalibus inelu so petiólo vix 1 12 poll.), spicâ ovoldeo-șubglobosâ (vił semipollicarì). P. Bistorta $\hat{\beta}$ capiltatum C. Koch iri Lininæâ 19, p. 16, et 22, p. 196. - Fớma alpina, depauperatá. ( $v . \nabla_{i}$ )

ઈ. oblongifolium, caule simplici, folị̂s utrinque glabris infimis oblongis (laminâ semipedali $1 \frac{\ddagger}{\text { a }}$ poll. fátâ) basi breviter attenuatả in petiolum longissimü vix decurrentibus, spicá oblongê. - In Américie bor.-occid., Bocky Mountains, Geyér n. 405 !' (v. s. in h. Shuttlew.)

\section{§ 2. Herboe rhizomate liynoso crasso ochreato, caulibus annuts ramosis; ramis 1-2-stachyis, internodiis longissimis.}

162. P. S PE Gros u M (Meisn. mon. p. 66* et in Wall. ṕl. As. rar. 3,p. 53), folíis omnibus ovatis cordatís acuminatis margine erispato-undulatis utrinque prominuto-reticulatis summis sessilibus, spicis solitariis cylindricis brevibus, bracteiés anguste lanceolatis, floribus magnis sémipatulis. ' $\nvdash$. In Nepaliâ (Wall. líst n. 1716, A!) Variat foliis glabvis ot parce puberulis eiliolatis, basi interdum subtrunctitis aut e sinu in petiolum productis, bracteis obtusiusculis aut longe acdminatis fére in setam excurrentibus. (v. s.)

163. P. AMPLEXIGAUJE (Don prodr. fl. Nepal: 70), folis ovatis vel ovato-oblongis sensim-longe acuminatis cordatís stupra sublæevibus subtus prominułó-nérvơsis puberulis margine obsolete revolutó tenerrime creniulato-undulatis sưmminis súbsessjlibus oblongo-lanceolatis subamplexicaulibus, spicis getninatis longissimis lirrearibus densilloris, bracteis longe acuminatis. $\mathscr{Y}$ In Nepaliâ, Kamån (Wall.) Simlâ; Mussooree, Ghoor etc. (Royle).-Meisn. mon. p. 51, Babingt. in Linn.Trant. 18, p. 96. P. pêtiolatum Don l. c. p. 70 (teste Bábingt.), Mleisn. mon. p. 51.

a. ambignum, spicis strictis densifloris, foribư majusculis subclausis (Wall. list $\mathrm{n}, 1716$, B ! Strachey. et Winterbottom herb. Himal. It. 12 ! 14!). P. ambiguum Méisn. in Wall. pl. As. rar. 3, p. 54 , Wight ie. t. 1797. P. amplexicaule Lindl. $!$ in Bót. Reg. 1838, misc. n. 117, ib. 1839 , t. 46 ! Cauḷes 2 -k-pedáles parum ramosi. Sficæ plerumque inæquales, alttera 1-2 poll., alterâ-4-5 poll. longâ, floribus sanguineis vel albis, magnit. $P_{;}$Bistortær, fere dimirlio minores quam P. speciosi. (v. s. sp. et v. c.)

$\beta$, oxyphyllum, spicis gracilibus laxiusculis (nonnunquam solitariis) floribus parvis patulis. - In Kamaon (Strach. et Winterbott. herb. Himal. n. 13!). P. oxyphyllum Wall. list n: 1715 ! Meisn. ap. Wall. l. c: p.54. (v. s.)

\$3. Suffrutices vel fruticuli, caule lignoso ramoso hypogoeo vel epigaro. radicante, internodiis contractis, ramis adscendentibus foliosis, annotinis spicigeris erectis. Folia coriacea, glaberrima.

164. P. VAc INI IF OL IU M (Wallich 1 list $n$. 1695), caule epigæo crasso tortuoso lacero-squamato, internodiis brevissimis, foliis lreve petiolatis_ovatis vel ellipticis

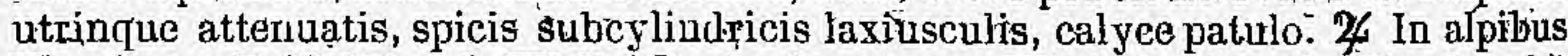
Hịmalayææ alt.12,000 ped: (Wall.! Royle, Strachey et Winterbott. herb. Himal. ì. 3!) Meisn. in Wall. pr. As. rar. 3 , p. 54 , Royle ill. Himal. p. 317, t. 8, f.-2, Babingt. 1. c. p. 96, Bot. Mag. t. 4622, Paxt. et Lindt. fl. gard. 2, n. 37. (v. v. c. et s, sp.)

*. obtusifolium, ramis contractis, foliis confertis parvulis obtusis, spicis solitbriis abbreviatis.

$\beta$. medium, ramis suberectis, foliis n1ajoribus acutiusculis vel breve acumiratis, spiccis solitariis.

$\gamma$. flägelliforme, ramis numerosis elongatis debilibus prostratis subpaniculatis apice plerumque spicas plures gerentibus.

165. P. AFFIN (Don prodr. fl. Nep. p. 70, non Steph.), caule hypogæo, ramis contractis apice epigæis foliosisque, anmotinis, simplicibus erectis 1 -stachyis, foliis lanceolatis acutiuseulis basi attenuatis infimis longe petiolatis margine revoluto undulato-crispulis utrinque tenuiter reticulato-venosis, spicis cylindricis compac- 


\section{poLyGondm. POLYGONACEF (A甘CTOR MEISNER).}

tis, calyce majusculo subpatulo. 24 In Nepalia, Kanaor (Wall: list n. 1692/ Strach. . et Winterbott. herb, Himal. n. 2 \%, Kunawìr (Royle), Meisn, tnon. p. 52, Bäbingt. in Linn. Trans. 18, p. $97^{*}$. P. Dunianum Spreng. syst. cur. jost. p. 154. P. Brunonis Wall.! list n. 1692 , Royle ill. Himal. p. 317, t. 80 , f. 3, Meisn. in Wall. pl. As: rar. 3, p. 54*, Paxt. et Liridl. fl. gard: 2, n. 37; (v. v. c. et s. sp.)

166. P. E mód (Meisn. jn Wall. pl. As. rar. 3 , p. $54^{*}$ et 54 , t. 287), caule lignoso epigseo prostrato radicante elongato tamoso conferte folíoso, ramis annotínis èrectis súmplìcibus, follis subsessilibus anguste lanceolatis utrinque ociualiter attenuatis acutis'margine revolpto integerrimis supra tiervis prominulis dense pennatim lineatis, spicis terminglibư axillarijusque jedunculatis geminatis linearibus laxiusculis, - calyce parvo inaperto. $\%$ In Kamaón (Wall. líst n, 16931), IKunawur (Royle). - Babingt. l. c. p. 98. P. Meisneri Wall.! list n. 1693! (v.s.)

\section{Sectio yi. Gephalophilon, Meisn. in Wall. pl. As. rar. 3 p. 59,} End. gen. p. 307.

Flores capi1ati. Galyx sémicarollinus, 4 -5-partitus. Stámina 8 vel rarius 6 . Glandulæ vel siluame perigynæe vullæ. Styli 3 vel raro 2 , filiformes, semiconnati, stigmatibus cetpitatis. Achænium calyce parum aucto sicco vel rarius subcarnoso totum inclusum, interdim semiadnatum, trigonum vel rarius lentieulare. Cotyledones accumBentes, ángustre $0=$ Herbọ Asiæe uustralis et Abyssiniæ, inermes, nunquam volubiles nec aquatice, ochreis membranaceis cylindricis circumscísse- vel oblique truncatis margine nudis vel rarius ciliatis; föliis integris vel siriuato-lubatis, pétiolis sæepius basi foliaceo-auriculatis, capitulis spluæeroideis solitariis geminatis vel corymboso-paniculatis, bracteis paleaceis planis vel vix vaginantibus. - Seclionun Persieariæ et Aconogoni \& 2. Meisn. Mon. p. 59 et 82.

\section{\$1. Didymocephalon Meisn. l. c_-Capitula geminatá, rarius solitaria. Caules graciles, debiles! Ochrece laxce. Folia plerumque tenera.}

167. P. DEL I CA T U U M, nanum, gtaberrimum, caulibus erectis filiformibus subsessilibus, ochreis hyalinis laceris, foliis sparsis distantibus subsessilibus ovatis cordatis eveniis internodio brevioribus, capitulis terminalibus axillaribusque sessilihus paucifloris folium subæquantibus squamato-bracteolatis, calyce 5-partito enerti, staminibus $8 ?$, achienio triquetro nitidissimo laciebus convexis. (1) In Kamaon, alt. 12,009 ped.' cum línenigia monandra legerunt et miscuerunt cl. Strachey et Winterbottom (herb! Himal. ǹ. 38 ! ex parte). Plantula digitalis, tenelia, habitu ad P. filicaule accelens, sed jam glabritie et omnibus par tibus minoríbus diverst. Internodia $4-9$ lin., folia $2-3$ raro $3-4$ lin. longa, $1 \frac{1}{2}-3$ lin. lata, subacuminato-acula; plana, non ciliata.. Ochrea subpersistentes. Galyx fructifer vix $\frac{2}{3}$ lìi: lóngus. Áchænium castaneum, angulis obtusiusculis, faciebus rhombeooblangis. (v, s. in h. soc. Linn. Lond.)

168. P. NUMMUL ARIFoLIUM, nanum, caulibus repentibus subcrespitosis ad nodos villoso-pubeseentibus, ochreis petiolum æequantibus subintegris pubescentibus, foliis orbicularibus ciliatis 1-nerviis eveniis, pedunculis terminatibus geminis sequilongis monocephalis, capitulis globosis 8-12-flor is, sæpe folko fultis, pedicellis calycem 5-partitum sequantibus, staminibus 5 , achienio subrotundo-lenticulari biconvexo nitido. $\odot$ In Kamaon, alt: 14,500 ped. (Strach. et Winterbott. Therb. Himal. n. 43 !) Caules 1?2-pollicares, radicantes: Folîa 3-4 lin. Ionga lataque, peliolum rquantia, integerrima, juniora subtus pilosiuscula. Calyx virescentialbus, circ. 1 lin. longưs, ènervis, eglandulosuș. Genitalia inclusa. Achænium castaneum; sub lente obsolete puncticulatúm, angulis obtusiusculis. (v. s. in h. soc. Linn. Lond.)

169. P. FILIG U LE (Wall. list, n. 1694 l), caule debili simplici glabro; foliis petio. latis ovatis oblongisve utrinque ochreisque brevibus adpresse pubescentibus, capitulis 1-3 folio fultis subsessilibus parvulis, floribus 5-partitis 8-andris hemitrigynis, achænio triquetro nitidulo angulis acutiusculis faciebus tenerrime puncticulatis. $\odot$ Iu Emodo ad Gossain Than et Ramaon (Wall.1); Seran (Royle). - Meisn. in Wall. pl. As. rar. 3, p. 59, Babingt. in Linn. Trans. 18, p. 104*. P. ciliatum Don Prodr. 11. Nepal. 73 ?-(non Lour.). Gapitula magnit, seminis Viciæ, rarius Pisi, bracteis inconspicuis. (v. s.) 
a. caspitosum (Meisn. 1. c.) cæspitoso-multicaule, subdigitale, foliis utrinque attenuatis capitulísque éxiguis. - Forma 'habitu simillixha Kœnigiæ monandrax, sed characteribus omnino abhorrens.

$\beta$. extenuatum (Neisn, l. e.), caulè pedałi filiformi simplicíssimo vélápice biffo lævi vel infra ciodos, parce retrorsum strigilloso, foliis paryis basi rotundatís vel ahrupte atteniantis, capitulis parvulis. (Wall, I Strach. ot Winterbott. herb. Himal. in. 37 !)

$\gamma$. alpestre (Meisn. l. c.), caule pedali et ultra erecto pauciramoso lavijusculo; foliis oblongo-lanceolatís .ovatisve basi cuneatis vel alorupte attenuatis capitulisque miajoribus. In Himalaya (Wall.! Hoffmeister! in h. reg. Berol.). P. alpèstro Watl. list. n. 1725 I (non G. A. Mey.). P..microplıyllum Klotzsch! mss. in herb. Princ. Waldemar).

170. P. н u IL E (Meisn, in Wall. pl. As, rar. 3, p. $59^{*}$ ), caulibus adscendentibus ramosis ochreisque subciliatis-hispidulis, foliis breve petiolatis ovato-orbicularirhombeis acutis obsolete pellucido-punctatis utrinque hispidulis, capitulis terminalibus axillaribusque solitariis parvulis, bracteis paleaceis lanceolatis pedunculisque eglandulosis glabris, floribus 5-fidis 5-6-andris hemidigynis; achænio biconvexo granulato. (In Nepaliâ (Wall. ! list n. 1700 ex parté, sub P. perfơớto), Kamaon (Strach. et Winterbott. herb. Himal. n. 45!). A P. perforato differt stamínum numero, achenio lenticulari, a P. Nepalensi omnibus partibus ${ }^{\top}$ minoribus, ab utroque foliis obsolete aut non pellucido-punetatis. (v. s.)

171. P. PER FORA TU M (Meisn. monogt. p. 83); caule elongato simplici vel ramoso, ochreis deciduis, foliis avatis obtusis 'basi subito cuneato-angustatis auriculatosemiamplexicaulibus pellucido-punctatis, capifulis parvis terminalibus geminatis axillaribusque solitariis, bracteis subscariosis glandulos $\varphi$-oeellatis, floribus 5-fidis 8-andris hemitrigynis, achænii trigoni faciebus ovatis granulatis. $\odot$ In Nepaliâ (Walt!), Mussooree (Royle), Kamaon YStrachey et Winterbott. herb Himal.n. 11!), Javâ (Đe Vriese! in herb. Meisn.), Ceylan (Thwaites n. 2251 !) - Meisn..ap. Wall. 1. c. p. 59. P. alatum Hamilt. mss. Sureng. syst. cur. post. p. 154. P. punctatum Ham. mss. Don prodr. fl. Nep. p. 72 (quod simul P. Nepalense.includere videtur); Babingt. in Linn. Trans، 18, p.105', De Bruyn in pl. Junghúlın. p. 308.

a. hispidulum (Meisn. apưd Wall. 1. c.), cullibus adscendentibus infra nodos, pedunculisque apice pilis patulis vel-retrorsis sæpe glanduliferis hispidulis, foliis in nervis utrinque hispidis glabrisve margine sæpe ciliatis, pedunculis axillaribus aphyllis folio multo longioribus, bracteis ovatis acutis. $P$. perforatum Meisn. Wall. list n. 1700 I ex parte. (v, s.)

ß. loevigatum (Meisn. 1. c.), ubique glabrum, caule erecto, folijs summis angúste lanceolatis linearibusque basi hastato-auriculatis, pedunculis plerumque divaricato-dichotomis sæpius paniculatis abbreviatis foliosis, bracteis subacuminatis. P. Nepalense Wall. list n. 1701 ! ex parte. (v. s.)

$\boldsymbol{\gamma}$. glaciale, caulibus nanis ( $1-1 \frac{4}{2}$ poll. longis), foliis impunctatis, - In mole glaciali Milam, Kamaon, alt. 13;000 ped. (Strach. et Wiuterbott. herb. Himal 1. 44!) P. punctatum y pygmæum De Bruyn in pl. Jungh. p. 309 ? P. capitatum Korthals, fide De Br. l. c. Videtur forma alpina, depauperata, vix propria sp. (v. s. in h. soc. Linn. Lond.)

172. P. NEPALENSE (Meisn. mon. p. $84^{*}$, et ap. Wall. 1 . c. p. 59), caule erecto vel adscendente ramoso, ochreis glabris, foliis summis sessilibus cordato-oplongis, inferioribus ovatis acuminatis $\mathrm{e}$ basi subcordatâ in petiolum cunento-alatự basi 'auriculato-amplexicanlem productis subtus glandulis subpellucidís immersis sparse punctatis, capitulis geminatis vel (raro) solitariis majusculis folio fultis, pedunculis apico glanduloso-hispidulis, bracleis scariosis acuminato-acutis, floribus urceolatis breve 4-5-fidis 6-8-andris hemidigynis, achterio scobiculato-reticulato. $\odot$ In Indiâ orient. (Wall.! Royłe etc.) et Abyssiniâ. - Freson.! in Mus. Senken berg. 3, p. 64, Babingt in Linn. Trans. 18, p. 106, Wight ic. t. 1804. Bracteæ obsolete glandulosíe oclrreæque eciliatæ. Calycis limbus in planta culta albus, in specim. indicis sæepe roseo-lilacinus. Variat preterea foliis 1-2 et interdum vix $\frac{1}{2}$ - pollicaribus. Achænium rarissime passim triquetrum: (v. v.c. et s. sp.)'

a. gtabrum (Meisn. ap. Wall. 1. c.), foliis utrinque glabris, capitulis distincte pedunculatis, calycé compresso-4-fido, achænio biconvexo. In Nepaliâ (Wall.l), Assam (Griffith 1), Maścarả, Canarâ, mont. Neilgherrỳ, efce, peníns. Ind. or. 
n. 610 । 968 l), Abyssinia (Ruppel! Schimper, n. 293 |). P. Nepalense Meisn. mon. p. $84^{*}$, t. 7, f. 2.'P. debile Steudel ! mss. in herb. Schimp. P. Metzianum Miquel! in pl/Metz, n. 610, et Flora 1849, p. 557 (forma parvifolia): P. guttuliferum Miquel ! in pl. Metz, n. 968.

3. scabridum (Meisn.1. c.), foliis subciliatis nervis hírtellis, capitulis sessilibus aut breve peduncilatis, ealyce compresso 4-fido; achæenio biconvexo. In Nepaliả (Wall.! n. 1701, ex parte), Kamaon (Strach. et Winterboft. herb. Himal. n. 9 !), mont. Neilgherry (Wight!), Abyssiniáa (Schimp. n. 303 l).

$\gamma$. Javanicum, foliis subeglandulósis glabris vel parce pilosiusculis, calyce 5-ffdo, achsenio triquetro. In Javæ centralis mont. vulcan. Dieng et Merapi, alt. 6,000 ped. (Junghuhn, de Vriesel-in herb. Meisn.). P. microcephalum Hasskarl in Florâ 1831, p. 561, haúd Don, fíde Trevir. apúd Hassk. 1. c.

173. P. Mrar 0e E PH A U M (Don yrodr. fl. Nepal. p. 72), caule elato gracili subramoso, ochreis breviciliatis, foliis oblongis acuminatis in petiolum cuneato-angustatis ciliatis eglandulosis, petiolo alato semiamplexicauli vel aptero basi foliolo reniformi ciliato utrinque auriculato, capitulis geminatis mediocribus aphyllis, pedunculis hispidulis glabrisve, bracteis subscariosis opacis oyalibus oblusis eglandulosís ciliolatis, floribus 5-fidis 8-andris hemitrigynís, achænio trigono obtusangulo granulato, () In Nepaliâ, Sillet, Asssam (Wall.! Hamilt.! Griffith !). - Meisn. mon. p. 82 *, apud. Wall. I. c. p. 59. P. staticiflorum Wall. list, n. 1704 ! (v. s.)

a. subvillosum (Meisn. apud Wall. l. c.), caule pedunculisque pilis fuscis patentibus hispidulo, foliis utrinque ochreisque molliter adpresso-pilosís. P. strigosum Hamilt. I mss. (non R. Br.), Wall. list, n. 1704/1!

B. glabrum (Meisn. 1. c.), caule, ochreis foliisque utrinque glabris. P. panduræ. forme Hamilt. I mss. (specim. e Dongtola, excl. planta e Goyalpara, quæe P. Chinense).

174. P. Wal ichir (Meisn. monogr. p. 83 *, t. 7 , fig. 1 , et apud Wall: l. c. p. 60), caule rameso glabro basi radicante, ochreis breviciliatis, foliis ovatis acuminatis eglandulosis glabris ciliolatis e basi şubcordatâ in petiolum apterum basi foliaceoauriculatim breviter: productis, summis cordato-lanceolatis amplexicaulibus , capitulis geminatis mediocribus, pedunculis glabris, bracteis scariosis ovatis obtusis eciliatis, floribus. 5-fidis 8-vel raro 6-andris hemitrigynis, achænio trigono obtusangulo granulattg-striato. $\odot$ In Nepaliâ (Wall. list, n. 1702!). - Wight ic. t. 1805. Forsan P. mícrocephali var, recedens folioram formâ, petiolis nunquam vere alatis, pedunculis longioribus glabrisque, bracteis nudis magisque scariosis subdiapbanis. (v, s.)

175. P. SPH R R OCEPHALUM (Wall. list, n. 1703!), caule radicante, ramis adscendentijus ochreisque eciliatis glabris, foliis subcordato-ovatis-acuminatis eglandulosis ciliatis subtas in nervis parce hispidulis, petiolo obsolete alato, capitulis subsolitarïis majusculis, pedunculó elongato, apice glanduloso-hispidulo, braèteis paleaceis ovato-lancéolatís acutis nudis, floribus $\mathbf{5}$-fidis $\dot{b}$-andris hemitrigynis, achænio obtuse triquetro granulato-striato. () In Nepdliâ (Wall.!), Meeróo (Royle), Kamaon (Strachey et Winterbottom herb. Himal. n. 10 । D Hoffmeister!), - Meisn. in Wall pl Ás. rar. 3, p. $60^{*}$, Babingt. in Linu. Trans. 18, p. $107^{*}$. P. podocephalum. Klotzsch! niss. in herb. princ.'Waldemar. Petioli ut videtur nunquăm foliaceo. auriculati. Capitula cerasi minoris magnitudine, solitaria vel rarius gemina altero subsessili. Flores pallide rosei majusculi. (v.s.)

176. P. с A і Iт A тUM (Hamilt. mss.), caule radicante ramoso cum ochreis foliisque pube purpurascente hispidulo, foliis ovatis vel ellipticis subacutis, petiolo brevissimo utrinque foliaceo-auriculato, capitulis geminatis vel solitariis ruajusculis densifloris, pedunculis inæqualibus apice hispidulis, bracteis paleaceis ovatis acutis nudis, floribus 5-fidis 8-andris hemitrigynis, achænio obtuse trigono obsolis'e granulato: భै? In Nêpaliâ, Kāmaon, Pundua (Wallı.! Royle, etc.), Ghinâ (Staunton! in herb. DC., specim. imperfect., foliis parvis) - Don prodr. fl. Nepal. p. 73, Meisn. mon. p. 82, Babingt. in Linn. Trans. 18, p. $107^{*}$. P. repens Wallich! list n. 1699, Meisn. in Wall. pl. As. rar. 3, p. 60. Folia stepe egregie inæquilatera et basi obliqua. Capitula globosa vel sæpius, saltem juniora, ovato-conica. (v. s.)

a. pingue (Meisn: ap. Wall. 1. c.), ramis elongatis laxis, foliis crassiusculis sæpe glabrescentibus, petioli auriculis magnis persistentibus, capitulis

XIV. 
cerasi magnítudine. In - Khasyâ (Wall.I), Tibet (Strach êt Winterbott. herb. Himal. n.81).

B. macilentum (Meisn.1. c:), ramis abbreviatis, internodiis contractis, folitis minoribus (vix semipollicaribus), petioli auriculis parvis fugacissimis, capitülis' magnit. pisi majoris. In Khasya (Wall.! Griff. n., 118 !).

177. P. R ÚN crina Tu (Hamilt. mss:); caule adscendènte ramoso, ochreis hispidis Breviciliátis, foliis lytato-3-5-lobis, lobo terminali maximo triangulari acuminato, petiolo basi biauriculafo, capitulis geminatis majusculis, pedunculis hispidis, bracteis' subscariosis oblongis acutis nudis, floribus 5 -fidis $\mathbf{6}$-vel 8 -andris hemitrigynis, achænio triquetro subgranulato. () In Népaliâ (Hamilt., Wall. list, n. 1698 l): - Don prodr. fl. Nepal: p. 73, Meísn. mon. p. 85, et in Wall. pl. As. rar. 3, p. 60. P. réticulatum de Bruyn in pl. Junghuhn, p. 309, ubi planta polymorpha dicitur et var. plures definiuntur. Folia 2-6-pollicaria, nunc molliter adpresso-jilosa ciliata vel glábrescentía, lobís lateralibus utrinsecus 1-2 plerumque obtusis. Capituli magnit: cerasi. Flores albídi vel virescentes vel incarnescéntes. Achænia matura non obseryata. ( $v$, s.)

$\beta$. Javanicum, caule, ochreis foliisque junioribus dense rufo-puberulis, lobo terminali ovato, lateralibus 1-2-jugis brevibus vel obsoletis, petioli auriculis 'magnis. In humidis montium .Javæ (Zollinger, n. 2169! de Vriese, in herb. Meiși.). P. truncatưm Zolling. in Flơ̂a 1847, p. 471, Walpers Anù. bot. 1, j. 548. P. corymbosum var. puberulum Blume, ex Zoll., Walp.1. c. (v. \$.)

178. P. sinuatum (Royle mss.), glabrum, caule procimbente tamoso, foliis lyrato-5-7-lobis, lobo terminali rhomboideo, lạteralibús auriçulisque petioli parvis obtusis, capitulis geminatis vel solitariis peluneulatis densifloris, bracteis ovatis obtusis, floribus 5 -fidis 5 -andris hemitrigynis, achænĩo obtusangalo-trigono faciebus valde canvexis nitidis. $\odot$ In Kunawur (Royle), Kamaon, alt. 8,500 ped. (Straehey et Winterbottom herb. Himal. n. 40 !), Caules subpedales, debiles, Ochrese interdum parce pilosiuscu, la. Folia pléraque pollice brévfora, rarius subbipollicdria, tenera, lobis lateralibus plerumque hijugis 3:6 lin. longis oblongis sinubusque rotundatis; magnit. cerasi minoris. Achænium sub lente minutissime functiculatum. Forsan mere precedentis forma parvifolia glabra. (v. s.)

\section{\$.2. Corymbocephalon (Meisn. in Wall. pl. As. rar. 3, p. 60). Capitula corymbosa; corymbis scepe subdichotomo-paniculatis. Ochreá oblique truncatce, eciliatce. Folia subcoriacea, indivisa.}

179. P. GH IN ENSE (Linn' sp. 1, p. 520), caule erecto ramoso, folis ovatis oblongiste, auriculis foliaceis ad basin petioli renifớmibus deciduis, corymbo simplici vel paniculato, yélunculis piloso-vel glanduloso-scabriusculis dichotomis trifidisve bracteis foliaceis cordatis suffultis, floribus 5 -fidis 8-andris hemitrigynis, achænio triquetro. $2 \%$ In Clinà (Staunton I Beechey, Meyen, etc.), Japoniâ, ins. Philippin., - Javầ et totà Indiâ orierit. a jugo'Himalayano ad Ceylonam et Malaccamom. - Meiśn. mon. p. 60, ct in Wall. jil. As. rar. 3, p. 60, Roxb. fl. ind. ed. 1832 ? p. 289 , Hook. et Arn. Bot. Beeclı. p. 208 et 269 , Babingt, in Linn. Trans, 18, p. 109 *, Wight ic. t. 1806. R. brachiatum Poir. P. córymbosum Willd, De Bruyn in pl. Jungh.p. 304. P. auriculatum Meisn. (v. infra var.). P. cymosum Roxp, 1. c. 2 , p, 289 (ñon Trevir.). Ampelygonum Chinense Lindl. in Bot. reg. 1838, misc. 113. Admodum variat staturấ, pubescentià, foliorum formâ, eorumque margine plano vel revolúto integerrimo vel undulato-crenulato crispulo, inllorescentiæ. ramositate, capitulorim magnitudine, ete. Folia plus minus acuminata et pellucido-punctáta, teste De Bruyn (1. c. p. 305, var. discolor) interdum subtus glauco-albicantia.

๙. Thunbergianum (Meisn. apud Wall. 1. c. p.60), foliis ovatis vel deltoideis basi subtruncatâ vel rarius subcordata in petiolum plus minuis' produçtis ramisque glabris vel subtus in nervis hispidulis, auriculis petioli caducis, corymbis subsimplicibus contractis eglandulosis hispidulis vel glabris, capitulís parvis. In Chinâ (Staunton! Gáudich.! in. 68 ! Hịds !), Japonia (Thumb.! :Zölinger, 1.. 202!), Assam (Wall.! Grill.!). Kamaon, Nepal., ete: (Royle, Strachey et Winterbott. leerb. Hímal. n. 36 ! Wall. list, n. 1707, C.! ct ex parte 1705, I.), Javâ (Zolling. n. 2167 l), mont. Neilgherry Penins. (Lesclien. n. 81!). P. polycephalum Wall. list, n. 1707! P. auriculatum Meisn. in Wall. Nist; n. 1705/6. P. corymbosum Willd. C. densiflorum Blume Bijdr. p. 533. Rumex timbellatus 
Houttuyn Pfl. Syst. 6, p. 388, t. 47, f. 3 (cx ic.). Coecolobn crispata Buchan. in. Roxb. I. ind. ed. 1832,p. 292 ? fide Wall. in sched. herb. Griff. (v. s:)

ß. scabrum, foliis subcordato-ovatis ŝurra punctato-scalıriuseulis nervo venisque subtus cum ochreis ramisque pubescentibus, capilulis mediocribus conferte corymboso-judniculatis, bractcis flores súbrquantibus acutis. Iń Jâvà (Zollínger, in. 2566 !). R. corymbosi var. subhastatam, aśperatn et puberam Blume conjungete, videtur. (v. s.)

\%. ovalifolium (Meiśn. 1. c. p, 60), folihs ovatis ovalibusve utrinque acuminatis ramisque glabris, petioli auniculis magtis cum petiolo seepe confluentibus, corymbis subpaniculatis dichotomis dense glanduloso-hispidulis, capitulis inajusculis; bracteis acuminatis flores subtequantihus. In India: (Wall. list, n. 1705, A.! E.! H.! 1. I ex parte), Penins, (Wiglit! Metz pl. Canara, n. 49 ! Neilgherry, n. 967!), ins. Philippin. (Cuming, n. 1641)). P. auriculatum Meisn. mon. p. 59. t. 6. Coccoloba Indica herb. Wighth I Folia flerumque reliquís vár. majora et margine in tegerrima plana, rarius subtevoluta et obsolete crispatoundulata. Gapitula cerasum subæquantia, bracteis floribustrue carneis vel purpurascentíbus rarius albidis. (v, s.)

8. brachiatum (Meisn. l. c. p. 61), folis ovatis oblongisve basi cordàtis vel rarius subbtruncatis subtus in nervo venisque hirtellis, coryinhis laxe paniculatis, jedunculis gräcilibus patulis subeglanduloso-seabriusculis, capitulis parvis, "bractẽis flore hrevioribus sæe obtusis. In Nepaliả (Wall. n. 1705, A: et F.; ex parte,'1706 I), Khasya et Assam (Wall.! Griff. n. 120!), Cochinechinâ (Gaudich.l In herb. DC.), Jàva (Hoffmansegg, n. 157 ! etc.). P. bracliatum Poir ! dict. 4, p. 15, Lam. ill. t. 315, f. 4, Meisn. mon. p. 59. P. patens Don fl. Nepal.p. 73 , Méisn: mon. p. 60. P. corymbosum Willd. d. asperum Blume bijdr. py 534. Foliá inargine ssepe revoluto plcrumque crisjato-xel undulato-crenulata, petioli auriculis minoribụs snlpersistentibuis. Capitula pisum subsquantia, Hloribus albis? (v. s.)

r. intermedium (Meisn., t. c. p. 61), foliis glaherrimis, inferioribus ovalibus, saperioribus oblóngo-lanceglatis dasi subtruncatis vel subito attenuatis, corymbis paniculatis, Cæt. ut \& (Wall, 13. 1105, F, ex parte). Auriculæ petiolares subpersistentes, s'spe inæruales. (v.'s.)

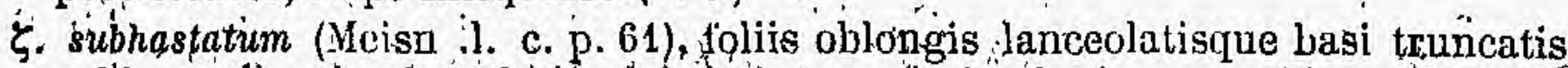
subhastatis vel subcordatis ghbris integerrimis planis, eorymbis, paniculatis paree eglanduloso-scabriusculis, capitulis parvis. In Nepaliâ et Assam (Wall.I n. $1605, F, 1600, A, B$, ex parte, 1707, B, Griffitli!). P. panduræformo herb. Handlt. e Goyal lara! (excl. sp. e Dongtola, cfr. $P_{n}$ microcephalum (3). P. corymbósum b. subhastátum Blume bijdr. p. 533 ? Foliq interdum subtus in nervo puberula, pétioli auriçulis parvis subdeciduis. Pẹdunculi abbreviati, pube minutâ cglandulosâ, capjitulis magnít. pisi. (v. s.)

n. corymbosum (Meisn. 1. c. p. 61), foliis oblongis lanceolatisque basi subito attenuatis integerrimis nervo subtus juberulo, corymbis simplicibus contrąctis (plerumque 3-ccphalis) hisplidulis eglandulosis, capitulis majusculis. In Javâ, Nepaliâ, Kamaon et Penins. (Whall. n. 1706, A, ex parte, Strach. et Wínteŕbott. herb. Himal. n. $36 \frac{1}{2}$ ! Wight!). P. corymbosum Willd.! sp. 2 , p. 452, Blume bijdr:- 533 (procipue var. a), Meisn. mon. p. 60 et 98 , Hassk. jul. Jav: Far. p. 218 *. P. zonulatam Nor. fide Hassk. in Tijd. íat. en phys. 8, p. 18. (v. v. c. et s. sp.)

Sectio vit. Ecinnocadoon Meisn in Watl.pl. As. rar. 3, p. 58, Endl. gen. p. 307.-Chylocalyx Hasskarl in Flóra 1842, Beibl. 2, p. 20.-Echinocaulos Hassk. cat. hort. Bogor. p. 85. - Polygoni sect. Helxine R. Br., èx parte. - Sect. Tiniar̀iæ $\$ 2$, Meisn. mon. p. 64 .

Calyx corollinus, 5-partitus, apterus, fructifer vix auctus immutatus. Stamina 5 , 6 vel 8. Stylus semi-2-3-fidus; stigmatibus exiguis. Achsenium lenticulare vel triquetrum. Cotyledones accumbentes. Herbe erectie vel subscandentes $\mathbf{i}$ caules graciles debiles smije 4-goni, infra nodos vel ubique retrorsum aculeolati, rarius subinermes; ochrew plerdnque tncmbranacoæ, cyllindrice, circuinscisso-truncatse, bási strigis vel aculeolis retrorsis coronatæ; folia basi truncata vel cordato-vel hastato-sinuata vel rariús attenuata; margitio nervoque scáhra vel spinulosa; pedunculi dichotomi spicis laxis filiformibus vel densifloris brevibus capituliformibus. 


\section{\$1. Trigyna, stylis 3 semiconnatis, achenio triquetro (cfr. P. horridum et rubricaule.)}

180. P. PERFoliatum (Liňn.' 'sp. 1, p. 521), ochreis foliaceis caưfe perfossis paten tibus, foliis peltato-triangularibus obtusis nervo subtus cum petiolo caưleque angulato-ramose pedunculisque retrorsum áculeatis, spieis solitariis brevibus densifloris, staminibus 8; stylo semitrifido. Z4 ! In Nepaliâ, Sillet, ete. (Wan. list, n. 1696 !), Jávâ (Blume, Zollinger, n, 848 !), Cochinchinâ (Lour.), Chinâ (Beechey), Japonia (Thunb.). - Burm. fl. ind. p. 90, t. 31, f. 2, Pluk. Alm. p. 87, t. 398, f. 1, Lam. ill.t. 315, f. 3, Roxb' h. Beng. p. 29 ; fl. ind. ed. 1832 , p. 2 . p. $288^{\circ}$, Blume bijdr. p. 535, Meisn. mon. p. 65, apud Wall, l. c. p. 59. Echinocaulos perfoliatus Hassk. cat. h. Bogor. p. 85, pl. Jav. rar. p. $220^{*}$. (v. s.)

181. P. Thun в E-R gII (Siels et Zucc. fl. Japon. fam. 2, p: 84.), caule decumbente ramoso inæqualiter angulato retrorsum aculeato, ochreis truncatis hirsutis ciliatis, foliis hastatis acuminatis inæqualibus villoso-strigosís, yetiolis brevibus aculeatis, "floribus in ramulis alternatim aggregatis " (spicis initerruptis?), bracteis ciliatis, stamínibus 7, stylis 3, achænio 3-gono lævi. @? In Japaưiâ. P. arifolium Thunb. fl. Jap. p.'168 * (non Linn.): Diagnosis nostra ad descr. Thunth. facta. Species a P. arifoliu Linn. procul dubio distincta achænio trigono, foliorum hirsutie et petiolis brevibus.

182. P. MEISNERIANU M (Giham, et Schl.! in Linnæâ 3, p. $40^{\circ}$, et 5, p. 90), caule subdichotomo cum ochrearum basi foliorumque nervis retrorsum strigoso vel aculeato, ochreis pilosis breviciliatis, foliis lanceolatis sensim attenuatis, sagittatis vel cordatis hirtellis vel glabriuscillis margine scabriusculis antrorsam ciliolatís, capitulis ovoideis oblongișve laxe paniculatis, pedunéulis dichotonnis glanduloso-hispidis, bracteiś glabriusculis, staminibus 5 stylisque ínclusis, achæenio obtusangulo lavi nitido faciebus ovatís convexis. $\%$ In Brasiliầ tropicâ et australi (Sellow! Tweedie !), prov. Minas Geraës (Mart.! Regnell, n. 233 !). - Meisn in Mart. fl. bras. fasc. 14, Polyǵ. p. 19, t. 1, f. 2. P. Chamissoanum Wedd. in Ann. se. nat. $3^{\circ}$ sér. 13, p. 254. P. refractum Mart.! mss. in herb. Acad. Monac. (v. s.)

B. Beyrichianum (Meisn. l. c.), ochreis glabriusculis, foliis lineari-lānceglatís subsessilibus basi cordatis. $\mathscr{C}$ In paludibus prov. Rio Janeiro (Beyrich! Karwinsky! Sommer! Lund!), Mexico (Schiede, n. 89!), Texas (Drummond, n. 177 !). Louisiañầ (Riddell I). - P. Beyrichianum Cham. ét Schì. ! in Linnæâ 3,

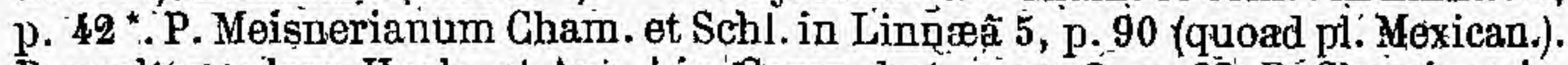
P. multangulare Hook. et Arn.! in Comp. hot. mag. 2, p. 62. P. Chamissonianum Steudel' (fide herb. Link.). P. geniculatum' Riddell! mss. in herb. Torr. et Arn. Vix varietas constans. Caulis aculeoli rariores et breyiores quam in P. Meisneriano, nec uncram in setulas elongati. Flores ex auctoribus paulo majores, nos vere interdum contrarium observavimus. (v. s.)

183. P. sa g It xa t u (Linn. h. Cliff. p. 151, t. 12, sp. pl. 1, p. 521), glabrum, caule prostràto vel scandente, angulis petiolisque retrorsum aculeolatis, ochireis angustis ciliolatís, foliis sagittato-lanceolatis, spicis subglobosis densifloris, peduneulis scabriusculis, bracteis ovatis vel lanceolatis imberbibus inferioribus acuminatis, staminibus 8 inclusis, stylo semitrifido demum subexserto, achænio subacutangulo nitido- lævi faciebus ovatis subconviexis. $\odot$ In Asiâ et Americâ boreali.-P. sagittatum $\alpha$ boreale Meisn. mon. p, 65. Variat aculeolis in caule petiolisque confertioribus rarisve, fortioribus minoribusve, petiolo ochreâ breviore vel pluries 'Iongiore, foliis 1-4 poll, longis, 3-12 lin. latiș, distincte, vel obselete pellucidopunetatis, apice auriculisque acutis obtuśisve, glabris vel rarius supra sparse adpresso-pilosiusculis, pedunculis minute retrorsum aculeolatis lævibusve, floribus albidis vel rubellis.

a. Sibiricum, foliis læevigatis margine nudis vix scabriusculis, nervo inermi vel subtus parce aculeolato. In Sibiriâ. - Gmel.I Sib. 3, p. 65, t. 13, f. 2, Lèdeb:! fl. ross. 3, p. 529. (v. s.)

B. Americanum, foliis margine setulis apicem spectantibus ciliolatis subtus in nervo densius aculeolatis. In Amer. bor., à Canadâ ad Floridam. - P. sagittatum Mich. fl. bor. Am. 1, p. 241, Torr. fl. 1, p. 407', Hook. fi. bor. Am. 2, p. 131. (v. s.) 
84. P. S rE Bondr, glaberrimum, caule k-gono, angulis cum foliorum nervo subtus - retrorsum aculeolatis, ochreis subimberbihus, folís sagittato-lanceolatis acutis margine nudis, sinu baseos profundo angusto auriculis acutis, petiolo brevissimo, capitulis geminatis racemosisıovatis dense paucifloris, pedunculis levíbus, bracteis ovato-øblongis acutis nudis plurifloris, staminibus 8 inclusis, stylo 3-partito demurn exserto, achénii angulis, obtusiusculis faciebus ovatis scrobiculato-punctatis. $\bigcirc$ ? In Japoniâ (Zollinger, n. 207!). P. sagittatum Thunb. fl. Jap. p. 167*?

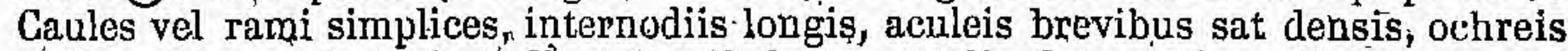
oblique? truncatis fissis. Folia 2+3 poll. logga, 6-8 lin. lata, petiolo 3 lin. longo vel superiorum nullo, margine lecvissimo nudo. Capitula 8-12-flora. Calyx 5-partitus tenuiter nervosus. A P. sagittato Linn. differt floribus dense capitatís trigynis achænio scrobiculato; a P. horrido foliorum margine levi, etc. (v. s. in herb. DC.,

185. P. MuRicatum (Meisn. mon. p. 74 *, et ap. Wall. 1.c. p. 58), caule basi radićante ramoso angulato cum petiolis parce asperulo vel aculeato, ochreis setosociliatís, folîis, ovatis oblongisvive acuminatis obtusis basi truncatis cordatis vel subhastatis glabris margine nervoque subtus scabriusculis; pedunculis subdichotomis asperulis levibusve, spicis brevibus filiformibus laxis, bracteis ovatis abutis subciliolatis 1-floris, staminibus 6, achænio majusculo acutangulo lævi nitido fäiebus ovatìs jlanis. $O$ ? In Nepaliâ et A'ssam (Wallich!). - $\mathrm{P}$. asperulum Wall. list, $\mathrm{n} .1724$ ! Affine P. arifolio et pedanculari, ab illo foliorum formâ, ab hoe spicis interruptis, ab utroque achænio triquetro, etc. distinctum. (v, s.)

3. auriculatum, foliis lanceolatis cordatis vel sagittatis, auriculis baseos divaricatis rotundatis vel rarius acutis, ochreis basidensius longiusque strigosis, 'pedunculis apice bracteisque glanduloso-pilosiusculis. In' itinere Assam leg. Griffith! (vi s. in h. soc. lịnn. Lond.)

\section{2. Digyna, stylis 2 (rarissime 3. cfr. $P$. horridum, rubricaule) semiconnatis, achoenio lenticulari vel rarius obtuse trigono.}

186. P. H ORRIDUM (Roxb. cat. h. Beng. p. 29 , fl. ind. ed. 1832, 2 , p. 291 "), glabrum, caule ramoso 4-gono cum petiolis brevibus costâque foliorum detse retrorsum aculeato sujperne dichotomo, ochreis angıstis setoso-ciliatis basi retrorsum strigosis, foliis cordate vel sagittato-lanceolatis margine scarioso retrorsum syinulosociliatis, spicis geminatis vel dîchotome paniculatis breve oblongis ovatisve densifloris, pedunculis glanduloso-scabriusculis, bracteis ovatis acuminatis ciliolatis obsolete striatis, staminibus 6-8, stylo semi-2-3-fido, achænio granulato-punctato biconvexo vel obsolete trigono, $\mathscr{F}$ ? In Nepalia, Kamaon, Bengaliâ, Sillet, Assam et utrâque peninsulà (Wallich list, n. 1697! Wiglrt! Metz, n. 969 ! Strachey et Winterbott. herb. Himal. n. 7l). - Mésn. in Wall. pl. As. rar. 3 , p $58^{*}$, Wight ic. t. 1803. P.isagittatum Don Nepal. p. 73. $\beta$ Indicum Meisn. mon, p. 65. A P. sagittato Linn. facile distinguitur jam spinolis in foliorum margine constanter retrorsis, basin spectantibus, ete. (v. s.)

187. P. нIs P DU DU आ (Blume bijdr. p. 535), caule subscandente cum ochreis petiolis nervoque foliorum subtus retrorsum hispidis, ochreis obtusis setose-ciliatis, foliis sagittatis, spicis subvirgatis... In montosis Javæ. Forsan P. horridi var.?

188. P. TE'T RA G.0 Nu M (Blume bijdr. p. 535), caule scandente 4-gono obvérse hispido. ochreis acuminatis nudis, foliîs ơvato-oblongis basi parum attenuatis glabris margine scabris, spicis subvirgatis, lloribus 6 -andris 2-gynis... In uliginosis editioribus montis Bürạngrang Javæ. Forsąn sequentis var., sed spicis ! subvirgatis discrepańs.

189. P. PEDUNGUAAE (Wallich ! list, n. 1718), eaule erecto? subinermi vel in angulis et infra nodos asperalo vel, retrorsum strigoso, ochreis subinberbibus basi tenuiter strigosis nudisve, foliis lanceolatis utrinque attenuatis margine non scarioso ciliolis antrorsis scabriusculis, petiola ochream subæquante, pedunculis dichotomis lævibus vel glandulgso-hispidulis̀, spicis breve oblongis subglobosisve, bracteis subimberbibus sulcato-striatis, staminibus 5, achienio biconvexo-subglo-

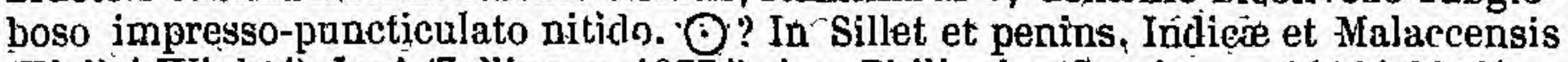
(Wall. ! Wight 1), Javấ (Zolling. n. 1377!), ins. Philippin. (Cuming n. 1484! 2281!)Wight ic. t. 1802. P. muricatum var-glabratum Wall. list $n .1697,61$ P. glabratum Meisn. in Wall. list. $\mathrm{B}$. 6285, P. dichotomum Blume bijrtr. p. 529.? Zolling. 
n. 614 ! (forma lrevis). Ab affinilìs, precipue P. harrido, caule subinermi, foliis hasi attehuatis, mạrginis cilir's apiesm (nec basin) spectantibus, etc. facile dignescendium. (v. s.)

3. subcordatum, folitis ovato-oblopgis basi subcordato-rolundatis yel brevissime attenuatis, hervo petiolis pedunculis cauleque inermibus læevibus, ochrearum basi parce retrórsum strigosâ. - In Javà. - An a P. tetragono Bl. satis distinctum ? (v: s. comm, a cl. de Vriese.)

190. P. R UBRICAULE' (Cham.l in Linnàeâ 8 , p. $130 \%$, glaberrimum, caule erecto angulato inermi; ochreis oblongis acutis inberbibus basi parce retrórsum aculeolatis inerimiluusve, foliis subsessibibus sagittato-lanceolatis acutis margine antrorşum scabriusçulis nèrvo subtus pẹtioloque retrorsum aculeolatis ssubtus glau. cescentibus, sjpicis geminatis subpaniculatis brevibus interruptis, bracteis breyibus laceris, staminibus 6 stylorfue 2 -partito-inelusis," achúnio "subglóbosotrigono laevi nitido angulis apice acutis infra obtusis. ()? In Brasiliâ (Sellow !) Meisn. in, Mart. fl. Bras. fasc. 14, Polvg. p. 20. Flor'es examinare nohis quidem non licuit, sed ex achenio distinete trigono procul dubio :3-gyni (nec 2-gyni, ùt ab auct traduntur) esse debent. (v. sp 4 unicum pauciflorum in herb. reg. Betolin.)

191. P. S т EL IGER U (Gham.! l. c. p. $131^{*}$ ), caule angulato, internodiis inermibus glabris, nodis petiolis nervague foljorum subtus parce retrorsum hispidis aculeolatisque, ochrois cylindricis truncatis hispidis ciliatis, foliis profunde sagittatis oblongis acutis anfrorsum ciliolatis juniorfbus jarce stellato-puberulis mox glabris vel nargine scabríusculis, pedunculis dichotomo-4-stachyis glandulosohispidis, spicís brevibus densifloris, bracteis imbricatis setoso-hispidis ciliatisque, staminibus 6-8 styloqùe bipartito inclusis, achanion... $\odot$ ? In Brașiliâ (Sellow!) Meisn. in Mart. 1 . bras. fasc. 14; Polyg.p. 20. Simillinum P. Beyrichii, sed distinetum omnibus partibus majoribus, pube stellatâ, etc. Folia majora 7-pollicaria, inoluso petiolo pollicari lobos basales deorsum productos ochreamque æquáté, pollisem lata, paginia inferiore semper 'glabriore nonnúnquam glaberrimấ: (v. $\mathrm{sp}$, ,pauciflorum sine fr. in herb. Reg, Berolin.)

192. P. s r i q su (R. Brown prodr. fl. Nov. Holl. p. 420), caule orecto ángulato cum ochrearum basi petiolis nervoque foliorum subtus strigoso vel aculeolato, ochreis cylindricis longis angustis bracteisque adpresse setulosis ciliatisque, foliis oblongo-lanceolatis acuminatis basi sagittatis subtruncatisve dense antrorsum ciliolatis utrinque parce setuloso-scabriusculis vel-grabrescentibus, spicis geminatis breve oblongis derasifloris; peduneulis glanduloso-hispidulis, bracteis imbri-

catis acutis, floribus 5-6- andris hemidigymis, achomio...... $\odot$ ? In Novâ Hollandiâ orientali et Tasmanniâ. (R. Br., A. Cunuingh. ! Gaudich! Verreaux l). $\rightarrow$ Meisn. mon. p. 85. P. arifolium Spreng. syst. 2, p. 258 . Habitus P. sagittati; sed strige tenuiores et longiores, plerumque densiores. Gaulis subsimplex. Oeln rea subphollicares; parte adpresso-pilosiusculpe. Folia 2-3 poll. longa, 10 h. lata, actita, utrinque minute puberula vel excepto nervo venisque glabra, lobis baseos' divanicatis acutis vel obtusis, petiolo circ. semipollieari. Spica subsemipollicares. $\left(v_{4}, s_{1}\right)$

193. P. A R IFOL I U (Linṇ. sp.I. p. 521), caule erecto angulato cum ochrearum basi petiolisque longis parce retrorsum aculeolato, ochrels brevibus pilosiuseulis ciliatis, foliis hastatis acuminatis lobisque baseos divaricatis acutis adpressę pilosiysculis vel subglabris, spicis axilarifu' terminalibusque subsolitaris brevibús hasi intorruptis, pedunculis subulanduloso-hilspidulis, bracteis ovatis iniberbibus inferioribus acuminatis 1-2-floris, floribus .6-andris hemidigynis, achani lentieularis facichus ovato-rhombeis levilius. $\odot$ ln Americâ bor. temper. ef calidiore. -Pluk. Amalth. p. 87, t. 398, f. 3, Willd. sp. 2, p. 453, Mich. fl. bor. Am. 1, p. 241, Torr. 1. 1, p. 407*, Mcisn. 17un. p. 65 (excl. syn. Thunb). Herha dehilis. ramosa, ochreis eirc. sqmipollicaribus tenerrimis truncatis mox lageris. Folia deltoidea vel late hastata, $1 \frac{1}{2}-4$ poll. Ionga, basi $1-3$ poll. lata truncata yel sinu lato leyi incisa, auriculis nume late friangularibus pollicarib̧us acutis, nunc (versus apicem caiulis) brevissimis ratundatiș vel nullis, petiolo 1-2-pollicari vel foliorum șperioruni multo liraviore. Spice cire. semipollicares, interdum geminatæ. Calyx demum subdeciduus. Achunium 2 lin. longum latumque. (v. s.) 
Sectio Virr. Trinami Meisn, monogr. p. 43 et 62, t. 4, P. Q. (exol. \$ .2). et in Wall. pl. As, rar. 3, p. 62, Endl. gen. p. 307, Webb et Berth. phyt. Canar. sect. 3, p. 221. - Fagopyri sp. Tourn. inst. p. 511, Moench meth. p. 290. - Helxines sp. Linn. gen. ed.1. - Bilderdykia Dumort, fl. belg. prodr. p. 18.

Calyx semilierbacens, virescenti-albidus; 5-partitus, fructifer auctus, iobis. 3 exteriaribus navictilaribus vel dorso in alam membranaceam diaphanam expapsis. Stánina 8 inclusa. Squamulæ perigynæ nullæ.: Styli 3 lịev́issimi vel subnulli, stigmatibus captitatis vel rarissime finbriatis. Achænium inclusum, triquetrum. Cotỳledones accumbentes. $(=0)$ - Herbo vel suffruticos inermes, plerqmque volubiles, radice fibrosâ, ochreis bracteisque membranaceis breve cylindricis oblique truncatis haud ciliatis, foliis cordatis hastatis vel sagittatis, petiolis sæpius basi subtus glandulą̧ porifợmi munitiș. (Meisn. mon. t. 5, fig. 18, d,)

81. Calyx apterus, demum modice auctus trigonus, angulis obtusis vel carinatis rarius obsolete alatis. Siggmata 3 subsessilia; capitatu. - Herbce minute puberulo vel demum glabrescentes. Caules volubiles. Folia cordato-avata acuminata, sinu lato profundo, lobis obtusis vel subacutis.

194. P. cIu INoDE (Mich. fl: bor, Am. 1, p. 241), ochreis bási coronâ ciliorum defle* xorumi decidueram cinetis, racemis terminalibus janiculatis axillaribusque simplicịbus laxis, 'achıenio læyi nitido apice subexserto. $భ$. In Amer. bor. a Ganadâ ad Floridam. - Törey l fl. 1, p. 406*, Meisn. mon. p.'63, t: 5 , f. 18-20, Höb́k. fl. bor , Am. 2, p. 131. Bedicelli bracteâ longiores, medio articulati, calyce fructifero medioeri aptero glabro dimidio breviores. (v. v. c. et s. sp.)

195. P. G GN v c yul y s (Linn. sp. 1, p. 522), prostratum vel scandens, ochrearum basi nudâ, florum fasciculis axillaribus vel racemos simplices interruptos apice aphyllos formantibus, achænio subopaco granulato-striato. $\odot$ In agris et incultis Europa totius, Caucaso !, Așiâ boreali !, Kunăwür (Royle), Afghanistan (Griffith n.1715! journ. 1008), Japoniâ (Thunb.), Americâ bor.l - Fl. Dan. t. 744. Engl, Bol. t. .941, Meisn. mon. p. 63, t. 4, P, Hook, fl. bor. Am. 2, p. 131, Babingt. in Linn. Trañs. 18, p. 112, Ledeb. A. ross. 3, p. 528. P. convolvulaceum Lam. fl. fṛ. 3, p. 239. Fagopyrum carinatum Moench meth. p. 290. Bilderdylkia Convolvulus Dumort. fl. belg. prodr. p. 18. Pedicelli appice articulati, calyce fructifero majusculo optuse trigono vel rarius obsoletealato duplo breviọres. (v. v.)

\$ 2. Calyx fructifer valde auctus, late álatus, alis diaphanomembranaceis apice latis rotundat is basi in pedicellum defluentibus.

Caules volubiles, scandentes. Folia cordato-ovata, acuminata. Stigmata 3 subsessilia, capitata.

196. P. D u Me т o R u (Linn. sp. 1, p. 521), glabrum, racemís axillaribus folio longioribus simplicibus aphyllis vel basi foliosis laxis vel interruptis, pedicellis infra

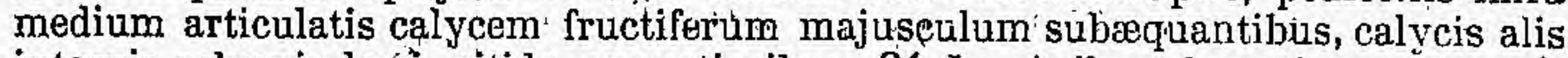
integris achænio læúi nitido angustioribus. $\not$ In sepibus dometisque Europæ mediæ et australis, Cauçasi !, A fghanistan (Griff.! n: 70, journ. 1040, 1719), Asiæ bor. - -Flor Dan. t. 756, Meisn. mon. p. 63 (excl. syn. P. scand.), Engl. bot. suppl. t. 2811, Ledeb. fl. ross. 3, p. 528. Fagopyrum membranaceum Moench meth. p. 290. F. dưmetorum Şchreb., ficle Stéud. Bilderdykia durnetorum Dumort. fl. belg. prodr, p. 18. Achpenium 2 lin. longum. (v. v.)

197. P. S C AN DENS (Linn. sp. 1, p. 522), glabrum, racemis axillaribus terminali busque simplicibus àpbylliș vel basi foliosis laxis vel interruptis, fasciculís multifloris, pedicellis medio articulatis calyce fructifero magno duplo brevioribus, alis integris apice dilatatis achænio lævi nitido sublatioribus. $\%$ In sylvis Ameriçe bor. a Canadâ ad Floridam, Louisianam et Missouri (Mich., Fraser! Moser ! Bramfield! Drummond $a_{1} 150$ ! Rugel n. 562 ! etc.). - Mich. fl. bor. Ama. 1, p. 240, Ell, slseteh 1. p. $459^{*}$, Torr. fl. 1 , p. 406 . Omuia fere P. dumetorum, sed calyx 
fructifer dimidio vel plus major, pedicello, duplo longior, alis apice latioribus et sinu distinctiore patulo ab invicèm separatis subcrenatis, et achænium brevius (1 $1 \frac{1}{2}$ lin. longum). Ala una vel rarius 2 vel omnes interdum desunt, fide:A. Gray in pl. Lindh. p. 51. (v. v. c. et s. sp.)

198. P. CRIS TA T M (G. Engelm. et A. Gray pl. Lindheimer in Boston Journ. of nat. hist. 5, p. 51, n. 296), floribus axillaribus glomeratis vel racemos fóliosos laxas formantibus, calycis fructiferi alis crenato-incisis, achænio lævi nitido. $\mathscr{F}$ ? In Texas (Lindheimer). - Walp. Ann. 3, p. 286. A præcedentibus præeter calýis alas differre dicittir foliis minus cordatis, magis triangularibus, basi subtruncatis, margine scabris, achænio minore (1 lin. longo) et caulè angulato-striato.

199. P. PTEROCARPUM (Wall. list $n .1690 \mathrm{l}$ ), floribus in axillis $3-5$ aggregatis aut in racemes axillares ôreves subsimplices páucifloros díspositis, pedicelliş própe medium articulatis calycem fructiferum magnnum æquautibus, alis integrịs, achế:nio granulato-striato. $\mathscr{Y}$ ? In Kaman-et Garwhal (Blinkw' $\downarrow$ Wall., Strachey et Winterbottom herb. Himal. n. 27 !' 28 !), Mussooree (Royle). - Meisn. in Wall. pl. As. rar. 3, p. 62, Babingt. ịn Linn. Trans. 18, p. 113*. A. P. dúmetorum et affinibus bene distinctum-inflorescentiâ pauciflorâ, achænio haud lævi et calyce fructifero quam illius dimidio majore. (v. s.)

200. P. M U L T I F L R U M (Thunb. fl. Japon 1, p. 169") glabrum; rhizomate tuberoso, paniculis axillaribus terminalibusque folio longioribus fere aphyllis laxifloris, phachi puberulä, pedicellis infra medium articulatis calyce fructifero mediocrí brevioribus, alis latis integris, achænio lævi nitidissima. $\nvdash^{4}$, In Japonia (Thunh, Zollinger. n. 212 !), Chinâ (L. G. Staunton! Fortune, A, 22 !). - Willda, sp. 2, p. 456, Meisn. mon.p. 64, t. 3, Q. P. Chinense Hauttuyn Pfl. Syst. 6, p. 453, t. 49, f. 3 (rion Linn). Pleuropterus cordatus Turcz.! Deead. 4 et 5 in Bull. Soc. Imp. Nat. Mosq. 4848 , n. 1 (ex Florâ 1848, p. 714. Ovulum false deseriptum, erectum (nec' inversum). Calycis fructiferi (magnit. P. dumetorum) facies, ovales basi subito cuneato-attenuatæ, apice profunde cordatæ, sinu lobis quasi decussantibus obtecto et abscon. dito. A præcedentíbus cæterum jam inflorescentiâ paniculatâ distinctissimum. (v. s. in h. DC.)

* Caules erecti (niec volubiles). Folia non cordata, Styli 3 breves, stigmatibus brevissime fimoriatis.

201. P. cuspidat Tu (Sieb. et Zuccar. Fl. Japon. fam. nat. 2, p. 84), glabrum, ćaule valido ramoso, ochreis brevisșimis deciduis, foliis petiolatis late ovatis vel ovatooblongis acuminatis basi truncatis vel breve cuneato-attenuatís utrinque elevatoreticulatis glabris, racemis axillaribus filiformibus laxifloris fasciculatis vel paniculatis vel rarius solitariis, bracteis ovatis obtusis plurifloris rhachique pulvereopuberulis, pedicellis capillaribus infra medium articulatis calyce fructifero, late 3-alato brevioribus, stylis subexsertis, achænio.... భ 4 . In Japoniâ (Siebọld, Zollinger n. 201!). P. Sieboldi hort. nonnull. De Vriese in Nederl. Kruidkund.Ar: chief. 2, p. 25k * et in Jaarb. d. Koninkl. NederI. Maatschap. van Tuinb. te Leyden 1850, cum ie. Flora 1851, p. 523. Ĺindl, et Paxt. mag. 1, p. 137 cúm fg. Paxt. Fl. Gard. 1852, 1, p. 137, fig. 90. Planta habitu et stigmatibus ad Miihlenbeckiam accedens, sed reliquis notis, præcipue floribus hermaphroditis et calyce fructifero sícco 3-alato longe recedens et omnino præcedentibus adsocianda. (v. v. e Japeniạ introd. in hort. Lindl. et. s. sp. in hẹrb DC.)

\section{Sectio Ix. Aconogonon Meisn. Monogr. p. 43 et 55 (excl. $\$ 2$ ), $t, 3, G$, et in Wall. pl. As. rar. 3, p. 61, Endl. gen. p. 307.}

Calyx corollinus, 5-partitus, eglandulosus, demum parum auctus, immutatus. Stamina 8. Stylus brevissimus, trifidus, stigmatibus capitatis. Achænium acutangulo-triquetrum, inclusum vel șemiexsertum, nitidım. Cotyledones accumbentes $(0 \Rightarrow$ ) albuminis sulco immerse. - Herbe vel frutices Europæ,-A sie et reg. Arcticæ, ochreis bracteisque membranaceis vel hyalinis oblique truncatis eciliatis, floribus racemoso-paniculatis, lacteìs vel subflavescentibus demum sæpe erubescentibus,

202. P. м о L e (Don prodr. fl. Nepal, p. 72), fruticosum, ramosum, undique molliter adpresso-pubescens, ochreis longis petiolum æquantibus, foliis oblongis utrinque 


\section{POLYGONÚM. POEYGONACEA (AUCTOR MEISNER).}

attenuatis subtus sêricéglanatis rarius hispidulis supra demum glabratis, panieulâ surbsimplici aphyllâ, racemis filiformibus laxis, bracteis 3-5-floris pedicellos breyes calycemque parvum glabrum æquantibus, calycis lobis æequalibus ovalibus, achænii inclusi nitîdi faeiebus ovato-rhombeis minutíssime punctatis. $\hbar$ In Nepaliấ et Pữdua (WWall. list 11. 1685, A I B ! ex parte), Meisn: mon. p. $56^{i}$ et ap. Wallich 1. \& : p. 61 (ex parte et excl. syi. Blume), Lindl. in' Bot. reg. 1841, misc. p. 66, Wight ic. t. 1807. (v: s.)

203. P.,P oL X A THós (De Bruyn, in pl. Jungh. p. 304*), ochreis internodio sublongioribus acutis cauleque ramoso hirssutis; foliis ellipticis breve petiolatis utrinque attenuatis acuminatisve subtus sericeis supra pilesiusculis parallele nervosis, paniculầ ramosissimầ diffusâ ramis divaricatis dense hirsutis, calyce patulo, achanii' rítidi rugulosi angulis rotundatis faciebus oblongo-ovatis con' eavis. $\mathscr{H}$ : In Javâ,(Jungh). Affine P. molli et paniculato, ab illo recedens achrenio epưnctato basi haud rotundato, ab hoc' fruetus formấ. Ochreæ bipollieares; interdum ajice spiraliter tortæ. Petíoli 9 lin. longi. Folia 6-7-pollicaria, 3 poll. lata. (De Bruyn).

204. P. R U D , fruticosum, ramis flexuosỉs sulcatis petiolisqúe retrorsum adpressohirsutis demum glabris, ochreis amplis parce adpresso-setulosis basi persistente truncatâ petioluim subæquante, foliis elliptico-oblongis acuminatis basi attenuatis ciliólatis tenuiter -pilosiusculis supra scaluriusculis subtus præter nervos demum. glabriusculis, nervo subtus dense lirsuto, paniculis folia subæquantibus ramis bracteisque patulo-hispialulis inferioribus ramosis, bracteis parvis 1-3-floris pedicellos subrequantibus; calycis lobis æcqualibus ovalibus, achænli.inclási nitidi faciebus 'ovato-rhombeis minutissime punctatis. 占. In Punduâ (Wall.! list, $\mathrm{n} \cdot \mathbf{1 6 8 5}$, B ex parte) et Khasya (Griffith! n. 119). Exceptís ramis egregie.flexuosis et distinctius sulcatis demúm feré glabris et foliorum pubescentiæ indole; omnia fere P. mollis, sed transitum ad hoc non observavimus. (v. s.)

205. P. FRoND'os M r glaberrimum, basi suffruticosum? ochreis laxis, folis petiolatis ovato: vel ovali- oblongis acuminatis basi rotundatis, paniculis folium subsequantibus subsessilibus, bracteis parvis 1-4-floris pedicellos demum crassiusculos subæéfuantibus, calyce parvo fruçtiféró coriaceo ovato-globoso achænium subæquante, achænio nitido angulis obtusiusculis faciebus ovato-rhombeis minute puncticulatís. $2 \mathrm{In}$ Kamaon, alt: 7500 ped. (Strachey et Winterbottom herb. Himal. n. 34 !). P. Hayii Strach. et Winterbott.! mss. sed hoc nomen rejiciendum, ne confundatur cum P. Hagei Royle, quod certe distinctum. - Caules vel rami stricti vel passim flexuosi, tenuiter lineati. Ochreæ pollicares, teneræ, tenuîter 6-8-nerviæ; demum fusces laceræe vel horizontaliter truncate. Fólia incluso petiolo $0^{-1}-1$ poll.

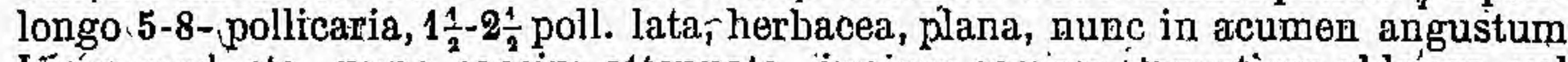
breve producta, nunc sensim attenuata, juniora semper ángustiora oblonga vel lanceolata et basi angustata. Cæet. P. mollis, a quo præter omnium partium (immo navellarum) glabritiem differt foliis adúltis subduplo latioribus basi semper rotundatis vel emarginalis (nec in petiolum decurrentibus) et petiólis longioribus. Achænium olivaceum.' (v. s. in h. Soc. Linn. Lond.)

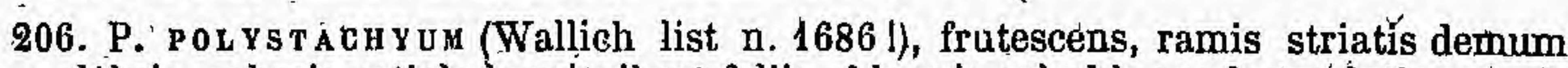
glabris, achreis petiolo longioribus;-foliis oblongis vel oblongo-lanceolatis acuminatis glabris vel subtus incanis, paniculis laxis, racemis subcontinuis, bracteis 1-2- floris, pedicellis exsertis tenuibus; calycis demum maǵni lobis inæqualíbus, achrenio...... 5 In Sirmore, Kamaon alt. 12,000 ped., Garwhal (Wall., Strach. et Winterbott. 1. c. n. 32 ! 33!), Cachemire (Royle), - Meisn. in Wall. pl. As. rar., 3, p. 61. Babingt. 1. c. p. 111*. Simillimum quidem P. molli, sed facile idignoscendum calyce triplo majore patentissimo, lobis 3 interioribus orbicularibus, exterioribus 2 dimidio minoribus ovalibus, pedicellis triplo longioribus, ete. Rami stricti vel apice flexuosi.

ia. glabrum (Meisn. '. c.), omnibus partibus glaberrimis. (v. s.)

$\beta$. pubescens (Mfeisn. 1. c.), caule, ochreis, petiolis, pedunculis bracteisque adpresse puberulis pilosisvè, foliis subtus subsericeo-lomentosis supra'gläbriusculis. (v. s.)

207. P. PAN ICUL A T U M (Blume bijdr. p. 533), suffruticosum, ramis gracilibus strictis

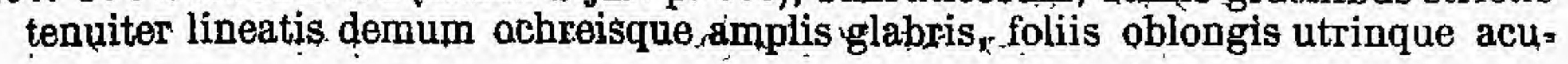


minatis ciliatis glabris vel subtus in vepis parallelis minute puberulis, paniçulis amplis laxis undique glabris, bracteis parvis acuminatis 1-3-floris, pédicellis exsertis calycem æquantihus, calycis lobis æqualibus, achænio inclús, nóltido faciebus ovato-rbombeis ninute puncticulatis. I In,sylvis mont. altiorum Javæ (Blume, Zollinger n. 1690 !). - Meisn. mon. p. 95, Be Bruyn in pl. Junghutin, p. $303^{*}$. Rami juniores pärce puberuli. Ochrearum basis persistens truncata petiolo multo brevior. Paniculiz rami simplices vel ramosi patuli debiles. Calyx fruetifẹr parum auctus, achæenium equans, clausus. A proximo P. polystachyo jam calyce multo

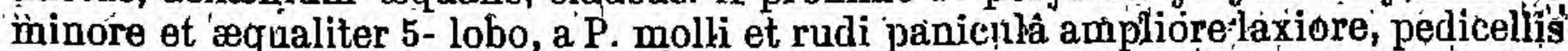
lóngíoribús ét płubesceńtiâ pareâ vel nullâ Tacile distinguendưm.' (v.s. in h. DG. et comm. a cl. de Vriese.)

208. P. HAGEI (Royle mss.) caula suffruticoso erecto suleata cum ramis gchreis pedunculisque scabrido-piloso, ochreis longis internodio brevioribus laxis laceris, foliis brevissime petiolatis lanceolatis apice lineari-attenuatis ciliatis suhfus lapata-velutinis supra pubescentibus, paniculis amplis aphylis ramis subsimplicibus, bracteis 3-6-floris pedicellos ppope apicem articulatos suhæquantibus, calycis lobis inæqualibus obtusis exterioribus 2 angustioribus, achæenio breviter exserto minutè puncțato: 5 In Nagkandâ (Royle). - Babingt. in Linn. Trans, 18, p. $110^{*}$.

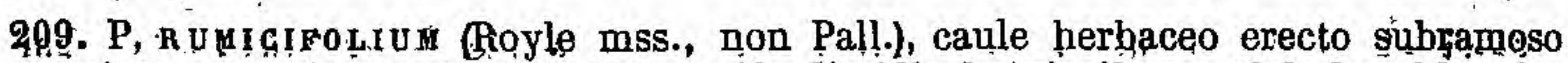
striato, ochreis longis laxis internodio dimidio brèvioribus petiolo brevi longioribus laceris fasi dense retrorsum pilosis nervis pubescentibus, foliis ovatis vêl cordatis pilosis vel supra subglabris margine undulätis ciliatịs, paniculæ ramis subsimplicibus, bracteis sub-1-tloris basi pilosis pédicelle brevioribus, calycis lobịs aqualibus obovatis obțisis genitalia dimidio superantibus, ąchænio...... \% In Kunawur (Royle) - Babingt, 1. 0. p. $112^{*}$.

a. ovatum (Babingt. l. c.), foliis ovatis subtus pilosis supra cauleque glabriusculis. P. ramoso-spicatum Klotzsch! in pl. princ. Walqemar t. \$7 inef: (v. s. sp. lect. a Dr. Hoffmeister'! in h. Princ. Waldemar.)

$\beta$. cordatum (Babingt l. c $)$, caule retrorsum piloso, ochreis densius pubescentibus, folits cordatis (quam in $\alpha$ multo minoribus) minus undulatis utrinque gequaliter brevipilosis.

$\gamma$ ? oblongum, caule glabro, ochreis pilosiusculis (nec basi densius pilosis) foliis lanceolato-oblongis utrinque acuminatis planis pilis brevibus adpressis supra racioribus cọnspersis subtus discoloribus, paniculâ parvâ, rhachi bracteisque hispiduliș. - In Kiamaon (Straehey et Winterbottom herb. Himal:.n. 35!). Folịa adulta 3-5-pollicaria, 16-20 lin. lata, haud uudulata, petiolo 3-5 lin.

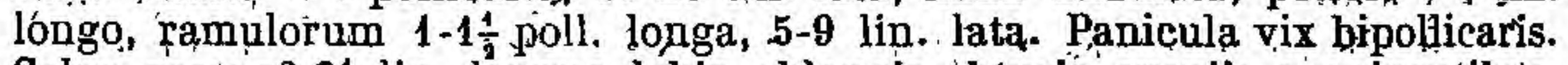
Galyx roseus $22 \frac{1}{2}$ lin. longus, lobis oblongis obtusis eveniis conniventibus. Genitalia inclusa. (v. s. in h. Soc.'Linn. Lond.)

210. P. тов т y as y (Don? Babingt, in Linn. Trans. 18, p. $110^{*}$ ), totum sericeo-pilosum, caule frutícosô ramøso sulcato, ochreis laxis dimidium internodium sühìquantibus laceris, foliis sessilibus orbicularibus vel ovatis, paniculis parvis condensatis, hracteis 1 - floris pedicello haud articulato longioribus, calyoe glabro, lobis obtıssis interioribus 3 orbiculatis exterioribus ovalibus angusfigribus, ache. . Aip..... ந In Nepalia (Don), Kunawur (Royle). - Don prodn. fl. Nepai, p. 71, Meiśn. map. p. 76, teste Baḅington, sed descriptio.Donịi aḷhorret \& spicis geminis' brevissimis tenuifloris.

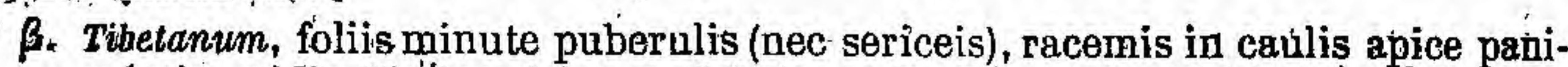
culatis, pedicellis bracteisque glabris. - In Tibet, alt. 15,000 pedd. '(Strachey et Winterbottom herb. Himal n. 47!). Caules sesquipedales, a medio subcorymboso-ramosi, cum ramiš leviter sulcato-lineati minute puberúli, inferne

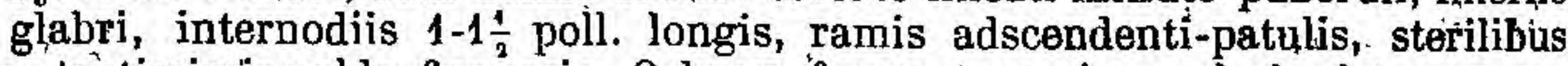
patentissimis valde flexuosis. Ochrea fuscæ, tenerrime vel obsolete venosostriata, internodio breviores, diu persistentes. Folia rigidiuscula nollicaria, 7-10 lin. lata, utrinque obtusa vel basi subcordata semiamplexicaulia, superióra dimidio minora basi angustata, nervo venisque primarís subtus léviter prominulis supra obsoletis, venulis invisibilibus. Racemi breve pedunculati $\frac{1}{2}$ ( poll. longi; folia superantes, termigales pauciramosi; axillares simípliéts șplitarii vel gemini, pedunculís puberulis, pedicellis subsolitariis braetésm 
glabriusculam -aquantibus . imà basi obsolete articulatis floreqúe glabris.

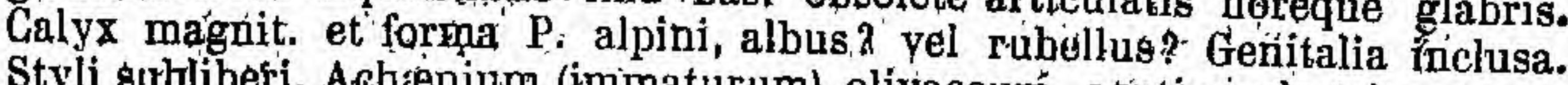
Styli gubliberi. Achionium (immaturum) odiwaceum, acutiuscule triquetrum. Planta junior pube brevi molli dense tecta, subcanescens. A plantâ Donianâ, quamvis a descriptione apud Don et Babingt. pluribus notis recedat, vix spe-

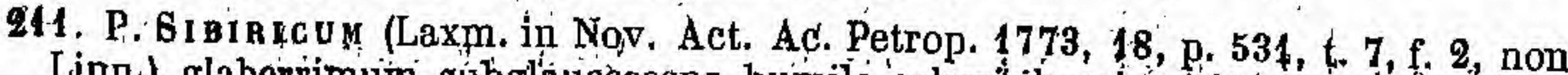
Linn), glaberrimuin, subglaucescens, humile, ochreís longiusculis angustisyenosostriatis persistentibus diu infegris, foliis crassiusculis petiolatis lanceolatis basi subito cuneato-attenuatis trumcatisve vel breve obtuséque biauriculato-hastatis planiis 1 -nerviîs subeveníis; racenis terminalibus simplicibus solitariiñs vel panicujatis, bracteis parvulis 3-6-floris demum remotiusculis, pedicellis apice articulatis calyce fructifero mediocri hutante brevioribus, achæenio incluso. 2 in salsis inde a sibirif arctiga usque ad Davuriam et Mongoliam Ghinensen $/$ Pallas I Fisch. ! Bungel Turcz. Tetc.) - Ledeb. I fl, ross, 3,p. 527. P. hastatum Murr. in Comm. Goetting. 1774, 5, p. 37, t. 6, Leddeb: fl. Alt. 2 , p. 80, ic. t. 361. P. crassifolium Miurp, in Linn. syst. veg. ed. 14, p. 378 , Willd. sp. 2, p. 453, Meisn. mon. p. 58 . P. Fumicifollum Pall. In . Willd. herb. n. 7672 P. arcticum Pall $t$ in Willd herb. n. 7675, Spreng. syst. 2, p. 258. P., coarctatum Pall. I in Willd. herb. n. 7677, Meisn. mox. p. 58, Cham, et Sebl. in Linnea 3, p. 39 (noy Pougl,). Prgcedenti âfine, sed jam foliis 'bene distinctum. Habitus Rumicum et Mựhlenbeckiarum

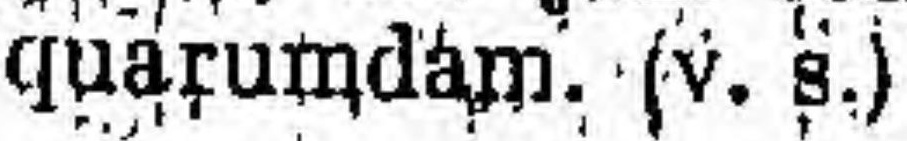

312. P, SERICEU (Pallas Reise 3, p. 286, 320), totum pube densâ brevi molli adpressa "sericeq-canum, caule subflexúoso ramoso, ochrẹ mediocribus laxispersistentibus, follis subsessilibus dvali-oblongis lańceolatisque basi attenuatis pube subtus densiore, racemis terminalibus et in summis axillis simplicíbus brevibus, inferiofibus 'sæepe fasciculiformibus, bracteis pedicellisque brevissimis, calyce mágno puberulo, achønio.!... Z In Sibiria Baicálensi et pavuriá (Pall., Bunge I Turez. 1).-Gmel. Sib. 3, p. 58, t. 9, f. 2, Willd. \$p. 2, p. 452, Meisn. mon. p, 58, Chan. et Schl. in Linned: 3 , p.39, Ledeb.l fi. ross. 3, p. 527. Caulis erectus vel adscendens, oehreis demum laceris. Folia $1 \frac{1}{2}-3$ poll. lơnga, $\frac{1}{2}-1$ poll. lata, acutiusoula; subtus magis sericeo incana. Racemi laxiflopi vix polliceń exce-
dentes. Calyx 2 lin. longus, rubellus? (vis.)

213. P. P O Y O OR H U M (Ledeb. I fl. ross 3, p. 524, excl. $\alpha$ et syn. P. ochreat. Willd.), exule erecto ramosó, ochreis amplis pubescentibus venoso-striatis mox laceris subdeciduis, foliis breve petiolatis ovatis oblongis lanceolatis linearibusve basi attenuatis vel rotundatis ciliolatis pubescentibus glabrisve, paniculâ terminali folia superante, racemis compositis multifloris, bracteis parvulis '2-3-floris, pedicellis exsertis 'fructiferis calyce brevioribus,' achæaio calycem aquante vel vix

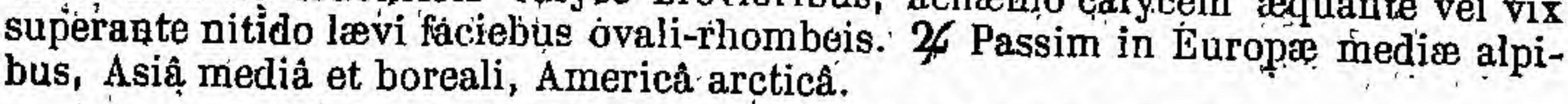

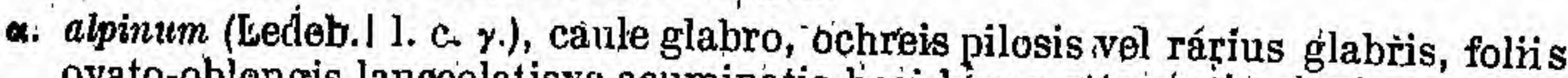
ovato-oblongis lanceolatisve acuminatis hasi breve attenúatis planis tenuiter

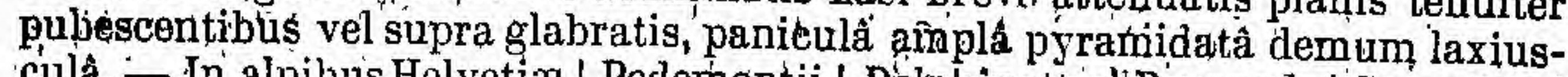
culâ. - In alpihus Helvetia ! Pedemontii ! Delphinatus !' Pyrenæis ! Carpathis ! Caucaso, Rossiẩ mediâ, Davuriâ, Sibíria l Afghanistan (Griff:l). P, alpinum All. Pedem. 2, p. 206, t, 68, f. 1, Willd. sp. 2, p. 451, Meisn.mon. p. 56, t. 3, G. P. Sibiricum Limn. fil. suppl. ps. 228 (non Rall.) P. acidum Pall. Reise 9, p. 25 etc., 3, p. 316 (fide Ledeb.). P. divaricatum Vill. Dauph. 3, p. 322 (non Linn.) v. v.

3. undulatum (Meisn mon. p. 56), caule erecto cum ramis erecto-patentibus glabró, ochreis pilosis, foliis ovato-oblongis lanceolatisve acuminatis basi breve attenuatis margine sæpius undulatis utrinque pilosis vel supra soabrius-

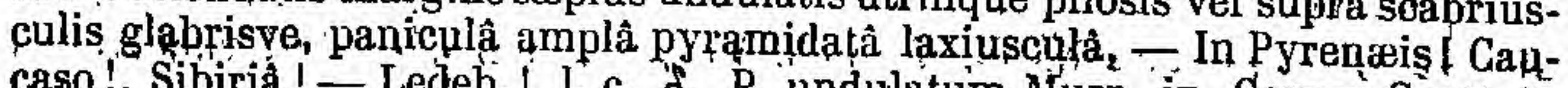

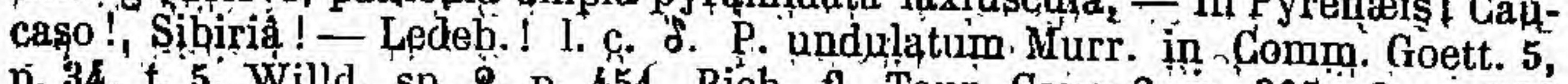
p. 34, t. 5 , willd. sp. $2, p_{i} 451$, Biob. fl. Taur. Cauc: $2, \mathrm{p}, 305,3$, p. 286 (excl. syn. Lipn. et Gmel.). P. ciliatum Willd. | herb. D. 7679 (nọn Lour.). Variptatis nomen vix meretur. (v. s..)

\%. lapathifolium (Ledeb.! l. e. p. 525, z.) caule erecto, ramis erecto-patentibus, inferioribus sterilibus abbreviatis, ochreis pilosis, foliis avatis ciliatis subtus

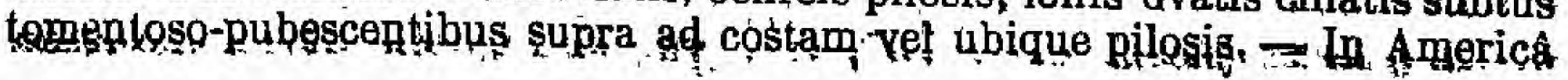


arcticâ ad sinum Kotzebue, etc. (Eschseholtz! Chamisso I). P. alpinum $\gamma$ lapathifoliưm Chàm. et-Sehl. ! in Linnææâ $\mathbf{3}$, p. 33, Hook. et Arn. Bot: Beech: p. 129, Hook fl: Bor, Am. 2, p. 131. (v. s. in h. Ledeb. et reg. Berolin.)

ઈ. diffusum (Ledebil l. c. n), ramis elongatis patentissimis, óchreís hîrsutis, foliì ovato-vel elliptico-lanceolatis cauleque subflexuoso pilosîs, paniculæ ramis superioribus simplicibus, inférioribus remotiusculis subramơsis. In SibiriâUralensi. P. diffusum Pall. in ,Willd. herb. n. 7674 ! Spreng - syst. 2, p. 255. Folia 1-2-pollicaria, 4-8 lin. lata, basi rolundatâ subșessilia, utrinque pủbescentia. (v. s.).

є. frigidum (Ledeb.1 1.,c. §), caule brevissimo, foliis oblongis ciliatis cæterum - ochreisque subglabris, panicalâ paryâ contractâ. In sinu'S. Laurentii (Cham.! Eschscholtz !). - P. aipinum ófrigidum Cham. et Schl.! in Linnæâ 3, p. \$̊. Hook. l. c: (v. s. in herb. reg. Berol. et Ledeb.)

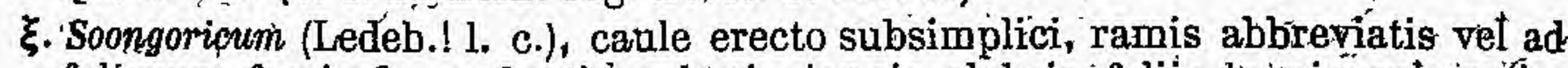
foliorum fasciculos reductis, ochreis longis glabris, foliis longiuscułe pefiolatis ovatis subcordatis glabriusculis, pániculà laxâ, racemis brevibus. In Sibiriæ Altaicæ deserto Soongoro Kirghisico (Schrenk! Karelin et Kirileif în herb. Soc. imp. N. C. Mosq. n. 1915 । P. Songaricum -Schrenk ! enum. pl. nov. 1, p. 8. (v. s.in h. Ledeb: et Mart.)

n. salignum (Meisn. mon. p. 57, $\delta$, sub P. divaricato), caúle gracili ramisque erectis glabris, ochreis brevibus glabris vel basi pilosiúseulís, folíis lanceolatis basi attenuatis vel superioribus sublinearibus, ciliatis glabris vel.tenuifer pilosiusculis vel scabriusculis, panieulâ amplầ laxấ, -pedicellis exsertis, achænio breviter exserto. In Sibirịa. - Ledeb I fl ross. 3, p.-524, $\beta$, Gmel. Sih, 3, p. 55, t. 9, f. 1. P. salignum Willd. enum. p. 430 (non herb. n. 7629, fol. 1 et 2 , cfr. P. divaricatum $\gamma$ ), P. angustifolium Pall. Reise 3, p. 230, 320, fide Ledeb. (non Poir. nec Don), P. crispum Hornem.! h. Hafn. 2, add. p. 962, P. ochreatum Willd. herb. n. T631! (fol. 1 glabrum, et fol. 2, pubescens), vix sp. pl. 2, p. 544, nec Lipn. Planta, saltem qualis in hortís nostris occurrit, forsan hybrida progenies ex P. alpino All. et diviaricato Linn., priori habitu, foliis majoribus, pubescentia et achænii formâ accedens, posteriori vero paniculầ laxiore, pedicellis calyce sublongioribus et jam sub florescentiâ exseritis nec non achænio cafycem $\frac{1}{3}$ superante. (v. v. e. et ś.)

214. P. LaXmanNi (Lepechin in nov. act. Acad. Petrop, 10, p. 414), caule humili ramosissimo, ramis dichotomo divarieatis, ochreis mediocribus laxis subdeciduis, folíis subsessilibus lipearibus lanceolatisve basi attenuatis margine subrevolutis hirsutis glabrisve, floribus in paniculam terminalen brevem vel racemum simplicem dispositis vel passim in summis axillis fasciculatis, pedicellis floreni subæquantibús infra apicem articulatis, achænio ealycem $\frac{1}{3}$, superante faciebus ovalirhombeis. Z̛ In Sibiriá Baicalensi et Transbaicalensi et- Davuriâ. - Ledéb.! fl. ross. 3, p. 526 .

a. genuinum (thedeb-! l. c.), caule apicem versus cum ochreis foliisque plas minus piloso. - P. Laxmanni Lepech. 1. c.,'Spreng. nov. proverít, p. 34, Meísn. mon. p. 57, Gmel., Sib. 3, p. 58, t. 11, f. 2, P. angustifolium Pál. Reise 3, p. 286, P. ramosum Fisch. mss, Hornem. h. Hafn. suppl. p. 45; Link enum. 1, p. 385, Cham. et Schl. in Linnæâ.3, p. 50, P. Davuriçum Willd. herb. n. 7676! (v. ষे. c.et s. sp.)

B. glabriusculum (Ledeb:! 1. c.), catle cum ochreis foliisque glaberrimó vel ad nodos parce pilosiusculo. P. riparium Georgi Reise, 1, p. $209^{\prime}$ (non Mart.); P. angustifolium Poir dict. 6, p. 139, Meisn. mon. p. 57 (non alior.). Formâ accedens ad $P$, divaricatum $\gamma$, sed ramificatione et inflorescentiâ discrepans. (v. S.)

215. P. piVA ICA u u (Linn. sp. 1, p. 520, non' Vill.), caule dichotomo ramisque gracilibus glabris, ochreis parvis glabris vel pilosiusculis deciduis, folins sub'sessilibus lanceolatis vel linearibus basi attenuatis glaberrimis vel rarius ciliolatis vel supra parce puberulis, paniculis laxis, racemis simplicibus, pedicellis subsolitariis apice articulatis calycem superantibus demum exsertis, achænio calycem dimidio superante faciebus oblongo-rhombeis. $\mathcal{F}$ In Sibiriâ et Davuriâ.Ledeb. fl. ross. 3, p. 526 .

a. glabrum (Meisn. mon. p. 57, excl. syn. Wall.); caule dichotamo-ramosissimo, 
ramis patentibus, foliis lanceolạtis planis, glaberrinís vel subciliatis, racemis elongatis interruptís. - Ledel./ 1. c., Gmel. Sib. 3, p. 57, t. K, f. 1. P. divaricaturn Linn. l. c., Willd. sp. 2, p. 451, P. flexuosium Pall. in Willd. herb. n. 7669. P. salignum Turcz. cat. Baical. n. 973, non Willd. (v. v. c. et s. sp.).

B. scabriáum (Ledeb.! l. c.), follis, scabriusculis ciliatis..(v. s.)

$\gamma$. angustissimum, caule debili erecto, ochreis laxis, foliis linearibos vel anguster lanceolatis planîs vel margine réxolutis, racemis subsimplìeibus ábbreviatis subcontinuis. - P. polymorphum angustissimum Ledeb.! fl. ross. 3, p. 524, P. ochreatum Linn. sp. 1, p. 517, Willd. sp. 2, p. 444 ? (non herb. cfr P. polymorphum $n$ ). Variat : 19 pilosum, caule ochreis foliisque pubescentibus. P. ochreatum Gmel.! Sib. 3, p. 51, t. 8 (fide herb. mus. Stuttgart.); $2^{\circ}$ glabrum, totum, excepto folioram margine pilosiuseulo, glạbrum. P, acidulum Willd.! enum. p. 429, berb, n. 7630! (fol. 1 et 2), Turcz.l pl exsice. 1829, in herb. DC.; P salignum Willd. herb, n. 7629! (fol. 1 et 2, nón enum.). P. riparium Georgi! in herb. Schreb. (non? Reise, cfr. P. Laxmanni $\beta$ ). P. divaricatum $\beta$ Meisn. mon. p. 57, excl. syn. Horn. (v. s.)

f. ? micranthum (Leded.\$ l. c.), foliis oblongo-linearibus ciliatis glabris, floribus duplo minöribus. Forsan distincta $\mathrm{sp}_{\text {, }}$ ex Ledeb.

\section{Species nimis obscurce vel nordum descripta.}

P. ADEN O T R I CHU M (Griffith ?), Report on bot. garcl. Calicutta, 1843, p. 39; ubi nil nìsî nomen.

P. A , Op écurorde S Turcz. ex Steudel nomencl. ed, 2 , II, p. 374. - In Sibiria Altaicâ.

P. G M E IN (Steud. 17om. ed. 2, II, p. 375), Gmel. Sib. n. 43, t. 11, f. 2. - In Sibiriât.

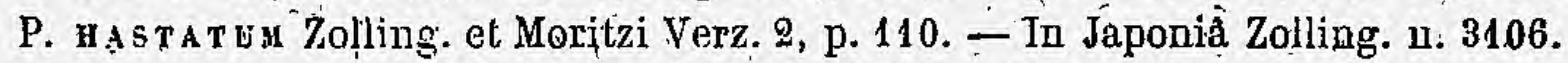

P. Hrss oplFonIUn (Bojer hor̨t, Maurit. 1837, p. 271, u. 2), non descript. - Ins. Mauritii.

P. INUNDat Um (Rafin. ex Steudel).

P, M в а т о жа и (Delile Mém. sur les, pl. qui croiss. spont, en Égypte, p. 12). Non descript. - Iu Egypto.

r. мuLrisetum (Delile, I. c.), * folio breviore. Vijdetur var. præcedentis. $n$ - In Agypto.

P, MEYENII (C. Koẹh in Linuæâ 22, p. 205), procumbens, glaberrimum, ramis adseenclentibus, fliliformibus subsimplicibưs, òchreis lanceolatotolobatis, follis crassiusculis oblongis planis subeveniis, floribus exsertis parvis solitariis campanulatis... In. cap: Syng-Moon, Macao (Mèen). - P. aviculare Walpers in act. Ácad. Leop. 19, suppl. 1, p. 407. Est yerisimiliter P. Roxburghii, supra, n. 40.

P. Niloticu a (Lehm. ex Steudi l. c.). - In Egypto.

P. ova t. m (Roth nov. pl. sp. pi 206, n. 4), glabrum, cánle erecto flexuoso simplici, ochreis laxissimis internodió longioribus, foliis subcordato-ovatis acuminatis crenulatis, floribus subcorymbosis 5-partitis (purpureis); braeteis imbricatoadpressis paleaceis cordato-ovatis fúcís, staminibus 5 stylo 3-partilo brevi longioribùs, uvario ovato. In Indiầ orient. (Heyne). - Méisn. mon. p. 92. An P. Chinense Linn. $\gamma$ ovalifolium nob:, supra, $n, 179$.

P. Pal ud os um (Griffith ?), Report on bot. gard. Calc. p.'39, ubi solum nomen.

P. PARVIFLORUM (Schott in Oken Isis, 1818, p. 821), ochreis internodia subæquantibus albo-membranaceis laceris, folits approximatis ellipticis glaucis glabris, floribus ochreas vix superantibus parvalis viridibus roseo nuarginatis. - - Circa Algesiras, ad vias. Videtur aut P., littốrale aut maritimuñ.

P. Punctatum (Rafin. anm. nat. 1820, p. 12. Opus a nobis non visum). An P. punctatum Ell.?

P. S r Rot t in M (Rafin. ibid.). An P: serotinum Ten.? Cfr. P. Persicaria $\alpha$ n. 134.

P. SERRA TU (Linn. 'sp. p. 517, non Poir.), foliis oblongis crenatis, floribus digynis. -In Mauritaniâ Shaw Afr. 489, Houttuyn Pfl. syst 6, p. 452. Forsan P. serrulatum Lag.? y. supra, n. 109. 
P. si Nu AT u (R. Br. in ${ }^{2}$ Salt Abyssin). Forsan Geratogonum sinuatum Hoch'st.?

P. SU B IN C A N U M (Mart. ex Steudel):

P. TE NER'U M (Spreng. syst. 2. p. 254), caule rámoso, foliis śpathulatiș glaucis, racemis filiformibus, pedicellis nutantibuts. - In Georgiả Amèr. bor. P. gracile Baldw. (ex Spr.). Est verisimiliter Polygajella gracilis Mêisn.

P. T u m d u.M (Delile 1. c. p. 12), a nodis tumidis. "- In Egypto circa Dámiate. Cfr. P. equisitiforme Sibth, supra, n: 4.

\section{Species exclusoe,}

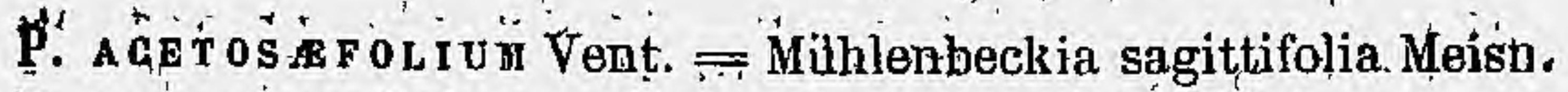

P. A cut a т च Lebm. = Fagopyrum cymosim Meiśi.

P. ADPRESSU Labïll. = Mühleribeckia adpressa Meion.

P. A Ŕ óréscens Fi: Flum. = Cóccolobá nitida H. H.,K.?

P. ARticulatum Linn. = Polygonella articulata Meisn.

P. ATRIPLICIF'oliuM Wall. = Ceratogonon atriplicifolium Meishn.

P. AUSTRALE Forst. = Mühlenbeckia australis Meisn:

P. B UXIF OLIUM M. Bieb. = Atraphaxiś (Tragopyrum) buxifolia Jaup. et Spach.

P. CaMPTIAN U⿱

P. с о м P L E X и м A. Cuñ. $\Rightarrow$ Mühlenbèckia complexa Méishn.

P. Gomptonianum hort.)

P. Gavgas IGu Hoffm. = Atraplaxis buxifolia Jaub. et Spj.

P. ci г га т и Kunze (non alior.). = Paronychia Chilensis DC.

P. ot Avucula T u mort. Par. $\Rightarrow$ Brunnichía cirrhosa Banks.

P. CORDA TU M hort. Berol. $=$ Mühlenbeckía variźns Meisn'.

P. c X m os u m Trevir. - Fagopyrum cymosum Meisn.

P. DecLinatum Fl. Flum. = Coccoloba declinata Mart.

P. DEPRESSU A A. Cunn, mss. = Mühlenbeckia parvifolia Meisii.

P. DIвOT R YS Don = Fagopyrum triangulare Meisn?

P. ELEGAN s hort. = Fagopyrum emarginatum" Meisn.

P. EMARGINAT UM Roth $=$ Fagopyram emarginatum Meisn.

P. FAG OPXR UM Linn. = Fagopyrum esculentum Moench.

P. FIM B RI Aт U of Ell. " $=$ Thysanella fimbriata A. Gray.

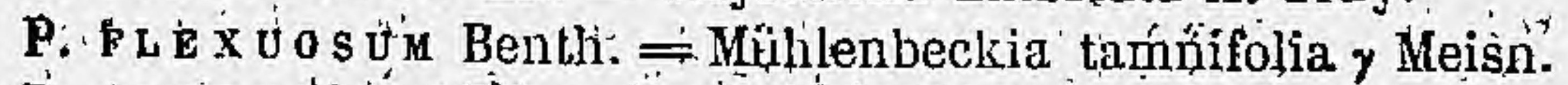

P. FL E X ós UM Heward. mss. = Mühlenbeckia flexuosa Meisn.

F. F u tescens Fl. Flum. = Coccoloba Gardneri Meisn.

P. F R U E S C ENS Linn. = Atraphaxis (Tragópyr.) lanceolata Jaub. et Spach.

P. FR U T I C U L O S U M Walp. = Mühlenbeckia rupestris Wedd.

P. G RAC I L E Nutt., BaldW: = Polygonella gracilis Meisn.

P. GRACI E hort. = Fagopyrum emärginatum Meišn.

P. GRANDI Z L OR,U M Bertol, = Antigonum Guatemalensé Ḿeisn.

P. GRAN D IFL O R U Willd. = Atraphaxis (Tragopyr.) grandiflora Jaub. et Sp.

P. H E T E R O P H Y L L U M Solland. mss. = Mühlenbeckia complexa Meişn.

P. i s ut c un D U M Lindl, Mühlenbeckia Chileasis $\beta$ Meisn.

P. й A C R о P T E R Uे M hort, = Fagopyrum emarginatum Meisu.

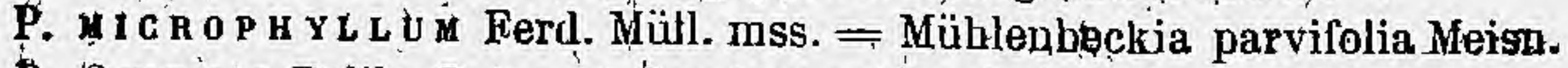

P. OW E I I Delile, Bojer. = Eeratogonon atriplicifolium Meisn.

P. PARYIF OU IU M Nutt.
P. POLYGA MU M Vent.

P. PY R A M I D A T U M Lois. = Fagopyrum ęsculentum $\beta$.

P. Q U A D R A N G U L A T U M Mart. et Gal. = Mühlenbeckia tamnifolia $\beta$ Meisn. . . :

P. sik i R u Desv. mss: = Fagopyrum Tataricum Gertn.

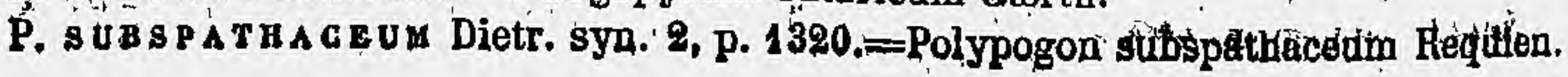


P. TAMNipouitu H: B. K. = Mühlenbeckia tamnifolia $\propto$ Meisn.

P. TAтARrou M Linn> = Fagopyrum Tataricum Gærtn.

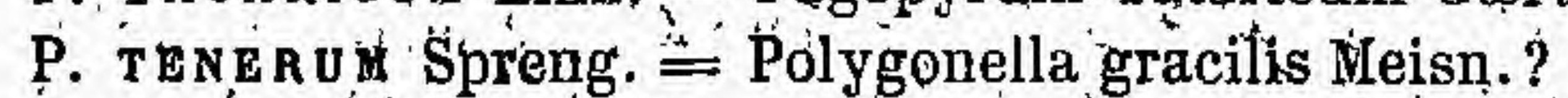

P. TrIanguiare Wall. $=$ Fagopyrum triangulare Meisn.

P. uvire a u Linn. = Coccoloba uvifera Linn.

P. vinidifl o RuM Poir. - Cannabis satiya L.! (Cfr. Roeper de Org.pl.p. 11).

P. YoL a AN I u M Benth. = Muthlenbeckla vulçanica Endl.

R. VorU Bı⿻ Túrcz. $=$ Fagopyrum triangulare Meisn.

XXIII. FAGOPYHUM Tourn. inst. 1, p. 511 (ex partB); t. 290, Gartn. Fr, 2, p. 182, t. 149, Moethch meth. p. 29,0 (ex parte), Cämpdr Rum, p. 18, Meisn. in Wall. pl. As. rar. 3, p. 63, gen. pl. vasc. p. $317^{\prime}$ (229), Éndl. gen. n. 1987. - Fafgotriticum J. Bauh. hist. 2, p.'993, Linn. in Adt' Holm. 1744, p. 117, t. 4. - Helxine Linn. gen. ed. 1, p. 116. - Polygonum Ádans. fam. 2, p. 270 (ex parte). - Polygoni sect. Hèlxine Linn. sp. 1 , p. 520; Willt., efc. (ex parte). - Sect. Fagopyrum Meisn. mon. p. 43 et $61, t .1, f g .5-16, t .4, R, S, T$.

Flores hermaphroditi. Calyx corollinus, æqualiter 5 -partitus, patens, fructifer non auctus. Stamina 8 , filamentis subulatís, antheris ovalibus versatilibus. Glandulæ 8 nectariferæ, hemisphæricæ, imo calyci insidentes, staminibus interjectæ. Stỳli 3 libevi, fylifờmes, decidui, stigmatibus obtusis vix incrassatis. Achænium triquetrum, majusculum, calycem longe superans, angulis acutis vel obtusis, interdúm dentatis vel in alam coriaceam expansis, pericarpio crustaceo tenui. Embryo axilis rectus, cotyledonibus latis foliaceis palminerviis contortuplicatis albumen fárinosúm semi-in volventibus. - Herbæ asiaticæ, rấdicéfibrosâ, caule ramoso erecto; ochreis brácteìique tenére membranaceis oblique truncatis imberbibus, foliis cordato-triangularibus hasiatisve palminerviis petiolátís vel summis subsessilibus amplexicaulibus, racemís subdichotomo-cymosis paniculatisve, pedicellis; fasciculatis tenuibus articuJatis, floribus albis vel roseis,

1. F. EScÚ L E T U M (Moench meth. p. 2́go), follis cordatis; lobis obtusis vel rotun datis, rácemis corymboso-paniculatis abbreviatis subconfluentíbus, àchtenio calycem longe superantẹ, angulis acutis apteris integrís, fáciebus ovato-triangularibus. $\odot$ In Asiâ centrali indigenum, inde a secculo XV in toto fere hemisphærio boreali, præcipue regionibus alpinis et magis sejtentrionalibits, tanquám planta cerealis eolitur, in Sibiriè, Nepaliâ (Wall. list; n. 1687!), Kunawur (Royles, Kamaon, alt. 11,500 ped. (Strach. et Winterbott. herb Himal. n. 29 I), Assam (Griff.1); Chind (Fortune, n. 111). - Meisn. in Wall. pl. As. rar. 3, p. 63, Babingt. in Linn. Trans. 18, p. 117, Ledeb. fl. ross. 3, p. 517. Polygonum Fagopyrum Linn: sp: 1, p. 522, Meisn. mon. p. 61 (exol. syn. Don), t. 4; R, Engt , bot. t. 1044; Metzger Europ. cereal, p. 69, t. 20, f. B. P. dioicum Hamilt. mss. Fagopyrum vulgare Erndl. virid. Warsaw. p. 42, Nees jun. gen. fl. germ. fase. 8 , cum ic. $F$. sagittatum Gilib. exerc. phytol. 2, p.435. Fagopyron sarfacenicum Dumort. fl. belg. prodr. p. 18: Nomina vernacula : Angl. : Buckwheat; Germ: :-Buchweizen, Heidekorn, etc; Gall. : Ble noir, Sarrasin, ; Poloñice : Tatarka; in Himąlayâ : Paphra et Kooltoo. De origine conf. ad Alph. DC. geogr. bot. p. 953. (v. v.)

F. pyramidatum; achsconfo apice angustato-elongato. - P. pyratridatum Loisel.! nouv. not. 19 ; f. gall. ed. 2,1, p. 285. Potius status monstrosus quam var. constans. (v., s.) ....

2. F. EMARGINATUM, glabrum, foliis hastato-cordatis longius aeuminatis, racemis dénsifloris, superiortbus conjugatis cymoso-pauiculatis , inferioribus simpliEibús pedunculatis, achæenio calycem longe superante late triangulari-về orbictlari-rímbeo apice obtusato, angulis acutis integris in alam coriaceam productis. O. In Ghịnấ: (Roth); Népaliâ (Don), ubi vịx spont. dieitur. Polygonum emarginatum, Roth catal bot. 1, p. 48, Willd. sp. 2, p. 454, Doil Nepal. p. 73, Meisn. mon. p. 62, Hetzger Eứrop. cerél. y. 70, t. 20, f. C. P. Nepálénsè hơrt. Elden., teste Fenźl

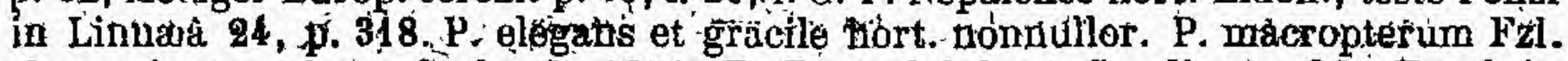
$\beta$ marginatum hort. Carlsruh 1851. F. Dryandri hart. Leodiens., fide Eenzl in 
Linnæâ 24, p. 232. Achæni facies sæpius látiores (saltem non angustiores) quam longæ. (v, v. et s. c.)

$\beta$. Kunawurense, caule, foliorum nervis subtis pedunculisque apice pubescentibus, achrenii faciebus ovatis. longioribüs quam latis apice non truncatis. Colitur in Kunawur (Royle). F. emarginatum Babingt. in Linn. Trans, 18, p. $118^{*}$. Forsan distincta species.

3. F. c YMo s u (Meisn. iń Wáll. pl. As. rar. 3, p. 63), rhizomate perengi multicipitï, eaule annuo orgyali, foliis cordato-triangalaribus hastatisve, summis angustatis, panieulâ amplâ cymæformi 2-3-chotomâ, racemis conjugatis subconfluentibus, achænio calyeem plus dimidio superante, angulis acutis apteris integris, faciebus ovato rhombeis apice.attenuatis. 26 In Nepaliâ (Wall. Jist, n. 1688 I), Mussooree ét Cachemire (Royle), Kamaon (Strach. et. Winterbotṫ herb. Himal, n. 30.l)-Babingt. in Linn. Trans -18, p. 149*, Lindl in bot. reg. 1846, t, 26, Paxt. fl. gard. 2, p. 163, curn. fig. Polygonum cymosum Trevir. delect. sem. h. Vratisl 1824, nav, act. Acad. C. Leop. N. C. 13 , p. $177^{\circ}$, Spreng. sỳst. 4, p. 155 , Reichenb. ic. exot: 2 , p. 29 , t. 176, Meisn. mon. p. 94. P. acutatum Lehm. cat. sem. h. Hamb. 1820 sq. et in nov. act. Acad. G. Leop, N. C. 14, 2, p. 816. P. emarginatum Wall. I list, n. 1688 (non Roth). P. rugosum Hamilt.! mss. ( $v_{\text {a }}$ v. c. et $\left.s ., s p.\right)$

4. F. TRIANGULARE (Meisn. ap. Wall: 1. c. p. 63), foliis cordato-triangúlaribus - hastatisve obtusangulis superioribusçue minus elóngatis; nervis subtus petieflisquíe apice puberulis, paniculis longe peduriculafis "diehotomís, racenis conjugatis - discretis divaticatís recurvis, achænii semiexserti angulis integrís obtusissimis incrassatis, faciebus ovatis. $\odot$ In Nepaliâ, Kamaon, Sirnore, Assam (Wall. lîst n: 1689 !), Ghinâ (Turcz:! fide sp. cult. e sem. Chỉens., sine fr., in herb. DC.). Polygonum triangulare. Wall. l list, n. 1689. P, dibotrys Don prodru tl. Nepal. p. 73 ? (synon. dubium propter fruct. ignot., forsan ad F. esculentüm aut cymosum spectans). P. volubile Túrcz. 1. c. et in Bulil: Soc. imp. No C. Mosqo 1840, p. 77. (v. s.)

5. F. Rо т U NDA т U M (Babingt. in Linñ. Transi 18, p4 117 ), caule subangulato internodiis hinc in latere fólio oppositó puberulis, folits triangulari-hastatis acutangulis páulo Tongioribus quam latis, nervis utrinque puberulis, rạcemis axillaribus paniculatis vel inferioribus simplicibus elongatis longe pełuncálatís, achinii cályce parvo pluries longioris. angulis integris basi incrassatis rotundatis superne acutiusculis, faciebus ovato-oblongis rugosis. ( In Kunawur (Royle) et Kamaon, alt. 11,500 ped. (Strach. et Winterbott. herb. Himal. $n_{+} 31$ l). P. occidentale herb. reg. Berol. (sp..cult.) $\Lambda$ præcedente nonniși achænio dimidio majóre, angulis apicem vorsus acutioribus et folịis pro longitudine látioribus distinctụm. (v.s. c.)

6. F. T А т A I с ч м (Gærta. fr. 2 , p. 182, t. 119, f. 6), glabrum, foliis plerumque Iatióribus qứm longis, racemis axillaribus terminalibusque simplicibús elongatis interruptis, achænio calycem parvum longe superante; angulis subincrassatis sinuato-dentatis, faciebus ovato-triangularibus: $($ In Tatarià, Sibiriâ, Nepaliâ

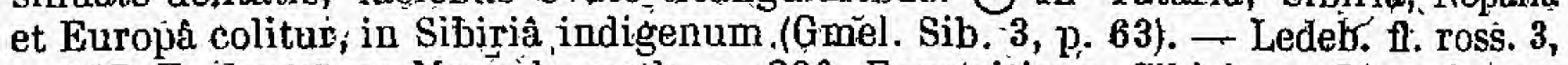
p. 517. F: dentatum Moench meth. p. 290. Fagotriticum Sibiricum Einn. in act. Holm. 1744, p. 117 , t. 4. Frumentum Saracenicum Act. nat. cur. 3, p. 4 . Polygonum Tataricum Linn. sp: 1, p. 521, Gmel.1 Sílb. 3, p. 64, t. 13̂; fig. 1, Don prodr. fl. nepal. p. 74, Meisn. mon. 62, t. 4, 8, Metzg. cereal. p. 69, t. 20,.A. P. sinarum Desv. (v. ช. c.) Subtribus IV. COCCOLOBEA C. A. Meyer in Mém. Ac. Pétersb. 6e sér.

Flores hermaphroditi vel polygamo-dioici. Calyx herbaceus., rarios coloratus, '5-partitus, fructifer clausus carnosus vèl tarde' marcęscens è̀t achænio plus minus adnascens, quoad formam immutatus, apterus. Stamina 8, filamentis subulatis, antheris versatilibus ovalibus. Styli 3 brevissimi, stigmatibus capitatis vel fimbriatis. Achærnium ovoideo-trigohum yel subglobosum, liherum vel seini-inferum, semitriloculare. Semen sulcato-trilobum. Albumen farinosum. - Frutices, nonnunquaim scandentes, vèl arbores, foliis sæpius coriaceis. 
XXIV. MUHLENBECKIA Meisn. gen. pl. vasc. p. 316 (227) et in pl. Preiss. 1, p. 623, Endl. gen. suppl. IV, 2, p. 151, n. 1990/1, Meisn. in Mart. fl. Bras. 14, p. 44, t. 22. Sarcogonum Don in Sweet Hort. Brit. 3, p. 577. - Coccolobæ sp. Ortega decad. p. 60, For'st. prodr. p. 176.-Polygoni sp. auct. Vent. t. 88, Labill. Nov. Holl. t. 127, Endl. ic. t. 87, Meisn. mon. t. 2, f. A. Bot. Mag. t. 3145, Hook. fil. fl. N. Zealand. p. 209.

Flores dioici vel polygamo-dioici. Calyx herbaceus, 5 -partitus, lobis margine subcorollinis æqualibus vel interioribus 2 minoribus, fructifer plus minus auctus succosus vel demum siccus. Masc. Stamina 8 , filamentis filiformibus calycem subæquantibus. Pistilli rudimentum nullum. Fem. vel hermaphr. Stamina 8, filamentis brevibus basi subdilalatâ in annulum obsoletum confluentibus, antheris minulis effoetis? vel glanduliformibus. Ovarium 3-gonum liberum vel imâ basi calyci adnatum, ovulo basilari atropo. Styli 3 breves vel subnulli, stigmatibus capitatis breviler fimbriatis vel papillosis lævibusve. Achænium ovoideo-trigonum, calyce baccato demum sicco inclusum vel apice exsertum, liberum vel vix basi adnatum, angulis basi obtusis vel obliteratis, endocarpio inflexo spurie semitriloculari. Semen ovoideum, sulcis 3 longitudinalibus profundis trilobum, lobis indivisis haud ruminatis. Albumen farinosum, album. Embryo marginalis, lobi unius sulco semiimmersus, subarcuatus, cotyledonibus angustis incumbentibus, radiculâ superâ. - Frutices vel súffrutices Americæ centralis et australis, insularum Oceani-Pacifici et Australiæ, caulibus ramisve sæpius volubilibus angulatis vel sulcatis, ochreis membranaceis cylindricis oblique truncatis imberbibus tenuiter venosis basi foliigeris mox laceris deciduis, foliis petiolatis penninerviis vel eveniis sæpius cordatis vel subsagittatis, floribus parvis indecoris albidis vel virescentibus axillaribus solitariis vel fasciculatis vel racemosis paniculatisve, pedicellis cum calyce articulatis.

\$1. Stigmata fimbriata, rarius integra (cfr. $M$. adpressa). Rami plerumque volubiles, foliis scepissime cordatis, racemis simplicibus vel paniculatis. Australice et Oceanice incola. - Sarcogonum Endl. gen. suppl. IV, 2, p. 51.

1. M. pol y в о т т а (Meisn. in pl. Preiss. 1, p. $\left.623^{\star}\right)$, fruticosa, glaberrima, dioica ? ramis parce ramosis sulcatis, ochreis laxis internodia subæquantibus deciduis, foliis subsessilibus coriaceo-subcarnosis lanceolatis oblongisve utrinque attenuatis acutis 1 -nerviis eveniis (sub lente glanduloso?-punctatis) margine plano integerrimis levibus, racemis axillaribus terminalibusque laxiuscule multifloris folio brevioribus simplicibus vel basi ramosis, masculis basi, femineis apice foliosis. J) In Australiâ merid.-occid. (Preiss n. 1353! Drummond! Morison!) Caules decumbentes, adscendentes, basi lignosi. Folia 1-4 poll. longa, 3-12 lin. lata. Racemi vel potius rami florentes 1-3 poll. masculi inferiores interdum 5-6 poll. longi. (v. s.)

2. M. GRAGILLIMA, suffruticosa? glabra, caule ramisque volubilibus gracillimis sulcato-angulatis, internodiis elongatis, ochreis brevibus laxiusculis laceris, foliis petiolatis herbaceis triangulari- vel cordato-ovatis sagittatisve acuminatis subtus obsolete penniveniis, racemis terminalibus axillaribusque simplicibus vel basi pauciramosis folia superantibus filiformibus, bracteis parvis remotis 1-3- floris pedicellos subrequantibus. 5? Circa Port Jaclison (Gaudich.!). Petioli $\frac{1}{2}-1$ poll. longi. Folia 1-2-pollicaria $\frac{1}{2}-1 \frac{1}{3}$ poll. lata, basi truncata vel cordata, auriculis acutis obtusisve, margine plano sub lente scabriusculo. Racemi $1 \frac{1}{3}-4$ poll. longi, plerique simplices, summi interdum basi ramulis 1-2 brevibus aucti, bracteis 2-5 lin. distantibus, pedicellis apice articulatis demum exsertis nutantibus. Calyx globosus, magnit. Polygoni avicularis. Stigmata 3 subsessilia, capitata, brevissime fimbriata. Fructus maturus ignotus. (v. s. in h. DG.)

3. M. A DPRESSA (Meisn. gen. 2, p. 227), glaberrima, caule fruticoso prostrato vel volubili ramisque flexuosis sulcatis vel angulatis, ochreis angustis internodio

XIV. 
dimidio brevioribus pauciveniis laceris deciduis, foliis petiolatis subcarnosis cordatis ovatis vel subrotundis subtus penninerviis supra eveniis margine undulatoerenulatis vel planis integris, racemis axillaribus terminalibusque subsimplicibus interruptis, bracteis brevibus pedicellos æquantibus, stigmatibus subsessilibius papillosis, achænio inclusb globoso-trigono angulis rotuñdatis. " In Novâ lf́ollandiâ extratropicà et Tásmanniâ. - Meisn. in pl. Preiss 1, p. 624 in notâ, Nees ibid. 2, p. 272, Schlecht. in Linnceâ 20, p. 575. Polygonum adpressum tabill.! Nov. Holl. 1, p. 99, t. 127, R. Br. Prodr. p. 420. Sarcogonum adpressum Don in Sweet Brit. Fl. Gard. ed. 3, p. 577.

a. rotundifolia, foliis late ovalibus vel suborbicularibus obtusissimis vel apiculatis basi rotundatis vel hastato-truncatiś. - In N. Holl. orâ orientàli ? australi (Behr! Stuart! Ferd. Müller !), austro-occidentali' (Lesson! Drumm. n. 704 ! Preiss n. 1205 I). Variat caule ramoso vel subsimplici, volubili vel subscandente vel in terrâ longe procurrente ramis erectis non volubilibus, foliis $\frac{1}{2}-2$ poll. longis latisque margine planis crispulisve. Bracteæ plurifloræ (v. s.)

$\beta$. hastifolia, foliis oblongis apice attenuatịs obtusiusculis vel apiculatis basi hastato-truncatis vel cuneato-attenuatis. - In N. Holl. australi (Ferd. Müll. H et ju sinu Macquarie Tasmannise (Gunn n. 325 ! Stuart !). M. Gunnii Hoolk, Gil. in Hook. Lond. Journ. 6, p. 278. M. hastifolia Ferd. Müll.! mss.' in h. Sonder. Polygonum adpressum Hook. in Bot. Mág. t. 3145. - Caules usque ad longit. 60 ped. in terra prorepentes, graciles, subvolubiles, sæ̃pe flexuosi. Ochréæe petiolum (usque ad 9 lin. longum) æiquantes. Folia herbacea vel subcarnosa, 1-3 poll. longa, 1-1 $\frac{1}{2}$ poll. lata, margine subintegra. Racemi folia æquantes, simplices vel basi ramosi, laxiflori, bracteis 1 - floris. Calyx fructifer globosus, magnit. Pisi, baccatus, edulis, unde planta "Macquarie-Harbour Grape vocatur. (v. s.)

4. M. A US TRA A IS (Meisń. 1. c. p, 227) fruticosa, glaberrima, ramis debilibus passim volubilibus striato-subangulatis, ochreis deciduis, foliis herbaceis ovatis subrotundisve basi obtusis emarginatis subtruncatisve obsolete penninerviis margine plano vel obsolete crenulato scabriusculis, racemis folio longioribus aplyyllis filiformibus laxifloris simpliciter patulo-ramosis rel rarius indivisiś, bracteis 1-2-floris, pedicellis demum exsertis, stylis reflexo-patentibus, stigmatibüs fimbriatis. J' In Novâ Zeelandiâ boreali, ad Sinum Insularum, Fretum Cook, Wangaroa, hlum. Hawa-Hawa etc., ubi Heruna et Pepo-ho vocatur (Forster ! A. Cunningh. ! D'Urville! Raoul! Hook. fil. ! etc.) et in Ins. Norfolk (Ferd. Bauer! A. Cunn.!) Coccoloba? australis Forst.! prodr. n. $176^{*}$. Polygonum australe A. Rich.! in D'Urville Voy. Astrolab. p. 178, A. Cunningh. ! in Ann. of Nat. Hist. 1, p. 454, Endl. fl. Norfolk. p. 42, iconogr. t. 87, Raoul! Choix p. 42, Hook. fil. fl. N. Zeal. p. 210 (excl. sjn. Labill.). P. baccatum Soland. mss. fide herb. Cunningh. I P. Coccoloba Steudel nom. ed. 2. 'Simillima M. adpressæ, similique modo varians, sed habitu graciliori, foliis herbareis et stigmatibus dignoscenda. A Forstero dicitur arborea (sed procul dubio ex errore) a Cunningh. et Rich. vero frutex volubilis. Stirpem Norfolkicam, nullo charactere certo distinguere possumus. Folia jun. 3- loba, fide Hook. fil. I. c. (v. s.)

5. M. varians (Meisn. in Schlecht. Bot. Zeit. 1852, 10, p. 347*), suffruticosa ? dioica? glaberrima, caule herbaeeo gracillimo volubili, ochreis angustis, foliis petiolatis ovatis acute acuminatis basi truncato-subeordatis aliis subpanduriformibus alis integerrimis, racemis axillaribus solitariis geminisve simplicibus bifidisve folio paullo longioribus subcontinuis, bracteis 1 -floris, floribus subsessilibus. 5 ? $\bigcup$ Patria ignotit. Colitur in horto bot. Berolin. sub nom. Polygoni curdati. Caules filiformes dextrorsum et sinistrorsum volubiles, licres, internodiis elongatis. Ochreæ albidæ, teneræ, anguste tubulosæ 3 lin. longu, juxta petiolum utrinque 1-nervi:e. Folia usque ad pollicom longa, prope medium utrinque sinu profundo obtuso lató vel angusto excisa jassimque integerrima, inferiorum petiolo limbum xquante. Racemi pavicutam terminialem foliosam 3-4- pollicarem constituentes, singuli circ. pollicares. Flores magnit. Polygoui avicularis, in specim. nostris nonnisi masculi. (v. s. c. comm. ab ann. $\Lambda$. Braun.)

6. M. FL ORULEN T A, frutículosa, ramosissima, dioica ? glaberrima, ramis divaricatis oulcato-striatis, foliis lanceolatis obtusis attenuato-subsessilibus enerviis; racemis 
axillaribus terminalibusque interruptis, bracteis plurifloris pedicellos bracteolatos subarquantiluus, staminibus exsertis. $f$ In Dumbey Bay, in Australia merid. prope Cap. Bernotlli. Fruticulus vix spithameus, ramulis sæpius fasciculato-conges tis, internodijs cigf. semipollicaribus, ochreis deciduis. Folia 6-8 lin. longa, extra medium latiora 2 lin. lata, basin versus sẹnsim attenuata, decidua. Racemi foliis delapsis paniculam hevem sinnulantes. Bractes fulvo-hyalinæ, ovato-acutæ, $1 \frac{1}{2}$ lin. longæ, flore paullo majores. Calycis 5 -partiti lopi ovales obtusi patentes. Stamina 8. Rudimentum pistilli nullum. Fem. ignota. (v. s. in h. Sonder.)

\section{§ 2. Stigmata papillosa. Fraticuli humiles vel prostrati, scepe radi-} cantes, raro subvolubiles, floribus axillaribus fasciculatis vél solitariis, rarius brevissime racemoșis.-Australice, Aceania et Americce occidentali-australis incolce. - Sarcogonella Meisn. mss. - Sectio Andinia Weddell in Ann. sc. nat: $3^{\mathrm{e}}$ sér. $13, p .255$.

7. M. с о м р сах (Meisn. gen. 2, p. 227 et in pl. Preiss 1, p. 624 in notâ), fruticulosa, glabra, ramosissima, ramis voluhililuus tereti-filiformibus, ochireis parris arcte tubulosis deciduis, foliis suborbicularibus obtusís basi jassim breve obtuseque hastato-biauriculatis, floribus $1-6$ in axillia subsessilibus vel racemosis. $b$ In sipu Insularum Novæ Zelandise (A. Cunningham /'Hook. fil.|) Polygonum complexum A. Gunn. mss. et in Ann. of Nat. Hist. 1, p. 45i, Boț. Mlag. 1846, app. p. 6, Hook. fil. 11. N. Zeal. p. 210 , Raoul choix p. 42. P. heterophyllum Soland. mss., fide lierb. Cunni. P. Complonianum et Camptianum hort., fide herb. Mart. Sarcogonim complexum Kunze! in Linnạ 17, p. 570. Planta monente cl. Hook. fil., admodum variabilis. Ḩabitus peculiaris, caules ramique uumèrosissimi, gracillimi, intricatc intertexti, massam laxam globosam formanies, passim volubiles, obsolete sulcati, juniores pulveraceo-pulicruli, internodiis usque ad pollicem longis. Folia late viridia, limbo 3-5 lins. longo et vix angustiore, peliolum iequante vel dimnidio tongiure, passim obovato vel retuso, subtus penninervi, supra evenio, margine plano levị, auriculis baseos brevisssimis obtusis vel nullis. Racemí puberuli, nunc brevissimi, nunc elongaț, quandogue paniculali. Calyx magnit. Polygonị avicularis, virescenti-albüus, fructifer parum auctus succulentus albus. Stigmata sessilia papillosa. Acliænium inclusum, nitidum, lave, faciebus ellipticis. (v. v. c. et s. sp.)

8. M. EpHedroides (Hook. fil. fl. Nov. Zealand. p. 211 * sub Polygono), fruticosa, diffuse ramosa, aphylla vel sparse foliosa, ramis flexuosis intertextis profunde sulcatis apice scabriusculiș, foliis petiolatiș sessilibusve parvis linearijus subhastatisve subacutis basi obtuse dilatatis, 'foribus spicatis solitariis axilfáribusque. † In ora orientali Novæ Zealandise borealis circa Ahuriri etc. (Colenso). Proxime affinis M. complexa, nec non M. australi, sed jam foliis ab utraque distincta. Halitu admodum varidns, caulibus prostratis nunc semipedalibus parce foliosis, Pólygono aviculari similibus, nunc pluripedalibus aphyllis junceis difusis. Qclirea breves, oblique truncatæ. Folia -1 poll. longa. Flores thasculi in spicas laxas slaj)errimas dispositi, feminei axillạres solitarii aut masculis parce interspersi. Stigmata haud descripta.

9. MI. AXILLARIs (Hook. fil. in Hook. Lond. Journ. 6, p. 278, fl. Nov. Zealand.p. 210), fruticosa, humilis, glaberrima, ramulis brevibus rectis vel flexuosis tenuibus, ochreis angustis internodiis brevioribus petiolum aquantibus dia persistentibus, foliis subcoriaceis ovalịbus subrotundisré integerrimis subeveníis, axillis 1-paucifloris, pedicelliso chreâ sulolongioribus. ந In Novâ Zealandiâ (Hooks. fil.); Australiâ felici (Ferd. Müll. I), circa Port Jacksnì (A. Cunn. I) et in Ins. Diemen (Gunn! in herb. Reg. Berolin., Stuart! in herb. Sonder). Polygonum depressum A. Gunn. I mss. in herb. P. micropliyllum Ferd. Müller! mss. in herb.' Sond. Meisn. mss. in herb. Sund. - Variat caulibus 1-2-pollicaribus dense ramosis, ramis brevibus ( $\alpha$ caspitosum, Müll. I mss.) et 6-9-pollicaribus gracilibuș laxe ramosis diffusis ( $\beta$ expansum Hüll. 1 msss.) glabris vel minute puberulis. Folia

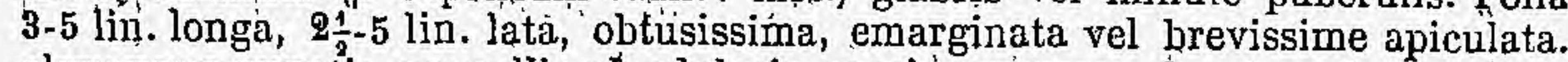
plerumque punctis nonnullis głandulosis opacis conspersa, haud cordata, petiolo 1-2 lin. longo. (v. s.) 
10. M. Flexuos a (Meisn. in pl. Preiss 1, p. $624^{*}$ ), dioica ? fruticosa glaberrima, ramulis erectis flexuosis sulcatis, ochreis parvis deciduis, foliis carnoso-coriaceis breve petiolatis ovatis acutis basi truncatis vel breve attenuatis crispulo-crenatis, floribus in axillis superioribus subternis, pedicellis vix exsertis, achænio calyce aucto sicco incluso subgloboso-trigono nitido angu lis rotundatis. $ち$ In Australiâ merid.occidentali (Preiss n. 1355 l) et Middle Island in Freto Bass (A. Cunningh. !) Poly . gonüm flexuosum Heward! mss. (v. s.)

11. M. RU PES T R Is (Wedd. in Ann. sc. nat. $3^{\bullet}$ sér. 13, p. $256^{\star}$ ), fruţiculosa subcaspitosa glaberrima, ramis diffusis basi radicantibus apice sulcato-angulatis, ochreis brevibus laxis diu persistentibus, foliis subsessilibus subcarnosis ellipticis lanceolatisque obtusis acutisve planis eveniis internodio longioribus, pedicollis in superioribus axillis 1 vel pluribus brevibus subexsertis, achænio calyce baccato incluso ovato obtuse trigono lævi nitido basi rotundato. $\hbar$ In rupibus montium altiorum Boliviæ, Peruviæ (Dombey! h. Mus. Paris n. 209 !), circa lacum Titicaca (Meyen). Polygonum fruticulosum Walp. in Nov. Act. Ac. Leopold etc. 19, suppl. 1, p. 407. Caules palmares subpedales. Folia 5-10 lin. longa, 3-5 lin. lata. Flores rari, plerumque solitarii vel gemini. Stigmata non vidimus. Achænium dimidio longius quam latum, faciebus convexis sub lente obsolete puncticulatis, angulis obtusis. (v. s. in h. DC. et Reg. Berolin.)

12. M. vul can I A , fruticulosa ramosissima glaberrima, ramis patentibus sulcatoangulatis dense foliosis ochreatisque basi radicantibus internodiis brevibus ochreis parvis deciduis, foliis subsessilibus subcarnosis rhombeo-ellipticis acutis basi cuneato-attenuatis eveniis planis vel margine recurvis, pedicellis in summis axillis 3-1 brevissimis, stigmatibus subsessilibus, achrenio calycem baccatum vix æquante ovato-trigono angulis basi obtusis. 5 In apice montis ignivomi Xetuch Mexici (Hartweg n. 562 !), in monte Pichinchâ Quito (Jameson n. 49 !), Azangaro, Peruvixe (Lechler n. 1748 !) M. volcanica Endl. gen. suppl. 4, 2, p. 51. Polygonum volcanicum Benth! pl: Hartw. p. 81 *. Habitus præcedentis, cujus forsan mera var. recedens ochreis deciduis foliisque minoribus, etc.Ochreæ fuscescentes, in ramulis subcontiguæe, truncate, integræ. Folia 4-7 lin. longa, 2-4 lin. lata, internodiis longiora. Flores alii hermaphroditi, alii masculi cum pistillo parvo sterili ? Calyx fructifer ovatus, vix 2 lin. longus. Stamina 8 , filamentis subulatis. Styli 3 breves, stigmatibus incrassatis papillosis. Achrenium sub lente obsolete puncticulatum. (v. s. in h: Shuttleworth et DG.)

§3. Stigmata papillosa (vix fimbriata) vel nuda. Frutices Americani volubiles, foliis basi truncatis cordatis vel cuneatis, racemis axillaribus simplicibus vel paniculatis, raro rhachi abbreviatâ fasciculiformibus. - Eumühlenbeckia, Endl. gen. suppl. IV, 2, p. 51.

13. M. SA G т t IF olia (Meisn. gen. 2, p. 227), glaberrima, ranis gracilibus volubilibus, foliis herbaceis acutis lanceolatis basi truncatis vel auriculato-subhastatis, rarius passim breve attenuatis, summis linearibus, infimis oblongis vel cordatoovatis, planis 1-nerviis subeveniis margine integerrimo læavibus, racemis solitariis folium sequantibus simplicibus aphyllirs sessilibus laxifloris, calyce demum aucto subbaccato, stylo brevi trifido, stigmatibus fimbriatis, achænio ovato obtusangulo lævi nitido incluso vel apice exserto. 5 Circa Buenos-Ayres (Bacle, n. 69 ! in herb. DC.) et in Brasilià merid., ubi salsa vocatur et decoctum contra syphilitidem præhet (Mart. I Sellow ! etc.).-Meisn. in Mart. fl. bras. fasc. 14, Polyg. p. 45, t. 22. Coccoloba sagittifolia Ortega decad. 5, p. 60, Spreng. syst. 2, p. 175.C. sagittata Poir. dict. 6, p. 64. Polygonum acetoséfolium Vent. h. Cels. p. 88, t. 88 *. Menispermum sagittatum Spreng. syst. 2, p. 155. (v. s. c. et sp.)

14. M. Chilensis, fruticosa glabra, ramis validis sulcatis, junioribus laxis volubilibus angulatis, foliis carnoso-coriaceis petiolatis triangulari-vel subhastatocordatis, ovatis oblongis lanceolatisque basi truncatis vel cuneato-attenuatis 1-nerviis eveniis margine subrecurvo integerrimo lævibus, racemis axillaribus terminalibusque solitariis simplicibus aphyllis laxiusculis rarius contractis fasciculiformibus, bracteis pedicellos subrequantibus, ach:enio incluso vel subexserto subgloboso acutiuscule trigono subopaco obsolete puncticulato. $\hbar$ In Chili et Peruvia. M. sagittrofolia hemy ill Gay hist. de Chile, p. $274^{*}$ (exrl. syn. Ort., 
Vent., Hook., Meisn.). Species a M. sagittifolia distincta habitu minus gracili, ramis demum rigidis strictis, foliis crassioribus, calyce fructifero fere sicco et achænio majore magisque globoso-ovato, apice tantum breviter trigono, minus nitido.

a. fascicularis, floribus axillaribus fasciculatís, rarius passim racemum folio breviorem vel in apice ramorum racemum aphyllum formantibus, foliis parvis ( $\frac{1}{2}$-vix 1 poll. longis), plerumque obtusissimis (Gaudichaud, n. 57! Bertero, - n. 187 \927! et ex parte 923 ! Cuming, n. 716! Lechler, n. 5\$1, at 2746!). Rumex hastulatus Smith! in Rees cycl. n. 29, Campd. Rum. p. 69 et 125 *, Remy in Gay, hist. de Ghile, p. 279. (v. s.)

$\beta$. injucunda, floribus axillaribus subsolitariis vel racemos foliosos brevissimos formantibus, foliis deltoideo-ovatis (1-1 $\frac{1}{2}$ poll. longis) acutiusculis. In Andibus editioribus inter Valparaiso et S. Iago (Mac Rae). Polygonum injucundum Lindl. in Bot. reg. 1829, t. 1250.

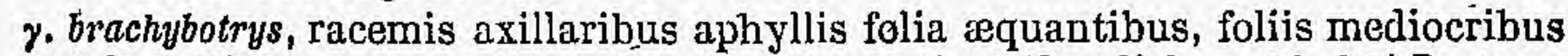
(vix pollicem excedentibus) obtusissimis acutisve (Gaudicl. n. 84, 85 ! Bertero, n. 923 ex parte, Lesson! Philippi ! Dombey, n. 211! (v. s.)

d. racemosa, racemis axillaribus folio longioribus $\left(1 \frac{1}{2}-3\right.$ poll. longis) gracilibus laxifloris, foliis subherbaceis sesquipollicaribus acutis.-In Cordillera de Mendoza (Bacle!), Valparaiso (Abadia, n. 283 !). Forma racemis longioribus et foliis plerumque angustioribus ad M. sagittifoliam accedens, sed non scandere videtur et achenium magis globosum. (v. s. in h. DC.)

15. M. тамNrouia (Meisn. gen. 2, p. 227), glaberrima, fruticosa, volubilis, ramis teretibus sulcatis apice angulatis, ochreis laxis, foliis subcarnosis pétiolatis cordato-ovatis acutis vel acuminatis tenuiter immerse venosis, racemis axillaribus solitariis geminisve simplicibus vel ramosis, pedicellis subsolitariis brevissimis, stigmatibus subsessilibus papillosis, achænio incluso globoso-ovato apice trigono nitido minute puncticulato. $亏$ In Mexico, Colombiâ, Boliviâ, Peruviâ, Quito (Jạmeson!) et (fide Cl. Gay) in Chile. A M. Chilensi differt foliis plerumque multo majo . ribus venosisque, racemis sæpins geminis ramosisve, achrenio nitido, etc. (v. s.)

$\alpha$. Humboldtii, ramis subflexuosis apice tantum angulatis, foliis ovatis acutis vel breve cuspidatis vel inferioribus obtusis, lobis baseos rotundatis, racemis junioribus pauciramosis foliosis, fructiferis paniculatis aphyllis folio longioribus, bracteis subcontiguis, pedunculís ramisque erassiusculis. In Colombiå (Humboldt $\mid$ in h. Kuntli | Moritz, n. 351 | Polygonum tamnifolium h. Kunth 1 in nov. gen. 2, p. $180^{\circ}$, Hook. et Arn. bot. Beech. p. 43, Remy in Cl. Gay. hist. de Chile, p. 270.

$\beta$. quadrangulata, ramis acute 4-gonis, junioribus flexuosis, foliis ovatis vel ovali-oblongis acuminatis, lobis baseos rotundatis, racemis paniculam demum folio longiorem aphyllam formantibus, pedunculis crassiusculis, bracteis contiguis demum remotioribus. In Venezuelâ (Funke, n. 318 !'Schlím, n.1164 !), Mexico (Galeotti, n. 455). M. quadrangulata Endl. gen. suppl. IV, 2, p. 51. Polygonum quadrangulatum Mart. et Galeotti in Bullet. Acad. Brux. 10, 1, p. 353.

$\gamma$. Hartwegii, ramis flexuosis obsolete angulatis, foliis ovali-oblongis attenuatoacuminatis basi angustatâ leviter cordatis lobis acutis vel obtusiusculis, racemis folio multo brevioribus simplicibus laxiusculis basi tantum ramulo folioque auctis, pedunculis tenuioribus. In Mexico (Hartweg, n. 561!), Quito (Jameson!), Peruviấ? (Matbews, n. 1166 !). M. Benthamii Endl. 1. c., Benth. in Hook Lond. Journ. 4, p. 622, in notâ. Polygonum flexuosum Benth.! pl. Hartw. p. 80 .

f. laxiflora, ramis teretibus vel obsolete angulatis, foliis ovatis rotundato-cordatis, paniculis folio longioribus mox aphyllis, floribus distantibus, peduncutis ramisque tenuioribus. In Colombiâ (Humb.! Bonpl. n. 2096! in herb. Willd. n. 7683 ! Linden, n. 1095 !), Peruviâ (Ruiz l), Quito (Jameson, n. 48 !). Coccoloba monoica fl. peruv. Ruiz! in herb. reg. Berolin.

16. M. LEP ОВ о R $\mathrm{R} S$, volubilis ? glaberrima, ramis gracilibus teretibus apice acute angulatis flexuosisque, ochreis brevibus deciduis, foliis ellipticis breve acuminatis vel cuspidatis, basi angustatà rotundato-cordatis immerse venosis subtus dense reticulatis, racemis subaphyllis folium æquantibus vel superantibus, femi- 
neieis basi bifidis, mascillis longioribus paniculatis fliformibus, bracteis remotis bifloris pedicellos vix superantibias, stigmatibus subsessilibus subpapillosis, achænio incluso globoso-ovató ol tuse trigono nitido obsolete puncticulato. II In Peruviâ, cirea Huanuco. Coccolola carinata Ruiz! mss. in herb. reg. Berolin, Omnia fere M. tamnifoliæ, præcipue var. \&. sed paniculie laxiores, tenutiores, pedutricúlis filiformibus, femineis a basi-bifidis (quasi geminis), masculis in ramos plures simplices 1-2-pollicares divisis, ramo infimo tantum sæpius folio fulto, bracteis 2-3 lin. ab invicem distantibus. Folia 2-2 poll. longa, 12-16 lin. latá, petiolo 3-8 lin. loǹgo, lobis traseos rarissime subricutis, venis paulo magis patulis et reticulationè densiore magisque conspicuâ quam M. tamnifoliæe. (v. s.)

17. Ḿ. Pe ư vi a Na, fruticosa scandens, ramis teretibus junioribus sulcato-subangulatis tomentellis, ochreis longis glabris, foliis subcoriaceis ovatis vel ovalioblongis acutiusculis leviter hastato-cordatis venis tenuibus patentibus subtus puberulis, racemis axillaribus subsessilibus folio brevioribuss, simplicibus vel rámosis subaphyllis subinterrupte densiflorìs, achænio semiexserto nitido, angulis supra - tilediutn acutis infra obtusis, faciebus ovatis subconcavis punctato-rugulosis. 5 In montibus altis humidis Montehuassi Peruviæ (Dombey, n. 210 In herb. Mus. páris. et $\mathrm{DC}$.). Rami adulti teretes rúgulosi et verruculosi, junibres elbngati gräciles sulbsinplices, plus minus striati, internodiis 1-3-pbllicaribitus. Ochrere arcte cylinárico-tubulosæe, subpollirares, oblique truncatæe, obsolete venosolineatæ; laceræ, diu persistentes, prope basin foliggeræ. Petioli 3-7 lin. longi, tenues. Folia $1 \frac{1}{2}-2 \frac{1}{2}$ poll. longa, 9-18 lin. lata, sinu baseos lafo lobisque rotundatis, venis primariis tenerrimis sub angulo fere recto or tis utrinque prominulis minute puberulis, venularum reticulo obsoleto immersa. Racemi-1-2-pollicares, aggregati vel paniculati, dense bractéati, glabri, passiḿ spatio 2-3 lin. longo interrupti. Calyx 2 lin. longus, subcampanulatus, semi-5-fidus, lobis subcarnosis demum marcescentibus patulis. Flores in specim. suppetentibus omnes abortu feminei, staminutò rudimentisminutis. Stigmata non vidimus. Ächænium liberum, nigrum, 2 lin. Iongum, faciebus, 1 lin. latis. Forsan sequentis var. (v. s.)

18. M. TIL I Á O L IA (Wedd. in Ann. sc. nat $3^{*}$ sér. $13, \mathrm{p}, 255^{*}$ ), fruticosa scándens, ramis crassis 6-gonis glabris internodliis longis, ochreis magnis puberullis petiolo sublongioribus; foliis herbaceis cordato-ovatis acuminatis utrinque puberulis costâ petioloque pubescentibus, racemis dense paniculatis ramulis brevibus patentibus; bracteis ovatis acutis plurifloris.... 5 Ad mont. Ililmiani Boliviæ (Pentland in herb. Mus. paris.).

XXV. COCCOLOBA Jacq. Amer.p. 37, 112, t. 73-78, obs. p. 18,-t. 8, 9; Linn. gen. p. 264, n. 678, Gartn. fr. 1, p. 214. t. 45, Lam. ill. t. 316, Meisn: mon. Polyg. prodr. t. 1, f. 4, t. 2, B. G., ej. gen. pl. vasc. p. 316 (227), et in Mart. R. bras. fasc. 14, Polyg. p. 23, Endl. gen. p. 308, n. 1990 ; suppl. IV, 2, p. 50. - Guajabara Plum. ic. t. 145. Polygoni sp. audet. Flor. flumin. $4, t .41-43$.

Flores hermaphroditi (rarius abortu passim unisexuales). Calyx heibaceus vel subcorollinus, infundibuliformis, subæqualiter 5-partitus, patèris, demum clausus, tubo accrescente plus minus carnoso, limbo immutato cotinivente. Stamina 8, ino calyci inserla, æqualia, inclusa vel exserta, 5 lobis alterna, 3 fobis interioribus anteposita, filamentis subulatis basi contiguis, antheris globóso-didymis dorso affixis versatilibus. Ovarium liberum vel calycis basi adñatum, trigono-ovatum, ovulo basilari orthotropo. Styli 3 liberi, filiformes, breves, stigmatibus capitatis integris. Achænium calyce sphæroideo subcarnoso arcte tectum eique sæpius infra adnatum, subtrigono-globosum vel ovoideum, angulis rotundatis obsoletis, pericarpio tenui crustacea, septis membranaceis incompletis semi-3 vel 6 -loculare. Semen subsessile, erectum, sulcis 3 vel 6 longitudinalibus 3 vel 6 -lobum, sullcato-rugosumi, ititegutriento membranaceo tenui. Albumen farinosum, ad péripheriam rumination sulcisque suis spermodermii plicas recipiens. Embryo axilis, rectus, cotyledonibus foliaceis latis subplanis, radiculâ superâ. - Arbores et frutices Americæ tropicæ et subtropicæ; ochreis coriaceo-membranaceis cylindricis truneatis eciliatis înfra înediự̂n foliigéris deciduis, folìis sparsis coriàcèis vel rarius hèrbảceis 
integerrimis ponninerviis plerumque reticulatis, racemis spiciformibus terminalibus vel axillaribus (ramulos axillares brevissimos vel nondum evolutos terminantibus) aphyllis sæe elongatis simplicibus vel rarius ramósís continuis cylinditicis vel filiformibus erectis vel pendulis, bracteis ochreiformibus menbranaceis plurifloris, pedicellis apice articulatis persisientibus singulis basị ochreolâ (sæpe obsoletâ) stipatis, floribus plerumque parvulis albis vel virescentibus rarius rubris, fructibus bacciformibus coloratis. - Genus floris structurâ Polygono proximum, habitu vero recedens et fructu distinctissimum, semine Müblenbeckiæ, Triplaridi, Ruprechtiæ èt Brunnichiæ affine. Specierum diagnosis propter foliorum et inflorescentiæ uniformitatem et fruclum plurimarum ignotum admodum difficilis, pro parte ex foliorum consistentiâ et nervatione (forsan secundum æetatem mutabilibus) derivata, erroribus nimis obnoxia. Subdivisiones sequentes mere provisoriæ, quamvis parum naturales et characteribus levibus innitentes, tamen specierum indagationem adjuvabunt.

\section{Paniculatce, racemis spiciformibus ramosis paniculámi simplicem aphyllam formantibus.}

1. G. P.oLYS T ACHYA (Ẅedd. in Ann. sc. nat. $3^{\circ}$ sér. 13, V, p. 261), arbuscula rạmulis sullcatis, junioriljus ochreisque fulvo-tómentosis, foliis herlyiceis petiolatis inferioríbus cordato-orbicularibus, superioribus obovatis oblongisve acuminatis basi obitúsis utrinque tenuiter elevato-venosis laxe reticulatis fulvo-tomentosis, supra demưn glabriusculis, panticula ramis brevibus indivisis racemis filiformibus laxifloris, rhachi bracteisque tomentellis, floribus subsessilibus, fructu parvo globoso obtuse acuminato. 5 In Brasilixe prov. Motto Grosso (Nart. herb. fl. bras. n. 1242 !), Bahiensi (Salzm.n. 474 l) et ad fl. Amazon. (Pœppig !, Spruce, n. 956 l).Meisn. in Mart. fl. bras. fasc. 14, Polyg. p. $43^{*}, t: 21$, fig. 1.P. latifolia Pœppig I pl. exsicc. (non Lam.). Arbuscula orgyalis, trunco gracili, ramis patentibus ramulis gracilibus demum glabris. 0chrese decidue, petiolo 6-12 lin. longo internodiisque junioribus sublongiores. Folia 3-12 poll. longa, superiora interdum elliptica basi leviter cordata, venarum reticulo supra obsoleto. Panieulæ ramulos breves terminantes ejusque foliis pluries longiores, semipedales, racemis digitalibus, pedunculo cammuni brevi bassi laxe vaginato, bracteis parvis rematipsculis sub-1-floris. Fructus magnit. Pisi, calycis limbo clauso obtuse acuminatus. (v. s.)

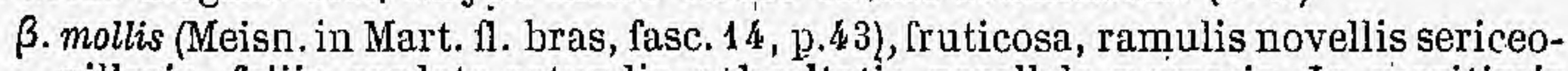
villosis, foliis cordato-rotundis subpeltatis parallele nervosis. In maritimis Brasiliæ prov. Bahiensis. - G. mollis Gasaretto nov. stirp. Bras. dec. 8, p. 72, n. 80.

2. G. paniculata (Meisn. in Mart. n. bras. 14, p. $43^{*}$, t. 20 , et t. 21, f. 2), ramulis sulcatis, ochreis enervibus petiolum æquantibus laceris, foliis herbaceis late ovatis breve aculeque acuminatis, leviter cordatis planis, supra immerse venosis, minutissime obsoleterque elevato-reticulatis glabris subnitidis, subtus elevato-venosis laxe reticulatis, junioribus ad-venulas cum ochreis ramulis pedunculisque tomentellis, paniculâ terminali aphyllâ, racemis patentibus filiformibus, bracteis parvis obtusis flore. subsessili brevioribus. I In Brasiliâ, ad f. Amazonum, (Pœppig! n. 2649 !), prov. Goyas (Pọll! Mart. herb. fl. bras. n. 1242). Ramuli patuli. Folia

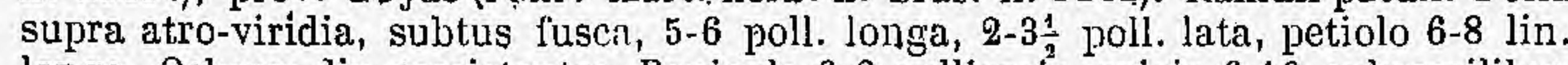
longo. Ochreæ diu persistentes. Panicula 6-8-pollicaris, spicis 6-10 subsessilibus simplicibus 3-5 poll. longis mutltifloris, hasi squuamâ ovatà, 1-2 lin. longâ, margine diaphanầ bracteatis, florự fasciculis 1-2 lin. distantibus. Calyx patulus, magnit. Pólygoni avicularis, tubo subnullo. Fruct. ign. A præecedente, præeter alias notas, pubescentiâ rariore et minore distincta. ( $\bar{v}$. s. in herb. Nart., Zuccar., DG. et reg. Berolin.)

3. G. LATIF oLiA (Lam. dict. 6, p. $61^{*}$, ill. t. 316, f. 4), arborea, glaberrima, ramulis pedunculisque profunde sulcatis, ochreis deciduis summis amplis laxis internodium superantibus petiolum subæquantibus, folị̣s coriaceis amplis, late obovatis sulorotundisve obtusis truncatis vel emarginatis, nervo costis. patentibus venisque subtus valde prominentibus; supra impressis, paniculâ terminali folium sub- 
æquante, racemis simplicibus semipatentibus, floribus subsessilibus bracteisque parvis. $\delta$ In Guianâ Gallicâ (Poiteau! Perrottet, n. $82 !$ ), Anglicâ et Batavâ (Schomb. n. 825, Hostmann et Kappeler, n. 682! Kegel, n. 277! 475 ! Wullschlægel, n. 450!) et in Venezuelà (Funke, n. 712 !). - Pers. syn. 1, p. 442, Meisn. in Linnæâ 21, p. 263, et in Mart. fl. bras. 14, p. 43, t. 19. G. grandis Benth. in Hook. Lond. Journ. 4, p. $624^{*}$ (quam quidem non vỉlimus, sed ex descr. a specie nostrâ distinguere nequimus). Arbor $40-45$-pedalis, foliis usque ad $1 \frac{4}{2}$ ped. longis. (v. s.)

\section{§ 2. Haplostachyoe, racemis spiciformibus simplicibus (rarissime basi ramulo ayctis).}

\section{¡ Folia orbicularia vel late ovata basi rotundata vel.cordata vel rarius pettatä.}

4. C. UVIFER A (Jacq. Amer. p. $112^{*}$, t. 73), arborea, glaberrima, foliis rigide coriaceis breve petiolatis suborbicularibus vel inferioribus late cordato-ovatis summis sæpe obovatis obtusissimis vel subacuminatis utrinque. penninerviis et tenuiter reticulatis, racemis terminalibus subsessilibus folio longioribus demum pendulis, pedicellis exsertis calyce parvo sublongioribus medio articulatis; fructu ovatoacuto subsulcato. 5 In littoribus arenosis ins. Antillarum (Sieber herb. Martin. n. 103 ! fl mixt. n. 381! Murray, n. 341 ! Poeppig! etc.), Colombiæ (Humb.), Surinam (Kegel, n. 984!), Floridæ austral. (Rugel, n. 180 !), Brasiliæ. (Mart.). Linn. sp. 1, p. 523, Willd. ! sp. 2, p. 457, Pluk. alm. p. 394, t. 236, f. 7, Catesby, Carol. 2, t. 96, Lam. dict. 6, p. 61 *, ill. t. 316, f. 2, Bot. mag. t. 3130, Meisn. in Mart. fl. bras. fase. 14 , Polyg. p. $422^{\circ}$. Guajabara racemosa Plum.ic. t. 145. Polygonum uvifera Linn. sp. ed. 1, j. 365. Folia receutia nitida, ex siccata opaca pallida. (v. v. c. et s. sp.)

$\beta$ ? ovalifolia (Meisn. l. c.), foliis late ovalibus obovatisve utrinque rotundatis basi emarginatis, racemo pedunculato longo filiformi laxo. In Brasiliầ-(Mart.!). - Meisn. 1. c. Forte n. sp., sed e fragmentis suppetentibus haud rite definienda. Petioli 5-6 lin. longi. Folia 4-5-pollicaria, poll. lata, supra subnitida, venis utrinsecus 3-5 patulis semiimmersis, venularum reti obsoleto vix prominulo, subtus opacis venis venulisque magis prominulis. Racemus (defloratus) 10-pollicaris, fasciculis 1-3 lin. distantibus. (v. s. in herb. Mart.)

$\gamma$ ? Leoganensis (Willd. sp: 2 , p. 457), racemis fructiferis erectis. In S. Domingo. - C. Leoganensis Jacqे. Am., p. 113, t. 178, fig. 33. Non satis nota, forsan propria sp. Folia duplo minora quam speciei vulgaris.

5. C. PU BES CENS (Linn. sp. 1, p. 523), arborea, ramis paucis brevibus crassis, foliis coriaceis sessilibus amplissimis cordato-suborbicularibus vel late ovalibus obtusis, subbullato-rugosis hirsuto-pubescentibus vel demum supra glabratis, subtus fortiter elevato-reticulatis, venis supra immersis, racemo terminali solitario erecto Poliis breviore, pedunculo brevi basi vaginato, pedicellis calyce longioribus, fructu ovato. 5 In sylvis montanis densis ins. Antill., Guianæ Anglicæ (Schomb.), et Batave (Kegel, n. 1339 !), Nexici (cult.? Schiede, n. 60!). - Pluk. phyt. t. 222 , f. 8 , Willd. sp. 2 , p. 457 , Lam. dict. 6 , p. $61^{*}$, Bot. mag. t. 3166, Benth. in Hook. Lond. journ. 4, p. 624, Meisn. in Linnæeâ 21, p. 264, et in Mart. fl. bras. 14, p. 42*. C. grandifolia Jacq. hist. Amer.p. 113. Arbor 60-80 ped, trunco gracili supra medium pauciramoso, foliis horizontaliter patentibus rigidis diametrum bipedalem attin. gentibus, pubescentiâ densâ brevi rudi. Flores virescentes, pedicellis demum 3 lin. Iongis. Fructus edules. (v. v. c. sine fl. et s. sp.)

6. C. RUgos A (Desf. cat. hort. paris. ed. 3, p. 389), urbuscula glaberrima gracilis, ramulis brevibus crassis sulcato-acutangulis, ochreis foliaceis amplis nervosis, foliis rigide coriaceis sessilibus amplis ovato-orbicularibus cordato-subamplexicaulibus obtusis bullato-undulatis venis reticulatis nervoque sublus prominientibus supra profunde impressis margine recurvo, racemo terminali solitario elato stricto, pedicellis calyce longioribus, staminibus exsertis, fructu ovato subtrigono. 5 In ins. Portorico et S. Thomas. - Wedd. in Ann. śc. nat. 3* sér. 13, p. 261, Planchon, in fl. des serr. et jard. 7, p. 160. C. macrophylla hort. paris. olim, Hook.l in Bot. mag. t. 4536, Paxt. flow. gard.1852, n. 191. C. bullata, magnifolia et rugosa herb. paris., ex Wedd. Arbuscula elegans, 20-30-pedalis, trunco subsimplici stricto sparse foliigero comá densà foliorum pedalium horizontaliter 


\section{coccoLoba. POLYGONACE A (AUCTOR MEISNER).}

patentium coronato, racemo bipedali et ultra stricte erecto pedunculato densifloro, rhachi sulcatâ, pedicellis, calycibus baccisque pulchre coccineis. Stamina (fide Hook.) 8-12 monadelpha. (v. v. flor. in herb. Kew. m. sept. 1850.)

7. G. emarginat A (Jacq. enum. Amer. p. 37 ; obs.! p. 18, t. 9), fruticosa glabra? ramis gracilibus, ochreis deciduis, foliis coriaceis petiolatis orbicularibus planis basi rotundata cordatis, apice sinu acuto exciso bilobis lobis acutiusculis, race-

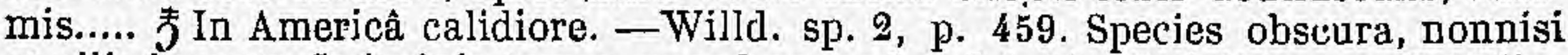
sterilis inventa, Jacquinio tamen quoad genus haud dubia. Petioli tenues, 6-10 lin. longi. Folia 3-pollicaria, sæpe paulo latiora quam longa, sinu baseos apicisque 3-5 lin. profundo, illo lato, hoc angustiore triangulari, venis primariis utrinsecus 5-6 patentibus intra marginem obsolete arcuatis, venulis reticulatis.

8. G. BARBADENSis (Jacq. enum. Amer. p. 37 ; obs. 1 , p. 18, t. 8, non Willd nec H. B. K.), arborea, glaberrima, ramis sulcatis, ochreis tenue membranaceis, foliis coriaceis petiolatis cordato-ovatis undulatis reticulatis, venis subtus prominentibus, racemo terminali folio longiore solitario, bracteis $2-4$-floris, yedicellis brevibus, staminibus exsertis. 5 In ins. Barbados (Jacq.) et S. Thomas (G. Ehrenberg).

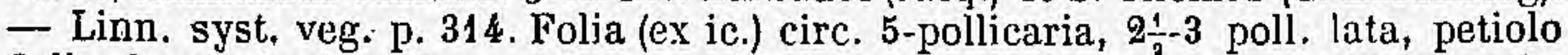
3 lin. longo, basi leviter cordata, venis utrinsecus 5-6 prope marginem arcuatis. Kacemi subpedales. Flores et fruclus ignoti. Folia in specim. Ehrenb. usque ad 4 poll. lata, haud undulata, rigidula, venulis utrinque subæequaliter dense reticulatis acute prominalis. Ochreæ arcte cylindricæ, 5 lin. longæ, opacæ, diu persistentes. (v. sp. steril. in herb. reg. Berolin.)

ß. Mexicana, ochreis summis rufo-tomentellis, petiolis crassis sulcatis supra concavis, foliis interrupte undulatis. In Mexico (Schiede, n. 1151!). Folia 6-8 poll. longa, 4-5 poll. lata, petiolo 5-6 lin. longo, reticulatione minus prominulà. Coet. ut in pl.Elırenb. An species distincta? (v. sp. steril. in herb. reg. Berol.)

9. L. populifoli (Wedd.I in Ann. sc. nat. 30 sér. 13, p. 257), glabra, ramulis gracilibus nitidis sulcatis, ochreis amplis laxiusculis basi diutius persistente, foliis subcoriaceis petiolatis obovato-orbicularibus subpeltato-cordatis abrupte breviacuminatis planis, supra subopacis minutissime reticulatis, subtus nitidis lævibus, nervo venisque primariis supra immersis, subtus prominentibus, racemis lateralibus solitariis pendulis folia æquantibus vel superantibus filiformibus densifloris, bracteis subunifloris obtusis floribusque 'subsessilibus parvis, fructu parvo ovato obtuso. F In Brasilise prov. Sebastianopolit. (princ. Neuwied!), Mínas Geraës (Mart.!), Bahiens. (Blanchet, n. 1486। et 1646). - Meisn. in Mart. fl. bras. fasc. 14, p. $40^{\circ}$, t. 18. C. costata Mart. I mss. C. alnifolia Casaretto nov. stirp. dec. 8, p. 71, n. 78 ? (ex descr., recedens tantum " foliis cartilagineis, bullatis, venis subtus interdum puberulis). "Frutex scandens? ex Wedd. (arborescens, ex Casar.). Folia usque ad 6 poll. longa, 5 poll. lata, petiolo semipollicari, verits secundariis subtus laxe anastomosantibus. Racemi ramulos laterales brevissimos terminanles, 3-8 poll. longi, pedunculo basi ochreâ magnà laxe vaginato. Baccæ rugosæ, magnit. grani piperis, achænio calycem æquante nitido fusco minute granulato-striato apice trigono. (v. s.)

10. C. óRREOLATA (Wedd.! 1. c. p. 259), glaberrima, ramis gracilibus tenuiter striatis, ochreis deciduis, foliis coriaceis petiolatis orbicularibus ovatisque obtusis vel abrupte brevi-acuminatis basi leviter peltato-cordatis utrinque opacis minute reticulatis, venis primariis nervoque supra immersis subtus prominulis, racemis lateralibus solitariis folia subæquantibus laxiusculis, bracteis 1-3-floris, bracteolis infundibuliformibus conspicuis $2-3$-fidis pedicellos patulos subsequantibus, fructu parvo subgloboso utrinque subacuminato. \& In Brasiliæ prov. Bahiensi (Blanchet, n. $3394 ! 3410 \mathrm{~B}$ ! et 3561 l). - Meisn. in Mart. fl. bras. fasc. 14, p. $40^{*}$. C. Blanchetiana Wedd. 1. c. p. 257 (species ex Blanchetii, n. 3561 constituta, sed hujus specimina nostra nullo modo a n. 3394 et $\mathbf{3 4 1 0}$ differunt). Folia 2-3-pollicaria.

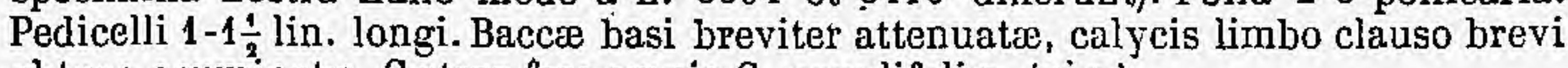
obtuse acuminatic. Cietera fere omnia G. populifoliæ. (v: s.)

11. C. CORDATA (Cham.! in Linnæà 8, p. $133^{*}$ ), arbuscula ramosissima glabra, ochreis petiolum brevem subæquantibus basi nervosâ diu persistente, foliis coriaceis suborbicularibus ovatisve obtusis subpeltato-cordatis tenuissime reticulatis, venis primariis subtus prominulis ad axillam barbatulis supra evanescentibus 
margine leviter recurvo, racemis terminalibus solitariis folio brevioribus erectis, rhachi ptrberulâ, pedicellis exsertis glabris, baccis sphæroideis. $\delta$ In Brasiliấ merid. (Sellow!). - Meisn. 1. c. p. 41 *. Arbuscula 15-pedalis, tamulis junioribus

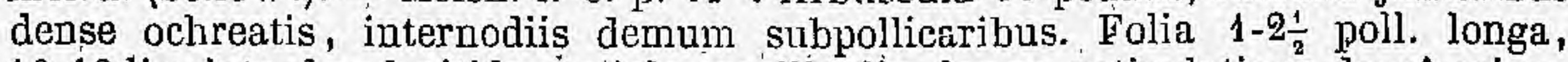
10-18 lin. lata, haud nitida, petiolo gracili 5 lin. longo, reticulatione densâ minutissimâ quidem, attamen (subtus prącipue) oculo jam nudo conspicuâ. Racemi 1-2-pollicares, pedicellis demum $1 \frac{1}{2}$ lin. longis. Baccæ magnit. pisi, achænio obtuse trigono-globoso lævi nitido. Variat foliis ovalibus et ovato-oblongis ${ }_{x}$ summis sæepe reliquis majoribus. (v. s. in h. reg. Berolin.)

12. C. Gandolleana (Meisn. in Mart. fl. bras. fasc. 14, Polyg.p. 41 *), ramị divaricatis, ochreis tomentellis deciduis petiolo brevi crasso longioribus, folíis rigide coriâceis opacis glaberrimis suborbicularibus obtusissimis vel obsolete acuminatis leviter cordatis haud reticulatis, venis ante marginem evanescentibus sippra immersis subtus vix prominulis, racemis terminalibus axillaribusque solitariis folio longioribus filiformibus laxifloris glabris, bracteis minutis acutis 1-floris pedicello tenui brevioribus. F In Brasiliæe prov. Bahiensi (Blanchet, -n. 1818!). Arborea? ramis cinerascentibus. Folia 1-1 $\frac{1}{2}$-pollicaria, levissima, petiolo 1-2 lin. longo, venis utrinsecus 5-6 marginem haud attingentibus, reticulatione immo șub lente vix̄ conspicuâ. Racemi sessiles, $1 \frac{1}{2}-2 \frac{1}{2}$ poll., erecti vel nutantes, pedicelli 1 lin. longi. Galyx ovatus, semi-5-fidus. Fruct. ignot. A simillimâ G. cordatât petiolo breviore crasso, foliis haud reticulatis, etc., facile dignoscenda. (v. s. in h. DG. et Shuttlew.)

13. C. ROTUNDIFOLIA, glaberrima, ramulis patentibus, ochreis brevibits opacis fugacibus, petiolis gracilibus supra 1-sulcis, foliis coriaceis orbicularibus leviter cordatis brevissime obtuseque acuminatis planis utrinque subæqualitet denseque prominulo-reticulatis, racemis termiualibus solitariis folio longioribus erectis filiformibus densifloris, pedunculo brevi vaginato, bracteis 1 -floris flơre sessili parvula- brevioribus. $\bar{J}$ ? Ad cap François ins. S. Domingo (C. Ehrenberg !). Frutex ? ramulis cinereis obsolete strialis et lenticelloso-verruculosis. Petioli teretes,

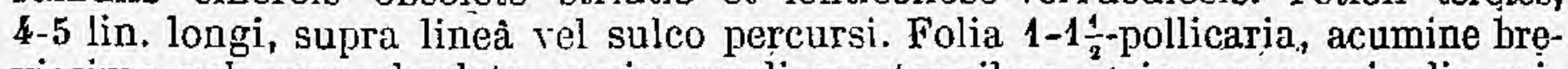
vissimo vel sæpe obsoleto, venis veuulisque tenuibus utrinque prominulis, primariis utrinsecus 5-7 angulo semirecto patentibus prope marginem arcuatis, venis transversis crebre junctis. Spicæe $2-2 \frac{1}{2}$ poll. longæ. A præcedentibus valde affinibus differt foliis minus coriaceis, parum rígidis, planis, reticulatione, etc., bene distincta. Folia quoad formam exacte conveniunt cum ic. C. Leoganensis Jàcq: Am. t. 178, f. 33, sed dimidio minora. Species à G. uviferâ longe diversa. (v. s. sine fr. in herb. reg. Berolin.)

14. G. PELTATA (Schott in Spreng. syst. cur. post. p. 405). "scandets, foliis coriaceis peltatis subrotundo-ovatis acutis lævibus, racemis erectis. "In Bràsiliâ (Scholt, fide Spreng., sed inter plantas Schottianas Musei imp. Vindob. non vidimus.)

15. C. Pel t gera (Meisn. in Mart. fl. bras. fasc. 14, Polyg. p. 39*, t. 17), scandens, ramulis sulcatis, ochreis brevibus laxis basi nervosis, foliis coriaceis petiolatis ovatis subrotundisque acuminatis vel obtusis basi cordatâ peltatiś utrinque elevató-reticulatis glaberrimis subnitidis, spicis terminalibus solitariis erectis follo subæqualibus, rhachi pedicellis crassiusculis calycibusque tomentellis. 5 ? In monte Corcovado, prope Río Janeiro (Mart:Y), circa Ega, ad fl. Amazon. (Pœppig, n. 2670!). C. scandeñ Póppigl mss. Ochreæ fusce, integra, actitæ, opace, apice subdiaphanæ, diu persistentes. Folia 3-8-pollicaria, 3-5 poll. lata, petiolo $1-1 \frac{1}{3}$ poll: longo, sulcato, paulo intra marginem vel pássim (in eodem specimine) ipsi márgini inserto. Racemi 4-6-pollicares, undique minute pulvereo-tohentelli, jedunculo 1-2-pollicari sulcato, bracteis ovatis concavis pedicello sublongioribüs calyce suburceolato, $2 \frac{1}{2}$ lin. longo triplo brevioribus. A G. peltatâ abhorret foliis haud levibus; sed nervorum reti acute prontinulo denso asperatis; a $\mathrm{C}$. cordatâ preterea discrepat foliis multo thajoribus. ( $\mathrm{v}$. s. in $\mathrm{h}$. Acad. Modac. et frus. Vindobon.)

16. G. Ma R II (Meisn. in Mart. fl: bras. fasc. 14, Polyg. $37^{\circ}$, t. 16), ramis validis, novellis cum ochreis brevibus deciduis rufo-tomentellis, foliis coriaceis petiolatis ellipticis vel ovali-oblongis subpeltato-cordatis utrinque nitidis gláberrimis mitiute denseque prominulo-reticulatis, racemis terminalibús solitäriis vel geminis 
folio longioribus filiformibus laxiusculis erectis, bracteis parvis ovatis 1-floris, bracteolis exsertis cyathitormibus subbilobis pedicollum brevissimum æquantibus vel superantibus. 5 ? In Brasilize prov. Minas Geraës (Martius ! Pohl! Lhotzky), Demerara (Parker! in herb. DC.), Guatemala (Friedrichsthal, 11. 398 !). Räni divaricato-rattosi, cinerel. Petioli 3-6 lin. longi, canaliculati. Folia obtusa vel breviter acuminata, $2 \frac{1}{2}-5$ joll. longá, $1 \frac{1}{2}-3$ poll. lata, veilis primariis utrinsecus $5-7$ subİmersis vel interdumi sujpra leviter insculptis, venularum reticulo subtus laxiore. Racemi 3-6-pollicares, basi swejius racemum accessorium plerumcue breviorem emitţentes, glabri vél rhachi bracteisquie minute tomentellis. Calyx 1 lin. longus. Fruct. ignotus. Accedit ad C. Guianensem, scd differt foliis latioribus, magis ovalibus, basi scmper cordatis, sinu petiolum equante, venis primariis paucioribus, reticulatione minutiore densiore. (v. s.)

17. C. CORDIFOLIA (Meisn. 1. c. p. $37^{*}$ ), glaberrima, ramis gracilibus tenuiter striatis, ochreis petiolum ditpuantibus tenuibus enervilis, foliis coriaceis ovatis cordatis obtuşis vel subacuminatis planis levibus utrinque obsolete subimmersoreticulatis, venis supra immersis subtus jrominulis, racemis terminalibus solitariis folio longioribus erectis densifloris basi interruptis, bracteis parvis sub-1-floris, floribus subsessilibus. F In maritimis Brasilice prov. Bahiensis (Salzm. n. 476 ! Blanch. n. 100 (et 3528 I). Frutex erectus, 8 jed, ramosissimus (Salzm.). Petioli $3-4$ lin. In lata, basi rotundatấ subpeltato-cordata, sinu angusto profundo, lobis contiguis, venis primaris prope marginem arcuatis tenuissimis vel sepe evanescentibus, reticulatione nonnunquan penitus obliteratâ. Racemi 4-6-pollicares, pedunculo basi arcte vaginato. Fruct. ign. A C. cordatâ ejusque affinibus jam glabritie perfectâ, foliorum magnitudine, etc., apprime distincta. (v. s. in h. DC. et Shuttlew.)

18. C. L a vis (Casarretto nov. stirp. bras. dec. 8, p. 71), fruticosa, súbdichotoma, : foliis coriaceis petiolatis ovatis vel ovato-subrotundis obtisis basi subcordatis margine subrevolutis utrinque glaberrimis subnitidis lævibus; venis paucis scepe parum conspicuis, racemis folio multo longiorilus. In Brasiliæe sinu Bahiénsi. T Meisn, 1. c. p. 41. Folia 3-3 $\frac{1}{2}$ poll. longa, $2-2 \frac{1}{2}$ poll. lata, petiolo $3-4$ lin. longo. Forsan cum C. cordifoliâ aut Candolleanâ identica.

19. C. KLOTzSGIANA, glabertima, ramis virgatis validis, ramulis subflexuosis sulcato-striatis, ochreis opacis deciduis, foliis coriaceis breve petiolatis ovatooblongis obtusis basi rotundatà emargínatis planis sụhopacis utrinque sub. tequaliter dense reticulatis, renis arcuatis venulisque tenuibus leviter prominulis, sjicis terminalibus solitariis subsessilibus folio longioribus filiformibus, bracteis 1-floris scariosis floribusque subsessilibus parvulis. 5 ? In Antill. ins. S. Thomas. Ramuli cinerci. Óchrese láxiuscule, fusce. Folia $2-2 \frac{1}{2}$ poll. longa, $1-1 \frac{1}{2}$ poll. lata, jetiolo $1-2 \frac{1}{2}$ lin. longo, apice attenuata, venis primariis utrinsecus $7-10$ semijatentibuis prope marginem arcuatis: Spica 5-7-pollicares, ereptæ vel nutantes, bräcteis jarvulis ápproximatis. A C: cordatâ et Barbadensi, quibus pluribus nótis accedit, differt vel foliorum forma et reticulatione ve spicis lonigloribus, etc. Proxime accedere videtur ad $G$. parvifoliani Polt., sed folia nec hitida, nec laxo (sed dense) réticulata. ( $\nabla . s$. sine fr. in h. Kunth!).

20. G. NUT ANS (Kunth in H.B. nov. gen. 2, p. 175\%), glabra, foliis subcoriaceis petiolatis obovatis cordatis hreve acuminatis reticulato-venosis supra nitidis, nervo ve-

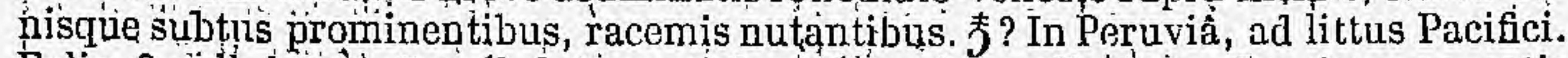
Folia 8 poll. longa, 5 poll. Iata, petiolo pollicari canaliculato. Species non satis nota, nee in herb. Kunth, nec iñ.Willdenowiano exstans.

21. C. о B оे А т A (Kunith in H. B. nov̀. gen. 2 , p. 176*), arborea, glabra, ramis junioribus vaginatis, ochreis striatis, foliis coriaceis petiolatis obovatis vel subrotundobbovatis acutis leviter coŕdatis utrindue subiequaliter et densiusicule eléváto-reticillatis supjra nitidiś, subtius opacis, racemis terrninalibus solitarils subsessilibus folio longioribus densissimè multiflóris gracilibus, bracteis imbricatis tenuibus obtusis 2-4-floris, floribus subsessilibus, staminibus exsertis. 5 In humidis NovaGranadæ. C. coriaced Willd. mss. in herb. n. 7704. Petioli 5-6 lin. Iongi, teretes,

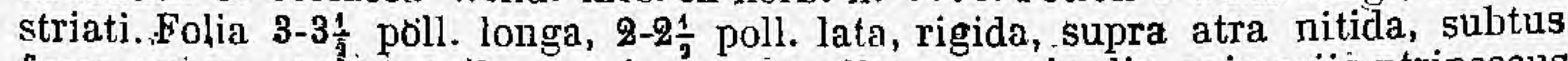
fusca opaca, venis tenuibus ulrinque cequaliter prominulis, primariis utrinsecus 
6-8 semipatentibus fere rectis prope marginem arcuatis. Racemi 4-5-pollicares, floribus albidis. (v. sp. Humb. in herb. Willd.)

22. C. r a mosissima (Wedd.! in Ann. sc. nat. $3^{\circ}$ sér. 13, p. 258), fruticosa, ramulis gracilibus albidis striatis junioribus fulvo-tomentellis, ochreis brevibus deciduis, foliis rigidis coriaceis brevissime petiolatis late ovatis subrotundisve utrinque rotundatis vel emarginatis glaberrimis denseque elevato-reticulatis, racemis terminalibus lateralibusve solitariis folio brevioribus erectis laxiusculis, bracteis exiguis sub-1-floris cum rhachi pedicellisque tenuibus puberulis, floribus parvulis, staminibus exsertis. $\bar{J}$ In Brasiliæ prov. Bahiensi (Blanchet, n. 2421!). Meisn. in Mart. fl. bras. fasc. 14, Polyg. p. 41 *. Rami patentes, nodis sæpe incrassatis, internodiis $1-1 \frac{1}{2}$ poll. longis. Ochreæ tomentellæ petiolum 1 lin. longum vix superantes. Folia $1 \frac{1}{2} 2 \frac{1}{2}$ poll. longa, 1 fere 2 poll. lata, ovalia, rarius ovata vel obovata, sicca rufo-fusca, venis tenuibus ante marginem subevanescentibus. Racemi 1-1 $\frac{1}{2}$-pollicares, breve pedunculati, pedicellis patentibus 1 lin. longis. Affinis C. ovatæ; Alagoensi et reticulatæ, sed vel foliorum formâ et reticulatione vel racemis distincta. (v. s.)

23. G. EX CELS A (Benth.! in Hook. Lond. Journ. 4, p. 624*), scandens, ramulis ferrugineo-pubescentibus demum glabratis verrucosis, ochreis petiolisque brevibus, foliis coriaceis ovalibus ovalisve breve acuminatis basi rotundatis vel cordatis reticulatis opacis supra glabris subtus ferrugineo-hispidulis, venis supra insculptis subtus prominulis, racemis axillaribus $1-3$ subfasciculatis folio brevioribus sessilibus gracilibus laxifloris, bracteis infundibuliformibus plurifloris pedicellos æquantibus rhachique puberulis, floribus parvis polygamis. (Schomb. coll. 1, n. 178! 400! coll. 2, n. 218 et 128 !) et Surinam (Wullschlægel n. 804), Meisn. in Mart. fl. Bras. fasc. 14, Polyg. p. 34*. Super arbores alte scandens. Petioli circa semipollicares, crassi, supra sulcati. Folia 6-8 poll. longa, 4-5 poll. lata, rigida, sicca nigricantía. Racemi in ramulis lateralibus brevissimis aphyllis valde approximati, fasciculos axillares simulantes, 2-3- pollicares. (v. s.)

24. G. FAstigiat A (Meisn. in Mart. fl. Bras. fasc. 14, Polyg, p. 34 *), ramis sulcatis glabris, ochreis petiolum subæquantibus nervosis junioribus tomentellis, foliis coriaceis ovalibus obtusis leviter cordatis supra glabris nitidis, venularum reticulo supra immerso tenerrimo subtus laxiore finlvo-puberulo, venis primariis supra impressis subtus fortiter expressis, racemis terminalibus et in summis axillis solitariis folio lofgioribus erectis filiformibus laxiusculis glabris, bracteis semiscariosis sub-1-floris, pedicellis brevissimis, 5 ? In Brasiliầ (Schott n. 5540!) et in Guianâ Anglicâ (Schomburgk ! n. 1262, ex parte). Rami virgatì stric̀ti, apice fastigiato-polystachyi. Ochre:e coriacese, opacæ. Petioli 5-6 lin. longi, teretes, puberuli. Folia 3-5 poll. longa, 2-3 poll. lata, supra quasi scrobiculato-reticulata. Racemi 5-8-pollicares, pedunculo brevi basi ochreis laxis margine scariosis vaginato, bracteis bracteolisque $\frac{1}{2}$ lin. longis ovatis patulis, pedicellis demum exsertis. Calyx 1 lin. longus: Proxime affinis G. excelsæ et Parimensi, sed foliis tenuioribus, uervatione, bracteis bene distincta. (v. s. in herb. Mus. Vindob. et Berolin.)

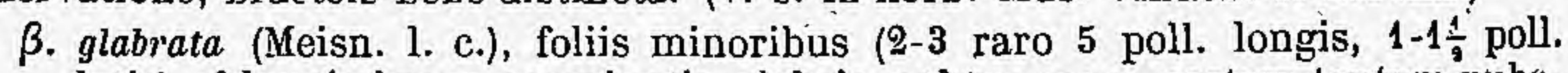
latis) oblongis breve acuminatis glabris, sultus secus costam tantum pubtrulis, racemos subæquantibus (Schott $n$. 5537! et ex parte 5540). Forma primo vultu satis discrepans, sed formis intermediis cum typo speciei connexa. (v. s.)

25. C. PARIMENSIS (Benth. l.c. p. 626), foliis subcoriaceis petiolatis ovatis ovalibusve breve acuminatis basi rotundatis vel cordatis reticulatis venis primariis supra impressis subtus prominulis, racemis lateralibus solitariis vel subfasciculatis folio brevioribus gracilibus laxiusculis, bracteis tubulosis sub-1-floris, pedicellis subinclusis caljce longioribus. J In Guianâ. - Meisn. in Marl. fl. Bras. fasc. 14, Polyg. p. 34 .

a. Schomburgkii, glaberrima, foliis ovatis. In Guianâ Anglicâ (Schomb.) ad Rio Uaupès (Spruce n. 2732 !) - Bentlı. l. c. Arbuscula vel frutex elatior, non scandens. Folia majora 6-7 poll. Ionga, 4-5 poll. lata.

B. Hostmanni, foliis ovalibus supra glabris subtus minute puberulis, venularum reticulo minuto supra vix prominulo obsoleto subtus laxiore acute prominulo. In Surinam (Hostmann n. 245!). Fulia 5-pollicaria, 3 poll. lata, petiolo, gracili 8-10 lin. longo. Racemi 3-4-pollicares, rhachi bracteisque sub lente pul- 
vereo-tomentellis, pedicellis $1-1 \frac{1}{2}$ lin. longis, floribus parvulis. Affinis C. excelsæ et ochreolatæ. ( $v, s$. in herb. Reg. Berolin. et Shuttl.)

26. C. R OSE A (Meisn. in Mart. 11. Bras. fasc. 14, Polyg. p. 33*, t. 14, f. 2); ramis sulcato-striatis, ochreis laxiusculis eveniis petiolo sublongioribus fulvo-tomentosis, foliis rigide coriaceis late ovalibus ovatisque basis rotundatà cordatis breviter acuteque acuminatis minute reticulatis margine recurvis supra glabris subtus ferrugineo-puberulis, venis venulisque supra impressis subtus prominulis, racemis axillaribus terminalibusque subsessilibus folio longioribus densifloris, bracteis ovatis purifloris puberulis pedicellos superantibus. 5 In Brasil. prov. Bahiensi circa Ilheos (Luschnath 1). Arbuscula subscandens, floribus roseis (ex Luschn. in Sched.). Rami juniores cum ochreis petiolis pedunculisque fulvo-tomentelli, demum glabrati, verruculosi. Petioli 5-6 lin. longi. Folia 2-3 poll. longa, circ. 2 poll. lata, exsiccata supra nigricantia, margine leviter recurvo, venis primariis utrinsecus 8-12 immersis sulciformibus, interstitiis minute denseque scrobiculato-reticulatis. Racemi 3-5 poll. longi, solitarii vel terminales quandoque tres fasciculati, bracteis

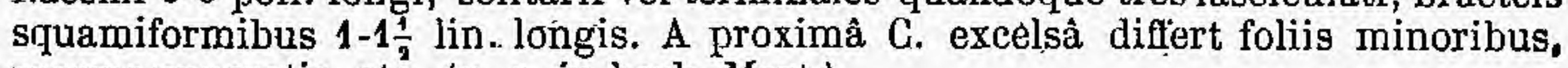
racemo superatis, etc. (v. s. in herb. Mart.)

27. C. Il HEENSis (Wedd! ! in Ann. sc. nat. 30 sér. 13, p. 258), glaberrima, ramis gracilibus striatis, ochreis teneris petiolum æquantibus deciduis, foliis herbaceis late ovalibus ovatisve breve acuminatis basi rotundatis vel leviter cordatis planis utrinque laxe subimmerso-reticulatis, racemis lateralibus solitariis folio sublongioribus nutantibus laxifloris, bracteis 1 - lloris pedicellisque brevissimis. 5 In Brasil. prov. Bahiensi circa Ilheos (Mart. herb. fl. Bras. n. 1240 ! Luschnath n. 37!) - Meisn. in Mart. fl. Bras. fasc. 14, Polyg. p. $36^{\circ}$. Arbuscula 20 ped., ramis propendentibus, flor. albis (Mart. in sched. herb. Ac. Monac.). Rami cinerei. Petioli 5-7 lin. longì. Folia usque ad 5 poll. longa, 3 poll. lata, tenue membranacea, venis prope marginem in arcus tenuissimos coëuntibus venulisque vix prominulis. Racemi ramulos laterales brevissimos ochreatos terminantes, $4-5$ poll. longi, bracteis inferne remotiusculis bracteolisque pedicellum includentibus $\frac{1}{2}-\frac{2}{3}$ lin. longis. Calyx magnit. Polygoni alpini, patens. (v. s.)

28. C. CARACASANA, ramulis leviter striatis, ochreis internodia brevia requantibus membranaceis tenuiter venoso-lineatis, foliis coriaceis petiolatis ovalibus obtusis basi rotundatis vel cordatis utrinque dense elevato-reticulatis, supra subnitidis glabris subtus in venis venulisque hispidulis, venis primariis supra immersis subtus venulisque grosse prominentibus, racemisterminalibus lateralibusque solitariis longis gracilibus densifloris, rhachi ochreisque minute glanduloso-punctatis glabris, bracteis plurifloris parvis, floribus subsessilibus. 5 In Colombia, ubi Uvero et la Geiba vocatur, circa Caracas, Venezuela, Costa Rica, etc. (Humb.! Bonpl.I n. 732 in Kerb. Kunth. et Willd., Vargas n. 30 ! et 30*! Otto n. 530 ! Moritz n. 304 ! 1109! Warscewicz n. 1! Karsten! Guatimala (Friedrichsthal !). C. Barbadensis Willd. I sp. pl. 2, p. 459, fide herb. n. 7706 ! Kunth! in H. B. nov. gen. 2, p. 175 (non Jacq.). Arbor 8-11- ped. (ex Otto), magna (ex Warscew). Ramuli cinerascentes, ochreati. Petioli 5-12 lin. longi, crassi, sulcati, glabri. Folia usque ad pedem longa 9 poll. lata, summa triplo minora basique rarissime breviter angustata, omnia apice rotundata vel passim leviter emarginata, venis primariis utrinsecus 9-13 prope marginem arcuatis. Racemi 6-12- pollicares, erecti. Fructus ignotus. (v. s.)

29. G. CAL о в о R R Y, glaberrima, ramis crassis rimoso-sulcatis, ochreis petiolo brevissimo crasso longioribus subpersistentibus, foliis crasse cariaceis ovato-oblongis cordatis acuminatis minute scrobiculato-reticulatis supra nitidis subtus opacis, venis prope marginem subevanescentibus supra immersis subtus venulisque tenuibus prominulis, racemo terminali subsessili folia æquante erecto stricto gracili laxiforo, bracteis minutis 1 - floris, pedicellis tenuibus flore duplo longioribus, fructu ovoideo obtuso. 5 ? In ins. Cubả circâ Havanam (Ramon de la Sagra n. 290 ! 544!) Verisimiliter arborea. Rani cinerei, validi. Petioli 2-3 lin. longi, lineam et plus lati. Folia 5-8 poll. longa, 3 poll. lata, acutiuscula vel plus minus attenuatoacuminata, sinu baseos vix $\frac{1}{2}$ poll. profundo angusto, venis primariis utrinsecus 7-9 prope inarginem tenuissimis arcus latos formantibus, tertiariis subtus laxe anastomosantibus tenuibus. Racemi 5-8-pollicares, basi vaginati, rhachi gracili sulcatâ cum pedicellis $3-4$ lin. longis patentibus calyceque ovali $1 \frac{1}{3}$ lin. longo pulchre * sanguinea. Fructus ovatus, subacuminatus, obtusus, $2-3$ lin. longus 
rugoso-costatus nigricans. Species insignis, pulchra, valde similis Polygono arborescenti Flor. Flumin. 4 , t. 43 , sed petiolis brevibus crassis, raceno laxióne, etc. discrepans. (v. s. in h. DG.) .

30. C. S T R I A T A (Benth. ! in Hook. Lond. Journ. 4, p. $626^{*}$ ), glaberrima, ramis virgatis cum ochrearum basi sulcato-striatis, foliis coriaceis breve petiolatis ovatis ellipticisve acuminatis basi rolundatís vel cordatis utrinque dense elevato-reticulatis, venis primariis supra subimmersis subtus prominentibus, racemis termịnalibus lateralíbussque solitariis folio sublongioribus filiformibus deńsifloris, bracteis | parvulis sub-1-florìs, floribus subsessilibus, fructu coronato.' J In Guianâ Anglicâ (Rich. Schoml. coll. II. n. 229 ! et 1265!) et in Brasil. provi. Bahiensi (Blanchet! in h. DG.). - Meisn. in Mart. fl. Bras. fasc. 14, Polyg. j. $36^{*}$. Videtur frutex laxe ramosus (decumbens, fide Blanchet), ramis cinereiș, junioribus acute sulcatis, nodis sæpe incrassatis. Ochreæe superne membranaceæe, bași coriaceâ grosse costato-nervosâ, costis plerumque post membraña destructioniem dịu persistentibus nodumque quasi coronâ processuum subulatorum erectorum cingentibus. Petioli crasśiusculi fere 3 lin. longi. Folia rigidula, $3-6$ poll. longa, $2: x-$ poll. lata, venis primariis utrinsecus $7-10$ tenuibus prope marginem arcuatis, venularum reticulo utrinque aqualiter prominulo. Racemi subsessiles, folium aquantes vel superantes, 3-5-poll. Flores 1 lin. longi (sulphurei, fide Blanch.). Bacca calycis tubo adnata ejusque limbo coronata. (v. s.)

31. Q. Cuja bensis (Wedd.! in Anu. sc. nat. $3^{\circ}$ sér. 13, p. 259), ramis gracilibus glabris tenuiter striatis, ochreis deciduis, folis subcoriaceis petiolatis qpacis ovatis oblongisve "obtusis basi rotundatâ leviter subpeltato-cordatis margine undulatis densiuscule prominulo-reticulatis supra glabris subtus in ienis puberulis, costarum axillís barbellatis, racemis terminalibus solitariis folio brevioribus laxiusculis, hracters parvis sub-1-floris rliachique fusco-tomentellis, pedicellis exsertis, fructu parvo subgloboso acuminato obsolete costato. $ђ$ ? In Brasiliæ prov. Matto Grosso circa Gujaba (Mart. herb. fl. Bras. n. 1241!) - Meisn. in Mart. fl. Bras. fasc. 14 , p. $37^{*}$. Frutex? scandens? ramulis cinereis. Fólia $2-4$ poll. longa, 1-2 $\frac{4}{2}$ poll. lata, petiolo 4-8 lin. longo tenui sulcato apice puberulo, limbi basi plerumque leviter cordati marginibus supra petiolum confluentlbus. Raceni 2-3-pollicares, pedunculo brevi basi obsolete ochreato, pedicellis fructiferis 2 lin. longis crassiusculis subrecurvo-patentibus. Baccæ magnit. Pisi minoris. Affinis C. Barbadensi. (v. s.)

32. C. GoUdOTIANA (Wedd. 1. c. p. 260), ramulis albicantibus rugoso-striatis, ochreis angustis internodio multo-brevioribus diu persistentibus, foliis rigidulis ovato-oblongis breve acuminatis basi rotundato-subpeltatis supra glaberrimis subtus ad costæe basin minute villosis "venatione sequali ", racemis terminalibus solitariis folio multo longiöribus gracilibus densifloris, rhachi angulatâ subglandulosâ, bracteis subrotunidis subbifloris, floribus subsessilibus, antheris inclusis, fructu oblongo breve jedicellato. $J$ ? In Novo-Granatâ (Goudlot in herb. Mus. Paris) et Brasilià? (Pohl). - Meisn. in Mart. fl. bras. fasc. 14, p. 35, t. 14, f. 1. Folia 3-4- pollicaria, 1 $\frac{1}{2}-2 \frac{1}{2}$ poll. lata. - Planta, quam hujus loci esise credimus, a Pohlio in Brasiliấ lecta et a Mus. Cres. Vindob. cum Zuccarinio communicata, a diagnosi. paullo recedit foliis elliptico- vel obovato-oblongis basi rotundatâ haud subpeltatis et pedicellis demum $1-2 \frac{1}{2}$ lin. longis validis patentibus. Folia vix rigida, opaca, supra haud reticulata, venis primariis supra impressis subtus cum secundariis tenuibus minute pubertulis prominulis venulárum reticulo tenerrimo immerso obsoleto. Racemi 5-6-pollicares, densiflori. (iv. s. sine fr. in herb. Zuccar.)

33. G. G AR DNERI (Meisn. in XIart. fl. bras. fasc. 14, Polyg. p. $36^{\star}$, t. 15), glaberrima, petiolis gracilibus supra sulcatis, foliis coriaceis ovalibus obovatisque acutiusculis basi rotundata subpeltato-cordatis subuitidis laxiuscule reticulatis venis venulisque supra scmiimmersis subtus prominulis, racemis terminalibus solitariis subsessilibus folio longioribus erectis cylindricis densifloris, rhachi crassiusculâ sulcatâ, bracteis plurifloris brevibus, pedicellis exsertis, floribus majusculis. 5 ? In Serra dos Orgaos Brasil. prov. Sebastianopolit. (Gardner n. 600 l). G. Vellosiana Casaretto? Nov. stirp. Bras. Dec. 8, p. 70, ex cit. Polygonum frutescens Flor. F́lum. 4, t. 44 (quæ icon quoad foliorum formam et magnitudinen cum nostrá exacte convenit, sed recedit petiolo 3-4 lin., in nostrâ. 8-10 lin. longo, racemo 
minus denso et floribus subsessilibus minoribus). Ochreæ haud striatæ. Folia

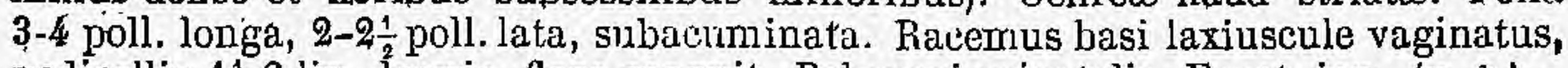
pedicellis $1 \frac{1}{3}-2$ lin. longis, flore magnit. Polygoni orientalis. Fruct. ign. (v. s.)

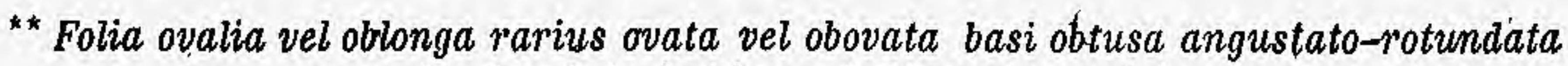 vel subcordata (rarius subattenuata acuta).}

34. G. Para ensis (Meisn. in Mart. fl. bras. 14, Polyg. p. $38^{*}$ ), glabra, ochreis coriaceis enerviis petiolo gracili canaliculato brevioribus deciduis, foliis subcoriaceis ovatis vel ovali-oblongis basi latâ rotundatà leviter cordatis utrinque nitidis haud reticulatis, racemís terminalibus solitariis folio brevioribus nutantihus filiformibus, rhachi tomentellâ, bractêis bracteolisque' subæqualibus parvis, pedicellis crassiuscnlis demum exsertis, baccis ovoideis obtusis levibus basi breviter attenuatis. $\delta$ ? In Brasiliæ jrov. Paraënsi et Rio Negro (Martius | Spruce n. 957 !). Rami juniores sulcati. Ochreæe 5-6 lin. longæ, arcte vaginantes. Petioli 8-12 lin.

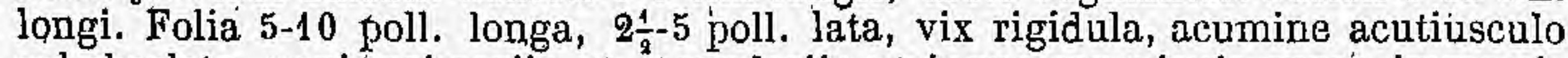
vel obsoleto, venis primariis et secundariis utrinque conspicuis supra immersis vel insculptis subtus leviter prominulis, venulis reliquis obsoletissimis vel plane invísibilibus. Racemi 3-5-pollicares, laxiusculi, floribus solitariis vel interrupte congregatis, pedicellis demum $1: 1 \frac{1}{2}$ lin. longis. Bacce Pisum cequantes. - Nimis affinis C. nitidæ, sed distincta foliis semper infra medium latioribus, basi magis rotundatis, haud reticulatis, lævissimis (v. s. in herb. Acad. Monac.)

35. G. NITID A (Kunth in H. B. nov. gen. 2 , p. $176^{*}$ ), arborea, glabra, ochreis leviter sulcatis petiolos subæquantibus summis puberulis, foliis coriaceis ovali- vel obo- vato-oblongis acutis basi rotumdatis cordatisve tenuiter reticulatis nitidis nervo venisque supra immersis subtus prominentibus, racemis terminalibùs folio demum longioribus pedunculatis erectis gracilibus densifloris, bracteis subbifloris puberulis, pedıcellis brevibus demum exsertis, fructu parvo ovato subacuminato. 5 ? In Colombjâ (Humb.), Brasiliæe prov. Para, Piauhy et Bahiens.-Meisn. in Mart. fl. Bras. faśc. 14, Polyg. p. $38^{*}$. Polygonum arborescens Flor. Flum. 4, t. 43\% Arborea? (ex Salzm. frutex subvolubilis). Rami sulcati. Ochreæ semipollicares, gilabriusculæ, summæ ferrugineo-puberulæ. Petioli $4-12$ lin. longi, semiteretes, angustê canaliculati, glabri. Folia 5-11 poll. longa, 2-6 poll. lata, parum rigidula, venis primariis utrinsecus 9-14 areuatis. Racemi 8-10-pollicares, nonnunquam in ramulis brevissimis pseudo-fasciculati, pedicellis patentibus $1 \frac{1}{2}$ lin. longis crassiusculis. Flores (ex Humb.) albi, suaveolentes. Stamina 8 inclusa. Fruct. magnit. Pisi, ovatus, obtusus, lævis. (v. s.)

a. rotundata, foliis basi angustatis rotundatis vel vix emarginatis. (Blanchet n. 647! 731 ! Gardner n. 2718! Lhotzky I)

$\beta$. cordata, foliis basi vix angustatis, plus minus cordatis. (Martius ! Blanch. n. 3048 ! 3049!3160 A !) G. pendula Salzm. pl. exsice $n$. 475 !

36. C. DIVERSIFOLIA (Jacq. hist. stirp. Am. p. 114, t. 76), arborea, ramis validis, ochreis deciduis, foliis subcoriaceis breve petiolatis acutis nitidis venosis, ramorum ovatis basi rotundatis cordatisve, ramulorum ovato-oblongis basi obtusis, racemis terminalibus solitariis sessilibus folia æquantibus erectis, fructu majus. culo globoso-ovato obtuso breve pedicellato apice umbilicato. 5 In ins. S. Domingo Willd. sp! $2, p$ 458, Hook. exot. fl. 2, t. 102. Arbuscula 10-pedalis, ramulis gracilibus. Petioli 3-5 lin. longi. Folia majora 4-5-pollicaria, 2-3 poll. lata, apicem versus sensim attenuata, ramulorum plus dimidio minora, venis (ex ic.) utrinsecus 8-11 patulis rectis prope marginem arcuatis, venulis non? reticulatis. Racemi 3-'pollicares. Fructus magnit. Cerasi minoris, pulpâ purpureâ edulí austeriusculâ (Jacq. l. c.). Huc spectare videtur specím. herb. Martii, cui ramuli cum ochreis sub lente pulveraceo-tomentelli, folia utrinque dense minuteque elevatoreticulata, cæt. cum descr. et ic. Jacq. l. c. bono congrua. (v. s. sine fl. nec fr.)

37. G. SwARTZII, glaberrima, ochreis arcte tubulosis deciduis, foliis coriaceis petiolatis ovatis ellipticisque obtusis basi rotundatis vel attenuato-acutis nitidis, supra dense subtus laxe vel obsolete prominulo-reticulatis, racemis terminalibus solitariis erectis filiformibus laxiusculis folio longioribus, bracteis bracteolisque subæqualibus ovatis obtusis florem sessilem demum exsertum subæquantibus. f ? In Indià occid. (Swartz! West I Forsyth I). Rami graciles, flavidi, tor- 
tuosi, subnodosi, juniores sulcalo-striati. Ochreæ membranaceæ enerviæ, petiolum canaliculatum æquantes 5-6 lin. longæ. Folia in eodem ramo ovata et elliptica, obtusa vel breve obtuseque acuminata, plana, 2-5 poll. longa, $1 \frac{1}{2}-2 \frac{1}{2}$ poll. lata, venis primariis tenuibus patulis utrinque æqualiter prominulis prope marginem subevanescentibus, venulis supra valde conspicuis subtus vel omnibus vel saltem ultimis obliteratis. Racemi 3-5-pollicares subinterrupti, pedunculo brevissimo basi arcte vaginato, rhachi sulcatâ, floribus quasi in glomerulos approximatis, glomerulis vero 1-2 lin. distantibus, bracteis fuscis. Calyx vix 1 lin. longus. Accedit ad C. diversifolium, sed foliorum nervatione ab eâ differt et potius C. microstachyæ similis. (v. s. in h. DC.)

B? Portoricensis, foliorum reticulo densiore utrinque prominulo subtus laxiore, venis primariis magis patentibus, racemo gracillimo semipedali, rhachi tènviore. - In montibus altis ins. Portorico. - Forsan propria sp. (v. sp. deflor. in herb. DC.)

38. C. FLAVESCENS (Jacq. 1. c. p. 114, t. 75), arborea, glabra, Tamis gracilibus, ocbreis deciduis, foliis coriaceis petiolatis ovali-oblongis obtusis mucronulatis basi emarginatis nitidis subeveniis, racemis terminalibus solitariis pedunculatis folia requantibus erectis, fructu subsessili ovato-globoso obtuso. 5 In ins. S. Domingo (Jacq., G. Ehrenberg I) - Willd. sp. 2, p. 458. Arbuscula 12- pedalis, foliis subrigidis fere eveniis flavo-viridibiss $2-2 \frac{1}{2}$ poll. longis $8-14$ lin. latis, mucronulo setaceo $\frac{1}{2}$ lin. longo spinescente vel deciduo, petiolo $2-3$ lin. longo, racemo recto, fructu atro-purpureo pisi majorìs mole, pulpâ rubicundâ eduli dulci (Jacq. l. c..). Ramuli patentes ramique cinerei læves. Ochreæ membranaceæe, anguste tubulosæ, 3-4 lin. longæe, glabræ, integræ. Folia plus minus cordata, novella tenera, adulta rigide coriacea, minutissime reticulata; venis primariis crebris patentissimis prope marginem obscure arcuatis supra immersis subtus leviter prominulis. Racemus vix pollicaris, glaber, pedicellis subsolitariis $1 \frac{1}{2}$ lin longis calycem elausum obovatum æquantibus, ex specim. Ehrenb. (v.s. in herb. reg. Berolin.)

39. C. S сн о в в RG K1 (Meisa. in Linnæâ 21, p. $265^{*}$ et in fl. Bras. fasc. 14, p. 33), ramis striatis, junioribus minutissime puberulis, ochreis petiolo brevi sublongioribus tomentellis diu persistentibus, foliis crasse coriaceis glaberrimis subnitidis ovalibus oblongis subrotundisve obtusis basi léviter cordatis supra minute insculpto-reticulatis, venis primariis nervoque suhtus modice prominulis marginem versus evanescentibus venularum -reticulo obsoleto vel nullo, racemis terminalibus lateralibusque subsolitariis folium subæquantibus densifloris, rhachi bracteisque puberulis, floribus subsessilibus. $₹$ ? In Guianâ Anglicâ (Schomb. n. 640 ! 981 !). Folia $1 \frac{1}{2}-2 \frac{1}{2}$ poll. longa, 824 lin. lata, petiolo $1 \frac{1}{2}-3$ lin. longo, margine plus minus recurvo. (v. s. in herb. reg. Berol. et Shuttlew.)

40. C. Brasiliensis (Mart.! et Nees in Nov. Act. Ac. Nat. Cur. 9, I, p. 30*, non Spreng.), glabra, ramis validis, junioribus sulcatis, ochreis tomentellis deciduis, foliis crasse coriaceis breve petiolatis ovalibus utrinque rotundatis emarginatisve minute reticulatis subtus punctatis, venis primariis prope marginem leviter recurvum subevanescentibus supra impressis subtus prominulis, racemis terminalibus subfasciculatis axillaribusque solitariis sessilibus folio sublongioribus erectis cylindricis densifforis, rhachi crassâ sulcatâ; bracteis sub-1-floris pedicellos breves crassos subæquantibus. J Iñ Brasiliæe, Campos Geraës (Princ. Neuwied !), in littore prov. Para et Bahiens. (Mart.!) - Meisn. in Mart. fl. Bras. fasc. 14, p. $32^{*}$, t. 13 , f. 1 . Frutex $4-5$-pedalis, flor. flavido-albis. Folia $1 \frac{1}{2}-2$ poll. longa, 10-14 lin. lata, haud raro apice æeque ac basi emarginata. Racemi terminales 1 vel siepe 2-3 approximati. - G. Brasiliensis Spr. est Rubiacea, fide Cham. in Linnæâ 3, p. 54, Hedyosmi sp. fide Mart. ib. 4, p. 36. (v. s. in herb. Mart. et Ac. Monac.)

41. C. ACROSTICHOIDES (Chamisso! in Linnæà 8, p: 132 "), ochreis petiolo brevi crasso longioribus ramulisque tomentosis, foliis rigide coriaceis obscure immersoreticulatis ovali-oblongis obtusis basi rotundatis vel emarginatis margine recurvis supra glabris subnitidis subtus fusco-tomentosis, racemis terminalibús subfasciculatis axillaribusque solitariis sessilibus folio longioribus gracilibus densifforis glabriusculis, bracteis 1 -floris pedicellum brevissimum æquantibus. $\%$ In $\mathrm{Bra}$ siliâ (Sellow I); Prov. Minas Geraës (Ackermann! Claussen n. 330 1). - Meisn. in Mart. fl. Bras. fasc. 14, p. 33, t- 13, f. 2. C. rubiginosa Mart. I mss. in herb. Omnia fere, exceptà pubescentia, G. Brasiliensis. (v. s. in h. Reg. Berol. et Mart.) 
42. C. Persicaria (Wedd. in Ann. sc. nat. 3. sér. 13, p. 256), ramulis striatis glabris, foliis rigidulis breve petiolatis ovato-lanceolatis acutiusculis basi angustatâ rotundatis vel subcordatis supra glabris subtus cum petiolo puberulis, racemis terminalibus solitariis breve pedunculatis folio brevioribus glabris, bracteis 2-3-floris, bracteolis junioribus vesicularibus ajiculatis, floribus subsessilibus. 5 In sylvis subhumidis Boliviæ Cisandince. - Frutex 9-12= pedalis, ramulis patulis, junioribus ochreis subscariosis vaginatis. Folia 1-2-pollicaria, 6-9 lin. lata, peliolo 2-3 lin. longo, nervatione non descriptâ. Racemi spicas Polygoni referentęs. Calyx pallide virens, antheris inclusis.

43. C. P IPERICARPA (Mart. ! mss.) glabra, ramis divaricato-ramosissimis nodosis internodiis brevibus, ochreis petiolo brevissimo sublongioribus deciduis, foliis rigide coriaceis ovali-oblongis obtusis basi rotundatis subcordatisve planis nitidulis utrinque æqualiter prominulo-reticulatis, racemis terminalibus solitariis folio duplo longioribus densifloris, bracteis parvulis subunifloris rhachique pulvereo-tomentellis, floribus subsessilibus, fructu parvo globoso. $\bar{J}$ In Brasiliæ sylvis inundatis prov. Bahiens., Minas novas, etc. (Mart.!). - Meisn, in Mart. fl. Bras. fasc. 14, Polyg. p. $32^{*}$, t. 12. Frutex 5-6-pedalis, ranulis læevibus vel rugosis nec striatis cicatrisato-nodosis, internodiis 3-6 lin. longis, foliis ochreisque deciduis. Folia 8-14 lin. longa, 5-7 lin, lata, petiolo $1 \frac{1}{2}$ lin. longo, venis primariis

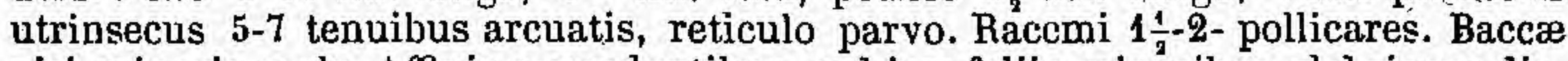
pisi minoris mole. Affinis præcedentibus, sed jam foliis minoribus glabrisque distincta. (v. s. in herb. Acad. Monac.)

44. C. M ARGINA T A (Benth. in Hook. Lond. Journ. 4, p. 626), glabra, foliis subcoriaceis ovali-oblongis acuminatis basi obtusis margine anguste sursum involutis tenuiter reticulatis, venis majoribus supra impressis, subtus prominulis, racemis folio longioribus gracilibus, pedicellis bracteâ, brevi latâ calyceque brevioribus. ‡? In Guianà Anglicâ (Schomb. coll. 2, n. 118, in herb. Berol. 216). - Meisn. in herb. fl. bras. fasc. 14, Polyg. p. 35. Folia pleraque 4-5 poll. longa, 2-2 $\frac{4}{2}$ poll. lata, racemi 5-10-pollicares, bracteis vix $\frac{1}{2}$ lin. longis, floribus C. excelsæ, ex Benth.

45. C. S T I TICAULIS (Wedd. 1. c. p. 261), ramis subvolubilibus elongatis flexuosis striatis, ochreis brevibus caducis, foliis coriaceis petiolatis oblongis obtusis vel breve acuminatis basi rotundatis vel acutiusculis supra glaberrimis nitidis immerse venosis, sublus fortiter elevato-reticulatis tenuissime puberulis, racemis lateralibus solitariis gracilibus flexuosis laxilloris, "rhachi subglandulosâ * . bracteis minutis 1 -floris, pedicellis calyce brevioribus patentibus. $₹$ In Brasiliæ prov. Minas Geraës (Glaussen 1 n. 280). - Meisn. in Mart. fl. bras. fasc. 14, p. $28^{*}$. Frútex scandens? ramis validis fuscis sulcatis albido-Ienticellosis. Folia $2-3 \div$ poll. longa, 12-20 lin. lata, petiolo crasso 4-6 lin. longo, sicca glaucescentia. Racemi 2-4-pollicares, rhachi ohsolete tomentellà, pedicellis crassiuscułis. Calyx 1 lin. longus, clausus, basi attenuatus, staminibus inclusis, stigmatibus subexsertis. Fructus ovoideus, 2 lin. longus, achænio subtrigono-globoso. (v. s. sine fr. in herb. DC.)

46. G. LuGrdula (Benth.l l. c. p. $627^{\star}$ ), ramis gracilibus lavibus ferrugineopuberulis mox glabratis, ochreis deciduis petiolisque brevibus, foliis subcoriaceis ovali-vel obovato-oblongis acutiusculis vel acuminatis basi obtusis utrinque tenuiter elevato-reticulatis nitidis glabris, racemis terminalibus axillaribusque solitariis folio subrqualibus sessilibus filiformibus densifloris, bracteis 1-3-floris, floribus subsessilibus parvis. $₹$ ? In Guianâ Anglicâ (Schomb. coll. 2, n. 947 I et in herb. Berol. n. 1262 ! Rich. Schomb. n. 81!). - Meisn. in Mart. fl. bras. fase. 14, Polyg. p. 31. G. stricta Klotzsch! mss. Ramuli cinerei, novelli tantum striati et puberuli. Ochreæ 3-4 lin. longæ, angustæ, puberulæ. Petioli 1-2 lin. longi. Folia tenuiter coriacea, $1 \frac{1}{\sqrt{2}-3} \frac{1}{2}$ poll. longa, 12-18 lin. lata, æequilatera, tenuissime reticulata, sicca atrofusca. Racemi $1 \frac{1}{2}-2 \frac{1}{2}$ poll. longi, nutantes? rhachi glabriuscula. (v.s).

47. C. ОВ т U SIF OL I A (Jacc. hist. stirp. Amer. p. 114, t. 74), glabra? ramulis gracilibus, ochreis deciduis, foliis coriaceis breve petiolatis oblongis utrinque obtusis Jaxiuscule reticulatis nitidis, racemis terminalibus solitariis erectis folia superan. tibus, baccis ovoideis breve pedicellatis nutantibus. 5 In Colombiâ (Willd. sp. $\mathbf{2}$, p. 459, non herb.) Arbuscula 12-yedalis, ramosissima, ramulis cinereis. Petioli 2 lin. longi. Folia $1 \frac{1}{2} 9 \frac{4}{2}$ poll. longa, 8-12 lin. lata, utrinque obtusissima, venis primariis utrinsecus $5-8$. Racemi fructiferi 2-3-pollicares, recti. Flores albi. Fruc- 
tus adstringentes, calyce apice apêrto, achænio nitido apice sæpius nudo. Ex desc. et ic. Jacq., quibus specimen circa Carthagenam a Billbergio lectum in herb. Berol. bene convenit, recedens tantum foliis utrinque sensin angustatis et vix pigídís. Venæ venulæque tenues levissíme prominulæe vel supra suljimmersæ. Racemus sessilis, densiflorus, bracteís parvulis fuscis patulis, bracteolis hyalinis 'cyathiformibus' subbilobis 1 -floris flavescentibus vix 1 lin. longis pedicellum æquantibus, flore parvulo. G. obtusifolia Willd. herb. vel infra sub G. reticulatâ. (fi. s. in herb. reg. Berol.)

48. C. MicRoSTAGHXA (Willd.I sp. 2, p. 459), glabra, ochreis petiolo brevioribus, caducis, foliis coriaceis ovatis obovatis vel oblongo-lanceolatis utrinque obtusis vel rarissime in petiolum brevem subattenuatis dense elevato-reticulatis, racemis lateralibus solitariis brevibus filiformibus laxiusculis, bracteis squamiformibus obtusis flore subsolitario sessili parvulo duplo brevioribus. 7 in ins. Antill, S. Crucis et S. Thomas. - Lam, dict. 6, p. 64. Rami subtortuosi, ramulis albidis obsolete striatis nodis subincrassatis. Ochreæ nonnisi in ramulis novellís spicigeris (3-8 - inn. longis 1-vel paucifoliis) superstiteș, 2 lin. longæ, opacæ, pulv̀eraceosubtomentellæ. Petioli 2-3' lin. longi, tenues. Folia rigidiuscule coriacea, 1-2 poll. longa, 6-12 lin. lata, subæquilatera, apice rotundata vel rarius attenuata obtusa, mutica, margine interdum recurvó, venarum reticulo denso utrinque subæqua-

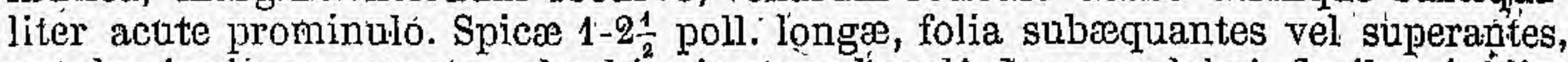
patulæe, juniores nutantes, rliachi minute puberulâ demum glabrâ, floribus $\frac{1}{q}-1^{\prime}$ ling. distantibus. Fruct. ign. (v. s. in herb. Willd. DG. Link. et Mart.)

ж. ovalifolia, feliis ovalibus vel oblongis utrinque æqualiter attenuatis $(10-14$ lint. latis). C. microstachya Willd: herb. n. 7703 ! (C. Ehrenberg, n. 240 ! in herb. reg. Berolin.).

B. lanceolata, foliis ovato-vel oblongo-lanceolatis utrinque magis angustatis vel infra meditum latioribus (6-10 lin. latis). C. obtusifolia Willd. herb. n. 7702! non sp. pl. nec Jacq.

49. C. SGANDENS (Casaretto nov. stirp. bras. dec. 8 , p. 70, n. 76), foliis coriaceis petiolatis obovatis vel obovato-oblongis utrinque obtusiusculis sujpra glabrís nitidis, subtus reticulatis opacis et (sub lente) minutissime pruinoso-pubertulis, racemis folia subrequantibus. F In Brasilià tropica, ad fl. Parahyba (Riedel): Meiśn. in Mart. fl. bras. fasc. 1/4, p. 28. Frutex scandens, rami teretes minutissime

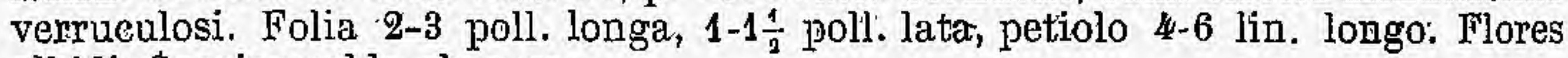
albidi. Species valde obscura.

50. G. PARVIFolia (Poir. dict. 6, p. $64{ }^{*}$, non Schott.), glabra ?'ramis diffusis tortuosis albidis lævibus, nodis superioribus incrassatis, foliis coriaceis petiolatis ovatis utrinque obtusis vel rotundatis nitidis laxe reticulatis, racemis terminalibus lateralibusque filiformibus folio longioribus, floribus parvis. $\bar{J}$ ? In Amerïcấ australi..... (Vahl in herb. Juss.). Folia 1-2 pollicaria, subtus minus nitida. Racemi 3-4 poll. longi, ramulos laterales aplyyllos birevissimos terminantes. Species obscura.

51. G. TENUIFOL1 (Linn. amoen. Acad. 5 , p. $397^{*}$ ), glabra? ochreis membranaceis, foliis herbaceis petiolatis ovatis obtusis vel subacuminatis, racemis terminalibus simplicibus, floribus sparsis pedicellatis 4-fidis. 尹? In Jamaicâ. - Brown Jam. p. 210 , t. 14, f. 3, Mill. dict. n. 5, Lam. dict. 6, p. 63, ill. t. 316 , f. 1 et 3 , Houttuyn Pfl. syst. 1, p. 497, WVilld. sp. 2, p. 460. Species valde obscura:

52, C. CUBENSIs, glabernima, ramis gracilibus: paniculato-ramulosis substriatis, internodiis ochreis petiolisque brevibus, foliis subcoriaceis ellipticis utrinque subacuminato-attenuatis tenuiter dense reticulatis, venis supra immersis; sublus leviter prominulis, racemis terminalibus solitariis ereetis folia demum subæquantibus laxifloris, bracteis exiguis-1-floris; pedicellis gracilibus patılis: flore sublongioribus. $J$ ? In ins. Cubâ (Linden, n. 2047 !). Ramuli albidi, nodulosi. Ochreæ

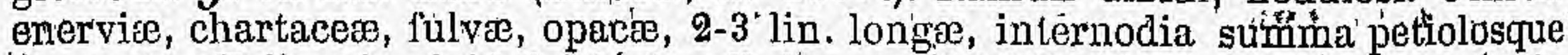

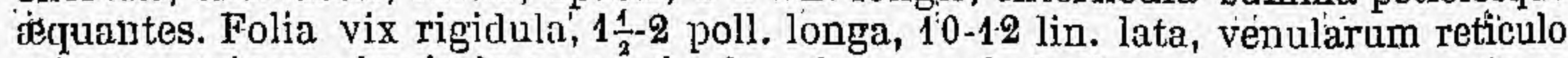
minuto utrinque lævissime prominulo subtus paulo laxiore vel minus conspicuo, venis primarís utrinsècus 5:6 prope marginemin arcuato-evanescentibus. Racemi 1-1:-pollicares; breve pedunculati, rhachi tenui sulcata, pedicellis $1 \frac{1}{3}$ lin. longis. Calyx patens, tubo turbinato. Stamina 8, calycem sequantia, stylos 3 breves superantia. (v.s. in berb. Shuttleworth.) 


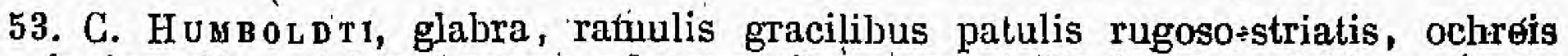
laxiusculis petiolum brevem supæcuantibus tomentellis deciduis, foliis coriaceis opacis ellipticis utrinque obtusis, vel ovatis basi emarginatis eleganter scrobiculato-reticulatis ; venis primariis supra semiimmersis subtus prominulis, racemis terminalibus solitariis folium superantibus densifloris, bracteis parvis 1-4-floris, pedicellis exsertis crassiuscillis patulis, fructu ovato olbtuso. 5 ? In Mexico (Humboldt ! et Bonpl, n. 4484! in herb. Willd.), circa Támpico (Berlandier, n. 105 !). C. rigida Wílld. 1 mss. in herb. n. 7705. Rami cinerascèntes, irregularitér rugosi. Petioli 2-5 lin. longi. Folia $1 \frac{1}{2}-4$ poll. longa, 10-24 lin. lata, interdum obsolete obtuseque acuminata vel basi rơtundata vel leviter cordatta, venis utrinséus 3-6 prope marginem in arcus tenuissimos latos cideuntes, venularum reticulo utrinque sequaliter expresso denso minuto prominulo. Racemi 2-3-pollicares, pedunculo basi ochrea laxâ vaginato, pedicellis $1 \frac{1}{2}$ lit: longis, fructu magnit. grani piperis. Valde quidem aflnis sequentibus et $\mathrm{C}$. ovate, sed racemis brevioribus, foliorum reticulatione, etc., distincta. (v. s.)

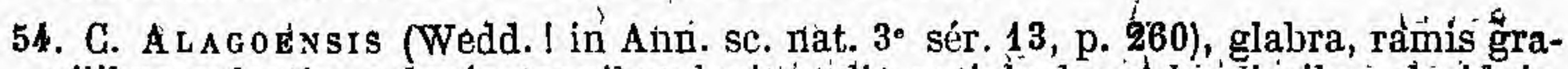
cilibus sulcatis, ochreis tenuibus laxitusculis petiolo brevi Iongioribus deciduis, folìis coriaceis ellipticis utrinque obtusis tenuiter, prominulo-reticulatis supra nitidis, axillis costarum subtuś barbellatis, racemis terthinaliłus solitartis folio longioribuis filiformibus densifloris, bracteis parvis 1-3-floris rlachique glabris, pedicellis brevissimis, staminibus exserti's, $\zeta$ In Brasilia prov. Alägoás (Gárdner, ñ. 1389 l). - Meisn. in Mart. fl. bras. fasc. 14, p. 31 *. Ramuli flavéscentes, tenuiter sulcati, internodiis $\frac{1}{7}-1$ poll. longis. Ochreæ tomentelle. Folia 2-3-pollicaria, 1 poll. lata, petiolo tenui $\mathbf{3 - 5}$ lin. longo, venularum reticulo supra laxiore. Rácemi 5-6-pollicares, basi subinterrupti, pedunculo basi laxiuscule vaginato, floribus mảgnit. Polyg. Persicarize. Farśan nuera var. C. ovatâ, recedens rácenoù loúgióné, foliis sublus opacis ad venularum axillas barbatulis. (v. s.)

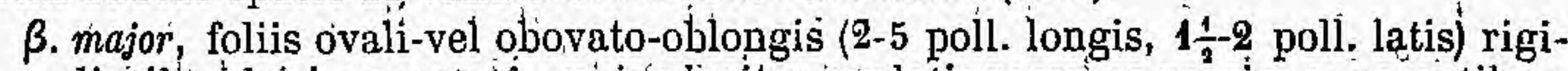
dioribus basi angustata sepiús leviter cordatis racemos passim superantibus, reticulationé fortiore. In Guatimala (Friedrichsthal! sine numero in herb. unủis. Vindobon.)

55. C. MIGRONEURA, ramulis substriatis glabris, ochreis angustis petiolum åquăhtibus glanduloso-punctatis vel tomentellis, foliis coriaceis ovalibus oblongisque utrinque obtusis glabris minute elevato-ieticulatis; racernis dxlliallbus terminalibusque solitariis folio longiónibus flliformibus densifloris erettis, rhàclí angulatâ bracteisque parvulis truncatis pulvereo-tomentellis 1-3-floris piedicellos xquantibus: $\bar{J}$ In Colombià circa Sancta-Martha (Purdia 1 in herb. Arnott). Rathi gracilés, demum exsulci, rimosi. Ochreæ subenervił̧. Folia consistentiâ Lauri nobílis,

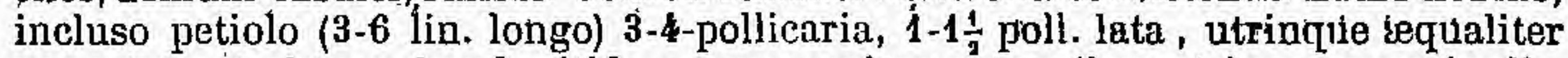
angustata et obtusa, haud nitida, nervo venisque tenuibus ulrinque.prominulis. Raceini, 5-8-pollicares, axillares aphylli vel plerumque ramulum 1-2-pollicarem paucifolium terminarites, gracillimi, breve pedunculati, bracteis contiguis vel infimis 1-2 liil. distanitibus, bracteolis exiguis, calyce 1 lin. longo stamina subxquaitte. Fruct. ignot. Simillima C. Alagoensi, sed foliis majoribus, reticulatione minutiore, racemo longiore, etc., bene distincta. (v. s. in herb. Arnott.)

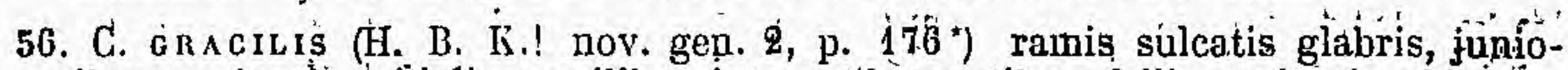
ribus vaginatis, petiolis gracilibus intus pubescentibus, foliis coriaceis oblongoellipticis utrinque obtusis vel basi acutiusculis glaberrimis nitidis ntrinque tenuitér. semiimmerso-ieliculatis, racemis terminalibus solitariis folio longioribus gracilibus laxis erectis, rhachi tenui bracteisque 2-4-Aoris acutis pubescentibus, pedicellis subexsertis glabris. 5 In Peruviâ (Humb. in, herb. Willd. n. 77011). C. Peruviana Willd. mss. in herb.n. 7700 ? (specim. nuiserum). Arbor 2:3-orgyalis. Petioli 4 lin. longi. Folia $1 \frac{1}{2}-9$ poll. louga, 1 poll. lata. Racemi 3-4-pollicares, floribus albis, staminibus calycem rquantibus. Similis procedenti et $\mathbf{C}$. . Humboldti, ab hac petiolo longiore, ab utrấque reticulatione, etc., dignoscenda. (v. s. in herb. Willd.)

57. C. LEP T оS т A H ४ (Benth. Bot. of the Sulphur, p. $159^{*}$ ), glabra, ramulis tortuosis, ochreis laxis petiolo brevioribus tomentellis mox glabris, foliis tenue coria . ceis, ovalibus obovatisve brevissime obtuseque acuminatis basi oblique rotundatis glabris opacis subtus eleganter prominulo-reticulatis, racemo terminali solitario 
longo gracili subsessili laxifloro, bracteis minutis sub-3-floris, pedicellis exsertis, baccả coronatâ? $\$$ ? Girca Libertad, in Colombià. Ochreæ 3-4 lin. longæ, subciliatæe. Petioli 5-6 lin. longi. Folia 3-4-pollicaria, 2-2 $\frac{1}{3}$ poll. lata, venis primariis utrinsecus 4-6 subtus prominulis, venulis ramosissimís. Racemuś 8-pollicaris, pedicellis vix $\frac{1}{9}$ lin. longis. Calyx 1 lin. longus, tubo demum ovario adhærente.

58. G. ov a T a (Benth. in Hook. Lond. Journ. 4, p. 627), glaberrima, ramis-patentibus, junioribus tenuiter striatis, netiolis ochream brevem subæquantibus, foliis subcoriaceis ellipticis ovatis lanceolatisve utrinque obtusis subacuminatis nitidis dense elevato-reticulatis, racemis lateralibus terminalibusque subsessilibus filiformibus laxiusculis, bracteis ovatis obtusis calyce demum dimidio minoribus, staminibus exsertis. 5 ? In Brasiliæ prov. Bahiens. et Rio Negro, Guianâ Anglicâ et Colombiâ. - Meisn. in Mart. ff. bras. fasc. 14, p. 31, t. 11. Formæ sequentes singulæ præterea ludunt foliis basi obtusis subrotundatis vel in petiolum attenuatis et apice obtusissimis vel brevissime et obtusiuscule acuminatis, racemis folio longioribus brevioribusve. (v. s.)

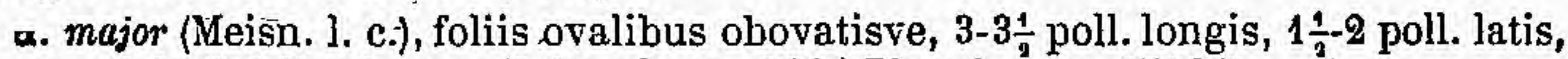
petiolo 3-4 lin. longo. (Schomb., n. 893 ! Blanchet, n. 2713 !)

$\beta$. minor (Meisn. l. c.), foliis ovalibus vel ovali-oblongis, sæpius obtusissimis, 1-2 poll. longis, 10-18 lin. latis, petiolo 1-2 lin. longo. (Schomb. $\mathrm{n} .531$ ! ex parte, Blanchet, n. 2668 ! Poppig, n. 2617, 2634 !). C. nitida Mart.I mss. in herb. Acad. Monac., non Kuñth.

y. lanceolata (Meisn. 1. c.), foliis, lanceolatis utrinque aftenuatis, 1 raro.2 poll. longis, 6-7 vel raro 10-12 lin. latis, petiolo 1-2 lin. longo. (Schomb. n. 531, ex parte.)

69. C. DECLINAT A (Mart.1 herb. fl. bras. p. 90,n. $66 \mathrm{I}$ ), glaberrima, ramulis patulis tenuiter striatis, ochreis tenue membranaceis brevibus, folijs herbaceis petiolatis ellipticis vel ovato-vel obovato-oblongis subacuminato-acutis basí obtusis acutisve utrinque reticulatis venis venulisque supra lævissime prominulis subtus subimmersis, racemis lateralibus terminalibusque solitariis sessilibus nutantibus folio -subáqualibus laxiusculis, bracteis 2-3-floris primariis brevissimis ovatis. F In Brasiliæ prov. S. Pauli, Bahiæe, etc.-Meisn, in Mart. fl. bras. fasc. 14, Polyg. p. $29^{*}$. (v.s.)

a. minor (Meisn. 1. c.), foliis ovali-oblongis basi rotundato-obtusis, $1 \frac{1}{9} \cdot 2 \frac{4}{8}$ poll. longis, 10-12 lin. latis, petiolo 2-3 lin. longo), racemis 1-1 $\frac{1}{2}$-pollicaribus, pedicellis brevissimis bracteam vix superantibus, Frutex 8-10-pedalis, flor. albis. (Princ. Neuwied! in herb. Mart.)

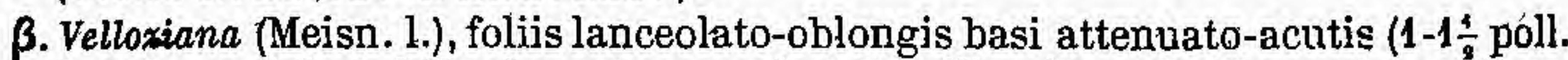
longis, petiolo 1-2 lin. longo), racemis 1-2-pollicaribus, floribus subsessilibus. - Polygonum declinatum Flor. flumin. 4, t. 41. Ex ic. videtur subscandens.

y. major (Meisn. 1. c.), foliis ovalibus basi attenuato-acutis, 2-3 poll. longis, 1-fere 2 poll. latis, petiolo 3-5 lin. longo, racemis longis (3-5 poll.), pedicellis demum bracteâ duplo longioribus $1 \frac{1}{2}$ lín. longis, bracteolis subinclusis pedicello brevioribus. In prov. S. Pauli (Mart. in herb. Acad. Mon.). An propria sp.?

60. C. racemulosa (Meisn. in Mart. fl. bras. fasc. 14, Polyg. p. $30 \%$, volubilis? glaberrima, ochreis petiolo tenui longioribus caducis, foliis herbaceis ellipticis vel subovatis breve acuminatis basi rotundatis vel brevissime attenuatis utrinque subnitidis densissime prominulo-reticulatis, racemis terminalibus axillaribúsque folio brevioribus nutantibus laxifloris, pedicellis sólitariis crassiusculis bracteâ minatà fultis bracteolâ hyalinâ turbinatâ 2-3-lohâ terminalis, flore inter bracteo-

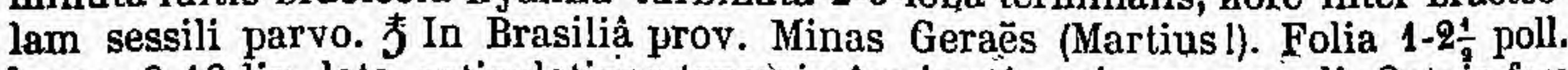
longa, 9-18 lin. lata, reticulatione tenerrimâ minutâ utrinque æquali. Ominia fere C. declinata, exceptis pedicellis apice (nec basi) bracteoliferis. (v. s. in herb. Acad. Monac.)

61. C. B R A C T E O L OSA (Meisn. 1. c. p. $30 \%$, ochreis petiolo gracili sulcato longioribus tomentellis caducis, foliis herbaceis ovalibus vel oblongo-ovalibus utrinque æqualiter attennatis acutiusculis glaberrimis supra opacis subtus subnitidis, venularum reticulo tenerrimo denso utrinque conformi subtus lævissime supra vix prominulo, racemis lateralibus solitariis folio brevioribus erectis, bracteis hyalinis 


\section{coccoloha. POLYGONACEE (AUCTOR MEISNER).}

tubulosis hinc fissis vel 2-3-partitis bifloris pedicellos tenues superantibus, floribus exsertis. 5? In Brasilix prov. Bahiensi (Mart.!) et Alagoas (Gardner, n.1390 l). Rami validi, sulcati, glabri. Ochreæe membranaceæ, pollicares, lacerse. Petioli 6-8 lin. longi. Folia 3-5 poll. longa, 1 $\frac{1}{2}-2 \frac{1}{2}$ poll. longa. Racemi axillares et ramulos

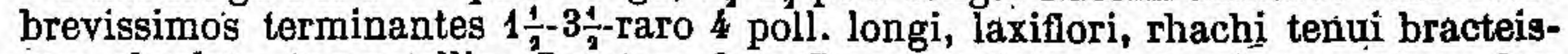
que obsolete tomentellis. Bracteæ fere G. ochreolatæe et excelsæ, cætera fere G. declinatæ. (v. s. in herb. Acad. Monac. et Mus. Vindob.)

62. G. GUIANENSIs (Meisn. in Linnæâ 21, p. 254 "), ramis obsolete sulcatis, junioribus ochreisque petiolo brevioribus rufo-puberulis, foliis coriaceis oblongis subacuminatis basi obtusis obliquis subcordatisve utrinque glaberrimis nitidis tenuiter reticulatis, venis primariis supra subimpressis, subtus acute elevatis secundariis utrinque prominulis, racemis solitariis vel geminatis subsessilibus folio subæqualibus gracilibus, rhachi glabrâ, bracteis subrotundis parvis, floribins subsessilibus, staminibus exsertis. 5 ? ₹? In Guianâ Gallicâ (Perrottet, n. 84 ! Poiteau ! Leprieur! herb. Mus. Paris, n. 127 I), Surinam (Hostmann, n. 506 ! Kegel, n. 492 ! Wullschlægel, n. 882 !), Brasiliâ (Pohl!). - Meisn. in Mart. fl. bras. fasc. 14, p. 29, t. 10. Arbor 15-20-ped. (fide Kegel), frutex scandens (fide Wullschlægel). Folia

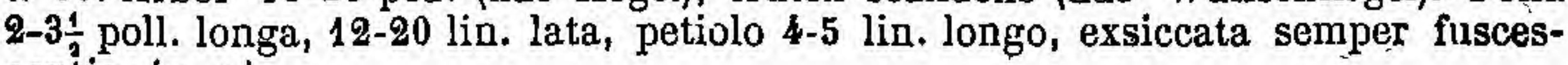
centia.. (v. s.)

a. vulgaris, foliis ovali-oblongis (2-4-poll., $1 \frac{1}{2}$ poll. latis) racemo æqualibus vel brevioribus. (Perrottet, n. 84 ! Kegel, n. 492 ! Leprieur! etc.)

$\beta$. angustifolia, foliis lanceolatis oblongis (5-7-poll., 1-1 $\frac{1}{2}$ poll. latis) utrinque magis angustatis racemo longioribus. (Perr. $n$. 84, ex parte).

$\gamma$. major, foliis ovali-oblongis (7-9-pollicaribus, 2-3 poll. latis) basi parum angıstatâ valde obliquis vel subcordatis racemo longioribus. (Herb. DGl o Cayennâ.)

63. G. FAGIFOLIA (Jacq. h. Schcenbrunn. 3, p. 55, t. 352), glabra, oclireis brevibus fuscis deciduis, foliis subcoriaceis petiolatis oblongo-ovatis acutis subundulatis nitidis basi obtusis suboblique rotundatis vel angustato-acutiusculis utrinque tenuiter denseque prominulo-reticulatis, venis ${ }^{n}$ arcuatis tenuibus supra immersis. subtus prominentibus, racemis terminalibns solitariis folio longioribus erectiusculis filiformibus laxinsculis, pedicellis subsolitariis brevissimis tenuibus, floribus parvulis. 5 ? Circa Caracas. Truncus 5-pedalis, ramosus, ramis gracilibus cinereis striatis. Petioli 6-8 lin. longi, tenues, sulcati. Folia 3-pollicaria, 1-1 $\frac{1}{2}$ poll. lata, petiolo 5-6 lin. longo tenui. Racemi 4-6-pollicares, breve pedunculati, gracillimi, continui, pedicellis vix lineam longis bracteam hyalinam æquantibus, floribus pallide virescentibus 1 lin. longis, staminibus subexsertis. Simillima C. laurifoliæ, sed petiolo longiore, floribus ninoribus, pedicellis brevissimis, etc., facile distinguenda. (v. s. c. ex Schœenbr. in herb. Jacq. patr. et fil.)

64. G. la UR IF olia (Jacq. h. Schœenbr. 3, p. 9, t. 267), glabra, ramulis striatis, ochreis angustis, foliis coriaceis petiolatis utrinque obtusis vel basi rotundatis nitidis tenuiter denseque prominulo-reticulatis, racemis terminalibus solitariis folia subæqnantibus erectis laxiusculis, floribus pedicellatis majusculis, staminibus inclusis, stigmatibus exsertis. 5 Circa Caracas.-Willd.I enum. 1, p. 431. Truncus 10-pedalis, supra medium diffuse ramosus, ramis cinereo-fuscis. Folia rigidula, 3-5 poll. longa, 1 $\frac{1}{2}-2$ poll. lata, petiolo 4-6 lin. longo crassiusculo. Racemi 3 poll. longi, breve pedunculati,-recti, bracteis 1 -floris, pedicellis 2 lin. longis calycem campanulato-infundibuliformem albido-virescentem subrequantibus. (v. s. c. in herb. Willd. n. 7699 !.)

65. G. FLORIDANA, glabra, ramulis striatis, ochreis membranaceis opacis subrufis, foliis coriaceis petiolatis ovatis ellipticisve utrinque attenuatis obtusis tenuiter denseque subimmerso-reticulatis, margine leviter recurvo, racemis termínalibus solitariis folio demum sublongioribaus erectis vel nutantibus laxiusculis, bracteis minutis bifloris, pedicellis calycem majusculum sıbæquantibus, staminibus exsertis, stigmatibus inclusis, fructu pyriformi-globoso lievi. 5 In Floridâ australi (Rugel, n .140l). Arbor 25-35-pedalis, ramulis patulis cinereis, internodiis circ. semipollicaribus, ochreis sub lente pulveraceo-tomentellis. Folia $1 \frac{1}{3}-3$ poll. longa, 1-2 poll. lata, venis primariis utrinsecus 5-7 tenuibus semiimmersis prope marginem arcuatis vel subevanescentibus, reticulo denso tenui vix prominulo subtus magis conspicuo. Racemi subsessiles, pedicellis 1-2 lin. longis, calycibus paten- 
tibus virescentibus. Bacca \& lin. longa, semi-6-locularis, alıumine ruminato. Simillima C. laurifoliæ, sed distincta foliis minus rigidis, reticulatione minus prominulâ, pedicellis plerumqué geminís', calyce basi attenuato, stạminịibus exsertis, etc.'(v. s.)

66. G. coRONA TA (Jacq. hist., stirp. Amer. p. 114, t. 77), glabra? ramis validis, ochreis, deciduis, petiolis brevibus gracilibus, foliis subcoriaceis oblongis attenuato-acuminatis basi obtusis nitidis venosis (haud reticulatis?), racemis terminalibus lateralibusque solitariis folio multo brevioribus pedunculatis erectis, baccis brevissime pedicellatis subglobosis majusculis breve óbtuseque acuminatis. 5 In Golombiâ, circa Carthagenam. - Mill. dict. n. 3, Pluk. alm. p. 394, t. 237, f. 4 . Houttuyn Pfl.Syst. 1, p: 495. G. punctata Willd. sp. 2, p. 459 ; enum. 1, p. 431. Arbuscula 15-ped. Petioli 4-5 lin. longi. Folia 6-pollicaria, 14-2 poll. lata, ex ic. non reticulata, venis utrinsecus 9-12 margine evanescentibus?'hrud aricuatis?

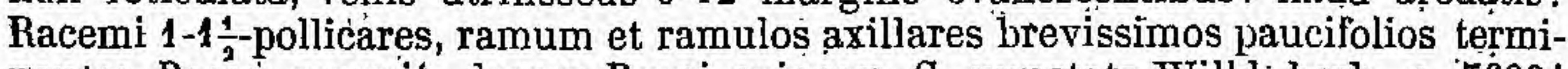
nantes. Baccæ magnit. drupæ Pruni spinosæ. C. punctata Willd: herb. n. 7698 ! (sterilis, culta) ab ic. Jaeq. discrepat foliis basin versus sensim angustatis acutiusculis et ad G. laurifoliam admodum accedit. (v. s. steril. in h. Willd. et Schreb., et sine nom. in l.. Jacq.)

67. C. PADIFORMIS, glaberrima, ramis gracilibus laxis, ochreis petiolo gracili longiusculo brevioribus deciduis, , folịs subcoriaceis oblongis subacuminatis basi angustatâ obtụsât subobliquis subopacis supra lævissimis subtus tenuissime laxeque subimmerso-réticulatis puncticulatis, racemis terminalibus lateralibusque solitariis folio brevioribus nutantibus laxifloris, bracteis minutis 1 -floris, pedicellis calycem majusculum patenten subæquantibus. 5 In Venezuela cịrcà Caraeas. (Moritz n. 377 l) Árbuscula mediocris (Moritz) facie Pruni Padi, rạmis elongatis cinerascentibus. Petioli 6-10 lin. longi. Folia 3-5 poli. longa, 1-2 poll. lata, vix rigidula, acuta vel obsolete acuminata, margine sæpius leviter undulata, venis primariin utrinsecus 7-9 tenuibus supra immersis ante marginem evanescentibus, subtus venulisque vix prominulis, interstitiis subtus obsolete minuteque reticulatis vel patius puncticulatis. Racemi 2-3-pollicares, patentes vel nutantes, pedunculo brevi basi ochreato, pedicellis tenuibus $1-1 \frac{1}{2}$ lin. longis. Calyx roseus vel

- purpureus (ex, Moritz). Stamina exserta. Fruct. ign. (v..s. in herb. DC., Shuttl. et Reg. Berulin.)

68. G. KUNTHANA, glaberrima, ramis dichotomis læviusculis, ochreis deciduis, foliis rigide coriaceis petiolatis late ovalibus planịs utrinque obtusis vel sụpacuminatis opacis vel supra subnitidis, venis primariis sujpra immersis subtus subprominulis, venulis nullis, racemis terminalibus solitariis folịo longióribus fịliforinibus laxiusculis erectis, bracteis brevissimis 1 - floris pedicello longipribus. 5 ? In ins. Antill. S. Thomas. G. excoriata rar. $\beta$ Poir. Kunthl mss. in herb. Petioli 3-5 lin. longi, supra anguste canaliculati. Folia $2 \frac{1}{2}-4$ poll. longa, $1 \frac{1}{2}-2 \frac{1}{2}$ poll. lata, fuscescentia, yeñis utrinsecus 5-8 semipatentibus ante marginem evanescentibus, venulis nullis visibilibus! Razemi 5-pollicares, rhachi gracili glabrâ, Jracteis remotiusculis albidis. Flơ. et fr. ignoti. - A simillimâ C. padiformi differt foliis rigidioribus, majoribus, reticulatione plane nullâ etc. (v. s̀. in h. Kunth ! comm. a Mus. Paris.)

69. G. Fas ic ulat a (Wedd. 1 in Ann. sc. nat. 3: sér. 13, p. 258), glabra, ramis virgatis internodiis elongatis, ramulis lateralibus brevissimiș ochreatis psendofasciculatim foliigeris, follis coriaceis brevissime petiolatis obovato-ohlongis optusis acutisve basi angustatẩ rotundatis leviter cordatis utrinque prominulo-reticulatis nitidis, venis supra semiimmersis subtus acute prominentibus, racemis lateralibus soli tarịis fasciculatisve folio longioribus densifloris strictis, bracteis exiguis plurif̣oris rhachique pulvereo-puberulis, pedicellis brevissimis. JIn Brasiliz prov. Bahiensi (Blanchet n. 796 !). - Meisn. in Mart. fl. Bras. fasc. 14, p. 27 \% F Fulex scandens? (Wedd.) Rami graciles, flavo-cinerei, rugulosi, donse lenticelloso-verruculosi, internodiis rectis $3-5$ poll. longis. Folia omnia ex ramulis $\frac{1}{3}-1$ poll. longis nascentia , approximato-sulfasciculata, 3-6 poll, longa; $1 \frac{1}{2}-2 \frac{1}{2}$ poll. lata, ex Wedd. oblusissima, ex nostris specim. acula vel brevissime acuminata, venis primaris ptrinstecus 8-11 tenuibus prope marginem arcuatim coeuntibus. Ochreæ laxæ, subcoriacea, petiolo 2 lin. longo crasso longiores. Racemi 6-8-pallicares. Affinis G. crescentipfoliæe, sẹd petiolis brevioribus, foliis minus rigidis planis etc. distincta: (v. sp. defloratum in herb. Shuttl.) 


\section{§ 3. Folia oblonga vel lanceolata, utrinque angustata, basi acuta (rarissime obtusa, cfr. C. Moritzii, crescenticefolia).}

70. C. CRESGENTIAFOLIA. (Cham.! in Linn. 8, p. 134 "), glaberrima, oehreis petiolum canaliculatum subæquantibus deciduis, foliis rigide coriaceis obovatooblongis subacuminato-acutis margine leviter recurvis utrinque tenuiter reticulatis subtus nitidis supra subopacis, venis primariis supra semiimmersis subevanescentibus subtus acute promiqulis confluentibus, racemis terminalibus lateralibusque solitariis folio longioribus strictis densifloris, bracteis parvis 1-3-floris, pedicellis exsertis, fructu majusculo ovoideo acuto. 5 In Brasiliæ prov. Bahiensi (Princ. Neuwied ! Mart. I Pohl !) et Rio Janeiro (Sellow 1). - Mart. berb. fl. Bras. p. 90 , n. 65 (excl. syn. Fl. Flum.), Meisn. in Mart. fl. bras. 14, p. 26, t. 8. Frutex

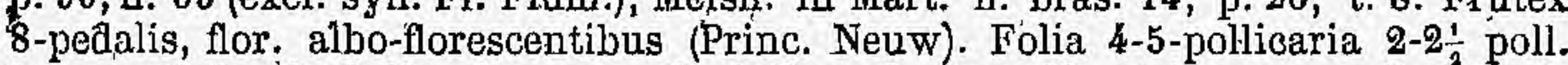
lata, petiolo 8-10 lin. longo, reticulatione laxiusculà utrinque semiimmersá. Pracemi 5-8 poll.; pedicelli demum incrassati 3 lin. longi. Bacca semipollicaris, achænio obscure trigono lævi, semine sub 6-loho. (v. s. in herb. Mart. et reg. Berolin.)

$\beta$. obtusata, folís utrinque obtusissimis basi emarginatis racemo longioribus supra submítidis subtus opacis, reticulatione supra obliteratá. (Claussèn n. 2013 !)

71. C. LONGEPENULA (Mart.! mss. in h. Ac. Monac. n. 759 ), scandens, ochreis laxiusculis opacis enerviis petiolo brevioribus evanescenti-tomentellis, folits subcoriaceis oblongis breve acuminatis planis basi attenuato-acutis vel rarius obtusis utrinque reticulatis, venis venulisque supra subimmersis subtus acute prominulis, rucemis terminalibus axillaribusque solitariis folio longioribus adscendentibus laxifloris, rhachi gracilì sulcatâ bracteisque 3:5-floris exiguis tomentellis, pedicellis exsertis calycem subæequantibus. 5 In Brasil. prov. Minas Geraës (Mart. 1 Lund!). - Meisn. in Mart. fl. bras. fasc. 14, p. 27*, t. 9. Rami torti fusci, substriati, albidoverruculosi. Oehrese juniores imbricatre. Petioli $4-6$ lin. longi, supra profunde sulcati. Folía modice coriacea, 2-6 poll. longa, 1-2 poll. lata, utrinque ærqualiter attenuata, interdum obtusa, exsiccatione nigrescentia, reticulatione supra magis conspicuâ. Racemi 1-2-pollicares. Flores virides, fasciculís 1-3 lin. distantibus. (v. s. in herb. Ac. Mon. et DC.)

72. G. MoR IT ZII (Klotzsch 1 mss. in herb. reg. Berolin), glaberrima, ramulis gracilibus sulcatis, ochreis opacis deciduis, foliis subcoriaceis breve petiolatis lanceolato-oblongis obtusiusculis basi angustatâ obtusis vel oblique rotundatis planis utrinque tenuiter denseque prominulo-reticulatis, racemis terminalibus solitariis filiformibus, rhachi tenui sulcato-angulatà, bracteis herbaceis 1-2-floris pedicello longioribus bracteolisque albido-scariosis semiexsertis acutis, floribus parvis. F In Colombiâ et Guiand. - Meisn. in Mart. fl. bras. fasc. 14, p. 27 *. Rami virgati, ramulis gracilibus striatis. Petioli teretes, canaliculati, 2-3 lin. longi, tenues. Folia 1-3-pollicaria, 6-14 lin. lata, utrinque subæqualiter attenuata vel apice subacuminata. Racemi subsessiles, bracteis subcontiguis vel inferioribus demum remotiusculis. Foliorum formâ accedit ad G. Guianensem, salicifoliam et plantagineam, sed nervatione bene distincta. (v. s.)

a. opaca (Meisn. 1. c.), foliis opacis spicâ (5-6-pollicari) brevioribus. In Colombiâ circà Valenciam (Moritz n. 550 !). Folia flavo-viridia.

3. lucida (Meisn. 1. c.), foliis utrinque nitidis spicas paillo superantibus. - In Guianâ Anglicâ (Schomb.! sine n. in herb. reg. Bẹrol.). Folia exsiccata fusca.

73. C. DENSIFR oNS (Mart 1 mss. in herb. Acad. Monac.), glaberrima, ramis leviter striatis, ochreis petiolum gracilem æquantibus deciduis, foliis modice coriaceis ovali-vel obovato-oblongis breve acuminatis basi obtusis vel subcuneato-attenuatis levibus (haud reticulatis) supra nitidis, venis supra immersis subtus prominulis, venulis inconspicuis, racemis lateralibus solitariis folia subæcuantibus gracilibus laxiusculis pendulis, bracteis 1-floris pedicello brevi dimidio brevioribus, floribus majusculis, staminibus longe exsertis. 7 ? In Brasiliæe prov. Rio Negro circa Ega (Mart. !). - Meisn. in Mart. 1l. bras. fasc. 14, Polyg. p. 26 , 1. 7.

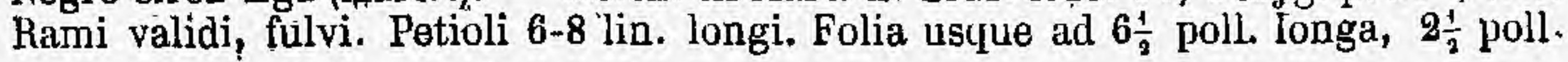


lata, venis primariis utrinsecus 6-8 ante marginem evanescentibus, reticulatione nullầ visibili. Racemi 4-7-pollicares, sessíles, basi ochreâ laxâ vaginati. Flores magnit. Polygoni orièntalis. - Accedit ad C. crescentiæfoliam, sed differt foliis minus rigidis, nervatione, racemis pendulis debilibus etc. (v. s.)

74. C. EXcoriat A (Linn. sp. 1, p. 425), glaberrima, ramulis gracilibus ochreis deciduis, foliis petiolatis oblongis attenuato-acuminatis basi angustatâ obtusis subobliquis cordatisve utrinque tenuiter prominulo-reticulatis nitidis, venis supra semiimmersis subtus prominentibus, racemis terminalibus lateralibusque solitariis folia æquantibus vel superantibus pendulis gracilibus densifloris, bracteis pedicello persistente brevioribus 1-floris florem parvum subæquantibus. 5 In Americâ trop. (Willd. herb. n. 7697 ! Swartz! in herb. DC.), ins. Portorico (Wydler n. 347 I), Guadeloupe, S. Thomas, Jamaica (Guming n. 49!). Plnm. ic. t. 146, f. 1 ? Mill. dict. n. 4, Willd.। sp. 2, p. 458, enum. p. 431 (excl. ? syn. Pluk.), Lam. dict. 6, p. 62*, Swartz f. Ind. occ. 2, p. 694. Arbor satis elata (Lam.), frutex (ex Sw.) ramulis cinerascentibus læviusculis. Folia $\frac{1}{2}-2-$ jedalia, usque ad 6 poll. lata, tenuia, demum coriacea, venis primariis utrinsecıs 9-12 tenuibus marginem arcuatis subevanescentibus. Racemi subsessiles, demum subpedales, pedicellorum parte persistente $1 \frac{1}{2}$ lin. longâ subdeflexo-patente. (v. s.)

75. C. NIVE A (Jacq. hist. stirp. Amer. p. 115, t. 78), glaberrima, ochreis membranaceis, foliis subcoriaceis breve petiolatis ovato-oblongis attenuato-acutis obtusisve basi attenuatầ obtusis vel emarginatis utrinque dense reticulatis nitidis, venis tenuibus venulisque supra semiimmersis subtus prominulis, racemis terminalibus lateralibusque solitariis folio brevioribus gracilibus densifloris erectis apice nutantibus, bracteis plurifloris, floribus subsessilibus parvis, fructibus niveis parvis ovatis acutis achænii apice exserto. 5 Ad rivulos ins. Antill., S. Domingo et Martinicà (Jacq), Jamaicâ, S. Barthelemi (Swartz, Caley! Forsstroem! in herb. Shutlew.), S. Thomas (Crudy in herb. Schreb.!). - Willd. sp. 2, p. 458, Swartz fl. Ind. occ. 2 , p. $693^{*}$, Lam. dict. 6, p. 63 * Arbor 20-30-ped., ligno albido duro, ramis cinereis. Petioli 2-3 lin. longi. Folia 3-6 poll. longa, 1-2 poll. lata et ultra, venis utrinsecus 11-13 prope marginem arcuatis. Racemi 2-3-pollicares subsessiles, floribus flavescentibus. Baccæ edules, dulces, magnit. seminis Viciæ, achæní atro nitido calycem album dimidio superante. A C. excoriatâ, exceptis foliis minoribus, rigidioribus, basi magis attenuatis et racemis brevioribus erectis vix distinguenda. (v. s.)

76. C. A CU M IN A A (Kunth! in H. B. nov. gen. 2, p. 176 ), ramis junioribus pendulis sulcatis vaginatis fuscescenti-pubescentibus, ochreis hirtis, foliis subherbaceis petiolatis oblongo-lanceolatis acuminatis basi acutis utrinque tenuiter laxeque elevatoreticulatis supra nitidis nervo venisque subtus petioloque pubescentibus, venarum axillis barbellatis, racemis terminalibus solitariis folio longioribus pendulis, bracteis remotiusculis sub-3-floris rhachique pubescentibus, bracteolis pluribus arcte adpressis, pedicellis glabris, fructu ovoideo parvo. 5 In Colombiâ, ad fl. Magdalenæ (Bonpland, n. 1479 I) et isthmum Darien. - Benth. Bot. Sulphur. p. 159, Meisn. in Mart. fl. bras. fasc. 14, p. 25. Lyperodendron coccoloboides Willd.! mss. in herb. n. 7693. Ochreæ petioli et folia novella setulis fulvis adpressis hirta. Petioli semi-

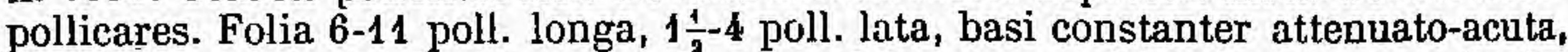
venularım reticulo tenui supra denso subimmerso subtus laxiore prominulo, venis primariis utrinsecus $20-24$ prope marginem arcuatis tenuibus supra subimmersis, subtus prominentibus puberulis. Racemi 8-10-pollicares, bracteis turbinatis, floribus rubris basi extıs puberulis. Achænium nigxo-fuscum, ovato-trigonum, acutum, magnit. pisi, calyce carnoso tectum. (v. v. c. sine fl. et sp. Humb.! in herb. Willd.)

77. C. Japurana (Meisn. in Mart. fl. bras. fasc. 14, Polyg. p. 25), ramulis novellis puberulis mox glabris, ochreis deciduis, foliis subherbaceis petiolatis elongatooblongis breve acuminatis basi acutis glaberrimis tenuiter laxeque prominuloreticulatis supra nitidis, racemis terminalibus lateralibusque solitariis folio brevioribus filiformibus laxiusculis pendulis, bracteis acutis 1-2-floris, rhachique rufo-tomentellis, floribus subsessilibus parvulis. $\bar{J}$ ? In Brasiliæ prov. Rio Negro, circa Ega et ad fl. Japura (Mart.). Folia usque ad 8 poll. longa, fere 3 poll. lata. Racemi 2-3-pollicares. Simillima quidem C. acuminatæ, sed jam foliis undique glaberrimis et racemis brevibus distincta. (v. s. in h. Acad. Monac.) 
78. G. Strobilulifera (Meisn. in Mart. fl. bras, fasc. 14, Polyg. p. 25 "), glabra, ramis dichotomis gracilibus levibus, ochreis brevibus deciduis, petiolo gracilí supra canaliculato, foliis semicoriaceis oblongis acuminato-acutis basi minus angustate obtusis vel brevissime attenuatis planis supra nitidis utrinque subrequaliter laxiuscule reticulatis, venulis tenuissimis semiimmersis, racemis terminalibus solitariis folio longioribus dernum longissimis subinterruptis, rhachi tomentella mox glabrâ, bracteís 1-floris, pedicello demum exserto bracteolis adpressis imbricato strobiliformi, floribus parvulis. $J$ ? In Colombià (Moritz!), ins. Ometepe, Guatimalâ, ubi Papaturillo vocatur (Friedrichsthal, n. 956 l). G. acuminata Klotzsch $1 \mathrm{mss}$. in h. reg. Berolin. Species inflorescentiâ maxime insignis ; racemi pedunculati, graciles, 5-6 poll. longi, erecti vel nutantes, rhachi filiformi glabrâ, bracteis ovatís acutiusculis margine scariosis primo subcontiguis (inferioribus tantum remotiusculis) demum' insequaliter distañtibus vel $2-3$ approximatis a reliquis spatio $2-4$ lin. longo separatis, pedicello squamulis fulvis obtusissimis dense imbricatis penitus abscondito strobilum oblongum obtusum 2-3 lin. longum simulante. Ramuli gracillimi, laxi, teretes, læeves, sanguineo-atrofusci, juniores cinerascentes substriati, internodiis 1-2 poll. longis. Folia 3-7-pollicaria, 1-2 poll. lata, petiolo 4-6 lin. longo, venarum axillis subtus barbellatis nudisve. Proxima quidem C. acuminatæ, sed præter inflorescentiam et glabritiem etiam differt foliis basin versus constanter minus angustatis ibique obtusioribus. (v. s. in herb. reg. Berolin. et Vindobon.)

79. G. viR ENs (Lindl. in Bot. reg. t. 1816), glabra, ramis gracilibus Iæevibus, ochreis arcte cylindricis brevibus, foliis subsessilibus ovato-lanceolatis obtusis basi angustatis haud reticulatis, racemis terminalibus axillaribusque solitariis brevibus laxiusculis patentibus pendulisve, bracteis 1-floris. 5 ? In Indiâ occidentali. Rami atropurpurei. Folia 2-5 polJ. longa, 1-2 poll. lata, basi obtusa vel acutiuscula (coriacea?), venis primariis utrinsecus 6-10 semipatentibus prope marginem late arcuatis, reticulatione (ex ic.) nullâ: Racemi $2 \frac{1}{2}$ poll. longi, folia minora æquantes, nutantes, toti flavo-virescentes, brevissime pedunculati, pedicellis 1-2 lin. longis tenuibus patentibus, calyce patente diametro $2-2 \frac{1}{2}$ lin., staminibus 10 , stylis 3 clavatis breve exsertis. Aff. C. obtusifoliæ Jacq. et microstachyæ Willd., fide Lindl.

80. G. plantaginea (Wedd.! in Ann. sc. nat. $3^{\circ}$ sér. 13, p. 257), ramis sulcatis, ochreis deciduis, foliis coriaceis breve petiolatis subnitidis glabris elliptico-vel obovato-oblongis obtusis basi attenuatis margine leviter recurvis haud reticulatis, nervo venisque utrinque semiimmersis, racemis laleralibus solitariis folio longioribus filiformibus densifloris, bracteis sub-1-floris parvis obtusis rhachique puberulis, bracteolis bilabiatis flore subsessili parvo brevioribus, stylis longiusculis staminibusque exsertis. $₹$ In Brasilire prov. Bahiensi (Blanchet, n. 14911).--Meisn. in Mart. 1 . bras. fasc. 14, Polyg. p. $24^{*}$. Frutex scandens (ex Wedd.), ramis livide cinereis acute sulcatis rimosis gracilibus, internodiis 1-3-polliqaribus, ramulis lateralibus novellis $\frac{1}{2}-1$ poll. Iongis paucifoliis racemo terminatis Folia 2-3-pollicaria, 7-14 lin. lata, petioIo 2-3 lin. longo, satis rigida, venis primariis utrinsecus 6-8 patulis vix arcuatis ante marginem cvanescentibus, venulis penitus immersis invisibilibus. Racemi 3-5-pollicares, patuli, pedunculo jrevi ochreâ longiusculâ vaginato. Flores polygami (ex Wedd.). Fruct. ignot. (v. s. in herb. DC.)

81. C. RIGIDA (Meisn. in Mart. fl. bras. fasc. 14 ,Polyg. p. $29^{\star}$ ), ochreis eaducis, petiolis brevibus canaliculatis dorso sulcatis ramulisque glabris, foliis rigide coriaceis obovato-oblongis ovalibusque utrinque obtusis dense prominulo-reticulatis glaberrimis supra nitidis subtus opacis malgine recurvis, racemis terminalibus solitariis folio longioribus erectis densifloris, pedunculo rhachi bracteisque dense rufo-tomentellis, bracteolis scariosis parvulis glabris pedicello crassiusculo longioribus. $ま$ ? In Brasiliâ (Schott, n. 5538I). Rami virgati, striati, cinerei, ramulis brevibus patentissimis foliosis racemo 3-5-pollicari terminatis. Ochreæ tenue membranaceæ. Petioli 3-4 lïn. longi. Folia crassiuscula, 1-2i poll. longa, 5-11 lin. lata, interdum brevissime obtuseque acuminata, supra livide viridia, subtus ferruginea, venis primariis utrinsecus 3-5 tenuibus supra immersis, subtus fortiter expressis. Calyx vix 1 lin. longus. (v. s. in herb. Mus. Vindobon.)

82. C. SALICIFolia (Wedd. l. c. p. 259), glaberrima, ramulis flexuosis tenuiter striatis, ochreis membranaceis deciduis, foliis herbaceis lanceolatis attenuatoacuminatis obtusis basi angustatà obtusiusculis utrinque tenuiter denseque subimmerso-reticulatis, racemis terminalibus solitariis subsessilibus folia subæquan- 
tibus filiformibus flexuosis laxiusculis, bracteis parvulis ovatis subbifloris, pedicellis brevibus exsertis. F In Brasiliæe prov. Rio Janeiro (Claussen, n. 4 ! et 2094!). Meisn. in Mart. fl. bras. fasc. 14, Polyg. p. 24*. Frutex scandèns (ex Wedd.) facie Ruprechtiarum quarumdam, ramis verruculosis, ochreis internodio brevioribus. Folia $2 \frac{1}{2} 3 \frac{1}{2}$ poll. longa, 9-12 lin. lata, plana, subnitida, reticulatione tenui subtus paulo latiore, venis utrinsecus 11-13 supra subimmersis, subtus prominulis prope marginem arcus tenuissimos formantibus. Racemi plerique nutantes, rhachi tenui striatâ, floribus vix $\frac{2}{8}$ lin. longis. (v. s. in h. Shuttleworth el Mus. Vindobon.)

\section{Species obscura, procul dubio excludenda.}

C. Tо тNEA (Hamilt. in Don prodr. fl. nepal. p. 74), fruticosa, ramis undique hirsutis, foliis lanceolatis acuminatis utrinque pubescentibus, ramis paniculatis,

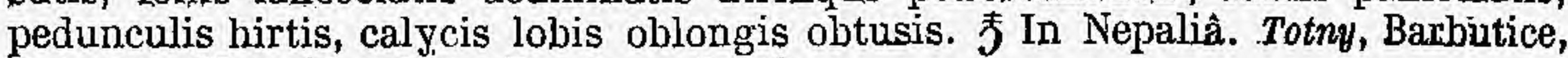
Patu-Swa, Nawarice dicta. Rami esculenti.

\section{Species exclusce.}

C. AUSTRALIS Forst. = Mühlenbeckia australis Meisn.

C. BRASILIENSIS (Spreng. = Hedyosmi sp. Cfr. Cham. in Linñæâ.4, p. 36.

$\begin{aligned} & \text { C. CRISPATA Buchan. } \\ & \text { C. INDICA Wight mss. }\end{aligned}=$ Polygonum Chinense L.

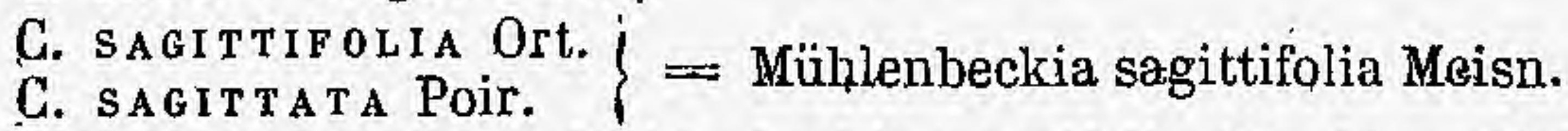

G. mo NoInc Ruiz. = Mühlenbeckia tamnifolia $\delta$ laxiflora Meisn.

C. CARINATA Ruiz. = Mühlenbeckia leptobotrys Meisn.

XXVI. CAMPDERIA Benth. in Bot. of the Sutphur, p. 159, t. 52, Endl. gen. suppl. IV, 2, p. 50, n. 1989/1, Meisn. in Mart. fl: bras. fasc. 14, Polyg. p. 22.

Flores hermaphroditi. Galyx subcorollinus, 5-partitus, maircescens, lobis æqualibus tubo longioribus demum auctis. Stamina 8, filamentis basi dilatatâ subconnatis, antheris ovalibus locúlis distinctis. Styli a breves, stigmạtibus capitatis. Fructus siccus, achænio trigono-elliptico-incluso calycis tubo immutato basi adnato. - Arbores vel frutices Americæ centralis, habitu omnino Coccólobæ nec nisi fìuctu exsucco ab hoc genere discedentes, racemis spiciformibus simplicibus solitariis subsessilibus.

1. G. FLORIBUNDA (Benth. 1. c. p. $160^{*}$, t. 52), glaberrima, foliis coriaceis breve petiolatis ovali-vel obovato-oblongis subacuminatis basi angustatâ leviter cordatis vel inæequaliter rotundatis utrinque dense elevato-reticulatis, racemis terminalibus densifloris folia rquantibus vel superantibus erectis, staminibus calyce brevioribus. 5 ? In Tiger-Island, Sinus Fonseca, Guatimala. Ramuli striati, cinerei, inter . nodiis brevibus. Ochree membranaceæ, fuscescentes, striatæ, 2-4 lin. longæ, petiolum crassiusculum æquantes. Folia 3-5 poll. longa, 1-2 poll. lata, obtusa, interdum " brevissime peltata. " Racemi 3-5-pollicares, crassiusculi, bracteis sca-

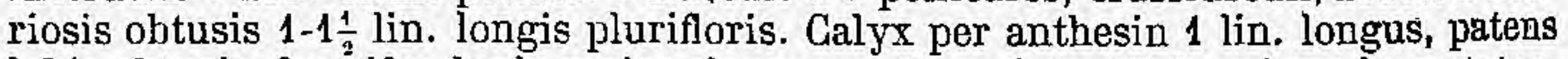
lobis olttusịs, fructifer duplo major clausus, sed consistentiâ formâque immutatus.

8. G. oracilis (Meisn. in Mart. fl. bras. fasc. 44, Polyg. p. $23^{\star}$, t. 6), glaberrima, ramis gracilibus striatis, folis subcoriaceis petiolatis ovatis ellipticisve obtusiusculis basi rotundatâ subcordatis nitidis utrinque tenuiter denseque prominuloreticulatis, racemis terminalibus folio longioribus gracilibus demum laxiusculis, bracteis 1 -3-floris pedicellos brevissimos æquantibus, genitalibus inclusis. $f$ ? In Brasilize prov. Rio Negro (Spruce, n. 958!). Facies fére Coccolobæ Guianensis. Ramuli pallidi parce lenticellis' oblongis albidis conspersi. Ochreæ membranaceæ nervoso-sulcata, petiolum 4-5 lin. longum tenuem æquantes, diu persistentes.

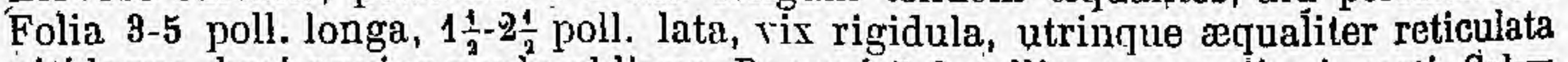
nitidaque, basi sæpius paulo obliqua. Racemi 5-6-pollicares, continui, recti. Calyx fructifer 3-4 lin. longus, coriaceus, clausus, obovato-trigonus, sepalis 3 exterioribus carinato-concavis, achænio acute triquetro imâ basi calyci adhærente, faciebus elliptico-rhombeis lævibus nitidis, semine 3-gono, nec trilobo. A G. floribundâ prsecipue racemis gracilibus el fructu dislincta. (v. s. in herb. DG. et Acad. Monac.) 
3. C. MEXIGANA, ochreis junioribus ferrugineo-tomentellis, petiolis longiusculis gracilibus, foliis coriaceis oblangis obtusis basi angustatâ emarginalo-rotundatis utrinque dense elevato-reticulatis opacis glabris, venarum axillis pilosiusculis, facemis terminalibus lateralibusque folio dupplo longioribus pendulís gracilibus densifloris, staminibus exsertis. F? In Mexici ditione Oaxaca, circa Teliuantepec (Andrieux, n. 115!) Foliis C. floribunde simillima, sed præeter notas jam indicatas discrepans petiolis tenuioribus 4-6 lin. longis, foliis minoribus (2-4-pollicaribus) racemis tenuioribus. Bracteæ exteriores coriacer, coloratæ (nigricantes), interiores membranaceæ pallidæ obtusłe. (v. s. in herb. DC. et Zuccar.)

Subtribus V. TRIPLARIDEA C.-A. Meyer in Mém. Acad. S.-Pétersb. $6^{\mathrm{e}}$ sér. $6, p .147$.

Flores dioici, rarius hermaphroditi. Calyx herbaceus 6 - (rạo 3-) partitus, fructiferi laciniis valde inæqualibus, exterioribus 3 in alas membranaceas erectas excrescentibus, interioribus multo minoribus vel nullis. Stamina 6 vel 9, imo calyci inserta, libera (in fl. fem. sterilia vel nulla), filamentis filiformibus antheris versatilibus. Styli tres superne papilloso-stigmatosi attenuati, rarius capitati. Achænium calycis tubo incjusum, liberum oblongum vel trigonum, pericarpio tenui crustaceo. Albumen farinosum, in peripheriâ ruminatum (an etiam in Podoptero?). Embryo axilis. - Frutices vel arbores Americæ centralis et australis, habitu Coccolobæ, racemis paniculatis.

XXVII. PODOPTERUS Humb. et Bonpl. pl. aquinoct. 2, p. 89, t. 107, Endl. gen. p. 309" n. 1996, Meisn. gen. p. 317 (228).

Flores hermaphroditi. Calyx herbaceus, 6-partitus, lobis 3 interioribus minoribus oblongis planis, exterioribus 3 navicularibus carinatis accrescentibus conniventibuus, cạrinâ membranaceo-alatâ, alâ diaphanậ in pedicẹl|um longe decurrente integerrimạa. Stamina 6 inclusa, lobis âlterna, calycis fundo inserța, aqualia, filamentis subulatis basi breviter connatis, antheris medio dorso affixis versatilibus ovalibus ut inque emarginatis. Ovarium liherum, oblongo-trigonum, ovulo basilari subsessili erecto. Styli 8 i filiformes, breves, divergentes, stigmatibus capitatis. Achænium calyce aucto membranaceo sicco 3-alato cuneato-obcordato inclusum, alato-triquetrum. Semen oblongum, teres. - Frutex Americæ tropicalis, incomptus, ramis flexuosis, ramulis apice spinescentibus, foliis sparsis sæpe spurie fasciculatis ochreisque membranaceis minutis deciduis, floribus præcocibus axillaribus fasciculatis, pedicellịs longis gracilibus basi articulatis et ochreolis squamiformibus minutis stipatis sursum trialatis.

P. Mexicanus (Humb. et Bonpl.! 1. c.), circa Vera Cruz Novæ-Hispaniæ (Humboldt !) et Manzanilla Bay (voy. Sulph.). - Kunth in H. B. nov. gen. 2, p. 181, Lam. ill. suppl. t. 940 , Bentl. hot. Sulphur, p. 160, n. 765. Rami graciles, ramulis brevibus spinescentibus. Folia ovali-vel obovato-ghlonga, acutiuscula, basi attenuata, subsessilia, herbacea, penninervia, minule pụberula, nollicaria, 6-8 lin, lała. Flarum fasciculi sessiles, $3 \cdot 6$-flori, pedicellis calycem æquantibus, gracilibus. Calyx fructifer circiter semipollịcaris. (v. s. in herb. Kunth. et herb. reg. Berol.)

XXYIII. TRIPLARIS Loefling in Linn. syst. nat. ed. 10, p. 881; gen. ed. Schreh. p. 57, n. 135, Jacq. Amer, p. 13, t. 173, f. 5, Aubl. Guian. t, 347, Lam. ill. t. 825, Gham. in Linnad 8, p. 136, Endl. gen. 1. 1997, Meisn. gen. p. $317(219$, excl. Ruprechtia) et in Mart. fl. bras. fasc.14, Polug. p. 47, t.15, 24, 25, Schomb. in Ann. of nat. hist. 1, p. 264, C.-A. Mey. l. f. p. 147. - Blochmannja Weig. ex Reichenb.! conspect. n. 4298. - Velasquezia Bertol. A. guatimal. p. 40,t.11.

Flores dioici. Calyx infundibuliforpmiş vel campanulatus, 6-partitus vel 6-fidus, lobis imbricatim biseriatis erectis planis, in fl. masc. subæqualibus, in 
fem. vałde inæqualibus, exterioribıs 3 (alis) accrescentibus elongatis lanceolatis oblongisve demum scariosis alæformibus 1-nerviis venoso-reticulatis tubo plerumque multo longioribus, interioribus 3 alteruis (petalis auct.) multo brevioribus tubo inclusis vel breviter exsertis eique inferne adnatis vel liberis, linearibus vel inferne dilatatis. Stamina 9, plus minus exserta, 6 calycis lobis alterna, et 3 lobis interioribus anteposita, filamentis capillaribus. Achænium calycis tubo inclusum et plerumque brevius, acutangulo-triquetrum, ovatopyramidale, faciebus subplanis. Styli 3 liberi vel imâ basi confluentes, breves, stigmatibus filiformibus minute papillosis. Semen achænio conforme. Embryo axilis, cotyledonibus foliaceis lalis, radiculâ superâ. - Arbores Americææ australis tropicæ, ramulis fistulosis Formicis hospitium præbentibus, plerumque plus minus sulcato-striatis, ochrearum deciduarum cicatricibus annulatis, foliis alternis herbaceis vel modice coriaceis petiolatis integerrimis ovatis oblongisve planis penninerviis deciduis, impressionibus longitudinalibus ad utrumque nervi latus 3-6 parallelis plus minus distincte striatis (vestigiis laminæ in vernatione revolutæ). Flores spicati vel racemosi, albi? vel virescentes, racemis in paniculas terminales congestis simplicibus bracteatis, masculis plerumque fasciculatis, fem. solitariis, bracteis alternis sessilibus ovatis oblongisve 1-floris fissis extus glabris, intus pubescentibus persistentibus, pedicellis apice articulatis.

\section{§1. Platypetaloe.-Calycis fructiferi lacinio interiores (petala auct. nonnull.), liberce subhypogynce, inferne dilatatce.}

1. T. CARAGASANA (Cham.! in Linnæâ 8 , p. 137 ), foliis subcoriaceis glabris elongato-oblongis basi obtusis subtus laxe reticulatis, nervo venisque supra immersis, subtus pilosiusculis, paniculâ patente undique subadpresso-pilosâ, calycis fructiferi tubo inflato-ovato, sinubus obtusis plicalo-intrusis, alis lanceolatis, lobis interioribus e basi ovali-oblongâ achænium æequante subito in acumeñ tubum superans lineari-lanceolatum glabriusculum productis. 5 In Colombiâ circa Venezuelam, Caracas, etc., ubi Palo Maria et Ceiba vocatur. Arbor habitu Populo Italice similis (Karsten). Folia $8-18$ poll. longa, $2 \frac{1}{2}-3 \frac{1}{2}$ poll. lata, petiolo 5-9 lin. longo, striis longitudinalibus utrinsecus $3-5$ obsoletis. Calyx fructifer 2 poll. longus, tubo semipollicari. Achænium calycis tubum subæquans acuminatum, faciebus ovatis lævibus nitidis radiato-venosis. (v. s.)

a. genuina, calycis lobis interioribus tubum breviter superantibus, acumine lineari laminâ ovali paulo breviore (Bredemeyer, n. 737, in herb. Willd. n. 18,465! Linden, n. 1! Moritz, n. 1110 ! Karsten!).

$\beta$. Vargasii, calycis lobis interioribus tuluum longe superantibus, acumine lineari venoso laminâ ovali plerumque paulo longiore. (Vargas, n. 33! in herb. DG., Bredemey. ז. 325 ! in herb. Jacq.)

2. T. SсномвURGKIANA (Benth. in Hook. Lond. Journ. 4, p. 628), foliis amplis ovatis utrinque acutiusculis venosis villosis, paniculâ hirsutissimâ, bracteis acuminatis, calycis fructiferi (junioris, hirsuti) alis oblongis tubo vix longioribus, lobis interioribus ovarium tubumque æquantibus eique basi adnatis ovatis petaloideis haud acuminatis. 5 ? In Guianâ Anglicâ (Schomb. coll. 1). - Meisn in Mart. fl. bras. fasc. 14 , Polyg. p. $48^{*}$. Folia usque ad 10 poll. longa, 6 poll. lata, striis longitudinalibus conspicuis, pube ferrugineâ in paginâ superiore adpressâ scabriusculâ, subtus copiosiore molliore. Paniculæ rufo-hirsutæ masculæ rami numerosissimi, 6-12 poll. longi, a basi densiflori, bracteis vix 1 lin. longis longe ciliatis, floribus subsessilibus parvis; feminea minore bracteis 4 lin. longis calycem æquantibus. Styli calycem subæquantes. Achænium jun. longitudine tubi.

\section{$\$ 2$. Stenopetala. - Calycis fructiferi lacinioe interiores lanceolato} vel lineares vel subulatce, inferne haud dilatatce.

- Calycis lacinia interiores achonio aquales vel breviores, saltem stylorum basin calycisque non superantes.

3. T. PAvoNII, foliis sublerbaceis ovalibus utrinque rotundato-obtusis tenuiter reti- 
thiplaris. POLYGONACEÆ (AdCTOR MEISNER).

culatis glabris, venarum axillis nervoque subtus puberulis, paniculâ amplâ sim. plici, rhachì bracteisque dense sericeo-villosis, floribus subsessilibus, calycis fructiferi tubo subtrigono-ovato pilosiusculo intus dense barbato, sinubus introrsum plicatis obtusis, alis lanceolatis basi attenuatis glabriusculis, lobis interioribus tubo paulo brevioribus ejusque basi brevissime adnatis, stylis faucem attingentibus, achænii faciebus ovato-ellipticis lævibus nitidis medio sulco lævi latiusculo excavatis subeveniìs. 5 In Peruviâ? (Pavon! Shuttlew.). Ramuli striati, glabri. Petioli subpollicares canaliculati. Folia 8-9 poll. longa. 5 poll. lata, striis longitudinalibus utrinsecus 4 obsoletis. Panicula folia superans, spicis geminatis

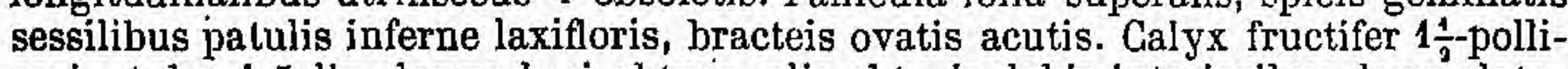
caris, tubo 4-5 lin. longo basi obtuso, alis obtusis, lobis interioribus lanceolatolinearibus intus medio pilosiusculis. Achænium vix acuminatum subevenium. Affinis T. Brasiliensi, Felipensi, Pœppigianæ el Noli tangere, sed calyce fructifero, achænio, etc., bene distincta. (v. s. in h. Shuttleworth.)

4. T. Guaya Quil ENsis (Wedd.! in Ann. sc. nat. 3॰ sér. 13, p. 264), foliis subcoriaceis breve petiolatis oblongis breve acuminatis utrinque obsolete immerso-reticulatis puberulis, paniculâ simplici, rhachi tomentosâ, bracteis pedicellisque dense sericeo-pilosiusculis, calyce fructifero utrínque adpresse pilosiusculo, tubo globosoovato, sinubus rotundatis subintrusis, alis oblongo-lánceolatis basi attenuatis, tobis interioribus subulato-linearibus tubum æquantibus ejusque basi breviter adnatis, stylis tubum superantibus, achænio abrupte acuminulato, faciebus late ellipticis exsulcis levibus nitidis radiatim venosis. 5 Circa Guayaquil (Gaudich. n. 3!). Ramuli striati, glabri. Folia 6-10 poll. longa, 3-4 poll. lata, basi rotundata vel attenuata, glabra vel subtus ad venas puberula, venulis intercostalibus tenerrimis subtus prominulis reticulo utrinque immerso obsoleto, striis longitudiualibus utrinsecus 5-6 valde conspicuis. Panicula fem. 6-8-pollicaris, racemis solitariis pedunculatis patentibus laxiusculis, bracters ovato-oblongis pedicellos subæquantibus 2-3 lin. longis. Calyx fructifer bipollicaris, tubo semipollicari, alis obtusis, loborum interiorum basi ad̉natâ 1 lin. longâ. Achænium calycis tubum squans, faciebus $3 \frac{1}{2}$ lin. latis. (v. s. in h. DC.)

5. T. FELIPENsis (Wedd. l. c. p. 263), foliis ovato-ellipticis elongatis breve acuminatis in petiolum brevem attenuatis utrinque sparse adpresso-pilosis tenuiter denseque prominulo-reticulatis, spicarum rhachi bracteisque sericeo-villosis, floribus subsessilibus, calyce fructifero utrinque pilosiusculo, tubo ovato extus longe piloso, sinubus angustissimis, alis oblongo-lanceolatis, lobis interioribus suathulato-linearibus imâ basi tubo adnatis achænium æquantibus glaberrimis, achænio tubum æquante àttenuato-acuminato, faciebus ovato-lanceolatis nitidis sulco obsoleto latiusculo excavatis. 5 In Colombiâ circa S. Felipe, Venezuela, Caracas (Humb.l), Funke et Schlim. n. 687 ex Wedd., 657 ! ex herb. Shuttl. at DC. T. Americana Kunth ! in H. B. nov. gen. 2, p. 182 (fide herb. Kunth, ex parte). Ramuli striati, verruculosi, glabri. Petioli 6-8 lin. longi, subcanaliculati. Folia 10-13 poll. longa, 3-6 poll. lata, acutiuscula, basi inæqualiter attenuata, striis utrinsecus 5-6 parum conspicuis. Panicula foliis hrevior, spicis patentibus sessilibus, bracteis $2 \cdot 3$ lin. pedicellis, $\frac{1}{2}$ lin. longis. Calyce fructifero 1 poll., tubo 3-4 lin. longo (v. s. in h. Kunth., DG., Shuttl.)

6. P. Pappigiana (Wedd. 1. c. p. 265), foliis elongato-oblongis acute angusteque acuminatis basi obtnsis utrinque minute subimmerso-reticulatis glabris vel junioribus in costâ et supra parce adpresse pilosis, paniculæ ramis pedicellísque fulvotomentosis, calyce fructifero utrinque bracteisque adpresso-piloso, tubo oblongo, sinubus latis subplanis, alis lanceolatis, lobis interioribus lanceolatis obtusiusculis imo tubo brevissime adnatis achænium cequantibus intus pilosis, achænii tubo multo brevioris faciebus late rhombeo-ovatis acuminatis. 5 ? In Peruviæe prov. Maynas ad Tocache, Huallaga (Pœppig, n. 1957!) Blochmannia Peruviana Pœppig! mss. in herb. Endlicher. Ramuli glabri. Folia subcoriacea, breve petiolata, 6-11 poll. longa, 3-4 poll. lata, striis utrinsecus $2-3$ vix visibilibus, venis primariis crebris supra impressis, subtus acute prominulis, junjorum costâ pilis 1-2 lin. longis adpressis conspersâ. Panicula folia superans, ramis patulis. Calyx fructifer

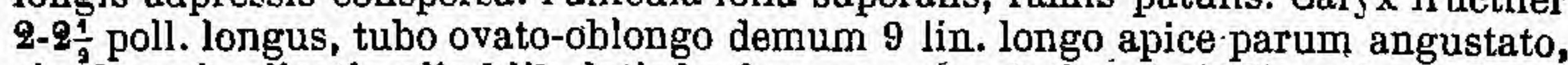
sinubus vix plicatis, alis 4 lin. latis basi parum angustatis subnitidis reticulo dense utrinque prominulo. (v. s. in h. reg. Berolin. et Vindobon.) 
7. T. Bras ILIANa (Cham.! in Linnæâ 8, p. $139^{*}$ ), foliis elongato-ovatis ellipticisve subacuninatis basi obtusis utrinque tenuiter denseque subprominulo-reticulatis glabris, paniculæe ramis subsericeo-villosis, bracteis persistentibus, floribus subsessilibus, calycis fructiferi tubo ovato utrinque villoso sinubus obtusis haud plicatis, alis lanceolatis, lobis interioribus ächænio brevioribus liberis lineari-lanceolatis, stigmatibus faucem superantibus, achænio tubum sibæquante, faciebus ovatis acutis lrevibus nitidis. $f$ ? In Brasiliæ prov. Minas Geraës (Sellow ! Lhotsiky! Pohl!). - Meisn. in Mart. fl. bras. fasc. 14, p. 48, t. 15, f. 2. Folia subherbacea, 8-10, poll. longa, 4-5 poll. lata, costâ glabrầ (vel rarius parce adpresso-pilosâ), axillis venarum vix unquam conspicue barbatulis, striis parum conspicuis, petiólo 6-8 lin. longo. Calyx fructifer subpollicaris, tubo 3 lin. longo, lobis interioribus tubo non adnatis. (v. s. in herb. reg. Beroliu. et Mart.)

8. T. Gardneriana (Wedd.! l. c. p. 265), foliis ovato-oblongis basi vix attenuatis utrinque tenuiter denseque prominulo-reticulatis glabris vel subtus adpresse pilosis, p̈aniculæ ramis villoso-tomentosis, floribus subsessilibus; calycis fructiferi tubo ovato-oblongo laxiuscule villoso, sinubus angustis acutis, alis lanceolatooblongis basi angustatis, lobis interioribus tubo brevioribus ejusque basi adnatis achænium æquantibus subulato-linearibus, achænio acumináto, faciebus ovatis hitidis subvenosis. 5 ? In Brasiliæ prov. Ceara (Gardner, n. 1829 !). $\rightarrow$ Meisn. in Mart. fl. bras. fasc. 14, p. $52^{*}$, t. 15, fig. 6. Ramuli graciles, striati, giabri. Folia subcoriacea, 3-6-pollicaria, subacuminata, $1 \frac{1}{2}-2 \frac{1}{2}$ poll. lata, petiolo 2-6 lin. lótigo crassiusculo, striis utrinsecus $3-4$ satis conspicuis. Panicula mascula foliis sublongior, feminea brevior, spicis inferne subinterruptis. Flopes masc. villoso-tomentosi, fem. juniores sericei, pedicellis demum 1-2 lin. longis. Galyx fructifer sesquipollicaris, tubo semipollicari intus tenuiter pilosiusculo, sinubus vix aut non intrusis, alis 3-4 lin. latis, lobis interioribus glabriusculis quartâ parte inferne calyci adnatis. Styli subinclusi. (v. s. comm. ab. am. Shuttlew.)

9. T. BONP L A D I AN A (Wedd. 1: c. p. 262), ramulis glabris, foliis ..., calycis frictifêri tubo subgloboso utrinque subadpresse piloso, sinubus dente láto rectiuśculo alis oblongis interposito auctis, lobis interioribus linearibus tubi basi adnatis achæniọ multo brevioribus, achænio tubum æquante, faciebus subroturdis nitidis leviter flabellato-sulcatis. 5 In Peruvixe prov. Marannon (Bonpl. in herb. Mus. Paris.). Meisn. in Mart. fl. bras. fasc. 14, p. 48. Arhorea, inflorescentiæ ramis horizontaliter patentibus bracteisque pilosis, calycis fructiferi 9 lin. longi, alis obtusis lobiscue interioribus utrinque pubescentibus, achienio late ovato-triquetro (Wedd.). Huc referenda nobis videtur T. Americana Bonpl. mss. n. 3599 ! in herb. Kunth., cui folia oblonga; 5- $\ddot{6}$-pollicaria, 2-3 poll. lata, utrinciue attenuato-acuminata, minute denseque subptominulo-reticulata, supra glabrá, súbtus puberula, striis obsoletissímis. Calyx fructifer pollicaris, pedicello 2 lin. longo hirsuto, tubo subgloboso, alis extra medium 3- $\dot{k}$ lin. latis infra angustatis, lobis interioribus achænio $\frac{1}{3}$ brevioribus. (v. s.)

\section{* Calycis fructiferi lobi interiores achanio longiores, tubum aequantes vel sappilus superantes.}

10. T. Peruviana (Fisch. el Mey. in Mërn. Acad. S.-Pétèrsb. 6• sér. 6, p. 149), foliis oblongis utrinque attenuatis tenuiter elevato-reticulatis glabris, paniculæ ramis tomentosis, bracteis sericeis pedicellos fructiferos hirsutos subrquantibus, calycis adpreśse pilosiusculi tubo late campanulato alis lanceolatis parum breviore, sinubus lobulo roturidato vel emarginato plano auctis, lobis exterioribus tubo fere ad faucem usque adnatis lobulos æequantibus anguste spathulato-linearibus basi non auriculális, achicenii tubo dimidio brevioris faciebus late ovatis lavibus nitidis. 6 ? In Peruviâ (Mathews, n. 1620 l). Ramuli tenuiter aculeque sulcati, glabri. Petioli

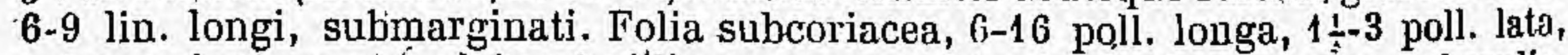
subacuminato-acuta, glabra (axillis venarum subtus barbatis venisque puberulis, ex Mey.), striis utriusecus $2-3$ obsoletis. Paniculæ axillares et terminales; folio breviores, spicis sessilibus densifloris patulis 2-4 poll. longis, rhachi tomentost. Stamina longe exserta. Calyx fructifer basi rotundatus, lobis interioribus medio pilosiusculis. Styli inclusi, lobulorum sinus angustos acutos haud attingentes. Acheoili anguli acuti. (v. sp. ơ et $q$ jun. in herb. Arnott.)

11. T. AURIGULATA, follis oblongis vel ovato-oblongis breve acuminatis utrihque laxe reticulatis ramulisque parce adpresso-pilosis demum glabris, paniculâ undi- 
que dense sericeo-pilosâ, calycis fructiferi tubo ovato, sipubus latis introrsum ṕlicatís obsolete lobulatis, alis lanceolatis, lobis interioribus tubo paulo longioribus eique ultra medium arlnatis linearibus pilosis basi auriculâ brevi ob̉tısâ pilosâ auctis, achænii tubo $\frac{1}{4}$ brevioris faciebus ovali-oblongis minute elevatopunctatis. 5 ? In Novâ-Granatấ? et Mexico (Pavon 1 in herb. Sh ittlew.). T. Amerieana Pavon! mss. Folia fere T. Arnottianæe, herbacea, basi rotundata vel breve attenuata, 6-8-pollicaria, 2 $\frac{1}{2}$-4 poll. lata, petiolo 4-7 lin. longo, reticulo supra immerso, subtus tenuiter prominulo, striis longitudinalibus obsoletis. Paticula terminalis, racemis pedunculatis patentibus densiuscule multifloris, pedicellis bracteas ovato-oblongas subæcquantibus 2-2 $\frac{1}{2}$ lin. longis. Calyx fructifer semimaturus subsesquipollicaris, basi rotındatus, utrinque adpresse pilosus, alis subpollicaribus 2-3 lin. latis obtusiusculis. Styli calycis lobos interiores subæquantes. Achænium breve acuminatum, acutangulum. (v. s. in h. Shuttlew.)

12. T. SuR In amensis (Cham.! in Linneâ 8, p. 138 *), foliis elongato-oblongis utrinque aitenuatis ramulisque glabris venulis immersis obsoletis, paniculse ampla ramis tomentoso-puberulis, bracteis persistentibus pedicellisque ipsis brevioribus dense pilosiusculis, calycis fructiferí tubo ovato dense hirsuto apice angustato infra sinus intrusos vel extrorsum recurvos concavo, alis lanceolatis basi angustatis, lobis interioribus anguste linearibus tertià parte inferne tubo adnatis, achænii tubo pauló brevioris faciébus late rhombeo-ovalis lævibus. 5 In Gưuianâ Gallicâ, Anglicâ, Batavâ (Hostmann, u. 1188, ơ), et Brasiliæ prov. Para. C. A. Meyer, l. c. p. 148 , Meisn. in Mart. fl. bras. fasc. 14, p. $49^{\circ}$, t. $24,25,26$, f: 2. T. Americana Aubl. Guian. p. 910, t. 347 ? (fig. 8 et 9 saltem non conveniunt). Artbor 40-50-ped (ex Kegel pl. Suriniam. n. 952, Mituel in Linneê 22, p. 75). Ramuli nigricantes; leviter sulcati, sæpe flexuosi. Folia herbacea vel subcoriacea, 3-15 poll. longa, $1 \frac{1}{2}-5$ poll. lata, striis utrinsecus $2-4$ conspicuis, venarum axillis subtus barbellatis nudisve, petiolo $\frac{1}{i}-1$-pollicari crasso. Paniculæ mascrilæ spicæ sæpe fascículatæ, calycibus infundibuliformibus vix 2 lin. longis sericeis, stamïnibus longe exsertis. Calyx fructifer sescuipollicaris, tubo \& lin. longo basi rotundato, sinubus lobulo obsoleto plicato-int truso vel extrorsum recurvo auctis, alis subsericeis demum glabriusculis basi obsolete 3-nerviis, lobis interioribus subglabris basi haud auriculatis. Styli breviter exserti. Achænium brevissime acuminatum, acutangulum, faciebus exsulcis obsolete venosis vix nitidis. (v. s.).

$\alpha$. Chamissoana (Meisn. l. c.), calycis fructiferi lobis interioribus tubum ærouantibus vel vix superantibus. T. Surinamensis Cham.11. c., ex parte et excl? syǹ. Valll. (Hostmann. n. 439! Wullschlogel, n. 802 ! Sieber! etc.)

$\beta$. Benthamiana (Meisn. l. c.), calycis fructiferi lobis interioribus tubo longioribus plus minus exsertís. T. Americana Rottboell. Surin. pa 7, t. 3? T. Surinamensis var. crassifolia Benth.! in Hook, Lond. journ. 4, p. 628, ex parte. Blochmannia Weigeltiàna Reichenb.! in Weigelt. pl. Surin. exsicc. (Aublet! in herb: DG., Schomburgk, n. 223! Spruce, n. 638!)

13. T. CUMINGIANA (Fisch. et Mey. 1. c. p. 148), foliis elongato-oblongis subtus pubescentibus venarum axillis nudis, calycis fructiferi sinubus 2 acutis tertio latiore rotundato, lobis interioribus subexsertis dimidio tubo adnatis subsetaceis. 5 ? In Colombiâ (Güning.). Folia maxima 16-18 poll. longa, 3-6 poll. lata, subtus pube ad'spersa. Calyx sesquipollicaris, alis 15 lin. longis, lobis interioribus angustissimis. Species nohis ignota. Omnia quæ vidimus specimina Cumingiana cum diagnosi et adumbratione 1 . c. insufficientibus haud congruunt.

14. GOLOMBIANA, foliis elongato-oblongis acutis in petiohum brevem attenuatís supra immerse venosis lævibus glabris, subtus elevato-costatis laxe reticulatis hispidulis, paniculâ undique sericeo-pilosâ, pedicellis brevissimis, calycis fructiferi tubo inflato-ovato hirsuto, sinubus introrsum plicatis, lobis interioribus tubum superantibus eique medium usque adnatis subulato-linearibus, achænio tubum subæquante, faciebus ovatis punctato-asperulis nitidis. 5 In Panamâ et Colombíâ (Cuming, n. 1108 I). T. Cumingiana Benth.? Bot. Sulph. p. 160 (non? Fisch. et Méy.). Ramuli tenuiter striati, apice puberuli. Folia subcoriacea, pedalia et ultra, 2-31 poll. lata, in petiolum 5-8 lin. longum decurrentia, nervo subtus parce adpresso-piloso, venarum axillis imberbibus, striis utrinsecus $3-4$ obsoletis. Paninícula patens, foliis superata, spicis subsessilibus densis, masculis fasciculatis, femineis solitariis. Calyx fructifer 18-20 lin. longus, tubo subsemipollicari, alis lanceolatis obtusis basi angustatis lobisque interioribus pilosiusculis. Styli tubum 
superantes, lobos interiores æquantes. Achænium acutangulum, sensim acuminatum, faciebus obsolete venosis. A T. Cumingiana descriptione pluribus notis essentialiter discrepat. (v. s. in lierb. Shuttlew. et Arnott.)

15. T. PURDIEI, foliis subsessilibus ovato-oblongis acuminato-subacutis basi rotundatâ inæqualiter cordatis utrinque tenuiter prominulo-reticulatis supra (exceptis venis) glabris, subtus puberulis; paniculæ ramis fliformibus cum bracteis persistentibus pedicellisque ipsas subsuperantibus dense adpresso-pilosulis, calycis fructiferi tubo ovali parce piloso, sinubus latiusculis rotundatis, uno alterove introrsum plicato, lobis interioribus tubum acpuantibus eique ultra medium adnatis subulato-linearibus, achænii tubo paulo brevioris faciebus ovatis lievibus nitidis. 5 Circa S. Martha Colombiæe (Purdie!) et ad $\mathbb{1}$. Barama Guianæ Anglicæ (Rich. Schomb. n. 1522 !). - Meisn. in Mart. fl. bras. fase. 14, p. 49*, t. 15, f. 3. Plurimis notis, ramulis, foliorum striis et pubescentiâ, calycis fructiferi magnitudine, etc., convenit cum T. Colombianâ, sed differt foliis herbaceis, 7-9 poll. longis, 3-4 poll. latis, petiolo subnullo, reticulatione, paniculà laxiore, spicis pedunculatis, pedicellis calycisque tubo longioribus (illis $2-3$ lin., hoc 8 lin. longis), alis basi vix angustatis, sinubus pluribus vel saltem uno plicatis, lobis interioribus tubum nunquam superantibus, etc. Planta Guianensis paulo recedit foliis subcoriaceis utrinque glabris, reticulatione minus prominulâ, calycis fauce magis plicatâ, lobis interioribus haud ultra medium adnatis. (v. s. in herb. Arnott. et reg. Berolin.)

16. T. Vaнl i a a (Fisch. et Mey. l. c. p. 148), foliis elongato-oblongis glabris, costâ subtus pilosâ, venarum axillis nudis, calycis fructiferi sinubus acutis, alis lanceolatis, lobis interioribus subinclusis fundo tubi adnatis oblongo-linearibus. $\hbar$ ? In Gayennâ (v. Rohr ). T. Americana Vabl symb. 2, p. 100 (excl.! syn. Aubl. et Rottb., cfr. G. Surinamensis). Palo santo Guianensium. - Sehomb. in - Proceedings bot. Soc. Lond. 1, p. 62 , t. 2 ; Ann. of nat. hist. 1, p. 264 . Bami glabri. Folia subpedalia, 3-4 poll. lata. Panicula sæpe pedalis, brachiata, ramis angulatis subsericeo-hirsutis, bracteis ovatis persistentibus pedicellisque æquilongis (2 lin.) birsutulis. Calyx fructifer sericeus, basi densius pilosus, intus pubescens, tubo urceolato, lobis interioribus (ex Vahl.) lineari-lanceolatis utrinque in medio lineâ villosâ. Achænium acutangulum; acuminatum, nitidum. Species insufficienter descripta, nobis obscura, a precedentibus haud certe dignoscenda; T. Surinamensi nimis affinis, attamen pluribus notis ab eâ discrepans.

17. T. ARNOTTIANA, foliis oblongis breve acuminatis basi rotundatâ inæqualibus glabris supra lrevibus venis immersis, subtus tenuiter laxeque reticulatis, inflorescentiø rhachi dense tomentosâ, bracteis remotiusculis dorso sericeis pedicellos breves superantibus, calycis fructiferi tubo ovato-oblongo inflato patenti-pilosiusculo, sinubus latis plicato-intrusis, lobis interioribus tubum requantibus eique tertiå parte inferne adnatis subulato-linearibus, achænio dimidium tubum subæquante subito acuminato, faciebus ovatis lævibus nitidis medio sulco lævi notatis obsolete venosis. 5? Ad flum. Guayaquil (Jameson!). Omnia fere T. Pœppigianæ, exceptis calycis lobis interioribus multo longioribus, achænium longe superantibus. Folia coriacea, 7-9-pollicaria, 3.4 poll. lata, petiolo semipollicari crassiusculo, striis utrinsecus 4 conspicuis. Inflorescentia in specim. suppetente racemus simplex 9 poll. longus, bracteis $2-4$ lin. distantibus oblongis acutis 3-4 lin. longis. Calyx fructifer $2 \frac{1}{2}$ poll. longus, tubo 7-8 lin. longo basi rotundato apice angustato, alis lanceolatis obtusis utrinque attenuatis glabriusculis 4 lin. latis, inferioribus inferne pilosiusculis, achænio subacutangulo fere dimidio longioribus. Styli tubi orificium attingentes. (v. s. in h. Arnott.)

18. T. Lindeniana (Wedd. in Ann. sc. nat. $3^{*}$ sér. v. 13 p. 2 fi6), foliis elongato-oblongis utrinque attenuatis glabris subtus ad venas puberulis tenuiter semiimmerso-reticulatis, paniculæe ramis cum bracteis pedicellum villosum superantibus calycibusque sericeo-pilosiusculis, calycis fructiferi tubo ovato intus pilosiusculo, sinubus rotundatis vel uno alteriore acuto, lobis interioribus tubum suhsuperantibus eique tertiá parte inferne adnatis anguste linearibus, achænii tubo paulo brevioris faciebus ovatis nitidis leviter flabellato-renosis. 5 In Novæ-Granadæ prov. Rio Hacha (Linden, n. 1618 !). Ramuli striatj, glabri. Folia herbarea, semipedalia,

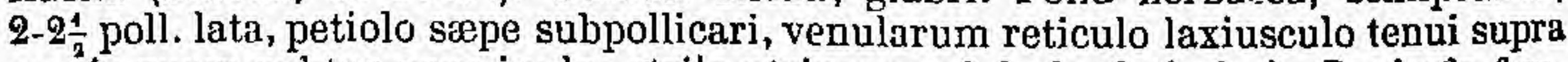
magis quam subtus prominulo, striis utrinsecus $3-4$ obsoletissimis. Panicula fem. terminalis, ampla, racemis patulis pedunculatis laxiuscule multifloris 3-6 poll. 
longis, bracteis 3-5 lin. longis pube adpressâ, pedicellis 2-3 lin. longis - pube

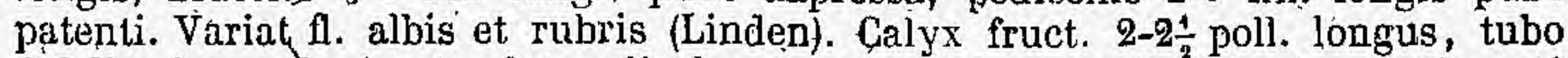
6-9 lin. longo bași rotundato, alis lanceolatis glabrescentibus basi subattienuatâ obsolete 3-nerviis- lobis interioribus adpresse pilosiusculis stylos æquantibus.(v.s. in herb. DC. et Shuttlew.)

19. T. NOLITANGERE (Wedd. 1. c. p. 264), foliis oblongo-lanceolatis utrinque acutis glabris, subtus ad costam puberulis, panicula ramis bracteisque dense velutinopilosis, calycis fructiferi tubo late ovato subinflato utrinque pubescente, sinubus subrotundis, lobis interioribus calyci haud adnatis stylorum apicem attingentibus lineari-lanceolatis, achæenii tubum requantis faciebus anguste ovato-ellipticis lavibus vel olssolete trisulcis. 5 In Brasiliæ prov. Matto Grosso, ubi Formigueira vocatur. - Mcisn. in Mart. fl. bras. fasc. 14, p. 49. Ramuli striati, glabri. Folia rigidula, 5-11 poll. longa, 3-4 poll. lata, petiolo 4-5 lin. longo. Panicula folia superans, ramis patentibus. Calyx fructifer 11-14 lin. longus, rufescens, pube utrinque molli inferne extus copiosiore, in alis lanceolatis breviorc et adpressâ,, interioribus basi medioque pilosiusculis. Achænium breviter acuminatum.

20. T. T OMENT OSA (Wedd.! I. c. p. 265 ), foliis ovatis altenuato-acuminatis basi rotundatis vel subcordatis adpresse pilosiusculis subtus dense subtomentosis venis tenuibus utrinque prominulis paniculse inferne foliosa racemis undique dense tomentosis, pedicellis tenuibus bracteas deciduas subsuperantibus, ealycis fructiferi tubo utrinque attenuato densius longiusque piloso intus puberulo, sinubus obtusis plicato-intrusis, lobís interioribus stylos tubumque requantibus huic dimidio adnatis subulato-linearibus, achænii tubo $\frac{1}{3}$ brevioris faciebus obovatis nilidis levibus subeveniis. 5 In Brasiliæe prov. Bahiensi (Blancliet, n. 2917! \& el verisim. n. 2736, $\left.\sigma^{7}\right)$ - Mejisn. in Mart. fl. bras. fase. 14, p. 51*, t. 15, fig. 4). Arbor mediocris, ramulis striatis pilosiusculis demum glabris. Folia subcoriacea, 3-6-pollicaria, 2-3 poll. lata, petiolo 2-4. lin. longo, summa in pl. masc. bipollicaria, vix 1 poll. Jata, basi attenuala, reticulo laxiusculo tenui, striis utrinsecus $3-4$ obsoletis, pubc molli adpressâ subsericeâ, subtus brevi densî, supra longiore rariore. Paniculæ masc. et fem. exdem, racemis simplicibus patentibus, masc. 3-5 poll. longis, laxiusculis, fem. 5-8-pollicaribus, pedicellis filiformibus 3 lin. lougis. Calyx fruct. $1 \frac{1}{2}$ pnll., tubus $\frac{1}{2}$ poll. longus, alis lanceolatis glabrescentibus basi attenuatis 1 -nerviis, $2-2 \frac{1}{2}$ lin. latis, lobis interioribus glabriusculis vix $\frac{1}{1}$ lin. latis. Achænium subito acuminatum, acumine brevi tulji orificium non attingente, faciebus apice basique sulco lato leviter excavatis interdum obsolete radiatim venosis. (v.s.)

21. T. RIEDELIANA (Fisch. et MeJ. 1. c. p. 149), foliis ellipticis ovatisve supra pubescenti-scabris, subtus pube densà adpressâ Iolosericeis, paniculæe ramis pilosissimis. $\delta$ In Brasiliâ circa Cazalvasco (Riedel). - Meisn. in Mart. 1l. bràs. fasc. 14. Polyg. p. 52. Arbor 20-pedalis. Folia vix 4 poll. longa, 2-3 poll. lata, striis longitudinalibus conspicuis. Cret. iguota. Forsan cum T. tomentosã aut Pachau identica.

22. T. Pacil A U (Mart.l mss. in herb. Acad. Monac. n, 871), foliis ovato-oblongis e hasi rotundatâ breve attenuatis supra glabris, subtus ad costam adpresse pilosis venis venulisque tenuibus supra immersis, subtus leviter prominulis, paniculæ ramis sericeo-incanis, pedicellis bracteas sericeas deciduas æequantibus persistentibus, calycis fructiferi tubo ovato piloso basi rotundato, sinubus abtusis introrsum plicatis, lobis interioribus tubum subsuperantibus eique ad medium usque adnatis stylos superantibus subulatis, achænii tubo $\div$ brevioris faciebus (llipticis lævibus nitidis. 5 In. Brasiliæ prov. Bahiensi, ubi Paxaüh vocatur (Mart.! Blanchet ! sine numero, in herb. Mart.).-Meisn. in Mart. fl. bras fasc. 14, p. 51 ${ }^{\star}$, t. 15, fig. 5. Nimis fere affinis T. lomentosæ, attamen recedens foliis basi breve attenuatis, minus pubescentibus, venis magis prominulis, caljcis alis latioribus (2 $\frac{1}{3}-3$ lin. latis). Calycis lobi interiores glabri, tubum requantes vel paulo superantes. Styli patuli, faucem haud attingentes. Achænium acuminatum, angulis subincrassatis obtusiusculis, faciebus, nune subovato-nune subobovato-ellipti(vis. (v. s.)

B. longipetala, calycis fructiferi lobis interioribus tubum plus minus (usque ad 2 lin.) superantibus. Ad Rio Maranhao Brasil. (Pohl! in lerb. Ceses. Vindob. et Zuccar.)

23. T. Mart IANA (Fisch. et Mey. 1. $\cdots$ p. 149), foliis ovato-ellipticis sultus glabriusXIY. 
culis venarum axillis nudis, calycis fructiferi sinubus acutis, Iobis interioribus longe exsertis tubo a basi ad tertiam partem adnatis lineari-setaceis. $\hbar$ ? In Brásiliâ (Riedel). - Meisn. in Mart. fl. bras, fasc. 14, p. 50*, t. 25, f. 2. Fólia duplo longiora quam lata, maxima 7-pollicaria, $3 \frac{7}{4}$ poll. lata, alia 4 pollicaria 2 poll. lata vel etiam minora.

§. oblongifolia (Meisn. 1. c.), foliis oblongis glaberrimis, calycis fructiferi tubô ovato parce piloso, lobis interioribus tubun dimidio stylosque paulo superantibus. Ad flum. Amazonum, prov, Para, et fl. S. Francisci, prov. Bahiens, (Mart.!). Folia 7-10-polliearia, 2-2-poll. lata, petiolo 6-9 lin. longo, 3 lin: Jato, supra súbplano, renis supra subimmersis, sulttus prominulis, venulis intercostalibus supra conspicuịs subprominulis, subtus immersis plane incotispicuis, striis longitudinalibus utrinsecus 3 obsoletis. Paniculie rami tomentosopüberuli, bracteis subadpresso-imbricatis ovatis 2 lin. longis dorso dense hirsuitis persistentibus, pedicellis brevibus. Calyx fruct. 16 lin., tubus 3 lin. longus, alis obtusiusculis 2-2\% lin. latis, lobis interioribus 6 lin. loñgis tix , lin. latis, ${ }_{1}$ glabriusculis, imo tubo breviter adnatis. Styli breviter exśerti. (v. s. in herb. Acad. Monac.)

\section{Species non satis notor:}

24. T. A in E I CAN A (Linn. sp. 1. 130), foliis petiolatis ovatis acuminatis, tspithamæis) spicis pilosis, bracteis ovatis acuminatiz parvis jilosıs, calyce, fructifero loigissimo, tubo ordto; alis lanceolatis patentibus, lobis interioribus tubum sequantibus \$rbulatis, achæenio ovato-triquetro. ち? In Americâ méril., circa Barcellonam. Loefling it. p. 256 .

25. T. PYRAMIDAL is (Jacq. Amer. p. 13, t. 173; f. 5), foliis maximis lanceolato-ovatis acuminatis; spicầ terminali longâ tenuj, calyce fruetifero (15 lin. longo) fúsco utrịque hirsuto-piloso, tubo semipollicari ovato basi rotundato fáuce angustatâ, alis lineari-lanceolatis subacutis basi attenuatis 1 -nerviis ( 2 lin. latis), lobis interioribus inclusis? acbænio nitido 3 -sulco. 5 In srlvis, cirea Carthagenam Veneżuèlæ (Jacq.). Adümbratio brevis, ab auctore ex memonia conscripta; calyx fruetifer solus ad naturam delineatus, absque dissectione. Species obscura, a Linnæo àliisque syzonymis T. Americanæ Linn. adscripta, ad quam cl. C.-A. Meyer nimis arbitrarie T. Caracásanam Chan. referendam censet, sed hujus calyx cum fig. apud Jacq. nequaquam convenit.

\section{Species dubice, forsan excludenda.}

T. MACR OCALYX (Cusaretto nov. stirp. decad. 9, p. 79, 11. 88); foliis subcoriaceis brere petiolatis late ovatis acutis vel obtusiusculis basi rotundatis rel subcordàtis subdistorle complicatis integerrimis glaljerrimis utrinque leviter reticulatis, raceniis femineis axillaribus aggrcgatis brevilus, calşce fructifero glaberrimo, alis oblongis obtusis. 5 In Brasilie pror. Rio Jan. Arbuscula, foliis supra intense viridibus subtus fuscis 3-4-pollicaribus, 2-3 poll. latis, petiolo 3 lin. longo, striis longitudinalibus nullis. Cal ycis fruct. alæ $1-1 \frac{1}{2}$ poll. longæ, 3-4 lin. jatse, reticulatæ. Pedicelli prope nnedium articulati. Flor. masc. jgnoti. Forsan eadem species ac Ruprechtia Lundii? Ofr. infra.

T. CRENATA (Casaretto l, c. p. 80, n. 89), ramis novellis forrugineo-tomentosis, follis subsessilibus ovatis undulatu-crispis crenatis supra puberulis demum glabratis, subtus pubescenti-tomentusis, racenis mase. axillaribus aggregatis brevibus,

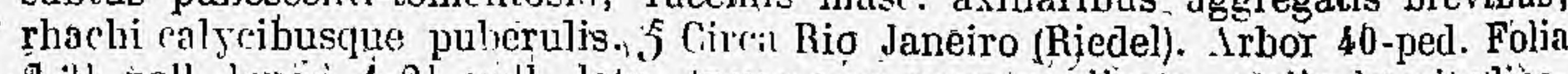
$2-3 \frac{1}{4}$ poll. longit, $1-2 !$ joll. lata, triussierse rugoso plicata; striis longitudinalibus subnullis. Flor. rubri, fem. ignoti. Forsan eadem ac Ruprcchtia carpinoidés? Cír. infrìa.

XX̃X. kUtPRECHTIA C.-A. Heyer in Mém. Acad. S. Petersb. $6^{\circ}$ sér. sc. math. et phys. $\boldsymbol{\theta}_{\text {, }}$ p. 148, cum ic., Meisn. in Mart. fi. bras. fasc. $14, p .53, t .26,27$. - Triplaridis sp. auct. sect. b. Endl. gen. mant. p. 35, n. 1997, Meisn. gen. 2, p. 368. -- Magonlia vell. Ror. fum. 4, $t .60$.

Flores dioici. Masc. Cályx pateris, 6-pariitus, lobis suborbicularibus planis subæqualibus vel interioribus paulo minoribus. Stamina 9 , imo calyćt inserta, libera, filamentis capillaribus, antheris exsertis. Pistilli rudimentum nullum. 
Fem. Calyx infundibulifớmis 3-vel 6-partitus, miarcescens, sinubus angustissimis acutis haud plicatis, lobis planis, interioribus 3 (petalis auct.) minóribus vel nullis, exteriolibus 3 post anthesin in alas eréctas inèmbranaceas reticulato-venosas (rarius coriaceas subenervias) excrescentibus. Siaminum rudimenta hulla vel minula filiformia calycis fundo inserta. Styli 3 brevissimi liberi, stigmatibus filiformibus papillosis. Achænium ovato-oblongum, 3ै-gonitom, sursum atlenuatum, angulis superne acutis infra oblusis vel rotundato-incrassatis, faćiebus lavibus nitidis sulco longitudinali profundo angusto exaratis rarius planis. Semen achænio conforme, e basi loculi erectum, funiculo flexuoso fultum, sulcis longitudinalibus 3-vel 6-lobàlum. Embryo in apice albuminis farinosi ruminati axilis, brevis, cotyledonibris latis tenuibus súbflexuosis; radiculâ superâ. - Arborès vel frulices Athievicæaustralis tropicæ, ramulis ǵracilibus, ochrcis membranacèis cylindricis oblique truncatis nudis plerumquár caducis, follits spai'sis subcoriaceis mediocribus integerrimis penninervis, striis jongitudinalibus nullis, floribus lasiuscule spicatis vel racemosis, masculis parvulis, spicis racémisve axillaribus solitariis vel fasciculatis et in paniculam termínalem simplicem vel compositam congestis, bracteis ochreiformibus parvis, pedicellis capillaribus articulälis:

\section{§ 1. ḦEXASEPALA. - Sectio Ruprechtia Endl. gen. mant. p. 35. -} Sect. Euruprechtia Meisn. in Mart. fl. bras. fasc. $\uparrow 4$, Polyg. p. 54.

Calyx femineus 6 -partitus; lobis 9 interioribus tubo basi adnatis eoque plus minus inclusis faciebus arluenii oppositis nusque sulcos tegentibus.

1, R. RAMIFL OR A (C.-A. Moy. 1. c. p. 150), foliis herbaceis petiolatis ovatis acuminatis venusis ramisque glabris, racemis lateralihus, rhachi villoso-tomentosâ, bractełs ovatis acuminatis 2 -4-floris, calycis fructiferi tabo oblongo utrinque subangustato hasi villoso, alis inearilyus obtusis glabriuseulis, lobis interioribus subulatis achrenii suleis jminersis, stylis basi achrenioque oblongo acuminato villosis. $y$ In sylvis Carthagenic Amor. morid. (Jacq.). Triplaris ramiflora Jaca. A mer. p. 14, Linn. syst. p. 128, Vahl symb. 1. 2; j. 100*. Arbor ramis diffusis. Folia e-4-pollicaria ovata vel subrotumdo-ovata. Spico laterales aggregata, jipollicares, dènsı, bradteis pedicellos brevissimos requantibus. Calyris alse pollicares. Áchtenium 6-sulcum.

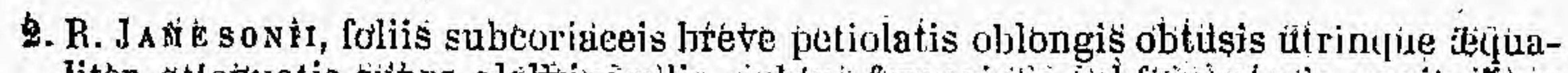
liter atlenuatis supra glabłiusculis, sublus ferrugrinè-subfomentosis, verì sứpra immersis, subtus ptominulis haud reticulatis, racemis femijness lateralibuis subsesşilibus brevibus recurvis undique puhescentibus, calycis fructileri tủjo siñbgloboso-orato tomentoso-jubescente, alis spatluilato-lanceolatis obtisis, labis interiöribus tubum rmuantibus semiliberis subulatis, aclierii ovati acuminati profunde 3-sulei angulis infrá medium incrassatb-rotundatis subra acutiüisculis. 5? Ad 11. Guasaguil (Janeson!). Ramuli graciles verruculosi, tenerrime sulcati, juniores puberuli. Folia pland, summa (inferiora desunit) bijollicaria, 6-8 lin. lata, petiolo tenut 2 lin: longo pubescète, paigina inferiore fertugineâ tomentóso pilosiusculâ. Racemi ramulơs laterales brevissimos paucifulios tcrminantes, thachi semipollicari, judicollis a lin. longis. Calyx fructifer 12-1/4 lin., tribus $2-2 \frac{1}{2}$ lin. longus, basi brevissime attenuatus, fance vix angustatò, alis $2 \frac{1}{2}-3 \frac{1}{2}$ lin. latis retictalatis veinis solis pilosiusculis, lobis, interioribus glabris. Styli brevissimi, stiginatibus conico-linearibus. Ptoxime affinis $\mathrm{R}$. raniflor: sed jam folis minoribus, raremis pedicellisifue breviluus, etc., bene distincta. (v. s. $Q$ in herb. Arnott.)

3. R. Guminari, foliis coriaceis stussessilibus ovatis basi reve angustalis utrinque glabris ; renis supra subimpressis. subtus cum renalis dense teticulatis acute prominulis, racemis laterabibus solitariis sessilily as densifioris ereetis pedibellisque brevibus, rhachi bracteisque tomentosis, chifris fiructiferi tubo obovat6 vel oblongo brevi-pilđso, alis spathitklatn-lincaribús obtusis, lobis interioribus subufato-linearibus infra mediumi adnatis achrinio dimidio hrevioribus, achionio oblongo àcuminato bus attenuato jufra medium glabro lercti-trigono àngulis rotundatis faciebus profunde sulcatis, supra pilosiusrulo obtuse triquetro. 5 ? In Panamá et Colombiâ (Cuming, n.11481). Ramuli glabri, vix sulcati, obsolete ver- 
ruculesi. Folia plana, subtus fusea, 4-5-pollicaria, $2 \frac{1}{2}-3$ poll. lata, petiolo vix lineam longo trassiusculo, costis subrectis yarallelis. Racemorum rhachis 6-8 lin. longa, bracteis ovatis parvis, jedicellis $1-\frac{1}{2}$ lin. longis supra medium articulatis. Calyx fructifer yollicaris, tubo 3 lin. longo basi attenuato apice parum angustato, alis reticulatis parce adpresso-pilosiusculis basi 1 lin. superne 2 lin. latis, lobis interioribus 2 lin. Iongis glabris. Styli liberi cum stigmatibus brevissimi. Achrenium \& lin. longum. Priecedentibus proxine quidem aceedit, sed notis indicatis certe distincta, (v, s, in herb. Arnott.)

4. R. cost A T A, foliis coriaceis breve petiolatis ellipticis ovatisve breve acuminatis basi obtuşà vel rotundatâ plicato-amplexicaulibus hauḍ reticulatis, nervo venisque supra immersis, subtus fortiter expressis, racemis femineis lateralibus terminalibusque 2-3 fasciculatis folio brevioribus densifloris dense fulvo-puberulis, calycibus fructiferis nulantibus basi attenuatis, alis membranaceis oblongo-lanceolatis 3-nerviis reticulatis, lobis interioribus anguste linearibus achænio brevioribus; achænio oblongo tubum superante ultra medium profunde 3-sulco, angulis tumidîs leviter 1 -sulcis glabris supra medium acutis pilosiusculis. $ђ$ ? In Guatimala (Friedrichsthal, n. 1179 !). Rami virgati, validi, ramulis patulis gracilibus strictis sulcatis, junioribus adpresse pilosiusculis mox glabris. Ochrex vix 1 lin. longæ,

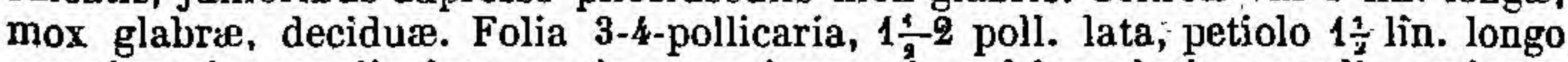
crassiusculo canaliculato, venis supra immersis vel insculptis, venulis utrinque nullis vel obsoletissimis. Racemi sessiles, bracteis ovatis acutis 2-3-floris pedicellos 1-2 lin. longos subæquantibus cum rhachi calycibusque pube brevi denså rufo-tomentosis. Calyx fructifer 12-16 lin. longus, tubo 3 lin. longo obconico enervi, alis medio 2-3 lin. latis, interioribus tubo semiadnatis dimidio achrenio paulo longioribus. Achænium 4-5 lin. longum, angulis inferne late rotundatis, stigmatibus oblongis stylisque brevissimis. Proxima $\mathrm{R}$. Cumingii, sed jam foliis haud reticulatis dignoscenda. (v. s. in herb. Mus. Vindobon.)

5. R. Lundi (Meisn. in Mart. fl. bras. fasc. 14, Polyg. p. 54 "), glaberrima, foliis coriaceis subsessilibus oblongis urinque obtusis vel brevissime acuminatis dense acuteque elevato-reticulatis subnitidis, racemis axillaribus fasciculatis subsessilibus folio brevioribus laxiusculis, calycis fruetiferi magni tubo brevissimo basi attenuato, alis lanceolatis, lobis interioribus inclusis achænio brevioribus imo calyci adnatis linearibus, achænii tubo duplo longioris ovato-oblongi nitidi angulis inferne tumido-rotundatis sulco lævi notatis supra acutis, faciebus supra leviter concavis infra sulco profundo exaratis. 5 ? In Brasiliæ prov. Rio Jan. (Lund ! Luschnath! Gomez, n. 38 !). Triplaris ramiflora et viridiflora Schott, n. 4562 ! $\sigma^{7}$ in herb. Mus. Vindob. Triplaris macrocalyx Casaretto nov: stirp. decad. 9, p. 79, n. 88 ?

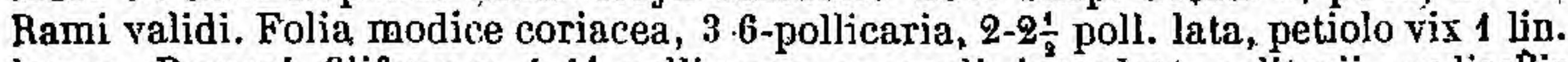
longo. Racemi filiformes 1-1 $\frac{1}{2}$-pollicares, masculi. interdum solitarii, pedicellis 2-3 lin. longis. Calyx fruct. 18-26 lin. longus, tubo 2 lin. longo in pedicellum medio articulatum sensim attenuato alis $2-3$ lin. latis reticulatis, lobis interioribus 3 . lin. longis apice acutiusculo recurvis. Achreniuim 5-6 lin. longum, obtusum, inferne tereti-ovoideum, supra acutangulo-triquetrum pyramidatum. (r. s. in herb. DC. et Mart.)

F. minor (Meisn. l. c.), calyce fructifero breviore (1-pollicari) alis latioribus ( 3 lin.) densius reticulatis, achænii (vix 4 lin. longi) parte superiore 3 -gonapyramidatâ breviore ( $\frac{1}{3}$ nec $\frac{1}{4}$ totius achænii). Forsan nov. sp., sed excepto calyce fruct. omnia ignota. (Blanchet, n. 11, in herb. Meisn.)

6. R. LAURIFOLIA (C.-A. Mey. I. c. p. 150), foliis subcoriaceis petiolatis lanceolatooblongis utrinque attenuatis glabris dense prominulo-reticulatis, spicis masculis axillaribus terminalibusque fasciculatis longis gracilibus laxiusculis tomentosopilosiusculis, femineis strictis, calyce fructifero utrinque sericeo-pilosiusculo, alis lanceolatis glabriusculis, lobis interioribus dimidio minoribus tubum paulo super rantibus eique ultra medium adnatis, achænio tubum rquante 6-sulco glabro. 7 In Brasilise prov. Bahiensi et Rio Janeiro (Sellow ! Pohl, n. 4561! princ. Neuwied! Blanchet, n. 106 ! Lund, n. 516 ! Luschnath !). - Meisn. in Mart. fl. bras. fasc. 14, p. $55^{*}$, t. 26. Triplaris laurifolia Cham. et Schl $!$ in Linnza 3, p. $55^{*}$. T. scandens Scholt! n. 4561, in herb. Vindobon. T. salicifolia Miq. in pl. Claussen, n. 2024! Scandens? ramuli graciles, ochreis diu persistentibus pilosiusculis. Folia 2-7-pollicaria, 1-8 poll. lata, petiolo 3-6 lin. longo. Spicæ masc. usque ad 7 poll. longæ, filiformes, florum fasciculis 1-4 lin. distantibus; fem. juniores, vix 4-pollicares. 
bracteis 1-floris. Calyx fruct. 1 poll., tubus 4-5 lin. longus, alæe basi haud attenuatæ. Acliænium lanceolatum, superne acutiưscule triquetrum faciebus concavis, infra teres 6-sulcum vel obtusangulo-6-gonum. Magonia scandens Vell. fl. flum. 4. t. 60, ex fig. fructus jun. videtur species. - R. laurifoliæ affinis, nisi forsan hæc ipsa. (v. s.)

7. R. SALICIF OLYA (C.-A. Mey. I. c. p. 150), foliis subcoriaceis breve petiolatis lanceolatis acuminatis utrinque tenerrime reticulatis ramulisque glabris, racemis terminalibus ramosis folio brevioribus puberulis, calycis fruetiferi glabrati tubo brevissimo turbmato, alis ovali-oblongis obtusis subenerviis, lobis interioribus lanceolatis achsenio dimidio brevioribus imo tubo adnatis, achænio tubum longe superante alas subæquante oblongo profunde 3 -sulco angulis latis obsolete 1 -sulcis. 5 In Brasiltse merid. prov. Rio Negro (Sellow !). - Meisn. 1. c. p. 55*, t. 27. Tríplaris salicifolia Cham, et Schl.! in Linnæâ 3, p. 56 *, Miquel, ibid., 19, p. 445. Arbor 18-20 ped., exceptả inflorescentiả glaberrima. Ochreæ brevissimæ, deciduæ. Folia 3-7-pollicaria, circ. 1 poll. lata, petiolo 1-2 lin. longo, venularum reticulo tenuiore et minus prominulo quam $R$. laurifolise. Panicule racemi singuli 1-2-pollicares, masc. glabriusculi. Calyx fruct. 6 lin., tubus vix 2 lin., pedicellus 4 lin. longus, alis 2 lin. latis, obsolete 3 -nerviis haud reticulatis subcoriaceis opacis. Aclıenium alis parum brevius. (v. s.)

8. R. TENUIFLORA (Benth. in Hook. Lond. Journ. 4, p. 629 ), folijs subcoriaceis breve petiolatis lanceolatis glabris utrinque venosis, ratemis ramosis folio brevioribus, calyce fructifero breve pedicellato tomentoso-puberulo, tubo brevissimo turbinato 3-gono, alis linearibus crassiusculis eveniis, lobis interioribus achænio tubum longe superante oblongo 3-sulco. 5 Ad flum. Rio Negro Brasiliæ æquatorialie (Schomb. coll. 1, n. 924 et 957, Spruce, n. 2236 !). - Meisn. l. c. p. 56" Triplaris tenuiflora Endl, gen. suppl. IV, 2, p. 55. Arbuscula foliis similis R. saliciffoliæ, sed iisdem rigidioribus et calyce fructifero bene distincta. Folia 2-5 (plérumque 3) poll. longa, $\frac{1}{2}-2$ poll. Jata, acuta vel obtusa, basi angustata. Pedicelli 1 lin. longi. Calycis alæ $B-8$ lin. longæ, 1 lin. latæ. (v. s. $\sigma^{7}$ in herb. Mus. Vindob.)

9. R. A E N TACEA (Meisn. in Mart. fl. bras. 1. , Polyg. p. 56 "), ramis sulcatis glabris, foliis coriaceis breve petiolatis lanceolatis vel oblongo-lanceolatis utrinque acuminatis acutisve glaberrimis nitidis dense prominulo-reticulatis, racemis fem. lateralibus aggregatis vel solitariis folio brevioribus densifloris cano-tomentosis, bracteis parvis ovatis acutis pedicello brevissimo longioribus, calycis lobis lanceolatis, exterioribus subsericeis e basi sensim attenuatis, interioribus dimidio brevioribus ovarium requantibus glabris basi angustatis. 5 ? Girca Barra in Brasiliæ prov. Rio Negro (R. Spruce, n. 12311). Rami validi ramulique patuli, stricti, cinerei. Ochrer deciduæ. Folia 2-5 poll. longa, 9-15 lin. lata, petiolo 1-3 lin. longo erassiusculo, reticulatione subtus laxiore. Racemi $\frac{1}{3}$-vix 1 poll. longi. Achæn. et stirps masc. ignota. Affinis R. tenuifloræe et brachyş̧tachyæe, sed jam sepalis interioribus haud setaceis distincta. (v. s.)

10. R. LAXifl or a (Meisn. in Mart. 1. bras. fasc. 14, Polyg, p. 56 "), folitis herbaceis? breve petiolatis elliptico-oblongis obtusis ütrinque glabris tenuiter denseque prominulo-reticulatis, racemis axillaribus solitaris, et in apice ramulorum congestis brevibus laxifloris, rhachi filiformi puberulâ, pedicellis capillaribus glabris calyce fructifero glabro basi attenuato, tubo brevissimo, alis linearibus basi attenuatis lobis interioribus tubo longioribus subulatis, achsenio dimidium, calycem æquante oblongo utrinque attenuato triquetro nitido glabro faciebus concavis (exsulcis?) angulis acutiusculis. $\$$ In Brasiliæ prov. Bahiensi et Minas Geraes (Blancbet, n. 3272 ! mas. et 3304 ! Pem., Widgren, n. 1028 !). Ramuli graciles, tenuiter sulcati, glabri, apice puberuli. Folia tenuia, plana, 1-3-pollicaria, 8-16 lin. lata, petiolo tenui 1-2 lin. longo. Racemi 1-2-pollicares, simplices vel basi ramosi, pedicellis masc. fasciculatis 1-2 lin., fem. subsolitariis 3-5 lin. longis. Cal. masc. $\frac{a}{4}$ lin. longus, subglobosus, glaber, ciliolatus, staminibus exsertis; fem. infundibuliformis, 2-3 lin. longus, demum subpollicaris, tubo vix 1 lin. longo, alis $1-1 \frac{1}{2}$ lin. latis 3 -nerviis, lobis interioribus $1 \frac{1}{2}$ lin. longis. Styli 3 liberi, breves, fere a basi stigmatosi. Achæinium 5 lin. longum, junius apice pilosiusculum, angulis basi hand incrassatis. (v. s.)

11. R. BRAGHYStacByA (Bentll.! in Hook. Lond Journ. 4, p.630"), foliis coriaceis $\therefore$ breve petiolatis ovatis sublanceolatisve obtusis basi rotundatis ramulisque glabris 
supra nitidis subeveniis, subtus opaciș obsolete venosis, racemis axillaribus terminalibusque brevibus, rhachi bracteis calyeibus foliisque junioribus tomentellis, calyce fructifero coriace brevissime pedicellato basi attenuato, tubo-brevissimo, alis ovato-oblongis achenium tomentellum profunde 3 -sulcum vix sujerantibus subcurinatis eveniis, lobis interioribus dimidio brevioribus setaceis. 5 ? In Guianà Apglicâ (Schorab. coll. 2, n. 345 et 541 , et coll. 1). -- Meisn. in Mart. n. bras. fasc. 14, p. 57*. Triplaris brachystachya Endl. gen. suppl: IV, 2, p. 55. Rami breves, ranosisșimi, sulcatí. Folia 1-3 poll. longa, 6-18 lin. lata, petiolo 1-2 jin. longo, reticulo immerso obsoleto, renis primariis paucis sublus prominulis. B̈acemi fruct. subpollicares. Calyx 6 lin., tụbus $1 \frac{1}{2}$ Jin. longus, alis 2 lin. latis. (v. s. in lierb. Shuttlew.) :

42. R. BRachyseral a (Meisn. in Mart. f1. bras. fasc. 44 , Polyg. p. $57^{\star}$ ), foliis sub'coriaceis hrove petiplatis ohlongo-ovalibus hasi obtusis utrinque glabris tenuiter denseque prominnulo-reticulatis, racemis axilłaribus solitariis geminisve folio plupies brevioribus, pedicellis brevissimis, calyce fructifero sulocampanulato glaber'rimo leviter reticulato, tubo subnullo, alis subtriangulari-oblongis, lobis interioribus achsonium dimidium aquantibus anguste linearibus glabris, achæenjo demum culyce vix dimidio breviore nitido glabro, angulis acutis basi subinerassatorotundatis, faciebus ovato-oblongis subplanis. 5 ? In Brasilise prov. Para, circa Santarem (Spruce, n. 523 !). Ramuli graciles, glabri. Folia obtusiuscula yel subacyminatá, basi sul)rotuirdata nec attenuata, 2-3 poll. longa, 1-1 $\frac{1}{2}$ poll. lata, subnitida, reticulatione utrirkque aqualiter prominulà. Racemi sape fasciculifnrmes, rhachi 6-10 lin. longâ bracteisque 1-3-floris puberulis, jedicellis prope basjn articulatis. Ualyx fruct. vix semipollicaris, semi-clausus, tubo $\frac{1}{3}$ lin. longo obconico, alis obtusiusculis 4-5 lin. longis, 2-3 lin. latis planis vel margine inferne recurvis. Ṕlanta masc. ignota. ( $\mathrm{v}$. s. in h. Acad. Monac. et DC.)

\section{\$ 2. TRISEPASE. - Sect. Apetalo Meisn. in Mart. fl. bras: fasc. 14, Polyg.p. 57.}

Calyx femineus 3-partitus, lobis interioribus (petalis auct.) nullis.

13. R. APETAL (Wedd. in Anu. sc. nat. 3- sér. 13, p. 268), foliis subcoriqceis gyatis oblongis obovatisve in petiolum brevem attenuatis integris vel sinuato-crengtis subtus in venis pubescentibus supra demum glabratis, racemis axillaribus confertis folio longioribus puberulis, ledicellis gracilibus, calycis fructiferi tuho campanulato achenio 6-sulco dimidio breviore tenuiter pubescente, alis oblungo-lanccolatis obtusis 3-herviis. 5 In Bolivià australi, id n! Pileomato (Wedd.). -Neisn. in Mart fi. bras. fasc. 14, j. 57 \% Arbuscula ramis patulis, ramulis apice puberulis. Folia 1-2\% poll. longa, 6-18 lin lata, acnta rel obtusa, rigidiuscula. Pedicelli demun - lin. longi. Calyx frupt. pollicaris, alis glabris vel ciliolatis. Achapil anguli inferné incrássati sulco insculpti quasi bilobi, superne acuti, facies sulco profundo exaralæ.

13. Sprucei (MLisn. 1. c. p. 58), foliis coriaceis venis supra impressis, subtus proninulis puberulis, reticulatione supra immersà obsolêtâ, subtus prominulà

laxinsculâ, racemis masculis axillaribus geminis vel summis solitariis vel subramosis. In Brasil. prov. Para, circa Santarem (Spruce, n. 639!). Racemi \$-5-pollicares strictiusculi, inferme nonnunquam ramum unum vel alterum emittentes. Fem. ignota. Ciet. cum discr. Wedd, l. c. bene congrua. (r. s. in herb. Acad. Monac. ét DC.)

14. R. apht rs (Wedd. 1. c. p. 268), foliis herbaceis breve petiolatis ovatis acutis integris vel sinuatis supra glabris, subtus molliter pubescentibus, racemis paniculatis folia vix æequantibus, calyce fructifero utrinque pubéscente, tubo bpevi ovato, alis oblongis obtusis, udlip niji lanceolati supeme 3 -alati alis eiliatis inferne incrassatis torulosis, faciebus sulco incequali. 5 In Bolivie Cisanding prov. Inquisivi dicta, alt. 1800 met.

45. B: Marti (Meisn. in Mart. fl. bras. fasc. 14, Polyg. p. $58^{*}$ ), foliis ....., spicis fomineis elongatis gracilibus densilloris, bracteis adpressis late ovatis obtusis extus glabris subplanis intus rhachique hirsutis, pedicellis ...... calycis fructiferi tubo Blobosg-ovato dense subadpresso-barbato, alis ghlongo-lanceolatis obtugis basi

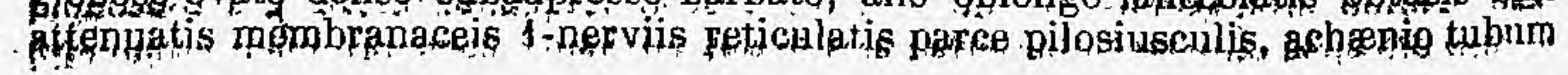


dimidio superante oyato acuminato rlabro levi nitido infra medium exsulco angulis rotundatis, supra duplo angustiorc acutangulo. 5 ? In sylvis inundatis ad fl. Itahype, prbv. Baliens. (Mart.!). Species iłsiguis, al) ounnibus distinctissima, cal'ycis alis 1 - (nec 3-) nervis bracteisque a Ruprechtiâ recedens et cum Trijlaride conveniens. Omnia, excéptis spicis fructiferis, ignota. Sjpicie 3-4-pollicares, bracteis $1 \frac{1}{2}-2$ lin. longis subrotundís. Galyx fruct. $12-14$ lin., titbus 2 lin. longus, basi rotupdatus, apice angustatus, sinubus angustis acutis, alis 9-3 lin. latis.' Acliænium e pasi ovata tereti exsulcà subito triquetro-attenpatum, angulis supra achtis deorsum deliquescentibus. Styli 3 libepi, filiformes, dimidium achaqnium æquantes, fere a basi papilloso-ștjgmátosi. (y. s. in lierb. Acad. Monac.)

\section{Species non sutis notoe (planta fem. nondum observata).}

16. R. Ca RPI Nordes (Meisn. in Mart. 11. bras. fasc. 14, Polyg. p. 58), foliis subdistichis subcoriaceis subsessilibus ovatis vel oblongo-ovalịbus acutis sinuatoundulatis plicato-costatis molliter pilosiusculis supra mox glabratis, venularum reticulo tenui semiimmerso supra denso subtus laxiusculo, racernis lateralibus subfasciculatis simplicibus vel basi ramosis subsessilibus folio brevioribus undique dense'cano-pilosiusculis. 5 Circa Rio Janeiro (Rjedel!). An eadem ac Triplaris crenata Casaretto nov. stirp. dec. 9, p. 80 ? (cfr. sujra). Arbor priealta (Riedel in sched.). Rami graciles, cinerei, glabri, vix striati, juniores dense pubescentes, pub brevi molli fulvà, ramulis subdistichis.' Folia 2-3 poll. longa, 12-20 lin. latà, 13reve acuminata, costis suppa sulciformibus, sultus acute promínentibus. Racemi axillares et in ramulis brevibus subterminales approximato-subfasciculati, 6-48 lin. langi, rhachi filiformi, bracteis floribusque subglobosis parvulis, pedicillis $1-1 \frac{1}{2}$ lin. longis supra medium articulatis, staminibus breviter exsertis. Fem. ignota. fv. $s$. in h. DG.)

17. R. Fagifolia (Meisn. in Mart. fl. Jras. fasc. 14, Polyg. p. 59 *), foliis herbaceis brove jetiolatis ovalibus accitis vel breve acuminatis basi attenuatis obtusisve integerrimis planis utrinque obsolete reticulatis glabris yel in nervis parce pilosiusculis, nervo venisque 'supra semiimmersis, subtus prominulis tenuipus, trace$\mathrm{mis}$ in apice ramulorum fasciculato-congestis sussilibus simplicibus vel basi rampsis undique dense pilosiusculis. 5 ? In Brasilige prov. Bahiensi (Blanchet, 11. 3277 1). An planta mascula $\mathrm{H}$. mollis Wedd.? quæ tamen discrepat foliis subtus molliter pubescentibus. Cum R. curpinoidi omnino convenit inflorescentià ot habitu, sed differt ramulis glabris, foliis tenuiorihus integerrimis, $2-3 \frac{1}{2}$ poll. longis, 1-2 poll. Latis, petiolo 2 lin. longo, venis subrectis parallelis haud impressis, racemis 1-2-pallicaribus. (v. s.)

18. R. gla U CA (Meisn. in Mart. fl. bras. fasc. 14, Pol yg. p. 60 *), ramis glabris, ochreis brevisssimis rulo-pilosiusculis deciduis, folips coriaceis subsessilibus obovatọ-vel ovali-oblongis obtusis hasi attenuato-achtis glaberrimis glaucis supra densissime prominulo-reticulatis, sultlus subimmerse penninerviis, racemis axillaribus subsolitariis simplicibus folio multo brevioribus recurvis, bracteis ovatis acutis sepalisque ciliolatis. J? In Serrâ de Acur'ui, prov. Bahleusis (Blanchet, n. 28481). Rami patuli, cinerei. Folia 1-1 - poll. longa, 6-9 lin. lata, opaca, margine leviter recurva, subtus pallidiora, venularum reticulo supra tantum conspicuo quasi scrobiculato. Racemi 6-9 lin. longi, nulantes, sessiles, densillori. Galyx sanguineus, glohosus, vix 1 lin. longus, 6-partitus, intus basi hirsutulus. Stamina 9. (v. s.) Subordo III. BRUNNICHIE C. -A. Meyer in Mém. Acad. S. Pétersb.
$6^{\circ}$ sér. sc. math. et phys. 6, p. 150 .

Ovulum e funiculo basilari libero longiusculo pendulum demum èrectum. Flọes herinaphroditi. Calyx 5-partitus. Stamina \&, filamentis subulatis vel capillaribus, antheris versatilibus. Stigmata 3 capitata, integra vel biloba. Achanium ealyce aucto sicco inclusuin vel circumdatum. Ochreæ obsoletæ.

XXX. ANTIGONON Endl. gen. p. 310, n. 1999, Meisn. gen. p. 316 (227), Hook. et Arn. bot. Beech. p. 308, t. 69 .

Calyx coloratus, 5-sepalus, sepalis inæqualibus, exterioribus 3 late cor- 
datis ovatisve, interioribus 2 oblongis. Stamina 8 æqualia, filamentis subulatis inferne connatis in cupulam subcarnosam calycis fundo insertam, antheris oblongis utrinque emarginatis. Ovarium trigonum, ovulo demum erecto, micropyle inferâ. Styli 3 inferne connati, recurvi, stigmatibus capilato-reniformibus. Achænium calyce aucto emarcido semiaperto inclusum, ovoideotriquetrum, 1-loculare, pericarpio tenui intus lævissimo. Semen basilare, erectum, pyramidalum. Albumen farinosum; sinuato-lobatum, ruminatum. Embryo axilis? antitropus, cotyledonibus....., radiculâ superâ. - Suffrutices Mexicani scandentes, ramis angulatis, foliis alternis petiolatis herbaceis cordatis integerrimis, petiolis basi- amplexicaulibus, ochreis oppositifoliis obsoletis squamiformibus, racemis oppositifoliis solitariis simplicibus aphyllis apice cirrhosis, fasciculis paucifloris bracteâ squamiformi fultis, pedícellis capillaribus articulatis.

\section{§1. Sepala 2 exteriora cordata, tertio semi-interiore obliquo semicordato.}

1. A. LEPT OPUS (Hook, et Aru. bot. Beech. p. $308^{\circ}$, t, 69), foliis ovatis acuminatis profunde cordatis in petiolım haud productis subtus ramisque tomentosis vel demum glabratis, racemis folio vix longioribus. 5 In Mexico occidentali (Andrieux, Beechey), San Lucas et San Blas (Hartweg, n. 104 !). - Benth. pl. Hartweg, p. 16, bot. Sulphur, p. 47 et 160 . Polýgonum eirrhosum Moc. et Sesse ic. fl. mex. ined., fide DC. Anrederæ sp.? Andrieux pl. exsicc. (fide ÊndI.), sed forsan a plantå Hookeri et Hartwegii distincta, pedicelli enim in illà apice (ex descr.) in hisce vero eirca

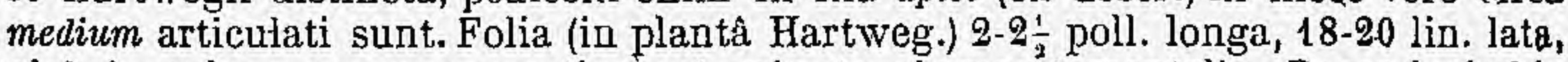
glabriuscula, summa angustiora et minute cinereo-tomentella. Racemi cirrhis 3 brevibus patentibus hamatis terminati, pedicellis demumn 4 lin. longis, paulo infra medium articulatis. Calyx fructifer 5 lin. longus, sepalis exterioribus fero 3 lin. latis. ( $\mathrm{r} . \mathrm{s}$. in h. Shuttlew.)

2. A. CORDATUM (Mrart. et Galeotti in Bullet. Acad. Bruxell. 10, n. 4, p. 14), caule pubescenti-hirto, foliis glabriusculis cordatis apice attenuatis, racemis folio raulto longioribus patentibus ferrugineo-pubescentibus, pedicellis articulatis. $\bar{J}$ In sylvis regionis callidæ Mexici, ad latus orientale Andium (Galeotti, n. 463), in ditione Oaxaca (Andrieux, n. 117! in herb. DC.). Rami-angulato-striati. Folia 2-4-pollicaria, $1 \frac{1}{2}-2 \frac{1}{2}$ poll. lata. Pedicelli $3-4$ lin., flores rosei 6 lin. longi. Cum sequento forsan mera var. præcedentis. (v. s.)

3. A. GINERASCENS (Mart. et Galeotti l. c. p. 14), foliis late oratis acuminatis e basi subcordatà in petiolum cuneato-productis cinereo-pubescentibus, junioribus subtomentosis, petiolis alatis villosis, racemis folio longioribus patentibus pubescentihirtis, pedicellis medio articulatis. $\bar{J}$ Circa San Blas, in Mexici orà occid. (Galeotti, n. 462), in ditione Oaxaca (Andrieux, n. 116 ! in herb. DG.). Rami 5-goni. Folia 2-pollicaria, 2-3 poll. lata. Pedicelli 6 -10 lin. longi. Flores rosei. Huc referenda nobis videtur planta Leiboldiana, n. 147 ! in herb. Kunze, cui flores dimidio minores quam Hartwegianæe. ( $v$. s.)

\section{§ 2. Sepala 3 exteriora ovata.}

4. A. GuATImaLense, foliis cordato-ovatis acutis breve petiolatis puberulis, racemis axillaribus solitariis patulis reflexisve pubescentibus cirrho ramoso terminatis interruptis, fasciculis stipitatis vel subsessilibus, bracteis ovatis acuminatis parvis. F In Guàtimalà (Velasquez). Polygonum grandiflorum Bertol. fl. guatimal. p. 12, n. $17^{*}$. Caulis 5-gonus, pubescens. Racemi preter cirrhos terminales nonnunquam suh florum fasciculis summis cirrho laterali brevi aucti. Calyx intus "glandulis stipitatis albo-diaphanis adspersus, n sepalis 3 late ovatis, interioribus angustioribus oblongis, omnibus acutis. Styli 3 recurvi, staminilous breviores, stigmatibus capitatis. Achænium trigonum. 
XXXI. BRUNNICHIA Banks in Gartn. fr. 1,p. 213,t. 45, Linn. gen, ed. Schreb. $n .777$ Nutt. gen. 1, p. 25.6, Endl. gen. n. 1998, Mejsn. gen. p. $316(227)$. - Rayania Walt .Carol. $p .198$.

Calyx coloratus, campanulato-infundibuliformis, 5-partitus, lobis æqualibus oblongis obtusiusculis demum auctis subcoriaceis conniventibus, carterum immutatis: Stamina 8 (vel 10, ex Gærtn.) requalia, inclusa, libera, fauci inserta, 5 lobis alterna, 3 lobis interioribus achæniique faciebus anteposita, filamentis capillaribus, antheris medio, dorso affixis versatilibus ovalibus utrinque emarginatis. Ovarium sessile, 3-gonum, ovulo e funiculo basilari libero pendulo, demum erecto. Styli 3 filiformes, breves, liberi, stigmatibus capitatis emarginatis. Achænium calyce coriaceo basi indurato-incrassato in alam pedicello adnatam decurrente inclusum, liberum, trigono-ovatum, angulis rotundatis, pericarpio crustaceo semitriloculari, septis incompletis membranaceis. Semen liberum, erectum; 6-sulcum. Albumen farinosum, ruminatum. Embryo in angulo lobi unius albuminis semiimmersus, antitropus, subcurvatus, cotjledonịbus anguistis, radiculâ superâ. - Frutex BorealiAmericants, scandens, ramulis angulatis, sterilibus in cirrhum ramosum excrescentibus, ochreis obsoletis, petiolis semiamplexicaulibus in lineam puberulam desinentibus, foliis lierbaceis ovatis cordatis, racemis terminalibus racemoso-paniculatis axillaribusque solitariis simplicibus elongatis multifloris, bracteis parvis ovatis subulato-acuminatis plurifloris, pedicellis subsecundis demum nutantibus filiformibus supra basin articulatis, articulo superiore accrescente calyce demum duplo longiore sursum dilatato hinc membranâ coriaceâ adnatâ e calycis basi decurrente falciformi fère ad basin usque alato. - Fallopra Adans. fam. 2, p. 28`, 277, huc referenda videtur ex descr. cirrhorum, nec vero ex cit. Pluk. t. 177, fig. 7, quæ verisimiliter l'olygonum (Tiniaria) scandens repræsentat.

B. cin RH OS A (Banks in Gurtn. fr. 1, p. 213, t, 45). III Carolinà (Fraser ! Bosc !), Loui * sianà, Alabanẩ (Drummond l), in paludosis Floridæe (Rugel!).-Willd. sp. 2, p. 731, Mich, 11. Jor, Jun. 1, p. 271, Pursl 11. Am. sept. 1, p. 273, Ell. sketch 1, p. 521. Rayania ovata Walt, fl. Carol, p. 198. Polygouum claviculatum hort. Par., fide Steud. (v, s.)

\section{Subordo IV. SYMMERIEE Meisn. in Mart. fl. bras. fasc. 14, Polyg.p. 5.}

Ovarium calycis lobis interioribus adhærens. Stamina indefinita. Ochreæ nullæ.

XXXIl. SYMMERIA Bentham in Hook. Lond. Journ. of bot. 4, p.630, Meisn. in Linnod 21 , p. 266, et in Mart. h. bras. fasc. 14, Polyg. p. 45, t. 23, Endl. gen. suppl. IV, 2, p. 55, n. 1997/1. - Thurnleyssera Mart. mss. - Amalobotrya Kunth. mss.

Flores dioici (rarius feminei panci masculis interspersi). Masc. Calyx subcorollinus, 6-partitus, patens, lobis rotundatis, exterioribus 3 minoribus. Stamina numerosa, brevia, filamentis subulatis, antheris majusculis versatilibus. Pistilli rudimentum nullum. Fem. Calyx herbaceus? $\cdot 6$-partitus, lobis biseriatis, extermis minoribus patentibus oblongis concavis interiorum margini adpressis haud accrescentibus, interioribus planis cordato-ovatis conniventibus erectis marginibus arcte invicem contiguis vel subcoalescentibus quasi tubum pyramidalem trialatum fructum includentem apice minute 3-crenatum formantibus, demum valde anctis spongiosn-coriaceis achænio adnatis. Ovarium trigonum. Stigmata 3 sessilia, brevia, Jobata (ex Benth.). Achænium inferum, calyce multo brevius pericarpio proprio tenui. Semen trigonum, ruminato-rugosum (ex Benth.) Embryo...-Arbor Americæ æqui- 
noctialis, habitu Triplaridis, ochreis veris nullis. petiolo amplexicanli anguste membranaceo-marginato, marginibus intra basin folii breviter productis, foliis coriaceis ovatis oblongisve integerimis penninerviis, 'floribụ paniculatis albis, masculis parvis glomerato-subsessilibus, femineis pedicellatis majusculis.

S. PAN ICULA TA (Bentli. 1. c.), ramplis junioribus pedunculisque ferrugineo-tomentosis, paniculis masculis elongatis ramis gracilibus divaricatis, femineis breviöribus densioribus, In sylvís Brasiliæ pror. Rio Negro et' Para (Siber! Mart. ! Pœeppig! Spruce f), Guianæ Anglicæ (Schomh.!) et ad. fl. Magdalenæ (Bonpland !). - Méisn. in Linnceâ 21, p. 266, et in , Mart. fl. bras. fasc. 14, Polyg. p. 46, t. 23. Amalèbotrya latifolia Kunth! mss. in h. (v. s.)

a. cordata (Meisn. 1. r.), foliis ovatis vel oblongis cordalis obtusis (Bonpl.n. 1472! in herb. Kunth., Schomb. n. 138 A.! Spruce, p.. 959 !). Folia 5-6, yolli. lopga, jụfra medium 2-4 noll. latą, petiolo 8-10 lin. lango.

8. oblonga (Meisn. l. c.), foliis ovali-oblongis subacuminatis acptiusculis basi

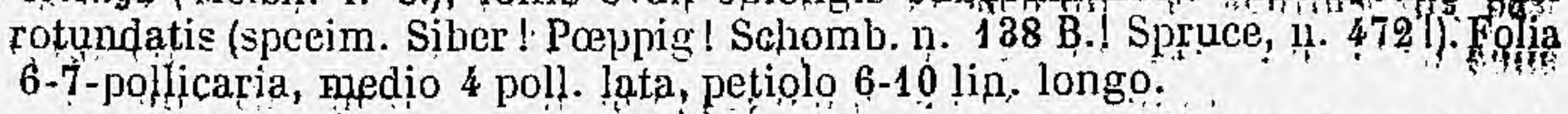

7. angustata (Meisn.). c. p. 267), foliis lapceolato-oblongis apice magis angustatis basi obtusis vel sụhcordatis. Thurnheyssera Tragopyrum Mart.! mss. in herb. Acad. Monac. (Poppig, n. 2862 ! Schomb: ñ. 138 ! excl. A. et B). Folia 4-8-pollicaria, 1-2 poll. lata, petiolo 3-12 lin. longo.

\section{Genus dubium.}

XXXIII. LASTARRLEA Remy in Cl. Gay hist. nat. de Chile, bot. 5, p. $289^{*}$, t. 58, t. 1.

Flores hermaphroditi, solịtarii. Calyx involucriformis persistenș, coriaceoherrbaceus, 6-fidus, lohis inæciualibus apice uncinato-acerosis. Stamina 3 , calycis fauci iuserta: lobis interioribus opposita, filamentis brevibus basi utrinque dente membranaceo comitatis, antheris ovoideo-globosis introrsis. 'ovarium liberum, sessile, 1-loculare, ovulo basilari orthotropo. Sigli 3 filiformes, bre vissimi, subliberi, stigmatibus capilatis. Achænium calyce incluşum, trịquetrum. Semen erectum. Embryo in axi albuminis farinosi antitropus subarcuatus, radiculà superâ, colyledonibus oblongis planis. - Herba chilensis, annua, multicaulis, subdichotome ramosa, ochreis stipulisve nullis, foliis infimis alternis superioribus floralibusque verticillatis, summis latioribus approximatis imbricatis. floribus in dichntomiis solitarijis sessilibus et in axillis foliorum summorum in spicam brevem densam approximatis inter folia absconditis.

L. Ghilensis (Remy 1. c.). (1) In siccis circa S. Iago, Goquimbo, Quillotg (Bertero. n. 228 et 959 ). Radix subsimplex, filiformis. Caules 2-4-pollicares, graciles, taxi. Folia radicalia, filiformi-linearia, 8-12 lin. longa, vix $\frac{1}{3}$ lin. lata, plana, acutiuscula, parce pilosa, superiora verticillata quaterna (vel passim 5-6-na.) breviora, tloralia ovalt-oblonga, 3-5 lin. longa, 1-2 lin. lata, apice acuta recurvo. Calyx tubulosus, pilossus.

OBs. Planta affinitatis dubiæ,--si' vere Polygonacea, nonnisi Eriogoneis adsocianda, propter oehrearum defectum, folia floralia verticillata,-sed forte potius Baronychiaceis'scleranthaceis adscribenda.

\section{ORDo CLXII. LAURACEAE.}

De presenti ordine a celeb. de Vriese propter magnam specierum copiam nondum absoluto, confer ad calcem volụminis. 


\section{Ordo CIXIII. MYRISTICACEE (1).}

Pistaciarum pars Aclans. fam. 2, p. 345. - Laurorum pars. Juss. grn. p. 81. - Myristicea Br. prodr. Nov.-Holl. (1810), p. 199. - Aristoloc' iæ, c. Reichb. consp. p. 86. - Myristickæ Barll. ord. p. 220. Lindl. introd. nat. syst. ed. 1, p. 23, Bllume Rumphia 1. p. 179, Endl. gen. p. 829, enrh. p. 418, Meisn. gen. p. 323, 329 el comm. p 241. - Myristicaceæ Horan. prim. lin. p. 61. Lindl. in/r. edl. 2, p. 15, reg. kingd, p. 301 («xcl. Hyalostemma qua Miliusa ex Hook $f$. et Th.). Hook. f. et Thoms. Al. ind. 1, p. 153, Alph. DC. hote sur les Myrist. in Ann. sc. nat. sér. 4, v. 4, p. 20.

Flores dioici. Perigonium (verisimiliter calyx) 3 -lobum, nunc in eadein plantâ 2-4-lobum, lobis æstivatione valvarı. Ștamina 3-18, sæpius 6-12, monad.]pha, filamentis nempe in stipitem glabrum connatis; antheris (ubi 3) cum lobis perigonii alternantibus (ex sect: Virola, (Ytoba), linearibus vel ovalihus, bilocilaribus, longitudinaliter extrorsurn dehiscentibus, circa aut super a picem stipitis dorso vel bași adnatis, sæepius connatis, nunc a medio vel a basi liberis; connectivis perspicuis, sæpe in dentem hrevissimum cuique antheræ proprium vel onnibus communem desinentibus Pollen sphæricum (ex M. fragrante, diospyrifoliâ) aut sphæricó-trigonum (ex M. sebiferâ, Otobâ). Ovarium superum; stigmate subsessili, vix biloho vel depresso-capitato. Ovulum e basi ovarii unicum, ąnatropum. Fructus carnosus, tarde valvis 2 , rarissime 4 dehiscens Semen sessile, arillodio basi cupuliformi, a medio sænius lohato et quasi lacerato, rubro vel aurantiaco, carnoso vel tenui, sape suaveolente inyolutum; tesiæ strato externo membranaceo vel carnoşulo, interno duro; raphe lineari, externe perspicuâ, a basi seminis ultra apicem extensâ, chalazâa inde non șolum superâ, sed paulo latérali , tumị̣̂âa ; endoplevrâ tenui, plicis interne auctâ, exsịccạtione a plicişs segregatấ; albụmine ruminato, plicis nempe ex endoplevrâ sese insinuantibus. Embryo minimus prope hilum ; cotyledọnibus divergentibus, ovatis, planis vel undulatis; radiculà brevị inferâ conicâ Arbores (rarius frutices) tropica, in Asiâ meridionali frequentiones, in Americâ australi non raræ, in insulis Áfricæ australis rarissin̨æ, in continente africano adhục incognitæ, sæe aromatic $æ$, succo acrido sæpe rubicundo scatentes; novellis et inflorescentiấ plerumque stellato-tımentosiș, foliis alterniş, disțichis, jntcgerrimis, sæpe pellucido-punctulatis, penninerviis, vernatione conduplicatâ, limbe nempe secus nervum centralem longitudinaliter involuto vel

(1) Auctore Alph. de Gandotle. 
plicato, nervis lateralibus patentibus, plerumque validis prope marginem arcuatis et sæe connexis, numero in quâque specie constante (1). Stipulæ nullæ. Racemi vel paniculæ axillares, interdum supraaxillares; floribus plerumque pedicellatis, parvis, externe stellato-tomentosis. Albumen sæpe sebaceum vel oleosum.

Ovaria et ovula rarissime duo, uno abortiente, dixit cl. Blume (Rumphia 1, p. 179), quod plures tanquam nexum cum diversis ordinibus grate salutaverunt. Nil tamen magis valet quam indicium ex monstro, et enim nulla speeies constanter ovaria aut ovula bina ostendit; ego, plurimis floribus apertis, nunquam vidi.

Tunica seminis est arillodium, nec arillus, qund jam suspicatus est $\mathrm{cl}$. Planchon ( Iém. sur les vrais et faux arilles, 1844, p. 33). Et enim circa endostomium oriri videtur, ut pote ex ovulis paucis in herbario dijulicare potui (Note, etc., in Ann. sc. nat. ser. 4, v. 4); cito accrescit post florationem; adhæret etiam junior parti inferiori seminis circa endostomium hilumque et aperturam minimam præbet ubi exostomium (tunc micropyle). Plicæ intra albumen mihi videntur ab endoplevrâ, nec nuclei formatio (Hook. f. et Th. fl. ind.), nam in semine juniore adhærentes vidi cum spermodermio toto.

Mares frequentiores, paniculis vel racemis pierumque longioribus, floribus numerosiorsbus, sed minoribus.

Ordo inter Proteaceas et Lauraceas ab ill. Brown collocatus, sed nulli ex ejus sententiâ vere proximus; prope Anonaceas positus a cl. Bartling (anno 1830), non sine causâ ; nunc ab ill. Endlicher, Hooker fil. aliisque juxta Anonaceas, Monimiaceas, Menispermaceas et Lardizabaleas enumeratus. Affinitas cum Anonaceis ex foliis integris alternis sæpe punctatis, perigonio (calyx?) trilobo valvari, formâ antherarum, seminis fabricâ et præsertim albumine ruminato; sed flores dioici, petala nulla, stamina connata vel antheris solum distincta, ovarium unicum, ovulum solitarium arillodio nec arillo minimo donatum, diversus. Monimiaceis convenit flore unisexuali apetalo ut in pluribus hujus ordinis et cotyledonibus divaricatis; differt veru foliis alternis, æstivatione floris, staminibus connatis, ovario unico, ovulo erecto, albumine ruminato, arillodii præsentiâ. A Menispermaceis tandem va!de diversus, præsertim staminibus (quando calyce isomeris) alternis nec oppositis. Anonaceæ et Menispermaceæ jam initio Prodromi adsunt ( $l$, p. 83); Monimiacex melius prope Urticaceas enumerandæ, ex cl. Tulasne (in litteris) ; ergo liceat præsentem ordinem prope Lauraceas enumerare, invitis characteribus, favente habitu.

(1) Numerus paulo incertus aut obscurus propter nervos inferiores et extremos minus distinctos, sed in semel constans videtur et characteribus specifieis idoneus. 
XYRISTICA Jinn. gen. ed. 1742, p. 524, Sw. prodr.p. 96 (qui primus et rectius quam plur. hod. characteres vidit), Lam. in hist. Acad. sc. anni 1788 (1791 divulg.), p. 152, Blume l. c., Hook, f. et Th. l. c., Benth. in Hook. Journ. bot. 1853, p. 1, Alph. DC. sér. 4, v. 4, in Ann. sc. nat. - Komakon Theophr.? Adans. fam. 2, p. 542.- MoschoIsaruon Diosc.

Characteres ordinis. - Præuntibus cl. Blume et Hooker fil., qui plantas viventes observaverunt, subgenera (sectiones) potius quam genera distincta admisi. Characteres graviores in ovaris et seminibus melius cognitis non spero; fructus et semina unitatem generis militant, sectionibus præterea diversis characteribus admodum et varie connexis.

\section{Sectio 1. Eumyristica. - Subgenus Myristica Blime, Rumphia 1, p. 181.} - Sect. Eumyristicæ sp. Hool. f. et Th. fl. ind. 1, p. 142.

Columna staminum cylindrica vel fusiformis, perigonio parum brevior; antheris 8.18, linearibus, dorso toto adnatis, sæe apiculatis, stipite communi multo longioribus. Cotyledones undulato-crispæ (an semper?).--Racemi nonnunquam supraaxillares, simplices; pedunculus perstans; pedicelli ex axillis, bractearum apice pedunculi umbellati vel solitarii; bracteola sub florc caduca. I'erigonium pro ordine majusculum, ovoideum vel oblongum. Nervi tertiarii foliorum reticulati, raro perspicui. Species omnes asiaticæ.

1. M. FR A G RAN (Houtt. hist. nat. 2, pars 3, p. 233), foliis ovato-ellipticis basi acutis apice acuminatis glabrescentibus, nervis lateralibus utrinque $8-9$, pedunculis supraaxillaribus, masc. paucifloris, fem.1-floris, pedicellis pedunculum subsequantibus, bractcolà sul) flore late ovatà squamiform, flore nutante, perigonio ovoideo semitrifido pedicellum subæquante extus pilis adpressis strigoso, antheris 9-12, fructu nutante ovoideo-globoso, arillo laciniato coccineo aromatico semen tegente. 5 Spont. in Moluccis, ubi olim exclusorie culta ; nunc in Philippinis (Cuming! 2418 in h. Boiss.), Mauritio (Sieb.! 126, 74 in h. Boiss., 258 in h. DC.), Brasilitit Lund ! 179, Guill.), Guyanà, ètc., colitur.:- Blume Rumphia ${ }^{*}$, p. 180, t. 55 . M. officinalis L. f. suppl. p. 265, Gærtn. fruct. 1, p. 194, t. 41 (excl. syn. Rumph.), Hook. exot. bot.* t. 155, 156, non Mart. Nux Myristica, Pala, Rumph. Amb. $2^{*}$. p. 14, t. 4. M. moschata Thunb. act. holm. 1782, diss. 1788. M. aromatica Lam. act., par. 1788, p. 155, t. 5-7, Zoll.! 392 (l.. DC.), 1313 (h. Boiss. et Deless.). Mrristica 515 Hohen. pl. ind. Muscade, Sonnerat voy. Nouv.+Guin. p. 194, t. 116-118. Folia 2-4 poll. longa, petiolo 5 lin. Flores 3-4 lin. longi. Fruetus magnit. mali persici minoris, lutel, longitud. 1-2-sulcati. Nucleus ellipsoideo-globosus. (v. s.)

2. M. FA r U (Houtt. 1774, nat. hist. 2, jars 3, p. 337, non Sw.), foliis ellipticis basi subacutis apice acutis vel acuminatis superne glabris subtus oehrascenti-sericeolepidotis, nervis lateralibus utrinque 15-20, pedunculis fl. masc, axillaribus petiolo brevioribus et crassioribus 5-8-floris, alabastro ovoideo pedicellis sublongiore extus ferrugineo-velutino, fructibus arrectis solitariis binis ternisve ellipsoideis dense ferrugineo-tomentosis, arillo completo Iacerato aurantiaco insipido. $\hat{\delta}$ In Moluccis, præcipue in Banda. - Blume ${ }^{*}$ in Rumph. p. 185, t. 59 funde descr. et syn. sumpsi). Nux Myristica masc. Clus. exot. 1, p. 14, Rumph. Amb. 2. p. 24, t. 5. M. macrophylla Roxb.! fl. ind. ed. 1832, v. 3, p. 846, non A. Gray, nec Spruce. Nux moschata fructu oblongo G. Baul. pin. p. 407, Rai. hist. 2, p. 1523. M. tomentosa Thunb. act. holm. 1782, p. 45. M. dactyloides Gærtn. 1, p. 195, t. 41 (except. plantå Malab.). M. spadicea Blume bijdr. p. 577. Folia 3-12 poll. longa, glabrescentia. Petioli 4-10.lin. longi. Fructus 2 poll. longi. Nucleus levissime aromaticus. M. fatua Moritzi in pl. Zoll. n. 1694, est Lauracea ex specim. meo flore junióre. Ex specim. Roxb. sub nom. macrophylli al ipso Roxb. in h. Lamb. nunc in h. Deless. et in meo, folia 6-9 poll. longa, iconi Blume conformia, flores feminei 1-3, apice pedunculi brevissimi, pedicello 2 lin. longo, perigonio oroideo 2 lin. longo. (v. s.)

3. M. SuCCEDANE (Blume Rumph. p. 186, in adnot.), foliis ellipticis utrinque acutis subtus ex albido-ochrascenti-lepidotis, fructibus ovoideis (seu globosis cum acumine) supraaxillaribus subsolitariis rufo-tomentosis. $\rightarrow$ In ins. Tidore Moluccarum (Reinwardt, ex Bl.). M. fatuæe valde affinis, sed foliis minus elongatis, nervis haud adeo crebris, fructibus minoribus magis ovoideis. Nuces satis aromaticæ ab incolis 
adhibitæ. Ex specimine sine fl. vel fructu a cl. Blume cum Mus. par. comm. folia glabra, 3-4 poll. longa, 1--9 poll, lata, petiolo canaliculato submarginato 4 lin. longo, nervis lateralıbus utrinçue 11-12, tertiariis non distinctis. (v. s.)

4. M. INERS (Blume! bijthr. p: 575 , Rumphia 1 , p. 18k,t. 58), foliis ellipticis utrinque acutis vel obtusis glabertimis subopacis pellucide plinctulatis nervis utroque latere 12-13, pedunculis axillaribus brevissimis, pedicellis masc. 3-5, fem. paucioribus, pedunculo longioribus, bracteolì late ovatì flori adpressâ perigonióque ovoideo pèdicellứn subrequante extus rufo-volutinis, columnả stamineâ fusiformi àpice conicâ, fructu subsulitario ovoideo cuspidato ferrigineo-pulverulento. 5 In sylvis inler. Jave (Blume! Kollmann ! in li. Buiss.), Philippinarum (Cuñing! 1570). M: montana Roxb. f1. ind. ed. 1832, r. 3, p. 846 (fide sjeciminum a hoxb. in h. Lamb., nunc in l. Deless. el meu): Folia 3-4 poll. longa, 1- $\$$ lata, saepius basí obtusa et apice acuta, sed variabilia, petiolo 6-7 lin. longo, nervis tertiariis non perispicuis. Bracteola lineam longa. Flores masc. $1 \frac{1}{2}$ lin. lofigi, lem. dujpló fere longióres, apice acuto trilobi. Anthera circiter 10, in acumen minimum communem desinientes. Fructus $1 \frac{1}{4}$ poll. longus, ex descr, arrecti, ex ic. patentes. Arillus Kermesinus, superne laciniatus. (v. s.)

5. M. CEYLANica (Alph. UC. in Ann. sc. nat. ser. 4, r. 4, j. 29), foliis tanceolatis basi longe angustatis glaberrimis pellucide punctatis, nervis lateralibus utrinque 13-18 cum tertiariis reticulatis distinctis, pedunculis axillaribus crassis petiolo multo brevioribus, floribus apice pedunculi umbellatis fem. 1.aueioribus, pedicellís pedunculo subbrevioribus, bracteol ta late ovatâ flori adpressả velưtinâ, périgoniniơ masc. ellipsoideo pedicello subbreviore extus velutino, columnâ stam. apiculatà,

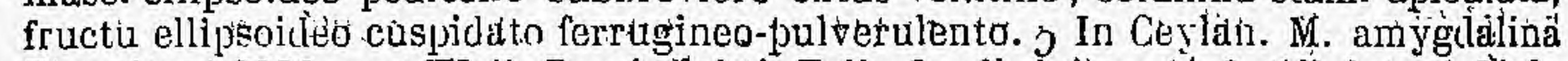
Thwaites! 2923, non Wall. Rami glalsri. Folia 6 poll. loñga, $1 \frac{1}{2}-2$ póll. lata, petìolo 7.9 lin. longo, novellis pallide puberulis cito glabì, nervis lateralibus inæqualibus, tertiariis in specim. masc. minus distinctis. Pedunculi 4 lin. longi ; jî̀ masc. apice pedicellos 23 cum vestigiis aliorum et gemmảs mininias gerentẹs. Pedicelli, bracteola apicis et perigonitum externe rufo-velutina. Flores masc. $z$ lin. longi. Fructus pollic. (v.s.)

6. M. ELLIPTICA (Wall. list 6798 a), foliis tenuibus lanceolatis vel obloilgo-lanceolatis ufrinque acutis glabris subtus glaucis, pedunculo supraaxillari brevi paudcifloro, floribus fasciculatis jedicellailis, fructu oblongo glabro, arillo apice lobato. 2 In Malayà ad Penáng el Singapur. - Hook. f. et Th. If. ind. 1, p. 162. Ramuli fusci, leves, glabri. Folia $6-10$ poll. longa, $-\frac{3}{3} \frac{1}{3}$ poll. lata, petiolo semipollíâri. Pedunculus semipull. Bráctea rotunda, eal jci adjressal. Perigenium masc: oblonğum, subinflatum, 3-dentatum, 4 lin. loggum. Culumna stam. breviter pẻdicelláta, cylinutrica, connectivo apiculata. Perigoniurn fem: urceolatum. Ovariuñ aureostrigositm, stipitatum. Stigma oblongum, hinc canaliculatum. Fructus $2 \frac{1}{2}$ poll, longus; valvis c̀rassis. Chalaza subapicalis. Descriptio a d. auct. cit. Spécimeñ Wall. vidi in ll. Deless: ubi lolia tuberculis millimis exsiccatione rugulosa; opáca, nervis lalerdibus utrinque circiter 12, parum distinctis; flores (masc.?) in sup. parte pédunculi approximatí, jedicello dup̣lo longiores; bracteola $\frac{1}{2}$ lin. longa. (

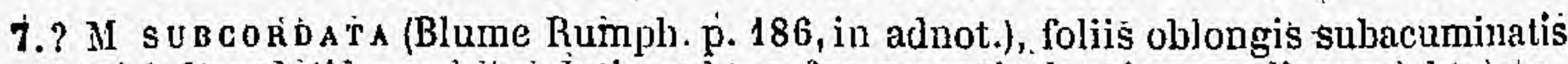
basi subcordatis seu rotundatis sthbtus fuscescenti-glaucis ramulisque subtomentosis, floribis glomeratis axillaribus (masc. tubulosis), fructibus sessilibus elongato-oroideis dense ferrugineo-lanuginuso-tomentosis. In sylvis marit. GuinexNove (Zippel.). A - Ny. fatud, ad quam proxime accedit, foliorum basi latà plerumque subcoriatà, venis (uervis lateralibus?j magis transversalibus, lructibus non pedicellatis pedunculo brevissimo communi axillari insidentibus, denique etiam forma elongáto-tubulosầ périantliii hl. mase. distinguitur, ex cl. auct.Ex.speeimine h. Mus. pár. dubio própter schedulam verisim. cum M. Horsfieldice transpositam, folia 7 poll. longa, 2 lata, petiolo $3 \mathrm{lin}$. longo, nervis lateralibus utrinque $2 \theta-29$, thde forsan sectiomis Coloneuræe.

8. M. EU G E NAFOLIA, famis teretibus glabrescentiljus, foliis ellipticis actuninatis basi acutis glabris subtus glancescentibus nervis lateralibus utrinque $10-13$ vi perspicuis, jedunculis fructiferiș jetiolo brevioribus axillaribus, pedicellisque 3-5 alternis et verticillatis glabrescentibus, fructu ellipsoideo pedicello sublongiore glabro hinc sulcato, arillodio medio et apice laciniato pingui. 0 In ins: Pingng (Gaudich.l in h. Deléss. of DC.). Folia $3-5$ poll. longa, 10-18 lin. lata, eoriacea, 
Mónistię. MYRIST1CACEA (Aoctón ALPH: DC.).

superne pitida, nervo centrali subtius eminente, aliis vero distinctis, petiolo 5 lin. longo graelli. Pedicelli fructiferi 6-8 lin: longi, pedunculo longiores. Fructus jollicures. (v. s.)

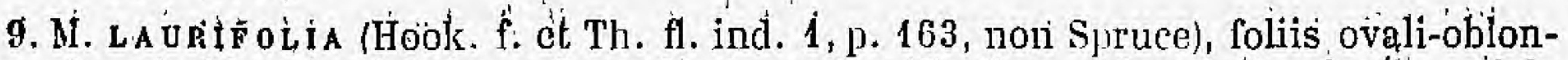
gis vel oblongis glabris, pedunculis (masc.) axillaribus abhreviatis crassis petiolo duplo triplove brovioribus, floriluns pedicello duplo longioribus bractê rotundatä hasi cinctis, aritheris circiter 9 apiculo communi terminatis, fructu ovali-tơmentoso. 3 In Ceylan (Walk. Gardn. Thw. in h. Hook.). Arbor cortice grisen vel rupescente rugoso. Ramuli lævigati, glabri, novellis vix puberulis. Folia utrinque obtusa vel acutiuscula, supra lucida, subtus pallida, consjicue oblique nervosa, 6-9 poll. longa, 2-4 lata, petiolo ulttapollic. Pedunculi plerumque bini, 3-6 lin. longi, ligntosi, cicatricibus bractearum ctebre notati. Pedicelli vix lin. longi. Flores ovales, denise tomentosi, bractế alpressâ, breviter 3-lobi. Columna stari. pedicellata, apice processu connectivi apiculata. Pedicellus fructifer 3-6 lin. longus.

10. M. D̈ OSPYRIFOLIA, foliis late ellipticis obtısis basi obtusissitnis glabris nervis lateralibus utrinyue 20-22, pedunculis axillaribus abbreviatis 2-3-floris cuün floribus brevissime perlicellatis petiolo multó brevioribus bractể et totâ inflorescentiầ rufo-velutinis, flore pedicello longiore ellipsoideo. I In Ceylan. M. tomentosa Thwaites! 416, non Hook. f. et Th. Racemi ralidi, glabri. Innovationes subvelutidè, rulie. Folis 6-8 joll. longá, 3 poll. lala, subcoriacea, petiolo, yalido $9-12$ lin. longo glabro, nervis tertiariis reticulatis. Flores 2 lin. longi, bracteầ late ovatà juniores involucrati. Perieclli et jedunculus contracti. Antherre in columnam fusilormam apiculatam stipite longiorem connatse. Ari eadem quam M. laurifolia? v. s:)

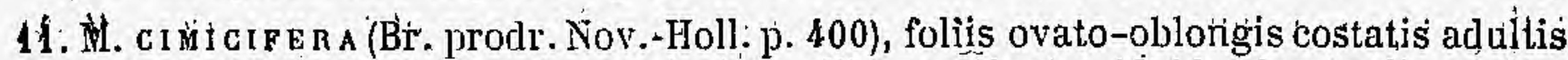
subtus glabris basi obtusâ, nervis lateralibus utringthe $13-14$, glomerulis axillapibus paucilloris floribusque subsessilibus, antheris sex. $g$ In Novà-Hollandiâ or. vel sej.t. intra tropicum. Phrasis ost cl. auctoriș, qui jlantam flọrif. masc. viderat. specimen comm. Ali. Cunningham sub eodem nomine, e Nova-Holl. orient. versus 170 lat. In hocce : ramus glaber, folia ovato-elliptica, 5 poll. lon'ga (incluso petiolo

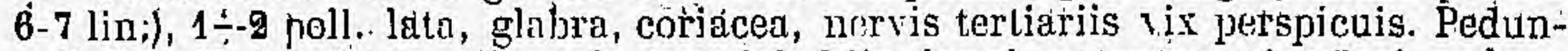
culi fructiferi axillates, lignosi, obconici, 4 lin. longi, patentes vel réflexi, rugosi, pilis brevibus rutis etänescentibus velutini. Fructus siepius 2, elongato-obovoidei, subactiti, pubc rufescente evanescente, $1 \frac{1}{2}$ poll. longi, 8-9 lin. lati. Arillus lacintiatus, tenuis, incompletus. (v. s.)

12. II. InUTiLis (Rich. herb. A. Gray Un. st. expl. exp. 1, p. 34), foliis lanceolatis acuminatis basi subobtusis subtus ferrugineo-puberulis adultis albicantibus nervis läteralibus utrinque 14-20, floribus supra-uxillaribus umbellato-congestis pedunçulo brevissimo vel subnullo, perigonio clavato-oblongo pedicellum subæquante 3-dentato, fructu oblongo apiculato demum glabrescente, árillo laciniato. $\delta$ In Tutuilà et Savaï archip. Navigatorum et Tongatabou Amicorum. Ramuli graciles.

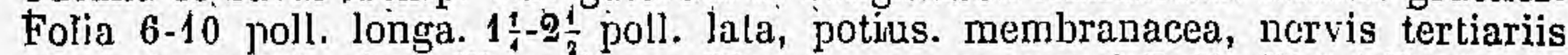
obscuris, petiolo vix jollicem longo. Flores mase. numerosi. Pedicelli 2-3 lin. longi, apice bracteann gerentes. Perigonium 2 lin. longum. Filamenta brevia connata.

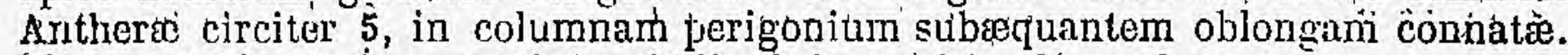

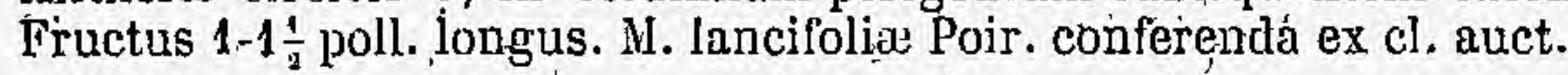

13. M. TUBIFL ORA (Blume Rumph. " p. 182, t. 56), foliis ellipticis basi acutis apice obtusiuscule acuminatis glabris, - pedunculis axillaribus lateralibusve paucifor is fetiolo brevioribus bractearum cicatricibus bracteisve asperatis, pedicellis pedunculo sublongioribus medio bracteolatis; flore masc.. cylindraceo apice sub lobis angustiore nutante pedicello longiore externe ut pedicelli et frericarpia obsolete lepidoto, fruetu cernuo ellipisoideo-obavoideo rostrato glabriusculo: $\$$ In NovàGuined atl oram Lowo (Zippel.). Folia fere ut in M. fragranti, paulo longiora. Flores masc. 6 lin. longi; flavidi. Columna staminea tubum perigonii tequans. Fruetus

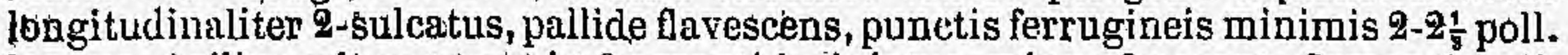
longus. Arillus minus quani in fragranti laciniatus, minus fragrans. Semen 2 poll. longus.

14. M. L Épдот A (Blwme! Rumph. " p. 183, t. 57), foliis lanceolalis basi acutis apice longe acuminatis subtus lejpidotis pallide ocliraceis demum argenteis, pedunculis axillaribus aut latcralibus fructiferis petiolo brevioribus crassis ut fructus ochraeéo-tomentosis, fructibus solitariis geminisve obovoideis cuspidatis pedicellis 
crassis pedunculo subbrevioribus fultis. $\mathcal{E}$ In orá Nove-Guinere et vicin, ins. (Zippel.). Irbor procera. Folia $2 \frac{1}{2} \div 4$ poll. longa, 12-18 lin. lata, petiolo semipoll. nervis later. utrinque 12-15 ex specim. in ll. Mus. par. a cl. Blume comm., nervis tertiariis in sicco perspicuis transversis. Fructus 15-18 lin. longus. Arillus hinc inde fenestratus. (v.s.)

15. M. L A N IF ol iA (Poir: dict. enc. suppl. IV, p. 35), ramis glabris, foliis lanceolatooblongis acutis, floribus ....., drupâ olivaformi subpubescente, arillo laciniato.-Ad fretum Bouton (Labill.). Folía anguste lanceolata, 3-5 poll. longa, mediocriter petiolata, superne nitida, subtus pallida subcinerea, nervis lateralibus tenuibus. Fructus laterales, vix pedunculati, bini ternive, forma oliva, sed brevióres, subfulvescentes. Vidi in herb. Graves a Webb. acceptam sub nomine M. lancifolix Poir. Specimina duo adsunt : unum e Javâ, aliud ex ins. Waigou a Labillard. lectum. In duobus rami glabri ; folia lanceolata, 3-5 poll. longa, 9-18 lin. lata, acuminata, basi acuta, opaca, glabra, suhtus non cinerea, sed pallidiora in sicco fulvescentia, petiolo 3 lin. longo, nervis lateralibus vix jerspicuis, numerosís, circiter 20; flores ign., pedicelli fructif. axillares, srepius gemini vel potius duo e pedunculo brevissimo, teretes, 2 lin. longi; fructus ovoidei, breriter cuspidati, semipollicares, tomento brevi fulvo; arillus semen ellipsoideum involvens, parum_laciniatus. (v.s.)

Sect. it. Caloneura Alph. DC. in Ann. sc. nat. sér. 4, v. 4, p. 29.

Perigonium et stamina sectionis Eumyristica. Inflorescentia masc. composita, ramis inferioribus paniculae sepius oppositis, pedicellis umbellatis bracteis vilgaribus basi circumdatis bracteolâque sæpius amplâ perigonium dıu amplectente apice donatis.-Folia magna, nervis lateralibus sæepius validis regularibus, unde nomen; nervis tertiariis transversis, plerumqué distiuctis. ... Omnes Asiaticæ.

- Nervi folionum pauci, non validi; tertiarii indistincti. Folia ideo, et-flores masc. omnino sectionis $1^{\text {re }}$; sed inflorescentia composita prasentis, et fructus ignotus. An sectio propria?

16.? M. sim i Ru (herb. Mus. par.), foliis ellipticis apice oltusis vel acutis basi abrupte angustatis sparsim tuberculatis subtus pallidis jilosulis, nervis lateralibus utrinque $9-10$, pedunculis masc. axillaribus petiolo subbrevioribus glabrescentibus, pedicellis ajjice ramorum umbellatis, brạcteis bracteolâque minimis pilosis, flore (juniore) oblongo subeurvato acuto pedicello duplo longiore pilis adpressis extus velutino, columnâ stamincà vix stipitatâ cyllindraceầ obtusâ. $\supset$ In Philippinis, ad Manille Caliwan (Callery! n. 34). - Alplr. DC. in Ann. sc. nat. isẻr. 4, v. 4, p. 29. Rami glalıri. Folia 4-5 poll. longa, 2 poll. lata, petiolo 6-9 lìn. longo; tuberculis utrinque distinctis minimis in vivo forsan non distinctis. nervis non validis, tertiariis nullis. Rami inflorescentip inferiores oppositi. Bractere circa basin pedicellorum et bracteole flori arlpresse $\frac{1}{8}$ lin. longá. Flores 2 lin. longi. Antherąe circiter 10, totâ longitudine commatie.-Ex inflorescentiâ et flore masc., sectionis Caloneuræ, sed nervatio potius Eumyristicæ. (v. s. a Mus. par. comm.)

* Nervi laterales foliorum validi, numerosi; tertiarii distincti. Bracteola floralis ampla.

17. M. в в А с т в А т А, novellis ferrugineo-tomentosis, foliis ellipticis obtuse acuminatis basi obtusiusculis superne glabris, subtus pilis stellatis adpressis evanescentibus albicantibus, nervis lateralibus validis, utrinijue 22-25, racemis folio duplo triplove brevioribus compositis, bracteâ amplâ obtusâ florem juniorem amplectente demum simplici vel fissà caducà extus cum perigonio racemisque ferrugineotomentosâ, perigonio masc. subgloboso 3 -lobo interne glabro. 3 In Philippinis (Ca)lery! 33, in h. Mus. par., Cuming! 1481, in h. Boiss. et Déless.). Culta in horto regio Mauritii (Pet. Th.! ex h. Mus. par. in meo, Boj.! Wall.) et in h. Calcutt. e Mauritio (Wall.!). M. sylvestris Sieb. pl. Maur. 75, in h. Boiss.! coll. 2, n. 365, in h. meo, Wall.! list 6800 , non Houtt. MI. Madagascariensis Vent.! in h. Deless. Boj.! hort.. Maur. p. 275, non Lam. Muscadier sauvage des Philippines mâle et M. Madagascariensis herb. Vent in herh. Deless.! M. Philippensis Lam. act. par. 1788, p. 161 , dict. 4 , p. 387 ? fide speciminis Callery, n. 33, in h. Mus. par. et aliorum in rod. herb. et apud Deless. Rami validi, apice tomentosi. Folia 8-10 poll. longá, 2:-3 poll. lata, extremitate truucata in specim., petiolo 9 lin. longo, nervis tertiaviis minimis. Racemi inflor. pauci, inf, oppositi apice $5-10$ flori. Pedicelli. per anthesin accrescentes, demum 4 lin. longi. Bracteola summo pedicello calycem simulans, deinde decidua. Flores 4 lin. longi. Starainn $15-20$, in columnam ellip. 
soideam? connata ; antheræ stipite multo longiores, connectivis in dentem brevem obtusum apice connatis. M. Philippensis Lam. quæ femina dicitur, nunc in herb. Juss. non visibilis. Ex descr. Lamarkii et specimine Callery sine numero in h. Mus. par. sub hoc nomine, fructus ovoideo-sphæricus tomentosus solitarius pedunculo valido poll. et ultra longo insidens. Folia interdum maxima, pedalia et sesquipe talia, nervis tamen non numerosioribus, et forsan ideo M. macrophylla Roxb. a pluribus in h. paris. vocata. (v.s.)

$\beta$. longifolia, foliis longioribus basi angustatis. In Philippinis (Cum,l 829, in h. Boiss. et Deless.). Folia 15 poll. longa, 2:-3 poll. lata, petiolo 15 lin. longo. Nervi ut in plantâ cultâ. Flores similes, bracteâ forsan citius cadente. (v. s.)

18.? M. SYL VESTRIS (Houtt. syst. 2, p. 326, non Sieb.), foliis lanceolatis acuminatis basi acutis breviter petiolatis, superne glabris, subtus rufescentibus ad nervosque tomentosis, pedunculis fructiferis petiolo multo longioribus, fructibus 1-5 ex eodom pedunculo pedicellatis nutantibus ellipsoideis vel obovato-ellipsoideis pedicello longioribus glabris, arillo completo insipido. 5 In sylvis Amboinensibus frequens, in Boero et T'ernalà Moluccarưm. Palala secunda Rumph. Amb. 2, p. 26, t. 6. M. salicifolia Willd. sp. 4, p. 871. Ramuli rufo-tomentosi. Folia sesquipedalia vel duas spithamas longa, 4 digitos lata, nervis later. validis ex ic. 13-16. Fructus nuci moschatæ similes, sed paulo minores, flavescentes, absque aromate. Species Blumeo videtur ignota, ex ejus verbo in Rumphiâ 1, p. 190, ad finem.

19. M. CоMмERsoni (Blume Rumphia 1, p. 181), ramulis foliis junioribus et inflorescentiâ ferrugineo-subvelutinis, foliis magnis oblongo-lanceolatis obtuse acuminatis basi in:equali-attenuatis glabris subtus canescenti-glaưis nervis later. utrinque 20, cymis in ramulorum apicibus alternis paucifloris, bracteâ sub flore fem. latâ abbreviatâ adpressâ fugacissimâ perigonio ovoideo ore 2-3-fido imo circumscisse deciduo, lobis ovatis erectis. $b$ Patria ign. an ins. Malaicæ? an ins. Mascarenhenses? Muscadier Pallabois Commers. in herb. Mus. par., ubirdescripsit cel. Blume. Folia pedalia et ultra, 3-4 poll. lata, coriacea. Petioli crassi. Cynæ fem. pollicares, in speciem corymbi approximat:e. Ovarium ferrugineo-subvelutinum, ovoideum. Stigma sessile, emarginato-bilobum. An perig. vere basi circumscissum? Planta non reperta in herb. Mus. par. anno 1855.

20. M. GUATTERIAFOLIA (Alph. DC. in Ann. sc. nat. sér. 4, v. 4, p. 20), novellis paniculis floribusque ferrugineo-tomentosis, foliis ellipticis obtuse acuminatis basi acutis pube pulverulentà ferrugineá superne cito caducâ subtus tarde, nervis lateralibus validis utrinque circiter 18 , paniculis petiolo æqualibus aut duplo longioribus, umbellis ramos secundarios inflor. terminantibus, bracteolâ sub flore latâ abbreviatâ caducâ, perigonio masc: ovoideo pedicello subæequali intus glabro 2-4-fido, lobis ovato-acutis erectis. $b$ In Philippinis (Cuming! 1582). Rami apice ferruginei. Folia 6-9 poll. longa, 2 $\frac{1}{2}-3 \frac{1}{2}$ poll. lata, petiolo 10-12 liu., longo. Flores 2 lin. longi. (v. s.)

21. M. MORINDAFOLIA (Blume! Rumph. p. 186, in adnot.), foliis oblongis maximis acuminatis basi rotundatis sive obiter subcordatis subtus ramulisque pallide ochrascenti-lepidotis, fructibus pedicellatis elongato-ellipsoideis ochraceo-furfuraceis. In Novâ-Guineâ (Zippel.). M. subcordatæa (ex Bl.) maxime affinis, sed longe robustior, ramulis non tomentosis, neque etiam foliis in paginâ dorsali, quorum nervi sunt longe distinctiores ac subtus circa marginem reticulato-anastomosantes. Denique baccæ subtus minus sunt latiusculæ, neque sessiles, sed brevi pedicello pedunculo communi insert:e, non ut illæ lanuginoso-tomentosæ, sed furfuraceæ. Ex specim. imperf. Mus. par. a cl. Blume comm.I folia 9 poll. longa, 3-4 lata, petiolo 10 lin., nervis lat. utrinque 25-30 unde ad præs. sectionem pertinere videtur; fructus 15 lin longi, subtomentosi. (v. s.)

V2. M. CAStanear fol in (A. Gray, Un. st. expl. exped. 1, p. 32 "), foliis oblongis seu oblongo-lanceolatis sensim acutis basi rotundatis glabris sublus albidis nervis later. utrinque 20-30, floribus axillaribus, masculis amentaceo-spicatis pedunculo incrassato sæpius furcato deflexo petiolo subbreviore, bracteis sub flore floribusque ferrugineo-pubescentibus, antheris $8-10$, fructu oblongo obtuso subapiculato ferrugineo-pubescente. 5 ln montibus ins. Ovalau, archip. Fidgi, frequens Ramuli crassi, rugosi, juniores ferrugineo-pubescentes. Folia 8-10 poll. longa, 3-4 poll. lata, coriacea glabra juniora imo, nervis tertiariis transversis, petiolo 12-18 lin.

IIV. 
Longo valida. Pedunculi simplices vel sæpius furcati, crassi, âubpóllicares, cicatrièibù bractearum squarrosi. Flores subsessiles, imbricàti, bráceteâ ovatâ subtensi. Antheræ lineares, inter se et cum axi centrali connatæ. Fructus $1 \frac{1}{4}$ poll. longus.

23. M. GRANDIFOLIA, folitis magnis obovato-oblongis basi angustatis glabris subtus álbidis, nervis lateralibus utrinque 35. 5 In montibus ins. Ovalau, archip. Fidgi. M. macrophylla A. Gray Un. st. expl. exped. 1, p. 33, non Spruce et Benth. nec Roxb: Arbor M. castanexlolix minori. Folia isque ad $2 \frac{1}{2}$ pedem longà, fere ôbov ata, a medio at basin ángustatà, nervis tertiariis vix perspicuis. Filoś ét fr. ígn.

/24.? M. HYPARGYRAA (A. Gray Un. st. expl. exp. 1, p. 33), foliis oblongis basi obtusis glabris subtus argentato-albidis, nervis lateralibus utrinquie 14-200, floribus 5-6 pedtuneuló brevissimo insertis pedicello sublongioribus, perigonio ferrugineopulverulento, antheris 8-10, fructı ovoideo-subgloboso tomeñtosulo. 5 In Tutuilà et Saraï archip. Navigatorum et Tongatabu arch. Amicorum. Folia 815 poll. longa, 4-6 poll. lata, subcoriacea apice subacuta vel abrupte acuta aut acuminata, nervis lateralibus subtus validis, tertiariis raro perspicuis, petiolo $1-1 \frac{1}{2}$ poll. longo. Pelunculi axillares. Pedicelli lineam longi. Bractéa ovata sub flore. Perigonium $1 \frac{1}{1}$ lin. longum: Andrecium oblongum. Flores fem. subsessiles, subglobosi, 3-fidi. Fructus magn. mali persici. Semen $1 \frac{1}{2}$ poll longum, 10 lin. latum. Arillus profunde laciniatus.

25. M. M L A A A IC A (Lam. aet. paris. 1788, p: 162), foliis angustó oblongis vel ellipitico-laneeolatis utrinque acutis vel obtusís glaberrimis subtu's glaucis, inflorescentiâ masc. axillari dichotone cyñosâ multiflor̂â pétiolo longiori, fem. pauçiliorâ, alabastro globoso extus pubescente, bracteâ latissimâ basin amplèctente fructu oblongo fulvo-incano, arillo lacunoso ex rubro flavescente lobis apice in conium eontortiplieatis. 5 In sylvis Malabariæe et Concan (Book. f. et Thoms. fl. ind. 1, p. 168). - Blume Rumph.* 1 , p: 163 . Palam Palca Rheede Mal. 4, t. 5 ? M. dactyloides Wall. list 6786 (fide Hook. et Th.), non Grertn. M. notha Wall. 6787 (fide ebr.).

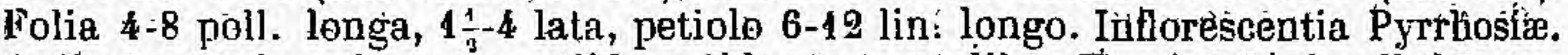
Antherce 15 in columnam solidam oblongan coalitre. Fìctus $2 \frac{1}{2}-3$ poll. lòngus. Arillus ex Rheed. minus aromaticus quam M. fragrantis, nuce vix âromaticù. Icon Rheedii bracteam floralem vix exhibet. An delapsa in specimine depicto? Flores in icone seorsim picti a floribus numeri 6786 Wall. in $\mathrm{h}$. Deless; omnino diffèrunt, nervique foliorum in ic. multo validiores. An species primitiva Rheedii et Lamarkii a plantâ Hookeri diversa, forsañ nostra M. panieulata, cujus folium et inflorescentíam præbet? Tunc phrasis et descriptio supra citatæe ad plantam Floræ indicæ, hec ad aliam tribuendæe essent.

26:? M. о в т UStrou A (Wall. list, 12. 6808), foliis obovato-oblongis rigidis sinfra glabris nitidis, subtus sparse puberulis fèritugineo-glaucis, panieulis fruêtifer̃is parce ramosis fusco-tomentosis, fructu oblongo-tomentoso, arillo subcompleto. 3 In Malayâ ad Singapur. Folia $6-12$ poll. longa, 3-4: lata, petiolo 1-1 $\frac{1}{2}$ poll. longo, nervis obliquis distantibus rectis apice arcuatis subtus pironouninèntíbus. Flores ign. Paniculæ fructif. $1 \frac{1}{2}$ poll. longæe. Fructus $\frac{2}{3}$ poll. longi. Sémeñ súbglobósum, testâ tenui.

27.? M. SUPEABA (Hool. f. ot Th. fl: ind. 1, p: 162); foliis lanceolatis utrinque acutis subtus tomento fulvo furfuraceis, paniculis furfuraceis elongatis ramosis, floribus majusculis ad apices ramulorum umbellatis, perigonio glabro ovali. $\$$ In ins. Penang. Ramuli tomentosi. Folia $12-18$ poll. longa, 3-7 lata, petiolo 9 lin. longo, firma, supra glabra, subtús laxe tomentosa. Panieulze in axillis foliorum delapsorum, 4-6, poll. longa, divaricato-ramosæ; ad ramilieationes bracteds pafvis rotundatis demum induratis munitæ. Umbellæ 3-7-floræ. Flores 2 lin. lóngi, pedicello aquales. Perigonium apice 3-4-lobum. Antheræ in columnam oralem sub-

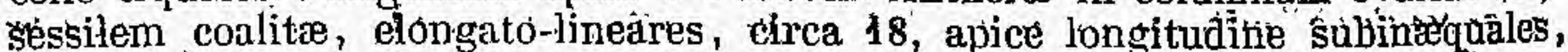
columnâ haud apiculatâ. De bracteâ sub flore tacent cl. auctòres, an dees t?

SËct, ì. Virola. - Genus Virola Aubl. Guy. p. 904. -Gen. Sebophoira Neck.
elem. p. 907.

Columna staminea cylindrico-penicillata; stipite èrassiușculo; antheris paücis

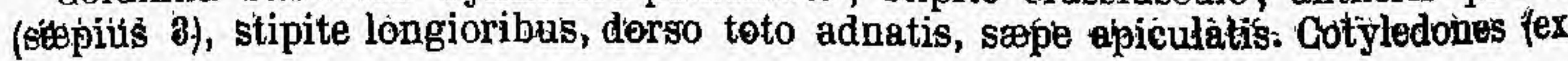


M. macrophyllä) ovatæ, divergentes, planæ.-Paniculie composite, frequenter supraaxillares, bracteis atque bracteolis sub flore destituler. Flores parvi, perigonio non solum externe, sed interne sapjius pubescente, infundiludiformi vel ubovoideo. Nervi laterales foliorium mediocres. - $\Lambda$ mericana (1).

28. M. SEBIPEn A (Sw. fl. Ind. oce. p. 1129), ramis petiolis pagina inferiore foliorum et inforescentiâ rulo-tomentosis, foliis wato-acutis vel acuminatis hasi cordatis nervis lateralibus utrinque 12-18, paniculis folio duplu-1 [uadruplo dsrevioribus, perigoniu infundibuliformi-ovoideo extus tomentosu intus puberulo, antheris : apiculis brevissimis terminatis, fructus subglobosi lomeuto forrugineo demum caduco, arillo tenui lacerato. i Frequens in sylv is paludosis et montibus Guyana, (Rob. Sclıomb. coll. 1, in. 711! coll. 2, 11. 588, 907, 991! Rich. Schomb. 906! 1402, 1713! Hostm.! 735, 638 a, 633, 635, in 1 . Graves et Deless., Kappler. 635, in li: Boiss.), prov. Para (Spruce!), Maynas (Popppig!) et S. Pauli (Lund!), in Peruviâ (Rivero! in h. Mlus. par.) et ad Panamam (Seem. bot. Her.).-Benth. in Hook. Journ. 1853, p. 5. Virola sebifera Aubl. Guy. p. 904, t. 345, f. 1-5. Folia sepias 7-8:poll. longa, 3 poll. lata, nunc majora, coriacea, superne glabra, petiolo $4-5$ lin. longo, nervis later. magis quam in aliis specimin. variantibus, sicpius a nervo centrali recte divergentibus inferioribus approximatis. Flores numerosissimi, pedicello subrequales, ebracteati, lineam longi. Fructus (ex spec. Spruce) 4-5 longi, (v. s.)

$\beta$. curvinervia, nervis lateralibus inferioribus ad originem arcualis obliquis, $b$ In prov. Cuyabâ, Brasiliæ inter. (Manso I 57, in h. meo). Primo adspectu speciem existimavi, sed nervi latcrales in eodem specimine variant, nune omnes recte a nervo centrali patentes, nunc inferiores basi curvati.

y. cordifolia, nervis lateralibus paucioribus (9-13). In pror. Goyaz (Gardn.! 3566).

M. sebifera ex Bentl. l. c. M. cordifolia Mart. harls.!

29. N. THEIODORA (Spruce, Benth. in Hook. Journ. 1853, p. 6), foliis breviter petiolatis amplis ovatis vel late oblongis acuminatis hasi late subcordatis subtus glaucis vix tomentosis impunctatis, paniculis decompositis folio brevioribus, fructu subgloboso furrugíneo-tnmentoso. 5 Circa Barra do Rio Negro Brasiliæe sept. Folia Tere II. sebiferie, sed sublatiora, minus cordata minusque subtus tomentosa, fruetu paulo majore pedicello crassiore et longiore. (Il. Bentham varietatem crediderit nisi Sjruce diversam speciem dixerit. Folia exsiccatione odorem Theæ spargunt.

30. M. Mocoa (Poppig! n. 2390, in ll. Boiss. et mco), foliis subtus et paniculis rufo-tomentosis, fóliis ovato-oblongis acuminatis basi obtusis, nervis lateralibus utriuqque 13-15, janiculis (fein.) folio $4^{\circ}$ brevioribus, pcrigonio obovoideo extus tomentoso intus pubcrulo, ovario tomentoso. $b$ Ad Maynas, in sylvis Yurimaguas. Folia 6-9 poll. longa, $1 \frac{1}{2}-3$ poll. lata, petiolo 5 . lin., superne glabra, opaca, nervis lateralibus inferioribus minus quam in N. sebiferâ approximatis, unde ut el folio basi non cordato differre videtur, Flores fem. numerosi, ebractcati, pedicellis fere lineam longis, nempe N. sebiferó fem. longioribus. (v. s.)

31. M. MAGROPHYLLA (Spruce! Benth. in Hook. Journ. 1853, p. 6, non Hoxb. nec A. Grayy, foliis magnis ellipticis vel obovato-ellipticis acutis basi obtusis glabris opacis nervis lateralilus utrinque 18-20, racemis (fructif.) axillaribus petiolo duplo longioribus, pedunculis et pedicellis crassis æqualibus, fructu globoso glabro rugoso pedicello majore. $\delta$ Prope Barra do Rio Negro Brasiliæe sept. Rami crassi, glabri. Folia 9-18 poll. Longa, 3-4 poll. lata, petiolo lín. longo absque vestigio tomenti, nervis tertiariis non distinctis, parenchymate (in siccu) ruguloso subtus ferrugineo, sed glabro. Fructus 6 lin. longi, $k-5$, ex nno pedunculo, demum hine fissi, nuce tamen et arillo cum carne adhserentibus. Albumen ruminatum et cotyledones ovatie divergentes. (v. s.)

32. M. GuSPID A T A (Bently. in Hook. Journ. 1833, p. 5), ramulis petiolis foliis subtus et inflorescentiâ rufo-tomentosis, tomento caduco, foliis ovato-ellipticis longe acuminatis basi rotundatis pellucide punctatis, nervis lateralibus utrinque 12-15, paniculis axillaribus vel supraaxillaribus laxis folio $3^{\circ}-5^{\circ}$ brevioribus, perigonio infündibuliformi-ovoíieo minimo extus tomentoso interne sublomentoso, anthéris 3-4, apiculis dentiformibus terminatis, fructu... 5 In prov. Rio Negro (Mart.! herb.),

(1) Myristicas Brasilienses in Flord brasiliensi mox descripturus sum, non sine auxilio speciminum herb. reg. Berolin. aliorumque. 
prope Barra, Rio Negro, Brasiliæe sept. (Spruce! 1794) et. in Peruviả (Pav. irı h. Boiss.)! Folia 7-8 poll. longa (incluso petiolo $4-5$-lin.), $2 \frac{1}{2}-3$ poll. lata, membranacea, nervis later. tenuibus, sed subtus eminentibus, tertiariis vix distinctis, superne glabris, subtus glabrescentibus. Inflorescentia M. sebiferæ, sed paulo gracilior. Pedicelli lineam longi. Flores paulo breviores. In speciminibus Pavonianis folia subtus pallida, nec fulvescentia ut in aliis, sed cæterum simillina. (v. s.)

33. M. P uNC T A A (Spruce! Benth. in Hook. Journ. 1853, p. 6), ramulis petiolis foliis subtus et inflorescentiâ pulverulento-tomentosis rufescentibus, foliis longe ovatolanceolatis basi rotundato-truncatis pellucide punctatis superne glabris, subtus rix tomentosis nervis lateralibus utrinque 20-21, racemis (fructif.) axillaribus compositis petiolo $2^{\circ}-3^{\circ}$ longioribus, fructu spherico ferrugineo-tomentoso, arillo tenui superne lacerato. 5 Ad Barra, prov. Rio Negro Brasil. sept. Rami teretes. Folia 6-8 poll. longa, $2 \frac{4}{2}$ poll. lata, acumine acutissimo, petiolo 3 lin. longo, nervis tertiariis non distinctis. Fructus in ramis secundariis inflorescentiæ insidentes, pedicello 1-2 lin. longo, fere maturi 4 lin. lati. Plantam verisimiliter masculam vidi in herb. Mus. par. sub nom.Virola, e Brdsiliâ. In hacce paniculæe folio triplo breviores, fulrotomentosæ; bracteæ et bracteolæ nullæ; flores ditı obovoi:lei, aperti campanulati, vix lineâ longiơres, majores quam in M. cuspïdatâ et M. membranaceâ, extus tomentosi, intus subtomentosi, antheræ paucæ, stipite multo longiores, muticæ. (v. s.)

34. M. MEMBRANACEA (Pœpp.I 2674 in h. Mus. par., 2647 in meo), ramis petiolis foliis subtus et inflorescentia fulvo-tomentosis, foliis ellipticis vel obovato-ellipticis acuminatis basi obtusis superne glabris membranaceis pellucide punctatis nervis lateralibus utrinque 16-20, paniculis compositis diffusis multifloris floribus minimis pedicello subbrevioribus, perigonio semi-3-fido ovoideo extus tomentoso interne subtomentoso, antheris 3-4 ? muticis stipite brevissimo longioribus. $b$ Ex itinere Peppigii, ideo verisimiliter e finitimis Peruviæ et Brasiliæ. Rami teretes. Folia 8 poll. longa, $8 \frac{1}{3}-8$ poll. lata, acumine acutissimo, petiolo 4 lin. longo, nervis lateralibus tenuibus subtns eminentibus, tertiariis transversis vix perspicuis, paginâ infer. pallidâ nervis rufis. Bracteæ nullæ. Flores masc. vix śmilineam longi. Antheræe stipite multo longiores. Descripsi e specim. meo meliore. (v. s.)

35. M. ELONGATA (Benth. in Hook. Journ. 1853, p. 5), foliis petiolatis lanceolatooblongis longe acuminatis basi rotundato-cuneatis subtus glaucis, paniculis brevibus ramosissimis, perigonio breviter 3 -fido, stipite antherarum brevissimo. 5 Ad Borba fluvii Madeira Brasiliæe (herb. Acad. Petrop.). Flores fere M. sebiferæ, sed minores. Folia diversissima, 6-9 poll. longa, $1 \frac{1}{2}$ poll. solum lata, apice in acumen longum producta. Antheras 6 dicit cl. auctor, sed verisimiliter 3 biloculares.

\section{Sect. iv. Sychnonedra Alph. DC. in Ann. sc. nat. sér. 4, v. 4, p. 30.}

Columna staminea cylindrico-penicillata; antheris paucis (sæpius 3); dorso toto adnatis, stipite subæqualibus, nunc apiculatis. Cotyledones... Paniculæ vel racemi compositi. Bractea fasciculum quemque florum amplectens, caduca; bracteola vero sub flore nulla. Flores parvi; perigonio obovoideo-infundibuliformi, non solum externe, sed interme nonnunquam piloso. Nervi laterales foliorum numerosi, unde nomen (ouxvos, creber, veupa, nervi). - Americanæ.

36. M. PERUVIANA, foliis oblongis acutis vel acuminatis basi obtusissimis petiolatis superne glabris, subtiss tomento minimo cuduco puberulis, nervis lateralibus utrinque 20-25, paniculis axillaribus aut supraaxillaribus diffusis folio brevioribus fulvo-velutinis, pedunculis glabrescentibus, bracteis ovato-lanceolatis caducis, perigonio obovoideo extus fulvo-tomentoso intus glabro, lobis $\mathbf{3}$ dentiformibus demum apertis, columnâ stamineâ apiculatâ, fructibus ovoideis fulvo-tomentosis. $b$ In Peruviâ (Rivero in h. Mus. par., Pavon! et in h. Mus. Berol. unde a Boiss. comm.). Rami glabrescentes. Folia $7-9$ poll. longa, 3 poll. lata, coriacea, petiolo 6 lin. longo crasso, nervis suhtus validis regularibus, modo M. sebiferæ, sed numerosioribus. Faniculæ masc. 3-6 poll. longæe, ramis infer. oppositis. Fásciculi florum - juniorum 10-15-flori densi. Bracteæ $1 \frac{1}{2}$ lin. longæ, acutæ, intus glabræ. Flores lineam longi, vix pedicellati. Fructus 8-9 lin. longi. (v. s. in h. meo, Boiss. et Mus. par.)

37. M. SURINA M ENSis (Roland. in Act. lit. hafn. p. 281-302), ramis junioribus rufopilosis, foliis oblongo-lanceolatis acutis basi abrupte et breviter petiolatis, tomento 


\section{MYRISTICA. MYRISTICACE无 (AUCTOR ALPH. DC.). 197}

minimo superne præsertim evanescente, nervis lateralibus utrinque 24-28, paniculis axillaribus aut supraaxillaribus diffusis folio brevioribus pallide velutinis, bracteis ovato-acutis caducis, perigonio obovoideo externe tomentoso interne glabriusculo, lobis 3 demum apertis, fructu ovali, arillo pingui. $\delta$ Frequens in Guianầ et vicinis terris, ex gr. in S. Vincent (Benth.), Tobago (Sw.), Guianâ gall.'(Sw.! Leprieur, 2681), hatavâ (Hostm.786, Kappler ! 1730, Wullschægel ! 855, 846), añglicâ (Rob. Schomb. 2 coll. 950! Rich. Schomb.! 1257), prope Para (Spruce!). M. fatua Sw, prodr. p. 96 (anno 1788), fl. Ind. occ. p. 1126, non Hoult., Benth.' in Hook. Journ. 1853, p. 4. M. sebifera var. longifolia Poir. dict. 4, p. 391. Pili ramorum longi, foliorum et inflor. brevissini pallidi. Folia 6-8 poll. longa, 10-15 lin. Jata, petiolo 1-2 lin. longo. Bractea cito caduca, 3 lin. longa. Flores intra bracteam 10-15 fasciculati, pressi, pedicellis inwqualibus sub anthesin accrescentibus, raro flore longioribus. Perigonium lineâ brevius. Antheræ 3, stipite subbreviores, muticæ, juniores? sub lente connectivis apice glanduliformibus terminatæ. Fructus 6-9 lin. lati, subvelutini. Arillus luteus, laciniatus. Odor aromaticus, fugax. (v. s.)

38. M. Brсину в A (Schott 1 in Spreng. syst. append. p. 409), ramis glabris, junioribus glabriusculis, foliis oblongo-lanceolatis acutis basi in petiolum cuneatis utrinque glabrescentibus nervis lateralibus utrinque $26-30$ vix distinctis, racemis axillaribus aut supraaxillaribus subsimplicibus folio multoties brevioribus pallide velutinis, bracteis ovato-lanceolatis caducis, perigonio utrinque subvelutino lobis 3 clemum apertis. $b$ In prov. Rio de Janeiro (Schott! in h. Mart.). Species cum M. officinali Mart. a cl. Bentham, imoque in herb. Marliano mixta, forsanque ab incolis confusa, nam M. officinalis Vicuiba aut Bicuiba quoque vocatur (ex Mart. Reise 2, p. 543); affinior tamen M. Surinamensi. A duobus differt nervis lateralibus subtus minime eminentibus, non nisi cólore distinctis, foliis basi non cordatis, sed acutis, puhe parciore. Folia 5 poll. longa, poll. lata, petiolo semipoll. Antheræ .paucre, stipite vix longiores. (v.s. in h. Mart. a Schott. comm.)

39. M. GARDNERI, ramis glabris, junioribus glabriusculis, foliis ovato-oblongis acutis basi in petiolum submarginatum angustatis cito glabrescentibus nervis lateralibus utrinque 16-17 tertiariis distinctis mínimis, racemis axillaribus subramosis folio multoties brevioribus floribus novellisque ferrugineo-velutinis, bracteis ovatis caducis, perigonio utrinque subvelutino lobis 3 demum apertis. 5 A Rio de Janciro (Gardn.!) n. 5.596). M. officinalis ex Benth. 1. c., sed differt foliis tenuioribus, petiolo ápice marginato, nervis minoribus cum tertiariis præsentibus. Folia in specimine meo 5 poll. longa, 12-16 lin. lata, limbo abrupte angustato, sed secus petiolum decurrente; juniora pellucido-punctata. Pubes ferruginea, pulverulenta, caducissima. Flores M. Surinamensis. Antheræ 3, mutics, stipite sublongiores. (v, s.)

40. M. SUBSESSILIs (Benth. in Hook. Journ. 1853, p. 4), ramulis foliis subtus ot inflorescentiâ pulverulento-flavescentibus cito glabrescentibus, foliis brevissime petiolatis oblongis acutis basi subcordatis, nervis utrinque 24-26 paniculis axillaribus et terminalibus folio $3^{\circ}-4^{\circ}$ brevioribus parum ramosis, pedunculis compressis, fasciculis florum in extremà parte pedunculi bracteâ fugaci ovato-acutâ cinctis, jerigonio obovoideo lobis 3 demum patentibus extus tomentoso, intus ad margines Joborum piloso, antheris 3-5 in apiculum brevern desinentibus, fructu oblongo-tomentoso.b In prov. Piauhy Brasil. (Gardn.! 2775). Affinis M. Surinamensi. Folia $4-5$ poll. longa, 15 lin. Iata, coriacea, subtus pallida, petiolo lineam longo. Inflorescentia denudata, foliis sup, et bracteis caducis, pedunculisque basi sine floribus, tomento rubiginoso parvo. Bractea cujusque fasciculi 2 lin. longa. Flores 12-15 in fascieulo, cum pedicello minimo vix lineâ longiores. (v. s. in h. meo et Boiss.)

41. M. OFFICINAL IS (Mart.! Reise 2, p. 543), ramis foliisque junioribus et inflorescentiâ ferrugineo-tomentosis, foliis oblongis acutis vel acuminatis basi subcordatis 'oriaceis superne glabrescentibus, nervis utrinque $29 \cdot 30$, racemis axillaribus folio brevioribus, bracteis ovato-acutis fasciculos florum juniorum amplectentibus caducis, perigonio 3-fido extus tomentoso, intus glabriusculo, antheris 3 stipite sublongioribus apiculo communi terminatis, fructu subgloboso glabro. $b$ In sylvis primævis Brasiliæe orient. in prov. Ilheos (Mart.! herb.), Rio et Bahia (Mart.! Herb. fl. bras. 650 ct 2359, Blanchet 1 1645). - Benth. in Hook. Journ. 1853, p. 3 (excl. syn.

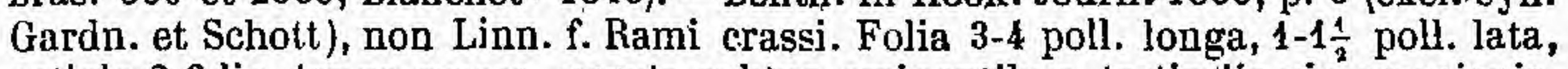
petiolo 2-3 lin. longo crasso, nervis subtus eminentibus, tertiariis vix perspicuis, paginà inf. stellato-pilosâ pallide rufescente. Racemi compresśi tomentosi. Fasci- 
culi flurum masc. ramos laterales breves terminantes. Bractea 2-3 lig. longa. Flores lineam longi, late infundibuliformes, pedicello lọngiores. Arillus tuber. Nux offici- nalis vix aromatica. (v. s.)

42. II. SESSILIS, ramulis foliis sultus et inflorescentia vix pulverulento-ferrugineis cito glabris, foliis sessilibus ovato-ellipticis basi subcordatis apice obtasis coriaceis, nervis lateralibus præcipuis utrinque 20-22, racemis axillaribus vel supraaxillaribus folio $3^{\circ}-4^{\circ}$ brevioribus, bracteis ovato-acutis fasciculis llorum juniorum amplectentibus, perigonio lobis 3 patentibus externe et al margines loborum tomentosulo, antheris 3 muticis stipite requalibus. $\$$ In prov. Cuyabà Brasiliz inter. (Manso! 39 in h. meo). Folia $4-6$ yoll. longa, $1 \frac{1}{2}-2 \frac{1}{4}$ poll. lata. Valde alfinis M. officinali, sed petiolus nullus, nervi laterales foliorum sæue inæquales, nempe 20-22 utringue preceipui versus marginem juncti et alii minores 5-8 cum præcipuis alterni ad marginem non porrecti. Pedunculi ut in M. officinali compressi, ramis infer. oppositis. Antheræ mutica, quod tamen ex 2 floribus solum observavi. (v. S.)

43. M. CARINATA (Benth.! in Hook. Journ. 1853, p. 3, specim. fructif.), foliis oblongis vel longe oblongo-obovatis obtusiusculis basi obtusis coriaceis, nervis lateralibus utrinque circiter 28 , paniculis fructiferis axillaribus vel supraaxillaribus folio brevioribus, fructu globoso hine carinato illine sulcato glabro. $5 \mathrm{Ad}$ Barra, prov. Rio Negro Brasil. sept. (Spruce!).. Cl. Benth. non sine dubio ad num. 1682 Spruce (M. gracilis mihi) præsentem retulit, sed folia longiora, 6-7 poll. longa, 12-18 lin. lata, petiolus 4 lin. longus, consistentiâ multo firmior (folio equidem vetustiore), et præsertim numerus nervorum lateralium multo najor. Nervi isti subtus valde distincti, in sicco brunnei; tertiarii vix perspicui. Limbus basi subcordatus. Fructus 9 lin. longus. Arillus ruber, tenuis, laceratus. (v. s.)

44. M. G R A ILIs (Alph. DC. in Ann. sc. nat. sér. 4, v. 4, p. 30), ramis gracílibus glabriusculis, foliis obovato-oblongis apice obtuse angustatis basi obtusis vel acutis membranaceis pellucide punctatis, nervis lateralibus utrinque circiter 18, paniculis supraaxillariłus ramosis gracilibus laxis subtomentosis, 'bracteis ovatoacutís, perigonio extus fulvo-tomentoso intus glabriusculo lobis 3 patentibus, antheris 3 mutieis stipite multo brevioribus. 5 Ad flumen Rio Negro Brassil. sept. (Spruce! 1682, specim. 1lorif.). M. carinata Benth.! in Hook. Journ. 1853, p. 2, quoad spec. florif. Folia 4-5 poll. longa, 10-12 lin. lata, quasi obtuse acuminata, basi olstusa in spec. meo, acuta in herb. Boiss., petiolo 2 liph. longo tomentosulo, nervis lateralibus parum distinctis, jilis paginæ inf. raris. Paniculæ 3 poll. longæ, laterales, ramis inferioribus oppositis basi cicatrices bractearum prebentibus. Faseiculi llorum masc. 3-5 flori, bracteâ $1 \frac{1}{2}$ lin. longî. Flores lineam longi, pèdicello submajores. ( $r$. s.)

45. M. veNoSA (Benth.l in Hook. Journ. 1853, p. 3), novellis ferrugineo-subtomentosis, foliis ellipticis obtusis vel obtuse acuminatis basi rotundatis obtusis vel acutis superne glabris, subtus glabriusculis et glaucescentibus, nervis lateralibus utrinque 16-20, racemis brevibus parce ramosis, bracteis ovato-acutis fugacíbus fasciculos florum amplectentibus, perígonio 3 -filo infundibuliformi extus fulvo-tomentoso, intus glabro, antheris 3 stipite brevioribus. 5 Prope Barra, prov. Rio Negro Brasiliæe (Spruce!) et Chicoplaya Peruviæe (Pav.! in h. Boiss.). Folia 4-5 poll. longa

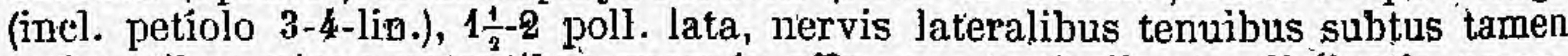
eminentibus minus patentibus quam in affin. sp., tertiariis uon distinctis, parenehymate pellucido, sed non punetato. Racemi axillares, 6-12 lin. longi in specim. nostris, fasciculis 3-7-floris. Perigonium vix lineam longum, pedicéllo majus. Specimina Pavoniana masc. et fem.; in hisce fructus ellipsoidei, 15 lin. longi, glabriusculi, pauci. (v. s.)

\section{sect. v. Отова Alph, DC. in Ann. sc. nat. sér. 4, v. 4, p. 30 ,}

Antherie 3, libere, eructse, stipite communi inflato multo breviores, oblongr, obtusissimæe, longitudinaliter sulcata, loculis 2 parallelis disjunctis subextrorsis. Perigonium infundibuliforme, profunde 3 -fidum. Fasciculi florum secus pedunculum alterdatim dispositi, bractea basi cincti. Bracteola sub flore nulla. Vernatío conduplicata, marginibus plus minus plicatis potius (quam involutis et inde (ir speeje 45 præsertim) plicx longitudinales nervos mentientes. Nervi laterales mediocres, nec valde numerosi. Affinitas quædam ex inflorescentia cum sect. Iryantheră, sed bracteola floralis nulla et antheræ diversæe. 
46. M. O x 0 B A (Humb. et Bonpl.! pl. æq. 2, p. 78, t. 103, ubi errores graves in ic. et descr.), novellis pilis adppressis cinnamomeo-sericeis, foliis ellipticis vel obovatoellipticis breviter acynịnatis basi in petiolum canaliculatum suljmarginatum abrupte angustatis superne glabris, subtus glabrescentibus, nervis lateralibus utrinque 12-15 prope marginem evanessentibus, racemis axillaribus, petiolo duplo triplove longioribus floribusque fụlvo-velutinnis, pedicellis secus pedunculum alternatim fașeiculatis, perigonio longitudine pedicelli profunde 3 -fido, lobis ovatooblongis obtusiusculis, fructu ovoideo utrinque subacuto. $\$$ In montibus juxta Mariquita Novo Granatensium, alt. 500 hexap. (H. et B.), ad Santa Ana las frias (Goudot I in h. Boiss.), ad Pueblo Nuevo Peruviæ (Pav.l in h. Boiss.) et versus Maynas, in sylvis Yurimaguas (Pœpp.1 2348, in h. Mus. par. et meo, sine num. in h. Boiss.). - Kunth in H. et B. noy. gen. 2, n. 156 (non leerb. Bertero et Balb. quæ Lauracea videtur), Alph. DC. in Ann. sc. nat. sér. 4, v. 4, j. 21, 24. XI. Cumara Pœepp.! in herb. Boiss. Folia 6-9 poll. long (incl. petiolo $49-18$ lin. longo), $2 \frac{1}{2}-4$ poll. lata, limbo secus margines sup. petioli continuo, nervis later. prope marginem conpexis, parenchymate opaco, in sicco rugosulo, demum subtus jallido, pervis tertiariis reticulatis. Folia novella subtus (in vernatione extus) sericea, superne glabra. Flores in ie. et descr. male descrijti, antheris brevibus pro stigmate sumptis. Specimina herb. Mris. par. authentica, sed valde imperfecta; meliora vidi in herb. Boiss. et meo. In hisce pedunculi-simplices, nine gemini, fasciculis fl. masc. alternatim onusti, bracteâ annulari minimâ (rèlictu bractex fugacisșimæ?) pedicellos' $3-12$ basi cingente; pedicelli $1 \frac{1}{2}$ lin. longi; flores in eodem pedunculo juniores angusti lineam longi et aperti ? lin. longi; perigonium intus glabrum; antheræ stipite communi triplo breviores diu adpressæ, per anthesin manifeste liberæ. Fructis ex specim. Goudiot. pauci, pollicares, glabriusculi, pedicello rigido 3 lin. longo, pedunculo toto pollicari, apice fissi. Ex Bonpland pericarpiurn oleosum, foetens; arilius alloidus. (v. s.)

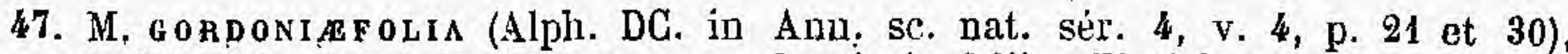
novellis pilis adpressis cinnamomeo-subsericeis, foliis ellipticis vel obovato-ellipticis apice rotundatis basi in petiolum canaliculatum submarginatum abrupte angustatis coriaceis superne glabriusculis, subtus tomento brevissimo ferrugineis, nervis lateralibus utrinque $20-23$ prope marginem anastomosantibus, racemis axillaribus (femineis) petiolo subæqualibus tloribusque fulvo-velutinis, pedicellis secus pedunculum alternatim fasciculatis crassis angulosis, perigonio pedicello sublongiore profunde 3-fido lobis ovatis obtusis, fructu ovoideo utringue subacuto. $b$ In Peruviâ, prope Huayaquil; valgo Coco (Pavon! in h. Boiss.). Rami giabrescentes. Folia 6-9 poll. longa (incl. petiolo 12-18-lin.), 2-3 poll. lata, exsiccatione subgranulata, nervo centrali et lateralibus patentibus non admodum validis, sed utrinque distinctis, plicxque 2 vel 4 longitudinales, nerves mentientes, in mediu limbi, nervo centrali paralleli, prope petiolum et apice confluentes, a vernatione 'orientes, in paginà inferiore solum distincti. Pedunculi sæje gemini. Bractea late ovata, 2 lin. longa, caducissima, fasciculos florum amplectens. Flores fers. 3-4 in fasciculo. Bracteola sub flore nulla. Perigonium fere 3 liu. longum, pedicello obco. nico continuum, interne glabriusculum. Ovarium ovoideum, tomentosum. Stigma sessile. Fructus immaturi 8 lin. longi, glabriusculi, pauci in racemo. Arillus laciniatus. Manifeste affinis M. Otobæ, sed 1. mase. ign.; folia obtusissima, nunc breviter mucronata, sed rotułdata minime acuta; novella utrinque sericea, mec pagíná super. in vernatione glalırâ. ( $\mathrm{r}$. s. in h. Boiss.)

\section{Sect. vi. Compsoneura.}

Antheræ 6, liberæ, erectæ, verticillatie, stipite communi longiores. Perigonium campanulatum, breviter 3-lobum. - Racemi axillares, compositi, ebracteati. Flores ebracteati. Folia nervis secundariis basi obliquis, tertiariis parallelis transversis. -Nomen ab elegantiâ nervorum.

48. M. SP R U C E I, glabra, foliis obovato-ellipticis obtuse acuminatis basi acutis memhranaceis pellucide subpunctatis, nervis lateralihus utrinque 7-8 obliquis, tertiariis crebris, racemis pétiolo $2^{\circ}-4^{\circ}$ longioribus, floribus masc. pedicello curvo equaglibus. 5 Prope San Gabriel, ad Rio Negro Brasiliæ sept. M. laurifolia Spruce! 11. 2361, in lierb. (non Hook. et Thoms. nec MI. laurina Bl.). Rami teretes, flexi. Folia 6-8 poll. longa (ingel. petiolo 8-9 lin. longo), 2-2: poll. lata; acumine longo vel Jrevi extremitate obtusat. Nerwi laterales e centrali oblique et curratim egre- 
dientes, nsique ad marginem folii porrecti nec inter se arcuatim connexi; tertiarii nervo primario perpendiculares secundarios transversim jungentes. Flores masc. numerosi, ad extremam partem ramorum inflorescentiæ subumbellati, $1 \frac{1}{2}$ lin, longi, glabriusculi, alabastro obovoideo, lobis ovatis subpatentibus. Antheræ 6 , lineari-oblongæ, muticæ. In medio verticilli antherarum, apice stipitis, umbonem quemdam acutum in 2 fioribus vidi, an constans? an ovarii vestigium? In herb. Mus. par. adest specimen femineum a Pœppig. comm. sub nomine M. capitellata, n. 1971, quod ejusdem speciei videtur. Folia simillima (ab infloresc. disjuncta). Flores minores quam in masc., brevius pedicellati, obovoidei. Ovarium tomentosum, ovoideum, subacutum. (v. s.)

Sect. viI. GYMnacranthera Alph. DC. in Ann. sc. nat. sér. 4, v. 4, p. 31.

Columna staminum cylindracea ; antheræ 3-5, stipite communi multo longiores, erectæ, dorso adnatæ, supra medium liberæ, apice muticæ. Perigonium obconicocampanulatum 3-fidum, extus et intus (ut in specim. Americanis) puberulum.-Paniculæ axillares, compositæ, bracteis ad basin ramorum, bracteolâ vero sub flore nullâ, pedicellis umbellatis. Nervi laterales mediocres. Nomen ex antheris apice liberis. -

49. M. FARQUHARIANA (Wall. list 6798, excl. a), foliis lanceolatis acuminatis basi acutis glabris rigide coriaceis, nervis lateralibus utrinque 12-15, paniculis masc. axillaribus compositis diffusis folio duplo-quadruplo brevioribus floribusque externe ferrugineo-pulverulentis, floribus ad apicem et secus ramos extremos inflorescentiæ umbellulatis aut subsolitariis pedicello sublongioribus ebracteatis̀; perigonio obovoideo subtrifido lobis ovatis erectis, antheris 4 ? stipite multo longioribus apice liberis. 5 In Indiâ, pŕope Mercara (Hohen. 541 l). - Hook. f. et Th. fl. ind. 1, p. 161 (excl. specim.e Philippinis et forsan aliis e penins. Malayanâ). Folia 7-8 poll. longa, 2 poll. lata, petiolo 6-7 lin. longo, nervis lateralibus tenuibus, versus apicem parum distinctis, tertiariis reticulatis minimis. Paniculæ masc. sæpius 3 poll. longæ, ramis patentibus 1-2 poll. longis, ex axillâ bracteæ lalæ obtusæ linèam longæ. Pedícelli graciles, lineam longi, bracteolis minimis basi intermixti, apice vero nudi. Flos 2 lin. longus, apertus obconico-obovoideus, interne glaber. Antherse vix lin. longæ, connectivo apice non producto. Gfr ad M. Malabaricam. (v. s. in h. Boiss.)

50. M. PANicOL a Ta (Alph. DC. in Ann. sc. nat. sér. 4, r. 4, p. 31), foliis oblongis ellipticis acuminatis basi subacutis glabris membranaceis junioribus pellucide- punctatis, nervis lateralibus utrinque 8-9, paniculis masc. axillaribus compositis foliis triplo quadruplove longioribus floribusque externe ferrugineopulverulentis, floribus ad apicem et secus ramos extremos inflorescentiæ umbellulatis pedicello sublongioribus ebracteatis, perigonio obconico-campanulato subtrifido lobis ovatis erectis, antheris 3-5 stipite multo longioribus apice liberis. $b$ In Philippinis (Cuming / 901). M. Farquhariana Hook. f. et Th. fl. ind.1, p. 161 partim. Rami glabri. Folia 4-6 poll. longa (inel. petiolo 5-6 lin.), 9-18 lin. lata. Flores vix lineâ longiores. Stipes infra antheras minimus. Antheræ loculis linearibus, adpressis, apice liberis acutis, connectivis muticis. Mixta cum M. Farquharianâ in Fl. ind.; differt vera præsens a num. $\mathbf{5 4 1}$ Hohenackeri foliis tenuioribus, , nervis lateralibus minus numerosis et magis obliquis, paniculis minus diffusis, minus ferrugineis, floribus minoribus latioribus, An specimina Malayana hic referenda? (v. s.)

Sect. vil!. Horsfieldia. - Genus Horsfieldia Willd. sp. 4, p. 872, non Blume. -Sect. Pyrrhosiæ sp. Blume Rumph. l. c. -Sect, Eumyristicæ sp. Hook.f. et Th. fl. ind. 1, p. 163.

Columna staminum elongato-obovoidea, antheris 6 , dorso toto adnatis, stipitem subæquantibus. Cotyledones ovatæ, planæ, divergentes. - Racemi compositi, ramis alternis, floribus masc. sessilibus minimis, fem. subsessilibus, secus ramos secundarios racemi et eorum extremitates in fasciculos dispositis. Bracteæ communes et bracteolæ cuique flori adpressæ. Perigonium obconicum vel ovoideum. Nervi tertiarii foliorum transversi, vix perspicui.

51. M. Hor SFIE L Dr A (Blume bijdr., p. 577, non Wall.), foliis ovato-oblongis acuminatis basi obtusissimis subtus pube steliatâ evanescente puberulis nervis utrinque 
13-14, paniculis axillaribus petiolo multoties longioribus furfuraceo-tomentosis, floribus extremitate ramorum inflorescentize dense glomeratis, masc. obpyramidatis sessilibus, ferm, ovoideis subsessilibus, antheris 6 , baccâ elongato-ovoideâ brevissime pedicellatà, arillo carnoso semen penitus tegente. $f$ In Ceylan (Thwaites! 221). - M. Iryaghedhi Giertn. fruct. 1, p. 196, t. 41, f. 4 (excl. syn. Burm. et Herm.). Horsfieldia odorata Willd. sp. 4, p. 872. M. Horsfieldii Blume Riumph." 1, p. 192, t. 63(masc.), Hook. f. et Th. 1. c. Pyrrhosa Horsfieldii Wight ic. t. 1857 (fem.). M. ferruginea Wall. list 6803, fide Hook. f. et Th., Zoll. 3263! Ramuli apice dense tomentosi. Folia subdisticha 5-8 poll. 3-3 $\frac{1}{2}$ poll. lata, basi subcordata, petiolo crasso 5-8 lin. longo. Racemi 2-4 poll, longi, masc. majores. Flores lineam longi eirciter viginti in quoque capitulo, bracteis latis ovato-acutis tomentosis mixti, mase. apies obtuso 3-4-lobi, glabri ; fem. 3-fidi extus velutini. Perigonium pirgue. Ovarium obovoídeo-trigonum, nempe nervo hinc carinatum et præterea utrinque tumefactum, ibique tomentosum. Stigma sessile, sublobatum. Bacca pollicem longa. (v, s. fem.)

\section{Sect. IX. Dictyoneura.}

Antherse paucæe circa discum concavum verticillatæ, stipite longiores. - Racemi compositi, ramis alternis, fasciculis florum secus ramos sessilibus approximatis, floribus turbinatis. Nervi laterales foliorum vix tertiariis majores, a medio limbi bifidi et anastomosantes; nervatio ideo reticulata, unde nomen.

52. M. Madagascariensis (Lam. Mem. Acad. se. par. 1788, p. 163, t. 4, opusc., t. 8, vol., ic. mal.), foliis ellipticis subacutis basi obtusis coriaceis superne glabris, subtus glabrescentibus nervis lateralibus utrinque 15-18 aliisque et tertiariis minoribus reticulatis, racemis axillaribus folio quadruplo brevioribus rufo-velutinis, floribus secus ramos racemi distichos sessilibus crebris turbinatis extus rufotomentosis. $b$ In Madagascar. Muscadier de Madagascar, ex ins. France, herb. Mus. par. in herb. meo, Colitur Mauritio (h. Deless.!).- Poir. dict. enc. 4, p. 338 (ubi descr.

E. Lam. iterata), non Bojer. Rami lignosi, glabri, cylindrici. Folia novella pallide velutina, adulta $4-5$ poll. longa, $1 \frac{1}{2}-2 \frac{1}{2}$ poll. lata, petiolo 5-6 lin. longo, ex ic. basi acuta, ex descript. ovalia, ex specim. meo basi oblusa, nervis lateralibus et aliis non subtus eminentibus, sed crebris reticnlatis et colore intensiore distinctis. Flores jun. masc, pedunculos laterales inflor'. $2-4$ lin. longos tegentes, $\frac{1}{3}$ lin. longi, intus glabri. Bractese dentiformes breves ad basin pedunculorum. Perigonium superne tomentosum, basi et intus glabrum, lobis 4 (an semper?). Columna staminea basi gracilis brevis, apice antheras 4-6 verticillatim gerens, medio depressa, antheris stipite longioribus. Fructus (ex spec. h. Juss. a Lam. obs.) ovoideus, ferrugineo-tomentosus. Culta in ins. Mauritio, saltem tempore Sonneratii, sed diversissima a M. Madagascariensi quam cl. Bojer cultam legit et comm.(v. s. in h. meo, et h. Graves.).

\section{Sect. $x$. IRYANTHERA.}

Columna staminum ovoideo-cylindrica, apice truncata; antheris 3 brevibus dorso inzertis, muticis, externe circa marginem supericrem columnæ verticillatis, stipite communi multo brevioribus. Perigoniuntsphærico-trigonum.-Fasciculi florum secus pedunculum communem, bracteâ basi inclusi. Flores breviter pedicellati, minimi, bracteolà adpressà basi stipati. Nervi laterales validi, prope marginem arcuati et manifeste connexi, tertiarii reticulati. - Antheræ sectionis Iryæ, unde nomen. Americana.

53. M. HoSt MANN (Benth.! in Hook. Journ. 1853, p. 7), foliis ellipticis acuminatis basi rotundatis cuneatisve coriaceis glabrescentibus nervis validis utrinque circiter 15 , pedunculis axillaribus petiolo $2^{\circ}-4^{\circ}$ longioribus nunc a basi bifurcatis, fasciculis florum sparsis e bracteà communi squamiformi, pedicellis gracilibus, bracteolâ floris bracteâ et inflorescẹntià totâ fulvo aut fulíginoso-tomentosìs, perigonio extus tomentoso, intus glabro. 5 In Guianâ ad Surinam (Hostm.! 1162 et 1161 in h. Boiss., 1162 et 1181 in h. Graves) et Cayenne (h. Mus. par. in l. meol). Rami petiolique fuliginoso-tomentosi, glabrescentes. Folia 5-7 poll. longa, 2-3 poll. lata, petiolo 3 lin. longo, nervis lateralibus utrinque circiter 15: præcipuis (aliis mediis minoribus) subtus eminentibus ad 3-4 lineas marginis arcuatis et connexis,

i tertiariis vix perspicuis, parenchymate in sicco ruguloso. Pili fol. juniorum pro ordine longi adpressi fuggaces non stellati. Bracteæ lineâ: breviores ovatæ. Bracteolæ 
minores. Perigonium $\frac{a}{1}$ lin. longum, pedicello 2 lin. Antheræ stipitem communem superantes, ellipsoideæ, sed profunde loculis \& divisæ; conneetivo apice abbreviato. Post antliesin noduli secus peduueulum ex bracteả et pedicellis ruptis. (v. 's.)

\section{Sect. XI. IRYA Hook. f. et Th. fl. ind. 15, p. 159,- Sect. Pyrrhosæ speçies Blume Rumphia 1, p. 190.}

Columna staminum pyriformis, apice concava; antheris brexibus ellipsoideis muticis externe circa marginem superiorem columnæ verticillatis, dorso toto adnatis, stipite communi brevioribus. Perigonium subglobosum bifidum. Cotyledones planæ divergentes.-Paniculæ compositis. Flores minumi, ad extremitates ramulorum panicula condensati, brevissime yedicellati. Bracteæe fugacissimæ ad ordinem ramerum inflorescentiæ. Bracteola sub flore nullia. Neryi tertiarii foliorum reticulati, - Seetio Pyrrhosie nimis proxima.

54. M. IRYA (Gærtn. fruct. 1, p. 195, t. 41), foliis ovato-oblongis acuminatis basi obtusis utrinque glabris, nervis utroque latere 10-12, paniculis laxis compositis glabriusculis, pedicellis brevissimis pubescentibus, floribus masc. glomerulatis compresso-turbinațis bifidis glabris, fem. late globosis, fructụ globoso-tuherculato-verrucoso, arillo completo. $\mathcal{E}$. In sylvis reg. inf. Jąa (Blume), Borngo (Lowe in Hook. f. et Th.), Martạaniææ et Moalmein (Wall. ib.) et Ceylan (Thwaites! 2620). -Hook. f. et Th. fl. ind. 1, p. 159. M. Javanica Blume bijdr. p. 576 et Rumphia 1 , p. $190^{*}$, t. 62. M. sjuherocarpa Wall. pl. As. rar. 1, t. 89, list 6796, cat. itin. burm. 1069 ! M, exaltata Wall, list. 6804, quoad specim. florif. e Moaknein. Folia magn. varia, sæpius 6-10 poll, longa, 2-3 poll. lata, petiolo 2-3 lin. solinm longo. Papiculæ axillares aut subaxillares, $4=\beta$ poll. longæ, pube ochreaceâ fugaci, bracteis cadueis. Flores mase vix lineam longi, 5-10 circiter glomerati. Anthera 6-7. Fructus (ex ic. Wall.) lutescentes, poll. lati, valvis 2 patentibus. Arillus aurantiacus (Bl.). Albumen inodorum. (v. s. fruct.)

\section{Sect. XII, PY̌rnhosa Blume Rumphia 1, p. 190 (excl. plerisque sp.), Hook. et Thoms. fl. ind. $1, p .160$.}

Stamina in massam globosam omnino antheriferam vix stipitatam coalita, Perigonium late subglobosum, profunde 2-3-fidum. Cotyledones..... Paniculæe compositæ, ramis alternis, pedicellis alternis et subumbellatis. Bractex basi ramorum inforescentiæ fugaces obscure; bracteola sub flore nulla. Flores parvi. Nervi tertiarịi foliorum reticulati, sepius non perspicui.

55. M. GLABR A (Blume bijdr. p. 576, Rumphia 1, p. 191, t. 64, f. 1), foliis lanceolatis vel obovato-oblongis acutis basi longe angustatis glabris nervis utriaque 14-15, paniculis axillaribus ramosis petiolo $2^{\circ}-4^{\circ}$ longioribus glabriusculis, floribus masc. globosis pedicellum subæquantibus, fructa ovali-oblongo, arillo subcompleto. 5 In Javâ, circa Singapore et in mont. Sillet. - Hook. f. et Thoms. fl. ind. 1, p. 161, Zoll.! pl. Jav. n. 1202 ! M. integra Wall. list 6799 (fide Hook. et Th.). M. floribunda Wall. list 6805 (ex eisd.). Rami rugulosi, glabri. Folıa 5-7 poll. longa, 1 $\frac{1}{-3}$ poll. lata, petiolo 9-12 lin. longo. Pubes tenuis, ex specim. meo Zolling,; in paginâ inf. foliorum, paniculse ramis et floribụs demum evanescens. Flores numerosi, segregati, vix lineam longi, 3 -fidi. Antheræ 9-12, in massam glohosam vix stipitatam coalitæ. Fructus ovalis, ultrapollicaris. Arillus tenuiter carnosus eqeçineus. (ex H. et Th.). Confer ad M. aruanam, infra, $n$. 77. (v. s.)

56. M. LAVIGATA (Blume Rumphia 1, p. 191, t. 64, f. 3 et anal.), foliis obovatoellipticis obtuse acuminatis basi acutis glabris nervis lateralibus utringue $\mathbf{1 6 - 1 8}$, paniculis (fem.) axillaribus ramosis folio triplo brevioribus petiolo multaties longioribus glabriusculis, floribus globosis pedicellum subæquatatibus. o In Mauritio a Commerson reperta et in Mus. jar. sérvata nomipe Muscadier sauvage à fruit globuleux (Blume 1. c. ex h. par, et in herb. meo a Mus. par, copmo.). Vix ex istâ insulâ credo, sed potius planta ibi culta e Philippinis aut Moluccis. Rami jụiores leviter fulvo-velutini. Folia 6-9 poll. longa, 2-3 poll. lata, petiolo 4-5 lin, longo, nervis later. parum eminentibus, tertiariis vix̄ perspicuis. Flores fem $\frac{1}{2}$ lin. Longi, 2-3-fidi, extus glabriusculi. Oxarium ovoideum tomentosum. Valde affinis M. glabræ: petioli longiores, flores majores, sed equidem feminei. (r. s.)

57. M. GL.0 B U LARIA (Blume Rumphia 1, p. 191, t. 64, f. 2, non Lam.), foliis oblongis

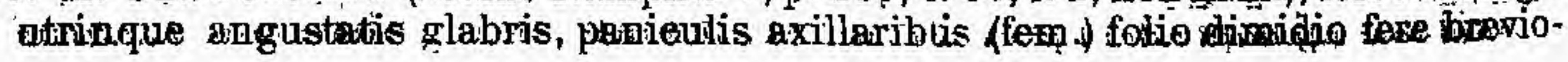


ribus multifloris ramosissimis ferrugineo-tomentosis, floribus (fem.) minimis glohosis ad apices ramorum paniculee fasciculatis brevissime pedicellatis, fructu ovoideo parvo. 5 In Amboina (Kumph.) et ad Malaccam (Griff. ex Hook. et Th.). Hook, et Th. fl. ind. 1, p. 160. Palala quinta seu Globularia Rumph. Amb. 2, p. 28, t. 9. Planta Rumphí folia liabet 4-5 poll. Ionga, 9-15 lin. lata, petiolo 2-3 lin., racemos laterales paucifloros; fruetus modo uvarum non maturarum, sed magis oblongos rufos rugosos et quasi arenosos; arillum sanguineum incompletum. Ilanta Blumei in phrasi describitur, et ad eam retulerunt el. auctores fl. indicæo arborem Malaccensem, ubi folia $\mathbf{4 - 5}$ poll. Longa, petiolo 8 lin. Longo, paniculæ masc. 2-3 poll., antlieræ in globum 3-4 lobum coalítæ. Ex ic. Blumei inflorescentia omnino M. glabra. Flores multo minores, $\frac{3}{4}$ lin. lati.

58. M, Lemanniana (Alph. DC, in Anu, sc. nat, sér. 4, v, 4, p. 31), foliis oblongis longe acuminatis basi obtusis glabris nervis lateralibus utrinque 13-14, racemis axillaribus compositis ferruginco-velutinis folio triplo brevioribus, floribus minimis globosis apice ramorum inflorescentiæ congestis vix pedicellatis glabris.bAd Malaeca (Lemann). Rami glabri. Folia subdisticha, novella puberula, cíto glabra, 6-7 poll. longa, 15 lin. lata, coriacea, nervis parum distinctis, petiolo 3 lin. longo. Inflorescentia M, Globularise. Flores mase. $\frac{1}{2}$ lin. longi, Antheræe 6 in massam stipite multo majorem connatæ. Flores fem, jgn. (v, s. in h. Boiss.)

O 59. M. Maсrотнугs (Míq, pl. Jungh. p. 172), folís amplis oblongis utrinque acutis vel obtusiuscule apiculatis basi nunc subcuneatis coriaceis glabris, paniculis (masc.) lateralibus folio duplo brevioribus subglabris patentim ramosís, perigonio globoso-obovoideo obtuso trigono glabro trifido, fructu globoso-ellipsoideo, s In Sumatræ sylvis, prope Tolbing. Innoyationes tenere subleproso-pulverulentæ.

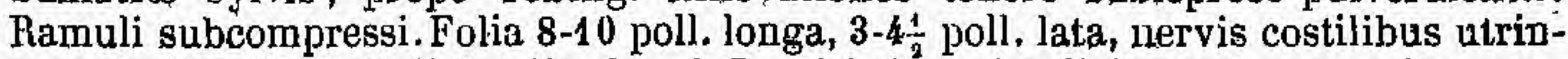
que circiter 16. Petioli 3-4 lin. longi. Rami inflor. simpliciter vel composite racemosi. Flores lineam longi. Columna stam, obovoidea trigono vertice subplana, tota lere antheris obtecta. Fructus gemini vel terni in inflorescentiâ nunc brevi sublaterali, subglabri, pollicares sed immaturi.

60. M. ARDISIafOLTA (Alph. DC. in Ann. sc. nat. sér. 4, v. 4, p. 31), foliis amplis ellipticis vel obovato-ellipticis utrinque subacutís vel obtusiuscule apiculatis coriaceis glabris nervis lateralibus utrixque 23-26, paniculis (masc.) folio duplo brevioribus subglabris patentim ramosis perigonio late globoso pedicellum æquante bipartito głabro, antheris 18-20 inflexis. o In Philippinis (Cuming! 1702). Rami glabri, læves. Inuovationes extremæ velutinæe, rufescentes. Folia 8-10 poll. longa, 3 poll. lata, petiolo 4 lin. longo, nervis lateralibus versum marginem arcuatis et connexis, tertiariis non perspícuis. Paniculæ 3.5 poll. longæ, ramis secundariis patentibus alternis 1-2-pollic., tertiariisque et ultimis granulato-subvelutinis giabrescentibus. Flotes numerosi, $1 \frac{1}{2} \mathrm{lin}$. lati, vix aperti. Antheræ in verticillum medio vacunm brevissime stipitatum conuatic, apice subliberæ; inflexæ ot ideo globum eflicientes, connectivo perspicuo non tamen apiculato. (v. s.)

61. M. WALLICHII (Hook. f. et Th. fl.ind. 1, p. 161), foliis anguste oblongis acutis basi rotundatis coriaceis supra lueidis, subtus pallidis (in sicco rufis) præserting secus costas et nervos tomentosulis, paniculis mase. elongatis ferrugineo-tomen. tosis, fem. brevioribus incrassatis, fructu oyali glabro. s Ad Malacca (Griff.) et Singapur (Wall.). M. Horsfieldii Wall list. 6806 (non Blume). M. Globulariæe simillima, sed partes novellæ dense tomentosæ et folía majora 6-9 poli. longa, $2 \frac{1}{2}-3$ poll. lata, petiolo 8 lin. longo. Nervi crebriores, subtus validi, versus marginem arcuati. Flores aliquanto majores, perigonio 3-4-lọbo, glabro. Pedicelli masc. brevissimi. Flor's fem. pedunculo simplici vel parum ramoso abbreviato (fructifero incrassato lignoso) inserti, perigonio globoso late 3-dentato. Ovarium globosum, tomentosum. Stigma sessile, capitatum. Fructus junior perigonio 3 -partito cinctus.

62. M. A MYGDALINA (Wall. pl. As. rar. 1, t. 90, list 6797, cat. ined. itin. burm. 1102 ! non Thwaites pl. Ceyl.), foliis cuneato-obtongis acutis basi angustato-acutis, glabris, nervis tenuibus ufrinque $11-13$, racemis fructif. petiolo $2^{\circ}-4^{\circ}$ longioribus, fructibus lateralibus ovatis nutantibus lævibus hinc sulcatis, arillo tenui apice laciniato-lacero. $b$ In Martabaniâ et ad Moalmein. Rami glabri. Folia 4-5 poll. longa, 1-1 poll. lata, in petiolum semipollic. angustata, glabra, coriacea, nervis parum distipetis. Fructus 2-4 in racemo, e viridi fuscescentes, pollicem longi, bjy vilyes. Arfilgts aurantíacus, parnm carnosus, lacinif́s trevibus apice supra nucleum reflexis. 
Nux et arillus aromate fere omnino carent. Specimen meum ab ipso Wallichio nuncupatum convenit cum icone. (v. s.)

B. Hookeri, foliis et paniculis longioribus, paniculis velutinis. M. exaltata-Wall. 6804, pro parte. M. amygdalina Hook. f el Th. fl. ind. 1, p. 160, pro parte. Folia ex Hook. et Th. 5-8 poll. longa, 1,-21, lata, petiolo semipoll.; panicule 3-5. poll.; perigonium globosum, plerumque trilobum; columna stain. glabra, 3-4-loba, antheris linearibus apice incurvis; flores parvi ut in M. Iryâ, numerosi, ramis inflor. dilfusis.' Genuina M. amygdalina Wallichị solum fructifera cognoscitur. Sub M. exaltatâ Wall. list. 6804 plures speries latent; cel. Hook. et Th. jam quxedam specimina ad M. Iryam retulerunt, sed ab ipso Wallichio specimina e Trogla hills ( $\mathrm{n} .1857$, cat. itin. burm., $6804 \mathrm{a}$, list) accepi quæ foliis magnis membranaceis, paniculis fructif. longissimis $\mathbf{5}$-pollicaribus, fructibus erectis oblongis basi angustatis arilloque incompleto a Mr. amygdalinâ toto cœelo differunt.

63. M. CRASSIF OLIA (Hook. f. et Th. fl. ind. 1, p. 160), ramulis validis, foliis ovalibus vel oblongis utrinque obtusis coriaceis, paniculis axillaribus ramosissimis pubescentibus, floribus ad apices pedunculorum fasciculatis, antheris 4 sessilibns ovalibus in columnam depresse globosam coalitis. 3 In penins. Malayana (Griff.). Cortex fuscus, rugosus, glaber. Folia crasse coriacea, nervis obliquis rectis apice tantum eurvulis subdistantibus, 5-9 poll. longa, $3-4 \frac{1}{2}$ poll. lata, petiolo 9 lin. longo. Paniculæ 4-6 poll. longæe, bracteis ad ramos primordiales subpersistentibus ovalibus. Perigonium plerumque bivalve.

64.? M. TOMENTOSA (Hook. f. et Th. fl. ind. 1, p. 161, non Thunb.), foliis obovatis vel caneato-oblongis basi attenuatis subacutis subtus pilis stellatis laxe tomentosis nervis later. 13-14, paniculis axillaribus laxe rufo-tomentosis masc. folio triplo brevioribus, perigonio glabro globoso. 5 In penins. Malayanâ ad Penang (Wall.! list, n. 9025, Potts! Gaudich.!). Tomentum caducum. Folia 5-8 poll. longa, 2-4 lata, obtusa vel acuta, petiolo 4-6 lin. longo. Panıcula 2-3-pollicares, ex Hook. et Th. ante expansionem bracteis deuse tomentosis involutæ. Perigonium 3-4-fidum. Eaniculæ fem. (ex spec. Gaudich.) minores, minus ramosæ, perigonio obovoideo glabro. Flores masc. vix lin.' longi, feminei submajores. Ovarium ovoideum tomentosum. (v. s.)

Sect. xIII. KNEMA Blume Rumphia 1, p. 187, Hook. f. et Th. fl. ind. 1, p. 155. - Genus Knema Lour. fl. coch. p. 741.

Columna staminum claviformis, perigonio duplo circiter brevior superne in discum concavum vel convexum dilatata ; antheræ circa marginem disci dentiformes, radiantes vel suberectæ, plus minus distinctæ, connectivo bene perspicuo cum materia disci et stipitis inferne continuo. Perigonium globoso-turbinatum, 3-gonum. Cotyledones planæ (ex Blume).- Pedicelli ad apicem pedunculi umbellati. Bractea superior a flore distans, caluea. Folia discolora; nervis tertiariis transversis. - Sectio magis distincta quam aliæe et forsan genus distinctum; inflorescentia tamen Eumyristicæ, columna staminum ab Iryâ el imo Pyrrhosâ parum diversa, et characteres in fructu nondum detecti.

65. M. HOOKERIANA (Wall.! list.6802, A, non B, qhod Laurinea?), ramulis dense floceosis, foliis maximis anguste obovato-oblongis vel lineari-oblongis basin yersus paulo angustatis basi subcordatis glabrescentibus, nervis validis utrinque circiter 30, petiolo tomentoso, inflorescentiâ ......, perigonio obovato-globoso semi-3-lobo extus laxe tomentoso, disco staminum parum concavo antheris 18 dentiformibus, fructu oblongo externe dense floccoso, arillo lobato. 5 In insulà Penang. - Hook. f. et Th, 11. ind. 1, p. 156. Ramulorum corlex facile separabilis, tomento floccoso tectus, ut omnes partes juniores. Folia cilu glabrescentia, petiolo solum semper floccoso, 1-2 podern longa, $3 \frac{1}{2}-8$ poll. lata, petiolo 9 lin. longo, nervis tertiariis transversis parvis. Perigonium 4 lin. longum. Fructus 2 poll. longus, valyis crassis, tomento luteo 2 lin. crasso intertexto notandus. Arillus carnosilus. (v. s. fructif.)

66. M. LONGIFOLIA (Wall.! list 6801), ramulis furfuraceis, foliis magnis oblongolanceolatis basi cordatis, rarius rotundatis apice angustatis oblusis glabris, nervis validis utrinque 23-30, fasciculis florum axillaribus petiolo brevioribus pedunculo 
et pedicellis brevissimis velutinis, antheris 12-18 circa discum concávum, fructu oblongo-tomentoso. 5 In montibus Khasia Bengalise or. (Wall.!), et in penins. Malay. ad Chittagong (Griff.). - Hook. et Th.! fl. ind. 1, p. 156. M. linifolia Koxb. 11. ind. ed. 1832, v. 3, p. 156? ex Hooli. et Th. Partes novellse dense tomentosæ. Folia (ex Hook. et Th.) formâ et magn. admodum varia, interdum lineari vel obovatooblonga, $\frac{1}{2}-1 \frac{1}{2}$ pedalia, 2-6 poll. lata, petiolo 9-12 lin. longo, subtus pallida, costâ basi furfuraceâ, nervis tertiariis transversis parvis. Pedunculus bracteis rotundatis parvis onustus; pedicelli medio bracteolati. Flos 4 lin. longus, ut pedicelli et pedunculus furfuraceus. Fructus bipollic. rectus. Arillus tenuis, labatus. (v. s.)

67. M. ER RATICA (Hook. f. et Th. fl. ind. 1, p. 156), ramulis tenuiter furfuraceis, foliis anguste lanceolatis vel late linearibus apice attenualis acutis basi acutis supra glabris subtus secus costam et rervos cinereo-furfuraceis, nervis lateralibus 23-26, floribus ad apicem pedunculi axillaris paucis, antheris 12 circa discum planum, fructu lato ovali vel subgloboso tomento brevissimo incano, arillo crasse carnoso apice lacero. $\delta$ In mont. Khasia Bengalize or., ad 2-3000 ped. alt. Ramuli adulti glabri. Folia 6-12 poll. longa, $1 \div-2 \frac{1}{2}$ poll. lata, petiolo $6-8$ lin. longo. P'edunculi axillares vix 3 lin. longi, lignosi. Pedicelli eorum apicem versus inler bracteas squamiformes fasciculati, 4-6 lin. longi, cinereo-jncani, sujpa medium bracteolam latissimam amplectentem minutam gerentes. Alabastra masc. subgloboso-triquetra. Fructus plerumque solitarii, 2-poll., minute fusco-puberuli. Arillus demum coccineus. Nucleus oblongus, obliquus. (v. s. comm. a cl. Hook. f.)

68. M. ATTENUAT A (Wall.! list 6791), ramulis teuuiter furfuraceis, foliis oblongolanceolatis longe angustatis basi acutis vel rotundatis glabrescentibus, nervis lateralilus utrinque 12-20, pedunculis asillaribus paucifloris, pedicellis pedunculo longioribus petiolo equalibus vel longioribus, perigonio subgloboso laxe tomen1oso, antheris 12 eirca discum planum, fructu ovali vel oblongo fulvo-tomentoso, arillo tenuissimo apice lobato. 5 In montibus Concan Indiu' prov. Bombay. Hook. f. et Th. fl. ind. 1, p. 157. Ramuli graciles, adulti glabrati. Folia secus costam et nervos subfurfuracea, demum glabra, 5-8 poll. longa, $1 \frac{4}{4}-2 \frac{3}{4}$ poll. lata, membranacea, nervis tertiariis transversis minimis, petiolo 5-6 lin. longo. Pedunculi 3-4-flori. Pedicelli apice bracteolati. Fructus sesquipollicaris. (v. s. imperf. spec.)

69. M. GIBBOSA (Hook. f. et Th.I fl. ind. 1, p. 158), ramulis glabriusculis, foliis anguste lanceolatis acuminatis basi acutis supra glaberrimis, subtus secus costam subfurfuraceis glabrescentibus nervis lateralibus utrinque 19-20, fruetu oblongotomentoso obliquo hine gibbo, arillo tenuí apice tantum sublacero. $b$ In montibus Khasia, ad or. Bengalix. Partes novellæ tenerrime furfuracese, cito glabrescentes. Folia 4-7 poll. longa, 1-1 $\frac{3}{4}$ poll. lata, petiolo 7-8 lin. longo; subtus pallida, in sicco flavescentia. Pedicellus fructus semipollic. pedunculo brevissimo. Fructus valvæ valde coriaceæ, intus castaneæ, nervosæe, rugulosæe. Semen obliquum, chalazà longe infra-apicali. Specimen e Tenasserim floriferum ejusdem spec. suspicantur cl. auctores; in hocce : pedunculi validi, semipoll., apice in ramos plures abbreviatos dense squamosos divisi ; pedicellí plures 3-6 lin. longi, medio bracteolati; perig. ferrugineo-pubescens, ovale vel campanulatum, semi-3-lobum; anthera 12 eirca discum. (v, s.)

70. M. con TI $\cos$ A (Hook. f. et Th.! fl. ind. 4, p. 158), ramulis glabratis, foliis elongato-ellipticis utrinque acutis vel obtusis glabris, nervis lateralibus 16-21, pedunculis axillaribus abbreviatis plurifloris pedicellis perigoniisque extus ferrugineovelutinis, pedicellis cum pedunculo petiolo brevioribus, floribus din globosis pedicello æqualibus aut duplo triplo minoribus, antheris 8-14 circa discum planum breviter stipitatum suberectis, fructu ellipsoideo-pulverulento, arillo subcarnoso. .5 In Javâ (Kollmam in h. Boiss.I Zoll.! 2650), Borneo (Hools. f.), Philippinis Cuming ! 844, 1309, 2315), Cochinchinâ (Lour.), penins. Malayanâ (Wall.l 6794) et Sumatrâ (Blume, Mic. pl: Jungh.). Knema corticosa Lour. fl. coch. p. 742 (fide specim. anth. a Hook. f. vis.). M. Globularia Lam. Mém. Acad. sc. Par. 1788, p. 162, t. 5 opusculi, 9 voluminis (non Rumph.). Knema glaucescens Jack in Mal. mise. et in Hook. comp. bot. mag. 1, p. 149, non Wall. M. glaucescens Hook. et Th. fl. ind. 1, p. 157, non Wall. M. Sumatrana Blume! Rumphia 1, p. 187. M. glauca Blume bijdr. p. 576, Rumphia *1, p. 182 , t. 60. M. lanceolata Wall. list, 6794 ! (non in $\mathrm{h}$. Deless. ubi est M. fragrans !). M. missionis Wall. list 6788, fide Hook. et Th. M. angustifolia Roxb. fl. ind. 3, p. 847, fide Hook. et Th. Folia 4-9 poll. longa, 1:2 poll. lata, petiolo 4-7 lin. longo, subtus pallidiora, nervis lateralibus 
validis, lertiariis parvis transversis. Bracteolæ squamiformes basi et ad apicem pedicellorum. Pedicelli 1-3 lin. longi. Antheræ magis approximatæ et erectæ quam in ic. Bl. Fructus 15 lin. Arillıs punicens multipart. maculis 2 basi luteis ex ic. Blumei, quæ cæeterum peccat in staminibus et bracteis. Variat magnit. foliorum, tervis lateralibus utrinque 16-21, longit. pedicellorum, numero florum et staminum, bracteolà nunc sub flore, nunc infra. Forma stam. constans. (v. s.)

71. M. IN TE R M E D A (Blume Rumphia 1, p. 187), ramulis glabriusculis, folíis oblongis lanceolatisve utrinque subacutis glabris, nervis lateralibus utrinque 15-18, pedunculis axillaribus minimis plurifloris pedicellis perigoniisque extus ferrugineotomentosis, pedicellis cum pedunculo petiolo brevioribus, floribus diu globosis pedicello duplo brevioribus, antheris 10-13 eirca discum superne in umbonem productum breviter basi stipitatum patentibus, counectivo pingui loculis validiore, fructu pyriformi ocliraceo-pulverulento. $b$ In Javâ (M. glauca Zolll. n. 1163! non Blume, Lobb 31 5, in h. Deless.) et ad Singapur et Malaccam (Hook. f. et Th. fl. ind. 1, p. 158). Folia fere M. corticosæ, paulo rigidiora et angustiora. Inflorescentia eadem, sed flores paulo majores, $1 \frac{1}{2}$ lin. longi et magis tomentosi. Stamina præsertim diversa; disco superne convexo umbonato; connectivo cujusque antheræe e materiâ disci manifesto, obtuso, loculis utroque lạtere parvis. (v.s.)

72.7 M. FURFUAGEA (Hook. f. et Th. fl. ind. 1, p. 159), ramulis petiolisque dense furfuraceo-tomentosis, foliis anguste vel lineari-oblongis utrinque obtusis acutisve glabris, nervis lateralibus 11-12, pedunculis petiolo duplo triplove brevioribus, pedicellis ....., flore fem. pyriformi dense tomentoso. 5 In ins. Penang, penins. Malayanæ. Knema glaucescens Wall.! list 6810, non Jack, nèc Myristica glaucescens Wall. quæ Lauracea. Tomentum ramorum juniorum et inflorescentiæ colore tabacino, facile detersum. Folia 4-7 poll. longa, 1-13 lata, potius acuta, petiolo 3-4 lin. longo. Flores et fructus mihi ignoti ; ex cl. auct. flores 3 lin. longi, fructus immaturi subglobosi dense tomentosi: M. intermediæe et $M$. laurinæe affinis vídetur. (v. s. spec. imperlect.)

73. M. L.A UR IN A (Blume! Rumphia 1, p. 189 ", t. 61), ramulis inflorescentiâ petiolo nervisque foliorum furfuraceo-tomentosis, foliis ellipticó-obovatis oblongisve acumina, tis vel acutis biasi sčpius obtusis, superne glabris nervo centrali glabrescente, nervis lateralibus utrinque 13-17 subtus pülverulento-tomentosis, pedunculis petioló duplo brevioribus pedicellisque brcvissimis et floribus dense tomentosis, perigonio turbinato, lobis $3-4$ acutis erecto-concavis, antheris 8 dorso circa discum concavum stipitatum insertis, fructu obovato-ellipsoideo rufo-tomentoso. $₹ 5$ in Javà et Nusâ Kambangan (Blume !). -Zoll.I n. 296, in h.meo, 996 in h. Deless. M. tomentosa Blume bijur. p. 577, non Thunb. Rami et nervi rufi. Folia 3-6 poll. longa, $1 \frac{1}{2}-2 \frac{1}{3}$ poll. lata, raro apice obtusa aut basi acuta, petiolo 3-4 lin. longo, nervis laterälibus subtus validis. Inllonescentia rufo-tomentosa, bracteis ad basin et apicem jedicellorum brevissimum. Flores fem. majores, 3 lin. longi. Stylus glaber. Fructus pollicaris. Arillus apice fissus. (v. s.)

74. M. GL о merat a (Miq. pl. Jungh. p. 171), innovationibus hirtulis, foliis ovato vel elliptico-oblongis acuminatis basi rotuudatis coriaceis, juvenilibus subtus in nervis stellato-hirtellis, adultis glabris, paniculis sessilibus glomerato-contractissimis liirtulis glabrescentibus, tloribus fem. sessilibus, perigonio globoso 3-fido glabro, fructu ovoideo acutiusculo glabrescente. 5 In Javà? (herb. Jungh.). Folia

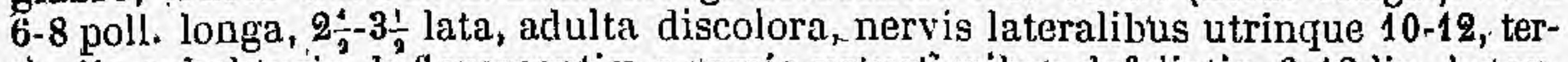
tiariis subobtusis. Inflorescentiæ e ramis vetustioribus defoliatis, 6-12 lin. longæ, glomerulum ramosum exhibentes. Flos lin. eirciter longus. Sectionis Knernæ dicit cl. auctor, folia vero M. Horsfieldia.

75. M. INSIP.IDA (Br. prodr. Nov.-Holl. p. 400), foliis oblongo-lanceolatis apice subatternatis basi acutiusculis, adultis subtus glabriusculis, glomerulis axillaribus paucifloris, baccis ovalibus maturis pulvereo-tomentosiusculis. g In Novâ-Hollandî́ or.-bor. intra tropicum. lolia; ait cl. auctor, Knemæ subsimilia et quenian inflorescentia convenit forsan ejusdem generis.

\section{Species dubice.}

46. M. a uminata (Lam. Mém. Acad. sc. Par. 1788, p. 164). In Madágascar. Malaomanguit, espece de rara, Poivre in herb. Juss. Folia minora quam in M. Madagas- 
cariensi, magis acuminata; nervis latenalibus eodem modo ramosis, supra lucidis, subtus albidis non vero tomenlosis, labitu fol. pyri. Rami glabri. Pedunculi juniores axillares, brevissimi, velutino-ferruginei. Specimina Javanica sub hoc nomine in herb. Ventenat, nunc Delessert, et in h. Webb et Graves, a plantâ Lamark forsan diversa, sunt alieni ordinis.

77. M. A RUA Na (Blume Rumphia 1, p. 191), foliis lanceolatis acuminatis basi acutis glabris, racemis früctiferis lateralibus folio duplo triplove brevioribus compositis, fructibus ovoideis subacutis. $\delta$ In Moluecis. Palala aruana Rumph. Amb. auct. p. 56, t. 24, f. 3. Fructus longit. digiti articuli, vix digitum crassi, hepatici coloris. Nux corrugata, fusco-nigricans, oleosa et inde aruenses in re medicú utuntur. Specimen adest, e Novâ-Guineả, sub illọ nomine comm. a cl. Blume cum Mus. par., M. glabra nimis proximum, sed flores nec fructus habel et inde differt forsan a plantâ Rumphìi.

78. M. CANARIPoRmis (Blume Rumphia 1, p. 191), foliis elliptico-acutis basi subacutis glabris, racemis axillaribus folio $\mathfrak{3}^{\circ}-4^{\circ}$ ve brevioribus compositis, floribus pedicellum subæquantibus, fructibus elongato-ellipsoideis, arillo inodoro. 3 In sylvis Amboinæ. Paläla canariformis-Rumpl. Amb. 2, p.'27, 1. 8. Ex Blume affinis videtur M. amygdalinse Wall. Ex Rumphio fructus parvi, sed ejus icon pessima flores tantum exhibet, ubi interdum calyx adest, an errore pictoris?

79. M. cinerea (Poir. dict. enc. suppl. 4, p. 35), ramis glabris, foliis ovato-lanceolatis utrinque acutis glabris, floribus ....., drupâ subrotundà tonentosâ rufâ apiculatâ. $b$ Ad fretum Bouton (Labill. in h. Deless.). Folia 6 poll. circiter longa, 2 poll. lata, subtus pallidiora, petiolo mediocri, nervis tenuibus. Drupa laterales, magnit. nucis avellina. Specimen authenticun non reperii Parisis, ubi nune herbaria Desf., Billard. et Lam. carent ; apud Deless. non inveni.

80. M. Luzoniç A (Blanco fl. filip. p. 664, ed. 2, p. 462), dioica vel polygama, foliis alternis lanceolatis basi obtusis integris superne glabris subtus puberulis, petiolo brevissimo, floribus masc. axillaribus medio rumbellatis, perigonio campanulato 3-fido. $b$ In ins. Luzon. Pedunculi 2 bracteis oppositis; pedicelli 1-bracteati. Nux major et inagis rotunda quam veræ Myristice, inodora, fructu tamen cum carne odoro. Duas alias species affines, absque nomine memorat cl. auctor (p. 665, ed. 2), quarum una verisimiliter est M. iners, in Philippinis crescens. Omnes inter plantas Cumingii procul dubio adsunt, sed recognoscendæ.

81. M. PARVIFLORA (Roxb. f1. ind. ed. 1832, v. 3, p. 847), foliis breviter petiolatis ovato-oblongis glabris, racemis $\mathrm{fl}$. fem. axillaribus longitudine petiolorum. $\mathrm{b} \mathrm{E}$ Moluccis in horto. Calcutt. tempore Roxb. culta.

82. M. PE t T A T A (Roxb. fl. ind. ed. 1832, v. 3, p. 846), foliis lanceolatis glabris superne nitidis, floribus masc. axillaribus fasciculatis rotatis, columnà staminum peltatâ 12 circiter antheris circa partem inferiorem marginis. E Moluccis cult. in horto Calcutlensi. Manifeste sect. Knemie, et probabiliter una e sp, cognitis.

83. M. SPICA a (Roxb. fl. ind. ed, 1832, v. 3, p. 847), foliis breviter petiolatis late lanceolatis glabris rigidis, floribus fem. numerosis in spicas breves solitarias axillarias dispositis, perigonio urceolato. E. Moluccis in horto Calcutt. anno 1798 et seq. culta.

84. M. TINGENS (Blume Rumph. 1, p. 190, sine descr.), foliis minoribus oblongis utrinque acutis glabris, paniculis fructif. lateralibus folio duplo brevioribus simplicibus, fructibus ovoideis parvis, arillo rubro.... b In Amboinse sylvis. Palala

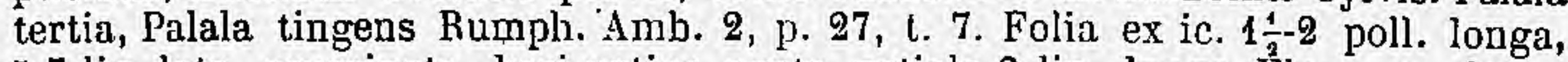
5-7 lin. lata. acuminata, basi potius acuta, petiolo 2 lin. longo. Flores ex descr. albidi, parvi. Fructus $20-30$ in eâdem paniculâ non ramosâ condensati, 7 lin. longi, extus virides, arillo tamen njberrimo et ad tingendum ab incolis adhibitum. M. microcarpa Willd. sp. 4, p. 871, pro parte. An sectionis Knemæ?

\section{Species non descriptce.}

M. HeYNeANA (Wall. list 6789). Myristica herb. Heyne. In Hook. f. et Th. fl. ind. non memorata.

M. MA GR OCARPA (Blume Rumph.p. 185, in adnot.). Nux Myristica quarta seu oblonga 
et maxima Camell, frut. et arb. in ins. Luzon. nasc. in Rai hist. 3, append. p. 58, sine descr.

M. M I C RANTHa (Wall. list, u. 6807). Ex herbario Finlayson, proptérea verisim. e Siam. Cl. Hook. f. et Thoms. fl. ind. 1. p. 159, specimen viderunt, nec tamen descripserunt. Proxima M. Iryæ, sed antheris magis numerosis et inde, aiunt, forsan species distincta.

\section{Verisimiliter excludenda.}

M. U VIF ORM IS (Lam. Mém. Acad. sc. Par. 1788, p. 166,) foliis lanceolatis acutis .margine undulatis superne glabris, subtus præsertim ad nervos subvelutinis, petiolo ad apicem bicalloso, racemis lateralibus fructiferis, fructibus numerosis pacemo condensatis ovoideis utrinque suljacutis apice stigmate 4-fido? donatis. $\checkmark$ In Molluccis (Sounerat). - Poir. dict. enc. 4, p. 391 (ubi deser. Lam. iterata). Folia 3-3 $\frac{1}{2}$ poll. longa, $1 \frac{1}{2}$ poll. lata vel latiora. Fructus maga. uvæ, 5 lin. longi. Arillus dubitss. Ex cel. Blume Rumphia 1, p. 190, species verisim. ab ordine diversa, præsertim propter petiolum biglandulorum, quod in Anonaceis interdum adest. Ex Lam. afinnis M. tingenti Rumph. forsanque eadem.

\section{Species exclusa.}

M. FinLAYSONIANA Wall. = Melodorum fulgens, Anonacea (ex Hook. et Th. fl. ind.)

M. GLAUGESGENS Wall. = Lauracea (ex Hook. f. et Th. fl. ind.)

M. INTEGRIFOLIA Steud nom = Myrica integrifolia Roxb.

M. Orinocensis Kunth in H. et B. nov. gen. 7, p. 191.=Euphorbiacea? forsan Schismatopera Klotzseh? ex Benth. in Hook. Journ. 1853, p. 1 .

M. SAPIDA Steud.nom. = Myrica sapida Wall.

M. SESQUIPEDALIS Wall. = Lauracea (ex Hook. f. et Th. fl. ind.)

M. num. 9017 Wall. = Alieni ordinis (ex Hook. f. et Th. fl. ind.)

M. num. 3325 Zoll. = Alieni ordinis. 


\section{Ordo CLXIV. PROTEACEA (1).}

Thymelæx, sect, 1. Adans. fam. 2, p. 284 (ex parte). - Aggregatæ Linn. philos. bot. ed. 2, p. 32, ord. nat. erl. Giseke p. 528 (ex parle). - Protex Juss. gen. p. 78. - Psydomorphytorum pars Neck. elem. 1, p. 105. - Proteaceæ R. Brown in Transact. Soc. linn. Lond. 10, p. 45, prodr. At. Nov.Holl.p. 363, suppl. I, Lindl. nat. syst. ed. 1, p. 68, $\epsilon d .2$, p. 198, veget. Kingd. ed. 3, p. 532, Mart. consp. p. 15, ordo 86, Endl. gen. p. 336, suppl. IV, 2, p. 74, encheir, p. 214, Meisn.gen. p. 331 (243) et in Mart. Al. bras. fasc. 14, p. 74, Schnitzl. iconogr. fam. fasc. 6, t. 113.

Flores hermaphroditi, rarissime abortu unisexuales, 4-meri. Calyx (perigonium) inferus, herbaceus vel petaloideus coloratus, regularis vel irregularis, marcescens vel deciduus, extus plerumque pubescens; sepalis 4 linearibus vel spathulatis, æstivatione valvatis vel apice imbricatis, liberis patulis vel in tubum conniventibus vel connatis; tubo sæpius hinc fisso; limbo nunc diu clauso et stigma retinente, runc æqualiter 4-fido, nunc 1-vel 2-labiato, lobis sæpius reflexis planis vel concavis cochleariformibus et tunc antheras foventibus. Stamina 4 (uno rurissime abortivo), sepalis opposita eorumque laminæ vel rarius ungui inserta, rarissime hypogyna, calyce nunquam longiora ; filamenta filiformia, plerumque brevissima (seu tota calyci adnata), inter se libera, rarissime pro parte connata; antheræ dorso vel basi affixæ, biloculares, lineares oblongæ ovatæ vel cordatæ, introrsum birimosæ, liberæ vel raro loculis contiguis vicinarum in lobum unicum demum bivalvem connatis, altero lobo tunc abortivo; pollen triangulare, angulis pellucidis, vel ellipticum vel lunulatum, raro sphæricum. Squamulæ vel glandulæ hypogynæ parræ, conspicuæ (rarius obsoletæ vel nullæ), nunc 4 sepalis alternæ, liberæ vel in urceolum annulumve (sæpe incompletum, dimidiatum, anticum) connatæ, interdum calycis fundo adnatæ, nunc pauciores vel unica (antica). Pistillum unicum, simplex, liberum; ovarium sessile vel stipitatum, 1-loculare, raro spurie biloculare, ovulum unicum vel duo collateralia vel plura biseriata, prope loculi basin vel apicem vel inedium suturæ affixa, anatropa, micropyle inferâ sæpe elongatâ, priminâ nempe hinc longitudinaliter fissâ nucleum partim denudante. Stylus terminalis, filiformis, raro brevissimus, persistens vel deciduus, calycem $æ_{\text {ifuans }}$ rectus, vel sæpius longe exsertus

(1) Auctore Meisner, prof. basil.

XIV. 
arcuatus et in alabastro recurvus; stigma terminale vel laterale, indivisum vel raro emarginatum vel bifidum, discoideum, capitatum, cylindraceum, subulatum, clavatum vel fusiforme, interdum basi vel medio nodulosum vel quasi articulatum, sulcatum vel læve, glabrum, rarius papillosum vel tomentosum. Fructus sæpius compressus, nunc ventricosus vel gibbus, lævis vel rugosus verrucosus echinatusve; nunc indehiscens, 1-locularis, 1-2-spermus, nucamentaceus (interdum papposo-comosus vel samaroideus vel drupaceus; nunc capsularis vel follicularis, longitudinaliter dehis-

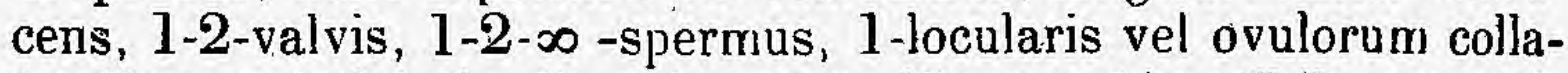
teralium priminis in dissepimentum liberum bipartibile connatis spurie bilocularis, valvis coriaceis vel lignosis. Semina suturæ affixa, sessilia, ovoidea vel globosa vel sæpius compressa, et in follicularibus) alata, testâ in pleiospermis quandoque hinc solutâ membranaceâ et septum spurium seminibus interpositum formanțe; umbilico hasilari vel laterali, chalazâ venosâ apicem vel latis umbilico oppositum occupante, raphe variâ, nunc bicruri, nunc obsoletâ. Albumen nullum. Embryo rectus, cotyledonibus 2 (quandoque pluribus) variis, radiculâ inferâ, umbilico proximẫ vel parallelâ. plumulâ vix conspicuâ. - Frutices vel arbores, rarissime herbæ, fere exclusive hemisphærii australis, præcipue extra tropicum, incolæ, nunquam scandentes nec aquaticæ, ramis sæpe verticillatis; foliis exstipulatis, sparsis, rarius oppositis vel vertioillatis, plerumque coriaceis persistentibus, planis vel teretibus, simplicibus integerrimis vel sæpius dentatis vel varie laciniatis vel pinnatiseclis pinnatisve, nonnunquam in eâdem stirpe diversiformibus, apice dentibusque sæpius mucronatis vel spinescentibus, supra sæpius nitidis, subtus albo-vel ferrugineo-tomentosis glabrisve, nervis pinnatis rarius palmatis vel flabellatis sæpius eleganter reticulatis; floribus terminalibus vel axillaribus capitatis, spicatis, umbellato-fasciculatis, racemosis vel paniculatis, raro axillaribus solitariis, capitulis spicısque sessilibus vel pedunculatis, imbricatim bracteatıs, nonnunijuam involucro generali (sæpe insigni, colorato) suffultis, rhachi rel receptaculo sæepius incrassato conico sphæroideo vel cylindrico alveolato paleaceo vel villoso vel rarius nudo; racemoruin pedicellis singulatim vel sæpius geminatim ex axillâ bracțæ ortis; bracteis persistentibus interdum incrassatis induratısque, vel deciduis, raro nullis; floribus sæpe speciosis odoratisque, albis, flavis vel rubris, rarissime coeruleis vel virescentibus, nonnullarum copiose melliferis, fructibus seminibusve haud paucarum edulibus, quarumdam caustico-acribus rubefacientibus. 


\section{CONSPECTUS DIVISIONUM.}

\section{Subordo I. NUGAMENTACEE.}

Frụctus indehiscens, 1-vel rarissime 2-spermus.

'Tribus I. Proteez. - Antheræ liberæ, calycis laminis concavis, rarius unguibus insertæ. Ovarium 1-loculare, 1-ovulatum. Fructus siccus, nucamentaceus vel samaroideus. Gen. 1-12.

Tribus II. ConOSPERMEA. - Antheræ primo cohærentes, vicinarum lobis contiguis loculum unicum formantibus, lobo altero abortivo. Ovarium 1-loculare, 1-ovulatum. Fructus nucamentaceus. Gen. 13-15.

Tribus III. ' Franklandex. - Antheræ calycis tubo adnatæ. Ovarium 1-loculare, 1-ovulatum. Fructus nucamentaceus. Gen. 16.

Tribus IV. Persooniex. - Stamina libera, calyci medio vel basi inserta vel raro hypogyna. Ovarium 1-2-locutare, loculis 1-ovulatis. Nux, samara vel drupa 1-sperma, raro 2-sperma. Gen. 17-26.

\section{Subordo II. FOLLICULARES.}

Fructus dehiscens, coriaceus vel lignosus, 1-2-valvis, 2-poly-vel rarissime 1-spermus.

Tribus V. GrevilLex. - Ovarium 1-loculare, 2-4-ovulatum. Folliculus 1-2-raro 4-spermus. Semina alata vel aptera. Gen. 27-37.

Tribus VI. ЕмвотнRIEA. - Ovarium $\infty$-ovulatum. Folliculus polyspermus. Semina alata. Gen. 38-42.

Tribus VII. BANKSIEE. - Ovarium 1-loculare, 2-ovulatum. Folliculus bilocularis, septo spurio e seminum collateralium testis concretis formato libero ligneo bifido. Gen. 43-45.

\section{Subordo I. NUGAMENTACEA.}

Fructus indehiscens, 1- vel rarissime 2-spermus.

\section{Tribus I. PROTEE EA.}

Antheræ liberæ, caljcis laminis concavis, rarius unguibus insertæ. Ovarium 1-loculare, 1-ovulatum. Fructus siccus, nucamentaceus vel samaroideus, 1-spermus. - Flores capitati, rarius spicati vel racemosi, rarissime solitarii. - Endl. gen. p. 336.

I AUtAA Bergius pl. Cap. p. 33, R. Brown in Linn. Trans. 10, p. 48 et 49, Endl. gen. n. 2119 , suppl. IV, 2, p. 74, Meisn. gen. p. 331 (243). - Conophori sp. Petiv. gâzophy̆l. $3, n .458, t .25, f . T$; ell. $8^{4}$, p. 40. - Scolymocephali sp. Herm. Afr. p. 20. - Lepjdoearpodendri sp. Boerh. Lugd. Bat. 2, p. 193, c. ic. - Protea s\}, Linn. Thunb. Andr. bot. repos. $t$. 76, 248. - Lepidocarpi ct Leucachendri sp. Linn.

Flores abortu dioici, masr. racemosi nudi, fem. capitati bracteati. Calyx 4-sepalus, regularis, sepalis in $\sigma^{\top}$ medio antheriferis. Squamulæ bypogynæ in $\sigma^{7}$ nullæ? in o 4 . Ovarium 1-loculare, 1-ovulatum (in $\sigma^{7}$ nullum). Stylus 
filiformis. Stigma obliquum, clavatum, cmarginatum, papilloso-hispidulum. Nux exserta, ventricosa, baribata. - Prutices Capenses, glaberrimi, ramulis floriferis umbellatis; foliis coriaceis, sparsis, sessilibus, angustis, integerrimis; inflorescentiâ terminali, racemis masc. nudis, capitulo fem. solitario globoso squamis subulatis involucrato, cincto foliolis intus auctis appendiculâ aceroso-multifida (capitulo quasi abortivo racemis exterioribus maris analogo, interdum florifero).

1. A. PINIFOLIA (Berg. pl. Cap. p. 33\%), foliis semitereti filiformibus acutis supra 2-sulcis concavis vel apice planis, floralibus conformibus, in $ᄋ$ omnibus capitulo Jongioribus subulato-acuminatis. F In Africal Capensis montibus, prope Hottentottsholland alibique (Roxburgh ! Burchell, n. 528! Ecklon et Zeyh.! Gueinzius! Krauss, n. 1998! Zeỷler, n. 3634! Drège! Kolbing! n. 10, 11, etc.). - R. Brown 1. c. p. 49. $f$ Conophorus Cupensis pini folio Petiv. l. c. t. 25, f. 7. Lepidocarpo. dendron Boerl. 1. c. p. 193, c. tab. Leucadendron cancellatum Linn. sp. ed.1, p. 91; ed. 2, p. 134. Protea bracteata T'hunb. rliss. p. 43, n. 24 ', t. 1, th. Cap. p. 128, n. 30 , Linn. fil. suppl. p. 118, Willd.! sp. 1, p. 517, herb. 1. 2416, 2422! Lam. ill. 1, p. 238, n. 1245, Poir. dict. 5, p. 652. $\sigma^{7}$ : Burm. Afr. p. 193, t. 70, f. 3. Leucadendron pinifolium Van Royen in Linn. mant. p. 36 ". Protea pinifolia Linn. mant. p. 187 , Thunb. diss. p. 41 , n. $20^{*}$, fl. Cap. p. 127 , n. $26^{*}$, Willd. sp. 1, p. 515 , herb. n. 2416 ! Lam ill. 1, p. 237, n. 1244, Andr. bot. repos. t. 76, Poir. dict. 5, p. 651. Folia summa circ. pollicaria, inferiora elongata $4-6$-pollicaria, $\frac{1}{4}-\frac{2}{3}$ lin. lata, rarins

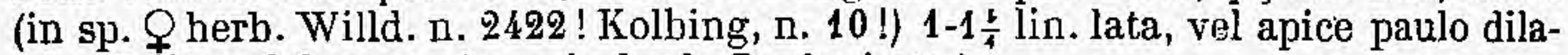
tata. Pollen globosum. (v. s. in herb. Banks.! etc.)

2. A. virellata (R. Brown! in Linn. Trans. 10, p. 50), foliis lanceolato-linearibus subspathulatis obtusis obsolete mucronulatis basi longe attenuatis planis venosis, floralibus in $\sigma^{7}$ conformibus, in 오 exterioribus capitulum superantibus obtusis acutisve, interioribus longioribus subulato-acuminatis. $₹$ In Africa Capensis monlibus variis locis (herb. Banks.! Linn.! etc., Ludwig ! Ecklon et Zeyh.! Drège! Krauss, n. 1029 ! Zeyher, n. 3633 ! Bot. reg. t.1015. ơ Protea lanceolata mss. ign. in herb. DC.! $\sigma^{\top}$ Prolea aulacen Thunb. diss. p. 46, n. 33, t. 2, fl. Cap. p. 131, n. 40, Willd. sp. 1, p. 520, Lam. ill. 1, p. 237, n. 1243, Poir. dict. 5, p. 651, P. pinifolia Linn.! herb. (non Mantiss.). O: P. umbellata-Thunh. diss. p. 47, n. 34, fl. Cap. p. 131, n. 141, Linn. fil. suppl. p. 118, Willd. sp. 1, p. 520, Lam. ill. 1, p. 237, n. 1242, Poir. dict. 5, j. 650, Andr. repos. t. 248. Folia $1 \frac{1}{3} 3$ poll. longa, 3-4 lin. lata. Pollen subglohosum, obtusissime trigonum. (v. s. in herb. Linn.! Banks.! etc.).

II. LEUCADENDRON Hermann, ex Pluken.phyt. t. 200, $f$. 1, R. Brown in Linn. Trans. 10, p. 48 et 50, Endl. gen. n. 2120, suppl. N, 2, p. 74, Meisn. gen. p. 331 (244). - Leucadendros Herm. cat., Pluk. - Conocarpus Adans. fam. 2, p. 284. - Argyrodendros Comm. hort. 2, p. 51, t. 26. - Gissonia et Chasme Salisb. parad.p. 57. - Euryspermum Salisb. ibid. t. 75, - Scolymore phali sp. Herm., Weinm. - Conocarpodendri sp, Boerh. - Protee sp. Thunb. Linn. Gertn. fr. 1, p. 239, t. 51, Lam. ill. t. 53, f. 1, 2 Wendl. h. Herrenh. t. 14.

Flores abortu dioici. $\sigma^{\top}$ et 9 capilali, capitulis involucratis, fem. imbricato-bracteatis strobiliformibus. Calyx 4-sepalus vel 4-partitus, regularis, sepalis apice conca vo antheriferis. Anthera 4 subsessiles, ovales vel oblongæ. Squamulæ liypogynæ 4. nonnunquam obsoletæ. Ovarium 1-loculare, 1-ovilatum. Stylus filiformis. Stigma obliquum, clavatum, emarginatum, papillosohispidulum. Nux vel samara 1-sperma. - Frutices vel rarius arbores Capenses, sæpe sericeo-incanæ vel varie pubescentes; foliis sessilibus vel rarius petiolatis, coriaceis, simplicibus, integerrimis, nonnunquam pro sexu heteromorplis; capitulis terminalibus, solitariis, sphæroidejs, fructiferis quandoque cylindricis oblongis, involucro nunc subuniseriali foliaceo, nunc pluriseriali imbricato coriaceo interdum colorato; strobili squamis coriaceis vel sublignosis, basi sæpius dilatatis et interdım connatis ; floribus parvis, indecoris, albis vel flavis? 


\section{\$1. Nux ventricosa, turgidá, aptera, stylo toto calyceque persistentibus.} (R. Br. 1. c. p. 52.)

1. L. ARGENTEUM (R. Brown / l.c. p. 52), ramulis dense foliosis incanis villosisque, foliis lanceolatis acutis argenteo-sericeis venosis, involucralibus capitulum globosum superantiluus patulis, bracteis imbricatis in $\sigma^{7}$ obovato-oblongis villosis, in 9 subrotundo-ovatis sericeo-tomentosis, calyce $\sigma^{7}$ sericco, $f$ plus duplo longiore barbato, nuce obovatâ compressâ obtusangulâ puberulâ. 5 Aıl radices et latera montium, circa promont. Bonæx-Spei (Sieber n. 5! Ecklon Un. itin. n. 43! Drège ! Krauss! etc.).-Bot. reg. t. 979. Scolymocephalos Africana, etc., Herm. cat. Weinm. phyt. 4, p. 293, t. 900. Leucadendros Al'r. etc., Pluk. t. 200, f. 1. Argyrodendros Afr. etc. Comm. hort. 2, p. 51, t. 26. Gonocarpodendron fol. argenteis, ete., Buerlı. Lugd. bat. 2 , p. 195 , c. ic. Protea argentea Liun. sp. 1, p. 94, Thunb. diss. p. 53, n. $48^{*}$, fl. Cap. p. 136, n. 67, Gertn. fr. 1, p. 239, t. 51, Willd.l sp. 1, p. 529, herh. n. 2249 ! Lam. ill. 1, p. 237, 53, f. 1. Incolis Silverbuom, Witteboom. Folia sessilia 3-6 poll. longa, $\frac{1}{3}-1$ poll. lała, basi vix angustata, apice culloso nigricantia, novella iureo-sericea. Capit. magnit. pomi minoris. Calyx $\sigma^{\top} 3-4$ lin., 9 circ. 10 lin. longus, fulvus, villis $3-4 \mathrm{lin}$. longris, pulchre articulatis. Capitulum . Iructiferum ovi ansorini mole, ovatum, rhachi crasșá. Stylus glaber. Nux 4-5 lin. longa, obtusissima, biconvexa. (v. v, c. et s. sp. in herb. Linn.l Banks! etc.)

2. L. PLUMOSU (R. Brown! in Linn. Trans. 10, j. 53), ramis laxiuscule foliosis, foliis lineari-lanceolatis muticis venosis basi attenuatâ tortis ramulisque tomentellis demum,glabris, capitulis folia recruantibus, bracteis ovatis obtusiusculis glaJris, calyce or glaberrimo; $?$ fulvo-plumoso, ńnce obovato-oblonga basi.longe pilosá., In rupestribus montanis circa Cap. Bonze-Spei (Ludwig! Drège! Gueinzius! Zeyher, n. 1433 ! etc.). Protea parviflora Linn. nant. p. 195*! mss. in herb. Thunb. diss. n. $40^{*}$, t. 4 , fl. cap. p. 133, n. $51^{*}$, Willd,! sp. 1, p. 524 , herl). n. 2436 ! $\left(\sigma^{7}\right)$ L. oljliqua Thunb diss. n. $39^{*}$, fl. Litp. p. $133,11.50^{*}$. P. plumosa Ait. h. Kew. 1, p. 127. P. arcuata Lam. ill. 1, p. 234, n. 1215 ? (excl. $\beta$ ). Gissonia collina Salisb., ficle Spreng. syst $1, j$. 456. Rami fastigiati, in $\sigma^{7}$ graciles ramosissini, in $Q$ valirliores virgati. Folia sessilia, in $\sigma^{\pi} \frac{1}{4}-1$ poll. longa, 1-2-raro 3 lin. lata, in duplo majora. Capitula sessilia, $\sigma^{\top}$ semipollicaria ovata oblonga basi turbinata, $\varnothing^{f}$ demum magnit. jomi minoris subglobosa, bracteis patulis, interioribus sericeis. Stylus capillaris glaber, stigmate parum incrassato subulato. Nux styli Jasi cordata, Liconvexa, 3.4 lin. longa, (v. s. in herb. Linn.! Banks.! etc.)

3. L. RETUSU M (R. Brown 1. c. p. 53), ramis tomentosis, foliis oblongo-spathulatis glabris basi attenuatis callo apicis subretuso, involucro pubescente, cal yce o ${ }^{\top}$ glabro, f plumoso 4 -partito, nucibus obovato-orbiculatis glabris. FIn arenosis et lapidosis inontanis circa Cap. Bonce-Spei usque ad alt. 3000 ped. (Drège!). Protea retusa Poir. suppl. 4, 1. $555^{*}$. Rami (ex specim. Drège) stricti, dense foliosi. Folia circ. 14 poll. longa, extra medium 3-4 lín. lata, obtusissima; mutica, plana, subreticulato-venosa, subtus puberula, mox glabrata, apicis callo flavo transverso sapius ruasi subcrenato-3-denticulato. Capitulum fructif. globosum, magnit. juglandis majoris, squamis late ovatis obtusis demum patulis inferne villosis superne glabriusculis haud recurvis, extimis lanceolatis oblongisque acutiusculis. Calycis $q$ tubo glabro, laminis setaceo-linearibus plumoso-barbatis opice spathulato obtuso glabris. Ovarium obovatum, apice pilosiusculum, stylo persistente glabro, stigmate clavato. Nucem maturam non vidimus. Hujus speciei stirps masc. nobis videtur L. spathulatum Drège a (L. retusum Buek) a fem. solummodo recedens foliis vix pollicaribus sæepius angustioribus 3-1 lin. latis, callo apicis parvulo simplici, capitulo magnit. cerasi minoris, squamis acutiusculis barbato-ciliatis cætcrum glabris, calycis laminis oblongo-linearibus totis glabris. L. discolor Buek a (non ! b,an c?-fide fragm. $\sigma^{7}$ in lierb. Sonder) forsan etiam huc referendum, recedens tamen foliis magis rugoso-striatis, apicalo calloso magis conspicuo. (v. s. in herb. Banks.! etc.)

4. I. SPATHULATUM (R. Brown l. c. p. 54), foliis oblongo-spathulatis basi attenuatis obsolete venosis ramisque glabris, involucri fructiferi squamis liberis subrotundoobovatis obtusissimis basi villosis apice glabratis, calyeis $\subsetneq$ unguibus barbatis lamiuis glabris, nucibus glabris obovato-subrotundis stylo demum toto deciduis muticis. F In planitiebus arenosis elevatioribus prope prom. Bonæe-Spei, m. Witsemberg, alt. IV (Zeyher, n. 1454 l). Protea mutica Poir. suppl. 4, p. $455^{*}$. Folia 
2-poll.; 8-10 lip. lata, calla apicis ex Br. acutiusculo retuso, ex sp. Zeyh. el Ludwig. obtuso recto. Capitulum Nuces paulo latiores quam longæ, 3 lin. late, biconvexæ. Squamulæ hypogynæ ex Br. in o longissimæ. L. spathulatum Buek in pl. Drège, ex parte saltem, non huc, sed ad L. retusum et crassifolium spectat. (v. s. in herb. Banks.! Ludwig ( etc.)

5. L. BUEKIANÙM, ramulis laxiuscule foliosis apice cano-tomentellis, foliis patulis spathulato-lanceolatis obtusis retusisve cum callo parvo mutico subrecurvo glaberrintis nitidis obsolete venosis, floralibus covformibus æqualibus coneoloribus vel basi rubentibus capitulum ơ globosum superantibus, bracteis ovatis glabris dense villoso-ciliatis, exterioribus capitulo parum brevioribus recurvis, calyce tenui toto styloque glaberrimo. 责 Circa Nieuwekloof, infra alt. 1000 ped., Afr. Capens. (Drège! docum. p. 78). L. discolor Buek b ! (nec a), an c? Frutex ramosissimus, ramis glabris, ramulis umbellatis adscendentibus. Folia rigidla, $1-i \frac{1}{2}$ poll. longa, 3-5 lin. basi 1 lin. lata, leviter rugosa, venis subimmersis parum dívếrgentibus, floralibus basi haud dilatatis. Capitulum $\sigma^{7}$ sessile, magnit. cerasi majoris, squamis imbricatis rubro-fuscis. Calycis laminie antheræque lineari-ablongo muticæ. Stigma parvulum, clavatum. Fem. ignota. Affine L. spathulato, retisso, glabro et decurrenti, sed clistinetum sive glabritie, sive foliorum formâ, etc. (v. s. $\sigma^{7}$ in herb. Shinttleworth et Sonder.)

6. L. Sessile (R. Brown! in Linn. Trans. 10, p. 54), foliis lanceolato-oblongis glabris bași obtusâ. $J$ In Africà Capensi (Masson! in herb. Bankiss), inter Grasbergrivier et Waterval, alt. 2500-3000 ped.. Drège, docum. p. 70 (non vidi, an vere hujus loci)? in rupestribus montanis Krlynriviersbergen, alt. IV-V (Zeyhẹr; n. 3640! 3641 !). Strabilus maturus magnit. ovi gallinaçei, squamis connatis patentitibus extus dense fusco-villosis; nuces delapsie. Ramúlus inferne glaber, apice subtomentosus, ex specim. Masson. Squamulæ hypogynæ longissime, ex Bír. (v. s. in herb. Banks ! et Zèher.)

\section{\$2. Nux ventricosa vel lenticularis aptera, undique marginibus pilosa.} - Stylus deciduus, basi tantum persistente. Calyx 4-partitus, diu persistens. (R. Brown. in Linn. Trans. 10, p. 54.)

7. L. ANGUSTA U M (R. Brown 1. c. p. 5 * $^{*}$ ), foliis pollice brevioribus lineari-spathulatis obtusissimis muticis concaviusculis ramisque glabris, capituli subglobosi squanis conniventîbus otatis pubescentibus, calyco plumoso, ntice subiglobosâ muticâ undique breve pilosiusculâ. $\bar{\zeta}$ Cap. Bonæ-Spei (Masson). L. linèare Steudel nom. ed. 2, 2, p. 34? Protea linearis Houtt. Pfl. sjst. ed. 3, p. 84, t. 19 ? R. Br. I. c. p. 217. Cfr. L. fusciflorum R. Rr. (infra p. 228) quod forsan ejusdem speciei var. P. angustata Poir. suppl. 4, p. $556^{*}$. Folia conferta, erectà, 8-9 lín. Jongá, apice vix calloso $1 \frac{1}{2}$ lin. lata, in eodem ramo passim dimidio angustiora. Capitula magn. cerasi minoris, squamis exterioribus majoribus. Galyx ad basin usque 4-partitus; nucem levissime compressam magnit. seminis Vicia vix sujerans. R. Br. l. c. (specim. authent. non vidimus)

3. latifolium, foliis obovato-oblongis obtusissimis basi attonuatis eveniis glabris capitulis ' $\sigma^{7}$ globosis folia iequantibus, squamis ovatis sericeo-tomentosis, calycis tubo villosiusculo, limbo cano sericeo. İ collibus prope Karsrivier (Ecklon!). Folia 6-8 lin. longa, 2-3 lin. lata. Capitula sessilia, magn. avellanæ. Calyx cano-tomentosus. Stylus glaber, stigmate oblongo-clavato. An propria sjp.? Proter nofas indicatas nec a L. angustato nec a L. imbricato multum discrepat et absque fem. haud tute dignoscenda. (v. sp. in herb. Ludwig. Mus. reg. Stuttgart.)

8. L. I B BICA TUM (R. Brown! in Linn. Trans. 10, p. 55), foliis imbricatis subistmipollicaribus lanceolato-linearibus obtısiusculis muticis basi hautd angustatis apicem versus sensim attenuatis enerviis planis vel supra concaviuscalis ramisifue glabris, capitulis globosis folia vix superantibus, sr uamis in $q$ dilatato-cuneatis retusis sericeo-tomentosis, calyco ot et $Q$ sericeo-pilosiusculo, nucibus undique comosis styli bași cuspidatis. J゙ An Africâ Capensi (herb. Banks! Ludwig! Ecklon! Drège!). Protea Levisana Linn.! mss, in herb. (nec, syst. nat. et nant.). Hami nigricantes, dense cicatricosi, jun. sủbumbellati breves dense foliosi apico tomen- 
telli. Folia 4-5 raro 6-7 lin. longa, $\frac{2}{3}-1-1$, lin. lata, plus minus rugulosa, ramos penitus abscondentia. Capitula magnit. avellanie, squamis in $\sigma^{7}$ lineatibus parvis. Stigma $\frac{1}{3}$ lin. Iongum, stylo triplo crassius. Squamæ liypogynæe ex Br. nuilı. (v. s.)

B. Dregeanum, foliis aceroso-linearibus obtusis basi vix angustatis utrinque subconvexis dorso temuiter 1 -sulcis vel (prrecipue in $\sigma^{7}$ ) exsulcis demum semipatulìs, capituli squamis subtruncatís, nuce ovato-globosấ pilosiusculấ dợso glabrescente. An sp. distincta? (Drège! Ecklon et Zeyher, n. 11 in herb. Sondèr). L. imbricatum b. Drège! Rami graciles, ramulis sæepe umbellatis. Folia 3-7 lin. longa, $\frac{i}{-}$ lin. lata, lævia, juniora tantum imbricata. Lapituli $\sigma^{7}$ êt $\rho$ squamis late cuneato-obovatis, in $\sigma^{7}$ parvulis..(v. s.)

$\boldsymbol{\gamma}$ : ?canaliculatum, ramis piberulis, foliis imbricatis lanceolato-linearibus. subacutis apice nec basi attenuatis suprr subcöncavis plerumque exsulcis, capitali $\wp$ squamis brevissime acuminatis, nuce .....(Drège! Niven! in herb. Mart.) L. imbricatum a, $\sigma^{\top}$ et $Q$ Drège $!$ L. tortum a et b, Drège olim. L. canaliculatum E. Mey.I olim in pl. Drège. L. angustatum Drège I L. polygaloides Link, fide Steudel. Pratea polygaloides Willd. herb. n. 24281 (sp. f jun.) et P. cine. rea Willd. herb. n. 2429, fol. 2 ! Fòlia plerumque 1 lin. lata, rugulosa vel lævia, Forma ad. L. angustatum valde accedens. (v. s.)

9. L. BRun rordes, ramis laxiuscule foliosis glabris, junioribus cano-tomentellis, foliis patulis semipollicaribus subulato-linearibus obtusiusculis muticis leevibus glaJuris basi vix angustatis supra planis vel concavis, subtus conyexis enervilis capjitulum globosum subrquantibus, involucri squamis sericco-tomentellis in $\sigma^{7}$ lanceolatis parvis, in $\mathcal{Q}$ Jate cuneato-obovatis obtusissimis integris, calyce toto villoșinsculo, núce subgloboṣât muticâ undique longiuscule albido-comosâ. $\bar{\zeta}$ Cap. Bonæ-Spei prope Groenrivier, alt. 2500-3000 ped. (Dregc !), in arenosis ad Rivier Zonder Einde, alt. I (Zeyher, n. 3652 I), Tulbagh (Mund! in herb. reg. Berolin.). L. imbricatum b. Drège ! L. inflexum Klotzsch I mss. specim. Mund I in herb. reg. Berol. (non herb. Willd.). L. Meyerianum Buek? in pl. Drège (fide frustul. manc. in herb. Sonder). Rami leviter cicatrisati, cinerei vel nígricantes, ramulis eorymbosis brevibus densius foliosiș. Folia 5-7 lin. longa, $\frac{1}{3}-\frac{1}{2}$ lin. lata, recta vel arcuata, exsulca vel dorso obsolete 1 -sulca. Capitula $\sigma^{7}$ magn. cerasi minoris, $f$ paulo majora, squamis liberis. Calyx totus pube lorevi albidà patulâ vel in $\sigma^{7}$ laminis adprossâ dense villosiusculıs. Stylus glaber, stigmale minuto clavato $\div$ lin longo, in $\bigcirc$ truncato. Nux $1 \frac{1}{2}$ lin. lata, leviter compressa. A simillimo L. imbricato dignoscitur folis minus confertis, nunquam adpressis, angustioribus, semiteretibus, apieem versus haud attenuatis, strobili squamis obtusioribus subtruncatis, calycis pube paulo longiore et stigmate minore. (v. s.)

10. I. BuXIFolium (R. Brown! in Linn. Trans. 10, p. 55*), ramis gracilibus dense foliosis tomentellis, foliis subimbricatis semiunguicularibus ovali-lanceolatịs eveniis junioribus cano-tomentellis, floralibus angustioribus, capituli $\subsetneq$ squamis dilatato-cuneatis calycibusque sericeis, nuce ovatẩ styli basi mucronatâ undi-

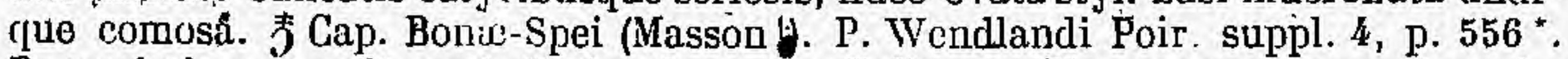
Ramosissima, ramis umbellatis elongatis. Folia sessilia, erecta, concaviuscula. Capitula $\sigma^{x}$ magnit. Pisi, $\&$ paulo majora. Caljeis $\sigma^{\top}$ laminse glabriusculce. Squamúlæe liypogynæ in $\sigma^{7} 4$ longa lineares, in $Q^{\prime}$ nullæ. Nuces diu calyce cinctæ. Protea imbricata Wendl. liort. Herrenhus. t. 14, excl. synon., recedens folis oblongis semuncialibus pilosis, strobilis longioribus, squamilis hypogynis, videtur aut hujus var. aut n. sp.; cfr. R. Br. I. c. obs. II. (v. s. in lıerb. Banks.)

$\beta$. dubium, foliis ovalibus utrinque aqualiter attenuatis acutiusculis, calycis laminis glabris, nuce transverse ovali (latiore quam longâ) subtruncatá demum muticâ glabratâ, ventre planiusculà, dorso valde convexà.-Proja Honigvalei, Ezelsbank, etc., alt. $3000-4000$ ped. (Drége!). L. dubium Buetk! in pl. Drège.

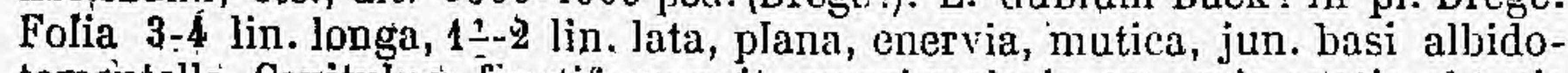
tomentella. Capitulum fructif. magnit. cerasi majoris, squamis ovatis obtusis sericeis, in $\sigma^{7}$ apice glabrescentilus. Nux $2 \div$ lin. longa, $3 \div$ lin. lata, stỵli basi demum decidua brevitor mucronata. Ciet. exacte ut in pl. Brown.

$\gamma$. ambiguum, foliis oblongo-lanceolatis acutiusculis basi parum anguslati obtusis, calycis laminis deuse sericeo-puberulis, nuce .... - Cap. Bone-Spei (Ecklon et Zoyher!). Folia paulo longiora et angustiora tham in vir. §. Capi tula fere magnit. cerasi, $\sigma^{7}$ in apice rami cory mboso-aggregata ramulis folio- 
sis semipollicaribus suffulta, squamis obtusissimis sericeis. Cæt. ut in pl. Brown. Forma hinc ad L. imbricatum y canaliculatum, inde ad L. buxifolium valde accẹdens. (v.'s. in hererb. Sonder.)

11. L. Levis A NuS (Berg. in act. Stockholm, 1766, p. 324 *, pl. Cap. p. $20^{*}$ ), ramis gracilibus glabris, junioribus puberulis, foliis confertis subsemipollicaribus obovato-spathulatis obtusissimis muticis basi attenuatis planis enerviis glabris, eapitulis folia superantibus globosis, squamis sericeis, $\sigma^{\top}$.ovatis, $Q$ cuneatoobovatis subapiculatis vel demum retusis basi connatis, cal. $\sigma^{\top}$, et $\$$ unguibus. puberulis laminis glabris, nuce muticâ undique comosâ. $亏$ In campís arenosis ericetisque prom. Bonæ-Spei (Masson l in herb. Banks., Burchell, n. 696! Ecklon, n. 44 ! Krauss ! n. 1050, 1062, Zeyher, n. 3947! Drège, etc.).-Boerh. Lugd. bat. 2, p. 202 c. ic., Burm. Afr. p. 267 , t. 100 , f. 2, Weinm. phyt. 4, p. 296 , t. 904 , a, R. Brown! in Linn. Trans. 10, p. 55. L. hirsutum Hoffmansegg, fide Steudel. Protea fusca Linn. sp. ed. 1, p. 95. Brunia Levisanus Linn. sp. ed. 2, p. 289. Protea Levisanus Linn. syst. nat. ed. 12,2 , p. 111 , mant. p $194^{*}$ (non herb. Linni.), Thunb. diss. p. 51, n. $43^{*}$, fl. Cap. p. 135 , n. 61 *, Willd.! sp. 1, p. 526, herb. n. 2442 ! Wendl. h. Herrenhus. t. 1. Protea hirsuta Willd. herb. n. 2430, ㅇ! (excl. sp. steril. quod L. tortum). Ramuli floriferi $\sigma^{7}$ umbellati, o subsolitarii, indivisi. Folia in $\sigma^{7}$

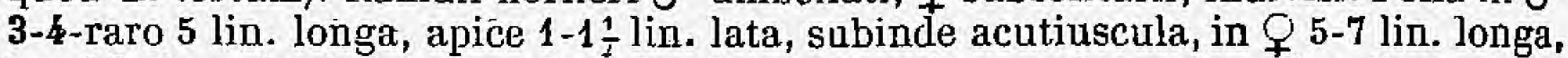
hand Iatiora, juniora puberula subimbricata, serius semipatula, exsiccatione rugulosa. Capitula $\sigma^{7}$ magn. cerasi minoris, fructifera ovato-globosa, magn. juglandis minoris. Flores aurei. Stigma ovali-clavatum, parvulum. Squamulæ hypogynæ nullæ. (v. v. c. et s. sp.)

12. L. PEDUNCULATUM, ramis virgatis, ramulis umbeltatis laxiuscule foliosis glabris, foliis semipatulis subunguicularibus semitereti-linearibus obtusissimis muticis basi attenuatis rectis glaberrimis, capitulis $\%$ sessilibus globosis, $\sigma^{\top}$ breve pedunculatis, bracteis membranaceis lanceolatis acutis glaberrimis, calyce $\sigma^{7}$ parce cano-tomentello, limbo demum glabrato, $ᄋ$ tubo breve villosiusculo, limbo ghabrescente, strobili squamis late obovatis inferne sericeo-tomentosis margine glabris undulatis subemarginatis, nuce ovali apiculatà glabrâ nrargine dense barbatà.

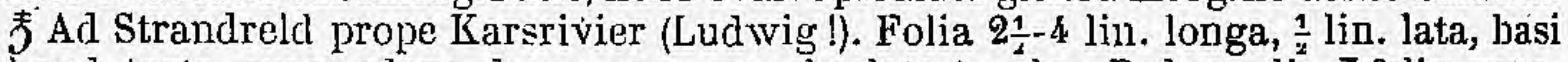
haud torta, supra plana dorso convexo obsolete 1 -sulca. Pedunculi $\sigma^{T}$-folia: superantes, 3-6 lin. longi, minute puberuli. Stylus tenuis glaber, stigmate fusiformiclavato $\frac{1}{3}$ lin. longo. Nux ventricosa $1 \frac{1}{4}$ lin. longa, 1 lin. lata, biconvexa, pulchre albo nigroque variegata, marginis pilis albidis 1 lin. longis. Cæt. L. Levisani, a quo preceipue distinguitur foliis dimidio angustioribus minus rugulosis et capitulis $\sigma^{T}$ pedunculatis. (v. s. in herb. reg. Stuttgart.)

13. L. T o II Tu ar (R. Brown in Linn. Trans. 10, p. 56), ramis gracilibus dense foliosis, junioribus puberulis, foliis erecto-patulis spathulato-linearibus obtusissimis muticis planis enerviis basi tortis glabris junioribus subsericeis, capitulis globosis $\sigma^{7}$ pedunculatis $Q$ sessilibus, calyce sericeo, unguibus in $?$ villosiusculis, strobili squamis rotuntlatis latis connatis callo-sericeis, nuce undique comosâ. Bonæ Spei (Ecklon!), in arenosis ad f1. Potrivier et Kíynrivier (Zeyher, n. 3650! 3651 ! $\beta$ !).-Bot. reg. t. 826. Protea torta Thunb. (liss. p. 45, 11. 31*, fl. Cap. p. 130 , n. 38, Willd. sp. 1 , p. 519 ? Jacc. h. Schœnbr. 4, p. 1, t. 401. P. cinerea Willd.! sp. 1 , p. 521*, herb. 11. 2429, fol. 1 ㅇ! (excl. fol. 2). P. hirta et Passerina hort. Ramuli fastigiati vel umbellati. Folia $\frac{1}{2}-1$ poll. longa, apice $\frac{1}{4}-\frac{1}{4}$ lin. lata, callo majusculo depresso subrotundo fusco. Capitula lutea. Nux obovata, 2 lin. longa, albo nigroque maculata, pilis albidis 2 lin. longis undique comosa. (v. s. c. in herb. Banks.! cx h. Kew., 1782 et s. sp.)

B. inflexum, foliis pollicaribus (12-15 lin. longis, 1-2 lin. latis), apice attenuatis, minus spathulatis. L. inflexum Klotzscl 1 mss. in herb. reg. Berolin. (excl. sp. ILund.). L. pruinosum Mlund! ibid. Protea inflexa Willd. enum, suppl. p. 7; herls. n. 2427 ! (v. s.)

14. L. CINEREUM (R. Br.! l. c. p. 57), foliis spathulato-linearibus argenteis, capitulis masc. sessilibus, nucibus cuneato-obovatis villosiusculis muticis. $\bar{J}$ Cap. BonæSyei (Masson!), Protea alba Thunl, diss. p. 46, n. $32^{\circ}$, 1 . Cap. p. 130 n. 39r Willd. sp. 1, p. 520, Lam. ill. 1, p. 236, v. 1233, Poir. dict. 5, p. 647. P. rinerea Ait. h. Ken. 1, p. 127, fem. (v. s, in herb. Banks.!) 
15. L. NITIDUM (Buek! mss. in pl. Drège), ramis gracilibus, foliis unǵuicularibus spathulato-linearibus obtusis muticis enerviis planis basi attenuatì laaud tortis ramulisque argenteo-sericeis, capitulis sessilibus globosis, bracteis late ovatis obtusis sericeo-velutinis, calyce toto sericeo-villoso, nuce obovato-oblongâ angustissime marginatâ muticå glaberrimâ. 4000 ped., Cap. Bonæ-Spei (Drège! docum.p. 74). L. cinereum E. Mey.! mss. in pl. Drège. Folia 6-12 lin. longa, 1 -2 lin. et basi vix $\frac{1}{2}$ lin. lata, callo apicis rhombeosubrotundo sappe obsoleto. Capitula $Q$ magnit. cerasi, $\sigma^{7}$ dimidio minora, fructifera mole juglandis, squamis, interioribus latissimis fulvo-vel albido-sericeis. Calyx diu persistens, aureo-sericeus. Nux 3 lin. longa, $1 \frac{1}{3}$ lata, submarginata, obtusissima, basi subcuneata, antice planiuscula, dorso convexa, nitida, tẹstà exteriore albâ rugosá, interiore fuscà opacâ. Species L. cinereo valde affinis, sed nuce pracipue bene distincta. (v. s.)

16. L. En a тum (Buek! mss. in p]. Drège), foliis lineari-vel lanceolutu-spathulatis obtusis enerviis basi attenuatis haud tortis ramisque subsericeo-incanis demum glaloratis, capitulis, sessilibus globosis, bracteis exterioribus acuminatis incanis, interioribus ovatis obtusis concuvis velutinis, calyce $\sigma^{7}$ albido-tomentoso, 9 fulvo-

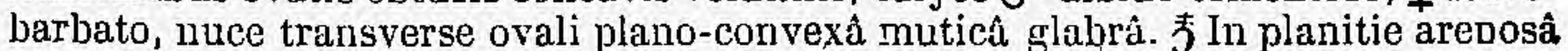
prope Ezelsbauk, alt. 3000 ped. (Dròge l docum. p. 74). L. cinereum b Drège! olim. A simillimo L. cinereo differt pubescentiâ minus sericeâ, demum evanidâ, foliis in Q majoribus, usque $6-10 \mathrm{lin}$. Iongis, $1 \frac{1}{2}$ fere 3 lin. latis, calycis $\sigma^{7}$ pube albà brevissimâ patulâ minus sericeá, et prỏcipue nuce glabrâ opacà latiore quam longâ. ( $2 \frac{1}{2}$ lin. longà, fere $3 \frac{1}{2}$ lin. latâ) haud) marginatâ, facie anticâ planâ lineá mediâ longitudinali lævissime carinata. Capitula ơ magn. ccrasi mediocris, $\bigcirc$ fructifera mole juglandis. (v. s.)

17. L. AURANT I GUM (Buek! Inss. I. c.), ramis validis, ramulis incano-tomentosis, foliis lineari-filiformibus obtusis muticis basi attenuatis sericeo-incanis, capitulis sessilibus globosis squamis ovato-oblongis in $\sigma^{\top}$ acutis sericeis, in $\subsetneq$ obtusis liberis superne demum glabris, calyce sericeo-villoso, laminis in $q$ plumosis, nuce

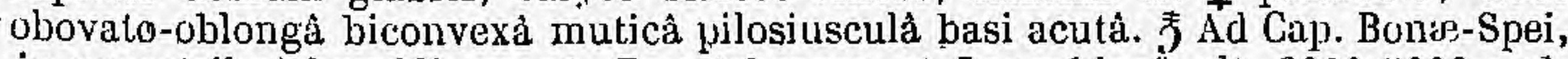
in rupestribus humidis mont. Zwartebergen et Langekloof, alt. 3000-5000 ped. (Drège! docum. p. 64 et 116). L. proteoides F. Mey. b! in pl. Drège. Rami nigricantes, crassitie pennæe anserine, foliorum cicatricibus subrotundis vix prominulis dense notati, ramulis corymbosis vel umbellatis albido-tomentosis dense foliosis. Folia extra medium $\frac{2}{5}$ lin. lata, in $\sigma^{\top} 1-1 \frac{1}{2}$ poll., in $Q$ usque ad 2 poll. longa, comjlanata, basi subteretia, enervia, subtus obsolete bisulca, undique pube brevi adpressa incana, jun. (precipue in $\sigma^{7}$ ) argenteo-sericea. (Capitula $\sigma^{\top}$ nagn. cerasi, $f$ fructifera mole pomi miuoris, -squamis planis $5.6 \mathrm{lin}$. Jongis, 4-5 lin. latis. Calyx ț-6 lin. longus, tubo glabro, laminis $2 \div$ lin. longis sericeo-villosis, $\sigma$ dimidio minor pube multo breviore. Stylus glaber, calyce lirevior, stigmate oblongo-cla. vato obtuso. Nux subtriquetro-oblonga, dorso rotundata, antice subcarinato-bifaciali, 2 lin. longa, 1 lin. lata, undique brevi-puberula. (v. s.)

18. L. Dnéer (E. Mejer! mss. in pl. Drìge), ramis validis, ramulis dense subad. jresso-foliosis apice palverulen to-cinereis, foliis semitereti filiformibus pollicaribus rigiclis muticis lrevibus glabris basi attenuatis supra canaliculatis, capitulis sessilibus globosis, squamis liberis ovatis obtusis glabris demum induratis laxiusculis, interioribus acuminato-oblongis ciliatis inferne tomentellis basi villosis. calycis tabo glabro, laminis angustissimis dorso longe plumosis, nuce obovatá biconvexả apiculatà dorso superne comoso-barbatâ. 宩 Ad Cap. Bonæ-Spei, in rupestribus mont. Zwarlebergen, alt. 5000 ped. (Drège! docum. p. 64). Omnia fere L. aurantiaci, sed folia rigidiora, crassiora, $\frac{1}{2}-1$ lin. lata, $8-15$ lin. longa, marginibus involutis supra quasi sulco lineari exarata, glaberrima, novella tantum pube tenui patulâ fugaci pilosiuscula. Capjitula fructifera magnit, juglandis, folia aquantia, diametro jollicari. Calyx diu persistens, laminis dorsu longe fulvopilosis. Stylus calycem æequans, glaber, stigmate elavato. Nux 2 lin. longa lataque, styli basi acuminata, apice longiuscule pilasa. Stirps masc. ignota. (v. s.)

19. L. сов хм в о suм (Berg. in act. Stockholm,1766, p. 325 ; pl. Cap. p. $21^{*} \sigma^{7}$ ), ramis virgatis strictis, ramulis umbellatis brevibus junioribus tomentellis, foliis unguicularilus lineari-subulatis attenuato-acutiusculis muticis basi haud angustatis enerviis planis vel semiteretibus glabris summis inferne parce ciliatis, capitulis 
sossilibus folia superantibus, $\sigma^{7}$ globosis, squamis exterioribus ovato-lanceolatis glabriusculis, + turbinato-obovatis, squamis ovatis acutis sericeo-villosis apice recurvo glabrescentibus, calycis laminis glabris, unguibus in $\sigma^{7}$ puberulis, in $ᄋ$ pilosis, nuce obcordatâ subcompressâ margine pilosâ. F In Cap. Bonæe-Spei mụltis locis (Masson! Roxburgh! in herb. Banks. et Soc. liun. Lond., Niven ! Ludwig! Ecklon! Gueinzius! Drège! docum. p. 101, 109, etc.) - R. Brown! in Linn. Trains. 10, p. 57, Bot. reg. t. 402, o7. Protea corymbosa Thunb. diss. p. 99, 44, n. 28 *, t. 2 , fl. Cap. p. 129 , n. 34 *, Willd. sp. 1 , p. 518 (non herb (1)), Andr. Bot. repos. t. 495 ㅇ. Protea bruniades Linn.! suppl. p. $117^{+} \sigma^{\top}$ (Gde herb. Linn.). Protea ericcefolia Willd.! mss. in herb n. 2424 ! $\sigma^{7}$. Rami validi, ramuli plerumque digitales, $\sigma^{7}$ seepius apice corymboso-polycephali, $Q$ indivisi monocephali vel secus ramum racemosi. Folia semipatula, acerosa, obtusa vel acutiuscula, læevia, supra plana vel canaliculata, recta vel arcuato-incurva, in . $\sigma^{7}$ 3-5 lin. longa patula, in $\phi^{6-9}$ - lin. longa ramo subadpressa vel in ramis sterilibus patula, involucralia conformia basi ciliata. Capitula fem. magnit. cerasi minoris, squamis basi connatis, nuascé dimidio minora. Stylus glaber, stigmate ovali-clavàto obtuso. Nucem noñ vidimus. (v. s. in herb. Banks., etc.)

\section{\$3. Samara glabra olata vel aptera, stylo fere toto calyceque deciduis. Strobili squamee distincter.}

20. L. DECORUM (R. Brown! in Linn. Trans. 10, p. 58), foliis oblongis veniosis callo recurvo, adultis glabris, junioribus ramisque sericeis, floralibus coloratis semiscariosis, strobili squamis extus tomentosis apice retuso parum coarctato glabris,

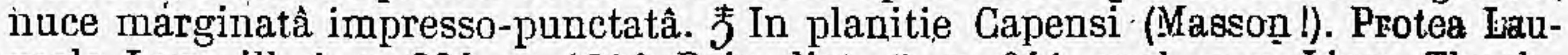
reola Lam. ill. 1, p. 234, n. 1214, Poir. dict. 5, p. 641, excl. syn. Linn., Thunh., Schrad. Protea conifera Willd. herb. 4. 2440, fol. 3 ? sp. sterile (fol. eæt. exclus.). (v. s. in herb. Banks.)

$\beta$. Drègeanum, foliis involucralibus in $\sigma^{\top}$ haud vel parum elongatis, interioribus dilatatis concavis ovato-oblongis acuminatis, margine angustissime diaphanis, ramis pubescentibus (Burehell, n. 294 ! Ecklon! Un. itin. ṇ. 44 ! Drège a! Gueinzius! Kolbing, n. 4 ! Protea marginata Willd. herb: n. 2450! (for!na

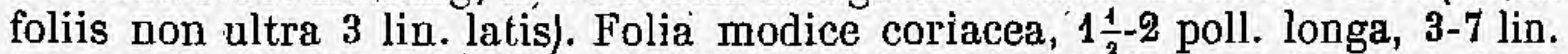
lata, utrinque obtusa, 'callo apieis tuberculiformi obtusissimo, floralia inferne paulo dilatata rubro-fusca. Capitulum $\sigma^{7}$ cylindrico-ovale pollicare, calycis unguibuts minute puberulis, laminis glaberrimis nitidis. Strobilus maturus $1 \frac{1}{2}$ poll. longus, diametro pollicari, obovato-cylindricus, squamis patentibus semiorbicularibus 5-7 lin. latis, margine leviter recurvo subundulato vel plano, exceptâ basi fulvo-tomentellâ glabrịs: Samara... (v. s.).

$\gamma$. Ecklonianum, foliis involucralibus in $\sigma^{7}$ ramis dimidio longioribus viridibus planis vel interioribus subcoloratis concavis margine angustissime diaphanis, ramulis pübescentibus glabrisve (Ecklon! Uun: itin, n. 44, ex parte, Eckilon et

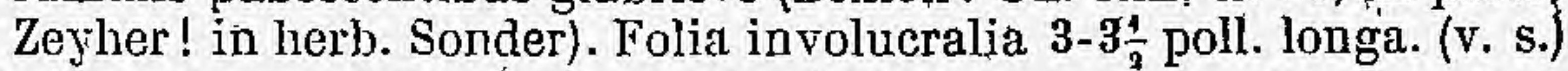

$\delta$ ? Zeyherianum, foliis involucralibus in $\sigma^{\top}$ rameis haud longioribus viridibus non dilatatis margine angustissime diaphanis, ramulis puberulis. - In rupestribus mont. Klynriviersbergen alibique. (Zeyher, n. 3640 ! $\mathbf{3 6 4 1}$ ! et? 3635 , Drège, sine num.). (v. s.)

६? obovatum, ramis glabris, foliis obovatis vel obovato-oblongis obtusissimis, floralibus majoribus vúridibus conniventibus, capitulo $\$$ oblongo-ovató (Drège, n. 8032, c! in herb. Xühlenbeck). Forte distincta $\mathrm{sp}$. Folia vix pollicaria, 5-7 lin. lata, ad insertionem 2-3 lin. lata, invohucralia conformia usque ad poll. longa, 10-14 lin. lata, strobilum vix superantia, omnia coriacea viridia dense reticulato-venosa, juniora dense ciliata, cæeterum glaberrima. Strobili squams apice glabrescentés. Samare, etc., omnino ut in typo speciei. L. decorum Buek in pl. Drège, multis locis lectum, cujus pauca tantum specim. vidimus, forsan plures formas nisi immo species inicludit. L. decorum var. minus Buek! (Drège docum. p. 116, IV, A, 11) nobis ad L. pubescens Br. pertinere videtur. ( $r$. s.)

(1) Protea corymbosa Thunb. "Willd. herb. 1n. 2423 ! (ramulus $\sigma^{\top}$ jun.) certe non huc, sed ad Bruniaceas, forte ad Raspailiam spectat. Specimen nimis jưvenile; 
21. L. $S R U A R R O S U$ M. (Rrown 1. c. p. 58), foliis lanceolato-oblongis callo reeurvo antice sulco lineari, adultis ramisque glaberrimis, capituli $q$ oblongo-ovati squamis sursum glabris dilatatis integris ciliatis, strobili recurvis undulatis. 5 Cap. Bonæ-Spei (o Niven $\downarrow$ in herb. Mart., Ladwig! Zeyher, n. 3639 ?). Masc. : Protea arcuata Lam. ill. 1, p. 234, n. 1215 ? P. obliqua *. Poir dict. 5, p. $642{ }^{*}$ ? excl. syn. Thunb. Linn. Boerhi.; fem. : Protea strobilina Linn.! mant. p. $192^{*}$ (fide herb. Linn.), Boerh, Lugd. bat. 2, p. 192, c. ic. fern.? Ramuli subumbéllati glabri. Folia rigida, 1-1 $\frac{1}{2}$ poll. longa, 4-5 lin. lata, glabertima, tenuitér venoso-rugulosa, infra medium angustata, basi tamen 1 lin. lata, callo apicís fusco obtuso plus miṇus recurvo antice sulco lineari obsoleto notato. Capitula ovata, magnit. cerasi, squa$\mathrm{mis}$ exterioribus majusculis ovatis cito revolutis, ciliis deciduis, receptaculi paleis fulvo-villosis, calycis limbo glabro (fide sp. $\sigma^{\top}$ Ludwig). Specim. ơ Niven. paulo recedit foliis raro pollice longioribus, plerisque 5-8 lin. latis, venis obsoletioribus. (v. s.)

22. L. CONC,OLOR (R. Brown l. c. p. 58), ramis breve villosis, foliis spathulatooblongis subcuneatis, utrinque obtusis venosis adultis glabris, callo obtuso recurva antice subrotundo, floralibus in $\sigma^{7}$ concoloribus, capituli $Q$ squamis retusis ciliatis basi tomentosis, floribus glabris. $\supset$ Caj. Bonx-Spei (Masson! $\sigma 7$ in herb. Banks.). ill rupestribus mont. Vanstadesberg, alt. IV, V (Zeyher, 11. 3638 ! 3636 !). Masc. : Protea arcuata $\beta$ Lam. ill. 1, p. 234, n. 1215 ? Protea globosa Andr. Bot. repos. t. 307, Bot. mag. t. 878. Protea obliqua $\beta$ Poir. dict. 5, p. 642 ? exel. syn. Boerh., Thunb ; Linn., Willd. Protea strobilina Don, fide Steudel, Willd. herb. n. 2443 ơ I Schrad. seri. Hannov. 1, p. 7, t. 1, . . (v. s. in herb. Banks., etc.)

$\beta$ ? insigne, foliís lanceolato-oblongis, involucralíbus paulo latioribus vix longiorîbus. - In lapidosis mont: Paarlberǵ. Draakensteen, Dutoitskloof, etc., alt. 100-2000 ped. (Drège). L. retusum Drège a! olim. L. insigne Buek! in pl. Drège. Rami virgati, validi, pube brevi albidâ patulâ diu persistente velutini. Folia lanceolata, basi obtusa, $1 \frac{1}{2}-2 \frac{1}{2}$ joll. longa, 5-9 lin. lata, juniora, minute velutina, mox glabra, callo terminali antice subrotundo concavo, venis tenuibus semiimmersis apicem versus evanescentibus ; floralia tenuiora et longiora, usque ad 3 poll. longa et 1 poll. lata, rubescenti-flava, glaberrima. Involucri $\supsetneq$ squamie glabre, exteriores ovatæ obtusæ, interiores sensim angustiores acuta, ciliatá. Calycis tıbus hispidus, limbus glaberrimus. Masc. non vidimus. (vi. s.)

$\gamma$. lanceolatum, foliis lanceolatis, involucralibus dimidio longioribus latioribusque.-Dutoitsklnof, alt. 1000-2000 ped. (Ludwig! $\sigma^{7}$, Brège! $Q$ docừm. p. 79). L. grandinorum Buek! in pl. Drège, n. 586 a ! Folia bipollicaria, 4-5 lin. lata. utrinque aqualiter angustata acutiuscula, tenuiter semiimmerse venosa, cum ramis breve velutini, tardius glabrescentia; involucralia reliquis latiora, 6-7 lin. lata, capitulum superantia rubescentia, ceterum similia. Capitulum $ᄋ$ magnit. pruni majoris (diam. fere $1 \frac{1}{2}$ poll.), squamis ovatis, exteriorihus obtusis glabris, interioribus sensim paulo longioribus acuminatisve, intimis lanceolatis longiuscule ciliatis. Càlycis tubus dense hirsutus, limbus glaber. Nuces non vidi. Forma accedens ad L. venosum et floridum. (v. s.)

d. ? ciliatum, foliis oblongis basi villoso-ciliatis, utrinque grossiuscule promintilovenosis, margine nerviformi subincrassato. Ciet. ignota. - In rupestribus circa Guadenthal, alt. $4000-5000$ ped. (Drège! docum. p. 116). L. ciliatum Buek ! in pl. Drège. Forsan propria sp. (v. frustuI. steril. in herb. Sonder:)

93. L. GRANDIFL ORUM (R. Brown in Linn. Trans. 10, p. 59), ramis temuissime tomentosis, follis lanceolato-oblongis, callo apicis antice subrotundo, adultis glabris, floralibus coloratis, capituli $\sigma^{7}$ et $Q^{\prime}$ squamis ovatis obtusiusculis glabris fucatis. F Cap. Bonæe-Spei, Euryspermum grandiflorum Salisb. parad. 105. Protea ciliata Desf. et.P. decora hort. Angl., fide Steudel. Species nobis obscura; specim. nuthent. enim non vidimus. An huc spectat L. grandiflorum Drège $b$ ? quod ron vidimus; non a, quod L. incolor $\gamma$ Iıob.), an etiam Zeyher, n. 3636 ?

84. L. ovaLE (R. Brown ! l. (. p. 59), foliis oblougo-ovalibus subeveniis callo obtuso, adultis glabris margine tomentosis; strobili squamis lanceolato-ovatis aeutis glaJoris, samaris apteris impunctatis extus ventricosis. F Cap. Bonæ-Spei, ad Palmiet Rivier (Nasson! et Roxl. in herb. Banks.). Protea strobilina Thunb. diss. p. 52, n. $44^{*}$, Al. Cap. p. 136, n. 62, ex R. Br. Protea glabra Thunb.I mss, fide sp. ơ in herb. 
Roemer (nune Shuttleworth) cujus adumbrat. hic addere liceat. Ramulus tomentosus (nec velutinus), folia modice córiacea, oblongo-ovalia, $1-1 \frac{1}{2}$ poll. longa, 8-10 lin. lata, basi parum angustata, glaberrima, subparallele 3-5-nervia, nervis tenuibus semiimmersis parce venosis vix anastomosantibus apicem marginesque versus evanescentibus, callo apicis obtusiusculo mucronulato antice triangulari concavo; involucralia omnino similia, nec majora, nec colorata, nec margine diaphana. Capitulum magnit. jruni, squamis exterioribus late ovatis acutiusculis recurvis basi puberulis, interioribus lanceolatis acutis erectis glabris. Calyx totus glaber, laminis linearibus. (v. s. in h. Banks.)

$\beta$ ? humifusum, ramis apice tomentellis, foliis glaucis glaberrimis, callo apicis obtusissimo retuso antice late triangulari, floralibus con formilus paulo latioribus viridibus vel basi apiceque rubescentibus subenerviis, capitulo ㅇ globoso magn. pruni (samaram et $\sigma^{7}$ non vidimus). - In lapidosis mont. Zwartebergen, alt. $1000-4000$ ped. alibique (Drège ! docım. p. 64 et 118). L. humifusum E. Mey.! in pl. Drège. (v. s.)

25. L. vENOSUM (R. Brown l. (i. p. 59), foliis ol,longo-laniceolatis venosis glabris, callo acuto, strobili squamis ovato-lanceolatis acutis ciliatis extra médium glabris, calycibus persistentibus, nuce apterả. $\$$ Cap. Bouæe-Spei.

$\beta$. oblongifolium, foliis ovali-oblongis, callo parvo mucroniformi acutiusculo antice late triangulari concavo, capituli $\sigma^{\top}$ globosi squamis glabris haud ciliatis, calycis tubo parce pilosiusculo, limbo giabro (Zeyher, n. $\mathbf{3 6 3 7}, \mathrm{O}$ in herb. Drège ?). Protea coriacea Willd.! mss. in lerb. n. 2445 . 0 !. Rami validi, apice tomentelli, mox glabri. Folia $1 \frac{1}{2}-2 \frac{1}{3}$ poll. longa, 8-11 lin. lata, utrinque æqualiter attenuata obtusa, undique glabra, callo recto vel vix recurvo, nervo venisque semiimmersis tenuibus, primariis nervo subparallelis, secundariis obsoletis apicem versus evanescentibus; floralia conformia, haud majora, paululum tenuiora, pallide rubescenti-flava, margine haud diaphana. Capitulum magnit. pruni minoris. Exceptis notis modo indicatis valde accedit ad L. decorum $\beta$ insigne, $L$. ovale et grandiflorum. (v. sp. Ludwig! in herb. reg. Stuttgart.)

26. L. DEGURRENS (R. Brown! J. c. p. 59), foliis lanceolato-spathulatis basi attenuatà subdecurrentibus concaviusculis ramisque glabris, calycis $Q$ tubo hirsuto, strobili squamis subrotundis demum glabriusculis, samaris cinereis obcordatoalatis biconvesis. J Gap. Bonæ-Spei (Nelson! in herb. Banks.), Franschehoek, etc. $\left(\sigma^{\top}\right.$ et $O$ Drège! docum. p. 119). Protea pallens Thunb. diss. n. $41^{*}$, exel. syn. omnib., ficle R. Br. Protea chamælea Lam. ill.1, p. 237, n.1240? Poir. dict. 5, p. 650*? Protea pallida Willd. herb. n. 2441! $\sigma^{\top}$. Rami (specim. Drège) graciles, stricti, sub-

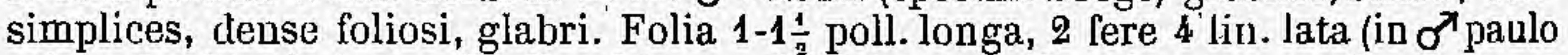
minora), obtusissima vel callo obtuso apiculata, enervia vel uervo medio venisque paucis immersis obscure notata, basi attenuata obsolete in ramum defluente (nec vere decurrente). Capitula foliis superata, $\&$ magnit. fere juglandis, $\sigma^{\top}$ duplo minora, squamis ovatis, exterioribus glabris, interioribus basi puberulis. Calyx $\sigma^{T}$ totus glaber, $f$ tubo parce hirsuto, limbo glabro. (v. s. in h. Banks., Willd., etc.)

27. L. GLABRU M (R. Brown! in Linn. Trans. 10, p. 60), foliis lineari-lanceolatis eveniis, adultis ramisque glabris, strobili squamis obtusissimis subretusis tuboque calycis nudis, samaris alatis rlaniusculis dilatatis nigris. F Cap. Bonæ-Spei $\left(\sigma^{7}\right.$ et Roxburgh! ! in herb. Banls.), in paludosis, ad fl. Klynrivier et in rupestribus mont. Zwarteberge (Zuher, n. 3642 !), Paarlherg (Drège locum. p. 86 ?). Rami vir-

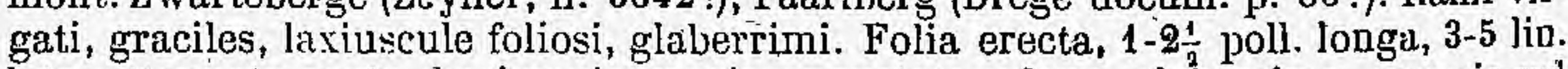
lata, attenuato-acuta, basi paulo magis angustata, plana, glaberrima, enervia vel passim obscure 1-nervia, jarce pennivenia, dense ninuteque rugulosa, margine haud diaphana, callo apicis parvulo mucronuliforni obtusiusculo subrecto; floralia haud vel parum longiona, dimidio vel duplo latiora, viridia, interdum infra medium paulo latiora et leviter erubescentia, margine anguste diaphana. Capitulum $O$ globosum, magn. juglandis (diam. fere 1 poll.), squamis coriaceis fuscis latis obtusissimis. Samaræe nigræe, subnitide, compressissime, suborbiculares, emarginatæ, muticæ, læves, circ. 3 lin. longæe latæque, alà tenui angưstâ apice fere 1 lín. latâ cinctie, nucleo leviter biconvexo parce impresso-punctato. Calyx $\sigma^{\top}$ glaberrimus. (v. s. in h. Banks., ete.) 
$\beta$. angustifolium, foliis elongato-linearibus, 2-3 poll. longis, 2-3 lin. latis (cæet. ut in pl. Zeylueri). L. virgatum d, Drège $\$$ ! (samaram et $\sigma^{x}$ non vidimus). simillimum L. adscendenti, sed diversum foliis longioribus, strobilo majore, squamis latissimis haud retusis. (v. s.)

\%. obtusatum, foliis brevioribus (1-1 $\frac{1}{2}$ poll. longis, $3-4$ lin. latis, apice parum angustatis obtusis, callo obtuso apiculatis, passim distinctius venosis. Capit. ignota (Drège, n. 2408, a! steril. iiı herb. Müblenbeck., et L. lanigerum Buek in pl. Drège l ex parte, excl. a). Exceptis notis indicatis omnia ut in specim. Zeyher. (v. s. steril.)

28. L. STRTCTUM (R. Brown! l. c. p. 60), foliis linearibus subulato-mueronatis ramulisque gracilibus glabris, summis conformibus æqualibus concoloribus capitulum superantibus, bracteis exterioribus capitulo florido longioribus glabris, in o7 ovatis acuminatis acutis, strobili fructiferi rotundatis dilatatis, calyce $\sigma^{\top}$ glabro, samarâ apterâ impresso-punctatâ. 春 In humidis saxosis Afr. Capensis, prope Stellenbosch, etc. (Roxburgh! Masson! in herb. Banks.), Groote Houhoek, etc, alt. 1000-3000 ped. (Zeyher, n. 3648! Drège!). Euryspermum salicifolium Salisb. parad. 75. Protea conifera $\Lambda$ ndr. Bot. repos.t. 541 , Poir. dict. 5, p. 649, A ? P. conica Lam. ill. 1, p. 237, n. 1237? Rami graciles, laxe foliosi, glabri. Folia $1 \frac{1}{2}-2$ poll. longa, $1 \frac{1}{2}-2$ lin. lata, basi parum anguslata, apice sensim attenuata et in mucronem tamen subulatum rectum $\frac{1}{2}-1$ lin: longum pallidum abeuntia (rarius apice breviter attenuata et mucronulata), apice venosa, tenuiler riguloso-striata, omnia glaberrima. Capitulum $\sigma^{\top}$ globosum, magnit. cerasi minoris, squamis ovatis capitulum æquantibus vel superantibus enerviis lævibus glaherrimis rubentibus opacis, exterioribus acuminatis. Calyx glaber. Fem. non vidimus. (v. s. in h. Banks., 'etc.)

29. L. п ам оs s s м м м (Buek! in pl. Drège), ramis gracilibus strictis glabris, ramulis laxe foliosis cano-tomentellis, foliis patulis lineari-lanceolatis utrinque attenuatis obsolete penniveniis glabris, callo apicis brevi obtusiusculo, floralibus interioribus capitulum dimidio superantibus oblongo-lanceolatis acuminatis rubescentibus, capitulo o conico-ovato demum subgloboso, squamis parvis lanceolatis villosiusculis, calyce toto incano-tomentosn. 7 Cap. Bonir-Spei (Drège, n. 8045 ! in herb. Muihhlenbeck.). Spccies in Drège. PI!. geogr. Document. non citata, accedens ad L. strictum et salignum, sed ab ntroque distincta foliorum mucrone obtuso vel nullo, involucro longiore, capitulo majore, calyce pubescente, et a posteriore præterea foliis glaberrimis. Ramuli subcorymbosi, breves, simplices. Folia vix rigidula, 1 $\frac{1}{2}-2$ poll. longa, 2-3 lin. lata, callo apicis palliclo interdum mucroniformi, plana, 1-nervia, levissime rugulosa; margine hand diaphana; floralia exteriora conformia, 8-12 lin. longa, glaherrima, larvișsime venoso-striata vel snblævia. Capitulum o magnit. cerusi mediocris, sessile, squamis parvis. Calycis tomentum adpressum, haud sericeum. Stigma clavatum. Fem. ignota. (v. s.)

30. L. EUCAL Y T IF o I U M (Buek ! in pl. Drège), glaberrimum, foliis lineari-lanceolatis aculis muticis basi attenuatis subevenis minute sulcato-striatis, capituli ơ squamis coloratis subeveniis acuminatis, exteriorum acumine foliaceo elongato viridi, interiorum sensim breviore subulato colorato. 5 In sylvà prope George, alt. infra 1000 ped. (Drège, n. 8044 ! docum. p. 123). Facies L. saligni et stricti. Rami

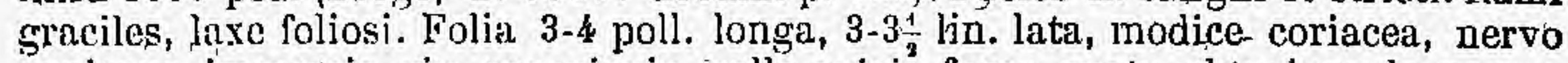
venisque immersis vix conspicuis, callo apicis fusco ovato obtusiusculo parum conspicuo antice sulco-lineari obsoleto. Involucrum $\sigma^{7}$ fusco-rubrum, bracteis exterioribus foliis rameis similibus 2-3 poll. longis, basi breve dilatatis coloratisque margine minute ciliatis, interioribus 6-12 lin. longis, 4 lin. latis, in acumen 2-4 lin. longum acutissimum (exsicratione? involuto-concayum) rectum productis, intimis sanguineis. Caly x slaberrimus, rubellus, laminis obtusis. Fem. non observata. Forsan mers var. I.. stricti, recedens inprimis foliis longioribus latioribusifue, mucronis subulati defectr, et involucro (cæteroquin omnipo simili) duplo majore. (v. s.)

31. L. viRgatum (R. Brown in Linn. Trans. 10, p. $60 \%$ ), foliis erectis linearibus attenuato-acutis muticis angustissime diaphano-marginatis ruguloso-striatis ramulisque strictis glaberrimis, floralibus -lineari-lanceolatis elongatis, strobilo ovato, squamis ovatis integris incano-tomentosis, samaris alatis emarginatis. 5 Circa urbem Cap. alibique (Ludwig! Pappe! Ecklon! n. 469! Drège! Zeyher, n. 3644! 
3645 ! 3650? Sieber fl. Cap n. 81 fl. mixt. n. $93 \sigma^{7}$ l etc.). Protea conifera Linn 1 mss. in herb. Linn. ex parte, Willd. herb. n. $2440 \sigma^{7}$, fol. 1 et 4 (cret. exclus.). Proted virgata Poir. suppl. 4, p. 556*. Protea pallens herb. Willd. n. 2439 , fol. 1 et 2 ! $O$

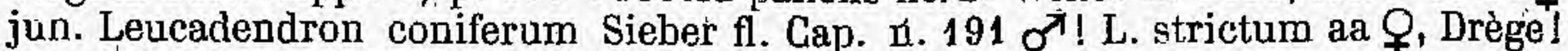
L. rubri-callosum Buek! in pl. Drège (ex parte forsan ad L. lanigerum spectans).

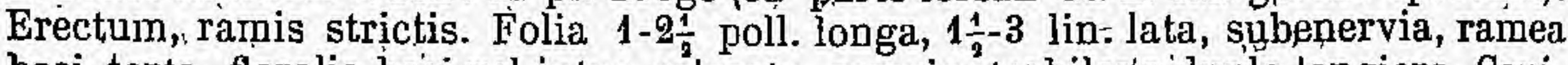
basi torta, floralia basi vel intus colorata, rameis strobilove duplo longiora. Capitulum magnit, ávellanæe, squamis ineanis vix sericeis, interioribus apice subcoarctatis. Species a sequen te agre distinguenda. (v. s. in h. Linn., Banks., Willd., etc., et v. v.c.)

32. L. A DSCENDEN (R. Brown! 1. c. p. 61), caule subulepresso, ramis adscendentibus glábris, foliis patulis erectisve lineari-lanceolatis utrinque attenuatis acutis muticis ruguloso-striatis glabris margine liaud vel vix diaphanis, floralibus lanceolatis dilatatis apice coarctatis concavis coloratis, strobili squamis ovatis inte gris incano-tomentosis, samaris alatis emarginatis. F Ad Cap. Bonde-Spei, in planitie et montibus, alt, 1000-3000 ped. vulgare (herb. Banks, I Sieber herb, Cap. i. 9! Ecklon, Un. itin. n. 469 ! Ludwig! Gưcinzius! Drege! Zeyher, n. 3649! Boivin, in. 560 ! 561! etc.).-Plulien. mant. 181, t. 229, f. $6, \sigma 7$, Boerh. Lugd. bat. 2, p. 200 et 203 , c. tab.? Breyn. cent. p. 21 , strobilus ad basin, tab. 9, Weinm. phyt. 4, p. 295, t .903, a ? Protea pallens et conifera Linn. mant. $193^{\star}$ et herb. $\sigma^{\top}$ et plurimor. auct. ex parte. P: conifera Willd. herb. n. 2440 , fol. 2 ! $\sigma^{7}$ (cæt. exclus.). Protea involucrata Willd. herb. ৩. 2444! $\bigcirc$. Protea obliqua Willd. herb. n. 2438 ? (forma parvifolia). L. adscendens Drège $\mathrm{a}, \mathrm{b}, \mathrm{d}$ ! e ? L. strictum Drège aa $\&$ ! L. virgatum Drège a $Q$ ! Euryspermum frondosum Sálisb., fide Spreng. syst. 1, p. 457. A simillimo precedente, cum plurimis notis convenit, dignóscitur foliis apice plus minus convolutis margine raro subdiaphanis, floralibus elongatis et inferne dilatatis in $\supsetneq$ sæpe $2 \frac{1}{2}$ poll. longis, rameis duplo latioribus 5-6 lin. Iatis plerumque pallidioribus vel (basi prosertim) rubescentibus margine sæpius diaphanis. (v. s. in herb. Linn., Banks., Willd., etc., et v.v. c.)

33. L. L anigenu (Buek ! in pl. Drège), ramis dense subvelutino-pilosiusculis, foliis lineari-lanceolatis utrinque parum angustatiș apice concavis obsolete venoso striatis cano-pilosiusculis demum glabris, callo apicis obtuso mutico, floralibus conformibus capitulum globosum superantibus, calyce glaberrimo, strobili squamis late ovatis sericeo-tomentosis apice subretuso patulo glabrescente, samarâ. planâ rhomboideâ emarginatâ glabrâ obsolete impresso-punctatâ apice lale alatâ.

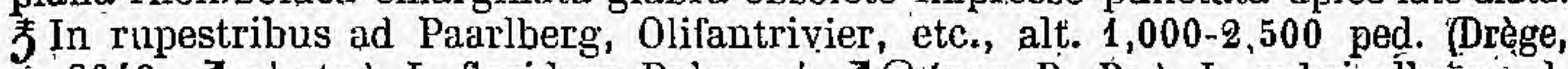
n. $8040 \sigma^{\top} \mathrm{a}$ ! etc.). L. floridum Drège a! $\sigma^{\top}$ (non R. Br.). L. rubricallosum d, $\sigma^{7}$ Buek! in herb. Sonder. Habitus L. adscendentis. Rami dense' patenti-pubes-

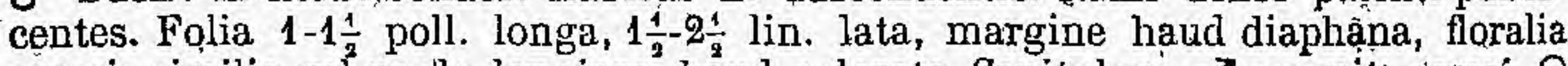
rameis similia vel paulo longiora, haud colorata. Capitulum $\sigma^{\top}$ magnit. cerasi, 우 mole juglandis. Stylus glaber, stigmate oblongo-clavato sulcato. Samará atrofusca, 3 lin. longa, fere 4 lin. lata, apjicis alâ $\frac{1}{2}$ lin. latâ. (v. s.)

$\beta$. lovigatum, foliis eveniis lævibus, subtus obsolete immerso-1-nerviis, ramulisque minute puberulis. - In lapidosis montanis, inter Hexrivier et Bokkeveld, alt. 3,000-4,000 ped. (Drège! docum. p. 114). L. heterophylium A. Mey.! in pl. Drège. Folia pollicaria, inferiora siepe dimidio breviora spathulatooblonga 2-3 lin, lata. Cret. ut in typo speciei. (v. s.)

34. L. CONCINNUM (R. Brown 1. e. p. 61 *), foliis subimbricatis lanceolato-oblongis obtusiusculis eveniis ramisque strictis glaberrimis, floralibus subconformibus pàulo longioribus somicoloralis, strobili squamis ovatis integris argenteo-tomentosis, samaris alatis emarginatis of Cap. Boux-Spei (Niven! in herr. Mart.), in rupestribus mont. Zwarteberge, alt. IV (Zeyher, n. 3642, ex parte).-Pluken. pliyt. t. 229, f. 4? Protea concinna Poir. suppl. 4, p. 556*. Frutex 10-pedalis (fide Niven). Folia conferta, erecta, uncialia, subconcava, nigrgine angustissime diaphano scabrinscula, callo apicis obtusiusculo, floralia $1 \frac{1}{2}$ poll. longa, strobilo maturo vix duplo longiora. Ramuli in specim. Gueinzianis adscendentes, apice pube patulâ imolli pilosiusculi. Folia circ. pollicaria, $1 \frac{1}{2}-2$ lin. lata, plana, tenuiter rugulosa, acutata cum callo obtuso fusco, basi vix attenuata; involucralia numerosa, æquilónga, $2 \frac{1}{2}$ lin. lata, margine latiuscule subitiaphana et intus rubescentia, dorso medio plerumque viridia. Cápitula $\sigma^{\top}$ et flores L. saligni. Calycis ungues pilosius: culi, lamina glaberrima. (v. s.) 
hencadeadron. PROTEACEA (adctor MEIstier).

$\beta$. latifolium, glaberrimum, folitis ovali-oblongis, calloso-acuminulatis, margine angustissime diaphanis (cret. ignota).- In monte Giftberg, alt. 1,500-2,000 ped. (Drège! docum. p. 71 et 198). L. acuminatum Búelk ! in pl. Drège (fide fragm. steril. in herb. Sonder). Folia 12-15 lin. longa, 6-7 lin. lata, apienllo vix $\frac{1}{2}$ lin. longo obtusiusculo antice concavo. (v. s.)

35. L. BALIGNUM (R. Brown in Linn. Trans. 10, p. 62), ramis apice tomentellis, foliis lanceolato-linearibus attepuato-acutis subulato-mucronatis basi vix angustatis venoso-striolatis sericeis, floralibus conformibus, capituli $f$ squamis sericeotomentosis sursum dilatatis retuso-bilobis margine glabris, calyce or glabro,

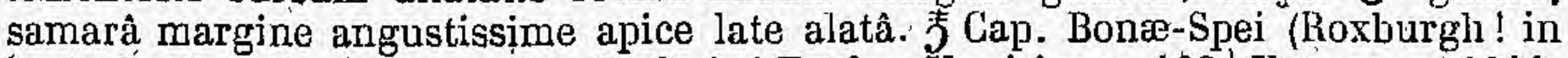
herb. Bariks), Zwarteberg, etc. (Ludwig! Ecklon Un. itin. n. 468! Krauss, n, 1044, Drège! docum. p. 106, Zeyher, n. 3646! et ex parte 3647 l). - Boerh. Lugd. bat. 2, p. 204, cum tab. Protea argentua $\beta$ Lirn. sp. ed. 1, p. 94 (excl. syn. Breyn. et Tourn.). Protea conifera $\alpha$ Linn. sp. ed. 2, p. 138 (excl. syn.), herb. Linn.l ex parte. Protea saligna Linn. mant. p. 1940 (excl. syn. Berg. ct Breyn.), Lam. ill. 1, p. 236, n. $\mathbf{1 2 3 5}$, Poir. dict, 5, p. $648 * 6$, Willd. herb. n. 2448 ! fol.1, et ex parte 2 . Protea sericeq Thunb. $?$ diss. n. 46 , fl. Cap. p. $136^{*}$, Willd.! sp. 1, p. 528, fide herb. n. 2447 ! Protéa inflexa Willd. enum. Protea diversifolia Willd. herb. et Euryspermum sericeium Salisb., fide Spreng. syst. 1, p. 458. Habitus L. virgati, folia L. adscendentis, sed adpressse sericea, acutiora, fere subulato-mucronata (acumine tamen breviore quam $L$. stricti), involucralia reliquis longiora et in $Q$ latiora, $2 \frac{1}{2}-3$ lin. Jata, basi fut margine vel intima tota flava vel rubicunda, glabra, interiora breviora evenia, capitula ovato-globosa, o màgnit. cerasi, fruçtifera juglandis majoris (diametr. 1 poll:). Variat ramis villosiuseulis (Mund, n. 25 ! Zeyler, n. $3646 \sigma^{\lambda}$ l), foliis 1-2-rarius (Zeyh. 11. $3646 \sigma^{7}$ !) 3 poll. longis, 2-3 lin. latis, plerumque adpressissime sericeis mox glabrescentibus et (in $\beta$ Mund, $n, 25$ !) dítius laxiusćue pilosiusculis, mucrone $\frac{1}{2}$-fere 1 lin. longo pallido, involucralibus capitulo parum vel duplo longioribus plus minus acuminatis. (v. s. in h. Linn., Banks., Willd., etc.)

ß. longifolium, ramis villosiusculis, foliis $2-3$ poll. longis, 2-3 lin. latis, muticis, mox glabratis, callo apicis obtusiusculo recto fusco, involucralibus ơ capitulo duplo vel triplo longioribus ovato-oblongis longe acuminatis dense tomentosis, acumine convoluto apice subulato (eæt. ut in typo speciei). Forte distincta sp. (v. s. sp. Zeyher, sub n. 3646, $\sigma^{7}$ ).

$\gamma$. linearifolium, foliis linearibus ( $1 \frac{1}{2}-2$ poll. longis, 2 lin. latis) subfalcatis apice attenuatis cum mucrone $\frac{1}{2}-1$ lin. longo, junioribus pube longiore laxiuscule sulvvillosis.-In Hottentottsholland (Mund, $\mathrm{n} .25, \mathrm{~b}$ !). k. cuspidatum Klotzsch! mss. in herb. reg. Berolin. Foliis angustis accedit ad L. floridum, sed hujus ic. Pluk. phyt. t. 229, f. 4, abhorret foliis multo brevioribus apice subito (nec sensim) attenuatis. (v. s.)

36. L. U IGINOS M (R. Brown l. c. p. 63), ramulis tomentosis pilosisve, foliis pollicaribus lanceolato-linearibus acutis basi vix angustatis subenervijs lævibus utrinque argenteo-sericeis, callo apicis parvulo acutiusculo, floralibus capitulum superantibus concoloribus conformibus vel interioribus latioribus ovato-oblongis breve acuminatis, strobili squamis sericeo-tomentosis dilatatis subretusis margine subundulato recurvis, calycis of tubo hirsuto, samarâ apterâ cuneato-obovatá truncatì lævi. F) Cap. Bonæ-Spei (Burchell, n. $2101^{\prime}$ ' Sieber herb. Cap. n. 7! $\sigma^{\top}$ lírauss, n. 1043, 1045), in planitie, prope Wynberg (Ecklon! $\sigma^{\top}$, Zeyher, n. $\mathbf{3 6 4 7}$ ex parte, $ᄋ$ Drège docum. p. 124), - Breyn. cent. 21, 1. 9 (excl. strobilo ad basin tab.). Protca saligua Thunb. diss. p. 53, n. 47 ${ }^{*}$, fl. Cap. p. 136, n. 66. Leucadendron salignum, a, Drège! $\sigma^{\top}$ 우. Rami virgati, graciles, ramulis corymbosis vel fastigiatis laxiuscule foliosis. Folia 10-16 lin. longa, 2-21 lin. lata, utrinque tomento arcte adpresso argentea, callo apicis fusco recto brevi sæpe mucroniformi; involưcralia pube densiore longiore sericea, interiora jræcipue in ơ dimidio latiora. Capitula globosa et ovali-globosa, magnit. cerasi-juglandis. Sumara nigra, opaca, submutica, 2 lin. longa, dorso subplana, antice obtuse subearizatto-convexa. A proxime alfini L. saligno folils brevịoribus magis sericeis et præcipue samarâ facile dignoscitur. (v. s.)

37. L. FLORIDUM (R. Brown! 1. c.p. 63), foliis lanceolato-linearibus sericeis supra villosis, callo apicis aeuto, floralibus subtus ramisque hirsutis, calyce $\sigma^{\top}$ piloso, strobili squamis tomentosis apioe dilatatis integris, samara apterâ. 
Cap. Bone-Spei, ad radices mont. Wynberg (Roxburgh! in herb. Banks:),-Pluk. phyt. 181. t. 229, f. 4. Protea saligna, o' et 0 , Andr. Bot. repos. t. 572 ? Species absque strobilo maturo a L. uliginoso vix distinguenda. (v.s. in herb. Banks.)

\section{\$ 4. Strobili squama connato. - Samara folïaceo-compressa, glabra. - Folia omnia vel ex parte fliformia. (R. Brown 1. c. p. 63.)}

38. L. Platyspersu in (R. Brown! in Linn. Trans. 10, p. $63^{*}$ ), glabrum, ramis erectis virgatis dense foliosis, foliis apice obtusis callosis, inferioribus tereti-filiformibus canaliculatis, superioribus floralibusque spathulato-linearibus lanceolatisve planis capitulum superantibus, strobili globosi vel oblongo-ovalis squamis duplicatis longitudinaliter connatis demum patentissimis rimis semicircularibus,

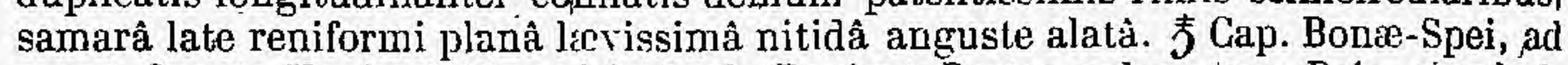
mont. Groote Houhoek (Ange! in herb. Bauks.). Protea polysperma Poir. suppl. 4, p. $556^{\circ}$. 7eyher, n. 3653 ! $\sigma^{7}$ (). Species distinctissima. Folia 1-2-pollicaria, rami primarii inferiora filiformia 1 -sulca, superiora canaliculata grarlatim apicem versus in laminam lineari-syathulatam concavam demum planam dilatata; ramulorum ultimorum omnia spathulata plana obsolete 1 -nervia evenia vix rugulosa $2-4$ lin. lata; in $\sigma^{7}$ minora, vix ultra $1 \frac{1}{3}$ poll, longa. Capitula $\sigma^{\top}$ ovoidea, magnit. cerasi minoris, squamis lanceolatis cano-sericeis, exterioribus glabratis; calycis laminis glabris. Strobilus maturus mole juglandis et ultra, squamis glabris, samaris duplo latioribus quam longis (7-9 lin. latis, 4 lin. longis), compressissimis luteo-fuscis obsolete mucronulatis basi leviter emarginatis, alâ tenerrimâ vix 1 lin latâ apice basique angustiore. (v. s. in h. Banks., etc.)

39. L. с омо ч м (R. Brown!1.c. p. 64), foliis inferioribus filiformibus, superioribus spathulato-lanceolatis obtusis mucronatis vel acuminato-acutis rugoso-striatis, strobilo oblongo, squamis basi connatis supra distinctis marginibus leviter inflexis subbarbatis, samarà subrotundà nigrâ. J In montibus circa Z rellendam (Masson! in herb. Banks.) et inter Sparrbosch et Tradow, alt. 1000-2000 ped. (Drège!). Prótea comosa Thunb. diss, p. $43, n, 25^{*}$, n. Cap. p. $121, \mathrm{n} .31^{*}$. - Willd. sp. 1, p. 517, Lam. ill. 1, p. 238, n. 1254, Poir. dict. 5 , p. 655 . Huc etiam spectare videtur Leucadendron erieifolium (excl. O⿱⺌兀) Drège! (L. comosum Buek!) cui habitus fere Isopogonis axillaris, ramuli stricti, apice puberuli; folia semierecta, spathulatolinearia obtusissima mutica, rigida, 10-12 lin. longa, apice $1 \frac{1}{2}-2$ 'lin. lata, plana, leviter rugoso-striata glabra, callo apicis obsoleto, infima angustiora passim subulata; capitula sparse axillaria et in apice rami approximata, sessilia (nondum evoluta), ovato-oblonga, 4-5 lin. longa, squamis adpressis ovatis obtusis canotomentosis demum glabris. Flores et samaram non vidimus. A descr. Thunb. tamen abhorret capitulis axillaribus foliisque. (v. s. in herb. Banks., etc.)

40. L. $\approx$ м U L U м (R. Brown! 1. c. p. 64), glabrum, foliis 1-2-pollícaribus mucronato-acutis, inferioribus tereti-filiformibus sulcatis, superioribus floralibusque lineari-vel lanceolato-spathulatis acutis vel apiculatis planis rugoso-sulcatis capitulum superantibus, capitulo of globoso, $q$ oblongo, squamis lanceolatis calycibusifue glabris, extimis in $\bigcirc$ margine Jjarbatis, strobilo ovato, squamis basi connatis supra distinctis patentissimis marginibus imberbibus recurvis, samarâ subrotundà vel ovali nigrà apice late, alatâ. . . Cap. Bonæ-Spei (Roxburgh! in herb. Banks.), in rupestribus mont. Langekloof alibique, alt. 1000-4000 ped. (Drège !). o Protea incurva Andr. Bot. repos. t. 429 ? (recedens foliis superioribus tix duplo latioribus). Chasme ramentacea Knight, fide Spreng. syst. 1, p. 458. Rami virgati,

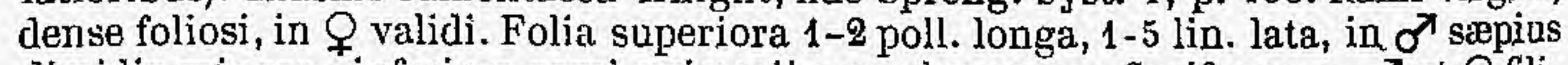
dimidio minora ; inferiora rami primarii ramulorumque floriferorum $\sigma^{\lambda}$ et $Q$ filiformia. Capituli o ó globosa, magnit. cerasi, cylindrica, 1-2 poll. longa, squamis extimis acuminatis 3-6 lin. longis. Strohilus maturus magnit. ovi anatini. Samaræ 3-4 lin. longæe, 3 lin. latæe, compressissimæ, subopaca, alâ apicis $1-1 \frac{1}{2}$ lin. latâ deorsum evanesconte. ( $v$. s.)

$\beta$. homeophyllum, foliis (saltem in oا) omnibus, otiam floralibus, filiformibus. Ad Dutoitskloof, alt. 1000-3000 ped. (Drège! docum. p. 79, 81). L. abietinum Drège! (non R. Br.). Ramuli tenues, glabri. Folia semipatula, recta, acutius-ula, mutica, 1-1 $\frac{1}{2}$ poll. longa, supra sulco tenui percursa, lævia, glabra. Capitulum $\sigma^{7}$ ovato-conicum, magnit. cerasi majoris, foliis superatum, squamis exterioribus ovato-oblongis obtusiusculis glabris, interioribus paleæformibus 
barbatis. Calyx et stylus glabri, stigmate oblongo-clavato sulcato. Fem. non observata. An distincta sp.? (v. s.)

41. L. A BIET IN U (R. Brown! in Linn. Trans. 10, p. 64), foliis omnibus filiformibus supra 1-sulcis vel canaliculatis obtusiusculis arcuato-incurvis, strobilo ovato, squamis late obovatis truncatis marginibus axibusque infra connatis supra distinctis emarginato-bilobis glabris, samarà.... F Cap. Bonce-Spei (Masson! in herb. Banks.), in collibus graminosis, ad latera mont. K]ynriviersberge (Zeyher, n. 3654 ! $\sigma^{7}$ et (). Protea teretifolia Andr. Bot. repos. t. 161, $\sigma^{7}$ et $Q$. Chasme teretifolia Salisb., fide Spreng. syst. 1, p. 458. Ramuli specim. Zeyher. breviter' patulo-puberuli, umbellati, conferte foliosi. Folia semitcreti-filiformia, patula, lievia, glabra, in $\oint$ 6-10 lin. longa, $\frac{1}{3}-\frac{1}{2}$ lin. crassa, magis arcuata, in $\sigma^{\top}$ breviora, unguicularia, summa vix 2 lin. longa.Capitulum ơ pedunculo brevi folla subæquante suffultum, eirc. 10-florum, magnit: pisi, bracteis exiguis ovatis glabris albo-ciliolatis, calyce glabro rubro 1 lin. longo, laminis obtusis ungue longioribus, antheris ovalibus muticis laminam æecuantibus, stylo glabro, stigmate fusiformi-clavato fere $\frac{1}{2}$ lin. longo. Strobilus maturus sessilis, ovato-globosus subpollicaris, squamis late obcordatis marginibus axibusque connatis demum patulis glabris apice rotundato bilobo leviter inflexis. Samaræ desunt. Species a L. corymboso', quocum in herbariis sæpe confusa, notis indicatis lacile distinguenda : capitulis or paucifloris foliisque in $\sigma^{\top}$ similis L. ericifolio, sed floribus glabris, etc., facile dignoscenda. (v. s. in herb. Banks., etc.)

12. L. ERIGIFOLIUM (R. Brown! 1. c. p. $66^{*}$ ), foliis confertis semipollice brevioribus omnibus semitereti-filiformibus muticis glabris, capitulis $\sigma^{7}$ çorymbosis breve pedunculatis paucifloris, squamis ovatis sericeis flore brevioribus, calyce gracili tomentoso. J Ad Caput Bonse-Sp. (Roxburgh! in herb. Soc. linn. Lond.), in rupestribus inter Sparrbosch et Tradow, alt. 1,000-2,000 ped. (Drège I docum. p. 116). Protea ericifolia Poir. suppl. 4, p. 557 *. L. ericifol. et comosum $\sigma^{\top}$ Buek! in pl. Drège (excl. ㅇ? cfr. L. comosum). Frutex erectus, ramosissimus, ramulis gracillimis tenuissime tomentellis apice subumbellatim 4-5-cephalis. Folia imbricato-erecta, demum patula, 2-5 lin. longa; vix $\frac{1}{3}$ lin. lata, obtusiuscula, supra subconcava. Capitula globosa, magnit. pisi, squamis vix 1 lin. longis, acutis vel exterioribus obtusis. Calycis laminæ unguibus longiores, antheræque apiculatæe lineares. Stylus glaber, stigmato clavafo, ovario squamulisque hypogynis nullis. Hujus, ni fallor, femina (cel. R. Brown ignota) est L. scabrum Steudel (in herb. Ludwig! Mus. Stuttg.). Habitus, rami, pubescentia, folia omnino L. corymbosi $\mathcal{q}$, sed capitula multo minora (magn. pisi), sessilia, foliis superata, turbinato-ovalia, pauciflora, squamis flores subæquantibus sericeis, exterioribus lanceolatis, interioribus ovatooblongis obtusiusculis integris basi cohærentibus apice recurvis, calycis parvi tubo jlumoso-barbato laminis oblongis apice glabris. Stigma et fruct. non vidimus. (v. s. in herb. Banks., etc.)

43. L. SCAвRU M (R. Brown l. c. p. 65), foliis omnibus filiformibus acutis canaliculatis imbricatis rectiusculis margine scabris pilosisve, strobili squamis marginibus axibusque infra connatis apice distinctis bilobis. 7 Cap. Bonæ-Spei (Hibbert). Huc spectare videtur Protea thyoides Smith! mss. in herb. Soc. linn. Lond., specim a G. Hibbert 1801 lect. Masc. rami graciles, dense foliosi, minute puberuli, umbellatim multiramosi. Folia erecta, subadpresse imbricata, subulato-acuta, semiteretia subincurva, margine ciliata et minute serrulato-scabra, 2-3 lin. longa, $\frac{1}{3}-\frac{1}{9}$ lin. lata, involucralia 4-5 lin. longa, juniora minute puberula. Capitula ơ sọlitaria, sessilia, oblonga, dense multiflora, 5-6 lin. longa, bracteis exterioribus angustissime linearibus ciliatis, interioribus brevioribus minutisque. Calyx vix 1 lin. longus, ruber? glaberrimns, an theris oblongis muticis. Stigma clavato cylindricum. Fem. folia quam in $\sigma^{\top}$ duplo vel triplo longiora, lævia, glabra, summa tantum obsolete scabra et parce ciliata. Strobilus ovatus, 5-6 lin. longus, squamis obtusis. Facies potius Sorocephali quam Leucadendri. (v. s.)

\section{§ 5. Species quoad sectionem dubia, feminis adhucdum ignotis.}

44. L. SERICEUM (R. Brown! in Linn. Trans. 10, p. 65), caule erecto, foliis lanceolatis semiunguicularibus sericeis, capitulis $\sigma^{\pi}$ sessilibus solitariis aggregatisve turbinatis, calycis unguibus pubescentibus, tuho gracili inferne stylo cohærente. 亏 Cap. Bonæ-Spei (Massón l). Protea sericea Linn. suppl. p. 118*. - Thunb. diss.

xIv. 
a. $46^{\circ}$, n. Cap. p. 136, n. $65 \%$. Habitus fere L. Levisani. Rámi puberuli, demum glabri. Folia 3-4 lin. longa, acuta, mutica, subadpressá, canò-sericea. Cäpitulum o7 magnit. pisi majoris, floribus sericeo-tomentosis. Stigma exserturn, clavatum, obtusum, $\frac{1}{q}$ lin. longum, atrum. (v. s. in herb. Banks.)

65. L. Glo bularia (R. Brown l. e. p. 65*), ramis strictis, ultimis sericeis, foliis lineari-spathulatis pollice brevioribus eienliis glabris basi attenuatá torlis, callo àjioncis obtusissimo, cápitulo ơ sessili depresso-globoso, squamis ovatis tomientosis, calyce gracili, unguibus styloque villosis, laminis glabris. 3 Cap. Bong-Spei (Roxburgh ! in herb. Banks.), in planitie arenơsâ, ad Simonsberg, Groeneklơoff, ete., infra alt. 500 ped. (Drège !). Protea Globularia Lam. ill.1, p. 236, n. 1233, t. 53, ĺ. 2 . -Poir. dict. 5, p. 647? exel. sỹn. Thunb. Erecta, ramosissima. Folia 6-9 lin. longa, apice $1 \frac{1}{2}$ lin. lata, inferiora breviora, summa confertiora. Bractexe eapitulo dimidio breviores. Squamulæ hypogynæ, 4 longæ, lineares, styli basi infernè adnatze. Simillimum L. pubescenti, sed foliis minoribus minus venosis ramisque glabris et stigmate tenuiore distinctum; nec non formis quibusdam L. Levisani, sed foliis duplo majoribus, etc., diversum. Specim. Dregeatia b. recedunt involucri squamis exterioribus demum glabris ciliatis $€ t$ stylo glabro. (v. s. in herb. Banks., etce:)

66. I. PUBESCENS (R. Brown! 1. c. p 66), ramis patula-villosiusculis, foliis spathulato-linearibus pollicaribus obtusis obliquis maticis ruguloso-striatis. pubésetentibus, cállo a apicis rotundo, junioribus sericeis, capitulo ơ sessilẹ globoso. involucrum tomentosum sulıerante, calyce sericeo-villoso, stylo pubescente. F Cap. Bonæ-Spei (Roxburgh ! in herb. Banks., Niven ! n. 61, iń herb. Sondér), pröp̆è Saldânhabaai, infra alt. 500 ped. (Drège docum. p. 113. Specim. non vidlínius). L. decorlum var. minus Buek ! in pl. Drège (locum. p. 116); fide specim: steril. in herb. Sonder. Rami virgati, ramulis umbellatis laxiuscule foliosis. Folia rigida; 1 poll. longa, 3 lin. lata, subvenosa (in specim. Niven linearia, vix spathulala, circ. 2 lin. lata, atrinque attenuata.) Capitula ơ magnit. cerasi mediocriś. Stigma clavatum, exsertum, $\frac{4}{2}$ lin. longum, obtusum, atrum. A prrecedente, cui monente ill. auct. maxime affine, præcipue pubescentiâ, a L. lanigero, cui etiam accedit, foliis minus ribidis, apice planis et presertim calyce minore laminisque haud glabris dignoscétidum. (v. s. in herb. Banks., etc.)

17. L.? D A P NOIDES, foliis imbricatis sessilibus ellipticis apice callosis, infُerioribus sericeo-villosis albis, superioribus glabris, capitulo terminali globoso calyceque glabro. ₹ Cap. Bonæ-Spei.' Protea dlaphnoides Thunb. fl. Cap. p. 135, n. $53^{*}($ in ejusd. disss: de Proteâ non occurrit). Frutex erectus molliter albo-hirsutuș, caule subsimplici pedali et ultra. Folia sesquipollicaria, integra. Bracteæ foliis latiores, p̣allidse, glabré. Cap̣itulum solitarium, magnit. nucis moschatæ (Thunub. l. c.). Species valde obscura, an Ximetis generis ex affinitate M. Hartogii?

18. L. CRASSIFOLIUM (R. Brown! in Liun. Trans. 10, p. 66 \%); glabram, glaucum, foliis crassis cuneato-obovalis subeveniis basi attenuatis apice rotundatís vel subtruncatis cum callo parvo acutiusculo subrecurvo ramulisque glaberrimis, involucrálibus conformibus, capitulis glubosis, squamis lanatis in of rhomboideis striatis liberis demum glabrescentibus induratis, caljce ơ' glabro, nuce apterà

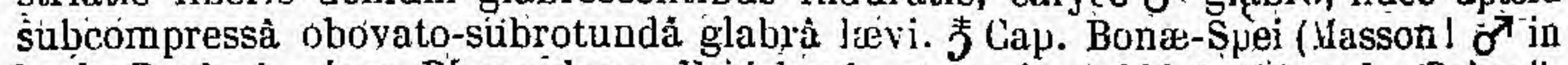
herh. Banks.), círca Bladuwberg, Ezelshank, etc., alt. 1,000-5,000 ped. (Drege!). Protea crassifolia Poir. sùypl, 4, p. $557^{\circ}$. L. concolor aa E. Mey.! olim in pl. Drège. L. sjathulatum Buek! $Q$ in pl. Drège (Jocum. p. 73 scr.). Rami (in sp. O Drège) tirgdti, sanguinci, glabri, juniores pallidi. Folia $1-1 \frac{1}{2}$ poll. longa, extra medium

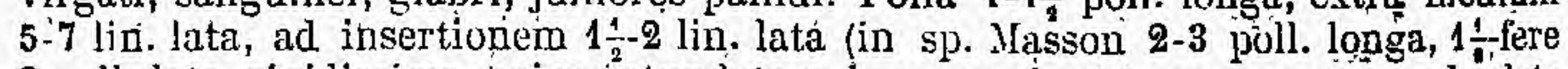
2 poll. lata, rigidissima, apice iotundato rubro-marginata), nonnunquam obsolete triplinervia, nervis immersis ante medium evanescentibus plerumque vix visibithbirs. Capitulum o (lefloratum) magnit. juglandis; squamis castaneis adpresșis, éterioribus subacuminato-acutis $6-7$ lin. latis basi fulvo-pubescentibus superne glabris arete venoso-rugulosis, mediis obtusis. Nux atrofusca, opaca, $2-3-\mathbf{3}$ lin. longa lalaque, mutica, semicompressa, dorso valde convexa, marginibus acutius-

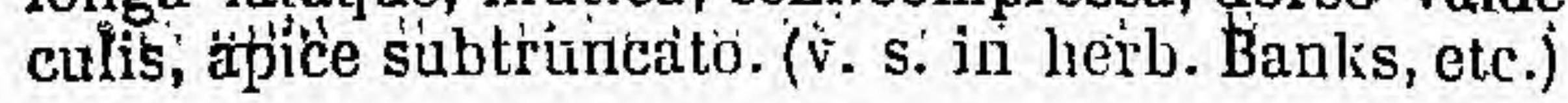

49. L. CARTILAGINEUM (R. Brown 1. c. p. 67 ), ramulis apice tomentellis, folits crassis eveniis glabris sjathulatis obtusissimis muticis basi anguste linearibus. flaralibus conformibus capitulum $\sigma^{7}$ globosuni superantibus, bracteis lañcéolatis

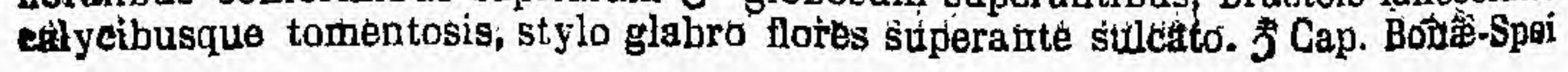


(Roxburgh! in herb. Banks., Niven ! in herb. Mart.), in collibus, prope Liliefontein et Ezelskop, alt. 4,000-5,000 ped. (Drège! docum. p. 68). Protea cartiliainea Poir. suppl. 4, p. 557\%. A precedente, eui proxime affine et simile, facịle dịstinguitur foliis̉ vix únquam pollice longioribus, sæepissime paulo brevioribus $2 \frac{1}{2}-5$ lin. latis, callo apicís transversali obtusissimo vel obsoleto, nervo venisque plerumque penitus invisibilibus, basi petioliformi vix 1 , lin. latà. Capitula magnit. cerasi, squämiis cal ycibusque fulvis, stylo atro-purpureo, stigmate oblongo-clavalo obtuso fere 1 lin. longo. Rami erecti, virgati, fastigiàti. Fem. ignota: Monente cel. auctore forsan proprii generis. (v. s. ín herb. Banks., etc.)

\section{Species obscurce et quoad genus incertee.}

50. L.? P Rо S т в А т и м, decurubens, ramis erectis villosis, foliis patentibus pollicaribus ellipticis substriatis callosis, capitulis subglobosis tomentosis, stylo calycem duplo superante, stigmate clavato. $\mathrm{J}$ Ad Cap. Boris-Spei. Protea prostrata Thunb. prodr. p. 27, fl. Cap. 1, p. 487, ed. Schult. p. 133, Roem. et Schult. sjst. 3, p. 355*. Protea (Leucad.) cinerea Ait.? Poir. dict. 5, p. 651. Frutex totus villosus, ramis capitulo solitario juglande dimidio minure terminatis, foliis approxínatis. Ad L. retusum (sujra, n. 3) accedens, ex R. Brown in Linin. Tráns. 10, p. 221.

51. L.? H IR UTUM, follis unguicularibus elliptico-linearibus mucronatis nervośis ramisque hirsutis, capitulo globoso tomentoso-hirsuto..... F Ad Cap. Bonæ-Spèi. Protea hirsuta Thunb. phytogr. Blatt. p. 12, fl. Cap. 1, p. 483, ed. Schult. p. 131 *, Roem. et Schult. syst. 3, p. $355^{*}$ (non Willd.). Frutex erectus, bipedalis et ultra, totus hirsuto-subtomentosus, ramis fliformibus. Folia sparsd, erecta, acuta. Capl: tulum terrninále solitarium, fertugineo tomentosum, magnit. pyri minoris (fide phytogr. Blatt.) vel ceraso paulo majus (fide fl. Cap.)

52. L.? овтUSАтUм, caule decumbente, foliis pollicaribus lineari-oblongis obtusis glabris, superioribus obovatis obtusissimis..... JAd Cap.Bonæ-Spei. Protea obtusata Thunb. phytogr. Blatt, p. 15, fl. Cap. 1, p. 48 i, ed. Schult. p. 133, Roem. et Schult, syst. $3, \mathrm{p} .356^{*}$. Caulis fruticosus, parum ramosus, pulverulentus, rufescens. Folia sparsa, secunda, rugosa. Capitulum terminale, magnit. avellanæ. Foliis accedere videtur ad Leucad. spaliulatum, Lẹvisanum et Globulariam.

53. L.? L A VE, foliis imbricatis unguicularibus oblongis lanceolatisve obtusiusculis lævibus glahris, capitulis terminalibus glabris, involucro brevi lævi.... J Aa Cap. Bonse-Spei. Protẹa lævis Thunb. fl. Cap. ed. Schult. p. $133^{*}$ (non R. Br.). Caulis fruticosus, glaber, subdichotomus, ramis subfastigiatis elongatis haud flexuiosis. Folia sẹssilia. $\mathrm{Ab}$ auctore cum sequente comparatur.

54. L.? CONIFERU, ramis flexuosis, foliis pollicaribus elliptico-lanceolatis acutis glandulà terminatis concavis subrugosis glabris, capitulis ovatis tomientosis:.... F Ad Cap. Bonæ-Spei. Protea conifera Thunb. diss. n, 42*, fl. Cap. ed. Schult. p. $135^{*}$ \{non? alior. $)$. Frutex erectus, 3 -pedalis et ultra, ramis verticillatis flexuoso-erectis ramulosis. Folia conferta, erecta. Capitula terminalia solitaria, magnit. pisi, involucro concolore. Forsan a L. adscendente, virgato vel stricto haud distincla.

55. L.? REтICULATUM, foliis lanceolatis digitalibus calloso-obtusiusculis elevatoreticulatis cauleque glabris, capitulo parvo glabro, squamis intimis subciliatis,

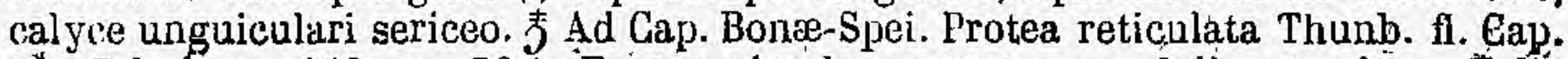
ed. Schult. p. 138 , n. 73 \% Frutex simplex, erectus, pedalis et ultra. Folia sparsa, sessilia, valde venosa, erecto-patentia. Capitulum terminale solitarium, magnit. pisi.

56. L.? R U G o 9 บ м, caule hirsuto, foliis imbricatis pollicaribus ellipticis acutis callosis ruggosis glabris, capitulo globoso fóliis vix coloratis obvallato et superato, squamis apice imprimis hirsutis. $\mathrm{F}$ Ad Cap. Bonæ-Spei. Protea rugosa Thunb. fl: Cap. ed. Schult. p. 135, n. $57^{*}$. Folia sessilia, alterna. Capitulit solitaria, magnit. nucia avellanie.

57. L.? TENUIFOLIUM, foliis unguicularibus elliptico-vel subspathulato-linearibus callosis acutis ramisque glabris, capitulo globoso parro glabro, calyce hirsuto. 5 Ad Gap. Bonæe-Spei. Protea tenuifolia Thunb. fl. cap. ed. Schult. p. 135; 11. 58 *

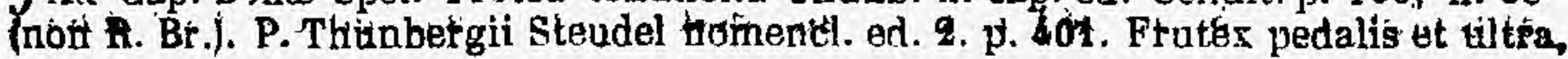


erectiusculus, purpurascens, gluber, ajjice ramulosus. Folia linearia, apice vix Jutiora, curva. Capitula solitarią, magnit. pisi, folìs non obvallata.

58. L.? PYRAMIDALE (Steudel nomencl.ed. 2, 2, p. 35), foliis imbricatis pollicaribus elliptico-vel ubovato-oblongis obtusis cum callo lævibus ramisque glabris, cajitulis globosis glabris, squamis ciliatis..... F Ad Cap. Bonæ-Spei. Protea pyramidalis Thunb. fl. Cap. p. 135, n. $59^{\circ}$. P. pallens $\gamma$ Thunb. ibid. Frutex erectus, pedalis et ultra, glaber, apice alterne ramosus, ramis subfastigiatis simplicibus. Folia inferne valde attenuata. Capitula solitaria, magnit. avellanæ, bracteis obvallantihus rameisque pallidioribus.

59. L.? ACUTUM, foliis pollicaribus erectis ellipticis acutis callosis obliquis ramisque glabris, capitulis ovato-subrotundis, squamis glabris, calyce hirsuto..... $5 \mathrm{Ad}$ Cap. Bonæ-Spei. Protea virgata Thunb. fl. Cap. ed. Schnlt. p. 133, n. 52 * (non alior.). Frutex erectus, ramosissimus, glaber, ramis verticillatis elongatis, ramulis alternis virgatis. Folia approximata, sessilia. Capitula solitaria, piso majora. Ab auctore cum P. parvifoliầ suâ (Leucad. plumoso) comparatur.

60. L. ? о DORA T u (Steud. nomencl, ed. 2, 2, p. 35), foliis erectis falcato-incurvis lineari-subulatis mucronatis basi attenuatis ramisque glabris, involucri squamis lanceolatis cinereis glabris, calyce villoso. F Ad Cap. Bonæ-Spei: Protea odorata Thunb. prodr. append. p. 187, fl. Cap. ed. Schult. p. 130, n. 36.R. Brown in Linn. Trans. 10, p. 217. Caulis fruticosus, fuscus, flexuoso-erectis, glaber, trichotomoramosus. Folia pollicaria et ultra. Capitula terminalia solitaria, magnit. avellanæ.

01. L. L IN IF OL I U (R. Brown in Linn. Trans. 10, p. 216), foliis lineari-spathulatis aversis basi attenuatis ramisque glabris, capitulo masculo sessili foliis circumvallantibus longiore, calycis tubo barbato, laminis stylisque imberbibus $5 . . .$. . Protea linifolia Jacq. hort. Schoenbr. 1, p. 11, t. 26. Sine dubio Leucadendri sp., et valde affine $L_{2}$ torto, sed distinctum capitulis masculis sessilibus et calycis laminis glabris.

62. L. FUSCIFL OR UM (R. Brown 1. c. j. 216), foliis lineari-lanceolatis glabris junioribus rectis basi attenuatis, capitulo femineo foliis circumvallantibus breviore, calycis tubo pilosiusculo, laminis plumoso-barbatis. $₹$..... Protea fusciflora Jaci. h. Schoenbr. 1, p. 11, t. 27. Certe Leucadendri sp. et monente ipso auctore forsan L. angustati var., cujus planta mascula forte Protea stellaris Sims Bot. mag. t. 881. Cfr. R. Br. 1. c. p. 217. Leucad. stellare L. Leuc. stellatum Sweet, ex Steudel.

63. ? L. TAUNCATUM, foliis sessilibus erecto-patulis unguicularibus obovatis acuminatis basi attenuatis ramisque glabris, capitulo foliis circumvallantibus dimidio breviore globoso truncato parvo tomentoso. F Ad Cap. Bonce-Spei. Protea truncata Thunb. fl. Cap. ed. Schult. p. 134 *. Frutex filiformis, flexuoso-erectus. Capitula magnit. Pisi, bracteis foliis similibus obvailata.

64. L.? M A RGINA TUM (Link, fide Steud. nom. ed. 2,2, p. 34), foliis lanceolatis acutis callosis basi attenuatis giabris margine piloso-sericeis, capitulo foliis lanceolatis albido-flavescentibus involucrato, squamis fuscis pilosis, calyce glabro. $\hbar$..... Protea marginata Willd. enum. suppl. p. 7 (vix ej. herb., cfr. L. decorum $\beta$, supra, n. 20). P. ciliaris Wendl., Voit. P. ciliata hort. Angl., fide Steudel 1. c. Leucospermum marginatum Spreng. syst. 1, p. 464. Est verisim. L. adscendens vel sp. huic affinis.

65. L.? V ERTICIL L AT UM, totum argenteo-sericeum, ramis verticillatis, foliis subimbricatis unguicularibus ellipticis, capitulis sessilibus glabosis parvis argenteis.... F Ad Cap. Bonæ-Spei. Protea verlicillata Thunb. phytogr. Blætt. p. 19, 1. Cap. p. 449 , fl. Cap. ed. Schult. p. $136^{*}$. Sorocephalus verticillatus Roem. et Schult. syst. 3, p. $391^{*}$, Steud. nom. ed. 2,2 , p. 401 et 613. Caulis bipedalis et ultra, erectus, ramosus. Folia ex phytogr. Bl. pollicaria, lanceolata. Capitula terminalia, solitaria, piso majora.

66. L. ? INV OLUCRATUM, foliis lineari-lanceolatis acutis callosis nervosis fere obliquis basi attenuatis glabris, capitulo sessili parvo tomentoso, involucro laxo sesquipollicari, squamis ovato-oblongis acuminatis concavis glabris basi subcoloratis, strobili fructiferi squamis villosis. JIn montibus Steenbergen, Cap. Bonæ-Spei. Protea involucrata Lichtenst. spicil. fl. Cap mss. Leucospermum? involucr. Roem. et Schult. syst. 3, p. 363*. Fruticosum, erectım, ramis subverticillatis. Folia ses- 
silia. Capitulum magnit. pisi majoris, fructiferum magn. pruni. Ex involucro potius Leucadendri quam Leucospermi species, nec forsan a $L$. virgato vel adscendento (supra n. 31 et 32) satis distinctum.

\section{Species non descripta.}

L. CAL L OSU M (Hoffmannsegg). = Prótea callosa Wendl., ex Steudel nomencl., ed. 9. 2, p. 34 .

L. FLA VEscens (Link ex Steud. l. c.).= Protea flavescens Willd. enum. suppl. p. 7.

L. POLYGALOIDES (Link., ex Steud. l. e. p. 35). = Protea polygaloides Willd. 1. c. p. 7, an Willd. herb.? Cfr. L. imbricatum R. Br. $\gamma$ (supra, n. 8). Protea canaliculata Andr., ex Spreng.

\section{Species exclusup.}

L. ACAUL ON L, = Protea acaulis Thunb.

L. CANCEL L A т M L. $\Rightarrow$ Aulax pinifolia Berg.

L. GONOCARPODENDRON L. = LeucospermumConocarpum B. Br.

L. GUCULATUM L. = Mimetes cucullata $\mathrm{R}$. Br.

L. CYANOIDES L. = Serruria cyanoides R. Br.

L. CYNAROIDES L. = Protea cynaroides L. et grandiflora Tlunb.

L. DIVARICATUM Berg. = Mimetes divaricata R. Br.

L. ELONGATUM Berg. = Serruria elongata R. Br.

L. G L O Е RAT U M L. = Serruria glomerata R. Br.

L. GRANDIFL ORUM Salisb. = Leucospermum grandiflorum B. Br.

L. нIR т UM L. = Mimetes hirta R. Br.

L. HYPOPHXLLOCARPODENDRON L. = Leucospermum Hypophyllum R. Br.

L. LEPIDOCARPODENDRON L. = Protea Lepidocarpon R. Br.

L. NAN M Berg. = Protea nana Thunb.

L. OLEAF OLIU B Berg. = Leucospermum olerefolium R. Br.

L. PH Y LIC OI DES Berg. = Serruria phylicoides R. Br.

L. PINIF OLIU M L. = Aulax pinifolia Berg.

L. PROTEOIDES L. = Mimetes purpurea R. Br.

L. PUBIGERU M Linn. herb. = Leucospermum puberum R. Br.

L. RAG EM osum Berg., L. = Spatalla ramulosa R. Br.

L. Repens L. = Protea mellifera et repens Thunb.

L. SCOLYM OGEPH ALUM L. = Protea Scolymus Tliunb.

L. ScOPARIUM E. Mey. = Sorocephalus lanatus $\mathrm{R}$. Br. $\beta$.

L. Serraria Burm. herb. = Serruria phylicoides R. Br.

L. Serraria Linn. = Serruria Burmanni R. Br, $\alpha$.

L. SERRARIa Linn. $\beta$. = Serruria glomerata $\mathrm{H}$. Br.

L. SPECrosuM L. = Protea speciosa L.

L. SPHAROCEPHALUM Berg. = Serruria Bergii R. Br.

L. spicatum Berg. = Nivenia spicata R. Br.

L. Thun Bergit EndI. = Protea ? glabra Thınb.

L. THYMRLAOIDES Berg. = Mimetes thymelæoides R. Br. 
III. PROTEA Linn. gen. ed. 1, n. 59, R. Brown in Linn. Trans. 10, p. 48 et 74, Smith exot. Bot. 1, t. 44, II, l. 81, Endl. gen. p. 337, n. 2123, suppl. IV, 2, p. 76, Meisn, gen. p. 331 (24). - Leucadendron Linn. gen. ed. 2, n. 74. - Lepidocarpodendron Boer $h$. Lugd. bat. p. 55, ex parte. - Scolymocephalus Herm. dendr. t. 9. - Vionæa Neck. Erodendron Salisb. parad. 67, 70,108. $\rightarrow$ Pleuranthe Salisb. - Gagnedi Bruce Abyss. 5, p. 52, c. ic. - Chrysodendron Vaill. herb.

Flores hermaphroditi, capitati, capitulo multifloro globoso, hemisphærico, turbinato vel oblongo, squamis coriaceis imbricatis persistentibus sæpe coloratis involucrato, receptaculo plano vel convexo vel ovato vel conicooblongo sæpissime glabro, paleis abbreviatis persistentibus nonnunquam in alveolas connatis. Calyx elongatus gracilis bipartibilis, limbo bilabiato, laminis 3 in labium cohærentihus sæpe aristatis, quarıâ liberâ. Anlheræ 4 calycis liminis concavis insertæ, subsessiles, liberæ, lineares, connectivo sæpius ultra loculos in apiculum glanduliformem vel suluulatum producto. Squamulæ hypogynæ 4. Ovarium 1-loculare, 1-ovulalum. Stylus subu|atus, persistens, rectus vel falcatus, inferne sæpius compressus. Stigma cylindraceum vel subulatum, continuum vel basi oblíque nodulosium genicúculatum vel subarticulatum. Nux stylo caudata, undique harbata, 1-locularis. - Frutices vel arbusculæ, Africæ australis et orientalis tropicæ, caule erecto vel rarius procumbente vel brevisșimo, folijs sparsis sessilibus vel peliplatis rigide coriaceis integerrimis planis vel canaliculatis venosis sæpe marginatis, cap:tulis terminalibus rarius lateralibus solitariis vel breve pedunculatis erečtis vel nutantibus plerumque magnis speciosis.

\section{Acrocephale. - Capitula terminalia.}

\section{\$1. Caulescentes. - Arbusculce vel frutices elatiores, caùle epigcoo $2-\infty$-pedali erecto.}

- Barbigerce--Involucri squame interiores (rarius et exteriores) apice pilis mollibus longis sapius atris dense villoso-barbata vel comosa.

1. P. coccinea (R. Brown in Linn. Trans. 10, p. $77 \%$ ), foliis obovatis vel oblongoobovatis utrinque obtusissimis vel basi angustatâ subemarginatịs prominulovenosis glabris, capitulo magno turbinato-ovali, siguamis extus glabriusculis, interioribus spathulato-oblongis apice rotundato margine fulvo-barbatis; calyce 2-3-pollicari, unguibus rufo-hirsutis, aristis filiformibus laminas inferne glabratas subrequantibus plumoso-barbatis dorso apiceque glabris, stylo valido compresso glabro, stigmate subcontinuo subulato acutiusculo exsulco basi obliquo. 7 In Africæ austr. monte Díaboli (Niven, Ecklon, Un. itin. n. 651), Dutoitsijoof, alt. 3,000-4,000 ped. (Drège! docum. j. 82), distr. Zwellendam, (Zeyher, n. 3655!). Roem. et Schult. syst. 3, p. 343* . P. rangiferina hort., ex Steudel. Frutex 4-5-ped., ramis crassis glabris apice dense imbricato-foliosis. Folia sessilia, crassiuscula,

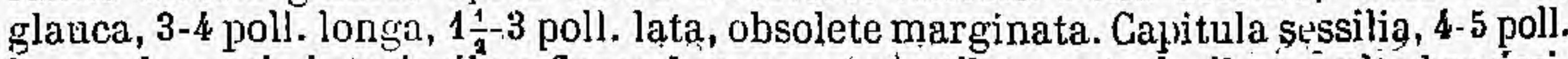
longa, bracteis interioribus flores breve sujerantibus, ex terioribus multo breviorihus ovatis obtusis ciliolatís. Calyx $2 \frac{1}{3}-3$ poll. longus, aristâ unà cæeteris breviore. Stylus calycem æquans, rectiusculus. Stigma 3 lin. longum, pallidum, basi haud nodulosâ, sed curvaturâ obsoletissimâ in stylum duplo crassiorem transiente.(v. s.)

2. P. Latifolia (R. Brown l. c. p. 75*), ramis tomentosis, foliis sessilipbus cordatoovatis obtusis reticulato-nervosis submarginatis glabris, capitulo magno, squamis sericeo-tomentosis, interıoribus flores æquantibus linearibus superne oblongodilatatis apice barbatis, calyce tripollicari tomentoso, aristis laminấ suhpluplo longioribus villoso-barbatis stylum puberulum superautibus, stigmate subulato recto sulcato obtusiusculo basi hinc noduloso. $J$ In arenosis et rujpestritibus Africx austr., mont. Zwarteberg, Vanstaadesberg, etc., alt. 2,000-5,000 ped. (Roxburgh! in herb. Banks., Drège ! Zeylıer, n. 3656!). - Bot. mag. t. 1717, Roem. et Schult. sysi. 3 , p. $342^{*}$, mant. p. 263 , P. radiata Andr. Bot. repos. t. 646, Bonpl. Malm. p. 144, t. 59? cfr. P. longiflora. Erodendron eximium Knight et Sal. Prot. p. 41. Frutex 6-8-pedalis, ramis apice foliis dense imbricatis omnino absconditis. Folia 
3-4 poll. longa, 2-3 poll. lata, crassa, amplexicaulia, margine obșolete nerviformi initerdium lanato. Capitulum folia semisuperans, turbinatum, magnit. pugni. Fḷores usılue ad $3 \frac{1}{2}$ poli. longi, laminis 3 inclusầ aristâ pollicaribus rufo-liirșutis apico longius purpureo-barbatis, quartạ exaristatà. Stylus $2 \frac{1}{2}$ poll. longus, rectịasculps, compresso angulatus, stigmatis nodulo basali hine valde conspjicuo. Species a P. compacta follis valde simili jam bracteis barbatis sligmateque facile dignoscenda. '(v. s. in herlj. Banks., etc.)

3. P. SPECT \BIL1S (Lichtenstein spicil. fl. Cap. mss.), foliis cordatis ovato-oblongis incrassato-marginatis reticnlato-venosis glabris, summis fongioribus oblongis basi attenuatis, involucri squamis exterioribus ovatis viscidis, interioribus longioribus angustioribusque, intimis flores superantibus longissimis linearibus convolutis tomenlosis ajjice ciliatis, calyce cano-tomentoso, stigmate capitato-conico. ₹ In collibus ad fl. Palmietrivier, Hottentotshollandskloof. - Roem. et Scluplt. šyst. 3, p. $284^{*}$. P. latifolia? Spr. syst. 1, p. 460. Mimetès spectabilis Steud. nomencl. ed. 2, p. 401, Roem. et Sch. mant. 3, p. 268. Arborea, ramosa. Folia sessilia, infécitora basi dilatata. Capitulum magnit. Cynaræ Scolymi. Ovarium pilis cinctum. An eadem ac P. spectabilis Willd.? qui P. compacta, infra, n. 30.

4. P. AURICULATA (Tausch in Florâ 1842, 1, p. 285), foliis glaucis glabris oblongis obtusis bași attenuatà cordatis auriculís oblique inflexịs subamplexicaulithus margine nervoque rủbris, capitulo turbínato, squämis sericeis, interioribus èlon. gatis jüpureo coloratis taibatis, calycis aristis lamina longioribus, stylo basi pubescente sub apice genjoulato. 5 ? Cap. Borıs-Spei (culta e semin. Ecklon. in hort. comitis Salm.). Suecies observante Ecklon P. grandifloræ affinís, nobis valde dubia, forsan a P. latifoliả liaud distinčta.

5. P. specros a (Linn. mant. p. 191), follis crässis oblongis obovatisve basi angustatis mucronato-acutiusculis marginatis subnervosis ramisque glabris, capitulis magnis, squamis sericeis ciliatis obtusis, interioribus elongatis, flores superantibus medíisque apice dense fusco-harbatis, calyce 3-pollicari sericeo, láminis breve aristatis, stýlo compresso inferne puberulo, stigmate tenui subacutó basi obsoleté noduloso. 5. In Airrice austr. montilıus usque ad alt. 3,000 ped. (Drège docum. p. 117, Krauss, n. 1042, etc.). - Sims Bot. mag. t. 1183, Andr. Bot. repos. t. 110, R. Br. l. c. p. 73 , Ro.m. et Schult. syst. 3, p. $343^{*}$. Leucadendrón speciosum Linn. mant. p. $36^{*}$ (excl. syn. Clusii). Protea $L$ pidocarpodendron $\beta$ Linn. syst. veg. XIII, p. 118 P. grandiccps Tratt. thesaur. t. 12. P. baṛlsata Lam. ill. 1, p. 236, n. 1228 . P. magnifica Andr. Bot. repos. t. 438, Link enum. alt. p. 113. P. obtusa Knight, ex Loudón encycl. ed. 1, p. 80, c. ic. Eŗodendron obtusum hort.? ex Steudel. E. magníficuni Salish., fide Sureng. syst, 1, p. 461. Arbuscula orgyalis (fide Thunb.), ramis validis erectis. Folia 3-6 poll. longa, 1-2 poll. lata, subimmerse nervosa vel subenervia. Capitula pvoidea, magnit. pugni, squamis omnibus albo-sericeis, exterioribus ovatis, intimis oblongis passim apice dilatatis, apicis barbâ rufo-fúscâ molli densissiṇà $2-3$ lin. longâ. Calyx 3 poll. longus, albo-sericeuś, laminis 5.6 lin. lapgis dorso interdum parce rubro vel albo-barbatis. Stylus

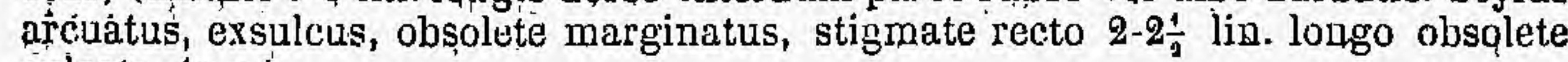
sulcato. (v.s.)

B. angustata, foliis oblongis acutiusculis inferne angustatis obsolete marginatis, calycibus $2 \frac{1}{2}$ poll., laminis 4 lin., aristis 1 lin. longis. - Ad Zwartebergskloof (Ludwig, n. 10! in herb. Mus. Stuttgart.), Onrustrivier, etc. (Zeyher, n. 3666, $\beta$ et $\gamma$ ! Oldenburg in herb. Banks!). Scolymocephali sp. Weinm. phyt. 4, p. 289 , t. 894 . Folia semipedalia, vix pollice latiora. (v. s.)

y. abovata, foliis obovato-oblongis obtusiusculis obsolete marginatis 3-4 poll. longis apice $1 \frac{1}{2}$ poll. latis. - In arenosis montium (Nelson! in herb. Banlis.), ad Klynrivierskloof (Zeyleer, n. $\mathbf{3 6 6 6}$ a l). Lepidocarpon fol. oblong., ett. Boerh. Lugd. bat. 2, 1. 185. c. ic. Weinm. 1. c. t. 893 a, Rouppell Cape flowers, t. $\beta$. (v. s.)

6. P. SCABRIDA (Thunb. phytogr. Blætt. p. 14, fl. Cap. 1, p. 507, ed. Schuit. p. 138\%), foliis lanceolatis marginatis glabris subscabridis, capitulo oblongo, squamis exterioribus ovatis, interioribus ublongis tomentosis intra apicem extus nigro-hirsutis margine ferrugineo-barbatis, floribus $\ldots . . .5$ Ad Cap, Bonæ-Spei. - Roem. et $\mathrm{Scliult.}$ syst. 3, p. 344, adnot. súb $P$. spieciosâ, cujus forsan mera var. Caulis simplex, erectus, pedalis et ultra. Folia sessilia, imbricata, $1 \frac{1}{2}$-digitalia, callis inconspícuis scabrida, nervo marginibusque luteis. 
7. P. MARginata (Thunb. phytogr. bl. p. 15; fl. Cap. p. 508; ed. Schult. p. 138*, non Willd.), caule hirsuto, foliis oblońgis calloso-acutis marginatis nervosis glabris, capitulo oblongo magno, squamis tomentosis, exterioribus ovatis achitis, interioribus linearibus apice spathulatis sub apice dorso margineque nigro-barbatis, floribus..... I Ad Cap. Bonæ-Spei. - Roem. et Schult. syst. 3, p. 345, in adnot. sub P. melaleuca, cui nimis affinis ridetur. Caulis simplex, pedalis. Folia subpetiolata, 1 $\frac{1}{2}$-digitalia, nervo marginibusque flavescentibus. Capitulum maximum.

8. P. maCROCEPHALA (Thunb. n. Cap.ed. Schult. p. $138 \%$ ), foliis lanceolatis imbricatis cauleque hirsutis, capitulo maximo oblongo hirsuto, squamis interioribus spathulato-oblongis obtusis ferrugineo-ciliatis, lloribus..... ₹ Ad Cap. Bon«e-Spei. Frutex simplex, curvato-erectus, pedulis et ultra, totus valde hirsutus. Folia sessilia, digitalia, apice glabriuscula. Forsan eadem ac P. incompta Br., infra, n.16.

9. P. VILLIFERA (Lindl. in Bot. reg. t. 1023), foliis glaucis obovato-oblongis obtusis muticis basi attenuatis marginatis eveniis pilis distantibus villosis capitulo oblongo brevioribus ramisque villosis, involucri squamis exterioribus glabris, interioribus lineari-oblongis roseis apice albo-barbatis. - Cap. Bänæ-Spei (in Angliâ culta). Folia sessilia, 3 poll. longa, 1-2 poll. lata ${ }_{r}$ cum ramis pilis longis mollibus tecta. Capitulum sessile 3-4 poll. longum, squamis exterioribus adpressis ovatis oblongisque obtusis, infimis apice sphacelatis. Affinis dicitur P. sppeciosæ.

10. P. patens (R. Brown in Linn. Trans. 10, p. 82 *), procumbens, ramis incanotomentosis breveque villosis, foliis anguste oblongis obtusiusculis subundulatis marginatis venosis villosis, involucro hemisphærico, squamis obtusis sericeis, interioribus mediisque apise atro-purpureo-barbatis, calyce sesquipollicari albolanato, aristis laminam iequantibus apice purpureis, stylo inferne compresso puberulo apice subulato incurvo glabro, stigmate acutiusculo, $₹$ In Africæ austr. montibus saxosis, prope Wilde River (Niven). - Roem. et Schult. syst. 3, p. 347 " P. speciosa patens Andr. Bot. repos. t. 543. Folia frequentia, secunda, basi subattenuata, 4-5 poll. longa, 7-9 lin. lata (ex ic. l. c. usque ad $1 \frac{1}{2}$ poll. lata, nervo roseo marginata). Capitulum sessile, magnit. pugni minoris, squamis interioribus nec dilatatis nec augustatis. Calycis stylum æquantis aristie ex ic. breves et stigma subulatum basi geniculatum. In specins. sub nom. P. speciosà Andr. in horto Bollwiller. culto, cum descr, plurimis notis bene congruo, video involucri squamas interiores spathulatas inferne valde attenuatas apice rufo-barbatas, calycem fere $2 \frac{1}{2}$ poll. longum, laminis medio glabriusculis, stylum nonnisi summo apice glabrum et stigma tenue $2 \frac{1}{2}$ lin. longum, obtusiusculum, basi hinc minute nodulosum. An potius P. Lepidocurpi var.? (v. s. c.)

11. P. LEPIDOCARPON (R. Brown in Linn. Trans. 10, p. 80), foliis lanceolatis acutis basi angustatis marginatis renosis punctato-scabriusculis ramisque glabris, capitulo ovoideo magno, squamis sericeo-tomentosis, exterioribus demum glabratis, interioribus flores superantibus elongato-spathulatis apice atro-barbatis; calyce piloso, laminis dorso glabris aristas setaceo-acuminatas intus rufo-barbatas subæquantibus, stylo recto calyce breriore pubescente, stigmate tenui basi hinc neduloso. $\delta$ In arenosis montibusque Africæ Capensis vulgaris (herb. I,inn.I Ecklon! Drège! Iirauss! n. 1032 ! Zeyher, n. 3657! 3659! etc.).-Roem. et Schull. syst. 3, p. 346 * Lejidocarpodendron fol. angustis, etc. Boerl. Ludg. bat. 2, p. 188, c. ic. Scolymocephalus Africana, etc. Weinm. phyt. 4, p. 289, t. 895. Leucadendron Lepidocarpodendron $\alpha$. Linn. sp. pl. ed. 1, p. 91. Protea Lepidocarpodendron Linn.! mant. p. $190^{*}$. P. speciosa Thunb. diss. n. $53^{*}$, fl. Cap. p. 139 , n. 76 , Willd. sp. 1 , p. 531. P. cristata Lam. ill. 1, p. 235. n. 1226, Poir. dict. 5, p. 644 (excl. syn. Roy, Linn., Andr.). P. grandiflora var. fol. undulatis, Andr. repos. t. 301 ? (ex Br.). Arbuscula orgyalis (Thunb.) vel frutex elatior, ramis glabris vel junioribus tomentosis subvillosisve. Folia rigida, erecta, 3-5 poll. Ionga, 5-7 lin lata, utrinque subreticulata minute elevato-puncticulata, margine plus minus nerviformi. Capitulum sessile magnit. pugni mediocris, folia parum superans, squamis exterioribus hand ciliatis. Calyx circ. bipollicaris, laminis linearibus, aristis introrsum longiuscule penuáto-pilosis. Stylus hinc sulcatus, vix dilatato-compressus, dense pilosiusculus, apice tantum glaber, stigmate sulca to acutiusculo, nodulo basali parvulo. (v. s. in herb. Linn., etc.)

12. P. MELALEUGA (11. Brown 1, c. p. 79), ramis pilosiusenlis, foliis lineari-lingu- 
latis margiriatis ciliatís, involucri elongato-turbinati squámis albo-ciliatis, exterioribus squarrosis, interioribus conniventibus spathulatis dorso nigro-tomentosis. 亏 Cap. Bonæ-Spei. - Roem. et Schult. syst. 3, p. 345 *. Lejidocarpon Boerh. Lugd. bat, 2, p. $289^{*}$, c. ic.? Scolymocephalus Weinm. phyt, 4 , p. 291, t. 898 ? Protea coronala Lam. ill. 1, p. 236, n. 1227 ? Poir. dict. 5, p. $645^{*}$ ? P. speciosa nigra Andr. Bot. repos. t. 103 . P. Lepidocarpon Ker in Bot. mag. t. 674, Rouppell Cape flow. $\iota$ 6,f. 3 ? Species ipsi auctori nonnisi ex iconibus eitatis et ineditâ Bauerianâ, quæe omnes exacte inter se conveniunt, cognita, nec sine hesitatione a P. Lepídocarpon separata, cujus forsan mera varietas. Huc relerendæe nobis videntur P. speciosa Willd. herb. n. 2453!' P. Lepidocarjon Drìge a! Ecklon et Zeyh. n. 7 ! in herb. Sonder. P. glauca Drège d! (nec a), Zeyher, n. 1456! P. villosa hort. Bollwiller, 1835, fide herb. Mühlenbeck. P. nigrita herb. DC. (sp. cult.)

13. P. PULCHELLA (R. Brown 1. 1, c. p. 81), ramis tomentellis, foliis lineari-lingulatis marginatis nitentibus scabriusculis, involucri squamis interioribus apice lanceolato-dilatato sericeo margine nigro-barbatis, calycis aristis laminan vix cequantibus, stylo pubescente. $J$ In Africe Capensis montibus circa Stellenbosch (Masson! et Roxburgh in herb. Banks). - Reichenb. fl. exot. 4, p 1, t. 218? P. pulchella Andr. Bot. repos. t. 27.0, el var. speciosa, ib. t. 442 ? Bot. reg. t. 20. P. speciosa var. et $P$. pulchella a et $b$, Drège $I$ in herb. Verisimiliter mera var. $P$. Lepidocarpi, recedens involucri squamis exterioribus subsquarrosis obsolete ciliatis, intimis apice dorso nudis margine barbà breviore rufâ sæpius deflexà ornatis. (v. s. in herb, Banks, etc.)

14. P. NERILFOLIA (R. Brown l. c. p. 81), foliis lineari-lingulatis lævibus opacis basi extus ramisque tomentosis, involucri squamis interioribus apice parum latioribus dorso argenteo-sericeis margine nigro-barbatis, calycis aristis laminas superantibus intus pennatis, stylo pubescente. $\frac{J}{f}$ Ad radices montium circa Cap. Bonæ-Spei (Ludwig, n. 10! in herb. Mus. Stnttgart., Krauss, n. 1033, Beitr. p. 139).

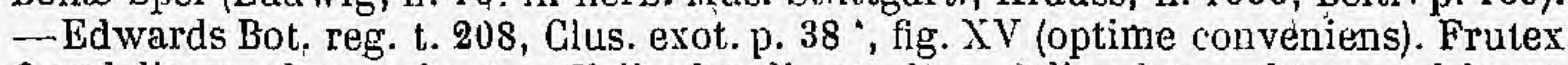
3-pedalis et ultra, robustus. Folia 4-poll. et ultra, 9 lin. lata, obtusa vel breve retuso-acuminulata, basi emarginata, margine subsimplici, dorso fortiter penninervia et in nervis (vel juniora undique) pubescentia. Capitulum 3 poll. longum, oblongo-turbinatum, basi squarrosum, squamis exterioribus fusco-sphacelatis, interioribus lineari-spathulatis. Calycis arista antice plumosa, barbà infra purpurascente supra subflavescente. Stylus compressus, strialus, ochroleucus, stigmate aciculari purpureo basi obsolete geniculato. (v. s. in herb. Banks.)

B. glauca, foliis glaucis? lanceolatis ueutis marginatis subimmerse venosis adultis glabris, involucro sericeo, sruamis exterioribus apice subrecurvo nudis, mediis apice breve fusco-barbalis, intimis elongato-spathulatis flores superantibus apice ad marginem dense nigro-barbatis, calyce tripollicari, unguibus' pilosiusculis, aristis longis laminam medio dorso glabram æquantibus intus rufo-barbatis. $₹$ Circa Paarlberg, Dutoitskloof, Hexrivier, etc., alt. 1,000-3,000 ped. (Drège! excl. d, Burke! in herb. DC.). P. glauca Buek! in $\mathrm{pl}$. Drège. Vix-species distincta, ne immo forsan var. constans, foliis capitulisque majoribus a $P$. Lepidocarpon recedens et $P$. barbigerse et macrophyliæ similior, a quibus vero bracteis aliisque notis satis distincta. Rami tementosi. Folia crassa, 3.6 poll. longa, 6-12 lin. Jata, utrinque parum angustata, callo obtusiusculo apiculata, larria, opaca, margine nerviformi haud ciliato, juniora basi subtus tomentosa. Capitulum sessile, folia cequans, obovatum, pugni mole. Calycis laminæ lineares $\div-1$ poll. longæ, dorso circa medium glahræ, aristis demum deciduis. Stylus rectus sulcatis, pubescerss, summo apice tantum glaber, inferne compresso-dilatato, stigmate tenui $2 \frac{1}{3}$ lin. longo sulca to acutiuscula, ngdulo basali hine conspicuo parvo. (v. s.)

15. P. BARBIGERA, foliis crassis oblongo-lanceolatis venosis basi vix angustata rotundatis, margine nerviformi incrassato, involucri squamis sericeo-tomentosis, intimis spathulatis flores subæquantibus apice longo denseque rufo-barbatis, calyce sub-4-pollicari, laminis aristisque ipsis longioribus dense longeque barbatis infra medium demum glabratis, quartà dimidio breviore setiformi, stylo calyce breviore recto inferne compresso puberule, stigmate basi hinc noduloso. $\delta$ In monlibus circa Dutoitskloof et Blaauwberg, alt. $3,000-5,000$ ped. (Drège!), inı rupestribus mont. Witsemberg, alt. IV.V (Zeyber, sine numero). P. speciosa Drège olim (ex parte). P. macrophylla Buek! in pl, Drège a et b (ex parte). Rami validi, apico 
tomentelli dense folipsi. Folia 4-7 poll. longa, 1-1- poll. lata. callo parva nigrescente obtusiusculo mucronulata, summa prope basin subtus laxe barbata, venis remiimmersis laxe subreticulatis. Capitulum magnum, foliis sıperatum, squamis omnibus obtusis, interiorum comâ terminali fülvâ, $2-3$ lin, longâ, densâ, vix crispatâ. Calyx $3 \frac{1}{-1}-4$ poll. longus; laminis inclıșà arista $1 \frac{1}{2}$ poll. longis, villis rectis subsecundis 3 lin. longis aurea-fulvis, terminalibus florum entralium purpureis erispis. Stylus $2 \frac{1}{2}$ poll. longus, rectus, rufus, apice tereti sulcato glaler, stigmate 3 lin. longo. Admodum similis P. neriifolix, sed distincta foliis majoribus, calyce longiore, stylum superante. (v. s.)

16. P. INcon PтA (R. Brown l. c. p. 83 "); foliis subherbaceis lanceolatis utrinque attenuatis acutiusculis lave venosis ramisque longe pilosis demum glabratis, involucro ovoideo' folia floresque sequante, słuamis oblongis glabris, interioribus apice orbiculato-dilatato margine dense villosis, calyce sub-3-pollicari louge lanatovilloso, aristis laminam requantibus villosis, stylo recto glabro, stigmate continuo tenụ. $₹ \mathrm{Ad}$ rad. montium jeninsulæe Cajensis (Sieber, n. 1! Ludwig! Ẹckłon! Drège! Krauss, n. 1630, lapsu typogr. sub nom. P. incorrupta Br., Beitr., p. 139, Zeyher, n. 3658 !). - Roem. et Seluult. syst. 3, p. 347*. Frutex erectus, patentivillosus. Folia modice coriacea, vix rigida, 3-4 poll. longa, 7-12 lin. lata, interdum basi rotundata. Capitulum pugni mole, foliis arcte cingentibus fere absconditum, sessile, squamis interioribus elongatis. Stylus calycem æquans, stigmate subulato basi haud noduloso. Forsan cum P. macrocephalâ Thunb. (supra, n. 8) identica. (v. s.)

17. P. FULVA (Tausch in Florâ 1842, 1, p. 285), foliis lanceolatis yenoșis marginatis glabris, junioribus brevissime ciliatis dnrso fue hasi subfloccosis involucro turhinato-sericeo, squamis interioribus elongatis fusco-barhatis, calycis aristis laminà longioribus fusio-hirsitissimis, stylo piloso apice subulato glabro. F Cap. BonzSpei (culta e sem. Ecklonianis in hort. comilis salm). Préecedenti affinis, teste Ecklon, nobis vero ad P. barbigeram et neriiformem nimis accedere videtur.

* Imberbes. - Involucri squama omnes imberbes, rarissime interiores apice breviter vel obsolete villosie vel cillatee.

18. P. MAC R OPHYLLA (R. Brown in Linn. Trans. 10, p. $78^{\circ}$ ), ramis apice cano-tomentellis, foliis crassis elongato-oblongis obtusis marginatis subimmerse venosis hasi breviter angustatis, capjitulo magno ovvoideo foliis breviore, squamis canotomentosis, intimis linearibus apice haud dilatato brevissime villosis paulo superantibus, calyce toto albo-tomentoso longerue villoso, apistis laminas æquantibus longe atro-harbatis, stylo exsulcn infra medium puhescente apice incurvo. $\%$ Ad latera montium Africæ austr. (Niven). - Roem. et Schult. srst. 3, p. 344 * Frulex 8-10-jedalis, ramis validis erectis. Folia summa dense imbricata, bași sxepe torta, 4-7 poll. lunga, 1-1 $\frac{1}{2}$ poll. lata, mutica, summa inferioribus longiora, capitulum plus minus superantia, laud reticulata. Capitula mole pugni, squamis obtusis, extimis oratis, mediis oblongis, intimis apice sappius rufo-tomentosis vel brevissime barbulatis. Calycis aristie villis patulis longis nigro-purpureis summis subcrispatis barbate.

ß. Dregeana, involucri squamis exteriorihus apice albo-villosis, intimis spathulatis, calycis laminis apice cum arịtis densissime rufo-villosis, stylo recto compresso apice brevissime geniculato, stigmate tenui. - Circa Dutoitslloof, alt. 3,000-5,000 ped. (Drège! docum. p. 82). P. macrophylla Drège a, ex parte. Involucri squamse intima apice 2-6 lin., inferne 1 lin. late, flores superantes. Calyx 3 poll. longus, laminis inclusâ aristâ 9-10 lin. longis, aristarum villis summis purpurascẹtibus (nec nigricantilyus). Stylus $2 \frac{1}{2}$ poll. Stigma $2 \frac{1}{2}$ lin. longum, suleatum. Cæt. ut in dest. Brown. 1. c. (v. s.)

$\boldsymbol{\gamma}$. Zeyheriana, involucri squamis exterioribus apice albido-villosis, intimis spathulatis, calycis laminis infra medium adpresse brevi-pilosis supja pube longiore laxiusculà hirşutis vel cum aristà densius barbatis, dorso interdum glabratis. - Cum G lecta (Drège! Ecklon et Zerher!). P. macrophyilla Drège a, ex partc. Calyx $2 \frac{1}{2}$ poll., laminis clim aristà 8 lin. longis, harbâ, fuscâ vel purpurascente 1 lin. longá. Stigma 2 lin. longum, nodulọ basali parvúlo. Cát. ut in $\beta$. (v. s.)

19. P. LONGIFloaA (Lam. ill. 1, p. 234, n. 1211), ramis tomentosis, foliis avatis pvalibus oblongisve obtusis immerse venosis glabris haud marginatis basi rotun- 
datis emarginatisve, capilulo turbinato-oblongo folia superante, squamis sericeis, intimis oblongo-linearibus florés subrequantibus margine apiccque albido-villosis, calyce 4-pollicari, unguibus, patulo-pilosiusculis, laminis hrevissime aristatis adpricsse pilosis dorso glabriescentibus, stylo calycem xeruante recto a basi subulato tenui sulcato glabro, stigmate continuo tenui spice minule capitellato. F In montibus Afriçe australiș (Herh. Banks.! Smitl !), cirra Atarquaskloof et Gpadenthiul, alt. 2,000-3,000 ped. (Drège! docum. p. 116, 117), circa Georgetown et in montibus W'interhock; Uitenlage, alt. 3,000 ped. (Krauss, n. 1075). - Poir. dict. 5, p. $640^{*}$, B. Brown 1. c. p. 76 , Roem. et Schult. syst. 3, 1. 343*. Conocarpodendron Boerh. Lugd. bat, 2, p. 199, c. ic. Scolymocephlalus Weinm. phyt. 4, p. 294, t. 902, b. Protea lacticolor Salisb. parad. 27. P. ochiroleuca Smith! exot. bot. 2, p. $43{ }^{*}$, t. 81. P. radiata Bonpl. ex Reíchenb. fl. exot. 4 , p. 35, t. 273 (cfr. P. latifolia). P. longiflora \% latifolia Klotzsch in lirauss beitr. p. 140. P. obliqua hort, Bollwill. 1835 ! (forma recedens tantum foliis summis lanceolatis subacutis utrinque attenuatis et involucro floribus 1 breviore). Erodendrum bomby (inum Salisb., ex Roem. et Schult. syst. 3, mant. p..263. Rami virgati, apice dense subimbricatofoliosi. Folia modice coriacea, 2-3 poll. longa, 1-1 $\frac{1}{4}$ poll. lata, haud reticulata, utrinque elevato-puncticulata, calló apjicis hrevissimo vel obsoleto. Capitulur 3-4 poll. longum, squamis adjressis, exterioribus ovatis mediisque spathulato-oblongis demum glabrescentibus margine scariosis, intimis sursum vix dilatatis. Calycis lamiñe circ. pollicares, pube sericeâ demum laxiusculâ albidâ vel rufâ, terinininali longiore. Stigma 7-8 lin. longum, tenuissimum, obsolete capitellatum basique subgeniculatum. (v. s. in herb. Smith, Banks', etc., et v. c.)

20. P. penicillara (E. Meyer! in pl. Drege), ramis apice tomentosis, foliis lanceolatis utrinque obtusiusculis obsolete venosis, adultis glabris, capitulo turbinatosphæroideo, squamis sericeo-villosis, intimis flores fquantihus lingllatis apice attenuato villis longioribus albis crispo-lanatis, calyce sesquipollicari, uniguibus breve rufo-hirsutulis, laminis exaristatis glabris apice penicillato-barbatis, stylo bipollicari crassiusculo recto compresso glabro, stigmate tenui apice ovato-cápitellato basi oblique noduloso. F In sylvis montibusque Africie austr. circa Dutoitskloof, Kromrivier, Omtata et Omsamwubo, etc., alt. 500-4,000 ped. (Drège!), Outenigua (Krauss, n. 1074), Vanstaadesberg (Zeyher, n. 3664!). P. Mundii Klolzsch in Olto et Dietr. gartenzeit. 1838, p. 113. P. longiflora var. Mundii Link, Kl. et Otto ic. pl. rar. 1, p. $55^{*}$, t. 22, et in Krauss beitr. p. 140. P. ovalis Buek $!$ ín pl. Drège. Bami graciles, laxiuscule foliosi, mox glabri. Folia modice coriacea, 2-3 poll. longa, 6-10 lin. lata, callo apicis venisque immersis obsoletis, juniora vilfosociliata utrinque puhe detergibili serieea. Capitulum magnit. pomi, squamis obtusis, intimis inlérne glabratis. Calyx $1 \frac{1}{2}-1 \div$ poll., laminæe 4 lin. longæxe, barḅa apicis albấ $1 \frac{1}{2}$ lin. longâ. Stylus $2 \frac{1}{4}$ poll. longus sulcatus, apice vix attenuatus, stigmate subulato fere 3 lin. longo sulcato, nodulo basi parum conspicuo. Speciès a P. longiflorâ certe distincta, non solum foliis angustioribuš et capitulo floribusque multo brevioribus, sed priecipue stylo ad apicem usque crassiusculo et stigmate hreviore orassiore distincte cápitellato. (v. s.)

ß. major, ramulis tomentosis, foliis ohlongis acutiusculis glaberrimis, squamarum inỵolucri comâ marginali serriceâ haud crispâ, calycis laminis semipollicaribus acutatis (nec tamen vere mucronatis), stigmate tenuiore (4-5 lin. longo, apicis capitulo seepe minus incrassato). Cret. ut supra. - In montibus, ad ostium flum. Nilynrivier, alt. II, IV (Zeyher, n. 3665! Drège!). P. ovalis Buek a, ex parte. Folia 3-3 $\frac{1}{2}$ poll. longa, $1-1 \frac{1}{4}$ poll. lata, callo apicis magis manifesto obtusiusculo. (v. s.)

21. P. овт Usrfolı (Buek! in pl. Drège), foliis oblongis obtusissimis basi attenulatis venosis ramisque glabris, capitulo oblongo-ovoideo, squamis glabris juniófibus breve albo-ciliatis, intimis longe sfathulato-linearibus flores superantibus margine diu albo-villosiusculis, calyce 4-pollicári incano-sericeo, aristís lamină plus duplo brevioribus, stylo infra medium compresso cano-puberulo apice subulato attenuato glabro haud curvato, stigmate continuo olituso. F In collibus prope Cap Aghillas, infra alt, 500 ped. (Drège! docum. p. 123), prope Qnrustrivier, alt. I (Zeyher, n. 3664!). Rami validi, stricti, vis apice tomentelli. Folia rigida, erecta, - poll. langa, 10-14 lin. lata, nec marginata nec basi obliqua, semiimmerse venosa, sub legte puncticulata, setpius leviter enuargihata, callo apicis subnullo, inferiora passiạ ôho-yatQ-oblonga dimidio breviora. Gapitulum magnít. pugni folià f́quans, 
squamis adpressis triangulari-oblongis obtusiusculis demum glabratis, intimis apice 2-3 lin.infra vixx 1 lin. latis. Calyx undique pube brevi adpressâ albido-sericeus, laminis fere 1 poll., aristis 3 lin. longis pube haud longiore tectis. Stylus calycem subæquans, rectiusculus, hine leviter 1 -sulcus, stigmate subulato 2 lin. longo sulcato apice hinc obsolete incrassato (nee capitellato) basi oblique subgibbo. Affinis P. formosæ, sed notis indicatis certe distincta. (v. s.)

22. P. GRANDIFLora (Thunb. diss. n. 51 *, fl. Cap. p. 137, n. 70), foliis oblongis obtusis venoso-reticulatis haud marginatis ramisque glabris, intimis obovatooblongis flores subæquantibus imberbibus, calyce bipollicari, unguibus glabriusculis, laminis linearibus sericen-tomentosis ultra antheram in cornu breve productis, stylo calycem superante tenui glabro basi compresso-dilatato, stigmate continuo tenui obtusiusculo. 5 In collibus montibusque Africæ Capensis, Tafelberg, Paarlberg, etc., alt. 1,000-3,000 ped. (Roxburgh et Nelson in herb. Banks.! Drège! Krauss, n. 1072, Ecklon et Zeyher!). - Willd.! sp. 1, p. 530, herb. n. 2452 ! R. Brown 1. c. p. 85 , Bot. mag. t. 2447 , Roem. et Schult, syst. 3, p. 348, mant. p. 265. Lepidocarpodendron Boerh. Lugd. bat. $2, p: 183^{*}$, c. ic. Scolymocephalos Weinm. phyt. 4, p. 28, t. 891. Protea cynaroides $\beta$ Linn. sp. ed. 1, p. 92, ed. 2 , p. 136. P. nitida Mill. ex Steudel. P. laurifolia Buek! in pl. Drège. Incolis Waagenboom. Arbuscula orgyalis (fide Thunb.), ramis validis glabris dense foliosis. Folia coriacea, 3-5 poll. longa, 10-24 lin. lata, venis confertis utrinque prominulis, callo terminali obtuso vel subrecurvo. Capitulum pugni mole, folia superans, squamis obtusis adpressis, exterioribus late ovatis margine omnibus nudis, junioribus dorso ferrugineo-vel albo-tomentosis vix glaberrimis. Calycis laminæ 9 lin. longe, acumine vix 1 lin. longo. Stỵlus demum tripollicaris, rectus, stigmate 4 lin. longo. (v. s. in herb. Banks., Willd., etc.)

B. angustifolia, (Ker in Bot. reg. t. 569), foliis lanceolatis, 6-8 lin. latis.-P. marginata Lam. ill. 1, p. 235, n. 1225.

23. P. В Uек IANA, foliis crasse coriaceis obovato-oblongis obtusis acutisve basi altenuatis enerviis haud marginatis ramisque glabris, capitulo ovato-globoso, squamis obtusis sericeo-tomentosis demum glabrescentibus, interioribus modice elongatis angustatis flores subæquantibus, calyce sesquipollicari $i$ laminis muticis dorso unguibusque glabriusculis, stylo demum 2-pollicari glabro tenui basi vix dilatato, stigmate apice simplici basi obsoletissime inflexo. $f_{5}$ In montanis prope Glan William et Grasbergrivier, alt. 1,000-3,000 ped. (Drège! docum. p. 70, 72). P. pyrifolia Buek! in pl. Drège (nomen nimis ineptum). P. grandiflora $\beta$ angustifol. Drège! olím. P. Banksii Klotzsch! mss. in herb. reg. Berolin. Folia raro 2 poll. excedentia, $\frac{1}{2}-1$ poll. lata, basi semper attenuata, passim lanceolata subacuminala. Capitulum magnit. pomi minoris, receptaculo conico, paleis obtusis demum concavis. Calycis laminæ 5-6 lin.-longæ, obtusiusculæ. Stylus $1 \frac{3}{4}-2$ poll. longus, basi sigmoideo-flexus, stigmate 2-3 lin. longo tenui obsolete sulcato obtuso. (v. s.)

24. P. nuPICola (Mund! mss. in herb. reg. Berolin.), foliis spathulatis subenerviis ramulisque glabris, capitulo sphæroideo mediocri, squamis obtusis sericeo-tomentosis, exterioribus demum glabratis, interioribus spathulato-oblongis flores subiequantibus, calyce sesquipollicari tolo dense fulvo-hirsulo, Iaminis breve aristatis densius lanatis dorso glabrescentibus, stylo ealycem parum superante valido compresso glabro inferne dilatalo, stigmate subcontinio brevi angulató-sulcato obtuso. In summo monte Winterhock, Afr. austr. (Mund!). Simillima P. Buekianæ, sed notis indicatis, iuprimis stylo, constanter, ut videtur, distincta. Folia plerumque paulo longiora et angustiora (4-6 lin. lata), basin versus longius attenuata, callo apicis parvulo obtuso subrecurvo. Stylus basi fere lineam latus, supra incurvus, stigmate vix $1 \frac{1}{2}$ lin. longo fere duplo quam in illà crassiore quasi prismatico (v. s.)

25. P. нIR т (Klotzsch! in Krauss Beitr. p. 140, non al:or.), foliis oblongis utrinque obtusis subvenosis haud marginatis ramisque pubescentibus, capitulo obovatogloboso basi turbinato, squamis tomentosis ciliolatis, interioribus flores subæquantibus oblongis, calyce sesquipollicari undique brevi villoso, laminis submuticis, stylo tenui compresso glabro, stigmate subulato obtuso basi obsolete geniculato. F In rupestribus mont. Magalisberg Caffrariæ (Zeyler, n. 1455!), Tafel-

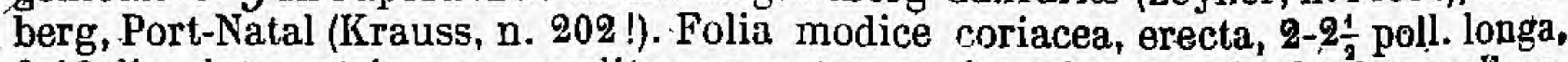
8-12 lin. lata, utrinque æqualiter angustata, apice obtuso vel obsolete calloso, 
margine angustissime diaphano ciliolato demum glabro, venis tenuibus utrinque parum conspicuis, paginà utråque pube brevi molli satís densâ subsericeo-canescente. Capitulum magnit. pomi minoris, squamis margine tarde glabrescentibus adp̣ressis, exterioribus late ovatis obtusis. Calyx pube fulvâ medioçri patulâ dense barbatus, laminis cum aristâ vix 1 lín. longâ $5-6$ lin. longis. Stylus calycem vix superans, lævis, apice per curvaturam lævissimam (nec nodulum) in stigma 3 lin. longum tenuiter sulcatum transiens. Accedit ad P. Buekianam et punctatam, sed jam capitulo basi attenuato et foliorum calycisque pubescentiâ facile distinguenda. (v. s. in herb. reg. Berolin.! Mus. Brit.! et Drège.)

26. P. RoUPPELLIE, foliis lanceolato-oblongis acutis marginatis extra medium latioribus infra cuneato-attenuatis obsolete verısis dense subsericeo-incanis, capitulo pedunculato magno globoso basi squarroso, squamis sericeo-tomentosis imberbibus, intimis spathulatis flores subæquantibus, calyce bipollicari fulvovilloso breve aristato, stylo calycem æequante compresso villoso, stigmate tenui basi noduloso, J In monte Magalisberg Caffrariæ (Zeyher, n.1457!). Simjlis P. grandifloræ, sed jam pubescentiâ distinctissima. Rami validi, dense foliosi, apice tomentosi. Folia erecta, rigida, 4 poll. longa, extra medium 1 poll. ad insertionem 2-2: lin. lata, parce prominulo-venosa, margine nerviformi subincrassato, pube molli adpressâ. Capitulum magnit. pugni, basi subdepressum, basi attenuatâ cum pedunculo brevissimo circ. 1 poll. longâ squamis recurvo-patulis dense squarrosâ, involucri squamis adpressis, interioribus margine laceris. Calyx 24-28 lin. longus, totus pube densâ patulâ crispulâ villosus, aristis longis laminâ quadruplo brevioribus: Stylus summo apice leviter sigmoideo glaber, stigmate tenui acute sulcatoangulato. (v. s.)

27. P. GAFFRA, folíis lanceolatis obtusis utrinque æqualiter attenuatis obsolete venosis haud marginatis ramisque glabris, capitulo pedunculato magno hemisphærico, squamis omnibus adpressis imberbibus demum gtäiris, interioribus apice latioribus, intimis anguste spathulato-oblongis flores subæquantibus, calyce sesquipollicari glaberrimo breve aristato, stylo tenui sulcato-angulato glabro, stigmate subcontinuo. $\$$ ? In rupestribus montis Magalisberg Caffrariæ, alt. IV (Zeyher, n. 1458 !). Similis P: Rouppellise, sed distincta omnium jartium glabritie, foliis utrinque æqualiter attenuatis, glaucis? haud marginatis, venis subimmersis sepe rix conspicuis, capitulo naulo minore, pedunculi turbinati subpollicaris squamis adpressis. Involucrum junius albo-tomentosum, squamis interioribus pollicaribus et ultra tenuissine lineatis. Calycis limbus acute 4-gonus cum aristis 1 lin, longis 6.7 lin. longus. Stylus calycem æquans, subfalcatus, basi vix $\frac{2}{7}$ lin. latus, sursum attenuatus et nodulo vix conspicno absque curyaturâ in stigma 4 lin. longum transiens. Ab affini P. Abyssinicâ facile distinguitır, foliis utrinque magis attenuatis, minus venosis, capituli formâ, calycis glabritie, etc. (v. s.)

28. P. A вyssinica (Willd. sp.-1, p. 522), foliis lanceolatis utrinque æqualiter attenuatis venosis haud marginatis ramisque glabris, capitulo subsessili magno turbinato-ohovato, squamis adpressis argenteo-sericeis imberbibus, intimis lingulatis flores æquantibus, calyce subsesquipollicàri fulvo-sericeo brevissime aristato, stylo calycem æquante compresso-filiformi, glabro, stigmate tenui basi leviter oblique noduloso. 5 In Abyssinir monte Lamalmon (Bruce), mont. Scholoda, prope Adoam, alt. 7,000-8,000 ped., etc. (Schimper, n. 900! Quartin Dillon). - R. Brown 1. c. p. 85, A. Rich. Voyag. Abyss. 5, p. 232. P. Gaguedi Gmel., ex Steudel. Guaguedi (nom. incolarum) Bruce Abyss. 5, p. 52, cum 2 tab. Caulis arborescens (fide Bruce) vel fruticosus (fide Schimp.). Folia coriacea, 4-12 poll. longa, 6-12 lin. lata, obtusa vel acutiuscula, luxe reticulata, sæpius margine angustissimo pallido tenui (nec nerviformi) vix diaphano cincta. Capitulum 2-3 poll. longum, magnit. ovi anserini, squamis obtusissimis sordide cano-vel fulvo-sericeis. Calycis laminæ tres unguibus æquilongæ mucronatæ dorso dense longeque fulvo-villosæe, quartâ paulo breviore muticâ dorso glabrâ 1-nervj. Stigma 4 lin. longum obtısiusculum. Antheræ longæ, lineares, glandulà brevi ovatầ apiculatæe, (v. s. in herb. DC. et Hochstett.)

29. P. RECONDITA (Buek ! in pl. Drège), foliis crassis glaucis obovatis obtusis obsolete marginatis venosis ramisque glabris, capitulo mediocri foliis superato sphæroideo, squamis glaberrimis, exterioribus demum patulis, in terioribus spathulatooblongis flores superantibus, calyce pollicari stylo superato parce barbato, laminis muticis demum glabris, stylo falcato compresso-dilatato glabro, stigmate tenui 
basi suhobliquo vix gibbo. $\$$ In rupestribus prope Ezelsbank, alt. 4,000-5,000 ped: (Drège, n. 2404 ! docum. j. 75). Rami patentes vel decumbentes? apice adscenderiti-incurvo 1-cephali. Folia $3-4$ poll. longa, $1 \frac{4}{2}-2$ poll. lata. Capitulum magnit. pomi mediocris, squamis exterioribus late ovatis apice triangulari obtusiusculis hasi induratis, intimijs elongatis oblusis. Stylus $1 ?$ poll. longus, pallidus, basi fere 1 lin. latus, obsolete 1 -sulcus, apice attenuatus, stígmate 2 lin. longo sulcato fuscu. Facies, fólia précipue, fere $\dot{P}$. coccinese, sed capitulum minus et ç̣t. chatácteres diversissimi. (v. s. capitulo fere deflorato.)

30. P. compacta (R. Brown $!$ in Linn. Trans. 10, p. 76), foliis sessilibus dense. imbricatis rigidis glabris ovatis vel ovall-oblongis obtusis calloso=apiculatis margine venosis basi cordatis rotundatisve, summis oblongis basi attenpatis, capjtulo magno sessili folia superante ovato-globoso, squamis tomentosis imberbibus margine hreve villoso-ciliatis, intimis spathulato-linearibus flores superantibus, calyce sub-3-pollicari cano-tomentoso, aristis laminam æquantibus longis, stylo glabro inferne compresso ajice breviter jucurvo, stigmate apice conico incrassato basi obliquo. J In montanis, eirca Fouhoek, etc. (Masson I in herb. Baniks., Ludwig! Ecklon I Krauss, n. 1073, Zeylier, n. 3660!). P. spectabilis Willd.I mss. in herb. n. 2458 ! Rami virgati, apice tomentelli, foliis absconditi. Folia summa 3-5 poll. lbngat, 1 poll. lata, inferiora $2-3 \frac{1}{2}$ poll. longx, $1 \frac{1}{2}-2$ poll. lata, passim suborbicularia, semiamplexicaulia. Capitulum magnit. jugni, bracteis obtusis, junioribus sericeis, dớso demum glal,rescentibus. Calyx $2 \frac{1}{-}-3$ poll., laminís inclusấ aristâ 10-12 lin. longis. Stylus fere rectus, stigmate 4 lin. longo pallido apicis conulo - lin. longo purpurascente $S$ pecies foliis proxime accedens ad $\mathrm{P}$. coccineam et latifoliam, sed bracteis imlerbihus, etc. distinctissima. $\Lambda$ n P. spectabilis Licht. (v. supra, n. 3) huc revocanda? (v. s. in herb. Banks., etc., et v. c.)

31. P. FORM $O S_{A}$. (R. Brown l. c. p. 79), foliis anguste oblongis obliquis venosis basi simplici marginibus ramisque tomentosis, involucri squamis ciliatis, intimis lingulatis imberbibus, calyce aristisque tomentosis, stylo glabro apice eurvato, stigmate apice incrassato. $\mathrm{J}$ In Africa austr.-Bot. mag. t. 1713 . P. coronala Andr. Bot. repos. t. 469. Erodendron formosum Salisb. parad. 16. Leucospermum formosum Knight Prot., fide Loudon encycl. ed.1, p. 82, n. 1352, cum ic., ex cit. Andr. Affinis ' $P$. compactee, ex Br. Specini. authent. non vidimus. Folia ex ic. 1. c. glaucescentia, 3-4 poll. longa, $1 \frac{1}{2}-2$ poll. lata, obtusiuscula, roseo-marginata, glabra. Involucrum intense roseum, squamis albo-ciliatis. Calycis laminæ violaceie.

32. P. PUNCTATA foliis crassis ovali-vel lanceolato-ohlongis immerse venosis haud marginatis glanduloso-puncticulatis glabris, junioribus sericeb-villosis, capifulo parvo globoso, squamis sericeo-tomentosis, exterioribus acutis, intimis flores æquantibus spathulatis demum patentibus glabris, calyce sesquipollicari supra ovarium piloso creterum glaberrimo, limbo breve bicornuto, stylo recto glabro stigmateque continuo tenui obtuso. $\%$ In arenosis et lapidosis humidis mont. Zwartebergen et prope Ezelsbank, alt. 3,000-5,000 ped. (Drège! docum. p. 64, 74, 75). P. carlescens E. Jley.! mss. P. coriacea Buek ! in pl. Drège. Rami graciles, laxiuscule foliosi, apice tomentosi. Folia $2 \frac{r}{2}$ poll. longa, $\frac{3}{s}-1$ poll. lata, subacuta, lævia, thinque dense vernicoso-punctata, juniora adpresse albido-sericea (fere ut in Stächyde Germanicâ). Capitulum folia vix superans, magnit. pruni majoris, extefiónibus late ovatis, intimis elongatis. Calycis lamine 7.8 lin. longæ, duabus mucronulo $\frac{1}{2}$ lin. longo obtuso nudo cormutis. Stץlus fere bipollicaris, imâ basi compresso-dilatatus, superne obsolete sulcalus,' stigmate exserto tenuissimo, nodulo basali nullo. Nomen Buekianum non admisimus, quia in herb. nonnullis etiam P. pyrifolise Buek (Buekianie nob.) adscriptum invenimus, et proterea, sicut et Meyerianum, parum significans. (v. s.)

33. P. L ONGIF OLIA (Andr. Bot. repos. t. 132, 133, 14k), foliis anguste lanceolatis obtusiusculis basi longe attenuatis submarginatis subeveniis ramisque glabris, capitulo ovato-oblongo magno, squamis acutiusculis glabris, intimis spathulatolinearibus flores æriuantibus, calyce 4-pollicari piloso, laminis 3 cohserentibius dorso glabris aristâ simplici ipsis duplo longiore longe barbatâ caudatis, quartà 1 bera submuticấ pilosa, stylo calyce breviore puberulo, stigmate basi oblique toduloso. F In Africa austr. (Uldenburgh! in lierb. Banlis.), Hottenttotsholland, Hangklipp, Palmietrivier, Houhoek, ẹte. (Ludwig I Drège! docum. pi 118, Krauss, fil: 1032, Zeyher, n. 3662 !). - R. Brown! in Linn. Trans. 10, p. 83, Edw. Bot. reg.

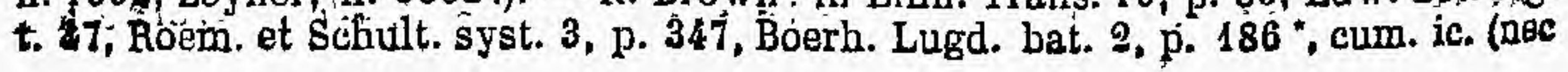


p. 188, ut apud Edwards citatur). P. Lepidocarpodendron Linn. herb. (Bide R. Br., sed nos ibid. subs hoc' nom. P. Lepiducarpon vidimus). P. Vidua Andr Bot. repos. recens. etc., 1801, append. p. 39 (fide Bot. reg.). P. Ligulæefolia sweet, Knight Pr. ex Loudon eneycl. ed. 1 , p. 80, n. 1328, cum cit. Andr. Bot. rep. t. 133. P. umbonalis Knight Pr. Londoni l. c. n. 1327 , cum cit. Bot. repos. t. 144. P. dodonæilólia Buek in $\mathrm{pl}$. Drège? (forsan distincta sp., nobis nonnisi e frustulis insulficientibus herb. Sonder. nota, recedens foliis 6-1 lin. latis et stylo nonnisi basi minute puberülo). Erodendron ligulietolium et umhonale Salisb. ex Spireng. syst. 1, p. $46 \mathbf{6}$. Habitus, folia, capitulum ferc P. Lepílocarpi, sed jam involucro imberlji facile ab eâ dígnoscenda. Folia 3-6 poll. longa, 3-4 lin. lata, àcuta vel obtusa vel callosoapiculata, vix ac ne vix marginata, sub lente albido-puncticnlata, passim obsolete venosa, demum patula. Cajitulum 4-5 poll. longum, basi brevissime turbinatum, squamis arcte adpressis, intimis apjice attenuatis acutiusculis. Calycis aristse 15 lin. longe (ex Bot. reg. t. 47 el specim. nostris simplices, ex ic. Andr. J. c. bifidæ), apicis barbầ nigricante. Stylus $2-2 \frac{1}{2}$ poll. longus, rectus, validus, apice glabro incurvo, stigmate 3 lin. lougo sulcati)-angulato. (v. s. in herb. Banks., clc.)

34. P. meLLIFER A (Thunb.I diss. n. $37^{*}$, 11. Cap. p. 132, n. 45), foliis lanceolatis basi longe attenuatis haud marginatis subvenosis lævibus ramisque glabris, capitulo magno ovato oblongo basi turbinato, squamis striulatis glaberrimis viscidis, intimis flores superantibus, calyce stylojuc iequilongo glabris, aristis lamină brevioribus apice barbatis, stigmate continuo. $\bar{J}$ vel 5 ln collibus campisque Africse capensis vulgaris (Tluunb! in herb. 'Banks., Sieber, n. 2! Ludwig! Ecklon, Un. itin. 11. 604 ! Drège! Krauss, n. 1035 ! etc.). - Boorh L. B. 2, j. 187, c. ic.,Weinm. phyt. 4, p. 289 , t. 896 , Curt. Bot. mag. t. 34t, Willd.l sp. 1, p. 522, herb. n. 2433, Wendl.! Herreuluus. 13, R. Brown 1. c. j3. 84, Rocm. el Schult. syst. 3, p. 348*, Rouppell Calıe flow. t. 7. P. rejens Linu.! mant. p. 189 * (non Thunh).).'Leucadendron repens Berg. in act. Stockli. 1766, p. 322. Erodendron mellifluum Salisb., ex spreng. syst. 1, p. 462. Incolis Sugarbosċl, Zuykurboschés, Tuljpboom, etc. Clirysodendron Africanum herb. Vaillant., teste Gaudich.! in herb. DC. Frutex vel árbuscula orgyalis, ramis palentibus apice adscenilentibus. Folia liete viridia, modice coriarea, 3.5 joll. longa, 3.6 lin. lata, obtusiuscula, callo minute apiculata. Capitula 3-4 poll. longa, attenuato-subpedunculatä, squamis pulchre sanguineoroseis obtusis tenuiter striatis melle copiose e floribus transudante viseidis. Calyx

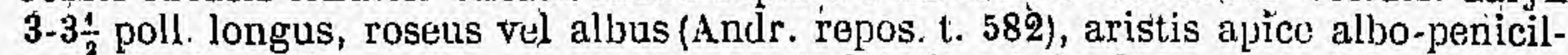
latis. Antheræ fere jollicares, mucroue subulato fere t lin. longo apiculatæ. Stigma slubulatum, sulcatum. (v. s. in herb..Banks., Willd. etc., et r. v. c.)

35. P. CAL OCEPHALA, foliis oblongo-lanceolatis obtusis basi attenuatis haud marginatis subereniis lævibus glabris, cajjtulo subgloboso sessili, squamís lævitbus glabris margine villoso-ciliatis liaud viscidis, intimis flores dimidio superantibias, calyce undique adpresse cano-piloso, aristis lamina multo brevioribus breve piløsis, stylo yilosiusculo, stigmate basi obsolete nodulogso. J? Cap. ' Boñæ-Spei (Ludwig!). Facie quidem precedenti simillima, sed præeter notas jam indicatas distincta : ranis apice cinereo-pulverulentis; foliis crassioribus, rigidis, subnitidis, usque ad 10 lin. latis, novellis aureo-sericeis; capitulo haud? mellifero, basi non attenuato, squamis levissimis (nee striolatis) margine untlique harbulâ albidà 1 lin. longà cinctis vol ajjice subnurlis, infimis dorso sericeo-incanis ; calÿce breviore (circ. 2 poll, laminis (12-15 lin. longis) totis aristisque æqualiter brevipilosis; antheris vix 3 lin. longis. Stylus subbipollicaris, gracilis, subulatus, apice attenuato glabro. (v. s. in lierb. Mus. reg. Stuttgart.)

36. P. Scol y u (Thunb. diss. ก. 36 *, fl. Cap. p. 132, n. 44), foliis lineari-lanceolatis acutis muticis bási longe attenuatis rugoso-striatis haud marginatis ramisque glabris, capitulo sessili mediocri foliis superato obovato-globoso', s juamis lievibus glabris obtusis, intimis flores requantibus, calyce pollice breviore glabro, lantinis fiuticis junioribus apice harbatis, stylo compresso falcato lietí glabro, stigmate subcontinuo tenui bási obliquo. F In Africa Capeusi vulgaris ('herb. Banks.!), in planitie arenosã montibusque usque ad alt. 4,000 ped. (Drège! Erklon Un. it. f. 656 ! Kraduss, n. 1034, Ludwig! Zeylier ! etc., Boerl. L. B. 2. p. 192, c. ic. ('orma brevifolia), Weinm. jhiyt, 4. p. 288 , t. 893 , f. 6, Willth.! sp. 1, p. 522, herb. n. 9434 ! Andr, repos. t. 409, Wendl. sert. Hannov. t. 20, Bot. mag. t. 698, R. Brơwn 1. e. p. 86, Roem. et Schult. syst: 3, p. $349^{*}$. Protea scolymocephala Linn. syst. p1.1. p. 271. P. angustifolia Salisb. prodr. 49. Leucadendiron scolymocieptuàtum 
Linn. sp. ed. 1, p. 92. Frutex erectus, 3-pedalis, ramulis corymbosis gracilibus, laxiuscule foliosis. Folia $2-4$ poll. longa, $1 \frac{1}{2}-2$ lin. lata. Capitula erecta, magnít. pruni et pomi minoris, denum obovata, squarnis junioribus ciliatis, exterioribus ovatis, interioribus oblongis, apice subdilatatis margine subscariosis.: Calyx 6-9 lin. longus. Stylus pollicaris, crassiusculus, stigmate 1 lin. longo obtusiusculo sulcato. (v. s.)

37. P. LANGEOLATA (E. Meyer! in pl. Drège), foliis lanceolatis acutiusculis muticis basi attenuatis ruguloso-striatis ramisque glabris, cajitulo sessili folia subequante mediocri globoso basi turbinato, squamis glabris lævilus obtusis, intimis flores subrquantibus, calyce ses;uipollicari glaberrimo laminis longis mucronulatis, stylo recto tenui glabro, stigmate exserto filiformi longo basi subobliquo. $\supset$ In collibus prope fl. Katferknils et Gauritzrivier, alt. 500-1,000 ped. (Drège! docum. p. 123). Folia $2 \frac{1}{2}$ poll. longa, 3.5 lin. lata, viridia, haud marginata, obsolete 1 -nervia, subevenia, callo apicis acutiusculo minuto. Capitulum magnit. pomi minoris, squamis omnibus arcte adjıressis convexis, exterjoribus late ovatis, interioribus anguste oblongís. Calycis lamina lineares, 8-9 lin. longe, mucronulo brevissimo corniformi obtuso apiculatw, antheris subrequilongue. Stigma 5-6 lin. longum, fere capillaceum, obtusiusculum, obsolete sulcatum, basi obsolete geniculatà cum stylo conlluens, calycem superans. Affinis P. Scolymo, at bene distineta. (v.s.)

38. P. EFFUSA (E. Meyer ! in pl. Drège), foliis glaucis? lanceolatis mucronato-acutis basi angustatis suheveniis ramisque glabris, capitulo sessili folia breve superante mediocri globoso, squamis glabris levibus obtusis, intimis apice dilatatis, caljce pollicari, laminis muticis margine basique parce setulosis demum unguibusque glaberrimis, stylo incurvo valido glabro, stigmate continuo brevi attenuato. Dutoitskloof, alt. 3,000-4,000 ped. (Drège t docum. p. 82). Præcedenti simillima, sed bene distincta. Ramuli adscendentes, subsecundi. Folia acutiora, 1-3 poll. longa, usque ad 6 lin. lata, 1-nervia, juniora obsolete renosa, mucronulo brevi obtusiusculo. Capitulum magn. pomi minoris, basi subdepresso-rotundatum, scruamis margine subdiaphano-scariosis, exterioribus late ovato-triangularibus, intimis oblongis. Calycis laminæe lineares, vix 3 lin. longæ, haud cornulæ. Stylus brevior, circ. 1 poll. longus, triplo crassior, falcatus, inferne vałde compresso-dilatatus, stigmate 2 lin. longo acutiusculo sulcato. (v. s.)

39. P. m ON.T a A (E. Meyer 1 in pl. Drège), foliis linearibus mucronulato-acutis subenerviis hasi valde attenuatis glabris, capitulo sessili foliis superato mediocri globoso, squamis sericeis demum glabris obtusis, interioribus oblongis calyces superantibus stylos subæquantibus, calycis unguibus glabriusculis, laminis pilosis, aristis brevibus, dense lanatis, stylo valido compresso glabro utriuque 1-nervi, stigmate attenuato basi oblique subnoduloso. J In rupestribus mont. Zwartebergen, alt. 5,000 ped. (Drège! docum. p. 64). Species dubia, e specim. subdeflorato tantum nobis coguita, forsan P. Scolymi var.? Recedit tamen ramis, ut videtur, decumbentibus, brevibus, junioribus puberulis; foliis raro ultra 1 lin. latis, minus rugulosis et nervo medio valde obsoleto vel plane inconspicuo; capitulo paulo majore, basi haud attenuato, squamis junioribus tenuissime sericeis; calyce breve aristato pubescente; stylo dimidio longiore $\left(1 \frac{1}{2}-\right.$ poll.) recto vel parum incurvo, stigmate $2 \frac{1}{2}$ lin. longo. (v. s.)

40. P. MUGRONIFOLIA (Salisb. parad. 24), folits linearibus longiuscule pungentimucronatis basi haud angustatis ramulisque glabris, capitulo subsessili foliis longe superalo globoso parvo, bracteis glabratis, exterioribus triangulari-acuminatis, interioribus llores subsuperantibus altenuato-acutis, caljce pollice breviore glabro, laminarum acumine brevi barbulato, stylo recto tenui glabro, stigmate continiso capillari. $J \mathrm{ln}$ arenosis Africe austr., prope Bergrivjer, etc. (Masson! et Roxb.! in herb. Banks.). - Sims Bot. mag. t. 933, Andr. Bot. repos. t. 500 . $P$. odoratissima Masson in herb. Ait. P. mucronata hort.? ex Steudel. Fruticulus erectus, facie P. Scolymi. Folia 1-2 $\frac{1}{2}$ poll. longa. Capitulum magnit. juglandis, basi in pedunculum vix 2 lin. longum imbricato-squamatum contractum, involucri squamis adpressis, exterioribus e basi latà rotundatâ triangularibus, junioribus ferrugineo-tomentellis, interioribus floriluusque albis. Calyx 8-9 lin. longus, Janinis anguste linearibus unguem subrequantibus violacois apice breve albido-barbatulis. Stylus subsetaceus. 
a. Brownii, foliis lanceolato-linearibus, involucri squamis lanceolatis mucronatis. - P. mucronifolia R. Brown 1. c. p. 86. (v. s. in herb.,Banks.)

$\beta$. Gueinzii, foliis linearibus $\left(\frac{2}{5}-1 \frac{1}{3}\right.$ lin. latis) planis vel marginibus recurvis supra convexis subtus sæpe canaliculatis, involucri squamis muticis, interioribus acutato-subpungentibus nec vere mucronatis. (v. sp. Roxburgh! n. 47! in herb. Soc. linn. Lond., - Guenz.!)

41. P. PENDULA (R. Brown! in Linn. Trans. 10, p. $87^{*}$ ), foliis crassis glaucis patulis lineari-lanceolatis subacutis vel obtusis patenti-mucronatis venosis basi attenuatis adultis glabris, capitulis pendulis parvis hemispharicis, squamis obtusis sericeis, interjoribus flores superantibus, calycis laminis submuticis barbatis, stylo vix unciali glabro apice simplici. 5 In Afried austr. (Masson $!$ in herb. Banks.), in mont. Witsemberg, alt. IV (Zeyher, n. 3687!). - Roem. et Schult. syst. 3, p. 350*. Fruticulus erectus, ramis glabris, ultimis tomentellis, floriferis apice recurvis. Folia conferta, 1-2 poll. longa, 2-3 lin. lata, marginibus subincrassatis subrecurvis, floralia reclinata. Capitula magnit. pruni, squamis arete imbricatis demım glabriusculis. (v. s.' in herb. Banks., etc.)

42. P. Nan a (Thumb.! diss. n. $29^{*}$, fl. Cap. p. 130, n. $35^{*}$ ), foliis subulatis mucronatis ramisque glabris, capitulis nutantibus jarvis hemisphæricis, squamis patulis ovato-oblongis obtusis striatis glabris, interioribu's flores subsuperantibus ciliolatis, calyce semipollicari rufo-hirsutulo, laminis muticis demum excepto apice glabratis, stylo exserto falcato glabro, stigmate tenui basi leviter noduloso. 5 In montosis Africxe austr. (Bergius in herb. Linn.! Thunb.I in herb. Willd. n. 2425 ! Ange! in herb. Banks., Niven, n. 31!). Dutoitskloof, Witsemberg, alt. 2,000-4,000 ped . (Drège! Zeyher, n. 1459 !). - Willd.l sp.1, p. 519, R. Brown!'l. c. p. 87, Roem. et Schult. syst. 3, p. $350^{*}$. P. rosacea Linn.l mant. p. $189^{*}$, Smith! exot. bot. 1 , p. 85 , t. 44. P. acutifolia Salish. parad. 2. Leucadendron nanum Berg. in act. Stockholm, 1766, p. $325^{*}$, pl. Cap. p. $22^{*}$ (excl. syn. Petiv.). L. pinifolium DC.! mss. in herb. Frutex bipedális, erectus, ramosus. Folia erecto-patula, subfloralia reclinata, 5-12 lin. longa, $\frac{1}{2}-\frac{2}{3}$ lin. lata, attenuato-mucronata, dorso convexa vel obtuse carinata, enervia, lævia, interumm marginata. Capitula in ramulis 1-2 poll. longis demum pendula et patula, diametro 1-1 $\frac{1}{2}$-pollicari, squamis exterioribus virescentibus, interioribus pollicaribus roseis vel purpureis. Stylus 9 lin. Stigma 1 lin. longum. Facies fere P. acerosæ et humilis, sed capitulis terminalibus, involucro glabro, etc., facile dignoscenda. (v. s. in herb. Linn., Banks., etc.)

\section{\$2. Subacaules. - Fruticuli humiles, caule epigcoo subnullo foliis breviore vel abbreviato decumbente.}

43. P. canaliculata (Andr. Bot. repos. t. 437), subdecumbens, foliis linearibus acutis eveniis lavihus supra concaviusculis ramisque glabris, capitulo parvo ovato, squamis concavis obtusis glabratis, interioribus subsericeis ciliolatis, calyce pollicari glabro, aristis penicillatim albo-barbatis laminà dimidio brevioribus, stylo glabro apice simplici. $\zeta$ In arenosis depressis Africæ austr., circa Langekloof (Niven, Roxburgh ! in herb. Banks.). - R. Brown 1. c. p. 88 *, Roem. et Schult. syst. 3, p. $351^{*}$, mant. p. 265 . Huc, nescio quo jure, in Spreng. syst. 1, p. 463, refertur Protea polygaloides Willd. enum. suppl. p. 7 (non descripta) quæ Leucadendron polygaloides Link, ex Steud. Fruticulus fide ic. Andr. 1. c.ramosus, ramis satis gracilibus laxiuseule foliosis, foliis $2-2 \frac{1}{2}$ poll. longis acutissimis, involucro hemisphærico patulo diam. 2-poll. sanguineo flores superante, stigma subulatum. In specini. Roxb. video folia 4-6 poll. longa, vix 2 lin. lata, obtusa, utrinque 1-nervia, evenia, sæpe plana. Capitulum (junius, clausum) ovatum, magnit. pruni. (v. s. in herb. Banks.)

44. P. L A vis (R. Brown ! in Linn. Trans. 10, p. $91^{*}$, non Thunb.), caulibus decumbentibus nanis, foliis glaucis elongato-linearibus acutis eveniis lavibus glabris basi attenuatâ planis, marginibus simplicibus recurvis, capitulo sessili mediocri hemisphærico, squamis obtusis subsericeis demum glahris ciliolatis, interioribus spathulato-linearibus, calycis subuncialis unguibus dorso glabriusculis margine laminisque muticis villosis, stylo calycem æequante arcuato compresso glabro, stigmate tenui basi hinc leviter noduloso. $ち$ In Africâ austr. (Masson I in herb. Banks.), mont.Witsemberg, alt. IV (Zeyher, n. 1460 !), Piquetberg, mont. Outeniqua, etc., alt. $1,500-4,000$ ped:' (Drège! docum. p. 73, 74, 76, 117). - Roem. et

xIV. 
Schult. syst. 8, p. 352 *, mant. p. 265, Bot. mag. t. 2439. P. longifolia Salish. parad. Lond. p. 37. Erodendron longifolium Knight et Salisb. Prot. p. 46. Folia secunda, \$-6 poll. longa. Capitulum magnit. pomi mínoris, erectum. Galyx 9 lin. Stigma 1 lin. longum. (v. s. in herb. Banks', etc.)

45. P. LOREA (R. Brown! 1. c. p. $93^{*}$ ), caulibus semisubterraneis nañis, foliis elonyatis tereti-filiformibus sphacelato-acutiusculis sulcatis lævibus glabris, capitule subpedunculato magno turbinato, squamis acuitiusculis sericeis, interioribus oblongo-linearibus, calyce sub-3-pollicari breve albo-lanato, laminà unấ unguibusque dorso glabris, aristis laminâ brevioribus', stylo calycem æquante récto glabro jufferne compresso, apice brevissime incurvo, stigmate basi noduloso. $\delta$ In Africà austr. (Masson! in herb: Banks.), ad Fransche Hoek (sub nom.'P. Aulax Hibhert, in herb. Smith l). - Roem. et Schult. syst. 3, p. $353^{*}$. P. coronata Curt., ex steudel. Folia conferta, pedalia, crassitie fili ligaterii. Capitulum 3 -pollicare et ultra, pedunculo brevi arcte imbricato-scruamato. Calyx $2 \frac{1}{2} 3$ poll. longus, dense lanatus. Stigna $3 \mathrm{lin}$. longum. Species a proxime afinibus (præcipue P. canaliculatâ, echinulatâ, repente) facile dignoscenda foliis veré teretỉbus; nec modo margine revolutis, punctis asperis amnino destitutis, calyce longiore, laminis dense tanatis et stylo apice leviter inflexo. (v. s. in herb. Banks. et Smith.)

46. P. TEN U IF Or. A (R. Brown 1.c. p. 90*), caulibus nanis, foliis longis lineáribus marginibus recurvis tereti-filiformibus junctato-scabriusculis glabris, capitulo sussili mediocri hemisphrerico, squamis pbtusis sericeo-tomentosis, intimis spathulato-linearibus flores vix æquantibus, calyce subsemipollicari updique hirsụto, laminis breve mucronatis, stylo filiformi falcato glabro, stigmate continuo tenui. 5 In montiluus Africa: austr. (Niven), circa Sparrbosch, alt. 1,000 ped. (Drège! docum. p. 120).-Roem. et Schult. syst. 3, p. $252^{*}$. P. revoluta Buels! in pl. Drège. P. lorea Drège olim (non h. Br.). Folia 6-12 poll. longa, 1-2 lin. lata, supra convexa, pleraque filiformia vix 1 lin. crassa subtus canaliculata, punctis elevatis modice scabra, passim multo breviora plana. Capitulum erectum, magnit pomi minoris. Calycis aristær vix $\frac{1}{2}$ lin. longæ. Stylús $15-18$ lin. Iongùs, rufus, utriñque sulco percursus, basi vix latior, in stigma fere $\mathbf{3}$ lin. longum obsolete sulcatum sensim attenuatus. Foliis simillima P. repenti, sed jam capitulo fere triplo minore diversa. Differt a $P$. loreâ foliís nec levibus nec vere teretibus; a $\mathrm{P}$. 'scabrấ foliis angustioribus eveniis minus scabris, calycis aristis brevioribus, etc.; a P. revolutâ foliis scahris, eapitulo erecto sericeo, calyce anistato hirsuto. (v. s.)

47. P. REPEN. (R. Brown 1. c.p. 92), caulibus decumbentibus nanis, foliis elongatolinearibus acutis muticis longe attenuato-subpetiolatis 1 -nerviis subeveniis papilloso-scabriusculis glabris, capitulo erecto turbinato-oborato, squamis tomentosis, interioribus malyine breve lanatis, intimis flores subequantibus, calyce hirsuto, Jaminis villosis aristâ longioribus, stylo calycem requante compresso-2-sulco inferne puberulo, stigmate continuo attenuato. $\delta$ In caropis arenosis Africæ austr. - Roem. et Schult. syst, 3, p. 353*.

๙. minor, 'oliis planis ( $2-4$ lin. latis), capitulo parvo (magnit. pruni), calyce bipollicari, laminis ubique patulo-rillosis. - P. repens Thunb. diss. $\mathrm{n} .38$ *, II. Cap. p. 132, n. 46, Willd. I s]. 1, p. 523. Leucadendron repens $\beta$ Linn. sp. ed. 1 , p. 92 (non Berg.). (v. s. in herb. Willd. n. 2435 !)

ß. major, foliis marginihus revolutis tereti-filiformibus (1 lin. crassis) passim subulanis minus scahris, capitulo magno (3-4 poll. longo), calyce tripollicarí, laminis adpresse sericeo-pilosis apice incurvo dense subcrispo barhatis. - In montibus, circa Dutoitskloof et Draakensteen, alt. 1,000-2,000 ped. Niven! Drège! docum. P. 79, 100, Gueinzius!). Lepidocarpodendron fol. longiss., etc. Boerh. Lugd. bat. 2, p. $190^{\circ}$, cum ic., Weinm. phyt. 4 , p. 290 , t. 897 a. P. canaliculata herb. Soc. linn. Innd. (non Andr.). P. Strobus nob. olim in herb. nonnullis. P. repens var.? fol. $1 \frac{1}{2}$-pedalibus vix punctatis R. Br. 1. c. p. 93 ? (v.s.)

48. P. вснINUlat A, caule nano, foliis elongatis filiformi-linearibus sphacelatoacuminatis papillis acutis sparso echinulatis laxe piloso-ciliatis demum glabris supra convexis eveniis sublus canaliculatis, capitnlo erecto sessili mediocri ovatosubgloboso, squanis omnibus obtusis eiliolatis demum nudis, exterioribus glabris, jnterioribus Đlores subiequantibus apice ferrugineo-tomentellis, calyce subhipollicari, laminis aristá breve tomosa mụlto longioribus adpresse, unguibus 
laxiuscule pilosis, . styla compresso glabro. 5 In graminosis distr. Caledon, alt. III-IV (Zeyher, n. 3670! Ludwig! in herb. Mus. Stuttgart.). Gaulis nanus decumbens? apjec in ramulos paucos brevissimos divisus, foliis spithammis. Capitulum magnit. ovi gallinacei majonis. Stylus arcuatus, demum $2 \frac{1}{2}$ poll. longus, infra medium hipe carinatus: Forte P. tenuifolixe var.? attamen foliis tenuioribus, egregie pchinulatis, capitulo non hemisphærico, floribus longioribus, etc., satis discrepans. (v. s.)

49. P. scaBra (R. Browiı! 1. c. p. $91^{*}$ ), caulibus nanis, foliis rigidis elongato-linearibus acutis planis vel margine recurvis obsolete venosis punctato-scabris, eapitulo sessili erecto mediocri turbinato-subgloboso, squamis rufo-tomentosis, interiorilus flores aquantibus, calyce subpollicari hirsutulo, unguibus dorso glabrescentibus, aristis densius villosis laminâ dimidio brovióribus, stylo subsesquipollicari tereti sulcate glabro, stignate continud. 5 In Africa australi, in mont. Winterhoeksberg, etc.; alt. 2,000-3,000 ped. (Drège, cujus specim. non vidimus.). - Roem. et Schult. syst: 3, p. $352^{*}$. Rami adscendentes, folio breviores. Folia conferta, erecta, 8-10 poll. longa, 2-6 lin. lata, basi longe attenuata, undique punctis elevatis asperula. Capitulum magnit. poini minoris, diam. $1 \frac{1}{2}$ pall., basi attenuatum, sqlumis obtusis demum glabrescentibus. Calyx 6-12 lin. longus, breve pilosus. Stylus vix $1 \frac{1}{2}$ poll. longus, subulatus, stigmate tenui fere $2 \frac{1}{2}$ lin. longa.

๙. minor, calyce vix semipollicari, aristarum villis flexuosis cinereis vel ferrugineis, capitulo turbinato-hemisphærico, foliis margine leviter recurvis. (v. sp. hoxburgh! in herb. Soc. linn. Lond.)

ß. Hibbertiana, calyce albo-lanato, aristarum lana longióre magisque implexú, stylo bipollicari vix arcuate, capitulo turbinato, foliis elongato-lanceolatis planis (herb. Hibbert.). An distincta sp.? R. Brown l. c. p. 93, obs.

$\gamma$. major, calyce pollicari, aristarum lañ brevi cinerea-albidà, stylo sesquipollicari arcuato, capitinlo subgloboso, foliis margine leviter recurvo subtus concavis (2-4 lin. latis) rectis scaberrimis. In Langelsloof. (Mundt! in herb. reg. Berolin., Ludwig! Gueínzius !).

§. stenophylla, calyce subpollicari, lanấ fulvâ, stylo sesquipollicari arcuato, capitulo subgloboso, foliis $1-1 \frac{1}{2}$ lin. latis arcuato-flexuosis minus scabris, margine valde revoluto subtus canaliculatis. - In collibus saxosis distr. Caledon, alt. IF-III (Zeyher, n. $3671 \mid 3673 \beta$ | cum $\gamma$ mix tâ). Forma P. echinulatæ simpilis, sed involucro, calyce, stylo bené distincta. (v. s.)

50. P. SGOLOPENDRIUM (R. Brown 1. c. p. 94*), caulibus nanis, foliis elongatolanceolatis marginalis venosis lavihus, capitulo subsessili erecto majusculo turbi'nato, squamis lanceplatis acuminatis apice tomentosis, calyce sesquipollicari dense brevipiloso, aristis laminâ dinidio brevioxibus densius lanatis, stylo calycem æquiante glabro inferne dilatato, stigmate tenuj basi obsolete noduloso. $ち$ In Africa, austr., mont. Winterhoek (Roxburgh! in herb. Banks, et soe. linn. Lond.), circa Dutoitslíloof, etc., itt. 2,000-3,000 ped. (Drège docum. p. 81, 114, non vidi). - Roem. et Schylt. syst. 3, p. 354*. Folia pedalia, $1 \frac{1}{2}$ fere 2 poll. lata, basi valdo attennata, venis prominulis ramosis, punctis nuinutissimis confertis vix elevatis. Capitula salítaria vel bina, quandorgue 3 poll. longa. Calyx $1 \frac{1}{2}-1 \frac{3}{4}$ poil. longus. Stylus arcuatus, stigmate 2 lip. longo, ovarii barbâ albâ. (v. s. in herb. Banks., etç.)

B. scabriuscula, foliis lineari-lanceolatis dense minuteque puinctato-scabriusculis, venis in nervum margini plus ininus recurvo proximum confluentibus. - In graminosis montium, ad fl. Dnrustrivier, alt. II-III (Zeyher ! n. 3672 ! Ludwig !). Folia 5-7 poll. longa, 3-5 lin. lata, passim subpedalia 1 poll. lata; sphacelatogcuta. Cat. ut in specip. Roxburgh, exceptâ calycis pube densiore et ovarii harbầ rufâ. Simillima P. scabre, sed folits minus scabris, magis venosis, involucro et floribus longioribus bene distincta. (v. s.)

51. P. REvaluta (R. Brown l. c. p. $90^{*}$, non Buek), caulibus nanis, foliis elongatis tanaliculato-semiteretibus acutis lævibus marginibus recurvis infia medium jarum attenuatis teretiusculis, capitulo brevissime pedunculato inclinato parvo, sruamis obtusis glabris, calycis unguibus margine lanatis dorso glabris, laminis sericeis muticis, stylo glabro apice simplici. $\mathcal{F}$ In montibus aridis Afrire austr. (Niven, Roxburgh! in herb. Sor, linn. Lond.), in lapidosis graminosis nont. Groute Hou 
hick, alt. II-IV (Zeyher, n. 3669 ßI), - Roem, et Schult. sysl. 3, p. 352 *. Caules bași divisi, nani, adscendentes. Folia 6-9. poll. longa, haud punctata. Capitulum magnit. pruni minoris. Forsan-mera var. p. angustata, cui saltem sjecim. Zeyheri foliis ex parte planis floribusque amnino conveniunt. (v. s. in hierb. Soc. linn. Lond., etc.)

52. P. ANGUSt A TA (R. Brown 1. c. p. 90), caulibus nanis, foliis lanceolato-linearibus planis marginatis venosis lævibus, capitulo inclincto hemisphserico, squamis obtusis glabris, calycis laminis mulicis, unguibus margine lanatis dorso glabris. $\$$ Ip mont. Houhoek (Niven, Roxburgh $\rfloor$ in herb. Banks.), Nieuwekloof, infra alt. 1,000 ped. (Drège locum. p. 78, specim. non vidi), ad ostium fl. Klynrivier (Zeyher, n. 3669 !). Specim. Zeyheri facie accedunt ad $\mathrm{P}$. Scolymum; caules vel rami breves adscendentes. Folia rigida, 4-6 poll. longa, 2-3 lin. lata, attenuato-acuta, hasi longe attentuata, 1-nervia, subenervia, rugulosa, margine nerviforni, punctis elevatis nullis; capitulum magnit. pruni, diam. 1 poll., ovato-globosum, squarhis junioribus ciliolatis; calyx pollicaris, lamivis sericeo-villosulis attenuato-acutiusculis muticis $2 \frac{1}{2}$ lin. longis; stylus calycem æquans, falcatıs, compressus, tenuis, glaber, stigmate continuo 1-lin. longo subulato. Species fatente ipso cel. auctore 1. c. forsan non satis distincta a P. acauli, cui revera specim. Roxburigh. 1. c., involucro, calycis laminis glabratis et stigmate conveniunt, attamen foliis semper angustis (non ultra 4 lin. latis) acuminato-acutis valde discrepant. (v. s. in herb. Banks., etc.). (v. s.)

53. P. TURBINIFL ORA (R. Brown 1. c. p. $93^{\star}$ ), caulibus nanis, foliis elongato-lanceolatis marginatis subundulatis laxe prominulo-venosis lævibus glabris attenuato-subpetiolatis, floralibus abbreviatis acutis, capitulo sessili erecto subturbinato-globoso mediocri, squamis obtusis tomentosis, interioribus apice lanatis, calyce pollicari cano-villosiusculo, aristis laminam æquantibus longius crispobarbatis, stylo recto compresso glabro, stigmate tenui basi hinc leviter noduloso $\zeta$ In montanis humidis Africa austr. (Niven, Ludwig! in herb. Mus. Stuttgart.).Roem. et Schult. syst. 3, p. 353* Erodendron turbiniflorum Salisb. parad. 108. Protea ćaspitosa Andr. Bot. repos. t 526 (calycibus albis, aristarum barbâ brevi fulvâ). Habitus et præcipue folia inferiora fere $\mathrm{P}$. acaulis. Caules nani, crespitosi, divisi. Folia 6-10 poll. longa, 1-1 $\frac{1}{2}$ poll. lata, obtusa (ex R. Brown acutissima), minutissime punctata, sed tactu non scabra, juxiora villosa, summa capitulum obvalIantia $\frac{1}{2}-2$ poll. longa submembranacea basi vix attenuata. Cápitulum diam. 2 poll. squamis roseis subincanis ciliatis. Calyx 15 lin. longus, stylum æquans. Stigma 2 lin. longum. (v. s.)

54. P. TENAX (R. Brown 1. c. p. $88^{*}$ ), ramis decumbentibus, foliis lanceolatis vel lineari-lanceolatis subacutis basi attenuatis subimmerse venosis punctato-scabriusculis haud marginatis, junioribus ramisque laxe pilosiusculis, capitulo sessili erecto mediocri hemisphærico, squamis obtusis sericeis mox glabratis, interioribus parum elongatis obovato-oblongis, calfce pollicari, unguibus glabriusculis, aristis lanato-barbatís laminâ lineari dorso glabrâ dimidio brevioribus, stylo recto compresso glabro. 5 In Africâ austr., circa Laegekloof (Niven, Roxburgh ! in herb. Banks.), in mont. Zuurebergen, alt. 2,500-3,500 ped, , et in littorali inter 0mtendo et Omsamculo (Drège! docum.p. 137, 154). - Roen et Schult. syst. 3, p. 350*. Erodendron tenax Salisb. parad. 70. Frutex diffusus, ramis hirsuitis vel glabris laxiuscule foliosis. Folia 4-6 poll. longa, 4-6 lin. lata, angustato-acuta cum callo parvo obtuso sphacelato, ramorum subsecunda. Capitula et flores P. açaulis. Stỳlus lævis, basi vix dilatatus. (v. s. in herb. Banks.)

$\beta$. latifolia, foliis elliptico-oblongis (4-5 poll. longis, usque ad 2 poll..latis), stylo apice leviter curvato ctum stigmate subarticulato. - In graminosis et rupestribus, circa Galgeboisch et Vanstaadesberg, alt. 1,000-2,000 ped. (Drège! docum. p. 118, 127, Zeyher, n. 3667, cum var. $\beta$ 1). P. caulesceñs E. Mey.! P. magnolixfolia Buek! in pl. Drège. Folia interdum in eodem specimine passim lineari-lanceolata, vix 3 lin. lata. (v. s.)

55. P. A ca u I s (Thunb. diss. n. 49*, fl. Cap. p. 137, n. 68), caule abbreviato ramisque depressis, foliis obovato-ohlongis marginatis lævibus subimmerse venosis basi attenuatis glabris, capitulo sessili inclinato mediocri hemisphærico, squamis oltusis glabris, interioribus flores æquantibus apice dilatatis, calyce subpollicari pilosulo, laminis cum acumine brevi obtuso adpresso-pilosis vel brevi-villosis dorso demum glabris, stylo falcato compresso glabro subexsulco, stigmate sub- 
continuo tenui. 5 In collibus Africæ austr. (Roxburgh! in herb. Banks.), ad fl Karsrivier (Ludwig 1), Paarlberg; Dutoitskloof, Piquetberg, etc., alt. 1,000-4,000 ped: (Drège I), Rivier Zonder Einde (Zeyher, n. 3668 !), in summis mont. Winterhoek, Uitenhage (Krauss, n. 1071). - R. Brown 1. c. p. 89, Roem. et Schult. syst. 3, p. 351 ", Bot. mag. t. 2065 , Boerh. Lugd. bat. 2, p. $191^{*}$ cum ic., Weinm. phyt. 4, p. 291 , t. 897, b. Leucadendron acaulon Wachend. Ultraj. p. 204, Linn. sp. 1, p. 92. P. nana Lam. ill. 1, p. '233 (non Thunb.). P. glaucophylla Salisb, parad. 11. Crr. Link en: alt. p. 11.4, Roem. et Schult. syst. 3, mant. p. 265 . Folia crassa, glauca? opaca, 4-8 poll. longa, 1-2 poll. lata, obtusa vel mucronato-acuta, infra medium cluneato-angustata, basi interdum petioliformi, nervo venisque immersis vel vix prominulis. Capitulum magnit. pomi minoris, diam. $1-1 \frac{1}{3}$ poll., involucro

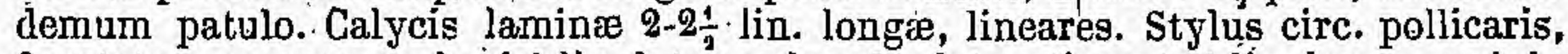
fere totus eompressus, basi 1 lin. latus, sulco obsoleto, stigmate 1 lin. longo, nodulo basali obsoletissimo: (v. s. in herb. Banks., etc.)

ß. arenaria, foliis subnitidis venis prominulis laxe reticulatis, capitulo dimidio majore, squamis interioribus flores vix æquantibus, calycis unguibus basi ciliatis supra glabris, stylo sulcato minus compresso (cæet. omnia ut supra).Circa Wynberg, Hottentottsholland, etc. (Burchell, n. 1! Ecklon, n. 11! Drège! docum. p. 74). P. angustata Drège olim (non R. Br.). P. arenaria Buek! in pl. Drège. P. acaulis a I Drège, ex parte. Folia sæpe pedalia, usque ad 2 poll. lata. (v. s.)

56. P. ELONGAT A (R. Brown 1. c. p. 90), caulibus nanis, foliis elongato-lanceolatis (pedalibus) planis marginatis venosis læevibus, basi valde attenuatâ lineari, capitulo hemisphærico inclinato, squamis obtusis glabris, calyce brevissime-aristato. 5 Circa Roode Zand Cascade (Niven). Planta nobis ignota, teste ipso cel. aúctoro "nimis afinis $P$. acauli, "verisimiliter cum hujus var. $\beta$ identica.

57. P. G Y A R OI DES (Linn. mant. p. 190), caulibus nanis indivisis, folis petiolatis subrotundo-obovatis ellipticisve venosis glabris, capitulo nıagno obovato-globoso demum patente, squamis acuminato-acutis, intimis lanceolatis flores superantibus, calyce tomentoso basi glabrescente, aristis laminâ dimidio brevioribus, stylo calycem wequante valido compresso apice incurvo, stigmate attenuato basi oblique noduloso: 5 In planitie Capensi montibusque usque ad alt. 3,000 ped., Tafelberg, Vanstaadesberg, Wynberg, Dutoitskloof, etc. (herb. Banks ! Ecklon ! Drège ! Krauss, n. 1076 ! Zeyher, n. 3655 ! etc.). -Willd.I sp. 1. p. 534, herb. n. 2459 ! R. Brown 1. c. p. 75 , Roem, et Schult. syst. 3, p. $342^{\star}$, Rouppell Cape flow. 't. 8 (forma $\alpha$ et $\beta$ ). Leucadendron cynaroides $\alpha$ Línn. sp.ed. 1, p. 92. Caules epigæi vix $\frac{1}{2}-1$-pedales, simplicissimi, crassi. Folìa cum petiolo 4-6 poll. longa, 1-2 poll. lata, rigida. Capitulum pugni majoris mole, sc[uamis apice roseis. Flores albi, inferne vireseentes. (v. s. in herb. Banks., etc., et v. v. c.)

ג. obtusifolia, foliorum laminâ suborbiculari vēl obovatà obtusissimâ basi loreve attenuatâ vel subemarginatâ, involucro sericeo, stylo infra medium pubescente. - Boerh. Lugd. bat. 2, p. 184*, c. ic., Weinm. phyt. 4, p. 287, t. 292, Bot. mag. t. 770, Reichenb. fl. exot. 4, p. 2, t. 219. (v. s. Burchell, n. 506, 2 I Drège $b$ ! ex parte et e l.)

B. elliptica, foliorum laminâ ovali vel lanceolato-ellipticâ utrinque attenuatâ acuta (rarius obtusâ); involucro sericeo, stylo inferne pubescente. - In mont. Outeniquâ, alt. 2,000-3,000 ped. (Drège I). P. petiolatá Buek! in pl. Drège. (v. s. Drège, n. 8050 l a, c, et ex parte, b.)

$\gamma$. glabrata, foliorum laminâ ellipticâ vel ovali-oblongâ utrinque attenuatà plerumque obtusâ, involucro glabro, squamis (infimis tantum exceptis) longe acuminatis, stylo toto glabro. In Zitzikammà (Krauss). - Andr. bot. repos. t. 288. P. cynaroides $\hat{\beta}$ elliptica Klotzsch in Krauss beitr. p. 139 ? (v. $s$. in herb. Mus. Stuttgart.)

II. Hypocephalae. - Capitula lateralia, prope basin caulis solitaria vel nonnulla approximata, pedunculo brevissimo aphyllo imbricatim squamato suffulta, inclinata, hemisphcerica, mediocria vel parva, involucro demum patente, receptaculo paleaceo.

58. P. coRD AT A (Thunb. diss. n. $60^{*}$, t. 5, fl. Cap. p. 140, n. 84 ), tota glabra, caule prostrato brevi squamato, ramis gracilibus adscendentibus, foliis remotis glaucis 
sessililıas cordatis subrotundis ovatisve nervosís, capitulo mediocri hemisphærico, squamis obtusis, stylo ealycem æquante subpollicari falcato compresso 5 In montanis, circa Hottentottsholland, ețe (herb. Banks! Ludwig̀! Eeklon! Mund! Zeyher, 11.3674 !),-Andr. Bot. repos. t. 289 , R. Browh 1. c. p. 94, Roém. et Schiult. syst. 3 , p. 354 * P: cordifolia Sing Bot. mag. t. 649 , Réichenb. fl. exot. 4, p. 35, t. 274. Fruticulus $\frac{1}{2}-1$-pedalis; pauciramosus. Folia rigida, 2-4 poll. longa, $1 \frac{1}{2}-5$ poll. lata, juniora rubro-marginata. Capitula magn: pomi minoris, squamis rubris, junioribus minute sericeo-puberulis, exterioribus apiée attenuatis, interiónibus subspathulatis. Stigma 1 lin. longum, obtusum, basi obsolétissime noduloștim, (v. s. in berb. Banks, etc., et v. v. c.)

59. P. AMPLEXIGAULIS (R. Brown! in Linn. Trans. 10, p. 95), humilis, ramis erectis conferte foliosis, folíis seśsilibus cordato-amplexicanlibus ovatis vel ovato-oblongis acutis 5-9-nerviis glabris, capitulo mediocri hemisphterico, squamis obtusis sericeo-puberulis demum glabris, interioribus ciliatis, calyce jollicari glaberrimo, jutifore apice breve barbellato, stylo glabró faleato compresso. $ち$ In A fricá austr. Másson! in herb. Banks., herb.Willd. n. 2460! Ludwig! Kolbing, n. 6!), Dutoitskloof, alt. 3,000-4,000 ped:' (Drège! docum. p. 82), mont. Zwartebergen, Caledon (Zeyher, n. 3675 !). P. repens Andr. Bot. repos. t. 453 (non Thurib.). Erodendrum amplexieanle Salisb. parad. 67. Caules vel rami 1-2-pedales, erecti. Fólia rigida,

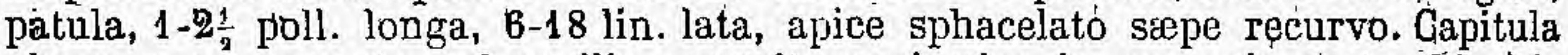
plerumque aggregata, subsessilia, magnit. pomi minoris, squamis ovato-oblongis flores subsuperantibus. Stylus demum $\frac{5}{4}$ pêll. longus, stigmate tenui $1 \frac{1}{2}$ lin. lóngé basi obsoletissime noduloșo. (v. s. in herb. Banks, Willd., etc.)

60. P. н чм IL Is (R. Brown 1. c. p. $95^{*}$ ), erecta, foliis linearibus acutis planis ramisque glabris, capitulo hemisphærico parvo', squamis obtusis. sericeis, exterioribus demum glabratis, interioribus spathulato-oblongis apice extus adpresse villosis flores æquantibus, - receptaculo conico paleis acutis, calyce subpollícari glabro mutico, stylo falcato comprèsso glabro, stigmate basi nodulosò. 5 In Africá ausitr. (Masson! in herb. Banks.), in collibus supra Zwellendam et in nohtit. Klynriviers. bergen, alt. II, III (Zeyher, n. 3676 !).P. Ilumiflora Adidr. Bot. repos. t. 532. P. humiflorens Willd. en. suppl. p. 7 ? 'P. humifusa hort.? P. leuranthe glastifolia Sališb., Gide Spreng. syst. 1, p. 463. Habitus P. nanæ et precipue P. acerosæ. Caulís vix palmaris. Folia patula, 1-2-fere 3 poll. longa, $\frac{1}{2}-\frac{3}{3}$ lin. lata, plana vel subcanalicalata. Capit. diametro circ. pullicari, squamis intimis apire pulje albidâ vel ferrugineâ seríceo-villosiusculis. Stylus fere $\frac{1}{2}$ lin. latus, stigmate 1-1 $\frac{1}{2}$ lin. longo, nodulo besali conspicuo parvo.' (v. s. in herl. Banks., etc.)

61. P. ACERoSA (R. Brown 1. c. p. 95 \%), erecta, foliis subulatis tenuíbus mucronulatis vèl demum muticis ramisque glabris, capitulo parvo turbinato-hemisphærico, squamis obtusis sericeo-tomentellis, jnterioribus spathulato-oblongis flores superantibus, receptaculo subconvexo-plano, paleis obtusis connatis, calyce unciâ breviore glabro, laminis muticis junioribus apice breve barbellatis, stylo pollicari. glabro falcato subulato tenui, stignate basi hinc leviter noduloso. $\frac{\partial}{\zeta}$ In Africâ austr. (Masson! in herb. Banks., Ludwig! Kolbing, n. 8), ad fl, Palmietrivier et mont. Houhoek, alt. 1,000-2,000 ped. (Drège! docum. p. 118,120, Zeyher, n. 3677!). - Bot. reg. t. 351, Roem. et Schult. syst. 3, p. $355^{*}$. P. abietina Búék! in pl. Drège. Caules erecti, subpedales, subunbellatim tamosi. Folia conferta, patula, rigidula, levia, filiformia, 7-12 lin. longa, vix $\frac{1}{2}$ lin, crašsa. Capitula subẩdgregala, subsessilia, diam. 1-poll. Calyx vix 9 lin. Iongus, apice demum imberbi. Stylus basí tantum compressus, stiginate 1 lin. longo, nodulo basali distincto minuto. Squarmulæ hypogynæ 4 albidie lineares acutæe 1 lin. longæ. A præceden̈te facile dignoscitur foliis styloque tenuioribus; etc. (v. s. in herb. Banks., ete.)

B. virgata, caule elatíore (3-4-pedali), foliís longioribus (1 poll. longis) R. Br. I.c. p. 95, obs. - In montosis, ad Rivier Zonder Einde (Niven). P. virgata Andr. Bot. repos. t. 577. Forsan propria species.

\section{Species non satis notce.}

62. P. acuminata (Sims Bot. mag. t. 1694), foliis tanceolato-linearibus acutis utrinque attenuatis planís glábris supra vehulosis, capitulo terminalí mediocri gvato, involucro demurm patente, squamis obtusis in terioribus spathulato-oblontis flores æquantibus margine atro-pubescentibus. 5 Cap. Bonæ-Spei. (i® Anglia, 1812, 
in hort. Lee et Kennedy culta).-Poir. suppl. 4, p. 562 *, Roem. et Schult. syst. 3, p. 351, mant. p. 265. Glabra, ramis sublexuosis rubris. Folia patentia, circ, 3 poll.

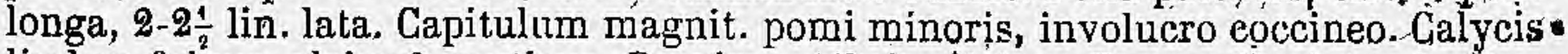
limblus fulvus glaber? muticus. Proxime dffinis dicitur P. canalículate (supra, n. 43), nec non ad P. lanceolatum speciesque huic proximas aecedere videtur.

63. P. veNosa (Lam. ill. 1, p. 234, n. 1212, non Thunb.), ramis villasis, foliis imbricatis ovatis tenuiter reticulato-venosis glabris, capitulis súbterminalibus 2-3-approximatis rotundatis, squamis puberulis angustis subulatis actimitiatísvé plerisque apice albo-barbatis, calyce pollicari styloque villoso. 5 Ad lap. BonwSpei (herb. Lam.). - Poir. dicl. 5, p. 640*, R. Brown in Linn. Trans. 10, p. 219; Roem. et Scluult. sysl. 3 , p. $355^{\circ}$. Folia sessilia, coplerta, 1-2-pollicaria. Capitula crassa, 2-3 prope apicem rami alproximätæ, squamis fuscis. Accedere dicitur ad P. longifloram Lam. (supra, n. 49), sed jam capitulís haud solitariis, calyce mülto breviore, etc., diversa.

64. P. VENULOSA (Steudel nomencl. ed. 2, p. 401), foliis imbricalis ellípticis oblusis calleso-mucronatis venosis glabris basi subtus margineque villosís, capitulo solitario cylindrico-oblongo squamis lanceolatis coloratis. $f$ ? P. venosa Thunb: fl. Cap. ed. Schult. p. 134* non Lam.). Frutex simplex, ereetus, villoso-tomentosus, pedalis el ultra. Folia sessilia, bipollicaria et ultra, glandulì terminata. Capitulum bracteis foliisque obvallatum, squamis pallidis glabris flores supefantibus foliis superatis. Flores...?

65. P.? g LA BR a (Thunb. diss. n. 52, prodr. p. 27, t1. Cap. ed. Schult. p. 138), toto glabra, foliis sessilibus erectis pollícaríbus crassis oblongis eveniis apice glandulosis, capitulo hemisphærico..... J Ad Cap. Bonæe-Spei. - Linu. syst. veg. ed. 14. p. 141. Frutex, foliis integris, capitulo terminali solitario magnit. ponni. Leueadendri?? sp. R. Brown in Linn. Trans. 10, p. 218. L. Thunbergii Lindl. gen. suppl. 4, 2, p. 75, sed propter capituli magnitudinem potius Proteæ sp. esse videtur. Cfr. Leucadendron ovale R. Br. (supra, n. 24), sed specim. P. glabræ Thunb. ibid. descripto parum convenit.

66. P.? o v a t a (Thunb. in Mém. Acad. Pétersb. 1813-14, p. 5.48, t. 17, 0. Cap̧. ed. Schult. p.139), tota glabra, foliis sessilibus sesquipollicaribus uvatis ubtusis, eapitulo terminali magno, squamis imbricatis ovatis. 7 Ad Cap. Bonæ-\$pei. Leucospermum? ovatum Roem. et Schult. syst. 3 , mant. p. $266^{*}$, ubi capitulum dicitur obovatum. Caulis fruticosus, erectus, ramosus, ramis alternis subfastigiatis. Folia plana, erecto-patula, 1 polt, lata, integerrima. Ad P. cynaroidem a Sprengelio (syst. 1 , p. 461) cum dubio refertur, sed ab hac jam foliis sessilibus ablarret. Potius P. compactae (supra, n. 30) affinis.

\section{Species non descripto, plurima verisimiliter ad atia genera pertinentes.}

P. ARBOREA (Link enum. alt. p. 113), ex Roem. et Schult. syst. 3, mant. p. 266.

P. ARBORESGENS hort.

P. ASPLENIFOLIA hort.

P. BRASSICEFOLIA hort.

P. carinata hort., ex Roem. et Schult. l. c. p. 266.

P. CAR N OSA hort. Garlsr.

P. CERIFE RA hort. Monac.

P. G IL IA A Is hort. Carlsr. (an Voigt, Wendl.? IU:ß Leucadendron marginatum Link.

P. crila t a hort. Breit., ex Roem. et Scliult. l. e. p. 266 (Serruria ciliata R. Br.?).

P. CONGOLOR hort. (án Leucadendron concolor R. Br.?).

P. DECLINATA hort.

P. DENS A Ait., ex Steudel (in hort. Kew. non exstat).

P. E R I C o I D E S hort. (forsan Leucadendron corymbosum $\sigma^{\text {ta }}$ vel L. ericifolium R. Br.).

P. GL A U C A Brouss. et hort.

P. GLU TINOSA hort.

P. G R A I I E A hort. Link enum, alt. p. 113, ex Roem. et Sch. 1. c. p. 260

P. ORANDIS hort. 
P. H I T E L L A hort.

P. IN CANA hort.

P. LA NGEOLATA hort. (nON? E. Mey.).

P. L A T E R I O L O R Hook. parad. Lond. t. 27, nomen delendum, sphalmate pro lacticolor (P. longiflora Lam., supra, n. 19) ortum.

P. LEUCANTHA hort.

P. LINGUIFORMIS hort.

P. MIGRANTEA hort.

P MoLh Is hort. (Spatalla mollis? vel Leucospermum molle R. Br.?)

P. MOL L ISsima hort. (Nivenia mollissima R. Br.?)

P. MUGR ONA T A Nois., ex Roem. et Schult. syst. 3, mant. p. 266.

P. MUL TIFIDA Nois. id.

P. Pass erina Desf. id. (Cfr. Leucadendron tortum.)

P. PINNA t a Gav. (Petrophilæ aut Serruriæ sp.?)

P. POLYGA cordes Willd. enum. suppl. p. 7. (Cfr. Protea canaliculata Andr., fide Spreng. syst. 1, p. 463, et Leucadendron polygaloides Link.)

P. RADULA hort.

P. RA D UL I F O I A Don, Link enum. alt.p. 113, Roem. et Schult. syst. 3, mant. p. 266.

P. REFLEXA hort.

P. RET R OF L EXA Dietr. Gartenlex. 7, B. S. 556 .

P. SETA C A hort. (Sorocephalus setaceus Br.?)

P. SPIRALIS hort.

P. STATICEFOLIA hOrt.

P. SUBAGAULIS hort.

P. TENELLA hort.

P. TRIDENTA TA hort.

P. UL I I I O S A hort. (Leucadendron uliginosum R. Br.?)

P. viseosA hort.

\section{Species exclusa.}

P. A ВгетіN A Lichtenst. = Spatalla pedunculata R. Br.

P. A BROT ANIFOLI A hirta Andr. = Serruria abrotanifolia Knight.

P. ABROTANIF-OLIA minor Andr. = Serruria emarginata Sweet.

P. A B R OTANIF OLIA odorata Andr. = Serruria odorata Sweet.

P. ABRotanifolia Andr. = Serruria phylicoides R. Br.

P. ACROCARPA Poir. = Serruria acrocarpa $\mathrm{R}$. Br.

P. Ac Uf E A Cav. = Isopogon anethifolius $\mathrm{R}$. Br.

P. ADSCENDENS Thunb. = Serruria adscendens $\mathrm{R}$. Br.

P. A MULA Poir. = Serruria semula R. Br.

P. ALBA Thunb. = Lencadendron cinereum $\mathrm{R}$. Br.

P. ALOPECUROIDES Lam. = Nivenia Sceptrum R. Br.

P. ANEMONIFOLIA Salisb. = Isopogon anemonifolius R. Br.

P. ANETHIFOLIA Salisb. = Isopogon anethifolius R. Br.

P. ANGUSTAT A Poir. = Leucadendron angustatum $\mathrm{R}$. Br.

P. A PIF OLIA Smith herb. = Isopogon anemonifolius Kn. et Salisb.

P. A R C UATA Lam. = Leucadendron squarrosum et? plumosum R. Br.

$P$. A RCUAт A $\beta$ Jam. = Leucadendron concoloì $R$. Br.

1. ARENARIA Poir. (non Buek) == Serruria arenaria R. Br.

P. ARGENTEA L. = Leucadendron argenteum R. Br.

P. ARGENTIFL O R A Andr. = Serruria triternata R. Br.

P. ATTENUATA Poir. = Leucospermum attenuatum $\mathrm{R}$. Br.

P. A ULACE a Thunb. = Aulax umbellata R. Br. $\sigma$.

P. A UST RA L Is Poir. = Spatalla propinqua R. Br. 
P. в васт тат а Thunb. = Aulax pinifolia Berg.

P. BRACTE oL A R IS Poir. = Spatalla bracteata $\mathrm{R}$ Br.

P. BREVI Fou IA Poir. = Spatalla brevifolia R. Br.

P. B nown I Poir. = Serruria diffusa R. Br.

P. BRUNia Des Linn. fil. = Leucadendron corymbosum Berg. $\&$.

P. BUXIF oL i A Poir. = Leucospermum buxifolium R. Br.

P. CALL OSA Wendl. = Leucadendron callosum Hoffmansegg.

P. CANDICANS Andr. = Leucospermum tomentosum R. Br. $\beta$.

P. CANDYCANS Thunb. = Nivenia ? candicans Roem. et Schult.

P. ca PItata Poir. $=$ Nivenia capitata $R$. Br.

P. Gapitulata Poir. = Mimetes capitulata $\mathrm{K}$. Br.

P. cAUDATA Thunh. = Spatalla caudata et Thunbergii R. Br.

P. cart Il ag INEA Poir. = Leucadendron cartilagineum R. Br.

P. СНAM

P. Cris R Is Voigt, Wendl. = Leucadendron marginatum Link:

P. cilista Desf. $=$ Leucadendron grandiflorum $\mathrm{R}$. Br.

P. ciliata hort. Angl = Leucadendron marginatum Link.

P. ciliata Poir. = Serruria ciliata R. Br.

P. CINEREA Ait. = Leucadendron cinereum R. Br.

P. CINEREA Willd. = Leucadendron tortum R. Br.

P. coARGTATA Thunb. = Serruria scariosa R. Br.?

P. $\operatorname{comos} \Lambda$ Thunb. = Leucadendron comosum R. Br.

P. COMPAR Poir. = Serruria compar R. Br.

P. congava Lam, = Nivenia coneava Roem. et Schult.

P. Congrna Poir. $=$ Leucadenilron coricinnum R. Br.

P. congestA Poir. = Serruria congesta R. Br.

P. coNicA Lam. = Leucadendron strictum $\mathrm{R}$. Br.

P. CONIFERA L. = Leucadendron adscendens et salignum R. Br.

P. CONIFERA Andr. = Leucadendron strictum R. Br.

P. CONIFER A A. Poir. = Leucadendron strictum R. Br.

I. conifera Willd. herb. = Leucadendron decorum R. Br.

P. coNIFERA Thunb. = Leucadendron coniferum nob.

P. CONOCARPA Thunb. = Leucospermum conocarpum R. Br.

P. cONOCARPA A. Poir. = Lencospermum ellipticum R. Br.

P. GORI A CE A Lichtenst. = Mimetes coriacea Roem. et Schult.

P. C O R I A GE A Willd. herb. = Leucadendron venosum R. Br. $\beta$.

P. CORY M B OS A Thunb. = Leucadendron corymbosum Berg.

P. CR A S IF OL I A Poir. = Leucadendron crassifolium R. Br.

P. CR INIFL ORA Linn. fil. = Leucospermum oleæfolium R. Br.

P. G R IN I T A Thunb. $=$ Leucospermum crinitum R. Br. $\alpha$.

P. с R I I I T A Jacq. Willd. herb. = Leucospermum crinitum R. Br. $\gamma$.

P. C R I T н I F OL I A Poir. = Serruria critlmifolia R. Br.

P. G U G U L L A T A L. = Mimetes cucullata R. Br.

P. c u c u L L A т А $\beta$ Lam. $=$ Mimetes Hartogii R. Br.

P. CYANOIDES L. $=$ Serruria eyanoides R. B.?

P. CYAN OIDES Thunb. = Serruria nitida R. Br.

P. CYGNEA Poir. = Serruria cygnea $\mathrm{R}$. Br.

P. DAP н 0 I DES Thunb. = Leucadendron? daphnoides nob.

P. DECIPIENS Poir. = Serruria decipiens R. Br.

P. DEG O R A hort. Angl, = Leucadendron grandiflorum R. Br.

P. DEGUMBENS Thunb. = Serruria decumbens R. Br.

P. DE G U B B N S Andr, = Serruria Niveni $R, B r$. 
P. DEG U B ENS Willd. herb. = Serruria gläberrima R. Br.

P. D гсно т о А Cav. = Petrophila puichella $\mathrm{R}$. $\mathrm{Br}$.

P. D I С о т о а Lam, = Mimetes dichotoma Roem: et Schult.

P. D I V A R I G A T A Linn. = Mimetes divarieata $\mathrm{R}$. Br.

P. DIVARICATA Andr. = Isopogon anemonifolius R. Br.

P. DIVAR I C A TA Willd. herb. = Mimetes thymelæoides R. Br.

P. DIVERSIF OLIA Poir. $\perp=$ Sorocephalus diversifolius R. Br.

P. DIVERSIF OLia Willd. = Leucadendron salignum R. Br.

P. Elevata Poir. = Serruria elevata $\mathrm{R}$. Br.

P. ElLiptica Thunb. = Leucospermum ellipticum $\mathrm{R}, \mathrm{Br}$.

P. в веста Thunb. = Serruria ? erecta nob.

P. ERIG F F LIA Willd. herb. = Leucadendron corymbosum Berg. $\sigma^{2}$.

P. ERICIFOLIA Poir, = Leucadendron ericifolium R. Br.

P. E RIOGE PIIALA Lichtenst. = Serruria squarrosa R. Br.

P. ERIOCEPHALA Willd. herb, = Serruria phylicoides et squarrosa R. Be.

P. ERos A Liclitenst. = Leucospermum grandiflorum R. Br.

P. EROSA Willd. herb. $=$ crinitum R. Br. $a$.

P. PLAGELLA RIS Poir. = Serruria flagellaris R. Br.

P. FLAVESGENS Willd. = Leucadendron flavescens Link.

P. FLORIDA Thunb. = Serruria florida R. Br.

P. FENICULAGEA Poir. = Serruria foniculacea R. Br.

P. FORMOSA Andr. = Leucospermum medium R. Br.

P. FUGrFolia Salisb. = Petrophila pulchella R. Br.

P. FURCELLATA Poir. = Serruria furcellata R. Br.

P. FU S CA Linn. = Leucadendron Levisanus Berg.

P. PUSCIFLORA Jacq. = Leucadendron fusciflorum R. Br.

P. GL A B E R R I M A Poir. = Serruria glaberrima R. Br,

P. GLOвоSA Andr. = Leucadendron concolor R. Br.

P. GL O B U L A R I A Lam. = Leucadendron Globularia R. Br.

P. GLOMERATA L. = Serruria glomerata R. Br.

P. GLOMERATA Thunb. = Serruria elongata R. Br.

P. GLOMERATA Andr. = Serruria pedunculata R. Br.

P. G L OM R A T A Willd. = Serruria adscendens R. Br.

P. GL OMERA T A Willd. herb. = Serruria ciliata et triternata R. Br.

P. Gust avi a a Poir. = Nivenia parvifolia R, Br.

P. н Е L V о I A Lichtenst. = Serruria cygnea R. Br.

P. н EL V OLA Willd. herb. = Serruria elongata R.Br.

P. HЕ T ER O Р Н L А Thunb. = Leucospermum diffusum R. Br.

P. H I B B E R T I Poir. =- Mimetes Hibbertii R. Br.

P. H I R S T A Thunb. = Leucadendron? hirsutum nob.

P. H I R U T A Willd, = Leucadendron Levisanus Berg.

P. Hinsuta Poir: = Serruria hirsuta R. Br.

P. нIRTA L. = Mimetes hirta R. Br.

P. HIR тA hort. = Leucadendron tortum R. Br.

P. нХРОРНУцц A Thunb. = Leucospermum Hypophylhm B. Br. $\alpha$.

P. HYPOPH XLL OGARP ODENDRON L. = Loucospermum Hypophyllum R. R. *.

P. IMBERBis Poir. = Sorocephalus imberbis.R. Br.

P. IMBRICATA Thunb. = Surocephalus imbricatus. R: Br.

P. IMBRIGATA Wendl = Leucadendron buxifolium R. Br.

P. INCURVA Andr. = Leucadendron æmulum R. Br.

P. INOUR VA Thunb. = Spatalla incurva R. Br.

P. INFLEXA Willd. = Leucadendron brunioides nob, et tortum Br. $\dot{\beta}$. 
P. INTERMEIA Poir. = Nivenia media $\mathrm{R}$. Br.

P. IN V. OL U CRATA Lichtenst, = Leucadendron? involucratum nob.

P. IN V OLUGRATA Willd, lıerb. = Leucadendron adscendens $\mathrm{R} ; \mathrm{Bt}$.

P. L a vis Tluunb. = Leucadendron? lreve nob.

P. LAGOPUS Andr. = Nivenia crithmifolia R. Br.

P. LAG OP US Thunb, = Nivenia Lagopus $\mathrm{R}$. Br.

P. LANata Thunb. = Sorocephalus lanatus $\mathrm{R} . \mathrm{Br}$.

P. LA UREOLA Lam. = Leucadendron decorum $\mathrm{R}$. Br.

P. L AXA l'oir. = Spatalla laxa $\mathrm{R} . \mathrm{Br}$.

P. Levisanus L. = Leucadendr. Levisan. et imbrioatum R. Br.

P. LINEAR is Houtt. = Leucadendr. angustatum $\mathrm{R}$. Br.

P. LINEAR Is Thunb: = Leucospermum lineare R. Br.

P. LINIFOL IA Jacq. = Leucadendron linifolium $\mathbf{R}$. Br.

P. Marginata Willd. = Leucadendron marginatum Link.

P. MARginata Willd, herl, = Leucadendron decorum R. Br. $\beta$.

P. Massoni Poir. = Mimetes Massoni R. Br.

P. MEDIU M Poir. = Leucospermum medium R. Br.

P. MaLlis Poir. = Leucospermum molle et Spatalla mollis $\mathbf{R}$. Br.

P. Moulissima Poir. = Nivenia mollissima R. Br.

P. митгс Poir. = Leucadendron spathulatum R. Br.

P. MугтIFOLIA T'hunb. = Mimetes mýrtifolia.R. Br.

P. Nectarina Schrad. = Lambertia formosa Sm.

P. Nitens Thunb. = Mimetes nitens Roem. et Schult.

P. niven I Poir. = Serruria Nivení $\mathrm{R}, \mathrm{Br}$.

P. NU.T ANs , Poir. = Leucospermum nutans R. Br.

P. OBLIQUA Thunb. = Leucadendron plumosum R. Br.

P. OBLIRUA Poir. $\alpha$. = Leucadendron squarrosum R. Br.

P. OBLIQUA Poir. $\beta$. = Leucadendron concolor $\mathrm{R}$. Br.

P. OBLIQUA Willd. herb. = Leucadendron adscendens $R$. BF.

P. ово vata Anur. = Serruria abrotanifolia Knight.

P. овтUS ATA Thunb. = Leucadendron? obtusatum nob.

P. aD ORATA Thunb. = Leucadendron odoratum? Steud.

P. PALLENS Linn. = Leucadendron adscendens $R$. Br.

P. PALLENS Thunb. = Leucadendron-decurrens R. Br.

P. PALLENS Willd. herb. = Leucadendron virgatum $R$. Br.

P. PAL L I D A Willd. herb. = Leucadendron decurrens R. Br.

P. PAR V IF L O A Linn. = Leucadendron plimosum R. Br.

P. PASSERINA hort. = Leucadendron tortum R. Br.

P. PAt ens Poir. = Leucospermum puberum R. Br. $\gamma$.

P. P AT U L A Thunb. = Serruria glomerata R. Br.

P. P A T U L A Willd. herb. = Serruria Burmanni R. Br. $\alpha$.

P. PA U G IFL ORA Poir. = Mimetes pauciflora $R$. Br.

P. PED U CUl A A Lam. = Serruria pedunculata $\mathbf{R}$. Br.

P. PEDUN C U A T A Poir. = Spatalla pedunculata $\mathrm{R}$. Br.

P. P II YLIC o I D s Thunb. = Serruria hirsuta $R$. Br.

P. Рн у г С о DES Thunb. = Scrruria villosa $\mathrm{R}$. Br.

P. P н Y I C O I D S Schmidt. = Serruria congesta $R$. Br.

P. РнуLrco I Es Willd. herb. $=$ Serruria congesta et arenaria $\mathbf{R}$. Br.

P. Pinifolia Linn. mant. = Aulax pinifolia Berg.

P. PINIF ol i Linn. berrb. = Aulax umbellata B. Br.

P. PINNata Andr. = Serruria pinnata R. Br.

P. PLUM IGERA Thunb. = Serraria simplicifolia R. Br. 
P. PLUMOSA Ait. = Leucadendron plumosum R. Br.

P. P OL Y G AL OIDES Willd. =Leucadendron polygaloides Link etL. imbricatum R. Br. $\gamma$.

P. POLYS PER M U M Poir. = Leucadendron platyspermum R. Br.

F. POLYSTACH A Poir. = Spatalla polystachya R. Br.

P. P R о C U М в E N S Linn. fil. $=$ Serruria decumbens R. Br.

P. PROLIFERA Thunh. = Spatalla prolifera R. Br.

P. PR OSTR A TA Thunb. = Leucadendron? prostratum nob.

P. PU BERA L. = Leucospermum puberum R. Br.

P. PUL C Hel a Schrad. (non Andr.). = Petrophila pulchella R. Br.

P. P UR P U R A L., Thunb. = Mimetes purpurea R. Br.

P. PYRAM I D A I I S Thunb. = Leucadendron? pyranidale nob.

P. PYRAMIDALIS. Poir. = Spatalla pyramidalis R. Br.

P. R ACEM OS A Thunb. - Spatalla ramulosa $\mathrm{R}$. Br.

P. R A C E M OS A Lichtenst. =- Spatalla laxa R. Br.

P. R A N G I F E R I N A Lee, ex Wendl. = Isopogon anethifolius.Knight et Salisb:

P. RET ICU L A TA Thunb. = Leucadendron? reticulatum nob.

P. R E T US A Poir. $=$ Leucadendron rétusum R. Br.

P. R OX B U R G I P Poir. = Serruria Roxburghii R. Br.

P. RUGOSA Thunb. = Leucadendron? rugosum nob.

P. SA L I G N A Andr. = Leucadendron floridum R. Br.

P. SALIGNA L. = Leucadendron adscendeǹs et salignum $R$. Br.

P. S A I I G A Thunb. = Leucadendron uliginosum $\mathrm{R}$. Br.

P. SALS OL OIDES Poir. = Sorocephalus salsoloides R. Br,

P. S C е P т и м Thunb. = Nivenia Sceptrum R. Br.

P. SCOPARIA Poir. = Serruria scoparia R. Br.

P. SERICEA L. = Leucadendron sericeum R. Br.

P. SER I C E A Thunb. = Leucadendron salignum R. Br. $\sigma^{7}$.

P. SER I G I F O L'I A Poir. = Spatalla sericea R. Br.

P. SET A GE A Poir. $=$ Sorocephalus setaceus R. Br.

P. SERR A R I A L. = Serruria Burmanni R. Br, $\alpha$.

P. SERRARI I I DES Smith = Serruria hirsuta R. Br.

P. SIMPLICIF OL IA Poir. = Serruria simplicifolia R. Br.

P. SPATALL OIDES Poir. = Sorocephalus spatalloides R. Br.

P. SPAтн U А т A Thunb. Nivenia spathulata et parvifolia R. Bŕ.

P. SPAт н UL ат A Poir. = Leucospermum spathulatum R. Br.

P. SPHAROCEPHA LA Houtt. = Serruria hirsuta et pedunculata R. Br.

P. SPHAR.OG E PBA L A L. = Serruria phylicoides R. Br.

P. S P H A R O C EPH A L U S Thunb., Willd. sp. = Serruria rubricaulis R. Br.

P. SPA AROCEPHALA Willd. herb. = Serruria Stilbe R. Br.

P. S PH A R OCE PHALA Poir. = Serruria scariosa et pedunculata-R. Br.

P. S P I G ATA Andr. = Nivenia media? et spicata? R. Br.

P. S P I A TA $L$, $=$ Nivenia spicata $R$. Br.

P. s P I c at a Willd. lierb. = Nivenia spicata et Lagopus R. Br. $\beta$.

P. $S Q$ U A R R OSA Poir. = Serruria squarrosa $R$. Br.

P. STELLAR Is Sims $=$ Leucadendron fusciflorum Br. $\sigma$ '.

P. Strlbe Poir. = Serruria Stilbe R. Br.

P. STRICTA Don = Leucadendron adscendens R. Br.

P. STROBILINA L. = Leucadendron squarrosum R. Br.

P. Strobilina Thunb. = Leucadendron ovale R. Br.

P. STROBILINA Schrad., Willd. herb. = Leucadendron concolor R. Br.

P. TENUIFOLIA Thunb. = Leucadendron? tenuifolium nob

P. TENUIFolis Smith herb. = Serruria Burmanni Br.u. 
P. TERETIFOLIA Andr. = Leucadendron abietinum R. Br.

P. THUNBERGII Steudel = Lelucadendron? tenuifolium $\mathrm{B}$. Br.

P. THYMELEOIDES Poir. $=$ Mimetes thymelæoides R. Br.

P. THYoIDes Smith hérb. = Leucadendron scabrum R. Br.

P. THY R SOIDES Lam. = Serruria elongata R. Br.

P. T OMENT OSA. Thunh. = Leucospermum tomentosum R. Br.

P. TоMENT 0SA Willd, herb.:= Leucospermum spathulatum $\mathrm{R}$. Br. B.

P. TORT A Thunb. = Leucospermum tortum R. Br.

P. Tот тA L. = Leucospermum Tottum R. Br.

P. TRIDACTYLITES Cav. = Isopogon anemonifolius $R$. Br.

P. Triternat a Andr. = Serruria millefolia Knight vel congesta R. Br.?

P. TRITRRNATA Thunb. = Serruria triternata R. Br.

P. rinusata Thunb. = Leucadendron? truncatum nob.

P. UмвеLLAт A L. $=$ Aulax umbellata $R$. Br.

P. VERT I CIL L A T A Thunb. = Leucádendron? verticillatim nob.

P. vestr a Lam. = Leucospermum ellipticum $\mathrm{R}$. Br.

P. vil o os a Thunb. = Serruria pilosa Roem et Schult.

P. vrLlos a Lam. = Serruria, villośa $\mathrm{R}$. Br.

P. VILL OS A Poir. = Leucospermum grandifiorum $\mathrm{R}$. Br.

P. vIL L OSA Willd. herb. = Leucospermum buxifolium $\mathrm{R}$. Br.

P. v I L o S A Jacq. in herb. Willd. = Mimetes thymelæoides R. Br.

P. VILL o SI U S CUL A Banks. = Leucospermum grandiflorum R. Br.

P. VI R G А т А Thunb. = Leucadendron? acutum nob.

P. VIRGATA Poir. = Leucadendron virgatum R. Br.

P. WE N L A N I I Poir. = Leucadendron buxifolium R. Br.

IV. LEUCOSPERMUM $R$. Brown in Transact. linn. Soc. Lond. 10, p. 48 et 95, Endl. gen. p. 337, n. 2124, suppl. IV, 2, p. 77, Meisn, gen. p. 331 (244). - Conocarpodendri sp. spuriæ Boeth. Lugd. bat. 2, p. 196 et 198. - Proteæ sp. Thunb., Linn., Lam. ill.t. 53, f. 3, Andr. Bot.repos. t. 17. - Leucadendri sp. Linn. - Leucadendron et Diastella Salisb.

Flores hermaphroditi, capitati, capitulo terminali multifloro globoso vel hemisphærico vel cylindrico-oblongo, receptaculo planiusculo paleaceo, involucro pluriseriali, squamis imbricatis adpressis. Calyx coloratus; labialus, unguibus 3 vel rarus omnibus cohærentibus, laminis distinctis concavis antheriferis. Antheræ 4 subsessiles, liheræ, ovales vel oblongæ, connectivo ultra loculos producto brevissime apiculatæ. Squamulæ 4 hypogynæ. Ovarium 1-loculare, 1-ovulatum, stylo filiformi deciduo, stigmate glabro plerumque incrassato clavato vel ovato-conico vel subulato, vel rarius turbinato oblique truncato, srepissime angulari vel sulcato. Nucula crustacea, sessilis, subglobosa, ventricosa, lævis, 1-sperma. - Frutices sæpius humiles, vel arbusculæ Africæ australis et tropicæ orientalis, plerumque pubescentes, foliis sparsis coriaceis sessilibus planis vel margine involutis nervosis vel enerviis integerrimis vel apice calloso-dentatis, dentibus muticis glanduliformibus, capitulis terminalibus vel e summis axillis solitariis sessilibus vel breve pedunculatis, floribus flavis.

Sectio 1. Conocarpodendron (Boerh. l. c. ex parte), Endl. gen. p. 338. - Involucri squamæ imbricatæ, persistentes, induratæ, $R$. Brown $l$. c. p. 96. - Proteæ sp. Linn. Thunb. Lam. ill. t. 53 f. $\ddot{3}$, Andr. Bot. repos. $t .17$.

- Stigma breve, crassum, turbinatum, oblique truncatum. Stylus validus, arcuatus, glaber.

1. L. NU Tans (R. Brown in Linn. Trans. 10, p. 98), foliis ovatis oblongisve utrinque obtusis apice 3-5-dentatis integrisque venosis glabris, capitulo terminali breve 
pedunculato nutante globoso, squamis ovatis acuminatis tomentosis, calyce pollicari tenuiter subsericelo-puberulo demum glabrato, stylo prælongo, stigmatis fácie ovali medio carinatâ. F In montoșis prope Zyellendam, Grote Houhoek, Zwartebergen, etc., alt. II-IV (Mașson ! in herb. Banks., Niven ! in herb. Mart., Mund ! in herb. reg. Berolin., Ludwig! Gueinzius! Krauss, n. 1039). Rami virgati, validi, tomentosi, hirsuti vel demum glabri. Folia conferta, sessilia, erasse coriacea, dentibus brevibus latis ohtusissimis, callis transversis semilunaribus depressis

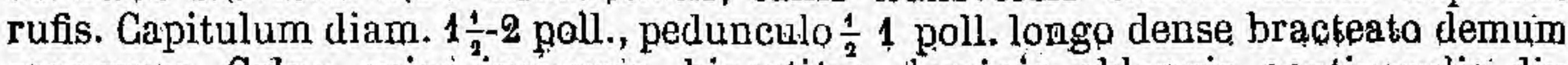
squarroso. Calyx apice incurvus, bipartitus, laminis ablongis acutiusculis diu colærentibus. Stylus $2 \frac{1}{2}$ poll. longus, glaber.

a. cordatum (R. Br. l. c., sine nom.), foliis basi cordatis vel emarginatis ovatis integris ( $1-1 \frac{1}{2}$ poll. longis) vel inferioribùs oblongis (bipollicaribus) 3-5-dętatis, interdum omnibus integertimis. (v. s.)

B. oblongum (R. Br. l. c., sine nom.), foliis oblongis vel lineari-oblongis ( $2-4$ poll. longis, 8 -20 lin. latis) basi vix angustatis obtusis nee cordatis, apice plerumque 3-5-dentatis. (v. s.)

* " Stigma longiuscutum eylindraceum vel fusiforme, stylo vix crassius, sulcatum. Slylu\$ validus, arcuatus, glaber:-

2. L. REFLEXu (Buek ! in pl. Drège), foliis lineari-oblongis platis acutiusculis apice 3-5-dentatis vel passim integerrimis basi attenuatis immerse venosis ramisque cano-tomentellis, capitulo terminali magno, pedunculo erecto bracteisque linearibus sericeo-villosis, floribus deflexis, calyce sesquipollicari, tubo pilosiusculo supra fisso, limbo sericeo-villosa, stylo longo tenui, stigmate cońtinuo subulato acuto. J Prope Wupperthal et Honigvaleí, alt. 2,000-4,000 jed. (Drège docurn. p. 73, 74). Rami erecti, virgati. Folia 1- fere 2 poll. longa; 3-5 lin. lata, sursum decrescentia, summa $\frac{3}{4}$ poll. longa, basi haud torta; apicis dentibus rufo-callosís obtusinsculis, terminali productiore 1-2 lin. longo; lateralibus parvulis, nervó venisıue utrinque semiímmersis apicem marginesque versus evanescentibus. Capitulum ovali-globosum. diam. 3 poll., pedunculo $1 \frac{1}{2}$ poll., receptaculo ovali fere 1 poll. longo, paleis 3-4 lin. longis lancealatis subsetaceo-acuminatis reflexis villosis. Calycis limbus $22-2 \frac{1}{2}$ lin.Jongus, acutus, diu clausus ef stigma rețens, demum 4-fidus. SStylus 2, demum 3 poll. longus, glaber, stigmate suleato fere 2 lin. longo haud incrassato basí obsolete oblique nodulosa. Species insignis, foliis accedens ad L. spathulatum, sed foliis dentatis haud spathulatis, basi haud tortis, capitulo majore, st jlo longo, stigmate, etc., distinctissima et revera L. Totto affinior. (v. s.)

3. L. GRANDIFL ORUM (R. Brown! in Linn. Trans. 10, p. 100), ramis, villosis, foliis ellipticis oblongisve utrinque obtasis venosis glabriusculis apice 3 -5-dentatis dẹntibùs callosis brevibus rotundatis, capitulo sessili, squamiś lanceolatis tíllosis, calyce subpollicari dense villoso; stigmate continuo cylindricò subfusifơrmi. I mantosis, circa Houhoek (Ludwig I Gueinzius !), Paarlberg, Drakensteenberge, alt. $500-2,000$ ped. (Drège! docum - p. 85,100). Protea villosiuscula herb. Banks! Protea villosa Poir suppl. 4, p. 566*. P. erosa Lichtenst. in herb.Willd. Leucadendron grandiflorum Salisb. parad. p. 116. Facie et plurimis notis convenit cum L. Cono-

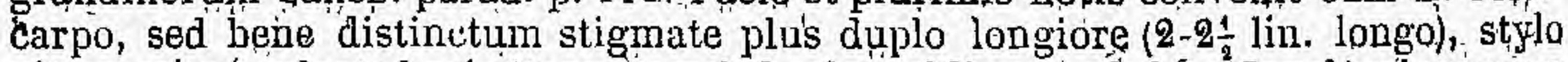
vix crassiore sulcato basi attenuato rel obsolete oblique noduloso. Involucri squamæ exteriores ovatæ, demum glabratæ. Calyx $1 \frac{4}{2}-2$ poll., stylus $2 \frac{1}{2}$ poll. longus. (v. $s$. in h. Banks., etc.)

4. L. GuEINzIr, ramis patenti-pilosis, foliis oblongis utrinque obtusís apicè attenuatis integerrimis vel raro passim brevissime 2-3-dentatis veñoso-reticulatis glabriusculis, capitulo sessili, squamis ovato-oblongis acuminatis villoso-ciliatis dorso glabris, calyce subbipollicari, unguibus patulo-pilosis, laminis deñse-longeque villosis, 'stigmate cylindraceo-fusiformi acuto basicue oblique geniculato. IIIn Africá Capensi (Gueinzius I). Forsan mere var. L. grandiflori, attameil constantêr - differre videtur stigmate longiore (3 lin. longo), basi leviter inflexo-geniculato et foliis apicem versus magis attenuatis rurissime passim dentatis. (v. si)

*** Stigma ovato-vel rarius oblongo-conicum, basi stylo multo crassius. Stylus validus, arcuatus, glaber.

5. L. CoN o GAR PUM (R. Brown! in Linn. Trans. 10, p. 99), ramis patentí-pilosis, foliis ovalíbus vel obovato-vel cuneato-oblongis reticulato-venosis glabniusculis apice 
3-Q-deptatis vel raro passim integris, dentibus callosis obtusis, capitulo magno sessili, squamis elongatis villosis, calyce sesquipollicari barbato, stylo hipollicari stigmate oblongo-conicu basi squali leviter marginato. 5 In campis montibusque peninsulæ Capensig, alt. 1,000-3,000 ped. (Thunb.! in herb. Banks., Niven! Ludwig ! Mund! in herb. Willd. n. 2413 ! Ecklon Un. itin. n. 470 I Sieber herb. Cap. n. 6 ! f. mixt. n. 97! Krauss, n. 1041! Bergius, n. 262! Drège!). Conocarpodendron Boerh. Lugd, bat. 2, p. 196 , cum if. Scolymocephalus Weinm. phyt. 4, 1. 292, t. 899, b. Leucadendron Conocarpodendron Linn. sp, 1, p. 93. Protea Conocarpa Thunb.! diss. p. 38, n. 14, fl. Cap. p. 126, n. 20, Lam. ill. t. 53, f. 3 (quoad stigma mala). L. Conacarpodendron Roem. et Schult. syst. 3 , p. $359^{*}$, Rouppell Cape flowers, t. 6, f. 1. Kreupelboom, Groudboom, etc.. incolarum. Rami virgati, validi, dense foliosi, pilis longis mollibus dense restiti. Folia sessilia, $1 \frac{1}{2}-k$ poll. longa, 10-24 lin. lata, glabra vel juniora minute tomentella ciliata suhtus basi rufo-villosa, basi obtusa, apicis dentibus apuroximatis plerumque 1 lin. longis et parum latioribus, callis obtusis, sinubus acutíusculis. Capitulum pugni mole, folia vix dimidio superanto. Calycis bipartiti unguibus laminisque dense rufo-villosis. Anthere brevissime apiculatre. Stylus glaber, stigmate $\frac{5}{4}$ lin. longo acutiuscnlo profunde sulcato basi haud obliquo. (v. s. in herb. Banks., Willd., elc., et v. c.)

6. L. ELLTP ICUM (R. Brown l. c. p. 98), ramis patulo-pilosis, foliis oblongis ntrinque obtnsis laxe reticulato-verrosis glabris apice 3-5-deritatis passimque integris. capitulo magno erecto, peduncilo brevi bracteato, involucri squamis ovatis acuminatis longe ciliatis dorso puberulis, exterioribus glabrescentibus, calyce pollicari longiusceule barbato, stylo bijollicari, stigmate ovato-conico basị obliquo líne gibbo. F In arenosis et montanis (Ludwig ! Ecklon! Drège! docúm. p. 119), Tulbaghskloof, alt. II, III (7eyler, n. 1461!), Paarl (Krauss, n. 1040). - Roem. et Schult. syst. 3, p. 358. Protea elliptica Thunb. diss. p. 39, p. 15 *, fl. Cap: p. 126, n. 21 *, Willd. sp. 1 , p. 512. P. vestita Lam. ill: 1, p. 239, h. 1259..P. cọnocarpa A, Poir. idict. 5, p. 6.57. Scolymocephalus APricanus, etc. Ray hist. 3; Dendr. p. 10 ? ex R. Br. l. c. p. 219 . Facies omnino L. Conocarpi, a quo facile distinguitur stigmate $\frac{1}{5}$ bre-

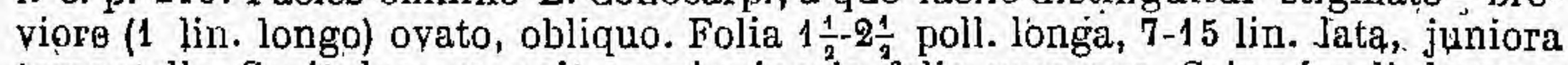
tomentella. Capitulum magnit. pomi minoris, folia superans. Calyx ${ }_{4}^{5}$ poll. longus, laminis ovalibus reflexis unguibusciue laxe rufo-barbatis. Antheræ oblongæ, brevissime apiculatæ. Stylus glaber, incurrus. Váriat foliis latioribus angustioribusque (in sp. Brège. n. $8056 !$ omnibus lanceolato-ublongis, sæpe vix 4 lin. latis, junioribus pilosiusculis), apicis callis acutiusculis obtusisve. (v. s.)

7. L. MEDIUM (R. Brown 1. c. p. 97), foliis lineari-oblongis 'integris passimque q-3-dentatis, cạllis acutis, basi' obtusâ, capitulis cernuis, sçuamis tenuissime pubescentibus cíliatis; stylo calycem hirsutum fere bis superante, stigmate hinc gúbboso. F In Africæ austr. montibus. P. medium Poir. suppl. 4, p. 566*. Species L. Tottum inter et ellipticum media, illi foliis, huic floribus fere exacte conveniens, fide R Br. l. c., Nec specimen authentica, nec Dregeana (docum. p. 73) vidimus).

3. formosum, foliis lanceolatis pubescentibus, bracteis involucri sphacelatis, - calycis unilabiati unguibus omnibus cohærentibus, stigmate ovato-oblongo vix gibboso. R. Br. l. c. p. 97. Protea formosa Andr. Bot. repos. t. 17, Tratt. thes. t. 10 Planta obscura, forsan n. sp. Ramus. villosus. Folia, 2-3 poll. longa, 9-12 lin. lata, integra, utrinque æqualiter attenuata, obtusa, mutica, ex ic. glaucescentia. Capitulum terminale erectum, magnum. Stigma conico-cylindraceum, 2-2 $\frac{1}{2}$ lin. longum. Nux globosa, glabra, magnit. pisi majoris.

8. L. ZЕХн日RI, ramis cano-tomentosis simulque patulo-pilosiusculis, foliis cuneatolinearibus lanceolatisve subacutis basi angustis apice 3-7-dentatis immerse venosis glabris, capitulis terminalibus et e summis axillis aggregatis breve pedunculatis mediocribùs, squamis ovatis acuminatis sericeis, calyce pollicari dense hirsuto, stylo sesquipollicari, stigmate oblongo-conico basi suboblique leviter incrassatomarginato haud gibbo. $\bar{F}$ In collibus prope Port-Elisabeth et Zwellendam, alt. I (Zeyher, n. 3680 ! 3682 I). Rami corymbosi, laxiuscule foliosi. Folia rigída, plana, 9-2 $\frac{1}{8}$ poll. longa, ab apice 3-7 lin. lato sensim attenuata, basi 1 lin. lata, apice callis 3-7 glanduliformibus obtusis dentata, rarissime passim integra, venis raris tenuissimis insculptis subparallelis apicem versus evanescentibus vel interdum nullis. Capitula sphæraidea, magnit. pruni majoris, erecta vel cernua, pedunculi 4-8 lin. longi, bracteis ovatis obtusiusculis patulis velutino-sericeis, involucri 
squamis exterioribus $3-4$ lin: longis basi tomentosis. Calyx bipartitus, laminis inflexis unguibus flavido-hirsutis. Stylus glaber, leviter arcuatus. Stigma $\frac{3}{4}$ lin. longum, obtŭsum, rugosum. Spècies ad L. medium, attenuatum et Tottum valde accedens, sed pluribus notis, imprimis stigmate, satis distincta. (v. s.)

ß. truncatum, foliis apice truncato 3-dentatis, dentibus brevissimis callosis obtusis, stylo pollicari calycem breviter superante, stigmate subcylindraceo obtusissimo basi oblique annulato vix incrassato. J In collibus calcareis țter Cap Aghillas et Polberg, infra alt. 500 ped. (Drège, z. 8957 !-docum: p. 122), Ludwig, n. 21! in- herb. reg. Stuttgart.). L. truncatum Buek! in pl.dprêge. Ex'ceptis notis modo indicatis, cum L. Zeyberi exacte convenit. Stigma paululum brevius et vix conicum. Pedunculi in specim. Oregeanis fere pollicares, squamis oblongis velutinis semipatulis obsiti. (v. s.)

9. L. LINEARE (Ћ. Brown!1. c. p. 96), foliis linearibus vel lanceolato-linearibus integerrimis vel apice 2-3-dentatis callo parvo apiculatis ramisque glabris, capituilo terminali breve pedunculato, squamis ovatis sericeo-tomentosis, călyce pollicari dense fulvo-piloso; stylo subpollicari, stigmate ovato-conico basi obliquo hinc gibboso. 5 In arenosis et rupestribus circa Paarl, Stellenbosch, Dutoitskloof, etce., alt. 100-2,000 ped. (Drège! docum. p. 79, 86, 97). - Roem et Schult. syst. 3, p. $556^{\star}$. Protea linearis Thunb. diss. p. 47, n. $35^{*}$, t. 4 (pedunculo insolite elon-

gato), fl. Cap. p. 131, n. 42,Willd.! sp. 1, p. 521. Fruticulus cubitalis erectus, patulo-ramosus, ramis strictis conferte foliosis. Folia patulă, 2-3 poll. longa, plerumque integerrima. Capitulum diametro $\frac{1}{2}$ fere 1-poll. Involucrum ovatum. Calyx bipartitus, laminis inflexis unguibusque dense fulvo-pilosis. Stylus hamatus, glaber, stigmate crasso $\frac{1}{2}$ lin. longo acutiusculo.

a. latifolium, folirs lanceolato-linearibus planis (3-4 lin. latis) passim brevissime 3-dentatis 'prominulo-venosis vel spurie triplinerviis subeveniisque margine scabriusculis, callo apicis albo-penıcillato demum glábro. K. líneare Drège a! ex. parte, et $b$ ! (v. s.)

B. angustifolium, foliis linearibus margine plus minus involuto canaliculatis teretibusve (1-2 lin. latis) integerrimis eveniis rugoso-sulcatis (v. sp. Masson! in herb. Banks., herb. Willd. n. 2432! Ludwig! Drège! a, ex parte.)

10. L. ATTENUATUM (R.-Brown! l. c. p. $96^{*}$ ), ramis gracilibus tomentosis, foliis cuneato-lanceolatis basi angustis apice 3-7-dentatis (raro integris) planis eveniis glabris, capitulo terminali globoso breve pedunculato subnutante, squamis ovatis acuminatis tomentosis adpressis pedunculi patulis, calyce pollicari bipartito laminis inflexis unguibusque hirsutis, stylo subbipollicari, stigmate pyramidaliconico sulcato. 7 In arenosis elevatioribus prope Zwellendam (Roxburgh ! in herb. Banks., Mund! in herb. reg. Berolin.), van Stadesberg, alt. 2,000-3,000 ped., etc. (Ludwig! Drège! Krauss, n. 1065, 1066, Zeyher, n. 3681!). - Roem. et schult. syst. 3, p. $357^{*}$. Protea attenuata Poir. suppl. 4, p. $566^{*}$. Ramuli juiniores (fide sp. Drège) patentim hispido-pilosi et cum foliis novellis tomentosi. Folia laxiuscula, 1 $\frac{1}{2}$-fere 3 poll. longa, prope apicem rotundatum vel subacutum, 3-7 lin., ad insertionem $\div-1$ lin. lata, dentibus 3:5 (rarius 7) 1-1 $\frac{1}{2}$ lin. longis brevissimisve, intermediis semper promíssioribus lateralibus interdum 2 -intermedio-3-dentatis, callo capituliformi obtuso vel acuto terminatis, nervo medio obsoleto, venis nullis. Capitula solitaria, magnit. pruni majoris vel pomi minoris, receptaculo ovoideo. Florum magnit. variabilis; calyx nunc pollicaris nune paulo brevior vel longior, stylo $1 \frac{1}{2}-2$-pollicari nunc $\frac{1}{4}$ nune fere dimidio brevior, Stigma circ. 1 lin. longum, basi vix oblique subincrassatum. Nux magnit. pisi, compresso-głoboşa alba, lævis, glabra. Species similis quidem L. Hypophyllo, sed capitulo majore, stigmate, etc., facile distinguenda. (v. s. in herb. Banks., etc.)

$\beta$. Dregei, foliis cuneatis, floribus majoribus (calyce $\div$ poll., stylo $2 \frac{1}{\tau}$ poll. longo) stigmate basi crassiore magisque gibbo-obliquo (fere $1 \frac{1}{2}$ lin. longo). L. attenuat. fol. angust. Drège $c !$ (v. s.)

$\gamma$. ambiguum, foliis oblongo-Janceolatis vix cuneatis circa medium (nec apice) latioribus (7-9 lin. latis) crassioribus basi minus altenuatis ( $1 \frac{1}{-1}$ lin. latis), venis immersis supra obsoletissimis nervoque basi subprominulis, capitulo floribusque majoribus (capit. magn. pomi mediocris, calyce 15 lin., stylo $9 \frac{1}{4}$ poll. longo), stigmate basi vix oblique tenuiore (1 lin. longo) minus conico: (Ecklon, et Zeyh. n. 7 ! in herb. Sond.). Forma valde accedens aA L. medium. (v. si) 
$\delta$ ? premorsum, foliis cuneatis attenuato-subpetiolatis, apice truncato vel rotundato obtuse 5-8-dentatis callosisve parum rigidis obsolete venosis glabris vel junioribus basi tomentellis. Prope Honigvalei, alt. 3,000-4,000 ped. (Drège! docum. p. 73. L. præmorsum Buek! in pl. Drège (fide fragm. steril. in herb. Sonder). Folia 2 $\frac{1}{-}-3 \frac{1}{2}$ poll. longa, 9-12 lin. lata. (v. s.)

11. L. Tотти (R. Brown l. c. p. 97), foliis lineari-oblongis planis utrinque vix attenuatis integerrimis vel raro 2-3-denlatis glabris obsolete prominulo-venosis 'basi latis, callo apicis acutiusculo, capitulis terminalibus et in summis axillis solitariis pedunculatis sphæroideis, squamis ovatis acuminatis pedunculisque demum patulis glabris, calyce pollicari, laminis inflexis unguibusque patulopilosis, stylo subbipollicari, stigmate ovato-conico brevi obtuso basi obliquà hinc gibbo. F In montosis, proje Roode Zant Cascade (herb. Banks.1), Tulbagh, Witsemberg (Zeyher, n. 1462 )), Dutoilskloof, alt. 1,000-2,000 perl. (Drège! docum. p. 78). - Roem. et Schult. syst. 3, 'p. 357*. Protea Totta Linn. mant. p. 191*, Thunb. diss. p. 55, n. 54, fl. Cap. p. 139 , n. 77, Lam. ill. 1, p. 235 , n. 1224, Willd. sp. 1, p. 532, Poir. dict. 5, p. 644. Frutex subdecumberls, ramis virgatis gracilescentibus laxiuscule foliosis patulo-pilosis glabrisve. Folia 1-2 poll. longa, 3-5 lin. lata. Capitula magnit. pomi minoris, pedunculo $1-1 \frac{1}{2}$ poll. longo, bracteis ovato-oblon. gis laxiuscule squamato. Involucri ovati squamæe exteriores semipollicares, juniores ciliolatæ. Calyx $12-15$ lin. longus, bipartitus, bracteis fere triplo longior, stylo leviter arcuato glabro fere dimidio brevior. Stigma $\frac{1}{2}$ lin. longum. (v. s. in herb. Banks., etc.)

\section{*n+" Stigma breve, ovali-oblongum vel clavatum, obtusum. Stylus tenuis, rectus, glaber.}

12. L. HXP O'P Y YLUM (R. Brown! in Linn. Trans. 10, p. 102), caule procumbente gracili pubescente vel demum glabro, foliis secundis cuneato-linearibus eveniis apice 3-vel raro 4-7-dentatis vel passim integris acutis, adultis glabris, capitulis pedunculatis, squamis ovatis obtusiusculis villoso-tomentosis, calyce semipollicari dense fulvo-villoso stylo breviter superato, stigmate clavato suleato basi obsolete geniculato vel æquali. F In arenosis depressis collibusque peninsulıe Capensis. Roem. et Schult. syst. 3, p. $361^{*}$. Folia sessilia, 2-4 poll. longa, 2-5 lin. lata, juniora tomentosa. Capitula terminalia solitaria vel 2-3 e summis axillis, magnıt. pruni, pedunculis $\frac{1}{2}-1$ poll. longis adscendentibus, involucri squamis adpressis, exterioribus pednnculisque demum patulis glabrescentibus. Calyx bilabiatus, 7 lin. Stylus tenuis rectus glaber, 8-9 lin. longus. Stigma vix $\frac{2}{3}$ lin. longum. Variat, præter formas sequentes, ramis tomentosis, villosis glabratisque, foliis glabris, puberulis et cano-tomentosis, capitulis subsessilibus, erectis vel nutantibus; magnit. cerasi majoris et prunj, bracteis ovalis vel suborbicularibus, calyce villoso et glabrescente, stigmate usque ad $\frac{1}{2}$ lin. longo.

a. vulgare, foliis planis 2-4 lin. latis apice inciso-3-7-dentatis, rarius passim integris, dentibus callisque parvis obtusis vel acutiusculis, stigmate basi obsolete geniculato vel passsim æquali. - Pluken. mant. t. 440, 1. 3, Boerh. Lugd. bat. 2, p. 198, c. ic.,Weinm. phyt. 4, 294, t. 902, f. a. Leucadendron Hypophyllocarpodendron Linn. sp. ed. 1, p. 93, Berg. Cap. p. 16*. Protea Hypophyllocarpodendron Linn. mant. p. 191. P. hypophylla Thunb. diss. p. 39 , n. 16 , fl. Cap. p. 126 , n. 22 , Willd. sp. 1, p. 513 . $\beta$ latifolia Klotzsch in Krauss beitr. p. 140, n. 1068. Leucospermum diffusum Sieber herb. Cap. n. 3 ! (non R. Br.) forma foliis plerisque integerrimis acutis. (₹. s.)

3. canaliculatum, foliis haud secundis, margine plus minus incurvo supra concavis vel canaliculatis (2-4 lin. latis), apice inciso-3-dentatis, callis obtusissimis sæpe incrassatis, stigmate basi leviter geniculato. L. canaliculatum Bnek! in pl. Drège (docum. p. 112, 113). L. Hypophyllum var. Drège! (v. sp. Ludwig ! et Drège!)

$\boldsymbol{\gamma}$ ? stenophyllum, foliis anguste linearibus canaliculatis (1-2 lin. latis) integris vel apice obsolete calloso-2-3-dentatis glaberrimis, stigmate subclavato-cylindrico obtıso basi attenuato æquali (nec geniculato). In distr. Zwellendam. L. Hypophyllum $\alpha$ angustifolium Klotzsch in Krauss beitr. p. 140, n. 1067? Propter stigmatis formam forsan propria species; sed eæt. omnia L. canaliculati. (v. sp. unicum in h. DC., comm. ex h. Delessert.)

13. L. SPAтнuдтum (R. Brown l. c. p. 101*), ramis patulis patenti-pilosis, foliis spathulatis obsolete venosis ramulisque incann-tomentosis, capituli mediocris

XIV. 
squamis oratis acuminatis cano-tomentosis, calyce villoso-tomentoso, pube brevi unguium jatulâ laminarum decumbente sericeâ, stylo calycem parum superante subpollicari, stigmate oblongo-clavato acutiusculo sulcato æcquali basi hauda annulato. F In Africâ Capensi (Niven). - Roem et Schult. syst. 3, p. $360^{*}$. Protea spathulata Poir. suppl. 4, p. 567* Capitulum magnit. juglandis minoris.

$\alpha$. Nivenii, foliis pollicaribus elliptico-spathulatis integris? callo apicis obtuso, basi lineari tortâ, adultis glabris, capitulis pedunculatis. - L. spathulatum R. Br. l. c.

$\beta$. dentatum, foliis oblongo vel obovato-spathulatis basi haud tortis apice rotundato breve 3-5-dentatis, dentibus callisque obtusis, tomento albido persistente?, capitulis terminalibus et in summis axillis suhsessilibus.. In collibus arenosis ad Olifantrivier, alt. 1,000-1,500 ped. (Drège! docum. p. 110), ad Pickenierskloof, alt. III (Zeyher, n. 1466! Auge! in herb. Banks.). L. tomentosum $\beta$ Drège a! Protea tomentosa Willd. herb.n. 2415 ! Folia 1-1 $\frac{1}{2}$ poll. longa ! 4-6 lin. lata. (v. s. in herb. Banks., etc.)

14. L. томелтоSUm (R. Br.! 1. e. 1. 101), ramis erectis patenti-pilosis, folís lineaTibus cuneatisve 3 -dentatis vel integris subeveniis ramisque cano-tomentosis, capitulis terminalibus et in summis axillis sessilibus mediocribus, squamis ovatis vel ovato-oblongis acuminatis ciliatis, calyce semipollicari pubescente stylum subequante, stigmate clavato-cylindraceo continuo basi requali vel obsoletissine obliquo. J In Africie austr. montibus (Masson! Thunb! in herb. Banks. et Linn. fil.!), in planitie arenosâ, prope Klịpfọntein (Zeyher, n, 1467!).- Roem. et Schult. syst. 3 , p. $360^{*}$. Protea tomentosa Thunb.! diss. p. $40, \mathrm{n} .18^{*}$, fl. Cap. p. 127, n. 24. Linn. fil.! suppl. p. 118. Folìa 1-2 poll: longa, 2-3 lin. lata, cállis glandulíformibus obtusissimis. Capitula magnit. juglandis. Calyx bipartitus, laminis reflexis. Antheræ brevissime apiculate. Stylus 7 lin. longus, calycem parum superans, stigmate $\frac{5}{4}$ lin. longo, stylo tenui rix duplo crassiore sulcato obtuso. Varietates sequentes formis intermediis inter se connexæ videntur.

a. Brownii, foliis linearihus canaliculatis eveniis (integris?f; ramis bracteisque tomentosis, calycis laminis barbatis. R. Br. 1. c. p. 102, a. (v. s. in herb. Bànks., Linn. fil., etc.)

ß. candicans, foliis lineari-cuneatis planis subvenosis 3-5-dentatis, ramis hirsutis, bracteis laminisque calycis tomentosis. - R. Br. l. c. p. $102 \beta$. Protea candicans Andr. Bot. repos. t. 294. Leucospermum candicans Loudon!.(v. s. in herb. Smitll.)

$\gamma$. acutum, foliis linearibus planis eveniis attenuato-acutis 2-3-dentatis integrisrque basi longe attenuatâ tortis, bracteis ovatis acuminatis calyce glabrescente dimidio brevioribus, ramis tomen̨tosis pilosiusculisque. - Z. tomentosum $\alpha$ Drège! Forsan eadem forma ac $\propto$ R. Br., sed calyx (an etiam junior?) parce minuteque pubescens, laminis dorso adpresse parceque puberulis, nec barbatis. Folia subbipollicaria, raro ultra 2 lin. lata. (v.s.)

§. Dregei, ramis tomentosis longeque patenti-pilosis, foliis linearibus utrinque vix attenuatis planis rel supra lævissime concavis apice subtruncato obtusissime_3-c'allosis vel rarius passim integris infra medium obsolete 1-nerviis passimque subvenosis, capitulis in ranorum apice plerumque 2-3 aggregatis, hracteis exterioribus ovatis scriceo-1omentosis, interioribus longioribus lanceolato-oblongis attenuato-acutis calycem subæquantibus extus glabratis, calyce minute pilosiuscculo, laninis longius pilosis mox glabris: Circa Groeneklouf et Dassenberg (Drègel docum. p. 113, 114). L. tomentosum $\gamma$ Drège a! b! R. Br. l. c. p. 102, $\gamma$ ?

$\varepsilon$ ? Ecklonii, foliis linearibus utrinque attenuatis acutis integerrimis enerviis canu-tomentellis ( $1 \frac{1}{2}-2$ poll. longis, $1-1 \frac{1}{2}$ lin. latis). Circa Groepekloof, infra alt. 5,000 ped., cun var. $\delta$ lert. (Drège! docum. p. 113). L. Ecklonii Buek $!$ in 13. Drègc (fide fragm, sine fl. in herb. Sonder.)

15. L. PU BER U M (R. Brown I.c. p. 100), foliis lanceolatis oblongisve acutis vel obtuse calloso-apiculatis jlanis prominulo-venosis integris rel passim apice 2 -5-dentatis ramisque pubescentibus, capitulis terminalibus et in summis axillis breve pedunculatis mediocribus, squamis oblongis acuminat is incano-villosis vel sericeis, calyce subsemipollicari longe pilosiusculo: dimidium stylum equante, stigmate enatocapifato equilaterali. F In montibus, circa Hotientottsholland (Masson! in herb. 
Banks., Niven!), Tulbagh, Caledon, Langekloof, otc. (Licklin! Ludwig! Drùge! Zejlibr, n. 1463 ! etr.). - Koem. et Scliuli. syst. 3 , p. $359^{\circ}$. Protea pubera Linn. mant. 192, Thunb. diss. p. 56, n. 56, 0. Gap. p. 140, n. 80, Willd.! sp. 1, p. 533 (excl. syn. Berg.). Leueadendron puljigerum Linn.l mss. in lierb. Diastella bryiflora Salisb., fide Spreng. syst. 1, 1. 464. hami virgati vel graciles, siepe corymbosi vel umbellati, laxiuscule (juniores dense) foliosi, patenti-pilosi vel villosiuseuli. Folia 6-12 lin. longa, 2-4i lin. latá. Cajpitula globosa, magnit. pruni minoris, seepe corymboso-approximata, pedunculo squarroso-bracteato. Calyx 5 lin. longus, tubo integro vel hine fisso, taminis reflexis. Antherı cordato-ovate brevissime apiculatæ. Stylus 10 lin. longus, rectus, tenuis, glaber. Stigma vix $\frac{1}{3}$ lin. longum, stylo triplo crassius, sulcatum, acutum vel obtusum, demum sæpe subglobosum. Variat, præter formas seq., ramis foliisque glabratis (Drège $\mathrm{f}$ ! in herb. DC.), pubescentiầ brevi subincanâ vel laxe pilosâ vel subvelutiná.

$\alpha$. lanceolatum, foliis apice magis quam basi attenuatis acutis vel subacutis integerrimis, capitulis plerumque corymboso-aggregatis. (Lichtenstein $I$ in herb. Willd. n. 2455 ! Drège a! etc., Kollbing, n. 9!). (v. s.)

B. subspathulatum, foliis basi magis quam apice attenuatis obovato-oblongis vel spathulato-lanceolatis ex apice obtuso apiculatis integerrimis vel passim 2-5-callosis dentatisve, capitulis plerumque solitariis. (v. s. sp. Ecklon! Drège $\mathrm{c}$ !)

$\boldsymbol{\gamma}$. patulum, foliis spathulato-linearibus acutiusculis integris adultis glabris, junioribus cum ramis patilis peduncillis bracteisque tomentosis, pedunculi bracteis lanceolatis, involucri ovatis acuminatis, calyce bilabiato breve villoso-tomentoso.-L. patülum R. Brown! l. e. p. 100*, Roem. et Schult. syst. 3, p. $360^{*}$. Protea patens Poir. şuppl. 4, p. 567 ${ }^{\star}$. A L. pubero nullo charactere sufficiente stabilique distinctun, inter $\alpha$ et $\beta$ ambiguum. Capilula magnit. avellanıe. Stylus 9 lin. longus, stigniate brevissime ovato. (v. sp. Masson! in h. Banks.)

f? dubium, foliis lineari-lanceolatis utrinque aequaliter attenuatis acutis integris, capritulis congestis, stigmate subclavato-ovali (fere $\frac{1}{2}$ lin. longo) obtuso. (Vịdi sp. Drège [!.)

16. L. BUXIF OLIUM (R. Brown l. c. p. 100), foliis imbricatis pollice brevioribus obovatis ovalibusque obtusis obsolete calloso-apiculatis muticisve integerrimís vel rarius passim ajpice 3-dentatis ramisque velutino-tomentosis, capitulis solitariis subsessilibus parvis, squamís ovato-triangularibus sericeis demum glabratis ciliatis, calyce subsemipóllicari hirsuto, stylo parum superato, stigmate oblongoclavato basi æquali brevissime turbinato. F In Africe austr. montibus (Masson I in herb. Banks., Ludwig! Ecklon I), ad mont. Hàngklip et Houhoek, alt. 1,000. 2-000 ped. (Krauss, n. 1063), in distr. Caledon (Zeyher, n. 3685, cum $\beta$ ). Protea buxifolia Poir. suppl. 4, p. 566*. P. villosa Willd. herb., fide Spreng. syst. 1 , p. 464. Rami dense foliosi, graciles, siepe umbellati. Folia sessilia, 5-10 lin. longa, 8-5 lin. Jata, plana, evenia. Capitula terminalia, globosa, magnit. cerasi, involucri squamis capitulo dimidio lmerioribus adpresse imbricatis. Calyx 5 lin. longus, densc rufo-hirsutus, tubo integro, laminis 4 disjunctis reflexis. Antheræ oblongæ, breve apiculats. Stylus 6-7 lin. longus, rectus, glaber. Stigma $\frac{1}{5}$ lin. longum, stylo duplo crassius, obtusissimum, sulcatum. (v. s. in h. Banks, etc.)

\section{Sect. II Diastella Salisb. Endl. gen. p. 338.}

Capitulum spliéroideum. Involucri squamic supra receptaculum planiusculum fastigiatæ, palcis angustis immutatis deciduis. Stylus capillaris, rectus, glaber. Stigma parvum, clavatum, obtusum, stylo parum vel vix crassius. $\rightarrow$ R. Brown in Linn. Trans. 10, $1,103$.

17. L. DIFFU S M (R. Brown l.c. p. 104 "), procumbens, ramis gracilibus adscendentibus laxe foliosis, foliis linearibus utrinque attenuatis aculiusculis integris vel 2-3-dentatis rugosu-striatis raniisque puberulis demum glabris, capitulis solitariis pedunculatis parvis, squimis ovato-vel oblongo-lanceolatis tomentosis, calfec blevi pilasó apice demum glabrescente, stigmate clayato vel eylindraceo-ohlongo basi leviter incrassato-annulato. F In Africà Capensi (Roxburgh, Ecklon! Ludwig ! Gueinzius! Eckl. et Zeylįcr, nl. 6!), in arenosis, ad Klynzivier et Potrivier, alt. I (Zeyher, 11, 3686 !).--Recm. et Schult. srst. 3, p. 362'. Protea heterophylla Thunl,. 
diss. p. 40, 11. 19, 11. Cap, p. 127, 11. 25, Willd. sp. 1, p. 515. Primâ fronte facile confundendum cum simillimo L. puberulo $y$ patulo, sed distinctum habitu laxiore,

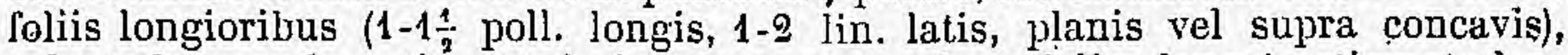
calyce demum 4-partito, 'stylo breviore et tenuiore ( 6 lin. longo), stigmate longiore $\left(\frac{1}{2}\right.$ lin. longo) tenui clavato, nec ovato. Capitula magnit. avellanæ, pedunculo 6-10 lin. longo, squamis obtusis recurvis remotiuscule bracteato, involucri squamis angustioribus adpressis fusco-vel incano-tomentosis. (v. s.)

18. L. PEDUNGULA TU (Klotzsch in Krauss Beitr. zur fl. d. Cap. p. 140, Flora 1844), ramis tenuibus elongato-flexuosis pubescentibus, foliis patentibus cuneato-lineatribus calloso-acutis evanescenti-puberulis, capitulis axillaribus pedunculo pubescente duplo brevioribus, bracteis lanceolato-Jinearibus villosis calyce piloso brevioribus, stylo longissimo, stigmate clavato. 7 In arenosis planitiei distr. Zwellendam (Krauss, n. 1069). Folia læete viridia, 14 lin. longa, 1 lin. lata. Capitula magnit. juglandis minoris. Calycis ungues cohærentes glabri. Monente cl. auctore àffine $\mathrm{L}$. diffuso.

19. L. CRINit UM (R. Brown in Linn. Trans. 10, p. 103), ramis villosis pilosisve, foliis ovalo-vel obovato-oblongis basi angustatis apice obtusis integris vel 3-5-dentatis tenuiter venosis pubescentibus demum glabris scabriusculis, capitulis subsessilibus mediocribus, squamis adpressis lanceolatis ciliatis junioribus apice penicillatis interioribus vel omnibus villosis flores subæquantibus, calyce semipollicari unilabiato villoso, stylo pollicari, stigmate tenui basi obsolete oblique noduloso. J In rupestribus mont. Houhoek, Zwartebergen, Dutoitskloof, Gnadenthal, etc., alt. 2,000-4,000 ped. (Zeyher, n. 3683, ex parte, et 3684 ! $\alpha$ et $\beta$ ).-Roem, et Schult. syst. 3, p. 361 $^{*}$, Capitula terminalia solitaria et ínterdum in summis axillis subsessilia, magnit. pruni. Calyx ' 6-7 lin. longus, hine fissus, laminis reflexis. Stigma stylo capillari vix crassius, cylindricum, $\frac{1}{n}$ lin. longum, obtusum. Species foliorum formâ bractearumque longitudine evidenter valde variabilis.

a. Thunbergii, bracteis omnibus villosis. - L. crinitum R. Br. l. c. L. molle Klotzsch! in herb. reg. Berolin. Protea crinita Thunb. diss. p. 38, n. 1.3. fl. Cap. p. 125, n. 19, Lichtenstein! mss. in herb. reg. Berolin. P. erosa Willd.!

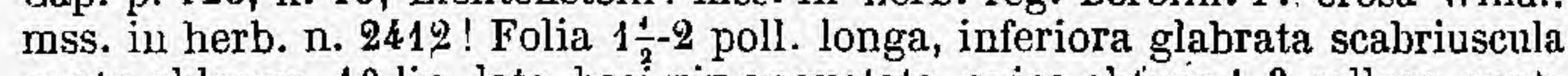
ovato-oblonga, 10 lin, lata, basi vix angustata, apice obtuso 1-3-calloso, superiora oblonga, 4-6 lin. lata, basi angustata, sæpius extra medium latiora, apice obtuse 1-5 callosa vel dentata, vel integra, diu tomentoşo-puberula, involucri squamæ omnes lanceolatæ, sæpe longe acuminatæ, usque ad 9 lin. longæ, interiores florem subæquantes, tenuiter tomentoso-pubescentes, apice dense barbatæ, demum glabrescentes. (v. s. in herb.Willd., etc.)

$\beta$. cryptanthum, bracteis exterioribus vel demum omnibus extus glabris, lanceolatis, longe acuminatis, calycem æquantibus. - L. cryptanthum Buek ! in pl. Drège (docum. p. 82 et 116). L. medium c Drège ! olim. in herb. Folia $1 \frac{1}{2}$, fere 2 poll. longa, 3-5 lin. lata, basi attenuata, nune inciso-3-5-dentata, paucis integris intermixtis, dentibus obtusis acutisve, nunc fere omnia integra obtusa, molliter tomentosa vel glabra. Cæet. nt in var. $\alpha$ (v.sp. Drège! Ludwig! Zeyher l)

$\gamma$. Jacquini, bracteis ovalibus oblongisque acutiusculis vix acuminatis calyce brevioribus (3-4 lin. longis) ciliatis glabris. Cæt. ut in var. $\beta$. - Protea crinita Willd. sp. 1, p. 511 (excl. syn. Berg. et Linn. fil.), herb. p. 2411! specim. Jacquin. (v. s.)

20. L. PENi cil L A Tum (Buels ! in pl. Drège docum. p. 85), ramis breve villosis, foliis oblongis et ovali-oblongis obtusis 1-3-callosis venosis adultis glabris, capitulis subsessilibus majusculis, squamis lanceolatis ciliatis sericeo-tomentellis demum glabratis, interioribus longe acuminatis flores superantibus apice barbatis, calyce semipollicari bipartito patulo-piloso, stylo pollicari, stigmate tenui cylindracco basi obsolete noduloso subobliquo. $\bar{f}$ In rupestribus mont. Paarl, alt. 1,0002,000 ped. (Drège! docum. p. 85), Houhoek, alt. IV,V (Zeyher, n. 3683! ex parte). Species L. crinitum inter et oleæfolium ambigua, priori foliorum nervatione et involucro similis, sed discrepans follis rigidioribus crassiusculis bàsi haud atte-

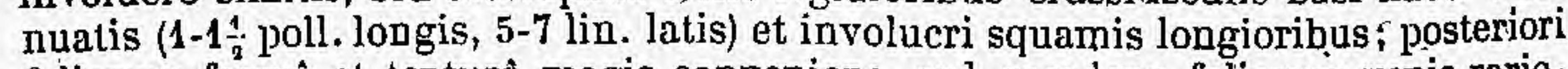
foliorum formâ et texturâ magis conveniens, sed recedens foliorum venis rarioribus sæe evanescentibus el vix anastomosantibus (nec reticulatis), capitulis 
majoribus (pruni majoris mole, sæpe 2-3 in unum congestis) involucri squámis flores superantibus (8-10 lin. longis) et stigmate nec oblongo nec capitato-cylindrico. Folia juniora tomentella, basi subtus villosiuscula. Stigma $\frac{1}{2}$ lin. longum, stylo vix crassius, obtusum, sulcatum. (v. s.)

21. L. OLEAFOLIUM (R. Brown! l. c. p.104), foliis ovali-oblongis vel sublanceolatis 3-dentatis integrisque basi haud angustatis dense prominulo-reticulatis adultis glabris, capitulis terminalibus 1-3 approximatis sessilibus, squamis calycem subæquantibus villoso-ciliatis, exterioribus ovatis, stylo calycem bilabiatum pilosum superante, stigmate oblongo. $亏$ Cap. Bonæ-Spei (Ange! in herb. Banks.). Leucadendron oleælolium Berg. in act. Stockholm, 1766, p. $320^{*}$, pl. Cap. p. $15^{*}$ (ubi stigma dicitur capitato-cylindiricum). Protea criniflora Linn. fil. suppl. p. 117*.

a. Bergii, foliis lineari-oblongis acutiusculis calloso-tridentatis, involucri squamis omnibus villosis. R. Br. l. c. var. altera. (v. sp. Ecklon! in lerb. Sonder.)

B. Brownii, foliis ovali-oblongis obtusis, involucri squamis exterioribus glabriusculis apicé barbatis. R. Br. 1. c. var. prior. Folia (fide specim. Gueinzianis, juvenil.) 12-15 lin. longa, 4-6 lin. lata, omnia integra apice attenuato obtuse callosa, quasi capitata, involucri squame exteriores vix 3 lin. longe. (v. s. in herb. Banks., etc.)

22. L. MOLLE (R. Brown 1. c. p. 103), caule procunbente?, foliis ellipticis acutis 2-3-dentatis integrisve subsericeo-pubescentibus mollibus, involucri squamis exterioribus glabriusculis, stigmate ovato. $ち$ Cap. Bonæ-Spei, ad latera montis Hangklip et ad flum. Palmietrivier (Krauss, n. 1036, Beitr. p. 140, an vere hujus loci)? Protea mollis Poir. suppl. 4 , p. 567*, nec p. 577). Proximum L. crinito, diversum figurà foliorum et forte caule procumbente, ex Br. l. c. Planta nobis obscura, stigmatis forma a sectione Diastellà abhorrens.

23. L. MUNDI, ramis cano-tomentosis, foliis rigidis obovatis oblongisque basi subcuneato-attenuatis apice 7-12-dentatis passim integris dense reticulatis junioribus tomentellis, dentibus obtusis apice callosis, capitulo terminali solitario sessili mediocri foliis superato, squamis calyce pluries brevioribus ovato-triangularibus acutis sericeo-villosiusculis, stylo calycem sericeum $\frac{1}{3}$ superante, stigmate tenui cylindrico. $\Rightarrow$ In montibus, prope Tradoun (Mund I in herb. reg. Berolin.). L. purpureum Mund! mss. l. c. L. crinitum Klotzsch! mss. ibid. Rami graciles, laxius quam affinium foliosi, tomentosi (nec patenti-pilosi). Folia pleraque 2 poll. Jonga, extra medium 1-1 $\frac{1}{2}$ poll. lata (nonnulla multo minora, elliptica vel oblonga, integerrima), dentibus plerumque 7-9 circ. 1 lin. Iongis latisque, venarum reticulo demum satis prominulo. Cæet. fere L. criniti $\beta$, sed involucri squamæ breviores, calycis pubescentia brevis adpressa et folia non scabriuscula. (v. s.)

\section{Sect, III. Rochetia.}

Capitulum elongatum, cylindricum. Involucrum deciduum.

24. L. Rоснетілим (A. Richard in Comptes rendus, Paris 1851, 1, p. 229), foliis ellipticis acutis basi attenuatis breve petiolatis integris glabris, capitulo terminali denso crasso, calyce tubuloso bilabiato extus sericeo, ovario pilis longis sericeis persistentibus (receptaculi paleis?) cincto, stylo subulato... 5 Circa Debbevar, ad rad. montis La Malmon Abyssiniæ (Rochèt d'Héricourt). - Rich. in Ann. sc. nat. 3. sér. 15, p. 369 , Voyage en Abyssin. 5, p. $232^{\circ}$, Walpers Ann. bot. 3, p. $327^{*}$. Arbor mediocris, pyramidalis. Folia sparsa, coriacea, 5-6 poll. longa, vix 2 poll. lata. Capitulum teres, $3-4$ poll. longum, involucro verisim. caduco (ignoto). Calyx sessilis, sepalis apice libero antheriferis, tribus inferne connatis, quarto libero. Anther: oblongæ, mucronatie. Ovarium sessile globosum.

\section{Species obscurn.}

L. PARILE (IKnight Prot., fide Loudon encycl. ed. 1, p. 82, n. 1358), ramis pilosis, foliis linearibus planis, bracteis glabriusculis ciliatis.

\section{Species exclusa.}

L. roR Mosu Mnight = Protea formosa R. Br. (fide ic. cit.).

L. MARGINA TU S Spreng. = Lelcadendron? marginatum Link.

L. ? оvятum Roem. et Schult. = Protea ovata Thunh, 
V. MIMETES Salisb. parad. Lond. p. 67, R. Brown in Trans. Linn. Soc. Lond. 10, p. 48 et 105, Reichenb. hort. bot. 1, t, 92, 93, Endl. gen. p. 338, n. 2125; suppl. IV, 2, p. 78, Meisn. gen. p. 331 (24k). - Hypophyllocarpodendrow Boerh. Lugd. bat. 2, p. 206, cum ic. - Conophori sp. Petiv. Mus. 62. - Lepidocarpodendri sp. Boerh. - Scolymocephali sp. Herm. - Proted et Leucadendri sp. Linn.

Flores hermaphroditi, capitati. Capitula axillaria, rarius terminalia, solitaria, pauci-vel rarius multiflora, nonnunquam folio superiore cucullatoamplexa. Involucrum polyphyllum membranaceum, raro coriaceum, sæpius coloratum, pluriseriale, imbricatùm vel dimidiatum. Receptaculum planum, paleis angustis deciduis vel nullis. Calyx 4-partitus, æqualis láciniis distinctis apice concavo antheriferis. Antheræ 4 subsessiles, liberæ, oblongæ vel lineares, connectivo plus minus ultra loculos producto apiculatæ vel submuticæ. Squamæ hypogynæ 4 distinctæ. Ovarium 1-loculare, 1-ovulatum, stylo filiformì recto deciduo, stigmate cylindraceo-subulato gracili plerumque acuto. Nux sessilis, ventricosa, lævis, 1-sperma. - Frutices Capenses habitı Leucosperni vel Leucadendri, foliis sparsis sèssilibus coriaceis planis vel cucullatoconcavis, integris vel calloso-dentatis, plerumque venosis pubescentibus, capitulis versus apicem ramorum axillaribus spicato-approximatis paucifloris, rarius terminalibus multifloris, floribus involucrisque rubris vel purpureis, pistillis calyee post expansionem flaccido longioribus.

\section{Sect. 1. Eumimetes Endl. gen. suppl. $I V, 2$. p. 78.}

Capitula axillaria, ovato-oblonga, 4-10 flora, sæpius spicam foliosam comosam formantia, involucri bracteis pluriseriatis membranaceis coloratis flores majusculos arcte amplectentibus et includentibus. Folia imbricata, plana, apice calloso-dentáta vel integerrima.

1. M. н в т A (R. Brown in Linn. Trans. 10, p. 105), ramis pilosis, foliis ellipticooblongis integerrimis planis enerviis hasi latiusculis ciliatis adultis glabris callo apicis obtuso, capitulis 6-10-floris, involucri folia æequantis flores superantis colorati bracteis oblongis acuminatis, calyce subpollicari flavo-piloso Iaminis longius barbatis, st.ylo sesquipollicari glabro apice attenuato, stigmate utrinque attenuafo obtusiusculo basi geniculato-noduloso. F In campis collibusque Africæ Gapensis (Thunberg! in herb. Banks., Bergius, n. 275 ! in herb. reg. Berolin., Ecklon! Un. itin. n. 527! Ludwig! Krauss, n. 1038, Beitr. p. 141 I). - Roem. et Schult. syst. 3, p. 379, Reichenb. ic. exot. t. 92, Boerh. Lugd. bat. 2, p. 194, c. ic., Weinm. phyt. 4, p. 292 , t. 899. Protea hirta Linn. mant. p. $188^{*}$, Thunb. diss. n. 55 *, fl. Cap. p. 139, n. 79 , Willd. sp. 1, p. 532, herb. n. 24541 Leucadendron hirtum Linn.l mss. in herb. Amuen., Acad. 6, p. $83^{*}$. Mimetes capitulata Sieber, n. 41.(non Br.). Folia pollicaria, 4-6 lin. lata. Capitula in axillis superioribus approximata, involucro rubro, bracteis oblongis eveniis pilosiusculis ciliatis, exterioribus multo brevioribus. Stigma fusiforme, $\frac{2}{3}$ lin. longum, sulcatum, stylo fere dimidio tenuius, nodulo basali manifesto. (v. s. in herb. Banks., Willd., etc.)

2. M. CAPITULATA (R. Brown 1. c. p. $106^{*}$ ), foliis ovatis vel inferioribus ovatooblongis integerrimis cucullatis subeveniis ciliatis ramisque molliter pilosis callo apicis obsoleto, capitulis 8-10-floris, involucri folia subsuperantibus flores æquantis bracteis ovato-oblongis, calyce longe rufo-villoso, stylo bipollicari glabro apice fusiformi-incrassato stigmate apice oblique conico-incrassato basi leviter noduloso. J In Africâ australi (Roxburgh! Ecklon! Gueinzius!), in palüdosis mont. Hottentottsholland (Zeyher, n. 3690 ! ex parte).- Roem. et Schult. syst. 3, p. 380'. Protea capitulata Poir.'suppl. 4, p. 568 * Folia pollicaria, 6-10 lin. lata, acutiuscula, juniora sericea, adulta glabrescentia. Involucrum folia paulo superans, adpresse pilosum. Calyx 15 linb longus, dense villosus. Antheræ lineari-oblongæ, acute apiculatse. Styli apex clavatus, 1-1 $\frac{1}{3}$ lin. longus, 4 -gonus, stigmate fere $\frac{5}{4}$ lin. longo, infra apicem conico-capitatum tenui cylindrico subsulcato. A præcedente, cui cæt. simillima, stylo stigmateque facile dignoscenda. (v. s.)

3. M. DEGAPITATA, foliis ovalibus vel ovato-oblongis integerrimis planis acutis ciliatis ramisque pilosiusculis, floralibus dilatatis rhombeis subsericeo-villosis 
involucro 4-5-floro brevioribus, bracteis oblongis lanceolatisque acuminalis flores superantibus, calyce fulva-plumoso, stylo subsesquipollicari, stïgmate cylindraceo apice simplici obtusiusculo. 5 In paludosis montium circa Hottentottsholland, prope ostjum fl. Klynrivier, alt. IV,V (Zeyher, n. 3690l ex parte). Exceptó stígmate capitulo terminali penitus (et certe nun per mutilationem) 'carente omnia fere præcedentis. Folia imbricata, mox patula, pollice hreviora. Involucri subsequilateralis bracteæ acutæ, $\frac{1}{2}-1$ poll. longæ, adpresse villosiusculæ. Calyx 9 lin., stylus 15 lin. Ionǵís, stigmate 1 lin. longo suldato. All stirps liybrida e M. capitulatạ et pauciflorâ enata? (v. s.)

4. M. pauciflora (R. Browín 1. c. p. $106^{*}$ ), ramis villosis, foliis ovalibus integerrimis planis obtusis vel callo obsoleto apiculatis $3-5$-nerviis subeveniis adpresse pilosis, involucro 3 -4-floro folia sujerante spathaceo-tubuloso, bracteis interioribys oblongo-lanceolatis acutis flore brevioribus ajpice sericeis infra glabris, calyce subbipollicari, unguilbus hirsutis, laminis glabriusculis; stylo subincluso glabro, stigmate tenui apice obssolete ovato-conico basi leviter noduloso. "3 In Africâ austr. (Roxburgh! in herb. Banks.), in montibus Outeniqua (Mund ot Maire! in herb. reg. Berolin.). - Roem. et Schult. syst. 3, p. 380 *. Protea pauciflora Poir. suppl. 4, 1. 568 *. Folia 12-15 lin. longa, 6-10 lin. lata, villoso-ciliata, juniora sericea. Involucra sesquipollicaria, rubra, hracteis tenuiter striatis, interiorilus 3 apice conniventibus, exterioribus 5 glabris 3-5-plo brevioribus. Calycis lamine parce pilg: siusculæ, glabrescentes. Stylus calycem vix superans superne angulatus haud incrassatus, stigmate $\frac{6}{4}$ lin. longo suleato apice vix incrassato. Habilus M. hirtæ, sed foliis; involucris, calyce stigmateque facile distinguenda. (v. s. in herb. Banks., etc.)

5. H. CUCULLATA (R. Brown 1. c. p. 107), ramis velutinis, foliis lineari-oblongis plunis subenerviis apice obtuso 3-dentatis vel 3-callosis adultis glabris, foralibus basi paulo dilatatis marginibus recurvis involucra subdimidiata 4-6-flora superantibus, bracteis lanceolatis acuminatis glabriusculis, calyce pullicari exserto fulvo-piloso, stylo subbipollicari tenui glabro, stigmate subulalo acutissimo basi leviter oblique noduloso. F In uliginosis Africe austr. (Nelson! in herb. Banks., Niven ! Beil ! Gueinzius ! etc.), circa Constantiam, Dutoitskloof, Ataquaskloof, Trado, alt. 5004,000 ped. (Drège! Zeyher, n. 3693 ! 3693 var.! 1478 ! 1478 $\beta$ !). - Roem, et Schult. syst. 3, p. $380^{\circ}$, Pluken. alm. p. 212, t. 304, f. 6, Boerl. Lugd. bat. 2, p. 206, cum ic., Weinm. phyt. 4, p. 297, t. 995 . Leucadendron cuclillatum Linn.! ed. 1, p. 93, Berg. in act. Stockh. 1766 , p. 320 *, pl. Cap. p. $14{ }^{*}$. Protea cucullata Linn. mant. 1. $189^{*}$, Thunb. diss. n. 17 , fl. Cap. p. 126 , n. 23 , Willd.! sp: 1 , p. 514 , herb.

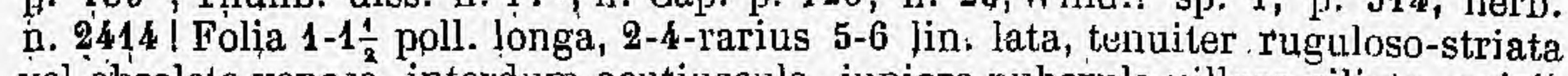
vel obsolete venosa, interdum acutiuscula, juniora puberula villoso-ciliata, apicis callis glanduliformibus passimque nıllis. Involucrum coloratum, vix pollicare, bracteis tenniter striatis ciliatis demum glabratis. Calyx 12-14 lin. longus, laminis densius longiusque-villosis. Antheræe lineares, longiuscule subulato-apiculatæ. Stylus apice haud incrassatus, -stigmate 2 lin. longo sulcato. (v. s. in herb. Linn., Banks.; Willd., etc.).

- $\beta$. brevifolza, "foliis unciâ brevioribus sublincaribus. " R. Br. l. ı. p. 108.

$\gamma$. Ludwigii, foliis pollicaribus glaberrimis, floralibus inferne nec dilatatis nec margine revolutis vix ciliatịs, bracteis vix semipollicaribus dense ciliatis, stylo vix sesquipollicari (Ludwig, n. $36 !$ in herb. reg. Stuttgart.). M. Ludwigii Steudel $!$ mss. l. c. Forsan propria species, sed unicum quod vidimus specimen præter notas indicatas çum M. cucullatâ exacte convenit. (v. s.)

6. M. Hartogri (R. Brown l, c. p: $108 \%$ ), ramis tomentusis, foliis lineari-vel subspathulato-oblongis planis obtusis 3 -dentatis passirnque integris villoso-ciliatis adultis glabris, floralibus supra sericeis inferne dilatatis margine reflexis cucullatis capitulum proxime inferius amplectentibus, iuvolucro 6-10-floro folio amplectente floribusque breviore tomentoso, calyce sesţuipollicari villoso, stylo bipollicari glabro, stignuate fusiformi setacuo-acuminato ljasi obsolete noduloso. 5 in collibus montibusque circa False Bay, Caledou, Zwellendam, etc. (Forster! MIisson! in herb. Banks., Niven! Bergius, n. 273! in herb. Berolin., Krauss, 11. 1037! Beitr. p. 141). - Roem. et Schult. syst. 3, p. 381 ", Boerli. Lugd. bat. 2, p. 205, c. ic., Weium. phyt. 4, p. 297, t. 906 a. Protea cucullata $\beta$ Lam. ill. 1 , p. 239, 11. 1258 , Arbuscula orgyalis, ramis patentibus. Folia $1 \frac{1}{2}-2 \frac{1}{2}$ joll. longa, 5-10 lin. lata, dorso leviter nervosa vel subenervia, juniora puberula, floralia apice angustato plana, 
Involucrum folio amplectente stylisque fere dimidio brevius, calycis ungues æquads, subdimidiatum, bracteis acuminatis, exterioribus pluries brevioribus. Receptaculi paleæ. subulatæ, lanatæ. Calyx feré 20 lin. longus, dense longeque rufo-villosus. Antheræ lineares, longe subulato-apiculatæ. Stylus apice angulatus,

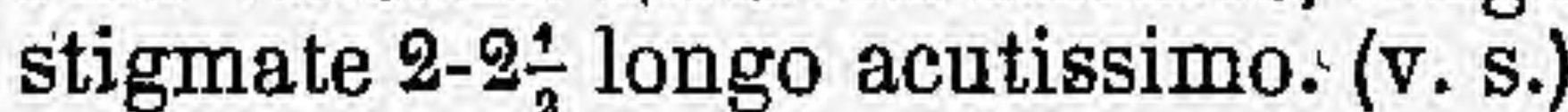

7. M. HI в BE R TII (R. Brown! 1. c. p. $108^{*}$ ), ramis tomentosis, foliis lanceolato-et ovali-oblongis planis 3-denticulatis (passim integris) subenerviis adpresse sericeovillosis, floralibus conformibus, involucro subpollicari subdimidiato coriaceo, bracteis ovalibus obtusis, calyce sesquipollicari longe fulvo-barbato, stylo bipollicari, stigmate filiformi recto basi leviter noduloso. F In alpinis humidis (Niven, Roxburgh! in herb. Banks., Mund et Maire ! Ludwig !), in rupestribus, prope Trado, George, alt. 1,000-2,000 ped. (Drège! docum. p. 116, 117). - Roem. et Schult. syst. 3 , p. 381 . Protea Hibbertii-Poir. suppl. 4 , p. $568^{*}$. Habitus M. cucullatæ, sed jam pubescentiâ argenteo-sericeâ facile dignoscenda. Folia $1 \frac{1}{2}-2$ poll.longa; $6-10$ lin. lata. Capitula 12-20?-flora, ex Br. 7-8-fl., turbinato-ovata, bracteis lævíbus ciliatis glabris, interioribus ex Br. sericeis. Antheræ lineares, longiuseule obtuiseque apiculatæ. Stylus apice haud tumens, stigmate $2 \frac{1}{2}$ lin. longo sulcato obtuso, ex Br. acutiusculo. (v. s. in herb. Banks., etc.)

8. M. MASSONI (R. Brown! l. c. p. 109\%), foliis ovatis oblongisque planis integerrimis acutiusculis venosis ramisque incano sericeis, floralibus conformibus capitulo 6-8-floro longioribus, involucro semipollieari æquilaterali, bracteis coriaceis ovalibus obtusis sericeo-puberulis villoso-ciliatis, calyce pollicari sericeo, stylo subbipollicari tenui glabro apice stigmateque subcontinuo tenui. 7 In montibus, prope Transche Hoek (Masson! Roxburgh! in h. Banks.), in paludosis montanis, ad Rivier Zonder Einde (Zeyher, n. 3688 l). - Roem. et. Schult. syst. 3, p. 381*. Protea Massoni Poir. suppl. 4, p. 568*. Folia 2 poll. longa, 8-15 lin. lata, in pl. Zeyheri dimidio angustiora, fere lanceolata. Involucrum ovato-globosum, coloratum, demum induratum. Receptaculum villosum, epaleatum. Antheræ filiformes, breve apiculatæ. Stigma $2 \frac{1}{2}$ lin. longum, filiforme, sulcatum, obtusiusculum, basi obsolete nodulosum. A simillimâ præeedente jam involucro calyceque breviore hujusque pube brevi adpressâ facile distinguenda. (v. s. in herb. Banks., etc.)

\section{Sect. II. OROTHamnos.}

Capitula terminalia, subsolitaria, sessilia, sphæroidea, involucro polyphyllo sulsuniseriali membranaceo colorato persistente, receptaculo plano-convexo paleis filiformibus villosissimo. Folia imbricata, integerrima, plana. - Orothamnus Pappe mss. in herb. Zeyhor.

9. M. ZEYHERI, ramis patenti-pilosis, foliis ovatis ovalibus oblongisque obtusis obsolete venosis villoso-ciliatis supra pilosis demum glaberrimis, involucri bracteis flores sequantibus ovalibus oblongisque subacuminatis venoso-lineatis extus villosis, calyce sesquipollicari patenti-piloso, laminis glabrescentibus, stylo glabro, stigmate subulato obtusiusculo basi oblique noduloso. F In paludosis montium Hottentottsholland, alt. V-VI (Zeyher, n. 3689 l). Orothamnus Zeyheri Pappe miss. l. c. Bot. mag. t. 4357, Flore des serr. et jard. t. 338. Frutex 6-8-pedalis, speciosus, habitu et char., excepto capitulo, omnino Mimetis sect. I. Rami virgati. Folia 1-2 poll. longa, 8-1 k lin. lata, coriacea, obsolete triplinervia vel enervia, apice callosa, juniora albo-ciliata, margine sæpe angustissiñe roseo. Capitıla magnit. pomi minoris, nutantia, interdum 2-3 ad rami apicem congesta. Involucrum roseım, diaphanum, circ. 12-phyllum, bracteis formâ et magnitudine foliorum basi attenuatis, nonnullis minoribus. Calyx luteus, 15-18 lin. longus, stylum tenuem æquans, 4-partitus, tubo 2 lin., laciniis linearibus 3 lin. longis. Antheræ lineares, breve apiculatæ. Stigma 3 lin. longum, attenuatum, sulcatum, apice haud inerassato conico-obtusum, obsoletissime capitatum. Nux (fide Pappe)-sessilis, venIricosa, junior tenuissime puberula. (v. s.)

\section{Sect. III. Pseudomimetes Endl. gen. suppl. $I V, 2$, p. 78.}

Capitula terminalia solitaria parva, multiflora, hemisphærica vel subglolısa, thoribus parvis, involucri pol phpylli squamis imbricatis. Folia parva, patula, plana vel subulato-filiformia, 
10. M. THXMELAOIDES (R. Brown! in Linn. Trans. 10, p. $109^{\circ}$ ), foliis imbricatis ovalibus obtusis eveniis ramulisque puberulis glabrescentibus, capitulis folia dimidio superantibus, stylo semipollicari calycem plumosım parum superante infra medium pilosiusculo, stigmate continuo tenui obtuso. $\bar{J}$ In Africà austr. (herb. Banks.! Roxburgh ! in herb. Soc. linn. Lond., Mund? in herb. reg. Berolin.! Eckl. et Zeyher! in herb. Sonder). - Roem et Schult. syst. 3, p. 382*. Protea thymelæoides Poir. suppl. 4, p. $568^{*}$. Leucadendron thymelæoides Berg. in act. Stọckholm, 1766, p. 324, pl. Cap. p. 19 *. Protea villosa Jacquin! in herb. Willd. n. 2437! P. divaricata Willd. herb. n. 2456! Folia 3-6 lín. longa, 3-4 lin. lata, mutica, callo nullo vel obsoleto, pube minutà laxiusculà ad margines densiore et minus fugaci. Capitula magnit. cerasi minoris, solitaria (ex Brown subadgregata). Receptaculi paleæ setaceo-linearcs, barbatxe, flore dimidio breviores. Stigma stylo haud crassius. An potius M. divaricatæe var. latifolia? Descriptio saltem Proteæ divaricatæ Thunb. diss. n. 57, M. thymelseoidem non excludit illique immo melius quam huic convenit. (v. s. in herb. Banks, Soc. linn. Lond., Willd., etc.)

11. M. MYRTIF OLIA (R. Brown! l. c. p. 110 ), erecta, foliis patulis linearibus lanceolatisve planis utrinque angustatis subvenosis integris vel passim apice 2-3-denticulatis ramisque pubescentibus demum glabratis, capitulis turbinato-hemisphæricis folia æquantibus, bracteis villoso-ciliatis dorso glabriusculis ovatis oblongisque dcuminatis, stylo glabro calycem dense plumosum parum superante, stigmate tenui brevissimo oblongo obtuso. F In Africâ austr. (Masson ! in herb. Banks, Niven! in herb. Mart.), inter Ylandskloof et Nieuwekloof, Goudinie, etc., alt. 1,000-2,000 ped. (Drège! docum. p. 77, 119).--Roem. et Schult. syst. 3, p. 382*'. Protea myrtifolia Thunb. diss. n. 50*, 1. Cap. p. 137, n. 69? (descr. habitu laxo, glabritie, etc., a plantâ nostrâ discrepans), Willid. sp. 1, p. 530 ? Folia pollice breviora, apice minute callosa, juniora subvilloso-pilosa. Capitula terminalia et in summis axillis sessília, magnit. cerasi, bracteis membranaceis fuscis, interioribus brevissime, exterioribus latioribus longius acuminatis. Galyx 4-5 lin. Iongus. Stigma stylo vix crassius, $\frac{1}{6}$ lin. longum. Formæ duæ (vix varietates stabiles) distingui possunt, utraque inter specim. Dregeana occurrens :

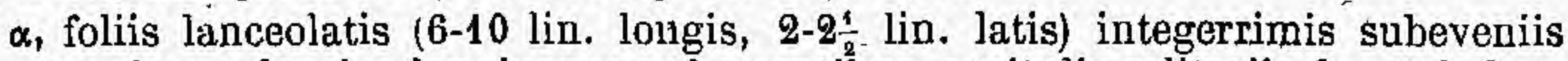
ramisque densius longiusque pubescentibus, capitulis solitariis, bracteis longioribus omnibusque acuminatis. (v. s.)

$\beta$, foliis sublinearibus (raro ultra 6 lin. longis, 1-2 lin. latis) rigidioribus passim calloso-2-3-dentatis, dorso tenuiter venoso-striatulis ramisque minus pubescentibus, capitulis sæpe geminis, bracteis interioribus late ovatis vel ovalibus obovatisve acutis vel abrupte acuminulatis. (v. s. in herb. Banks., etc.)

12. M. Divanicata (R. Brown! l. c. p. 111), procumbens, foliis patulis subunguiculáribus ovalibus obtusis planis integerrimis enerviis ramulisque gracilibus pubescentibus, capitulis subglobosis folia superantibus, bracteis flores subæquantíbus margine villosis dorso glabriusculis lanceolatis subobtusis, calyce stylum . uapillarem glabrum subequante, unguibus patulo-, laminis adpresse pilosis, stigmate tenui. F In campis collibusque Africe austr. (Masson! in herb. Banks., Bruyniere, n. 34 ! in herb. DC., Ludwig! Ecklon l), in arcnosis, prope Winterhoek. alt. 800-1,000 ped. (Krauss, 'n. 1054!). - Roem. et Schult. syst. 3, p. 383*. Leucadendron divaricatum Berg. in act. Stockh., 1766, p. 324, pl. Cap. p. $19^{*}$. Protea divaricata Linn.! mant. p. 194", Thunb. diss. n. 57*, fl. Cap. p. 140, n. 81. Mimetes

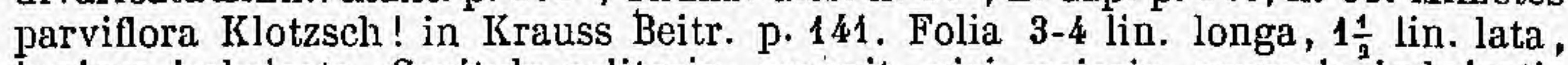
juniora imbricata. Capitula solitaria, magnit. pisi majoris, squamis imbricatis fuscis, receptaculo epaleato (ex Berg. villoso). Calyx fere 3 lin. longus. siigma stylo haud crassius. Variat bracteis oblongo-linearibus obtusis semifoliaceis, calycis laminis sericeis et bracteis lanceolatis acutiusculis subscariosis. (v. s. in herb. Linn., Banks., etc.)

13. M. IN TERM EDIA (Buek ! in pl. Drège), procumbens, ramis gracillimis laxe foliosis junioribus puberulis, foliis patentibus lanceolato-linearibus planis enerviis utrinque attenuatis obtusiusculis adultis glabris, capitulis turbinato-subglobosis, bracteis flores æequantibus lanceolatis acuminatis ciliatis dorso glabriusculis, calyce sericeo-piloso stylum capillarem pilosiusculum apice glabrum subæquante, stigmate tenuissimo. F In Africâ austr. (Ludwig, u. 7! Gueinzius! Eckl. et Zeyh.!), prope Palmietrivier et Houhoek, alt. 1,000-2,000 ped. (Drège! docum. p. 118, Zerher, n. 3694!). Rami longi, subfiliformes, Folia remotiuscula, 3-6 lin. longa, 
1-2 lin. lata, juniora minule puberula. Capitula solitaria, magnit. cerasi minoris, squamis imbricatis membranaceis fuscis, 3-4 lin. longis, vix 1 lin. latis. Species inter M. divaricatam et purpuream medium tenens, priori habitu et foliiș, posteriori bracteís accedens; ab illâ dịstincta stylo pubescente et foliis minus oḅtusis utrinque magis attenuatis, ab hac foliis oblongis planis et calycis Iaminis dense et subadpresse sericeo-pilosis. (v. s.)

14. M. PUR.PUREA (R. Brown [1. 1. c. p. 111) decumbens vel suberecta ramosissima, ramis adscendentibus erectisve tenuibus apice pubescentibus, foliis subulatolinearibus obtusis adultis glabris, capitulis turbinato-globosis, squamis oblongis lanceolatis atienuatis, , calycis unguibus adpresse cano-pubescentibus, laminis obtusis glabris, stylo breviter exserto glabro, stigmate tenui. J In cóllibus Africæ austr. frequens. - Roem. ot Schult. syst. 3, p. $383^{*}$. Leucadendron proteoides Linn. sp. ed. 1 , p. $91^{*}$, Berg. Cap. p. 24. Protea purpurea Thunb. diss. n. 26 , fl. Cap. p. 129, n. 32*, Linn. syst. veg. ed. 14, p. 138. Folia 3-10 lin. longa, $\frac{3}{3}-\frac{2}{3}$ lin. lata. Capitula magnit. cerasi minoris, receptaculo epaleato. Calyx vix 3 lin. longus, stylo breviter superatus, unguib+2s diu cohrerentibus.

\%. vulgaris, foliis canaliculatis planisque (3-8 lin. longis), junioribus ramulisque patenti-pilosiusculis, involucro pubescente, squamis exterioribus foliaceoacuminatis flores superantibus glabrescentibus, stylo breviter exserto. Protea salsoloides Thunb.! mss. in lierb. Banks. Mimetes homomalla Reichenb. in Sìeber herb. Cap. n. 189 ! Huc præterea spectant sp. Sieber fl. mixt. n. 95! Burchell, n. 217! Drège! Ecklon, 1814, 75! Eckl. et Zeyh. n. 5! Krauss; n. 1053, Zeyher, n. 1477! Wallich! in herb. Lindl, etc. (v. s. in herb. Banks., etc.)

$\beta$. Linnceana, foliis subsecundis canaliculatis subsemipollicaribus, junioribus ramulisque patenti-pilosis, involucro dense cano-pubescente, squamis acumiminatis flores æquantibus vel superantibus stylo breviter exserto. Protea purpurea Linn.! mant. p. 195*. (v. s. in herb. Linn.! Percheron! Burke! in herb. DG.)

y. brevifolia, foliis 3 lin. longis canaliculatis glabris (haud secundis), involucro flores subæquante; squamis vix acuminatis villoso-ciliatis dorso glabratis. (v. s. in herb. DC. ex herb. Puerari.)

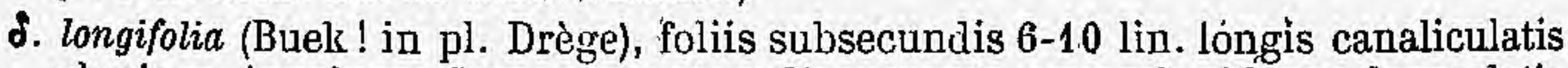
planisve, involucro flores æquante vel 'superante, squamis oblongo-lanceolatis subulato-acuminatis glabris, stylo longiuscule exserto. In arenosis circa Franschehoek, infra alt. 1,000 ped. (Drège c! docum. p. 101). (v. s.)

\section{Species obscurce.}

15. M.2 Diс нот ом а (Roem. et Schult. syst. 3 , p. $383^{\star}$ ), ramis dichotomis gracilibus glabris, foliis subpollicaribus ovato-oblongis obtısis sublinearibusque plandis, summis ramulisque subhirsutis, capitulis terminalibus aggregatis basi foliís non, nullis angustis involucratis, squamis ovalibus pubescentibus ciliatis flores subæquantibus, calyce pubescente styło breviter superato, 吕 Ád Cap. Bonæ̇-Spei. Protea dichotoma Lam. ill.1, p. 235, n. 1219 , Poir. dict. 5, p. $643^{\star}$. Species monente ill. R. Brown l. c. p. 220, verisimiliter ad Mimetes spurias referenda, fide Poir. l. c. M. diváricatæ affinis, sed foliorum formå et capitulis majoribus (magni. fere avellanæ) diversa:

16. M. PaluSTRIS (Knight Prot., fide Loudon encycl, ed. 1, p. 82, n. 1362), foliis ovato-lanceolatis pubescentibus, stigmate brevi basi prominente. Boerh. Lugd. bat. 2, p. 194, c. ịc.

17. M. Yaccinilfolia (Sweet, fide Loudon I.c.p. 82, n.1365), foliis anguste oboxatis glabriusculis, bracteis superioribus flores superantibus valde acuminatis. - Diastella vacciniifolia Knight, fide Steudel.

18. M.? NITENS (Roem. et Schult. syst. 3, p. 384), foliis ovatis integerrimis nervosis argenteo-tom ntosis apice obtusiusculo 1-callosis. I In promont. Bonæ-Spei (Thunb.). Protea nitens Thunb. fl. Cap. 1, p. 514, ed. Schult. p. 140. Folia sessilia, pollicaria, nitida, Forte potius Leucospermi vel Leucadendri sp.

19. M.? CORIACEA, foliis oblongis integerrimis sub-5-nerviis apice recurvato-cal"losis glabris; capitulo terminali solitario involucrato, squamis interioribus abbre- 
viatis. 5 In montibus Oranjekloof, Cap. Bonæ-Spei. Protea coriacea Lichtenstein spicil. fl. Cap. mss., ex Roem. et Schult. syst. 3, p. 384*. Caulis arboreus, ramis validis inter folia tomentosis. Folia sessilia, 2-3-pollicaria. Capitulum magnit. juglandis majoris, involucri siuamis foliaccis quarn folia longioribus et basi látioribus. Potius Leucadendri sp.? cfr. L. venosum R. Br. (supra', p.'220).

VI. PETROPHILA R. Brown in Transact. Soc. linn. Lond. 10, p. 48, et 67, prodr. p. 363 , suppl. p. 1, Endl. gen. p. 337, n. 2121, suppl. IV, 2, p. 75, Meisn. gen.p. 331 (244) et in pl. Preiss. 1, p. 491. - Petrophile Knight et Salisb. Prot. p. 92. - Atyli sp. Salisb.

l'lores hermaphroditi, capitati, rarius spicati, bracteis imbricatis persistentibus. Calyx regularis, 4-fidus, totus deciduus, laminis concavis staminiferis. Antheræ 4 subsessiles, ovales vel lineares, connectivo ultra loculos producto, brevissime apiculatæ. Squamulæ hypogynæ nullæ. Ovarium 1-loculare, 1-ovulatum. Stylus filiformis, basi persistente. Stigma fusiforme, continuum vèl circa medium constrícto-articulatum, totum vel medio vel in solo articulo superiore hispidulum. Nucula 1-sperma, plus minus compressa, alata (samara) vel aptera, ventre vel basi vel margine pilosa. - Frutices NovæHollandiæ extratropicæ orientalis, ausıalis et præsertim occidentalis; foliis sparsis rigidis tereti-filiformibus, rarius planis lobatis pinnatifidisve, rarius indivisis, nonnunquam in eadem stirpe diversiformibus, stomatibus amphigenis ; capitulis terminalibus axillaribusvé globosis vel ovatis 'vel rarius spiciformibus cylindricis solitariis vel rarius aggregatis, fructiferis strobiliformibuis, squamis induratis vel inferne invicem connatis, floribus albis vel flavis plerumque sericeo-villosis.

\section{Sect. I. Arthrostigma Endl. $l$. $c$.}

Folia indivisa, teretia vel rarius plana linearia. Stigma articulatum, articulo inferiore turbinato angulato glabro, superiore cylindrico acuminato tomentoso. Nux lónticularis, ventre margineque comosa. - K. Brown l. c., Meisn. in pl. Preiss. 1, p. 491,81 .

1. P. LINEARIS (R. Brown! suppl. p. 6), foliis planis aversis linearibus crassis basi attenuatâ teretibus eveniịs ramisque glabris, capitulis terminalibus axillaribusque subsessilibus, squamis late ovatis enerviis breve'acuminatis, infimis longioribus lineari-subulatis, calyce villosissimo, stigmatis articulis subequilongis, superiore barbalo apice glabro obtuso. 5 In Coloniâ Swan River (Fraser I Drummon'd coll. 1, n. 558 ! Preiss, Đ. 636 ! Morrison! Molloy !). - Meisn. in pl. Preiss. 1, p. 494: P. falcata A. Cunningh-! mss, in herb. Frutex 1-3-pedalis, ramis gracilibus laxiuscule foliosis. Folia 2-5 poll. longa, 1-3 lin. lata, glaucescentia?, basi teretia, apice acuto vel mucranulo siepe obliquo vel incurvo munita, nonnunquam obtusissima, falcata vel recta, marginibus obtrsis. Capitula globosa vel demum ovata, magnit. juglandis. Calyx 8-12 lin. longus, fulvo-villosus. (v. s. in herb. Brown, etc.)

2. P. ANGEPS (R. Brown! suppl. p. 5), foliis compresso-filifornibus linearibusve eveniis basi attenuatâ complanatis ramisque glabris, capitulis terminalibus súbsessilíbns, squamis ovatis acuminatis rectis glabris infra nervoso-striatis, infimis lineari-subulatis, calyoe sericeo-villoso, stigmatis articulo superiore hispidulo inferiorem parum superante. 5 Circa sinum Regis Georgii (Baxter !) et in coloniâ Swan River (Drumm. coll. 4, n. 261 l et.V, n. 394!). Fruticulus circ. pedalis, subdichotomo-pauciramosus, erectus, a bași inde conferte foliosus, Folia 2-3 poll. lónga, $\frac{4}{2}$-fére $1 \frac{1}{2}$ liṇ. lata, viridia, obtusa, cum mucronulo jnocuo deciduo, marginibus plus minus acutis. Càpitula magnit. cerasi majoris, ovata, squamis fuscis, infimis albidis. Calyx preve flavo-villosis. Nux lentieularis subrotundo-obovata, stylo diu persistẹte caudatâ, comâ basali albâ longe superata. (v. s. in herb. Brown, etc.)

3. P. ERIGIFoLIA (R. Brown! suppl. p. 5), foliis imbricato-adpressis brevibus teretibus obtusis subexsulcis lævibus glabris apice mucronulo vel callo punctiformi obliquo munitis, capitnlo terminali folia superante ovato; squamis ovato-lanceo latis acutis viscidis basi villosis, acumine glabro deciduo, calyce tenui piloso- 
stigmatis articulo superiore pubescente acuminato inferiorem tenuem subduplo superante. $\$$ Circa flum. Gordon, distr. Hay, prope sinum Regis Georgii (Baxter ! Preiss, n: 650!). - Meisn. in pl. Preiss. 1, p. 494. Frutex 2-3-pedalis, erectus, ramosus. Folia 2-3 lin. longa. Capitula magnit. juglandis, calycibus filiformibus squamas parum superantibus flavis superne glabrescentibus. Stigma infra medium obsolete articulatum. (v. s. in herb. Brown., etc.)

4. P. scabriuscula (Meisn. in pl. Preiss. 1, p. 495*), foliis laxiuscule imbricatis brevibus teretibus mucronulatis acutisve obsolete 1 -sulcis punctato-scabriusculis junioribus pubescentibus, capitulo terminali folia superante subgloboso, squamis oblongo-lanceolatis acutis inferne dense villosis, acumine glabro, calyce clavato villoso, stigmatis articulo superiore puberulo inferiorem turbinatum duplo superante. J In coloniâ Swan River (Drumm. coll. 1, n. 557l). Simillima quidem præxcedenti, at notis indicatis facile dignoscenda. (v. s.)

5. P. PHYLIGOIDES (R. Brown suppl. p. 6), foliis brevibus teretibus exsulcis, capitulo folia vix superante ovato, squamis ovatis ramisque tomento adpresso incanis... 5.In sinu Lucky Bay oræ austro-occid. (Baxter).

6. P. BREVIF OLIA (Lindl.! Swan River, in Bot. reg. 1839, appenid..p. 35, $\mathrm{n} .168$ ), follis pullicarihus teretibus mucronatis exsulcis lævibus ramisque glabris, capitulo terminali sessili ovato, squamis ovatis acutis subenerviis, infimis linearibus longe acuminatis, calyce dense sericeo-villos $\sigma$, stigmatis articulo superiore barbato interiore vix longiore. $ち$ In coloniâ Swan River (Drummond! Preiss, n. 631! 632! Gilbert1). - Meisn. in pl. Preiss. 1, p. 491 *. Fruticulus erectus, 1-1 $\frac{1}{2}$ pedalis, subsimplex. Folia laxiuscula, 8-14 lin. longa, $\frac{1}{2}-\frac{2}{3}$ lin. crassa. Capitulum magn. avellanæ vel juglandis, floribus 5 lin. longis aureo-villosis. (v. s. in herb. Lindl., etc.)

7. P. GRASSIFoLIA (R. Brown! suppl. p. 5), foliis digitalibus teretibus submuticis exsulcis lævibus ramisque glabris, capitulis terminalibus axillaribusque sessilibus ovato-globosis, squamis dilatato-orbicularibus muticis enerviis, infimis conformibus minoribus, calyce dense sericea-villoso, stigmatis articulo superiore stip-. poso inferiore vix longiore. $\zeta$ Circa sinum Regis Georgii (Baxter!) et promontor. Riche (Preiss, n. 630 ! Drumm. coll. 4, n. 2601). - Meisn. in pl. Preiss. 1, p. $492^{*}$. Fruticulus pedalis. Folia 2-7 poll. longa, 1 lin. crassa, obtusa vel acutiuscula. Capitula magn. avellanæ, squamis latioribus quam longis, obtusis. Calyx albidovillosus. Folia nonnunquam observantur passim denticulo uno alterove prædita, hinc forsan folia interdum vere laciwiata? (v. s. in h. Brown., etc.)

8. P. agicularis (R. Brown! in Linn. Trans. 10, p. 69, prodr. p. 364), foliis elongatis teretibus supra obsolete 1 -sulcis ramisque glabris, capitulis terminalibus axillaribusque sessilibus subglobosis, squamis glabris ovatis pungenti-acuminatis nervoso-striatis, infimis longioribus subulatis subfoliaceis basi dilatatis, calyce squamas vix superante adpresse sericeo-villoso, stigmatis articulo superiore barbato inferiore duplo. longiore. $J$ In Leeuwins Land. (R. Br.l), circa sinum Regis Georgii (A. Cunningham! Preiss, n. 626! Drumm. coll. 3, n. 242!). - Meisn. in pl. Preiss. 1, p. $494^{*}$, Bot. mag. t. 3469. Frutex 3-pedalis, strictus, simplex vel apice ramosus. Folia 2-6-pollicaria. Strobili squamæ acutæ striatæ. Calyx argenteo-sericeus. (v.s. in herb. Brown., etc.)

9. P. FILIF oLIA (R. Brown l. c. p. 69 et 364 ), folìs teretibus exsuleis, capituli squamis orbiculatis nervosis, stigmatis articulo superiore barbato inferiore vix duplo longiore. 5 In Leeuwins Land (R. Br.!). Exceptis notis indicatis omnia fere P. acicularis. (v. s. in herb. Brown.)

10. P. TERETIFOLIÁ (R. Brown! l. c. p. 68 et 364 ), foliis elongatis teretibus submuticis exsulcis ramisque glabris, capitulis terminalibus axillaribusque subsessilibus ovatis, squamis late ovatis enerviis puberulis, innfimis paucis vix longioribtis linearibus acuminatis, calyce dense sericeo-villoso, stigmatis articulo superiore stupposo inferiorem triplo superante. F In Leeiwins Land (R. Brown I A. Cunn.?), colonià Swan River (Drumm, coll. 4, n. 259 !). - Meisn. in pl. Preiss. 1, p. 492 : in notâ. P. longifolia A. Cunningh.I mss. in herb. (nec R. Br.). Simillima sequenti, sed stigmatis articuln superiore multo longiore, etc., facile distinguenda. (v. s. in herb. Brown., DC., etc.)

11. P. MEDIA (R. Brown suppl. p. 5), foliis elongatis teretîbus mucronatis vel demum muticis exsulcis ramisque glabris, capitulis terminalibus subsessilibus 
globosis, squamis ovatis acutis unerviis demum subreflexo-patentibus, infimis longioribus linearibus subulato-acuminatis, calyce sericeo-villoso, stigmatis articulo superiore inferiore param longiore barbato apice nudo. J Circa sinum Regis Georgii (Baxter! Preiss! n. 620! 629!) et in coloniâ Swan River (Preiss, n. 628! Drumm. coll. 2, n. 293.! III, n. 241!). - Meisn. in pl. Preiss. 1, p. $192^{*}, 2$, p. 245 . Frutex erectus; pedalis vel dodrantalis. Folia 3 poll. vel infima sæpe vix 1 poll. longa, nonnunquam subpedalia. Cæt. omnia P. l)revifoliæ, quæ forsan mera ejus var. (v.s. in herb. Brown, etc.)

12. P. LONGIFOLIA (H. Brown! suppl. p. 5), foliis longissimis teretibus acutis exsulcis ramisque glabris, capitulis terminalíbus lateralíbusque sessilibus ovatis, squamis glabris late ovatis breve acuminatis acutis, infimis longioribus e basi ovatâ subulato-acuminatis semierectis, calyce adpresse sericeo-tomentoso, stigmatis articulo superiore stupposo inferiorem parum superante. F Circa sinum Regis Georgii (Baxter! Drumm. coll.2, n. 241!), - Meisn. in pl. Preiss. 1, p. $493^{*}$.

$\alpha$. lorea (R. Br. l. c.), foliis caulem abbreviatum superantibus, capituli squamis subenerviis (Preiss, n. 623! et ex parte 625l). Folia 8-12 poll: longa, vix $\frac{1}{2}$ lin. crassa. Flores odori, paulo minores quam P. mediæ, pube brevi adpressã flavo-argenteầ. (v.s.)

A. caulescens (R. Br. ].c.), foliis inferioribus caule erecto ramoso brevioribus, capituli squamis obsoléte nervosis (Preiss, n. fi25, ex parte). Caulis subpedalis. (v..s.)

13. P. JUNCIF OL I A (Lindl.! Swan Riv. p. $35, \mathrm{n}, 169$ ), foliis longissimis teretibus acutis exsulcis ramisque apice glaucescentibus glabris, capitalis terminalibus lateralibusque subsessilibus ovatis, squamis glabris ovatis acutis subenerviis, infimis lineari-subulatis erectis, calyce adpresse sericeo-tomentoso, stigmalis articulo superiore inferiore duplo longiore barbato. F In coloniâ Swan River (Drumm. coll. 1, n. 556! III, n. 240 ! Preiss, n. 621! 622! 624! 627! Gilbert. n. 62 1).-Meisn. in pl. Preiss. 1, p. $493^{*}$. Excepto stigmate omnia fere præecedentis. Capitula interdum 8-12 dense aggregata. Flores suavissime citriodori. (v. s. in herb. Lindl., etc.)

\section{Sect. II. Pétrophile Endl. gen. p. 337.}

Folia teretia vel semiteretia pinnatim vel ternatim laciniata. Capituli, squamæ discretæ, raro basi connatic (cfr. P. seminuda, chrysantha). Stigma continuum vel obsolete articulatum.--R. Br. in Linn. Trans. 10, p. 69, prodr. p. 364, HI, Meisn. in pl. Preiss. 1, p. 495, \& \& (excl. P. Cunninghamii):

\section{* Nucula lenticulari-compressa, intus marginibusque comosa vel pubescens.}

14. P. SEM INUDA (Lindl.! Swan Riv. p. 34, n. 166), foliis teretibus biternatis glabris supra 1 -sulcis, segmentis pungentibus petioloque subæqualibus vel intermedio breviore, capitulis terminalibus sessilibus ovatis, squamis ovatis acutis inferne albo-lanatis, infimis minoribus lanceolatis extus ealycibusque glabris, stigmate fusiformi inferne glabro superne puberulo. 5 In coloniâ Swan River (Drumm. coll. 1, n. 561! 562! 572 ! Preiss, n. 633! 634! 635! 661!). - Meisn. in pl. Preiss. 1, p. 495*). Frutex bipedalis. Folia 2-3-pollicaria, rigida, 3-jartita, segmentis iterum 3-partitis vel lateralibus passim bifidis indivisisve. Capituli squamæ interiores inferne invicem cohærentes; dorso lanato-tomentosæ, acumine triangulari acuto patulo glabro flavo vel rufo demum deciduo, exteriores pungentes, intus sericexe. Calyx 4-5 lin. longus, luteus, glaberrimus. (v. s. in herb. Lindl., etc.)

15. P. pedunculata (R. Brown in Linn. Trans. 10, p. 70, prodr. p, 364), folíis teretibus supra 1 -sulcis tripinnatifidis ramisque glabris, scgmentis 3 -4-jugis divaricatis, 3-6-jugo-pinnatifidis vel passim dichotomo-multifidis, infimis petiolo longioribus, laciniis tenuibus submuticis, capitulis terminalibus et in summis axillis solitariis pedunculatis ovatis, squamis ovatis acuminatis cal ycibus stigmatibusque glabris. F In Novâ-Holl. orientali, cirea Port-Jackson (R. Brown! A. Cunningh.! Sieber herb. fl. Nov.-Holl. n. 20!).-Roem. et Schult. syst. mant. ad vol. 3, p. $262^{*}$, Guillemin ic. lithogr. $\imath$. 18. Species a sequentibus fere omnibus jam florum glabritie, a precedente capitulo pedunculo ipsi circiter æquilongo squamigero suffulto stigmateque undique glabro facile dignoscenda. Foliorum laciniæ Qppositæ vel alternæ acutiusculæ. Capituli squamæ omnes ovątæ. Calycis laminæ cuspidate. (v. s.). 
16. P. FASTIGIATA (R. Brown! 1. c. p. 70 et 364), foliis trifido-bipinnatis, laciniis fastigiatis erectis teretiusculis muticis, capitulis terminalibus sessilibus ovatis, squamis lanatis, calyce glabro. $\mathcal{J}$ In Leeuwin's Land (R. Br.). Foliorum laciniæ $\frac{1}{2}$ lin. crassæ, obtusa. Capitulum magnit. cerasi. Gæet. fere préecedentis, a quâ prasertim foliorum segmentis, haud divaricatis et capitulo sessili distinguitur. (v. s. in herb. Brown.)

17. P. DRUMm ONDI (Meisn. in pl. Preiss. 1, p. $496^{*}$ ), foliis teretibus pinnatis sulcatis pungentibus ramisque pubescentibus demum glabris, segmentis 3-5-jugis indivisis inferioribus petiolo subrerualibus superioribus decrescentibus, capitulo terminali sessili ovato, squamis ovato-lanceolatis acutis glutinosis; infimis glabris, superioribus majoribus inferne laxe lanuginosis, acumine calvo deciduo, calyce laxe piloso, stigmate barbato imà basi glabro.

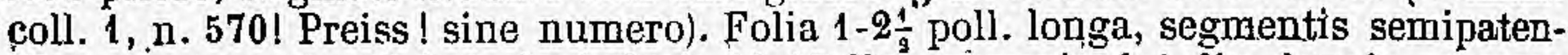
tibus semper simplicissimis, infimis 10-15 lin., summis 4-1 lin. longis; summa plerumque breve 3-fida. Capitulum fere P. ericifolio, paulo majus et flores graciliores quam P. seminudie, cui cteterum affinis. (v. s.)

18. P. TRITERNATA (Kippist in Hook. Journ. 1855, p. 67), ramulis velutinis, foliis teretibus triternatis exsulcis scabris junioribus puberulis, laciniis divaricatis pungentibus petiolo subduplo longioribus, capitulo terminali sessili ovato, squamis ovato-lanceolatis, infimis pungenti-acuminatis glutinosis, superioribus majoribus apice calvo striato deciduo, calycis laminis crispato-villosis, stigmate barbato. basi glabro. 5 In colonia Swan River (Drumm. coll. 5, suppl. n. 2). Folia rigida, novella tomentosa, adulta glabra, tuberculato-scabra. Capitúlum foliis nanis obvallatum. Calycis tubus intus villosus. Stigma inarticulatum, fusiforme. Nucula compressa, late obovata emarginata, tuberculis brevibus nigro-marginata longeque fimbriato-comosa; faciebus glabratis. Facie accedens, ad P. Drummondii, sed abunde distincta. (Kipp. in litt.)

19. P. s Essil is (Sieber $\hat{l}$ herb. fl. Nov.-Holl. n. 21), ramis apice cano-tomentellis, foliis teretibus glabris supra 1 -sulcis trifido-subbipinnatis, segmentis 3-1-jugis divaricatis petiolo .longioribus 2-5-fidis, laciniis indivisiş bifidisve acutiusculis, capitulis terminalibus subsessilibus ovatis solitariis vel aggregatis, squamis, late ovatis retusis cum acumine brevi deciduo ealyceque undique sericeis. $\supset$ Circa PortJackson (Caley ! Sieber, n. 21! A. Gunningh,!). $\rightarrow$ Roem, et Schult. syst. mant. ad vol. $3, p \cdot 252^{*}$, R. Brown suppl. "p. 6. Simlllima P. pulchellæ; at bene'distincta foliis plerumque dimidio minoribus (raro ultra 2 poll. longis), petiolo breviore et segmentis, laciniisque divaricato-patentibus. (v. s.)

20. P. canescens (A. Gunningham! mss. in herb.), foliis teretibus hi-nipimatifidis supra 1 -sulcis ramuliscue puberulis, segmentis 2-3-jugis semipatentibüs petiolo brevioribus, lacinulis 1-3-júgis obtusiusculis, capitulo terminali subsessili gvato, squamis ovatis breve acuminatis enerviis serieeis, floribus.... ₹ In NovâHoll. orientali interiore et circa sinum Moreton Bay (A. Gunn.! Baxter!).-R. Brown I suppl. p. 6. Habitus P. pulchelle, sed, folia minora, 1-2-pollicaria, juniora sericea, lacinulis 3-6 lin. Iongis muticis, petiolo plerumque segmentis longiore. Flores ignoti. Capitulum fructiferum magnit. cerasi rol pruni minoris. Nucula lenticularis ovata, styli basi caudata, margine intusque longe comosa, dorso pilosiuscula basique sulcata. (v. s. in herb. Brown., Cumn., Lindl., et.c.)

21. P. PULCHella (R. Brown! in Linu. Trans. 10, p. 69, prodr. p. 364), ramis apice cano-tomentellis, foliis teretibus trifido-bipinnatis glabris supra 1 -sulcis, segmentis 2-3-jugis semipatulis infirnis petiolum aquantibus, lacinulis 1-2-jugis acutiusculis, capitulis terminalibus sessilibus solitariis aggregatisve pyramidalis ovalis, squamis infimis linearibus glabris, superioribus late ovatis sericeis, acumine lineari recurvo glabro deciduo, calycis soricei laminis subacuminatọ-aculis, stigmate hispidulo. 5 Cirea Port-Jackson (R. Br.! Sieber, n. 19! fl. Inixta, n. 479! Mitchell! Gaudich.! ctc.) - Ruem. et Schult. syst. 3, p. $338^{*}$. Protea pulchella Schrad. sert. Hamnov. 2, p. 15, t. 7, Car. ic, 6, p. 33, t. 550, Sins Bot, mag. t. 796, Willd.! sp. 1, p. 507, herb. n. 2402 ! P. fucifolia Salisb. prodr. p. 48. P. clicbotoma Gav. ic. 6, p. $34, \mathrm{t} .551$. Pelrurdila fucifolia Knight et Salisb. Prot. p. 92. Rami conferte foliosi, sepu umbellati. Fulia semierecta, rigida, $2-4$ yoll. longa, lachíis 6-12 lin. longis, terminalí abbreviatà. Cápitula foliis obovalláta, circ. pollicaria, apice squamarum acumine recurvo subsifuamosa. Calyx sericeus, tomento sulphu- 
réo apicem versus breviore. Stigma continuum, fusiforme, angulatum, patentihispidulum. ( $\nabla$. s. in herb. Brown., etc.)

22. P. c RI \& P A T A (R. Brown! suppl. p. 6), ramis apice puberulis, foliis teretibus glabris bipinnatis, pinnis 1-2-jugis divaricatis pungentilus lóvibus supra 1-sulcis, pinnulis 3-fidis, terminali abbreviatâ, capitulo terminali sessili ovato; squamis ovatis acuminatis tomento crispato-incanis viscosis. 7 Circa sinum Regis Georgii (Baxter! Preiss, n. 647! Drumm. coll. 3, n. 248!). - Meisn. in pl. Preiss. 1, p. $496^{*}, 2$, p. 245 . Folia patentia rigidissima, 1-2-pollicaria. Capitulum demum ovalo-oblongum, subpollicare, bracteis interdum glabresçentibus. (v. s. in herb. Brown., etc.)

23. P. R I I D A (R. Brown ! in Linn. Trans. 10, p. 69, prodr. p. 364), foliis teretibus triternatis glabris, segmentis subiequalibus vel intermedio breviore supra 1 -sulcis rugoso-striatis, lacinulis abbreviatis submucronatis, capituto terminali sessili ovato, squamis late ovatis, caudato-acuninatis basi lanato-tomentosis; infimis lineari-subulatis ciliatis dorso glabriusculis, calyce dense sericeo-villoso, laminarum apiculo minuto glabro, stigmate medio hispidulo supra infraque glabro. 5 In Leeuwin's Land (R. Br.! A. Cunn.I Drumm.I coll. 1), circa sinum Regis Georgii

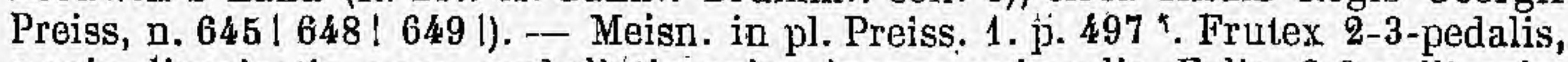
ramis divaricatis sæpe umbellatis apice incano-puberulis. Folia 2-3-pollicaria, fere dúplo crassiora quam P. crispate, lacinulis ultimis $\frac{1}{2}-1$ lin. lungis vel raro longioribus. Flores sulphurei, mágńit. el pubescentiâ P. linearis. Capitulum fructiferum pollicare, subcylindraceum, squamis patentibus, acumine glabro subrecurvo persistente. (v. s. in herb. Brown.; etc.)

24. P. C O N IFE R A (Meisn. in Huok. Journ. 1855, p. 67), ramulis apice púberulis, foliis rigidissimis teretiluus exsulcis levibus glabris basi attenuatis extra medium pinnatim 3-5-fidis, lobis divaricatis pungentibus lateralibus indivisis bifidisve capitulis terminalibus sessilibus ovato-oblongis, squamis late ovatis sericeoLomentosis acumine brevi calvo deciduo, calyce gracili sericeo-villoso, stigmate hispidulo. 7 Inter Glum. Moore et Murchison, in Nov.-HolI. occidentali interiore (Drumm. coll. 6, n. 167!). Folia $1 \frac{1}{2}-2$ poll. longa, $\frac{2}{3}$ lin. crassa. Calyx 6 lin. longus. Stigma fusiforme continuum. Capitulum fructiferum 8-10 lin. longum. squamis discretis nec hasi connatis, ut ex errore 1. c. dicuntur. (v. s. in herb. Shuttleworth.)

25. P. S E R R U R I AE (R. Brown! suppl. p. 6), foliis subsessilibus teretiusculis rigidis pungentibus trifido-bipinnatis supra 1 -sulcis, novellis ramisque pubescentibus, pinnis divaricatis, pinnulis brevibus sæpius bifidis, capitulis axillaribus sessilibus subglobosis, squamis ovatis acutis sericeis acumine brevi glabro, fructiferis patentibus, calyce subsericeo-villoso, laminis submuticis'. F In coloniâ Swan River (Fraser! Drumm.I coll. 1, Preiss, n. 642! 643! 644!), Australind. (Gilbert, n. 185!) et circa sinum Regis Georgii (Baxter !). - Meisn. in pl. Preiss. 1 p. $497^{*}$. Frutex 3-6 pedalis, squarrosus, ramis virgatis dense foliosis. Folia vix pollicaria. Flores 4-5 lin. longi, sulphurei. Capitulum demum ovatum, magnit. cerasi. Stigma gracile, superne puberulum, basi glabrum. (v. s. in herb. Brown, etc.)

26. P. G L A N U L I G R A (Lindl.! Swan Riv. p. 35. n. 170), foliis subsessilibus teretiusculis rigidulis vix pungentibus trifiids-bipinnatis supra 1 -sulcis ramisque patenti-pilosis tarde glabrescentilus, pinnis subdivaricatis, piniulis tenuibus indivisis bifidisve, capitulis axillaribus brevissime pedunculatis subglobosis, squamis oratis acutis bàsì sericeis superne glabrescentibus, calyce subsericeo-villoso, laminis glandulâ stipitatâ mịnute terminatis. 春 In coloniâ Swan River (Drumm.

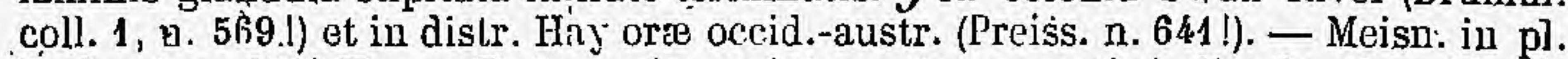
Preiss. 1, p. 498". Forsan P. Serruriæ varietas, attamen notis indicatis etiamsi lævibus constanter, ut videtur, distincta. Foliorum segmenta sæpius vix divaricata, mucronulo tẹpui deciduo. (v. s. in herb. Lindl., etc.)

27. P. G H R Y S N T A A (Meisn. in Hool. Journ. 1855, p. 68), ramis apice cano-tomentellis, foliis pinnatin 3-9-partitis glabris complicatis, laciniis sibparallelis indivisis teretibus pungentibus supra 1 -sulcis scabriusculis, capitulis terminalibus folia equantibus parvis, squamis basi connatis margine villosiusculis, calyce auren-villoso, laminis muticis, stigmate fusiformi medio pubcrulo supra infraque glabro. f In Novì-Hollandiâ occidentali interiore (Drum. coll. 6, n. 165l). Facies P. Serruriæ, sed bene dístincta. Fólia 6-9 lin. longa, petiolo 1-1 $\frac{1}{4}$ lin. longo, juniora 
erecto-subadpressa, demum patentia, laciniis semipatulis semper indivisis puncticulato-scabriusculis, junioribus albo-pilosis. Capitula solitaria, sessilia, magnit. pisi vel cerasi minoris, squamis late ovatis vel subrotundis obtusis acutisve lævibus, junioribus sericeis. Calyx 3 lin. longus, laminis acutis. Stylus basi pilosus. Nucula ovato-subrotunda, utrinque adpresso-pilosa margine villosa, dorso valde convexa, apice in alam ovalem acutam glabram producta. (v. s. in herb. Shuttlew.)

28. P. IN C ON S P I C U A (Meisn. in Hook. Journ. 1855, p. 68), ramulis patenti-pilosis, foliis subsessilibus teretibus pinnatim 3-5-partitis scabriusculis glabris supra 1 -sulcis; laciniis subparallelis mucronulatis, capitulis terminalibus foliis superatis, squamis pilosis, calyce- breviter albo-villoso, laminis muticis, stigmate parvo conico-subülato puberulo, samarâ glabrâ ciliolatâ. $\zeta$ In Novâ-Holl. occid. interiore (Drumm. coll. 6, n. 172!). Rami graciles, fastigiato-ramulosi. Folia 6-8 lin. longa; petiolo 1 lin. longo, plano vel subnullo. Capitulum sessile, foliis ex parte îndivisis ramulisque nascentibus superatum. Calyx tenellus, 5-6 lin. longus. Stigma $\frac{4}{2}$ lin. longum. Nucula vel samara $1 \frac{1}{2}$ lin. longa, fere plana, ovalis, alẩ terminali brevi obtusà secus margines angustissime decurrente. Ciet. fere P. chrysanthæ. (v. s. in herb. Shuttlew.)

\section{* Samara planiuscula, preter basin brevissime comosam glaberrima.}

29. P. D I V A R I G A T A (R. Brown! suppl. p. 7), foliis teretibus rigirlis sublævibus supra 1-sulcis trifido-bi-tripinnatis ramisque parce patenti-pilosis mpx glabris, segmentis divaricatis, capitulis terminalibus axillaribusque subsessilibus, squamis ovatolanceolatis inferne tomentosis acumine sphacelato pungente glabro, calyce ádpresso sericeo-velutino, stigmate superne retrorsum hispidulo. 5 Circa sinum Regis Georgii (Baxter! A. Cunn.! Drum. coll. 1, n. 568! Prèiss, n. 646!): 一 Meisn. in pl. Preiss. 1, p. $198^{*}$. P. intricata Lindl.! Swan River, p. 35, n. 171. Frutex 2-3-pedalis. Folia 1-3-pollicaria, rhachi plus minus arcuatâ et flexuosâ, pinnis 2-3-jugìs divaricatissimis sæpe subrefractis, pinnnlis 2-3-fidis vel indivisis 2-10 lin.-1ongis, terminali brevissimâ. Gapitula ovato-globosa, fructifera magnit. juglandis, squamis patentissimis liberis. Samara ovalis vel obovata. (v.s. in herb. Brown., Lindl., etc.)

30. P. CIRCINNA T A (Kippist in Hook. Journ. 1855, p. 67), ramulis pubescentibus, foliis longe petiolatis teretibus pungentibus glabris supra 1 -sulcis bi-tripinnatis circinnato-recurvis, pinnis 4 -5-jugis divaricatis, capitulo terminali sessili ovato, squamis late ovatis sericeo-tomentosis mucronatis, infimis folio nano terminatis, calyce sericeo-villoso, stigmate hispidulo superne glabro. F In coloniả Swań River (Drumm. coll. 5, suppl. n. 3). Folia 3-5-pollicaria, petiolo partem pinnatam æquante rel longiore supra canaliculato basi dilatato, pinnis suboppositis. Capitulum magnit. juglandis. Calyx pube brevi lutescente dense sericeis, laminis laxius villosis. Stigma fusiforme. Samara ignota. Cæet. fere P. divaricatæe, a quâ præter notas indicatas etiam stigmate dimidio longiore distincta. Kipp. in litt. delin.

\section{Sect. II. XeRostole Endl. gen. p. 337.}

Folia plana pinnatim vel trifido-laciniata vel biloba, rarius indivisa vel inferiora teretiuscula. Capitula axillaria vel terminalia, ovata, squamis discretis. Calyx sericeo-rillosus, gracilis. Stigma fusiforme continuun vel sæepius articulatum, articulo inferiore obconico truncato angulato, superiore tenui cylindraceo. Samara planiuscula; ovata vel oblonga, exceptâ basi brevissime comosa glaberrima - $R$. Br. in Linn. Trans. 10, p. 70, prodr. p. 365, IV, Meisn. in pl. Preiss. 1, p. 500, \& 4.

31. P. squa Ma ta (R. Brown in Linn. Trans. 10, p. 70, prodr. p. 365), ramulis puberulis, foliis glabris biternatis, segmentis petiolo subxqualibus, lacinulis anguste linearibus subulatisve pungentibus vel submuticis, capitulis axillaribus sessilibus ovatis, squamis ovatis acuminatis subpungentibus ciliatis inferne puberulis, stigmate continuo subutato glabro basi leviter turbinato-incrassato. F In Nori-Holl. occid.-australi. P. Cunninghamii Meisn. in pl. Preiss. 1, p. $499^{*}, 2$, p. 245. Involucrum stramineum.

a. major (Meisn.-1. c. p. 499), ramis firmis subcorymbosis, foliis subsesquipollicaribus rigidis, lacinulis linearibus planis vel concavis pungenti-acuminatis! Circa sinum Regis Georgii (R. Brown! Menzies in herb. Smith! Baxter! Fraser ! Preiss, n. 652! Gilbert!). P. squamata R. Br. 1. c. Foliorum lacinulæ $\div-1$ lin. 
latæe, planæ vel dorso convexo supra complicat,o-concavæ. Flores sulphurei. Radix amara, fide Preiss. (v. s. jn herb. Brown., etc.)

ß. brachyphylla (Meisn. l. c.), ramis giacilibus, foliis semipollicaribus rigidis, laciniis angustioribus semiteretibus submuticis. In (listr. Nelson (Preiss, n. 651!). Foliorum lacinula $1 \frac{1}{2}-2 \frac{1}{2}$ lin. Jonge, $1 \frac{1}{1}-1 \frac{1}{2}$ lin. lato. (r. s.)

$\gamma$. gracitis (Meisn. l. c.), caule simplici grncili, foliis subpollicaribus debilíbus, lacinulis angustissimis subteretibus muticis. Cirea sinum Regis Gerorgii (.1. Cunn.!). P. gracilis A: Cumningharn! mss. in lierb. (v. s.)

32. P. c oL o n A т A (Meisu. in pl. Preiss. 2, p. $246^{*}$ ), foliis biternatis ramulisque glaberrimis, segmentis petiolo rqualibus-longioribusve, lacinulis linearibus pungentibus, capitulis axillaribus sessilibus ovatis, squamis ovatis acuminatis vix. rigidis inferne ciliatis glabris, stigmatc articulato glabro, articulis subrequilongis, inferiore angulato-turbinato truncato, superiore suljulato. $\mathrm{F}$ Iu colonià swan River (Drumm. coll. 2, 11. 296!), circa Vasse (Gilbert, n. 155!). Folia circ. pollicaria, rigida, ladinulis $\frac{1}{2}-\frac{2}{5}$ lín. latis. Capituli squamue plus minus rubentes, swepe pulchre 'sanguinex. Cret. fere P. propinqua et squamat'r, cujus varietalem sistere credi posset, nisi stigmate egregie differat. (r. s.)

33. P. PROPINQUA (R. Brown! suppl. p. 7), ramis apice puberulis, foli is biternatis, segmentis petiolatis, laciniis omnibus spathulato-linearibus mucronulatis subvenosis, capitulis axillaribus sessilihus, squamis ovatis acuminatis pilosiusculis ciliatis, stignate articulato glabro. 5 In colonia Swan River (Fraser! Drumm. coll. I, n. 567 !). - Meisn.in pl. Preiss. 1, p. $501^{\circ}$, in notâ, et clir. ih. 2 , p. 246 , obs. ad P. coloratam quæ forsan hujus var. Folia $1-2$-pollicaria, lacinulis $\frac{1}{2}-2$ lin. latis. Stigma procedentis. (v. s. in lierb. Brown., etc.)

34. P. TRIFIDA (R. Brown! in Limn. Trans. 10, p. 70, prodr. p. 365), foliis trifidis venosis ramisque glaberrimis, laciniis cuneato-decurrentibus mucronatis, lateralibus lanceolatis integris, terminali longiore apice trifida, capitulis axillaribus terminalibusque. sessilibus subglohosis, scpuarnis sericeis demum glabris, interioribus ovatis, exterioribus lanceolatis acuminatis; stigmate contimuo anguste fusiformi medio puberulo. 5 In terri Leeuwin (R. Brownl) et colonià Swan River (Drumm. coll. 2, n. 576!).-Lodd. Bot. Cab. t. 1883, Jeisn, in pl. Preiss. 1; p. 501 ', in not:. Folia 2-3-pollicaria, lacinite plans, 2-3 lin. latir. laterales quandoque 3-fidæe et terminalis tunc 5 -fida. Capitulum fructiferum magnit. cerasi, squamis subrotunde-uvatis. (v.s. in herb. Brown., Sor.. linu. et Shuttl.)

35. P. BIL OBA (R. Brwwn! suppl. p. 7); foliis tripartitis junioribus ramisque pubescentibus, segmentis cuneatis semibifictis cum mucronulo lobulove brevi subulato interjecto, lobis semiovato-oblongis mucronatis venoso-striatis, capitulis axilla. ribus ovatis, squamis ovat is acuminatis sericeis, stigmate continuo tenui glabriusculo infra medium turbinato-incrasşato. ₹ In colonía Swan River, ad jugum Darling's Range, etc. (Fraser! Drumm. coll. 1, n. 566! Proiss, n. 656! 657!). Neŕsn. in pl. Preiss. 1, p. 500*. Frutex 4-pedalis, ramis gracilibus subvirgatis. Folia patula, rigida, $\frac{1}{2}-1$ poll. longa, plerumque complicata, infima nonnunquam biternata, lobis $\frac{1}{2}$-fere $3 \mathrm{lin}$. latis, rarissime anguste linearibus. Capitula deflorata vix piso majora. Calyx $4-8$ lin. longus, albo-vel aureo-sericeo-villosus. (v. $s$. in lierb. Brown., etc.)

36. P. PLUM OSA (Meisn. in Hook. Journ. 1855, p. 69), ramis incano-tomentosis novillis cum loliis patulo-sericeo-pilosis, foliis spathulatis minute puberulis, infimis passimque summis indivisis, reliquis apice dilatato complicato-trilobis penninerviis, lobis acutis vix divergentibus; capitulo terminali foliis superato globoso, squamis acutis sericeis mox glabratis, intimis sericeis plumosis, stigmate continuo fusiformi. $\zeta$ Ad flum. Moore in Nov,-Holl. occid. interiore (Drumm. coll. 6, a. 164!). Fruticulus cum radice 1-2-pedalis, erectus, apice umbellạtim ramulosus, ramulis novellis cum foliis eleganter argenteo-sericeis quasi plumosis. Folia $1-1 \frac{1}{2}$ poll. longa, attenuato-petiolata, infima et ex parte summà indivisa 1-2 lin. lata, relicyua njice 2-6 lin. lata 3 -loba, lobis 1-1 $\frac{1}{2}$ lin. latis, sinu angusto separatis tactu scabriusculis. Capitulum globosum, magnit.- cerasi majoris, squamis interioribus sxteriores dimidio superantibus flore brevioribus: Calyx gracilis, 5-6 lin. longus, luteu-villosus, sericeus. Stylus pollicaris capillaris, inferne piloșus, tarde deciduus. Stigma 1 lin. longum, fuscum, subsulcatum, apice basique glabrum. Samara cuneato-obovata, truncata, fere 2 lin. lata et parum longior, plana, ventre inferne

XIV. 
obtuse carinata puberula, bași brevițer albido-comosa. Species fóliorum formâ ad P. bilobarn et propinquam accedens, ceterum distinctissima. (v. s. in herb. Shuttleworth.)

37. I. нетеворнуцLA (Lindl.! Swan Riv. p. 35, r. 167), foliis elongato-linearibus basi longe attenuatis indivisis vel 2-3-partitis utrinque nervoso-striatis ramisque glaberrimis, capitulis axillaribus sessilibus ovatis, squamis ovatis acutis glabris ciliatis, stigmate articulato glabro. 5 In Novà-Hollandiâ austro-occidentali. Meisn. in pl. Preiss., 1, p. 501*, 2, p. 246. Frutex 7-8-pedalis, gracilis. Folia remotiuscula, patentia, 2-5 poll. longa, ad medium usque 2-3-loba, interdum in eddem stírpe passim indivisa. Capitula deflorata vix piso majora, squamis demum pateptibus incrassatis, obtusis nudis rugulosis. Calyx gracilis, pube brevi adpressâ aureo-sericens. Stigmá 2 lin. longun, articulo inferiore, turbinato superiorem subulatum tenuiorem subæquante. Samara subrotundo-ovata, ventre puberula; basi truncatâ brevissime albo-comosa, marginibus vix diaphano-membranaceis.

a. latifolia, foliis omnibus indivisis spathulato-linearibus (usque ad 3-4 lin. latis) ex apice obtuso mucronulatís, calyce 8-9 lin. longo (Preiss, n. 660! Drumm. coll. 3, n. 244 !).

B. intermedia, foliis promiscuis 2-3-lobis indivisisque (asque ad 3 lin: latis angustato-acutis vel passim obtusis mucronatis, calyce 6-7 lin. longo (Preiss, n. 658 ! 659 !).

$\gamma$. angustifolia, foliis pinnatim 3-5-lobis, lobis anguste linearibus (1 lin. latis) attenuato-mucronatis, calyce 5-6 lin. longo (Drumm. coll. 1, n. 571!). Fruticulus ramosior quam var. $\alpha$ et capitula minora. Hauc formam specifice distinctam censet cl. Kippist in litt., sed differentiæ insufficientes et formâ intermediii $\beta$ omnino invalidatæ nobis videntur. (v.s.)

\section{Sect. 1v. Symphyolepis Endl. gen. p. 337, c.}

Folia pinnatim vel trifido-laciniata, plana vel infima teretiuscula. Capitula terminalia et axillaria, breve pedunculata vel sessilia, ovata, squamis inferne inter se connatis. Stigma continuum, fusiforme, hispidulum. Samara membranacea, dilatata, planiuscula, glahpa, basi breviter comosa. - R. Brown in Linn. Trans. 10, p. 70, prodr. p. 365 , Meisn. in pl. Preiss. 1, p. 499, 83.

38. P. DIVersifolia (R. Brown! in Linn. Trans. 10, p. 70, prodr. p. 365), foliis 2-3-pinnatifidis, junioribus ramulisque puberulis mox glabris, superioribus planis venosis, pinnis cuneato-petiolatis 3-partitis vel pinpatifidis,-lacinulis decurrentibus oblongo-lanceolatis acutis ineiso-dentatis integrisve, infimorum laciniis lirearisubteretibus, capituli squamis late ovatis acutis sericeo-tomentosis demum glabratis, calyce villoso. J In Terrâ Leeuwin (R. Br.! Menzies! in herb. Smith., Gilbert, n. 82 !), circa sinum Regis Georgii (Preiss, n. 637!) et in jugo Darling's Range, distr. Murray (Drumm, coll. 2, n. 297 ! Gilbert, n. 139!). - Meisn in pl. Preiss. 1, p. $449^{*}, 2$, p. 246. P. adiantifolia et rhoifolia Smith! mss. in hoŕb. Frutex

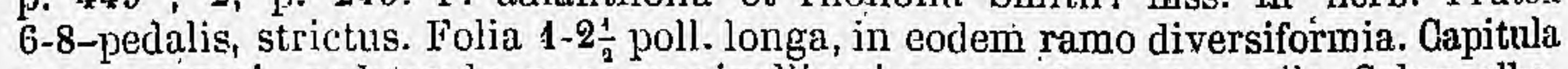
magn. cerasi, pedunculo nunc semipollicari squamato nunc nullo. Calyx albovillosus. Samara subbhomboiclea apice 3-loba. (v. s. in herb. Brown., etc.)

39. P. CARDUACEA (Neisn, in Hook. Journ: 1852, p. 182), foliis sessilibus oblongolanccolatis pinnatifido-dentatis acutis glabris, denlibus ovato-triangularibus 3-nerviis mucrunato-funguntibus infimis bilobis auriculæformibus, capituli squamis ovalis ar'utis glabris, calyce,... $\bar{J}$ In Norà-Hollandiâ occidentali interiore (Drumm. coll. 4, n. 262 !). Rami subvirgati, conferte foliosi, juniores pubescentes. Folia

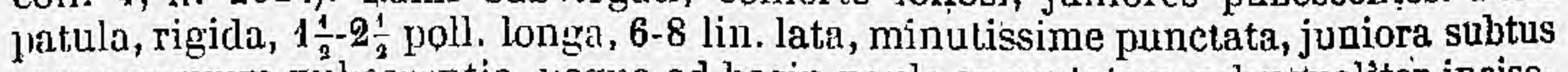
secus nervum. pulvesi'entia, usque ad hasin paulo angustatam subæqualiter incisodentata, dentibus oppositis circ. 3 lin. longis, nervis in mucronem rectum convergentilus. Cnpitula eire. pollicaria, pedunculo $2-4$ litb. longo adpresse squamato suffulta. Stylus brevis. Stigma fere 1 lin. longum, sulcatum, angulis hispidulis. Strobili squama: comnatie, demum sirje obtuse. Samara plana, tenuis, 4-5 lin. longa, 34 lin. lati, rlomboideo-ovata, acula, utrinque minute puberula, basi obsolete romosa. ( $\mathrm{r}, \mathrm{s}$. in herh. Shutileworth.) 


\section{Sect. v. GYLindrostrobus Endl. gen. suppl. IV,p. 76, e.}

Folia plana, tripartito-bipinnatifida. Capitula axillaria vel terminalía, ovata vel elongata, cylindrica, squamis ovatis discretis. Nucula intus margineque vel apice comosa. - Meisn. in pl. Preiss. 1, p. 502, z 5.

40. P. striat A (R. Brown ! suppl.p. 6), ramis patenti-pilosis, foliis nervoso-striatis scabriusculis trifido-bipinnatifidis, lobis lanceolato-linearibus mucronatis, capitulis axillaribus sessilibus ovoideis, squamis obtusis glabriusculis, intimis anguste oblongis ciliatis, calyce villoso, "stigmaté articulato. J In coloniả Swan- River (Fraser [), circa Perth et ad jugum Darling's Range (Drumm. coll. 1, n. 565! Preiss, n. 639 ! 640! Gilbert l). - Meisn, in pl. Preiss. 1, p. 502", 2, p. 246. Frutex 1-2-pedalis. Folia rigida, 1 $\frac{1}{2}-2 \frac{1}{2}$ poll. longa, lobis 1-2 lin. latis, petiolo lineariplano 5-12 lin. longo, 1-1 $\frac{1}{2}$ lin. lato. Galyx et stigma fere P. heterophyllæ, articulo superiore puberulo. Nux (ex Br.) comosa, apice angustata. (v. s, in herb. Brown., etc.)

41. P. AXILLARIS (Meisn. in Hook. Journ. 1855, p. 68), ramulis cano-tomentellis, foliis sessilibus bi-vel subtripinnatifidis lævibus glabris, lobis angiste linearibus pungentibus, capitulis axillaribus sessilibus ovatis, squamis acutis calycibusque sericeis, stigmate fusiformi inarticulato. ₹ In Noyâ-Holl. occid. interiore (Drumm. coll. 6, n, 166 !). Rami graciles, sulcato-striati, glabri, ramulis dènse foliosis.tomen-

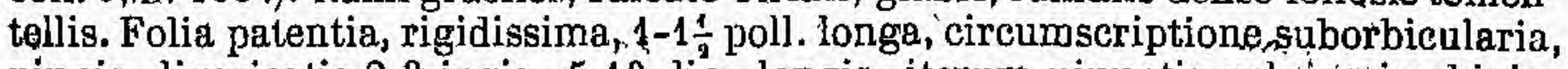
pipnis divaricatis 2-3-jugis, 5-10 lin. longis, iterum pinnatis vel passim bipinnatis, jugi infmis cæteris duplo brevioribus 2-3-lobis, rhachi marginata concala pinriulisque anguste linearibus subtus convexis et obsolete bisulcis striatisve $\frac{1}{3}-\frac{2}{3}$ lin. latis. Capitula solitaria, folium subæequantia, squamis 3 lin. longis denșe argenteo-sericeis demum glabratis fuscis. Calyx clavatus, 5-6 lin. longus, adpresse brevi-villosus argenteo-sericeus, laminis anguste oblongis. obtusis processii flliformi fuseo pilis abscondito apiculatis. Stigma $1 \frac{1}{3}$ lin. longum, sulcatum, minute puberulum, apice basique glabrum. Nuculạ ignota. (v. s. in herb. Shuttlew.) .

42. P. в Iт в R A TA (Meisn. in Hook. Journ. 1855, p. 69), ramulis cano-tomentellis, foliis attenuato-subpetiolatis biternatis læevibus glabris; segmentis linearibus cuneatis petiolo duplo latioribus nervoso-striatis apice 3-lobis, lobis lanceolatis pungenti-acutis, capitulo terminali globoso, squamis acuminalis viscidis interioribus tomentosis, exterioribus calyoibusque glabriusculis, stigmate fusiformi inarticulato. F In Novâ-Holl. occid. interiore (Drumm, coll. 6, n. 1681). Rami validi, striati, glabri, ramulis umbellatis adscendentibus densinscule foliosis apice tomen-

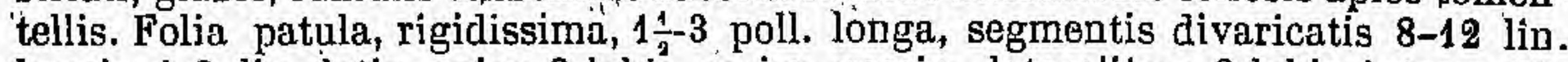
longis, 1-2 lin. latis, apice 3-lobis, rarius passinn lateralibus 2-lobis intermedio 5-lobo. Capitulum solitarium, sessile, magnit. juglandis, foliis patentibus cinetum. Calyx flavus? vel albidus viscidulus, gracillimus, laminis lineari-oblongis ultra partem concavam emtheriferam in cornu breve productis. Stigma $1 \frac{1}{3}$ lin. longum, parce puberulum, apice basique glabrum. Nucula (immatura) obovata, compressa, margine breviter apice longe albo-comosa, faciebus glabris. Species foliis accedens ad P. striatam et Isopogon ceratophyllum, ab utrấque tamen abunde distinctạ, inter utrumque genus quasi ambigua, posteriori fructu, magis tamen adhuc priori stigmate conveniens. (v. s. in herb. Sluttlew.)

43. P. Macrostachya (R. Brown! suppl. p. 7), ramis pubescentíbus, foliis attenuato-petiolatis trifido-bipinnatifidis nervoso-striatis scabriusculis, segmentis cuneato-linearibus oblongisve, lobis lanceolatis mucronatis, capitulis terminalibus axillaribusque sessilibus elongatis cylindricis; squamis acutis basi sericeis, calyce glabro, stigmale fusiformi inarticulato. F. In coloniâ Swan River (Fraser! Brumm. coll. 1, n. 575! Preiss; n. 638!). - Meisn. in pl. Preiss. 1, p. 502*. Habitus et folia fere P. strictæ. Capitula $1 \frac{1}{2}-2$ poll. longa, spiciformia. Calyx $4-5$ lin. Iongus, luteus? laminis mucronato-apiculatis. Stigma præcedentis. Nucula suborbicularis, toto margine albo-comosa. (v. s. in herb. Brown., etc.)

44. P. ShUt TLE OŔt Thana (Meisn. in pl. Preiss. 2, p. $246^{\circ}$ ), foliis nervoso-striatis trifidis ramisque glabris, segmentis divaricatis lanceolatis ducurrentibus mucronato-acuminatis petiolo cuneato subæqualibus, lateralibus inæequaliter bifidis integrisve, terminali subbreviore trifido, capitulo terminali breve pedunculato oblongo-cylindrico, squamis acutis sericeis, calyce głabro, stigmate fusiformi 
inarticulato. J In coloniả Swan River (Drumm. coll. 2, n. 298 !) Præcedenti arcte quidem affinis, sed bene distineta. Fol ia haud scabriuscula, segmentis $3-4$ lin.latis. Capitulum circ. pollicare, squamis demum obtusis. Nucula ovali-oblonga, undique comosa. (v.s. in herb. Shuttl. et Soc. linn. Lond.)

\section{Species non satis noto.}

45. P.? DUBIA (R. Brown! suppl. p. 7), ramulis tomento erispato pilisque strictis patulis villosis, foliis pinnatis canaliculatis, pinnis subulato-linearibus, infimis pinnatifidis, mediis bifidis, superioribus indivisis, capitulis terminalibus..... J In čloniâ Swan River (Fraser! suecim. capitulis nondum, expansis): Species propter stigma fructumque ignotum quoad genus omnino dubia, foliis accedens ad Isogogon. scabri nob. (non Lindl.) formam angustilobam, nec forsan ab eo specifice distincta.

46. P. RoEт (Endl. gen. suppl. IV, 2, p. 75, n. 60). Circa sinum Regis Georgii. Species nondum descripta, sectionis secundæ inter $\mathrm{P}$. canescentem et fastigiatam adscripta.

VII. ISOPOGON R. Brown in Trans. Linn. Soc. Lond. 10, p. 48 et 70, prodr, p. 365, suppl. p. 7, Knight. et Salisb. Prot.p. 93, Endl. gen.p. 337; n. 21.22, suppl. IV, 2, p. 76, Meisn. gen. p. 331 (244) et in pl. Preiss. 1, p. 503. - Atyli sp. Salisb.

Flores hermaphroditi, capitati, bracteis persistentibus imbricatis vel receptaculum planum paleaceum subinvolucrantibus decíduis. Calyx regulạris, 4-fidus, gracilis, diutius persistens, laminis concavis staminiferis. Antheræ 4 subsessiles, oblongæ vel lineares, connectivo producto apiculatæ. Squamulæ hypogynæ nullæ. Ovarium 1-loculare, 1-ovulatum. Stylus filiformis, deciduus. Stigma fusiforme vel cylindraceum, continuum vel-circa medium constricto-articulatum, glabrum vel in articulo inferiore solo puberulum. Nux 1-sperma, sessilis, aptera, undique comosa. - Frutices Novæ-Hollandiæ extratropicæ, orieitalis, australis et præsertim occidentalis, foliis sparsis rigidis teretibus planisve laciniatis vel rarius indivisis, summis sæpius approximato-subverticillatis capitulum involucrantibus, capitulis terminalibus axillaribusve solitariis subsessilibus globosis ovatisve strobiliformibus imbricatobracteatis, floribus roseis. - Genus Petrophilæ' habitu charactéribusque simillimum, stigmate et nuculâ præcipue dignoscendum. Sectiones duæ a cel. Brown propositæ (Eustrobilus et Hypsanthus Endl. gen. p. 337) majore specierum numero nunc cognito, non amplius servandæ nobis videntur, quia solum, quo innituntur, characterem, scil. involucri indolem, sæpius vix manifestum vel plane ambiguum et præterea parum naturalem, utpote species cæterum valde affines et foliis simillimas longe ab invicem separantem, invenimus.

\section{\$1. Folia tereti-fliformia indivisa. - Capitulum terminäle sessile, squamis imbricatis lanato-tomentosis.}

1. I. PETROPHIL OIDES (R. Brown I suppl. $p$. 7), ramis tomentosis, foliis crassilisculis mucronatis subexsulcis lævibus glabris, calycis tubo hirsutulo, laminís dorso glabris margine apiceque barbatis, stigmate fusiformi tenui glabriusculo medio subarticulato. J Circa sinum Regis Georgii (Baxter!) et in coloniâ Swan River (Drumm. coll. 1! Preiss, n. 679! 680!). - Meisn. in pl. Preiss. 1, p. 503 ${ }^{*}$. Frutex 3-pedalis strictus, ramis demum glabratis. Folia $1 \frac{1}{2} 2 \frac{1}{2}$ poll. longa, $\frac{1}{2}-1 \frac{1}{4}$ lin. crassa, passim subcomijressa. Capitulum magnit. jnglandis minoris. Calyx $4-5$ lin. longus, pubescentia albida. Stigma subfiliforme, infra medîum paulo constrictum, sub lente puberulum. (v. s. in herb. Brown., etc.)

2. I. SCABRIUSCULUS (Meisn, in Hook. Journ. 1852, p. 182), ramis cano-tomentosis demum glabratis, foliis spliacelato-submucronatis puncticulato-scabriasculis gla bris supra leviter 1 -sulcis, calyco glabro, laminàrum apice párce setuloso, stigrnate medio articulato infra puberulo. J In colonia Swan River (Drumm. coll, 4,n, 263 !) Folia 3-5 poll., rarius 2 vel usque ad 7 poll. longa, 1 Jin. crassa, recta, basi vix 
attenuata, suleo semper plus minus conspicuo nonnunquam satis profundo. Capitulum magniit. cerasi, sçuamis pưbe albâ sericeâ lanato-villosis, acứmine $\frac{1}{2}$ linn. longo glabriusculo adpresso. Gæet. fere I. petrophiloidis. (v. s. in herb. Sluuttlew.)

\section{\$2. Folia teretia trifido-vel pinnatim laciniata.-Capitula terminalia vel rarius etiam axillaria, sessilia, raro pedunculata, squamis imbricatis.}

3. I. TERETIFOLIUS (R. Brown! in Linn. Trans. 10, p. 71, prodr. n. 365), ramulis tomentosis, foliis levibus exsulcis trifidis pungentibus junioribus subsericeis, segmentis divaricatis $2-3$-fidis rarius indivisis biternatisve, capitulo terminali sessili subglobose, squamis ovatis villoso-tomentosis, exterioribus dilatatis demum glabratis, calyce serievo-pilosiusculo, laminis apice longius pilósis, stigmate fusiformi-infra medium subarticulatum puberulo. J In Terrâ Leeutwin (R. Br.I), circa sinum Regis Georgii (Preiss, n. 6811). - Meisn. in pl. Preiss. 1, p. 504*. Frutex 2-3-pedalis, ramis validis. Folia $2-4$ poll. longa, $1-1$ lin. crassa, segmentis $1-3$ poll. longis 3 -fidis vel rarius indivisis vel bis trifidis. Capitulum magnit. juglandis, squamis interioribus albido-tomentosis, fructiferis incrassatis deciduis. Calyx sericeus, flavescenti-argenteus.- Nucula ovata, styli basi caudata, undique albo-vel 'fulvo-comosa. (v. s. in .lierb. Brown., ctc., et v. v. c. in hort. Kew.)

3. cornigerus (Meisn. 1. c.), foliis crassioribus 3 -fidis, segmentis magis divaricatis plerumque petiolo brevioribus sepiusque indivisis bilobisve quam iterum trifidis. - In colonia Swan. River (Drumm. coll. 1! Preiss, n. 662, 668, 669, 675,677 ! Gilbert, n. 300!) et in distr. Hay (Preiss, n. 674, 685!). I. cornigerus Lindl.! Swan Riv. p. 34, n. 164.(v. s. in herb. Lindl., etc.)

4. I. PEDUNCULATUS (R. Brown suppl. p. 7), ramulis glaberrimis, foliis trifido-pinnatis glabris supra angustissime 1 -suleis, segmentis lateralibus bifidis, terminalis 3-fidi laciniâ mediá breviore, capitulo pedunculato ovato, pedunculo tomentoso. خ In coloniâ Swan River (Fraser).

5. I. VILLoSUS (Meisn. in Hook. Journ. 1852, p. 183), caule nano, foliis elongatis dichotomo-muultifidis subexsulcis sphacelato-mucronatis levibus glabris, junioribus villoso-tomentosis, capitulo terminali sessili globoso, squamis obovato-rhombeis setaceo-acuminatis calycibusque albo-villosissimis, stigmate cylindraceo sulcato glabro basi strumoso apice capitellato. 5 . In colonid Swan River (Drumm. coll. 5 , n. 399 !). Iffinis I. teretifolio, sed distinctissimus. Caulis circ. bipollicaris. Folia 6-10 poll. longa, minus rigida, tor vel quater dichotoma, nunquam trifida, laciniis ultimis $1-1 \frac{1}{2}$ poll. vel nonnunquam $5-2$ lin. longis. Capitulum magnit. juglandis. Calyx pụbe sericeả albâ vel flavescente lơngiusculì pateuti-villosus. Nucula ignota. (v, s. in herb. Shuttleworth.)

6. I. ANETHIFolios (Knight et Salisb. Prot. p. 94), foliis pinnatis supra 1-sulcis ramisque glabris, laciuiis 1-5-jugis mucronulato-acutis indivisis vel inferioribus srepe pinnatim 2-5-fidis, capitulis terminalibus et in summis axillis subsessilibus globosis, squamis ovatis, inferioribus acutis glabris, superioribus tomentosis cum acumine lineari-setaceo glabro, calyce sericeo, laminis dorso glabris nitidis apice breviter barbatis, stigmate subulato medio subarticulato infra puberulo $₹$ In NovâFollandià orientali, circa Port-Jackson (R. Brown! Sieber, n. 17 !): - R. Brown! in Linn. Trans. 10, p. 71, prodr. p. 365, Roem. et Schult. syst. 3, p. $340^{*}$. Protea anethifolia Salisb. prodr. p. 48. P. acufera Cav. ic. 6, p. 33, t. 549. P. furcellata Smith! mss. in herb. P. rangiferina Lee, ex Wendl. in herb. Roemer ! Rami virgati. Folia erecta, 4-5-pollicaria, laciniis 1-2 poll. longis, $\frac{1}{2}-\frac{2}{4}$ lin. crassis, subrugulosis, in mucronulum sphacelatum attenuatis. Capitulum diametro circ. pollicari, nonnunquam peduncilo brevissimo turbinato dense imbricato-squamato suffultum,

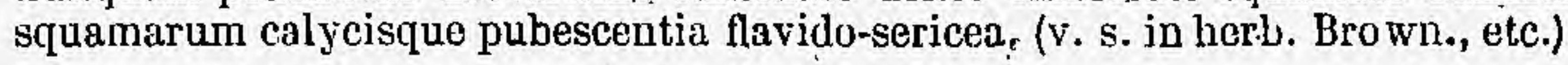

7. I. DIVERGENS (R. Brown! süppl. p. 7), foliis pinnatis sulcatis ramisque glabris, segmentis 1-3-jugis elongatis indivisis vel rarius 2-3-fidis terminali longiore, capitulo termináli sessili oblongo-ovato, sıuamis tomentosis, calycis glabri laminis apice albo-barbatis, stigmate tenui supra medium articulalo infru hispidulo. 5 In coloniâ Swan River (Fraser! Ylenzies! Drumm. coll. 1, n. 560! 573 ! Preiss, n. 667! 073! Gilbert, n. 306!). - Meisn. in pl. Preiss. 1n. 505 *. Frutex 3-4-pedalis, corymhoso-vel fastigiato-ramoso. Folia rigida, $2-4$ poll. longa, $\frac{1}{2}-\frac{2}{3}$ lin. crassa, obsolete 
rugosa, supra 1-sulca; laciniis sphacelato-mucronulatis vix pungentibus terminali solà vel omnibus 2-3-vel raro 3-5-fidis. Capitulum vix 14 lin, longum, squamis ovatis, infimis rostrato-acuminatis glabriusculis, superioribus dilatatis apiculo brevi subrečurvo tarde deciduo. Calyx 4-5 lin." longus, lilaçino-griseus. Stigma 2 lin. longum. Receptaculum ovoideum vel conicum, villosum. Nucula ovatooblonga, acuta, undique albo-comosa! (v. s. in herb. Brown., etc.)

8. I. HETER OPH YLUUS (Méisn. in pl. Preiss. 1 , p. $504{ }^{*}$ ), ramis apice puberulis, foliis crassinsculis sulcato-striatis glabris indivisis 3 -fidisque, laciniis integris vel rarius bifidis petiolum subrequantibus mucronatis, capitulo terminali inter folia simplicia ipso duplo longiora sessili, squamis late ovatis subsericeo-villosis, acumine brevi glabro..... ' J In Noyà-Hollandia austro-occidentali (Preiss, n. 672 1). Rami apice cinereo-subtomentosi. Folia erecta, $2-3$ poll. longa, fere 1 lin. crassa, fortiter sulcato-rugosa et sujpra 1 -sulca, floralia omnia et inferiorum nonnulla indivisa, reliqua semitrifida, laciniis sphaeelato-mucronulatis sæpe clavato-inerassatis, terminali quandoque furcatâ. Capitulum subglobosum, magnit. juglandis, sq̣uamis sordide albidis adpresse-villosis demum deciduis, recéptaculo conico-ovato sericeo-villoso. Cæat. ignota. (v. s.)

9. I. FoR M U US (R. Brown! in Linn. Trans. 10, p. 72, prodr. p. 366), foliis rugosis glabris supra 1-sulcis triternato-bipinnatifidis, laciniis divaricatis acutiş, capitulis terminalibus axillaribusque sessilibus subglobosis, squamis ovatis tomentosis villosisve acumine glabriusculo, calyce glabro, laminis apice breve barbatulis, stigmate supra medium articulato infra stupposo. $\delta$ In Terrấ Leeuwin (R. Brown!); circa sinum Regis Georgii et promont. Riche (Preiss, n. 776, 778, 783, 784, 687) et in colonià Swan River (Drumm. coll. 1; 2, n. 295, 3, n. 247, Gilbert, n. 61! Molloy!). - Bot. reg. t. 1288, Meisn. in pl. Preiss. 1, p. $506^{k}, 2$, p. 247. Frutex 2-3-pedalis, ramis conferte foliosis cinereo-tomentosis vel (præcipue in var. a) glabris. Folia süberecta, rigida, $1-3 \frac{4}{2}$ poll. longa, $\frac{1}{2}-\frac{2}{3}$ lin. crassa, plerumque regulariter 3 -ternata ramulorum sterilíum minus divisa vel passim simplicia, vix pungentía. Capitula magnit. cerasi, interdum brevissime pedunculata. Flores rosei, antherís luteis vel aurantiacis. Formæ sequentés forsan species dịstinctæ, attamen observantur formæ ambiguæe (v. g. Preiss. n. 683!) capituli squamis cum $\alpha$, reliquis vero notis omnino tum $\beta$ convenientes.

a. eriolepis, ramulis sæpius glabris, foliis minus rugosis, lacinitis saltem ultimis canaliculatis, capituli squamis omnibus late obovatis dense albo-tomentosis lanatisve, margine semicirculari acuminulato vel mutico fusco glabris (Preiss, n. 687 !). (v. 8.)

B. dasylepis, ramulis incano-tomentosis, fohiis magis rugosis, laciniis anguste 1 -suleis (nec unquam canaliculatis), capituli squamis ovatis acutis longiuscule tomentosis (sordide albídis), infimis longioribus oblongo-triangularibus apice vel lobis glabrescentibus. I. formosus R. Br.l fide sp. autograph. in herb. DG. (Drumm, n. 295! Preiss, n. 670 ). Gapitulum ob nucularum comam inter squamas prospicientem quasi sericco-villosum videtar. (v.s.)

10. I. ADENANTH OIDES (Meisn. in Hook. Journ. 1855, p. 69), ramulis incanis, foliis tenuibus ultra medium trifidis, lobis indivisis exsulcis mucronatis ramisque patulo-pilosis; capitulo terminali paryo, squamis sericeo-lanatis albis, ealyce glabro, laminis apice breve pilosiusculis, stigmate medio articulato supra tenui glabro infra anguste clavato tomentello. $尹$ In Novâ-Hollandiâ occidenitálí interiore (Drumm: coll. 6, n1. 171!). Species facie similis Adenanthæ sericeæ, et potius ad Petrophilas nonnullas, imprimis P. Serrurise accedens quam ad ullam Isopogonis speciem hucusque cognitam, sed stigmate fructuque omnino posteriori generi conveniens. Rami subcorymbosí vel fastigiati. Folia conferta, erectá, rigida, 7-10. lin. longa, petiolo brevi semitereti, laciníis teretibus 3-6 lin. longis, intermedià paulo longiore. Capitulum sessile, maguit: cerasi minoris, foliis ex parte indivisis dense cinctum et superatum, squanis parvis late ovatis acutis. Galyx pollicaris, gracillimus, laminis dorso nitidis apice minute albo-penicillatis. Stigma fusiforme, $1 \frac{1}{2}$ lin. longum, articulo superiore, subulato basi incrassato, inferioro anguste clavato. Nucula undique longe flavido-comosa. (v. s. in h. Shuttlew.).

\section{\$3. Folia plana laciniata, laciniis interdum canaliculatis.}

11. I. Aspen (R. Brown! suppl. p. 8), ramis pubescentibus, foliis punctato-stabriusculis pinnatis, laciniis 2 -4-jugis anguste linearibus canaliculatis dorso carinatis 
plerumque indivisis acutis, capitulis axillaribus sessilibus subglobosis, squamis imbricatis ovatis acuminatis patentibus membranaceis inferne villosiusculis, calyce glaberrimo, stigmate acutiusculo supra medium articulato infra puberulo. 5 In Coloniả S,wan River (Fraser ! Drumm. coll 1, n. 574 | Preiss, n. 689!), - Meisn. in pl. Proiss. 1, p. 505* . I. scaber Lindl.! Swan Riv. p. 34, n. 165 (non Bot. mag., ńec Meiśn. l. c.). Frufex pedalis, caule erecto simplici stricto. Folia conferta, érecta, in axillis sæpius fasciculata, 7-14 lin. longa, laciniis indivisis vel rarius semitrifidis vix $\frac{1}{2}$ lin. latis, sub lente parce papilloso-scabriusculis. Capitula magnit. cerassi, quandoque plura in unum magnum conflata. Cæt. fere I. divergentis. (v, s. in herb. Brown., Lind1., etc.)

12. I. n oSEUS (Lindl. in Bot: reg. 1842, misc. not. p. 39, n.37), ramulis tomentosis, foliis pubescentibus glabrisve scabriusculis biternatis, segmentis planis cuneatis subæqualibus, lateralibus 2-3-fidis, terminali 3 -fido vel pinnatim 5-7-secto, laciniis lateralibus lanceolatisve mueronatis canaliculatis venosis, capitulis terminalibus axillaribusque sessilibus globosis, squamis ovatis intimisclue lanceolatis acutis subsericeis tomentosisve, calyce glabro, laminis elongatis apice breve albocomosis, stigmate medio articulato infra stupposo. JIn coloniâ Swan-River (Drumm. coll. 1, n. 563! 56 k1. Collie! Preiss, n. 682 | 686 1).- I. scaber Meisn. in pl. Preíss. 1, p. 506 * (non Lindl.). Petrophila dubia R. Br. suppl. p. 7? (species obscura, foliis saltem huic simillima). Frutex4-7-pedalis, affinis I, aspero, sed distinctus foliis majoribus, planis, calycis límbo fere duplo longiore. (v. $\mathrm{s}$ in herb. Lindl., Soe. linn., etc.)

a. latiloba (Meisn. l. c. p. 507), foliorum segmentis egregie cuneatis distincte venoso-striatis apice 3-4 lin. latis breve trifidis. I. scaber Bot. mag. t. 4037, ic. optima, peccans tantum stigmatis articulo superiore pubescente. (v. s.)

B. angustiloba (Meisn. 1. c.), foliprum segmentis linearibus ( $\frac{1}{2}-1 \frac{3}{3}$ lin. latis) vix cuneatis profunde divisis minus venosis.-Syecim. multa v. g. Drumm. n. 563, inter $\alpha$ et $\beta$ medium tenent. (v. s.)

13. I. ANE M ONIFOLIUS (Knight et Salisb. Prot. p. 93), foliis biternatisectis bipinnatifidisque levibus, segmentis planis-cuneatis petiolo subteretı supra 1-sulcu plerumque longioribus, laciniis linearibus acutis eveniis semipatentibus, capitulo terminali sessili sphæreroideo, squamis late ovatis, 'exterioribus acutis glabris, interioribus stupposo-tomentosis apiculo glabro deciduo, calyce glabro, laminis apico pilosiuseulis, stigmate continuo tenui infra medium puberulo. 5 Cirea Port-Jacklison. - Brown! in Linn. Trans. 10, p. 79, prodr. p. 366, Lodd. Bot. cab. t. 1337, Ruem. et Scluult. syst. 3, p. 340*. Protea ancmonifolia Salisb. prodr. p. 48, Sims Bot. náag. t. 697, Andr. Bot. repos. t. 332. P. tridactylites Gav. ic. 6, p. 33, t. 548. P. apifolia Smith! mss. in herb. P. divaricata Audr. Bot. repos. t. 465? var.? fide R. Br. in Linn. Trans. 10, p. 218. Frutex 4-6-podalis. Folia 2-3-pollicaria. Capitulum magnit. juglandis. Flores flavi ex ic. et Link énum. alt. p. 111. (v. s.)

a. glaber (R. Br. suppl.p. 8), foliis adultis utrinque ramulisque glabris (R. Browil ! Sieber herb. N.-Holl. 11. 18! fl. mixta, 12. 480! Anderson, n. 59! (ctc.)

B. pubescens (R. B. l. c.), ramulis incanis sericeis, foliis adultis utrinque tenuissime pubescentibus. (Caley.)

14. I. petrotafis (A. Cunningham! mss.), foliis trisectis ramulisque tomentosopuberulis, segmentis subæqualibus petiolu semitereti brevioribus cuneato-linearibus planis divaricatis 2-3-partítis pinnatifidisve utrinque nerroso-striatis punctato-scabriusculis lacinulis aculis, capi tulo terminali subsessili sphæroideo; squamis latis tomentosis apiculo subulato glabriusculc abrupte cuspidatis, floribus... $5 \mathrm{In}$ Novâ-Hollandiả orientali interiore (A. Cunningh.!) et circa sinum Moreton Bay (A. Gunn. n. 8 ! in Mitchell exped. 1835, fide herb. Lemann.). - R. Brown! suppl. p. 8. Folia præcedenti similia, sed majora, incluso petiolo $1 \frac{1}{3}-3$ poll. longo, 21-5-pollicaria, lacinits $1 \frac{1}{2}-2 \frac{1}{9}$ lin. latis subparallelc striatis mueronatis, nltimis plerumque dentiformibus $2-1$ lin. longis, pubescentià brevi subdensà tarde evanescente. Capituli squamre sordide albo-tomentosx. Flor. et fr. ignoti. ( $r$. s. in hrerb. Brown., Gunn., DC., etc.)

15. I. C E.R A T O P Y Y L U S (R. Brown! in Linn. Trans. 10, p. 72, prodr. p. 366), fuliis bi-triternatis vel bifido-bipinnatis levibus glabris, segmentis petiolo canaliculato hrevioribus laciniisque divaricatis planis linearibus mueronato-acutis eveniis 
ruguloso-striatis, floralibus basi dilatatis sæpe simpliciter triflis, cápitulo terminali globoso, squamis ovatis oblongisque acuminatis inferne, sericeo-lanatis, calyce glabro laminis apice barbellatis, stigmáte tenui subarticulato infra medium puberulo. $亏$ In orâ meridionali, circa Port-Philipp (R. Brown!), Victoria et Adelaide (Latrobe! Ferd. Mïller!), Flinders Island in Freto Bass (Gunn. fide Hook. fil. in Hook. Lond. Journ. 6, p. 282*). I. horridus Ferd. Müll.! mss. Facies fere I. anemonifolii, sed folia rigidiora, pungentia, longius petiolata, laciniis divaricatis, capitula paulo minora:

3.? Mitchellii , foliorum laciniis angustioribus puncticulato-scabriusculis, vix rugulosis, ultimis sæpe semiteretibus, capitulis axillaribus breve pedunculatis. - In Novâ-Holl. orientali interiore (Mitchell l exped. 1835 et 36). Flores ignoti. Forsan sp. distincta. (v. s. in herb. A. Cunningh. et Eindl.)

16. I. BAXTER I (R. Brown suppl. p. 9), ramulis patenti-pilosis demum glabrescentibus, Poliis sessilibus cuneato-ubovatis trisectis utrinque nervosís puberulis mox glabris, segmentis grosse inciso-dentatis, dentibus lobisve mucronato-spinescentibus, capitulis axillaribus terminalibusque aggregatis sessilibas globosis, squamis exterioribus setaceis plumosis, interioribus oblongis lanceolatisque acutis eiliatis

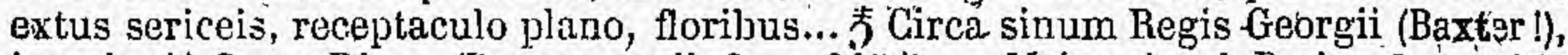
in colonià Swan River (Jrumm. coll. 3, n. 2451 ). - Meisn. in pl. Preiss. 2, p. 247, Bot. mag. t. 3539. Frutex ut videtur elatior, ramis erectis validis, sæépe umbellatis. 'Folia stirpis juvenilis indivisa vel apice dentata (ex Br.), adulttæ rigidissima, lævia, patula, 1-2 $\frac{1}{2}$ poll. longa, extra medium 3-loba, lobis $4-6$ lin. latis longisque subcuneatis apice in lobulos dentesve 3-5 ovatos vel tríangulares 1-3 lin. longos stepe, bilidos divisis, nervis venisque laxe reticulatis atriaque prominulis; Capitula singula magnit. ccrasi majoris, plerumque plura in unum mole pomi minoris arcte congesta, squamis interioribus vix 1 lin. latis. Flores (ex ic.) rosei. (v. s. in herb. Brown. et Shuttil.)

17. I. TRIPAR TITUS (R. Brown suppl. p. S), ramulis tomentosis, foliis cuneatis planis venosis glabris 3-lobis vel passim indivisis, lobis lanceolato-linearibus integerrimis basi attenuatis; capitulo terminali sessili subgloboso demum ovato, squamis cuneato-obovatis cum apiculo brevissimo tomentoso inferne glabris. 5 Cirea sinum Regis Georgii (Baxter), al flum. Gordon, distr. Kay (Preiss, n.666! Drumm. coll..3, n. 2461). - Meisn. in pl. Preiss. 2, p. 247. I. trilobus Meisn. ibill. 1, p. 507 *non R. Br.). Frutex $1 \frac{1}{3}$ pedalis. Folia 2-3-pollicaria, laciniis semipatentibus petiolo plerumque patlo brevioribus, $1-1 \frac{1}{2}$ poll. longis, $1 \frac{1}{2}=2$ lin. Jatis, obtusiuscule mucronulatis, terminali quandoque bificlâ. Capitulum defloratum, magnit. cerasi, fráctiferum $1 \frac{1}{2}$-pollicare. Calyx (ex spec. Drumm.) parvus, gracilis, luteo-albus, sub lente adpresse puberulus subscriceus. Stigma fusiforme, continuum, tenue, sulcatum, glabrum. Nucula ovato-oblonga, styli basi caudata, undique albo-comosa. Species, fatente ipso col. auctore; forsan mera var. sequen lis, ct revera ex ejụs diagnosibus saltom non elucch, qu'omodo differant. (v. s.)

18. I. TR I o B US (R. Brown in Iinn. Trans. 10, p. 72, prodr. p. 366), ramulis tomentosis, foliis cuncatis planis trilobis basi attenuatis petiolatis, lobis integerrimis... Jे In Terrà Leeuwin (R. Br.)

$\beta$ ? tridens (Uleisn. in Hook. Journ. 1855, p. 70), foliis petiolatis cuneato-oblongis rugoso-striatis glabris apice 3 -fidis vel tridentatis (passim integerrimis), lobis mucronatis lateralibus divergentibus, capitulo terminali globoso; squamis acuminatis albo-sericeis, floribus... $₹$ In planitie arenosâ, circa Diamond Spring, in Nov.-Holl. occirl. interiore (Drumm. coll. 6, n'. 170!). Forsan nova sp., cfr. Drumm. in Hook. Journ. 1853, p. 178, sed e specim. suppetent. hand sufficicienter dignoscenda, ab I. tripartito saltem certe distincta. Ramuli subcorymbosi, apice minute parceque cano-tomentelli. Folia erecta, rigida, $2-3$ poll. longa, apice 5-10 lin. lata, petiolo 8-14 lin. longo, subtereti supra 1-suleo vel subcanaliculato, laminâ' utrinquo nervis semiimmersis dense rugoso-striatà (passim sublevi), glaberrimâ, apice grosse 3-dentatâ, dentibus late triangularibus ovatisve mucrone brevi recto sphacelato pungentibus; infimorum summorumque nomnulla integerrima vel passim 2-3-mucronata', spathulata, 2 joll. louga, 2-5 lin. lata. Capitulum defloralum magnit. cerasi, squamis ircte adpressis 2-3 lin. longis, exterjoribus avatis, acumine brevi sphacelato, interioribus lanceolatis. Cret. ignota. ( $v$. $s$, in herb. Shuttlowis) 


\section{\$ 4. Folia plana, indivisa, integerrima (infimis interdum passïm trilobis, cfr. I. longifolium). - Capituli receptaculum planius- culum vel convexum, paleis deciduis tectum, squamis cinctum. rarius elevatum imbricato-squamatum.}

19. I. L 0NGIfoliu's (R. Brown! in Linn. Traus. 10, p. 73 , prodr. j. 366 ), foliis lineari-lingulatis elongatis venoso-striatis sphacelato-mucronulatis ramulisque glabris, capitulo terminali sessili subgloboso, squamis late cuneato-obovatis apiculatis toto dorso villosis, calyce adpresse sericeo-villose, stigmate inarticulato glabro, J In Terrâ Leeuwin (R. Br.!), circa sinum Regịs Georgii (A. Cunningh.! Preiss, n. 530 (665!). - Bot. reg. t. 900, Meisn. in pl. Preiss. 1, p. $507 \times$ Rami graciles. Folia 3-6-pollicaria, 3-rarius 5-6 lin. lata, in petiolum semiteretem longe attenuata, inferiora passim 3-fida. Capitulum magnit. juglandis majoris. Calyx sulfuren-argenteus, sericeus. Stigma fusiforme, tenue, sulcato-quadrangulum. (v. s. in herb. Brown., etc.)

20. I. A T TENUATUS (R. Brown! 1. c. p. 73. ct 366), foliis spathulato-oblongis lingulatisque longe attenuato-petiolatis mucronulatis licvibus ramisque glabris, capitulo terminali sessili globoso, squamis exterioribus ovatis acutis glabriusculis, interioribus villosis, calycis tubo glabro, laminis villosis, stigmate inarticulato glabro. J In Terrâ Leeuwin (R. Br. I Preiss, n. 663!), circa sinum Regis Georgii (A. Cunninght.!) ot in colonià Swan River (Drumm. coll. 2, n: 294 1). Caules vel rami simplices, 4-6-jollicares, apice conferte, inferne parce foliosi. Folia 4-8 vel infima 1-3 poll. longa, mucrone brevi sphacelato obtuso sæpe obliquo, nervis immersis. Capitulum magnit. juglandis. Calyx 4-5 lin. Jongus, laminis tubo parum brevioribus pube sericeà pallide flavidâ plumosis dorso glabrescentibus. Stigma tenue, cylindraceum, supra basin leviter constrictum subsulcatum.

$\alpha$. dilatatus, foliis summis oblongo-spathulatis (10-12 lin. latis) ex apice obtısissimo cuspidulatis 3-nerviis obsolete venosis, petiolo basi dilatato (Preiss n. 663 !) Folia inferiora attenuato-acuta sub-1-nervia. (v.s.)

$\beta$. angustatus, foliis omnibus lineari-spathulatis (3-6 lin. Iatis) apice attenuatoacutis 1 -nerviis eveniis, petiolo basi vix dilatato. (Drumm. coll. 2, n. 294 l) Folia inferiora interdum obsolete 3-nervia. (v. s.)

91. I. uncinatus (R. Brown ! suppl., p. 8), caulo ablbreviato vel subnullo aggregatopolycephalo, folíis elongatis lineari-gladiatis attenuato-acutis rugulosis glabris sublus prominulo-1-nerviis submarginatisque, acumine recurvo, capitulis sessilibus subglobosis, squamis ovatis villosis, calycis tubo fliformi, inferne glabro, laminis patulo-villosis, stigmate inarticulato e basi incrassatâ subulato purberulo. 亏 Circa sinum Regis Georgii (Baxter! Preiss, n. 758! Drumm. coll. 3, 12. 243!). - Meisn. in pl. Preiss. 1, p. $509^{*}, 2$, p. 247. Speóes distinctissima. Folia erecta, rigida, conferta, 6-12 poll. longa, 3-4 lin. lata, nonnulla interdum triplo minora, apice fere semper altenuato plus minus hamata. Capitula magnit. cerasi. Calyx 10 lin. longus, pubo dẹnsà sericcâ sulfureâ, laminis tubo multo brevioribus. Stigma 1 lin. longum. (v. s. in lierb. Brown., etc.)

22. I POLYGEPHALUS (h. Brown in Linn. Trans. 10, p. 73, prodr. p. 366), ramulis tomentosis, foliis lineari-oblongis mucronulatis, capitulis subaggregatis, bracteis omnibus lanatis, stigmate cylindraceo. $J$ In terri Leeuwin. (R. Br.)

23. I. SPII AROCEPHALUS (Lindl.I Swan Iiv., p. 34, n. 163), ramis patenti-pilosis tomentosiscue, foliis sessilibus lineari-lanceolatis mucronulatis nervosis puberulis scabriusculis, capitulis terminalibus axillaribusque subglobosis, squamis ovatis acuminatis villosis, calycis tubo glabro, laminis crispato-villosis, stigmate infra medium articulato stupposo supra subulato glabro. $\bar{J}$ In coloniâ Swan River (Drumm. coll. 1, n. 559! Preiss, n. 688! Gilbert!).-Meisn. in pl.Preiss. 1, p. 508*, Bot: mag. t. 4332 cum descr. optimà. Frutex 4 -pedalis, ramis virgatis strictis foliosis. Folıa rigida, 2-4 poll. konga, 2-5 lin. lata, summa sæpius $\frac{1}{2}-1$-pollicaria 1 lin. lata, juniora (ex Lindl.) sericea. Cupitula magnit. ccrasi vel juglandis, sessilia vel grove pedunculata, nunc omnia terminalia, nunc axillaria approximata spicam foliosam scipe semipedalem formantia, s'quamarun interiorum acumine subfiliformi. Calỵx 5-6 lin. longus, luteus, pube deusâ sericeâ sordide flavidâ. Stigma $1 \frac{1}{3}$ lin. longum, articulo inferiore breviore obovato. ( $\mathrm{r}, \mathrm{s}$. in herb. Lindl., etc.) 
24. I. L I NE A IS (Meisn. in Hook. journ. 1855, j. 69), ramis incanis, foliis sessilibus linearibus mucronulatis 1 -nerviis penniveniis puberulis basi attenuatis, capitulo terminali globoso, 'squamis acutis cano-puberulis, calyce. glabro, stigmate medio artículato infra clavato tomentello supra conico-subulató glabro. $ち$ In Novâ Hollandia occidentali interiore ad montes Gardener's Range prope Dundagaran. (Drumin. coll. 6, n. 169 ! cfr. Hook. journ. 1853, p. 178). Frutex pedalis. Ramuli subumbellati, juniores subvelutini. Folia semipatula, rigida, $1 \frac{1}{9}-2 \frac{1}{2}$ poll. longa; $1 \frac{1}{2}-2$ lin., basi vix $\frac{1}{2} \mathrm{Hn}$. lata, ex apice obtusiusculo mucronulata, nervo venisque utrinque prominulis, margine nerviformi basin versus sæpius incrassato. Capitulum magn. juglandis, foliis superatum, squamis ovato-oblongis demum glabrescentibus, interiøribus apice albo-barbatis. Calycis rosei laminte ołlongæ obtusæ. Spocies procedenti similis quidem, sed jam calyce glabro, stigmate etc., facile dignoscenda. (v. s. in herb. Shuttleworthi.)

25. I. SP ÁT H U L A T U (R. Brown ! suppl., p. 8) ramulis pubescentibus proliferis, foliis confertis pollide brevioribus cuneato-obovatis vel sublinearibus enervíis lævibus glabris apiculo acuto, capitulo terminali sessili foliis superato, squamis oblongolanceolatis acutis inferne albo-villosis, calycis tubo tenui glabro, laminis barbatis, stigmate subarticulato cylindraceo puberulo apice glabro. 5 Circa sinum Regis Georgii (Baxter ! Preiss !), Swan River (Drumm. !). - Meisn. in pl. Preiss. 1. p. 509 (excl. Preiss., n, 654.) II, p. 247.

๙. obovatus (R. Br. suppl. p. 9.), foliis obovatis planis, basi attenuatis (Drumm. coll. 3, n. 249 !). Folia 5-10 lin. longa, ex apice rotundato 2-3 lin. lato minute mucronulatá, basi vix 1 lin. lata. (v. s.)

ß. linearis (R. Br. l. c.), foliis linearibus vel subspathulatis canaliculatis dorso convexis (Preiss. n. 655 ! Drumm. coll. 5,n. 395!).-Bot. mag. t. 3450. Frutex 3-pedalis, corymboso-ramulosus. Folia 3-6 lin. longa, 1-2 lin. lata, acuta vel obtusa. Flores rosei. (v. s.)

26. I. BuXIFolius. (A. Brown ! in Linn. Trans. 10, p. 74, prodr. p. 367), ramis cano-tomentosis proliferis, foliis confertis subimbricatis sessilibus subpollicaribus ovatis vel oblongis vel obovato-oblongìs acutis mucronulatis 1 -nervijs eveniis lævibus glabris basi parum attenuatis, capitulo terminali sessili folia subæquante squamis lineari-subulatis, calycis unguibus glabris, laminis patenti-villosis, stigmate subcontinuo fusiformi glabrn. J In Terrà Leeuwin (R. Br !), circa sinum Regis Georgii (Preiss n. 654 !) et in Colonià Swan River (Drumm. coll. 5, n. 356!). I. spathulatus a obovatus Meisn. in 'pl. Preisss. 1. p. 509, quoad plant. Preiss. (non R. Br.) A præcedente differt foliis majoribus, basi vix attenuatis, nec unquam spathulatis, ad insertionem $1 \frac{1}{2}-2$ lin. latis, nervo subtus infra melium obtuse prominulo, stigmate glabro vix articulato, etc. (v. s. in herb. Brown., etc.)

27. I. AXILLARIS (R. Brown! 1. c., p. 74 et 367), folís sessilibus cuneato-vel spathulato-lingulatis mucronulatis subenerviis levibus ramulisque glabris, capitulis axillaribus sessilibus vel breve pedunculatis ovatis, squamis imbricatis ovatis obtusis ciliatis puberulis mox glabris, calycis tubo tenui glabro, laminis sericeo-villosis, stigmate fusiformi medio subconstricto infia tomentoso supra glabro. $う$ In Terrâ Leeuwin (R. Br. l), circa sinmm Regis Georgii (Preiss 11. 653 !). - Guillemin ic. lithogr. t. 19, Hook. ic. t. 438, Meisn. in pl. Preiss 1, p. 510. Frutex 4-5-pedalis, strictus, ramis gracilibus laxiuscule foliosis. Folia 1-3 poll. longa, 2-4 lin. latá, apice obtuso vel rotundato oblique sphacelato-mucronulata. Involúcrum fuscum, magnit. cerasi minoris, interdum pedunculo 3-4 lin. longo suffultum. Calyx 8-10 lin. longus. (v. s. in herb. Brown,, etc.)

28. I. LATIFOLIUS (R. Brown! p. 8), ramulis tomentosis, foliis cuneato-obovatis glabris, nervo venisque primariis subtus manifestis, capitulis depresso-globosis, receptaculo hemisphærico. : Circa sinum Regis Georgii (Baxter !)

$\beta$ ? Preissii (Meisn. in pl. Preiss. 1, p. $508^{k}$ ), ramulis glabris, foliis lánceolato-vel obovato-oblongis utrinque altemuatis, nervo venisque obsoletis. Ad montem Wuljenup, distr. Plantagenet (Preiss, n. 664!). Frutex 7-pedalis. Fólia inferiora 4 poll. longa, 14 lin. lata, superiora decrescentia, obtuse sphacelatoapiculata, subtus obscure triplinervia vel penitus evenia, summa capitulum vix superantia; novella cum ramulis sericeo-villósa. Capitulum terminale, sessile, demum conico-hemisphrericum, squamis obovato-oblongis albo-lanatis, acumine brovi acuto glabriusculo recurvo-patulo. Flores ignoti. (v. s.) 
$\gamma$. lanceolatus, ramulis apice tomentosis mox glabris, foliis lanceolatis utrinque æqualiter attenuatis - ln colonid Swan River. (Drumm. coll. 5, n. 397 !) Folia 1 $\frac{1}{2}-2 \frac{1}{2}$ poll. longa, 4-6 lin. lata. Involucri scuamæ intériores s. paleæe lineares, sebaceo-acuminata barbatæ reflexæ. Calyx gracillimus,fere pollicaris, glaber, laminis $1 \frac{1}{2}$ lin. longis apice albo-barbellatis. Stigmatis articulus inferior 4-gonus glaber, superior sublongior subulato-attenuatus dense patenti-stupposụs apice glaber. Cret. ut in vur. 3 . Nimis fere accedit ad I. Loudoni, attamen præsertim. calyce longiore stigmateque distinguendus, (v. s. in herb. Shuttl.)

29. I. PвотEA (Meisn. in Hook. Journ. 1852 , p. 183), ramis apice sericeo-incanis, foliis segsilibus elliptico-oblongis utrinque subæqualiter attenuatis planis lævibus eveniis apice obtuse sphacelato-callosis, capitulo terminali magno breve pedunculato folia superanto globoso, squamis arcte imbricatís, exterióribus late ovatis obtusis sericeis, interioribus lanceolatis, caljce tenui glabro, laminis apice brevo barbeliatis, stigmale infra - medíum articulato tomentoso supra patenti-hispidulo apice glabro. 5 In coloniâ Swan River (Drummond coll. 5, n. 398 !).-Pulchra speeies, foliis capituloque Proteis quibusdam Capensibus similis, ad Isopog. latifolium valde quidem accedens, sed, ni fallor, bene distincta. Rami cito glabrescentes. Folia 3-4 poll. longa, 12-15 lin. lata, nec cuneata nec obovata, subtus vel utrinque infra medium obsolete tri vel triplinervia, nervis brevi cursu evanescentibus interdum venâ unâ alterâvve connexis, venis cuettris inconspicuis. Capitulum diametro fere bipollicari, pro genere maximum, squamis adpressis convexis enerviis 4-5 lin. latis demum inferne glabresccntibus. Calyx 15 lin. longus, limbo tubo filiformi parum crassiore stlgmateque 2 lin. longo, hujus articulis sulcatis, superiore longiore injerne (sicut articulus inferior) flavo-tomentoso medio pilis rigidis albis subretrorsis barbellato apice subulato obtusiusculo glabro. (v. s. in h. Shuttleworth.)

30. I. LoudoN I (Baxter mss.), foliis sessililibus lanceolatis lingulatisve utrinque attenuatis sphacelato-apiculatis lævilous eveniis ramulisque glabris, capitulo terminali sessili globoso, squamis arcle imbricatis rotundatis apiculatis sericeis demum glabrescentibus, calyce glabro, laminis apice breve barbatis, stigmate articulato fusiformi medio stupposo-hispidulo, articulo superiore paulo longiore fere toto glabro. J Circa sinum. regis Georgii (Baxter). - R. Brown suppl. p. 9, Bot. Mag. t. 3421. An satis distinctus ab I. latifolio? cujus var. $\beta$ inter utramque speciem ambigua. Similis quoque $I$. attenuato, sed bene distinetus foliis brevioríbus (3-4 poll. longis) crassioribus, basi latiuseulẩ sessilibus, calyce (semipollicari purpureo) excepto apice laminarum glaberrimo, stigmale, etc.. (v. s. cult. in hort. Kew. in herb. A. Cunningh.)

31. I. cune a tus (R. Brown in Linn. Trans. 10, p. 73, prodr.p. 366), foliis oblongocuneatis obtusissimis, capituli squamis tomentosis, calyce glabro, stigmate fusiformi. F In terrâ Leeuwin (Menzies, in herb. Banlss.). Species obscura, e diagnosi nimis brevi a procedentibus evidenter proxime affinibus haud rite dignoscenda. Specim. a Menzies 1803, circa sinum Regis Georgii lectum in herb. Smith nobis ad I. latifolium $\beta$ pertinere videtur.

VIII. SERRURIA Salisb. Parad. Lond. $p .67$, R. Brown in Trans, Linn. soc. Lond. 40, $p$. 48 et 112, Endl. gen. p. 338, n. 2126, suppl. 4,2, p. 78, Meisn. gen. p. 331 (244). Serraria Burm. Afr. p. 264. - Protese et Leucalendri sp. Linn. Thunb. Andr. Bot. Repos. t. 264, 349, 447, 507, 512. - Holderlinia Neck. elem. 1, p. 106.

Flores hermaphroditi, capilati. Capitula globosa, indefinite multiflora, involucrata vel rarius nuda. Involucrum pluriseriale, persistens, squamis membranaceis imbricatis. Calyx subregularis, 4 -fidus, unguibus distinctis, laminis concavìs antheriferis pilosis vel rarius unâ vel omnibus glabris. Antheræ subsessiles, liberæ, ovales vel oblongæ. brevissime apiculatæ vel muticæ. Squamulæ hypogynæ 4 . Histillum calycem æquans, ovario 1-loculari, 1-ovulato, stylo filiformi deciduo, stigmate verticali glabro clavato vel rarius cylindrico plerumque sulcato. Nux brevissime stipitata, ovalis vel ventricosa, 1-sperma, barbata vel glabriuscula, interdum styli basi rostrala. - Frutices Capenses, facie Jetrophilæ, foliis sparsis coriaceis tereti-filiformibus trifido-pinnatifidis 
bipinnatifidisve rarius indivisis, capitulis terminalibus vel e summis axillis peduncalatis sessilibusve simplicibus solitariis vel corymbosis vel in capitulum compositum congestis mediocribus vel parvis, floribus sessilibus purpureis.

\section{\$1. Capitula simplicia, solitaria, umbellata vel corymbosa, pedunculo indiviso vel nullo, raro in ramulos nonnullos 1-cephalos aphyllos diviso. Sp. 1 et 5.}

"Capilule bractece exteriores vel omnes lato, ovata subito acuminate vel ovales membranacea, interdum demum indurata, rarius lanceolato (sp. 6 et 7).

1. S. GL A B E R IMA (R. Brown! in Linn. Trans. $10, \mathrm{p} .112^{*}$ ), adulta glaberrima, caulibus prostratis gracillimis, foliis remotis acutis subexsulcis 3 -fidis vel rarius pinnatim 5-fidis passim subbipinuatifidis, summis indıvisis, capitulis axillaribus terminalibusque paueifloris, bracteis seariosis, exterioribus ovatís acuminatis, interioribus subrotundis apiculatis, calyce glabetrimo vel junioris tubo sericeo. FIn montibus Houhook (Masson! ill herb. Banks, Gueinzius ! Zeyher, n. 3701!). - Roem. et Schult. syst. 3. 1. 363.* Protea rlaberrima Poir. suppl. 4, p. 569., P. decumbens Willd. herb. 11. 2398! Caules pedales et ultra, crassitie vix pennæ corvines, internodiis 1-2 poll. longis. Folia erecto-patula, 1-4 poll. longa, suppra obsolete 1 -sulca, novella cum ramulis sericeo-villosiuscula, laciniis attenuato-acutis muticis parte petiolari longioribus, lateralibus passim bifidis cum intermediả trifidà. Pedun!:uli circ. pollicares, axillares subnutantes, terminales erecti, squamis nonnullis ovatis 1-2 lin. longis obsiti. Capitula magnit. cerasi nredioceris, globosa vel demum ovoidea, squamis fuscis glaberrimis margine diaphanis, interioribus 2-3 lin. longis latisque brevissime acuminatis. Stigma calyce paulo superatum, cylindraccum, obtusum, basi nodulosum. (v. s. in herb. Banks., Willd. etc.)

$\beta$. pinnata, foliis pinnatim 5 -fidis passim bipinnato-7-fidis, summis 3 -fidis (simjlicilus nullis), capitulo terminali, bracteis exterioribus rostrato-acuminatis, pedunculi linearibus (2-4 lin. longis). - Circa Babylonsche Toorn (Zeyher n. 3700! Ecklon et Zeyh. n. 14!). Valde accedit ad S. simplicifoliam et diffusam, sed jam bractearum calycisque glabritie facile dignoscenda. (v. s.)

2. S. SIMPLICIF OLIA (R. Brown! l. c. p. $115^{\star}$ ), caule ereclo subsimplici apice puberulo, foliis indivisis vel passim trifidis canaliculatis glabris, junioribus hirsutis, capitulo termipali pedunculato, bracteis pedunculi distantibus lanceolatis glabritusculis, capituli subrotundis breve acuminatis subincano-tomentosis, calyce dense niveo-plumoso. 5 In arenosis prope Roodezant (Roxburgh ! in herb. Banks., Niven !), prope Groeuekloof', infra alt. 500 ped. (Drège! docum. p. 114), ad ostium 11. Potrivier, Onrustrivier, Klipfontein, etc. (Zeyher n. 3696 ! ex parte, 1469!). - Roem. et Schult. syst. 3 , p. $365^{*}$. Protea plumigera Thunb. A. cap. p.-121, n. 1*? Gir. Roem. et Schult. syst. 3, mant. p. 267. P. simplicifolia Poir. suppl. 4, p. 570." Folia 1-1 $\frac{1}{3}$ poll. longa, radicalia (ex Br.) elongata, crassiora, canali łatiore. Capitula solitaria, magnit cerasi, pedunculo pollicari tomentoso sparse bracteato breviora, globosa, bracteis 3 lin. longis latisque floribus superatis adpresse sericeo-pubescentibus margine dense villosiusculis, acumine recto $\frac{1}{2}$ lin. longo glabriusculo, pedunculi loracteis subadpressis lanceolatis acuminatis 2 lin. longis, 1 lin. latis pubescentibus. Stigma subcylindraceum. (v. s. in lierb. Banks. etc.)

3. S. HЕTEPOР Р YL A, caule erecto subsimplici glaberrimo, foliis subadpressis glabris, superioribus indivisis semiteretibus sphacelato-acutis, inferioribus pinnatis bipinnatisque, laciniis teretibus tenuibus conniventibus mucronato-acutis, capitulis corymboso-approximatis vel subsolitariis, pedunculis glaberrimis, capitulis globosis, bracteis scariosis glaberrimis late ovalibus breve attenuato-subacuminatís, ealyce densc fulvo-barbato, lamina unâ dorso glabriusculâ. $ђ$ In lapidosis montium ad ostium fl. Potrivier (Zeyher n. 3695! 3696! ex parte, Ludwig! Ecklon 1) S. Brownii $\beta$ et $\gamma$ nob. olim in pl. Zeyluer. Caules 1-2-pedales, inferno dense, superne laxe fuliosi, apice corymboso, 2-5-cephali. Folia 1-2 poll. Ionga, laciniis $\frac{1}{5}$-vix $\frac{1}{2}$ lin. crassis demum obtusiusculis. Capitula terminalia et in summis axillis, corymboso-approximata, rarius subsolitaria, magnil. cerasi majoris, dense multiflora, pedunculis $\frac{1}{2}-1$ poll. longis cum bracteis sparsis lanceolatis 3 lin. longis demum patulis glaberrimis. Capjituli bractea flores æequantes vel parum breviores, 
fusce, medio ruguloso-striat:e, margine diaphano lævissimx ciliolatæ, \&-5 lin. longas, 2-3 lin. latu, infime !anceolatir. Calyx rectus, 4 lin. longus, fulvo-barbatus sericeus, laminarum barbầ longiore 1 lin. longâ, quartâ apice tantum et quandoque in lineâ medià dorsali parce breveque barbellatà. Stigma 1 lin. longum, stylo glabro vix crassius, continuum, cylindraceum, obtusumn.-Forsan S. simplicifolize var., hanc inter et $\mathbf{S}$. lloridam quasi ambigua, illi habitu, liuic bractcis similior, attamen notis indicatis constanter, ut videtur, distincta. (v. s.)

4. S. FLORIDA (R. Brown! 1. c. p. 126), calle corymboso-ramoso, foliis omnibus pinnatis bipinnatisve tenujbus ramisque glabris, laciniis rlivergentibus mucronulato. acutis strpra 1-sulcis, capitulis approximato-corymbosis folia vix superantibus glohosis vel ovoideis pedunculo brevi glabro bracteato longioribus, bracteis scariosis glaberrimis magnis ovatis longiuscule attenuato-acuminatis, calyce recto, unguibus brevitér parceque, laminis longe denseque plumoso-barbatís, quartá demum glabriusculà. J In montanis circa Franschehoek (Masson! in hẹrb. Banks., Niven !), Dutoitskloof, Drakeusteenberge, Gnadenthal; ete., alt! $1000-4000$ ped. (Drige! Zeyher, n. 3695, b !): - Roem. et Schult. syst. 3, p. 372*. Protea Horida Thunb. diss. n. 2, t. 1, 1l, cap. p. 121, n. 3*, Willd.! sp.1, p. 506, herb, n. 2399! Rami arlscendentes, laxiuscule foliosi. Folia patula, 2.3 joll. longa, novella pilosiuscula. Capitula terminalia et c summis axillis, dense multiflora, magnit. cerasi majoris vè juglandis, pedunculis 6-9 fin. longis, bracteis lanceolatis 3-5 lin. longis sanguineo-fuscis demum pateritibus reflexisvo. Capituli bracteæ imbricatise 7-9 lin. longæ, 3-5 lin. latæ, medio obsolete venoso-striatic, juniores ciliatro. Calyx 5-6 lin. longus, laminarum barbâ sericeâ aureo-fulvâ 1 lin. longâ, quartâ breviore adpresssâ demum cxcepto apico deciduà. Stigma continuum, stylo capillarì glabro vix crassius, 1 lin. longum, cylindraceum obtusum. (v. s. in , herb. Banls. etc.)

5. S. FuRcellata (R. Brown! 1. c. p. 118 *), erecta; foliis omnibus semitrifidis supra 1 -sulcis ramisque virgatis glabris ${ }_{v}$ laciniis 2-3-firlis patulis mucronulatis, jedunculis terminalibus solitariis vel umbellatis conferte bracteatis glabris capitulum globosum subequantibus, bracteis scariosis oxitu-lanceolatis acutis ciliolatis glabris, pedunculi linearibus, calyce subincurvo, unguibus laminisque breve

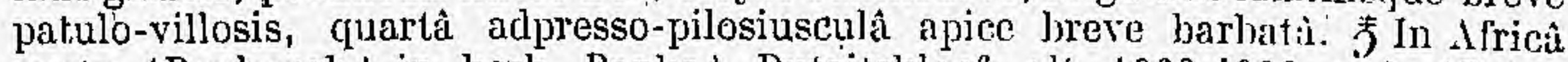
austr. (Roxburgh! in herb. Banks.), Dutoitskloof, alt. 1000.4000 peed. (Drège docum. p. 79-82). S. llorida var. et $\mathrm{S}$. scariosa Drige! mss. (non R. Br.). Protea furcellata Poir. 4, p. 571*. Leucadendron glomeratum herb. Linn.! ex parte (altera sp. est S. glomerata). - Roem. et Schult. syst. 3, p. $367^{*}$. Folial $1 \frac{1}{2}$ poll. longa. Pedunculi circ. semipollicares, bracteis linearibus obtusiusculis concaris 1-2 lin. longis imbricatis demum patulis tenti. Capitula magnit. cernsi, bracteis 3-5 lin. longis erectis vel apice demum patulis ibique subcarinatis, infimis srpe angustioribus lanceolatis. Calyx 4 lin. longus, pube sordide albidà $\frac{1}{2}$ lin. longâ, laminarum paulo longiore. Stigma 1 lin. longum, continuum, stylo haud crassius, cylindraceum, obtusum, atrum. Variat ramulis glabris et apice parce puberulis, foliis 1-2 poll. longis, $\frac{1}{3}-\frac{1}{2}$ lin. crassis, pedunculis solitariis vel $3-4$ unbellatis $\frac{1}{2}-1$ poll. longis, calycis villis $\frac{1}{2}-1$ lin. longis. (v. s. in herb. Banks., etc.)

6. S. S U в C O R Y M в O S A, g]abra, foliis subbipollicaribus bipinnatis, pinnis 2-3-jugis pinnatim 3 -5-fidis vel passim indivisis patulis mucronulatis supra 1 -sulcis, capitulis approximato-corymbosis pedunculo sparse bracteato subæequilongis globosis, bractcis membranaceis lavibus glabris dense imbricatis diinidio capitulo sublongioribus, exterioribus ovato-oblongis acuminatis mox patentibus, inferioribus lanceolatis margine longe fulvo-barbatis, calyce recto, unguibus laminisque 3 longe plumoso-barbatis, quartâ dorso glabriusculâ apice breve barbellatì. F In Africâ austr. (Niven! Brehm!). Rami adscendentes rel erecti, laxiuscule foliosi, foliis haud secundis, pinnis $\div$ lin. crassis demum mulicis petiolum iequantibus vel longioribus. Capitula terminalia et in summis axillis in corymbum 3-4-cephalum congesta vel passim solitaria', folia vix superantia, magnit. cerasi majoris, pedunculis glabris bracteis squamiformibus $1-1 \frac{1}{2}$ lin. Iongis triangularibus acutis demum patulis tectis, superioribus capitulo brevioribus, inferioribus sublongioribus circ. pollicaribus. Capituli squama fusce, enerviæ, haul punctatse, exteriores 3-4 lin. longæ ciliolatæ vel nudæ demum refless, interiores érecta. Calyx 3-4 lin. longus, villis densis patulis fulvis. Antheræ lineares subapiculatæ. Stigma, etc., S. furcellatæ, cui species proxime affinis, precipue inforescentiâ, bractearum calycisque pubescentià distinguenda. Inter \&̊ 2 et 3 , quibus propter inflorescentiam stricto jurc adsocianda (oret, nulli affinis. (v. s. comm, a cl. Sonder.) 
7. S. ScARIOSA (R. Brown in Linn. Trans. 10, p. 118*), erecta, folíis patulis sesquipollicaribus hipinnatis ramisque glabris, laciniis divaricatis calloso-acutis, pedunculis subumbellatis capitulo ovato-globoso paulo longioribus scuarrosis pílosiusculis, bracteis flores aequantibus lanceolatis glabriusculis apice patulis, omnibus scariosis carinatis, calyce villis arcle adpressis sericeo. $\%$ In Africa australi (Roxburgh! Niven! Brehm l), in montibus prope Klyneivier, Zwellendam (Krauss, n. 1059, Beitr. p. 141). - Roem, et Schult. syst. 3, p. 367 *. Protea sphærocephala Poir. dict. 5, p. $658^{*}$ (excl. syn.). Huc forsan spectat Protea coaretata Thunb. fl. Cap. p. $122^{*}$, cfr. Roem, et Schult. syst. 3, mant. p. 267. Rami graciles, laxiuscule foliosi, 1.cephali. Folia tenui-filiformia, potius biternata quam bipinnata, laciniis lateralibus bifidis vel indivisis, summa plerumque 3 -fida. Pedunculi $\frac{1}{\alpha}-1$ poll. longi, bracteis patentissimis carinato-concavis membranaceis rufis linearibus acutis acuminatis, 3-5 lin. longis, glabrís vel ad carinam puberulis, infimis puberulis. Præter bracteas carinatas glabriusculas et calycem adpresso-villosum omnia fere S. furcellatis. (v. s.)

8. S. DIFFUSA (R. Brown 1. c. p. $115^{*}$ ), ramis diffusis gracilibus glabris 1-cephalis, foliis patulis infimis deflexis subsesquipollicaribus tenuibus glabris pinnatim 3-5-fidis, laciniis indivisis mucronulato-acutis, capitulo pedunculum pubescentem subæquante globoso, bracteis e basi ovatâ lanceolatis scariosis concavis patulis acuminatis villosis, infimis pedunculique angastioribus glabriusculis, calycis unguibus laminisque omnibus dense patenti-plumosis. 7 In arenosis saxosis elevatioribus, prope Roode Zand, etc. '(Roxburgh I in herł. Banks., Niven ! Verreaux l). - Roem. et Schult. syst. 3, p. $365^{*}$. Protea Brownii Poir. suppl. 4, p. 570". Gaulis

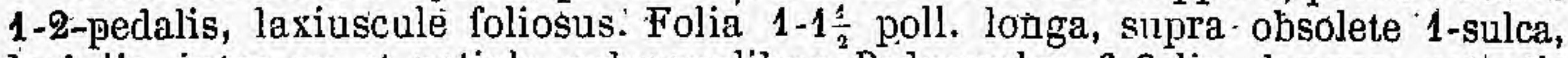
laciniis inter se et petiolo subrqualibus. Pedunculus 6-9 lin. longus, patentipilosiusculus (ex Br. tomentosus). Capitulum magnit. cerasi, bracteis 2-3 lin. longis. Calyx 4-5 lin. longus, rectiusculus, villis aureo-fulvis sericeis, laminarum fere 1 lin. longis, quartæ paulo brevioribus decúmbentibus. Stigma continuum, stylo capillari glabro parum crassius, 1 - lin. longum, cylindraceo-clavatum, obtusum. A proxime affini $\mathrm{S}$. scariosà et simillimà S. decumbente jam capitulo solitario simplici et calyce plumoso, nec adpresse sericeo, facile dignoscenda. (v. s. in herb. Banks., etc.)

9. S. GYGNEA (R. Brown l. c. p. $113 \%$ ), procumbens, ramis gracilibus secunde laxeque folịosis, foliis bi-vel tripinnatis supra 1-sulcis adultis ramisque glabris, laciniis obtusiusculis muticis, capitulis subcorymbosis pedunculo glabro remote bracteato brevioribus globosis, bracteis brevibus ovatis acutis glabris demum patulis, infimis majoribus acuminatis ciliolatis adpressis, calyce curvato undique adpresso sericeo. J In montibus Winterboek (Roxburgh, Gronov.! in herb. Banks., Niven! Ludwig ! Verreaux! etc.), Nieuwekloof, alt. 1,000 ped. (Drège! docum. p. 78, forma foliis sueto tenuioribus), Witsemberg (Zeyher. n. 1473!). Roem. et Schult. syst. 3, p. 363*. S. cyanea Drège! docum. p. 78, 221. S. colorata Zeyh.! mss. in herb. (forma insignis foliis sueto fere duplo crassioribus et capitulo paulo majore). S. hélvola Steudel nomencl. ed. 2, p. 400. Protea cygnea Poir. suppl. 4, p. 509*. Protea helvola Liclıtenstein, n. 94 ! in herb. reg. Berolin., spicil. fl. Cap. mss. Roem. et Schult. syst. 3, p. 379. Rami saje elongati, juniores eum foliis patenti-pilosi. Folia $1 \frac{1}{2}-3$ poll. longa, plerumque $\frac{1}{2}$ lin. crassa. Capitula terminalia et e summis axillis, magnit. parvi juglandis, pedumculis $1-2 \frac{1}{2}$ poll., involucri squamis exterioribus 2-3 lin., calycibus 5-6 lin. longis. Stylus glaber, stigmate nutante brevi cylindraceo. Variat (secundum R. Br.) bracteis involucralibus nullis. (v. s. in herb. Banks., etc.)

10. S. INCRASSATA (Buek! in pl. Drège), foliis subbipollicaribus tripinnatis tenuibus subexsulcis ramulisque patenti-pilosiusculis, laciniis-obtusiusculis múticis, capitulo terminali solitario pedunculato folia superante globoso, involucri floribus brevioris squamis adpressis ovato-triangularibus breve acuminatis ciliolatis dorso glabris, calyce incurvo adpresse fulvo-sericeo. F Circa Paarl, infra alt. 1,000 ped. (Drège l docum. p. 98). Folia conferta, haud secunda; obsolete sulcata, pube teruissimâ brevi. Pedunculus pollicaris, bracteis subimbricatis demum patulis ovatolanceolatis acutis, 2 lin. longis, ciliolatis glabris tectus. Capitulum nutans? magnit. juglandis, squamis 3 lin. longis, basi fere 2 lin. latis. Stylus incurvus, glaber, stigmate cylindraceo obtuso basi noduloso. Affinis S. cygneæ et scariosæe, ab illâ 
foltis haud securidis, tenuioribus, capitulo bracteisque majoribus, etc., ab hac bracteis flores æquantibùs basi dilatatis apice non patulis dignoscenda. (v. s.)

11. S. AGROCARPA (R. Brown! 1. c. p. $113^{*}$ ), erecta, folíis bipollicaribus bipinnatis glabris, junioribus ramulisque tenuissime pubescentibus, capitulis axillaribıs pedunculo remole bracteato apice puberulo lorevioribus; squamis ovato-subrotundis breve acuminatis tomentosis, calyce curvato sericeo. $\$$ ln Africâ austr. (Roxburgh! in herb. Banks.), in lapidosis, prope Bahianskloof et Gnadenthal, alt. 1,000-2,000 ped. (Drège! docum. p.115), Hessaquaskloof (Zeyher, n. 3706! ex parte). -Roem. et Schult. syst. 3, p. 364*. Protea acrocarpa Poir. suppl. 4, p. $570^{*}$ Pedunculi sæpe curvati, bracteis glabris. Capitulum magnit. cerasi. Stylus apice arcuatus, stigmate pendulo basi subcequali. Nux styli basi incrassatà pubescente mucronata, patulo-barbata. (v. s. in herb. Banks., etc.)

B. Ludwigii, capitulo terminali, solitario pedunculato, stigmate pendulo ovalicylindrico basi oblique amnulato-noduloso. - Circa Gnadenthal (Ludwig!). Rami graciles, laxiuscule foliosi, brevissime puberuli, apice pilis longioribus parce interspersi. Folia undique versa, 2 poll. longa, tenuia, laciniis semipatulis obtusiusculis. Involucrum cum pedunculo fulvo tomentellum. Cádyx fere semipollicaris, tenuis, pube brevissimâ sericeus. Stylus infra medinm pubescens. Stigma vix $\frac{1}{2}$ lin. longum. (v. s.)

\%. Zeyheri, capitulo terminali solitario, squamis longius acuminatis albidotomentosis, stigmate pendulo ovato-cylindraceo basi obsolete annulato subobliquo (cret. ut in $\beta$ ). Círca Hessaquaskloof ot Zwellendam (Zeyher, n. 3706 ! ex parte, et 3706 var. $\beta$ I). (v. s.)

12. S. SAXIcaLA (Buek $!$ in pl. Drège), erecta, foliis 2-3-pollicaribus tenuibus bipinnatis ramisque glabris, junioribus pilosiusculis, laciniis parum divergentibus obtusis, capitulis terminalibus subumbellatis pedunculo bracteato tomentoso brevioribus globosis, squamis córiaceis ovatis subacuminatis cano-tomentosis, exterioribus demum subrecurvo-patentibus, calyce incurvo cano-tomen toso. $₹$ In monte Piquetberg, alt. 2,000-3,000 ped. (Drège I docum. p. 76). S. adscendens Drège l' olim. Stígma demum erectum continuum, stylo tenui glabro vix crassius, cylindraceum. Nux longe rufo-barbata, styli basi pubescente breviter rostrata. Cæet. fere omnia S. acrocarpe, sed folia subduplo longiora, calycis pubesc. vix sericea, l aminx $1 \frac{1}{2}$ lin. longw. (v. s.)

13. S. FLA VA (E. Meyer! in pl. Drège), ramis virgatis strictis cano-tomentellis apice patulo-pilosiusculis, foliis distantibus patulis pollicaribus bipinnatis, laciniis vix divergentibus crassiusculis muticis, capitulis corymbosis ovatis, involucro floribus pluries breviore pedunculoque bracteato sericeo-tomentosis, squamis rhombeosubrotundis acutiusculis, infimis ovato-oblongis paulo longioribus, calyce arcuato aureo-fulvo sericeo, pube brevissimâ in unguibus semipatulâ, in laminis adpressâ. F In rupestribus inter Wupperthal et Ezelsbank, alt. 2,000-3,000 ped. (Drège ! docum. p. 74). Rami validi, internodiis semipollicaribus. Folia 12-15 lin. longa, laciniis $\frac{1}{3}$ lin. crassis, 3-5 lin. longis, obsolete ruguloso-sulcatis obtusis. Capitula terminalia el in summis axillis approximata, magnit. juglandis, pedunculis 1-1 $\frac{1}{2}$ poll. longis, squamis patulis lanceolatis obtusiusculis, 2 lin. longis, tomentosis remote bracteatis. Involucrum floribus 3-4-plo brevius, fulvum. Calyx 7-8 lin. longus, gracilis, pulchro aureo vel fulvo-sericeus, laminis 1 lin. longis ovalioblongis. Stigma $\frac{2}{3}$ lin. longum, stylo sigmoideo infra medium minute puberulo vix crassius cylindraceum, basi obsolete nodulosum subobliquum. Nux fulvo-bar, bata. Species insignis, ab affini $\mathrm{S}$. acrocarpâ habitu stricto robustiore, calyce lóngiore, stigmale, ctc., bene distincta: ( $\vee$. s.)

14. S. ELEVATA (R. Brown l in Linn. Trans. 10, p. 114), erecta, ramis stomentosis, foliis confertis sesquipollicaribus bipinnatis obtusiusculis pilosiusculis demum glabris, capitulis axillaribus corymbosis pedunculo tomentoso bracteato brevioribus, squamis cuneato-suborbicularibus mucronulatis sericeo-tomentosis, calyce arcuato leviter barbato. $\exists$ In arenosis Africæe australis (Nassou $l$ in herb. Banks), in rupestribus mont. Groote Houhoek (Zeyher, n. 3707?). - Roem. et Schult. syst. 3, p. 364*. Protea elevata Poir. suppl, 4, p. $570^{*}$. Folia inferiora glabra. Pedunculi folio plerumque longiores, interdum 3-pollicares, bracteis lanceolatis patentibus. Capitula magnit. cerasi, squamis interioribus submuticis. Nux barbata, submutica. (v. s. in herb. Banks., etc.) 
ß. subumbellata, foliis ramulisque patulo-pilosis tardius glabrescentibus, capitulis subumbellatis majoribus (magn. juglandis), calyce leviter incurvo (4-5 lin. longo) undique pube densà brevi patulà fulvo-piloso. - Inter Bergvalei et Langevalei, infra alt. 1,000 ped. (Drège ! docum. p. 109). S. subumbellata Buek $\mathrm{b}$ ! in pl. Drège (non a, qua $\mathrm{S}$. tomentosa E. Jler.). Stigna $\div$ lin. longum, stylo glabro apice incurvo parum crassius, cylindraceum, basi obsoletissime annulatum obliquum. Caet. ut in typo speciei. (r.s.)

$y$ ? Roxburghii, "foliis junioribus magis hirsutis, pedunculis brevioribus pancioribus, bracteis longius mucronatis, calycibus quandoque sericeis. Forte species distincta. " R. Br. l. c. obs. Planlam non vidimus, forsan cum S. vestíta identica.

15. S. vestit A (Buck! in pl. Drige, n.1476 a!), foliis patulis pollicaribus tripinnatis, laciuiis patulis tenuibus obtusiusculis exsulcis ramulisque patulo-pilosiusculis, capitulis corymbosis globosis, pedunculis folia superantibus tomentellis patentique pilosis, bracteis remotis lincaribus brevibus, involucri floribus plaries brévioris squamis subrotundis breve acuminatis adpressis sericeo-tomentosis, calyce tenui fulvo-sericeo apice incurro. 5 Ad mont. Piquetberg, Kromrivier, etc., infra alt. 1,000 ped. (Drège! docum. p. 104, 110, Zeyler, 11. 1472!). Pedunculi 1-3 poll. longi, luracteas paucas 1-2 lin. longas jatulas vel medio folia nonnulla gerentes. Capitula magnit. cerasi majoris. Calyx 4 lin. longus, púbe brevi adpressissimà fulvo-sericeà, laminis vix 1 linı longis. Stigma precedentis, cui, ut etiam $\mathrm{S}$. acrocarpx, simillima; differt a priore foliis brevioribus (raro usque ad $1 \frac{1}{2}$ poll. longis), capitulis floribusque jaulo minoribus et pracipue calycis pulje arcte adpressà ; a posteriore ramulis pedunculisque pubéscentibus, stigmate tenui, etc. (v. s.)

16. S. A It oni (R. Brown! 1. c. p. 114 ), crecla, ramis strictis tomentosis, foliis confertis pollice lervioribus tripartito-bipinnatis sericeo-1.onentosis subargenteis, lacinulis supra 1-sulcis :pice subrecurwo obtusiusculis, pedunculis corymbosis capitulo gloloso longioribus tomentosis, bracteis subulato-lanceolatis recurris, involucrisiguamis cuneato-subrotundis mucronatis glabriusculis, exterioribus angustioribus longius acuminatis, culyre toto plumoso barbato. F̂ In Africâ austr. (Masson! in herh. Banks.). - Roem. ei Schult. syst. 3, p. 304. Protea Aitoni Poir. suppl. 4, p. $670^{*}$. Pellunculi pollicares et ultra, cinereo-tomentosi. Capitula magnit. lere juglaulis, squamis subciliatis. Calyx 7-8 lin. longus, squamulse hypogynse 4, subulatæ, persisteutes. Stigma clavato-oblongum Jux sericeo-barbata, styli basi mucronata. (v. s. in herb. Banks.)

3. multifida, foliis breviter patulo-pilosiusculis (nec sericeis), bracteis exterioribus sericeo-tomentosis, jnterioribus glabris in lineâ mediâ tảntum margineque puberulis.-In collibus, circa Ezelshink, alt. 3,000-4,000 ped. (Drège! docum. p. 74). S. multifida E. Jerer! in pl. Drège. Forsan distincta species, sed ridimus tantum ramulum unicsm digitalem 1-cephalum. (v, s.)

17. S. томелтовл (E. Merer! in pl. Drige), ramis gracilibus cano-villosiusculis, foliis confertis patentibus pollicaribus trifido-tripinnatis cano-tomentosis, laciniis tenuibus exsulcis muticis, pedunculis corymbosis folia superantíbus tomentosovillosis, bracteis paucis lanceolatis acuminlatis patulis; capitulis globosis, squamis ovato-subrotundis hreve acuminatis sericeo-tomen losis flore triplo brevioribus, calyce tenui incurvo toto pube brevi patente fulvo-barbato. 3 In rupestribus mont. Píquetberg, alt. 1,000-2,000 ped. (Drège !). S. subumbellata Buek a! (nec b) in pl. Drège docum. p. 75. Folia 12-15 lin. longa, vix ac ne vix sericea, segmentis primariis 8-10 lin. longis, divaricatis, bipinnatifidis, laciniis $\frac{1}{s}$.lin. crassis, ultimis conniventibus rer tis obtusis 3 lin. longis. I'edunculi fore umbellati $1 \frac{1}{2}-2$ poll. longi, pube densà brevi patulà fulvà, bractcis raris tonıentosis 2 lin. longis. Capitula magn. cerasi majorıs vel juglandis. Calyx 4 lin., laminis anguste lanceolatis rix 1 lin. longis. Stylus glaber, stigmate clarato-cylindrico, $\frac{1}{2}$ lin. longo, basi attenuati obsoletissime noduluso. Alfinis $s$. Aitoni ot pedinculatie, sed notis indicatis satis distíncta. (v. s.)

18. S. PEDUNCULATA (R. Brown l. c. p. 119 \%), foliis confertis subbipollicaribus fere ad basin usque bi-rel tripinnatis ramisque strictis pilosiuseulis, segmentis divarjcatis exsulcis acutiusculis, capitulis solitariis vel subcorymbosis globosis, squamis flore duplo brevioribus ovatis acutiusculis sericeo-tomontosis apice demum recur- 
vis, calyce tenui incurvo, unguibus laminisque tribus fulvo-plumosis, quarta pube adpressâ brevi sericeâ. $\$$ In montanis, circa Roodezant (Brandt! in herb. Banks., Niven! Verreaux !), Tulbaghskloof et Nieuwekloof, infra alt. 1,000 ped. (Ludwig! Drège ( docum. p. 78). - Roem. et Schult. syst. 3, p, 367. Protea pedunculata Lam. ill. 1, p. 240, n. 1264. P. sphserocephala A Poir. dict. 5, p. 658. P. glomerata Andr. Bot. repos. t. 264. P. sphærocephala Houttuyn Pff. syst. 3, p. 72, t. 19, f. 1, A, B ? vel hue vel ad Serr; hirsutam spectare videtur, fide R. Brown in Linn. Trans. 10, p. 220. Frutex suborgyalis, ramulis sæpiús umbellatis. Folia $1 \frac{1}{2}-2$ poll. longa, $\frac{1}{5}$ lin. crassa, pube Đrevi tennui patulâ vel decumbente. Pedunculi $1 \frac{1}{2}-3$ poll. Jongi, fulvotomentosi, bracteis ovatis obtusiusculis 1 lin. longis patulis glabriusculis vel interdum foliis nanīs remote obsiti. Capitula magni. juglandis vel pruni. Calyx 8 lin. longus, pube densâ 1 hin. longâ patulâ, laminæ quartæ breviorc adpressâ. Stylus infra medium dense sericeus, supra glaber, stigmate continuo cylindraceoclavato. Nux ovato-oblonga, styli basi caurlata, adpresse rufo-hirsuta. (v. s. in herb. Banks. etc.)

19. S.' D REGEI, foliis patulis subsesquipollicaribus 2-3-pinnatifidis ramulisque hirsutis, pinnis divaricatis tenuibus lateralibus medium źquantibus, capitulis subsolitarfis pedunculo pubescente bracteis paucis oblongis vel foliis nanis 3-5-fidis obsito subbrevioribus, squamis ovatis acntis adpréssis, calyce curvato totó pube breviusculấ subadpressâ dense argenteo-sericeó. J In arenosis, ad fl. Bergriviẹ (Zeyher, n. 3698!). Prseter calycis pubéscentiam omnino diversam et folia plerumque breviora, sæpe vix pollicaria, omnia fere $\mathrm{S}$. jedunculatæ ideoque forsan potius ejus varietas. (v. s.)

20. S. scoparia (R. Brown l. c. p. $119 \%$, caule decumbente, ramis adscéndentibus hirsutis, foliis patulis subpollicaribus triternatis adultis glabris, laciniis divaricatis muticis, capitulis solitariis pedunculum bracteatum subpollicarem tomentosum subœquantibus globosis, squamis late ovatis villosis, calycis unguibus hirsutis, laminis densius barbatis, interioris barbà breviore: $z$ In arenosis, ad fl. Vierentwentigrivieren (Roxburgli! Niven!), - Roem, et Scliult. syst. 3, p. 308. S. hirsuta Buek! in pl. Drège, n. 8067, fide specim. mane. (non R. Br.). Protéa scoparia Poir. suppl. 4 , p. 571 . Folia 8-12 lin. longa, ad medium 3-fida, segmentis subæqualibus bipinnatis, lacinulis 3 lin. longis, jun. pilosis. Capit. magn. fere juglandis, squamis (fide specim. Niven) vix 3 lin. longis, e basi ovatâ in acumen subæquilongum lineare productis cano-pilosis margine villosis. Calyx incurvus, fere 6 lin. longus, pube patulâ densâ vix $\frac{4}{2}$ lin. longà aureo-liulvâ in laminâ quartâ vỉx breviore, sed subadpressâ. Stigma clavatum $\frac{2}{3}$ lin. longum. (v. s.)

21. S. S TIL BE (R. Brown! l. c. p. 120), erecta, ramis pubescentibus, foliis pollice brevioribus 2-3-ternatis, capitulis terminalibus subsessilibus ovatis, bracteis gvatis acutis acumine recurvo, calyce barbato. $\bar{J}$ In montanis Africæ austr. (Masson! Roxburgh! in herb. Banks), prope Bergvalei, Biedow; etc., alt. 1,000-3,000 ped. (Drège ! docum. p. 75, 109). Protea Stilbe Poir. suppl. 4, p. 571*. P. sphærocephala Willd. herb. n. 2404 In stirpe Dregeana, inter $\alpha$ et $\beta$ ambigua, sequentia observamus. Rami virgati, iterato umbellato-ramulosi, pilósiusculi, dense foliosi. Folia imbricato-adpressa, caulem penitus abscondentia vel paulo laxiora, infima 5-8 lin. longa biternata glabriuscula, summa 3-4 lin. longa, laciniís bifidis, omnia tenuia, vix $\frac{1}{5}$ lin crassa, 1-súlca submucronulata; juniora parce pilosiuscula. Capitula terninalia, solitaria, folia superantia, subsessilia vel pedunculo 3-5 lin. longo hirsuto bracteis nonnullis subulatis patulis munito suffulta, subglobosa, magnit. cerási majoris, bracteis membranaceis ovatis subabrupte acuminatis 3-4 lin. longis basi 2 lin. latis hirsutis, acumine patenti vel recurvo acutissimo. Calyx rectus? 3-4 lin. longus, totus pube densâ fulvo-sericeâ patulâ $\frac{1}{3}-1$ lin. longâ, in lamidâ interiore breviore et adpressa, villosus. Stigma clavatum vix $\frac{1}{4}$ lin. longum, stylo capillari glabro dimídio crassius. Nux brevissime stipitata, obovato-ovalis, læevis, glabra. Varietates sequentes, monentc ipso auctore, forsan species distinctæ.

a. subbiternata, foliis semuncia brevioribus imbricatis subbiternatis demum glabris, bracteis nucibusque glabriusculis.-R. Br. l. c. (v. s. in herb. Banks.)

$\beta$. biternata, foliis fere semuncialibus subimbricatis ramisque hirsutis, bracteis nucibusque barbatis. - K. Br. l. c. (v. sp. Niven! in herb. Sonder.)

$\gamma$. subtriternata, foliis semiuncià longioribus patulis subtriternatis, ramulorum floriferorum nanis, bracteis nucibusque hirsutis. - R. Br. l. c. An identica cum S. Brownii? 
22. S. BRowNI, erecta, ramis virgatis patenti-pilosissimis, foliis confertis patulis subpollicaribus triternatis subexsulcis, junioribus pilosiuseulis, láciniis acutiuseulis submuticis, capitulís terminalibuś solitariis subsessilibus folia superantibus ovato-globosis, squamis ovato-lanceolatis acuminatis dense villosis apice patulis, calyce recto, unguibus lamínisque 3 villoso-barbatis, quarta adpressissime sericeâ. F'In monte Tygerberg (Niven! n. 19, in herb. Sonder., Ludwig!). S. hirsuta Bergius! in berb. reg. Berolin. (non R. Br.). S. Stilbe $\gamma$ R. Br. l. c. p. 121?'(cfr. supra, n. 21). Differt a' S. Stilbe habitu 'robustiore, ramis validis, foliis constanter majorilus (7-10 lin, longis, $\frac{1}{3}$ lin. crassis, summis tantum sæpe nanis) laxioribus patulisque, canitulo magn. pruni vel fere juglandis, bracteis mimoribus, inferne minus dilatatis, et præcipue stigmate cylindraeeo $\frac{2}{3}$ lin. longo stylo vix crássiore basi obsolete noduloso. (v. S.)

23. S. F ENI C ULACEA (R, Brown I. c. p. 122 *), erecta, ramis umbellatis glabris, foliis patulis sesquipollicaribus bipinnatis capitula superantibus glabris, laciniis gracili-filiformibus acutissimis, capitulis terminalibus solitariis subsessilibus, squamis ovatis acuminatis ciliolatis glabris, calyce leviter arcúato toto adpresse argenteo-sericeo. F Girca Constantiam (R. Bì.). - Roem. et Schult. syst. 3, p. $\mathbf{3 7 0}$. Protea foeniculacea Poir. suppl. 4, p. 572 *. Trutex 2-pedalis. Folia tenuia, laciniis divergentibus supra 1-sulcis. Pedunculus nunc capitulnm globosum magnit. cerasi minoris subæquans imbricato-bracteatus, nume nullus. Bracteæ capitụli fere $\mathbf{3}$ lị. longæ, 2 lin. latæ, breve acuminatæ, pedunculi, breviores lanceolatæe demum laxiusculæ. Calyx incurxus, 3 lin. Jongus, fulvo-sericeus. Stigma subclavato-cylindraceum, stylo vix crassius, fere $\frac{1}{2}$ lin. longum. Facie,accedit ad S. glomeratam, sed inflorescentiâ, etc., bene distincta. (v. s.)

24. S. NEA vos A (Meisn. mss. in herb. reg. Stuttgart. 1846), erecta, ramis gracilibus densiuscule foliosis, foliis erectis sulpollicaribus tenuibus glabris supra 1-sulcis a medio pinnatiom 3-5-fidis, lacinirs vix divergentibus indivisis submucronatis capitulo folia superante subturbinato-globoso, bracteis dímidio capitulo longioribus coriaceis glabris ovato-vel oblongo-lanceolatis sulcato-3-5-nerviis acumine subulato remum patente, calyce incurvo argenteo-sericeo. " In In Africâ austr. (Ludwig $¥$ ). Ramí graciles vel subumbellati, glabri. Folia teretia, vix $\frac{1}{3}$ lin. crassa, laciniis 3-6 lin. lọngis acutiş. Pedunculus capitulo brevior, 3-4 lin. longus, bracteis sulbulatis 3 lin'. longis patentissimis recurvisve glabris dense squarrosús. Capit. magn. cerasi minoris, squamis fuscis, imbricatis, 4 lin. longis, bași 1-1 $\frac{\ddagger}{3}$ lin. latis, interioribus obsolete ciliolatis. Calyx $4-5$ lin. longus, tofus pube densâ minutâ adpressî sericeus. Stigma clavato-cylindraceum, $\frac{1}{3}$ lin. longum, in stylum attenuatum. Haljitu simillima S: ciliatæ, et affinis S. féniculaceæ, sed ab omnibus jam bracteis bene distincta. (v. s.)

25. S. cranoIbes (R. Brown l. c. p. 117\%), humilis, ramis gracilibus laxe foliòsis puberulis glabrisve, foliis patulis tenuibụs, supra 1-sulcis adultis glabris, superioribus hipinhatis, inferiorilbus brevioribus 3 -fidis, Jaciniis submuticis; cepitulis ferminalibus solitariis pedunculatis folia superantibus globosis, scquamis scariosis "Nato-sulhrotundis breve subulato-acuminatis villosis; calyce recto, unguibus láminisque 3 deuse plumoso-barbatis; quartấ glabriusculà. ₹ In collibus Africæ austr. (Kiggelaar! in herb. Banks., Niven!), Steenberg, Tygerborg, etc. (Mund! in herb. reg. Berolin.! Brège, n. 8086 ! docum. p. 112), Pluken. mant. p. 61, t. 345, f, 6. Leueadenđron evanuides Linn. sp. cd. 1, p. 93, Berg. pl. Ca1. p. $27^{\circ}$. Protea cya-

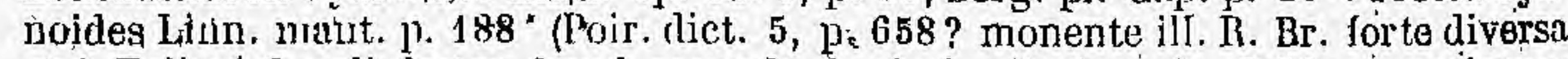
sp.). Folła $\frac{1}{2}-2$ polt. longa, haud secunda, juniork pilosiuscula, 3-fida, superiorum laetnies 9-8-fdat, infefiorum plerumque indivise. Pedunculus $\frac{1}{3}-1$ poll. longus, puberulus, bractois patulis lineari-subulatis $3-4$ lin. longis inferioribus foliaceis superioribus marg ne scariosis sparse tectus. Capitulum magn. fore juglandis, squamis dimidios flores wequantibus. Calyeis hąrba fulva patula fere 1 lin. langa. Stigma 'ylindraceum', stylo glahro vix crassius, 1 lin, longum. (v. s. in herb. Banlss., cic.)

* Gapituli bractea omnes angusta, lancealata vel subulata, rarissime, infime basi ovate (cfr. S. nervosa). Capitula terminalia solitaria, varo aggregata (cfr. S. pinnata hirsuta, squarrosa, phylicoides, cillata, congesta).

20. S. Pin Na A (R. Brown in Limn. Trans. 10, p. $116 \%$, prostrata, ramis elongatis simplicibus laxe foliosis, foliis secundis suhsesquipolliearibus temibus supra 
1-sulcis pinnatim 3-5-fidis ramisque patenti-pilosis, laciniis indivisis acutis, pedunculo adscendente bracteato tomentoso, capituli globosi squamis lanceolatis acuminatis villoso-tomentosis, exterioribus pedunculique glabriusculis, calyce recto sericeo, laminis apice breve barbatis.. In mont. aridis, circa Paarl, Draakensteen, Simonsberg, etc. (Niven, Roxburgh l' in herb. Banks., Drège l). S, diffusa b! c! Drège -(non R. Br.). - Roem. et Sćhult. şyst. 3, p. 365 *. Protea pinnata Poir. suppl r 4, p. 571 . Rami graciles, sǽpe pedales, decumbentes. Folia ereeta 1-1 $\frac{1}{8}$ poll. longa, $\frac{1}{3}-\frac{1}{2}$ lin. lata, semiteretia, demum glabra; laciniis divergentibus $3-8$ lin. longis, submucronulatis. Capitula globosa (ex R. Br. subaggregata) magnit. fere juglandis, pedunculo $\frac{1}{2}-1$ poll. longo, squamis subscariosis imbricatis dimidios flores superantibus, pedunculi brevioribus. Calyx interdum subarcuatus, pube brevi adpressâ albidå. Stigma exsertum, cylindraceum, stylo glabro parum crassius 1 lin. longum. (v. s. in herb. Banks., etc.)

ß. longifolia, foliis 3-4-pollicaribus 5-vel rarius 3-fidis, ladiniis subæqualibus. Protea pinnata Andr. Bot. Repos. t. 512.

27. S. ARENARIA (R. Brown l. c.l p. $117^{\dagger}$ ), ramis gracilibus, simplicibus, foliis confertis subpollicaribus tenuibus pinnatis trifidisve adultis glabris, laciniis indivisisacutis, capitulis pedunculo tomentoso longioribus globosis, squamis ovato-lancèolatis oblongisque acuminatis adpressis villosis, exterioribuis angustioribus glabratịs, calyce recto, laminis 3 plumoso-barbatis, quartâ unguibusque nudis. $\$$ In arenosis planitiei et monlium peninsulie Capensis (Roxburgh! in herb. Banks., Niven! Bergìis! Brehm! Ecklon, n. 3 b. et 4! Zeyher n. 1471!). Protea phylicoides Willd. sp. 1, p. 510, herb. n. 2407, fol. 21 (excl. fol. 1, 3 et 4). P. arenaria Poir. suppl. 4, p. 571*. Erecta vel decumbens, pedalis, parce ramosa, ramis foliisque patenti-pilosis vel demum glabris. Folia sæepius secunda, semiteretia subexsulca, submutica. Capitula magn. cerasi majoris, pedunculi bracteis patulis lineari-subulatis. Galyx 5 lin. longus. Stigma clavato-cylindricum, fere 1 lin. longum, in stylum glabrum attenuatum. Variat foliis 6-14 lin. longis et calycis laminis totis vel nonnisi apice barbatis, quartá unguibusque glaberrimis vel (ex Br.) parce patenti-pilosis. (v. s. in herb. Banks., Willd. etc.)

28. S. II R U TA (R. Brown l. c. p. $120^{*}$ ), erecta, foliis confertis subsesquipollicaribus tenuibus bipinnatis ramisque patenti-pilosis demum glabris, laciniarum mucronulo innocuo subinflexo, capitulo folia superante globoso, bracteis linearilanceolatis hirsutis dimidios flores subsuperantibus apice subulatis, calyce subin curvo toto dense plumoso-barbato, laminæ quaríx unguiumque barbâ breviore. ち In collibus saxosis circa Simons Bay (Roxburgh $!$ in herb. Banks., Niven 1). Hoem. et Schult. syst. 3, p. 368.* Protea phylicoides Thunb. diss. n. $0^{*}$, fl. Cap. p. 124, n. 13 (fide R. Br.), Linn.I mss. in herb. (quæ a R. Br. quidem ad S. phyli. coidem ducitur, sed huic calycis lamina interior nudiuscula). P. serrarioides Sol. Smith 1 -in herb. Linn. P. sphærecephala Houttuyn? (cfr. S. pedunculata, supra n.18) P. hirsuta Poir. suppl. 4, p. 572*. Frutex 2-3-pédalis, ramis umbellatis strictis.

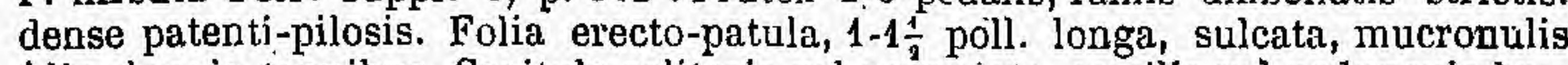
$\frac{1}{2}$ lín. longis tenuibus. Capitula solitaria vel aggregata, sessilia vel peduneulo bre viora, magn. fere juglandis. Calyx 5 lin. longus, villis aureo-fulvis, laminarum 3 circ. $\frac{2}{3}$ lin. longis. Stigma clavato-cylindricum, $\frac{2}{3}$ lin. longum, in stylum glabrum attenuaturn. (v. s. in herb. Linn., Banlss. etc.)

29. S. N.rVENI (R. Brown 1. c. p. 121*), decumbens, foliis patulis subpollicaribus bipintatifidis ramulisque glaberrimis, laciniarum mucronibus semipellucidis innocuis, capitulo subsessili foliis superato globoso, bracteis lanceolatis; exterio'ribus dimidios 1lores breve superantibus ciliolatis glalrris, interioribus sericeis apice glabriusculis, calyce dense barbato, laminâ interiore villis adpressis sericeâ. ち In mont. Zwarteberge (Niven), circa Muizenburg (Zeyber I. 3705 I Recedens calycis laminâ interiore glabbratâ, nec sericeâ).-Roem. et Schult. syst. 3, p. 369 * Protea decumbens Andr. Bot. repos. t. $3 \frac{39}{9}$ (recedens foliis $1-1 \frac{2}{8}$ poll. longis). P. Niveni 'Poir. suppl. 4, p. 572*. Humilis, spithamea, diffusa, ramosissima. Folia . ramorum procumbentium secunda, intus canaliculata, mucronibus acutissimis. Capitulum magn. cerasi, squamis breve acuminatis. Stigma cylindraceum, stylo vix crassius. (v. s.)

30. PLUMOSA, erecta, foliis patulis pollicaribus tenuibus biternatis bipinnatisque subexsulcis junioribus ramulisque püberulis, laciniis divergentibus mucronulatis, 
capitulo folia vix superante subsessili, bracteis oblongo-lanceolatis acutis adpressis sericeis ciliatis, exterioribus demum glabris, calyee subincurvo, unguibus omnibus laminisque 3 plumosis, quartâ adpresse sericeâ imberbi. 訪 Tupestribus mont. Tygerberg (Bérgius ! in herb. reg. Berolin., Ludwig ! Ecklon et Zeyhér n. 13!), Zwarteberg supra Caledon-(Zeyher 1.3704 !). Rami virgati, ramulis gracilibus densiuscule foliosis pube densâ brevi patulà decidıâ pilosiusculis. Folia teretia, sulco obsoleto vel nulîo, laciniis semipatentibus subæquálibus, mucrone brevi subincurvo spliacelato innocuo. Capitulum magnit juglandis, bracteis $3-4$ lin. longis 1-1 $\frac{1}{2}$ lin. latis pube brevi sericeis, exterioribus fuscis enerviis lavibus. Calyx 5 lin. longus, villis albidis 1 lin. longis patentibus, in laminâ quartâ brevissimis adpressis. Antherse lineares, minute apiculatæ. Stigma cylindraceum; stylo incurvo glabro haud crassius, basi obsolete nodulosum. - Affinis S. Niveni, cyanoidi et nitidæ; sed vel habitu, vel foliis, vel calycis pubescentià facile distinguenda. (v. s.)

31. S. viLLoSA (R. Brown! 1. c. p. 122*), erecta, foliis subpollicaribus patentibus subbiternatis junioribus ramulisque hirsutis, laciniarum mucrone acutissimo subincurvo, capitulo sessili foliis superato, bracteis lanceolatis acuminatis tomentosis, calycis unguibus adpresse tomentosis, laminis penicillato-barbatis. 7 In mont. prope Simons Bay (Thumberg ! Roxburgh! in herb. Bariks.), Constantiam, etc. (Niven ! Ludwig !). - Roem. et Schult. sjst. 3, p. 369*. Protea villosa Lam. ill. 1; p. 240, n. 1265. P. phylicoides Poir. dict. 5, p. 659* (excl. syn. Berg. et Thunb.). Frutex 2-pedalis et ultra, ramis umbellatis strictis. Folia demum glabra, vix pollicaria, rarius fere $1 \frac{4}{2}$ poll. longa, lacinïis parum divergentibus $\frac{1}{3}-\frac{1}{2}$ lin. crassis sulcatis, mucrone tenui incurvo vel rarius recto fere $\frac{1}{2}$ lin. longo pallido. Capitulum magn. cerasi majoris vel fere juglandis, interdum pedunculo 3 lin. longo dense patentibracteato suffultum, bracteis strictis subulato-acuminatís 4-5 lin. longis basi vix 1 lin. latis villoso-tomentosis exterioribus plus minus glabrís. Calyx rectus 4-5. lin. longus, Jaminarum 3 bárbâ densâ fulvo-vel albido-sericêa $\frac{1}{2}-\frac{2}{3}$ lin. longâ, quartæ decidua? vel subnulla. Stigma cylindrico-clavatum, stylo dimidio crạssius 1 lin. longum. (v. s. in herb. Banks. etc.)

32. S. NITIDA (R. Brown! 1. c. p. 124*), foliis subsesquipollicaribus pinnatifidis subbipinnatisque tenuibus ramisque glaherrimis, capitulo pedunculo squarroso luplo longiore, bracteis flores subæquantibus, exterioribus subulatis glabris, interioribus-sericeo-villosissimis, calyce stricto, unguibus pilosiusculis, laminis plumosobarbatis, interiore apice parce breveque barbatâ dorso nudiusculâ. $\bar{\zeta}$ In Hottentottsholland (Roxburgh! in herb. Banlks.). - Roem. et Schult. syst. 3, p. 370*. Gapitulum globosum, magn. avellance vel juglandis. Calycis ungues angustissimi. Stigma cylindraceum. (v.s. in herb. Banlss.)

33. S. A MULA (R. Brown l. c. p. $125^{*}$ ), ramis apice cinereo-tomentellis, foliis patulis sesquipollicaribus bipinnatifidis glabris, laciniis acutissimis, capitulo subsessili, bracteis flores subàquantibus membranaceis, . exterioribus lanceolatis tomentosis ciliatis, interioribus' minoribus villosis, calyce stricto, unguibus nudiusculis, laminis omnibus plumoso-barbatis. $ђ$ In mont. Frapschehoek (Roxb. in herb. Soc. Linn., fide R. Br., ubi non inveni). - Roem. et Scliult. syski. 3, p, 372*. Protea æmula Poir. suppl. 4, p. 573*. Frutex 3-4-pedalis. Capitulum magn. avellana majoris, interdum pedunculo brevissimo bracteis subulatis divaricatis tomentosis squarroso suffultum. Stigma cylindraceum.

34. S. PHYL I C OIDES (R. Brown 1. c. p. 125*), erecta, foliis patulis subbipollicaribus bipinnatifidis passimque pinnatifidis ramulisque glaberrimis, pedunculis subcorymbosis capitulo longioribus bracteis foliaceis subulatis squarrosis, involucro dimidium capitulum superante glabro, squamis exterioribus lineari-subulatis elevato-punctatis, interioribus lanceolatis læevibus, calyce stricto, unguibus glaber-

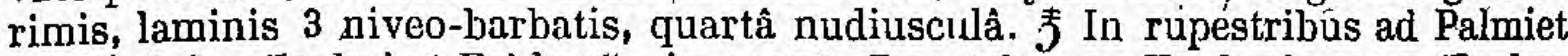
et Pótrivier (Ludwig ! Ecklon 1), in mont. Zwarteberge, Houhoek, etc. (Zeyher n. 3697I).-Roem. et Schult. syst. 3, p. 371*. Leucadendron Serraria Burman! in herb. DG. et Neocomens. L. phylicoides Berg. in act. Stockholm. 1766, p. 328, fl. Cap. p. $29^{*}$. Protea sphcorocephala Linn. mant. p. 188 (fide R. Br.). P. abrotanifolia Andr. repos. t. 507. S. parilis Knight P., fide Loudon Encycl. ed. 1, p. 82, n. 1378. P. eriocephala Willd. herls. n. 2403 , fol. 11 P. glomerata herb. Thibaud, n. 9 I in herb. DC. Rami virgati, laxi, foliosi. Folia $1 \frac{1}{2}-2$ poll. longa, $\frac{1}{3}-\frac{3}{5}$ lin. crassa, supra 1-sulca, laciniis 6-1.2 lin. longis indivisis vel rarius bifidîs abtusiusaulis. Pedunculi ramuliformes axillares et terminales subcorymbosi. Capitula magnit. avellanæ, 
Jracteis 3-5 lin. longis, interioribus ciliolatis nudisve planis coloratis, exterioribus pedunculique viridibus concavis demum patentibus. Calycis laminet 3 villis floridis 1-1 $\frac{1}{2}$ lin. longis plumoşe, quarta apice parce breveque adprosso-pilosiusculà caterum cum unguibus omnibus glaberrimâ. Stigma cylindraceum fere 1 lin. longum, stylo vix erassius. Facie et characteribus proxime accedens ad S. furcellatam, sed jam involucro bene distincta. (v. s.)'

35. S. SqUARROSA (R. Brown 1. c. p. 124\%), erecta, foliis patentibus subbipollicaribus pinnatifidis ramulisque glaberrimis, peduneulis subcorymbosis ramuliformibus squarrosis capitulo parum longioribus, involucri dimidio capitulo longioris squamis divaricatis, exterioribus tereti-linearibus foliaceis glabris, interioribus longioribus lineari-lanceolatis confertissimis parce patulo-pilosis, calycis laminis 3 penicillato-barbatis, intefiore unguibusque nudiusculis. 5 In Africâ austr. (Roxb., Niven ! Ecklon et Zeyh.!).-Roem. et Schult. syst. 3, p. 371*: Protea eriocephala Willd. herb n. 2403. ex parte, Lichtenstein n. 93 ! in herb. reg. Berolin. Roern. et Scluult. syst. 3, p. 379*. Serruria eriocephala Steudel nom. ed. 2, p. 400 . Protea squarrosa Poir. suppl. 4, p. 573.* - An potius var. procedentis, cui nimis saltem affinis videtur (specim, authent. non vidimus), recedens tantım bracteis levibus, interioribus pilosis. (v: s. in herb. Mart. et Sonder.)

36. S. c IL I A T a (R. Brown l. c. p. 123*), erecta ramosissima, ramis gracilibus laxius. cule foliosis jumioribus puberulis, foliis patulis subpollicaribus tenuibus pinnatis vel subbipinnatis vel biternatis mucronulatis glabris, capitulis subsolitariis pedunculo squarroso. longioribus, bracteis confertis lanceolatis acuminatis hirsuto-ciliatis dorso glabris clevato-punctatis, calyce subíncurvo toto argenteo-sericeo. $₹$ In arenosis planitiei Capensis (Roxb., Nelson! in herb. Banks., Niven! Ludwig! Ecklon, Un. itin. n. 45 ! Krauss n. 1057, Zeyher n. 1474! ex parte).-Roem. et Schult. syst. 3, p. 370* : Protea ciliata Poir. suppl. 4, p. 572*. Protea glomerata Willd, herb. 1]. 2406 , fol. 1 et 2 ! P. sphrerocephala Thibaud n. 6 ! in herb. DC. Folia erecto-patula, stibexsulca, laciniís divergentibus 3-6 lin. longis $\frac{1}{4}$ lin. crassis rectis vel subincurvis. Capitula turbinato-globosa, magn. cerasi, interdum aggregata. Bracteæ dimidio capitulo longiores, circ. 3 lin. Jongæ, interiores sæpius sanguineæ, pedunculi breviores concaves patentes ciliata vel nudx. Calyx 3-4 lin. longus, pube brevi densâ adpressâ. Stigma clavato-cylindricum, $\frac{3}{4} \operatorname{lin}$. longum. (v. s. in lierb. Banks., Willd, ẹtc.)

37. S. cONGESTA (R. Brown 1. c. p. $123^{*}$ ), erecta, humilis, ramosissima, laxiuscule foliosa, glabra, foliis pollice brevioribus tenuibus trifidis vel subbiternatis vel passim pinnatifidis indivísisve mucronulatis, capitulis solitariis vel aggregatis folia superantibus sessilibus, bracteis numerosis hneari-subulatis hirsutissimis dorso glahriusculis, calyce toto villis patulis dense barbato. 5 In arenosis Africa austr. (Roxb., Niven! etc.).-Roem. et Schult, syst. 3, p: 370*. Protea triternata Andr. repos. t. 337 ? Protea plinylicoides Schmidt in Florà 1830, p. 555 . (non alior.). P. con gesta Poir. suppl. 4, p. 573*. Habilus et char. plerique $S$. ciliatæ, sed calycis pubescentia longior (villis $\frac{1}{2} \div$ lin. longis flavidis) et patens, nec adpressa. Bracteæ dorso leves vel obsolete elevato-punctate. Rami umbellatí, ramulis siepe adscendentibus et folia tunc secunda. (v. s.)

4. laciniata, foliis $\frac{1}{2}-\frac{3}{4}$ poll. longis pinnatim 3-5-fidis, laciniis indivisis vel rarius bifidis, intermediẩ 3 -fidâ. - Protea plıylicoides Willd. herb. n. 2407, fol. 1! excl. fol. 2, 3, 4. (Zeyher n. 1474 ! ex parte.).

$\beta$. heterophylla, foliis $\frac{1}{3}-\frac{1}{2}$ (raro $\frac{2}{3}$ ) poll. longis semitrifidis (laciniis indivisis) passimque (præcipue summis) simplicibus subulatis sæpe incurvis subsecundis. S. congesta Drège ! docum. p. 112.

\section{§ 2. C'apitula composita, partialibus arcte congestis breve pedunculatis subsessilibusve.}

38. S. GLOMERATA (R. Brown ! l. (c. p. 128*) erecta, foliis patulis subbipollicaribus tenuibus bipinnatis ramisque demum glabris, laciniis divaricatis mucronulatis, pedunculo communi partialibusque brevibus squarrosis puberulis, capitulis partialibus multifloris, bracteis late ovatis acuminatis, exterioribus glabris, interioribus sericeis, calyce toto pube brevissimâ argenteo-sericeo, stigmate clavato. 5.In collibus saxosis (Gronov., etc., in herb: Banks.! Burchell, $\mathrm{n}$. 212 ! Bergius !), in 
arenasis circa Winberg (Ludwig! Ecklon n. 3! Zeyher n. 1476!).-Roem. et Schult. syst. 3, p. 374*. Serraria Burm. Afr. p. 265 , t. 99 , f. 2. Leucadendron Serraria $\beta$ Linn. sp. ed. 1, p. 94. L. glomeratum Linn. 'sp. ed. 2, p. 137. Herb. Linn. I ex parte (alterum specimen est $\mathrm{S}$. furcellata, vide supra n. 5). Protea glomerata Linn. mant. p. 187 (non. Thunb., cfr. S. elongata et crithmifolia). P. patula Thunb. diss. n. $4^{*}$, fl. Cap. p. 122, n. 5 ? S. artemisiæfolia Knight Prot, Loudon encycl. ed. 1, p. 82, n. 1369 cum ic., ex cit. Andr. Serruria foniculacea Sieber herb. Cap. n. 188! Rami umbellati, laxiuscule foliosi, glabri vel juniores pubescentes. Folia demum patentissima, $1 \frac{1}{2}-2$ poll. longa, $\frac{1}{3}-\frac{1}{2}$ lin. crassa, supra 1 -sulca, ad medium nsque divisa. Capitulum compositum magnit. juglandis vel pomi minoris, partialibus magn. cerasi, pelunculo communi brevi bracteis patulis late ovatis acuminatis glabris squarroso. Involncri squamis exterioribus fuscis enerviis, interioribus apice demum 'glabrescentibus. Calyx 3 lin. longús, demum subincurvus. Stigma vix $\frac{1}{2}$ lin. longum, stylo duplo crasssius, basi attenuatâ obsolete nodulosum. (v. s. in herb. Linn., Banks, etc.)

39. S. RUBRICAUL Is (R. Brown in Liln. Trans. 10, p. 128*), erecta, foliis subsesquipollicaribus biternatis suhbipinnatisque glabriusculis, pedunculo communi capitulo breviore glabro, capitulis partialibus pauciforis, bracteis scariosis ovatis ciliatis glabris, acumine recurvo, calyce villis adpressis sericeo, stigmate cylindraceo. F In Africâ austr. (Roxburgh ! in herb. Banks., specim. folìs usque ad 2 poll. longis, Commerson! in herb. Fée). - Roem. et Schult. syst. 3, p. 373 Protea sphærocephala Thunb. diss. n. $5^{\star}$ (excl. syz. omn.), fl. Cap. p. 122, n. 7? Rami stricti, rubicundi, glabri vel parce patulo-pilosi.Folia erecta, $1-1 \frac{1}{2}$ poll. longa. Peduncali partiales capjitulis suis breviores, pilosi vel glabriusculi. Stigma cylindraceum. Affinis S. adscendenti et glomerata, sed foliis brevioribus, bracteis etc. satis distincta. (r. s. in herb. Banks., etc.)

40. S. ADSCENDENS (R. Brown ! 1. c. p. $127^{*}$ ), procumbens, ramis adscendentibus laxe foliosis gracilibus, foliis patulis subbipollicaribus biternatis bipinnatisque glabris, laciniis parum divergentibus mucronulatis, pedunculo communi glabro squarroso partialibusque tomentosis brevibus, eapitulo foliis superato, partialibus imbricatis 6-7 floris, bracteis dimidio capitulo longioribus ovato-lanceolatis substriatis glabris vel interioribus cano-tomentosis, calyce incurvo toto pube brevi argenteo-sericeo, stigmate cylindraceo. 5 In montil. Kilyne Houhoek, Piquetberg, ad fl. Klynarivier, etc., alt. 2,000-3,000 ped. (Roxburgh ! in herb. Banks., Ludwig! Gueinzius ! Drège n. 8073! docum. p. 76. Zeyher, n. 3703!).-Roem. et Schult. syst. 3, p. $373^{\star}$, mant. p. 267. Protea adscendens Lam. ill. 1, p. 239, n. 1262, Poir. dict. 5, p. 658.* ? Rani rubicundi, glabri vel apice cano-puberuli, interdum erecti.

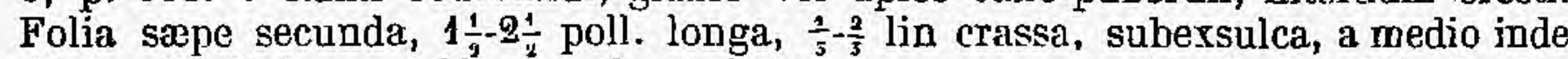
divisa. Capitulum ovoideum vel subglobosum, magn. cerasi majoris vel juglandis, e partialibus 5-7 conflatum, pedunculo suo longius, involucri bracteis sæpius sulcato-striatis adpressis acumine brevi recto vel patulo, interioribus incanis vel apice glabris, pedunculi sifuamis angustioribus concavis patulis. Calyx 4 lin, longus. Stigma $\frac{-1}{4}$ lin. longum, stylo vix crassius. (v. s. in herb. Banks., etc.)

41. S. PLAGELLARIS (R. Brown 1.c.p. 127*), procumbens, ramis adscendentibus laxe foliosis gracilibus foliisque patulo-pilosis demum glabratis, foliis secundis bipollicaribus bipinnatis tenuibus, laciniis divergentibus mucronulatis, pedunculo communi capitulo breviore sparse bracteato, capitulo ovato-globoso, partialibus 8-10-floris, bracteis ovatis acuminatis levibus ciliatis glabriusculis demum patentibus, calyce pube brevissimâ sericeo, stigmate subelevato-çlindraceo. $\zeta$ In arenosis et montanis cirea Simons Bay, Tafelberg, Casteelberg, etc. (Roxburgh ! in herh. Banks., Niven! Bergius n. 269! M[und! Ludwig!).-Roem. et Schult. syst. 3, p. 373*. Protea flagellaris Poir. suppl. $\mu .573^{*}$. Caulis basi divisus, ramis elongatiș. Folia $\frac{1}{5}$ lin. crassa, subexsulca, a medio divisa. Peduneulus communis subsemipollicaris, partiales 2-3 lin. longi, pilosiusculi (ex Br. subtomentosi), interdum recurvi. Capitula partialia 5-8, racemoso-congesta. Bracteæ ovato-oblongæ, fuscæ, parce adpresso-puberulæ, demum glabriuscula, ped unculares lanceolato-subulatæ glabra!, demum patentes. Calyx strictus vel subincurvus, pube adpressâ. Stigma $\frac{1}{2}$ lin. longum. Variat foliis haud secundis, usque ad 2 poll. longis crassioribusque. Nimis affinis $\mathrm{S}$ : adscendenti. (v. s. in herb. Banks. etc.)

12. S. DECUM BENS (R. Brown l. c. p. 126"), prostrata, glahra, ramis gracilibus, folís secundis bipollicaribus tripartitis, laciniis subæqualibus indivisis, pedunculis 
adscendéntibus gracilibus, partialibus brevilus, capjtalo subcunico (interdum abortu simplici), partialibus $4-6$ imbricatis $3-4$ floris, bracteis subrotundo-ovalibus breve acuminatis calycibusque subsericeis, stigmate cylindraceo $f \mathrm{I}_{1}$ rupestribus montanis circa Simons et False Bay (herb. Banks.!), Nieuwekloof, alt. 1,000-2,000 ped. (Drège! docum: p. 78).-Roem. et Schult. syst. 3, p. 372*. Protea decumbens Thunb. diss. n. 1, t. 1, fl. Cap. p. $1 \cdot 20, n \cdot 2$, Willd. sp. 1, p. 506 . P. procumbens Linn. fil. suppl. p. 116*. Serruria diffusa var. Drège I Habitu valde similis S. flagellari, diffusæe el simplicifoliæe. Folia ultra medium divisa, interdum (in specim. Drège) pinnato-4-5-fida, inferiora réflexa. Pedunculi terminales et stepe e summis axillis corymbosi, bracteis nonnullis parvis glabris obșiti. Capitulum compositum magnit. fere juglandis. Bracteæ interdum ovato-oblongee, attenuato-acuminatie, 3 lin. longæe, $1 \frac{1}{2}$ lin. latæ, exteriores cum pedunculo glabræ. Calyx levissime incurvus, villis arcte adpressis. (v.s. in herb. Banks. etc.)

43. S. RоXвURGHII (R. Brown l. c. p. $130^{*}$ ), erecta, foliis patulis semipollicaribus flabelliformibus bipinnatis ramisque gläbris, capitulo folia superante denso partialibusque subsessilibus, bracteis ovato-lanceolatis villosissimis acumine inferioribusque subulatis glabriusculis, calyce incurvo subadpresse villoso-sericeo, stigmate clavato-cylindraceò. 泰 Círca Paardeberg (Roxburgh ! in herb. Banks., Niven !), ad fl.Vierentwintigrivieren, infra alt. 1,000 ped. (Drège ! docum. p. 104, Zeyher, n. 1475!) Protea triternata Thibaud, n. 8! in lierl,. DG., Roem. et Schult. syst. 3, p. 375*. Protea Roxburghii Poir. suppl. 4, p. 574*. Frutex 3-4-pedalis, ramosissimus, ramis umbellatis puberulis demum ghabris laxiuscule foliosis: Folia 5-7 lin. longa, subexsulca, semitrifida, laciniis divaricatis 2-3-fidis pinnatisve minute mucronulatis. Capitulum magn. inter avellanam et prunum majorem, fulvo-villosum. Calyx 4-5 lin. longas, villis laxiuscule adpressís. Stigma fero 1 lin. longum, in stylum attenuatum, (v.s. in herb Bankș., etc.)

\section{§ 3. Capitula simplicia corymbosa vel racemosa, pedunculo communi ramoso aphyllo, interdum elongato.}

44. S. DEGIPIENS (R. Brown! in Linn. Trans. 10, p. 129*); ereeta, ranulis pulırulis, foliis erecto-patulis 1-2-pollicaribus tenuibus a medio pinnatis subbipinnatisque glabris, capitulis folia superantibus breve pedunculatis approximatis 5-6-floris, bracteis: ovatis pedunculisque adpresse cano-villosis, acumine brevi subulato grabriusculo exteriorum demum patulo, calyce incuŕvo adpresse argenteo-sericeo, stigmate subclavato-cylindraceo.J In arenosis Africas austr. (Roxburgh ! in therb. Banks.), Link enum. alt. p. 113*, - Roem. et Schult. syst. 3, p. $974^{*}$. Protea decipiens Poir. suppl. 4, p. 573. Ramosíssina, laxiuscule vel satis dense foliosa. Tolia subexsulca, $\frac{1}{3}-\frac{1}{2}$ lin. crassa, mucronulata, haud secunda. Corymbus vel capitulum compositum subglobosum, magn. cerasi, fere juglandis. Calyx 4-5 lin. longus, dense sericeus. Stigma continuuri, fere 1 lin. longum. - Species cum sequente quord inflorescentiam inter $\& 22$ (cui a cel. R. Br. adnumerantur) et $\& 3$ ambigia, sed postcrioris speciebus arctius affinis. (v. s. in herb. Banks. etc.)

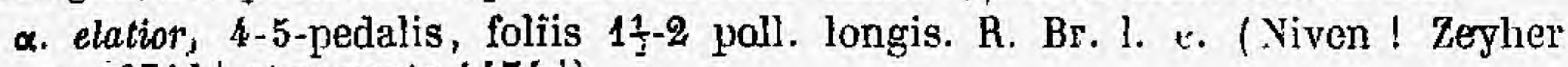
1.. 3711 ! et ex parte 1474!)

ß. humilis, 1-2-pedalis, foliis pollicaribus, braotearum acumine glabro (fusco). R. Br. I. c. (Niven! Drège n. 8074 ! docum. p. 11k.)

45. S. CompaR (R. Brown l. c. p. 129), erecta, foliis patulis subsesquipollicaribus tenuibus pinnatis capitula subsuperantibus ramisque gracilibes glabris, capitulis corymbosis breve pedunculatis pauciloris, bracteis ovatis sublanceolatisque canotomentosis acumine demum glabriusculo patulo, calyce incurvo pube brevi densà pattrlà cano-villoso. stigmate cylindraceu. F In collibus arenosis inter hromrivier et Bergvalei, etc, infra alt. 1,000 ped. (Drigge! docum. p. 110, Zeylher n. 3712 !). S. compar et \$. Purmanni var. Drègo! Protea comjar Poir. suppl 4, p. 574: Rami graciles, laxiuscule foliosi. Folia 1-1 $\frac{1}{4}$ poll. longn, $\div-\frac{1}{4}$ lin. rassit, supra obsolete 1 -sulca, infra medium divisa, laciniis $2-3$-fidis vel siepjus indivisis mucronulatis. Pelunculi commanes terminales et e summis axillis corymbosi, 5-7 lin. longi, glabri, bracteis 1-2 lin. longis lanceolabo-subulatis patulis obsiti, partiales capitulo breviores cano-tomentosi. Galyx 3-4 lin. longus. Stigma stylo vix crassius. - Monente ipso cel. auctore nimis affinis $S$. decípienti, priesertím calycis et involucri pubescentiâ distincta. Specim, Zeyheri pedunculis partialibus non 
longiorilus ad S. Kraussii accedunt, sed corymbo multiramoso, bracteis ovatis minoribus et foliis brevioribus dignoscuntur. (v. s.)

46. S. K RAUSSI, erecta, ramis gracilibus laxiuscule foliosis demum glabris, foliis erecto-patulis digitalibus tenuibus bipinnatis subbiternatisque glabris, laciniis parum divergentibus attenuato-mucronatiș, corymbo folia vix æquante pauciramoso, capitulis multifloris, bracteis adpressis lanceolatis acuminatis pedanculisque brevibus sericeo-tomentosis acumine glabriusculo, calyce recto dense plumoso-barbato, stigmate minuto clavato. 5 in Hottentottsholland (Ludwig! Gueinzius! etc;). Rami juniores minute parceque vel subcanescenti-puberuli. Folia 2-3 poll. longa, infra medium divisa, subexsulca, lacinits 6-10 lin. longis $\frac{1}{3}$ lin. crassis petiolo dimidio tenuioribus attenuato-acutis cum mucrone recto $\frac{1}{3}$ lin. longo tenui pallido. Pedunculi partiales 3-6 lin. longi, dense fulvo-tomensi, subsericei. Capitula globosa, magnit. cerasi, bracteas dimidio superantia, bracteis 2-3 lin. longis, peduneularibus longius acuminatis. Calyx vix 3 lin. longus; totus villis patulis $\frac{4}{2} \frac{1}{5}$ lin. longis flavicantibus sericeis tectus. Stigma vix $\frac{1}{4}$ lin. longum, in stylum attenuatum, atrum.-An eadem ac $S$. candicans? attamen differre videtur foliis glaberrimis, nec incanis, et pedunculis partialibus calyce longiorłbus, nec brevioribus. (v.s.)

17. S. CANDICANS (R. Brown l. c. p. 130) " foliis bipinnatifidis ramulisque incanis, capitulis racemosis paucifloris, pedunculis partíalibus calyce barbato brevioribus, J In Africâ austr. (Specim. authentiea non vidi. An huc Zeyher n. 3710? et S. candicans a Drège? certe non b nec $d$ ). "Facies $S$. Burmanni $\beta$ eique quam maxime affinis. "Br. l. c. Species diagnosi nimis brevi, omni adumbratione carente, ab affinibus vix dignoscenda, a S. Burmanni calyce saltem barbato distincta, forsan cum præcedente identica.

48. S. BuRanni (R. Brown1 1. c. p. 130), erecta, ramosissima, foliis patulis subbipollicaribus tenuibus bipingatis ramulisque glabris vel junioribus pubescentibus, laciniis divergentibus mucronulatis, corymbo multiramoso foliis subbreviore, pedunculis partialibus capitulo globoso multifloro brevioribus dense cano-tomentosis, bracteis adpressis cano-puberulis exterioribus ovatis, interioribus paulo longioribus ovato-lanceolatis, calyce reeto pube brevi adpressâ sericeo, laminis demum glabrescentibus, stigmate clavato-cylindraceo. $\bar{F}$ In depressis Afriç̋ Capensis vulgaris, $\hat{\beta}$ rarior, a planitie usque ad alt. 2,000 ped.-Roem. el Schult. syst. 3, p. $375^{\star}$. Folia $1-2 \frac{1}{2}$ poll. longa, vix $\div$ lin. crassa, supra 1 -sulca, juniorum pube brevi adpressâ cano-subsericeâ, rarius patulâ. Pedunculi partiales 2-8 lin. longi, capitulis magnit. pisi-cerasi dense multifloris, bracteis vix subsericeis 1 $\frac{1}{2}-2$ lin longis. Calyx 3-4 lin. longus, pube densâ albidâ vel flavescente brevi, in laminarum apice paulo longiore, laminis demum scepius totis glabratis vel apice tantum pilosiusculis. Stigma $\frac{1}{4}-\frac{1}{3}$ lin. longum, nonnunquam cylindricum. Nux subsessilis, ovato-globosa, pilosiuscula. Varietates a cel. auctore distinctæ, formis intermediis subconfluentes, vix stabiles. Specimina pleraque quoad folia ad $\alpha$, quoad calycem ad $\beta$ spectant. Variat præterea ramis glabris et láxe pilosiusculis vel apice tantum cano-tomentellis, densiuscule vel laxe foliosis, foliis subtripinnatis, capitulorum florumque magnitudine, calycis pube nunc densá brevi adpressissimế, nunc rariore vel in laminis subnullâ, nunc paulo longíore et minus arcte adpressâ. (v. s. in herb. Linn., Banks., Willd. etc.)

a. vulgaris, ramis foliisque pilosiusculis, capitulis turbinatis, bractearum acumine laminisque calycis demum glabriusculis.-R. Br. l. c. Abrotanoides, etc., Pluk. mant: 1, p. 329, f. 1. Serraria, etc., Burm. Afr. p. 264, t. 99, f. 1. Leucadendron Serraria $\alpha$ Linn. sp. ed. 1, p. 93. Protea Serraria Linn.! mant. p. $188^{*}$, herb. Linn.l ex parte (alterum specim. videtur diversa sp., sed haud rite determinandum), Thunb.! diss. n. $6^{\star}$, fl. Cap. p. 123, n. 8 (fide specim. Thunb.! in herb. Banks), Willd.! sp. 1, p. 508, herb. n. 2405! P. patula 'Willd. herb. n. 2401! P. tenuifolia Sol.? Smith ! in herb. Linn. Serruria foniculacea Sieber herb. Cap. n. $10 !$ ll. mixt. n. $94 !$ (fide herb. Sonder.). S. candicans b et d Drège! (Niven ! Ludwig ! Ecklon ! Un. itin. n. 754! Drège! n. 8072! Krauss, n. 1056! Zeyher, n. 3708! 3709! etc.)

B. subsericea, ramis foliisque subsericeis, capitulis basi obtusis, bracteis totis calycibusque sericeis. - R. Br. 1. c. (Ludwig! Verreaux! Drège, n. 8070 al Zeyber, n. 3699 ?). 


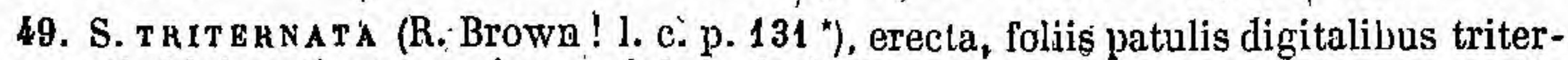
natis bipinnatisque ramisque glabris; laciniis semipatentíbus, corymbo composito amplo folia vix superantc, pedunculo communi cum bracteis sưis lanceolatis patulis glâro, partialibus gracilibu's 1-pleiocephalis sericeo-puberulis, capitulis globosis dense multifloris, bracteis ovatis acuminatis lanceolatisve sericeo-puberulis demum patulis, calyce tenui subincurvo argenteo-sericeo, stigmate minuto ovali-capitato. $\$$ Circa fl. Roodezant (Niven! Auge! Roxb.! in herb. Banks., Verreaux l), prope Nieuwekloof, mont. Tulbagh, alt. 1,000-2,000 ped. (Drège! docum. p. 77, Zeyher, sine numero) - - Roem. et Schult. syst. 3, p, 376 *. S. tridentata Dietr. synops. 1, p. 520. Protea triternata Thunb. diss. n. $7^{*}$, fl. Cap. p. 123, n. 10, Willd. sp.1, p. 509 . P. argentiflora Andr. repos. t. 447. P. glomerata Willd. herb. n. 2406, fol. 2 ! (excl. fol. 1). Serruria argentiflora Buek! in pl. Drège. Frutex orgyalis, ramis virgatis. Folia 3-5 poll. longa, novella sericea, pedunculo 1 lin. crasso, laciniis ultimis $\frac{1}{2}-1 \frac{1}{2}$ poll. longis, $\frac{1}{2}-\frac{2}{3}$ lin. crassis, sulcato-rugosis. Pedunculi partiales 1-2-pollicares. Capitula magnit. cerasi, bracteis $1 \frac{1}{2}-2 \frac{1}{2}$ lin. longis demum subrecurvis. Calyx $1-5$ lin. longus, pube densâ,brevi laxiuscule adpressâ. Stigma stýlo capillari duplo crassius. (v s. in herb. Banks., Willd., etc.)

50. S. ZEYHERI, foliis erectis digitalibus subtriternato-bipinnatis ramisque glabris, laciniis parum divergentibus tenuibus mucronato-acutis, corymbo folis superato subsimplici', ramis canescentibus indivisis vel apice racemoso-2-3-fidis, capitulis globosis dense multifloris, bracteis oblongo-lanceolatis glabris patulis, calyce tenui, tubo adpresse sericeo, limbo subgloboso glabro, stylo exserto, stigmate depressso-capitato umbonato. In lapidosis montium, circa Appelskrael, ad Rivier Zonder Einde, alt. IV. V (Zeyher I sine numero). Habitus, inflorescentia et bracteæ S. triternate, sed bene distincta folis fere duplo tenuioribus vix rigidis supra 1 -sulcis, pedunculis minus pubescentibus, bracteis glaberrimis, capitulis paulo minoribus, calyce breviore (2-3 lin. longo), limbo glaberrimo et stigmate paulo crassiore subgloboso. (v. s.)

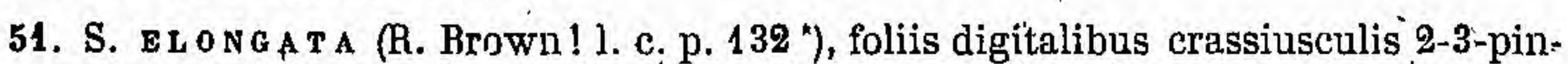
natis obsolete sulcatis ramisque erectis glabris, laciniis calloso-obtusíusculis, pedunctulo elóngato remote bracteato, corymbo vel racemo-subsimplici; capitulis globosis'multifloris squarrosis, bracteis scariosis ovato-lanceolatis pedunculisque glaburrimis acumine longo subulate recurvo-patente, calyce recto argenteo-sericeo, stigmate oblongo-clavato. $\hbar$ In mont. Hottentottsholland, Houhoek, Zwarteberg, etc. (Roxb., Masson! in herb. Banks., Niven! Drège! Krauss, n. 1055, Beitr. p. 140, Zeyher, $n .3702$ et var. $\beta$ !). - Roem. et Schult. syst. 3, p. $377^{*}$. Leucadendron elongatum Berg. in act. Stockholm, 1766, p. 327, pl. Cap. p. 27*. Protea glomerata Thunb. diss. n. $8^{*}$, fl. Cap. p. 123 , n. 11 (excl. syn. Linn. et? Burm.), Willd. sp. 1, p. 509. P. thyrsoides Lam, ill. 1, p. 240, n. 1267, Poir. dict. 5,p. 660 . P. helvola Willd. herb. n. 2400 ! (excl. specim. sub n. 94 var.). Serruria elongata? et triternata var. Drège / Frutex erectus, $1 \frac{1}{2}-2$-pedalis, subramosus, excepto calyce glaberrimus. Folia 3-4 poll. longa, $\frac{1}{2}-1$ lin. crassa, rugulosa; sulco obsoleto, lacinulis 2-6 lin. longis. Pedunculus 3-10 poll. longus, aphyllus, bracteis remotis lanceolatis acuminatis $3-4$ lin. longis subadpressis munitus, partiales $6-15 \mathrm{lin}$. longi, pauci-bracteati, 1 -vel rarius 2-3-cephali.Capitula magnit. cerasi 16-20-flora, superiora præcociora. Bracteæ rubro-fuscæ, 3 lin. longæ, acumine subulato basiu scariosam ovato-oblongam subæequante vel superante, exterıores carinatæ. Calyx 4-5 lin. longus, pube minutấ densâ adpressissimâ splendens. Stigma vix $\frac{1}{9}$ lin. longum, stylo duplo crassius. Variat (in specim. Drège) pedunculo vix pollicari, bracteis brevioribus ovatis vel 2 lin. longis, capituli lanceolato-subulatis haud recurvis, stigmate tenuiore. (v. s. in herb. Banks., Willd., etc.)

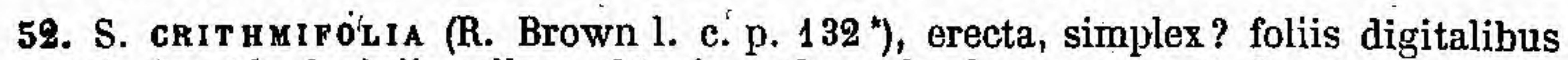
2-3-pinnatis, laciniis calloso-obtusis, pedunculo elongato remote bracteato partialibusque glabris, capitulis racemosis globosis multifloris, bracteis glaberrimis fatioribus quam longis, mucrone brevissimo obtuso recto, calyce semipollicari..... ‡ In Africâ australi (Niven). - Roem. et Schult. syst. 3, p. 377*. Protea crithmifolia Poir. suppl. 4, p. 574*. Folia 3-4 poll. longa. Pedunculus scapiformis infra racemum sæpe 8-10-pollicaris; racemus 8-10-cephalus pedunculo plerumque brevior, ramis (pedunc. partialib.) capitulo longioribus hasi dilatatâ cum processu scutelliformi rhacheos articulatis. Capit. sub-30-flora, magnit. avellanæ. Nux undique pubescens, pedicello brevissimo glabro rugoso. R. Br. - Specim. authentica 
vidi; Niveniana in herb. Mart. forsan huc spectant, sed bracteis ad S. elongatam accedunt. Varietatum sequentium una vel altera verisimiliter cum stirpe Brownianâ identica est, sed qurenam ? id propter stigma hujus non descriptum dijudicari non potest.

$\beta$. ambigua, excepto calyce glaberrima, scapis terminalibus 1 vel pluribus umbellatis folia longe superantibus, calyce pube brevi adpressissima fulvo-sericeo, stigmate ovali-capitato. - In mont. Zwartebergen, prope Hemel en Aarde (Ludwig l). Rami simplices, apice laxiuscule foliosi ; scapus 7-10 poll. longus, strictus, bracteis lanceolato-subulatis 3-5 lin. longis passim foliaceis remote obsitus, corymbi patuli ramis 1-2-cephalis squamis scariosis lanceolatis concavis 2-3 lin. longis paténtibus bracteatis, capitulis magnit. ceräsi, bracteis scariosis late ovatis breve acuminatis $2-3$ lin. longis ; stigma vix $\frac{1}{2}$ lin. longum, stylo subtriplo crassius. Cæt. ut in descr. Brownianâ. (v. s.) . ,

$\boldsymbol{\gamma}$. Ludwigii, excepto calyce glaberrima, scapo terminali solitario folia vix superante, calyce fulvo-vel aureo-sericeo, stigmaté tenui subfissiformi-cylindraceo. - Cum $\beta$ lecta (Ltidwig!). Rami apice ramosi denseque foliosi ; folia 4-5-pollicaria, laciniis 1 lin. crassis valde rugoso-sulcatis; scapus 4-6 poll. longus, validus, corymbi patentis ramis crassis 1-2-cephälis bracteis ovatolanceolatis patentibus prieditis; capitula magn. cerasi vel avellanæ, bracteis scariosis late ovalibus obovatisve patulis, subito in acumen subulatum circ.

7. 1 lin. longum subrecurvum productis, 3-4 lin. longis, $2 \frac{1}{4}$ lin. latis ; stigma stylo vix crassius. Cret. ut in $\beta$. (v. s.)

\section{Species non satis nota.}

53. S. A B R TANIFOLYA (KI. P., ex Loudon encycl. ed. 1, p. 82, n. 1367, c. ie.), foliis ultra medium bipinnatifidis pilosis, eapitulis sessilibus folia superantibus simplicibus. - Protea abrotanifolia hirta Andr. Bot. repos. t. 522, R. Br. in Linn. Trans. 10, p. 221. Rumi dense foliosi, glabri ; folia 1-1 $\frac{1}{3}$ poll. longa, tenuia, biternata; capit. magnit. fere juglandis; bracteœ erectæ; calyx roseus, laciniis breve barbatis; stigma cylindraceum, nigimm; ex Andr. ic."

54. S. ODORAT A (Sweet, fide Loudon 1. e. n. 1379), foliis bipinnatifido-filiformibus acutis pilosis, capitulo terminali simplici. - Protea abrotanifolia odorata Andr. repos. t. $545, \mathrm{R}$. Br. l. c. p. 221 . Ramuli steriles corymbosi capitulum superantes; flores odorati, exteriores demum refloxo-patentes, ex Andr. I. c. A præcedente vix distincta.

55. S. E M A R G.I N A T A (Sweet, fide Lou lon I. c. n. 1380), folitis ultra medium bipinnatifidis (ex ic. biternatis) pubescentibas, capitulis terminalibus et $e^{\prime}$ surnmis axillis simplicibus folia superantibus, bracteis basi seríceis. - S. arenaria Knight (non R. Br.), ex Steudel. Protca abrotanifolia minor Andr. repos. t. 536, R. Br. I. c. p. 221. Folia conferta, circ. pollicaria, tenuia, acuta; capitula magn. cerasi medio cris, bracteis lanceolatis acutis apice floribustue parvis roseis, calycis lacinils pilosiusculis, stigmate cylindraceo stylo vix crassiore, ex ic. l. c.

56. S. M ILLEF OLIA (Kn. P., fide Loudon 1. c. n. 1368), foliis a basi bipinnatis pilosis, pedunculis capitulo simplici aequalibus longioribusve, bracteis apice glabris, stigmate truncato. - Protea triternata Andr. repos. t. 337. Forsan S. congesta Br. (supra n. 37), ex R. Brown' l. c. p. 220. S.? triplicato-ternata Roem. et Schult. \$yst. 3, p. 378.

57. S. ERECTA , foliis palmaribus pinnatis bipinnatisque 3 -4-jugis erectis ramisque glabris, segmentis filiformibus, capritulo solitario sessili globoso folifis cincto sericeo-tomentoso. 5 Ad Cap: Bona-Spei. Protea erecta Thunb. fl. Cap. ed. Schult. 1, p. 124 , n. $12^{*}$. Erecta, exceptu capitulo ubique rlabra. Foliorum pinnula' sensim decrescentes. Capitulum magnit. corasi majoris. A cl. Steudel ad S. hirsutam redncitur, sed ab hàc, ut jam Thunb. expresse dixit, differre videtur caule sinplici, glahro, foliis majoríbus, eapitulo minure tomentoso nec laaato.

58. S. PL L A (Roem. et Schult. syst. 3, p. 378 "), foliis pollicaribus imbricatis trifido-pinnatis filiformibus ramisque pilosis, capitulis solitariis globosis parvis hirsutis. 5 Ad Cap. Bonæ-Spei - R. Brown in Linn. Trans. 10, p. 220 . Protea rillosa Thunb. phytogr. bl. p. 8, fl. Cap. 1, p. 458 , app. p. 186 , ed. Schult. 1 , p. 485 , 1. 16* (non alior.?). Gaulis erectus, 2 -pedalis, prolifer, totus pilosus, ramis verticillatis. 
Foliorum laciniæ acutæ. Capitulum nuce avellanà majus, squamis hirsutis. An a $\mathrm{S}$, hirsutâ satis distincta ?

59. S. B ERGII (R. Brown in Linn. Trans. 10, p. 220), foliis pollice longioribus trichotomo-multifidis ramulisque glabris, laciniis subulatis acutis supra ' 1 -sulcis, capitulis simplicibus solitariis sulpedunculatis subglobosis, bracteis cuneiformibus truncatis oum acumine villosis, inferioribus glabris, calycibus curvatis sericeis, stigmate turbinato-capitato. J Ad Cap. Bonæ-Spej. - Roem. et Schult. syst. 3, p. 377. Leucadendron sphærocephalum Berg. pl. Cap. p. $26^{\circ}$.

\section{Species non descripta.}

S. cor or a T A (Buek in pl. Drège, ex Drège docum. p. 109 et 221, III, E, a, 12). Inter Bergvalei et Langevalei, prope Zwartbastkraal, infra alt. 1,000 ped. An eadem ac S. colorata Zeyh:?, que nobis S. cygnea' , $_{\text {Br., supra, n. } 9 .}$.

\section{Species exclusa.}

S.? ALBIGaNs Roemn et Schult. = Nivénia candicans Roem. et Schult., v. infra, n. 12.

IX. NIVENIA R. Brown in Transact. Soc. Linn. Lond. 10, p. 48 et 133, Endl, gen.p. 338, n. 2127, suppl. IV, 2, p. 79, Meisn. gen. p. 331 (244), non Vent. — Paranomus Salisb. parad. p. 67. - Protee sp. Linn., Thunb., Andr. Bot. repos. $t .243$.

Flores hermaphroditi, capitati, capitulis 4-floris involucratis in spicam densam terminalem vel axillarem sessilem vel pedunculatam vel rarius in capitulum terminale congestis, singulis bracteâ unicâ subtensis, involucris 4-phyllis persistentibus, fructiferis induratis et paulo auctis, receptaculis planis epaleatis. Calyx regularis, 4-fidus, totas deciduus, laminis concavis antheriferis. Antheræ 4 subsessiles, lineares rel ovales, brevissime obtuseque apiculatæ. Squamulæ 4 hypogynæ. Ovarium 1-loculare, 1-ovulatum. Stylus filiformis, deciduus, superne angulato-sulcatús. Stigma verticale, clavatum, continuum, obtusum, stylo vix crassius, rarius conico-capitatum. Nux sessilis, ventricosa, nitida, 1-sperma, basi integra. - Frutices Capenses erecti, foliis sparsis coriaceis sessilibus vel petiolatis, superioribus integris dilatatis planis aut omnibus vel tantum inferioribus pinnatipartitis vel bi-triternatis, laciniis tereti-filiformibus supra 1-sulcis vel rarius linearibus canaliculatis planisve, spica terminali densâ, sæpe abbreviatâ, floribus purpurascentibus.

\section{\$1. Folia superiora integerrima R. Br. 1. c. - Spica sessilis vel subsessilis cylindrico-oblonga vel ovata, densa.}

1. N. S CEPTRUM.(R. Brown! 1. c.p. 134), foliis petiolatis glabris, summis cuneato-obovatis spathulatisve obtusis haud marginatis subenerviis, mediis cuneato-oblongis apice $\mathbf{3}$-fidis, inferioribus 3 -partitis segmentis 3 -fidis laciniisque tereti-filiformibus supra 1 -sulcis vel linearibus eanaliculatis, bracteis omnibus ovatis acuminatis velutino-tomentosis, calyce pube brevi adpressâ sericeo, stigmate stylo crassiore subfusiformi., In summis montibus Hottentottsholland (Roxburgh!! in herb Banks., Sparmann! in herb. Linn.), Zwarteberg, Galedon, - etc., alt. 2,000-3,000 ped., (Lildwig! Drège! docum. p. 118, Ecklon et Zeyher! Zeyher, n. 3713, cum var. $\beta$ !). - Roem. et Schult. syst. 3, p. 385*. Protea Sceptrum Gustavianum Sparm.! in act. Holm, 1777 , p. 55, l. 1, Linn.! suppl. p. 116. S. Sceptrum Thúnb. diss. n. 12 , fl. Cap. p, 125, n. 8*, Willd.! sp.1, p. 511, herb. n. 2410 ! (non? Lam. ill., ex R. Br.). P. alopecuroides Lam. ill. 1, p. 240, n. 1272. Leucospermum spathulatum Drège! olim in herb. Folia 2:4 poll. longa, superiora 6-12 lin, lata, semper glaberrima, juniora saltem glauca, inferiorum laciniæe calloso-obtusissimæe. Bractex floribus dimidio breviores, involucrales subtendentibus conformes, rufo-villosie vel tomentosı́, demum aucte .induratæ. Culyx 6-8 lin. longus, pube arcte adpressâ. Stylus capillaris 8-12 lin. longus, glaber, 4 -gonus. Stigma $\div$ lin. longum, stylo fere duplo crassius, basi obsolete nodulosum. Nux ovato-globosa, magnit. pisi. Variat foliis superioribus ovatis, obovatis ellipticisve utrinque attenuatis acutiusculis, planis vel saltem summis plus minus cucullatis, nunc 1-1 poll, longis apice obsolete 
eallosis, nune duplo longioribus, triplo latioribus obovatis cuncato-angustatis obtusissinis vel truncatis integris vel inciso 3 -dentatis, dentibus grosśius callosis, spicâ ovatâ vel oblongâ 1-3-pollicari, continuà densâ vel basi laxíusculâ. (v. s. in herb. Linn., Banks., Willd., etc.)

ß. splendens, foliis superioribus omnibus lanceolatis spathulatisve subcanaliculatis acutiusculis obsolete nervoso-rugosis, plérisque (summis omnibus) indivisis, inferioribus passim cupeato-semitrifidis, latiniis linearibus, capitulis inferioribus distinctis, bracteis calycibusque sericeo-splendentibus fulvoargenteis aureisve. (v. sp. Niven! in herb. Mart.)

9. N. MARGINATA (R. Brown l. c. p. $134 \%$ ), foliis superioribus subrotundo-reniformibus petiolo longioribus obsolete venosis anguste scarioso-marginatis ramisque glabris, involucri foliolis oblongis tomentosis subacutis apice bracteisque linearisubulatis glabriusculis, calyce adpresse sericeo, 'stigmate oblongo-clavato, ' 7 In mont. Africa austr. (Roxburgh, Ecklon et Zeyher!).- - Roem. ct Schult. syst. 3, p. $385^{*}$. Habitus N. Sceptri; foliá inferiora ignota, superiorum laminâ plerimque latiore quam longâ, usque ad 12 lin. latâ, 10 lin. longâ, rotundatâ vel brevissime acutatâ, glaucâ, obsolete flabellato-venosâ vel rugulosâ, basỉ subtruncatâ vel plús minus in petiolum cunealo-angustatâ, margine diaphano vix $\frac{7}{4}$ lin. lato. Spica 1 $\frac{1}{3}$-2-poll., pednnculo 4 lin. longo tomentoso bracteis nonnullis $3 \mathrm{lin}$. longis patulis et ad ejus basin conferte subverticillatis munito. Cæt. fere præcedentis, involucris tantum brevius tomentoso-incanis demum glabrescentibus, floribus paulo minoribus et stylo breviore tenuiore. (v. s. in herb. Banks., ef Sonder.)

3. N. Spathutata (R. Brown! 1. c. p. 135), foliis superioribus subrotundo-reniformibus petiolo vix longioribus subeveniis anguste scarioso-marginatis ramisque glabris, inferioribus pinnatifidis, laciniis canaliculato-linearibus filiformibusve, involucri foliolis oblongis tomentosis, calyce pube densâ patulâ sericeo-villoso, stigmate clavato-oblongo. J In mont. Africæ austr. (Masson! in herb. Banks;), in rupestribus inter Sparrbosch et Tradow, alt. 1,000-2,000 ped. (Drège! docum. p. 116). - Roem. et Schult. syst. 3, p. 385 *. Proten spathulata Thunb. diss. n: 58,

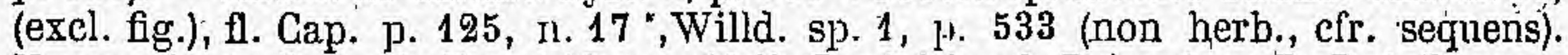
N. marginata Drège l.olim et N. parvifolia Buek! in pl. Drège (non R. Br.). Paranomus adiantifolius Salisb. fide Spreng. 1, p. 469. Folia circ. semipollicaria, petiolo 1 $\frac{1}{2}-2 \frac{1}{2}$ lin. longo, laminâ $4-5$ lin. latâ, juniora (scil. innovationum primaria)' subpollicaria, cuneato-linearia, 3-5-fida, laciniis nunc angustissimis 3-6 lin. longis; nune 1-2 lin. latis brevioribus. Spica pollicaris, basi-bracteis. subulatis glabriusculis stipata, involucri foliolis acutis obtusisve apice glabrescentibus, Calyx 4 lin. lońgus, fulvus, apice basique haud incrassatus. Cæet. N. marginatæ, à quâ præsertinu calycis pube haud adpressà dignoscitur. (v. s. in herb. Banks., etc.)

4. N. PARVIFolia (R. Brown! l. c. p. 135*), foliis superioribus cuneato-obovatis vel rhombeo-orbicularibus cucullatis petiolo longioribus flabellato-rugosis angustissime diaphano-marginatis glabris, infèriơribus bipinnatifidis, laciniis canaliculato-linearibus filiformibusve apice capitato-callosis, bracteis longe subulato-acuminatis glabriusculis, involucri foliolis subrotundis calycibusque velutino-lanatis demum induratis, stylo exserto lanato, stigmate capitato. J In mont. Africæe austr. (Masson ! in herb. Banks.), in rupestribus, circa Klyne Houloek (Drège, in herb. Mühlenbeck, Zeyher, n. 3717!).-Roem et Schult. syst. 3, p. 386 *. Protea Sceptrum Lam. ill. 1, p. 241, n. 1273 ? P. Gustaviana Poir. dict. 5, p. 663 ? (excl. syn. Sparm. et Linn.). P. spathulata Thunb. diss. t. 5 (qnoad figuram), Willd. herb. n. 2457 ! Nivenia spathulata Drège! olim. Folia glauca? superiora 6-12 lin. longa, 6-8 lin. lata, margine sub lente irregulariter crenulato vel lævi; inferiora bipollicaria et vltra, laciniis supra 1 -sulcis, callo apicis glanduliformi pallido. Spicæ solitariæ vel aggregatw, oblongæ, $1 \frac{1}{2}-2$ poll. longæ, sessiles vel pedunculațe, densiflorw, bracteis involucra æquantibus rectis rigidis, calycis pube fulvo-albidà sericeà. Stylus calyce subduplo longior, 8-10 lin. longus, angulatus, superne glabrescens, stigmate conico-hemispliærico acutiusculo. Priecedentibus valde quidem similis, sed stigmate distinctissima. (v. s. in herb. Banks., Willd., etc.)

\section{§ 2. Folia omnia trifido-pinnatifida vel bipinnata, vel rarius summa indivisa'sed haud dilatata.}

5. N. DREGEI (Buek! in pl. Drège), ramulis tomentellis, foliis glabris, inferioribus trifido-bipinnatis, mediîs trifidis, summis indivisis inferiorumque laciniis lineari- 
bus subspathulatisque obtusis canaliculatis, spicâ sessili ovato-oblongâ densâ, bracteis -coloratis tomentellis, subtendentibus cucullato-subrotundis apiculatis, involucralibus ovali-oblongis obtusis demum induratis, calyce sericeo, stylo glabro; stigmate subfusiformi. I In rupestribus mont. Zwartebergen, prope Klaarstrom, alt. 3,000-4,000, ped. (Drège! docum. p. 64). Sorocephalus diversifolius Drège! olim. Folia 1-2 poll. longa, pallide viridia (juniora forsan glauca ?), laciniis 1-2 lin. latis enerviis rugosis vel levibus, callo apicis pallido semigloboso sæpe obsoleto. Spica 1 -fere 2 poll. longa, bracteis rubris mox. glabrescentibus. Calyx involucro duplo longior, 7-8 lin. longus, pube denså subadpressâ aureo-splendens. Antheræe oblongæ, breve obtuseque apiculate. Stigma 1 lin. longum, obtusum, stylo glabro calycem requante superne angulato vix crassius, basi obsoletissime noduloso: Species insiginis, sequentium nulli affinis, potius ad $\mathrm{N}$. Sceptrum accedens, sed distinctissima. (v. s.)

6. N. spicata (R. Brown! in Linn. Trans. 10, p. $136^{*}$ ), ramis cano-tomentosis apice breve villosis, foliis subtriternatis glabris, laciniis conniventibus filiformibus canaliculatis tenuibus muticis, spicis ovato-oblongis pedunculo-longioribus, capitulis laxiuscule contiguis, bracteis ovatis acutiusculis rufo-villosis, subtendentibus pedunculique acuminatis velutinis, calyce ima basi barbato, unguibus diu cohærentibus tomentosis, laminis breve rufo-barhatis, stylo villoso apice glabro, stigmate ovali-clavato. $J$ In mont. Hottentottsholland; Lowryspass, Houhoek, Gnadenthal, Rivier Zonder Einde, ete., alt. 1,000-4,000 ped. (Ludwig! Ecklon! Drège! Zeyher, n. 3715! Koelbing! n. 7). - Roem. et Schult. syst. 3, p. 386 *. Leucadendron spicatum Berg. in act. Stockholm, 1766, p. 327, Cap. p. 25*, Linn.l mss. in herb. Protea spicata Linn.! mant. p. 187, Thunb. diss. u. 11, fl. Cap. p. 124, n. 15*, Andr. repos. t. 234 ? (a cel. R. Br. ad N. mediam citąta, sed soquo jure huc referenda). P. Lágopus Willd. sp. 1, p. 510, fide herb. n. 2408! Paranomus crithmifolius Salisb., ex spreng. syst. 1 , p. 469 . Folia 2 poll. longa, laciniis $\frac{1}{3}-\frac{2}{3}$ lin. latis haud divaricatis, callo apicis parvulo obtuso. Spicæe terminales solitariae vel subumbellatæe, 2-3-poll., pedunculis $1 \frac{1}{2}-2^{\prime}$ poll. longis, bracteis demum induratis. Calyx semipollicaris, involucro fere duplo longior. Stylus calycem requans, ad $\frac{4}{3}$ villosus vel pilosiuseulus, stigmate vix $\frac{1}{3}$ lin. longo obtuso. Nux ovata, nitida, stylo diu terminata, basi parum incrassata, sub cortice albido tenuissimo fusca. (v. s. in herb. Banks., Willd., etc.)

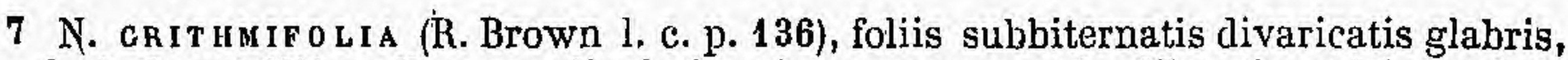
laciniis subfiliformibus canaliculatis apicem versus paulo dilatatis, spicis umbellatis conico-cylindraceis pedunculo parce bracteato vix longioribus, involucris alternis distinctis, foliolis obtusis adpresse tomentosis, bracteis subtendentibus ovatis acuminatis, calycis unguibus tomentosis, laminis breve barbatis, stylo ad medium usque villoso, supra glahro, stigmate... $\supset$ In montibus Africre australis (Niven), in rupestribus collium, ad fl. Hartebeestrivier, prope Caledon et Houhoek (Zeyher, n. $3716 \beta$ !). - Roem. et Schult. syst. 3, p. 387 ${ }^{*}$. Protea Lagopus Andr. repos. t. 243 , fide $\mathrm{R}$. Br. (sed nobis non minore jure ad $\mathrm{N}$. Lagop. referenda videtur). Protea crithmifolia Don ex Steudel. Monentc ipso cel. anctore a nimis affinis N. spicatro et forte haud distincta species, recedens tamen folijs divaricatis, lacinulis latioribus sursum paulo dilatatis, " etc. Specim. authentica non vidimus, sed Zeyberiana cum diagn. l. c. bene congruunt; stigna ovali-clavatum. A N. mediâ vix differunt risi calycibus involucro vix duplo, nec triplo, longioribus, involucro enim majore. Folia inferiora suepe dimidio minora et tenuiora quam superiora ejusdem rami, juniora pilosiuscula; rami cano-tomentosi. (v. s.)

8. N. MEDIA (R. Brown l. c. p. 137 ), ramis tomentcllis, foliis bi-vel subtriternatis, làciniis tereti-filiformibus vel angustissime linearibus planis acutiusculis glabris, spicis pedunculo parce bracteato breve villoso longioribus cylindraceis densis, involucris contiguis distinctis, foliolis ovatis acutis calycisque unguibus tomentosis, laminis breve sericeo-villosis, stylo infra medium pilosiusculo, stigmate subclavato. $₹$ In montibus Houhoek, Zwarteberg, Blaauwberg, Kaudeberg, Gift. berg, etc., alt. 1,000-4,000 ped. (Nivon ! Ludwig! Drège; a ! b! Ecklon et Zeyh. n. 15! Zeyher, n. 1479! 3716!). - Roem. et Schult. syst. 3, p. 387*. Protea intermedia Poir. suppl. 4, p. 575*. Protea spicata Andr. repos. t. 234 ? (recedens stylo toto glabro). Paranomus sceptriformis Salisb. fide Spreng. syst. 1, p. 469. Folia 1-2 poll. longa, superiora 3 -fida, laciniis lateralibus subsimplicibus $\frac{1}{2} \mathrm{lin}$. vel apice passim 1 lin. latis, callo apicis parvulo. Spicre umbellatæ vel solitariæ, $1 \frac{1}{-5}$ poll. 
longæ, pedunaulo 6-12 lin. longo. Involucra floribus subtriplo breviora, foliolis apice haud barbatisาcum bracteis subtendentibus pedunculique lanceolatis tomentosis. Calyx 5 lin. longus. Stylus dem $\mu m$ semipollicaris, circ. ad $\frac{1}{3}$ vel rarius ad .medium usque pilosiusculus, supra glaber, stigmate $\frac{1}{4}$ lin. longo vix tenuior. A proximâ N. spicatâ dignoscitur præsertim involucris minoribus tomentosis, nec villosis, et stigmate tenuiore. (v. s.)

9. N. LAG OPU'́ (R. Brówn ! 1. c. p. $137^{*}$ ), ramulis breve patulo-pilosiusculis, foliis bi-vel triternatis tenuibus subfiliformibus canaliculatis obtusiusculis demum glabris, spicis subsessilibus cylindricis densis, capitulis imbricatis, involucri foliolis subrotundis villoso-tomentósis, acumine brevi barbato, bracteis subtendentibus lanceolato-subulatis apice plumoso-barbatís, calycis unguibus tomentosis, laminis longiuscule barbatis, stylo infra medium pubescente, stylo clavato. $\delta$ In montibus circa Nieuwekloof; Hexrivierskloof, etc., alt. 500-2,000 ped: (Roxburgh! in herb. Banks., Niven! Verreaux ! Drège! Zeyher, n. 3714!). - Roem. et Sehult. syst. 3, p. $387^{*}$. Protea Lagopus Thunb. diss. n. 10, fl. Cap. p. 124, n. 14* Willd. sp. 1, p. 510, Andr. repos. t. 243 ? (clr. supra N. crithmifolia). Folia 1-1 $\frac{1}{2}$ poll. longa, juniora pilosiuscula, callo apicis obsoleto. Spicæ solitariæe, 2-4 poll. longæ, involucris flore- subduplo brevioribus. Stylus exsertus, demum semipollicaris, stigmate $\frac{1}{4}$ lin. longo parum tenuior. (v. s. in herb. Banks., etc.)

B. sericea, ramis cano-tomentosis, foliis adpresse sericeo-canescentibus. Grt. omnia ut in typo speciei ; folia et pubescentia N. mollissima, sed involucra et flores diversa. Protea spicata Willd. herb. n. 2409 ! Nivenia mollissima var. Klotzsch! in herb. Willd. (v. s.)

10. N. Mollis I ir a (R. Brown! I. c. p. 138'), ramis incano-tomentosis apice patentivillosiusculis, foliis bi-vel triternatis, sericeo-tomentosis albidis, laciniis teretifiliformibus obtusis, spicis ovatis densis, capitulis inferioribus distinctis, bracteis subtendentibus involucralibusque ovatis acutis dense villoso-tomentosis apice imberbibus, calyce basi sericeo-villoso, unguibus tomentosis, laminis longe plumoso-barbatis, stylo infra medium pulescente, stigmate gracili. 青 In montibus, circa Ezelsbank, alt. 3,000-4,000 ped. (Roxburgh I in herb. Banks., Drège ! docum. p. 74.).--Roem. et Schult. syst. 3, p. $388^{*}$. Protea mollissima Poir. suppl. 4, p. $\mathbf{5 7 5 *}$. Folia 1-2 poll. longa. Spices solitariæ, pedunculatæ vel subsessiles, 1-2 póll. longæ; involucri dimidium flor'cm subæquantis calycisque pubescentia densa fulva. Nux ovata, styli basi incrassata diu conico-apiculata. (v. s. in herb. Banks., etc.)

11. N. c A P I t A A A (R. Br̃own! 1: c. p. 138 *), ramis gradilibus ramulisque tomentosis, foliis brevibus biternatis passimque 3-fidis junioribns subsericeo-pubescentibus, laciniis tereti-filiformibus tenuibus, spicâ subsessili globosâ, involucrorum foliolis ovato-lanceolatis acutis demum glabriusculis, calyce toto patulo-villoso albido, stylo inferne pubescente, stigmate ovali-clavato minuto. $\delta$ In Africa austr. montibus, prope Brant Fly's Hill (Roxb., Masson l in herb. Banks.), Dutoitskloof, alt. 1,000-2,000 ped. (Drège! docum. p: 79), - Roem. et Schult. syst. 3, p. $388^{*}$. Protea capitata Poir. 4, p. 575 ". Facies potius Serrurice (v. g. S. Roxburghii et congestre) guam Nivenia. Folia 6-10 lin. longa, vix $\frac{1}{6}$ lin. crassa, supra 1 -sulca, mox glabra. Capitulum terminale compositum, magnit. cerasi vel pruni minoris, bracteis caṇopuberulis, exterioribus ovatis acutis subsericeis. Calyx sordide albido-villosus. Stylus subexsertus, imâ basi et supra medium glaber, stigmate parum tenuior. (v. s. in herb. Banlis, etc.)

12. N. candrcans (Roem. ut Scluull. syst. 3, p. 389), tota scriceo-tomentosa, foliis trifido-bipinnatis filiformibus argenteis, capitulis subsessilibus spicatis parvis,

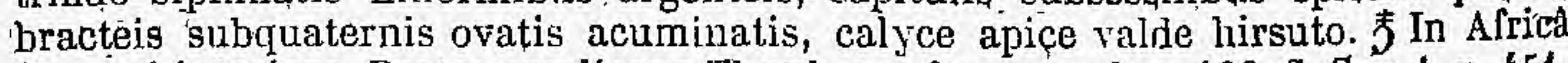
Gapensi interiore. Protea candicans Thunb. prodr. append, p. 186, fl. Cap.1, p. 451, ed. Schult. p. 123, n. $9^{*}$. Serruria? albicans Roem. et Schult. syst. 3, p. 378. Forsan eadem ac N. mollissima, fide R. Brown in Linn. Trans. 10, p. 221.

13.? N. C oncava (Roem. et Schult. syst. 3, p. 388), ramis villosiusculis, foliis subsessilibus imbricatis ovatis concavis enerviis subrugosis glabris apice subcallosis, capitulis aggregatis globosis, squamis brevibus ovalibus acutis oalycibusque pubescentibus. 5 Ad Cap. Bonæe-Spei. Protea concava Lam. ill. 1, p. 234, n. 1217, poir. dict. 5, p. 642. Proxime affmis dicitur N. spathulatæ, cfr. R. Brown in Linn. Trans, 10, p. 221, sed ex descr. inflorescentia vix congener videtur. 
X. SOROGEPHALUS R. Brown in Transact. Linn. Soc. Lond. 10,p. 48 et 139, Endl. gen. p. 338, n. 2128, suppl. IV, 2; p. 79, Meisn. gen. p. 331. (244.). - Soranthe el Spatalla-sp. Salisb. - Protere sp. Thunb. diss. $t$. 3, 5. Andr. bot. Repos, $t$, 527.

Flores hermaphroditi, capitati, capitulis 6-1-floris involucratis in spicam terminalem capituliformem basi imbricato-bracteatam vel nudam congestis, involucro partiali subuniseriali 3-6-phyllo bracteâ unicâ subtenso, fructifero haud mutato, receptaculo epaleato. Calyx regularis, 4 -fidus, totus deciduus, laminis concavis antheriferis. Antheræ subsessiles, ovales. Squamulæ hypogynæ. 4. Ovarium 1-loculare, 1-ovulatum. Stylus filiformis, deciduus, stigmate verticali, clavato. Nux brevissime stipitata vel basi emarginata, ventricosa, 1-sperma. - Frutices Capenses erecti, ramis virgatis, foliis sparsis rigidulis anguste linearibus planis vel filiformibus indivisis vel infimis interdum bipinnatifidis, capitulis subsessilibus, floribus purpurascentibus.

\section{Sect. I. Mischocaryon Endl. $l$. c.}

Spica nudiuscula. Involucra partialia 1-3-flora. Nux brevissime stipitata, basi integra. Folia filiformia, indivisa. - \& 1, R. Br. 1. c. sine nom.

1. S. SETAGEUS (R. Brown 11. c. p. 140 ), ramis strictis, foliis setaceis tenuibus lævibus ramulisque pubescentibus, mucrone setacęo sphacelata, inferioribus incurvis, spicâ sessili ovatê, involucris 1 -floris, calycis unguibus laxinseale tomentosis, laminis barbatis, stigmate ovato-conico $\bar{F}$ In Africa austr. (Roxburgh $!$ in herb. Banks., Niven!). - Roem. et Schult. syst. 3, p. 389*. Proteq setacea Poir. suppl. 4, p. $576^{*}$. Rami umbellati, tomentelli. Folia $1-1 \frac{1}{2}$ poll. Ionga', $\frac{1}{4}$ lin. erassa, teretia, supra obsolete 1-sulca, juniora pilosiuscula (ex Br. hirsuta). Capitulum sessile, magnit. cerași vel fore pruni, involncri squamis, ovato-oblongis. Stigma conico-ovatum, acutum, basi obliquum. (v. s. in herb. Banks.etc.)

2. S. SALSOLOIDE'S (R. Brown! l. c. p. 140*), ramulis crassiusculis glabris apice puberulis, foliis semitereti-filiformibus crassiusculis sphacelato-mucronulatis glábris supra 1-sulcis basi attenuatis, capitulo sessili ovato bracteolis paucis sublinearibus brevissimis subtenso, involucris 1 -floris, calycis unguibus dense patulotomentosis, làminis parce breviterque subadpresso-barbatis, stylo exserto glabro, stigmate oblongo-clavata. 春 In Africê austr. (Roxburgh! in herb. Banks., Niven ! Ludwig !' Ecklon n. 17!), in rupestribus montium circa Gnadenthal, alt. 4,000-5,000 ped, (Drège !'docum. p. 116. Krauss n. 1058!). - Roem. et Schult. syst. 3, p. 389*. Prótea salsoloides Póir. suppl. 4, p. 576*. Folia 6-12 lin. longa, $\frac{5}{4}$ lin. crassa, rugulosa. Capitúla solitaria vel interdum aggregata, magnit, cerasi minoris, involucri universalis bracteis paucis lanceolato-linearibus parvulis, partialium majoribus acuminatis tomentcllis glabroscentibus. Calyx canescens, 3 lin. longus, stylo tenui glabro fere dimidio hrevior. Antheræ breve obtuseque apiculatæ. Stigma continuum; vix $\frac{1}{6}$ lin. longum, ohtusum, atrum. Nux brevissime stipitata, ovoidea, involucrum æequans, puherula. (v. s. in herb. Banks. etc.)

3. S. I M BERBIS (R. Brown 1. c. p. 140*), ramulis pubesceritibus, foliis filiformibus subincurvis sulcatis acute mucronatis glabris, capitulo breve pedunculato subgloboso, involucris 3-floris, bracteis lanceolatis ciliatis acumine subulato glabro, calycis unguibus barbatis, laminis glabris, stigmate ovato-clavato. $亏$ In Africấ austr. (Niven). - Rocm. et Schult. syst. 3, p. 389*. Protea imberbis Poir. suppl. 4, p. 576*. Frutex ramosissimus. Folia uncialia, patula, parum curvata. Capitulum magn. corasi nigri. Stigma «quale. (ex R. Br. l. c. Specim. authent. non vidi.)

$\beta$ ? longifolius, foliis bipollicaribus tereti-filiformibus incurvis subrectisque minute scabriusculis, capitulo sessili ovato. - In lapidosis montinm ad Rivier Zonder Einde (Zeyher, n. 37181 excl. var. $\beta$ ). Forsan distincta species. Habitus S. scabridi, sed differt foliis teretibus, nec triquetris, dorso exsulcis, lævioribus longioribusque, et capitulo majore usque ad $2 \div$ poll. longo. (v.s.)

4. S. S CABRIDUS, foliis triquetro-filiformibus punctato-scaloriusculis supra concavis subtus bisulcis mucrone tenui inflexo, junioribus ramulisque pilosiusculis, capitulo sessili subglobose, involucris 2-4-floris, bracteis oblongo-lanecolatis acuminatis glabriusculis eiliatis, calycis unguibus breve pilosis basi laminisque gla- 
berrimis, stigmate ovato-conico. J In Africâ austr. (Verreaux! Ecklon et Zeyb. n. 16!), inter rupes mont. Winterhoeksberge prope Tulbagh, alt. 6,000 ped. (Mund! Zeyher n. 3718 var. $\beta$ !) S. njvalis Mund I mss. S. imberbis Klotzsch' ! mss. in herb. reg. Berolin. (non R. Br.). Rami graciles, stricti, subsimplices vel apice pátici ramulosi, densissime foliósi. Folia subadpressa, 10-14 lin. longa, vix $\frac{1}{3}$ lin. crassa, recta vel parum incurva, supra canaliculata, dorso obtuse carinata, punctis minutis sparse obsita et tactu scabriuscula, juniora pilis mollibus 1 lin. longis ciliata et hinc inde cum ramulis conspersa. Capitulum magnit. juglandis minoris, paulo depressum, folia parum superans, bracteis infimis subfoliaceis subulatis,-reliquis membranaceis rufis ovato-lanceolatis acutis 3-5 lin. longis læviusculis longe ciliatis, involucrorum partialium similibus sed dimidio minoribus. Càlyx 4-5. lin. longus ultra medium 4 -fidus; tubo dense albo-pilosiusculo, laminis ovali-oblongis obtusiusculis glabris. Stylus capillaris, glaber. Stígma subgloboso-capitatum acutiusculum, stylo triplo crassius. Ovarium pubesceus. A S. imberbi differt foliis scabriusculis, capitulo sessili majore, stigmate, etc. (v. s.)

5. S. PHXLICOIDES, foliis imbricatis acerosis carinato-triquetris mucronato-acutis basi haud attenuatis incurvis scrabriusculis dorso bisulcis ramulisque glabris, junioribus laxe piloso-ciliatis, capitulo sessili globoso, involucris 2-3-floris breve pedicellatis, bracteis ovato-lanceolatis ciliatis glabris, calyce stylum subæquante, unguibus brevivillosis, laminis omnibus dense longeque plumoso-barbatis, stigmate ovato. 5 In mont. Witsemberg (Mund ! in herb. Lindl. et Reg. Berolin., Zeyher n. 1468!). Folia 4-6 lin. longa, $\frac{1}{2}$ lín. lata. Capitulum magnit. avellanæ majoris, exinvolucratum. Stylus 5 lip-longus, capillaris, glaber, rectus vel apice incurvus. Nux subsessilis, obovato-oblonga, mutica, glabra. Similis S. Janato, sed differt ramulis glabris, foliorum ciliis fugacibus, capitulo solitario, involucris 2-3-floris, et calycis unguibus brevius pilosiusculis. (v. s.)

6. S. SPATALLOIDES (R. Brown in Línn. Trans. 10, p. 141*), foliis filiformibus patulis lævibus parum incurvis, juniơibus ramulisque pubescentibus, capitulis solitariis vel 2-3 aggregatis breve pedunculatis ovatis oblongisve, involucris 3-floris subpedicellatis, bracteis Ianceolatis acutis pubescentibus vel apice glabriusculis, calycis laminis longius barbatis, "stylo recto stigmate iequilaterali ovato, vel stylo apice incurvo stigmate subinæquali. 5 Girca Franschehoek (Niven, Roxburgh $!$ in herb. Banks.) - Roem. et Schult. syst 3, p. 390*. Protea spatalloides Poir. suppl. 4 , p. $577^{*}$. Frutex erectus, ramis umbellatis tenuissime pubescentibus. Folia -circ. pollicaria, dorso obsolete 1 -sulca, juniora pilosa. Capitula magnit. avellanæ, usque ad 1 poll. Ionga. - S spatalloides Buek! in pl! Drège (e mont. Zwartebergen etc., alt. 4,000-5,000 ped.; Drège docum. p. 64, 28) videtur sp. distincta, forsan noya, foliis omnino S. lanati ramulisque glabris, capitulo ovali vix semipollicari, bracteis lanceulatis glabris haud ciliatis, involucris sessi. libus 1?-floris, - sed specimina subpetentia nimis imperfecta. (v. s. in herb. Banks.)

\section{Sect. II. Gardrocaryon Endl. $l$. $c$.}

Spica subinvolucrata. Involucra 4-6-1lora. Nux basi emarginata.-Folia filiformia vel plana, rarissime infima bipinnatifida. - z 2. R. Br. l. c. sine nom.

7. S. TENUIROLIUS (R. Brown 1. c. p. $141^{\prime}$ ), ramulis villosiusculis, foliis imbricatis filiformibus brevibus acute mucronatis scabriusculis, junioribus hirsutis, capitulo sessili, involucris $2-\$$ subimbricatis paucifloris, bracteis lanceolatis barbatis apice glabriusculis, calycis laminis plumoso-barbatis, interiore 'nudiusculâ, stigmate ovato. F In montosis humidis prope Breede Rivier (Niven), Zwellendam (Krauss n. 1061 ? Beitr. p. 141).--Roem. et Schult. 3, p. 390*. Protea tenuifolia Poir. suppl. 4, p. 577* (non Sm.). Frutex 3-4-pedalis, facie Spatalle proliferæ, ramis vestitis rubicundis glabris. Folia semunciâ breviora. Capitulum magnit. pisi, e partialibus 2-k conflatum. Stylus strictus, stigmate, erecto æauilaterali (ex R. Br. 1.c. Specim. authent. non vidimus). S. tenuifolius Buek ! in pl. Drège (fide fragm. steril. in herb. Sonder.) abhorrens ramulís puberulis, foliis 6-8 lin. longis muticis læevibus, videtur species distincta aut forma S. lanati.

8. S. LaNA US (R. Brown 11. c. p. 142*), ramis puberulis, fuliis imbricatis subulatolinearibus apice submutico incurvis supra canaliculatis dorso obtuse carinato 1-nerviis parce punctato-scabriusculis piloso-ciliatis, capitulis subsessilibus soli- 


\section{sorocephalEs. PROTEACEA (adCTOB MÉISNER.). 305}

tarijs vel aggregatis globosis, ivivoluctis dense congestis 5-8-floris, hracteis baibafis lævigatis, exterioribus lineariłus subfoliaceis, interioribus menthranaceis ovatis lanceolatisque acutis, calj’ce toto plumoso-barluato, stigmatè conico clavato. JIn montibus $\Lambda$ fricxe austr: (Masson ! in herb. Banks.).- Roem. et Schrlt. 3, p. $390^{*}$. Protea lanata Thunh. diss. n. $30^{*}$, t. 3, fl. Cap. p. 130, n. 37, Willd.! sp. 1 , 1. 519 , herl. n. 2426 ! Soranthe ciliciiflora Salisb., fide Spreng. syst. 1, p. 470. Sorocephalus statilloides Sieber hexh.'Cap. n. 470 ! (non R. Br.). Rami graciles, pilosiusouli. Folía triquetía-filiformia, 4-8 lin. longa, - lin. lata, dorsó triquetra vel rotundata passim lávia. Capitula magnit av ellanw majoris, pcdunculo brevi loracteato vel subnullo. Involucra 5-7-phy̧lia, colorata. Strlus capillaris, glaber, rèctus, stigmaté vix $\frac{1}{5}$ lin. longo, atro. Nux brevissime stipitata, rugulosa, tenuissime pubescens, basi leviter enarginata. Tacie S. imbricato adeo sinnilis, ut gro ejus var. angustifolia haheri possit, 'sed formas intermediás hon observavimus : folia minus scabra et diutitus ciliata ; pedanculorum bracteæ foliis conformes, sed plus minus coloratæ, enerviæ, minores, involucrales minores, juniores pilosæ. (v. s. in herb. Banks., Willd., etc.)

$\beta$ ?, teretifolius, foliis teretibus fere rectis nitidis glabris læviúsculis, junioribus triquetro-filiformibus pilosiusculis, capitulis minoribus (magnit. cerasi), sctamis villoso-barhatis dorso glabris', calycis unguibus breve villoso-tomentosis, laminis omnibus Iongiuscule plumoso-barloatis, stigmate ovali-vel ovatoclavato nithus conico. - Círca Dutoitskloof,. alt. 3,000-4,000 per. (Drège'! docum. p. 81.). S. lanatus Buek !.Leucadendron ? scoparium E. Mey. a! (non c.) olim in pl. Drège. Folja 4-8 lin. longa, sub lente minute punctata, tactu haud sçabra, callo apicis recto subtriquetro-cónico obtusiuseulo pallido. Involucra rubro-fiusça, demum glabra. Calyx infra medium glaber. (v. s.)

9. S. DRE (B I. (Buek! in pl. Drège), ramis pabcrulis; fóliis semitereti-filifarmíbus obtusiusculis muticís exsulcis glaliris, capitulo sessili solitario globosó involucrato, bracteis adpreśse imbricalis ovationacutiusculis coloratis laevibus glabris ciliatis, inferioribus sterilibus, calycis tubo infra medium glabro, supra limboque

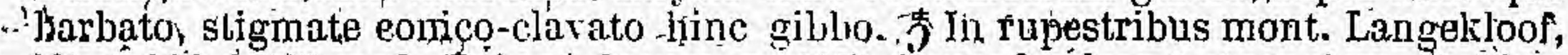
alt. 3,000-4,000 ped. (Drège I docum. p. 117). Leucadendron? scoparium L. Mey. $c !$ (nec a.) obim in pl. Drège. Facies, quidem et flores omnino $\mathrm{S}$. lanati $\beta$, sed folia breviora (A-5 lin- longa) et erassiora, supra plane exsulca, callo a jicis nullo vel obsoleto. Cajitulum magnit. cerasi minoris, squamis membranaceis fuscis $2-2 \frac{1}{2}$ lin. longis $1 \frac{1}{2}-2$ lin. Iatis pilis flavidis longiusculis tense ciliatis. Nux sessilis, obovatooblonga -olutusissima,' -mutica, pilosiuscila, 2 lin. longa, 1 lin. lata, busi parum attenuata obtusa. - Sorocephalus intermedius Buek !1. c., recedens sólummodo fọliis brevioribus (3-raro 4 hin. longis) et capitulo $\div$ minore, vix varietatis nomen meretur. ( $v$. s. specim. imperfecta, fere detlorata in berb. Mühlenbeck. et Sonder.).

10. S. I MBRICATE's (R. Brown!'l. c. p. 142*), ranis pilosiusculis demum glabris, foliis imbricatis oblongo-lancevlatis acutis inflexo-mueronulatis nervoso-suleatis dorso punctato-scabriuseulis piloso-ciliatis demum glalris, capitulis sulssessilibus solitariis vel aggregatís, bracteis. folia æequantibus mombranaceis coloratis oblon: gis aoutis scabriusculis ciliatis demum glabris, caly'cis tubo glabriuscuto papilloso, laminis barbatis, stigmate conico-clavato. 5 In montibus Africe austr. (herb. 'Banks! Soc. linn. Lond.! Niven, Verreaux !); inter Nieuwekloof' et' Ylandskloof, alt. 1,000-2,000 ped. (Dròge ! docum. p. 77).-Roem. etSchúlt. syst. 3, p. 391*. Protea imbricata Thunb. diss. n. 52*, fl. Gap. p. 436, n. 63, Willd.I sp. 1.p. 527, herb. n. 2446! Andr, Bot. repos. t. 517. Soranthie glanduligera Salisb. fide Spreng. syst. 1, p. 470. Frutex elegans, ramis sæpe pedalibus dense foliosis ramulisipue spithamxis plerumque umbellatis. Folia demum sempatula, 4-5 lin. longa, 1-1 $\frac{1}{2}$. In. lata, basi obtusa, venis a nèrvo medio parum divergentibus prominulís striata, punctis parum prominulis eonspersa tactu scabriuscula. Capitula subovata, magnit. pruni, siepius 2-3 aggregata el quąsí in unum conflata, singula pedunculo vix sempollicari bracteis alsscondito suffulta.' Bracten involucri generalis noiagnitucline formârue foliorum vel paula laticures; membranaecr, fuscie (rubro?), enerviæ vel passin apjice carinato-1-ncrvire, lipres vel vix scathriusculie; partialium similes sel dimidio minorès. Involucra 3-4-flora. Calyx 4-5 lirx. longus, lilácinus, tubo algustissimo alté clanso papilloso-juberulo, laminis dơrso comat patulà álbà vel

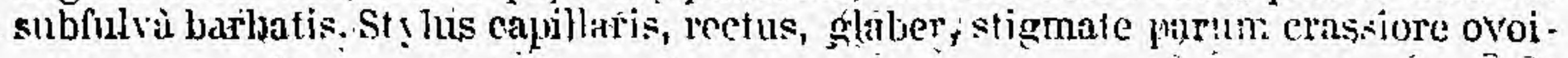

XIV, 
deo basi hinc sưbibibo. Nux́ obovato-obloiga, nutica, 2 lin. Ionga, fuscan. (v. s. in herb. Banks., Sòc. Linn. Lond.; Willd r etc.)

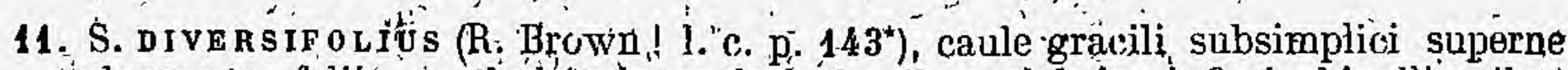
pubescente, foliis spathulate-lancélatis lævibus glabris, infimis bipollicaribus triffo-bipinnatifichs edabliculatis, superioribus semipollicaribus indivisis imbricatis obtusiusculis' subiconcavis, capituló solitarió sessili ovato óbtuso, calyciś unguibus laminișue barbatis, stigmate cylindraceo. I In saxosis montium prope Goud Rivier (Niven, Roxburghl l in lierb. Banks.).-Roem..et Schult. sysl. 3; p.391".

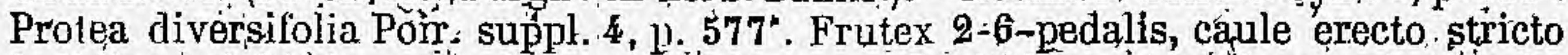
indiviso vel bifido, crassitie pennæ cygnex. Capitulum magnit." pruni minoris. (v. s. in herb. Banks.)

\section{Species exclusae.}

S, VERTIGILLAT US Stendel. = Leucadendron? vertícillatum nob.

S. DIVE RS IF qL I U, Drège olím. = Nivenia Dregei Buek.

$\therefore \rightarrow$

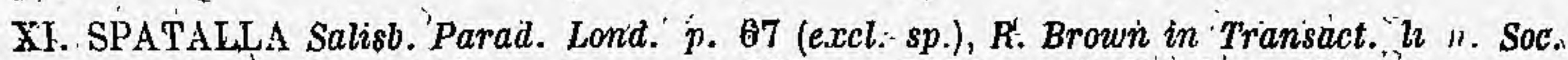
Lond. 10 , p. 48 et 143 , Endl. gen. p. 338, n. 2129, suppl.'IV; $2 ;$ p. 79, Meisn. gen. p. 331. (244). - Proteæ sp. Thunb. Poir.

Fores hermaphroditi, capitati, capitulìs 4 -1-floris involucratis spicatis vel racemosis, singulís bracteâ unicâ subtensis, in volucris $41-p h y l l i s$, fructiferis haud mutatis, foliolis liberis vel vix basi connatis subæqualibus aut inæqualibus in labia duo connatis, labio superiore indi viso sæpius longiore, inferiore (ântico) latiore 3-dentato vel 3-fido; laciniâ mediâ angustiore, receptaculó epaleato. Calyx subirregularis 4-fidus totus deciduus, laminis concavis antherifeitis, interiore plerumque majore. Antheræ subsessiles, ovales, brevíssime obtuseque apiculatæ, unấ (interiore) plerumque caterís majọre et in nonnưllis solâ fertilì. Squamulæ, hypogynæ 4 subulatæa. Ovarium 1-loculare, 1-ovulatum.' Stylius filiformis, deciduus. Stigma obliquuum, dilatatum, concavum vel convexiusculum. Nux brevissime stipitata, ventricosa, 1-sperma. Frutices Capenses ericoidei, foliis sparsis filiformibus indivisis, capitulis in spicas racemosve terminales pedunculatos vel sessiles digestis, floribus púrpurascentibus:

\section{Sect. I. Coilostigma Endl-gen. p. 338.}

Involucrum 1-florum. Calyx insulalis. Stigma concarum, cochleariforme. k. Br. l. c. p. 144.

1. S. Mollis (R. Brown in Linn. Trans: 10, p, 14\% *), foliis erecto-patentibus semipollicaribus strictis ramulišque gracilibuss sericeo-villošis; spicầ solitariâ sessili erectấ densả ramosâ, bracteís foliaceis pellicellos duplo superantibus, involứcro villoso 2-phijllo, foliolis integerrimis ovatis, exteriore latiore, calyce dense barLato, laminæ majoris villis marginalibus inflexis: 'f In montibus Africæe austr. (Roxburgh -) Foem. et Sohult. syst. 3, p. 392". Protea mollis Poir. suppl. 4, p. 577*, hee ibju. p. 567. Folia 7-8 lin. longa. Spica. vix uncialis, oblongo-cylindrica. Squamule hypogyno lineares, persistentes.

2. S. PEDUNCULAT A '(R. Brown! 1.' c. ]1. 144"), foliis subpollicaribus triquetro-filifơrmibus obtusiusculi basi valde attenuata adjessis-supra íneuryo-falcatis ramuTisque glabris, spicà pedunculatâ ereclà dense inłbricatâ, bracteis adpreesiś brevibus subulatis pedicullos crassiusculos subsuperantibus, involucro pédicellum suborjuanle bilabiato, Jahio inferiore laliore breviter 3-dentato, calyois unguibús tomentusis, Iaminis loreve niveo-villosis, majoris villis marginalihus infleł̣is, stylo çalycen iequante recto glabro, stigmate sulinclinato laterali ovali concavo, quce ôblongât involucrum dujlo superante. J In mont. Houhoek (Roxburgh l in . herly. Banks. Burnanu ! in herl, DC, Niven I Lichtenstejn, n, 112 I in herb! reg. Berolin., E(ckYon !), Zwarteberg et Eottentottslıollandsberge (Ludwig! Zeyher, n. 372, var. \&!), 
- Rdem. et Sclrult. syst. 3, p. 392 *. B: abictina Roèm et Schnlt. ï. p. 397. Protea jedunculata Poir. supjpl. 4, j. $578^{*}$. $\mathrm{l}$ ! racemosa Limn.! mss. in herb. (non Thunb). $\mathrm{P}$ abietina Willd. herb: n. 2418 ! Eolia valde, incurva, novella recta sericeo-pilosiuscula. Spica solitaria, 1-2-pollttcaris, demiam laxiuscula, peduneulo folíis lon-

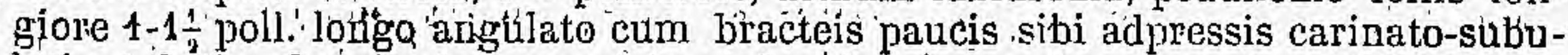
latis 1-2 lin, Iongis demun glabro: Involucrum subcampanulato-bilabiatum, cano-tomentosum, demunı glabrescens, labio supperiorc paulo longiore integro. Stigma dorso convexum, antice concavum cum papilla centrali. Nux obtusa, fulvopilosiuscula. (v. s. in herb. Baniks., Willd, etc.)

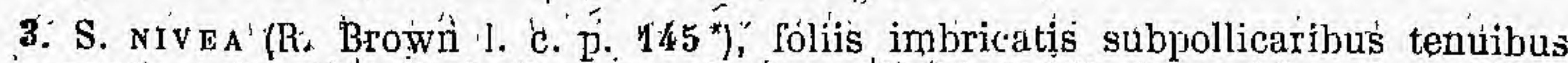
acutis subrectis; junioribus ramulisque, súbisẻriceo-piloșis, spicts subsessilibus erectis tensis imbricalis, bracteis foliaceis subulatis iñolucra breve pedicellata requantilisus, involuero campanulato calyce "sibtripio breviore inæqualiter sêmi4-fido sericeo, lolis ovatis acutiusculis, calyce subequall, unguibu's breviter lamiñis lónigius patulio-villosis nivéis, stylo calycem subrequante głabra subrecto,

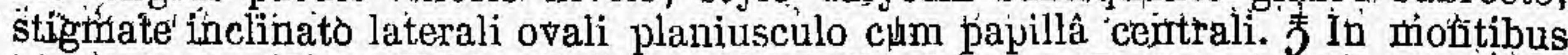
Africæa austr. (Níven, EckIon!), Hotten tôttshollandsberge (Zeyher, n. 3720 é̉ parte). - Roem. et Schult, syst. 3, p. $392^{\prime}$. Protea n̈ivea Poir. suppl. 4, p. 578*. Folia

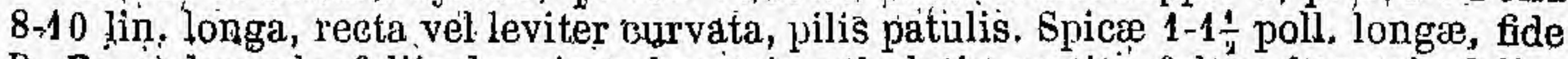
R. Br. pedunculo folís breviore bracteis stubulatis' vestitó fultzo., bracteis 2 lin. longis, involucro 1-1 $\frac{1}{r}$ lin. longo fúśco, ex Br. 2-phyllo, foliolo latiore profunde 3-rlentato, dente intermedio angustiore. Proxima S, ramulosæ et sericere, sed ab illâ distineta calycis pulrescentia et stiginate, ab hăc involucro pedicellata ejusque laciniis.latioríbus. (v. s.)

4. S. RAMUL os A (R. Brown! 1. c. p. 145\%), folijs confertis pollicaribus rectis vel subincurvis tenulbus arutis basi valde atteruatis' supra 1 -sul'cís ramisque gracilibus glabris, racenín breve pedunculatis simplicibus erectis densis, bracteis lancéolato-subulatís pedicéllös æequantibus, involucro câno-sericeo bipartito, Tabii latioris 3-fidi lachniis acuminato-acutis iatermèdià angustiore, labio superiore patlo longiore lanceolato dimidium ealycem subæequante, calyce dense tomentosoyíllọsó sericeo, lamin's majoris villis niärğinalijbue arcte inflexis, stylo calycern subsqcquante recto glabro, stigntate laterali subrotundo cochleariformi , papillà centrali. 5 in mont. circa Roorle Zand (Thunbergd in Kerb. Bánks.; Lichtenstein, 11. 110 ! in herb, reg. Bèrolin., Ludwig!), in lapidosis monte Groote Houlioek et Babylonsche Toorn (Zeylrer, n. 77! et 3721 ex partè). - - Roem. et Schult. syst. 3 , p. $293^{*}$. Loucadendron racemosum Linn. sp. ed. 1, p. 91 ? Berg. Cap. $p^{\star}: 23^{*}$. L'rotea racemosa Thüb.! diss. 11.21*? fl. Cap. p. 127, n. 27 (descriptio $S$. laxam et forte etiam alias species includere potest, sed specin. in herb. Banks. certe huc spectäl). Folí, recta vel incurva, ex ந̌r. canaliculata, novella scriceco-puberula. Racemi

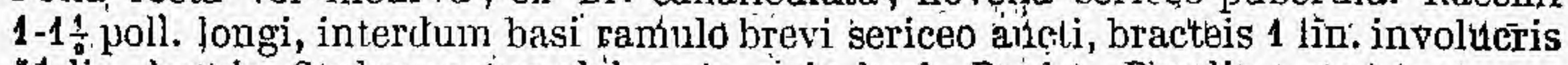
$1 \frac{1}{3}$ lin. longis. Stylus rectus glaber. (v. s. in lerb. Banis., Berolin., etc.)

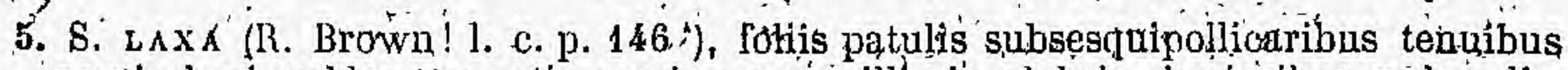
acutis basi valde attenuatis ramisque gracillimis glabris, junioribus puberulis, - racomis błevo pedúficulatis laxis, hracteis patulis subitlatís pédicello brevioribus, involúcri bipartití Iáciniâ anticẩ 3-partitâ, dente intermedio angustiore, pośticấ lanceolatâ, cályce breve villoso-sericeo, laține superioris cæterís duplo majoris villis tharginalíxót inflexís, stigmate läterali subrotundo concavo, nuce subsessili

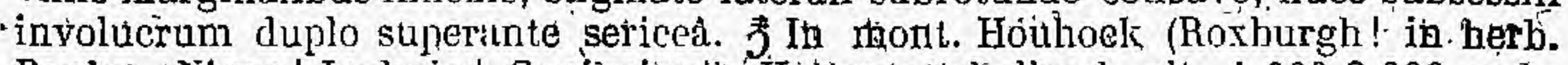
Banks,, Niven ! Ludwig! Gueinzius!); Hottentottsholland, alt. 1,000-2,000 ped., Zwellendam, ctc. (Drege! Krauss; n. 1648!): - Roem. et Schult. syst. 3, p. 293 *'. Protea laxa Poir. suppl. 4 , p. 578 . P. racémósa Jichtenstein! mss. i. 110, ex parte, et Willd. herb. 11, 2417!). Præcedentí simillima, sod distinctà peduncúlo pedicellisque longióribus, involuero, paulo minote. Rami laxiusculé foliosi. Folia $1-1 \frac{1}{2}$ poll. longa. Racemi $1 \frac{1}{2}-2$ poll. longi. Pedícelli 2-3 lin. longi, demum patentiśsimi, involucrum sericeum, 1 din. longum, lacinia súperiore paulo longiore. Núx oblonga. (v. s. in herb. Banks., Willd., etc.)

6. S. BR A C T E A T A (R, BroWn! l. c. p. 146 *), foliis subsesquipollicaribus curvatis obtusiusculis basi attenuatâ adpréssis supra patentibưs glabrị́̂, junioribus ramulisquè sericeis, spieis solitariis pedunculó longioribus imbricatis, bracteis teretibus involuora pedicellos subæqnantiá spperantibus, involucri 2-phylli foliolo latiore 
profunde 3-purtito, calycis unguibus adpresse tomentosis, laminis patula-barbatís, villis marginalibus haud inflexis: . In mont. Fransche Hoek (Masson! in herb. Banks., Ėcklon!). - Roern. et Schult. syst. 3, p. 394. . Protea bracteolaris, Pair. suppl. 4, p. $578^{*}$. Rami rigricantes, adpresse pilosi. Folia $1-1 \frac{1}{2}$ poll. longa, apice breviter penicillata, falcata vel sigmoidea, rarius passim recta. Spica $1 \frac{1}{5} 2^{4}$ polf. longa, involucrís superiorîbus pedicello paulo brevioribus. Stigma katerale, orbiculare, planum. (v. s. in herb. Banks., etc.)

7. S. S E R I C E A (R. Brotwn ], c, p. 147\%), ramis ramulisque virgatis glabris, junióribus sericeis, folijis imbricatis sempipolicaribus erecto-patentibus rectiuśculis serìceis, spicis solitariis sessilibus imbricalis, irvolucro subsessili bracteam æquante 2-phyllo, labio latiore 3-partito, laciniis subulatis, calycis unguibus tamentosis, laminis barbatis, villis marginalibus haud inflexis, stigmate inclinato ovalí planiusculo. F In montibus Africæ austr. (Roxb., Sieber fl. mixt. n. 471! fide Kerb, Sonder), Langekloof (Mund! in herb. reg. Berolin.) - Roem, et Schult. syst. 3, 1. 394*. S. ramulosa Sieber! l. c. S. polystachya Zeyher'! (non K. Bx.) et Phylica ahietina E. Mey.1 in herb. Drège. Protea sericifolia Poir. suppl.: 4, p. 578*. Folia tẹuía, supra obsoletissime sulcata plerúmque leviter jncurva. Spiea vix pollicáris. Stigma laterale. (v. s.)

8. S. PROLIFERA (R. Brown! in Linn. Trans. 10, p. $147^{\star}$ ), foliis confertis imbricatis subunguicularibus, junionoribus ramulísquve- sericeis, spicấ sêssilí conico-capitatâ, bracteis foliaceis, involucro subsessili 4 -phyllo, foliolis subulatis apice sphacelatis demum glabriusculis, calyce villis brevibus densissime sericeo-barbáto, laminse interioris duplo majoris villis marginalibus arcte inflexis, stigmate planiusculo. J. In mont. et paludosis Hottentottsholland (Masson ? in herb. Banks., Ludwig! Ecklon, ȟ. 18! in herb. Sonder, Zeyher, n. 3719!). - Roem..et Sehult. syst. 3, p. 394 *. Protea prolifera Thunb. diss. n. $27^{*}$, t. 4, fl. Cap. p. 129, n. 33, Linn. fil. suppl. p. 118, Willd - sp. 1, p. 518. Rami rubicundi, glabriusculi, ramulis tenellis umbellatis subsericeis dense foliosis. Squamulæ lrypogỹn 4 lineari-subulata. Folia erecta vel demum patula, tenuia, recta vel vix inçurva, setaceo-mucronulata, t5-8 lin. longa, (v. s. in herb. Banls., ete.)

0. S. coLORATA, foliis erecto-patulis subpollicaribus mucronulato-acutis basi vix attenuatis ramulisque glaberrimis, spićâ solitafiâ sủbsessili conico-capitatâ, inyo lucri subsessilis profunde 4 -partiti foliolis bracteisque subæqualibus - subulatis rectis coloratis adpressis pilositusculis, calycis unguibus breve pilosiusculis, laminis densissime patulo-villosis, villis marginalibus haud inflexis, stignàte inclinato suborbiculari planiusculo. J In lapidosis montium, ad Rivier zonder Eindé, alt. III, IV (Zeyher, n. 3718!). Rami gracillimi, debiles, ramulis umbellatis sanguineis laxiuseule foliosis. Folia 8-10 lin. longa, tenuia, recta vel subincurvá, supra 1 -sulca. Spica nutans, magnit. cerasi minoris, pedunculo inclínato '2 lin. longo bracteato, bracteis foliolisque iuvolucri sanguineis 2 Jin. Iongis calỳcis tułump subæquantibus adpresse pilosiuscutis. Calycis laminæ villis longiusculis flavidosericeæ. Stylus ealyeein subæquans, glaber, stigmatis papilla cèntrali. Inflorescentia S. proliferæ simillima et forsan mera ejus var., attamen notis iudicatis, prasertim calycis villis haud inflexis; satis discrépans. (vas.)

10. S. PYRAMIDALIS (R. Brown! le c. p. $148 \%$, foliis confertissimis erecto-patulis semipollicaribus tenuibus acutissimis strictis ramulisque pilosiusculis, spiệ. solitariâ sessili erectâ oblongo-pyramidali densá, involucro breve pedicellato púbescente 4 phyllo. foliolis lanceolato-subulatis patulis, calycis unguibus dense sericeo-villosis, interioris parum majoris villis marginalibus haud inflexis, stigmate subrotundo concavo. 5 In mont. circa Zwellendam (Roxburgh! in herb. Banks., Diven! Mund I), Grootvadersbosch (Lindwig!), in humidis,mont. Hottentottsholland (Zeyher! n. 3720, ex parte). - Raem. et Schult. syst. 3, p. 395*. Protea pyramidalis Poir suppl. 4, p. $578^{*}$. Ramuli umbellati. Folia 6 -10 lin. longa; passim leviter incurva. Spica 12-18 lin. longa, interdum basi ramosa, pedicellis víx 1 lin., bracteis $2-3$ lin., involucri, foliolis $1 \frac{1}{2}$ lin. longis. Calyois pubescentia flavescens. Receptaculum barbatum. Squamæ hypogyne 4 , lineari-subulat:e. (v, s.-in herb. Banlis., etc.)

11. S. POLYSTACHYA (R. Brown I I. c.p. 148 \%), folits confertis pollicaribus arcuatis tenuibus setaceo:acutís ramulisque pilosiusculis, spieis breve pedunculatis densiusculis, bractạis pedicellos ler superantíbus foliolisque 'involućri lanceolato- 
SPATALLA.

subulatis, ealyeis unguibus breve denseque pilosis, laminis subæqualibus longe plumosis, stignaate laterali subrotundo planiusculo. F In mont. Afrieæ austr. (Roxburgh $\downarrow$, in herb. Banks, Ecklon; n. 20!-in lierb. Sonder.), in rupestribus et humidis mant. Langekloof, Hottentottsholland, alt. 2,000 ped. (Drège, Zeyher! n.' $3720^{*}$, ex parte) - Roem. et Schult, syst. 3, p. $395^{*}$. Protea polystachya Poir. suppl. 4, p: 579*. Innovationes sericese. Spicie ramulos umbellatos terminantes sesquipollicares, erectæ vel nulantes' vel ex $\mathrm{Br}$. reflexæ; continuæ, involucris subimbricatis 4-phyllis, jedicellis vix-1 lin. longis, bracteis rectis vel plus minus recurvis calycis ungues aquantibus. Stylus glaber, calycem æquans, apice incurvo. Nux brevissime stipitata, tenuíssime pubescens. (v. s. in herb. Banks., etc.)

\section{Sect. II. Gyrtostigma Endl. gen. p. 338 .}

Involucrum 3-4-florum. Calyx subæqualis. Stigna convexiusculum. - R. Brown 1. c. p. 149.

12. S. I c.U RVA (R., Brown in Ling! Tràns, 10, p. 149), foliis laxiusculis patulis subpollicaribus incurvis tenuibus setaceo-mucronatis basi vix attenuatis glabris, junioribus ramulisque pilosiusculís., racemis pedunculatis, - bracteis lanceolatosubulatis' glabriusculis; involucro $3+4$-floro pubescente 4 -phyllo, foliolis ovatjs acuminatis, calyee toto brevi villoso, laminæ majoris villss marginalibus subinflexis, stigmato inclinato subrołundo umbonato. $\bar{J}$ In arenosis humidis Africæ austr. (Auge l' in hér h, Banks.), - Roem. et Schult. syst. 3, p. $395^{*}$. Folia 6-12 lin. longa, supra 1-sulca. Racenai solitarii vel síepius aggregali, 1-2 poll. longi. Involucrum $1 \frac{1}{1}$ lin. longum, dimidlum calycis tubum vix superan's. Calycis laminæ paulo longius quam ungues villose: Stylus glalser, apice inflexus. Nux involucro parum longior, pilosiuseula, -stylo diu persistente candata. ( $v$, s. in herb. Banks., etc.),

a. laxior, foliis pollicaribus glabriusculis, ràcemis aggregatis bipollicaribus laxiusculis pedunouló parum longiorihus, pedicellis jatentíbus, infimis bructeà - duplo longioribu's, involucro densiuscule adpresse pubescente sübtomentoso. - Circa Dutoitskloof, alt. 1,000-2,000 ped. (Drège, b ! docum. p. 79). S. incurva $\alpha$ R. Br. 1, c. Protea incurva Thunb. diss. n. 22, t. 3 , fl. Cap. p. 128, h. $28^{*}$, Wille. sp. 1, p. 516. Rami graciles, pedales et ultra, laxe foliosi: Folia 10,12 lin. longa, minus incurva. Pedícalli 1-3 lin. longi, supeviores bracteam aguantes, (v. s.)

B. densior, foliis semipollicaribus sericeis vel pilosíusculis tarde glabrescentibus, racemis solitariîs pollicaribus peduneulo 2-3-plo longioribus densiusculis, pedicellis inferioribas bracteam arruantibus, involucro mox glabreseente. Circa Dutoitskloof, alt. 3,000-4,000 ped. (Drège a! Ecklon, n. 19! in herl). Sond.), in mont. Witsemberg et circa Tulbagh (Zeyher, n. 1480!). S. incurva $\beta$, " forsan distincta sp: " R. Br. I. c. Folia 6-8 lin. longa, setaceo-mucronata, fere

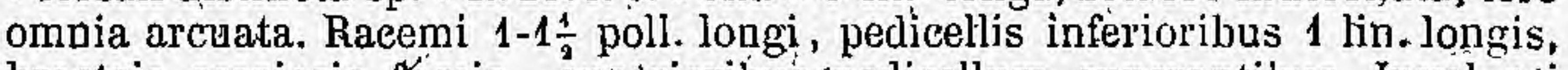
bracteis scariosis fuscis, superioribus pedicellum superantibus. Involucri cano-pilosiusculi foliolá subeequalia, ovata, brove subulato-acuminata. Calyx $2 \frac{1}{2}$ lin. longus, dense fulvo-tomentosus, vix sericeus, laminis brevissime vilİosis, unâ reliquis distinctconajorc. Stylus apice Jurcviter hamatus, stigmate paryùlo sulscapitato antice convexo. Nux subsessilis, ovoidea; involucrum vix superans, pilosiuścula. ( $\mathrm{v}, \mathrm{s}$.)

$\gamma$. Zeyheri, foliis subpollicaribus glabriusculis, racemis aggregatis brevissime pedunculatís bipollicaribus densiusculis, bracteis filiformibus coloratis basi vix dilatatis involucrum sericermm subæequántibus pedicello duplo longioribus. —In paludosis mont. ad Rivior Zonder Einde (Zeyher ! n. $3720 \beta$, ex parte). Folia 8-10 lin, longa. Pedunculi vix semipollicares, pedicellis 1 lin., bracters 2-3 lin. longis. Involucri fusco-sanguinei glabrescentis foliolá ovata, aeumine subulato $\frac{1}{2}$ lin. longo patulo. (v.'s.)

13. S. PROPINQUA (R. Brown!'l. c.p, 150 ), foliis semipollicaribus strictis ramulis que villósis, spicâ subpedunculatâ bi pollicari; bracteís foliaceis subulatís involu-: cra subsessilia tomentosa subbiflora æequantibus, calycis laminis subæequalibus pube brevi patulâ villosis. 5 In L frícà austr. (Auge! in herb. Banks.). Protea australis Poir. díct, suppl. 4, p. $579^{*}$. Folia rigidula, fere $\frac{1}{2}$ lin. crassa. Bractea inferores ovato-lánceolâtæ. Calyx ann plumosus. Stylus 3 lin, longus, stigmate... Nux tenuissime pubescens, stipite manitesto glabro fulta. (v. s. in herb. Banks.) 


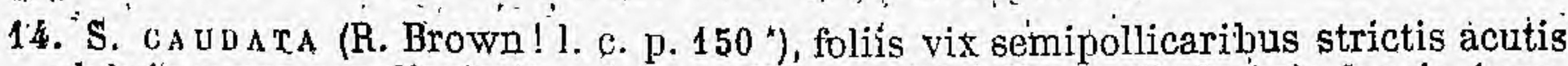
glabri's supra canaliculatis, spicis sessilibus pollicaribus cylindraceis densis, involiucris imbricatis subsessilibus coloratis, foliolis bracteisque ovato-1onceolatis acutis glabriusculis ciliatís, calyce subroquali broviter pátenti-villoso seficeo, stigmate convexo. F Circa Palniet Rivier (Masson!). - Roem. et Schult. syst. 3, p. $396^{*}$. Protea caudata Thunb. diss. L. 2 (excl. descr., quæ ad P. Thunbergir sjectat, fide R. Br.), Rami umbellati, glabriusculi. Sjicæ. sæpe 'aggregatæe, nonnunquam bipolliçăres, inyolucris carneis? sceptus 3 -floris. Nux tenuissime pubeseens.' (v. s. in herb. Banks.)

15. S. SRUAMATA, folihs's semiunguiculàribus acutis supra 1 -sulcis glabris'; spicis ovatis oblongisve subpollicaribus, involucrîs imbricatis glabresceñtibus toracteá lineari concavâ paulo longioribus profunde bijuartitis, labio superiore ovato-oblongo aculo, inferiore latiore 3 -fido subcarinato, dentibus acuminato-acutis, calycís nnguibus tomentellis, laminis inaequalibus villosis, "stigmate orbiculari"disciformi minute umbonato. F In Africâ austr. circa Elein (Ludwig ! in herb. reg:.Stuttgart.). Hami graciles, glabri, apico pilosiusćuli. Folia 3-4 liu. longas téretia, obsolete mucropulata, recta, apice breviter incurva, erecto-patula, juniora imbricata pilosiuscula. Spice 6-12 lin. lougre, solitaric vel $3-4$ aggregatx. Involucrum $2-2 \frac{1}{2}$ lin. longum, membranáceum, flavum vel rubrum, subnitidum, demum fere glabrum, hiflorum (interdum 1-f.\%), labio superiore indiviso 1-nervi, inferíore 3-nervi, dente intermedio ạıgustiore. Calyeis jubescentia alloa, laminà upâ nájore longius villosà, villis marginalibus haud inflexis. Stylus rêctùs, glaper, stigmate laterati. Nux subsessilis, ovadea, involucro brevior, pilosiuscula. Species a S. caudata cæterum simillimá maxime distịnctá in volucro majore, bipartíto, cuasi viernieoso subpitido. (v. S.)

16. S. Thun Be RGII (R. Brown l. c. p. 150 7, folís imbricatis vix semipollicarịpus acutis canaliculatis ramísque pilosis, spicâ sessilí cylindraceá denśâ, involucris brevissimne pedicellatis, foliolis bracteisque ovato-lanceolatịs villosis, calyce subaquali, laminis Jrevissime barbatis subsericeis, stigmate convexo. . . In mont. Africe austr. (Niveri): - Roem. et \$chult: syst. 3, p. $396 *$. Protea caudata Thunb. diss. n. 23 * (excl. ic, cfr. S. caudata). Fólía conferta, gàllyce longiora, stricta vel

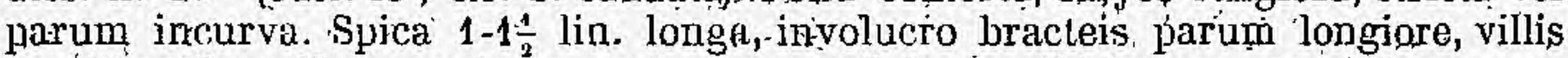
persistentibus. Nux tenuissime pubescens, stipite brevissima crasso glabro.

$\beta$. Dregei, ramulis cano-tomentellis vel demum glabris sanguineis, foliis teretibus albido-mucronulatis glabris, junioribus ramulisque sericeis, spicis solitariis vel agregatis subpollicaribus, pedicellis infimis fere 4 lin. longis, Jracteis subulato-acuminatis, cályce dense tomentoso-villosiusculo fulvo, laminis iṇer fualíbus paulo longius villósulis, stylo apice inflexo, stigmate planiusculo. - Circa Ezelshank et Blaauwberg, alt. 3,000-4,000 pedn(Drègélidocim. p. 73;.

74). S. incurva $\beta$. Drège I Folía 3-5 lin. longá, supra 1-sulca. Spicáintertum breve peduneulata. (v:s.)

17. S. BREVIF OLIA (R. Brown! 1. c. p. $151^{\star}$ ) foliis ereclo-patentibus s,ubtrilinea . ribus obtusiusculis sujtricquetris supra canalicúlatis subsericeo-villosiusculis, spicâ solitarià sessili densâ, bracteís lanceolato-suloulatis, involucro brevissime pedicellato pubéscente 2-3-floro, calyce sequali adpresse subsericeo-cano, laminis apice broviter villosiusculis, stígmate convexo, papilla elcvaliore. 5 In mont., Afr. austr. (Masson! Niven!). - Roetn. et Schult. syst. 3, p. $397 \%$ S. Jrevifolia Buek ? in pl. Drège (docum. p. 74, quam non vidi). Protea brevifólia Poir. suppl. 4 , p. $579^{*}$. Tami virgati, umbellati, pubescentes. Folia calyce breviora. Spica 1-1 $\frac{1}{2}$ poll. longa, rhachi pedicellis bracteis fue pubescentibus. 'Squamule hypogynæ 4 , subulatæ. (v. s: in lierb. Banks.)

XII. ADENANTTEOS Labill. Nov--Holl. $1, p .28, t .36-38, R$. Brown in Linn. Trans. 10, p. 48 et 151, prodr. A. Nov.-Holl. p. 367, suppl.p. 9, Entl. gen. $p .338, n .2130$, suppl. IV, 2, p. 80, Meisn. gen. p. 331 (244).

Flores hermaphroditi, axillares solitarii, aut terminales capitati vel solitarii. Involucrum 1-florum, 4-8-phyllum. 'Calýx gracilis, deciduus, tubo récto vel curvato dorso sepius fisso basi deminn circumscisso, limbi 4-partiti laminis aqualibus concavis ạntheriferis. Antheræ 4 subsessiles, lineares vel oblongæ, connectivo ultra loculos producto breviter apiculatæ, unâ sæapiuss 
abortivâ, squamulæ hypogynæ 4 calycis basi persistenti adnatæ. Ovariự 1-loculare, 1-avulatung. stylus filiformis, calyce longior, rectus, stigmate verticali cyljndraceo tenui vel subclayalo. Nux sessilis, ventricosa, 1-sperna. Frutices Novæ-Hollandize austro-occidentalis, foliis, sparsis indivisis vel sæpins apice dentatis trifidisve vel biternatim partitis, laciniis plerumque lineari-filiformilbus prope apicem subtus callo vel glandulâ sessili munitis, stomatibus amphigenịs vel hypogeniș, flọibus rubris luteisve.

\section{\$1. Planifolia - Foliá plana, integerrima vel rarius apice inceso-} dentata. Flares axillares solitarii, rubri, rarius terminales 2-3 aggregati. Calyx quasi unilabiatus; supra profunde fissus, laminis in cucullum stigma retinentem diu cohcerentibus. - Meisn. in $p l$. Preiss. 1, p. 510 .

1. A. LINEA BIS (Meisn. in Hook. Journ. 1852, p. 183), foliis linearibus integerrimis obtusis basi attenuatis ruguloso-striatis enerviis dorso apice glanduliferis adultis glabris, junioribus patenti-pilosis, capitulis terminalibus 3-1-floris, ínvolucri squamis 2-4 ovato-oblongis acutis, calyce arcuato breve villoso limbo' oxali-acuto diju clauso, stylo infra medium glałıro, supra patenti-pilosiusculo, stigmate parum crasssióre brevi subquadrangulo ób́tuso. I In coloniâ Swan River (Drunñmollç coll. 4 . n. 265!). Raini graeiles, ramulis adscendentibus sulsfiliformibus incano-puberulís "demun! glabratis sanguineo-fuscis. Folia séssilia, 'semiputula, $1-1 \frac{1}{2}$ poll.' longa, $\frac{1}{-}-1$ lin. lata, glandulâ subtëminalì orbiculari fuscâ. Capitula foliis oljvallantibus breviora, pedicellis brevịssimis canis bracteis pátcis oyalis minutis sparsẹ tectis, involucralibus 2-4 majoribus imbricatís 1-2 lin. 'longís. Calyx tubulosus 8 'lin. lóngus, 1 lin. crassus, supra fère ad basin ustue fissus, jułpe densẩ brevi paténit sordide albidà-sériceus. Stylus demum rectus, 12-14 lip. longủs, stigmate vix $\frac{2}{3}$ lin. 'longo obsolete sulcato basi levvitèr incrassato. (v. s.).

2. A. BARBrG E A (Lindl.! Swan River, п. 182), foliis oblongo-vel lineari-lanceolatis integerrimis obtusis triplinerviis venosis glabris, júnioribus ramisque patenti-

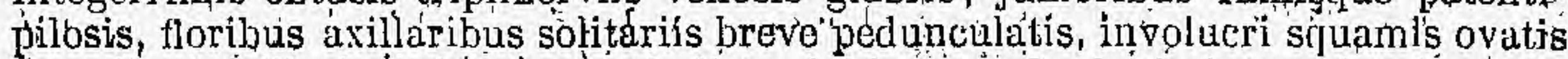
acuminatis 'villosis, calyee patenti-piloso, lobis ex tus barbatis intus glahris, stylo piloso démum glabrescenfe, stigmate ovali oblongo comjuressu salcato. J' In colonià Stwan River (Drumimond coll. $1_{1}$ n. 591!), in aremósis, ad montes Darlings Kango (Preiss; n. 7921). - Meisn. in pl. Preisss. 1, p. $511^{*}$. Folia $1 \frac{1}{2}-3$ poll.' longa, 2-4 lin. lata, apice óbsolete glandulósó-incrassata. Pedúnculi 2-4 liu. lungi. Flores coccinei. Anthera und abortival. Stigma $1 \frac{1}{2}$ lin. longum.' (v. s. in herb. Lindl., elcc).

3. A. овоуа т A (Labill.! Nov:-Holl. 1, p. 29*, t 37); follis sessilibus obovatis obtusís integerrimis obscure triplinerviis, glabris, floribus axillaribus solitariis brevissime pelunculatis, involucri sifuamis ovatis glabriusculịs calyce undique adpresse sericeo-canescente, lobis intu's glabris, styló piloso, stigmàte ovali-oblongo conpressso sulcató. F In coloniâ Swan River. (Labill.! MYlne ! Mangles I Drunm. coll. 1, n.' 592!), in arenosis, circa Guildford, (Preiss, n. 790!). - Lam. ill. t. '913, f.' ', R. Brown prodr. p. 367, Roem. 'et Schult. syst. 3, p. 398", Meisn. in pl. Preiss, 1, p. 51. ${ }^{*}$. Folia circ. pollicaria. Pedunculi $1-1 \frac{1}{2}$ poll longi. Flores miniati. Stigmă fere $1 \frac{1}{2}$ lin. longum. (v. s. in herb. DG., cte.)

4. A. venos a (Ḿeisn, in Houk. Journ. 1852, p. 183), foliis sessilibus obovato-ovalibus integerrimis breve acuminatis liasi obtusis, venoso-striatis subreticulatis glabris, junioribus puberulis, capitulis terminalibus 2-1-floris, calyce hisjojdulo folia vix superante, stylu gljaljro, stigmate tenui ejlindraceo. F Iu coloniấ Swan River (Drumm. coll. 1. n. 264 )). Rami firni ramulique subverticillati stricti, atrofusci vel cinerascentes, dênse foliosi, glabratí, juniores cano-vel fulvo-tomentosi. Folia rigida, semipatula, 8-10 lin. lonea, 4-5 lin. lata, lete viridia, apiculó mueronuliflormi obtusiúsculo eglanduloso, utrinque subparalléle striata et obsólete reticulata, subitide obscare trinervia, sub lerito puncticialata, tactu tanén lidvia, summa approximato-subverticillata caputulum obvallạtia. Calyx pilis brovibus patulis ninute glanduliforis lispidulis, dorsón tissus, limbo acuto mox 4-jartitu. Sífgna styło calycem duplo superante vix erassius, ubtusum, basí obsolele nodalosum. (v. s: in therb. Shuttleworth.) 
5. A. c UNEA TA (Labill.! 1. c. p. $28^{*}$, t. 36), foliis pétiolatís euneatis premorsoobovatis oblongisve apice dentato-crenatis obsolete triplinerviis ramulisque sericeo-tomentosis, pedunculis axillaribus terminalibusque 1 -floris petiolo sublongioribus, involucrísquamis ovatis acuminatis calycenue sericeis, lobis intus barbatis, stylo piloso, stigmate subulato. J In coloniâ Swan River (Labill ! Drumm. coll. 3, 11. 245!), ad Stirlings Térrace (Preiss, n. 793!)- - Lam. ill. t. 913, f. 1, R. Brown prodr. p. 367 , Roem. et Schult: syst. 3, p. $397^{*}$, Meisn. in pI. Preiss. 1 , p. $511^{*}, 2$, p. 247. A flabellifolia. Knight ét Salish. Prot. p. 96. A. crenata Willd. Spreng. syst. 1, p. 472. Folia 10-16 lin. Ionga, apice 4,6 lin. lata; dentibus 5 vel' rarius 3 brevibuis obtusis, raro 1 lin. longis. Pédunculi tenues 3-7 lin. longis Calyx longitudine folii: Anthera hna abortiva, conieo-filiformis.' Stigma, stylo haud crassius, basi obsolete nodulosum. (v. s. in herb. DC., etc.)

\section{Laciniatce.- Folia angustissime linearia vel teretia trifido- laciniata, rarius passinı indivisa. flores terminales, raro axillares, fasciculati vel rarius solitarii. Calyx lutescens vel ruber, lobis sty- loque citius liberis. - Meisn. in pl. Preiss. 1, p. 512.}

6. A. Mersnen (Lehm.! in pl. Preíss. 1, p. 512", 2, p. 248), foliis 3-partitis, junioribus ramisque pubescentibus, segmentis bifidis vel bis bifidis rel subjinnatifidis, intermedii trisecti lobis 2 -3-fidis, lacinilis teretiusculis obtusis apice extus glanduligeris, petiolo latiusculo plano, floribus terminalibus inter folla congesta basi villosa capjitatís, calyeis pilosiuscali lobis reflexis intus subbárbatis, stylo glabro, stigmate fusiformi. $\zeta$ Ad jugum mont. Barling's Ránge, distr. Nelson (Prêiss, n. 791 ! Drummond coll. 2, n. 301! Molloy!). Folia 9 lin. longa, laciniis pétiolo 1 lin. lato triplo angustioribus. Capitula 3-6-flora, involncellis 1-floris 4-phyllis bibracteolatis, squamis oblongis ciliatis. Calyx ruber? 9-10 lin. longus, demom rectus, stylo dimidio superatus. Anthera una abortiva. Stigma $\frac{1}{2}$ lin. longum, basi oblique incrassatum. ( $8 . \mathrm{S}_{\text {. }}$ )

7. A. P r o e u m B és (Meisn, in pl. Preiss. $1,1,512^{*}, \mathrm{II}, \mathrm{p} .248$ ), eaule ràmisque procumbentibus apice pubescentibus, foliis 3-partitis, segmentis indivisis apice extus glanduligeris petioloyue filiformibus, lloralibus parce patenti-pilosis mox glabris, fascieulis terminalibus 3-6-floris foliis longe superatis, involucellis calycibusque cano-pilosís, stylo glabro, stigmiate subulato. F In fruticetis sylvaticis ad montein Wuljenuj, distr. Plantágenel (Preiss, n. 589 bis ! Drumm. colk,3, n. 253 !). Rami graciles, fere flagelliformes. Folia circ. pollicaria, summa dimidionlongiora. Calyx 4 lin. Iọngus. stylo dimidio lorevior laminis liberis intus subnudis. Antheræ omnes perfectae. Stigma $\frac{1}{4}$ lin. longum, basi vix incrassatum. (v. s.).

8. A. Serige A-(Labill. Tov. Holl. 1, p. $29^{*}$, t. 38), ramulis laxe villosis, foliis arpresse seriecis biteruatis, laciniis filiformibus, petiolo brevi tereti, floribus terminalibus subsolitariis ljreve jedicellatis, involucri imbricati sériceo-tomentosi squamis interiorìbus ovatis acurninatis, calycis sericei lobis villosis intus hirsutulis, stylo glabro, stigmate sabulato. 5 In arenosis portus Regis Georgii et Prijcess Royal Harbour (Labill., R. Brotwu! Preiss, n. 788 ! Drumm, coll. 3 , n. 255!). -Lam. ill. t. 913 , f. 3, R. Brown! prodr' p. 367, Roem. et Schult. 'syst, 3, p. 398*. Heisn. in pl. Preiss. 1, p. 513*,2, p. 248. Arbusenla 12-18-pedalis, conferte subcorymboso-ramulosa. Folia $\frac{1}{2}-1$ poll, longa, lloralia dimidio majora, ségmentis 2-5-fidis teretibus haud rigidis, petiolo pedicelloque 1-2 lin. loñgo: Flores terminales 3-1, coccinei, 10 lin. Iongi. Antheræe omnes perfecta. Stylus if 4 lin. longus, inferne crassiuscalus, - sursum attenuatus, stigmate 1 lin. longo. (y. s. in herb. DC. etc.)

9. A. véutina (Neisn. in Huuk. Journ. 1852, 1). 183), foliis brevissime petiolatis biternatis ramulisque albo-villosis, laciniis tereti-filiformibus tenuibus ubtusis subeglandulosis, lacinía intormedià 2-3-fidà, lateralibus 3-4-partitis, lacinulis secundis parallelis, lloribus terminalibus subsolitariis folia vix superantibusłispidulis, laminis intus sériceo-barbatis, stylo glabro, calycem dimidio superante, stigmate subulato. S In colonia Swan River (Drummond coll. 1, n. 266 ). Rami elongati, subvirgati, stricti, interrupte corymboso-vel subverticíllato-ramosi, ramulis patulis simplicibus uñdirue fólíosis et puhe brévi densầ albâ patènti villosiusculis. Folia adpressa vel semípatula, sumna subverticillata plerumque fero 
duplo majora, laciniis primariis 3-8 lin. longis, secundariis ingequalibus 1-6 lin. longis patulo-pilosiasculis; petiolo pube densiore longiore pulchre albo-villaso. Stylus ćirc. 1 poll. longus, stigmate atlenuato sulcato acuto basi leviter incrassato. Nux sessilis, $2 \frac{1}{2}$ lin. longa, $1 \frac{1}{2}$ lin, lata, oblongá, leviter compressa, utrinque obtusa, rautica, pallide straminca, rugrtoso-striata, glabra, basi pilosiuscialâ, margine altero carinato subtrinervi. A proximis A. sericeì et apiculatá præcipue pubescentia indole, a posteriore insujer foliorum lacinulis apice rectis minute vel obsolete glandulosis dignoscenda. (v. s.)

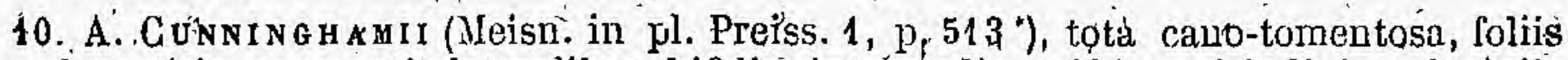
3-partitis, segmentis lateralibus bifidis, intermedio trifido vel indiviso, laciniis filiformibus yel anguste linearibus subeglandulosis obtusis petioloque supra planis, novellis floribusque subsericeis, pedunculis-axillaribus solitariis 1 -nloris petiolum squantibus, calycis laminis intus barbatis, stylo medio pilosiusculo infra supraque glabro, stigmate subulató. 春 In Australia interiore (A. Cumningham ! Preiss. n. 2621). A. terminalis A. Cunn.! mss. in herb., nee R. Br, Folia $1 \frac{1}{2}-2$ poll. longa. Pedunculi 4-5 lin. longi, involucri foliolis ovato-oblongis acutis. Calyx 12-14 lin. longus, stylo demum $\frac{1}{3}$ superatus. (v. s.).

11. A. TERMINALIS (R. Brown! in Linn. Trans. 10, p. 152, prodr. $p=367$ ), foliis tripartitis ramulisque pubescentibıs, laciniis filiformibus apice minute glanduligeris, lateralibus bifidis, intermedia indivisâ, floribus terninalibus solitariis ternisve subsessilipus, calycis villosi laminis intus calvis, stylo inferne piloso supra glabro, stigmate fusiformi. 5 Ad portum Lincoln (R. Brown !), in coloniâ Swan River (Preiss, n. 795!.796!), Encounter Bay, or: austr. (Ferd. Müller l).-End-. ic. t. 110, Meisn. in pl. Preiss, 1, p. 514. Folia 6-10 lin. longa. (v. s.) .

ß. piumosa, foliis sericeis tarde glabirescentibus, floralibus nóvellisque inferne pubje deñsâ patente albido-plumosis villosisve.-Ad portum Adelâide (Ferd. Müller !). Procumbens, demum adscendens. Folia superiora plerumque majora, usques ad pollicem longa. (v. s. cómm. a cl, Sonder.)

12. A. DR u m on D I (Meisn. in pl. Preiss, 1, p. 514, adnot. "); ramulis sericeo-tomertosis demum glabratis, foljis sulósessilibus adpresse pilosiusculìs 3 -partifis, segmentis filiformibus apice extus minute glanduligeris, lateralibús 2 -fidis intermedio indiviso, floribus terminalibus solitariis subsessilibus, calyce pubescente, laminis intus imbérbibus, stylo glabro, stigmate brevi conico. $\$$ In coloñia Swan River (Drumm. coll. 1. n.593!). A simillimà precedente pracipue stylo toto glabro stigmateque daignoscenda. ( $\mathrm{r}$. s.)

13. A. A proulata (R. Brown suppl. p. 9), ramis patenti-pilosis tomentosisque, foliis cumo-pubescentibus 3-partitis; floralibus inferne patenti-villosis, laciniis filiformibùs apice 'dorso glanduligeris 2-3-fidis vel rarius passim indivisis, floribus terthinalibus 3-1 subsessilibus foliis superatis; calycis pubescentis laminiśs intus adpresse barbatis, stylo glabro, stigmate subulato. J In aronosis ad sinum Regis Georgii (Baxter), coloniac Swan River, distr. Perth, Wicklow et Murray (Drummotıd ! Preiss, 1.' 787! 794! Gilbert, n. 7! etc.). - Meisn, in pl. Preiss. 1, p. $514^{*}$. Anthere omnes fertiles, habitus et folia fere A. sericea, sed non sericea, folia rigidiora et sub apice semper distincte glandaligera. (v. s.)

14. 1. PUNGENS (Meiśn. in pl. Preiss. 1, p. $515^{*}$ ), foliis teretibus crassis mucronatopungentibus supra 1 -sulcis apice breviter 2-3,fidis passimque indivisis, novellis: ramulisque tomentosis, floribus terminalìbus 3-8 aggregatis subsessilibus folia requantibus, calycis sericeo-tomentosi laminis intưs brevibarbatis, stylo villeso, stigmate cylindrico. 5 In Australià merid.-occid. interiore (Preiss, n. 671 !). Frutichlus humilis, habitu foliisque Petropliilas Hakeasque pungentes imitans. Calyx semipollicaris. Antheræ omnes perfectæe. Stigma stylo vix crassius, $\frac{1}{2}$ lin. longum. (v. s.)

B. simplicifolia (Meisn. 1. c. 2, p. 248), foliis omnibus indivisis.-In coloniả Swan River (Drumm. cull. 3, n. 256 !). Involacri squaræe intimæe oppositæ obovatooblorngæ obtusic concavice nuçem oblongarn costatam æequantes. (v. s.)

15. 1. A R M A T A (Meisn. in Hook. Journ. 1852, p. 183), foliis tereti-filiformibus rigidissimis ramisque glabris supra 1 -sulcis extra medium 3 -fidis, laciniis divaricatis pungenti-mucronatis, floribus'in summis axillis approximato-congestis folia subwquantibus pedicelliatis, calycis tubo extus tenuiter, laminis utrinque dense seficeis, stylo pilosiuseulo, stigmate cylindraceo. 5 In colonia Swan River (Drumm. 
coll. 5in. 400 !). - Simillima præcedenti, sed vix mera varietas. Rami virgati, juniores cano-puberuli. Folia majora, crassiura, usque ad $1 \frac{1}{2}$ poll. longa, $\frac{2}{3}$ liń. 'crassa, rariśsime indivisá, mucrone 1.lin longo. Pédicelli $2-3$ tin. Calyces 9-10 lin. lougi, laminis fere rluplo quam A. pungentis longioribus $1 \frac{1}{3}$ lin. longis. Stylus complanato-filiformis, padtenti-pilosus, flemum glabratus longe exsertuș. Stigma - lin. longum. (v. s.jin herb. Sluuth.)

\section{TRIBUS II. CONOSPERMEE Endl: gen. p. 338.}

Antheræ primum inter se cohærentes, vicinarum lobis contiguis localum unicum constituentibus demum discretis. Squamulæ hypogynæ nullæ. Ovarium ebconicum, 1-loculare, 1-ovulatum, Nux monosperma. - Flores liermaphroditi, spicati vel capitati, rarius paniculati, singuli 1-bracteati.

XIII. SYNAPHEA $R$. Brown in Transact. Soc. linn. Lond. 10,p. 48 et 155, prodr. $a$. Nov.: Holl. p. 369, suppl. p. 11, gen. rem. p. 606, t. 7, Lam. ill. t. 914, Endt., gen. p. 338, h. 2131, suppl: $I V, 2, \dot{p} .80$; ic. t. 32, Meisn. gen. 332 (245), pit. Preiss. 1, p. 527, 2 , p. 254 .

Flores spicati. Calyx tubulosus, ringens, deciduus, limbi 4 -fidi lobis basi staminiferis, superiore (postico) latiore. Stamina 4 inclusa, filamentis breyibus, superiore ananthero stigmati comato, fertilium antheris bilobis, lateralium lobo altero abớtivo-auriculæformi, intermedii (antici) ambobus perfectis. Stylus curvatự, -sursum incràssatus. Stigma obliquum, dilatatum, hìnc filamento sterili adnatum, inde bicorne vel acatum. Nux obovata, papposa. -Frutices Novæ-Hollandiæa ausło-occidéntätis, humiles, nunc subacaules, foliis sparsis coriaceis planis pulcherrime reticulatis cuneiformibus incisolobatis vel inferioribus indivisis, stomatibus amphigenis, petiolorum basi dilatatâ semivaginante, spicis axilläribus termninalibusque simpliçibus vel ramosis gracillimis laxis vel abbreviatis densis; bracteis alternis 1-floris cucullatis persistentibus, calyce sessili 4-partibili, flavo.

1. S, Favosa (h. Brown in Linn. Trans. 10, p. 156, prodr. p. 369), folitis oblongbcuneiformibus indivisis trilobisque lobis integris, petiolis spicisque glabris, sthigmate bicorni, J In collibus saxosis terræ Leeuwin, (R. Brown.)

$\beta$ ? lanceolala, foliis omuibus lingulato-lanceolatis spathulatisve acutís súbmuticis triplinerviis utrinque densissime poroso-punctatis glabris, petiolis laminâ brevioribus subteretilus ramulisque cano-pilosiusculis, spicis simplicibus? - In coloniâ Swan River '(Drummond coll. 3, n. 258 l). S. favosa ? Meisn, in pl Preiss. 2 , p. 251 . Folia 2-10 poll. Joriga, 5-7, lin. lata, plana, lete flayo-viridia, petioli basi vaginante nervoso-striatâ. Spicæ folio breviorès? (delloratæ) a basi inde laxe florifere, bracteis squamiformibus ovatis acutiusculis patulis glabriusculis ovarium villosum cequantibus. (v. s̀. sine fl. in herb. DC. et Shuttl.)

2. S. Díl A T A A (R. Brown I. c. p. 156 et 370 , gen, repn, t. 7), foliís cuneatis trilobis vel infimorum nownullis indivisís uṭinque reticulato-scrobiculatis glabris, lobis ineiso-dentatis muticis, petiolo laminam æquante vel longiore laxe piloso, spieis simplicibus folito brevioribus laxifloris, pedunculo bracteisque villosis, calyce puberulo, stigmate lato longe bicorni. J In saxosis terre Leeúwin (R. Brown,

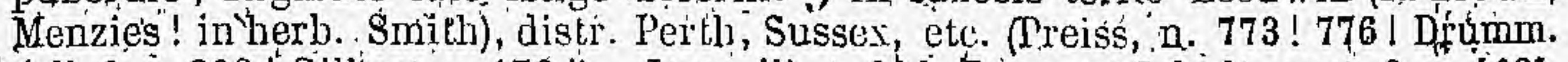
coll. 2, n. 303 ! Gilbert, 11. 179 !). - Lam. ill. t. 914, Room. et Schult, syst, 3, p. 4.p8*. Endl. iconogr. t. 32, Meisn. if preiss. 1; p. 527\%, 2, y. 251. Gonospermum reticulatum Smith! in Rees cycl. n. 5. Rlizoma repens? ramis paucis brevibus adscendentibus. Folia stepe subpedalia.'( $($." s. in herb. "Smith., DC., etc.) ?

3. S. DECORT́CAN S (Eindl.! Swan River 1. 32, n. 150), foliis planis utrinque reticuIato-favosis, Iałninấ petiolo piluso glalurove breviore tripartità glabrâ segmentisque divaricatis cunentis, Iateralilus 2-3-lobis, intermedii 3-partitị lobis 2-3-fidis vel passim indivisis' olsluse macronatis, spicis folia subsecquantibus "gracillibus indivisis rel inferne paucíramosis Taxiusculis, bracteis calycibusque glabrisis, stig- 
"mate lato truncató-sutborbitculari submutice. F'In colonià Swan River, ad fl. Cannipg (Arumm.! Preiss, .1. 780!). - Ileisn. jin pl.. Preiss. 1, p. 527, A simillimâ proctedentẹte et \$. favosa jam stigmate facile dignoscenda. (v.s. in herb. Lindl. etc.)

4. S. DKUm ondir (Meisn. in Hook. Journ. 1852, p. 183), foliis glabris utrinque tenuiter et subimmerse reticulatis subtus grosse nervosis, laminâ petiolo teretí breviore 3-lobâ, lobis cunèatị mucronato-3-dentatis subtrifilisve, lacinulis dentíbusve late triangularibus ovatisve integris vel rarius mucronato-2-3-dentatis, sinubus rotundatis vel obsoletis, spicis peclunculatis folía subæquantibus sionjlicibus glabriusculis laxifloris basi interruptis, bracteis late ovatis acutiusculis. ovarjum villosum subrecruạntibus' floribus... F In coloniâ, Swan River (Drummond coll, 3, n. 259 |). S, decortiçans var.? Meisu. in pl. Preiss. 2, pr 251. - Species propter flopes nondum visps obscura, verisimiliter distincta, foliorum formả et magnitudine similis S. dilatate, sed discrepans reticulatione tenuigre fere $\mathrm{S}$, polyporphiae, lobis latioripus haud anguśato-acutis, ranjulis petiolis pedunculoquo incano-puluertulis nec patenti-pjlosis el bracteis multo minoribus. (v. s.)

5. S. G RACILLIMA (Lindl, I l. c. n. 151), glabra, foliis longe jetiolatis utrinque reticulato-scrobiculatis 3-partitis vel passim, indivisis bifidiste, lolsis planis cuneatis 2-3-fidis integrisve sphacelato-mucronatis, pedunculis longissimis gracillimis indivisis vel infra medium bifidis, spicis laxifloris inferne interruptis, bracteis ovatis acutis culyce subtriplo_brevioribusovarium demum glabratum æer fuantibus, 1 stigmate lato jsemilunari-bicorni. F In coloniâ Swan River (Drumm. n. 588 !). Simillima sequenti, sed distincta fuliorum iervis et reticulatione paulo grossioriJus, ovarii pube breviore et minus persistente, et prosertim stigmate semilunari latiore quam longo in cornua duo satis lenga sinu lato separata produeto. (v. s. in herb. Lindl, et soc. Linn. Lond.)

6. S. petrokants (R. Brown.l. in Linn. Trans. 10, p. 156, prodr. p. 370), glabra, folìs longe pefiolatis utrinque scrobiculatato-reticulatis 3-partitis, segmentis 2-3fidis.integrisve, laciniis planis obtusis acutisve subriuticis, pedunculis gracillimis inferne pauciramosis, spicis laxifloris basi interruptis, bracleis ovatis acutis calyce brevióribus ovario villoso æaqualibus, stiemate ovato, cornubus 2 brevibus approximatis vel in rostellum conglutinatis. I Circa sinum Regis Georgii (R. Brown ( Preiss, n. 778 ! 784 ! Drumm. coll. 2, n. 302 !). - Meisn. in pl. Preiss. 1, p. 528 * $2,11.251$. Polypodium spinulosuth Burm. Ind. p. 233, t. 67, f. 1 ? Pedunculi folia plus minus superantes, sæepe jedales, glaberrimi vel vix apice inter flores adpressé pilosiusculi. Calyx 2 lin: longus, gląber. (v. s: in horb. DC:, etc.)

7. S. A c u T I O BA (Meisu. in p1. Preiss. 1, p. 528*), glabra, follis petiolo brevioribus 3-partitis utrinque reticulalo-favosis, segmentis tripartitís lobisque complicatis apice 2-3-fidis attenuato-atutis pungenti-mucronatis,; pedunculis gracillimis inforne pauciramosis, spicis basi interruptis, bracteis minutis ovatis flore quadruplu brevioribus, stignuate ovato Jrevissime bitido, ovario glabro. J Ad flum. Gygnorum et jugum mont. Darling's Range (Preiss, n. 777! 682! Drumm. n. 589! Gilbert n. 178 ?). Folia præcedentibus minora, 3-5-pollicaria, lobis sensim attenuato-acutis præecipue insignia. (y. s.)

8. S. PREIS SII (Meisn. 1. c. p. $529^{*}$ ), foliis glabris utrinque rcticulato-favosis, laminæ petiolo sublongioris 3 -partite segmentis elongatis subcanaliculatis 3 -fidis lacinitisque linearibus attenuato-acutis subpungentibns, pedunculis folio brevioribus indivisis subsericeis fere a basi laxiuscule floriferis, bracteis ovatis acutis flore dimidio brevioribus glabriusculis, strgmate ovato apice inflexo obtuso subemargipato. 3 Circa portum Princess Royal Earbour (Preiss, n. 7791). Folia incluso

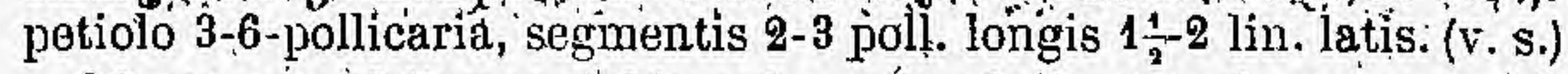

$\beta$ ? obtusata, foliorum lobis apice rólundatis obtusisve mucronulatis, - Swan

River (Drumm. coll, 3, n. 257!). - Meiș. in Rl. Preiss. 2, p. 251.' Forsan dis- tincicta sjecies. (v. s. flor, delapsisis.)

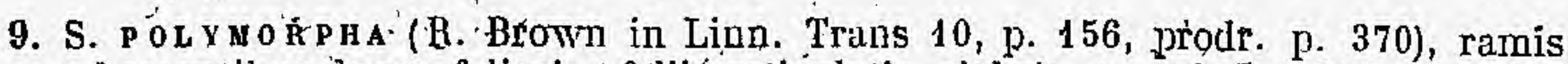
jubescentibus dense foliosis, folliis reticulatis glabris, rameis brevissime petiolatis 3-partitis, segmentis subcanaliculatis semitrifidìs spinoso-tridentatis vel lateralibus integris, spicis folio subbrevioribu's pedunculor sericeo Yongioribus densifforis, bracteis ovatis acutis floreque ipsis dimidio longiore glabris, stigmate oblongo acuminato indiviso, ovario pubescente. F In Leeuwin's Land (R. Brown). 
Girca sinum Regis Georgii (Preiss; n. 775! 784!) - - Meisn. in pl. Preiss. 1, p. 529 : Aboriginibus' Bindá. Frutex 3-4-pedalis. Folia inferiora cum petiolo $3-4$ poll., superiora subsessilia circ. 1 poll. longa: Spiçæ axillares solitariæe vel 2-3 fascict, latæ. (v. s.)

10. S. BRA ÁHYSTAGHY A (Lindll. Stwan Riyer p. 32, n. 152), ranulis cano-tomentosis foliosis, foliis supra leviusculis glabris, subtus reticulatis subsericeo-todnentosis demum glabris, inferioribus subsessilibus obovatis, mediis petiolo brevioribus supèrioribuscque eqdem multo longioribus 3-lobis, lobis ' 2-3-fidis, lacinulis apice spinoso-2-3-dentatis, spicis axillaribus fasciculatis, foliun subequantíbus simplicibus continuis,-bracteis acuminatis' flore glabriusculo dimidió brevioríbus ' pedunculisque pubescentibus, stigmate oblique peltato late obovato subemargi-' nato, ovario pubescente. 5 .In colohià S wan River (Drumm. coll. 1, n. 590 !. Preiss, п. 774! Gilbert n. 269! Morrison!).-Meisn. l. c. p. 530*. Frutex-2-3-pedalis, fforibus crocẹis, facie precedentis, sed notis indieatis, precipue stigmate, facile dígnoscendus. ( $\mathrm{v}$, s. in herb. Lindl., etc.).

11. S. piNNATA (Lindl:! 1. e. n. 153), subacaulis? folís planis nervosis reticulatofayosis glabris petiolum pilosiusculum subrequantibus, aliis lanceolatis integerrimis, aliis impari-pinnatis 1-3-jugis, foliolis lineari-kanceolatis utrinque attenuatis apice recurvo-mucronatis indivisis vel infimis 2-3-partítis, sjicis folia longe superantibus ramosis, floribus remotis glabris, ovario pubescentè. F In coloniấ Swan River, ad jugum-Darling"s Range (Drummond! Preiss, n. 783 !). $\div$ Meisn. 1. c. p. $530^{*}$. Folia simplicia $1 \frac{1}{2}-5$ poll. longa, $5-6$ lin. lata, pinnata duplo longiora, foliolis 2-3 lin. latis, Flores non vidimus. (v. s. in herb. Lindl., etc.)

XIV. CONOSPERIIUM Smith in Transact. linn. Soc. Lond. 4, p. 213, exot. bot. 2, t. 45; R. Brown in Tranś linn. Sòc. Lond. 10, p. 48 et 153, prodr. p. 368, suppl. p. 9, Endl. gen. p. 339 , n. 2132 , suppl. IV, 2, p. 80,-Meisn. gen. p. 332 (245).

Flores hermaphrodifi, spicati, capilati-vel paniculati. Calyx tubulosús, deciduus, limbo 4 -fido æquali vel sublabiato, lobo postico fornicat $\%$. Stamina 4 laciniarum basi inserta, inclusa ; filamenta brevia, antico ananthero; antheræ tres primo cohærentes, lateralium lobo exteriore abortivo. interiore cum lobo proximo antheræ intermediæ perfectæ. cơhærente et loculum unicum constituente denum secedente. Stylus filiformis, sursum incrassatus. Stigma libe-rum, obliquum. Nux obconica, 1-sperma, papposa. - Frutíees Novæ-tiollandiæ extratropicæ, habitu vario, foliis sparsis indivisis tereti-fitiformibus planisve integerimis, stomatibus amphigenis, pedunculis axillaribus terminalibusve, sæpe corymbosis paniculatisve, rarius capitulis subsessilibus, bracteis 1 -floris concavis persistentibus, floribus albis coeruleisve sericeis lantatisve, rarius glabiris.

\section{Sect. 1. Euconósermum Endl. l. c..}

Calycis subbilabiati limbus tubo brevior vel vix longior, Tobo posteriove (supe. riore) subgaleáto lasi, fornieato-concavo anterioribus planis látiore,- $\mathrm{R}$. Brown $\mathrm{l}$. ci. Meisn: in pl. Preiss. 1, p. 518.

\section{\$1. Eriostachya.-Spicca axillares et términales pedunculatoe, albo- lanata, corymbum vel paniculum terminalem formantes.}

\footnotetext{
* Folia lanceolata.
}

1. C. TR RPL INE R VIUM (R. Brown suppl. p. 11), ramis glabris foliosis, foliis lingulato-oblongis lanceolatisve attenuato-petiolatís planis triplinerviis venosis sericeis mox glabris, pedunculis elongatis subaphyllis ramosis spicis alternis laxifloris junioribus imbricatis, bracteis, e la tâ basi cuspidatis flore lanato vix duplo brevioribus. 5 vel $\%$ In sinu Regis Georgia (Baxter), colonià. Swan River (Drumnond), Meisị. in -pl. Preiss. 1, p. $519^{*}$. Frutex vel arbuscula 10-20-pedalis-(Preiss), Folia 2-4 poll. longa, $2=4$ vel rarius $6-9$ líp. lata, apiculo terminali sphacelato cras: siusculo.:

a. follis pedunculisque glabris, panicule ramis sericeis glabrisve, spicarum 
rhauh lanatix (Preiss, n. 739! 743! 747! Drumm. coll. 1, n. 577!).,- Meisn. l,c. (v. s.)

B. foliis novellis pedunculisque tenuissime sericeo-pubescentibus, panicule ramis sjieárumque rhachi lanatís (Preiss, n. 738!).-Meisn. I. c. C. lanifiorum Endl. nov. stirp. Jecad. p. 59, n. 67. (v.s.)

2. C. UNDUL A T UM (Lintll.! Swan Riv. p. 31, n. 147), ramis foliosis apice tomentosis, foliis subsessilibus' lanceolatis apiculatis basi angustatis triplinerviis venosis margine undulatis junioribus subsericeo puberulis, jedunculis elongatis aphyllis iramosis subsericeis, spicis subpaniculatis laxifloris dense albo-tomentosis, braeteis e tatâ basi cuspidatis flore triplo vel quadruplo brevioribus. 5 In colonia Swan 'River (Drummond in herb. Lindl.! Preiss, n. 757!).-Meisn. in pl. Preiss, 1, p. 520. Frutex 2-pedalis. Forsan precedentis var., recèdens tantum folis raro ultra 2 poll. longis, basi brevius attenuatis, plerumque (nec tamen constanter) undulatis, pedunculis longioribus, spicis laxioribus et floribus $\frac{1}{5}$ majaribus.' (v. s. in herb. Lindl., etc.)

ß. minus (Meism.-in Hook Journ. 1852, p. 184), ramis vix apice puberulis, foliis lanceolatis untrinque attenuatis sericeis haud undulatis, floribus paulo brevioribus (Drumm. coll. 5, n. 401 !). Folia 1-2 joll. longa; 2-3 liu. lata. Cæet. ut in typo speciei. (v. s.)

3. C. CRAS SINER VI U Meisn. in Hook. Journ. 1852, p'. 184), caule elotgato scapiformi basi tantum folioso tomentoso, foliis elongatis spathulato-linearibus acutis in' petiolum teretem longe attenuatis crasse 3 -nerviis marginatis remote venosis incano-tomentosĩs, marginibus refraetis, paniculâ corymbiformi, ramis bracteis calycìbusque pilis albis patentibus dense serice $\hat{\text { - }}$-villosis, bracters lanceolatis setaceo-acuminatis $=5$ In colonia Swan River (Drummond coll: 4, n. 2701). Subacaule? , Folia :radicalia, e rhizomate? lignoso $\frac{1}{2}-1 \frac{1}{2}$ poll. longo orta, congesta, $4-12$ poll. longa, 4-6 lin. lata, In ucrone-crassiusculo sphacelato recto apiculata, in petiolum 1-3-pollicarem supra sulcatum sensim attenuata, nervo venisque supra impressis sulciformibus subtus prominentibus crassis, nervis lateralibus margini refractó proximis v'el ipsis marginantibus. Scapus circ. bipedalis, erectus, strictus, teres, apice jterato corymboso-ramosus, squaras nomuullas longe distantes supra crebriores súbadpressas ovato-oblongas $7-6$ lip. longas fuscas extus incanas gerens. Panícúła 3-4-pollicaris densiuscula, ramis semipatulis scriceo-villosis, circiter a medio florigeris. Calyx ultra medium bipartitus, laciniis plumosis, superiore ovata concavâ, inferioribus 3 linearibus: Speeies insignis, foliis C. triplinervio, floribus $\mathrm{C}$. incurvo et disticho, inflorescentit $\mathrm{C}$. bracleoso quodammodo accedens, ab omnibus tamels distinctissima.? (v. s.).

4. C. BRACTEOSUM (Meisn. in pl. Preiss. 1, p. $518^{*}, 2$, p. 248), caule scapiformi ? foliis superioribus sessilibus imbricato-adpressis lanceolatis acutis semiamplexicaulibus eveniis ramisque incano-tomentosis, spicis in apice ramorum corymbosoapproximatis' simplicibus brere pedunculatis laxis albo-tomentosis, bracteis ovatis acutiusculis denum glabrescentibus florem niveo-villosissimum subrquantibus, $\zeta$ In Novî-Hollandiả australi-oceidentali interióre (Preiss, n. 746! Drumm. cołl. 3 , n. 252 !). Frutex (Preiss) habitu præcedenti accedens. Folia inferiora ignota, ramea semipollicaria, caulis vol scapus sesciuipedalis, apice subcorymboso-multiramosus, spicis $1-2$ poll. longis fere a basi florifuris. (v. s.)

\section{:- *Folua tereti-fliformia vel angustissime linearia.}

5. C. SGLER OPIYLL UM (Lindl.! Swan Riv. p. 30, n. 138), caule ramoso laxe folioso, ramis subtomentosis, folìis tereti-filiformibus clongatis cano-tomentellís demum glabris, pjedunculis elongatis paniculalo-polystachyis, bracteis late ovatis obcorclatisve cuśpidatis rliachique lanato-tomentosis cuspide glabrâ, calyce lanato villosissimo bracteam triplo superante. J̆ In coloniâ Swan River (D́rumm. coll. 1, n. 581! Preiss, n. 736! 741! 742! 744! 749! Molloy! Morrison!). C. Stcehadis Meisn. in pl. Preiss. 1, p. .524, an Endl. in Ann. Wien. Mus. 2, p. $208^{*}$, nov. stirp. decad. j. 60, n. 68 ? Frutex 3 -4-pedalis. Folia usque ad 6 poll longa, teretia, lævia vel obsoletissime lineata. (v. s.' in herb. Lindl., etc.)

6. C. CaNa liculat u M (Meisn. in pl. Preiss. 2, pa $250^{\circ}$; caule subsimplici laxiuscule folioso glabro, foliis longissimis" glabris semiteretibus supra canaliculatị, pedun- 
culis elongatis supra medium racemoso-polystachyis' lanatis, spicis pedunculatis laxiusculis, bracteis late oboxatís ealycequie subtriplo longiore lanatis, cuspide brevi glabrâ. JIn cqlonjâ Swan River (Drämm. coll. 2, n: 307!). Forsanl præecedentis varietas, attamen satis recedens habitu robustiore, foliis subpedalibus crassioribus, semper canaliculatis, etc. (v. s.)

7. Ć. IN C U Rí u (Lindl.! Swan Rív. p. 30, n, 139), rainis conferte foliósis puberulis superne aphyllis remotiuscule adpresserue squamatis glabris apieo conferte racemoso-palystaelıyis ${ }_{r}$ foliis tereti-filiformibus incurvis muticis süpra sulcatis, junioribus pilosjusculis, spicis laxifforis, bracteis ovato-lanceolatis flore-triplo breviorjribus glabris, calycibus rhachique sericeo-villosissimis. 7 In colonia Swan River (Drumm, coll. 1, n, 579. 2, n. 308!-Preiss' - n. 750! Gilbert, n. 101) - Meist: in pl. Preiss, 1, p. $523^{*}, 2$, p.250. Folia circ. pollicarăa, pube tenerrimâ rarâ patenti-pilosiusculâ demum glảbrà. Panicula ampla, interdum sesquipedalis, ramis pedalibus. (v. s. in herb. Lindl, etc.)

8. C. Dis тіснц м (R. Brown in Linn. Tranś. 10, p. 155, prodr. p. 369, suppl. p. 10), ramis conferte foliosis glabris, foliis patentibus tereti-filiformibus incurvis muticis glabris supra sulcatis, spicis peduneulatis folio longiọibus laxiuscule paucifloris, bracteis ovatis cuspidatis glabris flore densissime sericeo-villoś triplo brevióribus. 声 In oræ merid. sinu Luckey. Bay (R. Br.), King George's' Sownd (Baxter), colonia Swan River (Drumm. coll. 1, n. 580! Preiss, n. 740!). - Neisn. in pl. Preiss. 1, p. 522 * Frütex pedalis, ramulis sæpius umbellatís vix apice puberulis. Fólia circ. sémipolliearia, primo vultu dísticha, sed revera spiraliter disposita. Pedunculi tenues, 1-1 $\frac{\tau}{2}$ poll. longi, tomentosi, apice spicatim 3-6-flori, bracteis corulescentiviridibus subulatóàcuminatis., (v. s.)

9. C. Fr. I Fo Lu M (Meisn. in pl. Preiss. 1, p. $5233^{*}$ ), ramis subvirgatis cónferte foliosis glabris apice racemoso-polystachyis, foliis capillari-filiformibus subsulcatis glabris, spicis axillaribus çapituliformibus, pedunculis folio brevioribus indivisis tomentosis basi medioque bracteatis; bracteis ovatís aciminatis flore triplo brevioribus, glabriusculis coloratis, calycis tubo dense sericeo-villoso límbo glabriuseulo.b Ad flum. Gygnorum (Drumm. êoll. 1, n. 578! Preiss, n. 2624). Caules vel rami pedales, simplicissimi, ad apicen ustue foliosi. Folia 2-3 poll. longd, vix $\frac{1}{6} \operatorname{lin}$. crassa; debilia, summa breviora. Pedunculi: e summis axillis nascentes 6-9 lín. lońgi, apice 4-6-flori, racemum terminalem 2-3 poll. longum constituientes. Bracter 1:-lin. longæ; cœruleæ, basi sericeo-rillosæ. (v. s.)

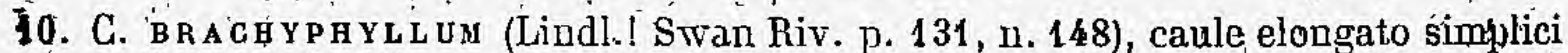
scapiformi subsericeo-puberulo vel demum glabro apice corymboso-polystacliyo, foliis tereti-filiformibus glabris, infimis confertis patulis incurvis 1-sulcis, superioribus remotiulsculis adpressis brevioribus, pédunculis lanato-toméntosis, spicis laxifloris, bracteis ovato-lanceolatis glabriuscalis coloratis, calyce sericeo,villosissimo triplo breviơi ibus. 亏 In coloniầ Swàn River (A. Cunńingham! Drummónd I Preiss, n. 751!). - Meisn. jn pl. Preiss. 1, p. 524*. Suffrutes circ. pedalis. Folia

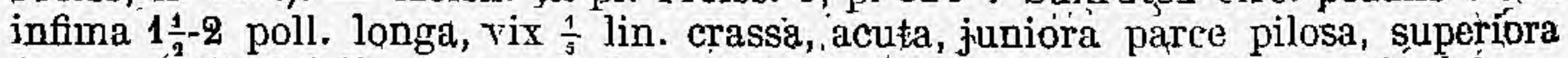

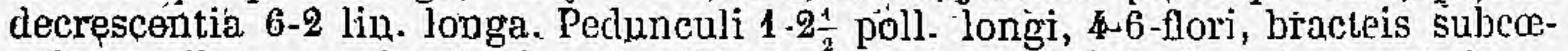
rulescentibus margine basique-lanátis. (v. s. in herb. Líndl., Cunningh., etc.)

\section{§ 2. Axillaria.-Spicoe axillares simplices folia subicequantes vel vix superantes, floribus häud lanatis. Caulis ad apicem usque foliosus, foliis subulatis.}

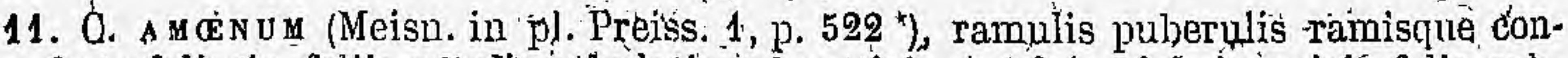
ferte foliosis, foliis patulio-subulatis sulmuticis exsulcis glabris; spicis foliạ subsuperantibus laxiuscule paucifloris, pedunculis tomentoso-puberulis, " bracteis ovatis acuminatis colloratis calycibusque minute puberulis. $\zeta$ Ad jùgum Darling's Range, distr. Perth (Preiss; n. 745! Drummond coll. 1, n. 583!). Frutex 1-2-pedalis. Folia 5-9 poll. longa, basi subancipitia, plerumque inçurva. Flores amcne cœrutei, (v. s.)

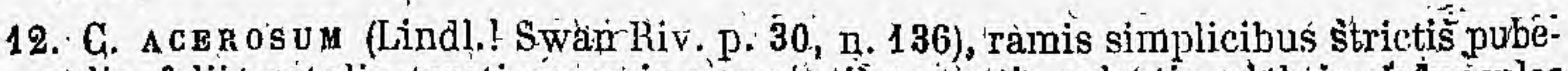
rulis, foliis patulis tereti-acerosis pungettibus rectis sulcatis glabris jedunculos tomentellos superantíbus, spicis gapituliformíbus paucifloris, bracteis obcordatis 
mucronulatis calycibusque glabriś. 5 Ad jugum. Darling's Rańge, distr. Perth (Drumm, coll. 1, silie numero, el 6, n.174 ! Preiss, n.786!). - Meisn. in pl. Preiss 1;

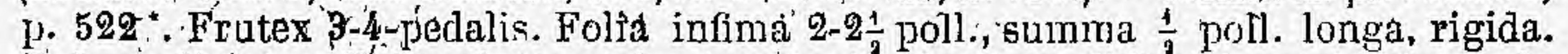
Pedunculi $\frac{1}{2}-1$ poll. longi, bracteis stramineis, floribus albis vel roseis? (v: $\mathrm{s}$. in 'hérb, Lindl., etc.)

\section{\$ 3. Corymbocephala.-Pedunculi axillares et terminales folia supe-} rantes simplices vel pauciramosi corymbum terminalem constituentes; floribris abbreviato-spicatis vel capitat is glabris vel puberulis nec lanatis. Caules vel rami ad apicem usque foliosi, folits planis lanceolatis vel linearibus; rarius acerosis.

13. G. ER I ctrou I UM (Smith ! in Rees cycli), ramis eréctis gracilibus plaberulis, foliis confertis pollice bievioribus fliformi-linearibus acutis glabris, junioribus subimbricatis, corymbe polycephalo, pedunoulis ' 'ólia longe superantibus subsericeis pauciramosis simplicibasve, bratteis ovatis acuminatis glabrescentibus flore, vix

- dimidio -breviaribus, calycis incano-tonientosi lobis oblongis obtusiusculis tubo 'duplo brevioribus: J Circa Port-Jackson (R. Btuwn! Gaudichaud! Sieber, n. 4.3! Anderson, n. 71! etc.).-R. Brown! in Linn. Trans. 10, 1, 154, prodr. p. 368, Rudge in Linh. Trans. 10, p. 292, t. 17, f. 1, Roem. et Schult. syst, 3, mant. 1J. 275*, Bot. mag. t. 2850 , Endil. ic. t. 31 . G. erectum hort. Knew. mss, fide Grah. in Edinb. Phil. Journ. 1828, p. 171. 'Rami siepjius longe simplices, subsericei, demum glabri. Falia parum rigida, 3-6 lin. infima usque ad 1 poll. longa, $1-\frac{1}{2}$ lin. lata, supra plana vel concava, subtus conrexá vol subcárinata, nervo plerumque-ineờispicuo: Pedunculi $1 \frac{1}{2}-2$ poll. longi, demum glabrati, capitulis denum in spicam subpollicarem excrescentibus. (v; s. in her]J. Smitlı., DC., etc.)

14. G: Lavandul trourum (A. Cunningham Imss. in herb.), ramis virgatis strictis subsericeo-pubescentibús, foliis confertis pallide brevioribus subaceroso-liuearibus ifucronilatis sericeo-puberulis glalırisve supra canaliculatis dorso subcarinatoúninerviis, corymbo pol ystacliyo, pedtunculis foliá longe superántibus sulbsimplicibus puberulis, spicis brevibus lasiusculis, bracleis late ovatis acuminalis gla- briusculis, calycis tubo gracili glabrescente limbum tomentosum superante. $\bar{J}$ In sinu Moreton Biry, oræe orient. (Allan Cunningluam!). - Mleisn. in pl. Preiss. 1, p. 519; adnol *. Sjecies medium quasi tenen's C. ericifolium inter et haxifolium; a priore habitu robustiore, folis crassioribus distinctius carinatis, floribus laxiuscule spicatis, a posteriore foliis minoribus, 5-8 lin. longis, $\frac{1}{2}-\frac{2}{3}$ lin: latis, spicis $\frac{1-1}{1}$ poll. 'longis, bracteis latioriłus, etc., distincta, forsan cum sequente (nobís obsscurâ) identica. (v. s.)

15. C.' s P IcA т u M (R. Brotwn suppl. p. 10), foliis linedaribus planis taucronatis sericeis modice patentibus, spicis pedunculatis elongatis laxiusculis. $F$ Circa PortJackson (Patersont). Monente cel. auctore forsan C. laxifolii yar.

16. G. TAX1POL I M (Smith ! in Rees cycl.), ramis strictiajunioribus juberulis, foliis confertis subpollicaribus lineasi-lanceolatis linearibusve acutis mucronulatísve plahis 1-nervifis eveniis puberulis vel glabratis, corymbo polycephalo, pedunculis tolia pluries superantibus sericeis ramosis, loribus capitatis, bracteis ovata-oblongis cuspidato-acuminatis pulberulis demum glajirescentibus calyce vix dimidio brevioribus, calycis cano-tomentosi lobis lanceolatis acutis tubo breviorihus : $F$ In Novẩ-Hollandia orientali extratropicali et australi. C. Falcifolium Ḱnight et Salisb. Prot. p. 95 ? fide R.'Br. Fornre sequentes $\alpha$ et $\beta$ primo vultu foliis satis discrepant, sed inforescentiâ, bracteis floribusque penilus conveniunt, immoque follia passim, præsertim súperiora, in utrâqủe similia oćcurrunt. Neque desunt specimina (v. g. Llotskyana!) inter $\alpha$ et $\beta$ ambigua. Folia in diagnosi Browniana basi torta dicta, sed in ipso spec̀im. Browhiano (in, lierb. DC.), pleraque haud torta observantur' Qnomodo, P. propinguum R. Br: (quod nơn vidi) dignuscendụm sit, nescio.

a. Smithii, foliis lineáribus ( $\frac{1}{2}-1$ lin. lalis) passim snbacerosis aoutis muticis vel obsolete mutcronulatis 1-nerviis margine sæypius paulo incrassato et (præcipue apicem versus) subrevoluto dirrso leviter bisulcis. +C. taxifolium Smith! mss' in lierb., Bot. mag, t. 2724 (Sicher, 11. 42, ex parte, herb. Lambert! DC., Nus. paris.! etc.). C. affine Scluult. in Roem. et Schult. syst, mant. vol. 3, p. $274^{*}$, ex descr. C. propinquum R. Br. suppl. p. 10. (v. s. in h. Smith, etc.) 


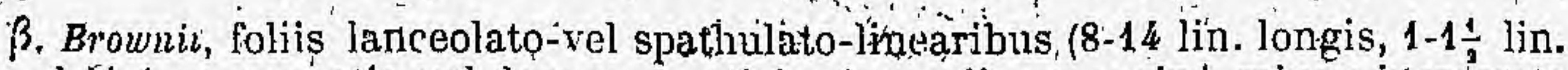
laťis) mucronatis vel dewum muticis 1-nerviis, margine minus incrassato recurvoque vel simplici. C. taxifolium R. Brown! prodr. p. -968 (fidè śp. autogr. in herb. DC.), Sieber! n. 42, ex parte, 11 . mixta, $\mathrm{n} .471$ ! (v. s.)

$\gamma$ ? Hookeri, foliis linearibus eherviîs, spicis folio brevioribus. - In Tasmanniâ. C. taxilolium Hók. fil. in Hook. Land. Jaurn. 6, p. 283. An species distincta?

17. C. LAN C E OLA T U (R. Brown suppl.-p. 10), fóliis semunciầ brevioribus linearilanceolatis acutissimis plinis evenils glabris subimbricatis patulisve, corymho terminali composito, partialirim pedunculis axillaribus. F Circa Port-Jackson (Cumningh,): CL (axifolio et imbricato affine, ex R. Br. Spesiem nec in: herb. Conningh. (nune dl. R. Heward) nec alibi vidimns ; neque o diagnosi a C. táxífolio satis distincta nobis videtur, nisi faliis brevioribus acutioribusque, sed hæ notæ vix suthicientes invariabilesque habendæ.

18. C. PATENS (Schlécht.! in Linnæê 20, p. $578^{*}$ ), ramis gracilibus laxiusculo foliosis, foliis patulis pollice brevioribus anguste spathulato-linearibus acutis muticis obsolete 1 nerviis meniis planis glabris, juniorilbus cum ramis peduriculis bracteisque minute puberulis, corymbo laxo, pedunculis elongatis subsimplicibus, floribus capitatis hractens ovalas lreve subulato-acuminatas glabrescentes vix dimidio superantibus, calycis tomentosi lobis oblongis acutis tuho basi subjinflato param bievioribus. F Cirea flum. Gamler el Light River, ad port. Adelaide, oræ 'australis (Belrr!'Ferd. Müller!). Valde áceedit ad C, taxifolitum $\alpha$, sed differt foliis subeherviis, basi magis attenuatis, pedunculis longioribus (ex descr. 2-3-pedalibus, floribus paulo minoribus. (v. s.).

19. С. LiNfFol vel spathulato-linearibus polliee breviuribus acutis vel ex apice rotundato mucronulalis. 1-nerviis venosis rugosulisve glabris, junioribus ramulisque gracilibus -minute puberulis, corrmbo laso, netlunculis elongatis ramosis glabriusculis, capitulis demum brese spiciformibus; bracteis flore dimidio brevioribus late ovatis apiculatis calyceque puberulis; lòbis tubo gracili brevioribus. $\bar{J}$ In insulâ Peel, Noreton Bay, oræ orient. (Allan Cunningh .I). - Meisn. in pl. Preiss: 1, p. 548 *, adgot. Monente inventore affine G. spicato . A G. taxifolio, cui etiam acceait, habitu gracihore, foliis minus rigidis, basi magis attenuatis plerumque runosis, etc., a C. patenti priccipre pedunculis glabriusculis ramosís dignọscitur. (v. s.)

20. C. SPHA C'E L A UM (Hook, in Nitchell exped. 'Prop. austr. p. 342), foliis eonfertis erecto-patulis elongato-linearibus basi attenuatis subfalcatis sjliacelatoracutiusculis planis -nerviis eveniis ramisque gracilibus subsericeo-incanis; corymbo folia parum superante, pedunculis ramosis capitulisque sericeis, bracteis flore multo brevioribus late oxatjs acuminulatis demum glabrescentibus, calycis limbo tubum gracilem subłequante infundibukari semi-4-fidlo, lobis ołlongis obtusiusculis. 5 In saxosis arenosis Tove-Hollandix orientalis interiopis subtropicæ (Mitchell, n. 324 !). Fruticulus humilis, albicans, habitu $\mathrm{C}$ : taxifolii, ramis simplicibus flavo-tomentosis subscriceis. Folin $2-4$ poll. Jonga, $\frac{1}{9}-1$ lin. lata, nervo medio conspicuo subtus parum prominulo, marginibus sepius leviter incrassatis. Pedunculi tenues, circ. 3 poll. longi, supra medium carymbosi-ramulosi. Bractexe vix 1 lin. longe, capitulorum jaulo majores. Calyx albus? vel flavus? 3-4 lin. longus, sericeo-puberulus, tubo anguste crlindrico, lohis-1-2 lin. longis. (v. s: in herb. Lindl.)

21. G. ACINAcifold un (Graham in Edinh. Phil. Journ. 1826, p. 171), foliis lineariacinaciformilous subconcavis mucronatis basi atlenuat is obsolete 1-nerviis eveniis, corymbo lax́o, pedunculis supra medium ramosis, bracteis coloratis aeutis calycibusque pubescentilus, Jobis acut is fubum rix anquantibus. F Colebatur in hort. Edinensi e seninibus a Frasero in Nov.-Holl. lectis el sub nom' G. ereeti missis. C.- acinacilorme Grall. ex Roem. et Schult. syst. 3, mant. p. 377*. Frutex crectus. Folia sußverticalia, rigida, $2-3$ poll., longa, passim tor ta. Bracteæe cœruleæ. Flores albi, orlore 0xyacanthe. Stigma clavatum (?). Ovarium sericeumy pappo sericeo injequali. An scecies a jriecedente aut sequente, procipuc var. $\beta$; satis distincta?

22. C. Mчт с нециі, ramis strictis dense foliosis sericeo-puberulis demum glabrescentîlbus, foliis semipatnlis elongato-linearibus obtusis mucronatis basi attenuatis planis obsolete 1-nerviis oveniis glabris, corymbo folia parum superante polyco- 
phalo densiusculo, pedunculis tenuibus sericeis supra medium ramosis, bracteis ovato-oblongis acuminatis floribusque subsericeo tomentosis. 5 In interiore Nov.Holl. orientali (Mitcliell! exped. anni 1836). Frutex lrabitu C. taxifolìi. Folia

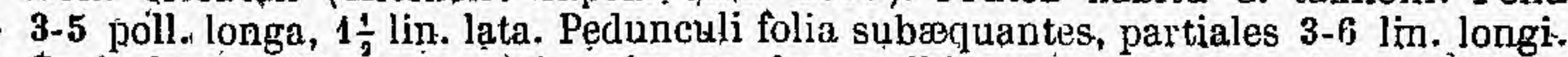
Capitula pauciflora, bracteis calycem dense albido-tomentosum subæquantibus. Species forsan cum yræcedente identica. (v. s. in herb. Lindl., flor. nondum expluns:)

' $\beta$ ? Dallachii, corymbo laxiusculo, calyce bracteas vix dimidio superante adpresse tomentoso, limbi lołjis tubo parum brevioribus aeutis. - In'montibus Grampians Australiæe feliçis (Ferd. Müller!). C. Dallachii Ferd. Müll.! miss. Antherarum loculi steriles filiformes, erecti, stylum subæquantes. Stigma reniforme. Pretered omnia ut in stirje Mitchellianà. (v. s. comm. a cl. Sonder.)

23. G. LONGIF OLIUM (Sníth! exot. bot. 2, p. 45, t. 8.2), ramis laxe foliosis tomentellis, fóliis elongàto-linearibus vel lingulato-lanceolatis mucronatis planis 1-nerviịs venosis vel subreveniris glabris, corymbo subśimplici polýcephalalo, pedunculo elongato scapiformi glabréseente, partialibus brevibus cano-sericeis sub-1-cephalis, bracteis ovatis acutis flore dimidio brevioribus glabrescentibus, calycis- sericeotomentosi lobis tubo brevioribus. J In Nova-Holl. orientali, circa Por R. Brown! in Linn. Trans. 10 , p. 154, prodr. p. 369, Trattin, l. 444, Roem. et Schult, syst. mant. vol 3, p. $275^{*}$. C. Smithii Pers. syn. 1, p.116. Folia ad insertíonem subdilatata el quasi cruribus 3 breviter ducurrentia. Pedunculus communis $\frac{1}{7}$-1-pedalis, partialibus plerumque indivisís. Capitula in spicam brevem excrescentia, rhachi paulo incrassatả eirc. pollicari glabratà. Flores pallide rusei vel albi:

a. lingulatum, foliis lingulato-lanceolatis in petiolum semiteretem vel canaliculatum longe attenuatis acutis obtusisve fortiter venosis, venis semipatentibus in nêrvium intramarginalem confluentibus, bracteis acutis vix acuminatis (Sieber herb. Nov.-Holl. n. 41 ! ex parte, Gaudieh.! in herb. DC, Hügel! in herb: Mart., 'etc.). - R. Brown suppl. it. 10, a. Folia 6-9. poll. longa, 5=9 lin. lata. (v.s.)

B. intermedium, foliis lineari-lanceolatis subpetiolatis utrinque attenuatis acutis vel subito acutalis nervoso-marginatis remote venosis; bracteis attenuatoacutís (Sisbır, n. 41, ex parte; A. Cinningh.) Gaudich.! etc.). C. longifolium Smith! in herb. Mart., R. Brown! in herb. DG. Hakea decurrens A. Cunn.! in herb. Mart., verisim, sch. dularum confusione (nec R. Br.). Folia 3-6 poll. longa, $1 \frac{1}{2}-3$ lin. láta: (v. s. in herb. Smaitl., Gumn., DG., etc;)

$\gamma$. angustifolium, foliis anguste linearibus vel compresso-filiformibus aculis basi vix. angustioribus obsolete 1-nervis marginatisque eveniis yel obscure veno-. sis, bracteis ovatis subabrupte acuminulatis (Siéber, n. 40 ! Anderson!). C. tenuifoliam Sieber! herb. Nov.LHoll,, n. 40, R. Br. suppl. p. 10, $\gamma$. G. commatatum Schult. in Roem. et Srdult. syst. mant. ad vol. 3, p.'275". - Fulia $2 \frac{1}{2}-6$ poll. longa, $\frac{1}{2}-1 \frac{1}{3}$ lin. lata. Varietas plerumque distinctisșima, $\operatorname{dum} \alpha$ et $\beta$ sxpe inter'se conflunt; attamer etiam inter $\beta$ et $\gamma$ forma intermediæ observantur. (v, s.)

24. C. TENurfolt or (R. Brown in Linn. Trans. 10, p. 154; prodr. p. 369); foliis olongatis filiformi-linearibus supra planis vel canaliculatis dorso subcarinatoconvexis marginatis eveniis ramisque glabris, a pice sphacelato acutis muticis sæpe hamatis, corymbo subsimplici oligoc 'phalo, pedunculo elongato tenui glauro, bracteis ovatis acatiusculis flore subtriplo brevioribus calycibuequuo car:opuberulis, lobis tubo lalíusculo duplo breviopibus. F Circa Port.-Jackson (A.Cunningh.! Siẹber !). - Grah. in Edinh. Yhil. Journ. 1825, Jun. 10, C. repens Sieber ! Jierb. N.-Holl., n. 45, Ruem. et Schult. syst. mant. vol. 3, p. $276^{\circ}$. Valde accedens ad C. longifoliuun ${ }_{2 .}$, sed vix ejưs var. Distinguitur ramis gracilibus prostratis, ramulis adscendentibu= vix apice puberulis, fơliis angustioribus, $\frac{1}{3} \div-\frac{1}{2}$ lin. latis, plerumque lungioribus, 6-12 vel raro 3 poll. longis, ped unculo plerumique folia parum superante levi vel vix basi obsolete striato apice eorymboso-pauciramoso ramis puberulis, bracteis brevioribus (1 liu. longis), calyce minore, 2 lin. longo. tubo ampliore. Folia subtus quasi bisulca. (v. s.)

25. C. NEn vosun (Neisn. in Hook. Journ. 1855, p. 71), ramis puberulis, foliis con fertis brevissime petiolatis oblongis pvalibusve glabris prominulo-3-nerviis venosisque, nervis làteralibus margini approxínatis, corynbo parro simplici, pedun- 
- acurninatis pubeyulis flore dimidio brevioribus, calyce gläbriziseuló limbón tubum

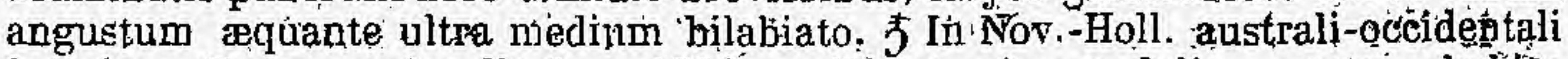
interiore (Drummond coll: 6, n. 175-1). - Frutex circ. pedalis, erectus, habititu C. elliptici. Folia rigida, plana! vel'apico plerumque complicata, obtusiuscula vel subretusa cum mucronulo obtuso subrecurvo deciduo, venis laxiiiscule subreticulatis. Pedunculi 8-12 lin. longi, graéiles. Galyx 3 lin. longus, carnens? vêl flavescens? limbus, campanulato-cylindricus purce puloerulus mox glabraturs 'tubo bracteam ærquante angustato giabro demum sublongior, lobis oblongis obtusiuseplis. Stigma incurvum, cucullatum, truncatum. Ovarium sericeum, apịce flavo: comosum.

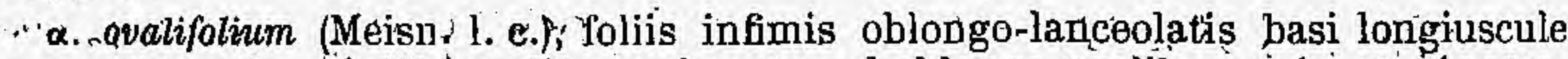
attenuatis, mediis ovalibus vel ovato-vel oblongo-ovalibus utrinque vix attenupatis obtusis, summis lanceolatis utrinque-æcrualiter attenuatis acutis: Radix subsimplex. Caulis simplex. Folia infima $2 \frac{1}{2}$ poll. longa, $7 ; 8$ lin: lata, miedia 6-12 lin. longa, 3-5 lin. lata, petiolo vix 1 lin. longo, summa pollicaria 2-3, lin. lata. (v..S.)

ß. subspathulatum (Meisn. 1. c.), foliis spathulato-laniceolatis linearibusve basi attenuatis passim ovalibus. - Caulis 'subeorymboso-ramosus. Folia eirć. 1. poll. longa, 2-3 lin, lata. Cæt. ut, ig, var. $\alpha_{-}$(v: s.)

26. C. ELLIP T I CU M (Smitb I in Rees Cycl.), ramulis incano-villosiusculis, foliis confertis imbricatis semipollicaribus ellipticis oblongis ohotatisve obtusis acutisve nucronulatis planis vel margine subrecurvis 1-nerviïs eveniis glabris, córymbo folía parum superante polycephalo, pedunculis ramosis sericeo-incaniș, bracteis ovatis acutis flore dimidio brevioribus glabrescentibus, calycis pubescentis lobis lanceolatís acutis tubo duiplo lirevioribus. J Eircá-Port-Jackson (Anderson; 'n. 145 ! Gaitdichaud! Lhotsky!, etè.).-R. Brown in Linn. Trans. 10, p. 153, prodr. 1..368. C: rigidum Knight et Salisb. Prot. p: 95. Rami sæpius díchotoni, adúltí glabri. Folia 4-7 lin. lohga, 2-3 lin: lata, in petiolum brevissimum quasi contracta, mucronulo innocuo. Pedunculi circ. pollicares, partiales dimidio breviores, capiLulis . 6-10-floris. Bractere $1 \frac{1}{2}-2$ lip. longø, plus minus acuminatæe. Stigma basi capillare, medio incrassatuni genuflexum album, supra, filiforme fuscum, apice inflexum compressum obtustum. Ozarium sericeum, apice setis rufiś cómosuru. (v. s: in herb.' Spwith., etc.)

27. G. і в вй́с ат и м (Sieber! herb. fl. Novi.-Holl. 1. 44), ramis villosiusculis, foliis confertis ímbricatịs semipollice brevioribus ovatis oblongis obofatisque acutis submuticis planis vel sujra concavis eveniis subenerviig glabris, corymbo oligocephalo follia parum sujurante, pedunculi, simṕplicibus capitulisqueincano-pubescentibus, bracteis ovatis actuminatiss flóre dimidio brevióribus glabrescentibus, calycis 'ưbo tobis durto longiọer 5 Circa, Port-Jackson (Cunningham, Sieber, r. 44 !). - R. Brown suypl. p. 9: A pracedente dignóscitur ramis elongatis subsimplicibas gracilibus, foliis minoribus 3-4 lin. lint. longis, 2 lin. latís, constantér acutis, mucronulo exigưo et corymbo simplici. (v. s.)

\section{4. Paniculata.-Caulis inferne: foliosus, supra subaphyllus elonga- tus paniculato-rainosus, ramis capitulo vel spicâ brievi tèrminatis, floribus haud lonatĭs.}

28. C. DE BIL E (Kiplist in Hook. Jourñ. 1855, p. 70), caule decumbente glabro, folịis pollicaribus anguste linearibus $t=$ nerviis glabris apice coniconcallosis, infimis elongatis' spathulatis attenuato-petiolatis obsolete venósis, paniculæe laxæe ramis adscendentibus racemoso-corymbosis, ultimis subsericeis imbricato-bracteatis, bracteji deciluis, capitulís paùcilloris, rliachi villosâ, flbibibùs glabriusçulis bracteas cordatas acuminatas coloratas duplo superantibus. 5 In Nova-Holl: australi-occidentali (Gilhert, n. 164). Folia infima 3-pollicaria, petiolo semítereti gracili, venis paucis tix conspicuis; caulina remotiuscula, dorso convexa, callo terminali sjliacclato acutiuseuló. Capjitula 5-10-flora, rhachí dẹmum elongatâ et paulo inerassatâ, bractcis vix ciliatis, fioribus cœruleis. '(Kipp. in litt. cum fig.)

29. C. c cerul EU ar (R. Browil in Linn: Trans. 10 ; p. 154; prodr. p. 369 ), caúle basi pubescente superne ajhyllo glăbro, foliis longe petiolatis lanceolatís acutis planis 
CONOSPERMdM. PROTEACE / AUCTOR, MEISNER).

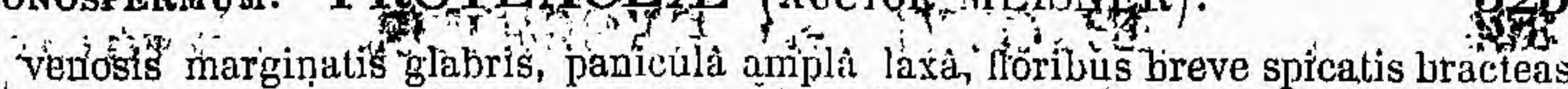
ovatas acumimatas' vix stuperantibus, calycis glabri tubo' linibo breviore." 7 In Leeuwin's Land (R. Br. Menzies! in herh. Smith.), eirca King Georges'Sound

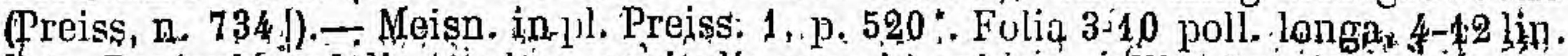
lata. Panicula pedális et ultra, capitulis mox in spicam pólice breviarem exeresceritibus, bracteis 2-3 lin. longis rhachiriue sericeg-villosiusculis demum glabrescentibus fuscis, caly̌ce cceruleo. (y. s. in herb. Smithl, etc.)

30. G. ma RGinat u (Meisn. in pl. Preiss. 2, p. $248^{\circ}$ ), caule gracillimo glabro a basi ramose ad apicem usque sparse folioso, folis longe petiolatis lanceolatis apicudatis-planis 1 -nervitis venosis marginatis glabris, capitulis laxe racemosis xix paniculatis, bracteis ovatis acutis calycis tiabri tubum limbo breviorem tequantibus pedunculisque puberulis. J. In coleniâ Swan River (Drummond coll. 2, n. 306 f)Precederitit valde affine, sed multo gracilius, caule ramisve foliosis tenuibus subsimpliçibus nec paniculato-ramosis, pedunculis axillaribus remotis brevibus subsimplicibùs. (v, s.)

31. C. Gu UACEUM' (Lindi.I Swan Riy., p. 30, n. 137), glabrum, foliis sessilibus linearibus açutis planis it-nevilis evẹniis, paniculæa amplæe aphylige ramis fllfformibus panciramosis simplicibusve, spicis brevibus oblongis, ibraeteis imbricatis rhachin pubescentem :equantilus membranaceis venoso-striatissoblongo-lanceoİtis flores parvulos longe superantibus demum semipatulis. F In coloniả Swan River (Drumm, coll. 1, n. 585! Preiss, n. 8551 1583! Gilbert, n. 114!). - Meisn. in

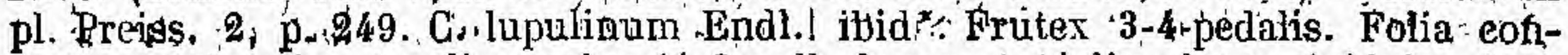

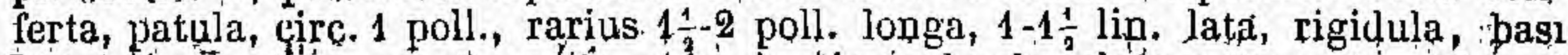
parum angustata, sæpe arcuata, apice mutico vel sphacelato-mucronato recto vel recurvo. Panicula $\frac{1}{-1}-1$-pedalis, rámis 6-12-pollicaribus, spicís 6-18 lin. longis, bracteis luteis a glaberrimis 4-6 lin" longis; $1 \frac{1}{2}-2$ lin. tatis. Calyx 1' lin: longus, giaber. (v, s. in heyb: Limdl., ete.)

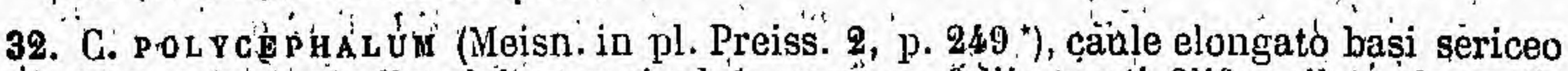
* superne fere aphyllo glabro paniculato-ramoso, foliis tereti-filiformibús elongatis glabris, panicułæ aṃplæ ramis patentíbus bracteâ subtoliaceâ subulatà suffultis, inferiớcibu's racemoso-pleiocephalis, capitulis hemisphiericis, bracteis obovatis

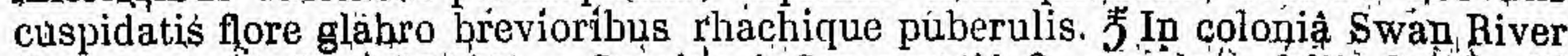
(Drumm. coll. 2, na 305 ). - Specces inforescentià C. coeruleó, foliis G. Hiugelii similis, coterum distinctissima. Caulis'vel panicula 1-2-pedalis et ultra. Folia 4-7 poll. longa, juniora minute caneséentí-puberula. (v. s.)

33:? C. E PHE DR OIDES (Kippist in Hools. Journ. 1855, p. 70), a basi ramosum, ramis remotis teretibus fere aphyllis cana-sericeis, foliis paucis brevissimis bracteiformibus friapgularịúus mucronatis basi latà ampléxicaulibus, spiçis capithlhformibus prope apicem ramuloram alternis sessilibus, rhachi canegcente denum peulo elongatâ, bracteis late pvatis acuminatis ghabriusculis ciliatis flore glabro pauio

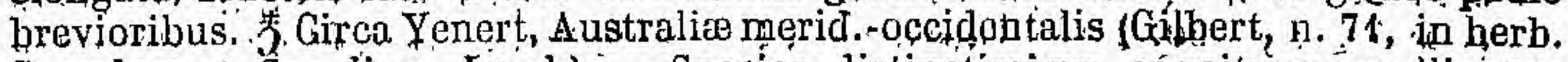
Saunders et Soc. linn, Eond.) - Species distinctissima, cógnitarum 'uulli arcte affinis, jhabitu an $C_{\text {e }}$ bracteosum-aecedens, sed díscrepans ramis junciformibus denudatisnonnisi ad ranificationes vel capitulorum basin foliis munitis, flopibus glabrís, etce An folla radicalia, quorum vestigia tantum in specim. observatis remanent, quandoque elongata teretia? caulina vix 3-6 lip. longa sunt (Kipp. in litt:f An potius ád \& Axillariorim referenda?

\$ 5. Scaposa-Caulis subsimplex, basi tantum foliosus, supra aphyllus scapiformis elongatus ebracteatus' "spicis paucis abbrétoratis corymbosis breve pedunculatis vel unicâ terminatus. Flores haud lanati.

34. C. Hti a E I (R. Brown mss, fide Endi. nov. stirp. decad. p. 58; n. 66\%), foliis elongatis semitcreti-filiformibus subcanaliculatis cauleque simplicissimo glabris,

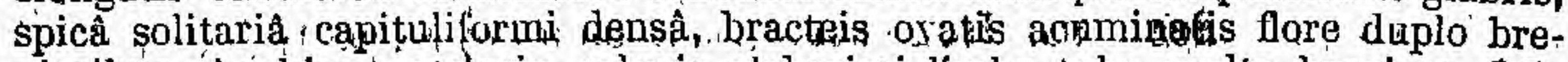
vioribus rhachique scriceis, calycis glaberimi 'limbo tubo multo breviore. $\bar{J}$ In colonia Swan River (Drumm. coll:1, a! 584! Preiss, n: 735\%)-Meisn. Preiss. 1; p. 521 * C. intricatum Lindl.! mss. in herb. Facies fere Armeriæ. Folia 2-4-pollicaria et ultra, nonnulła quandoque compressa. Scapus 1-2-pedalis; spica 
demum: subpollicaris, bracteis-floribusque cœrulescentibus. (v. s. in herb. Lindl., otc.)

35. G DEN Sil FL on u (Lind].I Swan Riv. p. 32, n. 149), foliis confertis tereti-filiformibus tena̛ibus scapoque patenti-jilusis, corymbu uligostachyo, pedunculis brèvibus, spicis capitaliformibus dense multiflot is, bracteis villusiš, inf rioribus filiformibus basi dilatatis, sujucrúuribus lanceùlatis coloratis glabrescentibuss flore brevioribis, calycis puberuli limbo tulum subsequante. 春 In colorià Swan River (Drumm. coll. 1, n. 582 ! Preiss, in. 2301, b!).-Meisn. in pl. Preiss. 1, p. 521 ". Habi-

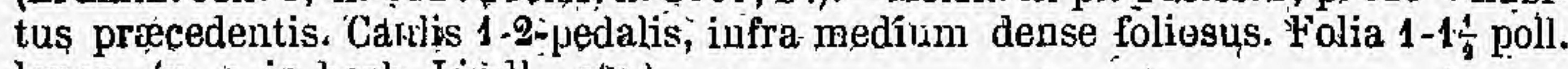
longa. (v.: s. in herb. Lindl., eto.)

36. C. B r own I (Meisn. in pl. Preiss. 2, p. 248*), glaberrimum, foliis sessilibus cuneato-lanceolatis vel obovato-ublons is ar utis mulicis, planis trinerviis venosis junióribus glaucis, nèrvis laterálíbus margini approximatis evanescentibus, seapo elongato, capitulis in racemum terminalem brevem congestis paucilloris, bracteis flore breviofibus ovatis acuninatis, calicis limlo tubum subiequante. $\$$ In colo-

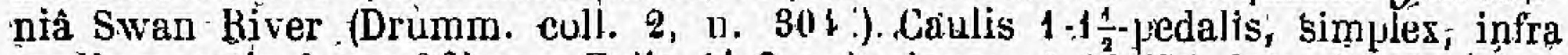
medium satis dense foliusus. Folja $1 \frac{1}{2}-2$ puli. longa, $5-10$ lin- lata. Scapts coompressus, peduneulis par tialibus $4 \mathbf{6}$ liu. lungis, capitulis subglobosis magnitndine pisi, braeteis et verisim. etiam floribus coruleis. ( $\left(v, \varepsilon_{\text {. }}\right)$

Sect. H. Cullorus R. Brown in Linn. Trans. 10, p. 155, prodr. p. 369.

Calycis limbus requaliter 4-partitus nec bilabiatus, lobis plands angastis caudatisve tubum equantibus vel luagiuribus. - Meisli. in ll. Preiss, 1, p. 525.

37. C. TERETIPOLIUM (R. Brownil l. c.), glabirum, caule basi folioso apice corymboso-panículato polystachyo, foliis -tereti-fliformibus longissimis rectis rigidis rugoso-sulcatis, sjicis brevibus, bracteis obovatis cus idatis flore multo brevioribus basi ruarnique puberulis, cal cis lohis tinearibus tubo gracili múlto lơngio-

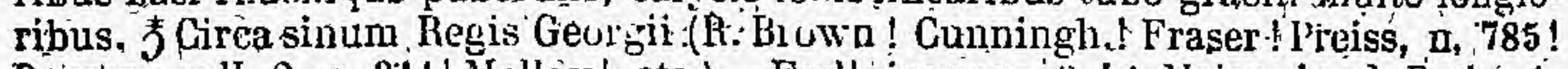
Drumm, coll, 2, n. 311! Molloy!, etc.) -End!. iconogr. t. 4', Meisn. in pt. Preiss.1, p. 525 . Frutex, ramis validis-bijedalibus et ultra Folia juncia, $12-14$ poll. longa, 1 lin. crassa, -mucronata vel splar, lato-acutiuscula. Flores 6-8 lin. longi, albi (in sicco ochruleuci), falce ämpliatà. (v. s. in herb. Cunn., etc.)

38. C. PETIOL ARE (R. Brown suppl, p. 11, caule albbreviato tomentoso, folis julanis lineari-gladiatis elongatis nervúsu-maryinalis venosis glaliris, petiolo tereti basi dilatato; capitulis terminalibus sulsessilibus e spiculis arete congestis naucílóris conflatis, bracteis ovatis oblongistue acuminatis juberulis, calycis tubo lyracteam subæquante glabriusculó, Fimbi trịilo longioris tọbis anguste linearî̉bus sericeovillosis. J Ad moplem Baldhead siuus Rigis Geongii (A. Gunningll... Baxter, Fraser ! Drumm: coll. 3, 11. 250 ? sturil. I'reiss, n. 757 1\% - Meisn. in pl. Preiss. '1, p. $525 \div, 2$, p. 250 . Caulis subsimplex, 1-6-jollicaris, a ice conferte foliosus. Folia rigida, crassiuscula, infina incluso retiolo 2-3-jullicari tedalia 6-8 lin., lata, summa triplu minora. Capitulum sphisroiddeum, mole juglandis, conflatum e spicis 3-4- brevissimis, Jjracteis demum muticis. Calj $\times$ 12-14 lin. longus. (v. s. fin herb. Cunn., etc.)

39. C. саріта тим (R. Browì in Linn. Trans. 10, p. 155, prodr. n. 369) caule abbreviato glabru, folris $p$ lanis anguste linc aribus longissimis tortilibus 1 -nerviis submarginatis puberulis glabrisve, I etiolo semiterei basi subdilatato, spiculis pancilloris in capitulum turmicale sul sessile arcté congestis, bracteis ovatis oblongisque acutis flore 1 arum 1 reviuribis glal ríusculis, calycis lolis angustissime

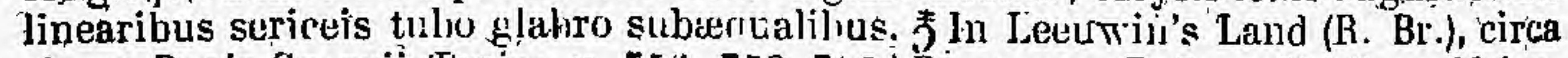
sinum Regis Getrgił (Treiss, n. 75“; 759, 7 , 0 ! Drımm, coП. 3, n. 251!). - Meisn. in pl. Preiss. $1,15.526^{\circ}, 2,11,251$. Folia $1-1,-1$ edalia, $\frac{1}{2}-1 \frac{1}{2}$ lin. lata, semper arcuata vel turta. (v.s.)

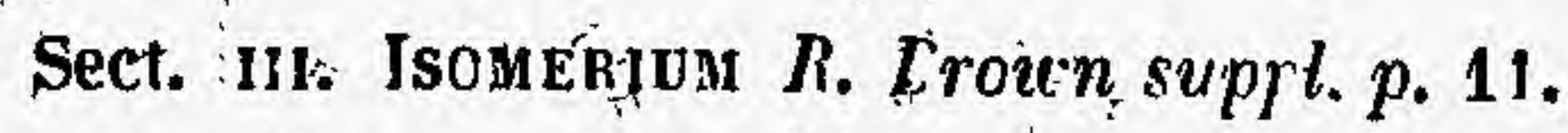

Calycis limbus rqualiter, 3-partitus, lobis tubo breví postice gillbo narum ton. gioribus angustis intus carinato-cunvexis - Meisn, in pl. Preiss. $1, \mathrm{p}, 520$.

40. C. PLexir os u Y (R. Br. l, c.l, glabrun, càule diehotome ramoso baśi tereti paucifolio, supra angulato, nphyllo paniculato bracteato, ramis llexuosis, foliis elongalo- 
lingulatis planis margínatis venosis, capitulis ramulos terminantibus paucifloris, calycihus extus bracteiłfuc obovatis sericen-pulyerulis, limbi-lobis Iänceolatis obtusis f Cirea sinum Re ris Grsorgii (3axt $r$, Preiss, Drummond, etc.). - Meisn. in jul. Preiss: 1 y $1 \% .52\left(i^{*}, 2\right.$, p. 251 . Ca lis bijeilalis et ultra, basi lignosus, ramis dichotomis nervosu-sulcatis vel acutè 4-5-an'r1] is, ramulis ertegie fexuosis. Folia rạra, cum petialo laminam suberuante 5-19 poll. longa, 3-6. lin. lata. Capitula eirc: pisi magnitudine, 3-6-1lora. Calyx 2 lin. longus, Loblis'albis vel extus pallide ccerileis rubellisve. (v. s)

-o. lavigatim, ramosissimnm, ramulis tenuioribus, angulis lievibus. (Drumm. coll. 2, n. 309! Molloy!)

B. Asperulum, minus ramosım, ramorum angulis foliorumque marginibus papilloso-scabris. (?russ, n. 753!, Drumm. coll. 2, 11. 310!, 5, n. 402 ))

XV. STİLINGIA Eńdl. gen. p. 339, n. 2133, iconogn. $t$. 22, suppl. IV, 2, p. 81, Meiśn. gen. p. 332 (24/). - Silnsia R. Brown in Linn. Truns, 10, pi 155, prodr. p. 369, suppl. p. $\varphi_{i}($ non.Pers.).

Flores hermaphroditi, capitati. Calyx remularis 4 -fidous, Iobis planis reflexop tenijbus. Stamina 4 exserta, supra medium fubi calycis inseita, filamentis complanatis prope ap cem geniculialis, antheris omnibus perfeclis didymis ovalibus unuticis primo coharentibus mox liberis. :tylus filiormis glaber, stjguale capifato-ililalato concrvo. Nux 1-sperma, obconica, pilosa. - l'ruti-

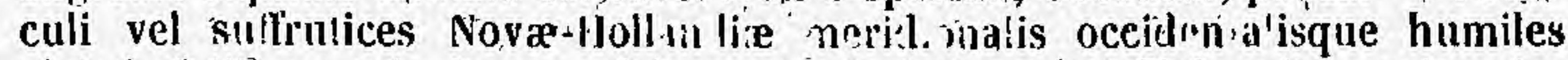
glabri, foliis sparsis ifonto dichotomis, laciniis tereti filiformilus vel rarus planís, slomatibus amphigenis, petiolis basi dilatatis, capitulis globosis parvis racemosis vel paniculatis, rarius sulsolitariis, involurro brevi vel nullo, pedunculo communi ciongaio fere aphyllo scapifor ini, floribus pàrvis glabris flavis,

\section{§1. Fulionum lacinice tereli-filiformes.}

1. S. tenetrouia (Meisn. in pl Preiss. 1, p. 515\%), caule subsulcato lavi folioso, foliis rigidis crassiuscults levibus supra 1-sulcis ter lifidis laniniis erectis vel vix divergentibus acutis, paniculie ramulis capituljo vix longioribus ohracteolatis, involncri.s juamis imbricatis gratis acutis cilialis. 5 In coloniâ Swan River (?reiss,

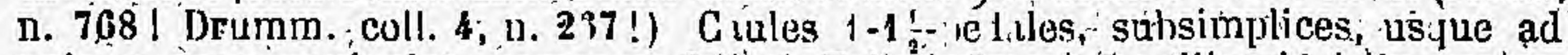
- apicem parcs paniculatı-ramosum foliosi. Eolia infima 2-3-podlicaria $\frac{1}{2}$ lin. crassa, superiura deereseentia, liciniis 4-8 lin. longis, petiolo subpollicari basi vix dilatato. Capitula piso parum majora, dense multilora, receptaculo conico 2 lín. longo albo-lanato. Flores $1 \frac{ \pm}{2}$ lin. longi. (v. s.)

2. S. AfFin Is (Meisn. l. c. p. 516\%), caule subsulcato scabriusculo folioso, foliis rigidis crassiuscalis subrugosis supra 1 -sulois ter quaterve bifidis laciniis ereectis 'vel vix divergentibus acutis, capitulis simpliciter racemosis, 'pedunculis elongatis ebracteolatis, involucri squamis imbricatis ovato laprceolatis aculis ciliatis. 5 Circa sinum Regis Georgii (Preiss, n. 770!) - Exceptả inIorescentiâ-omnia f'èe prrecedentis et forsan potius, ejusd um varietas.' (vas.)

3. S. intricat a (Veisn. in Ho k. Joura: 1852, p. 184), ramosissima, ramulis foliosis demum lignosis tenuiter sulcatis lievihus, folijs rigidulis longe petiulatis ter vel pluries diclıotomis, laciniis divaricatis acutis supra 1 -sulcis, panicula folia parum superantis ramis racemoso-3-6-cephalis, capitulis exinvolucratis? 5 In colonia Swan River (Drummoud! coll - 1, n. 268, vel ex, herb. Shuttl. 286). Fruticulus $1 \frac{1}{2}-$ pedalis, ranulis junióriburs licrluaceis' subangulato-sulcatts. teretibusve cun folis jeduncul's sque sub lente minute functato-scahriusculis. Folia 2-5 poll. longa, ter-sexies dichotoma, laçirulis 3-8 lin. longis vix $\frac{1}{2}$ lin..erassis. Pánicula rami bracteá squami formi ovatà 1-2 lin: longà suftultti, ped'unculis 5-10 lin. longis. Capitula magn. pisi majoris, involucro nullo nisi forsan deciduo, receptaculo pube brevi sordido alhâ sericeo-villoso. Forte mera var. $\mathrm{S}$. affinis, attamen satis discrepans foliis rigidiorihus divaricato-laciniatis, caule ilerato ramoso dense et intricate folioso, panicula composità breve pedunculatà nec longe supra folia elatata, pedunculis brevioribus, capitulis paulo minoribus. (v. s.) 
4. S. SIMP.LE (Lindi.l Swan River p. 30, n. 140); caulibus lévibus scapiforthibuls 1 isephalis bași foliosis superne 'lor ge nudis, folìis dichotomo-multifidis, laciniis subdivaricatis brevibus tenue filiformibus, exsuleis, capitullis densiflopis, involucri squamis ovatøalanceolatis acutis, $\hbar$ Iu cólonià Swan River; ad jugúm mont: Barling's. Range (Drummond coll. 1, 14. 586!.Preiss, n. 772 l).-Meisn. in pl. Preiss. 1, p. $516^{*}$ (†. s. in herb. Lindl., eto.)

5. S. TE N IF OL IA (Endl. gen. suppl. 4, 2, p. 81), caule subsulcato lǽvi subsimplici supperre aphyllo paticiramoso, foliroś flaccidis tenuibus subexsulcis : bis quaterve bifidis, lacinitis divarieatis obtusiusculis, capitulis simpliciter racemosis. vel sub-

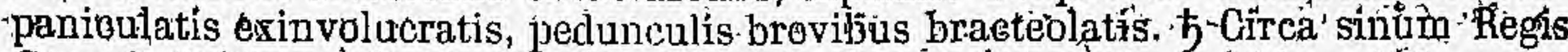
Georgii (R. Brown?). Simsia tenuifolia R. Br.! in Linn.:Trans 10, p. 152, proilr. p. 368. Inflorescentiâ variare videtur, in diagnosi cel. auctoris dicitur pauiculata, ramis submonocephalis, ipsius specimen vero autographum in herb. DC. sia,pum-exhibet submonocephalum. (v. s.).

6. S. ANETHIF oLia (Endl. iconogr. t. 23), caule dichotomo-ramoso superne fére aphyllo apice paniculate, folits diehotoma-multifidis, lacinijs sdivaricatissimis tenue filiformibus subexsulcis, peduirculis capitulo parum longioribus, involucri squamis minutis ovatis. 5 In Leeuwin's land (R. Brown), circa sinum Regis Georgii (A Cunningham! Baxter! Preiss, n. 771! Drumm coll: 4, n. 269).-Meisn. in pl. Preiss. $1, \mathfrak{p}_{.} .546^{*}$. S. acutifølia (sphalmate) tindl: gen. suppl. 4, 2, p. 81, n. 312. Exceptis capitulis involucratis a precedente vix distinguenda. (v. s.)

7. S. CA P IL L IF gLiA (Meisn. in Hook, Journ. 1855, p. 70), caule brevi, ramis gracilibus basi conferte foliosis supra aphyllis sparse ramulosis, ramulis filiformiburs elongatis indivisis 1-cephałlis; foliis flaccidis extra medium tuafer vel ultra dichotomis, laginiis teruibus exsulcis trovibus muticis, capitivis bracteatis; bracteis

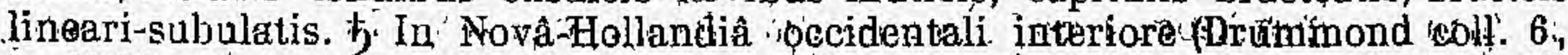
n. 173 !). Cáulis 1-2-pollicaris. Rami subbipedales, basi lignosi, ramulis apliyllís 6-12 poll. longis simplicissimis ohsolete'striatis. Folía 3-5 poll. longa, laciniís fere eapillaribus, Capitula magnit: cerasi minorìs, fláva, bràcteís câlyce $2 \frac{1}{2}$ lin. longo brevioribus. (v. s. comm. ab am. Shuttleworth.)

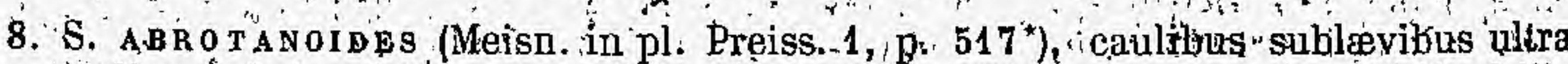
medium subșimplicibus dense foliosiś, supra aphyllis racemósonpolyótephalis, foliis brevibis teninibus bis vel ter bifidis, pedunculis longis ebracteolatis, capitulis laxiuscule mulfifloris, junolucri squamis minutis ovatis. $\mathbf{f}$ in coloniâ Swan River

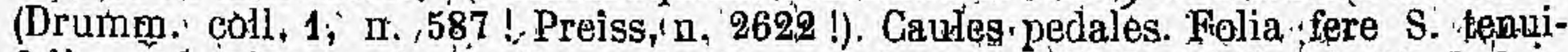
folite, sed minora, vix 1 poll. excedentia, tenuiora, laciniis haud divaricatis. Pedunculi 2-5-pollicares, çapitulis magn. cerasi, flor. 3 lin. Jongis. (vं. s.).

\section{\$ 2. Foliorum lacinioe plance, lineares vet lanceolato-lingulatoe.}

9. S. LAT IFOL IA (Steud. momenel. ed. 2, p. 644 ), caule a basi ramoso folioso gracili lævi; foliis aversis 2-3-fidis vel bis bifidis, laciniis linearibús - subvenoso-striatis sptracelato-acutis, capitulis paniculatis paucifloris, involucri squamís exiguis ovatis. 5 Circa sinum-Rogis Georgii (Baxter!), in sylvaticis ad fium: Cygmorum (Preiss, n. 767 !). - Meisn. in pl. Preiss 1 ; p. 517 ${ }^{*}$. Simsia latifolia R-- Brown suppl. p. 9. Suffrutex $1 \frac{1}{2}$-pedalis. Folia $2-5$ poll. longa, vix rigida, laciniis $\frac{4}{2}-1 \frac{4}{2}$ lin.

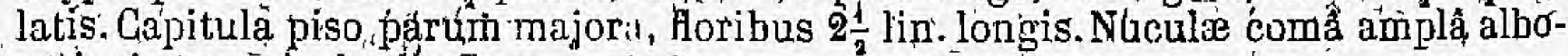
sericcâ. (v. s. in herb. Gunı, etc.)

10. S. Paniculata (Lindl. Swan Riv. p. 30; n. 141), eaule valido basi folioso simplici apice paniculato-polvcephato, foliis aversis rigidis nervoso-striatis bis vel ter bifidis, laciniis limeari langeplatis apice callosis, capitulis, breve pedunculatis pauciflotis, involucri scjuamis exiguis ovatis. † In coloniâ Swan Rìver (Drummond l Preiss, n: 7.69 !). - Meisn. in pl. Preiss. 1, j. $517^{\circ}$. Precedenti similis sed altior et robustior. Folia usque ad pedem longa, laciriis $\mathbf{3 - 5}$. lin. latis. Panicula amplissima, pedalis, fastigiata, aphylla." (v, s. in herb.,Lindl., etc.) 
Tribus III. FRANKLANDIEAE.

Stamina 4 medio calycis tubo inserta, inclusà, inter se libera, ańtheris linearibus filamentisque tubo arcte adnatis. Squamulæ hypogynæ 4 basi connatæ in vaginulam callycis tubo inferne adnatam. Ovarium 1-loculare, 1-ovulatiún. Nucula 1-sperma:

XVI. FRA NiKLANDIA $\stackrel{B}{B}$. Brown in Transact: Soc. linn. Lond, $10, p .48$ ét 157, prodr. f.: Nov.-Holl. p. 370, gen. remarks, p. 604, t. 6, suppl. p. 11, Endl. gen. p. 339, n. 2134 , iconogr: $t_{2} 52$, Meisn. gen. p. $332(244)$.

Flores hermaphroditi, l'egulares; spicali. calyx hypocraterimorplus, tubo gracili cylindrico recto persistente, limbi 4 fidi decidui lacini is æqualibus, astivatione induplicatis. Ovarium filiforme, stylo fusiformi, sligmate tur bijnato. Nuculla calycis basi cincta, stipitara, fusiformis, crustacea, striata, apice dilatała ịn vaginilam bievem subcyathiformem extus. pappigeram intus glabram. CotyJedones brevissinłæ. - Frutex Novæ-Hollandiæ austro-occidentalis, glaber, glandulis aurantiacis undique verruculosis, foliis sparsis tercli-filiformibus díchotomo-lacîniátis, stomatibus amphigenis, spicis axillaribus indivisis, floribłs alternis flavis singulis 1 -bracteatis.

F. Fu OIF olia (R. Brown! l. c.). J Girca sinum Regis Georgii (R. Brown ! Baxter ! Prëss, n. 755! Drumm. coll. 4, n. 271!) - Endl. ic. 452 , Meisn. in pl. Preiss. 1 ; j. 530. Frutex 4-pedális, strictus. Folila $2-3$ poll. longa, $\frac{2}{3}$ lín. crassa, rugososulcata, sparse gláillulosa, bis vel ter bififda, laciniis obtusiascrílis submuticis. Spice laxæ, 3-5 poll. Iongæ, rhachi jemüm subflexuósa, brácteis patulis ovatuóblongis 2 lin. Ióngis. Flores 18-20 lin. longi; laoiniis semipollicaribuis acuminatis basi margine subundulato-crispulis. (v. s. in herb. DC., Cunn., etc.)

\section{Tribus I $P$ E RSOONIE AE Endl. gen. $p .339$.}

Stamina 4, sepalorum medio vel basi inserta, rarissime hypogyna, antheriś liberis. Ovarium 1 -loculare, 2-ovulatum. Nucula, sảmara vel. drupa 1- (rarissime 2-), sperma.

XVII. SYMPHYONEMA $R$. Rrown in Irqnsact. Soc. linn. Lonà. 10, p. 48 et 157, prodr. p. 370 , suppl.p. 11, Reichenb. hort. bot. t. 107, Endl. gen. p. 339, n. 2135, súppl: IV, 2, p. 8i, Meisn. gent. p. $332 .(244)$

Flores hermaphroditi, regulares, spicati. Calyx profunde 4-partitus, decidius. Stámina sepalis ad mediun usque adnata, filamentis apice invicem cohærentibus, antheris distinclis. Glandulæ hỵpogynæ nullæ , Ovarium sessile, 2-ovulatum. Stylus filiformis ., stigmale subtruncato. Nuculá cylíndracea , 1-sperma. - Herbæ vel suffratices tovæ-Hollàndiæ orientalis, folijs inferioribus oppositis, superioribus sparsis, omnibus trifido-laciniatis, ${ }^{-s t o m a t i b u s ~}$ hypogenis, spicis terminalibus axillaribusque indivisis; bracleis atternis 1-floris cucullatis persistentibus, floribus flivis.

1. S. PAludosun (R. Brown! 1. e., prodr: p. 37-1), herbaceum, glaberrimum, foliís bjternatim seotis, laciniis semiteroti-subulatis mucrunato-acutis. $\not \mathcal{H}$ ? vel $\odot$ ? Circa Port-Jackson (R. Brown! Sieber herb. N.-Holl. n. 61). - Roem. et Schult. syst, mant. 3, p. $273^{*}$. S, montanum Endl. ic. t. 12 (non R. Br.). S: abrotanoides Sigber herb. fl. Nov:-Holl. h: 62 ! Rocm et Stohult. l. c.rp. 974 (Forma omnibus partibius paulo major). Hèrba erecta, pedalís; a basi pauciramosa. Folia remotiuscula, $\frac{1}{-1}$ poll longa; summa indivisa linearia sensim in bracteasabeuntia, media simpliciter: trifida, inferiorum segmenta 3-fida petiolo longiora $\div-\frac{1}{2}$ lin. lata. Cályx: $2 \div$ lin, longus. (v. s. in herb. Brown., DC., etc.) 
2. S. M оNтANUM (R. Brown!.]. c.), suffrutescens, follis bi-vel-triternatim sectis, laciniis linearibus planis acntis submuticis 1 -nerviis. $\$$ Girca Port-Jackson, atque Victoriam in orả australí. (Látrobe!)

a. Brownii, rhachi bracteisque frùetiferis glanduloso-pilosis. S. montanum R. Brown prodr. p; 371, suppl: p. 12, $\beta$.

$\beta$. Sieberi, undique glaberrimum. - R. Br. suppl. p. 11, a (excl. syn. S. abrotanoides, quod propter folia in nostris saltẹn specim. haud plana, subtus 1-sulca," potius au S. paludosum referendım censemus). S, montanum Sieber, n. 63! Reichenb. Hort. Bot.2, p. 3, t. 107, Roem. et Schult. I. c. p. 273 ${ }^{*}$, Anderson, n. 57, Gaudicl.! in herb. DC. - Basi sulfrutescens, canlibus sesquipedalibus

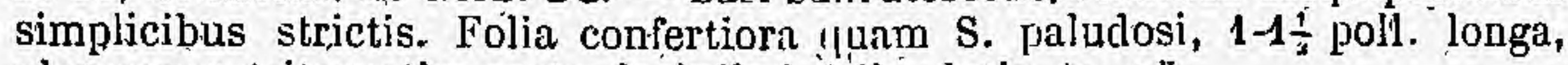
plerumque triternatim secta, laciniis $\frac{1}{-1}-1$ lin. latis. (v: s.)

XVIII. AGASTAGHYS $R$. Brown in Trans. Soc. linn. Lond. 10, p. 158, prodr. p. 371, suppl. p. 11, Endl. gen. p. 339, n. 2196, suppl. W, 2, p. 81, Meisn. gen. p. 332 (244).

Flores hermaphroditi, regulares, spicali. Calyx profunde 4-partilus, deciduus. Stamina sepalis ad medium usque adinala, filamenlis in fauce liberis brevissimis, antheris linearitus muticis. Squamule vel glandulæ hypogyna nullæ. Ova'fum sessile, trigonum , 1-ovulalum. Stylus filiformis, staminibus brevior, stigmate bilobo. Fructus.... - Frulex Tasmannicus, glaberpimus, foliis sparsis coriaceis lanceolatis intrgeirimis planis., stomatibus hypogenis, spicis num urosis terminalibus axillaribusque simplicibus laviuścule muliúfloris, bracteis alternis 1-flor is concavis persistentibus, floribus flavescentibus.

A. od o R a t a (R. Brown I.c..). J Ir ínsulẩ Diemen (Velson, Caley), ad sinum Recherche (Guñ, n. 1236!), Macquarie Harbour (Milligan, n: 358 !). Folia subsessilia, conlerta, circ. 2 poll, lunga, 3-4 lin. lata, rigida, obtusa vel emarginata mutica, subnitida, supra impresso-venosa, subtus evenia, margine plano rel subrecurro. Spica 3-4 poll. longie, bracteis ádpressis ovatis oblongísve obtusis flore dimidio brevioribus. (v.s.)

XIX. CENARRHENES Labill. Nov.-Holl. p. 36, $t .50, R$. Brown in Linn. Trans. 10, p. 158, prodr. p. 371, stcppl. p. 12, Lam. ill. t. 914, Endl. gen. p. 339, n. 2137, suppl. IV, 2, p. 81, Meisn. gen. p. 332 (244).

Flores hermaphroditi, regulares, spicati. Calyx 4 -sep̀alus, deciduus, sepalis apice angustatis. Stamina 4 , sepalorùm basi inserla, libéria. Glanclulæ̇ ? 4 hypogynæ, staminiformes. Ovarium sessile, 1-nvulatum. Slylus filiformis, deciduns, stigmate simplici. bunpa baccata, 1-sperma. - Arbror-Tasmannica, glaberrima, foliis sparsis rigide coriaceis lanceolatis obtuse dentato-serratis planis subeveniis nitidis, stomatibns hypogenis, spicis terminalibus axillaribu:que simplicibus, bracteis alternis $1-f l o r$ is con-avis.

C. N I T I D A (Labill.! l. c.). 5 In ìnsula Diemen (Labili.! A. Cunningh.1), circa Recherche Bay (Gunn, n. 556!). - R. Br. l. c., Lam. ill. suppl. p. 548, t. 914, f. 1, Poir; dict. 8, p. 85h, Roem. ct Schult. syst. 3, p. 404 " Habitus fere Agastachyos. Folin erecto-patula, 2-6 poll. longa, 6-12 lin. lata, in petiolurm brevem canaliculatum ronge attenuata, obtusa, mutica, passim spathulata, dentibus remotiusculis obtusissimis, ultimis brevioribús. Spicer folı vix superairtes, bracteis ovatis acutis demum patentibus, drupis subglobosis, magnit. pisi:- (v. s. in herb. Smith., DG, Lindl, etc.)

XX.? POTAMEIA Petit-Th. gen. Madagasc., $n .16$, Roem. collect.p. 199, Roem. et Schult. syst. 3, p. 31 et 476, Endl. gen. 'p. 340, suppl. $I V, 2, p .81,2.213711$, Meisn'. gen. p. $332(244$.

Calyx urceolatus, 4 -lobıs. Stamina 4 calycis lobis inserta, filamentis.brevi bus latis, antherarum lobis distinctis. Glandulæ hypogynæ 4 - sabrolundæ. Óvarium simplex, stylo subnullo. Drupa ovata, basi attenuata, 1-sperma, nuclei testâ (putamine ?) fragili, Embryo exalbuminosus, cotyledonibus cras- 
sis, rarlicufa latemali inferâ. - Fritex ramis erectis, follis alternis linearilanceolatis. floribus axillaribuls paniculatis parvis g!obulosis - Citnus non satis notum, alı anctore Laurineis adscriptum, verisimiliter tamen hujus loci, Cenartheni àffne.

P. ThouA Rs I I (Roem et Schult. syst. 3, p, 476). J Ad amnes ins. Madagascar. Cansiera Madagascariensis Spreng. syst. 1, p. 453.

XXI. PERSOONIA Smith in Transact. Soc. linn. Lond. 4, p. 215, exot. Bot. 2, t. 83, R. Brown in Linn. Trans. Soe. linn. Lond. 10, p. 160, prodr. p. 371, suppl. p. 12 , Labill. Nov.-Holl., 1, p. 33, $t$ 45, Gaitn. fr. 3, p. 218, t. 220, Endl. gen, p 341, n. 2138, suppl. IV, 2, p. 81, Meisn. gen. p. 332 (244).-Pentadactylon Gartn. l. c., Linkia Cav. jé. $4, p .01$, t. 389 , (non Pers.).

Flores hermaphroditi, áxil'ares solitarii vel rarins terminales vel racemosi: Calyx 4 -sepalus vel $h$-partitus, regularis vel rarius basi hinc gib'ius vel- saccatus, sepalis planis demum recrurvo-pafulis deciduis. Stamina medio sepalorum insurta, pxserta, libera, filamentis filiforinibus brevibus, antheris Jinearibus connectíyo- ultra locitos pondu'to apiculatis vel muticis. Glandulæ hypogyna 4 distincta. Ovarium stipitalịm vel rarius séssile, 1-loculare, 1-2-ovulatum. Stylus filif mitis, exscrus, rectus vel curvatus, rarius brevissimus crassus, stigimale capilato vel obtuso. Drupa baccala. putamine 1-2-loculari, loculis 1-spermis. - Frutices et arbusculæc Novæ-llollandiæ et , Novæ Zelandiæ, foliss sparsis raro passim opposilis. coriacris integertimis planis vel acerosis tiliformilusve floralibus interdum subaborlivis nanis, stom tilaus amphigenis. floribus flavis plerume axillaribus cloracteatis solitariis vel pancis fasciculatis breve pedunculatis, raritis racemosis altemis singulis 1-bracleatis vel in racemum terminalem spicifo:mem elongatum dispositis, fructu interdum cum stipitulo suo articulato, embryone sápe 3-5-cotyledoneo.

Sectio I. !yenOSTYLIS.

Stylus breviş crassus recurvus, stigmate truncato vel acutiușculo. Óvarium sessile vel subsessile.

\$1. Acranthero. - Antherce apiculata. Sepala diucohorentia, antica supra basin gibbo vel saccato, stizyma in cavo gibbositat is recipiente. Flares in racemum terminalem aphyllum vel apice tantum vel rarius undique foliosum scepe elongntum digesti. - Sectio. Sacculigera Ľ̉ndl. Swan Riv. in Bat. reg. 1839, append. p. 35.

1. P. s.A.c a t A (R. Brown suppl. p. 12), foliis filiformibus exsulcis elongatis laxis, calyce medio: antice saccato, ovario glabro, stylo ablorexiato. $₹$ In Novæ-Hollandiæ orâ occidentali. (Baudín.)

2. P. TERETIFOLIA (R. Brown in Linn. Trans. 10, p. 160, prodr. p. 372) ifoliis rigidis filiformibus exsulcis, calyce leviter saccato, stylis ovario brevioribus. In terrá Leeuwin (R. Br.). - Priori proxime accedens, sed distincta foliis brevioribus rigidisque et calyce minus alte saçato, teste cel. $\mathrm{R}$. Br. suppl. p. 12.

3. P. scopג prA (Meisn. in Heok. Journ. 1852, p. 185), ramis gracilibus junioribus tomentellis, folifs confertis rigidis tereti-frliformibus sphacelato-acutis rug@sostriatis glabris subtus 1 -suleis, tloralibus ennformibus, pedicellis axillaribus solitariis calyce tomentuso medio subventrícoso duplo brevioribus, jístillo sessili glabro, stigmate obtuso haud incrassato. F In coloniâ Swan River. (Drunmond coll. 4, n. 276 !). Rnmi sulvvirgati, ramulis adscendentibus subsimplicibus. Folia 2-3 poll. longa, $\frac{1}{2}$ lin. crassa, basi vix attenuata, irregụláriter rugosa, subtus manifeste 1 -sulea. Pedicrilli patuli, $2-2 \frac{1}{2}$ lin. lontri, crassiusculi, to nentosi. Calyx 5-6 lip. longıs, acutiuscilus, bași obtusus, medio antice dilatatıs ibique 2-lia. crassus. Antheræ process a lineari atro foculos, subæruante cuspidatæ. Pistillum calyce dimidio brevius, stỵlo ovario breviore et vix tenuiore recarvo, stigmate 
obliquo. Glandule : bypogyna parve, denticuliformes; Plantan Drummondii n. 276, cl. Kippist in litt. identicam declarat cum P. teretifolia R. Bz, fide specim autograph, in herb. Banks., sed tunc cel. auctor aut speciem nostram cum iffif confudisso aut ex errore illi folia exsulca in diagnosi tribuisse videtur, (v́. s. in herb. Shuttleworth.)

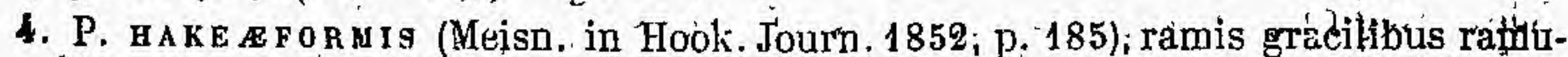
lisque patentibus incano tomentosis, foliis confertis patentisșimis rigidis teretifiliformilbưs sphacelato-acutis levibus glabris subtus 4 -sulcis', floralíbus ałbreviatis; pedicellis axillaribus subsolitarijs lirevibus dense approximatis' rầcem tum foliosum tel aphyllum cơnosuń 'fotmiantibus, calyce ghabro basi saccấto, fjistillo

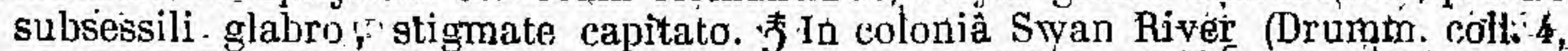
n. 275 !). Rami subvirgati. Folira 1-2 poll. Ionga, $\frac{1}{2}-\frac{2}{5}$ lin. crassa; submiltitia; apice recurva, hasi vix attenuata, sæe deflesa, juniora minute puberula, floralia raro

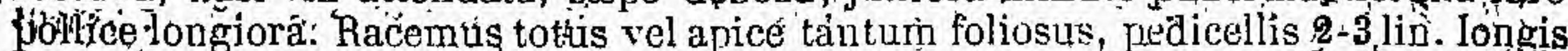
interdumg 'geminis, singulis nunt bractêâ lineàri acutâ villosâ ipısis breviore, nutúc

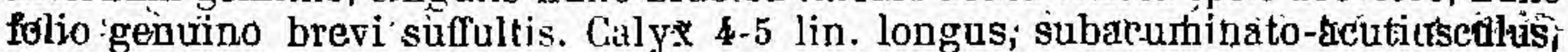
hasi antice, breviter rotundato-saccatus. Antheráappendice oblusâ atrấ superałæa, anteriores 2 (quæ sacculo proximæ) breviores. Sty̧lus crassús, ovarị brevior, saeculum versus recurvus, stigmate-cernuo subgloboso breviter umbonato. Glandulæ 'hypogynæ toinutæ, granuliformes. Fructus ignotus. Præecedentibus et P. mạcrö stachyæ valde quitlem affinis, sed vel foliis sulcatis, vel inflorescentił módo, vel ealyce glabro bene distincta. (v.'s. in therb. Shuttl.)

5. P. M A CR OSTA C HY A (Lindl.I Swan Riv. p. 35, n. 172), ramulis pedicellis, florilus Tue villósortomentosis, foliis laxiusculis tereti-filiformibus mucronatis glabris subtus sulcatis, floralibus siepius abbreviatis, pedicellis 'solitarîis calyce' medío antice saccató brevioribus, ovario sessili glabro apice’ recurv́o, stignnaté séssili

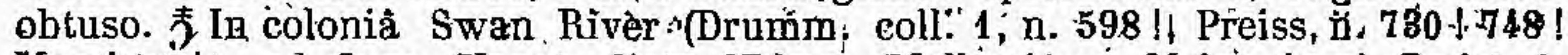
Morrison !), ad flum. Vasse, distr. Nelson (Molloy.l.). - Meisn. in p1. Preisš. 1, p. $5 \$ 1 \%$ Fratex $2 \frac{1}{2}-6$-pedalis, expansús, ramis gracilibus sópius simplicibus pedalibus a medio inde floriferis ibique aut aphyllis aut foliis nanis preditis racemum aphyllum apice comoso-foliosư⿱⺈ referentibus. Folia vix rigidula, 2-6-poll. longa vix $\frac{1}{2}$ lin. lața, subtus 1 -sulca vel rariús canaliculata vel bisulea, novella, pubescentia. Calyxx sulphưreus, semipollicaris: Antherarum apiculús loeulis dímidio brevior. Drupa (fidc Molloy nigra, gummi exsudans) basi attenuata, 1-sperină, acumine crassiusculo hamato-recurvo. ( $\mathrm{v}, \mathrm{s}$, in herb. Lindl., etc.)

6. P. SA UNDER SI A NA (Kippistin Hook. Journ. 1855, p. 7.2), ramulis cano-pubescentibus, folìis- rigridis complanato-filițormibus mucronatis utrinqué 2-4-sulcis pilosiusculis demum glabris purictato-scabriụsculis, pedicellis solitariis flore stbbrevioribus adpresse kirtis' bractea subulalà ipsis breviore vel rarius folliólongo suffultis, calyce saccato glabriusculo intus basi velutino, sepais apice breve connatis, ovarịo glabriuscùlo, stylo brevi crasso recurvo, stigmate obtuso. $f$ In coloniâ Swan River (Drumm: eoll. 5, suppl., n.. 4).-Folia 4-6-pollicaria punctis pirominulis micantibưs scaberula, novellá parce puberula, apice acuto sphacelato. recto mucronata, nervís 3 utrinque valde prominulis. Anthera obtuse apienlatæ. Ovarium sepalis dimidio brevius. Glandulæ hypogynæ triangulari-subulatæ, inæ: quales. Accedit ad P. Frảseri, sed abunde distincta foliis loṇgioribus èt prớsertint floris structurâa.

7. Р. с о м а т ' (Meiśn. in Hook. Journ. 1855, p. 71), foliis rigidis planis spathulatis mucronulatis utrinque dense sulcatis glabris, racemis terminalibus et e summis axillis sólitariís simplicibis folio longioribus conâ foliorum terminatis infra aphyllis undique cano-tomentéllis, calyce supra Jrasin sáccato, pistillo sessili glabro, stylo erasso recurvo, stigmate papilloso. 5 Girca Dundagaran in Novi-Holl. occid. interiore (Drumm. coll. 6, n. 178 ! Hook .Journ. 1853, p. 178). Frutex humilis (ex Drumm. 1. c:). Rami virgati, graciles, laxiuscule foliosi. Folia glauca (ex Drumm.); subsessilia, erecta, $2 \frac{1}{2}$-fere 5 poll. longa, basi vix 1 lin; 4-9 lin. lata, cuneatonattenuata, apice acutiuscuła' passim rotpondata vel émarginata cum mucronulo brevi sphacelato, venis subparallolis prominulis, dense sulcato-lineata, marginibus planis vel obsolete nervilormibus recurvisve. Racemi corymbos 6 -approximati, recti, patuli, 5 5-10 poll--longi, taxiuscale meltiflari, pedi-

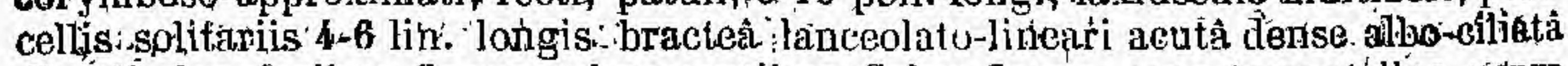
dimidio longioribus florem subæquantibus. Calyx flavus, cano-tornentélius, suppra 
basìn turhiniatam antice gibbere obtuso $1_{\text {i }}$ lin. longo munitus, apice subineurvug acutus, dentum 4-partitus. Antherie processu oblongo obtuso $\frac{3}{3}$. lin. longo apiculatæ. Glandulie hypogyne 4 hreves.obtust. (v, s. in herh. Shuttl.).

8. P. FAL LA TA (R. Brownil in Limn. Trans, 10 p.: 162, prodr. p. 373) arhòrescens, glaherrimà , folrig elongato'lánceolatis falcatis utrínque attenuatís muticis verioSis, floralibus abbreviatis linearibus, pedicellis subsolitariis calyce parum brevioribus, pistíllo stibsessili glalóno, stylo brevissimo crasso hamato, stigmáte truncato: 5 In Notá-Hóllandiâ subtropicâ orientali (Leichardt)' et tropicà, prope flum. Endéavour orse "septentr-orientalis, circa totum sinum Carpentarie et ín terirấ Arnhern. (R. Brown I A. Cunviingh.! Leitchardt). Arbušcula 15-pedalis, cortice lamélloso.. Folía rigida; glauco-viridia, pátula, 3-7 poll. longa, 6-18 lin. lata, súbpetíalatà, acurta vel obtiusa' àversa, Acaçiarum pliyllodia initântia, ténuiter venósa, flöralia linearia pedicelios superänilia. Flóós inlra apicem subfoliosium ramorum axillares, racemum 3-4-pollicaren simulanites. Calyx 5 lin. lỏngus, subacuminatoacutus, busi rotundatus, medio plus minus inçurvo-gribbus. Anthere processu oblongo obtusiusculo loculis dimidio breviore apiculate. Fructus edulis. Cfŕ. L̇eichardt, Tagebuch, p. 49, et in Hoòk, Lond. Journ. 6, p. 358. (v. s. in herb.'Brown., Cann., DC., etc.)

\section{\$2. Amblyanthera. - Anthera mutica, connectivo haud ultra loculos producto.}

9. P. Toku tÁ. Cunningham! in Bot. Mag: 'sub i. 3513), arlorea, foliis elongatolanceolatis vel subsjathulatis muticis 1 -nerviis subvenosis glabris, rácenis axillaribus tertininalibusque brevibus erectis rufo-tomentellis, bracteis ovatis, pedicellis brevissimis, calyce sequali, pistillo subsessilí glabró, stylo lurevissimo

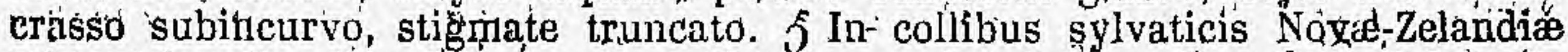
septentrionalis circa Wangaroa el Hokianga, insulisquue sinus Bay of Islands (Banks ét Soland.,'A: et R. Cünningham! Raoul; J.-D. Hooker !). P. Tora A. Cunn.! in Ann. of hát.. hist. 1, p. 378 , Raoul Choix p. 42. P. Toro Hook.! y., New Zeal. p.:219. Ineolis Toru, Toro vel Tora. Arbor 15-40-pedalis, sempervirens, venústa, cortice lavi, ramis grạcilibus, , epidęrmipte lamellatim seededente.: Folia patuda 3-8 poll, longa, 3-9 lin. lata, nitida , obtusiuscula vel subacuminata, basi longe, attenuat,a. Racemi pollicares; aphylli,,$b=10$-flori, bracteis pedicellisque vix 1 , lin. longis cuni rachi calyceque 3 lin. (ex Hook. 1 poll.) longo rufo-Lomentellis. Sepala acuta. An there mntica. Ovarium 2-ovulatum. Drupa baccata, putamine 2-loculari ! Glandule hypogyne 4 brevissinge. (y, s, in herb: Cunn., DG., etc.)

\section{¿Sectio I. LEPTOSTYLis.}

Stylus elońgatus calscem subæquans vel superans, filiformls vel subulatus, rectus vel rarius curvâtus. Calyx regularis, sepalis mox solutis planis recurviopàtulis.

\section{Series 1. Acrantherc. - Antherce connectivo, ultrá loculos productó apiculdatoe.}

\section{\$1. Uninervice. - Folits linearibus planis 1-nervils.}

10.' P. G RAMINEA (R. Brown! in Linn. Trans. 10, p. 164; prodr. p. 374), glabra, caule suffrúticoso abbreviato, ramis gracillimis, foliis longissìmis linearibus aculis 1-nerviis margine nerviformi plano vel recurvo, racenhís axillaribus elongatis aphyllis secundis, antheris aristatis ovario breve' stipitato glabro. † In terrâ Leeuwin (R. Br.), circa Princess Royal Harbour (Preiss, n. 725 I). - Meisn. in pl.

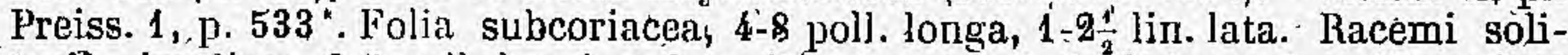
tarîi, simplices, $2-5$ joll. longi, subsessiles, bracteis 1 -floris lank:eolato-linearibua phanis, 1-2, lin. Iongis pedicellisque secundis 1 lin. longis crassiutsculis persistentibús. Sepala linearia $2 \frac{1}{3}$ lin. lónga, obtusa. Antheræ cuñ aristâ terminali loctilos æquante 1 lin. longæ. Ovarium stylo triplo brevius, cum stipite suo articulatum. (v. s. in herb. Brownin., etc.)

11: P. roRt1 roL IA (Aleisn-in Hook. Journ. 1852;-p. 185), follis patulis rigidis sessilibus lineari-lanceolatis acutis spiraliter tortis marginatis subtus 1-nervijs 
ramulisque juniorithus adpresse cano-pilosinsculís demum glabris, floribus axillaribus vel rarnalos foliosos terminantibus solitarin brevissime pedicêllatis futrosericeis, anthar breve apiculatis, ovario lowe stipritato juberul,y,-stylo tentui stigmate acuto. F In coloniả Swaì River (Orumm. coll. 4, n. 272 !). Caules e rhizomate plures, circ. pelale:, ereeti, tencies, ramulis patulis. Fulia 8-12 din. longa, $1-2$ lin. lata, his vel ler semperque dextrorsum torta, basi attenumta, evenia, supra sibenurvia glabra, nucrun'lo atrò innocuo, margine jucrassito. Ramuli flore terminati fuliuşi s,rpe brevissimi, interdụm umbillatu-vel subcapitato-approximati, pedicellis 1 -2 lin longis. 'Calyx sumipollicaris, urinque áttenualus, basi obtusus, apice acutiụsculus, juhe allyressà densa breyi sericans. Antherie ajicinlo subslato obtusiusculo alloido loculis dimidio breviore pler um jue reflexo terminatze. Glandale ty pogrnie minutie, Ovarium puhe brevi albida subsericeum. Stylus tenuis, glaber, s srsum attenuatus, stigmate laad incrassato. Accedit quo tammodo ad P. llexifoliam, sed foliis lioviluns, -liorum pubescentià, etc. bene distincta. (v.s. in herb. Shuttl.)

\section{\$2. Plurinervia - Foliis linearibus planis plurinerviis vel sulcato-lineatis.}

12. P. TRín R vis (Meisn. in Hook. Joum. 1852, p. 185), foliis patulis rigidis lineárispathulatis obtusis vel sphacelito-m!cronulatis elevatu-trinerviis levibus ramulisque glabrìs, racemis axiflarihts terminalibusque bre issimis 1 auciforis, calyce mutico ovario jue subsessili villusis. $T_{\Perp}$ culunia Swan Rir.F (Drumm. coll.5, suppl. n. 5 !). Ram ali cinerei, juniorés tomentelli. Folia el’assiuscula, 1-2 poll.

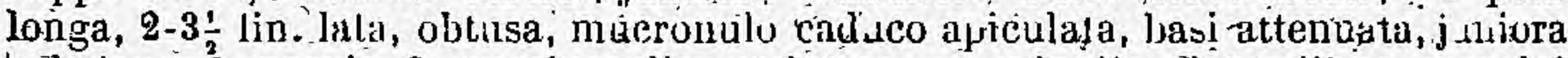
subglauca?, nervis 3 grassjusculis utrinque jrominulis, lat.ralihas margini approximatis, venis nullis vel raris obsoletis. Fedunculi vì $3-4$ lin. longi, 3-4-fori, infriores nomnun fuam 1-fluri ?, cum pedicellis vix 1 lin. longís ef'calyce subelavato obtuso 4 lin. longu pube densà s.riceâ ruló-villosi, bractuis ovalibus obtusis caducis subbreviores. Anthere apiculo. brevi oநtnso albido capitata. Glan-

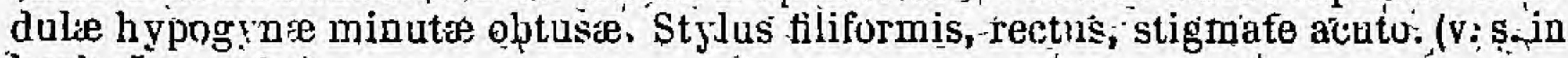
herb. Lemanin.)

13. P. RufIFLora (Meisn. in Hook. Journ. 1855 , p. 72), ramis puberulis, follis sessilibus patulis rigidis lanceølato-lin aribus obtusis mucronulatis lævibus glabris supra 3-nerviis, floribus axillaribus 'solitariis sessilibus dense rufo-viltusis' sericeis, orario brevissime stipitsto glabro. $\mathrm{f}$ In Novà-Hullandiâ oecidentali interiore (Drumm. coll. 6, n. 176). Rami graciles, canescenti-puberuli, juniores cum foliis novellis fulvo-suricei. Folia $1-2$ poll. longa, $2 \frac{1}{2}-3$ lin. latà, rotundato-obtusa cum mucronulo recto nigro, attenuato-subjyetiulata, plana vel margine leviter recurvo, nervo medio utrin jue prominulo, latêralibus margini proximis subtus inconspicuis venis raris jmpressis obsuletis vel nullis. Calyx 3-4 lin. longus, rectus, cylindricus, apice vix attenuato acato. Antheree sepalo dimidio breviores, apiculo sessili globoso pallicio. Glandulie hypogynæe parvulæ; obtusæe. Stylus filiformis, stigmate truncálo. Foliis pracedenti accedens, cetterum bene distincta. (v.s. in herb. Sliuttl.)

14. P. QUINQUENERVIS (Hooker ic. pl. t: 425 !), ramulis sericeo-puberulis, folis sessilibus lineari-spathulatis nervis $5-9$. parallelis elevato-striatis mucrovulatis glabris, pedunculis axillaribus solitariis 1 -floris foliu brevioribus calyoem glabrum æquantibus, ovario s'ssili. glabro. ' In colonià Swan River (Drimm. conl. 1. n. 596! Preiss, n. 531! 73i!). Frutex 5-7-pedalis, fastigrátus. Folia erecta.1-2 poll. longa, 2.5 lin. lata, juniora glauca? Variat floribus $2 \frac{1}{2}-5$ lin. longis; pedunculo nunc paulo brevioribus nunc longioribas. Sepala breve acuminata. Antherarum apiculus brevís obtizsus. Stylus rectus, sulcatus, persistens, sligmate truncato concavo. (v. s.)

15. P. striata (R. Brown suppl.p. 13), folíis linearibus mucrouratis utrinque elevato-striatis glabris, pelunculis axillaribus recurvis, calyce qvaríoque glabris. J Girca sinum Regis Georgii (Baxter).

16. P. strrol a a (Vuisn. in Hook. J.)tr. 1855, p. 72), razulis eano-pubescentíbus, foliis tortís linearl-lanceolatis sphacelato-mucronatis basi atténuatis utrinque 6-suleatis puncticulato-scabriuseulis, junioribus adpresse' hirtis, peduneulis axil- 
laribus solitariís erectis florem subæquantibus, sepalis acuminatis oxtus puberulis. F In coloniâ Swài River (Drumm. coll. 5 , surpil. n, 6). Frufex. ramosissimus. Folia, 1-1 $\frac{1}{2}$ poll. longa, $\frac{1}{2}-1$ lin. latta, mox glalora. Peduneuli 2 - fere 3 lín. longí. Anthera rum apiculus brevis obtusus. Pistillum jgnotum. $\mathrm{P}$, striata Br.? Kipp. in litt.', sed . pedanculis erectis cal ycibusçue haud glabris diversa. Forsan tamen mere ejus var.

\section{\$ 3. Filifolice - Foliis tereti-filiformibus vel ongustissme linearibus : 1-nerviis vel enerviris. Pedunculi axillares 1-fori.}

17. P. sur c a ta (Meisn. in Fook. Jourı. 1852 , r. 185), foliis ratulís rigidis angúśte linearibus vel comp.russo-filifou mibu's pun entibus tasi haud at tenuatis utrinque

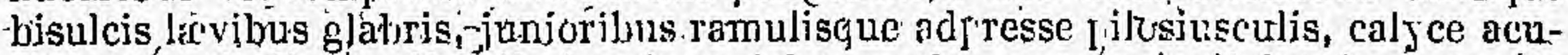
minato fedicellorue dimitio breviore glal ro, antherar um a irulo lcculcs æquante

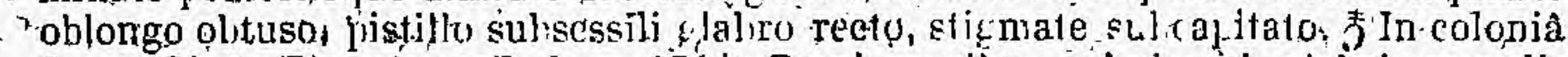
Swan River (Drumm: coll. 4, n 274!l. Bami graciles, sul,virgtij, glal,ri, ramulis

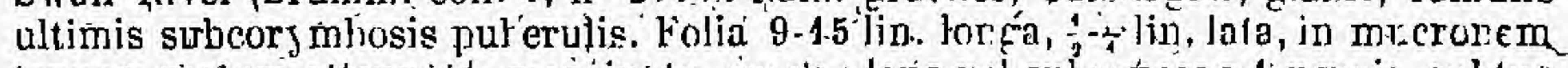

- tenuem rectum altenuad, marginata, sul Ia f lana vel sul concara 1 ncrvia, subtus

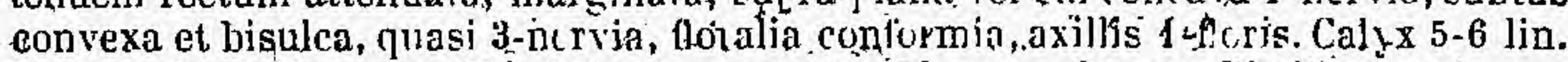
longus, basi obtusus. Glandule lypogy riæe ollongie uhtuser. listillum calycem «efuans. Stigma cernuum, de presso-capitatum. Accedit ad P. junijeerinam et precipue P. Frasteri, ab illâ jam foliis longioriluus magisque nervosis , ab hâe fưliis brevioribus vix purgentibas 'calyce glabro, ab utrâkue antheris lunge appendiculatis bene distincta. (v. s.)

18. P. Rudis (Meisn. in Hook. Journ. 1852, p. 185), foliis rigidulis subtrícquetro-filiformibus jungenti-acưtis supra cánalieulatis sulttus sonvexis obsolete bisulcis basi vix atfenuatis utrinque punetato-scạris, juniorihus 1 amulisque 1 alc nti-villcsis, flóribus sulsessilibı.s glalris, anllierapum a jiculo loculiss dimidio breviore, ovario suibsessili villos $d_{y}$ stiymate dejưseso-capitalo. J In colonłâ Swan hiver (Drumm. cull. 4 , n. 273 !). Bamí graciles, pilis mollibus allbis $1=1 \frac{1}{2}$ lin. longis patenti-villointusculi. Folia 12-15 lin. longa, $\frac{1}{2}$ lin, crassa, seplius incurva, punçis crystallinis elevatis dense consi ersa, apice sæe ins leviter recurvo; florália conformia. Fores rari, in summis exillis sulitarii. Caljx 4 lin. longus, 1 lín. crassus, cyllindricus, utrinque áttenuatus, sepalis breve áruminatis. Antherarnin apiculis ater, obtusus, Glandula liypogyne minutid, Pistillum calyeem ěequans, oyàrío cúm styli rectỉ basi sericeo-rilloso. (v. s.)

10. P. SCABRELtA (Heisn. in IIook Journ. 1855; p. 72), ramis dense, foliosis apice incano-lumentellis, folis erectis rigidis teretí-sabulatis obtusis sulmucronulatis, minute punctaté-scabriusculis gla] ris basi vix attenatis subtus 1 -surcis vel canaliculatis, florilons sessilibus rulo-hirsutulis, antleris capitato-apiculatis, ovario

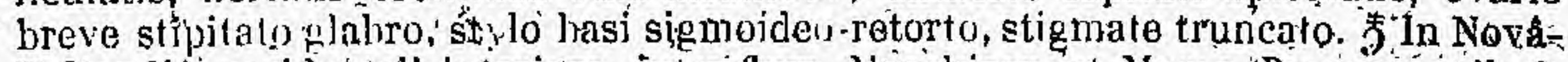
Hollnndiâ occidentali intertore, juler flum. Murchison et Moore (Drumm. coll. 6,

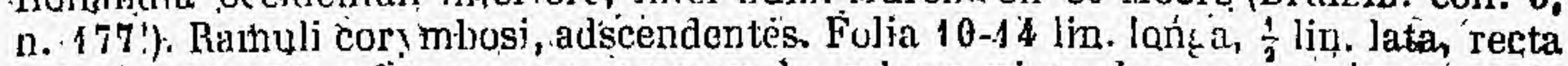
vel vix arcual'a, obtusa cum mucrenulo exigun nizro innoruo, suypra 'enervia convexa vel subplana, sulutus marginibus arcte revolul is 1-sulca vel angustissime canaliculala, floralia conformia, axillis $1-$ foris. Calyx 24 lin. longus, anguste cylindricus denise ferrugineo-tomentosus; sepalis acutis. Antherarun apiculus subglobosus albidus. Pistillum, cal rem sqquans, glaherrimum, sty to laterali filiformi basi insigniter lis retorto, st rumate jualo dilatato- $P$. curvifolio quodammodo aecedens, sed abunde distineta. ( 1 . s. in heib. Shuttl.)

20. P. Dr.L w w N I I Des (Veisn. in Hook. Journ. 1852, p. 185), ramulis deniz foliosis,

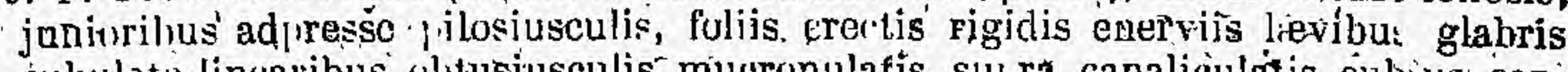
subulato-linearibus olitusiusculis mutronulatis suy rạ capaliculatis subius convexis basi tortis, cal , co brevissine pedicellaio glabro cus i. lato folia subrequante,

$\therefore$ antherarum apiculo sulgloboso, ovario breve sljpitato prlaliro rectư, stigmate obliniue truncato. F In colnnià Swan River (Drımm: 5, n. 403 !). Folia semipollicaria, $\frac{1}{s}-\frac{i}{2}$ lin. lata, sub lente puncticulata, plera jue more Dillwi niarum ita torta ut facies suy erior caualiculata exirorsum spectet, mucronulo innuedó exiguo decidun, marginibus suljincrassatis, floralia confurmia. Flores rari, solitarii. Pedicellüs $\frac{1}{2}$ lin., calvx 4 lin. 'longus, sepal is brevisssime mucroniformi-acurninatis'. Anthere sepalis: $\div$ breviores. Sitigma subcapitatum. Habitu accedit ad P. Chamepityn, acerosain, etc., sed jam antheris apiculatis distineta. (v. s.) 
21: P. Fraser I (R. Browa! subit: p. 12), ramulis cano-pubescentibus, folins compresso-filifonmibus' obtusiuṣulis mucronulatis utrinque bisulcis l\$vibus gla noveldis floribusque sericeo-villosis, an therarum apiculo brevi eonigo acuto, ovario stipitato villosp, stigninate obtuso. b. Ln colonia Swan River (Fraser ! Drumm. coH: 1 , n. 597! Preiss, n. 729 !).-Meisn. in. pl. Preiss: 1, p. 582 * Frutículus pedalis: Folia $1 \frac{1}{3}-\hat{\beta}$ poll. longa, $\frac{1}{8}-1$ lin. lata, rigida, vix pungentia, axillis superioribus $1-3$-floris. Pedicelli 1-3 lin. longi, basi 2-bracteati. Calyx flavus vel rufus, 5-7 lin. longus; sepalis acutis muticis. Stylus subulatus, reclus, glabrinsculus, stigmate depresso. (v. s. in herb. Brown, etc.)

22. P. micRogaR PA (B. Brown! in Linn. Trans. 10, p. 160, prodr p. 372), ramis puberulis, foliis laxis elongatis tereti-filifornibus acutis glabris subtus' 1-sulcís vel canaliculatis, floribus, breve pedicellatis tomentoso-villosiusculis, antherarum apiculo brevissimo rotundato, ovario subsessili glabro, stigmate minuto wìn (R. Brown!), circa sinum Regis Georgil (A. Cunningh. I Preiss, n. 7.28!) et in coloniâa Swan River (Drumm. coll. 3 n. 260!). Frútex 2-3-pedalis. Folia 3-5 poll. longa, vix rigida, plerumque arcuata, sulco sæe obsoleto. Pedunculi in superiotibus axillis $1-3$ calyce àcato mitico fulvo multọ breviores. Stylus crassiusculus, apice attenuatus et hamato-recurvus. Cæat. fere ṕ. Fraseri. (v. s. in . herb. Brown, etc.) $\left(x_{1}^{3}\right.$

\section{Series If. Amblyantherce, - Antherca mutick, connectivo ultra loculos

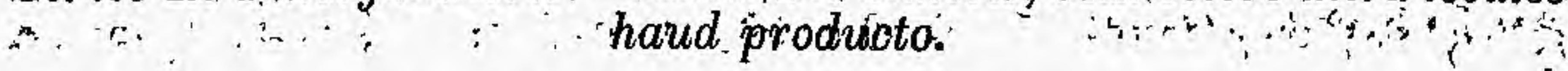

\section{\$1. Subulate.-Foliis tereti-filiformibus vel angustissime linearibus acerósisue.}

23. P. PINIFolia (R. Brown! l. c. p. 160 et 372), ramulis puberulis depse foliosis, -folî́s tereti-filifornmibus tenuibus acutis lævibus glabris subitus 1-sulcis, floralíbus nanị Aore brevioribus, racemo terminali comoso, calyce clavato obtaso pedicelloque dimidio breviore puberulo, ovario breve stipitato glabro, stylo recto, stigmate subcapitato. ‡ Girca Port-Jackson (R. Brown! A. Cunn.!). - Rudge in Linn. Trans. 10, p. 290, t. 16, f. 1, Roen. et Schult. syst. 3, p. 400 *. Ramuli graciles recti. Folia erecto-patulala" vix rigidula, $1-2$ poll. longa, $\frac{1}{4}$ lin. crassa, rectá vel recurvo-arcuata, sulco tenui vel opsóleto ; floralia 3-5 lin. longa, subulato-linearia, marginibus recurvis. Ramuli pars florigera racemiformis, $3-4$ poll. longa, comâ foliorum terminata, densse multiflora, pedicellis $1 \frac{1}{2}-2$ lin. longis cano-pubescentibus. Gal yx 4-6 lín. kongus, parce puberulus, supra basin 4-gono-globosam angustatus, sepalis lánceolatis obtusiusculis. Stylus tenuis, rectus, stigniate vix incrassato. (v. $\dot{s}_{i}$ in herb. Brown, etc.).

24. P. PALLIDA (Grah. in Jameson New-Phil. journ. 1828, p. $177 \%$ foliis patulis filiformi-línearibus canaliculatis mucronatis ciliatis adultis glabris, floralibusiconformibus, floribus approximato:congestis, pedicellis brevissimis, calyce subglahro, sepalis mucrone oblicue patulo apiculatis, ovario breve stipitato glabro, stigmate

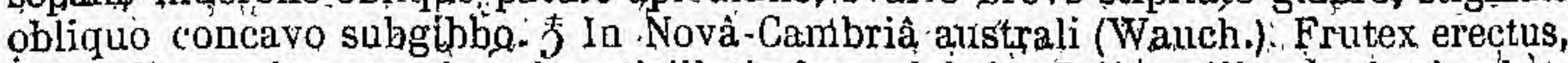
3-pedalis et ultra, ramis subverticillatis fere glabris. Folia pollicaria, basi subàttenuata adpressa subereçta, deinde patuilá, juniơra pance çiliata, floraliq tiaud abbreviata. Calyx luteus; $4 \frac{1}{2}$ lin. Inngus, supra basin contractus, apiculiș divergentibus. Anthere obțusæ. Stylus rectus vel sụpllexuosus, glaber. Ovarium 1-ovulatum. Verisimiliter a $\mathrm{P}$. tenuifóliâ laud distincta (Colebatur in h. Edinensi.).

25. 'P. TENUIF OLIA' (R: Brown. șuppl. p. 12), foliis patulis anguste linearibus aculis Emucronulatis 1 -nerviis levibus planis vel supra canaliculatis glabris, juniaribus ramulisque pubescentibus, floralibus canformibus, pedicellis solitanits calyceque parum longiore glabris, sepalis mucronato-apiculatis, ovario-subsessili glabro, stigmate truncato. J In insulâ Stradbroka (A. Guna.l) alibique, circa Moretọ Bay, oræ orien(al. (Fraser I Strange I). P. linariifolia A. Cunningham! mśs in herb. P. Strańgeana Kippist 1 mss. Rami graciles, corymbosi, pilosiusculi, laxiuseule

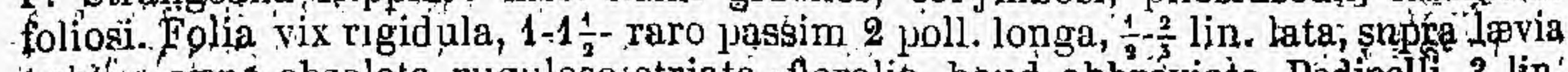
subtis sepe obsolete ruguloso-striata, floralia haud abbreviata. Pedicelli, $\mathbf{3}$ lin. lodgi, erecto patentes. Calys basi rotundatus. Ovarium subglobosum, stylo dịx pérsistente tenui recto. (v. S. in herbs. Brown., Cunn, et Soc. linn. Lond.). 


\section{PERSOONIA.}

26. P. ItNeArys (Andr. Bot. repos. t. 77), 'folits semierectis anguste linearibus "planis acutis 1 -riervlis súbmarginatis ruguloso-striatis levibus glabris, junioribus ramoliśque puberulis, floralilius abbreviatis, pedicellis solitariis cảlycecjue ipsis triplo longiore mutico lomertcllis, oyario stipitato glabro, stigmale subcapitato. J Girca Port-Jackson (k. Brown I A. Cunningh.l Gaudich.l d'Urville! Anderson, n. 107, etc.). - Vent. Malmais. t. 32, Sinis Bot. mag. t. 760, R'. Brown'l in' Linn. Trans: 10, p. 161, prodr. p. 372. P. angustifolia Kn. et Salisb. Prot. p. 99. P. pini-

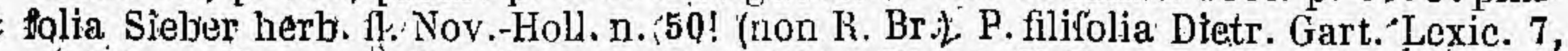
p. 100 , ex Roem. et Schult. syst. 3, p. $401^{\circ}$. P: tenuifoliæe proxime accedens, sed - jam đoris pubescentiâ facile dignoscenda, amni parte major, foliis $1 \frac{1}{2}-3$ poll, lopgis, confertioribus, semper strictis. Folia floralia nune 8-3 lin. longa vel passim 'vix abbreviata, nunc subulata nunc reliquis similia. Pedicelli 2 lin., flores 5 lin. longi. (v. s. in herls. Brown., Smitlr., DG., etc.)

' . $_{2}$ latior, foliis subduplo latioribus $\left(1 \frac{1}{2}\right.$, lin. latis.). Circa Tambo, Nov.-Holl. austral. (Ferd. Müller !): Codt. omnia ut in formấ vulgari. (v. s. comm. à cl. Sonder.)

27. P. CÁLEY (R. Brown! suppl. p. 13), ramulis minute puberulis laxiuscule foliosis, foliis patentibuts linearibus obtusis muticis enerviis levibus glabris planis vel margine recurvis, floralibus conformibus, pedicellis bravissimis calyceque tomentellis, sepalis acuminatis aristulatis, ovario breve stipitato glabrọ, stigmate obtuso. F In orâ orientali circa Jervis Bay (Caley l) et australi jrope Promonto Wilson (Baxter.). Valde accedit ad P. tenuifoliam, sed notis indicatis fieile'dignoscenda. Folia 7-12 lin. longa, $\frac{1}{2}-\frac{1}{4}$ lin. lata, mutiva. (v. s. in herb. Brown.)

28. P. N U TANs (R. Browa! in Linn. Trans. 10, p. 257, prodr. P. 373 ), ramulis laxiuscule foliosis, junioribus ninute puberulis, foliis patentibus rigidulis linearibus mucrunata-acutis planis subenerviis lævibus glabris, floralibus conformibus, pedicellis solitarias filiformiluus patentibus recurvo-arcuatis calyceque subæquilongo acumingto-acuto,glabrǐs, ovario stipitato glahro, slylo recto, stigmate truncáto. F Circa Part-Jacksoñ (R. Browa! A. Cunnn.! Gaudich.! Sieber !).-Rnem. et Schult. syst. mant. 3, p. $271^{*}$. P. linedris Sieber, herd. fl. N:-Holl., n. 46! fl. mixta, n. 472 ! (nec R. Br.). Folia plerumgue pollicaria 1.lin. lata, passim minora, vix pungentia, nervo quandoque sulifus prominulo. Pedicelli 5-6 lin. Iongi, nhtantes, tenues.' Calyx 4-5, tin. longus, sepalis brevissime acuminatis. Stylus tentis, stigmale, simplici. Drupa bilocularis. (v, s. in herb. Brown., etc.)

29. P. A Pí UL A TA (Meisn. in Hook. Jourrn. 1855, p. 73), ramis dense foliosis minute ¿puberulis, foliis patentibus vix rigidulis linearibus attehuato-acuminatis planis subenerviis lavibus glabris, floralibus conformibus, pediecllis patulis calyceque paulo longiore inutante głabris, sçpalis subulato-acuminatis, ovario stipitato glabro, stylo basi sigmoirleo-retorto, stigmate obtuso.: Circa Port-Jackson (A. Cunnipglam H. P. nutans A. Cunin.t (tron 'R, Br.). Oninia fere P. nutantis, sed fólia (pollicaria, recta: vel subarçuatat apicetn versus longius attenuata pedicelli 3 lin: longi, calyce semper breviores, et procipue sepala cuspide álbỉdê 1 lin. lóngâ - subulata (fere ut in P. acerosâ) demum patula apiculata et 'stylus in modum p. şcabrellæe basi egregie retortus! Differt prseterea a. P. tenuifoliâ ramulorum jube breviore et adpressâ, et a l'. Caleyi calyce pedicellato glabro. (v. s.in herb. DG., Mart., etc.)

30. P. a éros a (Sieber! herb. 11. Nov.-Holl., n. 59), glaberrima; foliis densis semi?"errectis lineárj-filifermibus mucrontro-acutis subpungenlibus lievibus supra eanaliculatis, floralibus conformibus, floribus in summis axillis cajitato-approximatis demum lateralibus folio brevióribus, calycis jedicello multo longioris kaminieis cuspidato-acuminatis, ovarịo stipitato glabro. J Circa Port-Jackson (Caley! A. Cunn.! Sieber, n. 59 !). - Roem. et Schult. syst. mant. 3, p. 269;, R. Brown! suppl. p. 13. Rami graciles. "Folia pollicaria, recta. Alabastra subcylindrica, quasi 4ccornia, sepalis scil. acumine sujJalato $\frac{1}{2}$ lin. longo patulo subrecurvo apiculatis. Stylus tenuis rectus, stigmate truncato. Cet. fire P. Chamepitos. (v. s.)

31. P. Guamapros (Cunningh.! in Field New South Wales, p: 329), folins confertis patentibus fitiformibus acutis, rectis lævibus glabris subtus 1-sulcis, jumioribus ramulisque puberulis, floralibros conformibus, floribus in summis axillis capitato-approximatis demum lateralihus folium sưbæquantibus subsessilibus 
parce puberulis, sepalis attentiato-acutis mutiois, ovarii villosi stipite brevi glabro, stigmate subcapitato. ₹ Circa Port-Jackson et Bathurst (Caley! A. Glinn.] Sieber, n. 53 !).-R. Brown! suppl': p. 13. P. gnidioides Sieber lin herb-fl. N.-Holl. n. 53, Roẹm. et Śchult. syst. mant. 3 , p 269! patentissima vel deflexa, 5-9 lin. longha $\frac{1}{4}$ lit. crassá, param rigidula, absolete mucronilata, supra convera, sub lente puncticulata sel tactu tamen non seabra. Cályx 5-6 lị. longus, sepalis linẹaribas sensión attentratis nec abrupte cuspidątis. Stylus rectus. (v. s. in herb. Brown., ete.)

32. P. Снам ápeuce (Lhotsky! mss: in herb.), humifusa, ramulis puberulis; foliis confertis patentibus rigidis linearibus acutis muticis subenerviis ruguloso-substriatis lævibus glabris planís vel dorso subconvexis, floralíbus conformibus vel passimabbreviatis, pedicêllis puberulis calyce glabro dimidio breviopibus, sepalís $^{2}$ sobacuminato-aeutis mulieis, ovario stijutata glahro. In aljunis cirea PortJackson (Lhotsky f) et circa Ballarat Australise-Felicis (D. Ferd. Müller F). P. suff fruticosa Ferd. Müll.! first gen. report, p. 17. Fide ipso mss. in herb. Fruticutus humilis, ramosissimus, rigidus, facie P. juniperinæ. Folia 4-7 lin. lónga, recta, *-1 lin. Jata, haud pungentia.; Flores infra apiceñ ramulorum rari, solitarii in axillis foliorum reliquis conforminum vel interdum subulatorum vix $2-3$ lin. longeram pedicellum vix superantium. Calyx 4 lin. Iongus, sepalis lanceolatis utrinque valde attemuatis. Stylus tenuis rectus, $\left(i_{-}, s_{.}\right)$

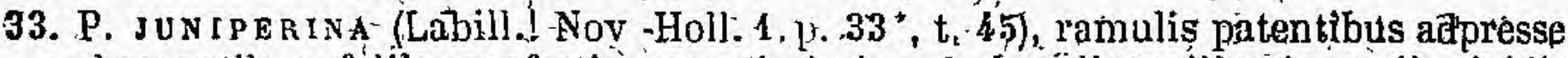
pubescentiluus, folliis confertis patentissimis subulatö-linearibùs 1-jerviis rigidis pungentibus planis lævibus' puberulis demum giabratis, floralibus, conformibus, pedicellis subsolitariis cal ycibusque pülnesrentibus, sepalis súbmucronato-atté-nuatis, ovario stipitato glabro, 'stilo recto, stigmate sub́ćajitato. 青 In insurá Diemen (Labill.! R. Br.! Gunn, n. 1238 i stuart!) et Nivæe-Holl, orà australi eirca Port-Plillfip (R. Br.! Latrobe!), Adelade (Terd. Mülter!). - R. Brown! in Linn. Trans. 10, fi. 160, jrodr. p. 3727). I. surrecta Ferd. Mill. in Árlelaide Deaulsch.

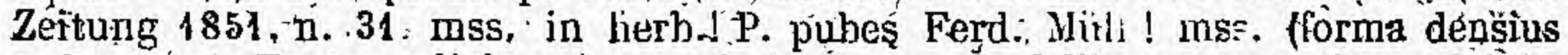
pubescens). Frutex ulicinus, ramosissimus, ramis foliisque patentibus rigidis. Folia 4 -10 lin. longa, $-\frac{2}{3}$ lin. lata, recta vel vix inctrra, supra plana vel vix concava, subtus plus minus convexa vel (pracifjte apjicen versus) carinato-triquetra. basi haud attenuata. 'Pédicelli $1-1 \frac{4}{2}$ lin. lóngĭ, jriterdum 'gemini. Calyx $4-5$ ' lin. lóngus, suhclavatus, adjuesse cano-pubescens. Stylus tonuis. Drupæ suligioliosæ, coeruleep, Hlauce, abartu-sæpe 1-lockTáress - P. surrecta, monente Ferd. Mïll. in litt., est sp. distineta, in colonixe South Australip mont. Lofty el Bugle Range crescens nẹc ultra mont. Grampians occidentem versus occurens, suffruticosa, procumbens, ramulis denique surrectis; foliis basi minus attenuatis, drupa. viridi obliqque avato-glohosâ 4-6 lin. löngâ, sț lo tenui recto 2 lin. longo infra apicem rostrafà, stipite vix $\frac{1}{3}$ lin. longo. Specim. vero Mulleriana herh. nostri nullo charactere essentiali a P. jiụiperinả distiéguendal. (v. s. in herb. DG., R.'Brown, etc.)

3. ulicina, ramulis glabrescentibus, foliris semierectis subrollicaribus glabris subtus, bisulcis. - Ja Tasmannjà (Gunn, n. 537 ex- jarte, 869 !)-

y. brevifalia, fuliis patentibus sulusemiuollicaribus (3-5 lin. longis) ramulisque densius cano-pubéscentibu's.-In Tasmannià (Gunn, n. 5371 ex jarte.)

\section{\$2. Asperifolice.-Foliis circiter pollicaribus, linearibus lanceolatisué,} plus minus elevato-punctat is scabris masgineque recurvis, floralibus conjormibus.

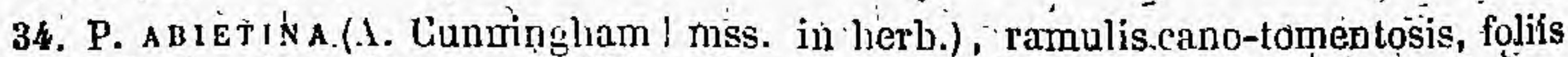
eonlertis. patentibus tereti-filiformibus acutiusculis ineurvis punctàto-scabrius-

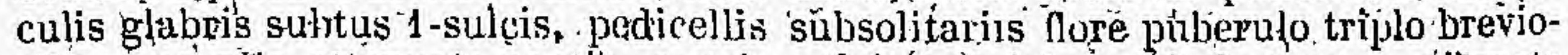
ribus, sejalis attenuato-acntis, ovario stijitáto glabro, stylo necto, stigmate obtuso. J In montium jugo Harvey's Range, distr. Wellington, Nóv:-Holl: orjentalis (A. Cunn I). P. fastigiata $A$. Cunn.l mss. in herli (non R Br.). Folia 1-1-1 poll. longa; $\frac{1}{4}- \pm$ lin. crassa, primu erecta puberula, deinde patentia glabra, parum rigidulär mutica, semper. plus minus arreuato-incurva tactugue scabra. Calyx:3 lin. longus, cylindraceo-conicus: surdide puberulus. Glandnla hypogyna obovatæ obtusez. P. curvifoliæe accedens, sed distincta folijs nec planis nec mucronàtis, subtus anguste 1 -sulcis nec cangliculatis. A.P. Pastigratà R. Rr. jant ovario glabro digrioscenda. (v. s. in herb. A. Cunningh.I) 
35.? P. FAStigiata (R. Brown suppl. p. 13), foliis lineari-filiformibus arcuatoincurvis muticis pubescentibus subtus canaliculatis, pedicellis confertis subumbellatis dimidium calycis pariter pubescentis sujerantibus, ovario styloque villoso. $J$ Circa Port-Jackson. (Fraser.)

36? GUR VIF OLIA(R. Brown suppl.p. 13), ramulis laxiuscule foliosis puberulis, foliis patulis, linearibus arcuato-incurvis submucronato-acutis basi attenuatis supra convexis enerviis dense puncticulato-scabris subtus canaliculatis, marginibus revolutis, floribus..., fructibus stylisque glabris. F Circa Port-Jackson, ad montes St-Georges' Hange, Lachlan River (A. Gunniugham!). Folia 6-10 raro 12 lin. longa, $\stackrel{2}{-}$ lin. lata, haud pungentia, marginibus arcle revolutis, subtus vere canaliculata nec mere 1-sulca, juniora puberula. Flores fructusque non vidimus. Foliis ad P. spathulatam accedit. (v.s. in herb. Brown et Cunn.)

37. P. н I Rs u a (Pers. syn. 1, p. 118), foliis patulis linearibus oblongisque muticis punctato-scabris margine recurvis ramulisque pubescentibus demum glabris, floribue in summis axillis subcapitato-approximatis demum lateralibus folia superuntibus pedicello multo longioribus hirsutis, sepalis muticis, ovario stipjitato villoso. 5 Circa Port-Jackson (R. Brown !).-R. Brown! in Linn. Trans. 10, p. 161, prodr. p. 372, suppl. p. 13, Rudge in Linn. Trans. 10, p. 291, t. 16, f. 2, Roem. et Schult. syst. 3, p. $400^{\star}$. Rami graciles. Folia 5-10 lin. longa, tarde glabrescentia, tactu scabriuscula, punctis elevatis plus minus confertis. Pedicelli.1 lin., calyces 5 lin. longi, pube laxiuscula dense rufo-villosi, rarius demum glabrescentes, tubo cylindraceo apice attenuato basi haud tumente. Ovarium brevissime stipitatum, sericeum. (v. s. in herb. Brown., Smith., etc.)

a. linearis (Endl. gen. suppl. 4, 2, p. 81), foliis linearibus (3-8 lin. longis,

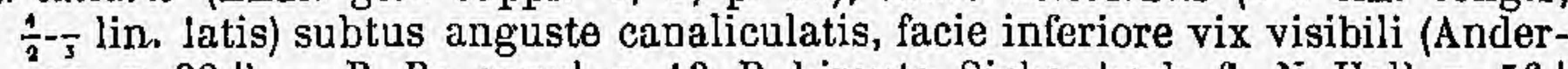
son, n. 98 l) - - R. Br. suppl. p. 13. P. hirsuta Sieber herb. fl. N.-Holl. n. 56 ! Bot. Cab. t. 327. P. arida Lhotsky! in herb. Shuttl. (v. s.)

$\beta$. subovalis (Endl. 1. $\mathrm{c}$ ), foliis oblongis subovalibus lanceolatisve ( $4-7$ lin. longis, 1-1 $\frac{1}{2}$ lin. latis) facie inferiore inter margines anguste recurvos conspicuâ, interdum linearibus subplanis, plerumque acutiusculis. R. Brown suppl. p.13. P. arida Sieber l. c., n. 55 ! Roem. et Srivult. syst. mant. 3, p. 270.(v. s.) $\gamma$. spathulata, foliis subspathulato-linearibus obtusis (5-7 lin. longis, $1 \frac{1}{2}-2 \frac{1}{2}$ lin. latis), extra medium latioribus (Sieber, 1. c., n. 529 !). P. mollis A. Gunu.! nou R. Br. (v. s. in herb. DC.)

38? P. FLEXIFOLIA (R. Brown in Linn. Trans. 10, p. 162, prodr. p. 372), foliis confertis lanceolato-linearibus mucronatis basi tortis margine scabris, calyce glabro. $₹$ ln terrâ Leeuwin (R. Brown.).--Lodd. Bot. Cab. t. 922. Folia excepto margine lævia, punctis crystallinis micantia. Habitus (fide specim. cult. in herb. Lindl.) P. nutantis, ramis tenuibus, foliisque laxe patentibus. Folia $1-1 \frac{3}{2}$ poll. longa, $1-1 \div$ lin. lata, recta, acuminata. Pedicelli 5-6 lin. longi, capillares, patentes, pistillum glabrum aquantes. Flores ex ic. flavi. Antheræ ignota. (v. s. fr. sine fl.)

39? P. s CABRA (R. Brown l. c. p. 162 et 373), foliis lineari-lanceolatis mucronatis utrinque scabris punctis crystallinis aliisque minutissimis opacis conspersis,

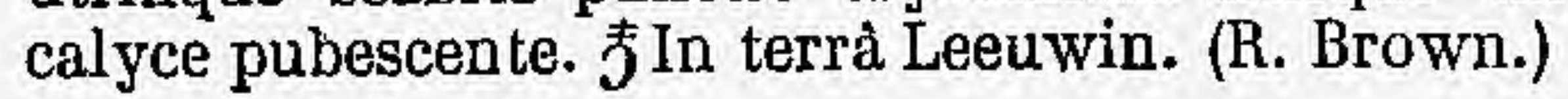

40. P. RIGIDA (R. Brown I suppl. p. 14), ramulis laxiuscule foliosis dense patentipilosiusculis, foliis patulis rigidis obovato-lanceolatis vel spathulato-linearibus mucronulatis subenerviis utrinque punctato-scabris, junioribus pubescentibus, pedicellis brevissimis floribusque dense brevivillosis, sepalis brevissime subulato-acuminatis, pistillo glaberrimo. 5 In montibus circa Port-Jackson (Caley 1 A. Cunn.!) et Australiæe Felicis (Ferd. Müller!). Formæ sequentes, etsi adspectu satis discrepantes, specifice tamen separari nequeunt. Folia etiam in var. $\beta$ passim plaua occurrunt. Pedicelli vix 1 lin., flores $4-5$ lin. longi. pube sat densâ rífâ subsericei. (v. s. in herb. Brown., etc.)

a. planifolia, foliis spathulato-lanceolatis obovatisve rectis planis vel margine vix recurvis ex apice sæpius rotundato subito mucronato-acuminatis, junioribus utrinque molliter adpresso-pilosis.-P. spathulata Sieber herb. N.-Holl., n. 51 I ex parte, Roem. et Schuit. syst. mant. 3, p. $271^{\circ}$. P. rigida Ferd. Müll.! Folia 10-14 lin. longa, 3-8 lin. Jata. (v. s. in herb. DC., elc.) 
ß. revoluta, foliis anguste lauceolatis spathulatisve attenuato-acutis margine revoluto subtus canalicrliatis vel 1 -sulcis plerumque incurvis, junioribus patulö-pubescentibus (Sieber, 1.511 in herb. Shuttl.). p. rigida A. Cunn.! in hérb. DC. P. spathulata A. Gunn.! in herb: propr. Folia 10-16 lin. longa, 2-3 lin. lata. (v. s.)

41? s pa t нul t a (R. Brown in linn. Trans. 10, p. 162, prodr. p. 373), foliis lanceolato-spathulatis mucronatis concayiusculis utrinque scaberrimis punctis crystallinis. In terrâ Leeuwin (R. Brown.).- Bot Cah. t. 1199 ? Rami graciles. Folia cìrc, pollicaria, 3-5 lin. lata, utrinque attenuata, acuta, scabriuscula. Pedicelli axillares, solitarii 2-3 lin, Jongi. Calyx luteus, conieo-cylindraceus, $5 \cdot 6$ lin. longus, 4-múcronatus, sepalis enim cornuto-acuminatis demum revolutis. (ex ic. cit.)

\section{§ 3. Parvifolioe. - Foliis patentibus vix semipollicaribus ovalibus linea- ribusve planis vel margine recurvis scabriusculis vel lcevibus, flora- liblis conformibus, pedicellis axillaribus solitariis.}

42. P. oxycoccoides (Sieber ! herb. fl. Nov.-Holl., n. 49), ramís gracillimis laxis, junioribus adpresse pułerulis, foliis oblongö-ovalibus lanceolatisve acatinsculis mutfcis planis vel margine subrecurvis subenèrvìis læevibus glabríś, pẹticellis glabris folio subdimìđio brevioribus demum recurvis, floribus erectî́....., drupis nutantíbus glabris: 'f Circa Port-Jackson (Siebêr, n. 49!)- - Roern. ef schult. syst. mant. vol. $3 ;$ p. $270^{*}$, R. Browh! suppl. p. 15. Diffuso-ramosissima, ràmis saepe elongatis flagelliformibus secunde ramulosìs, pube mínutâ. Folìa rìgidula, 3-5 lín. longa, 1-1 $\frac{1}{2}$ lin. lata, supra subconvexa, niervó plerumque penitus inconspicuo. Peaicelli 2 bin. longi. Flores rari, nobis ignoti, an antheræ mutice? Drupa ovalis utrinque acuta, abortu 1-locularis. (v. s. in herb. Brown, etc.)

43. P. THYM IFOLIA (A. Cunningh.! mss. in herb.), ramis gracilibus laxis, junioribus adpresse puberulis, foliis ovato-vel lanceolato-oblongis acutiușculis muticis enerviîs margine recurvis supra punctato-scabriusculis pilosiusculis dernum lavibus glabris, pedícellis folium subæquantibus erectís calyceque parum longiore mutico pistilloque glabris. $\hbar$ In Novâ-Holl. orientalî̀australi circa PortJackson et in distr. Argyle (A. Cunn.!). - R. Brown! suppl. p. 15. Forsañ præcedentis var., recedens folîis junioribus scabriusculis et plèrumque mínithoribus

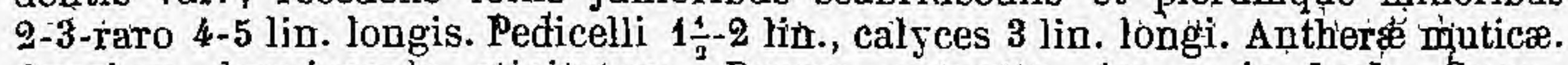
Ovarium longiuscule stipitatum. Drupæ nutantès. (v. s. in herb. Cunn., Brown., DC.)

44. P. MICR OPHXLLA (R. Brown! suppl. p. 15), ramulis gracilibus laxis folìisque junioribus minute patenti-pilosiusculis, foliis ovatis obovatis suborbioularibusve obtusis vel subacutis muticis enerviis margine recurvis supra convexis punctatoscabriusculis, pedicellis folinm subæquantibus patulis demum trutantibus ealyceque mutico pistillocue glabris. 5 Hab. cum prieced. (A. Gunn.!) eujus forsan mera var., vix distincta nisi foliis latioribus, $2-2 \frac{1}{2}$ lin. latis, $2 \frac{1}{2}-3$ lin. Iongis. Antheræ muticæ. Drupæ pendulæ, 1 sperma. (v. s. in herb. Cunn. et Brown.)

\section{\$4. Planifolioe. - Foliis ellipticis lanceolatisve planis vel margine leviter recurvis loevibus vel wix scabriusculis.}

- Axillares. - Pedicellis axillaribus 1-floris solitariis (raro geminis vel 2-pluriforis, cfr. $\boldsymbol{P}$. elliptica, marginata, cornilolia, Cunninghamii). Folia floralia conformia (rarc nana vel abortiva, cfr. P. ellipta, Laureold, marginata, connifolia, Guniiii.)

45. P. virgat a (R. Brown! in Linn. Trans. 10, p. 161, prodr.p 372), aŕborescens, cortice lkevi, ramulis pi]nsiusculis, foliis patentibus lanceolatis'linearibusve acutis vel mucronulatis planis 1 -nerviis lavibus glabris, calyce pedicello vix longiorc glabro, sepalis brevissime cuspidato-acuminatìs, pistiłlo glabro. 5 In Nov.-Holl. orientali tropicâ prope Sandy Cape ad Hervey-Harboúr (R. Browà H). Folia pârum riguda, verticalia, 10-15 lin. longa, nervo medio immerso vel vix conspicuo. Pedicelli patuli, 3 lin. longi, crassiusculi, recti. Antheræ muticæ. (v. s. $\alpha$ et $\beta$ comm. a cel. auctore.)

๙. linearis, foliis linearibus (1 lin. latis) acutis muticis subrugosis. 
$\beta$. lanceolata, foliis lanceolatis (2-2 $\frac{1}{2}$ lin. latis) basi attenuatis ex apice obtusiuscello mucronulatis.

46. P. LUCIDA (R. Brown 1. c.p: 161 et 372), arborescens, cortice scariòoso-làiuelloso, foliis lanceoldto-linearibus élongatis glabris, pedicellis erectis calycibusque pubescentibus, ovárii stipite inarticulato. 5 Girca Port-Jackson (Ferd. Bauer.). An antheræ mutica?

47. P. ANGUtat A (R. Brown I suppl. p. 14), ramulis angulatis glabris, foliis confertis erecto-patulis rigidis îneari-lanceolatis äcutis müticis lavibus glabris planis vel supra subconcavis häsi atteriuatis, pedicellis brevibus glabris..... J In montibus coeruleis prope Port-Jackson (A. Cunningh., i.. 39 1). Ramuli apice acute

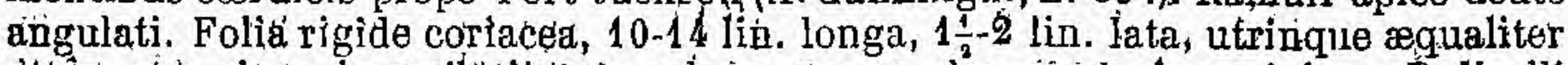
àttênuata, sicca irregtiläritèr rugulosa, nërvo plerumique inconspicuo. Pedicelli 1 lin. longi, crassiusculi. Cæet. ignota. (v. s. in herb. Brown. et Cunn.)

48. P. MoLtis (R. Brown! in Uint. Träns. 10, p. 161 ; prodr. p. 372), follis patulis vix rigidulis lineari-lanceolatis utrìnque longe attenuatis actitis muticis lævibus planis; supria obsolete venosis mox glâbris nitidis, subtus cum ramulis pedicellis oalyoibusque pube brevi dénsá pàtente holli fulvơ-viliosis, sepalis acutis mutiçis,

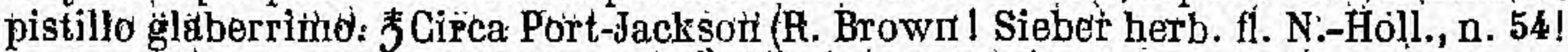

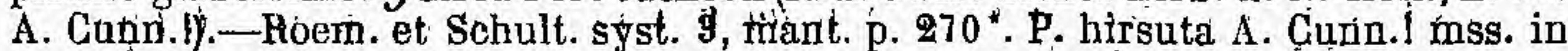
herb. Bd. (ton Pers.). P. myrsinites A. Cahn.? miss. in herb. propr. (specim. insufficiøtit.). Rami graeiles, subcorymhoso-ramosi, fástigiati, laxiuscule foliósi. Folia siegpitus oppositá, vix coriäcea, $1 \frac{1}{2}-2 \frac{1}{2}$ poll. longa, medio $2-4$ lin, latä, junilora supra pilosiuscưtà. Pedìcelli 1 lini. lontgi. Alabastrd cylindracea, acuta, 5-6 lin. longa, sepalis làneeolatîs aritherisque muticis demuni revolutìs. Ovarium ex Br. 2-ovulatum. Drupa globosà. (v. s. ît herb. Brown., Cưnil., etc.)

49. P. L EDIF̃oLiA (Á. Cunningham! mss, in herb.); ramulis breve patulo-puberulis rufis, foliis semipatentibus vix rigidulis lineari-lanceolatis obtusis eveniis minute punetato-scabiriusculis subtus discoloribus, junioribus parce adpresso-pilosiusculis, pedicellis calycthusque multo longioribus erectis pubescentibus, sepalis

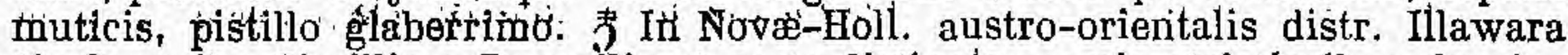
(A. Cunn.!).-Simillima P. molli, at certe distincta: ramis strictioribus densius foliosis, pubescentiâ breviore; fơlìs minus patentibus raro altra $1 \frac{1}{4}$ poll. Iongis apicem versus minus angustatis serriper obtusissinilis muticisque tidargine recurvis supra mimute elevato-punctatis subtids parce pilosiusculis mox glabris. Accedit quoque ad P. revolutam, sed jant foliis longioribus angustioribus, etc. dignoscenda. Calyx 4-5 lin. longus, obtusiusculus. Antheræ muticæ. Drúpä ovoidea, putamine 1-2-sperma crassa osseo poroso, poris punctiformibus numerosis materiầ resiinosấ sanguíneâ repletis.

50. P. Revoluta (Sieber! herb. fl. Nov.-Holl. n. 48), ramis gracilibus laxiuscule foliosis glabris, folits patulis rigidulis obovato-oblotigis rotunlato-obtusis vel brevissime apiculatis bàsi àttenuatis obsolete verlosis læovibủs planis vel nuargine leviter reeurvis supra glabris subtus adpresse pareieque puberulis subdiscoloribus mox glabris, pedicellis ramulisque junioribus sericeis, floribus.., pistillo glabro. J Circa Port-Jackson (Sieber, ñ. 48 ! A. Cunn.).- Roem. et Schult. syst. mani. 3, p. 272*, R. Brown suppl. p. 14. P. daphnoides A. Cunn., fide R. Br. I. c., an ex errore? (cfr. sp. sequent.). Folia 8-14 lin. longd, 3-5 lin. lata, sæipius obtusissitina, nunquam vere muoronata sed subito obtuse acuminulata, subtus pallidiora (et ex R. Br. subsericea). Flores nobis ignoti. (v. s. in herb. Brown.j etc.)

51. P. Daphordes (A. Gún.! mss. in herb.), caule prostrata, ramulis gracilibus laxe foliosis pubescentibus mox glabris, follis patulis rigtaulis avali-ablongis acuminulato-mucronatis basi attenuatis obsulete venosis lèvibư glabris planis vel margine subrecurvis, floribus... 5 In Novâ-Holl. orient: ad mổitën Bàngar prope Hunter's River, distr. Hunter (A. Gunningh.l): - R. Brownl suppl. p. 15. Folia 10-20 lin. longa, 4-6 lin. lata, parum rigidula, apiculó innocué, vètis pinnatis paueis tenuibus utrinque plus minus conspieuis. Flores non viaimìis. Præcedenti similis; sed facile dignoscenda foliis utrinque subæệualiter attentiatis nec apice latioribus nec abtusis, sưbtus comeoloribus. (v. s. in herb. Brown, et Cunn.)

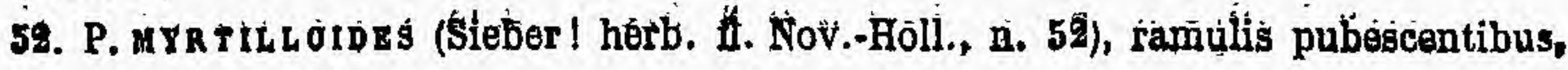


foliis confertis patulis rigidulis lanceolatis vel oblongo-lanceolatis attenuatoacutis submuticis obsolete 1 -nerviis eveniis planis glabriusculis, pedicellis calyceque longiore nutante puberulis, sepalis apice mucronulo patente cuspidatis, pistillo glabro. J In montibus cceruleis circa Port-Jackson (Sieber, n. 52 ! A. Cunningh.!). - Roem. et Schult. syst. mant. 3, p. 272*, R. Brown! suppl. p. 14. P. oleifolia A. Cunn.! mss. in herb. Species insignis præsertim calyce (more P. acerosæ) apice mucronulis 4 subulatis patentibus corniculato, 4-5 lin. longo, supra basin rotundatam leviter constricto. Pedicelli tenues calyce nunc dimidio nunc vix breviores. Drupa globosa, 1-2-locularis. Folia 10-18 lin. longa, 3-6 lin. lata, basi attenuata, sub lente utrinque elevato-puncticulata puberula, tactu tamen vix scabriuscula, mox glabra, floralia interdum multo minora et ex parte linearia florem vel immo pedicellum haud superantia. (v. s. in herb. Brown., A. Cunn., etc.)

53. P. GunNII (Hook. fil.! in Hook. Lond. Journ. 6, p. $283^{*}$ ), foliis patulis rigidis spathulatis linearibusve planis subenerviis eveniis lævibus junioribus ramulisque tomentoso-puberulis, pedicellis crassiusculis calyceque multo longiore clavato mutico tomentellis, sepalis acuminato-acutis margine undulatocorrugatis, pistillo glabro. ちIn Tasmanniâ. Frutex ut videtur humilis multiramosus, cortice lamelloso-scarioso, ramulis apice angulatis, partium juniorum omnium tomento minuto satis denso, in var. $\alpha$ subsericeo flavescente fugaci, in $\beta$ opaco sordide albido diutius persistente. Folia crassiuscula, atro-viridia, circ. pollicaria, obtusa vel acutiuscula, basi atteruata, sicca longitudinaliter vel sæpius transverse rugulosa, in $\alpha$ mox glabra nitida, in $\beta$ opaca. Pedicelli $1-1 \frac{1}{5}$ lin. longi, nunc folio genuino, nunc bracteà ipsis dimidio breviore obtusâ adpressâ fultí. Calyx 5-6 lin. longus, sepalis demum reflexis antherisque muticis. Drupa bilocularis. Varietates seq., etsi facie satis discrepantes, tamen specifice non esse separandas, cum cl. Hookero consentio.

a. dilatata, foliis obovato-spathulatis cuneatis (8-12 lin. longis, 3-4 lin. latis) apice rotundato vel retuso muticis vel brevissime apiculatis, calyce glabrescente, sepalorum laminâ ovali-lanceolatâ. May-day Plains. (Gunn, n. 870 ! v. s. comm. a cl. Lindl.)

B. alpina (Hook. fil. l. c.), foliis spathulato-linearibus ( $1-1 \frac{1}{2}$ poll. longis, $1 \frac{1}{2}-2 \frac{1}{9}$ lin. latis) obtusissimis muticis vel acutiuseulis vel subacuminatis, calyce canotomentoso, laminis anguste lanceolatis. --Ad lacum St-Clair (Gunn, n. 1237l) et Macquarie Harbour (Milligan, n. 738 l). (v. s. in herb. Lindl. et Soc. linn. Lond.)

54. P. LANGEOLATA (Andr. Bot. repos. t. 74), ramis virgatis ramulisque gracilibus erectis laxiuscule foliosis cum foliis junioribus pedicellis floribusque cano-tomentellis, foliis patulis subcoriaceis lanceolatis rectis utrinque attenuatis planisobsolete 1-nerviis venosisque lævibus glabris, sepalis pedicello multo longioribus acuminato-acutis muticis, pistillo glaberrimo, ovarii stipite inarticulato. $J$ Circa PortJackson et in Nov.-Holl. orient.-austr. interiore (R. Brown! Sieber! Gaudichaud! D'Urville! Andrews ! etc.). - R. Brown! in Linn. Trans. 10, p. 162 , prodr. p. 373, Roem. et Schult. syst. mant. 3, p. $271^{\star}$. Folia modice rigida, 1-3 poll. longa, floralia conformia. Pedicelli solitarii, flore 4-5-plo breviores. Calyx ex -Andr. ic. flavus. Antheræ muticæ. Drupa abortu 1-locularis.

$\alpha$. angustifolia, foliis lanceolatis vel lineari-lanceolatis (2-5 lin. latis) sæpissime acuminatis mucronatisve. P. lanceolata Andr. t. 74$\rfloor$ Bot. cab. t. 25 (Sieber herb. fl. N.-Holl. n. 57! Andrews! Mitchell ! exped. 18:6). P. ligustrina Knight et Salisb. Prot. p. 100. Linkia levis Cav. fide Thibaud! in herb. DC. Cfr. infra, n. 67, P. salicina. (v. s. in herb. Brown., DC., ete.)

B. latifolia (Endl. gen. suppl. 4, 2, p. 82), foliis oblongo-lanceolatis (7-9 lin. latis.) P. latifolia Andr. Bot. repos. t. 280 ! (herb. Smith!), R. Brown l. c., Lodd. Bot. cab. t. 1509 ? (forsan potius ad P. ellipticam referenda, recedens foliis ex ic. $1 \frac{1}{a}-2$ poll. latis nervosis, tamen non marginatis pedicellis basi folio destitutis racemum apice foliosum formantibus). P. lanceolata Lhotsky! in herb. Shuttl., forma insignis foliis inferioribus spathulato-oblongis ex apice rotundato abrupte acuminulatis sphacelato-mucronulatis, superioribus lanceolatis acutis utrinque æqualiter attenuatis. Specimina Sieberiana sub n. 57 ex parte huic var. accedunt. (v.s.) 
$\gamma$. glaucescens (Endl. l. c.), foliis glaucis? lineari-lanceolatis subito acuminatis

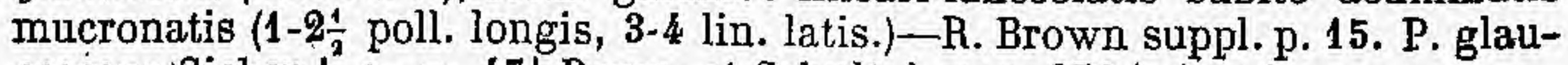
cescens Sieber 1. c., n. 47 ! Roem. et Schult. J. c. p. $271^{*}$. (v. s.)

55. P. OBLONGATA (A. Cunningh.! mss. in herb.), foliis semipatulis lanceolatis mucronato-acutis planis 1-nerviị subeveniis levibus ramisque glabris, pedicellis filiformibus demum nutantibus calyceque vix longiore glabris, sepalis acutis, ovario stylique basi pubescentibus mox glabratis, stipite glabro haud articulato. 5 Circa Port-Jackson et in Nov.-Holl. orient. inleriore, distr. Hunter (A. Cunn.!). -R. Brown! suppl. p. 14. P. planifolia A. Cunn.! mss. in herb. Habitus P. lanceolatæ, șed rami graciliores, haud stricti, glaberrimi, novelli tantum apice puberuli. Folia parum rigidula, 1-2 poll. longa, 3-6 lin. lata, apicem versus sensim attenuata breviter sphacelato-nucronata, infra medium sepius latiora, nitida. Pedicelli 5-6 lin. longi, tenues, apice dilatati, primo erecti, deinde recurvo-arcuati, Calyx acutiusculus, supra basin rotundatam angustatus, sepalis demum revolutis antherisque muticis. Ovarium stipite suo glabro vix longius, cnm parte inferiore styjli subulati recti cano-puberulum. Glandulæ hypogynæ brevi-filiformes, conspicuæ. (v. s. in herb. Brown. et Cunn.)

56 ? P. ELLIPTICA (R. Brown in Linn. Trans. 10, p. 164, prodr. p. 373), foliis ellipticis venosis, racemis lateralibus, calyce glabro, ovarii stipite articulato. $\mathbf{5}$ In terrâ Leeuwin. - P. elliptica A. Cunn.! in herb. a diagnosi auctoris discrepat floribus axillaribus solitariis vel rarissime geminis nec unquam racemosis, ideoque ad P. Laureolam, cui creteris notis exactissime convenit, referenda.

57. P. LA UR OLA (Lindl.! Swan River, p. 35, n. 174), glabra, foliis palulis subsessilibus ellipticis oblongisve utrinque attenuatis planis venosis, floralibus- conformibus vel passim subabortivis, pedicellis calyce mutico brevioribus, ovarii stipite brevi articulato. 5 In Novæ-Holl. austro-occid. coloniâ Swan River. (Drumm. coll. 1 et 4, n. 277 !), distr. Plantagenet et Sussex (A. Cunn.! Preiss, n. 726! 727!). - Hook. ic. t. 426, Meisn. in pl Preiss. 1, p. 532*. P. elliptica A. Cunn.! mss. in lierb., an etiam R. Brown ?, qure forsan ejusdem speciei forma floribus foliorum floralium abortu racemosis recedens. Folia parum rigida, 2-3 poll. longa, 10-15 lin. lata; floralia (saltem in specim. Cunningh.) nonnunquam nana, florem vix æquantia, unde flores simili modo ac in P. pinifolia, salicina, longifolia, etc., quasi racemosi evadunt. Calyx 4-5 lin. longus, sepalis inferne intus minute ciliolatis. Ovarii stipes crassiusculus vix 1 lin. longus, basi persistente glandulas lyypogynas obtusas æequante. (v. s. in herb. Lindl., etc.)

58. P. MARGINAt A (A. Cunningh.! mss. in herb.), foliis patulis ovalibus obovatisque basi attenuatis mucronato-apiculatis planis venosis submarginatis puncticulato-scabriusculis nitidis, junioribus ramulisque cano-pubescentibus, floralibus conformibus vel abortivis, pedicellis axillaribus 1-2-floris calyce parce puberulo apice 4-corni quadruplo brevioribus, sepalis breve subulato-acuminatis, ovarii villosi stipite basi articulato styloque glabro. $\mathrm{F}$ In Nov.-Holl. orientali circa PortJackson, Cugeegang, Erin Head, Bahhurst (A. Cunn.!).-R. Brown I suppl. p. 16. Habitus et dimensiones P. Laureolæ. Folia rigide coriacea, leviter scabriuscula, demum lævigata, margine obsolete nerviformi. Pedicelli 1 lin. longi, ex $\mathrm{Br}$. 1-2-flori, in nostris exempl. omnes 1-flori, in stirpe Andersonianâ (cxeteroquin haud diversâ) srepius folio nano angusto ipsos vix æquante fulti racemos laterales breves apice foliosos formantes. Calyx 5 lin. longus, mox fere glaber. Antheræ muticæ, dorso serice:e.

a. ovalifolia, foliis ovalibus oblongisve utrinque attenuatis. P. marginata A. Cunn.! (Anderson, n. 31 !). Folia $1-1 \frac{1}{2}$ poll. longa, 3-10 lin. lata. (v. s. in herb. Brown., DC., Shuttl., etc.)

$\beta$. obcordata, foliis obovatis, sæpe vix longioribus quam latis, ex apice rotundato vel subtruncato vel retuso vel emarginato breviter sphacelato-apiculatis. P. obcordata A. Cunn.! mss. in herb. Folia 6-14 lin. longa, 5-16 lin. lata. (v. s. in herb. Cunn.)

59. P. CORNIF OLIA (A. Cunn.! mss. in herb.), ramis virgatis ramulisque cum foliis junioribus pedicellis calycibusque tomentosis, folis patulis ovalibus oblongisque mucronatis utrinque attenuatis planis 1-nerviis subeveniis levibus mox glabris, tloralibus conformibus vel sepe caducis abortivisve, pedicellis brevissimis 1-2-flo- 
riș, sepalis breve cuspidato-acuminatis, ovarịi sericeo-villosi stipite basi articulato styloque glabro. 5 In Novà-Holl. orient. interiore et circa Moreton Bay (Fraser! Oxley et Cunningh.!).-R. Brown suppl. p. 16. P. tinifolia A. Cunn.! mass. in herb. Arbor 15-20 pedalis. Exceptâ pubescentiâ omnia fere P. Laureolæ, attamen folía plerumque minora, raro ultra $1 \frac{4}{2}$ poll. longa et acutiora. Antheræ muticæ. (v. s. in herb. Brown., Cunn., otc.)

60. P. Cunningham I (R. Brown ! suppl. p. 15), ramis gracilibus pubescentibus, foliis confertis patulis rigidiş subsessilibus late ovalibus ovatisque subacuminatoacutis inucronatis planis 1 -nerviis subeveniis nitidis lævilus glabris margine scabriusculis, floralibus conformibus, pedicellis subsolitariis filiformibus nutantibus calycem glabrum apice longiuscule 4-cornem subæquantibus, sepalis acumine setaceo recurva, cuspidalis, pistillo glabro. 5 Circa Port-Jackson et flum. Cugeegang (A. Cunn.!). Ramuli elongati, pube brevi densâ patulấ albidâ díu persistente. Cæt. omnia glaberrima. Folia 5-9 lin.' longa, 3-6 lin. lata, pleraque ovata. Calyx 4-5 lin. longus, cylindraceus, apicis cornubus subulatis 1 lin. longis - arcuato-patentibus. Antheræe muticæ. Ovarii stipes brevis (ex Br. elongatus), imẩ luasi articulatus, tarde rumpens. (v. s. in herb. Brown., Cuñ., etc.)

61. P. SER IGEA (A. Cunningh.I mss. in herb.), foliis obovatis vel cuneato-lanceolatis mucronulatis planis venosis lævibus ramulisque sericeís demum glabrescentibus, pedicellis pistillisque villosis. $\supset$ In montibus circa Port-Jackşan (Á. Cunn.). - R. Brown suppl. p. 14.

$\beta$ ? velutina, foliis obovatis basi attenuatis ex apice rotundato-obtuso acuminulatis muticisve obsolete penniveniis, venis 2 margini approximatis, utrinque cum ramulís pube densâ adpressâ (albidâ vel fulvâ) sericeo-splendentibus, floralibus conformibus, pedicellis solitariis demum nutautibus. 春 In NovaHoll, orient.-interiore circa Liverpool Plains (A. Cunn.I). P. velutina A. Gunningh.l mss. in herb. Meisn. in pl. Preiss. 1, p. 534*, in notâ. Ab inventore propria species putata, sed speciminibus suppetentibus defloratis a diagnosi P. sericese vix discrepat. Folia 8-18 lin. longa, 5-9 lin. lata, semipatentia, rigidula. Pedicelli 4 lin. longi. Ovarium breve stipitatum cum styli basi persistente breve villosum. (v. s. in herb. Cunn., DG., etc.)

" Racemosce. - Racemis axillaribus paucifloris aut terminalibus comosis, foliis floralibus nanis vel obortivis, rarius conformibus (P. media, longifolia, prostrata, attenuata).

62.? P. Prostrata (R. Brown in Linn. Trans. 10, p. 163, prodr. p. 373), caulo procumbente, foliis ovalibus obtusis margine pubescentibus, pedunculis axillaribus 1-paucifloris. $\mathrm{F}$ In Novâ-Joll. orient. subtropicâ, circa Sandy Cạpe (R. Browñ). Fructifera tantum lecta, floribus jgnotis.

63. P. A R TICULA A A (R. Brown! 1. c. p. 164 et 374), foliis patulis elongato-vel lineari-lanceolatis optusis utrinque attenuatis planis tenuiter venosis jevibus glabris, floralibus caducis? vel ahortivis bracteiformibus, racemis lateralibus pedun culisve 1-floris, calyce eum pedicello duplo breviore ramulisque tomentellis, sepalis acuminatis, pistilli glabri stipite supra basin articulato. JI tor terâ Leeuwin et circa sinum Regis Georgii (R. Brown! A. Cunn.!). P. glauca Smith? in fierb. Willd., fide Spreng syst. 1, j. 473. Ramuli debiles, laxe foliosi. Folia 2-3 poll. longa, 3-4 lin. lata, muțica, subcoriacea. Pedicelli 2-24 lin. longi. Calyx subclavatus, obtusiuscule breviterque acuminatus, 5 lin. longus. Antheræe muticæ. Stipitis ovarii articulus inferior glandulas liypogynas obtusas aquans. (v. s. in herb. Brown et Cunn.)

64. P. А т т Е U А А (R. Brown suppl. p. 16), foliis lineari-lanceolatis elongatis planis utrinque attenuatis eveniis lovibus glaberrimis, racemis axillaribus paucifloris, pedunculis tomentosis, piștillo glabro. 5 In orâ orient., circa Moreton Bay (Fraser).

65. P. M EDIA (R. Brown suppl. p. 16), folits latiuscule lanceolatis apuilateris utrinque attenuatis venosis, pedunculis axillaribus $2-3$ racemosis solitariisque. $\frac{F}{5}$ In montibus, circa Port-Jackson. (Fraser.)

66. P. M I T G H E L I I (Meisn. in Hook. Journ. 1855, p. 73), foliis patentibus lanceolatis acutis basi attenuatis 1 -nerviis obsolete venosis scabriusculis ramulisque tumentoso-puberulis, foralibus abbreviatis flores vix superantibus vel abortivis, 
pedicellis cum calyce dimidio longiore sericeo-tomentosis racemos axillares terminalesque breves apice foliosos formantibus, sepalis acutis muticis, ovario cum styli basi villoso. 3 In Novầ-Holl. orient.-australi interiore (Mitcheli l exped. 1836).

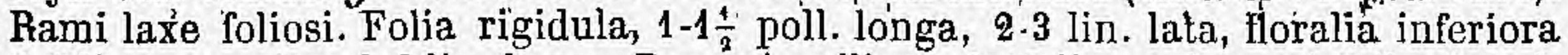
1-2 lin., superiora $4-6$ lin. longa. Racemi axillares 6-12 lin., calyces 4-5 lin. longi, fulvó-sericei. Anther: nuticæ. (v. s. comm. a cl. Lindl.)

67. P. sALICINA (Pers. syn. 1, p. 118), arborescens, cortice scarioso-lamelloso, foliis patulis aversis lanceolato-oblongis elongatis utrinque attenuatis inæquilateris planis yenosis lavibus glabris, junioribus cum ramuliș pedicellis calycibușque minute puberults, flaralibuis abortivis, pedicellis flore mox glabro dimidio brevioPibus racemos apice foliosos formantibus, sepalis muticís, pistillo glabro. $\bar{o}$ Circa Port-Jackson (R. Brown! A. Cunningh.! Sieber, n. 60! Gaudich.!). - R. Brown'! it Litn. Trans. 10, p. 163, prodr. p. 373, Roem. et Schult. syst. 3; n. $403^{*}$. Linkía lævis Cav. ic. 4, p. 61, t. 389 ? (cfr. supra, n. 54, P. lanceolata o). Persoonia latifolia Knight et Salisb. prot. p. 100. P. lanceolata A. Cunn.! mss. in herb. DC. (nop Andr.). Folia 3-5 poll. longa, 6-18 lin. lata, rècta vel falcata, subacuminato-t̂́nucró nata vel passim obtusă, subtus procipue laxe elevato-reticulata. Ranhorum pars florifera racemiformis 2-4-pollicaris, basi aphylla, apice foliosa. Pedicelli $1 \frac{1}{2}-2 \frac{1}{2}$ lin. longi, bracteả líneari ipsos subæquante vel infimi summique folio genuino suffulti vel nudi. Calyx $4-5$ lin. longus;' obtuse subacuminatus. Antheræ muticæ. Accedit ad P. lanceolatam, sed differt jam foliis majoribus, semper distincte venosis, floralibus plerisque abortivis, etc. (v. s. in herb. Brown., Smith., Cunn., etc.)

68. P. LONGIPoLiA (R. Brown I in Linn. Trans. 10, p. 164, prodr. p. 374), ramulis puberulis, folís patentibus elongato-lincaribus falcatis planis $\mathbf{1}$-nerviis rugosostriatis lavibus glabris, apice sphacelato obtuso, pedicellis subsolitariis flore brevioribus axilláribus aut in racemos laterales basi apiceque foliosos rarius áphyllos dispositis, sepalis subsericeo-puberulis muticis, pistilli glabri stipite articulato. f In terrâ Leeuwin (R. Brown ! A. Cunn.!), colonia \$wan River (Drumm. coll. 1, Preiss, n. 724! 732 ! Gilbert, n. 1!), ad flum. Vasse (Molloy, n. 43!). - Meisn. in pl. Preiss 1, p. 533 '. P. Drummondi Lirndl.l \$wan Riv. p. 35, n. 173. Ramuli graciles, laxe foliosi. Folia 3-12-pollicaria, 2-5 lin. lata, aversa, vix coriacea. Pedicelli 1-flori, 3-4 lị. longi, puberuli, interdum ǵemini. Alabastra conica, obtusiuscula, in sicco croceo-cinnamomea, semipollicaria. Antheræe muticæ. (v. s. in herb. Brown., Gunn., Lindl., etc.)

69. P. FERRUGINEA (Smith! exot. bot. 9 , p. 47, t. 83), ramulis sericeo-tomentosis demum glabratis, foliis confertis patulis ovalibus ovatis oblongisve planis venosis leovibus glabris spicis axillaribus terminalibusve brevibus aphyllis, bracteis laxiceolatis cum calyce multo longiore pedunculoque dense rufo-sericeis, sepalis muticis, avario villoso. F Circa Bort-Jackson (R. Brown! Sieber, n. 5.8!) et in Gipps Land, Australize Felicis (Dr Ferd. Múller l). - R. Brown! in Linn. Trạns. 10, 1. 163 , prodr. p. 373, Roem. et Schult. sist. 3, p. 403 * dict. class. hist. nat., ic. P. laurina Pers. syn. 1, 1 . 118. Ramí graciles, tarde glabrescentes. Foliâ $2-3 \frac{1}{8}$ pọll. lónga, 1 \&-20 lin. lata, brevissime subpetiolatá, accuta vel obtusiuscula cum api. culo sphacelato innocuo, vix rigidula, nervo venisque utrinque prominulis. Spicæ solitariæ, vix semipollicares, fere umbelliformes, paucifloræ, tomento adpresso dẹšo rufo-sericere, bracteis 2 lin. longis, inferioribus ovalibus, supèriợibus linearibus. Calyx sessilis, 5 lin. longus. Anthere muticæ. Ovarium brevissime stipitatum, cum stylo elongato tenui recto glabrum. Drupa ovata vel ellipticạ, 4-5 lin. longa, compressa, glabra, 1-locularis. (v. s. í herb., Smith., Brown., etc.)

\section{Species non descripte.}

P. FusGa hort., ex Steudel.

P. Ledhfolia Nois. (non? Cunn.), ex Roem. et Schult. syst. 3, mant. p. 273.

P. pruinosa Cunn., ex Steudel.

P. Pentadact YLon Steudel nomencl. ed. 2, 2, p. 308. Pentadactylon angustifo lium Gærtn. fil. fire Steud: 
XXII. BRABEJUM Linn. gen. n. 85, ed. Schreb. n. 1580, mant. p. 168, Juss. gen. p. 79, Lam. ill. t. 847, R. Brown in Linn. Trans. 10, p. 48 et 164, Endl. gen. p. 340, n. 2139, suppl. IV, 2, p. 82, Meisn. gen. p. 332 (244). - Brabyla Linn. mant. p. 137.

Flores polygami (plerique pistillo imperfecto masculi), regulares, spicati. Sepala 4 libera, æqualia, linearia, plana, decidua. Stamina 4 , flamentis brevibus sepalorum basi adnatis, antheris oblongis brevissime obtuseque apiculatis. Squamulæ hypogynæ in vaginulam connatæ. Ovarium sessile, 1-ovulatum. Stylus filiformis, stigmate verticali clavato. Drupa exsucca, subglobosa, vel elliptica, subcompressa, villosa, 1-sperma, putamine osseo. - Arbor Gapensis, foliis verticillatis coriaceis simplicibus serrato-dentatis, racemis spiciformibus axillaribus verticillatis indivisis, floribus fasciculatis, fasciculis 3-pluribus bracteâ communi suffultis.

B. Stellatifolium (Linn. sp. ed. 1, p. 121, ed. 2, p. 177, mant. p. $332 \%$ ). 5 In Africà australi, circa Paarl, Palmietrivier, etc. (Thunb., Verreaux! Drège! Zeyher, n. 3762 ! etc.). - R. Brown! l. c. p. 165. B. stellulifolium Linn. syst. veg. 13, p. 764, Hoult. Pfl. syst. 4, p. 647, t. 37, f. 1, Lam. ill. t. 847, Willd. sp. 4, p. 972, Roem. et Schult. syst. 3, p. $399^{*}$. B. stellatum Thunb. prodr.p. 31, fl. Cap. p. 156". Brabyla Capensis Linn. mant. p. 137\% (Pluk. alm. p. 47, t. 265, f. 3, Breyn. cent. 1, t. 1). Arbuscula orgyalis, sempervirens, ramis strictis apice tomentosis. Folia breve petiolata, 3-6 poll. longa, 6-18 lin. lata, lanceolata, utrinque attenuata, glabra, dense elevato-reiiculata, remote serrata, basi integra, dentibus brevibus obtusis acutisve. Racemi erecti, stricti, folio breviores, circ. digitales, undique tomentosi, bracteis ovatis obtusis flores æquantibus deciduis, pedicellis 2 lin. Iongis tenuibus, calycem æquantibus, sepalis albis extus rufo-tomentosis revolutis deciduis. Ovarium setoso-villosum. Drupa edulis, incolis Wilde Castanjes dicta, circ. pollicaris, tomentosa. (v. s. in herb. Banks., Lambert., etc., et v. c. in hort. Kew.)

XXIII. FAUREA Harvey in Hook. Lond. Journ. 6, p. 373, t. 15, Endl. genen. suppl. IV, 2, p. $82, n .2139 / 1$.

Flores hermaphroditi, regulares, spicati. Calyx clavato-tubulosus, æqualis, subtus stylo erumpente fissus unilabiatim reflexus demumque totus deciduus, laminis diu cohærentibus concavis muticis antheriferis. Antheræ 4 sessiles; oblongæ, mulicæ. Squamulæ hypogynæ 4 liberæ, membranaceæ, acutæ. Ovarium sessile, comosum, 1-loculare, 1-ovulatum. Stylus filiformis, rectus, gläber, deciduus, stigmate subclavato sulcato-tetragono obtusâ basi obsolete noduloso. Nux sessilis, ovata, barbata. stylo diu caudata, lineis 4 elevatis ex apice ad medium decurren tibus. - Frutex? vel arbuscula? Australi-Africana, foliis sparsis simplicibus integerrimis verticalibus, spicis terminalibus solitariis subsessilibus indivisis densifloris, floribus in thachi sulcatâ spiraliter 4fariis singulis bracteâ squamiformi suffultis.

F. SALIGNA (Harv.! 1. c.), foliis lanceolatis acuminatis attenuato-petiolatis planis venosis glabris, spicis elongatis cylindricis, rhachi bracteis calycibusque subsericeo-tomentosis. J Girca Magalisberg Gaffrariæ Natalensis (Burke | Zeyher, n. 71! et in herb. Drège, n. 1480!). Ramuli graciles, patentes, laxe foliosi, glabri. Folia

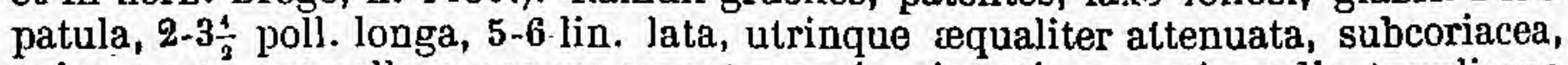
apice acuto nec calloso nec mucronato, venis pinnatis remotiusculis venulisque tenuibus anastomosantibus utrinque prominulis. Spicæ 3-4-pollicares, graciles, rectæ vel subflexuosæ, rhachi tenui, bracteis patulis ovatis concavis obtusiusculis tarde deciduis. Calyx rectus, 3-4 lin. longus, tubo basi subgloboso, limbo clauso ovali-oblongo obtuso, laminis tarde secedentibus 1 lin. longis antheras vix superantibus. Stylus calyce paulo longior, glaber, primo arcuatus semiinclusus, deinde rectus tolus(que exsertus, stigmate parum tenuior. (v. s.) 
XXIV. ANDRIPETALUM Schott mss., Endl, gen. p. 342, n. 2149, suppl. IV, 2, p. 82, n. 2139/2. Klotzsch in Linnoed 15, p. 53, et 20, p. 471, Mcisn. gen. p. 333 (245), et in Mart. A. bras. fasc. 14, p. 77. - Panopsis Salisb. - Andriajetalum Pohl pl. Bras. 1, p. 114, t. 91, 92. - Rhopalæ sp. Kunth in H. B. R. Br. - Roupalæ sp. A. Hich.

Flores hermaphroditi, regulares, racemosi. Calyx 4-sepalus, sepalis linearibus apice ovali-oblongo plano revolutis deciduis. Stamina 4 , sepalis basi vel medio inserta iisque æqualia, antheris ovalibus. Squamulæ hypogynæ 4, membranacæ, in urceolum 4 -dentatum connatæ. Ovarium hirtum, 1-loculare, ovulis 2 collateralibus orthotropis. Stylus filiformis, deciduus. Stigma terminale, clavalum vel cylindraceum, stylo parum crassius, subsulcatum. Nux drupa exsucca, globosa, 1-sperma. Sèmen apterum? exalbuminosum. Arbores Americæ tropicæ, foliis oppositis verticillatis sparsisve coriaceis simplicibus integerrimis nervoso-reticulatis, racemis axillaribus terminalibusque simplicibus vel raro basi ramosis solitariis vel fasciculatis multifloris pedicellis geminatis semiconnatis liberisve bracteâ communi minutâ fultis.

1. A. PоLXStachyA (Schott mss.), foliis oppositis sparsisque rigidis ovalibus obovatisque obtusis in petiolum brevem attenuatis margine recurvis utrinque dense elevato-reticulatis glabris subnitidis, nervo cum petiolo ramulisque minute puberulis demum glabris, racemis axillaribus terminalibusque corymboso-congestis folia superantibus densifloris dense ferrugineo-villosiusculis, pedicellis tenuibus subliberis, stylo calyce breviore ovarium vix duplo superante. $5^{\prime}$ In sylvis Nov.-Granadx, prope Pasto (Humb. et Bonpl.!), Venezuelie (Funke et Schlim, (:oll. 1845, n. 123!), prope Caracas (Linden, n. 14!). - Klotzsch! in Linnæâ 15, p. 53. Rhopola polystachya H. B. K.! nov. gen. 2, p. $154^{*}$, t. 121, Roem. et Schult. syst. 3, mant. p. $287^{\circ}$. Embothrium polystachyum Willd. herb. n. 2498! Folia incluso petiolo 1-5 lin. longo, 1-3-pollicaria, 6-15 poll. lata; in specim. herb. Willd. 4 poll. longa, 12-20 lin. lata, petiolo 10 lin. longo, basi rotundata, reticulo subtus acute supra obtuse prominulo vel semiimmerso. Racemi in summis axillis solitarii et terminales subramosi, $2-3$ poll. Inngi, sessiles, densiflori, lanato-velutini, pedi-

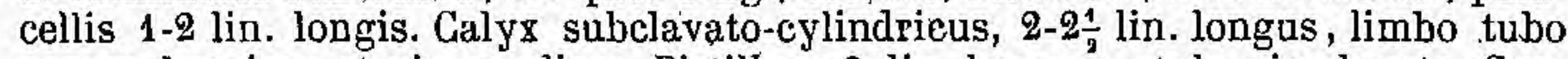
parum breviore et vix ampliore. Pistillum 2 lin. longum, stylo vix clavato. Gyathulus hypogynus glaber, acute 4-dentatus. (v. s. in herb. Willd., Kunth., Shuttl., Boiss.)

2. A. FERRUGINEUM, foliis oppositis vel suboppositis ovali-oblongis obtusis e basi rotundatâ vel subcordatâ in petiolum brevem vix productis margine planis utrinque dense elevato-reticulatis cum ramulis racemisque ferrugineo-tomentosis supra mox glabratis subopacis, racemis axillaribus terminalibusque corymboso-congestis folia vix superantibus laxiusculis, pedicellis crassiusculis subliberis, stylo calycem oquante ovario duplo longiore. 5 In Quito, circa Cuença (Pavon!). A. polystachyæ simillima quidem, sed notis indicatis satis distincta. Folia minus

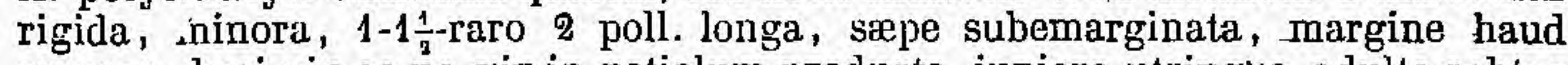
recurva, basi vix ac ne vix in petiolum producta, juniora utrinque, adulta subtus dense ferrugineo-tomentosa, basi srepius paulo obliqua. Pedicelli crassiores, breviores, $\frac{4}{2}-1$ lin. longi ; calyx paulo major, limbo tubo haud crassiore, tomento subvelutino; pistillum 3 lin. longum, ovarium longiuscule villosum, sursum vix incrassatum; cyathulus hypogynus brevissimus, acute 4-dentatus, glaber. Ne confundatur cum Rhopalâ ferrugineâ H. B. K., quæ präeter char. generis differt foliis majoribus, calyce glabriusculo, etc. (v. s. in herb. Boiss.)

3. A. SESSILIFOL IUM (Ḱlotzsch ! in Linnæâ 15, p. 53 ; ib. 20, p. 472), foliis verticillatis quaternis sessilibus obovato-oblongis breve acuminatis basi angustatâ obtusis utrinque acute elevato-reticulatis nitidis excepto nervo subtus puberulo glabris, racemis terminalibus quaternis folia æquantibus simplicibus erectis densifloris, pedicellis liberis flore demum longioribus cum calycibus pedunculis ramulisque junioribus subsericeo-tomentellis. $\delta$ In Guianâ Batavẩ (Anderson! in herb. Banks.), Gallicà (Leprieur !), Anglicà (Schomburgk, n. 634! 950!).-Meisn. in Mart. fl. bras. fasc. 14, p. $78^{*}$. Roupala sessilifolia A. Rich. in Mem. Soc. hist. nat. Paris. 1 , p. 106, Willd. sp. 1, p. 537. Ropala hameliæfolia Rudge Guian. 1, p. 22, t. 31. Rhopala sessilifolia R. Brown! in Linn. Trans. 10, p. 193, Roem. et Schult. syst. 3 , 
p. 430 ". Panopsis hamelifolia Salisb. fide Spreng. syst. 1, p. 482. Arbor 50-60-pêe., ramulis strictis. Folia 3-10 poll. longa, $1 \frac{1}{2}-3 \frac{4}{2}$ poll. lata, cuneato-oblonga, modice coriacea, venulis tenuibus itrinque sequaliter acutcque prominulis laxe reticulatis. Racemi umbellati, graciles, rhachi tenui, pedicellis liberis 3-6 lin.-longis fliformibus. Calyx subclavatus, 3 lin. longus. Flores odoratissimi. (v. s. in herb. Banks., DC., Berolin., etc.)

4. A. SUAVEOLENS (Klotzsch $!$ in Linnæâ $20, \mathrm{p} .472^{*}$ ), foliis verticillatis quaternis subsessilibus rigidis oblongis obtusis utrinque attenuatis glabris reticulatis supra nitidis venis semiimmersis obtusís; subtus opacis venis acute prominulis, racemis tẹrminalibus quaternis folia subæequantibus erectis confertifforis, rhachi glabriusculâ, pedicellis connatis calycem subsériceum xquantibus. 5 In sylvis montosis Colombix (Karsten, coll. 4, n. 28!). Arbor mediocris, ramis verticillatis, juníoribus fulvo-cinereis dense verruculosis. Flores odoratissimi. Galyx 2 lin. longus, flavido-fuscescens. Nux globosa, atro-fusca, granulosa, ajice brevissime umbonata, diam. 2 poll., putamine 1 -spermo suberoso 3 lin . crasso. Semen globosum, diam. 18 lin. A simillimo A. sessilifolio dignoscitur foliis rigidioribus crassioribus utrinque æqualiter attenuatis, reticulatione, pedicellis lorevibus basi connatis. (v̀. s. sine fr. in herb. reg. Berolin.)

5. A. CAYENAENSE (Klotzsch! mss. in herb. Berolin. sine descr.), foliis verticillatis quaternis subsessilibus obovato-oblongis breve acuminatis acutis cuneato-áttenuatis glabris utrinque subnitidis laxeque reticulatis, venis tennibus acute prominulis, racemis terminalibus quaternis gracilibus folia acquantibus vel șuperantibus confertifloris undique fulvo-tomentellis, pediccllis capillaribus liberis calyce longioribus. $\delta$ In Cayennâ (Leprieur! in herb. Mus. paris. et Kunth.), circa Carípi, prov. Para Brasiliæe (Spruce, n. 4811). - Meisn. in Mart. fl. bras. 14, p. 78 *. A. sessilifolium Benth ! mss. in Spruce pl. exsicc. Potius forsan mera var. A. séssilifolii, uui foliorum formâ floribusque convenit, attamen (an constanter?) différre videtur foliis minoribus, 2-5-raro 7-8 poll. longis, 1-2-raro 3-4 poll. latis, tenuioribus, minus rigidis nitidisque et presertim venulis multo tenuioribus. (v. $s$. in herb. reg. Berolin. et Mart.)

6. A. MUL TIF L ORUM (Schott mss., fide Endl. suppl. IV, 2, p. 82), ramulis gracilibus mox glabris, foliis oppositis sparsisque breve petiolatis lanceolatis obtusis muticis basi attenuatis utrinque grossiusculo elevato-reticulatis -supra nitidis glabris subtus opacis junioribus parce pilosiusculis, racemis terminalibus axillaribusque folia superantibus corymbosis laxifloris subsericeo-tomentellis, pedicellis calyce demum duplo longioribus. $\hat{\xi}$ In montibus, circa Río de Janeiro (Pohl l' Riédel ! Lund!). - Meisn. in Mart. fi. bras. 14, p. 77*. Andriapetalum reticulatum Pohl! fl. Bras. 1, p. 115 *, t. 92. Rhopala multiflora Schott in Spreng. syst. 4, p. 403. Arbor ramis junioribus petiolisque minute puberulis . Folia $2 \frac{1}{2}-4$ poll. longa, 6-12 lin. lata, satis rigida, pleraque opposita, suprema sæe alterna, venularum reticúlo grossiusculo inæquali. Racemi simplices vel basi pauciramosi, pedicellis liberis patentibus tenuibus $4-5$ lin., floribus 3 lin. longis demum glabriusculis. Antheræ brevissime apiculatæ. Ovarium subsessile, rufo-villosum, stylo glabro calycem æquante, stigmate vix incrassato clavato obtuso sulcato. (v. s. in herb. Mart., Zuccar., DG., etc.)

7. A. RUBESGENS (Schott mss., fide Endl. l. c.), ramis cinereis, novellis cum foliorum nervo racemisque fulvo-tomentellis, foliis sparsis subsessilibus oblongo-linceolatis utrinque breviter angustatis obtusiusculis glabris venis tenuibus dense elevalo-reticulatis racemis terminalibus solitariis folia subæquantibus, pedicellis calyce duplo longioribus. $\$$ In Brasiliw prov. Goyaz (Pohl!) et Para, prope Santarem (Spruce, n. 649 !) et in Guianâ Anglicâ (Schomburgk, n. 69!). - Meisn. in Mart. fl. bras. 14, p. $77^{\circ}$. Andriapetalum rubescens Pohl ! fl. Bras. 1, p. 114, t. 91. Arbor 30-pedalis. Folia interdum subojposita, 3-5-pollicaria, 12-15 lin. lata, notice rigidula, pulchre reticulata, nervo medio rubente, venis primariís in nervulum submarginalem repandum confluentibus. Racemi simplices, floribüs pallide luteis. Grot. præcedentis. (v. s. in herb. Mart., Zuccar., DG.; Shuttl., reg. Berolin.)

$\beta$ ? acuminatum, foliis breve acuteque acuminatis utrinque petioloque brevi giabris, pedicellis dernum scmipollicaribus. - Ad flum. Uapès, prov Para (Epruce, n. 2574 !). Andripet. n. sp.? Benth.! mss. in Spruce pl. exsicc. Folliorum reticulatio videtur variabilis, in specim, juniorihus tenuiór minusque 
prominula, in floriferis grossior acute prominula, omning ut in typo speciei. (v. s. in herb. DC.)

8: A. SPRUCEr, ramulis glabris, foliis oppositis sparsisque breve petiolatis oblongolanceolatis acutiusculis obtusisve basi attenuatis dense elevato-reticulalis minute adpresso-pilosiusculis, juniopribus subtus subsericeis, racemis terminalibus axillaribusque folia superantibus undique fulvo-tomentosis subsericeis, pedicellis calyce subbrevioribus. $\delta$ ? In Brasiliæ prov. Rio Negro, circa Barra (Spruce, n. 1817!), A. rubescens? Benth ! mss. in Spruce pl. exs. Forsan potius A. rubescentis var., sed præter notas jam indicatas discrepans foliis tenuioribus, vix rigidulis, minoribus, 3-4-vix 5 poll. longís, apice vix attenuatis reticulatione tenuiore, petiolo manifesto 2 lin. longo, pedicellis $1 \frac{1}{2}-2$ lin. tantum 'longis cum rlachi calyceque densius tomentosia. (v. s. in herb. DC.)

XXV. GUEVINA Molina Chil.p. 198, ed. 2, p.279, Juss, gen. p. 424, R. Brown in Trans. Soc. Linn. Lond. 10, p. 48 et 165, Eschscholtz in Mem. Ac. Petersb, 10, p. 281, Endl. gen. p. 340, n. 2440 , Meisn. gen. p. 331 (244). - Nebu Feuill. 3, p. 46, t. 33. - Quadria Ruiz et Pav. gen.fl. peruv prodr.p. 16, t. 33, fl. peruv. 1, p. 63, t. 99, f, b. Gartn. Mi. fr. 3, p. 220, t. 220 .

Flores hermaphroditi, irregulares, racemosi. Calyx 4-sepalus, deciduus, sepalis apice concavo antheriferis, 3 revolutis, quarlo erecto. Anlheræ 4 subsessiles, ovatæ, conectivo ultra loculos brevissime producto obtuse apiculatæ. Glandulæ hypogynæ 2 anticæ. Ovarium subsessile, hirsutum, 1-loculare, 2-ovulatım. Stylụs filiformis, erectus, glaber, stigmate oblique laterali ovali umbonato-convexo. Dripa subcarnosa, putamine osseo 1-spermo. Semen sübglobosum, amygdalinum. - Arbor Chílensis, folits alternis impari-pinnatis, foliolis corirceis dentatis. racemis axillaribus simplicibus tomentosis, pedicellorum paribus 1-bractéatis.

G. Aveutana (Mol. 1 . c.). $\mathcal{f}$ In sylvis montanis Chili australis usque ad $45^{\circ}$ lat. austr. et ultwa (Pavon in herb. Boiss., Dombey ! in herb. DC., h. 191, Eschscholtz! d'Urville !), circa Talcahuano (Pœeppig coll. Chil. II, n. 20, diar. 465), Concepcion (Cuming, n. 804!), Valdivia (Bridges! Philippi,'r1.150! Lechler, o. 532 !).-R. Brown 1. c. p. 16f, Cl. Gay, hist. de Chile p. 312". Quadria heterophylla Ruiz et Pav.l fl. per. 1, p. 63, t. 99, f. b, 2. Avellana Grertn. fil. fr. 3. p. 220. Avellana Guevuin et Nefuen Ghilensium. Arbor circ. 30-pedalis. Folia 5-14 poll. longa, foliolis 2-5 jugis oppositis vel passim alternis, brevissime petiolulatis vel sessilibus ovatis vel cuncato-obovatis subrotundisve 1-4 poll. longis, 8-24 lin. latis, nervosis. Racemi crect, $2-4$ poll. longi, breve pedunculati, densillori, pedicellis 1 lin. longis cum calyce 5 lin. longo, rhachi, ramulis et folicrum paginâ inferiore pube brevi patulâ fulvạ densiuscule tomentosis. Drupa edulis, globosa, breve apiculata, pedicello subexcentrice inserta, magnit. cerasi, dura, glaberrima, demum nigra rugulósa nitida, semine amygdalinro formâ gustuque avellanæ, in Chili et Peruviâ amygdalorum instar vario usui adhibetur. (v. s.)

XXVI. BELLENDFNA R. Brown in Transaat. linn. Soc.' Lond. 10, p. 48 et 166, prodr. p. 374, suppl. p 16, Guillemin ic. lithogr. t. 7. -Bellendenia Endl. gen.p. 340, n. 2141, Meisn. gen.p. 332 (244).

Flores hermaphroditi, regulares, racemosi, ebracteati. Sepala 4 æqualia, lihera, lanceolata, plana, patentia, caduca. Stamina 4 hypogyna, sepalis anteposita et breviora, filamentis liberis, antheris basitixis erectis oblongo-linearibus muticis. Glandılæ hypogynæ nullæ. Ovarium cum stipite suo brevi articulatum, obovatum, 1-loculare, 2-ovulatum. Stylus terminalis, brevis, filiformis, rectus, demam deflexus, stigmate simplici ohtuso haud dilatato. Nux compressa, oboyala, infra apicem hinc stylo reflexo marginique adpresso hamata, 1-2-sperma, margine altero magis arcuato subalato neirvulo tenui intramạrginali comitato. - Frutex Tasmannicus, erectus, foliis sparsis planis inciso-dentatis inermibus, stomatibus amphigenis, racemis terminalibus pedunculatịs ebracteatis, pedicellis sparsis solitarîs vel raro geminis, 
B. MONTANA (R. Brown 1.c. p. 166 et 374 ), foliis breve petiolatis cuneato-obovatis subeveniis glaberrimis apice trifido-dentatis, dentibus obtusis mutieis intermedio truncato vel emarginato vel 3-dentato, pedunculo folia superante nudo apice cum pedicellis flore longioribus puberulo, racemo ovato, calyce glaberrimo. $₹$ In monte Wellington ins. Van Diemen (R. Brown! A. Cunningh. I Gunn, n. 282 !). - Guillemin ic.t. 7. Folia conferta, suberecta, 9-15 lin. longa, 3-6 lin. lata, interdum obsolete triplinervia et parce venosa. Pedunculi erecti 1-2 poll., racemi 1 poll., pedicelli patuli tenues 3-4 lin. longi, flore albo dimidio longiores, persistentes. Nux samar roidea, colorata, semipollicaris, deflexa. (v. s. in herb. Brown., DC., etc.)

\section{Subordo II. FOLLICULARES.}

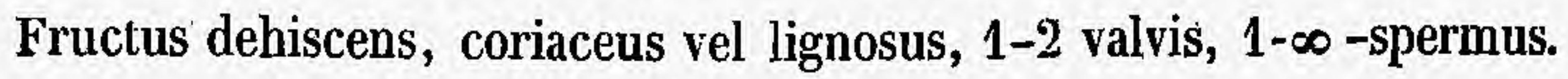

\section{Tribus V. GREVILLEAE.}

Ovarium 1-loculare, 2-4-ovulatum. Fructus 2-spermus, raro 4- vel abortu 1-spermus. Semina alata vel aptera. - Grevilleæ Hakeæ Endl. gen. p. 340. - Rhopaleæ Meisn. gen. p. 333 (245) ex parte.

XXVII. STRANGEA Meisn in Hook. Journ. $1855, p .66$.

Flores axillares, solitarii..... calyce styloque deciduis. Glandula hypogyna nulla? Folliculus spongioso-coriaceus, ovali-oblongus, utrinque attenuatus, compressus, lævis, 1-locularis ? bivalvis, semine solitario ? longe alato. Frutex? Novæ Hollandiæ orientalis, foliis sparsis coriaceis integerrimis, fructibus axillaribus solitariis. - Stirps ex specimine unico floribus carente nimis imperfecte cognita, nulli tamen generi bene adsocianda; a Persooniâ, cui habitu et inflorescentiâ accedit, fructu dehiscente semineque alato longe abhorret, Grevilleæ verisimilitel proxima, sed floribus solitariis discrepans, semine ad Xylomelum accedens, sed inflorescentia diversa et folliculus verisimiliter 1-(saltem non poly-) spermus.

S. LINE A R IS (Meisn. 1. c. p. $67^{*}$ ), glabra, ramis gracililus, foliis erecto-patulis anguste lineari-spathulatis obtusis muticis subenerviis, folliculis pendulis. $₹$ ? Circa sinum Moreton Bay (Strange!). Ramulus teres, simplex. Folia 2-pollicaria, extra medium 2-2: lin. lata, basin versus valde attenuata, crassiuscula, plana, obsolete lineata. Folliculi in inferioribus axillis solitarii, subsessiles, in stipitem 3 lin. longum crassiusculum deflexum sensim attenuati, 18-20 lin. longi, breve acuteque acuminati, plus minus compressi, marginibus obtusissimis 1 -snlcis valvis demum subplanis levibus intus vix concavis. Semen atrum, 10 lin.'longum, 3 lin. latum, lanceolatium, utrinque attenuatum, planum, membranaceum, utrinque? alatum, alæ uno margine tenuiter nerviformi, nucleo..... imperfecto. (v. sp. 1, sine

fl. in herb. Soc. linn. Lond.)

XXVIII. MOLLOYA Meisn. - Fitchia Meisn. (non Hook.) et Grevillea? cynanchicarpa Meisn. in Hook. Journ. 1855, p. 75.

Flores axillares, solitarii..... Glandula hypogyna antica, semi-annularis, calycis fundo obliquo adnata. Ovarium stipitatum villosum, stipite hinc calycis basi adnato. Stylus crassiusculus, rectus, deciduus, stigmate laterali suborbiculari plano obtuse umbonato dorso convexo. Folliculus coriaceo-lignosus, lanceolato-oblongus, utrinque attenuatus, glaber, 5-6-costatus, 1-valvis, 1-spermus. Semen apice longe alatum. - Frutex Novæ Hollandiæ occidenta:lis, foliis sparsis coriaceis integertimis, stomatibus amphigenis, pedicellis axillaribus erectis. - Genus non satis notum, Strangeæ affine, a Grevilleâ inflorescentiâ, folliculo et semine solitario discrepans.

M. GYNANCH ICARPA, ramis strictis apice cano-puberulis, foliis crassiusculis linearibus acutis lævibus 1 -nerviis subeveniis glabris, pedicellis brevibus cano-tomen: 
tellis, stylo puberulo. $亏$.In planitie arenosâ ad flum. Moore, Nov.-Holl. occid. (Drumm. coll. 6, 190!). Grevillea? cynanchicarpa Meisn. in Hook. Journ. 1855, p. 75*. Fruticuli 3-4-pedales, ramis virgatis glabris apice corymboso-ramulosis canescentibus dense foliosis. Folia erecta, rigida, 2-6 poll. longa, 2-3 lin. lata, attenuato-petiolata', plana, acuta cum mucronulo vix pungente, nervo crassiusculo levissime jrominulo subtus immerso. Pedunculi patuli, 3 lin. longi, graciles, 1-flori. Calyx ignolus. Pistillum 8-9, lin. longum, ovario albo-sericeo 1 lin., stipite $2 \frac{1}{2}$ lin. longo crassiusculo glabriusculo toto calycis fundo adnato, stylo canopuberulo, stigmate 1 lin. longo glabro. Folliculi erecti, $1 \frac{1}{2}-2 \frac{1}{4}$ poll. longi, 4 lin. crassi, subfalcati, fusci, glabri, obtusiusculi, tostis 5-6 longitudinalibus crassiusculis obtusis, sulcis profundis angustis. Semen (ex Drumm. in Hook. Journ. 1853, p. 182) 1 poll. longum, samare. Fraxini simile. (v. s.)

XXIX. GREVILLEA $R$. Brown in Transact. Linn. Soc. Lond. 10, p. 49 et 168, prodr. p. 375, suppl.p. 17, Endl. gen. p. 340, n. 2143, suppl. IV, 2, p. 83, Meisn. gen. p. 332 (245) et in plant. Preiss. 1, p. 534. - Embothrii sp. Smith Nov.-Holl. t. 9, 10. Cav. ic. t. 386, 387. - Lyssanthe Knight et Salisb. Prot. p. 117 (non R. Br.). - Stylurus Knight et Salisb. l. c.p. 115 (non Rafin.). - Anadenia R. Br. l. c. p. 165, 374, 16, Endl. gen. p. 340, n. 2142, suppl. IV, 2, p. 82. - Manglesia Endl. gen. suppl. I, p. 1379 , n. $2142 / 1$, suppl. IV, 2, p. 83 .

Flores hermaphroditi, racemosi vel fasciculati, rarissime subsolitarii. Calyx 4-fidus vel 4 -sepalus, deciduus, sepalis linearibus spathulatisve apice concavo antheriferis, nunc subinæqualibus cohærentibus in calycem irregularem clavato-tubulosum incurvum supra fissum, limbo antrorsum revoluto 4 -fido vel clauso et stigma diu retinente, nunc rarius æqualibus liberis rectis demum revolutis. Antheræ sessiles ovatæ vel oblongæ, muticæ. Glandula hypogyna unica fere complete annularis aut dimidiata antica, rarius minuta aut nulla. Ovarium stipitatum vel rarius sessile, ovoideum aut antice ventricosum, 1 -loculare, 2-ovulatum, stipite libero vel rarius calycis basi adnato. Stylus sublateralis elongatus arcuatus vel demum rectus, rarius abbreviatus et incrassatus. Stigma aut laterale vel oblique sublaterale, disciforme planum vel concavum vel convexum vel medio mucronatum, raro cornutum; aut terminale depresso-capitatum convexum vel conicum. Folliculus coriaceus vel lignosus, cernuus, ventricoso-ovatus vel rarius compresso-oblongus vel subglobosus, mucronatus vel sæpius stylo toto persistente rostratus, lævis vel subcostatus vel verruculosus vel echinulatus, 1-2-valvis , 2-1-spermus. Semina subrotunda, ovalia vel oblonga, aptera vel submarginata apiceque brevissime alata, aut undique latius alata. - Irutices vel rarius suffrutices arboresve Australasiæ, pilis, dum adsunt, plerumque medio affixis, foliis sparsis coriaceis planis vel raro subteretibus, indivisis integerrimis aut varie dentatis vel laciniatis, margine sæpe revolutis refractisve, stomatibus hypogenis vel rarius amphigenis, racemis axillaribus vel terminalibus nunc abbreviatis sæpe fasciculiformibus interdum secundis, rarius ramosis, pedicellis geminis vel raro pluribus solitariisve bracteâ communi deciduâ suffultis, floribus rubris vel rarius flavis albisve, nornunquam oblique pedicello insertis.

\section{Subgenus I. EUGREVILLEA.}

Calyx irregularis, limbo plus minus incurvo clauso vel demum fisso 4-lobo vel unilabiatim deflexo. Glandula hypogyna manifesta. Stylus filiformis vel complanatus, haud strumoso-incrassatus. Stigma laterale vel obliquum vel rarius terminale, disciforme vel hemisphæricum planum concavum vel convexum, nunquam pyramidato-conicum.

\section{Sectio I. Plagiopoda R. Brown in Linn. Trans. 10, p. 174; prodr. p. 379.}

Calyx basi obliquus, ovarii stipiti hinc adnatus, cui utrinque sepala 2, alterum supra alterum, inserta sunt. Glandula hypogyna annularis vel semiannularis: Folia integerrima, rarius laciniata. 


\section{§ 1. Brevistyla. - Stylus calycem cequans vel vix supéraris. Racemi brevissimi vel fasciculiformes. Folia indivisa.}

1. G. Drum undi (Meisn. ini pl. Preišs, 1, p. 536 , 2, p. 252), foliis lineari-lanceolatis acutis ramulisque laxe pilosis supra denium glâbratis, floralibus angustissimis, fasciculis terminalibus 6-12-תoris sưbsessilitbus, calyce extưs glabriusculo intus ad faucem barbato, ovarii viflosi stipite styloque brevissìmo glabris, stigchate Iaterali orbiculari plano. 5 In coloniâ Swan River (Ṕreiss, n, 2623! Drummoǹd coll. 3, n. 327! 4, n. 335!). Fraticủlus humilis. Folia coṇferta, patưlä, vix coriacea, cire. pollicaria, $\frac{1}{2}-1 \frac{1}{2}$ lin. lata, 1 -niervia, evenià, lævià, inferiora plana, superiora margine revoluta, floralia involücrum simulantia subtus canaliculata

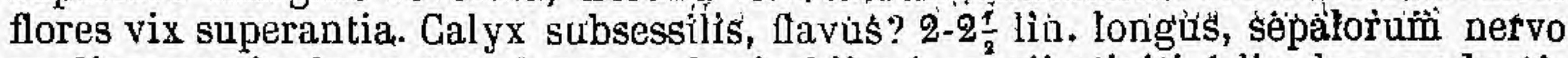
medio prominulo costato-4.gonus, basi obliquaâ ovarii stipiti 1 lin. longo adnatâ,

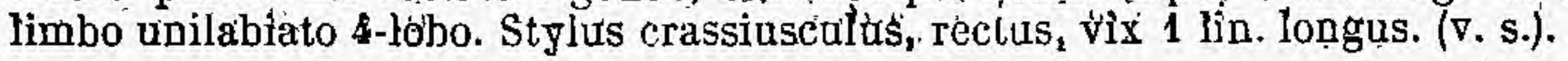

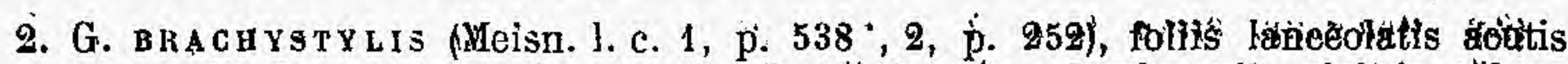
subeveniis basi attertuatis margine revollttis sutpra loevinusculis glabris subbtus adpresse pilosis, racemis terminalibus axillaribusque brevissintis 4-6-floris, eàlyce pedicello longiore subventricoso rufo-villosiusculo intés pubescente, ovario lánato, stylo brevissimo puberulo, stigmate laterali ovato-oblongo acato subicóncavo umbonato. F In Nov.-Holl. austro-occid. distr. Sussex (Preiss, n. 714, ex parte, et $717 !)$, in colơià Swan River (Drumm. coll. 2 , п. 322 !). Frutex $1 \frac{1}{2}$ pedalis, rämnlis laxe foliosis glabris vel puberulis. Folia rigifle cortaced, $1 \frac{1}{2}-2 \frac{1}{2}$ poll. longa, $2 \frac{1}{2}-5$ lin. lata supra obsolete venosa vel evenia sub lente punetibulata vì scabriäsedila, subtus sericeo-canescentia. Racemi sæepius récurvi, rhachi 2-4 lin. longà. Galyx coccineus, $3-3 \frac{1}{2}$ lin. longus, tubo subcostato basi obliquâ ovarii stipiti $\frac{1}{4}$ lin. longo âdnato, limbo clauso valde incurvo demum supra fisso 1-labiato. Stylus vix 1 lin. longus crassiusculus, stigmate fere $1 \frac{1}{2}$ lín, longo subaeuminato antice subconcavo própe basin obtuse umbonato. Speciès facie F; floribundæ simillìima. (v. s.)

3. G. PINIF OLIA (Meisn. in Hook. Journ. 1852, p. 186), foliig tereti-filiformibus tenuibus sphacelato-micronulatis 1 -sulcis levibus junioribus pilosiusculis, fasciculis axillaribus paucifloris, pedicellis flore dimidio brevioribuś, éalyce extus rufo-pưberulo intus ad faucem barbatô, ovario vilíosọ, stýlo inferne pilosiuscillo, śtigmate laterali obovato subconcavo. Ĵ̀ colơnî Swaí River (Drümm. coll. 4, n. 281!). Rami graciles, apice dense foliosi puberuti. Folia erecta, 1-2 poll. Ionga, $\frac{1}{3}$ lin. crassa, recta, rigida, mucrone niğro deciduo deminum obtusa. Areemi sessiles vel potius fasciculi 2-5-flori, pedicellis tenuibus rufo-puberulis. Calyx 4 lín. longus basi attenuatâ oblịquầ ovarii stipiti glabro 1 lin. longo adnatus, limbo globoso incurvo demum recto 4-partilo. Pistillum calycern æquans, stylo crassiuseulo, śtigmate $\frac{i}{2}$ lin. longo leviter umbonâto. (v. s.)

\section{2. Longistylat. - Stylus calycem longe superans. Folia indivisa vel laciniata. Racemi ovales vel elongati.}

4. G. RIGIDIssIma (Ferd. Müller ! miss.), ramulis cinereo-tomentellis, foliis rigidissimis ultra medium 3-partitis glabris margine arcte rèvolutî̌ supra convexis enerviis subtus bisulcis, laciriis divaricatis linearibus mucronato-pungeritibus subæqualibus indivisis vel intermediâ passim 3-partitâ, racemis axillaribus brevibus, calyce gracili subsericeo-puberulo intus pistilloque glaberrimo, stigmate terminali obliquo convexo. $₹$ In pinetis circa Gawlertown prope Adelaide et flum. Murray (Ferd. Müll.!) - Meisn: in Linnseâ 26, 1853, p. 356 *. Frutex 5-8-pedalis. Ramuli breves, rigidi, dense foliosi. Foliorum segmenta 1 lin. lata, 6-10 lin. longa, parte petiolari 3-5 lin. longâ basi attemuatâ, nervo subtus adpresse pilosiusculo. Racemorum rhachis vix pollicaris, bracteis caducis. Calyz ruber, 8 lin. longus, túbo 1 lin. crasso utrinque attenuato, limbo subgloboso $1 \frac{1}{4}$ lin. longo incurvo demum recto 4 -partito Glandula hypogyna angusta calycis fundo ovarique stipiti adnata indeque inconspicua. Pistillum demum fere pollicare, stipite 4 lin. Ionge infra medium calycis basi obliquæe hinc adnato. Folliculus (ex Müll. in litt.) sobovatus, compressus, 4-6 lin. longus, stylo persistente caudatus, rugulosus. Semine ovato-semiorbicularia, plano-convexa, margine anguśto cráassoque ciñcta, fulva. (v. s.) 
5. G. L oNGist Y LA (Hooker in Mitchell exped. inter. trop. Austr. 1848, p. 343). folís lange linearibus indivisis margine subrevolutis supra glabris subtus ramulisque albo-tomentosis, racemis terminalibus oblongo-ovatis, calyce glandulosopuberulo, ovario sericeo hirsuto, stylo longissimo grabro, stigmate laterali oblongo. F In rupestribus montanis prope Pyramides, Nov.-Holl. or. interioris (Mitchell, n. 316! 345! in h. Lindt.). Frutex 7-8-pedalis. Folia palmaria yel ulthra basi attenuata. Flores 10 lin. longi, purpurei? Ovarium stipitatum, serhiglobosum. (v. s. in h. Lindl.)

6. P. NEGLECTA (R. Brown append. Sturt exped. centr. Austr. p. 24), foliis pinnatifidis subtus niveis, laciniis linearibus. $\mathrm{F}$ In Nov.-Holl. orient.-interiore (Sturt). Forsan varietas G. longistylæe, cui plurimis notis convenit, ex $\mathbf{R}$. Br. 1. c. Huc referenda nobis videtur planta a cel. Mitchell lecta : ramis minute sericeo-tomentosis cinnamomeis teretibus apice subcompresso-angulatis, foliis coriaceis vix rigidis 6-10 poll. longis pinratim 2-5-partitis, lacinitis linearibus $1 \frac{1}{2}-2$ lin. Iatis acutis cum mucronulo sphacelato innoouo, racemis 1-2 poll. longis dense multifloris erectis, pedicellis 3-4 lin. longis tomentellis, calyce parce pulerulo viscoso? 8 lin. longo valde incurvo basi obliqua ovarii stipiti $1 \frac{4}{2}$ lin. longo adnato, stylo fere sesquipollicari, stigmate G. longistylæe. (v. s. in herb. Lindl.)

7. G. juncifour a (Hook. in Mitchell exped. trop. Austr. 1848, p. 341), foliis elongátis angustissime lincaribus semiteretibus acutis indivisis glabris margine revolutis, racemis ovatis multifloris, pedicellis ealycibusfue sericeis, ovario longissime àkbo-sericeo, stylo glabro. $\frac{7}{\text { In }}$ planitie ad montem Pluto, Nov.-Holl. orient. interior: (Mitchell !). Rami tomentosi subsericei, teretes, apice subangulati. Folia rigida, ompia indivisa. Racemi 3 demum 6 poll. longi. Ovarium ex Hook. diagn. sessile, attamen species sectioni Plagiopodæe adscripta a cel. Brown in Stirt append. p. 24. Follioulus oblique ovatus, sericeo-tomentosus. (v. s. in h. Lindl.)

8. G. veNuSt A (R. Brown! in Linn. Trans. 10, p. 175, jrodr. p. 379), foliis subsessilibus elongatis pinnatifidis 3 -fidis passimque integerrimis, laciniis lanceolatis obtusis apiculatis basi attenuatis planis venosis lævibus supra minute puberulis subtus sericeis, racemis terminalibus pedunculatis erectis foliis superatis, pedicellis calyce glaberrimo basi valde obliquo parum brevioribus, ovario styloque hirsuto, stigmate laterali ovali convexo. $\bar{\zeta}$ In montanis ad promontor. Townsend, Nov.-Holl. oræ orientalis (R. Brown l). - Guillemin ic. lithogr. t. 11. Ramuli tomentelli. Folía 2-5 poli. longa, pluraque 3-partita basi cuneala, laciniis 2-5 lin. latís integerrimis vel intermediâ passim 2-3-fidà, 1-nervia, pennivenia, venis prope marginem venâ tenui junctis, margine subrecurvo. Rácemi 1-2-pollicares, laxiusculi. Calyx semipollicaris. Pistillum pollicare. Folliculus (immaturus) ablongus muticus utrinque attenuatus pilosus. (v. s. in herb. Brown., DC., etc.)

9. G. Goodir (R. Brown! 1. c. p. 174 et 379), caule prostrato, foliis petiolatis oblongis integerrimis utrinque obtusis mucronulatis margine undulatis glabriusculis reticulatis 3-nerviis, nervis lateralibus tenuibus margine approximatis, racemis dxillaribus terminalibusque elongato-pedunculatis erectis, pedicellis calyce sericéo-püuberulo basi valde obliquo dimidio brevjoribus, ovario villoso, stylo superne glabro, stigmate laterali ovali subconvexo. ‡ In terrà Arnhem, ad sinum Carpentarie (R. Brown!).-Guillọm. ic. lithogr. t. 16. Rami graciles, glabriusculi, juniores subcompresso-angulali. Folia remota, patentia, incluso petiolo 2-3 lin. longo, 2-4-pollicaria, 8-15 lin.l ata, pilis bicruribus adpressis parce puberula vel ex Br. glabra. Racemi cum pedunculo 3-5 poll. longi, laxiuscule multiflori. Calyx 6-7 lin. longus. Pistillum sesquipollicare, stylo tenui basi parce piloso. (v. s. in herb. Brown, etc.)

Sectio I. Aphanoptera Meisn. in pl. Preiss. 1, p. 535, obs. 2.

Calyx basi æqualis rotundatus vel attenuatus, ovarii stipiti haud adnatus. Folliculus coriaceus vel sublignosus, ovatus vel oblongıs, rarius suborbicularis, stylo plerumque toto persistente caudatus. Semina ovalia, compressa, angustissime marginata vel apice solo brevissime alata.

\section{\$1. Lissostylis. - Stylus glaber vel rarius tenuiter pilosus vel 'tomen- tosus (nec lanatus). Stigma laterale vel rarius terminale, planum}


vel subconvexum glabrum. Folliculus lavis vel rarius costatus. Folia indivisa, in paucissimis passim laciniata (cfr. G. bracteosa, concinna). Racemi breves, scepissime fascieul iformes, vel interdum flores axillares subsolitarii.-Meisn. in pl. Preiss. 1, p. 536.-Lissostylis et Ptychocarpa R. Brown in Linn. Trans. 10, p. 169 et 172, Prodr. p. 376 et 378 .

a. Oleoideo. - Folia latiuscula, raro angusta, lcevia, subtus sericea vel canescentia supra vel rarius utrinque glabra, plana vel marginibus revolutis vel scepius refractis pseudo-trinervia. Calyx plerumque majusculus, 4-12 lin. longus. Pistillum stipitatum, glaberrimum, rarissime subsessile vel pubescens.

10. G. ExuL (Lindl. not, of ornam. plants, etc., in hortic. Transact. 1852, p: 14, in. notâ), foliis oblongis retusis basi angustatis subtus glaucis leviter tomentosis 3-nerviis venosis, racemis paniculatis secundis sericeo-tomentosis, pistillo calyce pluries longiore glaberrimo, orario longe stipitato basi gibboso, stigmate medio conico. F In orâ orientali insulæe Novæ-Caledoniæ. Affinis dicitur G. Ghrysodendro, sed jam foliis integerrimis distinctissima. Fructus ignotus ; an stigma laterale? an terminale obliquumve?

11. G. GILLIVRAYI (Hook. in Journ. of bot. et Kew Gard. misc. 1854, p. 358, in notâ, ibid. 1855, t. 7), foliis breve petiolatis oblongis obtusis breve mucronatis 1 -nerviis laxe reticulato-venosis margine recurvis supra glabris subtus ramulisque sericeis, racemis lateralibus breve pedunculatis simplicibus elongatis dense multifloris albo-sericeis, pedicellis calyce brcvioribus, stylo glabro longe exserto, stigmate terminali oblique truncato medio apiculato. 5 In summitate insulæ Pino* rum, prope Novam-Caledoniam (Macgillivray et Milne). Frutex humilis, ramis robustis, junioribus aureo-sericeis. Folia coriacea, suberecta, 2-3 poll. longa, 8-10 lin. lata, petiolo 2-3 lin. longo, venis pinnatis copiosis subparallelis apicem versus petentibus venulisque raris laxe anastomosantibus. Racemi numerosi, in apice ramulorum lateralium brevium subaphyllorum solitarii, erecto-patentes, indivisi, 4-5-pollicares, cylindrici, oblongi, obtusi, rhachi crassâ, pedicellis 1-2 lin. longis. Calyx 5-6 lin. longus, hinc fissus, labiatus, limbo refleso 4-loho. Pistillum circ. sesquipollicare, stylo gracili, stigmate mucronato-umbonato.

12. G. LA U R IFolia (Sieber ! in lierb. fl. Nov.-Holl. n. 26), procumbens, foliis petiolatis ovatis oblongis lanceolatisve mucronatis venosis marginc recurvis supra lævibus glabratis subtus ramulisque sericeis, racemis axillaribus terminalibusque pedunculatis simplicibus brevibus secundifloris, calyce subsericeo puberulo intus glaberrimo, ovario stipiteque villoso, stylo glabro, stigmate terminali obliquo convexo. J Circa Port-Jackson (Caley, A. Cunningh ! Sieber, n. 26! Anderson, n. 72 !). - Roem. et Schult. syst. mant. 3, p. $279^{\circ}$, R. Brown I simpl. p. 17. G. humifusa A. Cunn. mss. in herb. Facies fere G. Goodii. Caulis procumbens, laxe ramosus foliosusque, graciljs, glaber. Folia patula, coriacea, obtusa vel acuta,

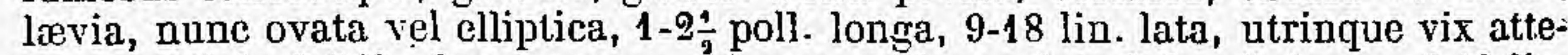
nuata pétiolo 3-6 lin. longo, nune oblonga-ret lanceolata 2-6 poll. longa, 6-18 lin. lata utrinque attenuata petiolo $\frac{4}{2}-1$ pollicari, venis pinnatis utrinque prominulis parallelis rectis in nervum submarginalem excurrentibus, paginâ superiore demum glaberrimâ nitidá, inferiore fulvo-sericeâ. Racemi circ. pollicares, subrecurvi, dense multiflori, calycibus subsemipollicaribus pedunculisque adpresse ferrugineopuberulis. Pistillum pollicare, ovarii stipite libero $1-1 \frac{1}{2}$ lin. longo villoso. (v. s. in herb. Brown, Cunn., etc.)

13. G. Mi queliana (Ferd. Müll. definit. of rare pl., etc., Melbourne, 1355, p. 50 *. n. 40), foliis breve petiolatis oblongo-ellipticis obtusis mucronulatis margine leviter revolutis supra subeveniis punctato-scabriusculis subtus venosis ramulisque molliter puberulis, racemis terminalibus simplicibus folia rquantibus nutantibus cano-pubescentibus, calycis tubo intus inferne lanato, pistillo demum glaberrimo, stigmate laterali ovali plano. $\%$ Circa mont. M'Millan, terræ Gippsland, Australiæ Felicis (D' Ferd. Müller!). Habitu, præcipue foliis, ad G. laurifoliam 
GREvillea. : PROTEACE E (AdCTOR MEISNER).

accedens, sed notis indicatis optime distincta. Ramuli graciles, teretes, sicut foliorum

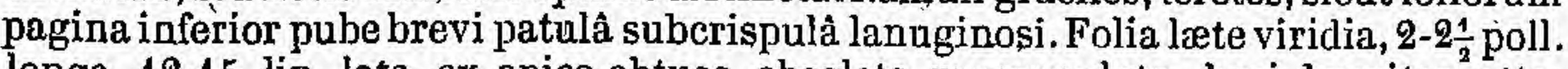
longa, 12-15 lin. lata, ex apice obtuso obsolete mucronulata, basi breviter attenuata, venis pinnatis supra immersis vel penitus inconspicuis, subtus prominulis parcegue anastomosantibus, petiolo tenui 1-2 lin. longo. Racemi breve peduneulati, $1 \frac{1}{2}-2$ poll. longi, densiuscule multiflori, pedicollis 2 lin. Iongis cum rhachi calycibusque dense cano-pubescentibus. Calyx gracilis, 10 lin. longus, tubo recto glabrescente intus infra medium dense lanato, limbo inflexo parvo globoso. His. tillum subpollicare, totum glabrum, ovario stipitem suum subæquante 1 lin. longo, stigmate suborbiculari 1 liz. longo obsolete umbonato. (v. s. in herb. Sonder.)

14. G. Victor I E (Ferd: Müll. first general report, p. 17, et definitions, etc. Melbourne, 1855 , p. 31 , n. 25 *), erecta, ramis gracilibus apice subcompressis sericeis, foliis breve petiolatis lanceolatis acutis planis utrinque venosis lævibus supra glabris subtuis sericeis, racemis terminalibus et e summis axillis nutantibus folio brevioribus basi pauciramosis, pedicellis brevissimis calycibusque cupreo-sericeis, pistillo subsessíli glaherrima, stigmate laterali ovali convexo. F In montibus Buffalo Range Australiæ Felicis (D' Ferd. Müll.!).-Meisn. in Linnæeâ ined..... Rami teretes, laxe foliosi, demum glabri. Folia patula, parum rigida, $2-4$ poll. longa, 5-8 lin. lata, utrinque æequaliter attenuata, plana vel margine leviter reeurva, petiolo vix semipollicari, mucronulo innocuo sphacelato obsoleto, venis pinnatis subparallelis supra prominulis subtus subimmersis, reticulatione subnullâ, pagin'à superiore læete viridi glabrâ (juniore adpresse pilosiusculâ), inferiore pallidà albidosericeâ, pube tenerrimà densâ adpressissimâ. Racemi $2-2 \frac{1}{2}$ poll. longí, demum arcuato- (nec refracto-) penduli, basi racemum unum alter'umve vix pollicarem simplicem emittente, pedunculo communi partialibusque 4-8 longis rhachique albido-sericeis. Pedicelli vix 1 lin. longi. Calyx semipollicaris, gracilis, totus pulchre sericeo-tomentosus cupreo-rufus, tubo sub-4-angulo cylindraceo recto basi attenuato intus glabro, limbo subgloboso obtusissimo Jeviter inflexo obliquo diu clauso vix 1 lin. longo. Glandula hypogyna brevis, semiannularis. Stigma levissime umbonatum. Folliculus subsessilis, stylo semipollicari arcuato-caudatus, 8-9 lin. longus, elliptico-lanceolatus, utrinque attenuatus, acutiuscule -gonus, lœvis, atro-fuscus, tenuiter lignoso-crustaceus, ventre dehiscens. Semina ignota. (v. s. comm. a cl. Sonder.)

15. G. DI M о R P A (Ferd. Müller! in Transact. philos. Soc. of Victoria, 1, p. 21 *), ramis gracilibus apice angulatis sericeo-tomentellis, foliis subsessilibus lanceolatis lincaribusve sphacelato-acutis supra lævibus glabris subtus sericeis margine recurvo vel anguste refracto spurie 3-nerviis, raccmis axillaribus fasciculiformibus, subsessilibus paucifloris, calyce gracili cupreo-sericeo intus medio dense lanato, pistillo stipitato glaberrimo, stigmate laterali subrotundo-ovali umbonato. $\%$ In Australiâ Felici (Mitchell 1), mont. Grampians, Serrâ et Victoriâ (D* Ferd. Müller !). Admodurn accedit ad G. oleoidem et Seymouriæe, sed jam inflorescentiâ, calyce minore graciliore, etc., facile dignoscenda. Folia rigide coriacea, valde variabilia, subtus albido vel fulvo-serícea, mucronulo nigro vix pungente, marginibus punctato-scabriusculis. Racemi vel fasciculi 6-12-flori, pedunculo communi rhachique 1-3 lin., pedicellis 1.2 lin. Iongis. Calyx semipollicaris, limbo globoso inflexo. Pistillum pollicare, stipite ovarium æquante, stigmate marginato.

a. lanceolata, foliis lanceolatis (2-4 poll. longis, 3-7 lin. latis) basi vel utrinque attenuatis supra obsolete penniveniis (Mitchell exped.1835-36, n. 301! Ferd. Müll.I). G. dimorpha a latifolia Ferd. Müll:! l. c.. (v. s. in herb. R. Cunningh. et comm. a cl. Heward et Sonder.)

E. linearis, foliis anguste linearibus (3-5 poll. longis, 1-2 lin. latis) utrinque attenuatis eveniis (Ferd. Müll.!). G. dimorpha $\beta$ angustifolia Ferd. Müll. L. c. (v. s. comm. a cl. Sonder.)

16. G. oL E ordes (Sieber! in herb. fl. Nov.-Holl. n. 35), foliis lanceolatis mucronulatis basi attenuatis subpetiolatis margine angustissime refracto vel recurvo spurie 3-nerviis supra lævibus glabris subtus sericeis, racemis terminalibus axillaribusve subsessilibus brevissimis recurvis, calyce $\frac{3}{4}$-pollicari gracili dense sericeo, tubo intus ultra medium barbato, pistillo subpollicari glaberrimo, stigmate laterali late ovali. J Circa Port-Jáckson (Caley! Sieber, n. 35! Hïgel!). - Roem. et Schult. syst. mant. 3, p. $277^{*}$, Reichenb. hort. bot. 2, p. 2, 1. 204, R. Brown !

XIV. 
suppl. 19. 17. Rami virgati, stricti, apice angulati tomentelli, demum teretes glabrati. Folia 2-3 poll. longa, 3-7 lin. lata, rigida, obtusa vel acuta, margine plerumque recunva potiusquam refracta, nervo marginali vel submarginali sub lente elevato-punctato tactu tamen parum scabriusculo. Racemi pauciflori, ramulos laterales breves foliosos terminaútes et cum iisdem recurvi, pedunculo 3-4 lin. longo a basi florifero, pedicellis flore multo brevioribus. Calyx 8-9 lin. (ex $\mathrm{Br}$. 1 poll.) longus, rufo-sericeus, basi attenuatus, limbo glob,oso incurvo mox recto. Ovarium stipite suo subbrevius. A simillimâ G. dimórphâ $\alpha$ præcipue calyce longiore pistillum aquante dignoscenda (v. s. in herb. Brown., etc.)

17. G. SEYMOURI A (Sweet $!$ mss. in herb. DG.), foliis linearibus utrinquenattenuatis acutis mucronatis margine anguste recurvo vel refracto scabriusculis supra lævibus glabris venosis subtus sericeis, racenis terminalibus lateralibusque fasciculiformibus multifloris recurvis, calyce semipollicari tenui parce sericeo-puberulo, tubo intus medio dense barbato, pistillo pollicari glabro, ștylo apicè puberulo, stigmate laterali ovali. 5 In ins. Diemen (fide Sweet l. c.) et Nov.-Holl,'orient. austr. interiore, circa George's River (Mac Arthur, n. 214 1 ). G. planifolia R. Brown (fide Loudon), Lodd. Bot. cab. t. 1737? (ic. recedens pistillo 16 lin. longo glaberrimo). Folia $2-3 \frac{1}{2}$ poll. longa, $1 \frac{4}{2}-2 \frac{1}{2}$ lin. lata, rigida, stricta, venis pinnatis s,upra plus minus conspicuis. Pedunculus communis vix semipollicaris, a basi flóriger, pedicellis 1-2 lin., calycibus 6-7 lin. longis, tubo basi haud attenuato, limbo globoso mox reclo demum reflexo 4-lobo. Pistillum tenue, 11-13 lin. longum, stigmate $\div$ lin. longo, ovario stipite suo breviore. Proxime affinis præecedenti et G. strictæ, sed jam styli apice minute parceque puberulo, nec glaberrimo nec sericeo, etc., dignoscenda. Nomen Brownianum non servavimus, quia nobis incertum et insuper parum signiffcans. (v. s. In herb. Lindl. et cult. ex h. Birmingham 1839, in herb. DC.)

18. G. PUN I E A (R. Brown ! in Linin. Trans. 10, p. 169, prodr. p. 379), foliis subpollicaribus lanceolatis oblongis ovalibusve obtusiusculis mucronulatis margine acute refractis supra obsolete venosis lævibus glabris subtus sericeis, racemis terminalíbus lateralibusque brevibus reçurvis, calyce semipollicari sericeo-pilosiusculo, tubo intus dense lanato, pistillo sesquipollicari glaberrimo, stylo tenư, stigmate laterali obliquo orbiculari. J Circa Port-Jackson (R. Brown! Sieber, n. 31! Anderson!), Victoria (Latrobe !), ad fretam d'Entrecasteaux, ins. Diemen (fide herb. DC.). - Roem. et Schult. syst. mant. 3, p. $276^{*}$, Lodd. Bot. cab. t. 1357, Bot. reg. t. 1319. Embothrium sericeum $\beta$ minus Smith! Nov.-Holl. p. 25, t. 9, f. $5 \beta$. Grevillea sericea Lodd. Bot, cab. t. 880 ? (recedens pedicellis 4-5 lin. longis, an jgitur polius G. dubra?). Lysanthe. speciosa Knight et Salisb. Prot. p. 118 ? Ramuli conferte foliosi; juniores angulati tomentelli, floriferi breves plus minus recurvi. Folia

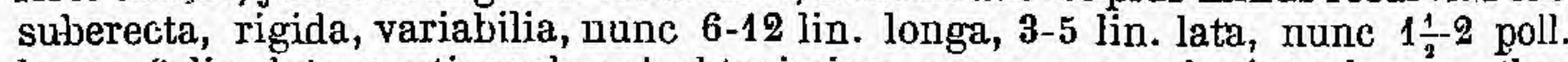
longa, 3 lin. lata, acutiuscula vel obtusissima cum mucronulo, interdum spathulata, margine angustissime vel latius refracto subtus plus minus concava vel immo subcanaliculata, rarius plana. supra quandoque minute puncticulata, attamen tactu haud scabra. Racemi fasciculiformes, pedicellis 1-1 $\frac{1}{2}$ lin. longis. Calyx cylindricus, puiniceus, subferrugineo-sericeus, limbo globoso incurvo tubo quadruplo breviore diu clauso. Ovarii stipes fere 1 lin. longus. Folliculus ovato-oblongus, semipollicaris, stylo toto persistente caudatus, levis. (v. s. in herb. Brown, Smith, etc.)

49. G, ou B I A (R. Brown! 1. c. p.169 et 376), folì șubpollicaribus lanceolatis oblongisve acutis mucronatis subeveniis margine acute refractis súpra lævibus glabris subtus sericeis, racemis terminalibus lateralibusque brevibus recurvis, calyce subsemipollicari sericeo-puberulo, tubo intus dense lanato, pistillo 3 -pollicari glaberrimo, stigmate laterali obliquo suborbiculari antice convexo. $\delta$ Circa Port-Jačkson (R. Brown! Sieber, n. 603! Anderson, n. 66l). - Bot. mag. t. 3798 *. Species G. puniceam inter et sericeam ambigua, observante ipso cel. auctore priori nimis aflinis, ex nostrâ sententiâ sequenti proprius accedens; ab illâ facile dignoscenda pistillo 8-9 lin. longo nunquam pollicem attingente, ovarii stipite paulo longiore 1-1 $\frac{1}{2}$ lin. longo, pedicellis calyce $\frac{1}{3}$ nec dimidio vel triplo brevioribus; a sequente jisdem notis et calyce minus dense pubescente. Folia margine sope punctato-scilbriuscula. (v. s. in herb. Brown, DG., etc.)

2. G. SERICEA (R. Brown! ]. c. p. 170 et 376), foliis subpolliearibus ovalibus oblongls lanceolatisve, obtusis acutisve mucronatis subeveniis margine acute 
refractis supra levibus glabris sublus sericeis, racemis terminalibus lateralibus; que brevibus recurvis, calyce vix semipollicari dense sericeo, tulo intus inferne breve barbato, pistillo semipollicari glaberrimo, stigmate laterali late ovali. J Girca Port-Jackson (R. Brown! A. Cunn.! Sieber, n. 38! Mitchell! exped. 1836). Embothrium sericeum $\alpha$ Smith! Nov.-Holl. p. 29, t. 9, f. 1-4, Andr. Bot. repos. t. 100 , Bot. mag. t. 862 . E. cytisoides Cav. ic. 4, p. 60 , t. 386 , f. 2 . E. cinereum Thibaud! in herb. DC. Iysanthe sericea et cytisifolia Knight et Salis》. Prot. p. 118, 119. Folia omniuo-fere G. punicea et similiter variabilia, sed plerumque minora, $\frac{1}{2}-1$ poll. longa, ramuli floriferi erecti, apice tantum recurvi, Llores $\frac{1}{3}$ minores et jrasentim pistillum fere dimidio brevius. Pedicelli 1-1 $\frac{1}{2}$ lin. longi. Ovarium stipite suo 1 lin. longo sublongius. Folliculus semipollicaris, oblongus, subventricosus, ecostatus, granulatus, stylo toto caudatus, stipite 1 lin. longo crasso. (v. s. in herb. Brown., Smith, etc.)

21. G. DrF Fu A (Sieber ! herb. fl. Novi.-Holl. n. 36), ramulis tereti-filiformibus tomentellis, foliis patentibus subpollicaribus linearibus utrinque attenuatis mucronulatis vix rigidulis eveniis margine angustissime recurvis vel subrefractis sulstus sericeis, racemis breve peduncnlatis reeurvis brevissimis, calyce sulssessili parvo sericeo recto intus infra medium breve barbato, pistillo parum longiore glaberrimo, stylo črassiusculo, stigmate laterali pvali. t Circa Port-Jackson (Caley! Sieber, n. 36!). - Roem. et Schult. syst. mant. p. 279 *, R. Brown! suppl. p. 17. Fruticulus patenti-ramosissimus, laxe foliosus. Folia 5-12 lin. langa, 1-1 $\frac{1}{2}$ lin. lata, acuta vel obtusa, subtus pube densât fulvâ vel ferrugineâ sericea, supra læevia glabra. Ramuli floriferi recurvi, racemis cum pedunculo circ. semipollicaribus densífloris. Calyx 3-4 lin. longus, extus demum glabrescens, ruber? limbo globoso recto. Pistillum 4-5 lin. longum, ovario stipitem requante. (v. $s$. in herb). Browin., etc.)

22. G. LINEARIS (R. Brown ! in Linn. Trans. 10, p. 170, prodr. p. 376), ramulis acule angulatis glabratis, foliis, subbipollicaribus linearibus acutis margine recurvis vel angustissime refractis licvibus supra glabris subtus sericeis, racemis axillaribus terminalibusque erectis brevibus subsecundis, calyce parvo sericeo, tubo pedicellum àquante intus dense barbato, pistillo breve exscrto glaberrimo, ovario stipite suo vix longiore, stigmate obliquo: J Circa Port-Jackson (R. Brown! Sieber, n. 30, Anderson l). - Bot. cab, t. 858, Roem. el Schult. syst. 3, mant. 1. 277", Bot. mag. t. 2661. Embothrium linearifolium Cav. ic. 4, p. 59, t. 386, 1. 1. E. cytisoides $\beta$ Cav. descr. p. 64. E. lineare Andr. repos. t. 272. E. sericeum $\gamma$ angustifolium Smith! New-Holl. p. 27, t. 9, f. 6. Lysanthe linariæfolia 'Knight et Salisb. Prot. p. 119. Rami graciles, laxe foliosi, glabri, ramulis filiformibus'apice triquetris vel subancipitibus, novellis parce adpresso-puberulis. Folia patula, vix coriacea, 1-1 $\frac{1}{2}$ raro $2 \frac{1}{2}$ poll. longa, 1-2 lin. lata, utrinque attenuata vel rarius apice obtusiuscula, mucronulata, 1 -nervia, subevenia, excepto margine plana, subtrs pilis adpressis plus minus ferrugineo-sericea. Pedunculi terminales vel axillares basi. foliosi, 6-12 lin. longi, cum pedicellis 2-3 lin. longis bracteis linearibus parvulis

- calyce foliisque novellis parce fulvo-sericeis. Caly 3 lin. longus, limbo globoso inflexo diu clauso, tubo intus infra medium dense barbato. Pistillum 4-5.lin. longum, stigmate convexo. (v. s. in herb. Brown., Smith, etc.)

23. G. STUA R'T II (Meisn. in Linnæeà 26, 1853, p. 357), ramulis gracillímis teretibus subsericeo-tomentellis, foliis herbaceis subbipollicaribus linearibus acutis pungenti-mucronatis margine leviter recurvis subtus sericeis, racemis axillaribus folio brevioribus umbelliformibus pedunculo paucifolio cum pedicellis floribusque æquilongis sericeo, pistillo calycem dimidio superante glaberrimo, ovario stipite suo longiore, stigmate terminali obliquo. $\mathrm{F}$ In Tasmanniẩ (Stuart l). G. amplifica Ferd. Müller! mss. in herb. Ommia fere G. Linearis, sed vix mera var. Differt præcipue ramulis haud angulatis, foliis planis vel leviter margine recurvis nec unquam refractis, sæpius supra obsolete trinerviis, nervis lateralibus margini approximatis, floribus paulo minoribus, stigmate umbonato, etc. (r. s. comm. a cl. Sonder.)

24. G. RIPARIA (R. Brown / 1. c. p. 170 et 377), ramulis acute angulatis glabris, foliis 13 -pollicaribus linearibus acutis mucronatis margine arcte refractis levibus supra glabris subtus sericeis, racemis axillaribus terminalibusique umbelliformibus subnutantibus subsecundis, calyee parvo sericeo, tubo pedicellum æquante intus 
dense barbato, pistillo breve exserto glaberrimo, ovario stipite suo peulo breviore. $\bar{J}$ Circa Port-Jackson (R. Brown ! Sieber, n. 30! A. Cunningh:! Anderson! Lhotsky! etc.). G. linearis Sieber! herb. fl. Nov.-Holl. n. 30, Roem. et Schüt. syst. mant. 3, p. $277^{*}$, Endl. iconogr. t. 33 (peccans stylo apice pilosiusculo). Forsan mere varietas $G$. linearis, ægre distinguenda ramis firmioribus, foliis strictioribus margine distinctius refractis, etc. Variat $1^{\circ}$ foliis abbreviatis latiusculis $1 \frac{1}{2}$ poll. longis, 1 $\frac{1}{2}-2 \frac{1}{2}$ lin. latis (Sieber! Anderson! Lhotsky!), forma cum G. lineari fere confluens, foliorum margine refracto angusto; $2^{\circ}$ foliis anguste linearibus strictissimis louge attenuatis $2-4$ poll. longis, $1.1 \frac{1}{1}$ lin. latis, margine refracto latiore (R. Brown ! in herb. DC, Anderson, n. 7!); $3^{\circ}$ foliis angustissimis 1-2 poll. longis, $\frac{1}{\mathrm{~S}} \mathrm{1}$ lin. latis, vix rigidulis subtus demum glabris. G. riparia A. Gunn. in herb. (v. $\mathrm{S}$. in herb. Brown., DC., etc.)

25. G. StRicta (R. Brownll.c. p. 170 et 377), foliis lanceolato-linearibus acutis mucronatis marginibus refractis costâque denticulato-scabris, stylo apice sericeo. 万 Circa Port-Jackson (R. Brown l). Excepto habitu stricto rigidiore et foliis margine scabris omnia fere G. linearis. (v. s. in herb. Brown.)

26. G. ENDL I G ERIANa (Meisn. in pl. Preiss. 1, p. 546), ramis gracilibus angulatosulcatis glabris, foliịs elóngato-linearibus lanceolatísve planis utrinque sericeis obsolete nervoso-marginatis vel inferioribus 3-nerviis, racemis axillaribus termirıalibusque brevibus densis apicifloris, calyce parvo pedicellum subæquante glabro intus barbato, sepalis mox liberis, pistillo longe exserto stipitato glabro, stigmate laterali ovali. 5 In mont. Darling's Range, coloniæe Swan River (Preiss, n. 6981). Frutex 7-pedalis, ramis paucis elongatis laxe foliosis, junioribus sericeis. Folia 2-4 poll. longa, 1-3 lin. lata, vix coriacea. Racemi vix pollicares, subsessiles, ('ircum circa dense multiflori, rhachi sericeâ, pedicellis capillaribus glabris, bracteis parvulis caducis. Calyx incarnatus, 2 lin. longus, incurvus. Glandıla hypogyna conspicua. Pistillum 5-6 lin. longum. (v. s.)

27. G. GAP I TEL L A TA (Meisn. in Hook. Journ..1852, p. 187), ramis virgatis ramulisque teretibus villoso-tomentosis, foliis patentibus rigidis sesquipollicaribus lanceolatis venosis mucronatis basi attenuatis margine latiuscule refracto vel revoluto scabriusculis subtus sericeis, racemis lateralibus capituliformibus breve pedunculatis recurvis densifloris, calyce subsessili parvo sericeo apice inflexo intus breve barbato pistillum glaberrimum subæquante, stigmate laterali ovali. 亏 Circa Port-Jackson (A. Cunningh.!). G. diffusa A. Gunn.! mss. in herb. (non Sieber). Species habitu stricto, rigido, foliisque ad G. oleoidem, floribus vero ad G. diflusam valde accedens, ab utrâque certe distincta. Folia 12-18 lin. longa, 3-5 lin: lata, obtusa vel acuta, supra lævia glabra, margine $\frac{1}{4}-\frac{1}{3}$ lin. lato refracto vel recurvo, sed paginæ inferiori haud adpresso. Ramuli floriferi recti. Calyx 3-4 lin. longus, limbo globoso incurvo tarde erecto. Pistillum 4 lin. longum, breve stipitatum, stylo tenuiore quam G. diffusæ. (v. s. in herb. DC. et Mart.)

98. G. OB TU SIF OLIA (Meisn. in Hook. Journ. 1852, p. 187), ramis gracilibus ramulisque tomentellis, foliis patulis sessilibus subherbaceis pollicaribus 'spathulatolinearibus rotundato-oblusis mucronulatis 1-nerviis eveniis margine anguste revolutis subtus sericeis, racemis lateralibus brevibus subrecurvis secundifloris, calyce parvo cum pedicello dimidio breviore rhachique glabro intus cano-puberulo, pistillo pollicari glaberrimo, stylo tenui, stigmate laterali ovali convexo. $\bar{\zeta}$ In coloniâ Swan River (Drummond coll. 4, n. 278!). Ramosissima, ramulis tenuibus apice angulatis. Folia conferta, modice coriacea, 8-14 lin. longa; 1-2 lin. lata, basi attenuata, mucronulo minuto obtusiusculo, margine recurvo nec refracto, supra plana vel convexa lævia glabra, subtus pube minutâ adpressâ fulvo-sericea. Rảmuli floriferi 1-1 $\frac{1}{2}$ poll. longi, recurvo-patentes. Calyx 3-4 lin. longus, fere rectus, basi rotundatus, demum 4-partitus. Pistillum 12-14 lin. longum; ovarium cernuum, basi antice gibbum, sursum sensim attennatum, stipite suo 2 in. longo pedicellum æquante longius. Folliculus oblongus, subventricosus, 5-6 lin. longus, utrinque attenuatus, castaneus, lævis, obsolete costatus, cum stylo recto toto persistente sesquipollicaris, tenue crustaceus. Affinis hine G. diffusæ ot paucifloræ, inde G. lineari, sed abunde distincta. (v. s.)

29. G. PAUCIFL ORA (R. Brown! in Linn. Trans. p. 171, prodr. p. 377), ramulis teretibus tomentellis, foliis semipatulis polliearibus linearibus obtusis mucronulatis basi attennatis subeveniis lævibus planis vel margine angustissime recurvis 
GREVILLEA. PROTEACE

subtus subsericeis mox glaberrimis, fasciculis lateralibus 2-4-floris subsessilibus erectis, calyce parvo tenui paree puberulo mox glabro apice incurvo pistillum subsequante. $\%$ Circa Port-Lincoln, oræ meridionalis (R. Brown!). Rami graciles, tenues, laxiuseule foliosi, juniores cano-subsericei. Folia parum rigidula, subspathulata, 1-1 $\frac{1}{2}$ poll. longa, 2-2 $\frac{1}{2}$ lin. lata. Pedicelli axillares sæpius gemini, tenues, 1-1 $\frac{1}{2}$ lin. longi, pube minutà persistente canescentes. Calyx 3-4 lin. longus, basi atienuatus, junior parce puberulus, tubo mox glabrato. (v. s. in herb. Brown. et DC.)

30. G. A R G YROPHYL LA (Meisn. in Hook. Journ. 1855, p. 75), ramulis apice angulatis subsericeo-tomentellis, foliis cuneàto-oblongis obcordato-bilobis penninerviis margine angustissime recurvis supra glabriusculis subtus cano-sericeis, racemis axillaribus terminalibusque capituliformibus folio brevioribus, calyce parvulo sericeo pistillo glaberrimo subduplo superato, stigmate terminali oblique truncato. $\bar{J}$ In Novâ-Holl. occid. interiore (Drumm. coll. .6, n. 179!). Rami graciles, erecti, corymbosi vel fastigiati, teretes, glabrescentes, juniores cano-tomentelli subsericei sulcati apice angulati. Folia erecta vel semipatula, subsessilia, rigida, 1-1 $\frac{1}{2}$ poll. longa, apice 4-6 lin. lata, apice inciso-biloba, sinu angusto subrecurvomucronulato, lobis obtusis mutieis 1-3 lin. longis, $1 \frac{1}{2}-2$ lin. latis. Racemi circ. $\frac{3}{4}$ poll. longi densiflori albido-sericei, pedunculo tenui, pedicellis vix 1 lin. longis. Calyx $1 \frac{1}{2}$ lin. longus parce adpresso-pilosiusculus, demum glabrescens, limbo globoso incurvo. Pistillum 2-3 lin. longum, stipitatum, tenue, stigmate subrotundo vix umbonato-convexo. Obs. Sub eodem numero exstat specimen sterile, ramulis et pubescentiâ fertilibus conveniens, sed egregie discrepans foliis omnibus linearibus vel anguste lanceolatis integerrimis utrinque attenuatis acutis 1-2 poll. longis, 1-3 $\frac{1}{2}$ lin. latis, junioribus sericeo-splendentibus. An var.? an species distincta? (v. s. in herb. Shuttleworth.)

31. G. BAUER I (R. Brown ! in Linn. Trans. 10, p. 172, prodr. p. 378, suppl. p. 19), ramulis teretibus puberulis, foliis patulis subherbaceis oblongis ovalibusve obtusis vel retusis mucronulatis basi vix attenuatis planis venosis mox glabris margine scabriusculis, racemis terminalibus lateralibusque subsessilibus fasciculiformibus, calyce semipollicari inflato incurvo pedicelloque tenui glabro intus infra medium barbato. pistillo superato, ovario sessili styloque hirsuto, stigmate laterali ovali. J Circa Port-Jacksson et in mont. cœruleis. Folia 6-14 lin. longa, 2-5 lin. lata, levia, vix rigida, interdum acutiuscula, passim mutica. Pedicelli glabri nunc calycem subæquantes, nunc dimidio breviores. Flores pallide virescenti-lutei, interdum erubescentes. Pistillum 9 lin. longum, carneum, stigmate plano viridi. (v. s. in herb. Brown., etc.)

a. pubescens, foliis junioribus semper et adultis sæepius supra pubescentibus.R. Brown suppl. p. 19. G. pubescens Hook. exot. fl. t. 216, Grah. in Edinb. Phil. Journ. 1826, p. 172 ? Roem. et Schult. syst. 3, mant. p. 378 *, Spreng. cur. post. p. 46, Bot. cab. t. 1229 . (v. v. c.)

B. glabra, foliis junioribus adultisque utrinque glaberrimis.-R. Br. l. c. G. daphnoides Sieber herb. fl. Nov.-Holl. n. 25! Roem. et Schult. syst. 3, mant. p. 281" G. myrtillifolia A. Cunn.! mss. in herb. (v. s. in herb. Cunningh., etc.)

b. Myrtilloidec. - Folia latiuscula ovata elliptica vel lanceolata, plana vel margine recurva vel revoluta (nec refracta), supra punctato-scabriuscula, subtus vel utrinque cano-pubescentia vel sericea. Racemi terminales vel laterales breves recurvi vel fasciculi axillares subsessiles pauciflori. Calyx mediocris vel parvus, incurvus, pubescens, raro glabriusculus. Stylus sapius pubescens. Stigma laterale. Ovarium sessile, rarissime stipitatum.

32. G. MUGRONULATA (R. Brown! in Linn. Trans. 10, p. 173, prodr. p. 378), ramis puberulis, foliis patulis subherbaceis pollice brevioribus obovatis obtusis apiculatis tenuiter venosis margine vix recurvis supra scabriusculis glabris subtus adpresse pilosiusculis, racemis terminalibus umbelliformibus paucifloris subrecurvis, calyce subsemipollicari tumidulo utrinque obtusissimo glabriusculo intus basi barbato pistillum subiequanté, ovario sessili villoso, stylo pilosiusculo, stigmate suborbiculari plano. J Circa Port-Jackson (R. Brown! Gaudich.l). — Sweet 1. 
Austral. 1. 38. Lysanthe podalyriæfolia Knight et Salisb. Prot: p. 117. Rami teretés, laxiuscule foliosi. Folia 3-8 lin. longa, 2-4 lin. lata, vix rigidula, abrupte mucronato-aouminata, supra minutissime punctato-scabriuscula, subtus parce pilosiuscula. Pedunculus 3-8 lin. longus, demum glaber, pedicellis 2 lin. longis tenuibus. Calyx (ex ic. viridis) 5-6 lin. longus, basi inflato-rotundatus, junior rectus dense sericeus; deinde incurvus et excepto limbo fere glaber. Stylus (ex ic.) purpureus, stigmate viridi. (v.'s. in herb. Brown et DG., et v. s. c.)

33. G. cINEREA (R. Brown! 1. c. p. 173 et 378 ), ramulis breve villosis, foliis patulis rigidulis pollicaribus oblongo- $v e l$ obovato-lanceolatis acutis mucronatis margine recurvi's supra vènosis junctato-scabriusculis puberulis glabratisve subtus villosotomentosis subsericeo-ferrugineis, racemis terminalibus brevibus recurvis laxe paucifloris rufo-villosiusculis, calyce semipollicari subinflato glabrescente utrinque obtusissimo, pistillo pollicari, ovario sessili villoso, stylo hirśuto, stigmate obovato planiusculo. ‡ Girca Port-Jackson (R. Brown! Anderson, n. 4!' Síeber! n. 579! et ex parte 39!). - Lodd. Bot. cab. t. 857. Ramuli graciles, teretes, 'laxiuscule foliosi; pube brevi patulâ molli tarde deciduâ dense villosiusculi. Folia 9-16 lin. longa, 3-4- rarius 6 lin. lata, utrincuo attenuata, subpetiolata, supra interdum satis scabra. Racemi breve pedunculati, 6-9 lin,, pedicelli $1 \frac{4}{2}$ lin. longi. Calyx virescens, incurvus, 6-7 lin. longus, $1 \frac{1}{3}$ lin. latus, límbo globoso. Pistillum 11-12 lín. longum, rufo-hirsutum, stigmate 1 lin. longo. (v'. s. in herb. Brown., DC., etc.)

B. myrtacea, foliis semipollicaribus ovatis ovalibusve acuminato-acutis mucronátis supra magis scabris. - Girct Port-Jackson (Sieber, n. 39! ex parto, A. Cunn.l). G. mprtacea Sieber! herb: fl. Nov.-Holl. n. 39, Roem. et Schult. syst. mant. 3 , p. $280^{*}$, B. Brown! suppl. p. 19. G. acuminata A. Cinningh.'! mss. in herb. (nec? R. Br.). Admodun similis G. mucrontatate; sed pistillo constanter longiore, etc., bene distinctà. Specimina Sieberiana nonnúlla cum G. cinereâ genuina exacte congruunt, alia hanc inter et G. myrtaceam ambigua, in eodem srepe ramo folia majora et minora ovata oblonga et lanceolata ostendunt, ita ut stirps 'Sieberiana vix tanquam varietas ab illâ separari possit. (v. s.)

34. G. A C U mín a T A (R. Brown ! 1. c. p. 173 et 378), ramulis breve villosiusculis, foliis patulis irgidis subpollicaribus lanceolatis longiuscule attenuato-acuminatis mucronatis subeveniis margine recurvis' supra punctato-scabris glabris subtus breve villosiusculis fulvo-subsericeis, racemis terminalibus lateralibusque brevibus paucifloris lanato-tomentosis, calyce parvo mutico pistillum sessile hirsutum subæquante, stigmate suborbiculari. F Circa Port-Jackson (R. Brown) et in montibus, ad Bul'ga road, versus Hunters River (A. Gunn. n. 33!). - Sweet fl. Austr. t. 55. G. attenuata A. Cunningh.l mss. in herb. Meisn., in pl. Preiss. . 1, p. 538 *, in notâ. Forsan G. cinerea var.? recedens tantum foliis constanter lanceolatis vix pollicem attingentibus, 2 $2 \frac{1}{2}-3 \frac{1}{2}$ lin. latis (ex Sweet 1. c. 3-5 lin.), apicem versus longius acuminatis magisque scabris, pube subtus breviore subadpressât et calyce vix 4 lin. longo. Flores ex Br. demum glabriusculi, ex Cunn. demum lanati. (v. s. in herb. Brown, DG., Gunn.)

35. G. MONTANA (R. Brown! 1. c. p. 172 et 378), ramulis tomentellis, folíis patulis rigidulis subpollicaribus lanceolatis muoronulatis basi attenuatis margine recurvis revolutisve subeveniis supra læviusculis glabris subtus sericeís, fasciculis terminalibus lateralibusque subsessilibus nutantibus subbifloris, calyce subsemipollicari reclo utrinque attenuato pedicelloque subrquilongo puberulo, pistillo sessili hirsuto superato, stigmate laterali ovali obtuse umbonato. $\bar{F}$ Circa Port-Jackson (R. B́rown l), in mont. Cœruleis et àd Bulga road (A. Cunn.n. 32 ! Hïgel !). G. uniflora A. Cunn. mss. in' herb. Ramuli graciles, teretes, laxiuscule foliosi. Folia 8-1.2 lin. longa, 2-4 lin. lata, acutiuscula cum mucronulo innocus sphacelato, subtus fulvosericea, supra subnitida dense puncticulata et tactu vix scabriuscula. Pedicelli erecti, 4-5 lin. longi, tenues puberuli (ex Br. glabri). Calyx cylindraceus rectus, demum glabrescens, laminis breviter subacuminatis. Pistillum 8-9 lin. longum, laxiuseule pilosum. (v. s. ill. herb. Brown., Gunn., Mart., etc.)

36. G. ARENAA I A (R. Brown! l.c. p. 172 et 378), ramulis tomentellis, folis patulis subrigidulis pollicaríbus oblongo-lanceolatis obtusis mucronulatis margine subrecurvis supra puberulis venosis læviusculis subtus sericeis, racemis terminalibus lateralibusque subsessilibus paucifloris recurvis sericeo-tomentosis, calyce pedi- 
GRevillea. PROTEACE $A$ (adctor MEISNER).

cello pluries longiore semipollicari incurv̄n breviter acuminato, pistíllo pollicari sessili tomentoso, stigmate ovali subconvexo. F Ad flum. Napean, circa Port-Jackson (R. Brown! Hügel $\downarrow$ ), in distr. Argyle (Mac Arthur, n. 133!).-Bot. mag. t. 3285. Lysanthe cana Knight et Salisb. Prot. p..117. Præcedenti similis, sed inflorescentia diversa et folia majora, plerumque pollice longiora, 10-16 lin. longa, 2-5 lin. lata, basi minus attenuata, læviora, juniora undique sericea. Racemi semipollicares subsessiles laxe 4-6-flori, pedicellis 1 lin. longis. Calyx junior rectus, deinde valde incurvus, subinflatus, basi rotundatus, apice acutatus. Ovarium pube longiore sericeum. Stigma 1 lin. longum. (y. s. in herb. Brown, Lindl., Mart. et v. c.)

37. G. FER RUGINEA (Sieber ! herb. fl. Nov.-Holl. n. 27), ramulis villosiusculis, foliis patulis subcoriaceis pollicaribus lanceolatis oblongisve obtusis apiculatis basi attenuatis margine leviter recurvis supra tenuiter venosis læviusculis puberulis glabratisve subtus adpresse sericeo-villosis ferrugineis, racemis lateralibus brevissimis paucifloris cano-tomentosis, calyce pollice breviore incurvo basi attenuato, limbo inflato longe ácuminato, pistillo pollicari, ovario sessili villoso, stylo patulo piloso, stigmate planiusculo. J Circa Port-Jackson (Sieber, n. 27!). - Roem. et Schult. syst. mant. 3, p. $280^{*}$, R. Brown I suppl. p. 19. Præcedentibus arete affinis, calyce præsertim distincta. Folía penitus fere $\mathrm{G}$. arenariæ. Racemi sessiles.

- Pedicelli 1-2 lin. longi. Galyx 9-10 lin. longus, junior rectus, deinde valde arcuatoinflexus, supra medium coniens dilatatus, laminis in acumen lineare 2 lin. longum sensim attemuatis. (v. s.)

38. G. CANESGENS (R. Brown! suppl. p. 18), ramulis tomentosis, foliis patentibus rigidulis pollicaribus obovato-oblongis obtusis apiculatis margine recurvis supra lævibus subeveniis incanis demum glabrescentibus subtus incano-velutinis, racemis terminalibus brevibus recurvis densifloris tomentosis, calyce semipollicari subinflato basi rotundato, limbo incurvo acuminato, pistillo pollicari sessili tomentoso, stigmate ovali. 5 Circa Port-Jackson, in mont. Coruleis, et ad Macquarie et Cox River (A. Cunn.I). - Bot. mag. t. 3185. G. cinerea A. Cunningh.! in Field N. S.Wales, p. 329 (non R. Br.). Folia 8-15 lin. longa, 3-5 lin. lata, basi attenuata, ex apice rotundatc obtuse mucronulata, supra cana vel demum glabrata, subtus pube molli patulâ den'se fulvo-tomentosâ, nec serícea. Racemi subsessiles, semipollicares, pedicellis 2-3 lin. longis. Calyx 5-6 lin. longus, junior rectus, deinde valde incurvus, pube lơngiore tomenloso-villosiusculus; intus pubescens, laminarum acumine 1 lin. longo. Ovarium brevivillosum, stylo dense incano-tomentoso, stigmate 1 lin. longo. (v. s. in herb. Brown., Cunn., etc., et v. s. c.)

39. G. OBTUSIFLORÁ (R. Brown! suppl. p. 19), ramulis tomentosis, foliis confertis subpollicaribus lanceolato-linearibus obtusiusculis mucronulatis margine revolutis supra punctato-scabriusculis mox glabrescentibus nitidis subtus canaliculatis sericeis, calyce pistillum subsemipollicare subæquante laminis abtusis, ovario sessili villoso, stylo toto pilosiusculo, stigmate late ovali. J Prope Bathurst A. Cunningh.! herb: propr: n. 197 !) Habitu similis G. australi, sed omni parte major et inflorescentia diversa. Ramosissima, ramulis teretibus dense foliosis. Folia patula, rigida, crassiuscula, 8-12 lin. lónga, 1-2 lin. lata, basi attenuata, supra convexa, evenia, puberula, mucronulo innocuo subrecurvo sæpe deciduo. (v. s. in herb. Brown et Cunn.)

40. G. AUSTRAlIs (R. Brown! in Linn. Trans. 10, p. 171, prodr. p. 377), ramosissima, ramulis tomentosis, foliis confertis ${ }_{3}^{-1}-1$ pollicaribus oblongis lanceblatis subulatisve acutis mucronatis margine recurvis revolutisve supra levibus pilosiusculis glabrisve subtus sericeis, fasciculis axillaribus terminalibusque paucifloris, calyce parvulo sericeo pistillum subsessile glaberrimum subæquante; stig. mate suborbiculari convexo. $f$ In ins. Diemen, circa Launceston, New Norfolk, Marlboroughi, Hampshire Hills, Western mountains, South Esk, etc. (R. Browp.l Gunn-! J. D. Hook.), var. $\zeta$ etiàm in Australiâ merid. in montibus Barossá et Gabboros, alt. 6,000 ped. (Ferd. Müller!). - Hook. fil. in Hook. Lond. Journ. 6, p. 282. Ramosissima, humilis. Ramuli juniores subsericei. Folia patula, rigida, 3-12 lin. longa, juniora parce adpresso-pilosa. Fasciculi folio breviores, sessiles. Pedicelli vix 1 lin. longi. Calyx 2 lin. longus, sericeus, tenuis, intus glaberrimus, limbo globoso incurvo. Stylus 3 lin. longus, demum rectus. Stigma umbonato-convexum. Folliculus 3-4 lin. longus, ovatus, levis, utrinque acutus, stylo toto persistente paulo longior.

a, planifolia (Hook. fil. l. c. y), ramis erectis conferte foliosis, folis obovato- vel 
lanceolato- vel lineari-oblongis subplanis vel margine leviter recurvis (Gunn, n. 535 l). Folia 5-9 lin: longa, 1-2 lin. Iata: (v.s.)

B. brevifolia (Hook. fil. I. c. $\varepsilon$ ), depressa, dense foliosa, foliis parvulis lineari- vel obovato-oblongis margine leviter recurvis vel subplanis (Gunn, n. 1260!). Folia $2 \frac{1}{2}-\frac{1}{1}$ lin. longa, $\frac{1}{2}-1$ lin. lata. (v. s.)

$\gamma$ montana (Hook. fl. l. c. $\delta$ ), depressa, dense foliosa, foliis brevibus linearilanceolatis (Gunn, n. 199!). Forma cum precedente confluens. (v. s.)

§. erecta (Hook. fil. l. c. a), ramis erectis laxiuscule foliosis, foliis lanceolatis vel lineari-subulatis margine revolutis subtus subcanaliculatis (Gunn, n. 730!). Folia 3-6 lin. longa, $\frac{1}{2} \cdot 1$ lin. lata. (v. s.)

2. linearifolia (Hook. fil. 1. c. $\beta$ ), ramis erectis laxiuscule foliosis, foliis anguste linearibus margine revolutis subtus canaliculatis (Gunn, n. 534! ex parte). Fólia 5-10 lin. longa, $\frac{1}{2}-1$ lin. lata. (v. s.)

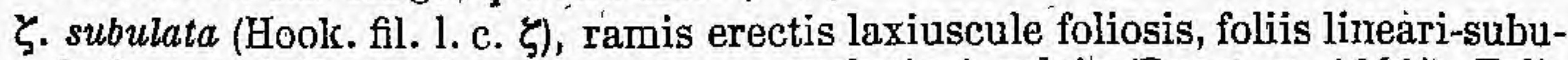
latis marginibus ad costam usque revolutis 1 -sulcis (Gunn, n, 1240!). Folia 3-5 lin. longa, $\frac{1}{2}-\frac{2}{3}$ lin. lata. (v. s.)

n. tenuifolia, ramulis erectis dense foliosis, foliis subpollicaribus filiformi-subulatis acutissimis glabris subtus 1 -sulcis, calycis tubo intus inferne barbellato. - In Tasmanniâ, circa Port-Dalrymple, Launceston, etc. - R. Brown! Gunn, n. 534! ex parte, Stuart! G. tenuifolia R. Brown! in Linu. Trans. 10, p. 171, prodr. p. 377. Folia 8-12 lin. longa, $\frac{1}{4}-\frac{1}{3}$ lin. lata, vix rigidula, mucronata, sæpius incurvo-arcuata, teretia, marginibus revolutis' plerumque contiguis subtus 1 -sulca vel rarius haud contiguis canaliculata. Calyx fulvo-sericeus. Glandula hypogyna semiannularis vel conspicua. Formá a var. planifoliis $\alpha-\gamma$ valde quidem discrepans, sed formis intermediis, præsertim $\varepsilon$ et $\zeta$; arctissime cum iisdem connexa nulloque charactere stabili specifice separanda. (v. s. in herb. Brown., Sonder.)

41. G. Meisneriana (Ferd. Müll.! in Linnæâ 26, p. 357, sub G. asperâ), foliis pollicaribus linearibus obtusis marginibus arcte revolutis subtus canaliculatis sericeis supra enerviis ramillisque minute subsericeo-pilosiusculis, racemis axilfaribus brevissimis fasciculiformibus, pedicellis flore parum brevioribus, calyce pistillum æquante styloque ferrugineo-piloso, ovario subsessili albo-villoso, stigmate cochleariformi. $\not \supset$ In promont. Cape Riche, oræ occid.-australis (Preiss, n. 712!). G. aspera! $\beta$ linearis Meisn.! in pl. Preiss. 1, p. 537. Rami laxe foliosi. Folia patula, sessilia, rigidula, mucronulata vel submutica. Calyx circ. 3 lin. longus, incurvus, pistillo paulo longiore, intus ad faucem albo-barbatus. Differt a sequente foliis angustioribus, margine magis revolutis, supra enerviis pubescentibus vel tarde glabrescentibùs punctis nonnisi minutissimis leviter scabriusculis, inflorescentiâ, calyce fére $\frac{1}{3}$ breviore, stylo piloso, stigmate minore. (v. s.)

42. G. ASPER A (R. Brown l in Linn. Trans. 10, p. 175, prodr. p. 377), ramulis incano-tomentosis, foliis 1-2-pollicaribus lanceolatis linearibusque utrinque obtu-sis sphacelato-mueronatis margine recurvis revolutisve supra penninerviis glabris punctato-scabris subtus sericeis, racemis axillaribus folio brevioribus recurvis ferrugineo-pubescentibus, pedicellis calyce pistillum glabrum stipitatum æquante dimidio brevioribus, stigmate cochleariformi. $尹$ In orẩ meridionali, Flinders Land (R. Brown I), Port-Lincoln (Ferd. Müller !). Folia rigida, usque ad $2 \frac{1}{2}$ poll. longa, 2-4 lin. lata, breve petiolata, subtus argenteo- vel fulvo-sericea. Racemi circ. pollicares. Calyx 4-5 lin. longus, subventricosus, limbo globoso inflexo, tubi basi ovarii stipiti tenui adnato tamen non obliquo. Stylus brevis crassus. Proxima præcedenti, nec non valde accedens ad G. fasciculatam, sed jam foliis nervosis et pistillo toto glabro facile dignoscenda. (v.s. in herb. Brown et comm. a cil. Sonder).

43. G. A L P I A (Lindl.! in Mitchell exped. London 1839, ex Ann. des sc. nat. 1841, 15, p. 62), foliis linearibus lanceolatisve obtusis muticis margine revolutis eveniis supra punctato-scabriusculis glabriusculis subtis ramulisque adpresse pilosis, racemis terminalibus fasciculiformibus ereetis paucifloris ferrugineo-tomentosis, calycis pistillum semipollicare subrequantis limbo acuto, ovario sessili albidovilloso, stylo dense rufo-hirsuto, stigmate subrotundo planiusculo. $\delta$ In monte William alpium Australiæ Folieis (A. Cunningh. I in Mitch. exped. 1835-36, Ferd. Müll.!). G. alpina $\alpha$ Lindl.! 1. c. (excl. $\beta$ ). G. oreophila Ferd. Müll. first gen. report, p. 17. Erecta, ramulis strictis teretibus laxiuscule foliosis subsericeo-puberulis. 


\section{grevillea. PROTEACEÆ (auctor MEISNER).}

Folia patula, rigidula, supra convexa et plus minus scabra, nune 6 lin. longa, 1-1 $\frac{1}{2}$ lin. lata, marginibus valde revolutis, subcontiguis, subtus canaliculata vel 1 -sulca, nuuc fere pollicaria, 3 lin. lata, marginibus minus revolutis, supra puberula vel glabrata. Racemi sessiles, brevissimi. Calyx pedicello duplo longior, 4-6 lin. longus, incurvus, subinflatus, basi rotundatus, limbo subacuminato. Pistillum 6-7 lin. longum. Species cum sequente forsan potius ad sect. Eriostylin removenda. (v. s. in herb. Lindl. et comm. a cl. Sond.)

44. G. LL P E T R IS (Meisn. in Hook. Journ. 1852, p. 187, et Linnæâ 1853, p. 354), foliis semipollicaribus ovalibus oblongis linearibusve muticis margine recurvis vel revolutis supra convexis eveniis puberulis punctato-scabriusculis subtus ramulisque villoso-tomentosis, racemis terminalibus fasciculiformibus recurvis paucifloris ferrugineo-tomentosis, calyce pistillum semipollicare subæquante, limbo obtusissimo, ovario sessili albido-villoso, stylo dense rufo-hirsuto, stigmate subrotundo planinsculo. 5 In montibus Australia Felicis, monte William (Mitchell! exped. 1835-36), mont. Grampians, Disappointment, Dandinang, Loddan et Buffalo Range, ad Broken Goulburne et Orans River (Ferd. Müller!), locis depressis calidioribus, nec in alpestribus, ex Müll. in litt. G. alpina \& Lindl.! 1. c. G. Dallachiana Ferd. Müll.! first gen. report, p. 17. Diffusa, ramis divaricatis intricato-ramosissimis, teretibus, adultis glabris laxiusıule foliosis. Folia patentia, rigidula, 3-4- rarius 6-8 lin. longa, $\frac{2}{3}-2 \frac{1}{3}$ lin. lata, obtusiuscula, pube brevissimâ vel longiore. Cæt. omnia G. alpin:e, sed constanter distincta calyce paulo minore, sæpe vix 3-4 lin. longo, et limbo globoso nec acuto. (v. s. in herb. Lindl., Cunn. et comm. a cl. Sonder.)

$\beta$. helianthemifolia (Meisn. in Hook. Journ. 1852, p. 187), foliis subtus adpresse villoso-subsericeis, calyce parce puberulo glabrescente. - Circa Port-Phillip (Latrobe !). Folia sessilia, obovato- vel ovali-oblonga, 3-5 lin. longa, 2-3 lin. lata. Racemi laterales, breves, umbelliformes, 6-12-flori, basi foliati, patentes vel recurvi. Folliculi sessiles, stylum persistentem subæquantes, ovatooblongi, ecostati, cano-pubescentes. (v. s.)

45. G. си п Y S орнал (Ferd. Müller! mss. in herb. et first gen. report, p. 17), ramulis tomentosis, foliis pollicaribus ovali-oblongis acutiusculis submuticis margine recurvis supra nitidis obsolete venosis lævibus glabris subtus velutinotomentosis, racemis terminalibus subsessilibus umbelliformibus recurvis dense rufo-lanatis, calyce inflato basi gibbo pistillo sessili hirsuto breviter superato, stigmate late obovato convexo. F In Australiâ Felici (Ferd. Müller l). - Meisn. in Linnæâ 26, 1853, p, 357. Ramuli graciles, laxe foliosi. Folia coriacea, subsessilia, 8-14 lin. longa, 3-7 lin. lata, utrinque obtusa, nucronulo exiguo innocuo vel nullo, supra sub lente minute punctata, sed tactu haud scabra, subtus pallidiora, tomento flavescente nec albido nec fusco nec unquam sericeo. Racemi basiflori. Pistillum 10 lin. longum, ovario albido, stylo crassiusculo recto rufo-hirsuto, stigmate fere 1 lin. longo.Valde affinis G. floribundæ, sed floribus paulo majoribus, tomento pallidiore magisque flavescente, pistillo longiore et foliis, quibus præcedentibus accedit, bene distincta. (v. s. comm. a cl. Sonder).

46. G. FLORIBUNDA (R. Brown I suppl. p. 19), ramulis tomentosis, foliis subbipollicaribus spathulato-oblongis lanceolatisve obtusis mucronulatis margine recurvis supra venosis lævibus cano-puberulis tarde glabrescentibus subtus adpresse fulvosericeis, racemis terminalibus breve pedunculatis recurvis dense rufo-lanatis, calyce semipollicari inflato pistillum sessile lanatum subsuperante, stigmate late obovato planiusculo. F In collibus circa Bathurst, ad flum. Hunter (A. Cunningl.! Fraser 1 in monte Owen (Mitchell exped. 1836, n. 146!). - Hook. in Mitch. exped. 1836 , p. 212. G. autumnalis Lhotzky! m\&s. in herb. DC. Frutex laxus vel diffusus, humilis, ex Mitchell, ramulis gracilibus patulis laxe foliosis. Folia fere G. oleoidis, sed margine recurva vel revoluta nec refracta, 1-2 poll. longa, 3-6 lin. lata, supra denaum subnitida. Racemi pulchri, 1-2-pollicares, undique pube densâ patulâ subsericoà rufo-lanati, basiflori, pedicellis circ. 1 lin. longis. Calyx sueto amplior, valde curvatus, utrinque obtusissimus, tubo $2 \frac{4}{2}$ lin. lato, laminis cito sejunctis reflexis. Ovarium albido-villosum. Stylus crassus rufo-hirsutus, mox rectus, calyce haud longior. Stigma 1 lin. longum, dorso glabrum. Folliculus ventricoso-ovatus, 5 lin. longus, stylo toto persistente rostratus fulvo-lanatus, haud costatus. (v. s. in herb. Brown., Cunn., DC., Lindl. et v. s. c.) 


\section{c. Rosmarinoidece. - Folia linearia, rarius lanceolata, margine recurvo vel revoluto, plèrumque subteretia, subtus canaliculata vel 1-sulca, cano-pubescentia vel punctato-scabriuscula, raro glabra. Racemi ter- minales vel axillares, breves, recurvi, plerumque glabri.}

\section{* Calyx pubescens.}

47. G. LAVA NDULA Ge (Schlecht. ! in Linnæâ 20, p. $586^{*}$ ), folíis linearibus lanceolatis oblongisve utrinque attenuatis acutis mucronulatis margine revolutis supra demum glabratis punctato-scabriusculis subtus ramulisque cano-pubescentibus, racemis terminalibus fasciculiformibus, calyce subsemipollicari styloque parce puberulo, pistillo pollicari, ovario breve stipitato sericeo, stigmate oblićue truncato subrotundo umbonato convexo. F Circa Adelaide coloniæ Australiæ meridionalis (Behr! Ferd. Müller !). - Lemaire ill. hortic. 1855, t. 61, fide DC. Ramuli graciles, laxiuscule foliosi, apice cum foliis junioribus pedicellis calycibusque adpresse cano-puberuli. Folia patula, circ. pollicaria. Racemi suberecti, rhachi vix semipollicari vel subnullâ, pedicellis 2-3 lin. longis. Calyx. subinflatus; valde incurvus, utrincue obtusus, limbo densius pubescente, tubo glabrescente intus parce puberulo basi barbato. Pistillum demum rectum. Folliculus pubeséens, laevis. Species excepto calyce styloque pubescentibus, simillima G. rosmarinifoliæ et nutanti. (v. s.).

a. latifolia (Meisn. in linnæâ 26, p. 354), foliis ovali- vel oblongo-lancéolatis (4-5 lin. latis) supra convexis margine fortiter recurvis, facie inferiore incanâ. visibili.

ß. lanceolata (Meisn. 1. c.), foliis lanceolatis (2-3 lin. latis) planis vel margine recurvis.

$\gamma$ ? angustifolia (Meisn. l. c.), foliis anguste lanceolatis linearibusve (1 $\frac{4}{2}-2$ lin. latis) planis vel plerisque margine revoluto teretibus, facie inferiore tunc penitus absconditâ.-In Australiâ Felici, circa Barossa range et Salt creek (F. Müll.I): Forsan distincta sp., recedens stylo breviore, sed specim. nostrum insufficiens.

48. G. Rose a (Lindl. in Paxton fl. Gard. 2, 1852, n. 386, t. 56), foliis lineari-lanceolatis pungentibus margine revolutis supra subasperis subtus adpresse sericeis, fascicinlis terminalibus paucifloris, calyce sericeo stylo glaberrimo dimidio superato, ovario stipitato villoso, stigmate oblique depresso. $亏$ In Nov-Eoll..... Calyx roseus. Folliculus ovalis, mucronatus, lævis, tomentosus. Secundum cl. Henfrey ad G. lavandulaceam reducenda (cfr. Mohl et Schl. Bot. zeit. 1852, p. 787), sed differre videtur foliis subtus sericeis et præcipue stylo glaberrimo.

49. G. RA Mu OSA (Ferd. Müll.! mss. in herb.), foliis lineari-subulatis mucronatis lævibus enerviis margine arcte revoluto subtus 1 -sulcis, junioribus fasciculatis ramulisque cano-pubescentibus, racemis terminalibus folium subrquantibus paucifloris patulis basi paucifoliis, calyce subsemipollicari, tubo glabrescente limbo dense sericeo-cano, pistillo subpollicari, ovario subsessili sericeo, stylo glabro, stigmate oblique truncato subrotundo. 5 In sinu Encounter. Bay oræ australis (Stuart!). Folia patula vel recurva, rigida, subpollicaria, supra convexa, demum glabrata. Caet. G. nutantis. Forsan G. Javandulaceæ var.? ex Ferd. Müll. in litt., sed ex nostrâ sententiấ jam calyce pubescente bene distincta. (v. s. comm. a cl. Sonder.) -

50. G. sulphurea (Cunningh.! in Field N. S.Wales, p. 329), ramulis tomentósis, foliis linearibus subulatisve subpungenti-acutis margine revoluto subtus canaliculatis vel 1-sulcis utrinque glaberrimis lrevibus, racemis lateralibus brevibus subsessilibus dense multifloris, calyce semipollicari gracili puberulo, pistillo pollicari longiuscule stipitato glaberrimo, stigmate laterali subörbiculari convexo. 3 . In montibus circa Port-Jackson (A. Cunn.! Sieber, n. 28! Ańderson, n. 116! Lhotsky !). -R. Brown suppl. p. 17, Bot. cab: t. 1723. G. aciphylla Sieber! herb. fl. Nov.-Holl. n. 28. G. acifolia Spreng. cur. post. p. 46. G. acicularis Schult. in Roem. et Schult. syst. mant. 3, p. $278^{*}$. Rami graciles, erecti. Folia pseudo-fasciculata, rigidula, 6-12 lin. longa, juniora marginibus revolutis subtereti-subulata vix $\div$ lin. lata, adulta vel inferiora plus minus explanata $1-1 \frac{1}{2}$ lin. lata, mucrone tenui recto acu- 


\section{GREVILLEA. PROTEACEAE (AUCTOR MEISNER).}

tissimo. Racemi ramulos laterales foliosos terminantes folia vix superantes erecti vel demum subrecurvi, jedicellis 1-1 $\frac{1}{2}$ lin. longis. Calyx luteus, 6-7 lin. longus, inflexus, intus dense sericeo-barbatulus. Stylus rectus, validus. Ovarii stipes fere 2 lin, longus. Folliculus semi-ovatus, lævis, 3-4 lin. longus, stylo toto caudatus. (v. s, in herb. Gunn., Brown., etc., et v. c.)

51. duniperina (R. Brown $\mid$ in Linn. Trans. 10, p. 171, prodr. p. 377), ramulis pubescentibus, foliis aceroso-linearibus pungenlibus supra lovibus glabris margine angustissime refracto vel recurvo subtus canaliculatis vel 1--sulcis parce adpresso-pilosis glabratisve, racemis lateralibus terminalibusque fasciculiformibus subsẹssilibus, calyce semipollicari gracili subsericeo-pubernlo, pistillo pollice ireviore glaberrimo, stigmate laterali subrotundo subconvexo. F Circa PortJackson (Caley!-Gordon, Sieber, n. 34 ! Anderson, n. 103!). - Bot. reg. t. 1089, Bot. cab. t. 1003, Guillemin ic. lithogr.'t. 8, Roem. et Schult.' syst. mant. 3, p. 279 *. Divaricato-ramosissima, ramis patenti-pubescentibus vel villosiusculis rufis. Folia' pseudofasciculata, patentia, plerunque semipollicaria (in plantâ cultâ saltem usque ad pollicem longa) $\frac{1}{3}-\frac{2}{3}$ lin. lata, subtus fulva pílisque raris adpressissimis bicruribus conspersa vél demum glabratá. Calyx carneus (ex iconibus virescens). Nimis affinis præcedenti, sed præter notas jam indicatas pistillo breviore, circ. 10 lin. longo dignoscenda. (v. s. in herb. Brown., etc., et v. s. c.)

52. G. TRINERVIS (R. Brown suppl. p. 18), ramulis cano-tomentellis, folis acerosolinearibus rigidis mucronulato-pungentibus supra obtuse 3-nerviis lævibus glabris subtus sericeis marginibus anguste refràctis recurvisve, racemis lateralibus fasciculiformibus subnutantibus, calyce subsemipollicari subsericeo-puberulo intus dense lanato pistillo glaberrimo stipitato parum superato, stïgmate laterali ovali subconcavo. F Circa Port-Jackson (Fraser!) et in distr. Argyle (Lhotsky!). Folia patula, crassiuscula, 5-6 lin. longa, $\frac{1}{2}-1$ lin. lata. Calyx 5 lin. longus, limbo globoso inflexo diu clauso, tubo demum late hiante intus exceptấ imâ basi pube brevi patulâ dense fulvo-lanato. Pistillum 6-7 lin. longum. Cæet. fere G. juniperinæ. (v. s. in herb. Brown. et Fée.)

\section{* * Calyx extus glaberrimus, valde incurvus.}

53. G. Rosmarinifol ia (Gunningh.! in Field N. S. Wales, p. 328), ramulis canotomentellis, foliis linearibus utrinque attenuatis acutis mucronatis margine revolutis subtus sericeis supra punctato-scabriusculis junioribus puberulis, racemis terminalibus lateralibusque brevibus recurvis, pedicellis calycem subæquantibus apice dilatatis patellæeformibus, calyce semipollicari subinflato utrinque rotundato intus pilosiusculo inferne dense barbatulo, pistillo subsessili subpollicari glaberrimo, stipite ima basi antice barbellato, stigmate laterali ovali. 5 Circa Port-Jackson, in mont. coeruleis et ad Cox River (A. Cunn.! Sieber, n. 33! Gaudich.! Anderson, n. 71! 171l). - Sweet fl. Austr. t. 30, Lodd: Bot. cab. t. 1479, R. Brown! suppl. p. 20. G. riparia Sieber I herb. fi. Nov.-Holl. n. 33, Roem. et Schult. syst. mant. 3, p. 278* (non R. Br ).- Habitus G. sulphureæ. Folia 1-2 poll. longa, 1-2 lin. lata, rigidulä, supra convexa, demum lævigata. Racemi erecti vel nutantes, rhachi cum pedunculo 6-10 lin. longa. Calyx 4-5 lin. longus, puniceus vel roseus. Pistillum 10 lin. longum, rectum, stipitis basi antice constanter albo-barbellatâ. Folliculus lævis, cum stylo persistente pollicaris, oblongus. - Pedicelli apex more Eschscholtziæ paulo dilatatus nonnunquam obsolete crenatus, in hac specie et G. lanigerâ observandus a. cl. Lemaire (Ill. hortic. 1855, sub t: 61) perperam pro calyce vero, recte contra a cl. Decaisne et Planchon (Bullet. Soc. bot. Franc. 1855, p. 86) calycodis nomine pro pedicelli dilatatione habetur. (v. s. in herb. Cunn., Brown, DG., etc., et v. c.)

54. G. LANIGERA (A. Curningh.! mss. in herb.), ramulis tomentosis, foliis patulis rigidís semipollicaribus oblongis linearibusve obtusis apiculatis margine recurvis revolutisve suprà punctato-scabriusculis puberulis subtus incano-tomentosis, racemis terminalibus subsessilibus brevibus recurvis paucifloris, calyce subsemipollicari utrinque rotundato, pìstillo pollice breviore, ovario sessili villoso, stylo crassiusculo piloso apice glabro, stigmate laterali. $\mathrm{F}$ Ad flum. Lachlan et Morumbidgee (A. Cunn.!), Menero Plains (Lhotsky!), Yass et Nargus (Mac Arthur 1), promont. Wilson (Ferd. Müller l). - R. Brown suppl. p. 20. Rami dense foliosi, teretes, pube molli patulâ fulvâ vel albidâ dense tomentosi. Folia 4-9 lin. longa, minute 
cano-puberula, tactu vix scabriuscula. Racemi 3-6 lin. longi, rhachi pedicellisque glabrís. Calyx 4-5 lin. longus, arcte incurvus, utrinque roturiatus, intus pilosiusculus infra medium dense barbatus. Pistillum 9 lin. longum. (v. s. in herb. Cunn., Brown, ete.)

a. planifolia, foliis oblongo-linearibus ( 2 lin. Iatis) planis vel margine vix recurvis cano-tomentosis supra tarde glabrescentibus vix scabriusculis (Mac Arthur, n, 137!).

ß. revoluta, foliis linearibus marginibus valde revolutis subtus canaliculatis supra scabriusculis (A. Cunn.l Mac Arthur, n. 136! 139! 140! et? 135, formâ recedens calyce apice parce puberulo, andistincta sp.?). G. autumnalis Lhotsky! mss. in herb.

55. G. Latro bé (Meisn. in pl. Preiss. 1, p. 539*, in notâ), ramulis tomentellis, foliis patentibus subpollicaribus subulato-linearibus pungentibus margine revolutis utrinque parce adpresso-pilosiusculis supra convexis scabriusculis lævibusve subtus canaliculatis, racemis axillaribus terminalibusque brevissimis recurvis, calyce semipollicari, pistillo pollice breviore sessili, stigmate laterali ovali. $\zeta$ In Novà-Holl. australi et orientali. Simillima G. rosmarinifoliæ, sed foliis brevioribus plerumque tenuioribus angustioribus læevibusque, stylo breviore, etc., dignoscenda.

a. leiostylis, pistillo imà basi tautủm antice pilosiusculo, caterum glaberrimo, foliis lævibus subtus vix sericeis. Circa Port-Phillip (Latrobe!).

ß.? dasystylis, ovario sessili dense pilosiusculo, stylo puberulo apice glabro, folîis lævibus subtus vix sericeis. - Circa Fort-Phillip alibique in Australiâ Felici (Ferd. Müller!). Forma exceptis notis indicatis cum $\alpha$ exacte conveniens, pistillo piloso vero accedens ad G. 'lavandulaceam, sed ab hac certe distincta foliis lævibus, calyce ampliore subinflato extus glaberrimo et pistillo sessili breviore 7 lin. tantum longo. (v. s.)

$\gamma$ ? scabrifolia, ovario sessili dense villoso, stylo puberulo apice glabro, foliis supra scabris subtus sericeis $\left(\frac{1}{2}-2\right.$ lin. latis) apice minus attenuatis. - Circa Sydney (Anderson, -n. 24 !),

56. G. Nut aNs (Meisn. in Hook. Journ. 1852, p. 187), foliis patulis subpollicaribus subulatis pungenti-mucronatis margine revolutis subtus 1 -sulcis supra minntissime punctato-scabriusculis ramulisque, incano-puberulis, racemis terminalibus axillaribusque brevibus -subsessilibus recurvis, pistillo pollice breviore calycem dimidio superante subsessili imâ basi antice barbellato cæeterúm glaberrimo, stigmate laterali hemisphærico ovali. $亏$ In Novâ-Holl. orient. interiore (Mitchell exped. 1836, n. 219!): Forsan G. glabellæ var., attamen distiucta foliis majoribus (sæpe pollicaribus, $\frac{1}{3}-\frac{1}{2}$ lin. latis) rigidioribus, pubescentibus, supra sub lente puncticulatis immoque tactu paulo scabriusculis, pedicellis dimidio brevioribus. Calyx pedicello triplo longior, arcte involutus, apice basique rotundatus, intus superne pilosiusculus inferne dense barbatus. Stylus crassiusculus, stigmate umbonatoconvexo. (v. s. comm. a cl. Lindl.)

57. G. GLABELLA (R. Brown suppl. p. 20), ramulis tomentellis, foliis subpollicaribus filiformi-subulatis mucronato-acutissimis lævibus glabris subtus 1 -sulcis, spicis terminalibus brevissimis recurvis, pistillo pollice breviore subsessili imâ basi antice barbatulo caterum glaberrimo, stigmate laterali lute ovali. $\not$ in montibus circa Port-Jackson (A. Cunningh.!) et in Nov.-Holl. orient. interiore (Mitchell exped. 1856, n. 199!). G. acicularis Gunn.! mss. (non Schult.). Ramuli dense foliosi. Folia suberecta, rigidula, 8-10 lin. longa, vix $\frac{1}{4}$ lin. crassa, teretiá vel obsolete triquetra, Iævissima. Flores specim. Cunn. delapsi. Specim. Mitchell. a diagnosi auctaris recedunt floribus non spicatis, sed racemosis, pedicello tenui $2 \frac{1}{2}$ lin. longo, calyce circ. semipollicari arcte inflexo subinflato utrinque rotundato intus piloso infra medium dense barbato, pistillo 8-9 lin. longo. (v. s. in hèrb. Cunu. et Lindl.)

58. G. DIVARICATA (R. Brown ! suppl. p. 20), ramulis filiformibus tomentellis, foliis subsemipollicaribus subulatis mucronato-aculis glabris subtus 1-sulcis supra minutissime punctato-scabriusculis, racemis terminalibus folia vix superantibus recurvis ovatis paucifloris, calyce reniformi intus parce piloso inferne dense barbato, pistillo subsemipollicari glaberrimo subsessili, stigmato laterali suborbiculari. $亏$ In montibus circa Port-Jackson et Cugeegang (A. Cunningh.I). Frutex ut 
videtur diffusus, ramis gracílibus patulis. Folia patentia, 3-6 lin. longa, $\frac{1}{3}$ lin. lata, tactu vix scabriuscula, marginibus revolutis subtus contiguis. Racemi semipollicares, pedicellis calyce dimidio brevioribus. Cætera G. ericifoliä, sed calyx intus parcius pilosus. (v. s. in herb. Brown. et Cunn.)

59. G. ERIGIFoliA (R. Brown I suppl. p, 20), foliis semipollicaribus subulato-linearibus mucrouulato-acutis subtus 1 -sulcis vel canaliculatis supra punctato-scabriusculis ramulisque patulo-pilosis, racemis terminalibus folia superantibus oblongis breve pedunculatis' recurvis dense multifloris, calyce intus toto dense barbato, stylo brevi crasso hirsuto, stigmate laterali subrotundo. F In montibus circa Port-Jackson et prope flum. Lachlan (A. Cumningh.I). G. phylicoides Cunn.! mss. (non R. Br.). Rami grariles pube brevi sordide villosiusculi. Folia satis conferta, rigidula, haud jungentia, 5-7 lin. longa, $\frac{1}{2}$ lin. lata, juniora pube brevi molli villosiuscula, adulta glabrescentia minute puncticulata, subtus (ex Br.) sericea. Racemi ramulos breves terminantes circ. pollicares, bracteis membranaceis linearibus patulis pedicello sublongioribus deciduis. Calyx pedicello dimidio longior, fere in orbem arctissime inflexus, utrinque rotundatus, intus totus pube flavâ inferne densiore barbatus. Cætera priecedentis. (v. s. in herb. Brown. et Cunn.)

$\beta$. Mülleri, foliis pollicaribus (10-14 lin. longis) revoluto-teretibus passimque lineari-lanceolatis planis (2 lin. latis) subtus incano-tomentellis. - Ad flum. Delalits et inter Ovens et Maday Hills Australiæe merid. (Ferd. Müller). G. Latrobei var. montana Ferd. Müller! mss. in herb. Sonder. Forma valde accedens ad G. nutantem et -seabrellam, sed ab illâ foliis egregie scabris, ab hac racemo longiore nutante, etc., distincta.,(v. s.)

60. G. SCABRELLA (Meisn. in Hook. Journ. 1852, p. 187), ramulis cano-pubescen. tibus, foliis subpollicaribus subulatis subpungentibus punctato-scabris puberulis dernum glabrescentibu's subtus 1 -sulcis, racemis umbelliformibus subsessilibus multifloris, calyce intus adpresse piloso medio dense barbato, ovario sessili villosa, stylo pilosiusculo apice glabro, stigmate laterali hemisphærico. F Circa Nargus in Nov.-Holl. orient. australi interiore (Mac Arthır, n. 134 l). Folia conferta, semierecta, 8-12 lin. longa, $\frac{1}{3}$ lin. lata, teretia, mucronato-acuta. Racemorum rhachis 4-5 lin. longa. Calyx 5 lin. longus, ventricosiss, incurvus. Pistillum 7 lin. longum, stylo crasso incano-pilosiusculo. Stigma late ovale, antice concavum, obtuse umbonatum. Cæat. G. ericifólise, a quâ foliis magis scabris styloque longioribus, calyce dimidio majore, etc., facile dignoscenda. (v. s. in herb. Lindl.)

d. Hakeoideo. - Folia anguste linearia vel tereti-filiformia (in G. bracteosâ passim 3-partita), marginibus arctissime refractis recurvisve, subtus 2- vel 1-sulca vel rarius subplana, supra lovia. Racemi terminales vel axillares breves vel fasciculiformes, floribus parvis gracilibus.

61. G. FIL IF OL IA (Meisn. in $\mu l$. Preiss. 1, p. 547 $7^{*}$, ramis gracilibus angulato-sulcatis demum glabris, foliis semitereti-filiformibus elongatis laxis enerviis sericeis apice uncinatis, racemis axillaribus terminalibusque pedunculatis brevibus densis, calyce parvo intus barbato extus pedicelloque subæquilongo glabro, pistillo stipitato glahro longe exserto, stigmate laterali ovali. F In Novâ-Holl. austro-occidentali interiore (Preiss, n. 699!). Folia $4-6$ poll. longa, $\frac{1}{3}$ lin. lata, haud rigida, supra planiuscula vel obsolete 1 -sulca. Racemi pollice breviores, apiciflori. Calyx 2 lin. longus, demum 4-partitus. Glandula liypogyna manifesta, semiannularis. Pistillum 3-4 lin. longum, stigmate convexiusculo. (v. s.)

62. G. HAKеоIDEs (Meisn. in pl. Preiss. 2, p. $252 \%$ ), ramulis apice sericeo-incanis foliis subtereti-filiformibus mucronulatis lavibus glaucis glabris subtus bisulcis corymbis axillaribus tèrminalibusque multifloris brevissimis, calyce parvo pistilloque breviter exserto glabro, stigmate terminali subobliquo orbiculari. $J$ In colonia Swan River (Drummonl coll. 2, n. 325 ! 326 !). Faciés. Hakearum pugioniformium.

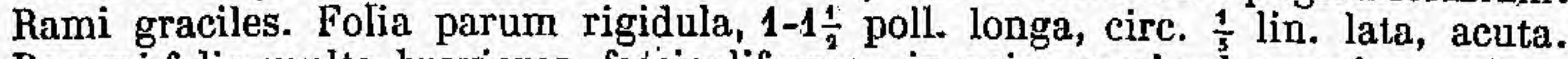
Racemi folio multo breviores, fasciculiformes, in apice rami vel ramulorum brevium fere aphyllorum sessiles, rhachi 2-3 lin. longâ. Calyx pedicello parum longior, tenuis, limbo globoso inflexo diu clauso, sepalis demum liberis utrinque glabris, 
Glandula hypogyna exigua. Pistillum vix 3 lin. longum, brevistipitatum, stylo apice incurvo, stigmate subconvexo.' (v. s.)

63. G. вRAGH y tachya (Meisn. in pl. Preiss. 2 , p. $254^{*}$ ), ramis apice cano-puberulis, foliis anguste linearibus mucronulatis margine revolutis lævibus glabris supra planis obsolete 3 -nerviis subtus bisulcis, racemis terminalíbus subsessilibus brevibus multifloris, pistillo stipitato glabro subsemipollicari calycem puberulum breve superante, stigmate laterali ovali. 春 In coloni $\hat{a}$ Swan River (Drumm. coll; 2 ,

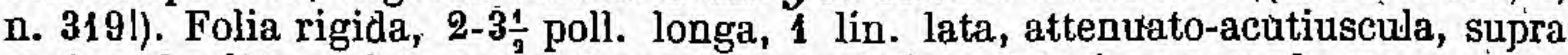
potius obsolete striata quanm 3-nervia; marginibus obtusis usque ad nervum arcte revolutis (nec refractis), subtus profunde 2-sulca. Racemi circ: semipollicares, erecti, densiflori, puberuli, pedicellis brevissimis. Calyx gracilis, incurvus, ..... longus. (v. s.)

64. G. BRAG.TE OSA (Meisn'. l.,c.p. 254*), ramis apice remote foliosis pedunculisque sericeo-puberulis, foliis elongatis anguste linearibus indivisis passimque tripartitis sphacelato-acutiusculis glabris marginibus acute refractis supra vix convexis immerse 1-nerviis subtus bisulcis, racemis axillaribus terminalibusque brevibus densifloris diu bracteatis, pistillo semipollicari longe stipitato calyceque pàrvo glabro; stigmate laterali oblongo.'JIn coloniâ Swan Rivè (Drumm. coll. 3. n. 269!). Rami graciles, subsimplices, parce foliosi, sæpe scapiformes, ramulis brevibus sæpe aphyllis racemo terminatis. Folia rigida, $1 \frac{1}{2}$ rarius 344 -pollicaria, vix 1 lin. lata, nonnunquam passim irregulariter 3 -fida, supra subnitida plana, marginibus acutis. 'Racemi semipollicares, quasi involucrati, rhachi brevissimâ canescente, bracteis membranaceis pallidis diu persistentibus late ovalibus obovatisve, 3-4 lin. longis, unguiculatis ciliolatis patulis. Calyx 3 lin. longus, gracilis, incurvus. Pistillum 7-8 lin. Iongum, stipite fere stylum æquante, stigmate anguste panduríformi. (v. s.)

65. G. NUDI FL ORA-(Meisn. in Hook. Journ. 1852, p. 186), ramis apice aphy̧llo séapiformi parce sericeo-puberulis, foliis elongatis anguste linearibus obtusis mucronulatis glabris minute punctato-scabriusculis supra planis subenerviis margine obtuse refracto subtus hisuleis, racemis axillaribus terminalibusque brevibus ebracteatis laxe paucifloris, calyce parvo glabriusculo, pistillo subsemipollicarri subsessili glabro, stigmate laterali subrotundo. J In coloniîa Swan River (Drùmm. coll. 5 , n. 406 !). Habitu et foliis similis G. bracteosæ, sed jam floribus ebracteatis majoribus et foliis opacis minutissime scabriusculis facile dignoscenda. Folia indivisa, 3-6 poll. longa, 1 lin. lata, marginibus rotundato-obtusissimis. Racemi subpollicares, breve pedunculati, semierecti, in ramorum extremitate subaphyllà longe remoti quasi racemum compositum interruptum pedalem vel ultra constituentes. Pedicelli 2-3 lin. longi, tenues. Calyx $4-5$ lin. longus, pistillo vix brexior, incurvus, extus fere glaber, intus inferne barbatus. Folliculus sessilis; 4-5 lin. longus, dense granulatus, ecostatus, stylo cormutus: (v. s. in hèrb. Shuttlew.)

66. G. Lemanniana (Meisn. l. c. p. 187), ramis cano-tomentosis, foliis sesquipollicaribus anguste linearibus mueronulatis lævibus glabris margine acutiuscule refractis supra subconvexis subtus bisulcis vel canaliculatis, racemis terminalibus brevibus subsessilibus recurvis dense secundifloris, pistillo calycem sericeum longe superante, ovario stipitato: villoso, stylo glabro, stigmate inflexo-laterali subrotundo. F In coluniâ Swan River (Drumm. coll. 5, n. 405!). Folia rigida, indi-

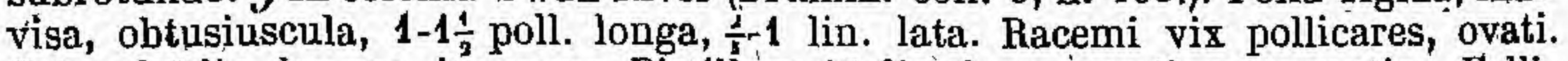
Calyx 4-5 lin. longus, incurvus. Pistillum 10 lin. longum, stigmate mutico. Folliculus ignotus. Species foliis simillima G. concinnæ et præsertim G. coccinese, sed ab utrâque primo vultu distincta, racemis duplo brevioribus recurvis ovatis (nec erectis oblongis fere spiciformibus), ramis haud sericeís, foliis angustioribus, margine non revoluto, minus acute refracto, stylo tenuiore, ovario distincte stipitatọ, et a G. concinnâ insuper foliis omnibus indivisis. (v. 's. in herb. Shuttl. et Lemann.)

67. G. HEW ARDIANA (Meisn. l. c. p. 186), ramulis cano-tomentosis, foliis digitalibus anguste linearibus obtusis mucronulatis lævibus glabris margine acutiuscule - refractis supra subplanis subtus bisulcis subcanaliculatisve, racemis terminalibus brevibus subsessilibus erectis dense secundifloris, pistillo calycem sericęum longe superante, ovario subsessili villoso, stylo glabro, stigmate termipali subojilique truncato. J In coloniâ Stran River (Drumm. coll. 5, n. 404!). Ramulorum pubbes- 
centia, foliorum structura/et flores omnino G. Lemannians, sed constanter, ut videtur, differt racemis etiam fructiferis erectis, stigmate, ovario subsessili et foliis plerisque longioribus 2-3 poll.' longis supra vix convexis. A G. coccineả, cui foliis stigmateque propius accedit, discrepat racemo breviore haud spiciformi, ramis haud sericeis et folliculo minus distincte striato. (v. s. in herb. Sluuttlew.)

68. G. co ca INe a (Meisn. in. Hook. Journ. 1855, p. 76, sub n. 33), ramulis sericeotomentosis, foliis bipollicaribus anguste linearibus integerrimis obtusis mucronulatis basi attenuatis margine acute refractis supra convexis lævibus glabris subtus bisulcis apicem versus canaliculatis, racemis terminalibus oblongis erectis subsessilibus dense secundifloris, pistillo calycem sericeum longe superante, ovário subsessili, villoso, stylo glabro, stigmate terminali oblique truncato. $\bar{J}$ In monte Manypeak, prope sinum Regis Georgii (Preiss, n. 711!). G. concinna Meisn. in pl. Preiss. 1, p. 545*. Species a G. concinnâ R. Br.! certe distincta foliis nunquam, ut videtur, laciniatis, margine acute refractis nec revolutis, pistillo breviore, etc., attamen hanc speciem arctissimå aflinitate cum præcedentibus connectens, et cum eâ has inter et Colothyrsos ambigua. Folia erećta, rigida, 1-2 poll. longa, 1-1 $\frac{1}{2}$ lin. lata, subtus (si facies inter margines costamque visibilis) incano-puberula (nec fulvo-sericea). Racemi circ. pollicares. Calyx vix 4 lin. longus, coccineus, fulvosericeus, incurvus. Pistillum 10-12 lin. longum. Folliculus ovatus, subcostatostriatus. (v. s.)

69? G. conginna (R. Brown! in Linn. Trans. 10, p. 172, prodr. p. 377, suppl. p. 18), foliis sesquipollicaribus linearibus mucronulatis indivisis passimque trifidis vel pinnatifidis' margine obtuse revolutis supra convexis lævibus glabris subtus canaliculatis ramulisque sericeis, racemis terminalibus oblongis recurvis subsessilibus dense secundifloris, pistillo subpollicari calycem sériceum longe superante, ovario subsessili villoso, stylo glabro, stigmate terminali oblique truncato. $亏$ In orầ merid. circa Lucky Bay (R. Brown! Baxter !). - Sweet fl. Austr. t. 7, Bot. reg: t. 1383. Folia pleraque pollicaria 1 lin. lata, acuta vel obtusa, basi attenuata, interdum subspathulata, nunc omnia indivisa (R. Br: prodr. l. c.), nune passim (præsertim stirpis juvenilis) superne cuneato-dilatata (2-3 lin. lata) et plis minus profunde inciso-trifida (vel ex R. Br. suppl.) pinnatifida, lacinis parum divergentibus linearibus 1-nerviiis. Racemi subpollicares. Stylus apice subdilatatus. Cæt. præcedentis, ubi differentias indicavimus. (v: s. in herb. Brown., Cunn., DC.)

70. G. Pinaste R (Meisn. in Hook. Journ. 1855, p. 76), ramulis apice fulvo-sericeis, foliis digilalibus filiformi-linearibus obtusiusculis mucronulatis lævibus glabris margine arcte revolutis supra subplanis subtus bisulcis, racemis lateralibus patentibus vel recurvis oblongis laxilloris, calyce parvo pistilloque'subpollicari glabris,

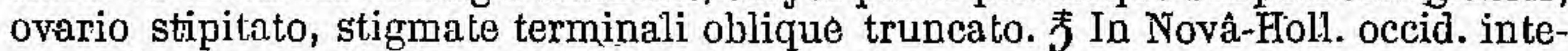
riore (Drunm. coll. 6, n. 182!). Fastigiato-ramosa, ramulis gracilibus mox glabratis. Folia erecta, vix rigida, $2-4$ poll. longa, $\frac{1}{2}$ - vix 1 lin. lata, integerrima, complénata, mucrouulo pallido innocuo. Racemi axillares et ramulos breves terminantes, 1-1 $\frac{1}{2}$ poll. longi, rhachi sericeâ demum glabrâ, pedicellis flore dimidio brevioribus tenuibus. Calyx 4 lin. longus, basi tumidulus, intus minute puberulus, limbo globoso inflexo. Glandula hypogyna semiannularis, crassiuscula, adnata. Ovarium lineare, stipite fere ' 2 lin. longo, stylo deciduo, stigmate parvo. Folliculus semipollicaris, ovali-oblongus, lævis, utrinque acutus. (v, s. in herb. Shuttl.)

71. G. PAR VIF L ORA (R. Brown in Linn. Trans. 10, p. 171, prodr. p. 377), ramulis glabriusculis, foliis subulato-linearibus lævibus margine refractis, calyce parvulo pistillum stipitatum 'equante extus ferrugineo intus obsolete barbato. $亏$ Circa PortJackson (R, Brown). Pistillum 2 lin. longum, pedicello ovarium vix æequante. Huc spectare videtur specim. Sieber, n. 634, in herb. DG. : ramulis gracilibus conferte foliosis glabris, junioribus subangulatis ; foliis 2-4 poll.1ongis, $\frac{1}{2}-1 \frac{1}{2}$ lin. latis, acutis mucronatis vix rigidulis, margine angustissime refractis recurvisve, subtus bisulcis, súbsericeis, floribus parnulis rufo-sericeis.

72. G. M I GRANTHA (Meisn. in Linnæâ 26, 1853, p. 358), ramulis adpresse pilosiusculis, foliis subpollicaribus subulato-linearibus mucronulatis glabris margine arcte rovoluto obtuso scabriusculis subtus bisulcis, racemis terminalibus umbelliformibus brevissime pedunculatis, calyce parvulo pedicello vix longiore parvulo sericeo intus glaberrimo, pistillo calycem subæquante sessili glabro, stigmate terminali 
obliquo. F In Australiâ Felici (Ferd. Müller !). G. parviflora F. Müller. first general report, etc., p. 17. Forsan præcedentis var., attamen pluribus notis satis discrepans. Folia 8-12 lin. longa, vix $\frac{1}{2}$ lin. lata, in mucronulum attenuata, marginibus rotundato-obtusis (nec refractis) sub lente scabriusculis. Pedicelli 2-3 lin. longi, cum calycis basi limboque globoso demum erecto ferrugineo-sericei. Pistillum $1 \frac{1}{2}$ lin. longum. (v. s. comm. a cl. Sonder.)

73. G. CONPERTIFolia (Ferd. Müller $I$ in Trans. philos. Soc. of Victoria 1, p. $22{ }^{*}$ ), ramulis subsericeo-incanis, foliis subpollicaribus rigidis linearibus sphacelatomucronulatis margine acite relractis supra planis lævibus glabris subtus bisulcis, fasciculis terminalibus sessilibus dense multifloris, calyce parvulo sericeo, pistillo subsemipollicari stipitato glabro, stigmate terminali obliquo. F In subaipinis mont. William et Zero, alt. 5,000 ped., et in mont. Grampians Australiæ Felicis (F. Müll.!). Diffusa, ramulis conferte foliosis albido-pubescentibus. Folia patula, stricta, 9-15 lin. longa, 1 lin. lata, rarius angustiora, tenuiter 3-nervia, nervis lateralibus marginantibus, paginâ inferiore inter costam margìnesque fortiter prọminulos pilis longiusculis adpressis incano-sericeá. Fasciculi foliis breviores. Calyx gracilis, 2 lin. longus, intus medio dense barbatus, extus albido-sericeus, limbo globoso suberecto glabriusculo apice fulvo-puberulo. Pistillum exsertum, vix 6 lin. longum. Proxime affinis præcedentibus nee non valde accedens ad G. strictam et trinervem, sed ab illis jam foliis latioribus rigidisque, a posterioribus foliis lævibus floribusque bene distincta. (v. s. comm. a cl. Sonder.)

e. Manglesioidece. - Folia lanceolata vel cuneato-oblonga, indivisa passimque apice 2-3-fida, lavia, plana vel margine recurva vel refracta, mucronata. Racemi axillares terminalesque pedunculati, breves, basiflori. Calyx parvus, subregularis, demum 4-partitus. Pistillum stipitatum, glabrum, stylo filiformi, stigmate oblique laterali planiusculo. Glandula hypogyna manifesta.

74. G. DIVERSIFOLIA (Meisn. in pl. Preiss. 1, p. $547^{*}$ ), ramulis angulatis glabris, foliis lanceolatis attenuato-petiolatis subtriplinerviis glabris apice passim 2-3-fidis vcl 2-3-mucronatis, calyce extus pedicelloque brevi subsericeo, stylo breviter exserto, stigmate ovali. J In coloniâ Swan River, distr. Sussex (Drumm, coll. 1, Preiss, n. 697!). Frutex 10-15 pędalis, ramis gracilibus teretibus laxe foliosis, junioribus tenellis acute compresso=angulatis. Folia patula, parum rigida, circ.

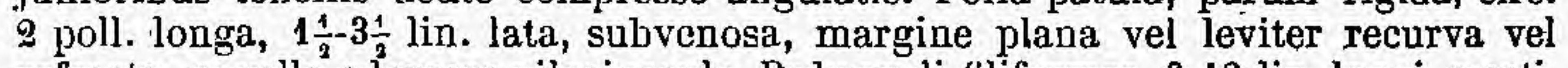
refracta, novella adpresse pilosiuscula. Pedunculi filiformes, 6-12 lin. longi, erecti, corymbo fasciculiformi terminati. Calyx 2 lin. longus, intus basi barbatus, limbo globoso incurvo. Pistillum 3 lin. longum. (v. s.)

ß. lobata (Meisn. 1. c. 2, p. 255), foliis nervoso-marginatis plus minus refractis plerisque profunde 2-3-lobis, lobis divaricatis (Drumm. coll. 2, n. 316!). Foliorum lobi 4-10 lin. longi, sæpe partem indivisam cuneato-linearem æquantes. (v. s.).

$\gamma$. rigida, foliis crassioribus rigidulis margine magis revolutis indivisis passimque 3-fidis (Drumm. coll. 4, n. 286!). Folia 1-2-pollicaria. Racemi 6-9 lin. longi, rhachi pubescente, pedicellis fructiferis 5-6 lin. longis glabris. Glandula hypogyua conspicua. Stylus deciduus. Folliculus brevissime stipitatus, ventricosoovalis, muticus, 5-6 lin. longus, tumidus, utrinque rotundatus, tuberculosorugulosus, glaber. (v. s. in herb. Shuttl.)

75. G. MANG LES I OIDES (Moisn. 1. c. 1, p. $547^{*}$ ), ramis villosiusculis, foliis sessilibus lanceolatis attenuatis vel obovato-oblongis cuneatis apice passim 2-3-fidis molliter pubescentibus supra demum glabris, ealyce pericelloque subæquilongo extus glahriusculo, stylo breviter exserto, stigmate subrotundo. F In coloniâ Swan River, distr. Sussex et Plantagenet (Preiss, n. 720! 723! Drumm. coll. 2, n. 317!). Frutex 8-pedalis, polymorphus. Folia patula, rigida, 1-2 poll. longa, 3-5 lin. lata, venosa, margine recurva vel refracta. Racemi folium subæquantes, floribus secundis. Calyx 2-3 lin. longus, extus fere glaber, intus medio barbatus. Stylus diu persistens. Folliculus 5 lin. longus, ovalis vel oblongus, rugulosus. (v. s.)

3. sericea (Meisn. 1. c. 2, p. 255), ramulis jncano-tomentosis, foliis sericeo-tomentosis demum supra glabris plerisque breve 3-fidis, dentibus subæqualibus 
spinuloso-mucronatis intermedio plerumque 3-cuspidato (Drumm. coll. 2, n. 318 !). Racemi dense multiflori, rhachi subpollicari. (v. s.)

§ 2. Eriostylis. - Pistillum stipitatum (rarius sessile), totum dense hirsutum vel lanato-villosum, stigmate laterali, rarissime terminali (cfr. G. umbellulata) sapius cochleariformi antice vel rarius utrinque glabro interdum cornuto. Folliculus ecostatus, pubescens. Folia omnia, indivisa, margine recurva vel revoluta, rarius plana, nunquam refracta, plerumque punctato-scabriuscula. Flores fasciculati vel subumbellati vel brevissime racemosi, dense villosi, mediocres vel parvi, limbo inflexo parum irregulari. - Meisn. in pl. Preiss. 1, p. 539. - Eriostylis R. Brown in Linn. Trans. 10, p. 173, prodr. p. 378.

76. G. BUXIFOLIA (R. Brown in Linn. Trans. 10, p. 174, prodr. p. 379), ramulis dense foliosis pubescentibus, foliis semipollicaribus ovatis ellipticisve acutis mucronatis margine recurvis supra glabris punctato-scabris subtus adpresse fulvu pilosís, fasciculis terminalibus multifloris sessilibus pistilloque semipollicari laniıto-liirsutis, stigmate orbiculari appendice ipso longiore villosâ recurvà cornutà. J Girca Port-Jackson (R. Brown! Gaudich.! d'Urville! A. Cunn.! Sieber, n. 37! 11. mixta, n. 477! Anderson! etc.), Port-Phillip et Victoria? (Latrobe !). - Bot. reg. t. 443, Bot. cab. t. 1562. Embotlırium buxifolium Smith! New Holl. p. 29, t. 10, Andr. Bot. repos. t. 218. E. genianthum Cav. ic. 4, p. 60, t. 387, Thibaud! in herb. DC. Stylurus buxifolia et? collina Knight et Salisb. Prot. p. 115, 116. Rami virgati, ramulis plerumque subumbellatis. Folia patula, rigida, subevenia, nunc ovata vel late ovalia 3-6 lin. longa, 2-4 lin. lata, nunc oblonga et lanceolata 4-7 lin. longa, 2 lin. lata, sujura plus minus scabra puberula mox glabra, subtus pube adpressâ pallide virescentia vel fulva vel ferruginea. Pedicelli 3-4 lin. longi, caljeem subcquantes adpresse rufo-pilosi. Pistillum 7-8 lin. longum, calycem demum paulo superans et cum co pube minus adpressâ pałlide fulvẩ hirsutum ; stigmatis cornu fure 1 lin. longum. (v. s. in herb. Brown., Smith, etc., et v. s. c.)

77. G. PHYLICOIDES (R. Brown! 1. c. p. 174 et 379), ramulis laxiuscule foliosis villoso-tomentosis, foliis subpollicaribus lanceolato-linearibus acutis mucronulatis margine revolutis vel subrefractis supra glabris punctato-scabris subtus villoso-tomentosis, fasciculis terminalibus subsessilibus multifloris pistilloque vix scmipollicari lanato-tomentosis, stigmate ovali appendice ipso breviore villoso recto cornuto. 5 Girca Port-Jackson (R. Brown! Sieber, n. 29! Anderson, n. 65l).Roem. et Schult. syst. 3 , mant. p. 281 . A simillimà præeedente facile dignoscitur ramorum pube densiore, plerumque ferrugineâ, foliis longioribus angustioribus (6-11 lin. longis, 1:-2 lin. latis), calyce pistilloque brevioribus, stigmate minore, cornu $\div$ - vix $\frac{1}{2}$ lin. longo; a sequente : stigmate distinctius cornuto, pedicellis pistillisque paulo longioribus, foliis subtus ramulisque haud sericeis, sed villosotomentosis. (v. s. in herb. Brown., etc.)

78. G. SPHACELAt A (R. Brown! J. c. p. 174 et 378), ramulis laxe foliosis apice sericco-tomentellis, foliis pollicaribus linearibus lanceolatisve mucronulatis margine recurvis vel planis supra glabris minute punctato-scabriusculis vel lavigatis subtus sericeis, fasciculis terminalibus subsessilibus pistilloque brevi sericeovillosiusculis, stigmate ovali submutico. $弓$ Circa Port-Jackson (R. Brown ! A. Cunn !). G. phylicoides A. Cunningh.! mss. in herb. DC. G. sericea Lhotsky! in herb. Shuttl. (non R. Br.). Folia patentissima, acuta vel obtusa, nunc herbacea, plana, 1-1 $\frac{1}{2}$ poll. longa, 1-2 lin. lata, supra adpresse pubescentia fere lævia; nunc rigide

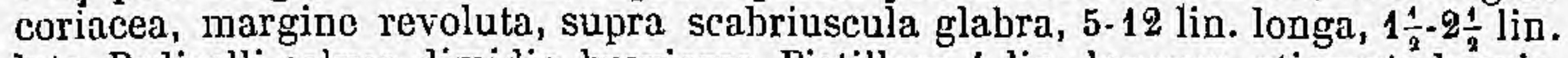
lata. Pedicelli calyce dimidio breviores. Pistillum \& lin. longum, stigmate brevissime apiculato. Præcedenti valde affinis, sed vix mera varietas. (v. s. in herb. Brown., etc.)

79. G. Fas c iculata (R. Brown! suppl. p. 20), foliis sublipollicaribus lanceolatolinearibus acutis margine revolutis supra punctato-scabriusculis glabris subtus ramulisque sericois, fasciculis subsessilibus paucifloris, calyce subventricoso jedicollo sublongiore pistillum sessile æequante adpresse pilosiusculo intus ad faucem 
barbato, ovário siyloque lirsuto, stigmate hemispharico subconcavo glabro. ђ Circa sinum Regis Georgii (Baxter, Preiss, n. 718!) - Meisn. in pl. Preiss. 1, p. $536^{*}$. Frutex 5 =pedalis, ramis gracilibus apice compressis. Folia $1 \frac{1}{2}-2 \frac{1}{2}$ poll. longa, 3-3 $\frac{1}{2}$ lin. lata, corjacea, apice sphacelato-aeuta, evenia vel obsolete venosa. Fasciculi $4-6$ flori, ramulos laterales brevissimos paucifolios terminantes. Calyx coccineus, 3-4 lin. longus, incurvus, cum pedicello styloque rufo-pubescens. Ovarium albido-barbatum. Stigna cochleariforme, nutans, muticum, subumbonatum, glabrum. Folliculus ventricoso-ovatus, 6-7 lin. Iongus, ecostatus, sericeus. Species hinc præcedentibus, inde G. aspere affinis Eriostylin inter et Lissostylin ambigua. (v. s. in herb. Brown et Preiss.)

a. divaricata (R. Br. l. c.), foliis rameis divaricatis, adultis supra depilatis.

ß. stricta (R. Br. l. c.), foliis rameis erectis, adıltis supra pubescentibus.

80. G. DEPAUPERATA (R, Brown! suppl. p. 21 !), fohis ovalibus ellipticisve sphacelato-muçonatis margine recurvis supra scabris subtus adpresse incano-pilosis, floribus solitariis pedunculatis, calyce extus adpresse piloso intus barbato, pistillo hirsuto, stigmate obovato mutico convexiusculo. F Circa sinum regis Georgii, (Baxter). (v. s. in herb. Brown.)

81. G. BRownIr (Meisn. in pl. Preiss. 1, p. $537^{\star}$ ), ramulis puberulis, foliis pollice brevioribus elliplicis oblongisque margine recurvis supra glabris punctato-scabriusculis subtus incanis mucronulo sphacelato obtuso, fasciculis axillaribus terminalibusque subsessilibus paucifloris, calyce pedicello sublongiore, pistillo semipollicari breviore adpresse pilosiusculo intus ad faucem barbato, ovario subsessili villoso, stylo pilosiusculo, stigmate hemísphærico mutico. .J Circa sinum Regis

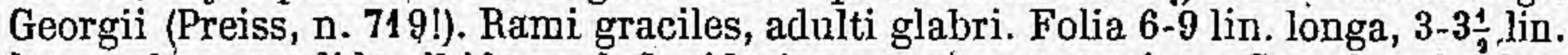
lata, subtus sordide albido- vel flavido-tomentosa, nec sericea. Cæet. fere fasciculatæ, sed stylús fere duplo longior, calycem superans, gracilior, minus pubescens et stigma magis recurvum brevissime umbonatum. (v. s.)

82. G. occidentalis (R. Brown! in Linn. Trans. 10 p. 173, prodr. p. 378), foliis sesquipollicaribus lanceolatis linearibusve acutis margine revoltatis supra glabris punctato-scabriusculis subtus ramisque junioribus sericeo-canescentibus, fasciculis terminalibus axillaribusque, calyce parvo pedicello vix longiore cum pistillo breviter stipitato parum longiore lanato, stignate ovali obtuso dorso villoso, antice plano submutico. 5 In Leuwin's Land, circa sinum Regis Georgii (R. Brown! Preiss, n. 713!) et in colonià Swan River (Drumm.!). - Meisn. in pl. Preiss 1, p. 539,2, p. 252). Frutex 2-6-pedalis, ramis gracilibus apice toméntellis. Folia $\frac{1}{2}-2$ polt. longa, 1-4 lin. lata, apice sphacelato acuta. Fasciculi 6-12-flori, pedunculo 3-18 lin. longo, puberulo fere aphyllo suffulti vel subsessiles, pedicellis 3 lin. longis fusco-puberulis apice dilatatis. Calyx albido- vel rarius fulvo-lanatus. PistilIum 4-5 lin. longum, stigmate vix concavo obsolete umbonato. Folliculus ventricoso-oblongus stylum subiequans, canus. (v. s. in herb. Brown, etc.)

u. lanceolata (Meisn. 1. c.), folíis lanceolatis planis margine anguste revolutis, fasciculis sæpius pedunculatis. (Drumm. coll. 2, 11. 270!)

ß. linearis (Meisn. 1. c.), foliis linearibus abbreviatis margine valde revolutis supra convexis subtus canaliculatis, fasciculis subsessilibus. (Baxter I in herb. A. Cunningh.)

83. G. oXystgma (Meisn. in pl. Preiss. 1, p. $540^{\circ}$ ), foliis pollicaribus ellipticis lanceolatis linearibusve mucronatis margine revolutis recurvisve supra glabris levibus, subtus incanis, fasciculis axillaribus terminalibusque sessilibus, pedicellis calyce parvo longioribus cum sepalis demum liberis, cum pistillo paulo longiore subsessili tomentoso-villosis, stigmate hemisphærico utrinque glabro antice concavo medioque mucronulato. f) In coloniâ Swan River (Drummond! Preiss!). Præter notas indicatas omnia præoedentis, sed constanter distincta. Rami pubescentes vel glabri. Folia vix ultra pollicem longa, nunquam scabra, supra subnitida. Pedicelli 3-6 lin. longi. Calyx vix $2 \frac{1}{2}$ lin. longus, albus.

a. heterophylla (Meisn. 1. c.), foliis ramorum adultis ellipticis vel ovali-oblongis margine leviter recurvis supra venosis, ramulorum linearibus margine valde revolutis subtus canaliculatis (Drumm. coll. 1, Preiss, $n .715$ ! et ex parte 714). Hakea pilulifera Lindl.I Swan River. p. 36, n. 178. (v. s. in herb. Lindl., ete.)

B. acerosa (Meisn. 1, c.), foliis confertis crassiusculis subacerosis supra convexis 
venosis subtus 1 -sulcis vel anguste canaliculatis, infimis subinde planiusculis (Preiss, n. 710! 716!).

$\gamma$. tenella (Meisn. l. c.), foliis lineari-subulatis eveniis subtus 1 -sulcis vel canaliculatis, rameis subinde lanceolatis planiusculis subvenosis (Preiss, n. 714! ex parte, Drumm. coll. 1, n. 629 !).

84. G. UM B LL ULA т A (Meisn. in pl. Preiss. 2, p. 252 \%), foliis subsesquipollicaribus subulato-linearibus mucronato-acutis margine revolutis supra levibus glabris subtus 1 -sulcis vel canaliculatis ramulisque sericeis, fasciculis axillaribus terminalibusque subsessilibus, pedicellis calycem subæquantibus rufo-jubuerulis, calyce parvo demum 4-partito pistilloque sessili parum longiore albo-lanatis, stigmate oblique laterali ovali complanato submutico. J In coloniâ Swan River (Drumn.

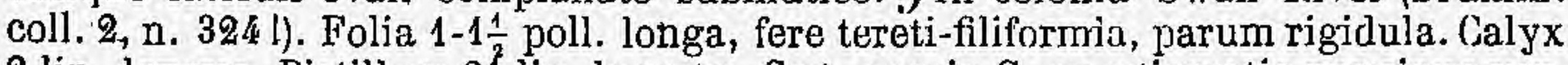
2 lin. longus. Pistillum $2 \frac{1}{2}$ lin. longưm. Cæet. omnia G. oxystigmatis præcipue var. tenellæ, sed stigma constanter diversum. (v. s.)

85. G. Gandolleana (Meisn. 1. c. p. 5t4 *) foliis pollicaribus lanceolatis linearibusque sphacelato-mucronatis margine recurvis vel revolutis supra lævibns glabris subeveniis subtus incanis, fasciculis axillaribus terminalibusque subsessilibus, pedicellis calyce parvo longioribus cum sepalis demum liberis pistilloque vix longiore lanato-villosissimis, ovario subsessili, stigmate laterali oblongo planiusculo mutico dorso villoso in processum spathulatum ipso longiorem glabrum - circinatum abeunte. F Ad flum. Cygnorum (Drumm coll. 1, n. 628 I Preiss, n. 2625!): Flores et pedicelli sulphureo-villosi, fere 3 lin. longi, sepalis postícis longioribus apice auriculato-appendiculatis. Pistillum 5-6 lin., stigma fere $2 \frac{1}{2}$ lin. longum. Cæt. fere omnia G. oxystigmatis, sed stigma diversissimum. (v. s.)

86. G. scabra (Meisn. in pl. Preiss. 1 , p. $541^{*}$, in notâ), ramis puberulis, foliis pollicaribus subtereti-acerosis pungentibus supra echinulato-punclatis glabris subtus 1 -sulcis, fasciculis axillaribus terminalibusque sessilibus, pedicellis calyce parvo longioribus cum sepalis tarde liberis pistilloque haud lorıgiore villosis, ovario subsessili, stigmate laterali e basi ovatâ subconcavâ in processum spathulatum ipso longiorem circinatım producto dorsó tomentoso. River (Drumm. coll. 1, n. 627l). Folia rigida, dense punctato-aspera, marginibus revolutis subtus fere contiguis subteretia, sæpe spurie fasciculata. Cict. fere G. Candolleana, sed flores paulo majores, densius longiusque aureo-villosi, pistillum vix 3 lin. longum, stigma paulo brevius, basi rotundatum nec attenuatum. (v. s.)

\$ 3. Calothyrsus - Pistillum stipitatum vel rarius sessile, stylo elongato glabro vel rarius pubescente, stigmate laterali vel rarius terminali vel obliquo. C'alyx majusculus incurvus. - Folia pinnatim vel bipinnatim laciniata, rarissime indivisa, plana vel margine recurva vel refrasta. Racemi terminales, rarius axillares, plus minus elongati, simplices vel ramosi, interdum spiciformes. - Meisn. in pl. Preiss. 1, p. 541. - Grevillea stricte dicta R. Br. prodr.p. 379. - Sectio Calothyrsus R. Br. in Linn. Trans. 10, p. 175.

\section{a. Folia pinnata vel bipinnata, laciniis anguste linearibus subtereti- busve maryinibus revolutis refractisve rarius planis.}

87. G. Prets SII (Meisn. in pl. Preiss. 1, p. 543*, 2, p. 253), ramulis pedunculisque villose-tomentosis, foliis sesquipollicaribus glabris glaucis? pinnatis vel hassim bipinnatis, segmentis filiformi-linearibus snbmuticis subtus bisulcis, racemis axillaribus terminalibusque folia subæquantibus dense multifloris, calyce parvo glabrescente intus ad faucem tomentoso, pistillo subpollicari stipilato glaberrimo, stigmate oblique laterali parvo convexo. F In coloniâ Swan River, distr. Perth (Preiss, n. 709! Drumm. coll. 1, n. 637! Mangles!). Frutex 3-5-pedalis, facie G. (Conogynes) critlumifoliæ, scd abunde distinctus, ramis fastigiatis. Folia con-

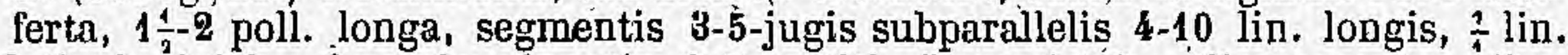
latis, indivisis vel passim pinnatim 3-7-partitis. Racemi 1-2-pollicares; subsessiles, 
secundi. Calyx coccineus, 3 lin. longus, incurvus, minute subsericeus, demum ferc glaber. (v. s.)

88. G. PECTINATA (R. Brown! suppl. p. 23), ramulis apice tomentellis, folijs subsesquipollicaribus rigidis pinnatis, laciniis approximatis parallelis indivisis subulatis tenuibus mucronulatis glabris supra tenuiter bisulcis subtus convexis subrugosis, ..... J In orà meridionali inter Cape Arid et Lucky Bay (Baxter !). Folia 1vix $1 \frac{1}{3}$ poll. longa, laciniis 6-9-jugis oppositis alternisque subcompresso-teretibus 3-8 lin. longis, $\frac{1}{4}$ lin. latis, munquam, ut videtur, divisis. (v. s. in lierb. Brown., sine (l. nec fr.)

89. G. GTENOPHYLA (Meisn. in Hook. Journ. 1852, p. 186), ramis apice tomentellis, foliis subsesquipollicaribus rigidis glabris pinnatis, laciniis paralleloapproximatis linearibus obtusiusculis mucronulatis indivisis vel inferioribus passim bifidis subtus bisulcis supra planis, racemis lateralibus simplicibus vel ramosis brevibus laxifloris, calyce mediocri puberulo, pistillo pollicari stipitato glaberrimo, stigmate laterali oblongo. J In coloniâ Swan River (Drumm. coll. 5, suppl. n. 407!). Rami graciles, laxe foliosi. Folia petiolata, circumscriptione ovalia; 1-1 $\frac{1}{3}$ poll., segmenta 5-9 lin. longa, $\frac{1}{2}-\frac{2}{3}$ lin. lata, margine arcte revoluto obtusa, supra plana obscure 1-nervia vel nervoso-striata. Racemi 1-2-pollicares, aphylli, subrecurvi, plerum tue inferne pauciramosi, rhachi subflexuosâ, pedicellis 2 -3 lin. longis. Calyx cylindraceus, 5-6 lin. longus, incurvus, parce sericeo-canus, glabrescens, intus puberulus. Ovarii stipes $1 \mathrm{lin}$. longus. Simillima quidem G. pectinata, sed certe distincta foliorum segmentis crassioribus, magis complanatis, subtus (nec supra) bisulcis, etc. (v. s. comm. a b. Lemann.)

90. G. PUNGENS (R. Brown! in Linn. Trans. 10, p. 175, prodr. p. 379), ramulis incano-tomentellis, foliis pollicaribus rigidis pinnatis supra glabris subtus sericeis, laciniis patentibus linearibus decurrentibus pungenti-acutis indivisis vel infimis sxpe 2-3-fidis, racemis terminalibus mediocribus recurvis, pistillo semipollicari stipitato calyceque glaberrimo, stigmate laterali ovato. $亏$ Circa sinum Carpentaria (R. Brown! Leichardt). Frutex 2-5-pedalis, habitu G. ctenophyllæ, sed folia subsessilia, circumscriptione ovata, 1-1 $\frac{1}{2}$ poll. longa, lacinia 4 -6-jugæ, remotiores, oppositæ, semipollicares, basi 1 lin. latæ, attenuato-mucronatæ, superiores sensim breviores, margine recurvo vel refracto nervíformi. Racemi inćluso pedunculo bipollicares, rubri, glaberrimi, pedicellis 1-2 lin. longis. Folliculus semipollicaris, oblongus, punctato-granulatus, glaber, styli basi acuminatus, in stipitem 2 lin. longum crassum attenuatus. (v. s. in herb. Brown. et DC.)

91. G. B A X T E R I (R. Brown suppl. p. 22), foliis pinnatis utrinque sericeis, lacíniis subpollicaribus angustato-linearibus mucronatis, racemis erectis, calyce pistilloque sericeis, stigmate dilatato subverticali convexo. 亏 In orâ ạstrali circa Cape Arid (Baxter).

92. G. H u ELII (Meisn. in pl. Preiss. 1, p. 543*), ramis apice tomentosis, foliis sesquipollicaribus rigidis bipinnatis demum glabris, laciniiś $\mathbf{2 - 4 - j u g i s ~ l i n e a r i b u s ~}$ pungentibus subtus bisulcis, racemis axillaribus terminalibusque subsessilibus brevibus recurvis, calyce subsemipollicari gracili sericeo intus glabro pistillum glaberrimum stipitatum subæquante, stigmate laterali ovali parvo. $\zeta$ Iu coloniâ Swan River, distr. York (Drumm. coll. 1, n. 634! Preiss, n. 691!). Frutex procumbens. Folia petiolata, 1-2 poll. longa, segmentis 6-12 lin. longis, $\frac{1}{2}$ lin. latis, subplanis, attenuato-mucronatis marginibus ad nervum usque revolutis pinnatim 3-5-partitis vel passim indivisis, lacinulis petiolo subæqualibus 2-6 lin. longis: Racemi circ. pollicares, basi interdum pauciramosi, undique pube minutà adpressá dense subsericeo-rufi, pedicellis tenuibus $1 \frac{1}{2}-3$ lin. longis. Calyx puniceus, 5-6 lin. longus, vix inclusus, diu clausus. Pistillum calyce vix longius, stipite $2 \mathrm{ln}$. longo, stylo tenui, stigmate vix latiore $\frac{1}{3}$ liu. longo. Media quasi inter G. ctenophyllam et pungentem, a priore distincta foliis crassioribus bipinnatis, laciniis remotioribus magisque divergentibus, calyce intus glabro, ovarii stipite longiore, stylo breviore; a posteriore foliis subtus bisulcis, floribus pubescentibus, etc. (v. s.)

93. G. T II E L E M A N I A N A (Hïgel in Endl. nov. stirp. decad. 1, p. 6, n. $8^{*}$ ), foliis subsesquipollicaribus trifido-bipinnatifidis, segmentis somipollicaribus angustissime linearibus apice obtuso mucronulatis subtus bisulcis glabris, junioribus ad presse juberulis, racemis trrminalibus ovatis densifloris, pedicellis subverticil- 


\section{GREVILLFA.}

latis calyce glabro multo brevioribus, pistillo pollicari, ovario stipitato, stylo gla-

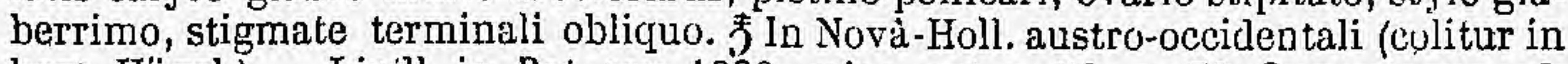
hort. Hügel.). - Lindl. in Bot. reg. 1839, misc. not. p. 54, n. 72. Quæcumque sub hoc nom. in hortis herbariisque vidimus specimina ad $\mathrm{G}$. Wilsoni spectant, sed ab hâc descriptio 1. c. discrepat foliis simpliciter trifidis (nec bi-triternatis), laciniis obtusis minute submucronatis, racemo denso, stylo calýceque glabro, laminis tantum margine ciliatis et ovarii stipite manifesto 2 lin. longo.

94. G. Wiusoni (A. Cunningh.! iu Wilson narrat. Voy, round the world, 1835, p. 273, in notâ), ramis junioribus cano-tomentosis, foliis subsesquipollicaribus 2-3-ternatis glabratis, laciniis divaricatissimis rigidis lineari-accrosis pungentibus sujura planiusculis 1 -nerviis subtus bisulcis, racemis axillaribus terminalibusque laxiusculis basi plerumque ramosis, pedicellis calyce semipollicari glabro intus basi piloso longioribus, ovario subsessili villoso, stylo pollicari inferne hirsuto, stigmate laterali ovato. F Inter King George's Sound et Swan liver (Wi!son! in herb. Cunn.) et in colonia Swan River (Drumm. coll. 1, n. 631! Preiss, n. 692!). G. Lindleyana Meisn. in pl. Preiss. 1, p. 542*. G. Thelemanniana herb. Brown! Lindl.! (non Hügel, fide descr.). Frutex erectus, 3-5-pedalis. Folia juniora adpresse pilosiuscula subsericea, demum cum ramis glabrata. Racemi sæpe 2-3-pollicares coccinei, pedicellis 6-12 lin. longis. Stylus apice tantum glaber. Cæet. præecedentis, quis-forsan hujus var, aut inacurrate descripta. (v. s.)

95. G. Triparti t A (Meisn. in Hook. Journ. 1852, p. 186), foliis pollicaribus rigidissimis tripartitis ramisque demum glabris, laciniis integerrimis subrqualibus subulato-linearibus pungentibus in petiolum brevem decurrentibus margine acute refractis subtus bisulcis, racemis lateralibus brevissimis paucifloris, pedicellis calyce subsemipollicari cano-puberulo duplo brevioribus, pistillo pollicari sessili glabro, stigmate laterali ovali magno. F In .coloniâ Swan River (Drumm. coll. 4. n. 285 !). Rami virgati, elongati, pauciramosi, juniores puberuli. Folia conferta, siepe spurie fasciculata, patula, læte viridia, 1-1 $\frac{1}{2}$-pollicaria, laciniis 5-7 lin. longis, $\frac{1}{2}-1$ lin. latis, mucronatis supra planis immerse 1 -nerviis, subtus junioribus in sulcis cano-puberulis. Racemi ramulos axillares vix semipollicares cano-tomentosos terminantes. Calyx 5-6 lin. longus incurvus, intus pilosiusculus, basi inflatus, limbo globoso. Stigma 1 lin. longum, subplanum. Glandula hypogyna parva. Accerlit ad prucedentes, sed jam foliis simpliciter 3-partitis, inflorescentia et pistillo facile dignoscenda. (v. s. in herb. Shuttl.)

96. G. ASPARAGOIDES (Meisn. l. c. p. 186), ramis cano-tomentellis, foliis pollicaribus rigidis 2-3-ternatis glabris margine nerviformi acuto refractis, laciniis divaricatis subulato-linearibus pungentibus petiolo subrequalibus subtus bisuleis, racemis terminalibus lateralibusque subsessilibus brevibus recurvis Jaxifloris, pedicellis calycem subsemipollicarem puberulum subæquantibus, ovarjo sessili villoso, stylo longe oxserto glabro, stigmate terminali obliquo parvo subrotundo. 亏 In coloniả Swan River (Drumm. coll. 4, n. 283 !). Ramuli graciles. Fołia 1-1 1-poll. Ionga, supra plana 1-nervia nitida bi- vel rarius triternata, laciniis sequalibus 3-5 lin. longis, $\frac{1}{2}-\frac{2}{3}$ lin. latís. Racemi nutantes, folio breviores, rhachi cano-velutinâ. Calyx 5-6 lin. longus, incurvus, utrinque rotundatus apice villosiusculus. Glandula hypogyna parva. Pistillum 9-10 lin. longum, stigmate inclinato depressocapitato marginato vix $\frac{1}{2}$ lin. lato. A precedente folís tenuioribus, pistillo, etc., facile distinguenda. (v. s. in herb. Shuttl.)

97. G. ARM IGER A (Meisn. l.c. p. 186), foliis rigidissimis sesquipollicaribus biternatis supra punctato-scabriusculis subtus bisulcis ramulisque cano-tomentellis, laciniis divaricatis subulato-linearibus pungentibus petiolo subarualibus margine revoluto obtusis, racemis terminalibus subsessilibus bipollicaribus erectis, calyce subsessili parvo villosinsculo stylo glabro longe superato, ovario sessili villoso, stigmate terminali depresso-capitato parvo. J In colonià Swan River (Drumm. coll. 4, 11. 284 !). Rami divaricati, juniores cum foliis ferrugineo-velutini. Folia supra subconvexa, enervia, opaca, puncticulata, margine revoluta nec refracta. Racemi $2-2 \frac{1}{2}$ poll. longi, multiflori, undique pube brevi densâ albo-viltosi. Calyx 3-4 lin. longus. Pistillum 8-9 lin. longum. Folliculus ventricoso-semiovatus, 5 lin. longus, 3 lin. latus, ecostatus, cano-tomentosus, muticus, stylo toto deciduo. Cat. fere G. asparagoidis et tripartitæe. (v. s. in herl. Shuttl.)

98. G. Tenetifolra (Ieisn. in pl. Preiss. 2, p. $255^{\star}$ ), ramis apice puberulis, foliis 
teretibus sulcato-angulatis glabris semitrifidis spinescentibus, intermediâ sæpius indivisâ, corymbis axillaribus subsessilibụs folio brevioribus dense multîfloris, calyce parvulo glabriusculo, pistillo semipollicari stipitato glabro, stigmate laterali ovali. F In colonià Swan River (Drumm. coll. 3, n. 271!!). Folia conferta, rigida, 1-2 poll. longa, $\frac{1}{2}$ lin. crassa, laciniis plerumque petiolo paulo longioribus, 8-10 lin. longis, mucronatis, lateralibus 2-3-fidis, intermediâ fere semper indivisâ. Corymbi pollice breviores, rhachi canescente, pedicellis 2-3 lin. longis calycem parce pilosiusculum demum glabrum æequantibus. Stigma $\frac{1}{3}$ lin, longum, tenuiter marginatum, convexiusculum. Facie valde accedit ad G. (Conogynen) biternatum, sed foliis stigmateque distinctissima. (v. s. in herb. Shuttl.).

99. G. Hookeriana (Meisn. in pl. Preiss. 1, p. $546^{*}$ ), ramis cano-tomentosis, foliis elongatis lineari-filiformibus pinnatim 3-9-fidis glabriusculis laciniis acutis supra planis lævibus margine revoluto obtusis subtus bisulcis, spicis bipollicaribus axillaribus terminalibusque subsessilibus erectis, calyce parvo sericeo-villosiusculo, ovario sessili villoso, stylo exserto glabro, stigmate terminali súbobliquo convexo. F In cọloniâ Swan River (Drumm. coll. 1, n. 633! 72! 6, n. 184! Preiss, n. 2626 !). Frutex fastigiato-ramosus, innovationibus ferrugineo-tomentosis. Folia rigidula, 3-5 poll. longa, $\frac{1}{2}-\frac{2}{3}$ lin. lata, tomentella, demum glabrata, sub lente puncticulata, tactu tamen lævia, omnia pinnata, laciniis parum divergentibus,

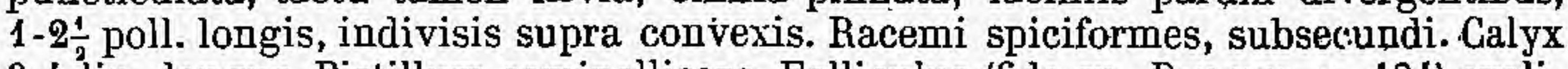
3-4 lin. longus. Pistillum semipollicare. Folliculus (fide sp. Drumm. n. 184) ovalioblongus, obtusus, in stipitem attenuatus, glaber, parce leviterque verruculosus, subsemipollicaris, stylum rectum æquans. Valde accedit ad G. eriostachyam, sed spicis brevioribus magis lanatis, floribus minoribus, stigmate, etc., facile dignoscenda. (v. s.)

100. G. TETRAG ONOL OBA (Meisn. in Hook. Journ. 1852, p. 186), ramis sericeotomentosis, foliis digitalibus pari- vel impari-pinnatis lævibus glabris, laciniis 2-3-jugis anguste linearibus mucronulatis indivisis acute tetragonis margine nerviformi refractis subtus bisulcis, spicis terminalibus digitalibus erectis dense secundilloris, calyce parvo subsericeo-tomentoso pistillo dimidio superato, ovario sessili piloso, stylo glabro, stigmate terminali truneato orbiculari marginato. J In coloniâ Swan River (Drumm. coll. 4, n. 282 !). Rami subvirgati, ramulis gracilibus apice angulato-striatis fulvo- vel cano-tomentellis. Folia conferta, rigida, 2-4 poll. longa, juniora subsericeo-puberula, laciniis oppositis, 1-2 $\frac{1}{2}$ poll. longis, $\frac{2}{3}$ lin. latis, supra planis petiolo conformibus et plerumque longioribus. Spica 2-3-pollicares, breve pedunculatæ, strictæ. Calyx subsessilis, 3-4 lin. longus, incurvus, diu clausus. Glandula hypogyna minuta. Pistillum demum rectum, 7-8 lin. lougum, stigmate depresso-turbinato minute umbonato. A G. Hookerianâ valde affini distinguitur ramulorum florumque pubescentiâ sericeầ in calyce et racemi rhachi breviore adpressâque, foliorum lobis margine refracto nec revoluto acute 4 -gonis, stylo longiore, etc. (v. s. in herb. Shuttl. et Lemann.)

101? G. RIGENS (A. Cunningh.! mss. in herb.), foliis digitalibus pinnatis, laciniis 5-7-jugis elongato-linearibus sphacelato-acutis margine recurvis supra lævibus glabris obsolete 1-nerviis minute venoso-striatis subtus sericeis, racemis termmalibus semipedalibus simplicibus erectis, floribus glabris. ‡ In orâ orient. tropicâ circa promontor. Flinders (A. Gunningham !). Folia rigida, 3-5-pollicaria, laciniis patulis parallelis oppositis alternisve 2-3 lin. longis, 1 lin. latis. (v. s. in herb: Brown. et Cunn.)

102. G. DRYANDRI (R. Brown! in Linn. Trans. 10, p. 175, prodr. p. 379), ramulis subsericeo-tomentellis, foliis elongatis pinnatis lævibus glabriusculis, laciniis 6-12-jugis anguste linearibus elongatis sphacelato-acutis margine arcte revolutis supra 1-nerviis eveniis subtus bisulcis, racemis terminalibus pedunculatis elongatis erectis laxiusculis pistillisque sesquipollicaribus glaberrimis, calyce semipollicari oblique inserto, ovario longe stipitato, stigmate laterali oblongo $\Rightarrow$ Circa sinum Carpentaria (R. Brown!). Ramuli teretes, demum glabrati. Folia 4-6-pollicaria et ultra, laciniis $2-4$ poll. longis, $\frac{1}{2}$ lin. latis, supra subconvexis enerviis, sublus junioribus sericeis. Racemi 4-6 pollicares, sæpius inferne ramosi. Calyx sulsventricosus, fauce intus pilosulâ. Ovarii stipes pedicello longior, 3 lin. longus, calycis tubum requans. Stigma 1 lin. longum, subconcexum. (v. s. in herb. Brown., etc.) 
103. G. GALIPTERIS (Meisn. in Hook. Journ. 1852, p. 187), foliis semijedalibus laciniis 6-12-jugis elongato-linearibus mucronulatis margine leviter recurvis supra lavibus glabris 1 -nerviis venoso-striatis subtus sericeis, racemis terminalíbus elongatis erectis laxiusculis, calyce pollice breviore oblique inser to pistilloque bipollicari glaberrimis, ovario longe stipitato, stigmate laterali oblongo. $亏$ In insulis Goulburn et orâ septentrionali (A. Cunningham !). G. Dryandri A. Cunn.! mss. in herb. (non $\mathrm{R}$. Br,). Omnia jriecedentis, exceptis foliorum laeiniis latioribus 1-3 lin. latis, planis vel margine levissime recurvis (nec adpresse revolutis), facie inferiore conspicua, et calyce pistilloque $\frac{1}{3}$ longioribus. An G. Dryandræe var.?, sed folia nimis discrepantia, fere eadem ac G. refractæ et rigentis, quæ vero inflorescentiâ, etc., distinctre. (v. s. in herb. Cunn.)

104. G. THYRS OIDES (Meisn. in Hook. Journ. 1855, p. 77), ramis tomentosis, folis digitalibus pinnalis glabris, laciniis 8-14-jugis subulato-linearibus mucronatis punctato-scabriusculis margine acute refractis subtus bisulcis, paniculâ terminali thyrsoideâ lónge pedunculatâ, racemis elongatis, calyce mediocri subinflato canopubescente, ovario stipitato villoso, stylo pollicari pilosiusculo, stigmate terminali oblique truncato subrotundo., In Novâ-Holl. occid, intér. Dunctagaran et Smith River (Drumm. coll. 6, n. 183! Hook. Journ. 1853, j. 178). Frutex prostratus, ramis virgátis 'subsimplicibus dense foliosis albido-tomentosis. Folia rigida, $3 \subset 4$ pol]. longa, complicata, petiolo gracili tereti $1-1 \frac{1}{2}$ poll. longo submarginato, laciniis oppositis $1-1 \frac{1}{2}$ poll. longis rlachique $\frac{1}{2}-\frac{2}{2}$ lin. latis indivisis, terminali proximis subtriplo breviore: Pedunculus pedalis et ultra, superne glaber, renuotc bracteatus, prope apicem recurvo-nutantem racemos 3-4 gerens; bracteis foliaceis lanceolatis ácuminatis'3-4 lin. longis glabriusculis subadpressis, inferioribus gemmam ramuli vel racemi ovatam imbricato-bracteatam pubescentem foventibus ; racemis incluso jedunculo partiali $1-2 \frac{1}{2}$ poll. longo, bracteis subulatis adpressis sparse obsito 4-6 poll. longis cylindraceis densis basifloris, pedicellis 1 lin. longis crassiusculis hirsutis. Calyx 3-4 lin. longus, ventricosus, incurvus, demum 4-partitus, roseus. Ovarium subglolsosum, albido-villosum, stipite fere 2 lin. longo pubescente, stylo tenui prelongo tenuiter piloso, stigmate vix $\frac{1}{2}$ lin. lato subumbonaio. Proxime affinis $\mathrm{G}$. Dryandri, sed foliorum lobis dimidio brevioribus, floribus multo minoribus puljescentibus, etc., bene distincta, foliis accedens ad G. refractam, Leucadendrow, inflorescen lia ad G. polystachyam; forsan ad sect. Cyclopteram pertinens. (v. s. in herb. Shuttl.)

105. G. BANKSII (R. Brown! in Linn. Trans. 10, p. 176, prodr. p. 379), ramulis sericeo-tomentosis, foliis semipedalibus pinuatim 3-12-fidis, laciniis elongatolanceolatís linearibusve decurrentibus sphacelato-obtusiusculis margine recurvis 1 -nerviis lævibus subtus sericeis supra glábratis obsolete venosis, racemis terminalibus pedumculatis erectis ovato-cylindricis dense multifloris, calyce semipollicari tomentello, pistillo sesquipollicari, ovario sessili villoso; stylo glabro, stigmate terminali infleso orbiculari. J In orâ orientali tropicâ (K. Brown!), Port-Bowen (A. Cuna.1). Frutex elegans, rámulis dense fulvo-tomentosis teretibus. Folia 3-8 poll. longa, laciniís oppositis alternisque 2-4 poll. longis, 2-4 lin. latis, junioribus mucronulatis ntrinque adultis subtus fulvo-sericeis, petiolo 1-2-pollicari basi tereti tenui. Raremi folia superantes, sæpe paniculati, 1-3 poll., pedicelli $1 \frac{1}{2}-2$ lin. longi. Calyx 7-8 lin. longus, cylindricus, sordide fulvo-tomentellus, intus glaber, basi haud attenuatus, limbo globoso inflexo. Stylus tereti-filiformis, tenuis, stigmate vix $\frac{1}{2}$ lin. lato marginato convexo (v. s. in lierb. Brown., Cunn., etc.).

ß. stylo crassiore, complanato. - In collibus lapidosis, ad flum. Brisbane, prope Moreton Bay (A. Cunningh.!). Cuet. omnino ut in specim. Brown. (v. s. in herb. DC., Lindl. et Mart.)

106. G. Caleyi (R. Brown! suppl. p. 22), foliis subsemipedalibus subsessilibus pimnatis, laciniis 10-20-jugis patentissimis jollicaribus linearibus decurrentibus margine revolutis supra levibus glabriusculis subtus ramulisque dense lanatovillosis subsericeo-fulvis, racemis terminalibus pedunculatis erectis digitalibus laxiusculis, calyce subsemipollicari villosulo, intus glabro, pistillo pollicari, ovario stipitato villoso, stylo glabro, stigmate terminali oblique truncato. $\zeta$ Circa PortJackson (Caley! A. Cunn.!). - Bot. mag. t. 3133. G. blechnifolia A. Cumningh.! mss. in herb. Species elegans, distinctissima. Rami graciles, teretes, pube molli longiuscula patente dense villosi, fulvi vel cinerei. Folia patula, vix rigidula, circumscriptione oblonga, ab imâ basi inde pinuata, laciniis opposilis vel rarius 
alternis parallelis angulo recto a rhachi divergentibus, $7-15$ lin. longis, $1 \frac{1}{2}-2 \frac{1}{2}$ lin. latis, rectis acutis vel obtusis cum apiculo recurvo sinu plerumque duplo angustioribus supra laxe pilosiusculis obsolete 1-nerviis venosisque. Racemi 2-3-pollicares, pedicellis 1 lin. longis. Calyx cylindraceus, incurvus, haud inflatus, utrinquo obtusus, pube brevi patulâ densẩ ferrugineus. Ovarii stipes villosus. Stigma convexum. Folliculus erectus, falcato-oblongus, subcompressus, 7-9 lin. longus, 4 lin. latus, stylo toto caudatus utrinque attenuatus, fulvo-tomentosus, stipite erasso fere 2 lin. longo. Semina ignota. (v. s. in herb. Brown., Cuun., etc.)

\section{b. Folia inciso-dentata (passim integra) vel pinnatisecta, rarius bipin- natifida vel angulalo-dentata, segmentis latiusculis mucronatis planis vel margine angustissime recurvis.}

107. G. ASPLENIFOLIA (Knight et Salisb. Prot. p. 120), foliis elongato-linearibus pinnatifido-incisis integerrimisque subtus tomentosis, racemis folio ter brevipribus, calyce pubescente, stylo glabro.J Circa Port-Jackson (Caley!). R. Brown! in Linn. Trans. 10, p. 175 , prodr. p. 379. Similis sequenti, sed distincta foliis profundius incisis subtus cinereis nec sericeis, pube flexuosâ. (v. s. in herb. Brown.)

108. G. LONGIFOLIA (R. Brown! suppl. p. 22), foliis elongato-lanceolatis attenuatis acutis inciso-dentatis passim integerrimis margine recurvis supra immerse subr venosis glabris subtus ramulisque junioribus sericeis, racemis axillaribus terminalibusque pedunculatis erectis dense secundifloris, calyce subsemipollicari sericeo intus glabro, pistillo pollicari, ovario breve stipitato sericeo, stylo glabro, stigmate terminali subohliquo capitato. J Circa Port-Jackson (Caley!) et in montibus ccruleis (A. Cunningh.!). Frutex 6-10 pedalis. Rami graciles, apice striati vel subangulati. Folia 3-8 poll. longa, 3-10 lin. lata, utrinque, sed præcipue apicem versus attenuata, nunc tota nunc nonnisi medio grosse serrata, dentibus patulis triangularibus 1-2 lin. longis mucronulatis. Racemi 1-2-pollicares, rhacbi angulatà demum glabratâ, pedicellis 1 lin. longis. Calyx incurvus. Folliculus erectus, subventricoso-cblongus, vix compressus, 5 lin. longus, utrinque attenuatus, stylo pollicari caudatus, lievis, stipite $1 \frac{1}{3}$ lin. longo. (v. s. in herb. Brown, Cunn., etc.)

109. G. cIRSIIFOLiA (Meisu. in pl. Preiss. 2, p. $253^{*}$ ), foliis peliolatis elongatis lineari-lanceolatis remote inciso-serratis planis supra venosis adpresse pilosis demum glabris subtus eveniis ramisque sericeis, racemis axillaribus pedunculatis folium sulwequantibus demum laxifloris, pedicellis calyce parvo sericeo pistillum iequante longioribus, ovario sessili piloso, stylo glabro, stigmate laterali hemisphærico umbonato. J In coloniâ Swan River (Drumm. coll. 3, 11. 2.67!). Rami jrostrati? elongati, graciles, apice compresso angulati et cum foliis junioribus perlunculis floribusque pube tenerrimà cupreo-sericei. Folia secunda, parum rigidula, 3-6 poll. longa, 2-5 lin. lata, petiolo cuneato-lineari 1-1 $\frac{1}{2}$-pollicari, dentibus scaleno-triangularibus 1-2 lin. vel infimis 4-12 lin. longis, 1 lin. latis, margine subrecurvis planisve, sinubus acutis vel subrectangulis, paginâ inferiore pulchre sericeâ cupreâ vel demum albidâ. Racemi incluso pedunculo pollicari 4 poll. longi, juniores nutantes, pedicellis $3-4$ lin. longis bracteâ dimidio breviore subulatà caducâ fultis. Calyx vix 3 lin. longus, intus glaber, supra lissus, unilabiatim. deflexus explanatus et stigma diu retinens. Stylus crassiusculus, complanatus, arcuatus. Folliculus (junior) ventricoso-ovoideus, 3 lin. longus, stylo toto $1 \frac{1}{2}$ lin. longo persistente longior, rufo-tomentosus. Species foliis ad G. longifolium accedens, cæterum vero ab omnibus distinctissima. (v. s. in herb. Shuttl. et Lemann.)

110. G. Bipinnatifida (R. Brown! suppl. p. 23), foliis 3-8-jugo-bipinnatifidis planis nervoso-marginatis supra reticulatis subtus lævibus, laciniis triangularibus oblongisve spinoso-mucronatis, racemis axillaribus terminalibusque digitalibus recurvis laxiusculis, pistillo pollicari, ovario sessili calyceque semipollicari tomen-

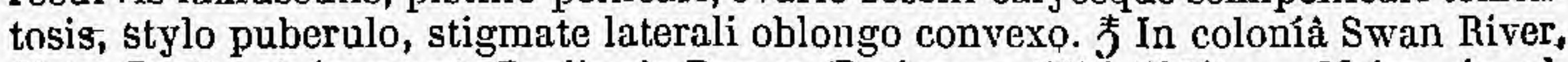
distr. Perth, et in mont. Darling's Range (Preiss, n. 707! 708!). - Mcisn. in pl. Preiss. 1, p. $541^{*}$. Frutex procumbens, elegans, pubescentià, foliorum divisione, racemi florumque magnitudine satis variabilis. Folia rigida, 1-2 poll. longa, circumscriptione late ovata, in peliolum circ. pollicarem cuneato-linearem angustata, sinubus segmentis angustioribus plerumque obtusis, rhachi 2-5 lin. latâ. Racemi 2-5 poll. longi, ubique pube brevi viscidulâ? fulvo-tomentosi, pedicellis 3-5 lin. longis, floribus puniceis vel miniatis. 
a. vulgaris (Meisn. l. c. p. 542), ramulis teretibus brevibus cano-tomentosis, foliis omnibus bipinuatifidis parce pilosiusculis glabrisve. (v. s. in herb. Brown. et Preiss.)

B. glabrata (Meisn. 1. c.), ramulis sulcato-striatis vel costato-angulatis foliisque glabris, summis simpliciter pinnatifidis. (v. sp. Drumm. in herb. DC.)

111. G. ACANThifolia (A. Cunn.! in Field N. S. Wales, p. 328, cum ic.), erecta, ramis strictis angulato-sulcatis glabris, foliis subsessilibus rigidis bipollicaribus oblongis pinnatifidis glabris margine refracto recurvis, laciniis 3-6-jugis triangularibus oblongisve pungentibus inferioribus 2 -3-fidis sinubus acutis, racemis terminalibus spiciformibus subsessilibus subdigitalibus erectis dense secundifloris sericeis, bracteis ovatis diu jersistentibus, pistillo subpollicari, ovario subsessili villoso, stylo glabro, stigmate terminali obliquo subrotundo. 5 Circa Port-Jackison et ín mont. coruleis, alt. 3,400 ped. (A. Cunninigh.! Sieber, n. 32 ! d'Urville! Anderson, n. 120 ! etc.). - Roern. et Schult. syst. mant. 3, p. 281 ", Hook. exot. f1. t. 216 , Lodd. Bot. cals. t. 1153, R. Brown! suppl. p. 22, Bot. mag. t. 2807, Lindl. in Paxt. fl. Gard. 1852, n, 576, cum. fig.). Frutex rigidus, cardniformis. Folia usque ad 3 poll. longa, plus minus complicata, segmentis inferioribus usque ad' 1 poll. longis reliquis paulo longioribus cuneatis, laciniis basi 2-3 lin. latis 1 -nerviis sabvenosis. Racemi 2-3-pollicares, ante expansionem conico-oblongi strobiliformes imbricatobracteati nec secundi, floribus brevissine pedicellatis demum in unum latus versis. Calyx 4 lin. longus, dense brevi-villosus, limbo globoso inflexo diu clauso. (v. s. in herb. Cunn., etc.)

112. G. GAUdicha UdI (R. Brown! in Gaudich. Bot. Voy. Freycinet, p. 443, t. 46), procumbens, ramis gracilibus erectis apicc subangulatis sericeo-tomentellis, foliis subpetiolatis rigidis subdigitalíbus ovatis pinnatifidis utrinque venosis planis vel margine subrecurvis supra glabris subtus junioribus adpresse pilosiusculis, laciniis 2-4-jugis oblongis pungentibus, basilaribus passim bifidis, sinubus acutis, racemis terminalibus axillaribusque subbipollicaribus erectis sericeis, bracteis ovatis diu persistentibus, pístillo pollice breviore, ovario lirsuto breviter stipitato, stylo glabro, stigmate terminali oblique hemisphærico. 5 Circa Port-Jackson, in mont. cceruleis (Gaudich., $\Lambda$. Cunningh.! Anderson, n. 115!).-R. Brown! suppl. p. 22. G. acanthifolia var. quercifolia A. Cunn. mss. A precedente, cui inflorescentiâ, bracteis; calyce omnino convenit, facile distinguitur jubescentiâ ramulorum racemorumque brevi arlpressâ et præcipue foliis ambitu late ovatis, $2-2 \frac{1}{2}$ poll. latis, planis (nec complicatis), margine vix recurvis (nec refractis), venis nervulo intramarginali conjunctis, sinubus plerumque angustissimis, laciniis infimis usque ad $1 \frac{1}{2}$ poll. longis raro bifidis, et pistillo breviore 9 lin. longo.(v. s. in herb. Brown., DC., etc.)

113. G. REPENS (Ferd. Müller! in Linnæâ $26, \mathrm{p} .355^{\circ}$ ), procumbens, ramis elongatis gracilibus teretibus apice puberulis, foliis rigidulis digitalibus oblongis obtusis mucronatis basi cuneato-attenuatis margine recurvo spinoso-dentatis undulatis sinubus rotundis utrinque prominulo-venosís subsericeo-canescentibus supra demum glabris, racenis terminalibus axillaribusque folio brevioribus patulis dense secundifloris subsericeo-puberulis, pedicellis calyce mediocri vix dimidio brevioribus, pistillo subpollicari, ovario breviter stipitato villoso, stylo glabro, stigmate oblique laterali ovali. 5 In collibus Australiæ Felicis, circa 11. Watts, Loddan et Goulburn (Ferd. Müll.!). Frutex longe supra terram prorepens, ramis subsimplicibus laxe foliosis. Folia parum rigida, plana, 2-4 poll. longa, 8-14 lin. lata, petiolo 2-4 lin. longo, dentibus 1-2 lin. longis sæpius geminatim approximatis altero minore, sinubus igitur incqualiibus $2-3$ lin. latis. Calyx $4-5$ lin. longus. Cæt. fere G. acanthifoliæ, sed racemi breviores laxiores et pubescentia tenuior. (v. s. comm. a cl. Sonder.)

114. G. ILICIFOLIA (R. Brown! suppl. p. 21), foliis subpetiolatis rigidis bipollicaribus obovatis oblongisve cuneato-attenuatis inciso-pinnatifidis planis ramulisque tomentoso-sericeis supra demum glabratis utrinque venosis, lobis dentibusve ovato-triangularibus.mucronatis, sinubus rotundis, racemis terminalibus folia subæquantibus subrecurvis dense secundifloris sericeo-puberulis, pedicellis brevissimis, bracteis ovatis diu persistentibus, pistillo pollicari calycem dimidio superante, ovario subscssili villoso, stylo glabro, stigmate terminali oblique truncato-convexo. J In Novæe-Holl. orầ australi. - F. Müller in Linnæâ 26, p. 355. 
Plúrimis notis convenit cum G. Gaudichaudii, sed facile dignoscenda foliis minus profunde incisis, lobis igitur brevioribus, sinubus rotundatis, ete.

u. attenuata (R. Brown l. c.), foliis attenuato-cuneatis extra medium incisodentatis, dentibus spinescentibus, dimidio inferiore indiviso longiore, margine recurvis supra venosis. - Ad Port Lincoln (R. Brown! A. Cunn.! Ferd, Müll.!), Port-Phillip (Latrobe!). Anadenia ilicifolia R. Brown! in Linn. Trans. 10, p. 167, prodr. p. 375. Grevillea Behrii schlechtend. in Linnæâ 20, p. $585^{*}$. Folia $1 \frac{1}{2}-2$ poll. longa, 6-9 lin. lata. (v. s. in herb. Brown, etc.)

B. dilatata (R. Brown! l. c.), foliis dilatato+cuneatis dentato-incisis tam latis quạn longis margine refracto-recurvis supra reticulatis, dentibus spinescentibus. - In Kangaroo Island (Baxter! Fraser!), a lacu Torrens ad Guichen Bay, lacum Alexandria et Port-Phillip (cum var. $\alpha$ Ferd. Müll.). Folia vix unquam pollice longiora. (v. s.)

$\gamma$ quercina, foliis obovato-oblongis, dimidio superiore pinnatifido-dentato inferiore æquali integerrimo cuneato, dentibus mucronulatis planis vel marginc vix recurvis. - Circa Port-Phillip (Latrobe I). Videtur stirps junior. (v. s)

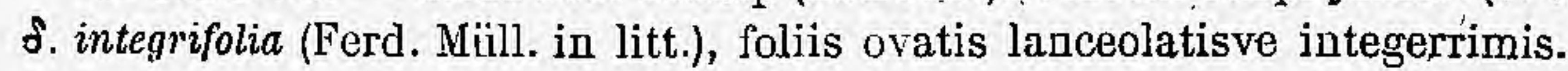

115. G. Variabilis (Lindl.! in Nitchell exped. inter. east Austr. 1839, ex Ann. se. nat. 2" sér. 15, p. 62), foliis rigidis bipollicaribus elliptico-oblongis extra medium pinnatifido-dentatis angulatisve infra cuneato-attenuatis integerrimis venosis ramulisque tomentosis supra glabrèscentibus margine subrecurvis, lobis late triangularibus mucronato-pungentibus, sinubus latis rotundatis, racenis terminalibus pollicaribus tomentosis, bracteis late ovatis acutis..... J In mønte William, Grampians, Australiæ Felicis (Mitchell! exped. 1836). Forsan mera var. præcedentis, recedens preserertim pubescentiầ copiosiore laxiusculâ subcrispâ haud sericeà, in paginà superiore diu persistente. Flores vidimus nonnisi juniores inexpansos. (v. s. in herb. Lindl.)

116. G. AQUIF OL IUM (Lindl.! I. c., Ann. sc. nat. l. c. p. 62), folis petiolatis bipollicaribus ovato-oblongis pinnatifido-dentatis kenosis margine refracto-recurvis ramulisque velutino-tomentosis suprá tarde glabrescentibus, dentibus late triangulari-ovatis pungentibus, sinubús latis rotundatis, racemis terminalibus pollicáribus dense villosis, bracteis ovatis acutis diu pérsistentibus, pistillo pollicari calycem longe superante, ovario breviter stipitato villoso, stylo glabro, stigmate terminali oblique truncato. $₹$ In monte William, jugi Grampians Australiæ Felicis (A. et R. Cunningh.! in Mitch. exped. 1835 et 36). G. agrifolia hort., fide-Steudel.

a. truncata, foliis ovatis basi truncatis àpice haud attenuatis, 15 lin. latis. (Cunn. n. 194! 232! 233 ! Ferd. Müller!). G. Aquifolium Lindl.! in herb. Differt a G. variabili et ilicifoliâ : foliis haud cuneato-attenuatis, sed ad basin truncatam usque inciso-dentatis et pubescentiâ magis patulà brevivillosâ nec tomentosâ. (v. s. in herb. Lindl.)

$\beta$. attenuata, foliis ovato-oblongis (9 lin. latis) apice attenuatis basi breviter cuneato-angustatis (R. Cunn. n. 244!). G. Aquifolium var.? Lindl.! in herb. Pubescentia brevior, rarior, evanescens. Foliorum lobi profundius distincti, 3-5 lin. longi, 2 lin. lati; infimi sæpius dente brevi vel mucrone accessorio aucti. (v. s. in herb. Lindl.)

117. G. DUм ет оR Uм (Mcisn. in Hook. Journ. 1852, p. 187), foliis rigidis bipollicaribus planis jextra medium pinnatim 3-5-fidis infra cuneato-attenuatis margine refracto-recurvis ramulisque sericeo-tomentosis supra venosis mox glabriusculis nitidis, lobis divaricatis lanceolatis spinescentibus sinubusque acutis, racemis terminalibus brevibus ebracteatis sericeis, calyce pistillum vix semipollicare subæquante tenui, ovario breviter stipitato villoso, stylo glabro, stigmate laterali ovali convexo. J In Australiâ Felici? (R. Cunningh. n. 210! in Mitcheli exped. 1835)., Rami graciles, laxe foliosi, glabri, juniores subangulati tomentelli. Folia 3-loba, lobo intermetio sape insequaliter 2-3-fido, laciniis 6-12 lin. longis, 2-21 lin. latis apice attenuatis; occurrunt passim folia lanceolata integerrima. Racemi breve pedunculati, demum subpollicares laxiusculi, cum floribus brevissime pedicellalis pube minutâ adpresse'sericei. Calyx gracilis, 3-4 lin. lougus, incurvus, basi attenuatus. Pistillum 4-5 lin. longum. Valde quidem præcedentibus affinis, séd prócipue flore berie distincta. (v. s, in herb, Gum.) 
118. G. Lов а т A (Ferd. Müller! in Trans. philos. Soc. of Victoria 1, p. 22 *), foliis obovato-oblongis ovatisve pinnatim 3-5-lobis in petiolum brevem cuneato-attenuatis leviter nervosis margine angustissime refracto obtusis supra minute puberulis subtus ramulisque incano-tomentosis, lobis patentibus-lanceolatis attenuatis pungentibus infimis sæpe bicuspidato-truncatis, , sinubus latis subrectangulis, racemis terminalibus oppositifoliisque folium æquantibus secundifloris demum recurvis, calyce semipollicari ovarioque stipitato sericeo-tomentosis,' pistillo subpollicari, stylo glalsro, stigmate oblique laterali subrotundo. I In deserto, secus fl. Murray, prope mont. Swan Hill, Australiæe Felicis (Ferd. Müll.I). Frutex 3-6-pedalis, amplus, ramis patentibus angulatis. Folia rigida, 1-2 poll. longa, 10-15 lin. lata, supra pallide viridia opaca, subtus alba, haud sericea, margine nerviformi, venis patentissimis, secundariis supra conspicuis subtus obsoletis vel nullis, laciniis 5-7 lin. longis, 2-3 lin. latis, inferioribus quadrangularibus. Racemi $1 \frac{1}{2}-2$ poll. lougi,

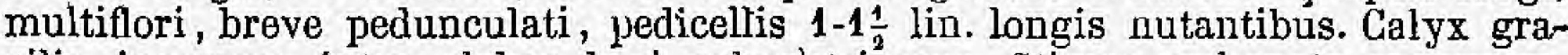
cilis, incurvus, intus glaber, basi subventricosus. Stigma umbonato-convexum. Foliis G. Dumelorum similis, sed floribus distínctissima. (v. s. sine fr. in herb. Sonder.)

$\beta$. Sturtii, foliis vix longioribus quam latis subtus cum ramulis calycibusque fulvo-tomentosís, pistillo 9-10 lin. longo.-In dumetis planitiei ad fl. Murray (Sturt! 1836). G. Stırtii A. Cunningh.! mss. in herb. (non R. Br.). Accedit ad G. ilicifoliam, variabilem et Aquifolium, sed pubescentiæ indole, calyce gracili, etc., bene distincta. (v. s. in herb. Cunn.)

119. G. INSIGNIS (Rippist! in litt. 1852"), foliis rigidis glaucis breve petiolatis digitalibus elliptico-oblongis sinuato-denlatis planis marginatis reticulatis basi truncatis ramulisque glaberrimis, dentibus angulisve spinoso-mucronatis remotis, racemis terminalibus subramosis glaberrimis, pedicellis semipollicaribus calycem tnmidulum æquantibus, ovario breve stipitato villoso, stylo vix exserto basi villoso, stigmate laterali orbiculari. J In coloniâ Swan River (Drumm. coll. 5, suppl. n. 12!). Tota pruinoso-glauca, ranulis teretibus. Folia rigidissime coriacea, 2-3 poll. longa, 1-2 poll. lata, ad basin usque spinoso-dentata vel subangulata, dentibus mucronibusve rectis .circ. 1 lin. longis, 4-6 lin. distantibus, venulis utrinque prominulis sat dense reticulatis, margine obsolete nerviformi plano. Racemi breve peduuculati, apiciflori. Flores speciosi, purpurei, valde incurvi, intus basi villosi, limbo recurvo secundo. Glandula hypogyna obsoleta vel calycis basi inflato adnata. Stylus crassus complanatus vel antice canaliculatus, apice glaber. (v. fragm. comm. a cl. auct.)

120 ? G. GunNingham ir (R. Brown! suppl. p. 23), glaberrima, foliis subsessilibus rigidulis cordato-ovatis amplexicaulibus inciso-dentatis utrinque dense elevatoreticulatis, dentibus triangularibus longe mucronato-pungentibus, racemis axillaribus folio subbrevioribus paucifloris, pedunculis tenuibus passim 1-2-phyllis demum recurvis, calyce parvulo int $\mu$ s parce barbato pistillum stipitatum glaberrimum subæquante, stigmate laterali-oblongo. 5 In littore arido sinus Montague oræ boreali-occidentalis tropicæ. (A. Cunn.!). G. carduifolia Cunn.! mss. Frutex 10-pedalis, ramis gracilibus teretibus densiuscule foliosis. Folia patentia, tenue

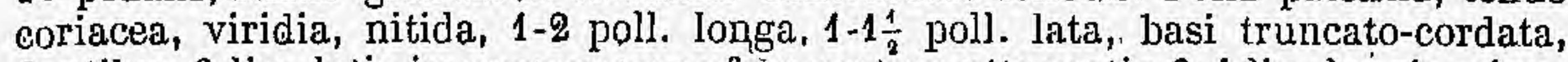
dentibus 9 lin. latis in mucronem rufam rectum attenuatis $2-4$ lin. longis, sinubus rolundatis. Pedunculi filiformes, quandoque gemini, circ. pollicares, apice

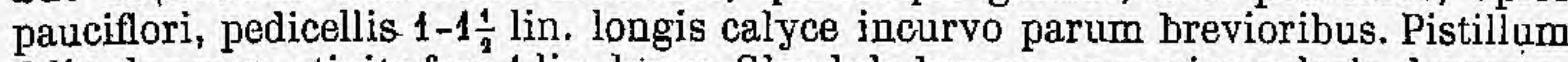
3 lin. longum, stipite fere 1 lin. longo. Glandula hypogyna semiannularis, depressa. Folliculus cernuus, ovali-oblongus, inflatus, 4-5 lin. longus, 2 lin. latus, lævis, glaber, stylo toto 2 lin. longo caudatus, stipite vix lineam longo. (v. s. in herb. Brown., Gunn., etc.)

\section{Sect. Hi. Gycloptera R. Brown in Linn. Trans. p. 10, p. 176; Prodr. p. 380.}

Folliculi lignei, late ovati compressi vel subglobosi, plerumque styli basi tantum mucronati vel mutici. Semina alẩ latiusculâ undique cincta. Stylus deciduus, rarius persistens, stigmate terminali oblique truncato vel conico-capitato rarius lateralj. Calycis basis ovarii stipiti haud adnata. 
\$1. Angulatce. -Foliis coriaceis planis latiusculis angulato-vel inciso dentalis, dentibus mucronatis vel spinescentibus, junioribus ramulisque pubescentibus, demum glabratis. Racemi simplices, axillares, folia haud superantes, parviflori.

121. G. ANGULATA (R. Brown! suppl. p. 34), ramulis angulatis tomentellis, foliis ovali-oblongis angulato-3-9-dentatis infra medium subcuneato-attenuatis integerrimis laxe prominulo-reticulatis adultis glabris, angulis dentibusve brevibus remotis pungenti-mucronatis, racemis folium subrequantibus pedunculatis erectis dense multifloris, calyce parvo intus barbato extus pistilloque dimidio longiore stipitato glaberrimo, stignuate laterali ovali. $\mathrm{J}$ In insulà Sims, prope sinum Goulburn oræ septentr. (A. Cunn.!). G. ilicifolia A. Cunn.! mss. (non R. Br.). Ramï subvirgati, graciles, laxiuscule foliosi, apice angulati cano-tomentelli. Folia petiolata patula, rigidula, glauca? $1 \frac{1}{2}-2 \frac{1}{2}$ poll. longa, 9-12 lin. lata, ferc G. ilicifolix et monticole, dentibus angulisve $3-6$ lin. distantibus, sinubus levissime arcuatis vel rectilineis. Racemi pedunculo breviores, vix pollicares, pedicellis 1-2 lin. longis tenuibus. Calyx 3-4 lin. longus, extus glaber, Intus pilis rectis patulis albo-barbatus. Pistillum 7-8 lin. longum, ovarii stipes $\frac{1}{2}$ lin. Iongus, stylus tenuis, deciduus, stigmate obtusissime umbonato. Folliculus ventricoso-ovatus, muticus, 5 lin. longus, vix compressus, utrinque rotundatus, lævis, uitidus. (v. s. in herb. Brown., Cunn., DC., etc.)

122. G. W г с к н А м I (Meisn. in Hook. Journ. 1852, p. 187), ramulis teretibus tomentellis, foliis ovatis sinuato-5-9-dentatis basi breviter cuneato-attenuatis venosis minute subimmerso-reticulatis adultis glabris, dentibus triangularibus spinescentibus, racemis folio brevioribus recurvis glabris, calyce intus parce pilosiusculo pistilloque breviter 'stipitato parvulis, stigmate laterali ovali. $亏$ Circa Usborne's Harbour oræ occidentali-borealis (Wickham! 1839, in exped. Beagle). Proxima quidem $G$. angulate, sed notis indicatis certe distincta. Folia crassiora, rigida, pleraque sesquipolliee breviora, sinuato-dentata, nec unquam mere angulata, clentibus cum mucrone $2-4$ lin. longis, sinubus rotundis $3-4$ lin. latis, venularum retieulo denso fere immerso. Racemi 6-12.lin. longi. Pistillum 2 lin. longum, stylo complanato crassiusculo puberulo persistente, stigmate planiusculo. Folliculus parvus, ventricoso-ovatus, stylo toto caudatus, lævis. Semina ovali-oblonga, plano-convexa, alâ angustâ tenui albâ cincta, dorso lævia. (v. s. in herb. Cunningh.)

123. G. A GRIFOLIA (A. Cunn.l mss. in herb.), foliis cuneato-obovatis obtusis extra medium angulatis. vel-spinoso-dentatis glabriusculis utrinque venosis denseque prominulo-reticulatis, racemis folio brevioribus recurvis dense multifloris, calyce mediocri sericeo intus dense barbato extus demum pistilloque duplo longiore stipitato glabro, stigmate inflexo laterali late ovali. 5 In ins. Lacrosse et ad Cape Pond oræ septentrionali-occidentalis (A. Cunningh.!). - R. Brown suppl. p. 24.

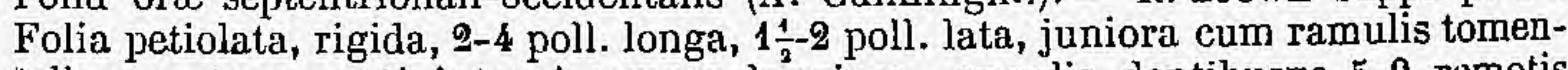
tella, parte cuneatâ integrâ semper longiore, angulis dentibusve 5-9 remotis mucronatis, sinuhus lævissimis fere rectilineis $4-10$ lin. latis, reticulatione grossiore magisque prominulâ quam G. Wickhamil. Racemi incluso pedunculo brevi 1--2 poll., pedicelli 2 lin., calyces 4 lin. longi. Pistillum 8-9 lin. longum, stylo tenui, stigmate $\div$ lin. longo marginato convexo. Folliculus subglobosus, muticus, cum stipite suo brevi crasso 10 lin. longus, nitidus, lævis, pericarpio 1 lin. crasso supra (Hakeæ more) dimidio crassiora. Semina ovalia, plana, alâ 1 lin. latâ cincta, dorso cristato-rugulosa. (v. s. in herb. Brown., Gunn., DG., etc.)

\section{§ 2. Pinnata, - foliis pinnatipartitis vel bipinnatifidis, laciniis lan-} ceolatis vel linearibus vel fliformibus margine recurvis revolutis refractisve subtus vel utringue sericeis vel tomentosis. Racemi scepius elongati, nonnunquarn paniculato-ramosi.

124. G. IELIOSPERMA (R. Brown! in Linn. Trans. 10, p. 176, prodr. p. 380), foliis clongatis pinuatis subbipinnatisque, junioribus ramulisque minute puberulis, laciniis 4-7-jugis lanceolatis utrinque venosis reticulatis supra dense lineatis, 
infimis sæpe petiolatis passimque bipinnatifidis, paniculis axillaribus subterminalibusque folio brevioribus, racemis laxifloris, cal yce mediocri intus harbellato ex tus pistilloque prælongo stipitato glaberrimis, 5 Circa sinum Carpentaria (R. Brown!) et Port-Raffles or:e septentr. (A. Cunn. n. 206!). Arbuscula 12-15-pedalis. Folia 6-12 poll. longa, modice rigida, glabriuscula, laciniis oppositis altern isve $2 \frac{1}{2}-5$ poll. longis, 3-9 lin. lątis utrinque a htenuatis obtusis cum apiculo brevi sphacelato vel obsoleto infra medium śepe obsolete 3 -nerviis, nervo venisque primariis subtus magis conspicuis laxe anastomosantibus, venularum reticulo supra densissimo areolis angustissimis sulciformibus, petiolo communi tereti. Panicula 5-6-pollicaris, breve pedunculata, racemis alternis patulis 2 poll., pedicellis tenuibus $3-4$ lin. longis. Calyx subsemipollicaris, oblique insertus. Pistillum 1 poll. ct ultra longurn, stipite calycem subæquante líbero. Folliculusebovato-subglobosus, 5-6 lin. longus, submuticus, lævis. (v. s. in herb. Brown., Cunn., DG., etc.)

125. G. PYRAMIDALIS (A. Cunn.! mss. in herb.), foliis aversis glaucis? elongatis pinnatis passimque ljpinuatis glabris, junioribus ramulisque sericeo-tomentellis, laciniis gladiatis subfalcatis utrinque attenuatis nervoso-striatis, racemis paniculatis elongatis pedunculatis densifloris, calyce parvulo utrinque cum pistillo vix longiore glabro, ovario stipitato, stigmate terminali conico-capitato. 5 Ad Regent's River orie septentr. (A. Cunn.!). - 1. Brown! suppl. p. 25. Mrbuscula 15-pedalis. Folia rigida, 6-12 poll. longa, demum glabra, laciniís 4-pluri?-jugis 3-9 poll. longis, 3-7 lin. latis indivisis vel passim pinnatis, petiolo basi tereti superne rhachique ancipiti antice plano compresso. Panicula terminalis ampla, subpedalis, racemis divaricatis $3-5$ poll. longis rectis, pedicellis brevissimis. Calyx 2 lin. longus, albus? unguibus cito solutis, limbo globoso incurvo diutius clauso. Ovarii stipes calyce dimidio brevior. Stigma orbiculare, marginatum. (v. s. in herb. Brown., Cunn., DC.)

126. G. ROBUS TA (A. Cumningh.! mss. in herb.), foliis elongatis bipinnatifidis multijugis, laciniis lanceolatis attenuato-acutis supra glabris subvenosis subtus ramulisque scriceis, racemis axillaribus terminalibusque subsessilibus elongatis strictis basi sæpe ramosis, calyce mediocri pistilloque pollicari stipitato glaberrimis, stigmate terminali subobliquo conico-capitato. $\$$ Circa sinum Moreton Bay et ad flum. Brisbane, ubi Silk-oak vocatur (A. Cunn. n. 133!).-R. Brown! suppl. p. 24. Arbor circumfer. 7-9 pedum, 80-100 ped. alta (Gunn. in sched.). Folia patula, modice rigida, 1-2-pedalia, 6-12 poll. lata, segmentis primariis 5-12-jugis semipatentibus attenuato-petiolatis 3-7 poll. longis, pinnatim 7-15-fidis sujerioribus sensim brevioribus et minus divisis, laciniis decurrenti-confluentibus subtus plus minus sericeis discoloribus canescentibus vel fulvis, sinubus acutis. Racemi cylindrici, 3-7 poll. longi, semierecti, dense multiflori, pedicellis 4-6 lin. Iongis patentissimis vel deflexis glabris fructiferis subpollicaribus parum incrassatis. Calyx 5-6 lin. longus, gracilis, limbo subgloboso inflexo. Pistillum glabrum, stipite 1 lin. longo, stylo diu persistente, stigmate $\frac{-}{3}$ lin. lato. Folliculus ovalis, 7-8 lin. longus, 3 lin. latus, subcompressus, apiculatus, granulatus. Semina obovata, alâ circulari 1 lin. lata. G. venusta Cunr.. (non R. Br.) videtur var. foliis pinnatis foliolis pinnatifidis, ex Br. l. c. (v. s. in herb. Brown., Cunn., etc., et v. v. \&.)

127. G. UmвRAтісA (A. Cunn.l mss. in herb.), foliis bipinnatifudis, segmentis 3-8-jugis, 2-7-fidis vel passim integerrimis, laciniis lanceolatis submuticis utrinque attenuatis supra subimmerse reticulato-venosis glabriusculis nitidis subtus ramulisque adpresse fulvo-tomentosis vix sericeis, racemis axillaribus simplicibus rectis pedunculatis folio brevioribus..... $\delta$ In sylvis umbrosis siccis ad fl. Brisbane et Moreton Bay (A. Gunn.!). Arbor 20-30-pedalis, monente inventore (in sched.), a præcedente distincta, non satis nota; folia minora, 4-10 poll. longa, rigidiora, tomento vix sericeo; flores ignoti; pedicelli fructi feri subpollicares; folliculus late ovalis, valde compressus, laevis, 9 lin. longus, 5 lin. latus, marginibus subacutis. (v. s. in berb. Cunn.)

128. G. HETEROPHYLLA (A. Cunu.! mss. in herb.), foliis pinnatifidis indivisisque elongato-lanceolatis attenuato-petiolatis margine subrecurvis utrinque dense penninerviis sericeis supra glabrescentibus, racemis axillaribus terminalibusve refractis, calyce-sericco, pistillo stipitato glaberrimo. of In sinu Cambridge Gulf orse occidentali-septentrionalis (1. Cunn. n. 410!). - R. Brown! suppl. p. 24. Frutex 10-15-pedalis, ramis strictis teretibus demum glabris tenuiter sulcatis et granulato-punctatis, junioribus fulvo-sericeis. Folia rigidula, 5-9 poll. longa, fulvo. sericca, passim integerrima, usque ad 1 poll. 1ata, pleraque pinnatim 3-9-partita, 
laciniis vix divergentibus 3-5-poll. longis, 3-12 lin. latis, petiolo pluries longioribus acutis vel obtusiusculis sæpius acuminatis 1 -nerviis venis crebris angulo valde acuto ortis vix $\frac{1}{2}$ lin. distantibus rectis supra prominulis subtus sæpe obsoletis pulchre parallelo-striatis. Flores non vidimus. Racemus fructifer subpollicaris, subsessilis, rhachi refractâ crassá tomentosâ, pedicellis 3 lin. longis crassis. Folliculus subglobosus, apiculatus, diametro fere pollicari, nitidus, leviter granulatus. Proxima G. refractæ, cujus fórsan var. foliis latioribus, ex Br. l. c. (v. s. in berb. Brown., Gunn., DC.)

$\beta$ ? velutina, foliis pinnatis 4-7-jugis, laciniis abbreviato-lanceolatis sessilibus remotiusculis parallele semipatentibus ramulisque pube patulâ fulvo-vélutinis vix sericeis. $\bar{J}$ In insulâ Greville et ad Regent's River oræ occidentaliseptentr. (A. Gunn.1). G. velutina A. Cunningh.I mss. in herb. Forsan distincta species, nobis non satis nota, ex Cunn. in sched. media inter G. heterophyllam. refractam et ceratophyllam. Folia 3-6-pollicaria, laciniis 6-jugis cum vel absque impari, 8-10 lin. distantibus basi minus attenuatis, circ. 3 poll. longis, 6-9 lin. latis, tomento haud adpresso. Flores et fructus ipsi inventori ignoti. (v. s. in herb. Gunn., DC.)

129. G. REFRAGTA (R. Brown ! in Linn. Trans. 10, p. 176, prodr. p. 380), foliis pinnatis passimque indivisis, laciniis 3-6-jugis anguste linearibus elongatis mucronulato-acutis margine recurvis supra glabriusculis penninerviis subtus ramulisque junioribus sericeis, racemis refractis divisis, calyee sericeo, pistillo glaberrimo. Ad sinum Carpentaria ( $R$. Brown l). Rami graciles, glabrati, tenuiter sulcatolineati, dense foliosi, apice cano-tomentelli vix sericei. Folia erecta, rigidula,

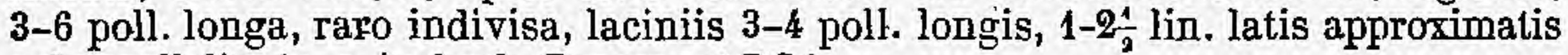
subparallelis. (v. s. in herb. Brown. et DG.)

130. G. GERA T OPAYLLA (R. Brown 1. c. p. 177 et 380), foliis 2-3-fidis indivisisque

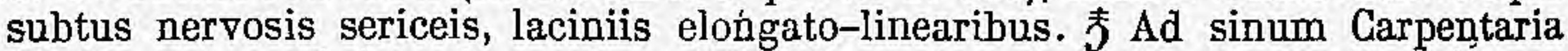
(R. Brown). - Leichardt tageb. p.216. Flores ignoti. Folliculus ovalis, glaberrimus.

131. G. oBLIQUA (R. Brown! suppl. p, 25), foliis aversis elongatis pinnatis subbipinnatisque, pinnis 5-6-jugis longe linearibus planis apice sphacelatis mucronatisve subenerviis lævissime striatis glabriusculis junioribus ramulisque sericeis, racemis paniculatis rhachi bracteisque glabris.... 吕In orâ septentr. (Leschenault), ins. Enderby archipelagi Dampieri (A. Cunningh.!). Folia 7-15 poll. longa ${ }_{2}$ 3-6-juga, rhachi petioloque teretibus, laciniis 5-8 poll. longis, 1-2 lin. latis, crassiusculis inferioribus 2-5-fidis. Flores et fructus ignoti. (v. s. in herb. Brown., Cunn. et DC.)

132. G. LEU CADENDR ON (A. Cunn.I mss. in herb.), foliis aversis sericeo-tomentosis bipinnatis, pinnis 5-7-jugis, pinnulis 1 -3-jugis anguste linearibus vel compressofiliformibus subenerviis mucronulatis, petiolo tereti, racemis paniculatis rhachi

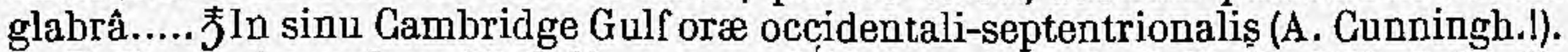
- R. Brown! suppl. p. 25. Folia parum rigidula, subsemjpedalia, lacitiiis $2-4$ poll. longis, $\frac{1}{-1}$ lin. latis, lævibus margine haud recurvis, petiolo rhachique teretibus exsulcis. Flores ignoti. Folliculus suborbicularis, compressus, 8 lin. longus, lævis, viscidus, junior sericeus, stipite 3 lin. longo sursum incrassato. (v. s. in herb. Brown, et Cunn.)

133? G. LEU G OP TER IS (Meisn. in Hook. Journ. 1855, p. $76^{*}$ ), tota cano-tomentosa, foliis pinnatis, laciniis 10-12-jugis anguste linearibus elongatis mucronatis mar-

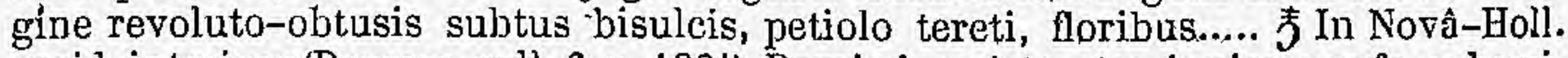
occid. interiore (Drumm. coll. 6, n. 188!). Rami virgati, teretes, juniores rufo-subsericei. Folia conferta, erecta, vix rigidula, 8-10-pollicaria, laciniis oppositis alternisque 3-7 poll. longis rhachique semitereti $1 \mathrm{lin}$. latis nigro-mucronulatis supra planis enerviis levibus vel obsoletissime immerso-1'nerviis, petiolo tereli $1-1 \frac{1}{2}$ poll. longo. Specim. nostra sterilia. In herb. Hookeriano cl. Kippist vidit racemos specimini adjectos (an ejusdem stirpis?) terminales panictilatos dense multifloros, pedicellis flore brevioribus? glabris, calyce extus glabro basi intus dense villoso....., pistillo longe stipitato glaberrimo, stylo pollicari complanato, stigmate laterali obovato marginato convexo, folliculo ventricoso-ovali 9 lin. longo, 6 lin. lato, mucronato glaberrimo fulvo subcrustaceo. Seimina ignota. Inter fl. Moore et Murchison, 1853, leg. Drumm. (Kipp. in litt.).Videtur planta a cl. Drummond in Hook, 
Journ. 1853 , p. 179, commomorata : frutex 4-5-pedalis, foliis pinnatis 15 poll. longis, 9 poll. latis, pedunctilis folia simplicia gerentibus 6-8-pedalibus racemis vel paniculis pedalibus, floribus albis suaveolentibus. An potius stirps a cl. Drummond l.c. ad calcem, p. 182, indicata? pericarpio globoso tenui, seminibus hemisphæricis apteris? (v. s. sine fl. nec fr. in herb. Shuttlew.)

134. G. GHRYSODENDR O'N (R. Brown! in Linn. Trans. 10, p. 176, prod. p. 379), ramis velutino-tomentosis, foliis laxis pinnatis bipinnatisque passim simplicibus, segmentis $\mathbf{5 - 1 0 - j u g i s ~ e l o n g a t i s ~ a n g u s t e ~ l i n e a r i b u s ~ a t t e n u a t o - m u c r o n a t i s ~ s e r i c e i s ~}$ supra glabrescentibus subtus bisulcis, racemis terminalibus elongatis erectis, calyce mediocri ovarioque subsessili villoso-tomentosis, stylo pollicari glabro, stigmale oblique terminali marginato. $\$$ Circa sinum Carpentaria (R. Brown I Leichardt tageb. p. 214, 216), in Croker's Island, circa Port-Essington, oræ septentr., prope Endeavour River, oræe orient. trop. (A. Gunn.I), in Novâ-Holl. orient. interiore subtrop. (Mitchell !). G. pteridifolia Knight et Salisb. Prot. p. 121.G. Mitchellii Hook! in Mitch. Journ. exped. trop. Austr. Lond. 1848, p. 265 (non Meisn.). - Cfr. R. Brown in Sturt exped. centr. Austr. append. p. 24. Arbor 10-15-pedalis (Cunn.). Folia haud rigida, 6-14 poll. longa, plerumque simpliciter pinnatifida, rarius passim bipinnata vel indivisa, laciniis 6-12 poll. longis, 1 - raro 2 lin. latis decurrentibus, subtus sericeis, marginibus refractis obtusiusculis, petiolo 2-3-pollicari semitereti. Racemi 5-7-pollicdres, pulcherrimi, aurantii (Leichardt l. c.), pedicellis 2-3 lin. longis, semiverticillatis patentissimis apice turbinatis cum rhachi validâ calyce ovariocue pube brevi patulâ lanato-tomentosis. Calyx 4 lin. longus, haud inllatus, sepalis cito sejunetis a basi persistente attenualâ deciduis. Stylus tenuis, stigmate orbiculari angustissime marginato convexo. Folliculus ovatus, compressus, 6-7 lin. longus, stylo caudatus, fulvo-tomentosus. Semina oblonga, plana, alà fere 1 lin. latâ undique cincta, dorso lævia. (v. s. in, herb. Brown., Cunn. Lindl., etc.)

135. G. M гт GH ELlir (Meisn. in Hook. Journ. 1855, p. 77, non Hook.), ramis velutino-tomentosis, foliis rigidis pinnatis passim indivisis elongatis anguste linearibus obtusis submucronulatis incano-tomentosis supra glabrescentibus margine revoluto rotundatis subtus bisulcis, racemis axillaribus terminalibusque subsessilibus erectis densifloris subsecundis, calyce subsemipollicari inflato pilosiusculo intus glabro diu clauso, laminis breve cornutis, pistillo subpollicari, ovario sessili villoso, stylo glabro, stigmate laterali ovali. interiore (Mitchell I exped. 1846, n. 371, 426, 477). G. pinifolia Hook. in herb. Lindl.! A præcedente simillimâ quïdem apprime dislinguenda folijs rigidis incanotomentosis nec sericeis et præcipue calyce majore ventricoso-inflato, sepalis tarde (si unquam) solutis duplo latioribus extus parce viscido?-pilosiusculis, et stigmate laterali vix marginato planiusculo. A G. Sturtii differre videtur ramorum pube patulâ nec arcte adpressâ, et foliis angustioribus 1 - vix $\frac{5}{4}$ lin. latis, summis $1 \frac{1}{2}-2 \frac{1}{2}$ poll. longis, plerumque 2-3-fidis. Racemi 2-3 poll. longi, pyramidato-oblongi, lutei? pedicellis 3-4 lin. Iongis. Galyx oblique insertus. Folliculus ignotus. (v. s. in herb. Lindl. et comm. a b. Lemann.)

136? G. ER 10S T A ну A (Lindl.! Swan River, p. 36, n. 181), ramis tomentosis, foliis elongatis angustissime linearibus pinnatim 3 -5-fidis passimque indivisis tomentellis scabriusculis mucronulatis margine refractis acutis compresso-tetragonis subtus bisulcis, spicis elongatis erectis dense multifloris, rhachi lanatâ, calyce semipollicari villosiusculo, sepalis demum liberis, ovario sessili villosissimo, stylo exserto glabro, stigmate obliquo subcochleariformi marginato. $\mathrm{J}$. In coloniâ Swan River (Gaudich.! Drummond coll. 1, n. 636!2, 328! Mangles 1). - Meisn. in pl. Preiss. 1, p. 544 *, in notâ. Folia fere G. Hookerianæ (supra, n. 99), sed longiora, inferiora 5-9 poll. longa, usque ad 1 lin. lata, tactu scabriuscula, 3-vel rarius 5-fida, segmentis 3-6 poll. longis, summa breviora et constanter? indivisa, supria manifeste immerse 1-nervia. Spicæ terminales, interdum corymbosæ vel subpaniculatæ, 2-5-pollicares. Calyx subsessilis, incurvus, pube brevi dense fulvo-villosus, intus glaber. Pistillum 8 lin. longum, stigmate inflexo-sublaterali obtuse convexoumbonato margine undulato cincto. Folliculus ovato-oblongus, ventricosus, pubescens, striatus. Semina nobis ignota. Species præcedentibus proxime afinis videtur, attamen etiam Calothyrsis, præcipue Hookerianæ, foliis saltem valde similis. (v. s. in herb. Lindl, etc.)

137? G. S TURT11 (R. Brown append. Sturt's exped. central Austr. p. 23), ramis 
adpresse ineanis, foliis indivisis paucisque passim bificlis anguste linearibus elongatis 1 -nerviis incanis supra demum glabratis margine arete revolutis, racemis oblongis vel cylindraceis, rhachi pedicellis calycibusque inexpansis patulo-pubescentibus glutinosis, ovario sessili,-stylo glabro. 5 In Novà-Holl. orient. subtropicâ interiore (Sturt, Mitchell). Arbor 15-pedalis, ramis teretibus. Folia 6-10 poll. longa, vix 3 lin. lata. Thyrsus terminalis, 2-4-pollicaris, tloribus aurantiacis.

138? G. Pteros per rira (Ferd. Müller! in Trans. philos. Soc. of Victoria 1, p. 22, n. $\left.47^{*}\right)$, racemis sericeo-tomentellis, foliis elongatis filiformi-linearibus indivisis passimque 2-3-partitis sphacelato-acutis glabriusculis supra convexis tenuiter sulcato-lineatis margine revoluto-obtusis subtus bisulcis, racemis axillaribus pedunculatis folia superantibus densifloris, calyce semipollicari cano-tomentoso intus styloque parum Jongiore glabro, ovarjo breve stipitato villoso, stigmate oblique laterali ovato. $\bar{J}$ In collibus arenosis versus confluxum fl. Murray et Murrumbidgee (Ferd, Müller !). Erecta, ramis gracilibus teretibus laxe foliosis. Folia glauca, rigidula, 5-7 poll. longa, $\frac{1}{2}$ lin. lata, in mucronem sphacelatum attenuata, pleraque indivisa, juniora minute puberula. Racemi elongati, in summis axillis alterni, pedicellis $1 \frac{1}{2}$ lin. longis rhachique cano- vel rufo-tomentellis. Calyx tenuis. Pistillum 9 lin. longum, tenue, stigmate subumbonato-convexo. Folliculus globosus, cinereo-tomentosus, cuspidulatus, diametro 4-5 lin. Semina ovata, plana, lavia, circumcirca membrauaceo-alata. G. angustatée affinis, ex Müll.; ex nostrấ sententiâ vero G. sericostachyæe proxima et folìs racemisque simillima, sed distincta foliis paulo angustioribus suprá striatís, floribus minoribus, stigmate paulo majore ovato nec orbiculari. (v. s. in herb. Sonder.)

\section{§ 3. Simplicifolice. - Foliis anguste linearibus lanceolatisve indivisis integerrimis.}

139? G. SERICOSTACHYA (Meisn. in Hook. Journ. 1852, p. 186), ramis incano+ tomentosis apice sericeis, foliis fililormi-linearihus rigidis sphacelato-mucronatis margine refracto obtusiusculis utrinque convexis bisulcis lavibus glabris, racemis terminalibus pedunculatis crectis cylindricis laxiuscule multifloris, calyce parvo extus ovarioque stipitato sericeo-villosis-stylo glabro longe superatis, stigmate oblique truncato. f In coloniâ Swan River (Drumm. coll. 5, suppl. n. 10l). Primo vultu G. eriostachyæe simillima, at notis indicatis certe distincta; rami graciliores; folia 3-5 lin. longá. $\frac{3}{4}$ lin. lata, omnia indivisa, supra 3-nervia, nervis prominulis lateralibus marginantibus; pedunculi teretes, tenues, fulvo-sericei (nec subangulato-striati lanato-tomentosi), racemi bipollicares, obtusi, haud compacti, pedicellis 1-2 lin. longis rhachique villosiusculis; calyx vix \& lin. longus, sepalis cito sejunctis intus glabris, laminis breviter sericeo-rillosis, unguibus adpresse sericeis; pistillum 6-8 lin. longum, stylo tenui apice vix dilatato, stigmate orbiculari submarginato fere plano. Fructus ignotus. (v. s. conm. a b. Lemann.)

140. G. ANG US TA TA (R. Brown! suppl. p. 24), foliis łaxis longissimis anguste linearibus acutis planis levibus subtus 3 -nerviis sericeis smpra minute lineatis glabriusculis, basi decurrente cicatrice postice attenuatâ... ₹ Ad promontor. Cleveland orce orientalis tropice (A. Cunn.' $n$. 361 !). Ramuli graciles, filiformes, summo apice tomentelli. Folia $8-12$ poll. longa, 1 lin. lata, cetcrum iis $\mathrm{G}$. polystachyæe similia. Flores fructusque ignoti. (v. s. in herb. Brown et Cunn.)

141. G. rоду тасну A (R. Brown! in Linn. Trans. 10, p. 177, prodr. p. 380), foliis laxis elongato-linearibus sphacelato-acutis maroine subrecurvis subtus parallele 3-5-nerviis sericeis supra minute lineatis ramulisque cano-tomentellis mox gla bratis, fanicula terminalis racemis alternis densitloris patulis, calyce parvo seri ceo pistillum glabrum stipitatum subequante, stigmate terminali obliquo conico capitato. 5 ? In Novæ-Holl. orà orientali intratrop. (R. Brown !). G. parallela Knight et Salisb. Prot. p. 121. Rami apice conferte foliosi. Folia patula, vix rigidula, 3-8 poll. longa, 1-3 lin. lata, sipe falcato-vel circinnato recurva, subtus nervis 3-5 subequalibus tenuibus parallele strata fulvo-sericea, supra subenervia dense minuteque (Graminum more) vel obsolete lineata, juniora cum ramulis prbe minu. tissimâ subcanescentia, insertionis cicatrice brevi rotuudatâ. Panicula folia sul) aguans, racemis breve pedunculatis 1-2 poll., pedicellis 1 lin., calycibus incurvis 3-4 lin. longis. Stylus tenuis, calycom vix superans, stigmate anguste marginato, papilla centrali lirevi conicit: Follic, ignoti. (r. s. in lierl. Brown., etc.) - 
142. G, strite (R. Brown! 1. e.p. 177 et 380), foliis strictis lincari-ensiformibus subtus multinervijs sericuis, insertionis cicatrice longiore quam lati utrinque acutâ, racomis terminalibus alternis, pistillo semipollice breviore, stigmate verticali dejuresso-conico. 5 ? Ad sinum Carjentaria (R. Brown !).-R. Brown in ajppend. Sturt's exped. Centr--Austr. p. 24. Folia semper phus quam 10-striata, interstitiis sericeis nervis ipsis vix dimidio angustioribus. (v. s. in herb. Brown.)

143. G. Lineata (R. Brown in append. Sturt's expel. Centr.-Austr. 1). 24), folis lineari-ensiformibus enerviis subtus striis decem paucioribus elevatis interstitia bis-terve latitudine superantijus, insertionis cicatrice latiore quam longà utrinque obtusâ, racemis terminalibus alternis, pistillo semipollice breviore, stigmate conico. 5 In Noval-Holl. orient. subtrop. interiore, lat. austr. 29-30 ! (Sturt). Procedenti simillima quidem, attamen notis indicatis procul dubio essentialiter distincta.

144. G. G в B os A (R. Brown! in Linn. Trans. 10, p. 177, prodr. p. 380), foliis elongato-lanceolatis integerrimis utrinque attenuatis acutiusculis planis 1 -nerviis penniveniis ramulisque cano-tomentellis, racemis elongatis, stigmate conico, folliculo crassissimo suligibboso. 5 ? In orâ orientali intratrop., circa Endea vour River (Banks et Soland. 1770) et Cape Flinders (A. Cumningl,!). G. glauca linight et Salisb. Prot. p. 121. Folia superiora $3-4$ poll. longa, 1 poll. lata, rigidula, pubs densâ minutầ molli subtus fulvâ, petiolo brevi tereli. Folliculus compresso-globosus, valde ventricosus, diamotro verticali ferc $1 \frac{1}{2}$-poll., longitudinali et transversali pollicari, pericarpio levi crasse lignoso. (v. s. in herb. Cunn. et R. Brown.)

145. G. Mimosordes (R. Brown! 1. «., p. 177 et 380 , suppl. p. 25), glaberrima, foliis glaucis? aversis cnsiformi-oblongis subfalcatis integerrimis acutis subparallele multinervis laxe reticulatis, racemis paniculatis, floribus parvulis, jistillo stipitato, stigmate terminali conico-capitato, folliculo deflexo suborbiculari compresso apiculato viscido. 5 Ad sinum Carpentaria (R. Brown!), Careening Bay, oræe occid.-septentr. (1. Cumn. n. 177! (et in Novâ-HoH. órient. subtrop. interiore (Lcichardi tageh. p. 20). Arbuscula (Leich.) ramis validis remote foliosis. Folia situ, formà et texturâ phyllodia Acaciarum imitantia! rigida, plana, 5-8 poll. longa, 1-1 $\frac{4}{2}$ poll. lata, utrinque attenuata, basi petioliformi $3-4$ lin. longa com!ncsso-tri(Juetra subtus acute carinata, laminæ margine inferiore fere recto superiore plus minus arcuato. Panicula 5-8 poll. longa, ramis patentiłus a basi floriferis, pedicellis brevissimis. Pistillum vix 3 lin. longum, ovarii glabri globosi stipite stylum tenuem requante. Folliculus 6-8 lin. longus et vix angustior, late ventricoso-ovatus, nigricans, lievis, stipite 2 lin. longo crasso. Semina obovata, alâ angustâ cincta. (r. s. in herb. Brown., Cunn. et DG).

\section{Subgenus II. Conogyne. - Grevillea sect. Conogyne R. Brown suppl.} p. 21, Meisn. in pl. Preiss. 1, p. 549, et genus Anadenia B. Br. in Linn. Trans. 10, p.166, prodr.p. 374, suppl.p.16,Meisn.l.c p. 551.

Calyx parvus, regularis rectus, rarius irregularis incurvus, basi requahi. Pistillum stipitatum, stylo toto tenui filiformi rarius incrassato (cfr. G. triloba, pulchella, tenuiflora), stigmate terminali conico vel rarius fusiformi (in solà G. quercifoliâ laterali plano). Glandula hypogyna minuta obsoleta vel nulla. Folliculus ovoideus, tumidus, plerumque rugulosus verruculosus vel echinulatus, abortu (constanter?) 1-spermus, pericarpio crustaceo vel tenere lignoso. Semina aptera vel raro anguste alata (cfr. G. intricata). - Frutices Novæ-Hollandisc prosertim austro-occidentalis, foliis et inflorescentiâ variis. - Anadeniam nullo charactere certo distinguere possumus. Cfr. Meisn. pl. Preiss. p. 535, obs. 1.

\section{§ 1. Integrifolice. - Foliis simplicibus, integerrimis, interdum in eâdern stirpe biformibus. Racemi spiciformes, erecti, siepe ramosi. Calyx parvus pistillum subcequans.}

146. G. INTEGRIFOLIA, foliis oblongis obtusis marginatis basi attenuatis obsoleto 3 -nerviis utrinque ramulisque sericeis, spicis terminalibus pedunculatis densis apicifloris, calyee glaberrimo, glandula hỵpogyni nullâ, ovario Jjrevissime stipi. lato, stylo filiformi declinato, stigmate incrassato conico obtusíusculo. $\succsim$ Circa York jn coloniâ Swan River (Roii). Anadenia integrifolia Endl. in Ann. Wien. Mus,

XIV. 
2, \}. 209 , nov. stirp. decad. 1,88, 11. 98 * Ramuli subcompressi. Folia eoriacea, jipollicaria. Spicde-3-pollicares, floribus parvulis.

147. G. Shutteeworthíni (Meisn. in pl. Preiss. $2, p .258^{*}$ ), foliis cuneatorecurvo-apiculatis marginatis utrinque nervosis glabris, racemis terminalibus gracilibus basi ramosis erectis densis hasifloris glaberrimis, pistillo subsessili calycem rectum vix superante, stigmate brevi conico obtuso. F In colonià Swan River (Drumm. coll. 2, n. 299! tlor. et 3, n. 266! fr.). Rami tcretes, apice adpresse puberuli. Folia ripida, 1 poll. longa, 4-8 lin. lata, petiolo 2 lin. longo vel nullo, apice rotundato brevissime complicato et recurro-apiculato, mucronulo nigro. Racerni $1 \frac{1}{2}-2 \frac{1}{2}$ poll. longi, florum evolutione adscendente I Calyx flavis, vix 2 lin. Jongus, rectus. Glandula hypogyna minuta calycis fundo adnata. Folliculns sessilis, erectus, semiobcordatus, subfalcatus, mucrouatus, compressus, glaber, margine stylári suberecto deplanato vel subcarinato, altero valde arcuato obtuso, valvulis coriaceis levibus. Semina 2 oblonga, compressissima, apice basique brevialata. Præcedenti sane proxima, sed bene distincta. (v.s.)

148. G. POL Y B OT R Y A (Meisn. in Hook. Journ. 1852, p. 185), ramulis pedunculisque tomentellis, foliis lanceolatis acutiusculis submuticis planis eveniis glabris, paniculà terminali pyramidatà aphyllâ, ramis patulis alterne 2-8-stachyis, spicis densis peduneulatis gracilibus, calyce subsessili incurvo puberulo pistillo glabro demum superato, stigmate brevi conico basi marginato. 5 In-coloniâ Swan River (Drumm. coll. 4, n. 279!). Rami virgati, corymboso-vel fastigiato-ramosi, ramulis teretibus subangulatisve fulvo-incanis. Folia conferta, rigida, basi attenuata, sessilia, 12-15 lin. lon 3 lin. lata, nervo medio tenui apicem versus evanescente. Paniculæ corymbiformes, spicis breve pedunculatis 1-2-pollicaribus ébracteatis. Calycis limbus globosus, inflexus, adpresse pubescens, diu clausus, tubo glabriusculo. Glandula hypogyna semiaunularis, minuta. Pistillum demum 3-4 lin. longum, ovarii stipite brevi. Folliculi ignoti. (r.s.)

149. G. BIFORM is (Meisn. in pl. Preiss. 2, p. 258*), ramulis frondeque biformi juniore sericeo-puberulis, folís ramorum sterilium cuneato-obovatis acutis planis trinerviis, fertilium filiformi-linearibus actis utrinque nervoso-striatis, racemis terminalibus simplicibus vel pauciramosis erectis gracilibus densifloris glaberrimis, pistillo stipitato calycem rectum breviter superante, stigmate cylindraceoconico obtuso basi oblique annulato. J In coloniâ Swan River (Drumm. coll. 3, n: 265 ! coll. 6 , n. 181 !). Pluribus notis au $\mathrm{G}$. Shuttleworthianam valde accedit, sed beno distincta stigmate, foliis ramulorum fertilium, etc. (v.s.)

150. G. DIDу мовот Rу A (Meisn. in Hook. Journ. 1852, p. 186), ramulis pedunculisque cano-tomentelis, foliis tereti-filiformibus acutis glabris basi attenuatis supra tenuiter lineatis subtus leviter bisulcis, racemis terminalibus geminatis vel subracemosis erectis densiusculis, pedunculo communi semibifido vel rarius 3 -4-stachyo, calyce incurvo sericeo-puberulo, pistillo sessili glaberrimo dimidio superato, stiginate conico brevi basi marginato. 5 In coloniâ Swan River (Drumm. coll. 4 , n. 280!). Bami teretes, glabri, ramulis eor.ymbosis tenuibus. Folia rigida, $2-4$ poll. longa, vix $\frac{1}{2}$ lin. lata, sphacelato-submucronulata, juniora puberula. Pedunculus communis circ. bipollicaris, plerumque suberualiter bifidus, passim indivisus vel 3-4 ramosus, ad divisiones bracteâ lineari 2-3 lin. longà stipilatus. Racemi 1-2-pollicares, cylindrici, ebracteali. Caljx vix 2 lin: longus, pedicello parum longior, pube arlpressì. Glandula hypogyna nulla? Stigma margine membranaceo plicato-ercnato cinctum e medio processu conico brevissimo obtuso apiculatum, fere latius quam longum. Folliculi ignoti. Præcedentibus floribus similis, foliis vero stigmateque distinctissima. (v. s. in herb. Shuttl.)

151. G. CAPILLARIS, ramis sublexuosis pubescentibus, foliis elongato-filiformibus subcanaliculatis subsericeis basi attenuatis, callo terminali acuto deciduo, spicis subterminalibus pedunculatis cylindraceis basilloris densis glabris, ovario brevis. sime stipitato, stigmate conico apjice subtruncato. F Inter 11. Cygnorum el siumm Regis Georgii (Rö̈). Anadenia filifolia Endl. nov. stirp. decad. 1, p. 88, n. 99 *. A. Roëi Endl. gen. suppl. 4, 2, p. 83,? Folia 2-3-pollicaria. Spicæ subbipollicares, floribus brevissime pedicellatis. Folis simillima videtur G. filifoliæe nostræ (supra, n. 61), sed jnflorescentia et stigmate longe abhorrens. 


\section{\$2. Angustilobce.-Foliis 3-partitis vel bi-tripinnatisectis, segmentis linearibus vel rarius tereti-filiformibus mucronato-pungentibus. Calyx parvus, pistillum subcequans.}

152. G. PE T ROPH LOIDES (Meisn. in pl. Preiss. 2, p. $257^{*}$ ), ramulis apice puberulis, foliis terelibus rigidlis elongatis tripinnatis glabris, segmentis vix divergentibus pancijugis supra 1 -sulcis, spicå terminali pedunculatẩ simplici erectà oblongâ densiflorâ ebracteatâ glaberrimâ, calyce recto, laminis lanceolatis acutis, stigmate subulato-conico. 5 In coloniâ Swan River (Drumm. coll. 3, n. 300! 5, suppl. n. 8!). Rani validi, subsimplices, glabri, conferte foliosi, florentes superne aphylli gemmiferi pedunculum semipedalem 1-stachyum sistentes. Folia 3-5-pollicaria, crassiuscula, strieta, laciniis vix divergentibus teretibus vel obsolete striato-angulatis supra 1-sulcis vel subcanalieulatis sphacelato-mucronulatis demum muticis, primariis oppositis petiolo longioribus $2-4$-jugis inferioribus $2-3$ poll. longis superioribus decrescentibus, seeundariis 1-2-jugis indivisis vel 2-5-fidis, lacinulis 2-18 lin. longis. Spica 1-2-pollicaris, rhachi glabrà. CaIyx subsessilis, 3 lin. longus, glaber. Glandula hypogyná parvula, erecta. Pistillum brevissime stipitatum, glabrum, stigmate tenui f'ere 1 lin. longo acuto basi oblique submarginato. (v. s. in herb. Shuttl. et Lemann.)

153. G. INTRICATA ( Meisn. in Hook. Journ. 1855, p. 74), foliis rigidis elongatis tereti-filiformibus triteruatis obsolete 1 -sulcis ramisque glabris, segmentis divaricatisstmis subrequalibus mucronatis, pedunculo oppositifolio foliis longiore pauciramoso, racemis patulis, pedicellis demum deflexis, calyce....., stigmate conico brevi, folliculo ventricoso-verruculoso glahro. 5 In Bowes Country, distr. Champion, Nove Holl. occidentalis interioris (Drumm. coll. 6, n. 189! Hook. Journ. 1853, p. 179). Fruticulus multicaulis 2-3-pedalis (Drumm. l. c.). Folia 3-5 poll. longa, $\frac{1}{1}-\frac{1}{3}$ lin. crassa, juniora puberula, laciniis 1-2 poll. longis. Rami graciles glabri. Pedunculus 5-8-pollicaris, junior parce sericeo-puberulus, racemis 2-3 peduneulatis distantibus 1-2 poll. longis. Flores ignoti. Pedicelli fructiferi 3 lin. longi, graciles, glabri. Folliculus brevissime stipitatus ovalis, tumidus, ventricosus, 5-6 lin. Jongus, stylo 2 lin. cum stigmate $\frac{1}{2}$ lin. lougo caudatus vel muticus levissime rugulosus, pericarpio lignoso tenui. Semina (tide cl. Kippist in litt.) elliptico-oblonga, planiuscula, undique anıguste alata. (v. s. in herb. Shuttl.)

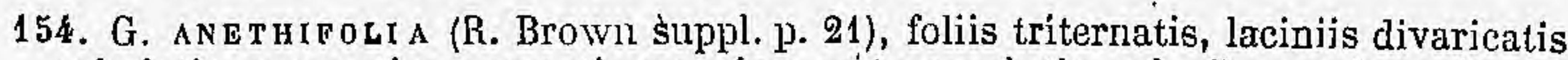
subulatis pungenti-mucronatis margine arcte revolutis, calycibus pedunculisque glaberrimis, bracteis caducis, stigmate conico. $\bar{J}$ In montibus prope Port-Jackson (A. Cunn., Baxter). Anadenia anethifolia A. Gunn. mss.

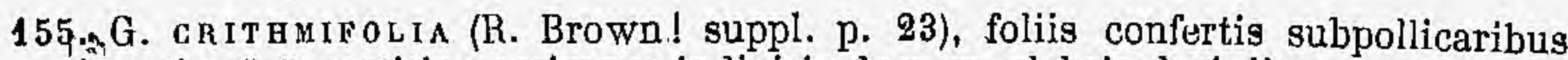
pinnatim 3-5-partitis passimque indivisis demum glabris, laciniis anguste linearibus planis acutiusculis supra enerviis subtus bisulcis, racemis terminalibus fasciculiformibus folia vix superantibus junioribus globosis imbricato-bracteatis, rhachi ramisque villosis, pedicellis capillaribus calyce incurvo glabro intus pilosiusculo longioribus, pistillo stipitato glaberrimo, stigmate brevi conico, folliculo echinulato. J In colonia Swan River, distr. Perth (Fraser! Drumm. coll. 1., n. 625! Preiss, n. 599| 690!).-Meisn. in pl. Preiss. 1, p. 544*. Grevillea Sternbergiana hort.! Frutex 1-4-pedalis, ramis erectis, fastigiatis, strictis. Folia 6-10 lin. longa, pallida, plantæ spontaneæ subglauca, juniora patulo-pilosiuscula, pleraque 3-fida, laciniis vix $\frac{1}{3}$ lin. latis planis subpungenti-mucronulatis semper indivisis. Capitula juniora piso vix majora, Hakearum more squamis ovatis puberulis deciduis arcte adpressoimbricata, demum in racemum semipollicarem densiflorum excrescentia, pedicellis 3-6 lin., floribus vix 2 lin. longis. Glandula hypogyna exigua. Folliculus ventricoso-ovatus, semipollicaris. Semina oblonga, aptera, acute marginata, hinc carinato-convexa exsulca. (v. s. in herb. Brown., etc.)

156. G. ти Iт R R At A (R. Brown ! suppl. p. 21), foliis rigidis subdigitalibus bi- vel triternatîs, laciniis divaricatis aceroso-linearibus pungentibus supra planis 1 -ner. viis submarginatis glabris subtus bisulcis ramulisque sericeis, racemis axillaribus terminalibusque brerissimis densifloris, calyce styloque glabro, ovario subsessili

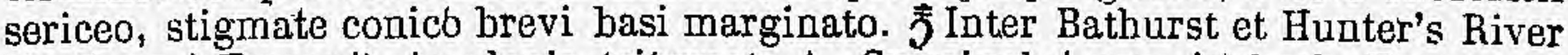
(A. Cunn.I Fraser !). Anadenia triternata A. Gunningh.! mss, in herb. Frutex, ut 
videtur, diffusus, intricate ramosissimus foliosusfue. Folia patula, conferta, $1 \frac{1}{2}-3$ poll. longa, promiseue bi- et triternata, subnitida, segmentis petiolo longioribus, lateralibus 2-3-fidis vel rarius pinnatim 5-fidis, lacinulis 4-10 lin. Jongis attenuato-mucronatis. Racem sessiles, semipollicares, sericei, pedicellis calyce $1 \frac{1}{2}$ lin. longo subineurvo brevioribıs. Folliculus junior ventricoso-ovatus, stylo brevi toto caudatus, dense foliosus. Glandula hypugyna certe adest, sed minuta. (r. $\mathrm{s}$. in herb. Brown., Cunn., DC.)

157. G. BREvicuspis (Meisn. in pl. Preiss. 2, p. $256^{*}$ ), foliis rigidis pollicaribus semitrifidis súpra subenerviis ramulisque glabris subtus 1 -nerviis adpresse jubcrulis, segmentis divaricatis linearibus pungentibus margine recurvis, lateralibus cuneatis intermedio duplo longioribus jassim 2-3-fidis, racemis axillaribus terminalibusque brevibus glaberrimis, stylo subpersistente stigmateque ,conico brevibus, folliculo obovato verruculoso. $\bar{J}$ In coloniâ Swan River (Drumm. coll. 2, n. 321 !). Tamuli angulati. Foliorum laciniæ $\frac{2}{3}-1 \frac{1}{2}$ lin. late, margine subtus anguste (nec ad nervum usque) rccurvo, intermedià 1.2 lin. 'longâ. Pedunculi interdum basi ramosi, pedicellis fructiferis 3 lin. longis. (v. s. in herb. Shuttl.)

158. G. LертовотRYS (Neisn. l. c. 2, p. $256^{*}$ ), ramis gracillimis, foliis elongatis bipinnatis, petiolo longo semitereti, segmentis alternis multijugis pinnatim 3-9-partitis anguste linearibus pungen tibus margine revolutis stupra eveniis glabris subtus 1 -nerviis bisulcisve subsericeis, racemis axillaribus terminalibusque folia æquantibus laxis, pedunculo rhachique elongatis filiformibus, calyce incurvo cano. puberulo, pistillo stipitato glabro, stigniate brevi conico. $\bar{J}$ In colonià Swan River (Drumm. coll. 3, n. 268!). Rami sesquipedales, tenues, laxe ramosi, glabriusculi. Folia rigidula, 4-8-pollicaria, petiolo laminam bipinnatam subæquante vel longiore tenui, rhachi parum latiore lineari rectầ vel vix flexnosâ, pinnis 5-9-jugis fere semper alternis patentibus 1-2 poll. longis, superioribus sensirt. magis approximatis brevioribus ninus divisis simplicibusve, pinnulis plerumque upposilis $3-15$ Jin. longis, $\frac{1}{2}-1$ lin. latis attenuato-mucronulatis subtus subsericeo-canescentibus. Racemi 3-5-pollicares, summi inferne pauciramosi, pedicellis capillaribus $2-4$ lin. Iongis rhachique parce adpresso-pilosiusculis. Calyx circ. 2 lin. longus albido-subsericeus, limbo arcte inflexo diu clauso. Glandula hypogyna exigua. Stylus vix exsertus, capillaris, stigmate e basi turbinatà marginatĥt conico acuto. (v. s. in herb. Shuttl.)

159. G. TRIL 0 b A (Meisn. in Hook. Journ. 1855 , p. 74), ramis virgatis lanato-tomenlosis, foliis subbipollicaribus rigidis semitrifidis margine acute refractis supra plano-convexis penninerviis glabris subtus latiuscule marginatis ad costam canopuberulis, laciniis divaricatis subæqualibus lanceolato-linearibus pungentibus indivisis, racemis terminalibus brevibús sessilibus nutantibus cano-pubescentibus. stricti, ramulis semipatentibus gracilibus, sordide flavescenti-cinereis. Folia patentia, subsessilia, $1 \frac{1}{2}-2 \frac{1}{2}$ poll. longa, lobis parti petiolari subæqualibus $12-16$ lin. lorigis, $1 \frac{1}{2}-2$ lin. latis supra prominulo-renosis attenuato-mucronulatis, insertionis cicatrice obtusà haud dilatatâ, axillis gemmam ovato-globosam parvam imbricatosquamatam albido-lanatam foventibus. Racemi ramulos breves terminantes, 1-2-pollicares, multiflori. Pedicelli fructiferi (fide cl. Kippist in litt.) semipollicares vel breviores, recurvi, folliculo ventricoso-ovato dense obtuseque tuberculato bre. viter stipitato glabro, seminibus plano-convexis lævibus angustissime marginatis. Flore nobis ignoto, speciem propter similitudinem quamdam cum G. ramosissimà huc refulimus, sed propter stylum (ide Kipp.) breve strumosum forsan potius Manglesiis adsocianda foret. (v. s. in herb. Shuttl.)

\section{§3. Latiloba. - Foliis inciso-dentatis vel laciniatis lobis latiusculis planis vel margine refractis recurvisve.}

160. G. RAMоsissima, foliis rigidis subbipollicaribus trifido-bipinnatis supra subeveniis glabriusculis nitidis subtus ramulisque fulvo-tomentosis, segmentis divaricatis 1 -3-jugis lineari-oblongis 1 -nerviis marginatis apice 2 -5-filis pungentiacutis margine refractis, racemis terminalibus brevibus recurvis dense multifloris, calyce incurvo ovarioque subsessilibus sericeis, slylo glabro, stigmate brevi conico basi marginato, folliculo falcato-ovato levi tomentoso striato. I In montibus circa Port-Jackson (Calcy! Baxter!), Bathurst, Cugeegang River et Liverpool Plains 
(A. Cunfi. n. 35 201!). Anadenia Calcyi R. Brown! suppl. j. 16. Diffusa ? ramosisșima, dense fóliosa. Folia patula, ambitn late ovalia, 1 -2 poll. longa, nune trifida, laciniis apice 2-3-fidis, nunc bipinnatifida, laciniis 2-3 lin. latis decurrenti-confluentibus 2-3-jugis cum impari trifidis vel inferioribus terminalique sæpius pinnatim 5-fidis, lacinulis triangulari-lanceolatis attenuato-spinescentibus margine

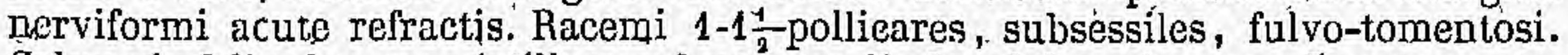
Calyx vix 2 lin. longus, pistillum subæquans; limbo globoso incurvo demum recto. Glandula hypogyna obsoleta. Folliculi 4-5 lin. longi, ventricosi, stylo brevi rostrati. Semen obloogum, plano-convexum, apterum, live. (v. s. in herb. Brown., Cunn., DC.)

161. G. TRIFID (Meisn. in pl. Preiss. 1, p. $553^{\%} \%$; foliis sessilibus supra eveniis lævibus glabris sultus recurvo-marginatis_sericeis, infimis digitalibus oblongolinearibus inciso-dentatis pinnatifidisve 1-nerviis, supérioribus subpollicaribus cuneatis trilobis triplinerviis lobis integris vel tridentatis spinescentibus, racemis axillaribus folium subequantibus densifloris glabris, pedicellis flore longioribus, jistillo stipitato calycem 4-sepalum superante, stigmate brevi basi marginato, folliculo ovali subgranulato. J In terrrâ Leeuwin (R. Brown !), prope sinum Regis Georgii (Preiss, n. 701!). Anadenia trifida R. Brown I in Linn. Trans. 10, p. 167, prodr. p. 375, suppl. p. 16. Frutex bipedalis, caule erecto stricto parce ramoso sericeo mox glabro. Folia rigida, infima 1-3 poll. longa, 3-4 lin. lata, superiora $1-1$ poll. longa, apice 5-7 lin. lata, subtus albiclo- vel fulvo-sericea. Calyx 2 lin. longus rectus glaber. Glandula hypogyna nulla. Pedicelli fructiferi 5 lin. longi. Folliculi cernui, tumidi, glabri, fere læves, stylo diu caudati. ( $v$, s. in herb. Brown., etc.)

162. G. PUL G HEL $\dot{A}$ (Meisn. l. c. p. $553^{*}$ ), foliis subsessilibus pollicaribus pinnatipartitis junioribus ramisque hirsutis, rhachi strictâ angustissimâ, lobis 3-7-jugis patentibus cuneato-obovatis pinnàtim 3-5-fidis vel passim integris margine recurvis supra punctato-asperulis, dentibus spinescentibus, racemis axillaribus termi nalibusque folio brevioribus densifloris glaberrinnis, pedicellis flare subbrevioribus, calyce 4-sejalo pistillum stipitatum apice sigmoideo-incrassatum xequante, stigmate brevi acuto, folliculo viscido. J Circa sinum Regis Georgii (R. Brown! A. Cunn.! Preiss, n. 700!), in jugo Darling's Range (Gilbert!). Auadenia pulchella R. Brown! in Linn. Trans. 10, p. 167, prodr. p. 374. Habitus præcedentis. Fol rígidula, 1-2-pollicaria, rhachi semitereti $\frac{1}{2}$ lin. lata, segmentis oppositis 3-7 lig longis, 3-5 lin latis, infinis multo minoribus obliçuis deflexis. Racemi vix pollicares, apiciflori, interdum basi ramosi, pedicellis $1 \frac{1}{2}$ lin. longis. Calyx albus (Preiss). alaher sepalis liheris angustis laminâ levitér dilatato-concavà. Glandula hýpd,

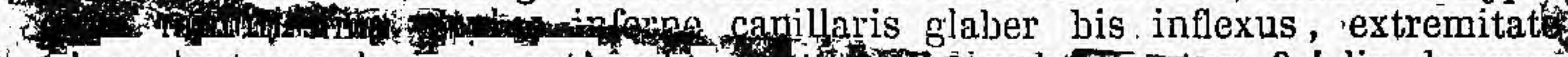

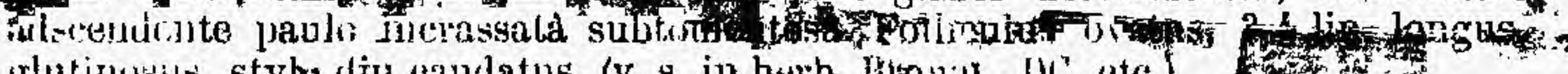
glatinusis, styk, diu eaudatus, (v. s. in herb. browil., DC. etc.)

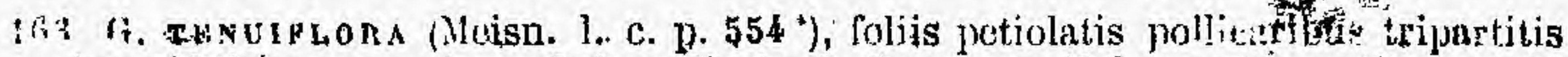
yimuatifidisve nervosis scalpiusculis juuipribus riunulisifue pubescantibut, segHetwe eúneatis 3-lobis vel pinnatin 5 -fillis, lacinits indivisis vel apice spinusotridentatis, vol 3-mucronatis, : raconth terminglibus axillaribustue simplicibus folio siepe longioribus glabriusculis, pistillo stipitato calycem 4 -sepatum rante, stylo puberulo apicc incrassato denum recto, stigmate subulato-conico, folliculo ventricoso suhcompresso marginato. J In coloniầ Swan River (Drumim. coll. 1! Preiss, n. 702, 703, 704!). Anadenia tenuïflora Lindl.! Swan River, p. 31,

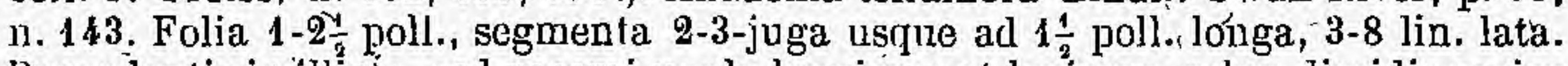
Preeedenti simillinia, sed raccmi paulo longiores et laxiores, calyx dimidio major obsolete puberulus, stigma tenuius. (v. s. in herb. Lindl., etc.)

164. G. FLEXU OSA (Meisn. l. c. p. $553^{*}$, in notâ), glaberrima, foliis petiolatis bipinnalifidis lævibus, rhacli flexuosâ angustâ, segmentis 4-6-jugis alternis retroversis pinnatim 5-7-lobis planis subeveniis marginatis, lobis triangulari oblongis spinescentibus, racemis axillaribus terminalibusque peduntulatis densifloris, pedicellis calycom 4-partitum subæquantibus, pistillo stipitato exserto, stigmate brevi capitato-conico. F In coloniâ Swan River (Drumm. coll. 1, n. 613!). Anadenia flexuosa Lindl.! Swan Riv. j. 31, 1. 142. Rami apice compressi. Folia rigidula, subglauca, 4-6 poll. longa, rhachi obtusangulo-flexuosâ, nune alatà, 1-2 lin. latâ. ' nunc semitereti supra eanaliculatâ, segmentís $1-1 \frac{1}{2}$ poll., lacinulis 2-5 lin. longis, 
2-3 lin., latis. Pedunculi 14-2-pollicares supra medium floriferi, interdum basi panciramosi, racemis cylindricis, pedicellis 2 lin. longis. (v. s. in herb. Lindl. et Shuttl.)

165. G. RUDIS (Meisn. in Hook. Journ. 1855, p. 73), foliis rigidis subbipollicaribus cuneato-spathulatis apice 3 -fidis passimque integerrimis penpinerviis sublus nervoso-marginatis junctato-scabris supra levibus, junioribus ramisque patentipilosis, lobis ołlongo-triangularibus syinescentibus, racemis terminalibus pedunculatis cylindricis, pedicellis calyeem rectum puberulum scquantibus, ovario - subsessili hirsuto, stylo glabro apice clavato, stigmate brevi conico, folliculo viscido-pubescente. J In Novà-Holl. occid. interiore, inter llum. Moore et Murchison (Drumm. coll. 6, n. 180!). Caulis 1-2 pedalis, erectus, gracilis, a basi ramosus, sat dense foliosus, ramis apice subaphyllis remote bracteatis, bracteis foliaceis sessilibus subadpressis 3-8 lin. longis ovali-lanceolatis nucronatis scabris 1 - vel obso-

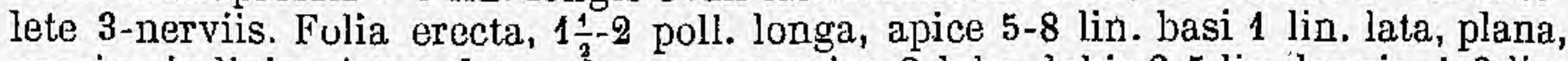
passim indivisa lanceolata, plerumque apice 3-loba, lobis 2-5 lin. longis, 1-3 lir. latis mucronatis, intermedio' passim 3-dentato, sinubus acatangulis. Racemi 1-2-pollicares erecti, basiflori, interdum ramosi, pedicellis $1 \frac{1}{2}$ lin. longis rhachique hispidulis. Glandula hypogýna nulla. (v. s. in herb. Shuttl.)

166. G. m ON т I OL A (Meisn. in pl. Preiss. 2, p. 259), foliis rigidis subbipollicaribus elliptico-oblongis sinuato-dentatis nervosis basi cuneatâ integris supra glabris subtus ramulisque subsericeo-canescentibus, dentibus spinescentibus, racemis axillaribus terminalibusque folio subbrevioribus glaberrimis, bracteis caducis, pedicellis calycem incurvum pistillo stipitato glabro breviter superatum subisquantibus, stylo apice vix dilatato, stigmate brevi basi marginato. Swan River (Drumm. coll. 1! Preiss, n. 696!). Anadenia Aquifolium Lindl.! Swan Riv. p. 31, n. 145. Grevillea Aquifolium Meisp. in pl. Preiss. 1, p. 551* (non Lindl.). Frutex bipedalis. Folia 1-2 poll. longa, 8-12 lin. lata, sessilia, dentibus utrinque 3-5 mucronatis, sinubus rotundatis. Racemi 1-1 $\frac{1}{2}$ poll. longi, densi, pedunculati, plerumque recurvi. Calyx 2 lin. longus, subregularis, mox 4-parlitus, utrinque cum pistillo 3 lin. longo glaber. Glandula Irypogyna minuta. Folliculus sublignosus, ovalis, ventricosus, $4-5$ lin. longus, muticus obsolete verruculosus. (v. s. in herb. Lindl., etc.)

167. G. SYNAPне a. (R. Brown! suppl. p. 23), ramis gracilibus angulatis adpressopuberulis, foliis rigidis subglaucis longe attenuato-subpetiolatis digitalibus- pinnatifidis trifidisve submarginatis supra læevibus glabris subeveniis, subtus parce pilosiusculis, lobis divaricatis oblongis 3 -fidis passim indivisis mueronatis 1 -nerviis, racemis axillaribus terminalibusque densifloris, rhachi puberulà, bracteis esducis, calyce incurvo pistilloque vix longiore stipitato glabris, stigmate terminali parvo conico-capitato. 5 In coloniâ Swan River (Fraser! Drumm. coll. 1 et 2, 口. 313! Preiss, n. 694! et ex parte 702 !). - Meisn. in pl. Preiss. 1, p. 552*. Anadenia gracilis Lindl.! Swan Riv. p. 31, n. 144. Suffrutex 1-2-pedalis, laxe foliosus. Folia $2-4$ poll. Longa, semitripartita vel inferiora pinnatim 5-7-partita, fiirte petiolari laminam æquante cuneato-lineari apice $1 \frac{1}{2}-2 \frac{1}{2}$ lin. latâ infra valde attenuatâ, segmentis $1-1 \frac{1}{3}$ poll. longis $2-3$ lin. latis vix cuneatis apice plerumque in lobos 2-3 divaricatos 3-7 lin. longos attenuato-spinescentes divisis. Racemi cylindrici, 1-2-pollicares, breve pedunculati, basi interdum ramosi, demum recurvi, pedicellis 1 lin. Iongis. Calyx albus 2 lin. longus, mox 4-partitus. Glandula bypogyna nulla. (v. s. in herb. Lindl., Shuttl., etc.)

B. latiloba (Meisn. in pl. Preiss. 2, p. 259), foliis trilobis, lobis dilatatis, intermedio productiore spinoso-3-dentato vel 3 -fido, latcralibus plerumque integerrimis, sinubus rotundatis vel rarius acutis (Drumm. coll. 2, n. 313!). Folia glauca, $2 \frac{1}{2}-4$ poll. longa, $1 \frac{1}{2}-2$ poll. lata, cuneato-attenuata, apice vel ad medium usque trifida. (v. s. comm. ab am. Shuttl, et Lemann.)

168. G. QUERGIFOLIA (R. Brown! suppl. p. 23), ramulis gracilibus angulatis puberulis, foliis rigidulis digitalibus oblongis basi cuneato-attenuatis pinnatifidis vel sinuato-dentalis marginatis nervosis glaberrimis, lobis mucronatis integris vel passim apice 2-3-dentatis, racemis terminalibus axillaribusque pedunculatis folia superantibus cylindricis, bracteis ovatis ciliatis tardius deciduis, calyce curvato glabro intus barbellato pistillum stipitatum glabrum subæquante, stigmate oblique laterali planiusculo, folliculo echinulato-rugosissimo. J In coloniâ Swañ River 
(Drumm. coll. 1, n. 619! Preiss, n. 693 ! Gilbert!). - Icisn. in pl. Preiss. 1, p. 551*. G. brachyantha Lindl.! Swan Riv. p. 31, n. 180. Habitus priecedentis. Folia tenuiora, 2-6 poll. longa, parte petiolari l,reviore $\frac{1}{-1}-1$ poll. longa, lobis utrinque

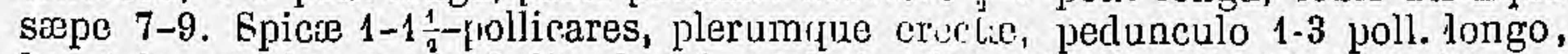
bracteis membranaceis 2 lin., longis striatis albo-ciliatis, rhacti pedicellisque florem æquantibus puberulis. Calyx lilacino-roseus (Preiss); 2 lin. loigus. Stylus tenuis, brevis, stigmate disciformi demum antice convexo. Folliculus uvatus, styli hasi rostratus cum stipite brevi crasso lere pollicaris dense cristato-rugulosus. Species, quamvis stigmate a sectionis chiractere discrefans of inflorescentiin G. bracteosc (supra, 11. 64) valde similis, propter glandula liypogynæ defectum et evidentem cum præcedentibus afficilatem huc relerenda nobis vídebatur. (v. s. in herb. Blown., Lindl., etc.)

\section{Subgenus III. Manglesia. - Genus Nanglesia Endl. gen. suppl. p.1379, n. 2142/1. Meisn. gen. 2,p. 245 (non Lindl.).}

Calyx parvus, regularis, rectus, glaber, demum 4 -partitus, limbo ante expansionom globoso. Glandula hypogyna minuta; antica, semiannularis. Pistillum stipitatum, glaberrimum; stylus strumosus (cfr. tamen G. acrobotrya) ovario parum longior et vix tenuior, basi constrictus vel attenuatus, stigmate terminali acute conico vix longior, demum deciduus. Folliculus ovoideus, turgidus, sæpius tuberculatus vel echinulatus, pericarpio tenui vix, lignoso. - Frutices Novæ-Hollandiæ austro-occidentalis, foliis trifido-laciniatis planis vel subulatis, racemis vel corymbis axillaribus basifloris simplicibus vel ramosis, pedicellis geminis filiformibus elongatis, bracteis fugacissimis. - Meisn. in pl. Preiss. 1, p. 548.

169. G. ACR OB OTRYA (Meisr. in Hook. Journ. 1855, p. 74), ramis idcano-tomentosis, floralibus elongatis apice aphyllis, foliis cuneato-obovatis penninerviis sublus subscriceo-incanis margine arcte revolufis apice inciso-5-7-dentatis summis diminutis trifidis, dentibus pungenti-mucronatis, racemis terminalibus breve ramosis sparso foliosis, stylo crassiusculo, haud strumoso. J In Novà-Holl. occid. interiore, inter flum. Moore et Murchison (Drumm. coll. 6, n. 185!). Rami virgati, teretes, florales elongati graciles recli apice fere aphylli. Folia subsessilia, rigida, 1-1 $\frac{1}{2}$ poll. longa, 8-11 lin. lata, basi angustata, bis triplinervia, dentibus triangularibus 1-2 lin. longis nigro-mucronatis. Racemi axillares breves, folio parvo trifido fulti, approximati, quasi spicam 4-5-pollicarem componentes. Pedicelli capillares calyco dimidio longiores. Pistillum gliberrimum, stipite capillari, stylo crassiusculo recto (nec strumoso) basi vix atìenuato, stigmate cylindraceo-conico obtuso. Folliculus ignotus. Species stylo a Manglesiis veris recedens et potius ad Conogynen accedens, reliquis notis vero omnino huc spectans. (v. s. in herb. Shuttl.)

170. G. G L A B R A TA (Meisn. 1. c. 1, p. 549, 2, p. 255), glaberrima, foliis cuneatis attenuato-petiolatis planis triplinerviis semitrifdis, lobis indivisis vel 2-3-fidis mucronato-pungentibus, racemis pedunculatis simplicibus vel basi ramosis, styli

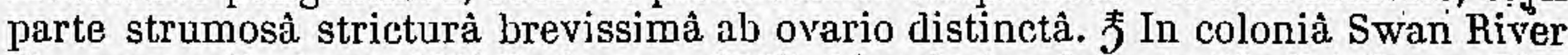
(Drumm. coll. 1, 71. 621! Preiss, n. 695!). Manglesia glabrata Lindl.! Swan Riv. 1. 37, n. 183. M. cuncata Endl. nov. stirp. decad 1, p. 25, adnot. Anadenia Manglesii Grah. in Hook. ic. t. 337. Grevillea Manglesii hort. Frutex 6-pedalis, erectus. Folia 1-2-pollicaria nervulo marginali vel intramarginali cincta. Flores albi. Folliculus dense echinulato-tuberculatus vel angulosus, in pedicello subpollicari deflexo adscendens. (v. s. in herb. Lindl,, etc., et v. v. c.)

171. G. ов Iт нороди (Meisn. in pl. Preiss. 2, p. 256 ), glaberrima, foliis cuneiformibus longe attenuato-subpetiolatis planis triplinerviis apice trifidis, lobis subæquilongis anguste lanceolatis integerrimis attenuato-spinescentibus lateralibus recurvo-subfalcatis, racemis axillaribus pedunculatis basi ramosis, stylo supra strumoso infra filiformi. F In colonià Swan River (Drumm. coll. 2, n. 314 !). Folia 2 $\frac{1}{2}-3 \frac{i}{2}$ poll. longa, ad divisionem 5-6 lin. lata, passim indivisa spathulato-linearia, obsolete nervoso-marginata, lobis parte petiolari multo brevioribus 6-10 lin. longis basi $1 \frac{1}{2}$ lin. latis. Racemi folio breviores. Cætera, excepto stylo, G. glabratæ. (v. s. in herb. Shuttl. et Lemann.)

172. G. VESTITA (Meisn. 1. c. 1, p. 548, 2, p. 255), foliis cuneatis apice trifidis passim indivisis ovalibus pungenti-mucronatis triplinerviis ramisque tomentoso-villo- 
siusculis su[ma glalırescentibus, corymbis subsessilibus simpliciluus vel tjasi ramosis, rhachi pubescente, stylo infra strumam brevissime constricto. $J$ ln coloniâ Swan River.

a. dilatata (Meisn. 1. c.), foliis sessilibus, lobis brevibus trianguláribus vel ovatooblongis (Drumm. coll. 1, n. 620! Prciss, n. 721! 722 !). Manglesia vestita Eudl. nov. stirp. decad. 1, p. 26, n. $32^{*}$. Frutcx 2-9-pedalis, ramis sepe elongatis

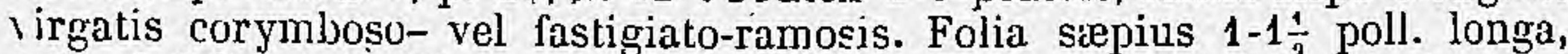
apice 4-8 lin. lata. Flores albi, suaveolentes. Folliculus G. glabrate. (v. s. et v. c.)

B. angusiata (Meisn. 1.c. p. 5\&9), foliis attenuato-petiolatis denum glabriusculis, lobis dimidiam laminam æquanti]sus longioribusve lineari-oblongis (Drumm.

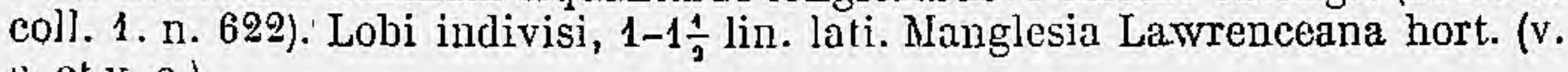
s. et v. c.)

\%. subbiternata (Meisn. 1. c. 2, p. 255), foliis ultra medium trifidis, lobis semipatentibus, lateralibus sæpius 2-3-fidis intermedio breviore indiviso, laciniis attenuato-acutis basique petioliformi subcuneatâ anguste linearibus (Drumm. coll. 2, n. 320!). Sequenti valde accedens. (v. s.)

173. G. TRIDENTIFER A (Mleisn. I. c. 1, p. 549, in notà), foliis subpollicaribus 3-partitis, lobis divaricatis lineari-subulatis pungentibus utrinque bisulcis vel supra planis indivisis passimque 2-3-fidis petiolo multo longioribus, corymbis sessilibus folio brevioribus simplicibus. $J$ In culonià Swan River. A præcedente vix satis distilıcta?

a. ylaberrima (Mcisn. 1. c.), omnibus partibus glabris. - Manglesia tridentifera Endl. nov. stirp. dec. 1, p. 25, n. 31.

B. pubescens. (Meisn. 1. c.), ramis petiolisque dense cano-villosis, corymbi rhachi foliisque junioribus pilosiusculis (Drumm. coll. 1, n.623! in herb. Sliuttl.)

174. G. enina E A (MFeisn. in Hook. Journ. 1855, p. 74), ramis incano-tomentellis, foliis confertis rigidissimis pollicaribus teretibus biternatis pungentibus glabris laciniis semipatentibus subtus bisulcis, racemis folia subæquantibus subsimplicibus, rhachi subscriceo-canà, calyce adpresse pilosiusculo, folliculo ventricoso lævi. 5 In Novà-Holl. occid. interiore (Drumm. coll. 6, n. 186!). Facies G. crithmifolia et Hakeæ erinaceæ, lissocarphæe et teretifoliæ. Rami virgati, ramulis confertis brevibus dense foliosis, junioribus sericeis. Folia subulata, obtuse 3-gona, circ. pollicaria, juniora adpressa pilosula, petiolo 2-3 lin. longo segmenta equante vel breviore, lacinulis $3-5$ lin. longis, $\frac{1}{4}$ lin. crassis attenuato-mucronatis indivisis vel intermediả 2-3-fidâ. Racemi axillares ct terminales, simplices vel basi ramulo brevi aucti, sessiles, densiflori. Calyx $1 \frac{1}{2}$ lin. longus. Glandula hypogyna annularis brevissima. Stylus infra apicem incrassatum angustatus, deciduus, ovarii stipitem 1 lin. longum sequans, stigmate conico brevi. Pedicelli fructiferi circ. 3 lin. longi, tenues, glabri, recurvi. Folliculus cernuus, $k$ lin. longus. (v. s. in herb. Shuttl.)

175. G. вiтеin at a (Mleisn. in pl. Preiss. 1 , p. $549^{*}, 2$, p. 256), ramis cano-tomentosis, foliis rigidulis lineari-subulatis bipollicaribus lævibus glabris biternatis, laciniis divaricatis petiolo longioribus mucronatis subtus bisulcis, racemis sessilibus folio brevioribus erectis, rhacli tomentosà, pedicellis caljce glabro longioribus glabris, stylo crassiusculo stigmateque brevibus, follıcuło verruculoso basi subsaccato. J In coloniâ Swan River (Drumm. coll. 1, 11. 624! 2, n. 315! 323!). Facies G. anethifoliæ et triternatie. Foliorum lacinie 8-18 lin longæ, $\frac{1}{2}-\frac{3}{5}$ lin. latæ, supra planæ vel convexæ. Pedicelli fructiferi 6-8 lin. longi, recurvo-patentes. GJandiıla hypogyna parvula antica. (พ. s. in herb. Shuttl. et Lemann.)

176. G. PANiculata (Meisn.1. c. p. $550 \%$ ), ramulis glabris, foliis rigidulis digitalibus angulato-filiformibus pungentibus levibus glabris 3 -fidis, laciniis elongatis divaricatis rectis 2-3-fidis indivisisque utrinque bisulcis, racemis ramosis folio brevioribus glaberrimis, pedicellis capillaribus flore multo longioribus, stigmate acuto, folliculo ventricoso echinulato-rugoso. 3 In coloniâ Swan River (Preiss, n. 705 ! 717 a!). Frıtex 7 -pedalis, ramis gracilibus teretibus pruinosis, novellis foliisque adpresse puberulis. Foliorum lacinise 1-2-pollicares, petiolo longiores, vix ${ }_{3}^{1}$ lin. crassie, nervo utrinque prominulo marginibusque arcte refractis sul- 
cato-tetragone. Racemi axillares et ramulos brevissimos terminantes, $1-1 \frac{1}{2}$ poll. longi, basi 2-3-ramosi vel rarius simplices, pedicellis 4-6 lin. longi. Glandula lyyjogyna minuta antica. Folliculus ccrnuus, 3 lin. longus, rugis cristulisve brevibus acutis dense echinulatus. (v. s.)

\section{Species obscurce et indescriptce.}

G. ST YL OSA (Knight et Salisb. Prot., fide Loudion encycl. ed. 1, p. 84, n. 1415), foliis lanceolatis subtus pubescentỉbus, stylo prælongo compresso dorso piloso.-Forsan eaden ac G. Seymouriæ Sweet, supra, n. 17.

G. BER B ERIF OLIA (Colvill., Sweet), cx Steudel nomencl. ed, 2, 1, p. 705.

G. Flind E R II (Cunningh.), ex Steud. 1. c.

G. IN D UT A (Ferd. Mïller first general report, p. 17).

G. MUCRONIFOLIA (Cunningh.)

G. Podalyriaźlia (Colvill., Sweet), ex Steudel f. c. - An G. mucronulata R. Br.?

G. podocarPifolia (Sweet), cx Steụd. 1. c.

G. TR IF U R C A A (Colvill., Sweet), ex Steud. 1. c. - An Hakea trifurcata?

\section{Species exclusce.}

G. L OREA R. Br. (olim) = Hakea lorea R. Br.

G. PYRIF ORMIS lort. = Xylomelum pyriforme Sm.

G. SILAIFOLIA Don = Lomalia silaifolia R. Br.

G. тrisect a Ferd. Müll. = Hakea purpurea Hook.

XXX. HAKEA Schrad. sert. Hannov. p. 27, $t .17$, Cav. ic. 6, p. 24, t. 533-535, R. Brown in Linn. Trans. 10, p. 178, prodr. R. Nov.-Holl. p. 381, suppl. p. 25, Endl. gen. p. 341, n. 2144, suppl. IV, 2, p. 85, Meisn. gen. p. 332 (245). - Conchium Smith in Linn. Trans. 4, p. 215, Gartn. fil. fr. 3, p. 217, t. 219. - Embothrii sp. Andr. Bot. repos. t. 215. - Banksia sp. Smilh Gartn. fr. 1, p. 221, t. 47, f. 2.-Lambertice sp. Gartn. fil. fr. $3, p .216, t .217$.

Flores hermaphroditi, racemosi vel fasciculati. Galyx (Grevilleæ) irregularis, 4-fidus, unilabiatus vel 4-sepalus deciduus, sepalis linearibus vel spathulatis apice concavo antheriferis. Antheræ sessiles, ovatæ vel oblongæ, breve apiculatæ vel muticæ. Glandula' hypogyna dimidiata, antica, raro biloba. Ovarium stipitatum, 1-loculare, 2-ovulatum. Stylus filiformis, adscendens, deciduus. Stigma terminale vel obliquum planum vel conicum. Folliculus ovatus ventricosus vel gibbus vel oblongus, rarius globosus, lævis vel tuberculatus cristatusve, excentrice 1-locularis, 2-spermus, bivalvis, valvis crasse lignosis corticatis prope apicem cornutis (calcaratis) vel muticis. Semina compressa, tenere membranaceo-alata, nucleo plano-convexo dorso lævi vel rugoso-cristato vel tuberculoso vel echinato aut undique alâ subæquali cincto aut margine uno vel utroque basique aptero, alâ terminali plerumque nucleo majore, basilari parvâ vel nullâ. - Frutices vel arbusculæ Australasicæe, rigidæ, foliis sparsis coriaceis 'sæpe glaucis teretibus planisve integerrimis vel laciniatis dentatisve sæpe in eâdem specie variantibus vel biformibus, stomatibus amphigenis, fasciculis racemisve plerumque axillaribus, gemmis floriferis globosis ovatisve sessilibus squamis scariosis ovatis imbricatis deciduis involucratis, pedicellis geminatim 1-bracteatis sæpe coloratis, floribus parvis albis vel ochroleucis, raro majusculis rubris. 
$\$ 1$. Folia amnia tereti-fliformia, rarissime passim subcompressa vel plana vel semiplana ( $c f r$. H. bifrons, sulcata, microcarpa) vel stirpis juvenilis trifida (cfr. H. Preissii).

\section{a. Capsulae ecalcaratce, (cfr. H. Milligani). Folia teretia lavia, nec striata nec angulata.}

1? H. L 0 REA (R. Brown suppl. p. 25), ramulis glabriusculis, foliis sesquipedalibus pendulis subexsulcis apice hinc strià depressà olssoletà notatis, cicatricis punctís vascularibus ternis medio a lateralibus remoto basi approximato, racemis thyrsiformibus erectis flore cum pedunculo multoties longioribus, involucro nullo, pedunculis calycibusque patenti-tomentosis, stigmate 4 -gono truncato-pyramidato, capsulà..... 5 In Novà-Holl. orientali tropicả, ad sinum Shoalwater Bay (R. Brown) et subtropicà interiore (Sturt, fide R: Br., Nitchell! 29 sept. 1846, fide herb. Lindl., Leicharit tageb. p. 20). Grevillea lorea R. Brown in Linn. Trans. 10, j. 177, prodr. p. 380, append. Sturt exped. centr. Austr. p. 24. Arbor 18-24 pél. alta, foliis $1 \frac{1}{3}-2$ ped. longis pendulis (Leichardt l. c.) Species ob fructum adhuc incognitum quoad genus dubja, ab ipso cel. auctore tamen huc revocata propter ovula alà nucleum superante terminata. (

2. H. Guningh a ir (R. Brown suppl. p. 26). ramulis incano-tomentosis, foliis pedalibus pendulis exsulcis apice sphacelato-attenuatis, cicatricis punctis vascuJaribus ternis medio lateralibus approximato a basi remoto, racemis erectis, involucro nullo, capsulis compressis intus lavibus. $\mathrm{J}$ In orà septentrionali-occidentali, circa sinum Bay of Rest (A. Cünn.). H. longifolia .1. Cunningh. mss.

3. H. FRASER (R. Brown suppl. p. 26), ramulis glabris, foliis elongatis recurvis exsulcis glaberrimis, cicatricis punctis vascularibus ternis medio centralü, racemis subcorymbosis flore cum peduncilo 2-3-plo longioribus, involucro nullo,

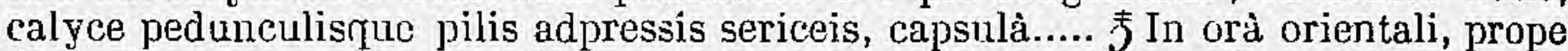
flum. Hastings et Appsley (Fraser!). Frutel elatus, ramis teretibus glabris apice subtomentosis. Folia $6-8$ poll. longa, $\frac{2}{5}$ lin. crassa, sphacelato-acuta, glaberrima, basi attenuata. Racemi in summis axillis approximati, subsessiles, nutantes, circ. pollicares. Calyx pedicellum aquans, 3 lin. longus; flavus; adpresse sericeo-puborulus. (v. s. in herb. Lindl.)

4. Н. РдатYSPERM (Hook. ic. t. 433), foliis crassis elongatis strictis pungentibus exsulcis glabris basi attenuatis, fasciculis axillaribus paucifloris, calyce parto adpresse puberulo pistillo glabro brevissime stipitato dimidio superato, capsulâ compresso-globosâ magnâ crassissimà nuuticà leviusculâ, valvis intus medio lacunosis, seminibus orbicularibus alâ latâ undique cinctis nucleo compressissimo hinc lævi inde cristis fibrillisque membranaceis laceris molliter echinulato. $\Rightarrow$ In colonià Swan River (Drumm. coll. 2, n. 329! 4, n. 287! Preiss, n. 551!). - Meisn. in pl. Preiss. 1, p. 555, 2, p. 259 *. Frutex? ramis validis apice subsericeo-tomentosis albidís. Folia 2 poll. longa, $1-1 \frac{1}{4} \mathrm{lin}$. crassa, mucrone recto.'Involucrum nullum? Flores 5-6 lin. longi. Capsula 1-1 $\frac{1}{2}$-pollicaris. Semina nigricantia, alâ 4-5 lin. latâ undique æequali tenerrimâ. (v. s.)

5. H. RECURVA (Meisn. in Hook. Journ. 1852, 1. '207), glaberrima, ramis virgatis strictis, foliis elongatis crassis mucronatis exsulcis patentissimis deflexisve recurvoarcuatis basi haud attenuatis, involucris axillaribus brevissime pedunculatis, racemis brevissirnis pedicellis flore longioribus, pistillo sessili calycem superante

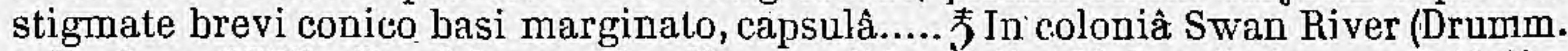
coll. 4, n. 288!). Rami longe simplices, valid. Folia $2 \frac{1}{2}-5$ poll. longa, $1-1 \frac{1}{3}$ lin. crassa, mucrone recto nigro 1-1 $\frac{1}{2}$ lin. longo acutata, pungentia, pleraque semideflexa. Involucrum pedunculo 1 lin, longo stipitatum, ovoideum, magnit. 'pisi, squamis latis rotundatis arcte adpressis glabris. Racemi multiflori, rhachi 3 lin., pedicellis 5-6 lin. Iongis glabris. Calyx inflexus, $2 \frac{1}{2}$ lin. longus, glaber, medio constrictus. Glandula liypogyna majuscula. Stylus 4 lin. longus. Ovarium absque ullo calcarium indicio. Racemi summi (constanter?) approximati et quasi in capitulum terminale congesti, insignes bracteis 6-8 lin. longis subdiaphano-membranaceis fulvis merlio sericeis in unguem 4-5 lin. longum, 1 lin. latum angustatis. Foliis H. platysperma simillima, floribus vero certe distincta. (v. s. in herb. Shuttl.) 
6. H. viRGATA (R. Brown suppl. p. 26), foliis exsulcis minutissime pubescentibus, mucrone recto sphacelato attenuato, racemis axillaribus abbreviatis, rhachi ramulisque tomentosís incanis, capsulâ ccalcaratâ..... J In orá orientali N.-Hollandiæ, circa flum. Lachlan (Cunning.).

7. H. L ONGI C Ú S P IS (Hooker! in Milchell exped, trop. Austr. 1848, p. 397), ramulis gracilibu's glabris, junioribus peduneulisque sericeis, foliis patulis subdigitalibus exsulcis glibris mucrone recto longiusculo pungentibus basi attenuatis haud decurrentibus, racemis axillaribus pedunculatis subpollicaribus, pedicellis calycibusque subrquilongis glabris, capsulà ovato-oblongâ compressâ utrinque attenuatâ lravi, seminis nucleo obovato rugoso margine basique aptero, alà terminali acutâ ipso parum longiore. F Prope montem Riddell, inter flum. Maal et Gwydir, Nove-Holl. orient. subtropice (Mitchell exped. 1846, n. 449 et 478!). Rami teretes, fusci, epidermide albidà deciduâ, novelli cum foliis pedunculisque pube minutâ adpressâ rufo-sericei. Folia 2 - rarius $3-4 k$ poll. longa, $\frac{1}{3}-\frac{2}{3}$ lin. crassa, in mucronem acutissimum 1 lin. longum fuscum vel nigrum attenuata, insertionis cicatrice obtusà deorsum haud productâ. Pedunculi erecti, tenues, 6-12 lin. longi, interdum folıa 1 - vel 2 gerentes, supra medium dense multiflori, pedicellis filiformibus circ. 3 lin. longis. Capsula pollicaris, 5-6 iin. lata, subobliqua, breve acuminata, ecalcarata, cinerea. Seminis ala $7 \mathrm{lin}$. longa, 4 lin. lata, nucleo $4-5 \mathrm{lin}$. longo apice rotundato. Affinis H. virgatæ, sed pluribus notis recedens. (v. s. in herb. Lindl.)

8. H. EPIGLOT TIS (Labill.! Nov.-Holl. 1, p:30, t. 40), foliis adscendenti-erectis subdigitalibus mucronulatis exsulcis basi attenuatis ramisque glabris, fasciculis axillaribus, pedicellis calycibusque iisdem longioribus adpresse sericeis, capsulâ medioeri refractà semilunari compressà lævi acumine carinato incurvo hamatâ, seminis nucleo oblique obovato laviusculo margine basique aptero, alà terminali obovatâ ohlusâ ijso majore. F In 'ins. Diemen (Labill.1), cir'ca Marlboro' et NewNorfalk (Gunn, n.1235! 729!).- R. Brown in Linn. Trans. 10, p. 179, prodr. p. 382, Roem. et Schult. syst. 3, j. 418, Conchium epiglottis Willd. enum. 1, p.141. C. teretifolium Grertn. fil. fr. 3, p. 217, t. 219. Rami dense foliosi, fusci, juniores puberuli. Folia basi incurva, dein recta vel leviter arcuata, 2 rarius 3 poll. longa, $\frac{1}{-}-\frac{2}{3}$ lin. crassa, apice subito in acumen breve contracto, mucronulo minuto nigro sæpe deciduo. Fasciculi plerumque pauciflori, pedicellis $1-1 \frac{1}{2}$ lin. longis calyce dimidio brevioribus, tomento brevi denso albido-sericeo. Stylus calyce parum longior. Capsula deflexa, 6-9 lin. longa, 3-4 lin. lata, subnitida, acumine 1-1 $\frac{1}{2}$ longo inflexo sæepins stylo toto caudato, pedicello brevi crasso. Seminis ala $2 \frac{1}{2}$ lin. longa, 2 lin. lata. (v. s. in herb. DC., etc.)

9? H. MILLIG ANr (Meisn. in Hook. Journ. 1852, p. 207), ramulis tomentellis, folijs patulo-adscendentibus digitalibus exsulcis pungenti-apiculatis basi subattenuatis glabris, fasciculis axillaribus, pedicellis calycibusque subrequilongis sericeis, capsulâ refractâ semilunari subcompressấ lóevi acumiñe carinato hamatá, semine semilunari, nucleo lævi basi attenuato aptero, alà terminali æquilongâ oblongâ acutâ ipso latiore.. In ins. Diemen occidentali, cirça Macquarie Harbour (Milligan, 11. 737!). A simillimâ procedente differt, præter notas jam indicatas, foliis miuus confertis, Jasi semipatentihus, $3-4$ poll. longis, paulo crassioribus, mucrone conspicuo persistente; pedicellis 3 lin. longis, tomento minus adpresso, calyce paulo majore; capsula acumine longiore, crassiore, seminis nucleo vix 1 lin. longo basi tenui, alâ angustiore $1 \frac{1}{3}^{\circ}$ lin'. latâ, sed longiore ( 3 lin. longâ) et acutâ. Capsula forsan breve bicalcarata? in specim. nostr. apice mutilata. (v. s. in herb. Soc. linn. Lond.)

10. H. PamPLINIANa (Kippist! mss.), ramulis adpresse puberulis, folis' curvatis exsulcis mucrone recto pungentibus adultis glaberrimis basi. haud attenuatis, Aloribus in pulvino axillari sessili fulvo-tomentoso fasciculatis pedicellisque subrquilongis dense sericeis pistillo sessili glabro dimidio brevioribus, stigmate obliquo conico-convexo margine subundulato, capsulâ..... F In Australiầ meridionali, circa Adelaide (Grey!). - Meisn. in Hook. Journ. 1855, p. 115. Folia longitudine variabilia, basi paulo incrassata, juniora dense ferruginea insertionis cicatrice rotundatâ (nec ut in $H$. rostratâ 3 -angulari). Flores albi, odore Ireos. Species non satis nota, affinis præcedenti, H. rostrat:, obliqux et strictæ. (Herb. Soc.linn. Lond. , comm. a cl. Pamplin., v. s. fragm.)

11. H. OBLIQU A (R. Brown in Linn. Trans. 10, p. 180, prodr, p. 382), ramis tomentosis, foliis teretibus...., calyce sericeo, glandulâ bypogynâ pedicelli apici obliquo 
adnatà, capsulà gibbosâ subnodosà.... J In terrà Lecuwin (k. Brown). - Lodd: Bot. cab. t. 1682. Folia ex ic. 2-4-pollicaria, circ. 1 lin. crassa, attenuato-acuta, pungentia; flores subsessiles, albi, circ. 3 lin. longi. Huc referenda nobis videntur specim. ex Adelaide (n. 74!) et Drumm. coll. 2, n. 329 el 330, quibus ramuli graciles, subflęxuosi, teretes, juniores subsericeo-tomentelli vel incani; folia patentia, 2-2 $\frac{1}{9}$ poll. longa, $\frac{1}{2}-\frac{3}{3}$ lín. crassa, glabra, exsulca, acutato-mucronata, pungentia, basi vix attenuata nec decurrentia; fasciculi axillares subsessiles, multillori, pedicellis calyceque triplo longiore adpresse sericeo-tomentosis nitentibus, glandulâ semiannulari pedicelli apici obliquo adnatâ nigricante; stigmate laterali, orbiculari, umbonato. Capsula non suppetit. Specim. Drumm., n. 329, recedunt foliis crassioribus et calyce minus sericco, forsan potius ad H. leucopteram referenda, quæ absque fructu vix dignoscenda. (v. s. in lierb. Shuttlew.)

12. H. ADNATA (R. Brown suppl. p 26), foliis exsulcis tenellis ramulisque sericeis adultis glabratis, mucronulo patente, capsulis gibbis apice compressis, seminibus utrinque alatis, alâ baseos nucleo aliquoties breviore. $\bar{J}$ In orẩ australi (Baxter). Nonente ipso cel. auctore nimis affinis $\mathrm{H}$. oblique.

13. H. в R с с у р те R A (Meisn. in Hook. Journ. 1852, p. 208), ramulis tenellis diffusis flexuosis apice dense sericeo-tomentellis, foliis patentibus vel adscendentibus tenuibus breve mucronatis glabris, floribus....., capsulà sessili late ventricosoovatâ obtusà muticà compressâ rugosâ supra subgibbâ, seminis nigri nucleo late obovato tuberculato vel echinato, margine inferiore tọto anguste alató, alâ terminali late triangulari obtusà nucleo dimidio breviore: (Drumm. cull. 4 , n. 291 !). Folia pollicaria, $\frac{1}{3}$ lin. crassa, in mucronem nigrum vix $\frac{1}{2}$ lin: longum attenuata, juniora cum ramulis argenteo-sericea, insertionis cicatrice brevi icutiusculâ. Capsulæ aggregatæ, refractæ, pollicares, 9 lin. latæe, valvis parum convexis. Semina atro-fusca vol nigra, nucleo valde compresso $7-8$ lin. longo, 5-6 lin. lato, alâ marginali fere 1 lin. latâ, terminali 3-4 lin. longâ latàque. Affinis H. leucopterce, sed notis indicatis satis distincta. ( $\mathrm{v}$. s. in herb. Shuttl.)

14. H. LEUCOPTERA (R. Brown in Linm. Trans. 10, p. 180, prodr. p. 382), ramis erectis virgatis subflexuosis, folijs fructu duplo longioribus......, capsulis ovatis infra gibbosis supra compressis, seminibus albo-cinereis. $₹$ In terrà Flinders oræe australis (R. Brown). H. leucocephala Dietr. syn. 1, 1. 531 (sphalmate!). Huc forsan spectat planta Drummondii coll. 5, suppl. n. 13, cujus fructus ignotus.

15. H. R о S т R A т (Ferd. Müller! in first gen. report, p. 17), ranulis gracilibus apice cinereo-tomentellis, foliis patulis digitalibus mucronato-acutatis exsulcis glabris; fasciculis axillaribus sessilibus, pedicellis tenuibus calyceque sublongiore sericeis, pistillo sessili glabro, capsulâ ovali-oblongâ falcato-incurvâ compressẩ rugosâ, rostro compresso lato adscendente acuminatà, seminis alâ falcato-oblongâ nucleo duplo longiore secus ejus marginem superiorem anguste decurrente. 7 In montibus Lolty Range, prope Adelaide, et ad limites austro-occidentales coloniæe Victoria (F. Mïller !). - Meisn. in Linnæà 26, p. 259. Rami teretes. Folia $2 \frac{1}{2}-3 \frac{1}{3}$ poll. longa, $\frac{1}{2}$ lin. crassa, muicrone recto nigro purigente. Fasciculi 6-10-flori. Calyx 3-4 lin. longus. Pistillum 5 lin. longum, stigmate terminali conico-capitato. Capsula crasse lignosa, 14 lin. longa, 8-9 lin. lata, rostro 3 lin. longo, 4 lin. lato acuto ? (mutilato). Seminis ala 6 lin. longa, 3-4 lin. lata. Affinis H. obliquæe et leucoptere, sed certe distincta. (v. s. comm. a cl. Sonder.)

16. H. FuExils (R. Brown in Linn. Trans.-10, 1. 180, prodr. p. 382), foliis filiformibus parum compressis, capsulà ellipticà acutiusculâ modiico convexâ læcìi. $尹$ Cirea Port-Phillipp (R. Brown). Huc forsan referenda est planta Drummondii, coll. 2 , n. 331 ? cui rami graciles, adsccndentes, apice minute puberuli mox glabri, folia semipatula, 10-20 lin. longa, $\frac{1}{2}$ lin. crassa, exsulca, teretia et passim semiteretia, lævia, glabra, glauca? Inucronulo nigro vix pungentia, basi attenuata haud decurrente; fasciculi axillares paucifluri; calyx subsessilis, pube brevi fulvà dense villoso-tomentosus; stigmate nutante, obliquo suborbiculari umbonato. Capsula jgnota. H. flexibilis Ferd. Müll.! in Linna ầ 26 . p. 359 ; in deserto ad flum: Murray crescens, propter fructum ignotum dubia, fide specim. in herb. Sonder. verisimiliter sjeciom distinetam (forsan II. subsulcatex affinem) sistit : ramulis virgalis subflexuosis glabris, foliis patentissimis recurvisve leviter arcuatis $2-2 \frac{1}{-1}$ poll. longis; $\frac{3}{4}$ lin. erassis mucronato-acutatis supra 1 -sulcis et preterea rugoso suban- 
gulatis glabris, fasciculis dense unultiforis glabris, pedicellis capillaribus calyce vix 2 lin. longo brevioribus, pistillo glabro, stigmate conico.

17. H. Gandolleana (Meisn. in pl. Preiss. 2, p. 262), ramulis puberulis, foliis semitereti-filiformibus linearibusque immerse 1 -ncrviis enerviisque glabris, pedicellis axillaribus fasciculatis calycem dense villosiusculum subæquantibus, pistillo subsessili glabro, stigmate vix exserto sublaterali ovali umbonato. $z$ In colonia Swan River (Drumm. coll. 1, n. 605 ! Preiss, n. 603 !). H. falcata $\beta$ ? subuninervis Meisn. l. c. 1, p. $572^{*}$. Forsan mere var. H. flexilis? Cum plantâ Drummondii, n. 331, saltem omnibus notis convenit, exceptis foliis plerisque anguste linearibus (nunquam teretibus) $1 \frac{1}{2}-5$ poll. Inngis, 1 fere 2 lin. latis, margine subincrassatis, supra planis vel concavis subtus plus minus convexis, pedicellis longioribus calyceque paulo majore. Capsula ignota. (v. s.)

18. A. RUgos (R. Brown in Linn. Trans. 10, p. 179, prodr. p. 381), caule diffuso, foliis pollicaribus fructu parum longioribus exsulcis mucrone recto pungente acutatis glabris, fasciculis multifloris sericeis, pedicellis calycibusque jistillum sessile glabrum subæcuantibus, stigmate terminali conico-umbonato, capsulâ refractî̀ obovatâ curvatî̀ utrinque cristatâ rugosâ, acumine subulato lævi adscendente, seminis alà terminali cuneato-obovatá in nuclei ipsi brevioris margines haud decurreute. 3 In orce australis terrâ Flinders (R. Brown), ad Port-Lincoln, Ade-

; laide et flum. Murray (Ferd. Müller!).-Linnæa 26, p. 360. Ramuli (stirpis Müllerianæ) apice puberuli, mox glabri; folia patula, 10-14 lin. longa, $\frac{2}{3}$ lin. crassa, mox glaberrima, basi vix attenuata haud decurrentia; fasciculi axillares sessiles; calyx Q-2 $\frac{1}{2}$ lin. longus, adpresse albo-sericeus; capsula 8-9 lin. longa, styli basi 2-3 lin. longa incurvo-rostrata, cristì oblique transversâ parum prominulâ denticulatâ ; semen nigrum, 5 lin. longum, nucleo obovato rugoso, alâa apice dilatatâ. ( $v$. s. comm. a cl. Sonder.)

19. H. S EM I PL A A (Ferd. Müller! first gen. report, p. 17), glaberrima, ramulis gracilibus, foliis confertis pollicaribus mucronatis basi attenuatis, aliis teretibus basi supra 1 -sulcis, aliis compressis anguste linearibus enerviis supra subplanis subtus convexis, capsılia sessili folia subæquante ovatâ acutiusculâ muticẩ basi incrassatà verrucosầ apice compressá lơvigatâ, scminis alâ ovatâ nucleo paulo majore et secus ejus margines ad basin usque anguste decurrente. $\bar{J}$ In Novà-Holl. orient. interiore (Mitchell! experl. 1836), circa Brighton et Victoria, Australix Felicis (Ferd. Nüller !). - Mcisn. in Linnæà 26, p. 359. Frutex pluripedalis, satis strictus, ramulis dense foliosis rubrofıscis, epidermide tenui albidà deciduâ. Folia 12-16 lin. longa, $\frac{1}{2}-1 \frac{1}{2}$ lin. lata, obtusiuscula cum mucrone brevi recto sphacelato. Flores ignoti. Capsula in apice ramuli lateralis brevis foliosi solitaria, vix pollicaris, verrucis rotundatis livibus versus apicem evanescentibus. Hujus formam peculiarem (forsan speciem distinctam) cl. Müller in terrâ Gipps Land legit : foliis omnibus terelibus (serniplanis nullis) 10-20 lin. longis, $\frac{1}{3}-\frac{1}{2}$ lin. crassis exsulcis, pedicellis axillaribus sessilibus multifloris, pedicellis 1 lin. Jongis parce adpressopilosiusculis, floribus flavis 2 lin. longis glaberrimis, capsulà ignotâ. Affinis H. nodosæe et flexili. (r. s. comm. a cl. Lindl. et Sonder.)

20. H. NODOS A (R. Brown in Linn. Trans. 10, p. 179, prodr. p. 382), foliis erectis subpollicaribus compressiusculis pungentibus exsulcis ramulisque glabris basi angustatâ apicerjue decoloribus, pedicellis pubescentibus, calýce glabro, capsulis folio subrequalibus ovatis obtusis apice subcompressis inferne nadoso-gibbosis rugosisque, seminibus atris leevissimis, alà obovatâ secus nucleum dimidio breviorem triplo angustiorem decurrente. F Circa Port-Phillip (R. Brown), in colonià Swan River (Preiss, n. 606! Gilbert! Drumm. coll. 5, n. 412!). - Meisn. in pl. Preiss. 1, p. 555*. Frutex 10-12-pedalis (Preiss). Folia interdum (sāltem in specim. Preiss.) omnia teretia, nequaquam compressa. Pedicelli 3 lin. longi. Stigma oblique truncatum. Capsula eum stipite brevissimo crasso pollicaris, subventricosa, mutica. Semina atrofusca. (v. s.)

21. H. pROPINQLA (A. Cunningh.l in Field I. S. Wales, p. 327), ramulis sulcatoangulatis adpresse puberulis vel demum glabris, foliis semipatentibus pollicaribus crassiusculis exsulcis grlabris basi attenuatis mucrone brevi recto pungente, pedicellis hirsutis calye'm glaherrimum parvulum sulsæquantibus, stigmate mutico, capsulà foliis longiore compresso-subglobosâ gibbâ obtusâ valde tuberculatâ. $J$ ln montibus cœruleis, prope Port-Jackson (A. Gunn.! Sieber! n. 11). H. pachyphylla 
Sieber! herb. Novæ-Holl. n. 11, Roem. et Schult. sjst. mant. 3, p. 282*, R. Brown suppl. p. 26. Folia 1 - rarius $1 \frac{1}{2}$ poll. Ionga, $\frac{1}{3}$ lin . crassa, sub lente elevato-puncticulata, insertionis cicatrice obtuse ovato-triangulari brevi. Pedicelli $1-1 \frac{1}{2}$ lin. longi, pube patulâ brevi fulvà dense villosiusculi. Capsula magnit. juglandis majoris, more fere H. pandanicarpæ tuberculata. (v. s. in h. Cunn., etc.)

22. H. PUgioniforis (Gav. Anal. de hist. nat. 1, p. $213^{*}$, ic. 6, p. $24^{*}$, t. 533), foliis patentibus pollicaribus exsulcis pungentibus basi attenuatis ramulisque glabris, calyce cum pedicello ipso breviore sericeo vel hirsuto, capsulâ ovato-lanceolatâ reetà rostrato-acụminatâ infra medium transverse echínato-cristatâ, seminis nucleo obovato ruguloso margine basique aptero, alâ terminali oblongâ acutiusculà nucleo haud latiore dimidio longiore. Tasmanniâ.-R. Brown in Linn. Trans. 10, p. 178, prodr. p. 381, Bot. cab. t. 353, Herb. de l'amat. t. 217, Reichenb. nugaz. t. 23. Prater formas sequentes variat foliis $\frac{5}{4}-1 \frac{1}{2}$ - raro $2 \frac{1}{1}$ poll. longis, $\frac{1}{2}-1$ lin. crassis plus minusve patentibus apicem versus sæpius paulo incrassatis, subtus interdum obsolete 1-sulcis novellis ramulisque sericeo-tomentosis, insertionis cicatrice obtusâ vix ac ne vix productâ. Involucri ovati squamæe late ovatæ, obtusæ, glabræ. Pedicelli $1-2$ lin. longi. Capsula 7-9 lin. longa, cristis crassiusculis vel tenuioribus.

$\alpha$. sericea, pedicellis calycilpusque pube adpressá sericeis.-R.Brown l. c. p. 179. - Circa Port-Jacksou (Sieber, n. 13! Verreaux! Lhotsky! etc.), in coloniấ Victoriâ et terrâ Gippsland (Ferd. Müller), Tasmanniâ (Stuart!). - - Roem. et Schult. syst. 3, p. $417{ }^{*}$. Banksia teretifolia Salisb. prodr. p. 51. Hakea glabra Schrad. sert. Hannov. p. 27, t. 17. H. pugioniformis Cav.! 1. c. H. glauca Kn. et Salisb. Prot. p. 106. Conchium longifolium et pugioniforme Smith in Linn. Trans: 10, p, 121*. G. corniculatum Smith! mss. iu herb. Lambertia teretifolia Gærtn. fil. fr. 3, t. 217. Folia raro pollice longiora, sæpe breviorá. (v. s. et v. c.)

ß. hirsutu, pedicellis calycibusque pube brevi laxiusculà hirsuto-tomentosis. R. Brown 1. c. p. 179. - In Tasmannià (R. Brown, Gunn, n. 731! Evverett!), circa Victoria (Latrole!). 'H. parilis Knight et Salisb. Prot. p. 106. Folia plerumque pollice longiora, usque ad $2 \frac{1}{2}$ poll. longa, tenuiora. (v. s. et v. c.)

23. H. M I T H E L I I (Meisn. in Hook. Journ. 1852, j. 208), foliis patulis pollicaribus pungentibus glabris supra 1 -sulcis basi haud angustatis, capsulâ subsessili ovatâ tumidâ acutâ muticâ lêvi, seminibus niçris, alâ triangulari-ublongâ acutiusculâ hinc secus nucleum aquilongum decurrente. 5 In N.-Holl. orientali interiore (Mitchell exped. 1836, n. 208!). Ramuli laxiuscule foliosi, teretes, apice subsulcati puberuli. Folia 6-18 (plerumque 12) lin. longa, $\frac{4}{2}$ lin. crassa, supra! nec subtus leviter 1-sulca, jotius subulato-acutata quam mucronata, insertionis cicatrice haud productà. Flores ignoti. Pedicelli fructiferi vix 1 liu. longi. Capsula 5-6 lin. longa, 3 lin. lata, fulva; nitida. Seminis ala fere 2 lin. longa, basi $1 \frac{1}{2}$ lin. lata. (v. s. in herb. Lindl.)

\section{b. Capsula ecalcaratce. Folia teretia striata vel sulcato-angulata.}

24. H. subsulcata (Meisn. in pl. Preiss. 1, p. 555*), foliis tenuissime sulcatolineatis sphacelato submucronatis junioribus ramulisque adpresse, sericeo-pilosiusculis, capsulâ folio multo breviore ovato-oblongâ breve acuminatâ lavi basi subgibbosâ, sumine atro, alâ obovato-oblongâ hinc secus nucleum læviusculum decurrente. J In coloniâ Swan River (Preiss, n. 607! Drumm. coll. 5, suppl. ๓. 5?) Frutex 7 -pedalis, tarde glabrescens. Folia $1-3$ poll. longa, $\frac{1}{2}$ lin. crassà, vix pungentia, lineis lóngitudinalibus vix prominulis undique dense striala. Flores ignoti. Capsulæe fasciculate, cum stipite pedicelloque brevibus crassis 10-12 lin. longæ, rectæ, subventricosæ. Semina atrofusca, fere H. nodosæ, sed. paulo minora, nucleo valde convexo et parce verruculoso-punctato. (v. s.)

25. H. Lehmaniana (Meisn. 1. c. p. $557^{*}$ ), ramulis apice puberulis, foliis tenuibus obsolete sulcato-angulatis sphacelato-mucronulatis glabris : capsulis sessilibus ventricoso-ovatis breve acuminatis undique sparse echinato-tuberculosis cristatisque, semine nigro, nucleo hinc convexo ruguloso utrinque alato basi aptero, alà terminali ovato-triangulari acutiusculà. 5 Ad flum. Gordon, distr. Hay, prope

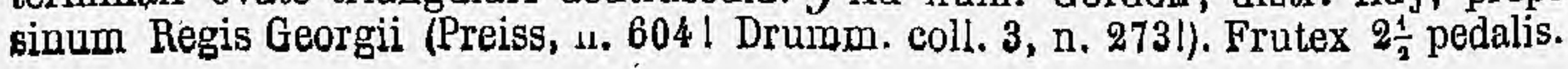


Folia 1-1 $\frac{1}{2}$ vel inferiora interdum 3 poll. longa, sulcis plus minus obsoletis. Capsula pollicaris, seminis ala fuscescens, nucleu vix longior. (v. s.)

26. H. su'L c a t A (R. Brown in Linn. Trans. 10, p. 180, prodr. p. 382, suppl. p. 27), ramulis puberulis, fọliis confertis patulis angulato-filiformibus profunde 5 -6-sulcatis sursum attenuatis mucronulatis imà basi dilatatis; infimis quandoque spathulatis planis nervosis basi atlenúatis, lloribus fasciculatis glabris, capsulà sessili ovatâ acuminatà lievi. 青In terrâ Leeuwin (R. Br.) et colonià Swan River (Drumm. coll. 1, n. 599! 5, n. 411! Preiss, n. 608, 609| 733!), -Mcisn. in pl. Preiss. 1, p. 556 *

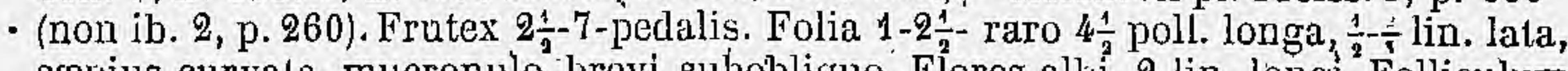
sepius curvata, mucronulo brevi subobliquo. Flores albi, 2 lin. longi. Folliculum maturum non vidimus. (v. s. in herb. Cunningh., ete.)

27. H. MeISNeriana (Kippist ! in Hook. Journ. 1855, p. 114), glabra, foliis erectis teretibus undique subsulcatis basi attenuatis, floribus axillaribus breviter subspicatis, stigmate breve exserto conico, capșulâ breve stipitatà oblique ovatâ rostralo ${ }^{2}$ acuminat anguste alato, alâ terminali nucleo subduplơ majore obtusiusculâ. austro-occidentali (Drumm. coll. 3 , n. 2721 5, suppl. n. 16! 6, n. 191!). H. sulcata Meisn. in pl. Preiss. 2, p. 260 (nec ib. 1, p. 556, nec R. Br.) et in Hook. Journ. 1852, p. 208, ex parté. Ramuli angulato-striati glalri. Folia erecta, 2-3 poll. longa, subclavato-teretia, recta, 10-striata, apice in mucronulum rectum sphacelatum subito contracta, imâ basi vix-dilatata, juniora ferrugineo-pubescentia. Pedunculus communis semipollicaris, tomentosus, pedicellis brevissimis floribusque glaberrimis. Pistillum sessile, stýlo angulato-sulcato breviter exserto, stigmate conico basi dilatato-marginato. Caysula breve pedunculata, interdum subspathulata, longiuscule acuminata. (v. s.)

28. H. scoparra (Meisn. in pl. Preiss. $1^{*}$ p. $556^{*}$, in notâ), foliis erectis elongatis angulato-filiformibus crassis profunde 4 -5-sulcis basi parum dilatatis vix incrassatis junioribus ramuliscque apice angulatis subsericeo-puberulís, floribus fasciculatis glaberrimis, pistillo subsessili calycem dimidio superante, stigmate elongato cylindrico-conico, capsula..... J In colonià Swan River (Drumm. coll. 1, r. 600! Gilbert, n. 301). - Bot. mag. t. 4644. Rami virgati. Folia pleraque 6-8-pollicaria, 1 lin. crassa, adscendenti-subincurva, sphacelato-acutiuscula vix pungentia, angulis $4-5$ (nunguam pluribus) obtusis. Pedicelli dense fasćiculati, calycem 3 lin. longum subiequantes. Pistillum 5 lin. longum, stigmate parum incrassato $\frac{2}{7}$ lin. longo. Capsula (ex Kipp. in litt.) fere sequentis, sed major. Forsan mera var. H. sulcata. (v. s.)

29. H. Gíвенті1 (Kippist in Hook. Journ. 1855, p.115), ramulis teretibus adpresse pubescentibus, foliis gracilibus angulato-filiformibus paucisulcatis' attenuatomucronatis elevato-puncticulatis glabris basi paulo dilatatis, spicis axillaribus fasciculiformibus versus apicem ramorum dense congestis glaberrimis, ovario subsessili, stigmate breviter exserto conico, capsulâ parvà ovatâ acuminatâ sparse tuberculatà, seminis nucleo tuberculato utrinque anguste alato, alà terminali ipso breviore acutiusculâ. $\bar{f}$ In coloniâ Swan River (Gilbert, п. 391). Ramuli demum glabri. Folia 1-2 poll. longa, longiuscule attenuato-pungentia. Involucrum glabrum. Stigma basi marginatum. Capsula vix semipollicaris. Seminis nucleus valde convexus. Valde quidem affinis H. scoparia, sed foliis brevioribus tenuioribus, etc., distincta.

\section{c. Capsulce apice bicomes vel 2-calcarato. Folia omnia teretia indivisa lavia.}

30. H. PREIS.SII (Meisu. in pl, Preiss. 1, p. $557^{*}$ ), foliis patentibus pollicaribus crassiusculis mucronulatis exsulcis ramulisque glabris, stirpis juvenilis 3 -fidis, capsulâ' subsessili folio breviore oblongâ verruculoso-punctatầ apice subcomjresso truncato-subbicorni, semine albido nucleo subrotundo-obovato hinc convuxo rugoso margine basique aptero, alà terminali ipso longiore oblongà obtusà. 5 Circa York in colonià Swan River (Preiss, n 617 bl). Arbor circ. 30 pedum. Folia conferta, fere 1 lin. crassa, apice obtusiusculo mucronulo sphacelato brevi recto armata, hasi vix attenuata, insertionis cicatrice obovata punctis 3 vascularibus prope medium approximatis. Flores ex Preiss flavi. Pedicelli fructiferi fasciculati, lin, longi, crassiusculi, glabri. Capsula 7-8 lin. longa, basi attenuata, 
inferne subteres, apiccm truncatum versus leviter compressa, cornubus seu calcaribus brevissimis divergentibus obtusiusculis. Semen lutescenti-albidum. Species folìis H. propinquæ similis, fruetu distinctissima. (v.'s. sine fl.)

31. H. S TR I c т A (Ferd. Müller ! mss.), ramulis gracilibus teretibus, foliis sesquipollicaribus rectis exsulcis acutato-mueronatis basi attenuatis, capsulâ folio duplo breviore ovatâ lavi apice bifariam compressâ truncatà et breviter bicorni, seminis

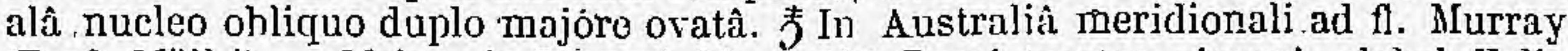
(Ferd. Müll.!). - Meisı. in Linnæâ 26, p. 360. Rami teretes, cinerei, glabri. Folia 1 lin. crassa, nonnunquam fere bipollicaria, mucrone recto sphacelato sape fere 1 lin. longo. Flores ignoti. Capsula incluso pedicello fere 3 lin. longo circ. pollicaris, subventricosa, valvis hæmispherico-convexis versus apicem truncalum simul a dorso et latere compressis (tamen non angulatis) et in cornu breve obtusum (apicem faciei dorsalis formans) cxcuntibus. Scrninis nucleus ovatus, alâ $\$$ lin. longâ latâque, secus nuclei marginem superiorem fere ad basin usquc decurrente. Præcedenti valde affinis. (v. s. comm. a cl. Sonder.)

32. H. M I CROC A RPA (R. Brown in Linn. Trans. 10, p. 182, prodr. p. 383), foliis subbipollicaribus attenuato-pungentibus ramulisque glabris teretibus exsulcis passim compressis 1-sulcis infimis ex parte planis anguste linearibus 1 -nerviis incrassato-marginatis, pedicellis calycibusque subiequilongis glaberrimis, capsula subsemipollicari oblongâ obtusà compressâ basi attenuatâ, calcaribus brevissimis patentibus acutis deciduis, seminis nucleo lkeri margine basique aptero, alà terminali ipso latiore parum longiore. $\mathrm{J}$ In ins. Diemen (R. Br.) et Australià merid.orientali. - Lodd. Bot. cab. t. 219 , Bot. reg. t. 475.

u. Tasmannica, ramulis sulcato-striatis glabris rarius apice puberulis, pedicellis calycem aquantibus vel sublongioribus, fructiferis tenuibus, capsulâ atrofuscâ semipollice breviore, seminis nuclei impressione levissimả.-Ad fretum d'Entrecasteaux (herb. DC.1), circa Launceston (Gunn, n. 20! 210 ! etc.). Ramuli graciles. Folia adscententi-semierecta, $1 \frac{1}{3}-2$-rarius 4 poll. longa, $\frac{1}{2}-\frac{1}{5}$ lin. crassa, mucrone recto fusco 1 lin. longo, basi vix attenuata, insertione breviter producta, 3-gona vel subtridentala. Pedicelli capillares $2-3$ lin. Iongi, fructiferi haud longiores pro more generis tenues $\frac{1}{3}$ lin. crassi. Capsula plerumque umbellato-aggregatæe, 5 lin. longæe, 2 lin. latæe, minute granulatæ, valvis coriaceis parum convexis basin versus paulo incrassatjs. (v. s.)

ß. Bathurstiana, ramulis lævibus vel obsolete striatis adpresse puberulis rarius glabris, pedicellis calyce plerumque brevioribus (1-1\% rarius $2 \frac{1}{2}$ lin. longis),

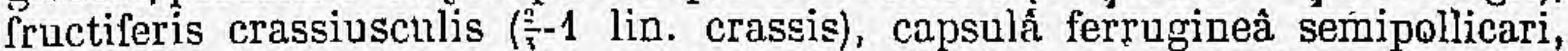
nuclei impressione profunda. - In planitiebus circa Bathurst (Paterson!), Cox River (A. Cunn.!), Lower Menero (Lhotsky, n. 315!), in coloniâ Victoriâ et alpibus Austrałiæ (Ferd. Müller l). Frutex paucipedalis-orgyalis. Folia $\frac{2}{3}-1$ lin. crassa. Capsula lævior. Semina sordide cinereo-fusca, nucleo oblique obovato fere læevi, alà ovatà obtusà hinc ultra medium nuclei decurrente. (v. s.)

33. H. BIFRONS, glabra, foliis aliis teretibus vel semiteretibus supra 1 -sulcis vel subcanaliculatis, aliis (ramorum inferioribus) planis angusto lanceolatis linearibusque ulrinque attenuatis mucronatis 1-nerviis incrassato-marginatis, capsulâ semipollicari oblongâ compressả utrinque attenuatâ acutâ, calcaribus gracilibus patulis incurvis, seminis alâ ovatâ obtusâ hinc secus nucleum sublävem hreviorem semidecurrente. $\%$ In collibus promontorii WVilson (Ferd. Müller!). H. ulicina Ford. Müll. in herb. (non R. Br.) Frutex 3-6-pedalis, plerumque parum ramosus, ramis dense foliosis teretibus exsulcis. Folia, $1 \frac{1}{2}-3$ poll. longa, $\frac{2}{3}-3$ lin lata, mucrone brevi recto pungenti, lanceolata, intèrdum obsolete jarceque pennivenia. Flores ignoti. Capsula axillaris, solitaria, leviter rugulosa, pedunculo $2-3$ lin. longo crassiusculo, valvis basi vix tumidulis, calcaribus $1 \mathrm{lin}$. longis acutis. Semen nigrum, nucleo oblique obovato ferc levi quam ala $\frac{1}{3}$ breviore el fere dimidio angustiore. H. microcarpæe valde affinis, at bene distincta, folia vero teretia multo rariorá quam semiteretia et plana. (v. s. in horb. Sonder.)

34. H. A Cicula Ris ( $R$, Brown in linn. Trans. 10, p. 181, prodr. p. 383), foliis patulis pollicaribus rectis pungentibuis glabris subtus olosolete 1 -sulcis basi haud attenuatis, jedicellis hirsutis florem glaberrimum subrquantibus, capsulâ crassâ ovatâ tuberculato-rugosâ superne gibbì apice compresso breviter hamato-apicu-

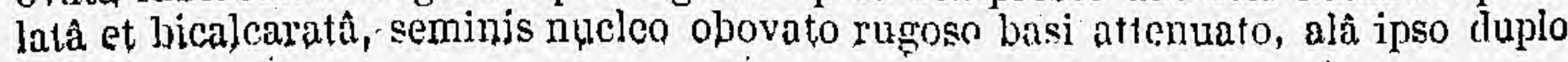


longiore late oblongå obtusâ hinc secus nucleum decurrente. FCirca Port-Jackson (R. Brown, Sièber, n. 10! fl. mixta, n. 481, Verreaux ! Anderson, n.85! Lhotsky ! etc.). - Roem. et Schult. syst. 3, p. 420', Reichenb. Mag. t. 24, Endl. iconogr. t. 24. H. sericea Schrad. sert. Hannov. p. 27. Banksia tenuifolia Salisb. Prodr. p. 51 ? Conchium aciculare Vent. Malm. t. 111. C. compressum Smith! in Linn. Trans. 9. p. 121. Ramuli teretes, juniores adpresse sericei. Folia conferta 9-18 lin. longa, $\frac{1}{3}-\frac{1}{2}$ lin. crassa, in mucronem brevem attenuata, sulco tenui nunc prope basin tantum, nunc ultra medìum conspicuo, nunc nullo, insertione brevissime productà obtusả. Pedicelli 1 $\frac{1}{2}-3$ lin. longi.Capsula 12-14 lin. longa, 9 lin. lata, grosse rugosotuberculata, hinc crassissime lignosa, apiculo calcaribusque 1 lin. longis gracilibus. Seminis ala 6-7 lin. longa, 4 lin. lata. Hujus forma, nisi forte distincta spec. ésse videtur H. brachyrhyncha Ferd. Müll. first gen. report p.17, fido herb. Sonder, cujus capsula ignota, recédens floribus paululum majoribus foliisque sippe paulo crassioribus. (v. s. in herb. Smith., etc.)

35. H. DECURRENS (R. Brown suppl. p. 27), ramulis sulcato-angulatis glabris, foliis patentibus subsesquipollicaribus rectis pungentibus glabris subtus 1 -sulcis basi haud attenuatis, insertione deorsum productâ adnatâ, pedicellis sericeis calyce glaberrimo triplo brevioribus, capsulẩ ovato-oblongà inferne tumidâ tubèculoso-rugosâ superne compressà lævi breve calcaratâ, seminis nucleo obovato ruguloso utrinque anguste alato, alâ terminali ipso subduplo longiore oblongi obtusâ. 责 In oræ orientalis montibus prope flum. Macquarie (Fraser) et Liverpooâ Plains (A: Cunn.!).- Cum H. aciculari facile confundenda, sed bene distincta ramulis angulatis glabris, foliorum insertione breviter decurrente, pedicellis brevioribus (1-1 $\frac{1}{2}$ lin. longis) pube parciore subadpressâ sericeis, calyce $3-4$ lin. longo, et prosestim capsulâ angustiore, inferne 6 lin. latâ, minus gibbosá tumidâ, parte compressâ longiore, valvis hinc minus crassis et seminis nucleo utroque margine alato. (v. s. in herb. Cunningh.)

36. H. viтт Aт A (R. Brown in Linn. Trans. 10, p. 182 ; prodr. p. 383), ramulis tomentosis, foliis exsulcis glabris fructu duplo longioribus, capsulà ovatâ cquilaterâ convexiusculâ a basi dehiscens intus laçunosâ, seminis alâ obovatâ. огæ anstralis terrâ Flinders.

37. H. PA TUL A (R. Brown suppl. p. 27), foliis patulis divaricatisve, pedicellis calycibusque glabris, capsulis subsolitariis bicalcaratis, seminis alâ semilanceolatâ. 㠩 In montibus prope Port-Jackson (Fraser). Huc referendam credimus plantam ab Andersonio lectam (n. 81, in herb. Schuttl.), ramis gracilibus laxiuscule foliosis teretibus tenuiter sulcatis glabris, epidermide cinereâ detritâ demum sanguineofuscis nitidis ; foliis semierectis circ. 2 poll. longis $\frac{1}{2}-2$ lin. crassis glahris basi vix attenuatis, insertionis cicatrice acutiuscule triangulari haud decurrente ; fasciculis axillaribus multifloris, pedícellis 2-3 lin. longis calycibusque æquilongis glabris : capsulâ ignotâ.

38. H. LIS OSPEA A (R. Brown in Linn. Trans. 10. p. 180 ; prodr. p. 382), ramulis junioribus involucrisque incano-sericeis, foliis digitalibus exsulcis pungentibus glabris basi subattenuatis haud decurrentibus, pedicellis sericeis calyce glaberrimo brevioribus, capsulâ ventricoso-ovatâ gibbosâ obtusâ subrugosâ rimosâ brevissime bicalcaratâ, valvis crasse lignosis, seminis alâ obovatâ obtusâ hinc secus nucleum dimidio breviorem obovato-oblongum lævem decurrente. $\%$ In ins. Diemen (R. Brown, Verreaux! etc.), monte Wellington (Gunn, n. 536!) et circa Marlborough (Gunn, n. 210?). Rami virgati, teretes, laxiuscule foliosi. Folia 2-3 rarius 4.5 poll. longa, $\frac{2}{3}$ lin. crasssa, imâ basi attenuatâ, apice in mucronem rectum $\frac{1}{9}$ lin. longum fuscum sensim attenuata, insertionis cicatrice obtuse triangulari brevi pallidâ. Pedicelli $1 \frac{1}{2}-2 \frac{1}{2}$ lin. longi, parce minuteque adpresso-puberuli. Calyx 3-4 lin. longus. Capsula pollicaris, 9 lin. lata, cinerea, opaca, leviter rugosa et fissurata. Semen 9 lín. Iongum, alâ 6 lin. longâ apiçe latiore rotundatâ 3 lin. latâ. (v. s. et v. v. c.)

39. H. G I в в О A (Cav. ic. 6, p. $24^{*}$ ", t. 534 ), foliis patentibus subbipollicaribué pun gentibus subtns obsoletissime 1 -sulcis passimque exsulcis junioribus patentipilosiusculis pedicellis calyce glabriusculo brevioribus ramulisque hirsutis, capsula gibbosâ, seminis alâ semiellipticâ, nucleo lacunoso basi marginato. ‡ Circa Port-Jackson (R. Brown, Sieber, n. 14! etc.). - R. Brown in Linn. Trans. 10, p. 181 ; prodr. p. 382. Roem. et Schult. syst. 3. p. $419^{\circ}$. Banksia gibbosa Smith in 
While Voy. p. 224, t. 22, f. 2. Willd. sp. 1, p, 536. Banksia pinifolia \$alisb. prodr. p. 51. H. pubescens Schrad. sert. Hannov! p. 27, Willd. en. suppl. p. 140 ? H pinifolia Salisisb. Prot., p. 107. Gonchium gibbosum Smith! in Linn. Trans. 9, p. 119 * C. spharoideum Smith, l. c. p. 120. G. pubescens Willd. G. cormintum Gærtn. All fr. 3, p. 216, t. 212. C. corniculatüm hort. (cfr. H. pugioniformis, supra n. 22. Folia pleqrumque $1 \frac{1}{9}$ poll. longa, $\frac{1}{3}$ lin. crassa, mucrone fere 1 lin. longo recto, sulco aut plane nullo aut subtus infra medium plus minus visibili, insertione obtusà baud productâ. Involucra ovato-oblonga, acuta, squamiș interioribus oblongis acutiusculis, junioribus medio sericeis. Pedicelli hirsuti 1-2-lin. Calyces 3-4 lin. longi plerumque glaberrimi. ( $\mathrm{v}$. $\mathrm{s}$. in herb. Smith, etc. et v. c. sine fr.)

40. H. TEP H R OSPERM (R. Brown suppl. p. פ6), foliis fructu duplo longioribus exsulcis mucroné pătenti sphacelato pungentibus ramulisque virgatís glabris, cappsulà gibłbósâ apice compressâ brevissime obtuseque bicalcaratâ, seminibus cinereis. F In montibus prope Port-Jackson (Gunningh.). - Capsula (ex cl. Kippist in litt. cum fig.) ovata, apice sensim attẹnuata et complanata; seminis alâ nucleo sưbtriplo longior et latior, attenuato-acutissima, hinc secus nucleum anguste decurrens. Species, monepte cel R. Brown, proxima H. Lelucopterse, sed foliorum mucrone patenti ẹt capsula calcarata facile dignoscenda. Gonehium drupaceum Giertn. fil. fr. 3, p. 217, t.219 (cfr. R. Brown in Lino. Trans. 10, p. 221) videlur aut hiec ipsa aut sp. fructu saltem proxime afinis.

41. H. Kip PIS t in ANa (Meisn. in Hook. Journ. 1855, p. 115), foliis exsulcis mucropatis 'ramulisçue glabris, floribus..., capsulâ ovatà gibbosâ lævi à aice subito compressâ acütà breyişsime bicalcaratâ, seminis alâ nucleo vix duplo majore secus ejus marginem obliquum late decurrente. 5 In coloniâ Swan River (Drùmm. coll. 5 , suppl. h. 14!) H. tephrosperma? Meisn. in Hook. Journ. 1852, p. '20't (non R. Br.). A

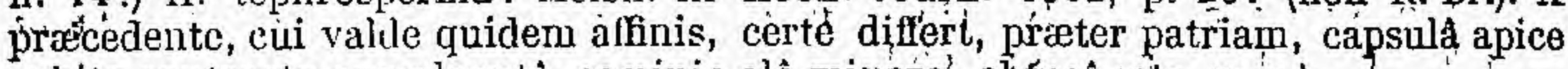
subito contracto-complanatâ, seminis alâ minore, obtusâ, etc. (v. s.)

49. H. cyclo pтена (R. 'Brown in Linn. Trans. 10. p. 182; prodr. p. 383), foliis frúctu duplo longíoribus ramulişque glaberrimis, capsulâ gibbosầ iñtus lacunonosa, seminibus utringue alatis, alâ inferiore nucleum sưbsequapte. $\mathbf{z}$ In oræ auşitralis terrà Flinders (R. Br.). Flores ignoti.

43. H. crRcu Mal a ta (Meisn. in Hook. Journ. 1855, p. 114), ramulis apice incanotomentéllis, follis pollicaribus mucronatis exsulcis glabris basi haud attenuatis, capsisulẩ comṕresso-subgIobosâ ventricosà sub acuminhe compresso bicalcarratâ, seminỉbus undique alầ cinctis, nucleo cristato-tubercúlato alam terminalem acutam xquante làtèralibus subduplo latiore. F In N.-Hollandià occidentảli intêriore. (Druinm. coll. " 4, n. 290 !, flor. 6 , n. 192 ! ( Tr.). Rämi graciles, ramulis adscendenti-erectis. Folia semipatentia, 10-12 lin. longa, $\frac{2}{2}$ lin. (rassa, mucrone 1 lin. Iongo recto tenui fuscơ pungentia, insertione óbtisẩ paululum deorsum productâ. Genmæe terminales parvule, ovatæ, flavidæ, squamis adpresse imbricatis ovatis glabriusculis, exterioribus subcarinato-1-nerviis. Involucrum pubescens, squaitiss ovatis mucronatis ciliatis, extimis angustatis folio brevissimo terminatis. Flores in pulvino terminali sessili pubescente fasciculati, cum pedicello ipsís sublongiore demum glaberrimi- Pistillum sessile, glabrup, calycem paulo superans, stigmate subobliquo vix convexo. Glandula hypogyna magna, crassiuscula. Capsula terminalis? solitaria, breve crasseque pedicellata, 9 lin. longa, haud gibbosa, rugúlosa passimque veríuqulosa. acumine depresso $1 \frac{1}{2} \mathrm{lin}$. longo utrinque in rostrum vel ealear falcatum crassiuscule. subulatum acutum 2 lin. longum plerumque deciduum producto. Semen atrum, nucleo obovato $2 \frac{1}{2}$ lin. longo, alâ terminali'late triangulari, bașilari nuçleo vix angustiore: (v.s. in herb. Shuttl.).

44. H. Sт R M 9 S A (Meisi. in Hook. Journ. 1852, p. 208), foliis subhipollicarihus exsulcis mucrone recto pungentibus basi vix attenuatis ramisque glabris, capsulâ peduncuTó crasse strumoso suffulta ob̉ique obovato-globosî acuminulatâ supra gibbosâ, calcaribus 2 patentibus basi crassis, semine undique alata, alâ terminali obtusissima semicirculari nucleum tuberculațum subequante, lateralibus basilirique subrequalibus. J In coloniâ Swan River (Drumm. coll. 4, n. $289 !)$ - hami validi, fastigiato-ramosi, gemmis axillaribus oblongis acutis pilosiusculis, squamis paucis acutis. Folia 1 $\frac{1}{2}$ 2-poll. longa, $\frac{1}{3}$ lin: crassa, mucrone 1 lin. longo basi pallido, insertionis cicatrice parvâ ovali. Flores ignoti. Capsula solitaria, pedunculo 6-8 lin. longo crasso insidens, fere pollicaris, acumine brevi acuito, parte 
ventrali ultra apicem prominente, rubro-fusca, irregulariţer rugulosa et - quasi leprosa, calcaribus validis $2 \frac{1}{2}$ lin. longis acutis? (in specim. nostr. mutilatis) valvis crassissime lignosis. Seminis nucleus 5-6 lin. longus obovatus hinc valde con-

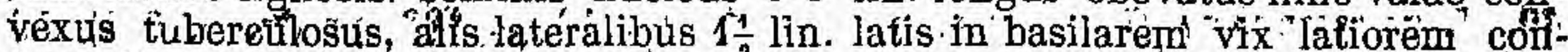
fluentibus. Affinis quidem $H$. cyclopteræ, sed discrepans folis brevioribus; saltem fructu haud duplo lóngioribus, capsulke pedunculo egregie incrassato; seminis alậ inferiore nucleo dimidio vel plus brëviore, êc. (v. s. in herb. Shuttl.)

\section{§2. Folia qut omnia tereti-filiformia pinnatifida, aut indivisis teretibus vel planis integerrimis mixta.}

45. H. SuAveo LeNs (R. Brown in Linn. 'Trans. 10, p. 182 ; prodr. p. 383), foliiş digitalibus omnibus teretibus promiscue indivisis; q-3-fidis pinnatifidisque pungentibus suprạ 1 -sulciș, floribus racemosis glabris, rhachi tomentosâ, cajsulẩ ovatâ ventricosâ basï subgihbosà breviter 2-calcaratâ, seminis alâ àcutiusculấ nucleum

- lævem margine basique ajterum æquante. F In terrâ Leeuwin (R. Brown) colonia

- Swan River (Preiss, ㄲ. 605 !).-Meisn. in pl. Preiss. 1, p. $558^{*}$. H. gibbosa Labill.! mss. in herb. DC. (non Cấv.) H. pectinata Colla hort. Ripul. p. 63, upp. 2, p. ‘2 20 *,

t. 11? (vix differre videtur, nisi forsan stigmate olavato et floribus inedoris) H. heterophylla et pinnata hort: Frutex 7 -pedalis, ramis ralidis apice minute puherulis. Folia adscendentia, 2 - $h$-poll. Ionga, 1 lin. crassa, basi parum attenuata, nunc pleraque indivisa, nunc pleraque pinnatim 3-5-fida, juniora parce adpressopilosiuscula. Involucrum subsericeo-canum. Capsula rugosa cum stipite brevi orassa pollicaris, calcaribus vix 1 lin. longis crassis subcompressis obtusiusculis vix divergentibus. Semina atrafiusca. (v. s. et v. c.).

46. H. LASIOCARPHA (R. Brown suppl. p. 27), ramulis puberulis, foliis pollicaribus - eompresso:filiformibus pungentibus lævibus glabris supra $t$-sulcis pingatim 37-5idis passimque simplicihus laciniis teretibus indivisis subexsulcis, orymbis axillarihus spssilibus folio breviaribus, involucro rhąehique pubescentibus, pedicẹlliss floribusque glabris, capsulâ brevissime oḅtuseque 2-calcaratâ. J Circa sipụum Regis Geargii (Baxter), ad flum. Cygnorum (Preiss, n. 5941 Drumm. call. 1, n. 617 ?).- Meisn. in pl. Preiss. 1, p. 561* Frutex 2-3-pedalis. Folia nunquam

- bipinnatifida, rhachi petioloque semper depresso-semiteretibus. Flores parvi, abtä, odore fere Pruni spinosæe. Pístillum" scssile, glabrum, calycem æequans, stigmate brevi acute conico. (v. s.)

47. H. LISSQ GA R PHA (R. Brown suppl. p. 27), foliis subpollicarihus terelibus pinpatim 3-7-fidis scabriusculis juniarihus ramulisque pubesentibus, segmentis indiyisis vel passim bifidis pungentibus exsulcis, petiolo supra deplanato 1-sulco, chrymhis axillaribus subsessilibus folio breviopibus, involucro glaberrimo, thạchi jurevi villasà, peg̣icellis floribusque glabris, capsulậ ovatâ læevi breviter acuiteque

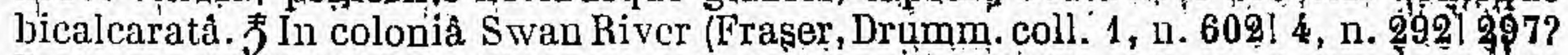
Preiss, n. 597! 598 !). - Meisn. in pl. Preiss. 1, p. 559 ", et in Hook. Journ. 1852, 'p. 208 (uhi lapsu typogr:' legitur H. lisiocarpa). H. petrophiloides hort. Frutes 3 -pedalis arectus. Folia dense punctato-scabritiscula raro pollicem attingunt, segmentis 3-6 lin. longis sæepe alternis, inferioribus subinde bifidịs. Pedicelli 1-3 lin. loggi, capillares. Flores albi vel incarnati, odore Pruni spinosæ, ealyce fecto vix $1 \frac{1}{2}$ lin. longo pistillum subsessile glabrum subæquante, stigmate teriminali brevi acute conico. 'Capsula refracta, 5-6 lin. longa, 4 lin. lata, valvis rotundato-convexis. Semina atra, nucleo, hine anguste alațo alam terminalem ovatam subæquante, (v. s. ot v. c.)

48. 耳. BIPINNA TIFIDA (R. Brown suppl. p. 28), foliịs sesquipollicaribus teretibus levibus trisectis, junioribus ramisque pubescentibuss, segmentis 2-3-fidis biternatísque pungentibus cum petiolo ipsis breviore subtereti supra 1 -sulcis, corymbis axillaribus subsessilibus folio brevioribus, rhachi villosâ, jnvolucri squamiş suppefioribus apice subsericeis inferioribus floribusque glabrị̦, cạpșlâa ovatâ læeviuscula breve bịcalcạatata. J In colonị̂ Swan River (Preiss, n. 592, 595, 596, 602 !) Meissn in pl. Preiss. 1, p. 560*. Frutex 2-9-pedalis, squarrosus. Folia 1-1 i poll.

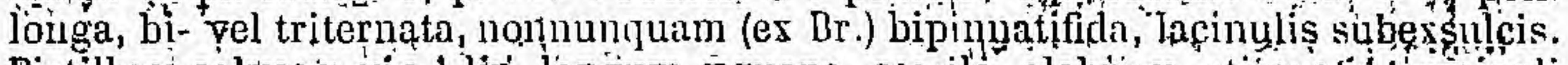
Pistillum calycem vix $\div$ lin. longum soquans, sessile, glabrum, stignate terminali brevi acute conico. Capsula pollicaris, leviter ventricosa, acumine birevi subicom-

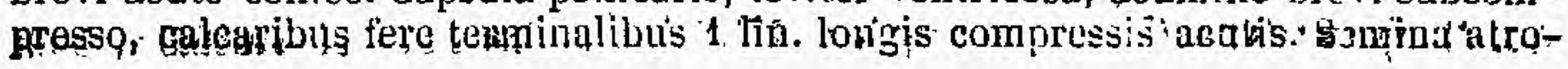


fusca, alâ ovato-oblongâ acutiusculâ, nucleo obovato ruguloso hinc alato ipsâ paulo breviore. (v. s.)

49. H. trifuRcata (R. Brown in Linn. Trans. 10, p. 183, prodr. p. 383), foliis teretibus pungentibus lævibus glabris sericeisve subtus 1-sulcis trifidis indivisisque passim planis ovalibus integerrimis submuticis, floribus axillaribus fascicılatis pubescentibus, stigmate laterali ovali, capsulâ oblongà compressâ ecalcaratâ verruculoso-punctatâ, seminis nucleo margine basique aptero alam terminalem oblongam obtusam zquante. $亏$ In terrà Leeuwin (R, Br.) et colonià Swan River (A. Cunn.! Drumm.! Preiss!). - Roem. et Schult. syst. 3, p. 420*, Meisn. in pl. Preiss. 1.p. 558 *. Frutex 3-9-pedalis, fastigiatus. Folia valde variabilia, sæe in eodem ramo diversiformia ; alia teretia 1-3 poll. longa, $\frac{1}{3}-\frac{1}{2}$ lin. crassa, indivisa vel 2-3-fida, segmentis 6-18 lin. longis integris vel raro bifidis, alia sparse occurrentia plana, ovalia vel oblonga, 6-18 lin. longa, 4-7 lin. lata, subevenia, submarginata. Fasciculi 3-6-flori, sessiles, pedicellis 1-2 lin. longis vel nullis. Calyx 3 lin. longus, pistillum sessile glabrum subæquans. Stigma antice subconcavum, umbo-

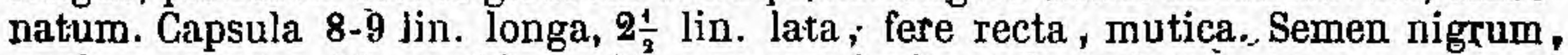
nucleo cuneato-oblongo hine valde convexo leviter tuberculato-rugoso.

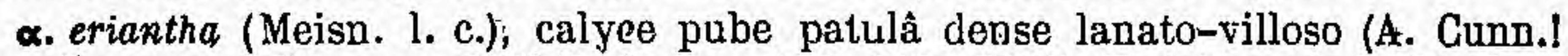
Drumm., coll. 1, n. 626! Preiss, n. 610, 618, 619!). H. trifurcata R. Br. I. c. H. mixta Lindl.! Swan River, p. 35; n. 177 (cui folia nequaquam exsulca, fide herb. Lindl.). H. tricruris Lindl.l l. c., n. 179. Forma foliis planis semper? earens, stigmate vero minime diversa, fide herb. Lindl.! Conchium trifurcatum Smith! in Linn. Trans. 9, p. 122. (v. s. in herb. Smith., Gunn., Lindl., etc.).

B. sericantha (Meisn. l. c. p. 559), calyce pube brevi adpressâ rarescente sericeo (Preiss, n. 591!). Ciet. omnia ut in var. $\alpha$. (v. s.)

50. H. Bou C H EANa (Kunth Ind. sem. h. Berolin. 1844, p. 9, ex Linnæá 18, p. 499), foliis filiformibus trifidis rarius indivisis pungentibus, nonnullis lanceolatis integerrimis pungenti-acutis, calyce sericeo-hírsuto, capsulâ..... $\bar{J}$ In ins. Diemen (colitur in h. Berolin.). A simillimâ $H$. trifurcatâ differre dicitur foliis trifidis gracilioribus planis anguste lanceolatis acutis. Attamen forsan ejusdem var.

51. H. erina CEA (Meisn. in pl. Preiss. 1, p. 559 \%), ramis pubescentibus, foliis pollicaribus patentibus teretibus lævibus demum glabris trifidis, segmeptis divaricatis bifidis exsulcis pungentibus, petiolo tereti subtus 1 -sulco, fasciculis axillaribus sessilibus paucifloris, pedicellis calycibusque æquilongis lanato-tomentosis, stigmate laterali lineari-oblongo obtuso. $\bar{\zeta}$ In coloniâ Stvan River (Drumm. coll. 1, n. 601! Preiss, n. 601 l). Frutex bipedalis, erectus. Folia rigidissima, omnia teretia, segmentis petiolo subæqualibus vel sæe brevioribus. Calyx 3 lin. longus, fulvotomentosus, pistillum sessile glalırum æquans. Stigma fere 1 lin. longum, stylo parum latius, antice subconcavum obtuse umbonatum. Capsula ignota. Præcedentibus affinis, at facile dignoscenda. (v. s.)

52. H. PUR PUREA (Hook. in Mitchell exped. trop. Austr. 1848, p. 348), ramis apice puberulis, foliis rigidissimis teretibus subexsulcis lævibus glabris semitrifidis, laciniis spinescentibus lateralibus bifidis intermediâ simplici, fasciculis axillaribus sesslibus glabris, pedicellis calycem semipollicarem subæequantibus, pistillo pollicari glabro, stigmate laterali ovali, capsulâ ovatâ acuminulatâ ecalcaratâ. 5 In Valle Warrego (Mitchell exped. 1846, n. 399!), circa Melbourne (Ferd. Müller I). - Meisn. in Linnæâ 26, p. 358. Grevillea (Sciadanthus)-trisecta Ferd. Müll. first report, p.17, fide mss. in herb. Rami satis dense foliosi. Folia erecta, 1-2 poll.longa, $\frac{1}{9}-\frac{2}{3}$ lin. crassa, basi haud attenuata, passim subtus obsoletissime 1-sulca, mucrone recto 1 lin. longo fusco, segmentis petiolum æequantibus. Involucrum non vidimus. Fasciculi 5-6-flori, rhachi sericeầ brevissimâ, pedicellis 5-6 lin. longis. Calyx coccineus, pro more genèris maximus, 6-7 lin. longus, ulrinque glaberrimus, basi oblique insertus, tubo supra fisso; limbo globoso reflexo. Glandula hypogyna obsoleta. Ovarium parvulum, subsessile. Stylus complanato-filiformis, stigmate $\frac{4}{a}$ lin. longo plano papillâ centrali obtusâ. Capsula incluso stipite brevi crassiusculo pollicaris, subobliqua, cinerea, subtuberculata vel fere lævis, crasse lignosa. Species insignis, flore Grevilleam simulans, sed capsula omnino Hakeæe. (v. s. comm. a-cl. Lindl. et Sonder.)

53. H. Hratcara (R. Brown suppl, p. 27), foliis filiformibus pinnatifidis, laciniis 
indivisis bifidisve exsulcis, involucri squamis glaberrimis, capsulà ecalcaratå lævi. $\exists$ Circa sinum Regis Georgii (Baxter).

\section{\$3. Folia plana spinoso-dentata vel varie laciniata, rarius repanda vel subintegerrima (cfr. $H$. repanda, smilacifolia, ceratophylla). rarissime passim compresso-filiformia vel subteretia.}

\section{a. Capsula apice bicalcarata.}

54. H. VARIA (R. Brown in Linn. Trans. 10, p. 183, prodr. p. 383), foliis glaucis pollicaribus pungentibus ramulisque glabris, aliis compresso-filiformibus teretibusque indivisis trifidisque : upra 1 -sulcis, aliis planis eveniis linearibus spathulatisve pinnatifidis vel apjice $\mathbf{2 \cdot 3}$-denlatis integrisve, corymbis folio brevioribus, rhachi pubescente, calyce pistilloque subrequalibus glabris, stigmate conico-capitato, capsulâ oblớngâ subcompressâ sublærvi, calcaribus brevibus obtusis, seminis alâ nucleo oblongo paulo longiore ovatà obtusâ hinc decurrente. Ĵ̉n terrà Leeuwin (R. Br.), coloniâ Swan River (Preiss, n. 600!). - Meisn. in pl. Preiss. 1, p. 561*. Frutex 8-pedalis, diversifolius, ramorum inferiorum foliis minus divisis. Corymbi axillares et ramulos breves terminantes, subsessiles, multiflori, rhachi pubescente, involucri squamis ciliatis superioribus sericeo-villosis. Flores albi. Pistillum sub: sessile. Capsula subpollicaris, secus suturam inferiorem parce tuberculata, caterum lævis. (v. s.)

55. H. TUBER C ULATA (R. Brown suppl. p. 28), ramulis tomentosis, foliis pollicaribus viridibus planis glabris cuneato-oblongis spathulatisve extra medium inciso-dentatis trifidisve, dentibus spinescentibus. summis passim indivisis linearibus teretibusve, corymbis folio multo brevioribus, calyce pistillo subæqualibus glabris, stigmate conico-capitato, capsulâ ovato-oblongâ superne compressâ undique sparse tuberculatâ, calcaribus brevibus, seminis alâ nulucleo obovato margine fere aptero

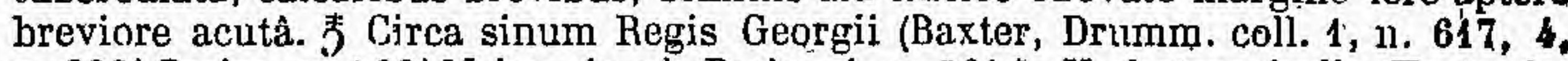
n. $299 !$ Preiss, n. 593! Meisn. in pl. Preiss. 1, p. 561 *. H. heterophylla Hook. ic: t. 437. Nimis affinis præcedenti. (v. s.)

56. H. LINEARIS (R. Brown in Linn. Trans. 10, p. 183, prodr. p. 384), glaberrima, foliis omnibus planis lanceolatis remote spinuloso-paucidentatis integrisque eveniis impunctatis lievibus, corymbis folio multo brevioribus, rhachi glabrâ; stig. mate terminali depressso-umbonato, capsulâ compressiusculâ. 吕 In terrâ Leeuwin (R. Br.), circa sinum Regis Georgii (A. Cunn.! Preiss, 11. 583, 585! Drumm. coll. 2. n. 335! Gilbert! etc.). - Sweet fl. Austr. t. 43, Bot. reg. t. 1489, Meísn. in pl. Preiss. 1, p. 562, 2, p. 260 . Folia $\frac{1}{2}-2 \frac{1}{2}$ poll. longa, 1-5 lin. lata, nune fere omnia integerrima, nunc pleraque vel omnia denticulis mucronulatis utrinque 2-5 armata. Involucrum subgloboso-ovatum, glabriusculum. Flores albi, leviter odorati. (v. s. et v. c.)

57. H. FLORIDA (R. Brown 1. c. p. 183 et 384), foliis lanceolatis linearibusve acutissimis spinoso-paucidentatis subeveniis minute punctatis margine seabriusculis junioribus cum ramulis corymborumque rhachi brevissimà pubescentibus, flori-

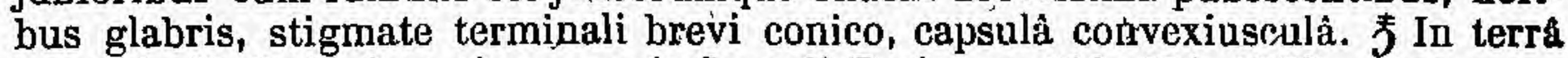
Leeuwin (R. Br.), circa sinum regis Georgii (Preiss, n. 582, 584, 587!).-Bot. mag. t. 2579, Meisn. in pl. Preiss. 1, p. 562. Frutex 6-pedalis, ramulis hispido-pubescentibus interdum mox glabrescentibus. Folia 12-18 lin. longa, 1-2 lin. lata. Corymbi axillares et terminales subsessiles fasciculiformes. Involucrum precedentis, cui species valde similis, stigmate præcipue et pubescentià distinguenda. (v. S., et v. c.)

$\beta$ ? latifolia (Meisn. 1. $c^{*}$.) i foliis oblongis et oblongo-lanceolatis obscure venosis apice obtuso mucronatis muticisve, basi attenuatis, capsulâ globoso-ovatâ rugosâ subtuberculatâ (Preiss, n, 586, 5891). H. flờida Link en. alt. p. 117? Forsan distincta species, recedens foliis pollice longioribus 4-5 lin. latis, obsolete veinosis, apice non attenuatis, sed sẻpe rotúndatís mucronulatis, dentibus brevissimis vel passim nullis. Capsula polticaris, ventricosa, supra valde gibba, crassa, prope apicem sabcompressa et calcaribus 2 divaricatis brevissimis armata. Seminis ala obóvato-oblonga, acutiuscula, secus nucleum ipsả breviorem utrinque decurrens. (v. s.) 
58. H. NITIDA (R. Brown l. c. p. 184 et 384), follis digitalibus rigidissimís glaucis lanceolatis oblongisve pungenti-mucronatis spinuloso-paucidentatis integrisque utrinque altenuatis immerse venosis opacis vel subnitidis lævibus ramulisque glapherrimiș, capsulà șubgibbosâ. 5 In terrâ Leeuwin (R. Br, , Goloniâ Swán Rị́vếr (Preiss, n. 577 ! Drumm. 4, n. 2981). - Bot. mag. t. 2246, Meisu, in pl. Preiss. 1 , - p.-563 ${ }^{*}$, in notà, 2, p: 260 . Àrbuscula 15-piedalis, gracilís (Preisś). Folia $1-4$ poll. longa, 5-10 lin 'lata, hàud puntatà, in śp'écim. Drumm. vix àc ne vị $x_{3}$ in sp. Preiss. nequaquam nitida. Involucrum $\mathrm{H}$. floridæ. (v. s. et v. v. c. sine fr.)

59. H. A т теNUATA (R. Brown l. c. p. 183 et 384), ramulis pubescentibus, folijs subgláuiois glabris ébivato- vel spathulato-oblongis cuneało-attenuatis extra medium inciso- vol spinulose-dentatis vel passim integerrimis pinnatifidisve obsolete venosis impunctatis lævibus, fasciculis axillaribus stubsessilibus glabris, stigmate nterminali depresso-conico.5 In terra Leeuwin (R. Br.), colonià Swan River (Drumm. coll. 1; n. 615! Preiss, n. 590!). - Meisn. in pl. Preiss. 1, p. 563 *. Frutex 1-2-piedalis. Folia $1-1 \frac{4}{2}$ poll. longa, prope apicem rotundatum vel subtruncatum acutumve semper mucrọnatum 3-8 lin. Jäta, dentibus utrinque 2-4, sinubus rotundatis. Ttholucrum cum pedicellis floribusque gläbrum. (v. s. sine fr.)

6̈. H, I I I GIF o L IA (R. Brown 1. c. p. 184 et 384 ), ramis tomentosis demum glabratis, foliis ovalibus subpetiolatis sinuato-dentatis spinulosis eveniis lævibus Glăbris, capsulẩ ventricoso-ovatâ lævi apice compressâ, calçaribus patentibus longitusculis. $亏$ In terrâ Leeuwin (R. Br.), circa Cape Riche, prope sinum Regis Georgii (Preiss! Drumm.!). - Meisı. in pl. Preiss. 1, p. 563. Conchium mucronatum Cels, fide Spreng. syst. 1, p. 480. Fratex 5-pedalis. Folid rigidissima, crassa, opaca vel subnityda, infra medium integerrima attenuàto-petiolata supra utrinque 8-5-dentata, dentibùs mucrone in var. $\alpha 1-1 \frac{1}{2}$ lin., in $\beta 1 \frac{1}{2}-2 \frac{1}{2}$ lín. longo spinessèèntibus. Involucra tomentosa. Flores ignoti. Capsula cum peduneulo 2-3 lin. longo crassiusculo circ. pollicaris, subgloboso-ovata, apice breviter attenuato acutiuscula, calcaribus $1 \frac{1}{2}$ lin. longis subincurvis acutìs. Semina nigra, nucleo-cuneato-

- ob́ovato leviter ruguloso hinc anguste alato, alâ termináli ovato-oblongà acutâ nucleo súbdimidio longiore. Foliis valde accedit ad $\mathrm{H}$. tuberculatam, sed omnia ovalia et capsula diversa.

a. minor, foliis pollicaribus, capsulâ intus scrobiculatâ (Preiss, 11. 564!.Drummg. coll. $\dot{4}$, n. 299 l quæ inter $\alpha$ et $\beta$ ambigua). Folia 3-5 lin. lata, evenia. (v. s.)

$\beta$. major, foliis sesquipollicaribus, capsulâ intus lævi. - H. intermetia Hook. ic. t. 445. Folia 6-7 lin. lata, subvenosa (Drumm.).

61. H. cRIst a t a (R. Brown suppl. p. 28), glabrā, foljis digitalibus obovatis spinosodentatis immerse venosis basi attenuatis ramulisque glaberrimis glaucis, stigmate terminali depresso convexiusculo, capsulâ ovatâ crassâ apicè compressầ secus minaỉginem inferiorem utrinque cristâ longitưdinali dentatâ in calçària excurrente auctâ. J In coloniâ Swan Rivèr (Fraser), ad jugum Darling's Range (Drumm. coll. 1, n. 614 I Preiss, n. 546!). - Hook. ic. t. 443, Meisn. in pl. Preiss. 1, p. 564 *' Frutex 6-8-pedalis, ramis virgatis apice pruinosis. Folia 2-3 poll. longa, 1-2 poll. latta, rigida, apice rotundata, rarius breviter attenuata. Racemi axillares folio multo breviores, subsessiles, 6-8 lin. longi, rhachi pubescente, involucro pedicellis floribusque glabris. Stigma parvum, fere discoideum, subumbonatum. Capsula $1 \frac{1}{2}$ poll. longa, subrugosa, margine superiore basin versus tumido-incrassato, Seminis ala oblonga obtusa nucleo hine convexo læviusculo utrinque inæquáliter alato lóngior. (v. s. et v. c.)'

62. H. A U R I C U L A T A (Meisn. in Hook. Journ, 1855, p. 116), ramulis puberulis, foliis rigidissimis glaucis glabris extra medium cuneato-obovatis subtruncatis spinoso5-7-dentatis lobatisve immerse penniveniis infra attenuatis linearibus 1-nerviis integerrimis basi auriculato-dilatatis spinuloso-serratis, fasciculis áxiliatribus sessilibús paucifloris, calyce tomentello, stigmate terminali rotundo con véx’e, capsulá ovatà echinato-verrúcosà $\mathrm{J}$ In N.-Holl. occid. interiore, circa Dundagaran (Drumm. coll. 6 , n. 197!' Hook. Journ. 1853, p. 179). Rami virgati, stricti, ramulis conferte foliosis minute puberulis apice súbangulatis. Folia sessilia, patulá, $1 \frac{1}{2} 2 \frac{1}{2}$ poll. Ionga, apice 9-12 liń. medio 1-2 lin., basi 4-6 lin. lata, auriculis semiovatis 5-6 lin. longis, apicis dentibus lohisve 1-5 lin. longis, 1-3 lin. látis triangularibus recti-lineis mücrone $\frac{3}{3}$ lin. loñgo tecto pungentibus, dente terminali plerumque proxi-

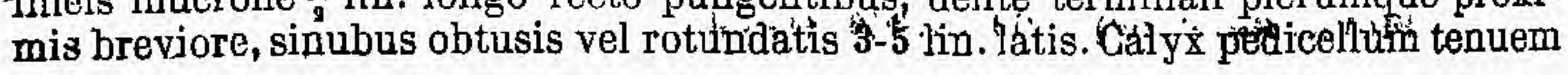


æquans, vix 2 lin. longus, rufo-tomentellus, incurvus. Capsula (fide cl. Kippist in litt.) breviter stipitata, sub apice calcarata, tuberculis cylindricis dense tecta, cinerea, intus lævis; seminis alâ nucleum subrequante. Snecies foliis H. attenuatain inter et glabellam medium tenens, ab utràyue tamen bene distincta. (v. s. sine fr. in herb. Shuttl.)

\section{b. Capsula ecalcarata.}

63. H. GLABELla (R. Brown suppl. p. 28), glaberrima, foliis cordato-amplexicaulibus cuneato-obovatis oblongisve dentatis vel passim integerrimis immerse subyenosis, stylo calycem superante, stigmate terminali obliquo depresso-conico, capsulâ ellipticâ compresșầ obtusầ rugulosâ sparse echinulato-verruculosâ. $\bar{J}$ In Aưstraliả merid,-occidentali. - Meísn. in pl. Preiss. 1, p. 564*. Frutex 2-8-pedalís, squarrosus. Folia conferta, patentia, rigida; viridia vel juniora, saltem glauca, 1-3 poll. longa, prope apicem 9-14 lin. lata ibique triangularia vel subtriloba 3-cuspidata' vel rarius subattenuata vel subtruncata et spinuloso-pluridentata; baseos auriculis rotundatis haud dilatatis sæpius inucronulis pluribus inargine armatis. Inflorescentia H. cristatæ. Calyx H. floridæe, sed fere triplo major, purpureús, fragrans. Stylus demum exsertus, 5-6 lin. longus, stigmate suhcapitato. Capsula pollicaris, 5 lin. lata, fere recta, tubereulis paucis brevissimis vel filiformibus rigidís sparse consitar Seminis nucleu's niger, obovatus, tubereulato-rugosus, hine alatus guam ala terminalis oljlonga obtusa cinerascens brevior.

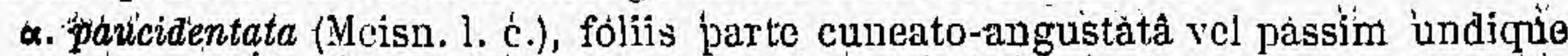
integerrimis vel subintegerrimis. - In coloniâ Swan River (Fraser, Drumin. coll. 1! Preiss, n. 541, 544, 545!). H. glabella R. Brown l. c. (v. s.)

B. denticulata (Meisn. 1. c.), Poliis ad basin usque plus minus spinuloso-denticulatis. Círea sinum Regis Georgii (Baxter), ín jugo Darling's Range, colonia Swan River (Drumm. coll. 1, n. 612! Preiss, n. 538, 542!). It denticulata R. Brown suppl. p. 28. Capsula nondum observata. (v. s.)

64. H. PRostrata (R. Brown in, Linn. Trans. 10 , p. 184 , prodr. p. 384), caule prostrato, ramulis' hispidulis, foliís obovatis oblongisve cuneatis vel subpanduræformibus basi cordatâ subdilatatâ amplexicaulibus apjice angủlato-dentalis vẻ tọto margine remóte spinulosis immerse subvenosis glabris, corymbis axillaribus súbsessilibus folio trevioribus rhachi brevissimẩ pubescente, pedicellị floribusque glaberrimis, stylo exserto, stigmate obliquo sullaterali ovali convexo, capsulâ ellipticâ verruculosâ. J In terrâ Leeuwin (R. Br.), circa sinum Regiṣ Georgị (Preișs, n. $540,543,549,564$ !), in coloniâ Swall Ríver (Drumm. cọll. 3, n. 278!). - Meisn. in $\mathrm{pl}$. Preiss. 1 , p. $565^{\circ}, 2$, j. 260 . Frutex prostratus, foliis novellis pubescentibus; præcedenti similis et capsula omnitio conveniens, foliis magnitudine et formà variabilibus, sed stigmate majorc fere latterali, etc., bene distinctus. (v. s.)

65. H. AMPLEXICAULIS (R. Brown 1. c.. p. 184 et 384 ), glabra, foliis ovali- rel lán' ceolato-oblongis sinualo-deutatis undulatis basi latà cordatâ amplexicaulibus subvenósîs, dentîbus spinosis, corymbís axillaribus brevissińíis, stylo exsérto, stig. mate súblateráli rotundo athtice conico-convexo, cajsulầ ovato-oblongà äcutà

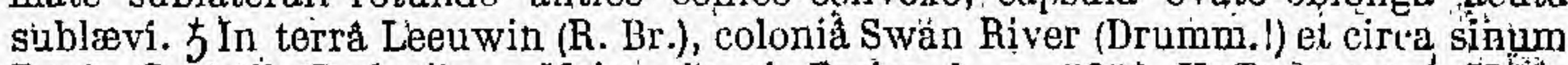
Regis Georgii (Preiss!). - Meisi, in pl. Preiss, 1, n, 585*, Hoffmànnsegg Verzz. Nachtr. 2, jj. 37, Roem. et Scluult. syst. 3, mant. p. 378. Frutex prostratus (R. Br.),

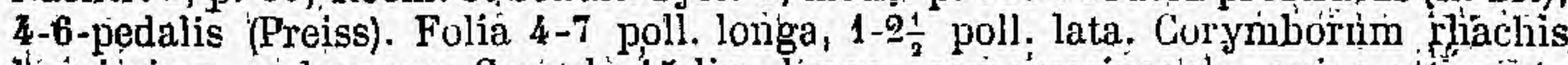
brévissima, pubescens. Capsulà 15 lin. longa, compressiuscula, apice attenüato ádscendente acuta, prope basin sparse verrucnlosa, cæelerum lævis. Seitinis nucleus hínc rugosus, margine apterus, quäm ala terminalis multo brevior. Cät. H. glabellæ:

๙. latifolia (Meisn. 1. c. p. 566), foliis ovali-ollongis basi haud dilatatis (Drumm.I). H. triformis Lindl.! Swan hiv. p. 36, n. 175. ( $\mathrm{x}$. s. in herb. Lindl. et DC. . :

B. angustîfolia (Meisn. 1. e.), Ioliis lanceolatö-oblongis basi rotunidato-dilalatis (Drumm. cotl. 1 , h. 610 ! Preíss, $n$. 548! et ex parte 549!). Folia bâsí 2 líi. lata, deinde ad apicem usque $1 \frac{1}{2}-1$ boll. lata. (v.s.)

66. H. UNDULATA (R. Brown l. c. p. 185 et 384 ), foliis obovatis attenuato-subpetiolatis undulatis spinuloso-dentatis triplinerviis venoso-reticulatis glabris novellis - ramulisque apice sericeo-pubarulis, corymbis axillaribus, rhachi brevissimâ squamisque involucri apice puberulis, calyce jẹedicellisque glabris, stigmate termisali 
cylindrico-conico basi dilatato, capsulà ovatà ventricosâ laxeviusculà. 5 In terrà Leeuwin (R. Br.), coloniâ Swan River (Drumm. coll. 1, n. 613! Preiss, n. 560l). $\rightarrow$ Hook. ic. t, 447, Meisn. in pl. Preiss. 1, p. 566. Anadenia hakeoides Lindl.! Swan Riv. p. 30, n. 146. Frutex 2-4-pedalis. Folia 2-3 poll. longa, 12-15 lin. lata. Calyx albus, $1 \frac{1}{2}$ lin. longus, stylum equans. Capsulse solitarixe, breve crasseque pedunculatæ, pollicares, crassie, apice compresso breviler attenuatæ. Semina nigra nucleo alam acutam subrequante. (v. s. in herb. Lindl., etc.)

B. subintegervima (Meisn. l. c.), foliis oblongo-lanceolatis acutis margine plano vel vix undulato parce minuteque denticulatis integerrimisque (Preiss, n. 569!). Folia 5-6 lin. lata. Admodum accedit ad laurinam et repandam, et cum iis forsan unius speciei varietas, a posterioribus tamen recedens foliis mucronato-acutis, nervatione et capsulà, a priore capsulâ rostratâ, minus ventricosà. (v.s.)

67. H. HEPANDA (R. Brown suppl. p. 30), ramulis pubescentibus, folits sessilibus planis ovato-oblongis obtusiuscule mucronulatis basi obtusissimis subcordatisve trinerviis grosse reticulato-venosis glabris, margine scabriusculo vel lævi remote repando vel integerrimo, ralycibus dense fasciculatis pedicello longioribus glabris stylo dimidio snperatị, stigmate terminali conico, capsulâ late ovatâ acuminatâ.

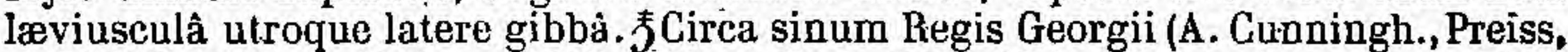
n. 547! Drumm. coll. 3, n. 279!).-Bot. cab. t. 1750, Meisu. in pl. Preiss. 1, p. 568", 2, p. 261. H. ferruginea Sweet! fl. Austr.t. 46, Bot. mag. t. 3424. Frutex 5-pedalis, ramis gracilibus, novellis cum foliis fusco-seficeis. Folia patentia, $1 \frac{1}{1}-2 \frac{4}{2}$ poll. longa, 7-14 lin. lata, margine interdum minute denticulato-scabra. Fasciculi axillares subsessiles multiflori cum involucro glaberrimi. Calyx circ. 3 lin. longus, pallide sulphureus. Capsula 7-14 lin. longa, basi 6-7 lin. lata, supra depressa, sulbtus ventricosa, obsolete verruculosa. Seminis nigri nucleus obovatus, hinc convexus subverrucosus, hinc anguste alatus, inde basique apterus, quam ala terminalis angustata acuta sublongior. (v.s.)

68. H. SMILACIFor IA (Meisn. in pl. Preiss. 1, p. 567\%), foliis subsessilibus ovatis acuminatis subcucullatis spinescenti-mucronatis multinerviis venoso-reticulatis margine nerviformi subrepando lsevibus utrinque ramulisque pubescentibus, floribus axillaribus aggregatis subsessilibus glabris stylo parum superatis, stigmate terminali conico, capsulà parvâ ovato-oblongâ acutầ læviusculâ nitidà. niả Swan River (Preiss, n. 535, 536!). Frutex $1 \frac{4}{3}$ pedalis, pauciramosus. Folia patentia, subglauca, 1-2 poll. longa, 8-14 lin. lata, molliter puberula, nervatione H. cucullatæ. Flores 3-4 lin. longi. Capsula 4-6 lín. longa, inferne turgidula, sparse verruculosa, supra medium subcompressa. Semen nigrum, nucleo obovato hinc valde convexo dense ruguloso utrinque basique anguste alato, quam ala terminalis acuta subbrevior. Species inter $\mathrm{H}$. repandam, cucullatam el conchifoliam medium tenens, sed notis indicatis bepe distincta. ( $v$. s.)

69. H. с ONCHIFOLIA (Hook. ic. t. 432), ramis villosis laxiuscule foliosis, foliis sessilibus deflexis cucullatis reniformi-cordatis acutis multinerviis grosse reticulatis impresso-puncticulatis glabris margine plano repando spinuloso-dentatis, floribus axillaribus fasciculatis pedicellisque glabris, stigmate terminali e basi incrassatâ conico-subulato, capsulầ ovato-oblongâ attenuato-acutà løoviusculà, valvis parự crassis, seminis nucleo obovato ruguloso hinc anguste alato, alâ terminali ipso subbreviore ovato-triangilari obtusiusculâ valvè lalitudinem aquante. $\supset$ In colonia Swan Hiver (Drumm. coll. 1, n. 611!).--Meisn. in pl. Preiss, 2, p. 261. H. cureullata $\beta$ conchifolia Meisn. ibid. 1, p. 567. Sequenti valde quidem similis, at bene distincta capsulả plus duplo angustiore, fere dimidio breviore, vix semipollicari, semiovatà, semine, etc. (v. s. in herb. Shuttl.)

70. H. cuc ul a t A (R. Brown suppl. p. 30), ramis villosis dense foliosis, foliis sessilibus patulis cucullatis reniformi-cordatis breve acuminatis multinerviis grosse reticulatis elevato-puneticulatis glabris margine undulato-denticulatis, floribus axillaribus fasciculatis pedicellisque glabris, stigmate terminali cylindraceo-conico basi vix incrassato, capsulâ ovatà ventricosâ acutiusculâ leviter rugosả verruculosâ, valvis crasse lignosis, seminis nucleo rugoso hine anguste alato alam termi-: nalem attenuato-acutiusculam valvâ angustiorem aquante. $\bar{\zeta}$ Cirea sinum Regis Georgii (Baxter, Preiss, n. 537!). - Hook. ic. t. 441, Meisn. in pl. Preiss. 1, p. 566*. (ezcl. $\beta$ ), 2, p. 260 , Bot. mag. t. 4528. Frutex 8-10-pedalis, strictus, pauciramosus. 
Folia minus glauca, 3 poll. lata, juniora pubescentia, infima plantæ juvenilis ovata fere plana. Fasciculi axillares, sessiles, dense multiflori, folio multo breviores. Involucrum cum calyce 3-4 lin. longo pedicellum æequante violacenm (Preiss) vel roseum (Bot. mag.). Capsula circ. pollicaris, valvis valde convexis apice margineque compressis. (v. s.)

71. H. V IC T ORIAE (Drumm. in Bot. mag. 1848, compan. p. 2*), ramis strictis villosis, foliis sessilibus spinoso-dentatis reticulatis levibus glabris, inferioribus sparsis. planis elongato-oblongis 3 -nerviis basi attenuatis sinuato-dentetis passim subintegris, superioribus dense imbricatis cucullatis' erecto-patulis cordato-orbicularibus penninerviis, floribus fasciculatis breve pedicellatis glabris, stigmate terminali e basi incrassatả conico-subulato, capsulâ subsessili ovatâ ventricosâ lævi supra gibbosâ, seminis nucleo itrinque ad basin usque alato quam ala terminalis ovata dimidio breviore. ${ }^{\prime}$ Circa West Molint Barren, prope sinum Regis Georgii (Drumm. coll. 4, p. 3001). Frutex 12-14-pedalis, caule ramisve? virgatis longis simplicibus. Folia inferiora plantæque juvenilis plana, 8-12 poll. Ionga, $1 \frac{1}{2}-2 \frac{1}{2}$ poll. lata, margine nerviformi ad basin usque dense vel remote spinoso-dentata vel infra medium integerrima, sinubus rotundatis, venis paucis laxe anastomosantibus ; floralia approximato:subverticillata, latiora quam longa, 3-5 poll. lata, densius pennivenia et reticulata, sæpius emarginata, margine undulata et undique crebre dentata, dentibus pungentibus 1-2 lin. longis, recentia medio albido-lutea, sequentibus annis aurantia, demum sanguinea. Involucra axillaria, sessilia, ovata, obtusissima, cerasi minoris mole, squanis imbricatis rotundatis lanato-tomentosis albidis, receptaculo hemisphærico villoso, fasciculis folio absconditis. Calyx 7-9 lin. longus, anguste tubulosus, hine fissus. Pistillum subpollicare, breviter stipitatum. Capsulæ subsolitariæ, pollicares, 9 lin. latæ, obliquæ, acutiusculæ, ecalcaratæ, cinereæ, fissuratæ, crasse lignosæ. Semen fere semiovatum, nucleo elliptico vel obovato hinc valde convexo, leviter tuberculato, basi aptero, hinc anguste inde late alato, alâ terminali acutiusculà. $-\mathrm{H}$. Drummondii G. Don in Loudon encycl. suppl. ined. videtur hujus var. aut planta juvenilis, fide cl. Kippist in litt. (v. s. in herb. Shuttl.)

72. H. BAXTERI (R. Brown suppl. p. 28), foliis petiolatis planis flabellato-cuneatis margine superiore rotundato spinuloso-multidentatis cæterum integerrimis immerse multinerviis lævissimis glabris novellis cum floribus ramulisque ferrugineotomentosis, cajsulâ ovato-oblongà subgibbo-ventricosâ rugosâ, acumine brevi compresso obtusiusculo, seminis nucleo hine anguste alato inde basique aptero quam ala terminalis attenuato-acuta breviore. FCirca sinum Regis Georgii (Baxter) et Cape Riche (Preiss, n. 553! Drumm. Goll. 4, n. 295!). - Hook. ic. t. 439-440, Meisn in. pl. Preiss. 1, p. 569. Frutex 5-8-pedalis. Fulia crassa usque ad 3 poll. lata et plerumque panlo breviora quam lata. Fasciculi axillares pauciflori. Calyx pedicello longior, 3-4 lin. longus, încurvis, dense rufo-tomentosus, subsericeus. Capsula incluso pedicello brevi crasso subpollicaris, vix 1 poll. lata. Seminis nucleus obovato-oblongus, tuberculato-rugosus, niger, alå cinerascente.-H. salisburyoides hort., cujus fructus adhuc iguotus, aut huc aut ad sequentem spectat. (v. s. et v. c.)

73. H. B Rownry (Meisn. in pl. Preiss. 1, p. 569 ", et 2, p. 261), foliis petiolatis planis cuneato-flabulliformibus margine superiore rotundato spinuloso-multidentatis cæterum integerrimis subenerviis lævissimis glabris novellis cum ramulis floribusque ferrugineo-tomentosis, capsulâ crassissimâ gibbosọ-subglobosâ demum reticulato-fissuratà, acumine brevissimo adscendente compresso, seminis nucleo utrinque basique anguste alato quam ala late terminalis acuta longiere. $\bar{\zeta}$ Prope flum. Gordon, distr. Hay (Preiss, n. 552! Drumm. coll. 4, n. 296! Gilbert, n. 118? steril., valde ad sequentem accedens). Capsula bipollicaris, 1\% poll. crassa, apicem versus gibba. Ciet. fere omnia H. Baxterí. (v. s.)

74. H. FLABELIF OLIA (Meisn. in Hook. Journ. 1855, p. 116), ramulis apice parce puberulis, foliis planis obverse triangularibus rectilineo-cuneatis longioribus quam latis apice truncato serratis cæterum integerrimis venis immersis dense flabellatolineatis demum eveniis, dentibus muticis, sinubus semilunaribus, fascioulis axillaribus subsessilibus multifloris, calyce tenui rufo-sericeo pistillum glabrım subæquante, stigmate terminali brevi conico, capsulà..... ₹ Prope Hill River, N.-Holl. austro-oceid. interioris (Drumm. coll. 6, n. 1961 l Elook. Journ. 1853, p. 179). Ramuli 
graeiles, excepto apice glabri. Folia 1 1 -2 poll. Iónga, apice circa 1 pólt latá, deritibús $\frac{1}{1}-1$ lin. longis latisque. Pedicelli abbido-sericei, tenues, calyce fore 3 lín. long incurvo breviores. Frutex mul to minor juap̧ $\mathrm{H}$. Brownil cajsulaque minore diver-

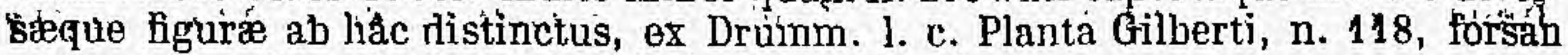
potius huc referenda. (v. s. sine fr. in horh. Shuttl.)

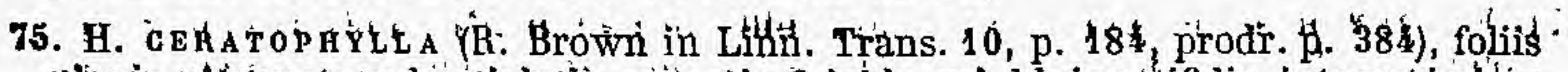
planis attenuato-subpetiolatis cuneatis 3 -lobis vel bipinnatifidis integerimisivo lineari-lánceolatis subeveníis adultis glabris, fasciculis axillaribus sessilibús, caly cibus pedicello longioribius sericeis pistillo glabro parum superatis, śtigmate termínali subobliquo diepresśn conico-umbonàto, capsulá oblongâ levi utrinquée atte-

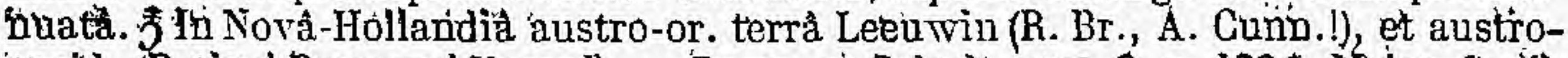
occíd. (Preiss! Drumm:! Vasse !). - Roem. et Schult. syst. 3, p. $422^{*}$, Meisn. in pi. Preiss. 1, p. $569^{\star}, 2$, p. 261 . Conchium ceratophyllum Smith in Linn. Trans. 9, p. 124. Frutex 2-5-pedalis, strictús, foliis valde et quidem scpe in eoulem specimine diversiformibus 1-6 poll. longis, 1- 6 kin. Jatis mucronulatis, junioribus ramulisque apice sericeo-tomentosis. Calyx H. flabellifolia. Pistillúm 4-5 lint. longum; subsessile. Capsulæe aggregata, pollicares, subteretes, ferc rectie, minute rugulosæe. Semintus ala oblonga, obtusa, nucleo obovato rugoso utrinque basique aptero fere bínílitio Iontigior.

a. laciniata (Meisn. 1. c. p. $\mathbf{5 6 9}$ ), foliis cuneatis 3-lobis vel bipinnatifidis, lobis 2-3-ficlis pinnatifidisve rarius indivisis oblongis laneeolatis linearibusve divarícatis (Preiss, n. 580! 581! Drumm. coll. 2, n. 334!). H. acanthophylla hort. angl. Link enum. alt. p. 118, Roem. et Schult. syst. mant. 3, p. 283 . Folia

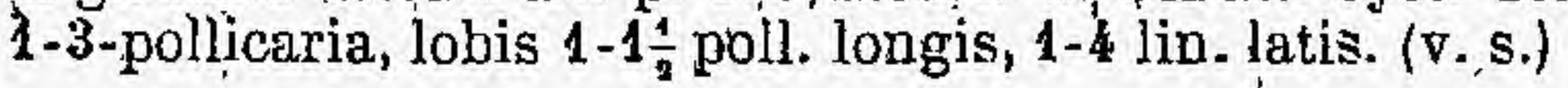

ß. subintegrifolia (Meisn. l. c. p. 570), foliis omnibus lineari-lanceolátis attenuatoacutis integerrimis vel passim apice 5-3-dentatis 2-3-fidisve (Preiss 1 n. 5 79 Molloy !). A. myricæfolia Ait.? A. Cunningh.! riss. in herb. Folia 2-6-pollicarfa, 2-6 lin. lata. (v. s.)

$\boldsymbol{\gamma}$. tricuspis (Meisn. 1. c.). foliis omnibus lanceolatis deorsum longe attenuátis apice rotundato exciso vel subtruncato breviter 2-3-dentatis vel 2-3-muerouatis creterum integerrimis (Preiss, il. 588!). Folia 2-5 poll. longa; 3-7 lín. lata. (v. s.)

\section{\$4. Folia plana integerrima plurinerivia vel venoso-strïalá, ránius triplinervia vet pennivenia venis apicem petentibus (cfr. H. macio- carpa, crassinervia, lasiantha, mimosoides, floruterita). Capsila ecalcóráta, rárissime sub́calcaratá (cfr. H. cýclocaría).}

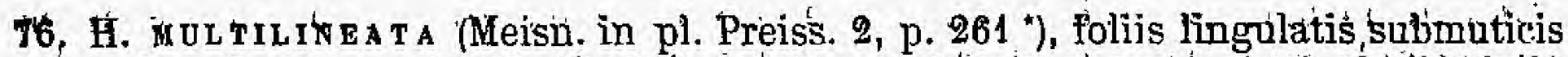

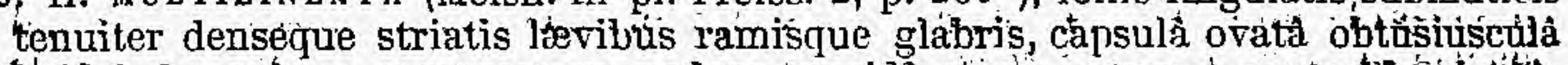
lovi infra apicem compressum nodoso-turgidẩ secús suturam acute bichárinátá, seminis nucleo læeviusculo hinc anguste alato quam ala terminalis ovatá obtása sublongiore. J In colonià Swan River (Drumm_coll. 3, n. 275!, coll. 5, suppl.n. 48. Rami virgati, gemmis axillaribus ovatis glabris. Folia viridia, rigida, erecta, 3-7 poll. longa, 5-8 lin. lata, basin versus longe attenuata, apice rotundato sphacelato mucronulo obsoleto caduco munita, utrinque nervis 14-20 tenuibus immersis requalibus parallele lineata. Corymbi axillanes subsessiles, 4-5 lin. Jongi. Fuores ignoti. Capsulæe in jedunculo brevi crasse subfasciculatæ, 9-10 jin. longæ, crasse dignosa. (v. s. in herb. Shuttl, et Lemann.)

77. H. ARBORESCENS: (R. Brown ! in Linn. Trans. 10, p. 187, prodr. p. 386), ramthis tomentellis, foliis lanceolato-linearibus sphacelato-acutis longe attenuato-subjetiolatis immerse pluxinerviis olosolete striatis glabris, fasciculis axillaribus breye pedunculatis nudis, calyce parvulo subsessili pedunculoque communi subsericeotomentosis, capsulâ ecalcaratà..... 5 Circa sinum Carpentaria (R. Brown !) et Cánbridge Gulf (A. Cunningh.!). Ramuli laxe foliosi, graciles, teretes. Folia $\mathbf{3}-\mathbf{5}$ poll. longa, $\mathbf{3}$ lin. lata, nervis 3-5 tenuibus levissime prominulis subparallele striata, houd rigida, glauca? mucrone innocuo nigro. Pedunculus $2-3$ lin. Calyx vix 9 lin. jongus $x_{2}$ ufo-gericous. Sequenti proxime affinis, teste $A$. Cunn. in herb. (v. S, sine ir. in herb. DC., Cunn.) 
78.? H. A croc ARPA (Gnnningh. mss.), foliis linearibus elongatis obsolete nervôsis sericeis; floribus racemosis, involucro nullo? capsula elliptica acutâ ecalcaratâ intus lavi. 5 In sinu Cygnet Bay oræ septent.-occidentalis (Cunningham). R. Brown suppl. p. 30. Affínitate propius accedit $H$. lorea et Cunifinghamii quam stenophyllæe et arborescenti, 'ex R. Br. 1. c. An folia plurinervia?

79. H. LEUCADEN BR ON (Meisn. in pl. Preiss. 1, p, 572 \%), ramulis apice puberulis, foliis sessilibus lanceolatis subimmerse plurinervins glabris breve sphacelato-aplculatis, fasciculis axillaribus multifloris, pedicellis calyce parvulo tomentoso pistillum aquante longioribús, stígmaté oblíquo ovali umbonato, càpsula ventricoso-globosat apiculata láevius'culà, seminis orbicularis nulıcleo obovato hinc subconvexo rugoso undique alato. ' 5 In coloniâ Swan River (Drumm. coll. $1, n .6031$ Preíss, in. 508, 572, '578!): Frutex 1-3-pedalis. Folia 1-3 poll. longa, 2-5 lín. lata, vîridia vel subglauca, utrinque attenuata, nervis 3-5 immersis interdum obsoletis. Involuerum glałrum. Pedicelli $1 \frac{1}{2}-5$ lin. longi, cum calyce 1 lin. lontigo dense albidopluberuli. Pistillum sessile glabrum. Capsula vix pollicaris, ćrassà, ecalcarata, apiculo brevi actscendente. Seminis nncleus niger, olbotatus, hinc grosse rugosus

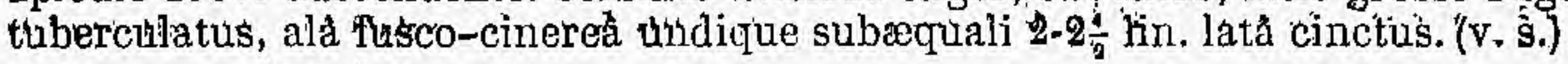

80. H. INCRASSATA (R. Brotvn p. 29), foliis lineari-lanceolatis sphacelato-acutis utrinque attenuatis obsolete $3-5$-nerviis eveniis ramulisque glabris, capsula refractâ sulsgloboso-ovata gibbosâ lievi apjiculo adscendente, pedunculó brevi crasso. J In coloniâ Swan River (Fraser fr., Drumm.? flor.). - Hook. ic. t. 442. Ramuli teretes, stricti. Folia (ex ic.) 2-4 poll. longa, 3-5 lin. lata. Capsula nutans, 14 lín. lớgá, suturá tepressâ valleculam formante. Sínililimà videtur H. Leucadendro, yd quam forsan specimina Drummondiana florifera referenda, sed differt capsulẩ $\frac{1}{s}$ majore et pédunculo incrassato.

81. H. Lasia Th A (R. Brown suppl. p. 29), ramulis tomentoso-lanatis, follirs subsessilibus torsione verticalibus ovalibus lanceolatisque sphacelato-mucronulatis immerse triplinerviis submarginatis junioribus adpresse puberulis, fascienlis axillaribus subsessilibus, pedicellis calyce villoso pistillum glalorum wquante brevioribus pubescentibus, stigmate tateráli ovali plano umbonato, capsulâ lanceolatâ subcomjuressá lavi. J Circa sinum Regis Georgii (Baxter! Preiss, n. 570, 573!) et Swan River (Eraser, fide A. Cunn.! in herb. DC.) - Meisn. in pl. Preiss. 1, p. 571*. Frutex 7-peda'lis, ramis gracilibus teretibus. Folia patula, viridia, 1-2 poll. longa, 3-7 lin. lata, utrinqu'e æequaliter atteriuata, lanceolata acuta passimque ovalia vel obovata obtusa, nervis penitus immersis tenuibus ante apicem evanescontibus, margine obsolete nerviformi vel simplici. Fasciculi 3-6-flori, involucro glabro, squamis ciliatis, pedicellis 2 lin. longis ferrugitieis. Calyx 4 lin. Yongus, dense flavido-hirsutus, gracilis. Capsula subpollicaris, utrinque attemuata, obtúsa. Semina non vidimus. Proxime affinis videtur H. laurince, quæe capsulà gibbosâ diffeŕt. (v. s. in herb. Cunn., etc.)

82. H. L AU RIN A (R. Brown suppl. p. 29), folis potiolatis elliptico-lanceolatis muticis neryosis marginatis, capsulá gibbà lævi. $亏$ In orá australi inter Cạe Arid et Lucky Bay (Baxter).

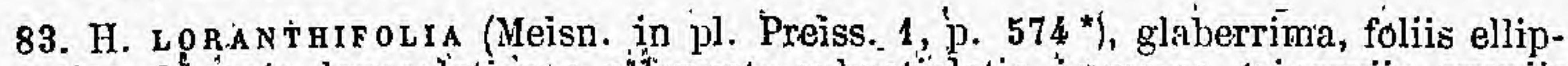
tico-oblongis lanceolatisque altenuato-subpetiolatis immerse trinerviis eveniis margine scabriusculis acumine brevi sphacelato subpungente, fasciculis axillaribus subsessilibus dense multifloris, pedicellis calycem parvum stylo vix superatum subæquantibus, stigmate terminali cońlico, capsulâ subsessili ventricoso-ovatâ acutâ nitidâ beviusculâ, seminis nueleo verruculoso hinc alato alam terminalem obtusiusculam subrequante. 5 In colonia Swan River (Drumm. coll. 1, n. 606! Preiss, n, 567!). Frutex 6-pedalis. Folia-rigida, viridia vel glauca, $1 \frac{1}{2}-2 \frac{1}{2}$ poll. longa, 5-10 lin. lata, acumine vel muorone 1-2 tin. longo. Cailyx 1 lin. longus, albus. Pistillum sessile glabrum, stigmate parvulo. Cajsula 8 lin. lon'ga, basi rotundata, nbsolete rugosa parceque rerrucosa. Semen nigrum, alá marginali lineam latâ, altero margine basique aptero. (v. s.)

84. H. on TuSA (Mcisn. in Hoolk. Journ. 1852, p. 209), ramulis sericeo-tomentellis, folits sesŝilibus oblongo-lanceolatis utrinque attenuatis obtusis semịmmerso 3-nerviis éveniís levibus glabriš, capsulâa subsessili yentricoso-ovatẩ breve acumi-

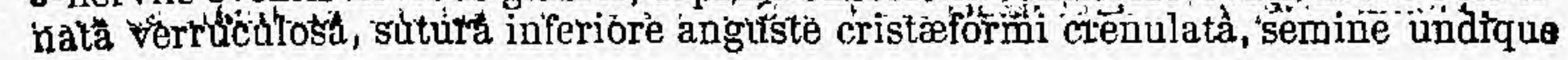




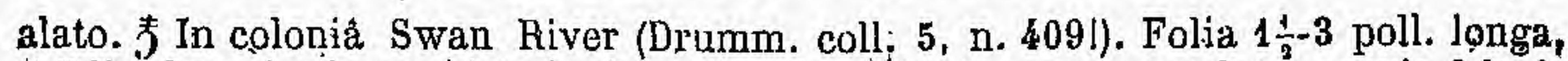
5-7 lin. lata, juniora sericea, apice sphacelato obsolete mucronulato, nervis 3 leviter prominulis tenuibus parallelis ante apicem evanescentibus, margine simplici vel obsolete nerviformi levi. Flores ignoti. Capsula vix gibba. Semen nigrum, nucleo alà terminali oblongà dimidio breviore. Præcedenti proxima, sed, capsulầ et semine essentialiter distincta. (v.'s. in herb. Shutul, et Lemann.).

85. H. CRASSIFolía (Meisn. in pl. Preiss. 1, p. $57.0 \%$ ), foliis aversis breve petiolatis crassis ovalibus oblongisque inæquilateris sphacelato-mueronulatis immerse plurinerviis novellis ramulisque tomentosis, fasciculis axillaribus sessilibus, calyce sericeo pistillo parum superato, stigmate nutante obliquo depresso, capsulâ obovatâ compressâ breve acuminatâ tessellatâ breve crasseque pedunculatâ, semine undique alato, alâ terminali nucleo hinc dènse echinulato breviore. 5 Circa Cape Riche, prope sinum Regis Georgii (Preiss, n. 550! Drumm. coll. 4, n. 293!). Frutex 10-pedalís. Folia patula, lete viridia, subnítida, yerticalia, $1-4$ poll., longa, $6-12$ lin. lata, petiolo 1-2 lin. longo compresso, marginibus obtusis lævissimis, superiore plerumque magis arcuato, nervis 5 subparallelis immersis obsoletis. Involucrum tomentosum. Calyx 5 lin. longus, gracilis, allsus, cum pedicello parum breviore ferrugineo-subsericeus. Pistillum 7 lin. longum, subsessille, glabrum, stigmate orbiculari brevíssime umbonato. Capsula 18-20 lin. longa et vix minứs lata, areolato-fissurata, basi intruso-depressa, pedunculo 3-4 lin. longo crassuque. Semina nigra, 1 poll. longa, 7 lin. lata, alâ marginali et basali 1-2 lin. latâ. Sequenti et H. lasianthæ affinis, at bene distincta; (v. s.)

86. H. Hook ERIANA (Meisn. in Hook. Journ. 1852, p. 208), foliis sessilibus, aversis crassis spathulato-lingulatis obtusis eveniis inferne obsolete plurinerviis ramisque glabris, fascicutis axillaribus' subsessilibus sericeis, pedicellis argenteis calyce rufo dimidio brevioribus, stigmate terminali oblique truncato umbonato, capsulà magnâ ventricoso-obovatâ crassissimả grosse rugosâ dense rimoso-reticulatâ apice compresșâ secus sutüram superiorem obtuse crístatâ, seminís nucleo rugoso-echinulato margine aptero quam ala terminalis ovata subdimidio breviore. $J$ In coloniâ Swan River (Drumm. coll. 5, n. 413 !). Rami virgati, summo apice cum foliis novellis sericeo-tomentelli. Folia ereeta, 2-5 poll. longa, 5-8 lin. lata, longe quidem attenuata, sed haud vere petiolata, mucrone terminali brevi obtuso nigro deciduo

I sæpius apicem folii emarginatum relinquente. Fasciculi multiflori, pedicellis tenuibus albidis, calyce $2 \frac{i}{2}$ lin. longo rufo vel coccineo? Capsula incluso stipite 8 lin. longo erassissimo $2 \frac{1}{4}$ poll. longa, 1\% yoll. crassa, ecalcarata, irregulariter rugosa et fissuris superficialibus inæequaliter depse areolata, apiculo crásso obtuso vix 2 lin. longo recto, suturâ superiore infra medium utrinque cristâ 2 lin. altầ obtusâ comitatâ. Semen 15 lịn. longum, 6-7 liri. latum, nucleo oblique obovato, alâ acutiussulâ. H. crassifoliæ proxima, sed jam capsulạ bene distincta. (v. s. in herb. Shuttlew. et Lemann.)

87. H. PANDANICARPa (R. Brown suppl. p. 29), foliis óblongo-linearibus ex apice oltuso sphacelato-apiculatis basi attenuatis immerse plurinerviis eveniis, capsulâ magnâ subgloboso-ovatà gibbosâ tuberculis ovato-conicis undique-dense tessellatâ, seminibus ellipticis undique alatis. F In orà meridionali, inter Cape Arid et Lucky Bay (Baxter). - Hook. ic. t. 434. Species insignis, fractu ab omnibus distinctissima. Ex ic. videtur glabra. Folia aversa? sessilia, 3-5 poll. longa, 5-8 lin. lata. Flóres ignoti. Capsulæe axillares, solitariæ, crasse pedunculatæ, diametro circ. bipollicari, tuberculis e busi ovatầ rotuudatâ 3-5 lin. crassâ in acumen breve conicum oblusiusculum subangulatum contractis.

88. H, ELLIPTICA (R. Brown in Linn. Trans. p. 187; prodr. p. 386), foliis subsessilibus ovalibus oblongisve utrinque obtusis mucronulatis prominulo-multinerviis reticulatis novellis ramisque tomentoso-puberulis, fasciculis axillaribus subsessilibus dense multifloris glabris, pedicellis calyce stylo parum superato longioribus, stigmate terminali conico, capsulâ ovatâ gibboso-ventricosầ breve acuminatà læviusculâ nitidâ. . In terrầ Leeuwin (R. Br.), circa Princess Royal Harbour (Preiss, n. 558!). - Roem. et Schult. syst. 3, p. $424^{*}$, Link enum. alt. p. 118, Meisn. in pl. Preiss. 1, p. 568*. Conchium ellipticum Smith! in Linn. Trans. 9, p. 123. Frutex 8-pedalis, innovationibus ferrugineo-tomentosis. Folia patentia, $1 \frac{1}{2}-3$ poll. Ionga, 10-20 lin, lata, margine lavi integerrima vel passim obsolete subrepanda, stirpis juvenilis sæpe oblongo-lap̣ceolata acuminata, mucronulo terminali sphacelato 
obtuso sæepe deciduo, nervis primariis 5.9 subparallelis interéostalibus tenuibus. Pedicelli 4-5 lin., flores 3-4 lin. longi. Capsulie fasciculatæ, sessiles, 16 lin. longæ, crassæ, latere leviter gibbie, vix rugulosæe. Semen nigrum, nucleo tuberculato hinc latiuscule alato inde basique aptero quam ala terminalis ovata obiusa paulo breviore. Species foliis floribusque ad H. repandam, valde accedens. (v. s. in herb. Smith., etc.)

89. H. Crassinervia (Meisn, in pl. Preiss. 1, p. $578^{*}$ ), foliis ovato-orbicularibus utrinque breve acuminatis sphacelato-acutiusculis marginatis prominulo-reticulatis 1-nerviis penniveniis, junioribus ramulisque subsericeo-puberulis. 5 ln colonia Swan River (Preiss, n. 559!). Frutex 8-pedalis. Folia glaurea? subrotunda, $1 \frac{1}{2}$ poll. longa lataque, rarius late ovata $2-3 \frac{1}{2}$ poll. longa, conferte pennivenia, venis primariis apicem petentibus intra marginem arcuatim anastomosantibus, petiolo 2-4 lin. longo ad insertionem incrassato tuberculato-tridentato. Cret. ignota. Affinis sequenti, sed nervatione distincta. (v. s. sine fl. nec fr.)

90. H. petrolaris (Meisn. in pl. Preiss. 1, p. $577^{*}$ ), foliis petiolatis ellipticis acuminatis marginatis triplinerviis laxe prominulo-reticulatis junioribus ramulisque subsericeo-puberulis, fasciculis axillaribus dense multifloris, pedicellis calyce glabro stylo superato sublongioribus, stigmate terminali subcylindraceo, capsulâ oblongâ nitidâ, seminis nucleo lavi undique alato. F In coloniâ Swan River (Drumm. coll. 1, n. 607! Preiss, n. 557!). Frutex 6-pedalis, ramis laxe foliosis gracilibus. Folia glauca, incluso petiolo 4-6 lin. longo semitereti- 2-3-pollicaria, 10-14 lin. lata, utririque requaliter attenuata, apice sphacelato obtusiuscula, margine nerviformi. Involucra axillaria, brevissime pedunculata, ovata, sericea, mox glabra, magnit. cerasi minoris. Corymbus capituliformis, densissimus, rhachi brevissimâ velutinâ. Calỳx $2-3$ lin. longus, incurvus. Pístillum sessile, 5 lin, longum, glabrum, stigmate stylo parum crassiore fère 1 lin. longo. Capsula 15 lin. longa, fere recta, ecalcarata, subrugosa, apicem versus supra paulo gibba, subacuminata. Semen nigrum, nuclẹo anguste oblongo alisque marginalibus 1 lin. latis, alâ terminali acutầ ipso parum longiore. (v. s. et v. c.)

91. H. N E U R O PH Y L A (Meisn. in Hook. Journ. 1855, p. 117), glabra, foliis sessilibus rigidissimis lanceolato-- vel elliptico-oblongis acuminatis utrinque prominulo3-nerviis laxe reticulatis marginatis, pedicellis axillaribus fasciculatis pistillum glabrum subæquantibus, stigmate terminali conico, capsulâ crasse pedunculatâ deflexâ ovalâ ventricosâ breve acưminatâ verruculosâ, semine seniovato-lanceolato, nucleo ruguloso hinc aptero basi brevissime alato, alâ terminali obtusấ hinc late decurrente prope basin sinu parvo excisâ. $\bar{\zeta}$ Circa montem Lesueur, N.-Holl. occid. (Drumm. coll. 6, n. 195! Hook. Journ. 1853, p. 180). Rami virgati, ramulis apice compresso-subangnlatis. Folid patula, viridia (juniora subglauca?) $1 \frac{1}{2}-2 \frac{1}{2}$ poll. longa, 8-14 lin. lata, acumine 1-1 lin. Iongo nigra-mucronulato obtusiusculo, basi breve attenuata ad insertionem obtuse 3-dentata, dente intermedio breviter deorsum producto, 'margine nerviformi sæe obsoleto. Involucrum parvum, ovatum, glabrum, sinamis rotundatis, infimis diu persistentibus. Fasciculi axillares sessiles, pulvino parvulo ovato tomentoso fulti, pedicèlls glabris tep̣uibus. Calyx ruber (Drumm.). Pistillum sessile, 4 lin. longum. Stigma $\frac{1}{2}$ lin. longum, basi anguste marginatum. Capsulæe subsolitariæ, pedunculo vix 2 lin longo, 2-3 lin. crasso fultæ, 12-14 lị. longæ, 8 lin. latie, attenuato-acumínatæe, acutiusculæ , ecalcaratæ, cinereæ, leviter verruculosæ, sæpe irregulariter rugosæ. Semen atrum, 8-9 lin. longum, $3 \frac{1}{2}$ lin. latum, nucleo obovato ruguloso-tuberculato, alâ terminali oblongé obtusâ ipso $\frac{1}{3}$ breviore. Affinis præcedentibus et $H$. lorainthifoliæ, sed jam capsulà semineque distinctissima. (v. s. in herb. Shuttl.)

92. H. E U C A L Y P т O I D E S (Meisn. in pl. Preiss. 1, p. 573*, 2, p. 262), foliis elongatolingulatis attenuato-petiolatis prominulo-triquintuplinerviis subeveniis ramisque glabris, fasciculis axillaribus sessilibus, capsulis aggregatis hrevercrasseque pedicellatis ovatis crassis læviusculis ventre acute carinatis apice compresso obtusis, seminis nucleo lævinsculo undicrue alato. F Circa Cape Riche et sinum Regis Georgij (Preiss, n. 565! Drumm. coll. 3, n. 274! 4, n. 294 !). Frutex 10-pedalis, ramis gracilibus apice subangulatis. Folia modice coriarea, patula, 5-10 poll. longa, 5-10 lin. lata, sæpius falcatá, nervis 3 vel 5 ex ipsá basi vel paulo süpra ortís subparallelis, venis raris obsoletissimis vel nulis, margine plus minus nerviformi, insertione triangularí. Involucra sessilia, ovato-glohosa, apice sericea, mox glabra, squamis latis rotundatis ciliolatis. Flores ignoti. Capsulæ 5-7-fasciculata, 1 poll, 
longæ lateque, cinereæ, subnitidæ. Semen nigrum, nucleo obovato-oblongo parqco verruculoso quam ala terminalis attenuata obtusa paruni breviore. (v. s...et v. c. sine fl.)

23. H. Gin a R A (R. Brown in Linn. Trans. 10 , p. 186, prodr. p. 385, ramulis teretibus involucrisque tomentosis; - foliis èlongato-lancelatis sphacelato-apiculatis attenuato-subpetiolatis prominulo-3-nerviis venosis submarginatis 'soabriusculis

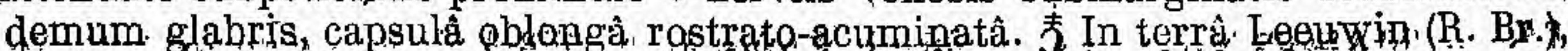
circa sinum Regis Georgii (Baxter). H. canescens hink enum. alt. p. 118, Raem. et Schult. syst. mant. 3, p. 28,4. H. tricostata Hook. ic. t. 435-436. H. serigea hort. Habitiıs H. dactylaidis. Folia 3-6 poll. longa, 4-9 lin. lata, crassiusoula, Figida, ex apice obtuso vel rotundato cum apicula $\frac{1}{3}-1$ lin. longo nigricante dempming obtuso, sub lente minute scabriuscula, cinerea, juniora sericea, margine nerviformi paulo incrassato, nervis 3 papallelis frarius passim unico) utrinque valde promialis, venis intercostalibus remotis sæpe obsoletis. Involucra axillaria, sessilia, avoidea. Flores ignoti. Capsulæ sæepius fasciculatæ, breve crasseque pedunculatá, efecta, vix pollịcares, réotæ, verruculosie, ex Br. compressæe. (v. v. c. sifné fl. ñế fr.)

94. H. PYCNQNEU A A (Meisn. in Hook. Journ. 1855, p. 117), ramis apice cano-tomentellis, foliị sessilibus rigidissimis, elongato-linearilus mucronatis glabpis hasi attenuatis ritrinque crasse trinerviis subeveniis, nervis lateralibus marginantilus, capsulis fasciculatis ovatis subyentricosis acutiusculis sublevibus, seming ohloggo, nucleo tuberculato undique alato. $亏$ In jugo montium Moresby's fangé (Drumm. cóll. 6, n. 193! Hook. Joutn. 1853, j. 179, ad calcem, ef ? p. 313). Rami virgati, graciles, teretes, sulcato-lineati. Folia 5-7 poll, longa, 2-3 lin. lata, plus minus fálcatá, acutiuscula cum mụcronulo sphaceláto, juniora pube minutisssimâ adpressâ alhido-sericeâ, nervis lateralibus sáe paulo intramarginalibus, venis interdum

nonnullís tenuioribus oostis interjectis î́sque parallelis folium pseudo-5-nervium reddentibus. Calyx ruber (Drumm.). Capsula plures in apice pedunguli axillaris 4-5 lin. Iongi crassi tomentelli approximatie singula pedicello glabru fere 3 . lin. longo crässóque fultæ, 7-8 lin. longe, 4-5 lip. latæ, ecalcaratæe, sparse verruculoso-areolatse, fulvo-cineres, nitidæ, haud gibbosæ. Semen semipollicare, nucleo obovato tuberculato alam terminalem acutam requante, alâ latéráli una pasilariqụe angustissimâ, alterâ duplo latiore nuclei latitudinem subơquante. Accedit ad sequentum el H. ulicinam, sed foliis subinermibus, hervis multo crassioribus, cepפيlâ, eto., facile dignoscenda. (v. s. in herb. Shutțl.).

95. H. F A G A T A (R. Brown suppl. p. 29), ramulis tomentellis, foliis linearibus sub*falcatis cuspidato-acuminatis 3-nerviis eveniis lavilus glabris basi atitenuatis, fasciculis axillaribus subsessilibus densifloris, pedicellis brevibus floribusque gla-

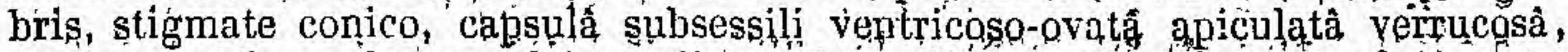
semine ovătb, nucleo ruguloso undique alato alàm terminalem acupam gequante. \% Circa sinum Regis Georgii (Baxler, Drumm. call. 2, n. 333! Gilber!!), - Meisn. in pl. Preiss. 1, p. 572, excl, var. $\beta, 2, p .262$ ). Habitus $H$. dactyloidis, at hene distincta. Folia $1 \frac{1}{3}-2$ poll. longa, $2-3$ lin. lata, nervis parállelis utrinque prominulis, margine simplici haud incrassato, apiculo 1 lin. longo aurantiaco apice nigro obtusiusculo. Pedicelli vix 1 lin longí flare parum breviores. Stigma basi márginatum. Capsula 6-8 lin. longa, subsessilis, apiculo brevi subrecto obtusiusculo. Semen nigrum, nucleso obovato valde convexo, hinc latiuscule inge basique angúsiste alato. (v.s.)

96. H. T R Iy R vis (Meisn. in Hook. Journ. 1852, p. 209), ramulis apiç tomentellis, foliis sessilibus lineari-lanceolatis utrinque attenuatis sphacelato-mucronulatis prominulo-trinerviis obsolete venosis glabris nitidis, pedieellis brevibus floribusque parviśs glapris, capsulà sessili ovata attenuato-roslratấ lexpiusculâ, seminis

- núcleo obovató sublevi hinc angustissime alato alam terminalem ablongam subáquante. F In coloniă Swan River (Drump. coll. 5 , ‥ 408!). Ramuli teretes, mox glabri. Folia 1-2 poll. longa, 3-5 lin. lata; minute crystallino-punctata tamen læyia, hervis 3 tenuibus a margine invicemque equidistantibus ùtrinque prominulis ante apicem évanescentihus, veris paucis laxe anastomosantibus sæpe oblitefatis. Involucra ąxillaria, sessilia, ovata, squamiş ovatis glabriusculís. Capșuła fere 1 poll. louga, basi 6-7 lin. crassa, ecalcarata, obsolete parceque papil lașa rostro

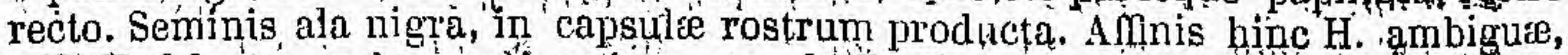
inde H. falcate, sed copsula majore, etc., factile dignosconda. (v. s, in herb. Shuttl. ét'Lemann.), 
97. H. A M BiguA Meisn. in pl. Preiss. 2, p. $260 \%$ \% ramis, villoso-tomentosis, folis sessilibus lanceolatis sphacelato-apiculatis prominulo-5-nerviis reticulatis glabris, fasciculis axiltarihús 'sesssilibus, capsulẩ breve pedunculatầ semiavațo-oblongầ attenuato-rostrata levitiscula terninglem oblongam obtusiusculam valvâ angustiorem subequante. I In coloniâ Swan River (Drumm. coll. 3, n. 2771). Folia $\frac{1}{2}-2 \frac{1}{2}$ pall. longa, 3-5 lip. lata, basi parum átténuata, juniora adpresse sericeo-pilosiuscula. Invóluor s squame agoutiusculæ, puberulæ, demum glabræ. Capsulæ sólitariæa, rostro 2 lin. longo reçto. Semnnìs ala in valvæ rostrum haud extensa, uucleo interdum $\div$ longior. Folija valde similis H. undulato $\beta$, sed capsula diversa. (v. s. sine fol. in herb. Shuttl.)

98. H. DACTYLOIDES (Cav. ic. 6 , p. 25 *, t. 535), ramulis sulcatis, fólis aversis linearibus lanceolatis oblongisve mucronatis basi attenuatis triplinerviis venasis vel subeveniís, pedicellis axillaribus dense fasciculatis pilosis calyce glabro sublongioribus, stigmate conico, capsulâ ovatâ ventricơsâ apiculatâ supra gib̆bââ, seminis nucleo lævi hìnc latiuseule alato alam terminalem ovatam acutain æquánte. 5 Circa Port-Jackson (R. Br., etc.): - R. Brown in Linn. Trans. 10, p. 186, prodr. p. 385 , Roem. at \$chult. syst. 3 , p. 424 $4^{\natural}$. Banksia oleéfolia Salish. prodr. 1, 54 , (non Qav.). Frutex elatior, ramis strictis laxiuscule foliosis. Folia erecta vel patúla, 2-4 poll. longa, 2-9 lin. łata, mucrone brevi sphacelato, venis intercostalibus femotis obliquis, insertionis cicatrice brevi triangulari vel subtridentat. Fascículia subsessiles, mulliflori, floribus parvis, cum pedicello alhidp-subsericeo $a$ lin. longis. Capsula pollicaris verruculosa vel suplevis, demum fissurata, valvis valde conyexis. Formo sequentes vix vapietales stahiles sistunţ. f. ferruginea Lodd. Bot. cab. t. 1501 (non Sweet!) inter a et $\beta$ ambigua videtur.

a. Latifolia, foliis obovata-oblongis janceolatisque apice attenuatis vel acuminatis, venis anastomosantibus.-R. Br. 1. c. (Sieber, n. 12/ Anddrson, n. 62 / Lho'tzky I vanis submulliss), Banksia dactyloides Gærtn. fr. 1, p. 221, t. 47, f. 2, Lam. ill. 5. 54, f, 3. Halkea dactyloides Cav. 1. c. H. nervosa Knight et Salisb. Prot, p. 108. Conchium dactyloides Vent. Malm. t. 110, Smith! in Linn. Trans: 9, p. 13. C. nervosum Willd. enum. 1, p. 141. (v. s. in herh. Smith., etc., ot v. c.)

$\beta$ angustifolia, foliis anguste lanceolatis linearibusque apice sensim atfenyatis, venis obsoletis. - R. Br. 1. c.- Sydney (Verreaux I).-Bot. mag. t. 3760.'Conchium nervosum Sims! in herb. Mart. (v. s.)

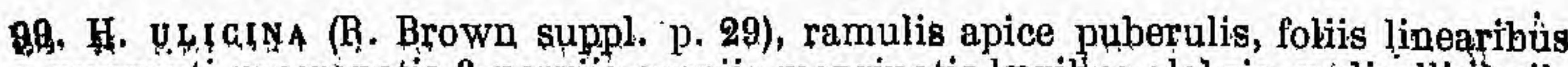
pungenti-mucronatis 3-nerviis evenis marginatis lævibus glabris, pedicellis axillarihus fissciculatis brevibus floribusque parvis glabris, stigmate terminall conico, capsulis erectis ovatis acutis, J Circa WiIson's-Promontory (Baxter), port Phillip (Latrobe!) et in N.-Holl, orient.-austr. interiore (A. Cunn.? Mitchell exped. 1835,

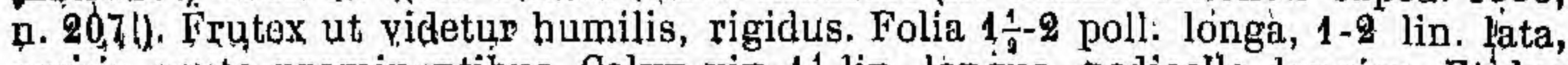
nervis acute prominentibus. Calyx vix $1 \frac{1}{2}$ lin. longus, pedicello longior. Sttylus capillaris, 2-3 lin. longus, stigmate basi incrassato. Capsula semipollicaris, ventricosa, sverpuculosa (ex Br. lavis). Semen nigrum, nucloo cristato hinc alato inde marginatô, alâ terminali ipso parum longiơre oblonga acuta. (v. s.)

ß? angustifolia, foliis elongato-linearibus, longe attenuato-acutis marginatis søpius 1-nerviis. - Circa Twofold Bay (Baxter !). H. stenophylla Baxter! mss. (nec Cunn., B. Br.). H. angustifolia hort. Angl. Folia 5-8 poll. longa, 1 lin. Tata. Eorsan species distincta. (v. s. steril. in herb. Cunn. et cult.)

$\gamma$ ? macrocarpa, capsulâ pollicari oblongo-ovatâ breve acuminatâ, seminis alâ terminali obtușâ. - In montibus Grampians Australiąa Felicis (Fend. Müllex b). famuli pice cinereo-tmentelli, mox glabrescentes. Folia patentissima, $1 \frac{1}{2}-2$ poll. longa, 2-2: lin. lata, loviter recurvo-falçata, nervoso-manginata, utrinque nervis 3 parallelis satis prominulis obtusis percursa. Gæt. ut in typo speciei. (v. s. sine flor. in herb. Sonder.)

\section{5. Folia plana integerrima 1-nervia. Capsula 2-calcarata (cfr. H. mimosoides, florulenta).}

190. H. GXGLogarpa (Lindl.!'Syan River, p. 36, n. 176), foliis oblongis vel spathulato-ohlongis attenuato-subpetiolatis obtusiusculis immerse plurinerviis ramisque glabris, fasciculis axillaribus sesşilibus multifloris, pedicellis calyci subæễ $u a-$

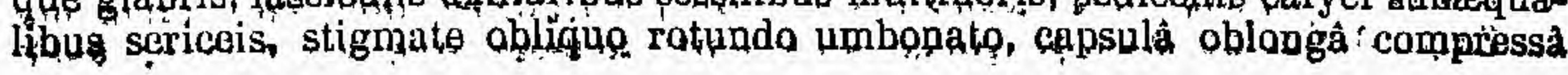


in annulum curvatâ brevissime cristato-calcaralâ, semine semilunari, nucléo obovato margine fere aptero hinc rugoso quam ala terminalis lata obtusa breviore. ђ In coloniâ. Swan River (Drumm. coll. 1, n. 609! Preiss, n. 576! Gilbeŕt).-Meisn. in pl. Preiss. 1, p. 573 $3^{\circ}$. Frutex 5 -pedalis, gracilis, ramis apice angulatis. Folia glauca, 3-7 poll. longa, 9-24 poll. lata (fide $\mathrm{cl}$. Lindl. nonnunquam lobata), nervis 3-5 immersis vel subprominulis apice evanescentibus, apice sphacelato obtusiusculo. Calyx 4-5 lin. longús, adpresse albido- vel flavido-sericeus. Pistillum sessile, 6-7 lin. longum, glabrum. Capsula bipollicaris in orbem diametr. 15-18 lin. curvata, valvis plano-compressis $8 \mathrm{lin}$. latis dense rugulosis puncticulatisqué apice hinc calcaris loco in cristam brevem latam compressam rotundatam exeuntibus. (v. s. in herb. Lindl., etc.)

101. H. M M OSO IDEs (A. Gunnnigh.! mss. in herb.), foliis oblongo-lanceolatis utrinque attenuatis apice sphacelatis immerse 1 -nerviis venosis glabris; venis apicem petentibus, floribus axillaribus aggregatis sessilibus glabris, capsulâ..... $う$ Circa Redcliff Point, prope Moreton Bay (A. Cunn.!). Species non satis nota, foliis præcedenti accedens, sed floribus glabris, etc., distincta. Folia glauca? subcoriacea, semipedalia, 14 lin. Jata, petiolo brevissimo tereti, apice sphacelato mutico, venis primariis utrinque 1-3 alternis nervo subparallelis, anastomosibus raris obsoletis. (v. s. sine fr. in herb. Cunn.)

102. H. FL O R U E T A (Meism. in Hook. Juurn. 1855, p. 116), glaberrima, foliis lanceolatis obtusis submutieis attenuato-subpeticlatis immerse triplinerviis paucivenosis, pedicellis axillaribus fasciculatis calycem subæquantibus, stigmate terminali obliquo discoideo subconvexo, capsulâ... J Circa sinum Moreton Bay (Strange!). Ramuli graciles, sulcati. Folia glauca? modice coriacea, 3-5 poll. longa, 6-12 lin. lata, recta vel subfalcata, apice sphacelata, revera pennivenia, sed venis 2 prope basin ortis plerumque magis conspicuis et ad apicem usque excurrentibus nervo subparallelis folium triplinervium simulantibus, margine obsolete nerviformi haud incrassato Corymbi axillares, subsessiles, multiflori, iuvolucro parvulo rhachique brevissime ferrugineo-puberulis, pedicellis tenuibus 3-4 lin. longis floribusque glaberrimis. Pistillum sessile, calycem demum breviter superans. Species præcedentibus 2 proxima nec non $H$. salignæ foliis accedens sed bene distincta. (v. $s$. in herb. Soc. linn. Lond.)

103. H. SALIGNA (Knight et Salisb. Prot. p. 108), glaberrima, foliis subcoriaceis glaucis lanceolatis ulrinque attenuatis muticis eveniis nervo immerso, fasciculis axillaribus subsessilibus, pedicellis calyce sublongioribus stigmate laterali ovali convexo, capsulâ ovatà ventricosâ attenuato-stipitatâ tuberculatâ supra gibbosâ apice compresso brevissime carinato-bicalcaratâ, seminis nucleo oblongo hinc semialato alæ terminalis ovatæe obtusæ subæquilongo duplo angustiore. $₹$ Circa Port-Jackson (R. Brown, Sieber, n. 607! A: Cunn.! etc.). - R. Brown in Linn. Trans.10, p.185, prodr. j. 385, Sweet fl. Austr. t. 27, Roem. et Schult. syst. 3, p. 423, H. salicifolia Sweet $!$ mss. in herb. DC. Embothrium salignum Andr. Bot. repos. t. 215. E. salicifolium Vent. Cels. t. 8. Conchium salignum Smith ! in Linn.Trans.9, p. 124. C. salicifolium Gartn. fil. fr. 3, p. 217. Frutex elatior, ramulis gracilibus, foliis 3-5-poll. longis, 3-9 lin. latis, apice sphacelato obtusiusculis. Pedicelli 3 lin. longi. Capsula incluso stipite 12-14 lin. longa, breviter tetragono-acuminata, calcaribus brevibus acutis deciduis carinam relinquentibus.(v.s. in herb. Smith., etc., et v. c.)

104. H. OL EIF OLIA (R. Brown in Linn. Trans. 10, p. 185, prodr. p. 385), foliis lanceolatis vel lineari-lanceolatis pungenti-mucrontis attenuato-subpetiolatis immerse 1 -nerviis penniveniis submarginatis junioribus ramulisque sericeo-juberulis, corymbis axillaribus terminalibusque subsessilibus, pedicellis floribusque subæquilongis glabris, stigmate terminali conico obtuso, capsulâ subgibbosoovatâ subtuberculoso-rugosâ, calcaribus brevibus divaricatis, seminis nucleo hinc semialato alam terminalem latiusculam subæquante. $ђ$ In terrá Leeuwin (R. Br.), circa sinum Regis Georgii (A. Cunn.! Preiss, 11. 554, 556! Drumm. coll. 5, n. 410!). - Roem. et Schult. syst. 3 , p. $422^{*}$, Meisn. in pl. Preiss. 1, p. 571*. Conchium oleifolium Smith 1 in Linn. Trans. 9, p, 124. Hakea ligustrina Knight et Salisb. Prot. p. 108. Frutex 10-pedalis vel arbuscula 25-ped. (Preiss). Folia $\frac{1}{2}-3$ poll. longa, 3-5 lin. lata, basi haud torta. Involucrum ferrugineo-lomentosum vel sericeum. 1 Calyx 3 lin. longus, stylo parum superatus. Capsula sæpe fasciculatæ, 10-12 lin, 
longæ, apice subcompressæ, calcaribus fere horizontaliter patentibus 1-1 $\frac{1}{2} \mathrm{lin}$. longis rectis. Seminis nucleus rugosus, uno latere scmialatus, altero apterus. Facie valde accedit ad $H$. lasiantham, sed bene distincta foliis liaud verticalibus, nervatione, capsulâ, etc. (v. s. in herb. Smith., Cunn., et v. v. c.)

105. H. GLAvat a (Labill.I Nov.Holl. 1, p. 31\%.t. 41), glabra, foliis aversis crassis oblongis obtusis pungenti-mucronatis enerviis basi attenuatis marginibus obtusissimis, floribus racemosis glabris, capsulà stipitatâ ovatâ compressẩ lı́evi calcaribus brevibus, seminis nucleo lævi utrinque basique angustissime alato quam ala terminalis ovata obtusa minore. 7 In terrả Leeuwin (Labill.! R. Br., Baxter !).R. Brown in Linn. Trans. 10, p. 187, prodr. p. 386, Roem. et Schult. syst. 3, p. 425*.

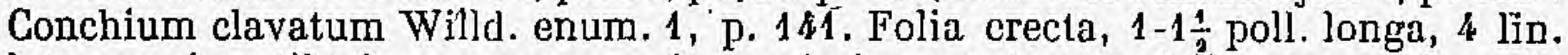
lata, quasi cartilagineo-carnosa, apice paulo jncrassata sæepe 1 lin. crassa. Capsula cum stipite 2-3 lin. longo pollicaris, 4-5 poll. lata, calcaribus ferc 1 lin. ab apice remotis adscendentibus vix 1 lin. longis obtusiusculis, pedunculo brevi crasso. Semen fuscum, nucleo subconvexo. (v. s. in lierb. DC., Cunn., etc.)

106. H. MEGAL OSPERMA (Meisn. in Hook. Journ. 1855, p. 117), glabra, foliis sessilibus rigidissimis glaucescentibus oblongis obtusissimis muticis cum puncto sphacelato subexcentrico basi atlenuatis immerse 1 -nerviis obsolete venosis marginatisque, capsulâ magnâ ovali acutâ compressâ, valvis extra medium leviter gibhosum obtuse carinatis, carinâ in calcar compresso-triangulare productâ, semine magno undique alato. $\%$ In monte Lesueur, N.-Holl. occid. (Drumm. coll. 6 , n. 194 ! Hook. Journ. 1853, p. 180). Rami validi. Folia horizontalia, $1 \frac{1}{2} 2$ poll. longa, 7-10 lin. lata, obsolete nervoso-marginata, passim obsolete pennivenia, venis tenuibus impressis apicem peteritibus supra levissime sulcifarmibus. Flores ignoti. Capsula terminalis? solitaria, in pedunculo $4-5$ lin. longo crasso sessilis, fere 2 poll. longa, 15 lin. lata, subacuminato-acuta, cinerea, subnitida, leviter verruculoso-punctata, faciebus prope medium leviter rotundato-bigibbosis supra carinatis, carinà semipollicari crassâ obtusâ apice $1 \frac{1}{2}$ lin. altà in cornu compressotrianguiare rectum obtusiusculum $2 \frac{1}{3}$ lin. longum exeunte. Semen atrum, 15 lin. longum, 9-10 lin. latum, oblongo-ovatum, utringue obtusum, nucleo late obovato truncato quam ala terminalis $\frac{1}{3}$ breviore, alis lateralibus aqualibus basilarique ipso dimidio angustioribus. Species insignis, foliis ad H. crassifoliam accedens, sed foliis haud aversis, capsula, etc., distinctissima. (v. s. in herb. Shuttl.)

\section{§6. Folia plana integerrima 1-nervia, interdum nervoso-marginata, raro enervia (cfr. H. stenophylla). Capsula ecalcarata.}

107. H. E R I A т н A (R. Brown suppl. p. 29), ramis glabriusculis apice sulcato-angulatis, foliis sessilibus elongato-lanceolatis linearibusque utrinque attenuatis immerse 1-nerviis subeveniis glabris, pedicellis axillaribus fasciculatis calycibusque adpresse sericeis, stigmate laterali oblongo convexiusculo, capsulâ ovatâ ventricosà compressâ rugulosà, seminis nucleo alam ovatam subxequante margine aptero. ₹ In orà orientali, prope flum. Hastings (Fraser), circa Sydney? (Anderson!), circa Tambo et Mitta Australix meridionalis (Ferd Müller l). Pamuli graciles, tenues, laxe foliosi, apice parce adpresso-puberuli. Folia 4-6 poll. Ionga, 3-7 lin. lata, haud rigida, falcata vel recta, breve acuminata, sphacelato-mucronulata, demum mutica, passim obsoletissime nerviformi-marginata, venis plerumque obliteratis. Pedicelli 2 lin., calyces fere 3 lin. longi, tomento adpresso albido-fulvo sericei. Pistillurr subsessile, glabrum, calycem vix superans, stigmate $\frac{2}{3}$ lin. jongo. Capsula (fide specim. Müller) nunc 7-8 lin. longa, vix 5 lin. lata, nunc 10-12 lin. longa, 6-8 lin. lata. Semen nigrum, nucleo obovato alam ovalem vel ovatam obtusiusculam basi obliquam subrequante vel subdimidio breviore. Species folïis proxime accedens ad $\mathrm{H}$. salignam, cateroquin distinctissima. (v. s.)

108. H. STEN OРнYLLA (A. Cunningh. mss.), foliis angustato-linearibus enerviis

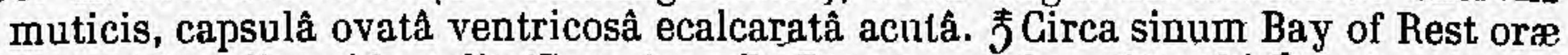
septentrionali-occidentalis (Cunn.). - R. Brown suppl. p. 30, ubi H. arborescenti (supra, n. 77) maxime affinis dicitur.

109. H. S TEN O C A P A (R. Brown suppl. p. 29), glabra, ramulis apice angulatis, foliis linearibus vel lanceolato-linearibus planis sphacelato-mucronatis 1 -nerviis margine nerviformi punctato-scabriusculis, fasciculis axillaribus sdssilibus, calyce

XIV. 
pedicellis longiore stylo vix superato, stigmate terminali conico, capsulâ linearilanceolatâ rostṛato-acuminatâ subfalcatâ. J゙ In coloniâ. Swan River (Frảser, Drumm.! coll. 1, Preiss, p. 574, 575l). - Hook. ic. t. 444, Meisn. in pl. Preiss. 1, p. 575*. Frutex 2-pedalis (Preiss), ramulis gracilibus. Folia rigida, glaucescentia, 2-5 poll. longa, 2-4 lin. lata, pennivenia vel evenia. Corymbi sessiles, parvi, rhachi vix 1 lin. lon̆gâ villosulâ. Calyx vix 2 lin. longus. Capsulæe (èx ic.) subsessíles, sụbsolitariæ, $1 \frac{1}{2}$ fere 2 poll, longæ, basi vix 3 lin. latæ, læves. (v. s.)

110. Н. с О В м в о А (R. Brown suppl. p. 28), ramulis involucrisque incano-tomentosis, foliis lanceolato-linearibus pungenti-mucronatis basi attenuatis 1-nerviis subeveniis marginatis glabris planis vel supra concavis subtus curinatis, floribus glabris, stigmale subcylindraceo, capsulâ ovatâ, ventricosâ lievi acuminne conico recto. 5 Circa sinum Regis Georgii (Baxter !) et Cape Riche (Preiss, n. 566, 571!). - Meisn. in pl. Preiss. 1, p. 574 . Frutex 2-pedalis, corymboso-ramulosus. Folia rigidissima, viridia, 1-3 poll. longa, 1 $\frac{1}{2}-3$ lin. lata, basin versus longe angustata, sæpius leviter complicata indeque subtus plus minus carinata. Involucra axillaria ovata, squamis ovatis acutis. Capsulæ solitariæ, subsessiles, 10 lin. longæ, cinereæ, acumine 2 lin. longo obtusiusculo liaud compresso. (v. s. in herb. Cunn., ete.)

111. H. Carina a a (Ferd. Müller! mss. in herb.), ramulis apice subsericeo-puberulis, foliis rigidis linearibus mucronatis utrinque attenuatis subincrassato-marginatis eveniis glabris nervo subtus fortiter prominente supra obsoleto, fasciculis axillaribus sessilibus involucroque glabris, stigmate terminali discilormi conjco-mucronhato, capsulà ovatâ acuminatà levi, seminis nucleo alam ovatam subæquante

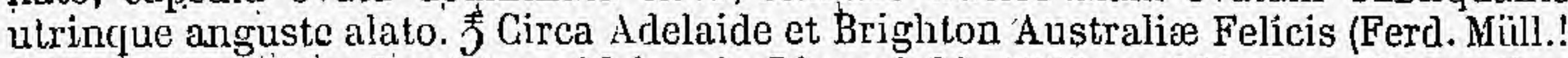
êt herb. Soc. linn. Lond.). - Meisn. in Linnæấ 26, 1853, p. 360. Ramuli graciles, apice sulcati vel subangulati, innovationibus adpresse puberulis. Omnia fere H. corymbose, sed involucrum glabrum. Folia minus crassa minusque spathulatoatlenuata.

a. planifolia (Meisn. 1. c. p. 361), foliis elongato-linearibus planis margine vix incrassatis, $3-5$ poll. longis, $2 \frac{1}{3}-5$ lin. latis. (v. s. sine fr.)

B. trigonophylla (Meisn. l. c.), foliis anguste linearibus planis vel sæpius carinatotriquetris nargine incrassatis $1 \frac{1}{2}-2 \frac{1}{2}$ poll. longis, $1-1 \frac{1}{2}$ lin. latis. (v. s.)

112. H. MAPGINATA (R. Brown in Linn. Trans, 10, p. 185, prodr. p. 385), ramulis puberulis, foliis lanceolatis planis pungenti-mucronatis 1-nerviis subeveniis margine nerviformi lavibus adultis glabris, pedicellis axillaribus fasciculatis calycibusquee subæqualibus stylo superatís glabris, stigmate terminalì conico, capsulâ

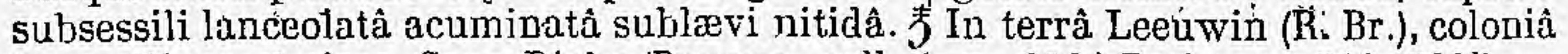
Swan River et circa Cape Riche (Drumm. coll. 1, n. 604 | Preiss, n. 562, 563!). Meisn. in pl. Preiss. 1, p. 575 *. Frutex 7-pedalis. Folia patentía, sesślila, circ. pollicaria, 2-4 lin. lata, juniora subtus adpresse pilosiuscula. Flores H. stenocarpæ. Gapsula 7-8 lin. longa, recta, parce subverruculosa, acumine brevi. (v. s.)

113. H. M х т т Id es (Meisn. in pl. Preiss. 1, p. $577^{*}$ ), foliis sessilibus ovalibus suborbicularibúsque pungenti-mucronatis 1 -nerviis venosis lævibus glabris, pedicellis axillaribus fasciculatis calyceque ipsis Iongiore stylo longe superato glahris, stigmate terminali conico-cylindraceo, capsulâ parvâ ovatâ turgidâ læviusculâ acumiriulatâ, seminis nucleo angusle alato-marginato apice brevissime alato. $\hat{F}$ In colonia Swau River (Drummond coll. 1, n. 608! Preiss, n. 534! Molloy l). - Bot. mag. t. 4643, Lem. Fl. des Jard. t. 272. Frutex adscendens, ramis gracilibus apice minute subsericeo-canescentibus. Folia patula, rigida, 4-8 lin. longa, 3-4 lin. lata. Florés miniati, pedicellis 1-2 lín., calycibus 3 lin., pistillis 5 lin., capsulis 4-5 lin. longiș. (v. s.)

114. H. cos t a t a (Meisn. 1. c. 1, p. $575^{*}, 2$, p. 262), foliis breve linearibus lanceolatisve pungentibus 1 -nerviis margine subnerviformi scabriusculis junioribus ramulisque villosis, pedicellis axillaribus fasciculatis calyceque ipsis longiorc stylo superato glabrís, stigmate terminali conico, capsulâ súbsessili ventricosoovatâ acutầ tứrgiça læviusculà, seminis nucleo undique alato, alầ terminalí ipso

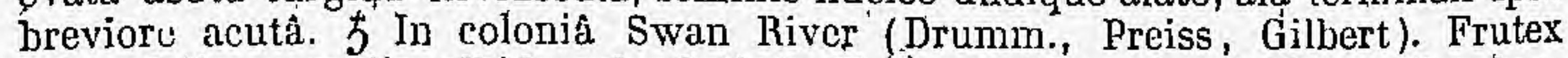
1-2-pedalis, ramulis albidu subvelutinis. Folía crassiuscula rigida, pollice breviora, mucronata, viridia. Involucrum villosum. Flores $\mathrm{H}$. myrtoidis. Capsula subgloboso-ovata, 4 lin. longa, subnitida. Seminis nucleus obovatus niger rugosoLuberculatus; alâ fusco-cinereâ. 
๙. linearis (Meisn. 1. c. p. 576), foliis linearibus utrinque icqualiter attenuatis, summis fere subulatis subtus bisulcis, inferioribus lanceolatis (Drumm.coll.1, 2 , n. $332 !$ ad $\beta$ accedens, Preiss, n. 533! Gilbert, n. 59!). Folia 3-6 lin. longa, $\frac{1}{2}-1$ lin. lata, costtâ crassiusculâ subtus prominulâ, marginibus subrecurvis incrassatisve. (v. s.)

B. lanceolata (Meisn. l. c.), foliis lanceolatis subspathulatisve obsolete venosis (Preiss, n. 532 I). Folia 4-8 lin. longa, 1 $\frac{1}{2}-2$ lin. lata, costâ tenuiore, margine subnerverviformi. (v. s.)

115. H. RUSCIFou a (Labill. N.-Holl. 1, p. $30^{*}$, t. 39), ramulis hirsutis, foliis ellipticis oblongis obovalisve pungenti-mucronalis 1-nerviis eveniis supra margineque punctato-scabriusculis adul tis glabris, involucro seciceo, pedicellis calyceque ipsis breviore pistíllum acquanto glabris, stigmate terminali depresso-conico, capsulà pedicellatấ oblongâ compréessầ granulato-puncticulatâ, seminis nucleo margìne Jasique angustissime alato alam terminalem obtusam æquante. JIn terrả Leeuwin Labíll., R. Br.), circa sinuin Regis Georgii (A. Cunn.I Preiss. n. 613, 614!) et in Colonia Swan River (Drumm. coll. 1/ 3, n. 276! Preiss, n. 611, 612, 615, 616!). R. Brown in Linn. Trans. 10, p. 186 , prodr. p. 385, Roem. et Schuli. syst. 3 , p. $423^{*}$, Lindl. in Bot. reg. 1841 , misc. p. 73 , Meisn. in pl. Preiss, 1, p. $576{ }^{*}, 2$, p. 262. Conchium ruscilolium Willd. enum. 1, p. 141. Frutex 2-8-pedalis, ramis densé foliosis villoso-tomentosis hirsutiscue. Folia crassiuscula, $0-18$ lin. longa, 3-4 lin. lata, mucrone recto 1-2 lin. Tongo, sessilia aut petiolo subtereli 1-3 lin. 'ongo fulta, jtmiora pubescentia. Fasciculi axillares et ramulos breves terminantes sessiles, folio breviores, pedicellis 3-4 lin., floribus 2 lin. longis. Capsula 10 liñ́n. longa, 4 lin. lata, obtusa, fure recta. Scmen nigrum, alâ fusco-cinereâ. (v. s. in lierb. DG., etc.)

\section{Species obscurce.}

H. DRUPAGEA (Roem. et Schult. syst. 3, p. 426). - Conchium drupaceum Gærtn. fr. 3, p: 217, t. 219. Preter iconem fructus ignola. Cfr. R. Brown in Linn. Trans. 10, p. 221. Nobis aut H. tephrosperma, ant species huic fructu proxime affinis esse videtur; cfr. supra, n. 40.

H.? L ANIGERA (Tenore fl. napol. 1, p. 22, n. 20, t. 6), arborea, ramis verticillatis adscendentibus, junioribus lanatis, foliis confertis rigidis teretibus mulronatis glaucis, junioribus pubescentibus, calyce subglabro, capsulâ pyriformi rostro bicorni. $\delta$ In Novâ-Holl. - Roem. et Schult. sy'st. 3, p. 425.

H.? LONGIFOLIA (Dum. Cours, ex Roem. et Schult. syst. 3, p. 425), foliis patentibus rectis teretibus apice sphacelatis cire. 3 poll. longis cauleque glabris. Ciet. ignota.

H.? TENUIF OL a (Dum, Cours, ex Roem. et Scl. l. c.), caule pubescente, foliis numerosis teretibus apice fuscis $1-1 \frac{1}{2}$ poll. longis glabris, junioribus parce adpressopilosis. Ceet. ignota.

H. M A G OC AR PA (II. Belved., ex Roem. et Schult. syst. 3, mant. p. 378), glabra, foliis lanceolato-lincaribús glaucis 1 -nerviis apiculatis margine subinvolutis. - In Australiâ.-Hoffmansegg, Verzeichn. 2 Nachtr. p. 127. Folia 2 poll. Ionga, vix 2 lin. lata, fere in petiolum subconvolutum angustata. Cæt. ignota. Forsan H. microcarpa, ex Hoffm. l. c.

\section{Species non descriptoe.}

H. ANGUSTIFolia Nackay, ex Steudel nomencl. ed. 2, 1, p. 718.

H. CAR DUIF oL I A Lodd. id.

H. EG II INA TA Mackay id.

H. FerR UGine $\Lambda$ Gunn., ex Steud. An H. repanda R. Br.?

H. H E T E R OP Y Y L L A hart. Angl. (an Hook.?).

H. LА м веRтII Sweet.

H. L A TIF OLIA Lodd.

H. Pectinat a Dum. Cours 11, p. 424. An H. suaveplens R. Br.?

H. PETROPHIL OIDES Nackay. $A$ H. lissocarpha R. Br.?

H. sU в UL A T Cunn. 


\section{Species exclusce.}

H. PuBESCENS hort. Cels = Banlssia oblongifolia Cav.? vel serrata L.?

H. PYRIFORMIS Cav. = Xylomelum pyriforme Sm.

H. R OBRIGA UL Is Cels, Colla = Stenocarpus salignus R. Br.

XXXI. LANBBRTIA Smith in Trans. Soc. Linn. Lond. 4, p. 214,t. 20, R. Brown ibid. 10, p. 188, prodr. fl. N.-Holl. p. 386, suppl. p. 30, Endl. gen. p. 341, n. 2145, suppl. IV, 2, p. 86, Meisn. gen.p. 332 (245). - Proteæ sp. Wendl. sert. 4, p. 5, t. 21.

Flores hermaphroditi, regulares, solitarii vel fasciculati, involucrati. Calyx tubulosus, 4 -fidus, laciniis planis staminiferis spiraliter revolutis. Antheræ subsessiles, lineares, acuminatæ. Squamulæ hypogynæ 4 -liberæ vel in vaginulam connatæ. Ovarium stipitatum, 1-loculare, 2-ovulatum. Stylus filiformis, stigmate subulato sulcato. Folliculus sessilis, coriaceo-ligneus, ovatus vel cuneato-obovatus, compressus, acuminatus, prope apicem bicornis vel muticus, rotundato-gibbus, sæpe echinatus, 2-spermus. Semina marginata. Frutices Novæ-Hollandiæ extratropicæ præsertim australi-occidentalis, ramis sæpius verticillatis, foliis ternatim verticillatis integerrimis vel spinoso-dentatis, slomatibus hypogenis, involucris terminalibus solitariis coloratis imbricatis 1-7-floris erectis deciduis, receptaculo plano nudo.

1. L. I NERM Is (R. Brown! in Linn. Trans, 10, R. 188, prodr. p. 387), foliis sessilibus obovato- vel spathulato-lanceolatis linearibusque obtusis integerrimis muticis eveniis margine recurvis supra glabris subtus ramulisque tomentosis, involucri 7-flori squamis interioribus lanceolatis calyceque dimidio longiore glabris, stylo longissime exserto glabro, folliculo lævi hine corruto inde rotundato. $\bar{\zeta}$ In orâ australi, circa Lucky Bay (R. Brown!), sinum Regis Georgii et Cape Riche (Drummond coll. 1, n. 594 ! Preiss, n. 763, 764!). - Meisn. in pl. Preiss. 1, p. $578^{*}, 2$, p. 263. L. Drummondi Gardner in Fielding sert. t. 22 (forma foliis subspathulatis). Frutex 6-8-pedalis. Folia 6-8 lin. longa, $1 \frac{1}{2}-3$ lin. lata, basi attenuata, subtus canotomentosa vel ferrugineo-sericea. Florum fasciculi coccinei vel sulphurei, viscidi, involucri squamis interioribus 8-9 lin. longis, 1-2 lin. latis obtusis. Calyx 16 lin. longus, parcissime pilosus. Stylus 18-20 lin. longus, stigmate 2 liu. longo continuo acuto vix tenuior. Folliculi acumen 2 lin. longum. (v. s. in herb. Brown., DC., etc.)

2. L. ER IGIF OLIA (R. Brown! suppl, p. 30), ramis tomentellis, foliis breve linearibus obtusis muticis margine revolutis supra venosis puberulis demum glabris subtus canaliculatis vel 1 -sulcis, involucri 7 -flori squamis interioribus calyce dimidio brevioribus, stylo glabro, stigmate subulato acuto, folliculo hinc cuspidato inde mutico. F Circa sinum regis Georgii (Baxter! Drumm. coll. 3, n. 264l). - Meisn. in pl. Preiss, 2, p. 263 ${ }^{*}$. Præcedenti arcte affinis, sed bene distincta. Folia 4-7 lin. longa, vix $\frac{1}{2}$ lin. lata. Involucri squamæ lanceolat:e, pilosæ. Flores rubri, stigmate fere 2 lin. longo. (v. s. in lierb. Bromn. et Shuttl.)

3. L. UNIFL ORA (R. Brown! in Linn. Trans. 10, p. 188, prodr. p. 386), foliis petiolatis ovalibus obovatisque mueronatis reticulatis scabriusculis glabris novellis ramulisque pubescentibus, involucri 1-flori squamis anguste linearibus acutis floreque glabris, folliculo levi hinc cuspidato inde mutico. J In terrà Leeuwin (R. Brown!), circa sinum Regis Georgii (Baxter! Preiss, n. 762! Drumm. coll. 3, n. 261!). - Meisn. in pl. Preiss. 1, p. $578^{\circ}, 2$, p. 263. Frutex gracilis 8-10-pedális. Folia cum petiolo 1-2 lin. longo 6-14 lin. longa, 3-6 lin. lata, plana vel margine leviter undulata, sparse puncticulato-seabriuscula. Involucrum glabrum, squamis interioribus 3-5 lin. longis acutis, exterioribus scnsim brevioribus obtusis. Calyx 12-14 lin. longus, coccineus, glaber. Pistillum 16 lin., stigma 1 lin. longum. Folliculus sessilis, 3-4 lin. longus, cornu fere 2 lin. longo acuminato, angulo superiore rotundato-gibbo. - Vuriat (sıecim. Baxter) fioribus minoribus et foliorum limbo suborbiculari 3.5 lin. longo petiolo parum longiore. (v. s. in herb. Brown, etc.)

4. L. RARIfL ORA (Meisn. in pl. Preiss. 2, p. $263 \%$ ), ramis puberulis, foliis subsessilibus línearibus indivisis submuticis utrinque glabris reticulatis margine recurvo 
subundulato-reticulatis, involucri 1 -flori squamis linearibus calyce medio tomentoso multo brevioribus, stylo inferne pubescente stigmate tenui subulato, folliculo lævi hinc rotundato inde rostro cequilongo recto acuminato. F In coloniâ Swan

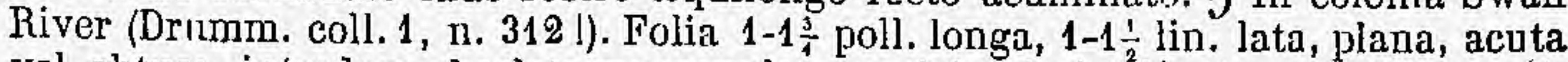
vel oblusa, interdum obsolete mucronulata, petiolo vix $\frac{1}{2}-1$ lín. longo. Flores rari, precedentibus breviores, folia circumstantia vix æequantes. (v. s. in herl). Shuttleworth.)

5. L. MULTIFL OR A (Lindl.I Swan River, p. 32, n. 154), ramulis angulatis apice puberulis, foliis sessilibus linearibus integerrimis mucronulatis transverse venosis glaberrimis margine plano levíbus, involucri 7-19-flori squamis interioribus flore dimidio brevioribus linearibus apice puberulis, calycis stylo piloso 1 superati lobis apice pilosiusculis, stigmate basi subnoduloso. folliculo lævi hinc breve cuspidato inde longe bicorni. F In colonjà Swan River (Drumm. coll. 1, n. 595, 6, n. 198 ! Preiss, n. 766!), ad flum. Vasse (Molloy l).-Meisn. in pl. Preiss. 1, p. 579*,

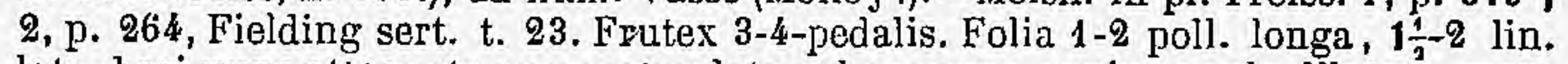
lata, basi nunc attenuata nunc rotundata vel suprema sæepius paulo dilatala, margine sæpe recurvo. Involucri squamæ vix 1 lin. latie, cinnamomeæ, tenuiter, striatæ. Flores 7 vel 9 vel $13,15,17,19,20$. Calyx 12-15 lin. longus, aurantiacus, tubo glabro aut parce puberulo. Folliculi acumen conicum, obtusiusculum, 1 lin. longum, cornua triplo longiora recta parum divergentia sulcata. Cl. Drumnond plantam suatm n. 198, floribus septenis rubris, pro specie distinctâ habere videtur (cfr. Hook. Journ. 1853, p. 180, el 1855, p. 118, n. 49), sed nostra saltem specim. tam florifera quam fructifera nullo modo a plantà Lindleyani differunt. (v. s. in herb. Lindl., etc.)

6. L. FORMOSA (Smith! in Linn. Trans. 4, p. 214, t. 20), ramulis apice puberulis, foliis linearibus danceolatisve integerrimis pungenti-mucronatis 1 -nerviis reticulatis margine recurvis supra nitidis glabris subtus tomentosis demum glabratis, involucri 3- vel 7-flori squamis interioribus calycem :equantibus vel superantibus, calyce extus glabro intus stylorgue piloso, stigmate continuo elongato-subulato, folliculo sublævi acuminato longe hicorni. \$ Circa Port-Jackison (R. Br.! Gaudich.! d'Urville! Sieber, n. 24! Lhotskiy! etc.) et in Australià merid. circa Victoria (Latrobe!). - Cav. ic. 6 , p. $31^{\prime}$, t. 547 , R. Brown I in Linn. Trans. 10 , p. 188, prodr. p. 387, suppl. p. 30 , Bot. cab. t. 80 , Bot. reg. t. 528 , Reichenb. 1 . exot. t. 145. Protea nectarina Wendl. sert. IIannov. 4, p. 5, t. 21, Andr. Bot. repos. t. 69, Bot. cab. 1. 80. Folia $1-2 \frac{2}{2}$ poll. longa, $1 \frac{1}{2}-2 \frac{1}{2}$ lin. lata, mucrone fere 1 lin. longo. Capitula punicea. Involucri squame exteriores ovatio acute glabriuscule, interiores lineari-oblong:e obtusiusculæ dorso medio sericese. Calyx pollicaris, stylo $\frac{1}{5}$ superatus, stigmate $1 \frac{4}{2}$ lin. longo. Folliculus olıovatus, cornubus valvâ sublongioribus 4 lin. longis, lateralibus lævibus vel obsolete echinato-verrucosis. Variat foliis magis lanceolatis $6-9$ lin. longis, 2 lin. latis, subtus ferrugineo-vel incano-tomentosis, sensim vel subito attenuatis. (v. s. in herb. Smith., Brown., DG., etc., et v. c.)

7. L. PROPINQUA (R. Brown! suppl. p. 30), ramulis teretibus pubescentibus, foliis sessilibus oblongo- vel cuneato-linearibus obtusis mucronulatis integerrimis vel apice 2-3-dentatis vel 2-3-mincronulatis reticulatis planis glabris, involucri 7-flori squamis interioribus calyceque vix longiore glabris, stylo piloso longo exserto, stigmate attenuato-subulato, folliculo bicorni undique echinato. 5 Prope sinum Regis Georgii (Baxter!). Nimis affinis sequenti, cujus forsan var., recedens tamen foliis parum rigidulis apice nunquam adeo dilatatis, plerumque 2 lin. latis, mucronulis tenuibus brevissimis. Stylus a cel. auctore dicitur glaber, sed in specim. ab ipso accepto certe laxe pilosus observatur. (v. s. in herb. Brown.)

8. L. eghinata (R. Brown 1 in Linn. Trans. 10, p. 189, prodr. p. 387, suppl. p. 31), ramis pubescentibus, foliis subsessilibus obovato-oblongis cuneatis reticulatis glabris apice 3-5-dentatis, dentibus pungenti-mucronatis, involueri 7-flori squamis glabris interioribus calycis glabri vix apice puberuli dimidium superantibus, stylo superne glabro infra piloso, stigmate tenui æquali, folliculo echinato hinc rostrato inde bicorni. ₹ In orâ australi circa Lucky Bay (R. Br.), prope sinum Regis Georgii (Baxter! A. Cunn.! Preiss, n. 761!).-Meisn. in pl. Preiss. 1, p. 579*. Frutex 7-pedalis. Folia viridia, rigida, 6-9 lin. longa, inferne 1-2 lin. lata integerrima, apice dilatata 3-4 lin. lata 3-loba, lobis 1-2 lin. longis latisque spinescentibus integris vel intermedio sæpius 3-mucronato vel breve. 3-dentato. Calyx 
aureus, 12-14 lin. longus, stylo fere dimidio brevior. Folliculus L. formosæ, sed paulo minor, undiqne vel solummodo secus margines spinulis sæpe 1 lin. longis echinatus. (v. s. in herb. Brown., Lindl, etc.)

$\beta$. intricata, ramulis densissime foliosis hirsutis, foliis dilatatis $\mathbf{3}$-lobis, lobis spinoso-2-3-dentatis. Rami dense pilosi, densissime ramulosi et foliosi (more Dryandræ cryptocephalæ), foliis 8-10 lin. longis, 6-8 lin. latis. Folliculus ut in specie genuinà. (v. s. sine fl. in herb. Sonder.)

9. L. ItIGIFOLIA (Hook. ic. t. 553), ramulis puberulis, foliis subsessilibus ovatis vel cuneato-obovatis superne spinoso-paucidentatis passim integris reticulatis glabris, involucris axillaribus sessilibus 7 -floris, calycis lobis apice styloque pilosis, stig̣mate continuo tenui. $\delta$ In coloniâ Sw̧an hiver (Preiss, n. 766! Drumm. coll. 3, 11, 262 !). - Meisn. in pl. Preiss. 1, p. 580*, 2. p. 264. Frutex verisimiliter humilis, ramulis foliisque ternatim et quaternatim verticillatis. Folia glauca? 3-6 poll. longa, 3-4 lin. lata. Flores flavi, folia vix superantes. Involucri squamæ interiores 4 lin. longæ, $\frac{2}{s}$ lin. latæ, obtusæ, glabræ, calycis tubum æquantes. Folliculus ignotuis. (v. s.)

\section{Species non descripta.}

L. LONGIFolia Lodd., ex Steud. nom. ed. 2, 2; p. 6.

\section{Species exclusa.}

L. TERETIFoLIA Gærtn. fil. = Hakea pugioniformis.

XXXII. XYLOMELUM Smith in Trans. Soc. Linn. Lond. 4, p. 214, R. Brown ibid.10, p.189, prodr. p. 387, suppl.p. 31, Endl. gen. p. 341, n. 2146, suppl. IV, 2, p. 87. ic. t. 47, 48, Meisn. gen. p. 333 (245), - Banksia pyriformis Gertn. fr. 1, p. 220, t. 47, r. 1. Hakea pyriformis Cav. $6, p .25, t .536$.

Flores abortu polygami, regulares, dense spicati. Sepala 4 spathulato-linearia, apice subconcava, revoluta. Stamina 4 , sepalis supra medium inserta, isque revolutis exserta; antheræ subsessiles, lineares, connectivo ultra loculos breviter producto obtuso. Glandulæ hypogynæ 4 liberæ. Ovarium stipitatum 1-loculare, 2-ovulatum. Stylus filiformis, deciduus, stigmate continuo verticali clavato obtuso. Folliculus incrassato-ligneus, ovato-oblongus, tomentosus, excentrice 1-locularis, 2-spermus. Semina apice elongato-alata. - Arbores Novæ-Hollandiæ, foliis oppositis coriaceis nervosis integerrimis vel præsertim plantæ juvenilis dentatis, stomatibus hypogenis vel amphigenis, spicis axillaribus oppositis simplicibus cylindricis densifloris, florum paribus t-bracteatis, infimis hermaphroditis, superioribus ovarii abortu stigmateque minore imperfectis, folliculis solitariis magnis tomentosis intus suturá dehiscentibtis extus siccatione partibilibus.

1. X. PYRIF ORME (Knight et Salisb. Prot. p. 104), foliis petiolatis ovato-vel lanceolato-oblongis acuminatis reticulatis nitidis ramisque glaberrimis summis integerrimis inferioribus dentatis, spicis subsessilibus, rhachi cum bracteis calycibusque lanàto-tomentosis, stigmate obovato. 5 Circa Port-Jackson (R. Br., Phillip! Sieber, n. 23! Anderson! etc.)--R. Brown in Linn. Trans. 10, p. 189, prodr. p. 387, suppl. p. 31, Roen. et Schuilt. syst. 3, p. 427, Reichenh. hör. bot. 1, p. 61, t. 90, Eadl. ic. t. 47 , 48. Banksia prriformis Gærtn. fr. 1, 1. 220, t. 4.7, f. 1, Lam. ill. t. 54, í. 4. Hakca pyriformis Cav. ic. 6, p. $25^{*}$, t. 536. Conchium pyriforme Willd. enum.1, p. 141. Grevillea pyriformis hort. Arbor mediocris. Folia 3-6 poll. longa, 1-2 poll. lata, paginis discoloribus, inferiore solà stomatiferî. Spicæe foliorum approximatione sæipius 4-6 congeste, 2-3 poll. longæ, erectæ, donsissimæ. Calyx semipollicaris, tomento denso adpresso pilis patentibus mixto. Stylus calyceǹ æquans, junior infra medium lanatus, demum ğlabratus. Folliculus 4 poll. longus. Seminis ala sursum attenualn, nucleo duplo longior (1). (v. s.)

(1) Hujus var.? vel forsan n. sp. " folliculis minoribus et minus pubescentibus quam X. pyriformis, " ad, sinum Carpentaria legit Leichardt, Tagebuch übets. vel Zuchold, p. 216 sine descr: 
B. salicinum, foliis elongato-lanceolat1s. R. Brown suppl. p. 31. - Circa sinum Moreton Bay (A. Gumn.). X. salicinum A. Cunningham! mss. (v. s. in herb. Cunn.)

2. X. ANGUSt fFolium (Kippist et Meisn. in Hook. Journ. 1852, p. 209), ramulis foliis junioribus pedunculiscpe adpresse sericeis, foliis lanceolato-linearibus acuminatis longe, attenuato-jetiolatis integerrimis vel subrepandis basi tortis adultis glabris, folliculo oblongo-ovato, seminis alâ flavo-fuscâ nucleoque maculatis. 5 ? In coloniâ Swan River (Drummond coll. 5, suppl, n. 7!). Rami demum glabrì, fusco* rubri. Folia opposita, late viridia, concoloria, cum petiolo 5-6 lin. longo 4-5-pollicaria, 3-4 lin lata, marginata, 1-nervia, pennivenia. Flores ignoti. Folliculus $2 \frac{1}{2}$ poll. Iongus, $1 \frac{1}{2}$ poll. latus (multo minor quam X. pyriformis), intus sponto dehiscens, extus arcte cohæerens, corlice cinereo-tomentoso rimis numerosis satis profundis transverse fisso. Semen 2 poll. longum, obovato-oblongum, sordide fusce flavum, pulcherrime fusco-mácilatum, nucleo 8-9 lin: longo cuneato-obovato basi acuto apice oblique truncato hinc convexo inde concavo, alâ ovali-oblongå obtušsâ. (v. fragm. cum fig. comm. a cl. Kippist.)

3. X. OGCIDE NTALE (R. Brown suppl. p. 31), ramulis foliis junioribus pedunculis calycibusque cano-tomentosis, folijs petiolatis ovatis ellipticis oblongisque venosis demum glabris ramorum floriferorum summis integerrimis inferioribus passim dentatis, spicis breve pedunculatis, stigmate subclavato oblongo. 5 In sinu Geographorum oræe australi-occidentalis (Fraser), coloniâ Swan River (Drumm. coll. 1, I. 616 ! Preiss, ǹ. 754!). - Hook. ic. t. 446, Meisn. in pl. Preiss 1, p. 580*. Arbor circ. 25 ped. alta. Folia interdum ternatim verticillata, $3-5$ poll. longa, $1 \frac{1}{2}-2$ poll. lata, sæpe inciso- vel sinuato-dentata (omnino Ilicis Aquifolii, sed haud nitida) dentibus àcutissimis, sinubus rotundatis, utrãque paginẩ slomatiferà. Spjica in singulis axillis 1-3, folio sublongiores, 4-5 poll. longæ. Calyx 4-5 lin. longus, stylum inferne pilosum iecruans. Folliculus fere 3 poll. longus. Semen bipollicare, alẩ cinnamomeâ acutâ nucleum atrofuscum fere duplo superante. (v. s.)

XXXIII. ORITES $R$. Brown in Trans. Soc. linn. Lond. 10, p. 189, prodr. A. N.-Holl. p. 387 , suppl.p. 31, Endl. gen. p. 341, n. 2147, suppl. IV, 2,p.87, Meisn. gen. p. 333 (245). Oritina $R$. Br. in Linn. Trans. 10, p. 224. - Tropocarpa D. Don. mss.

Flores hermaphroditi, regulaies, spicati. Sepala 4, linearia, mox libera, apice recurva, decidua. Stamina 4 sepalis supira medium inserta ; antheræ subsessiles, ovatæ vel oblongæ, muticæ. Glandulæ hypogynæ 4 liberæ, breves. Ovarium sessile, 1-loculare, 2-ovulatum. Stylus filiformis, strictus, stigmate verticali continuo vix incrassato obtuso. Follicúlus coriacèus, loculo subcentrali 2-spermo. Semina erecta, apice vel utrinque alata. - Frutices arboresve. Novæ-Hollandia et Tasmanniæ, foliis alternis coriaceis planis integris dentatisve subtus stomatiferis, aut teretibus integerrimis undique stomatiferis, spicis axillaribus terminalibus brevibus erectis, floium paribus 1-bractéatis.

\section{Sectio 1. Edorites Endl. gen. p. 341, suppl. p. 87.}

Semina basi aptera. Antheræe sepalis revolutis exsertæ. Folia plana vel marginibus revolutis teretia, subtus 1 -sulca, stomatibus hypogenis. Flores suliccssilêt.

1. O, EXGELSA (R. Brown! suppl. p. 32), arborea, glalra, foliis petiolatis lanceolatis utrinque attenuatis nuticis reticulatis integerrimis passimque paucidentatis, spicis subsessilibus in paniculam terminalem congestis, rhachi puberulä. $\delta$ Ad fontès flum. Hastings, prope port. Maququaric N.-Holl. orientalis (Fraser ! cfr. Oxley Journ. p, 314). Tropocarpa D. Don! mss. in herb. Soc. linn. Arbor speciosa, 40-60 ped. alta. Folia cariacea, lote viridia, 4-6 poll. longa, 9-12 lin. lata, glabra, supra nitida, subtus pallidiora opaca, dentibus aut nullis aut paucis remotis brevibus acutiusculis, petiolo semipollicari. Spicse e summis axillis et terpinales 3 bipollicares, laxiusc日læ, bracteis parvis squamiformibus decidujs. Calyx glaber, 3 lin. longus, stylum æquans. Stigma haud incrassatum. Ovarium glabrum, ex Br. pubescens. (v. s. in herb. Brown, DC., Cunn.)

$\beta$ ? lancifolia; folits integerrimis obtisis, ovaŕio folliculocque sericeiś. -- In montibus Latrobe; Wellington; Munyan, Mitta-Mitta, etc., alpium Austrakiæe, alt. 
5,000-6,000 ped. (Ferd. Müller!). Orites lancifolia Ferd. Müll. definit. af rare pl., etc. Melljourne 1855, p. 31, n. 26.

2. O. Diver sifolia (R. Brown in Linn. Trans. 10, p. 190, prodr.p. 388), fruticosa, ramulis tomentosis, foliis sessilibus lanceolatis utrinque attenuatis mucronulatis integerrimis passimque apice denticulatis 1-nerviis eveniis adpresse puberulis supra mox glabratis nitidis, spicis terminalibus sessilibus, floribus glabris, ovario villoso, folliculo sericeo falcato-oblongo, suturà truncatâ vel leviter excisâ. $\bar{J}$ In summis montibus insulæ Diemen (R. Brown! Everett!). Folia plana, 1-1 $\frac{1}{2}$ poll. longa, 2-4 lin. läla, in eodem ramulo integerrima et apice denticulis mucronulisve obtusiusculis 3-5 prædita: Spicæe sessiles, folia æquantes. Flores præcedentis. Folliculus 6 lin. longus, nutans, breve acuminatus, basi attenuatus. (v. s. in herb. Brown., DC., Lindl.)

3. O. Mrliganz (Meisn. in Hook. Journ. 1852, p. 209), fruticosa, glabra, foliis breve petiolatis ovalibus dentatis 1 -nerviis penniveniis nitidis, spicis breve pedunculatis folio longioribus, ovario sericeo, folliculo ovato rostrato-acuminato. 5 In monte Sorrel, prope Mactuarie Harbour Tasmanniæ occidentalis (Milligan, n. 739!). Rami crassiusculi, dense foliosi, ramulis gláberrimis sæpe umbellatis. Folia rigidissima, crassiuscula, læete viridia, glaberrima, 10-12 lin. longa, 6-8 lin. lata, petiolo 1-2 lin. longo, dentibus utrinque 2-4 æqualibus $\frac{1}{2}-1$ lin. longis submucronulatis obtusisve, sinubus acutis obtusisque, venis supra impressis subtus obtuse prominulis, anastomosibus nuilis. Spicæ subbipollicares, densifloræ, rhachi calycibusque glabris. Stylus \& lin. longus, calycem paulo superans, stigmate leviter incrassato. Folliculus cum rostro 4 lin. Iongus, (v. s. in herb. Soc. linn. Lond.).

4. O. Revoluta (R. Brown! in Linn. Trans. 10, p. 190, prodr. p. 388), fruticosa, ramulis sericeo-tomentellis, foliis linearibus muticis integerrimis margine revoluto teretibus subtus 1-sulcis vel canaliculatis incavo-tomentosis supra glabris, spicis sessilibus, rhachi ovarirsque villosis, calyce glabro, folliculo sericeo elliptico recto acuto, suturà rotundatâ. 亏) In summis montibus insulæ Diemen (R. Brown! A. Cunn.! d'Urville!), monte Wellington, etc. (Gunn, n. 286!). - A. Rich. sert. Astrolab. p. $70^{*}$, t. 25, f. 1 , J. Hook. fil. fl. Tasmann..... Folia conferta, subpetiólata, vix pollicaria nec 1 lin. crassitie excedentia, lævia, supra obsolete 1-nervia. Spicæ 1-1 $\frac{1}{2}$ poll. longæ. Flores præcedentibus paulo minores. Stylus calycem breviter superans, capillaris, stigmate leviter incrassato. Folliculus tomentoso-sericeus, utrinque attenuatus, styli hasi mucronatus. (v. s. in herb. Brown., DC, Cunn., etc.)

Sectio II. Amphiderris $R$. Brown suppl. p. 32, Endl. $l$. c. - Genus Oritina R. Br. in Trans. Soc. Linn: 10, p. 224.

Semina utrinque alata. Antheræ sepalorum laminis concavis inclusæ. Folia subulato-teretia, supra 1-sulca, stomatibus amphigenis.

5. 0. A I I ULAR IS (R. Brown! suppl. p. 32), foliis petiolatis subulatis pungentimucronatis nitidis ramulisque glaberrimis, spicarum rhachi ovariisque sericeis, calyce glabro, folliculo glabro' oblongo apice rotundato extra medium styli basi divergente rostellato. . In monte Wellington et Tabulari insulæ Diemen (R. Brown! A. Gunn.! d'Urville! Gunn, n. 285! etc.). - A. Rich. sert. Astrolab. p. 71*, t. 25 , f. 2, Hook. fil. fl. Tasmann..... Oritina acicularis R. Br. in Linn. Trans. 10, p. 224*. Folia conferta, 1-1 $\frac{1}{2}$ poll. longa, 1 lin. crassa, in petiolum $2-3$ lin. longum egregie attenuata, spicis longiora. Flores brevissime pedicellati. Folliculus circ. 6 lin. longus. (v. s. in herb. Brown., Cunn., DC., etc.)

XXXIV. RHOPALA Schreb. gen. n.144, R. Brown' in Trans. Soc. Linn. Lond. 10, $p .190$ (excl.sp. phur.), Pohl pl. Brasil.1, p. 106, t. 86, 88 et 90, Endl. gen. p. 341, n. 2148, suppl. IV, 2, p. 87, Meisn. gen. p. 333 (245) et in Mart. fl. brasil. fasc.14, p. 79, t. 31-33. - Roupala Aubl.Guian. 1, p. 33, t. 32, Juss. gen. p. 79, Lam.ill. t. 55, Gertn. fil. fr, 3, p. 212, t. 217. - Rupala Vahl symb. 3, p. 20. - Leinkeria Scop. introd. n. 1607. Embothrii sp. Ruiz et Pav. R. peruv. t. 98, 99. — Ropala Rudge pl. Gug.p. 26, t. 39.

Flores hermaphroditi, regulares, racemosi. Calyx subclavato-cylindricus, rectus, sepalis 4 linearibus apice concavis demum liberis recurvis deciduis. Stamina 4 , exserta, supra medium sepali inserta, filamentis brevissimis, 
RHOPALA.

antheris linearibus vel ovalibus muticis vel brevissime apiculatis. Glandulæ hypogynæ 4 liberæ. Ovarium sessile, 1 -loculare, ovulis 2 collateralibus. Stylus filiformis, erectus, diu persistens, stigmate terminali clavato obtuso. Folliculus coriaceo-lignosus, ovalis, compressus, rostratus, lævis, 1-locularis, 2-spermus. Semina compressissima, oblonga, undique cincta ala tenerrime membranaceâ enervi apice basique elongatâ, nucleo centrali. - Arbores fruticesque Americæ tropicæ præsertim Cisandinæ, foliis sparsis coriaceis simplicibus dentatis rarius integerrimis vel passim impari-pinnatipartitis, racemis axillaribus terminalibusque simplicibus solitariis vel aggregatis, pedicellis geminatim 1-bracteatis liberís vel semiconnatis.

\section{A. Simplicifolice. - Foliis omnibus simplicibus, integerrimis vel scepius dentatis (cfr. $R$. montana et complicata).}

\section{$\S 1$. Foliis omnibus integerrimis.}

1, R. м Y RT I DEA (Pœppig et Endl.! nov. gen. 2. p. $35^{*}$, t. 149), foliis subpollicaribus lanceolatis obtusis planis utrinque reticulatis glabris, racemis axillaribus folia subæquantibus, rhachi ovarioque puberulis, sepalis glabris, stigmate simplici obtuso. 5 In rupibus basalticis Tvun-Leuvu, prope mont. ignivomum Antucensem, Chili australis (Pœpp.!). Embothrium myr lifolium Pœppig! mss. in herb. Zúccar. Chilensibus : Radal. Rami graciles, ramulis umbellatis dense foliosis glabris. Folia sparsa, erecta, coriacea, 8-15 lin. Ionga 3-5 lin. lata, obtusa vel obsolete obtuseque mucronılata, in petiolum brevissimum attenuata, supra subnitida, venis utrinque semiimmersis laxinscule prominulis, margine obsolete nerviformi. Racemi solitarii, sessiles, semipollicares vel parum longiores, pedicellis brevissimis ebracteatis puberulis. Sepala 2 lin. longa, laminâ vix longiore et fere plana. Filamenta medio sepali inserla, antherâ ovali-oblongâ muticâ exsertâ albâ sublongiora. Glandulæ hypogynæ ovoidee, glabre. Ovarium subsessile.'Stylus subulatus rectus, calyce paulo brevior, stigmate simplici haud incrassato, nec clavato. Capsula semiovalis, utrinque attenuata, lævis, glabra, subpollicaris, longitudinaliter dehiscens. Sem. ignota. Species insignis tam facie quam characteribus nonnullis, sepalis apice haud excavatis, filamentis infra laminam insertis antherâ sublongioribus et præcipue stigmate. a Rhopalis genuinis recedens et forsan genus vel subgenus proprium constituens. (v. s. sine fr. in herb. Zucoarini, nunc Univ. Monacens.)

2. R. zoranthoIdes (Meisn. mss. in herb. Mus. Vindob. 1854), glaberrima, foliis cartilagineis petiolatis ovatis ovalibusque obtusissimis supra nitidis subtus opacis venis supra impressis subtus obsoletis racemis axillaribus folia subæquantibus densifloris, pcdicellis brevissimis liberis crassis, calyce clavato, pistillo glaberrimo. 5 ? In montibus Guatimalæ (Friedrichsthal, n. 1225!). Verisimiliter arborea, fotorem putridum spargens (Friedrichsth. in sched.). Rami crassi, rugosi, ramulis conferte corymbosis brevibus dense foliosis, novellis rufo-tomentosis. Folia cras-

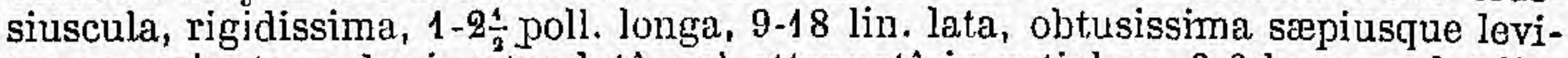
ter emarginata, e basi rotundatâ vel attenuatâ in petiolum 3-6 longum $\frac{2}{3}-1$ lin. latum decurrentia, marginibus obtusis præcipie basin versus recurvis, nervo venisque apicem petentibus supra insculptis subtus immersis evanescentibus vel obliteratis, reticulatione supra minutà subtus penitus nullà. Racemi 2-3 poll. longi, sessiles, recti, patuli, terminales folia superantes, rhachi pedicellis persistentibus $\frac{1}{2}$ lin. longis demum quasi tuberculatà. Calyx 4 lin. longus, basi parum tumidulus, limbo fere $1 \frac{1}{2}$ lin. longo obtuso. Sruamulæ hypogyn $* 4$ membranaceæ, triangulares, brevissime. Stigma subclavatum, obtusum, sulcatum, stylo vix crassius. Accedit quodammodo ad R. cordifoliam, sed folis nunquam dentatis, etc., bene distincta. (v. s. sine $\mathrm{r} r$. in herb. Mus. Cæs. Vindobon.)

3. R. SсномвURGKII (Klotzsch! in Linnsea 20, p. 474"), ramulis foliis novellis racemisque dense ferrugineo-tomentosis, foliis breve petiolatis ovalibus obtusis ovatisve breve acuminatis, supra mox glabris subtus diu tomentosis, venis tenuibus supra immersis subtus levissime prominulis dense reticulatis, racemis folio longioribus nutantibus donsifloris; pedicellis calyce triplo brevioribus subliberis crassiusculis, ovario rufo-villoso. $\mathcal{E}$ In montibus Roraima Guianæ Anglicæ (Rich. 


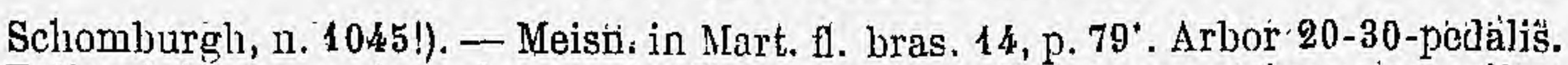
Folia rigida, sæpe in eodem ramo diversa, alia ovalia obtusa utrinque sequaliter

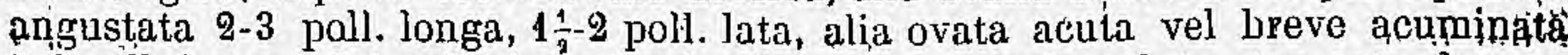
5-6 poll. longa, 3-4 poll, lata, basi rotundata vel subcordata, tomento demum detrito subtus reticulata supra subnitidi, jetiolo 3-6 lin. longo crassa, Racemi axillares solitarii, 6-10 poll. Iongi, fomentr brovi denso ferrugineo undique sublanuginosi, pedicellis $1 \frac{1}{2}-2$ lin., callycibus 5 lin. Iongis. Stylus sensim in stigma subincrassatus. ( $\mathrm{s}$. s. in herb. reg. Berolin. et Sliuttl.)

4. R, FERRUGINEA (Kunth in H. et B. nov. gen. 2, p. 153*), foliis potiolatis obovato: oblongis obtusis basi angustatis retículatis glabris, júníoribus cum ramis pedunculis pediccllis ovarijsque ferrugineu-tomentosis, racemis axillaribus geminis folio brevioribus, calyce glabriusculo, glandulis hypogynis subrotundatis, stigmate élavato. 5 In Peruvie prov. Bracamoros (IIumb. et Bonpl.). - Roem. et Schulé: syst. 3 , mant. p. $288^{*}$. Arbor, ramis glalsis verrucosis: Folia cirç: 3 poll. longa, plana, demum ntrinque glabra, petiolo subpollifari. Racemi erecti, vix $\mathbf{3}$ poll. longi. Antherce sessiles. Spëcim. Humb. néc in herb. 'Willd. nec in herb. Kunth. exstat.

ß. minor, foliis minoribus apice rotundatis vel emarginatis basi obtusis parum angustatis supra demum subnitidis immerse venoșs haud reticulatis suhtus diu tomentosis. - In Venezuelæ monte Sillà de Caracas (Linden, n. 15! Funk et Schlim coll. 1845, n. 133 !). Folia $2-2 \frac{1}{3}$ poll. longa, $1-1 \frac{1}{2}$. poll. lata, petiolo 2-4 lin. longo, juriora utrinque laxe prominulo-reticulata et cum ramulis ferrugineo-tomentosa. Racemi 3-5-pollicares. Caljx stylum basi hirsutulum æquans, 5 lin. longus, limbo vix tumidulo. Stigma atrum, $\frac{1}{2}$ lin. longum, stylo duplo crassius. Affinis R. Schomburgkianæ, quxe foliis majoribus; racemis longioribus; etc., facile dignoscenda. Cave ne confindas cum Andripetalo ferrugineo, quod præeter char. genericos discrepat fluribus dense tomentosis, etc. (v. s. in herb. Ges, Vindobon., Shuttl., Boiss., etc.)

5. R. SUAVEOLENS (Klotżsch! in Linnæâ 20, p. $473^{*}$ ), foliis longe petiolatis ovatis vel ovali-oblongis acutis planis utrinque breve acuminatis haud reticulatis glaberrimis supra subnitidis subtus opacis venis leviter prominulis versus marginem evanidis, junioribus ramulisque subsericeo-tomentosis, racemis breve pedunculatis folio longioribus laxiusculis undiqque dençe fulro-tomentosis sublianatis, pedicellis subliberis calyce pluries brevioribus, ovario fulvo-villoso. $\xi$ In savánis circa Roraima Guiane Anglice !Schomburgk coll. 1842-1843, n. 544! ex parte et 855!). - Meisn. in Mart. fl. Jras. 14, p. 80 . Arbor 60-80 pedum. Folia rigida, excluso petiolo, 2-5 poll. longa, $1 \frac{5}{4}-3$ poll. lata, vịidia, subeongoloria, petiolo i-3 poll. longo gracili. Racemi axillares solitarii, 4-6 poll. longi. Calyx pedicello 3-4-plo longior, 4-5 lin. longus, tubo limibum sefuante et parum angustiore. Stylus sensim in stigma obtusum leviter inerassatus. (v. s. in herb. reg. Berolin. et Shuttl.)

B. minor (Aleisn. 1. c. p. 80), foliis minoribus sæpe complicatis subtus obsolete reticulatis et diutius pubezcentibus, flornm tomento subsericeo-velütino (Schomburgk 1 n. 544, ex parte). Foliorum lamina $1 \frac{1}{3}-2 \frac{1}{3}$ poll. longa, $1-1 \frac{1}{2}$ poll. lata, petiolo 3-6 lin. longo. Giet. ut in specièi typo. (v. s. in herb. Cos. Vindob. et Boiss.)

6. R. овтUSATA (Klotzsch! in Linnæà 15, p. 54, et in. Hook. Journ. 4, p. 321), foliis ovali-oblongis obtusissimis planis glabris in peliolum leviter subdecurrentibus haud reticulatis supra nitidis sublus opacis, yenis primariis utrinque leviter prominulis reliquis obsoletis, racemis subsessilibus folia superantibus glabris, pedicellis calyce triplo brevioribus infra medium connatis, ovario tomentoso. 5 ? In insulis flum. Rio Negro Guianæ. Angliçe (Schomburgk, n. 215! ex parte, fide Kl.) et circa Barra, Barcellos et San Isabel Brasilize borealis (Spruce, n. 968! 1945!). Meisn. in Nart. fl. bras. 14, p. $80^{\circ}$. Frutex? remis gracilibus glabris. Folia excluso petiolo $4-12$ lin. Iongo, 2-6-pollicaria $1-2 \div$ poll. lata, rigida, supra létê viridia; sublus fúlva, margine interdúm recurro. Racemi axillares, solitarii, 3-7 poll. longi, pedicellis crassiusculiș $1 \frac{1}{2}-2$ lin., calycibus $4-5$ lin. longis. Stýlus glaber, stigmate clavalo subincrassato. Folliculus ventricoso-ovalis, compressus, glabríusculus, stylo rostratus et cum eo semipollicaris. (v. s.' in herb, reg. Berolin.; 'Ac, Monaic. et DC.) 


\section{RHOPALA. PROTEACE ¿ (AUCTOR MEISNER).}

7. R. Thomestana (Moricand! pl. nouv, d'Amér. p. 172*, t. 100), ramulis apice tomentellis, foliis petiolatis ovalibus suborbicularibusque breve acuminatis obtusisve supra obsolete dense reticulatis nitidis subtus opacis, racemis folio longioribus laxiusculis, rhachi pedicellis liberis ovariisque ferrugineo-tomentosis, calyco glabro. 7 ? In Brasiliæe prov. Bahiensi, circa San Thome (Blanchet, n, 3578!). Meisn. in Mart. fl. bras. 14 , p. $80^{*}$. Rami graciles, demum glabri. Folia 1-2 poll. longa, 9-15 lin. lata, in petiolum 4-7 lin. longum breviter attenuata, supra satuTate viridia, reticulatione supra satis densâ subimmersấ subtus plane nuḷầ. Racemi axillares solitarii vel rarius gemini, 2-4 poll. longi, pedicellis flore subtriplo lurevioribus. Calyx. 3 lin. longus, basi tumidulus, limbo subgloboso. Stylus glaber, stigmate clavato duplo tenuior. A proxime affini $\mathrm{k}$. obovatâ foliis minoribus, nervatione, pedicellis tomentosis, etc., facile dignoscenda. (v. s. comm. a b. Moricand.)

8. R. NITIDA (Rudge! Guian. 1, p. 26, t. 39), glaherrima, foliis petiolatis ellipticis breve acuminatis planis dense semiimmerso-reticulatis nitidis racemum superantibus vel subrequantibus, pedicellis subliberis tenuibus cum calyce parum longiore pistilloque toto glaberrimis. 5 ? In Guianâ Gallicâ, circa Cayennam (Martin!) et Anglicà (ex Mey.).-R. Brown in Linn. Trans. 10, p. 191, Roem. et Schult. syst. 3, p. 428, mant. p. 284, Meyer fl. esseq. p. $77^{*}$, Meisn. in Mart. N. Uras. 14, p. 81. Folia incluso petiolo 8-19 lin, longo, 4-10-pollicaria, 2-3 poll. lata; integerrima. Racemi 5-6 poll. longi, laxiusculi, pedicellis-2 liil longis tenuibus vix basi connatis. Calyx 3 lin. longus, limbo ovali obtuso. Glandule hypogynæ obtusa, semiconnatw. Pistillum calycem æquans glaberrimum, stigmate vix incrassato. (v. s. in herb. Bankss.)

\section{§2. Foliis dentatis vel passim integerrimis.}

9. R. montana (R. Brown 1 in Linn. Trans. 10, p. 191, excl. syn. Willd.), foliis ellipticis breviter acuterjue acuminatis subintegerrimis in petiolum gracilem dimidiam laminam subæquantem decurrentibus complicatis vel demum planis supra subnitidis subtus opacis utrinque laxe semiimmerso-reticulatis glabrisque, racemis folio longioribus confertifloris subsericco-tomentellis, pedicellis subliberis calyce dimidio brevioribus, ovario fulvo-sericeo, stigmate clavato. 春 vel $\hat{f}$ In Guianẩ Ánglicâ (Aublet! L. Richard!) et Anglica (Mley. esser. p. 78, Rich. Schomb. n. 963i). Roem. et Schult. syst. 3 , p. $428^{*}$, mant. p. 284 , Klotzsch! in Línneâ 20, p. 472 , Mcisn. in Mart. 1l. bras. 14, p. $81^{*}$. Roupala montana Aubl.! Guian. 1, p. 83*, t. 32, Lam. ill. 1, p. 243, t. 55 , Poir, dict. 6, p. $316^{*}$. R. frondosa L. Rich.! mss. in herb. Kunth. Rupala montaria Vahl symb. 3, p. 20, Gærtn. fil. fr. 3, p. 212, t. 217, suppl. 1, t. 27. Frutex 7-8-ped. (Aubl.). Arbor 40-50-pedalis (Schomb.). Folia rigida, 2-3 poll. longa, 12-20 lin. Jata, in jetiolum gracilem 10-14 lin. longum decurrentia, integerrima et passim obsolete paucidentati. Racemi terminales et axillares, solitarii vel gemini, 5-6-pollịcares, subșessiles, tomento minuto flavido vel fulvo, florihus 3-4 lin. longis odoratis. Stigma stylo paulo crassius. (v. s. in herb. Banks., Kunth. et reg. Berolin.)

10. R. MEDIA (R. Brown!l. c. p. 191), foliis ellipticis acute acuminatis subintegerrimis in petiolum gracilem laminâ 3 -4-plo breviorem decurrentibus planis obsolete laxe reticulatis supra nitidis subtus opacis, venis supra immersis subtus primariis prominulis reliquis subimmersis, racemis folio longioribus laxiusculis parce subsericeo-tomentellis vel glabriusculis, pedicellis calyce triplo brevioribus liberis, ovario fulvo-sericeo, stigmate vix incrassato. f? In Guianâ Gallicâ, circa Gayenne (Rohr! L. Rich.! herb. Mus. paris. n. 76! 77! 78! in herb. Viudob.) et Colombia (Moritz, n. 909!). - Roem. et Schult. syst. 3, p. 428, Klotzsch l in Linn:eâ 15, p. 53, Mcisn. in Mart. 11. bras. 14, p. 81. Rupala montana Willd.! sp. 1, p. 536, fide ej. herb. n. 2488! R. montanæ nimis affinis et forsan mera ejus var. Folia in specim. Aublet (herb. Banks.) plerarque simplicia, passim pinnatim 3 -foliolata, foliolis ovatis integerrimis subobtusis dense reticulatis opacis ; racemi rufo-tomentosi, floribus subsessilibus. Similiter a diagnosi recedit specim. Goudot! in herb. Boiss., cui tamen folia omnia simplicia. (v. s. in herb. Banks., Willd., Shuttl., reg. Berolin., ces. Vindobon.)

11. R. COMPLICATA (Kunth! in H. et B. nov. gen. 2, p. 153*, t. 119), foliis ovatis longiuscule attenuato-acuminatis e basi late rotundatà in petiolum decurrentibús subintegerrimis complicatis glabris utrinque opacis laxe reticulatis, venis remotis 
semiimmersis vel demum supra obliteratis, racemis folia æquantibus vel superantibus laxiusculis tomentosis, pedicellis calyce duplo brevioribus liberis, ovario fulvo-tomentoso, stigmate subincrassato. 5 vel 7 In Colombiæ Sierra de Barbula, prope Porto Cabello, etc., usque ad Jl. Orenoco (Humb. et Bonpl.! n. 752 et in herb. Willd. n. 9489!), Llanos de Barcelona, Angostura (Moritz !), Guianâ Anglicâ (Rich. Schomburgk, n. 846!), ins. Tabogà in sinu Panamâ (Bentll. Bot. Sulph. p. 161). Roem. et Schult. syst. 3, mant. p. 286, Klotzsch in Linneeâ 20, p. 473, Meisn. in Mart. fl. bras. 14, p. 82*. Embothrium Chaparro Humb.? in mappấ Bot. æquinoct., R. Br. in Linn. Trans. 10, p. 221. E. curvatum Willd. herb., fide Spreng. syst. 1, p. 482. Arborea (Humb., Benth.) vel fruter 6-8-pedatis (Schomb.). Folia crasse coriacea, slaucescentia, $1 \frac{1}{2}-5$ poll. longa, 1-3 poll. lata, integerrima vel rarius passim remote obtuseque paucidentata, peliolo 10-14 lin. longo sæpe ad basin usque limbo decurrente angustissime marginato. Racemi 3-5-pollicares, tomento pallide rufo nunc denso nunc rarescente, pedicellis $1-1 \frac{1}{2}$ lin. longis, floribus odoratissimis. A R. monlanâ vix satis distincta.-R. complicata Linden cat. de pl, exot. cult., etc., pour 1853, n. 8, ex Schlecht. Bot. Zeit. 1853, p. 717, cui tribuuntur folia composita jrofunde dentata, est sine dubio species distincta R. adiantifoliæ affinis. (v. s. in herb.Willd., Kunth. et reg. Berolin.)

12. R. томеNтоSA (Pohl! pl. Bras. 1, p. 108, t. 87), folis ovalibus vel ellipticooblongis acute a'uminatis utrinque æqualiter attenuatis paucidentatis integrisque utrinque prominulo-venosis obsolete laxeque reticulatis supra glabris subnitidis subtus opacis cum petiolo ramulisque fulvo-tomentosis tarde glabrescentibus, racemis folia æequantibus vel longioribus tomentosis laxiusculis, pedicellis flore brevioribus subliberis, calycis limbo glabrescente, ovario incano, stigmate parum incrassato. 5 ? In campis Brasiliæ.-Meisn. in Mart. fl. bras. 14. p. $82^{*}$. Rami teretes, apice dense rufo- vel cano-tomentosi vel sublanuginosi. Folia excluso petiolo 9-12 lin. longo, 3-6-pollicaria, $1 \frac{1}{2} 2 \frac{1}{2}$ poll. lata, passim obovata, supra pallide viridia, semper acuminata. Racemi axillares, solitarii, subsessiles, fulvo- vel canotomentosi. Pedicelli calycis tubum requantes vel breviores. Calyx 5 lin. longus, limbo ovali tubum subequante et vix ampliore. Ovarium albido-pubescens. Stigma stylo parum crassius, obtusum.

a. integrifolia, foliis integerrimis, rarissime passim obsolete dentatis. - Circa Santa-Cruz, prov. Goyaz (Pohl, n. 2624!). $\alpha$ geminata Meisn. l. c. (ex errore). Dentes extra medium folii rarius occurrentes pauci, brevissimi, obtusi. (iv. s. in herb. Nus. Cæs. Vindob., Mart., Shuttl.)

$\beta$. dentata, foliis extra medium dentatis vel passim integris, dentibus obtusis vel rarius acutıs. - In Brasilià meridionali et prov. Goyaz (Sellow, n. 387! Pobl! Helmreichen, n. 209!), $\beta$ Sellowii Meisn. olim l. c. R. ovalis Klotzsch! in Linnæâ 15, p. 54, fide herb. reg. Berolin. (non Pohl). Folia sæpius ovata, mox glabrescentia, subtus ad costam plus minus tomentosa. Valde accedit ad R. Gardneri $\alpha$, sed discrepat foliorum nervis fortioribus magisque puberulis, racemis dense tomentosis et pedicellis brevioribus. (v. s. in! herb. reg. Berolin. et cæs.Vindobou.)

13. R. ovalis (Pohl 1 pl. Bras. 1, p. 107, t. 86), ramulis glabris, foliis ovalibus breviter acuteque acuminatis subintegerrimis in petiolum marginatum attenuatis utrinque prominulo-nerrosis glabris supra nitidis, racemis folio longioribus minute parceque puberulis, pedicellis calycc subtriplo brevioribus calyce vix clavato demum glabro limbo tubo fere dimidio breviore, ovario cano-tomentoso, stigmate cylindraceo vix incrassato. $\mathcal{F}$ In prov. Goyaz, Brasil. (Pohl, n. 1938!). Meisn. in Mart. fl. bras. 14, p. $83^{*}$. Rami virgati, cinerei. Folia incluşo petiolo 9-12 lin. longo, 4-5-pollicaria, 2-2 $\frac{1}{2}$ poll. lata, pleraque integerrima, passim dente uno alterove parvo obtuso prædita. Racemi axillares solitarii, subsessiles, 6-8 poll. longi, bracteis squamiformibus minutis fuscis ovatis acutis adpressis 1 lin., pedicellis 2 lin. longis. Calycis limbus tubo vix crassior. Stylus 4-5 lin. longus. Ovarium sessile. Differt a simillimâ R. Gardneri pedicellis styloque paulo longioribus, stigmate tenuiore, elc., et a R. tómentosà, foliis plcrumque latioribus, breve cuspidato-acuminatis, ramis floribusque demum glabris, etc. (v. s. in herb. Cres. Vindob., Mart. et Shuttl.)

14. R. GARDNERI (Meisn. in Mart. fl. bras. fasc. 14 , p. $83^{*}$, t. $31, f$. 1), ramulis apice pubescentibus, foliis ovatis vel ellipticis acute acuminatis in petiolum longum 
attenuatis dentatis integrisve supra subnitidis subtus fuscescentibus utrinque glabris elevato-venosis obsolete laxeque reticulatis, nervo subtus petioloque tomentellis, racemis folio subrqualibus densifloris incano-tomentellis, pedicellis subliberis brevissimis, calyce clavato parce puberulo limbo tubum dimidio tenuiorem subæequante, ovario dense albo-villosulo, stigmate parum incrassato. 5 ? In Brasilì prov. Minas Geraës. Nimis affinis H. ovali et forsan mera ejus var., præter notas jam indicatas recedens foliis longius acuminatis, venis mágis conspicuis, racemis sæepius folio brevioribus, tomento minuto in calyce 3-4 lin. longo rarescente, pedicellis vix 1 lin. longis.

$\alpha$. dentata (Meisn. 1. c.), foliis extra medium plus minus dentatis, rarius passim integerrimis, infra medium sensim attenuatis, petiolis ramuhsque diutius villosiusculis (Gardner, n. 5169!). Folia sæpe ulrinque aqualiter acuminatoattenuata nec ovata $2 \frac{1}{2}-4$ poll. vel passim vix $1 \frac{1}{2}$-poll. lata. Forma accedens ad R. nervosam, sed jam nervatione et petiolo longo facile dignoscenda. (v. s. in herb. Shuttl., DC., Boiss., etc.)

B. integrifolia (Meisn. 1. c. p. 83, t. 31, f. 1), foliis integerrimis vel raro passim dente uno alterove obtuso vel obsolete præditis e basi rotundatâ subito vel rarius sensim attenuatis distinctius reticulatis, petiolis glabratis (Gardner, n. 5168! Vauthier, 1. 428 l). Forma cum $\alpha$ fere confluens. (v. s. in herb. Shuttl., Vindobon., etc.)

$\gamma$. angustata (Meisn. 1. c.), foliis lanceolatis vel oblongo-lanceolatis utrinque aqualiter acuminato-attenuatis glabris integerrimis vel passim obtusissime undulato-dentatis racemo tenuiter tomentello demum glabrescente. brevioribus. - In prov, Goyaz (Gardn. n. 4356!). Folia 3-4 poll. longa, 9-18 lin. lata, venis primariis numerosioribus magisque parallelis, petiolo 6-12 lin. longo. Racemi 5-6-pollicares. (v..s. in herb. Caes. Vindobon.)

15. R. c ORDIFOLIA (herb. Kunth.! nov. gen. 2 , p. $152^{*}$, t. 118), folis subrotundoovatis cordatis planis remote grosse dentatis subintegerrimisque glaberrimis laxe reticulatis venulis subimmersis, racemis folio longioribus densifloris, rhachi pedicellis subliberis ovariisque ferrugineo-tomentosis, caljce subclavato rufo-pubescente, stigmate parum incrassato. 5 In collibus prov. Jaen de Bracamoros Peruviæe (Humboldt!). - Roem. et Schult. syst. 3, mant. p: $286^{*}$. Embothrium cordifolium Willd., fide Steudel. Arbuscula 1-2-orgyalis, ramosissima, ramis glabris. Folia crasse coriacea, 4-pollicaria, petiolo fere 1 poll. longo. Racemi axillares, solitarii, 7-8 poll. longi. Calyx albus, fide herb. Willd. n. 3557 , pedicellis tenuibus subliberis 2-3-plo longior, 4-5 lin. longus, limbo tubum subæquante parum crassiore obtusissimo. Antheræe sessiles. Glandule liypogynæ liberæ, carnosæ, oblongæ, glabre. Stigma clavatum, stylo parum crassius. (v. s. in herb. Willd. n. 2499l)

$\beta$. subintegerrima, foliis integerrimis vel passim dente uno alterove brevi obtuso præditis diutius tomentosis. - In Novà-Granadà (Funk et Schlim, n. 1629!). Folia incluso petiolo circ. semipollicari $2-3$ poll. longa, $1 \frac{1}{2}-2$ poll. lata, ovalia vel orbicularia, utrinque elevato-venosa, laxe vel obsolete reticulata, supra demum nitida. Racemi 3-5-pollicares, deflorati recurvo-arcuati. (v. s. in herb. Shuttl.)

16. R. LU CEN S (Meisn. in Mart. fl. bras. fasc. 14, p. $84^{\star}{ }^{\star}$, t. 31, f. 2 ), foliis ellipticis ovatisve breve acuminatis in petiolum gracilem marginatum decurrentibus obtuse undulato-dentatis vel passim subintegerrimis supra nitidis opacis utrinque-elevato-venosis vix reticulatis ramulisque glaberrimis, racemis folio longioribus ferrugineo-tomentosis laxiusculis, calyce pedicellis subliberis quadruplo longiore glabrescente. 5 ? In Brasiliæ prov. Bahiensi (Blanchet, n. 3243!), et Serra dos Orgaos prov. Rio de Janeiro (Gardner, n. 5846! 5848!). Rami apice subcompressi, juniores minute tomentelli. Folia satis rigida, $1 \frac{1}{2}-3$ poll. Jonga, 1-2 poll. lata, sope subrhombea, infra medium integerrima, subtus opaca, petiolo 5-10 lin. longo, dentibus sinubusque 1-2 lin. latis obtusis. Racemi 5-7-pollicares, yedicellis vix imâ basi connatis. Calyx 3-4 lin. longus, limbo obtuso $1 \frac{1}{2}$ lin. longo demum fere glabro. Stylus tenuis, rufus, glaber, 3 lin. longus, stigmate vix duplo crassiore atro. (v. s . in herb Shut.tl., DC., Boiss., Mus.Vindob., etc.)

17. R. GLABRAT A (Klotzsch! mss. in herb. reg. Berolin.), adulta glabra, foliís ellip. ticis acutis in petiolum brevem decurrentibus inæqualiter obtuse dentatis infra medium rel passim totis integerrimis haud reticulatis supra nitidis, nervo venis- 
que primariịs supra immersis obsoletis subtus leviter prominulis intra marginem subrecurvum arcuatim connexis venulis inconspicuis, racemis.... 5 ? In Bràsiliâ australiore (Sellow !). - Meisn. in Mart. fl. bras. 14, p. 84 *. Folia rigida, 2-3 poll. longa, 15-24 lin. lata, viridia, juniora cum ramulis novellis minute ferrugineotomentosa, mox glaberrima, dentibus $\frac{1}{x}-1$ lin. longis remotis vel subnullis vel crebrioribus circ. 2 lin. distautibus semper obtusis sinu obtusangulo separatis, venarum secundariarum anastomosibus raris vel nullis. Petioli 5-6 lin. longi.. Cæt. ignota. An a R. Brasiliensi satis distihcta? Affinis quoque R. lucenti, sed recedens foliis crassioribus haud reticulatis subtus minus opacis, ctc. (v. sp. 2 steril. in herb. reg. Berol.)

18. R. NERyos'A (Klotzsch! in Linnæê 15, p. 50), foliis oblongo-ellipticis acutis apice basique equaliter attenuatis obtusiuscule dentatis basi integris utrinque dense elevato-retirulatis glabris, petiolis brevissimis ramulisque fulvo-tomentosis, racemis.... 5 ln Brasilià, verisim. australi (Sellow, n. 11231). - Meisa. in Mart. fl. bras. 14, p. 84*. Arbuscula 10-pedalis, ramulis apice subvillosis mox glabratis. Folia 3-4 poll. longa, $1 \frac{1}{2}$ poll. lata, concoloria nitida (Sell. in sched.), ex sicco opaca, supra viridia, subtus fuscescentia, dentibus $1 \frac{1}{2}-2$ liu. distantibus, $\frac{1}{2}-\frac{2}{4}$ lin. longis, petiolo 1-3 lin. longo. Cret. ignota. Accedit ad R. Brasiliensem, sed distincta petiolis brevissimis, venis etiam supra acute prominulis, etc. (v. sp. 1 sterile in herb. reg. Berolin.)

19. R. DENTAt A (R. Brown! in Linn. Trans. 10, p. 192), foliis glaucis? opacis ovato-lanceolatis longe acuminatis complicatis basi longe attenuatis remote subuncinato-dentatis, nervo venisque primariis ulrinque proninulis reticulo nullo vel obsoleto immerso, racemis folium superantibus tomentellis, pedicellis liberis calyce glabrescente dimidio brevioribus, ovario rufo-tomentoso. 5 ? In Guiauâ Gallicâ (Alex. Anderson l). - Meisn. in Mart. fl. bras. 14, p. $85^{*}$. Folia incluso petiolo circ. pollicari 4-6 poll. longa, $1 \frac{1}{2}-2$ poll. lata, acumine lineari, dentibus uncinatoacutis obtusisve. Racemi axillares, 5-7 poll. longi, tomento minuto, pedicellís 1 $\frac{1}{2}-2$ lin., calycibus 3-4 lin. longis, limbo obtuso. Stigma clavatum, subtruncatum. (v. s. in herb. Banks.)

20. R. MAGROPODA (Klotzsch! in Linnzea 20, p. 474*), foliis longe petiolatis elliptico-oblongis complicatis acute acuminatis glabris remote obtuse dentatis passimque integerrimis supra nitidis, venis utrinque conspicuis immiersis tenuibus paucis parce anastomosantibus, racemis folio longioribus densifloris, rhachi ferrugineâ, pedicellis liberis calycibusque triplo longioribus incanis, ovario sericeo, stigmate vix incrassato. F In vallibus Aragua Colombide (Karsten 1). Frutex 6-8-pedalis, ramulis subverticillatis, junioribus apice tomentellis. Folia rigida, viridia, 2-3 poll. longa, 10-12 lin. lata, utrinque attenuata, subtus opaca, petiolo gracili 12-18 lin. longo puberulo superne marginato-canaliculato basi tereti, venis primariis tenerrimis penitus immersis, venulis raris haud vere reticulatis. Racemi axillares, solitarii, subsessiles, 5-7 poll. longi, jedicellis 1 lin. longis, tomento breviore et pallidiore quam rhacheos, Calyx 3 lin. longus, clavatus, limbo obtuso glabrescente. Stigma stylo vix crassius. Forsan mere var. R. dentatx, præcipue foliis minoribus recedens. (v. s. in herb.reg. Berolin. et Kunth.)

21. R. BoISSIERIANA, foliis ovatis longe angusteque acuminatis basi rotundatâ in pètiolum longum marginatum brévissime decurrentibus remote obtuseque dentatis vel passim subintegerrimis glabris supra subnitidis immerse venosis sublus tenuiter elevato-venosis obsolete laxeque reticulatis, racemis folio longioribus densifloris subtomentellis mox glabris, pedicellis subliberis calyce triplo brevioribus, ovario rufo-tomentoso, stigmate clavato. 5? In Nuvis-Granatæ prov. Pampelona et Ocana (Linden, n. 1359 ! Schlim, il. 134!). R. Pamplonensis Linden? cal. pl. exot. cult. 1853, n. 8. non descripta. Folia incluso petiolo $1-1 \frac{1}{2}$-pollicari 4-5 poll. longa, $1 \frac{1}{2}-2$ poll. lata, plana vel complicata, subconcoloria, subtus opaca, in acumen 6-12 lin. longum 1 1 -2 lin. latium aculum sensim attenuata, dentibus 3-6 lin. distantibus brevibus obtusis valde inaqualibus. Racemi axillares solitarii vel gemini, subsessiles, 5-6-pollivares, stricti, tomento minuto obsoleto. Calyx 3 lin. longus, luteus, apice basique parum tumidulus, limbo tubo breviore. Stigma stylo brevi parum crassius. Affinis R. dentate et macropode. (v. s.' in herb. Boiss, , DG. et Mus. Vindobon.)

22. R. RHOmbIfolia (Mart. mss.! in herb. Ac. Monac.), foliis ovali-oblongis acu- 
tiusculis vel subacuminatis in petiolum brevem cuneato-attenuatis remote obtuseque dentatis infra medium vel passim totis subintegris utrinque leviter elevatovenosis adultis ramulisque glaberrimis supra nitidis, racemis folio brevioribas laxiusculis xufo-tomentellis, bracteis pedicello dimidium calycem æquante diplo brevioribus, calyce glabrescente limbo subgloboso, ovario ferrugineo-tomentoso, stigmate subclavato. 5 et $亏$ In Brasiliæ prov. Minas Geraës, Serra de Caracu (Martius 1), Alto de Boa Vista et Serra de Moamy (Sellow, n. 3561). - Meisn. iu Mart. fl. bras. 14, p. 85 ;, t. 32, f. 2 . R. longepetiolata Klotzsch 1 in herb. reg. Berol. (nec Polil l), Arbor (Mart.) vel frutex 6-pedalis (Sellow). Folia rigida, incluso petiolo 3-5 lin. longo marginato 2-4 poll. longa, 6-12 poll. lata, mutica, subtus opaca rufidula. Racemi axillares sessiles, bracteis minutis acutis. Ovarium sessile, stylo 2 lin. longo, stigmate vix incrassato. Valde quidem accedit ad R. longepetiolatafti, sed distincta foliis multo rigidioribus sujra nitidis plerumque minoribus, petiolo racemisque brevioribus, tomento ráriore ferrugineo nec cano, atc. (v. s. in herb. Ac. Monac., Reg. Berolin. et Kunth.)

23, R. Longepetrolata (Pohl! pl. Bras. 1, p. 109, t. 88), foliis oblongo-ellipticis olstuse acuminatis serrato-dentatis basi in petiolum longum attenuatâ apiceque integris utrinque elevato-nervosis ramisque glabris, racemis folio brevioribus laxiusculis tenuiter puberulis, bructeis pedicello dimidium calycem subæquante parum brevioribus, calyce demum glahro, limbo oblongo, ovario cano, stigmate clavato oblongo. 5 ? Circa Rio de Janeiro (Pohl, n. 4884. l).- Meisn. in Mart. fl. bras. 14, p. 85*. Rami virgati, stricti, glabri. Folia herbaceo-coriacea, vix rigida, utrinque attenuata, sılbmucronulata, laminâ $3-5$ poll. longa, petiolo $1-1 \frac{1}{2}-$ pollicari submarginato. Racemi axillares, solitarii, subsessiles, $3-5$ poll. langi, tenuiter puberuli, bracteis oblongis acutiuseulis, pedicellis domum 2 lin. longis. Galycis limbus tubc dimidio brevior et parum crassior. Stylus 3 lin. longus. (v. s. in herb. Cæs., Vindols. et'Mart.).

24. R. GRANDIF OLIA (Klotzsch! in Linnæâ 15, p. 56), foliis ovalibus oblongis vel obovato-oblongis roturidato-obtusissimis multidentatis e basi integrâ parum angustatâ in petiolum brevem sùbdecurrentibus laxe relicunlatis opacis glabris margine leviter recurvis, venis venulisque subtus prominulis supra subimmersis, deptibus sinubusque obtusis, racemis... 5. In Brasiliâ, verisim. australi (Sellow !). - Meisn. în Mart. fl. bras. 14, p. $86^{*}$. Rami virgati, rugoso-sulcati, glabri. Folia modice

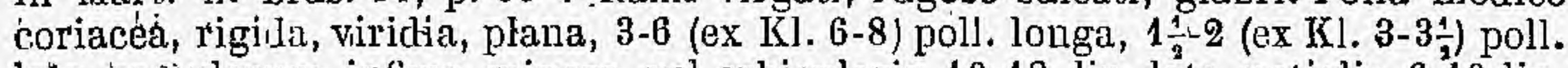
lata, ranulorum infima minora vel orbicularia 10-18 lin. lata, petiolis 6-10 lin. longis subteretibus, novella vel summia lineari-oblonga, 2-4 poll. Ionga, 6-7 lin. lata, supra subevenia. Species non satis nota, (v. s. 1 sterile in lierp. reg. Berrolin.)

25. R. ово ов т A (Kunth I in H. et B. nov. gen. 2, p.153*, t.120), foliis petiolatis qbovatis brevissime acuminatis basi cuneato-attenuatis extra medium remote dentatis passimque integerrimis, immerse reticulatis opacis glabris, venis primariis supra insculptis subtus prominulis, racemis folio sublongioribus, pedicellis liberis cum rhachi ramisque novellis ferruginęo-tomentosis..... 5 In montibüs dfrca Popayan, Quito (Humboldt! n. 1905). - Roem. et Schult. syst. mant. 3, p. 287*. Arbor

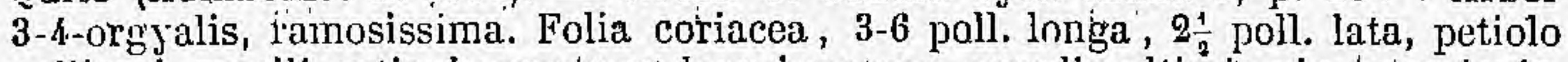
pollicari gracili, reticulo venarum laxo immerso, venulis ultimis vix conspicuis. hacemi axillares et terminales solitarii. Flares ignoti. Racemus fructifer semipedalis, pedicellis vix 2 lini. longis, Folliculi scssiles, subfalcdtơ-oblbngí, utrinque attenuati, styli basi adscendenti-rostrati, læves, pollicares, 3 lin. longi. Semina undique alata, lineari-oblonga, recta, 10 lin. longa, 2 lin. lata, alà tenui diaphanâ encrvi, nucleo ovato-oblongo compressissimo atro 2 lin. longo, chordâ rẹctâ ex nuclei apice attenuátó éxcurrente punctum pelliucidum in apice alæ (initropylen?) haud-attingente, cliordầ alterâ a nuclei extremitate rotundatâ (folliculi apicem spectante) arcuatim ad umbilicum in margine ale paulo infra ejus extremitatem positum vergente. (v.s. sine fl. in herb. Willd. n. 2492 !)

26. R. Peruviana (R. Brown in. Linn. Trans. 10, p. 192), foliis petiolatis ovatis oblongisque inæqualiter dentatis passimque integerrimis utrinque brevissime acuminatis leviter venosis rufo-tomentosis supra demum glabrescentibus, racemis folia aquantibus vel breve superantibus laxiusculis ramulisque dense ferrugineotomentosis, perlicullis subliberis calyce glabrescente 3-4-plo brevioribus crassiusculis. $\delta$ ? In Peruviæe montibus frigidis (Ruiz! Pavon !). - Roem. et Schult. syst, 3, 
p. $429^{*}$. Embothrium monospermum Ruiz et Pavon! ff. per. 1, p. $63^{*}$, t. 98 , Willd. herb. n. 2502! Pavon! in herb. Boissier. Folia herbacea, plana, incluso petiolo 6-12 lin. longo 2 -4-pollicaria, $\frac{1}{2}-2$ poll. lata, interdum basi subrotundata, dentibus remotis brevissimis sinubusque obtusis rarius crebrioribus acutioribusque, venis subtus magis conspicuis sæpe laxe reticulalis diutius densiusque tomentosis. Racemi axillares, solitarii, subsessiles, 3-4-pollicares, recti, sublaxiflori, pedicellis 1 lin. lorgis. Calyx 3-4 lin. longus, limbo ovali dimidium tulsum parum angustiorem æquante ,demum fere glabro. Follieuli subfalcato-oblongi, compressi, utrinque attenuati, styli basi apiculati, tomentosi, demum glabrafi, 1 poll. longi, 4-5 lin. lati. (v. s. in herb. Willd, et Boiss.)

27. R. BRAsILIENSIS (Klotzsch $\mid$ in Linnæâ $15, p .55$ ), ramulis cum foliis novellis racemisque dense oclaraceo-tomentellis, foliis longe petiolatis ovalibus utrinque attenuato-acutis vel rarius basi rotundato-subcordatis ohtnse dentatis laxe reticulatis subtus tomentosis glabrescentibus venis supra immersis subtus prominulis, racemis folio brevioribus densifloris, pedicellis brevissimis subliheris, ovario rufovilloso, stigmate clavato. SI In Brasiliâ meridionali (Sellow, n. 386! 1357!) et prov. Minas Geraës (Glaussen, n, 121! 1000! Widgren, n. 1007!). - Meisn. in Mart. fl: bras. 14. p. $86^{*}$, t. 32 . R. ochrantha Mart,! mss. in herb. Folia rigida, plana, 4-9 poll. Jonga, 2-4 poll. lata, basi vel ad medium uscque integra, supra subnitida, glabra, subtus livida, petiolo 1-3-pollicari. Racemi axillares solitarii, subsessiles, 3-4 poll. longi, bracteis ovatis acutis ferrugineo-tomentosis. Calyx pedicello 3-4-plo longior, clavatus, limbo ovali tubo parum crassiore et vix climidio breviore. Stigma stylo duplo crassius, sulcatum. Folliculi elliptico-oblongi, compressi, utrinque attenuato-acuti, obsolete venosi, circ. 1 poll. longi, 5-6 lin. lati, demum glabrati. -R. glabrata Klotzsch (cfr. supra n. 17) forsan huc reducenda est.-(v. s. in herb. reg. Berol., Mart., Lind\}., Kunth., etc.)

$\beta$. levigata (Meisn. in Mart. fl. bras. 14, p. 86), foliis supra subimmerse obsoleteque reticulatis subtus subglabris, dentibus mucronulatis sæe antrorsum uncinulatis demum muticis. - Prope Cachoëira prov. Minarum (Claussen, n. 324! 498 !). Foliorum forma ut in typo. (v. s. in herb. Boiss.)

$\gamma$. velutina (Meisn. l. c.), foliis late ovatis caudato-acuminatis grosse obtuse dentatis utrinque velutino-tomentosis et elevato-reticulatis, tomento supra rariore pallidiore adpresso, subtus denso ferrugineo patulo. - In Brasiliâ meridionali (Sellow, n. 1358!). R. velutina Klotzsch! in Linnæa 15, p. 54*. Procul dubio nera variatio insignis tomento fortiore et foliorum acumine 6-12 lin. longo. (v. sp. 1 sterile in herb. reg. Berolin.)

$\delta$ ? subintegra (Meisn. 1. c.), foliis ovatis subacuminatis obtusis integris vel apicem versus obsolete repando-dentatis subtus laxe reticulatis, venulis ultimis inconspicnis.-In prov. Bahiensi (Blanchet, n. 3243!). Forsan species distincta, sed specim. nonnisi imperfecta observata; quic tamen ipse cl. Klotzsch ad R. Brasiliensem retulit. (r. s. sine fl. in herb. reg. Berol.)

๕.? macropoda (Meisn. 1.c.), foliis longe peliolatis ovatis ovalibus obovatisve basi breve attenuatis, dentibus remotis obtusis vel obsoletis. - In prov. Rio de Janeiro (Schott!). Folia modice coriacea, petiolo 3-4-pollicari tereti 1 lin. crasso haud canaliculato ad insertionem inerassato et breviter deorsum producto, laminầ 4-7 poll. longâ, 3-5 poll. latà, glabrà, opacâ vel supra subnitidâ subtus fuscescente, venis ut in var. $\alpha$, venulis tenuissimis laxe subimmersoreticulalis. Ciet. ignota. Forsan species distincta. (v. sp. 1 sterile in herb. cæs. Vindobon.)

B. Pinnatce. - Folia vel omnia vel ex parte (proesertim stirpis juvenilis et ramorum sterilium) impari-pinnata vel pinnato-partita, foliolis segmentisve dentatis (cfr. supra $R$. montana et complicata).

28. R. Pони1і (Meisn. in Mart. 1. bras. fasc. 14 p. $89^{*}$, t. 33), petiolis crassis ramisque villoso-tomentosis demum glabris, foliis rigidis pinnatisectis integrisque ovatis ellipticisve utrinque aeuminatis irregulariter serratis supra glabris nitidis dense impresso-reticulatis subtus costatis obsolete laxeque reticulatis lanatotomentosis, racemis conferlifloris dense rufo-lanatis. F In Brasiliæ prov. Minas Geraës. Racemi in summis axillis solitarii, sessiles, 6-12 poll. longi, undique dense rul'o-tomentosi, pedicellis bracteà late ovatâ oblusa ruplo longioribus calyce dími- 


\section{RHopata. PROTEACE 庄 (AdCTOR MEISNER).}

dio brevioribus, demum elongatis $3 \mathrm{lin}$. longis liberis tenuibus. Calyx clavatus, 3-4 lin. longus, stylum tenuem æquans. Stigma clavatum. Ovarium rulo-villosum. Folliculi glabrescentes.

a. simplicifolia (Meisn.l. c.), foliis omnibus indivisis vel rarius passim lobatis uncinato-serratis ovatis subtus dense diuque ferrugineo-tomentosis racemos æquantibus vel superantibus (Pohl! Ackermann !). Fólia excluso petiolo 1-3-pollicari tereti valido 3-5 poll. longa, 2-3 poll. lata, grosse serrato-dentata, e basi latâ subrotundatâ vel parum attenuati brevissime in petiolum producta. (v. s. in herb. Mart, et Zuccar.)

ß. dimorphophylla (Meisn. l. c.), foliis subtus mox-glabratis in eodem ramo pinnatipartitis simplicibusque racemo brevioribus (Mart.! Schïich!). R. heterophylla herb. Ac. Monac. 1 (nion Pohl). R. diversifolia herb. Zucc. (non R. Br.). Folia in eodem ramo alia simplicia, clliptíca, utrincue squaliter attenuata, obtuse dentata, infra medium integra; alia pinnatim 3-11-foliolata, foliolo vel lobo terminali reliquis multo majore ovali vel sủbrhombeo dentato (foliis sinplieibus conforni)-lateralibus subsessilibas oppositis altcrmisve oblongis lanceolatisve inæquilateris sæpe falcatis integerrimis vel jaucidentatis 2-4 poll. longis, $\frac{1}{2}-1 \frac{1}{2}$ poll. latis. (v. s. in herb. Ac. Monac. ct Cess. Vindobon.)

$\gamma$ ? multijuga (Meisn. 1. c.), foliis omnibus? pinnatis elongatis, foliolis 7-9-jugis grosse serratis demum glabrescentibus, lateralibus valde olıliquis basi dinidiatis. - R. Corcovadensis hort. Folia cubitalia et ultra, foliis oppositis vel suloppositis, dentibus hamatis paucronatis. In hortis nondum floruit. Forsan species distincta. (v. v. in h. Soc. hortic. Lond., Herrenluus., ete.)

29. R. márophyla (Schott! mss., Pohl pl. Bras. 1, p. 112), foliis pinnatis, foliolis 7 -jugis breve petiolatis ovatò-oblongis acumioatis grosse serratis basi dimidiatoobliquis laxe reticulalis glabris, venis supra semiimmersis subtus acute prominulis tenuiljus. $\bar{\jmath}$ ? In Brasiliâ, circa Tocaia (Schott, n. 4882 !). - Meisn. in Mart. fl. bras. 14 , p. 91". Folium modice coriaceum, fere bipedale, supra nitidum, subtus opacum rufescens, foliolis 5-8 poll. longis, terminali rhombeo $4 \frac{1}{2}$ poll. lato, lateralibus dimidio angustioribus, dentibus 1-3 lin.'longis acutis plus minus incurvosubmucronulatis. Caet. ignota. Valde accedens ad R. Pohlii $\gamma$ et Brasiliensem, recedens tamen foliorum consistentià parum rigidâ et nervatione. (v. nil nisi folium in herb. Ces. Vindobon,)

ß. puberula (Mcisn. 1. c.), foliis 2-4-jugis passimque simplicibus tomentoso-pubescentibus supra glabrescentibus, terminali late ovato. - Circa Barbacena (Pohl!). Folia inferiora pinnata, summum indivisum basi subtruncatum, magnitudine et forma foliolo terminali inferiorum conveniens. ( $\nabla$. sp. sterile in herb. Cæes. Vindob.)

30. R. DIY E sif o lia (R. Brown in Linn. Trans. 10, p. 193, nee Schot1), folis poly morphis serratis utrinque tenuissime denseque elevato-venosis tomentosis supra glabrescentibus, aliis simplicibus ovato-oblongis, aliis pinnatifidis pinnatisve 2-5-jugis, racemis folio longioribus laxiusculis dènse rufo-tomentosis, pedicellis subliberis. 5 In Muna Peruvise (Ruiz! Pavon!).-Foem. et Schult. syst. 3, p. 429*. Embothrium pinnatum Ruiz et Pav.! fl. per. 1, p. 63, t. 99. Folia petiolata, ramulormm sterilium subherbacea dense ferrugineo-tomentosa supra tarde glabrescentia, alia indivisa serrata basi nonnunquam auriculato-iricisa, alia pinnatim 3-11-foliolata, foliolis distinctis vel summis basi confluentibus, terminali majore elliptico serrato, lateralibus oppositis vel suboppositis oblongis obliquis dentatis vel subintegerrinis; ramorum fertilium incluso jetiolo subpollicari $2 \frac{1}{2}-5$ poll. longa, 1-2 poll. lata, rigide coriacea, indivisa. elliptico-oblonga, serrata, utrinque subacuminata, supra scmiimmerso-venosa glaberrima nitida, subtus elevato-venosa subreticulata fulvo- vel cano-tomentosa. Racemi axillares solitarii, subsessiles, pedicellis 2 lin. longis tenuibus. Folliculi sessiles, subpollicares, semilunares, compressi, fulvo-tomentósi, styli diu persistentis basi rostrati vel mucronati, levissime venoso-striati, marginibus obtusis. (v. s. sine fl. in herb. reg. Berolin. et Boiss.)

31. R. ADIANTIFOLIA (Klotzsch ! in Linnæa 15, p: 56 "), folijs subherbaccis imparipinnatis, rhachi tereti gracili ferrugineo-tomentosâ, foliolis 5 -6-jugis subsessilibus attenuato-acuminatis serratis vel passim integris supra glabris opacis dense elevato-reticulatis subtus fulvo-tomentellís laxe reticulatis, terminali rhombco, latc- 
ralibus elongato-trapezoideis incequilateris subfalcatis basi breve attenuatâ obliquis vel dimidiatis, racemis.... 5 In Serra do Caraca prov. Minas Geraës Brasiliææ (Sellow, n. 1360!). - Meisn. in Mart. fl. bras. 14, p. $88^{*}$. Folia viridia (nec glauca) haud rigida, 3-7 poll. longa, foliolis oppositis alternisve dentatis vel raro passim integris, terminali 2 - poll. longo, fere 1 poll. lato, infra medium cuueato-attenuato integcrrimo, lateralibus 12-18 lin. longis, 6-8 lin. latis, Adiantorum more obliquis, dentibus vix 1 lin. longis acutiusculis, sinubus obtusis. Foliola (fide specim. Sellow! in lierl. Arus. Brit.) interdum omnia integerrima. Flor. et fr. ignoti. (v. s. in herb. reg. Rurolin. et Mus. Brit.)

$\beta$ ? grandidentata (Nlcisn. in Mart. 11. Bras. 14, p. 89), foliis' 8-11-jugis exceptâ rhachi nervoque loliolorum rufo-tomentoso glabris, foliolis supra nitidlis subtus opacis grosse serratis, venis supra immersis obsoletis subtus levissime prominulis tenerrimis laxe reticulatis. In Costa-Rica et Veragua, Panama (Warscevícz, n. 5!). Folia pedalia ct ultra, foliolis 2-3 poll. longis, 10-14 lin. latis, dentibus 2-3 lin. longis acutis muticis, simubus subacutis. Forsan propria species aut stirps juvenilis, folia enim omnino herbacea. (v. s. steril. in herb. reg. Berolin.).

32. R. G R AcIL Is (Meisn. in Mart. fl. bras. 14, p. 90*), foliis paucijugịs? ramisque gracilibus glabris, foliolis subherbaceis rhombeo-ellipticis acutis onnibrís æéqualiter cuneato-attcnuatis extra medium serratis subnitidis immerse pauciveniis, lateralibus sessilibus, terminali pétiolato dequaliter majore, racemo terminali longe pedunculato recto simplici vel bifido laxifloro fulvo tomentello. 5 ? In monte Corcovado, prope Rio de Janeiro (Schott, 11. 4468!). Ramuli glabri, internodiis $1 \frac{1}{2}-2$-pollicariluus. Folia inferiora ignota, summa 2-4 poll. longa, foliolis $3-5$ vix rigidulis, 9-18 lin. longis, 6-9 lin. latis, infra medium vel passim undique integerrimis, venis vix prominulis tenuissimis, reticulatione penitus nullâ, rhachi filiformi supra 1 -sulcâ. Racemi $1 \frac{1}{2}-2$ poll. longi, pedunculo 2-3-pollicari, bracteis nonnullis sterilibus subulatis $2-3$ lin. Iongis infimis interdum folio simplici nano terminatis olsito, jedicellis liberis $1 \frac{1}{2}$ lin. longis. Calyx \& lin. longus, demum glaber. Ovarium dense rufo-hirsutulum. Stigma clavatum. Forsan mera var. R.' adiantifoliæe: (v. s. in herb. Cies. Vindobon.)

33. R. hетеворнуцla (Pohll pl. Bras. 1, p. 111, t. 90), foliis coriaceis remote obtuse-dentatis rel passim basi integris utrinque elevato-nervosis glabris supra subnitidis, aliis simplicibus dohatisque ellipticis oblongisque acuminatis in petiolum longum attenuatis, aliis impari-pinnatis, racemis densifloris; pedicellis rhachique dense puberulis, calyce glabriusculo. 5 In Brasiliâ. - Meisn. in Mart. fl. bras. 14 , p. $88^{\star}$. Rami virgati, dense foliosi, juniores cinerei. Folia glaucescentia? juniora tenuissime puberula, mox glabra, subtus fulva, sæpe in eodem ramo diversiformia. Racemi axillares solitarii vel gernini, subsessiles, circ. 3-pollicares, pedicellis 1 lin. longis bracteâ squamiformi ovatâ longiores. Calyx 3-4 lin. longus, stylum tenuem paulo superans. Stigma clavatum.

a. variifolia (Meisn. 1. c.), foliis promiscue simplicibus indivisis lobatis pinnatisque. - In sylvis prov. Sebastianopolit. et S. Pedro do Sul (Mart.! Schott, n. 4885! Sellow!). R. diversifolia Schott in Tieu. med. Jahrb. 6, n. 2, p. 161, Roem. et Schult. syst. 3, mant. p. 286 (non R. Br.). Folia simplicia 3-5-polli-

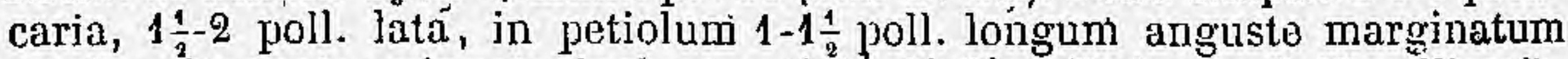
sensim altenuata; pinnata incluso petiolo $1 \frac{1}{2}-2 \frac{1}{3}$ poll. longo 6-12-pollicaria, foliolis oppositis alternisve 2-4 poll. longis, $6-12$ lin. Jatis, terminali foliis simplicibus conformi. (v. s. in herb. Cæs.Vindob., reg. Bèrolin. et Mart.)

B. pinnata (Neisn l.c.), foliis omnibus pinnatis sæepe elongatis, foliolis 2-6-jugis, lateralilus sessilibus oblique lanceolatis subfaleatisve basin versus attcnuatis. terminali majore regulari. - Circa Rio de Janeiro (Pohl! Schott, u. 4885! ex partc). Folia s:epe pedalia, cet. ut pinnata sub var. $\alpha$ descripta. (v. s. in herb. Zuccar. et Cæes.Vinudob.)

34. R. ELEGANS (Schott! mss, Pohl pl. Bras. 1, p. 112), glabra, foliis sulscoriaceis 9-12-jugis, toliolis lanceolatis acuminatis serratis, lateralibus falcatis hasi valde inæqualibus, terminali regulari haud majore, venis tenuibus sujra subimmersis subtus luviter expressis, reticulo laxo obsoleto, racemis..... 5? In Brasiliâ (Schott, n. 4880!). - Meisn. in Mart. 11. bras. 14, p. $90^{*}$. Rami graciles, tenuiter striati. Folia incluso petiolo 2-3-pollirari gracili tereti 10-14 poll, Jonga, loliolis 2-4 poll. 
longis $5-8$ vel basi usque ad 12 lin. latis, dentibus $\frac{1}{2}-1$ lin. longis mucronulatis subhamatis sinubus 2-3. lin. latis obtusis, venis omnino $R$. heterophyllæ, cujus forsan mera var. (v. s. steril. in herb. Ces. Vindob.)

35. R. AFFinis (Pohll pl. Bras. 1, p. 112), glaberrima, foliis subcoriaceis 6-7-jugis, foliolis breve petiolulatis oblongis acuminatis grosse spinescenti-serratis basi oblique attenuatis dimidiatis integerrimis sujra nitidis glense subtus laxe prominulo-reticulatis, terminali Iatiore regulari cưpeato, racemis.... 5 In Brasilise prov. Minas G(raës (Pohl 1). - - Meisn.' in Mart. fl." bras. 14, p. 91 *. Folia consistentia li. adiantifolixe, incluso pétiolo $2 \frac{1}{3}-3 \frac{1}{2}$ poll. longo gracili tereti $14-16$ poll. longa; foliolis 4-5 $\frac{1}{2}$ poll, longis, lateralibus 15-18 lin. latis rectis (nec falcatis), terminali 2 poll. lato oblongo-rhombeo, venularum reliculo tenui prominulo supra satis denso, dentibus 1-2 lin. longis, 1 lin. latis, subincurvis, sinubus rotundatis. Gæet, ignota. Forsan R. elegantis vel heterophylle vạr. vel status juvenilis. (v. s. steril. in herb. Gœs. Vindobon.).

36. R. MA R T I (Meisn. in Mart. fl. Juras. Sasc. 14, p. 87*, t. 32, f. 3), foliiis rigidis ramisque glabris pinnatis simplieibusque ovatis vel ellipticis acuminatis extra medium remote dentatis vel passim integris utrinque opacis, venis primariis supra vix prominulis relicfuis nervoque immersis snbtus ornnibus acute prominulis, racemis folio brovioribus tomentosis densiflorís, pedicellis calyce grlabrescente subtriplo brevioribus. \& In Brasiliai et Costa-Rica. Rami virgatí, strícti. Racemi axillares, solitarii, sessiles, 2-4-pollicares, pedicellis vix 1 lin. longis, bracteis sfluamiformibus exiguis deciduis. Calyx 3-4 lin. longus, limbo ovali dimidium tubım subsequante. Ovarium sessile, fulvo-sericéum. Stylus tenuis, ruḅer, cum stigmale clavato fere 4 lin. longus.

a. simplicifolia (Meisn. 1. c.), foliis omnibus simplicibus late ovatis vel ellipticis breve acu teque acuminatis muticis levissime dentatis in petiolum marginatum glabrum subito attenuatís. - In prov. Minas Geraës (Mart.!) et Costa-Rica et Veragua (Warscewicz, 11,6 ! ex parte). R.Veraguénsis Klotzsch! mss. in lierh. reg. Berolin. Folia incluso petiolo $1-1 \frac{1}{2}$ pollicari, $3 \frac{1}{2}-6 \frac{1}{2}$ poll. longa, $1 \frac{1}{3}-3$ poll. lati, luasi rotundata, dentibus remotis obtusis vel passim nullis. Raceurorum tomentum rulum. (v. s. in herb. Ac. Monac. et reg. Berolin.)

E. pinnata (Meisn. l. c.), foliis omnibus vel ox parte pinnatis, rhachi canaliculatâ glabrâ, foliolis 5-7-jugis sulssessilibus acute vel obtuse dentatis vel passim subintegerrimis, lateralibus valde obliquis.-In prov. Bahiensi (Mart.), CostaRica et Veragua (Warscewicz, n. 7 ! et ex parte, n. 6). Folia 3-12-pollicaria, foliolis 3-13 uvatis val ovato-lanceolatis $\frac{1}{2}-3$ poll. longis, $\frac{1}{2}-2$ poll. latis, supra sæpe nitidis, lateralibus bași plus minus dimidiatis, terminali majore regulari. Racemi cano-tomentosi. (v. s. in herb. Ac. Monac. et reg. Berolin.)

\section{Species exclusce.}

R. Cochinchinensis R. Br. = Helicia Cochinchinensis Lour.

R. C HR Y S OGENIA Mart. = Adenostephanus incana Klotzscl.

R. EXCELSA Roxb. = Helicia excelsa Blume.

R. HAMELIAFOLIA Rudge = Andripetalum sessilifolium Klotzsch.

R. IN \& QUAL Is Pohl = Adenostephanus inxecfualis Endl.

R. Molugcana Roxls. = Helicia attenuata Blume.

R. Moluccana R. Br. = Helicia Moluccana Blume.

R. MOLUCCANA Jack. = Helicia petiolaris Benn.

R. MULTIRLORA Schott, Spr. = Andripetalum multiflorum Schott.

R. ORGANENis Gardn. = Adenoslephanus Organensis Endl.

R. PINNAta Lam. = Adenostephanus Guyanensis Meisu.

R. POLYSTACHYA herb. Kunth: = Andripetalum polystachya Schott.

R. R о вUS т A Roxb. $=$ Helicia robusta Wall.

R. Serrata Reinw. = Helicia Jaranica Blume.

R. SERRAta R. Br. = Helicia serrata Blume.

R. SESSILIFOLIA Rich. = Andripetalum sessilifolium líl. 
XXXV. ADENOSTEPHANUS Klotzsch in Linned 15, p. 5i, Endl. gen. suppl. II, p. 37, et $I V, 2, p .87, n .2149$, Meisn. gen. 2, $p .369$, et in Mart. fl. bras. fasc. 14, p. 92, $t$. 34-36. - Euplassa Salisb. - Dieneckeria fl. Flumin. 1, t. 105.-Didymanthus Klotzsch mss. - Rhopalie sp. Pohl.

Flores hermaphroditi, subirregulares, racemosi. Calyx subclavato-cylindricus, curvatus, sepalis linearibus apice concavo antheriferis demum liberis revolutis deciduis. Antheræ subsessiles, ovatæ. Glandulæ hypogynæ 4 in annulum persistentem connatæ vel subliberæ conniventes. Ovarium stipitatum vel sessile, 1 -loculare, ovulis 2 collateralibus pendulis. Stylus arcuatus, persistens, stigmate laterali compresso antice convexo snbumbonato. Fructus..... - Arbores vel frutices Brasilienses et Guianenses, foliis sparsis herbaceis vel subcoriaceis abrupte pinnatis, foliolis cum rhachi articulatis dentatis integrisve, racemis in summis axillis solitariis geminisve rarius terminalibus, pedicellis geminatis obscure 1-bracteatis connatis vel subliberis.

1. A. IN RUAL IS (Endl. gen. suppl. IV, 2, p. 87), foliolis 2-3-jugis ovali-oblongis obtusis integerrimis basi inæqualiter attenuatâ margine pubescentibus çeterum glabris utrinque elevato-reticulatis, racemis folio brevioribus dense ferrugineotomentosis, pedicellis semicounatis calyce brevioribus, ovario glabro. 5 In Brasilise prov. Goyaz, Piauhy, Pernambuco et Minas Geraës (Pohl, n. 2303! Gardner, n. 2951! Claussen!). - Meisı. in Mart. 11. bras. 14, j. 92*. Rhopala inæqualis Pohl! pl. Bras. 1, p. 110 , t. 89 . Ramuli juniores cum petiolis racemisque dense ferrugineo-tomentosi. Petioli cum rhachi 3-5-pollicares, jugo infimo $1 \frac{1}{2}-2$ poll. a basi distante, foliolis oppositis subsessilibus, ultimis uscrue ad 6 poll. 'longis, 2-2 $\frac{1}{2}$ poll. latis, inferioribus plus minus brevioribus. Racemi axillares solitarii,' pedunculati, 4-5-pollicares. Calyx 4 lin. longus, tubo pedicellum equante, limbo globoso cernuo. Glandulæ hypogynæ discretie rotundat:. Stigma ovale, convexum. (v. s. in herb. Cixs.Vindob., Mart., DC., Boiss., etc.)

2. A. SELL OWII (Klotzsch $!$ in Linnæâ 15, p. 52*), foliolis remote 5-6-jugis ovatovel ovali-oblongis acutis remote minuteque serratis vel passim subintegris utrinque tenuiter denseque reticulatis supra glabratis nitidis subtus puberulis fuscis, racemis folium sequantibus laxiusculis cum ramis petiolis folisque junioribus dense ferrugineo-tomentosis, pedicellis semiconnatis calycem æquantibus, ovario glabro. 5 In Brasiliâ meridionali (Sellow, n. 1356!) et prov. Sebastianopol. (ex FI. Flum.). - Meisn. in Mart. fl. bras. 14, p. 92*. Didrmanthus Sellowii Klotzsch 1 mss. olim in herb. reg. Berol. Dicneckeria legalis Fl. Flum. 1, t. 105. Arbuscula sesquiorgyalis. Folia $1-1 \frac{1}{2}$-pedalia, jugis $1 \frac{1}{2}-2$ poll. distantibus, 4-5 poll. longis, 2 poll. latis subinæquilateris, petiolulo $2-4$ lin. longo, denticulis minutis mucronuliformibus. Racemi axillares, solitarii, pedicellis 4-5 lin. longis. Glandulæe hypogynæ in annulum brevem truncatum connatæ. (v. s. in herb. reg. Berolin., Lindl., Cæs.Vindobon.)

3. A. INGANa (Klotzsch! in Linned 15, p. 52\%), foliolis 4-5-jugis ovali-oblongis utrinque angustatis brevc acuminatis remote serratis elevato-reticulatis vel supra demum lævigatis glabratis nitidis, racemis folia æruantibus densifloris cum ramulis petiolis foliisque junioribus dense incano-vel-ful ro-tomentosis, pedicellis basi connatis calyce dimidio brevioribus, ovario hirsutulo. 5 In Brasiliâ meridionali (Sellow, n. 14471) et prov. Minas Geraës (Mart.! herb. bras, n. 891! Claussen, n. $67 ! 142$ ! et coll. 1840, n. 25 !).-Meisn. in Mart. nl. Bras. 14, p. $93^{\circ}$, t. 34 . Rhophala chrysogenia Mart.! herb. Il. Bras, n. 891. Didymanthus incana Klotzsch ! mss. olim in herb. Arbor orgyalis. Folia 5-8-pollicariu, foliolis coriaceis 2-3 poll. longis 1-2 poll. latis sæope inæequilateris infra medium sicpius integris, dentibus 4-9 lin. distantibus brevibus muticis, renarum reticulo sat denso utrinque subæqualiter prominùlo vel supra denum venis immersis obliterato, petiolulis 2-5lin. longis. Racemi terminales vel axillares genini. Cillyx 3 liu. longus. (v. s. in herb. reg. Berolin., Gos. Vindob., DG., Lindl., Mirt. elı.)

4. A. ORGANENSIs (Endl. gen. suppl. IV, 2, p. 87), ramulis petiolis foliis subtus racemisque tomentellis, foliolis $3-5$-jugis ovalibus utrinque obtusis sæpius mucronulatis remote minuterque serratis vel passim integerrimis elevato-reticulatis supra 
subnitidis glabris, racemis folium sequantibus densifloris, pedicellis conuatis calyce adpresse fulvo-tomentello quadruplo breviorijus, ovario sericeo. 5 In mont. Serra dos Orgaos prov. Rio de Janeiro (Gardner, n. 615!). - Meisn. in Mart. fl. Bras: 14 , p. $93^{*}$, t. 35. Rhopala Organensis Gardner 1 in Hook Lond. Journ. 4 , p. 135. Arbor 60-pedalis. Folia 5-6-pollicaria, jugis 10-12 lin. distantibus, foliolis $1 \frac{1}{2}-3 \frac{1}{2}$ poll. longis $1-1 \frac{1}{2}$ joll. latis coriaceis apice siepius subtruncato-rotundato minute recurvo-mucronulatis, denticulis mucronuliformilsus, reticulatione fere A. incane, petiolulis 1-2 lin. longis. Racemi axillares solitarii subsessiles, tomento minuto flavido, pedicellis 1 lin. longis crassiusculis. Calyx 4-5 lin. longus. Stigma vix incrassatum, convexum. (v. s. in herb. Shuttl., Vindobon., etc.)

5. A. Lax I f ora (Meisn. in Mart. 11. Bras. 14, p. 94*), foliolis 4-5-jugis ovali-oblongis ovatisque extra medium remote serrulatis reticulatis pubescentibus subtus elevato-costatis, costis petiolis ramis racemisque fulvo-tomontosis, racemis folio sublongioribus laxifloris, jedicellis connatis calyce brevioribus, ovario adpresse hirsuto. 5 In Brasilice Prov. Minas Gerä̈s (Regnell! Widgren, n. 1006 !). Plurimis notis convenit cun A. Organensi et incana sed facile dignoscenda, a priore racemis laxis et pubescentia indole ; posteriore petiolis ramisque tardius glabrescentibus, foliolis minus acutatis vel sepe obtusissimis, reticulatione densiore, denticulis minoribus, calyce $4-5$ lin. longo pedicellis 2-3-plo longiore, etc. (v. s. in herb. Sonder.)

6. A. NITIDA (Meisn. 1. c. p. 94"), foliolis 4-5-jugis ovali-oblongis acutis obtusisve rumote sèrratis elevato-reticulatis supra glaberrimis nitidis subtus in nervo venisque parce pilosiusculis demum subglabris, racemis folio brevinribus densiloris cum petiolis ramisque junioribus ferrugineo-tomentellis, pedicellis infra medium connalis calycis tubum subaquantibus, ovario rufo-villoso. 5 ? In Brasilise Prov: Bahiensi (Blanchet, n. 3574!). Folia rigide coriacea, opposita et subopposita. Calycis limbus globosus, tubo duplo brevior. Stigma oblongum, obtusum, antice convexum. Species inter $\Lambda$. incanam et Organensem subambigua, a jriore recedens foliis subtus fere glabris, racemis solitariis; a posteriore foliolis majoribus, 3-5 poll. longis $1 \frac{1}{2}-2$ poll. latjs basi magis attenuatis, dentiluus majoriluus, racemis pedunculatis, pedicellis $1 \frac{1}{2}-2$ lin. Jongis, etc. (v.s. in horls. Dr. et Shutu.)

7. A: B A II IENSIS (MLisn. l. c. p. $94^{*}$, t. 36), foliolis 2-5-jugis ovalibus obovatis oblongisque subacuminatis basi attenuatis remote serrulatis vel passim integerrimis dense elevato-reticulatis supra demum glaberrimis subnitidis subtus in venis parce pilosiusculis, margine levissime rccurvo, racemis folio requalibus longioribusve cum petiolis ramulisifue junioribus ferrugineo-tomentosis, pedicellis inferne connatis calyce brevioribus, ovario rufo-hirsuto. 5? In Brasilia prov. Bahiensi circa Igreja Velha (Blanchet, n. 3456!). Petiolus cum rhachi 3-5-pollicaris, pube rariore minusque ferrugineà quam racemi tumentellus el cum ramis demum glabrescens, petiolulis $2-4$ lin. longis, foliolis coriaceis oppositis, junioribus supra parce puberulis, infimis $1-1 \frac{1}{2}$ poll. a basi distantibus, superioribus sensim longioribus, ultimis 1-3 poll. longis 8-10 lin. latis, dentibus yaucis brevissimis acutis vel obtusis srpe in uno vel utroque margine nullis, acumine vix 1 lill. longo obtuso sæpius mucroniformi. Racemi axillares solitarii, 5-7 poll. longi, pedicellis $1 \frac{1}{2}-2$ lin. Iongis basi vel ad medium usque connatis. Calyx 3 lin. longus, limbo globoso. Gyathulus hypogynus subinteger. Stigma oblongum, obtusum, antice papillosum. Species jam foliolis parvis ab omnibus facile dignoscenda. (v. s. in herb. DC., Shuttl., Vindobon., etc.)

8. A. Guranensis (Meisn. ]. c. p. 95*), ramulis tomentellis, foliolis $\mathbf{3}$-4-jugis late ovatis obtusis vel acutiusculis integerrimis glaberrimis supra nitidis subtus opacis reticulatis, venulis semiimmersis, racemis terminalibus folio brevioribus tomentosis, pediccllis liberis? calyce brevioribus, ovario stipitato glabro ? 5 ? In Guianà-Gallicâ (Martin ! L. Richard) et Anglicâ (Mey.). - Roupala pinnata Lam. ill. 1, p. 243, Poir. dict. 6, p. $317^{*}$, Rudge pl. Guian. 1, p. 25, t. 38, R. Brown! in Linn. Trans. 10, p. 222 ", Meyer Esseq. p. 79, Roem. et Schult. syst. 3, p. 430* Euplassa meridionalis Salisb., fide Spreng. syst. 1, p. 482. Foliola opposita, $3 \frac{1}{2}$ poll. longa, 2 poll. lata, petiolulo semipollicari. Racemi solitarii, pedunculati, erceti, tomento cinereo-ferrugineo. Stigma papillâ centrali umbonatum. (v. s. in herb. Banks.) 
XXXVI. HELICIA Lour. A.Cuchinch. p. 83, ed. Willd. 1, p. 105, R. Brown Prot. N.-Holl. suppl. p. 32, Blume in Ann. Sc. nat. 2e sér. 1, p. 211, Endl.gen. p. 342, n. 2150, suppl. IV, 2, p. 87, Meisn. gen.p. 333 (245.), Bennett in Horsf. pl. Jav. rar. p. 81, t. 18 (non Pers.). - Helittophyllum Blum. Bijdr. p. 652. - Castronia Noronha Relat. pl. Jav. in Tijdschr. voor Nat. en Phys. 8, p. 414 ? fide Hassk ibid.-Rhopalæ sp. Asiatica auct. R. Brown olim in Trans. soc. Linn. Lond. 10, p. 91, ,. 4-6.

Flores hermaphroditi, regulares, racemosi. Calyx clavato-cylindricus, rectus, sepalis 4 subspathulatis infra apicem antheriferis demum liberis revolutis deciduis. Antheræ subsessiles lineares vel ovales, apiculatæ vel muticæ. Glándulæ liypogynæ 4 libeiæ vel connatæ. Ovarium breve stipitatum vel sessile, 1-loculare, ovulis 2 adscendentibus. Stylus filiformis. stigmate verticali clavato. Folliculus coriaceo-lignosus, indehiscens, abortu 1-spermus. Semen subglobosum, apterum. - Arbores, vel frutices Asiæ tropicæ continentalis et insularis, foliis sparsis vel passim oppositis, herbaceis vel coriaceis simplicibus dentatis integrisve, racemis axillaribus vel terminalibus simplicibus, pedicellis geminatim 1-bracteatis liberis vel semiconnatis.

\section{$\S 1$. Folia integerrima (cfr.tamen H. Moluccana).}

1. H. Molucgana (Blume in Ann. des sc. nat. 2 e sér. 1, p. $216^{*}$. excl. syn. Roxb. et Jack), glaberrima, foliis obovato-oblongis obtusiusculis planis venulosis subreticulatis, racemis axillaribus lateralibusque cum ovariis squamulisque hypogynis liberis glabris. 5 In ins. Amboynâ Molucc. (Chr. Smith !).- Bentrett! in Horsf. pl. Jav. p. 83. Rhopala Moluccana R. Brown! in Linn. Trans. 10, p. 191. Arborescens. Petioli brcves, basi dorso incrassati. Folia 6-8 poll. longa, vix 3 poll. lata, obtusa vel breve acuminata, utrinque glabra, flavo-viridia, rarissime (fide sp. Smith) denticulo uno alterove obtuso jrædita. Racemi plerumque solitarii folio longiores vel breviores, 3-4 poll. longi, subsessiles, pedicellis semiliberis rix $1 \frac{1}{2}$ lin. longis, floribus decoris odoratissimis. Calyx 5 lin. longus, stylum æquans. Stigma ovale, obtusum, $\frac{2}{3}$ lin. longum, $\frac{1}{3}$ lin. crassum, sordide cinereum. (v. s. in herb. Banks.)

2. H. PETIOLAR is (Bennett! in Horsf. pl. Jav. p. 84), foliis coriaceis longe petiolatis obovatis obtusis subnitidis glabris laxe reticulatís, venis supra semiimmersis, racemis axillaribus folio sublongioribus, pedicelis calycibus ovariisque glabris, squamulis hypogynis connatis? 5 ? In Singapore, et culta in horto ins. Penang (Jack 1). - Rhopala Moluccana Jack ! in Calcutta Journ. p. 208*, Malay. misc. n. 2, p. 10, Wall. list, n, 1041 ! (non R. Br. nec Roxb.). Folia specim. Wall. 6-8-pollicaria, incluso petiolo usque ad 1 poll. longo. (v. s. sine fl. in herb. Mus. Brit.)

3. H. ZeYLANica (Gardner! mss. in herb. Thwaites), glaberrima, foliis oblongo-vel obovato-ellipticis obtusis in petiolum brevem attenuatis, venis utrinque prominulis tenuibus laxe reticulatis, racemis axillaribus folium æquantibus laxifloris, pedicellis gracilihus imâ' hasi connatis dimidium calycem demum rquantibus, calyce longo tenui ovarioque glabro, glandulis hypogynis obtusis semiconnatis. 5 ? In ins. Ceylon (Thwaites, n. 690 !). Folia modice coriacea, plana, subopaca, 4-5 poll. longa, $1 \frac{2}{5}-2$ poll. lata, petiolo subsemipollicari. Racemi solitarii, subsessiles, pedicellis 3-4 lin. longis. Galyx 8-9 lin. longus, basi parum tumidulus, limbo clauso oblongo obtuso $1 \frac{1}{2}$ lin. longo $\frac{1}{2}$ lin. crasso. Stigma stylo parum crassius. Nimis allinis H. petiolari. (v. s. in herb. DC.)

4. H. OBLONGIF OLIA (Bennett ! in Horsf. pl. Jav. p. 83), glaberrima, foliis subsessilibus oblongis acuminalis loasi attenuatis racemum laxiflorum subrequantibus, pedicellis sulbliberis, scfuamulis hypogynis in annulum obsolete ciliato-dentatum

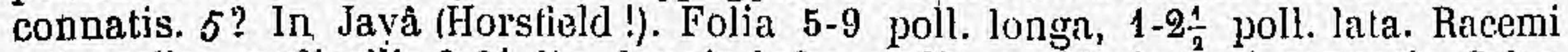

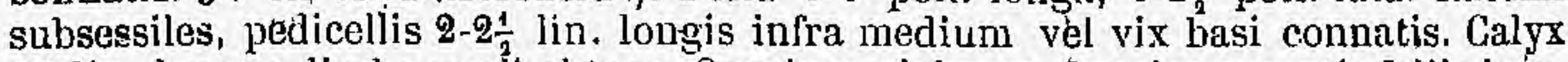
10 lin. longus, limbo ovali obtuso. Ovarium glabrum. Species exceptis foliis integerrimis H. attenuatic et obovatie simillima. (v. s. in herb. Mus. Brit.)

5. H. LoRANT I ordes (Presl Epimel. Lot. p. 247 *), foliis breve petiolatis coriaceis ohovatis obtusis basi attenuatis utrincue elevato-reticulatis glabris supra nitidis, racemis axillaribus folio duplo longioribus, rhachi calycibus ovaris ramulisque novellis ferrugineo-tomentosis, pedicellis semiconnatis crassiusculis calyce triplo 
brevioribus, squamulis hypogynis liberis glabris. 5 ? In insulæ Luzon Philippinarum prov. Albay. (Cuming, n. 858!) Folia rigida, incluso petiolo 3-6 lin. longo 2-5-pollicaria, 9-18 lin. lata, supra læte viridia nitida, subtus pallidiora opaca, exceptâ basi nervi medii petiolocme evanido-tomenteHis glaberrima, venarum reticulo denso subtus acutius prominulo. Racemi solitarii, 5-7 poll, longi, fere a basi dense floriferi, tomento denso rufo, in calyce pallidiore et demum rarescenfe.

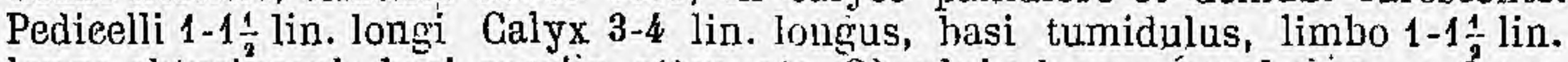
longo obtusiusculu basi sensim attenuato. Glandulie lyyjogýn:o breves, subcarnosæe, ovario 3-4-plo breviores. Stigma clavatum, $\frac{2}{3}$ lin. longum, sulcatüm, obtusum, cum stylo vix dimidio tenuiore nigricanis. (v. s. in herb. Shuttl., Boiss., etc.)

o. H. ovata (Bennett in Horsf. pl. Jav. p. 84), foliis subsessilibus ovatis utrinque acutis glaberrímis, racemis axillaribus, pedicellis brevissimis cum calycibus ovariisque levissime tomentosis. 5 In Sumatrà circa Tappanuly (Jack). Rhopala ovata Jack in M'Clelland Calcutta Journ. 4, p. 358 et Malay. misc. n. 7, p. 95, Walpers ann. 1, p. 592. Arbuscula. Folia alterna et opposita, 10 poll. longa, 6 poll. lata, late ovata, interdum acuminata, marginibus revolutis, venis conspicuis. Racemi ex axillis foliorum lapsorum. Squamæ hypogynæe liberæ ?

7. H. SA Licrfolia (Presl Epimel. bot. p. $247^{*}$ ), foliis lancoolatis obtuse acuminatis in petiolum. brevissinum angustátis racemum xquantibùs ramulisque glaberrimis, bracteis linearibus acutissimis pedicellos æquánlihus calycibusque tomentosis, glandulis hypogynis liberis obtusis, ovarió hirsutissimo. 5 ln Martabaniâ Regni Birmaniç circa Moulmine (Heller,). Ramuli juniores angulati, Pețiji 2-3 lin. longi. Folia sparsa, 1 poli. longa, cire. 1 joll. lata, coriacea, Jiete viridia, subtus pallidiora, reticulato-venosa, venis arcuatim anastomosantibus. Racemi axillares, solitarii, subșessiles, ferrugineo-tomentelli, bracteis patentibus circ. 1 lin. longis, pedicellis basi connatis. Calyx 4 liı. longus. Glandulse hypogynæ 4 ovato-subrotundæe oxtus puberulie. Stylus calycem æquans, stigmate clavatooblongo obtuso 8-sulcato. Ovarium sessile, ferrugineo-hirsutum. Fructus ignotus.

\section{§2. Fotia dentata vel serrata vel passimintegerrima.}

8. II. L ANGIFOLIA (Sich. et Zuccar. fl. Jalion. fam. nat. 2, p. 74 *), glabra, ramis angulatis, foliiš breve petiolatis oblongo-lanceolatís oblongisve utrinque attenuatis acuminatis extra medium remote argutedie serratis integrisve racemos cylindricos subsuperantibus, pedicellis semiconnatis parce pilosis, calyce squamis hypogynis semiconuatis ovariodine glabris. 5 ? In Japoníá (Siebold). Petioli vix

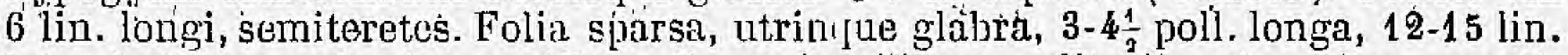
lata, dentibus subspinescentibus. Racemi axillares, solitarii, subsessilegs, erecti, rhachi glaljâ, pedicellis 2-3 lin. longis ultra medium connatis bracteam lanceolatam superantibus ad divisionem hracteolis 2 exiguis auctis. Calyx basi globosus, supra cylindrico-filiformis, laminis anguste oblongis obtusis. Antherc lineares, obtuse mucronatæ. Squamæ rotundatæ, uvario cylindrico dimidio breviores. Stylus stamina subæquans, stigmate clavato.

9. H. А т т Е U А А (Blume in Lini. sc. nat. 20 sér. 1, p. 210*), glaberrima, foliis oblongis utrinque acuminatis integerrimis vel apice paucidentatis reticulito-venosis racemos axillares subæquantibus, squamis hypogyuis connatis orariis fue glaluris. 5 In ins. Penang (Jack), Javă (Blume) et montibus Punduæ (Wall.!). Bennictt! in Horsf. pl. Jav. p. 83. Rhojala Moluccanä Roxls. 11. Ind. ed. Carey et Wäll. 1, p. 364 *, Roem. et Schult. mant. vol. 3, p. $284{ }^{*}$ (non R. Br. nee Jack). R. attenuata Jack in X'Clelland Calcutta Jouru. IV, p. 352 (208), miśc. Jal. pl. n. 2, p. 10, Walp. Ann.. bol. 1, p.592. R. racemosa Roxb.! mss. in lierb Ind. Soc, Linn. Lond. Arborescens, ramis teretibus. Folia coriacea plerumque alterna, in petioluin brevem attenuata; ex Jack l. c. oyata 10-11 poll. longa integra vel interdum prope apicem 1-2-denticulata; ex Blume l. c. oblonga vel lanceolato-oblonga, 5-16-pollicaria, 2-3 poll. lata, longo acuminata submucronulata, integra vel raro superne repando-dentata, lete viridia; ex Bennett et specim. Wall. subsessilia, elliptica,

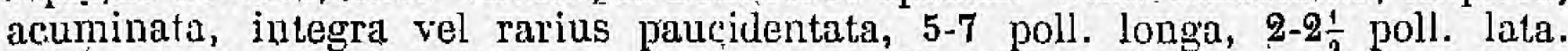
Racemi solitarii, 7-11-pollicares, subsessiles, cylindrici, pedicellis ex Blume 2-3 lin. longis, imis subcoalescentibus; ex specim. Wall. $\frac{1}{2}-i \frac{1}{2}$ lin. longis, ad medlium vel 
apicem usque connatis. Calyx pollicaris, flavescens, odoratissimus. Antheræ oblongæ, apiculate. Squanie subtruncatæ, fere totæe in urceołum connatæ. Ovarium breviter stipitatum. Stigma clavatum. Folliculi bipollicares, ovoidei, utrinque attenuati, costis 6 obtusis subangulati.(v. s. in herb. Mus. Brit.)

10. H. о в о vа т а (Bennett ! in Horsf. pl. Jav. rar. p. 83), glaberrima, foliis subsessilibus obovato-oblongis breviter obtıseque acuminatis basi subcuneato-angustatâ obtusis, vel subcordato-rotundatis extra medium vel undique remote uneinatoserratis vel passim subintegris utrincue dense elevato-reticulatis supra nitidis, racemis folio longioribus laxiusculis, pedicellis brevibus, calyce pollicari, glandulis hypogynis in urceolum 4-crenatum connatis. 5 ? In Javà (Horsfield ! Hoffmannsegg!). Rami apice subcompresso-angulati. Folia alterna vel subopposita, sub-

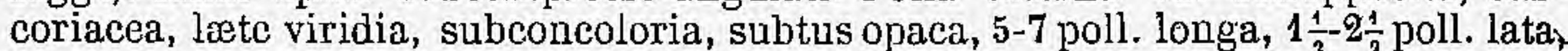
juniora lanceolato-oblonga, petiolo crasso vix 1 lin. longo, dentibus raris valde irregularibus brevibus acutis 7-10 lin. distantibus, venis tenuibus. Racemi 6-7-pollicares, breve pedunculati, bracteis ovato-subulatis minutis deciduis, pedicellis $1-1 \frac{1}{2}$ lin. longis apice in patellam dilatatis. Calycis limbus ovalis, $1-1 \frac{1}{2}$ lin. longus. Stylus fulvus, stigmate atro clavato sulcato. Nimis affinis H. attenuatre. (v. s. in leerb. Mus. Brit., Mart. et Boiss.)

$\beta$ ? minor, foliis subintegerrimis, calycibus $8-9$ lin. longis. Cæt. omnino ut in specim. Hoffrìannsegg., etc. In Javâ (Zollinger n. 2599 l). - An potius ad H.oblongifoliam (supra n. 4.) referenda et forsan cum eã ad R. attenuatam reducenda? (v. sp. manc. in herb. DC.)

11. H. Java Nic a (Blume in Ann. des sc. nat. $2 e$ sér. 1, p. 217*), glaberrima, foliis brevissime petiolatis ellipticis vel obovato-oblongis subacuminatis breviserratis basi angustatâ integrâ obtusis subcordatisve, venis utrinque immersis laxe reticulatis, racemis folio brevioribus, pedicellis brevibus basi connatis, calyce subpollicari, glanilulis lyynggynis liberis acutis. 5 In montibus Jave, alt. 3,000 ped. (Reinwardt! Kollmann! Horsfield, Junghuhn! Zollinger, n. 3023! Verzeichn. 2, p. 117). - Bennett ! in Horsf . pl. Jav. p. 81*, t. 18. Hassk. cat. alter hort. Bogor. p. 94. Rupala serrata hein wardt ! mss. Blume cat. h. Buitenzorg, p. 42. Helittophyllum Javanicum Blume Bijdr. p. 652. Frutex arborescens, elegans. Folia sparsa vel subverticillata, coriacea, subopaca, petiolo crasso brevissimo vel subnullo, 6-14 poll. longa, $2 \frac{1}{2}-4 \frac{1}{2}$ poll. lata, constanter inæequaliter grosse-serrata. Racemi axillares, solitarii vel gemini, 5-7-pollicares, pedicellis vix 2 lin. longis. Calyx gracillimus, flavidus vel albus, limbo subgloboso-ovali 1 lin. longo. Stylus ruber, stigmate nigricante clavato 1 lin. longo sulcato. H. obovatæ proxime accedens, sed foliis majoribus, hervis minus prominulis et præcipue squamis hypogynis liberis facile dignoscenda. (v. s. in herb. Mart. et Zucc., Mus. Brit., DG., etc.)

12. H. Gumingrana (Presl Epimel. Bot. p. 246*), glaberrima, foliis subsessilibus oblongo-lanceolatis breve acuminatis extra medium remote mucronato-serratis vel passim integerrimis basi angustato-acutis, venarum reticulo laxo supra subimmerso subtus leviter prominulo, racemis folio longioribus laxiusculis, pedicellis brevibus basi connatis, calyce -pollicari, glandulis hypogynis liberis obtusis. 5 ? In ins. Philippin. Luzor, prov. Cayayan (Cuming, n. 1262 !). Folia sparsa, modice coriacea, lete viridia, subconcoloria, opaca, 4.7 poll. longa, 1-2: poll. lata, in petiolum crissum 1-2 lin. longum sensim attenuata, dentibus paucis brevibus remotis acutinsculis vel passim nullis. Racemi axillares, solitarii, subsessiles, 5-10 pollicares, pedicellis 2 lin. longis basi vel ad medium usque connatis. Calyx 9-10 lin. longus, limbo ovali obtuso $1 \frac{1}{2}$ lin. longo. Glanduls hypogynæe carnosæ, ovatæ, rufæ, glabræe. Stigma nigricans, clavatum, sublæve, stylo rufo duplo crassius. (v. $s$. in herb. Sluttl. et Boiss.)

13. H. R OBUS ^ (Wallich! list, n. 2702), glaberrima, foliis obovato-oblongis obtusis vel acuminatis acute serratis infra medium subintegerrimis in petiolum brevissimum subcuneato-attenuatis venis tenuibus dense reticulatis supra subimmersis subtus prominulis, racemis folio brevioribus, pedicellis brevibus semiliberis, calyce subpollicari, glandulis liypogynis in cyathulum 4 -crenatum connatis. $\xi$ In Silhet (F. Desilva!) ct Tavoy (Wall.!). - Blume in Ann. sc. nat. $2^{\circ}$ sér. 1, p. $220^{*}$, Bennctl! in Horsf. pl. Jav. p. 83, Hassk. cat. alter loorti Bogor. p. 94. H. macrophylla Wall: lișt, n. 3661! Rhopala robusta Roxb.l fl. ind. ed. Carey et Wall. 1, p. 363, Roem, et Schull syst. mant. 3, p, 285, Wight ie. 1. 101. Arbor alla. Petioli crassi, 
vix 2-3 lin. longi. Folia modice coriacea, 6-12 poll. longa, 5-6.poll. lata, supra læte viridia subnitida, subtus rufescentia opaca. Racemi axillares 1-3, sat dense multi-

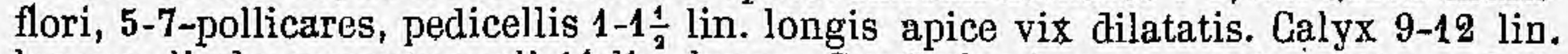
longus, limbo anguste ovali $1 \frac{1}{2}$ lin. longo. Gyathulus hypogynus truncatus subciliatus. Stigma cylindraceo-subclavatum, stylo vix crassius. (v. s. in herb. DG. et Mus. brit.)

14. H. castane af olia (Meisn. mss. in herb. Boiss.), glaberrima, foliis subsessilibus oblongis acuminatis utrinque attenuatis undique dense acuteque uncinatoserratis basi obtusis rotundatisve, venularum reti utrinque immerso inconspicuo, racemis folio brevioribus laxiusculis, pedicellis subliberis, calyce subpollicari, glandulis hypogynis in annulum obtuse crenulatum connatis. 5 ? In ins. Philippinis Cuming, n. 2338!). Petiolus crassus vix 1 lin. longus. Folia 10-12 poll. longa, 3 poll. lata, subcoriacea, opaca, supra lęte subtus livide viridia, dentíbus $1 \frac{1}{-}-3$ lin: distantibus $1-1 \frac{1}{2}$ lin. longis acutis incurvis, nervo medio utrinque fortiter prominulo, venis utrinsecus circ. 10 tenuibus. Racemi incluso pedunculo $1 \frac{1}{2}$ poll. longo,

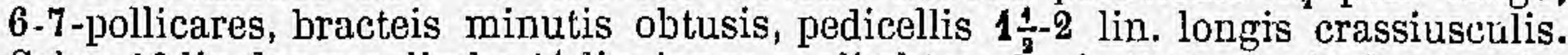
Calyx 10 lin. longus, limbo $1 \frac{1}{2}$ lin. longo ovali obtuso basi attenuato. Stylus tenuis, rufus, nitidus, stigmate nigricante clavato $\frac{1}{2}-\frac{2}{3}$ lin. longo obtuso obsolete sulcato. Proxima H. robustee, sed diversa foliis ad basin usque serratis, dentibus magis approximatis majoribusque, cyathulo hypogyno glabro, etc. (v. s. in herb. Boiss.)

15. H. EXGELSA (Blume in Ann. sc. uat. $2^{\circ}$ sér. 1, p. $219^{*}$ ), foliis obovato- vel cuneato-oblongis versus apicem obtusum vel acuminatum grosse obtuseque serratis utrinque leviter laxeque elevato-reticulatis, racemis densifloris ramulisque junioribus ferrugineo-pubescentibus, pedicellis semiliberis calycibusque brevibus, ovario rufo-hirsuto, squamis hypogynis liberis rotundis glabris. 5 In Bengaliæ sylvis, circa Chittageng (Roxb.!). - Bennett! in Horsf. pl. Jav. p. 84. Rhopala excelsa Roxb.! fl. ind. ed. Carey et Wall. 1, p. 365*, Roem. et Seluult. syst. mant. 3, p. $285^{*}$, Wight ic. t. 190 . Arbor magna. Folia alterna, firma, glabra, læte viridia, 5-7 poll. longa, usque ad 2 poll. lata, dentibus raris obtusis. Racemi axillares et terminales, solitarii vel gemini, pedunculati, ${ }_{2}$ pedicellis $1 \frac{1}{2}-2$ lin. longis. Stylus 4 lin. longus. (v. s. in herb. Mus. Brit.)

$\beta$. edentata, foliis elongatis integerrimis. - In orà Martabaniæ, circa Amherst et Moalmyne (Wall.!). R. excelsa Wallich list, n. 1038! Folia 12-15 lin. longa. Gæt. ut in typo. (v.s.)

16. H. S, RRAT A (Blume 1. c. p. 215 "), foliis elliptico-oblongis obtusiuscule acuminatis remote serratis basi attenuatâ integerrimis subreticulato-venosis, racemis axillaribus folio brevioribus ovariisque rufo-tomentosis, pedicellis semiliberis, calyce semipollicari, squamis hypogynis liberis ciliatis. 5 In insulâ Moluccanâ Nusalaut (Chr. Smith!), et Archipel. Malayico (Roxb.), Amboyna (Zippel.).-Bennett ! in Horsf. pl. Jav. p. 84. Arbor vespertílionum Rumph. Amb. auctuar. p. 17, t. 10 . Rhopala serrata R. Browul in Linn. Trans. 10, p. 192, Roxb. 11. ind. ed. Carey et Wall. 1 , p. $365^{*}$, Roem. et Schult. syst. mant. 3, p. $285^{*}$. Helittophyllum parviflorum Zippel. mss. ex Blume. Rami apice subangulati minute ferrugineo-puberuli. Folia alterna vel nonnunquam ternatim subverticillata, coriacea, subsessilia

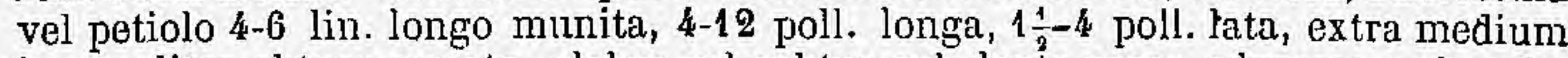
inæqualiter obtuse serrata, glabra vel subtus sub lente parce adpresso-puberula, interdum undulata. Racemi solitarii vel gemini, 3-4-pollicares, subsessiles, laxiusculi, pedicellis 2 lin. longis, ad nedium vel $\frac{2}{3}$ usque connatis. Calyx 7 lin. longus, laminis lanceolatis acutis. Stylus capillaris, stigmate parum incrassato-obtuso nigricante. Folliculi subglobosi, magnit. cerasi majoris, furfuraceo-leprosi. Semen subglobosum. (v. s. in herb. Banks.)

17. H. PHILPPINENSIs, foliis elliptico-oblongis subacuminatis subreticulatis, sæpius ad basin attenuatam usque acute scrratis, racemis axillaribus folio brevioribus laxifloris, pedicellis calycibusque parce minuteque rufo-puberulis mox glabratis, squamis hypogynis semiconnatis glabris, ovario glabro. 5 ? In ins. Philippinis (Guming, n. 1537!). H. serrata $\beta$ Boissieriana Meisn. Inss. olim in herb. Boiss. Folia 6-7 poll. longa, 3 poll. lata, tenuiora quam $H$. serrater, cceterum similia. Racemi breve pedunculati, juniores nutantes, pedicellis $1-1 \frac{1}{3}$ lin. longis breviter comutis. Calyx $7-8$ lin. longus, limbo ovali obtuso. Stylus tenuis, demum 10 lin. 
longus, rufus, stigmate $\frac{1}{3}-\frac{1}{2}$ lin. longo crassiusculo ovali obtuso nigricante. Valdo accedit ad castanex foliam, sed distincta foliis minus rigidis basi semper attenuatis nee rotundatis, dentibus minoribus rectiusculis, racemis puberulis; etc., et a H. attenuatâ et oblongifoliâ partim iisdem notis et squamis hỵpogynis semiliberis. (v. s. in herb. Boiss. et Mus. Brit.)

18. H. C о G I IN CH IN EN is (Lour.! n. coch. p. $83^{*}$, ed.Willd. 1 , p. $105^{*}$ ), glaberrima, foliis petiolatis ovato-ellipticis ljreve acuminatis extra médium minute sërratis vel passim integerrimis utrintue łeviler prominulo-reticulatis, racemis axillaribus folia suboquantibus densifloris, squamis hypogynis semiconnatis. 5 In sylvis Cochinchine (Loureito!) et Assam (Grillill1). - Roem. et Schult. syst. 3, p. $306^{*}$, Blume in Ann. se. nat. $2^{\circ}$ sér. 1, p. $21^{4} 4^{\dagger}$, Bennet in. Horsf. pl. Jav. p. 82. Rhopala Cochinehinensis R. Brown! in Liun. Trans. 10, p. 192*; thoom. et Schult. syst. 3, p. 429`. R. robusta Sprerig. Sist. 1, p. 482, (ex parte - non Roxb.). Arbor mediocris. Petioli 2-6 lin. longi. Folia alterna, rigide coriacea, supra læete viridia nitida, subtus fuscescentia opaca, $2 \frac{1}{2}-4$ froll. longa, 18-20 lin. lata, interdum utrinque æqualiter attenuata, acumine acito vel obtuso vel nullo, dentibus $2-4$ lin. distantibus obtusiusculis, venis tenuilus utrin'que subequaliter promiüulis. Racemi solitarii, breve pedunculati, 4-5 pwll. longi, pedicellis cire. 1 lin. loggis. Calyx gracilis, cum pistillo glaberrimus, 7-8 lin. lougus, limbo fere 2 lin. longo ovali crassiusteulo. Squamæ bypogynæ minuta, ttcutiusculæ, glabræ. Stigma clavatum. (v. s. in herb. Banks. et Lemann.)

\section{Species non descriptoe.}

H. GLAB A A A. - - Rhopala glabrata Wallich list, p. 29, n. 1039. - In Tavoy (W. Gomez). Est H. roluusta Wall. (sujpra, n. 13), fide Endl. gen. suppl. IV, 2, p. 87 . H. sp. (Zollinger syst. Verzeiclin. 1, p. 118) Java et Sumatra. Zoll. n. 597 et 1594.

X̀XXVII. KNIGHȚI R. Brown in Trans. Soc. Linn. Lond. p. 193, $t .2, \dot{E} n d l$. gen. p. 342, n. 2151, suppl. 4, 2, p. 88, Meisn. gen. p. 333 (245).

Flores hermaphiroditi, regitulares, ràcemosi. Calyx tubulosus, rectus, sépalis 4 linearibus apice subconcavis mox liberis demum revolutis Stamina 4 sepalis supra mediüm inserta iisque revolutis exserta, filamentis brevissimis, äntheris linearibus aculis, connectivo ultıa loculos brevissime producto. Glandulæ hypogynæ 4 liberæ. Ovarium sessile, 1-loculare, 4-ovulatum. Stylus filiformis, rectus, stigmate verticali continuo subclavato-cylindraceo sulcatơ. Folliculus coriaceus, fusiformis, I-spermús. Semina apice alata. - Ärbóres et frutices Novæ-Hollandiæ et Novæ-Caledoniæ, foliis sparsis, peliolatis, coriaceis, simplicibus dentatis integrisve penninerviis, racemis capitulisve axillaribus, pedicellorum paribus 1-bracteatis:

\section{Sectio I. EDKNightia Endl. gen. suppl. IV, $2, p .88$.}

Flores laxiuscule ramosí, bracteis parvulis. Folliculus coriaceus, stylo toto persistente caudaius.

1. K. EXGESA (R. Brown! 1. c. p. 194*, t. 2), arbored, ramulis pubescentibus, folliis oblongis obtusis muticis obtuse dentatis nervosis supra nitidis glabris subtus opacis junioribus tomentellis, racemis subsessilibus, rlachi, calycibus follicülisque rufo-tomentosis. 5 In Novit-Zeelandiâ septentrionali, prope Tołagá, Mercury Bay, Howa-Howa (Banks!), Wangaroa, Bay of Islands ( $\Lambda$. et R. Cunningi.! Hook. fil., etc.). - Roem. et Schult. sysı. 3, p. 431*, A. Guinn. in Ann. of nat. hist. 1, p. 378, Raoul Choix p. 42, Hook. fil.! 11. N.-Zcul. p. 219. Rewa-reya jucolarum. Arbor 80-100-pedalis, trunco strictu, ramis crectis, comâ pyramidali, ligno facile fissili pulchre rubro fusconue variegato. Folia 3-6 polj. longa, 1-2 poll. lata, serraturis sinubusque subrequalibus oblusis. Racemi 2-3-pollicaros, patentes, pedicellis 2 lin. longis, bracteis deciduis. Calyx gracilis, cylindricus, 15 lin. longus. Folliculi 1-1 $\frac{1}{2}$ joll., incluso st ylo $2 \frac{1}{2}$ poll. longi, teretes, 3 lin. crassi, utrinque attenuati, secus suluram obsolete sulcati. (v. s. in herb. Banks., Cunn., etc.) 
Sectio II. EUcarpha R. Brown suppl. p. 3, adnot. sub Orit.

Flores dense capitati, bracteis magnis caducis involucrati. Stylus deciduus. Folliculus lignosus. Semina ignota. - Verisimiliter genus proprium, ex R. Br. 1. c.

2. K.? sтrовіLiNa (R. Browñ suppl, p. 32), fruticosa, foliis obovato-oblongis subspathulatis integerrimis venosis, capitulis axillaribus peduneulatis obovatis, calyce glabro, folliculo oblongo line gilıboso. J In Novâ-Caledonià (Laliill, qui ex errore Nov-Floll. australi-oceid. indicavit.). Embothrium strobilinum Labill. N.-Holl. 2, p. 116, Il. Brown in Linn. Trans. 10, p. 222, Roem. et Schult. syst. 3, p. $432^{*}$. Knightia integrifolia A. Cunningh. in Ann. of nat. hist. 1, 1. 378, in notà. Frutex orgyalis, ramis erectis. Gemmis florigeræ axillares, solitariæ, pedunculatæ, strobiliformes, bracteis imbricatis magnis ellipticis ovatisve mox deciduis. Stylus caducus.

Tribus VI. EMBOTHRIE E.

\section{Ovarium $\infty$-ovulatum. Folliculus polyspermus. Semina alata.}

XXXVIII. LMBOTHRIUM For'ster gen. p. 15, $t .8$ fig. g-m (cat. exclus.); Lam. ill. t. 55, f. 2, Ruiz et Pav. R. peruv. p. 1, (i2, t. 96, R. Brown in Trans. Soc. Linn. Lond. 10, p. 195, Endl. gen. p. 342, n. 2152, suppl. IV, 2, p. 88, Meisn. gen. p. 333 (245).

Flores hermaphroditi, subirregulares, chymbosi. Calyx elongáto-iubulosus tubo gracili basi oblique inserto hinc longitudinaliter fisso. limbo subgloboso 4-fido, laminis concavis antheriferis demum revolutis. Antheræ 4 subșessiles, ovali-oblongæ, muticæ. Cilandula hypogyna ünica, semiannularis. Ovarium stipitatum 1 -loculare, $\infty$-ovulatum. Stylus filiformis, persistens, stigmate verlicali clavato-fusiformi. Folliculus oblongus, coriaceo-lignosús, 1-locularis, 1 -valvis, polyspermus. Semina compressa, pelliculâ cellulosâ fuscâ interstincta, apice in alam truncatam producta, alâ pellucidâ pallidâ hinc nervosomarginatâ, nervo seu chordâ tẹnui ante apicem refiactâ jux́ta marginem subparallele recurrente et secus nucleum ad umbilicurm usque deciurrente.Frutices et arbuscula Americæ australis occidentalis et antareticæ, glabræ, ramulis quandoque gemmarum squamis persistentibus obsitis, foliis sparsis simplicibus integerrimis, racemis terminalibus brevibus fasciculiformibus exinvolucratis, pedicellis libcris geminatim 1-bracteatis, floribus coccineis glaberrimis.

1. E. c oc c Ine Un (Forst.' 1. c.), foliis subsessilibus coriaceis ovalibüs muticis utrinque obtusis basi attenuatis subtus opacis pallidis subeveniis sapra subnitidis nervo venisque insculptis, pedicellis.calyce brevioribus, pistillo calycem pollice breviorem vix superante, stigmate fusiformi-cylindraceo stylo vix crassiore sulcato. 5 ? Ad littora freti Magellanici (Banks et Spland., Forster, Commerson), Port-Fapine et Chiloe (King I), Sandy Point (Lechler, n. 1064!), in Chili australi, prope Valdiviam (Lechler, n. 546!). - Linn. fil. suppl. p. 128, Forst. in comm. Soc, reg. Goetting. 9 , p. 24 , Lam. dict. 2 , p. $351^{\circ}$, ill. t. 55, f. 2, Gav. ic. 1, p. 63, t. 65, R. Bŕown in Limn. Trans. 10, p. 196, Rocm. et Schult. syst. 3, p. 431*, Hook. fil. 1l. antarct. 2, p. 341, Bot. mag. t. 4856. Ixora coccinea Commerson in herb. Catas parviflora Juss. herb. ex Roem. et Schult. Ciruerillo et Notro incolarum, ex Cl.Gay hist. de Chile, 5, p. 307*. Folia $1-2$ - raro 3 poll. longa, $\frac{1}{2}-1$ poll. lata, subtus pallidiora vel interdum glaucescenti-albida, venís arcuatis supra sulciformibus laxe anastomosantibus subtus obsoletis vel nullis. Racemi subsessiles, rhachi brevissimà. Galyx 7-9 lin. longus, pedicello $\div$ vel dimidio longior. Folliculus incluso stylo ipso parum breviore incrassato rectı et stipite 2 lin, longo subbipollicaris, leviter venoso-sulcatus. (v. s. in herb. Banks., Smith., reg. Berolin., etc.)

2. E. LANGeOLATUm (Ruiz et Pav. 01. per. 1, p. 62*, t. 96), foliis loreve petiolatis subherhaceis ovalibus oblongis lanceolatis vel lineari-lanccolatis obtusis mucronulatis basi vel utrinque attenuatis diseoloribus opacis vel supra subnitidis 1-nerviis subeveniis, podicellis calycem pollicarem stylo superatum infuantibus, stigmate oblongo-fusiformi crassiusculo læevi. $尹$ In Chili australi, Araucaniâ, circa Concepcion (Ruiz et Pav., Dombey!), Antuco.(Pœppig! coll. 3, n. 39, diar. 675), 
Arique, prov. Valdivia (Cuming ! Lochler! n. 720! Philippi! Bridges ! etc.), et Peruvia? (Dombey, n. 194 ! in Mus. paris., fide herb. DC., sed loci indicatio verisim. falsa). - R. Brown in Linn. Trans. 10, p. 196, Poir. dict. suppl. 2, p. 547, Roem. et Schult. syst. 3, p. 432*, Cl. Gay hist. de Chile, p. 307*. Ut præcedens vocatur Ciruelillo vel Giruerillo Hispanorum, Notru vel Notro Aboriginum, ex Philippi et Gay. Rami plerumque graciles, pauciramosi. Folia vix coriacea, 1-4 poll. longa, 4-12 lin. lata, interdum attenuato-acutiuscula, venis nunc utrinque plane nullis nunc tenuissimis supra potius rquam subtus conspicuis intra marginem evanescentibus vel arcuatim coeuntibus, petiolo $2 \mathrm{lin}$. longo vel subnullo. Racemi terminales pedunculati, rhachi 2-pollicari, laterales (ramulos brevissimos terminantes) subsessiles multo breviores. Calyx 12-14 lin. longus. Pistillum demum sesquipollicare. (v. s. in herh, reg. Berolin., DC., Kunth., Shuttl., Boiss., etc.)

3. E. GILLIESI I, foliis sessilibus coriaceis pollice brevioribus oblongo-lanceolatis acutis muticis utrinque attenuatis eveniis subtus obsolete 1 -nerviis, pedicellis brevibus, calyce longo gracili demum ad basin usque 4 -partito stylo breviter superato, stigmate vix inerassato. In $^{\prime}$ rep. Platensi, circa Mendoza (Gillies l). Glaberrima, ramis teretibus fuscis minule elevato-punctatis. Folia sparsa, 6-10 lin. jonga, 3-4 lin. lata, integerrima, plana," lrevia. Corymbus terminalis sessilis, abbreviatus, 6-10-florus, pedicellis 2 lin. longis, squamà ovatâ acutå $1 \frac{1}{2}$.lin. longâ concavá fultis. Calyx 14-16 lin. longus, limbo clavato oblongo $2 \frac{1}{2} \mathrm{lin}$. longo acuto. Antherre ovales. Stigma obtusum. $\sigma_{b}$ s. sine fr. in lierb. Lindl.)

\section{Species excluser.}

E. A L N F OL I U M Popp. = Lomatia obliqua R. Br. $\gamma$.

E. A N G U T I F O L I U M Sm. = Grevillea linearis $\mathrm{R}$. Br.

E. B IPIN NA T U M Willd., fide Sm. = Quid?

E. B UX IF O I I M Sm. = Grevillea buxifolia R. Br.

E. Cil A P A R A o Humb.= Rliopala complicata Kunth?

E. crNeRE U M Thib. herb. )

E. COR D I F O L I U Willd. $\}=$ Rhopala cordifolia Kunth.

E. GR I T H I F O I U M Sm. = Lomatia silaifolia $\mathrm{R}$. Br.

E. CUR VA T U Willd. = Rhopala complicala herb. Kunth.

E, c X T Is o I E s Cav, = Grevillea sericea et linearis R. Br.

E. DENTA T U M R.et Pav. = Lomatia dentata R. Br.

E. E M A R I N A T U R. et Pav. = Oreocallis grandiflora Br. et Ruizii Kl.

E. FER RU G INE U I Cav. = Lomatia ferruginea R. Br.

E. GEN I A T н U М Cav. = Grevillea buxifolia R. Br.

E. G R A N IF L O H U L Lam. = Oreocallis grandiflora R. Br.

E. н е R в A с е U м Lam. = Lomatia silaifolia R. Br.

E. h I s U T U M Lam. = Lomatia obliqua R. Br.

E. I I G I O I a Poir. = Lomatia ilicifolia R. Br.

E. L I с а R E Audr. = Grevillea linearis R. Br.

E. LINEARIF OL I U Gav. = Grevillea linearis R. Br.

E. L ONG IFOL I U POir. = Lomatia longifolia R. Br.

E. M I U s Steud. = Grevillea punicea R. Br.

E. MONOSPERMU Ruiz et Pav. = Rhopala Peruviana R. Br.

E. MU C RONA T U Willd. herb. = Oreocallis grandiflora R. Br.

E. MY R I O I D ES Gærtn. = Lomatia longifolia R. Br.

E. м х т т F о I U м Pœpp. = Rhopala myrtoidea Pœpp. et Endl.

E. OBLI Q U U R. et Pav. = Lomatia obliqua R. Br.

E. P IN A T U M R. et Pav, = Rhopala diversifolia R. Br.

E. PINOL Domb. = Lomatia dentata $\mathrm{R}$. Br. $\beta$.

E. P OLY S т с ну и м Willd. herb. = Andripetalum polystachya Kl.

E. и U B R I A U L E Giord. = Stenocarpus salignus R. Br.

R. RU RAL E Domb. = Lomatia obliqua R. Br. $\beta$. 
E. S A L I G I r O L I U M-Vent. = Hakea saligna Kn. et Salisb.

E. SA I G N u м Andr. = Hakea saligna' Kn. et Salisb.

E. SER I C E U M Sm: = Grevillea sericea, linearis et punicea R. Br.

E. SI LA I F O LI U M SnI. = Lomatia silaifolia R. B.

E. SPA T H U L A T U M Cav. = Telopea speciosissima R. Br.

E. SPECIOSIS S I U M Sm. = Telopea speciosíssima R. Br.

E. SP E c I os u m Salisb. = Telopea speciosissima R. Br.

E. S T R O В I L I N M Labill. = Knightia strobilina R. B.

E. S Y L V A T I c U м Pœpp. = Lomatia dentata R. Br. $\alpha$.

E. T IN C T O R I U Labill. = Lomatia polymorpha et tinctoria R. Br.

E. TR UNG A T M Lábill. = Telopea truncata R. Br.

E. UмвецLат и и Ferst. = Stenocarpus Forsteri R. Br.

XXXIX. OREOGALLIS R. Brown in Trans. Soc. Linn. Lond! 10, p. 48 et 196, Endl. gen. p. 342, n. 2153, suppl. IV, 2, p. 88, Meisn. gen. p. 333 (245). - Embothrii sp. Ruiz et Pav. R.per. 1, p. 62, t. 95.

Flores hermaphroditi, subirregulares, corymbosi. Calyx longe tubulosus, oblique inșertus, hinc longitudinaliter fissus, limbo cernuo subcorymboso 4-fido, laminis concavis antheriferis. Antheræ subsessiles, ovatæ, muticæ. Glandula hypogyna semiannularis. Ovarium longe stipitalum, 1-loculare, $\infty$-ovulatum. Stylus filiformis, stigmate oblique laterali orbiculari-dilatato discoideo subconcavo vel umbonato. Folliculus cylindraceus, 1-locularis, polyspermus. Semina apice membranaceo-alata.-Frutices Andium Peruviæ, speciosi, foliis sparsis petiolatis coriaceis simplicibus integerrimis subtus discoloribus, corymbis terminalibus subsessilibus exinvolucratis folia superantibus demum thyrsoideis, pedicellis geminatim 1-bracteatis liberis, floribus coccineis glaberrimis. - Glandula hypogyna secundum ill. R. Brown nulla, sed certe adest, in 0 . Ruizii valde conspicua, in 0 . grandiflorả vero ovarii stipiti arcte adpressa et subadnata ideoque facile prætervidenda.

1. O. GRANDIFL OR A (R. Brown in Linn. Trans. 10, p. 197), foliis ovalibus oblongisve utrinque tenuiter laxeque elevato-reticulatis demum glabris supra subnitidis, junioribus ramulisque cano- vel ferrugineo-tomentosis, pistillo sesquipollicari crassiusculo, stigmate subconcavo, glandulâ hypogynà obsoletâ. $\bar{\xi}$ In frigidis Peruviæ, prov. Tarma, Huanuco, Huamalies, Machimparrani, Picahuay, etc.-Klotzsch! in Linnæâ 15, 57, ib., 20, p. 475. Embothrium emarginatum Ruiz et Pav.! fl. per.1, p. 62. t. 95. E. grandilorum Lam. dict. 2, p. 354, Willd. sp. 1, p. 538. E. mucronatum herb. Willd. n. 2490, 2491. Ramuli strictiusculi. Petioli 5-10 lin. longi, teretes, tarde glabrescentes. Pedicelli infimi calycem subæquantes, superiores breviores. Bracteæ diu persistentes. Calyx 14 lin. longus, tubo $1 \frac{1}{2}$ lin., limbo 2 lin. crasso. Pistillum 16-18 lin. longum, stylo fere 1 lin. crasso. Formæ seq. vix varietates stabiles sistunt.

$\alpha$. emarginata, foliis ovalibus utrinque rotundatis apice plus minus emarginatis supra tarde glabratis subtus ramisque dilu denserue ferrugineo tomentosis (Dombey! herb. Mus. paris. n. 196! in herb. DC. et reg. Berolin.). Folia 2-5 poll. longa, $15^{\circ} 24$ lin. lata. (v. s.)

$\beta$, obtusifolia, foliis oblongis apice rotundato-obtusis passin subemarginatis vel mncronulatis basi attenuata in petiolum breviter productis utrinque mox glabratis (Ruiz et Pavon! in herb. Berolin., Shuttl., Boiss., Mathews, n. 810,

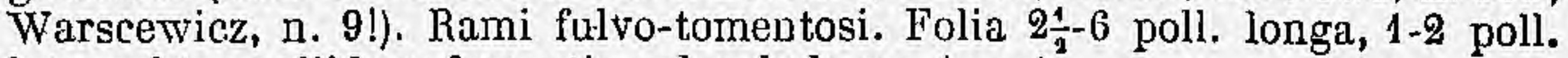
lata, subtus pallide rufeseentia vel subglauca. (v. s.)

$\boldsymbol{\gamma}$. acutifolia, foliis oblongis acutis sæpe mueronulatis, raro passim obtusis, in petiolum breviter attenuatis, cito glabratis. (Ruiz et Pav., in herb. Shuttl. et Boiss.). Cat. ut in $\beta$. (v. s.)

2. O. Ruız (KKlotzsch ! in L̇innæâ 20, p. 474), foliis oblongis obtusis subemarginatisque mucronulatis glabris. in petiolum breviter attenuatis utrinque leviter elevato-venosis subreticnlatis supra subnitidis suhtus glaucis, pistillo demum bipol- 
licari tenui, stigmate umbionato, glandulâ hypogynâ crassiuscule prominulâ. 春 In Peruviâ, circa Huanuco (Ruiz !), Loxa (Warscewicz, 11. 8!), (luito (Hârtwèg, ń. 831!). Rami glabri vel rarius fulvo-tomentelli. Folia plerumque rigidiora cuam 0 . grandifloræ et minora, vix unquam ultra $2 \frac{4}{2}$ poll. longa, 9-12 lin. Jata, petiolo 5-8 lin. longo. Racemus densior, corymbosus nec thyrsoideus, rhachi ramorumque apice pruinoso-glaucis, pedicellis calyce semper dimidio vel plus brevioriljus, bracteis pilosiusculis deciduis. Calyx 12-14 lin. longus, limbo 1-1 $\frac{1}{2}$ lin. crasso. Stigmạ minus. Folliculus stipitatus, oblongus, utrinque altenuatus, rostratus, cum stipite 5 lin. longo rostroque valido 4 poll. longus.-Embothriwm grandiflorum Bonpland! in herb. rug. Berolin., quamvis a cl. Klotzsch 0 . grandiflorce adjectum, certissime ad 0 . Ruizii pertịnet, cum plàntâ Hartwegianâ enịm omnimodo convenit. (v. s. in herb. reg. Berolin., Shuttl., Boiss., etc.)

XL. TELOPEA R. Brown in Trans. Soc. Linn. Lond. 10, p. 197, prodr. fl. N.-Holl.p. 388 , suppl. p. 32, Endl. gen. p. 342, n. 2454, suppl. IV, 2, p. 88, Meisn. gen. p. 333 (245). - Hylogyne Knight et Salisb. Prot. p. 126. - Embothrii sp. Smith, Cav., Salisb.

Flores hermaphroditi, irregulares, racemosi, involucrati. Calyx pedicello oblique insertus, tubo supra fisso 1-labiatus, labii 4-lidi lobis concavis antheriferis. Antheræ 4 subsessiles, ovales, muticæ. Glandula hypogyna uníca, subannularis. Ovarium stipitatum, 1-loculare, multiovulatum. Stylus filiformis, rectus, persistens, stigmate continuo incrassato oblique laterali convexo. Folliculus cylindraceus, polyspeṛmus, pelliculâ cellulosâ opacâ seminibus singulis interpositâ. Semina apice alata, apice truncata vel rotundata, hinc immarginata, raphe bicruri, crure adscendente oblicjuo, descendente recto marginali in verticem nuclei desinente. - Frutices Novæ-Holl. anstrali-orientalis et Tasmanniæ, ramulis determinatis vel nullis, foliis sparsis coriaceis simplicibus penninerviis dentatis integrisve, stomatibus hypogenis, corymbis terminalibus eapitulum simulantibus, involucro colorato-imbricato munitis; pedicellorum paribus 1-bracteatis, bracteis deciduis, floribus eoceineis.

1. T. SPEGIOSISSIMA (R. Brown! 1. c. p. 188 et 388 ), glabeŕrima, foliis petiolatis planis cuneato-oblongis obovatisve obtusis muticis acute inciso-dentatís reticulato-nervosis supra nitidis elevato-punctirulatis, corymbo ovato densifloro. $f$ In montibus, circa Port-Jackson et Bathurst (R. Bromn! Sieber, fl. N.-Holl. n. 22 ! fl. mixt. n. 483 ! etc.). - Roem. et Schult. syst. 3, p. $432^{*}$, Reichenb. 0. expt. t. 159. Embothrium speciosissimum Smith! N.-Holl. 1, p. 19*, t. 7, WVilld. sp. 1, p. 537, Bot. mag. t. 1128 . E. spathulatụm Cav. ic. 4 , p. $60^{*}$, t. 388 , Gærtn. fil. fr. 3, p. 214, t. 218, Spreng. syst. 1, p. 483. E. speciosum Salisb. parad. p. 111. Hylogyne speciosa Knight et Salisb. Irot. p. 126. Waratah incolarum (cfr. Meredith notes and sketches of N. S.Wales, p. 65). Gaulis erectus, 6-8-pedalis, simplex vel rarius apice pauciramosus candelabriformis. Folia viridia, 6-10 poll. longa, $1 \frac{1}{2}-3$ poll. lata, petiolo pollicari, dentibus integris vel serratis. Corymbus pugni mole, bracteis oblongis usque ad 4 poll. longis acutis tenuiter venoso-striatis junioribus apice rufo-pubescentibus, pedicellis infimis pollicaribus calycem subinflatum aquantibus. Seminis ala sæpius truncata. (v. s. in herb. Brown., Smitl.,, etc.)

2. T. TRUNCATA (R. Brown! l. c. p. 198 et 389), foliis sessilibus spathulato-oblongis oblusiusculis nuticis integerrimis vel jassim paucidentatis recurvis supra impresso-venosis licviluus glabris nitidis subtus subeveniis junioribus rammlisque tomentosis, corymbo foliis breviore. J In montibus insulæ Diemen præcipue australioris (R. Br.! Labill. I Scott I d'Urville!), monte Wellington (Gunn, n. 175!). Roem. et Schult. syst. 3, p. $433^{*}$. En bothrium truncatum Labill.! N.-Holl.1, p. 32*, t, 44. Hylogyne australis Knight ot Salisb. Prot. 1, 127. Ramuli velutino-tomentosi. Folia subglauca? 2-4 poll. longa, extra medium 4-9 lin. lata, apice rotundata vel acutiuscula, juniora 'pube minutâ adpressâ subtus cano-tomentoșa suj̣ra parciore fugáci, mox glabrata. Coryınbus sessilis, rhachí circ. pollicari, liracteis ovatooblongis pollice breviorilus júnioribus extus tomentoso-lanatis, pedicellis demum 6-10 lin. longis. Folliculus falcutu-oblongus, utririque attenúatus, inclusó stipito 2 lin. et stylo toto 10 lin. longo 2-3-ppllicaris, teres, 5 lin. crassus, lavis, glaber. Seminum ala ex Br. apice rotundata, ex specim. Labill.! truncata. (v. s. in hérb. Brown., DG., ete.) 
XII. LOMATIA R. Brown in Trans. Soc. Linn. Lond. 10, p. 199, prodr. A. N.-Holl. p. 389, suppl. p. 33, Endl. gen. p, 342, n. 2155, suppl. IV, 2, p. 88, Meisn. gen. p. $333(245)$. Embothrii sp. Smith, Cav. - Tricondylus Knight et-Salisb. Prot. p. 121.

Florès hermaphroditi, irregulares, racemosi. Calyx unilabiatus, sepalis 4 liberis secundis àpice concavo recurvo immerse antheriferis. Antheræ $4 \mathrm{sub}$ sessiles, ovatæ, muticæ. Glandulæ hypogynæ 3 secundæ. Ovarium stipitatum, 1-loculare, 'multiovulatum. Stylus filiformis, persistens, stigmate obliquo vel laterali dilatato subrotundo planiusculo. Folliculus ovali-oblongus, subteres vél compressus, bivalvis, polyspermus, pelliculà seminibus înterpositâ. Semina apice vel utrinque alata, raphe marginali totam alam uniformiter cellılosam cingente in apice rinclei desinente. - lirutices et arbusculæ Australasiæ et Americæ austro-occidentalis, foliis sparsis coriaceis pinnatim laciniatis vel dentatis vel passim integerrimis, interdum in eâdem stirpe heteromorphis, stomatibus hypogenis, racemis terminalibus axillaribusve simplicibus ramosisve nunc elongalis laxis nunc abbreviatis corymbiformibus, pedicellorum paribus 1-bracteatis, involucro nullo, floribus ochroleucis, rarius rubris?

\section{Seclio i. Eulomatia Endl. gen. p. $3 \measuredangle 2$.}

Semina apice elata, basi aptera, nucleo farinâ sulphureâ consperso: Flores racemosi ochrolieuci. - Frutices Australașicœ, unica sp. Chilensi.

1. L. ILICIFOLIA (R. Brown in Liun. Trans. $0, p 200$, prodr.p. 390, suppl. p. 33), foliis ovatis oblongis sublanceolatisve spinoso-dentatis reticulatis adultis glabriusculis, racemis elongatis, calyco pedicellum æequante adpresse pubescente, pistillo glaberrimo. In Inov.-Holl. oricnt. et austr. Embothrium ilicifolium Poir. suppl. 2, p. 551 .

u. ovata (R. Br. suppl. p. 33), foliis oblongo-ovatis, racemis e summis axillis terminalibusque. - In orâ auslrali, circa Port-Phillip (R. Br.) et orientali, prope Twofold Bay et Wilson's promontory (A. Gunningh.)

B. glabrata (R. Br. 1. c.), Coliis elliptico-lanceolatis, petioliş ramulisque adultis glabris, racemis terminalibus. - Girca Port-Jacksou.

$\gamma$. axillaris (R. Br. 1. c.), foliis elliptico-lanceolatis, petiolis ramulisque pubescentibus, racemis axillaribus. - Circa Wilson's promontory (Baxter).

¿. pinnatifida (Hlook. in Bot. macr. t. 4023), foliis clliptico-oblongis inciso-serratis passimque pimnatifidis, laciniis lanceolatis dentatis, racemis terminalibus basi ramosis. - Colitur in horto kew. Folia semipedalia, 1 $\frac{1}{2}-2 \frac{1}{2}$ poll. lata. Racemi 8-10 poll. loṇgi, floribus pchroleucis.

2. L. Fra serr (R, Brown suppl. j. 34), foliis ovato-oblongis grosse dentatis utrinque -reticulatis basi subcuneatâ integerrimâ acutis supra demum glabriusculis subtus ramisque junioribus sericeis, racemis axillaribus terminalibusque, pistillo glaberrimo. F In montibus, circa Port-Jackson (Fraser), ad flum. Delalite (Ferd. Müller!). Frutex 5-8-pedalis, erectus. Rarni virgati, stricti, subsericeo-puberuli, demum glabri. Folia incluso petiolo semipollicuri gracili 3-5 poll. longa, 12-15 lim: lata, rigida, acuta vel obtusa, supra subnitidà, subtus sericea, venarum reticulo laxiusculo utrinque subaqualiter prominulo, dentibus subequalibus 2-4 lin. distantibus 1-1 $\frac{1}{2}$ lin. longis inermibus, sinubus obtusis. Foliis accedit ad L. dentatam, cseteroruin distinctissima. (v.,s. sine fl. nec fr. in herb. Somler.)

3. LONGIFOLIA (R. Brown in Linn. Trans. 10, p. 200, prodr. p. 390), ramulis apice sericeo-pubcrulis, foliis elongato-linearibus lancedatisve submuticis glabrís extra medium remote breviserratis passim integerrimis, racemis axillaribus laxifloris, calyce pedicellum aquante pistilloque longe stipitato glabris, stigmate laterali subrotundo umbonato-convexo. F Circa Port-Jackson (R. Brown! Sieber, etc.). Bot. reg. t. 449, Roem. et Schult. syst. mant. 3, p. $288^{*}$. Embothriam myricoides Gærtn. fil. fr. 3, p. 215, t. 218 ? E. longifolium Poir. suppl. 2, p. 551. Tricondylus myricafolius linight et Salisb. Prot. p. 122. Frutex elatior, ramis gracilibus strictis mox glabris, junioribus sulcato-subangulatis. Folia 3-6 poll. longa, 2-7 lin. lata, acuta vel obtusa, basin versus longe attenuata ibique integerrima, pennivenia. 
Racemi folia subæquantes vel superantes. Calyx 5 lin. longus. Ovarii stipes gracilis, calycis tubum æquans, stylo longior. Folliculus incluso stipite 3 lin. styloque $1 \frac{1}{2}$ lin. longa 12-15 lin. longus, semiovali-oblongus, teres, glaber, obsolete impressovenosus, utrinque attenuatus.

a. reticulata, foliis reticulatis, venis utrinque prominulis, pedunculis calyoibusque pube minutâ rarâ sericeis. (v. sp. Brown.! in herb. DC. et Phillip. in herb. Lemann.)

B. subevenia, foliorum venis tenerrimis subimmersis vel obsoletis, pedunculis calycibusque glaberrimis. (Sieber, n. 16 ! n. mixt. n. 473!). (v. s. et v. c.)

4. L. sinuata (R. Browh suppl. p. 33), ramulis angulatis pubescentibus, foliis sinuato-pinnatifidis, lobis inciso-dentatis, adultis supra glabris subtus parce adpresso-pubescentibus, racemis axillaribus. $\bar{J}$ In oræ orientalis montibus versus Lachlan (Fraser).

5. L. P oL y о R Pн а (R. Brown! in Linn. Trans. 10, p. 200, prodr. p. 389), foliis linearilanceolatis obtusiusculis muticis integerrimis dentatisve vel pinnatifidis 1 -nerviis eveniis junioribus cum ramulis racemisque tomentosis supra demum glabratis, corymbis terminalibus brevibus subsessilibus, pedicellis calycem puberulum subæquantibus. $\bar{J}$ In montibus insule Diemen oricntalis' et occidentalìs (R. Brown! Labill.! etc.).--Peir. suppl. 2, p. 550 . Embothrium tinctorium var. Labill. N.-Holl.1, p. 31, t. 42. Fotia 1-2 $\frac{1}{2}$ poll. longa, 2-4 lin. lata, sessilia, conferta, integerrima, rarius passim apice 3-paucidentata vel pinnalifida. Corymbi folia vix superantes, laxiusculi, rarius $2-3$ poll. longi. Calyx circ. sennipollicaris; pube brevi rufâ sericeo-velutinus, interdum mox glabratus. Folliculus serniovali-oblongus, utrinque attenuatus, lævis, glaber. (v. s. in herb. DC., etc.)

$\alpha$. cinerea (R. Brown l. c.), foliis lineari-lanceolatís integerrimis margine recurvis, subtus cinereo-tomentosis, folliculo semipollicari. - In monte Wellington (R. Brown! Gunn, n. 1241!), ad flum. Gordon, prope. Macquarie Harbour (Milligan, 10. 404!).

B. rufa (R. Br.l.c.), foliis lanceolatis vel lineari-lanceolatis incisis vel pinnatifidis passim integerrimis subtus rufo-tomentosis, folliculo. subpollicari. - Embothrium tinctorii var. Labill.! in herb. DG.

6. L. TINC T ORIA (R.Br.l.c. p. 199 et 389), foliis pinnatifidis rarius bipinnatifidis integerrimisque planis subeveniis.glaherrimis vel sulj tus ramulisque junioribus minute adpresso-pubcrulis, laciniis linearibus 1 -nerviis obtusiusculis mucronulatis, racemo terminali elongato glaberrimo, pedicellis calyce sublongioribus. $尹$ In ins. Diemen (R. Brown! Labill.! Verreaux I), Flinders Island et New Norfolk (Gunn, n.1! 1242!). - Roem. et Schult. syst. 3, p. $434^{*}$, Bot. mag. t. 4110 . Enlbothrium tinctorium Labill.I N.-Holl. 1, p. $31^{*}$, t. 43, Poir. suppl. 2, p. 550 (excl. var.). Tricondylus tinetorius Knight et Salisb. Prot. p. 122. Pulvis semina obtegens aquâ infusus colorem roseum largitur (Labill.). Accedit ad sequentem, serl fácile dignoscenda foliis minus rigidis, láciniis linearibus (nec cuneatis) obtusiusculis, venis nullis ant obsoletissimis immersis, plerumque indivisis et vix divergentibus, junioribus subtus puberulis, racemo breviore 3-5-pollicari. folliculo angustiore semiovali-lanceolato. (v. s. in herb. DC., etc.)

7. L. SILAIFOLIA (R. Brown! l. c. p. 199 et 389 , suppl. p. 33 ), glaberrima, foliis pinnatim vel bipinnatim laciniatis venosis lacinulis linearibus cuneatisve mucronulato-acutis dentatis integrisve, racemis elongatis, pedicellis calycem subwquantibus. $\bar{\jmath}$ In Norâ-Floll. orientali (R. Br., etc.). - Bot. mag. t. 1272, Herb. amat. t. 144, Roem. et Schult. syst. 3, p. $433^{\star}$. Embothrium silaifolium Smith! న. Holl. p. 23 , t. 8 , Willd. sp. 1 , p. 537, Poir. suppl. 2, p. $551^{*}$. E. herbaceum Cav. ic. 4, p. 60 , t. 388. E. crithmifolium Sm. ex Steudel nomencl. ed. 2 . Tricondylus silaifolius Knight et Salisb. Prot. p. 122: Grevillea silaifolia Don hort. Cantabr. p. 6. Frutex vel suffrutex? 1-3-pedalis. Folia modice coriacea, 3-5 poll. Ionga, 1-2 poll. lata, petiolo plerumque longiora, lacinulis 1-2 lin. latis decurrentibus. Racemi usque ad picdem longi, simplices vel basi divisi. Calyx 7-8 lin. longus. Stylus ovarii stipite brevior, stigmate orbiculari. Folliculi penduli, semiovali-oblongi, læves, glabri, pollicares, stipite 4-5 lin. longo.

a. angustifolia (R. Br. suppl, p. 33), foliis bipinnalifidis, pinnulis cuneato-linearibus incisis mucronalis,--Circa Port-Jackśson (R. Brown! Gaudich.! d'Urville! 
Sieber, n. 15! Anderson!). Embothrium silaifolium Smith! in herb. (v. s. in herb. Smith., DC., etc.)

B. Latifotia (R. Br. l. c.), foliis pinnatis, pinnis inferioribus pinnatifidis superioribus incisis dentatisve lineari-lanceolatis venis utrinque prominulis reticulatis. - Circa Port-Jaclisson.

\%. pinnata (R. Br. 1. c.), foliis pinnatis supra reticulatis subtus obsolete immersovenosis, pirnnis lineari-lanceolatis paucidentatis, dentibus muticis. - Circa Moreton Bay (Fraser).

8. L. FER RUGINEA (R. Brown in Linn. Trans. 10, p. 200), foliis bipinnatifidis, junioribus cum ramulis racemisque tomentosis supra denum glabratis, pinnis 5-8-jugis patentibus pinnulisque 2-5-jugis oblongis vel cuneatis acutis integerrimis rel paucidentatis, racemis axillaribus terminalibusque simplicibus folio lrevioribus recurvis, pedicellis calyce inflato brevioribus. 5 vel 5 In Chili australi littorali, eirca S. Carlos de Chiloe (Cavanill., Née! in herb. Humboldt, Phil. Parker King! Cuming, n. 41 ! etc.), Valdivia et Arique (Bridges! Lechler, 11.426 !), et in Chonos insulis (Darwin, Hook. fil.). -- Roem. et Schult. syst. 3, p. 434*, Philippi in Schlecht. bot. Zeit. 1852, p. 922, Lindl. in Paxt. fl. Gard. 2, n.437, Cl. Gay hist. de Chile 5, p. 310*, Hook. fil. fl. antaret. p. 342. Embothrium ferrugineum Cav, ic. 4, p. 59', t. 385, Willd.! mss. in herb. 2494 ! Romerillo, Romarilla, Piune et Fuinque incolarum, ex Gay l. c. Frutex 10-12 ped. (Cuv.) vel arbor 30-pedalis (Lechler). Folia patula, 3-6 poll. longa, pinnis suboppositis 1-2-pollicaribus, pinnulis 4-8 lin. longis, sæpius alternis vel deeurrenti-confluentibus subrnucronulatis supra impresso-1-nerviis eveniis subtus fulvo- vel ferrugineo-tomentosis. Racemi subsessiles, 2-3 poll. longi. Calyx 7-8 lin. longus, ferrugineo-tomentosus, colore ex scarlatino et aureo mixto (Philippi), tubo subventricoso-inflato, fauce constrietâ, limbo globoso. Pistillum glaberrimum, ovarii stipite stylo 3 lin. longo paulo breviore. Folliculus incluso stipite semipollicari fere 2 poll. longus, 3-4 lin. Jatus, oblongus, rectus, parum compressus, stylo basi breve acuminatus, longitudinaliter plurisulcatus vel sublævis, glaber; lævis, opacus, marginibús obtusis, altero erecto, altero arcuato fisso. Seminis ala oblonga oblique truncata, margine exteriore nerviformi, altero latiore tenuiore opaco, nucleo alâ 5-6-plo breviore obovato marginibus basique aptero. (v. s. in herb. Willd., etc.)

\section{Sectio Iı. A mphiloma Endl. gen. p. 342.}

Semina utrinque alata, ald baseos evasculosâ, nucleo absque pulvere sulphureo. Frutices vel arbusculæ Americæ australi-occidentalis, foliís breve dentatis subintegrisque, racemis abbreviatis corymbiformibus.

9. L. Dentata (R. Brown in Linn. Trans. 10, p. 201), folis ovalibus oblongisque in petiolum brevem attenuatis glabris remote denticulatis infra medium integerrimis margine leviter recurvis, supra subeveniis, subtus tenuiter prominulo-penniveniis, corymbis lateralibus bracteatis cum ramulis foliisque novellis minute tomentosis, stigmate ovali dorso cum stylo toto ovarioque piloso. $\xi$ vel 5 In sylvis Chili australis. - Roem. et Schult. syst. 3, p. 435*, Klotzsch in nov. act. nat. cur. 19, suppl. 1, p. 411. Embothrium dentalum Ruiz et Pav. fl. peruv. 1, p. 62, t. 94, a, Poir. suppl. 2, p. 549*. Incolis : Pinol et Guarda fuego. Folia alterna et passim opposita, supra læte viridia interdum niticla, subtus vel utrinque opacn subglaucescentia. Corymborum rhachis brevissima, bracteata, tomentosa. Galyx pedicello demum brevior, limbo ovato-globoso quam tubus duplo crassiore.

$\alpha$. acutifolia, foliis modice coriaceis ovalibus oblongisve acutis cuneatis vel utrinque subrequaliter attenuatis, dentibus obtusis acutisve, racemis folio brevioribus, calyce pedicellum subæquante pallide fulvo-tomentoso. 5 Circa Miseta de Antuco (Pœppig!), in prov. Chiloe et Valdivia (Cl. Gay, Phílippi, n. 23! Lechler, n. 463 , a! b!). L. dentata Cl. Gay, hist. de Chile, p. 309* L. sylvatica Pæppig coll. 3, n. 41! Embothrium sylvaticum Prepp.! diar. 853. Arbor 20-pedalis (Philippi). Folia $1 \frac{1}{2}-2$ poll. longa, 6-12 lin. lata, petiolo 2-3 lin., calyce 4-6 lin. longo. (v. s.)

$\beta$. obtusifolia, foliis rigide coriaceis cuneato-obovatis oblongisve obtusis obtuse dentatis racemo rufo-velutino superatís, pedicellis calyce longioribus. $₹$ Circa Coucepcion et Valparaiso (Dombey, n. 195! Cuming, 11. 118!). Embothrium Pinol Dombey! in herb. Mus: paris. et DC. Frutex 10-pedalis (Guming.). Folia 
sæpe subsessilia, raro pollice longiora, 6-8 lin. lata. Calyx 6-7 lin, longus. Folliculus incluso stipite 4-5 lin. longo stylum subæquante 20 lin. longus, semiovałi-lanceolatus, utrimque attenuatus, parce pilosiusculus. (v. s.)

10. L. OBLIQUA (R. Brown 1. c. p. 201), foliis ovatis vel ovato-oblongis obtusis obtuse dentatis vel passim integerrimis basi rotundatâ vel in petiolum subattenuatà sæepe obliquis utrinque leviter prominulo-venosis glabris supra nitidis subtus discoloribus opaćis, racemis in summis axillis subsessilibus folì subæqualibus ebracteatis dense rufo-villosiusculis, sty-lo inferne pilosiusculo, stigmate orbiculari glăbro. $\bar{J}$ In Quito et Peruviâ, cirea Savagura, Guença (Humboldt, n. 3307! Hartweg, n. 830!), prov. Cachapoyas (Nathews!), in Chili prov. Goncepcion et Puchacay (Ruiz et Pavon! Beechey! Lechler, n. 538 a! 3093!). - Roem. et Schult. syst. 3 , p. $435^{*}$, Cl. Gay. hist. de Chile, p. 308*. Embothrium obliquum Ruiz et Pav.! fl. per. 1, p. 63, t. 97, Willd. herb. n. 2500, Poir suppl. 2, p. 550*. E. hirsutum Lam. enc. 2, p. 355, ill. p. 245, n. 1286, Willd. sp. 1, p. 538. Raral, Radal et Nogal incolarum (Gay). Folia afterna, coriacea, incluso petiolo 3-12 lin. longo subtereti 2-5 poll. longa, 9-24 lin: lata, subtus 'livida rel rufa, juniora puberula, dentíbus 2-4 lin. distantibus valde inæequalibus semper brevissimis obtusis hamatisve subundulatis. Gemmæ axillares ovate, squamis arete imbricatis ovatis acuminatis incanis. Calyx 4-5 lin. longus, limbo obtusissimo tubo vix ampliore. Stigma laterale, $\frac{2}{5}$ lin. latum, hinc convexum, marginatum. Folliculus cum stipite 3 lin. longo 1-1 $\frac{1}{2}$ poll. longus, semióvali-oblongus, leviter falcatus, parum compressus, glaber, sublævis, styli basi breviter apiculatus. Semina cuneato-oblonga, 4-5 lin..lauga, 2 lin. lata, apice truncata, basi attenuatâ breve alata. (v: s.)

ß. subrntegrifolia, foliis subopacis integerrimis passimque apicem versus paucidentatis, racemis laxioribus folio brevioribus laxius pilosiusculis, calyce apice dense hirsuto.-Circa Valparaiso (Cuming, n. 381!). L. opaca Klotzsch ! mss. in herb. reg. Berol. Embothrium' rurale Dombey! mss. in herb. Mus. paris. n. 193! (v. s.)

$\gamma$. alnifolia, foliis rleusius dentatis, dentibus sæpe acutiusculis, racemis folio plerumque brevioribus.-Circa Valdiviam, Concepcion, Antuco (Pœppig! Lechler, n. 538!). L. alnifolia Pọpp. coll. 3, n. 40! Embothrium alnifolium Peppig diar. 665! Nogall Valdiviensium. (v. s.)

11. L. GhILensis (Glaud. Gay hist. de Ghile, p. $310^{\star}$ ), glabre, foliis breve petiolatis oblongis vel oblongo-lanceolatis integris obtusis mucronatis supfa sublævibus nitidis subtus venosis, folliculis subsessilibus oblongis rostratis. $尹$ In Arancaniâ boreali. Frutex mediocris, ramis gracilibus apice dense foliosis. Folia coriacea, Buxo similia, pollicaria vel breviora, 3-4 lin. láta, petiolo vix 1 lin. longo. Florés ignoti. Folliculi secus ramos racemosi, subsessiles, lignosi, 8 lin. longi, 3-4 lin, lati, oblongi, stylo longo indurato rostrati, læves. Semina haud observata.Videtur species bene distineta, præcedentis var. $\beta$ quodammodo accedens.

XLII. STENOCARPUS R. Brown in Trans. Soc. Linn. Lond.10, p. 201, prodr. fl. N.-Holl. p. 390, suppl.p. 34, Endl.gen. p. 343, n. 2156, suppl. IV, 2, p. 88, Meisn. gen. p. 333 (245). - Cybele Knight et Salisb. Prot.p. 123. - Embothrií sp. Forst. - Agnớstus A. Cunn.mss. - Hakeæ sp. Cels, Colla.

Flores hermaphroditi, irregulares, umbellati. Calyx tubulosus, dorso fissus, sepalis diu unilabiatim cohrentibus demum disjunctis apice concavo antheriferis. Antheræ sessiles, ovatæ, muticæ. Glandula hypogyna unica, semiannularis. Ovarium stipitatum, multiovulatum. Stylus filiformis, demum rectus, deciduus, stigmate oblique laterali subrotundo planiusculo. Folliculus linearis vel cylindraceus, polyspermus. Semina pelliculâ interpositâ sejuncta, basi alata. - Frutices vel arbores Australasiæ, foliis sparsis coriaceis integerrimis vel laciniatis, stomatibus hypogenis, umbellis axillaribus vel terminalibus pedunculatis, involucro nullo, floribus ochroleucis vel aurantiacis.

1. S. FORSTERI (R. Brown ! 1. c. p. 201), glaberrima, ramulis gracilibus, foliis oblongis obtusis attenuato-subpetiolatis integerrimis subenerviis, pedunculis terminalibus folia subæeqnantibus paucifloris, pedicellis calyce sublongioribus. $₹$ In Novâ-Caledoniâ (Forster ! Labill.l).-Labill, sert. p. 21, t. 26. Embothrium umbel- 
latuth Forst.! gon. p. 16, t. 8, fig. a-f, Lam. ill. t. 55, f. 1, Willd. sp. 1, p. 538 . Cỷbele umbellifera Salisb., fide Spreng. syst. 1, p. 484. Rami teretes. Folia 10-18 lith. longa, 3-6 lin. lata, mutica, evenia vel tarissime subtus obscure triplipervia. Umbelles solitarix, 6-8-flore, pedicellis 5-6 lin., calycibus 4-5 lin. longis, limbo in alabastro inflexo globoso. (v.s. in herb. Smith.)

2. S. S L L G N US (R. Broẃn ! lic. p. 202, prodr. p. 391), glabèrrimus, ramiś gracilibus, foliis subsessilibus lanceolatis utrinque attenuatis acutis muticis immerse venosis, pedunculis axillaribus terminalibusque folia subaquantibus multifloris, pedicellis calyce sublongioribus. J Girca Port-Jacksson (R. Brown!).-Bot. reg. t. 441. Hakea rubricaulis Cels, Colla! hort. Ripul. p. 63, append.1, p.114*, t. 3, Roem. et Schult. syst. 3 , mant. p. $378^{\star}$. Embothrium rubricaule Giord. observ. 1837. Folia vix coriacca, 2:4 poll. longa, 5-7 lin. láta, attenuato-acuminata, proprie 1-tervia, sed venis primariis prope basin or tis sæje magis conspicuis quasi triplinervia, veais feliquis impressis vel obsoletis. Pedunculi 1-2-pollicares, interdum geminati, pédicellis 4-5 lin., calycibus 3-4 lin. longis. (v. s. et v. v. c.)

3. S. MILNE I (Hook. Journ. 1854, p. 359*), glabra, ramis gracilibus strictis, foliis linearibus pinnatim 3 - rarius 5 -fidis passimque integerrimis, segmentis linearibus obtusis muticis simplicibus vel passim pinnatifidis, pedunculis axillaribus folio bitevioribus subsexfloris. F In summo monte insule Pinorum, prope ins. Norfolk (Milne, n. 118, Naegillivray, n. 855). Lomatia Milnei Hook: Journ. 1855, t. 7. Habítus Grevillese linearis. Folia 2-3 poll. longa, ex Hook. in diagn. ex parte subbipinnalifida, ex icone vero simpliciter pinnata passimque indivisa, laciniis oppositis 1 lin. latis petioloque basi attenuatis apice glanduloso-callosis ecostatis subreticulatim rugulosis marginibus parum reflexis. Peduuculus $1-1 \frac{1}{2}$ poll. longus, involucri foliolis parvis subulatis, pedicellis apice incrassatis calyculatis. Ovarii ex ic: puberuli stipes calyee 4-5 lin. longo parum brevior, stylo dimidio longior. Stigna laterale, orbiculatum, ex ic. ovale. Fructus ignotus.

4. S. GUNNINGHAMI (R. Brown suppl. p. 34, hon Hook.), foliis oblongis obtusiusculis basi attenuatis planis paginis concoloribus nervis $4-5$ alto immersis, ealycibus pedicellis pedunculo ramiulisque toméntosis. $\zeta$ In Novæè-Holl. orâ boreali-occideirtali, circa Van Sittart Bay (A. Cunn.)

5. S. sinuatus (Endl. gen. suppl. 4, 2, p. 88), foliis amplis petiolatis glaberrimis pinnatisectis vel stirpis junioris passim indivisis segmentis patentibus 3-5-jugis lincari-oblongis vel cuneato-decurrentibus apice 2 -3-lobis integrisve 1 -nerviis dense reticulatis, lacihulis obtusiusculis muticis, umbellis axillaribus terminalibusque compositis 5 -radiatis, umbellulis multifloris, pedicellis calyce subpollicari tomentoso multo brevioribus. 5 Ad flum. Brisbane, prope Moreton Bay $\Lambda$. Cunn! Birlwill.). S. Cunninghami Hóok. in Bot. mag. t. 1263, Flore des serres et jard.

- 1847, t. 7 (non R. Br.). Agnostus sinuatus A. Gunn.I mss. in herb. Loudon hort. Brit. append. 1, p. 580 . Arbor speciosa, sempervirens, 40-50-pedalis. Folia rigide coriacea, patentia, 1-2-pedalia et ultra, scgmentis 6-12 poll. Iongis; plantæe juvenillis oblonga, pinnatiloba vel apice 2-3-fida, passim integcrrima, lobis triangulari oblongis muticis. Umbellæe radii pedunculo communi subsquales, 2-3-pollícares, patentes, centrali erecto, pedicellis 3 lin. longis tomentosis. Calyx scarlatinus, antheris stigmateque luteis. Ovarium dense sericcutn, stipite slyloque glabris. Folliculus teres, elongatus. (v. s. in herb. Cunn., etc.; et v. v. c. in hort. Kew., Chiswick, etc.)

\section{Tribus VII. BANKSIE $A$.}

\section{Ovarium 1-loculare, 2-ovulatum. Folliculus bilocularis, septo spurio e seminum collateralium testis concretis formato libero ligneo trifido.}

ẊiII. BANKSIA Linn. fil. suppl. p. 127, R. Brown in Transact. Soc. linn. Lond. 10, p. 202, prodr. Al. Nov.-Holl. p. 391, suppl. p. 34, Endl. gen. p. 343, n. 2157, suppl. IV, 2, p. 88, Meisn. gen. p. 333 (246), non Forst. (vide Pimelea), nec Domb. (v. Cuphea), nec Banksea Koen, (que Costus speciosus).

Flores hermaphroditi, regulares, capitati vel spicati. Calyx 4 -partitus; rarius 4-fidus, rectus vel falcato-incurvus, marcescens, diu persistens, sepalis apice 
oblongo acuto concavo antherifero diu cohærentibus interdum aristato-acuminatis. Antheræ 4 subsessiles, lineares, connectivo-breviter superatæ vel muticæ. Squamulæ hypogynæ 4. Ovarium sessile, 1-loculare, ovulis 2 collateralibus supra medium marginis affixis. Stylus filiformis vel subulatus, rectus vel falcatus, deciduus, calyce multo longior, raro æqualis. Stigma terminale, capitalum vel clavalum vel cylindraceo-subulatum continuum aut basi vel medio nodoso-subarticulatum, plerumque sulcatum. Folliculi lignei, spicæ rhachi incrassatæ semiimmersi, ovales, compressi, bi valves, biloculares, dissepimento e seminum testis connatis formato libero ligneo bifido. Semina nigra, apice cuneato-alata, nucleo lacunæ dissepimenti semiimmerso. - Frutices arboresque Novæ-Hollandiæ et Tasmanniæ, foliis sparsis vel rarius verticillatis rigide coriaceis planis vel rarius marginibus revolutis subteretibus dentatis incisis vel pinnatifidis raro integerrimis sæpius (præsertim stirpis juvenilis) diversiformibus, stomatibus hypogenis, spicis terminalibus vel raro lateralibus (ramulos brevissimos terminantibus) solitariis gibbosis ovatis vel cylindraceis oblongis subsessilibus, involıcro universali nullo rarius oligophyllo haud imbricato, floribus rubris flavis vel albis sessilibus geminatis, paribus 3-bracteatis, bracteâ mediâ seu exteriore majore, lateralibus 2 interioribus minoribus, folliculis basi cum axi fructifero conferruminatis horizontalibus raro verticalibus et tunc subsolitariis.

\section{Sectio I. Eubanksia Endl. gen. suppl. 4, 2, p. 88.}

Stylus calyce longior hiuc unguibus citius solutis arcuatim exsertus (raro subæequalis (cfr. B. Lindleyana, læevigata, Baueri, ornata, latifolia, Caleyi, Lemanniana), stigmate laminis diu cohærentibus incluso. Spicæ floriferæ cylindraceæ vel sphæroideæ, fructiferæ folliculis plurimis transversis. - Banksiæe veræ $R . B r$ l. $c$.

\section{§1. Abietince. - Folia conferta, anguste linearia, marginibus arcte} revolutis teretia, subtus 1-vel 2-sulca vel canaliculata, integerrima vel brevissime spinuloso-dentata.

1. B. pUlGHella (R. Brown in Linn. Trans. 10, p. 202, prodr. p. 391), ramulis pilosis, foliis tenuibus patulis subsemipollicaribus obtusis muticis integerrimis lævibus glabris subtus 1 -sulcis, spicis ovatis vel subglobosis, calycis tubo lanatotomentoso, limbo styloque glabro, stigmate depresso:capitato nutante. 吕 In terrâ Leeuwin (R. Br., A. Cunningh.!), coloniâ Swan River (Drummond coll. 2, ì. 338l). - Meisn. in pl. Preiss. 2, p. 264. Frutex verisimiliter hunilis. Folia 3-5 poll. longa, vix $\frac{1}{2}$ lin. lata. Spica pollicem haud excedens, floribus initio deflexis rubris? Calyx 3-4 lin. longus, limbio orato-globoso $\frac{2}{3}$ lin. longo. Stylus $9-11$ lin. longus, nitidus, fulvus, demum rectus apice tantum attenuato breviter hamatus, stigmate parvulo atro conspicuo. (v. s.)

2. B. MEISNERI (Lehm. in p]. Prejss. 1. p. $582^{*}$ ), ramulis cano-puberulis, foliis patentibus deflexisque semiunguicularibus acerosis apice incurvo submucronulatis subtus 1-sulcis, spicis ovalibus, calycis unguibus tomentosis laminis glabris, stigmate depresso-capitato, folliculis depressis undique lanuginosis. $\succsim$ In N.-Holl. occid-australis, distr. Hay (Preiss, n. 488! Drumm. coll. 2, n. 282!). Frutex

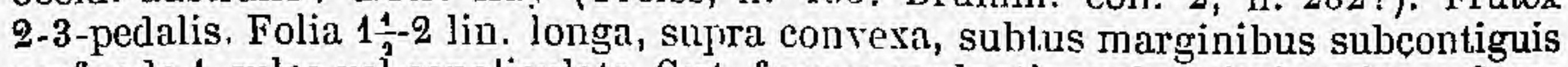
profunde 1 -sulca vel canaliculata. Caet. Cere pracedentis, sed capitula minora flores patentes, nec deflexi, calycis pube breviore, stylo 7-8 lin. longo, stigmate paulo majore. (下.s.)

3. B. SPHAROCARPA (R. Brown in Linn. Trans. 10, p. 203, prodr. p. 391), ramulis cano-tomentosis, foliis 1-2-pollicaribus acerosis in tegerrim is mucronulatis lævibus glabris subtus hisulcis vel subcanaliculatis, capitulis globosis, calycibus totís sericeo-pilosis, stigmate brevi subulato hasi subincrassato, folliculis transversis vel obliquis ventricosis apice compressiusculis. J Circa sinum regis Georgii et flum. Gygnorum (R. Br., A. Cunningh.! Drumm. coll. 1, n, 648, 649! 2, n. 336! Preiss, n. $486,487,494,497$ !). - Meisn. in pl. Preiss. 1, p. $581^{*}, 2$, p. 264. Irutex 
2-4-pedalis. Folia pleraque pollicaria, supra plano-convexa, subtus deplanata, nervo sepius inter margines revolutos conspicuo, apice obtuso brevissime mucronulato. Capituli receptaculum ovoideum, croceo-lanuginosum. Calycis ungues laminæque pilis longiusculis rufis subserices. Stylus glaberrimus, pallidus, hamatus, stigmate $\frac{1}{2}$ lin. longo subconico. Strobiluš fructifer magnit. ovi gallinacei, folliculis crebris margine glabris. (v. s.)

$\beta$. glabrescens, calycis unguibus jube brevi adpressâ sericeis, laminis glabris vel apice basique tantum puberulis, stigmate paulo breviore. (Drumm. coll. 1 , sine numero, et 2, n. 337 ! v. s. in herb. DC. el Shuttl.)

4. B. Pinifolia (Meisn. in Hook. Journ. 1855, p. 118), ramis validis, ramulis gracilibbus albido-tomentellis, foliis subdigitalibus anguste linearibus integerrimis acutis mucronulatis levibus glabris supra planis subtus leviter bisulcis, capitulo globoso folia sequante, calyce toto fulvo-sericeo, laminis muticis apice longius villosis, stylo glabro adscendente apice recurvo, stigmate continuo eylindraceo obtuso basi leviter incrassato. 5 ? In Nov.-Holl. occid. interiore (Drumm. coll. 6, n. 1,99!). Forsan arborescens? ramis virgatis. Folia sparsa, 2-3 poll. longa, $\frac{\div}{4}$ lin. lata, attenuato-subpetiolata, supra immerse 1 -nervia evenia, marginibus arcte recurvis costre contiguis subtus quasi 3-lineata. Capitula pugni mole, sessilia, quandoque subovata. Calyx 14 lin. longus, limbo 3 lin. longo subtereti, laminis lanceolatís apice breve penicillatis. Antliere brevissime apiculate. Stylus $1 \frac{1}{2}$ poll. longus, albiclus, upice attenuatus, stigmate atro sulcato obtuso $\frac{2}{3}$ lin. longo. Simillima quidem precedenti et sequenti, sed foliis calyce stigmateque longioribus et capitulo fere duplo majore facile dignoscenda. (v. s. sine fr. in herb. Shuttl.)

5. B. NU T $\Lambda$ N (R. Brown in Linn. Trans. 10, p. 203, prodr. p. 391), ramulis glabris, foliis pollicaribus subtereti-filiformibus mucronulatis lævibus glabris subtus 1-sulcis, spicà ovatâ nutante, calycibus erectis sericeo-tomentosis, stigmate brevissime clavato, folliculis apice dilatatis depressis. $\bar{J}$ In terrà Leeuwin (R. Br.) et coloniâ Swan River (Preiss, n. 499! Drumm. coll. 3, n. 281!). - Meisn. in pl. Preiss. 1, p. $581^{*}, 2$, p. 264. Ramuli subangilato-sulcati. Folia patula, tenuiora quam B. sphærocarpæ, nervo medio subtus marginibus revolutis subcontiguis occultato. Folliculi undique tomentosuli, apice haud turgidi. (v. s.)

6. B. ERICIF OLIA (Linn. fil.! suppl. p. 127), ramulis puberulis, foliis unguicularibus anguste linearibus omarginato-bidentatis cum vel absque mucronulo intermedio, marginibus recurvis integerrimis, supra convexis lovibus glabris subtus canaliculatis, spicis cylinuricis elongatis, bracteis tomentosis apice glabrescentibus, infimis subulatis, calyce adpresse sericeo, stigmate capitato. " 3 Circa Port-Jackson (Banks| R. Br., Sieber licrb. 11. N.-Holl. n. 7! Verreaux! etc.-Willd. sp. 1, p. 536, Cav. ic. 6, p. $27^{*}$, t. 538 , Andr. repos. t. 156 , Bot. mag. t. 738 , Tratt. tab. t. 450 , R. Brown in Linn. Trans. 10, p. 203, prodr. p. 391, Roem. et Schult. syst. 3, p. 437*. Rami virgati. Folia conferta, semipatentia, 3-7 lin. longa, apicis denticulis brevissimis acutis. Spice 5-7 poll. long:e, densissimæ, interdum breve pedunculatæ, pedunculi'bracteis subulatis. Stylus 15 lin. longus. (v. s. in herb. Linn. fil., Bonks., etc., et v.-c.)

7. B. SPINULOSA (Smitlı! New Holl.1, p. 13* t. 4), ramulis puberulis, foliis angusle lineáribus prope apicem acute 3 -dentatum margine recurvo spinuloso-paucidentatis vel passim integerrimis supra convexis punctato-scabriusculis glabris subtus bisulcis vel canaliculatis incanis, spicis,cylindrico-oblongis, bracteis calycibusque sericeis, stigmate parvo vix incrassato obtuso. F Circa Port-Jackson (R. Br., Sieber, n. 1! Verreaux! etc.j. - Willd. sp. 1, p. 536, Cav. ic. 6, p. $26^{*}$, t. 537, R. Brown in Linn. Trans. 10, p. 203, prodr. p. 392, Andr. Bot. rep. t. 457, Roem. et Schult. syst. 3, p. $437^{*}$ B. denticulata Dum. Cours 2, ed. 7, p. 108 ? B. microstachya hort. (non Cav.), ex Roem. et Schult. syst. 3, p. 144. Folia con-

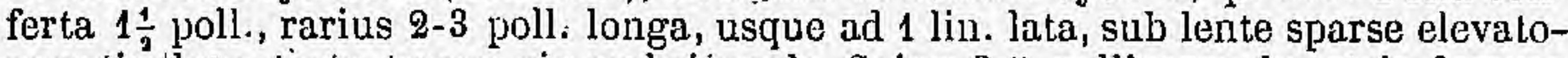
puncticulata, tactu tamen vix scabriuscula. Spicæe 3-5-pollicares, bracteis demum glabratis, infimis subulatis. Calycis tubus intus basi imberbis. Stylus glaber cum calyce longitudine varians nunc $1 \frac{1}{2}$ nunc vix 1 poll. longus. (v. s. in herb. Smith., etc., et v. c.. in lserb. Kíew.)

8. B. TRIGUSPIS (Meisn. in Hook. Journ. 1855, p. 118), foliis anguste linearibus integerrimis apice 3-cuspidulatis acutisve eveniis levibus ramisque glabris margine revolutis subtus bisulcis, spicis cylindraceo-oblongis folia iequantibus, brac. 
teis tomentosis, calyce subsericeo-puberulo, stylo tenui adscendente apice recurvo, stigmate parvo ovato obtuso. $J$ ? In summo monte Lesueur et jugo Gardner's Range Australia occid. (Drumm. coll. 6, n. 205! Hook. Journ. 1853, p. 181). Rami virgati, graciles. Folia sparsa, 3-5 poll. longa, 1 lin. lata, petiolo tenui 2-3 lín. longo, apice' simpliciter acnto vel plerumque truncato vel emarginato cum mucronulo crassiusculo innocuo apiculis lateralibus obtusiusculis longiore, facie inferiore marginibus revolutis penitus abscondità, supcriore nervo impresso leviter 1-sulcâ. Spicæ sessiles, 4-5 poll. longæ, bracteis obtusis fusco-tomentosis, infimis subuilatis alluido-tomentosis, floribus infimis stylisque demum deflexis. Calyx subpollicaris, pube minutâ rufâ, limbo ovali $1 \frac{1}{2}$ lin. longo, 4-gono, obtuso mutico, unguibus basi intus imberbibus. Stylus $1 \frac{1}{2}$ poll. longus, teres, albidus, glaber, stigmate styli apice vix crissiore $\frac{1}{4}$ lin. longo. Proxima $B$. spinulosæ, sed jam foliis spicisque longioribus facile dignoscenda. (v. s. sine fr. in herb. Shúttl.)

\$2. Salicince.-Folia linearia vel elongato-lanceolata, plana vel margine leviter recurva, dentata vel inciso-serrata raro integerrima, facie inferiore visibili plerumque cano-tomentosa, adulta supra glabra, interdum verticillata, plerumque longe cuneato-attenuata, semipollice angustiora, 2-5 lin. lata, rarissime latiora (cfr. B. Bntegrifolia, compar, marginata, media, prionotes, Menziesii.)

9. B. Cunningham I (Sieber ! pl. exsicc.), ramulis pubescentibus, foliis anguste linearibus obtusis mucronulatis muticisve integerrimis vel extra medium paucidentatis planis vel margine recurvis subtas niveis eveniis, spicis cylindrico-oblongis, bracteis calycibusque sericeis, tubo intus basi imberbi, stigmate parvo obtuso vix incrassato. F Circa Port-Jackson (Sieber herb. fl. N.-Holl. n. 6! A. Cumningh.l) et Wilśon's promontory (Baxter). - Roem. el Schult. syst. mant. 3, p. 289*, Reichenb. hort. bot. 1, p. 58, t. 81, R. Brown! suppl]. p. 35. B. ledifolia A. Gunn.! mss. in herb. B. littoralis Lindl. in Bot. rég. t. 1363 (non R. Br.). Frutex orgyalis. Rami dense foliosi, patenti-pilosi. Folia B. spinulosée simillima, sed latiora $1 \frac{1}{2}-2$ lin. lata, plana et pagina inferior semper visibilis, stirpis juvenilis (cultæ) passim ultra medium vel ad basin usque serráta, dentibus mucronatis patulis nec inflexis. Spica 3-5-pollicares. Bracter juniores villosiusculæ. Calyx 9 lin. longus; fulvus, style atro-purpureo apice recurvo, stigmate globoso flavo. (v. s. et v. c.)

10. B. collina (R. Brown in Linn. Trans. 10, p. 204, prodr. p. 392), fruticosa, foliis linearibus subtus venosis spinuloso-dentatis, denticulo terminali proximis breviore, spicis....., bracteis obtusis apice tomentosis, calyce intus basi imberbi. $\supset$ in orâ orientali, circa flum. Hunter (R. Br.).

11. B. o C G I DEN T AL IS (R. Brown 1. c. p. 204 et 392), fruticosa, ramulis glabris, foliis elongato-linearibus apice truncato-3-denticulatis margine recurvo extra medium spinuloso-serratis integrisve subtus eveniis niveis, spicâ elongatâ cylịndricâ, bracteis late triangularibus acutis apice glabris, calycibus marcescentibus sericeopuberulis intus basi pubescentibus, stigmate minuto sphacelato, folliculis ventricosis tomentosis apice compressiusculo nudis. F In terrà Leeuwin (R. Br.), circa sinum Regis Georgii (Preiss, n. 491!), in colonià Swan River (Drumm. coll. '3, n. 283!). - Bot. mag. t. 3535 , Meisn. in pl. Preiss. 1, p. 582*, 2, p. 264, Lindl. in Paxt. mag. 1, t. 35, Flore des serr. et jard. 6, t. 636. Frutex erectus, 6-8-pedalis. Folia 2-4 poll. longa, 1-2- raro 3 lin. lata. Spicre 4-5-pollicares, bracteis infimis elongatis subulatis. Calyx coccineus, gracillimus, taminis demum glabrescentibus. Stylus pollicaris, hamatus, glaberrimus. (v. s.)

12. B. LITTORALIS (R. Brown 1. c. p. 204 et 392), arborea, ramulis tomentosis, foliis elongato-linearibus margine leviter recurvo spinuloso-serratis basi attenuatâ integerrimis subtus eveniis albido-tomentosis, spicì elongatì cylinrlricâ, bracteis late triangularibus obtusis apice tomentosis, calyce deciduo tomentoso intus basi pubescente, stigmate parvulo sphacelato, folliculis compressis tomentosis. 5 In terrâ Lecuwin (R. Br.), coloniâ Swan River (Drumn. coll. 1, n. 647! Preiss, n. 479, 498!), circa sinum Regis Georgii (Preiss, n. 4!)6!).-Meisn. in pl. Preiss. 1, p. 583*, Bot. mag. t. 3060. B. tomentosa hort. (non Forst.). Arjuscula 20-40-pedalis. Plurimis'notis convenit cum $B$. occidentali, sed folia majora, $2 \frac{1}{2}-4$ lin. lata, serraturis 
majoribus. Spice 8-10-pollicares. Calycis tomentum densius el vix sericeum. B. prionophylla Ferd. Müll.l first gen. report, p. 17, et is Linnæà, 26, p. 353 (in Australia Felici lecta, sed nonnisi specim. sterilibus nobis cognita) nobis huc spectare, auctori vero (in litt. 1855) ad B. Cunninghamii reducenda videtur.

13. B. cyliNdrostachy (Lindl.! Swan River, p. 34, n. 162), arborea, ramulis tomentosis, foliis elongato-linearibus margiue subplano subrqualiter serratis basi attenuatà integris subtus venosis albido-tomentosis, spicâ cylindricâ, elongatâ, calycibus glaberrimis marcescentibus, stigmate conico oblongo, folliculis turgidis volutinis margine òbtusis. $\delta$ In colonià Swan River (Drımm. coll.11 Preiss, n. 475!). - Meisn. in pl. Preiss. 1, p. 583*. Arbor 40-pedalis, aboriginibus Mangeit dicta. Folia 4-5 lin. lata, supra nitida, plerumque fere ad basin usque serrata, dentibus 2-3 lin. distantibus obtusiusculis, margine plano vel vix recurvo. Spicææ 5-6-pollicares densissima. Flores quam in præcedentibus minores, albi, stylo 8-9 lin longo, hinc 1-sulco, stigmate fere $\frac{2}{3}$ lin. longo fusco apice pallido. Folliculi horizontales, transverse ovales, fere 1 poll. lati, 6 lin. crassi, nec compressi. Ab affinibus præecedentibus jam calyce glaberrimo et stigmate bene distincta. (v. s. ịn herb. Lindl., ete.)

14. B. Lindeyana (Meisn. in Hook. Journ. 1855, p. 120), foliis lanceolato-linearibus truncatis serrato-denticulatis basi longe attenuatis ramulisque glabris subtus concoloribus obsolete transverse venosis reticulatis albo-punctatis, marginibus leviter recurvis, dentibus muticis, simubus rotundatis, spicà ovoideả basi sterili, bracteis cano-tomentosis, calyce styloque subæqualibus glaberrimis, limbo acute 4-gono, stigmate cylindraceo basi obsolete noduloso. 5 ? Prope flum. Hutt. Austr. occid. (Drumm. coll, 6, n. 204 ! Hook. Journ. 1853, p. 481 2). Frutex decumbens? 3-4-pedalis, capitulis 4-5 poll. longis, flavis? (Drumm. 1. c.). Rami virgati, validi, ramulis gracilibus glabris. Fólia sparsa, sıbpetíolata, 3-5 poll. longa, 3-4 lin. lata, supra cvenia, nervo immerso, subtus leviter reticulata, areolis punctiformibus allo-tomentellis, dentibus $\frac{1}{4}-\frac{1}{2}$ lin. longis, sinubus semilunaribus $1 \frac{1}{2}-2$ lin. Iatis. Capitulum sessile, falia superans, fere 3 poll. longum, $2 \frac{1}{2}$ poll. crassum, rhachi cylindricê fusço-tomentosâ, bracteis adpressis triangularibus ácutis albido-tomentosis, infmis sterilibus. Calyx pollicaris, leviter arcuatus, limbo subincurvo diu clauso inæugualiter 4 -gono acutangulo tenuiter multisulcato, laminis fere 3 lin. longis línearibus muticís. Antheræ connectivo glanduliformi fusco conico-apicu-

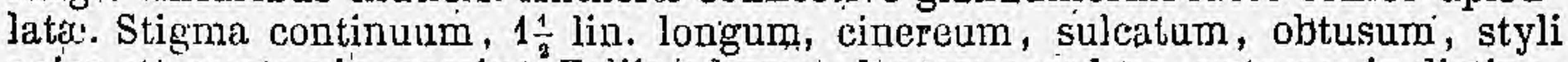
apice attenuato vix crassius. Foliis ad precudentem accedens, cateroquin distinctissima, forsan potius ad sect. 2 Isotylin releganda. (v. s. śine Pr. in herb. Shuttlew.)

15. B. marginata (R. Brown in Linn. Tratis. 10, p. 204, prodr. p. 392), fruticosa, ramulis villosiusculis, follïs sparsis linearibus apiće truncato 3-cuspidatis margine recurvo spimuloso-dentatis integrisque subtus incano-tomentosis venis inconspicuis, sjpicâ oblongâ, bracteis apice glabris, calyce sericeo marcescente, stylo tenui glabro, stigmate minuto obtuso. 3 Cirea Port-Jackson (R. Br. etc.). - Roem. et Schult. syst. 3, p. $438^{*}$. B. ferrea Vent., fide Spr. syst. 1, p. 485. B. oblongifolia Lodd. Bot. cab. t. 2\$1? (non Cav.). B. hypoleuca Holfmannsegg, Verzeichn. 2, Nachtr. p. 66*, ex Roem. et Schult. syst. 3, mant. p. 379. Planta culta, floribus ignotis, a B. marginatê verisiny. non distincta, nisi, forsan foliis majoribus, 2-3 poll. longis, 6 lin. latis, magis dentatis. Folia 1-2 poll. longa, 2-3 lin. lata. Spicse $1 \frac{1}{2}-3$-pollicares. Stylus 10 lin. longus, albidus. rectus, valde attenuatus, stigmate atro apice pallido haud tenuior. Accedit ad B. Cunuinghamii, sed foliis latioribus margine minus recurvis, stylo, etc, facile dignoscenda.

a. Oavanillesii, erecta, orgyalis, spicâ foliis plerumque integris longiore (A. Cunningh.! Sieber, n. 8! ex parte, Gaudich.! Verreaux !). - R. Br. l. c. B. marginata Cav. ic. 6 , p. 29 , t. 544 ; (v. s.)

B. microstachya, erećla, orgyalis, spicâ foliis spinuloso-dentatis breviore (Sieber ! n. 8 ! ex parte). - R. Br. l. c., Lodd. Bol. cab. t. 61. B. mierostachya Cav. ic. 6 , p. 28, t. 541. excl. syn. Linn. B. præmorsa hort. Dum. Cours 5, p. 105, ed. 2, 2, p. 419 , (v. s. et cult. ex h. Kew. in herb. DC.)

$\gamma$. humilis, diffusa, humilis, spicâ foliis cuneatis spinuloso-dentatis planiusculis breviore. - R. Br. l. c. 
16. B. DERRESSA (R. Brown 1. c. p. 205 et 393), caule prostrato, ramulis hirsutis, foliis elongato-cuneatis truncatis mucronulatis spinuloso-dentatis subtus obsolete costatis venulis inconspicuis, spicâ folia vix sequante, bracteis omnibus tomentosis obtusis. J In ins. Diemen australiori (R. Br.). Species non satis nota. (v. sp.-incertum in herb. BC.)

ß. subintegra (Meisn. in Hook. Journ. 1852, p. 210), foliis sparsis subverticillatisque linearibus vel lineari-lanceolatis obtusis vel enarginatis cuneato-attenuatis margine recurvo intcgris vel passim paucidentatis subtus incanis obsolete venoso-costatis reticulatisque, spicâ oblongâ, calyce incano vix sericeo, stylo tenui, stigmate subincrassato. - In monte Wellington, ins. Diemen (Gunn, n. 1234 !), Ramuli tomentosi simulque pilis patentibus longiusculis'dense rufo-hirsuti. Folia $1 \frac{1}{2} \cdot 3$ poll. longa, $3-4$ lin. lata, pleraque integerrima, inferiora ad basin usque brevi-serrata, dentibus acutis, nervatione floribusque B. marginatæ. Spica 2 joll. longa, ovoidea. (v. s. comm. a cl Lindl.)

17. B. Patula (R. Brown l. c. p. 205 et 393 ), caule diffuso, ramulis tomentosis, foliis pollicaribus cuneato-linearibus truncatis mucronulatis integris vel paucidentatis subtus reticulato-venosis, spica bracteis obtusis apice tomentosis, calyce

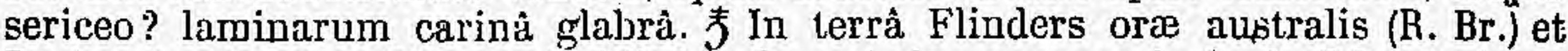
Recherche Bay ins. Diemen (Labill.! et Gunn! sine numero in herb. DC.). B. integrifolia et marginata Labill.! mss. in herb. DG. Species obscura. Specimina qum vidimus incerta, a $B$. depresså $\beta$ solummodo differunt ramulis tomentosis nec hirsutis et foliis subtus distincte reticulatis rarissime paucidentatis.

18. B. AUSTRALIS (R. Brown l. c. p. 206 et 393), arborea, ramulis tomentosis, foliis 1-2-pollicaribus linearibus apice truncato vel rotundato vel rarius bidentato-emarginato mucronulatis margine recurvo integerrimis vel passirn paucidentatis supra eveniis subtus niveis reticulatis vel subeveniis; spicâ oblongâ, bracteis obtusis tomentosis, caljcc sericeo-incano, laminarum carinà obsoletẩ glabrescente. 5 In ins. Diemen (R. Br., Cunningh.! Gunn! sine numero), N.-Holl. australi circa PortPhillip (R. Br., Ferd. Müller ! Linnıea 26, p. 353, Stuart!) et Port-Jackson (S'́eber, n. 3!). - Bot. reg. t. 787 (forma foliis plerisque dentatis, spicâ subglobosâ), Roem. et Schult. syst. 3 , mant. p. $290^{*}$, B. integrifolia Schlecht. in Linnæâ 20, p. 584 (non R. Br.). Arbor magna (teste Gunn). Ramuli patentes; dense foliosi, tomento pulvereo sordide incani vel ferruginei. Folia sparsa vel passim subverticillata,

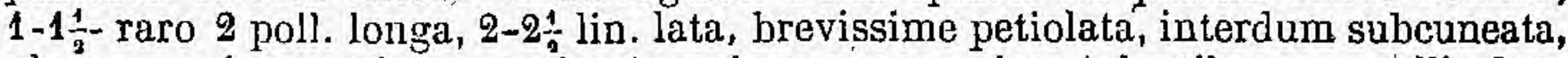
plerumque integerrima, passim (pracipue prope apicem) dentibus nonnullis brevissimis munita, nervo supra impresso subtus prominente, venis venulisque nune inconspicuis, nunc manifestis dense reticulatis. Spicæ 2-3 poll. longæ, sæpius laterales, patentes vel recurva, bracteis calycibusque fulvis sericeo-nitentibus. Stylus 9-t0 lin. longus, tenuis, glaber, rectus, stigmate parvo atro paululün clavato-incrassato obtuso. (v. s.)

19. B. Gun II (Meisn. in Hook. Journ. 1852, p. 210), fruticosa, ramis incano-tomentosis, foliis subpollicaribus cuneato-linearibus apice emarginato rotundato-subbilobo mucronulatis marginerecurvo integerrimis subtus ineanis eveniis subreticulatisve, spicâ oblongâ, bracteis obtusis tomentosis, calyce pube minutâ subsericeo, laminarum carinâ obsoletà sericeà vel glabratâ, stylo tenui, stigmate subincrassato-clavato. $\bar{J}$ In littore circa George Town, prope Port-Dalrymple, ins. Diemen septentr. (Gunn, n. 1233!). Frutex 2-7-pedalis, erectus, ramis patentibus dense

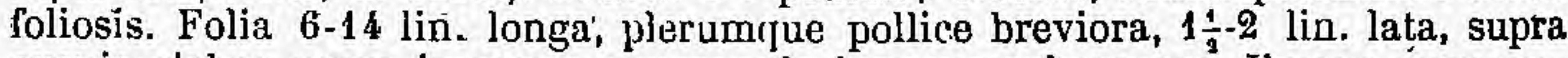
evenia glabra nervo impresso, mucronulo innocuo subrecurvo. Forsan mera var. B. australis, attamen satis discrepans staturâ minore, foliis brevibus nunquam dentatis, stylo stigmateque paulo crassioribus, etc. (v. s. sine fr. comm. a cl. Lindl.)

20. B. Insula Ris (R. Brown in Linn. Trans. 10, p. 206, prodr. p. 393), foliis sparsis verticillatisque lineari- vel cuneato-oblongis apice rotundatis mucronulatis sulitus reticulato-venosis, spice bracteis obtusis extus tomentosis, floribus....., folliculis compressis apice glabris. $7 \mathrm{In}$ insulis freti Bass littoribusque ins. Diemen (R. Br.). Species obscura, teste R. Br. B. integrifolia nimis affinis, et tunc a præcedentibus, quibus ex diagn. simillima videretur, procul dubio distincta.

21. B. INTEGHIFOLIA (R. Brown 1. c. 11. 206 et 393), arborea, ramulis cano-tomentusis, foliis verticillatis vel passim sparsis lanceolatis vel cuneato-oblongis planis 
vel margine recurvis apice truncatis vel rotundatis acutisve mucronulatis integerrimis vel sinuato-dentatis supra eveniis subtus niveis distincte reticulatis, spicá oblongâ cylindrica, bracteis tomentosis, calyce adpresse sericeo-incano, stylo pollicari sursum valde attenuato, stigmate continuo haud incrassato, folliculo tomentoso. 5 In N.-Holl. orientali et australi.-Roém. et Schult. syst. 1, p. $439^{*}$. Species, teste ipso auctore, polymorpha et sequenti nimis affinis. Folia in var. $\alpha$ et $\beta$ 2-3 poll. longa, 3-8 lin. lata, marginibus recurva, passim dentata, verticillis 4-5-phyllis. Spicæ 3-4 poll. longec. Stigma subsulcatum.

a. minor, arbor parva vel mediocris, foliis oblanceolatis integris basi attenuatis sæpius acutis, bracteis interioribus geminatis obtusis exteriore acutâ dimidio minoribus. - R. Br. l. c. - Circa Port-Jackson (Sieber, n. 4! Verreaux!) - ef prope Moreton Bay (A. Cunn.!). B. integrifolia Linn. fil.! suppl. p. 127, Willd. sp. 1 , p. 535 , Cav. ic. 6, p. 30, t. 546. B. spicata Gartu. fr. 1 , p. 221 , t. 48. B. olesefolia Cav. ic. 6 , p. 30, t. 545. B. glauca Gav. ibid. p. $31^{\star}$. B. compar A. Cunn.! in herb., nec R. Br. (v. s.)

$\beta$. major, arbor magna, foliis lanceolato-oblongis integris sæpius obtusiusculis basi acutis, bracteis geminatis obtusis exteriore acutiusculâ haud dimidio brevioribus. - R. Br. l. c. - In orâ australi circa Port-Philipp. (R. Br.).

$\gamma$. dentata, foliis cuneato-oblongis truncatis vel rotundatis planis extra medium vel usque ad basin longe attenuatam spiuuloso-paucidentatis, sinubus rotundatis, rarius passim integerrimis. - B. macrophylla Link enum. alt. p. 116, Roem. et Schult. syst. 3, mant. p. 290. B. integrifolia hort. Kew.l Edinb.I Bolwill.l etc, Stirps hortensis, folifis 3-5 poll. longis, apice sæepius 4 poll. latis. (v. v. c. in hort. Kew., etc.)

22. B. compar (R. Br: 1.c. p. 207 et 393), arborea, ramulis junioribus tomentosis, foliis sparsis passimque verticillatis lingulato-oblongis integerrimis obtusis mucronulatis demum muticis basin versus longe attennatis margine leviter recurvis sujra obsolete venosis subtus niveis subeveniis, spicâ oblongâ cylindricâ, bracteis tomentosis, calyce sericeo-incano, stylo pollice breviore apice víx attenuato, stigmate basi oblique nodoso. 5 In orà orientali intratrop. ciroa Keppel Bay (R. Br.). Forsan, ut jam ipse suspicabatur cel. auctor, præcedentis var., attamen, fide specim. hort. Ket., præter nolas indicatas constanter differre videtur foliis vix cuneatis, apicem versus attenuatis, 3-6-raro 9 lin. latis subtus tenuiter reticulatis (ex Br. eveniis) et prsecipue stylo breviore, stigmate lrevi basique subnodoso. (v. v, c. in h. Kew.)

23. B. pALUdosa (R. Brown 1. c. p. 207 et 304), fruticosa, ramulis glabris, foliis sparsis passin verticillatis cuneato-oblongis lanceolatisve obtusiusculis margine recurvo serratis integrisve basi attenuatis subtus niveis distincte costato-venosis reticulatis, spica cylindricâ oblongâ, bracteis obtusis tomentosis apice glabrescentibus, calyce sericeo, stylo semipollicari tenui, stigmate vix incrassato. 5 Circa Port-Jackson (B. Br., Sieber, n. 9! Gaudich.! etc.). - Bot. reg. t. 697, Bot. cab. t. 392, Roem. et Schult. syst. 3, mant. p. 291*. Folia 2-3 poll. longa, 5-9 lin. lata, plerumque sparsa, nunc cuneato-attenuata extra medium latiora et pleraque dentata infra integra, dentibus obtusiusculis 1 lin. longis, terminali brevi suljtruncato mucronulato, sinubus rotundatis, nunc lanceolata, ntrinque æqualiter attenuata pleraque integerrima, passim extra medium vel ad basin usque paucidentata. Spicæ 2-5 poll. longæ, 1 poll. crassæ. Stigma continuum, subsulcatum. Folliculi valde compressi, circ. semipollicares, lanà rulâ hirsuti, margine glabrescentes. Cæt. fere ut in B. compar, sed stylus brevior. (v. s. et v. v. c. in hort. Kew.)

24. B. verTiGillata (R. Brown 1. c. p. 207 et 394), arborescens, ramulis apice tomentosis, foliis verticillatis petiolatis lanceolatis obtusis muticis adultis integerrimis subtus niveis eveniis, spicà cylinưricâ elongatâ, bracteis obtusis tomentosis infimis subulatis apice hirsutis, stylo calycem sericeum vix superante, stigmate minuto obtuso 5 In terrâ Leeuwin (R. Br., A. Cunn.!), circa sinum Regis Georgii (Preiss, n. 493! 495? Drumm. coll. 4, n. 304 !). - Ait. h. Kew. ed. 2, 1, p. 216*, Hook. exot. 11. t. 96, Meisn. in pl. Preiss. 1, p. 583 *. Arbuscula 18-ped. (Preiss). Verticilli plerumque 6-folii. Folia incluso petiolo $2-4$ lin. longo 2-3-pollicaria, 4-6 lin. lata, stirpis juvenilis sæpius apice paucidentata. Spicæ 6 poll. Iongæ. Flores pollicares, fere B. littoralis. (v. s. sine fr. in herb. DC., etc.)

25. B. MEDIA (R. Brown suppl. p. 35), ramulis cano-tomentosis, foliis sparsis petio- 
latis cuneato-lanceolatis truncatis serratis basi attenuatâ integris margine planpis supra eveniis subtus costato-venosís reticulàtis venuliss glabratis lacunis punctiformibús albo-tomentosis, spicầ cyllndricâ ovali, calyce marcescente unguibus sericeo-puberulis basi laminisque glabris, stylo pollicari, stigmate parvo ovąicapitato. 5 ? In orâ austraḷ inter (Cạpc Arid et Luclíy Bay (Bịxtèr). - Bot. mag. t. 3120. Folia 3-4 poll. longa, 4-6 lin. Jata, dentibus obtusiusculis muticis, terminali truncato vel rotundąto obsolete niticronulato. Spica \& poll. longá, crassa. Calyx 10-12 lin. longus, parce minuteque puherulus, laminis oblongo-lanceolatis muticis. Stigma basi oblique subannulatum. Fulliculi immersi, 'glabriusculi. (v. v. in h. Kew.)

26. B. Aтtenuat (R: Brown, in Linn. Trans. 10, p. 209, prodr. p. 395), arborea, ramis apice tomentosis, foliis sparsis sessilibus lanceolato-linearibus truncátis emarginatisve obtuse mucronulatis dense serfatis basi longe attepuatis supra èveniis subtus dense clevato-costatis reticulatis' [ue renis glabris lacunis tomentosis, spicâ cylindricà oblongâ, bracteis lanato-hirsúlịs, stỵlo subpollicari tenui calycem glabrum breviter superante, stigmate oblongo vix incrassato. $\delta$ In terrâ Leeuwin (R. Br.), circa sinum Regis Georgii (1. Cunningh.!), in coloniâ Swan River (Đ̈rumm. coll. 3 , n. 286!). - Meisn. in pl. Preiss. 2, p. 264. Arbuscula irregulartis (Cunn.), ramis dense foliosis. Folia 3-6 poll. longa, 3-5 lín. lata, ex ipso fere apice præmorso deorsum sensim attenuata et sequaliter serrata vel rarius infra medium integra, juniora subtus sordide cano-tomentosa (haud nivea), dentibus $\frac{1}{2}-1$ lin. longis, 2-3 lin. distantibus sinubusque fere rectangulis acutiusculis, margine anguste recurvo nerviformi. Spica semipedalis, bracteis fusco-lànatis. Calyx 8 lin. longus. Stylus albidus, nitidus, glaber, 10 lin. longus, diu eurvatus, stigmate $\frac{1}{2}$ lin. longo continúo lævi nigro apice pallido. Folliculi tomentosi. (v. s. in herb. DC. et Shuttlew.)

27. B. ELATYOR (R. Brown 1. c. p. 209 et 395), arborea, ramulis tomentosis, foliis elongato-linearibus subtruncatis scrratis basi attenuatis subtus reticulatis demum glabriusculis, spicâ cylindricâ elongatâ, brasteis imborlibus calycibusque tomentosis, stylo glaberrimo, stigrnate ovali-clarato. 5 In orâ orientali tropicâ et subtrop., ad Sandy Gape (R. Br.) et ins. Strádbroke, prope MIureton Bay (A. Cunningh.!). Arbuscula 15-20-pedalis. Folia sessilia, 4-6 poll. longa, 6-8 lin. lata, juniora secus nervum rufo-tomentosa, ceterum glaberrima, margine tenuiter nerviformi. Spica 6-8 poll. longa, diametro 3-pollicari. - Planta Cunninghamii, a Brownianâ, quam non vidimus, forsan distincta; plurimis notis convenit cum B. æmulâ (an ejus var. angustifolia?), recedens tantum foliis rarissime ultra 6 lin. latis, costulis subtus minus prominulis et stigmate paulo majore. (v. s. in herb. DC.)

28. B. L EVIGATA (Meisn. in Hook. Journ. 1852. p. 210), ramulis cano-tomentellis, foliis sparsis elongato-linearibus subtruncatis planis serratis basi integrâ attenuatis utrinque eveniis nitidis glabris subtus minute punctatis, spicis subglobosis, bracteis subulatis rufo-barbatis, calyce sericeo apice longius barbato stylum subpollicarem glabrum subærquante, stigmate eylindraceo brevi haud inerassato. 5 ? In coloniâ Swan. River (Drumm. ooll. 5, n. 414 !). Rami virgati, cinerei. Folia 3-5 poll. longa, 3-4 lin. lata, dentibuns $\frac{4}{-1}-1$ lin. longis, $2-6$ lin. distantibus sinubusque fere rectangulis aeutis muticis vel demum outusis, terminali mucronulato proximos yix superante, paginâ inferiore areolis minutis albidis sub lente impressis dense punctatâ. Capitulum ramulum lateralem brevem aphyllum terminans, 2 poll. longum, bracteis exterioribus lineari-subulatis 3 - $\uparrow$ lin. longis pubescentibus, înterioribus longioribus pube patulâ longiore rufa barbatis Calyx 9-10 lin. longus, tenuis, pube minutâ adpressà albidâ in apice laminarum longiore sericeus, unguibus cito solutis capillaribus, laminis diutius cohærentibus. Stylus teres, tenuis, pallidus, glaber, sensim transiens in stigma ipso haurl crassius fulvum vix $\frac{1}{b}$ lin. longum obtusiusculum. Species foliis ad B. attenuatam, floribus -ad B. Baueri accedens, ab omnibús distinclissima. (v. s. in herb. Shuttl.)

29. B. Hookeriana (Meisn. in Hook. Journ. 1855, p. 119), ramis rufo-tomentosis, foliis sparsis elongato-linearibus truncatis mucronulatis dense scrratis basi attenuatis utrinque subeveniis concoloribus glabris, capitulo folia subæquante ovato, bracleis infimis subulatis recurvis hirsutis, calyce pollicari, unguibus puberulis, laminis fulvo-villosis, stylo sesquipollicari apice subincrassato, stigmate tenui fusiformi medio oblique noduloso. F Inter Tea-tree Swamp et llum. Irwin, N.-Holl. occid. (Drumm. coll. 6, n. 2021 Hook. Journ. 1853, p. 180). Frutex 5-6-pedalis, 
ramis virgatis strictis. Folia lurevissime petiolata, $4-6$ poll. longa, 3 lin. lata, dentibus scaleno-triangularibus acutis muticis latioribus quam longis rectilineís subtus obsolete immerso-2-3-nerviis puncticulatisćque, sinubus obtusangulis. Capitulum terminalé, subsessile, amplum, bracteis infimis 6-8 lin. longis. Calycis lamince lineares, muticæ: Stylus arcuatus, teres, løvis, glaber, apice purpurascens el paululum tumidulus. Stigma fere 2 lin. longum, medio oblique incrassafum (nec vere arliculatum), supra subulatum sulcatum, obtusum. Species insignis, capitulo floribusque fere sequentis et B. Victoriæe, foliis quodammodo ad B. lævigatam el attenuatam accedens. (v. s. in herb. Sliutllew.)

30. B. PRionotes (Lindl.! Swan Biver, p. 34, n. 160), arborea, ramis tomentosis, foliis sparsis petiolatis elongatis late linearibus trunçatis sinuato-serratis, subtus tenuiter venosis reticulatis venis glabrescentibus lacunis subniveis, spjicâ ovatâ, stylo calycem lanato-villosissimum demum longe superante apice incrassato, stigmate fusiformi medio sulrnoduloso. 5 In coloniâ swan River (Preiss, n. 476! Drumm. coll. 3, n. 288!). - Meisn. in. pl. Preiss. 1, p. 584*. Arbor circ. 30-pedalis. Folia 5-7 poll. Jonga, 5-8 lin. lata, dentibus æequi- vel inæquilateris, sinubus olstusangulis, venis sul,tus vix prominulis, lacunis minutis albidis. Capitulum pugni mole. Calyx 10-12 lin. Iongus, undìque lanugine densâ fulvî̀ patulâ subsericeà tectus, initio stylum subæequans, deinde multo brevior. Stylus sesquipollicaris, glaber, infra ajpicem constrictum broviter strumosus. Stigma 2 lin. longum, medio leviter incrassatum, supra sulcaitum, infra atterruatum leve. (v. s. sine fr. in herb. Lindl., etc.)

31. B. Menzísi (R. Brown suppl. p. 36), arborea, ramis tomentosis, foliis sparsis petiolatis elongatis late linearibus truncatis obtuse sinuato-denticulatis subtus venoso-costatis reticulatis tomentosis venis glabrescentibus, capitulo ovato, squamis tomentosis aculiusculis, calyce sericeo deciduo, stylo longe exserto apice tumidulo, stigmate fusiformi. f In coloniâ Swan River ([raser, Drumm. coll. 1! Preiss, n. 477!). - Meisn. in pl. Preiss. 1, p. 584. Arbor circ. 35-pedalis, rámis validis sordide cano-tomentosis. Folia cum petiolo 3-6 lin. longo 8-10-pollicaria 7-14 lin. lata, supra evenia nitila, subtus venis patentissimis prominulis egregio costulata venulisque intérstitialibus tenuibus dense reficulata et minutissime rufotomentella, margine obsolete recurvo nerviformi. Capitulum 4-5-pollicare. Calyz 12-14 lin. longus, adpresse flavido-sericeus, laminis lineari-lanceolatis 3 lin. Iongis. Stylus adscendens, 18 lin. longus, glaber, purpurascens. Stigma 2 lin. longum, stylo haud crassius, sed basi stricturâ ab eo distincturn, continumm, utrinque attenuatum, supra medium sulcatum, infra leve. Follieuli transversi, 12-14 lin. lati, depressi, tomentosi, apiculati ibique $\mathbf{3}$-fidi. (v. s.)

\section{§ 3. Quercince. - Folia cuneato-oblonga obovata vel ovalia, serrata vel inciso-dentata vel rarius pinnatifida, medio vel apice saltem semipollice latiora.}

32. B. coccinea (R. Brown in Linn. Trans. 10, p. 207, prodr. p. 394), fruticosa, ramis tomentosis, foliis late oratis obovatis oblongisve truncatis remote denticulatis supra eveniis subtus costato-venosis reticulatis tomentosis nervo costisque glabrescentibus, capitulo subgloboso, bracleis subulatis calycibuscque lanatis, stylo sesıuipollicari, stigmate ronico-oblongo basi annulato incrassato. .) In terrâ Leeuwin (R. Br.), circa sinum Regis Georgii (d'Urville! Preiss, 0. 481! Drumm. coll. 3, n. 28\& 1). - Mcisn. in pl. Preiss. 1, p. 585*. Ffutex 6-8-pedalis. Fólia sparsa, breve petiolata, circ. 3 poll. longa, 1-2 poll. lata, denticulis mucroniformibus obtusiusculis; plantwe juvenilis inciso-dentata, basi cuneato-attenuata, subtus nivea. Capitulum magnit. pomi minoris, folis obvallantibus fere occultatum. Calyx pol. licaris, cáccineuś, albido vèl fulvo-lanatus, tubo diu clauso. Stylus purpureus, glaber. Stigma i lin. longum, atrum, obsolete sulcato-angulatum, c bạsi paulo incrassatâ annuliformi attenuatum, obtusum. Strobilus ovatus, mole ovi gallinacei, polycarpus, folliculis 4 lin. latis receptaculi lanugini immersis transversis depressis tomentosis. (v. s.)

33. B. Sceptrum (Meisu. in Hook. Journ. 1855, p. 120), ramis tomentosis, foliis oblongis premorsis remote obtuse denticulatis basi breve attenuatis supra eveniis subtus transverse immerso-striatis reticulatisque areolis albida-tomentosis, spicà spitlıamreâ foliạ longo superante cylindricâ, calycis tubo villoso laminis adpresse 
sericeis, stylo sesquipollicari sigmoideo, stigmate fusiformi sulcato obtuso basi noduloso. 5 ? In planitie arenosâ, prope flum. Hutt, N.-Holl. occid. (Drumm. coll. 6, n. 206! Hook. Journ. 1853, p. 181). Rami validi, cinereo-tomentosi. Folia -sparsa, breve petiolata, erecta, $2 \frac{1}{2} 3$ poll. longa, 10-12 lin. lata, truncata vel emarginata cum. mucronulo innocuo, margine simplici plano levissime sinuato- vel repandodenticulato, denticulis 2-3 lin. remotis brevissimis muticis. Spica 8 liu. longa, $2 \frac{1}{-3}$ poll. crassa, bracteis infimis sterilibus subulatis. Calyx sulfureus, pollicaris, laninis 3 lin. longis lanceolatis muticis: Antheræ glandiflâ fuscâ conicâ apieulatæ, Stylus teres, adscendens, ajpice attenuato recurvus, infra medium parce pilosiusculus. Stigma crassiusculum, 2 lin.' Jongum, 8-sulcatum. Species innsignis, spicà omnium facile maximâ, ponderosâ, , accedens quodammodo ad B. Baueri, mẹdiam, occidentalem et eylindrostachyam, sed ab omnibus distinctissima. (v. s. sine fr. in herb. Shuttlew.)

34. B. Ba U E R I (R. Brown suppl.p. p. 35), arborea? ramulis tomentosis, foliis cuneatolanceolatis oblongisque mucropatis serratis basi valde attenuatis supra subeveniis subtus elevato-costatis reticulatisque tomentosis, spicà oblongâ, calyce marcescente, unguibus breve villosis setaceo-aristatis, stylo bipollicari apiee incurvo, stigmate continuo attenuato. 5 ? In montibus circa sinum Regis Georgii (Baxtér, Drumm. coll. 4, n. 303!). Folia sparsa, petiolata, 3-6 poll. longa, 4-8-rarius 12-1,4 lin. lata, juniora mucrone subulato $1-1 \frac{1}{2}$ lin. longo recto deciduo terminata, ad basin usque sinuato-dentata, dentibus oppositis acutis 1-1 $\frac{1}{2}$ lin. longis fere isocelo-tríangularibus rectilineis, sinabus $3-5$ lin. latis rotundatis, facie superiore glabrâ lèvi vel leviter impresso-venosâ, inferiore fulvo-tomentosâ prominulo-reticulatâ, venis glabrescentibus_lacunis demum albido-tomentellis. Spicæ juniores ovatæ, demum oblongæ, 3.6-pollicares, bracteis rufo-lanatis, inferioribus acutis. Calyx pistillum subrequaus, ung'uibus angustissimis basi glabris supra pube brevi patulâ fulvầ lanatis, laminis anguste linearibus 3 lin. longis lanâ longiore albâ dense villosis in aristam capillarem' 3 lin. longam erectam atram pilosiusculam produetis. Stylus glaber, calycis aristis superatus, stigmate breviter subulate subsulcato. (v. s. in lierb. Shuttl. et v. c. in horto Kew.)

35. B. or Na T A (Fertl. Müller ! mss. in herb.), ramulis cano-tomentosis, foliis cuneatooblongis truncatis dense spinescenti-serratis glabris supra eveniis subtus costatovenosis albo-puncticulatis spicâ cylindricâ oblongâ, bracteis ovatis acuminatis patulis rufo-barbatis, calyce stylum æquante pollicari toto subæqualiter patulopiloso, laminis subulato-acuminatis, stigmate vix incrassato cylindraceo brevi. $J$ Versus Villungam in jugo Marble Range's, prope Adelaide, et in mont. Grampians, Encounter Bay, etc. (Ferd. Müll.!). - Meísn. in Linnæâ 26, p. 352. Frutex orgyalis et ultra, nınquam arborescens (F. Müll: in litt.). Folia sparsa et passim verticillata,

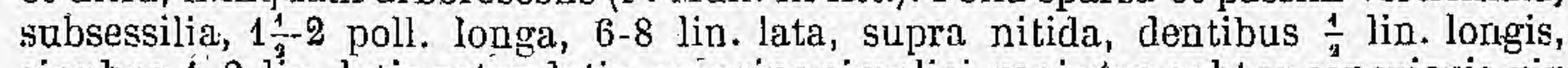
sinubus 1-2 lin. latis rotundatis, margine simplici venisque subtus conspicuis vix prominulis nervoque glabris, lacunis minutis albido-tomentellis. Spica circ. 3-pollicaris. Calyx 12-14 lin. longus, gracillimus, rectus, diu clausus, pube copiosâ fulvâ patula in laminis longiore sericeo-villosus, laminis lanceolatis ultra antheram in acumen subulatum villosum produetis cum eo $2 \frac{1}{2}$ lin. longis. Stylus tenuis, gila')errimus. Stigma $\frac{2}{5}$ lin. longum, stylo vix crassius, sulcatum, basi obsolete nodulosum. Species foliis ad B. mediam, flore ad B. Bancri accedens, ab omnibus bene distincta. (v. s. sine f'r. comm. a cl. Sonder.)

36. B. Latirolía (R. Brown in Linn. Trans. 10, p. 208, prodr. p. 394), fruticosa, ramulis villoso-tomentellis, foliis clliptico- vel obovato-oblongis obtusis spinuloso-serratis basi attenuatis supra obsolete immerso-venosis glabratis subtus elevato-reticulatis costatisque lanato-tomentosis, spicâ ovatâ, calyce marcescente, unguibus sericeo-puberulis, laminis glabris muticis, stylo tenui breve exserto, stigmate continuo brevi vix incrassato. F Circa Port-Jackson (R. Br., Sieber, n. 5371).-Roem. et Schult. syst. 3, p. 441*, Bot. mag. t. 2406. B. Robur Cav. ic. 6, p. 29, t. 543. B. uneigera et dilleniæfolia Knight et Salisb. Prot. p. 112,113. B. fagifolia Hoffmannsegg Verzeichn. Nachtr. 2, p. 66, Roem. et Schult. syst. 3, mant. p. $379^{*}$. Folia sparsa, breve petiolata, patentia, rigidisșima, 6-9 poll. longa, $1 \frac{1}{2}-3$ poll. lata, apice rotundata vol subomarginato-truncata, rarius subacuta, molliter pubescentia, clemum supra glabra, margine leviter recurvo, dentibus 1-2 lin. longis uncinato-incurvis, sinubus rotandatis, costis parillelis patentilun $2-3$ lin. distantibus. Spica 3-4 poll. longæ, bracteis acutiusculis rufo-velutinis, infimis e 
basi incrasstâ, subulato-acuminatis. Calyx pollicarís. Stylus 15 lin. longus, pallidus, nitidus, apice atfenuatus. Stigma $\frac{1}{3}$ lin. lin. latum, stylo vix crassius, atrum, obsolete sulcatum, obtusum. (v. s. sine fr. in herb. Smith., etc., et v. c. in h. Kew.)

37. B. MARCEscens (R. Brown 1. c. p. 208 et 395), fruticosa, ramulis tomentósis, foliis cuneato-oblongis truncatis margine simplici extra medium obtuse dentatis supra eveniís subtus obsalete reticulatis lacunis albidis, spicâ cylindricâ elongatâ, calyce marcescente glaberrimo, laminis muticis, stylo sesquipollicari tenui, stigmate minuto subovato, folliculis orbicularibus depressis glabris. J In terrâ Leeuwin (R. Br., Menzies !), circa sinum Regis Georgii (Preiss, nl. 484! Drumm. coll. 3, n. 285!), - Bonpl. Malm. p. 11A, t. 48, Meisn. in pl. Preiss. 1, p. 586. B. præmorsa Andr. repos. t. 258, et Cav., ex Smith in Rees cycl., Tratt. thesaur. t. 21. B. aspleniifolia Knight et Salish. Prot. p. 113 (exćl. syn. Salisb. prodr.). Frutex 6-pedalis, ramis dense foliosis. Folia sparsa, petiolata, 1-2 poll, longa, 5-7 lin. lata, brevidentata, stirpis juvenilis subtus incana sæpius ad basin usque inciso-serrata, dentibus mucronatis. Spica semipedalis, crassa, floribus rubris? Stylus glaber, stigmate bassi oblique subincrassato. Folliculi 8 lin. lati, rugulosi, margine obtusi. (v. s. in herb. Smith., etc., et v. ¿. jun,)

38. B. OBL ONG.IF OLIA fCąv, ic. 6, p. $28^{*}$, t. 542), fruticosa, ramulis tomentosis, foliis cuneato-oblongis truncatis breve serrato-dentatis passim subintegris supra eveniis glabris subtus costatis reticulatís nerviformi-marginatis incanis, spicâ ovali oblongâ, ealyce sericeo, stylo pollicari tenui, stigmate vix inerassato ovato-oblongo. \% Circa Port-Jackson (R. Br., Sieber, n. 5! Verreaux !).-R. Brown in Linn. Trans. 10, p. 208, prodr. p. 394, Roem. et Schult. syst. 3, p. $440^{*}$, mant. p. 291,-Lodd. Bot. cab. t. 241? (an potius ad B. marcescentem referenda?). B. salicifolia Cav. 1. c. p، 31? B. asplenifolia Salisb. prodr. p. 51. B. longifolia herb. Thibaud! in herb. DC. Conchium pubescens Willd. en. 1 , p. 141 . Hakea pubescens h. Cels., nec Schrad. Folia sparsa vel passim verticillata, breve petiolata, 2-4 poll. longa, 6-12 lin. lata, margine leviter recurvo nerviformi. Spica 3-pollicaris, bracteis majoribus acuminatis. Calyx vix 10 lin. longus, totus pube brevi adpressâ flavo-sericeus. Stylus pallidus, glaber, stigmate parvulo continuo lævi atro.Affinis præcedenti, B. mediæ, integrifoliæ et paludosæ. (v. s.)

39. B. serrata (Linn. fil.! suppl. p. 126), arborea, ramulis tomentosis, foliis elongato-lanceolatis truncatis serratis basi attenuatis supra subeveniis subtus incanotomentosis costato-venosis tenuissime reticulatis demum glabratis margine simplici, spicâ ovatâ vel cylindricâ, calycis unguibus sericeo-puberulis laminis incunis, stylo subbipollicari basi tomentello, stigmate cylindraceo sulcato basi oblique incrassato. 5 Circa Port-Jackson (R. Br., Sieber! Gaudich.! etc.). - Lam. ill. 1. p. 242 , t. 54 , f. 1, Willd. sp. 1 , p. 535 , Cav. ic. 6 , p. 27 , t. 540 ? (forsan potius B. æmula?), Andr. repos. t. 82 (forma foliis sueto profundius serratis), R. Brown in Linn. Trans. 10, 1. 209, prodr. p. 395, Roem. et Schult. syst. 3, p. 442* B. conchifera Giertn. fr. 1, p. 221, t. 48, f. 1. B. dentata Wendl. h. Herrenhus. t. 8 ? (non Linn.). B. mitis Knight et Salish. Prot. p. 1.12. B. semula Sieber herb. Al. N.-Holl. n. 2! (ex parte, nec R. Br.). B. undulata Lindl:! in Bot. reg. t. 1316. B. longifolia Don. Conchium pubescens Willd. enum. p. 141? Hakea pubescens h. Cels? ex Steud. Folia sparsa, petiolata, 3-6 poll. longa, 7-12 lin. lata, apice parum, basin versus longe attenuata, truncata-mucronulata vel rarius subacuta, plana vel margine interdum undulata, dentibus 1-2 lin. longis acutis leviter ourvilineis subacuminatis rarius obtusis, sinubus acutangulis obtusisve nunquam rotundatis, costis subtus leviter prominulis reticulo minuto immerso. Spica 4-6 poll. longa, bracteis rufo-pubescentibus, inferioribus acuminatis acutis. Calyx 18 lin. longus, laminis muticis. Stylus arcuatus, stigmate $\frac{3}{4}$ lin. longo. Folliculi dense rufo-tomentosi. (v. s. in herb. Linn. fil., Lindl., etc., et v. c. in h. Kew.)

40. B. EMULA (R. Brown in Linn. Trans. 10, p. 210 , prodr. p. 395), fruticosa, ramulis tomenlosis, foliis elongato-lanceolatis truncatis acute serratis basi attenuatis supra subeveniis subtus elevato-costatis minute immerso-reticulatis tomentosis demum glabratis, splicâ ovatâ; calyce adpresse sericeo puberulo, stylo sesquipollicari basi tomentello, stigmate ovato-cajitato obtuse 4 -gono basi oblique incrassato. 5 Circa Port-Jackson (R. Br., Sieber, n. 2 ! ex parte).--Bot. mag. t. 2671, Bot. reg. t. 688 , Roem. et Schult. syst. 3 , mant. p. $291^{*}$. B. serrata White voy. p. 222, 
tab. tertia? (ex Br.). B. scrratifolia Salisb. prodr' p. 51? B. serræfolia Knight et Salisb. Prot. p. 112? Præcedenti simillima quidem, at notis indicatis, præesertim stigmate, bene distincta. Foliorum serratura satis variabilis, dentibus rectilineis vel plus minus curyilineis, sinubus rectangulis vel obtusanguliś rarius acutangulis nunquam rotandatis. Bractere tomentosæ, obtusæ. Calycis laminæe muticæ. (v. s.)

41. B. G AL $\mathbf{E}$ (R. Brown suppl. p. 35), folìis linearibus truncatis serrato-dentatis basi attenuatis subtus venoso-coslatis reticulatis vonulis glabratis lacunis tomentosis, spicâ..., calycis laminis mutícis glabriusculis, stigmate angulato-cylindraceo angulis hispidulis, folliculis emersis. 3 ? In montibus, jrope sinum Regis Georgii (Baxter).

B.? sinuosa (Meisn. in Hook. Journ. 1852, p. 210), ramulis incano-tomentosis, foliis cuneato-lanceolatis truncatis sinuato-dentatis planis glabris hasi attenuatis supra eveniis subtus immerse costalis albido-punctatis, dentibus acutis, sinubas rotundatis, capitulo sphæerico globoso, calycis unguibus parce sericeo-tomentellis lamínis glaberrimis stylo incluso recto glabro, stigmate contiuuo eylindraceo sulcato, angulis hispidulis. $\bar{\jmath}$ ? In colonià Swan River (Drumm. coll. 4, n. 301!). Folia sparsa, petiolata, 2-4 poll. longa, 5-8 lin lata, supra nitida, dentibus patentibus 1-2 lin. longis scaleno- vel rarius fere isocelo-triangularibus, sinubus 3-5 lin. latis semper rotundatis, parté cuneatâ plerumque integrâ interclum ultra medium extensâ, costis venulisque parum conspieuis, lacunis punctilormibus. Cepitulnm bipollicare et ultra, axi vix pollicari, bracteis rufo-tomentosis apice obtuso glabrescentibus. Calyx coccineus? rẻctus, 9 lin. longus, limbo clavato 4 -gono mutico obtuso nnguibus parum breviore. Stigma $1 \frac{1}{2}$ lin: longum, stylo albido gracili hatid crassius, basi obsolete nodulosum. Forsan species distincta, an sectioni secunda accensenda? (. .6. sine fr. in herb. Shutti.)

42. B. LeMANíana (Meisn. in Hook. Journ. 1852, p. 210), ramulis incano-tomentosis, foliis obovato-oblongis obtuse dentatis glabris basi attenuatis supra obsolete venosis stubtus immerse costatis reticulatis lacunis punctiformibus albis sinubus acutangulis, capitulo globoso mutante, cályce styloque requilongo undique glaberrimis, stigmate cylindraceo sulcato angulis hispidulis. $\bar{f}$ ? In colonià Swan River (Drumm. coll. 4, n. 302 !). Folia $2-3$ lin. longa, 1 poll. lala, apice rotúndato vel rarius truncato deque ac marginibus plerumque ad basin usque subrqualiter densiuscule dentata, dentibus 1 lin. longis scaleno-triangularibus muticis, sinubus 2-3 lin. latis. Capituli squamø infime subulatæ. Calys pollicaris. Cot. fere omnia B. Caleyi $\beta$ (v. s. sine fr. in herb. Shuttl.)

43. B. Quercif ol ia (R. Brown in Linn. Trans. 10, p. 210, prodr. p. 396), fruticosi, foliis euneato-oblongis inciso-ser ratis vel grosse sinuato-dentatis ramulisque glabris subtus venosis obsolete reticulatis, capitulo ovato, calyce semipollicari stylum glabrum subrequante sericeo, Jaminis aristatis glabrescentibus, stigmate minute obtusso. J In terrâ Leeuwin (R. Br.), circa sinum Regis Georgii (A. Cunn,! Preiss, n. $489 !$ ). - Bot. reg. t. 1430 , Meisu. in pl. Preiss. 1, p. 585*. Frutex 6-pedalis. Folia sparsa, sessilia, rarius subpetiolata, 2-4 poll. longa, 5-12 poll. lata, plana, dentibus-triangularibus mucronatis, simubus obtusangulis vel planta juvenilis acutis angustioribusque. Capitulum $1 \frac{1}{2}$ poll. longum, bracteis parvis apice triangulari glabris, infimis subulatis. Calyx rufo-sericeus, laminis aristà subulatá $1 \frac{1}{2}$ lin. longâ glabriusculà primo recurvâ deinde rectâ terminatis. Stigma continuum, sphacelatum. Folliculi glabriusculi. (v. s.)

44. B. DENT A T A (Linn. fil.! suppil. p. 127), arborescens, ramulis tomentosis, foliis elongatis cuneato-oblongis truncatis sinuato-dentatis undulatjs basi attenuaris subtus costatis venulosis jiveis, sinubus obtusangulis rotundatisve, spich cylindricà elongata, bracteis tomentosis acutis, calyce sericco-deciduo. 5 In orâ orientali intratrop., prope Erudeavour River (Banks et Soland.! A. Cunningh.!), et Arnhems Land oræ septentr. (R. Br.). - R. Brown in Linn. Trans. 10, 1. 210, prodr. p. 396. Arbuscula 15-20-pedalis (1. Gunn.), ramulis validis. Folia 6-8 poll. longa, 2 poll. lata, dentibus inæqualibus mucronulatis muticisve, sinubus $2-4$ lin. profundis. Spica semipedales, axi $\frac{1}{2}$ poll. crasso, loracteis patulis acutis echinato. Folliculi tomentósi. (v. s. in herb. Linn. Hil., Cunn., etc.)

45. B. PRostrata (R. Brown suppl. p. 36), caule rostrato-tomentoso, foliis elon- 
gatis pinnatifidis supra glabris subeveniis lobis ovatis intègerrimis subtus plurinerviis roticulatis lacunis albido-tomentosis, spica cylindraceâ oblongâ,, calyce lanato marcescente styllum suljpollicarem glabrum subæquante, laminis muticis mox glabratis, stigmate minuto apice subincrassato. $\Rightarrow$ Circa sinum Regis Georgii (Baxter, Preiss, n. 480l Drumm. coll. 3, n. 289!). - Bot. reg. t. 1572, Meisn. in pl. Preiss. 1, p. 587 * Frutex repens, foliis spicisque erectis (Preiss). Folia sparsa, petiolata, 5-12 poll. longa, lobis 5-12 lin. longis, 3-8 lin. latis, deorsum decrescentibus obtusiuscule mucronatis, sinubus obtusangulis rarius subacutis. Spica 3 -4-pollicaris, rufo-tomentosa, bracteis infimis subulatis. Calycis laminie pilis longioribus quam ungues barbate, mox glaherrime. Stylus 8-9 lin. longus, tenuis, stigthate $\frac{1}{2}$ lin. lango continuo atro, Folliculi transversi, obovati, 8 lin. longi, 6 lin. lati, depressi, mutici, hirsuti. (v. s. et v. c.)

46. B. GOODIr (R. Brown suppl. p. 36), caule abbreviato, folijs oblongis sinuatodentatis subtus venoso-costatis reticulatis venis glabratis lacunis tomentosis, spicâ loliis obvallatâ, bracteis infimis subulatis villosissimis, calycis unguibus villosis laminis acuminatis glabratis, stigmate ovato sulcato. $\mathrm{J}$ In montibus circa sinum Regis Georgii (Baxter).

47. B. BARBIGERA (Meisn. in pl. Preiss. 2, p. 264 *), caule abbreviato tomentoso, foliis oblongis grosse sinuato-dentatis pinnatifidisque sinubus obtusis lobis divaricatis triangularibus integris.acutis muticis utrinque leviter costato-venosis subtus obsolete reticulatis lacunis albido-tomentosis, spicâ ovato-oblongâ foliis breviore, bracteis infimis lineari-subulatis elongatis villosissimis, calycis unguibus pubescentibus laminis dorso glabris apice barbatis, stigmate minuto conico-capitato. J In coloniấ Swan hiver (Dfumrn. coll. 3, n. 290!). Caulís decumbens vel adscendens. Folia sparsa, petiolata, supra plerumque subeveria. Sirica foliis ipsam superantibus obvallata, bracteis infimis $1-1 \frac{1}{2}$ poll. longis, pilis mollibus 2 lin. longis patentibus croced-rufis vel sordide albidis dense villosis. Calycis laminæ apguste oblongæe, diu colıerentes, toto dor'so glabrøe lœeves, apice con̛â rulầ laxiusculà

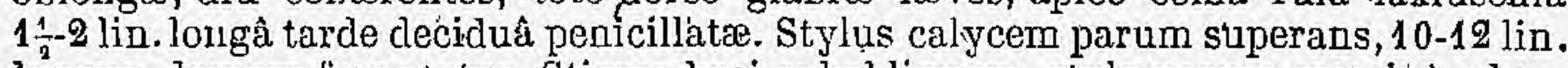
longus, demum fere rectus. Stigma basi subobliquum, stylo parum crassius, obtusum, subangulatum, atrum, apice pallidum. Forsan potius B. Goodii var.? ad B. repentem pluribus notis accedens, sed jam foliorum lobis integris, bracteis longioribus, etc., distincta: (v. s. sine fr. in herb. Shuttl.)

48. B. REPENS (Labill. Voy. 1 , p. $412^{*}$, l. 23 , N.-Holl. 1, p. 118), caule prostrato tomentoso, foliis elongatis pinnatifidis supra,glabris, lobis oblongis obtuse sinuatodentatis passimque integris utrinque plurinerviis reticulatis lacuniis subtas albidotomentosis, sjicà ovato-ohlorigâ, calycis stylo dimidio brevioris unguibus puberulis låminis villosis, stignate continuo subattenuato. I In terrâ Leeuwin (Labill., R. Br.), ad fl. Gordon, circa sinum Regis*Georgii (Preiss, n. 483! Drumm. cóll. 3, n. 291!).-R. Brown in Linn. Trans. 10, p. 211, prodlr. p. 396, Meisn. in pl. Preiss. 1, p. 586* B. polypodiifolia Knight et. Salisb. Prót, p. 113. Folia erecta, sparsa, petiolata; subpedalia, lobis pollicaribus $3-\mathbf{4}$ lin. latis patentibus vel sưbfalcatoAdscendentibus basi conflueritibus, dentibus brevibus muticis, sinubus rotundatis tel passim in dentem lulualumve brovem productis. Spica adscendens, 4 poll. longa, bracteis infimis subulatis. Galycis laminæ lanceolate, muticæ, lanatæe. Stylus subsesquipollicaris, glaber, stignate obsoleto. (v. s. sine fr.)

49. B. S OLANDR I (R. Brovn suppl. p. 36), arborea, ramulis tomentosis, foliis oblongis truncatis pinnatifidis basi cuneatã integris supra subeveniís subtus niveis costato-venosis tenuiter reticulatis lobis latis oblique ovatis acutiusculis sinubus acutis, spicâ cylindrico-oblongâ, calyec stylum pollicarem subiequante marcescente unguibus villosiusculis laminís glabrìs, stigmate minuto subcapitato. 5 In montibus circa sinum Regis Georgii (Baxter, Drumm. coll. 4, h. 305!). Ramuli subcompresso-angulati, fulvo-tomentelli, simulque patenti-pilosiusculi. Foliā sparsa, petiolata, modice coriarea, 6-8 poll. longá, 2-3 poll. Iata, plana, supra glabrata, lobis utrinsecus 4-6 oppositis alternisve ovato-triangularibus scalenis 9-18 lin. latis, sinubus nunquam nervum attingentibus, set $6-10$ lin. ab eo distantibus, loborum costis subtas prominulis parallelis, venularum reticulo parum conspicuo minuto. Spica 4 poll. longa, follis obvallata et superata, bracteis omnibus obtusis rufo-lanatis. Calyx albido-sericeus, lamînis muticis. Stigma stylo pallido initido vix cłassius, atrum, obtusum. (v، s. et v. c. in h. Kew.)' 
$\beta$ major, foliis subpedalibus (9 poll. et ultra longis, 5 poll. latis) irregularitex sinuato-lobatis.-In montibus Mongerup, prope sinum Regis Georgii (Drumm.). B. Hookeri Drumm. in Bot. mag. 1848, compan. p. 1.

\section{§4. Dryandroidece. - Folia elongato-sblonga vel linearia pinnati- partita, lobis integerrimis, ad costam usque distinctis vel basi tantum confluentibus, sinubus acutis.}

50. B. GRANDIS (Willd. sp. 1, p. 535), arborea, ramulis tomentosis, foliis oblongis glabris, lobis ad costam usque distinctis late ovato-triangularibus ácutis plurinerviis utrinque reticulatis lacunis subtus albido-tomentosis, spicâ cylindricâ elongatâ, calycis decidui unguibus villosis laminis muticis glabris, stylo prælongo, stigmate oblungo obtuso. 5 In terrâ Léeuwin (R. Br.), prope flum. Cygnorum et Cape Riche (Preiss, n. 474! 492 !). - R. Brown in Linn. Trans. 10, p. 210, prodr. p. 396, Meisn. in pl. Preiss. 1, p. $587^{\circ}$. Arbor circ. 40-pedalis. Folia sparsa, breve petiolata, pedalia et ultra, lobis 12-20 lin. longis, 12-18 lin. latis, subisoscelis, alternis, rarius oppositis, nervis 3-6 subparallelis supra impressis subtus prominulis, margine simplici. Spica subpedalis, bracteis infimis subulatis villosis. Calyx 1 poll. longus, limbo oblongo acuto 4-gono. Ștylus' 30 lin. longus, albidus, glaber, stigmate $\frac{2}{5}$ lin. longo paululum incrassato sphacelato apice pallido. Strobili fructiferi crassi tomentosi tuberculati, polycarpi, folliculis immersis transversis 6-8 lin. latis depressis glabris. (v. s.)

51. B. BAXTERI (R. Brown suppl.p. 36), fruticosa, ramulis villosis demum glabris, foliis oblongis truncatis glabris, lobis ad costam usque distinctis triangularioblongis acuminato-acutis supra eveniis subtus immerse plurinerviis reticulatopunctatis lacunis albido-tomentosis, spicâ globosâ, calyce persistente stylum subæquante villoso laminis acuminatis sericeo-plumosis, stigmate attenuato subulato. J Circa sinum Regis Ceorgii (Baxter, Preiss, n. 485! Drumm. coll. 4, n. 306!). - Meisn. in pl. Preisș. 1, p. 587*. Frutex 6-8-pedalis, Folia sparsa, peliolata, 21-6 poll. longa, lobis circ. 1 poll. longis, 6-10 lin. latis pungenti-acutis. Capitulum magnit. aurantii majoris, foliis obvallatum, bracteis infimis villosis. Calyx 15-18 lin. longus, laminis anguste lanceolatis, 4 lin longis albido-, unguibus fulvovillosis. Stylus $18-22$ lin. lungas, persistens, pilosus, apice glaber. Stigma $1 \frac{1}{2} \mathrm{lin}$. longum, basi subincrassatum. Strobilus oligocarpus, folliculis transversis 20 lin. latis crassis tomentosis. (v. s.)

52. B. specios A (R. Brown! in Linn. Trans. 10, p. 210, prodr. p. 396), arborea, ramulis velutino-tomentosis, foliis elongato-linearibus truncatis supra minute scrobiculato-reticulatis glabratis subtus niveo-lomentosis, lobis ad nervum usque distinctis ovato-triangularibus acuminulatis margine recurvis 3-5-nerviis obscure reticulatis, spicâ ovatâ, calycis unguibus pilosulis laminis muticis lanato-villosis, stylo breve exserto pilosiusculo apice incrassato glabro, stigmate fusiformi infra medium constricto lævi sụpra sulcato. 5 In terrâ Leeuwin (R. Br.f). - - Bot. reg. t. 1728, Bot. mag. t. 3052. B. grandidentata Dum. Cours, fide Steudel nomencl. ed. 2, p. 184. Folia sparsa, breve petiolata, 8-10 poll. longa, 8-10 lin. lata, basi atienuata, lobis oppositis vel alternis summis interdum imã basi confluentibus 4-6 lin. longis et vix angustioribus, plerumque isoscelis, acumine brevi acutiusculo recto vel adscendente. Capitulum 5-6-pollicare, bracteis infimis subulatis rufo-tomentosis. Calycis pubescentia albida haud sericea. Stylus $1 \frac{1}{2}$ poll. longus, calycem vix superans, validus, apice clavato-incrassato subtus 1 -sulco. Stigma 2 lin. longum. Folliculi tomentosi. (v. s. in herb. Brown. et v. c. in h. Kew.)

53. В. Viстові A (Meisn. -in Hook. Journ. 1855, p. 119), ramis lanato-tomentosis, foliis elongato-linearibus tomentosis supra demum glabratis eveniis, lobis late triangularibus acumiuatis imâ hasi confluentibus subtus immerse 6-8-nerviis albo-punctatis, capitulo ovato, calyce pollicari basi glabro unguibus puberulis laminis linearibus muticis dorso fulvo-villosis, stylo exserto glabro apice incrassato, stigmate fusiformi. $亏$ In planitie arenosâ, prope flum. Hutt, N.-Holl. occid. interioris (Drumm. coll. 6, n. 203! Hook. Journ. 1853, p. 181). Frutex 12-15-pedalis, ramis validis fulvo-tomentosis. Folia sparsa, bene petiolata, 6-10 poll. longa, truncata? subconcoloria, nervo utrinque elevato, lobis fere isoscelis 5-8 lin. longis latisque, margine plano subtus obsolete nerviformi, sinubrs acutis $\frac{1}{2}-1 \frac{1}{2}$ lin. a 
nervo distantibus. Stylus fere $1 \frac{1}{2}$ poll. longus, arcuatus, stigmate medio leviter incrassato supra conico-cylindrico sulcato infra attenuato. Cæet. B. speciosæ, cui sane proxima, sed abunde distincta. (v. s. in herb. Shuttl.)

54. B. ELEGANS (Mfeisn. 1. c. p. 119), ramis apice albido-tomentellis; foliis elongatolinearibus utrinque glabris subconcoloribus lobis imâ basi confluentibus late ovato-triangularibus acuminatis subtus obsolete 3-5-nerviis vix punctatis, capitulo ovato-globoso, calyce stylum rectum glabrum gequante deciduo pollicari puberulo laminis obtusis glabris, stigmate contifiuo attenuato cylindrico. $\delta$ In Valley of the Lakes, circa flum. Hill (Drumm. coll. 6, n. 200! Hook. Journ. 1853, p. 180). Arbuscula, ramis adscendentibus ralidis. Folia sparsa, J,reve petiolata, 10-12 poll. longa, 6 lin. lata, truncata? nervo utrintue elevato, lobis fere isoscelis 2-3 lin. longis basi 3-4 lin. latis margine obsoletissime nerviformi, venis subtus vix visibilibus, sinubus acutis $\frac{1}{2}-1$ lin. a nervo distantibus. Capitulum subsessile, ' bipollicarc ef ultra, bracteis inferioribus sterilibus subulatis 6 , lin. longis brevivillosis flavo-fulvis supra basin triaugularem deciduis, floribus mctallico-virescentibus (Drumm.). Cälycis ungues mınute puheruli, lamine oblongæ obtusæ sulcatæe glabræ. Stigma sulcatum. Folliculi (ex Drumm. l. c.) substantiâ ceraceâ albẩ conspersi, verrucosi. (v. s. sine fr. in herl. Shuttl.)

55. B. Gandolleana (Meisn. 1. c. p. 118), ramis apice albido-tomentellis, foliis elongato-linearibus, lobis ad uervum usque distinctis ovato-triangularibras acutis supra eveniis glabris subtus elevato 3-nerviis scrobieulato-reticulatis concoloribus glabris vel niveis, capitulo ovoideo, calyce stylo subpollicari arcuato glabro superato, unguibus sericeo-juberulis laminis glabris, stigmate subcontinuo conicocylindrico basi attenuato. $ち$ Circa Dundagaran et flum. Hill, N. - Holl. occid.(Drumm. coll. 6, n. 201! Hook. Journ. 1853, p. 180, species prima). Caulis subterraneus, repens, ramis epigæis erectis validis biperdalibus. Folia sparsa, breve petiolata, 1-1 $\frac{1}{2}$-pedalia, 5-8 lin. lata, truncata, mucronulata, basi attenuata, adulta glabra, nervo supra sulciformi subtus elevato crasso, lobis 3-5 lin. longis, basi 3-4 lin. latis isoscelis subtus eleganter reticulatis. Capitulum-bipollicare, breve pedunculatum, bracteis infimis sterilibus subulatis erectis cano-tomentellis. Calyx 9 lin. longus, laminis muticis diu in clavum oblongum sulcatum cohærentibus. Stigma sulcatum. Folliculi (ex Drumm.) majores quam specierum affinium. Flores melle scatentes sicut ii B. grandis aliarumque specierum ab incolis Mangite vocantur et comeduntur. (v.s. sine fr. in herb. Shuttl.)

56. B. DRYA NDR OIDES (Baxter mss.), fruticosa, ramis tomentosis, foliis elongatolinearibus, lobis isoscelo-triangularibus muticis margine recurvis utrinque euerviis eveniis subtus niveis, cajitulis lateralibus ovatis parvis, calyce stylum semipollicarem glabrum subæquante sericeo laminis glabrescentibus, stigmate minuto eapitato.5Cirea sinum Regis Georgii ol Gape Riche (Baxter, Preiss, 11. 490! Drumm. coll. 3, n. 287!).- Sweet 11. Austr. t. 56, R. Brown suppl. p. 36, Mcisn. in pl. Preiss.1, p. 588*. Frutex 1-2-jedalis, subsimplex, strictus. Folia sparsa, sessilia, 4-6 poll. longa, lobis ad nervum usque discretis, 3 lin. longis, basi 2 lin. latis, acutis, subtus albo-tomentosis. Capitula ramulos laterales brevissimos paucifolios terminantia 1-1 $\frac{1}{2}$ poll. longa. Calyx rufo-sericeus, laminis oblongis muticis demum glabris. Folliculi transversi, depressi, 10 lin. lati, glabrati, margine obtuso sulco exarato: (v. s. et v. c. in li. Kew.)

57. B. BrownI1 (Baxter Inss.), arborescens, ramulis gracilibus demum glabratis, foliis linearibus, lobis parallelo-approximatis linearibus falcatis muticis subtus niveis 1-nerviis eveniis margine recurvo, capitulo terminali oblongo, calyce sericeo subpersistente stylo glabro longo supcrato, stigmate minuto obtuso. 5 Circa sinum Regis Georgii (Baxter, Preiss, n. 478!'Drumm. coll. 5, n. 415!). - R. Brown suppl. p. 37, Meisn. in pl. Preiss. 1, p. 588. Arbuscula 10-20-pedalis, ramis fastigiatis, junioribus tomentosis. Folia sparsa vel 3-6 subverticillata, subsessilia, 2-4 poll. longa, lobis ad nervum usque discretis 3 , lin. longis, $\frac{1}{2}-1$ lin. latis, obtusiusculis. Capitula 4-6-pollicaria, crassa, sessilia, cylindrica, bracteis tomentosis infimis subulatis. Calyx 8 lin. longus, laminis anguste lanceolatis acutis. Stylus ruber? demum 20 lin. longus, apice hamatus, stigmafe vix incrassato sphacelato. Folliculi transversi, semiexserti, suborbiculares, depressi, 0 lin. Jati, tomentosi, margine acuto. (v, s. et v. v. c.) 
Seçtio II. Isostyuis $R$. Brown prodr. p. 396.

Calyx stylum rectum subaquans, inguibus diu in tubum hinc fissum cohærentibus, laminis cito liberis. Capitulum subdepresso-globosum, floribus fastigiatis, fruetiferum fellicuto subsolitario verticali. - Meisn. in pl. Preiss. 1, p. 589. $\Rightarrow$ is is

58. B. I I ICIF ol i A (R. Brown in Linn. Trans. 10, p. 211, prodr. p. 396, suppl. p. 37), arberea; ramis tomentosis, foliis oblongo-oxatis extra medium spinoso-dentátis supra eveniis nitidis subtus obsolete venosis glabriusculis albido-punctatis, calycis tubó sericeo-pdbertilo apice limboqué glabro, stigmate brevi eylindríco tenui obtıso: 5 Circa sinuth Kegîs Georgii (R. Br.) et flum. Cygnorum (एreiss, 1. 482 !). - Meisn. in pl. Preiss. 1, p. 589*. B. Aquifolium Lindl.! Swan Riv. p. 34, n. 161.

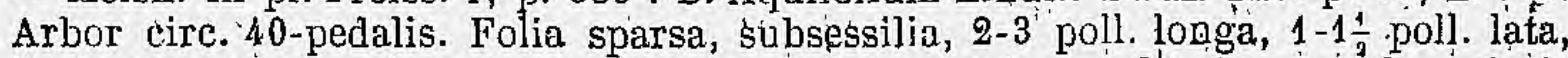
basi cuneata, margine jlana vel subundulata, juniora subtụs puberula, stirpis juvenilis elongatis inciso-pinnatifidis, den tibus brevibus latis mucronatis vel muticis. Capitula terminalia, magnit. pruni majoris, rèceptaculo hemisphæricó depresso, magnit. dvellanæ, squamis obtusis velutinis. Calyx pollicaris, ruber? laminis lanceolatis acutis glabris. Stylus glaber, pallide roseus? stigmate sphaeelato. Folliculi 1-2 ver'ticales, raro $3-10$ 'subhorizontales. (vis s. in herb. Lihdlin etc.)

\section{Species nimis obscurce et indescripta.}

B? LONGIFOLIA (Don, ex Dietr. Gartenlex. 2, p. 150), caule erecto; ramis gracilibus virgatis, foliis longis linearibus súhstriatis, floribus solitariis, frùctibis"ovatis rugosis.--In Noviâ-Cambriâ australi.-An Persootliæe sp.? ex Dietr. Nachtr.; forsan Brabeji species, fide Roem. et Schult. syst. $3 ;$ p. 444.

B. CUNEIF L IA (Hoffimannsegg Verzeichri. Nachtr. 2, p. 64), foliis oblongo-vel lanceo-

- lato-cuneiformibús subjuræmorsis grosse subequaliter mucronulato-serratis subtus allio tomentosis obsolete reticulatiś, costâ glabrâ. 5 - Roẹm. et Schult. syst. 3, mant. p. $379^{*}$. Folia $4-5$ poll. l'onga, 1 poll. làta, in petiolum brevem sensim angustata. Aflinis dicitur $\mathrm{B}$. marcescenti (supra, n. 37), sed dịstincta foliis majoribus, dentibus numerosioribus, sìnubus rectilịneo-angulatis, subtus magis niveis mịnus distincte reticulatis. Flores ignoti.

B. 'RETICULATA (Hoffmannsegg 1. c. p. 67), foliis oblongís acutiusculis crebre spinuiloso-serralis subtus tomentosis laxe reticulatis, costâ audà. $\delta$-Reem. et Schult. l. c. p. $379^{*}$. Folia 4 poll. longa, vix 1 poll. lata, utrinque equaliter attenuata, subsessilia. Aflinis dicitur B. serratæ, sed diversa foliis paulo majoribus, serraturis duplo crelrióribus minus divergentibus, tơmento densiore, costâ tẽnuiore, venis minus regulariter parallelis, reticulatione laxiore minusque conspicuaa:

B. HUGEL II (R. Brown m'ss., ex Endl. gen. suppl. IV,'2, p. 89, n. 683).

B. HYPOLEUCA (Hoffmannsegg l. c. p. 66 , Roem. et Schult. l. c. p. $379 *$ ), videtur B. marginatæ forma, t. supra, n. 15.

B. minos ordes, h. Cantabr. ex Dietr. Gartenlex. 2, p. 150

B. LONGIFOLIA (Besf.

B. RUBRA (Don..., Dietr...).

B. VILLOSA (hort.).

B. VIRENS (Don.).

Species non-descriptæ, nomine tantum nobis cognitæ, ex Roem. et Schult. syst. 3, mant. p. 292, el Steudel nomencl. ed. 2, p. 165.

\section{Species exclusce.}

B. A в YS In Ic A Bruce = Hagenia Abyssinica, ex Steudel.

B: D А с́т YL OIDES Gærtn. = Hakea dactyloides Cav.

B. Gr B o os A Gav. = Hakca gibbiosa Cav.

B. Gnidia Forst. = Pimelea Gnidia Willd.

B. HETEROPHYLA hort. = Hakea suaveolens R. Br.

B. in s cul if o Rims Gærtn. = Apocynea, ex R. Br. in Linn. Trans. 10, p. 224 (Cèrbera musculiformis Lam.) (1).

B. Nivea Labill. = Dryandra nivea $\mathrm{R}$ Br.

(1) Planta fere ignota, in Apocynac. supra omissa (Alph. DC.). 
B. OL E E B OLIA Salisb. (non Cav.). = Hakea, dactyloides Cav.

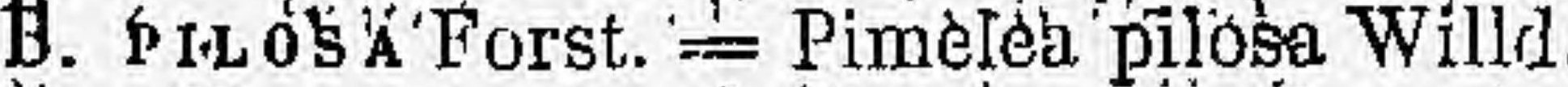

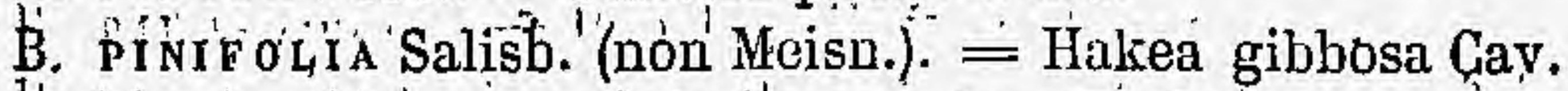

B. PINA T A hort. = Hakeà suaveolens R. Br.

B. PROSTRATA Forst. (non Br.). = Pimelea prostrata Willd.

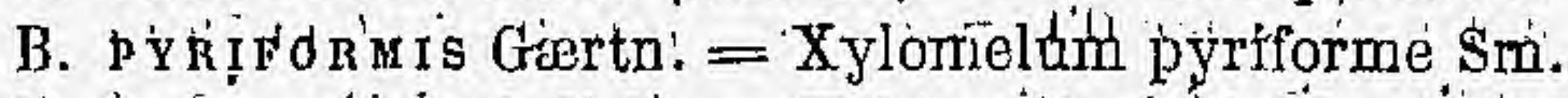

B. TENUIfótia Salisb. = Hakea acicularis Kn. et Salish.

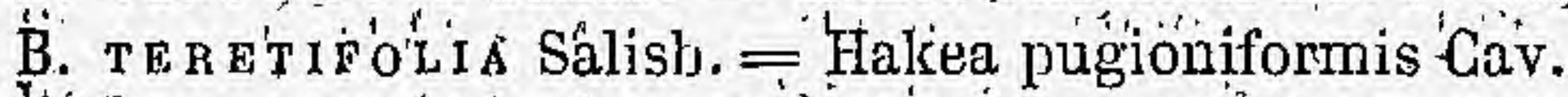

B. т ом EN T OSA Forst. = Pímelea pilosa Willd.

XLIV. DRYANDRA $R$. Brown in Trans. Soc. Linn. Lond. 10, p. 211, t. 3, pnodr. A. Nov.IIoll. ṕ. 396, suppl. p. 37, Endl. geñ. p. 343, n. 2158, suppl. IV, 2, p. 89, Meisn. gen. p. 333 (246) (non Thunb.). - Josephia Knight et Salisb. Prot. p. 110.

Flores hermaphroditi, regulares, capitati. Calyx 4-partitus vel 4-fidus, laminis concavis antheriferis. Antheræ subsessiles, connectivo pleíumique ultra loculos producto breviter apiculatæ. Squamulæ / hypogynæ. Ovatiutn sessile, 1 - loculare, ovulis 2 collateralibus supra medium marginis affixis post foecundationem cohæérentibus 'et' plerumque (ut in Banksiâ) disssepimentum spurium' formantibus. Stylus filiformis, plerumque redtus et calyce vix' tongiơt. Stignad cońtinuum vèl bási oblique annulato-j̣ncrassátum, subulatum vel'cylindrícum vel clavatum, sulcátum, rarius læve. Folliculus ligneus, dissepimento membranaceo libero bifido vel nulló. Semina apice alata. - Frutices vel arbusculæ Novæ-Hollandiæ austro-occidentatis, plerumque humiles, ${ }^{1}$ ramis sparsis vel umbellatis, foliis sparsis coriaceis serratis vel inciso-lobatis'vel pínnatifidis, rarissime integerrimis, plantæ juvenilis plerumque conforhíbus, stomalibus hypogenis, capitulis terminalibus lateralibusve sessilibus fóliis obvallatis globosis hemisphrericis, involucro propirio pluriseriali adpresse inibricato, receptaculo plano vèl convexó, palêis angustis vel rarius nullis.

Sectio J. Eudryandra Meisn. in pl. Preiss: 1, p. 589.

Eolliculus bilocularìs, dissepimento spurịo e seminum testis connatis formato ligneo semibifido.

\section{\$1. Ilicina. - Folia plana cuneato-ovata vel oblonga grosse inciso-dentata vel infrä medium integra.}

1. D. PRAMORSA (Meisn. in pl. Preiss. 1, j. $265^{*}$ ), ramulis tomentosis, foliis obovatis 1 oljlongisque sinuato-dentatis supra subeveniis glabris suljtus costato-venosis incanis; dentibus triangularibus' acitis; sinuljus acutiusculis, Involuctró floribus quadruplo breviore, squamis acutis exterioribus tomeftosis interioribus longioribus' angustis sericeis, calyce brevi-villoso stylum 'aefuante, 'stigmate vix 'erassiore cylindraceo. 5 In colonia Swan River (Druntnod coll. 2, n. 339!). Folia subpetiolata, 1-2 poll. longa, 8-10 lin. lata, truncata vel emarginata; mutica, plus minus' cuneata, constanter ad basin usque denitatá, subtus albido-tomentośa, dèntibus subecualibus ovato-triangularibus 2-3 lin. longis, 3-4 lin. latis, pungentitibus, sínuum angulo obtuso vel acuto nunquam rotundato, margine subredurvo blsolete'nerviformi, costis subtus conspicuis parallelis tenuibus immersis' glabratis, venulis reticulatis obsoletis vel nullis. Capitula terminalia, sessilia, magnit. pruni znajoris, squamis interioribus ollongo-linearibus intus glabris striatis: Calyx 14-16 lin. longus, pube aureâ densâ brevi; in lamiinarum.apiee longiore croceâ. Stylus calycem æruans, tenuis, rectus, glaber, stigmate subcontinuo obtusiusculo sulcato. (v. s. in herb. Sliuttl.)

" $\beta$.' elongatá (Meisn. in Hook. Journ. 1852, p. 210); ramis gracilibus tomentosis simulque patulo-pilosis, folis oblongis pinnatifido-dlentatis, dentibus ovatotriangularibus mucronato-spinescentibus (Drumm. coll. 5, n. 4221). Fulia 3-5 poll. longa, 12-15 lin. lata, dentibus 3-5 lin. longis latisque. (v. s. in herb. Shuttl. ét Lemánn.)

2. D. QUERGTF OLIA (Meisn: in Hook. Journ. 1852, p. 210), ramulis incano-tomen D. QUencr, 
tosis, foliis obovato-oblongis acutis pinnatifido-dentatis glabris supra evenis nitidis subtus prominulo-costatis scrobiculato-reticulatis lacunis alpidis, dentibus ovato-triangularibus pungentibus, sinubus acutis; involucri squamis linearibus attenuato-acutis exterioribus plumosis basi tomentosis interioribus pilosis calycem sericeum basi tomentosum . equantibus, stylo longe exserto, stigmate cylindraceo elongato. 5 In coloniâ Swan River (Drumm. coll. 4, n. 307!). Rami virgati, validi, longe subsimplices. Folia conferta, erecta, sessilia vel summa petiolata, rigidissima, 3 poll. longa, 12-18 lin. lata, ad basin usque grosse dentata, dentibus patentibus acutis vel breve spinescentibus planis mediis isoscelis 3 lin. longis latisque rectilineis vel subovato-triangularibus passim dente minore auctis, inferioribus scalenis. Capitula terminalia globosa, folia subsequantia, diametro 1-2-pollicari. Involucri squamæ subulato-acuminatæ, interiores adpresse pilosiusculæ, exteriores patulo-villosæ basi cano-tomentosæ. Calyx 15 lin. longus, aureo-sericeus, supra basin glabram breve cano-tomentosus. Stylus 2 poll. longus, rectus, tenuis, glaber, stigmate 2 lin. longo sulcato basi obsolete noduloso. D. cuneatæ accedens, sed bene distincta (v. s. in herb. Shuttl.)

3. D. cuneat a (R. Brown in Linn. Trans. 10, p. 212, prodr. p. 397), ramulis canotomeńtosis, foliis cuneato-obovatis inciso serratis; dentibus spinescentibus planis subtus costatis scrobiculato-reticulatis tomentosis, sinubus rotundatis, involucro floribus demum multo breviore, squamis linearibus attenuato-acutis sericeotomentosis, stylo calycem sericeo-villosiusculum subrequante, stigmate tenui subulato. $亏$ Jn terrà Leeuwin (R. Br.), circa sinum Regis Georgii (A. Cunning.! Preiss, n. 525! Drumm. coll. 3, n. 292 !). - Wendl: fil.' in Bot. Zeit. 1819, p. 133, Meisn in pl. Preiss. 1, p. 590*, 2, p. 266. Folia $1 \frac{1}{2}-3$ poll. longa, extra medium 10-20 lin. Jata, supra evenia glabra nitida, plerumque ad basin usque dentata, rarius basi cuneata integra, petiolo 1-3 lin. longo vel nullo, dentibus plerumque rectilineis scalenis cum mucrone $1 \frac{1}{2}-2 \frac{1}{2}$ lin. longis, sinubus nunquam acutis. Involucri squamæ subrequilonge, læves, exteriores passim pinnatim spinulosæe vel foliaceæ. Calyx circ. pollicaris, sulphureus, laminarum villis longioribus. Stylus 14-15 lin. longus, tenuis, glaber, demum rectus. Stigma subsulcatum, acutiusculum, basi obsoletissime nodulosum. Forma 2 a cel. auctore 1. c. indicatre invicem confluere nec varietates stabiles sistere nobis videntur. (v. s. in herb, Cunn., etc., et v. v̀. in herb. Kew.)

4. D. FLORIBUNDA (R. Brown 1. c. p. 212 et 397), foliis cuneato-obovatis oblongísve inciso-serratis, dentibus spinescentibus planis subtus tenuiter venosis reticulatis vel punctatis, sinubus rotundatis, involucri floribus longe superati squamis glabriusculis ciliatis, interioribus linearibus striatis, exterioribus brevioribus ovatis lævibus, calycis stylum subæquantis unguibus páberulis laminis glabris, stigmate continuo tenui subclavato. JIn terrâ Leeuwin (R. Br.), coloniâ Swan River (Brumm. coll. 1, n. 638! 639! Preiss, n. 520! 521!). - Bot. mag. t. 1581, Wendl. fil. in Bot. Zeit. 1819 , p. $133^{*}$, Meisn. in pl. Preiss.1, p. 589*. Josephia sessilis Knight et Salisb. Prot. p. 110. Frutex 5-8-pedalis, satis variabilis, juvenilis pilis longis mollibus hispidus. Ramuli nunc glabri nunc pubescentes. Folia conferla, sessilia vel breve petiolata, 1-2 poll. longa, 6-10 lin. lata, supra glabra nitida, alia egregie cuneala extra medium tantum dentata, alia (et quidem in eodem ramo) ad basin usque dentata, subtus vel utrinque minute reticulata vel potius punctata glabrata, venis immersis, lacunis sæpe albido-tomentellis. Involucri squamæ exteriores 2-3 lin. longæ, 2 lin. latæ. Calyx citrinus, circ. pollicaris, stylo tenui demum breviter superatus, stigmate obsolete sülcato obtuso. Cat. fere D. cuneata. (v. s. et v. v.c.),

$\beta$. cordata (Meisn. in pl. Preiss. 2, 265), foliis ovali- vel obovato-oblongis basi vix angustatá corclatis (Drumm. coll. 2, n. 344 !). Folia bipollicaria, summa passim cunealo-attenuata, apice tantum aut arl basin usque spinoso-dentata. (v. s. iu herb. Shuttl. et Lemann.)

\$ 2. Runcinatce.-Folia lanceolata vel late linearia elongata, sinuatopinnatifida, sinubus latis obtusis vel rotundatis, raro acutis (cfr. D. armata), lubis basi confluentibus vel breviter lateque decurrentỉbus planis vel margine recurvis subtus tomentosis raro glabris. Capilula lateralia, raro terminalia.

5. D. мвията (R. Brown in Limn. Trans. 10, p. 213 , prodr. p. 397), foliis oblongo. 


\section{DRYANDRA. PROTEACE $E$ (ADCTOR MEISNER).}

lanceolatis, sinubus acutis, lobis divaricatis oblongo-triangularibus spinescentibus scalenis decurrentibus planis subtus 3 -nerviis reticulatis lacunis tomentosis, capitulis terminalibus, squamis exterioribus ovatis glabratis interioribus oblongis sericeis, calyce sericeo-puberulo laminis superne glabris, stylo brevi exserto basi pubescente, stigmate' tenui cylindraceo obtuso. F In terrà Lecuwin (R. Br.), circa sinum Regis Georgii (A. Cunn.!) et fum. Cygnorum (Drumm. coll. 11 coll. 5, n. 421! Preiss, n. 519!). - Wendl. fil. in Bot. Zeit. 1819, p. $134^{*}$, Meisn. in pl. Preiss. 1, p. 590*, Bot. mag. t. 3236. D. favosa Lindl.! Swan Riv. p. 33, n. 155 (non Meisn. in pl. Preiss. 1, p. 593, quoad specim. Preiss, n. 524, quie verisim. Banksiæ sp. aff. B. speciose). Frutex 2-4-pedalis, ramis apice cano-tomentosis vel (ex Br.) glabris. Folia subsessilia, 2-3 poll. longa, lobis 2-5 lin. longis basi 1-3 lin. latis rectis vel levissime retrorsum fâlcatis supra eveniis nitidis subtus cano-tomentosis demum subglabris concoloribus, versus apicem basihque folii decrescentibus, terminali proximis longiore. Capitula sessilia, magnit. prupi majoris, involucro floribus $\frac{1}{3}$ breviore. Calyx flavus, laminis linearibus obtusis basi tantum cum unguibus pube brevi patulâ sericeis. Stylus pollicaris; tenuis, pallidłus; stigmate continuo, $1 \frac{1}{2}$ lin. longo, fusco, leviter sulcato. (v. s. in lierb. Lindl., etc.)

6. D. CARDUACEA (Lindil.! Swan Riv. p. 33, n. 156), ramulis glabriusculis, foliis sessilibus lanceolatis semipinnatifidis basi euneatâ integris, sinubus 'acutis, lobis patentibus triangularibus decurrentibus pungentibus planis' subtus cano-tomentosis obsolete venosis, cappitulis lateralibus, squamis lanceolatis glabris interioribus ciliatis exterioribus subulato-acuminatis, calyce sericeo laminis glabriusculis, stylo breviter exserto glabro, stígnate brevi oblongo. $\bar{J}$ In coloniâ Swan Ríver (Drumm. coll. 1! coll. 2, n. 340! Preiss, n. 516!).-Meisn. in pl. Preiss. 1, p. 591*, Bot. mag. t. 4317. Frutex 12-pedalis, ramis gracilibus laxiuscule foliosis mox glabratis. Folia patula, modice rigida, 2-6 poll. longa, 4-8 lin. lata, grosse inciso-dentata, subtus canescentia vel juniora nivea potius puncticulata quam reticulata, deatibus inæqualibus 3-12 lin', distantibus mucronatis, margine plano vel subrocurvo. Capitula ramulos axillares breves apice foliosos terminantıa, ma'gnit. juglandis, involucro floribus subtriplo breviore. Calyx sulphureus, stỷlo 10 lin. longo capillari vix $\frac{1}{3}$ brevior. Stigma $\frac{1}{2}$ lin. longum, stylo paulo crassius subangulatum. (v. s. in herb, Lindl., etc.)

7. D. RUNC.rNA A (Moisu. in Hook. Journ. 1852, p. 210), foliis petiolatis longis runcinato-pinnatipartit is sinubus latis obtusis, lobis divaricatis late ovato-triangularibus acutis basi decurrente rhachin anguste marginantibus subtus 2-3-nerviis reticulatis tomentosis margine recurvis, capitulis lateralibus subsessilibus, squamis glabris obtusis, exterioribus vratis interioribus oblongis calycem glabrum basi villosiusculum suberuantihus, stylo exserto glabro, stigmate longo oylindraceo sulcato. $J$ In colunia Swan River (Drumm. coll. $4, n$. 318!). Caulis nanus, circ. digitalis, crassus, adscendens, apice divisus in ramulos sıljverticillatos 1-2-pollicares conferte foliosos inferne adpresse imbricato-squamatos. Folia. 8-10 poll. longa, acuta, supra evenia glabra nitida, subtus ferrugineo. vel rlemum albidotomentosa, sinubus 3-10 lin. latis, lobis rectis vel leviter retrorsum falcatis 4-8 lin. longis fere isoscelis, parte secus rhachin decurrente 1 lin. latä, nervis 2 rarius 3-5 subtus prominulis parallelis glabratis, venularum reticulo tenui siepius obsoleto. Petiolus 2-6-polliearis, fillfformis, anguste marginatus. Capitula ad ramorum originem plura approximata, subclausa, ovoidea, magnit. ovi gallinacei mediocris, squamis fuscis nitidis, jun. tomentellis? interioribus 12-18 lin. longis, 2-3 lin. latis. Calyx circ. pollicaris, supra basin albido-pubescens, cæterum glaberrimus, laminis linearibus acutiusculis fere 3 lin. longis. Stylus subarcuatus, demum fere 18 lin. longus, stigmate haud crassiore continuo 2 lin. longo obtuso. Species insignis involucro ad.D. proteoidem, foliis ad Banksiam prostratam accedens, ab omnibus distinctissima. (v. s. in herb. Shuttl.)

8. D. No BIL Is (Lindl. Swan Riv. p. 33, n. 158), ramis incauo-tomentosis villosisque, foliis longis linearibus runcinato-pinnatipartitis, sinubus latis obtusangulis, lobis divaricatis late triangularibus acutis decurrenti-subeonfluentibus subtus plurinerviis reticulatis cano-tomentosis margine leviter recurvis, capitulis lateralibus subsessilibus, squamis exterioribus ovatis villoso-tomentosis folio lineari serrato terminatis interioribus angustis acutis flore multo brevioribus, calyce supra basin glabram stuposo-lanato supra sericeo, stylo glabro, stigmate cylin-

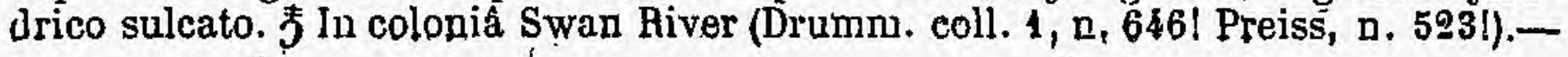


Meisn, in jol. Preiss 1, p. $592^{*}$, Bot, mag. t. 4633 . Frutex 7-pedalis, exectus. Folia 6-8-pollicania, 4-8 lin. lata, scssilja rel breve petíolata, fere ad mervum usque incisa, sinubus 3-6 lin. latis interdum acutangulis, lobis 3-4. lin. longis latisque isoscelis rectilineis vel scalenis rectis vel ajice subrecurvis, passim ut in D. runcipatâ decurrentibus. Capitulưm subglobosum, yomi minoris mole. Calyx 12-15 hin. longus; unguibus minufe puberulis, laminis apice dense fulvo-villosis, Stylus calycem æquans vel demum subbijollicaris rectus. Stigma $1 \frac{1}{2}$ lin. longum utrinque paulo attenuatum basi obsolete nodulosum. (vi s, et v. c. in h. Kew:)

9. D. PLU M.0SA (R. Brown in Linn. Trans. 10. p. 214, prodr. p. 398), ramulis tomentosis, foliis, elongato-linearibus runcinato-pinnatipartitis, sinubus obtusisis acutisve lobis divaricatis late isoscelo-triangularibus acutis subtus leviter plurinerviis ineano-tomentosis, capitulis lateralibus subsessilibus, squamis pilosis exterioribus ovatis vel ovato-oblongis folio tenui serrato vel aristâ terminatis, interioribus angustis muticis flores superantibus, calyce supra basin glabram lanata, laminis sericeis, stylo glabro, stigmate cylindraceo sulcato. $\delta$ in terrà Leeuwin (R. Br.), circa sinum Regis Gedrgii et Cape Riche (A. Gunn.! Preiss, h. 507! Drumm. coll. 4, p. 310!). — Wendl. fil, in Bot Zeit. 1819, p.135*, Meisn: in pl. Preiss. 1, p. 592 " (ulji involucrum imperfecte, scil. nonnisi capituli junioris, desçriptum). Frutex bipedalis, foliis dense intertextis. Calyx 8 lin. longus, stylo tenui parum brevior, pube rufâ crispâ lanatus, laminis subadjoresse pilosis apice subbarbatis. Stigma vị $\frac{i}{2}$ liv. longum, continuum. Cæetera fere.D. nobilis, a quà præterea differt staturd humili, folijs plerumque angustioribus, lobis isoscelis, haud decurrentibus, etc. (v. s. et v. c. in h. Kew.)

\section{§3. Serrata. - Folia linearia, inciso-pinnatifida veí pinnatïpar- tita, sinubus angustis acutis, lobis brevibus latis planis fere isoscelo- triangularibus basi contiguis vel confluentibus, inferiorïbus tantum nonnunquam breviter decurrentibus; subtus tomentosis. Capitula terminalia.}

10. D. S TUP OSA (Lindl.! Swan Riv. p. 33, 11. 157), ramis villosissimis, foliis pinnatifidie lobis subrequilatero-triangularibus pungenti-acutis subtus plurinerviis subreticulatis margine leviter recurvis, cajitulis terminalibus axilláribusque ses. silibus, squamis tomentosis interioribus oblongis obtusiusculis flore multo brevioribus, calyce supra basin glabram lanato Jaminis sericeo-villosis, stylo glabro, stigmate fusiformi suleato. J゙ In coloniâ Swan River (Drumm. coll. 1, n. 643! Preiss, n. 502!). - Mèisn. in pl: Preiss. 1, p. 591*. Fratex 10-pedałis. Folia conferta, subsessilia, 3-5 poll. longa, 3-5 lip. lata, acuta, ad basin usque serrata, dentibus subæqualibus plerumque rectilineis submucronato-acutis subtus albido= vel ferrugineo-tomentosis. Capitula magnit. pruni majoris, sape approximato-subaggregata, squamis intericribus circ. semipollicaribu's. Calys 12-14 lin. longus, ungtuium pube ferrugineâ fuscâ. Stỵlus 15-18 lin. longus, stigmate $1 \frac{7}{2}$ lin. longo baisi obsolete noduloso. (v. s. in herb. Lindl., etc.)

1i. D. SER R (R. Brown suppl, p. 38), ramis glabris, foliis linearibus pinnatifidis planis supra reticulatis glabris subtus cano-tomentosis subenerviis eveniis, lobis subacquilatero-triangularibłs mucronatis, capitulis lateralibus sessilibus, squamis lancenlatis puberulis, calyce sericeo, stylu glabro, stigmate brevi,clavato. $\partial$ Girca sinum Regis Georgii (Baxler, Preiss,.n. 513 ! Drumm. coll. 3, n. 296!). - Meisp. in pl. Preiss. 1, p. 591*. Frutex 10-12-pedalis, strictus, ramis gracilibus. Fòlia breve peliolata, 2-4 poll. Ionga, 3-5 lin. lata, dentribus plerumgue leviter scalenis, mucrone ténui $\frac{1}{2}$ lin. longo subincurvo acutissimo. Capitula axillaria vel ramulos brevissimos apice foliosos terminantia, magnit. cerasi vel juglandis. Calyx sulphureus, undique sericeus, stylo subpollicari capillari brevior. Stigma vix ${ }_{3}^{t}$ lin. longum, pallídum, continuum, obtusiusculum. (v. s,)

12. D. Mucronulata ( $\bar{R}$. Brown! in Limn. trans. 10 , p. 213 , prodr. p. 398), caule subsimplici, foliis elongato-linearibus pinnatificlis lobis isoscelo-triangularibus mucronulatis planis subtus niveis, involucro tomentoso squamis interioribus

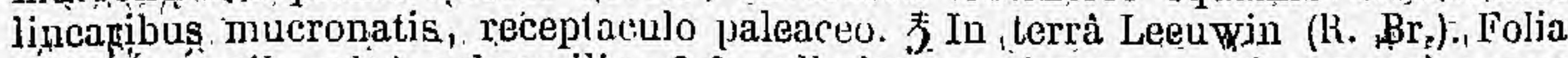
(fide sp, steril. cult.) subsessilia $a_{j}$ 6-8, poll. longa, plecrumguc ad nervum, usque incisa, lobis $2-4$ lin longis latisque sæepissime paulo longioribus quam latis ovatis 
vel triangularibus sæipius (presertim inferioribus) paullo scalenìs, suprä, evenniis glabris, subtus 2-3-1rerviis obsolete reticulatis incanís vel, fulvis. (v. s. sine flor. in herb. Cunningh.)

13. D. FOLIOLATA (R. Brown suppl. p. 38), foliis elongato-linearibus inciso-pinnatifidis truneatis cum mucronulo lobis scaleno-triangularibus acutiusculis' parallele neryosis subtus niveis, involucri squamis plerisque foliolo nano appendiculatis, "calycis semipallicaris stylo $\frac{1}{3}$ brevioris unguibus laministue villosissimis, stignate subexsulco duplo longiore quam lato basi incrassato. $\bar{J}$ Circa sinum Regis Georgii (Baxter). - Meisn. in pl. Preiss. 2, p. 266, excl. cit. pl. Drummond.

14. D. M U тा A (Meisn. in Hook. Journ. 1852, p. 211), ramulis incano-tomentosis apice palenti-pilosis, foliis elongato-linearibus obtusis profunde pinnatifidis, lobis șcaleno-triangularibus obtusiusculis muticis supra eveniis subtus incanis plurinerviis reticulatis margine subrecurvis terminali parvulo obtuso, capitulis axillaribus sessilibus, squamis demum recurvis ex terioribus tomentosis obtusis interioribus attenuato-acutis apiç scriceis, calyce stylum glabrum, subæquante unguibus lanatis lamiuis sericeis, stigmate minuto levissime incrassato obsolete sulcato obtuso. F In colonja Swan River (Drumm. coll. 4, n. 309!). Rami virgati. Folia petiolata, 5-8 poll. longa, 4-8 lin. lata, lobis 3-5 lin. latis, plerumque paulo latioribus quam longis, margine antico breviore subrecto plano, exteriore curvilineo leviter, recurvo. Capilula approximata, globosa, magnit: pruni minoris vel cerasi, squamis exterioribus demum plus minus recurvis sape folio paryo terminatis. Stylus 9 lin. longus, tenuis. Folliculi oblique ovati, 4 lin. longi, biconvexi, rufo-tomentosi, demum glabrati, reticulato-striati, margine obtuso apixe, compressiore. Hic cum . foliplata qfuam non vidimus identica creditur a cl. Kippist in litt., nobis vero pluribus notis, presertim tlere, satis differre videtur. (v. s. in herb. Shuttl.)

15. D. OBTUSA (R. Brown in Linn. trans. 10, p. 214 , prodr. p. 398), caule decumbente tomentoso faliis breviore; foliis elongato-linearibus pinnatipartitis, lobis oblongo-triangularibas, obtusissimis muticis. margine incrassato recurvis subtus incano-tomentosis subeveniis, capitulo. terminali, squamis oblongis obtusiusculis demum glabris linealis flores requantibus, exterioribus ovatis brevibus, calyce styloque iccquilongis basi puberulis supra glaberrimis, sligmate subulato sulcato.

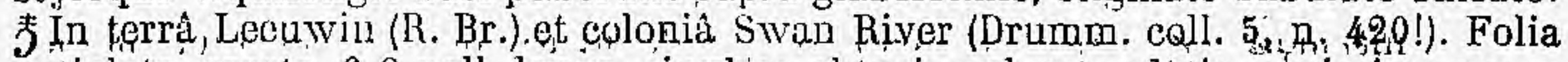
peliolata, orecta, 6-8 poll. longh, sinulius pbtusis vel rotundatis sieprissime nervo contiguis, loljis patentissimis planis vel, furtis, 2-4 lin. Iongis, 1-2 lin. latis, margine circumcirca rovoluto incrissatis supra convexis eveniis glabris subtus fulvovel'albo-tomentosis obsolete reticulatis vel sæpe eveniis basi contiguis vel brevissime decurrentibus. Capitulum basi in pedunculum arhyllum semipollicarem attènuatum, involucro juniore rufo-tomentoso, squamis interioribus fere 2 poll.longis. Calycis lamin validus, apice attenuatus, basi cum calycis unguibus parce pilosiusculus., stigmate haud erassiore fere 2 lin. longo basi obsolete noduloso. (v. s. in lierb. Cunn., Shuttlew.)

16. D. BAXTER (R. Brown! suppi, p. 38), ramulis, cano-tomentosis apice patentipilosis, foliis elongato-linearibus pinuatipartitis lobis scalenó-triangularibus oubmuticis margine incrasșato recurvis sultus niveis 1 -nerviis vel, enerviis, capitulis lateralibus, involucro lanato flopibus dimidio breviore, squamis angustis, calyce silylum pollicarem glabrum subæquante inferne lanato scriceo, laminis longe barbatis demum calvescentibus, stigmate attęnuato obtuso. F, Circa sinum Regis Georgii (Baxter, Preiss, 11. 500!). - Meisn., in pl. Preisss. 1. p. $593^{*}$. Frutex 4-6.per(alis, ramis foliisque dense intertextis. Fulia petiolata, patula, vis rigida, plus minus curvata vel flexuosa, 3-6 poll. longa, 2-3. lin. lata, ad costam usque incisa, lobis æequalibus 1-1 $\frac{1}{2}$ lin. longis latisque; acutis, haud retieulatis. Capitula subsessilia, foliis fere abscondita, magnit: pruni, squamis extus sordide albido-villosis demum recurvo-patentibus, exterioribus oblongis folio pinnatifido-terminatis, interioribus linearibus subulatis muticisve intus glabris striatis. Stylus crassiusculus, pallidus, in stigma subulatum subsulcatum attenuatus. (v. s. in herb. Cunningh., etc.)

17. D. Formos A (R. Brown in Linn. trans. 10 , p. 213, t. 3, prodr. p. 397), ramulis tomentosis, foliis elongato-linearibus pinnatipartitis lobis scaleno-triangularibus muticis planis subtus obsolete venosis tomentosis, capitulis terminalibus latèra- 
libusque squamis flore dimidio brevioribus sericeo-tomentosis exterioribus ovatis, calyce stylum glabrum subrequante basi lanato supra sericeo-piloso laminis apice longe barbatis, stigmate tenui subfusiformi sulcato. F In terrà Leeuwin (R. Br.), circa sinum Regis Georgii (Preiss, n. 501 ! Drumm. coll. 3, n. 293!).--Wendl. fil. in Bot. Zeit. 1819, p. $134^{*}$, Bot. mag. t, 4102, Meisn. in pl. Preiss. 1, p. 593 . Frutex 8-40-pedalis. Folia breve petiolata vel sessilia, patula, vix rigida, 3-6 póll. longa, 2-3 lin. Jata, subtus albida vel fulva, lobis rqualibus fere ad costam usque divisis margirye plano vel leviter recurvo anteriore recto exteriore curvilineo. Capitula magnit. pomi minoris, pulchre croceo-aurea, squamis exterioribus sape folio pinnatifido terminatis; interioribus oblongis linearibusque muticis intus striatis glabris, receptaculo dense paleaceo villoso. Stylus 15 lin. longus. (v. s. et v. c.)

18. D. NIVEA (R. Brown! in Linn. trans. 10, p. 214, prodr. p. 398), folíis elongatolinearihus caulem abbreviatum glabrum subequantibus pinnatipartitis, lobis sealeno-triangularibus acutis subtus niveis, capitulo terminali sessili foliis longe superato, squamis erectis flore dimidio lrevioribus angustis muticis glabratis ciliatis, calycis semi-4-fidi stylo glabro $\frac{1}{5}$ brévioris tubo glabro ungues sericeos aquante laminis barbatis, stigmate brevi conico-cylindrico obtuso basi oblique incrassato. J In terrâ Leeuwin (R. Br.), circa sinum Regis Georgii et-flum. Cygnorum (A. Cunn.! Preiss! Drumm.!). - Roem. et Schult. syst. 3, p. 446, Meisn. in pl. Preiss 1, p. 594*, 2, p. 267. Canlis erectus, $\frac{1}{2}-1$-pedalis, simplex vel apice umbellatim brevj-ramosus. Folia erecta, sessilia vel rarius breve petiolata, parum rigida, 5-10 poll. longa, 3-6 lin. lata, lobis ad nervum usque distinctis vel basi anguste conjunctis acutis vel inucronulatis margine planis vel recurvis rectilineis leviter curvilineis nonnunquam breviter decurrentihus. Capituluḿ maguit. pruni, squamis oblongis linearibusque. Calyx 12-15 lin. longus, pube brevi patulâ rufâ vel canâ, laminis interdum demurn glabrescentibus. Stylus 1-1 $\frac{1}{2}$ poll. longus, tenuis, pallidus, stigmate $\frac{1}{2}$ lin. longo atro. Forme sequentes interdum in eodem individuo reperiuntur.

$\alpha$. venosa, foliorum lobis adscendentibus subtus 1-3-nerviis sæpiusque reticulatis, stigmate paullo incrassato. - R. Br. l. c. (Preiss, n. 504, 506! 510! Drumm. coll. 1, n. 641! 645! 2, n. 346!). Banksia nivea Labill. Voy. 1, p. 413, t. 24, Nov.-Holl. 2, p. 118. Josephia rachidifolia Knight et Salisb. prot. p. 111. (v. s.)

B. subevenia, foliorum lobis plus minus divaricatis enerviis eveniis vel passim 1-nerviis, stigmate stylo vix crassiore. - R. Br. 1. c. (Preiss, n. 508! Drumm. coll. 1, n. 640! 4, n. 313! 5, n. 419!h. Forma sepius ad D. Lindleyanam valde accedens. (v. s. et v. c. in h. Kew.)

19. D. B R own I (Meisn. in pl. Preiss. 1, p. 595*), foliis caule glabro órevioribus longe linearibus pinnatipartitis lobis scaleno-triangularibus acutis margine recurvis subtus 1-3-nerviiis reticulatis niveis inferioribus remotis angustis rectis vel falcato-recurvis, capitulis terminalibus lateralibusque sessilibus, squamis exterioribus folio pinnato terminatis vel longe subulato-acuminatis, interioribus angustis acutis glabris ciliatis caljce dimidio brevioribus, calyce semi-4-fido, tubo supra basiu glabram dense sericeo lanato, unguibus pilosiusculis, laminis parce barbatis, stylo 2-pollicari longe exserto, stigmate minto basi vix incrassato. $\bar{F}$ Circa sinum Regís Georgii (Preiss, n. $509 !$ Drumm. coll. 4, n. 313!). Valde quidem D. niveæ propinqua, sed vix mera var. Caulis 2-3-pedalis. Folia 10-18 poll. longa, rigidiora, lobis muticis superioribus obtüsiusculis constanter margine recurvis subtus nervosis reticulatisque, inferioribus 3-6 lin. ab invicem distantibus leviterque recurvo-arcuatis, infimis angustatis $\frac{1}{2}$ lin. longis fere spiniformibus. Calyx fere 18 lin. longus, laminis demum subimberbibus. Stylus bipollicaris ! stigmate vix crassiore $\rightarrow$ lin. longo atro. (v.s.)

20. D. LINDLEYAA (Meisn. 1. c. p. $598^{*}$ ), foliis caule ramulisve brevibus multo longioribus linearibus strictis truncatis pinnatipartito-serratis, dentibus scalenotriangularibus acutis margine recurvis subtus niveis subenerviis, capitulo terminali sessili, squamis interioribus flore dimidio brevioribus angustis obtusis soriceo-tomentosis, exterioribus brevioribus subulatis, calycis stylo sesquipollicari $\div$ brevioris semi-4-fidi lubo glahro unguibus laminisque villosis, stigmate subincrassato brevi. F In arenosis umbrosis circa Pointwater coloniæ Swan River (Preiss, л. 511!). Aboriginibus Budjan audit.' Species inter $\mathcal{D}$. niveam, pracipue. var. $\beta$, 
D. Brownii et longifoliam quasi ambigua, attamen, ni fallor sui juris. Differt a D, niveâ foliis longioribus, 10-12 poll. longis, 2-vix 3 lin. latis, rigidioribus, lobis margine recurvo supra convexis, stylo longgiore, etc.; a D. Brownii et longifoliâ foliorum lobis omnibus contiguis approximatis inferioribus brove tantum decurrentibus, stylo breviore, eto., (v. s.)

\section{\$ 4. Marginata. - Folia anguste linearia dense pinnatifida, sinubus} acutis, lobis brevibus scaleno-triangularibus ad costam usque distinctis contiguis vel breve decurrentibus margine forliter reourvo subincrassato supra convexis subtus concavis niveis.

21, D. STENOPRION (Meisn. in Hook. Journ, 1855, p. 122), caule repente? ramis breyibus apice foliosis glabris, foliis lougis dense, approximato-verticillatis, lobis adscendentibus acutis muticis subtus subnervosis, capitulo..... 5 In N.-Holl. occid. interiore (Drumm. coll. 6, n. 2121): Caulis hypogæus? ramis adscendentibus 2-3 poll. longis inferne nudis. Folia in, verticillis $\mathbf{3 - 4}$ lin. distantibus disposita, petiolata, 6-12 poll. longa, $2 \frac{1}{2}$ lin. lata, lobis 1 lin. longis latisque rectis leviter - curvilineis supra lavibus glabris subtus incanb-tomentosis obsolete 2-3-nerviis scrobiculatisque infimis spinuliformibus sinu 2-3 lin. lato separatis angustissime decurrentibus. Ciet. ignota. Species sequentibus proxime sane affinis, nec non D. Lindleyanie et Brownii quodammodo accedens, sed ab omnibus primo vultu satis distincta. (v, s. sine f1. in herb. Shuttlew.)

22. D. ELEGANS (Meisn. in Hook. Journ. 1852, p. 211), ramis gracilibus glabris, foliis sparsis elongatis petiolatis, lobis muticis subtus obsolete venulosis infmis minoribus remotioribus breve decurrentibus, capitulis axillaribus sessilibus, squamis exterioribus numerosis filiformibus folio apice sernato terminatis, mediis ovato-lanceolatis subsericeis, intimis spathulato-linearibus glabris flores superantibus, calyce stylum ærquante 4-partito supra basin glabram fulvo-lanato unguibus laminisçue glaperrimis, stigmate tenui cylindraceo. J In colonià Swan River (Drumm. coll. 4, n. 3171). Rami dense foliosi, juniores pulseruli. Folia ereeta, 3-6 poll. longa, 2-3 lin, lata, recta vel incurva, truncata cum micronulo, basi integra in petiolum subfiliformem $\frac{1}{2}-2$ poll. longum angustissime decurrente, lobis adscendentibus margine antico $1-1 \frac{1}{9}$ lin., exteriore 2-3 lin. longo, sinu acutangulo. Capitula in summis axillis sessilia, approximata, diametro bipollicari, squamis mediis oblongis acutiusculis 4-7 lin. longis, 2-3 lin. latis, fuscis puberulis mox glabrescentibus intus glabris leperrime striatis, intimis 12-15 lin. longis, $\frac{x}{3}-1 \frac{1}{2}$ lin. latis obtusiusculis demum recurvo-patentibus. Calycis basis gamophylla, 3 lin. longa, apice dense albido- vel fulvo-lanata, laminis anguste linearibus aeutis 2 lin. longis. Stylus pollitaris, glaber, stigmate haud crassiore continuo obtusiusculo suhsulcato. Folliculi oblique obovati, cuneati, compressi, nitidi, radiatim striati, glabri, 4-5 lin. longi, 3-4 lin. lati, margine obtuso subundulato. Hæc a cl. Kippist (cfr. Hook. Journ. 1855 , p. 122, in notâ) identica creditur cum D. tenuifoliâ R. Br., cui capitulorum magnitudine involucro floribusque sane convenit, sed differt petiolo breviore, foliis strictiusculis, lobis den'se approximatis thargine magis revolutis, etc. Propius accedit ad D., stenoprion, secl differt ramis elongatis, foliis sparsis, lobis obtusiusculis, etc. A sequentibus discrepat sive involucro; sive floribus, nec non capitulis multo majoribus, etc. (v. s. in herb. Shuttlew.)

23. D. PUL OHELLA (Meisn. l.c. p. 211), ramis glabris, foliis sparsis et pseudo-fasciculatis subsessilibus elongatis truncatis mucronulatis, lobis acutis brevo decurrentibus, capitulis axillaribus subsessilibus, squamis lineari-subulatis interioribus flore $\frac{1}{3}$ brevioribus apice plumosis, calyce pollicari basi glabro, unguibus hispidulis, laminis sericen-pilosis carinâ dorsali glalratâ, stylo sesquipollicari glabro, 5. In. coloniâ Swan River (Drumm. coll. 4, n. 312!). Rami apice densissime foliosi. Folia patula, 4-5 poll. longa, sinubus 2 lin. latis, lobis vix 1 lin. longis latisque, margine exteriore valde revolúto costæ subcontiguo jaginam inferiorem abscondente. Stigma styli apice attenuato crassius, $\frac{3}{3}$ lin. longum, sulsangulatum, basi oblique nodulaso-inerassatum. Sequenti simillima, sed tam foliis quam floribus, præcipue stylo multo longiore, facile dignoscenda. (v. s. in herb. Shuttlew.)

24. D. Kippistrana (Meisn. in Hook. Journ. 1855, p. 122, in notà), ramis apice puberulis, foliis sessilibus bipollicaribus truncatis mucronulatis, lobis brevibus 
acutis subtus costato-venosis, capitulis, termainalibus axillaribusque subsessilibus, squamis pubescentibus lineari-subulatis flore dimidio hrevioribus interioribus apice plumosis exteriorihus plerisque. folio nano serrato ferminatis, calyce semipollicari basi glabro, unguibus laminisque șericeo-villosis, stỵlo subpollidari inferne pilosiusculo, stigmate clavato. ₹ In coloniâ Swan River (Drumm. coll. 4, M. 343!). D. foliolata Meisn. in pl. Prusss. 2, p. 266, excl. diagn., et in Hook. Journ. 1852 , p. 210 (non R. Br.). Rami graciles, laxiuscule foliasi, mox glabri, Folia pat, yla, satis rigida, scepius arcuata, ad basin usque æqualiter șerrata, lobis patentibus subrectilineis, margine antico $\frac{1}{2}$ vix 1 Tin., exteriore 1 - farius 2 lin. longo, facie inferiore demum sumper visibili, Capitula depıresso-globosa, diam. pollicari, floribus flavis? Stigma triplo longius yuam latum, $\frac{1}{2}$ lin. latum, obtusum, lave, basi obsoletissime nodulosum. Species, monente el. Kippist, a D. folíolalà $\mathrm{R}$. Br distinctá (fide spécim. in herb. Mus: Brit.), a jriecedentibus sequentibusque sive foliis sive floribus discrepans. (v.s. in-luerb. Shutıl.)

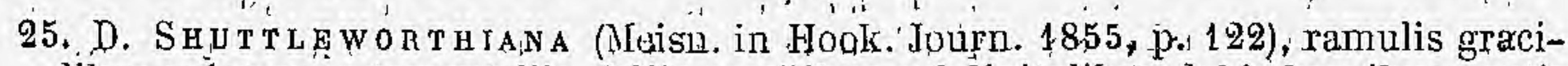
libus apice cano-tomentellis, foliis sessilibus subdigitalibus, lobis brevibus acutis subtus enerviis, eveniis, cajitulis lateralibus comgregatis subsessilibus, squamis ecuminatis interioribus llore sublongioribus plumosis, calyce subpollicari angustissimo stylum gequante supra basin glabram sublanato supua glaberrimo laminis ungue vix latioribus subulatis ultra antheram longe productis, stigmate subulato. $f$ In N.-Holl. occid. interiore, circa Dundagaran? (Drumm. coll. 6, n. 208! Hook. Journ. 1853 , p. 181, prima species?). Folia $1 \frac{1}{2}-4$ poll, plerumque $2-3$ poll. longa, truncata vel apiculata, caterum fere D. Kippistianse, sed lobi nervis venulisque destituti. Capitula circ. 12, valde approximata, vel immo contiguia, ramulos vix 3 lin, longos aphyllos dense imbricato-squamatos terminantia. Involucri squam:e numerosissimæ, e basi triangulari adpressâ paryâ longe acuminatæe, exteriorum acumine $8 \mathrm{~lm}$. longo śetaceo demum recurvo subdeciduo, interiorum póllicari anguste lineari acuto patentissimo. Stylus glaber, crassiusculus, sursum attenuatus, stigmate continuo concolori obtusiusćulo. (v. s. in herb. Shuttlew.)

26. D, scle R OPH y L a (Meisn. 1. c. p. 123), ramis glabris, folín subsessilibus rigidissimis bipoldicaribus, lobis acutis subtus plurinerviis obsolete reticulatis, capitulis terminalibus subsessilibus corymbosis. folits superatis, squamis exterioribus oblongis folio terminatis interioribus ovatis setaceo-acuminatis; calyce pollice-breviore stylum basi pilosiusculum æijuante angustissimo unguibus palulo-pilosulis, laminis lanceolatis sericeis glabrescentibus, stigmate conico-cylindrico. $う$ In N.-Holl. occid. interiore (Drumm, coł. 6, n. 209!). Rami virgati. Folia sparsa et axillaria fasciculata, dura, truncața cunr apiculo, basi attenuatâ brevi-seepe integra, 2- vel rarius 1 proll. Jonga, 3 lin. lata, lobis patentibus gequalibus reetis $1-1 \frac{1}{2}$ lin. longis basi $1 \frac{1}{2}-2$ lin. latis, margine fortiter revoluto. Capitula ramulos brevissimos corymbosos terminantia, globosa, magnit. juglandis. Involucri squamæe folio $1-1 \frac{1}{2}$. poll. longo pinnatifido terminata, intcrioribus basi ovatis rufo-tomentosis cum acumine setaceo 8-10 lin. longis. Calyx 9 lin. longus, unguium pube rufâ patulâ laminarum flavâ adpressì. Sty̧lus subulatus, incurvils, pallidus, stig:nafe $\frac{1}{2}$ lin. longo obsolete sulcato, basiçue subnotuloso fuscescente apice albido. Præcedentibus et D: serratuloidi affinis, sed foliis crassioribus rigidissimis floribusque bene distindta. ( $\mathrm{v}$. $\mathrm{s}$. in herb. Shuttlew.)

27. D. SQU.ARROSA (R. Brown suppl. p. 38), ramulis glabrik, foliis remotiusculis sessilibus patulis subbipollicaribus acutis, lobis brevibus acutis breve decurrenZibus, capitulis axillaribus terminalibuscjue pedunculatis folia involucrantia subæquantibus, squamis glabriuseulis subulato-linearịus aristato-acuminatis apice recurvis flore triplo-brevioribus, calyce semipollicari nnguibus sericeis, lamínis obtusis styloque: parum longiore glabris, stigmate clavalo. J Circa sinum Regis Georgii (Baxtèr, Drumm. coll.- 2, n. 342!). - Meisn. in pl. Preíss. 2, p. 266. Rami graciles, strictiusculi, rubro-fusci, sulcati, novelli puberulf. Folia ràmea jollicem distantia, $1 \frac{1}{2}-2 \frac{1}{2}$ poll. longa, ramulorum breviora magisque approximata; pleraque semicomplicata, omnia ad basin usiquo pinnatipartita, lobis adscendentibus 1-2 lin. longis, vix 1 lin. latis, attenuato-acutis breve decurrentibus sinubus 2-3 lin. latis. Podunculi 3-10 lin. longi apice folia capitulum inyolucrantia approximato-verticillata reliquis similia gerentcs, infra paucifolii vel aphylli, Capitula magnit. Centauree Cyani, dense multiflora, Iutea? Calyx ad basin usque adpresse 
flavo-sericeus, limbo oblongo glaberrimo. Stylưs 7-8 lin. longus, tẹuis, glaber, rectus, stigmate duplo crassiore $\frac{1}{3}$ lin. longo subangulato basi obsolete noduloso. (v. s.)

\section{Pectinato. - Folia circumscriptione lanceolata vel elongato- oblonga, ad costam usque pinnatipartita, lobis linearibus parallelis pluries longioribus quam latis.}

28. D. SERRATÚ L oIDES (Meisñ. in Hook. Journ. 1855, p. 123), ramulis gracilibus cano-tomentellis, folis breve petiolatis subbipollicaribus lobis attenuafo-acutis planis vel margine vix recurvis subtus ubsolete 1-nerviis scrobiculatis canotomenlosis, cipitulis lateralibus, squamis exteriori]Jus uvatis apice sericeis, interiuribưs majorilus subulaț-acuminatis mox glalıratis , calyce semipollicari, basi glalırú unguibus laminisçue albido-sericéis, stylo jollicari inferné pubescente, sligimate sulsulato. JIn N.-Holl, occid. interiore, círca flum. Moore (Drumm. coll, 6, n. 213! Hook. Jqurn. 1853, pi, 182 !). Caulis a basi ramosus denseque foliosus. Folia sparsa, modice rigida, vix jungentia, lanceolata, acuta, pleraquie $1 \frac{1}{2}$ poll. longa, 5-7 lin. lata, petiolo 3-7 lin. longo teretiusculo gracili, nervo supra immerso vel sulcifurmi extra medium cranido, lobis semipatentibus linearibus sulnuucronatis 3-4 lin. longis basi 1 lin. latis breve decurrentibus. sujpra evcniis glabris subtus obsolete reticulatis albidis, terminali proximis subæquali, sirubus 1-2 lin. latis. Capitula subsessilia, ramulos dense approximatos brevissimos apice foliosos terminantia , involucro glabro magnit. cerasi. Calycis jubescentia subadpressa, laminse lanceolatæ 2 lin. longec. Stylus tenuis, leviter incurvus, infra medium villosiusculus, stigmate atro $\frac{5}{4}$ lin. longo acutiusculo sulcato basi obsoleté incrassato. Species facile dignoscenda; foliorum formâ accedens ad D. armatam (efr. supra, n. 5), sed diversa consistentiâ tenuince, floribus, etc. Hzec a cl. Drummond (t. c.) ad Hemiclidiam referri videtur. Fructus nobis ignotus. (v. s. in herb. Shuttl.)'

29. De nana (Meisni. 1. c. p. 121), caule nano simplici apice denșe folioso mónoceplaalo, foliis petiolatís digitalibus lópis pungentiluus planis subtus 1-3-nerviis scrobiculatis tomentellis subconcoloribus, capitulo sessili, squamis calyce dimidio brevioriluus subulatis pilosis, calyce pollicari scmi-4-fido, tubo incano supra basin glabram densius tomentoso 4-gono, limpo diu clauso parce ferrugineo-puberulo, stylo bipollicuri recurvo inferne pilosiusculo, stipmate crasso uvato. I In N.-Holl. occid. circa Dundagaran (Drumm. coll. 6, n. 210 ! Hook. Journ. 1853! p. 181). Caulis liypogicus? adscendens, 1-5-pollicaris, indivisus. Folia rigida, crecta, 3,-5 poll. longa, 5-7 lin. lata, petiólo subpollicari gracili sultereti, nervo supra leviter sublus crasse prominente, lobis patentibus attenuato-acutis 3-4 lin. longis, $\frac{1}{-1}-1$ lin. latis rectis vel subfalcatis angustissime decurrentibus, margine, haud recurvó, sinubus 1-2 $\frac{1}{2}$ lin. latis. Calycis limbus ovalis, 2 lin. longus, obtusus, laminis lanceolatis. Stylus 26 lin. longus! amethysstinus, ultra medium rectus et pilosiusculus, supra attenuatus. glaber recurvus. Stigma fere 1 lin. longum, $\frac{1}{2}$ lin. crassum, obtusum, sulcatum, infra medium annulatum turbinatum. Species jam habilı et slylo proslongo distinctissima. (v. s. comm. ab am. Shuttlew.)

30. D. ARCTOTIDrs (R. Brown! suppl. p. 39), foliis caulem brevern æquantibus vel superantibus petiolatis; lobis pungentibus enerviis subtus niveis, margine incrassato recurvo, capitulo terminali sessili, squamis caljce dimidio brevioribus oblongis linearibusque glabriusculis ciliatis, calycis subsesquipollicaris basi tubulosâ glabrit, unguibiss laminisque harbatis dimidlo breviore, stylo bipollicari glabro, stigmate subsylindrico brevi. 5 In montibus, circa silum Regis Georgii (Baxter! Preiss, n. 515! 518! Drumm. coll. 5, n. 418!): - Bot. mag. t: 4035, Meisn. in pl. Preiss. 1, p. 596". Habitus D. nanæ, sed folia rigidiora, 4-6 poli. longa, juniorum lobis planis subtus obsolete 1-3-nerviis. Calycis basis tubulosa, 5-6 lin. longa, unguium barba albida, laminarum rufa. Stỵlus 20-24 lin. longus, tenuis, albus, stigmate atro vix crassiore $\frac{3}{2}$ lin: lengo subconico obtuso leviusculo. (v. s. in herb. Cunningh., etc., et v. v. in h. Ikew.)

31. D. T On T LFoLIA (Kippist! in Hook. Journ. 1855, j. 121), foliis caule cano squamoso apice ramosó longioribus jetiolatis, lobis muticis aversis tortisve subtus grosso 1 -nerviis scroliculatis tomentêllis, margine crassiusculo recurvo, capjitulo terminali sessili, squamis exterioribus foliaceis subulatisque, interioribus flore 
dimidio brevioribus lineari-oblongis ciliatis, calyce subsesquipollicari villoso, tubo semi-4-fido infra glabro, stylo bipollicari glabro, stigmate brevi conicocylindriço. ち In N.-Holl. occid. interiore (Drumm. coll. 6, n. 211!). Forsan mere var. D. aretotidis, attamen pluribus nolis satis discrepans, præcipue foliorum lobis inermibus semper plus minus tortis subtus subconcoloribus manifeste nervis 1-2 prominulis notatis scrobiculatisque, infimis fere subulatis 3 lin. distantibus. Stylus 24-26 lin. longus, 1-sulcus, stigmate obtuso basi oblique subinerassato. (v. s. in herb. Shuttl.)

32. D. FRASERI (R. Brown suppl. p. 39), foliis caule erecto ramoso glabro multa brevioríbus subsessilibus lobis subtereti-subulatis pungentibus sublus 1 -sulcis vel canaliculatis niveis, capitulis terminalibus lateralibusque, squamis linearisetaceis !lore dimidio brevioribus pubescentibus, calycis subpollicaris pilosiusculi basi tubulosậ brevi glabrâ, lạminis demum glabrescentibus stylo sesquipollicari glabro, stigmate longiứsculo cylindrico tenui obtuso. J In colonià Swan River (Fraser, Drumm. coll. 1, n. 642 ! Preiss, n. 517!).--Meisn. in pl. Preiss. 1; p. 596*. Frutex 2-3-pedalis, caule erecto vel adscendente gracili, ramis brevibus. Folia rigida, 2-4 poll. longa, rhachi $\stackrel{2}{=}$ lin. latâ subtus bisulcà, lobis 4-6 lin. longis, $\frac{4}{2}$ lin. latis, 3.5 lin. distantibus, sæepe tortis, plus minus patentibus, rectis vel sæepe recurvofalcatis, attenuato-acutissimis, marginibus revolutis subtus subcontiguis. Capitula dense multiflora, diam. 1-1 $\frac{1}{2}$ pollicari, foliis involucrantibus vix superata. Stylus adscendens, pallidus, stigmate haud crassiore $1-1 \frac{1}{2}$ lin. longo cinerascente obsolete sulcato. (v. s. et $r$. v. in h. Kew.)

33. D. GIBSIOIDES (Meisn. in Hook. Journ. 1852, p. 211), foliis sessilibus bipollicaribus acutis margine recurvis, lobis remotiusculis- patulis linearibus attenuatospinescentibus basi decurrente rhachin angustissime marginanlibus subtus canotomentosis 1 -nervits obsolete verulosis, capitulis axillaribus sessilibus, squamis incano-villosis exterioribus ovato-lanceolatis acuminatis, interioribus angusto linearibus sericeis fiores ææquantibus, calyce sericeo, laminis demum styloque gla-

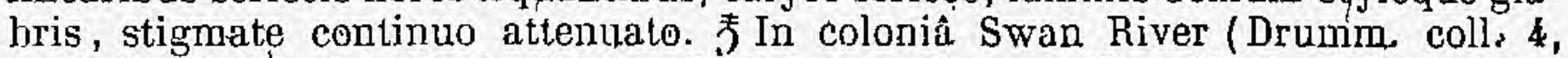
n. 308!). Rami virgati, densissime foliosi, ramulis novellis villosis. Folia erectopatula, rigidissima, ad basin usque laciniata, nervo supra imjresso ante apicem evanescente, lobis 2-5 lin. distantibus 4-6 lin. longis, 1 lin. latis rectis, sinubus subacutis. Capitula ovoidea, magnit. juglandis, foliis dense obvallata et subabscondita, squamis interioribus 9 lin. longis, vix 1 lin. latis, demum glabriusculis. Affinis D. seneciifoliæ et horridæ, ab illâ involưcro, ab hâc foliorum lobis rhachique latioribus, etc., distincta. (v. s. in herb. Shuttl.)

\section{$\S 6$. Decurrentes. - Falia linearia, plerumque elongata, pinnatifida, lobis plus minus remotis brevibus scaleno-triangularibus vel denti- formibus decurrenti-confluentibus.}

34. D. SENEGIIFOLIA (R. Brown suppl. p. 39), foliis subtus niveis infra medium integerrimis, lobis distantibus linearibus 1 -nerviis, terminali proximis longiore, involucri squamis interioribus subulatis patulis plumoso-villosis; calycis laminis jilosis. J In montibus, circa sinum Regis Georgii (Baxter).

35. D. hoRRIDA (Meisn. in Hook. Journ. 1852, p. 211), foliis erectis elongatis attanuato-petiolatis pinnatipartitis, rhachi anguste marginatâ lineari, lobis remotis patulis sinu brevioribus lineari-subulatis spinesceutibus enerviis subtus incanis, margine revoluto, capitulis lateralibus sessilibus, squamis linearibus barbatis, interioribus flores subxtyuantibus setaceo-acuminatis, calyce pollicari stylum glabrum iequante supra basin glabram dense lanato, unguibus glabriusculis, laminis glabris, stigmate continuo attcnuato. F In colonià Swan River (Drumm. coll. 4, n. 314 1). Rami virgati, densissime foliosi. Folia rigida, stricta, 3-6 poll. longa, attenuato-acutissima, rhachi $\frac{2}{5}-1$ lin. latî supra sulco lævi obtuso percursâ, lobis 4-7 lin. distantibus 2-3 lin. longis spinescentibus basi $\frac{7}{7}-1$ lin. latis supra convexis subtus canaliculatis sordide niveis, petiolo 1 -2 poll. longo angustissime marginato. Capitula ramulos brevissimos dense foliosos terminantia, squamis dorso glabrescentibus, interioribus demum recurvis. Calyx.12-14 lin. longus, laminis linearibus obtusis fere 3 lin. longis. Stylus' rectus, pallidus, stigmate tonui levi. Videtur D. seneciifoliæe proxime affinis, sed pluribus notis discrepat. (v.s. in herb. Shuttl,) 
36. D. concins a (R. Brown suppl. p. 38), foliis sessilibus utrinque attenuatis acutis lobis modice distantibus patentibus rectis basi latiusculis spinescentibus margine recurvis subtus incanis obsolete nervosis, capitulis axillaribus breve pedunculatis, involucro foliis obvallato tomentello flóribus multo breviore, squamis parvis exterioribus ovatis acutis interioribus Jongioribus angusti's obtusis, calyce stylum subpollicarem glabrum subiequante basi lanato, unguibus sericeo-puberulis, laminis glaberrimis, stigmate cylindrico tenui. 7 In montibus, circa sinum Regis Georgii (Baxter, Drumm. coll. 2, n. 341! 3, h. 295).-Meisn. in pl. Preiss. 2, p. 266. Habitus et inflorescentia D. carduacer. Rami graciles, glabri, apice minute puberuli. Folia 6-8 lin, distantia, patentia, rigidissima, 3-6 joll. longa, fere ad nervum usque inçisa, supra nitida evenia vel obsolete retículata, sinubus subrectangulis, lobis 5-9 lin. distantibus oppositis alternisque 2-3 lin. longis basi 1-2 lin. latis subæquilateris subtus sacpius distinete reticulatis, rhachi infra lobos lineari vel subcuneatả 1-1 $\frac{1}{2}$ lin. lata. Capitula ramulos axillares 3-5 lin. lóngos apice tantum foliigeros terminantia, pruni mole, involucro vix cerasi magnit., squamis carescentibus, interioribu's glabriusculis. Calyx aureus, imâ basi glaber, laminis lanceolatis. Stylus tenuis, rectus. Stigma pallidum, vix $\frac{1}{2}$ lin. longum, obtusum, subsulcatum, basi obsoletissime nodulosum. (v. s.)

37. D. vESTITA (Kippist $\mid$ in Hook. Journ. 1855, p. 121), ramis tomentosis undique squamis subulatis villosis dense tectis, foliis subverticillatis linearibus acutis inciso-serratis basi attenuatå integris margine revolutis subtus reticulatis canotonientosis, dentibus remotiusculis patul is brevibus scaleno-triangularibus acutis, capitulis ramulos breves terminantibus inter folia sessilibus, squamis linearisubulatis dense fimbriato-ciliatis interioribus flores subequantibus, calyce stylum glabrum subæquante inferre tomentoso, limbo 4-gono glabro, stigmate subulato. J In coloniâ Swan River (Drumm. coll. 5, suppl. n. 20!). Rami erecti, validi, tomento rufo demum canescente, squamis spiraliter curvatis. Folia in verticillos 1-2 pollices distantes congesta, 3-4 poll. longa, rigida, stricta, subtus dense prominuloreticulata, rhachi infra dentes $2-2 \frac{1}{2}$ lin. lata, lateribus fere. parallelis, dentibus 2-6 lin. distantibus plerumque oppositis patentissimis vel leviter arlscendentibus 1-2 lin. longis basi 1 lin. latis demum obtusiusculis, sinubus subrectangulis. Stigma acutiusculum, vix striatum. (v. s. fragm. comm. a cl. Kippist.)

38. D. HewA R DXNA (Meisn. in, Hook. Journ, 1852, p. 210), ramulis puberulis, foliis subsessilibus elongatis lineari-lanceolatis utrinque attenuatis supra eveniis subtus cano-tomentosis margine recurvo, rhachi infra lobos cuneatả, lobis remotis divaricatis subæquilatero-triangularibus brevibus spinescentibus sublus obsolete 1-nerviis, sinubus subobtusangulis, capilulis axillaribus sessilibus, involucro floribus duplo breviore, squamiș anguștis acutis, cxterioribus cano-tomentosis, calycis stylo pollicari glabro superati unguibus sericeo-villosis laminis glaberrimis, stigmate cylindrico tenui. J In coloniâ Swan River (Drumm. coll. 4, n. 315!). Proxime accedens ad D. concinnam, sed distincta foliorum lobis latioribus (siepe 3 lin. latis), longius (8-12 lin.) distantibus, subtus haud reticulatis, rhachi magis cuneatâ; involucri squamis interioribus attenuato-acutissimis, calycis basi haud lanatâ, sed pilis sericeis patulis similibus ac unguium paulo tantum longioribus vestitâ ; stylo 13-14 lin, longo calycem breviter superante, stigmate ipso vix crassiore con tinuo obtuso lævi. (v. s. in herb. Shuttl.)

39. D. LONG IF OLIA (R. Brown in Linn. trans. 10, p. 215 , prodr. p. 398), ramulis pubescentibus, foliis petiolatis longissime linearibus utrinque attenuatis profunde serrato-pinnatifidis margine recurvis subtus incano-tomentosis obsolete costatovenosis, lobis scaleno-triangularibus decurrentibus sinubusque acutis, capitulo terminali sessili, bracteis elongato-linearibus acuminatis flores subrequantibus ciliatis dorso glabratis, calyce stylum glabrum æequante subsesquipollicari supra basin glabram lanato, unguibus pilosinsculis laminis parce setulosis demum glabris, stignhate attenuato. $F$ In terrâ Leeuwin (R.' Br.), circa sinum Regis Georgii (A. Cunningh. .). - Wendl. fil. in Bot. Zeit. 1819, p. 137, * Bot. mag. t. 1582. Folia conferta, 6-18 poll. longa, supra evenia, nervo inmpresso, rhachi inter lobos cuneatâ 1-2 lin. latâ, lobis 3-10 lin. distantibus plus minus adscendentibus rectis 2-4 lin. longis basi $1 \frac{1}{2}-2$ lin. latis, passin et præsertim stirpis junioris magis approximatis 2-3 lin. latis sinu angusto acuto separatis. Capitulum globosum, diam. 1-1 $\frac{1}{2}$-pollicari. Stigma continuum, leve, basi obsolete nodulosum. (v. s. et v. c. in h. Kew, et Glasgow.) 
40. D. cou os A (Meisn. in Hook. Journ. 1852, p. 211), ramis glabris, foliị subsessi-

libus longissimis anguste linearibus aculis remote pinnatifidis basi integris supra convexỉs nervo sulciformi, margine recurvis, subtus niveis venosis, lobis brievibus lineari-subulatis recurvo-falcatis, capitulis axillaribus subsessilibus, squamis flóres cequantibus glabris exferioribus ovato-oblongis aristato-acuminatis, interioribus longioribus lanceolatis acutis ciliatis, calyce supra basin glabram lanato, unguibus puberulis, laminìs sericeis, stylo subpollicarì basi lanato, stígmate cylindrico. ₹In coloniấ Swan River (Drumm, coll. 4 , n. 313!). Folia confertiśsima, rigida, sepe pedalia, ultra medium vel passim ad basin usque pinratífida, rhachi 1 lin. latâ infra lobos lineari lateribus parallelis, l'obis patentibus 5-10 lin. distantibus decurrentibus. Capitula ovato-globosa, squamis interioribus muticis. Calyx 10 lin. longus, lanâ supra hasih brevi fulvà, laminarum pube adpressâ. Stylus rectus, tenuis, stigmate 1 lin: Iongo subsulcato basi noduloso. Folia p. horridæ similia, sed multo majora et capitula omnino diversa. (v. s. comm. ab am. Shuttlew.).

41. D. PR отеоIDEs (Lindl. Swan Rir. p. 33, n. 159), ranuis glabris, foliis subsessilibus strictis longis anguste linearibus acutis remote pinnatifidis margine récurvis subtus 'cano-tonentosis subreticulatis, lobis patentibus brevibus triangularibus spinescentibus, sinubus rectangulis, capitulis axillaribus; squamis sericeis glaljrescentibus ciliatis, exterioribus ovatis muticis, interioribus. longioribus angustioribusque obtusis flores'superantibus, stylo bipollicari calyceque subấequillongo glabris, stigmate elongato tenui. 5 In coloniâ Swan River (Driurmim coll. '1 Preiss, n. 503!): - Meisn. in pl'. Preiss. 1, p. 598*. Frutex 4 -pedalis. Fơlia 6-8 poll. Iónga, rigidissima, fere ad hasin usque spinoso-ser'rata, rhachi $1 \frac{1}{2}-2$ lin. latấ, màrginibus subparallclis, nervo supra sulciformi, lobis 5-6 lin. distantibus $1-1 \frac{4}{2}$ lin." longis decurrenti-confluentibus rectis vel subrecurvis supra eveniis. Capitula pedunculo vel potius ramulo brevissimo aplyyllo suffulta, involncro ovato, pomi mole, demum patente, squamis adpresse imbricrtis sericeo-tomentosis glabrescentibus, exterioribus acutis, jnterioribus sxepe longioribus usqué arl $2 \frac{1}{2}$ poll. longis. Galyx usque ad basin vix puberulam 4-partitus, laminis linearibus 4 lin. longiș" antheram longe superantiluis. Stigma 3 lin. longum, continuum, sulcatum; obtusiusculum. (v:'s.)

42. D. TENUIFOLIA (R. Brown in Linn. trans. 10, p. 215, prodr. p. 398), ramis glabris, foliis sparsis laxe patulis petiolatis longe, angusteque linearibus subtruncatis remotiuscule serrato-pinnatifidis margine recurvis"subtus̀ hiveis, dentibus patulis brevibusl decurrentibus enerviis subrecurvis, sinubtis acutis, capitulis axillaribus, squamis muticis sericeis demum glabrafis cilialis, exferioribus ovatis actis, interioribus flores 'ecuantibus líneari-oblongis óblusis, cal jce stylum polli-

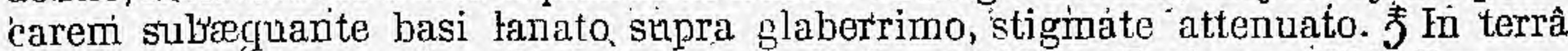
Leeuwin (R.' Br., A. Cunnịgh.!) et coloniâ Swan River (Preiss, n. 505! Drumm. coll: 3, n.294! 5, n. 417!). - Wendl. fil. in Bot. Zeit. 1819, p. 137 * Meișn.'in "pl. Preiss. 1, p. $597^{*}$, Bot. mag. t. 3513 . D. uncata A. Cunn!! mss. in herb. DC. Folia confertissima, curvata vel flexuosa, núnquam stricta, 4-8 poll. 'longa, extra' 'merlium (raro ad basin usque) sertata, 'petiolo filiformi, rhachi inter lobos cuneatâ, 1-1 $\frac{1}{2}$ lin. latć, dentỉous $3-6$ lin. distantibus vix 1 lim. longis obtusis acutísve, stirpis juvenilis magis approximatis vel contiguis $2-3$ lin. longis, 1-2 lin. latis supra obsolete reticalatis. Involucrum ovatum magnit prtzni. Calyx basi rufo-lanatus, laminis angustissimis fere 3 lin. longis unguibusque glabris. St.jlus imâ basi pilosiusculus,'stigthate continuo $2 \frac{1}{2}$ lin. longo sulcato. (v. s. et v. v. c. in h. Kew.)

43. D. FER RUGINEA (Kippist! in Hook. Journ. 1855, p. 123), caule abbreviato, ramulis dense imlinricato-squamatis junioribus tomentosis, foliis subpedalibus angusto lińearibus acutis extra medium-remote pinnatifidis margine revolutis subtus ferrugineo-tomentosis, lobis brevibus jatulis trianguláribus acntís subenerviis, capitulis terminalibus subsessilibus, squamis glabriu'sculiss; exterioribus ovatis ciliatis, interioribus flores' subsuperantibus linearibus obtusis apice fulvotomentosis, calyce stylum bipbllicarem subaciuante, unguibus basi dense ciliatis, laminits glaberrimis, stigmate cyliudrico. J In colonià Swan River (Drumm. coll. 5, h. $416 !)$. D. proteoidi et tenuifoliæ arcte quidem allinis, sed caule brevi, foliis longioribus, calyce, etc., salis distincta. Folia margine fortiter recurvo suljtus quasi canaliculata, lobis 4-6 lin. distantibus scalenis $1-1 \frac{1}{3}$ lin. longis latisque subtus interdum obsélete 1 -nervíis, rhachi inter lobos lineari 1 lín. latâ laterihus parallelis. Involucrum ovatum, magnim, squánín exterioribus acutiusculis al bo- 
ciliatis, intimis 2-3 poll. longis. Calycis ungues supra glabri, laminæ longe lineares. Stylus 'calycem! paluló superans, basi parce pubescens, stigmate sulcato. Fólliculi numerosi, oblique oboviati, compressissimi, tenuiter radiato-striali, demum glabri' nitidi, (v: s. fragm. comm. a cl.'Kippist.)

44. D. CRY P T OGE PHALA (Meisn. in pl. Preiss. 1, p. $596^{*}, 2$ p. 267), ramis canovillosis, "foliis fasciculatis sparsisque arcuato-deflexis linearibus acutis extra medium 'renkotiuscule pinnatifidis margine recurvis subtus niveis, lobis linearibus pungentïbus enervíis, sinubus acutis, rhachì angustissimâ, capítulis lateralibus parvis, squamis flores superantibus subulatis, exterioribus longioribus pinnatim spinulosis, calyce semipollicári stylum glabrum sủbæquante supra basin glabram lanato, lacinits, pilosiusculis, laminis demum glabratis, sligmate attenuato. F Cirica sinum Regis Georgii (Preiss, n: 514 ! Drumm coll. 3, n. 297! 4, n. 316!). Frutex̃ 21-pedalis, strietus, foliis undique densissime tectus et absconditus. Folia nonnisi summa erecta, reliqua deflexa, rigida, 2-3 poll. longa, laciniis utrinsécus 3-5 semipatentibus intervallo $3-4$ lin. longo separatis, 1-2 lin. longis rectis vel subfalcatìs rhachique $\frac{1}{2}$-raro 1 lin. latis supra sub lente punctato-scabriusculis. Capitula vix cerasi magnitudine, foliis dense obvallata et subabscondita. Species hahitu peculiari insignîs, fóliis D. tenuifolix el séneciifoliæ accedens, cæterum vero distinctíssima. (v. s.)

§ 7. Acrodontce. - Folia lanceolato-linearia extra medium 3-5-dentata passimgue integerrima basi attenuata. Capitula terminalia sessilia, foliis obvallata et superata.

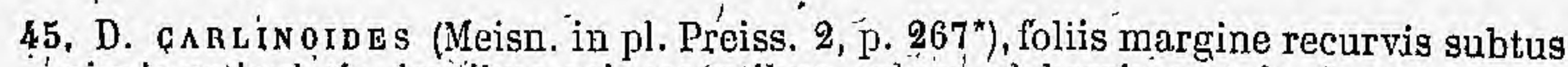
niveis reticulatís dentijus spinescentibus, calyce glaberrimo stylo demum superato, stigmaté cylindrico. J In coloniâ 'Swap River (Drumm. coll. 2, n. 3451). Frutex erectus, ramulis subcorymbosis cano-tomentellis. Folia $1-1 \frac{1}{2}$ poll. longa, alia extra médium 2-3 lin. lata et dentibus 2-3 vel raro 4 armata, dentibus lateralibus patentibus 1 lin. longis latisque terminali multo majore; alia 'integerrima 1-2 lin.' láta utrinque attenuata. Capitula magnit. juglandis mediocris, squamis exterioribus folifformibus, interioribus brevioribus subulatis setaceo-acuminatis plumosociliatis apice glabratis: Calyx 7.8 lin'. Iongus. (v. s.)

46. D. TRIDENTAtA (Meisn. in Hooli. Journ̈. 1855, p. 120), foliis planis submarginditis subtus reticulatis subconcoloribus tomentellis, calyce pubescente, laminis sericco-villosiusoulis, stylo exserlo sigmoideo, stigmote cylindraeeo. J In N.-Holl. öcciḍ. cirça Dundàgaran (Drımḿn. coll. 6, n. 207, Hook. Journ. 1853; p. 181). Caulis subterraneus repens (Drummi), ramis epigeis suhpedalibus gracilibus plerumque indivisis, junioribus puberulis. Folia sparsa, rigida, subsessilia, 1-2 poll. longa, apicem versus 2-3 lini. lata, cuneato-linearia, supra nitida evenia vel obsoletissime reticulata, margine plano vel levissime recurvo, dehtibus mucronulato-acutis vel demum obtusis vel passim nullis, lateralibus vix 1 lin. longis, terminali multo majore. Capitula ramulos laterales circ. pollicares terminantia, magnit. pruni, foliis obvallantibus basi paulo dilatatis, sq̣uamis e basi lanceolatâ tomentellâ setaceo-subulatis flores subpquantibus patulo-pilosiusculis, intimis hrevioribus.' Calyx flavus;' subpolliearis, pube brevi patúlâ fulvâ in anguibus rariơre minutấ, in laminis densiore et longiorc tectus, laminis lanceolatis fere 2 lin. Iongis dí cohæzrentibus. Stylus 15 lin. long'ús, sübulatus','glaber, arcuato-adscendens, apice leviter recurvus, stigmate concolore continuo $\frac{\hbar}{\mathrm{T}}$ lin. lougo obtusiusculo haud incrassato subsulcato. Species foliis D. carlinoịdi proxima, flore vero distinctissima. (v. s. in herb. Shuttl.)

\section{§ 8. Haplophylloe. - Folia ómnia integerrima.}

47. D. SPECros A (Meisn. in Hook. Journ. 1852, p. 211), foliis subulato-linearibus mucronatis margine arcte revolutís subtus juxta nervum lineâ niveà striatis. capitulis terminalibus nutantibus, squamis lineari-subulatís ciliatis, interioribus flores superaitibus, calyce pallicari supra basin glabram lanato supra styloque incluso glabro, stigmate continuo sụbulato obtuso. F In coloniậ Swan River (Drumm. coll. 5, suppl. n. 19!). Rami graciles; densiuscule foliosi, ramulis incdno-tomentosis, Folia breve petiolata, rigida, recta; 2-4 poll. longa, vix 1 lih. lata, basi attenuata, supra convexa glabra nitida nervo impresso obtuse sulciformi, subtus sub- 
plana lineâ tenui niveo-tomentosâ inter marginem viridem et nervum fultum decurrente. Capitula brevissime peduneulata, ovata, magnit. pryni, involucro demum semipatente, squamis numerosissimis plumoso-ciliatis rectis adpressis vel infimis demum patulis recurvisve, intimis circ. $1 \frac{1}{2}$ poll. Iongis basi $\frac{1}{2}-1$ lin. latis, exterioribus sensim brevioribus, ciliis densis fere 1 lin. longis fulvis. Calyx supra basin albo-villosus, laminis anguste linearibus obtusiusculis. Stylus 'calycem æquans, glaber, stigmate haud crassiore subsulcato. (v, s. comm. a b. Lemänn.)

\section{Sectio II. Diplophragma - R. Brown suppl. p. 37.}

Folliculus bilocularis, dissepimento spurio e seminum testis connatis formato plano membranaceo ad basin usque in lamellas 2 facile sèparabili quibus semina conformia apice alata alâ persistente extus adplicata. - Fruticuli humiles, caule ramisque brevihus, foliis elongatis pinnatipartitis bipinnatifidisque, capitulis terminalibus subsessilibus majusculis.

48. D. BipinNatif IDA (R. Brown suppl. p. 39), caule decumbente tomentóso, ramis adscendentibus squamatis, foliorum laciniis linearibus mucronulatis margine revolutís supra pilosiusculis subtus tomentosis 1 -nerviis, superioribus pinnatifidis inferioribus indivisis, capitulo ovato-oblongo, squamis tomentosis, exterioribus ovatis acutis, interioribus longioribus, intimis flores superantibus lineari-oblongis obtusis, calyce stylum glabrum æequante, unguibus inferne villosis, laminis glabris, stigmate obsoleto acutiusculo. I In montibus coloniæ Swan River (Fraser, Drumm. coll. 1, n. 644 ! Preiss, n. 522 !). - Meisn. in pl. Preiss.1, p. $599^{*}$. Folia 6-12 poll. longa, circumseriptione spathulato-oblonga, supra punctato-scabriuscula, segmentis ad nervum usque separatis patentibus parallelis 1-3 lin. ab invicem distantibus vix decurrentibus rectis vel arcuatis $1-1 \frac{1}{2}$ lin. latis superioribus 1-2 poll. longis pinnatim 3-7-fidis, inferioribus decrescentibus plerumque inlegerrimis, infimis 3 lin. longis. Involucrum magnit. ovi gallinacei, basi demum glabrescens. Calyx 20 lin. longus, basi tubulosâ glabrâ, laminis anguste linearibus 3 lin. longis. Stylus apice attenuatus sulcatus fuseescens, stigmate continuo sulcato-subconico. (v. s.)

49. D. Preissi ( (Meisn. in pl. Preiss. 1, p. $599^{\star}$ ), caule glabro esquamato, foliorum laciniis supra glabris subtus tomentosis 1 -nerviis linearibus acutis margine recurvis, superioribus pinnatifidis, inferioribus indivisis, capitulo subgloboso, squamis linearibus, exterioribus basi dilatatâ pưbescentibus superne glabris, interioribus triplo longioribus flores subæquantibus glabris apice setaceo-acuminato infus barbatis, calyce stylum basi pilosiusculum subæquante, unguibus laminisque villosis, stigmate minuto subcapitato. J Circa flum. Gordon, distr. Hay (Preiss, n. 528! Drumm. coll. 2, n. 301!), Præter notas jam indicatas a simillimâ uræcedente differt foliis brevioribus, lævibus, raro ultira 6 poll. longis, passim simpliciter pinnatis, margine minus recurvo, capitulo minore, stylo exșulco. $(v, s$.

\section{Sectio ni.' Aphragma $R$. Broun suppl. p. 37.}

Folliculus 1-locılaris. Semina leviter cohærentia, apice alata, alâ persistente arachnoideâ flexuoso-fibrosâ extus aucta, membrauâ crustaceâ conformi solubili fibris longitúdinalibus et transwersalibus contextâ. Caulis abbreviatus. Folia elongata, circumscriptione oblonga, ad nervum usque pinnatipartita, laciniis integerrimis subtus tomentosis glabrisve plurinerviis. Capitula terminalia sessilia globosa.

50. D. PTERIDIFoliA (R. Brown in Linn. trans. 10, p. 215, prodr. p. 399), foliis caule abbreviato tomentoso longioribus subtruncatis supra denum glabris eveniis subtus tomentosis, lobis patentissimis linearibus attenuato-acutis basi dilatatâ confluentibus margine planis vel revolutis subtus 1 - vël 3 -nerviis reticulatis sinubus rotundatis, involucro floribus dimidio breviorc, squamis ovatis obtusis velutinotomentosis, calyce sesquipollicari stylum subequante supra basin glabram stup. poso-lanato, unguibus puberulis, laminis sericeis, stigmate cylinadraceo. $\zeta$ In terrâ Leeuwin (R. Br., A. Cunn.l Drumm. coll. 1!). -- Bot. mag.' t. 3500. Fruticulus humilis, sape subacaulis. Folia pedalia et ultra, juniora tomentosa sepiusque simul hispida, lobis $1-1 \frac{1}{3}$ poll. longis, $1 \frac{1}{2}-3$ lin. latis, supra planis vel convexis enerviis, subtus incanis vel ferrugineis sinubus lobos subæquantibus vel plerumque multo latioribus, rhachi sublus tereti. Capitulum diametro 1-2-pollicari. Calycis lamiræ elongato-lineares obtusæ. Stylus validus, sılcatus, basi pilosiusculus, 
stigmate fere 2 lin. longo angulato basi obsolete noduloso. ( $\nabla$. s. et v. v. c. in h. Kew.)

ß. blechnifolia (R. Brown suppl. p. 38, in notâ), foliorum làciniis obtusis mucronulatis margine recurvis basi haud dilatatis. $\bar{J}$ Circa sinum Regis Georgii (Menzies, Drumm. coll. 5, n.423! in herb. Lemann.). D. blechnifolia R. Brown in Linn. Trans. 10, p. 215 , jirodr. p. 399. (v.s.)

51. D. CALOPHYLLA (R. Brown suppl. p. 40), caule abbreviato, ramis floriferis prostratis folio brevioribus infra squamatis apice foliatis, foliis pinnatifidis lobis semiovato-lanccolatis divaricatis parallele nervosís plerisque sinu acutangulo latioribus, involucri squamis lineari-lanceolatis tomentosis, calycis laminis villosis apice penicillatis. 5 In montibus, circa sinum Regis Georgii (Baster! Drumm. coll.4, a. 319!). (v. s. in herb. Cunningh. el Lemann.)

$\beta$. acaulis (Meisn. in Hook. Journ. 1852, p. 211), caulc brevissimo, foliis longis ad nervum usque pinnatipartitis, loblis patentibus sinu acutiusculo plerumque multo latioribus oblongis acutis muticis planis basi vix dilatatis subtus incanis parallele 3-5-nerviis obsolete reticulatis, involucri squamis lanatotomentosis acuminatis flore dimidio brevioribus, calyce stylum bipollicarem æquante unguibus stajposo-lanatis, laminis adpresse sericeis apice breve penicillatis. - In coloniâ Swan River (Drunnm. coll. 2, n. 300!). Radix fusiformis. Caulis simplicissimus, vix pollicaris. Folia erecta; petiolata, 1-1 $\frac{1}{2}$-pedalia, basi attenuata, juniora utrinque puberula, rlachi sulstus dense rufolanatâ vel hirsutâ demum glabratâ, lobis 1 poll. longis, 5-9 lin. Iatis, supra enerviis glabris. Capitulum magnit. D. pteridifoliæ. siylus validus, glaberrimus, stigmate haud crassiore $2 \frac{1}{2}$ lin. longo sulcato basi obsoletc noduloso. (v. s. in herb. Shuttl.)

52. D. Nervosa (R. Brown in Sweet (1. Austral. t. 22, prodr. suppl. p. 39), foliis caule tomentoso longioribus subtruncalis, lobis patentibus linearibus oblongisque mucronatis basi dilatatâ subconfluentibus margine recurvis subtus 1-plurinerviis tonrentosis, sinubus latis obtusis, involucro floribus dimidio breviore tomentoso, squamis exterioribus ovatis, interioribus longioribus angustioribus muticis, calyce pollicari stylum glabrum xquante supra basin glabram lanato-tomentoso superne sericeo, laminis apice penicillato-barbatis, stigmate attenuato. $\stackrel{f}{\jmath}$ In orà australi, inter Cape Pasley et Cape Arid (Baxter), circa sinum Regis Georgii (Preiss, n. 512! Drumm. coll. 4, n. 320! 5, 11. 423, in herb. Shultl.).-Weisn. in pl. Preiss. 1, p. $600^{*}$, Bot. mag. t. 3053. Frutex erectus, humilis (R. Br.), repens (Preiss), habitu, caule, tomento D. bipiunatifidæ. Folia 6-18 poll. longa, subsessilia, lobis eirc. 1 poll. distantibus oppositis alternisque, 10-18 lin. longis, 2-3 lin. latis (stirpis junioris latioribus), supra glabris subtus fulvo-canescentibus vel ferrugincis nune. 1- nunc parallele 3-5-nerviis, venulis nullis vel obsoletis, margine anguste recurvo, nervis supra obsoletis vel nullis. Involucrum velutinum atrofuscum vel fulvoalbidum. Calycis laminæ 3 lin. longæ, angustissimæ, antheram longe superantes, aristâ brevissimâ mucronatı vel mutiçe. Stylus subexsulcus, pallidus, stigmate fusco tereti obtuso basi vix incrassato. Folliculi obovato-suborbiculares, basi cuneati, 6 lin. longi, tenuiter flabellato-sulcati, rufo-lanati vel glabrati, margine compresso obtuso. (v. s. el v. v. c. in h. kew.)

53. D. DRum ondi (Meisn. in pl. Prciss. 2, p. 267"), foliis caule brevi longioribus planis, lobis divaricatis triangulari-oblongis pungenti-acutis sinus acutos subæequantibus inferioribus decurrentibus subtus convergenti-3-5-nerviis tenuiler reticulatis tomentosis demum glabratis, involucri squamis linearibus villosissimis, calyce..... 5 In coloniá Swan River (Drumm. coll. 3, n. 2991 et? 5, n. 418, 419). A D. nervosâ facile distinguenda foliis subtus reticulatis margine haud rerolutis, involucro, etc. (v. s.)

XLV. HEMICLIDIA R. Brown suppl.prodr. $l$. Nov.-Holl.p. 40, Endl. gen.p. 3k3, n. 2159 , Meisn. gen. p. 333 (246). - Dryandrac sp. R. Brown olim.

Flores hermaphroditi, regulares, capitati. Calyx 4 -fidus, Jaminis concavis antheriferis. Squamul:a 4 hypogynæ. Ovarium 1-loculare, 2-ovulatum, ovulis 2 collateralibus testâ invicem cohærentibus in dissepimentum arachnoideum simplex (nec in lamellas a separabile) cum ovulo abortiente basi alato ab 
ovulo altero maturesceñte solutuın. Folliculus 1 -sperimus, šubcrústacéus, undique barbatus, hinc apice dehisceus, inde rumpens. Semen ventricosum, apterum. - Frutex Novæ-Hollandiæ austro-occidentalis, habitti omnino Dryandræ, foliis subtus tantum stomatiferis, involucro imbricato, receptaculo plano.

H. BAXTERI (R. Brown 1. c.), ramis pubescentibus, folijs cuneato-oblongis incisopinnatifidis supra eveniis glabris subtus costatis reticulatis venis glabrescentibus laeunis cano-tomentosis, lobis lanceolatis spinescentibust decurrentibus terminali abbreviato, enpitulo terminali sessili foliis obvallato, calyce stylum æquante supra basin glabram stupposo-tomentoso, unguibus sericeo-puberulis, laminis glabris, stigmate subfusiformi obtuso. F In terrầ Leeuwin (R. Br.), circa Cape Riche (Preiss, n. 527! Drumm. coll. 4, n. 321i). - Bot. reg. t. 1455, Meisn. in pl. Preiss. 1, p. 601. Dryandra falcata R. Brown in Linn. Trans. 10, p. 213, prodr. p. 397. Frutex 5-pedalis, facie omnino I)ryandro armatso (cfr. supra, n, 4), sed folia latiora, 1-1 $\frac{1}{2}$ poll. lata, minus profunde incisa, sinubus subacutis, lobis magis patentibus subreeurvo-falcatis longe mucronatis, terminali proximis breviore; involucri squame interiores subulato-acuminate; calyx gracillimus, laminis oblongis obtusis; stylus $1 \frac{1}{2}$ poll. longus, terıuis, glaber, stigmate vix crassiore $\frac{2}{5}$ lin. longo exsulco basi obsolete noduloso. (v. s.)

\section{Genus dubice affinitatis.}

CYLINDRIA Lour. fl. Coch. ed. Willd.1, p. 86, R. Browi in Trans. Soc. linn. 10, p. 224, Endl. gen. p. 343, Meisn. gen. 2, p. 243.

Calyx (involucrum?) inferus, persistens, tubulosus, brevis, 4-fidus, lobis patentibus coloratis acutis. Corolla (calyx?) tuberculosa, 4-fida, laciniis lineàribus acutis carnosis in tubum cylindraceum conjunctim protensis apice cucullatis. Stamina 4; antheræ subsessiles, cucullis lacinarum inclusæ, subrotundæ, compressæ, 2-loculares. Ovarium ovatum; stylo brevissimo, stigmate 4-fido. Bacca exsucca, parva, subrotunda, 1-sperma (nigra). Semen globosum, lanuginosum. - Arbor Cochinchinensis, folijs oppositis siniplicibus laniceolatis subserratis glabris, pedunculo subterminali multifloro. - Genus valde obscurum, fide Koenig (Ann. of bot. 1, p. 392), vix ab Oleá distinctum; sed specim. ab eo examinata, etsi ab ipso Lour. missa, forsan ab is in tl. Coch. descriptis diversa erant, obs. cel. Brown l. c.

G. RUBR A (Lour. l. c.). 5 In Cochinchinâ. 


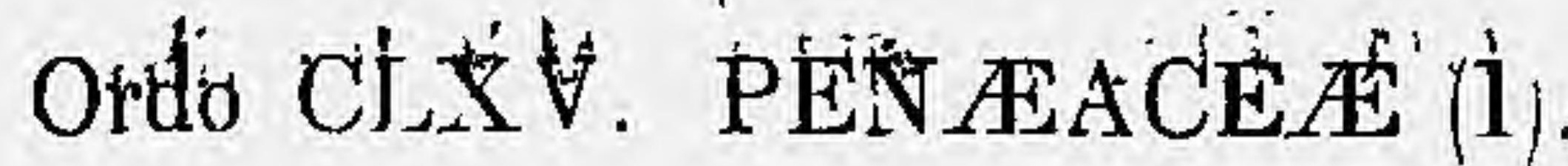

Genera inc. sedis Jušs. ğen. (1789), p. 419. - Penæaceæ $R$ : Brdwn (1820) verbatim; ex Linidl: introd. ed. 1, p. 71, Sweet hort. Brit. (1827), p. 488, Guillem. dict. class. (1828); v. 13, p. 171 (omnes sine descr.). - Dicotyl. inc. sedis Bartl. bíd. (1830), pj. 428. - Pénæaceæ DC. insc. ante 1830.Penæacề Kunth in Linn. 1830, p. 476 (excl. Geissoloma), Lindl. introd. to bot. (1830), p. 71 (excl. eod. gen.), Endl. ench. (1841), p. 213 (excl. Geissolomeis), Adr. de Juss: Ann: sc. nal. sér. $3 ; v, 6, p .15, t .1-3$ (excl. Geissoloma), Endl. gen suppl. 4, p. 72 (excl. eod.gen.), Lindl. veg. kingd. ed. 2, pi: 577 (excl. eod.)

Calyx (aut si mavis perigonium) coloratus, persistens, accrescens, 4-lobus; tubo cylindraceo; lobis æstivatione valvari aut reduplicato-valvari, 2 bracteæ exteriori et axi inflor. oppositis, 2 laterálibus. Petala 0. Stamina 4, fauci calycis inserta, ejus lobis alterna; filamentis plerumque brevissimis; connectivo sapius pingui; lo culis 2, introrsum connectivo adnatis, eo sæpe brevioribus. Pollen ovoideo-sphæricum, 6-8-sulcum (ex Mohl in A. Juss. cit.). Ovariuın Jiberum, 4-loculare, loculis lobis calycis oppositis, columnâ centrali nullâ. Ovula anatropa, in quovis lóculo 2 a basi erecta, vel 4 in mediâ parte afigulı interno inserta, 2 erectá, 2 pendentia. Sívlus teres vel angulis 4 cum loculis alternantibus. Stigma 4 -lobum aut stigmata 4 , lobis vel stigmatibus cuin loculis alternantibus (2). Capsula loculicida, valvis e basi styli in 4 ruptâ acuminatis. Semina ovulis abortu manifesto pauciora, pro situ ovulorum erecla vel rarius pendentia, oblong'a; testâ nitidâ, nunc minute purıctulatâ; endoplevrâ membranaceâ; hilo basi excdvato; funiculo brevissimo tumido albo; raphe hinc inter testam ét endoplevram filiformi extrorsâ fácile sểgrè̉gatâ. Albumen 0. Embryo carnosus, conico-ovoideus; radiculà extremitate versus hilum obtusıssimâ imo concavâ; cotyledonibus 2 minimis, ex rimâ solum perspicuis. - Frutices vel suffrutices capłenses; sempervirentes, foliis oppositis, sæpe imbricatis, integris, pënninerviis, planis vel rarius ericoideis; stipulis? minutissimis; glanduliat muctoniformibus, vel sæpius setis axillaribus stipulas minimimas simulantibus; floribus solitariis in axillis foliorum superiorum, id est bractearum foliis nunc similium, nunc formâ vel colore diveêrsarum; bracteolis per paria dispositis ; floribus subseśsilibus, plerumque approximatis, sapius cum bracteis et bracteolis rubentibus, nunc flavis. Habitus Epacridearum Ericacearumque.

(1) Auctore Alph. de Candolle.

(2) Gharacter in tribu 2 obscarus, forsan diversus. 


\section{Tribus I. PENEAE.}

\section{Ovula in basi cujusque loculi gemina erecta. - Bracteolæ duæ aut nullæ?}

I. PEN王A Linn. hort. Gliff. p: 37, gen. $n .138$, Juss. gen. p. 419, Gartn. f. fr. 3,p. 243 , t. 225, f. 2, Kunth in Linn. 5, p. 676 (excl. sp.), Adr. Juss. in Ann. sc. nat. sér. .3, v. 6, p. 22, t. 1, f. 1 (non Penaa Plum. qua Polygala, nec Penaa Lour. mihi ign.). - Penæea sect. Eupenæa Endl. gen. suppl. 4, n. 73.

Calycis tubus vix limbo longior, bracteâ subæqualis, præfloratione valvatâ. Filamenta brevissima; antheræ loculi connectivo crasso multo breviores, bivalves, margine valvarum timbrillis crebris ciliato. Ovarium læve, loculis basi biovulatis. Stigmata 4 , complanata, cruciata, singulo secus stylum inde tetrapterum in vittam membranaceam loculis alternam decurrente. Capsula calyce aucto persistente tecta, 4-locularis, loculide 4-valvis. Semina erecla. - Suffrutices capenses, ramosi; foliis planis, jntegris, summis in bracteas latiores abbreviatas persistentes coloratas subito transeuntibus; setulis interdum axillaribus; bracteolis minimis, binis; floribus in axillis superioribus solitariis, approximatis, coloratis.

1. P. mu GR ONA t a (Linn. sp. ed. 2, p. 162), foliis inferioribus ovato-acutis caducis, mediis e basi latâ subcordatà ovato-acuminatis, 'supremis subito in bracteas latiores breviores cordato-cuspidatas transeuntibus, bracteolis linearibus bractea multo hrevioribus, tubo calycis florentis bractean vix superante. 5 Ad caput Bonæ-Spej, in parte occid. (omnes auct.) et prope Port-Natal (Guenzius! IV, 185).- - Burm.? in herb. DG., Meerb. ic. t. 51, f. 2 (ic. undique pessima), Vent. Malm. t. 87 (ubi fig. 3, 4. erroneæ), Lodd. Bot. cab. t. 1770, Sieb.! n. 60, Drège! jl. exs., Zeyh.! 3726 et 3727, in h. Boiss., Krauss ! ibid., Kolbing ! 35, ibid., in h. Vindob., Ecklon l,622, in h.Vind., Adr. Juss. in Ann. sc. nat. sér. 3, v. 6, p. 22, t.1, f.1 (anal. accuratiss.). P. fucata herb. Boivin! in herb. Boiss. et in meo, sub numero 557. P. imbricata Eckl.I n. 623, in h. Vind., non Grah. Rami inferne, sæpius defoliati, foliis ubi adsunt non crebris, parum erectis, 3-6 lin. longis, 2-3 lin. latis. Ramuli subvelutini, foliis erecto-inflexis crebris, 3 lin. longis, $2 \frac{1}{2}$ latis. Bractex anilloræ, coloratæ, concavæ, latitudine folio submajores, sed breviores, quasi auriculata. Flores 3 lin. longi. Ex Vent. flores et luractere llavæ, ex Lodd. flores flavi et bracteæ purpurascentes, ex specim. siccis flores bracterque nunc flavescentes nunc rubicundi. (v.s.)

B. microphylla (Eckl, ex Zeyher ! in herb. Boiss.), foliis minoribus patentibus apice recurvis, floribus minoribus. - Ad cajut Bona-Spei. Folia 2-3 lin. longa, recurvata nec incurvata. Varietas rerisim. loci sicci. (v. s.)

\%. Dregei, foliis erectis patentibus vel reflexis. - Pcnæa, n. 8160 , Drège! P. mucronatæ affinis Juss. 1. c. P. Dregei Endl. gen. suppl. 4, p. 73, sine descr. An planta loci sterilis, foliis inde frequenter retortis? (v. s. in herb. reg. Ber., Boiss. et Deless.)

2. P. ova t a (Eckl, et Zeyh.! pl. exs.), foliis ovato-ellipticis subpetiolatis utrinque subacutis obtusisve erectis planis in bracteas breviores cordato-hastatas auriculatas subito transeuntibus, bracteolis lineari-spathulatis bractcâ multo brevioribus, tubo calycis florentis bracteam vix superante. 5 Ad caput Bonæ-Spei. - A. Juss.! 1. c. sine descr. Penca Drège! jl. exs. 8159 (qua P. mucronatis var. Dregei affinis Juss. 1. c. et P. affinis Endl. gen. suppl. 4, 11. 73). Flores priccedentis, bracteá simili modo latissimà concarî, sed folia omnia secus ramos minus approximata, internodiis parum longiora, 3-5 lin. longa, $1 \frac{1}{2}-2 \frac{1}{2}$ lin. lata, non coriacea. (v. $\mathrm{s}$. in h. Boiss., reg. Ber. et Deless.)

B. intermedia, brateolis obovato-oblongis.-Ad caput Bonc-Spei.-Penra, 8156, Drège I P. media inter ovatam ut myrtoidem, ex A. Juss.! 1. c., sine clescr. P. intermedia Endl. gen. suppl. 4, p. 73, sine descr. P. myrtoides multiflora Krauss I pl. exs. n. 1213, et Flora 1845, p. 76. P. mJrtilloides Meisn. in Hook. Journ. 1843, p. 456 bis (fide synon.). Omnia presentis, nisi forsan bracteolæe sepius latiores. P. myrtilloides Thunb. 1l. cap. p. 149 , eadem videtur aut $P$. myrtoides Drège, sed ex descript. incertum. (v. s. in herb. Boiss., Vindob. et Deless.) 
3. P. M YR T of DES (Drège! pl. exs., sine num., non Drège 2,83 , in herb. Deless.), foliis sessilibus ovatis vel ovato-ellipticis obtusis planis in bracteas breviores latissimas cordatus auriculatas obtusas subito transeuntibus, bracteolis obovato-oblongis bracteâ multo brevioribus, tubo calycis bracteam vix superante. 5 Ad caput BonæSpei, in Zwellendam mont. (Drège et Mey. zwei Pfl. Docum. p. 210). - Limn. suppl. p. 122 ? A. Juss.! 1. c sine descr. (excl. plerisque synon.). P. ovata? var. mucronata in Eckl. et Zeyl. in l.. reg. Ber.! P. n. 22, Mund. et Maire, ib.! Folia latiora quam in P. ovatâ ot omnino sessilia, inleriora ramorum próeser tim basi latà inserta, erecta vel patentia, 6-9 lin. longa, 3-4 lin. lata, vix coriacea, nervo extremitate submucronato. Bractere 3-4 lin. latæ, vix 3 lin. longæ. Bracteolæ $1 \frac{1}{1}$ lin. longæ, ut in præeced. angustæe, subacutre. Flores præcedentis. (v. s. in h. Boiss., reg. Ber. et Deless.)

4. P. MYPTIPOLIA (Endl. gen. suppl. 4, p. 73, sine descr.), foliis elongatis bracteisque obtusiusculis, foliis ramorum linearibus inferioribus caducis superioribus confertis, bracteis inferioribus lanceolatis, aliis e basi latâ subcordatâ auriculatâ acuminalis, bracteolis linearibus bractea multo brevioribus, calyce bracteam vix superante. 5 Ad caput Bonse-Spei (Drìge! 8155, a), ad ripas Notsinakamma (Krauss!). Pensea an a myrţoide diversa? A. Juss.! 1. c. P. Cneorum Meisn. in Hook. Journ. 1843, p. 456 bis, Krauss in Florâ 1845, p. 77. Rami inferne denudati. Folia subcrecta, 9-12 lin. longa, 1 $\frac{1}{2}-2$ lin. lata, sessilia, nervo centrali distincto. Glandulse stipulaceæ yix perspicuæ, sed sete brunnex minima interdum intra axillam folii. Bractex $2 \frac{1}{2}-3 \mathrm{lin}$. longæe, acumine ut foliorum non acuto, unde ut et formà bractearum a P. Cneorum differt. (v. s. in herb. Boiss., reg. Ber. et imp.Vind.)

5: P. GNe OR u (Lam. ill. n. 1581, non Krauss), foliis lineari-lanceolatis acutissimis, bracteis inlerioribus lanceolalis aliis obovato-acuminatis folio latioribus brevioribusque, bracteolis linearibus bracteâ multo minoribus, calyce toto bracteam non superante, lobis calycinis acutis. 5 Ad caput Bonce-Spei.-Poir. dict, 6, p. 541. P. foliis lanceolatis acutis ILeerb. ic. t. 51 , f. sinistra (2 ex textu, 3 ex ic.). P. myrtoides Drège, n. 2, 83, in herb. Deless. (non lı. Ber.,Vindob., nee ejusd. alia specim . sine num.), herb. ren. Ber.! ex h. Kunth. Specimina a Lambert anno 1816 comm. omnino cum icone Meerb. et descr. Lam. conveniunt, ut pote ex icone rudi et descr. incompletà dicere licct. Rami erecti, virgati, sulıquadrangulares, ut tota planta

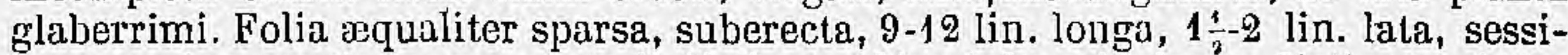
lia, margine tenuia, nervo contrali distincto. Glandule stipulacese distinctie, $\frac{1}{5}$ lin. long:1, dentiformes vel bifidx, vel auriculatæe hine dentatu. Folia floralia sæpius 2 lanceolata. Bractcic e basi obovata abrupte acuminatce. Flores 3-4 lin. longi. (v. s.)

6. P. aGutifolia (1. Juss.! Ann. se. nat. sér. 3. v. 6, p. 22), foliis lineari-lanceolatis lanceolatisve basi acutis apice acutissimis, bracteis lanceolatis aut rhomboideis acutis florom in fuantibus, bracteolis lineari-lanceolatis flore triplo brevioribus, lobis calycinis subulatis. 5 . Ll caput Bonse-Spei (vetus collector, verisimiliter Thunberg, in herb. Deless., Mund et Maire in h. Ber., excl. specimine). P. myrtilloides herb. Berol. partim in herh. Deless. Rami juniores acute 4 -goni, demum teretes. Folia 6-3 lin. longa, 2-1 lin. lata, jervo medio subtus prominente, setulis 3-4 in axillâ (ut in P. myrtifoliâ et interdum in P. Cneorum). Bractere caducre, sub eodem flore formâ variantes, lateraliter plus minus angulosie, semper acuminatæ, folio breviores. Bracteolie angustæ, lineares. Lobi calycini magis acuminati quam in omnibus aliis, num vero character constans sit non satis patet. Specimina quædam foliis simillima, propter calycis lobos acutos in P. Cneorum cadunt. (v. $\mathrm{s}$ in h. Doless. et reg. Ber.)

\section{Species exclusce.}

P. $\Lambda$ C U т A Thunb. = Brachysiphon acutus.

P. в А в а т а Endl. = Stylapterus barbatus.

P. ER I cordes Eudl. = Stylapterus ericoides.

P. For os A Thunb. = Sarcocolla formosa.

P. FRuticulosa L. f. = Stylapterus fruticulosus.

P. FUCATA L. mant. $=$ Sarcocolla fucata.

P. Fuc at a Zeyher = Sarcocolla squamosa.

P. F U C A T A herb. Lamb. $=$ Glischrocolla Lessertiana.

P. Fuscat A Poir. = Brachysiphon imbricatus. 
P. IM вR Iсат A Grah. = Brąchysiphon imprieątus.

P. L A TE RIFһ ORA Linn. f. = Endonema Thunbergii.

P. Linna I Adr. Juss. = Sarcocolla fucata.

B. LONGILORA Meerb. = Sarcocolla longiflora.

P. Marginata Iinn. = Geissoloma marginatum.

P. fur TDA Lour. = Ordinis alieni, ignoti.

P. SARCo G OLA Berg. = Sarcocolla fucata.

E. SARG 0 GOLLA Lam. = Sarcocolla fucata ?

P. SQ

P. squ A o sa Linn. mant. = Sarcocolla squamosa.

P. SCANDENS Lour. = Diversi ordinis, ign.

P. TET RAG oNA Berg. = Sarcocolla squamosa.

P. TOMENTOSA Thunb. = Diversi ordinis (1).

II. STYLAPTERUS Adr. Juss. Ann. sc. nat. sér. $3, v .6, p .23, t .1$, f. 2. - Peneæ sectio Stylapterus Endl. gen. suppl. 4, p. 73 .

Calycis tubus limbo paplo longior, bracteis subæqualis, præfloratione yalyatâ. Tilamenta brevissima ; antheræ loculi connectivo crasso multo breviores, bivalves, margine valvarum fimbriis crebris ciliato. Ovarium scabriusculum, loculis biovulatis. Stylus 4 -angularis. Stigmata 4 , complanata, cruciata. Capsula ut in Penæâ, sed bracteis bracteolisque cadncis et calyce lacerato plușminus denudata. Semina erecla. - Suffrutices capenses, foliis planis vel aceroso-ericoideis ; floribus in axillis bractearum solitariis, approximatis ; bracteâ et bracteolis 2 tenuibus, sæpe ciliatis, caducissimis (interdum deficiențtibus ?); setulis frequenter in axillis foliorum, bractearum et bracteolarrum. - Characteres leves, habitus vero a Penæâ diversus.

\section{${ }^{\text {}}$ Species vera, foliis planis.}

1. S. FRUTr culoses (A. Juss.! l. c. t. 1, ubi solum anal. sed accuratiss.), foliis obovatis inferioribus obtusis superioribus acutiusculis, bracteis caducissimis ovato-acutis subciliatis. 5 Ad caput Bonæ-Spei. Penæa fruticulosa L. f. suppl. p. 121, Poir. dict. 6, p. 540, Endl. gen. suppl. 4, p. 73, sine descr., Drège! pl. exs., Ecklon! 624 , in h. Vind. Rami cinerei, glabri. Folia secus ramos dequaliter sparsa, opposita, $1 \frac{1}{\frac{1}{1}}-2 \frac{1}{2}$ lin. longa, $\frac{3}{4}-1$ lin. lata, glabra, nervo basi solum distincto. Flores in axillis superioribus, caduci. Setæe in axillis foliorum superiorum et bractearum persistentes. Bracteæ pellucidœ, nervo centrali clonatæ in mucronem desinente, lineam longer. Flos $1 \frac{1}{2}-2$ lin. longus, sub-4-fidus, lobis erectis lanceolatis, calyce demum rupto lacęrato pistillum nudum linquente. (v. s.)

B. Boivini, foliis inferioribus subacutis, superioribus acutis. 5 Ad Simons Bay St. fruticulosus Boivin pl. exs. (v. s. in herb. Boiss.)

$\because$ Species dubia, foliis acerosis, ericoideis, bracteis ignotis, nullis aut caducis.-Brachysiphon sectioni 1 affines et forsan congeneres.

2. S. B A R B A T U S (A. Juș.! l. c.), foliis acerosis subtus canaliculatis in axillis utrinque fasciculum pilorum longum lanuginosum prebentibus. 5 Ad caput Bonæ-Spei (Roxb. in herb. Deless.!). Penaea barbata Endl. l. c. sine descr. Ramuli juniores 4-goni, angulis serius hebetatis. Pili axillarum lopgi, albido-rufi, simplices, post folia cadentes.

(1) Penaa tomentosa Thunb. (Geissoloma? tomentosum A. Juss. Ann. sc. nat. sér 3, v. 6, p. 27), fide specim. capensis a Delessert olim cum patre comm. est planta alieni ordinis a Penæaceis et Geissolomaceis valde recedens. Folja, ut dixit Thunb., opposita, tomentosa, sed $1 \frac{1}{2}-2$ lin. longa (nec lineam longa), pvata; flores axillares, solitarii, intra bracteas folio subsimiles ; calyx gamosepalus, sub-5-partitus, extus pubescens, lobis ovatis, interne basi glandulis 5 abtusis stipatis; petala 5 , obovata, lóbis calyc. alterna, iis paulo longiora, glabra, sestiv. ignotâ; stamina 5 , monadelpha, filamentiș glabris, apice liberis, antheris 5 ovatis medio insertis versatilibus bilocularipus; ovarium sterile? stigma pilosum antheris cinctum. Frutex verisimiliter masculus, ad Euphorbiaceas forsan referendus? 
Folia $3-4$ lin. longa, $\frac{1}{9}-1$ lin, lata, crebra, acutissima, glabra, margine sulitus revoluta ef quusi crassiofa. Flores ad summa folia axillares, ijs subeequales, solitariis pedicello brevissimo setụlis \& brevịłus coronate. Bracțea ex folio in axillâ barbato, braeteole raræ caducæ? ' lineari-lanceolatæ folio triplo breviores. Calycis tubus subinflatus, laciniis acuminatis paulo longior., Stylus brevis, 4-gonus, cujus anguli e stigmatibus decurrunt, cum totidem angulis ovarii verrucosi alternantes. Capsula et semina ordinis, ex Adr. Juss. (v. s. in herb. Deless.)

3. S. ERIC OIDES (A. Jusș.l l. c.), foliis acerosis subtus canaliculatis in axillis setulas brevissimas jrebentibus. $5 \Lambda$ d cuput Bonæ-Spei (Roxb. in herb. Lamb. nunc in herb. Deless., Webb et meo). Penæa ericoides Endl. l. c. sine descr. Ramuli 4-goni, angulis serius hebetatis et evanidis. Folia $3-4$ lin. longa, $\frac{1}{2}$ lin. lata, glabra, acuta, frequentia, margine subrevoluto canaliculata. Setules $2-3$ ex utroque latere folii, minimine. Flores ad axillas sup. solitarii, pedicello (ex Juss.) brevissimo insidentes utrincue in pulvinulum fusecscentem cicatriciformem (bractolearum rudimenta) extenso, setulis brevissirnis nonnullis in trorsumn marginatum; meo sensu cicatrices apice perlicelli bracteolas caducissimis setulis basi donatas indicant, sed in specimine frustra quasivi. Calycis tubus florens 2 lin. longus, postea major, 8-costatus, vernicoso-lucidus, lacipiis brevioribus, angustis, acuminatis. Stylus brevis, 4-gonus, apjice 4-fidus, ovarium 8-angulum. Ovilla 2 in loculo vidi. Semen obovattocompressum, leve, lilo tumido albo, ut in S. fruticoso. (r. s.)

III. BRACHYSIPHOX Adr. Juss. in Ann. sc. nat. sér. 3, v. 6, p. 24, t. 2, f. 3, Endl. gen. suppl. 4, p. 73 .

Calycis tubus oblongus; lobi tubo subæquales, æstivatione valvatâ vel sæpius reduplicato-valivatâ. Filamenta brevissima; antheræ loculis connectivo crasso adnatis illoque brevioribus, valvis margine nudis. Ovarinm læve, oblongum, loculis 4 , ovulis 2 e fundo cujusve loculi erectis. Stylus filiformis, teres. Stigma parvum, 4-lobum. Capsula 4-valvis. Semina oblonga. - Suffrutices capenses; foliis planis, raro acicularibus ; floribus in axillis bractearum solitariis, versus apicem ramorum plus minus approximatis. Brevitate tubi, staminibus non exsertis et habitu a Sarcocollâ differt.

\section{Sectio I. Euclissa Endl. $l$. $c$.}

Asstivatio valvata. Folia acicularia.

1. B. FRICAFOLIUS (A. Juss.! 1. c.), foliis acicularibus acutissimis. $ち$ Ad caput Bonæ-Spei (Roxb. in herb. Deless.l ab herb. Lamb.). Rami glabiri, angulis e fóliis decurrentibus 4 -goni. Folia 6 lin longa, $\frac{1}{2}$ lin. lata, in axillà setulas brevissimas vel pulvinulum prebentia. Flores ad summa folia axillares, brevissime pedicellati, pedicello utrinque in pulvinulym apice setuliferum cicatrisatum (bracteolis delapșis?) inftato, 4 lin. longi. Tubus oblongo-ovatus, laciniis erectis acuminatis. Antherie subsessiles connectivo loculis multo majore. Stylus filiformis, subexsertus. Stigma cruciato-4-lobum. Ovarium oblongum, 4-costatum, glaberrimum. Hujus generis, ait cl. auctor, propter antherarum stylique fabricam, accedit proeedenti præfloratione (ut videtur) valvatâ, ințer utrumque fere medius. Stylaptero ericoidi equidem valde affinis et forsan congener. (v. s. in herb. Deless.)

Sectio. II. ANachissa Endl. l. c.

Estivatio reduplicatim valvaț. Folia ovata vel obovata.

* Folia glabra . Bractece omnes fertiles. Loculi connectivo multo breviores.

9. B. IMвRІGAтUS (A. Inss.! 1. c. p. 25 , t. 2, f. 3 ), foliis late ovato-acutis, bracteâ ohovato-mucropatâ, brạcteolis oblongo-linearibus bractẹa brẹvioribus, tubo calycis bracteâ subbreviore bracteolis sublongiore. $\zeta$ Ad capui Bonæe-Spei. Penæa squamosa Linn. sp. p. 162 ? (non mant. p. 331, nec Lam.), herb. plurim. vet., Drègel pl. exs., Krauss. in herb. Boiss.! Penæa fucata herb. vet. plurim., Lam. ill.-1, 1. 317 , t. 78 , f. 1 . Reprea fuscata Poir. dict. 6 , p. 540. Penæa imbricata Grah. in Bot. mag. t. 2809 . Folia approximata, juniora quadrifaria erecta, serius patentia, -5 lin. longa, 3-4 lin. lata, subcarnosa, glabra, nervo medio distincto. Bractea 
2-3 lin. longa, 1-2 lin. lata, bracteolæque multo angustiores lineares vel obovatolineares subdenticulato-ciliatæ. Calyx per anthesin vix 3 lin. longus, tubo lobis vix longiore, in fructu 5 lin. longus. Ex icone lobi calycis rosei, tubus et bracteæ subrosex. (v. s.)

3. B. Acutus (.1. Juss.! 1. c. p. 25 , sine descr.), foliis late ovato vel obovato-acutis, bracteâ obovato-acuminatà, bracteolis lanceolatis acuminatis bracteà sublongioribus, tubo calycis bracteâ bracteolisque cito longiore. 5 Ad caput Boniı-Spei. Penæa acuta Thunb. t1. cap. ed. Sch. p. 150 (erroribus gray. admiss.). Sarcocolla acuta Lunth in Linn. 1830, p. 678, sine descr., Zeyher! pl. exs. n. 3728, in herb. Boiss. Folia fere B. imbricati, sed frequenter oborata et magis acuta. Differt precipue bracteolis in alabastro bracteam superantibus tubo calyess sublongioribus accuminatis. Estivatio cal reis eadem; tubus post anthesin angustior, 3-4 lin. longus. Lobi ovati acuti aut potius mucronati, in præced. vix mucronati. Ex descript. Thunb. folia alterna, lineam longa, aliaque aut falsa. aut alius plantæ. (v. s. in herb. Búiss., Deless.)

" Folıa glabra. Bractea omnes fertiles. Bracteole nulle (ex Sond.), forsan caduca delapse? Loculi connectivo multo breviores.

4. B. PUPESTRIS (Sond. in Linn. 1850, r. 23, p. 101), foliis brevissime petiolatis obovatis obtusis, bracteis obovatis, tubo calycis bracteâ vix longiore. $J^{\dagger}$ Ad caput Bonæ-Spei, prope Kleinriviersherg. Sarcocolla rupestris Eckl. et Zeyl. msc.! Fruticulus ramis glabris. Folia erecta, carnosa, $4-6$ lin. longa, 2-3 lin. lata, petiolo $\frac{1}{2}$ lin. longo, superiora minora. Sete axillares minutissime, nunc mueroniformes. Flores rubri, umbellato-congesti, in asillis fol. sup. solitarii. Pedicelli lin. longi. Bractex setacex, folizcex, subcoloratie; bracteole nullie ? Tubus cal. 3 lin. lougus, lobi ovato-acuti, 2 lin. Stamina, ovula, styli ut in congen. observata. Semina lineari-oblonga, nitida. (v. s. in h. reg. Ber.)

5. B. If U Du (Sond. in Linn. 23, p. 102), foliis petiolatis uratis mucronulatis, bracteis folio parum majoribus. 5 Ad Zwellendam Africæ capensis (Mund). Rami glabri, juniores pruiposi. Folia $1 \frac{1}{4}$ lin. longa, in petiolum semilinearem canaliculatum angustati, patula, demum subrecurva, crassa, mucronulo brevissimo. Stipulæ minutissimæ, mucroniformes. Flores in apice ramorum solitarii, rarius 2-3-cymuloso-congesti, pedunculo 1-1 $\frac{1}{2}$ lin. longo. Bractere foliaceæ, subcoloratæ. Bracteolæ nullæ. Calyx rubens, tubo 4 lin. longo, lobis late ovatis acutis tubo triplo brevioribus. Antherse filamenta brevissima subequantes, loculis basi subdivaricatis. Semina oblonga, nemina in imo loculo.

** Folia ciliata. Bractere inferiores steriles. Loculi connectivo subbreviores. - Sarcocolle accedens, sed filamentum fere nullum.

6. B. SPEcrosus (Sond. in Linn. 1850 , p. 103), folis imbricatis obovato-cuneatis rotundato-obtusis mucrone glanduloso obtuso terminatis margine cartilagineo denticulato-ciliatis, bracteis latissime obovatis folio amplioribus fimbriatis glanduloso-mucronatis inferioribus sterilibus, floribus capitulatis, bracteolis oblongis ciliatis bracteâ subbrevioribus, tubo calycis bracteà sublongiơre. ${ }_{\supset}^{+}$Ad caput BonæSpei, prope Kleinsriviersberg et Hemel en Aarde in montosis (Zeyher ! 5725). Sarcocolla speciosa Ecklon! in herb. Boiss. Fruticulus $1-1 \frac{1}{2}-$ pedalis, ramis inferne nudis, superne foliis tectis. Folia 3 lin. longa et lata, superiora paulo majora gradatim in bracteas $4-5$ lin. latas longasque coloratas transeuntia. Flores $5-6$ in capitulo, pedicello $\frac{1}{3}$ lin. longo suffulti. Bracteolæ 2 oppositie oblonga, apice glandulosæe ul bracteæ foliaque, 4 lin. Iongæ, vix lin. latæ. Tubus calycis florens 3 lin., deinde 6 lin. longus, apice purpureus. Lobi tubum florentem requantes ovato-acutæ. stamina, ovarium, ovula congrenerum. (v. s.)

IV. SARGOGOLL.I kunth in Linn. 1830, p. 677, A. Juss. in Ann. sc. nat, sér. 3, 6, p. 25 (excl. S. Lessertiana). - Sarcocollæ sect. Eusarcocolla Endi. gen. suppl. 4, p. 73.

Calycis tubus oblongus, lobis per anthesin tubo subbrevioribus, æstivatione reduplicato-valvatâ. Stamina lobis calycinis reflexis exserta; antheræ tilamento æquales, erectæ, loculis connectivo subæquales, marginibus valvarum integris. Ovarium læve, loculis 4 , bi-ovulatis. Stylus gracilis, teres, stigmate 4-lobo capitato terminatus. Capsula valvis 4 acuminatis. - Suffrutices capen- 
ses, foliis planis, imbricatis ; stipulis? verrucæformibus, nigricantibus ; bracteis ampliatis, coloratis, sæpe unctuoso-resinosis, inferioribus sterilibus; bracteolis angustis; floribus apice ramorum approximatis tubo accreto persistente colorato bracteas cito superante.

1. S. squAmos A (Endl.l gen. suppl. 4, p. 74, sine descr.), foliis late obovatis obtuse mucronatis, mucrone glanduloso, bracteis imbricatis folio majoribus late obovatis obtusis submucronatis ciliatis unctuoso-rcsinosis, bracteolis bracteå brevioribus linearibus vel lineari-spathulatis ciliatis, calycis tubo longitudine bract,ce postea longiore. 5 Ad caput Bonæ-Spei. Penæea squamosa Linn. mant. p. 331 (non sp. pl.), Bot. reg. t. 106. Penæa tetragona Berg. cap. p. 36 (fide Bot. reg. et specim. herb. Burm. in meo). Tithymali Myrsinitis sp. arbusc. Ethiop., etc., Pluk. mant. p. 183, t. 446, f. 2 (pessima. sine f1.)? Penæa Sarcocolla Linn. sp. p. 162 ? (non Thunb.), Poir. dict. 6, p. 358 (non Lam.), Krauss.l jul.exs. in herb. Boiss. S. fucata Zeyh.! 3722, in herb. Bolss. Omnium vulgatior. Folia jun. erecta, vet. patentia, 5-8 lin. longa, 4-6 lin. lata, in ic. Bot. reg. nimis acuta, suprema nunc ciliata. Bractex convexa, inf. steriles, omnes 6-8 lin. latse et long:e. (v. s.)

2. S, FUCATA, foliis late, obovatis oblusis vel obtuse mucronatis, muerone glanduloso, bracteis imbricatis folio. subsinilibus glabris aut arl apicem subeiliatis unctuoso-resinosis, bractcolis linearibus bracteam iequantibus, calycis tubo longitudine bractea serius longiore. $\zeta$ Ad caput Bonæ-Spei. Penra fucala Linu. mant. p. 199. Pensea Sarcocolla Berg. tap. p. 35 (ubi descr. bona jam a Linn. cit., nec P. sarcocolla L. sp. cum nomen Burgii mutaverit). S. Linnæi A Juss.! l. c. p. 25. (sine descr., sed citato syn. Dregei) et t. 2, f. 4, LE, D et S (anal. incompl.). Penæa Sarcocolla Thunb. 1l. cap. ed. Sch. p. 190? (ubi flores errore? lutei dicuntur). Descripsi specimen Dregei sub nom. Pen. Sarcocollæ in herlr. Boiss. Folia ibi $4-6$ lin. longa, 3-4 lin. lata, erecta, glandulà minus quam S. squamosco distinctâ; bractere obtusæ vel acutæ, convex:e, sed minus amplæe quam in S. squamosà vixque rars, ciliatz. Stylus longit. staminum (ex Berg. et spec. Dreg.), in S. squamosâ paulo longior (ex Bergio, an semper ?).Tabula rudis Lamarkii ill. 78, f. 2, forsan huc referenda, nec tamen Poir. descriptio. Vix in herbariis a S. squamosâ differt; an vere distincta? an $\mathrm{x}$ vivo melius definienda? Flores pauciores videntur, sæpe solitarii. (v. s. in herb. Boiss. et Deless.)

3. S. MINoR, foliis obovatis mucronatis, mucrone non glanduloso, bracteis imbricatis folio subsimilibus glabris unctuoso-jesinosis, bracteolis linearibus liractea æqualibus vel longiorilus, calỵcis tubo bracteam requante serius multo longiore. t Ad caput Bonæ-Spei.(Zeyh.! 75, 5 in h. Boiss.). S. fucata minor Eckl. ex Zeyh. l. c. Folia 3-4 lin. longa, 2 $\frac{1}{2}-3$ lin. lata, mucrone obtusiusculo minime aut rarissime glanduloso. Bracteæ paucæ ovato-acutæ vel obovato-cuspidatæ, rarissime apicem versus hinc inde cilialx. Bracteole apíce sxepe revolute variabiles. Calycis fructiferi tubus 8-8 lin. longus; lobi oblongo-elliptici reflexi $3-4$ lin. longi. Stamina exserta. Stylus filiformis, stamina subæquans aut lineis $3-4$ longior. Sligma capitato-4-lobum. Valvie cepsulares subulatre. (v. s. in l. Boiss. el imp. Vind.)

4. S. Formosn ( $\Lambda$ dr. Juss.! 1. c. p. 25 , sine deser., pl. 2, f. 4, F), foliis obovatomucronatis vel elliptico-acutis, mucrone obtuso nunc glanduloso, floribus terminalibus solitariis, bractcis 6 gradatim folio magis ac magis longioribus subciliatis, inferioribus ovalo-acutis, superioribus obovato-acutis calycis tubum florentem æquantibus. 5 Ad Simons Ba 5, capilis Bon:c-Spei (Boivin! n. 555). P. formosa Thunb. fl cap. ed. Sch. p. 149, herb. Berol.! (a Bergio), et ex eo in herb. Deless.! Fruticulus vix pedalis, e caudice lignoso ramosus. Rami cinerascèntes, cicatrisati. Folia infer. 4-6 lin. longa, 3-4 lin. lata, obóvata, obtuse mucronata vel obtusa, pleraque delapsa, super. minora, approximala, potius obovato-acuta, acumine obtusiusculo. Bracteæ 2 exteriores folio rix májores, 2 supra ovato-acute majores, 2 florales obovato-acutic 7-9 lin. Jongæ, omnes concavæe, coloratis? Lobi calycis 3,4 lin. longi, æstiv: congenerum. Connectivum extus tuberculosum, flavum? oblongurn, filamento parum longius. Stylus stam. æqualis. Ovula 2 in loculo quoque. (v. s. in herb. meo, Boiss., reg. Ber. et Deless.)

\section{Species dubia.}

S. LONGIFL ORA, foliis rhomboideis acutis floribus 4-fidis purpureis tubo longissimo. Penæa longiflora Meerb. ic. t. 51, f. 1. Ex icone verisimiliter pessimà (ut aliæ 


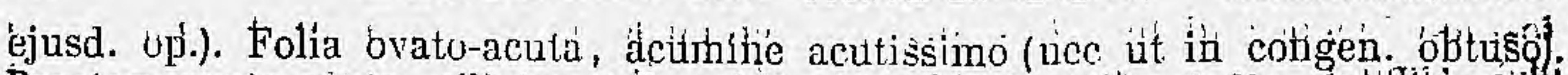
Bractex ovato-acutæ ciliate; túbus calycis extra bractéas 9 lin. lobigntí, lobli patentes, ovato-acuminati, tubo düpló triplove brevíores; stamina hon exșerta; flos totus coruteus, nec purpureus ut in descr. dicitur. An fabula autetoris?

\section{Species exclüser.}

S. AcUT A Kunth $=$ Brachysiphon acutus.

S. Lessertiana A. Juss. = Glischrocolla Léssertiana.

S. RETZIOIDES Eckl. et Zeyh. = Endonema retzioides.

S. RUPEST RIS Eckl. et Zeyh. = Brachysiphon rupestris.

S. SPECIOSA EckI. = Brachysiphon speciosus.

\section{Tribus II. ENDONEMEAE.}

Ovula 4 in quovis loculo, versus mediam partem ảngulo inteíno sitá, 2 adscendentia, 2 pendentia, ideoque radicula nunc infera nune supèra (1): - Bracteolæ 2-4.

V. GLISCHROCOLLA. - Sarcocollæ sect. Glischrocolla Enäl. gen. suppl. $\ddot{4}, \ddot{p} .75$.

Calycis tubus oblongus, 4 costatus; lobis tubo subbrevioribus, æstivatione reduplicato-valvatâ, cum costis tubi alternantibus. Filamenta staminum crassa, brevia ; antheræ cordato-ovatæ, loculis oblongis connectivo verruculoso longioribus introrsis. Ovarii lævis loculi 4 , singuli circa medium anculo interno 4-ovuliferi; ovulis geminis collateralibus, duobus superioribus adscendentibus, duobus inferioribus pendulis, raphe in omnibus extrorsâ. Şylus filiformis, stigmate (ex Juss.) obsolete 4-lobo terminalus. - Suffrutex càpensis, foliis planis imbricatis, pro Ordine magnis; floribus in vertice ramorum approximatis; pedunculis (ex Juss.) dichotomis; bracteis folio majoribus, coloratis; bracteolis 2 coloratis oblongis angustis vittæformibus ad dichotomias et paulo infrà florem quemque sitis. - Sarcocollæ lıabitus, sed̀ oyulorum situs (nec solum numerus) differt. Endonemati proprior ex ovulis, sed inflorescentia, antheræ et situs loculorum differunt.

G. Les S e r t i na. Sarcocolla Lessertiana A. Juss.! l. c. Penæa fucata herb. Lamb. a Masson lecta, nunc in herb. Deless. Rami dichotomi, angulis cristæformibus ab insertione fol. decurrentibus 4-goni, leves. Penicilli minimi duo in axillis foliorum. Folia decussata, internodiis sesquilineam longis imbricata, ovata, 1-1: $\frac{3}{4}$ poll. longa, $\frac{1}{2}-1$ lata, marginata, coriacea, nervo medio subtus prominente; superna (bracteæ steriles ut in Sarcocollis) majora, colorata, non glutinosa. Flores pollicares, tubo 9-10 lin. longo, uervis 4 sub sinubus, lobis ovatis. Stylus in floribus ob́s: truñcatus. (v. s. in herb. Deless., ubi specimen unicum.)

VI. ENDONEIA A. Juss. in Ann. sc. nat. sér. 3, v, 6, p. 19, 26, pl. 3 (ubi anal. solum).

Calyx longe cylindraceus; lobis ovato-acutis, tubo brevioribus, æstivatione valvatâ, intus incrassalis ideoque fere trigonis. Filamenta in alabàstro apịce intus plicata, deinde erecta, longiludine fere antheræ aut longiora ; antheræ ovatæ, loculis connectivo vix brevioribus initio plicaturâ filamenti reflexis et extrorsis demum erectis et introrsis, rimis margine integris dehiscentibus. Ovarium læve, 4 -loculare; ovulis 4 in medio quovis loculi angulo interno inser-

(1) Stigmata forsan erga loculos ovarii alitèr quam in tribu 1 posita, nemje loculis superposita. Hoc tamen in Glischrocollex autopsià unicâ imperfeclâ mihi videluatur et cl, $\Lambda$ dr. de Jussien in 1. 3 Endonematis exhibuit, sed observatio in sicco cum floribus raris non facilis et icon Juss. altera (n. 2) in simili charactêre erroneảa. Géissoloma (typus ord. sect.) stigniata loculis superposita præbet. 
tiš, 2 eìectis, 2 pendulis. Stylus gracilis, tubum calycis æquans. Stigmata 4 , parva. Cápsild oblónga, loctilicide 4 valvis dehiscens. Semina in quovis loculo abortu 1-2, erecta vel pendentia pro ovulis evolutis, oblonga, nilida, sub lente punctulata, basi excavata funiculo albo tumido ibi (tanquam raphe distincta funicularis) usque ad apicem penetrante. Albumen nullum. Embryo carnosus, obovoideus; radicula supera aut infera pro ovulo evoluto, obtusa imoque depressá ; cotylledones extremilate minius obtusâ, ex riinâ minimâ transversẩ solum sub lente perspicuæ. - lirutices capenses; floribus solitariis, in axillâ folii coloratis; bracleis (bracteolis alior. gen.) per paria oppositis imbricatis.

* Foliis planis latis; bracteis ovato-oblongis; antheris filamento sublongioribus.

1. E. Th U B E R I I (A. Juss.! 1. c. p. 25 , sine deser., t. 3), foliis crebris sessilibus ovatis obtusis glabris, floribus lateralibus cum pedicello folium gequantibus, bracteis octo oblongis a basi ad florem gradatim longioribus, iuferioribus obtusis, súperioribus subacıtis tubum calycis non superantibus. $\%$ Ad caput Bonæ-Spei (Roxb. in lierb. Lamb. nunc Deless.!), prope Guadenthal (Drègel in h. Ber. et Vindob.). Penæea laterillora Thunb, naturf. magaz. Berlin. 1, t. 3, f. 2. Geissoloma lateriflorum Drège! in h. Ber. Rami glabri, ex fóliis decussatis subquadranguli. Folia 6-10 lin. longa, 4-6 lin. lata, coriacea, nervo centrali panlo eminente, lateralibus paucis obliquís parum distinctis. Flores pollicares. Lobi calycini oblongo-acnti, 4 lin. longi, pingues. (v. s. in herb. Deless., rég. Ber. et imp. Vind., sed autopsiam florum in specimin. unicis non tentavi.)

"Foliis anguste linearibus, margine revolutis; bracteis rotundatis, caducissimis; antheris filamento brevioribus.

2. E. RETZIOIDES (Sonder 1. c.), foliis sessilibus anguste linearibus acutis margine revolutis nervo subtus eminente, bracteis 4 rotundatis flore multo minoribus, inferioribus minoribus mucronatis, $5 \mathrm{Ad}$ Zwellendam capitis Bona-Spei (Eck], et Zeyh.! 3724). Sarcocolla relzioides Eckl, et Zeyh.! msc. Ramuli teiragoni, ut tota planta glabri. Folia erecta, internodiis longiora, 9-15 lin. longa, lineam lata, rigida, superne sub lente juncticulata. Bracteie glabræ, convolute suborbiculares, inferiores acumine brevi, interiores duplo majores, $2 \frac{4}{2}$ lin. longæ, pedicellüm basinque floris tegentes. Flores pauci, laterales, jun. 12 lin., dein 18 lin. longi, sanguinei, lobis lanceolatis erectis. Filamenta fauci imposita, ligulata, erecta, 3 lin. longa. Ovarium 4-sulcum. Capsula $8 \mathrm{lin}$. Semina $2 \frac{1}{2}$ lin. longa. (v. s. in herb. Boiss., reg. Berol. et imp. Vindob.)

\section{Ordo CLXVI. GEISSOLOMACE $\approx$ (1).}

Penæacearum species Linn., Thunb., Kunth in Linnocâ 1830, p. 678. - Geissolomeæ (post Penæaceas) Endl.ench.p. 214.Genus anom. post Penæaceas Endl.gen.p. 385. - A genuinis Penæaceis exclud. Adr. Juss. in Ann. sc. nat. sér. $3, v$ v. 6 , p. 19, 27, t. 4, n. 6. - Geissolomaceæ Sonder in Linn. 23 (1850), p. 105 (absque chàr. ord.).-Penæacearum gen. Lindl. veg. kingd. ed. 2, p. 578 et 577, fig. 7-10.

Calyx gamosepalus, 4-partitus, bracteis bifariam imbricatis squamosis stipatus, persistens, lobis ovatis, mucronatis. Fstivatio imbricativa; lobis 2 exterioribus folium et axim spectantibus, superiore inferiorem margine amplectente, duobus inte-

(1) Auctore Alph. de Candolle, 
rioribus lateralibus, uno alterum amplectente. Stamina 8 , imo calyci inserta, 4 cum ejus lobis alternantia oppositis subbreviora; filamentis longiusculis, calyce tamen breviorihus; antheris filamento multoties brevioribus, ovoideis, basi bilobis, erectis, versatilibus, mucronulatis, connectivo vix manifesto, loculis subintrorsis longitudinaliter dehiscentibus. Ovarium liberum, 4-lobum, 4-loculare, ovulis in quovis loculo binis collateralibus ab apice pendulis, anatropis; styli 4 , loculorum sive angulorum continuatio in unum pyramidato-acuminatum coadunati, facile solubiles, ciemum a basi segregati; stigmata minima 4 , terminalia. Loculi et stigmata lobis calycinis alternantia (ut dixit Juss. 1. c. p. 19, non vero ut in suâ icone.) Capsula 4-locularis, superne suturis 4 longitudinalibus loculicide dehiscens. Semina in loculis solitaria, ovata, subcompressa, lævia, ex apice funiculo brevi pendula, inter bilum et micropylem extremitate superiore sulcata, utroque latere sulci inflata. Albumen carnosum (ex Sonder). Embryo (ex eod.) centralis, longitudine fere albuminis, rectus; cotyledonibus linearibus, carnosis; radiculâ superâ brevi, cylindricâ, obtısâ; plumulâ inconspicuâ. — Frutex capensis, habitu Buxi; foliis oppositis, penninerviis, ovato-subcordatis, integris, margine crassiori cinctis; - stipulis nullis; gemmis terminalibus acutis sericeo-pilosis, foliis vero glabrescentibus ; floribus axillaribus, solitariis, intra bracteas ovato-acutas per paria inæquales brevissime pedicellatis; calyce bracteisque membranaceis ; bracteis pemninerviis ; lobis calycinis potius parallelinerviis, nervo centrali non majore, nervis $3-4$ aliis utrinque æqualibus marginem versus rarioribus.

Valde differt a Penæaceis æstivatione calycis, numero duplici staminum, antherarum formâ, semine albuminoso radiculâque brevi.

GEISSOLOMA Lindl. herb. ex Kunth, Adr. Juss. l. c. (excl. Penad tomentosa), Sond. l.c. - Genus nor. DC. msc. alim.

G. M A R G I N A T U M (A. Juss. 1. c. t. 4, n. 6). J In parte montosâ austro-occid. Afriçe capensis, prope Voormansbosch (Zcyher! 3729), Clanwilliam (Eckl. et Zeyh), Zwellendam (Mund, Drège, 9561, in Sonder cit.). Penæea marginata Linn. mant. p. 199, Thunb. fl. cap. ed. Schult. p. 150, Vent. Alalm. 1. 87, f. 1 (ubi solum flos). Rami juniores puberuli. Folia 6-12 lin. Jonga, 3-8 lin. lata, internodiis spilus longiora, obtusa vel obtuse mucronulat.. Florcs laterales et innovationes sape ultra florum regionem. Bractea 6 , duobus infor. erga folium lateralibus vix lineâ longioribus subciliatis, 2 mediis paulo majoribus, supremis tandom $3 \mathrm{lin}$. Iongis glabriusculis et acutioribus erga inferiores ef lohos laterales calycis oppositis. Lobi calycis 5 lin. longi, albi (ex Thunb.), ovato-elliptici, cusjide nunc subulato terminati. Filamenta ligulata, nervo intus prominente subtrigona, 3 lin. longa. Capsula 3 lin. longa, subligmosa. Semini 1\% lin. longa, flava. (v. s.)

\section{Species exclusa.}

G. L A TER IF L O R U M Drège = Endonema Thunbergii (supra, p. 491).

G.? томектов и жаlp. = Ign. - Confer ad notam supra, p. 486. 


\title{
PRODROMUS
}

\section{SYSTEMATIS UNIVERSALIS}

\author{
REG N I VGETABILIS.
}

Ordo CLXVII. THYMEL $Æ A C E Æ(1)$.

Thymelææ Adans. fam. 2, p. 14 (excl. sect. 1), Juss. gen.p. 76 (excl. Quisquali), $R$ Brown prodr. Hl. Nov.-Holl. p. 358, Lindl. nat. syst. ed. 1, p. 75, Barll. ord. nat. p. 114, Kunth in Linnceâ 5, p. 667, Mart. consp. p. 14, ordo 79, Meisn. in Linnaâ 14, p. 385; in Denkschr. d. bot. Gesellsch. in Regensb. 3, p. 274, gen. pl. vusc. p. 323 et 330 (242). et in Marl. A. bras. fasc. 14, p. 61.-Vepreculæ Linn. philos. bot. ed. 1, p. 33, ord. nat. ed. Giseke, p. 414 (ex parle).- Passerinæ Rüling ord. nat. $p .51$ (ex parte).-Aclithrophyta Neck. elem. p. 173 iex partel. - Daphnoideæ Vent. tabl. 2, p. 235 (ex parle), Endl. gen. p. 329, suppl. 4, 2, p. 59, encheir. p. 208, Schnizl. iconogr. fam. fasc. 8, t. 109. Daphneæ Reichenb. consp. p. 82. - Thymelineæ Dumort. anal. p. 15 et 18. - Thymelaceæ Lindl. nat. syst. ed. 2, p. 194 (excl. Anthoboleis), veg. kingd. ed. 3, p. 530 (excl. Hernandiaceis). - Daphnaceæ C.A. M y. in Bullet. Acad. St-Pétersb. 4, n. 4, Ann. st. nat. 2 sér. 20, p. 45. Aquilarinee $R$. Brown, Congo, $p$ 25. DC. prodr. 2, p. 59. Bartl. ord. p. 420, Lindl nat syst. ed. 1, p. 77, Royle ill. Himal. p. 171, Endll.gen. p. 332, encheir. p. 210, Mrisn. gen. p. 73 (53), Decsne in Ann. sc. nat. $2^{\circ}$ ser. 19.p. 35.Aquilariaceæ Lindl. Nat. syst. ell. 2, p 196, veg. kingl. ed. $3, p .579$.

Flores hermaphroditi vel rarius unisexuales polygamo-dioici, 4- vel rarius 5-meri. Calyx inferus, corollinus vel rarius herbaceus, gamosepalus, tubulosus, infundibuliformis, campanulatus vel urceolatus, extus plerumque (quandoque et intus) pubescens,

(1) Auctore C. F. Meisner.

XIv. 
deciduus vel marcescens; tubo continuo vel supra basin articulatim rumpente, basi fructiferâ tunc persistente; limbo 4-vel 5 -lobo, lobis conniventibus vel patentibus, æqualibus vel alternis (in alabastro interioribus) paulo minoribus, rarius bilabiatim valde inæqualibus, restivatione imbricatis $(2-3$ exterioribus, 2 interioribusł; fauce nudâ vel barbatâ vel squamulis glandulisve perigynis (petalis?) vel filamentis brevibus (staminibus sterilibus?) numero loborum æqualibus (et tunc iisdem plerumque alternis) vel duplis triplisve auctâ. Squamulæ hypogynæ 4-8 exiguæ, membranaceæ vel subcarnosæ vel filiformes, ovario circumpositæ, liberæ vel in annulum vel cyathulum integrum vel lobatum concretæ, interdum calyci adnaı, rarius obsoletæ vel nullæ. Stamina (fertilia) 2 vel $4-5$ vel 8 vel 10 , seil. dimidio vel æquali vel duplici numero laciniarum calycis et tunc plerumque biserialia, fauci vel tubo inserta, seriei superioris calycis lobis opposita, inferioris /sæpe deficientis iisdem alterna et ad sinus vel paulo infra inserta (in floribus femineis exigua, imperfecta vel nulla); filamenta filiformia vel complanata, calyci usque ad medium tubum vel faucem vel loborum basin adnata indeque nunc inconspicua vel brevia inclusa, nunc elongata, exserta; antheræ biloculares, ovales, oblongæ vel lineares, basi vel dorso affixæ vel adnatæ, erectæ aut versatiles, rimis 2 longitudinalibus introrsum (rarius latere) dehiscentes, inter $\mathbf{d} / \mathrm{m}$ connectivi prolongatione brevi obtuse apiculatæ; pollen sphæroideum vel oblongum, læve vel 3-sulcatum 3-tubum (Hassal in Ann et Mag. of nat. hist. 9, p. 555). Pistillum unicum, raro (in solis Aquilarineis) duo omni parte in unum connata; ovarium liberum 1-vel 2 -loculare, ovulo nunc solitario prope apicem loculi lateri styligero appenso anatropo, nunc rarius 2-3 collateralibus vel superpositis; stylus simplex, lateralis (infra apicem marginis ovuligeri ortus) vel terminalis, filiformis, deciduus, vel sæpe urevissimus aut nullus; stigma capitatum, sphæroideum vel rarius subclavatum, integrum vel submarginatum, papillosum (sæpe quasi hispidulum), rarius læve. Fructus indehiscens, nucamentaceus, drupaceus vel baccaceus, 1-rarius 2-locularis, loculis 1 vel raro 2.3-spermis, rarissime (in Aquilarineis) capsularis bivalvis, valvis apice medio placentiferis; pericarpium membranaceum, coriaceum vel fibroso-lignosum. Semina pendula, anatropa, recta, funiculo obsoleto, rhaphe laterali, chalazâ apicem, micropyle basin loculi spectante, testâ tenui vel crustaceâ, rarius fibrosolignosâ. Embryo inversus, orthotropus, rectus, albumine (si adest) inclusus, radiculâ superâ brevi rectâ, cotyledonibus plano-convexis carnosis lævibus enerviis per germinationem epigæis et in folia subherbacea viridia conversis, plumulâ inconspicuâ. Albumen nullum, rarius tenue parcum, rarissime carnosum copiosum. - 
Frutices, rarius arbores vel herbæ, cortice tenaci, libro fibroso, succu acri caustico ; pili, dum adsunt, simplices; folia exstipulata, sparsa vel opposita, simplicia, indivisa, integerrima, sæpius coriacea nitida, basi articulata, plerumque angusta, nervatione pinnata; inflorescentia terminalis vel rarius axillaris; flores capitati, fasciculati, umbellati, racemosı vel spicati, raro solitarii, plerumque ebracteolati, cun pedicello aut receptaculo articulati, sæpius invulucro communi (interdum colorato) cincti, purpurei, albi, lutei vel virescentes, rarissime cœrulei, sæpe pulchelli odorati, extus sæpius sericeo-pubeicentes

Jenkirsia Grift: in Cale. journ. of nat. hist. 6, n. 13, Endl. gen. suppl. 4, 2, p. 69. est Miquelia Meisn inter Phytocreneas, teste Brown in Horsf. pl Jax. rar. p. 245.

\section{DIVISIONUM CONSPECTUS DIAGNOSTICUS.}

Subordo I. THYMEIEA.

Ovarium 1-loculare, ovulo unico, rarissime 2-3 ? prope apicem loculi parieti styligeræ appenso.

Tribus 1. DAPHNEe. - Squamulæ vel glandulæ perigynæ (calycis fauci vel medio tubo insertæ) nullæ.

Subtribus I. Hemistemonere. - Stamina calycis lobis dimidio pauciora (sc. 2). Genus 1.

Subtrib. II. Isostemoneed. - Stamina calycis lobis numero æqualia (sc. 4). Gen. 2-4.

Subtrib. III. Diplostemonece. - Stamina calycis lobis dupla (sc. 8 vel 10). Gen. 5-23.

Tribus. II. GNIDIEE. - Squamulæ vel glandulæ perigynæ variæ, calycis fanci vel rarius tubo insertæ ejusque lobis staminibusque plerumque alternæ.

Subtribus I. Isostemonea. - Stamina calycis lobis numero æqualia (sc. 4). Gen. 24-26.

Subtrib. II. Diplostemonea., - Stamina calycis lobis dupla (sc. 8 vel 10). Gen. 27-33.

Subordo II. AQUILARINEE.

Ovarium aut 2 -loculare, loculis 1 -ovulatis, aut 1 -loculare, placentis 2 parieralibus 1 -ovuligeris.

Tribus III. GYRINOPEx. - Squamula perigyna variæ, calycis fauci insertæ, staminibus al'erna, libere aut in cornnam connata. Gen. 34-37.

Tribus II. DRYmispermed. - Squamula perigynæ nullæ. Gen. 38-39. 
Subordo 1. THYMELEE Juss. gen. p. 76, R. Brown prodr. p. 358. Ovarium 1-loculare, 1- vel rarissime 2-3? ovulatum.

\section{Tribus I. DAPHNEAE.}

Squamulæ vel glandulæ perigynæ nullæ.

Subtribus I. HEMISTEMONER.

Stamina calycis lobis dimidio pauciora.

I. PIMELEA Banks et Solander in Gartn. fr. 1, p. 186,t. 39, f.1, Dryand. Ann. of bot. 2, p. 505, Smith Nov.-Holl. 1, p. 31, R. Brown prodr. A. Nov.-Holl. p. 359, Wikstr. Thym. in act. Holm. p.118, 270 et 273, Endl. gen. p. 331, n. 2098, suppl. 4, 2, p. 60, Meisn. gen. p. 330 (242), et in pl. Preiss. 1; p. 601, 2, p. 268. - Banksia Forst. char. gen. n. 4. (non alior.). - Cookia Gmel. syst. 1, p. 24 (non Sonner.). - Thecantlues Wikstr. l. c. p. 269 et 271, Endl. ic. t. 11. - Pimelea el Calyptrostegia C. A. Meyer in Bullet. Acad. St.-Pétersb. 4, p. 71.-Heteroliena et Gymnococca Fisch. et C. A. Mey. Index sem. hort. Petrop. 1845, p. 46, Ann. des sc. nat. $3^{-}$sér. 5, p. 372,Walp. Ann. 1, p. 585. - Macrostegia Turcz. in Bull. Soc. Mosc. 1852, 3, p. 177. Flora 1853, p. 743. - Passerince sp. Forst., Thunb., Linn. fil.

Flores hermaphroditi, raro polygami vel dioici. Calyx coloratus, regularis. tubulosus, limbo 4 -fido patente vel demum reflexo, fauce esquamatâ. uubo continuo vel sæpius supra ovarium articulatim rumpente, parte superiore deciduâ vel inferiore persistente. Stamina 2, fauci inserta, calycis tobis exterioribus opposita; flamentis plerumque conspicuis exsertis. squamula hypogynæ nullæ vel rarius obsoletæ. Stylus lateralis, capillaris. conspicutus, inclusus vel exsertus. Stigma capitatum. Nux calyce inclusa, libera.1-sperma. Semen inversum. Embryo orthotropus, radiculầ superâ. Albumen parcum. - Frutices, sulfrutices vel rarissime herbæ Novæ-Hollandiæ, Tasmanniæ et Novæ-Zeelandiæ, foliis opposilis vol rarius sparsis, summis seu floralibus sæpius majoribus et interdum coloratis approximatis vel verticillatis involu-

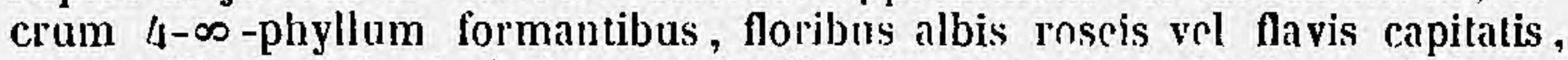
raro axillaribus fasciculatis vel subsolitariis, rarissime spicatis, capitulorum receptaculo hemisphærico vel subgloboso pubescente persistente.

\section{Sectio I. TheCantrHes.}

Involucrum gamopliyllum, infundibuliforme, 4-fid um, foribus demum superatum, Flores pedicellis membranaceo-dilatatis liberis aut involucro semiadnalis stipitati. Calyx infudibuliformı, gracilis, lobis ovitto-oblongis tubo angusto articulato multo brevioribus. Genitalia exserta. - Herbe Novæ-Hollandic tropicæ, glaberrimæ, caule erecto subsimplici, foliis oppositis subsessililus. - Genus Thecanthes Wikstr. 'Thym. p. 271. - Generis Calyptrostegia sect. 1. Theranthes C. A. Meyer l. c. p. 71. Endl. gen. suppl. $4,2,1,60$.

1. P. GornuCopia (Soland.! mss.), foliis lanceolatis vel subspathulatis utrinquo acutis, involucri lobis ovato-lanceolatis acutis. $\odot$ Ad Bustard Bay, Gape Grafton et Endeavour River oræ orientalis (Banks et Soland.), et sinum Carpentarie (R. Brown I). - Vahl enum. 1, p. 305, R. Brown! prodr. p. 359. Thecanthes Cornucopiæ Wikstr. Thym. p. 271*. Calyptrostegia Cornucopiæ Endl. gen. suppl. 4, 2, p. 60. Herba circiter perlalis, verisimiliter annua, radice tibrosâ, caule erecto, debili, tereti, simplici vel apice pauciramoso, internodiis $\frac{1}{4}-\frac{5}{i}$ poll. longis. Folia sessilia, $\frac{1}{2}-1$ poll. longa, obsolete 1-nervia, evenia, inferiora spathulata obtusa circ. 3 lin. lata, superiora sensim angustiora acuta. Involucrum terminale, pedunculatum, erectum, 8-10 lin. longum, lobis ovato-deltoideis acntis erectis. Flores 6-10, involucrum vix superantes, glaberrimi, pedicellis inæqualibus, éx parte involucro semiadnatis vel adglutinatis. Calycis lobi vix 1 lin. longi, tubo filiformi 3-4-plo breviores, genitalia exserta subæquantes. (v. s. in herb. Smith. et DC.) 
2. P. pUNICEA (R. Brown prodr. p. 359), foliis lanceolato-lincaribus-attenuato-acutis, involucri lobis late ovitis obtusissimis. $\odot$ In terrâ Irnhem et sinu Carpentarje (R. Br.).-15indl, ic. t. 11: Thicenthes punicea Wickstr. 1. c. p. 272. Calyptrostegia punicea Liıdl. gen. supp]. 4, 2, p. 60. Folia 6-10 lin. longa. Involuerum [1uniceum, 4 lin. longum. Cieterum prucedenti similis, sed omnibus partijus paulo minor.

1

Sectio II. Eupinelea.

Flores capitati vel fasciculati, raro solitarii. Involucri foliola discreta, 1 -pluriserialia. Drupa sicca, caljec vol toto vel cjus basi sulà persistente tecta. - Prmelea et Calyptrostegie spi. Endl. gen. suppl. 4,2, p. 60,61 .

§1. Heterolonna (Eudl. gen. p. 331).--Capitula termirialia. Involucri 4-(rarissime 5-8) phylli folia rameis plerumqu dissimilia, magnitudine, sive formâ et texturâ discrepantia, scepe colıruta. - Frutices Novee-Hollandice et T'asmannice, foliis oppositis.

3. 1'. colliva (R. Brown prodr. P. 359), foliis decussatis sulssesssilibus linearib) Jongis trincrviis, involucralilus ovetis utrintjue glabris capitulum suldequantibus, calycis tubo soriceo. 5 In Nova-Hollàndia tropieà (k. Br.). - - Wikstr. Thym. 1. $27 k$.

4. P. Linordes. (A. Cunningh. in Ficld New soutl Wales, p. 320, ex Limnet 2, litt* p. 121), fuliis oblongo-linceplatis apice callosis internodio plus dujulo longioribus, involucralibus late ovatis aculis glabris capitulo subbrevioriluus, calycis tubo villosissimo, ore 4-punctato, staminibus exsertis stylum subrquantibus. $₹$ In paludibus et ad cataractas montium Cocruleorum (.1. Cunn.). Calyptrostegia linoides lindl. gen. suppl. 4,2, p. 61.

5. P. MARGINAта, foliis rigicle corinceis sessilibus lanccolatis linearibusque acutis interuodio duplo longioribus planis nervoso-marginatis eveniis glabris, involucralibus ovato-oblongis flores subequantibus nervosis glabris, calyce adpresse sericeo-villosiusculo articulato, basi persistente parce pilosiusculat, lobis anguste ublongis obtusis tubo gracili cylindrico quadruplo brevioribus genitalia exserta vix superantibus stylo demum superatis. F In Nove-Hollandia occidentalis regionibus interioribus, ad Wellington Valley et flum. Macquarie (A. Cunningh.!). l'. linoirles A. Cumn.! mss. in lierb. DC. Forsan cum pracedente identica, cujus diagn. tamen purum convenit et nomen nimis ineptum. Rami stricti, conferti, foliosi. Folia 7-10 lin. longa, 1-2: lin. lata, demum patula, exsiccatione corulescontia, jreter nervum medium et marginaules subtus fortiter expressos evenia vel passim parce pennivenia, involucralia parum dissimilia, attamen basi semper latiora. Calyx 8-9 lin. longus, tubo angustissimo cylindraceo. (v. s. in herb. Cunn.. Soc. linn. Lond., DG., etc.)

6. P. GER NUA (R. Brown prodr. p. 359), lulhis spathulato-lineariljus 1-nerviis eveniis, involucralibus ovatis ulıjique glabris capilulum subæquantibus, calyce supra irticulationem pilosiusculo. 7 In Tasmannià (Labill.!). - Wikstr. Thym. p. 274. P. spatluulata Labill.! Nor.-Holl. 1, p. 9, t. 4, Lam. ill. t. 902, f. 1. P. linifolia A. Ciuno! in herb. ex parte. Calyptrostegia spathulata C. A. Mey. in Bull. Acad. rétersb. 4, p. 71. An a P. linifoliâ Sun. satis distincta? (r. s. in h. DG. comm. ab ipso auctore, sed specim. deflorata.)

7. P. виE vifol ra (R. Brown l.c. p. 359), foliis linearibus internodia vix superantibus, involueralibus ovatis capitulo $\frac{1}{4}$ brevioribus, interioribus intus villosiuseulis, calyce supra articulationem pilosiusculo. $ఫ$ In Nové-Hollandise orâ australi (R. Browu).-Wikstr. 1. c. p. 275. Calyptrostegia brevifolia C. A. Mey. 1. c.

8. P. L IN I F o I a (Smitlı! Nov.-Holl. p. 31, t. 11), foliis subpetiolatis linearibus ramisque glabris, involucralibus late ovatis 1 -nerviis eveniis glabris capitulo $\frac{1}{2}-\frac{1}{3}$ brevioribus, receptaculo hemispliarrico longiuscule villoso, calycis sericeo-villosi lobis oblongis obtusis tubo gracili articulato multo brevioribus, basi persistente tarde glabrescente, genitalibus exsertis lolos subacquantibus. $亏$ In Novâ-Hollandià orientali. - Vahl enum. p. 305, Bot. mag. t. 891, R. Brown prodr. p. 359, Wikstr. Thym. 
j. 274, Herb. amat. fasc. 36, t. 208, 13ot. cab. t. 1668 (var. albiflora). p. filamentosa Rudge in Linn. Trans. 10 , p. 287 , t. 14, f. 1 (mala). P. involucrata Banks et Sol. mss. Passerina involucrata Thumb. Mus. nat. Aead. Ups. 13, p. 106, fide Wikstr. 1. c. Calyptrostegia linifolia C. A. Mey. 1. c. j. 71. Species variabilis, ramis elongatis ramulisıue gracilibus satis dense foliosis. Folia herbacea, 6-10 lin. longa, 1-2 Jin. lata, 1-nervia, evenia vel obsoletissime paucivenia, semper acutínscula et nervo medio apice subincrassato sæpiusque paululum excurrente apiculata ; involucralia duplo latiora, evenia vel ohsolete venosi, olstusiuscula vel attenuatosubacuminata, siejo levitor rubescentia. Recuplaculum magnít. pisi, pilis fere 2 liı. longis sordide albidis dense villosum. Flores involucrum equintes vel plus minus (rarius dimidio) sujerantes, extus ubique subirejualiter scriceo-cani, jube subadpressấ sat densâ, lobis tulo cylindrico circ. triplo brcvioribus apice longius burbatis.

$\boldsymbol{\alpha}$. Smithiana, foliis lierbuceis semierectis lanceolatis $(1-2$ liı. latis $)$ acutis su\}eveniis, involucralibus capitulum subæequantibus eveniis, calycibus penicillato-villosis. - Girea Moreton Bay (A. Cumn. n. 25!), Sydney, etc. P. lirifolia Smith ! l. c. fide ej. herb. (v. s.)

3. Brownii, foliis subcoriaceis lanceolato-linearibus (1-2 liu. latis) subeveniis, involucralibus capitulo dimidio brevioribus eveniis, calyce densius villosiusculo, basi persistente demum glabrà. - In regionibus interioribus (A. Cunn.! Nitchell! exped. 1845). (v.s.)

$\gamma$. Andersonii, foliis subcoriaceis oblougu-vel spathulato-linearibus (1-2 $\frac{1}{2}$ lin. latis passim olssolete jenniveniis, involucralibus capitulum subrequantibus, calycis lobis villosis. - Circa Port-Jackson (Sieber! Lhotsky!). P. ligustrina Sieber, n. 207! n. mixta, n. 476! (non Labill.). Forma nimis accedens ad P. cernuam.

$\delta$. tenella, folijs herbaceis linearibus (4-6 lin. longis, 1 lin. latis) ereniis, involucralibus sueto minoribus ovato-oblougis viridibus capitulo $\frac{1}{3}-\frac{1}{2}$, brevioribus, calycis lobis brevius penicillatis. - In montibus Coeruleis (A. Cunn.! circa Moreton Bay (Strange !). P. linoides hort., non Cunn. (v. s. et v. v. c.)

- ? abietina, foliis coriaceis linearibus acutis ( $6 \mathrm{Jin}$. longis, $\frac{1}{2}-\frac{2}{3}$ lin. latis), subutus concavis (rarius planis) eveniis, nervo supra impresso vel obsoleto subtus acute promimulo, involucralibus ovatis vel uvato-oblongis purpurascentibus 1 -nerviis eveniis capitulum subæquantibus, calyce sericeo, lobis non penicillatis. - Circa Port-Jaclison (Siebor, n. 206!). Forsan distineta species. Folia fere P. paludosæ $\beta$ mucranatæ, sed breviora et mutica et flores minores. (v: s.)

$\zeta$ ? subnervosa, foliis coriaceis oblongo-vel spathulato-lanceolatis acutis veI obtusiusculis (5-7 lin. longis, $1 \frac{1}{2}-3$ lin. latis) 1 -nervijs vel passim obsolete triplinerviis venosisve, involucralibus semicoloratis ovatis submucronulatis interdum obsolets paucivenis capitulo vix $\div$ brevioribus, calycis lobis apice vix villosis. - Illawara (A. Cunn.! Hügel I), circa Sydney (Anderson !). Forsan cum P. collinà identica? ( $v$. s.)

9. P. Nu T A is (Meisn. iu Linnad $26,1,348^{\circ}$ ), foliis subsessilibus herbaceis linearibus obtusiusculis hasi attenuatis 1 -nerviis ramisque gracilibus glabris, involucralibus 4 capitulum inelinatum aequantilsus late ovatis breve acuminatis 1 -nerviis eveuiis glaberrimis. receptaculo velutino, calyce parce subsericeo, basi persistente hirsutá demum glabrescente, lobis lanceolatis tubo 4-plo brevioribus stylo sujeratis, antheris semiexsertis. 5 In Tasmannia, circa Georgetown (Gunn, n. 623! Stuart!). P. linifolía Gınn ! Ferd. Müll.l (non Sunith). A verẩ P. liniloliâ, cui sane simillima, capitulis constanter plus minus nutantibus, calyce minore parceque pubescente, stylo exserto, etc., bene distincta. (v. s.)

10. P. Gunntngamir, foliis subcoriaceis sessilibas internodio longioribus linearibus muticis planis subeveniis ramisque glabris, involucralibus $\$$ herbaceis coloratis ovatis obsolete venosis utrinque glabris capitulo $\frac{1}{3}-\frac{1}{3}$ brevioribus, receptaculo parvulo velutino, caljec dense subsetaceo-villoso, loljs tubo articulato duplo brevioribus oblongis obtusis genitalia exserta suł:erantibus. F In Novâ-Hollandiâ australi (Baxter! Latrobe!) et orient., circa Liverpool Plaius (Ä. Cunningh. n. 34 l). P. denticulata A. Cunn.! mss. Ramuli florỉleri monocephali circ. pollicares in rpice rami elongati subsimplicis quasi in racemum foliosum disjositi. Folia 4-7 lin. longa, $-1 \frac{1}{2}$ lin. lata, obtusiuscula, cocrulescentia, subtus obsolele venosa, involucralia acuta vel minute articulata, rubescentia et secus margínem coerules- 
centia, haud ciliata, 3-4 lin. longa, 2-3 lin. lata. Receptaculum globosum, pube

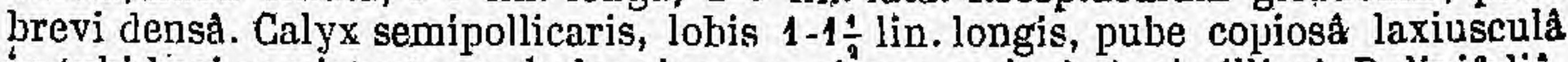
in tubi basi persistente paulo longiore magisque sericeâ. A simillimâ P. linifoliâ, præter notas jam indicatas distinguitur foliis rigidulis, calycis pube multo copiosiore longiore laxiusculâ minus sericeâ et in loborum apice haud penicillatâ. (v. s.)

11. P. PALUDOSA (R. Brown prodr. p. 360), foliis linearibus internodio longioribus, involucralibus 4 ovatis intus subsericeis capitulo dimidio brevioribus, calycis tubo sericeo. Jౌ Circa Port-Jackson (R. Br.), circa Bathurst (A. Cunn., Stephenson, n. 144 I. (v.s. in herb. Soc. linn: Lond.)

B. foliosa, foliis confertis erectis subsessilibus herbaceis linearibus obtusiusculis muticis 1 -nerviis eveniis, involucralibus capitulum subsuperantibus ovatooblongis acutis utrinque glabris, calyce subsericeo-cano, basi persistente parcius hirsutâ, lobis lanceolato-oblongis tubo triplo brevioribus genitalia demum exserta dimidio súperantibus. - Circa Sydney (A. Cunn.l Anderson!).

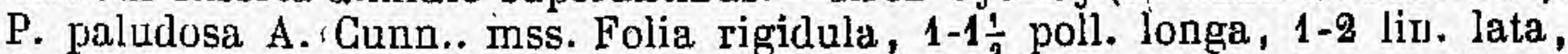
floralia viridia vel subcolorata, 1 -nervia, evenia. Calyx 6-7.lin. longus. (v. s.) $\gamma$ mucronata, foliis confertis erectis sessilibus linearibus mucronatis utrinque altenuatis 1 -nerviis subeveniis margine leviter recurvis, involucralibus capitulum subæquantibus coloratis intus pilosiusculis. - Circa Sydney (Anderson !). Internodia brevia. Folia circ. pollicaria, 1- raro $1 \frac{4}{2}$ lin. lata, muerone recto persistente. Gætera ut in $\beta$. (v. s.)

12. P. LINDLEYANA, foliis subcoriaceis brevissime petiolatis internodio-multo longioribus linearibus utrinque obtusiusculis 1 -nerviis eveniis ramulisque glabris, involúcralibus ovato-ohlongis evanescenti-1-nerviis utrinque glabris capitulum æquantibus, calyce dense sericeo-villoso, lobis tubo articulato angusto 3-4-plo brevioribus oblongis obtusis genitalia exserta vix superantibus. $\%$ Ad portum Macquarie Tasmanniæ occidentalis (Midligan, n. 396! Gunn, n. 623! Lindl. in herb. Mart.). P. cernua Gunn' mss. Facies præcedentium, folia P. paludosæ $\beta$, mutica, sed capitula dimidio minora, involucri foliola angustiora, $2-3 \frac{1}{2}$ lin. lata. Calyx 5-6 lin. longus, pube undique squali adpiressâ, tubo angustiore, fauce leviter constrictâ, lobis vix 1 lin, longis. (v.s.)

13. I. ANGUStifOLIA (R. Brown prodr. p. 360), foliis linearibus obtusiusculis ramulisque glaberrimis, involucralibus 4 capilulo brevioribus ovatis, interioribus intus sericeis, calycis dense sericei basi persistente longius villosâ, lobis tubo triplo brevioribus oblongis obtusiusculis genitalia parum superantibus. $尹$ In NovâHollandià australi et occidentali (R. Br.). - Wikstr. Thym. p. 275, Meisn. in pl. Preiss. 2, p. $269^{*}$. Calyptrostegia angustifolia C. A. Mey. 1. c.

a. minor (Mcisu. 1. c.), ramulis tenellis, foliis internodio brevioribus aut subæqualibus (vix $\frac{1}{2}$ lin. Jatis) involucralibus orbiculari-ovatis acutiusculis subenerviis capitulo 2-3-plo brevioribus (2:-4 lin. longis, 2-3 lin. latis). - In NovâCambriâ australi (Fraser !). (v. s. in herb. Shuttleworth.)

ß. major (Meisn. 1. c.), ramis fortioribus, foliis latioribus (usque ad 1 lin. latis) internodio longioribus, involucralibus subrotundis breve acuminatis tenuiter venosis capitulo dimidio brevioribus (3-5 lin. longis, 3 lin. latis). - In coloniầ Swan River (Drumm. coll. 1 et 3, n. 287!). (v. s.)

y. Drummondii (Meisn.l. c.), involucri foliolis subrotundo-ovatis vel ovato-oblongis obtusiusculis margine angustissime diaphanis, capitulo $\frac{1}{3}-\frac{1}{2}$ brevioribus obsolete venulosis (4-6 lin. longis, 3 lin. latis). Cæt. ut in $\beta$. $\frac{2}{2}$ Ad sinum Regis Georgii (A. Cunn.!) et Swan River (Drumm. coll. 3, n. 237! 6, n. 215!). (v, s.)

$\delta$ ? calvescens, caulibus simplicibus gracillimis, foliis linearibus utrinque attenuatis subacutis 1-nerviis glabris, involucralibus ovatis sensim attenuatis 1-nerviis eveniis eciliatis utrinque glabris capitulo 2-3-plo brevioribus, calyce parcius sericeo-piloso, basi persistente adpresse piosiusculâ (nec patentivillosâ). - Circa sinum Regis Georgii (A. Gunn.!). Folia 6-9 lin. longa, 1 lin. vel summa 2 lin. lata, internodio longiora. Involucrum viride. Propler involncrum glabrum et calycis pubescentiam diversam' forsan species distincta. (v. s. in herb. DC. et Mart.)

14. P. Gororans (A. Cunn.! mss. in herb.), 'foliis sessilibus lanceolato-linearibus mutícis utrinque attenuatis internodia æquantibus vel superantibus subtus 1 -ner- 
viis obsolete venosis ramulisque glabris, involucralibus 4 coloratis capitulo bre. vioribus late ovatis acuminatis obsolete 1 -nerviis eveniis intus pilosiusculis, calyce densc suriceo-tomentoso, basi persistente longius patenti-villosâ, lobis tubo articulato 3-4.plo brevioribus, antheris semiexsertis, stylo incluso. 5 Circa Glenfinlas et flum. Eachlan, in Novà-Hollandiâ orientali interiore (A. Cunningham, n. 10!). Rami tenucs, erccti. Folia conferta, demum semipatula sæpiusque cœrulescentia, obtusiuscula, 8-12 lin. longa, 1-1 $\frac{1}{2}$ lin. lata; involucra purpurascentia. Simillima $P$. augustifolia, sed involucro et calyce facile distinguenda. (v, s.).

$\beta$. apiculata, foliis Jinearibus muticis obsolete 1 -nerviis eveniis, involucralibus orbicularibus brevitor apjiculatis subenerviis eveniis capitulo dimidio brevioribus tenuiter ciliatis intus sericeis. - Circa Batliurst et ad flum. Macquarie (A. Cumn. in. 116!). Rami dichotomo-vel corymiboso-ramosissimi. Folia 6-8 lin. longa, $\frac{1}{2}-1$ lin. lata, utrinque attenuata, summa paulo latiora acuminata.; involeralia $4-5 \frac{1}{2}$ lin. longa, $3-4$ lin. lata, abrupte acuminata, acumine $\frac{1}{2}-1$ lin. longo acutiùsculo. Cæet. ut in typo. (v. s.)

15. P. KER V OSA (Nleisn. ill pl. Preiss. 2, p. $269^{*}$ ), foliis lanceolato-linearibus atteuuato-acutiusculis subtus 1 -nerviis obsolete venosis ramulisque glaberrimis, involucralibus \& fores subæquantibus late ovatis acuminatis multinerviis eciliatis interioribus intus subsericeis, calyce subsericeo-villoso, basi persistente villosissimâ, loljis lanceolatis tubo gracili sextuplo brevioribus genitalia paulo superanlibus. F In colonia Swan River (Gilbert!). /Calyptrostegia nervosa Waljers ann. j. 324. Involueri foliola viridia, 5-6 lin. longa, infra medium 3-4 lin. lata, acumine 2 lin. longo siepius complicato, nervis tenuibus acute prominulis flabellatis. Calyx 5-6 lin. longus, lobis $\frac{1}{2}$ lin. longis. Cret, fere $P$. angustifolim. (v. s.)

16. P. PET R OP H L A (Ferd. Müll.! in Liuneâ 25, p. 442"), ramulis sericeo-puberulis; foliis coriaccis séssilibus oblongis utrinque subacutis muticis glabris subtus deuse prominulo-penniveniis, involucralibus 4 , parum latioribus ovato-oblongis nervosis glabris flores superantibus, receptaculo tomęntoso, calyce sericeo, basi persistente tumilulâ demum glabrescente, lobis oblongis obtusis tubo articulato multo brevioribus stylum parum superantibus, antheris semiinclusis. 5 In Novæ-Hollandiæ uustralis montibus Flinders Range (Ferd. Müller !).-Meisn. ju Linnæâ 26, p. 3\$7*. Rami dichotomo-corymbosi. Folia interúodio longiora, semipatula, 4-6 lin. longa, 2 lin. lata, remum plus minus ccerulescentia, involucralia similia, busi tamen scmper paulo latiora, 2-2 $\frac{1}{2}$ lin. lata. Calyx $3 \frac{1}{2}$ lin. longus, medio articulatus. A proximà P. nervosâ facile dignoscerida, foliis brevioribus, latioribus magisque nervosis, involucralibus parum latioribus vix acuminatis, etc. (v. s.)

17. P. Prerssir (Meisn. in pl. Preiss. 1, p. $601^{*}$ (non Schlecht.), foliis lanceolatis acutiusculis eveniis ramulisque glabris, involucralibus 4 ovatis acutis ciliatis capitulo $\frac{1}{1}$ brevioribus, receptaculo villoso, calyce dense sericeo-villoso, basi persistente longius laxinsque pilosâ, Jobis ovato-oblongis tubo 3-4-plo brevioribus, antheris subsessilibus semiinclusis, stylu incluso. $J$ In coloniâ Swan River (Preiss: II. 1266! Drumm. n. 554!). P. Neypergiana hortul., fide Decaisne, in Revue hortic. 1852 , p. 80. Rami elongati, graciles, parce ramosi. Folia 6-8 lin. longa, $2 \frac{1}{2}-3 \frac{1}{2}$ lin. lata, subtus obsolete 1-nervia. Flores 9-12 lin. longi, pallide rosei, basi persistente demum glabrescente. (v. s.)

$\beta$. Gilberti, involucm foliolis intus pubesceutibus margino non ciliatis. - In Australiâ occidentali, legit Gilbert (v. s. in herb. Shuttl.).

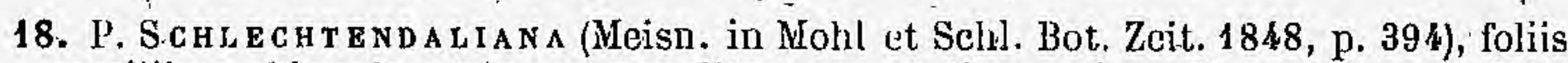
sessilibus oblougis -utrinque æequaliter angustalis acutiusculis vel mucronulatis 1-nerviis subtus parce venosis ramulisque glabris, involucralibus ovato-oblongis interioribus ciliatis capitulum aquantibus, ealyce dense subsericeo-piloso, basi persistente glabrà, lobis oblongis obtusis tubo gracili pluries brevioribus stamina breviter exserta sujerantibus stylum subsequantibıs. 5 In' arenosis, eirca Adelä̈de Novæ-Holl. australis (Belır, n. 50!). P, Preissii Schlecht. in Linnæâ 20, p. 581 (non Meisn.). Caly ytrustegia Schlechtendaliana Walp. ann. 3, p. 324. A verâ P. Preissii, cui sane valde accedit, notis indicatis beno distincta. Folia herbacea, circ. pollicaria, involucralia parum dissinilia, attamen semper basi paulo latiora (nec angustata). Calyx vix semipollicaris. (v. s.)

19. P. LANata (R. Brown prodr. p. 360), foliis ovali- vel lanceolato-oblongis acutis subenerviis ramulisque glabris, involucralibus 4 capitulum subæquantibus ovatis, 
albido-marginatis intus sericeis, calyce patulo-piloso, basi persistente dense sericco-villosà, lobis lanceolatis demum glabrescentibus tulo vix triplo brevioribus slamina exserta parum superantibus stylo superatis. $尹$ İ Novâ-Hollandiá meridionali (R. Br.), coloniâ Swan River (Preiss, n. 12791). - Wikstr. Thym. p. 276, Meisn. in pl. Preiss. 1, p. 604*. Calyptrostegia lanata Endlr gen. suppl. 4, 2, p. 61. Species distinctissima involucri foliis rameis subsequalibus, jarum latioribus, coriaceis viridibus secus marginem decoloribus diaplano-membrauaceis. (v. s.)

20. P. s т и с т а (Meisn. in Linnæà 26, j. $348^{*}$ ), foliis herbaceis sessilibus lanceolatis utrinque aqualiter attenvatis acutiusculis eveniis ramiśque striclis glabris, involucralibus capitulo demum $\frac{1}{4}$ brevioribus ovatis acuminato-acutis viridibus obsolete venosis angustissime albiclo-marginalis intus sericeis, calyce adpresse sericeo, loljis oblongis obtusis tubo brevioribus genitalia exserta parum superantibus. 3 In arenosis, prope portum Adèlaïde ct mont. Lofty ranges, ad flum. Murray (Ferd. Müller !). P. angustifolia F. Müll.! mss. (non R. Br.). Fruticulus paueipedalis, ramis gracilibus sæe longe simplicibus. Folia internodio parum longiora, 8-12 lin.

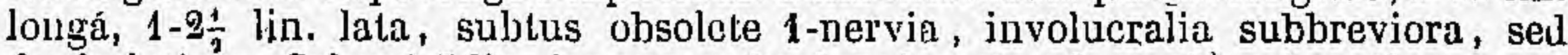
duplo latiora. Calyx 6-7 lin. longus, pulo densà arete adpressâ, quâ notâ et involucro species a P. lanata facile dignoscenda. (v. s.)

21. P. тINCTORIA (Meisn. in pl. Preiss. 1 , p. 608*), foliis coriaceis petiolatis elliptico-lanceolatis acutiusculis evenis caulergue subsimplici glabris, summis majoribus, involucralibus 4-5 flores subæquantibus herbaceis oblongis ciliatis utribrue glabris, calyce articulato....., basi persistenti hirsutà. $\supset$ Circa sinum Regis Georgii (Preiss, n. 1280!). A prascedentibus jam involucro facile dignoscenda. Folia intense cyano tincta. (v.s.)

22. P. G LAUG A (R. Brown! prodr. p. 360), foliis oblongo- vel lineari-lanceolatis acutis glaucis eveniis glabris, involucralibus 4 capitulo dimidio brevioribus ovatis vel ovato-olslongis acutis enerviis intus sericeis, interioribus ciliatis, calyce sericeo, basi persistente nudiusculà, lobis oblongis obtusis tubo gracili 3 -4-plo brevioribus gênitalia superantibus. 春 In Novâ-Hollandiâ orientali', australi et Tasmanniâ (R. Br.I Gandich.! d'Urville! A. Cunn.! Hügcl! Verreaux! Anderson I Ferd. Mïiller ! etc.). Formø $\alpha$ et $\beta$ in N.-Holl. tam orientali quam australi et Tasmanniả crescunt; $\beta$ in colonia Victoriâ et South Australiầ frequentior (Ferd. Müll.). - Rudge in Linn. Trans. 10, p. 286, t. 13, f. 2, Wikstr. Thyym. p. 275, Bot. cab. t. 1611, Meisn. in Linnæea 26, p. 349. Galyptrostegia glauca C. A. Mey. l. c. p. 71. Frutex ramosissimus, ramulis glabris. Folia 3.7 lin. longa, $1 \frac{1}{2}-2 \frac{1}{2}$ lin. Iáta, utrinque attenıata, sæepe enervia, summa paulo majora, involucralia $2-3$ lin. lata, interiora plerumque dense villoso-ciliata. Receptaculum brevius vel longius villosum.

a. minor, capitiulis parvis, involucri foliis quam caulina summa parım latioribus capitulo vix dimidio brevioribus, calyce dense villoso, lobis oltusiusculis barbatis. - P. campicola A. Cunn.! mss. (v. s. sp. Cunn.! Verreaux! etc.)

ß. major, capitulis floribusque majoribus, involucri foliis ovatis minus acutis quam caulina fere duplo latioribus capitulo dimidio brevioribus, calyce magis adpresse sericeo-villoso, lobis oblongis acutiusculis. - P. humilis Lindl. in Bot. reg. t. 1268, non R. Br. (v. s. sp. Inderson! Latrobe! Ferd. Müll.! etc.).

y.? subenervia (Meisn. in Linnæâ 26, p. 350), foliis marginibus involutis supra concavis dorso convexis, nervo obsoleto, receptaculo longo barbato. Get. ut in $\alpha$ et B. - Circa Port-Lincoln (Ferd: Müll.!).

23. P. INTERMEDIA (Lindl. in Bot. reg. t. 1439), foliis patentibus lanceolatis acutis basi attenuatis eveniis ramisque glabris, involucralibus 4 similibus vel parum latioribus subovatis capitulo $\frac{1}{3}$ brevioribus, interioribus ciliatis intus adpresse pilosiusculis, calyce tenui serjceo-tomentoso, basi persistente glabriusculâ, lobis oblongis tuho triplo brevioribus villosis antheras breve exsertas superantibus stỹlo longe sujeratis. J In Norà-Hollandiâ.....-Grah. in Edinb. phil. Journ. '1839, p. $421^{*}$. Plurimis notis convenit cum $P$. glaucâ, attamen vix mera ejusdem varietas. Rami debiles. Folia herbacea, vix glauca, patentia vel deflexa, 6-10 lin. longa, 2- vix 3 lin. lata, juniora mucronata, superiora sensim paulo latiora; involucralia usque ad 4 lin. lata, viridia, 1 -nervia, breve acuterje acuminata, decidua. Receptaculum hemisphæricum sordide villosum. Flores albi, 5-6 lin. longi. Species stricto jure Phyllolenis accensenda, sed inter eas nulli affinis. (v. v. c.) 
24. P. MODESTA (Mcisn. in pl. Preiss. 2, p, 268 ${ }^{*}$ ), foliis sessilibus internodio longioribus lanceolatis obtusiusculis subvenosis ramulisque glabris, involučralibus capitulo demum dimidio brevioribus late ovatis aculiusculis subenerviis glabris, calyce medio villoso supra infraque pube breviore rarioreque pilosiuscnlo, lobis tubo triplo brevioribus oblongis genitalia subsuperantibus. F In colonia Swan River (Drumm. coll. 3, n. 238 !). - Walp. aun. 3, p. 323. Folia 4-6 lin. longa, 1 $\frac{1}{2}$-2-raro $2 \frac{1}{2}$ liu. lata, nervo venisque obsoletis; ínvolucralia haud longiora, sed duplo latiora, viridia, sæpe subacuminata et flores 5-6 lin. longos subsequantia. Calyx tarde articulatim rumpens. Species a $\mathrm{P}$. glaucâ præcipue calycis pubescentiá divers diguoscenda. (v. s.)

25. P. Hu MIL Is (R. Brown! prodr. p. 361, non Lindl.), caule nano pubescente, foliis internodio subæqualibus oblongis obtusis 1 -nerviis subvenosis glabris, invotucralibus flores subæquantibus ovatis. calyce adpresse sericeo-hirsuto, lobis oblongis acutis tubo gracili multo brevioribus genitalia exscrta superantibus. $\hbar$ In Tasmanniả (R. Br.! Gunn!), Novâ-Hollandià australi (Fraser l), circa Victoria et PortPhillip (Latrobe! Ferd. Müll.!). - Wikstr. Thym. p. 278. Fruticulus digitalispithamæus, ramis corymbosis subsímpllicibus brevibus subadpresse hirsuto-pilosis.

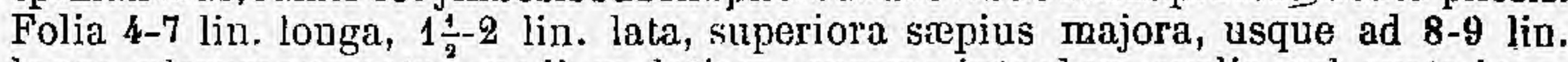
longa, plerumque extra medium latiora, summa interdum ovalia vel ovata involucralibus similia (unde species ad alteram generis sectionem a cel. auctore relata erat, sed arctiore alfinitate cum Heterolæenis connectitur), involucralia semper nervo et renis nonnullis tenuibus notata. Calyx circ. semipoilicaris, articulatus. (v. s. in h. DG., Sniith., etc.)

$\beta$. myrtifolia (MIeisn. in Linnæa $26, j .350$ ), foliis subacutis obsolete venosis marginatisque, involucralibus apjicem versus attenuatis. - Circa Adélaïde, Guichen Bay et Melbourne (Behr ! Ferd. Mïller !). P. myrtifolia Schlecht. in Linnæẩ 20, p. 582, Walp. ann. 1, p. 584. Rami interdum glabriusculi. Folia involucralia 4-5 lin. lata, obsolete paucivenosa vel passim evenia. (v. s.)

26. P. oratifolia, foliis herljaceis breve petiolatis ovalibus acutiusculis subrenosis ramulisfue pilosis, inrolucralibus 4 parum latiorilsus capitulo paucifloro paulo brevioribus, calyce pilosiusculo, basi persistente glabrescente, lobis ovatis obtusis tubo angusto triplo brevioribus, antheris semiexsertis, stylo. incluso. F Circa Port-Jackson (Gaudichaud I). Rami circ. spithamæi, debiles, pube sat densá patulà tecti, internudiis 3-5 lin. longis. Folia 4-5 lin. longa, 3 lin. lata, patula, obscure venosa, laxiuscule pilosa, supra demum glabrescentia; involucralia conformia, vix latiora parumque breviora, densius pilosa, margine ciliata. Capitula 3-6-flora. Calyx 4-5 lin. longus, pube parcâ brevi subadpressâ, lobis vix 1 lin. longis. A proxime affini $P$. humili jam foliis latioribus pubescentibus et petiolo $\frac{2}{3}$ lin. longo fultis distincta. (v. s. in h. DC.)

27. P. DECUSSATA (R. Brown prodr. p. 360), foliis decussatis sessilibus ovalibus obovatisve eveniis ramulisque glalıris, involucralibus 4 ovato-subrotundjs semicoloratis utrinque glabris, calrre infra medium patenti-piloso supra breviter adpresseque pubescente, lobis oblongo-lanceolatis tubo continuo subtriplo brevioribus stamina exserta vix supertutibus. 5 In Novâ-Hollandiâ austro-occidentali (R. Br., Menzies! 1803, Labill.! A. Cunn.!), circa sinum Regis Georgii (Preiss, n. 1272 ! Drumm, coll 3, n. 286 !). - Wilistr. Thym. p. 276, Bot. cab. L. 1283, Sweet fl. austr. t. 8, Meisn. in pl. P'reiss. 1, ]. 602, 2, p. 270. P. ferruginea Labill.! Nov.-Holl. 1, p. 10, t. 5. Heteroliena decussata C. A. MeJ. in Bull. Ac. St-Pétersb. 4, p. 71. Fruticulus 1-2-pedalis. Folia subcoriacea, 3-6 lin. longa, 2-4 lin. lata. Involucra ante expansionem subglobosa, magn. cerasi, sæepe pulchre sanguinea. Calyz roseus, 6 lin. longus. Squamuln hypogynes 4 minute in annulım subconnatæ. (v. s. et v. v. c.)

B.? diosmafolia, foliis oblongo-lanceolatis obtusis vel jassim acutis, staminibus breviter exsertis stylo superatis. - P. diosmefolia Lodd. Bot. cab. t. 1708. Folia 6-8 lin. Ionga, 2-3 lin. lata. Planta obscura, ex icone insufficiente haud certe dignoscenda.

28. P. RIGIDA, foliis sessilibus decussatis rigidis obovato-oblongis obtusis vel subacutis basi attenuatis margine revolutis subtus discoloribus 1 -nerviis ramulisque glabris; superioribus latioribus planis, involucralibus coloratis capitulo parum brevioribus late ovatis acuminulatis subenerviis utrinque glabris, calyce setuloso- 
piloso, lobis oblongis tulso articulato triplo brevioribus genitalia exserta vix superant tibus. F Circa Moreton Bay (A. Cunningh.l). P. collina A. Gunn.! mss. ex parte (non R. lir.). Folin xoriacea, cuneato-oblonga, 4,6 lin. longa, extra medium

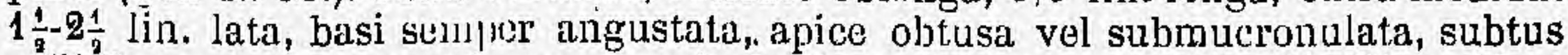
pallidiora, nervo supra impresso vel obsoleto subtus prominulo. Similis quidem P. decussatie, sed notis indicatis, satis distipcta. (v. s. in herb. DC. et Mart.)

29. P. RoSEA (R. Brown prodr. p. 360), folitis lanceolato-linearibus mucronulatoaculis obsolete venosis ramulisque glabris, summis parum Jatioribus involucralibus \& lanceolato-ovatis acuminatis flores sequantibus utrinque glabris, calyco gracili hautl articulato basi patenti-piloso supra pube brevi adpressà subsericeo, lobis oblongis tubo tenui triplo brevioribus genitalia exserta breviler superantibus. 寿 In Novâ-Hollandiâ austro-occidentali (R. Br.). - Bot. mag. t. 1458, Bot. cab. t. 88, Wikstr. Thym. p. 276. Heterolæna rosea G. 1. Mey. 1. c. Rami debiles, internodiis inferioribus 2-3 lin. summis 6-10 lin. longis. Folia herbacea, plana, inferiora 6-8 lị. louga, 1 lin. lata, summa duplo latiora et dimidio longiora, ulrincue atleuuata; involucralia herbacea, acutissima, 8-10 lin. longa, 2:- 4 lin. lata, infra medium latiora et plus minus rubescentia. Receptaculum villosum. Calyx roseus, $5-7$ lin. Tongus. (v. s. c.)

$\beta$. Hendersonii, foliis mucronulatis subvenosis, involucralibus ovatis acuminatis subeoloratis basi ciliatis nudisve, receptaculo longiuscule villoso, calyce - superne subsericeo infra medium patentim hispido basi g/abriusculo. Cæt. ut in typo speciei.--Circa sinum Regis Georgii tt in colonià Swan fiver (Fraser l Preiss, n. 1276! 1262! Drumm. n، 550! Gilbert, 11. 40! Morrison, n. 103!). P. Hendersoni Grah. in Bot. mag. t. 3721, et in Edinb. phil. Journ. 1839, june. P. rosei XIeisn. in pl. Preiss. 1, p. $602^{*}$. P. lispida A. Cunn.! in herb., ex parte. Fruticulus pluripedalis. Folia plus minus coriacea sitpiusque manifeste jrommulo-pennivenia, apice marginibusctuc demum recurvis, involucralia uscjue ad 5-6 lin. lata. Forma nullo charactere specifico stajoili a verà P. roseà distincla. (v. s. et v. v. c.)

$\gamma$. calocephala (MIeisn. in pl. Proiss. 1, j. 602), ramis elongalis strietis, foliis subpollicaribus, capitulís majoribus, floribus albis magis sericeis involucrum viride superantibus. Crt: ut in $\beta$. - Circa Pertli (Yreiss, nl. 1267 f). Forsan sjécies distincta, yrimo vulı quidem sátis a formis pracedentibus discrepans, atlumen verisimiliter nomnisi formann vegetiorem sistens. Rami 1-1;-pedales. Folia 10-14 lin. longa, obsolete senosa, submutica, involucralia 8-10 lin. lati, minus acuminati.-Calyx 10-11 lin. longus, jube densiore et longiore, sulıra nedium adpressà sericeà. (v. s.)

30. P. HISPIDA (R. Brown prodr. p. 360), foliis lanceolatis linearibusve eveniis muticis, involucralibus 4 capitulo dimidio -brevioribus ovatis eveniis intus subsericeis, calyce supra medium adjresse pilosiusculo infra hispido, lobis lanceolatis extus hispidis tulo continuo tenui nulto brevioribus genitalia superantibus. F Circa sinum Brgis Georgii (R. Brown, A. Cunningh.!). - Wikstr. Thym. p. 276, Bot. reg, t. 1578, Bot. cab. t. 1966, Bot. mag. t. 3459. Heterolena hispida C. A. Mey. l. c. Facie plerisque characteribus convenil cum P. roseâ, sed constanter differt foliis herbaceis planis obtusiusculis muticis vix ultra 8 lin. longis, involucralibus brevioribus ot calycis (rosei) lobis longioribus dorso pilis longiusculis patentibus hispidis. (v. s. ot r. v. c. in hort. Kew.)

31. P. MENKEANA (Lehm.I mss.), foliis subimbricatis lanteolato-linearibus muticis coriaceis eveniis iamisque glabris, involucralibus 8 biseriatis capitulo parum brevioribus viridibus ovalibus ovatisque, calyce articulato 'xtus ubique patulohispido inferme longins densiusque piluso, lobis oblongis tubo dimidio brevioribus genitalia vix superantibus. JIn Novâ-Hollańdiâ austro-occidentali interiore (Preiss, n. 1269!).--Micisn. in pl. Preiss. 1, p. 684*. Calyptrostegia Menkeana Endl. gen. suppl. 1,2, p. 61. Fruticulus pedalis, ramis caulibusque erectis simplicibus strictis superne conferte foliosis apice monocephalis. Folia 4-7 lín. longa, 2 lin. lata, obtuśíluseula, dorso 1-nervia vel superiora enervia. Capituluin magnit. pruni, involucro pallide viridi submembranaceo, foliis interioribus ciliatis intus pilosiusculis, floribus 8-10 lin. longis luteis. (v. s.)

3. dubia, involucra flores soquante vel parum superante, foliolis haud ciliatis. Gæl. ut in typo, ex Turez. in Bull. Soc. Mosc. 1852, 3, p. 179, sub Calyptrostegiâ Drummondii (Drumm. n. 427, quam non vidimus). 
32. P. SUAVEOLENS (Meisn. in pl. Preiss. 1, p. $603^{*}$ ), foliis patulis lineari-lanceolatis acutis muticis eveniis ramisque glabris, involucralibus 8 biseriatis capitulum subaquantibus ovalo- vel lanceolato-oblongis acuminatis submembranaceis venosis ciliatis glabris, calyce ubique æequaliter patenti-piloso, lobis oblongis tubo tenui demum articulato $3-4-p$ lo brevioribus genitalia exserta superantibus. $\zeta$ Circa Pertl colonix Swan River (Preiss, n. 1268! Drumm. 11. 548!). Calyptrostegia suaveolens Endl. 1. c. Fruticulus 1-2-pedalis, caulibus erectis apice corymboso-pleio-

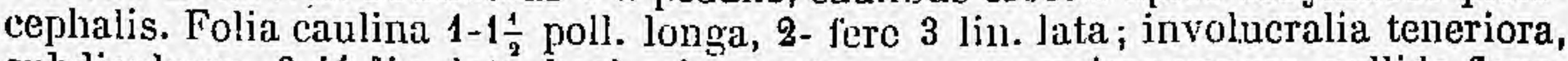

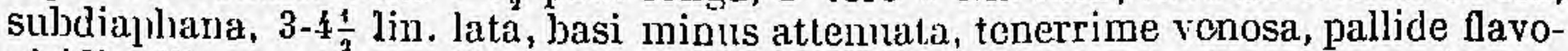
viridia. Flores circ. pollicares, sulpluurci, suavculentes, calycis basi persistente demum glabrescente. (v. s.)

33. P. SPEctabil is (Lindl.! Swan Riv. pl. in Bol. reg. 1839, app. p. 41; n. 193), foliis lanceolato-linearibus ncutis vel mucronulatis glaucis obsolete venosis ramisque glalris, involucralibus 4-6 coloratis submembranaceis capitulo brevioribus owatis rel ovato-oblongis, calyce continuo infra mellium longe patenti-piloso supra adpresse sericeo, lobis lanceolatis tubo anguste infundibuliformi multo brevioribus genitalia vix superantibus apice longius pilosis. $\frac{f}{\text { In }}$ coloniâ Swan River (Drumm. coll. 1, 3, 11. 283! et ex parte 284!), ad flum. Murray (Gilbert, n. 8!). But. reg 1841 , t. 33, misc. n. 18, Mcisn. in pl. Preiss. 1, p. 603, in notà, 2, p. 270 , Bot. mag. t. 3950. Heteroliena spectabilis Fiscl. et C. A. Mey. ind. sem. hort. Petrup. 1845, p. 46, Bull. Ac. St-Pétersb. 4, p. 71. Ann. sc. nat. 3• sér. 5, p. 373. Ilabitus $P$. suaveólentis. Folia $1-1 \frac{1}{2}$ poll. longa, 2-3 lin. lata, brevissime petiolata, basi minus attenuata obtusa, apice subpungenti-acuta, semper plus minus manifeste jennivenia, involucralia rubentia. Capitula mole pomi minoris, floribus circ. pollicaribus carneis demum pallidis inodoris. (v. s. et v. v. c.)

$\beta$.? Verschaffeltii, foliis pulverulento-incanis, inferioribus Ianceolatis oblongisque, floralibus ovatis: calycis lobis dimidium tubum subecquantibus. Cíet. ut in P. spectabili.P. Verschaffeltii Morren in Ann. Soc. agric. de Gand, 3, p. 584. Stirps in hortis cnata, forsan hybrida.

34. P. Lehmannana (Meisn. in pl. Preiss. 1, p. 603*, 2, p. 270), foliis coriaceis lanceolatis acutis subeveniis ramisque glabris, involucralibus 4 capitulum sulwquantibus ovato-oblongis breve acuminatis subcoriaceis viridibus glabris, calycis tubo anguste infundibulari supra ovarium hirsuto demum rumpente, infra supraque glabrescente, lobis lanceolatis tubo multo brevioribus genitalibus superatis. 5 Circa sinum Regis Georgii (Preiss, 11. 1271! Gillsert, n. 8! ex parte). Caly!'trostegia Lehmanniana Endl. gen. suppl. 4, 2, p. 61. Valde quidem accedil ad $\mathrm{P}$. spectabilem, sed distincta foliis rigidioribus apicem versus minus attenuatis supra saltem subeveniis, summis latioribus ovato-oblongis 4-6 lin. latis, involucro, calyce supra medium adpresse hirsutulo nec sericeo vel cito glabrato, etc. (v. s.)

B. nervósa (Meisn. in pl. Preiss. 2, p. 270), foliis subinarginatis, nervo venisque subtus plus minus conspicuis, floribus minoribus.-Circa Swan River, ex Drumm. coll. 3, n. 284 ! ex parte. (v. s.)

35. P. PHYSODES (Hook. ic. t. 865), foliis imbricatis sessilibus ovali-oblongis acutis 1 -nerviis eveniis glabris, involucralibus 4-6 flores superantibus coloratis concavis conniventibus, calyce pilosılo, lolis subalatis tubun medio constrictum æquantibus genitalibus longe superatis. 5 In interioribus coloniæ Swan River (Drummond, n. 424, et suppl. n. 84). Macrostegia erubescens Turcz. in Bull. Soc. imp. Mosc. 1852,3, p. $177^{\star}$, Flora 1853, p. 743 . Species insignis. Folía conferta, superne arcte imbricata, 12-20 lin. longa, 6-9 lin. lata. Capitula nutantia, pomi minoris mole. Involucrum ovato-globosum, 2 poll. longum, flavo-rubrum, subclausum floresifue omnino abscondens, foliolis late ovalibus obtusis demum deciduis. Receptaculum depressum villosum. Calyx articulatus, basi persistente glabrâ, fauce (ex Turez. 1. c) inter stamina plicatà, ques vero plicæe apud Hook. l. c. nec in descriptione, nec in icone (ab accuratissimo Fitch delineatâ) indicantur ideoque aut casnales aut plane illuşoriæe aut saltem nimis leves et ar genus proprium (Macrostegiam Turcz.) constituendum insuflicientes nobis videntur.

36. P. MACROCEPHALA (Hook. in Bol. mag. t. 4543), foliis sessilibus coriaceís glaucis oblongis acutiusculis 1 -11erviis eveniis ramisque glabris, involueralibus 4-6 ovatis coloratis eapitnlo brevioribus glabris, calyce articulato toto subequa- 
liter sericeo-villoso, loljis ovalibus tubo multo brevioribus genitalibus superatis. 腾 In coloniâ Swan líver (Drumm. coll. 5, n. 426!). Calyptrostegia macrocepliala Walp. ann. 3, p. 324. C. Drummondii Turez. in Brll. Soc. imp. Mose. 1852, 3, p. 178", Flora 1853, p. 743 . Rani virgati, graciles, sat dense foliosi. Folia 10-24 lin. longa, 3-6 lin. lata, mutica, interdum obscure pennivenia; involucralia haud longiora, sed circ. duplo latiora purpurascentia. Receptaculum hemisphæricum, breve villosum. Calyx 8-9 lin. longus, dense patulo-villosus, flavescenti-albus. Species hinc præcedentibus et P. floribundæ, inde etiam P. tinctoriæe et Preissii affinis, sed ab omnibus bene ristinefa. (v. s.)

37. P. FLORIDUNDA, foliis sessilibus patulis ovali-oblongis acutiusculis subeveniis ramulisque glabris, involucralibus 4 capitulo $\frac{1}{3}$ brevioribus herbaceis late ovatis vel ovato-oblongis acutiusculis concavis parce venosis glabris, calyce articulato pube brevi adpressâ dense sericeo, basi persistente densissime albo-villosà, lobis oblongis tubo tenui multo brevioribus genitalịbus superatis. F In Australiâ occidentali interiore (Drumm, coll. 6, n. 214l). Ramuli corymbosi, laxiuscule foliosi. Folia subcoriacea, glauca? 7-12 lin. longa, 3-6 lin. lata, utrinque attenuata, 1 -nervia, venis pinnatis obsoletis vel nullis; summa paulo majora, saltem latiora, obovaí-elliptica. Capitula breviter pedunculata, sæpe nutantia, magnit. juglandis, dense inultiflora, involucro viridi vel basi rubescente deciduo, receptaculo depresso-hemisphicrico breve villoso. Calyx 8-9 lin. longus, flavus, extus albidosericeus. Affinis P., macrocephalæ, physodi et Preissii; sed tam foliis quam calyce facile dignoscenda. (v, s. comm. ab am. Shuttleworth.)

38. P. uigustrina (Labill.! Nov.-Holl, 1, p. 9, t. 3), foliis herbaceis ovalibus lanceolatisque obtusiusculis penniveniis ramulisque glabris, involueralibus $4-5$ capitulo $\frac{1}{2}-\frac{1}{2}$ hrevioribus coloritis subrotundo-ovatis venosis ciliatis extus glabris intus sericeis deciduis, calyce articulato. minute sericeo-pubescente, basi persistente laxiuscule pilosâ, lobis oblongis tubo triplo brevioribus stamina suherquantibus stylo superatis. J Circa Port-Jackson et in Tasmannià (Labill.! R. Brown! Gunn!). - R. Brown prodr. p. 360, Wikstr. Thym. p. 275, Bot. reg. t. 1827. Calyptrostegia ligustrina C. A. Mey. I. e. Rami graciles, stricti, lase foliosi, internodiis $\frac{1}{2}-1$-poll. longis. Folia sessilia, patula, 1-2 poll: longa, 5-10 lin. lata,.mutica, venis tenuibus apicem petentihus; involucralia 4 vel rarius 5, rubescentia, 5-7 lin. longa, $k-6$ lin. lata, intus pubescentia vel demum glabrata. Capitula pedunculata, subglobosa, densissime multiflora, niagnit. juglandis minoris, receptaculo ovato breviter velutino. Calyx gracilis, pube minutà dense sericeus. Stanina (ex Bot. reg. t. 1827) interdum inclusa, stylus semper exsertus, calycem plerumque superans. (v. s. in lerb. Smith., DG., etc., et v. ‥ c.)

39. P. H YPERICINA (Hlook. in Bol. mag. L. 3330), foliis herbaceis ovalibus oblongisque acutis penniveniîs ramulisque glabris, involucralibus 4-8 capitulo duplo hrevioriluus late ovatis eveniis persistentibus pedunculoque dense sericeo-incanis, calyce artículato toto subsericeo-tomentoso, lobis ovatis tubo duplo brevioribus stylum sujerantibus staminibus superatis. 7 Circa sinum Regis Georgii (Baxter). Calyptrostegia hypericina C. A. Mcj. l. c. Habitu, foliis capitulo pedunculato fere omnino convenit cum $P$. ligustrinâ, involucro vero minore, ejusque et calycis pubescentian, stylo lireviore, noc non foliis constanter aculis superioribusque sensim latioribus ellipticis facile distinguitur. (v. v. c.)

40. P. é at a (Ferd. llïll.! mss. in herb. et First general report; ctc. p. 17), foliis lanceolatis acutis basi oltusà subsessiliłbus supra cveniis subtus tenuissime penniveniis ramulisque glabris, involucralibus 4 capitulum longiuscule pedunculatum iequantibus herbaceis ovatis oblongisve acutis suhereniis utrinque glabris, calyce articulato sericeo-tomentoso, basi persistente longius pilosâ, lobis oblongis dimidium tubum genitaliaque exserta subequantibus. $尹$ In Novæ-Hollandiæe or a australi, ad 11. Darby, Wilson's promontory, flum. Glenelg et circa Rivoli Bay (Ferd. Müllor!). - Mrisn. in Linna'i 26, p. 349 . Precedentibus arcte affinis et foliis presertim valde similis, at notis indicatis, precipue involucro, bene dis-

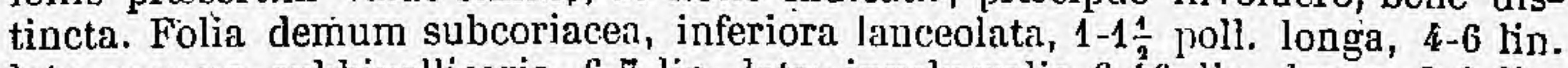
lata, summa subhijollicaria, 6-7 lin. lata; involucralia 6-10 lin. longa, 3-6 lin. lata, viridia vel plus minus purpurascentia. (r. s. comm. a cl. Sonder.) 
\$2. Phyllolana (Endl. gen. p. 331). - Capitula terminalia. Involucri 2-4 vel rarius 6-phylli folia rameis aqualia et conformia, nec latiora. - Frutices Nova-Hollandice et Tasmannioe, foliis oppositis ramisque glaberrimis.

41. P. S y Viest RIS (R. Brown't pradr. j. 361), glabra, foliis herbaceis lanceolatis acutis, involucralibus 4-6 capitulo pedunculato brevioribus, receptaculo hemisphærico brevissime villoso, calyce glabro, tubo infundibuliformi articulato supra basin persistentem inflatam angustissimo, lobis ovato-oblongis staminibus superatis. $亏$ Circa sinum Regis Georgii (R. Br.! Preiss, n. 1270! Drumm. n. 551!), Wilsstr. Thym. p. 277, Bot. reg.t. 1582, Bot. cab, t. :965, Bot. mag. t. 3276, Meisn. in pl. Preiss. 1, p. 605. Calyptrostegia sylvestris C. A. Mey. iu Bull. Ac. St-Pétersb. 4 , p. 71. Rami graciles, laxiuscule folirsi. Folia patula, 10-18 lin. Ionga, $2 \frac{4}{2}-4$ lin. lata, utrinque attenuata, 1-nervia, ever ia, Calyx pallide roseus, 8-9 lin. longus, tubo supra basin tumidam fliformi ibicque tarde rumpente, fauce infundibuliformi

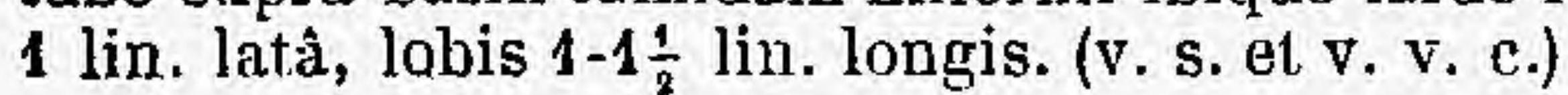

42. P. GRACILFF oRA (Hook. in Bot. mag. t. 3288), glabra, foliis coriaceis lanceolatis vel ovali-oblongis acutis, involucralibus capitulo breviter pedunculato brevioribus decìduis, receptaculo ovato-conico velutino, calyce glabro, supra basin parum inflatam articulato, tubo subinfundibuliformi, lobis oblongis stamina subæequantibus. 责 In coloniá Swan River (Drumm. coll. 3, o. 289! Preiss, n. 1274!).Meisn. in pl. Preiss. 1, p. $605^{\star}, 2$, p. 270 . Calyptrostegia graciliflora Endl. gen. suppl. 4, 2, p. 61. Rami plerumque, breviores, validiores. Folia confertiora, glauca vel viridia, polliee plerumque breviora, 3-5 lin. lata, interdum capitulum suJ. sequantia. P. sylvestri simillima quidem, at notis indicatis, prosertim calycis tubo superne parum dilatato, facile dignoscenda. (v. s.)

43. P. SUL I U UREA (Meisn. in Mohl et Sch]. bot. Zeit. 1848, p. 396), ramis elóngatis subsimplicibus vel corymboso-ramosis, foliis coriaceis glaucescentibus ovalibus subrotundisque 1-nerviis eveniis, involucralibus 6-8 vix majoribus capitulum subrequantibus, calyce articulato adpresse sericeo-puberulo, lobis ovalibus tubo 2-3-plo brevioribus genitalia cxserta vix superantibus. $\frac{\hbar}{\zeta}$ In coloniâ Swạn River (Drumm. coll. 1, et 3, n. 549, Preiss, n. 1278! Morrison!). P. Dava Meisu. in pl. Preíss. 1, p. 605* (non R. Br.). Calyptrostegia sulphurea Walp. ann. 3, p. 325.

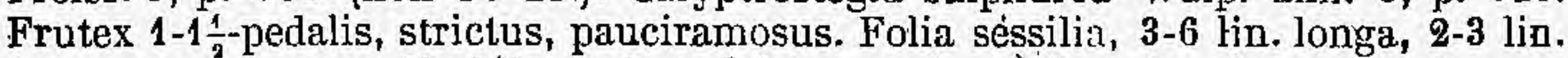
lata, summa sape dimidio majora, obtusa vel acutiuscula, interdum demum corulescentia; involucralia vix vel parum majora, viridia vel subrubescentia, interdum angustissime albido-marginata intus`sericeo-pilosiuscula. Calyx 7-8 lin. longus, plus minus dense sericeo-pubescens, basi persistente paulo longius, sed etiam adpresse pilosâ. (v. s.)

44. P. M IтснELLII, foliis coriaceis spathulato-linearibus muticis subtus venosis ramulisque glabris, involucralibus 4 subconformibus minoribus capitulo duplo brevioribus, calyce gracili toto equaliter sericeo-tomentoso, lobis oblongis tubo articulato 4 -plo, brevioribus antheras exsertas superantibus siylum subrequantibus. $\hbar$ In Novâ-Hollandià orientali interiore subtropicâ, ad Depot Camp 29 (Mitchell, n. 557!). P. colorans Mitchell! exped. into Irop. Austr. p. 362 (non A. Curn.). Fruticulus, ut videtur, humilis, corymboso-ramosus, ramulis rubris glabris dense foliosis, internodiis $2-4 \mathrm{lin}$. longis. Folia sessilia, semierecta, corulescentia, 5-7 lin. longa, 1-1 $\frac{1}{2}$ lin. lata, basin versus cuneato-attenuata, obtusa vel acutiuscula, supra enervia, subtus nervo venisque paucis vix prominulis notata; involucralia circ. 3 lin. longa, $1 \frac{1}{2} 2$ lin. lata, cæterum rameis similia. Receptaculum parvulum (diam. 1 lin.), argenteo-villosiusculum, 8-10-florum. Calyx 5-6 lin. longus, pube brevi undique requali adpressà dense sericcus, albus? A verâ P. colorante cunn. (supra, n. 14) tam foliis quam involucro longe differt. (v. s. comm. a cl. Lindley.)

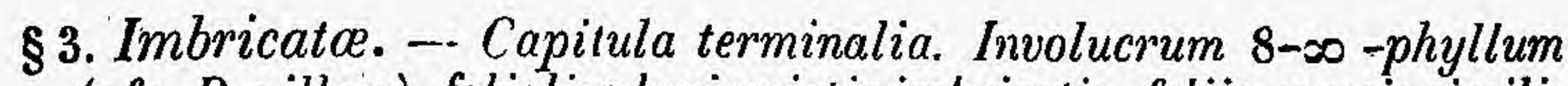
(cfr. P. villosa), foliolis pluriserial is imbricatis, foliis rameis similibus angustis, raro latioribus dissimilibus (cfr. P. imbricata). Calyx gracilis, pubescens, lobis tubo pluries brevioribus. - Frutices humiles 
Novce-Hollandia australis et occidentalis, foliis alternis oppositisque plerumque hirsutis.

45. P. LONGIPLORA (R. Brown! prodr. p. 361), foliis sparsis oppositisque linearibus obtusis dorso ramisque pilosis demum glabratis, involucialibus $8-10$ villosis capitulo brevioribus, calyce adpresse sericeo-villoso articulato, lobis lanceolatis acutís dimidium tubum requantibus, antheris subsessilibus exsertis, stylo incluso. $\hbar$ Circa sinum Regis Georgii (R. Br.! Fraser ! Preiss, n. 1263! Drumm. coll. 3, n. 2881), circa Augusta (Gilbert, n. 332 !).-Wikstr. Thym. p. 279, Bot. mag. t. 3281, Meisn. in pl. Preiss. 1, p. 606, 2, p. 271. Calyptrostegia longiflora Endl. gen. suppl. 4, 2, p. 61. Frutex $1 \frac{1}{2}$-pedalis, erectus, ramis gracilibus apice corymbosis. Folia plerumque sparsa, coriacea, semierecta, 3-7 lin. longa, vix $1 \mathrm{lin}$. lata, dorso convexa obsolete 1-nervia, florália sæpius paulo breviora basiquo latiora. Capitulum multiflorum, magnit. pruni minoris. Calyx 5 lin. longus, pallide roseus? (v. s.)

46. P. PHYLICOIDES (Meisn. in pl. Preiss. 2, p. 271*), foliis sparsis passimque suboppositis linearibus obtusis dorso subcarinato-1-nerviis ramisque pilosiusculis demum glabris, floralibus 6-10 paulo majoribus capitulo parum brevioribus subdenticulatis, calyce articulato Jjasi piloso supra dénse subseríceo-lanato, lobis dimidium tubum subrequantibus oblongis obtusis, antheris exsertis, stylo incluso. $\zeta$ In orà australi, circa Port-Phillip (Latrobe!), Guichen Bay, Rivoli Bay, etc. (Ferd. Müller 1). - Meísn. in Linnæâ 26, p. 352. Cil yptrostegia phylicoides Walp. ann. 3, p. 324. Folía 2-3 lin. longa, subcarinata, summa sub lente márgine elevato-punctata. Gupitula vix cerasi magnit., 6-10-flora, floribus fragrantibus (Müll. in litt.). Calyx supra basin persistentem parce pilosam pube brevi sublanatus vix sericeus. Cæet. fere P. longifloræ. (v. s.)

47. P. IM B I C A T A (R. Brown prodr. p. 361), foliis imbricatis lineari-oblongis subtus pubescentibus demum glabris, floralibus numerosis utrinque sericeis, calyce hirsutissimo. $ち$ InNovä-Hullandiâ australi-occidentali (R. Br.).-Wilistr. Thym. p. 279.

$\beta$. Baxteri, caule ramisque abbreviatis superne pubescentibus, folifs glabriusculis superioribus ciliatis, floralibus haud vel parum latioribus capitulo $\frac{1}{3}-\frac{1}{2}$ brevioribus dense villoso-ciliatis dorso sericeis glabratisve, calyce tarde articulato breviter villoso, lobis oblongis tubo pluries brevioribus stamina subzquantibus stylo superatis. $\delta$ In orâ australi (Baxter! Fraser !), circa sinum Regis Georgii (Preiss, n. 1273!), Toodjay, Swan River (Gilbert !). P. imbricata Meisn. in pl. Preiss. 1, p. 605:. P. Baxteri A. Cunn.! mss. in herb. Fruticulus pedalis vel nanus, dense ramosus foliosusque. Folia $2-5$ lin. longa, 1-1 $\frac{1}{2}$ lin. lata, mox glabra. Flores rosei, 4-5 lin. Iongi. Receptaculum parvulum velutinum. (v. s.)

y.? gracillima, ramis elongatis laxis demum denudatis ramulis filiformibus glabris, foliis dorso adpresse pilosiusculis glabratisve, floralibus numerosis lanceolatis vel passim ovatis adpresse pilosis glabrisve capitulo dimidio brevioribus, calyce tarde articulato infra medium sericeo-villoso supra hispidulo lobis lanceolatis tubo triplo brevioribus genitalia subæquantibus. 5 In colonià Swan River (Drumm. n. 552 !). P. microcephala $\beta$ major Meisn. in pl. Preiss. $1, p .606$, in notâ (non R. Br.). B. imbricata $\beta$ glabrata Meisn. ib. 2, p..270. Forsan species distincta, facie saltem a var. $\beta$ valde discrepans, sed characteres differontiales sufficientes constantesque frustra quæruntur (v. s.)

48. P. A м m о cha is (F. Müll. in Hook. Journ. 1857, p. 24), foliis sessilibus dense imbricatis angustato-lanceolatis acutis subcoucavis 1 trinque cano-sericeis, flora. libus conformibus capitulum plerumque pauciflorum æquantibus, floribus dioicis extus sericeis, calycis masculi tubo continuo lobis ovatis fere triplo longiore, feminei infra medium patenti-villoso supra sericeo, stylo incluso. $\bar{I}$ In arenosis, ad fl. Sturt Australise centralis. Frutex paucipedalis, patens, dichotome ramosissimus vel rarius simpliciter ramosus et stricte erectus. Folia $2-4$ lin. longa, 1-1 $\frac{1}{2}$ lin. lata. Flores lutei. - Videtur aflinis P. imbricate et sericese.

49. P. CR IN I A (Lindl. in Bot. mag. 1838, misc. p. 59, n. 109), foliis oppositis linearibus supra glabris subtus cauleque albo-villosis, floralibus numerosis imbricatis angustioribus flores requantibus, calycis tubo villoso, limbo suprá glabro, genitalibus longe exsertis. $ち$ In coloniâ Swan River. Fruticulus pulchellus, floribus niveis odore debili Heliotropio subsimilis. Verisimiliter mera var. præcedentis vel sequentis. 
50. P. NA NA (Grah. in Edinb. phil. Journ. jul. 1840), foliis sparsis lineari-lanceolatis acutis dorso ranisque subhirsuto-pilosis floralibus conformibus numerosis capjtulo subæequalibus laxiusculis, calyce continuo sericeo basi patenti-piloso lobis tubo triplo brevioribus lanceolatis aculis genitalia subsquantibus. 5 Cirea sinum Regis Georgii (A. Cunn.!) et in coloniâ Swan River (Pruiss,.n. 1275! 1277! Drumm.! n. 533 vel 553, coll. 3, n. 236! Gilbert! Morrison !). - Bot. mag. t. 3833. Meisn. in pl. Preiss. 1, p. 606, 2, p. 272 P. pílibunda 1 . Cunn.! mss. in berb. Calyptrustegia nana Endl. gen. suppl. 4, 2, p. 61. Fruticulus 1-2-pedalis, corýmboso-ramosus. Folia 3-6 lin. longa, 1-1 $\frac{1}{2}$ lin. Jata, cum ramis et. involuero pilis patulis allis 1 lin. longis plus minus dense hirsutis. Capitula dense multillora. Calyx albus, circ. semipollicaris, infra medium pilis patentissimis 1-1 $\frac{1}{2}$ lin. longis supra duplo brevioribus subadpressis dense vestitus. Hanc ad $\mathrm{P}$. imbricatam $\mathrm{R}$. Br. referendam censet cl. Kippist in litt., sed cum diagnosi non convenit et a P. imbricatâ nostrâ saltem, præcipue var. $\gamma$ primo vultu distincta est. (v. s.)

$\beta$. glabrifolia, foliis ciliatis ntrinque glabris, summis tantum pilosis (Drumm.! coll. 3 , n. 236 , ex parte).

51.? P. VILLOSA, ramosissima, foliis oppositis? hrevissime petiolatis lineari-lanccolatis margine revolutis subtus ramisque villosis, involucralibus 4 latioribus capitulo dimidio brevioribus, calycis tubo toto adpresse villoso infra medium articulato lobis subtriplo longiore, antheris subsessilibus exsertis. $\bar{J}$ In colonià Swan River (Drumm. coll. 5, n. 428). Calyptrostegia villosa Turcz. in Bull. soc. imp. Mosc. 1852, n. 3, p. $178^{\circ}$, Flora 1853, p. 743. Caulis erectus. Folia (an opposita, an sparsa sint, non dicitur) erecta, obtusiuscula, inferiora internodiis parum, superiora duplo longiora. Capitula circ. 20-flora. Filamenta in fauce inclusa brevissima. Orarium apice barbulatum. Affinis dicitur sequenti, sed ạb eâ et pracecdentibus jam involucro 4-plıyllo, etc., differre videtur.

52. -P. OCT OPHYLLA (R. Brown / prodr. p. 361), foliis sparsis passimque oppositis nblongo-linearibus utrinque obtusis ramisque molliter laxeque pilosis, floralibus conformibus paulo minoribus numerosis capitulo brevioribus, calyce articulato villoso, basi persistente demum glabrescente, lobis tubo multo brevioribus oblongis

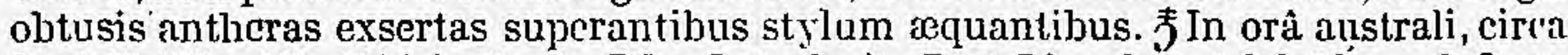
Port-Phillip (R. Bi.!! in herb. DC, Latrobe!), Port-Lincoln, Adelaïde, ad flum. Murray, etc. (Behr! Ferd. Müller!):-Tikstr. Thym. p. 279, Meisn. in pl. Preiss. 2, p. 271. Plurimis notis cum $\mathrm{I}$. nadi conveniens, sed bene distincta pubescentia iensiore, molliore et præcipue calyce urticulato. (v. s.)

- . Behrii, foliis dense scricco-villosis plerisque oppositis (Behr, u. 53!). P. Behrii Schlecht. in Linnæeâ 20 , p. $583^{\circ}$, Walp. ann. 1, p. 585 . (v. s.)

$\gamma$. viminea, foliis dense cano-pilosis abbreviatis sparsis, inferioribus oppositis (Behr, n. 54! F. Müll.I). P. viminea Schleclit.! l. c. p. $583^{k}$, Walp. ann. 1, p. 585. Folia vix ultra 4 lin. longa, pube adpressà densâ albidà potius canâ quam ' sericeâ. Cum $\beta$ potius formam quam varietatem stabilom, certe saltem haud speciem propriam sistit. (v. s.)

53. P. PETR E A (Meisn. in Linnæà $26, \mathrm{p}, 347^{\circ}$ ), foliis sparsis linearibus acutiusculis 1 -nerviis eveniis subtus minute puberulis margine dense villoso-ciliatis demum glabrescentibus, floralibus conformibus æqualihus numerosis capitulo subbrevioribus, calyce articuláto tuloo patenti-villoso, fauce limboque parce puberulis, lobis lanceolatis obtusis tubo subtriplo brevioribus genitalia æuquantibus. $\Rightarrow$ Circa Adelä̈de (Ferd. Müller !). Et hæec forsan mera var. P. ottophyllie, attamen pubescentiæ indole, calyce paulo breviore (5-6 lin. longo) lobisque respectu tubi longioribus satis distincta videtur. (v. s. comm. a cl. Sonder.)

54. P. vi trifera (Meisn. in pl. Preiss. 2, p. $271^{*}$, non Cumn.), foliis oppositis oblongo-lanceolatis obtusiusculis subtus ramulisque molliter pubescentibus, floraribus conformibus minoribus confertis floribusque vix longioribus dense sericeovillosis, calycis lobis tubum articulatum subrequantibus lanceolatis staminibus parum stylo longius superatis. $\%$ In coloniâ Swan River (Drumm. coll. 3, n. 239l). Calyptrostegia villifera Walj. ann. 3, p. 324. Habitus præcedentium, sed bene dịstincta foliis latioribus (5-8 lin. longis, 2-3 lin. latis) pube brevi subadpressâ sat dense pilosiusculis, summis capituloque (globoso dense multifloro, magnit. cerasi) egregic villosis, et præcipue calyce breviore vix ultra 3 lin. longo. (v, s. comm. ab am. Shuttleworth.) 


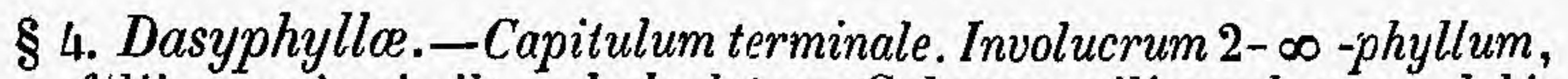
foliis rameis simile, vel obsoletum. Calyx gracilis, pubescens, lobis tubo brevioribus. - Frutices Tasmannici, foliis oppositis subtus vel utrinque incanis vel dense adpresso-pilosis.

55. P. CINEREA (R. Brown ! prodr. p. 361), foliis subsessilibus lanceolato-oblongis obtusiusculis supra glabris subtus ramulisque incano-villosis, floralibus 2 capitulo paucifloro longioribus, calyce continuo incano-villoso, lobis ovato-oblongis

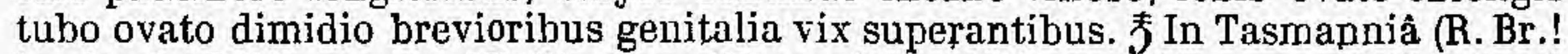
in herb. DC.), monte Wellington (Fraser!). - Wilistr. Thym. p. 282. Rami graciles; laxiuscule foliosi. Folia patula, subcoriacea, 8-14 lin. longa, 3-6 lin. lata, supra glabra, obscure impresso-penninervia. subuts villis albidis adpressis subsericeo-incana, floralia conformia, sed minora. Calyx 3 lín. longus, sericeus, tubo ovato-oblongo, fauce angústátâ. Nucula sicca, apice pilosiuscula. (v. s.)

56. P. INCANA (R. Brown prodr. p. 361), ramulis cinereis, foliis distinclis ovatis margine recurvis subtus incano-tomentosis supra glabris. $亏$ In Tasmannid (R. Br.): -Wikstr. Thym., p. 282, Bot. reg. 1838, t. 24. Heterolæna incana C. A. Mey. in Bull. Acad. St-Pétersh. 4, p. 71. A sequente verisimiliter haud specifice distincta.

57. P. N Ive A (Labill.! Nov.-Holl. 1, p. 10, t, 6), foliis subpetiolatis late ovalibus orbicularibusve margine recurvis supra glabris subtus ramulisque incano-tomentosis albidis, floralibus 2 vel 4 conformibus capitulo multifloro brevioribus, calyce articulato villoso-tomentoso, lobis ovalibus tubo triplo brevioribus, genitalibus exsertis. F In Novæe-Hollandiæ orâ australi? (R. 'Br.) et Tasmanniâ (Labill.! R. Brown! d'Urville! etc.).--R. Brown! prodr. p. 361, Wikstr. Thym. p. 283 , Hook. fil. in Hook. Lond. Journ. 6, p. 281, Walp. ans. 1, p. 584: Heterolæna nivea C. A. Mey. 1. c. Fruticulus pluripedalis, ramis gracilibus corymbosis incanotomentosis vel albo-lanatis. Folia coriacea, juniora imbricata plana, mox remotiora et patentia internodio demum sepius breviora, raro paulo longiora, margine recurva, magnitudine et formâ variabilia, basi interdum cordata. Flores albi. Species satis varians, formæ tamen sequentes vix validis limitibus interstinctæ.

a. erecta (Hook. fil. 1. c.), foliis ovatis subrotundisve, ramulis elongatis capitulo solitario terminatis. P. nivea Labill.! in herb. Roem., R. Brown! in herb. DC., etc. Folia 4-5 lin. longa et sæpius æquilata. Calyx circ. semipollicaris, lobis genitalia superantibus. (v. s.)

$\beta$. thyrsoidea (Hook. fil. 1. c.), caule ramisque erectis, ramulis confertis sxepissime polycephalis (Gunn, Verreaux !). P. incana R. Br.? 1. c., Lindl, in Bot. reg. 1838 , t. 24 . Folia plerumque præcedente paulo minora, sursum decrescentia. Calyx paulo brevior, lobis genitalia subæquantibus. (v. s. et v. v. c.)

$\gamma$. nummularia (Hook. fil. l. c.), erecta vel basi prostrata, foliis late ovato-oblongis orbiculatisque basi cordatis, (v. s. in herb. DC. et Mus. paris.)

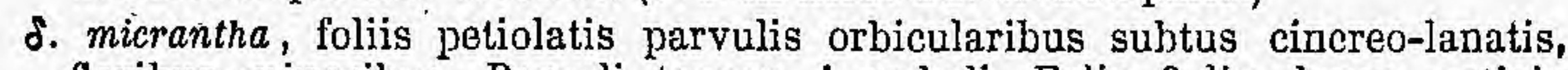
floribus minoribus. Ramuli tenues, 1-cephali. Folia 3 lin. Ionga, petiolo manifesto $\frac{1}{2}$ lin. longo. Calyx vix 4 lin. longus, incano-tomentosus, lobis stamina subsuperantibus styylo breviter superatis. (v. v. c. in horto Monac.)

58. P. SERIGEA (R. Brown! prodr. p. 361), foliis ovatis vel ellipticis obtusis planis

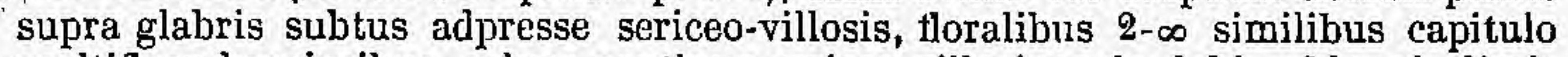
multifloro brevioribus, calyce continuo sericeo-villosiusculo, lobis oblongis dimi . dium tubum subrequantibus genitalia subsuperantibus. $\bar{J}$ In monte Tabulari Tasmannire (R. Br.! A. Gunn.! Gunn, 1842, n. 288). - Wilistr. Thym. p. 281, excl. $\beta$. Ramuli graciles, 1-cephali, cano-puberuli. Folia internodio longiora, imbricata, demum patentia remotiora, 3-8 lin. longa, 2-4 lin. lata, coriacea, sessilia vel summa saltem brevissime petiolata, interdum margine demum recurva, floralia rameis sæepe paulo majora. Calyx 6-7 lin. longus. Species a P. niveâ, çeterum simillima, foliis subtus sericeis nec incanis, facile dignoscenda. (v. s. in herb. DC., A. Cunn., etc.)

59. P. MrLuigani (Meisn. mss. in herb. Soc. linn. Lond.), foliis imbricatis lanceolato-oblongis utrinque adpresse denseque sericeo-villosis, floralibus $\infty$ similibus capitulum multiflorum subequantibus, calyce continuo villosiusculo, lobis ovatis dimidium tubum subsequantibus genitalia exserta superantibus. $\bar{J}$ In monte

XIV. 
Sorrel, prope Macquarie Harbour, Tasmanniæ occidentalis (Jos. Milligan I): Rami humiles, crassiusculi, iterato-dichotomi, dense cicatrisato-annulati, juniores sericeo-villosi. Folia decussata, herbacea? sessilia 3-6 lin. longa, 2-4 lin. lata, plana, obtusiuscula, pube densâ molli pallide flavescente longiusculâ adpressâ pulchre sericeo-splendentia. Calyx 5 lin. longus, pube brevi subadpressâ sericeus, tụbo tenui cylindraceo. Species insignis, a præcedentibus jam foliis dense imbricatis supra nunquam glabrescentibus distincta, facie valde similis. P. arenariæ, sed foliorum pubescentiâ densiore molliore et calyce dimidio longiore gracili faeile dignoscenda. Fructus ignotus. (v, s.)

§ 5. Micrantha._Capitula terminalia plerumque pauciflora. Involu-

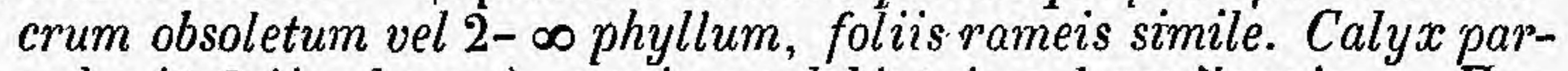
vulus (1-2 lin. longus), continuus, lobis tubo subcequilongis. - Fruticuli Nova-Hollandia. orientalis et australis, foliis oppositis, supra vel plerumque utrinque glabris.

60.2 P. cLAvat a (Labill.l Nov.-Holl. 1, p. 11*), foliis herbaceis lanceolatis acutiusculis venosis subtus ramulisque adpresse pilosiusculis, floribus dioicis, capitulis masculis pedunculatis nudis, calyce cano. $\bar{\zeta}$ In Novæ-Hollandiæ orâ australi (Labill.! R. Br.! Gaudich.! in herb. DG.), circa sinum Regis Georgii (A. Cunn.! specim. dellorata ideoque quoad speciem incerta, foliis vix pollicaribus, pedunculo longioribus, receptaculo fem.? exinvolućrato subgloboso magnit. seminis Viciæ minoris villoso). - Wikstr. Thym. p. 279. Rami graciles. Folia patentia, 1-2 poll. longa, $2 \frac{1}{2}-5$ lin. Lata, brevissime petiolata. Pedunculi $\sigma^{7} \frac{1}{2}-1$ poll. longi, $Q$ plerumque breviores, capitulo magn. pisi majoris. Receptaculum masc. ovatum vel oblongum, 2 lin. longum, breve villosum. Calyx ơ vix $1 \frac{4}{2}-2$ lin. longus. Fruet. non vidimus. (v. s. et v. v. c.)

61. P. vmbratica-(A. Gunn.I mss. in herb.), foliis coríaceis lanceolatis mueronulato-acutissimis venosis subtus ramulisque adpresse puberulis, floralibus similibus capitulo subsessili multo longioribus decidnis, calyce sericeo-pilosiuscula $7 \mathrm{Al}$ basin jugi. montium, prope Moreton Bay (A. Cunningh.I). Frutex ramosissimus, ramulis filiformibus sericeis demum glabratis conférte foliosis, internodiis $2-3$ lin., demum 6-8 lin. longis. Folia rigidula, subsessilia, patula, inferiora oblongc-vol ovato-lanceolata, 12-14 lin.-longa, 3-4 lin. lata, superiora duplo vel triplo minora, 5-7 lin. longa, 2 lin. lata, subtus parce pilosiuscula, demum glabrata. Capitula 2-4-flora, grani piperis magnit., demum sæpe lateralia, pedunculo nullo vel vix

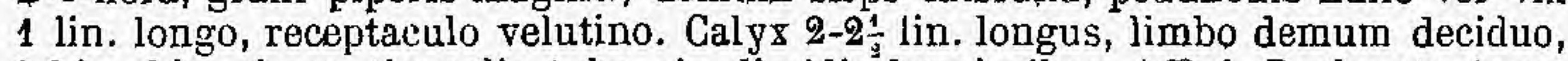
lobis oblongis acutiusculis tubo vix dimidio brevioribus. Affinis P. clavatæ (рræcipue specim. Gunningh.) et forsan P. latifoliæ, quam non vidimus; a priore distincta foliis minoribus acıtissimis rigidulis, cápitulis subsessilibus, floribus hermaphroditis (?), receptaculo hemisphærico velutino, etc. (v. s. in herb. Cunn., DC., etc.)

62. P. FLAVA (R. Brown prodr. p. 361), ramis dichotomis, junioribus puberulis, foliis coriaceis ovalibus orbicularibusve subeveniis glabris, floralibus 4 conformibus capitulo parum lòngioribus, calyce continuo incano-sericeo, lobis ovalibus dimidium tubum æquantibus, genitalibus subinclusis. 7 In Nova-Hollandiâ australi et Tasmanniâ (R. Br.! in herb. DC., Stuart).-Wikstr. Thym. p. 278, Meisn. in Mohl et Sehlecht. Bot. zeit. 1848 , p. 395* . Cal yptrostegia flava Endl. gen. 4, 2, p. 61, Walp. ann. 3, p. 325. Rami graciles, glabri, iterato-dichotomi, juniores adpresse pilosiusculi. Folia conferta, imbricata, demum distantia patula, internodio sæpe breviora, sessilia, plana, 1-nervia, obtusa vel subacuta, 3-5 lin. longa; 3-4 lin. lata, demum cœrulescentia, involucralia $4-6$ lin. longa et sæepe vix angustiora decidua. Capitula

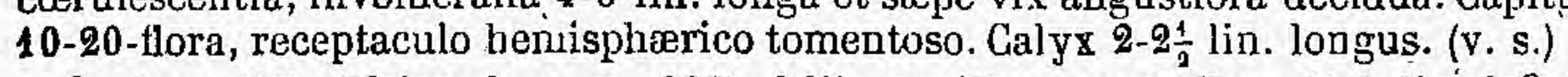

3. diosmafolia (Meisn. 1. c. p. 396), foliis ovalihus minoribus (2-3 lin. loñgis, $1 \frac{1}{2}-2$ lin. latis), floralibus latioribus sed vix longioribus. - In Nová-Hollandiấ orientali et australi interiore, ad flum. Lachlan (A. Cunn.!), circa Adelä̈do (Behr, n. 51!), ad flum. Murray et Spencer's et St-Vincent's gulf (F. Müll.). P. diosmifolia A. Cunningh.! mss. in herb. (non Lodd.). P. dichotoma Schlecht.! in Linnæeâ 20, p. $581^{\dagger}$, Walp. ann. 1, p. 584. Folia interdum vix cœrulescentia, obsolete venosa Involucrum floribus æquale vel paulo brevius. Flores albi, ex Müll, in litt. (v. s.)

y. parvifolla, foliis ovalibus (3-4 lin. longis; $1 \frac{1}{3}-2$ lin, latis) subtus prominulo. 
pauciveniis, floralibus sublatioribus, flores (2 lin, longos) vix superantibus.Círca Port-Lincoln' (Ferd. Müller I). P. parvifolia Meisn. in Linnæâ 26, p. 3k5*" Folia flavo-viridia, rarius cœrulescentia. Cum $\beta$ potius lusum quam varietatem stabilem sisteris. ( $v$, s. comm. a cl. Sonder.)

63. P. SERPYLLIF OLIA (R. Brown prodr. p. 360), glabra, erecta, ramosissima, foliis confertis subrotundo-ovalibus obovatisve obtusis eveniis, floralibus 4 conformibus capitulo sessili 4-6-floro longioribus, receptaculo puberulo, calyce continuo glabro lobis tubum subæquantibus, genitalibus inclusis. F In Australid meridionali (R. Br.), in arenosis littoraliluus coloniæ South Australia et Victoria, St-Vincent's gulf, Port-Lincoln, etc. (Ferd. Müll.!). - Wikstr. Thym. p. 277. Frutex densus, orgyalis vel altior (F. Müll. in litt.). Folia sessilia, opposita, subeoriacea, læete

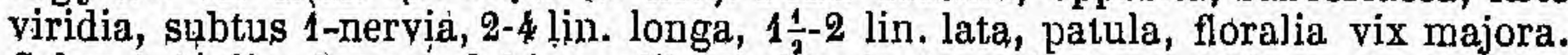
Calyx 1-1 $\frac{1}{3}$ lin. longus, lobis ovalibus obtusis. (v. s. in herb. DC., ex herb. Mus. paris., et comm. a cl. Sonder.)

64. P. c L U y T I01DEs (Meisn. iu pl. Preiss. 2, p. 271*), glabra, folís spathuláto- vel lanceolato-oblongis obtusiusculis cum mucronulo recurvo deciduo subenerviis, floralibus paulo latioribus capitulo 3-5-floro longioribus, receptaculo puberulo, calyce continuo glabro, lobis tubo turbinato sublongioribus stanina exserta superantibus, stylo incluso. F Círca Port-Phillip (Latrobe!). Proxima sane P. serpyllifoliæ, sed jam foliis magis coriaceis, angustioribus, mucronulatis, ete., facile dignoscenda. (v. s.)

65. P. P Y G M A A (Ferd. Müll. et, Stuart! mss.), cæspitoso-fruticulosa nana dense foliosa glabra, foliis ovali-oblongis ciliatis, capitulo 1-3-floro, subbrevioribus, calyce continuo glabro, lobis tubo anguste infundibuliformi brevioribus antheras exsertas superantibus dorso apice pilosiusculie, stylo incluso. 5 In mont. altissimis Tasmanniæ (Stuart 1).-Meisn. ín Linnæâ 26, p. 346*'. Calyptrostegía cluytioides Walp. ann. 3, p. 324. Rami dichotomo-corymbosi, glabri, circ. pollicares. Folia imbricata, demum patula, subcoriacea, acutiuscula, mutica, 2 lin. longa, 1-14 lin. lata, floralia haud majora. Calyx albus, $2 \frac{1}{2}$ lin. longus. Præcedentibus valde accedens, sed jam staturâ pusillá distincta. (v. s. in herb. Sonder.)

66. P. ALPINAA (Ferd. Müll.! mss.), foliis lanceolatis obtusiusculis eveniis ramulisque glabris, floralibus 4 latioribus capitılum 10-15-florum subæquantibus, calyce cano-pubertto, lobis tubo dimidio brevioribus genitalia superantibus. $\zeta$ In montibus Cabboras Australiæe Felicis, alt. 6,000 ped. (Ferd. Müller l). Fruticulus digitalis, ramulis gracilibus adscendentibus. Folia imbricata, demum patula, 3-4 lin. longa, 1-1 $\frac{1}{2}$ lin. lata, subsessilia, floralia vix 3 lin. longa, 2 lin. lata. Calyx 3 lin. lon. gus, subsericeo-puberulus. Habitus P. prostratæ, folia fere P. cluytioídis, ab utraque jam calyce longiore et pubescente facile distinguenda. (v. s. in herb. Sonder.)

67. P. HEWARDIANA (Meisn. in Linneầ 26, p. 346"), erecta, ramosissima, ramis gracilibus, junioribus puberulis, foliis oblongo-lanceolatis muticis subvenosis glabris, floralibus 4-6 similibus capítulum 6 -10-florum superantibus, calyce exiguo sericeo, lobis tubum æequantibus genitalia exserta superantibus. $\bar{\zeta}$ In Novâ-Hollandiâ australi-orientali interiore (Mitchell! exped. 1835). Rami pedales, erectí, stricti. Folia sessilia, patula, subcoriacea, 3-5 lin. longa, 1-2 lin. lata, plus minus distipcte pennivenia, venis interdum prominulis. Calyx 1 lin. longus. Species a præcedentibus jam habitu graciliore, laxiore et floribus minoribus sericeis bene distincta. (v.' s. comm. a cl. Lindl. et Heward.)

B.? elachantha (Meisn. l. c.), foliis oblongo-linearibus obtusis (2-3 lin. longis, 1 lin. latis) everiiis. - In Australia Felici (Ferd. Müll.!). P. elachantha Ferd. Müller I first gen. report, p. 17. (v. s. comm. a cl. Sonder.)

§ 6. Epallage (Endl. gen. p. 331, suppl. 4, 2, p. 61).-Capitula terminalia vel fasciculi axillares pauciflori sessiles vel ramulum lateralem brevem terminantes, involucro nullo vel spurio foliis rameis simili. Calyx parvus, lobis tubo gracili brevioribus. - Frutices, suffrutices vel herba Nova-Hollandice orientalis, australis et Tasmannice, foliis alternis vel passim (prosertim inferioribus) oppositis. Pimeleæ sect. 5, R. Br. prodr. p. 362.

68. P. sıMPLEX (Ferd. Müll.! in Linnæå 25, p. $443 \%$ ), caule trerbaceo snbsimplici 
erecto apice pilosiusculo, foliis sparsis linearibus obtusiusculis subenerviis glahris, floralibus similibus capitulo terminali paucifloro brevioribus, calycis tubo villosulo, fauce constrictâ, limbo parvulo sericeo demum deciduo, genitalibus inclusis. $\odot$ In Australiâ meridionali interiore, circa Cudnoka (Ferd. Müller!). Meisn. in Linnæâ 25, p. 351. Herba spithamæa vel digitalis, tenella. Folia 3-6 lin. longa, $\frac{1}{2}-1$. lin. lata, internodium squantia vel superantia, erecta, juniora jarce adpresse pilosa, floralia æequalia vel minora. Calyx 2 lin. longus, limbo flavo.Valde affinis P. trichostachyæ Lindl. (fide Müll. in litt.) nec non P. propinquæ Cunn., sed notis indicatis satis distincti. (v. s. comm. a cl. Sonder.)

69. P. PROPIN QU X (A. Cunningh.! mss. in herb.), foliis sparsis vel passim oppositis oblongo-lanceolatis acutiusculis ramulisque adpresse hirsuto-pilosis supra demum glabratis, junioribus sericeis; capitulis terminalibus axillaribusque subsessilibus submultifloris folia æquantibus, calyce articulato dense sericeo, lobis iequalibus tubo gracili 2-3-plo brevioribus. $₹$ Circa Bathurst (A. Cunn.!) et Holdfast Bay, prope Adelä̈de, St-Vincent's gulf (Ferd. Müller!). P: congesta A. Cunn.! mss. in herb. n. 153. P. gracilis F. Mïll.! ex parte. Species, monente A. Cunn. in sched., medium tenens P. curvifloram inter et gracilem; forsan prioris mera var., attamen præter notas indicatas satis discrepans pubescentiâ densiore magis adpressâ, calyce

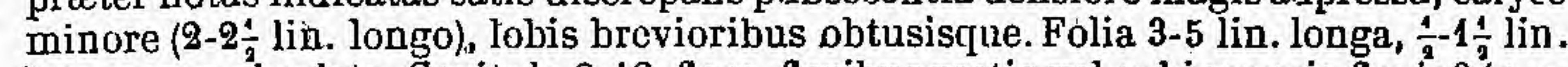
lata, nervo obsoleto. Capitula 8-12-flora, floribus rectis vel subincurvis flavis? (v. s. comm. a cl. Heward et Sonder.)

70. P. CURVIFLORA (R. Brown prodr. p. 362), foliis sparsis passimque oppositis oblongo-linearibus supra glabris subtus ramulisque adpresse sericeo-hirsutis, capitulis termínalibus axillaribusque subsessilibus paucifloris folia superantibus, calyce articulato sericeo, lobis inæqualibus angustis tubo gracili curvato duplo brevioribus. $ち$ In Novà-Holl. orientali, circa Port-Jackson, Bathurst, etc. (R. Br.! herb. Banks.! Smith! etc., d'Urville! Sieber, n. 205! fl: mixta, n. 474! A. Cunn.! Anderson! etc.). - Rudge in Linn. Trans. 10, p. 285, t. 13, f. 1, Wikstr. Thym. p. 283. P. thymifolia Presl bot. Bemerk. p. 107 (ex cit. Sieber, forma foliis sueto brevioribus), Walp. ann. 1, p. 585 . Calyptrostegia curviffora G. A. Mey. in Bullet. Ac. St-Petersb. 4, p. 71. Species variabilis, ramis nunc elongatis pluripedalibus gracilibus subsimplicibus, nunc brevibus corymbosis strictis, foliis nune 2-5 lin.

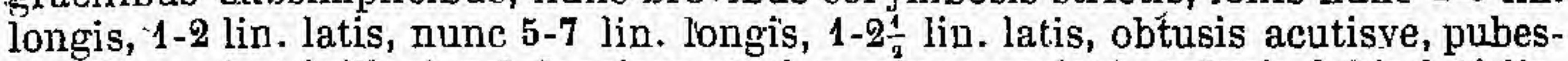
centiâ parcâ strigillosâ vel densiore et plus minus sericeâ, calycis lobis :-1 - $\frac{1}{4}$ lin. longis, sed hæ variationes certos stabilesque limites haud offerunt. (v. s.)

71. P. GRA CILIS (R. Brown prodr. p, 362), foliis ollongo-linearibus basi attenuatis subtus pilosiusculis, rameis passim oppositis, capitulis terminalibus axillaribusque paucifloris, calyce sericeo recto, lobis æqualibus. $\bar{f}$ In Tasmanniâ (R. Br.) et Australiâ Felici (Ferd. Müll.!). - Wikstr. Thym. p. 284. Calyptrostegia gracilis Endl. gen. suppl. 4, 2, p. 61. P. curvifloræ nimis affinis, attamen distincta videtur ramis fastigiato-multiramosis, ramulis filiformibus erectis, foliis confertioribus plerumque majoribus (6-7 lin. longis, 1-2 $\frac{1}{2}$ lin. latis) supra tarde glabrescentibus, pubescentià ubique rariore breviore haud setulosâ nec sericeâ, calyce paulo majore, 5 lin. longo, dense sericeo, tubo minus gracili, lobis ovatis latioribus obtusis vix aut non inæqualibus. (v. s. in herb. Smith., etc.)

B. sericea (Meisn. in Linnæâ 26, p, 351), ramulis calycibusque dense sericeis. In Novâ-Hollandià orientali-australi, ad flum. Lachlan (A. Cunn. n. 5!), in Australiâ Felici, circa Port-Phillip et Victoria (Latrobel Ferd. Müller l).

72. P. M I R RANтн A (Ferd. Müll.l mss. in herb.), foliis oppositis sparsisque oblongolanceolatis obtusis ramulisque dense cano-pubescentibus, floralibus ovatis, capitulis terminalibus et in summis axillis sessilibus, calyce recto dense sericeoincano, tubo articulato tumidulo, lobis exiguis, genitalibus inelusis. 5 In Australiâ meridionali, ad flum. Murray et Gawler, in montibus Lofty Ranges (Behr, Ferd. Müller l).- Meiscí in Linnæâ 26, p. 351. Præcedentibus, præesertim P. propinquæ, arcte affinis, sed distincta pube densiore molliore breviore minus sericeâ, et præcipue foliis floralibus reliquîs florerque brevioribus basi latioribus, calyce paulo breviore, limbo minore et deciduo. Fruticulus humilis, corymboso-ramosus. (v. s. comm. a cl. Sonder.)

73. P. MULLER (Meisn. in Linnæa 26, p. 351*), foliis oppositis passimque sparsis oblongo-lanceolatis obovatisque obtusis basi attenuatis eveniis cano-pubescen- 
tibus supra mox glabris, floralibus conformibus capitulo (terminali) parum brevioribus, calyce recto articulato minute sericeo-puberulo, lobis æqualibus glabriusculis tubo angusto vix dimidio brevioribus obtusis, genitalibus inclusis. I In Australiâ meridionali, circa Holdfast Bay, Gawler Town et Lyndoch Valley (Behr! Ferd. Müll.!y. P. gracilis F. Müll. mss. ex parte. Proxima P. gracili et propinqux, sed diversa habitu minus gracili, ramis satis validis, ramulis sape corymbosis, foliis plerisque oppositis majoribus (7-10 lin. longis, 3-6 lin. latis), pube brevi adpressissimâ haud sericeâ, etc. Calyx 3-4 lin. longus, flavus. (v. s. comm, a cl. Sonder.)

§ 7. Malistachys (Endl. gen. p. 331, suppi. 4, 2, p. 61).-Flores axillares solitarii vel aggregati sessiles vel ramulum brevem terminantes, involucro proprio nullo. Folia sparsa vel opposita. Frutices Novoe-Hollandice orientalis, australis et occidentalis. - Pimelex sect. 4, R. Br. prodr. p. 362.

74. P. hirsuts, tota laxiuscule sericeo-hirsula, foliis inferioribus oppositis superioribus sparsis herbaceis' breve petiolatis oblongo-ovalibus ovatisque acutis patulis, floribus solitariis folium æquantibus, calyce articulato adpresse pilosiusculo, lobis acutis túbo duplo brevioribus, genitalibus inclusis. $ち$ In Novâ-Hollandiâ orientali, circa Tomalh et Newcastle (Rich. Cunningham!). p. congesta? Ricl. Cunn.1 P. villifera A. Gunn.I mss. in herb. Fruticulus, verisimiliter humilis, ramulis laxis debilibus, innovationibus dense sericeis. Folia 3-4 lin. longa, 2- fere 3 lin. lata, plana, evenia, petiolo tenui $\frac{1}{2}-1$ lin. longo. Flores rati, basi persistente ovato-oblongà demum 1 $\frac{1}{3}$ lin. longâ. (v. s. in herb. Cunn. et comm. a cl. Heward.)

75. P. ARGENTEA (R. Brown prodr. p. 362), foliis oppositis lanceolatis utrinque

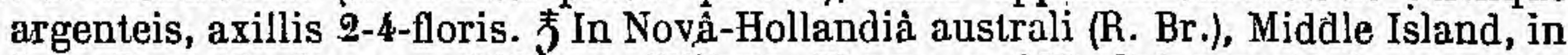
fréto Bass (A. Cunn. n. 362?).-- Wikstr.-Thym. p. 283. Calyptrostegia argentea C. A. Mey. in Bull. Ac. St-Petersb. 4, p. .71, Planta, fide specim., Gunningh. saltem, a sequente Preissianà, quam olim proP. argenteâ habuimus, eerte distincta : foliis laxiusculis (nec imbricatis) semipollice distantibus, plus duplo longioribus, omni-

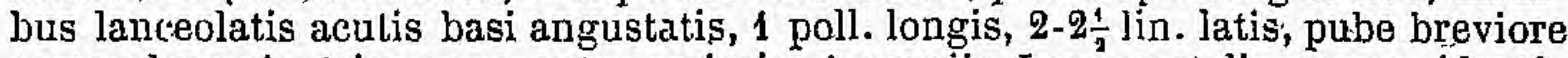
arcte adpressâ utrinque argenteo-sericeis, 1-nerviis. Locus nalalis quoque identitatem cum plantâ Preissianâ valde improbabilem reddit. (v. s. sine fl. in herb. Gunn. et comm. a cl. Heward.)

76. P. VESTITA, foliis oppositis subimbricatis ovali-lanceolatis ramulisque sericeovillosis, summis ovatis flores subæquantibus, axillis 2-8-floris, calyce articulato pilosiusculo, basi persistente demum glabrâ, limbo minuto, antheris inclusis, stylo exserto. $J$ In montibus coloniæ Swan River (Preiss, n. 1265!). P. argentea Meisn. in pl. Preiss. 1, p. 607* (non R. Br.). Frutex 3-5-pedalis, ramulis fastigiatis adscendentibus apice in spicam foliosam densam exeuntibus. Folia 3-5 lin. longa, 2-3 lin. lata, obtusiusculà. Calyx 3 lin. longus, tubo supra basin persistentem tumidam anguistissimo. Species a verả $P$. argenteâ distincta pubescentiâ longiore minus arcte adpressâ, foliis floralibus latioribus ovatis 3-4 lin. latis, etc. (v. s.)

77. P. ShUtтLEWorthIANA, dioica, föliis oppositis sparsisque lerbaceis patulis oblongo-lanceolatis obtusiusculis ramulisque villosiusculis supra glabrescentibus, floralibus similibus minoribus basi attenuatis flores æquantibus, axillis 2-6-floris, calyce articulato, lobis tubo filiformi glabriusculo dimidio brevioribus apice pilo-

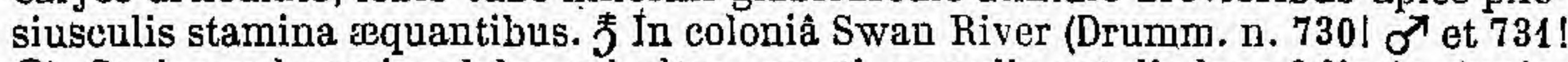
Q). Caules vel rami pedales vel ultra, erecti, ramulis patulis laxe foliosis, junioribus dense albo-villosiusculis nune a basi nunc apice tantum floriferis. Folia caulina sparsa, circ. pollicaria, 3.4 lin. lata, brevissime adpresso-pilosiuscula supra demum glabrescentia; floralia 2-3-plo minora, densius pilosa subsericea. Calyx circ. 3 lin. longus, tubo in $\sigma^{\top}$ basi pilosulo, in $\&$ glaberrimo, lobis in $ᄋ$ exiguis in $\sigma^{\top}$ duplo majoribus. Stylus inclusus. Species precedentibus et sequenti affinis quidem, sed jam foliis pubescentia et flor. dioicis optime distincta. (v.s. in herb. Shuttl. et Saunders.)

78. P. MYRIantha (Meisn: in pl. Preiss. 1, p. 607\%), divica, foliis sparsis patulis ramulisque striceo-tomentosis inferioribus oblongo-lanceolatis superioribus dimi- 
dio breviortbus ovato-oblongis flores superantibus, axillis 2-8-floris; calyce articulato puberulo, limbo tubum capillarem (pedicelliformem) subæquante stamina exserta vix superante. F. In coloniâ Swan River (Preiss, n. 1264!). Calyptrostegia myriantha Endl. gen. suppl. 4, 2, p. 61. Frutex 4-pedalis, ramis gracilibus fastigiatis conferte foliosis et fère a basi flor'fer'is. Folia inferiora pollicaria 2-3 lin.

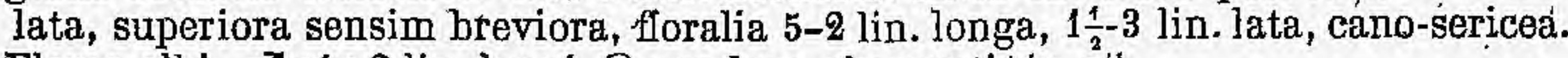
Flores albi, $\sigma^{7}$ vix 2 lin. longi, $\$$ nondum observati. (v. s.)

79. P. AXIFLORA (Ferd. Müll.! first gen. report, p. 17), foliis distantibus patulis oppositis linearibus utrinque attenuatis acutis flores longe superantibus ramulisque glabris, axillis multifloris, calyce subsericeo-incano continuo, lobis dimídio tubo vix brevioribus stamina exserta superantibus. F In montanis bumidis coloniæ Vịctoria Australiæ Felicis (Ferd: Múll.!). - Meisn. in Linnæâ 26, p. 345*. Frutex pluripedalis. Rami gracillimi, elongati, a basi inde floriferi, internodiis usque ad 1 poll. longis. Folia herbacea, subsessilia, 1-2 poll. longa, 1-2 lin. lata, subtus obsolete venosa. Calyx 3 lin. longus. Species insignis, hinc P. m yrianthæ, inde drupaceæ affinis, ab omnibus distinetissima. (v. s. comm. a cl. Sonder.)

\$ 8. Charistachys (Endl. gen. p. 331, suppl. 4, 2 p. 61):-Flores parvi, in spicam terminalem aphyllam, interdum brevissimam, dispositi. Folia alterna vel opposita, floralia nulla vel bina, rameis similia. - Fruticuli vel herbce Nova-Hallandice orientalis, australis et T'asmannio. - Pímeleæ sect. 3, R. Br. prodr. p. 362.

80. P. s picat A (R. Brown prorlr.p. 362), glaberrima, foliis oppositis ovali-oblongis lanceolatisque acutiusculis obsolete venosis, spicâ juniore brevissimâ subsessili folia vix superante, demưn elongatâ nudâ, floribus polygamis, calycis limbo tubum articulatum sequante genitalia superante. 5 Circa Port-Jackson, Paramatta, etc. (R. Brown! A. Cunn. n 62! Rudge in Linn. Trans. 10, p. 288, t. 14, f. 2, Wikstr. Thym. p. 283. Calyptrostegia spicata Endl. gen. suppl. 4, 2 p. 61. Fruticulus humilis, ramis gracilibus debilibas, internodiis 6-12 lin. longis. Folia herbacea, subsessilia, 6-12 lin. longa, 2-3 vel rarius 4-5 lin. lata, lete viridia, basi attenuata vel rotundata. Spica 15-20-fiora, junior capituliformis, floribus brevissime pedicellatis gracilibus $2 \frac{1}{2}-3$ lin. longis, flavis? glaberrimis. Rhachis fructifera subpollicaris, denticulata, internodiis circ. 1 lin. longis. (v. s. in herb. Smith., DC., Gunn., etc.)

81. P. Flliformys (Hook. fil, in Hook. Lond: Journ. 6, p. 280), glabra, caule prostrato gracillimo, fóliis oppositis lineari-oblongis ellipticisve subacutis, spicâ brevissimâ capituliformi, rhachi pilosâ, calycè pedicellató glabrato, tubo gracili, lobis elongatis, staminibus exsertis. 5 In Tasmanniâ, cirea Launceston (Gunn, Lawrence). - Walp. ann. 1, p. 584 *. Caulis pedalis, simpliciusculus, parce foliosus. Folia brevissime petiolata, 6-9 lin. longa, plana, marginibus tenuiter recurvis. Flores 5-6 in capitulum terminale spicamve brevissimam dispositi brevissime pedicellati, parce sericei, mox glaberrimi. Monente el. auctore affinis P. spicatì, sed distinctissima.

82.? P. TRIGHоSтAchy (Lindl.! in Mitchell exped. trop. austr. p. 355, in notis), annua, foliis alternis linearibus, pilis paucis adspersis, spicis terminalibus laxis villosissimis. @ In Novâ-Hellandiấ orientali interiơé, ad flum. Maranỏa (Mitchell! exped. 1846). Calyptrostegia? trichostachya Walp. ann. 3, p. 325. Flores parvuli, virides. Species affinis P. simplici, ex Ferd. Müll. in litt. (v. s. in herb. Lindl.)

83.? P. LATIFofia (R. Brown prodr. p. 362), foliis alternis oblongis basi acutâ pubescentibus subtus subsericeis, capitulo terminali sessili vel oppositifolio pedunculato multifforo spicato, calyce villosa. J In Novâ-Hollandiâ tropicâ (R. Br.). Wikstr. Thym. p. 284. Calyptrostegia latifolia Endl. gen. suppl, 4, 2, p. 61.

\section{Sectio III. Gymnococca.}

Capitula terminalia, involucro proprio nullo, foliis floralibus rameis similibus. Calyx haud articulatus, demum totus deciduus et fructum nudum relinquens. Drupa carnosa vel sicca. Álbumen crassitıs. - Frutices Novær-Hollandiæe, Tasmanniæe et Novó-Zeelandiæ, foliis oppositis.-Bantsia Forst. Char. gen. n: 8, t. 4 (non Linn.).-- 
Cookia Gmel. syst. 1, p. 24 (non Sonner.). - Gymnococca Fisch. et C. A. Mey. index sem. hort Petrop. 1845, p. 46, et in Bullet. Acad. St-Petersb. 4, p. 71, Ann. des sc. nat. $3^{\circ}$ sér. 5, p. 372, Walpers ann. 1, p. 585, Endl. gen. suppl. 4, p. 59, n. 2091. Pimelea et Calyptrostegia sp. C. A. Mey. et Endl. l. c.- Plures species; etsi earom fructus sit ignotus, affinitatibus cousa huc relatæ sunt. Nonnullarum fructus, teste cl. J. D. Hooker, aut solummodo " subbaccatus, " aut " nunc siccus nunc baccatus est $n$, unde liçuet Gymnococcam certis firmisque limitibus a Pimeleầ non separari ideoque nonnisi jro ejuslem sectione, nec genere proprio, haberi posse.

84. P. DRUPACEA (Labill.l Nov.-Holl. 1, p. 10, t. 7), ramis apiee subsericeo-canis, foliis ovali-oblongis planis subtus puberulis, floralibus capitulo longioribus, calyce cano-sericco, lobis tubo duplo brevioribus genitalia superantibus, drupa carnosâ nigrâ. $\neq$ In Tasmanniâ (Labill.! R. Br.! Hügel! Lhotsky ! Everett!), circa Sealers Cove, prope Wilsons's promontory, in Nov.-Holl. orâ australi (Ferd. Müller in litt..).

- R. Brown! prodr. p. 361, Lam. ill. t. 902, f, 2, Wikstr. Thym. p. 282, Lodd.I bot. cab. t. 540, Sweet fl. austr. t. 52, Gymnococca drupacea Fisch. et C. A. Mey. 1. c., Walp. and. 1, p. 585. Habilus et folia fere P. cinerer. Rami graciles, laxe foliosi, juniores tomentosi. Folia herbaced vel demum coriacea, subsessilia, patula; obtusiuscula, 1-1 $\frac{1}{\mathrm{j}}$ poll. longa, 3-6 lin. lata, interdum dimidio minora, sublus venosa parceque adpresso-pilosiuscula. Capitula terminalia vel demum lateralia, sessilia,

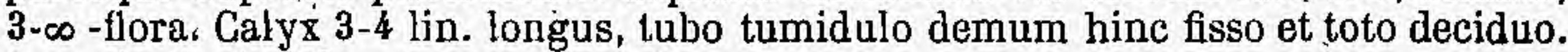
(v. s. in herb. DG., etc., et v. v. c.) .

85. P. MICROGEPHALA (R. Brown prodr. p. 361), diffuse ramosa, glabra, foliis linearibus lanceolatisque eveniis, floralibus 4 similibus capitulo paucifloro sessili longioribus deciduis, receptaculo ovato calyceque cano-tomentosis, lobis tubo dimidio lrevioribus genitalia parum superantibus. $亏$ In Novâ-Hollandiâ meridiodionali (R. Br.) et orientali.-Wikstr. Thym. p. 278, Meisn. in pl. Preiss. 2, p. 271, adnot. sub P. imbricatà (nec ibid. 1, p. 601, in notâ). Calyptrostegia microcephala Endl. gen. suppl. 4, 2, p. 61 (excl. syn. Meisn.).

a. lanceolata, foliis lanceolatis utrinque sequaliter attenuatis obtusiusculis Circa. Port-Jackson (Fraser, Gaudich.l), "Ile stérile " (herb. Mus. paris.!). Erecta, humilis? ramis $1-1 \frac{1}{2}$-pedalibus strictis vel diffusis. Folia herbacea vel vix coriacea, $4-12$ lin. longa, 1-3 $\frac{1}{2}$ lin. lata. Calyx 2 lin. longus. Fructus igriotus. (v. s. in herb. DC.)

ß. elongala (Mcisn. in Linnæâ 26, p. 350), ramulis elongatis, foliis linearibus, floralibus sæejius paulo latioribus. - In Novà-Holl. merid., a flum. Murray, montib. Flinders Range, et lacu Torrens usque ad Spencer's et St-Vincent's gulf (Ferd. Miill.I). P. dístiuctissirna Ferd. Müller ! first gen. report, p. 17. Aschenfeldtia pimeleoides. Ferd. Müll.I mss. in herb. Frutex dioicus, densus, 5-10 ped. altus, ramis ultimis cernuis, gracillimis laxis. Folia subcoriacea, 12-18 lin. longa, 1-1 $\frac{1}{9}$ lin. lata, subtus interdum obsolete venosa. Flores clilute flavi vel viriduli. liructus nudus, ovoideus 4-5 lin. longus, 2-3 lin. crassus, succosus, $\theta$ fulvo-flavus, nitidus, translucens (F. Müll. in litt.). Plantam masc. non vidimus. Capitula fem. 6-12-flora. (v. s, comm. a cl. Sonder.)

$\gamma$. linariafolia, foliis linearibus utrinque attenuatis acutis, floralibus minoribus. - In montibus Peol's Range, ad flum. Lachlan, et circa Moreton Bay (A. Cunningh.!). P. linariifolia A. Cunn.I mss. in herb. Frutex sæep 7 -pedalis, ramulis gracilibus debilibus. Folia herbacea, 10-15 lin. Ionga, 1-1 $\frac{1}{2}$ lin. lata. Capitula 6-12-flora, magnit. cerasi minoris. Cæet. ut in $\beta$, a quâ vix distinguenda. Fruct. ignot. (v. s. in herb. Cunn., DG. et Soc. linn. Lond.)

86. P. paUGIFlora (R. Brown prodr. p. 360), dioica? glaberrima, ramis laxis tenellis, folijs herbaceis lanceolato-linearibus, floralibus 2 similibus capitulo paucifloro longioribus deciduis, receptaculo exiguo nudo, calycis lobis tubum subrequantibus, staminibus subinclusis. $\ni$ In Tasmanniâ (R. Br., Stuart, n. 40 ! F. Müll. in Linnæà 26, p. 352), in montibus, prope Moreton Bay et ad flum. Lachlan (A. Cunn.! n. 4 et 14).-Wikstr. Thym. p. 277. P. ramulosa A. Cunningh.! in herb. n. 14. P.-parviflora Lodd.! mss. in herb. Smitl. P. lanceolata hort. Noisette! fide herb. DC. Habitus et folia P. microcephalæ, sed jam flore glaberrimo distincta. Folla $4-9$ lin. longa, $\frac{1}{3}-1$ - raro 2 lin. lata, utrinque attenuata, acuta vel obtusiuscula, subenervia. Capitula 4-8-flora. Calyx masc. infundibuliformis, flavus ? 2 lin. 
Iongus; fem. nor vidimus. Fructus (jun., specim. ex Moreton Bay) nudus, rugosus, carnosus? demum nigresscens. (v. s. in herb. Smith., DC., Cunn., etc., et s. c.)

87.? P. L ONG IF OLI A (Banks et Solander ! mss. in herb. Banks.), glabra, foliis linearivel oblongo-lanceolatis planis subtus venosis, floralibus similibus brevioribus 'vel paulo latioribus capitulum multiflorum superantibus, calyce sericeo-cano, lobis

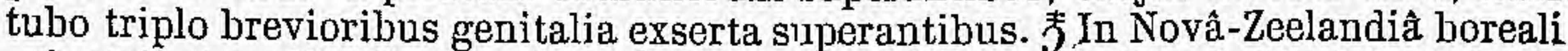
orientali et mediâ (Banks.et Soland.l anno 1769, Colenso, Aukland, Sinclair, Nelson, Bidwill). - Smith in Rees Cycl.,Wikstr. Thym. p. 280*, Hook. fil. fl. Nov.-Zeal. p. 220*. Passerina longifolia Thuab. in Muš. nat. Ac. Upsal. 22, p. 32. Frutex erectus, 2-6-pedalis, ramis gracilibus atris glabris. Folia subcoriacea, brevissime petiolata, 2-3 poll. longa, 5 lin. lata, acuta, utrinque attenuata, glaberrima, subconcoloria (ex Hook. supra sæpe nitida, subtus opaca vel glauea), nervo supra. impresso subtus prominulo, venis subparallelis supra obsoletis. Capitula magn. cerasi (diam. $1-1 \frac{1}{2}$ poll., ex Hook.), flor. albis odoratis $\frac{1}{2}$ poll. longis, tubo continuo gracili, receptaculo parvo hemispherico brevissime sericè-villoso. Fructus parvus (siccus) calycis fundo inclusus ovato-oblongus, integumento atro-crustaceo, ex Hook. (v.s. in herb. Smith.)

88. P. virGata (Vahl enum.! p. $306^{\text {") }}$, ramis gracilibus laxe foliosis apice adpresse pilosis, foliis herbaceis patulis lineari-lanceolatis acutis eveniis. supra glabris. subtus parce adpresse pilosulís glabratisve, nloralibus conformibus capítulo 8-10-floro longioribus, calyce dense sericeo-villoso, lobis tubo continuo dimidio brevioribus genitalia superantibus, fructu baccato vel sicco. 5 In Novâ-Zeelandiâ (Banks et Soland! 1769, Forster), bay of Islands (A. et R. Cunningh.l Hook. fil.1). - Wikstr. Thym. p. 280, Roern. et Schult. syst. 1, p. 275", A. Gunningh.! in Ann. of nat. hist. 1, p. 377, Raoul choix, p. 42. P. axillaris Banks et Soland.! mss. Passerina axillaris Thunb. in Mus. nat. Ac. Upsal. 13, p. 100. Kai-kai-atuaniu, incolarum, i. e. victus magni dei, fide Cunn. et Raoul. Frutex circ. pedalis, 'erectus. Rami elongati, subsimplices, demum glabrati, leviter cicatrisato-tuberculati. Folia subsessilia, 8-12 lin. longa, 1-2 lin. làta, acuta; novella utrinque pilosula, supra mox subtus tardius glabrata. Calyx $4-5$ lin. longus, roseus? lobis ovatis obtusis, stylo incluso. Fructus (ex Hook. fil.) nuenla obovata basi calycis carnosâ inclusus, baccaceus, edulis, sed sæpe exsuccus. (v. s. in herb. Banks., Smith., DG., Gunn., etc.)

B. pilosa, folips lanceolatis utrinque ramulisque diutius densiusque adpresse pilosis, junioribus sericeo-villosiusculis. $\bar{J}$ In fruticetis montanis Novæ-Zeelandiæ, insulæ mediæe (Forster! 1773, Stephenson, n. 36!). P. pilosa Willd. sp. 1, p. 50, Vahl enum. 1, p. 306*, Lam. ill. t. 9, f. 2, Wikstr. Thym. p. 278, Roem. et Schult. syst. 1, p. 275, A. Rich. sert. Astrolab. 1, p. 172, A. Cunn. l. c. p. 377, Raoul choix, p. 42. Banksia tomentosa Forst. char. gen. 8, t. 4, fig. k.n. Banksia pilosa Forst.! in Act. Upsal. 3, p. 174. Passerina pilosa Forst. prodr. p. 28, n. 171. Frutex semiorgyalis. Folia 6-10 lin. longa, $1 \frac{1}{2}-3$ lin. lata, obtusiuscula. Flores pauciores, breviores, albi. Cæt. omnino P. virgatæ. (v. s. in herb. Banks., Smith., Schreb., Shuttl., etc.)

89. P. GNidiA (Banks et Soland. mss.), erecta, foliis laxe imbricatis coriaceis lanceolatis ovatisque acutiusculis 1 -nerviis apicem versus complicato-concavis ramulisque glaberrimis, floralibus sæpe paulo latioribus capitulum laxe multiflorum æquantibus, calyce subsericeo-villoso, lobis tubo gracili dimidio brevioribus stamina superantibus, stylo subexserto. I In totâ Novâ-Zeelandiâ, præcipue insulâ mediâ, secus fretum Cookii, etc. (d'Urville! Colenso, Lyall, etc.). -- Willd. sp. 1,

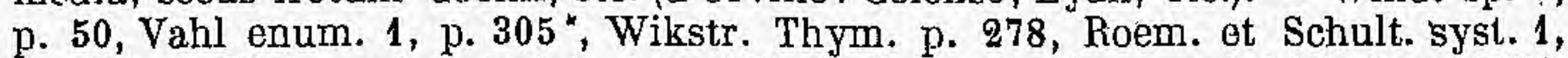
p. 27k, A. Rich. sert. Astrolab. 1, p. 171, A. Cunn. in Ann. nat. hist. 1, p. 377", Raoul choix, p. 42, Hook. fil. fl. New-Zeal. p. 221*. Banksia Gnidia Forst.l char. gen. p. 8, t. 4, fig. a-i, et in Act. Upsal. 3, p. 173. Pesserina Gnidia Forst.! prodr. p. 28, n. 170, Linn. fil.! suppl. p. 226. Cookia Gnidia Gmel. syst. 1, p. 24. Frutex (ex Hook. suffrutex 3-5-pedalis) 2-3-orgyalis, erectus, ramosissimus, excepto flore glaberrimus (ramulis ex Hook. interdum puberulis). Folia laxe 4 -fariam imbricata, demum patula vel recurva, brevissime petiolata, 4-5 lin. longa, 1 lin. lata, subtus carinata, costâ marginibusque subincrassatis. Calyx albus vel extus erubescens, odoratus, lobis lineari-oblongis vel subspathulatis. Species hinc P. virgatie, inde P. prostratæ proxime accedens ideoque non obstante fructu ignoto huc relata. (v: s. in herb. Linn. fil., Schrel5., DC.) 
ß. Menziesii (Hook. fil. fl. N.-Zeal. p. 222), ramulis glaberrimis, foliis ellipticovel oblongo-lanceolatis vel lineari-oblongis. - In Dusky bay N.-Zelandiæ australis (Menzies ! 1803). Monente cl. Hook. fll, forsan species distincta, sed non salis nota. (v. s. in herb. Smith.)

90. P. Prostrata (Banks et Soland.! mss.), humilis, procumbens, ramulis erectis pubescentibus glabratisve, foliis imbricatis coriaceis ovatis oblongís lanceolatisve obtusis planis vel carinato-concavis glabris, floralibus similibus capitulum 6-8-florum superantibus, calyce subsericeo-cano, lobis iubum subæquantibus, genitalíbus exsertis, fructu ssepius baccato. 5 Per totam Novam-Zeelandiam vulgaris (Banks et Sol.I 1769, Forst. 1773, R. et A. Cunningh:! d'Urville ! Stephenson, n. 37! Hook. fil., etc.). - Willd. sp.1, p. 51, Lam. ill. t. 9, f.1, Vahl enum. 1, p. 306", Wikstr. Thym.p. 277, Roem. et Schult. syst. 1, p. 274, A. Rich. sert. Astrolab. 1, p. 174, A. Cunn.l in Ann. nat. hist. 1, p. 377, Bot. reg. 1839, misc. p. 56, n. 81, Raoul choix, p. 42, Hook. fil.! fl. N.-Zealand. 1, p. $220^{\circ}$. P. levigata Gærtn. fr. 1, p. 186, t. 39, f. 1. Banksia prostrata Forst.l char. gen. p. 8, n. 4, Act. Upsal. 3, p. 175. Passerina prostrata Forst. prodr. p. 28, n. 172, Linn. fil. suppl. p. 227. Cookia prostrata Gmel. syst. 1, p. 241. Fruticulus polymorphus, prostratus, rarius erectus, ramulis plus minus cicatrisato-nodulosis, sericeis vel glabratis, apice conferte foliosis. Folia 2-3 lin. longa, 1-2 lin. lata, brevissime petiolata, encrvia, interdum obovata, demum patula vel recurva. Flores parvuli, 2 lin. longi, albi vel rubelli, calycis lobis obtusis. Bacca alba. (v. s. in herb. Linn. fil., Smith., Schreb., DC., etc., et v. v. c.)

$\beta$. repens (Hook. fil: 1.c. p. 221), caulibus prostratis subrepentibus gracilibus, foliis remotis obovatis.

$\gamma$. Urvilleana, procumbens, ramulis adscendentibus dense cicatrisatis sericeo-r villosis, foliis 4 -fariam imbricatis mox patulis vel recurvis late ovatis vel ovato-oblongis crassiusculis, antheris vix exsertis. - $P$. quadrifaria Banks et Soland. mss, fide Hook. P. lævigata $\beta$ Banks mss. in herb. Smith.! P. Urvilleana A. Rich:! sert. Astrolab. p. $227^{*}$, A. Cunn.! in Ann. of nat. hist. 1 , p. 377, Raoul choix, p. 42, Hook. fil. fl. N.-Zeal. 1 p. $221^{\text {* }}$. Gymnococca microcarpa Fisch. et Mey.? ind. sem. hort. Petrop. 1845, p. 46, Ann. sc. nat. $3^{\circ}$ sér. 5, p. $373^{*}$, Walp. ann. 1, p. 585. Præter notas indicatas nimis leves nullo modo a prostratầ distinguenda. (v. s. in herb. Cunn., DC., etc.)

$\delta$. vermicularis, ramis itera to umbellatis dichotomisque densissime eleganterque annulato-nodulosis glabris, foliis arcte 4 -fariam imbricatis patuljs obtusis crassiusculis, capitulis \$-6-floris folia subæquantibus. - In Novâ-Zeelandiâ (Stephenson, n. 39!). P. prostrata var. quadrifaria Hook. fil. in Hook. Lond. Journ. 3, p. 416. Forma insignis, attamen vix species distincta. Rami vix spithamæi, toti eleganter annulati, exceptis folinrum delapsorum axillis albopilosulis ubique glaborrimis. Flores minuti. Receptaculum parvum albo-villosum. (v. s. in herb. Boiss.)

01. P. Arenaria (A. Cunningh.! mss. in horb.), humilis, ramis erectis vel adscendentibus, foliis confertis palulis deflexisve coriaceis ovalibus orbiculatisque planis enerviis supra glabris subtus ramulisque adpresse sericeo-villosis, floralibus conformibus capitulum 5-10-florum subæequantibus, calyce villoso, lobis obtusissimis tubo dimidio brevioribus genitalia exserta superantibus, fructu baccato. 5 In arenosis Novæ-Zeelandiæ mediæ et borealis (Banks et Sol.! 1769, R. Cunningh.! n. 317! A. Gunn. n. 117! Stephenson, n. 59! 60! Colenso, n.13! Edgerley! Dieffenbach, Hügel ! etc.).-A. Cunn.I in Aun. of nat. hist. 1, p. 577, Bot. mag. 3270, Hook. fil. fl. N.-Zeal. 1, p. $221^{*}$. P. villosa Banks et Soland.! mss. P. sericea $\beta$ Wikstr. Thym. p. 282. Passerina villosa Thunb. in Mus. nat. Ac. Ups. 13, p. 106. Gymnococca arenaria Fisch. et Mey. ind. sem. hort. Petrop. 1845, ex Ann. sc. nạt. 3• sér. 5, p. 373, Walp. ann. 1, p. 586. Outato-Rangha incolarum ex Cunn. 1. c., Raoul choix, p. 42. Ante-taranga, ex Hook. l. c. Procumbens vel erecta, $\frac{1}{2}-2$-pedalis, ramis validis corymbosis vel dichotomis. Folia sessilia, 3-7 lin. longa, 2-4 lin. lata, plerumque obtusiuscula. Calyx 4-5 lin. longus. Fructus subbacatus, majusculus ab incolis edilur qui et cortice Broussonnetia instar ad conficiendam telam utuntur. Species facie accedens ad P. sericeam, sed bene distincta. (v. s. in herb. Smith., Cunn., DG., etc.)

92. P. LYALLII (Hook, fil. fl. New-Zeal. 1, p. 222 ), caulo elongato-prostrato, foliis 
laxe imbricatis lineari-oblongis vel elliptico-ovatis acuitis supra concavis glabratis subtus convexis pilis longis laxe sericsis, floralíbus capitulo 3 -4-floro sablongioribus, calyce sericeo, lobis ovatis obtasis tubo parum brevioribus. $ち$ In NovâZeełandiâ mediâ et australî, ins. Ruapuka ct Port-William (Lyall, Golehso). An a P. arenarià satis distiucta? Differre dicitur colore in sicco pallide flavo-viridi (nec fuscescente), caulibus prostratis pedalibus et ultra, validis, flexibilibus, foliis plerumque angustioribus (rarius elliptico-ovatis) et floribus paucioribus.

\section{Species non descriptce.}

P. GRANDIflora Don hort. Cantabr. ed. 6, p. 5, ex Wikstr: Thym, p. 284; Steudel nomencl. ed. 2. - In Noviâ-Hollandiâ.

P. PRINIFolia Nois., ex Steudel l. c. - Ibid.

\section{Subtribus II. ISOSTEMONEA.}

Stamina calycis lobis numero æqualia.

JI. DRAPETES Lam. in Journ. d'hist. nat. $1, n .5, p .186, t .10, f .1$, Banks in Gertn. fr. 3, p. 199, t. 215, Juss. in Ann. Mus. 7, p. 479, Foir. dict. suppl. 2, p. 523, t. 945, f. 1, Wilsstr. Thym. p. 284, Endl. gen. p. 330, n. 2097, suppl.4, 2, p. 61, n. 2094, Meisn. gen. p. $330(242)$.

llores hermaphroditi, 4-meri. Calyx coloratus, infundibuliformis, tubo tenui supra ovarium articulato, parte superiore deciduâ, fauce esquamatâ, limbo 4-fido. Squamulæ hypogynæ nullæ. Stamina 4 fauci inserta, Jobis alterna, filamentis exsertis, antheris basifixis ovalíbus apiculatis. Ovarium 1.ovulatum, ovulo pendulo. Stytus sublateralis, stignate capitato papillosohispidulo. Nucula calycis basi persistente inclusa, 1-sperma. Semen..... Suffruticulus nanus, caspitosus, musciformis, foliis decussato-oppositis sessilibus parvulis dense imbricatis, fasciculis terminalibus paucifloris pedunculatis, involucro 4-phyllo persistente, floribus exiguis.

D. auscordes (Lam.! l. c. ill. t, 915, f. 1). ち In Magellaniâ (Commerson I in herb. Lam.), Fuegia (Banks et Soland., King, etc.), ins Maclovianis (d'Urville!), Hermite Island, cap-Horn (Hook. fil.!). - Poir. suppl. 2, p. 523*, Gaudieh. in Freycin. Voy. Uranie, p. 133, d'Urville, in Mem. Soc. hist. nat. paris. 4, p. 605, Pers. syn. 1, p. 148. D. muscosus Roem. et Schult. syst. 3, p. $333^{*}$, Hook. fil.! bot. antaret. voy. 1, p. 343 (non Ej. fl. N.-Zeel.), Cl. Gay hist. de Chile, p. $317^{*}$. Plartula sufruticulosa, 1-3-pollicaris, ramosa, ramulis tenuibus, inferne defoliatis. Folia oblongolanceólata, 2-2 $\frac{1}{2}$ lin. Ionga, vix lineam lata, obtusiuscula, adpresse pilosa, summa paulo majora. Pedunculi simplices ereeti, demum 3-5 lin. longi, nudi. Involucri foliola minuta, squamiformia, setuloso-barbata, flores snbæquantia: Calyx vix 2 lin. longus, puberulus, lobis linearibus erectis. Stylus capillaris, stamina æquans, (v. s. in h. Lam., DC., et comm. a cl. J. D. Hooker.)

III.? CANSJERA Juss. gen. p. 448, Roxb. Corom. t. 103, Roem. et Schult. syst. 3, p. 20, Endl. gen. p. 331, n. 2103, Meisn. gen. p. 330 (243), cfr. Benth. in Linn. Trans. 18, p. 671. sq. - Candjera Decsne in Ann. sc. nat. 20 sér. 10, p. 37.

Flores heirmaphroditi, 4-meri. Calyx coloratus, campanulato-urceolatus, totus deciduus, fauce esquamatâ, limbo 4-dentato reflexo. Squamulæ hypogynæ 4 discretæ, liberæ, staminibus alternæ, denticulatæ. Stamina 4 hypogyna? imo calycis fundo inserta ejusque lobis opposita, filamentis capillaribus liberis inclusis, antheris basifixis subgloboso-didymis breviter exsertis. Ovarium sessile, glabrum, carnosum, loculo prope medium sito parvulo, placentâ basilari centrali, ovulo primum reflexo deinde erecto. Stylus terminalis, filiformis, stigmate exserto capitato leviter 4 -sulcato. Fructus nudus, siccus? ovoideus, putamine crustaceo abortu? 1-spermo. Semen (ex Benth.) demum erectum, umbilico basilari lato. Embryo in apice cavo albuminis carnosi rectus, radiculâ brevi inferâ, cotyledonibus oblongis, plumulà inconspicuâ. - Frutices Asiæ tropicæ scandentes, foliis sparsis subcarnosis inte- 
gerrimis glabris, spicis axillaribus simplicibus solitariis aggregatisve, floribus parvis flavis basi bracteâ minutâ stipatis. - Genus dubiæ affinitatis, secundum cl. Bentham et Decaisne 1. c. propter ovarii seminisque structuram, Olacaceis adscribendum et inter eas Opilice plurimis characteribus conveniens, sed flore monochlamydeo gamosepalo ab illo ordine valde abhorrens, a Thymelceis vero, exceptâ staminum inseltione subhypogynâ et placentatione, non dissentiens. Planta a cl. Bentham l. c. (p. 679) descripla " calyce minimo et corollâ 4-dentatâ " prædita, monente jam cl Decaisne 1. c. p. 3i, a verâ Cansjerâ Juss. et ad Myrsineaceas, forsan ad Choripetalum, pertinere videtur. Secundum $\mathrm{cl}$. Benthain l. c. p. 674, ovarium ante fecundationem ovulis 3-4 ex apice placentæ basilaris pendulis, postea vero constanter ovulo unico demum erecto gravidum esse videtur.

1. C. RHEEDII (Gmel. syst. 1, p. 280), ramulis minute puberulis, foliis ovato- vel elliptico-oblongis acuminatis glabris, spicis fasciculatis vel solitariis crassiusculis, calycibus inediocribus rhachique minute puberulis. 引) In perinsulâ Indiæ orientalis, Malabariâ, Coromandel (herb. Heyne! Wall. list, n. 104s! Hook. fil.!); Ceylonâ (Thrwaites, n. 489!), in ins. Philippinis, ubi Bignaipogo vocatur (Blanco). - Roem. et Schult. syst. 3, p. 334, Meisn. in Regensb. Denkschr, 3, p. 290*, Blanco fl. de Filipin. ed. 1, p. 73 ? Wiglit ic. t. 1861 . C. Malabarica Lam. dict. 3, p. 433 , ill. t. 289. G. scandens. Roxb. Corom: 2, p, 1, t. 103, Tratt. arch. t. 13, Pers.syn. 1, p. 148. Daptne monostachya el polystachya Willd. sp. 2, p. 420. Thjeru-caniram vel Tsjeru-cansjeram Rlıeede Malab. 7, p. 3, t. 2. Sheru-valli-caniram Rheede ib. p. 7, t. 4. Frutex scandens, 10-12-pedalis, frondosus, sempervirens. Folia patula, 1 $\frac{1}{2}-3$ poll. longa, 10-16 lin. lata, basi breviter attenuata vel rotundata, petiolo 1-2 $\frac{1}{2}$ lin. longo, venis paucis immersis apicem petentibus evanescentibus, venulis subnullis. Spicæ plerumque geminæ, subsessiles, subpollicares, densiusculæ, tloribus patentibus 2 lin. longis, bractejs exignis. (v. s.)

2. C. Lертозтаснул (Benth.! in Hook. Lond. Journ. 2, p. 231), foliis ovato-vel oblongo-lanceolatis longe acuminatis ramulisque glabris, spicis fasciculatis vel solitariis tenellis, calycibus parvulis rhachique minusissime puberulis. F) In Novâ-Hiherniâ (Hinds, Barclay). Folia 2-3 poll.longa, 10-12 lin. lata, apicem versus longe attenuatá, petiolo vix 1 lin. longo, venis obsoletis. Spica vix pollicares, rhachi tenui, floribus $1 \mathrm{lin}$. longis. Squamulæ hypogynæ suborbiculares, apice truncato obscure 3-dentatæ Cæet. præecedentis, a quấ spicis tenellis calyceque dimidio minore apprime dignoscitur. (v. s. comm. a cl. Lindl.)

\section{Species dubice, forsan non congeneres.}

3. C.? gnossularioines (Blanco flora de Filipinas, ed. 1,p. 73), foliis ellipticis apiculatis margine præsertim pilosiusculis, spicis terminalibus longis densis amentiformibus, calyce 4 -fido, staminibus squamisque 4. 5 In ins. Philippinis, ubi Cabogbog vocatur (Blanca). Arhor circ. 40-pedalis. Flores omnes bermaphroditi, omnino C. Rheedei. Cum sequente ad gen. Aptidesma et Stilago accedere dicitur.

4. C.? PENT ANDRA (Ḅlanco l. c.), foliis ovàlibus mollibus villosis, floribus racemosis valde villosis, obtuse 5 -dentatis, staminibus $5.5 \mathrm{In}$ ins. Philippinis, ubi Bignai pogo appellatur. Arbor circ. 20-pedalís. Cæet. tit in C. Rheedei.

IV. SCHOENOBIBLUS Mart. et Zuccar. nov. gen. 1, p. 65, Meisr. gen. p. 330 (242), et in Mart. A. bras. 14, p. 65, t. 28, f. 1, Endl.'gen. suppl. 4, 2, p. 69, n. $2106 / 12$.

Flores dioici, 4-meri. $\sigma^{\top}$ Calyx corollinus, 4-partitus, tubo brevissimo infundibuliformi, fundo piloso, fauce esquamatà, lobis patentibus linearibus intus glabris. Squamæ hypogynæ nullæ. Stamina 4, exserta, calycis lobis opposita iisque inferne adnata et subæquilonga, filamentis filiformibus, antheris oblongis dorso supra basin affixis. Pistilli rudimentum nullum. ㅇ..... Arbor vel frutex Brasiliensis, foliis sparsis, umbellis terminalibus pedunculatis.

S. DAPHN OIDES (Mart. et Zucc.! 1. c.). 5 ? In sylvis inundatis, ad flum. Japura, prov. - Rio Negro (Mart.l). Rami diohotomi, laxe foliosi, glabri. Folia herbacea, oblongo. 
lanceolata, acuminata, acutiuscula, longe attenuato-subpetiolata, venosa, glabra. Fasciculi in apice ramorum racemosi vel subpaniculati, pedunculis bracteâ linearifiliformi fultis, pedicellis 4-6 lin. longis basi ebracteatis. Calyx masc. albus, $2 \frac{1}{2}-3$ lin. longus, minute puberulus, fere ad basin usque 4 -partitus, lobis $\frac{1}{3}$ lin. longis. Fem. ignota. (v. s. in herb. Acad. Monac.)

\section{Subtribus III. DIPLOSTEMONEE.}

Stamina calycis lobis numero dupla, scilicet 8 , vel 10.

V. DAPHNOPSIS Mart: et Zuccar. nov. gen. 1, p. 65, Meisn. gen. p. 330 (242), et in Mart. fl. bras. 14, p. 65, t. 28, f. 2, 3, Endl. gen. suppl. 4, 2, p. 69, n. 2106/13. - Hargas. 'seria Schiede et Deppe mss., C. A. Mey. in Bull. Acad. St-Petersb. 4, n. 4, Ann. sc. nat. sér. 20, p. 51, Endl. gen. suppl. 4, 2, p. 68, n. 2106/8. -Nordmannia Fisch. et C. A. Mey. ibid., non Ledeb. - Daphnes sp. Americanæ aucl.

Flores dioici, 4-meri. Calyx subherbaceus, infundibuliformis vel subcampanulatus, continuus, 4-fidus, lobis intus sæpius puberulis, tubo basi intus piloso, fauce esquamatâ. Squamulæ hypogynæ 4 , membranaceæ, liberæ vel connatæ. $\sigma^{\top}$ Antheræ 8, duplici serie in fauce subsessiles, ellipsoideæ, latere rimả dehiscentes. Rudimentum pistilli. ㅇ Calyx totus persistenšs vel demum deciduus. Staminum rudimenta nulla vel ininuta, Ovarium sessile, glabrum, 1-ovulatum. Stylus terminalis brevissimus, stigmate capitato. Drupa vel bacca? ovata, calyce cincta vel nuda, sicca, fibrosa, 1-sperma. Semen exalbuminosum.- Arbores vel frutices Americæ tropicæ, foliis sparsis planis, capitulis vel umbellis pedunculatis, solitariis vel cymosis.

\section{§1. Pedunculi solitarii, simplices, 1-cephali.}

1. D. MA R T I (Meisn. in Mart. fl. bras. 14, p. 66*, t. 28, f. 2), foliis herbaceis oblongis breviter acuteque acuminatis basi attenuatis venosis utrinque-punctato-asperulis glahris, umbellis masculis axillaribus, pedunculo brevi pedicellisque flore longioribus pilosiusculis, calycis pilosiusculi lobis ovatis acutis tubum æquantibus, squamis liypogynis 4 liberis setiformibus, fem..... 5 In monte Corcovado $\mathrm{pr}$. Rio de Janeiro (Mart. n. 119!). Arbuscula 6-8-pedalis, ramis apice foliosis. Folia 10-12-pollicaria, 2-4 poll. lata, petiolo 3-6-lin. longo semitereti crassiusculo. Pedunculi filiformes, circ. semipollicares, apice 6-10-flori, pedicellis 2-3 lin. longis umbellatis demum brevissime racemosis. Calyx albus, $1 \frac{1}{2}$ lin. longus, lobis inlus glabris. Pistilli rudimentum setiforme pubescens. (v. s. in h. Acad. Monacens.)

2. D. BRASILIENSis (Mart.!' et Zucc. nov. gen. 1, p. 65), ramis junioribus tomentosis, foliis subcoriaceis breve petiolatis lanceolato-oblongis basi attenuafis supra glabriusculis subtus sericeo-incanis, fasciculis masculis in ramorum apice fere aphyllo racemosis, calyce pedicellum æquante sericeo-tomentoso, lobis ovatis obtusis tubum subæquantibus, annulo hypogyno minuto repando-dentato. 5 In Brasilia prov, S.-Pauli, Minas Geraës et Serra do Rio Negro (Mart.l Widgren, n. 1004 !). - Meisn. in Mart. fl. bras. 14, p. 66" t. 28, f. 3. D. dioica Mart.! mss. in herb. Ac. Monac. n. 640. Arbor 12-15-pedālis, ramis laxis propendentibus subdichotomis, ramulis gracilibus laxe foliosis. Folia 2-4-pollicaria, 8-12 lin. lata, obtusa vel acuta, infra medium sensim angustata, petiolo 1-2 lin. longo. Pedunculi axillares, circ. semipollicares, dense sericeo-pilosiusculi. Calyx infundibuliformis 2 lin. longus, virescens, utrinque albido-sericeus, in fem. demum paulo auctus et subinde 5 -fidus. Ovarium glabrum. Drupa subsicca, ovata, venoso-rugosa, 5 lin. longa. (v. s. in herb. Ac. Monac. et Sonder.)

3. D. HUмвоLDтI, foliis coriaceis elliptico-vel obovato-oblongis reticulatis ramulisque patulo-pubescentibus supra demum glabris, capitulis axillaribus terminalibusque in ramorum apice congestis, pedicellis brevissimis pedunculisque sericeis, calyce infundibuliformi hirsuto, lobis ovatis acutis tubo inflato brevioribus, ovario glabro. 5 Ad rad. montis ignivomi Tuguragua, Quito, alt. 7, 400 ped. (Humb.! Bonpl. n. 3209!). Daphne macrophylla Kunth in H. et B.! nov. gen. 2, p. 151", Kunth syn. 1, p. 446. D. lancifolia Wikstr. Daph. p. 40, Thym. p. 307. D. laurifolia Willd. herb. n. 7550, fol. 1! Arbor 3-4-orgyalis, cortice foetidissimo, ramulis angulatis. Folia 3-6 poll. longa, 15-26 lin. lata, futrinque attenuata acuta vel passim obovata 
obtusa, supra minute denseque scrobiculato-reticulata, nervo venisque supra immersis subtus prominentíbus dense reticulatis, petiolo $2-5$ lin. longo: Pedunculi 4-5 lin., pedicelli I lin. longi. Capitula multiflora, magnit. cerasi. Calyx albuș, subcampanulatns, $2 \frac{1}{2}$ lin. longus, diu persistens. Drupa ovata, 5-7 lin. longa, stigmate demum sessili coronata. (v.s. in herb.Willd. et Kunth.)

$\beta$ ? Boissieriana, foliis oblongis obtusis utrinque adpresse setuloso-pilosis, calyce sericeo-tomentoso, lobis tubum subaquantibus. 5 ? Circa Huayaquil (Pavon!). Rami di-trichotomi, divaricati, glabri, laxe foliosi. Folia 2-k-pollicaria, 10-20 lin. lata, petiolo 2-3 lin. longo. Pedunculi 8-10 lin. longí, dense adpressopubescentes. Calyx sessilis, fere 3 lin. longus, lobis intus puberulis. Ovarii rudimentum exiguum, subsessile, glabrum. Squamulæ hypogynæ 4 , ligulares, obtusæ, ovarium æquantes, subcarnosæ, glabræ, basi connatæ? Fem. ignota. Cút. omnia plantæ Humboldtianæ. (v. s. in herb. Boiss.)

4. D. BONPLANDIt, foliis herbaceis oblongo-obovatis obtusis basi attenuato-acutis obsolete reticulatis ramulisque glabris, pedunculis lateralibus cano-tomentosis, calyce pedicellum requante sericeo, lobis ovatis obtusis tubo vix brevioribus. $\hat{\xi}$ In Mexico, circa Vera-Gruz (Humb.I Bonpl. n. 4487! Beyrich! F. Müller I), Plan del Río (Schiede). Daphne Bonjlandiana Kunth!synops. 1, p. 447*, Cham. et Schl. in Linaæa 5, p. 89. D. Lagetto? Bonpl.l mss. in herb. Willd. D. obovata Willd. mss. in. herb. p. 7549! Wilsstr. Daph. p. 40, Thym. p. 307. Hargasseria Mexicana C. A. Mey, in Bıll. Ac. St-Petersb. 4, n. 4. Ann. sc. nat. 1843, 20, p. 51. H. Schiedeana Endl. gen. suppl. 4, 2, p, 68. Arbor procerrima (Kth.), ramis ultimis gracilibus plerumque dichotomis. Fólia 3-5-pollicaria, 1-1 $\frac{1}{2}$ poll. lata, apice sæepius rotundata, petiolo 2-3 lin. longo, venis tenuissimis subimmersis laxe reticulatis. Pedunculi supraaxillares, solitarii, masc 8-12 lin. graciles, fem. 4-5 lin. longi, crassiusenli. Umbellæ 8-16-floræ, pedicellis masc. 2-3 lin., fructiferis 2 lin. longis. Calycis tubus anguste infundibularis; lobis utrinque tomentellis. Ovarium glabrum, breve stipitatum, stylum requans, stigmate simplici obtuso. Squame hypogynie ligulares, liberæ. Flores fem. haud observati. Drupa a calyce demum denudata, sessilis, ovato-globosa, flavo-vifidis, rugosa, magnit. pisi majoris, stigmate subsessili coronata. (v. s. in herb. Willd., Kunth., etc.)

$\beta$. mollis, foliis subtus ramulisque junioribus pube mollissimâ tectis, calycis lobis pube longiore villosiusculis. - Circa Papantlam (Schiede). Daphne Bonplandiana Cham. in Linnæâ 6, p. 364 .

5. D. Bogotensrs, ramulis puberulis, foliis coriaceis ovalibus oblongisıue obtusis reliculatis adpresse pilosis supra clemum glabrescentibus nitidis, pedunculis axitlaribus, . pedicellis fem: brovissimis, calyce subcampanulato cano-sericeo, lobis ovatis acutis tubum squantibus, staminum rudimentis 8 , ovario sessili glabro, stigmate sessili, annulo hypogjno brevissimo repando. ҒIn Colombiâ, inter urbem Bogota et Zipaquira (Hartweg, n. 1366!), et? prope Santa-Marta (Purdie, cfr. D. Purdiei). Thymelar Benth.! pl. Hartweg. p. 247. Frutex sempervirens, 6-8-pedalis, ramolis conferte foliosis. Folia 1-2 poll. longa, 6-10 lin. lata, petiolo 1-2 lin. longo, pilis mollibus subtus copiosioribus conspersa, venularum reticulo denso supra prominulo. Pedunculi 3-6 lin. longi, cani, pedicelli vix $1 \mathrm{lin}$. longi, flore triplo breviores. Capitula dense multiflora. Calycis tubus mox tumescens, ovatus. Stamina sterilia minuta, quæ sinubus opposita biloba basi incrassata glanduliformia. Flor. masc. ignoti. (v. s. in herb. Boiss.)

6. D. Caracasana, foliis rigide coriacejs obovato-oblongis obtusis utrinque prominulo-reticulatis niticlis ramisque glabris, novellis cano-sericeis, capitulis axillaribus in ramorum apice raccmosis sericeo-canis, pedicellis brevissimis bracteis parvulis caducis suffultis, oalyce fem. campanulato, lobis ovatis obtusis tubum subæcquantibus. ₹ In Colombiâ (Karsten, n. 2111). Daphne Caracasana Klotzsch! mss. in herb. DG., etc. Riami stricti, cinereo-fusci, ruguloso-striati, albido-punctati, satis dense foliosi. Folia crassiuscula, $2 \frac{1}{2}-4 \frac{1}{7}$ poll. longa, 1-2, poll. lata, in petiolum brevem lusi articulatum attenuata, læete viridia, egregie reticulata. Pedunculi folia subtendentia subsquantes, post florum fructuumque lapsum persistentes patentes vel subrecurvi, graciles, $1 \frac{1}{2}$ poll. longi, sericeo-cani deraum glabriusculi. Capitula 10-10-flora, pedicellis $\frac{1}{2}-1$ lin. longis, bracteis sericeo-villosis. Galyx 2-2 lin. longus, lobis intus glabris, 2 exterioribus concavis apice barbatis, jnterioribus 2 planis imberbibus. Cæet. ut in D. Bogotensi, quie forsan ejusdem. var., recedens foliis minoribus minus coriaceis, venis primariis magis 
patentibus, reticulatione tenuiore, pedunculis brevioribus, etc. Flores masc. ignoti. (v. s. in herb. DC. et Shulttl.)

7. D. PURDIEI, ramulis apice gemmisque velutino-tomentosis, foliis subherbaceis oblongis supra glabris, subtus adpresse canescenti-pilosis laxiuscule reticulatis, pedunculis lateralibus' incanis apice incrassatis, capitulis obsolete' bracteatis

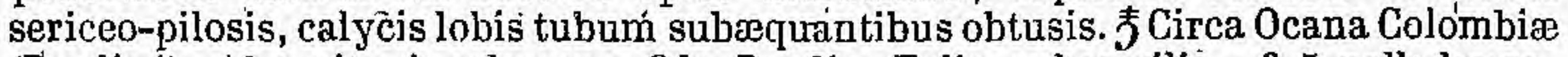
(Purdie 1). Ahousila incolarum, fide Purdie. Folia subsessilia , 3-5 poll; longa, 1-1 $\frac{1}{2}$ poll. lata, acuta vel obtusa, basi attenuata, nervo stipra sulciformi, venis primariis semiímmersís, venularum reticulo obsole to vel demum leviter prominulo densisssimo subtus laxiusculo, pubescentià molli longinsculâ adpressâ. Capitula in corymbum terminalem foliosum disposita, hemisphærica, circ. 20-flora, magnit. cerasi, pedunculis oppositifoliis $1 \frac{4}{2}-2$ poll. longis gracilibus, lobis intus 'tomentellis. Fem. ignota. Proxima D, Bogotensi et Pavonii ; a priore distincta foliis vix coriaceis supra glabris, subtus densius pubescentibus, ete.; a posteriore foliis vix petiolatis bașin versus magis attenuatis subtus distincte reticulatis. Succus cansticus, vesicatorius dicitur. (v. s. $\sigma^{7}$ in herb. Arnott.)

8. D. PA 0 NII, ramis tomentosis, foliìs coriaceis ovali-oblongis obovatísque obtursis vel emarginatis venosis subtus dense cano-pilosiusculis supra glabriusculis nitidis, pedunculis lateralibus, pedicellis flore dimidio brevioribus, calyce masc. infundibuliformi, lobis ovatis obtusis dimidium tubum æquantibus, cyathulo hypogyno repando. $\bar{~}$ "? Iñ Peruviâ, circa Palca (Pavon!) Daphne? emarginata 11. peruv. n! 134, Pavon! mss. in herb. Boiss. Rami suboppossti, patentes. Folia sparsa et subopposita, 2-3-pollicaria, 10-16 lin. lata, interdum emarginata, petiolo tereti 2 lin. longo. Pedunculi axillares et oppositifolii, 1-1 $\frac{1}{2}$ poli. longi, cum pedicellis 1-2 lin. longis floribus ramisque densissime flavescenti-tomentosi. Fàsciculi multiflori. Calyois lobi intus tomentelli. Pistilli rudimentum cyathulo membranaceo crenato inclusum، Fem. ignota. (v. s. in herb. Boiss.)

9. D. SwartzIr, ramis glabris, foliis coriaceis lanceolatis obtusiusculis utrinque attenuatis supra glabris reticulatis nitidis, subtus glaucescentibus adpresse-pilosiusculis, pedunculis axillaribus elongatis, pedicellis brevibus, calyce incano, lobis lanceolatis acutis reflexis. 5 In montibus altis Jamaicæ australis (Swartz I). Daphne occidentalis Sw.! prodr, p. 63, fl. Ind. occ. 2, p. 685*, Wikstr. Daphne p. 22*, Thym. p. 300. Arbuscula, ramis gracilibus laxe foliosis. Folia subpetiolata, 2-4 poll. longa, 5-8 lin. lata, basi valde attenuata, venarum reticulo supra acute prominulo denso subtus obsoleto. Pedunculi $1=1 \frac{1}{2}$ poll. longi, filiformes, puberuli, apice in

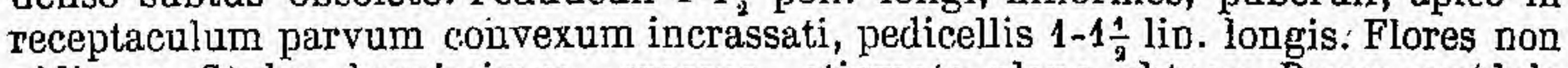
vidimus. Stylus brevissimus, crassus, stigmate plano obtuso. Drupa pendula glabra. (v. s. sine fl. in herb. DC.)

10 D.? GUBENSIs, foliis coriaceis subsessilibus lanceolatis obtusis muticis basi attenuatis margine recurvis utrinque penniveniis ramulisque glabris, capitulis terminalibus lateralibusque breve pedunculatis, calyce dense albo-tomentoso $\mathbf{5}$-fido, lobis ovatís acutiusculis tubo conico dimidio brevioribus, staminibus 10 exsertis, annulo hypogyno exiguo subintegro. $\%$ In insulæ Cubæ prov. Nimanima (Linden, n. 21091). Rami virgati, sæpe dichotomi, ramulis corymboso-ramosissimis gracilibus cicatrisato-dentatis. Folia sparsa, 8-12 lin. longa, 3-5 lin. lata, subtus pallidiora, venis subtus prominulis supra venulisque immersis. Pedunculi 3-6.lin. longi, glabri. Capitula 8-12-flora, ebracteata, receptaculo parvo convexo-discoideo dense albo-tomentoso. Calyx sessilis, subcoriaceus, albuss, demum 4-5 lin. longus, tubo conieo-cylindraceo basi rotundato sursum angustato intus sericeo-piloso, lobis 5 quincunciatim imbricatis inæqualibus intus glabris. Stamina 10 fauci inserta, filamentis brevibus exsertis, superioribus paulo longioribus dimidium lobum æquantibus, antheris ovalibus. Annulus hypogynus membranaceus, imo calyci semiadnatus. Pistillum sterile longe barbatum, ovario exiguo, stylo antheras inferiores altingente piloso, stigmate vix inerassato obtuso. Fem. ignota. Species insignis, floribus 5-meris et stylo elongato a genere discrepans et ad Ovidiam accedens, sed dioica et ínflorescentia omnino Daphnopseos. (v. s. in herb. DG. et Shuttl,)

11. D. SALIGIPOLIA, foliis coriaceis lanceolatis reticulatis nitidis ramisque glabris, pedunculis axillaribus folio brevioribus tomentosis, pedicellis brevissimis, calyce jnfundibuliformi tomentoso, lobis ovatis obtusis, ovario glabro, stylo brevi. $₹$ In 
Mexici planitie temperatà, prope Cuernavaca, alt. 3,200 ped. (Humboldı! Galeotti, n. 524 ?), Daphne salicifolia Kunth! in H. B. nov. gen. 2, p. $150^{*}$, synops. 1, p. 446 (non Lam.). D. elccagnoides Humb. in Willd. herb. n. 7551! Wikstr. Daph. p. 40, Thym. p. 308. D. Mexicana Spreng. syst. 2, p. 236, Mart. et Galeotti in Bull. Ac. Bruxell. 10, n. 4, p. 20 ?.Hargasseria salicifolia Endl. gen. suppl. 4, 2, p. 68. Frutex fotidus. Folia sparsa, 2-4 poll. longa, 4-8 lin. lata, obtusa mutica vel acutiuscula, utrinque attenuata, venis tenuibus immersis supra sæpe sulciformibus subtus levissime prominulis. Pedunculi in' summis axillis solitarii, 5-7 lin. longi. Capitula subglobosa, 8-20-flora, ebracteata, pedicellis vix lineam longis obconicis. Calyx 2 lin. longus, lobis intus tomentellis. Ovarium sterile minutum, oblongum, glabrum. Fem. ignota. (v. s. deflor. in herb. Willd. et Kiunth.)

12. D. CESTRIFOLIA, foliis subcoriaceis obovato-lanceolatis obtusis reticulatis glabris supra nitidis, capitulis axillaribus terminalibusque pedunculatis, calyce infundibuliformi sericeo-piloso, lobis ovato-oblongis acutis reflexis, ovario glabro. F In Nove-Granatæ jugis, prope, Guaduas, alt. 3,500 ped. (Humb.! Bonpl. n. 1746! Hartweg, n.1367। Galeotti, n. 523?), Daphne cestrifolia Kunth 1 in. H. B. nov. gen. 2, p. 150*, syn. 1, p. 446, Benth. pl. Hartweg, p. 247, Mart. ct Galeotti, 1. c. p. 20 ? Hargasseria eestrifolia Endl. gen. supıl. 4, 2, p. 68. Frutex 2-3-orgyalis, ramis

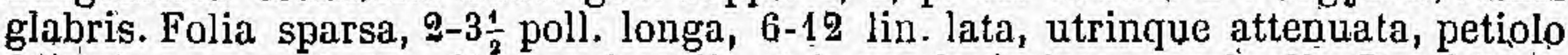
4 lin. longo, yenis tenuibus, primariis utrinque levissime prominulis. Rami florigerí apice nonnunquam dichotomi et foliorum abortu vel lapsu cymoso-oligocephali, capitulis globosis 6-10-floris, pedunculis incano-tomentosis' 8 lin. longis, pedicellis brevissimis, fructigeris 2-3 lin. longis. Calyx albo-flavescens, $2 \frac{1}{2}$ lin. longus, diu persistens. Drupa ovato-globosa, rubra, magnit. D. Mezerei. Flor. fem. ign. Forsan potius var. D. salicifolise? (v. s. fructif. in herb. Kuntl. et Shuttl.)

13. D. LINDENI, foliis coriaceis lanceolatis obtusis longe attenuato-subpetiolatis immerse venosis utrinque opacis ramulisque glabris, pedunculis axillaribus filiformibus floribusque sericeo-puberulis, calycis parvuli pedicello brevioris lobis ovatis obtusis. 7 In Mexico, distr. Mirades, alt. 1,000 ped. (Linden, n. 95!). Folia subtus venis tenuibus dense reticulata. Pedunculi 6-8 lin. longi, apico incrassati, 6-10-flori, pedicellis 2-2 $\frac{1}{2}$ lin. longis tenuibus, Calyx fem. $1 \frac{1}{2}-2$ lin. Iongus, tubulosus, fance angustatâ, limbo connivente subgloboso dimidium tubun æquante. Filamenta superiora sterilia brevia, inferiora nulla. Ovarium substipitatum, glabrum, stylo brevissimo, stigmate capitato. Annulus hypogynus obsoletus. Mas ignot. Forsan D. cestrifoliæ var. vel status junior, attamen foliis basin versus longius attenuatis et reticulationis ińdole primo vultu distinguenda. (v. s. in herb. DC.)

\section{§ 2. Pédunculi terminales dichotomo-cymosi, polycephali.}

14. D. TINIFOLIA, foliis coriaceis ovali-oblongis reticulatis nilidis ramisque glabris, podunculis floribusque subsericeo-tomentosis, calycis lobis ovatis acutiusculis tubo brevioribus, squamulis hypogynis 4 liberis ligulatis. 5 In montihus excelsis Jamaicæe australis (Swartz!), Martinicâ (Sieber !), Cul)â (de la Ossa!), Guadeloupe (Chr. Krauss !). Daphne linifolia Swartz ! prodr. p. 63, fl. Ind. occ. 2, p. 683'. Wikstr. Dapli. 1, p. 13* ${ }^{*}$ Thym. p. 297. Nordmannia tinifolia Fisch. et Mey. mss. Hargasseria tinifolia Endl. gen. suppl. 4, 2, p. 68. Nom. vernaculum Noseburn tree propter naturam causticam. Rami dichotomi, apice laxe foliosi. Folia sparsa, 8-5-pollicaria, 10-18 lin. lata, petiolo 3-4 lin. longo, acuta vel obtusiuscula, utrinque subacuminata, venarum retículo denso subtus plus minus prominulo. Pedunculi Jjis vel ter dichotomi. Capitula 10-20-flora, evolutione centripeta, receptaculo parvo convexo. Flores ex Swartz $\widehat{\Upsilon}$, sed in staminiferis pistillum nunquam perfectum, quamvis magis ac in aliis speciebus evolutum, invenimus. Masc. Calyx subinfundibuliformis, $2 \frac{1}{2}$ lin. longus, tubo angustissimo, lobis demum reflexis. Antherie subsessiles. Squamæ hypogynæ subcarnosæ, obtusæ, ovario elliptico breviores. Stylus brevis, obtusus. Fem. Calyx subcampanulatus, $1 \frac{1}{2}$ lin. longus, persistens. Stamina rudimentaria 8 in fauce biseriata. Ovarium subsessile, ovatum, glabrum, stylo terminali brevissimo, stigmate subcapitato. Drupa magnit. pisi, ovata, rugulosa', flavo-viridis hinc purpurascens. Gaet. maris. (v. s. in herb. DC. et Mart.)

$\beta$. Cumingii, foliis subcoriaceis utrinque laxe prominulo-reticulatis nitidis, cymis masc, divaricatis, floribus primo sessilibus, demum pedicello $3.4 \mathrm{lin}$, 
longo suffultis. - In Jamaicâ (Cuming, n. 56!). Forsan sp. distincta, sed specim. suppetentia imperfecta. (v. s. in herb. Shuttl.)

\section{Species dubia.}

15. D.? CRASSIF OLIA, foliis crassis rigidis subsessilibus ovato-ellipticis supra nitidis subtus pallidis ramisque glabris, floribus axillaribus terminalibusque aggregatis pedunculatis villosis, lobis ovalibus subreflexis tubo brevioribus. f? In St-Domingo (Nectoux in herb. Desf.). Daphne crassifolia Poir. dict. suppl. 3, p. 316 * Folia sparsa, passim opposita, alia subcuneiformia rotundato-obtusissima, alia utrinque subacuta, subtus rugosa. Flores ramulos laterales brevissimos abortivos terminantes, pedunculis inæqualibus suhpollicaribus filiformibus villosis. Calyx parvus; albidus. Floris structura ignota, sed species patriæ causâ verisimiliter huc spectans, cum præcedentium unâ vel alterâ forsan identica.

\section{OVIDIA (1) Daphnes sp. Kunth, in H. et B. et Cl. Gay.}

Flores 4-meri, abortu diclines, dioici ? Calyx infundibiliformis, 4-fidus, extus pubescens, intus glaber, lobis subæqualibus, fauce esquamatâ.' Stam. 8, duplici serie fauci inserta, superiora exserta, filamentis conspicuis, antheris ovalibus dorso prope basin affixis. Pistillum sterile, glabrum. Annulus hypogynus subinteger. of Antherarum rudimenta 8 , glanduliformia, in fauce biseriatim subsessilia. Ovarium squamulis hypogynis 4 exiguis cinctum. Stylus lateralis vel subterminalis elongatus exsertus, stigmate capitato. Fruct.....? (ex Gay bacca pyriformis disco villoso insidens). - Frutices Americæ occidentali-australis, habitu Daphnes, foliis subcoriaceis, pedunculis terminalibus vel demum lateralibus simplicibus ebracteatis, floribus umbellatis breve pedicellatis. Genus a Daphne, Wikstrœmiâ et Daphnopsi stylo elongato, a prioribus et Edgeworthiâ insuper floribus diclinibus distinctum, dicatum divo poetæ qui Daphnes metamorphosin in Laurum pulcherrimis versibus illustravit.

1. O. ANDINA, foliis sessilibus herbaceis obovato-oblongis obtusis basi attenuatis obscure venosis ramulisque glaberrimis, pedunculis terminalibus, calycis masculi tubo infundibuliformi pedicello parum limbi lobis ovatis obtusiusculis duplo longiore, staminibus exsertis, ovario glabro. 5 In monte Pico de Pilque Andium Antucensium, Chịli auștralis, alt. 7,000 ped. (Pœeppig coll. n. 115, diar. n. 834!), Cordillera de Ranco (Lechler, n. 2953!). Daphne Andina Poepp.! diar. n. 834, Pœpp. et Endl. nov. gen. 2, p. $60^{*}$, t. 191, Gl. Gay hist. de Chile, p. 314 ". Fraro-voqui Chilensium. Rami stricti, dichotomi, apice páucifolii. Folia sparsa, sessilia, passim opposita, 1-2 poll. longa, 8-12 lin. lata, obtusissima, basi vel rarius utríqque attenıata, venis pinnatis tenuibus confertis, venulis obsoletis. Pedunculi semipollicares, apice in receptaculum parvum convexum incrassati, umbella 8-10-flora. Masc. Calyx 4-5 lin. longus, albus?, minute puberulus, tubo in pedicellum 2-3 lin. longum attenuato, lobis patentibus $1 \frac{1}{3}$ lín. Jongis stamina dimidio superantibus. Filamenta æqualia, $\frac{1}{3}$ lin. longa. Pistillum glaberrimum, calycis tubum æquans. Squamulæ hypogynæ 4 vix conșpicuæ subconnatæ. Fem. Calyx subcampanulatus, vix 3 lin. longus, lobis tubum subæquantibus. Antherarum rndimenta 8 glanduliformia in fauce subsessilia. Ovarium sessile, apice puherulum, stylo exserto. Bacea? ovata, $2 \frac{1}{2}$ lin. longa, lævis, a calyce demum supra basin circumscisso denudata.

2. 0. PILL 0-P I L L , foliis sessilibus coriacels lanceolatis acutis basi attenuatâ obtusis venosis glabris, novellis ramulisque adpresse puberulis, fasciculis terminalibus multifloris subsessilibus folia æquantibus sericeo-puberulis, calyce masc. pedicellum æquante infundibuliformi lobis oblongis acutiusculis tubo tenui paulo longioribus staminibus exsertis, pistillo sterili glabro. $J$ In Ghile australi, prope Valdiviam et Arique, ubi Pillo-Pillo vocatur (Lechler, n. 5301 Philippi, n. 164 ! excl. a). Daphne Pillopillo Cl. Gay hist. de Chile, p. 515*. Frutex 3-4-pedalis et ultra, ramis virgatis strietis defoliatis, ramulis adscendentibus conferte foliosis. Folia

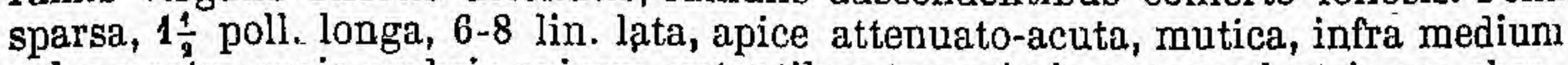
subcuneata, venis crebris apicem petentibus tenerrimis supra vel utrinque obso-

(1) Ovidia Hafn. (ubi ?) est Commelynæ sp., ex schedulis nostris (A. DG.). 
letís. Fasciculi 8-12-flori. Calyx sensim in pedicellum attenuatus et cum eo 8-9 lin. longus, alabastro clavato, lobis 2 lin. longis stamina $\frac{1}{3}$ superantibus. Filamenta conspicua. Annulus hypogynus brevis, subinleger. Fem. ignota. Species a congeneribus jạm calycis magnitudine et formâ, ab 0 . Humboldti et Andinâ præterea foliis sessilibus minoribus, etc., distincta. Forsan tamen mera hujus var., cfr. Gay 1. c. Sæpe :statum quemdam morbosum ostendit, scilicet colorem flavescentem et præcocem foliorum florumque lapsum, Cortex valde acris, emeticus et laxans a Chilensibus inter remedia popularia adhibetur, teste Gay l. c. p. 316. (v. s.)

3. O. PARVIFLORA, foliis sessilibus coriaceis obovato-lanceolatis obtusis breviter apiculatis muticis basi attenuatâ obtusis venosis glabris, junioribus subtus ramulisque adpresso-pilosiusculis, fasciculis terminalibus paucifloris subsessilibus foliis involucrantibus subsericeis superatis sericeo-puberulis, calyee fem. pedicellum subæquante campanulato, lobis ovatis obtusis tubo tumidulo æquilongis, antheris effotis sessilibus exiguis, pistillo glabro, gtylo laterali. $\delta$ In sylvis Chilensibus (Philippi, n. 164, a!). Ovidia Pillo-Pillo, Hohenack,! in Philippi pl. exsicc. (nec Meisn.). Incolìs Pillu-Pillu, teste Philippi. Arbuscula 12-pedalis, plurimis notis cum præcedente conveniens (an ejusdem stirps fem.?), sed distincta foliis obtusioribus, venis distinctioribus supra impressis subtus prominulis reticulatisque, fasciculis 6-8-floris, calyce fere triplo minore, etc. Anther: imperfectæ 8, minutie, in fauce sessiles. Ovarium annulo hypogyno minuto crenato cinctum, stylo medioori, stigmate exserto: Floribus proxime accedit ad 0 . Humboldti et Andinam, sed differt foliis sessilibus multo minorilbus, etc. (v. s.)

4. О. Ниивоцдтг, foliis petiolatis subcoriaceis obovato-oblongis breve acuteque acuminatis obsolete retículatis ramulisque glaberrimis nitidis, fasciculis subterminalibus, calyce fem. breviter pedicellato subsericeo, lobis ovato-oblongis acutis reflexis tubo subcampanulato dimidio brevioribus, pistillo glabro, stylo subterminali exserto. F In altå planitie prov. Popayan, inter Sacondonoy et La Ere, alt. 6,300 ped. (Humb.! Bonpl. n. 2110!). Daphne anomala Kunth in H. et B.! nov. gen. 2, p. $151^{*}$; synops. 1, p. 447 . Folia 5 poll. longa, fere 2 poll. lata, petiolo 2 lin. longo, venis tenuibus, primariis levissime prominulis, reliquis immersis supra fere obliteratis. Fasciculus multiflorus prope apicem rami lateralis, pédunculo 4 lin., pedicellis $1 \frac{1}{2}$ lin. longis. Calyx albus, 3-4 lin. longus, adpresse pilosis. Antheræ 8, minutæe, glanduliformes, biseriatim in fauce subsessiles. Ovarium stipitatum, cyathulo hypogyno brevissimo crenato libero arcte cinctum. Stylus filiformis, stigmale capitatu e fauce breviter exserto. Masc. ignot. (v. s. sp. manc. in herb. Kunth.)

VII. FÚNIFERA Leandro de Sacramento msc., C. A. Mey. in Bullet. Acad. st-Pétersb. 4, n. \&, Endl. gen. suppl. 4, 2, p.'69, n. 2106/15, Meisn. in Mart. l. bras. 14, p. 67. Lagetta Mart. nov. gen. 1, 63, t. 34 (non Juss.). - Neesia Mart. mss. - Boscia Vell. fl. Flumin. 4, p.150, t.11? (non alior.)

Flores dioici, 4-meri. Caly $x$ herbaceus, tubulosus vel campanulatus, utrinque pubescens, 4-fidus, lobis æqualibus, fauce esquamatå. Squamulæ hypogynæ 8 parvæ, lineari-setaceæ, in fundo calycis pilis sericeis interpositæ. $\sigma^{\prime}$ Stamina 8, duplici serie fauci vel tubo inserta, inclusa, filamentis brevissimis, antheris erectis ovatis. Pistilli rudimentum villosisșimum. 웅 Calyx persistens, limbo connivente. Staminum rudimenta nulla. Ovarium hirsutum, 1-loculare, ovulo 1 pendulo (ex Mart. 1-3). Stylus terminalis, filiformis, persistens, demum lateralis, stigmate capitato papilloso. Drupa sicca, calyce coriaceo inclusa, pericarpio crustaceo, pyrenâ 1 (rarius 2-3, fide Mart.) fragili. Semen exalbuminosum. - Frutices Brasilienses, libro tenaci deductili textili, foliis herbaceis oppositis sparsisve, racemis vel fasciculis terminalibus vel in summis axillis solitariis subsessilibus bracteatis paucifloris.

1. F. utruis (Leandro mss.), foliis herbaceis lanceolatis acutis fere eveniis subtus sericeo-canescentibus, racemis terminalihus et in summis axillis solitariis subsessilibus, calyce tubuloso, lobis erectis tubo multo brevioribus, staminibus inclusis, filamentis brevissimis. F Circa Rio de Janeiro (Mart.! Pohl, n. 4436! Guillemin, n. 794 ! Lund, n. 169 ! Gardmer, n. $812 ! 5597 !$ etc.). - Meisn. in Mart. fl. bras. 14, 
p. 07*. Daphne Bresiliensis Raddi Bras. add. p. 12. D. Thereminii Lhotzky mss. in herb. DG. Lagetta funifera Mart. et Zucc.l nov. gen. 1, p; $66^{*}, t$. 34 , Neesia daphusides Mart.! mss. in Sched. n. 18. Embira l. Imbira branea Brasiliensium. Frutex 5-6-jedalis. Folia sparsa, rarius opposita vel ad ramificationes 3-4 subverticillata, 3-4 poll. longa, 3-12 lin. lata, subtus fuscescen ti-hirta subserícea. Racemi terminales, masc. etiam axillares, semipollicares, 5-10-flori, basi bracteis linearibus pedicelloś persistentes subæquantibus 2-3 lin. longis stipati, floribus nutantibus deciduis, feminei subsessiles, sæpius 1 -flori, bracteati. Calyx viridis, circ. 3 lin. longus, dentibus ovatis acutis erectis. Antheræ infra faucem subsepssiles, superiores semiexsertæ. Stylus calycem subæquans rel demum superans. Drupa magn. avellanæ, sicciuscula, 1 - rarius 2 -3-pyrena, pyrenấ ovato irigonâ. (v. s.)

2. F, Fascicuz a a (Meisn. in Mart. fl. bras. 14, p. 68*), foliis subcoriaceis oblongolanceolatis utrinque attenuatis laxe semiimmerso-reticulatis glabris, pedunculis axillaribus aggregatis fasciculo 5-8-floro terminatis puberulis, calyce pedicellum æquante campanulato utrinque puberulo, lobis tubo iequalibus patentipus, staminibus exsertis, filamentis conspicuis. 7 In prov. Minas Geraës (Widgren, $n$. 1025!). Folia sparsa, breve petiolata, 4-6 poll. longa, 10-12 lin. lata. Pedunculi terni, rarius 2-1, filiformes, circ. pollieares, floribus fasciculatis vel brevissime racemosis ebracteatis, pedicellis nutantibus cum calyce articulatis $1 \frac{1}{2}-2$ lin. longis persistentibus. Calyx 2 lin. longus, utrinque cano-puberulus, lobis ovatis demum reflexis. Stamina calycis lobis subiequilonga. Rudimentum pistilli parvulum, pilosum, stigmate faucem attingente. Squamulie hypogynic 8, liberæ, lineares, obtuse. Fem. ignota. (v. s. in herb. Sonder.)

\section{Species nondum descripta.}

F. uatifolia C. A. Mey. in Bull. Ac. St-Péterb. 4, n. 4, Endl. gen. suppl. 4, $2, \mathrm{p} \cdot 69$.

VIII, LAGETTA Juss. gen. p. 77, Lam. ill. t. 289, Wikstr. Thym. in Act. Ac. Holm. 1818, p. 293, Gartn. fr. 3, t. 215 , Endl. gen. p. 332, n. 2106 (exul. syn.), suppl. 4, 2, p. 69, n. $2106 / 16$, Meisn. gen. p. 331 (243), Bot. reg. t. 4502. - Daphnes sp. $s w$.

Flores hermaphroditi, 4-meri. Galyx coloratus, tubo ovato oblongo, supra ovarium demum circumscisse decidıo, fauce angustatâ esquamatâ, limbo 4-fido. Squamulæ hypogynæ.....? Antheræ 8 , inclusæ, in tubi apice biseriatim subsessiles, ovatæ. Ovaritum sessile, 1-ovulatum, hirsulum, stylo terminali brevi, stigmate subclavato. Nucula pisiformis, pilosa, calycis basi persistente cincta, 1-sperma. Semen albuminosum. - Arbor Antillana, libro reticuliformi fibroso textili, foliis sparsis, spicis teru,inalibus simplicibus pedunculatis ebracteatis.

L. Livt ta RIA (Lam. dict. 3 , p. 376 et 440 , suppl. 3, p. 236, ill. t. 289); glabra, foliis ovatis suhcordatisve acutis reticulatis nitidis, spicis pedunculatis laxe multiforis. In moutibus altioribus Jamaicæ (Sw.), distr.Vere, Clarendon et Elisabeth (Purdie), Hiispaninlie (Swartz), St-Domingo (Bertero!). - Wilistr. Thym. p. 294, Hool. in Kew. gard. misc. 2, t. 4, Bot. mag. t. 4502, Lindl. ill Paxton fl. gard. 1, n. 60, cum ic. xylogr. Lem. n. jard. t. 19, Browne Jam. p. 371, t. 31, f. 5, Sloane Jam. p. 137; hist. 2 , p. 22, t. 168, f. 1-3, t. 169, f. 1. Daplune Lagelto Swartz prodr. p. 63, 11. Ind. occ. 1, j. $680^{*}$. Lagetto Lunan hort. jam. 1, p. 473. Lagelto, Lace-bark vel Gawse tree, Bois dentelle Jamaicensium. Arbor 20-30-pedalis. Folia coriacea? Jete viridia, 2-5 poll. longa, 1-2 poll. lata, hreviter acuminata, petiolo 2-3' lin. Jongo cum ramo articulato. Spice erecte, incluso pedunculo circ. pollicari, 3-4 poll. long'e, 15-20-floræ. Calyx subcarnosus, campanulatus, albus, glabor, 4-5 lin. Iongus, lobis ovalis aculiusculis patentibus tubo ovalo pluries brevioribus. Corticis interioris strata fibrosa retiformia vario usui terhnico inserviunt. ( $r$. fragm. in herb. DE.) 
IX. DIRGA Linn. diss. Chenon, 1751, gen. ed. 5, n. 437, ed. 6, p. 192, n. 486, amon. Acad. 3, p. 12, t. 1, f. 7, Duham. arbr. p 211, t. 88, Lam. dict. 3, p. 289, ill. $t .293$, Schleuhr. Handb. 1,p. 337, t. 107, Juss. gen. p: 77, Wikstr. Thyin. p. 270 et 309, Endl. gen. p. 329, n. 2091, suppl. 4, 2, p. 67, n. 2106/6, Meisn. yen. p. 330 (242). - Dolia Adans. fam. 2,p. 285.

Flores hermaphroditi, 4-meri. Calyx coloratus, turbinato-campanulatus, utrinque glaber, tolus deciduus; limbo obsique truncato subrepando, fauce nuda. Anuulus hy pogynus minutus, crenatus, calycis fundo adnatus. Stamina 8 , tubo intra medium uniseriatim inserta, filamentis capillaribus exsertis ad insertionem cum denticulis $\varnothing$ minutis alternantibus, allerne brevioribus, antheris basilixis oblongis obtusis. Ovatium sessite, glabrum, ovulo pendulo. Stylus sublateralis, 'ilitormis, exsertus, stigmate vix incrassato obtuso. Bacca nưda. Semen exalbuminosum, testâ crusiaceâ. - Frutex Boreali-Americanus, ramis virgatis, foliis sparsis herbaceis deciduis venosis, floribus axillaribus fasciculatis pallide tlavis.

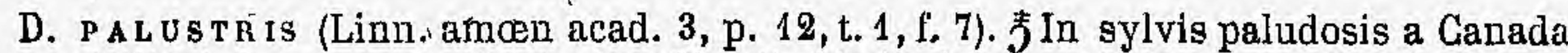
ad Virginiam usque, licutucky (Short), Massachusetts (Uakes l): - Pursh $\mathrm{t}$. bor. Am. 1, p. 268, Bot. r甘g. t. 292, Hook. 11. bor. Am. 2, p. 138. Frutex 5-8-pedalis, glaber. Folia brevissime petiolata, oblongo-lanceolata, acutiuscula, $1 \frac{1}{2}-2 \frac{1}{2}$ poll. longa, 8-10 lin. lata. Pedicelli plerumque terni, $1 \frac{1}{2}$ demum 3 lin. longi, nutaules ebracteati. Calyx 5-6 lin. longus, subinllatus, limbo subrepaudo. Styllus stamina exserta superans, deciduus. Bacca ovata, obtusa, 3-4 lin. longa. (v. s. sp. et v. y. e.)

X. GOODALLIA Benth. in Hook. Lond. Jour'n. of bot. 4, p. 633 (non Bowdich), Endl. gen. suppl. 4, 2, p. 67, u. 2106/5, Meisn. in Mart. fl. bras. 14, $\not$. 68.

Flores dioici, 5-meri. Caly $x$ late tubulosus, 5 -lidus, tubo intus villoso, fauce esquamalâ, lobis erectis. Squamulie 10 perigynæ prope basin tubi, lineares, glabræ. o Stamina 10, fauci inserta, calyce breviura, alterna (quæ lubis opposita) paulo lóngiora. Pistilli rudimentum ninimum vel nullum. 우 Stamina nulla. Squamæ hypogynæ milnutissinæ, lunge hispidæ. Uvariun hirsutissimum, ovulo 1 penduo. Stylus tiliformis brevis, apice dilatatus in stigma capitatum crassum papillosum. l'ructus calyce parum atcto inclusus, vix carnosus, ovoideus, apice attenuatus, hispiulus. semen exalvuminusum, testâ crusıaceâ. - l'rutex ciuyañensis, folius sparsis, spicis capituilormibus terminalibus sessilibus paucifloris.

G. GuYANEN sis (Benth.! l. c.). J In sylvis Guyane anglicæ (Schomburgk coll. 1, n. 142 ! ex parte). - Meiss. I. c. Kami divaricato-ramusissimi, ramulis tenuibus, junioribus sericeo-pilosulis. Folia brevissime petiolata, herbacea, elliptica, ubtusa, basi cuneata vet rotuudata, tenuiter denseque venosa, glabıa, 12-14 liw. louga, 8-10 lin. lata. Fasciculi fúlio breviores, 2-3-tlori. Cialyx : ubcampanulatus, 3-4 ln. longus, brevissime pedicellatus, cano-sericeus, lobis lџtearibus tubum æuquantibus. (v. s. comm. ab am. Shuttleworti.)

XI. LASIADENIA Benth. in Hook. Lond. Journ. of bot. 4, p. 632 *, Endl. gen. suppl. 4, 2, p. 68, n. 2106/9, Meisn. in Mart. R. bias. 14, p. 69, t. 29 .

Flores hermaphroditi, 5-meri. Calyx herbaceus, persistens, tubo cylindraceo tenui, demum tumidulo oblongo, lauce esquamatã, limbi 5-partiti lobis patentibus. squamulæ hypogynæ o ininutæ, longe burbatæ. Stamına 10 inclusa, 5 intra faucem inserta lovis opposila, 5 medio tubo inserta illis alterna; antheræ subsessiles, ublonga. Uvarium oblougum, hisprdissimum, ovulo ex apice loculi pendulo. Siylus lateralis, bresis, tenuis, apice expansus in stigma crasse capitalum 10 -costatum, costis verticalibus papilosis. Drupa sicca, 1-sperma, pubescens, pericarpio osseo tenui. - lrutex Guianensis, foliis sparsis, capitulis terminalibus paucifloris. 
L. RUPEST R IS (Benth.! 1. c.). J In rupibus, ad Hio Negro Guianæ anglicæ (Schomburgk, n. 899!), et in sylvis Japurensibus et circa Barra prov. Bio Negro Brasiliæ (Mart.I Spruce, n. 1198! 1232 !). - Meisn. 1, c. p. $69^{*}$, t. 29. Frutex hurmilis, divaricato-ramosissimus, ramulis tenuibus, junioribus sericeo-pilosis. Folia subsessilia, herbacea, ovata vel ovali-lanceolata, acuta vel obtusa, basi rotundata,

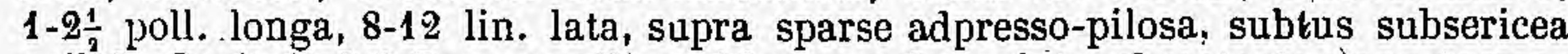
pallida. Capitula 3-6-flora, sessilia vel breve pedunculata, ebracteata, cano-tomentosa. Calyx albo-viridis, semipollicaris, tubo 10-costato intus glabro, lobis lancsolatis acutis 3 lin. longis utrinque tomentosis. (v. s. in herb. DG. et Acad. Monac. et comm. ab am. Sluuttl.)

XII. PEDDIEA Harvey in Hook. Journ. of bot. $1840,2, p .266, t .10$, Endl. gen. mant. p. 36 , n. 2106/1, suppl. 4, 2, p. 69, n: 2106/14, Meisn. gen. p. 331 (243). - Cyathodiscus Hochstelt. in Flord 1842, p 240, Endl. gen. mant. p. 65, n. 2009/1, Meisn. gen. 2, p. 368. - Psilasolena Presl in Abhandl. d. Boehm. Gesellsch. ser. 3, 5, p. 532, bot. Bemerk. p. 102, Walp. ann. 1, p, 588. - Harveya Plant (non alior.). - Cestri sp. E. Mey.

Flores hermaphroditi, 4-5-meri. Calyx coloralus, deciduus, tubo subconícocylindrico continuo, fauce esquamatâ, limbi 4-5-fidi lobis brevibus revolutis. Stamina 8 vel 10 inclusa, supra medium tubi biseriatim inserta, antherís subsessilibus oblongis obtusis. Cyathulus hypogynus membranaceus, repandodentatus, ovarii basin cingens. Ovarium 1-loculare, 2?- vel 1-ovulatum, ovulis pendulis anatropís. Stylus filiformis, calycis tubo brevior, deriduus, stigmate depresso-capitato. Drupa nuda, 2 ?-1-pyrena. Embryo exalbuminosus. - Frutices Africæ australis glabri, cortice tenuissimo, ramis sæpe dichotomis, foliis sparsis vel suboppositis subsessilibus, umbellis terminalibus pedunculatis, pedicellis basi articulatis:

1. P. HARVEYI, foliis herbaceis venosis obovato-oblongis, pedunculo ebracteato pedicellis floribusque subæquilongo, pistillo dimidium calycis tubum æquante, ovario apice hinc pubescente 2 ?-ovulato, drupâ 2-pyrenấ? f Circa Port-Natal (Peddie). P. Africana Harv. 1. c. t. 10. Folia (ex ic.) 2-2 $\frac{1}{2}$ poll. Ionga, 10-14 lín. lata, breviter et obtusiuscule acuminata. Pedunculus $6-7$ lin., pedicellj 3-5 lin., flores 6-7 lin. longi. Ovarium stylo antheras inferiores attingente fere dimidio brevius. Drupa ovata, obtusa, 4 lin. longa.

2. P. DREGEI, foliis subcoriaceis oblongis obsolete venosis, pedunculo basi bracteato pedicellis flores subequantibus longiore, pistillo calycis tubo triplo breviore, ovario glabro 1-ovulato, drupâ 1-pyrenà. $\bar{\zeta}$ Circa Port-Natal, in sylvis infra alt. 400 ped. (Drège! Plant! Krauss, n. 427). P. Africana R. W. Plant pl. Natal. exsicc. n. 14! Cestruun umbellatum E. Mey.! mss. in herb. Drège. Cyathodiscus umbellatus Hochstett. in Florâ 1842, p. 2/0. Psilosolena umbellata Presl, 1. c. bọt. Bemerk. p. 102, Walp. ann. 1, p. 589. Rami virgati, sparse ramosi. Folia 3-4-pollicaria, 12-1 4 lin. longa, obtusiuscula, basi attenuata. Pedunculus 1-2-pollicaris, basi bracteis nonnullis subfoliaceis coloratis sessilibus oblongo-lanceolatis obtusis 3-5 lin. longis munitus. Umbella 6:10-floræ. Stylus $\frac{5}{4}$ lin. longus, ovarium subrequans, antheras inferiores haud attingens. Species, si differentia indicatæe constantes et icon P. Harveyi accurata, certe bene distincta.

XIJI. DAIS Linn. sp.ed. 2, p. 556, gen. ed. 6, p. 215, n. 540, Juss. gen. p. 77, Gartn.fr. 1, p. 187, t.39, f. 3, Lam dict. 2, p. 254, ill. t. 338, Wikstr. Thym. in Act Holm. 1818, p. 270 et 348 (excl. sp plur.), Endl. gen. p. 330, n. 2093, suppl. 4, 2. p. 66, n. 2106, Meisn. gen. p. 330 (242), et in Linnad 14,p. 388 (excl. sp. 2 et 3), G. A. Mey. in Bull. Ac.St-Petersb. 4, n. 2, Ann. sc. nat. $2^{\circ}$ sér. 20, p. 48 et 51.

Flores hermaplsroditi, 5-meri. Calyx coloratus, infundibuliformis, tubo gracili continuo vel demum supra ovarium rumpente intus medio præsertim pubescente, limbo patente 5 -lobo regulari, lauce esquamatâ. Cyathulius hypogynus membranaceus ovarii basin cingens. Stamina 10 duplici serie fauci inserta, filamentis conspicuis selaceis, alternis brevioribus, superioribus vel omnibus exsertis; antheræ oblongæ, 5 inferiores sæpe semiinclusæ: Stylus lateralis, capillaris, exsertus, stigmate capitato papilloso. Bacca carnosa vel 
sicca? calycis basi inclusa. - Frutices Capenses et Madagascarienses. foliis sparsis vel oppositis majusculis planis venosis, capitulis terminalibus pedunculatis solitariis involucro 4 -phyllo biseriali cinctis.

1. D. G отINIF OLI A (Linn. sp. ed. 2, p. 556), foliís oppositis alternisque oblongis vel obovatis acutis utrinque subconcoloribus glabris obsolete reticulatis, involucro floribus dimidio breviore, foliolis late ovatis tomentosis exterioribus dorso glabratis subenerviis, calyee sericeo, lobis lanceolatis tubo subcylindrico subduplo brévioribus, stylo exserto. $\mathrm{F}$ In Africả Capensi orientem versus, circa Buffelrivier, Omtata, ete. (Drège!). - Curt. Bot. mag. t. 147, Lam. dict. 2, p. 254 ", ill. t. 368, f. 1, Willd. sp. 2, p. 579, Wikstr. l. c. p. 348, Herb. amat. t. 214, Meisn. in Linnæá 14, p. 388. Frutex 4-6-pedalis. Folia demum subcoriacea, 1-3 poll. longa, 10-16 lin. lata, petiolo 1-3 lin. longo, nune obtusissima, nune plus minis acula vel breve acuminata. Capitula magnit. juglandis, pedunculo 1.3-pollicari apice turbinatoincrassato. Involucrum coloratum, demum fuscum, foliolis erectis sulycoriaceoherbaceis rotundato-obtusissimis vel subacuminulatis enerviis vel exterioribus obsolele nervoso-striatis' 5-7 lin. longis. Calyx circ. pollicaris, lilacinus, fauce infundibuliformi, intus glabrà, tubo tardissime supra ovarium rumpente, lohis 2-3 lin. longis stamina dimidio superantibus stylo sæpius paulo superatis. Ovarium glabrum, apice barbatum, cyatluulo hypogyno triplo longius. Stigma crassiusculum.

a. parvifolia (Meisn. l. 'c.), foliis ellipticis subpollicaribus ( $($. s.)

$\beta$. major (Meisn. l. c.), foliis ovalibus ovatis obovatisve $1 \frac{1}{2}-2$ poll. longis. (i. s. et v.v.c.)

$\gamma$. laurifolia, foliis lanceolato-oblongis utrinque attenuatis, 2-3 poll. longis, circ. 1 poll. Iatis. - D. laurifolia Jacq. coll. 1, p. 146. ic. rar. t. 77. Stirps culta, ignotæe patrix, verisimiliter hue spectans et potius forma vegetior quam variatio constans.

2. D. GLAUGESGENS (Decaisne in Ann. sc. nat. 1843, 20, p. 51, in nota), foliis oppositis sparsisque ellipticis ovatisque utrinque obtusiusculis glabris subtus glaucescentibus et tenuissime reticulatis, involuero floribus 2-3-plo breviore, foliolis ovatis oblongisve, interioribus sericeis, exterioribus excepto margine glabris 1 -nerviis, calyce sericeo-cano, lobis ovato-oblongis tubo dimidio brevioribus, stylo vix exserto. $亏$ In Madagascariæe prov. Emirna (Bojer !). D. Madagascariensis Bojer! mss. 1833, in herb. DC. (non Jam.). Avouhou incolarum, qui e fibris librí chartam parant. Plurimis notis valde quidem ad præcedentem accedit, atlamen bene distincta : foliis vix ultra 1-1 $\frac{1}{2}$ poll. longis, discoloribus, distincte venuloso-reticulatis, pedunculis tenuibus folio brevioribus 6-8 lin. longis, capitulis minoribus, paucifloris, involucri foliolis 2-3 lin., calycibus 6-7 lin. longis, tubo intus ad faucem usque pubescente. Cyathulus hypogynus dimidium ovarium æquans (v.s. in herb. DC. et Zuccar.)

\section{Species dubia, verisimilitẹ excludenda.}

3. D.? CANESCENS (Bartl. in Linnced 14,p. $388^{~}{ }^{\text {}}$ ), foliis sparsis subimbricatis oblongis obtusiusculis utrinque cauescentibus, involucralibus 6-8 lineari-oblongis obtusis subsericeo-canescentibus, calyce sericeo-piloso, lobis lineari-oblongis obtusis. $F$ In Africâ Capensi (herb. reg. Berolin.). Rami validi, ramulis flexuosis apice folioso canescontibus infra aphyllis noduloso-cicatricosis. Folia erecta, 2-4 lin. longa, plana, basi attenuata, dorso 1-nervia; involucralia erecta, semiuncialia, margine subscariosa, intus fere brunnea. Capitula 3-6-flora. Calycis tubus filiformis, pollicaris, basi persistente longe barbatâ, lobis tubo quadruplo brevioribus æqualibus obtusissimis intus glabris margine subrevolutis, fauce esquamatà. Antheræe lineares, 5 in fauce et 5 paulo infra, - an sessiles? - tunc species verisimiliter ad Arthrosolen vel Lasiosiphon referenda.

4. D.? ER I о G E P H L A (Lichtenst., ex Bartl., 1. c. p. 389), foliis sparsis linearibus submucronatis concaviusculis ramulisque glaucescentibus glaberrimis, involucralibus 6-8 oblongo-lanceolatis acutis extus villosis, interioribus majoribus. Capensi, prope Leeuwenfontein (Lichtenst.). Ramuli breves, dense foliosi. Folia vix imbricata, brevissime petiolata, 3-6 lin. longa, nervo subtus prominulo subcarinata, involucralia fusca, margine pallidiora. Capitula multiflora. Calyx..... Verisimiliter Arthrosolenis sp. 


\section{Species obscura vel non descripta.}

D. PUR PU REA Gaudich., ex Steudel nomencl. ed. 2, 1, p. 479.

D. URTICAF OLIA hort., ex Steud,, ibid.

\section{Species exclusce.}

D. ANTHYLLOIDES Eckl. et Zeyh. = Lasiosiphon anthylloides Meisn.

D, ARGENTEA Eckl. et Zeyh. = Lasiosiphon Meisnerianus Endl.

D. A RGENTEA $\beta$ Eckl, et Zeyh. = Lasiosiphon pulehollus Desne. $\alpha$.

D. coccinea Gaudich. = Pseudais coccinea Desne.

D. cuneara Lam. = Lasiosiphon cuneatus Desne.

D. DISPERMA Forst. = Drymispermum ? Forsteri Meisu.

D. DUBI 0SA Blıme = Drymispermum Blumei Desne.

D. DuBios a Desne. = Drymispermum laurifolium Desne.

D. LAURIFOLIA Blanco = Drymispermumlaurifolium Desne.

D. LINIF o IA Lam. = Lasiosiphon linifolins Desne.

D. MA DAG A SCARI E NSis Lam. = Lasiosiphon Madagascariensis Desue.

D. OCTANDRA Burm. = Drymispermum Burmanni Desne.

D. OWenI Eckl. et Zeyh. = Lasiosiphon triplinervis Desne.

D. Pu в ESCEN Lam. = Lasiosiphon pubescens Desne.

D. SERYCEA Lam. = Lasiosiphon anthylloides Meisn.

D. SP ICA A Endl. = Stellera spicata C. A. Mey.

D. virgata Lichtenst. = Arthrosolen polycephalus L. A. Mey:

XIV. DAPHNE Linn. syst. nat.ed. 1 (1735), gen. ed 1, (1737), p. 110, n. 311, ed.6, $p$ 192, 485, Juss. gen. $p .77$, Wikstroem diss. de Daphne, 1817, ed. 2, 1820, Thymel. in Act. Holm. 1818, p. 294 (excl sp. plur.), Nees jun. gen. fl. germ. fasc. 7, t. 1, Endl. gen. p. 330.n. 2092, suppl 4,2, p.67, n 2106/7 (excl. sp. nonnull.), Meisn. gen. p. 330 (242), et in Regensb. Denkschr. 3, p 282.-Thymelæa Tourn. inst. p. 594, $t 366$ (excl. sp. plur.). Scop. Carn. 1, p. 276, Garln fr. 1, p. 188, t. 39, fig. 4. - Scopolia Linn. fil. suppl. p. b0 et 409 (haud alior.). - Eriosolena Blume bijdrag.p. 651. - Roumea Wall. mss. - Mezereum et Daphne-C. A. Mey, in Bull. Ac. St-Pélersb. 4, n. 4.

Flores hermaphroditi, 4-meri. Calyx coloratus (rarius viridis), tubulosus vel infundibuiliformis, totus deciduus vel rarius persistens, tubo eontinuo, limbo regulari 4-partito patente, fauce esquamalâ. Disctus hypogynus obsoletus vel minutus annularis interdum bievissime urcenlaris vel dinidiatus. Antheræ 8 duplici serie fauci insertæ, subsessiles, oblongæ, subinclusæ. Stylus terminalis, brevissimus vel-nullus, stigmale capitato. Bacca carnosa vel coriacea nuda, vel subsicca calyce diu inclusa. Semen nucamentaceum, testâ crustaceâ. Albumen uullum vel parcum. Embryo carnosus, cotyledonibus plano-convexis. - Frutices vel rarius arbusculæ in Europâ, Afrìâ boreali et Asiâ crescentes, cortice caustico, libro fibroso tenacissimo textili, foliis sparsis vel raro oppositis coriaceis sempervirentibus vel rarius herba-

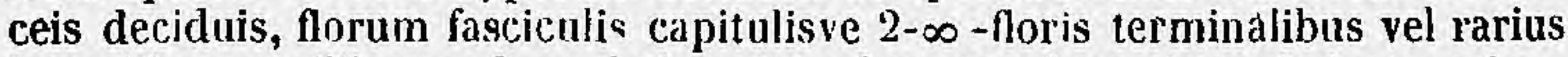
lateralibus sessilibus pedunculatisve interdum involucralis rarissime pauiculatis vel noribus axillaribus racemosis, calyce albo vel roseo vel luteo vel virescente, sæpe odoratissimo.

Sectio. I. Mezereum Spach. hist. vey. phan. 10 p. 439.

Folia herbacea, decidua. Calyx deciduus (cfr. D. alpina). Bacca carnosa, nuda, rarius demum subsicca ( ( f $\mathrm{f}$. $\bar{D}$. alpina). Albuminis lamina tenuissima. - Genus Mezereum C. A. Mey.l. c.

* Flores laterales pracoces, 3-7-fasciculati.

1. D. MEZEREUM (Linn. sp. ed. 1, p. 356), foliis sjarsis lanceolatis acutiusculis basi attenuatis tenuiter venosis glabris, fasciculis subtrifloris, calycis lobis late ovatis 
tubum suljsericoum subsquantibus. F In sylvis Europæe verisimiliter totius, ab Hispanià? et Italia ad Suecianı et a Caureaso ad Sibiriam Altaicam arcticamque usque - Sclıkulır Handb. t. 107, Blackw. herb. t. 582, Batsch analys. flor. 1, p. 84 , l. 9, Lam. ill. t. 290, f.1, Fl, dan. t. 268, Engl. But. t. 1381, Wikstr: diss. ed. 2, p. $5^{*}$, Thym. p. 295, Nees jun. gen. Il. germ. 3, t. 46, Reichenb. ic. fl. germ. 11, p. 15, t. 556, Mert. et Hook. Deutschll. Flora 3, p. 43, Ledeb. fl. ross. 1, p. 546, Hayne Arzn. Gew. 3, t. 43. D. Liotardi Vill. Dauph. 3, p. 516, ex Lois. fl. gall. ed. 1, 1, p. 226, ed. 2, p. 279. Thymelsea priecox Gilib. exerc. phytol. 1, p. 7. Th. Mezereum. Scop. Carn. p. 270, Mezereum ollicinarum C. A. Mey. Beilr. 5, n. 112, bull. Ac. St-Pétersb. 4, n. 4. Firuter 2-4-uedalis. Folia 2-3 poll. longa. Fasciculi 2-4-flori ex axillis foliorum unıi preterıti nascentes, juniores squamis parvis imbricati. Calyx roseus (rarius atropurpureus Van Houtte fl. d. serr. 1850, p. 187, t. 502. D. Houtteana Planclion, Paxton, 1. gard. 1851, 1, n. 221). Baccæ coccineæ: (v. v.)

ß. albida, noribus albidis, baccis nlavescentibus.-Passim in Lithowiâ, Germaniâ, Galliâ, Helvetià. - Ait. Kew. ed. 1, 2, p. 25, Wikstr. 1. c. D. albiflora Wolf èt Schœllenljach Willd. Brum. 3, t. 33.

2. D. GENK ^ (Sicb. ot Zucc. f1.jap. 1, p. 137*,t.75), foliis oppositis lanceolatis, junioribus ramulisque sericeis, fasciculis 3-7-floris, calyce sericeo-villoso, lobis ovatis obtusis tuho dimidio brevioribus. F Colitur in hortis Japonicis, e Chinà introducta (Siebold, Zolling, n. 230!). Frutex 2-3-perdalis, tortuosus. Folia 6-9 lin. longa, circ. 3 lin. lala, petiolo vix 2 lin. longo sericeo, juniora adpresse sericeo-albida, supra demum calva. Flores 6-7 lin. longi, lilacini, interdum coütanei, tubo subeylindrico $1 \frac{1}{2}$ lin. lato. Uvarium villosum Annulua hypogynus obsoletus. Cortex, sicut apud nos Mezoreum, ut rubelaciens, flores interne ut hydragogum, febrifugum et anthelminlhicum in usu medico sunt.

3. D. ForTUNE I (Lindl.! in Journ. hortic. Soc. Lond. 1, p. 147", 2, p. 34, t. 1), foliis subcoëtaneis oppositis sparsisque ovalibus oblongisve tenuiter venosis utrinque adpressc pilosiusculis, fasciculis 3-4-horis lateralibus subsessilibus vel ramulos brevissimos terminantibus exinvolucratis basi imbricato-bracteatis, calyce sericeo, lobis ovatis obtusis tubo gracili parum brevioribus. J In Chinæ prov. Chusan, Ningpo, Shangai, Clevkiang (Fortune, n. 8! et A. 15!), ins. Hong-Kong (Hinds, ex Benth. in Hook. Journ. 1853, p. 196). - Walp. ann. bot. 1, p. 582, Van Houlte fl. des serres $3, t$. 208. Frutex 2-3-pedalis, ramulis fastigiato-corymbosis pubernlis. Fólia deridua, breve petiolata, 1-1 $\frac{1}{2}$ poll. longa, 6-9 lin. lata, obtusa vel acutiuscula, juniora sericea. Gemmæ florales laterales, $\theta$ vetustis axillis nascentes; 2-4-florse, bracteis squamiformibus ovatis sericeis deciduis imbricater. Calyx lilacinus, 8-10 lin. longus. Squamula hypogyna semiannularis. Antheræ inclusæ. Ovarium attenıato-stipitatum, apico puberulum: Planta secundum Zuccar. in Hook. Lond. Journ. 6, p. 45, identica cum D. Genkwa, secundum cl. Lindley vero (Bot. reg. 1847, adnot. ad t. 48), bene distincta, recedens enim foliis latioribus, petiolis brevioribus, toribus majoribus, ovario subsessili infra medium glabro. (v. s. sp. et v. in herb. Lindl. et DC.)

\section{** Flores terminales, fasciculati vel capitati exinvolucrati.}

4. D. AltaIcA (Pall. fl. ross. 1, p. 53, t. 35), foliis coëtaneis sparsis subsessilibus laneeolatis oblongisve acutiusculis mucronatisve glabris basi attenuatis, fasciculis 2-5-floris, calyce subsessili, lobis ovatis tuba pủbescente vix dimidio brevioribus, ovario glabro. F In Sibiriâ Altaicâ et in Soongoriá Chinensi, ad lacum Saisang Nor (Pall., Patrin, Ledebour! Karelin et Kiril, n. 434 ! Schrenk). - Willd. sp. 2, p. 422, Wikstr. Daphne, p. 25 *, Thym. p. 301, Bot. cab. t. 399, Bot. mag. t. 1875, Ledeb.! fl. alt. 2, p. 71, fl. ross. 3, p. 548. D. Indica Schangin in Pall. N. Nord. Beitr. 6, p. 109 (non Linn.). Folia 1-2-pollicaria, subvenosa. Flores in api'e rami vel ramulorum lateralium brevissimorum sæepe aphyllorum sessiles vel brevissime pedicellati, ebracteali, circ. semipollicares, ałbi, tubo cyjlindrico, lobis nunc ovali-oblongis nunt late ellipticis obtuse mucronulatis , Antheræ superiores semiexsertæ. Annulus hypogynus minutus. Baccæ carnosæ, ovato-globosææ. (v. s. in herb. Ledeb., DC., elc.)

5. D. CAUCA SI A (Pall. Il. ross. 1, p. 53*), foliis sparsis sessilibus lanceolatis obtusis mucronulatis basi altenuatis glaucis glabris, fasciculis 2-20-floris, calyce subsericeo-canescente, lobis ovatis oblóngisve tubo gracíli dimidio brevipribus, ovario 
apice 'puberulo. $\mathrm{J}$ In provinciis .Caucasicis (Güldenst.), Iberià (M. Bieb., Tilesius ! Wilhelms! Fischer! Hohenack.!), Cartiliniâ, ad tlum. Csani (Szovits!), Kachetiâ, Somchetiâ, Imeretià, Mingreliâ (Eichw.), Daghestan (C. Koch), nec non in Ucraniæ? sylvis montosis (Tscherniaeff! in herb. DC., sub nom. D. oleoidis).--Ledeb.! fl. ross. 3, p. 549. D. Caucasica $\beta$ cognata C. Koch in Linnæâ 22, p. 611. D. Cueorum Güldenst. it. 1, p. 191 (non L.). D. salicifolia Lam. dict. 3, p. $438^{*}$, M. Bieb. Taur. Cauc. 1, p. 299, Wikstr. Daphne p. 38*, Thym. p. 307, non Kunth in H. et B. D. euphorbioides Muss. Pusk., ex Steudel nomencl. p. 483. Frutex 2-3-pedalis et ultra, virgatus, diffusus. Folia conferta, herbacea vel demum subcoriacea, oblonga

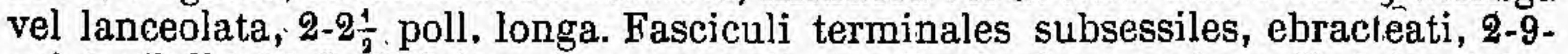
vel (ex Pall.) 20-flori. Calyx albus, magnit. corollæ Syringæe, tubo cylindrico, lobis usque ad $2 \frac{1}{2}$ lin. longis, 2 lin. latis vel dimidio angustioribus, obtusis vel acutis. (v. $\mathrm{s}$ in herb. Ledeb., DG., etc.)

6. D. S о PнiA (,Kaleniczenko in Bull. Soc. imp. Mosc. 22, 1849, p. 311", t. 3), foliis sparsis subsessilibus glabris subtus glaucis obovato-oblongis mucronulatis basi cuneato-attenuatis, fasciculis terminalibus subsessilibus bracteatis, calycis lobis ovatis acutis glabris tubo adpresse puberulo triplo brevioribus. 7 In Rossiæ mediæ prov. Kursk, distr. "Korocza et Belgorod, secus rivum Donez, et in prov. Charkow, distr. Volczansk, ad rivùm Kozinka (Kalenicz.), nec non in Ucraniâ et Rossià australi (ex Ledeb.).-Walp. an11. 3, p. 326*, Ledeb. fl. ross. 3, p. 548. Frutex orgyalis et ultra, ramis gracilibus subfiliformibus. Folia supra subnitida, formả et magnit. D. Mezerei. Flores numerosi, subsessiles; magnit. D. odoræ, albi, odore Heliotropii et Hyacinthi, tubo pilis nuinutis albidis adsperso. Bracteæ ovato-Janceolatæ, acutæ, concavæ, reticulato-venosæ, dimidium calycis tubum-subæquantes, flavo-virescentes, persistentes. Bacca pedicellata, ovato-globosa, miniata. Valde quidem ad D. Altaicam accedere, sed floribus bracteatis, etc., satis distincta videtur.

7. D. Al piNa (Linn. sp. ed. 1, p. 356), foliis sparsis lanceolatis acutiusculis obovatisve obtusis subeveniis utrinque ramulisque adpresse pilosiusculis, fasciculís terminalibus 5- $\infty$-floris ebracteatis, calyce subsessili sericeo tarde deciduo, lobis ovatis oblongisve acutis tubum æquantibus, ovario pubescente, baccâ subsiccâ. 5 In alpibus Croatiæ, Dalmatiæ, Carnioliæ, Carinthiæ, Austriæ (Hoppe! etc.), Helvetiæe, Galliæe australis, in Pyrenæis, Italiâ, Istriâ, Apennino (Savi, Bertol.), Hispaniâ (Asso).-W.illd. sp. 2, p. 418, Lodd. Bot. cab. t. 66, Wikstr. Daphne, p. 23 *, Thym. p. 300, Sturm D. fl. 22, t. 9, Mert. et Koch D. fl. 3, p. 45, Reichenb. ic. A. germ. 11; p. 14, t. 553. D. candida Wittm. summ. pl. 2, p. 514. Thymelæa alpina Âll. Pedem. 1, p. 132. Th. candida Scop. fl. carn. ed. 2, 1, p. 277. Fruticulus

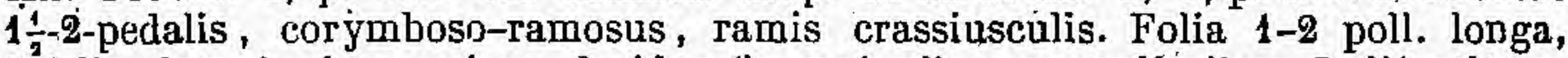
3-6 lin. lata, juniora sericea, decidua (in regionibus australióribus, Italiâ sàltem, fide Savi Bot. etr. 2, p. 229, sempervirentia, sed species forsan non identica). Flores albi, odori, 5-6 lin. longi. Antheræ superiores exsertæ. Bacca (ex Host) oblonga, rubella, hinc suturà longitudinali sulciformi notata. (v. s. et r. v.)

Seclio II. Daphnanthes C. A. Mey. l. c. Ann. sc. nat. 18/43, p. 52, excl. D. alpina.

Folia coriacea, persistentia. Flores terminales capitati vel fasciculati. Calyx tarde deciduus, subpersistens. - Sect. Cneoroides Spach in plant. or. t. 305 , anno 1850 .

${ }^{*}$ Bacca coriacea vel sicca (rarius carnosa, cfr. D. Blagayana).

8. D. CNEORU i (Linn. sp. ed. 1, p. 357), foliis sparsis sessilibus spathulato-vel lineari-lanceolatis acutis vel obtusis cum apiculo plicato recurvo nitidis glabris, capitulis 6-10-floris, calyce incano-puberulo, lobis ovatis obtusiusculis tubo duplo brevioribus, ovario puhescente. 5 In montanis Europre fere totius (exceptis. insulis Mediterraneis? Britannicis, Scandinaviâ, Rossiâ interiore?), in Germaniâ passim Austriâ ! Bavariâ! Prussià ! Poloniâ ! Hungariâ! Lithuaniâ! Volhynià ! Helvetiâ ! Alsatià! Galliâ australi et occidentali! Pyren:eis.! Italiâ superiore (Bertol.) (1), Hispaniá l-Willd. sp. 2, p. 422, Curt. Bot. mag. t. 313, Bull. herb. t. 121, Jacq. fl, austr. 5, p. 12, t. 426, DC. fl. fr. 3, p. 357, Wikstr. Daphne, p. 26, Thym. p. 301,

(1) Sub nom. D. Cneorum specirn. in Italià lecta nunquam ad hane speciem, sed ad D. striatam referenda se invenisse asseruit Sieber, tide Tratt. Arch. d. Gewecliskunde 1, p. 120. Nos specim. Italiana harum specierum nondum vidimus. 
Mert. et Koch D. fl. 3, p. 46, Bertol. fl. ital. 4, p. 338 (excl. $\beta$ ), Ledeb. fl. ross. 3, p. 548, Reichenb. ic. fl. germ. 11, p. 14, t. 554, n. 1176. D. odorata Lam. fl. fr. ed. 1, 3, p. 222. Thymelæa Cneorum Scop. Carn. ed. 2, p. 257, All. Ped. 1, p. 133. Fruticulus digitalis-pedalis, pulchellus. Folia 5-12 lin. longa, 1-2 $\frac{1}{2}$ lin. lata, quo angustiora, eo acutiora esse solent et vice versà, sæpe apice rotundato subemarginata. Flores subsessiles, circ. semipollicares, rosei vel purpurei vel rarius'albi, suaveolentes, interdum glabriusculi, sed ovarium tamen constanter pubescens. (v. v. et s.)

$\beta$. Verloti, foliis apice subtruncato vel emarginato mucronulatis, calyce 7-8 lin. longo, lobis bis vel ter lougioribus quam latis (2-2 lin. longis) obtusis. - In lapidosis calcareis infra St-Eynard, prope Grenoble (Verlot! 1856! D. Verloti Godr. et Gren. fl. fr. 3, p. 59. (v. s.)

9. D. Striata (Trattinick Arch. d. Gewæchskunde 1, p. 120, t. 133), glaberrima, foliis sparsis sessilibus lineari-lanceolatis obtusis mucronulatis basi attenuatis nitidis, capitulis $\infty$-floris, calyce glabro, lobis ovato-lanceolatis acutiusculis tubo gracili 3-4-plo brevioribus, ovario glaberrimo. 5 In Carpathis, alpibus Carinthiæ, Tyroli, Bavariæ, Helvetiæ, alt. 5-7,000 ped., in Pyrenæis? in Apnliâ ? Neapoli?Wahlenb. fl. carp. p. 111, Wikstr. Daphñe p. $29^{*}$, Thym. p. 301, Koch synops. fl. germ. ed. 1, p. 621, Reichenb. 11. excurs. p. 164, ic. fl. germ. 11, p. 14, t. 554 , n. 1177. D. Cneorum Wahlenb, veg. et clim. Helv. p. 72, $\beta$ Gaud. Helv 3, p. 31, Bertol. fl. ital. 4, p. 339, $\gamma$ Mert. et Koch D. fl. 3, p. 46. Species præcedenti !simillima quidem, sed distincta foliis plerumque paulo longioribus et angustioribus minuscue coriaceis, calyce ovarioque glaberrimis, tubo paulo longiore apiceque magis infundibuliformi. Bracteæ coloratæ, laté ovales obtusæ, calyce duplo breviores, decidur. (v.. .)

10. D. PE T R A A (Leybold ! in Regensb. Bot. Zeit. 1853, p. 81, 18.55, p. 346*, cum ic.), glabra, foliis spathulato-linearibus obtusissimis muticis nitidis, fasciculis sessilibus 3-5-floris ebracteatis, calyce cano-puberulo, lobis ovalibus tubo tepuiter striato triplo brevioribus, ovario pilosiusculo. 5 In monte Tombea Judicariæ, Tyrol. austral., alt. 5,000 ped. (Leybold I Hausm. 11. Tyrol. p. 1480*. Fruticulus nanus, habitu D. striatex, foliis etiam ad D. microphyllam accedens. Folia sessilia, in ramulorum apice conferta, patula, 2-4 lin. longa, apice $\frac{1}{3}-1-$ raro $\frac{5}{4}$ lin. lata, 1-nervia, evenia, mutica, plana vel complicato-concava, margine subincrassata, immo novella glaberrima. Fasciculi terminales sessiles pauciflori, bracteis nullis nisi caducissimis. Calyx brovissime pedicellatus, folia superans, 6-7 lin. longus, roseus, tubo cylindrico tenui apice nec dilatato nec constricto, lobis $1 \frac{1}{2}$ lin. longis fere 1 lin. latis alterne obtusis acutisque. Antheræ superiores semiexsertæ. Ovarium sessile, stigmate subsessili. (v. s. comm. a cl. Sonder.)

11. D. M GROPHYLLA, glabra, foliis sparsis subsessilibus subcuneato-obovatis obtusis, floribus terminalibus solitariis? sessilibus parce puberulis, lobis oblongis obtusis tubo gracili cylindrico quadruplo brevioribus, ovario apice pubescente. 5 In rupestribus Eubœe (Aucher-Éloy, n. 2518, Beck! in herb. Zuccar.). Fruticulus decumbens? ramosissimus, ramis tortuosis crassiusculis cinereis sæpe pedalibus cicatrisato-tuberculosis demum subspinescentibus, ramulis ultimis tenellis rubrofuscis laxe foliosis. Folia patula, coriacea, 2-3- rarius 4-5 lin. longa, 2 lin: lata, in petiolum brevissimum attenuata, apice rotundata vel sæpius apiculo brevissimo obtusiusculo sæpe plicato-subrecurvo acuminata, plana, glabra, evenia, subtus 1-nervia. Plores rari, semipollicares, minute puberuli vel demum glabri. (v. s.)

$\beta$. angustifolia, foliis dimidio angustioribus obovato-oblongis linearibusque.- - In Eubœâ (Aucher-Éloy!), circa Athenas et in rupibus prope Eleusin. (v. s. in herb. Zuccar.)

12. D. oLEOIDES (Schreb. decad. 1, p. 13, t. 7, sed in herb. Schreber, nunc Acad. Monac., frustra quæritur), foliis subsessilibus obovatis lanceolatisve acutis basi attenuatis eveniis subtus vel rarius utrinque parce adpresso-pilosis demum glabris supra nitidis, fasciculis paucifloris ebracteatis, calyee sericeo-piloso, lobis ovatis lanceolatisve acutis tubo subinflato parum brevioribus, ovario adpresse pilosiusculo. $5 \mathrm{Ab}$ Hispaniâ ad Armeniam et Himalayam. - Linn. mant. 1, p. 66, Willd. sp. 2, p. 423 (excl. syn. Lam.), M. Bieb. Cauc. 1, p. 299, Lodd. Bot. Cab. t. 299, Wikstr. Daphne p. 37*, Thym. p. 306, C. Koch in Linnæâ 22, p. 614, Ledeb. 1. ross. 3, p. 548. D. Caucasica M. Bieb. p. 78 ? (non Pall., ex Led.). Fruticulus palmaris-pedalis, ramosus. Folia 6-15 lin. longa, 3-6 lin. lata, acuta vel obtusa 
chm vel absque brevi apiculo, plana, sulutus plus minus glanduloso-punctata, novella utrinque pilis adpressis conspersa, supra mox glabrà nitida. Capitula 3-6-flora, bracteis nullis nisi cadiucissimis. Calyx 4-6 liñ. longus, pube densâ adpressâ sericeo-canescens. Antherio superiores semicxsertæe. Ovarium totum pubescens breve stipitatum, stigmato sessili. Annulus hypogynus brevis.

๙. brachyloba, calycis lobis ovatis cuspidato-acutiusculis trbo sesquibrevioribus. - In Olympo Bitlynico (Noë!), Tauro (Balansa!), circá Torium Armeniæ, alt. 6,500 ped. (Huet du Pavillon!). D. olevides Griseb. spicil. 1l. rumel. Qे, p. 320 . D. sericea Noë pl. exsice. n. 893! (non Vahl). D. buxifolia Huet du Y'av.! pl. exsicc. (forma inter $\alpha$ et $\beta$ ambigua). Ramuli rugulosi, glabrati. Flores rosei? Plantam Grisebachii non vidimus, Noëana omnino huc spectare videtur, a verả D. sericeả Vahl enim discrepat foliis minus coriaceis margine haud revolatis, ete. (v, s.)

$\beta$. jasminea, calycis lobis lanceolatis acutis tubum suburuantibus vel vix dimidio hrevioribus. - In Corsicấ (Phil. Thomas! liequien! Soleirol t), Sardinià (MForis!), Italic̀, mont. Aprutịi (Niclrali, Ten., Bertol., etc.), Siciliæ mont. Nebrodensib., alt. 3,000-4,000 jed. (Gussone! Heldr.l Huet du Pavillon I), Hispaniá austr., Sierrà Nevadâ, alt. 4,000-5,000 ped. (Boiss.! Bourgeau, i. 1475!), Griecit, Peloponeso, Titygeto (Bory St-Vinc, Heldr.!), Maceloniæ inont. Athro, all. 3,000-6,000 ped. (d'Urville! Griseb.l), Eubæâ (Sנłruner'!), Cretạ (Tournel.; Sieber!), Asià minore, monte Tauro (Kotschy, n. 424, 425! 280 !), Tmolo et Olympo Bithyrico (Boiss.! Noë! Griseb.I Thipke), Sipylo prope Smyrnam (Aucher-Êloy, n. 783!), Libano et Antilibano (Boiss.!), Syriả (Elreub.!), Cappadocià (Auch.-El.n. 2216 ! in herb. DC., n. 2513, ex Spach), circa Damascum (herb. DC.), in Himalayà boreali-occid., alt. 3,000-7,000 ped. (Thomson !). D. jasminea Sibth. et Smith prodr. fl. græe. 1, p. 260, fl. græca t. 358, Griseb.! l. c. p. 320. D. Juxifolia Sibtl. et Sm.l. c., fl. greeca t. 357 ? (non Vall, fide Sparh, Boiss.). D. glandulosa Bertol. amœen. ital. p. 356, fl.ital. 4 , p. 337, T'en. f1. Neap. pr. suppl. 4, p. 8, Guss.! pl. rar. p. 156, Spr. syst. 2, p. 237, Reichenb. 10. excurs. p. 164, ic. 11. gorm. 11, p. 14, t. 553, n. 1174, Hampe in Florà 1842, 1, p. 78, Gren. et Godr. fl. fr. 3, p. 58. D. Lucida Lois.! nouv. not. 17, fl. gall. ed 2, 1, p. 280, t. 25 (forma fol. lanceolatis mox glaberrimis). D. oleoides auet, plurim., Jaub. et Spach ill. pl. orient. t. 305, Boiss.! voy. en Esp. 2, p. 557. D. collina d'Urville (non Sm., ex Griseb.), Kotschy it. Cilic. 1, 0. 280! D. alpina Spruner in herb. (non Linu. fide Hampe l. c.). D. Cretica Steud, nomencl. 1, p. 483 ? D. sericea Kotschy! pl, exsicc. (non Valul). Ramuli levviusculi, pubescentes. Flores albi, inodori (ide Griseb.). Stirps variabilis, staturâ digitali ad pedalem usrue, foliis in specim. Europeris raro

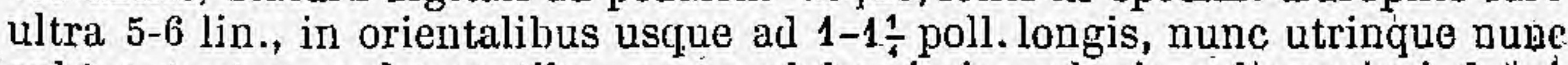
subtus tantum pubeșcentibus nuṇe glaberrimis, calycis pube sericcà deñsă subvillosà vel rariore adpressà. (v.s.)

13. D. B UXIF OLIA (Vahl symb. 1, p. 29), ramulis incano-tomentosis, foliis subsessilibus obovato-oblongis obtusiusculis utrinque adpresso-pilosis vel demum supra glabris lucidis, capitulis 3-6-floris, calyce sericeo, Jobis ovatis obtusiusculis tnbo subduplo brevioribus, ovario incano-sericeo. 5 In -Armeriià (Tournef., Brouss.), provituciis Transcaucasicis (Nordm., fide Ledeb.). - Wikstr. Daplme, p. 34*, Thym. 1. 303, Jaub. et Spach ill. pl. or. T. 306, Ludeb. f. ross. 3; p. 548, Koch in Linneà 22, p. 612. Species a D. oleoide eggre distjnguenda, forsan mere ejuslém var., reccdens calycis lobis brevioribus suhobtusis of foliis immo adultis utrinque pnbescentibus. Frutex pedalis. Folia 3-7 lin. longa. Bracter lineares, dimidium calycis tubum subrequantes, tomentosæe (ex Led.). Calyx 5-6 lin. longus, albus. Annulus hypogynus carnosus cupuliformis. Ovarium brevissime stipitatum, totum pubescens.

14. D. BLAGAYANA (Freyer ! in Florà 1838, 1, p. 176), foliis sessilibus obovato-vel oblongo-lanceolatis obtusis basi attenuatis planis tenuiter venosis ramisque glabris, capitulis multifloris, bracteis sericeis imbricatis exterioribus obovatis, interioribus angustioribus calycis tubum subsequantibus, cal yce parce pilosulo, lobis ovato-oblongis obtusis tuloo brevioribus, ovario puborulo, baccì carnosê. $\zeta$ In monte Lorenziberg, prope Biellichgrätz Carniolize (Freyer I Reichent. fl. germ. exsicc. n. 1320) et in monte Goestingerberg prope Gratz, Styrise--Koch Taschenb. 1844, p. 447, Reichenb. ic. fl. germ. 11, p.14, t. 550, n. 1180. Facies, exceptá 
inflorescentiâ, fere D. Laureolæ. Caúles subsimplices, sæpe vix spithamæi: Folia sparsa, glaberrima, coriacea, 1-1 $\frac{1}{2}$ poll.,longa, 6-9 lin. lata, obtusissima vel submucronulata. Capitılum terminale magnit. juglandis. Bracteæ membranaceæ, 4-7. lin. longæ, oblusissimie, interiores cuneato-lineares, exteriores duplo latiores steriles, demum decidue. Calyx sessilis 6-8 lin. longus, lutea-albus, parce, adpressopubescens, lobis $1 \frac{1}{2}-2$ lin. longis tubo cylindrico nunc parum nume dinidio brevioribus. Antherie superiores semiexsertæ. Ovarii stipes annulo hypogyno membranaceo circ. 'dimidio longior. Bacca (ex Frey. ap. Reichenb. 1. c.), alba; subdiaphana. (v.'s.)

15. D. collina (Smith! sjicil. 2, t. 18), ramulis dense villoso-tomentosis, foliis ublongo-lanceolatis obusis attenuato-subpetiolatis subevonìis supra glaberrimis nitidis sublus adpresse cano-pilosis margine recurvis, capitulís basi imbricatobracteatis, bracteis squamiformibus parvis noltusis calycibusque dense sericeocanis, lobis ovatis obtusis tubum subæquantibus, ovario sericeo. $\$$ Circa Neapolin, Gaëtam, etc. (Schlangenbusch! Sibthorp! Huet du Pavillon!), in Hetrurià, etc. (Bertol.), Istria ? (Brign.), in Bithyniâ (Grisebach!).-Willd. sp. 2, p. 423 (excl. syn. Vahl.), Bot. mag. t. 428, Duham. arb. 1, t. 10, ed. nov. t. 2, Wikstr. Dapline p. 32 * (excl. syn. $\rightarrow$, Thym. p, 302, Guss. pl, rar. p. 156, Bot. cals. t. 1348, Sibll. fl. greec. t. 359, Reiclienb. fl. excurs. p. 164 , ic. fl. germ. 11, p. 14, t 554, 11. 1178, Bertol. 11. ital. 4, p. 340, C. Koch in Linnæà 22, p. 613. D. australis Cyr. pl. rar. 3. t. 16 (ex́ herb. Berol., fide KJocl l. c.). D. al pina Savi due cent. p. 98 (fide Ber tol.). Frutex pedalis et ultra, corymboso-ramosus. Folia rigida, 1-2 poll. longa, 5-8 lin. lata. Capitula terminalia seppiusque in summis axillis sessilia approximata, pauciflora, bracteis late ovalibus $1-2$ lin. longis. Calyx rosens, 6-8 lin. longus, tubo 1 lín. lato, lobis scepe emarginatis. Antheræ superiores subexsertæ. Aniulus hypogynus brevis. Ovarium sessile, canum, stigmate sessili..(v. s. sj. et v. v. c.)

B. Neapolitana (Lindl. in Bot. reg. t. 822), foliis utrinque glabris.-D. Neapolitana Lodd. Bot. cab. t. 719, ex Lindl.

16. D. SERICEA (Vahl, symb. bot. 1, p. 28), ramulis puberulis, foliis spatluulatolanceolatis obtusis subeveniis supra, glaberrimis nitidis subtus adpresse pilosis sericeisve, capitulis bracleatis, bracteis squamiformibus parvulis oblusis calycibusque dense sericeo-canis, lobis ovatis obtusis tubo triplo brevioribus, ovario pilosiusculo. F In Cretà (Tournef., Brouss., fide Vahl, Sieber ! Heldreich l), in Oriente (André! Labill.! Boiss.! inter Lataquia et Aleppo (Oliv.!), Asiâ minore, Ciliciâ (Aucher-ḱloy, n. 902! 2516! 5291! Balansa, n. 716).-Willd. sp. 2, p. 423, Desf. in Ann. Mus. 10, p. 297. t. 20, oj. élhoix d. pl. p. 15, t. 9, Wikstr. Daphne, p. 35*, Thym. p. 305, G. Koch in Linnæâ 22, p. 612. D. oleæéfolia Lam. dict. 3, p. 440*. D. argentea Clark (non Sm., fide Griseb.). Forsan mera var. D. collinæe, cui plurimis notis convenit, recedens tuntum foliis plerumque pollice brevioribus subtus minus dense pilosis sericeis neo incanis, bracteis minoribus et precipue calycis lobis brevioribus. Inflorescentia in utrâque specie eadem. Variat foliis usque ad $1 \frac{1}{2}$ poll. longis. (v. s.)

17. D. ELIS A (Vis. revis. pl. minus cogn. h. Patav. 1855, p. 2, mem. istit. ven. sc. 1856 , v. 6, p. 247 , t. 2), ramulis puberulis, foliis oblongo-obovatis obtusis gläbris margine subrevolutis, junioribus floralibusque margino pilosiusculis, floribus terminalibus aggregatis pedunculatis lanuginosis, lobis subcordato-ellipticis obtusis emarginatisve. F In Moxico (procul dubio ex errore). D. Blagayana hort. (non Freyer), Mohl et Schl. Bot. Zeit. 1856, p. 476. Inter D. Cueorum et collinam medium tenere dicitur, priori similis floribus folia superantibus, sed diversa foliis lobisque calycis latioribus, floribus pedicellatis, etc.; a D. collinâ, cui foliis similior, discrepat præsertim foliis glabris.

18. D. CAGHEMIREANA, ramulis puberulis moX glabris, foliis subsessilibus rigidis lanceolatis mucronatis eveniis glaberrimis, capitulis axillaribus breve pedunculatis aphyllis folio dimidio brevioribus demum racemiformibus ebracteatis, calyce brevissimo pedicellato dense incano-sericen, lobis ovatis acutis tubo cylindrico mox inflato dimidio brevioribus, ovario sessili tubum subæquante incano. F In Himalayæ Cachemirensis mont. Pir-Panjohl (de Hügel! in herb. Zuccar.). Rami

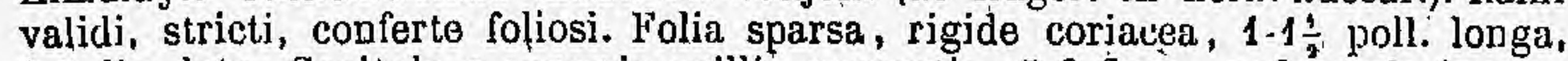
4-5 lin. lata. Capitula o summis axillis nascentia, 5-8-flora, pedunculo incano 4-5 lin. longo ebracteato fulta, mox in spicam vel racemum brevissimum excres- 
centia, rhachi 2-3 lin. longâ, pédicellis $\frac{1}{2}-1$ lin. longis. Calyx semipollicaris, tubo mox valde ampliato ovato. Antheræ superiores semiexsértie. Annulus hypogynus obsoletus. Hæc verisimiliter identica cum D. coriaceâ Royle ill. Himal. p. 321, quæ nondum descripta. Valde accedit ad D, gnidioidem Spach et mucronatam Royle, sed (ex ic.) differt ramulis haud sericeis, foliis latioribus et præsertim inflorescentiâ. (v. s. comm. a b. Zuccarini.)

19. D. GNIDIOIDES (Jaub. et Spach ill. pl. or. t. 304, cum descr., non Szovits), ramulis corymbosis conferte foliosis pulverulento-puberulis, foliis sessilibus rigidis lineari-lanceolatis pungenti-mucronatis basi attenuatis eveniis glabris, fasciculis terminalibus axillaribusque sessilibus paucifloris bracteatis, calyce cano-tomentoso, lobis ovatis obtusis tubo parum brevioribus, ovario villoso. $尹$ In Syriâ, inter Halep et Latakjah (Oliv. el Bruguière), prope Cacame (Erd! ! n. 12, in herb. Zuccar.), in Caramania prope Cylindro (Olivier! in herb. DC.), ins. maris Egei (Oliv. et Brug.), Cos et Eubœâ (Aucher-Éloy, n. 524! 2514!), Samos (d'Urville, n. 169!). D. oleoides d'Urvilte enum. p. 45 (excl. syn.). Frutex ramosus, 2-3-pedalis, flore albido (d'Urv. in sched.). Folia sparsa, 12-16 lin. longa, 2 vix 3 lin. lata. Fasciculi 2-8-flori, plerique terminales, bracteis oblongis acutis 2 lin. longis dorso purpurascentibus glabris margine lanato-tomentosis eaducis. Calyx 3-4 lin. longus, diu persistens, tubo demum ovoideo brevissime pedicellato. Fructus magn. písi, vix carnosus. Species præcedenti proxime accedens, sed foliis angustioribus minus crassis et inflorescentia distincta, a sequentibus jam foliis crassioribus rigidis mucronatisque facile dignoscenda. (v. s. in herb. DG., Boiss., Zucc.).

20. D. M U CRONATA (Royle ill. Himal. p. 322, t. 81, f. 2), ramis junioribus sericeis foliis alternis lineari-lanceolatis mucronatis basi attenuatis glaberrimis, floribus terminalibus 2-3 aggregatis sessilibus, calyce incano-villoso, lobis ovatis acutis tubo dimidio vix brevioribus. J In Kunawur (Royle). Rami (ex ic.) cinereo-fusci, folia evenia, læte viridia, flores 6-7 lin. longi, roseo-albi. Bacce coccineæ, globosæ, magn. pisi. A præcedente, cui a cl. Spach conjungitur, differre videtur habitu laxiore, floribus minoribus ebracteatis?

B: Affghanica, ramulis glabris vel junioribus puberulis (haud sericeis), foliis obsolete venosis, capilulis 3-8-floris.-In Affghanistan, circa Chughuda Serai (Griffith, n': 1366! 1367!) et Beloochistan superiore, alt. 4,500 ped., ubi Peepul vocatur et camelis valde obnoxia dicitur (Stocks, n. 859). D. acuminata Stocks

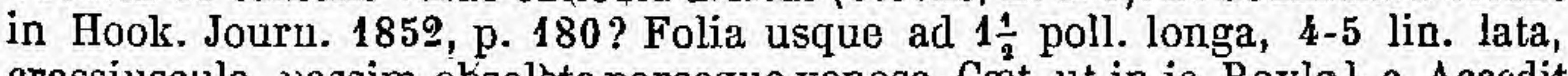
crassiuscula, passim obsolete parceque venosa. Cæet. ut in ic. Royle l. c. Accedit ad D. acuminatam, sed differt foliis rigidioribus, floribus ebracteatis, etc. (v. s. in herb. Griff. et comm. a b. Lemann.)

21. D. A cum ma t a (Boiss. et Hohenack. in Kotschy pl. exsicc. Pers. austral.n. 551!), ramis gracilibus, foliis rigidulis lineari-lanceolatis acutis vel breve acuminatis basi angustatis subeveniis glabris, capitulis terminalibus subsessilibus bracteatis, calyce dense tomentoso, lobis ovatis obtusis tubo crasso 2-3-plo brevioribus, ovario pubescente. $\bar{J}$ In Kurdistaniæ mont. Kuh-Delu et Gara (Kotschy, n. 323! 551!), Assyriâ, Elamont (Aucher-Éloy, n. 2515! 2818! 5309!), in mont. Seidchadschi, distr. Khoi Aderbeidschan (Szovits!). - Boiss. diagn. n. 12, p. 103. D. salicifollia Auch.-Éloy! mss. in herb, (non Lam.). D. gnidioides Szovirs! mss. in herb. (non Jaub. et Spach). Frutex 4-6-pedalis, habitu foliisque fere D. Gnidii. Rami subcorymbosi, laxiuscule foliosi, nunc glabri (specim. Kotschy) nunc cinereo-tomentosi (sp. Auch. n. 2818!). Folia usque ad 2 poll. longa, 2-3 poll. lata, basin versus sensim attenuata, subcoriacea, parum rigidula, haud pungentia, passim obs̀oleto pennivenia. Capitula \&-12-flora, receptaculo hemisphærico tomentoso, demum sphæroideo, magn. pisi, pedicellis brevissimis crassiusculis cum calyce articulatis persistentibus quasi tuberculato. Bracteæ parvulæ caducissimæ. Cal yx 3 lin. longus tubulosiss, persistens, fructifer 5-6 lin. longus, tubo oblongo $1 \frac{1}{2}$ lin. lato. Annulus hypogynus minutus. Planta e mont. prope Dalechi, Persiæ austr. (Kotschy, n.189!), recedens ramis divaricatis albido-cinereis, foliis rigide coriaceis subglaucis vix pollicaribus 3 lin. latis basi minus attenuatis, forsan specifice distincta, sed nonnisi sterilem vidimus. (v. s. in herb. Boiss., DC., Ledeb., etc.)

$\beta$. Kochii, foliis summis squamiformibus sericeis, floribus terminalibus aggregatis sessilibus. - In distr. Nagdchewan (H. Schmidt). D. angustifolia C. Koch in Linnæâ 22 , ก. 611, Walp. ann. 3, p. 326. 


\section{* Bacca camosa, succosa.}

22. D. ODOR A (Thunb. fl. jap. p. $159^{*}$, non Lour), foliis sparsis sessilibus ovalibus oblongisve acutis nitidis glabriś, floribus terminalibus aggregatis sessilibus glabris bracteatis, calycis lobis cordato-ovatis obtusis tabo dimidio brevioribus, ovario glabro. J In Japoniâ (Thunb.). - Banks ic. Kæmpf. t. 16, Wikstr. Daphn. p. 19', Thym. p. 299, Sieb. et Zuce. fl. jap. fam. nat. 2, p. 75 ? D. Japonica Thunb. in Mus. Ac. Ups. $13 ;$ p. 106 ? excl. $\gamma$ (non? Sieb. et Zucc.). Sjico Kæmpf. amœn. exot. 5 p. 844 . Ramuli novelli tenuissime pubescentes. Folia pollicaria. Capitula circ. 11-flora, bracteís foliaceis lanceolatis glabris calyce duplo brevioribus. Calyx túbulosus, purpureus, 2-3 lin.'longus. Antlieræ superiores exsertee.

23. D. Sinensis (Lam. dict. 3, p. 438), ramulis pubescentibus, foliis ovalibus oblongisve utrinque attenuatis venosis glabris nitidis, fasciculis terminalibus sessilibus multifloris bracteatis, calyce sericeo-puberulo, lobis oblongis acuminatis tubo parum brevioribus, ovario glabro. F In Chinâ. - Wikstr. Daphne, p. 21 *, Thym. p. 299. D. odora Lour. Coch. 1, p. 237, ed.Willd. p. 292, Ait. h. Kew. ed 1, 2, p. 26, edl. 2, 2, p. 411, Smith exot. bot. t. 47, Jacq. h. Schœabr. 3, p. 54, t. 351, Bot. mag. t. 1587, Bot. cab. t. 1927. D. Japonica, $\gamma$ Thunb. Mus. nat. Ac. Ups. append. 18, p. 4 (ex Wikstr.). D. Indica hort. Herb. amat. 2, t. 105 (non Linn.). Frutex elatior. Folia $1 \frac{1}{2}-4$ poll. longa. Capilula dense multiflora, bracteis foliaceis lanceolatis acutis glabris 5-7 lin. longis deciduis. Flores suaveolentes, 6-10 lin. longi, albi, extus pássim rosei. Cyathulus hypogynus conspicuus. Variat floribus roseís. D. odora var. rubra Sweet Brit. fl. gard. ser. 2, t. 320 (excl. syn. Wall.). Forsan mera var. D. odoræ, culturâ producla. (v. v. c.)

B.? hybrida, foliis oblongo-lanceolatîs utrinque attenuatis acutis, fasciculis paucifloris, calycis lobis ovato-oblongis acutiusculis tubo dimidio brevioribus, ovario sericeo. - D. hybrida Lindl. in Bot. reg. t. 1177, Sweet Brit. fl. gard. 2, 1. 200, Colv. cat. ed. 3, p. 35. D. Delphini et Dauphini hort. D. australis, Bot. reg. 1838 , t. 56 ? (cfr. D. collina). Hybrida dicitur progenies ex D. collinâ et Sinensi orta, florum odore foliisque huic, calyce illi similis. Folia fere D. Laureole, sed apice magis attenuata, saturate viridia, subtus pallidiora, juniora ciliata subtus minute parceque pilosiuscula. Fasciculi eirc. 6-flori. Alabastra clavata, acuta, atropurpurea ; flores aperti roseo-violacei, lobis intus pallide lilacinis. Antheræ lateritia. (v. v. c.)

24. D. Ja A onic A (hort. Lugd. ex Sieb. et Zucc. in Abhandl. d. math. pliys. Kl. d. Bair. Acad. 4, 3, p. 199"), ramis glabris, fọliis e basi longe attenuatâ oblongis vel oblongo-lanceolatis obtusis glabris supra nitidis, capitulis axillaribus hreve pedunculatis 8-12-floris bracteatis, pedunculis pubescentibus, calyce glabro, lobis ovatis acutiusculis, ovario glabro. $亏$ In Japoniâ.-Walp. ann. 1, p. 582. D. triflora Lour. Coch. p. 291 ? ex Zuccar. 1. c. (cfr. infra, n. 35). D. Japonica Thunb. in Mus. Ac. Ups. 13, p. 106 ? (c[r. D. odora Thunb.), Paxt.- Mag. 8, t. 175 ? Rami subverticillati. Folia sempervirentia, subsessilia, 1\%-3 poll. longa, 6-10 lin. lata. Flores in ramis anni priecedentis axillares et terminales. Pedunculi 3-4 lin. longi, nutantes, demum erecti, apice jncrassato tomentoso-hirti, bracteis memubranaceis ovatoJanceolatis acutis ciliatis. Calyx viridis, tubo eylindraceo. Variat (fidé iconis Japonicæ) capitulis subśessilibus 3-4-floris.

25. D. PAPYPAGEA (Wall. fide Seud. nomencl. ed 2, p. 483), folis lanceolatis oblongisve venosis ramisque glabris, fasciculis terminalibus lateralibusque sessilibus bracteatis, calyce inlundibuliformi pubescente, lobis ovato-oblongis tubo brevioribus, ovario glabro. $\bar{J}$ In mont. Himalayâ, alt. 5,000-9,000 ped., Nepaliâ (Hamilt., Wall.l Royle), Kamaon (Blinkworth), Khasyà (Griff. et Wall.! Hook. fil.!), ad Pir Panjohl in Cachemire (rle Hügel!), in syylvis Ghiounlà et a Kohauti ad Ilahabad (Jacquemont), Sikkim (Hook. fil. et Thomison !).--Ieisn. in Deulkschr. rl. Regensb. Bot. Gesellsch. 3, p. $282^{*}$, Decaisne in Jacquem.Voy. Bot. p. $143^{*}$, t. 148 (optima), Walpers ann. 1 , p. 582 . D. odora Don prodr. $n$. nepal. p. 68 (non? Ait. et excl.? syn.). D. cannabina Wall. in Asiat. research. 13, p. 315, t. 7,8 , list, n, 1045 ! (non Lour.). D. payrrifera Hamilt. Inss. fide Wall.! in herb. DC. Nimis affinis D. Sinensi, attamen distincta foliis longioribus angustioribusque, 3-5 poll. longis, 7-9 lin. latis utrinque magis attenuatis, plus minus petiolatis et floribus brevioribus, 5-6 lin. longis. E tenacissimo ramorum libro et (fide Jacquemont l. c.), e radicibus in Indiâ chartæe papyraceæ species conficitur. Cfr. Wall. in Act. Soc, 
Asiat. Calcutt. vol. 13, Moorcroft in Asiat. research. 12, Hodgson in Journ. As. Spc. of Bengal. 1, p. 8, Royle.ill. p. 321. (v.s.)

$\beta$. latifolia (Wall.! list, n. 1045, (F), foliis lanceolato- vel elliptico-oblongis, calycis lobis acuminatis.--In Punduà et Silhet (Wall.! l. c.), Khasyâ (Wall. et Griff.! Hook. fil. et Thoms.!). Folia 4-5 poll. longa, 15-16 lin. lata, petiolo 3-4 lin. longo. (v. s.)

y. parvifolia, foliss minoribus, ovali-oblongis. - Supra Juggur; Bootan et in Khas) (Griff. n'-130! in herb. Berolin.). Folia 1-2 joll. longa $a_{4}$ 8-10 lin. lata, - sæpius subtus distincte venosa. (v. s. comm. a b. Lemann.)

26. D. Bн оL UA (Hamilt. ex Don prodr. fl. nepal. p. 68), folìs sparsis coriaceis lanceolatis utrinque acutis glabris, floribus jedicellatis, calycis sericeo-villosi lobís sulurotundo-ovalibus retusis, stigmate sessili capitato. $\bar{J}$ In Nepaliâ, ubi Nawarice Bholu Swa vocatur. Species obscura, forsan a D. papyraceà haud distincta.

Sectio ili. Gnidium. Spach. hist. veg. phan. 10 p. 443 (excl. sp. b).

Folia subcoriacea, annua. Racemi terminales ramosi, ebracteati. Calyx demum totus deciduus. Bacca carnosa.

27. D. GNiDIU M (Linn. sp. ed. 1, p. 357), ramis gracilibus junioribus pulverulentopuberulis, foliis lanceolato-línearibus mucronatis grabris, paniculâ simplići brevi demum aphyllâ cano-tomentellâ, pedicellis dimidium calycem æequantibus,

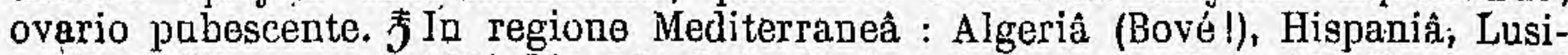
tanià (Willkomm, n. 169! Pinard! Boiss.!), ins. Canariens., Teneriffà (Brousson.! Chr. Smith!), Palmâ (Blauner I), Nicææe (Röper!), in Galliâ merid., Corsicâ, Sardinia (Thomas 1), Liguriâ, Livorno, etc. (Bertol.), regno Neapolitano (Moric.!), Dalmatià (Reichenbb.), Græciâ. - Duham. arb. 2, t. 23, Lodd. Bot. cab. t. 150, DC. fl. fr. 3, p. 358*, Sibth. et Sm. fl. græc. t. 356, Wikstr. Daphne p. 14*, Thym. p. 297, Hayne Arzneigew. 3, t. 45, Bertol. fl. ital. 4, p. 341, Reichenb. ic..fl. germ. 11, p. 13, t. 553, n. 1173, Gren. et Godr. fl. fr. 3, p: 60. D. paniculata Lam. fl. fr. 3, p. 222. D. Cridium Boiss. voy. Esp. 2, p. 557. Thymelra Guidium All. fl. pedem. 1, p. 153. Frutex 2-5-pedalis, ramis corymbosis erectis simplicibus. Folia conferta semipatula, 1-1 $\frac{1}{2}$ poll. longa, $2-4$ lin. lata, basi attenuata, acuminato-mucronata, evenia vel obsolete pennivenia. Fasciculi pauciflori terminales et e summis axillis orti, breve pedunculati, folium subæquantes, foliis mox delapsis paniculam; simplicem $1-1 \frac{1}{2}$-pollicarem fórmantes, primo capituliformes, deinde racemum circ. semipollicarem sistentes, pedicellis demum 1-1 $\frac{1}{2}$ lin. longis. Calyx campapulatoinfundibuliformis 3-4 lin. longus, albus vel rubellus, lobis ovatis obtusis tubo parum brevioribus.Annulus hypogynus obsoletus. Drupa ovata, rubra, magn. pisi. (v. s.)

28. D. R о и в A, ramis gracilibus apice tomentellis, foliis coriaceis lanceolato-linearibus attenuato-submucronatis eveniis glabris supra nitidis, paniculâ brevi compositâ aphyllà cano-tomentellâ, pedicellis calyce triplo brevioribus, ovario pubescente. J In Chinâ (unde in lort. Calcutt. introduxit Reeve, teste Wallich! in herb. Zuccar.). Roumea Chinensis Wall.! mss. l. c Omnia fere D. Gnidii, sed folia magis coriacea, rigida; paniculæ rami iterum ramosi, pedicelli vix 1 lin., calyces vix 3 lin. longi. (v. s. comm. a Zuecar.)

\section{Sectio IV. LAUREOLA.}

Folia coriacea, coëtanea, perennantia, racemi axillares 2-pluriflori, interdum prope rami apicen congesti capitılum men tientes. Bacca carnosa.- Sect. Evdaphne C. A. Mey. in Bull. Ac. St-Pétersb. 4, n. \& (ex parte). - Sect. Laurcola et Laureoloides SpachL hist. vęg. phanr. 10, p 444 et 445 .

29. D. GL OMERA A (Lam. dicl. 3, p. $438^{*}$ ), glaberrima, foliis lanceolatis vel ovalilanceolatis basi attenuatis obsolete venosis, lasciculis e summis axillis or tis breve pedunculatis 3-6-floris in capituli sjeciem arcte congestis, floribus sessilibus bracteas deciduas superantibus, calycis Jobis oblongis tubo duplo brevioribus, ovario glabro. ち In Cappadociâ (Tournel.), lberiâ (M. Bitb., Fisch.I), regione alpinâ et subalpinâ Caucasi, mont. Kiasbeck et Kiaischaur, alt. 5,000-8,000 ped. (C. A. Mey.), prov. Guriel et Adschar (Szovits! Nordm.!), Somchetiâ (Hohenack. n. 37l), Imeretî́ (Güldenst.), cirea Trapezum, alt. 7,000-8,000 ped. (Huet du Pavillon I), in Arme- 
ria (C. Koch). - M. Bieb. fl. cauc. 1, p. 299, Wikstr. Daphne, p. 31 ; Thym. p. 302, C. Koch in Linnæâ 17, p. 310, ib. 22, p. 612, Walp. ann. 3, p. 326, Ledeb.! tl. ross. 3, p. 547, Jaub. et Spach ill. pl, or. t. 303, cum deser. D. comosa Adam, in Weber et. Mohr Beitr. 1, p. 53. D. Mezereum Güldenst. Reise 1, p. 422 ! (ex Ledleb.). Fruticulus spithamous vel parum altior, superne parce ramosus. Folia in apice ramorum approximata, cire. pollicaria, 4-5 lin. lata, plerumque obovato-oblonga, obtusa vel acuta, nitida. Pedunculi infra apicen rami ejusque folia nondum perfecte evoluta axillares, 2 vel plures, 1-5 lin. longi, basi bracteis submembranaceis ovatis lanceolatisve 1 lin. longis stipati, fasciculis florum 2-15 sessilium terminati, glabri. Calyx 6-7 lin. longus, pallide incarnatus suaveolens tubo gracili cyjindrico. Aṇnulus hypogynus conspicuus. (v. s. in herb. DG., Ledeb., ete.)

ß. pauciflora, capitulis 3-1-floris, floribus bracleas parum superantibus. - In montibus lmeriæ confinibus, all. 4,500 ped. D. Imerica C. Koch in Linnæa 22, p. 613, Walp. ann. 3, p. 326. Potius forma depauperata quam jropria var. D. glomeratee, cui ceet. notis penitus convenit.

\%. nivalis (C. Koch in Linnæeà 22, p. 613), repens vel erecta, ramosa, pedunculiz axillaribus brevibus 3-floris, floribus, 2-bracteatis, calycis lobis tubo plus duplo brevioribus ellipticis. - In mont. Ponticis ot mont. Kasbek, alt. 6,0008,000 [ied.-Walp. ann. 3 , p. $326^{\star}$.

30. D. L a un éla (Linn. sp. ed. 1, p. 353), glaberrima, foliis oblongo-vel obovatolanceolatis acutis basi attenuatis venosis nitidis, racemis subsessilibus bracteatis 5-10-floris, pedicellis brevissimis, calycis lobis ovatis acutis tubo infundibuliformi triplo brevioribus, ovario glabro. $\zeta$ In Europâ mediâ et australi, a Scotiả australi et mari Baltico usque ad Hispaniam ( Willkomm, n. 821! Boiss.), Lusitaniam (Link), Siciliam (Guss.) et Macedoniam (Friv.! Griseb.), in Olympo Bithynico (Sibth., Griseb.), monte Pico ins. Azóric., alt. 3,000-4,000 pecl. (Guthniek ! Un. itin. n. 28! Seubert (1. azor. p. 30).-Blackw. hérb. t. 62, Engl. Bot. t. 119, DC. fl. fr. 3, p. 357*, Bull. herb. t. 57, Jacq. fl. austr. 2, p. 49, t. 183, Bot. mag. t. 206, Wikstr. Daph. p. 9*,Thym. 296, Hayne Arzneigevv. 3, t. 44, Mert. Koch D. Il. 3, p. 44*, Reichenb. ic. fl. germ.14, p.14, t. 555, n.1179, Griseb. Rumel. 2, p. 321, Boiss. voy. Esp. 2, p. 55. D. major Lam. fl. fr. 3, p. 221. D. multiflora Thore! mss, Grat. in Gay cor. Endress. p. 19, sine descr. Thymelxea Laureola Scop. Carn.1, p. 276, All. Pedem. 1, p. 132. Frutex 1-2-rarius 5-pedalis, erectus. Folia $1 \frac{1}{2}-5$ poll. longa, $8-12$ lin. lata. Racemi nutantes; $\frac{1}{2}-1$-pollicares, pedicellis brevissimis basi lıracteâ submembranacết obovato-oblongâ obtusâ deciduâ fultis. Calyx bracteâ subbrevior, circ. 3 lin. longus, luteo-viridis. Bacca demum nigræe. (v. s.)

3. latifolia (Cosson nol. pl. crit. p. 45), foliis latioribus obovatis vel oblongoobovatis obtusiusculis basi in petiolum brevem attenuatis.-In regione montanâ regni Granatensis (Bourgeau pl. exs. Esp. 1849, n. 433).

y.? Philippi, foliis subdecurrentibus, bracteis flores parvulos æequarlibus vel superantibus. - In Pyrenæis, circa Bagnères de Bigorre (Philippe). D. Philippi Grenier in Arch, de la 1l. de Fr. et d'Allem. 1853, p. 282, Gren. et Godr. fl. fr. 3, p. 58. Calyx triplo minor dicitur quam speciei valgaris. Forsan species distincta, ulterius observanda.

31. D. Pontra (Linn. sp. ed. 1, p. 357), glaberrima, foliis elliptico-oblongis obovatisve basin versus cunezto-attenuatis venosis, floralibus multo minoribus herbaceis vel squamiformibus, pedunculis 1-2-0oris filiformibus ebracteatis, pedicellis brevibus, calyce gracili, lobis lanceolatis tubo anguste cylindrico parum brevioribus, ovario breviter stipitato glabro. $\zeta$ In montibus Punti, usque ad alt. 2,000 ped.. Bosphori (Olivier I d'Urville' Castagne! Noé! Aucher-Eloy, n. 2517!), Thracia (Griseb.), Olympi Bithynici (Aucher-Eloy, n. 585! 2517! 5290! Griseb.!), Caucasi (Tardent!), in prov. transcaucasicis, Imerètià (Szovits !), Mingrelià et Gurià Nordm.!).-Lam. dict. 3, p. 438*, Andr. Bot. repos. t. 73, Bot. mag. t. 1282, Wikstr. Dapl. p. 11*, Thym. p. 296, Griseb.l f]. Rumel. 2, p. 321 , Ledeb.l fl. ross. 3, p. 547. Frutex 2-3-pedalis vel-altior, ramis rubro-fuscis. Folia 1 $\frac{1}{3}-4$ poll. longa, 1-2 poll. lata, basi lata sessilia, oblusa vel acuta vel breviter acuminata, pedunculos fulcrantia 3-7 lin. longa, tenuiora, viridia vel sæpe membranacea flavescentia. Pedunculi nutantes, tenues, florem subæquantes, plerumque apice breviter bifidi biflori, rarius 3-vel 1-flori, rarissime racemoso-pauciflori, ebracteati. Calyx ochroleucus vel virescens, tubo $4-6$ lin. longo, lobis anguste lanceolatis attenuato-acutis paten- 
tibus. Anuulus hypogynus brevissimus crassiusculus. Stylus brevis filiformis. (v. s. sp. et v. v. e.)

ß. Szovitsii (G. Koch in Linnæa 22, p. 611), pedunculịs bifloris distantibus flore folioque florali 2-3-plo longioribus. - In Imeretiâ, alt. 1,500-3,000 ped. (Szovits).-Walp. ann. 3, p. 326 .

\section{Sectio v. Eriosólena.}

Folia sparsa, coriacea. Capitula lateralia pedunculata, pauciflo"a, involucrata, involucro 2-vel 4-phyllo membranaceo clauso, deinde aperto deciduo, pedunculo filiformi aphyllo ebracteato. Calycis lobi æstivatione contorti, alterni breviores. Cyathulus hypogynus subuliformis integer, nunc brevissimus. Bacca carnosa.-Meisn. in Regensb. Denlsschr. 3, p. 283 . - Scopolia Linn. fil. suppl. p. 60 et 409, Juss. gen. p. 438, G. A. Mey. I. c. (non Jacq. nec Sopn.).-Genus Eriosolena Blume bijdr. p. 651, Endl. gen. p. 331, n. 2104, suppl. 4, 2, p. 68, n. $2106 / 10$.

32. D. PENDULA (Smith ic. ined. 2 , p. $34^{*}$, t. 34 ), ramis gracilibus, foliis breve petiolatis oblongo-lanceolatis utrinque acutis venosis glabris, capitulis longe pedunculatis nutantibus, involucro 2-phyllo, calycis sericeo-víllosi lobis ovatis acutis tubo cylindrico pluries brevioribus. 5 In Javâ (Thunb.). - Willd. sp. 2, p. 419, Wikstr. Daph. p. 12*, Thym, p. 296. D. Javanica Tbunb. Mus. nat. Ac. Upsal. append.11, p. 4 (ex Wikstr.). Scopolia composila Linn. fil. suppl. p. 409, G. A. Mey: in Rull. Soc. imp. Mosc., ex Ann. sc. nat. 1843, 20, p. 49. Rami eloñgati, laxe foliosi, juniores pubescentes. Folia sparsa, juniora pubescentia, adulta glabra. Calyx 4-5 lin. longus, flavus, nervosus, tubo lineari, lobis 1 lin. longis.

ß. montana, foliis subtus glaucis - In sylvis montanis Javæ. (Blume, Lobb. n. 2471).D. montana Meisn. in Regensb. Denkschr. 3, p. 284. Eriosolena móntana Blume bijdr. p. 651, Hassk. cat. fl. Bogor. 1844, p. 92. Capitula 10-12-flora, involucro sanguineo glabro. Calyx albidus. Variat foliis 3-4-pollicaribus ( $\alpha$ macrophylla Hassk. 1. c.) el duplo minoribus ( $\beta$ minor Hassk. ib.). Flores, fide Hassk. 1. c., interdum 5-meri, 10-andri. Ovarium apice penicillato-villosum. (v. s.)

$\gamma$. concolor, foliịs utrinque coloribus. - In Javæ prov. Bandong et monte Salak, alt. 2,000-5,000 ped. (Zoll. n. 1696 ! in herb. DC.). Eriosolena montana Zolling.! Verzeichn. 2, p. 116. Folia $1 \frac{1}{2}-2 \frac{1}{2}$ poll. longa, 6-9 lin. lata, subtus vix pallidiora, petiolo $\frac{1}{2}-1 \frac{1}{2}$ lin. longo. Pedunculi e veteribus axillis orti, circ. pollicares, filiformes, erecti, deinde penduli, involucro jun. clauso magn . pisi. Calyx 4=5 lin. longus. Stylus brevissimus, stigmate ovato magno. Cyathulus hypogynus hinc fissus. Cret. ut in $\beta$, (v. s. in herb. DC.)

33: D. WALLICHII, foliis oblongo-lanceolatis acuminatis renosis ramisque glabris, pedunculis brevibus, involucro 2-phyllo subtomentoso caduco, foliolis obtusis, calyce sericeo-villuso, bobis oblongis acutis tubo pluries brevioribus, interioribus parum minoribus, cyathulo hypogyno tubuloso, ovario apice barbato. $\hbar$ ? vel $\bar{\partial}$ In Punduà (R. Smith !) et Khasyâ, alt. 4,000-6,000 ped. (Wall.! Griff. n. 129 ! Hook. fil. et Thoms.!). D. involucrata Wall. in Asiat. research. 13, t. 6, list, n. 1050! Spreng. neue Entdeck. 2, p. 257, Meisn. in Regensb. Denlkschr. 3, p. 283*. Eriosolena Wallichii Meisn. gen. 2, p. 242, Endl. gen. suppl. 4, 2, p. 68. Scopolia involucrata C. A. Mey. l. c. Rami virgati, laxe foliosi. Folia subcoriacea, 3-6-pollicaria, 6-15 lin. lata, petiolo 1-2 lin. longo, subtus pallidiora. Pednnculi solitarii, 2-3 lin. longi, puberuli. Involucri foliola membranacea, ovalia, obtusa, 4 lin. longa, 2-3 lin. lata, fusca, tomentella, evenia. Flores 6-8 in receptaculo exiguo pubescente sessiles, flavi? vel pallide carnei? semipollicares, flavido-villosi, tubo cylindrico, lobis $1 \frac{\div}{5}$ lin. longis. Stylus fere ovarii longitudine. Specim. in Assam a b. Griffith lectum (herb. Mart.) pedunculis dimidio longioribus, 6-1.2 lin. longis. Ad D. pendulam valde accedit. (v. s.)

34. D. L ONG IFO L1 (Meisn. in Regensb. Denkschr. 3, p. 285*), foliis elongato-lanceqlatis utrinque longe attenuatis venosis glabris, pedunculis subtomentosis demum petiolo pluries longioribus, involucri 4 -phylli foliolis acuminatis pubescentibus caducis, calyce tomentoso lobis oblongis acutis tubum angustum subæquantibus, interioribus brevioribus, annulo hypogyno minuto, ovario glabro, 5 ? vel $z$ ? in Nepaliâ, Punduâ aut Silhet (Wall.l). Folia 5-6-pollicaria, medio 7-9 lin. lata. Pedunculi demum sesquipollicaress: Calyx $4-5$ lin. longus. (v. s.) 


\section{Species obscurce.}

35. D. T R F L o R A (Lour. Coch. 1, p. 236, cd. Willd. p. 291), foliis lanceolatis glabris,

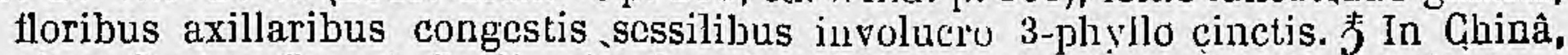
circa Canton (Lour.). Caulis simplex, 3-pedalis, ramis adscendentibus. Folia breviter petiolata. Involucra 3-flora. Calyx tubulosus, 4-5-fidus. Stamina 8 inclusa. Bacca 1-sperma. Species observante Zuccarini, forsan cum D. Japonicâ Sieb. et Zucc. (cfr. supra n. 24) identica, serl involucri causâ jotius sectioni Eriosolenæ accensenda.

- 36. D. A UR EA (Poir.in dict. encycl. suppl. 3, p. 310), ramis nodosis superne pubescentibus, foliis confertis crassis ovato-oblongis acutis obtusisve hasi attenuatis subtus tomentosis, floribus terminalibus subfasciculatis subsessilibus villosis, lobis erectis lanceolatis acutis tulınm cyhitrdricum subæquantilsus. 3 In Oriente (Labill. in herb. Desf.). Folia 6 lin. longa, 2 lin. Iala, supra subglabra, subtus flavo- vel demum cinereo-tomentosa. Calyx 6 lin. longus, jube cinerascentialbidâ. Verisimiliter a D. oleoide aut sericeâ haud distincta.

37. D.? DECANDRA (Blume bijdr. p. 650), arborescens, foliis alternis ovalibus acutiusculis basi oblique attenuatis serrulatis glabris, floribus axillaribus glomeratis 5-meris 10-andiris. 5 Ad pedem montis Tjerimaj Javæe (Blume). Propter folia \& serrulata "verisimiliter alieni ordinis.

\section{Species exclusa.}

D. Americana Mill. = Daphnopsis sp.?

D. Andina Pepp. = Ovidia Andina Meisn.

D. AN o M A A HBK. = Ovidia Humboldti Meisn.

D. Aquil ARIA Blanco. = Wikstrœmia ovata C. A. Mey.?

D. ARGENTATA Lam. = Thymelæa nitida Endl.

D. ARG ENTEA Sibth. et Sm. = Thymeliea Tartonraira $\beta$ Meisn.

D. BONPLANDIANA Kunth = Daphnopsis Bonplandii Meisn.

D. BrASILIENSIS Raddi = Funifera utilis Leand.

D. caLYGINA Berger. = Thymelæa dioica All.

D. G A L Y C INA Lam. = Thymelæa nivalis ? vel calycina Meisn.

D. CALX GINA Lapeyr. = Thymelæa calycina Meisn.

D. CANDICANS Lam. = Thymelæa Tartonraira All.

D. CANESCENS Wall. = Wikstrumia canescens Meisn.

D. CANNA B IN A Lour. = Wikstrœmia viridiflora Meisn.

D. CANNA B IN A Schauer = Wikstrœmia Indica G. A. Mey.

D. Garacas ana Klotzsch = Daphnopsis Caracasana Meisn.

D. GESTRIF OLIA HBK. = Daphnopsis cestrifolia Meisn.

D. C ORIDIF OLIA Lam. = Thymelea coridifolia Endl.

D. CRASSIFoliA Poir. = Daphnopsis? crassifolia Meisn.

D. DECANDRA Blume = alieni ordinis.

D. DroIcA Gouan = Thymelæa dioica All.

D. ELEAGNOIDES Willd. = Daphnopsis salicifolia Meisn.

D. emarginat a Pav, = Daphnopsis Pavonii Meisn.

D. ERIOGEPHALA Wall. = Lasiosiphon eriocephalus Desne.

D. ER IOGEPHALA Royle = Lasiosiphon Hügelii Meisn.?

D. F E T' D A Forst. $=$ Wikstrœmia Indica C. A. Mey.

D. GARDNER I Wall. = Edgeworthia Gardneri Meisn.

D. H XPERIGIFOLIA Wall. = Stellera hypericifolia Endl.

D. INA M NA Gardn. = Wilistrœmia inamœna Meisn.

D. Indiga L. = Wikstromia Indica C. A. Mey.

D. IN ICA var.? Bentl. = Wikstrœmia viridiflora Meisn.

D. LAGET T O Bonpl. = Daphnopsis Bonplandii Meisn. 
D. LAGEт т $0 \mathrm{Sw} .=$ Lagetta lintearia Lam.

D. LaNCIrolia Wikstr. = Daphnopsis Humboldti Meisn.

D. LANUGIN OS A Lam. = Thymelæa canescens Endl.

D. I A UR IF o I I Willd. = Daphnopsis, Humboldti Meisn.

D. MAGROPH XLLA HBK. = Daphnopsis Humboldti Meisn.

D. Mexicana Spr. = Daphnopsis salicifolia Meisn.

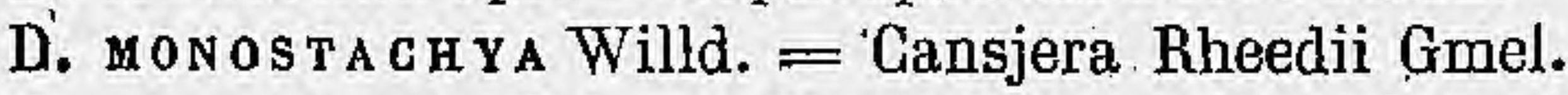

D. MY R TIF oLIA Poir. = Thymelæa velutina Meisn.?

D. NITIDA Vahl = Thymelæa nitida Endl.

D. ö ovata Willd., Wilsstr. = Daphnopsis Bonplandi Meisn.

D. occrDentalis Sw. = Daphnopsis Swartzii Meisn.

D. o p p ositif olia Hamilt.= Wikstrœmia canescens Meisn.

D. orientaL Is Willd. = Thymelæa villosa Endl.

D. OSYRóndES Vahl =, Thymelæa Tartonraira $\beta$ Meisn.

D. PAPY RIFE RA Sieb. et Zucc. = Edgeworthia chrysanthą Lindl.

D. PAugrfl ora Spanoghe = Wikstronia Spanoghii Desne.

D. Pil L 0-p IL L o Gl. Gay $=0$ vidia Pillo-Pillo Meisn.

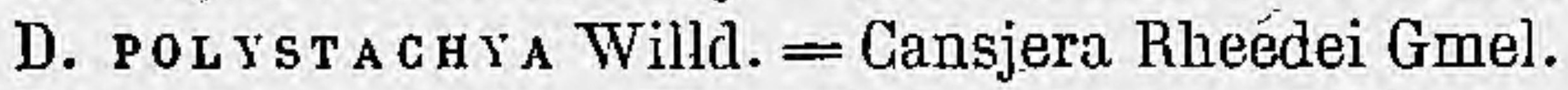

D. PUBESCEN L L. = Thymrelæa pubescens Meisn.

D. rosmarinoides Burm. prodr. fl. cap. p. 12, ex Wikstr. Daphne, p. 4, Thym; p. 308, = Passerinæ? sp. penitus obscura.

D. R OTUNDIFOL IA Forst. $=$ Wikstrœmia rotundifolia Desne.

D. SALIGIFOLIA HBK. $=$ Daphnosis salicifolia Meisn.

D. SERIGEA DOn = Wikstromia canescens Meisn.

D. S RUARR OSA L. = Gnidia carinata Thunb.?

D. TART ONRAIRA L. = = Thymelæa Tartonraira All.

D. Tн е R е м I г I Lhotsky = Funifera utilis Leandro.

D. Tн ES о I DES Lam. = Thymelæa thesioides Endl.

D. Tнчмед А A L. = Thymelæa Sanamunda All.

D. TINIF OLIA $\mathrm{Sw}$. = Daphnopsis tinifolia Meisn.

D. т о m к т о S A Lam. = Thymelæa tomentosa Endl., cfr. Thymelæa Tartonraira $\beta$.

D. VER M I C U A T A Vahl = Thymelæa tinctoria Endl.

D. VIL LOSA L. = Thymelæa villosa Endl.

D. VIRGA T A Wall. = Wikstrœmia virgata Meisn.

D. VIR IDIFL OR A Wall. = Wilsstrœmia viridiflora Meisn.

D. (ERI OS OLENA) VIRIDIFL ORA. Mor. et Zolling. = Wikstrœmia Candolleana Meisn.

Obs. ERiosolena afFin is Zolling.! Verzeichn. 2, p. 116, est Rubiacea !

XV. EDGEWORTHIA Meisn. in Denkschr. d. Regensb. Bot. Gesellsch. 3 p. 280, t. 8, gen. pl. vasc. p. 330 (242), Endl. gen. suppl. 4, 2, p. 66, n. 2106/1 (non Falconer, de qua confen ad prodr. 10, p. 526, not.). - Daphnes sp.Wall. Siebold.

Flores hermaphroditi, 4-meri. Calyx coriaceus, coloralus, persistens? tubulosus, 4-fidus, villoso-tomentosus, intus glaber, lobis aequalibus, fauce esquamatâ. Annulus hypogynus exiguus ovariii słịpitem cingens, membranaceus, 4-lobus. Stamina 8, duplici serie fauci inserta, filamentis brevissimis, antheris subsagittato-oblongis, superioribus semiexsertis, inferioripus inclusis; Ovarium substipitatum ovoideum, dense setuloso-comosum, ovulo 1 pendulo. Stylus terminalis, inclusus, inferne filiformis barbatus, stigmate subclavatoincrassato papilloso obtuso. Fruct..... Frutices Nepalenses et Chinenses, foliis sparsis, herbaceis coëtaneis, capitulis in summis axillis pedunculatis solitariis, dense multifloris, involucio foliaceo deciduo, receptaculo hemisphærico villoso. 
1. E. GARDNERI (Meisn. l. c. p. $280^{*}$, t. 6), foliis petiolatis oblongo-ellipticis utrinque acutis-supra glabris subtus pilosiusculis; pedunculis apice turbinato-incrassatis folio dimidio brevioribus, calyce subvilloso-tomen toso $\mathrm{F}$ In Nepaliâ (Wallich !), Bootan, mont. Mishmee (Griffith I), Sikkim, alt.: 5,000-7,000. ped. (Hook. fil.!). Daphne Gardneri Wall.d in Asiat. rescarch. 13, p. 388, 1. 9, list, n. 1044! Don prodr. fl, nepal. p. 69, Walpers ann. 1, p. 583: Trutex ramis virgatis, junioribus pubescentibus. Folia 2-pollicaria, 10-15 lin. lata, petioln 1-3 lin. longo; venis tenuibus. Pedunculi $\frac{1}{2}-1 \frac{1}{2}$ poll. longi, simplices, ebracteati, superøe canescentes. Gapitula hemisphærica, magn. pruni minoris. Involucrum hiseriale, 7-9-phylfum, foliolis lineari-lanceolatis acuminalis 4-6 lin. longis flores æequantibus. Receptaculum tuberculosum, sericeum. Calyx flavus? lobis ovatis obtusis tubo crasso tríplo brevioribus. (v. s.)

2. E. CHRYSANTHA (Lindl.! in Jouru. hortic. soc. 1, p. 148, Bot. reg. 1847, t. 48), foliis subsessilibus elliptico-oblongis acutis utrinque attenuatis parce adpressopilosis, capitulis terminalibus brevissime pedunculatis, calyce sericeo-villoso $\Rightarrow$ In Ghinæ prov́. Chusan (Fortune, `n. 159!). - Van Houtte fl. d. serr. t. 289. E. papyrifera Zuccar. in Abhàndl. d. math. phys. Kl. d. Bạir. Acad. 4, 3, p. 199*, et in Hook. Loud. Journ. 6, p. 46; Walpers ann. 1, p. 582. Daphne papyrifera Siebold in Act. Batav. 12, p. 24, Hassk. cat. h. bogor. alt. p. 92. Mitsmata Japonensium, fide Hassk 1. c. Frutex humilis, ramis apice foliosis. Folia 7-9 poll. longa, pabe minutấ molli arcte adpressâ. Capitula subglobosa, diametro circ. bipollicari. Involucrum.....? Calyx aureus, fere pollicaris, lobis ovatis obtusis subacuminatis. Annulus hypogynus dimidiatıs? Ovarium subsessile, villosum. Stigma subulatum. (v.s.sp. et c. in herb. Lindl.)

XVI. WIKSTROEMIA Endl. prodr. fl. Norfolt. p. 47, gen. pl. p. 332, n. 2105, suppl. 4, p. 68, n. 2106/1, iconogr. t. 22, Meisn. gen. p. 331 (243), et in Dénksch. Regensb. Bot. Ges. 3, p. 286, Decaisne in Jacquemont voy. bot. 144, t. 149, C. A. Mey. in Bullet. Ac. St-Pétersb. 4, n. 4 (non Schrad., nec Spr.).-Capura Linn: mant. p. 224.-Diplomorpha Meisn. in Regensb. Dénkschr. 3, p. 289, G. A. Mey. in Bull. Acad. St-Pẹtersb. 4, n. 4. Daphnes sp. Linn. fil. et auct. plur.

Flores hermaphroditi, 4-meri. Calyx coloratus, demum tótus deciduus, tubo cylindrico vel infundibuliformi continuo, limbo 4 -fido æquali, demum sæpius a tubo deciduo, fauce nudâ. ऽquamæ perigynæ nullæ, hypogynæ 4 parvulæ lineares, liberæ vel inferne connatæ. Antheræ 8 in summo tubo biseriatæ, subsessiles, inclusæ, Ovarium 1-loculare, ovulo pendulo anatropo. Stylus terminalis brevis vel subnullus, stigmate capitato. Bacca drupacea, interdum sicca, a calyce demum hinc fisso tarde secedente denudata. Semen inversum. Albumen nullum? vel parcum. Embryo axilis. - Arbores vel frutices Australiæ, Oceaniæ et Asiæ tropicæ et subtropicæ, foliis oppositis vel rarius sparsis herbaceis vel vix coriaceis venosis deciduis; pedunculis terminalibus axillaribusque simplicibus vel rarius corymboso-ramosis apice plurifloris; floribus sessilibus vel brevissime pedicellatis subcapitatis vel axi excrescente demum breviter spiçatis vel racemosis.

\section{Sectio I. Euwikstroemia.}

Bacca succosa, nuda. Semen exalbuminosum?-Folia omnia opposita (raro passim subsparsa). Flores capitati vel lasciculati vel breviter racernoso-spicati.

1. W. INDICA (C. A. Mey. in Bull. Ac. St-Pétersb. 4, n. 4, Ann. sc. nat. 2" sér. 20, p. 50); foliis subcoriaceis petiolatis ovali-vel lanceolafo-oblongis utrinque acutis venoso-reticulatis ramulisque glabris, facciculis terminalibus subsessilibus paúcifloris, ealyce pedicello multo longiore puberulo diu persistente, lobis oblongis obtusis tubo dimidio brevioribus, ovario sessili apice pilosiusculo, stigmate subsessili, squamulis hypogynis in cyathulum 4-dentatum demum fissum connatis. In Oceanià, ìns. Societatis (Forster! Beechey, Moerenhout! Lípine, n. 152 ! etc.), Novâ-Hollandiâ tropicà et orientali (R. Br.), Chinâ (Osbeck, Wachéll, n. 138!), Luzon, ins. Philipp. (Mleyen; Blanco I). Daphne Indica Linn. spec. 1; p. 511, R. Brown prodr. p. 362, Wikstr. Daphne p. 17*, Thym. p. 298, Hook. et Arn. Bot. Beech. p. $68,94,209$, t. 15 , Guillem. in Ann. sc. nat. 2. sér. 7, p. $188^{*}$, Blanco fl. de 
Filipin. ed. 1, p. 309. D. fœida Linn. fil. suppl. p. 223, Forst.! prodr. n. 168, Blanco 1. c. p. 308*? D. cannabina Schauer in nov. Act. Leop. 19, suppl. 1, p. $411^{*}$ (non Lour.). Cajura purpurata Linn. mant. p. 225. Wikstrœmia Forsteri Decaisne in Jacquem. voy. bot. p. 146 , Ann. sc. nat. $2^{\circ}$ sér. 20, p. 50 , in notâ, Walp. ann. 1, p. 589. Avau-o-a@ (fide Forst.) vel Oao (Moerenh.) vel Ooau (Lépine) Taitensium. Frutex arborescens, ramulis dichotomis. Folia patentia, 1-2 poll. longa, 6-8 lin. lata, yenis pinnatis tenuibus, petıolo circ. 1 lin. longo. Fasciculi 8- $\infty$-flori. Calyx 3-4 lin. longus, parce minuteque pubescens. Species foliorum formâ et magnitudine ludens; varietates fixe tamen haud distinguendæe. Florum fasciculi demum in spicam brevissimam excrescere solent. (v. s. in herb. Schreb., DC., Arnott, etc.)

2. W. ROTUNDIFOLIA (Desne. in Jacquemont voy. bot. p. 146), ramulis pubescentibus, foliis herbaceis brevissime petiolatis late ovalibus utrinque obtusis vel rotundatis venosis glabris, capitulis terminalibus brevissime pedunculatis, calyce tenui sericeo, lobis ovatis obtusis, ovario glabro. $\%$ In Oceanize insulis Rotterdam seu Namoka (Forst.!) et Tonga Tabu (fide Linn:). - Decsne in Ann. sc. nat. 2" sér. 20, p. 50, in notà, Walp. ann. 1, p. 589. Daphne rotundifolia Forst.l prodr. n. 169, Linn. fil. suppl. p. 223, R. Brown prodr. p. 363, in adnot., Wikstr. Daphne p. $16^{*}$, Thym. p. 298. Præcedenti valde quidem affinis, sed ramulis puberulis, foliis latioribus (10-12 lin. Jatis) obtusis, etc., facile distinguenda. (v. s. sine fl. in herb. Schreb., Acad. Monac.)

3. W. ova т a (C. A. Mey. in Bull. Ac. Petersb. 4, n. 4, Ann. sc. nat. 2० sér. 20, p. 50), foliis herbaceis breve petiolatis ovatis subacuminato-acutis venosis ramulisque glabris, pedunculo terminali capitulum pauciflorum rquante pilosiusculo, calyce glabriusculo, lobis ovalibus obtusis tubo gracili multo brevioribus, stigmate subsessili, ovario glabro, cyathulo hypogyno bipartito, lobis incisis. 5 In ins. Philippinis (Cuming, n. 458!). Daphne Aquilaria Blanco fl. de Filipinas, ed. 1, p. 310 ? (Descr. satis bene conveniens, exceptis foliis subcarnosis et ligno aromatico-resinoso, nigro albo-maculato). Rami graciles. Folia remota, 1-2 poll. longa, 10-20 lin. lata, petiolo 1-2 lin. longo. Pedunculi circ. semipollicares, 5-9-flori, pedicellis vix $\div$ lin. longis in rhachi fere 1 lin. longà racemosis, sed fasciculum vel umbellam simulantibus. Involucrum nullum. Calyx albus? cylindraceus, basi rotundatus, extus circa faucem parce pilosiusculus, lobis 1 lin. longis. (v. s.)

4. W. CANDOLLEANa, ramulis novellis pedunculis calycibusque parce puberulis, foliis herbaceis brevissime petiolatis ellipticis utrinque acutis vel basi obtusis dense penniveniis vix reticulatis glabris, fasciculis breve pedınculatis 6-10-floris, pedicellis brevissinis, calyce gracili, lobis tubo basi tumidulo multo brevioribus, ovario glabro stigmateque subsessili, squamis hypogynis 4 liberis oblongis. $₹$.In Javæe prov. Gundang Merak et insulis austro-orientalibus (Zollinger, n. 2424 !). Eriosolena viridiflora Moritzi et Zolling. in Arch. nat. en Genesk. Nederl. Ind. 1844, p. 615, Zolling. 'syst. Verzeichn. 2, p. 117, WaIp. ann. 1, p. 588. Folia 10-20 lin. longa, medio 10-14 lin. lata. Pedunculi 2-3 vel demum vix 4 lin. longi, terminales et e summis axillis. Calyx 4 lin. longus, flavescenti-viridis, lobis tubo 4-5-plo brevioribus oblongis obtusis. Forsan potius W. androsæmifoliæ var. latifolia?, attamen pluribus notis satis discrepans. Foliis similior W. Indicæ et ovatæ, sed sive foliorum formâ et texturâ, sive pedunculi longitudine vel pubescentiâ, vel calycis lobis brevioribus, etc., facile distinguenda. (v. s. in herb. DG.)

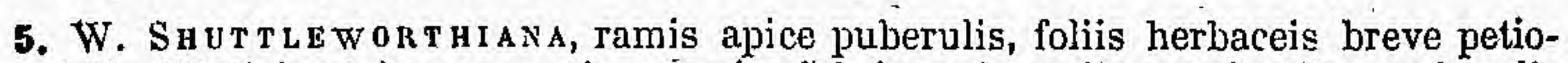
latis ellipticis utrinque acutis venosis glabris, pedunculis lerminalibus puberulis fasciculo 6-8-floro sublongioribus, pedicellis brevissimis, calyce glabriusculo, calycis lobis obtusis tubo triplo breviorilous, ovario apice parce pubescente, stylo

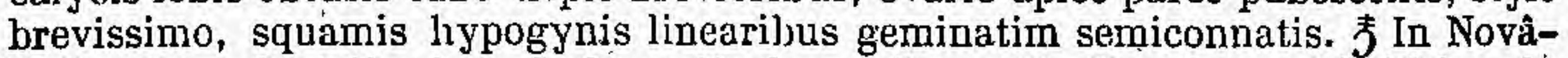
Hollandia orientali, circa Sydney (Anderson l). - W. Shuttleworthii Meisn. in Denkschr. d. Regensb. Bot. Ges. 3, p. $287^{\circ}$, Decsue in Jacquem. voy. bot, p. 145. Ann. sc. nat. 2e sér. 20, p. 50. Ramuli graciles, laxe foliosi. Folia circ. pollicaria, 6 liu. lata, petiolo vix $\frac{2}{3}$ lin. longo puberulo, venis tenuibus subtus prominulis vix anastomosantibus. Capitula primo sessilia, demum pedunculo 4-6 lin. longo, aphyllo fulta, pedicellis vix $\frac{1}{2}$ lin. longis. Calyx 3 lin. longus; parcissime puberulas vel glaher. Ovarium apice setulis nonnullis conspersum. Hae forsan Daphne Indica R. Br. (nec? Linn.), sed a W. Indica (cfr. supra n. 1), pluribus notis satis distincta. (v. s. comm. ab am. Shuttlew.) 
6. W. NU TANS (Champion, cx Benth. in Hook. Journ. 1853, p. 19.5 *), foliis lierbaceis ellipticis utrinque acuminatis glabris, racemis brevibus nutantibus ebracteatis pedunculatis 4-8-1loris, pedicellis brevissimis, talycis lobis tubo triplo brevioribus ovarioque glabris, squamis hypogynis 4 angustis per pariá connatis. 7 In Happy Valley insulæ Chinensis Hong Kong (Ghamp.). Folia pleraque 1 poll. longa, $\frac{1}{9}$ poll. lata, ramulorum vegetiorum interdum fere duplo majora, subtus pallicla. Pedunculi 3-9 lin. Tohgi, rhachi plus minus excrescente interdum semipollicari, pedicellis raro 1 lin. longis. Calyx 5-6 lin. longus, lobis oblongis obtusis' 1-1 $\frac{1}{2}$ lin. longis. Stylus brevis. Proxima dicitur.W. Shuttlewortlianse, sed diversa inflorescentiâ, floribus longioribụs, etc. An a W. ovatâ satis distincta?

7. W. A U S T R A I Is (Endl. fl. Norfolk. p. 47*, ic. t. 22), glabra, foliis petiolatis oblongis acuminatis venosis, racemo terminali pedunoulato laxo, pedicellis brevissimis, calycis lobis ovatis tubo duplo brevioribus, stigmate subsessili, squamis hypogynis linearibus basi breviter connatis. 7 In Insulâ Nurfolk (Ferd. Bauer). Frutex, ramis teretibus laxiuscule foliosis. Folia 5 poll. longa, $1 \frac{1}{2}$ poll: lata, utrinque angustata vel basi rotundata, petiolo 4 lin. longo, nervo subtus valde prominente, venis subtilissimis subtus pulchre reliculatis. Racemus bipollicaris, 8-10-florns, pedicellis vix 1 lin. longis. Calyx pallide virens, 8 lin. longus, glaber, lobis subacutis. Drupa baccata, sanguînea, ovata. (v. s. in herb. Lindl.)

8. W. SANDWIGENSIS, foliis herbaceis petiolatis ovato-oblongis attenuato-acutis basi rotundatis tenuiter venosis ramisque glabris, capitulis terminalibus subsessilibus multifloris demum elongatis, calyce sericeo lobis tubo dimidio brevioribus, ovario glabro apice stigmateque subsessili hirsuto, cyathulo liypogyno 4-partito. F Ad sinum Byron, ins. Sandwic. Owyhee (jun. 1825, Macrae l). Ramuli graciles divaricato-dichotomi, novelli pubescentes. Folia remota, circ. 2 poll. longa, 1 poll. lata, petiolo 3-4k lin. longo. Capitula densiflora, rhachi pubescente primo vix 34 lin. longâ, deinde excrescente pollicari, defloratầ dense denticulato-cicatrisatà. Pedicelli $\frac{1}{2}$ lin., calyces $2 \frac{1}{2}$ lin. longi, graciles; lobis ovalibus obtusis. Squamæ hypogynæ 4, lineares, aculee, vix basi comnať̃e, integra vel subdentate, ovarium æquantes. (v. s. in herb. DG., comm. a Soc. horticull. Lond.)

9. W. CunNinghamir, foliis subcoriaceis brevissime petiolatis ovalibus tenuiter immerse venosis ramisque glabris, fasciculis terminalibus subsessilibus 8-10-floris, pedicellis brevissimis, calyce glahriusculo, lobis dimidium tubum subseguantibus subacuminatis, ovario sessili apice brevissime barbellato, stigmate subsessili, squamis hypogynis 4 filiformibus liberís., 3 In insulà Norfolk (jun., jul. 1830, A. Gunningham, n. 34 !). Corrijong insulanorum (Cunn. in sched.). Frutex 10-pedalis, ramis dichotomis cicatrisato-dentatis apice conferte foliosis, novellis puberulis. Folia opposita, patula, 1- fere 2 poll. longa, 10-12 lin. lata, vix rigida, acutiuscula vel basi vel utrinque obtusa vel rotundata, haud acuminata, juniora subtus ad nervum parce pilosiuscula, reticulatione supra non vel vix visibili subtus obsoletâ, petiolo 1 lin. longoo. Kacemi fasciculiformes brevissimi, folia proxima parva subsuperantes, rhachi cum pedunculo 2-4 lin.- longo. Calyx 5-6 lin. longus, parcissime adpresso-puberulus mox glaber, tubo cylindraceo basi attenuato, limbo in alabastro acuto, lobis ovatis. Anthlerarum series contiguæ, superiorum apicibus exsertis. Squamæ hypogynæe dimidium ovarium æquante. Fructum non vidimus. Valde quidem accedit ad W. australem et Sandwicensem, sed a priore distincta floribus vix racemosis, ovario apice pilosulo, squamis hypogynis liberis, a posteriore calyce plus duplo majore, squamis hypogynis ovario dimidio brevioribus, ab utrâque foliorum magnitudine et formâ. (v. s. in herb. Cunn. et comm. a cl. Heward.)

10. W. Spanoghir (Decaisne in Jacquem. Voy. Bot. p. 146, Ann. sc. nat. 2e sér. 20, p. 50), glaberrima, foliis lanceolatis utrinque attenuatis subtus glaucescentibus reticulato-venosis, pedunculis gracillimis cernuis, flori'Jus brevissime pedicellatis glaberrimis. F In insulâ Timor (Spanoghe) et? Chinầ (Gaudich. n. 67!). - Walpers ann. 1, p. 589. Daphne pauciflora Spanoghe mss. in berb. Lugd. Bat. n. 21, fide Dcsne. Rami (in plantà Chinensi) oppositi, graciles, stricti, glabri, internodiis pollicaribus et ultra. Folia lierbaced, opposita, subsessilia, $1 \frac{1}{2}-2$ poll. longa, 4-6 lin. lata, subtus pallidiora et tenuiter reticulata, utrinque acuta. Pedunculi terminales et e summis axillis solitarii, tenues, erecti, glabri, 3.5 lin. longi, 4-6-flori, floribus subsessilibus fasciculatis. Calyx circ. 5 lin. longus, parcissine pilosiusculus, lobis 
tubo anguste infundibulari vix dimidio brevioribus. Ovarium subsessile, glabrum, apice puberulum. Stylus conspicuus, brevissimus. Squamulæ hypogynæ, 4 seti= formes, libere, ovario breviores. (v. s. sp. Gaudich. in herb. DG.)

11. W. ANDRos latis lanceolatis acutis discoloribus, pedunculis axillaribus terminalibusque folio brevioribus, floribus subcapilatis glaberrimis, calycis lobis oblongis. ₹ fn Javâ (Leschenault), -Walp. ann. 1, p. 589.

12. W. vinidifl or a (Meisn. in Denkschr. d. Regensb. Bot. Ges. 3, p. 286 "), glaberrima, foliis subsessilibus ovali-oblongis obtusis vel retusis venosis, spicis terminalibus brevibus subsessilibus, calycis lobis obtusis dimidium tubum subæquantịbus, 'squamis hyjogynis 4 filiformibus lịberis. $\mathcal{J}$ In Cochinchinâ (Loưr.), Chinâ (Vachell, Calléry, fide Desne.), Hong Kong (Hinds, n. 1471), Singaporo (Lobb, n. 326!). Dapline cannabina Lour. Coch. p. 291 (fide specim. Lour. in herb. Mus. paris., teste Decaisne in Jacquen. voy. p. 149), non Wall. D. viridiflora Wall. list, n. 1049!-1). Indica L. var.? Benth. in Hook. Journ. 1853, p. 195. Diplomoriphà? viridiflora G. A. Mey. in'Bull. Ac. St-Pétersb. 4, n. 4, Endl. gen. suppl. 4, 2, p: 66. Rami graciles, sæpe dichotomi; cicatricibus dentiformibus. Folia conferta, patula, herbacea, demum subcoriacea, 9-16 lin. longa, 4-7 lin. läta, utrinque æqualiter angustata, venis tenuibus vix anastemosantibus, petiolo obsoleto vel vix.1 lin. longo. Spicæ solitariæ, simplices, ebracteatæ, 4-6 lin. longæ, 6-10-floræ. Calyx subsessilis, 3-4 lin. longus, glaberrimus, tubo infundibuliformi basi demum tumidulo. Ovarium glabrum squamas hypogynas dimidio superans. Fructus ignotus. Forsan ad sect. seq. referenda. (v. s. in herb. DG., Shuttl. et comm. a b. Wallich.)

13. W. GIInENSIS, foliis herbaceis brevissime petiolatis lanceolato-oblongis utrinque æqualiter attenuatis parce venosis ciliatís supra glabris subtus ramulisque novellis spàrse adpresșe pilosis, rácemis capituliformibus pedunculatis folio brevioribus, calyce subsessili gracili rhachique sericeo-puberulis, lobis obtusis tubo triplo brevioribus, ovario sessili apice minute setuloso, squamis hypogyinis 4 liberis linearibus. F In Chinâ. W. Indica C. A. Mey. mss. in herb. Zùccàr.! (nunc Univ. Monacens.). Folia opposita, circ. pollicaria, 5-6 lin. lata, venis paucis tenuibus, plerumque obsoletis. Pedunculi terminales et e summis axillis solitararii simplices, tenelli, cum rhachi brevissimâ 10-12-1lerâ 6-7 lin. longi minute cano: puberuli. Calyx 4-5 lin. longus, tubo anguste cylindrico. Antherarum series contíguæ, superior exserta. Squamæ hypogynæ ovario dimidio breviores. Fructus ignotus. Species, ad W. salicifoliam et canescentem proxime accedens, forsan ad sectionem seq. removenda, sed ab utràque sive foliis sive pubescentiâ minutâ et rarâ, etc., satis distincta. (v. s. in herb. Zuecar. et Lindl.)

14. W. 'S A I I G F o I A (Decaisne in Jacquem. voy. Bot. p. 144*, t. 149), foliis subherbaceis breve petiolatis oblongo-lanceolatis acutiusculis venosis glabris, petiolis ramulis pedunculisque adpresse subincano-puberulis, capitulis subsessilibus demum in spieam brevem aphyllam pedunculatam excrescentibns, calyce breve pedicellato gracili cano-sericeo, lobis obtusis tubo 3-4-plo brevioribus, ovario stipitato toto puberulo, squamulis hypogynis \& linearibus liberis? $\mathrm{J}$ In Mossouree Indiæ Himalayerisis '(Jacquemont). - Decsne in Ann. sc. nat. 2c sér. 20, p. 50, Walp. ann. 1, p. 589. Frutex pluripedalis, ramis virgatis, demum glabris. Folia remota, internodium ptrum superantia, semipatula, opposita vel passim alterna, 2-21 poll. longa, 10-12 lin. lata, subtus glaucescentia, pennivenia, haud reticulata, petiolo circ. 1 lin. longo. Peduneuli terminales et e summis axillis interdum gemini, folio dimidio breviores, 1-1 $\frac{1}{2}$ poll. longi, apice capitato 6-8-flori, capitulo primo inter folia 2 parva decidua subsessili, deinde aphyllo in spicam vix semipollicarem elongato. Calyx $4-5$ lin. longus, tubo angusto cylindrico, lobis ovalioblongis, altcrnis (interioribus) paulo brevioribus. Antheræ inelusse, serie inferiore remotẩ in medio tubo sità. Squamulæ bypogynæ ovario multo breviores, ex ic. interdum? por paria copnatæ. Fructus ignotus. Species verisimiliter ad sect. seq. spectans, W. canescenti nimis aflinis.

Sectio? Ir. Diplomorpia Meisn. in Denkschr. Regensb. bot. Gesellsch. 3, p. 289 , sub $n .4$.

Nucula crustacea sicca, a calyce denium hinc fisso tarde denudáta. Semen albuminosum. Embryo axilis, Folia sparsa vel passim (rarius omnia?) opposita. Flores 
spicati vel racemosi. - Genus Diplomorpha C. A. Mey. in Bull. Acad. St-Pétersb. 4 n. 4, Endl. gen. suppl. 4, 2, p. 66, n. $2106 / 2$.

15. W. SU USPICATA foliis oppositis herbaceis brevissime petiolatis oblongo-lanceo. latis acutis subtus ramisque cancscenti-pilosis, spicâ terminali subsessili simplici pauciflórâ capituliformi juniore foliosá, calyce gracili adpresse cano-piloso subsericeo, lobis obtusis tubo demum ovato supra ovarium in collum constricto multo brevioribús erectis, stylo capillari ovarium apice pilosum subequante, squamulis hypogynis obsoletis. $ち$ In Caffrariâ, inter Omsamculo et Omcomas (Drège I Ecklon et Zeyh. n. 92 !). Passerina subspicata Meisn. in Linnæâ 14, p. 395*. Arthrosolen subspicatus Endl. gen. suppl. 4, 2, p. 63. Species calyce haud articulato e genere Arthrosolen excluditur. Habitu phurimisque notis ad Wikstrœmiąm canescentem valde accedit. Rami ǵraciles. Folía 8-12 lin. longa, 3.7 lin. lata, obsolete pärcequo venosa, Galyx $4-5$ lin., stylus $1 \frac{1}{2}$.lin. longus. (v. s.)

16. W. CANESCEN.S (Meisn. 1. c. p. $288^{*}$ ), ramis virgatis apice tomentosis, folits sparsis herbaceis breve petiolatis lanceolatis oblongisve venosis acutis canepubescentibus supra demum glabrescentibus, pedunculis terminalibus et in summis axillis tenuibus indivisis, spicis pauciflorís capituliformibus, calyce graclii cano-tomentoso, lobis obtusis tubo multo brevioribus, ovario pubescente, gquamults hypogynis 4 discratis linearibus. F In Nepaliá (Wall.t Hook. fil.l) et Kamaon montibưs, alt. 5,000-7,000 ped. (Blinkworth!) et Khasyâ (Thomson l), Assam (Griffilh!).-Decsne in Jacquem. voy. p. 145. Daphne canescens Wall.! list, n. 1046: D. sericea Don prodr fl. nepal P. 69 (non Vahi). D. oppositifolia Hamilt. mss, ex Don. Diplomorpha canescens G. A. Mey. in Bull. Ac.- St-Pétersb. 4, n. 4, Endl. gen. suppl, 4, 2, p.66. Frutex ut videtur elatior. Folia sparsa, passim approximata vel opposita, 1-2 poll, longa, 4-12 lin, lata, summa sæpius dimidio minorá, interdum pedunculo breviora, subtus pallida vel glancescenti-albida, pube molli parutún copiosá subadpressâ if nervis densâ, venis subtus,prominulis plus minús dense reticulatis, petiolo $\frac{1}{2}-1$ lin. longo. Capitula 5-10-flora, sessilia foliis 2 fulta, vel aphylla pedunculo 3-6 lin. longo simplici stipitata, rhachi demum paulo excrescente cúrc. 3 lin. longâ pedicellis brevissimis cum flore articulatis dense denticulatá. Calyx 4 lin. longus, continuus, diu persistens. Nucula semiovata, glabriuscula. Álbümon fárinaceum. (v. s.)

17. W. VIRGATA (Meisn. l. c. p. $289^{*}$ ), ramis virgatis, ramulis tenellis apice puberulis, foliis sparsis herbaceis petiolatis lanceolatis obtusiusculis venosis subglabris, spicis filiformibus simplicibus vel basi 3-fidis folia subæquantibus multifloris steriteo-incaris, calyce tenui, lobis obtusis, ovario pubescente, squamulis hypogỳtis 4 lineàribús liberis. F In Kamaon (Blinkworth ! Hügel!). Daphne virgata Wâllf. list, n. 1047! Diplomorpha virgata C. A: Mey. I. c. Forsan mera var. D. canescentis, attamen præter notas indicatas satis discrepans habitu graciliore, ramulis et præsertim pedunculis tenellis longioribusque, foliis subconcoloribus glabriusculis, floribus paulo minoribus. Flores primo sæpius capitulum subsessile basi diphyllum, deinde spicam semipollicarem pedúnculo 10-12 lin. longo fultam sistunt. (v. s.)

18. W. I $A$ mana, foliis sparsis subcoriaceis'brevissime petiolatis oblongis utrinque attenuatis obtusis parce adpresso-pilosulis subtus pallidis tenuiter venosis, pedunculis folio brevioribus filiformibus floribusque breve pedicellatis racemoso-capitatis sericeo-incanis, calyce gracili, lobis obtusis tubo basi attenuato 3-4-plo brevioribus, ovario adpresse puberulo stipitato, squamulis hypogynis 4 liberis filiformibús. F In Ceylan (Thwaites, n. 2206!). Daphne inámœna Gardner ! miss. in

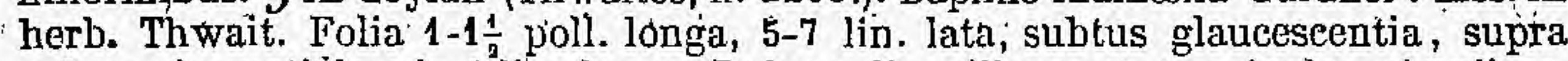
subevenia, petiolo vix 1 lin. longo. Pedunculi axillares et terminales, simplices, aphylli, floribus fasciculatis demum breviter racemosis. Calyx 3-4 lin. longus, lobis demum deciduis. Ovarium totum parce puberulum, stipite squamulas requante. Affinis præcedentibus et W. Ghinensi, sed distincta folis confertiorihus (1-2- raro 3 lin. distantibus) haud acuminatis, utrinque pubescentibus, pedunculis simplicibus, racemis brevibus (3-4 liu. longis), ovario stipitato, etc. (v. s. in herb. DC.)

19. W. GHAM DAPHNE, foliis oppositis sessilibus subcoriaceis lanceolatis utrinque acutis obsolete venosis ramisque glaberrimis, capitulis corymbosis multifloris calyce sericeo, lobis obtusis tubo triplo brevioribus, ovarig apice pilosiusculo, 


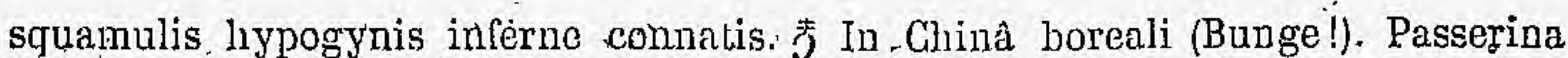
Chamædaphne Bunge! enum. pI. Chin. bor. p: 58. Diplomorpha. Chamædaphne G. A. Mey. in Bull. Ac. St-Pétersb. 4, n. 4, Endl. gen. suppl. 4, 2, p. 66. Rami graciles. Folia satis conferta, 1-1 $\frac{1}{2}$ poll. longa, $2 \frac{1}{2}-4$ lin. lata, 'late viridia, subtús subglauca. Capitula terminalia et in summis axillís pedunculata corymbum demum aphyllum constiturentia, pedunculis 1-3 lin. longis, intèrdum apice 2-phyllis. Calyx 3-4 lin. longus, diu persistens, tubo anguste cylindrico demum tumidulo, lobis ovalibus. Stigma subsessile. Ovarium basi attenuatum. Fructus siccus ovatus. (v. s. in herb. DC., Ledeb., Mart.)'

\section{Speries dubice.}

STELLERA? Ganpi et ST. JAPONIC.A, infra insertæ, sunt forsan Wikstrœmiæ species.

XVII. COLEOPHORA Miers in Ann. of nat. hist. 2, 7, p. 196, Meisn. in Mart. fl. bras. fasc. 14, p. 70 .

Flores hermaphroditi, 4-5-meri. Calyx coloratus, infundibuliformis, tubo a basi ad medium usque coarctato ibique intus hirsuto supra extusque glabro, fauce esquamatâ, limbo 4 - vel rarius 5 -fido, lobis acutis reflexis fimbriatociliatis: Stamina 8 vel 10 , biseriatim fauci inserta, exserta, filamentis brevibus inflexis, antheris ovato-rotundatis subversatilibus, connectivo dorsali crasso. Gyathulus hypogynus ovarii stipitem filiformem cingens, e toro glanduloso parvo calycis basi adnato ortus, infundibuliformis, petaloideus, glaber, calycis dimidium æquans, 4-fidus, lobis linearibus erectis. Ovarium stipitatum, oblongum, gibbosum, pilosum, ovulo ex apice loculi pendulo. Stylus termiralis? filiformis, ovario æquilongus, inclusus, glaber, stigmate capitato. Fruct..... Arbor Brasiliensis procera, trunco gemmulifero, gemmulis aggregatis imbricatim multibracteatis, foliis....., floribus racemosis.

G. GEMM I L O RA (Miers 1 . c.). 5 In sylvis primævis mont. Serra d'Estrella prov. Rio de Janeiro. (Miers)--Meisn. I. c. p. $70^{\circ}$. Folia ignota. Gemmæ magnit. pisi, e cortice ortæ, conglobatæ, involucrates,-bracteis suborbiculatis concavis $x$-lobatis, lobis rotundatis erenato-incisis fusco-rubris pilosis margine longe albido-ciliatis. Racemus $1 \frac{1}{2}$.uncialis, erectus, glaber, pedicellis alternis cum flore articulatis. Ċalyx airrantiacus. Cyathulus hypogynus flavus.

XVIH. STELLERA Gmel. in Linn. diss. Dasson (1747), amon. acad.1, p. 399, sp. pl.ed. 1, p. 559 , gen. pl. ed. $5, n .439$, ed. $6, n$. 488, G. A. Meyer in Bullet. Aead. St-Petersb. 4, n.4, Endl. gen. suppl. 4,2, p. 62, n. 2098.-Chamæjasme Amman Ruth.p. 16, t. 2.-Passerinæ sp. auct.

Flores hermaphroditi, 4-6-meri. Calyx coloratus, hypocraterimorphus, tubo gracili cylindraceo vel infundibuliformi, supra ovarium articulato, parte inferiore tumescente persistente, fructum includente, superiore deciduâ, limbo 4-5-6-fido, lobis patentibus sıbæqualibus, fauce esquamatâ. Cyathulus vel annulus hypogynus membranaceus; parvulus, obliquus, integer vel subbilobus. Stamina 8 vel rarius 10 vel 12 , duplici serie infra faucem inserta, filamentis brevissimis, antheris oblongis inclisis vel superioribus semiexsertis. Ovarium subsessile, apice obtuso barbatulum. Siylus terminalis vel sublateralis, conspicuus, sed ovario multo brevior, stigmate ovoideo papillosobispidulo antheras haud attingente. Nucula calycis basi laxe tunicata, ovatooblonga, pericarpio crustaceo tenui. Embryo albumine tenui inclusus. - Herbæ perennes et fruticuli Asiæ occidentalis' mediæ et borealis, foliis sparsis lanceolatis, floribus in ramorum extremitate racemosis vel spicatis vel subcapitatis mediocribus flavis vel albis rubescentibus.

\section{Sectio 1. Chamestellera $C . A . M e y . l$. $c$.}

Herbe perennes vel suffrutices; caules e rlizomate plures herbacei annui simplicissimi erecti, foliis sparsis subsessilibus, floribus in capitulum terminale rarius demum in spicam brevem congestis glabris. 
1. S. HY PER RI Folia (Endl. gen. suppl. 4, 2; p. 63), glabra, caulibus debilibus, foliis ovatis oblongisque acutis venosis ciliatis basi obtusis rotundatisve, involucralibus 8-10 conformibus capitulo 8-10-floro longioribas, floribus 5-meris 10-andris, calycis lobis ovali-oblongis obtusis tubo triplo brevioribus, ovario toto piloso. $\mathcal{\psi}$ ? In Srinaghur Indiæ borealis (Kamroop !). Daphne hypericifolia Wall. list, $\mathrm{D} .1048$ ! Wikstromia? hypericifalia Meisn. in Denlsschr. der bot. Ges. Regensb. 3, p. 287*. Habitus omnino sequentis, sed folia latiora; pleraque elliptica, 7-10 lin. longa, $3 \frac{1}{2}-4 \frac{1}{2}$ lin. lata, margine tenuiter ciliata. Calyx 5 lin. longus. Cyathulus hypogynus dimidiatus, bilobus. (v. s.)

2. S. Cham J J A m (Linn. amcen. Ac. 1, p. 400), glaberrima, caulibus gracilibus, foliis lanceolatis oblougisve acutiusculis subvenosis, summis capitulum sessile involucrantibus conformibus flores subæquantibus, floribus 5 -meris 10-andris, calycis lobis ovalibus obtusissimis tubo anguste subinfundibuliformi multo brevioribus, ovario apice subglabro. $\mathcal{F}$ In pratis et lapidosis Sibiriæ Transbaicalensis (Gmelin l in herb. Mus. Stuttgard., Georgi in herb. Schreb.! Turcz.!) et Davuriæ (herb.' Ledeb.1). - Willd. sp. 2, p. 429. Chamæejasme radice Mandragoræ Amm. Ruth. p. 16, t. 2. Passerina Stelleri Wikstr. in Act. Holm. 1818, p. 321, Ledeb.l fl. ross. 3, p. 546. P. Chamæjasme Fisch! mss. in herb. Mart. Caules e rhizomate crasso sæpe numerosi, digitales-palmares, stricti, virides, conferte foliosi. Folia 5-10 lin. longa, 1-2 lin. lata, plana, subtus venis paucis tenuibus prædita. Capitula 6-15-flora. Calyx 5-6 lin. longus. Antheræ superiores semiexsertæ. Cyathulus hypogynus obliquus, dimidiatus, integer. Ovarium apice sub lente brevissime barbellatum. (v. s.)

3. S. Con cinNa (Edgeworth in Linn. Trans. 20, p. $88 \%$ ), glabra, caulibus virgatis, foliis late lanceolatis acutis, capitulis subglobosis, floribus 5-6-meris 10- vel 12-andris, ovario hirsuto. $\mathcal{F}$ In Himalayâ, prope Niti, alt. 10,000-11,000 ped. (Edgew.). - Walpers ann. 1, p. 583. Rhizoma subterraneum, sublignosum, multiceps. Caules erecti, herbacei, foliosi. Capitula multiflora. Flores odoratissimi, albidi, tubo rubro. Coronula hypogyna brevissima, denticulata. Species inflorescentiâ præcedenti, folíis vero sequenti accedere dicitur.

4. S. Altarca (Thieband in Pers. enchir. 1, p. 436), glaberrima, caulibus gracilibus, foliis lanceolatis oblongisve acutiusculis subvenosis, capitulis ovoideis demum in spicam brevem elongatis, floribus 4-meris 8-andris, calycis lobis oblongo-lanceolatis acutis tubo gracili duplo brevioribus, ovario apice puberulo. \% In subalpinis regionum Caucasicarum (C. A Mey.), Sibiriæ Altaicæ (Lam. Ledeb.I' Bunge! Schangin) et in deserto Soongoro-Kirghisico (Schrenk). S. Chamæjasme. Schangin in Pall. neue Nord. Beitr. 6, p. 38 (non Linn.). Passerina racemosa Wikstr. l. c. p. 320, Ledeb.! fl. alt. 2, p. 72, ic. pl. Ross. t. 374, fl. ross. 3, p. 545. Caules e rhizomate plures, erecti vel adscendentes, palmares-subpedales, imâ basi interdum ramosi et sublignescentes. Folia circ. pollicaria, 2- fere 3 lín. lata. Capitulum 10-15-florum, ovoideum, demum in spicam oblongam circ. pollicarem aphyllam excrescens. Flores brevissime pedicellati, 6-7 lin. longi, juniores (fide Wikstr.) tenuissime pubescentes. Cyathulus hypogynus dimidiatus. (v. s.)

\section{Sectio Ir. Dendrostellera $C . A . M e y . l . c$.}

Suffrutices caulibus lignescentibus ramosis ; foliis sparsis, subsessilibus; floribus in spicam terminalem plus minus elongatam (rarius abbreviatam) congestis, exinvolucratis, pubescentibus, inferne demum dense villoso-lanatis, 4-meris 8-andris.

5. S. s P I A A A (C. A. Mey. 1. c.), foliis coriaceis oblongis vel obovato-oblongis acutis costato-venosis glabris, spicis capituliformibus vel oblongis, calycis lobis ovatolanceolatis acutis tubo albo-villoso triplo brevioribus glabris, ovario adpresse piloso. 5 In montibus inter Chuznee et Cabul (Honigberger). Dais spicata Endl. sert. Cabulic. p. $5^{*}$, t. 3 . Frutex pälmari-pedalis, a basi ramosus, ramis gracilibus simplicibus strictiusculis apice plerumque puberulis. Folia internodiis subæqualia, eirc. semipollicaria, petiolo $\frac{1}{2}$ lin. longo, supra obscure viridia, subtus pallidiora. Spica pollicaris, ebracteâta, densa, rhacbi denticulatâ pubescente, tloribus sessilibus patentibus 3 lin. longis apice subincurvis, tubo patenti-lanato basi subventricoso, lobis aurantiacis acuminatis. 0varium sessile, stylo terminali sesquilongius. Stigma subglobosum. 
6. S. Lessertir (G. A. Mey. 1. c.), foliis dvali-oblongis lanceolatisque trinerviis submarginatis ramisque glabris, spicis demum elongatis, calyce anguste subinfundibuliformi basi villosissimo superntt sericeo-pilosiusculo, lobis glabrescentibus ovato-oblongis acutiusculis tuljo triplo Jrevioribus, ovario apice barbato. $\zeta$ In Oriente : Persiâ, circa Kermancha; Teheran et Schiras (Michaux, Olivier! Aucher-Elơy; n. 2520! 2897! 5287!); monte Elbro, prope Derbénd (Kotschy, n. 3211). - Jaub. el Spach ill: pl. Or. t. 301, cum descr. S. Persica Endl. gén. suppl. 4, 2, p. 63. Passerina Lessertii Wikstr. in Act..Holm. 1818, p. 346. P. Peŕsica Boiss.! diagn. 7, p. 85. Rami graciles, debiles, subcorymbosi. Folia 1-1 $\frac{1}{2}$ poll. longa, 4-7 lin. lata, plerumque brevissime acuminata, egregie nervosa. Spica jutiores subglobosex, demum usquie ad 3-6 poll. longæe, llbribuś remotiusculiš, rhachi cano-villosiusculà. Calyx 7-8 lin. lonǵus. Cyathulus hỵpogyniủs oblique truncatus. Ovarium apice setulis brevibus coronatum. Stigma ovale. (v. s. in Kerb. DC., Boiss., etc.)

B. Afghanica, foliis. lanceolatis utrinque attenuatis acutis, spicis abbreviatis. calycis tubo inferne sericeo-villoso superne, incano, lobis ovato-lauceolatis, 万In Afghania (Grifithl n. 1368 a! journ, 529). Folia 6-12 lin. longa, $2-4$ lin. lata. Spicæ pedunculatæ globosæ, demum ovato-oblongæ, pedunculo glabro, rhachi pubescente. Calyx 5-6 lin. tongus. (v. s. in herb. Lemann, nune Univ. Cantabrig.)

7. S. GR I F I т н I , foliis ovalibus oblongisque acutis basi obtusis subevëniis ramisque catro-pílosiusculis, spicis pedunculatis oblongis demum elongatis laxiusculis, calycis tubo subinflato patentim sericeo-villosissimo lobis ellipticís aculis gläbris triplo longiore, ovario apice hinc pilosiusculo inde glabro. J In Afghaniâ (Griffith! journ. n. 546). Forsan potius præcedentis var. pubescens. Folia 6-8 lin. longa, 3 - fere 5 lin. lata, supra glabrescentia. Spicæ juniores oblongæ densifloræ, demum 1-2 poll. longæ laxiusculæ, rhachi canâ. Calycis basis pilis longioribus patentissimis sericeo-lanata. Ovarium oblongum, sursum attenuatum, apice uno latere tantum brevissime pubescens, nec barbâ circulari coronatum, stylo breviore, stigmate fere globoso. Annulus hypogynus exiguus: (v. s. in herb. Lemann.)

8. S. STAC н X OIDES (Schrenk! enum. pl.- nov. 2, p. 16), foliis lineari-lanceolatis utrinque attenuatis acutis subeveniis ramisque glabris, spicis abbreviatis $s_{2}$ calyce sericeo-cano basi breviter villoso, lobis lanceolatis acutis túbo subtriplo brevioribus, ovario apice barbulâ coronato basịue hinc puberulo. 5 In Sibiriæ Altaicæ deserto Soongoro-Kirghisico versus mont. Alakul (Schrenk) et fl. Emel et Lepsa (ǨKarelin et Kíril. herb. Soc. imp. Mosq. n. 1934!). - Jaub. et Spach ill. pl. Or. p. 302, cum descr. Passerina Ammodendron Kar, et Kiril:1 enum. pl. Alt. p. 144, n. 742. P. stachyoides Schrenk! in Bull. Ac. St-Pétersb. 10, p. 253, Ledeb:! fl. Tross. 3,p. 546. Rami filiformes, attamen lignescentes. Folia 6-10 lin. longa, 1-2 lin. lata. Spicæ subsessiles ovatæ, densæ, demum oblongæe, circ. bipollicares, bieviter pedunculatæ. Cæt. feraS. Lessertii. (v. s. in herb. DC., Ledeb.; etc.)

\section{Species quoad gênus incertoe.}

9. S.? GANPI, ramis virgatis canescenti-hirtis, foliis sparsis. subsessilibus ellipticis vel superioribus lancểolatis subtus ad veriás pílosis vel novellî́s canescenti-hirtis, capitulis axillaribus pedunculatis 10-12 floris demum racemosis, calycis tubo extus canescenti-hirto, lobis brevibus obtusis, ovario hirto, stigmàte dépresso-căpitato papilloso. 5 In Japoniầ. Passerina Ganpi Siebold et Zuccar. Al. jap. fam. nat. 2 , p. $77^{*}$, n. 696, el in Abhandl. math. phys. Kil. der Ki. Bair. Acad. d. Wissenscl. 4 , 3, p. 201, Walpers ann. 1, p. 583, cum syn. Stellera Japonica Sieb. Suffruticosa, ramis rectis simplicibus vel superno ramosis. Folia approximata, 10-15 lin: langa, 4-6 lin. lata, utrinque attenuata acuta vol obtusa, sæpe mucronata, supra glabra vel parce pubescentia. Pedunculi in superioribus axillis canescentes, floribus brevissime pedicellatis fasciculato-capitatis demum subspicatis. Calyx tubus 5-6 lin. longus, cylindricus, tenuis. Stylus brevissimus. Præcedentibus omnino congener videtur.

10. S.? J A P ONICA (Siebold in Batav. Verhandl. 12, p. 22), ramis gracillimis divaricatis, foliis oppositis petiolatis ovatis vel ovato-ellipticis acutiusculis obtusisvo basi rotundatis utrinque glabris, racemis terminalibus simplicibus vel basi trifidis fastigiatis paucilloris, pedunculo filiformi stricto, pedicellis brevissimis, calyce 
glabro, lobic oblongis obtusis, ovario apice piloso, stigmate capitato muricato. $\hbar$ In Japoniâ. Passerina Japonica Sieb. et Zuccar. 1. c. p. $76^{*}$, n. 695 , et l. c. p. $200^{*}$, Walp. ann. 1, p. 583, cum syn. Stellera Japonica Sieb. 1. c. Frutescens, ramis annuis gracillimis patentibus. Folia constanter opposita, 6-18 lin. longa; petiolo 1-3 lin. longo. Racemi vel fasciculi fastigiati 8-12-flori, floribus decussatis albis, pedicellis apice articulatis. Calycis-tubus cylindricus sursum clavatus. Sqúamulæ hypogynæ nullæ? Ovarium cllipticum, basi attenuato-substipitatum, stylo brevissimn sublaterali. Nux sicèa, elliptica, calyce inclusa. Forsan Wikstrærniæ species, et quidem, monentibus ipsis auctoribus, $W$. virgatæe inflorescentiâ valde similis, Species a præcedente evidenter distinctissima, quamvis synonymon idem ab ipsis auct. utrique tribuatur.

\section{Species non descripta.}

S. Dic но от ом Fisch., Sweet hort. Brit: 1839 , p. 592, Passerina dichotomá Steud. nom. $\odot$ Dahúria.

\section{Species exclusa.}

S. ANNU A Salisb. : Thymelæa artensis Lam.

S. PASSERINA L. = Tltymelæa arvensis Lam.

S. Hedyoris Ehrenb. = Thymelea Aucheri Meisn.

S. PUE ES E ENS Guss. = Thymelæa, arvensis $\beta$ Meisn.

XIX. THYYMEL EAA Tourn. inst. p. 594 (excl. sp. plur. et $t$. 366), Endl. gen. suppl. 4, 2, p. 65.-Lygia Fasano in Atti tell' Ac. di Napoli, 1787, p: 235, t. 19, C. A. Mey. in Bull. Ac. St-Pétersb. 4, n. 4. - Stellera Gertn. fr. 1, p. 186; t. 39, f. 2 (non Gimel.). - Piptochlamys et Ghlamydanthus C. A. Mey. l.c. - Passerinæ, Stelleræ et Daphnés sp. anct. Nees jun: gen. fl. germ. $4, t .47$.

Flores hermaphroditi vel abortu unisexales, 4-meri. Calyx herbaceus vel coloratus, urceolatus vel infundibuliformi-tubulosus, totus persistens vel tarde deciduus, tubo continuo, limbo 4 -fido, regulari, fauce esquamatâ: Squamulæ hypogynæ nullæ. Stamina 8 , summo tubo duplici serie inserta, filamentis brevissimis inclusis, antheris ovalibus, superioribus exsertis inclusisve. Stylus lateralis vel raro terminalis brevissimus, inclusus, stigmate capitato papilloso. Nucula calyce persistente inclusa vel rarissime demum nuda. Albumen nullum vel tenuissimium embryonem includens, Cotyledones plano-convexæ. - Fruticuli vel suffrutices, raro herbæ, Europæ mediæ et australis, Africæ borealis et Asiæ occidentalis et borealis, foliis sparsis, floribus axillaribus solitariis aggregatisve plerumque parvulis inconspicuis bräcteolatis virescentibus vel flavis, rarius albis vel rubellis.

\section{Sectio I. Lygra Fasano $l$. $c$.}

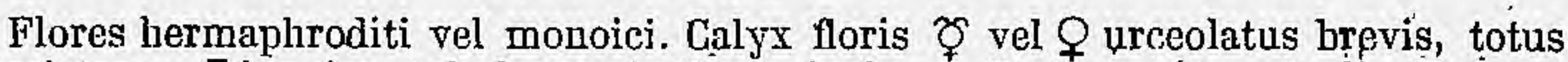
persistens, $\sigma^{\top}$ longior, tubulosus. Antherie incluse. Stylus subterminalis. Embryo albuminiś laminâ tenui inclusus. - Herbæ vel suffrutíces canlibus gracilibus subsimplicibus erectis, foliis sparsis angustis, floribus axillaribus solitariis aggregatisve parrulis bractcatis indeceris, calycis lobis conniventibus.

1. T. ARVENSis (Lam. fl. fr. 3, p. 218), annua, foliis linearibus vel lanceolatolinearibus acutis cauleque glabris, noribus hermaphroditis, bracteolis ovatis ciliatis, culyce puberulo lobis ovatis obtusis tubo latiusculo $2-3$-plo brevioribus. $\odot$ In agris Europæe mediæe et australis totilıs, borealis passim, in Africât boreali, Asià occiđontali et boreali, Sibiriầ Altaicà (Gmelin! Ledub.! Schrenk, n. 128, Kotschy, n. 353! Karelin et Kíril, n. 1935! etc.), Persià (Aucher-Eloy, n. 5288!), Barbariâ, Algeriâ (Desf., Bovél etc.). Stellera Passerina Linn. sp. ed. 1, p. 519, Jacq. coll. 1, p. 65, ic. rar. 1, t. 68, Lam. ill. 1. 293, Schkulh Handb. t. 107, Grertn. fr. 1, p. 186, t. 39 ; f. 2 , Willd. sp. 2 , p. 429 , DC. A. fr. 3, p. $361^{\star}$, Nlert. et Koch Deutschl. Flora 3, p. 47, Bertol. 11. ital. 4, p. 346, Boiss. voy. Esp. 2, p. 554, Reichenb. ic. 1. germ. 11, p. 12, t. 550, 1 . 1167. S. annua Salisb., ex. Wikstr. Lýgid Passerina Fasano l. c, C. A. Mey. l. c. Passerina annua Wikstr. Thym. in Act. 
Holm. 1818, p. 320, Nees jun. gen. fl. germ. 3, t. 47, f. 1-17, Ledeb.! 1. ross. 3 , p. 645. P. Stellera Ram. mss., ex DC. l. c., Coss. et Germ. fl. paris. p. 478. Caulis erectus, strictus, corymboso- vel fastigiato-ramosus, rarius simplex, $\frac{1}{2}-1 \frac{1}{2}$-pedalis, ad apicer usque foliosus. Folia patula internodio æqualia vel plertmque longiora, 1-10 lin. longa, $\frac{1}{2}-1$ lin. lata, interdum passim opposita, axillis 1-3-floris, bracteolis flores virescentes subæquantibus. (v. v. et $\mathrm{s}$. $\mathrm{s}$.)

$\beta$. pubescens (Ten. syll. fl. neap. append. 1, p. 365), caule gracillimo supra cum foliis parce pubescente. $\odot$ In Siciliâ, prope Panormum (Guss. L. Huet du Pavillon !), Persiâ, inter Bagdad et Alep (Olivier!), Besch-Abur (Kotschy, n. 389!). Stellera pubescens Guss.! fl. sic. prodr. 1, p. 466, suppl, 1, p. 114. Atti di storia nat. Bologna 1830,3 , fasc. 7 , p. 57. Passerina pubescens Guss. fl. sic. 1, p. 451. Lygia pubescens C. A. Mey. l. c. Exceptâ pubescentiầ nullo modo a plantâ vulgari distinguerida. Specim. Kotschyana, n. 389, insignia caule patulo-piloso, foliis brevibus (2-3 lin. longis) acutissimis basi obtusis (1 lin. latis) tarde glabrescentibus. vix tamen propria speciess. (v. s. in herb. DG., Ledeb., Boiss.)

2. T. Gilicica, glabra, basi suffrutescens, caulibus annotinis adscendentibus simplicibus, foliis linearibus acutis, superioribus valde abbreviatis, floribus monoicis, bracteolis linearibus parvulis axillisqué glabris, calyce parce pilosiúsculo, lobis tubo multo brevioribus. $\not$ vel $\hbar$ In montibus Ciliciæe, circa Güllek Boghas, alt. 3,800 ped. (Kotschy, n. 234 bl). Caulis subterraneus brevis multiceps lignosus, ramis annotinis $6-10$ lin. longis adscendentibus indivisis vel imâ basi pauciramosis laxe foliosis. Folia sparsa, sessilia, patula, plana, 1-nervia, 3-4 lin. longa, $\frac{1}{2} \cdot \frac{2}{3}$ lin. lata. surculorum sterilium subspathulata, $1-1 \frac{1}{4}$ lin. lata. Flores in axillis superiorìbus 2-1 sessiles, folium 1-2 lin. longum æquantes vél superantes, lutei, bracteolis folio similibus, sed dimidio minoribus. Calyx masc. $2 \frac{1}{2}-3$ lin. langus, anguste infundibuliformis, pistilli rudimento minuto; fem. conico-tubulosus, $1 \frac{1}{2}$ vix 2 lin. longus, absque ullo staminum vestigio. Cæt. Th. arvensis. Species a præcedente jam floribus monoicis, a sequente foliis latioribus, ab utrâque habitu, caulibus haud strictis facile dignoscenda. (v. s. in herb. DC.)

3. T. A U G HERT, perennis, caulibus longis gracillimis glabris, foliis anguste linearibus acutis glabris, superioribus valde abbreviatis, axillis villosis, floribus monoicis, bracteolis ovatis acuminatis subciliatis, calyce pilosiusculo, lobis oblongis obtusis tubo parum brevioribus. $\mathcal{\nvdash}$ vel $ち$ ? In Syriâ (G. Ehrenberg!), Asiá minore, circa Brussa, monte Libano et Sinai (Aucher-Eloy, n. 2522!2532!-2537!), in Cappadociâ ad Euphratem (Chesney, n. 189!), in monte Tauro, prope portus Ciliciences (Balansa, n. 715! Kotschy, n. 426!), Persià, circa Schiras (Kotschy, n. 443!). Stellera Hedyotis G. Ehrenb.! mss. in herb. Syriac. Mus. reg. Berelin. Passerina annua Aucher-Eloy, n. 2522! Kotschy, n. 443! Caules e basi lignescente plures, 2-3-pedales, filiformes, recti, simplicissimi vel rarius medio-in ramos paucos elongatos simplices divisi, basin versus defoliati. Folia sparsa, internodio plerumque vix longiora, erecta vel semipatula, inferiora 6-10 lin. longa, $\frac{1}{4} \frac{1}{2}$ lin. lata, superiora sensim breviora usque ad 3-1 lin. decrescentia, semipatentia, axillis inde a medio caule floriferis 1 -2-floris. Flores abortu unisexuales. Calyx $\sigma^{7}$ folium subæquans $1 \frac{1}{2}$ lin longus, túbo tenui lobis subduplo longiore, antheris 8 cum rudimento pistilli; $Q$ dimidio brevior, tubo lobis iequante, staminum restigio nullo, ovario pubescente, stylo brevi filiformi incluso. Species insignis, ad T. arvensem proxime quidem accedens, at notis indicatis distinctissima. (v. s. in herb. reg. Berolin., DC., Boiss.)

Sectio ir. Chlamydantruus C. A. Mey. in Bullet. Ac. St.Pétersb. 4, n. 4.

Calyx infundibuliformi-tubulosus vel rarius urceolatus, totus persistens. Antheræ inclusæ vel superiores semiexsertæ. Stylus lateralis, rarius' subterminalis. Semen exalbuminosum.

\$ 1. - Suffrutescentes. Caule basi tantum lignoso et ramoso, ramis annotinis erectis simplicibus, foliis herbaceis angustis, floribus axillaribus, calyce anguste infundibulari-tubuloss.

4. T. virgata (Endl. gen. suppl. 4, 2, p. 66), foliis linearibus vel anguste lanceolatis obtusiusculis puberulis, junioribus cum ramis calycibusque sericeo-canis, 
axillis plurifloris, calyce folio breviore, lobis lanceolatis tubo gracili duplo brevioribus. 5 In Algeria, circa Ttemsen (Desf.), circa Saïda (Cosson! Balansa, n. 257!), in Marocco (Brouss.), ad Tanger (Salzm.!), Passerina virgata Desf. f1. atlant. 1, p. 331, t 95, Wikstr. Thym. 1. c. p. 341. Chlamydantluus virgatıs C. 1 . Mey. in Bull. Ac. St-Pétersb. 4, i. 4. Caules seu rami armotini circ. pedules, rigiduli. Folia conferta, 6-12 lin. longa, 1-2 lin. lata, flavo-viridia, obsolete venosa, pilosiuscula, demum glabrata, superiorum axillis 2-5-floris. Flores hermaphroditi. Calyx subcylindraceus, 3 lin. longus, totus pube densâ adpressâ cano-sericeus, intus flavus, lobis obtusiusculis. Antheræ inclus:e. (v. s.)

5. T. SA Nam Und (All. Pedem. 1, p. 132, n. 485), glabra, foliis lanceolatis et ovatooblongis acutis venosis, floribus in superioribus axillis 1-3 folio brevioribus polygamo-monoicis, calycis lobis lanceolatis acutis tubo infundiluulari subduplo brevioribus. $ち$ Circa Nicæam (All.), el, in monte Baldo? (Pona), jn Galloprovinciâ, Occitaniâ, Cataloniâ, Barbariâ ? Daphne Thymelæa Limn. sp.p. 509, Lam. dict. 3, p. $434^{*}$, Ger. fl. galloprov. t. 17, f. 2, DC. 1l. fr. 3, p. 356*. Passerina Thyrnelæa DC. 1. c. 6, p. 466, Wilsstr. Thym, l. c. p. 331, Nees juu. gen. fl. germ. 3, t. 47, f. 22-26, Reichenb. ic. 1l. germ. p. 13. Chlamydanthus Thymelæa C. A. Mey. 1. c. Thymelæa Bauhini Endl. gen. suppl. 4, 2, p. 66. T. Gneorum. Reichenb. ic. fl. germ. t. 551. Canles digitales-pedales, debiles. Folia sparsa vel passin opposita, viridia vel glaucescentia, $6-10$ lin. longa, 2-4 lin. lata, minute ciliata vel nuda, floralia inferioribus conformia vel paulo latiora, infima seepe vix 1 lin lata. Flores ชิ infundibuliformes et $ᄋ$ subcylindrici dimidio breviores. Calyx flavus, 4-5 lin. longus, interdum tandem basi fissus et deciduus, glaberrimus vel rarissime in tubo parce pilosiusculus. Stylus lateralis, brevissimus, persistens. Nucula ovatooblonga, sub epidermide albidâ tenui nigrâ granulata. Semen acuminatum. (v. s.

$\beta$. pubescens, foliis utrinque parce pilosiusculis.-Circa Fréjus et Telonem. (v. s. comm. a Loiseleur.)

6. T. THESIordes (Endl. gen. suppl. 4, 2, p. 66), caulibus apice adpresse pilosiusculis, foliis linearibus obtusiusculis pubescentibus glabrisve, floribus in snperioribus axillis 1-3 folio brevioribus polygamo-dioicis, calyce puberulo, lobis ovatís obtusiusculis tubo vix dimidio brevioribus. 5 In Hispaniâ, circa Valentiam (Léon Dufour !). Daphne thesioides Lam. dict. 3, p. 437*, ill. t. 290, f. 4, Pers. syn. 1, p. 437. Passerina thesioides Wikstr. Thym. J. c. p. $333^{*}$. P. linariæfolia Pourret, fide Wikstr. Chlamydanthus thesioides C. A. Mey. 1. c. Caules digitales. Folia 3-6 lin. longa, $\frac{1}{1}-\frac{1}{2}$ lin. lata, inferiora conferta et jlerumque angustiora, superiora remotiora. Calyx flavus, 2 lin. Jongus, cylindraceus. Ovarium apice tenuissime puberulum.

$\beta$. elliptica, tota minute tomentoso- vel velutino-puberula, foliis glaucis $\operatorname{mox}$ glabratis ciliolatis, surculorum sterilium anguste linearibus confertis, fertilium lineari-oblongis obtusissimis obsolete 1 -nerviis eveniis flores æquantibus. 5 In regione montanâ calcareâ Sierræ Nevadæ, alt. 6,000-7,000 ped. (Boiss.l), Sierra de Sagra et de Baza (Bourgeau, n. 1472!). Passerina velutina Boiss.! elench, p. 81, n. 173 (non Bourr. nec Cambess.). P. elliptica Boiss.! voy. en Esp. 2, p. $556^{*}$, L. 158. Chlamydanthus ellipticus C. A. Mey. 1.c. Thymelæa elliptica Endl. 1. c. p. 66. Caules 3-5-pollicares. Folia 3-7 lir. longa, 1-2 $\frac{1}{2}$ lin. lata, basi attenuata, utrinque minute pilosiuscula, axillis 1-2-floris. Calyx 2-3 lin. longus.

7. T. Go RIDIF oLIA (Endl. 1. c. p. 66, excl.? syn. Linn.), caulibus superne pubescentibus, foliis anguste linearibus obtusiuseulis glabris, floribus in summis axillis subsolitariis approxirnato-subeapitatis folia superantibus, calyce dense cano-puberulo, lobis tubo infundibulari parum brevioribus ovatis glabriusculis. $\hbar$ In Hispaniæ prov. Galiciâ (Jos. de Jussieu!). Thymelæa humilis fruticosa Coridis folio flore luteo Juss.l in herb. Daphne coridifolia Lam.! dict. 2 , p. $\mathbf{4 3 6 *}$, ill. t. 290 , f. 3, Pers. syn, 1. p. 435. Passerina coridifolia Wikstr. Thym, l.c. p. 334*. Fruticulus basi ramosus, ramis diflusis laxis digitalibus. Folia sparsa et opposita, patentia, 2-3 lin. longa, $\frac{1}{3}$ lin. lata. Spicæ terminales capitulíformes, sæpe comosæ. Calyx bracteolis 2 minutis ovatis puberulis stipatus, 1-1 $\frac{1}{3}$ lin. longus, lobis obtusis. Ovarium villosum. (v. s. in herb. Lam.) 


\section{\$2. Fruticulose.-Caule humili, iterato ramoso, toto lignescente, foliis coriaceis vel rarius herbaceis, floribus in summis axillis capitato- approximatis vel rarius remotiusculis sparsis, calyce anguste infun- dibulari vel urceolato.}

8, T. VIL 0 S A (Endl. 1. c, p. 66), ramis gracilibus apice pubescentibus, folíis sparsis et spuric fasciculatis herbaceis lauceolatis eveniis laxe hirsutis, floribus axillaribus subsolitariis ramulosque brevissimos terminantibus folia subrequantibus dioicis? palyce infundibulari parce hirsuto, lobis lançeolatis tubo tenui duplo brevioribus, 亏 In Lusitaniæe prov. Algarbiâ (Welwitsch, n. 403! Bourgeau, n. 2025!), Hispaniâ, circa San Roque (Gav., Wilkomm. n. 670!), Gibraltar (Juss., Boiss., etc.), ins. T'eneriffâ (Bory S.-Vinc.l), Mauritaniâ, Tanger (Salzm.l Boiss. et Reuter l), et? Oriente (herb. DC.). Daphne villosa Linn. sp. ed. 2, 1, 1, 510, Lam. dict. 3. p..435*. Passerina villosa Wikstr. Thym. 1. c. p. 332 , Boiss.! voy. en Esp. 2 , p. $555^{*}, \dot{t} .157$, f. B. P. Tingitana' Salzm.! mss. in herb. Chlamydanthus villosus G. A. Mey, l. c. Frutioulus nunc decumbens? laxe ramosus, nunc multicaulis erectus circ. pedalis, ramis sæpe pedalibus subsimplicibus. Folia conferta, patula, 4-7 lin. longa, 1-2 lin. lata, obtusiuscula, demum glabrata margine ciliata. Flores 3-4 lin. longi,

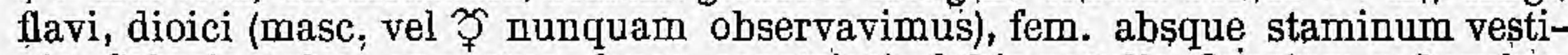
gio. Calycis tubus angustus, fauce constriotà, lobis patulis. Ovarium puberulum stylum lateralem tenuem æequans. Species habitu inter \& 1 et 2 ambigua. (v. s.)

9. T. NITIDA (Endl. 1. c. p. 65), ramis fastigiatis vel corymbosis; ramulis confertis nanis dense foliosis fasciculiformibus, foliis imbricatis linearibus obtusis sericeis, floribus in ramulorum apice paucis aggregatis folia æquantibus hermaphroditis, caljce cylindraceo sericeo, lobis tubo angusto triplo brevioribus. 5 In Mauritaniâ, circa Tunetum, Mascar (Desf.), in montibus Algeriæ, circa Oran, etc. (Bovée! Boiss: et Reut.l Balansa, n. 255!), in Hispaniâ, cirea Valenciam (Léon Dufour, n. 491!), in regione alpinâ calcareâ prope Alfocar (Boiss.). Daphne nitida Vahl synib. 3, p. 53 , Willd. sp. 2 , p. 418. D. argentata Lam. dict. 3 , p. 436 ? (efr. infra T. Tartonraira $(\beta)$. Passerina nitida Desf. fl. atlant. 1, p. 331, t. 94, Wikstr. Thym. i. c. p. 339, Boiss. voy. en Esp. 2, p. 555. Fruticulus palmaris-subpedalis, erectus, ramis lignosis, junioribus sericeis. Folia dense approximata, herbacea, 3-5 lin. longa, $\frac{1}{3}-\frac{\hat{x}}{4}$ lin. lata, basi angustata, pubo minutâ adpressầ sericeo-splendentia. Flores 3 lin. longi. (v.s.)

10. T. Dior a (All. fl. pedem. auctuar. p. 9), glaberrima, subdecumbens, folits herbaceis spathulato-linearibus obtusis, floribus axillaribus subsolitarijis polygamodioicis, bracteolis linearibus acutis, calycis tobis ovato-lanceolatis acutis tubo 2-3-plo brevioribus. 5 In alpinis Pyrenæorum et Galloprovinciæ (Lapeyr.! Gouan! DG.! Thomas! Rerquien! Lois.! Benth.! Rugel! etc.), Pedemontii, Col-de Tende (All.). - Reichenb. ic. fl. germ. 11, p. 13, t. 551, Endl. l. c. Daphne dioica Gouan! ill. p. 27, t. 17, f. 1, Lam. dict. 3, p. 435*, Willd. sp. 2, p. 416. D. calycina Berger fl. basses Pyrén. 2, p. 211 (excl. syn.), ex DG. fl. fr. 6, p. 366. Passerina dioica Ramond in Bull. Soc. philom. n. 41 , DG. l. c. 3, p. $359^{*}$, Wikstr. Thym. l. c. p. $33.5^{*}$, Greu. et Godr. fl, fr. 3, p. 61. P. empétrifolia Lapeyr. hist. abrég. pl. Pyrén. p. 212. Fruticuhtus palmari-subpedalis, plus minus ramosus, ramis tẹnuibus demum denudatis foliorum cieatricibus dense verruculosis. Folia imbricata, mox patula, 2-6 lin. longa, $\frac{1}{2}-1$ lin. lata, basin versus sensim attenuata, plana, evenia. Flores in ramulorum extremitate sparsi, axillares solitarii vel gemini, 3-4 lin. longi, flavi, demum purpurascentes. Caly infundibularis, lobis patulis acutis. Ovarium sericeo-puberulum, stylo brevissimo laterali. Semen acuminatum. (v. s.)

11. T. viRESaENs, ramosissima, ramis crassis, junioribus puberulis, foliis herbaceis spathulato-lincaribus, obtusis planis, fasciculis terminalibus 5-10-1loris, floribus folia æquan tibus polygamis calyce minute sericeo-puberùlo, lobis oblongis obtusiusculis subduplo brevioribus. $ち$ In Algeriâ, ad fontes 1 . Oued-Abdi et in sylvâ Lambèse (Balansa, n. 1007!). Passerina virescens Cosson et Durieul in Balansa pl: d'Algérie 1853, n. 1007 ! Valde quidem affinis similisque T. dioicæ, sed notis indicatis bene distincta. Rami plerumque corymboso-ramösi, crassiusculi, pulverulento-albidi, mox defoliati, sæpe tortuosi. Folia subcoriacea, pallide viridia, subenervia, mox patentia, summa 4-5 lin. longa, 1-1 $\frac{1}{8}$ lin. lata, inferiora ejusdem 
ramuli duplo minora. Flores semper ramulos novellos breves terminantes, verisimiliter dioici, alii $\mho_{+}$, alii $\sigma^{7}$ cum pistillo imperfecto? nano, alii $ᄋ$ absque staminum vestigio. Calyx anguste infundibularis, adpresse sericeo-puberulus, lobis apice glabriusculis, tubo in 8 turgescente ovoideo, fauce constrictâ, Ovarium puberulum, stylo brevi laterali. (v. s. in herb. DC.)

12. T. GALYGINA, ramis abbreviatis superne puberulis, foliis coriaceis linearibus attenuato-acutis glaberrimis margine recurvis, floribus axillaribus subsolitariis folío multo hreviobribus polygamis? bracteolis ovatis obtusis concavis glabris, calyce latiuscule infundibulari puberulo. 5 In Pyrenæorum valle Vicdessos et monte Bexnadouze, etc. (Lapeyr.! Ramond !). Dapline calycina Lapeyr.! Act, Toulous. 1, p. 209 , t. 15 , Lam. dict. 3, p. $43,5^{*}$. Passerina calycina DC. fl. fr. 3, p. $360^{*}{ }_{2} 6$, p. 366, Wikstr. Thym. l. c. p. 337”, Gren. et Godr.fl.fr. 3, p. 62 (excl. syn.P. nival.). p. juniperifolia Lapeyr. $\alpha$ abr. Pyr. p. 213. P. tinctoria (S angustifolia Boiss. voy. Esp. 2 , p. 556 ? $\beta$ calycina Eindi, gen. suppl. 4,2, p. 66 . Fruticulu's nanus, parce ramosus, subdecumbens, ramis brevibus patentibus adscendentibus crassiusculis dense foliosis. Folia 5-7 lin. longa, 1-1 $\frac{1}{2}$ lin. lata, basi vix angustata obtusa, subenervia, eciliata, supra convexa, subtus marginibus plus minus recurvis cencava. Flores flavi, ex DC. hermaphroditi, ex Wikstr. dioici. Nos nonnisi masculos vidimus. Bracteolæ 2 adpresśæ, $\frac{1}{2}$ lin. longæ.' Calyx 2 lin. longus, parce adpressopuberulus, fauce fere 1 lin. latà, lobis ovatis obtusis tubum obconicum subrequantibus. Species a T. tinctoriâ, cui certe jroxime affinis, facile dignoscęla foliis glaberrimis apicen versus semper attenuatis, plus minus acutis; et calyce puberulo. (v. s. in herb. DG. et Acad. Monac.)

13. T. NIVALIs, ramis brevihus glabris, foliis coriaceis oblongo- vel spathulatolinearibus extra medium latioribus utrinque obtusis glabris 1 -nerviis dorso conyexis, junipribus margine ciliatis, floribus axillaribus solitariis dioicis folio multo brevioribus, calyce glabro. 5 In Pyreneis cditioribus, circa mont Perdu et Port de Gavarnie (Ramondt). Passerina pivalis Ramond in Bull. Soc. philom. n. 41, t. 9, f. 4 , pC. fl: fr. 3, p. $359^{*}, 6$, p. $366, \beta$ Loís. fl. gall. ed. 2,1, p. 281 . P. juniperifolia $\beta$ Lapeyr. abr. Pyr, p. 213. P. tinctoria $\beta$ angustifolia Boiss. voy. Esp. 2, p. 556, forsan potius huc quam ad T. calycinam spectat. Species ut videtur rara, procedentem inter et sequentem vere ambigua hujusque forsan mera variètas, receddens foliis (excepto margine) floribusque glabris. A priore vero foliis ciliatís et bassin nec unquem apicem versus attennatis calyceque glabro distincta. (v. s. in herb. Lam. et DC.)

14. T. TINCтоRIA (Endl. gen. suppl. 4, 2, p. 66), ramulis brevibus cpassiusculis cicatrisato-tuberculatis, foliis coriaceis linearibus utrinque obtusissimis tomentellis subenerviis supra concavis, lloribus axillaribus subsolitariis polygamis? bracteolis ovatis; calyce glaberrimo late infundibulari foliis multo breviore, lobis ovatis tubum æquantibus. ち In Hispaniæ prov. Arragoniâ (Vahl, Reuter!), Valen. ciâ (Dufour l), Cataloniâ, circa Barcelonam et Tarragonam (herb. DC.!), Murciâ, Navarrâ (ex Boiss.), Lusitaniâ (herb. Zúccar.), Galliâ merid., a đC Chartreuse Valbonne, prope Pont-Saint-Espril in h. DG. Sanamunda vermiculata Barrel. ic. t. 231. Daphne veriniculata Vahl symb. 1, p. 28*. Passerina tinctoria Pourret chlor. Narb. p. 27, Mém. Ac. Toul. 3, p. 323, Lapeyr. abr. Pyr. p. 213, Wikstr. Thym. p. 339", Boiss. voy. Esp. 2, p. 556 (excl. $\beta$ ), Gren, et Godr. 11. fr. 3, p. 62. P. hirsuta Asso stirp. Arrag. n. 343 (non Linn.). Chlamydanthus tinctorius C. A. Mey. l. c. Fruticulus humilis, córymboso-ramosus, ramis crassiusculis, inferne defoliatis glabris, apice puberulis. Folia subcarnoso-crassiuscula, patula, 3-6 lin. longa, 1 lin. lata, semper obtusa, basi haud angustata, pube minutẩ molliter subtomentosâ. Flores T. calycinæ, sed glaberrimi. (v. s.)

15. T. VELUTINA, foliis crassiusculis obovato-vel lineari-oblongis obtusissimis basi attenuatis utrinque ramisque dense villoso-tomentosis subsericeis, floribus axillaribus aggregatis bracteolisque subrotundis cano-tomentosis, calycis lobis avatis obtusis tubum æquantibus. 5 In ins. Teneriffà (Brouss.!), Gataloniâ (herb. DG.I), ins. Balear. (Cambess.I). P्asserina velutina Pourret Cambess. euum. pl. Balear. p. $183^{*}$, Mém. Nus. 14, p. 304 (non Boiss.). ? Daphue myrtifolia Poir. dict. suppl. 3, p. 315. Habitus et folia fere T. tinctorix, sed pubescentia undique densior brevi-villosa vel sericeo-lanata, folia basi semper angustata plerumque majora vel saltem latiora, $1 \frac{1}{2}-3$ lin. lata. Fasciculi axillares pauciflori fere T. Tartonrairæ et hirsutz. (v. s. in herb. DG. et Boiss.) 
16. T. TART ONR AIRA (All. fl. pedem. $1, p .133, \mathrm{n} .486$ ), tota argenteo-vel flavidosericea, foliis coriaceis obovatis vel obovato-oblongis nervosis, floribus axillaribus aggregatis polygamis, bracteolis ovatis obtusis imbricatis, calyce folio breviore, lobis obtusis tubum subáquantibus. 5 In littorali Mediterraneo : Hispaniâ (Boiss.!), Galliâ australi, Nicese, in Corsicâ, Sardiniâ, Barbariâ? regno Neapolitano, Sicilià (Tenorel Heldreich l), Græciâ, Peloponeso. (Sprựer! Boiss.! Kotschy l), Cretâ (Sieber !), Cypro (Broussonnet 1), Bosphoro (Beaupré), Chio, Rhodo, Asiâ minore (Aucher-Eloy, n. 10091 2519), - Bertol. fl. ital. 4, p. 343. Reichenb. ci. fl. germ. 11, p. 13, t. 552. Sanamunda argentea latifolia Barrel ic. t. 221. Daphne Tartonraira Limn. sp. ed. 1, p. 356, Vahl symb. 3, p. 53, Lam. dict. 3, p. $436^{*}$, ill. t. 290 , f. 2 , DC. fl. fr. 3, p. $357^{*}$. D. candicans Lam. fl. fr. 3, p. 221. Passerina Tartonraira Schrad. neu. Journ. 4, 1, p. 89, DC. l. c. 6, p. 366, Wikstr. Thym. 1. c. p. 327 ", Sibth. et Sm. fl. græc. t. 354. Chlamydanthus Tartonraira C. A. Mey. 1. c., Griseb. spicil. t1. rumel. 2, p. 322. Fruticulus palmari-pedalis, iterato ramosus, totus sericeo-canescens, albidus vel fulvescens, ramis divaricatis rigidis. Folia coriacea, imbricata, mox patula, 5-10 lin. longa, extra medium

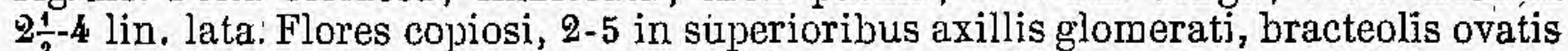
obtusis tomentosis imbricatis stipati, albidi. Calyx $1 \frac{1}{2}-2$ lin. longus, lobis patulis tubo obconico subæquilongis. Antherwe superiores exsertæ. (vis.)

B. angustifolia (d'Urville enum. pl. Archipel. p. 42, n. 350), foliis spathulatolinearibus canis vel subsericeis, bracteolis sæpe acutiusculis. - Grescit promiscue cum typo speciei, sed prævalens in regionibus magis orientalibus, Græciâ, Syriâ, etc., Tschesme (Olivier !), Smyrnẩ (Balausa, n. 373!), nèc non in excelsioribus Sierræ Nevadæ et Tejedæ (Boiss.!).-Boiss. voy. Esp. 2, p. 555. Sanamunda argentea angustifolia Barrel. iı. t. 222. Daphne argentea Sibth. et Smith fl. græc. 1, p. 258, t. 355, Sieber I herb. Cret. D. angentata et? tomentosa Lam. dict. 3, p. 436. D. osyroides Vahl herb., ex Wikstr. Thym. p. 328. Passerina tomentosa Wikstr. l. c. p. 332? Chlamydanthus argenteus C. A. Mey. 1. c. Thymel:ea argentea Endll. gen. suppl. 4, 2, p. 65, C. Koch in Linnæâ 22, p. 610. Folia extra medium vix ultra 1 lin.' lata, plerumque minus sericea. Florum glomeruli copiosiores. Cæt. omn. ut in typo speciei. (v. s.)

$\boldsymbol{\gamma}$. calvescens (Gren. et Godr. fl..fr. 3, p. 63), foliis oblongo- vel spathulato-linearibus glabratis nervosis.--In Corsicâ, inter Ponte d'Asco et Ponte alla Leceia (Phil. Thomas!).- Passerina Thomasii Duby! Bot. Gall. 1, p. 406. Thymelæa Thomasii Endl. 1. c. p. 66. T. Tartonraira $\beta$ Thomasii Reichenb. ic. fl. germ. 11, p. 13 , t. 552, n. 1172. Forma insignis foliis haud argenteis, vix ac nevix tomenti reliquias inter nervos retinentibus, glaucescentibus, cæteroquin a formâ vulgari haud cliversa. (v. s.)

17. T. M I GROPHYLLA, caule adscendente virgato fastigiato ramosissimo, ramis rigidis $\operatorname{mox}$ aphyllis alhido-tomentosis, foliis coriaceis ovalibus lanceolatisque planis sericeis, floribus in apice ramulorum brevissimorum 3-5 sessilibus polygamo-monoicis folia superantibus, calyce $\sigma^{\top}$ cylindraceo sericeo, 9 ovato brevivilloso, lobis ovatis obtusis conniventibıs. 5 In Algeriæ distr. Saïda et circa Biskra (Cosson! Balansa, n. 256! 826!), in deserto Tunetano (Kralik, n. 333!). Passerina microphylla Coss. el Durieu! in Balansa pl. exsicc. Alger. n. 826. Frutex 1-2-pedalis, rigidus, caule valido, ramis patulis strictis vel adscendentibus simplicibus vel

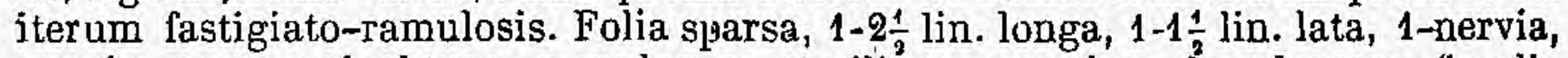
evenia, acuta vel obtusa, ramulorum sterilium remotiuscula adpressa, floralia dense imbricata ovali-subrotunda, demum patula. Fasciculi 3-5-flori pseudo-axillares, scil. ramulos brevissimos foliosos lerminantes. Calyx flavus, masc. $2 \frac{1}{2}$ lin. longus, cylindricus, basi angustatus, tubo pube brevi patulà villoso, lobis sericeis tubo duplo (in fem. dimidio) brevioribus. Ovarium obovato-oblongum, basi attenuatum, glabrum, apice parce pilosiusculum, in fl. masc. obsoletum. Stylus dimidium ovarium aquans. Nucula sessilis, ovata, viridis, lrevis, suturis 2 conspicuis. Alhnis T. canescenti, sed habitu vegetiore (potius T. hirsutæ et Tartonrairæ), ramulis firmis rigidis, pubescentiâ jn ramis minute tomentosâ; in foliis adpresse sericet (nec patulâ), etc., satis distincta. (v. s. in herb. DC.)

18. T. CANE S ENS (Endl. gen. suppl. 4, 2, p. 65), ramulis debilibus tomentosis, foliis herbaceis lanceolatis vel ovato-oblongis acutis dense sericeo-villosiusculis, capitulis terminalibus paucifloris passimque axillaribus subunifloris, calyce folia subaquante sericeo-cano, lobis ovatis obtusis tubo tenui cylindrico duplo brevioribus. 
5 In Marocco (Schousb.), Hispaniâ qustrali (herb. DC.), circa Gibraltar, (Willkomm, n. 654!), Estepona Arrdalusise, etc. (Boiss.!). Sanamunda altera Clus. Hisp, ic. p. 176. Daphne lanuginosa Lam. dict. 3, J. $436^{*}$. Passerina canescens Schousb. Marocc. p. 176, Willd. sp. 2, p. 432, Wikstr. Thym. 1. c. p. 342, Boiss.! voy, en Esp. 2, p. 5.54 ", t. 157, fig. A. Chlamydantlus canescens C. A. Mey..l. c. Fruticulus decambens, staturâ habituque T. liirsuta, sed jam pubescentiâ laxiusculá et inflorescentiá facile distingnendús. Caulis 2-pedalis et ultra, inferne aphyllus, supra fastigiato-ramosissimus, ramulis patulis filiformibus brevibus albide-velutinis. Folia conferta, $1 \frac{1}{2}-2 \frac{1}{2}$ lin. longa, patula, juniora imbricata adpressa sericáa. Flores lutei. (v. s:)

\section{Sectio III. Piptochlamys C. A. Mey. in.Bull. Ac. St-Petersb. 4, n. 4.}

Calyx demum (tardissime) totus deciduus. Nucula nuda.

40. T. H IRsuta (Endl. gen. suppl. 4, 2, p. 65), decumbens, ramosissima, foliis coriaceis ovatis subrotundis oblongisve obtasis enerviis subtus glabris supra cum ramulis calycibusque albo-tomentosis, fasciculis axillaribus terminalibusque paucifloris folia aquantibus, floribus polygamis, calycis lobis ovatis obtusis tubum brevem late infundibularem snbæquantibus. I In toto ambitu maris Mediterranei : Hispaniấ (Clus., Boiss., etc.), Lusitaniâ (ex Wikstr.), Sardiniâ (Thomas!), Corsicâ, -Balear., etc. (Cambess.!), Gallía australi, Nicææ, littorali Liguriæ, Istriæ, regni Neapohitani, in Siciliâ, Zanto (Margot 1). Constantinopoli (Noë 1), Cretâ, Syriâ, Ægypto (Ehrenberg !, Aucher-Eloy; 1n. 25211), Arabíâ petræâ (Boiss.l), Al'geriẩ (Desf., Schimper! Bové! Balansa, n. 825!), Passerina hirsuta Linn. sp. ed.1, p. 559, Vahl symb. 1, p. 29, Desf. fl. Atl. 1. p. 330*, DC. fl. fr. 3, p. 360, Wendl. obs. bot. p. 18, t. 2, f. 16, Wikstr. Thym. l. c. p. $326^{\star}$, Sibtl. et Sm. fl. græc. t. 360 , Bot. Mag-t. 1949, Nees jun. gen. fl. germ. 3 , t. 47, f. 21, Bertol. fl. ital. 4, p. 344, Reichenb. ic. fl. germ. 11, p: 13, t. 550. P. Metnan Forsk. fl. regypt. arab.-p. 81 . Piptochlamys hirsuta C. A. Mey. 1. c. Ann. sc. nat: 1843, 20; p. 52. Chlamydanthus hirsutus Griseb. spicil. fl. rumel. 2, p. 547. Caules 1-2-pedales, graciles, fastigiatoramosi. Folia 2-3 lin. longa, supra concava, subtus convexa, juniora imbricatoadpressa, demum patula, floribus vix longiora.

a. vulgaris, foliis ovatis vel ovato-oblongis supra modice concavis dorso glabris Q $-3 \frac{1}{2}$ lin. longis, $1 \frac{1}{2}-2 \frac{4}{2}$ lin. latis. (v. v. et s.)

ß. polygalafolia (Endl. 1. c.), foliis ovatis utrinque tomentosis, dorso demum glabratis. - Circa Massiliam (Requien 1).-DC, fl. fr. 3, p. 72, 6, p. 366*. P. polygalæfolia Lapeyr. fl. Pyren. p. 214. P. hirsuta $\beta$ vestita Gren. et Godr. fl. fr. 3, p. 63. Folia sæpe ovato-lanceolata, fere plana. Calyx persistens vél tarde basi rumpens. (v. s.) $\boldsymbol{\gamma}$ rotundifolia, foliis suborbiculari-ovatis obtusissimis $1 \frac{1}{2}-2$ lin. longis latisque
dorso glabris. - Circa Collioure (Phil: Thomas!). (v. s.)

d. angustifolia, foliis anguste ovato-oblongis lanceolatisve acutiusculis supra canalieulato-concavis apice sæue inflexis dorso glabris. - Circa Carthagenam (Gaudich.l), Massiliam (A. Rich.l), Pozzuoli, prope Neapolim (Heldraiceh l), in Sardiniâ (Phil. Thomas!), Siciliâ (Jan !), Algeriâ (Bové!), Cretâ (Sieber!),

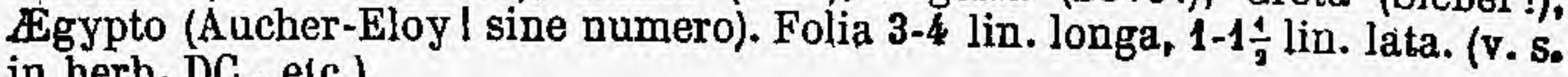
in berb. DG., elc.)

\section{Species obscurce.}

20. T. ORIENTALIS, foliis subcarnosis lanceolatis obtusig glabriusculis, floribus axillaribus. J In Oriente et Hispaniâ. Passerina orientalis Willd. sp. 2, p. 431, cum syn. Sanandunda 1 Clus. hist. 1, p. 88, et Gron. orient. 126, Wikstr. Tkym. p. 330. Firsan mere forma glabrata T. tinctoriæ aut hirsutæ. Ab Endlichero inter sequentis synonyma citatur.

21. T. томект 0 s (Eudh. gen. suppl. 4, 2, p. 66), foliis oblongis obtusis utrinque sericeo-tomentosis, floribus axillaribus sessilibus. $ち$ In Oriente. Daphne tomentesa Lam. dict. 3, p. 436. Fruticulus habitu T. Tartonrairæ, sed elatior, foliis longioribus albido-tomentosis fere sericeis. Verisimiliter identica cum T. Tartonrairâ $\beta$ angustifoliâ, cfr. supra n.16. 
22. T. PUBESGENS, caule pubescenté, foliis lanceolato-linearibụs, flóribus lateralibus aggregatis sessilibus. 5 ? In Austriâ (Jacq.): Daphne pubéscens Linn. Inant. p. 66, Lam. dict. 3, p. 435, Willd. sp, 2, p. 417*. Passeríná pubescens Wikstr. Thym. p. 332. Caules simplices, pubescentes. Folia alterna, remota, nudiuscula, submueronata, anqua. Flores in axillâ' 5 vel pauciores, folio breviores, tubo filiformi angusto pubescente. Willd. l. c. ubi a Daphne Thymelaà diversâ dicitưr, 'Tnde huic affinis videtur: Loci natalis indicatio verisimiliter falsa; quam planta auctoribu's Austriacis plane ignota sit. Patria sécundum Vahl Hispania est (fide Wikstr. 1. c.), igitur forsañ pro Austriâ legèndum est Asturia. Specienn a Wikstr. 1.'c. cum T. thesiojide vel coridifoliâ identicam esse suspicatur.

\section{Sípecies exclusa.}

T. A LPINA Mœnch. = Daphne alpina L.

T. GN EO R u All = Daphpe Gneorum L.

T. G м I I и All. $=$ Daphne Gnidium L.

F. I A UR E A Seop. = Daphne Laureola L.

T. MEzEREu All. = Daphne Mezereuุm. L.

T. PA A c o X Gilib. = Daphne Mezereum L.

XX. DIARTHRON Turcz. in Bull. Soc. imp. Mosc. 1832, 5, p. 204, ibid. 1852, 2, p. 464, t. 11, Endl. gen. p. 330, n. 2096, suppl. 4, 2, p. 63, n. 2099, Meisn. gen. p. 330 (242), Jaub. et Spach ill. pl. Om. $t .105$, Ledeb. fl. ross. 3, p. 544.

Flores hermaphroditi, 4-merí. Calyx glaberrimus, tubo herbaceo supra ovarium : constricto articulato, parte inferiơre persistente, superíore deciduâ, fauce esquamatâ, limbo colorato 4 -fido erecto. Annulus hypogynus exiguus. Stamina fauci inserta, inclusa, vel 4 uniseriata lobis opposita, vel 8 biseriata, seriei inferioris calycis lobis alterna, antheris subsessilibus'oblongis. Ovarium glabrum, ovulo pendulo.' Stylus lateralis vel subterminalis brevis, stigmate parum incrassato obtușo. Nucula calyce inclusa, 1-spèrma. Semen parce ajlbuminósum. - Herbæ Asiæ mediæ, foliis spàrsis linearibus, spícis têrminalibus lateralibusque ebracteatis, floribus parvulis.

4. D. LINIF ol I U (Turcz.! 1. c.), foliis linearibus vel lanceolato-linearibus obtusis, calycis tubo viridi levi, limbo purpureo, staminibus 4. $\odot$ In lapidosis, ad flum. Tschikoi Șibiriæ Transbaicalensis (Turcz.! enum. Chin. n. 28, cat. Baical. n. 995). - Turcz.! in Bull. Soc. Mosc. 1852,2 , p. 465 , t. 11, Ledeb.l fl. ross. 3, p. 544. Tota glaberrima. Caulis circ. palmaris, erentus, tenuis, superne pauciramosus. Folia sparsa, subsessilia, 4-8 hin. longa, $\frac{1}{5}-1$ lin. lata. Spicæ primo capituliformes densifloræ, demum $\frac{1}{2}-1$ poll. longæ inferne laxæ. Calyx subsessilis, circ. 2 lin. longus, limbo purpureo vix $\frac{1}{3}$ lin. longo, diu persistente, lobîs acutis, tubo subventricoso-inflato enervi. Ovarium sessile, stylo prope apicem obtusum laterali. (v. s. in herb. DG. et Ledeb.)

2. D. vesiculosum (C. A. Mèy, in Bull. Ac. Petersb. 4, n. 4), foliisa lanceolato-linearibus obtusiusculis, calycis tubo albido nervoso-striato punctulato, staminibus 8 . OIn Persiâ, prope Teheran (Oliv. et Bruguière), Gappadociâ (Aucher-Eloy, n. 2534), in distr. Khoi, prov. Aderbeidschan (Szovits I), circa Talysch (K. Schmidt, fide C. Koch in Linnæa 22, p. 609). Turcomania boreali (Karelin l), in deserto Soongoro-Kirghisico, circa Tarbagatai, ad đum. Lepsa et Ajagus (Kàrel. et Kiril: n. 435l). D. carinatum Jaub. et Spach ill. pl. Or. t. 105. Passerina vesiculosa Fisch.

$\therefore$ et Mey. in Bull, Soc. imp. Mosc. 1839, p. 170, Karel. et Kiril. enum. pl. Alt. n. 801, enum. pl. Soongor. n. 741, Ledeb.I fl. ross. 3, p. 445 . Herba erecta, spithăhæapedalis, ramosa. Folia 6-9 lin. longa, interdum parce pilosula. Spicæ usque ad

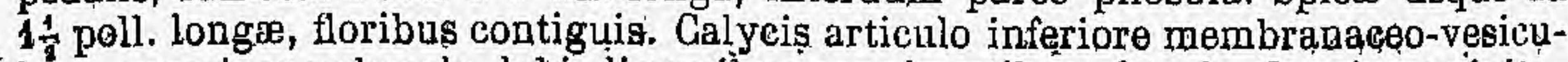
loso, superiore puberulo, lobis linearibus conniventibụg obtusis. Ovarium stipitatum. Cet. ut in D. linifolio. (v, s. in herb. DC., Ledeb., Boiss.) 
XXI. ARTHROSOLEN C. A. Meyer in Bulletin Acad. St-Petersb. 4, n. 4, Ann. sc. nat. 2. ser. 20, 1843, p. 48 et 52, Endl.gen. suppl. 4, 2, p. 63, n. 2100. - Passeriure sp. aucict.

Flores hermaphroditi, 4 vel rarius 5-meri. Calyx coloratus, infundibuliformis, limbo regulari 4-5-partito patente, fauce esquamatâ, tuhô infra medîm articulato, parte sủperiore deciduâ, inferiore persistente. Squamulæ hypogynæ nullæ. Stámina 8 vel 10, fauci biseriatim inserta, antheris subsessilibius oblongis linearibusve, superioribus semiexsertis, inferioribus inclusis. Stylus lateralis, filiformis, ovario longior, faucem vel antheras inferiores attingens, inclusus, stigmate capitato papilloso. Nucula calycis basi inclusa, ovoidea. - Frutices vel suffrutices Africæ australis et orientalis, foliis sparsis yel rarius oppositis sessilibus, floribus axillaribus subsolitariis vel terminalibus capitatis involucratis.

\section{§1. Spicati. Flores axillares, spicam foliosam vel demum nudam formantes, 4-meri, 8-andri, bracteati.}

1:A. A picat US (G, A. Mey. 1. c.), foliis sparsis passimque oppositis ovali- vel obovato-oblongis acutiuseulis basi attenuatis planis cveniis ciliatis supra glabris subulus adpresse pilosis, floralibus conformibus florem subæquantibus, floribus sparsis, calyce adpresse pubescente, lobis ovatis oblongisve tubum subæquantibus. $F$ In arenosis planitiei Capensis, circa Wynberg, Duylsersvalei, in collibus, círca îlyn Drakensteen, inter cap Agulhas et Potberg,-alt. 400-500 ped., Zwellendam, etc. (Thunb., Drège! Ecklon et Zeyh.! Krauss, $n_{4} 754$ ! etc.). Passeriná spicata Linn. fil. suppl. p. 226, Thunb. fl. cap. p. 75, Wendl. obs. p. 19, t. 2, f., 19, Willd. sj. 2, 1. 433, enum. p. 426, Wikstr. Thym. l. c. p. 346, Bot. cab. t. 311, Meisn. in Linnæâ 14, p. 398. P. lateriflora hortul. ex Wikstr. Struthiola littoralis Wendl. ex Enrll. 1, c. S..imbricata hortul. Genista spicata Eckl, et Zeyh.! næss. in herb. Drège. Erutex pluripedalis, corymboso-ramosissimụs, ramis virgatis, cicatrisato-verruculosis, junioribus gracilibus deise foliosis pubescentibus. Folia sessilia, $2 \frac{1}{2}-5$ lin. longa, $1 \frac{1}{2}-2 \frac{1}{2}$ lin. lata, herbacea, tarde glabrescentia, juniora imbricata canescentia. Flores in superioribus axillis solitarii, sessiles, bracteolis 2 angustis acutis lateralibus duplo longiores. Calyx 4-5 lin. longus, tubo angusto basi intus puberulo, lobis $1-1 \frac{1}{2}$ lin. longis acutis vel obtusiusculis glabrescentibus. Stylus antheras inferiores attingens. Nucula ovato-oblonga, levis, apice parce adpresse pubescens. Variat foliis junioribus subsericeis (Krauss, n. 754 !) et canescentibus, qu:e Gnidia spicata $\beta$ canescens Eckl. et Zeyh. herb. n. 94 ! (v. s. et v. v. c.)

2. A. orNaTus, foliis oppositis passimque sparsis oblongo-lanceolatis acutis basi vix atteruatâ obtusis planis margine dorsoque laxe pilosis mox glabratis summis majoribus imbricatis, floribus in summis axillis dense congestis subcapitatis folia superantibus, calyce piloso, lobis ovatis acuminatis glabrescentibus tubo dimidio brevioribus. 7 In arenosis Africe Capensis (Eclil. ct. Zeyh. t), ad Klynrivier, alt. 1 (Zeyher, iz. 3755!). Gnidia vesiculosa Eckl. et Zeyh.! herb.'n. 1. Species pulchra, A. spicato proxima, sed jam foliis floribusque fere dujlo majoribus, pubescentiâ laxâ, etc., facile dignoscenda. Ramuli corymbosi, breviores, robustiores, pubescentes, mox glabri ${ }_{r}$ cicatricibus minus prominulis acutiusculis. Folia coriacea, 5-7 lin. longa, 1 $\frac{1}{8}-2$ lin. lata, apicem. yersus attenuata, minute rugulosa, mox glabra, superiora sensim paulo longiora. Flores in spicam terminalem brevem, capituliformem foliis intermixtam dense congesti, in singulis axillis solitariis bibracteolatis. Calyx albus? vel rubellus? hypocraterimorphus, 9-10 lin. lơngus, tubo folia rquante intus glaberrimo superne ampliore, lobis 2-2: lin. longis, fauce (fide Eckl. in sched.) "vesiculis, squantularum forsan loco, " munitâ, in 'sicco obsolete transverse-rugulosâ. Antheræ superiores semiexsertæ. Stylus dimidium calycis tubum æquans. Ovarium apice sericeo-comosum. Fruct..... (v. s.)

ß. Gueinzii, ramulis foliisque tarde glubrescentibus, calyce minore. - Loco non indicato legit Gueinzius! Inter A. spicatum et ornatum subambigua; huic tamen foliorum formâ, pubescen lịâ laxâ et inflorescentiâ similior, discrepans solummodo ramulis pubescentibùs, floribus $\frac{1}{\mathfrak{s}}$ minoribus (albis) el stylo paulo breviore. (v. s.) 
3. A. gym о cibus tenuibus adpresse pilosis, ' foliis sparsis vel passim oppositis lanceolatolinearibus acutis subtus in nervo margineque ciliatis cæeterum glabris, spicis terminalibus demum laxiusculis aplıyllis, calyce anguste cylindraceo piloso lobis parvulis obtusis erectis. 5 In Africâ Capensi, circa Mooyplants, alt. 5,000-6,000 ped. (Drège l). Passerina gymnostachya Meisì. in Linnæà 14, p. $397^{\circ}$. Suffrutex subspithamæus, caulibus herbaceis erectis, sepe indivisis, pube flavidâ canescentibus, internodiis 2-6 lin. longis. Folia semipatula, sessilia, plana, supra glabra, 5-6 lin. longa, $1 \frac{1}{2}$ lin. lata, infima (quandogue opposita) summaque dimidio minorà. Spicæ subsessiles 1 $1 \frac{1}{2}-2$-pollicares, erectæ, simplices, inferne demum interruptæ; junioresfoliasæ, floribus in rhacheos pilosæe denticulis solitarii, sessiles, alterni, ebracteati, circ. 4 lin. longi, basi persistente ovatâ demum glabrescente. Nuçula ovàta; lævis, apicc parce adpresse-puberula. (v. s.)

\section{§2. Capitati, - Flores terminales, capitati, involucro folioso vel scarioso cincti. \\ -Flores 4-meri, 8-andri.}

4. A. InconspicuUs, humilis, ramosus, fuliis oppositis vel subverticillatis ovatooblongis lanceolatisve acutis adpresse subsericeo-pubescentibus, involucralibus conformibus capitulum pauciflorum subæquantibus, calyce angusto sericeo, lobis tubo dimidio brevioribus erectis. JIn Africâ Capensi (Drège, n. 7372 !). Passerina? inconspicua Meisn. in Linnæâ 14, p. $397^{*}$. Fruticulus circ. palmaris, corymbosoramosissimus, ramulis puberulis. Folia herbacea, patula, $2-4$ lin. longa, $1-1 \frac{1}{2}$. lin. lata, novella sericea, involucralia 4 reliquis omnino similia et æequalia vel pauło majora. Species admodum similis Griidiæ inconspicuœ, sed calycis fauce plane esquamatâ, pubescentiâ tenuiore, etc., certe distincta. (v. s.)

5. A. LAXU S (C. A. Mey. l. c.), diffuse ramosissimus, ramulis filiformibus elongatis laxis cano-pubescentibus, foliis sparsis linearibus obtusis muticis supra concavis subtus convexis glabriuseulis, involucralibus conformibus capitulum 4-8-florum subsequantibus, calyce gracili adpresse piloso, lobis tulo 3-4-plo brevioribus erectis. . Circa promont. Bonæ-Spei (Thunb.! etc.), in monte-Tabulari (Eckl. n. 366! Drège!), versus Campsbaay (Eckl. et Zeyh. n. 93!), Groenpoint (Zeyh. n. 3769!), etc. - Presl bot Bemerk. p. 107. Passerina laxa Linn. fil. suppl. p. 226, Thumb. fl. cap. p. 376, Wendl. obs. bot. p. 20, t..2, f. 20, Willd. sp. 2, p. 433, Bot. cab. t. 755, Wikstr. Thym. p. 346, Meisn. in Linnæà 14, p. 396. P. tenuiflora Willd. enum. 1, p. 426, Wikstr. l. c. p. 342, Bartl. in Linnæâ 14, p. 403 *. Fruticulus pluripedalis, ramulis junioribus debilibus canis. Folia herbacea, patentia, 3-5 lin. longa, $\frac{1}{3}-\frac{1}{3}$ lin. lata, dorso sépe subcarinata, novella subimbricata pilosiuscula, mox glabra vel penicillo pilorum terminata, involucralia exacfe similia vel paulo latiora. Calyx 3-4 lin. longus, lobis ovatis obtusis. Nucula nigra, transverse ruguloso-granulata, apice pilosiuscula. (v. s.)

6. A. PIMELE OIDES, glaber, caule ramisque gracilibus erectis, feliis sparsis subulato-linearibus acutis, capitulis 8-16-floris, involucro 4-8- $\mu$ hyllo, foliolis biseriatim imbricatis scariosis ovatis subulato-acuminatis flores subæquantibus, calyce anguste cylindrico pubescente, lobis tubo multo brevioribus erectis. 5 ? In monte Magalisberg Caffrariæ (Burkel 1843). Frutex? vel suffrutex? caulibus ramisve 1-2-pedalibus teretibus inferne lignosis subsimplicibus superne corymboso-ramosis, ramulis filiformibus herbaceis. Folia erecta, 3-6 lin. longa, $\frac{1}{4}-\frac{1}{2}$ lin. lata attenuato-acuta, basi haud angustata, enervia, glaberrima, plana vel plerumque supra concava dorso convexa. Capitula magnit. cerasi minoris' vel dimidio minora, juniora ovoidea, demum hemisphærica. Involucri glabri foliola exteriora foliis similia vel latiora 1-nervia margine-scariosa, interiora tota scarioso-membranacea colorata? (in sicco fulvo-flava), 2 lin. lata, subenervia plana glabra vel margine ciliatá. Receptaculumm ạbo-villosum. Calyx 3 lin. longus, parce cano-pilosínsculus, basi persistente glabrată, lobis ovatis obtısiusculis $\frac{"}{3}$ lin. longis. Antheræ superiores semiexsertæ. Stylus lateralis, ovario glabro vix longior, dimidium calycis tubum subæquans. (v. s. in herb. DG.)

\footnotetext{
*Flores 5-meri, 10-andri.
}

7. A. POLXCEPHALUS (C. A. Mey. l. c.), ramosissimus, glaber, ramis gracilibus 
erectis, foliis sparsis lanceolato-lincaribus acutis, capitulis ovoideis 4-6-loris, involucro 3 -seriali imbricato, foliolis membranaceis ovali-oblongis puberulis, calyce involucrum longe siperante gracili, lobis tubo tenui multo brevioribus patentibus. $\hbar$ In Africâ Capensi (Lichtenstein! Burchell, n. 2222-1522!), circa Nieuwkerkshoogte, Nieuweveld, Winterweld, etc., alt. 3,000-5,000 ped. (Drège l), ad fl. Vischrivier, inter Tarka et Cradock (Eckl. et Zeyh.!), ad 11. Stirkdroom (Zeyh. n. 14931). Passerina palycephala E. Mey. in pl. Drège, Meisn. in Linnøâ 44 , p. 390*. Dais virgata Lichtenst. I (fide specim: autogì. in lierb. Ledebour). Fruticulus circ. sesquipedalis, ramis strictis, internodiis $3-6$ lin. longis. Folia rara, 3-6 lin. longa, 1-1 $\frac{1}{2}$ lin. lata, basi attenuata, plana. Capitula magnit. cerasi, breviter pedunculata. Involucrum cylindraceum vel ovato-conicum, eoloratum, foliolis subscariosis, minute subsericeo-puberulis; obtusis vel passim breve acuminatis vel acutiussculis, intimis obovato- vel ovato-ablongis concavis 3-5 lin. longis, exterioribus sensim brevioribus, extimis parvulis subrotundis. Receptaculum sericeo-pilosum. Calyx 6-10 lin. longus, flavus? limbo patente basi longe villoso, lobis ovali-oblongis obtusis $1 \frac{1}{2}$ lin. longis demum șe glabrescentibus. Antheræ superiores semiexsertæ. Stylus faucem attingens. (v. s.)

8 A. Galocephalus (G. A. Mey. 1. e.), villoso-pubescans, ramis subsimplicibus virgatis, foliis sparsis oblongo-lanceolatis obtusiusculis, involucralibus conformibus imbricatis sericeis flores subæquantibus, eapitulis subglobosis. multifloris, calyce gracili villoso, lobis tube multe brevioribus erectis. 5 Circa Omsamwubo, Omcomas et Port-Natal, alt. 200-1,500 ped. (Drège, n. 4664 ! docum. p. $158, \cdot \mathrm{V}$, c, 25). Passerina calocephala Meisn. in Linnæa 14, p..393*. Rami cubitales, graciles. Folia herbacea, 5-12 lin. longa, 3-5 lin. lata, utrinque attenuata, plana, adpresse pilosa, juniora sericea. Capitula solitaria, subsessilia, magnit. juglandis, dense multiflora, involucri foliolis herbaceis foliis caulinis conformibus, receptaculo turbinato-hemispharico albo-villoso. Calyx 6-8 linr.- longus, albido-villosus, sericeus, basi persistente glabrescente, lobis circ: 1 lin. longis. Nuçula oblonga, sub epidermide nitidâ pellucidâ minute ruguloso-granulata. (v. s.)

9. A. SERIcocephalus, caule erecto pauciramoso pilosiusculo, foliis sparsis linearibus acute acuminatis' 1 -nerviis glabris, capitulis globosis multifloris, involucro deciduo vel nullo?, calyce receptaculi pilos vix superante tenui sericeo, lobis tubo multo brevioribus. 5 (ex Juss. $\mathscr{4}$ ) In mont. Macalisberg Gaffrarixe (Zeylier, n. 1494 !). Caules subpedales, basi lignescentes, inferne demum glabrescentes. Folia 6-12 lin. longa, 1-1 $\frac{1}{2}$ lin. lata, supra canaliculata, subtus ner vo conspicuo percursa, tamen haud carinata. Capitulum pedunculo aphyllo 2-3-pollicari suffultum, magnit. juglandis, absque involucri vestigio. Calyx 4 lin. longus, basi persistente receptaculoque longe villosis, limbi lobis obtusis vix $\frac{1}{2}$ lin. longis. Nucula ovata granulato-punctata. Species hinc ad præcedentem, inde ad A. pimeleoidem accedens, sed ab utrâque notis ì̀dicatis bene distincta. (v. s. in herb. Drège.)

\section{Species exclusce.}

A. ANThyllordes G. A. Mey. = Làiosiphon anthylloides Meisn.

A. subspicatus Endl. = Wikstrnomia subspicata Meisn.

XXII. PASSERINA Linn. gen. ed.1, p..341, n. 856, hart. Cliff. p. 146, t. 11, C. A. Meyer in Bull. Acad. St.-Petersb. 4, n. 4, Endl. gen. suppl. 4,'2, p. 62, n. 2097. - Passerinæ sp. auct.

Flores hermaphroditi, 4-meri. Calyx corollinus, hypocraterimorphus, tubo mediocri tenui supra ovarium angustato et demum rumpente, parte inferiore fructum arcte includente persistente vel demum hinc fissâ déciduâ, limbo 4-partito patente deciduo, lobis æqualibus, fauce esquamatá. Squamulæ hypogynæ nullæ. Stamina 8 , simplici serie fauci inserta, filamentis subulatis exsertis' basi dilatatâ subcohærentibus, antheris ovalibus. Stylus prope apicem o varii glabri laterạlis, faucem æquans, stigmate semiexserto capitato papilloso. Nucula calycis tubo persistente inclusa, rarius demum denudata, ovata, pericarpio crustaceo. Enbryo albumine inclusus, cotyledonibus carnosis plano-convexis. - Frutices Capenses ericoidei, ramulis tomentosis vel ultimis 
lanatis, foliis decussalim opposilis parvis aceroso-linearibus dorso convexis, floribus parvis rubris frequentibus in summis axillis solitariis subsessilibus in spicas terminales sæpe comosas vel abbreviato-capituliformes dispositis, singulis bracteâ plus minus dilâtatâ fultis.

1. P. FiLif ormis (Linn. h: Cliff. p. 146, t. 11), ramulis puberulis, folits acerosolinearibus triquetris acutiusculis basi haud latioribus, spicis multifloris terminalibus vel demum comosis, bracteis ovatis oblongisve acutis vel rostrato-acuminatis vel lanceolatis acate carinatis nervoso-sulcatis, calycis lobis ovalibus oblơngisve obtusis. 5 . $\mathrm{h}$ promontorio Bonæ-Spei vulgaris. -Thunb. jrodr: p. 75, fl, chp. p. $374^{*}$, Wendl. obs. p. $18^{\prime}$, t. 2 , f: 15 , Willd. sp. 2, p. 429 , Poir. dict. 5 , p. $40^{*}$, 'Wikstr. l, c. p. 324, Meisn.' in Linnæâ 14, p. 399. P. pectinata hork. ! et todd. cat. 1816, p. 18 ? Frutex ericoideus, elatior, ramis gracilibus, ramulis filiformibus. Folia $1 \frac{1}{2}-6$ lin. longa, $\frac{1}{4}-\frac{1}{3}$ lin. crassa. Flores folia subæquantes, rosei, tubo capopuberulo.

a. vulgaris (Meisn. 1. c. p. 399), foliis ramo adpressis rectis vel vix incurvis glabris (Sieber, n. 74 ! Burchell, n. 66! 473! Ecklon, n. 508! Kŕebs, n. 282 ! Drège! Gueinzius! Zeyh. n, 3782 !). P. corymbosa Eckl.1 mss. in herb (Eckl. et' Zey.1. n. 40 !). (v. S:)

B. falcifolia (Meisn. 1. c.), foliis acutiusculis dorso acute carinatis arcuato-incurvis glabris.- Circa Ruigtèvalei et Vanstaadesberg (Drège! n. $7373 \mathrm{~b}, 7374 \mathrm{a}$, Zeyh. n. 3778!). Folia $2-5$ lin. longa, plerumque basi apiceque tantum ramo contigua. (v. s.)

y. comosa (Meisn. 1. c.), foliis 4-stichis arcte adpressis rectiusculis obtuisiusculis dorso convexis vel obtusissime carinatis, superioribus pilosulis comá brevi densâ albidâ terminatis, spicis semper comosis, bracteís ovato- vel obloṇgorhombeis obtusiusculis nervis carinâque mininus prominulis vel obşoletís. Circa Krakeelkraal; alt. 3,500 ped. (Drège !). Forma insignis, folíis rậịulos eleganter tetraquetros reddentibus, bracteis haud acuminatis. (v. s.)

d. squarrosa, foliis abbreviatis rigidis rectis obtusis, bracteis foliaceis ovatis breve acuminatis demum patulis spicam terminalem squarrosam reddentibus foŕtiter nervoso-sullcatis carinatis. - In collibus, inter fl. Conga et Zondagsrivier, distr. 'Uitenhage, alt. 2, Langekloof, distr. George, alt. 3, et prope Cradockstad et Port-Elisabeth (Ecklon, n. 598! Zeyh. n. 3779!). Forma ormhibus fore notis, exceptis bracteis (qưe omnino P. fliformis) cum P. rìgidâ conveniens. Calyx extus fere glaber, tubo vix apice puberulo. (v. s, in hèrb. Sonder.)

2. P. PALEACEA (Wikstr. Thym. in Act. Holm. 1818, p. 323), ramulis apice lanâ densâ incraseatis, foliis linearibus obtusis dorso convexis glabris, floribus racemoso-spicatis glabris, calycis lobis oblongis obtusis, bracteis paleaceis ovatis obtusis. J Ad caput Bonæ-Spei (Sparrman, in herb. Swartz et Thunb., Drège! Ludwig!). - Meisn. in Linnæà 14, p. 400. P. salsolæfolia herb. Lam. (ex parte), Poir. dict. 5 , p. 41 . Lachnea paleacea herb. Banks., ex Wikstr. Habitus P. filiformis et forsan potius ejusdem varietas. Ramuli laxi, glabri, apice lana-brevi albd dense tecti et quasi incrassati. Folia 1-1 $\frac{1}{1}$ lin. longa, obtuse triquetra, adpressa, subimbricata, ovato-linearia, acutiuscula. Spica breves, demum comosee. Bracteæ paleaceæ, coloratee, imbricatee, late ovatæe, $1 \frac{1}{2}$ lin. longæe latxque, obtused, haud acuminatæ, convexæ vel obsolete obtuseque carinatæ, enerviæ, læves, targine scariosæe, calycis tubum æquantes: (v. s.)

3. P. ERICOIDES (Linn. mant: 1, p. 236), ramulis puberulis, foliis adptessis brevissimis linearibus vel ovato-oblongis obtusis truncatisve dorso convexis apice. compresso-carinatis, spicis terminalibus brevibus, bracteis late ovato-rhombeis obtusis vel acuminulatis norvoso-sulcatis, calycis lobis subrofundo-ovalibus obtusis. J In Africa Capensi (Sparrman! in, horb. Schreb.), circa Port-Elisabeth, Witbergen, Onderbokkeveld, ețc. (Drège! Zeyber ! n. 318! Gueinzius! etc.), vitenhago (Eeckl. et Zeyll. n. 82!). - Poir. dict. 5, p. 41 ? Wikstr. ]. c. p. 325, Mrets̀n. in Linnsed 14, p. 401. P. glomerata Thunb. prodr. p. 75, fl. cap. p. 374 ? Lachnæa conglomerata Ling. sp. ed. 1 , p. 560, Willd. sp. 2, p. 434 ? cfr. Meisn. 1. e. p. 419. Omnia fere P. paleacers, sed bracteis majores, semper plus minus nervosa-8ui- 
catæ, crassinsculæ. Spicæ capilulum ovoideum parvum referentes, raro demum comá foliorum superatæ. Ramuli nonnunquam apice lanato-tomentosi. (v, s.),

4. P. RIGIDA (Wikstr. l. c. p. $326 \%$, ramulis rigidis, foliis 4 -fariam inbricatis minutis ovatis obtusis glabris, floribus in summis axillis solitariis, tubo pubescente, lobis oblongis obtusis. $)$ In Africâ Capensi (Sparrmann in herb. Thunb.), ad fl. Kœgarivier (Zeyh. n. 3777 l Eckl. et Zeyh. n. 117, 11! forma inter $\alpha, \beta$ et $\gamma$ ambigua). - Meisn. in Linnæâ 14, p. $402 *$. Habitus præcedentium. Ramuili puberuli vel lanato-tomentosi. Folia linearia, obtusa, $1-2$ lin. longa, $\frac{1}{2}$ lín. lata, basí æqualia vel paulo latiora, dorso rotundato-convexa vel apice præsertim triquetra. Spice paucifloræ. Bracteæ late ovato-rhombeæ, obtusæ vel acutiusculæ, dorșo . fortiter acuteque carinatæ nervisque (interdum obsoletis) rugoso-sulcatie. (v. s.)

a. comosa (Meisn. l. c.), foliis ramulo adpressis nitidis obtusiusculis dorso convexis apice vix carinatis, spicis comosis, bracteis folia íquantibus oyatooblongis subenerviis', calycis lobis angıste oblongís. - Ad Zwartkopsrivier et Krakakamma (Ecklon!: Zeyh. n. 3780! 37811). P. ericoides et pendula Eekl. et Zeyh. herb. $\mathrm{n} .41$ ! 44 !

3. tetragont (Meisn. 1. c), follis semipatulis invicem 4-fariam arete adpressis ramos 4-gonos reddentibus obtusis, spicis terminalibus haud comosis, bracteís subrolundis vel ovatis obtusis carinatis distincte nervosis, calycis lobis oblongis. - Círca Ezelsbank et Stormberg, alt. 4,000-6,000 ped. (Drège l).

$\gamma$, truncata (Meisn. 1. c.), foliis ramulo adpressis vel semipatulis truncatis compresso-subcarinatis, spicis bracteisque ut in $\beta$, calycis lobis ovalibus hrevioribus.-Girca Wupperthal, Róodeberg et Liliefontein, alt. 4,500 ped. (Drêge! Eckl, et Zeyh, n.

\section{Speciés.non descripto.}

P. INGURVA Wendl.

P. CURRESSINA Wendl.

\section{Species exclusce.}

P. AMMODENDRON Kar. et Kiril. = Stellera stachyoides Schrenk.

P. ANNUA Wikstr. = Thymelæa arvensis Lam.

P. Annua Aucher-Eloy $\Rightarrow$ Thymelæa Aucheri Meisn.

P. ANT HYLLOIDES Linn. fil, = Lasiosiphon anthylloides Meisn.

P. ANTHYLLOIDES $\propto$ Thunb. $=$ Gnidia virescens Wikstr.

P. Axillaris Thunb. = Pimelea virgata Vahl.

P. BRUNIADES et BRUNIÓIDES Eckl. et Zeyh. = Lachnæa penicillata et axillaris

Meisn.

P. Gal o Gephala Meisn. $\doteq$ Arthrosolen calocephalus G. A. Mey.

P. oalycina DC. = Thymelæa calycina Meisn.

P. самpanulata E. Mey. = Cryptadenia hreviflora Meisn.

P. C'ANESCENS Schousb. = Thymelæa canescens Endl.

P. с A PIтA A A L. = Lachnæa capitata Méisn.

P. CEPHAL OPH ОRA Thunb. = Lachniea eriocephala. L.?

P. СН А $А$ DA PHNE Bungo = Wikstrœmia Chamædaphne Meisn.

P. Cram \& Jas me Fisch. = Stellera Chamæjasme l.

P. Снам жла мие Schangin = Stellera Aftaica Thieb.

P. G Il iata L. = Gnidia? ciliata Méisn.

P. Gilia t A Thunb. = Grypttadenia ciliata Meisn?

P. Coridirolia Wikstr. = Thymelæea coridifolia Endl.

P. Dichотом A Steud. = Stellera dichotoma Fisch.

P. Dror ca Ram. = Thymeliea dioica All.

P. DODECANDRA L. = Struthiola erecta $L$.

P. ELLIPTIGA Boiss, = Thymelea thesioides $\beta$ Meisn. 
P. EMPETRIFOLIA Lapeyr. = Thymelæa dioica All.

P. ERI OCEPHA A Thunb. = Lachnæa globulifera Mcisn.

P. FILIFormis' Mill. (non L.). = Struthiola erécta $L$.

P. G A N P I Sieb. et Zucc. = Stellera ? Ganpi Meisn.

P. Gmo B.osA Lan. = Lachnæa alpina Meisn.

P. GNidia Forst. $=$ Pimelea Guidia Banks et Sol.

P. GRANDIPL ORA L. = Cryptadenia grandiflora Meisn.

P. G Yanosta Chy A Meisn. = Arthrosolen gymnostachys C. A. Mey.

P. HIRSU TA Asso = Thymelæa tinctoria Endl.

P. нг Rs U т L Ling. = Thymelæa hirsuta Endl.

P. J A P O N I A A Sieb. et Zucc. = Stellera ? Japonica Meisn.

P. In G ON S I G U A Meisn. = Arthrosolen inconsṕicuus Meisn.

P. IN V o L U C R A T A Spreng. = Lasiosiphon linifolius Dene. $\beta$ Meísn.

P. INvOLU GRAT A Thunb. = Pimelea linifolia Sm.

P. JUN I PER I F O I A Lapeyr. = Thymelæa calycina? vel nivalis? Meisn.

P. LA VIGATA L. = Gnidia oppositifolia $L$.

P. L A T ER I PL O R A Wendl. = Arthrosolen spicatus C. A. Mey.

P. LAXA L. = Arthrosolen laxus C. A. Mey.

P. LESS ER T I Wikstr. = Stellera Lessertii C. A. Mey,

P. LINARIAEOLIA Pourr. = Thymelæa thesioides Endl.

P. L INEARIF OLIA Wikstr. = Gnidia linoides $\beta$ major ? Meisn.

P. L I N o I DES Thunb. = Guidia linoides Wikstr.

P. LONGIF OL IA Thunb. = Pimelea longifolia Banks et Sol.

P. MetNA N Forsk. = Thymelæa hirsuta Endl.

P. M I C O PHYLLA Coss. et Dur. = Thymelæa michophylla Meisu.

P. NERvOSA Thunb. = Lachnæa nervosa Meisn.

P. NERvosa Wikstr. = Lachnæa striata Meisn.

P. NITIDA Desf. = Thymelæa nitida Endl.

P. NIVAlis Ram. = Thymelæa nivalis Meisn.

P. ORIENTALIS Willd:= Thymelæa orientalis Meisn.

P. PENTANDRA Thunb: = Lonchostoma obtusiflorum Wikstr.

P. Persica Boiss. = Stellera Lessertii C. A. Mey.

P. PILOSA Forst. $=$ Pimelea virgata $\beta$ Meisn.

P. Planifolia Burm. conf. ad Lachnæam alpinam Meisn.

P. Polycephala E. Mey. = Arthrosolen polycephalus C. A. Mey.

P. P OL YGA L AE OL I A Lapeyr. = Thymeliea hirsuta Endl. $\beta$.Meisn.

P. PRostrata Forst. $=$ Yimelea prostrata Banks et Sol.

P. PUBEsctons Guss. = Thymelsea arvensis Lam. $\beta$ Ten.

P. PUBESGENS Wikstr. = Thymelæa pubescens Meisn.

P. PURPUREA Wilistr. = Lachnra eriocephala L. $\beta$ Meisn.

P. RACEMOSA Wikstr. = Stellera Altaica Thieb.

P. SALSOL AEOLIA herb. Berolin. = Bruniacea? vel Phylucæ sp.?

P. SERIGEA L. = Gnidia sericea L.

P. SETosa Thunb. = Gnidia setosa Wikstr.

P. spicata Linn. fil. $=$ Arthrosolen spicatus C. A. Ney.

P. STACH Y O IDES Schrenk. = Stellera stachyoides Sclirenk.

P. Stellera Ram. = Thymelæa arvensis Lam.

P. STELLER I Wikstr. = Stellera Chamæjasme L.

P. StRIAT A Lam. = Lachnæa striata Meisn.

P. sтвіста Thunb. = Gnidia stricta Wikstr. et? G. Wikstrœmiana Meisn.

P. subsplcata Meisu. = Wikstrœmia subspicata Meisn. 
P. Tartonata Schrad. = Thymelæa Tartontaira All.

P. TENUIFloka Willd. = Arthrosolen laxus C. A. Mey.

P. THESIOIDES Wikstr. = Thymelæa thesioides Endl.

P. Тн омаsı Duby = Thymelæa Tartonraira $\gamma$ Meisn.

P. THUNBERGII Wikstr. = Gnidia sericea L.?

P. Tнумец A A DC. = Thymelæa Sanámunda All.

P. TINGT,ORLA Pourr. = Thymelæa tinctoria Endl.

P. rING ToRIA $\beta$ Boiss. = Thymelæa calycina Meisn.

P. Tingitana Salzm. = Thymelæa villosa Endl.

P. томеNтоSA Wikstr. = Thymérea tomentosa Endl.

P. UNIFLORA L. = Gryptadenia uniflora Meisn.

P. VELU TINA Boiss. $=$ Thymelæa thesioides $\beta$ Meisn.

P. VELUtina Pourr. = Thymelæa velutina Meisn.

P. Ves I G U L o A Fisch. et Mey. = Diarthron vesiculosum C. A. Mey.

P. vil L os A Thunb. = Pimelea arenaria Cunn.

P. viLL OSA Wikstr. = Thymelæa villosa Endl.

P. virescens Coss. et Dur. = Thymelæa virescens Meisn.

P. virGata Desf. = Thymelæa virgata Endl.

\section{EHYMOCOCGA.}

Bacca carnosa, nuda, semine nucamentaceo, testâ crustaceå lævi. Cæetera omnia et habitus Passerinæ. Bracteæ foliis subconformes.

C. EM PETR OI DES (Meisn. mss. in herb. DC.). 5 In collibus arenosis, ad sinum Tafel bai et in Strandvalei (Eckl.1 Zeyh.l). Passerina filiformis var. crassifolia Eckl. et Zeyh. herb. n. 39! Fruticulus laxe ramosissimus, simillimus Passerinæ filiformi et rigidæ, ramulis cano-tomentosis. Folia opposita, laxiuscula, triquetro-linearia, obtusa, 1-1 $\frac{1}{2}$ lin. longa, internodio subæqualia, crassiuscula, lævia vel rugulosa, basi paulo latiora, floralia basi fere 1 lin. Iata acuminata. Flores axillares, solitarii, sessiles, spicam comosam sparsifloram formantes. Galyx Passerinæericoidis, sed minor, deciduus, tubo crassiusculo oblongo puberulo, lobos subrotundos virides nervosos glabros æquante, fauce puberulâ. Stamina lobis haưd longiora. Stylus brevis. Bacca globosa, rubra?, magnit. pisi minoris. Semen ovatum, subcompressum, nigrum, nitidum. (v. s.)

\section{Tribus II. GNIDIEAE.}

Squamulæ perigynæ variæ; calycis fauci vel rarius tubo insertæ, ejusque lobis staminibusque plerumque alternæ, petaloideæ vel glandulares vel corniculiformes vel rarius filiformes.

\section{Subtribus I. ISOSTEMONER.}

\section{Stamina calycis lobis numero æqualia, scilicet $u$.}

XXIV. KELLERIA Endl. gen. suppl. 4, 2, p. 61, n. 2095. - Drapetis sp. Hook.

Flores hermaphroditi, 4-meri. Calyx coloratus, infundibuliformis, totus deciduus, tubo continuo, limbo 4 =fido æquali patulo. Squamulæ 4 , breves, obtusæ, integræ, fauci insertæ, staminibus alternæ, ad basin loborum calycis sessiles. Stamina 4 , fauci inserta, lobis alterna, filamentis exsertis brevibus subulatis, antheris ovatis obtusis. Squamulæ hypogynæ nullæ. Ovarium 1-loculare, apice pubescens, ovulo pendulo. Stylus terminalis, filiformis, deciduus, stigmate capitato exserto. Nucula nuda, ovata. Embryo in axi albuminis carnosi copiosi orthotropus. - Fruticulus Novæ-Zeelandiæ, habitu Drapetis. florum fasciculis sessilibus, involucro proprio nullo. 
K. Dieffen B ACHi (Endl. 1. c.), foliis dense jmbricatis linearibus obtusis apiç barbatis, fhoribus terminalibus fasciculatis. $\delta$ In montibus insulte mediae et septentrionalis Novæ-Zeelandiæe (Dieffenb., Bidwill, Colenso, Hook. fil.). Drapetes Dieffenbachii Hook.! in Lond. journ. 2, j. 497, t. 17, Hook. fil. fl. Nov.-Zeả. 2; p. 222 . Fruticulus ericoideus, caule repente ramosissimo, gracili, 6-12-pollicari. Folia adpressa, vix 2 lin. longa, dorso convexa subcarinata, stumma flores æquan* tia. Calyx brevissime pedicellatus, puberulus. (v. s. com.m. a cl. Hook.)

B. Lyallii, foliis dense imbricatis lineari-ligulatis obtusis apice margineque ciliatis, floribus terminalibus solitariis. $\zeta$ In Novæ-Zeelandiæ insulâa australi et parte australi insulæ mediæ (Lyall!). Drapeles muscosa Hook. fil. I fl. Nor.Zealand. p. 223* (non Fl. anlaret.). Caulis repens elohgàtus robustus, ramis erectis glaberrimis. Folla basi latiora, vix 1 lin. longa, pallide viridié. (v. 3. comm. a cl. Hook.)

XXV. DAPỸNOBRYON. - Drapetis sp. Hook. fil.

Flores hemaphroditi, 4-meri. Calys coloratus, infundibuliformis, totus deciduus, tubo continuo, limbo \$-fido æquah patulo. Glandulæ 8 discretæ; geminatim approximatæ, ad basin loborum sessiles, paribus staminibus alternis. Stamina 4, fauci inserta, lobis alterna, filamentis exsertis brevibus subulatis, antheris ovatis obtusis. Ovarium sessile, obovatum. Stylus lateralis, filiformis, exsertus, stigmate capitato. Fructus.... - Suffruticuli Tasmanici el Borneenses habitu Đrapetis, fasciculis terminalibus paucifloris, involucro proprio nullo, receptaculo parvulo hemisphærico villoso. .-Genus nimis affine Kelleriæ, solummodo glandulis faucis discretis (nec contiguis connatisye) et stylo laterali distinctum. Nomen, ex Jaẹvin et Gevov, propter habitum muscîformem.

1. D. TASMANI ouM, caule prostrato erassiusculo ramoso glabro, folis ltnearisubulatis obtusis concavis nervosis longe ciliatis apice extus sericeo-barbatis, - calycis tubo sericeo, lobis lanceolatis apice pilosis, ovario glabro. $\hbar$ In montibus - Tasmanniz occidentalis, alt. 3,000-4,000 ped. (Gunn!). Drapetes Tasmannica Hook. n.fil. in Hook. Journ. 1853, p. $299^{*}$, t. 7. Folia 1-1 $\frac{1}{2}$ poll. longa. Florum fasclouli sessiles, foliis subbreviores. Fructús ex Hook. descr. 1. c. a bacca ovoidea compressé, " sed ex ic. ibid. potius siccus videtur. (v. s. comm. a cl. Hook. fil.)

2. D. E R I c o I D E s, caule erecto corymboso-ramoso, folijs subulato-linéribus obtı. siusculis striatis margine dorsoque apicem versus sericeo-villosis, calycis villosi, lobis ovalibus, ovario apice barbato. $\frac{5}{\partial}$ In ins. Borneo monte Kini-Balu, alt. 8,500 ped. (Low!). Drapetes ericoides Hook: fll.! 1ni Hook. ic. t. 895. Ramuli satis validi, cicatrisati, Falia $\$-2 \frac{1}{9}$ lin. longa. Flores paulo majores et dęsius villosopubescente quam D. Tasmannici. (v. s. comm. a cl. Hook. til.)

XXVI. STRUTHIOLA Linn. mant. 1, p. 4, n. 1244, gen. cd. Schreb. p. 86, n. 216, nuss: p. 77, Lam. ill. t. 78, Gartn. fr. 3, p. 194; t. 125, Roem. et Schult. syst. 3, p. 20 et 330, n. 915, Meisn. in Linnad 44, p. 463, gen. p. 330 (243), Endl. gen. p. 331, n. 2099, suppl. $4,2, p .61, n .2096$. - Belvala Adans. Fam. 2, p. 285. - Nectandræ sp. Berg.Passerinæ sp. Mill., Linn.

Flores hermaphroditi, 4-meri. Calyx blbracteolatus, coloratus, tubo gracili cylindrico lobis ovarioque multo longiore demum supra ovarium circumscisso deciduo, fauce ampliatâ, limibo 4-partito, lobis æqualibus patentibus. Ġan dulæ 8 vel 12 vel rarius 4 , summæ fauci insertæ, exsertæ, carnosæ vel corneæ, oblongæ, singúlæ basi coronâ setularum nitentium dense cinctæx, erectæ, basi in annulum subcarnosum prominulum confluentes, dum 4 cum calycis lobis alternantes. Squamulæ hypogynæ nullæ. Antheræ 4 in fauce subsessiles, inclusæ, lobis alternæ, lineares, dorso connectivo ultra loculos producto adnatæ, obtuse apiculatæ. Ovarium sessile, stylo laterali, capillarí, calycis tubum æquante, stigmate capitato papilloso. Nucula calycis basi per:- 
sistente inclưsa. Semen albuminosum. - Frutices vel suffrutices Capenses, ericoidei, ramis plerumque gracilibus strictis, foliis oppositis vel rarissime sparsis coriaceis sessilibus plerumque linearibus omnibus conformibus floribus in superioribus axillis solitariis geminisve sessiljbus albis rubellis luteisve plerumque extus pubescentibus.

\section{Glandula faucis 8 , geminatim sinubus insertae.}

1. S', virgata (Linn. mant. 1, p. 41), foliis linearibus vel lanceolato-linearibus obtusis ciliatis vel utrinque ramulisque pubescentibus, ealyoe folium parum vel vix dimidio superante, tubo adpresse piloso, lobis ovatis obtusiusculis glandulas setasque faucis sequilongas parum superantibus. 3 In Africâ Capensi, a flum. Garip usque ad sinum Algoa, usque ad alt. 5,000 ped. fere ubique. - Lam.I dict. 3, p. 315 , Poir. dict. 7 , p. $76^{\circ}$, Wikstr. Thym. p. 286 (excl. syn. Lam.), Thunb. 11. Cap. p. $382^{*}$, Roem. et Schult. syst. 3, p. 330, Meisn. in Linnæê 14, p. 464 . S. ciliata Andr. Bot. repos. t. 149 (non Lam.). S. glauca Sieb. pl. Cap. n. 183, fide Presl bot. Bemerk, p. 108. S. rubra Andr. 1. c. t. 139. Rami virgati. Folia opposita 3-6 lin. longa, $\frac{1}{3}-\frac{2}{3}-$ raro 1 lin. lata, conferta, semipatula. Species admodum variabilis. Varretatum sequentium formæ extremæ facile pro tot speciebus distinetis haberi possunt, sed formis intermediis arcte inter se oonnectuntur.

a. Linnacana (Meisn. 1. c.), foliis obtusis dorso 3-costatís junioribus breviter ciliatis demum glaberimts, floribus folio parum longiorilius glabrescentibus, limbo patente.-Drège, n. 38317335 ! Ludwlg! Ecklon!' Zeyh. n. 3796! etc. Folia $\frac{1}{2}-1$ lin. lata, dorso convexa, raro fere plana et obsolete nervosa, juniora pubescentia, flores 4-5 raro 6-7 lin. longi; lobis interdinı reflexis. (v. s. in herb. Lam., Smith, DG., etc.)

$\beta$. pubescens (Meisn. 1. c.), foliis obtusiusculis dorso 3-costatis vel sublævibus pilis albis minus fugacibus margine ciliatis apiceque penicillatis, floribus folio duplo longioribus (5-7 lin. longis) limbo patente.-Drège, n. 383, éx parte! Ecklon et Zeyh. n. 51! Krauss, n. 766!. S. pubescens Retz, obs. 5, p. 26, Bot. mag. t. 1212 ? Roem. et Sthult. syst. 3, p. 330 *. S. virgata Sm. exot. bot. 1, p. 89 , t. 46 . (v. s.)

$\gamma$. subvillosa (Meisn. 1. c. p. 465), foliis obtusiusculis nervoso-striatis pube albidâ sųbądpressâ tardius cvanescente subvillosis ciliatisque, floribus folio, 3-4-plo: longioribus glabrescentibus, lobis reflexis.- Drège, n. 482 ! ex parte. S. villosa herb. Vahl (non Wikstr.). Folia 3-4 lin. longa, $\frac{2}{3}$ lin. lata: Flores 8-10 lin. longi. ( $\mathrm{v}, \mathrm{s}$.)

\&. glabrescens (Meisn. 1. c.), foliis glabris, junioribus obsolete ciliatis et penicillo exiguo terminatis, floribus folio duplo longioribus parce pilosiusculis, limbo patulo.-Drège, n. 7336! 7339 ! Ecklon et Zeyh. n. 541 Hahenack. pl. Kolbing, n. 15 ! Zeyh. n. 1482 ! ex parte, etc. Folia pleruxque angustissima. Calyx 6-10 lin. longus, tubo tenui. Forma ad S. angustifoliam proxime rocedens. (v. s.)

8. glabriflora (Meisn. in Hook. Lond. Journ. 2, p. 455, et Krauss Beitr. p. 143), foliis obsolete ciliatis, floribus glabris.-Krauss, n. 767 ! Eckl. el Zeyh. n. 56!. Flores gracillimi, 8-10 lin. longi, folia 2-3-plo superankes. (v. s.)

n. incana, ramulis apice dense incanis vel sericeo-villosis, foliis ciliatis penicillatis, calycis tubo dense pubescente, limbo glabrescente (Mundt, n. 24! Zeyh. n. 3734! ex parte). S. incana Lodd. Bot. cab. t. 11, Eckl. et Zeyh.l in herb. n. 53, ex parte. Flores folio parurn vel dimidio longiores, 5-7 lin. Longi, graciles. (v. s. in herb. Kunth., Sond., etc.)

2. S. ANGUSTIF OLIA (Lam. ill. 1, p, 214), ramulis dense albo-lanuginosis, föliis subadpressis acerosis obtiusis dorso convexo 1-3-nerviis margine apiceque albociliatis, calyce folium subtriplo superante pubescente, tubo terui, lobis parvis patentibus oblongis, faucis glandulis setulas parcas superantibus lobos dimidios æquantibuas. ₹ In Africà Capensí, circa Pikenierskloof, Ezelsbank, etc., alt. 1,0003,000 ped. (Drège!), Zeekoevalei, Zwarteberg, etc. (Zeyher, n. 3733!). - Poir. dict. 7, p. 477*, Roem. et Schult. syst. 3, p. 331, Meisn. in Linnæâ 14, p. $466^{\circ}$. Species pracedenti nimis affinis, cum ejus var. $\delta$ et $n$ fere confluens, attamen faucis setulis constanter paucioribus brevioribusque, calycis limbo minore, ramis graciliorihus 
incanis, foliis brevioribus 2-3 lin. longis haud difficile dignoscenda. A sequen to jam tloribus fere duplo majoribus differt. (v. s.)

3. S. PARVIFLORA (Bartling! mss.), ramulis apice canescentibus, folìis patulis acerosis acutiusculis dorso convexo subenerviis glabris, junioribus obsolete ciliatis, floribus folio subæquilongis glabris, lobis acutis glandulas setulis æequilongas duplo superantibus. 5 In Africâ Capensi, usque ad alt. 3,000 ped. (Ludwig! Krébs, n. 284! Zeyher, n. 60!), in lapidosis et montibus Zuurebergen, at fi. Zwartkopsrivier, Vanstaadesrivier, Port-Elisabeth, 'Zitzikamma, distr. Uitenhage, George et Albany (Drège, n. 7334! Krauss, n. 769! Ecklon, n. 626! Zeyh. n. 3731! etc.). Meisn. in Linnæâ 14, p. 467 *, in Hook. Lond. Journ. 2, p. 455, Krauss Beitr. p. 143. S. lutescens Eckl. et Zeyh. mss. in herb. n. 61! Ramuli apice 4-goni. Folia 2-4raro 6 lin. longa, $\frac{1}{2}$ - raro fere 1 lin. lata. Flores 3-4-raro 5 lin. longi, lobis ovatovel lanceolato-oblongis tubo tenui pluries brevioribus. (v. s.)

4. S. LiNeARILOBA (Meisn. in Linnæâ 14, p. 468 *), ramulis apice 4-gonis, foliis semipatulis acerosis dorso convexis subenerviis glabris, junioribus obsolete ciliatis, floribus folio duplo longioribus, tubo tenui, lobis linearibus aculis glandulas setulis æquilopgas triplo superantibus.. In Africâ Capensi. Habitus et folia fere S. angustifoliæe et parvifloræ, sed folia mox glaberrima, calycis lobi anguste lanceolati acuminati $1 \frac{1}{2}$ fere 2 lin. longi.

a. glabra, ramulis calycibusque glaberrimis, tubo folia vix superante lobis dimidio longiore. - In rupestribus montis Blaauwberg, inter Boschkloof et Honigvalei, alt, 3,000-4,000 ped. (Drège! docum. 73, 3, A, d, 7). \& Retziana Meisn. 1. c. p. 469. S: juniperina Retz. obs. 3, p. 26, Bot. cab. t. 75 ? Willd. sp. 1, p. 692, Poir. diet. 7, p. 478, Ait. fl. Kew. ed. 2, 1, p. 271? Roem. et Schult: syst. 3, p. 331 . S. erecta Gurt. Bot. mag. t. 222 ? $\beta$ subulata Lam. ill. 1, p. 314, Poir. dict. 7, p. 478. Flores vix semipollicares, rubelli? ex Bot. mag. albi: (v. s.)

B. pubescens, ramulis calycibusque adpresso-pubescentibus. - Ludwig! Eckl.! Zeyh.! Kolbing in pl. Hohenack. p. 14!). $\beta$ Steudeliana Meisn. l. c. Pubescencentia tam ramulorum quam florum nunc parca subdecidua, nunc densa, canescens, persistens. Calyx folia longe superans, 8-10 lin. longus, rarius dimidio fere brevior, (v. s.)

5. S. E R E C T A (Linn. mant. 1, p. 41), glaberrima, ramis apice 4-gonis, foliis patulis lanceolato-linearihus acutis subplanis dorso $1-3$-nerviis eciliatis, floribus folia dimidio superantibus, lobis ovato-oblongis acutis glandulas setulasque subæquilongas subtriplo superantibus. $尹$ In planitie montibusque Africæ Capensis usque ad alt. 1,000 ped. vulgaris:

a. vulgaris, foliis lanceolato-linearibus dorso plerumque 1-3-nerviis (Burchell, n. $208,440,441 !$ Sieber herb. Cap. n. $64 ! 248$ ! fl. mixt. n. $85 !$ Eckl. in pl'. un. itin. n. 28 ! Ludwig 1 Drège n. 383 et 482 ex parte, etc., Krauss, n. 750 ! 760! Zeyher, n. 3730! etc.). - Wendl. obs. p. 9, t. 2, f. 10, Lodd. Bot. cab. t. 74, Wikstr. Thym. p. 289, Willd. sp. 1, p. 692, Lam.! herb. Poir. dict. 7, p. 478 (excl. B), Thunb. fl. cap. p. 382 ? Bot. mag. t. 2138 , Meisn. in Linnæá 14 , p. 469 , excl. B. S. tetragona Retz. obs. 3, p. 25. S. subulata Lam. ill. n. 1568 ? S. pendula Salisb. hort. Albert. p. 282 (fide Wikstr.). S. glabra Roem. et Schult. syst. 3, p, 331". Thymelæa Burm. Afr. p. 127, t. 47, f. 1? Passerina dodecandra Linn. syst. nat. ed. 2, p. 1004, sp. ed. 2, p. 513. P. filiformis Mill. dict. ed. 6 (fide Bot. mag.). Nectandra tetrandra Berg. pl. Cap. p. 133*. Rami graciles, stricti. Folia conferta, 3-4- raro 5-6 lin. longa, $\frac{1}{-2}$. fere 1 lin. lata, basi haud angustata. Flores 5-6 lin. longi, rosei vel albi, lobis acuminatis 1-1 $\frac{1}{2}$ lin. longis plus minus nervoso-striatis. (v. S. et v. v. c.)

$\beta$. ambigua, foliis lanceolatis (1-1 $\frac{4}{2}$ lin. latis) 3 -nerviis vel nervoso striatis (Eckl. et Zeyh. n. $91 !$ ). Caet. ut in rar. $\alpha$. Forma foliis valde accedens ad $S$. ovatam $\beta$, sed diversa floribus brevioribus ( $5-7$ lin. longis), lobis distincte nervosostriatis, foliis 3-4 lin. longis pluri- nec 1-nerviis. Folia ramulorum sterilia penitus ut in var. $\alpha$, nec latiora. (v. s. unic. in herb. Sond.)

6. S. ECKL ONIANA, glabeprima, ramis apice tetragonis, foliis lanceolatis acutis basi parum angustatâ obtúsis subplanis dorso obsolete nervoso-striatis lævibusve, ealyce folia superante, faucis setis copiosis glandulas superantibus lobos ovato- 
oblongos acuminatos subæquantibus. $F$ In montibus prope Grotvadersbosch (Mundt!), et ad flum. Gauritz, alt. 4, distr. Zwellendam (Ecklon et Zeyh. n. 59!). Hahitus, foliorum-florumque forma et dimensiones fere $S$. erectx $\gamma$ et ovatæ $\beta$, sed ab utràque insigniter differt faucis barbâ densissimâ duplo longiore lobos subæequante, a priore preterea glandulis minoribus et foliis margine haud scariosis, a posteriore foliis obsolete nervoso-lineatis nec unquam distincte 1-3-nerviis. Folia 6-7 lin. longa, marginjbus incurvis supra concava. Flores 9-10 lin. longi. (v. s. in herb. Sonder.)

7. S. ova t a (Thunb. prodr. p. 76, 1l. cap. p. 382), glaberrima, ramulis sublævibus apice 4-gonís, folîs ovatis oblongisve acutiusculis subplanis dorso obsolete 1-3-nerviis, calyce folio pluriès longiore, lobis ovatis acute acuminatis, glandulis setulas superantibus lobis dimídio lorevioribus. 春 In Africâ Capensi (Thunb., etc.).-Andr. Bot. repos. t. 119, Bot, cab. t. 141? Willd. sp. 1, p. 693, Ait. h. Kew, ed. 2, 1, p. 272, Roem. et Schult. syst. 3, p. 333*, Wikstr. Thym. p. 290, Meisn. in Linnæấ 14, p. 471, excl. $\beta$.

a. myrsinites, foliis ovato- vel elliptico-oblongis ovalibusve, - In montibus circa Dutoitskloof, Giftberg, Winterhoek, Gnadenthal, Tulbagh, Stellenbosch, etc. alt. 1,000-3,000 ped. (Drège, 7341! etc., Eckl1.! Zeyh. n. 3738!). S. myrsinites Lam.! ill. 1, p. 314, Poir. dict. 7, p. 478*. S: ovata $\alpha$ longiflora

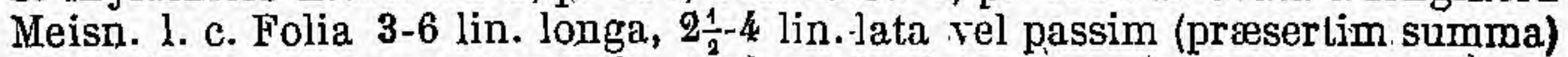
angustiora, plerumque 1-nervia, rarius obsolete. 3-nervia, rarissime obscuro nervoso-striata. Flores carnei, 8-10 lin. longi, tubo gracili, lobis 1-1i lin. longis. (v. s. in herb. Lam., etc.)

$\beta$. lanceolata, foliis lanceolatis 1-nerviis vel subenerviis. - Circa Dutoitskloof (Drège, n. 1199! Ludwig ! Gneinzius | Kolbing, n. 12), Zwellendam, Vanstadesberg, Groote Houhoek (Eckl!! Zeyh. n. 3732 ! $3737 \beta$ !). S. lanceolata Retz. obs. 3, p. 26 ? S. erecta $\beta$ lanceolata Meisn. in Linnæa 14 , p. 470. Folia 3-6 lin. longa, $1 \frac{1}{2}$-raro 2 lin. lata, summa interdum inferioribus paulo latiora. Cæt ut in var. $\alpha$. Forma ad S. erectam valde accedens, sed foliis latioribus et floribus multo longioribus constanter distincta. (v. s.)

y.? scariosa, foliis lanceolatis attenuato-acuminatis amplectentibus 1-3-nerviis tenuiter striatis margine subdiaphano-scariosis summis inferne dilatatis.

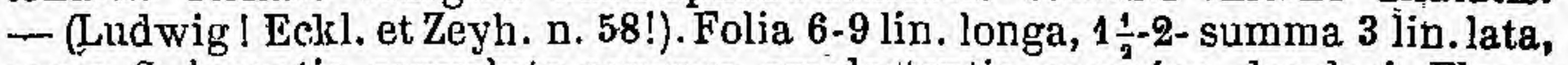
more $\mathrm{S}$. lucentis convoluto-concava amplectentia, margine decolori. Flores 10-12 lin. longi. Forsan propria sp. (v. s. in herb. Mus. Stuttgart. et Sonder.)

8. S. TUBER CUL OSA (Lam.l ill. 1, p. 314), ramis puberulis dense tuberculoso-cicatricosis, foliis imbricatis ellipticis ovatisve acutis obsolete 1-3-nerviis glabris, calyce folia vix dimidio superante glaberrimo, lobis ovatis acutis glandulas setulis breviores duplo superantibus. $\bar{F}$ In Africâ Capensi, circa Grootradersbosh, Uitenhaye, Krakakamma, etc. (Ludwig! Eckl. n. 56! 627! Zeyh. n. $3737 \gamma$ et $\delta$ 1).-Poir. dict. 7, p. 479 *, Roem. et Schult. syst. 3, p. 333, Wikstr. Thym. p. 291. S. Vahlii Wikstr.? ibiḍ. S. ovata $\beta$ breviflora Meisn. in Linnæâ 14, p. 471. S. ovatæe valdo quidem similis, sed certe distinctà. Folia densius approximata, vix 1 lin. ab invicem disstantia, pulvino tuberculiformi jnserta, subadpressa, 3- raro 4 lin. longa, 1 $\frac{1}{2}-2$ lin. lata, plerumque obsolete 1 -nervia vel enervia. Calyx 5-6- raro 8 lin. longus, lobis vix 1 lin. longis. (v. s. in herb. Lam., etc.)

9. S. HIR S UTA (Wikstr. Thym. p. 290), ramis apice hirsutis, foliis ovali-oblongis subplanis ciliatis dorso nervoso-striatis pilosis demum calvescentibus, calyce foliis subiequilongo glaberrimo, lobis ovatis acutis glandulas setulis parcis sublongiores dimidio superantibus. J In Africà Capensi (Thunb.! Niven! Ludwig !), Outeniqua? (Lichtenstein), ad fl. Knysna, distr. George (Krauss, n. 764!), prope Kaymansgat, alt. 600-800 ped. (Drège, n. 7340! Eckl. el Zeyh. n. 95!). - Meisn. in Linnéeâ 14, p. 476, excl. $\beta$. S. ovata $\beta$ Thunb. Mus. Ac. Ups. 13, p. 106, fide Wikstr. S. grandis Bartl.? mss. in herb. Berol. Thymelæa Burm. Afr. t. 47, f. 2 ? Rami validi, virgati,

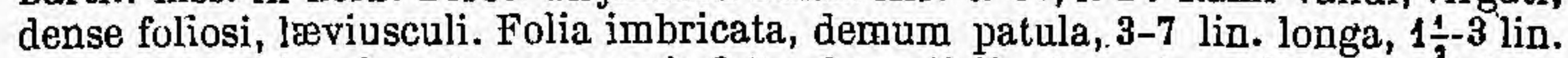
lata; acuta vel rarius obtusa, nervis 3-5 subparallelis plus minus distincte striata. Flores 4-6 lin. longi, lobis $\frac{1}{2}-\frac{2}{3}$ lin. longis. Species foliorum formâ et magnitudine præcedentibus, nervatione $\mathrm{S}$. Mundtii et striatæ similis, ab illis foliis pubescentibus striatis, ab hisce glandularum faucis numero, etc., bene distincta. (v. s. in herb. reg. Berolin., Stuttg., DC., etc.) 
10. S. LUGeNs (Poir.l in dict. 7, p. 477 \%), ramis virgatis superne pubescentibus, folis imbricatis lance $l a t i s$ oblongisve acuminatis acutis amplectentibus striatomultinerviis glabris ciliatis demum nudis, calyce folium parum superante pubescente lobis ovato-oblongis glabrescentibus glandulas setulis copiosis æequilongis dimidjo superantibus. $亏$ In planitie Capensi, monte Tabulari, Diaboli, etc. (Sieber, n. 185! Ecklon, 785! ex parte, Un. itin. n. 65! Krauss, n. 768! Drège! Ludwig!), circa Seekuhvalei et Wupperthal, usque ad alt. 3,000 ped. (Eckl.! Zeyh. n. 60!).Wikstr. Thym. p. 287, Roen. et Schult. syst. 3, p. 332, Meisn. in Linnæê 14, p. $478^{*}$. S. virgata Houttuyn Pfl. syst. 5 , p. 358 , t. 40, f. 2 . $\beta$ Willd. sp. 1, p. 691 . S. ciliata Lam. ill. 1, p. 314, Poir. 1. c. (excl. cit. Andr.). S. glatuca Nois. (fide herb.

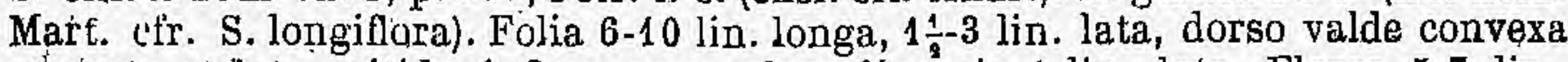
et acute striata, nitida, infima swe plana linearia 1 lin. lata. Flores 5-7 lin., Iobi 1 lin. longi. Spẹcies vulgaris in herbariis plerumque cum S. virgatâ commixta, at certe distincta. (v. s. in herb. Lam.)

11. S. LONGIFL ORA (Lam.I ill. 1, p. 314, t. 78), ramis gracilibus apice 4-gonis puberulis, foliis imbricatis amplectentibus ovato- vel lineari-lanceolatio subacuminatis oblusiusculis tenuiter striatis glabris ciliatis demam nudis, calyce foliis 2-3-plo longiore dense subsericeo-cano, lobis ovato-oblongis squamas setulas parcas aquantes dimidio superantibus. 5 In planitie montibusque Gapensibus (Niven I Burchell, n. 709! Siéber, n. 185! ex parte, Ludwig! Ecklon, n. 784 ! et ex parte 785 ! Krauss, n. 768! Zoyher, n. 3735! etc.), circa Paarl, Duilcervalei, etc., infra alt. 500 ped. (Drège! n. $383, \mathrm{~b}, \mathrm{~d}, 7342^{\circ}, \mathrm{b}$ !) - - Poir. diet. 7, p. $476^{*}$; Wikstr. Thym. p. 292, Meisn. in Linnæà 14, p. 479. S. pubescens Sims in Bot. mag. t. 1212? $\beta$ Retz. obs. 3 p. 26. S. glauca Nois. fide herb. DC. (cfr. S. lucens). S. Tubra Don h. Cantabr. p. 31. Thymelæa Burm. Afr. t. 47, f. 1. Flores 8-12 lin. longi, dense flavido-tomentosi (ex Bot. mag. rubri vel flavescentes), plerumque in ipso ramorum apice numerosi in spicam foliosam dense congesti. Cat. fere onania s. lucidæ. (v. s. ip herb. Lam., etc.)

\section{\$2. Glandula faucis 12 , ternatim calycis sinubus inserto.}

12. S. RIGIDA, ramulis teretibus puberulis, foliis semipatulis rigidis lanceolatis acutiusculis dorso convexo sublicvibus glabris margine involuto dense ciliatis, summis haud latioribus, calyce foliis subduplo longiore glaberrimp, lobis ovatooblongis glàndulas setulis copiosis subbreviores dimidio superantibus. 7 Ad flum. Breederivier, inter Sebastians Baay, Rhinosterfontein et Port-Beaufort (Garnot! Ecklon!). Ramuli graciles, dense folioši, demum leviter tuberculoso-cicatricosi. Folia opposita, juniora imbricata, pallide viridia, 3-5 lin longa, $\frac{2}{5}-1$ lin. lata, bași vix angustata, nunquam manifeste nervosa nec carinata, demum (exsiecatione?) levitér rugoso-striata, supra canaliculata. Bracteolæ lineares, ciliolatæe, folio plus duplo breviores. Flores 8-9 lin. longi, lobis lineam longis, fauce inflatâ dimidio longioribus. Setulæ flavæ. Species ad S. tuberculosam valde áccedens, at foliis angustis, floribus majoribus et præcipue glandularum numero constanter duodeno satis distincta, a sequentibus jam florum glabritie foliisque facile dignoscenda. (v. s. in herb. Mus. Stuttgart. et Kunth.)

13. S. MARTIANA, ramulis gracilibus pubescentibus; foliis imbricatis lanceolatis acutis basi semiamplectentibus dorso sulcato-3-5-nerviís punctato-scabriusculis parce pilosis ciliatis demum nudis, calyce foliis dimidio longiore pilosiusculo, lobis oblongís acute acuminatis glandulas tenues setulas copiosas subæquantes dimidio supperantibus. $亏$ In Africâ Capensi (Niven!). Ramuli elongati, simplices. Fólia

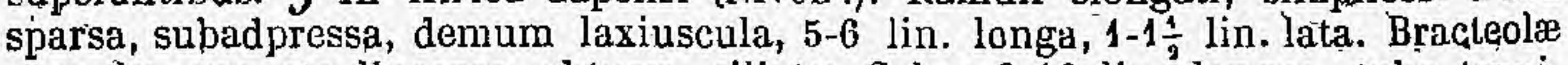

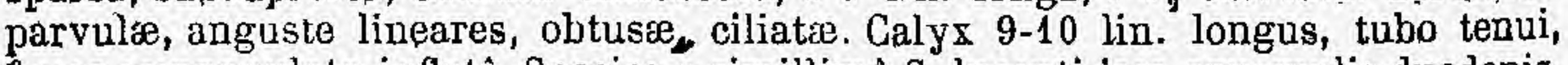
fauce campanulato-inflatâ. Spẹcies a simillimâ $S$. lucenti jam squąmulis duodenis, a sequentibus. sive foliis angustis, sive floribus longioribus, satis distineta. (v. s. in herb. Mart.)

14. S. cH RY S A N TH (Lichtenst. spicil. fl. Cap. mss.), foliis imbricatis ovato-obiongis obtusiuseulis 5-nerviis, junioribus ramisque dense pilosis, calycis tubo longo filiformi, faucis setulis aureo-sericeis. $J$ Ad montem Witsemberg, prope Tulbagh (Lichtenst.). - Roem. et Schult. syst. 3, p. 393. An flores puhescentes? (cfr. S. tomentosa, infra u. 17). 
ß. Dregei, folliis semiamplectentibus breve acuminatis nervoso-sulcatis glabris dense ciliatis, catyce folio subduplo longiore puberulo, ìbis glabrescentibus ovato-oblongis obtusiusculis glandulas setulís subbreviores parum superantỉjus. 5 In rupestribus montanis, inter Sparrbosch et Tradow, alt. 3,0004,000 ped. (Drége, n. 7342, a I docum. p. 117, 4, A, 15). S. chrysantha Meisn. in Linñâ $14, \mathrm{p} .473^{*}$. Valde similis $\mathrm{S}$. lucenti, sed præeter faweis glandulas duodenas distincta foliis latioribus, 3-4 lin. longis, calyce longiore, 9-11 lín. longo, parce adpresso-puberulo, faucis setulis longioribus flàvidis lobos, subæquiantibus. Accedit quoque ad S. argenteam $\beta$, sed itidem floribus distincta. (v.s.)

15. 8. D O D EGA PETALA (Bartl. mss. in herb. reg. Beroli), ramulis superne 4-gonis hirsutis, foliis adpresso-imbricatis ovato-oblongis oblusis apice subrecurvis dorso convexo-capinato obsolète sulcato-rugosis glabris junioribus sericeo-ciliatis, calyce foliis plus duplo longiore sericeo-tomentoso, lobis brevibus ovatis obtusis glandulas setulis æequilongas vix superantibus. $\bar{F}$ Prope Tradow; in terrâ. Oúteniqua (herb: rég. Berolin.). - Meistr. in Linneea 14 , p. $475^{\star}$. Folia semipollicaria et ultra; supra concava, nervo medio subtus manifesto, reliquis obsoletis. Calycis limbus $1 \frac{1}{2}$ lin. longus, setulis pallidis.

$\beta$. Kraussi $i$, foliis obtusis 3-5-nerviis, inferioribus oblongis lanceolatisque planis, superioribus ovato-oblongis semiamplectentibus haud acuminatis flore subtriplo brevioribus, calyce parce puberulo, "lobis glandulas setulis æquales vix superantibus. 3 In monte Duyvelsberg, alt: 2,000 ped. (Krauss, n. 7631). S. dodecapetala Méisn. in Hook. Lond. Journ. 2, p. 455, Kranss Beitr. p. 143. Rami validi, longe simplices. Folia 6-7 vel inferfora 8-40 lin. longa, 3-4 lin. lata, obtusa, nervis 3 in inferioribus sæpè 5 tenuibus subparallelis leviter prominulis in foliis floralibus sæpe obsoletis. Calyx 12-14 lin. longus, tubo tenui minute adpresso-puberulo, lobis 1 lin. longis glabriasculis. Faucis setulæ copiosæe, albidæ. Forsan potius præcedentis var., attamen foliorum nervatio satis diversa. (v. s.)

16. S. ARGENTEA (Lehm. ind. sem. h. Hamburg. 1831, p. 7), ramis virgatis pubescentibus, foliis ovatis vel subrotundis nervoso-striatis nitidis glabris dense ciliatis summis semiamplectentibus inferioribus planis, ealyce foliis dimidio longiore dense sericeo-cano, lobis parvis ovatis obtusis glandulas setulis dimidio longiores parum sưperantibus. $\Rightarrow$ In montibus Zwartebergen, alt, 2,500-3,500 jed., 'et planitie, inter Cap Agulhas et Potberg, distr. Caledon (Drège, n. 7345! 7346! EckIon et Zeyh, .n. 46! Garnot in herb. Kunth.). S. Dregeana Moisn. in Linnæâ 14, p. 472*. Rami virgati, validi, ramosi, densissime foliosi. Folia quadrifariam imbricata, primo adpresşa, deinde patentia vel deflexa, 3-5 lin. longa, obtusiuscula vel obtusissima, ciliis brevibus densis quasi albo-marginata, dorso obsolete multinervia vel nervis tenuibus parallelis prominulis dense lineata. Flores 6-7 lin. longi. (v. s.)

$\beta$. oblongata, foliis ovatis oblongisque dense nervoso-lineatis. - In montibus Zwartehoogdens, inter Grahamstown et Hassagaybosch, distr. Allaany.(Ecklon et Zeyl n. 628! Niven! Burchell, n. 3486!). S. aurea Eckl. et Zeyh. herb. n. 45 l et 50 bl). Rami abbreviati, adscendentes, corymboși. Folia 5-8 lin, longa, superiora 3 - fere 4 lin, inferiora vix 2 lin. lata, nervis tenuibus prominulis parallelis subtus plerumque dénse lineata. Flores 8 lin. longi. Cæt. ut in typo. (v. s.)

$\gamma$. laxior, foliis minus dense imbricatis patulisve oxato-oblongis lanceolatisque nervoso-striatis apice sæpe subrecurvis. - In planitie, inter Krakakamma ef Vanstadesriviersbergen, distr. Uitenhage (Ecklon !). S. formosa Eckl. et Zeyh. herb. n. 47! Folia 3-5 lin. Ionga, 2-3 lin. lata. Flores, etc., ut in var. $\beta$, quậcum per grarlus insensibiles confluit. (v. s. comm. a cl. ${ }^{x}$ Sonder:)

17. S. Tom ENT OSA (Andr. Bot. repos. t. 334), foliis imbricatis ovali-oblongis obtusiusculis dorso 3-5-nerviis pilosiusculis, superioribus latioribus semiamplectentíbus, infimis planís lineari-lanceolatis, junioribus ràmulisque dense cánq-villosiusculis, calyce foliis parum longiore cano-tomentoso, lobis parvulis glandulas setulis copiosis aureis subbreviores vix superantibus. $\frac{7}{3}$ In Africâ Capensi (Niven), mont. Groote Houhoek, circa Hottentottsholland, Klynrivier, etc., alt. 3-4, distr. Zwellendam et Caledon (Ecklon! Zeyh. n. 3740I)-Ait. h. Kew. ed. 2, 1, p. 272, 
Roem. et Schult. syst. 3, p. 333, Wilistr. Thym. p. 292. S. villosa Wikstr. ib. p. 288 ? S. chrysantha Eckl. et Zeyh. herb, n. 48! non? Lichtenst. Rami elongati,

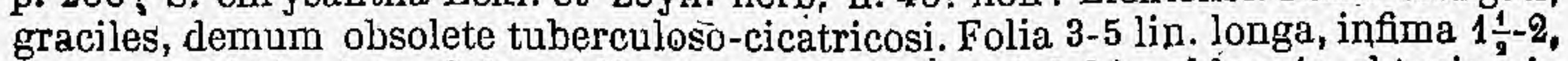
summa 3-3 $\frac{1}{2}$ lin. lata. Calyx 6 lin. longus, tubo tenui, lobis oblongis obtusis vix $\frac{3}{3}$ lin. longis. Facie simillima S. hirsute, sed floribus pubescentibus, limbo dimidio minore, gropdulis 12 nec 8 , etc., bene distincta. A S. chrysanthâ Licht., saltem $\beta$ nostra (cir. supra n. 14) certe distincta calyce fere dimidio minore, foliis pilosis, etc. Si vera S. chrysantlía cum S. tomentoså identica est, tunc hujus synonymis adscribenda, var. $\beta$ nostra vero ut species propria servanda erit. (v. $s$. comm, a cl. Sonder.)

18. S. Mu NDT I (Eckl.! mss. in herb. п. 49), ramulis villosiusculis, foliis fortiler nervoso-sulcatis ciliatis glabris, superioribus subamplectentibus ovatis oblongisve, inferioribus planis vel canvexis lanceolatis linearibusve, calyce foliis parúm longiore glaberrimo, lobis parvis ovato-oblongis glandulas setulasque vix superantibıs. $\zeta$ In montibus, circa Tulbagh, Hottentottsholland, Klyurivier, etc., distr. Cap., Zwellendam; Worcester et Caledon (Mundt ! Ludwig ! Eckl.!.Zeyh. n. 3739 ! Drège, n. 7337 !). S. hirsuta $\beta$ glabrescens Meisn. in Linnæà 14, p. 476 . S. striata Eckl. et Zeyh. herb. n. 50! ex parte (non Lam.). Fruticulus 1-2-pedalis, caule erecto valido, ramulis sæpe corymbosis demum tuberculoso-cicatricosis glabratis. Folia promiscue opposita et sparsa, confertissima, imbricata, demum patula, 2-4 lin. longa, superiora $1 \frac{1}{2}-2 \frac{1}{2}$ lin. lata, inferiora dimidio angustiora obtusa sæpe vix 2 lin. longa carinata, omnia nervis parallelis acute prominentibus dense striata, juniora longiuscule albo-ciliata cáeterum glabra. Calyx 5-6 lin. longus, tubo tenui. Primo vuitu facile confundenda cum $S$. hirsıtâ et striatâ, sed ob utrâque jam glandularum fauciș numero bene distincta. (v. s.)

\section{§ 3. Glandulae faucis 4, calycis lobis alternce.}

19. S. STRIA t A (Lam.! ill. 1, p. 314), ramulis pubescentibus, foliis ovatis oblongisve subacutis planis vel superioribus subamplectentibus acute nervoso-striatis ciliatis glabris, calyce foliis parum longiore cano-piloso, lobis glabrescentibus oblongis acutis glandulas setis subrqualibus dimidio superäntibus. 5 In planitio Capensi (Niven! Sieber, n. 184 ! fl. mixta, n. 88! Ecklon, n. 782! Zeyh. n. 3737!) et mont. Tygerberg, Tafelberg, alt. 1 (Mundt! Eckl.!), circa Dutoitkloof, alt.1,5002,000 ped. (Drège, n. 7744 ! docum. p. 79, 3, A, e, 9). - Poir. dict. 7, p. $476^{*}$, Wikstr. Thỹm. p. 288 , Meisn. in Linnæê 14, p. 477". S. ịnbricata Andr. Bot. repos.' t. 113, Pers. syn. 1, p. 149 , Herb. amat. 3, p. 184 , Róem. et Schult. syst. 3, p. 332, Eckl. et Zeyh. herb. n. 57! S. virgata Weudl. obs. p. 9, t. 2, f. 9 (fide Bartl.), Willd. sp. 1, p. 690 (ex parte), Link! en. 1, p. 111 (fide herb. Roep.). S. lateriflora Hornem. h. Hafn. 2, p. 955 (teste Wikstr.), Roem. et Schult. syst. 3, p. 330. S. sulcata Schmidt in Usteri annal. 6, p. 120, Wikstr. Thym. p. 292 ? S. brevifolia Willd. herb. sub S. virgatâ (fide Barti.). Folia S. Mundtii. Flores 4-6 lin. longi, tubo dense adpresso-tomentoso, lobis attenuatis 1 lin. longis. (v. s. in herh Lam., etc., et s. c.)

B. angustifolia (Meisn. in Hook. Lond. Journ. 2, p. 556), foliis lineari-lanceolatis, superioribus paulo longioribus. - In arenosis planitiei Capensis (Krauss, n. 765!). Folia 1- vix 2 lin. lata. Cset. omnia ut in typo. (v. s.)

\section{Species non descripto.}

5. GLAUCA Loddig. cat. 1807 , p. 33, Donn hort. Cantabr. ed. 6, p. 40 (non? Nois., cfr. S. lucens et longiflora). Forsan eadem ac S. incana Lodd. t. 11 (ex Wikstr. Thym. p. 293) quæ S. virgata $n$ incana nob., supra n. 1.

S. L A X A Nois., ex Roem. et Schult. syst. mant. ad vol. 3, p. 260.

S. OPPOSITIFOL I A et SUPERBA cat: hort. Liverpool. p. 176, ex Wikstr. 1. c.

8. S т R с т A Donn hort. Cantabr. ed. 6, p. 40, ex Wikstr. l. c., eadem ac S. erecta Curt. (nom Linn.), fide Steudel nomencl. ed. n. 2, p. 648, cfr. S. lineariloba, supra I. A.

\section{Species exclusce.}

6. Іи в г сата hort. $=$ Arthrosolen spicatus C. A. Mey. 
S. L.ATERIRL ORA Wendl.

S. L i т ror a l I.s Wendl, ex End́l. $\}=$ Arthrosolen spicatús G. A. Mey.

S. NAN A L: = Gnidia nana Wikstr.

\section{Suibtribus II. DIPLOSTEMONEA.}

\section{Stamina calycis lobis numero dupla, scilicet 8 vel $\mathbf{1 0}$.}

XXVII. CRYPTADENIA Meisn. in Linnoed 14, p. 404, gen. p. 330 (242), Endl. gen. suppl. 4, 2, p. 63, n. 2101. - Passerina sp. Linn. - Calysexícos $\$$ p. Eckl. et Zeyh. mss.

Flores hermaphroditi, 4-meri. Cályx coloratus, infundibuliformis, tubo supra ovarium articulato, pàrte inferiore persistente, superioré deciduâ, fauce pubescente esquamata, limbo regulari 4-partito, lobis tubo æquilongis vel longioribus patulis intus glabris. Glandulæ 8 , oblongæ, sessiles, subuniseriales, medio tubo adnatæ, staminibus alternæ. Squamulæ hypogynæ nullæ. Stamina 8, calycis tabo supra glandulas biseriatim insekta, seriei superioris exserta lobis opposita, inferioris infra sinus semiinclusa, filamentis capillaribus inferne tubo adnatis barbatis, antheris ovalibus. Ovarium glabrum. Stylus lateralis, capillaris, calycis tubum æquans, stigmate capitato papilloso. Nucula calycis basi hirsuta inclusa, - Fruticuli Capenses ericoidei, ramosi, folils decussatim oppositis sessilibus coriaceis linearibuis vel subacerosis glabris, floribus terminalibus subsolitariis lilacinis vel roseis extus sericeis.

1. C. GR A DIFL, ORA (Meisn. in Linnæa 14, p. 405); foliis adpressis crassiusculis lineäribus 'vel spathulato-oblongis vel obovatis concavis dorso rotundato-convexis vel apice subcarinatis margine nudis, summis latióribus, noribus majusculis, tubo bractets subsuperante, lobis obtusiusculis. 5 Ad 'montes Paardeberg, Houhoek, Tygerberg, Leeuwenberg, etc., infra alt. 500,ped., in planitic Capensi, distr. Somerset, Clanwilliam, Rietvalei, etc. (Niven I BurchelI,-n. 163! Ludwig! Drège! Eclil. n. 361! Zeyh.! Krauss; n. 756!). - Meisn. in Hook, Land. Journ. 2, p. 552. Thymelsed Burm. Afr. t. $46, f .1$ et 2. Passerina grandiliora Linn. fil. suppl. p. 226, Wikstr. Thym. p. 345. Calýsericos grandiflora et canaliculata Eckli. et Zeyh.! mss. in herb. Fruticulus humilis. Folia plerumque linearia, 2-4 lin. longa, 1-1 $\frac{1}{2}$ lin: lata, acutarvel obtusa, nervo dorsali prominilo sæepe nervo laterali comitato. Calyx 5-6 lin. longus, subcaruosus, lobis ablongis obtusiusculis tubp sublongiơribus.' (v, s.)

$\beta .2$ latifolia, foliis óvalibus oblongisque planis margine leviter incurvis, calyce dimidio minore, tuba folia subıequante, lobis avatis obtusis. Forsan sjecies distincta. Folia $2 \frac{1}{2}-4$ lin. longa, $1 \frac{1}{2}-2 \frac{1}{2}$ lin. lata, acuta, enervia. Calycís lobi 4-4 $\frac{1}{2}$ lin. longi, 3 lin. lati. (v. s. sp. unicum in herb. DC.)

2. C. UNIFLORA (Meisn. 1. c. p. 406), foliis patulis linearibus acutis vel nfucronatis dorso acute carinatis margine nudis, suminis haud latioribus, floriburs majusculis, tubo braicteas superante, lobis acutiusculis, 7 In planitie Gapensi montibusque Tygerberg, Piquetberg, etc., ad Saldanbabaay, etc., vulgaris (Sonnerat! Niven! Drège! Ecklon, n. 362 ! Krauss, n. 1835! Zeyher, n. 1484,1485 , et ex parta 3744 ! etc.) - - Bot. mag. t. 4143 . Thymelæa Burm. Afr. t. 48, f. 1. Prisserina uniflora Liun. sp. p. 560, Lam.! ill. t. 291, f. 1, Wilsstr. Thym. p. 344. $\propto$ purpurea Berg. Cap. p. $128^{*}$. Calysericos uniflora Eckl. et Zeyh.''mss. in herb. A priccedente et sequente præterea dignoscitur ramis graciliorihus, foliis tenuioribus acutioribus scepe subpungentibus usque ad 6 lin. longis, calyce teneriore, pube magis adpresse sericen, tubo angustiore apice mintas dilatato, lobis acutioribus tubo sæpe brevioribus. Specimina juniora primo anno jam floredtia, quasi herbacea, insignia sunt foliis subadpressis tenuibus sape yix 2 lin. longis. (v, s.) ,

3. C. BRE vifL ORA (Meisn. I. c. p. 406), foliis patulis linearibus acutis dorso convexis margine nudis summis sublatioribus, floribus Inediocribus, tubo lolis ovatooblrngis acutiusculis bracteisque breviore. F In planitie Capensi, circa Tulbagh, Caledon, ad flum. Bergrivier, in monte Tabulari, etc. Niven ! Eschischoltz ! Lalande ! Drège! Ecklon, n. 360 ! Zeyh. n. 3744 ! ex parte, etc.). Thymelæa Burm. Afr. t. 48 ,

XIV. 
f. 2. Passerina uniflora $\beta$ alba Berg. Cap. p. 1.29? P. campanulata E. Mey. mss. in herb. Drège. $P$. grandiflora Bot. mag. t. 292 ? Calysericos ${ }^{\curvearrowright}$ tabilaris, subulata et parviflora Eckl. . et Zeyh.! mss, in herb. Planta inter-G. grandifloram et unifloram ambigua, potius forsan prioris formam sistens. Calyx crassiusculus, $2 \div-3$ lin. longus, albus ? dense sericeus, lobis latioribus tuboque semper dongioribus. Folia fere C. unifloræ. (v.'s.)

4. C. GIL IA T A (Meisn. 1. c. py. 407), folins lanceolato-linearibus obtüiusculis muticis dorso rotandato-convẹxis margine junioribus ciliatis, superiöribus sensim majo"ribus, flórlbuś gemizis mediocribus, tubo bracteas æquante lobís ovato-oblongis acutis longiore. F Cìrca Drakensteen, alt, 500 ped. (Drëge! docum. p. 100, 3, D, a, 12). Passerina cikiata Thunb. fl. Cap. p. 377, an Linn. sp. ed. 1, p. 559? Berga Cap. p.126* Wikstr. Thym. p. 330? excl. cit. Burm.? (descriptio recedens if foliis sparsis 'oppósitis obtusis apice villosis »). P. uniflora Drège, h? Ramùli corymbosi, rígidí, jilosiusculi, dense Poliosi. Folia imbricata; demum semipatula, $3-4$ lin. longa, $A$ liñ. lata, basi vix angustata, apicem versus sensim attenuata, summa paulo inajôra usque ad $1 \frac{1}{3}$ lin. lata, Calyx 4 lìn. longus." (v. s.)

5. G. FIL I Ca u lis (Meisn. 'l. c. p. 407*), foliis semipatúlis aceroso-linearibús acutis glabris dorso convexis, floribùs terminalibus et'in summis axillis solitariis parvis, tubo - lobis ovato-oblongis paulo breviore. - J In Africâ Capensí (Drègé, ñ': 7367!), circa.Witsenberg, Żwàrteberg, ete., distr. Caledan, ad flum. Buffeljagdriviel et Rivierżonder einde (Ecklon! Zeýher, n. 1846! 3747 ! 3748!). Gnidia geaistefolia Eckl. et Zeyh.1 mss. in herb. hami pedales ét ultra, gracillimi, laxi, rarius

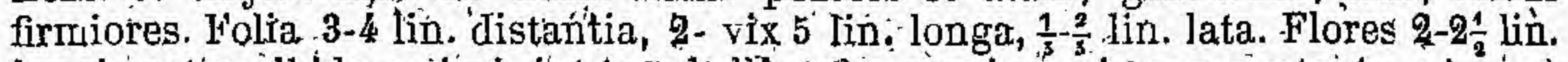
longi, extus albido-sericei; intưs rubellî̀, tubo ovarium vix superante. (v. s.)

XXVIII. LACHNAA van Royen in Linn. gèn. ed. 2, p. 165, n. 382, Juss. gen. p. 77, Lam. ill. t. 292, Gartn. fr. 3, p. 195, t. 215, Endl. gen. p. 330, n. 2094, suppl. 4, 2, p. 64, n. 2193 , Neisn. in Linnoed 14, p. 408, gen. p. 330 (242). - Lachară (lapsu typogr.?) van Royen in Linn. syst. nat. ed. 2, p. 22. - Radojitskjya Turcz; in Bull, Soc. Mosc. 1852, p. 176. - Lachnææ, Passerinæ ot Gridiæ sp̀ auct. - Gonophyllæ sp. ECkl. et Zeyli. mss.

Flores hernaphroditi, 4-meri. Calyx cöloratus, infundibuliformis, utrinque pubescens (rarissime intus glaber!; tubo supra ovarium ang̀ustato et demum circumscisse deciduo, linbi 4-partiti patentis lobis æqualibus vel biląbiatim inæqualibus: Squamæ hypogynæ nullæ, perigynæ 8 ,(stamina sterilià ?) simplici vel duplici serie fauci infra stamina insertæ iisque ạlternæ, inclusæ vel semiexserta, filiformes vel squamuliformes, in faucis pube subabsconditæ. Stamina 8, biseriata, exserta, superiora loborum basi, inferiora fauci inserta, filamentis conspicuis, antheris basifixis ovalibus oblongisve obtusis. Ovarium sessile, głabrum, stylo laterali capillari, stigmate capitato papilloso exserto. Nucula ovoidea, calycis basi persistente inclusa: Semen albuminosum. Frutices Africa australis, ramis gracilibus, foliis oppositis sparsisve, floribus terminalibus capitatis involucratis nudisve, rarius subsolitariis vel axillaribus. - Genus a Grýptadeniâ squamularum perigynarum situr et indole, a Gnidiâ piræertim filamentis conspicuis plus minus exşertis distinctum.

\section{Sectio I. \$pHaroclinidum Meisn. in Linnae $14, p .409$.}

Capitula terminalia, floribus in receptaçulo communi-globøsó sessilibụs. Rámi vírgati, tuberculato-cicátrisalí. - Lachñaa Zín., Låm:

\$1. Exinvolucrata. - Capitula majusculä, dense muiltiflora, involucro propirio destituta, foliis a caulinis haud diversis cincta. Receptaculum tuberculatum, pube brevi velutino-tomentosum, nec lanuginosum. Calyx villosus, tubo gracili ovarium pluries superante. Folia sparsa, dénse appraximata, latiuscula, plana, glabra.

1. L. BuXIforia (Lam.! dict. 3, p. 373*, ill. t. 292, f. 1); foliis ovalibus ovatisve, 
calycis dobisinter se requalibus ovato-oblongis acutis tubo 2-3-plo brevioribus, faucis squarnts compresso-filiformibus subexsertis: 7 In rupestribus montanis, circá Dutoitskloof, alt. 1,500-3,000 ped. (Sonnerat! in herb. Lam., Drège ! docum. p. 81, 3, A,, 10 10. - Meisn. in Linnæd 14, p. 410. L buxifolia a virens Sims in Bot. mag. t. 1657. Gnidia filamentosa Linn. flir suppl p. 224, Willd. sp. 2, p. 425,

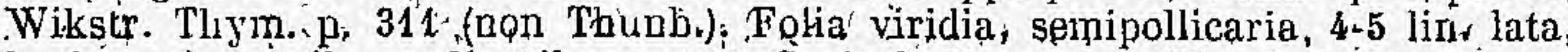
basi nervis tenuibus radliantibus 1 otata. Capitula diametro pollicari et ultra, receptaculo magnil pisi. Flores luteo-albidi, pollicares, tubu ovario 3-4-pho longiore. (v. s. in herb. Lam, étc.)

. glanca (Sims in Bot. mag. t. 1658), foliis glaucis. - Lr buxifolia Andr. Bot. repos. t. 524. L. glauca Salisb. parad. Lond. 109, Hort. Kew. ed. 2, 2, p. 415. Gnidia grandis hort.

2. I. MáR A TH A, foliis obovato-vel ovali-oblongis obtusis, calycis Jobis inequalibus, anterione oblongo lateralibus linearibus tubum subæquantibus triplo-longiore, postico iisdern dimidio breviore; squamplis faucis ligulatis obtusis brevibus, inferióribus semiinclusis. 3 In Africâ Capensi, loco proprio tiuud indicato (Eckl. et Zeyh.1). Fachnẹea buxifolia Ecklon et Zeyihen! mss. in herb. (non Lam.). Faeies L. buxifoliæ, sed calyce irregulari distinctissima et L: filamentosix affinior, a:quâ facile dignoscitur calyce duplo majore, 15 lin: longo, tubo minus gracíli et ratione loborum breviore. Folia imbrieata, subenervia, summa conformia parum majora. Cálycis lobus anteriór 8.11 lin. longus, $2 \frac{1}{2}-3 \frac{1}{2}$ lip. latus, laterales 3 lin. longi, $i \frac{1}{2}$ lin. lati. (v. s. in herb. Sonder.)

3. L. FILAMENTOSA (Meisn. in Linnea $14 r$ p. 410), folris elliptico-oblongis acutis, calycis lobis inæqualibus lineari-oblongis obtisis, anteriore tubum æquante reliquis inter se æqualibus subdujlo màjore, faucis squamulis brevibus lanâ abscónditis. 5 In Africè Capensi (Thunb.), Cederbergen, prope Konigvalei, alt. 3,0004,000 ped. (Drìge 1 docum, p. 73, 3, A, d, 10). Gnidia filamentosa Thnnb. fl. cap. p. 378 (non alior.). Folia 3-5 lin. lónga, 2-3 lin. lata: Capitula paulo minora quam L. buxifolize, cui cæterum, excepto calyce irregunlari, válde similìs. Flares 8-10 lin. longi, flavido-älbi vel pallide roseo-purpurascentes. (v.s.)

B. major, foliis dense imbricatis ellipticis oblongisve, ramulerum floriferorum superioribus sensim majoribus; floralihus dilatatis'ovatis, floribus majoribus. J In declivibus altit. quinte mont. Winterhoeksberge, jrope Tulbagh (Eckl. et Zeyl. n, 72 1), L. glauca Eckd, ef Zeyh. in herb: (non Salisb.): Folia :usque ad 8-10 lin. longa, $3-4 \div \frac{7}{2}$ lin. lata, infima interdum vix 2 lin. lata. Florès magnitudine varialilés, ùsque ad 1 pôll. longi; lobọ antico tunc 2 lin. lato. Cæt. ut in typo speciai, (v. s. in herb. Sonder.)

\$2. Involucratce. - Capitula bracteis 4 vel pluribus submembranaceis formâ et magnitudine a foliis discrepantibus latioribus sape coloratis involucrata: Receptacalum lànâ densissimâ florum insertionem occultante tectum. Cialycis tubus lobis parum vel vix longior. Folia decussatim opposita, rarius sparsa, linearia, dorsa convexa vel carinata, glabra.

4. L. ERTOGEPHALA (Linn. sp. ed. 1, p. 560 , ed, $2{ }^{\prime}$ p. 514), foliis imbricatoadpressis linearibus obtusis carinatis, summis latioríbus villoso-eiliatis, involucri foliolis late rhombeo-ovalibus flores subrequantibus, calycis lobis inaqualibus, anterioribus lineari roblongis inter se æqualibus quarto jostico fere dimidio majoribus, faucis squamulis brevissimis in Iană latentibus. JIn Africâ Capensí (Thúnb., Sonneral! in herb. Lam.), in mont. Hotlentottsholland (Mundı! Eckl. et Zeyh.! n, 32, 101), Houksoek (Ludwig ! Krauss !), Paardeberg, Dassenberg, Niuwekloof, etc., alt. 300-1,000 ped. (Drège I docum. p. $102,3, \mathrm{D}, \mathrm{a}, 2$, et p. 78, 3, A, e, 6).-Willd. sp. 2, p. 434, Gærln. fr. 3, t. 215, Andr. Bot-repos.t. 104, Bot. mag.t. 1295, Lam.! dict. 3, p. $374^{*}$, ill. t. 292 , f. 2 ; Herb. amat. 4, t. 234 (excl. syn. Thunb.? efr. L. globulifera), Meisn. in Linnæầ 14, p. 411 *. L: spharocephala Burm. prodr. fl. cap. p. 12 ? Passerina cephalophora Thunb. fl. cap. p. 375, Wikstr. Thym. p. 322. Rami validi, densissime foligsi. Folia $3-5$ lin. longa, $\frac{1}{4}-1$ lin. lata, summa oblonga - vẹl ovata acuminata margine rubentia et albo-villosa. Capitula solitaria; vel 
corymboso-aggregata, magnit- $\mathrm{L}$. filamentos $x$. Involncri foliola 4=5 lin. Iata longaque vel paulo longiora, acuta vel breve acuminata, tota, nel margine sanguinea, receptaculi lana longa albila sericea. Galyx albidus vel purpureus; tubo filiformi 4-5 lin. longo, lobis utrinque pubescentibus, anticis 3-4 tin. longis, quarto postico minore remotiore. Squahulæ faucis minutæ. ( $\nabla$. s. in herb. Lam., etc.)

B. purpurea, foliis longioribus semipatulis, floribus majoribus purpureis. if $^{3}$ In arenosis montium, eirca Tulbagh (Ëckl. et Zeyh n. 31! 77!) L. purpurea And̦r. Bot̂.repos. t. 293, Ait. h. Krew. ed. 2, '2, p. 415, Bot. mag. t. 1584, Lodd. Bot. cab. t. 273. Passerina purpurea Wikstr. Thym. p. 323. Folia 6-8 lin. longa. Flores subpollicares. ( $v$. s. in herb. DG. et Sonder.et v. v. c.)

5. A U R E A (Ecklon et Zeyher! mss. in herp.), foliis sparsis linearibus lanceolatisque acutis glabris summis latioribus, involucralibus oxalibus apiculatis margine scariosis capilulo brevioribus, calycis lobis intus glabris. postico parvilo tubum æquante, anteriorilsus triplo longioribus, intermedio majore, faucis squamulis brevibus exsertis. F In montibus Klynriviersbergen., prope Hemel en Aarde, alt. quintâ, distr. Galedon (Ecklon!). Caules vel xami? simplicissimi, circ. pedales, erecti, graciles, undique conferte foliosi, glabri. Folia sparsa, subadpresse imbricata, 1-6 lin. longa, 1- vel summa - usque ad 2 lín. lata, dorso obtuse convexa, supra eoncava, lete viridia, súbenervia,-mutiça. Capitula terminalia solitaria vel gemina, inter-folia sessilia, diametro circ. pollicari. Involucrum 8-10-phyllium, patens, foliolis 2-3-seriatis 6 lin.-longis, $2 \frac{1}{2}-4$ lin. latis, medio viridibus obsolete 3-nervins margine latiuscule scariosis decoloribus apice obtuso apieulato purprpurascentibús. Calyx aureus, 8-9 lin. Iongus, extus sericeo-pilosuș, tubo villoso, lobo postico 1-1 $\frac{1}{2}$ lin. longo, an teriorum intermedio 6-7 lin. longo, usque ad 2 lin. lató, lateralibus $4-5$ lin. longis, 1 lin. latis. Faucis squamulæ luteæ. (x. s. comm. a cl: Sonder.)

6. L. GLO BU L IF E RA (Meisn in -Línnæâ 1 \&, p. $412^{*}$ ), foliis oppositis línearibus pụngenti-acutis dorso convexis summis vix majoribus, involueralibus scariosis eapituio parvo multifloro brevioribus late ovatis acutis, calyee parvivo sericeo, lolis æqualibus ovatis, faucis squamulis filiformibus exsertis. I In arenosis, circa Goudinie, alt. 800-1,000 ped. (Drège! docum. p. 119, 4, B; b,-5), mont. circa Tulbagh et Brakfontein, alt. 3-4, (Ecklon. et Zeyh.:): Gonophylla setosa Eckl' et Zeyh.l mss. in herb., excl. syn. Thunb. Passerina eriocephala Thunb. fl. cap. p. 3.75? nec alior. (propter capitula parva et calycem " 'æqualem a potius huc quam ad L. efiocephalám Lam. spectare videtur)- Frutex pluripedalis, ramis gracilibos glabris. Folia opposita, remotiuscula, semiadpressa, 3 lin. longa, $\frac{1}{3}-\frac{1}{2}$ lin. 'lata, summa subcarinata. Capituła cerasi minoris mole, 3-5 capitato-congesta, rarius solitaria. Involuerum 4-phyllum, foliolis 3-4 lin. longis, $2-3$ lin. latis acutis vel acuminulatis viridibus glabris demum paleaceis fuscescentibus deciduís. Reccptaculum globosum, magnit. pisi majoris, dense albido lanatum. Calyx 2 'lin. lóngus, lobis tubo vix brevioribus intus: glabriusculis flavo-albidis? vel lilacinis. (v. s. cornm. a cl. Drège et in herb. ĐC. ex herb. Lambert, herb. Sender.)

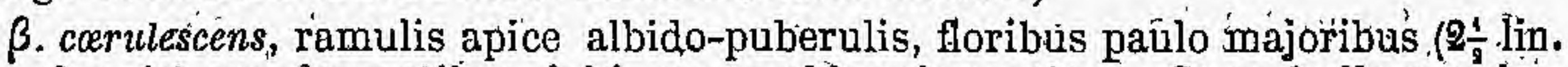
Iongis) corulescentibus, lobis ovata-eblongis acutis. - Gonophylla coerulescens Eckl. et Zeyh.! mss. in herb. (v. s. comm. a cl. Sonder.)

L. AM B I G A (Meisn. in 'Linnæâ 14, p. 417'), folii's sparsis aceroso-linearibus pungenti-acutis, involucralibus scariosis oratis acutis capitulo parro paucifloro parum brevioribus, calyee sericeo-villoso parvo, lobis æqualibus ovato-oblöngis, faucis squamulis filiformibus exsertis. 7 In Africæ Capensis montibus, circa Dutoitskloof, alt. 2,500-4,000 ped-(Drège! docum. p. 82, 3, A, e, 11)! Ramuli abbreviati, satis validi, nigricantes, cicatricibus dense tuberculati, glabriuseuli. Folia eonferta $_{r}$ laxiuscula, 2-4 lin. longa $\frac{1}{2}$ - fere 1 lin. láta, dorso subconvexa, 1 -nervia, glabra. Capitula terminalia, solitaria, 2-8-flora, Involucrum 2-3-seriale, foliolis imbricatis, $2 \frac{1}{2}-3$ lin. longis, leviter nervoso-striatis, rubellis vel fuscis ${ }_{2}$ glabris. Receptaculum parvuhrm, velutinum. Calyx 2 sere 3 lin. longus, pube denșẩ brevi sericeâ haud adpresså villosus, tubo ovarium vix superante lobos æequante. Species valde similis $L$. nervosæ, sed foliis floribusque minoribus et priesertim involuero distineta.

a. major (Meisn. 1, c. p. 418), foliis lanceolato-linearíbus parum eonvexis; caji- 
tulis 4-8-flonis, floxibus majoribus flavido-albìdis involucrum plerumque manifeste superantibus (Drège, n. 7368, a.! (v. s.)

B. minor (Meisn. 1. c.), foliìs angustissime lineari-acerosis complicato concavis, capitulis 2-rarius 4 -floris, floribus minoribus niveís involucrum parum suporaṇtibus. (Drège, n. $7368, \mathrm{~b}$ ! v. s.)

8. L. BUR C H E ELII (Meisn. l. c. b. 420), foliis oppositis lanceolato-linearibus acutis subplanis, involucralibus parvis ovatis obovatisve, capitulis terminalibus axillaribưsque sessilibus paucifloris, calyce parvo, lobis ovato-oblongis, faucis squamulis brevissimis. I In Africà Capensi. Habitus fere L. ambiguæ; at distincta foliis oppositis remotioribus majoribus, floribus, etc.

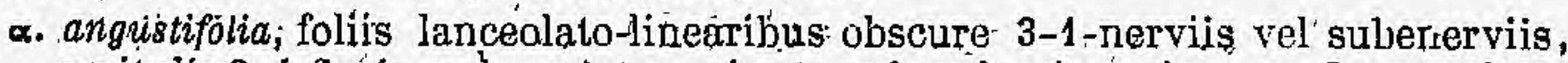
capitulis 2-4-floris, calyce éxtus minute puberulo vix sericeo. - In montỉbus distr. George, alt. 5 (Drège, n: 7370 l Ecklon et Zcyh.J). L. Burchellii Meisn. 1. c., cum descr. Gridia tenưiflora Eckl. et Zeyl.! mss, in herb. Folia 3-5 lin. longa, $\frac{1}{2}-1$ lin. lata. Capitula in summis axillis opposita vel alterna, approximața. Involucrum imbricatum, foliolis intimis 4 membranaceis fuscis obtusis subenerviis. Receptaculum cxiguum. Calyx 2-2: lin. longus, rubellus? involucro vix longior, tubo lobis breviore. (v. s.)

ß.? latifolia, foliis ablongo- vel subovato-lanceolatís dorso 3-nerviís, capitulis 6-12-floris, calyce dense sericèo. - ln montibus, ad flum. Vánstadesrivier, alt. 2-4, distr. Uitenlage (Eçklon, n. 78! Zeyher, n. 3757!). Gonophylla nana Eckl. et Zeyh.! mss: in herb. (ex parte). Folia usque ad 2 lin. longa, nervis subtus acutiuscule prominulis subparallelis. Capitula plerumque terminalia, floribus cano-sericeis. Gæt. ut in var. $\alpha$. Forsan tamen species distincla. (v, s. comm. a cl. Sonder.)

\section{Sectio Ir. Conoclinium Meisn. in Linnoed 14, p. 413.}

Capitula terminalia vel subterminalia, pauci- vel multiflora, exinvolucrata, receptaeulo crassiusculo conico-hemisphærico tomentoso tnljerculato interdum demum elongato cylindraceo. Flores parvi, re'gulares; utrinque pubescentes, tubo limbum subrequanto vel breviore. - Fruticuli ramis gracilibus, folís sparsis semipatulis.

9.: L. sтr a t a (Meisn. 1. c. p. $415^{\star}$ ), ramis puberulis, foliis ovato-oblongis Ianceolatisve acutis subplanis ciliatis subtus nervis $3-5$ subparallelis prominulo-striatis, capitulis subsessilibus vel breve pellunculatis. $\zeta$ In Africâ Capensi (Thụnb. $)_{2}$ mont. Wintherhoeksberge, alt. 2,500-3,000 ped. (Drège I docum. p. 77, 3, A, e, 3), prope Tulbagh (Ecklon!). Passerina striata Lam.! herb., ill. t. 291, f. 2, Poir. in diet. enc. 5 , p. 44*. P. nervosa Wilistr. Thym. p. 328? ox cit. Lam., non Thunb.? (cfr. L. nervosa). Gonophylla tervosa Eckl. et Zeyh.! mss. in herb. Fruticulus elegans, corymboso-ramosus, conferte foliosus. Folia sessilia, glabra, 3-5 lin. longa, 2-2 $\frac{1}{2}$ lin. lata, subpungentia, basi obtusiuscula, læte viridia, supra enervia, subtus 3-5-costata. Capitula 8-16-flora, cerasi mediocris mole, pedunculo 2-4 lin. longo vel subnullo. Receptaculum parvum, haud extrescens. Calyx $2 \frac{1}{2}$ lin. longus, rubellus vel albus, lobis ovato-oblongis acutis. Fançis squamulæ ligulares, fere-1 lin. longæe, semiexserta. $\left(\mathrm{v}_{*} \mathrm{~s}\right.$. in herb. Lam;, etc.)

10. L: caprtata (Meísn, 1. c. p. $44^{*}$ ), foliis aceroso-linearibus pungenti-acutis subenerviis glabris, capitulis solitarijs laxiforis hemisphæricis vel demum conicis pedunculo apice turbinato receptacnloque sericeo, calyce extus toto sericeo-villosiusculo, lobis tubum subæquantibus, faucis squamulis filiformibus semiexsertis. F In planitie arenosâ et montibus promontorii Bonæ-Spei et distr. Żwellendam (Sonnerat! Thunb., Niven! Ludwig ! Drège! Ecklon! Zeyh:! etc:). Thymelæea Burm. Afr. t. 43, f. 3. Passerina capitata Linn. amcen. 6, p. 88, Lam.! herb., ill. t. 291, f. 3, Poir. dict. 5, p. 41, Thunb. prodr. p. 75, fl. Cap. p. 376, Wikstr. Thym. p. 329, Wendl. Beob. t. 2. Lachnæa phylicoides Lam !! herb., dict. 3, p. 374. Rami nunc elongati gracillimi pauciramosi sæpe dichotomi, nunc abbrevĩati firmiores subcorymbossi, glaberrimi vel apice minute puberuli. Folia laxiuscula, 3-8 lin. longa, $\frac{1}{3}$-fere 1 lin. lata, arl insertionem semper paltida, dorso convexa enervia vel subcarinato-1-nervia, rarius plana. Pedunculi 2-4 lin. longi, sursum plus minus

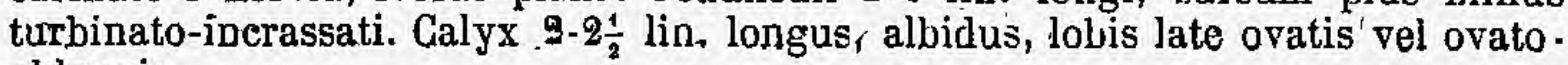
oblongis. 
a. patciffora (Meisn. 1.. c.), capitulis ' 8 -10-foris, receptaculo brevi conico-hemispbcerico, foliis angúste acerosis complicato-canaliculatis, ramis gracilibus (Drège!-Krauss, n, 76, ! etc.). Gonophylla-acuminata, et pro parte. G." conglomerata et capítata' Ecklon ot Zeyh! mss. in herb (v: s. in herb, Lam., D. ., e.c.)

B. mutiflora (Meisn: I, -e), capitulis multifloris, receptaculo demüm elongato cylindraceo-conico spiraliter tuberculato, foliis latioribus subplanis, ramîs

". finionioribus (Drège! spécim. ad Dieprivier lecta, Burchell, n. 191, 712 I Eckl, et Zeyh., 5.1484 ! Krauss, n. 761 !). Receptaculum demum 4-6 lin. longum, $2 \frac{1}{2}$ lin. érasșum. (v. s.)

11. L. DEN S IFLARA, foliis aceroso glabosis dense multifloris, pedanculo apice turbinato cano-tomentoso, receptaculo Jate ovato-corfico villosiusculo haud excrescente, calyce tomentello, lobis tubo denum glabriusculo longioribus, fauce squamulis filiformibus semiexsertis; \$'In planitic Capensi et distr. Caledon (Niven I Ludwig I Eelilon ! Zeyh. n. 1483!). L. phylieoides Lam. ill. t. 292, f. 3 ? non hierb:" (cfr. infra L. diosmoides). Lachna et Gonophtrlla capitata et conglomerata Eckl. et Zeyh.!-mss. in herb. (ex parte). G. pliylicoides Eckl. et Zeyh.! mss. ib. Folia et florum structura penitas Li: capitatze, quăcum. hucusque confusa et in hèrbariîs sæpe mixta. Differt vero ramis maggis ramosis, minus gracilibus, pedunculo apice minus incrassato; capitulis globosis 20-floris et ultra, receptaculo (immo juniore) magis tumido ovoideo scrohiculato (nec tuberculato), pube sordidấ brexi villosiusculo, magnit. pisi minoris, calyce ủtrinque pube breví albidâ vix ac ne vix sericeâ extus demum rarescentè tomentoso, lobis tubo fere duplo longioribụs. (v. s: in herb. DG., Mart, , Mus. Stuttgatt; etc.)

12. L. A L PIN A, foliis imbricatis spathulato-linearibus obtusis płanis 4-nerviis ramulisque glabris, capitulis heinisphæricis dense multifloris, pedunculo nullo vel vix dilatato, receptaculo parvo convexo tomentoso, calyce utrinque sericeo-villosiusculo; lobis oblongis tubo sublongioribus, faucis -squamulis parvis filiformibus subexsertis. F. In monte Winterhoeksberg, prope Tulbagh, alt. 6,000 ped. (Ecklon I). Gonophylla alpina Eclslon et Zeyh.! mss. - in herb. A'n passerina globosa Lam. ill. t. 291 , f. 4 ? quie ex ic. cum nostrâ satis bene convenit, sed ic. Búrm. Afr. t. 46 , f. 3, a Wikstr. Thym. p.329, łuc citata (P. planifolia Burm.) longe abhorret, flore potilis Crystadeniam referens, et propter folia punctata yerisimiliter alieni ordinis, forsan Diosmea quadam. Frutticulus humilis, ramis corymbosis atrofuscis dense eicatrisato-tuberculatis. Folia sparsa, subadpressa, paflide viridia, 3-4 lin. longa, 1 lín: lata, basi attenuata, plana vel margine leviter incurvó, nervo parum conspicuo, Capitula magnit. avellanæ minofis, 15-20-flora, sessilia foliisque paulo superata, deinde pedunculo semipólicari gracili villoso- suffulta.-Receptaculum 'magnit, grani pipéris, scrobiculatum. Flores (ex sched.) albi. Caet. L. capitatæ. (v. s. in herb. Sonder.)

\section{Sectio II. Microchinium Meisn. in Linnoeâ 14, p. 416.}

- Flóres sessiles terminales subcapitati vel subsolitari, rarims axillares solitarii. Involucrum proprium nulfum. Receptaculum obsoletim. Calyx parvus, regularis. utrinque pubescens, tubo limblum æquante vel breviore. Faucis squamulæ ligulares brevissimæ. Frutices vel suffruticuli foliis sparsis vel oppositis linearibus vel subacerosis.

13. L. DT o s n o ID E (Meisn. 1. c. p. $418^{\star}$ ), ramis gracilibus, foliis sparsis acerosolinearibus acutis, eapitulis terminalibus sessilibus 2-10-floris, calyce canescentitomentello, lợis ovatis ołbtusiusculis. $亏$ In Africæ Capensi distr. George, alt. 1,0002,000 ped.

a. elatior (Meisn. 1. c. p. 419), ramis virgatis strictis, foliis confertis junioribus sibailpresso-imbricatis dorso plus minus convexis, floralibus paralo dilatatis, capitulis 4-10-floris (Drège ! Jcklon! Krause, n: 773!). L. phylicoides Lam. ill. t. 292,1 . 3 ? non herb. nec dict. 3, p. 374 (cfr. Iu. eapitata et densiflora). Gonophylla acuninata et Gnidia tenuiflora Eck]. et Zeyh! mss. (ex parte). Rami pedales el uftra, ramulis conferte corymbosis.tenuibus glabris. Folia 2-5 lin. longa, $\frac{1}{3} 1 \frac{1}{2}$ lin. lata, dorso 1 -nervia plus minus convexa vel subcarinata, 
-lloralia inferne plus minus dilatata usque ad 1 lin. lata. Capitula interdum plura arcté approximata. Flores 2 lin. longi, rubelli? (v. s.)

ß.tenella-(Meiśn. 1. c.), ramis tenuibus adscendentibus, foliis remotiusculis sape oppositis patentissimis vel deflexis subplanis, floralibus haud dilatatís, eapi-

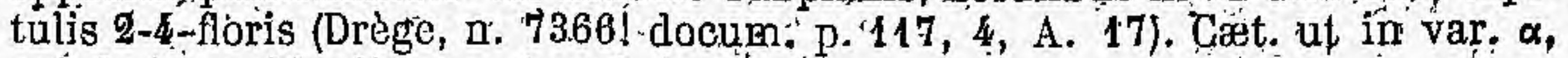
sed facies valde diversa. (v. s.)

$\gamma$.? major, foliis crassioribus' latioribus dorso rotundato-convexís supra concavis, floribus majoribus 3 lin, longis. Gæet. ut in var. $\alpha$ (Zeyh.!). Calysericos parviflora Eckl. et Zeyh.! mss. in herb. ex parte. Forsan species distincta (Läehnæa crassifolia nob. in herb. Sond.). Folia rigida, arcte approximata adpressa, 2-3 lin. longa, $\frac{1}{2} \frac{2}{3}$ lin. .lata, interdum obsolété 3-nervia, apice sæpe incurvo. Capitula maguit. cerasi minoris, 6-12-flora. Calyx 3 lin. longus, althus? tubo bísi glabro lobis breviore. Squamulæ faucis, glandulares. (v. s. in herb. Drègo et sọnd.).

14. L. NER vo.sa (Meisu. $i$, c. p. 417 ), ramis gragilibus puberulis, foliis - sparsis aceroso-linearibus pungentibus dorso convexo 3-nervifis', floralíbus 'latioribus 3-5-nerviis, capitulis terminalibus corymboso-aggregatis paucifloris, calyce mediơcri śericeo-villoso, lobis oblóngịs 'acutis. F In 'Africa Capensi (Niven! Drège! n. 7365!), circa Grootvadersbosch. et Zwellendam (Ludwig!t Ecklon! Zeyher, n. 3767!). Gonophylla stricta Eckl. et, Zeyh. I'mss. in herb., (forma foliis minoribus, 3-4 lin. longis, subulatîs). Passerina nervosa Thunb. fl. cap. p. 375? Wikstr. Thym. p. 328 ? (excl. syn. Lam.; cfr. supra. L. striata). Rami súbvirgati, elongati, subsimplices. Folia glabra, 5-7 lin. lónga, 1 lín... lata. Capiţula inter folia basi paulo dilatata sessilia, 2-4-flora. Galyx 3-4 lit, longus, albido-villosus, intus glabrescens, lobis tủbo dinplo longioribus intus lilacinis? Squamulæ fancis compresso-filiformes, exsertse. (v. s.).

15. L. gR Acru Is (Meisn. l. c. p. 421 *), ramis gracilibus, foliis oppositis semipatulis linearibus obtusiusculis planis glabris dorso 1 -nerviis, floralibus haud latioribus, capitulis terminalihus 2-4-ftoris, calyce parvo sericeo-puberulo, lobis ovalibus obtusis tubo brevissimo longioribus. 5 In montanis, circa flum. Hexrivier, alt. 3,000-4,000 ped. (Drège, n. 583! docum. 1. 114, 4, A, 6). Rami tenuês, strieti, glabri. Folia internodiis subrqualia, 2-4 lin. Ionga, vix 1 lin., lata, floralia 4 vel

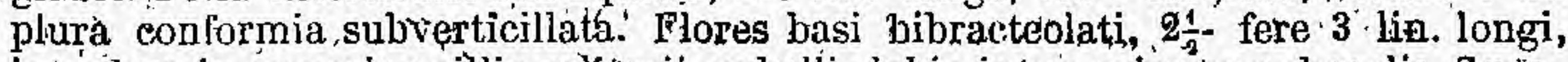
interdun in sumnis axillis solitarii, rubelli, Jobis intus nibute: puberulis. Sqựmulx faucis brevissimie ohtusæe subglandulosæ. (v. s.)

16. L. ERIC oIDES, ramulis tenuibus puberulis, foliis oppositis sparsisque linearibus obtusis carinatis incurvis demum glabris, capitulis terminalibus.3-6-floris calyce parvulo utringrue puberulo, lobis oyatis obtusis tabo angustó glabro longiơribus. $J$ In montibus, circq. Groolvadershosch et Voormansbosch. alt. 3-5, distr. Zweflendam (Ludwigl' Zeyher, n. 3776!), Gonophylla ericoides Éckl. et Zeyh.! mss. iu herb: h. 72 et 90 . Fruticulus tenellus, spithamæùs-pédalis, radice fihrosạ, cálule erecto tènui larvi superne corymboso-' vel fastigiato-ramóso. Folia conferta, subrdpressa, demum patula, 1-3 lin. longa, $\frac{1}{2} \frac{2}{3}$ lin. lata, falcato-inćurva, rarius reeta, supra concava, subtus acute cärinata. Capitula magnit. pisi, floribus $1 \frac{1}{2} \operatorname{lin}$. longis rubellis. Squamulæ perigynæ glanduliformes, minuta, in faucis barbâ sergiabscondita. Variat,: $\alpha$ ) foliis $1-1 \frac{1}{2}$ lin. longis obtusis plus. minus areuatis fortiter carinatis glaberrimis vel novellis tantium apice penieillo minuto albo barbatis, et $\beta$ ) foliis inferioribus acerosis acutis rectis 2-3 lin? longis apice albo-penicillatis demum nudis, summis breviaribiss, obtusiusculis subarciatıs, floribus pulue copiosiore et longiore villosiusculo-tomentosis. (v. s. in herb. Mus. Stuttgart. et comm. a cl. Șonder.)

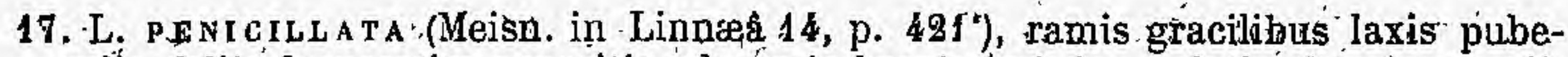
rulis, foliis decussatim oppositis adpressis brevissimis lanceolatis obiusis complicato-triquetris margine apiceque dénse albo-villosulis demum glabris, floribus terminalibus solitariis sessilibus parvulis argenteo-sericeis, lobis ovato-oblongis acutis tubo basi angusto glabro brevioribus. 3 In rupestribus, inter Sparrbosch et Trado, alt. 2,000-3,000 ped. (Drège!), in montibus, prope flum. Gauritzrivier, alt. 4, distr. George (Ecklon!). Passerina bruniades et brunioides Eckl. et Zeyh.! mss. in herb. (ex parte). Facies et folia Passering filiformis. Folia 1-2 lin longa, 
$\frac{1}{9}$ lin. latà, acutiuscule carinata, juniora apice penicilio brevi villorum seticeorum niveo-barbata. Calyx vix 2 lin longus, intis rubellus. Squamulæ faucis exigur petaloidęæ? 'obtusæ, semiexsertæ. (v. s.).

18. L. AXILLAR Is (Meisn. l.c. p. 422*), ramulis filiformibus puberulis, foliis oppositis patulis parvulis subtriquetro-subulatis glabris, floribus axillaribus vel raro terminalibus subsolitariis parvulis utrinque glabris, fauce barbatâ, lobis otatis acutiusaulis tubo longioribus. 5 In Africâ Capensi (Drège, n. 7371!), in montibus, ad flum. Gauritzrivieier, etc., distr. George (Ecklon! Zeyher, n. 2163!), in planitie, Zoetendalsvallei, distr. Zwellendam (Krauss, $n$. 1265 bis !).-Meisn. in Hook: Lond. journ. 2, p. 552. Radojitskya Capensis Turcz.l in Bullet. Soc. imp. Mosc. 1852, n. 3, p. $176^{*}$, Flora bot. Zeit. 1853, p. 743 (fide cit. pl. Zeyh.). Passérina brunioides Eckl. et Zeyh.! mss. in herb. (ex parte). Fruticulus laxus, ramis arcuatoflexuosis, ramulis tenellis. Folia internodiis síbæequalia, 1-2 lin. longa; tenuia, dorso convexa vel obtuse carinata. Flores passim terminales, rubelli'? vix $1 \frac{1}{2}$ lin. longi, in apice ramulorum nonnunquam 3-4 aggregati. Squamulæ faucis exiguæ, glandulosær? subexsertæ. (v. s.)

\section{Spécies exclusa.}

L. C ONGL OMERA TA L. = Passerina ericoides L.?

L. ER I OCE P HALA Heyne = Lasiosiphon eriocephalús. Desne.

L. PAL E A CEA Banks herb. = Passerina paleacea Wikstr.

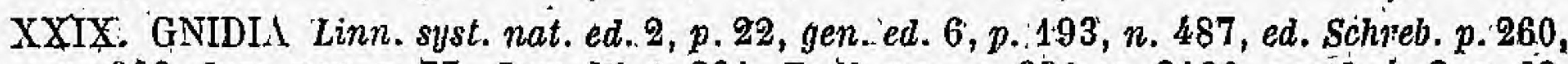
n. 666, Juss. gen. p. 77, Lam. ill. t. 291, Endl. gen. p. 331, n. 2100 , suppt. 4, 2, p. 63, n. 2102 , Meisn. in Linnad 14, p. 123 (excl. sect. 1), gen. p. 330 (243). - Struthia van Royen in Linn.gent. ed. 2, p.154,n. 380,-Dessenia Adans. fam. 2, p. 285. - Nectandra Berg. cap. p. 131, Juss. l.c. (non alior.). - Thymelina Hoffmansegg Verzeichn. 1,p. 198 (ex parte), f. 2, -Endl. gen. p. 331, n. 2101.- Canalia F. V. Schmidt neue Pfl. Prag. 1793, n. 5, f. a, b. - Epichroxantha et (ex parte) Calysericos Eekl. et Zeyh. mss.

Tores hermaphroditi, 4-meri. Calyx coloratus, infundibuliformis, tubo supra ovarium demum circumscisso deciduo, limbo 4-partíto regulari. Squamulæ 4 vel 8 summæ fauci ad sinus insertæ, singulatim vel geminatim staminibus superioribus alternæ, exsertæ, petaloideæ vel carnosæ, bilobæ vel integræ, glabræ vel rarius tómentosæ. Antheræ 8 fauci biseriatim insertæ, subsessiles, superiores lobis oppositæ semiexsertæ vel rarissime abortivæ, lineares vel oblongæ obtusæe, dorşo prope basin affixæ. Annulius hypogynuș nullus aut exiguus, plerumque obsoletus. Ovarium sessile, stylo laterali capillari calycis tubum æquante, stigmate capitato papilloso. Nucula calycis basi persistente inclusa. Semen parce albuminosum. - Frutices vẹl suffrutices Africæe australis et orientalis tropicæ, ericoidej; ramis gracilibus, foliis sparsis vel oppositis plerumque angustis, floraibus interdum majoribus verticillatis involucrum formantibus, floribus terminalibus capitatis, raro solitariis vel axillaribus vel breve spicatis, albis lavis rubellis vel lilacinis extus plerumque pubescentibus.

\section{Sectio I. Eugnidia Endl. gen, suppl. 4, 2, p. 64.}

Flores terminales capitati vel subsolitarii, nunquam spicati.

\section{\$1. Antherse superiores (quce calycis lobis opposita) abortivoe, seilicet deficientes, vel inferioribus dimidio minores effoto, vel ruidi- mentaria.}

1. G. ANOMALA (Meisn. in Linnaed 14, p. $435^{*}$, excl. $\beta$ ), foliis inferioribus sparsis, superioribus oppositis ovalibus vel ovato-oblongis obtusiusculis dorso 3-5-nerviis utrinque ramulisque sericëo-pilosis, capitulis 4-8-floris, ealyce gracili sericeovilloso, faucis siquamis 8 subcarnosis clavatis basi-eetılosis. 7 In rupestribus mon- 
tanis, circa Lowryspass, alt. 1,500-2,000 ped. (Drège, n. 7348 a! docum. p. 84, 3. A, e, 23), circa' Houhoek; Palmiet et Potrivier (Eeklon 1), Hottentottshollandsberge, alt. 4-5 (Zeyh.. n. 37.64 l). Eckl. et Zeyh: $n_{*} 6 ! \cdot 56$ !). G. argentea Eckl.! injherb, Ludwig. Rami graciles, cum folïs dense albido-villosi inferne demum glabrescentes. Folia 4-6 lin. longa, 24-4 lin. lata, subplana vel supra, præsertín basin versus, concava, involucrantia cæeteris sæpius paulo majora magisque sericea. Calyx 6-8 lin. Iongus, pallide flavus'? sericeo-splendens, lobis oblongo-láriceolatis subacutis. Glandulæ lineari,spathulatæ, obtusæ, Jobis dimidio breviores, basi setulis minutis cinctæ. Antheræ superiores nunc nullæ, nunc parvæ effectæ. Antulus hypogynus manifestus, parvulus albido-membranacess. Ovarium glaberrimum. (v. s.)

2. G. HAR V EY A A (Meisn, l. c. p. 437 \%), ramulis apice ineano-puberrulis, foliis oppositî́s verticillatísque ovalibus obtusissimis dorso 3-5-nerviis adprèsse subsericeo-p̃ilosis subtus demum glábrís, capitulis bifloris, calyce albido-yilloso, faucis glandulis 4 lineari-oblongis undique glaberrimis. $ち$ In Africâ Capensi (Drège !). Fruticulus sesquipedalis subsimplex: Folia $4 \frac{1}{2}-5 \frac{1}{2}$ lin. longa, 2-3 lin, lata, pleraque quaternảtim vertícillata, dorsó demum glabra, supra dense sericeo-cana, involucrantia haud majora. Calyx gracilis, foliis ćrc. dimidio longior, lobis oblongis obtusiusculis. Faúcis glandulæ flavæe; subacutæ, basi setulis destitutæe. Staminum superiorum filamenta eastrata exigua. Præcedenti proxime accedens, at jam glandulis faucialibus 4 noc 8 bene distincta. (v. s.)

\section{§ 2. Antherce octo perfectop; aquales. Faucis squamulce glaberrince.}

a. Calyx extus dense cano-pubescens vel villosus vel sericeus. Holia ínvolucrantia cateris conformia vel rarius paulo majora vel minora.

3. G. SGABRIDA (Meisn. 1. c. B. 446"), ramis puberulis, foliis sparsis lanceolatólinearibus acutis puncticulato-scabriusculis dorso obsolete 3-nervi piloșiusculis demum glabrescentibus summis piloșis, capitulis 6-8-floriș, calyce tomentoso, lobis lanceolato-olılongis acutis faucis squamas 8 subpetaloideas dimidio superantibus. $\overline{7}$ In montanis, prope George, alt. 1,000-2,000 ped: (Drège, n. 7356! docum. p. 117, 4, $A_{1} 19$ ), ad-summitatem montis Diaboli, alt. 5 (Ecklon !), ad ostium flum. Klynrivier et circa Tulbaghskloof et Zwarteberg, alt. 4-5 (Zeyh. n. 3743!). G. elongata Eclkl. et Zeyh. herb. n. 3! 4 ! Rami stricti, elongati, simplices vel apice, corymboso-polycephali. Folia conferta, subcoriacea, 6-9 lin. longa, $\frac{3}{3}-1 \frac{4}{2}$ lin. lata, attenuato-acuta, haud pungentia, jumiora pube albidâ pilósula et ciliata, involucralia circ. 8 paulo minora patula. Calyx 8-9 lin. longus, tubo gracili, lobis vix $\frac{1}{2}$ lin. longis, $\frac{2}{3}$ lin. latís, intus puberulis. Squamæe oblongæ, subacuminatæe, lutex. Anther: superiores ovales inferioribus linearíbus dimidio breviores, attamen perfectæ. Variat foliis plus minus læevigatis. (v. s.)

4. G, ruBescens (Berg. pl. Cap. p. 124*); ramis atris apice pubescentibus, foliis coriaceis sparsis suboppositisque ovato-oblongís vel lanceolatis planis enervits punctato-scabriusculis adpresse pilosis demum glabris, summi æaqualibus, capitulis 4-8-floris, calyce subsericeo-cano, lobis ovato-oblongis tubo multo breviorihus, farncis glandialas 4 ovatas bifidas triplo superantibus. \% In promont. BonæSpei (Berg., Burchell, n. 576 ! Ludwig ! efc.), monte Tabulari et Steenberg, alt, 3-5 (Eck1. n. 2!'Un. itin. n. 359 I Zeyh. n. 3759!).- Meisn. in Linnæâ 14, p. $438^{\star}$ : G. tomentosa Linn: sp. ed. 1, p. 512? Wikstr. Thym. p. 317, Thunb. fl. cap. p. 381. G. punctata Lam.I herb., dict. 2, p: 765* G. scabra Thunb. 1. c. p. 380 ? Calýsericos typica Eckl. et Zeyl. herb. n. 62! ex parte. Rami nigricantes, cicatricosofuberculati. Folia imbricata, deinde patula, 4-7 lin. Longa, 2-3 lin. lata, obtusa vel acutiuscula, dorso margineque punctis albis scabriuscula. Calyx 8-10 lin. longus, cano-villosus, tubo gracili, lobis 2 lị. longis acutiusculis. Squamæ subcarnosæ flavæ. (ì. s. in herb. Lam., etc.)

5. G. GÉPHAL OTES. (Lichtenst. mss. in herb. Willd. n. 7575!), ramulis superne pilosis, foliis coriaceis sparsis suboppositisque Janceolatis obtusiusculis dorso convexo obtuse nervoso-striatis punctato-scabriusculis ciliatis demún- lrevibus glabris, summis latioribus acuminatis, capitulis 4-6-floris, calrce sericeo, lobis ovatis tubum subæquantibus, glandulis 4 parvulis bifidis. 5 In arenosis et rupestribus montium Houhoek, Hottentottsholland, Nieeuweberg et Klynriviersłlọ,oof, 
distr. Galedon, alt. 2-5 (Zeyh. n. 3743! 3745! G. grandiflora Meisn, in pl. Zeyh. (non? Willd.). Calysericos argentea Eckl. et Zeyh. herb. n. 63। et (ex parte) G. typica.E. et Z. jb. n. 62 ! Species insignis, $G$. pubescentem inter et scabridam medium tenens, a posteriore, cui habitu folísque omnino convenit, distingurenda ramis diu pilosis, cicatricibus minus próminulis, 'foliis junioribus dorso' plús minus pilosis, et presertim calycis sericei (neè cano-tomentosi) lobis 3-4-plo majoribus, 4-5. In. longis, 2-2 $\frac{1}{2}$ lin. latis, faucis squamulis vero parvulis ovatis bipartitis; a G. pubescente, cui calyce squamulisque similior, differt foliis longioribus angustioribus ( $6-7$ lin. longis, $1 \frac{1}{2}-2$ lin. latis) dorso rotundato-convexis subacuminatis, calyce majore pulchre sericeo, lobis duplo majoribus -utrinque pubescentibus. Flores videntur rosei, lobis venoso-reticulatis. Antheræ superiores inferioribus dimidio minores, sed, ut videtur, perfectis. Sicut species affines variat - foliis latioribus angustioribusqué (nune vix 1- lin. latis) dorsó nervosó-striatís rugosisve et subenerviis, plus minus scabris lævigatis̀quo. (v. s. in herb. Willd., DG. et comm. a cl. Sonder.)

6. G. PENICIL LATA (Lichteníst.! mss. in lięrb. Wil!d. n. 7576) foliis oppositis sparsisque linearibuis obtusis complicato-çonvexis enerviis levibus ramulisque glabris junioribus ciliatis, capitulis 2-6-floris, calyce sericeo, lobis tuabum subæequantibus lanceolatis acutis, squamis 4 parvulis petaloideis bipártitis. 'ち In Africâ. Capensi (Lichtenst.!-Sonnerat! Nivan!), cirça Lo wysys-pass, alt. 1, 500-2,0.00 ped., in montanis humidis (Drège l docum. p. 84, 3, A, 2. 23), Hottén tot tsholland, alt. 4-5 (Zeyh. n. 3742 !). - Meisn. in Linnæâ 14, p. 448. Facies fere Gryptadeniæe. unifloræe et in herbariis passim cưm hâc commix ta occurrens. Fruticulus ut videtụr humilis, corymboso-ramosus, ramulis terìibus. Folia $3-4$ lín. longa, $\frac{1}{2}-\frac{2}{3}$ lin. lata', apice plerumque purpurascentia, summa pilis albis dense ciliata apiceque penicillata, inferiora plus minus denudata, floralia imbricata subadpressa paulo longiora. Calyx albido-sericeus, tubo fere 4 lin. longo infundibuliformi basi angustissima, lobis patentibus fere 3 lin. longis, 1 lin. latis, ịtus glabris lilacinis. Squamulæ

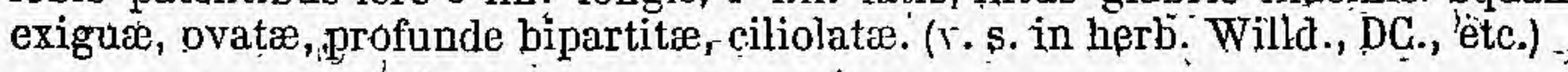

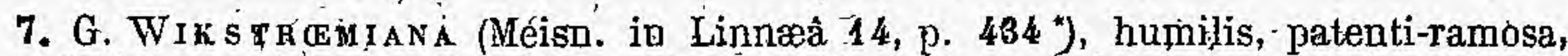
foliis oppositis patulis oblongo-lanceblatís utrinque adpresse subsericeo-pilosis, floralibus majoribus, capitulis 2-4-floris, calyce sericeó lobis tulo multo brevioribus angustis obtusis, squamis 4 exiguis petaloideis lineari-subulatis. 5 ln montibus Sneenwhergen et Compasberg, prope. Paardekraal, alt. 4,000-5,000 ped. (Drège, n. 7369! docum. p. 55, 1, c, 7). G- stricta Wikstr. Thym. p. 315? Passerina stricta Thunb. prodr. p. 76, fl. Cap. p. 377 ?-(ex Wikstr.). Rami vix palmares,

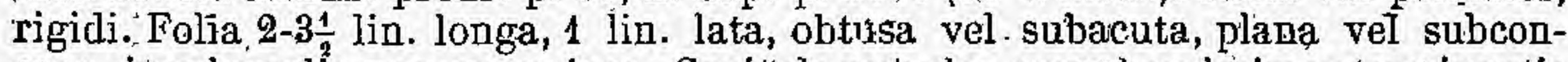
cava, involucralia parum majora. Capitularamulos sæepe-brevissimos terminantia et tunc quași lateralia. Calyx 4-5 lin. longus, tubo angusto, lobis vix 1 lin. longis, $\frac{1}{3}$ lin. latis. (vi. s.)

8, G. INGON.PICUA (Meisn. I. c. p. $433^{\circ}$ ), humilis ramosissima, folîs oppositis patulis reftexisve oblongis planis ramulisque adpresse pilosis supra demum. gla* bris, floralibus minoribus, capitulis bifloris, calyce sericeo-vithosiuscúlo; lobis tubo trulto brevioribus angustis oblusiuseulis, squamis 8 exiguis petaloideis. $\hbar$ In Africâ Capensi (Drège, n. 7349!). Rami breves, ramulis divaritatis tuberculosocicatricosis superne adpresse, strigoso-pilosiș. Foliza conferta; decussata, 3-5 lin. longa, 1-3 lin. lata, acutiuscula, supra minute puberula demum glabra; subtus adpresse rufo-setulosa, florália $2-3$ lin. longạ, 1 lin. lata novellaque subsericea. Calyx ,4-5 lin. longus, extins albido-pilosu's, intus likacinus glaber, squamulis albịs. (v. s.) .

9. G. LIN OIDES (Wikstr. Thym. p. 316), herbacea, caulibus ramulisque filiformibus glabris, foliis oppositis subulato-linearibus acutis glabris, involucralibus æequalibus ciliatis, floribus terminalibus solitariis sericeis; lobis tubun subæquantibus oblongis acutis, squamis 4 bipartitis petaloideis. $\odot$ vel $\not 2$ ? In humidis graminosis montium Hottentottsholland (Thunb.), Páarlberg, alt. 1,000-2,000 ped. (Drège L docum. p. 87, 3, A, e, 27), 'ju sumnitate montis Tabularis (Eckl.|. $)_{j}$ in valle Breederivier, inter Worcester et Tulbagh (Ludwig!), ad Rivier Zonder Einde (Zeyh. п. 3774 !). - Meisn. in Linnæà 14, p. $449^{*}$. Passerina linoides Thứnb, prodr. p. 75, fl.cap. p. $375^{\circ}$. Caules tenelli, fere capillares, recti, nunc subsimplices pedales, nunc e basi sublignosâ vel radice cæspitoso-conferti adsiendentes; iterato-ramosi 
digitales-palmares. Folia internodio subrqualia, 2-5 lin. longa, $\frac{1}{4}-\frac{1}{2}$ lin. lata, patula, plana vel convexa, dorso 1-3-nervia, Calyx 3-4 lin.'longus, albidus, adpresse sericeo-pilosiusculus, tubo tenui, fauce infundibuliformi, lobis patulis $1-1 \frac{1}{2}$ lin. longis, Squamie lineares acutæ, flavæ, glabræ. (v. s.)

$\beta$ ? major, suffruticosa folris rigidulis subimbricato-adpressis. 5 ? In summitate montis Tabularis, distr. Cap., et Tulbaghberge, distr. Worcester (Ecklon !). Calysericos hnarifolia Eckl. et Zeyh.: herb. n, 69! Passerina linearifolia Wikstr, Thym: p: 343* ? Ramuli tenues quidem, sed rigidi, sulbligrıosi, conforte foliosi. Folia rigidula, acuta. Flores paulo majores. Cot. ut in tỹjo speciei, attamen fortasse distincta species, sed specim: nostra Insufficientia. (v. s. in hẻrb. Sonder.)

10. G, sERICEA (Linn. mant. alt. p. 375), foliis oppositis ovalibus obtusiusculis ramùlisque adpresse sericeo-pilosis, capitulis 2 -4-1loris, calyce sericeo, lobis obtjrsiusculis glandulas 8 clavatas vix dimidio superantibus. $\%$ in collíbus montíbusque Africæ Capensis (Thunb., SSonnerat! Berg.! ete.). - Thunb. fl. Cap. p. 381, Wikstr. Thym. p. 318; Wendl. Beob. t. 2. G.'oppositifolia Thunb.? 1. c. (non Linn.). Thynelea sericea Burm. Afr. t. 49, f, 2 ? Nectandra sericea Berg. pl. Cap. p. $131^{*}$. Thimelina sericea Hotfmannsegg, ex Steud. 1. c. Passerina sericea Linn. sp. ed. 2, 'p. 510. P. Thunbergii Wikstr. Thym. p: 343? Fruticulus erectus, ramis fastigiatis vel subcorymbosis. Folia imbricata, demum patula, ad ramificationes sepe quaterna verticillata, pube molli utrinque plus minus sericea; summa interdum paulo majora. Calyx 4 lin. Iongus, dense adpresso-pilosus albido-sericeus, lobis circ. 1 lin. longis, Ovarium glabrum. Annulus hypogynus exiguus, obsoletus,

a. vulgaris, foliis ovalibus oblongisve enerviis planis adpresse pubescentibus; summis aqualibus vel vix majoribus. - Circa Wynberg, Kampslraai, Hassagaybosch, Baviansrivier, diștr. Albany, ad montem Tabularern, etc. (Drège! docum. p. 106, 3, D, b, 7, Eckl.! Zeyh. n. 3760! Krauss, n. 7711). G. sericea Lam.! dict. 2, p. 766", ill. t. 291, f. ,3, Meisn. in Linnæâ 14, p. 435. G. azuręa Burchell! cat. geogr. n. 1316. Folia conferta, subadpressa, 3 vel passim ad ramifuationes vel floralia $4-5$. lin. longa, $\frac{1}{2}-3$ lin, lata. ( $v$, s. in herb. Lam. DG., etc.)

B? glabrescens, foliis 1 -nerviis subconoavis glabrescentibus, inferioribus linearioblongis, superioribus sensim majoribus, supmis ovato-oblongis 3-nerviis. - In monitibus, circa Capstadt, Buffeljagdrivier et Grootvaderbosch, distr. Zwellendam (E)kl. et Zeyh. herl. n. 12 ! Zeyh. n. 3761!). Folia immo juniora parce puberula, vix purpurascentia, inferiora 3-6 lin.'longa, 1-2 lin. lata, summa 6-7 lin. longa, 3-4 lin. lata, nervis 3 subparallelis tenuibus vel obsosetis. Calyx 5-6 lin. longus. Forte propria spècies. attamen folis exceptis nervís calyceque a var. $\alpha$ haud essentialiter distincta, (v: s. comm. a cl. Sonder.)

$\gamma$.hirsuta, foliis ovali-oblongis vel inferioribus linearibus planis vel concavis suberierviis rarhisque pube densiore seríceo-hirsutis, summ is latioribus. - In montibus Langekloof, distr. George, et Zwartebergen, distr. Caledon (Eckl. et Zeyh. a. 63!). G. nana Eckl. et Zeyh. herb. n. 22 ! (non? Wikstr.), et G. phylicifolia Eckl. et Zeyh. herb. n. 20. Folia 3-9 lin...longa, 1-3 lin. lata, pube nunc adpressa, nunc laxiusculâ molliori. Caet. ùt in var. $\alpha$. (v. s. comm. a cl. Sonder.)

11. G. BuRMANN (Fekl, et Zeyh. mss. in herb. n. 13! excl. cit. Burm.), ramulis patulis tenellis adpresse pilosis, foliis oppositis lanceolatis acutis planis enerviis utrinque adpresse pilosis sericeo-splendentibus, summis hand majoribus, capitulis bifloris, calyce sericeo, lobis lanceolatis acutis, squamis, 4 exiguis petaloideis hipartitis. 5 In lapidosis montis Leonis, alt. 2 (Eckl. n. 85 ! Sieber herb. Cap. n. 63!). Præcedenti valde quidem affinis, at jạm squamis faucialibus satis distincta; habițus laxior, ramuli debiles, pubéscentiă paulo longior magisque splendens;

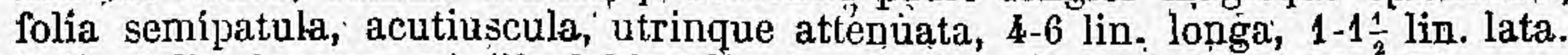
Calyx 5 lin. longus, gràcilis, Jobis 1 lî̀n. longis. (v. s. in herb. DC. et Sond.)

12. G. S TRigrLLos (Meisn. in Linnæâ 14, p. 459), foliis oppositis lanceolatis vel linearibus acutiuseulis planis 1 - vel 3 -nerviis utrinque ramisque hirsuto-pilosis, floralibus subequalibus verticillatis, capitulis terminalibus et in summis axillis sessilibus 2-1-floris, calyce sericeo, lobis lanceolatis acutis, squamis 8 lineari- 
sețaceis brevibus. 5 In Africâ Capensi, distr. Uitênhage (Drège! $\Omega .3538$, a, ex parte, Eckl.1) et in Caffraria- montibus, prope flum. Macanin, alt. 5-6-(Ecklon I). G. Caffra Eckl. et Zeyh. herb. -n. 14 | Fruticulus multicaulis vel ramosus, yix, spithameus, ramis erectis strictis cum foliis pilis laxiusculis modiee hirsutis tarde glabrescentibus. Folia subeoriacea, 3-5 lin. longa, 1-2: lin. lata, floralia interdum paulo latiorà. Calyx albụs, çerulescens (ex Eckl.), 4-5 lin.-longus, deuse adpresssopilosus, sericeus; squamis petaloideis basi setulis cinctis. Ovarium apice parce pilosiusculum. Ad G. Burmanni proxime accedens, sed pubescentiâ, squamis faucialibus, etc., satis distincta: (ves.).

13. G. NoDIFL O RA (Meisn. 1. c. p. 458'), canescenti-pubescens, follî́s 'sparsis suboppositis verticillatisque linearibus planis 1-nerviis, floralibùs 'ạqualíbuś, capitúlis terminalibus axillaribusque sessilibus paucifloris vel floribus passim ad ramifieationes verticillatis; calyce sericeo-villosiusculo, lobis ovatis obtusis squamas 8 petaloideas lineares superantibus. 5 In Africe Capensi distr. Zwellendam et 'Uiteṇhage et terrâ Tambulki (Drège, n. 3538, ex parte, et 4666! Eckl: n. 631! Zeyh. n. 3770! Verreaux!). G. cæspitosa Eokl. et Zeyh. herb. n.-18! Fruticulus palmari-subpedalis, facie præeedentis. Folia subcoriacea, 4-8 lin longa, 1- raro $1 \frac{1}{2}$ lin. lata, acuta vel obtusa, pube brevi molli, demum evanescente: Capitula, 3-6-flora, in summis axillis sessilia approximata vel terminalia, sed sæpius ramulo uno alterove ex involuciri axillis evoluto demum, superata et verticillum' mentientia. Calyx 5 lin. longus, coerulescens (ex Eckl.), tubo supra ovarium angustato, fauce infundibuliformi, squamis exiguis. Ovarium pubeseens. Var. $\hat{\beta}$ verticillata, olim 1. c. a nobis distincta cum typo speciei omnino confluit. (v. s.)

14. G. ALBICANS, foliis oppositis ovali-oblongis obtusis subconcavis subenerviis dense cano-pilosis summis majoribus sericeis, capitulis -2-4-floris, calyce villoso, lobis ovalibus obtusis squamas 4 petaloideas integras dimidio superantibus. Ж ? et $\zeta$ In Africà Capensi.

a. tenella, herbacea? caule ereoto spithamæe tenui simplicissimo, foliis imbricatis subadpressis, inferioribus lineaxibus obsolete 1 -nerviis glabriusculis. $\mathcal{F}$ In monte Constantiaberg, alt. 2,000 ped. (Krauss, n. 776!). G. tenella Meisu. in Hook. Lond. Journ. 2, p. 454* Radix fibrosa. Caulis strictus, 1-cephalus. Folia infima 2-4 lin. longa, vix 1 Jin. lata, supẹriora sensim majora et canescentia, summa soriceo-candicantia, 4-5 lin. longa, 3 lin. lata. Calyx 5 lin. longus, flavus vel rupellus villogsiuscưlus, lobis vix 1 lin. longis. Squamæ ovatæ, obtusæ, flave. (v. s.)

B. elatior, fruticosa, ramosa, foliis mox patulis omnibus owalibus oblongisye subenerviĺs summis vix majoribus. $\delta$ Girca Dutoitşklool (Drège, n. 7348, b!), mont. Houhoek et fl.Palmiet et Potrivier (Ecklon!). G. anomala $\beta$ villosissima Meisn. in Linncea 14, p. 436. G. tómentosa Eckl. et Zeyh. herb. n. 10! (nou Thunb.). Rami pedales et ultra, dichotomi ét umbellati, graciles. Folia 5-6 lin. longa, 3 'lin. lata, ad ramificationes sæpe 4 verticillata, novella albido sericea pube nunc adpressà nunc longiore laxiuscülâ villosâ, adulta subtomentoso-cana, passim obsolete 1 - vel 3-nerví. Cret. ut var. $\alpha$. Ovarinm glaberrimum. Annulus hypogỹnus manifestus, parvulus. (v.s.)

$\gamma$ ? grandiflora, fruticosa, ramosa, foliis imbricatis canis vel sericeo-viliosis demum glabrescentibus subnervosis, floribus rinajoribus. 5 Ad montes, prope Palmietrivier et Franschehoek, alt. 4-5, distr. Stellenbosch (Eckl. n. 52 ! 91!): Ramuli dense elevato-cicatricosi. Flores 8-9 lin. longi. Gæet. ut var. $\beta$. (v. s. in herb. Sonder.).

15. G. cHRYSOPHYLLA, ramis gracilibus glabratis, foliis oppositis imbricatis ovalibus obtusis planis enerviis ramulisque sericeo-splendentibús, summis vix majoribus, cápitulis 2-4-floris, calyce parvo sericeo, lohis ovatis obtusis squamas 4 sübcarnosas ovato-oblongas integras dimidio superantibus. 5 Ad flum. Karsrivier (Eckl. n. 86!). Omnia fẹre G. albicantis $\beta$, sed folia confertiora et pube densâ adpressissimâ pulchre aureo-sericea, calyx 3-4 lin. longus, ovarium apice puberulum et annulus hypogynus subnullus. ( $r$. s. comm, a cl. Sonder.)

16. G. I mBnicata (Linn. fil. suppl. p. 225), folits oppositis semipatulís oblongis lanceplatisque, obtusis planis 3-nerviis ramulisque cano-tomentosis demum glaJrescentibus; capitulis terminalibus passimique axillaribus subsessilibus 2-4-floris, 
calyce cano-villoso, lobis ovatis subacutis glandulas 8 lineares acutas vix dimidio superantibus. J In Africá.Capensi (Thunb.). - Wikstr. Thỳm. p. 318, Lodd. Bot. cab. t. 890 ? Thunb. fl cap. p. 381 , Meisn. in Linnæà 14, p. 437*-

a. genuina, ramis elongatis gracilibis, ramulis tenellis, foliis remotiusculis internadio subsqualibus, junioribus supra sericeis, floralibus paulo majoribus. - Circa Longevalei et Heorelogement (Dirège! docum. p; 109, 3, E, a, 9, Zeyh: n. 1497, b et $\mathrm{c}$ ). Rami pedales et ultra, fastigiati, ramulis erectis.

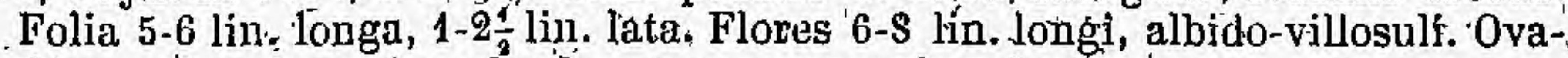
rium piberulum. Annulus hypogynus parvulus. (v. s.)

B. incana, ramulis brevibus corymbosis, foliis confertis incano-tomentosis, floralibus haud majoribus. - Circa He'erenlogement, Pickeniersklóof et ad Olifantsrivicr, distr. Clanwilliam (Zeyh.. n. 14.97, el 3763!). G. incana Eckl. et Zeyh. herb. n. 15!. Forma ad G. sericeam aocedens, sel characteres essentiales ómnino ut vạr. $\alpha$. (v. s.)

17. G. DE NUDATA (Lìndli in bot. reg. t. 757), ramis virgatis gracilibus apice pubescentibus, foliis oppositis oblongis obtusis planis utrinque jilosis vel demum glahris' dorso 3-5-nerviis, floralibus æqualibus verticillatis, capitulis multifloris, całyce villoso, lobis ovato-oblongis subacutis, scuamis 8 petaloideis ovato-oblongis parvis. p. 123, 4, C; b, 2, Zeyh.!). - Spreng. syst. cur - post. p. 152, Meisn, in Linnæâ 14, p. $441^{*}$. G. tomentọsa Hook. in bot.'mag. t. 2761 (excl. syn. Berg.: et? Thumb.). $G$. virescens 'Lckl, et Zeyb. herb. n.11! in Wikstr. Thym. p. 317? Frutex pluripedalis. Folia herbacea, decussata, patula, internodium æequantia vel diminio longiora, 6-12 lin. longa, 3-4́ lin. lata, pube molli laxiuscula haud serjceâ, nervis tenuíbus. Capitula. 4- $\infty$-flora, interdum lateralia subsessilia. Calyx 8-12 lin. longus, gracilis, pallide flavus, lobiș $1 \frac{1}{2}$ lín. longis, squiamas albidas longe superantibus. Ovarium apiçe pilosiusctulum. Anıulus hypogyou's manifestús, parvulus. (v.s. et v. v.c.)

18. G. CANIFL OR a (Meisti. in Linnæâ 14, p. 440*); foliis sparsis et suboppositis lanceolatis oblongisve obtusis subenerviis subtus glabris, supra ramulisque albido. tomentosis, floralibus subæqualibus, eapitulis 2-4-1loris, calyce cano-tomentoso, lobis ovatis obtusis glàndulas 8 lanceolatas parum superantijus. I In monte Giftberg, alt. 2,000-2,500 ped. (Drège, n. 7357 ! docum. p. 71, 3, A, c, 6), et prope flum, Gauritz, distr. Zwellendam (Eckl. n. 23!). G. taxifolia Eckl. et Zeyh. herb. ń. 23! Rami virgatí, graciles. Folia coriacea, eonferta, patula; 2-4 lin. longa, $1+1 \frac{1}{2}$ lin. lata, supra plus minus concava. Capitula sæpe lateralia, sciticet ramules breyissimos terminantia. Calyx 7-8 lin. longus, pủbe albịdâ haud sericeâ incanus, lobis 1 lin: longis intus 'flavis. (v. s.).

ß. Eckloniana, corymboso-ramosissima, ramulis brevibus dense foliosis, foliis utrincue adpresse cano-villosiusculis dorso demum glabris. - Circa sinum Saldanhabaay, distr. Cap. (Ecki..!)., G. andromedífolia Eckl. et. Zeyh. herb. n. 21 ! (v. s. comm. a cl. Sonder.)

19. G. s CABRA (Thunb. prodr. p. 76), ramis gracilibfis. puberulis, foliis sparsis vel suboppositis lineari-sulbacerosis acutis dorso convexo punctato-scabriusculis, floralibus æqualibus, capitulis terminalibu's et in summis axillis sessilíbus $2-1$-floris, calyce incana-tomentoso, lobis oblongis subacutis glandulas' 8 lineares fere dimidio superantibus. $\supset$ In campis collibusque Karrobideis, inter Koekmanskloof et flum. Gauritz, distr. Zwellendam (Ecklon!! Zeyh, n. 1496! Drège, n. 3537!). Wikstr. Thym. p. 313, Thunb. fl. Cap. p, 380, Meisn. in Linnæấ 14, p. 460* G. priestleyæfolia Eckl. et Zeyl. herb, n. 24! Rami lednes, pedáles; simplices vel

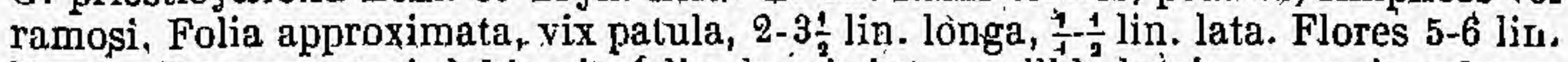
longi, albo-tomentosi, lobis vix 1 lin: longis intus pallide luteis, squamis subcarnosis croceis obtusis. (v. s.)

20. G. Gemintflora (E. Mey.l mss. in pl. Drèg.) ramis vix apice puberulis, folijs oppositis linearibus acutis complicato-concavis enerviis glabfis, summis majoribus supraque sericeo-puberulis, capitulis, terminalibus, lateralibusque sessilibus bifloris, ealyce sericeo-splendente, lobis ovatis acutis glandulas 4 ovatas bifidas parum superantibus. $D$ In collibus, inter Mierencasteel et Zwartdoornrivier, alt. 800. ped. (Drègel docum. p, 95, 3, $\mathrm{C}_{,}, 5$ ). $\rightarrow$ Meiśi.: in Linnæâ 14, p. 441'. Habitu- 
præcedentium. Folia coriacea, ,5- 7 lin. longa, 1-1: lin: lata, summa painlo: latióra vel ovato-larfceolata usquìe ad 2 lin. lata. Rlores 8-10 lin. longi, pube densâ ádpressissimà fulvã pulchrê splendentes, lobis $1 \frac{1}{2}-$ fere 2 lin. longis, squaruis carnosis orassiusculis rubro-fuseis. (v, s.)

3. brevifolia (Meisn. 1. c. p. 442), ramulorum foliis superioribus imbricatis ovatolaneeolatis acutis, inferioribus minombus -remotiuseulis. - Circa Hexriviershoogté; alt. 2,000-3,00,0 ped. (Drègel doutum.; p. 114, 4, A, 6). Folia súmma circ. 3 lin. longa. Flóres pallidiores, 6-8 lin. longi, lobis 1 lin: longis. Cxat. ut in typo. (v.s.)

21. G. OP P OSIT I F o L IA (Linu. sp. ed. 1, p. 358), foliis decussato-oppositís ovatis vel ovali-oblorigis acutis planîs ramiș que glaberrimis subtus 1-nervís ' floralibus atualibus margine sanguinès, capitulis 4-6-floris, calyce cano-pubescente, lobis obtusis squamas 4 subcarnosas oblongas integras päum süperantibus. Capensi (Thunb., Sonnerat! Burchell, n. 559! Ludwig!), in monitibus Tafelberg, Paarlberg, Dutoitskloof, usque ad alt, 3,000 ped. (Drège ! docum. p. 79, 81, 3, A, $e, 9,10 f_{2}$ circa Tulhagh, HottentottshoHand, Zwellendam, Klynrivier, Gráhamstown, Sliurfdebęrg, etc. (Eckl.! Zeyh. 'n. 3756! Krauss, n. 758!' etc.), Uitentage (Haryey!). - Lam.! dict. 2, p. 766*, ill. t. 291, f. 5, Bö. reg. 't. 2, Bot.mag. t. 1902, Bot. repos. t. 225, Wikstr. Thym. p. 312, Meisn. in Linnêa 14, p.431 (Aon Thunb.). G. løvigata Thunb. prodr. p. 76 , fl. Cap. p. 379*, Bot. repos. t 89 ,WendI. obs. 15, t. 2 , f. 14. G. latifolia hortul. Thymelæa Burm. Afr. t. 49, fig, 3. Passerina lævigata Linn. amon: 4, p. 312, sp. de. 2, p. 513. Nectandra lrovigata Berg. pl: Cap. 1. 134*. Rami virgati, gracil's, ramulis sanguineís. Folia subcoriacea, imbricata,

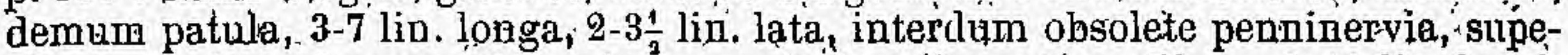
riora margine vel præesertịm apice sanguinea yel purpurea. Flores 6-10 lin. longi, tubo infundibuliformi rubente substriato, labis oblongis 1 lin. longis, intus fiavis, squamis obtúsis fuiscescentibus. (v. s. il :herb. Lam., Da., etc.)

\section{b. Galyix extus glaber vel parce pubescens, nec sericeus neo incano-tomentosis. Folia} inwolucrantia sapiuls eaterís majora ${ }_{,}$sailtem iatiora.

22. G. S ÜBORDATA (Meism. in Linpad 14, p. 430*), foliis oppositis brevissime petiolatis herpaceis ovato- $\phi$ blongis leviter cordatis planis ramisque glabris, floraribus haud-majoribus, capitulo 2 -4-floro, calyce glabriusctilo, lobis ovato-oblongis açutis sciuamas 8 petaloídeas superantibus $\mathrm{J}$ In nemorosis, eirca Morley, Africæ Capensis orientalis; alt. 1,000-1,500 ped. (Drège, n. 4670 ! docum. ij. 448, V, b, 35). Rami elongati, graciles. Folia distantia, patentia, adulta pollicaria, 6-8 lin. lata, acutipscula, basi rotundata emarginata, tenuiter 1 -nervia pennivenia, petiolo $\frac{1}{-1}$ lin. Iongo, superiora miriora. Calyx 5-6 lin. longus, lateus? junior parce pilosiusculus, mox glabratus, squamis oblongo-lanceolatis albis ? ( $\mathrm{v}$. s.)

23. G. н и м I Is, caule ramisque filiformibus laxis piłosiusculis , folis oppositis sessilibus herbaeeis oblongis utrinejue acutis planis obseure 1 -nerviis pilosis, floralibus æqualibus, floribus terminalibus geminis et in summis axillis sohtariis sessilibus pilosiusculis, lobis oratis tubo subbrevioribus squamas 4 pétaloideas ovato-oblongas dimidio superantibus. 5 Inter lapides; in cácìmine montis Tabularis (Eeklon et Zeyli. n. 89!). Suffruticulus ? circ. pedalis, ramis debilibus patulis, pitis albidis fere 1 lin. longis patulis tarde evanescentibus. Folia remota, inferiora internodio duplo breviora, pafula, 3-6.lin. longa, $1 \frac{1}{2} \cdot 2$ lin. lata, evénia, pilis haùd copiosis subadpressis, fugacibus in margine confertioribus et subpersistentibus. Calyx 3-4 lin. longus, latiuscule infundibuliformis, lobis acutiusculis. Antheræ ovales. Facies quodammodo-Arthrosolenis spicati. (i. s. in herb. Sonder.)

24. G. corLAcEA (Mèisn. in Linnæeà 14, p. 454"), glaberrina, foliis oppositis sesși- libus coriaceis ovali-oblongis acutis planis dorso 3-5-nerviis, floralibus subaqualibus, capitulis $2-1-1$ squamis 4. petaloideis parvis. 5 In montibus Zurebergen et Wiuterhoek, distr. Uitenliage, alt. 1,000-3,000 ped..(Drège, n. 7363! docuth. p. 135, V, a, 24, Krauss, n. 7571 ), in collibus Karrooideis, ad flum. I Koega, Langerivier, ${ }^{*}$ Zwartebèrg et Vanstadesberg (Eckl.! Zeyl. n. 3754!). Ejpichroxantha ovata Eckl. et Zeyh. herb. n. 81 . Fruticulus palmaris vel sjithamæus, ramosus, undique glaber, ramulis tenuibus apice compressis vel 4-gonis; Folia erecta vel pátula, basi obtusa vel rotundata, inferiora 3-5 summa 6-7 lin. longa, illa $\frac{1}{9}-2$ lin, flomalia $2-3$ lin. Iata 
nervis tenuibus subtus parum prominulis, lateralibus margine approximatis. Calyx 5-6 lin. longus; flavus? lobis acutiusculis $1 \frac{1}{2}$ lin. longis, squamis albidis. (v. s.)

25. G. SONDERIANA, ramulis dense albido-villosinsculis, foliis oppositis coriaceis ovato-oblongis apice attennatis obtusiusculis subenerviis supra concavis margineque longiúscule aĺba-villlpsis, floralibus æqualibus, floribus terminalibus subsolitariis laxe pilosis, lobis ovatis actutis tubo dimidio brevioribus gquamas petaloi-

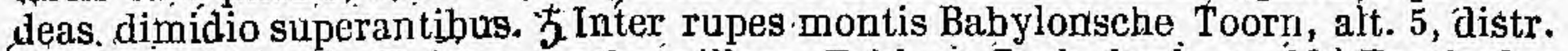
Caledon (Ecklon !)-Epichroxantha villosa. Eckl. et Zeyh. Kerb. n. 82! Frutículus humilis, ramis dense patenti-pubescentibus. Folia fere G. coriaceæ, séd subacuminata, obtusiuscuła, marginibus involutis plus minus concava, supra margineque jube albat sat densế. longiuscule villosa, subtus enervia vel passim, præsertim floralia, ohsolete.1-rervia. (v.s. in herb. Sonder.)

26. G. S т Y Ре L IOIDES (Meisn. in Linnæa 14, p. $453^{\prime}$ ), ramulis subquadrangulis apice puberulis, foliis opposilis cơraceis lineari-lánceolatis pungènti-açutis planis glabris dorso 3 -5-nerviis, floralibus latioribus, capitulis 3-1-floris, calyce puberulo, lobris oblongis acutis tubo duplo brevióribus squamas - petaloiddeas dimidio superantibus. 3 .In montibus Zuurebergen, alt. 2,000-2,500 ped. (Drège, n. 651 docum. p. 137, V, a, 28), circa Varistadesberg, Win (erhoeksberge ct Port-Elisabeth, distr. Uitenhage, Zwvartehoogdedis, Steenberg, Baviaansrivier, Hassagáybosch, etc. (Eckl.1 Zeỵh. 3753!). Epichroxántha pungens Eékl. ét Zeyh. herb. 11. 83! et ex parte E. simplex E. et Z. Species inter G. coriaceam et juniperifoliam medium tenens, illi foliorum nervatione accedens, sed foliis' angustioribus, 1-1 $\frac{1}{2}$ lin. latis, et calyce ramulisque puberqlís distincta; , huic foliorum fornâ similhor, sed nervatione

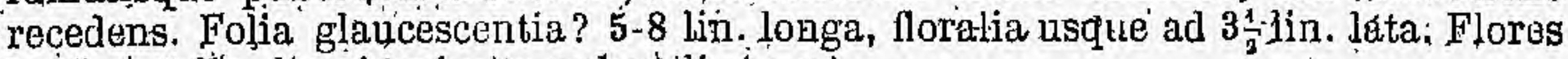
lutei, 4 -5 lín. longi, minute puberuli. (F. s.)

27. G. J UNIPE R IV OLI A (Lam. ldirct. \&, p. $765^{*}$ ); ramis virgatis, ramulis apice subquadrangulis puberulis, foliis sparșis passimque oppositis lanceolato-linearibus acutis glabris 1-nervijs vel enerviis, floralibus latioribus ciliatis stupra pilosiusculis giabrisve, capitulis 2 -k-floris, calyce subglaberrimo, lobis ovatis acutis tubo duplo brevioribus squamas 4 petalơidsas bilobás? dimidio superantibus. F In Africa Capensi (Sonnerat l), circa Sinfonsberg, Paarł, Lowryspass, Stellenbosch, att. 5002,000 ped. (Drègé I Krauss, n. 774.1), in planitie, circa urbem èt móntib. TafelDuyvels-Tygerherg, Houhơls, etc. (Eckl.! Un. itin. n. 363, 365, 632! ex parte, Zeyh.n. 375013752 ! ex parte). - Meisn. th Linnea 14, p. 450 *. G. viridis 'Berg. pl Cap. p. 125. G. pinifolia Linn. fil, suppl. p. 225 (non alior.). G: acerosa Gmel. sýst. nat. 2, 1, p. 633. G. Sparmanni Mill. dict. ed. Martyn 3, ex Wikstr. Thym. p. 311. G. simplex Sims Bol. mag. t. 812, excl.? syn. Linn. et Breyn. Epichroxantha juniperifolia Eckl. et Zeyh. herb:(ex parte) 'et E. simpléx. Eckl. et Zeyh. ib. Species variabilis. Rami erecti; plérumque derise corymboso-ramülosi. Folia coriacea, 3-6 lin. longa, 1-2 lin. lata, nune perfecte enervia, nuuc nervo unico notata, superíora rarissime obsolete 3-5-nervia, floralia inferioribus duplo xel intérdum parum latiara. Receptaculum breviter villosum. Flores $\ell_{-5}$ lin. lóngi, glaberrimi vel rarius minute parceque puberuli, squamis albidis. (v: ș. in hrệrb. Lam., etç., et v. v. c.) $\because$.

B. uncinata (Meisn. in Linnæầ 14, p. 451), foliis apiculo uncinato-incurvo terminatis, summis vix latioribus obsolete 3-nerviis nudis. - Girca Stellenbosch Drège, n. 1187, b! Docum. p. 103, reg. 3, D, a, 20). Potius lúsus quám forma constans, ad G. subulatäm valde accedens. (v. s.)

$\gamma$. pibigera (Meisu. 1, c.), foliis. subenerviis, superioribus' sensim 'Játioribus, summis dense congestis eilliatis supra laxe pilosis subtus interilum absolete 3-nerviis. - Gircá Pàrlberg (Drège! Docum. p. 87, 3, A, e, 27), Zoetendalsvalei, distr. Zwellendam (Krauss, n. 755! formâ folìs valde ad G. styphelioidem accedens), prope Appelskraal, ad Rivier Zoneer Einde (Zeyhi, n. 3749!). G. simplex Linn.mant. 1, p. 672, Wikstr. Thym. p. 313? (v. s.)

28. G. SUB ULATA (Lam.! dict. 2, p. 765 ), ramulis apice tetragonis puberulis, folìs sparsis oppositisque linearibus acutis glabris subenervits, superioribus subulatoacuminatis dorso convexis supra canaliculatis haud latioribus ciliatis nudisve,

- capitulis 2-3-florís, calyce subglaberrimo, lạbis tubo dimidio brevioribus acutîs, 
squamis 4 petaloideis bipartitis parvis. J.In Africâ Capensi (Sonnerat! Burchell, n. $124 ! 725$ ! Sieber, n. 186! fl. nixta, n. 87!), in planitie Capensi, montib. Thafel et Dutyvelsberg, Zeekuhvalei, etc: (Drège, n. 1187, a। Docum. p: 107, 3, D, b, 9, Ecklon! un. itin. n. 363, 365, ex parte, Ludwig!'Krauss, n. 808! Zeyh. n. 3752 ! ex parte). - Meisn. in Línnæa 14, p. $449^{\circ}$. G. biflofa Wikstr. Thym. p. 314, vix Thunb. Il. Cap. p. 380, cujus descr. saltem pluribus notis abliorret. G. simplex 'Linn. mant, 1, p. 67'? Epichroxantha simplex et juniperifolia Eckkl. et Zeyh. herb. .n. 84, ex parte. Thymeliea Athiopica Passerinæe foliis Breyn. cent. 1, t. 6. Fortasse mera var. G. juniperifoliæ, recedens tantum foliîs angustioribus, $\frac{1}{2}$ - vix 1 lin. latis, apicem versus semper attenuatís:fere subulatis concavisque, floralibus hạd latioribus. (v. s. in herb, Lam., ete.) : .

29. G. Parviflora (Meisn. in Linnzâ 14, p. 453\%), humilis, glaberrima, foliis oppositis subherbaceis lineari-línceolatís acutis planis subenerviis; floralibus subæqualibus, floribus terminalibus vel demum lateralibús subsolitariis, calyce foliis breviore, squamis integris 4 ? petaloideis parvulis $\zeta$ In monte. Piquetberg, alt. $1,500-2 ; 000$ ped. (Drìge, n. 65! ex parte, Docum. pi 76, 3, A, 4,23 ), in planitie, inter 'Witsenberg et Kurfdeberg, alt. 4 (Zeyl. n. 1487 !). Fruticulus ramositus, balmaris-vix spithaniæus. Flores $2 \frac{1}{2}-3$ lin. longı. Cæet. G. juniperifoliæ et forsan potius hnujus var. (v, s.)

- $\quad$. debilis, ramulis tenellis, foliis herbaceis enerviis capitulis 2-3-floris. $-\mathrm{Ad}$ latera mońtium, prope Gnadènthal et Appelskraal, ad Rivier Zonder Einde, diștr. Caledon (Eckl.! Zeyh. n 1487 !). G. polygalæfolia . $\beta$ lanceolata Líchtenstein! mss. in herb. Ledebour. G. lanceolata Lichtenst. in herb, Willd. n. 7573! et herb. Kunth. Epichroxantha debilis Eckt. et Zeyh. ir herb: 11. 851 Folia havid ultrì 3 lin. longa, $\frac{2}{3}$ lin. lata, Flores (teste Lichtenst. in sched $)$ in eâdem plantầ rubri et flavi. (v. s. in herb. Willd., K'Kunth. et Sonderí)

30. G. DEGURREN' (Meisu. l. c. p. 451"), ramulis anguste alato-tetragonis, foliis, oppositis subcoriaceis lanceolato-linearibus acutis planis 1-nerviis, floralibus æqualibus, floribus: terminalibus vel dernum lateralibus solitariis late infundibuliformibùs, lobis angustis acutis tubo dimidío brevioribus squamas 4 petaloideas integras? dimidio superantibus. $J$ In montibus, circa urbem Câp, Tafelberg, Leeuwenberg \& Dúyvelşbeng, Kasteelberg, Hottentottsholland (Drège! Ecklon, n. 364! 633! Ludwig ! Krauss, n. 777!). G. biflora Thunb. prodr. p. 76? fl. Cap; p. 380 ? Wikstr. Thym: p. 314? Epichroxantha biflora Eckl. et Zeyh. herb.-i. 87! Species præcedentibus valde similis, at bene distineta et facillime dignoscenda ramulis aläto-angulatis, nec non calyce 5 lin. Jongo faucem versus magis dilatato, etc. (v. s.)

31. G. PALLID A (Meisn. l. č 3. $442 \%$ ), glaberríma, ramulis teretibus, foliis sparsis herbaceis-lanceolato-linearibus acutis-planis subtus obsolefe 1-nerviis, floralibus æequalibus, capitulis 4-6-floris, calycis lobis tubo tenui glaberrimo triplo brevioríbus ovatís acuminatis dorso apiceque parce setulosis squamas 8 subearnosas oblongas dimidio superantibus. F In Gaffrariâ,-circá Omtendo (Drège, $n$, $466 \mathrm{zl}$ Docum. p. 154, V, c, 51. Rami graciles, subsimplices. Folia pallida, subglanca? erecto-patula, 4-6 lin. longa, $\frac{1}{2}-1$ lin. laț. Reseptaculum albo-setulosum. Flores 6-7 lin. longi, hutei? tubo inferue filiformf́, superne anguste infundibuliformi; lobis $1 \frac{1}{2}$ lin. longis, extus setulis patzis adpressis decíduis conspersis. Squamæ fuseæ, obtusæ. (v. S.)

32. G. MEYER I (Meisn. l. c. p. 443\%) glaberrima, ramulis teretibus, folị̂s sparsis herbaceis lanceolato-linearibus obtusiusculis planis subenerviis, summis longioribus acutis, capitulis 6-8-floris, calycis lobis ovato-oblongis obtusiusculis tubo gracili multo-brevioribus squamas 8 subpetaloideas Jneares basi setulis cinctas parum superantibus. F Prope Kaspenskloof, ințer Uitkomst et Geelbekskraàl, alt. 2,000 péd: (Drège, n. 2974! Docum. p. 95, 3, C, 2). Rami graciles, laxiuscule foliosi. Folia patula, lete viridia, 6 vel summa $7.8 \mathrm{lin}$. longa, 1 lin. lata, infima multo breviora obtusa. Calyx 8-10 lin. longùs, graeilis, flavus, lobis $1 \frac{1}{2}$ lin. longis. Squamæ lineari-lanceolatæ obtusæe, bași setulis brevibus albis cinctæe. (v. s.)

33. G. CARINATA (Thunb. prodr. p. 76), ramis gracilibus, ramulis pilosiluseulis, foliis sparsis herbaceis linearibus obtusiusculis 1 -nerviis planis vel leviter carinatis glabris, floralibus latioribus lanceolatis oblongisve, capitulis $6-\infty$-floris, 
calyce pilosiusculo, lobis brevibus obtusis squamas 4 profunde bipartitas subcarnosas obovatas longe superantibus. $ђ$ In Africâ Capensi (Thunb.), ad flum. Zwartkops et Vanstades-Rivier, circa Roodeberg et Mósselbaay, Zoetendalsvalei, distr. Zwellendam, etc. (Drège! Zeyh. 11. 3771! 3772 !). - Wikstr. Thrym, p. 312, Meisn. in Linnæá 14, p. 444, Eckl. et Zeyh. herb. n. 6! G. polystachya Berg. pl. Cap. p. $123^{*}$ (ex Wikstr.), Thunb. fl. Cap. p. 380. G. imberbis Dryand. in h. Kew. ed. 2, 2, p. 412, Bot. cab. t. 1958 ? Bot. mag. t. 1463. G. pinifolia Wendl. obs. 15, t. 2, f. 11 (non Linn.). G. simplex Andr. Bot. repos. t. 70, Herb. amat. 2, t. 128 (non Linn.) D. squarrosa Linn. sp. p. 511? (curn syn. Burm. Afr. t. 49, f. 1, quæ abhorret floribus pedunculatis calyculatis), ex Wikstr. l. c. Thymelina simplex Hoffmansegg Verzeichn. 1824, p. 196. Frutex 8-pedalis, erectus, dense foliosus. Folia patula, læete viridia, 3-6 lin. longa, $\frac{1}{2}$ vix 1 lin. lata, involucralia proximis plerimquo longiora, 4-5 lin. longa, 1-2 lin. lata. Flores pallide lutei, parce pilosiusculi, 6-7 lin. longi, squamis pallidis. (v. s. et v. v, c.)

34. G. ов т usiss im a (Meisn. in Linnæá 14, p. $432^{*}$ ), glabra, foliis oppositís coriaceis linearibus obtusissimis complicatis dorso convexo vel carinato 1 -nerviis, floralibus majoribus ovali-oblongis planis basi 3-5-nerviis ciliolatis, capitulis 4-floris, calycis puberuli lobis oblongis obtusiusculis squamas 8 subcarnosas angustas dimidio superantibus. 5 In mon te Roodeberg, alt. 3,000-4,000 ped. (Drège, n. $7359 !$ docum. p. 69, 3, A, a, 7), prope Caledon, alt. 3 (Eckl. et Zeylh. n. 97!), in collibus Karrooideis, inter Zondag- ct Coega-Rivier, Uitenhage (Zeyl.!). G. obtusifolia Bartl. mss.? Meisn. 1. c. p. 461". Rami virgati. Folia crassiuscula, viridlia. 3-5 lin. longa, $\frac{1}{2}-1 \frac{1}{2}$ lin. lata, ramulerum erecta imbricata, involucralia 2-3 lin. Jata, lierbacea, interdum acutiuscula, viridia vel purpurascentia. Calyx 6-8 lin, longus, flavus vel rubescens, minute adpresso-pilosus, lobis $1 \frac{1}{2}$ lin. longis. Squamæe oblongo-lineares, obtusce, fuscæ. (v. s.)

35. G. Involucrata (Steudel! in Schimp. pl. Abysss. sect. 2, n. 770), glabra, basi suflrutescens, caule erecto superne herbaceo racemoso-ramoso, foliis sparsis linearibus acutis planis 1 -nervís, capitulis pedunculatis paucifloris, involucri foliolis 5 membranaceis ovalibus obtusis flores subrquantibus, receptaculo longe barbato, calyce gracili puberulo, lobis'brevibus, squamis 4 subcarnosis lanceolatis. 5 in Abyssiniæ montibus, inter Sana et Terrfera (Schimp.!) el prov. Chiré (Quartin-Dillon). - A: Rich. voy. Abyssin. 5, p. $234^{\circ}$, Walpers ann. 3, p. 325. Frutex (ex Rich.) bipedalis et ultra, subglaucus, ramulis simplicibus filiformibus monocephalis. Folia herbacea, 5-8 lin. longa $\frac{2}{3}-\frac{5}{4}$ lin. lata, 1 -nervia. Capitula terminalia, magnit. fabæ, 6-12-flora. Involucrum fuscum, foliolis imbricatis inæqualibus evoniis. Calyx 3-4 lin. longus, parce pilosiusculus (ex Rich. valde sericeus), lobis oblongis tubo subinfundibuliformi tenui articulato triplo brevioribus. Squamæ glabræ, inlegræ, obtusæ (ex Rich. bifidæ). Ovarium glaberrimum. (v. s. in lierb. Boiss.)

36. G. MICROGEPHALA, glabra, basi suffrutescens, caule ramisque erectis gracillimis, foliis sparsis subulato-linearibus aculissimis subcarinatis, capitulis subsessilibus paucifloris, involucri polyphylli foliolis membranaceis coloratis ovatolanceolatis ciliatis floribus demum superatis, calyce tenui puberulo basi receptaculoque longe villoso, lobis brevibus, glandulis $\$$ cylindraceis obtusis. 5 In CafIrariæe monte Magalisberg (Zeyher, n. 1492 !). Caules e basí lignescente plerumque plures, verisimiliter annui, circ. pedales, vix pennæ corvine crassitie, plus minus ramosi, ramis subcorymbosis teretibus tenuiter striatis. Folia conferta, erecta, 3-6 lin. longa, $\frac{1}{3}-$ vix $\frac{2}{3}$ lin. lata, plerumque leviter incurva et supra canaliculata, nervo. subtus leviter prominulo. Capitula magnit. cerasi minoris vel pisi, subgloJosa, interdum breve pedunculata. Involucri foliola 3-5 lin. Jonga, 1 $\frac{1}{2}-2 \frac{1}{2}$ lin. lata, rufo-straminea, nec diaphana nec nitida, persistentia. Receptaculum convexum, pilis albis calycis basin persistentem demum glabram subsuperantibus barbatum. Calyx 4 lin. longus, basi barbatus, supra articulationem minute pilosiusculus, lobis oblongis tubo duplo breyioribus, squamis carnosis atroluscis glabris. (v. s.)

\section{\$3. Antherce 8 perfectce. Faucis squamc 4 dense incano-tomentosa.}

37. G. pinifolia (Linn. sp. ed. 1. p. 356, ed. 2, p. 512, non suppl. nec Wendl.), ramulis glabris conferte foliosis, foliis sparsis aceroso-linearibus acutis mucronatisve carinatis glabris, involucralibus latiorihus lnnceolatis oblongisve 1- vel

XIV. 
3-nerviis, capitulo multifloro, calyce dense cano-pubescente, lobis squamisque

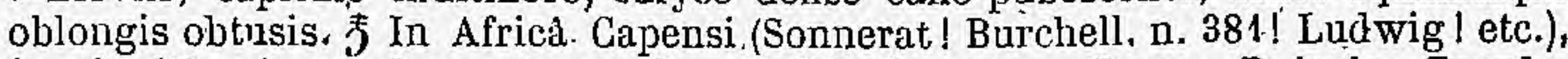
in planitie, circa urbem, et montibus Tafel-, Leeuwen-, Tyger-, Duivels-, Paarde.. berg, Houhoek, Hottentottsholland, Klynriviersberge, Elandskloof, distr. Caledon, etc. (Drège! Eckl. in pl. un. itin. n.110! 358! Krauss, n. 752! Zeyh.n. 3758!). - Berg. pl. Cap. p. $122^{*}$, Thunb. prodr. p. 76 , n. Cap. p. $379^{*}$, Lam.l dict. 2, p. 764, ill. t. 291, f. 1, Willd. sp. 2, p. 424 (excl, syn. Linn. fil. et Wendl), Andr. Bot. repos. t. 52, Lodd. Bot. cab. t. 7, Bot: reg. t. 19, Bot. mag. t. 2016, Wikstr. Thym. p. 310, Meisn. in Linñâ 14, p. 445. Rapunculus Burm. Afr. t. 41, f. 3. G. radiata Linn. mant. 1, p. 67, Bot. cab. t. 29, Wendl. obs. 15, t. 2. Canalia daphnoides Schmidt in Florâ 1830, p. 555. Rami graciles. Folia conferta, erecto-patula, 6-10 lin. longa, $\frac{1}{2}-\frac{2}{3}$ lin. lata, involucralia 6-8 lin. longa, 2 lin. lata, mucronata, fuscescentia, 1-vel rarius 3-nervia. Calyx 8-12 lin: longus, lacteus, vespere præsertim fragrans, tubo gracili, lobis obtusis squamas fere dimidio superantibus. Variat foliis 4-5 lin. longis. (v. s. in herb. Lam., DG., etc., et v. v. c.)

$\beta$. ochroleuca (Edw. Bot. reg. t. 624), gracilior, foliis patentibus læete virentibus obtusis, involucralibus stellatis, floribus extus ochroleucis, lobis squamas vix superantibus. - G. ochroleuca Lodd. Bot. cab. t. 1184 .,

\section{Sectio II. Phidia Endl. gen. suppl. 4, 2, p. 64.}

Flores in summis axillis solitarii, in spicam brevem interdum capituliformem deinde excrescentem foliosam vel demum aphyllam approximati.

38. G. SETOSA (Wikstr. Thym. p. 315), foliis inferioribus oppositis, superioribus sparsis aceroso-linearíbus acutis planis nervoso-striatis ramulisque glabris, floralibus æqualibus, capitulis 2-12-floris demum in spicam brevem aphyllam excrescentibus, calyce sericeo, lobis ovatis brevibus glandulas 8 vix superantibus. $\hbar$ in monte Paardeberg (Thunb.), distr. Caledon, alt. 2 (Eckl.! Drège.!), in collibus Karrooideis, inter flum. Koega et Zwartkopsrivier, distr. Uitenhage (Ëckl.!).-Meisn. in.Linnæâ 14, p. 447. G. Caledonica Eckl. et Zeyh. herb. n. 19! et G. stricta Eckl. et Zeyh. ib. n. 17! ex parte. Passerina setosa Thunb. prodr, p. 76, fl. Cap. p. 376. Fruticulus erectus, ramosus, circ. pedalis, laxiuscule foliosus. Folia subcoriacea, nunc 4-7 lin. nunc 7-9 lin. longa, $\frac{1}{2}$ lin, lata, 1 - vel obsolete 3 -nervia, passim subcarinata. Spicá demum subpollicaris. Calyx 4-5 lin. longus, tenuis, sat dense adpresso-pilosus sericeus, lobis $\frac{2}{5}$ lin. longis obtusiusculis. Ovarium adpresse setulosum. (v. s.) .

39. G. THESIOIDES (Meisn, in Linnæâ 14, p. 457 ), ramis apice pilosiusculis, foliis sparsis vel passim oppositis verticillatisve linearibus vel inferioribus spathulatooblongis obtusiusculis planis 1 -nerviis glabris, spicis terminalibus foliosis interruptis, floribus folia subæquantibus pilosiusculis, lobis brevibus squamas 8 subcarnosas superantibus, $\zeta$ In Africâ Capensi.

a. laxa, caule ramisque elongatis gracilibus laxis, foliis herbaceis patulis - In montibus Zuurebergen, alt, 1,800 ped. (Drège, n. 7353! docum. p. 136, V, A, 27), circa Vanstadesberg, Elands- et Zwartkopsrivier, alt. 2-3, distr. Uitenhage (Eckl. n. 630! Zeyh. n. 1499! 3754 !). G, coerulea Eckl. et Zeyh. herb.' n. 16! (non Burch.). Fruticulus circ.bipedalis, erectus; ramosus, internodiis 4-8 lin.

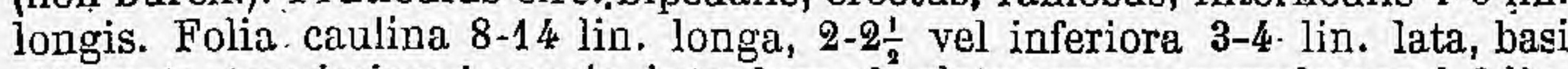
attenuata, tenuissime 1-nervia, interdum obsolete venosa, ramulorum 4-6 lin. longa, $\frac{1}{2}-1$ lin. lata, novella obsolete ciliolata. Capitula terminalia paucifora et in summis axillis 2-1-flora subsessilia, demum in spicam 1-1 $\frac{1}{2}$ pollicarem foliosam excrescentia. Calyx 5 lin. longus, tenuis, flavus? subsericeo-pilosiusculus, lobis oblongis obtusis vix $\frac{2}{5}$ lin. longis, squamis glandulosis? oblongis basi setuloso-ciliatis. (v. s.)

$\beta$. condensata, caule ramisque abbreviatis strictis rigidis, foliis subcoriaceis dense confertis subadpressis. (Ludwig!). Folia rigida, distincte 1- nervia. (v. s. in herb. Mus. Stuttgart.)

40. G. RACEM os A (Thunb. prodr. p. 76, f1. Gap. p. $380^{*}$ ), foliis sparsis sessilibus herbaceis obovato-oblongis planis 1 -nerviis ramisque glabris, spicis terminalibus aphyllis, floribus demum remotiusculis adpresse setulosis lobis tubo duplo brevioribus squamas 8 subcarnosas parum siperantibus. 5 In Africâ Capensi (Thunb.), 
in collibus, circa Lauwskloof et Groenekloof, alt. 400 ped. (Drège! docum.p.1.02, 3, D, a, 25). - Wikstr. Thym. p. 315, Meisn. in Linneaa 14, p. $456^{*}$. Fruticulus circ. spithamæus, ramis rigidis patulis strictis apice subangulatis. Folia remotiuscula, patula, glauco? víridia, 5-6 lin. longa, 2-3 lin. lata, obtusa vel submucronato-acuta, obsolete venosa. Spicæ $4-8$ lin. longæ, rhachi post florum lapsum dentatâ, dentibus villosiusculis. Calyx 5 lin. longus, parce subsericeo-pilosus, lobis lanceolato-oblongis, squamis lanceolatis obtusiusculis, basi-ciliolatis. (v. s.)

41. G. OVALIF OLIA (Meisn. in Linnæå 14, p. 455^), foliis oppositis breviter petiolatis herbaceis ovalibus acutis penniveniis ramulisque adpresse pilosis, spicis terminalibus pedunculatis aphyllis capituliformibus demum paulo elongatis, 'calyce sericeo, lobis acutis squamas 8 petaloideas lineares dimidio superantibus. 7 In Caffrariâ, prope ostium flum. Omsamculo (Drège, n. 4669 ! docum. p. 156, V, c, 16). Wikstrœmia ovalifolia Decaisne in Jaquemont voy. p. 146. Rami graciles, ramiulis tenuibus corymbosis, internodiís circ. pollicaribus. Folia patula, 10-14 lin. longa, 6-8 lin. lata, utrinque subæqualiter angustata, petiolo vix 1 lin. Iongo. Spicæ

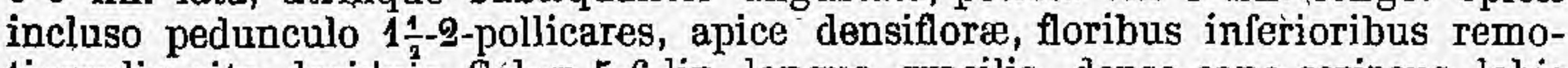
tiusculis cito deciduis. Calyx 5-6 lin. longus, gracilis, dense canorsericeus, lobis $1 \frac{1}{4}$ lin. lơngis. Stylus calycis tubo dimidio brevior, diu persistens. Species habitu, præsertim inflorescentiâ, admodum accedens ad Wikstrœmiam, sed floris structurâ omnino cum Gaidiâ conveniens. (v. s.)

\section{Species obscurce.}

42. G. ARGENTEA (Thumb. prodr. p. 76, fl. Cap. p. 381), foliis sparsis obovatis acutis tomentoso-argenteis basi attenuatis, floribus capitatis sericeis, squamis 8 (ex Wikstr. 4) carnosis exsertis. 5 Ad cap. Bonæ-Spei.-Wikstr. Thym. p. 318. Caulis erectus, pedalis, glaber, ramis brevibus nodulosis, ramulis (ex Wikstr.) argenteovillosis. Folia sessilia, unguicularia (obtusa, venis rubentibus, ex Wikstr.), tenuis sime tomentosa, obscure sericea, erecto-patula, superiora approximata.Calyx intus purpureus, lobis (ex Wikstr.) oblongis obtusis. Videtur ex affinitate G. sericeæ et albicantis.

43. G. MULTIFL ORA (Bartl. mss., Linnæa 14, p. $462^{*}$ ), humilis, erecta, ramulis sericeo-pilosis, foliis sparsis subimbricatis linearibus obtusiusculis dorso convexiusculo subcarinato-trinerviis utrinque pilosis, junioribus sériceo-nitentibus, floralibus paulo latioribus obtusioribus, capitulis terminalibus 2-5-1loris, calyce sericeo-hirsuto, lobis brevibus ovatis obtusis, squamis 8 lanceolà lís limbo duplo longioribus. 5 Ad cap. Bonæ-Spei (herb. reg. Berolin.). Frutex spithamæus, ramis superne dense ramulosis foliosisque pilosis. Folia erecta, pallide viridia, supra concaviuscula. Flores 4-5 lin. longi, folia floralia æquantes. Calyx albido-sericeus, tubo supra basin ovato-oblongam filiformi, lobis vix 1 lin. longis, squamis petaloideis? flavis acutiusculis. Antheræ inclusæ. Videtur G. strigillosæ et albicanti affinis.

44. G. SPARSIFL ORA (Bartl. mss. 1. c. p. 462'), erecta, foliis sparsis subimbricatoadpressis lineari-lanceolatis acutis glabris dorso convexo subenerviis, junioribus ramulisque subhirsutis, floralibus patulis basi hirsuto-barbatis, floribus in summis axillis solitariis capitato-congestis, calyce sericeo-tomentoso, lobis tubo filiformi quadruplo brevioribus late ovatis acutiusculis squamas 8 petaloideas? oblongas glabras fere triplo superantibus. 5 In Africæe Capensis terrâ Outeniquâ (herb. reg. Berolin.). Frutex pedalis et ultra, ramis paucis erecto-patulis apice conferte ramulosis. Folia circ. 3 lin. longa, basi subattenuata. Calyx albus, folio duplo longior, squamis obtusis. Antheræ 4 in fauce, 4 in tubo occultæ. Hinc ad G. juniperifoliam $\beta$, inde ad $G$. nodifloram accedere videtur.

45. G. NANA (Wilistr. Thym, p. 316), humilis, erecta, foliis sparsis imbricatis linearibus convexis obtusis scabris pilosis demum glabris, floralibus purpurascentibus albo-pilosis, capitulis terminalibus multifloris, calyce hirsuto-tomentoso, lobis lanceolatis acutis, glandulis pluribus, staminibus $4 .{ }^{\dagger}$ In summis montibus, prope Rodezant (Thunb.). Struthiola nana Linn. syst, veg. 14, p. 164, suppl. p. 128, Thunb. prodr. p. $\mathbf{7 6}$, fl. Cap. p. $383^{*}$. Fruticulus palmaris, ramis paucis fastigiatis. Folia vix unguicularia, subcarnosa, floralia valde pilosa, ccerulescentia, calyce 
villoso breviora. Species foliis sparsis et præcipue floribus terminalibus capitatis involucratis a Struthiolâ abhorrens ideoque recte ad Gnidiam relata, quoad stamina 4 aftinis $\mathrm{G}$. anomala.

46. G. viRESCENS (Wikstr. Thym. p. 317), foliis sparsis vel oppositis lanceolatis oblongisve obtusis brevissime petiolatis ramulisque villoso-pubescentibus, capitulis terminalibus paucifloris, calyce villosiusculo, laciniis lanceolatis obtusiusculis, squamulis 8 , ovario villoso. 5 Ad cap. Bonæ-Spei. Passerina anthylloides $\alpha$ Thunb. Mus. nat. Ac. Ups. 13, p. 106. Simillima dicitur Lasiosiphoni anthylloidi, sed floribus 4-meris foliisque minus villosis distincta.

47. G.? s tricta (Wikstr. Thym. p. 315), ramis rigidis, ramulis verrucosis albotomentosis, foliis patılis minutis ovátis oblongisve acutiusculis concavis utrinque villosulis, capitulis paucifloris, calyce pubescente, lobis linearibus obtusis..... 5 Ad cap. Bonæ-Spei. Passerina stricta Thunb. prodr. p. 75, fl. Cap. p. 377' (clr. G. Wikstromiana, supra n. 7). Caulis pedalis et ultra, glaber, ramis brevissimis sparsis egregie verrucosis. Folia (ex Thunb.) 1 lin. longa, obtusa, tomentosa. Squamæ faucis a Wikstrœmio non describuntur, sed adesse videntur quum species ab eo a Passeriuâ ad Gnidiam translocata sit.

48. G. A CUTIFolia (Wikstr. 1. c. p. 315), glaberrima, folijs oppositis ellipticis acutis, capitulis terminalibus 2-3-floris, calyce glabro, lobis lanceolatis obtusiusculis..... 万 Ad cap. Bonæ-Spei. Monente ipso auctore G. bifloræ suæ (G. subulatæ Lam., supra n. 28) proxime affinis, et flores interdum ramulo excrescente demum laterales.

49. G.? PHilip pinica, arborescens, foliis oppositis brevissime petiolatis ovatis acutis glabris, floribus axillaribus breve pedunculatis racemos compositos formantibus, calyce infundibuliformi 4-dentato, fauce villosâ, squamis (" petalis ") \& parvis unguiculatis ovalibus, staminibus 8 biseriatis, filamentis calyce longioribus. 5 In Angat, ins. Philippin. Gnidia oppositifolia Blanco Flora de Filipinas, ed. 1 , p. 299 *, ed. 2 , Manila, 1845 , p. $208^{*}$. Arbuscula altit. humanæ. Flores albi. Antheræ ovatæ, incumbentes. Pistillum staminibus brevius, stigmate simplici. Fructus in fundo calycis, 1-spermus. Stirps floris structurâ, si recte descripta, cum Gnidiâ quidem conveniens, serl inflorescentiâ valde abhorrens, a Lasiosiphone et Aquilariaceis petaliferis præterea floribus 4 -meris recedens.

G. GRANDIFL ORA (Willd. enum. suppl. p. 21), non descripta.

G. cYANEA Burch. ex Steudel nombncl. ed. 2, 1, p. 697. - Verisimiliter eadem ac G. azurea Burch., cfr. G. sericea $\alpha$, supra n. 10.

G. FL A va Lindl., ex Steudel 1. c. Non descripta.

\section{Species exclusce.}

G. Caffra Meisn. in pl. Zeyh. = Lasiosiphon Caffer Meisn.

G. с A P I т A т A Linn. fil.= Lasiosiphon linifolius Desne.

G. cune at A Meisn. = Lasiosiphon Meisnerianus Endl.

G. DAPHNAF OLIA Bojer = Lasiosiphon Bojerianus Desne.

G. DAPHN $A$ F OL IA $\alpha$ Linn. fil. = Lasiosiphon pubescens Desne.

G. DAP H A FOLIA $\beta$ Linn. fil. = Lasiosiphon Madagascariensis Desne.

G. DREGEANA Meisn. = Lasiosiphon Dregeanus Endl.

G. ERIOCEPHAL A Meisn. = Lasiosiphon eriocephalus Desne.

G. ER OCE PIIA L Ralph. = Lasiosiphon speciosus Desne.

G. FIL A M EN T 0S A Tlrunb. = Lachnea filamentosa Meisn.

G. FIL A MENT OSA Linn. fil. = Lachnea buxifolia Lam.

G. G L A U C A Sims. = Lachnæa buxifolia Lam.

G. G R A N I S hort. = Lachnæa burifolia Lam.

G. H U G E I I Mcisn. in herb. Zucc. = Lasiosiphon Hïgelii Meisn.

G. IN SULAR Is Gardn. = Lasiosiphon insularis Meisn.

G. Kra u S I AN a Meisn. = Lasiosiphon Krraussii Meisn.

G. M A CR OPETAL А Meisn. $=$ Lasiosiphon macropetalus Meisn. 
G. M I G R O P H Y L L Meisn. = Lasiosiphon microphyllus Meisn.

G. M ONT I C O L A Miquel = Lasiosiphon Metzianus Miquel.

G. PEN T A D R A Thunb. = LonchosLoma olstusiflorum Wikstr.

G. PUL C HEL L A Moisn. = Lasiosiphon pulchellus Desue.

G. S IS PARENS IS Gardn. = Lasiosiphon Sisparensis Meisn.

G. SPLENDEN S Meisn. = Lasiosiphor splendons Endl.

G. TE N U IF L O A Eckl, et Zeyh. = Lachnæa Burchellii $\alpha$ Meisn. et L. diosmoides Meisn.

G. т о M N т O S A Eckl. = Lasiosiphon anthylloides Meisn.

G. TRIPLINER VIS Meisn. = Lasiosiphon triplinervis Desne.

G. VILL os A Meisn. in pl. Zeyh. = Lasiosiphon Burchellii $\propto$ Meisn.

XXX. LASIOSIPHON Fresenius in Flord 21, 1838, p. 602, Decaisne in Jaquemont voy. bot. p. 147, Meisn. gen. 2, p. 368, Endl. gen. suppl. 4, 2, p. 66, n. 2106/3, Walpers ann. 1, p. 586. - Enkleia Griff. in Galcutta Journ. of nat, hist. 4, n. 13. - Gnidise sect. 1, Peutameræ Meisn. in Linnoed 14, p. 424, - Gnidiæ sect. Dingia Gardn. Gnidiæ, Passerịæ, Daidis et Daphnes sp. auct.

Flores hermaphroditi, 5-meri. Calyx coloratus, extus pubescens, intus glaber, tubo gracili supra basin longe pilosam circumscisse deciduo vel rarius continuo (?), limbo 5-partito regulari patente. Squamæ 5 petaloideæ, fauci ad sinus insertæ, antheris superioribus alternæ, exsertæ, glabræ, inlegræ vel bifidæ, interdum obsoletæ. Antheræ 10 fauci biseriatim insertæ, subsessiles, dorso prope basin affixæ, lineares vel oblongæ; obtusæ. Annulus hypogynus membranaceus ovarii basin cingens, parvulus vel obsoletus. Cæt. Gnidiæ. Frutices Africæ australis, orientalis tropicæ, Madagascarienses et Indici, foliis sparsis oppositisve herbaceis, capitulis terminalibus sæepe pedunculatis p̈lerumque multifloris involucro proprio polyphyllo cinctis, receptaculo hemisphærico villoso.- - Genus satis naturale, quam vis characteribus nimis levibus dỉstinctum, a Gnidiâ nonnisi floribus 5-meris, a Daide antheris subsessilibus inclusis diversum.

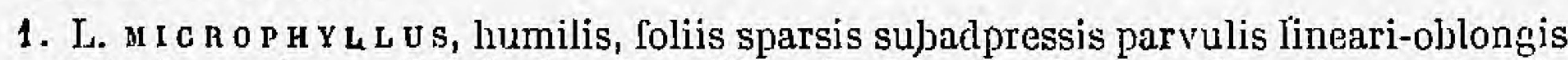
obtusis ramisque glabris, involucralibus duplo majoribus ovatis, calyce puberulo vel glabro, lobis brevibus obtusis, squamis exiguis. $b$ In collibus, ad flum. Garip (Drège, n. 2976, a! docum. p. 94, 3, B, 12), in lapidosis Karrooideis, circa Bockfontein, distr. Colesberg (Zcyher, n.1489!). Gnidia microphylla Meisn. in Linnæà 14, p. $432^{*}$. Fruticulus vix palmeris, ramis rigidis divaricatis. Folia $1 \frac{1}{2}-4$ lin. longa, 1-1 $\frac{1}{2}$ lin. lata, subcarnosa? dorso obtuse carinato 1-nervia, superiora minora et subenervia, involucralia membranadea, colorata, plana, enervia, 4-5 lin. longa, 2-3 lin. lata, extus basi minute puberula. Receptaculum pilis albis involucrum wquantibus villosum. Calyx semipollicaris, cano-puberulus vel (in pl. Dregeanâ) glaber, lobis ovatis 1 lin. longis (in pl. Zeyheri emarginatis?). Squama in pl. Zeyheri integræ, in Dregeanâ. bipartitæ? Specimina meliora Zeyheriana, fores 5-meros exhibentia, cum Dregeanis imperfectís cæterum bene congrua, speciem Gnidiis 4-meris huc transferre suadebant. (v.s.)

2. L. CAFFER, ramulis filiformibus pubescentibus, foliis sparsis linearibus acutis venosis glabris, involucralibus latioribus capitulum sessile 3-5-florum subæquantibus, calyce dense sericeo; lobis oblongis tubo subtriplo brevioribus, squamis minutis linearibus integris. 5 ? In Caffrariæ monte Magalisberg (Zeyher, $n$. 1488!). Fruticulus, ut videtur, debilis, gracilis, ramulis paucis teretibus. Folia conferta, erecta, læte viridia, 5-7 lin. longa, 1-1 $\frac{1}{9}$ lin. lata, utrinque attenuata, basi obtúsa, marginibus plus minus involutis supra concava, dorso plano vel convexo 1-nervia pennivenia, involucralia 4-6 haud longiora, 2 lin. lata. Calyx 8-10 lin. longus, lobis $2 \frac{1}{2}$ lin. longis obtusis vel subacuminatis. (v. sp. unic. in herb. Drège).

3. L. GLAUCUS (Fresen. in Florả 21, 1838, p. 602), foliis sparsis lanceolatis glaucis, calyce infundibuliformi hirsuto basi ventricoso hirsutissimo, squamulis 5 petaloideis. $亏$ ln Abyssiniæ montibus, prope Gondar (Riippel). Frutex circ. 10-pedalis. 
4. L. B U R C H E L I I, ramulis villoso-pubescentibus, foliis sparsis lanceólatis linearibusro summis latioribus imbricatis, involücralibus sericeo-villosis capitulo sessili dense multifloro dimidio brevioribus, calyce sericeo, lobis tubo angusto 3-4-plo brevioribus ovalibus obtusis apice sericeo-comosis squamas oblongas obtusas integras longe superantibus. $₹$ In Africà australi. Sequenti proxime accedens, sed distincta foliis minoribus, 3-4 lin. longis,$\frac{1}{2}-1$ lin. latis, utrinque æqualiter attenuatis, junioribus pube laxiusculâ nec adpressâ villosis, calýcé breviơore, 6-8 lin. longo, lobis latioribus, squamis angustioribus integrisque.

a. villosus, foliis lanceolatis acutis utrinque adpresse pubescentibus tarde glabrescentibus. - Ad pedem montium Stormbergen (Eckl. et Zeyh.! Burchell, n. 2203!). Gnidia villosa Meisn. in herb. DG. et Sond. Folia sưmma dense imbricata. Ovarium glabram vel vix apice puberulum. (v. s. in herb. DC. et Sonder.)

B. glabrifolius, foliis linearibus obtusiusculis glabris, involucralibus sericeis. $=$ Ad flum. Vaalrivier (Zeyh. n. 1490!). Caulis erectus, subpaniculato-ramosus. Folia 5-6 longa, 1 lin. lata. Geet. ut in var. $\alpha$. (v. s. in herb. Drège.)

5. L. UI E I S E R IA N U (Endl. gen. suppl. 4,2,p.67), ramulis pubescentibus, folïis sparsis spathulato-oblongis lanceolatisve adpresse cano-sericeis, involucralibus similibus capitulo subsessili multifloro multo brevioribus, calyce pube adpressâa brevi sericeo-cano, lobis lanceolatis obtusis, squamis parvis bitidis. F In Africée Gapensis distr. Uitenhage. Gnidia cuneata Meisn. in Linnæa 14, p. $427^{*}$. G. argentea Zeyh. pl. exsicc. n. 86! (an Thunb.? cfr. supra sab Gunidiâ). Dais' argentea Eckl. et Zeyb. herb. n. 3̇ 3 ! (excl. var. (3). Frutex ramis virgatis inferie remotiuscule foliosis vel demum aphyllis. Folia 6-10 lin. longa, basin vèrsus semper cuneato-attenuata, utrinque pube copiosâ adpressissimâ canescentia, juniora conferta subadpressa sericeo-splendentia, adulta patula vix sericea; involueralia hadd majora, sed utrinque subæqualiter attenuata, acutiuscula. Calyx 12-14 lin. longus, lohis circ. 2 lin. longis.

a. spathulatus (Meisn. l. c.), foliis obovato- vel spathulato-lanceolatis. - In collibus, ad flum. Vischrivier, alt. 600-800 ped. (Drège, n. 4657! 7351! docum. p. 142,V, A, 54, Ludwig! Ecki.! Zeyh. n. 3766! Krauss, n. 759!): Folia semper extra medium latiora, 3-5 lin. lata, rotundato-obtusa vel brevissime acuminata. (v. s.)

$\beta$. angustifolius (Meisn. l. c.), foliis anguste lanceolatis utrinque attenuatis vix spathulatis.-Ad flum. Klyn-Vischrivier, alt. 2,000 ped. (Drège I docum. p.138, V, A, 31). Folia 2-3 lin. lata, acutiuscula. (v. s.)

6. L. MACROPETALUS, folis sparsis spathulatis acutiusculis utrinque ramulisque adpresse pubescentibus junioribus sericeis, involucralibus haud latioribus, capitulo demum dimidio brevioribus, calyce subsericeo-cano lobis obtusis squamas ovales integras vix superantibus. 5 Circa Port-Natal, inter flum. Umlaas et Umslutie (Krauss, n. 237!). Gnidía macropetala Meisn. in Hook. Lond. Journ. 2, p. 553,

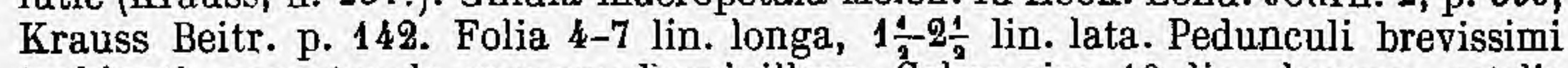
turbinati, receptaculo convexo brevivilloso. Calyx circ. 10 lin. longus, petalis 1 lin. longis, $\frac{2}{3}$ lin. latis. Simillima L. Dregeano, sed jam petalis magnis distincta. (v. s.)

7. L. D R E G E A U S (Endl. gen. suppl. 4, 2, p. 67), ramulis apice 'adpresse cano-villosis, foliis sparsis spathulato-oblongis mucronulatis utrinque adpresse pilosulis, involucralibus subsericeis ciliatis hand latioribus capitulo dimidio brevioribus, calyce sericeo-villoso, lobis obtusis, squamis minutis ovatis. 7 Circa Port-Natal (Drège, n. 4661! docum. p. 160, V, c, 39). Gnidia Dregeana Meisn. in Linnæâ 14, p. $426^{*}$. Habitus et folia omnino L. Mesneriani $\alpha$, sed pubescentia rarior, nounisi in foliis junioribus subcanescens, et calyx multo brevior, 6-8 lin. longus, dense argenteo-sericeus, squamis integris? (v. s.)

8. L. PUL C HELL US (Decaisne in Jacquem. voy. p. 149), foliis sparsis lineari-lanceolat is subspathulatis mucronato-acuminulatis obtusisve, involucralibus vix latioribus spathulatis capitulo subsessili dimidio brevioribus ciliatis calyce dense adpresso-sericeo, lobis obtusis, squamis parvulis ovato-oblongis. $\bar{\zeta}$ In Africâ australi.-Walp. ann. 1, p. 587. Gnidia pulchella Meisn. in LiunæA 14, p. 425*. Habitus 


\section{IASIOSIPHON. THYMELÆACEÆ (AUCTOR MEISNER).}

præecedentium, sed jam pubescentiâ foliorum nullâ aut obsoletâ, immo in involucro minutissimâ distincta. Faucis squamæ interdum bifidæ?

a. glabratus (Meisn. 1. c.), foliis glabris majorihus. - In Caffrarie monte Katberg, alt. $4,000-4,500$ ped., et inter Omtata et Omgaziana (Drège, n. 4662, a! 7954 !), in magnâ Karroo, distr. Grafreynet (Eoklơn !). Dais argentea $\beta$ depressa Eckl. et Zeyh. bërb., sub n. 33! Pami virgati, graciles. Folia 6-12 lin. longa, $1 \frac{1}{2} 2 \frac{1}{2}$ lin. lata, obtusa cum mucronulo vel attenuato-acuta. Calyx pollicaris, cano-sericeus, lobis anguste oblongis 2 lin.-longis. (v. s.)

ß.? dasyphylhis (Meisn. l. c.), foliis minute puberulis parvis (Burchell, n. 12081), ad flum. Gamka et Zondagrivier, alt. 1,700-2,500 ped., et circa Gaaup, distr. Beaufort (Drège, n. 2976, b! Zeyh. n. 1491l). Humilis? ramis abbreviatis. Folia 2⿺辶-5 lin. longa, obtusa, basi attenuata. Calyx 8-10 lin. longus. Forma depauperata vel forshan species distincta. (v. s.)

9. L. LINIF oL IUS '(Desne 1. c.•p. 148), folirs sparsis lanceolato-linearibus acutis, involucralibus latioribus ovato- vel lanceolato-oblongis capitulo pedunculato dimidio-brevioribus, calyce subsericeo-puberulo, lobis ovali-oblongis obtusis, sciuamis exiguis rotundatis. $\bar{J}$ In Africâ australi, distr. Uitenhage et Caffrariâ, ad flum, Camtoos (Thunb.). - Walp. ann. 1, p. 587. Gnidia capitata Linn. fil. suppl. p. 224, Thunb. prodr. p. 76, fl. Cap. p. 378 (excl. cit. Burm.); Willd. sp. 2, p. 426, Wíkstr. Thym. p. 314, Meisn. in Linnæâ 14, p. 424*. Dais linifolia Lam. dict. 2, p. $255^{*}$, ill. t. 368 , f. 3, Pers. syn. 1, p. 471, Eckl. et Zeyh. herb. n. 36 ! Rami elongati, graciles, ramulis pedonculisque minute puberulis. Folia 8-15 lin. longa, 1-2 lin. lata, attenuato-acuta vel inferiora, spathulata ex apice-obtuso mucronulata, demum remotiuscula; involucralia 6-7 lin. longa, 2-3 lin. lata. Pedunculi $\frac{1}{2}-1$ poll. longi, apiee paulo incrassato cinereo-tomentosi. Calyx 10-12 lin. longus, pube brevi densà cinerascente subsericeus, lobis 2 lin. longis.

๙. pubescens (Meisn. l. c.), foliis involucroque plus minus ineano-pubescentíbus. -In Caffrariâ et dístr. Uitenhage, ad flum. Camtoos, Vanstades ot Bralkrivier. inter Gelkau et Basche, circa Grahamtown, in montibus Windyogelberg et Zuurebergen, alt. 3,000-5,000 ped. (Drège, n. 4665! etc., Eckl.! Zeyh. n. 3751!). Involucri foliola subenervia. (v. s.)

B. glabrata (Meisn. 1. c.), foliis involucroque glabris. - Circa Ado, alt. 1,0001,500 ped. (Drège! docum. p. 132, V, a, 2, Krebs, n. 286! Eckl. n. 636!), in monte Magalisberg (Zeyh. n. 1495!). Passerina involucrata Spreng., fide Zeyh. in herb. Ledebour. Involucri foliola distincte nervosa. (v. s.)

10. L.' S P LENDENS (Encl. gon. suppl. 4, 2, p. 67), foliis sparsis lineari-lanceolatis utrinque attenuatis acutis ramulisque argenteo-sericeis, involucralibus haud latioribus capitulum sessile subæquantibus, calyce sericeo, lobis oblongis obtusis, squamis minutis ovatis. F Girca Port-Natal (Drège, n. 465 b! docum. p. 159, V, c, 33). Gnidia splendens Meisn. in Linnæâ 14, p. 428. Tota pube densâ adpressá sericeâ argenteo-splendens. Ramuli graciles. Folia patula, subpollicaria, 2 lin. lata, plus minus distincte triplinervia. Calyx 7-9 lin. longus. (v.s.)

11. L. TRIPLINER VIS (Desne in Jacquem. voy. p. 149), foliis sparsis lanceolatis acutis mucronulatisve basi obtusis triplinerviis utrinque ramulisque adpresse pilosulis, involucralibus subæqualibus capitulo sessili brevioribus, calyce albidosericeo, lobis oblongis acutis', squamis exiguis ovatis. $\bar{J}$ In Caffrariâ, prope ostium llum. Omtendo (Drège, n. 4662 I docum, p. 154, V, c, 6), ad sinum Delagoa (Owen in herb. Ecklon !). Gnidia triplinervis Meisn. in Linnââ 14, p. 429*. Dais Owenii Eckl. et Zeyh. herb. Rami virgati, elongati, rámulis palulis superne albido-sericeis. Folia

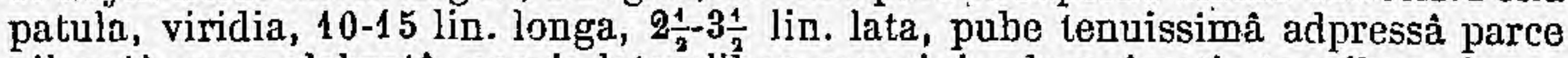
pilosulà, mox glabratâ, nervis lateralibus margini adproximatis tennibus; invoIncralia paulo minora, interdum paulo latiora. Calyx 12-15 lin. Iongus, tubo gracillimo albido-sericeo demum laxiuscule piloso, lobis 3 lin. longis, vix 1 lin. latis. (v.s.)

12. L. ANTHXLLIDES, foliis confertis imbricatis lanceolatis oblungisve obsolele nervosis utrinque adpresse pilosis, involucralibus similibus capitulo stibsessili multo brevioribus, calyce sericeo-villoso, lobis ovato-oblongis aculis, sqnamis obsoletis. $亏$ In Africæ australis distr. Zwellendam, Albany, Uitenlage et Caffrarià (Thunb., Sonnerat! Eckl.! Ludwig! Kirebs, a. 285! etc.). Passerina anthylloides 
Liun. fil. suppl. p. 226, Thunb. prodr. p. 76, f. Cap. p. 377, Wikstr. Tlyym. p. 347, Meisn. in Linnæeâ 14, p. 392, et in Hook. Lond. journ. 2, p. 521. Dais sericea Lam.! herb., dict. 2, p. 767. D. anthylloides Eckl. et Zeyh. herb. n. 3765! 35! Arthrosolen anthylloides G. A. Mey. in Bull. Ac. St-Petersb. 4, n. 4, Endl. gen. suppl. 4, 2, j. 63. Gnidia tomentosa Eckl.! in herb. (non alior.), cfr. Gnidia virescens Wikstr. Thym. p. 317 (supra n. 46). Frutex staturâ, foliis, pubescentiâ, valde varians. Rami nunc elongati virgati vel graciles subsimplices, nunc breves corymboso-ramulosi, dense foliosi. Capitula ampla, dense multiflora. Calyx 12-15 lin. longus, pube brevi patulà sericeà dense villósus, lobis 3 lin. longis, $1 \frac{1}{2}-2$ lin. latis, squamulis ad sinus minutissimis denticuliformibus vel quandoque nullis?

u. vulgaris (Meisn. in Linnæà 14, p. 393), foliis lanceolatis oblongisve minoribus 1-norvijis adpresse pubescentibus villosiusculis vel subsericeis, summis sericeo-villosis. In Africa australi (Burchell, n. 2203!), ad flum. Vanștadesberg, inter Zandplaat et Komga, usque ad alt. 3,000 ped. (Drìge, n. 7347! 4659!), ad flum. Knysna Krauss, n. 772 !), Zwarteruggens, prope Grahamstown, Uitenhage (Eckl. et Zeyh. n. 35!). Folia adpresse imbricata, 4-8 lin. longa, 2-3 lin, lata, acuta vel obtusiuscula. (v. s.)

$\beta$. macrophylla (Meisn. 1. c.), foliis oblongis vel ovali-oblongís obsolete triplinerviis adpresse villoso-pilosis, summis sericeis. - Inter Omsamcaba, Omtendo et Omsamculo (Drège, n. 4658 ! docum. p. 152 et $154, \mathrm{~V}, \mathrm{~b}, 64$, et V, c, 8), in mont. Tafelberge, prope Port-Natal, alt. 2,500-3,000 ped. (Krauss, n. , 779! 282 !). Folia demum patula, 10-14 lin. longa, 5-6 lin. Jata, acutiusciula vel obtusa, nervis lateralibus obsoletis. (v. s.)

$\gamma$. glabrescens (Meisn. 1. c.), foliis oblongis triplinerviis supra glabriusculis subtis parce pubescentibus summis vix sericeis. -- Girca Port-Natal (Brège! docum. p. 159, V, c, 34), ad Vanstadesberg, alt. 2-3 (Zeyh. n. 3765!). Folia imbricata, 5-8 lin. longa, 3-5 lin.' lata, acutiuscula vel rotundato-obtusa. (v, s:)

13. L. KRaussi , caulibus ramisve herbaceis subsimplicibus, foliis sparsis ovalibus lanceolatisve nervosis glabris, involucralibus minoribus capitulum pedunculatum dense multiflorum subæquantibus ciliatis subenerviis, calyce sericeovilloso, lobis ovalibus obtusissimis squamas oblongas obtusas dimidio superantibus. $ち$ In montibus Caffraria, circa Port-Natal (Krauss). Gnidia Kraussiana Meisn. in Hook. Lond. Journ. 2, p. 552 ${ }^{\circ}$. Caulis imâ basi suffrutescens ; rami certe herbacei, subsimplices, 1-cephali, semipedales. Folia sessilia, viridia, rigidula, circ. pollicaria, utrinque pennivenia, venis tenuibus apicem petentibus subparallelis venulisque immersis vel leviter prominulis. Pedunculus 1-4-pollicaris. Capitulum magnit. juglandis, hemisphærıcum, involucro sub-1-seriali 8-12-phyllo ciliato. Calyx 8-9 lin. longus, tubo cylindrico albido-sericeo, hasi persistente longe niveopilosả, lobis (nec petalis, ut ex errore typogr. I. c. dicuntur) $1 \frac{1}{2}$ lìn. longis, 1 lin. latis.

a. pubescens (Meisn. 1. c. p. 553), calle patenti-piloso, foliis lanceolatis oblongisve acutiusculis, inferioribus ciliatis, jnvolucralibus lanceolatis obtusis pedunculoque dense sericeo-pilosis (Krauss, n. 455!). Folia 12-16 lin. longa, $4-5$ lin. lata, infima et involucralia multo minora. (v. s.)

$\beta$, glabratus (Meisn. 1. c.), foliis ovalibus vel obovato-oblongis obtusis vel obtuse acuminulatis cauleque glaberrimis, involucralibus pedunculoque parce pilosulis (Krauss, a. 455, b l). Folia 10-12 lin. longa, 6-8 lin. lata; involucralia ovąto-oblonga, 7-8 lin. longa, 3-4 lin. lata, dorso glabrescentia. (v. s.)

$\gamma$. angustifolius, foliis lanceolatis acuminatis acutis ramisque demum glaberrimis, involucralibus ovato-lanceolatis adpresse sericeo-pilosiusculis. - In monte Magalisberg (Zeyh. n. 1889!). Rami corymbosi. Folia 8-12 lin. longa, 2-4 lin. lata, involucralibus acuminatis enerviis. Pedunculus 3-4-pollicaris, apice paulo incrassatus. (v. s.)

14. L. B OJER I AN US (Decaisne in Jacquem. voy. p. 149), ramulis sericeo-canis, folits sparsis anguste lanceolatis acutis attenuato-subpetiolatis 1-nerviis tenuiter venosis utrinque adpresse pilosiusculis, involucralibus ovato-oblongis acutis utrinque subsericeo-canis capitulum pedunculatum subæquantibus, calyce sericeo-cano, lobis ovalibus obtusis, squamis 4 parvulis' obovatis integris. $\mathcal{F}$ In Madagascarixe monte Antougome, prov. Emirnæ (Bojer 1). - Walpers ann. 1, p. 586. Gnidia daphnoides Boj. mss.! Ramuli tenues, leviter cicatricoso-tuberculatí. Folia 
herbacea, læte viridia, $1 \frac{1}{2}-2$ poll. longa, 3-4 lin. lata, utrinque attenuata, acúta vel obtusa submucronulata, pube tenui brevi subsericeá; involueralia quina 5-7 lin. longa, 3 lin. lata, acuminata, obsolete 1-nervia, evenia, cano-tomentosa. Receptaculum imberbe. Calyx 6-7 lin. longus, lobis 1 lin. longis. (v. s. in herb. DC, et Zuccar.)

15. L. Mapagascariensis (Decaisne 1. c. p. 148) foliis sparsis brevissime petiolatis ovalibus obovatisve obtusis ramisque glabris, novellis subtus parce sericeojilosulis, , jnvolucralibus $4-5$ similibus acutis deciduis capitulo pedunculato dimidio brevioribus, calyce gracili villoso, lobis oblongis obtusis squamas 5 dimidio superantibus. F In Madagaseariâ (Commerson). - Walp. ann. 1, p. 587. Gnidia daphnæfolia $\beta$ glabra Linn. fil. suppl. p. 225, Willd. sp. 2, p. 428, Wilkstr. Thym. p. 319. Dais Madagascariensis Lam. dict. 2, p. 254", ill. t. 368, f. 2. Ramuli debiles, apice conferte foliosi, cum pedunculis foliorumque nervo dorsali minute canopuberulis. Folia herbacea, extra medium latiora, 1 $\frac{1}{2}$ poll. longa, 5-10 lin. lata, obtusa eum vel absque mucronulo exiguo papillæformi, tenuiter pennivenia. Pedunculus pollicaris et ultra. Involucrum inapertum subglobosum, erostre, cerasi minoris mole, foliolis membranaceis? fuscis enerviis extus medio albido-sericeis (ex Desne. abrupte acuminatis basi conferruminatis). Calyx 6-7 lin. longus, lobis 1-1 $\frac{1}{4}$ lin. longis squamas petaloideas obovato-oblongas obtusas dimidio superantibus. (v. s. in herb. DG.)

16. L. PUBESGENS (Decaisne 1. c. p. 148), foliis sparsis subisessilibus cuneatoobovatis ramulisque cinereo-puberulis subtus incano-tomentosis, involucralibus lanceolatis capitulo breviter pedunculato dimidio brevioribus, calyce sericeo. 5 In Madagascariâ (Commerson). - Walp. ann. 1, p. 587. Gnidia daphncefolia $\alpha$ lirirsıta Linn, fil. suppl. p. 225; Willd. sp. 2, p. 428, Wikstr. Thym. p. 319. Dais pubescens Lam. dict. 2, p. $255^{*}$. Preter notas indicatas a pracedente differre dicitur foliis floribusque minoribus, pedunculo 4 lin. longq, attamen potius, ut jam Linnæus censuit, ejusdem varietas esse videtur.

17. L. R OS T RA T US, foliis sparsis attenuato-subpetiolatis spathulato-oblongis obtusis venosis ramisque glabris, novellis utrinque parce adpresso-puberulis, involucralibus 5-6 Jiberis e ba'si ovatâ subito acuminatis cajitulum pedunculatum subæquantibus sericeo-puberulis mox glabris, calyce cano-sericęo, - lobis oblongis obtusis squamas 5 dimidio superantibus. 5 In Madagascarià orientali (Boivin, n. 2384 l). Folia late viridia, $1-1 \frac{1}{2}$ poll. longa, extra medium 5-7 lin. lata, plerumque obsolete mucronulata, interdum emarginata, mox glaberrima. Pedunculi 4-12 lin. longi. Involucrum inapertum egregie rostrato-acuminatum, foliolis 6-8 lin. longis, 3 lin. latis, basi haud conferruminatis inferne fuscis margine membranaccis, acumine obtuso vel acutiusculo viridi. Receptaculum depresso-hamisphæricum, scricco-villostm, villis calycis basin persistentem parmm superantibus. Calyx 4-5 lin. longus, tubo tenui, lobis 1 lin. longis. Squamule faucis lanceolatx acuta. Ovarium sessile glaberrimum. Annulus hypogynus membranaceus brevissimus. Giet. L. Madagascarjensis, cujus forsan mera varietas, attamen involucro rostrato, floribus minoribus, etc., satis discrepans. (v. s. in herb. DC.)

18. L. ERIOCEPHALUS' (DCsne 1. c. p. 148), foliis sparsis herbaceis lanceolatis acutis venosis ramulisque glabris, involucralibus parvis capitulo breviter pedunculato parum brevioribus imbricatis ovali-oblongis acutis cano-tomentosis exterioribus glabrescentibus deciduis, calyce albo-villoso inferne longe piloso, lobis oblongis obtusis, squamis 5 minutis subcarnosis obovatis emarginatis. $\$$. In peninsulâ. Indire orientalis (Heyne!), montibus Neilgherry (Noton! Perrottet! de Hügel! Hohen. n. 974 !), Ceylan (Thwaites, n. 469!).-Walp. ann. 1, p. 586. Lachnæa eriocephala Heyne mss. Daphne eriocephala Wall. list, n. 1051! Gnidia eriocephala Meisu. in Regensb. Denkschr. 3, p. $292^{*}$, Wight ic. t. 1859 . Frutex erectus, 3-20-pedalis et

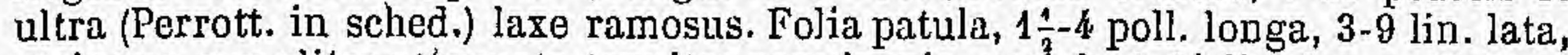
utrinque æqualiter attemuata tenuiter pennivenia, petiolo 1-1 $\frac{1}{2}$ lin. longo. Pedunculi $2-4$ lin. longi. Capitula magnit. juglandis, densc multiflora. Involucrum ovoidcum, biseriale, 6-10-phyllum, foliolis 4-6 lin. longis, 2-3 lin. latis, utrinque pubo brevi adpressâ subsericeâ albido-tomentosis, exterioribus dorso calvescentibus fuscis. Receptaculım hemisphrericum velutinum. Calyx 6-7 lin. longus, lobis circ. 1 lin. longis. Cyathulus hypogynus membranaceus, integer, ovarii pilosi stipitulum cingens. (v. s.) 
B. Zeylanicus, foliis summis subtus ramulisque dense piloso-pubescentibus. - In ins. Ceylon (Macrae! in herb. Ledeb.)

19. L. Sisparensis, foliis sparsis oblongis obtusiusculis venosís ramulisque glabris, floralibus ovato-oblongis utrinque sericeo-villosis capitulo subsessili parum brevioribus, calyce fusco-villoso basi longe piloso, lobis ovatis obtusis, squamis obcordatis. 5 In declivitate occidertali montium Neelgherry, circa Sisparah (Gardn.). Gnidia Sisparensis Gardn. contrib. towards a Flora of Geylon, 1846, p. 15, ex Miquel analect. 2, p. 2, Wight ic. t. 1860. Subárborea, ramis dichotomis. Folia

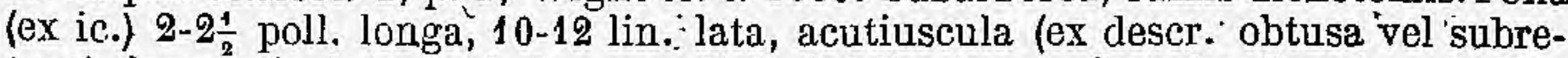
tusa), laxe reticulata, basi obtusa, petiolo $\frac{1}{2}-1$ lin. longo. Cset. fere L. eriocephali, a quo præter pubescentiam capituloram fuseescentem pluribus notis bene distincta dicitur.

20. L. HUGLII, foliis sparsis subsessilibus coriaceis lanceolatis acutis basi vix attenuatâ rotundatís obsolete penniveniis ramulisque glabris, involucralibus parvis capitulum subsessile æquantibus herbaceis ovato-oblongis acutis canescentibus, calycis tubo villosissimo lobis extus sericeo-tomentosis, squamis $\mathbf{5}$ petaloideis parvulis linearibus. 5 In Himalayâ.(L.-B. de Hügel). Daphne eriocephala Royle ill. p. 321 ? Folia $1 \frac{1}{2}-2$ poll. longa, $3-5$ lin. lata, minute pungenti-mucronulata. Calyx fere pollicaris, squamis subfiliformibus indivisis. Cæt. fere L. eriocephali, sed capitula fere duplo majora. Ovarium apice albo-comosum, infra parce pilosum. (v. s. in herb. Zuccar.)

21. L. SPECiosus (Desne in Jacquemont voy. p. 147, t. 150), foliis sparsis brevissime petiolatis herbaceis? lanceolatis oblongisque acutiusculis venosis ramulisque glaberrimis, involucralibus parvis capitulum breve pedunculatum subæquantibus oblongis acntiusculis incanis exterioribus glabriusculis, calyce pilošo, lobis ovatis obtusis squamulas 5 lineares bifidas dimidio superantibus. 7 In Indiæ montibus, inter Carli et Candalah (Jacquèm:), in Decean (Cahléry), circa Poonah (Perrottet).Walp. ann. 1, p. 586. Gnidia eriocephala Ralph enum. p. 113, Grah. list, 2-4. (ex Desne.). Frutex 12-15-pedalis. Folia 3-5 poll, longa, 6-12 lin. lata, utrinque attenuata, basi obtusa, petiolo vix 1 lin. longo, venis confertis tenuibus subtus prominulis reticulatis. Pedunculus vix semipollicaris. Invohucrum 10-12-phyllum, imbricatum, campanulatum, demum patens, foliolis 3-serialibus, $6-10$ lin. longis, 3-4 lin. latis, subvenosis. Calyx 8-10 lin. longus, luteus, tubo tenui, sifuamulis crassiusculis stamina superantibus. Ovarium pilosum, basi attenuatâ cyathulo membranaceo cinctâ.

22. L. Metzinaus (Miquel analecta bot. Ind. 2, p. $3^{\star}$, t. 1), foliis sparsis sessilibus coriaceis lanceolatis utrinque attenuatis acutis venosis ramulisque glabris, involucralibus minoribus capitulo súbsessili brevioribus ovali-lanceiolatis acutis incanis exterioribus glabriusculis, calyce hirsuto infra medium tumidulo longius barbato, lobis oblongis obtusis, squamulis 5 brevibus linearibus integris. $f$ In peninsulæ Indiæ montibus Ghats, prope Nilgunda territorii Canara et Mahratta australioris (Metz.). - Miq. in. Florâ 1853, p. 761. Gnidia monticola Miquel in sched. pl. Metz., Flora 1849, p. 557. Folia $1 \frac{1}{2}-3$ poll. longa, $2 \frac{1}{2}-5$ lin. lata. Capitula globosa, diam. pollicari, densiflora. Involucrum polyphyllum, biseriale, foliolis exterioribus herbaceis, interioribus brevioribus. Calyx circ. $5 \frac{1}{2}$ lin. longus, squamulis petaloideis, luteis subspathulatis obtusis.

23. L. IN S U L A R Is, foliis sparsis brevissime petiolatis subcoriaceis lanceolatis acutiusculis basi obtusis' obsolete venosis subtus ramulisque adpresse villoso-pilosis, involucralibus parvis capitulo breve pedunculato parum brevioribus oblongis incanis, calyce brevivilloso, lobis oblongis obtusis, squamis subcarnosis? linearibus parvulis. $=$ In ins. Ceylon (Thwaites, 'n. 29131). Gnidia insularis Gardn. contrib. towards a Flora of Ceylan, 1846, p. 15 (ex Miquel anal. Ind. 2, p. 2). Folia 2-4 lin. longa, 6-8 lin. lata, utrinque attenuata, supra glabra, subtus evenia, pube molli dense pilosâ, venis tenuibús confertis subimmersis supra conspicuis vel obsoletis. Capitula magnit. juglandis terminalia et in summis axillis subsessilia vel pedunculo 2-4 lin. longo suffulta. Ciet. L. eriocephali. (v. s. in herb. DC.)

24. L. SCANDENS (Endl. gen. suppl. 4, 2, p. 67), scandens, foliis spansis vel suboppositis ullipsóideis obscure reticulatis subtus pubescentibus, floralibus demum ampliatis scariosis reticulatis, capitulis racemoso-paniculalis subconicis pauci- 
floris 1 -bracteolatis, pedunculis demum elongatis medio biluracteatis, calyce brevissime pedicellato, lobis erectis, squamulis bifidis. 亏) In Malaccâ (Grifir.). Eukleia Malaccensis.Griflith in Calcutta Journ. of nat, hist. 4, 1843, n. 13, p. 234, in notâ, Flora 1844, p. 234, Walp. ann. 1, p. 587. Habitus fere Linostomatis, floris structura Gnidia. Fructus subrotundus drupaceus (?) nudus vel calycis basi spathaceâ fissâ stipatus. Pedunculorum bracteolæ inconspicuæ̣, canaliculatæ.

\section{Species obscura.}

25. L. cunearus (Desne in Jacquem. voy. p. 149), foliis obovato- vel lariceolatocuneatis ramulisque incano-sericeis, involucralibus capitulo breve pedunculato dimidio brevioribus linearibus erectis, calyce sericeo-incano gracili. F In Madagascariâ ? - Walp. ann. 1, p. 587. Dais cuneata Lam. dict. 2, p. 255, ex Dcsne. 1. c. (sed hoc cit. erroneum; nam hoe loco nonnisi D. pubescens et linifolia exstant, neque alibi D. cuneata invenienda). Foliis et pubescentjâ ad L. Meisnerianum (Gnidiam cuneatam Meisn. olim) accedere videtur, sed hujus involucrum longe diversum.

XXXI. DIGRANOLEPIS Planohon in Hook. ic. 8, t. 798, Niger flora, $p .496, t .49$, Walpers ann. 1, p. 588.

Flores hermaphroditi, 5-meri. Calyx coloratus? hypocraterimorphus, deciduus? tubo elongato gracili continuo? limbo 5-partito regulari patente. Squamæ 10 (ex ic. 5 semibifidæ) petaloideæ, fauci insertæ, lobis oppositæ. Stamina 10, fauci biseriatim? inserta, filamentis filiformibus alterne inæqualibus, longioribus exsertis, antheris dorso prope basin affixis oblongis obtusis. Cyathulus ${ }_{i}$ hypogynus membranaceus tubularis, ovarii stipitulum includens, 5-crenatus. Ovarium breviter stipitatum, semiovatum, ovulo prope apicem appenso. Stylus terminalis, longus, inclusus, deciduus, stigmate lineari-clavato papilloso. Drupa ? exsucca, stipitulata, subglobosa, mesocarpio nitentifibroso. Semen globosum, integumento membranaceo. Cotyledones hemisphæricæ, carnosæ. Radicula brevissima. - Frutex? Africæ tropicæ occidentalis, ramulis gracilibus foliisque alternis distichis, floribus axillaribus sessilibus solitariis, bracteolis nullis.

D. Dis т I н A (Planch. I. c.). 万 In Sierrâ Leone (G. Don in herb. Soc. hort. Lond.). Walp. l. c., Hook. Niger fl. p. 497, t. 49. Ramuli novelli cum petiolis calycibusque pube adpresșâ vel patente subsericei vel hispiduli, internodiis $4-8$ lin. longis. Foliar subsessilia, patula, rigide herbacea, oblique subtrapezoideo-oblonga, plana, acuminata, obtusiuscula, 1-2 poll. longa, 6-10 lin. Iata, glabra, nitida, subtus flavescentia, 1-nervia, venis pinnatis tenuibus. Calyx 15-18 lin. longus, basi vix tumidulus, lobis oblongis acutis 3 lin. longis squamas vix superantibus. Frùctus magnit. avellanæ, lævis, apice pilosulus styli basi apiculatus.

XXXII. LINOSTOMA Wallich list, n. 4203, Endl. gen. p. 331, n. 2102, suppl, 4, 2, p. 67, n. $2106 / 4$, Meisn. gen.p. 330 (243), Denkschr. d. Bot. Gesellsch. in Regensburg 3, p. 293, t. 7,-Sect. Eulinostoma Meisn. in Mart. fl. bras. fasc. 14, p. 71. - Nectandra Roxb. fl. ind. ed. 1832, 2, p. 425 (non alior.).

Flores hermaphroditi, 5-meri. Calyx coloratus, semi-5-fidus, deciduus, tubo continuo, campanulato, lobis æqualibus patulis. Squamulæ 10 fauci insertæ, staminibus alternæ et brevioies, petaloideæ, oblongo-lineares, glabræ, exsertæ. Stamina 10 fauci inserta sub-1-serialia, lobis breviora, flamentis subulatis exsertis, alternis (quæ sinubus inserta) brevioribus, antheris dorso adnatis oblongis obtusis. Annulus hypogynus nullus. Ovarium sessile, ovoideum, hirsutum, ovulo pendulo. Stylus terminalis, capillaris, exsertus, stigmate capitato papilloso. Drupa? nuda vel (ex Roxb.) bacca sicca. Albumen parcum, carnosum. - Frutices Indici, foliis oppositis penniveniis, flaralibus submembranaceis diversiformibus, umbellis terminalibus:

1. L. DECANDRUM (Wahl.! list, n. 4203), foliis ramulisque glaberrimis, inferioribus coriaceis lanceolatis acuminatis venis tenuibus parallolis dense transverse lineatis, 
floralibus cordato-oblongis obtusiusculis laxe venosis, calyce extus glabro, tubo campanulato intus piloso, ovario villoso. J In montibus silhet (Roxb.! H. Bruce!), circa Chittagong (Hook. fil. et Thoms.!).-Meisn. in Regensb. Denkschr. 3, p. 293*, t. 7, Walpers ann. 1, p. 587. Nectandra decandra Roxb. fl. ind. ed. 1832, 2, p. 425. Rami graciles, internodiis 1-2-pollicarihus. Folia læe viridia, supra nitida, 2-3 poll. longa, 8-12 lin. lata. petiolo 2-3 lin. longo supra sulcato, venis creberrimis tenuibus immersis (supra obsoletis) Calophylli more sub angulo fere recto e nervo excurrentibus rectis parallelis -marginem subtus nerviformem petentibus. Folia ramulorum floriferorum tenuia, ovata vel oblonga, subsessilia, basi emargi-

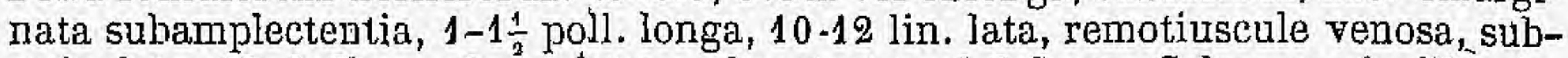
reticulata. Umbellæ pedunculatæe, ebracteatee, 4-6-floræ. Calyx semipollicaris, demum hinc fissus laceratus deciduus, lobis lanceolatis acutiusculis stanina parum superantibus, squamis obtusis. Stylús inferue pilosus. (v. s.)

2. L. PAUCIFLORUM (Griffith in CaIcutta journ. of nat. hist. 4, p. 234, adnot.), subscandens, foliis obovato-ellipticis apice rotundato cuspidato-mucronatis, calyce gracili, tubo fauceque intus glabris. $J$ In collibus, prope Stativa, Sincapore (Griff.). - Walp. ann. 1, p. 587, A præcedente differre dicitur foliis 2-3-plo minoribus, floralibus subnembranaceis, umbellis 2-3-floris et faucis squamulis multo minus staminiformibus.

XXXIII. LOPHOSTOMA Meisn. mss, in herb. Acad. Monac.-Linostomatis sect. 2 Meisn. in Mart. fl. bras. fasc. 14, p. 72.

Flores hermaphroditi, 5-meri. Calyx coloratus, tubulosus, marcescens, tubo continuo cylindraceo gracili, limbo 5 -fido règulari patente. Squamulæ 10 fauci insertæ, staminibus alternæ et breviores, oblongæ, obtusæ, dense barbatæ, exsertæ. Stamina 10, fauci inserta, lobis breviora; subuniserialiả, filamentis filiformibus exsertis, alternis (quæ sinubus opposita) brevioribus, antheris dorso adnatis oblongis obtusis. Annulus hypogynus nullus. Ovarium sessile, hirsutulum, ovulo prope apicem appenso. Stylus terminalis, capillaris, diu persistens, stigmate subexserto capitato papilloso. Drupa? sicca, calyce membranaceo marcescente ampliato inelusa, disco hypogyno incrassato glandulari? margine sulscrenato insidens, ovoidea, rostrato-acuminata, pericarpio crustaceo lævi..... - Frutices vel arbores Amazonici, ramulis gracilibus, foliis oppositis vel suboppositis coriaceis nervatione floralibusque Linostomatis, pedunculis terminalibus axillaribusque apice subcorymboso-patuciramosis, floribus racemosis ebracteatis, pedicellis brevissimis persistentibus. Genus Linostomati plurimis characteribus conveniens habituque simillimum, sed inflorescentiâ, calycis formâ, squamis faucialibus barbatis et præcipue fructu, antea nimis imperfecte nobis cognito, satis distinctum.

1. L. GALOPHYLLOIDES (Meişn. mss. in herb. Ac. Moni.), glabrum, foliis oblongis caudato-acuminatis, pedunculis apice racemoso-pluriramosis, calyce extus glabro. .7 In Brasiliæe æquinớctialis provinciâ Rio Negro, circa Barra (R. Spruce, n. 967! 1305?). Folia ramulis articulatim inserla, decidua, 2-5 poll. longa, 1-2 poll. lata, petiolo crassiusculo téreti supra sulcato $2-3$ lin., acumine lineari acuto $4-6$ lin. longo, venis immersis tenerrimis creberrimis supra obsoletis. Racemi rami distichi, 6-8 lin. longi, pedicellis vix $\frac{1}{2}$ lin. Tongis demum quasi dentati. Calyx extus glaber, 7-8 lin. longus, tubo tenui intus puberulo, limbo in alabastro acuminato, lobis oblongis obtusis. 1 lin. longís. Squamulæ flamenta breviora xequantes. Fructus (immaturus) fere $1 \div$ poll. longus, 9 lin. latus, calyce vesicæformi lacero inclúsus, rostro recto styligero 2-3 lin. longo terminatus, levis, glaber. (v. s. in herb. Acad. Monac. ot DG.)

2. L. ovarum, glabrum, foliis ovatis obtusiusculis, pedunculis apice bifidis, calyce extus puberula. 春 Circa Barra, prov. Rio Negro (R. Spruce, n. 1461!). Folia $1 \frac{1}{2}-2$ poll. longa, 8-12 lin. lata, nunquam acuminata, passim acutiuscula, venis magis obliquís subtus leviter prominulis, petiolo $1-1 \frac{1}{2}$.lin. Iongo. Calyx pube ferrugineât densâ minutissimâ tomentellus, alabastro haud acuminato. Cæet. præcedentis. (v. s. sine fr. in ler], DC.) 
Subordo II. AQUILARINEÆ (1). Aquilarinæ $R$. Brown Congo, p. 25 (443), DC. prodr. 2, p. 59, Bartl. ord. p. 420, Lindl. nat. syst. ed. 1, p. 77, Royle ill. p. 171, Endl. gen. p. 332, encheir.p. 210, Meisn. gen.p. 73 (53), Schnizl, iconogr. fam. 2, $t$. 110. - Aquilariaceæ Lindl. nat. syst. ed. 2, p. 196, veg. kingd. ed. 3, p. 579. Thymelæacearum tribus Dcsne. in Ann. sc. nat. $2^{\mathrm{e}}$ sér. 19 (1843), p. 35 .

Ovarium aut 2-loculare, loculis 1-ovulatis, aut 1-loculare, placentis 3 parietalibus 1-ovuligeris. Cæt. Thymelæarum. - Arbores vel frutices Asiæ tropicæ et Oceaniæ.

\section{Tribus III. GYRINOPEAE.}

Squamæ perigynæ variæ, calycis fauci insertæ, staminibus alternæ, liberæ vel in coronam dentatam coronatæ. Flores hermaphroditi, 5 -meri.

XXXIV. AQUILARIA Lam. dict. 1, p. 49, ill. t. 356, Cav. diss. 7, p. 377, t. 224, DC. prodr. 2, p. 59; Royle ill. Himal. p. 173, t. 36, Arnott in Lindl. nat. syst. ed. 2, p. 442, Hook. ic. t. 6, Endl. gen. p. 333, n. 2111, Moisn. gen. p. 73 (53), Roxb. et Colebrook in Linn. Trans. 21, 3, p. 199, t. 21. - Ophispermum Lour. fl. coch. ed. Willd. 1, p. 344. - Agallochum Rumph. Amb. 2, p. 34, t. 10.

Calyx coriaceus, campanulatus, 5-fidus. Squamæ faucis 10 , exsertæ, pilosæ, basi in coronam connatæ, hypogynæ nullæ. Stamina 10 , filamentis calycis tubo adnatis apice breviter libero subexsertis, antheris basifixis oblongis obtusis. Annulus hypogynus nullus. Ovarium sessile, 1-loculare (ex Roxb. 2-loc.), placentis 2 parietalibus prope apicem ovulum pendulum anatropum gerentibus. Stylus nullas vel stamina superans, stigmate convexo vel bifido papilloso. Capsula lignosa, obovata', compressa (ex Roxb. et Colebr. l. c. 2-locularis) bivalvis, valvis medio placentiferis. Semina 2 vel abortu solitaria, plano-convexa, rhaphe dorsali (?) membranaceâ, chalazâ spongiosâ descendente. Albumen nullụm. Embryo inversus. - Ar̄bores Asiaticæ, foliis sparsis, floribus axillaribus terminalibusque umbellatis vel subsolitariis.

1. A. Áa g осна (Roxb. cat. h. Calcutt. p, 33), foliis brève petiolatis elliptico-vel lanceolato-oblongis acuminatis basi attenuatis glabris, umbellis subsessilibus. $\hat{f}$ In Bengaliâ orientali, circa Goalpara (Hamilt.), et montibus Silhet et Assam (Roxb., Wall. list, n. 7250!), DC. prodr. 2, p. 59, Roxb. fl. ind. 2, p. 422, Royle, ill. p.173, t. 36 , f. 1, Roxb. et Colebr. in Linn. Trans. 21, 3. p. 199*, t. 21. Arbor maxima, verum lignum Agallochum seu Calambac, seu Aggur, seu Tuggur, seu Aloes præbens (Roxb., Royle l. c.). Folia disticha, rigida, 2-6 poll. longa, 1-2 poll. lata, lævia, glabra, nitida, conferte pennivenia, novella subsericea, sæpe subsessilia. Fasciculi (ex Arn.) axillares 7-flori, sessiles, pedicellis 3-5 lin. longis (ex ic. Royl.), in corymbum brevem pedunculo $3-4$ lin. longo fultum approximati. Flores inodori. Calyx flavo-virescens, $2 \frac{1}{2}$ lin. longus, utrinque puberulus, persistens, lobis oblongis acutis reflexis intus glabris tubo parum brevioribus. Antheræ squamas ovatas vix superantes. Stigma subsessile, capìtatum, indivisum. Capsula (immatura ?) oblonga, 6-8 lin. longa, tomentosa. (v. s. in herb. DC.)

2. A. SEGUNDARIA (DC. prodr. 2, p. 59), foliis petiolatis ovato-vèl ovali-oblongis sensim acuminatis.... 5 In Moluccis. Agallochum secundarium Rumph. Amb. 2, p. 34, t. 10. Species nonnisi ex ic. nota, a præcedente verisimiliter haud distincta.

(1) Jam in Prodromo, vol. 2, p. 59, enumeratæ, sed loco non proprio et nimis incomplete. Non inutile ideo judicamus, eas hic iterum describere. 
Cfr. Collebr. 1. c. p. 202 . Folia $1 \frac{1}{2}$ fere 3 poll. longa, $\sqrt[10-15]{ }$ lin. lata, petiolo $2-3$ lin. longo (ex ic.)

3. A. MALAGCENSis (Lam. dict, 1; p. $49^{*}$, ill. t. 356 ), ramulis subvillosis, foliis ovatis abrupte acuminato-mucronatis glabris, petiolo brevi piloso. 5 In Malaccâ et in Happy Valley ins. Hong-Kong (Hinds.). $\rightarrow$ DC. prodr. 2, p. 59, dict. sc: nat. t. 248, Benth. in Hook. Journ. 1853, p. 195, A. ovata Cav, diss. 7 , p. 377, t. 224, Willd. sp. 2, p. 629. Bois d'Aigle (Sonnerat). Garo de Malacca, Lam. 1. c. Ab A. Agallochâ vix satis distincta, foliis tantum plerumque, nec tạmen' semper, latioribus et floribus majoribus, ex Benth. 1. c. Colebr. in Linn. Trans. 21, p. 202.

4. A.? Снinensis (Spreng. syst. 2, p. 356), foliis lanceolatis undulatis, nitidis, floribus terminalibus solitariis, calyce 6 ?-partito, stylo stamina persistentia superante apice bifido. 5 In Chinâ australi. Ophùspermum Sinénse Lour. Coch. ed. Willd. 1, p. 344, Poir. in dict. sc. nat. 18, p. 161, DC. prodr. 2, p. 59.

\section{Species obscura, verisimiliter èxcludenda.}

5. A. PENTANDRA (Blanco fl. de Filipin. ed. 1, p. 373*); foliis sparsis verticillatisque subsessilibus lanceolatis acutis vel emarginatís glabris, racemis termizalibus compositis, squamis faucialibus 5 calycis lobos æquantibus, staminibus 5 sinubus insertis cum squamis alternantibus. 5 In insulis Philippinis, loco Angat (Blanco). Arbuscula, ramis furcatis, ligno albo duro. Folia 4 poll. longa, 1 poll. lata, margine anguste membranacea, sicut fructus odorem gratum fortem spargentía. Calyx $\mathbf{5}$-fidus, lobis concavis apice villosiusculis, squamis æquilongis et concoloribus. Filamenta calycis lobis breviora, antheris corniculiformibus. Ovarium ovale, stigmate sessili rotundato. Capsula globosa, magnil. seminis ciceris, basi in stipitulum attenuata, valvis 2 vel raro 3 medio septum angustum gerentibus. Semina 13-14 prope basin septi inserta, compresso-reniformia, pulpâ tenui involută, sicut fructus amara. Species, si descriptioni fides habenda, jam fructus polyspermi causầ e genere, immo ex ordine, expellenda.

XXXV. GYRINOPS Gartn. fr. 2, p. 276, t. 140, DC. prodr. 2, p. 60, Arnott in Lindl. nat. syst. ed. $2, p .442$, Hook. ic. t. 5 ; Endl. gen. p. 333, «. 2140, Meisn. ger. p. $73(53)$.

Calyx coloratus, infundibuliformi-tubulosus, gracilis, intus glaber, limbo 5-partito regulari. Squamæ faucis in coronam erectam 10-crenatam glabram connatæ. Antheræ 5 in fauce sessiles, inclusæ, calycis lobis oppositæ, dorso affixæ, lineares, obtusæ. Annulus hypogynus nullus? Ovarium longe stipitatum, utrinque attenuatum, pubescens, 2-loculare, loculis 1-ovulatis. Stylus terminalis, cylindraceus; deciduus, stigmate compresso-sphæroideo indiviso. Capsula stipitata, coriacea, loculicide bivalvis. Semina solitaria, caudâ (funiculo umbilicali?) fungoso-suberosâ versus capsulæ fundum descendente aucta. - Frutex Zeylanicus, habitu Aquilariæ.

G. Walla (Gertn. l. c.). 产 In Ceylon. - DC. 1. c., Arnott 1. c., Hook. ic. t. 5. Tota colore aurantiaco suffusa. Fiami graciles, libro tenacissimo. Folia sparsa, oblonga, breve obtuseque acuminata, basi attenuata subpetiolata, $3-4$ poll. longa, $1-1 \frac{1}{2}$ poll. lata, pennivenia, glabra? Umbellæ axillares, ebracteatæ, 3-5-floræ, pedunculo pedicellisque circ. 2 lin. longis. Calyx aurantiacus, 9 lin. longus, angustus, basi attenuatus, extus parce puberulus, lobis patentibus ovatis acutis vix 1 lin. longis. Capsula spathulato-oblonga, compressa, obtusa, circ. pollicaris.

XXXVI. GYRINOPSIS Decaisne in Ann. sc. nat. $2^{\circ}$ sér. 1843, p. 41, t. 1, B.

Calyx coloratus, tubulosus, utrinque pubescens, limbo 5 -fido regulari. Squamæ faucis 10 , crassiușculæ, breves, staminibus alternæ, villosæ. Antheræ 10 in fauce sessiles, subbiseriatæ, medio dorso affixæ, oblongæ, obtusæ, subinclusæ. Annulus hypogynus nullus. Ovarium breviter stipitatum pilosum, biloculare, ovulis in loculis solitariis appensis anatropis. Stylus. subcentralis, cylindraceus, brevis, inclusus, stigmate cernuo? ovoideo, integro hispidulo. Fructus..... - Frutex Philippinensis, habitu Aquilariæ. 


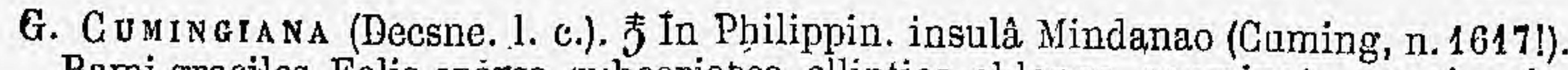
Rami graciles. Folia sparsa, subcoriacea, elliptico-oblonga, acuminata, pennivenia,

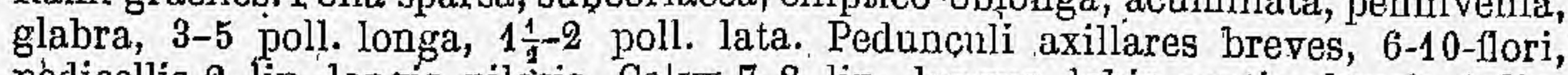
pédicellís 2 lin. longis pilösis. Calyx 7-8 lin. longus, lobis_ovatis obtusis 1 lin. longis. (v:'s. in herb. Shuttlew.)

XXXVII. LEUCOSMIA Benth. in Hook. Lond. Journ. 2, p. 231, Bot. Sulphur, p. $179, t .57$.

Calyx longe tubulosus, limbo 5-fido. Squamæ faucis 5; lobis alternæ. Stamina 10, summo tubo biseriatim inserta, superiora lobis opposita, filamentis brevibus, antheris linearibus versatilibus. Ovarium basi vaginulâ brevi integrâ cinctum, bilocułare. Stylus filiformis longus, stigmate oblongo crasso leviter emarginato. Drupa sarcocarpio tenui, putamine crasso lignoso 2-spermo. Semina exalbuminosa. Cotyledones crassæ. - Arbor? Oceanica, foliis oppositis, floribus capitatis.

L. Bur Net T IANA (Benth. 1. c."). 5 ? vel 7 ? In insulis Feejee (Hinds et Barclay). Glaberrima, foljis breve petiolatis subcoríaceis ovatis vel ellipticis vel summis suborbicularibus breve acuminatis reticulato-venosis nitidis $2 \frac{1}{2}-3 \frac{1}{2}$ lin. Iongis, Capitulum terminale, breviter pedunculatum, circ. 10-florum; involucro deciduo. Calyx 2-pollicaris, extus glaber, basi apiceque subampliatus, tubo intus hirsuto, lobis crassis oblongis obtusis concavis 3-4 lin. longis. Squamæ faucis parvæ, ovate. Ovarium villosum. Drupa compresso-globosa vel subdid.yma.

\section{Tribus IV. DRYMISPERMEAE.}

Squamæ perigynæ nullæ. Flores hermaphroditi; diplostemonei, 4- vel rarius 5-meri. Filamenta filiformia, conspicua. Stylus elongatus. Ovarium basi annulo hypogyno cinctum, 2-loculare, ovulis in loculis solitariis prope apicem septi appensis. Bacca subdrupacea, 2- vel abortu 1-locularis, 1-sperma, sarcocarpio fibroso. Semina exalbuminosa. Cotyledones carnosæ.

XXXVIII. PSEUDAIS Decaisne in Ann. sc. nat. $2^{\circ}$ ser. $19, p .40$.

Calyx clavato-tubulosus, limbo brevi 5-dentato regulari, fauce nudâ. Stamina 10, inclusa, filamentis tubo ad medium usque adnatis supra liberis glabris, antheris ovalibus dorso inferne adnatis. Stylus filiformis, inclusus, deciduus, stigmate subpeltato umbilicato. Drupa ovoidea, nuda. Seminis testa tenuis. - Frutex foliis oppositis, floribus capitatis。

P. cocainen (Desne. k. c.). J In insula Rawak: Dais coccinea Gaudich. in Freycin. voy. Uranie, p. 443 , t. 44 . Ramuli stricti. Folia herbacea, breve acuminata, basi rotundata, reticulato-venosa, glabra, supra nitida, subtus pallidiora, inferiora oblonga circ. pedalia, 3 poll. lata, petiolo 3 lin. Iongo basi incrassato, summa 3-4-plo breviora ovalia. Capitula axillaria? et terminalia, solitaria, multiflora, magnit. pomi minoris, pedunculo subbipollicari, involucro floribus breviore. Calyx 15 lin. longus, coccineus, glaber, infra medium angustatus, limbì dentibus erectis $\frac{1}{3}$ lin. longis obtusis.

XXXIX. DRYMISPERMUM Reinu. sylloge nov. pl. Ratisbon. 1828, p. 15, t. 2, Decaisne l. c. p. 38, $t .1$, A. - Phaleria. Jack Malay misc., ex Hook. Comp. Bot. mag. 1 p. 156.Dais sp. Roxb., Blume.

Calyx coloratus, hypocraterimorphus vel infundibuliformis, limbo 4 -fido subæquali, fauce nudâ. Stamina 8 , summo tubo simplici ? serie inserta, filamentis tubo adnatis exsertis, alternis (quæ lobis opposita) longioribus, antheris ovalibus dorso connectivo crassiusculo adnatis. Ovarium sessile, basi disco cupuliformi submembranaceo cinctum, glabrum. Stylus terminalis, 
filiformis, exsertus, stigmate capitato papilloso. Drupa ovoidea, nuda. Seminis testa subcrustacea. - Arbores fruficesve Moluccarum, foliis oppositis vel subsparsis coriaceis breve petiolatis, pedunculis axillaribus terminalibusve solitariis, floribus capitatis vel umbellatis involucro communi cinctis.

1. B. UR N S (Reinw. l. c. p. 15 , n. $35^{\circ}$ ), foliis subsessilibus late lanceolatis acuminatis glaberrimis, floribus fasciculatis lateralibus vel rarius terminalibus, calyce infundibuliformi brevissime incano-puberulo, lobis rotundatis staminibus stylo longioribus dimidio superatis, drupâ głobosâ. $\xi$ In Celebes (Reinw:). - Decaisne l. c. p. 39. Arbor speciosa. Folia oipjosita. Flores sessiles, albi, fere sesquipollicares, bracteis involucri pluribus obtusis, receptaculo communi foveolato. Stamina summo tubo inserta, filamenta lobis duplo longiora: Stigma globosum, integrum vel didymum. Ovarium oblongum. Drupæ globosæ, rubræ, magnit. cerasi, carne albidâ subdulci insipidâ, pyrenis 2 plano-convexis.

2. D. Phaleria, foliis breve petiolatis ovato-lanceolatis longe acuteque acuminatis glaberrimis, capitulis axillaribus brevissime pedunculatis, calycis tubo longo glabro? lobis ovatis, stylo staminibus paulo breviore, drupâ subpyriformi JIn Sumatrà (Jack). Phaleria capitata Jack Mal. misc. in Hook. comp. Bot. mag, 1, p. 156*. Frutex. Folia opposita vel subopposita, 8 poll. longa, petiolo incrassato. Pedunculi sæepius ex axillis foliorum delapsorum nascentes. Involucri bracteæ plures, obovato-oblongæ. Flores sessiles, magni, albi, Jasmino similes, fauce perviâ glabrâ. Stamina longiuscula, exserta. Drupæ aggregatæ, apice rotundatæ, basi acute; corticose, 2-loculares, 2-spermie. Nímis affinis D. urenti, sed recedens caule fruticoso, nec arboreo, foliis petiolatis et drupis subpyriformibus.

3. D. BLUMEI (Dene 1. c. p. 39), foliis oblongo-lanceolatis utrinque acuminatis glabris, capitulis axillaribus terminalibuisque subsessilibus, floribus extus glabris. 5 ? In sylvis montanis Javæ et in ins. Nusa Kambang (Blume)! - Zolling. n. 2402 ! ex distrib. 1847, nec 1846, Zólling. Verzeichn. 2, p. 117. Dais dubiosa Blume cat. pl. Buitenzorg, 1823, p. 69, Bijdr. p. 651, Plutonia, Noronha relatio plant. Jav., fide Hassk.in Tijdschr. voor nat. en phys, 8, p. 415. Folia opposita (ex Blume), subopposita. Drupæ kermesinæ 1-2-sjermæ, ex Hassk. cat. fl. bogor. alter. 1844, p. 92, in notâ. Filores albi, ex Zolling. Verzeichn. 2, p. 117. Planta Zollingeri sequentia ostendit : glabra. Rami stricti, dichotomi. Folia opposita, subcoriacea,

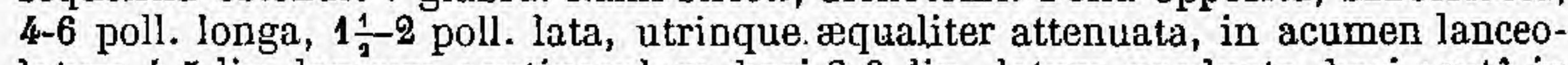
latum 4-5 lin. longum acutiusculum basi 2-3 lin. latum producta, basi acutâ in ¿petiolum 2-3 lin. longum marginatum supra concavum crassiusculum basi-articulatum quasi decurrentia, nervo venisque primariis (utrinsecus 6-9) tenuibus supra subimnersis subtus parum prominulis intra marginem obsolete arcuatin anastomosantibus, venularum reti obsoleto laxo. Capitula in axillis foliorum delapsorum sessilia, solitaria, 6-8-flora, bracteis 6-8 herbaceis lanceolatis vel spathulatis obtusis 3-4 lin. longis glabris eveniis patulis involucrata. Calyx 10-12 lin. longus, tubo angusto subfiliformi basi apiceque paululum ampliato, lobis patentibas ovalibus obtusis 2 lin., longis, intus apicem versus sub lente tomentellis'. Stamina æqualia, lobos stylumque paulo superantia. Pistillum totum glabrum; ovarium oblongum, cyathulo membranaceo crenato ad medium usque cinctum. Drupa sicea ovoidea, utrinrue atteuuata, 4-5 lin. longa, styli basi submucronata, lævis, fusca, glabra. (v. s. in herb. DC.)

4. D. LAURIF oLIUn (Desne 1. c. p. 39, t. 1, A), foliis breve petiolatis oblongis vel elliptico-oblongis acuminatis basi attenuatis, capitulis terminalibus multifloris, calyce exlus subincano-puberulo, stylo stamina superante. 5 ? In ins. Timor. Dais dubiosa Decaisne, herb. Timor, in nouv. amm. Mus. 3, p. 41 (non Blume). Huc spectare videtur " Dais " ex ins. Timor in herh. DC. (comm. a Mus. paris.) cui folia opposita, 3-5 poll. longa, 1-1 $\frac{1}{2}$ poll. lata, oblonga, utrinque subacuminata, acutiuscula, glabra, uervo supra sulciformi subtus prominente, venis utrinsecus 10 patentibus prope marginem arcuatim coeuntibus venulisque tenuibus laxe reticulatis subtus leviter prominulis supra obsoletis. Capitulum terminale, pedunculo 2 lin. longo squamato-bracteato, involucro nondum aperto subgloboso magnit. cerasi, foliolis herbaceis ovatis 4 lin. longis, 3 lin. latis, eveniis glabris, interioribus apice calyeibusque tomentellis. (v, s. in herb, DC.) 
5. D. AMBIGUUM, foliis lerbaceis petiolatis clliptico-oblongis utrinque xqualiter attenuatis tenuiter venoso-reticulatis ramulisque glabris, capitulo terminali subsessili 8-floro, involucri foliolis oblongis lanccolatisve obtusis glabris, calycc extus cano-puberulo basi glabrescente, lobis stamina suhæquantibus sty!o waulo longioribus. 5 ? In Javà (Zollinger, Il. 2402 !' $\mathrm{ex}$ distrih. 184f, nec 1847). D. laurifolium ?

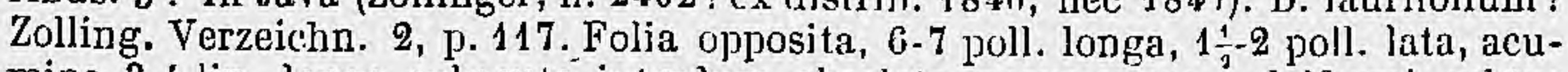
mine 3-4 lin. longo subacuto interdum obsoleto, nervo supra sulciformi subtus prominente, venis utrinsecus $9-15$ patulis jrope marginem arcuatim auastomosantihus venulisque tenuibus laxe reticulatis subtus leviter prominulis supra obsoletis. Cset. et fr. D. Blumei, a quo præcipue differt calyce minore, 9 lin. longo extus pubescente, lobis tubo angusto dimidio brevioribus. (v. s. in herb. DC.)

6. D. Pernottetianum (Desne. l. c. p. 40), foliis petiolatis late ellipticis breve acuminatis nervosis, capitulis axillaribus terminalibusve multilloris, calyce extus puberulo, lobis intus apicem versus tomen tosis, stylo stamina æquantc. $\delta$ ? In ins. Lucon, circa Manilam (Perrottet? in herb. Mus. paris.).

7. D. Cum InaIr, foliis subcoriaceis breve petiolatis oblnngis basi obtusiusculis apico magis attenuatis obtuse subacuminatis ramulisque glabris, capitulis axillaribus? ct terminalibus breve pedunculatis, calyce extus glabro, lobis oblongo- vel ovatoovalibus intus apicem versus tomentellis, staminilus lobos breviter stylum longius superantibus. 5 ? In ins. Luçon, provincià Tajabas (Cuming, n. 703l). Dais laurifolia Blanco 11. de Filipinas, ed. 1, p. 375? Folia $4-5$ poll. longa, $1-1 \frac{1}{2}$ poll. lata, petiolo 2-3 lin. longo crassiusculo supra concavo marginato basi paulo deorsum prodncto, venis primariis utrinsecus 8-12 patentibus tenuibus prope marginem arcuatim junctis cum nervo medio utrinque leviter prominulis, venularum reti laxo immerso subtus conspicuo. Calyx pollicaris, tủbo tenui apicem versus anguste infundibulari. Stamina æequilonga, lobos $\frac{1}{5}$ superantia. Stylus loborum medium attingens, stigmate depresso-capitato subdidymo majusculo.Valde accedit ad D. laurifolium et Perrottetianum, scd ab utroque differt calyce extus glabro et stylo staminibus breviore. (v. s. in herb. Shuttlew.)

8. D. BuRmanni (Desne. 1. c. p. 40), foliis breve petiolatis late ovatis vel obovatis acuminatis, capitulis axillaribus, calyce extus subpuberulo, stylo stamina subæquante. 5 ? In Indiầ orientali.... Dais oetandra Burm. fl. ind. p. 104, t. 32, f. 2, Linn. mant. 1, p. 69, Willd. sp. 2, p. 580 (excl. $\beta$ ), Wikstr. Thym. p. 348. Icon Burmanni, folia exhibens utrinque attenuata et flores 5 -fidos 10 -andros, tam ab ejusdem auctoris descriptione, quam (teste cl. Decaisne) ab ijsius Burmanni specimine autographo in herb. Delessert servato abhorret, cui folia obovata et flores 4 -fidi extus puberuli.

\section{Species obscura.}

0. D.? FORSTERI, foliis ovato-lanceolatis enerviis, floribus 8-vel 10-andris. 5 ? In insulâ Tongatabu. Dais disperma Forst. prodr. p. 33, n. 192, Willd. sp. 2, p. 580 , Wikstr. Thym. p. 349. 


\section{Ordo CLXVIII. ELÆAGNACE}

Elæagnorum pars Juss. gen. p. 74. - Elæagnoidearum pars Vent. tabl. II, p. 232. - Elæagneæ $R$. Br. proarr. $A$. N. Holl. p. 350, Ach. Rich. mon. des Eléagnées in Mém. de la Soc. d'hist. nat. de Paris I, p. 375-408, t. 24, 25, Bartl. ord. nat. p. 113, Endl. gen. plant. p. 333, Meisn. gen. pl. I, p. 329, II, p. 24l, Sclnizlein iconogr. fam. nat. fasc. VIII. - Elæagnideæ Dumort. anal. p. 15 et 18. Elæagnaceæ Lindl. introd. ed. 2. p. 194.

Flores hermaphroditi, interdum pistilli abortu masculi v. dioici, regulares. Perigonium inferum, simplex, rarius usque ad basin bipartitum (diphyllum), plerumque longius breviusve tubulosum, limbo bi- vel quadripartito (partitionum numero interdum aucto), rarius conico integerrimo, sæpissime intus colorato. Discus tubum perigonii investiens, ad faucem vario modo prominens, rarius ex glandulis octo constans. Stamina rarius libera, plerumque cum perigonio connata et laciniis ejus numero æqualia et alterna, rarius dupla, tunc opposita et alterna; filamentorum liberâ parte brevissimâ. Antheræ biloculares duplici rimâ dehiscentes, dorso affixæ. Pollen obsolete trigonum. Pistillum simplex, liberum; ovarium perigonii tubo dein accrescente inclusum; stylo erecto elongato simplici, inferne nudo, superne majore ex parte in altero latere stigmatoso. Fructus unilocularis, monospermus, pericarpio membranaceo, arcte induviatus tubo perigonii drupam mentiente, extus plus minus carnoso, intus osseo vel cartilagineo, limbo perigonii deciduo v. obliterante. Semen erectum, anatropum, funiculo nullo v. brevissimo basali; embryo erectus albumine angusto cinctum, radiculâ inferâ, cotyledonibus angustis, plumulâ minutâ. - Arbores et frutices in Asiæ tropicæ et subtropicæ montosis inprimis crescentes, per Europam et Americam borealem rariores, in Americâ tropicâ rarissimæ, argenteolepidotæ et radiato-pilosæ, ramulis sæpe spinescentibus, rarius sarmentaceis. Folia alterna, rarius opposita, simplicia, penninervia, integerrima, breviter petiolata. Stipulæ nullæ. Gemmæ nudæ. Flores in axillis inferioribus ramulorum et innovationum solitarii v. aggregati, sessiles $\mathrm{v}$. pedicellati, hinc interdum in spicas v. racemulos axillares collecti, rarius in cymas dichotomas axillares dispositi, lutei vel rarius albidi, sæpe fragrantes. Fructus aciduli v. insipidi, lutescentes v. rubri, partim edules.

(1) Auclore D. H'. L. von Schlechtendal. 
I. HIPPOPHAE $L$. gen. (ed. 1764) p. 517, n. 1106, Juss. gen. p. 75, Ach. Rich: monogr. Eloeagn. in Mém. de la soc. d'hist. nat. de Paris, I, p. 387, 400, 402, t. 24, f. 2, Endl.gen. pl. p. 334, n. 2112, Meisner gen. I, p. 329, II, p. 242, Lam. illustr. t. 808, Nees gen. pl. A. germ. 3, n. 19, Gaertn. d. fruct. I, p. 199, t. 42,-Bhamnoides Tournef. Inst. coroll.p. 52.-Rhamni sp. patrum botan.--Osyridis spec. Scopoli.

Florés dioici (quandoque monoici Schk.) ad basin ramulorum brevium lateralium amenta mentientium dispositi. Masculi in axillis bractearum deciduarum sessiles; perigonio diphyllo; staminibus 4 (interdum 3), filamentis subnullis, antheris oblongis utrinque obtusis. Fæminei in axillis foliorum solitarii, pedicellati, perigonio lubuloso, apice anguste bifido. Pistillum simplex (rarius duplex ex OEder in fl. Dan.), a perigonio præler stigma exscrtum inclusum, ovario uniloculari, uniovulato, stylo brevi, stigmate elongato acuto. Fructus ex perigonio increscente et succulento drupaceus, monopyrenus, putamine obovoïdeo, nitido, altero latere sulcato, semine unico conformi. Arbusculæ fruticesve Europæ et Asiæ mediæ,-lepidoti, ramis sæpius spinescentibus, foliis alternis linearibus, floribus præcocibus.

1. H. внАм Nо1DES (L. sp. pl. ed. 2, p. 1452), foliorum basi in petiolum attenualorum pagina inferâ ramis junioribus perigonioque argenteo-micanti-lepidotis, lepidibus omnibus margine tantum partitis, perigonii masculi phyllis subrotundoellipticis (vix 1 $\frac{1}{2}$ lin. longis), antheris brevioribus (háud lincam longis). $J$-Crescit in arenosis et argillosis per littora insulasque maris Baltici, australioris saltem et medii, dein per littora maris Germanici, rarius in Scotiû et Norvegià, frequentius in Daniâ, Germaniâ, Belgiâ, Hollandiâ, Anglià orientali et Galliâ septentrionali, I'requens porro occurrit in ripis insulisque glareosis et arenosis torrentum et fluviorum ex Alpium jugo defluentium, in planitiem usque cum iis descendens; in provinciis Caucasicis ad Persiam borealem usque reperitur nec non in Sibiriæa Uralensis, Altaicæe, Baicalensis fluviorum ripis. - Fries summa veg. Scand. p. 53, Fl. Dan. t. 265, Ledebour fl. Ross. 3, p. 552, Koch syn. cd. 2, p. 740, Reichenb. icon fl. Germ. et Helv. XI, t. 549, f. 1165, Host 1l. Austr. 2, p. 660, Schkuhr Handb. 3, p. 463, t. 321, Hook. el Arn. brit. fl. ed. 6, p. 377, Engl. Bot. VI, t. 425, Lejeune et Court. fl. Belg. comp. 3, p. 279, Kops fl. Bat. t. 100, Nutel fl. franc. 3, p. 145, Gaudin 11. helv. 6 , p. 279 , Pollini fl. Veron. 3, p. 174. Osyris rhamnoïdes Scop. Carn. 2, p. 261. - Frutex 4-12 jed. altus, foliorum supra viridium lon-

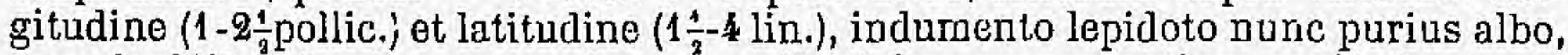
nunc lepidibus fuscis opaco, spinarumn culturâ fere evanescentium copiâ, fructuum colore mox vitellino, mox rubro. In hortis quoque occurrit forma ramis junioribus pendulis. (v. v. sp, et cult.)

2. H. SAligifolia (Don prod. fl. Nepal. p. 68), foliorum !anceolatorum utrinque obtusorum paginâ inferà ramis junioribus perigonioque albo-tomentoso-lepirlotis, lepidibus albis fere usque ad basin partitis, perigonii masculi phyllis elongato-ellipticis ( 2 lin. paulo superantibus), antheris majoribus crassioribus (2 lin. longis). 5- F In Nepaliâ prolıe Sirinagur (Kamroop), in montibus Himalayảh ad Gossain Than et Kamaon (Wallich l), ad Kunawur (Royle).-Loud. cnc. of trees, p. 699. c. ic. 1369. H. conferta Wall. cat. n. 4032 ! Royle illustr. p. 323. Arbor, frutexve - 15-20- pedalis, folia duplo majora ac in specie Europłeâ evaderc possunt ceterum iis Stlicis viminalis similia. Bacca ${ }_{\text {ex }}$ icone Loudonianà brevior, subdepressoglobosa. (v. sp. masc. Wallich. absque foliis.)

II. SHEPHERDIA Nutt. gen. of North-Amer. plant. II, p. 240 ;818), Ach. Rich. l. c. p. 389, 401, 402, t. 24 , fig. 3 (flor. fomin.), Endl. gen. pl. p. 334, n. 2113 , Meisn. gen. I, p. 329 et II, p. 242. - Hippophaës spec. L. Juss. Pursh, etc.-Leptargyreia Raf. in Americ. monthly Mag. 1819.

Flores dioici ad basin ramulorum brevium lateralium racemulos formantes. Masculi in axillis bractearum pedicellati, perigonio profunde 4-partito, staminibus $8 \mathrm{cum}$ totidem glandulis alternantibus, subsessilibus, fauci insertis, limbo brevioribus. Fominei in axillis foliorum oppositi, perigonio ovoïdeotubuloso, limbo quadripartito patente, fauce glandulis 8 contiguis cincto. 
l'istillum simplex, ovarium tubo perigonii inclusum, uniloculare, uniovulatum, styli elongati acuti altero latere longe stigmatoso. Fructus ex increscente peıigonio succulentus drupaceus, monopyrenus, putamine subovoïdeo nitido; semine unico conformi. - Frutices v. arbusculæ Americæ septentrionalis, lepidotæ, ramulis interdum spinescentibus. lolia opposita ovalia. Flores præcoces.

1. S. CANADENSIS Nutt. gen. II, p. 241), ramis ferruginco-lepidotis, foliis ovalibus vel ovato - ellipticis acutiusculis basi obtusis supra dein glabrescentibus, subtus alljis stellato-pilosis et ferrugineo-lepidotis, filamentis glabris. $尹$ Ad fluviorum lacuumque ripas per Canadam (Kalm) nsque ad castellum, Franklin ad lluvium Mackenzie et ab insulà Terrâ novâ et sinu IIudsonis usque ad montes petrosos (Rocky mountains), nec non in Ameriçe orà occidentali-boreáli (Menzies) -Ach. Rich. monogr. l. c. p. 406, t. 24, f. 3, Hopk. fl. bor. Amer. 2, p. 138, Loudon enc. of trees, p. 700 c. ic. Hippophrë Canadensis L. sp. pl. erl, 2, p. 1453, Michx. 1. bor. Amer. 2, p. 227, Purslı fl. of nortlı Amer. I, p. 115, Richards. app. p. 38. lirutex 6-8-ped. Drupe luteæ, lepidotæ, dulcescentes, vix edulcs. (v. s.)

2. S. ARGENTEA (Nutt. 1. c. p. \$40), foliis ellipticis vel oblongo-ovatis obtusis basi atlenuatis, utrinque cum ramis et floribus argenteo et leviter ferrugineo lepidotis, filamentís pubescentibus. $5 \mathrm{Ad}$ fluviorum ripas per interiores Americæ septentrionalis regiones, ad fluvium scil. Missouri et in cum lluentes inde a Platle-river usque ad Saskatschawan (Richardson, Drummond). - Ach. Rich. Elæagn. l. c. p. 406, Hooks. fl. bor. Amer. 2, p. 138, t. 178, Lond. enc. of trees, p. 700 c. ic. Hipjophaë-argentea Pursh fl. of north Amer. I, p. 115. Arbuscula $12-18$ ped., floribus luteis, drupis scarlatinis, pollucidis, edulibus. Indianis : Metheoo-meeva, i. e. bacca sanguinea.

III. CONULELA Ach. Rich. Elaagn. l. c. p. 391, t. 25, Endl. gen. pl. n. 2114, Meisn. gen. $I, p .329, I I, p .242$.

Flores dioici. Masculi ignoti. Fæminei in racemis ramosis lateralibus. Perigonii tubulosi limbo conico apice perforato integro, dein circumscisse deciduo. Discus conicus integer, limbo sublongior, ex fauce oriens. Pistillum simplex a perigonio inclusum, apicem partis stigmatosæ styli ex disco emittens. Fruclus ignolus. - Arbuscula Guianensis, sparse lepidota ; foliis oppositis, petiotalis, ellipticis, utrinque acutis, $3-5$ poll. longis, $1 \frac{1}{2}-2 \frac{1}{4}$ poll. latis, sparse lepidotis ; inflọrescentiâ axillari, foliis breviore, argenteo-lepidotâ.

C. GuIANENSE (Acl. Rich. J. c.). -- In Guianâ gallicà a. 1789 detexit L. Cl. Richard (1.DC.!), serius legerunt MIartin et Poiteau (1. DC.! Kunth! nuric mus. Berol.), ad Acarouany (P. Sagot, 11. 846, in h. DC.l).

IT. ELAEAGNUS L. gen. n. 159, Juss. gen. p. 75, Ach. Aich. monogr. Elaagn. l. c. p. 381, 400, 402, t. 24, f. 1, Lam. ill. gen. t. 73, Gaertn. fruct. 3, p. 203, t. 216, Nees j. gen. pl. fasc. 3, t. 18, Endl. gen. pl. n. 2115, Meisn. gen. pl. I, p. 329, II, p. 242.

Iflores hermaphroditi v. pistilli abortu masculi. Perigonìi tubus ovarium liberum includens, limbus inferne cylindraceo-campanulatus v. tubulosus, superne in lobos quatucr (rarius plures $5-8$ ) præfloratione valvari partitus, intus coloratus Discus glanclulosus ad faucem varius. Stamina quatuor (rarius plura) perigonio adnata, Jobis alterna, filamentis brevissime liberis, antheris oblongis dorsifixis, rimâ duplici internâ dehiscentibus. Pollen trigonum. Ovarium uniovulatum, stylo simplici terminatum basi nudo mox in altero latere stigmatifero, recto (apice interdum circinato, Nees). Fructus perigonii tubo accrescente induviatus, pseudo-drupaceus, limbo dein deciduo, putamine ex perigonii pariete interiore orto, oblongo, osseo, octostriato v. sulcato fructum verum, pericarpio membranaceo lectum, styli basi apiculatum, monospermum includente. Embryo albumine angusto cinctus; radiculâ inferâ; colyledonibus basi emarginatis in semine anatropo, cujus testæ membra- 
naceæ nucleus adbæret. - Arbores fruticesve Asiæ inprimis mediæ, raræ in Europî australi ct Americâ boreali, lepidotæ v. stellato-pilosæ, ramulis sæpe spinescentibus; foliis alternis petiolatis integerrimis, floribus pedicellatis axillaribus, solitariis aggregatisve' v. racemulos breves axillares foliatos formantibus, intus luteis albisve, fructu carnoso siccove.

\section{* Species americana.}

1. E. A RGENTEA (Pursh 11. Am. sept. I, p. 114), fruticosa, stolonifura, haud spinescens, ramis junioribus ferrugineo-lepidotis, foliis latius angustiusve ellipticis utrinque acutiusculis vel lanceolatis undulatis, superne argenleo-lepidotis, subtus densius et lepidibus fórrugineis adspersis, floribus pluribus axillaribus deflexis fructibus globoso-ovoïleis octosulcatis. F In Canadâ (Sheppard) et ad sinum Hudsonis (Nuttall), ad fluv. Saskatchavan usque ad montes Rocky mountains dictos (Richardson, Drummond) et in ripis abruptis argillosis fluv. Missouri 6uperioris (Lewis) inter $48^{\circ}-69^{\circ}$ lat. bor. - Nutt. gen. I, p. 97, Hook. 11. bor. Amer. 2, p. 137, Loudon enc. of trees, p. 697. E. commutata Bernh. in Thur. allg. Gartenztg. II, p. 95. Shepherdia argentea hort. plurim. - Frutex 8-1.2 ped., late sub terrả repens. Folia $1 \frac{1}{2}-2$ poll. longa, 6-12 lin. Iata. Flores extus argenteolepidoti, intus pallide lutei, glabri, fragrantes; perigonium 5-6 lin. longum, tubo late ovali, limbo infundibulari. Fructus Cerasi minoris fere magnitudine, siccus, farirosus, edulis. (v. s. et v.)

\section{** Species veteris orbis.}

2. E. HORTENSis (Marsch. Bieb. fl. Taur. Cauc. II, p. 112), arborea vel arborcscens, sæpius spinescens, foliis petiolatis oblongis in lanceolatam ellipticamve vergentibus formam, subtus dense argenteo-lepidotis vel stellato-pilosis, supra plus minus viridescentibus et calvescentibus, floribus axillaribus solitariis pluribusve pedunculatis erectis, perigonii argenteo-lepidoti tubo ellipsoideo basi magis quam superne angustato, limbi latioris campanulato-tubulosi lobis triangularibus acutis intus pilosulis dimidium haud æquantibus, disco conico glabro, stylo glabro, fructibus ellipsoideis vel ovoideo-ellipsoideis. $5 \mathrm{Ab}$ Hispania australi et Gallii austro-orientali; ubi forsan antiquitus efferata, primum sponte suá provenit in insulis maris Adriatici et đ̂̉ææi, in Græciâ et Turciâ passim, pontus Euxini littora eingit, hinc per Asiam minorem et ÆEgyptum borealem usque austrum versus descendit, illinc littora maris Caspici, isthmum Caucasicum et Persiam borealem habitat, borcam versus in Sibiria Uralensi et Altaïcâ usque ad Chinam borealem occurrit, sæpius eodem tractu et inter eosdem parallelos culta.-Formæ sequentes forsitan species sunt.

a. angustifolia, inermis vel spinosa, foliis angustioribus sæpius longioribus floribus paulo majoribus intense luteis odoratis, stylo antheras superante, fructu minore sicco insipido.- Locis occidentulibus et septentrionalibus hxc sola occurrit, frigoris satis paticns. E. angustifolia L. sp. pl. ed. 2, I, p. 176. Ach. Rich. monogr. l. c. p. 383 , t. 24 , f. 1. Boiss. voy. Esp. II, 560 , DC. fl. franc. lII, p. 354, Koch syn. ed. 2, p. 740, Reichb. icon. fl. Germ. XI, t. 549, f. 1166 , Sibth. fl. Græca, t. 152, Griseb. fl. Rum. II, p. 319, Forsk. fl. Constant. p. XX, Pall. 1. Ross. I, p. 10, t. 4, Bot. Reg., t. 1156. E. spinosa L. amœn. acad. IV, p. 305. E. incanus Lam. fl. franc. III, p. 476. E. argentea Mloench meth. p. 638. Zizyphus albus Clus. hist., p. 29. (v. v.)

ß. Songarica (Bernhardi in sched., E. angustifolia songarica Fisch in sched.), spinescens el inermis, foliis angustioribus et brevioribus magis stellato-lepidotis, floribus paulo minoribus pallide luteis minus odoratis, stylo antheras æquante, fructu breviore? - Ex Sihiriâ songaricà orta in hortis botanicis colitur, frigoris satis patiens. (v. v.)

y. Orientalis, inermis, foliis plerumque latioribus basi sæpe ovatis utrinque argenteo-lepidotis vel stellato-pilosis supra viridioribus, floribus intus obsolete lutescentibus (Pallas), fructu majore olivieformi (dactyliformi) obsoletissime octangulari (Pallas) sapido eduli. - In Persiâ et ad mare Caspicum plerumque culta, sic ut in Asia minoris et Eggypti hortis, in Kirghisorum desertis passim spontanea ; frigoris apud nos impatiens sub diu coli nequit. -E. orientalis L. mant. p. 41, Pall. fl. Ross. I, p. 11, t. 5, Rich. mon. l. c. p. 404. E. tomentosa Manch meth. p. 638. (v. v.) 
Prieeunte Marschallio has tres formas conjunctas proponimus, quas flore et fructu magis quam folijs et indumento distinctas credimus si auctorum verbis fides. Conf. Bot. Zeitg, X, p. 817.

3. E. Joongroftir (Wall. list n. 4031 !), fruticosa ? inermis ? ramulis foliis utrinque et floribus dense argenteo-lepidotis, foliis petiolatis anguste lanceolatis utrinque plus minus acutis, floribus axillaribus breviter pedunculatis 2-3, perigonii tubo anguste cllipsoïdeo basi magis quam apice angustato, limbi latioris campanulato-tubulosi lobis triangularibus intus stellato-pilosis dimidio brevioribus, disco brevi conico in margine setuloso, stylo glabro, fructu... Ad Luddak (Moorcroft!) Habitu suo valde affinis formæ angustifoliæ et Songaricæ E. Kortensis sed antecellit nitore argenteo et differt flore. (Frustula vidimus in herb. DC.)

4. E. LA Tifolia (L. sp. pl. ed. 2. p. 177, excl. synon. nonnull.), Pruticosa scandens, ramulis sarmentosis argenteo-lepidotis, foliis ellipticis utrinque acutis supra purpurascenti-maculatis et obsolete lepidotis dein plane glabris, floribus dense argenteo-lepidotis in racemulos axillares brevissimos paucifloros dispositis, perigonii tubo ellipsoídeo utrinque attenuato, limbo campanulato-tubuloso sub lobis brevibus triangularibus acutis intus lepidotis constricto, stylo glabro, disco vix prominulo, fructu (rotundo ex Plukenetio dubie citato). F In insulâ Ceylan; an quoque in ins. Javâ (Blume bijdr. p. 607)? E. latifolia Ach. Rich., monogr. l. c. p. 404 (excl. syn. E. triflora Roxb. et Burm. thes. fl. Zeyl. p. 92, tab. 39, f. 2.) Elæachnus foliis oblongis acuminatis maculatis Burm. thes. fl. Zeyl. p. 92, tab. 39, f. 1. - Specimen Royeni in h. DC. exacte congruit cum icone citatâ Burmannianâ satisque differre videtur tam ạb alterâ formâ Burmannianâ, quam ab E. triflorâ Roxb., a cel, Ach. Nichard cum latifoliâ conjunctâ. - Folia 2 $\frac{1}{2}-3$ poll. longa, 16-18 lin. lata, maculis variæ magnitudinis, interdum ut dicitur deficientibus, variegata. Racemuli brevissimi floribus sæpe tribus breviter pedicellatis gracilibus.

$\beta$. rotundifolia, fruticosa? ramulis ferrugineo-lepidotis, foliis breviter petiolatis rolundato-ovalibus plus minus in petiolum acutatis apice obtusis vel brevissime et obtise subacuminatis, supra purpurascenti-maculatis et impressopunctatis, subtus cum petiolis floribusque densissime ferrugineo et argenteolepidotis, floribus in racemulos axillares brevissimos dispositis, tubo perigonii cylindraceo basi attenualo, limbi latius campanulati laciniis ovatis acutiusculis intus lepidotis et stellato-pilosis, antheris cum stylo inferne densius piloso ex fauce exsertis, disci perigonio adnati margine breviter pubescente, fructu (oblongo. sulcato argenteo-lepidoto, ex Burm.). - In insulà Ceylan E. foliis rotındatis maculatis Burm. fl. Zeyl. p. 92, t. 39, f. 2. Elæagnus sp. 11. 2264. Thwaites! in h. DC. Wælembilla Zeylonensibus id est Ambilla sarmentosa. Folia in specim. Thwaitesiano majora el basi acutiora quam in icone, $4 \frac{1}{2}-4 \frac{\tau}{4}$ poll. longa, $2 \frac{1}{2}$ et paulo ultra in medio lata. (v. s.)

$\gamma$. triflora (E. triflora Roxb. fl. Ind. ed. Carey, I, p. 459, excl. syn. Burm.), fruticosa, magna, ramis eximiis scandentibus, ramulis lateralibus recurvatis dein spinescentibus, foliis oblongis obtusis, supra glabris, subtus argenteo et ferrugineo-lepidotis, floribus axillaribus ternis albis, tubo brevi quadrangulari, limbi lobis cordatis extus leviter lepidotis intus glabris, stylo longitudine perigonii, antheris in fauce sessilibus, fructu succculento oblongo, putamine 8-sulcato molli et lanuginoso. $亏$ In ins. Sumatrâ, ex quả a. 1804 in hortum Calcuttensem introducta est. - Folia 2-3 poll. longa, 1-2 p. lata. Fructus pallide aurantiacus pulpả molli (Roxb. l. c.).

5. E. FERRUGINEA (Ach. Rich. monogr. 1. c. p. 387 et 404), arbuscula, ramulis inermibus, junioribus ferrugineo-lepidotis, adultis pulverulento-cinereis, foliis latius angustiusve ellipticis apice acutis vel interdum abrupte acuminatis breviacutis obtusisve, supra glabris viridibrus, subtus ferrugineo-lepidotis, floribus axillaribus fasciculatis 3-4 lepidoto-ferrugineis, perigonii tubo ellipsoideo apice non c:onstricto, limbi multo latioris subquadranguli superne angustioris lobis late ovatis acruminatis intus stellato-pilosis, disco brevi prominulo, stylo glabro, fructı ....... 5 In insulá Javâ (Leschenault, Zollingèr). E. spadicea Savi mem. soc. Moden. XXI, p. 175, t. VI, f. 1-5? E. punctata cat. pl. Burdir. Torino 1835 ? E. Breyniastrum Fisch. in litt. (h. DG.). Capparis Breynii hortul. ex Viviani l'orto di Padova. E. latifolia Zoll. syst. Verz. 2. p. 117 ex collect. ejus n. 373 et 1829. E. ferruginea Zell.! coll. 11. 1829 (h. DC.), - Differt ab E. latifolià ferrugineo lepidum colore 
inferam foliorum paginam, ramos juniores, pedunculos cum perigonio dense tegentium, foliis magis acuminatis, floribus majoribus. E. spadicea Savi l. c. an eadem sit species haud certissimum, attamer et sequens E. Gussoni Gasp. forsan conjungenda est. Eandem speciem variis in Italiæ horlis cultam variis nominibus ornavisse videntur botanici ițalici. Clar. Zollinger scandentem et subscandentem in fruticulis et ad sepes dicit baccamque esse acidam et edulem quam Bibirkuda indigense adpellant. (v. s.)

B. Gussoni (E. Gussoni Gasparrini obs. h. Bocca di Falco p. 9 et 10), fruticosa, ramulis suhspinescentibus atro-ferrugineo-lepidotis, foliis oblongis subacuminatis basi quandoque attenuatis, supra dein viridibus et fore nudis, subtus lepidoto-aureis, floribus paucis pedunculalis axillaribus lepidoto-ferrugineis intus albidis, perigonii tubo ellipsoideo utrinque angustato, limbi inferâ parte subrquadrangulari, superæe campanulatæ lobis ovatis acutis medio intus lepidotis, disco nullo, stylo (glabro?), fructu....... F Patria ignota, in liortis italicis culta. - Speciei auctor elegantem fruticem dicit, affinem habitu Chrysophyllo Cainito, et ab E. ferruginea distinctam floribus magis solitariis, haud fasciculatis, limbo magis distincto a tubo, disco nullo ! cujus absentia antem speciem a genere romovere non posset.

6. E. Tншагтеsir, fruticosa, ramulis, petiolis foribusque axillaribus ex argenteo et ferrugineo lepidotis, foliis hreviter petiolatis late ovalibus ellipticisve basi obtusissimis apicc Jeviter et obtuse acuminatis, supra viridibus et primum lepidibus ferrugineis adspersis dein his evanescentibus punctatis, subtus viridi- ferrugineo-lepidotis dein expallescentibns, floribus subsessilibus axillaribus, perigonii tubo cylindrico basi angustiore, limbi latioris ovoidei lobis brevíbus late triangularibus intus stellato-pilosis, antheris in fauce positis, stylo inferne stellato-piloso, disco brevi crassiusculo cum limbo connato, fructu ....... . . In iòsula Ceylan (Thwaites, n. 2724, in l. DC.). - Folia non solum insignia sunt colore læte ferrugineo seul ctiam formâ late ovali et hasi obtusissimâ, majora eorum 2-3 poll. longa, 18-20 lin. in medio lata. Flores haud 3 lin. longi. (v. s.)

7. E. KoL OG A, arbuscula, ramulis inermibus dense ferruginco-]epidotis, foliis ellipticis apice obtusis rarius acutiusculis basi plus minus acutatis rarius obtusiusculis, supra viridibus lævibus, subtus cum floribus dense ex argenteo et ferrugineo-lepidotis, floribus pedicellatis deflexis in ramulis brevibus foliosis axillaribus dein excrescentibus, perigonii tubo subcylindrico inferne attenuato, limbo latiore urceolato-tubuloso sub lobis late ovatis acutis intus stellato-pilosis brevibus leviter constricto, disco brevi tubuloso, stylo inferno dense stellato-pilosa, fructu ellipsoideo $n$ rrinque paululum angustato ....., putamine tenui ..... 5 In monfibus Neilgherry dictis Indise orient. (Leschenault, Perrottet, Metz). E. latifolia Wight ic. t. $1856 \mid$ F. latifolix forma Miquel in plant. exs. Hohenack. Nilagir. n. 976! Frutex subsarmentosus, 10-20-ped., ramosus; flores albi ; fructus elules aciduli (Perrottet in h. DC.). Arbuscula 15-18 ped, indigenis Kologa (Leschen. in h. DG.). Precedentibus similis quidem, sed distincta foliis minoribus obtusioribus, stylo piloso, etc. (v. s.)

8. E. A R B ORE A (Roxb. fl. Ind. ed. Carey I, p. 461), arborca, ramulis sæpe spinescentibus ferrugineo-lepidotis, foliis subcoriaceis late ellipticis basi obtusis acutisve apice breviter acuminatis v. ovali-lanceolatis, supra dein glabris et impressopunctatis, subtus argenteo et ferrugineo-lepidotis, floribiss pluribus axillaribus pedunculatis ex argenteo et ferrugineo-lepidotis, perigonii tubo ellipsoideo utrinque angustiore, limbo inferne hypocraterimorpho campanulato sub lobis dimidium intrantibus erectis triangulari-acuminatis et fere mucronulatis breviter constricto, disco subnullo, stylo glabro, fructı magno olivæformi oblonge cylindraceo (exsiccato juniore costato argenteo). 5 Ad Narainhetty Nepalensium (Hamilton), in Nepalià superiore et inferiore (Wallich!), in montibus Garrow, ubi Sheashong adpellatur (Roxb.). - Ach. Rich. monogr. El. l. c. p. 405., D. Don prodr. fl. Nepal. p. 67, Wall. cat. n. 4027 A.! E. armatus Hamilton mss. fide Don. E. acuminata h. Angl., Link. en. I, p. 4112 E. argentea Colla h. Ripul. t. 28? - Plantæe hortensis hisce sub nominibus ubviæ speoimina vidi sicea non florentia, hinc dubia, quamvis foliorum forma convenit. Fide speeiminum Wallichii diagnosis facta est. Roxburghii descriptio et diagnosis nimis breves. Drupa fructu Oleæ europææ multo major comeditur. (v. s.) 
ß. dendroidea, arborea, ramulis brevibus spinescentibus, floriferis patentibus adscendentibus, junioribus dense albo-lepidotis. foliis breviter petiolatis membranaceis oblango-ellipticis basi acutiusculis $\%$ obtusiusculis apice attenuato-acuminatis, supra viridibus el disperse, subtus densissime argenteo-lepidotis nitentibus, floribus argenteo-lepidotis in racemos axillares dispositis, ........., fructu (juniore exsiccato) ellipsoideo utrinque attenuato costato argenteo-lepidoto. 5 Elæagnus arborea Lindl. in sched. (herb. propr.) Elreagnus in Khasyce montibus lect. a b. Griffithio n. 128 (Lindley in h. Berol.). An Eleagnus Wall. cat. it. Burm. n. 1396 in h. DC.? - An species? E. arborex forsan status junior. Diversa videbatur : foliis tenuioribus, magis oblongis, longius acuminatis, parcius argenteis, lepidibus minoribus densissimis. Folia $3 \div-4-$ poll. longa, $1 \frac{1}{2}-1 \frac{3}{5}$ poll. lata. (v. s.)

9. E. WALLICHIANA, arborea?, ramulis argenteo-lepidotis, foliis petiolatis membranaceis late $\mathrm{v}$. obovato-ellipticis basi obtusis v. obtusiusculis apice breviter acutis obtusisve, supra dein glabris viridibus impresso-punctatis, subtus densissime argenteo ét lutescenti-lepidotis nitentibus, floribus in racemos breves axillares dispositis breviter pedicellatis, perigonii tubo anguste ellipsoideo, limbo latiore inferne cylindraceo-urceolato sub lobis late triangularibus brevibus intus stellato-pilosis leviter contracto, fauce pilosâ, disco subrıullo, styli majore_inferâ parte stellato-pilosâ, fructu (juniore sicco) oblongo ellipsoideo ex argenteo et lutescenti lepidoto. 5 ? In regno Birmanorum ad Tooug-dong leg. Wallich! E. macroplyylla Wall. cat. it. Burm. n. 812! (non Thunb.), ex loco natali quoque E. latifolia D? Wall, cat. n. 4028, e Toong-dong. - Foliorum substantia firmior quam in precedente, ac lenuior quam in E. arboreâ. Folia majora $4 \frac{1}{2}$ poll. longa, medio $2 \frac{2}{3}$ poll. lata. Lepides argenteæ minores majoresque lutescentes, sæpius et argenteis umbo lutescuns. (v. s.)

10. E. PARVIFOLIA (Royle illustr. p. 323. t. 61, f. 1), fruticosa?, ramulis argenteolepidotis interdum spinescentibus, foliis petiolatis membranaceis parvis majoribusve ellipticis utrinque obtusis v. apice acutis basi sæpius plus minus angustatis hinc late vel obovato-lanceolatis, supra dein calvescentibus viridibus, subtus argenteo-lepidotis cum paucis lepidibus fuscis, floribus sæpius ternis longiuscnle peduncalatis in racemulos ramulosve foliosos axillares dispositis argenteo-lepidotis, perigonii tubo anguste ellipsoideo utrinque angustato, limbi anguste infundibularis lobis ovatis acuminatis intus puberulis, disco subnullo, stylo subglabro, fructu (juniore sicco) brevi ellipsoideo basi attenuato apice acutiusculo argenteo-lepidoto.- In Nepalià (Wallich), Sirmore (Webb et Gérard), Kamaon (RB.), Chinà (Fortune A. 77 in h. DC!).--Loudon enc. of trees, p. 1117, Wall.! cat. n. 4026. A. B. C. Lindley in Bot. Reg. 1843. t. 51. E. reflexa Desne. et Morren in Ann. d'hort. de Paris, 1841, Allg. Thür. Gartenz. 2, p. 95, Schlecht. in Linn. XXV. p. 191. E. umbellata Thunb. fl. Jap. p. 66.t. 14 ? - Planta a cl. Royleo depicta differt a Wallichianâ : foliis basi late ovatis. Planta hortensis foliorum magnitudine maximopere variat, aliis $\frac{1}{0}$ poll., aliis 3 poll. longis. Thunbergii $\mathrm{E}$. umbellata floribus minoribus, si iconi est fides, diversa apparet. (v. s.)

11. E. conferta (Roxb. fl. Ind. ed. Carey I, p. 460), fruticosa, magna, ramis sarmentosis ferrugineo-lepidotis, foliis breviter petiolatis ellipticis vel oblongoellipticis utrinque acutis acuminatisve vel oblusiusculis supra dein glabris viridibus, subtus dense argenteo et ferrugineo-lepidotis, floribus in racemulos brevissimos multilloros axillares dispositis argenteo et ferrugineo-lepidotis, perigonii tubo cylindraceo (apice non angustato), limbo latiore subquadrangule campanulato sub lobis late triangulis intus parce stellalo-pilosis leviter constricto. disco subnullo, stylo ad basin dense piloso, fructu oblongo succulento (Roxb.): $₹$ In India orientali, in montibus ad Silhet Bengalixe, ad Sirinagur et Sirmore in Nepalià (Wallieh), in Prome (Wallich). - Ach. Rich. monogr. 1. c. 1. 385 et 405. Wall. cat. 11.4025 ! Loud. enc. of trees, p. 697. f. 1365. E. grandifolia Bojer in litt., culta in h. b. ins. Mauritii (ll. DC.). Petjoli 3-4 lin. longi; folia 2-6 poll. longa, 10 lin. ad $2 \div$ poll. lata. Lepides haud pure argentex sed flavescentes, aliæ aureoicrfuginex. Flores dense aggregati in foliorum axillis coloris straminei. Fructus ruber. Bengalis : Guara. (v. s.)

12. E. GAUdICHAUdianA, fruticosa?, inermis?, ramulis, petiolis foliorumque paginâ inferâ ferrugineo-lepidotis, foliis breviter petiolatis late ellipticis basi 
obtusis apice acutinsculis margine subrevolutis supra dein glabris et impressopunctatis, floribus paucis axillaribus breviter pedunculatis ex argenteo et ferrugineo-lepidotis, perigonii tubo brevi anguste ellipsoidco superne leviter contracto, limbi latioris infra subquadrangule tubulosi lobis late triangularibus intus lepidotis et pilosis tertiam partem ejus æequantibus, disco brevissimo annulari, stylo fere toto sparsim stellato-piloso, fructu .......... In Cochinchinả (Gaudichaud h.

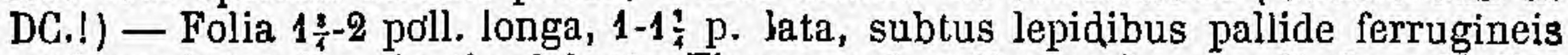
umbone intensius tinctis obducta. Florum tubus lineam longus, limbus $3 \frac{1}{2}$ lin. metiens, lobis circ. lineam longis. (v. s.)

13. E. GONYANTHES (Benth. in Hook. Journ. of Bot. July 1853, n. 54, p. 196), fruticosa?, inermis?, ramulis fusco-ferrugineo-lepidotis, foliis breviter petiolatis subcoriaceis ellipticis $v$. oblongo-ellipticis basi plus minus angustatis apice plus minus obtusatis margine leviter revolutis supra dein glabris impresso-punctatis, subtus densissime ferrugineo-lepidotis, perigonii tubo ellipsoideo utrinque angustato, limbi latioris subquadrangule tubulosi lobis, late triangularibus acuminatis, intus medio lepidotis dimidium æquantibus, disco subnullo, stylo glabro, fructu ....... ₹? In Chinâ prope Macao (Parker, h. Berol.!), Chinà, Moho hills (Parker h. DG.l), Lapa hills (id. ibid.). Petiolus $2-3$ lin. longus, lamina $2 \frac{1}{-1}-3$ poll. longa, 11-16 lin. lata. Perigonii tubus tam linbi partem integram quam lobos hac latiores, 3 lin. longos æquat. - Specimina Parkeriana e Chinæ Lapa hills, ramis patentissimis et deflexis fruticem debiliorem aliisque incumbentem indicare videntur. Flores non aderant. (v. s.)

14. E. TENUIF L ORA (Benth. in Hook Journ. of Bot. July 1853, n. 54, p. 197), fruticosa?, inermis?, ramulis fusco-lepidotis, foliis petiolatis parvis coriaceis ellipticis utrinque plus minus acuminatis vel lanceolatis margine leviter revolutis, supra dein viridibus impresso-punclatis, subtus dense ferrugineo-lepidotis, floribus longius pedunculatis in racemos breves axillares dispositis ex argenteo et fusco lepidotis, tubo perigonii ellipsoideo ntrinque leviter attenuato, limbi anguste tubulosi sensim latioris lobis ovato-triangularibus acuminatis intus pubescentibus, tertiazn ejus partem æquantibus, disco brevi, stylo glaberrimo, fructu …...... $₹$ ? In Chinâ, Fortune n. 114, h- DC.!). - Elegans species. Petiolus 3-4 lin. longus, lamina $1-1 \frac{3}{4}$ poll. longa, 6-10 lin. lata. Florum tubus $1 \frac{1}{2}$-linearis, ejusdem longitudinis lobi, interjectâ limbi parte 3-lineari. Lepidibus argenteis perigonium vestientibus aliæ insident magnæ ferrugineæ, pedunculus vero cum tubo fuscoferrugineis tegitur. (v.s.)

15. E. LouREIRII (Champion in Hook. Journ. of. Bot. July 1853, n. 54, p. 196), fruticosa?, inermis?, ramulis foliis subtus floribus dense ferrugineo-lepidotis, foliis petiolatis ovatis ......... supra viridibus, floribus in racemulos breves axillares dispositis solitariisve longe perlicellatis, perigonii amplo tubo superne constricto, limbi tubuloso-campanulati integrâ parte lobis interne parce pilosis plus duplo longiore, disco ......., stylo glabro, fructu ......... 5? In montibus Parker et Gough insulø Hongkong, Chinæ (Champion). - An E. latifolia Lour. 11. Cochinch. p. 89? non Linnæi. Lepides magnæ fusco-ferrugineæ. Perigonii tubus $1 \frac{1}{3}$ lin. longus, limbus totus cum lobis 3 lin. longis octolinearis.

16. E. PER от тетIr, fruticosa?, inermis?, ramulis ferrugineo-lepidotis, foliis petiolatis ellipticis oblongisve basi obtusis acutiusculisve apice nunc obtuse acuminatis nunc obtusiusculis margine leviter revolutis, supra dein glabris et impressopunctatis, subtus ex argenteo et ferrugineo-lepidotis, floribus breviter pedunculatis in racemulos breves axillares nunc in ramulos paucifolios mutatos dispositis ex argenteo ct pallide ferrugineo lepidotis, perigonii tubo brevi ellipsoideo basi attenuato apice leviter contracto, limbi dilatati late campanulati lobis latiús triangularibus intus stellato-pilosis dimidium æquantibus, disco planiusculo, stylo glabro, fructu (juniore sicco) late ellipsoideo ferrugineo-lepidoto, putamine sulcato. F? In Manilâ insulâ (Perrottet, h. DC.!). - Petiolus ad 4 lin. longus, lamina 4 pollices longitudinem haud attingeus, pollicem in medio lata. Perigonii limbus 3 lin. longus, lobis igitur fere sesquilinearibus. Pedunculus brevissimus dein elongari videtur in fructu. (v. s.)

\section{Species minus notor. .}

17. E. Cuming Ir, arbuscula? frutex ?, ramulis inermibus dense ferrugineo-lepida- 
tis dein denudatis nigris (forsan atropurpureis in vivo), folijs breviter petiolatis, ellipticis basi acutis, apice brevius longiusve acuminatis, supra viridibus maculisque purpureis variegatis, iufra dense argenteo et pallide ferrugineo-lepidotis, floribus in racemulos axillares petiolis equilongos dispositis argenteo lepidotis lepidibus ferrugineis magnis adspersis, perigonii tubo subcylindrico, limbi late campanulati lobis late ovatis subacuminatis intus sparse stellato-pilosis, antheris cum stylo glaberrimo sab fauce inclusis, disco brevissimo glabro, fructu... In insulis Philippinis (Cuming! n. 460, herb. DC.).-Folia maxima cum petiolo circ. 4 lin. longo 4 -pollicaria, $1 \frac{1}{2}$ poll. circ. in medio lata, alia dimídio minora. (v. s.)

18. E. RIGIDA (Blume bijdr. p. 638), inermis, foliis oblongo-lanceolatis utrinque acutis rigidis supra punctatis subtus argenteis fusco-lepidotis, pedunculis axillaribus subternis unifloris. - In ins. Javà, in cacumine montis Burangrang. Affinis E. angustifoliæ (Blume). - An E. rigida Hassk. cat. h. Bogor. p. 93, n. 4., quæe scandens et spinosa dicitur, eadem?

19. E. JA Vaniga (Blume bijdr. p. 638), caule scandente, ramis subspinosis, foliis ovali-oblongis obtusiusculis basi rotundatis supra nitidis subtus spadiceoargenteis, pedunculis subgeminatis axillaribus subumbellatis multifloris, fructu olivæformi.-In insulà Javâ in sylvis montanis Salak. Fl. Jun. Jul.-Hassk. cat. h. Bogor. p. 93, n. 2.-Var. foliis basi acutiusculis subtus argenteis. Cum præcedente. Sept. fruct.

20. E. uม ве L а ат A (Thunls. Al. Jap. p. 66, t. 14), fruticosa, inermis, ramulis teretibus erectis ferrugineo-fuscescentibus punctato-scabris, foliis fasciculatis obovatis obtusis, supra nudiusculis argenteo-punctatis, subtus argenteis, floribus pedunculatis axillaribus pluribns aggregatis subumbellatis cernuis, pedunculis tlore brevioribus, perigonio ovato. J In Japonix monte, Fakona; incolis : Hawa-SiroGomi. Fl. Apr. Majo. Folia unguicularia. Pedunculi vix lineam longi. E. multifloræ nimis affinis (Thunb), - An hæc et multiflora ad E. parvifoliam pertineant?

21. E. MU TIFL o RA (Thunb. f1. Jap. p. 66), fruticosa, inermis, ramis raris patentibus fusco-ferrugineis punctato-scabris, foliis breviter petiolatis obovatis obtusis sæpe seminudis lepidibus argenteis adspersis, subtus totis argenteo-lepidotis, floribus axillaribus aggregatis, pedunculo argenteo flore longiore, perigonio clavato oblongo. $\vec{J}$ In Japoniấ. - Folia subjollicaria, petioli lineam longi (Thunb.).

22. E. CRIS PA (Thunb. fl. Jap. p. 66), arborea, inermis, ramis divaricatis cinereis punctato-scabris, foliis brevissime petiolatis lanceolato-oblongis oltusis undulatis, supra nudis fuscescentibus punctatis, subus argenteis, floribus in ultimis ramulis angulatis albidis solitariis sparsis, pedunculo flore breviore. 5 In Jap̣oniâ ubi ab incolis Gomi adpellatur (Thunb). - Blume bijdr. p. 639, Hassk. cat. h. Bogor., p. 93 ? qui fruticem declarat, an igitur eadem? - Folia $1 \frac{1}{2}$ poll., petioli vix lineam longi, flores non in axillis sed in ultimis ramulis sparsi (Thunb.).

23. E. G LA B R A (Thunb. fl. Jap. p. 67), arborescens, inermis, ramis nudiusculis fuscis, ramulis cinereo-rufuscentibus punctato-scabris, foliis breviter petiolatis ovato-oblongis acuminatis, supra viridibus glabris, subtus rufescenti-lepidotis, interspersis lepidibus ferrugineis, floribus solitariis geminisve erectis, pedunculo perigovio breviore. 5 In Japoniâ (Thunb.). - Blume lijjdr. p. 639 , Hassk, cat. h. Bogor., p. 93. Folia sesquipollicaria, petioli unguiculares (Thunb.).

24. E. MACROPHXLLA (Thunb. fl. Jap. p. 67), arborea, ramis teretibus striatis tuberculatis cinereis punctato-scabris erectis, ramulis angulatis, foliis rotundatoovatis supra glabris viridibus sublus argenteis, floribus axillaribus aggregatis pedunculatis suberectis. 5 In Japoniâ, in Papenberg et Kosido utroqué (Thunb.). Kotai vulgo Gommi, it. Fon Gommi Kaempf. amœn. exot. fasc. V, p. 789. - Folia pollicaria, petioli semipollicares, pedunculi longitudine floris. Differt ab E. orientali, cui folia oblonga ovata : foliis rotundato-ovatis argenteis; ab E. latifolià : foliis miagis rotundatis, ramulis inermibus nec spinescentibus (Thunb.).

25. E. P U NGENS (Thunb. Il. Jap. p. 68), arborea, caule erecto fusco scabro, ramis teretibus flexuosis aphyllis, ramulis foliosis rigidis apice spinescentibus, foliis oblongis obtusiusculis undulatis supra glabris viridibus subtus argenteo-lepidotis, interspersis lepidibus ferrugineis, floribus axillaribus subgeminis erectis, 
pedicellis flore brevioribus. 5 In Japoniâ prope Ńagasaki, in Kosido alibiquo (Thunb.). - Sjnu Kotai, vulgo Axin Gornmi Ksempf. amœn. exot. p. 789. E. pungens Blume bijdr. p. 639, Hassk. cat. l. Bogor. p. 93. - Caulis orgyalis, folia pollicaria (basi interdum subcordata ex Blume), "petiolus unguicularis. Differt ab E. spinosâ : ramulis spinescentibus, foliis oblongis latioribus, floribus subternis majoribus. (Thunb.)

26. E. A Ing a Ro. Arbuscula, trunco ereeto, ramis non spinescentibus pendulis. Folia alterna lanceolata dvata, nargine quasi dentata, supra punctis elevatis instructa, subtus albicantia. Petioli brevissini. Flores axillares sæepíus solitarii, pedunculis longissimis. Perigonium quadrangulare, punctis elevatis adspersum, lobis ovatis. Stylus subulatus perigonio paululum brevior ; fructus oblongus carnosus, perigonio coronatus, angulosus cum foveis parvis, putamine anguloso; semen lanẩ cinctum, - In ins. Marilâ, satis communis ad Puebla de S. Jose et ad margines viarum. Fl. oct. - E. angustifolia Blanco Flora d. Filipininas, p. 74. - Planta tres ulnas alta Fructus maturus ruber, haud gratus propter austeritatem. Tagalis : Alingaro (Blanco). Ex descriptione mancâ ab E. angustifoliâ Linn. diversa videtur.

27. E. SALICIF OLIA (hort. et verisimiliter Loud. enc. of trees and shrubs, p. 697, f. 1366, ubi ut videtur errore speciei auctor citatur D. Don, sed ubi?), fruticosa inermis, ramulis ferrugineo-lepidotis, petiolo brevi cum paginâ inferâ foliorum argenteo-lepidoto, adspersis lepidibus ferrugineis raris, paginâ superâ viriuli et pilis stellatis serius evanescentibus puncta impressa relinquentibus adspersâ, laminà plus minus oblongà utrinque oblusả vel oblusiusculâ vel apice plus minus acutatà, floribus axillaribus solitariis geminisve argenteo-lepidotis, perigonii tubo ellipsoideo apice attenuato, limbo inferne tubuloso versus tacinias triangulares acutas intus albas et stellato-pilosas sensim dilatato, antheris cum stigmate uncinato faucem vix superantibus, stylo parce stellato-piloso, disco perigonio adnato viridi, fructu (pyriformi ex ic. Loud.). - Locus natalis ignotus, in hortis colitur frigoris apud nos impatiens. Loudonis icon valde diminuta minime bona, flores parvos solitarios, folia oblonga vel ovato-elliptica apice acutiuscula basi obtusiuscula, leviter undulata depingit.

\section{Species nomine tantum notce.}

E. CHRYSOPHYLLA hortul. An E. ferruginea?

E. CYANEA Ait. ex Steud. nomencl. 1.p. 544. quid?

E. DACT YLIFORMIS hort. ad E. hortensis formas pertinere videtur.

E. ERIVANENSIS Fisch. et hort. Sub E. hortensi in hortorum indicibus hospitatur.

E. FLAVA hortul.

E. Fusca ? hortul. - Pepin in Lem. hortic. univ, 3c ann. p. 304.

E. Nepalensis hort. Dyck. p. 99. Gum E. confertà conjungitur in Bosse Handb. 2. p. 17.

E. TrFLIENSis Fisch. et hort. Visiani l'Orto bot. di Padova p. 77, formis E. hortensis adnumerat.

\section{Species exclusa.}

Ela a gus undulata et Myrsine undulata Phytopol. est Shawia paniculata Forst. DG. prodr. V, p. 78 (Ind. sem. h. regii Genuensis a. 1855, p. 14, in notâ).

\section{Genera dubia vel exclusa.}

V. OGTARILLUM Lour. fl. Coch. p. 113.

Perigonium simplex hypocraterimorphum superum (?), tubo tetragono brevi (infera limbi pars), limbo 4-partito, laciniis acutis carnosis. Stam. 4, filamentis brevissimis, ori tubi insertis ; antheræ oblongæ biloculares incumbentes. Pistillum simplex; germine oblongo, stylo turbinato staminibus longiore, stiginate crassiusculo. Bacca oblongo-ovata, aquosa, monosperma, Semen oblongum, arillatum, membranâ tenaci octogonâ. Frutex erectus ramis 
scandentibus inermibus. Folia alterna lanceolata glabra integerrima. Flores pedunculati axillares solitarii albi. Bacca rubra.

0. Fruticosum (Lour. l. c.). - In sylvis Cochinchine. Ghày khut indigenis (Lour.).

AEXTOXICON Ruiz et Pav. fl. per. prodr. p. 131, t. 29, syst. veg. fl. Peruv. et Chil. p. 260.-Aextoxicum Endl. gen. pl. n. 5881, Hook, icon. pl. I, t. 12 (planta mascula).

Hucusque Euphorbiaceis adjectum cel. Grisebach (Syst. Bem. üb. d. ersten Pfl. Saml. Philippi's u. Lechler's, p. 14) Elæagneis subjungere suadet, quibuscum lepidibus, folis integerrimis pauciveniis, inflorescentiâ et fructu drupaceo monospermo reverâ convenire videtur; sed flos femineus quum plane ignotus sit, pericarpii indoles quum nos fugiat, quum floris masculi compositio pluribus abhorreat nec embryo congruat, melius ducimus incertis inserere generibus. 


\section{Ordo CLXIX. GRUBBIACEE (1).}

Genera Empetro, Ericis et Onagris affinia Juss. gen. p. 162 et 321 . - Ophirex, tribus Santalacearum Reich. consp. p. 79. - Grubbiaceæ (in gen. Santalaceis affin.) Endl. gen. p. 326. - Bruniacearum pars Decsne Ann. sc. nat. sér. 2, v. 12, p. 157. Ophiriaceæ (Bruniac. affin.) Arnott in Hook. journ. of bot. 1840, v. 3. p. 266. - Grubbiaceæ (Bruniaceis adnexæ) Endl. ench. (1841) p. 403. - Bruniacearum pars Lindl. veg. kingd. ed. 3, p. 785. - Hamamelidacearum pars Gardn. in Hook. journ. $1849, p .321$, sine descr.

Flores hermaphroditi, in strobilum connati. Perigonium inferne ovario adnatum, superne 4-partitum, lobis (petala?) caducis, ovato-acutis, extus pilosis, intus glabris, æstivatione valvari. Stamina 8 , nempe 4 lobis alterna sublongiora et 4 alterna subbreviora, omnia basi loborum vix adhærentia; filamentis lineari-ligulatis; antheris apice filamenti adnatis, erectis, bilocularibus, loculis longitudinaliter valvâ dehiscentibus. Ovarium inferum, disco anguloso tectum, junius (ex Decsne) biloculare, ovulo ex angulo superiore utrinque a pariete pendente, per anthesin pariete ruptâ uniloculare et quasi placentâ centrali apice ovuliferâ donatum. Ovula 2 ovata, compressa, non simplicia? stylus brevis, apice truncatus vel subbilobus. Nuculæ lateraliter connatæ, alveolâ disci et stylo coronatæ, monospermæ. Semen inversum, subsphæricum, parietis reliquias lateraliter et ovulum abortivum squamiforme superne gerens. Embryo rectus, cylindricus, in medio albuminis carnosi, eo vix brevior; radiculâ superâ, obtusâ, cotyledonibus acutis adpressis multo longiore. - Frutices Capenses, habitu Phylicarum et Bruniacearum ; foliis oppositis, exstipulatis, integris, lineari-lanceolatis, margine subtus revoluto; strobilis in axillis foliorum superiorum, bracteis 2 lateralibus semper alisque floribus propioribus interdum donatis.

Semen in Grubbiâ hirsutâ et strictâ optime vidi et ovula in G. rosmarinifoliâ et hirsutâ. Dehiscentia cujusque loculi antherarum (ex herb. meo et Boiss. solum in G. strictâ videnda) adhuc investiganda, e valvâ præcipuâ longitudinaliter versus interiorem partem floris flexâ fieri videtur.

Ordo medius inter Santalaceas et Bruniaceas (2). Differt a prioribus habitu, inflorescentiâ, staminibus cum lobis vix basi adhærentibus, antheræ formâ, ovulis verisimiliter non simplicibus et presertim ovario (ex Decsne, nam flores juniores non habui) biloculari; a

(1) Auctore Alph. De Candolle.

(2) De Bruriaceis (Prodr. 2 p. 43) confer ád Brongniart, Ann. sc. pat. ser. 1, v. 8, 1. 368 . 
posterioribus defectu loborum aut calycis aut corollæ, æstivatione valvari, antherarum formâ, embryone multo longiore; a duobus ordinibus numero staminum erga lobos duplicato, floribus connatis.

GRUBBIA Berg. pl. Cap. p. 90, t. 2, Schreb. gen. p. 260, Juss. gen. p. 162, Endl. gen. p. 327, Klotzsch in Linn. 1839, p. 378, Harvey gen. s. Afr. p. 410. - Ophira Burm. in Linn. mant. p. 229, Schreb. gen. p. 259, «.662. - Ophira Lam. ill. t. 293.

Caracteres ordinis.

Sectio t. Ophira. - Genus Ophira Burm. et Linn. ll. cc. (non Lam.). Genus Grubbia Berg. Klotzsch, $l l$. $c c$.

Strobili pauciflori (plerumque 3 -flori), bracteis 2 lateralibus squámiformibus involucrati; bracteis magis internis nullis.

1. G. R os a a Rinif obia (Berg. in Act. Holm. 1767, p. 33, t. 2, plant. Cap. p. 90, t. 2), ramulis foliisque subtus tomentosis, foliis linearibus superne scabris, squamis 2 involucri glabris hemisphæricis bifidis sub fissurâ carinatis lobis rotündatis, tomento loborum perigonii densissimo albo. $三$ In Africâ Capensi (Drège!) frequens in monte Tabulari et Hottentotts Holland (Thunb.). - Thunb. fl. Cap. ed. Sch. p. 373, Drège 1 pl. exs. Ophira stricta Linn. nrant: p. 229. Rami glabrescentes. Ramuli ad originem foliorum præsertim pubescentes. Folia 3-5 lin. longa, ex margine revoluto linearia et $\frac{1}{2}-1$ lin. lata, superne punctis elevatis aspera. Fasciculi florum lineam lati, lanà albâ extra involucrum brunneum læve insignes. Squamæ involucri flore vix breviores. Pili circa tubum perigonii longissimi acuminati, dorso loborum longi saccati, in disco breviores acuti, onnes albi. Fructus e nuculis 3 connatis, $1 \frac{1}{3}$ lin. latus, lineam altus et crassus, involucro basi cinctus, discis breviter pilosis el marginibus superioribus nucularnm longe hispidis. (v.s.)

2. G. hinsut a (E. Mey. in pl. Drège !), ramulis foliisque subtus tomentosis, foliis, lineari-lanceolatis superne pilosis, squamis 2 involucri ovatis glabriusculis integris, lobis perigonii ...... nuculis extus pubescentibus. J In Africæ Capensis mont. austro-occidentalibus ad Wupperthal (Drège, docum., p. 73). Rami glabrescentes. Ramuli ad originem foliorum præsertim et pagina inferior foliorum tomentosa, tomento flavido. Folia 3 lin. longa, $\frac{5}{4} l i n$. lata, petiólo brevissimo hispido, liribo ybasi latiore quam prioris sp., pilis superne subadpressis. Flores ign. Strobilus maturus squamis triplo longior, obovoideo-compressus, $1 \div$ lin. latus, lineam lougus et crassus; strlis brerissimis, discis scutiformibus crenulatis pilis brevibus raris pubescentibus. (v. s. in h. Boiss.)

Sectio If. Strobilocarpus. - Genus Ophira Lam. ill. t. 293 (non Burm. in Linn.). - Genus Strobilocarpus hílotzsch in Linnoed 1839, p. 380.

Strobili multiflori, bracteis 2 lateralibus folio brevi similibus, aliisque bracteis 4 brevioribus latioribus intra priores basi strobili cruciatim dispositis caducis.

3. G. Stricta, ramulis adpresse pilosulis quadrangulis striatisque, foliis longe lineari-lanceolatis breviter apiculatis superne glabrescentibus scabro-tıberculatis subtus dense et adpresse sericeis, strobilis 15-20-floris, bracteis præcipuis lateralibus strobilo duplo brevioribus lanceolatis, aliis rhomboideis extus pilosis, lobis perigonii extus velutinis, strobilo maturo glohoso discis florum accretis crustaceis tecto. J In Africà Capensi, ad montes Outeniquabergen (Krauss !). Ophira stricta Lam. 1. c. (non Burm.). Strobilocarpus diversifolius Klotzsch l. c. Gr. rosmarinifolia Krauss! exs. in h. Boiss. (non Berg.). Rami glabrescentes. Folia pollicem longa, $1 \frac{1}{2}-2$ lin. lata, marıine plus minus revoluta, nervo valido, pilis superne adpressis paucis caducis, subtus flaro-sericeis creberrimis, limbo in petiolum lineam longum angustato. Strobili llorentes ovoidei 2 lin. longi, fructif. ovoideoglobosi 3 lin. longi. Bracteæ præcipuæ persistentes, $\frac{3}{4}$ lin. longæ, dorso adpresse pilošæ, basi ciliatce; aliæ interiores $\frac{1}{3}$ lin. longæ, Jatissimæ, adpressæ, fugaces, lobis perig. pulescentiâ similes sed iis latiores. Loculi antherarum valvis 2 valde inæcqualibus introrsâ multo majore (aut si mavis valvâ unicà) longitudinaliter dehiscentes. Nuces lignosæ, sæpius vacuæ, discis amplis quasi resinosis tectæ. (v. s. in h. meo et Boiss.) 


\section{Ordo CLXX. SANTALACE $\nexists$ (1).}

Elæagnorum et Caprifoliorum pars Adans. fam. plant. p. 80 et 150. - Elæagnorum et Onagrorum pars Juss. gen. $p .75$ et 321. - Santalaceæ Brown prodr. Nov.-Holl. p. 350, gen. rem. p. 36. - Santalearum pars Reichb. consp. p. 78. Santalaceæ Bartl. ord. p. 112, Endl. gen. p. 325 (excl. gen. Oclarillo), Lindl. veg. kingd. p. 728 (excl. eod.), Alph. DC. note sur fam. Santal. in Bibl. univ. Genève, sept. 1857.

Flores hermaphroditi vel polygamo-dioici, plerumque monochlamydei, raro (in flor. fem. trib. ${ }^{\text {x}}$ ) dichlamydei; tubo nempe perigonii a pedicello non distincto, ovario plus minus connato et sæpe ultra ovarium inferum productó, apice plerumque verticillum unicum, rarius (in flor. fem. trib. $1^{x}$ ) verticillos 2 loborum gerente; lobis verticilli unici aut verticilli interioris mumero 5-4-3, basi sæpius connatis, æstivatione valvari vel raro subvalvari, cadúcis vel persistentibus, basi articulatis vel tubo continuis, intus medio plerumque fasciculo pilorum cum antherâ oppositâ junctis. Stamina lobis verticilli unici aut interioris opposita, eorum basivel parte liberâ tubi inserta; filamentis brevibus ; antheris apice filamenti erectis vel sæpius dorso insertis introrsisque, bilocularibus, nunc 4-locellatis, rimis longitudinalibus aut ore lato sursum dehiscentibus. Discus epigynus frequenter perspicuus, nunc margine liber et tunc lobis cum staminibus alternantibus crenatus. Ovarium inferum, vel (in Santalis) initio liberum deinde connatum (Henfrey, Trans. linn. soc. 22 , t. 17, f. 1 et 2), vel (in Anthoboleis) basi solum adhærens, uniloculare, interảum fere plenum. Stylus inclusus, apice integer vel 2-3-4-5-lobatus, lobis (ubi numero staminum) staminibus nunc alternis (Osyris Rhoiacarpos, Exocarpus, Thesidium) nunc oppositis (Leptomeriæ, Choretra). Placenta basilaris, centralis, erecta. Ovula 2-3-5 ex apice aut parte inferiore placentæ pendentia, ubi numero stigmatorum iis supposita (Osyris compressa, Abyssinica, Santalum angustifolium), simplicia, nempe integumentis destituta; sacculo embryonali longe exserto, sursuin curvato, embryonem et endospermium extra nucleum gignente (2) Fructus nucamentaceus vel rarius baccatus, indehiscens, constans exocarpio quodam (fructu proprio alieno) tenui, mesocarpio sæpius indurato, endocarpio tandem, juniore pulposo, deinde exsiccato, demum a mesocarpio distracto semen involvente. Semen abortu unicum, inversum,

(1) Auctore Alph. De Gandolle.

(2) De hisce memurabilibus confer ad Brongn. Ann. sc. nat. 1827 p. 294 t. 43 , Griffith Trans. linn. soc. 18 , p. 58, t. 1-3, Decsne Ann. sc. nat. ser. 2 , v. 11, p. 114, v. 13 p. 300, t. 17,18 et p. 487 , tandem et præsertim Henfrey Trans. linn. soc. 1856, v. 29 p. $69, \mathrm{t} .17$ et 18 . 
reliquiis endocarpii, placentæ et ovulorum abortientium plus minus asperatum. Albumen (endospermium proprie dictum) carnosum. Embryo in medio endospermii rectus ; radiculâ superâ, cotyledonibus linearibus vel oblongis dorso convexis longiore. - Herbæ vel frutices, rarius arbores, per temperata omnium fere terrarum sparsæ, in Asiâ, Europâ, Africâ australi et Novâ Hollandiâ frequentiores, in Africâ et Americâ æquinoxialibus ignotæ; sæpius parasiticæ, nempe haustoriis radicibus diversarum plantarum (l), aut ramis, modo Visci (conf. ad Henslowiam). Rami frequenter ex marginibus et nervo foliorum decurrentibus angulosi vel striati. Folia exstipulata, sæpius alterna, nunc opposita, integra, penninervia aut nervis lateralibus obliquis 3-5-nervia, sæpius angusta, frequenter abbreviata squamiformia, raro petiolata, basi plerumque adhærentia nec articulata. Flores albi, virescentes aut sordide flavi rubrive, sæpe minimi; inflorescentiâ terminali cum folia opposita, sæpius foliis alternis indefinitâ, floribus tunc spicatis vel capitatis, vel sæpius in cymulas extra-axillares dispositis, pedunculo folio florali connato; bracteolæ sæpius 2 , laterales, bracteâ foliove florali interiores, florem solitarium aut flores in cymulâ laterales comitantes; pedicelli nulli aut breves et perigonio continui. Fructus plerumque parvi et caduci, nervis primariis sub centro loborum perigonii, secundariis alternis nunc ramosis interdum nullis.

Ordo staminibus oppositilobis, ovulis nudis e placentâ centrali pendentibus, fructu indehiscente et semine unico albuminoso, facile agnoscendus, fæcundatione præsertim insignis. Myzodendro proximus, aliisque plantis parum cognitis ut Myzodendron Loranthaceis errore adscriptis, ubi placenta centralis et orula pendentia (2). Omnes mediæ inter Olacaceas (3) et Loranthaceas, a prio-

(1) Mitten in Lond. journ. of bot. 1847, p. 146, t. 4, gallice transl. in Ann. sc. nat. févr. 1847 , p. 127 , t. 8 , Kunze in bot. Zeit. 1847, p. 361 , gall. transl. in Duch. rev. bot. 2, p. 341 .

(2) Myzodendron egregiis investigationibus Brownii (Trans. linn. soc. 19, p. 232), Hookeri filii (Fl. antarct. 2, p. 289, t. 104-107 ter) et Hoffmeisteri (jn Griseb. Bemerk. ub. Philippi und Lechl. Pflanz. p. 47 c. ic.) illustratum, atque inter Loranthaceas a cl. auctoribus relictum, placentam liberam apice ovuliferam, ovula nuda sacculum. que exsertum anatropum Santalacearum probet, et hisce characteribus distat a Visco (Decsne mem. Gui t. 2, Ann sc. nat. ser. 3, v. 13, t. 11, Schleiden Beitr. p. 23, Trevir. in Florâ 1842, p. 701 , Schnitzl. in Gen. plant. 1l. germ. fasc. 25 c. ic.) et quibusdam veris Loranthaceis ubi placentatio satis cognita, ut Loranthus Deppeanus (ex Schleid. 1. c.), Passovia (Karsten in bot. Zeit. 1852 , p. 305 c. ic.), Tupeix propriæ (Hook. f. 1. c. p. 293), ubi ovulum adest basilare unicum erectum sine placen là sacculo atropo. Plures species in Loranthaceis adluuc male cognitie ulterius investigandre, e quibus pauca verisimiliter ad Santalaceas, aliæe ad Myzodendraceas (antheris, polline et setis ovarii a Santalaceis diversas), alixe forsan ad novum ordinem adhue ignotum transferendie.

(3) De Olacaceis, olim in Prodromo descriptis (1, p. 531), confer ad Renth. in Trans, linn. soc. 18, p. 676 , et Miers in Amn. and mag. of nat. hist. sept. 1851. 
ribus diversæ placentâ (nec pariete) ovuliferâ, a posteriuribus ovulis pendentibus, a duobus ordinibus verisimiliter sacculo embryonali exserto anatroro, sed ovula et fœcundatio in pluribus generibus, præsertim Olacacearum, adhuc ignota.

Situs floris erga inflorescentiam variat. Plerumque flos terminalis in cymulâ aut unicus in axillâ bracteæ ita jacet ut sinus unus perigonii axim spectet, lobo uno (in floribus pentameris vel trimeris) vel sinu (in fl. tetrameris) bracteam spectante(1); rarius et solum in quibusdam floribus tetrameris ( 2 ) lobus unus axi respondet, alio bracteæ opposito. Inde in floribus tetrameris prioris dispositionis lobus exterior (inferior) deest, in trimeris lobi desunt duo laterales bracteææ propiores. Flores tetrameri secundi typi lobo non inferiore carent nam flore ad numerum quinque casu revertente (3) typus communis iterum adparet, lobo inferiore bracteæ opposito, sinu axim spectante. Flores laterales cymularum aliter variant, sed in paucis observare potui.

Verbum perigonium in præsenti ordine optimum ut pote aliquid obscurum et complexum, nec proprie calycem, corollam vel eorum basim indicans. Et énim si recte florem intellexi, omnibus fere speciebus attente observatis et quoad partes floris delineatis(4), Buckleyâque detectâ, ad demonstrationem natum genus, distinguenda sunt in perigonio : $1^{\circ}$ pars inferior, a pedicello basi nunquam distincta, ovarium sæpius tenens, quæ in Thesio aliisque generibus cum lobis superne continua calycis tubo similis videtur, in Choretris vero quibusdam, Nanódeâ, Comandrâ aliisque apice truncata vel constricta, sæpe inter lobos articulatos denticulata, potius pedicelli terminatio apparet; $2^{\circ}$ sepala, in omnibus fere deficientia, in Backleyæ feminâ foliacea tubo imposita ; $3^{\circ}$ petala, basi plus minus connata, medio intus staminigera, basi sæpe articulata et tunc insertione paulo interiore, in Buckleyâ feminâ ubi verticillus exterior adest et in omnibus aliis ubi deest simitia.

Pili antheram cum lobo perigoniali opposito in plerisque jungentes antheræ proprii a pluribus dicuntur (unde nomen gener.

(1) Myoschilos, Quinchamalium, Arjona, Thesium (Euthesium) rostratum, pratense, compressum, crassifolium, Thesium (Discothesium) squarrosum, Thesium (Frisea) capifatum, Boissieranum, Thesidlum globosum pentamerum, Exooarpi omnus, uhi flores pentameri, - Osyris compressa, Thesium (Euthesium) alpinum, eupḩrorhioides, Omphacomeria acerba, Pyrularia Cejlanica, Santalum angustifolium, Cygnorum, forsan Cervantesia, ubi flores tetrameri.

(2) Thesidia omnia fl. tetrameris, Leptomeria Billardieri tetramera, Exocarpus orlorata tctramerà.

(a) Leptomeria Billardieri, Exocarpus odoratus et Thesidium globosum, floribus en $=11$ peotameris.

(4) Delineationes analytice in herluario meo jacent.

XIV. 
Comandra), tobo ab aliis. Ego magis perigonio adhærentes vidi, ab eo nunquam segregatos sed interdum ab antherâ juniore vel provectiore facile distractos, unde perigoniales potius existimo, firmante monstro a cl. Reissek observato (Linnæa 17, p. 641, t. 19, f. 11 et 14), ubi staminibus Thesii in folia mutatis pili in medio loborum, nec dorso antherarum foliacearum, remanebant.

Genus Cevallia Lag. est Calycerea, saltem non Santalacea Glischrocaryon Erıdl. est (ex jpso auct.) Loudonia Lindl. Haloragearum. Conf. ad Endl. gen. 6139. - Helwingia Willd. certe a Santalaceis distans, est typus ordinis, Helwingiaceæ, prope Hamamelideas ex Decaisne in Ann. sc. nat. sér. 2, v. 6, p. 69 , t. 7. - Nyssa, typus ordinis ex Juss. dict. sc. nat., 35, p. 267 et plerisque auctoribus, post Santalaceas sæpe enumérata. (Endl. gen. p. 328), valde differt ovulo ex apice loculi pendente, stàminibus numero duplici loborum, magnitudie cotyledonum, etc., atque habitu. Cl. Brongniart (enum. gen. p. xxx), prope Combretaceas et Alangiaceas, cum dubio, collocavit; Lindley (Veg. kingd. p. 720) Alangiaceam affirmat. Lobi caducissimi petala videntur, ex insertione intra cupulæ calycinæ marginem. - Pseudanthus Endl. est Euphorbiacea, ex Decsné in Ann. sc. nat. sér..2, v. 12, p. 157. - Schapfia (1) Schreb. ovario certe per majorem partẹm

(1) SchœPFIA. - Characteres generici supra dicti (Prodr. 4,-p. 319) paulo mutandi. Flos « basi calyculatus " est flos intra cupulam inæqualem insertus, cupulà e bracteâ majore et bracteolis 2 vel rarius bracteolâ unicâ constante. Corolla est perigonium Santalacearum, quod reverâ corollæ analogum videtur; ejus lobi medio intus fasciculum pilorum præbent ad antheram tendentem, ut in Santalaceis fere omnibus. Ovarium est basi et fere usque ad apicem 3-loculare, apice uniloculare, ovulis 3 ex summâ parte parietum in augulo supremo loculorum pendentibus fusiformibus.

Species hucusque mihi cognitæ sunt :

1. S. arborescens (Roem. et Sch., DG. prodr. 4, p. 319). Ex ins. Antillanis. Cl. Bentham (Trans. Linn. soc. 19, p. 678) suspicatur n. 2593 Blanchet, e montibus Jacobinæ prov. Bahiensis, eamdem esse, quod dubium mihi videtur, sed iconem Vahlii non possideo. - 2. S. flexuosa (Røem et Sch. DC. l. c.). - 3. S. fragrans (Wall. DC. I c.), ubi char. ovarii observavi et cupulam bractearum 3-lobam. - 4. S. acuminata (Wall. mss. DC. l. c.), priori valde affinis, ubi folia magis apice acuminata, basi minus acuta, non vero obtusa. - 5. S, jasminodora (Sieb. et Zucc. fl. Jap. fam. nat. $₫$, p. 11"), foliis e basi rotundatà ovatis acuminatis acumine subfalcato, racemis 3 -5-floris, perigonio 4-5-lobo, staminibus 4-5. E Japoniâ. - Tandem speciès americanæ novie :

6. S. M Ex 1 aAnA, foliis ovatis vel ovato-ellipticis basi subaculis apico obtusis, peduneulis in axillis solitaris geminisve apice 1-3-floris, pedicellis flore multoties brevioribus, cupulâ bractearum patente bilobà lobo externo majore ovato altero breviore subtridentato. 5 Ad Tlacolula ditionis Oaxacæ Mexici, non parasitica. Loranthacea Andrienx I exs. n. 345. Rami lignosi, rugosi ; ramuli angnlosi cum foliis et flore in sicco nigricantes. Folia alterna, crebra, 12-15 lin. longa (incl. pétiolo 1.2 lin.), 5-8 lin. lata, nervis lateralibus vix distinctis. Pedunculi 2-3 lin. longi, pedicellis vix lineam longis terminati. Flos 3 lin. longus, eylindraceus. Cupula lineam lata, margine subciliata, non triloba ut in aliis spec. Lobi 5 perigonii tubo quadruplo breviores, demum revoluti, medio intus pone antheras pilosi. Ovarium congencrum. Stigma.globosun 2-3-partitum. (v.-s.)

7. S. B RASILIENSIS, foliis ellipticis basi subacutis apice acutis coriaceis, pedun- 
triloculari apice solum uniloculari, ovulis parietíbus medio connexis nec placentâ fliformi liberâ suspensis a præsenti Ordine differt. Videtur potius Olacacearum genus, ut dixerunt cl. Bentham (Trans. Línn. soc. 18, p. 678) et postea cl. Miers (Ann. of nat. hist. sept. 1851, p. 175), nec Loranthacea, ut supra in Prodromo $\{4$, p. 319$)$, aut ordo proprius ut proposuit ill. Blume (Mus. L. B. 1, p. 175).

\section{Tribus I. BUCKLEYEÆ.}

Flores feminei dichlamydèi; lobi exteriores foliacei, ex apice tubi cum ovario connati; interiores lobis perigonii aliarum Santalaceárum simillimi, cum prioribus alternantes. Flores masculi monochlamydei; lobi interioribus florum femineorum similes, medio staminiferi. Placenta apice ovulifera. - Forma magis evoluta Ordinis.

I. BUCKLEYA Torr. in Amer. journ. of sc. 1843,v. 45, p. 170, Asa Grayl nole on gen. Buckl. ibid. 1854, new ser. v. 18.

Flores dioici. Feminei dichlamydei. Tubus avario connatus. Lobi exteriores (calyx) quatuor, interdum 5 vel 6 , lanceolati, tarde decidui, nervo centrali per tubum decurrente, æstivatione ignotâ, evolutione ante sequentia organa (fide A. Gray). Lobi interiores (petala) perigonio aliarum Santalacearum similes, numero quatuor, ovato-aculi, exterioribus alterni et duplo breviores, uninervii, puncto nec torâ basi obtúsła inserti, æstivatione modice imbricati (1), post florationem ante lobos exteriores caduci. Stamina nulla, ne vestigium. Stylus inclusus, in flore bisulcatus, apice 4-lobus, lobis cum staminibus alternantibus (fide Gray), in fructu juniore bifidus, lobis apice subbilobis. Fl. masculi monochlamydei, lobis 4 (lobis vulgaribus Santalacearum ex habitu et insertione staminum similibus), ovato-acutis, æstivatione valvari, per anthesin patentibus. Stamina 4 , lobis opposita, eorum basi inserta; filamento gracili, libero; antherâ subglobosâ, filamento minore, biloeulari, rimis longitudinalibus subintrorsum dehiscentibus. Pollen læve, ovoideum. Discus concavus; lobis staminibus alternis, iis multo brevioribus, ovatis. Pistillum nullum. Ovarium $f$. femin. inferum, uniloculare. Ovula (ex fray) 3 vel 4 , minima, simplicissima, ex apice placentæ centralis crassæ liberæ loculum parvum implentis pendentia. Fruclus oblongus, externe subcarnosus (drupa ex Torr.), 10-sulcatus, putamine longitudinaliter sulcato, crustaceo (ex Torr.), potius durro? Semen (ex Torr.) endocarpio adhærens, embryone in axi albuminis carnosi copiosi recluso gracili. - Arbuscula (ex Torr.) aut frutex (A. Gray) Americæ borealis, foliis oppositis vel suboppositis alternisve,

culis in axillis solitariis geminisve apice $\uparrow$-3-floris, floribus (junior.) intra bracteas sessilibus, cupullâ. uractearum e bracteâ bracteisque 2 interiorihus brevioribus amnibus late ovato-acutis subpuberulis constante. s Ad Jgreja Velhạ prov Bahiensis (Blanchet 1 3360). Rami lignosi, subtortuosi, albidi, ramüli in sicco nigrescentes. Folia pollicem longa, 6-8 lin. lata, in petiolum 2 lin. longumangustata, apice acuta vel acuminata, siepius falcata. Flores in specim. juniores, linean longi, ovoidei, bracteâ duplo longiores. Antheræ tres, a basi profunde bifirlæ. Ovarium semi-inferum, pars infera minor, pars supera hemisphierica carnosa. Stylus apice capitatus. Loculus in parı inferiore ovarii, placentâ vel parjete erectá apice ovula 3 ? gerente divisus. (v.s.)

(1) Ex As. Gray, qui plantam viventem observavit. In fl. masc. equidem siccis, estivatio valvaris mihi videtur. Pyrularia, verum Santalacearum genus, similem. variationem præbet. 
distichis, vix petiolatis, integris, penninerviis, ovato-acuminatis; gemmis ovoideis acutis e foliis minimis imbricatis ovato-acutis constantibus; tloribus mascilis in cymulas ramos terminantes dispositis, pedicellatis, circa basin pedicellorum bracteolis caducissimis stipatis; femineis solitariis apice ramorum, pedunculo suffultis, bracteis 4 inæqualibus ad apicem pedunculi donatis.

Genus insigne, typum evolutum Ordinis reddens. Placenta centralis et stamina lobis opposita Santalaceam sine dubio designant. Flores masculi omnino Osyridis vel alii generis Santalacei, lobi vero exteriores florum femineor um, a bracteis diversissimi propter situm in vertice tubi, omnibus characteribus calyx dicendi, quâ interpretatione verticillus vulgo unicus perigonii Santalacearum et inde Loranthacearum et Proteacearum esset corolla aliarum piantarum analogus, calyce plerumque deficiente.

B. DISTICHOPHYLLA (Torr. 1. c.). 5 vel $\zeta$ in Tennessee Americæ borealis, presertim in montanis. Borya distichophylla Nutt. gen. am. 2 p. 232. Rami læves glabri. Ramuli graciles, ut nervi foliorum pedunculique pulverulento-velutini. Folia 9-18 lin. longa, 3-5 lin. lata, petiolo $\frac{1}{2}$ lin. longo, inferiora ramorum minori, superiora majora, basi obtusa, apice acuminata, tenuia, nervis lateralibus vix perspicuis,margine ciliolata. Gemmæ $\frac{1}{4}-1$ lin. loøgæ, in sícco flavescentes. Pedunculus fl. masc. lin. longus, pedicelli hunc subiequantes. Flos mase. $1 \frac{1}{2}$ lin. latus. Pedunculus fl. fem. lineam longus. Pedicellus a tubo ovarii non distinctus, hasi tamen bracteatus ut in masc. Bracteæ majores $\frac{1}{2}-\frac{3}{4}$ lin. longæ foliis extremis rami alternæ, minores prioribus paulo superiores cum ís alternantes lanceolatæ apico (ut interdum priores) apice bilobæ. Floris tubus lineam longus, cito accrescens, velutinus, lobi exteriores extus et margine puberuli 1 $1 \frac{1}{1}-2$ lin. longi, anguste lanceolati, demum 5 lin. longi, $1 \frac{1}{4}$ lin. lati, nervatione et pube parcâ brevi foliorum; interiores ut in fl. masc. ovato-acuti exlus et margine puberuli, medio intus glabri, lineam longi, $\div$ lin, basi lati. Fructus 8-9 lin. longus, demum apice nudus et solum disco umbilicatus, basi in stipitem 1-2 lin. longum angustatus, apice obtusus, 10-nervius. Semen non inveni, nec pläcentam in 2 floribus apertis. (v. s. a cl. Torr. et Gray et a Rugel. comm. in h. meo et Boiss.)

\section{Tribus II. SANTALEE.}

Flores hermaphroditi vel rarius dioici, semper monochlamydei (1), tubo cum orario connato, lobis æstivatione stricte valvari, masc. et hermaphroditis medio staminigeris.

\section{Subtribus I. THESIEA $A$.}

\section{Placenta gracilis, apice ovulifera.}

JI. QUISCHAMALIUM Molina hist. nat. Chili, trad. fr. p. 331 (char. falsis), Juss. gen. p. 75, Lam. ill. t. 142, Ruiz et Pav. A. Per. 2, p. 1, t. 107, Brongn. in Voy. Duperrey (Coquille), $t, 51$ et 52, Endl. gen. p. 325, Cl. Gav Hist. nat. Chili, 5, p. 318.- Quinchimali Feuill. journ. obs: 1725, p. 57, t. 44. - Quinchamala Willd. sp. p. 1217.

Involucellum cuique flori calycem liberum mentiens, urceolatum, 4-dentatum, dente uno majore externo, 2 minoribus lateralibus, ultimo axi opposito. l'erigonium ab involucello liberum, ovario adnatum, supra ovarium tubulosum et tarde caducum; lobis 5 , oblongis, æqualîbus, tubo brevioribus, apice externe calloso-dentatis, utrinque glabris, labo uno externo (denii

(1) Gupula externa Quinchanalii est manifeste involucellum flori alienum, bracteit et bracteolis aliorum generum analogum. Denticuli minimi calycodium, Plancl. pi Decsne. bull. soc. bot. Fr. 1855, p. 86 ) in Choretris paucis et passim in aliis apice tuli inter lobos non sine difficultate visibiles, nunquam evoluti, continuatio marginis tulii (e pedicello formati ?) videntur, ut in Loranthaceis Proteaceisque nommullis, a lousis externis foliaceis radureis Buckldyie diversissimi. 
majore involucelli opposito). Stamina 5, supra basin loborum perigonii inserta, iis breviora ; antheris filamento extremitate insertis lineari-öblongis. Ovarium inferum, diu cellulis farctum. Ovula 3 , ex apice placentæ centralis cylindricæ rectæ pendula. Discus epigynus, per anthesin accrescens, prismaticus. Stylus e centro disci filiformis. Stigma depresso-capitatum. Fŕuctus nıonospermus, involucello globoso indurato cinctus, disco et diu perígonio terminatus. Semen ovarium tenue implens, inversum. Albumen carnosum. Embryo in apice albuminis rectus vel paulo oblíquus, radiculâ superâ, cotyledonibus 2. adpressis longiore. - Herbæ chilenses et peruvianæ, radicibus parasiticæ (Kunze in bot. Zeit. 24 mai 1847, annuæ vel suffrutescentes, e collo pluricaules; foliis alternis, integris, linearibus vel oblongis; floribus ad apicem ramorum dense spicalis, sessilibus, cum involucello in alveolis lobatis puberulis insertis, luteo-aurantiaciš. - Genus in ordine anomalum, minus tamen ex anthogenesi, nam in alabastro 1/6 lin. breviore lobus externus involucelli alios præcedit floremque triplo superat, ut bractea in Santalaceis omnibus.

1. Q. wajus (Brongn. in Voy. Coquille, t. 51, f. A, sine descr.), caulibus erectis apico sul)ramosis, foliis linearibus acutis sparsis, supremis margine scabris, involucello glabro, floribus majusculis $\mathcal{\psi}$ ? In Chili prov. mediis et merid., prope Coquimbo frequens (Gl. Gay), in montibus Mendozæ (Bacle!), in Chili (Cuming ! 1238 in herb. Boiss., Bridges! ib. sine num.). Q. Chilense Philippi! pl. Chil. n. 399, Bert.! n. 581 ex parte. Q. elegans Presl epim. p. 246 ? Caules e radice crassiusculâ 2-4, erecti, 8-12 yoll. alti, glảbri. Rami 1-2 sub spicâ, breves, inæquales. Folia 6-12 lin. longa, $\frac{3}{4}$ lin. aut lineam lata, glabra, irregulariter disposita, suprema sub lente tenuiter serrulata. Alveolæ rachis cupuliformes minimæ lacinjato-puberulæe. Involucellum in flore lineam, in fructu $1 \frac{1}{2}$ lin. longus, lobis acutis, uno manifeste longiore. Perigonium 7-8 lin. longum, luteo-aurantiacum, dentibus ad apicem loborum manifestis. Antheræ filamento sublongiores. Stylus stamina paulo superans. Discus epigynus demum 5-angulus, prismaticus, $\frac{3}{4}$ lin. longus. (v.s.)

2. Q. G R A C'IL E (Brongn. in Voy. Coquille, t. 52, sine descr.), caulibus simplicibus ad scendentibus; foliis lineari-filiformibus acutis, involucello glabro $\odot$ ? In Chili a littoro maris ad medios montes (Cl. Gay), in prov. Valdiviensi (Philippi! n. 324 in l. Boiss.) Q. Ghilense gracile Hook. bot. Beechey, p. 44 (sine descr. sed ubi folia filifornsia dicuntur). Q. Chilonse Bert.! n. 581 partim et 1271 in h. DC.), Poepp.! 61 diarii (h. DC.). Quinchamala tenuis Steud. nom. ed. 2 (fidé numeri 581 Bert. citati). Q. Clilense Walp. in Act. Acad. nat. cur. 19, suppl. 1, p. 412 ? (ex longit. fol. in alt. sp. infra memoratâ). Q. brevillorum Presl epim. p. 246 (fidé descript. ct syn. Bert.). Radix gracilis. Caules e collo 2-5, erecti vel adscendeutes, 3-9 poll. longi, sæpius minores quám Q. Chilensis. Folia 6-12 lin. longa, $\frac{1}{3}-\frac{1}{2}$ lin. lata, in eorlem caule latit. variantia. Areolæ pubescentes minimæ circa originem florum. Caules apice foliaque sub lente sparse puberula, pube evanescente. Lobi involucelli acutiusculi. Flores 4-6 lin. longi, luteo-aurantiaci. Antheræ filamento æquales. Icon a Decaisne delineata fructum verisim. non maturum exhibet; in specimide yuodam herbarii mei discus epigynus in fructu prismaticus 5-gonus $\frac{1}{2}$ lin. longus et embryo semine dimidio solum brevior (nec minimus) cylindricus. (y. s.)

3. (.) GHILENS (Lam. ill, p. 125 t. 142), minus, caulibus simplicibus adscendentibus, foliis linearibus acutis abbreviatis, dentibus involucelli apice præsertim puberulis demum glabris. $\mathcal{F}$ ? In montibus Chili merid. (F'euill.) et sept. (Cl. Gay), ad Cobija (Gaudich.l in h. DC.), et forsan in Peruvia ad Tíssaioma (Q. linifol. ILoyen ?). Quinchamali lini folio Feuill. journ. 1725, n. 57, t. 44. Q. procumbens Ruiz el Pav. fl. per. 2, p. 1, t. 107? (mala). Q. ericoides Brongn. voy. Coquille, t. 51, (sine descr.). Cl. Gay hist. Chil. 5, p. 320. Q. linifolium Meyen ex Walp. in act. Acad. nat. cur. 19, suppl. 1, p. 412? (ex char. laciniarum cal. intus villos. et fol. brevibus). Radix (cx Feuill.) 5-6 poll. longa, lignosa. Caules e collo 2-5 adscendentes vel humifuse, 3-9 poll. longi. Folia sæpius 4-6 lin. longa, raro 9 lin. (ex Feuill.) $\frac{1}{3}-\frac{2}{3}$ lin. lafa. Lobi involucelli obtusiusculi. Flores semipollieares. Tubus perigonii viridis, lobi lutei (ex Feuill.). Icones Feuillei et Brongn. conveniunt, Lamarkii Feuilleo mutuata. Sliecinen Gaudich, o Cobija caules lobosque perigonii interne sub lente 
puherula exhibet, quod in iconibus verisimiliter negligentiâ caret. Invołucellum junius puberulum, presertim extus apice ut in ic. Brongn. (a Decaisne delin.). Areolæ margines pubescuntes circa originem florum. Discus epigynus post anthesin $\frac{i}{3}$ lin. longus. (v. s.)

B. parviflorum, involucello glabriusculo, floribus 3 lin. Iongis. - E Irov. Coquimbo (Cl. Gay in h. DC.). Caules plurimi divergentes, nunc apice ramosi. Folia 3-6 lin. longa, $\frac{1}{2} \div$ lin. lata. Flores 3 lin. solum longi. An specimen casu retortum, aut species distincta?

4. Q. D о в в у I (Brongn. in Voy. Corquille, t. 52, B, sine descr.), caulibus subsimplicibus arlscendentibus, foliis lineari-oblongis acutis, involucello glabro. ( ) In Peruviâ? (ex nom. viatoris) Caules in ic. sejtem e radice parvâ divęrgentes, 3-5 poll.

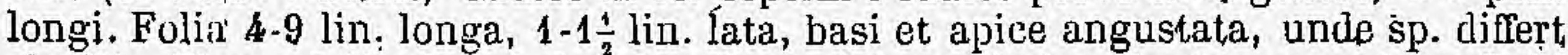
$\mathrm{ab}$ aliis. Flores 5 lin. longi. Involucellum glabrum in ic., dente uno majore. Lobi perigonii tubo duplo breviores. Stigma inclusum.

\section{Synonymon dubium.}

Quinchamala Fruticulosa Steud nom.' ed. 2. Ex synon. Q. procumbentis R. et Pav. esset Q. Chilense Lam.; ex syn. 1271 Bert., Quinchamalium gracile aut majus, nam Bertero duas sp. miscuit et Q. majus fruticulosum potius videtur.

\section{Species exclusa.}

Quinghamala Patagonica Spr. = Arjona tuberosa.

III. ARJONA Cav. ic. 4, p. 57, t. 383. - Arjoona (err. typogr.?) Endl. gexl. p. 325, et suppl. $4, p .58$.

Perigonium tubo cylindrico, apice infundibuliformi ; lobis 5 , nno bracteam spectante, penicillis squamiformibus pilorum transverse septiferum sub centro cujusve lobi. Stamina 5 , intra faucem sub fasciculis pilorum inserta, filamentis gracilibus; antheris ublongis, introrsis, paulo infra medium dorsi filaménto suspensis. Pollen (immersum) 3-gonum, angulis obtusis rumpens. Ovarium inferum, carnosam. Ovula 3 , ex apice placentæ liberæ centralis filiformis pendentia. Discus epigynus convexo-annularis. Siyłus filiformis. Stigmata 3 (nunc $2-4$ in ead. plantâ), linearia, brevia. Fructus bracteis bracteolisque inclusus, ovoideus, disco et vestigiis laceratis perigonii tectus, monospermus. Semen pericarpium (subcarnosum?) implens, albumine carnoso, embryone recto centrali, radiculà superâ. - Herbæ vel fruticuli Americæ merid. australioris; radice palari, radicellis sæpe tuberculiferis; caulibus sæpius simplicibus, divergentibus; foliis alternis, sessihibus, confertis, rigidis, 1-7-nerviis, acutis, floribus apice ramorum spicatis; bracteâ bracteolas basinque floris amplectente; bracteolis 2 interioribus oppositis, unâ tamen versus axim inflorescenliæ alteram tegente, persistentibus, ut bractèa et perigonium extus pilosis.

1. A. Rus GrF oura (Pœpp. pl. Ghil. 50, ex Walp. in Act. nat. cur. 19, suppl.,1, p.112, $\mathrm{n}, 137$ et diarii 536 in h. DG.l), fruticulosa, ramis glaberrimis, foliis imis ovato lanceolatis 7-nerviis glabris, aliis lineari-lanceolatis subulatis 5 -nerviis glabriusculis, bracteâ lanceolatâ bracteolisque ovato-acutis extus pilosis, perigonii tubo cylindrico superne infundibuliformi externe (basi exceptâ) piloso, interne (penicillis exceptis) glabro, lobis extus adpresse sericeis interne glabris. 5 In Chili cordillerâ San Ferñando (Walp. l. c.). Ex specimine meo Poppigíi caules șive rami 3-6 poll. longi e basi communi surgentes, simplices; folia approximata, inferiora 3 lin. longa, $1 \div$ lin. lata, media et superiora 5-6 lin. longa, vix lin. lata, juniora sub lente tenuissime puberula, omnia cuspide aculissimâ rigidă ; bracteæ 3-4 lin. longæ acutæ vel acuminatæ intus glabræ; bracteolæ ovato-acutæ, vix linea longiores, intus glabræ. Perigonium $7+8$ lin. longum, interne penicillis minimis exceptis glabrum. Stamina intra faucem. Stigmata 3 , originem stam. vix attingentia., (v. s.)

2. A. TUBekos (Cav. ic. 4, p. 57, t. 383, ead. q. icon in Poir. suppl. ad ill. t. 421), 
herba sublignescens, ramis glabrescentil)us, foliis pubescentibus glabratisve, imis ovato-acutis 7-nerviis, aliis lanceolatis acutis 5-nerviis, bractea bracteolisque ovato-acutis extus pilosis, perigonii tuho cylindrico superne infundibuliformi utrinque basi exceptâ piloso, lobis externe adpresse sericeis interne basi exceptâ glabris. 4 5 In siccis Americæe merid. portu Deseado (Nee ex Cav.), montium centralium Chili ad Talcaregue et prov. Coquimbo (Cl. Gáy!) - Cl. Gay hist. nat. Chili 5, p. 323. Quinchamala patagonica Spreng. syst. 1, p. 537 (propter ic. Cav. cit. ex nomine forsan id var. $\beta$ referenda). Radix cylindrica, gracilis, radicellis (fido Cav.) tubercula ovoidea 1-6 lin. longa gerentibus. Caules sive rami e radice surgentes, 4-6 poll. alti, subsimplices. Folia approximata, minus quam in ic. rudi Cav, pilosa, pilis sub lente brevissimis sæpe evanéscentibus, aliisque longis rarioribus (an mucor?), ima 2 lin. longa, $1 \frac{1}{2}$ lin. lata, alia 3-6 lin. longa, $\frac{1}{2}-2$ lin. lata, omnia cuspide acutissimâ rigidà. Bracteæe 3-4 lin. longæ. Bracteolæ bracteâ triplo minores, ovato-acutæ (nec 3-lobæ ut in ic. Cav.). Perigonium ut in præced. sed interne pilosum et penicillis majoribus, lobis apice magis callosis. Stigmata 3-4, linearia (nec ut in ic.) stam. originem non attingentia, sæpius mediam tubi partem vix superantia. (v. s.)

3. Patagonica, foliiś sæpius minoribus glạbratis. In Patagoniâ, ad Sandy point (Lèchler! 1129). A \& Patagonica Hombron et Jacquinot in Voy. pôle Sud, t. 15 (fide auèt.), Hook. fl. antarct. 2, p. 342 (ubi verisim. varietas A. tuberosæ dicitur). Ex specim. Lechler. radix omuino ut in ic. Gav. A. tuberosæ, elongata, radicellis tuberculos minimos hinc inde fræbentibus; caules ramique ic. Cav. valde similes; folia ima deficientia, caulina in eâd. plantâ 1-4 lin. longa, 5-nervia. Bracteæ floresque omnino ut in A. tuberosâ, stylo forsan sæpius longiore staminum originem attingente, sed in eo variant flores A. tuberose. Primo adspectu div. species, studio varietas loci frigidioris depauperata. (v. s.) .

3. A. PUSIL L A (Hook. f. fl. antarct. 2, p. 342), caule erecto gracili simplici vel diviso, foliis laccidis elongato-linearibus uninerviis acuminațis, bracteâ glabratâ margine solum ciliatâ, bracteols extus pilosis, perigonio extus sericeo-tomientoso, fauce tubi ampliatâ. - In freto Magellanico. Herba 2-3-pollic. Folia suberecta, $\frac{1}{2}-\frac{3}{1}$ unciæ longa, fere 1 lin. lata, flaccida, sæepius recurva, 1 -nervia, apice acuminata, marginibus subenerviis glaberrimis plerumque recurvis. Flores pauci. Bractea $2 \frac{1}{2}$ lin. longa. Bracteolæ interiores in tubum apice inæqualiter 3-4-fidum ovario subadhærentem obscure coalitæ (ex verbis cl. auct; in aliis sp. bracteolæ invicem implexæ sed non coalitæ, integræ, aliquid simile monstrant). Perigonium $\div-\frac{3}{4}$ unciæe longum, lobis ovato-oblongis, fauce inter stamina barbatâ, pilis brevibus flaccidis artieulatis creberrime transversim striatis. Antherarum apices subexserti. Stigmata 3 , intra tubum.

IV. MYOSCHYLOS Ruiz et Pav. prodr. p. 41, t. 34, . Per. 3, p. 20, t. 242, Endl. gen. p. 327, Cl. Gay hist. nat. Chil. 5, p. 326.

Perigonium 5-lobum, persistens; tubo obconico ; lobis ovato-acutis, utrinque glabris, subpatentibus, lobo uno bracteam spectante. Stamina 5, basi loborum sub centro inserta ; filamentis brevibus; antheris ovatis, basi emarginatâ apice filamenti insertis, bilocularibus, introrsis. Ovarium inferum, carnosum. Placenta centralis, erecta, cylindrica, apice ovula 3 ? reflexa gerens, uno tantum fnecundalo. Discus epigynus planus. Stylus brevis. Stigma 3-gonum, lobo uno bracteam spectante. Fructus ovoideus, drupaceus, perigonio immutato coronatus, monospermus. Semen (ex Gay) lave, rotundatum, embryone parvo cylindrico intra albumen copiosum. - Frutex chilensis, habitu in ordine anomalus, foliis alternis ovatis; ramulis floralibus amentiformibus ex axillis foliorum anni præcedentis ante folia evolutis; floribus parvis in ramulo sessilibus approximatis; bracteâ et bracteolis 2 lateralibus cuique flori.

M. OBLONGUS (Ruiz et Pav. I. c.). In Chili fere toto àb Aconcagua ad Chiloe (Cl. Gay l. c. Plilippi pl. Chil. 243 ! Lechler ph. Chil. 1305 !) et Peruviâ (Dombey! ex schedulâ specim̀. a Mus. Par. sủb n. 190 comm., sed potius a Dombeýo in Chili aut Peruviâ lectus). Codocoypu dictum, id est pabulum animalis Mus Coypus.a Molina 
vocati, unde nomen gencricum. Folia ovata, undulata, apice mucronulata, $6-12$ lin. longa, basi in petiolum 1-3 lin. longum angustata, juniora pulverulento-puberula. Spicula: 2-3 lin. longic, ovoidej, bracteis Iloribusque pluribus tecte. Bracteæe ct bracteolee subsimiles, ovato-acute, glabræ, persistentes, $\frac{1}{2}-\frac{3}{4}$ lịn. longæ. Flores purpurci, plurimi steriles, lineà breviores, glabri, lobis perigonii sapra tubum transverso sulcatis. Drupa (ex R, et P.) purpureo-atra, magnitudine pisi. (v. s.)

V. PYRULARIA Mich. fl. bor. Am. 2, p. 231 (anno 1803). - Hamiltonia Muhlenb. in Willd. sp. 4, p. 1114 (anmo 1805), non Koxb. - Sphærocarya Wall. in Roxb. $n$. Ind. 2, p. 371, tent. fl. Nepal. p. 19, t. 10 (in Wight ic. t. 255 iterata. - Scleropyrum Arn. in Journ. of zool. and bot. n. 12 (ex cit. Wight). - Scleropyron Arn. in Magaz. of zool. and bot. 2, p. 550 (ex cit. Enall. suppl. 2, p. 105).

Flores hermaphroditi vel unisexuales, priores et masculi inferne subglobosi, feminei turbinali. Perigonium 5-4-fidum, lobis æstivatione valvari (interdum subimbricatâ). Pili longi intricati vel squama (saltem in $\mathrm{n}$. hermaph.) ovata fimbriata e basi lobi cujusque ad antheram tendens ibique pilis adhærens. Stamina (1. herm. et masc.) lobis opposita, eorum basi inserta ; filamento brevi, nunc apice bifurciıto; antherâ ellipsoideâ, biloculari, loculis valde distinctis longitudinaliter dehiscentibus. Uiscus cupulifornis, margine 5-lobus, lobis ovatis obtusis pinguibus cum lobis perigonii alternantibus. Ovarium in fl. herm. semi-inferum, parvum; in fl. fem. inferum. Placenta junior recta minima, cito sub anthesi elongata et contortuplicata. Ovula $2-3$, apice placentæ divergentia rel pendentia. Stylus inclusus, pinguis, apice in fl. herm. 2-3-lobus, lobis obtusis; in fl. fem. (ex Mich.) depresso-capitatus. Drupa infera, pyriformis, apice umbilico depresso et lobis perigonii non accretis patentibus coronata, putamine tenui verruculoso monospermo. Semen albumine carnoso oleoso (ex $P$. pụberâ forsanque in aliüs); embryone minuto, radiculâ superâ. - Fitutices arboresve boreali-americani et asiatici; foliis alternis, integris; spicis racemisve elongatis, pubescentibus; floribus in axilla bractea sessilibus vel pedicellatis, extus pilosis.

\section{§1. Filamenta apice integra.}

1. P. PUBERA (Mich. 1. c.), frutex inermis, foliis ovali-oblongis acutis puberulis pellucide punctatis, racemis spiciformibus terminalibus. $₹$ In montibus Carolina et Virginiæ (Mich.), a Pensylvanià ad Georgiam (Nutt.). Hamiltonia oleifera Mlulıl. 1. c. Oleum acre per totan plantam, presertim in albumine, sparsum. Rami læves, glabri. Ramuli sericeo-pul)escentes. Folia 2-3 poll. longa, 9-15 lin. lata, in jetiolum 3-4 lin. longum angustata, acuminata, tenuia, punctis minimis pullucidis oculo armato punctulati, nervis lateralibus utrinque $4-5$ nervoque ecntrali et petiolo puberulis. Spicse jubescentes, ramos terminantes; fl. herm. $1 \frac{1}{2}-2$ poll. longæ, multiflorie, lloribus approximatis sed solitariis pedicello $\frac{3}{4}$ lin. longo fultis; florum femin. spica breviores, l:auciflore. Bractefe (in herm.) ovato-lanceolatæ, caducissina, pubescentes, bracteolæ nullee? Flones hermaphr. $1 \frac{1}{4}$ lin. lati, alabastro gloJuso, extus pilosi, lobis cleinum reflexis, uvato-acutis, túlum æequantibus, margine velutinis. Drupa 7-9 lin. Ionga, 5-6 lin. Jata, vix pubescens, umbilico lato. (v. s. in h. med fruetif., ill l.. Boiss. a Torr. llorif. et fruct.)

2. T. EDULIS, arbor incrmis, folis ovato-oblongis utringue acutis subtus ad nervos pilusis carnosulis, racemis masculis terminalibns el axillaribus, floribus femineis solitaririis. 5 In Nepalià (Wall.) et mont. Khasiæe et Sikhim, alt. 4-5000 pèd. (Hook. f.! in l. reg. luer.) Splyerocarya edulis Wall. 1. c. Wighlt 1. c. Scleropyri spec. Wigltt et Aru. in Edinb. phil. journ. 1833, v. 15, p. 180. Folia 3-6 poll. longa (incl. petiolu 3 lin.), 1-3 poll. lata, nervis 7 lateralibus precipuis distinctis inferioribus approximatis sulboppositis subtus jilosis, cecterum glabra. Racemi $\mathbf{1 - 3}$ poll. longi. Flores ux je. Wall. nunc (masc. et lierm.?) secus racemos axillares et terminales $1-2$ joll. lungus 10-30-floros dispositi, tulso abbreviato; feminei, in eod. ramo, solitarii, axillatres, pedicello 3 lin. longo, tu bo oblongu obovoideo semipollicari lobis mult to longiore. Drupa edulis, 2-2 $\frac{1}{3}$ poll. longa. Flores herm. et masc. mecum in littera communi"avit Ilook. fil. ubi placentam contortuplicatam, apice ovula 2-3 patenti-rccurva, 
ut in sp. americanà observavi, et inde ic. Wall. falsa. Stylus iu hisce nunc apico bilobus, sxpius vero capitato-lobatus. Pili pone antheras longi, potiusquam squamie ut dixit Wall. (v. s. fruct. in h. reg. ber.)

03. P. moschifena, arbuscula spinosa, foliis ellipticis acuminatis coriaceis supra glabris subtus pubescentibus. 5 In sylvis montanis Javie occidentalis (Blume) et in Sumatrâ (Korth. in Miq. 11. Ind. bat. 1, p. 778). Sphærocarya móschifera Blume Mus. Lugd. bat. 1 p. 245 . Arbor mediocris, ramosissima, ad ramulos sæpe geminatos

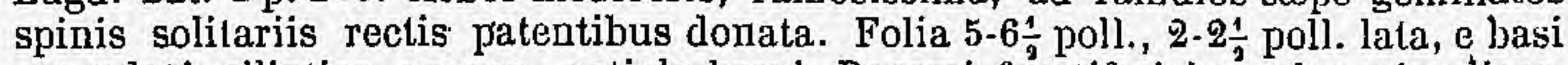
rotundatâ elliptica, venosa, petiolo brevi. Racemi fructiferi laterales, simplices. Drupa majuscula, pyriformis, depresso-umbilicata et limbo perigonii 5-6-fidi coronata, lutescens. Putamen rugosum. Caro moschata. Descriptio ex Blume l. c., Cl. Níquel addrit. folia $5 \cdot 8 \frac{1}{2}$ poll. longa.

\section{§ 2. Filamenta apice bifida.}

4. P. Wallighiana, passim spinosa, foliis ovatis vel ovato-lanceolatis acutis vel obtusis, rhachi masculâ densiflorâ, floribus pentameris. I In Malabariầ (Rheede, Perrottet!). Idu-Mulli Rheed. Malab. 4 t. 18. Scleropyrum Wallichianum Arn: olim l. c. Sphærocarya Wallichiana Wight. cat. n. 948, Wight et Arn. in Edinb. journ. 15, p. 180. Rami validi, juxta folia spinis in ic. Rheedii conicis vel longe acuminatis frequentibus, in plantâ nostrâ et ic. Wightii conicis brevibus raris, quæ spinæ rami abortientes videntup. Folia $3 \frac{1}{2}-6$ poll. longa, $1 \frac{1}{2}-2 \frac{1}{2}$ poll. lata, pctiolo 2 -4 lin. longo; glabra, supra lucida, nervis lateralibus distantibus utrinque 3-4. Spicæ axillares, solitariæe, geminæ ternatæve, folio duplo triplove breviores. Bractea minuta, extus pubescens, lanceolata, sub quoque flore masc: Bracteolic nullæ. Alabastrum 'masc. lineam longum, bracteâ triplo longius, obovoideum. Tubus perigonii masc. turbinatus, fem. obconicus. Lobi glabri, excepto fascioulo jirlorum interno ad antheram tendente. Fructus cum pedicello 15 lin. longi. (v. s. masc. a Mus. par. comm.).

$\beta$. Bertii, foliis basi subcordatis, spicis masc. densifloris crassis, $b$ In peninsulâ Indise. S. Wallichianum Bertie in Wight ic. t. 241. Ex folio sequenti affine.

5. P. CEYLANICA, foliis ellipticis utrinque obtusis vel subacutis, rachi masculà laxiflord, floribus tetrameris. o In Insulâ Ceylan. Scleropyrum Wallichianum Thwaites 1 pl. exs. n. 2555 (non Arn.). Rami validi, teretes, non spinosi (sed in alterâ specie rami superiores similiter.nudi).Gemmæ ovoideo-acutæ, puberulæe. Folia 3-4 poll. longa, $1 \frac{1}{2}-2$ poll. lata, in petiolum 4 lin. longum basi abrupte angustata, coriacea, nervis ntrinque 4-5. Spica masc. (in specim. unico) bijollicaris, solitaria, floribus medium usque laxis, apice approximatis nec tamen jut in ic. Wiglit. densis. Bracteæ lanceolatæ, $\frac{1}{5}$ lin. longæ, pilosie. Flos masc. vix lineâ longior. obovoideus, 4-fidus, lobis extus glabriusculis. Fasciculi pilorum et antheræ precedentis. Stylus apjice 4-lobus, lobis (in fl. masc.) erectis acutis, nec reflexis obtusis ut in fl. fem, in Wight. ic. Filamenta prope antheram divisa, loculis distinctis approximatis. Flos fen. et fruct. ign. (v. s.)

\section{Species dubice vel indescriptor.}

6. SPHAROCARYA LEPRosa (Dalzull ined.). E Concan in Indiâ boreali. - Specimen fructif. vidi in herb. Mus. par. a cl. Hook.' f. et Thoms. communicaturi. Ex eo rami Jignosi, teretes; folia alterna, elliptica, petiolata, utrinque subacuta, petiolo 5-7 lin. longo, limbo 3-4-poll. pallido punctulato, nervis lateralibus ntrinque 2-6 suljpatentibus (nec ut in $\mathrm{P}$. eduli obliquis); fructus axillares vel extra axillares, singuli vol gemini, obovoidei, in stipitum brevem basi angustati, immaturi semipollicares, vestigiis loborum 5 et stylu gracili terminati. Flores prseterea mecum in litt. communicavit cl. Hook. f. unde genus níbi dubium videtur. Et enim flos (jam provectus) lineam solum longus, tubo glabro turbiriato, supra basin bracteam unicam rotundatam subciliatam prebet in congeneribus non videndam; lobi 5 ciliolati, rotundati, brevissimi, patentes, extus glabri (in aliis pilosi); vestigia quxdam petalorum? aut disci? intra lobos; stylus conicus; ovula 3-4 ex apice placente centralis pendentia, sed placenta recta, minus quam in congen. segregata. An Olacacea? (v. s.)

SPHAROCARYA vestita (Wall. litt. n, 7207). E, Sillet, Non descripta. 


\section{Species exclusa.}

Cl. Nuttall (gen. Am. 1 p. 157) suspicatur Celastrum macrocarpum Ruiz et Pav, ad genus Hamiltoniam (sive Pyrulariam) pertinere, sed chdracteres ex ic. et descr. diversissimi.

VI. HENSLOWIA Blume Mus. Lugd. bat. $1, p .243, t .43$ (non Walb.) - Visci sp. Blume olim, DC. prodr. v. 4. - Tupeiææ spjec. Korth., Blume fl. Jav. ic. (non text.). - Dendrotrophe Miq. $\pi$. Ind. bat. $1, p .779$.

Flores monoici. Perigonii pars libera 5- raro 6-fida, persistens; lobis triangularibus, inflexis, medio intus fasciculo pilorum donatis. Stamina lobis perigonii opposita, eorum basi inserta; flamenta subulata, minima ; antheræ introrsæ, dorso apice filamenti insertæ, loculis didymis rimâ transversali dehiscentiæ subdivisis. Discus epigynus concavus vel convexus, margine non liber. Ovarium inferum. Ovula $2-3$ ? ex apice placentæ centralis pendenlia. Stylus brevis. Stigma 3-5-lobum. Fructus ovoideus vel globosus, carnosus, putamine duro 5-6-lobo vel lobis superpositis 5-10-lobo. Semen unum. Embryo (ex Blume) centralis, rectus ; radiculâ superà, clava to-filiformi, obtusâ, cotyledonibus multolies longiore. - Fruticuli Asiæ meridionalis, præsertim archipelagi indici, ramis aliarum plantarum pậasitici (ultimâ sp. dubiâ terrestri), habitu et flore Visci, sed foliis alternis, nervis foliorum 3 vel ex divisione lateralium quinqtre, cymulis axillaribus solitariis vel in eâdem axillâ pluribus uni-vel plurifloris. - Ex habitu et statione ramis parasíticâ ad Loranthaceas accedit, nec non Schœpfiæ (supra p. 622) folia alterna propter, sed characteribus ordinis, antheris et nervatione foliorum differt. - Nomen Henslowia Bl. vetustius est (cum Henslowia Wall. sit Grypteronia Blume), e't nomen Dendrotrophe recens, ultimæ speciei, quæ non parasitica, contrarium.

\section{\$1. Parasitica, modo Visci; floribus in pedunculis brevibus sparsis unicisve.}

1. H. v в в El a т A (Blume! Mus. L. B. 1, p. 243), foliis obovatis basi cuneatis apice rotundatis ex bifurcatione nervorum lateralium 5-nerviis, pedunculis uni-vel sæpius apice umbellato-paucifloris, drupâ turbinato-globosâ. $\hbar$ In sylvis archipelagi indici, præsertim Javæ!, in ramis maxime Castaneæ Javanicæ parasitica. Thesium spathulatum Blume bijdr. p. 646. Viscum umbellatum Blıme ib. p. 666, DG.I jrodr. 4 p. 279. Tupeia umbellata Blume fl. Jav. Loranth. fasc: 40-42, t. 27 sino descr. Korth. ov. Tupeia p. 11 (Molkenb. pl. Jungh. 1, p. 117. Dendrotrophe umbellata Miq. fl. Ind. bat. 1, p. 779. Ramuli subtrigoni. Folia 1-2 $\frac{4}{2}$ poll. longa, $\frac{1}{3}-1 \frac{1}{2}$ poll. lata, in petiolum 2-3 lin. longum angustata, coriacea. Cymulæ axillares, petiolp subæequales. Flores viriduli, abortu monoici, ebracteati ex auct. (an bracteis bracteolisque minimis caducis?). Lobi perig. ovato-acuti, inflexi. Loculi antherarum rimâ fere transversali dehiscentes (Blume). Fructus magn. pisi minoris, ex Bl. (v. s. specim. quoad flores imperf.)

2. H. RETUSA (Blume Mus. L. B. 1, p. 243), foliis spathulatis apice rotundatis vel sape retusis; pedunculis 1-lloris sub flore bracteolatis, drupâ ellipseo-globosá putamine osseo tuberculato-rugoso. $\hbar$ In sylvis inferioribus ad montem Slamat Javæ supra arbores. H. umbellata var. $\beta$ Miq. l. c. (qui vero specinaitha authentica non ait vidisse). Folia 1-1 poll. longa, $\frac{1}{2}-\frac{3}{4}$ poll. lata.

3. H. PAUGIFLORA (Blume Mus. L. B. 1, p. 244), folis obovatis vel obovato-oblongis apice obtusis vel siepius rotundatis, pedunculis uni vel spicato-paucifloris sub flore ebracteolatis, drupà subglobosâ, putamine testaceo striato. $ち$ In arboribus montis Patuhæ Javæ. H. umbellata var. $\gamma$ Miq. 1. c. (qui specimina authent. non ait vidisse). Folia 1-2 poll. longa, $\div-1 \frac{1}{\zeta}$ poll. lata. Drupe majores quam in H. retusâ et putamine multo tenuiore extus striolato. 
4. H. VARIANs (Blume! Mus. L. B.1, p. 244, t. 43), foliis obovatis vel, obovato-oblongis basi acutis vel cuneatis apice obtusis vel sæepius, rotundatis ex bifurcatione nervorum lateralium 5-nerviis, pedunculis solitariis geminisve unifloris'sub flore bracteolatis, drupâ ellipsoideo-globosâ, putamine osseo rugoso-sulcato $ち$ In Borneo. Thesium spathulatum Korth. herb. (non Blume). Dendrotrophe varians Mlic. fl. Ind. bat. 1, p. 780. Folia 1-3 poll. longa, $\frac{3}{4}-\frac{1}{3}$ poll. lata, petiola ta. (v. s. in herb. Mus. par.)

ß. crassifolia (Blume ibid.), folîis crassioribus obsolete nervosis.

5. H. CaSSI A Folia (Blume Mus. L. B. 1, p. 244), foliis e basi cuneatâ anguste elliptícis vel elliptico-oblongis apice obtusis vel rotundatis, pedunculis uni vel spicatopaucifloris sub flore ebracteolatis, drupà ${ }^{2 . . . . . . .5 ~} 5$ In Borneo (Korthals). Dendrotrophe cassiæfolia Miq. fl. Ind. bat. 1, p. 780 Folia $2 \frac{1}{2}-6$ poll. longa, $1 \frac{1}{2}-2 \frac{1}{3}$ poll. lata, passim sub-5-nervia. H. varianti aflinis ex cl. Miquel.

6. H. LOBВIAN , foliis lale obovatis basi acutis apice rotundatis trinerviis subtus punctato-verrucosis pedunculis brevissimis 1 - 5 fasciculatis unifloris bracteis minimis florem usque imbricatis, flore femineo pedunculum subæquante. 5 In $\mathrm{Sin}$ gapore (Lobb I 334 in h. Boiss.). Rami teretes; ramuli subangulosi. Folia 1-1 $\frac{1}{2}$ poll.

- longa (incl. petiolo cuneato 3 -lin.), 9-15 lin. lata, coriacea, punctis minimis in sicco eminentibus, nervis lateralibus marginem versus passim ramosis. Pedunculi lineam longi. Bracteæ vix perspicuæ, ex cicatricibus potius videndæ. Flos femineus tubo nunc gracili nunc obovoideo, lævi, lineam longo, apice 5 lobo; lobis triangularibus, inflexis, $\frac{1}{2}$ lin. longis, medio pilis ad antheras tendentibus pilosis. Stigma 5-lóbum, lobis perigonii opposita, patentia. Ovarium ........ (v. s.)

07. H. REINWARDTIANA (Blume 1. c. p. 244), foliis breviter petiolatis e hasi acutà late subrotundato-obovatis apice rotundatis coriaceis 3-5-nerviis, floribus subsessilibus vel foliorum lapsu subracemosis 4-5-bracteolatis, drupâ elbngato-ovoideâ, putamine testaceo striato 5 In Borneo (Korth.), Sumạtrâ (fide Miq.) et Javâ (Reinw. Jungh.). Tupeia Reinwardtiana Bhume f. Jav. Loranth. t. 28, Korth. ov. Tupeia

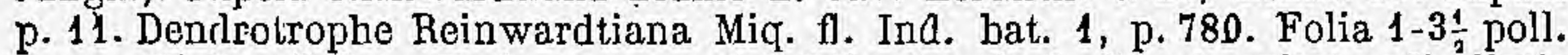
longa, 2:-3 poll. lata. Ex icone racemi 3-6 lin. longi, floribus breviter pedicellatis secus racemum sparsis, rarius in axillà folii solitariis; bracteæ basi pedicelli et jrope florem ovato-acutæ minimæ; perigonium cylindraceum, apice 4-5-lobum; ovarium tubum implens, plenum, intra lobos umbonatum, stylo minimo terminatum.

8. H. Spicata (Blume Mus. L. B. p. 244), foliis distincte petiolatis e basi acutå vel cuneatà ellipticis vel spathulatis apice acutis vel rotundato-obtusis 3-nerviis coriaceis, spicis axillaribus paucifloris, bracteis 1-floris, floribus basi contractà subpedicellatis subturbinatis glandulis resinosis conspersis. In Borneo (Korth.), archipelago indico (Blume). Dendrotrophe spicata Miq. fl. Ind. bat. 1, p. 780. Folia $\div 2$ poll. longa, 6-12 lin. lata.

9. H. PHILIPINENSIs, foliis obovatis e basi cuneatâ petiolatis apice rotundatis trinerviis coriaceis, pedunculis pluribus fasciculatís petiolo subæqualibus 3-4-floris, floribus brevissime pedicellatis subglobosis hexameris, bracteis -circa basim pedunculorum ovatis minimis, bracteolis sub flore fere nullis, drupâa ...... 5 In Philippinis (Cuming 12255 in h. Boiss.). Rami subteretes. Folia 12-15 lin. Jonga (incl. petiolo 3 lin.), 5-7 lin. lata. Fasciculi pedunculorum axillares, bracteis $\frac{1}{3}-\frac{1}{2}$ lin. et pedunculis $2-4$ lin. Iongis constantes. Flores $\div$ lati, apice præsertim̈ pedunculi inserti, in specimine masculi, basi turbinati, cæterum globosi, 6-partiti. Specimen sub eod. numero Cuming. cursorie vidi in h. Mus. par. el similem dixerim H. spicatæ Bl. cujus specimen authenticum ibi jacet. Attamen flore serius in h. Boiss. dissecto niumerus partium differt ut alia forsan. (v. s)

10. H. B UXIF oL i A (Blume I Mus. L. B. 1, p. 244), foliis parvulis e basi breviter açutâ ellipticis vel obovatis apice rotundatis obscure 3-nerviis, peduncalis brevissimis umi-vel ex apice paucifloris sub tlore bracteolatis, drupâ globosà, putamine os̀seo rugoso. 5 In archipelago indico (Bl.), in Borneo (Korth.) Dendrotrophe buxifolia Miq. fl. Ind. bat. 1, p. 781. Folia 3-8 lin. longa, 3-6 lin: lata. Flores fem. ex specimine authentico in herb. Mus. par. delineavi et descripsi, ubi alabastra ovoidea vix lineam longa semi-5-fida; lobi 5 triangulares inflexi medio intus stamigeri, 
ovarium umnino inforum, stylus brevissimus, stigma 3-lobum patens, placenta centralis filiformis. fructus junior globosus, putamen transverse sectum fero 6-loculare nempe 6-lobum medio vacuum et placentâ percursum, senen unum apice placenta. (v. s.)

11. H. oRANULATA (Hook. f. et Thoms. in herb. Mus. par.!), cortice verruculoso, foliis obovatis basi cuneatis apice obtusis obscure 7-nerviis, fasciculis florum (fem.) 1-2-floris, bracteis ovatis obtusis subciliatis crebre imbricatis. $b$ In Khasiâ Inditt or. alt. 5-6000 ped. Rami lignosi, verrucis minimis rugulosi. Folia 8-12 lin. longa, 4-6 lin. lata. Fructus juniores obovoidei, 3-4 lin. longi. Bracteæ lineamn Jonge latreque, pedunculo 2 lin. longo adpressæ. (v. s. in herb. eit. a cl. anct. comm.)

B. Sikkimensis, foliis latioribus 9-nerviis. 5 In Sikkim Indiæ alt. 5-7000 ped.

JI. granulata Hook. f. et Th. ibid. I An species diversa? (v. s. ibid.)

§ 2. Dubia species, terrestris; floribus masculis apice pedunculi brevis condensatis, 5 lateralibus, uno centrali, florem unicum simulantibus; ovulis et semine non satis cognitis.

12. H. HETERARTH (Hook. f.! in h. Mus. par.), cortice verruculoso, foliis obovatis cllipticisve basi cuneatis apice obtusis 3-5-nerviis, pedunculis in axillâ folii umbellatis sapius 5-3 nunc solitariis bracteis ovato-acutis minimis basi stipatis, floribus masculis apice perdunculi congestis subsessilibus, uno centrali ebracteato, 5 aliis exterioribus verticillatis bracteis totidem late ovatis imbricatis calycem mentientibus circumdatis, fructu apıce pedumculi solitario ovoideo intra bracteas minimas ovato-acutas sessili. F In Nepálià (Wall.!), in Indià bor. late diffusa (Bentll.). Viscum heteranthum Wall.! DG.! prodr. 4 p. 279. Yiscum platyphyllum Spreng. in DC. prodr. (V. latifolium Hamilt.)?. H. fratescens Benth. fl. Hongk. in llook. juurn. 1853 p. 194. Frutex non párasiticus (ex Champion a Benth. cit.). Specimen meum Wallicl. ramos præbet lenticellis elongatis rugosos, ramulos punc-

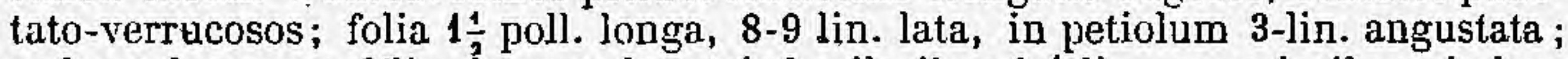
peduncułos masc. 3'lin. longos, lracteis basilaribus $1-1$ lin., superioribus vix longrioribus sublatioribus patentibus; flores obovoideos ${ }_{4}^{3}$ lin. longos; stylum nullum. In altero specimine Walliclii femineo fructus $1-1 \frac{1}{2}$ lin. longi, carnosuli, putamine duro 5-lobo; semine uno lobato vel seminibus quinque placentæe centrali filiformi lateraliter adfixis? intra lobos nidulantibus, embryone..... (v. s.)!

VII. OSYKIS Linn. gen.ed. 1, 4.743, Juss. gen. p. 75, Lam. ill. t. 802, Gartn. f. carp. 3 , p. 204, t. 216, Nees jun. gen. pl. A. germ. fasc. 3, t. 20, Decsne in Ann. sc. nat. sér. 2, v. 6. t. 6, Endl. gen. n. 2078 - Casia Cam. Lob. etc. Tourn. inst. p. 664, t. 488 et cor. p. 53. - Colpoon Berg. pl. Cap. p. 38.

Flores dioici, subhermaphroditi, vel hermaphroditi. Perigonium tubo in fl. masc. gracili, în aliís obconico; parte liberâ abbreviatà, caducâ, profunce 3 -4-lobâ; lobis ovato-acutis uno in fl. trimeris bracteæ opposito, omnibus in 0. tetrameris erga axim et bracteam lateralibus, pilis in medio pautcis vel nullis ab antherâ distirrctis evanescentibus. Stamina 3-4, filamento brevi. antherâ biloculari. Discus concavus, lobis rotundatis, partem superam et integram perigonii vestiens. Ovarium carnosum, inferum. Stylus brevis. Stigmata $3-\ell$, lobis perigonii alterna. Placenta in cavilate mininâ ovarii pinguis nidulans, recta, brevissima, apice ovula sæpius 3 , nunc 2 vel 4 gerens. Ditupa ovoideo-globosa, vestigiis loborum et disci coronata. Semen drupam implens, albumine copioso, embryone in superiori parte brevi paulo obliquo, radiculâ superâ. cotyledonibus lanceolato-terelibus semi-incurvis radiculâ lon rioribus. - Frutices vel arbores, circa mare Mediterraneum, in Abyssiniâ, Africt australi et India crescentes ; ramis angulatis; foliis alternis vel rarius oppositis, planis, mucronatis ; floribus masculis apice pedunculi congestis, femineis solitariis paucisve; bracleis et bracteolis caducis (præserlim 11. nasc.); punctis parum distinetis in textu foliorum tlorumque. 


\section{Sectio I. Euosiris. - Genus Osyris austorum.}

Flores dioici, masculis/vere unisexualibus, femíneis fere hermaphroditis. - Folia alterna.

1. 0. A LBA (Linn.sp. p. 1450), foliis lineari-lanceolatis vel lineari-obovatis acutis vel mucronatis, cymis axillaribus, masculis multifloris, femineis 1 -paucifloris, perigonio trilobo. J In regione maris Mediterranei, a Lusitaniâ (Welwitsch! n. 515) et Asturiís (Du Rieu! n. 235), ad Constantinopolim (Castagne! h. DC., Auch. Eloy! 2529 in h. Boiss.); Smyraam (h. Boiss.) et Syriam (Labill.! ib. Ehrenb. in h. reg. ber.l), ab Algeriâ littorali (Bové! 30, Mutel fl. fr. 3, p. 144) et Siciliâ (Guss. srrn. 2, p. 625) ad Galliam austro-occid. (Lesson fl. Rochef. p. 437), montem Bourget Sabaudiæ (Huguenin in herb. Boiss.!) et Istriam (h. DC.!). - Lam. ill. t. 802 (mala), Schkuhr Handb. t. 319, Decsne in Ann. sc. nat. sér. 2, v. 6, t. 6 (anal. solum), Nees jun. gen. pl. fl. germ. fasc. 3, ic. 20 , Reichb. ic. fl. germ. t. 548. Ram: virgati, striati. Ramuli angulosi. Folia erecta, sæpius 6-9 lin. longa, 1-2 lin. lata, sessilia. Racemi folio breviores. Bracteæ pleræque caducæ, quædam foliace:e fl. fem. persistentes. Tubus perig. in fl. masc. gracilis, lobi late ovati intus, fasciculo parvo pilorum donati ; in fem. tubus obconicus, lobi ovato-acuti, glabri. Drupn ovoideo-sphærica, 2-3 lin. longa. (f. s.)

2 O. Lanceo lat a (Hochst. ét Steud. in pl. exs. un. itin. 1832, herb. Boiss. I), foliis lanceolatis vel oblongo-multifloris, femineis uni rarius 3-floris, perigonio 3-4-partito. $亏$ In penins. ibericâ merid. frequens, usque ad Olisipponem (Welw.! h. Boiss.), circa Tanger (Salzm.!), Oran (Balansa ! 1852, n. 306, Bové !) et Alger (Schimp.l in Hochst. et Steud. exs., Munby fl. Alg.). Casia hispanica procerior myrtifolia Tourn. inst. p. 664. 0. quadripartita Decsne in Ann. sc. nat. sér. 2, v. 6, p. 65, t. 6, Boiss.! voy. bot. Esp. 2, p. 558. 0. quadrifida Salzm.! pl. exs. Hami superiores angulosostriati. Folia erecta, crebra, 6-12 lin. longa, 2-4 lin. lata, basí angustatâ vix petiolata, coriacea, subevenia. Cymæ folio breviores. Bracteæ lanceolatæ, caducæ. Flores fere 0 . albæ, pilis loborum longioribus, ex auctoribus sæpius tetrameri, ex herb. meo et Boiss. fere semper trimeri, unde'nomen vetustius ab Hoclast. et Steud. propositum melius. Drupa 3-4 lin. longa. (v. s.)

3. 0. A в YSSINICA (Hochst.l in pl. Schimp. sect. 1, n. 281), foliis elliptieis basi in petiolum brevem angustatis apice acutis vel acute mucronatis glaucis, cymis axillaribus, masculis multifloris, femineis uni- rarius 2-3-floris, perigonio profunde 3-fido. F In montosis siccis Ábyssiniæ frequens, vulgo Keraz (Schimp.1 sect. 1, planl. Adoens. 281 ; coll. anni 1854, in h. meo, n. 235 a, anni 1853, in $1_{1}$. Boiss., n. $235^{\mathrm{b}}$ ).-A. Rich. tent. fi. Abyss. 2, p. 236 . Fusanus alternifolia R. Br. in Salt voy. (ex sched. Hochst.). Rami erassi, superiores angulati. Folia 6-18 lin. longa (incl. petiolo lin. longo), 4-8 lin. Lata, rigida, margine sæpius jallidiora indurata, nervis lateralibus vix perspicuis. Cymæ axillares, variantes, folio breviores vel æquales, simplices vel divisæ. Flores masc. umbellulati, bracteis lanceolatis minimis caducis; feminei rariores, majores; onnes fere ut in 0 . lanceolatâ, cui valde affinis. Pili loborum pauci, in fl. fem. nulli. Drupa ellipsoidea 4 lin. Ionga. - Stamina fl. fem. non omnino sterilia; pollen in quibusdam vidi. (v. s.)

4. O. ARBOREA (Wall!! list, n. 4035), arborescens, folijs elliptico-lanceolatis vel elliptico-obovatis basi in petiolum brevem angustatis apice acutis vel mucronatis, cymis axillaribus et terminałibus folio subbrevioribus, masculis apice muultifloris, femineis unifloris. - $\supset$ In Nepaliâ (Wall.!), Kamaon (Hook.! h. ber.), ad Simlit (Hugel $i$ in h. vindob., n. 721) et Massuri (id.l n. 356). Rami angulosi. Folia nervis lateralibus plerumque distinctis, rámorum non floriferorum majora, ohovato-

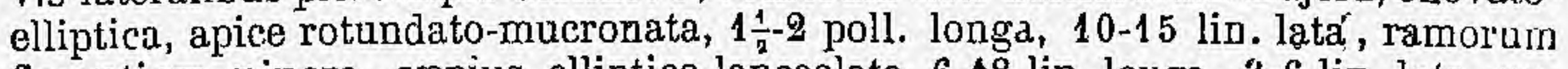
florentium minora, sæpius elliptico-lanceolata, 6-48 lin. louga, 3-6 lin. lata, petiolo in omnibus a limbo non distincto circiter lineam longo. Pedunculi mase. 2-4 lin. longi, apice flores 5-6 umbellulatos gerentes. Bracter caduce, lanceolater, $\frac{1}{3}$ lin. longæ. Tubus floris masc. gracilis $\frac{1}{2}$ lin. longus, lobi 3, ovati, medio íntus pilis raris donati. Flores fem. apice pedunculi solitarii, 2 lin. longi, obcon ci. Stigmata 3, Ovula congenerum. (v. s.)

5. O. W I G н ті NA (Wall.! list, n. 4036), frutescens, foliis elliptico-lanceolatis rel elliptico-obovatis basi in petiolum angustatis apice,acutis vel mucronatis, cymis 
axillaribus et terminalibus folio brevioribus, masculis apice multifloris, femineis 1-3-floris. 5 In montibus peninsulæ indicée frequens (Wight) el Ceylonâ (Thwaites! 53). - Wight ic. t. 1853. Fruticosa (Wight 1. c.), 3-4-pedalis (Leschen. $\mathrm{n} .150$ in herb. DC.). Rami angulati. Folia sæepius obovata vel obovato-elliptica, 6-18 lin. longa, 4-9 lin. lata, ir petiolum a limbo vix distinctum 1-2 lin. longum angustata, coriacea, sicca sæpe ruguloso-punctata, in specimine uno Wall. et ceylonensi lanceolata, in alio Wall. (h. berol.) ut in icone obovato-elliptica, in specim. Leschen. obovata vel elliptica. Flores ut in 0 . arboreâ, paulo majores? pilis omnino destituti (ex specim. Lesch.) aut pilis raris. Drupa obovoidea, 3 lin. longa. Staturâ in herbariis non cognitâ quædam specimina 0 . arborea a presenti non differunt. An species vere diversæ? An drupæ characterem præbendæ? (v. s.)

Sectio II. Colpoon. - Genus Colpoon Berg. pl. Cap, p. 38, t. I, f. 1.liusani sp. Juss. gen. p. 75, Br. prodr. fl. Nov. Holl. p. 355, Harv. gen. Cap. p. 298.

Flores hermaphroditi, nunc subunisexuales. - Folia opposita. - Spec. Capensis.

6. O. COMPRESSA, foliis ellipticis vel obovato-ellipticis basi in petiolum brevem angustatis apice acute mucronatis glaucis, pedunculis folio brevioribus, floribus obconicis tetrameris. F In Africa australi per totam fere coloniam capensem (Drège et Mey. 2 Pfl. Doc. p. 186). Golpoon compressum Berg. l. c. Fusauus compressus Murr. Lam. ill. t. 842, Drège ! pl. exs., Krauss ! pl. exs., Boivin! n. 547, Sond. Flora 1857, p. 365. Santalac., n. 42. Eckl. et Zeyh. 1505 fide Sond. 1. c. Fusanus K̇rebs ! exs. 290 in b. berol. Rami robusti. Ramuli angulosi, fóliis tecti. Folia 6-12 lin. longa, 3-8 lin. lata, in petiolum lineam longum angustata, coriacea, fere evenia. Bracteæ lineari-lanceolatæ 1-2 lin. longæ. Flos lineam longus. Stigmàta 4, lobis alterna. Ovula 4, sub stigmatibus sita. Drupa 4 lin. longa, obovoidea, vertice umbilicata. Omnes fere characteres, habitus, forma foliorum et imo puncta minima in textu aliarum sp. generis Osyridis, sed folia opposita. Flores ab Harvey moncecii polygami dicuntur, ex autopsiis iteratis hermaphroditi mihi videntur, sed character variabilis et parum distinctus in toto genere. Numerus partium floris et ovulorum in 0 . lanceolatà variat. (v. s.)

B. obbongifolia, foliis longioribus. F. Ad Winterhoek. Sideroxylon inerme Krauss I in h. yind. Folia 12-15 lin. longa, 4-6 lin. lata. (v. s.)

\section{Species exclusce.}

0. JA poNics Thunb. $=$ Helwingia ruscifolia.

0. PELт А т A Roxh.=Mappa? peltata Wight ic. t. 817 .

0. R H A N OIDES Seop.= Hippophae rhamnoides.

O. S C Hо B ER I Pall.= Nitraria Schoberi.

VIII. RHOIAGARPOS. - Santali sp. Spreng. in herb. germ. - Hamiltoniæ sp. Harv. gen. s.afr.pl.p. 298.

Flores hermaphroditi, pentameri (raro hexameri). Perigonium tubo gracili, obconico ; lobis ovato-acutis, persistentilus, medio intus fasciculo pilorum donatis. Stamina filamenı tenui, anıherâ biloculari, ovoideâ. Discus epigynus subconcavus, lobis obtusissimis brevibus. Stylus cylindrico-conicus. Stigmala 5 , brevia, lobis perigonii alterna. Ovarium inferum, carnosum. Placenta cylindrica. Ovula quinque, ex apice placentæ rectæ pendéntia. Drupá ovoidea, lobis perigonii paulo accretis coronala. Semen (ex Harv.) intra putamen osseum. - I'rutex vel arbuscula Capensis; ramis junioribus tetragonis; foliis oppositis planis ; cymis axillaribus et terminalibus, ramulis brevibus apice 1-5-floris, bracteis persistentibus. - Fructus rubri carnosi eduntur et a colonis Granatum sylvestre vocantur (ex Zeyh. in Harvey), unde nomen genericum : Pots. Punica Granalum et $x_{5}=\pi c \xi$ fruclus. - Genus affine Osyridi, præxcipue O. compressæ ubi folia opposila, sed numerus partium floris differt, et præterea bracteæ et lobi perigonii persistentes characteres parum variabiles in piæsenti ordine inveni. A Comandrâ (Hamiltoniả americanorüum) omñino differt. 
R. CAPEN Sis. $\bar{J}$ vel 5 . In Africâ australi. Santalım Capense Spreng. ex h. germ. Drège! in h. vindob. Hamiltonia Capensis Harv. l. c. Z̈eyh.! n. 3786 in h. Boiss., Ecklon! id. num. in h. vindob. sine nom., Drège 2376 a in h. vindob., Sond. in Florâ 1857, p. 365, Eekl, et Zeyh., n. \&2 (fide Sond.). Folia stricte opposita, ovata, basi-subsessilia cordata, apice acuta vel obtusiuscula, coriacea, margine sæpius recurva; 6-24 lin. longa, 5-10 lin. lata, nervis lateralibus distinetis reticulatis. Folia minima acuta in axillis stipulas interdum simulantia. Cymæ 4-8 lin. longæ, rammlis 1-2 lin. longis, apice flores paucos bracteas et bracteolas lanceolatas lineam longas persistentes gerentibus. Alabastra globosa, lineam longa, tubo pedicellari longiofa. Fructus immaturus granáto multo minor, lobis calycinis sul)erectis lineam longis. (v. s.)

\section{OSYRIDICARPOS. - Thesii spec. auctorum.}

Flores hermaphroditi. Perigonium basi ob́conicum ; parte liberâ elongatâ, cylindraceo-infundibuliformi, cadıcâ, apice 5-lobâ. Fasciculus pillorum e medio cujusque lobi ad antheram tendens. Stamina 5 , sub lobis in summâ parte tubi inserta, filamentis tenuibus antheras biloculares æquantibus. Discus non perspicuus. Ovarium inferum. Stylus elongatius, apice obtusus vel subtrilobus. Placenta filiformis, intra cavitatem ovalii contortuplicata, apice 3-4ovulata. Drupa ellipsoidea, ex vestigiis perigonii cupulâ 5 -angulari minimâ coronata. Semen... - Frutices vel suffrutices Africani, foliis alternis, planis, 3-nerviis, acutissimis ; pedunculis axillaribus, brevibus, sæ̇piús unifloris, nunc 4-floris; bracteâ bracteolisque sub flore minimis; floribus pro Ordine majusculis. - Folia et drupa Osyridis unde nomen ; ovarium vero, placenta et præsertim perigonium diversa. In hisce magis affinis Thesio, sed habitus, drupa enervis perigonio superne caduco, et forma floris differunt.

1. O. S Снитекі АN US, foliis anguste lanceolatis, floribus plerumque solitariis pedunculo triplo longioribus non gibbosis. 7 In Abyssiniæ monte Scholodâ ditionis Adoensis (Schimp.? pl. adoens. sect. 1, n. 404) et in ruderatis sepibusque regni Tigre (Dillon). Thesium Schimperianum Hochst.I pl. exs. Schimp. num. cit. A. Rich. tent. fl. Abyss. 2, p. 235. Rami virgati, striati. Ramuli juniores, bracter et pars inferior floris oculo armato pulverulento-velutiná. Folia approximata, sparsa, patentia, 9-15 lin. longa, 2-3 lin. lata, in petiolum vix lineâ longiorem angustata acutissima. Pedunculi petiolo equales, nunc apice 3 -flori. Flos $3-3 \frac{1}{2}$ lin. longus. Bractea ovato-oblonga, $\frac{1}{2}$ lin. longa, tubo floris adpressa ; bracteolæ dentiformes, multo minores. Lobi perigonii demum reflexi. Stigma obscure 3-lobum. Fructus ign. (v. s: in h. Boiss. et imp. vindob.)

2. O. NATALENSIs, foliis ovato-acutis, flóribus sæpius ternatis, gibbis callosis 5 externe supra basin perigonii. J In Africâ australi oc̀cid. prope Kachu d. Drège ! ex E. Mey. Zwei Pfl. geo. Docum. p. 142), Port Natal (Gueinzius! exs. 122). Thesium macrocarpum E. Mey. et Gueinzius, 1. c. Rami omnino jræcedeutis, cui sine dubjo proxima species. Partes juniores vix ac ne vix oculo armato pulverulentæ. Folia alterna, patentia, 8-16 lin.-longa, 3-6 lin. lata, in petiolum 1-2 lin. longum angustata, acutissima, tenuia. Pedunculi petiolum equantes, raro uniflori, bracteâ et bracteolis tunc abortivis denticulis solum perspiciendis, sæpius 3 -flori, flore (:entrali ebracteato, lateralibus bracted plerumque evolutâ foliaceâ 1-2 lin. lungâ petiolatâ acutissimâ bracteolisque duabus dentiformibus minimis dọnatis. Flos 3 lin. longus, formà omnino prioris, sessilis, parte inferầ perigonii obconicâ angustâ lineam. longâ, gibbis seu verrucis externis quinque abi pars supera perigonii ab inferd segregatur cum nervis centralibus loborum alternantibus. Stigma obtusum. Drupa 4 lin. longa, 3 lata. (v. s.)

X. COMANDRA Nutt.gen. 1,p. 107, Endl.gen.n. 2076, Asa Gray bot. n. st p. 397.-Thesii sp. olim. - Hamiltonial spec. Spreng. syst. 1, p.831. - Thesium sect. Thesiosyris Reichb. R. excurs. 1, p. 157 (non consp.). - Darby'a A. Gray in Amer. journ. sc., 1846, ser. $2, v .1, p .386$.

Flores hermaphröditi, ràro unisexuales. l'erigonii parś libera campanulata, persistens, 5-(rarius 4)-loba ; lobis basi transverse sulcatis et ángustatis. Fas- 
ciculus pilorum, e basi internâ lobi cujusve ad antheram tendens ubique adhærens, junior tamen et serius facile segregatus. Stamina lobis opposita ; filamento lineari ; antherâ ovoideâ, biloculari, loculis longitudinaliter dehiscentibus, basi discretis non vero divergentibns. Pollen (immersum) glọbosotrigonum. Discus epigynus, concavus, fundo perigonii adharens, ad sinus loborum liber et 5-lobus. Ovarium inferum, nec originem loborum perigonii attingens. Placenta filiformis, erecta, cavitate ovarii longior, ideo contortıplicata, apice ovula sæpius 3 geréns. Stylus filiformis. Stigura capitellatum. Nux ovoidea, perigonii parte liberâ coronata. Semen inversum. Embryo in apice albuminis carnosi rectus, radiculâ superâ. - Frutices vel sæpius fruticuli, ex Americả boreali et Europâ ; ramis annotinis floriferis folia squamiformia basi servantibus; foliis plerumque alternis, integris, penninerviis, sape punctatis et apice mucronato-glandulosis ; floribus ingratis, virescentibus, fere ut in Apocyno androsæmifolio, in ordine majusculis; nervis frtictus quinque sub centro loborum, vix distinctis, subramosis. - Genus Thesio nimis affine, non pilis pone antheras diversum, ut aiınt, sed longitudine filamentorum, loculis basi discretis, magnitudine loborum disci, inflorescentiâ umbellatâ et foliis amplioribus, id est characteribus vix genericis.

\section{Sectio 1. Eucomandra.}

Flores hermaphroditi. - Folia alterna.

\section{- Cyma terminales. Pili loborum aurei.}

1. C. U м веL L ат і (Nutt. gen. 1, p. 157), foliis elliptico-obovatis mucronulatis membranaceis, cymis multifloris, lobis perigonii erecto-patentibus. $\bar{J}$ In siccis et rupestribus Americæ septentr. a lacu Huron (Hook. fl. bor. am.) et Novà Angliâ! ad Georgiam (Beck bot. n. st. 1, p. 308), Alabamam (h. Boiss.!), Californiam (Hartw.l 1946), Rocky mountains (Hook. l. c.) et Oregon (id.).-Hook. fl. bor. am. 2, p. 139, t. 179. Reichb. ic. fl. germ. 11, p. 547, f.1163. Benth. pl. Hartw, p. 334. Thesium umbellatum Linn. sp. p, 302. Thesium corymbulosum Mich. fl. bor. am.1, p. 112. Hamiltonia umbellata Spr. syst. 1, p. 831. Caules subherbacei, 8-10-ped. (A. Gray bot. n. st.), e radice sublignosầ erecti, striali, glabri. Folia ima caulis vel ramorum annotinorum ovato-acuta, squamiformia, 9-15 lin. longa, 3-7 lin. lata, basi attenuata, apice subglanduloso-mucronata, glaberrima, venis reticulatis punctisque sparsis pellucidis. Corymbi terminales. Bractere sæpius 2 lin. longæ, $\frac{1}{2}-\frac{5}{4}$ lin. latæ. Pedicelli graciles, circiter lin. longi, a tubo vix distincti. Flos 2-3 lin. ]ongus. Lobi erecti, margine et præsertim apice crassiores ibique subpapillosi. Drupa globosa, exsucca, 2 lin. longa (v. s.).

2. C. ELEGANS (Reich. fil. ic. fl. germ. 11, t. 547, f. 1162), foliis oblongo-lanceolatis obtusis vel acutis basi longe angustatis, lobis perigonii erecto-patentibus. $\zeta$ In arenosis Banatus (Rochel, Heuffel!) et Moldavia inferioris (Guebhard!). Thesium elegans Rochel plant. Ban. 'p. 36, t. 4, f. 11, Reichb. hort. bot. n. 19, t. 19 (ead. icon. in fl. germ. iter.). Sectio Thesiosyris Reichb. fl. exc. germ. 1, p. 157 (non End1.). Radix repens, in arenà extensa, caules 6-14-pollicares adscendentes striatos sublignosos emittens. Folia ad basim ramorum floriferorum squameformin, ovato-rotundata, 1-2 lin. longa, media 6-12 lin. longa, 1-2 lin. lata, basi angusstata, apice obtusa, summa potius breviora acutiora, omnia (exceptis squamis inferioribus) erecta, sparse pellucidn-punctata, apice albido-glandulosa. Cymie 3-7-floræ, terminales. Rractere lineam longes, Jineari-subulatæ. Pedicelli graciles 1-2 lin. longi. Flos 2-3 lin. longus. Lobi divurgentes, non patentes, ovato-acuti, margine subincrassato priesertim et interne papilloso-puberuli. Antlieræ et pili ut in C. umbellatà. Disci lobi lati, subemarginati. Ovula seppius 3. Nux ovoideoglobosa, magn. jisi (v.s.).

3. C. PALLIDA, foliis lividis inferioribus elliptico-oblongis aculis supremis dineari-acumimatis, lobis perigonii erecto-patentibus. $\zeta$ Prope Clear Water, Oregon (Rev. Spalding ! sub nom. erraneo C. lividie Hook. in h. meo et Boiss.). Caules semipedales, sublignosi, striati, erecti, apice solum ramosi. Folia non pellucila, 
ima squamæformia, late ovata, 2 lin. longa; media 8-10 lin. longa, 2-3 lin. lata, mucronato-acuta, summa variabilia, pleraque 1-2 lin. solum lata et 5-7 lin. longa, quedam latiora vel angustiora breviora. Gymæ paucifloræ. Bracteæ linearilanceolatæ, 2 lin. longæ. Pedicelli graciles, lineam longi. Flos ut in C. umbellatâ, sed lobi magis papilloso-velutini præsertim ad marginem et intus. Differt a C. um. bellatà precipue foliis angustis elongatis ramorum non florentium. (v. s.)

$\beta$. angustifolia, foliis mediis et superioribus omnibus lineari-acutis. $\hbar$ In Novo Mexico (Wright! n. 1783 in h. Boiss.). Folia ima ut in specimine oregonensi. (v. s.)

** Cyma laterales. Pili loborum (an semper?) albi.

4. G. I I I D A (Richards. app. p. 9), sarmentosa, foliis alternis ellipticis flaccidis concoloribus, cymis lateralibus sub-3-floris, lobis perigonii patentibus. 5 A Terrà Novà et Labrador usque ad Mackenzie river versus $69^{\circ}$ lat. et Rocky mountains.-Hook. 11. bor. am. 2, p. 139, t. 179, f. B. Hamiltonia sarmentosa Spreng. syst. 1, p. 831. Sarmentum, ait Richardson, inter muscos repens radicem refert et caules alternatim edit; caules spithamai simplices, suffruticosi, erecti, inferne teretes, superno obsolete triquetri, basi squamis fuscis ellipticis acutiusculis muniti quæ sensim superne in folia mutantur; folia venosa, obtusa, nervo excurrente apiculata, flavoviridescentia, concolora, subsessilia ; umbella 2-3-flor:, foliis mixtæe, pedunculatæ ; calyx (tubus perig.) campanulatus, lobis virido-fuscis; stylus crassus ; nux globosa, calyce coronata, rubra, magnit. pisi sativi : variat foliis rugosis flavomaculatis reticulatisque. Ex icone Hook. folia alterna, 12-15-lin. longa, 5-6 lin. lata, nervis lateralibus distinctis; bracter minimæ lanceolate sub jedicellis.

\section{Sectio 11. Darbya. - Genus Darbya A. Gray, l. $c$.}

Flores dioici. Folia opposita - Cymse laterales ut in præcedentc. Pili loborum albi.

5. C. DARBYA, foliis plerumque oppositis ellipticis membranaceis subtus pallidioribus, cymis lateralibus sub-5-floris, lobis perigonii patenti-reflexis. $ち$ In Georgia prope Macon (Darby), Carolina sept. prope Lincolnton (Curtis) et in montibus Alabamre dictis Rocoons (herb. Boiss.!). Darbya umbellulata A. Gray 1. c. Rami teretes, lignosi, nigricantes. Ranuli annotini foliacei, breves, herbacei, subteretes, basi squamulis ovatis subacutis brunneis lineam longis donati. Folia fere omnia opposita, nunc alterna, 12-18 lin. longa, 5-8 lin. lata, tenuia, pallida, pellucida, vix punctulata, nervis lateralibus distinctis, basi in petiolum brevem angustata, apjice obtusa vel nervo excurrente apiculata. Cymse 3-5-flore, axillares, foliis duplo breviores, pedunculo gracili. Pedicelli 1-2 lin. longi, tubo perigonii continui. Bractere delapsa. Flores in specimine masculi, 5 et rarius 4 -meri. Tubus perigonii obconicus. Lobi ovato-acuti, patenti-reflexi, margine subpapillosi, medio intus pilis longis albis cum antherâ diu connexis donati. Antheræ congenerum. Stylus uullus. Ovarii rudimentum inferum, ubi placentam filiformem vidi. Folia et fl. omnino G. lividte ex icone Hook. Fructus ignoti. Descriptio A. Gray congruit. (v. s.)

X1. THESIUM Linn. gen. ed. 1, n. 173, Thunb. Thes. diss. 4•, Juss. gen. p. 75, Gartn. fr. 2, t. 86, Endl. gen. p. 326, Brongn. Ann. sc. nat. 1827, $t .43$ (de ovulis et semine), Decsne Ann. sc. nat. ser. 2, v. 13, p. 300, t. 11 (de ovulo), Irmisch in Flo $a 1843, p .523$, t. 7 (de germin.), Nees jun. gen. plant. h. Germ. fasc. 7 c. ic., Alph. DC. esp. nouv. du genre Thesium prés. à la Soc. phys. et hist. nat. Genève, le 28 mą 1856, br. 8॰. Genè̀''. 6 juin 1857 (1), Sond. enum. Santal. Afr. austr. in Flord 21 jun. et $1 /$ jul. 1857. Alchimille sp. Tourn. inst. p. 508. - Rhinostegia Turcz. in Rull. Soc. imp. Mosc. $1843, p$. 56 .

l'lores hermaphroditi. Perigonii pars libera nunc lypocraterimorpha, sæpius infundibuliformis vel campanulata, 5- raro 4 -loba, persistens vel (in sect. Psilothesium) tarde decidua ; sinı uno axim spectante, lobis medio plerumque fasciculo pilorum ad antheras tendente donatis (in $\$ 2$ sect. Friseæ

(1) Nomina mea spec. capensium in l1. reg. Berolinensi deposita mense mart. 1857 cum plantis Berolinum misi. 
medio glabris). Stamina e basi cujusque lobi vel paulo infra, filamento lineari, antherà oblongà biluculari, loculis longitudinaliter dehiscentibus. Discus epigynus plerumque indistinctus, nunc unargine brevi liber (sect. Discothesium). Ovarium inferum. Stylus stamina attingens vel multo brevior. Stigma obtusum vel capitatum, nunc ubscure 2 -3-lobum. Placenta filiformis, erecla, sæpitus cavitate ovarii longior et tunc sinuata vel contortuplicata, interdum (in spec. div. seclionum) brevis rectaque (1). Ovula 3, ex ápice placentæ pendentia. Nux ellipsoidea, caduca, perigonii parte liberâ sæpius coronata, nervis primariis sub lobis sitis et secus pedicellum decurrentibus, secundariis alternantibus totidem vel ex bifurcatione numero duplici, nervulisque transversis sæpe donala. Embryo in axi albuminis carnosi, radiculâ supeṛ̂́ cotyledonibus longiore. - Herbæ vel fruticuli, in temperatis veteris orbis et Africæ auștralis non rari, quidam (sect. Psilothesium) in Brasilia meridionali, hucusque in Americấ boreali et regionibus æquatorialibus ignoti; foliis alternis, plerumque angustis glabrisque, 1-3-nerviis, raro 5-nerviis, nervo centrali sub folio decurrente; floribus axillaribus solitariis, vel sæpius cymis 3-5floris, in axillâ folii sen bracleæ sessilibus aut (folio cum peduncúlo connato) pedunculos extra axillares terminantibus; floribus solitariis præter bracteam sæpius bibracteolatis, centralibus cymarum bracleâ cymæ tantum donatis, lateralibus tunc brabteà et bracteolis donatis; cymis prælerea laxis vel approximatis, unde inflorescentia paniculata vel spicæ, imo capitula; perigoniis albis, virescentibus, flividis aut raro purjurascentibus?

Sectiones valde naturales, non vero genera distincta, cum transitus ubique adsint el characteres non theoretice magni momenti. Sectiones enim Chrysothesium et Psilothesium Thesio alpino aliisque longitudine tubi aflines; Discothesium, pluribus sp. capensibus proxima ; lirisea pilis perigonii solum differt, Etheothesium habitu.

\section{Sectio t. Chrysothesidm Jaub. et Spach ill. pl. or. $t .10 \%$.}

Perigonium longe hypocraterimorphum, lobis 5 , ut vulgo in genere persistentibus. - Flores spicati, in axillâ bracteæ et bracteolarum solitarii.

\section{Pars adhorens tubi lanata et inde fructus lanuginosi (2). - Species annua.}

1. T. STE L E R OIDES (Jaub. et Spach, ill. pl. or. 2, t. 104*), antuum, caulibus erectis superne ramosis ramisque strictis angulato-striatis, foliis filiformibus subtriquetris erectis mucronatis, spicis virgatis elongatis apice densifloris, bracteâ flore multo breviore fructu sublongiore bracteolisque fructu subbrevioribus glabris lineari-subulatis, tubi perigonii parte adhærente lanatâ, parte liberâ lunge hypocraterimorphâ, laciniis tubo toto triplo brevioribus, nuce ellipsoideâ lanatâ perigonio marcescente terminatâ. $\bigcirc$ In Cappadocià ad Euphratem (Aucher-Éloy 2531 in h. Boiss.! Mus. par. et Webl). Planta subpedalis, glaberrima (exceptâ basi perigonij), habitu Stelleræ Passerinæ, @-5-caulis. Radix gracilis. Folia sparsa, carnosula, subcarinata, 10-15 lin. longa, $\frac{1}{-1} \frac{1}{3}$ lin. lata. Spicæ 1-4-pollic., basi lasæ. Bractea et bracteolæe 2 eujusve floris sessiles vel subsessiles, bracteâ 2-3 lin. longa, bracteolis $1 \frac{4}{2}$ lin. Flos totus 4-5 lin. longus, flavus (ex auct.), tubo supra ovarium gracili, 3 lin. longo, lobis lineari-lanceolatis margine inflexis non auriculatis, medio pilosis. Stylus tubum superans. Nux $1 \frac{1}{4}$ lin. longa, sub pilis costata. Placenta contortuplicata filiformis apice 2 (ex ic.), 3 - (ex obs. meâ) ovulata. (v. s.)

(1) Quando placenta recta in descript. specif. dixi; ubi níhil siruato-contortuplica . tam vidi.

(8) In ordine rarissimum ! 


\section{§ 2. Pars adhorens perigonii glabra. - Suffrutex.}

2. T. A UREUM (Jauh. et Sp. jll. pl. or. 3, t. 300\%), suffrutex cæespitäns glaher, rádice et caudice brevi lignosis, ramis erectis simplicibus angulosis, fotiis crebris margine papilloso-denticulatis, imis ovatis imbricatis, ceteris lanceolato vel linearisubulatfs, floribus ćapítato-spicatis, bracteâ folio simili flore vix bireviore aut equali bracteolis sublongiore vel duplo longiore, perigonii glabri par̂̀te liberà liypocratcrimor liâ, lobis ovato-lanceolatis tubo toto $4 \cdot$ bievioribus, fructu......... $\zeta$ In Cappadociâ (Aucher-Eloy I n. 2535, in h. Delessert fide num. ab auct. cit. in vol. 2 t. 104, nota). Radix valjda, a caudice vix distincta. Fami 2-4-pollic. Folia glaucescentia, crassiuscula, uninervia, ima minima, pleraque $3 \cdot 7 \mathrm{lin}$. longa, $\frac{1}{2} \operatorname{lin}$. lata. Spice ovoidea; 6-10 lin. longæe. Bractea et bracteulæ cujusve floris subsessiles, lanceolato-acuminatæe, subfalcatex; bracteâ 4-5 lin. longâ, bracteolis 2-3 lin. longis. Perigonium flavum sub anthesi 4 lin. 1 ngum, lobis 5 margine subinflexis non auriculatis. Stylus perig. aquans vel paulo superans. Placenta (ex ic.) filiformis, tortuosa, auice 2-ovulata. Fructus ign.

Sectio II. Euthesium Alph. DC. esp. nouv. Thes. p. 1. - Genus Thesium et pars spec. Capensium R. Brown prodr. N. Holl. p. 353. - Sect. Thesium et pars Thesiosyris Reich. consp. p. 80, Endl. gen. p. 326.

Perigonium breviter hypocraterimorphum vel sæpius campanulatum aut infundibulare, parte liberá 5-rarius 4 -fidà, persistente, marginibus loborum integris vel auriculato-dentatis, glabris vel papilloso-puberulis. - Herbæe vel rarius suffrutices, asiatici, europai capensesve, inflorescentià raro spicatâ, sæepius ramosâ, pedunculis nempe extraaxillaribus simplicibus aut dichotomis.

\$1. Bracteola prater bracteam nullo. - Pedunculi apice hinc bracteâ, illins cállo et in medio flore unico terminati. Inflorescentia fructifera foliis sterilibus producta. Lobi perigonii inflexi, sine auriculis. S'ylus longus. Plicenta basi recta, superne sinuatocontortuplicata. Nux longitudinaliter nec transverse nervosa.

\section{$1^{0}$ Lobi perigonii post anthesin erecti:}

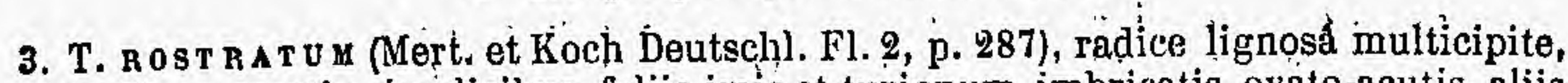
caulibus erectis simplicibus, foliis inis et turionum imbricatis ovato-acutis, aliis longe linearibus erectis, racemo simulici, pelunculis semierectis, bracteâ liñeari pedunculum subæquante fructu breviore vel sublongiore, lobis perigonii tubi parte libera infundibuliformi æqualibus demum erectis, fructu ellipsoideo subsessili succoso parte superả perigonji duplo fere breviore nervis 10 subramosis parum distinctis. $\not$ In jratis siccis et glarèsis, secus torrentes etc., Bavariæ , Tyroli $!$ et Helvetise orient. - Reichb. ic. 5, f. 650 , ic. fl. germ. 11, f. 1159, Fl. Gall. et Germ, exs. 336 bis! cent. 4, n. 36 ! Radix tortuosa. Caules 4-8 poll. alti, striáti. Folia ima 1-3 lin. longa, caulina 6-24 lin. longa, $\frac{1}{4}-\frac{1}{2}$ lin. lata, uninervia, pellucide punctata. Pedunculi 2-4-lin. Bractea 2-6 lin. longa, papilloś-serrulata. Flos sub anthesi 3 lin. longus. Lobi ovato-lanceolati, non diu patentes, tubo supra ovarium paulo constriclo. Fructus 2.4 liu. longus, drupâ lineam longẩ vix carnosâ. Th. àl. pino flore et fructu subsimile. - An hic referend. T. macranthum Presl. (nón Fenzl), ex Wolfner in Florâ 1856, p. 561, e Bohemiâ? Descriptio non differt, nísi char. internis florum ubi errores suspicor. (v. s.)

\section{2* Lobi perigonii post anthesin plus minus involuti.}

4. T. en a ate а т м (Hayne in Schrad. journ. 1800,1, p. 33, t. 7), radice gracili, caule unico vel caulibus paucis erectis simplicibus, foliis imis ovato-acutis vel oblongis raris, aliis anguste vel late linearibus 3 -nerviis obtusis, racemo simplici, pedunculis semierectis, bracteá lineari pedunculo fructuve longiore, lobiş perigonii parte liberâ tubi late campanulatâ subbrevioribus, fruclu exsucco ovoidểo pedicello pingui sublongiore lobis plus minus involutis $2^{\circ}$ triplove longiore nervis $\mathbf{5}$ primariis parvis aliis evanidis. \% In graminosis el sylvaticis Daniæ I Germaniæ bor, occid.!, Bohemia (Ekon. Fl. Bohm. 2, p. 37), Lithuania, Volhyniæ, Podoliæ, 
usque ad Pensa et ultsa Ural ad Slatoust. - Mert. et Koch Deutschl. FJ. 2, p. 288, Reichb. ic. bot. 5, f. 649 , ic. fl. germ. 11, f. 1158 , Dietr. fl. boruss. t. 416 , Ledeb. fl. Ross. 3, p 543. T. pratense Fl. Dan. t. 1705, non Ehr. T. monophyllum Gilib. exerc. 2, p. 428 ? T. comosum Roth, catal. 2, p. 29. Radix annua ex habitu, perennis ex auct. Caùlis interdum pauciramosus, basi flexuosus, 5-8-poll., striatus. Folia ima 2-4 lin. longa, alia 6-18 lin. longa, $\frac{1}{2}-2 \frac{1}{2}$ lin. lata. Pedunculi 3-5-lin. Bractea 3-8-lin., integerrima. Flos cum pelicello2 2 lin. longus. Pars libera perig. campanulata. Fructus totus $2-2 \frac{1}{2}$ lin. (v. s.)

\section{§ 2. Bracteolce 2, proter bracteam.}

\section{- Stylus stamina plerumque attingens aut superans (1). Stigma capitatum.}

\section{A. Nux longitudinaliter solum nervosa, nervulis nempe tertiariis aut nullis aut obliquis nec transversis.}

10 Pars supera et integra perigonii cylindracea, fructu angustior, non indurata. Lobi in fructu erecti apice inflexi non tamen involuti.

5? T. MULTIC AULE (Ledeb.I fl. Alt. 1, p. $276 \%$, radice lignosâ validâ multicauli, caulibus erectis a medio ramosis, caule ramisque racemo simplici elongato terminatis, foliis imis ovatis aliis lineari-oblongis vel linearibus enerviis, pedunculis erecto-patentibus unilloris, bracteâ lineari fructum iequante vel superante, bracteolis linearibus fructu brevioribus, parte superiore perigonii profunde 5 -fidà , lobis angustis a medio ad basin auriculatis, nuce longe ellipsoideà perigonio deflorato duplo triplove majore nervis primariis 5 secundariisque ramosis basi exceptà parum distinctis. Z In Sibiriâ Altaicâ (Ledeb ! in h. vind.) et orient. (Fisch.!) - Ledeb. ic. t. 237, fl. Ross. 3, p. 541, Bong. et Mey.!, suppl. fl. Alt., n. 245, non herb. Szowitz, nec herb. Hook. (conf. ad n. 31, 21 et 22). Radix albida, inferne ramosa. Caules 1-3-pedales, striato-sulcati, glabri. Folia ima squamiformia, 1.2 lin. longa ; cxtera 9-18 lin. longa, lineam lata, glabra, apice cartilagineo albido acutiusculo. Flores $1 \frac{1}{3}$ lin. longi. Bractea et bracteolæ longitudine variabiles, glaberrimæ, integræe, lineari-acutæ. Bracteolæ 2-3 lin. longæ; bractea duplo triplove major. Stylus stam. superans. Nux cum perig. vix inflexo 3 lin. longa, brevissime stipitata, minime carnosa sed tenuis et facile rupta. Species sequentibus non vere affinis, ex flore potius Th. Szowitzii proxima sed fructu non transversim reticulato. (v. s.)

$\beta$, Karelinii, fructu cylindrico-ellipsoideo nervis 5 primariis validioribus. $\%$ In montosis apricis deserti Soongoro-Kirghisici. T. multicaule Kar. et Kir.! n. 437.

6. T. SAXAт ILE (Turcz.l pl. exs. olim), radice lignosá, caulibus erectis angulosis basi simplicibus a medio ramoso-paniculatis, foliis linearibus uninerviis, ramis inferioribus axillaribus folio subæqualibus semipatentibus multifloris, superioribus extra-axillaribus 1 -floris, bracteâ fructu subbreviore vel sublongiore bracteolisque duplo triplove brevioribus linearibus acutis, perigonii lobis parte integrât duplo longioribus medio auriculatis, nuce ovoideâ stipite suo $3^{\circ}-^{\circ} \mathrm{ve}$ longiore perigonio supero sublongiore nervis 10 validis oblique sparsim ramosis. $\not{F}$ In Sibiriæ subalpinis ad fluvium Oka (Turcz.! anno 1836) et in glareosis Dahuriæ (iid. fl. baik.). T. refractum (pro parte) Ledeb. fl. Ross. 3, p. 539. T. pratense Turcz. f). Baik., p. 80 , in Bull. soc. Mosc. 1851, non Ehrh. Species valde distincta, habitu et inflorescentiâ $T$. chinensis, sed fructu diversissima. Caules 9-poll. e radice seu caudice lignoso. Folia 9-15 lin. longa, lineum lata, erecta, obtusa vel subacuta. Pediculli uniflori secus super. Partem ramorum et cauliss $\lrcorner$ mipatentes, $1-1 \frac{1}{2}$ lin. longi, ut vulgo ex tra-axillares. Bractea 1-2 lin. longa, bracteolæque $\frac{1}{2}-1 \frac{1}{2}$ lin. long:r vix ac ne vix oculo armato serrulatx. Lobi auriculis rotundis inflexis a margint bene distinctis. Placenta apice sinuata, in ovario carnoso nidulans. Nux cum perigonio $1 \frac{1}{-}-2$ lin. longa, nervis eminentibus æqualibus. (v. s.)

(1) In Th. Wightiano et brachyphyllo stylus abbreviatus sed stigma ut in aliis capitatum. 
7. T. ALPINUM (Linn. sp. p. 301), radice descendente gracili, caulibus diffusis simplicibus vel parce ramosis, racemis elongatis, pedunculis unifloris abbreviatis Iructiferis subsecundis non patentibus, foliis linearibus uninerviis, bracteâ fructu inulto longiore bracteolisque fructu subbrevioribus lineari-lanceolatis, parte liberå perigonii elongatâ 4 -fidà lobis ovatis utrinque sub medio auriculà ubtusâ auctis, nuce ellipsoideả stipite suo vix duplo longiore perigonio basi constricto æquali vel subbreviore nervis primariis 5 et secundariis 10 ramosis subæqualibus. $\psi$ In montosis et alpinis Europæ, a Wexio Sueciæ (Wahl.! fl. p. 1051) et Carpathis (Zawadski fl. Gal. p. 29) usque ad Alpes, imo montes Arverniæ (DC.1), Pyrenæos (DC.I), A penninum Pistoriensem (Mich. in Bertol. fl. it. 2, p. 745), et Picenum (0rsini in h. Boiss.l), Bosniam (Sendtn.! 242 in h. Boiss.).-Jacq. fl. Austr. 5, t. 426. Svensk bot. t. 611, Sturm ic. v. 3 (opt.), Labram ic. schw. Pll, Reichb. ic. fl. Germ. 11, t. 1151 (mala, præcipue flores), non Desf. nec Florum paris. nec rossic. 'l'. linophyllum Linn. Suec. n. 211, fide Wahl. (non L. sp.). T. Weickerianum Opiz in Bohm. fl. 2, p. 41 ? Caules 6-12-poll., striati. Folia turionum ovata vel ovato lanceolata, 1-3 lin. longa ; caulina 6-15 lin. longa, raro lineam lata. Racemi apice spiciformes. Pedunculi infer. raro 5 lín. longi, sæpius 2-1 lin. Bractea 4-12 lin. longa; bracteolæ 1-2 lin. longæ, oculo armato ut bractea tenuiter subserratie. Flos 2 lin. longus, limbo plerumque 4-fido, rarissime (in ead. plantâ) 5-fido. Ovarium pulpâ farctum. Placenta subsinuata, non contortuplicata, junior recta in pulpá omnino nidulans. Drupa proprie dicta lineam longa, perigonio basi anguste cylindraceo terminata.-T. alpinum Pall. et Georgi, e Rossiâ et Sibiriâ, cel. Ledeb. ignotum, est veris. alia sp. - T. alpinum Patrin in h. Juss.!, sine flore vel fructu est diversissima planta. (v. s. et v.)

$\beta$, tenuifolium, foliis anguste linearibus, racemis non secundis, tubo perigonii supra ovarium paulo longiore, nuce ideo perigonio superiore duplo breviore. Z In Styriæ glareosis et sterililibus. T tenuifolium Sauter! in h. Boiss, et J. Müller, id. in Koch syn. ed. 2, p. 718. Reichb. ic. fl. germ. 11, f. 1156. Frustra diversitatem vere specificam quæesivi. In $T$. alpino racemi non senıer secundi, folia interdum angustissima, perigonium fructus plerumque nucem æquans nunc tamen $1 \frac{1}{2}$ lin. longum nuce lineam longà. Icon Reichenbachii bona quoad habitum, sed lobi perigonii pessime figurati, et enim in presenti ut in vero $T$. alpino numerum quatuor et auriculas in medio cujusque lateris observavi, Nervi fructus similes. (v. s.)

$\gamma$, carnosum, foliis anguste linearibus subcarnosis supra convexis subtus subcanaliculatis, fructu perigonio tubuloso apice involuto duplo breviore. $\mathscr{F}$ In Bohemiæ collibus prope Dobrisch. T. carnosum Wolfoer in Florâ 1856, p. 562. Planta flavo-virens, ramulis non secundis, quod in Th. alpino non rarum. An a var. $\beta$. diversum?

8. T. PRATENSE (Ehrh. herb. n. 12), radice descendente, caulibus pluribus erectis vel adscendentibus basi sæpius simplicibus a medio paniculato-racemosis, pedunculis sæpius unifloris raro 2-3-floris patentibus, foliis lineari-lanceolatis unillerviis, bracteâ fructu subbreviore vel sublongiore bracteolisque fructu brevioriJus lineari-lanceolatis, parte liberà perigonii abbrevialâ profunde 5-fidâ, lobis ovato-oblongis sub medio utrinque auriculâ obtusissimâ marginatis, nuce ellipsơideâ stipite suo vix duplo longiore perigonio æquali vel subbreviore nervis primariis 5 et secundariis 10 ramosis subæqualibus validis. $\mathcal{F}$ In pratis præcipue montanis Europe temperatæ, in regione Caucasi circa castellum Bambori (si cel. I.edeb. fl. Ross. 3, p. 542, non erravit, sed milì valde dulium) et Sibiriâ orient. (wx specim. h. Vent. in h. Deless. a Patrih coll., mihi dubio quoad origin.). Bractea, bracteolæ foliaque juniora oculo armato tenuiter subserrata. Medium inteT. alpinum et divaricatum. A priore differt: radice sæepe validiore, turionibus ver ramis sterilibus per florationem in basi plantæe rarioribus, inflorescentià panicul latâ, præsertim ramis patentibus non secundis, floribus pentameris, parte liberà jerigonii erga lobos subbreviore sublatiore lobis minus auriculatis, placentà magis torsà, nervis fructus validioribus. Formæ sequentes distinguendæ.

a, grandiforun, caulibus erectis, pedunculis inferioribus sæpius trifurcatis 3-floris, flore fructuque elongatis majoribus. $\%$ Circa Salzburg. T. pratense Kunze in 1. Boiss.! Caulis pedales, non graciles, angulati. Folia $1-1 \frac{1}{2}$ poll. longa $\frac{3}{4}-1$ lin. 
lata. Poduneuli patentes vel imo retroflexi. Flores 3 lin., fructus cum stipite et perigonio 4 lin. longi. Nux proprie dicta $1 \frac{1}{4}$ lin. longa. Forma videtur e loco alpino pingui. (v. s. in h. Boiss.)

$\beta$, vulgare, caulibus erectis vel adscendentihus gracilibus plerumque a medio paniculato-diffusis. $\not{F}$ In Bohemiâ (Mertens et Koclı), Saxoniâ (Reichb. fl. p. 109), frequentior in Germaniả merid.!, Lotharingiẩ Godrou fl., Jurasso gallico (FI. Gall. et Germ. exs. 926 !), Helvetiả ! Delphinatu (Mut. fl. Dauph. ed. 2, p. 546), Arverniâ (Lecor et Lam. cat. p. 324) et in Asturiis (Durieu! exs. n. 234). T. pratense Ehr. (fide sjec. ejusd. loci a Wallr. comm.), Reichb. ic. bot. f. 647, ic. fl. germ. 11, f. 1157 (lobis perig. in 2 fig. non satis auriculatis), Mert. et Koch Deutschl. fl. 2, p. 284* excl. synl. angl., Godron fl. Lorr. 2, p. $265^{*}$, Nees gen fl. Germ. fasc. 7; t. 1, non Fl. Dan. T. linophyllum DC.I fl. fr. parlim. T. decumbens (Gmel. $\mathbb{A}$. Bad. (fide Mert. et Koch). T. brevicolle Presl fl. Cech. (fide ejusd.). Caules 8-15 poll. alti, strjati, parum angitosi basi scepius denudati. Folia $1-1 \frac{1}{8}$ poll. longa, $\frac{3}{4}-1$ lin. lata. Bractea 2-9 lin. longa. Bracteolie $1 \frac{1}{2}-2$ lin. longe. Flos vulgo 2 lin. longus. Fructus cum stipite et perigonio 2-3 lin., nux proprie dicta lineam longa. (v. s. et v.)

y, Pyrenaicum, caulibus adscendentibus vel decumbentibus? gracilibus, racemis simplicibus, pedunculis bracteis brarteolisque puberulis. $\mathcal{F}$ In Pyrenæis ad Llaureati, Madres, elc. T. Pyrenaicum Pourret! in Men!. Acad. Toul. 1788. Pili albị, breves, in margine et Iervis frequentiores. (v. $s$. in h. Deless.)

$\delta$, contractum, caulibus humilibus decumbentibus vel adscendentibus, racemis contractis. 2 In Pyrenieis ad Port de Venasque (DC.I anno 1807) in monte Brezons prope Genevam (DC.!) et in A'pibus austriacis prope Gastein (h. reg. berol.1). Forma verisimiliter e locis rupestribus elatis. Radix cylindracea vel tortuosa superne caules ramusve plurimos graciles 3-6 poll. longos flexuosos varie rliffusos emitt:ns. Folia tenuia, acuminata, sicca nigrescentia, 4-9 lin. longa. Racemi densifluri, pedunculís inferioribus 1-2 lin. longis. Flores in specim pyren. minures quam vulgaris. (v. s.)

20 Pars supera et integra perigonii late campanulata vel infundibuliformis, fructu an gustior, non indurata. Lobi per malurationem plus minus involuti.

9. T. DIVARICATUM, radice descendente ramosâ multicauli, foliis linearibus acutis uni vel subtrinerviis, ramulorum angulis foliis superioribus bracteis bracteolisque margine scabro-denticulatis, bracteolis fructu brevioribus, lobis perigonii basi utrinque auriculâ undılato-dentatâ donatis, nuce ellipsoideâ pedicello suo $2^{\circ}-4^{\circ}$ longiore nervis primariis basi crassioribus secundariis 10 ramosis vix minoribus, nervulis tertiariis obliquis minoribus. Ұ In Europâ mediâ et circa mare Mediterraneum. Ex specim. innumeris herb. mei, Boiss., reg. berol. et imp. vindob. sequentes formæ ab unà ad alteras transeunt, quie saltem omnes angulos superiores bracteasque scabro-ciliatas, auriculas perigonii et nervos nucis similes præbent. Linnæus plantam cultam initio cognovit (ex Smith Engl. bot. t. 247), T. ramoso veris. adscribendam; postea diversas adjunxit præsenti speciei ut patet ex synonimis, præsertim e cit. Sauvagesii plantæ monspessulanæ quæ nulla nisi T. divaricatum Jan esse debuit. Nux lineam longa, umbone convexo vel cylindro nunc hasi constricto varie terminata. (v. s.)

$\alpha$, divaricatum, caulibus erectis vel adscendentibus, paniculæ pyramidalis ramis demum patentibus, bracteâ fructu breviore aut vix longiore, nucè pedicello suo dipplo longiore perigonio involuto umbonato triplo majore. $\mathscr{\psi}$ In Hispaniâ frequens (h. Boiss.l, etc.), Algeriâ (Boiss.!), Galliầ metid.l usque ad Lugdunum (h. DG. et Boiss.!), imo circa Parisios in sylvâ St-Germain (Kunth! în h. reg. ber.) ubi tamen var. $\delta$ frequentior, Italiâ ! Dalmatiả (Vis.I Mull.! Noé I 563 in h. Boiss. ), Carniâ (h. Boiss.!), Thraciâ (ib.! et Griseb.), Bosnià (Sendtn.l 244), Asià Minore (Thirkel in h. Boiss. Auch. Eloy in h. Deless.! n. 2530, Balansa 1854, n. 379), Tauriâ (Pareyss! h. Boiss.) Thesium floribus sparsis Sauvag. Monsp. 48. T. linophyllum Desf. fl. Atl. 1, p. 205 (ex(l. syn.), DC.I fl. fr. 3, p. 352 (excl. syn. et quibusd. specim. herb.). T. divaricatum Jan in Mert. et Koch Deutschl. Fl. 2, p. 285, Koch syn. ed. 2, p. 717, Reichb. ic. bot. 5. t. 456, ic. fl. germ. 11, t. 543, f. 1155, Bourgeau, pl. exs. Hisp. 1851 , a. 1475. T. linophyllum var. Vis. stirp. Dalm. p. $\$ 9$ (postea T. divaricatum 
ejusd. fl. Dalm. 1, p. 222). T. humifusum Boiss.l voy. Esp. 2, p. 55 (excl. syn.) Caules 9-12 poll. alti. (v. s.)

$\beta$, humifusum (Duby ! bot. gall. p. 408), caulibus prostratis elongatis șimplicibus vel ramosis, ramulis floriferis æqualibus brevibus demum patentibus, bracted fructu subbreviore, nuce pedicello suo triplo quaḋruplove perigonio supero basi contracto duplo longiore. 24 In sabulosis maritimis prope Sables-d'Olonne Galliæ occid. (DC.!). T. humifusum (forsan var. linophylli) DC.! fl. fr. suppl. p. 366. Radix 3-4-pollicaris, descendens, basi ramosa, superne multiceps. Caules pedales et ultra, basi graciles, ubique foliosi. Folia 3-8 lin. Ionga, lineam lata, carnostula, stbenervia, acutiuscula. Ramuli floriferi secus majorem partem caulis 2-3 lin. longi, apice 1-flori 3-bracteati. Bractea et bracteolm ovato-lanceolatæ scabro-ciliatæ. Bracteæ 1-2 lin., bracteolæ lin. Jongæ. Lobi perig. passim subscabri. Nuces perigonii parte liberâ basi constrictâ apịce cy̛lindraceâ subapertâ terminatæ, an omnino maturie? (v. s.)

$\gamma$, gracile, cáulibus gracilibus adscendentibus elongatis simplicibus vel ramosis, ramulis floriferis æequalibus demum patentibus, bracteâ lineari-lanceolatâ fructu śquali vel longiore, nuce pedicello duplo longiore perigonio supero cylindraceo vix aut duplo majore. $\mathcal{F}$ In sylvâ Fontaịnebleau dictá ipse legi. T. alpinum Kunth! in h. ber. (ex eod. loco nat.). Caules 6-10 poll. longi. Folia linearia, 6-9 lin. longa, vix lin. lata. Inflorescentia elongata fere var. $\beta$, sed bractete et bracteolæ angustiores, bractea $2-4$ lin. longa, perigonium ut in $\beta$ longiusculum nec tamen supra nucem contractum. Specimina qusedain seq. a præsenti vix differunt. (v. s.)

$\delta$, Gallicum, caulibus adscendentibus vel diffusis sæepius ramosis, inflorescentia anguste pyramidali, ramiulis demum subpatentibus, bracteâ fructu subæequali raro longiore, nuce pedicello suo perigonioque supra umbonato duplo triplove longiore. $భ$ In Lotharingia (Godrun I Schultz!), circa Bisontium (h. Boiss.l), Parisios ! forsan în Angliâ (conf. ad var. ser.), in Austriâ (ex ic. Reichb. 1153 ad præs, var. potius quam ad ramosum ut videtur refer.). T. Gallicum \$chultz lin lit. 1833 ex ejusd. sched. T. humifusum Schultz! 0. Gall. exs. n. 51 et 51 bis, Coss. et Germ. fl. Par. 2 p. 481, Godr. fl. Lorr. 2 p. 266, Reichb. ic. fl. Germ. 11 t. 542 f. 1153. Neilr. fl. Wien. suypl. p. 130. T. Hussenoti Hussen. Chard. nanc. p. 114, Voigt in Florà 1838 p. 645. Pars inferior plantæe interdum ut superior scabriuscula. (v. s.)

s, Anglicum, humile, caulibus adscendentibus vel diffusis foliisque gracilibus, ramulis demum patentibus, bracteâ fructu subæquali, nuce ut in var. præced. 26 In Angliâ merid. prope Croydon (Dikson! $\mathrm{n} .5$ in h. Willd.), Londimum (Mackreight! Soc. bot. Edinb. in h. Boiss.). T. humifusum Bab. man. Brit. f. ed. 2 p. 277. T. linophyllum Dikson! l. c., vix tamen Engl. bot. t. 247, quæ icon male delin. plantam majorem, potius var. $\&$ exhibet. Ex specim. h. Boiss. et Willd. caules 3-4 polliç., folia 3-4 lin. longa. (v. s.)

10. T. P A R N A S I, radice tortuosâ sursum multicipite stoloniforâ, caulibus gracilibus adscendentibus simplicibus, ramulis floriferis subpatentibus unifloris, foliis anguste linearibus vix uninerviis cum bracteis brateolisque glaberrimis margine lævibus, bracteâ fructu longiore, bracteolis eo brevioribus, lobis perigonii integris, sịnubus margine incrassato excisis, nuce ellipsoideâ stipite suo vel perigonio superne involuto $3^{\circ}-4^{\circ}$ longiore nervis primariis 5 et secundariis 10 ramosis subæqualibus tertiariis obliquís raris minoribus. 24 In editioribus Parnassi (Guicciardi in Heldr.! fl. gr. exs. n. 2911. Radix 2-4 poll. longa, inter lapides flexa, ramosa, stolonibus tenuibus flexuosis. Caules 3-4-poll. Folia ima pauca, 2-3 lin. longa, obtusa; media 4-7 lin. longa, $\frac{1}{2}$ lin. lata, acuta. Bractexe 2-3 lin. longæ, bracteolæ 1-2 lin., omnes angustæe acuminatæ. Inflorescentia, flos et fructus T. ramosi; nisi guod pedunculi minus erecti, bractéæ et bractẹolæ læves, lobi perig. nunquam auriculati bași ad sinus margine in oculum minimum ovalem excisi. (v. s. in h. Boiss.)

11. T. R A M osum (Hayne in Schrad. journ. 1800 p. 30 t. 7, excl. loc. nat. Palatin. ex Koch.), radice descendente superne multicipițe nunc stoloniferâ, caulibus erectis adscendentibusve a medio ramosis, paniculæ elongatæ ramis ramulisque unifloribus semierectis, foliis linearibus uni-vel subtrinervịis, superiọilibus bracteis brạcteolisque dentticulato-scabrịs, bracteâ fructư longiore agut multo longiore

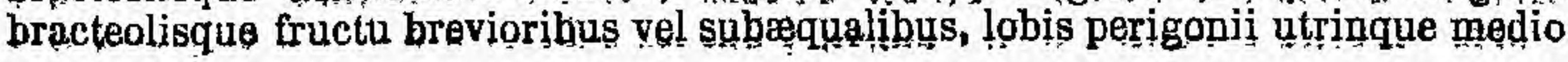


breviter dentatis vel integris nuce ellipsoideâ stipite suo vel perigonio superne involuto triplo quadruplove longiore nervis 5 primariis et 10 secundariis ramosis subacqualibus tertiariis obliquis raris minimis. そ In Europâ orient. et Asiâ uccid. ab Austrià inf. (Welw.! Czagl! in h. Buiss-), Hungariâ 1 pascuis alpinis Dalmatixe (Vis. fl.) et Macedonise (Griseb. spic. et Friederichst.) ad Syriam (Elirenb. in li. reg. ber.1), Ali-Dagh prope Cæsaream Capadociæe (Balansa 315 !), Caucasum merid. (Wilmsen!), desertum salsum Soongoro-Kirghis. (Kar. et Kir. 438!) Sibiriæequæ (Pall. in h. Vind.!) loc. non delinitis, in Tauriâ (Parreyss.! 473 in h. Vind.) et prope Volgam (h. Boiss.!) non rarum.- Reichb. ic. bot. 5, f. 646, ic. fl. Germ. 11, f. 1154, Koch syn. ed. 2, p. 71 Wilms.! exs. Ledeb. fl. Ross. 3, p. 540 (iro parte?). T. Palatinum Roth per error. ex Koch. T. decumbens Doll en. p. 113, fide Neilr. Nachtr. fl. Wien. p. 130. T. linophyllum Pall.! in h. Vind. Ehrenb.! in h. ber. T. pefractum Kar. et Kir. n. 438, non Mey. Radix sæpe gracilis, modo plantæe annuæ. Caules 6-9-poll., anguloso-striati. Folia ima ovata vel oblonga, minima; alia 6-12 lin. longa, $\frac{3}{4}-1$ lin. lata. Bractea 3-6 lin. longa. Bracteolæ $1 \frac{1}{2}-3-$ liu. Lobi perigonii in speciminibus austriacis simillimis nunc dentati, nunc edentati, dentibus auriculis T. divaricati ubi adsunt multo minoribus. Nux lineam longa, stipite fere nullo aut semilin. Flos angustior quam $\mathrm{T}$. divaricati, cui valde affin. sp. (v. s.)

$\beta$, asperulum, caulibus ramis bracteisque ad apgulos vel margires præsertim et alibi scabro-asperulis. $\not{F}$ In Persià ad Tassarend (Buhse! in h. Boiss.). T. asperulum $h$. Boiss. Subcinereum. Specimina Wilsem. var. $\alpha$ ad præs. var. accedunt. (v.s.)

12. T. BYzantinUM, radice lignosâ validà, caulibus ramosis, ramis axillaribus racemo simplici laxo prusertim constantibus, foliis longe linearibus 1-nerviis, bracteâ fructu sublongiore ant subbreviore bracteolisque brevioribus linearibus, lobis perigonii medio utrinque auriculatis, nuce globoso-ellipticâ stipite suo vel perigonio valde involuto duplo triplove longiore nervis primariis et secundariis æqualibus ramosis validis tertiariis oblique junctis. \& Circa Constantinopolim in collibus (Olivier.!). Radix ex specim. h. Mus. par. cylindracea 3 lin. sujerne lata, longit. ignotâ. Caules 6-8 poll. longi, adscendentes, ramis patentibus nunc secundis. Pedunculi uniflori, 4-5 lin. longi, subpatentes. Folia 9-15 lin. longa, $\frac{1}{2}-1$ lin. lata, acutiuscula. Bractea 1-4 lin. longa, bracteolæqne $1-1 \div$ lin. Iongse lineari-lanceolatæ ad lentem vix margine scabriusculæ. Auriculæ loborum undulatie. Fructus totus $1 \frac{1}{2}$ lin. longus, non caducus (in affin. caducus), stipite plus minus distincto, . lobis perigonii omnino involutis, nuce erebre striatâ demum fissù. Affine T. ramoso et T. divaricato (v. s. in h. meo et berol. a Mus. par. comm. et ill Mus. par.)

13. T. I T a LICUM, radice descendente gracili superne multicipite, caulibus adscendentibus humilibus subramosis, foliis linearibus mediis et præsertim superioribus - margine scabriusculis, paniculâ elongatâ, ramulis uniflorulis semipatentibıs, bracteâ fructu multo longiore bracteolisque fructu longioribus linearibus margrine asperulis, lobis perigonii non auriculatis, nuce ellipsoideà sessili fortiter striatà. $\mathcal{F}$ ex Guss. et Ten., $\odot$ ex specim. meo et ic. Guss. In montibus Lunensibus (Bertol.), $\Lambda$ prutii (Guss.) et Sardiniae (Moris!). T. intermedium Bertol. olim amœn. it. p. 345, Guss. pl. rar. p. 98 t. 20 f. 1, Moris I stirp. Sard. elench. 3 p. 11, Ten. ก. Nap. 3 p. 213 , non Schrad. T. linophyllum Bertol. (serius) fl. it. 2 p. 739. Caules 2-3 poll. Folia ima pauca ovato-acuta lineam longa, media 3-6 lin. longa subenervia. Ramuli floriferi 1-3 lin. longi, apice bracteâ longissimâ (3-9-lin.) $\frac{1}{2}$ lin. latâ, bracteolis $2-3$ lin. longis acutis cum flore terminati. Flox 5-lobus. Nux mihi ign. Species non satis cognita. (v. s.)

14. T. Diffusum (Andrz. ex Besser.l pl. exs.), radice stoloniferâ perenni multicauli, caulibus diffusis ramosis striatis, foliis linearibus 1 -nerviis, ramulis floriferis brevibus unifloris, bracteâ lineari fructu duplo longiore vel sublongiore, bracteolis fructu æqualibus, perigonii lobis non auriculatis, nuce ovoideâ pedicello suo duplo triplove longiore nervis 10 validis subæqualibus nervulisque tertiariis obliquis reticulatâ. $\mathcal{\nvdash}$ In Podolià anstrali. T. ramosum Bess.l en. pl. Volh. (sine descr.), non alior. Radix gracilis, oblique ramosa el stolonifera ut in T. intermedio. Caules 4-8-jollicares. Pars superior plantæ oculo armato secus angulos et margines tenuiter papillosa. Ramuli floriferi secus caulem vel ramos alterni, 1-3 lin. longi, ut vulgo basi nudi. Folia $4-9$ lin. longa, $\frac{1}{2}$ lin. lata. Bractea 3-6 lin. longa, -ut folia 


\section{THESIOM. SANTALACE E (AUCTOR ALPH. DC.).}

angusta acuta. Bracteolæ 2 .lin. longæ, lineares, acutæ. Flos $1 \frac{1}{2}$ lin. longus. Stylus stam. non superans. Nux lineam longa, perigonio iuvoluto minimo. - Ex nervis tertiariis nuculæe crobris distinctis nune transversis ut et obliquis accedil ad species seq. subdivisionis (n. 30 et seq.), sed habitu et lobis involutis præsentibus magis affinis. (v.s. in h. meo et h. Gay.)

15. T. H MALENSE (Royle, ill. p. 322 ubi solum nomen, Edgew. Trans. linn. soc. 20, p. 88), glaucum, glabrum, caulibus procumbentibus ramulosis, foliis linearibus 1 -nerviis crassiusculis, bracteâ elongatâ bracteolis duplo triplove longiore, nuce..... lobis perigonii ad basin involutis coronatả. - In apricis glareosis Himalayæ occid. ad Choupal (Royle)-et Garhwal (Edgew.). Pedicelli (pedunculi ?) longiusculi, 1-flori. Perigonii limbus ultra medium 5-partitus, lobis acutiusculis, supra stam. barbellatis, apice subcucullatis. Stylus longiusculus. Ovula 2. Fructis induratus. Facic T. intermedii. - Hæc omnia e descr. Edgew. cum pluribus sp. europæis aut sibiricis conveniunt, sed nervi fructus non describuntur aliaque ignorantur. Confer ad T. pachyrhizum (n. 22) forsan diversissimum sed ejusd. regionis.

16. T. INTERMEDIUM (Schrad. spicil. fl. germ. p. 27, non Bertol.), radice stoloniferâ, caulibus erectis adscendentibusve superne paniculatis, paniculâ pyramidali, ramulis divergentibus vel patentibus uni-rarius 2-3-lluris, foliis lineari-lanceolatis linearibusve acutis trinerviis, bracted fructu sublongiore bracteolisque eo brevioribus lanceolatis, lobis perigonii sub medio utrinque auriculati $\div$, nuce ovoideooblongâ pedicello duplo longiore, nervis 5 primariis parvis secundariis 10 vix perspicuis. $\%$ In pratis montanis et inter virgulta Germaniæ centr. et merid. et in Helvetiâ occid. prope Genevam (Müller !). - Koch syn. ed. 2, v. 2, p. 716, FI. Gall. et Germ. exs. cent. 2, n. 50! T. linophyllum Poll. Palat. 1, p. 238 (fide Koch), Vis. fl. Dalm. 1, p. 222 (fide syn.). T. linophyllum var. intermedium Wallr.! in h. DC. Caules $6-10$ poll. longi. Folia sæpius anguste linearia. Drupa lin. longa. Planta T. montano minor, stolonifera, foliis angustioribus, nuce angustiore longius pedicellatà minus nervosâ. Quid T. intermedium e Rossiâ, Sibiriâ et Gaucaso, in Ledeb. 11. Ross. 3, p. 540 ? (v. s.)

$\beta$, fulvipes, pedicello demum succoso drupam squante cum infer. parte drupœ colorato. In Germaniâ et Rumeliâ (Noë! h. Boiss.). - Koch l. c. T. fulvipes Griesselich in Florà, 22, p. 17.

17. T. M о т т и M (Ehr. herb. exs. n. 2), radice descendente ramosâ superne mul licauli, caulibus erectis a medio paniculatis, panicula pyramidalis ramulis patentibus obliquisve simplicibus unifloris vel dichotomis trifloris, foliis lanceolatis vel lineari-lanceolatis longe acuminatis 3-nerviis, bracteâ fructu sæepe breviore b́racteolisque semper brevioribus lanceolatis, lobis perigonii utrinque a basi ad medium auriculatis, bracteolis fructu brevioribus, nuce late ovoideà pedicello multo majore nervis primariis 5 basi validis superne mediocribus secundariis 5 minoribus tertiariis obliquis minimis. $\mathcal{F}$ In montosis asperis Germaniæ orient. a Saxonià et Bohemia (h. vind.!) ad montes Vogesos (Godr. fl. Lorr. 2, p. $265^{*}$ ), limites Helvetie (Koch! Wallr.! Döll! Rhein. fl.), Rhıetiam (h. Boiss.!), Tyrolum (Hausm.! fl. p. 755), Austriam inf. (Neilr. fl. suppl. p. 130), Transylvaniam (h. ber !)., in olympo Thessaliæ (Heldr.! h. Boiss.), Piceno (Orsini ! ib.), collo Tende (Boiss. I). Koch! syn. ed. 2, p. 716, Fl. Gall. et Germ. exs. 4, n. 35 ! Reichb. ic. bot. 5, t. 452. ic. fl. Germ. 11, t. 546, f. 1161. T. linophyllum Hayne in Schrad. journ. 1799, t. (i (ubi solum anal.) fide Koch, var. $\beta$ Bert. fl. it. 2, p. 740 excl. syn. div. T. Bavarum Schrank 1 . Bav. n. 420. Stolones rulli. hadix sæpe valida. Caules $1-1 \frac{1}{2}$ ped recti.

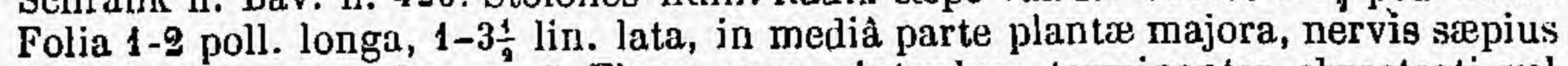
3 distinctis raro et obscure 5 . Flores ramos interdum terminantes ebracteati vel unibracteati, alii ramulos laterales bracteâ lanceolatà fructu breviore vel longiore bracteolisque brevioribus donati. Drupa vix lin. longior. Ubi radices et nuces desunt sp. dubia. - Germinatio ab Irmisch in Florâ 1843, p. 523, t. 7, descripta. (v. s.)

18. T. Refractum (G. A. Mey.! in Bull: acad. Petersb. 7, p. 340, non Kar. et Kir.), radice descendente multicauli, caulibus erectis vel obliquis superne ramoso-paniculatis, ramulis extremis toriferis subpatentibus, foliis linearibus subtrinerviis, bracteis bracteolisque lineari-lanceolatis scabro-ciliatis, bracteolis fructu brevioribus, lobis perigonii non auriculatis, nuce ellipsoideo-oblongâ pedicello sublongiore perigonio supero involuto duplo longiore, nervis 5 primariis parum distinctis 
secundarinis 10 ramoșis minoribus. 4 In Sibiriâ Altaicâ (Ledeb.), deserto SoongoroKirghisico (Bong. et Mey.), Baikalensi (Ledeb.) et Davuriâ (id.)-- Bong. et Mey. suppl. fl. Alt. n. 144*, t. 13, Ledeb. fl. Ross. 3, p. 539 (excl.syn. T. saxatile). T.ramosum Ledeb. fl. Alt. excl. syn. (fide ipsius Ledeb.), Bunge en. Alt. p. 14, non Hayne. T. linophyllum Pall. it. 2, p. 458 (fide Ledeb.). Radix fibrosa. Caules 6-18 poll., læ-

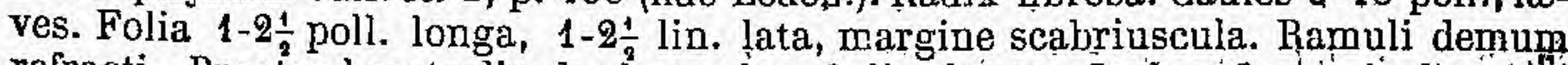
refracti. Bractea bracteolis duplo major, 3 lin. longa. Stylus flore' vix breviớr. Nux $1 \frac{1}{2}$ lin. longa. (v. s..

19. T. L ONG I P L I U (Turcz.1 cat. Baik. n. 999, fl. Baik. 2 , p. 78), radice plerumque multicauli, caulibus erectis superne paniculatis ramulis paniculæ subpatentibus, foliis linearibus 1-nerviis vel subenerviis, bracteâ fructu plus minus longiơro bracteolisque to subæqualibus vel brevioribus linearibus scabro-ciliatis, lobis perigonii medio utrinque auriculatis, stylo perigonium æquante, nuce ovoidéoellipticâ pedicello duplo longiore nervis 5 primariis validis secundariis 5 subramosis minoribus. $\mathcal{Y}$ Iṇ Sibiriẩ prope Irkurtzk, trans Baịlsal, in Dahuriâ et Mongoliâ. - Ledeb. A. Ross. 3, p. 541. T. linophyllon Patrin ! in h. Deless. Turczan ! cum signe dubit. anno 1834 in h. DC. T. Rytschowii Fisch.l in h. Deless. DC. et Mus. par. Variat ab 8 poll, ad 2 ped. altitudinis. Folia $1-3$ poll. longa, sæpius lineam, raro 2 lị̂n. lata, enervia vel nervo centrali distinctó, aliis vix in sicco videndis. Bractere et bracteolæ graciles. In eâdem plantâ bracteø. per fructific. nunc 3 nunc 6 lin. longæe. Flores $1 \frac{1}{9}$ lin. longi, tubo obconico-cylindrico, limbo campanulato 5-fido. Stylus quam in Th. montano vel intermedio multo longior. Drupa exsucca vix lineâ longior, périgonio deflorato triplo major, nervis 5 majoribus aliisque lateralibus in siceu distinctis. (v. s.)

$\beta$, Vlassovianum, flore mịnore. T. Vlașsovịanum Fișch.! mșs. Iṇ Dahuriâ. (v. s.)

20. T. BAs N IN I A U M (Turcz. in Bu]]. Mosc. 1852, n. 4, p. 470), erectum uni-aut multiçule, radice fusiformi, folïjs linearibus utrinque attenuatis uninerviis, bracteâ fructu oeties bracteolis 4* longioribus, nuce subgloboso-ellipticâ perigonio déflorato duplo longiore. $\mathcal{Y}$ In Sibiriâ baiksalensi (Basnin) et Mongoliâ chineasi (Kuznętsow). A T. longifolio facile dignoscitur bractearum longitudine. - Nihil addit cl. auctor. Ledebour (fl. Rnss. 3, p. 543) plantam non cognovit. An var. T. longifolii quam Fischer sub nom. T. Vlassoviani comm. ubi bractea interdum 8 lin. obtinet?

21. T. A l a та y I cu M (Kar. et Kir.! pl. exs. n. 1936), radice repente, caulibus erectis subsimplicibus, foliis oblongo-linearibus vix 1 -3-nerviis, pedunculis erecto-patentibus, bracteâ flore longiore bracteolisque flore brevioribus linearibus marginge papillosis, lobis perigonil auriculatis, nuce turbinatâ (ex Kar. et Kir.). $\mathcal{G}$ In Sibirịæ Altaica desertis et alpinis.-Ledeb. f. Ross. 3, p. 541. Caules 6-8 poll. alti, sulitarii ex Ledeb. versimilius plures radice repente longiusculâ. Folia inua obovạtọ-ọlọnga

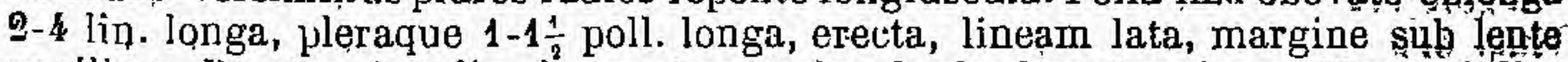
papillosa. Bractea 3-5 lin. longa, bracteolæe duplo fere breviores. Flores 2 lin. longi, infundibuliformes. Stylus lobis subbrevior. Placenta apice contortuplicata. Nux (ex Kar. et Kir. en. pl. Soong.) perigonio deflorato $4^{\circ}$ longiore. An satis a Th. repente div.? Specimina ejusd. sp. aut affinis ex Himalayâ bor. occid. attulerunt cl. Hook. f. et Th., qua ad herb. reg. ber. et par. sub nomine Thesii multicaulis (cum T. pachyrhizo nostro confusa) miserunt. A presenti differunt solum bracteolis floro sublongioribus, sed fructus ign. et ideo planta dubia (v. s. comm. ab ill. soc. Mosg.).

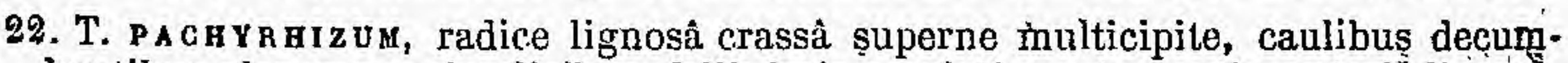
bentibus plerumque simplicibus, foliis imis rosulatis ovato-acutis, cæeteris linearîbus enerviis mucronatis, racemo elongato laxo, pedunculis unifloris semipatentîbus, bracteâ bracteisque lineari-lanceolatis margine tenuissime papilloso-scabris, bracteâ fructum superante, bracteolis eo brevioribus, lobis perigonii margine nuọn auriculatis, stylo stamina paulo superante, nuce ellipsoideâ brevissime pedicellatâta perigonii limbo involuto duplo longiore nervis primariis 5 basi validis secundarilis basi exceptâ subæqualibus ramosis. $\mathcal{Z}$ In Himalayâ bor. occid. T. multicaule Hook et Thoms. in h. reg. ber.! (excl. spet:im. duobus latifoliis), non Ledeb., nec herh. Szowitz. Radix in specimine obs. 3-5 lin. lata, obliqua, cylindracea, longit. ign. Turiones plures e folis squamiformibus 1-2 lin. longis imbricatis. Caules $\mathbf{3}=9$ poll. longi, verisim. e rupibts pendentes aut varie adscendentes, striați, lavés. Folia cqulina 6-12 lip. longa, $\frac{4}{2}-1$ lin. lata, inferiora obtusiusecula, sup. acuta, gla- 
bra. Pedunculi gradatim decreseentes 3-1 lin. longi, apice 3-bracteati. Bractea foliis similis, 9-3 lin. longa, bracteolæe $3-1 \frac{1}{2}$ lin. longæ. Flos $1 \frac{1}{2}$ lin. longus. Perigonium sub-5-fidtum, lobis obtusis apice cucullatis intus præter pilorum fasciculum sparsim sub lente papilloso-velutinis. Fructus cum perig. 2 lin. longus, nervis non validis. Confer. ad Th. Alatavicum et T. Himalense. (v. s.)

23. T. EXUL, glabrum, radice..., caulibus superne ramosis angulosis, foliis paucis anguste cylindraceis acutis, paniculse ramis suberectis, pedunculis simplicibus vel semel aut bis dichotomis, bracteâ sub ramulo inflorescentił aut sub flore bracteolisque lanceolatis aculis integris flore brevioribus fructu multolies minoribus, lobiș perigonii sụb medio utrinque 1-2-dentatis, nuce ellipsoideâ subsessili nervis primariis 5 et secundariis 5 basi exceptâ æqualibus ramosis $ち$ ? In Africâ australi Capensi. T. spinosum Portenschlag. (non L.). Caulis vel ramus? pedalis, basi sublignosıs. Folia 4-12 lin. longa, $\frac{1}{1}-\frac{1}{1}$ lin. lata, basi superne paulo canaliculata et dorso carinata cæterum teretia. Perlunculi secus ramos semipatentes, nunc simplices 3-4 lin. lungi, sæepius divisi 5-8 lin. longi. Bracteæ et bracteolæe plano-concavæ, dorso carinatæ, margine integerrime ; bractese minus acute $\frac{1}{2}-1$ lin. longen; brac teolke vix breviores angustiores acutiores. Flos $1 \div$ lin. longus, formâ omnino ut in T. divaricato, lobis minus dentatis. Stylus stam. superans, apice capitatus. Nux $1 \frac{1}{2}$ lin. longa. lubis perigonii valde involutis, nervis distinctis fere ut in T. divaricato, sed stipite fere nullo. Facie magis quam ulla species capensis Thesiis europæis similis et quasi exul ab Eurojâ, unde nomen. (v. s. in h. vindob.)

24. T. SPINUI,OSUM ramis gracilibus apice angulosis, foliis lineari-subulatis rigidis semipatentibus, fluribus secus ramos sparsis breviter pedunculatis solitariis, bracteâ a jice pexlunculi en lungiore lanceolato-subulatâ flore duplo triplove breviore, bracteolis lanceolato-subulatis bracteâ subbrevioribus rigidis, purte liberâ perigonii profunde 5 -fidâ, lobis sub medio marginibus undulatis brevibus inflexis subauriculatis, stylo autherarum apjices attingente, nuce... - $\hbar$ In Africà Capensi (Drege! 8175 , a, in 1 . vind. et Deless.'. Folia inf. non virli, superiora ramulorum $1-1 \frac{1}{2}$ lin. longa, arumine ut bractearum el bracteolarum albido spinuloso. Pedunculi extraaxillares $\frac{1}{2}$ lin. longi. Bractea et bracteolse e basi pingui subulato-spinosæ. Flos breviter pedicellatus, $\div$ lin. lungus, $\frac{1}{2}$ lin. latus, basi obconicus, lobis ovato-triangularihus margine vix auriculatis. Stigna capilatum. Placenta ut vulgo in genere contortuplicata. Species inter T. exulem et Th. spinosum media. (v. s.)

25. T. W I G т IA N M (Wall. list n. 4037), radice multicipite, caulibus suffrutescentibus diffusis decumbentibus brevibus ramosis, foliis lineari-lanceolatis acutis glabriusculis, floribus proje ajjicem ramorum solitariis binisve, bracteâ lineari-lanceơlatà subulatâ nuce vix longiore, bracteolis bractıâ vix breviuribus, placentå rectâ, nuce ovoideá sessili nervis 10 nervulisque tertiariis rarum distinctis obli-

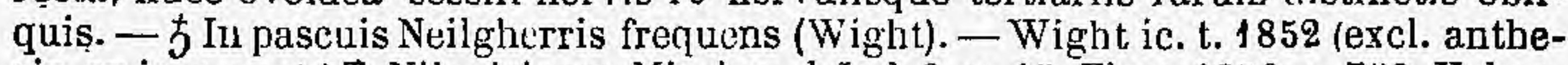
ris, ex ipso auct.) T. Nilagiricum Miq.! anal. Ind.3, p. 15, Flora 1853, p. 768, Hohen. pl. Ind. or. Nilag. n. 973. Suffrutex humilis, vegetatione Thymi Serp. lli. Çaules 2-4 poll. longi, foliosi, angulosi. Folia ima 1-2 lin., media et sup. 3-4 lin. longa, margine oculo armato subglanduloso-denticulata integrave, sæpe apice alba. Bracteæe 3 lin. longæ. Perigonium supra 5 -fidum, lobis margine inflexis papilloso-pilosis (minus tamen quam in icone Wightii). Stylus parte liberâ perigonii multo brevior. Stigma capitatum crassum. Placenla cylindrica, recta, apice 3 -ovulata, ovulís $\theta$ funiculo pendentibus. Nux $1 \frac{3}{4}$ lin. longa, lobis approximatis $4^{\circ}$ longior. (v. s.)

$\beta$, radicans, caulibus abbreviatis, foliis subbrevioribus pallidioribus. $\mathcal{F}$ In pratis montanis Abyssiniee. T. radicans Hohen:! in pl. Schimp. sect. 1 n. 168, sect. 2, n. 1130, A. Rich. tent. fl. A byss. 2, p. 235. Ex autopsiâ flores T. Wightiano simillimi. Diversitas plante verisimiliter ex loco natali sicciore aut altiore. (v. s.)

26. T. ВRA СН Х Н YLLUM (Boiss.! diagn. ser. 1 n. 5 , p. 48), pallide virescens, radice ramosâ perenni multicipite, caulibus abbreviatis prostralis simplicibus, foliis oblongo-ellipticis obtusis vel acutis, bractels lineari-oblongis folio longioribus acutis, bracteolis linearibus łracteâ triplo brevioribus acutis, lobis perigonii non auriculatis, nuce ellipsoideâ breviter pedicellatâ 10-nerviâ nervulisque tertiariis oblique anastomosantibus. 2 In herbidis sterilibus regionis alpinæ Tmoli (Boiss.I), Tech-Daeh (Calwert ! 605 et Huet du Yav.! in h. Boiss.), montis Argæi (Balansa! 316 in h. Boiss.) et Taụri (Balansa!). Radices fibrosæ, collo interdum valido. Caules 
2-4 poll. longi, basi sxpius nudi graciles albidi, supra foliosi angulati. Folia ima 1-2 lin. longa, media 3 lin., superiora (bractese) 5-6 lin. longa. Flores spicati, vix ‘um bracteis pedunculati. Bractese et bracteolæe margine glabræ, undulato-subiıtegrar. Perigonium j-fidum, lobis margine glabriusculis. Stylus perigonio multo brevior. Stigma capitatum crassum. Placenta sinuoso-torta,3-ovulata. Nux lineam longa. (v. s.)

$3^{\circ}$ Pars supera et integra perigonii in fructu lata, indurata, cum nuce ellipsem furmans. Lobi in fructu erecti aut involuti.

27. T. LI в AN о T с с M (Ehrenb. in herb. reg. berol.1), radice validâ superne multicipite, caulibus floriferis sterilibusque abbreviatis cæespitantibus simplicibus, foliis turionum acicularibus, caulium linearibus acutis uninerviis, floribus spicatis, singulo bracteâ fructu longiore bracteolisque brevioribus lineari-lanceolatis scabrosubserratis stipato, perigonii lobis medio aurieulatis, nuce cum parte liberâ perigonii ellipsoideâ sessili lobis valde involutis multo longiore nervis primarijs 5 parvis aliis nullis. $\mathscr{H}$ In Syriæ monte Makmel prope nives mense julio (Ehrenb.). hadix simplex vel ramosa, sæpe tortuosa, caulibus plerumque longior. Caules diffuse crespitosi, 1-3 poll. longi, angulosi. Folia turionum in specim. rariorum anguste linearia, 2-2 $\frac{1}{2}$ lin. longa, caulina basi ovato-acuta, lineam longa, alia 2-3 lin. longa, $\div-\frac{1}{2}$ lin. lata, omnia ut bracteæ obscure scabra. Spicæ vix semipollicares, 5-10-floræ. Bractea 2 lin. Ionga, bracteolæque dimidio fere hreviores sæpe falcatee. Flos lineam longus. Perigonium 5-fidum, lobis ovato-acutis, apice uncinatis, margine inflexis et medio sublobatis. Stylus stamina vix superans. Nux tota $1 \frac{1}{1}$ lin. longa, umbone parvo lobis omnino involutis coronata, parte liberá perigonii indurata, præsertim inter nervos ubi maculæ flavæ ovatæ ex eo proveniunt. Habitu T, brachyphyllo, fructu potius T. rupestri accedit. Placenta subsinuata, apice 3-ovulata. (v. s. in h. reg. ber.)

28. T. RUPESTRE (Ledeb.! fl. Alt. 1, p. 277*, ic.fl. Alt. t. 241), radice lignosâ descendente, caulibus numerosis simplicibus confertis, foliis bracteisque linearibus margine papilloso-scabris, racemis simplicibus paucifloris pedunculis patentibus, bracteâ fructum subæquante vel eo sublongiore, bracteolis fructû brevioribus, perigonii parte liberâ integrâ ventricosâ lobis sublongiore, lobis margine sub medio auriculatis, fructu cum parte ventricosâ superâ ellipsoideo vel oblongo lobis apjroximatis terminato nervis primariis $\mathbf{5}$ et secundariis ramosis æqualibus a basi usque ad medium (ubi pars libera incipit) striato. $\%$ In rupibus Sibiriæ Altaícæ. Radix (ex ic.) superne 6 lin. crassa, inferne ramosa. Caules e collo plurimi, 3-7-pol- licares, laterales adscendentes, centrales erecti. Folia 6-10 lin. longa, lineam lata, utrinque acutiuscula, enervia. Pedunculi uniflori, inf. 2-4 lin. longi. Bractea 2-6 lin. longa, nervo carinali donata. Bracteolæ 1-2 longæ, angustæ. Lobi perigonii ovati, ex ic. per anthesin patentes. Fructus primo adspectu anomalus, aliis major, propter partem integram et sup. perigonii parte inferâ non angustiorem levem, totus $2 \frac{1}{2}$ lin. longus, brevissime stipitatus. (v. s.)

29. T. REPENS (Ledeb.! A. Alt. 1, p. 274 , ic. t. 233 , fl. Ross. 3 , p. 539), radice gracili repente, caulibus simplicissimis trectis, foliis oblongo-linearibus 1-3-nerviis, bracteolis bracteâ dimidio brevioribus, omnibus linearibus florem superantibus glabris, lobis perigonii auriculatis, nuce globosâ....... \& In Sibiriâ Altaicâ Bailialensi et in Davurià, Turcz.! fl. Baik. 2, p. 77. T. pumilum et T. nanum Patrin! in h. Juss. Caules 3-5 poll. alti, e radice repente passim surgentes, rarissime (fide Turcz.) subramosi. Folia ima 3-5 lin. longa, pleraque 8-12 lin. lonea et lineam lata. Pedunculi uniflori sæpius 3 lin. longi, in apice plantæe vulgo nulli et ibi folia sive bractea steriles approximata. Bractea sæpius 6-10 lin.longa, in speciminibus ejusd. loci nunc pollicaris nunc 3 lin. longa. Bracteolæ sxpius 3 lin. longæ, nunc 2 lix. ; omnes lineares, ut folia margine integræ. Flos campanulatus, breviter pedicellatus. St ylus lobos fere æquans. Nux matura mihi ignota, perigonio deflorato ex auct. $3^{*}-40$ longiore; ex specimine immaturo h. Mus. paris. pars libera et integra perigonii inlata lutescens lobis subinvolutis terminata. (v. s.) 


\section{B. Nux longitudinaliter nervosa nervulisque tertiariis obliquis et transversis reticulata.}

1- Pars supera et integra perigonii cylindracea lobos æquans، Lobi per matırationem vix inflexi. - Flore et fructu ad Th. alpinum accedit.

30. T. G HINENSE (Turcz. in Bull. Mosc. 1837, p. 157), caulibus numerosis ramosis, foliis elongato-linearibus acuminatis 1 -nerviis, nuce globosâ sessili inter costas reticulatim rugosâ perigonii apice tantum: involuto, bracteà inferiori fructumı paulo superante lateralibus eodem brevioribus. - In Chinâ bor. (Kirilow). T. rugulosum Bunge! ined. ejusdem regionis, cum phrasi quadrat. In eo caules plures

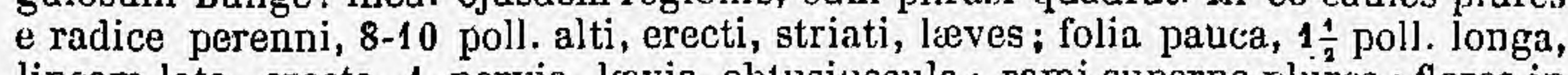
lineam lata, erecta, 1-nervia, levia, obtusiuscula ; rami superne plures ; flores in axillis bractearum sessiles vel cum bracteis breviter stipitati; bractea $3-4$ lin. longa, bracteolæ vix lineâ longiores, ut bractea lịıeari-acuminatæ, nervo donrsali et margine serrulatæ ; flores lineam longi, obconici ; pars liberâ perigonii 5 -fida, lobis margine non auriculatis; stylus stam. 110n superans; nux $1 \frac{7}{4}$ lin. longa, ellipsoidea, jerigonio vix mutato cylindraceo duplo major ; lobi perigonii dorso costat $i$ nempe nervis primariis fructus medio percursi. (v. s.)

20 Pars supera perigonii profunde 5 -fida. Lobi post anthesin varie inflexi angusti (T. Billardieri excepto). Placenta in prioribus recta, in ultimis ut vulgo contorluplicata. - Species sæpe fruticulosæ.

31. T. Szow ITSII, radice..., caulibus erectis a medio ramosis, foliis anguste linearibus mucronulatis carnosulis subteretibus enerviis, pedunculis sparsis 5-1-floris simplicibus vel apice breviter bifurcatis flore tunc uno centrali, bracteâ bracteolisque lanceolatis, priore florem raro æquante vel superante sæpius multo minore, bracteolis bracteá brevioribus, lobis perigoniii anguste lineari-oblongis parte in. tegrâ vix longioriljus margine inflexis non auriculatis cito apice involutis, stylo stamina superante lobis subæequali, placentâ rectâ, nuce ellipsoideâ lobis perigonii crispato-involutis duplo fere longiore 10-nerviâ nervulisque tertiariis transverse reticulata. $\mathcal{F}$ In montibus Aderbeidsehon district. Khoi (Szowits!) et eremo argilloso salso circa Nakitschiwan (id.I). T. multicatile Fisch. C. A. Mey. in h. DC., Szow. in h. reg. ber.! non Ledeb. nec Hook. f. et Th. in h. Hook. Habitus et caules omnino T. macranthi. Folia sæe longiora, $\frac{1}{2}-2$ poll. longa, $\frac{1}{2}$ lin. lata. Podunculi longiores, nunc bifurcati. Flores paulo minores, lobis magis involutis erga tubum hrevioribis. Placenta recta, apice 3-ovulata. Fructus forsan diversus, sed in T. macrantho ignotus (v. s.)

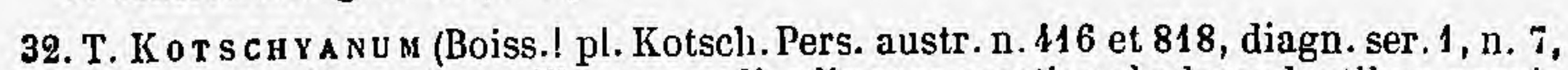
p. 86), radice lignosâ, caulibus e caudice lignoso erectis vel adscendentibus parvis foliosis subramosis, foliis imis ovato-acutis lanceolatisve ciliato-denticulatis, caulinis nulto longioribus linearibus 1 -nerviis erectis acutis integris, pedunculis brevihus unifloris vel dichotome 3-floris, bracteâ flore longiore bracteolisque brevioribus lineari-lanceolatis subdenticulatis, lobis perigonii margine inflexis a medio ad basin subauriculatis, stylo stamina superante, placentâ rectâ, nuce ellipsoideâ sti. pite suo duplo triplove longiore lobis perigonii vix crispatis æquali nervis 5 primariis et 5 secundariis ramosis subæqualibus nervulisque tertiarijs transversis validis reticulata. 5 In montibus prope Schiraz et circa Persepolim (Kotschy: sp. florif.) et circa Ispahan (Auch. Eloy! n. 5292 in h. vindob. et Boiss. specin. fructif.). T. macrocarpon Mlichx. in h. Mus. par.! Fruticulus 5-8 poll., radice non crassả sed lignosâ a caudice vix distinctâ. Caules annotini inferne subteretes, superne angułoso-striati, glabri. Folia ima squamiformia, 1-3 liss. longa, cætera 9-1 5, lin. longa, lineam lata. Ramuli floriferi breves, inferiores axillares, sup. extraaxillares, uniflori bracteâ bracteolisque 2 terminati, 2-3-flori bracteâ et ad basin cujusque floris bracteolis 2 stipati. Bractexe 4-8 lin. longæ, bracteolæ 1-3-lin. Flos $3 \frac{1}{2}$ lin. longus. Lobi elongati parte integrà liberà triplo longiores. Placenta recta, apice 3-ovulata. (v. s.)

33. T. IM PRESSU M (Steud. in Iiotschy? pl. Alep. Kurd. 411 ed. Hohen. 1843), radice lignosâ validà, caulibus basi lignosis ramosis ercctis, foliis imis ovato-acutis lanceolatisve ciliato-denticulatis, caulinis multo longioribus linearibus 1-3-nerviis 
acutis integris, ramis floriferis dichotome divaricatis, floribus solitariis ternisve, bracteâ fructu sublongiore vel breviore bracteolisque brevioribus lineari-lanceolatis subdenticulatis, lobis perigonii niargine subinflexis non auriculatis, placentà rectâ, stylo stamina superante, nuce ellipsuidea stipite triplo gerigonii lobis vix dijplo longiore nervis primariis 5 et secundariis 5 ramosis validis requalibus nervulisguo tertiariis transverse reticulatà. 5 in Kurdistan (Kotsch) !), in vineis prope Barputh vel Starjuth ? (Noé herb. n. 863! in h. Buiss.). Radix a caudice lignoso multicipite parum distincta. Caules 8-12 poll. alti, inferne subteretes, apice anguloso-striati, glabri, cum foliis colore pallido. Folia ima vel turionum annotinorum 1-3 lin. longa, imbricata; cæetera $\frac{1}{2}-2$ poll. longa, $\frac{1}{2}-2$ lin. lata. Rami et pedunculi rigidi, modo Erjngiorum divergentes. Cuique flori bractea $2-9$ lin. longa, $\frac{1}{4}-1 \frac{1}{2}$ lin. Iata

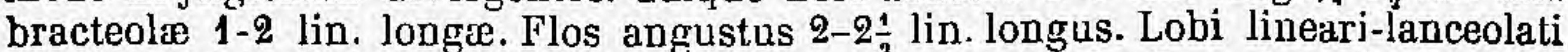
parte liberà duplo longiores. Placenta filiformis, recta, apice 3-ovulata. Nux matura fere 2 lin. longa, stipite carnoso $\frac{1}{2}$ lin., lubis varie crispatis. (v. s.)

34. T. BILLARDIERI (Boiss.! diagn. ser. 1, n. 5,p. 48), basi suffrutescens, caulibus ramosis, ramís angulosis striatis folinsis, fuliis radicalibus imis caulium squamiformibus obovatis minimis dein obovato-linearibus, plerisque linearibus acutis subfalcatis, ompibus bracteisque ad lentem serrulatis, racemo laxo spiciformi, pedunculis brevissimis 1-3-floris, bracteà lanccolatà pedunculo fructuque multo longiore, bracteolis angustioribus fructu subrequalibus, lobis perigonii sub medio utrinque auriculatis, placentà rectà nuce globoso-ellipsoideà stipite suo triplo lobis perigonii immutatis duplo longiore nervis 5 primariis el 5 secundariis ramosis subiequalibus nervulis tertiariis transverse reliculatis. 5 In Syriæ monte Dgebel Cher (Labill.!) et circa Tokat Asice Min. (Restalozza! in h. Boiss.). Radix jgn. Rami annotiui 6.9 poll. longi, flexuosi, arlscendentes? simplices, e basi lignosấ verisimiliter humili folia inferiora pauca lineam longa olstusa vel mucronala, dein cito longiora acutiora gerentes. Folia pleraque 9-12 lin. longa, $1-2$ lin. lata. Pedunculi axillares vel extra-avillares, $1-3$ lin. longi. Flos vulgo centralis cum 2 lateralibus junior. Perigonium totum vix linea longius. Stylus brevis staminum basim solum attingens, sed stigma capitatum et affinitas generalis cum hisce, nec Thesiis capensibus. Drupa cum perig. 2 lin. longa, lobis non inflexis vix cucullatis terminata. (v.s. in h. Boiss.)

35. T. marit im u (C. A. Mey.! Verz. Pflz. Caucas. p. 40), glaucum, humile, caulibus procumbentibus ramosis, foliis carnosulis, imis ovat is imbricalis serrulatis mucrouatis, aliis sjarsis linearibus enervijs acutis integris, racemis elongatis, pedunculis basi 1-3-floris brevibus apjice 1 -floris sessilibus, bracteå bracteolisque serrato-papillosis basi racemi liueari-lanceolatis fructu longioribus, apice ovatolanceolatis fructu aqualibus vel brevioribus, lobis perigonii margine inflexis sub medio fere auriculatis, stylo stamina sujerante lobos æquante, nuce ellipsoi: deâ perigonio supero basi constricto vix longiore nervis jrimaris et secundariis subsimilibus nervulisque tertiariis reticulatâ. $\mathcal{Y}$ In littore arenoso maris Casjii prope Baku. Radix ign. Pars infer. plantæ lignosa, turiones parvos foliis miñimis onustos binc inde priebens. Rami e turionibus anni anterioris $2-8$ poll. longi, angulosi, glabri. Folia turionum lineam longa ; ramealia 6-9 lin. longa, lineam lata. Peduncali inferiores 2 lin. longi, extra-axillares, gradatim minores. Bractea in infer. 3-5 lin. longa, bracteolæ 2-3 lin.; superne bractea 1-3 lin., bracteolæ lineam longe. Pars libera perig. profunde 5-fida, lobis marginatis non dentatis. Placenta contorta. Nux linea vix longior, perigonio lineam longo terminata. (v. s. in h. Boiss. et Mus. par.)

36. T. MACRANTHUM (Fenzl l in Florâ 1843 , p. $401^{*}$ ), radice lignosâ validâ multicauli, caulibus erectis a medio ramosis, foliis anguste linearibus mucronatis carnosulis enerviis, pedunculis sparsis brevibus, floribus apice pedunculi cujusque $3-1$, bractea bracteolisque lanceolatis, priore florem raro æquante sæpius duplo breviore, bracteolis bracteâ brevioribıns, lobis perigonii anguste lineari-oblongis parte integrà duplo triplove longioribus margine inflexis non auriculatis demum apice incurvis, stylo stamina superante lobis subietuali, fructu... $\mathscr{F}$ in Mesopotamià (Kotschy! 1841, n. 122, in h. vind. et Boiss.). Caules 1-2-juedeles, firmi, sulcato-striati, glabri. Folia ima juuca, squamiformia, ovato-acuta, lineam longa, catcra 6-18 lin. longa, $\frac{1}{2} 1 \mathrm{ln}$. lata, erecta, subcarinata, basi frequeritia. Racemi - pedunculis dissitis secus ramos. Pedunculi inferne 3-5 lin. longi, apice subnulli. 
Bracteæ et bracteolæ integræ, vix ac: ne vix margino papjillosæ, carnosulæ, bracteí gepius 2 lịn. longâ, bracteolis duplo sæpius minoribus. Flores 3 lin. longi. Lobi post antliesin divergentes, apice solum involuti. Placenta a medio contortuplicatosinuosa. (v. s.)

37, T. HETEROPHYLLU (Boiss.! in Ann. sc. nat. ser. 4, v. 2, p. 254), monocarpicum? radice verticali subsimplici, caulibus e collo pluribus procumbentibus striatis lævibus, folis radicalibus sessilibus oblongo-lanceolatis pinguibus subenerviis acutiusculis apicem versus calloso-papillosis, caulinis lineari-subfalcatis acutis margine papilloso-denticulatis, ramulis 1-5-floris e basi fere caulium lateralibus, bracteis fructu longioribus bracieolisque eo brevioribus lineari-acuminatis papilloso-dentatis, lobis perigonii sub medió marginatis, stylo stamina superante lobos æquante, nuce ellípśoideâ 10 -nervià nervulisque transversis reticulatâ limbo périgonii vix longiore. (1)? In Asiâ Minore, locis sterilibus elatis Cappadociæ (Téhihatcheff). Cappadociấ ad Euphralem (Auch. Eloy! n. 2533, sed in h. Mus. par. plantæe 2 diversissimix adsunt sub hoc numero, una ex ins. Scioto dicta quse præsens speciés, altera e Cappadocid ad Euphratem quæ Th. græcum Boiss.), prope Cæsaream Capparl. (Balansa! 317, anno 1856, in h. Boiss.), in Tauro (Balansa! 767 a Boiss. det., Kotschy! 559). Radix non valida. Caules 6-poll. in spec. Tchih., 9-12-poll. in spec. Bal. Folia radicalia (ex Boiss.) pollicaria, 3-3: lin. latt. Caulitia (in spec. Bal. 767) 6-9 lin. longa, lineam lata. Ramuli sæejius 3-tjori et crtidue flori sepius bractea et bracteolie, foliis subsimiles sed magis serratio. Bractea 3-6 lin. longa, bracteolæ duplo minores. Flos 2 lin. longus. Lobi a medio ad bàsim auriculâ longâ inflexâ marginati. Drupa subsessilis, cum limbo perig. 3 lin. longa. (v. s.)

3. Pars supera perigonii 5-fida. Lobi sæpius ovati vel oblongi, post anthesin infllexi non tamen involuti.-Species Capenses vel hemisphærii borealis, sæpe annuse.

38. T. Hum the (Vahl symb. 3, p. 43), radice annuâ simplici caule a bási ramoso, ramis ähgulato-striatis dense foliosis, folis linearibus 1.nerviis superioribus j.ræesèrtimn scabro-serrulatis, floribus subsessilibıs, bracteis approximatis longe lineatiluts acuminatis ut bracteolæ multo breviores flore tamen longiores denticulatosctabris, lobis perigonii non auriculatis, nuce ellipsoịdeâ nervis 5 primariis basi præsertim validis secundariis 5 ramosis subæqualibus nervulisque tertiariis obliguis reticulatâ. (1) In collibus aridis Hispanive merid. (Boiss. voy. Esp. 2. p. 232, Bolurgeau! 436), Algeriæ (Bové! Balansa! 110), regni Tunetani (Vahl, Kralik! 331, a), Sardiniæ (Moris! Thomas!), Siciliæ (Guss. Hutt!), Calabriæ (Guss. Heynier !), Græclé (Durv.l Heldr.1), Asire Min. prope Smyrnam (Balansa in h. Boiss.!), Libani (Gaillardot! 827 ih.), Palæstinæ (Boiss.l), Egypti (Olivier! h. DC. Ehrenb. in h. ber.) et in arvis ins. Canariæ (Webb !). - Guss." pl. rar. p. 98, t. 20, f. 2, Reichb. ic. bot. t. 705, f. 947 (ubi nux mala), Webb phyt. Can. p. 232. T. alpinum Desf. 1. Atl. (fide Webb.), non L. Radix perpendicularis. Caules 3-6 poll. alti, ramis e

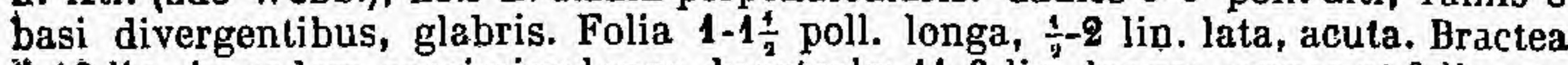

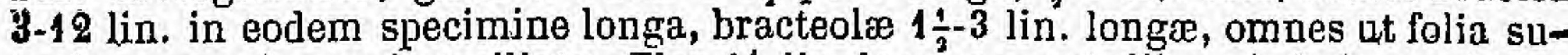
periora margine scabro-ciliatæ. Flos $1 \frac{1}{3}$ lin. longus ; parte libera inferiore subbrevior. Placenta apice contortuplicata. Stylus antheras non superans. Nux lined vix longior. (v. s.)

$\beta$, subreticulatum, nuce tenuiter 10 -nerviâ oblique vix reticulatâ. (1) In arvis Austriæ inf. (Welw.!), graminosis ins. Lesina Dalmatiæ (Portensehl. in h. Vindob.l), in Calabriâ (Reynier! h. DG.) et Græciâ ad Naupliam (Zuccar.), Napoli de Romania (Berger in Zuccar.). T. humile Koch syn. 2, p. 716, Vis. fl. Dalm. 1, p. 223. T. Græcum Zuccar.l plant. nov. fasc. 2, p. 14*, non Boiss. et Spruner. Forma frequens videtur in regionibus minus siccis aut borealibus ubi nuces male maturæ. Radix semper tenuis, nec valida et perennis ut in Th. Græco Boiss. et Sp. Specimina quæd. h. Vind. ex Atticâ et Calabriâ, quo ad nuces media inter varietatem et veram speciem. In varietate nuces sæpe stipitatæ. (v.s.)

39. T. B ER GER I (Zuccar." pl. nov. fasc. 2, p. 16), perenne, caule adscendente ramoso angulato elongato, foliis lineari-subulatis integerrimis, racemo basi composito, bractea bracteolisçue duplo brevioribus folio similibus, nuce breviter stipitatầ

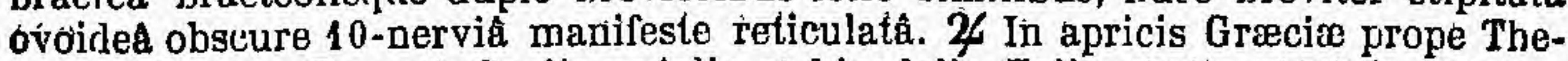
bas, Melissam (Berger). Caulis pedalis et bipedalis. Folia erecto-patentía, tnućro- 
1ıata, enervia, glabra, cauliná 15 lin. çirciter longa. Pedunculi angulati, 4-5 lin. longi. Stylus starnina subæquans. Nuculæ in specim. immaturæ, eleganter reticulatæ. An satis a Th. Græeo Boiss. et Spr. diversum? Caules multo majores ait cl. Boiss. sed in Thesio suo græco fere petales interdum vidi.

40. T. G P. A CU M (Boiss. et Spruner in Boiss.! diagn. ser. 1, n. 5, p. 47, non Zucc.), pereane, glaucescens, caulibus numerosis abbreviatis decumbentibus angulatis, foliis linearibus subenerviis superioribus scabrido-serrulatis, floribus subsessilibus, bracteâ lineari-acuminatâ bracteolisque multo brevioribus flore longioribus denticulato-scabris, lobis perigonii sub medio utrinque auriculato-dentatis, nuce ellipsoideâ 10-nerviâ nervulis tertiariis transverse crebre reliculatâ. $\mathcal{G}$ In siccis montanis Græciæ (Heldr.!), Gretie (Raulin! 192 in h. Boiss.), Naxos (Oliv.! in h. DC.), Asiæ Min. ad Smyrnam (Balansa! 380), in Cappadociâ ad Euplratem (Auch. Eloy ! 2533 in h. Mus. par., non id. num. e Scioto qui Th. heterophyllum), in Bulrardagh (Tchihatch.! in h. Boiss.) et in Syriâ (Blanche ! 109, 760, Gaillarlot |1041, Boiss.I). Caules 4-9 poll. longi, prostrati vel adscendentes, inflorescentiâ simplici vel subramosâ. Folia sæpe patentia, 4-9 lin. longa, lineam lata, carnosula, acuta. Bracteæ, flores et fructus T. humilis. Nuces nervulis transverse potius quam oblique reticulatæe el præsertim radix crassior perennis. (v. s.)

41. T. conpressum (Boiss. et Heldr. pl. exs. Anat. et Boiss. diagn. ser. 1, n. 12, p. 104), radice verticali simplici, caulibus e collo pluribus divergentibus medioque erectis virgutis basi subramosis, floribus sessilibus longe et basi laxe spicatis, foliis linearibus carnosis mucronatis in bracteas ovato-acuminatas cito transeuntibus, bracteâ bracteolisque axi communi sessilibus flore brevioribus, nuce oblongầ 5-nervià inter nervos reticulatà. (1) vel (2) In salsis hyeme inundatis planjtiei Koniah Asiæ min. (Heldr. et Boiss.! Balansa! 314 in h. Boiss.) Habitu et infloresc. distinctissimum. Caules 5-10 poll., striati, glabri. Folia 6-10 lin. longa, lineam ad maximum lata, glabra, cuspide calloso, in bracteas cito minores apice $\frac{1}{2}$ lin. longas mutata. Bracteæ et l)racteolæ ovato-acutæ, squamiformes, persistentes, sub lente tenuiss. ciliatæ. In inf. parte ramorum flores jam adsunt in axillis foliorum 5-6 lin. longorum, sed tune bracteolæ ut supra minimæ $?$ lin. longæ. Flores sæpius solitarii raro inferne bini ternive, lineâ breviores. Nux lineam longa, breviss. pedicellata. Placenta ut vulgo sinuato-tortuosa 3-ovulata. (v. s.)

42. T. MADAGAS CARENSE, annuUm, caule erecto superne ramoso, foliis rarissimis squamiformibus lanceolatis minimis adpressis, fasciculis florum 1-7-floris alterna. tim secus ramos insertis sessilibus, bracteâ fasciculi bracteâque et bracteolis florum lateralium ovato-acutis ciliolatis, bractcolis bracteam superantibus flore brevioribus, parte superâ perigonii profunde 5 -fidâ, lobis lanceolatis margine subvelutinis, stylo stamina paulo superante, placentâ rectâ, nuce ellipsoideâ sessili, perigonii parte liberâ cylindricâ æequali nervis 5 primariis validis 5 secundariis æaqualibus apice bifidis nervulisque obliquis reticulatâ. $\odot$ In pratis humidjs prov. Emirnæ Madagascar (Bojer!). Planta pedalis, radice tenui ramosâ. Caulis et presertim rami angulosi. Folia $\frac{1}{2}$ lin. longa. Bracteæ fere lineam longæ, bracteis et bracteolis fasciculi imbricatis, inde planta Juncum vel Cyperum referl. Sola species ubi bracteolæ bracteam superant. Flos vix lineam longus. Nux vix linea longior, bracteis et bracteolis tecta. (v. s. a cl. Bojer comm.)

43. T. DECUR RENS (Blume! ined.), radice parvà, caulibus annotinis adscendentibus erectisve a medio ramosis, foliis imis approximatis ovatis vel oboratis, aliis anguste linearibus nervulis marginalibus nervoque centrali carinato decurrente donatis, pedunculis nullis, floribus in axillis bractearum subsessilibus solitariis, bracteâ anguste lineari fructu $2^{0}-4^{\circ}$ longiore bracteolisque fructu brevioribus papillososerrulatis, lobis perigonii non auriculatis, stylo staminibus parum breviore, nuce ellipsoideâ perigonio sublongiore nervis 10 rcqualibus ramosis nervulişque tertiariis transversis reticulatâ. $\mathcal{Z}$ In Japoniâ. Radix (ex h. Yus. par.) pollicaris, tenuis, inferne ramosa. Caules annotini e basi lignosâ, 7-8 poll. longi, striato-angulosi. Folia ima 1-2 lin. longa, alia 6-10 lin. longa, $\frac{4}{3}$ lin. lata, nervo dorsali multo majore. Bractea fuliis similis. Bracteola $\div$ lin. solum longa, lanceolate. Flos lineam longus, ohconicus. Pars libera perig. 5 -fida, lobis in fructu subinflexis, non involutis. Placenta ignota. Nux lineam longa, perigonio $\frac{1}{2}-\frac{3}{4}$ lin. longo superata. T. difluso subsimile, perig. fructus longiore. (v. in h. Ber., Vindob. et Mus. Par. a Mus. Lugd. bat. comm.) 
$\beta$ ? longibracteanum, liracted frnctu 4-6-plo longiore, flore tetramero. - In insulis Lod Qhoo. T: australe Hook. et Arn. bot. Beeclicy voy. p. 270, non Br. An species distincta? Propior' videtur T. decurrenti quam T. australi non solum patriâ sed characteribus. Perigonium 4-fidum (ex auctor.), an semper ? Lobi perigonii margine pallidiores non marginati, cum in T. australi longitudinaliter marginati sint (ex Br.) vel potius margine inflexi et dente seu lobo manifesto donati (ё specim. Bauer.).

44. T. A U S T ARE (Brown prodr. fl.Nov. Holl. p. 353), caulibus adsèendentibus a medio ramosis, foliis imis ovatis obtusis minimis, aliis longe linearibus.nervo centrali basi valido decurrente, racemis elongatis subsimplicibus, pedunculis unifloris bractea multo hrevioribus apice fere nullis, bractcà longe lineari fructu $5^{\circ}-7^{\circ}$ ve longiore, bracteolis lineari-lanceolatis fructu scqualibus, lobis perigonii medio utrinque dentatis, stylo staminiluas jarum breviore, nuce cllipsoideâ subsessili perigonio apice vix inflexo sublongiore nervis 10 ramosis đequalibus et nervulis obliquis reticulatâ. $\mathcal{Z}$ In Novæ Hollandiæc orâ orient. merid. et in Van Diemen. Caules annotini e bási lignosâ surgentes, 9-1 0 poll. alti, angulosi. Folia ima squamiformia 2 lin. longa ; alia sparsa, 1-2 poll. longa, $\frac{1}{-}-\frac{1}{1}$ lin. lata, acuta, nervis lateralibus obscuris fere 3-nervia. Pedunculi in basi racemi 1-2 lin. longi, ex tra-axillares, gradatim minores. Bractea et luracteolæ foliis similes; nervo dorsali carínatæe, margine subintegræ, bractêa in flore 2 liu., deinde pollicem longa, bracteolis initio 1 lin. deinde 2 lin. longiş. Flos lineam longus, obconicus, parte liberâ perig. 5 -fidâ, lobis apice et margine inflexis dente utrinque manifesto lobiformi. Nux $\frac{3}{4}$ lin. longa, perigonio superne $\frac{4}{2}$ lin. (v. s. in h. imp. vind. specim, a Bauero muncupata, e collibus siccis Van Diemen, et in h. Deless.)

45 ? T. viRENs (E. Mey. in Drège pl. exs.l), scabriusculum, ramis angulatis alternatim vel dichotome divisis, foliis anguste linearibus acutis patentibus, ramulis floriferis terminalibus, floribus 1-5 distantibus, bracteâet bracteolis angustelinearibus subulatis flore brevioribus apice pedunculi extra-axillaris, flore tubulosoinfundibuliformí, perigonii lobis oblongis parte integrả et liberâ subbrevioribus apice vix uncinatis margine papilloso-subvelutinis, stylo perigonium subæequante capitellato, placentâ rectâ, nuce... ち In Africâ australi orientalí (Mey. et Drège 2 Pfl. geo. Docum. p. 226). Ramus gracilis, sublignosus, sub lente cum foliis bracteis bracteolisque pulverulento-scaber. Folia superiora pauca, 2 lin longa, $\frac{1}{4}$ lin. lata, rigidiuscula. Bractea floris lineam, fructus 2 lin. longa; bracteolx foris $\div$ in fructus $1 \frac{1}{1}$ lin. longa, demum omnes patentes, pedicellum $\frac{3}{1}-1$ lin. longum terminantes. Flos $1 \frac{3}{4}$ lin. longus, extus glaber. Lobí interne fasciculo pilorum donati ad antheras tendentium et præterea margine præsertim tenuissime velutini.Placenta 3-ovulata, ovulis fúniculo distincto pendentibus. Fructus in spec. delapsi. (v. s. in h. imp. vindob.)

46. T. ANG UL os UM (Alph. DC. csp, nouv. Thes. 6 juin 1857, p. 2), ramis erectis o nervis foliorum decurrentibus grosse 3-4-angulosis inter angulos depressis, foliis erectis lineari-acuminatis planis, floribus laxe spicatis in axillis foliorum superiorum 5-3-1 fasciculatis folio duplo brevioribus brevissime pedicellatis, flore centrali ex folio fasciculi sessili vel stipitato bracteato, lateralibus bracteà lineari-lanceolatâ flore sublongiore et bracteolis lineari-laniceolatis duplo brevioribus donatis, - parte liberá perigonii profunde 5-fidâ, lobís linearibus apice vix uncinatis margine subvelutinis, staminibus lobos subæquantibus y stylo apicem antherarum attingente, fructu parte liberâ perigonii multo longiore. $\zeta$ ? In Africâ australi circa Port Natal (Guenzius! n. 365 in h. vindi.). Species anomala, costis obtusis sed validis pallidis distinctissima. Rami juniores nunc torsi, costis 2 interdum compressi. Folia 3-6 lin. longa, rara, subulata, margine integro et nervo centrali pallidiora. Flores 1\%-1 $\frac{1}{2}$ lin. longi, alabastro obtuso. Bracteæ $2-3$ lin. longæ, bracteolieque variabiles glaberrimæ et integræ. Filamenta e basi loborum; antheræ lineares biloculares filamento subæquales, prope apicem lobi pilis luteis ti adhærentes. Placenta contortuplicata, apice conico 3-ovulata. Fructus junior ovoideus 5-nervius, vix stipitatus, cum perigonio erecto 3 lin. longus. T. racemosum Bernh. (infra n. 66) quod cl: Sonder suspicatur simile, forsan ex errore numeri citati, videtur diversissimum. (v. s.)

IIV. 
** Stylus abbreviatus, raro stámina attingens, apice truncatus vel stigmate obtuso non capitato. - Omnes Capenses, -suffrutescentes.

\section{A. Filores longe pedicellati, in axillâ foliorum solitarii vel gemini. - Species habitu distincta.}

47. T. s PINos u M (Linn. suppl. p. 161), lignosum decumbens ramosum, foliis crebris e basi solidâ decurrente trigonâ superne canaliculatà subulato-spinosis, floribus in axillis inferioribus ramorum solitariis geminisve longe pedicellatis, bracteolis subulatis in axillâ bracteæ lateralibus bracteâ pedicelloque multoties brevioribus, flore pedicello duplo triplove breviore, parte ińferâ perigónii obconicâ, parte liberâ 5-fidâ lobís margine subauriculatis, nuce glọbosâ pedicello graêlili subæquali périgonio clauso terminali obtuso majore inter nervos 10 ramosos et nervulos obliquos foveolatâ. $ђ$ In Africa capensis parte austro-occid. (Drège ! 2 Pfl. geo. Docum. Eckl. et Zeyhi. n. 38 ex Drège in Linn. 20, p. 211.). - Thunb.! prodr. p. 45, fl. Cap. ed. Sch. p. 209, diss. Thes. p. 6, Drêge ! exs., Eckl. et Drège n. 1504, in h. vind.! (Zeyh. 1504 in h. Boiss.!). Dedumbens, ex Thanb. diss. Rami in herb. 7 poll. longi, juniores angulosi, rámulis patentibus simplicibus foliosis. Folia seu spinæ 3 lin. long:c initio erectre in axillis aut apice ramulorum fasciculatæ, dein patentes et firmæ. Pedicellị $1 \frac{1}{2}$ lin. longi, sæpius solitarii. Bracteolæ $\frac{1}{4}-\frac{1}{2}$ lin. longæ. Ovarium a pedicello parum distirictum. Placenta'sinuata. 3-ovulata. Pars libera et integra perigonii pinguis costata, lobis plerumque inflexis unde flos globosus. Fasciculus pilorım parvus in medio loborum. Stylus stam. non superanis. Nuces raræ, lineam longæ, perigonio supero duplo fere majores. (v.s.)

\section{B. Flores breviter pedicellati vel sessiles.}

48. T. L I Е A т и м (Linn. suppl. p. 162), lignosum, ramis rigidis ercetis vel patentibus cylindricis striatis demum spinescentibus, foliis raris linearibus acutis vel obtusis glabris, llóribus in ramulis' laxe spicatis solitariis, bracteâ et bracteolis sessilibus' squamiformibus ovato-acuminàtis ciliatis pedicello brevioribus, parte inferâ perigonii a pedicello vix distínctâ gracili deinde incrassatà oblongà pàrte superâ late urceolatâ, disco plano crasso, lobis ovatis interue presertim ad pargines subvelutinis apice vix uncinàtis, stylo stamina attingente, nuce.... 5 In Âfricæ Capensis parte occid. (Drège et Mey.PA. geo. Doeum. p. 226, Zeyh.! 1502 in h. Boiss., Eckl:- et Drège n. $39,103,4$ in h. Boiss. ber.! et vind.l sine nom., n. 1502 ; ibid.! sine nom:, Burch.! n. 1412).-Thunb.! diss. p. 6, ft. Calj. ed. Sch. p. 582, Drège! exs. in h. vind. ber. èt Boiss. T. rigidum Sond. in Flơrâ 1857, p. 354. Specim. h. Willd. a R. et Sch. miss. est div. species. - Fruticulus spinosus, habitu Genistæ, Ephedræ, etc. Rami crassi, breves. Folia 3 lin. longa (ex ramo non florif. Zeyheri), $\uparrow$ lin. lata, plana, subpatentia. Bracteæ $\frac{1}{2}-1$ lin. longæ. Bracteolæe breviores. Flos cum pedicello $1 \frac{1}{2}$ lin. (v. s.)

49. T. PALLtou M (Alph. DC. esp. néuv. Thes. 6 juin 1857, p. 2), cinerascens glabrjusculum, caulibus ramis foliisque erectis, ramis angulatis, foliis linearibus acutis, pedunculis semi-erectis semel aut bis dichotomis medio bractoâ lanceolatâ subulatâ donatis, bractèâ simíli bréviore in dichotomiâ; flơribus lateralibus bracteâ et bracteolis subæqualibus lanceolatis acuminatis flore sublongioribus stipátis, lobis perigonii ovato-lanceolatis apice paulo uncinatis margine papillosopilosis, plaçentâ rectà, nuce.... 5 In Africâ austr. Capensi ab occid. ad orientem (Drège! $8170, a$, in h. vindob. E. Mey. et. Drège 2 Pllanz. geo. Docum. p. 226.). Caules in specimine 8 poll. alti, e hasi lignosd surgentes, inferne teretes, superne anguloso-striati, sub lente cum foliis materie pulverulentâ vel pilis raris brevissimis scabriusculi, potius tamen colore contextus in sicco pallidi. Folia 5-10 lin. longa, $\frac{1}{2}-\frac{5}{4}$ lin. lata, vix 1 -1ervia, non tenuia, in caule acuta, in ramis acuminata. Braclea in medio pedunculi 4-6 lin. longa, uvinervia. Peduneulus 3-8 lin. longus usque ad dichotomiam, ramulis inde brevioribus patontibus. Flos lin. longus et latus. Bractea floris $1 \frac{1}{4}$ lin., bracteolæ vix breviores. Stylus stamina æ.quans, obtusus. (v.s. in h. imp. vindob.)

50. T. s т R I с r и м (Berg. pl. Cap. p. 73), glabrum, caulibus ranisque erectis striatis, foliis erectis basi adpressis oblongo-linearibus acutis crassiusculis, floribus apice ramorum subnmbellatis, pedunculis semel aut pluries dichotomis abbreviatis 
bracteå dichotomiæ bracteolisque juxta llores laterales lanceolatis flore fructuque brevieribus integris, lobis perigoníi ovato-oblongis apice breviter cucullatis margine papilloso-pîlosis, stylo abbreviato, nuce ovoideâ stipite crasso vel lobis perigonii conniventibus $2^{\circ}-4 \circ$ majore nervis primariis et secundariis subrqualibus nervulisque trañsversì tarde manifestis reticulatâ. $\delta$ Ad Caput B. Spei (Eckl. et Zeyh. n. 15, 1, 12 et 16, 75, in herb. reg. ber.! et vind.! Eckl.I Un. itin. n. 59 in h, vind., Drègel $8166, b$, in h. ber., 8165 , a, ex specim. imperfect, in $h$, Deless., 8162, ib., ex alt. spec. Imperfect.3. Linn. mant. p. 214, Thunb. herb.! lit. $\alpha, \beta$, (excl. aliis), Thunb.! in h. Willd. 5081, fl. Cap. ed. Sch. p. 210 , Banks! in h. vind., herb. Burmann! Krauss! in h. Boiss. Zeyh.! Link! in h. reg. ber. (non Eekl. et Zeyh.). T. euphorbioides h. Jacc.I (non L.). T. robustúm Bernh. in Linn. 1845 , p. 79, (fide Sond. Flora 1857, p. 361, qui plantam vidit). Thesium Zeyher, ฉ. 3792 (fide Sond. ibid.). Rami in herb. pedales, stricti, inferne cylindracei, superne obtuse angulosit. Folia $3 \times 8$ lin. longa, $\frac{1}{3}-\frac{1}{2}$ lin. lata; dorso convexa, supra plano-concava, intervallis breviơra. Fasciculi florpm 3×8, lin. lati. Bracteæ $1 \frac{1}{2}-2$ lin. lơngæ, brasteolæ $\frac{1}{2}-1$ lin. Flos $\frac{3}{5}$ lin. longus Lobi ex cucullo brevi obtusi. Stylus apice truncatus, stam. inferior. Nux cum-stipite et lobis 2 lin. longa, stipite 5-costato, nervulis transversis et obliquis. (v.'s.)

$\beta$, pingue, pallidior, foliis obtusis. vel brevissime acutis, bracteis crassioribus. 5 In parte austro-occid. Africæe capensis $(8166, a$, Drège! in $h$, vind.). Planta 8166; b, ejusdem, jam plerisque aliis speciminibus herbariorum pallidior. Folia præsentis 5-e lix. longa, erecta, rigida (nec apice extús flexa), dorso usque ad apicem convexa, intus medio anguste canaliculata. Flbres ef fructus similes. Stylus longior, an semper? (v. s.)

51. T. PIN IF OLIU M (Alph. DC. esp. nouv. Thes. 6 juin 1857, p. 2) glabrum, rạmis lignosis, foliis longe et anguste linearibus crassiusculis carinatis subaçutis erectis nunc secundis, floribus apice ramorum umbellato-fasciculatis, pedunculis abbreviat's dichotomis 8 -flotis bracteis floris, centralis et lateralium oblongis longitudinaliter plicatis obtusiusculłs florem vix superäntibus, bracteolis florum lateralium bractea stubsimilibus florem fere æquantibus, lobis perigonii ovato-lanceolatis apice sưbuncinatis interne præsertim ad thargines velutinis, stylo stamina attingęnte, nuce ellipsoided stipite triplo lobis perigonii conniventibus duplo longiore nervis primariis 5 validis secundariis 5 minoribus nervulisque transversis reticúlatâ. $ち$ In Africå capensi (Zeyher! 3791 in h. Boiss., Eckl. et Zeyl.! 3791 in h. vind.). T. corymbillorum Sond. in Florà 21 jun: 1857, p. 354. Rami veteres robusti, cylindrici, substriati, juniores angulosi. Folia crebra, intervallis multo longiora, $9-15$ lin. longa, $\frac{1}{2}-\frac{5}{4}$ lin. lata, 1 -nervia, dorso convexa, in sicco rugulósa.

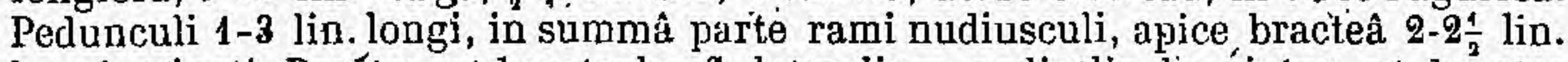
longâ stipati. Braćtea et bracteolæ fl. lateralium pedicello longiores, ut bractea margine tenuiores undulatæ glabræ plicatæ prope apicem non angustiores et inde vix acutre. Flos $1 \frac{1}{2}$ lin. longus. Lobi non cucullati. Nux cum stipite et lobis 2 lin. longa. (v. s.)

52. T. ERECTIRAMOSUM, caulibus lignosis, ramis crebris erectis dense foliosis, foliis linearibus erectis vel demum subpatentibus acutis vel obtusis crassiusculis margine tenuioribus, floribus in apice ranorum 1-5, bracteâ bractéolisque subæqualibus flore sublongioribus fructu multo brevioribus oblongis acutis nitargine incurvo tenuioribus inlegrís, lobis perigonii apice cucullatis margine tenuissime velutinis, nuce obovoideâ stipite triplo lobis conniventibus quadruplo longiore læ̉vi nervis primariis 5 basi eminentibus c:eterum minimis solự̄ percursâ. 5 In Africâ australi (Eckl. el Zeyher $21,5 \dot{6}, 6$ in h. vind. et reg. ber.!Eckl. et. Zeyh. \$6, 56, 6 in h. vind.! et h. ber. sine fl. et fr., Zeyher 21, 56, 6, et 4, 51, 7 in h. Boiss.l forsan Ecklon et Drège 36, 56, $6 \mathrm{inh}$ h. vind.I T. quïnqueflorum Sond. in Florå 1857, p. 354 et 404 . Caules ex specim. robusti, cylindracei. Rami ramulique erecti, simplices vel dichotomi, apice angulosi. Folia 2.4 lin. longa, $\frac{1}{2}-\frac{3}{4}$ lin'. Iata, intervallis longiora, subcarinata. In fasciculis plurifloris flos vulgq centralis bracteatus, laterales bracteâ et 2 bracteolis stipati. Bracteæ $\uparrow \frac{1}{2}$ lin. longæ, prope apicem præcípue marginatæ. Flos lineam et ultra longus, alabastro obovoideo. Stylus conic 0 -truncatus, stamina attingens. Nux sicca, cum stipite et lobis fere 3 lin. longa, minime tranśversim reticulata, solum 5-nerviá. Specimina Eckl. et Zeyh. (Eckl. et Drège) 36 diversa sunt ex Sond. et forsan T. pauiculati, quod vix credo, sed specim. mala. (v. s.) 
53. T. Folros u a, caulibus lignosis, ramis erectis simplicibus vel dichotomis dense foliosis angulosis, foliis linearibus erecto-falcatis acutis crassiusculis margine tenuioribus, florilsus in apice ramulorum 1-5, bracteâ bracteolisque folio subsimilibus tenuioribus florem quemque superantibus fructu subrequalibus margine incurvo integris, lobis perigonii apice cucullatis margine tenuiter velutinis, nuce ellipsoideâ stipite quadruplo lobis conniventibus triplo longiore nervis 10 nervulisque reticulatis iugulosà. $\supset$ In Africæ Capensis mont. austro-oceid. (Ecklon et Zeyh. n. 27, 4, 2 in h. reg. ber.l et imp. vind.t Drège 8164 , a, in h. vind.! T. capitatum var. interruptum Krauss, in h. vind. et in Florà 28, p. 80. Rami robusti. Folia 5-7 lin. longa, propter plicaturam longit. $\frac{1}{3}$ liu. lata, intervallis multo longiora. Flores inter. Polia vel potius bracteas latentes, $1 \frac{1}{2}$ lin. Iongi, pedunculum brevem terminantes. Bractea pedunculo longior, 3 lin. longa, falcata, marğine tenuis. Bractcolæe 1 $\frac{1}{2}-2$ lin. longæ. Tübus perig. obconicus, sulcatus; pars libera, 5-fida, semiaperta. Stylus abbreviatus. Nux tota 2 lin. longa. (v. s. in h. reg. ber.)

54. T. P A I C U L A U M (Linn. mant. p. 51, non Thunb., fide Sond. qui plant. authent. L. in herb. Holm. vidit), caule tereti lignoso, ramis dichotomis erectis substriatis nudliusculis, foliis minimis erectis lanceolatis acutis, ramulis floriferis axillaribus el terminalibus apice sapius 3-floris, floribıs lateralibus bracteâ et bracteoliş oblongis subacutis integerrimis glabris flore brevioribus donalis, perigonii superne 5-fidi lobis cucullatis margine papilloso-subtomentosis, stylo brevissimo truncato, nuee obovoideà stipite 5-costato duplo majore perigonio superne connivente umbonatâ nervis primariis 5 basi exceptà medioeribus sccundariis 5 vix minoribus et nervulis obliquis transversisque reticulatâ. 5 Ad Caput $B$. Spei, parte austr. occid. (Sonnerat in h. DC. Eckl. et Drège 20,1, 11 in h. vind.! et h. ber.! Ecklon et Zeyher 53 in h. ber.! Zeyl. n. 3802 (ex Sond. Flora 1857, p. 361), herb. Jacq. nunc imp. vind.! Ecklon! 796 et 797 in h. vind. T. strictum $\delta$ (planta déxtr.) et $\gamma$ (pl. sinistr.) licrb. Thunb.! (non alia specim.). T. strictum Krauss.! in h. vind. (non Berg. nec ideo L. mant.). 'T. paniculatum Willd.! herb. n. 50s4. Descriptiones T. paniculati Lina. mant. et Thunb. fl. Cap. (T'. Thunbergiarium nob.) valde differunt, sed prior imperfecta et posterior e duabus speciebus seripta. T. fragile Spreng.! in h. Willd. n. 5083, 1, non L. T. cucullatum Alph. DC. olim in herh. Caules $1 \frac{1}{2}-2$ ? pedales, ut tota planta glabri. Rami interdum subcompressi (var. $\beta$ Sond. 1 . c.). Folia $\frac{1}{3}-1 \frac{1}{2}$ lin. longa, basi crassiuscula, apice acuto tenuia. Hamuli floriferi nunc 1 vel 5 -flori, sæpius 3 -flori, foliis adpressis sparsim tecti. Flos centralis ebracteolatus. Bractea lateralium vix $\frac{1}{2}$ lin. longa, bracteola subbreviores. Flos $\frac{3}{4}$ lin. longus, basi obconicus, a medio subglobosus, pinguis. Stylus stam. non attingens. Lobi valde cucullati, medio glabri excepto fasciculo staminum. Nux cum stipite $2 \frac{1}{4}$ lin. longa, lobis perig. stipite brevioribus conniventibús. (v. s.)

$\beta$, apertum, lobis perigonii supra nucem plerumque divergentibus. $\hbar$ Ad Capnt B. Spei (Chamisso! n. 12 in h. reg. ber.). Omnia simillima sed major pars fructuum lobis, scmipatentibus, uno tamen ejusdem plants lobis conniventibus. (r. s.)

55. T. KREBSI I (Alph. DC. esp. nouv. Thes. 6. juin 1857. p. 1), caulibus e basi lignoså subherbaceis ramisque erectis, foliis anguste linearibus erectis acutis 1-3-nerviis cum ramis bracteisque tenuissime scabro-puberulis, pelunculis gracillimis erectis 1-3-floris medio bracteâ anguste lineari elongatà stipatis, bracteolis florum lateralium anguste linearibus flore et fructu sulıæequalibus, parte superà perigonii 5 -fidâ sublobis inflata, lobis margine papilloso-subdentatis, stylo obtusiusculo altitudine staminum, placéntâ rectâ, nuce ovoideâ slipite aul lobis conniventibus quadruplo longiore nervis 10 parum eminentibus cum nervulis obliquis et transversis reticulatá. 26 In Africà australi capensi (Krebs! 291 in h. reg. ber.). Planta in specimine 8-poll., caulibus ramis foliisque gracilibus erectis, habitu Th. australis et Th. decurrentis, sed formâ floris et placentâ rectâ distans. Folia 3-6 lin. longa, $\frac{1}{4}$ lin. lata. Pedunculi pauci extra-axillares. Bractea foliis similis, 3-4 lin. longa. Bracteolæ floris 1-2 lin., deinde 2-3 lin. longae. Flos linea brevior, tubo obconico gracili, parte supera inflatâ, lobis apice et margine plus minus inflexis. Fructus e lloribus centr. solum, cum stipite et lobis fere 2 lin. longus. Ex unico flore aperto placenta recta, ovula 4 (an casu ?) funiculo suspensa. Ex Sonder in Fl. 1857, p. 403, idem est quam T. acutissimum (infra n. 64), sed div. videtur. (v. s. in h. r. ber.)

56. T. J IxсIforium (Alph. DG. esp. nour. Thes. 6 juin 1857, p. 1), glaberrimum, 
ramis (caulibus?) crectis gracilibus nudiusculis striatis, foliis remotis erectis anguste linearibus acutis carinatis, peduncnlis terminalibus apice 3-7-floris nudis, pediccllis braetea bracteolisque subsequalibus flore duplo brevioribus lanceolatis terminatis, parte liberâ perigonî̉ campanulatâ 5 -fidâ, lobis apice subuncinatis margíne tenuiter vehtutinis, stylo stamina attingente, fructu... భ ? In Africả capensi (Eckl. et Zeyh. n. 55. 1, 11. in h. ber.l). T. virgatum Sond. in Florâ 1857, p. 361 et 402 , non Lam. Rami vel caules? in 'specimine pedales, herbacei, süperne ramosi, sepius dichotomi. Folia 3-4. lin. longa, $\frac{1}{2}$ lin. lata, acuminata, dorso convexa. Pedunculi folio oppositi, ramum ideo terminantes, 4-10 lin. longi, apice semel, his terve breviter dichotomi. Bractea floris centralis lincam longa, aliorum breviores; bracteolæ fl. latcralium $\frac{4}{2}$ lin. longæ. Flos lineam longus, tubo inferiore obconico, parte liberâ amplà fere ut in T. divaricato. Species forsan n. 23 magis aftinis, sed stylo tamen paulo minore et lobis margine non dentatis. (v. s.)

57. T. N I g R о м о N T AN U M (Sond. in Florâ 1857, p. 361), suffruticulosum, 4-5-pollicare, glabrum, ramis tetetiusculis, foliis rameis squameformibus minutis ( $\frac{1}{2}$ lin. longis) acutis, caulibus inferioribus paucis lineari-trigonis, ramulis paniculígeris, paniculie ramis subsecundis, floribus minutis sessilibus, bracleis ovatis cuspidatoacuminatis florem sequantibus vel superantibus apice patulis, perigonii limbo campanulato lobis acutis supra glabris. 5 In Africã australi, locis siccis inter Zwarteberg et Rivier Zonder Einde (Zeyher n. 3813.)

58. T. DREGEANUM, caule tereti lignoso, ramis dichotomis diffusis substriatis, foliis minimis erectis lanceolatis acutis, ramulis floriferis axillaribus et terminalibus gracilibus apice sæpius 3-floris, floribus lateralibus bracteâ et bracteolis oblongis actitis integerrimis glabris đore brevioribus donatis, perigonii superne 5 -fidi lobis ovatis paulo cucullatis margine merlioque intus tenuiter papilloso-subtomentosis, stylo truncato basin staminum attingente, nucc obovoideâ stipite 5-costato abbreviato perigoniove supra connivente minimo $4^{\circ}-5^{\circ}$ ve longiore nervis primariis 5 basi excepta mediocribus secundariis 5 vix minoribus et nervulis obliquis transversisque reticulatâ. $\hbar$ In Capitis B. Spei regione austro-occid. (Drège! n. 8167, $a$, in h. Boiss. Deless. imp. vind. et reg. ber.). Rami tenuiores, magis diffusi et minus rigidi quam in T. paniculato ; flores paulo majores; bracteie magis acutæ ; lobi minus cucullati intus superne non glaberrimi; stylus longior; nux erga stipitem et umbonem superiorem major. Folia 1 lin. longa, acutissima. Flos fere lincam longus, basi obeonichs, a medio subglobosus, pinguis. Nux cum stipite obconico 2 lin. longa, lobis perigonii stipite brevioribus vix distinctis. - Conf. ad T. leptocaule, infra n. 60. (v. s.)

59. T. PAR VIF OLXU M (Alph. DC. csp. nouv. Thes. 6 juin 1857, p. 3), ramosissimum, adscendentibus lignosis teretibus substriatis, foliis remotis brevissimis dentiformibus ovato-acutis glabris, in ramulis ovato-lanceolatis subciliatis, floribus ad apicem ramulorum $1-5$. spicato-capitatis, bracteâ bracteolisque ovato-acuminatis acumine excepto ciliatis florem quemque amplectentibus eo Juplo brevioribus, lobis perigonii apice concavis margine papilloso-pilosis, stylo brevissimo, nuce ellipsoídeâ bracteis multo longiore stipite brevissimo lobis conniventibus duplo triplove longiore 10-nervià nervulisque transversis et obliquis multo minoribus reticulatâ. $\supset$ In Africâ austr. extratropic. (Eckl. et Zeyh. n.19,91 in h. reg. ber.). Sequenti simillimum et eamdem speciem dixerim nisi lobi perigonii non obscure ad marginen apice subpapillosi, sed manifeste pilis crassis papilliformibus albis $a b$ apice ad basin margine donati. Cæeteris attente observatis folia ramulorum panlo minus acuta, bracteæ erga florem subbreviores minus acutæe, flores magis congesti, tandem nux nervulis transversis minoribus et prope sinus perigonii minime tumens. Hanc spec. cl. Sond. (Flora $1857 \mathrm{p}$. 404) sectionis Friseæ dicit, sed pili perigonii, quamvis manifesti, a barbâ longấ et pentente valde diversi. (v. s. unic. specim. in h.r. ber.)

60. T. LEPTOC A ULE (Sond. in Flord 1857, p. 362 et 404), ramosissimum, ramis adscendentibus lignosis teretibus substriatis, foliiş remotis brevissimis denti formibus ovato-acutis glabris in ramulis ovato-lanceolatis acuminatis subciliatis, floribus apice ramulorum spicatis, bracteà bracteolisque ovato-acıminatis acumine excepto ciliatis florem quemque amplectentibus eo parum brevioribus, lobis perigonii apice concavis margine glabris, stylo brevissimo, nuce ellipsoideà bracteis multo longiore stipite brevissimo lobisve couniventibus triplo longiore 10-nervia 
nervulisçue transversis et obliquis reticulatà. 5 In A fricà australi (Eckl. et Zeylı. $11.11,82$ in ll. reg. ber.! Eckl. et Zeyh. 28, 44, 6, in h. ber.! Eckl. et Zeyh. 17, partim, ex Sond. Fl, 1857, p. 404, Eaklon et Drège, 28, 44, 6. in h. vind.! T. divaricatum Graham! herb. in h. Deless. (specimen n., 82 a Bowie coll.), non Jan. T. Jrevifolium Alph. DC. esp. nouv. Thes. p. 3. Fruticulus perlalis? caule lignoso denudato tereti, ramis multiramulosis. Folia $\frac{1}{2}-1$ lin. longa, decurrentia; in basi ramorum subpatentia, glabrata; superiora erecta, acuminata, fnagis ac magis modo bractearụm ciliata. Bracteæ basi laț̇ concavâ, $\frac{3}{4}$ lin. longæ. Bracteolæe paulo minores. Cịlia non regularia sub lente potius marginem denticulatum effrientia. Perigonium profunde 5 -fidum. Lobi apice crassi, cucullati, margine aculo armato vix ac ne vix apice papillosi. Nux $1 \frac{1}{4}$ lin. longa. Confer ad procedentem et ad n. 82 .

$\beta$, glabriusculum, foliis glabris, bracteis et bracteolis fere non ciliatis. $\zeta$ In Africâ capensi ad Doornhoogte (Eck!. et Zcyli. n, 17 in h. reg. ber.! Idem ac num. 8167 Drège, ex Drège in Linn. 20, p. 211, sed nurn. 8167, a, in h. Boiss. et reg. ber. est T. Dregeanum). Rhinostegia brevifolia Turcz. in-Bull. soc. Mosc. 1843, p. 57 (quæ num. 8167 Drège dicitur a cl. auctore)? T. brevifolium. Sond. in Florâ 1857, p. 361, ubi synonymon Zeyher n. 50 datur. Omnia T. leptocaulis folia solum ramealia glabra, bracte:e et bracteolæ minus dentato-ciliatæ. Fruticulus totus 6 poll. Gl. Sonder Fl.p. 404, monet sub num. 17 et 28 , div. plantas distrib. fuisse. Var. $\beta$ distinctam sp. ait, frrctu diverșo, quem non descripsit. (v. s.)

61. T. SELAGINEUM (Alph. DC. esp. nouv. Thes. 6 juin 1857, p. 3), ramis scabriusculis basi teretibus apice angulosis, foliis anguste linearibus patentibus aculissimis glabris, floribus apice ramulorum 3-7 subumbellatis, flore centrali bracteato et interdum unibracteolato, lateralibus bracteatis et $2-3-4$-bracteolatis, bracteis bracteolisqne lanceolatis acuminatis integris glaberrimis flore subæqualibus, perigonii parte liberâ 5 -fídâ ad sinus externe bullis 5 notátẩ, lọbis apice vix uncinaatiș margine et apice velutino-barbatis, stylo abbreviato, nuce ellipsoideậ, stipite aut lobis conniventibus dupIo longiore nervis primariis 5 validis secundäriis 5 minoribus èt tertiariis abliquis reticulatà. 5 In Africâ capensi occident. (Drège ! a. 8172 in h. vind. et Deless. E. Mey. et Drège! 2 Pfl. geo. Docum. p. 226). Rami extreni graciles, tamen lignosi. Folia ericoidea, $1-2$ lin. longa,,$\frac{1}{4}$ lin. lata, dorso convexa, oculo armato non scabriuscula. Ramuli florif, axillares vel terminales oppositifolii, 3-6 lin. longi. In eod. ramo bracteolas 2-3-4 vidi, unâ ex accessorịis bracteæe oppositâ. Bractęa floris centralis 1 lin. longa, flórum later. et bracteolæ subbreviores. Stylus stamina vix attingens, stigmate minimo. Nux lineam longa, cum stipite et perigonio fere 2-lin. Ex longitudine papillarum apicis marginumque loborum accedit ad sp. sectionis Frisece, sed barba tamen brevior et stamina lobis nec tubo inserta. Differt a T. Thunbergiano meo (n. 86) quocum junxit cl. Sonder (Flora 1857, p. 404) bracteis bractøolisque glaberrimis, numero bracteolarum, barbâ breviore, sinubus bullatis, insertione staminum. Sequenti valde affinis. (v. s.)

62. T. ERIC FF OLIUM (Alph. DG: esp. nouv. Thes. 6 juin 1857, p. 3), ramosum gia brum, ramulis foliosis erectis apice bracteis, floribusque dense imbricatis, foliis auguste linearibus trigonis acutis erectis demum semipatentibus, , spiculis terminalibus 5-9-floris, singulo flore bracteato et bibracteolato, brạcteà florem vix superante bracteolisque subbrevioribus lanceolatis subacutis, lobis perigonii ovatis apice subinflexis glabris, stylo abbreviato stamina vix attingente, nuce minimâ ovoideâ stipite aut lobis perigonìi conniventíbus 4o longiore nervis 5 primariis et 5 secundariis mediocribus nervulisque paucis obliquis. $\$$ In Africâ australi (Zeyh.! 3805 in h. BQiss., vind. et ber.), in mont. austro-occidu. (Drège I 7174 in h. reg: ber. et in h, Deless., veris. 8174 ex h. vind.t. et syn. Krauss. in Linnzed 20, p, 511, Eckl. et Zeyh. n. 26, 1, 11 in h. reg. ber.! non in h. viud. nec 26 Zeyh. in h. Boiss.). T. ramellosım Sond. in Florà 21 jun, 1857, p. $\mathbf{3 6 2}$. Habitus Ericæ. Rami diffusi vel erecti. Folia $1 \frac{1}{2}=2 \frac{1}{2}$ lin. longa, $\frac{1}{5}$ lin. lata, crassiuscula, ri= grida, intervallis longiora. Spiculæe apice ramorum numérosæ, 2-4 lin. longæ, pallidiores, floribus inferne distfnctis, superne approximatis. Bractea cujusve floris $\frac{s}{4}$ lin. longa, bracteolæ $\frac{1}{2}$ lin., omnes paulo pingues, sessiles, imbricatæ. Flos $\frac{1}{2}$ lin. longus. Placenta contortuplicata, ovulis 3 funiculis brevibus donatis. Nứculæ raræ $\frac{3}{6}$ lin. solum longæ. (v, s.)

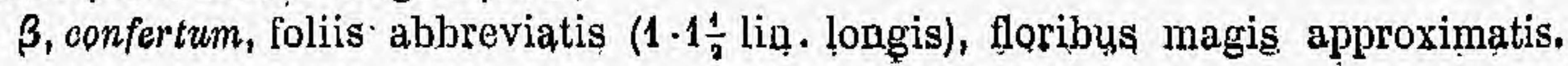


$5 \mathrm{~T}$. confertum herł. Willd. n. 5079 , ct l. Link, nunc in h. reg. lser.! (verisimiliter a loco siccu, non indicalo). T. panicalatum h. Portenschl. ef Jacq. in h. vind.! non alior. (v. s.)

63. Т. с оми ит т т и (Sond. in Florâ 1857, ․ 362), fruticulosum, pedale, glabrum, caule ramosissimo paniculatb ramisquie teretibus; foliis sjarsis, in ramulis ultimis frequentioribus subulatis carinatis (lineam longis); floribus in apice ramulorum ternis quatcrnisve capitato-aggregatis, bracteis acutis florem æequantibus nuco $4^{-}$brevioribus, perigonii limbo campanulato lobjs supra glabris margine papillo. sis, nuce majusculá costątà rugulosả glabrâ. $ち$ In Africả austr. ad planitiem montis Tabularis et verticem Kasteelberg (Licklon), in sabulosis capensibus'(Zeyh. 3806). A T. ramelloso (T. ericerfolium nob:) foliis, inflorescentiâ et imprimis fructı multo majore, a T, paniculato Thunb. (T. Thunbergianum nob. n. 86), cni habitu simillimum, glabritic, foliis et floribus non barbatis facile distinguitur. Nux 1 $\frac{1}{2}-2$ lin. longa.

64. T. A c U TI S s I U M (Alph: DC.esp. nouv. Thes. 6 juin 1857, p. 4), scabriusculum, caulibus o radice pluribus diffusis ramosis teretibus, foliis linearibus acutis erectis uninerviís, ramulis floriferis secus ramos foliosis ad apicem laxe multifloris div chotomis, flore singulo braeteâ bracteolisque donato inguste linearibus acutissimis flore longioribus patentibus demum reflexis, stylo conico pingui nuce ellipsoideá pedicello obconico triplo lobis perrigonii conniventibus duplo longiore nervis 5 primariis 5 secundariis vix minoribus et nervulis obliquis transversisque reticulatâ. ' 5 In Africâ australi (Eckl, et Zeyh. 22, 2, 1 in h. ber.!, Eckl. et Drège 22, 2, $1 \mathrm{in} \mathrm{h}$. vind:!!. T. strictum, $\varepsilon_{\text {. }}$.Thunb.! herb. et inde T. apiculațum Sond. in Florà, 21 jun. 1857, p. 357 (excl. specim. T, corniculati E. Mey.). Radix descendens, lignosa, 3-5 lin. lata. Caules 8-10 poll. longi, ipsâ basi tenues; rami apice angulosi: Folia 3 lin. longa, $\frac{1}{3}$ lin. lata, orecta vel rarius patentia, ramulorum florif. et ' bractex 1-2 lip. longa. Bracleæ et bracteolæ cum pedunculis varie divergentibus vel recurvatis, unde inflorescentia aciculis curvis apice albidis intricata. 'Flos $\frac{1}{2}$ lin, longus, carnosulus, in alabastro superne et basi conicus. Lobi óvato-acuti, fasciculo pilơrum excepto glabri. Placenta contortuplicata intra conum styli penetrans. Nux $1 \frac{1}{2}$ lin. longa. Affinis Th. corniculato, sed discus margine non liber. $(r, s$.

65. T. SRUARrosun (Linn. suppl. p. 162), glabrum, ramis diffusis vel erectis apice striatis in ramulos multifloros divisis, foliis linearibus acutis carnosulis obscure 1-3-nerviis patentibus, ramulis floriferis axillaribus foliosis sæpius 3-7-fioris, pedunculis 1-3-floris pedicellis bracteisque demum divaricato-patentibús, bractêâ lineari-lanceolatâ florem vix æquante, bracteolis bracteâ subsimilibus perigonii partì superâ profunde $\mathbf{5}$-fidâ, lobis ovatis apice uncinatis glabris, placentà rectâ, stylo stamina vix attingente, nuce obovơideo-globosà subsessili lobis conniventibus triplo longiore nervis 5 primariis et 5 secundariis æqualibus nervulisque transversis et obliquis reticulatâ. $\delta$ In Africa australi interiore (Thunb.!), prope Algoa Bay (Forbes! a soc. hortic. Lond. comm.) et in dunis Zitzikamma (Kraussl in h. reg. berol. et Boiss.), - Thunb.! herb. $\alpha$ et $\beta$, prodr. p. 46, 1l. Cap. p. 211, Sond. in Florà 1857, p. 361 et 405 . T. multillorum Alph. DC. esp. nour. Thes. p. 4. T. corniculatum Krauss 1. c. non Meyer. Thesíum Zeyh. 3804; ex Sond.l Zeyher! n. 26, 58, 8 in h. Boiss. Ecklon, Zeyh. 26, 1, 11 in h. Deless.! et Eckl. et Drège 26, 1, 11 in h. vind.l (non Eckl. et Zeyh. in h. reg. ber. quod T. erioxfol.). T, hispidulum Zeyh.! in h. reg. ber. (non Lam.). Habitus Thymi. Caules lignosi, in herrb. 6-7-poll., teretes. Rami foliosi. Folia 3-4 lin. longa, $\frac{n}{2}$ lin. lata, rigidiuscula, intervallis sapius

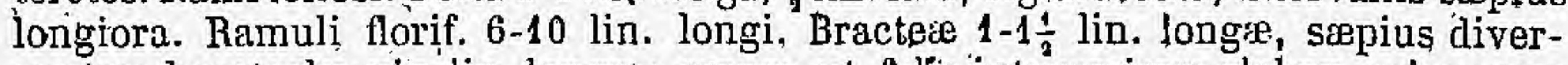
gentes; bracteolæ vix lin. longæ; omnes ut folia integerrimæ glabræ apice sæpe albidæ. Flos lin. longus, basi obconicus. Placenta rectá, brevis, 3-ovulata, avulis funiculo brevi jendentibus. Nux (e specim. Krauss) $1 \frac{1}{2}$ lin., nervis basi costatis. Specimina Krauss. interdum (in li. Boiss.l) in foliis-bracteisque scabriuscula, Thunhergii aliaque glaberrima. Affinis $\mathrm{T}$. galioidi, sed discus non distinctus et placenta recta. (v. s. in h. meo, ber., Boiss., etc;)

66. T. RA CE M o SU M (Bernh. in pl. Lirauss. Florâ 1845, p. 79), suffruticosum glabrum, caulibus angulosis simpliciter ramosis, foliis sessilibus lanceolatis linearilus carinatis margine pellucidis acıtis, floribus solitariis breve pedunculatis involucello triphyllo circumdatis racemum. terminalem formantibus, limbo floris 5-partito lobis carinalis apice incurvatis intus nudis. $\stackrel{+}{J}$ In graminosis Africe australis, ad 
latera montium Tafelberg, Natal. Nec numerum, necdescriptionem addit el. auctor. - Verisimiliter una e priccedentibus sjeciebus. Ex cl. Sonder Florâ 1857, p. 357, numerus 1500 Zeyheri, e Magalisberg, mili ignotus, hic referendus, ut et planta Eckl. et Zeyl. sine num. o regione inter Gariep et Caledon. Ex eod. nuperrime (Fl. 1857, p. 403) eadern est species quam Th. meum angulosun (supra n. 46), sed in hocce flores non solitarii et plura valde distincta. Num. 385 Kraussii ibi memoratus est mihi ignotus.

67. T. COR YM BULIGE R UM (Sond. in Flód 1857, p. 362), suffruticosum, - -1 -pedale, glabrum, multicaule, ramosissinum, foliis in caule ramisque primariis paucis lineari-trigonis, in ramulis frequentioribus adpressis squamæeformibus ovatis acutis ( $\frac{1}{2}$ lin. longis), racemis corymbosis 5-6-floris ramulos terminantibus, pedunculis (lineam longis) apice 3 -bracteatis, bracteis subrquilongis lateralibus angustioribus perigonii tabum equantibus, limbi lato-campanulati lobis acutis supra glabris. 5 In A fricâ australi ad Zwarteberg prov. Caledon (Écklon), prope Caledon (Zeyher 3812).

68 ? T. GRASSIF OLIUM (Sond. in Fllorå 1857, p. 355), glabrum, radice perpendiculari basi simplici, caule a hasi ramoso, ramis erectis radice parum longioribus inferne cylindricis apice subangulosis, foliis alternis aut suboppositis lanceolatis crassis dorso carinatis intus concavis semipatentibus, floribus per majorem partem ramorum spicatis solitariis, bracteâ folio simili flore longiore bracteolisque bracteâ vix brevioribus basi carnosis margine tenuibus integris, lobis perigonii ovatolanceolatis apice subinflexis margine glabris, stylo brevi, nuce ovoidea bracteolam subæquante stipite lobisve perigonii conniventibus triplo longiore nervis 5 primariis et $\mathbf{5}$ secundariis ramosis subæequalibus striatâ. (1)? In Africà Capensi (Scholl! in h. vind., Eckl. et Zeyl. n. 34, 56,6 in h. ber ! Eckl. et Drège n. 34, 56, $G$ in h. vind.!). T: spinosum Jacq. in h. Willd.! 5086 et in h. vind.! non Linn. T. fragile h. Link ! in l. ber. et b. Jacq.l in herb. Willd. (non Linn.). T. sedifolium Alph. DC. ined. in div. herb. Exsiccatione nigricans. Radix omnino plantæe annuæ, 3-poliicaris, superne tamen ut basis ramorum potius lignosa. Rami 3-4, e basi plantæ 3-5 poll. alti, laterales longiores adscendentes. Folia $1 \frac{1}{2}-2$ lin. longa, $\frac{3}{4}$ lin. lata, decurrentia, e basi latà angustata, acuta vel obtusiuscula $a_{+}$in hasi ramorum intervallis breviora patentia, apice approximata suberecta, ad bracteas gradatim transeuntia. Bracteolæe $1 \frac{1}{2}$ lin. longæe, acutæ, basi cum bracteà et pedicello per spatium breve connate. Flores omnes axiHares, juniores obovoidej, lineam longi. Nuces raræ, cum stipite et perigonii lohis 1 ? lin. longa, nitidse, minime transversim reticulate. - Species hic propter florem et patriam eollocata, habitu affinis T. humili ; (n. 38) ct Thesidiis. Flores casu Tetrameros frustra quæsivi. Miror num in tali monstro lobus ante axim esset? tunc enim Thesidium dicerem invito fl. hermaphr. (v.s.)

\section{Sectio III. ETheотнеsium Alph. DC. esp. nouv. Thes., p. 4.}

Pars libera perigonii sub-5-partita, persistens, lobis non barbatis. - Fruticulus foliis bracteisque amplissimis subcarnosis, habitu Sarcocollæ (Penæacearum) in præsenti Ordine anomalo, distinctus, characteribus tamen genericis destitntus, imo sectionalibus vix ab Euthesiis capensibus diversus.

69. T. E U P Ho R B I o I DE S (Linn. mant. p. 214), sufrutex erectus ramosus, foliis alternis vel suboppositis sessilibus ample ovato-rotundatis subcordatis carnosulis enerviis, bracteis amplis foliaceis ovatis apice ramorum imbricatis in axilla 3-floris, bracted et bracteolis 2 cujusve floris lateralis ovatis oblongis obovatisve flore brevioribus vel subrequalibus, flore obconico pedicello ovarioque 5 -sulcatis, perigonii parte liberâ sub 5-partitâ, lobis margine inflexis submarginatis, stylo abbreviató, nuce ovoiḍed pedicello multoties longiore perjgonii parte superả conicâ triplo longiore, nervis primariis 5 et secundariis totidem ramosis multo minoribus. JIn Capitis B. Spei regione austro-occid. (Drège 1 Boivin! Verreaux ! Zeyh. 3787, etc.) at circa Port Natal (h. vind.!, a Popp. comm.). - Berg. pl. Cap. p. 7i.. Thunb.! Il. Cap. ed. Sch. p. 211 , Drège I exs., Hohen.! pl. Kolbing. T. amplexicaule Linn. mant. p. 213 (fide deser. et horb. Jacq. et Willd.!). Caulis pedalis et ultra, teres, sæpius ramis dichotome divisus. Rami erecti, striati, foliosi. Folia internodiis majora amplexicaulia, 6-9 lin. longa lataque, obtusa vel acuta, ut tota planta glabra et in herb. nigrescentia. Bracteie imbricatæ, foliaceæ, 6-3 lin. longæe latæque, integerrime, cum peduuculo axillari conuata et ita breviter petiolatæ. Fasciculi flo- 
rum axillares sæpius 3 ; nunc 1 vel $\mathbf{5}$-flori, inclusi, flore uno centrali ebracteolato, lateralibus bracteatis et bracleolatis, flore unico centrali ramum totum terminante, vicinis provectiore. Flos carnosus, fusiformis, $2 \frac{1}{3}-3$ lin. longus, tubo infero obco-

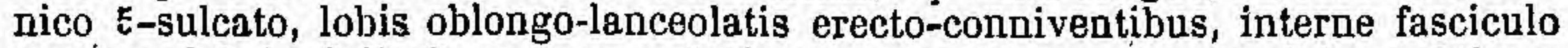
excepto glabris. Callositas externe sub sinu quoque. Antherie ovato-globosie. Stigma minimum, truncatum, riedio depressum, staminum originem non attingens. Drupa cum perigonio supero 3 lin, longa. Placenta sinuosa, filiformis, apice 3-ovulata, ovulis funiculo ipsis requali suspensis. Semen intra putamen durum carne parcâ tectum. Embryo cylindricus, radicula cotyledonibus sublongiore. (v. s.)

Sectio. Iv. Discothesiug Alph. DC. esp. nouv. Thes., p. 5.

Pars libera perigonii 5-fida, late infundibuliformis vel campanulata, persistens, lobis non barbatis. Discus planus vel concavus, pinguis, margine brevi liber.-Flores fere specierum capensium sect. Euthesii ubi interdum discus omnino adhærens apparet.-Fruticuli eapenses, ramis sæpe gracilibus scandentibus, foliis sæpe carnosulis, inflorescentiâ sæepius dichotome divaricatâ, bracteolis inæqualibus.

70. T. S CANDENS (E. Mey.! in h. vind, et zw. Pflanz. geo. Docum., p. 226), ramis flexuosis striatis, foliis longe et anguste cyliudraceis carnosis acutis demum patentibus et reflexis, pedunculis patentibus medium versus nec basi folio stipatis semel aut bis divaricatis in angulis unifloris, bracteolis florum lateralium dentiformibus, nuce ovoideâ perigonli lobis erectis triplo vel quadrıplo longiore subenervił́t verruculosâ. $ち$ In Africâ capensi (Eckl. et Drège ! 32 in h. vind, et ber., 3795 in h. vind., Zeyh. 3795 ex Sond. Flora 1857, p. 354). Caules vel rami basi sublignosi, cylinuracei. Folia rara, 1-2 $\frac{1}{2}$ poll. longa, $\frac{1}{2}-\frac{3}{4}$ lin. lata, suprema tenuiora. Pedunculi extraaxillares, folio 3-5 lin. supra originem donati, apice flore unico caducissimo vel abortivo terminati, ramis 2 medio bracteâ patente flexuosà donatis apice aut iterum bifuricatis aut $\mathbf{3}$-floris. Bracteolæe ovato-acute, dentiformes, flore multo minores. Flos vix lineam longus latusque. Drupa 3 lin. longa, dura. (v. s. in h. cit.)

71. T. TRIFLOR UM (Thunb.! herb., Linn. suppl. p. 162), ramis flexuosis inferioribus teretibus superioribus angulosis striatis, foliis lanceolatis vel lineari-lanceolatis planis 1-3-nerviis acutis basi callo persistente insertis, fedunculis ex eodem callo nascentibus aut saltem cum basi folii brevissime connatis 1-3-5-floris sæepius semel dichotome divaricatis $\mathbf{3}$-floris, bracteis apice pedunculi lanceolatis ramulorum basi connatis, bracteolis florum lateralium ovato-lanceolatis, nuce ovoideà perigonii lobis erectis vel subconniventibus $4^{\circ}$ longiore 5 -nervià nervulis transversis et obliquis reticulatâ. $\zeta$ In capitis $B$. Spei parte austro-occid. (Eckl. et Drège, n. 33, 2, 7, in h. vind.l et ber., Boivin! in h. Boiss., Verreaux! in h. Deless., Zeyh. 3794 in h. vind.! Zeyher 3797 (ex Sond. Flor 1857 , p. 354), Urège! 8180 in h. vind., Zeyh.! 33 in h. Boiss., in herbariis interdum cum n. 32 Eckl. et Z. mixtum). - Thunl.! prodr. p. 46, fl. Gap. ed. Schult. p. 211. T.planifolium Alph. DC. esp. nouv. Thes. p. 5. Habitus Chenopodiaceæ. Pallide virens. Rami 6-12-poll., recti vel curvi. Folia in eod. ramo 6-12 lin. longa, 1-3 lin. lata, erecta, patentia vel recurva. Pedunculi 3-12 lin. longi. Insertio foliorum et pedunculi plerumque nodosa, in velust. ramis perspicua, ramulum anno sequente interdum emittens. Flos omnino D. scandentis. Drupa sessilis, 2 lin. longa, vix hinc inde prater nervulos verrucosa. (v. s. in div. herb., nuper in h. Thunb.)

72. T. G ALI O IDES (Alph. DC. esp. nouv. Thes. p. 5), glabrum, caule erecto tereti, ramis erectis vel adscendentibus gracilibus angulosis, foliis brevibus linearibus subplanis carnosulis enerviis acutis demum palenti-reflexis, pedunculis patentibus basi vel paulo supra folio stipatis apice 1-2-3-chotomis in angulis urifloris,-bracteis basi aut paulo supra basin ramulorım bracteolisque oppositis florum lateralium lanceolatis demum patentibus, lobis perigonii apice uncinatis, nuce obovoideâ stipite $6^{\circ}$ perigonio supero $5^{\circ}$ majore nervis primariis 5 secundariis 5 vix minoribus et nervulis reticulatà. $\zeta$ In Africâ Capensi (Eclkl. et Drège 23, 36, 9 et 30,81 iu h. vind.! et ber.! Verreuux ! in h. Boiss.). Radix valida, tortuosa. Caules 8-10-poll., basi lignosi. Folia 3-4 lin. longa, $\frac{1}{3}$ lin. lata. Pedunculi omnes fere iequalcs, $2-2 \frac{1}{3}$ lin. longi, demum valde patentes, pedicellis florum lateralium accretis divaricatis. Bracté et bracteola persistentes, $\frac{1}{2}+\frac{3}{4}$ lin. longæ, oppositie margine hinc breviter dentato commexæ. Flos vix lin. longis et altus. Discus pinguis, margine subdistinctus. Nux unica in specim. Verr. h. Boiss, cum stipite et perigonio 
2 lin. longa, Habitu T. squarrosi L., sed foliis ]racteisque brevioribus; racemis magis elongatis, flore minore êt præsertim placentâ ut vulgo.in gẹn. conlortuplicatà el disco distinetum. (v. s.s.)

73. T. coR NI cul A TU M (E. Mey. et Drègé in h. vind.! Deless.! non Krauss), ramis inferne cylindricis striatis superne angulosis, foliis brevibus anguste linearibus acttis imis carnosulis patentilsus sepe falcatis, pedunculis apice aut in laterali parte rámorum dichotomis, ramulis inflorescentiæ bracteis bracteolisque recurvatis intricatis, bracteầ e'dichotomiis vel e medio pedunculi et bracteolis florum lateralium anguste lincaribus acutissimis flore longioribus, nuce ovoideâ sessili lobis perigonii conniventibus duplo majore 10-nerviẩ pervulisque transversis reticulatâ. t In Africs australis parte orient. Ex Sond. Flora 1857, 1. 357 est var. Thesii sui apioulati (T. acutissimum nob.) et ad hanc varietatem refert 1 . 22. Ecki. et Zeyh. supra, p. 659) et 3816 Zeyheri. Ramus unicus in hepb.cit. rèctus, ramosus. Ramuli nunc apice floriferi, nunc lateraliter et tunc folia juniora in apice. Flores cum pedunculis bracteisque globos intricatos $4-8$, lin. latos formantes. Folia $2-3 \frac{1}{2}$ lin. longa, $\frac{1}{6}$ lin. lata, acumine albo recurvo. Bracteæ et bracteolæ foliis similes, breviores.Partes omnes materiem pulverulentam sub lente præbentes, sed vero glabræ. Pedunculi medio vel apice bractea douati, in angulo uniflori, ramulis later. bracteatis et prope florem bracteolatis. Discus crasșus intra florem patentem $\frac{1}{2}$ lin. latum; núnc 4 -merum Nux lineam longa. (v. s.)

Sectio v. Frisea (1). - Sectio vel genus? Br.prodr.fl. Nov. Holl. p. 533. Sectio Frisea Reich. consp. p. 80, Endl. gen. $p, 326$, Alph. DC. esp. nouv. Thes. p. 6.

Perigonii campanulati, infundibuliformis vel tubulosi, pars supera 5 -fida, persisterıs; barba densa ex apice et margine loborum intus pendens. Stamina e tubo potius quam basi loborum nascentia. - Species omnes Capenses, suffrutescentes aut basi sublignosa, habitu sæpe specierum Capensium sectionis Euthesii, nuce nervis et nervulis transversis simili modo reticulatâ.

§1. Fasciculus pilorum a medio loborum ad antheras tendens ut in plerisque congeneribus. - Flores in prioribus spec. capitati; in sequentibus capitellati, capitulo pauci-unifloro; in ultimis solitarii.

74. T. GN ID I A CE U M (Alph. DG. esp. nouv. Thes. 6 juin 1857, p. 7), cinerascens, ramis striatis, foliis crebris erectis rigidis lineari-subulatis dorso convexis margine tenuiter subserratis integrisve, lloribus a medio vel apice ramorum dense spicatis, bracteâ et bracteolis folio subsimilibus florem fere æquantibus, stylo miṇimo, nuce obvoideâ subsessili parte liberâ perigonii subbreviore ejus lobis apice divergen-ntibus coronatâ nervis 10 obtusis medioẹibus nervulisque transversis minimis reticulạtâ. $ち$ İn' Africâ Capensi orientali (E. Mey. et Drège 2 Pfl. geo. Docum., p. 226). T. imbricatum Drège! herb. et l. c. (non Thunb.). Thesium Eckl. et Drège, n. 8, 36, ' 9 in h. vind,l Eckl, ot Zeyh.l id. num. in h. ber., Krebs.! 386, ín h. ber., Zeyher, id. num. in h. Boiss.l Boivin ! ibid. T. Dregei Sond. in Florâ 1857, p. 356, ex eod. p. 406. Thesium 3801 . Eckl. et Zeyh. ex Sond. 1. c. Fruticulus 6-10-pollic. Rami floriferi sæepius erecti, elongati. Folia $2-4$ lin. longa, $\frac{1}{-1}-\frac{1}{1}$ lin. lata, intervallis longiora, ideo sæpe imbricata, in specim. pristinis Dregei vix serrulata, sepius (prosertim superiora) sub lente serrulata. Bracteæ 2-3-lin., bracteolæ $1 \frac{1}{2}$ lin. longæ, ut folia subserrulatæ. Flores 2 lin. longi, non erecti, bracteis crebris mixti. Alabastra ovoideo-conica. Maculæ 5 sub sinubus externe e vacuo sub epidermide in sicco constantes. Pars oblonga perigonii profunde 5-fida, lobis oblongo-lanceolatis. Nux (ex spec. Drège in h. Deless.) cum perigonio tato 3 lin. longa, lobis non conniventibus distincta. (v. s.)

$\beta$, Zeyheri (Sond. l. c. ), foliis teretiusculis squarroso-patulis, spicâ breviore, bracteâ florem æquante. - Ad Zwartoberg et RY̛vièr zonder Einde (Zeyli. n. 3807).

(1) Interdum Frisca in auctoribus, sed nomen primitivum in Linn. mant., p. 213 est. Frisea. 


\section{THEŞIOM.}

75. T. BoISSIERANUM, ramis crebris diffusis adscendentibus puberulis, foliis approximatis suberectis lineafibus acutis glabris integris dorso convexis, floribus apice ramulorum capitatis bracteà et bracteolis folio similibus florem requantibus integris, stylo brevissimo, nuce ovoided stipite $4^{\circ}$ longinre parte sup. perigonii sublongiore nervis 10 subæqualibus ct nervulis tertiariis reticulatâ. $t 5$ In Africâ Capensi (Verreaux !). Fruticulus cum radice 8-12-pollicaris. Caulis parsque inferior ramorum valde ligtasi, cortice fusco glabrescente vesligiis foliorum crebre asperato. Ramuli foliis tecti, pubescentes. Folia $\$$ lin. longa, $\frac{1}{5}$ lin. lata, rigida. Fasciculi florum terminales 5-9-flori, bràctès mixti, e cymulis partialibus constantes. Flos lineam longus, tubo inforne obconico, medio inflato et ad sinus 5-bullato, superne cylindraceo 5 -fido. Barba loborum non longa. Stamína minima. Placenta eongenerum. Nuces in speciminibus immatura cum stipite et perigonio $1 \frac{1}{1}$ lin. longue (v. s. in herb. ditissimo amici Boiss.).

76. T. CARINA T U M (Alph. DC. esp. nouv. Thes. 6 juin 1857, p. 7 ), ramis erectis foliosis striatis apice angulosis, foliis erectis crebris linearibus acutis dorso carinatis margine subintegris, floribus apice ramulorum capitatis bracteâ et bracteolis folio similibus florem sequantibus margine serrulatis, stylo minimo, nuce ellipsoideâ stipite $4^{\circ}$ longiore parte liberâ perigonii cylindricâ subsquali nervis primariis 5 secundariis 5 paulo minoribus tertiariisque minimis reticulatâ. 5 In Africa Capensi (Eokl. et Zeyh. 2, 1,12 in h, ber.l Eckl. et Drège 2, 1, 12 in h.

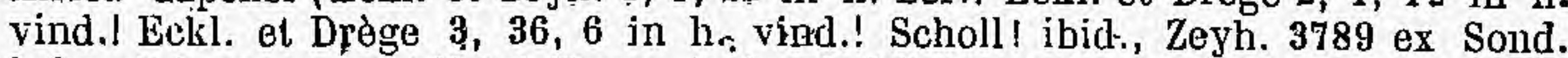
infra cit.), prope port Natal (Pcepp. in h. vind.!). T. capitatum $\beta$ Thunb.! in herb. Upsal. T. capitatum Willd. herb.! n. 5080 (non Linn. nec Willd. sp.). T. assimile Sond. in Flora 1857, p. 360. Fruticulus cum radice 8-15-pollic. Rami lignosi, superne divisi. Folia 3-12 lin. sæpius 5 lin. longa, $\frac{1}{2}$ lin. lata, margine attenuata sub lente non omnina integra, superne plana vel concava, subtus acute carinata. Gapitula 5-9-flora, foliis bracteisque mixta. Bractese 2 liv. longæe et bracteolie subbreviores margine magis quam folia plicate attenuatæe et serrulatæ. Flos $1 \frac{4}{2}$ lin. longus, parte liberâ perig. 5-fidả, ad sinus externe 5-maculatâ. Pili ab apice et marginiJus lobormm longe pendentes, albi. Stamina in mediả parte tubi. Stylus stam. inferior, truncatus. Nux lineam longa, stipite minimo; perigonio supero lin. longo lobis couniventibus. Habilus T. pinifolii. (v. s.)

77. T. C A P I T A T U (Linn. sp. p. 302), erectum, ramosum, ramis striatis, foliis crebris ereclis linearibus acutis carinatis subintegris, floribus apice ramorum capitatis, bracteà cujusque floris ovato-acuminatà planiusculà dorso urinervi margine lato attenuatâ et' irregulariter denticulatâ florem xquante, bracteolis lanceolatis bracteâ subbrevioribus margine et carinâ attenuatis denticulatisque, stylo antherarum apicem attingento, nuce ellipsoideâ subsessili perigonii parte liberâ columnari breviore nervis 10 non validis et nervulis obliquis fere nullis. $\hbar$ In Africà Capensi austro-occid. (Krauss ! in h. Boiss. Sieb.! sine num. in h. vind. Mey. et Drège 2 Pfl. geo. Docum. p. 226, Eckl. et Drège n. 1, 78 in h. vind.! et Eckl. et Zeyh. in ber.. Zeyh. 3788 (ex Sond. Flora 1857, p. 360). - Thunb. diss. p. 9, fl. Cap. ed. Sch. p. 209, Drège ! l.c. et pl. exs. Krauss ! T. capitatum y Thunb.! in h. Upsal. T. capitatum Thunb.l. c. (non div. herb.).T. levigatum hort. Kew. ined. ex Banks in h. vind.! Fruticulus bipedalis, ramis lignosis. Folia erecta, rarius inferiora patentia vel reflexa, 3-12 lin. longa, $\frac{1}{4}-1 \frac{1}{4}$ lin. lata, latiora vix carinata, superiora ad bracteas transeuntia id est margine albo pellucido denticulato aucta. Capitula 15-20-flora. Flores 3 lin. Iongi, bracteis mixti. Bracteæ 3 lin. longæ, 2 basi latæ, convexæ non carinata. Bracteolæ $8 \frac{1}{2}$ lin. longæ, bracteis angustiores et alato-carinatæ. Lobi perigonii acominati. Stylus multo longion quam in affin. Nux $1 \frac{1}{4}$ lin. longa, perigonio $1 \div$ lin. superata. Tria specimina sub nom. T. capitati adsunt in herb. Thunberg. quæ tot spec. diverswe. Confer ad præced. et sequentem. (v. s.)

78. T. scA B R U (Linn. sp. p. 302 ? Thunb.! herb. prodr., p. 45), erectum, ramosum, ramis striatis glabris, foliis crebris demum patentibus aut reflexis linearibus acutis margine carinåque scabro-dentatis, floribus apice ramorum capitatis, bractea ot bracteolis cujusque floris oblongis acutis florem subæquantibus margine pellucido scabro-dentatis, stylo minima, nuce ellipsoideâ subsessili parte liberâ perigonii cylindracea vix lougiore nervis 10 parum eminentibus nervulisque obliquis reticulatà. 5 In Africâ Capensi austro-oçcid. (Drège ! Eøkl. ot Drège 14, 1, 11 in h. vind.! Eckil. et Zeyh. in h. reg. ber.!). T. scabrum Drège ( exs. in h. vind. et 
Boiss.! E. Mey. et Drège 2 Pfl. geo. Docum. p. 226, sine descr., Krauss. in h. Boiss.! et vind.! Thunb.! fl. Cap. p. 209 (ubi errore folia 1 lin. longa dicuntur). T. capitatum Banks in h. vind.! (non L. et Thunb.). Fruticulus 1-2-pedalis, caule ramisque lignosis cylindricis, non scabris. Folia 3-8 lin. Jonga, $\frac{1}{9}$ lin. Ionga, approximata, api ce ramorum imbricata, grosse ad marginem et carinam scabra. Capitula 7-15flora, nec longo pedunculo nudo fulta ut dixit Linnæus. Flores bracteis mixti. Bractea 1-2 lin. longa, foliis vicinibus latior et margine pallida. Bracteolap 1-1 $\frac{1}{2}$ lin. longre. Flos $1 \frac{1}{2}$ lin. Stylus truncatus. Nux cum perigonio 2 lin. longa. (v. S.)

$\beta$, gracile, ramis, foliis capitulisque gracilioribus. 5 In Africà Capensi austrooccid. T. scabrum, b, Drège! in h. ber., E. Mey. et Drège 2 Pll.geo. Docum. p. 226 . (v. s.)

$\gamma$, denudatum (Sond. in Florâ 1857, p. 361), foliis vix scabro-dentatis. $\stackrel{\jmath}{\jmath}$ In Africâ Capensi. T. capitatum \& Thunb.! in herb. Upsal. (v. s.)

79. T. P U BESCENS (Alph. DC. esp. nouv. Thes. 6 juin 1857, p. 7), orectum, undique pubescens, cinereum, ramis striatis, ramulis patentibus, foliis creloris erectis linearibus teretibus acutiusculis, floribus apice ramulorum capitellatis, bracteå et bracteolis lanceolatis acuminatis ciliatis florem aquantibus, stylo antherarum apicem attingente, nuce... 5 In Africâ Capensi (Ecklon et Zeyher n. $\mathbf{5 4}$ in h. reg. ber.!). T. hirtulum Sond. in Florà 21 juin 1857 , p. 359 . Species pube distinctissiraa, T. capitato affinis. Rami cylindracei, rigidi; ramuli floriferi laterales, pauci, graciles. Folia 3-4 lin. longa, $\frac{1}{3}-\frac{1}{2}$ lin. lata, undique pilosa. Capitula densiflora, 3 lin. solum lata, 8-10-flòra. Bracteæe et bracteolæ subæequales $1 \frac{1}{2}-2$ lín. longæ, dorso subconveræ. Flos junior obovoideus, parte superà non profunde 5-fidà. Barba loborum alba stamina usque pendens. Filamenta sub lobis inserta. (v. s.)

80. T. Gapitellatum (Alph. DG. esp. noliv. Thes. 6 juin 1857, p. 7), caule ramis. que erectis, foliis linearibus acutis erectis demum falcato-patentibus crassiusculis dorso convexis, capitulis terminalibus paucifloris, bracteâ et bracteolis laneeolatis florem æequantibus integris vel subundulatis intus concavis, stylo minimo, nuce obovoideâ stipite $\dot{4}^{\circ}$ perigonii parte liberâ‘ $3^{\circ}$ ? longiore nervis primariis 5 secundariis minoribus 5 et nervulis obliquis reticulatà. 5 In Africa Capensi (Eckl. et Drège in h. vind.! n. 4, 51, 7, id. num. Eckl. et Zeyh. in h. Deless.! non in h. ber.). T. brachycephalum Sond. in Florà 1857, p. 360 , ex ipso auct. ibid, p. 406 . Fruticulus cum radice ramosà pedalis. Caulis ramique lignosi, parce foliosi, inferne cylindrici, superne angulosi, ut folia et bractere glaberrimi. Folia 1 $\frac{1}{2}-3$ lin. longa, intervallis subæqualia, $\frac{1}{2}$ lin. lata. Eapitula 1-7, sæepius 3-5-flora, pedunculo oppositifolio terminali circiter 2-3 lin. lorigo fulta. Bractea 1-1 $\frac{1}{2}$ lin., bracteolæ lineam longæ. Flores in herb. nigricantes, pilis vero internis albis. Nux (unica imperf. in specim.) lineam longa. (v. s.)

81. T. DE NSIFL O R M (Alph. DC. esp. nouv. Thes. 6 juin 1857, p. 7), caule ramisque erectis, foliis linearibus acuminatis semierectis crassiusculis dorso convexis, capitulis terminalibus ovato-globosis densifloris, bracteâ -ovato-acuminatâ vix carinatâ. flore æquali aut sublongiore, bracteotis ovato-lanceolatis acuminatis carinatis ut bractea margine subintegris, stylo minimo, nuce... 5 In Africâ Capensi (Ecklon et Zeyher 4, 51, 7, in h. ber.! Verreaux in h. Boiss.!). Sub num. 5 Eckl. et Zeyh. in quibıisd. collect. si recte intellexi cl. Sond. in Florâ 1857, p. 406. Rami inferne validi, ramosi, ramulis erectis $3-5$ poll. longis, prope capitulum paucifoliosis. Folia 3-6 lin. longa, intervallis in basi ramorum subæqualia, $\frac{1}{2}$ lin. lata, superiora margine tenuiora. Capitula 4 lin, longa, 3 lin. lata, bracteis et bracteolis erectis acutis flores densos tegentibus. Flores (an semper ?) 3 intra bracteam 1:-2 lin. longam. Bracteolæ cujusque floris valde carinatæe, inlus concavæ, margine magis quam bractea subdenticulatæe, lineam longæ. Flos vix lineâ longior. Descripsi specim.h. ber.ubi certe pili adsunt antheram cun lobo jungentes. Differt a T. spicato invito cl. Sond. l. c. (v. s.)

$\beta$, Linkii, foliis brevioribus. $ち$ E capite B. Spei (h. Link ! nunc reg. ber.). Rami simillimi, recti. Fohia (superiora) 2-3 lin. longa. Capitula fructifera globosa, 4 lin. lata, bracteis latioribus, margine pallidioribus. Nuces subsessiles, ovoided, lineâ paulo longior, perigonio supero cylindrico-ovato duplo longiores, nervis 5 primariis validis, secundariis subminoribus, nervulis obliquis reticu- 
latis. Eadem sp. videtur, xtate diversa. Folia in aflinibus longitudine variant. (v. s.)

82. T. CA PIT T L IF L O R M (Sond. in Florå 1857, p. 363), ramis teretibus lignosis adscen* dentibue vel erectis numerosis, foliis raris, inferioribus..., superioribus ovato vel lanceolato-acuminatis brevibus glabris adpressis demum patentibus, capitulis 5-31-floris apice ramulorum, bracleis sterilibus 1 -2 prope flores ovato-acutis subciliatis, fertilibus et bracteolis late ovato-acutis ciliolatis subæqualibus flore brevioribus, stylo minimo, nuce ellipsoideâ vel obovoideâ stipite $5^{\circ}$ perigonio supero obtuso $3^{\circ}$ longiore nervis 10 validis et nervulis obliquis crebris reticulatâ. 5 In Africâ Capensi (Zeylıer ! in h. ber. sine num. et Verreaux in h. Boiss.l Eckl. et Zeyh.! 18, 1, 11 in h. ber.; idem ac Dregei n. 8169 e Gnadenthal, fide Drège in Linn. 20, p. 211, non tamen Drège 8169 in h. Turczan. de quo conf. ad sp-dub.). T. lineare Spreng. ined. in herb. ber.! Ex Sond. hic referendi num. Zeyh. 3811, partem num. 17 Eckl. et Zeyl., de quo confer ad T. leptocaulon (supra n. 60, et 47 Eckl. et Zoyh. (cujus specimen imperf. in h. ber. vidi.). Fruticulus 6-12-poll., inferne uudus, superne ramosus; rami folia rara $\frac{1}{2}-\frac{3}{4}$ lin. longa. Ramuli floriferi rigidi, 2-9 lin. longi, foliis adpressis raris apice ad bracteas transeuntibus. Bracter rotundato- vel late ovato-acutæe, membranaceæ; bracteolæ subminores cum bracteis imbricatæ, similiter lacerato-subciliatæ. Flos linea brevior. Nux lineam longa, perigonio supra $\frac{1}{2}$ lin. coronata, stipite minimo. (v. s.)

83. T. CONFINE (Sond. in Florả 1857, p. 363), suffruticosum, subpedale, glabrum, u ramosissimum, ramis teretibus attenuatis, foliis squamieformibus $\left(\frac{1}{2}-1\right.$ lin. longis) subulatis adpressis, floribus 4-6 minutis alternis spicatis, bracteis ovatis cuspidatoacuminatis ciliolatis flore brevioribus, perigonii subtubulosi (lineam longi) 5 -fidi lobis barbatis. 5 In Africâ austr. ad pedem montis Witbergen, inter Gariep et Caledon fluv. (Zeyher). Præcedenti proximum ex Sond.

84. T. EU P H RA S O IDE S (Alph. DC. esp. nouv. Thes. 6 juin 1857, p. 8), humile, ramosissimum, subcinereum, ramis teretibus, foliis raris in caule anguste linearibus acutis patentibus dorso teretibus superne canaliculatis glabris, in ramis lanceolatosubulatis multoties brevioribus semierectis subciliatis, fioribus 1-3 in apice ramulorum, bracteâ et bracteolis lanceolatis acuminatis flore brevioribus ciliolatis, stylo minimo, nuce ellipsoideâ, stipite duplo perigonio supero vix duplo longiore nervis primariis 5 validis secundariis 5 vix minoribus nervulisque obliquis reticulata. 5 In Africâ Cajensi (Ecklon et Drège in'h. vind.! n, 37, 84, Eckl. et Zeyh. in h. ber.l id. num.). T. strictum, $\delta$, specimen sinistr. herb. Thunb.l (non alia). T. Hottentottum Sond. in Florâ 1857, p. 363 (fide ejısd. p. 407). Radis ramosa et caulis semipedalis ramis duobus basi oppositis plantam annuam indicant, lignosa tamen. Rami diffusi vel erecti, rigidi, oculo armato non scabri sed punctulati. Folia inferiora, in plur. specim. deficientia, 6-12 lin. longa, $\frac{1}{4}-\frac{1}{4}$ lin. lata, duo ima pollicaria opposita (cotyledones?); ramealia dentiformia, acutissima, $\frac{4}{2}$ lin. longa. Ramuli floriferi rigidi, subangulosi, axillares, apice folia sive bracteas 4-6 præbentes. Flos lineam longus, bracteis $\frac{1}{3}-\frac{3}{6}$ lin. Pili inter lobum et antheram adsunt ut in aliis, invito cl. Sonder. Nıx $1 \div$ lin. longa, parte superâ perigonii cylindraceâ lin. longấ (Iuam stipes minore. (v. s.)

85. T. Mí номенiA (Alph. DC. esp. nouv. Thes. 6 juin 1857, p. 8), subcinereum, caule ramisque adscendentibus humilibus, foliis inferioribus anguste linearibus acutis, superioribus brevioribus lanceolatis acuminatis; ramulis extremis foliiferis apice 1-3-5-floris, bracteâ bracteolisquc lanceolatis concavis integris vix ciliolatis acuminatis subæqualibus tlore duplo brevioribus, stylo brevi, nuce obovoideâ stipite duplo perigonii parte liberd vix duplo longiore nervis primariis 5 secundariis 5 vix minoribus et nervulis obliquis reticulatâ. 5 In Africà Capensi austrooccid. versus Berg-river (Drège : 8168, D, in h. vind., E. Mey. et Drège 2 Pfl. geo. Docum. p. 226). Fruticulus in specim.8-pollic., caule sive ramo e basi-adscendente tereti denudato a medio ramoso. Folia pauca in parte infer. ramorum 3 lin. longa, gracillima; pleraque secus ramos el ramulos vix lineam longa, erecta vel falcatopatentia, a basi concavâ extus convexì acuminata, intervallis paulo breviora. Ramuli floriferi 1:3-4 versus apicem ramorum, sæpius 3 lin. longi.,Bractea et bracteolie folio subsimiles, acumine frequenter reflexo; bracteolis bracteâ vix brevioribus. Flos lineam longus. Stylus originem stam. vix attingerss. Nux cum stipite et 
perigonio cylindrico 2 lin. longa. Hánc sp. non descripsit cl. Sond., ipso monente, in Flor. 1857 , p. 407. (v. s.)

86. T. ThUNBER IANUM, humile, ramosissimum, ramis teretibue scabro-pilosiusculis extremis gracilibus non rigidis, foliis linearibus læviusculis, floribus 1-3-5 apice ramulorum; hracteâ et bracteolis lanceokatis acuminatis flore brevioribus ciliolatis, stylo minimo, nuce ellipsoideấ stipite duplo perigonio supero vix duplo longiore nervis primariis 5 secundariis 5 vix minoribus et nervulis obliquis teticulatâ. ち In Africa Ópensi ad mont. Bockland. T. pániculatum Thunb.l herb., prodr. p. 45, fl. Gap. ed Schult. p. 210 (non Linn.). Specimers authenticum semipedale, basi lignosum, ramis diffusis multiplicibus. Folia 3-1 lin. longa $\frac{1}{4}$ lin. lata. Flos 1 lin. longus. Bracteæ et bracteolæ pro numero florum variantes, $\frac{1}{4}$ lin. longæ. Perigonium omnino T. euphrasioidis, T. Micromeriæ et T. tenuis; equidem species omnes affines. Differt a priori ramulis non rigidis plerumque flexis, foliis crebrioribus non a basi ad apicem diversissimis, scạbritie magis distinctâ minine cinereâ; ‘ T. Micromeriâ colore non cinereo, ramis scabro-pilosis, foliis rarioribus minoribus; tandem a T. tenui ramis non lævibus, foliis latioribus, floribu's raro solitariis, bracteis minus rigidis et acutis. Confer ad T. hispidulum Lam. in spec. dub. (v. s. in h. Ups.)

87. T. TENUE (Bernh. in Krauss pl. Cap. in Flora 1845, p. 81), ram bus teretibus strbstriatis, ramis lævibus diffusis gracilibus, foliis anguste linearibus acutis glabris demum patenti-reflexis, ramulis floriferis glabris secus ramos axillaribus 6 -bracteatis flore solitario terminatis floribusque interdum lateralibus, bracteis lanceolato-subulatis erectis imbricatis subdenticulatis florem non superantibus, stylo brevissimo, nuce ovoideâ luracteis duplo stipite triplo longiore lobis perigonii obtuse conniventiłus umbonatâ nervis primariis $\mathbf{5}$ secundar̆is $\mathbf{5}$ subæqualibus et nervulis obliquis reticulatâ. $亏$ In Africâ australi, prope Constanciam (Krauss ! h. Boiss.), (Eckl. et Zeyh. 24, 83, 7 in h. ber., Zeyher ! 83 in h. Boiss.), circa Port-Natal (h. vind.! a Pœepp. cornm.). Caules in herb. 1-2-pedales, lignosi, glabri. Folia sparsa, $2-4$ lin. longa, $\frac{1}{6}$ lin. lata, superne canaljeulata. Ramuli florif. 3-5 lin. longi, semper axillares, basi nudi, bracteis apice 6 initio per paria fere approximatis deinde inferioribus alternis segregatis, margine tenuissime subserratis, basi crassiusculis concavis. Flos $\frac{5}{4}$ lin. longus, bracteis solum $\frac{4}{2}$ lin. Pars infera perig. obconiça. Lobi ovato-lanceolati, non appenticulati, pilis albis densis. Stylus infra stamina. Nix lineam longa, cum perig. umbonato ovoidea. (v. s.)

88. T. ZEYHERI (Alph.DC. esp. nouv. Thes. 6 juin 1857 , p. 8), ramis lignosis tortuosis striatis foliisque scabris, foliis ramorum raris linearibus patentibus planiusculis, ramulorum linearibus carinatis subpatentibus, floribus apice ramulorum solitariis ternisve, bracteẩ bracteólisque subæqualibus florem æquantibus lanceolato-acuminatis concavis dorso carinatis scabris, flore ovoideo, stylo apices antherarum attingente, nuce.... 5 In Africâ Capensi (Zeyherl n. 114, in h. Boiss.). T. Transgapinum Sond. jin Florà 1857, p. 356, fide ips. p. 407. Specimen deformatum, truncatum; ramis intricatis aut divergentibus validís. Folia infer. $4-5$ lin. longa, $\frac{1}{2}$ lin. lata, crassiuscula, non carinata ; super. $1-2 \frac{1}{2}$ lin. longa, $\frac{1}{3}$ lin. láta, vix acuta, nervo dorsali et margine magis scabra. Flores 2 lin. longi, bracteis cincti, apice pedunculi brevissimi vel ramuli. Alabastrum obtusum, pallidum. Lobi ex pilis intricatis basi coadunati. Stamina infra lobos inserla, antheris partim intra lobos. Ovulis funiculis longiusculis pendentibus - - Th. virenti (n. 45) ex flore quodam modo affine, sed lobi barbati. (v.s.)

89. T. L O EELX IDES (Alph. DC. esp. nouv. Thes. 6 juin 1857 , p. 8), ramis angulosis cum foliis linearibus glabris cinerascentibus, floribus axillaribus vel pedunculos brevissimos terminantibus solitaris ternisve, bracteâ flore sequali aut sublongiore bracteolisque flore subbrevioribus aut requalibus lanceolato-acuminatis carinatis subdenticulatis, flore basi obconico superne pvoideo profunde 5 -fido; lobis ex apice barba pendente pilosis margine tomentosis, stylobasi an therarum attingente, placentâ rectâ, nuce ovoideo-ğlobosâ subsessili perígonio supero connivente quadruplo longiore nervis primariis 5 validis securidariis 5 minoribus tertiariis transversis et obliquis. " In Africâ Capensì (Fekl. et Zeyh. 25, 33, 10 in h. ber., excl. specimine non floric.), in interioribus ad Litakun (Lemue! in h. Deless.). T. recurvifolium Sond. in Florâ 1857, p. 356, fide ejusd. p. 407, Ramus vel caulis? 4-5-poll., basi lignosus, ramis pluribus alternis vel dichotomis. Folia $4-6$ lin. longa, $\frac{3}{2}$ lin. 
lata, crassiuscula, exsiccatione? rugulosa, dorso convexa. Flores secus ramos et apice sparsi, sessiles axillares vel stipite extra-axillari 1-2 lin. longo fulti, $2 \frac{1}{2}$ lin. longi, Bractea 2-3 lin. longa, bracteolæe 2 lin., primo adspectu integræe. Alabastrum ovoidéo-acutum, basi obeonicum. Lobi pone antheras pilosi, apice barbâ albâ donati, marğine inflexo puberuli, cæterum glabri. Discus perigonio connatus sed prope sinus interne perspicuus. Placenta rectâ a præcedentibus differt. Th. vírenti (n. 45), sectionis diversæ. affine. Nuces ex specimine Litakun descriptee, cum perigenio toto 2 lin. longæe. (vis.)

\section{\$2. Fasciculus pilorum pone antheras nullus, sed pili quidam aurei minimi altitudine insertionis flamentorum in fauce dispositi. - Flores spicati.}

90. T. FRISEA (Linn. mant. p. 213, non Thunb.), caulibus simplicibus palmaribus duriusculis, folís linearibus basi angustioribus patentibus, floribus in racemum sive spicam terminalem dispositis sessilibus approximatis alternis secundis, bracteis propriis (bractcolæ) duabus lateralibus, perigonio 5 -fida, lobis lanceolatis apice et margine fibrillis inflexis lanatis, nuce rugosâ. - Ad caput B. Spej (KKœnig). Nihil ampilius in Linn. nisi claraeterès omnibus Thesiis capensibus communes. Planta igitur male cognita.

$\beta$, Thunbergii, caulibus pluribus ramosis et simplicibus, foliis oblongo-lanceolatis carnosulis acutis. 5 In Africæ Capensis maritimis sabulosis ad Verlooren Valley. T. Frisea Thunb.1 in herb. Upsal, diss. p.10, fl. Cap. ed. Sch. p. 210. T. funale h. imp. vindob.l (non L.). Ex speciminibus authenticis Thunbergii : caules ramique procumbentes passim radicantes, radicibus adventitiis gracilibus ; planta tota pedalis, inferne sublignosa'; folia non rará, 5-8 lin. longa, 1-1 $\div$ lin. lata, oblonga, basi angustata vix petiolata, apice acuta, patentia, superne plana, subtus plus minusve convexa nunc plana; pedunciuli ramos terminantes, fere aphylli ; flores sæpius ternati, fasciculis breviter pedunculatis vel sessilibus ad apicem pedunculi communis approximati spicam latam aut ovoideam nune secundan formantes; bractea et bracteolæe subininores ovato-acutæ, subciliatx, flore duplo triplove minóres; perigonium 1-1 $\frac{1}{\text { lin. }}$. lơngum, tubo obconico in pedicellum minimum basi angustato, parte liberâ 5-fida, lobis acutis ab apice barbat's, medio intus glabrịs, fauce pilosiusculâ ; stylo minimo apice capitato; placenta contortuplicato-sinuata; nux ellipsoidea stipite triplo perigonioque supero triplo major, nervis 10 et nervulis transversis reticulata, lineam longa.Verisimiliter species Linnæi. (v. s. in b. Thunb. et vindob.)

91. T. D E B L E (Brown prodr. Nov, Holl.p. 353, sine descr, Banks in h. vind.), eaule debili adscendente vel decumbente pauciramoso teretiusculo, foliis anguste linearibus elongatis carnosulis acutis, tloribus ternatis vel solitariis apice ramorum laxe spicatis pedicellatis, bracted bracteolisque paulo brevioribus lanceolatis margine subdenticulatis pedicello vix longioribus, stylo minimo, nuce... 万In Africì Capensi (Brown, Banks l, h. ber. a Nus. paris. accept.!).- Spreng-syst. 1, p. 831 ? (ubi flores bracteà breviores dicuntur). Caules 8-12 poll. longi, inferne flexıosi nudi, superne sparsim foliosi. Folia 5-9 lin. longa, $\frac{1}{2}$ lin. lata, patentia. Spic $x$ elongatec, 6-12 lin. longæe. Flores lineat longi, pediccllo $\div$ lin. fulti. Alabastra ovoideo-acula. Bracteæ $\frac{1}{4}-\frac{1}{9}$ lin̈. Iongæe, ut bracteola oculo armato denticulis vel ciliis minimis raris margine donatis. Pars libera perigonii profunde 5-fida, lobis acutis. - Valde aflinis Th. Friseæ, sed folia angustiora minus carnosa. (v.s.)

$\beta$, Ecklonis, humilius, spicis abbreviatis densifloris. 5 In humidis mon tis Tabulæ versus septentr. (Ecklon! 795 in h. vind.). Spicre et llores Th. amblystachyi sed bractè.e et bracteolæ ut in præsenti non in tegræe et folia latíora $\frac{1}{1}-\frac{1}{2}$ lin. lata. Nuces juniores adsunt globose, subsessiles, perigonio supero cylindraceo breviores, nervis 10 parvis et nervulis transversis rugulosæ. (v. $\dot{\mathrm{s}}$.)

$\boldsymbol{\gamma}$, humile, humilius, vix lignosum, spicis abbreviatis, fasciculis inferioribus florum breviter pedunculatis. - Ad Gaput B. Spei prope Bergrivier (Ecklon et Zeyl. n. 45, sine nom. in h. ber.!). T. Frisea Sond. in Florâ -1857, p. 359, quoad num. 45 Eckl. et Zeyh. T. debile Zeyher ! sine num. in h. ber. Caules e radice lignosâ ramosâ tortuosâ decumbentes, 3-4-pollic., foliosi. Folia 
4-5 lin. longa, $\frac{1}{4}-1$ lin lata. Inflorescentia junior, serius verisimiliter diversa. Bracteæ et bracteolæe papilloso-denticulatæ. (v. s.)

92. T. FUNALE (Linn. sp. p. 302), caulo ramisque teretiusculis virgatis adscendentibus flexilibus, foliis raris, inferioribus anguste linearibus dorso teretibus acuminatis, superioribus lanceolato-acuminatis erectis multo brevioribus, spicis clongatis tenuibus ramos fere aphyllos terminantibus, floribus solitariis ternisve in axillâ bractere flore æequalis aut brevioris, bracteolis flore duplo brevioribus bracteisque lanceolato-acuminatis, stylo minimo, nuce ellipsoideâ subsessili, perigonio supero vix breviore nervis prínariis 5 secundariis $\mathbf{5}$ subminoribus et. nervulis obliquis reticulatà. $\zeta$ In Africâ Capensi occid. (Drège ! 2 Pfl. geo. Docum. p. 226, Zeyher, n. 3803, 3808 et 3810, ex Soud in Florâ 1857, p. 358) et orient. ad Port-Natal (Poeppig. in h. vind.!) - Thunb.! diss. p. 7, fl. Cap. ed. Sch. p. 209, Drège! in h. vind., Eckl. et Zeyher 49,85 in h. ber.! Banks ! ibid. T. adpressifolium Sond. in Florâ 21 jun. 1857, p. 358 (quoad numerum 49 E. et Zeyh.). Rami vel caules inferne lignosi, teretes ; ramuli extremi graciles, elongati, subteretes. Folia duplicis natura : inferiora ramorum et caulis longe et anguste linearia, in plerisque speciminibus rara delapsa ; superiora 1-14 lin. longa e basi latâ subulata; omnia ut bracteæe et bracteolæ glaberrima, integra. Spicæ 6-15, sæpius 8-12 lin. longæ, acutæ, graciles. Bracteæ foliis similes. Flos centralis vix lineâ longior, stipite cum ovario extus non distincto, flores laterales breviores. Lobi apice barba albâ aut (in sicco) rufescente donati, margine subtomentosi, medio glabri. Pili lutei breves circa originem staminum. (v. s.)

ß. Caledonicum (Sonder in Florâ 185\%, p. 359), foliis recurvatis, spicâ abbreviatâ, floribus subternis. - Prope Caledon (Eckl. et Zeylı. n. 51).

93. T. S I с A т U (Linn. mant. p. 214), caule ramisque orectis strictis subangulatis, foliis erectis inferioribus raris longe et anguste linearibus acutis dorso teretibus, 'superioribus lanceolato-linearihus acuminatis multo brevioribus, spicis terminalibus ovoideis vel ovoideo-oblongis, floribus solitariis ternisve in axillâ bracteæ flore subæqualis, bracteolis bracteà angustioribus vix brevioribus omnibus lanceolatis acuminatis carinatis demum margine ampliato attenuatis, nuce ellipsoidea subsessili perigonio supero vix breviore nervis primariis 5 secundariis 5 subminoribus et nervulis obliquis reticulatâ. 5 In montibus Africe Capensis (Linn.), in Africà Capensi (Eckl. et Drège, 5,1,11 in h. Vind.! Eckl. et Zeyh. 6, 4, 2 in h. ber.? Eckl. et Drège 6, 4, 2 in h. Vind.? Krauss! ibid.). - Thunb.! herb. fl. Cap. ed. Schult. p. 209 (T. funali junxit in Diss. de Thes. p. 7.) T. spicatum Drège, pl. exs. in 1. Vind. T. diversifolium et T. subnudum Sond in Florả 1857, p. 359 et 360 (fide descr. et num. cit.). Caulis pedalis, superne ramosus. Folia infer. 12-18 lin. longa, $\frac{1}{2}$ lin, lata; super. 3 lin. longa, $\frac{1}{2}$ lin. lata, convexa nec cylindracea. Spicæ densifloræ, 4-6 lin. et serius 8-12 lin. longæ. Bracteæ et bracteolæ per anthesin fere ut in T. funali, deinde latiores membranacex, $1 \frac{1}{2}$ lin longre. Flos T. funalis. N'ux cum perigonio 2 lin.' longa. - Per anthesin facile a Th. funali distinctum, postea difticile. Pili certe nulli pone antheras in specim. Thunb., in 5, 1, $11 \mathrm{~h}$. her. et Drège h. vind .: unde et aliis char. a T. densifloro (n. 81) differt. Perigonii pars supera profunde 5-fida. Specirnina 6, 4, 2, supra cit. forsan ad Th. funale referenda. (v. s.)

94. T. aм ви у sт аснуим (Alph. DC. esp. nouv. Thes. 6 juin 1857, p. 6), caulibus erectis et diffusis gracilibus pauciramosis, foliis filiformibus non raris omvibus elongatis, spicis ovatis obtusis ramos ramulosque terminantibus, floribus ternis in axilla bractea flore brevioris, bracteolis flore triplo brevioribus bracteisque lanceolato-acuminatis, stylo minimo, nuce stipitatâ..... ந In Africà Capensi (Ecklon et Drège 10.1.11 in h. vind.!, h. DC.! ex h. Deless., Eckl. et Zeyh. 10.1.11 in h. ber.!). T. monticolum Sond. in Florà 21 jun. 1857, p. 359, Loci nat. ex Sond. sunt Worcester, mons Tabularis, Hottentot/s-Hollandberge et Kleinrivicrsberge Caledon. Caules 5-8 poll. alti, basi teretiusculi, apice subangulosi. Folia aqualiter sparsa, 3-8 lip. longa. $\frac{1}{3}$ lin. tata, intervallis sape longiora, semipatentia, acuta. Spice 4-8 lin. longæ, floribus approximat is majoribus quam in T. funali. Pars nuda sub spica 4-6 lin. longa. Flos 1: lin. longus. Bracteæ et bracteolæ integerrimæ, glabrre. Bractea lin. longre. Alabastrum basi obconicum, apice ovoideo-acutum. Barba perigonii in sicco fulva. Pili breves in circulum circa originem staminum dispositi, flavi, pone antheras nulli. Nomen cx spjcâ obtusâ. Descripsi spec. Eckl. et Z. - An a T. funali satis diversum? (v. s.) 
95. T. MIGROP OG ON (Alpli. DC. esp. nouv. Thes. 6 juin 1857, p. 6), radice perpendiculari, caulibus pluribus erectis brevibus simplicibus subaugulosis, foliis erectis inferioribus fliformibus superioribus lanceolato-acuminatis, spicis termiualibus laxis, floribus solitariis axillaribus, bracteà lanceulatà acuminatâ flore subbreviore. bracteolis similibus flore duplo brevioribus, perigonii par te liberâ 5 -fidà, lobis apice concavo et margine breviter barbalis, stylo minimo, nuce.... $\mathcal{\psi}$ in Africà Capensi (Eckl. et Zeyher n. 12. 51. 8 in h. ber.1). T. patentiflorum Sond. in Flora 21 jun. 1857, p. 357 (fido ejusd. p. 406). Radix 3-pollic.. indivisa, supcrne caules 3-6-pollic. proferens, basi vix lignosos, cæterum herbaceos, graciles, ut in Th. funali nunc apice paulo flexuosos. Folia inferiora 4-6 lin. longa, intervallis longiora, $\frac{1}{3}$ lin. lata; superiora 3 lin. longa, intervallis breviora, alpressa, subulata. Spica 6-12 lin. longæ, floribus basi distinctis. Bractea $1 \frac{1}{1}-1$ lin. longa; bracteolæe $\frac{3}{4}$ lin. longe, omnes ut folia glabræ integre. Flos $1 \frac{4}{2}$ lin. longus, basi obconica gracili pedicellatus, limbo ut in Th. funali globoso. Lobi apice concavi, ibi margine barbâ brevi albâ donati et infra margine tomentosi. Pili nulli pone antheras. Antheræ intra lobos longiusculee, filamentis infra lobos. I'ili lutei breves, circa originem filamentorum sparsi. Ex pilis brevibus loborum accedit ad Thesia sectionis Euthesii, Th. cucullato, etc., sed haljitus et creteri char. floris præsentium. (v. s.)

96. T. JUNGEUM (Bernh.! in Florâ 1845, p. 80), suffruticosum annuum? caulibus ramosis, ramis teretiusculis virgatis adscendentibus, foliis distantibus squamrformibus triangtlari-acuminatis margine scariosis, floribus sccus ramos extremos elongatos sparsis solitariis sessilibus, bracteâ et bracteolis folio similibus bracteolis bracteâ aqualibus multo angustioribus flore duplo brevioribus, parte liberâ perigonii 5-fidâ lobis acutis interne sub apice et e marginibus pilis pendentibus barbatis, stylo minimo, nuce globosâ sessili perigronio supero ovoideo duplo longiore 10 -nerviẩ et nervulis obliquis transversisque reticulata. $5 \bigcirc$ ? In Alricà Capensi (Eckl. et Zeyh. 46. 4. 2 in h. ber, Eckl. et Drège 46.4. 2 in h, vind., Eckl. et Zeyher $! \mathrm{n} .13$ in h. ber.), ad Zitzikamma (Kranss.l in h. vind. et Boiss.). T. paronychioides Sond. in Florâ 1857, p. 359 (fide descr. et num. 13). Planta cum radice 9-15 poll. alta, primo adspectu aphylla. Radix perpendicularis, inferne ramosa. Caules e collo multiplices. Rami elongati, Eæpe simplices. Folia duo (cotyledones?) longe et angusto linearia, cylindrica, $\frac{+}{+}$ lin. lata, acuta, sub basi caulium opposita; cretera omnia $\div-\frac{3}{4}$ lin. longa, e basi latå acuminata, demum subpatentia. Spicæ elongatæ, laxæ. Bractea et bracteolæe foliis vix breviores, margine magis scariosre et subdenticu. latæ. Bracteolic bracteí duplo angustiores, longit. sequales.i Flos lineam longus. Nux lineam longa, perigonio $\frac{1}{2}$ lin. obtuso vel acutiusculo terminata. (v. s.)

97. T. FLEXU os UM (Alph. DC. esp. nouv. Thes. 6 juin 1857 , p. 6), caulibus diffusis, ramis teretiusculis patentibus spicisque prosertim flexuosis, foliis distantibus adpressis squamseformibus ovato-vel lanceolato-acuminatis margine scariosis, floribus secus ramos extremos elongatos sparsis apice approximatis solitariis sessilibus, bracteâ et bracteolis folio similibus flore sublorevioribus, bracteolis bracteâ vix angustioribus sublongioribus dorso carina scarioso-denticulatâ auctis, parte liberâ perigonii 5 -fidâ, lobis acutis, stylo minimo, nuce globosâ sessili perigonio supero ovato-cylindraceo vix duplo longiore 10 -nervia et nervulis obliquis transversisque reliculatâ. ந In Africâ Capensi (Eckl. et Zeyh. 0. 2.3 in h. ber.1 Eckl. et Drège 9. 2. 3. in h. vind.l). T. spicatum Drège (pro parte) in Linn. 20, p. 211, non L. T. junceum Sond. in Florá 21 jun. 1857, p. 359, quo ad num. 9 Eckl. et Zeyh. Species cum radice 6-10-poll., diffusa, forsan annua quamvis lignosa. Th. junceo valde proxima, tamen spicis flexuosis, ramis horizontalibus aut varie flexis, et priesortim bracteolis majoribus dorso cristato-carinatis certe distincta. Folia, bracter et bracteolæ ut in T.junceo margine albo-scariosæ, demum lacerato-dentatæ, præsertim bracteæ et bracteolæ. Flores lineam longi. Nux' lin. longa, perigonio supero $\frac{s}{4}$ lin. (v. s.)

98. T. MACR OS A Gну (Alph. DC. esp. nouv. Thes. 6 jun. 1857, p. 6), ramis erectis elongatis subsimplicibus, foliis remotis inferioribus ramorum ovato-lanceolatis acutis vel obtusis, aliis lanceolatis et lineari-lanceolatis acuminatis, floribus longe spicatis solitariis ternisve, bracteà pracipuâ lanceolatà acuminatâ flores aquante, bractea cum bracteolis florum lateralium lanceolatis acuminatis, bracted duplo bracteolis triplo flore brevioribus, parte superâ perigonii 5-fidà, lobis acutis, stylo minimo, nuce ovato-globosî stipite duplo perigonio supero erecto triplo ma-

XIV. 
jore, nervis primariis 5 mediocribus'secundarijs 5 parvis nervuliscue paucis obliquis et transversis. 5 In Africâ Capensi (Drège! Eckl. et Drège 7. 76 in hi. vind.!, Eckl. et Zcyh. 7. 76 in h. ber.! et Deless.!, Zeyl. 7. 76 in h. Boiss.!) et orientem versus ad Port Natal (Guenzius! n. 407 in h. Boiss. et 531 in h. vind.). T. spicatum, a, Drègo! in h. vind. (non ejusd. in h. Deléss.!, nec L., ubi spicæe oblongæ). T. sparteum Sond. in Florâ 21 jun. 1857, p. 358, fidc cjusd. p. 406 . T. Natalense Sond. ibid. (a -Guenzio lectum, descriptione cum num. cit. Guenzii quadrante). Rami virgati, 6-10-poll., teretiusculi, ut folia et bractese glaberrimi. Folia inferiora quædam ramorum 2-3 lin. Ionga, lineam interdum lata, crassiuscula; pleraque 3-6 linlonga, $\frac{1}{2}$ lin. lata, subulata, sæpíus erecta, nunc semipatentia. Spicæe 1-3-poll.. vetustiores imo 5-pollic., floribus tunc ut folia remotis. Bractea cujusque fasciculi 1-1 $\frac{1}{2}$ lin. longa, subulata. Flos lin. longus, barbâ (in sicco) albâ, albido-rufâ, vel rufá intra lobos. Nux $1 \frac{1}{2}$ lin. longa. (r.s.)

99. T. Рн XLL OS т A GH Y M (Sond. in Florà 1957, p. 355), suffruticulosum, glabrum, caulibus 3-k-pollicaribus erectis subramosis, foliis adpressis approximatis linearisubulatis calloso-apiculatis (4-6 lin. Jongis), floribus axillaribus approximatis sessilibus folio duplo brevioribus bracteas laturales lineares foliaceas aquantibus, perigonii tubulosi profunde $\mathbf{5}$-fidi lobis obtusiusculis barbalis (lineam longis). 5 In Africà Capensi ad rupes prope Port Elisabeth et Zwartlopsrivier (Zejh. n. 3800).

100. T. El a t IUs (Sond. in Florâ 1857, p. 355), fruticosum, pluripedale, glabrum, ramis patentibus teretibus, toliis carnosis lineari-trigonis carinatis in caple remotis (6-8 lin. longis) in ramulis approximatis plus duplo brevioribus quadrifariam patentibus, floribus in axillis foliorum supremorum solitariis spicam foliosam expibentibus, bracteis lateralibus trigonis fore subbrevioribns, perigonii tubulosi 5 -fidi (circit. 2 -lin.) lobis barbatis. $亏$ In Africa Capensi ad Olifantsrivier, Driefontein (Zeyh. n. 1503 ex parte).

101. T. ECKL ONIANUM (Sond. 1. c. p. 356), glabrum, sesquipedale, caulibus numerosis prostratis teretibus, ramis adscendentibus, foliis homomallis lanceolatis acuminatissimis subtus concavis carnosis, racemis axillaribus pedicellatis nutantibus 5-8-floris folio sublongioribus, bracteis flore longioribus, intermedià oblongolanceolatá margine membranaceà, lateralibus duplo angustioribus et parum brevioribus, perigonii tubulosi 5 -fidi lobis barbatis apice acuto glabro, nuce majusculà globosâ elevato-costatâ inter costas rugulasâ nitidà. - In planitio Cáponsi (Ecklon). Species, ex cl. auctore, distinctissima cum nullà aliâ confundenda. Fdlia caulina poil. longa, $1 \frac{1}{2}$ lin. lata. Racemus crolutus cum pedicello circiter poll. longus.

102. T. GRISE U II (Sond. 1. c. p. 357), suffruticulosum, glabrum, undijue punctis minutis glandulosis obsitum, caulibus numerosis 2-4-pollicaribus rliffusis, foliis erectis lincari-teretiusculis acutis ramulorum duplo brevioribus (2 lin. longis), racemis spicatis antc anthesin densis-comosis $\left(\frac{1}{2}-1\right.$ poll. longis) uvolutis laxiaribus, bracteis lanceolatis, lateralibus flore bracteâque intermediẩ brevioribus, perigonii tubulosi 5 -fidi ( $\frac{1}{2} \mathrm{lin}$. longi) lubis obtusiusculis barbatis. b In Africa australi, inter 11. Gariep et Caledon, basi mantis Witherge, ad 4-5000 ped. alt. (Zeyher).

103. T. VEGALISM ONTANUM (Sond. l. c. p. 358), sulfruticulosuns, semipedale, glabrum, caule ramisque erectis, foliis inferiorihus filiformi-trigonis (circ. A fim.) superioribus duplo triplove minoribus apice patnlis, horibus axillaribus sessilibus spicam remotifloram exhibentibus, bracteis lanceolatis flores requantibus perigonii tubulosi profunde 5 -fidi (lineam longi) lobis barbatis. 5 In Africà austr. a d Magalisherg (Zeyh, n. 1501).

104. T. NAR'IFL oR U (Sond. 1. c. p. 364), annuum, spithamaum, glabrum, caulibus gracilibus tenuibus subramosis angulatis, foliis sparsis tereti-subulatis acutis pollicaribus, superioribus brevioribus, floribus in apice ramulorum binis ternisve, bracteis lateralibus flore brevioribıs, intcrncdic florem aequante, perigonii tubulosi (lineam longi) 5-fidi laciniis acutis barbatis. (In Africa austr. ad Tulhaghskloof prov. Worcester (Eckl. et Zeyh. Santal. 11. 56). - $\Lambda$ n Thesidium propter radicem annuam, invito perigonio barbato?

\section{Seclio vi. Psicothesium.}

Pars libera perigonii sub-5-partita, laciniis linearihus angustis demum cadu* 
cis. - Speries annure, Brasilienses (aliis omnibus e vetere orbe), graciles, fere aphylla, floribus laxe spicatis, ideo habitu Leptomeria et quarumdam specierum Capensium Thesii. Fructus omnino congenerum. Lobi perigonii medio in superiore parte fasciculo vulgari pilorum ad antheram tendentium donati, cseterum glabri. Filamenta antheris multo longiora, basi loborum inserta. Stylus elongatus, obtusus. - Genus distinctum primo adspectu videtur, sed characteres omnes passim in Thesiis veris adsunt, exceptâ caducitate loborum quæ solum tarde evenit et sine articulo transverso. - Descriptiones fusiores ad cel. Martii Flor. brasil. misi.

105. T. BRASILIENSE, annuum, ramis erectis gracilibus, foliis raris lanceolatis adpressis minimis, spicis laxis gracillimis, floribus solitariis sessilibus, bracteâ flore $4^{\circ}$ breviore bracteolisque subbrevioribus lanceolatis, parte superâ et integrà perigonii ovoideâ inter nervos subinflatâ laciniis linearibus erectis caducis duplo breviore, nuce ovoideà sessili nervis 5 primariis validis 5 secundariis paulo minoribus apice bifidis et nervulis obliquis transversisque reticulatâ. $\odot$ In Brasilize campis ad Mugi das Gruzes prov. Sancti Pauli (Lund In. 722 in.h. meo), in Brasiliâ merid. (Sello!148 in h. r. ber.). Planta $12-15$ poll. alta, radice parvâ, caule ramisque striato-angulosis. Folia $\frac{\div}{4}$ lin. longa, e basi ovatâ acuminata. Flores secus ramos 3-5 poll. longas sparsi, 2 lin. longi, in axillis foliorum superiorum sive bractearum $\frac{1}{2}$ lin. loñgarum. Bracteolæ ut bractea sessiles, ovato-acuminatæ. Pars supera et integra perigonii bullis 5 in fructu bene perspicuis ut in pluribus Thesiis inflata;

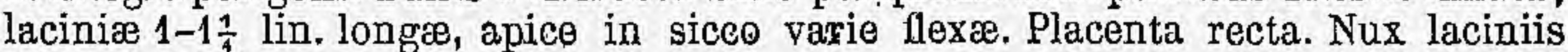
delapsis $1 \div$ lin. longa (v, s.)

106. T. APHYLLUM (Mart.l herb.), annuum?, ramis erectis, folis raris lanceolatis adpressis minimis, spicis rectis, floribus solitariis sessilibus, bracteâ bracteolisque fere aqualibus ovato-acuminatis flore $4^{\circ}-5^{\circ}$ brevioribus, parte superá et integrâ perigonii ovoideá laciniis linearibus erectis post florationem apice inflexis demum caducis duplo fere breviore, nuce ovoideâ sessili nervis primariis 5 validis secundariis 5 vix minoribus sursum bifidis et nervulis obliquis transversisque reticulatâ. $\odot$ ? In Brasiliâ (Mart.l in h. DC.), in Brasiliâ merid. (Sello! 1305 in h. reg. ber.). Hlanta erecta, subpedalis, primo adspectu aphylla. Folia $\frac{1}{2}$ lin. longa, in bracteas similes secus ramos transeuntia. Rami angulosi, rigidiores, crassiores quam in T. Brasiliensi. Flores secus ramos basi distantes, medio et apice magis ac magis proximi, 2 lin. longi. Bracteæ et bracteolæ $\frac{1}{2}$ lin. longa, rigidiores et basi latiores quam in T. Brasiliensi. Nux paulo major, apice non bullata. (v. s.)

\section{Species dubice.}

107. T. а м в I G U U M (Ten. fl. Nap. 3 p. 312), e regno neapolitano. Planta ex descr. non extricanda, quam Bertol. fl. it. 2, p. 740 sub. T. linophyllo cum pluribus aliis enumerat.

108. T. GL OBSERULFL ORUM (Sond. in Florâ 1857, p. 355), suffruticosum, pedale, glabrum, ramis erectis striato-angulatis, foliis patulis trigono-filiformibus acutis (semipollic.), floribus 3-5-glomeratis axillaribus, glomerulo folio $3 \cdot$ breviore, brac1 teis ovato-lanceolatis carinatis submembranaceis apice recurvato trigonis flore fructuque longioribus, perigonii minuti 5 -fidi lobis glabris, nuce ovatà striatâ. $\zeta$ In Africâ Capensi ad Zwellendam legit Mundt.

109. T. H ISPIDULUM (Lam. ill. n. 2789 , dict. 7. p. 630), caulibus panictulatis diffusis, foliis lineari-subulatis cauleque et plerisque plantæ partibus ex pilis brevissimis vix perspicuis scabriusculis, florum fasciculis terminalibus et lateralibus sessilibus, bracteis folio subsimilibus. 5 Ad caput B. spei (Sonnerat). Caules 4-6 poll., graciles, tortuosi, rugosi. Folia 3 lin. Ionga vel ultra; subrecurva. - Hujus varietas glabrata est Th. paniculatum Thunb. (not Linn.) secundum . Sonder FIora 1857, p. 363 , sed cl. auctor plantam Lamarcliii non vichisse ait.

110. T. procumbens (C. A. Mey. Verz. Pfl. Cauc. p. 40), caulibus procumbentibus ramosis, foliis linearibus subnervosis, racemis simplicibus secundis, bracteis tribus inxequalibus, calycis tubo 5-partito, laciniis tandem conniventibus apice inflexis drupâ oblongà subbrevioribus. - In pratis Caucasi occidentalis alt. 400-1200 hexap.

111. T.? SERRAt Ua (Kif. ex Dietr. syn. 1, p. 878), caule adscendente simplicissimor 
foliis lanceolatis ulringue attenuatis medio serratis, calycibus 4 -fidis. $\nLeftarrow$ In Bannatu.

112. T. VIRGATUM (Lam. ill. 2, p. 123, dict. 7. p. 627), ramis erectis virgatis nudiusculis, foliis subulatis brevibus remotissimis, floribus subumbellatis terminalibus. \& In Africà Capensi (Sonnerat ) Caules recti, glabri, rugosi, grano piperis minores.

T. HоскеАлU, е Bohemia. Opiz, Fl. Boehm. 2, p. 41-46. Varietates veriT. HUt TERIANUm, ex Hungariâ. $\{$ similiter, ex speciminibus authenticis obser-

T. UMBROSUM, e Bohemiâ. $\}$ vandæ.

T. Turczanin owII (Sond. in Florâ 1857, p. 354, sine descr.). Rhinostegia longifolia Turcz. in Bull. soc. Mosc. 1843 , p. 57 . Numerus 8169 Drège pl. Cap. ex Turczaninow, sed hic numerus ex Drège in Linnæà 20 p. 211 est Eckl. et Zeyh. 18.1.11 quem vidi in h. reg: ber. et ad Th. lineare Spreng. retuli. Similem dicit num. $\mathbf{3 7 9 0}$ Zeyheri cl. Sonder. 1. c. Error forsan irrepsit in herb. Turcz. aut in typographiâ. Th. lineare ad sect. Friseam pertinet; planta Turczan. est sectionis meæ Euthesii, prope T. cucullatum, strictum, etc., sed descriptio incompleta cum pluribus convenit. Genus Rhinostegia a Thesionon differt. Thesii longifolii Turcz. e Sibiriâ, nomen præsenti vetustius.

\section{Species nomine tantum cognitce.}

T. Bi BR C TEA T U (I'urcz. in Steud. nom.) - In Sibiriâ.

T. Eifaliense (Steud. nom.). T. strictum Dumortier; $110 n$ L. - E Belgio.

T. CILIATUM.

T. CRASSIFOLIUM. R. Brown prodr. fl. Nov. Holl. p. 353. - Onunes Capenses. -

T. ERICOIDEs. $\quad \begin{aligned} & \text { Nomina rerisimiliter in herb. ill. auctoris aut Mus. brit. ad- } \\ & \text { sunt, sed species absque dubio sub aliis nominibus postea }\end{aligned}$

T. SPARTEUห. descriptæ fuerunt, et vera divulgatio a phrasi aut descriptione

T. TERETIFOLIUM. pendet.

\section{Species exclusce.}

T. AUSTRALE Cunn. = Choretrum pauciflorum.

T. GoL poon Thunb. = Osyris compressa.

T. CORYMBUL OSUM Mich. = Comandra umbellata.

T. DRUPACEUM Labill. = Leptomeria Billardierii.

T. ELEGANS Rochel. = Comandra elegans.

T. FRAGILE L. = Thesidium podocarpum.

T. FAAGILE Thuub. = Thesidium fragile.

T. GLOBOSUMA. DC. = Thesidium globosum.

T. IM B R I Ga U u Thunb.! fl. Cap. ed. Schult. p. 208. - Specimen authenticum herb. Upsal. floribus fructuque caret. Ex foliis oppositis (in Fl. Cap. pessime descriptis) ad diversum ordinem pertinet.

T. LINE ATUM herb. Willd. (non Linn.) = Polygala?

T. L EPT OSTA GHYUM A. DG. = Thesidium leptostachyum.

T. MACR O C AR P a E. Mey. et Drège. = Osyridicarpos Natalensis.

T. MICR OCARPUM A. DC. = Thesidium microcarpum.

T. PнYL I cordes E. Mey. in plant. Drège. = Rhamnea, forsan Phylica, ex specimine authentico herb. Delessert. Petala adsunt concava, lobis calycinis alterna; antheræ intra petala nidulantes, iis oppositæ. Ovarium inferum. Ovula erecta in loculis.

T. PODOCARPUM A. DG. = Thesidium podocarpum.

T. SCHIMPERIANUM. = Osyridicarpos Schimperianus.

T. SPATHULATUM Blume. = Henslowia umbellata.

T. ST R I c T U M $\gamma$ herb. Thunb.l specimen dextr. = Planta dir. Ordinis, calyce clonata.

T. Strigulosum A. DG. = Thesidium strigulosum.

T. ขM ВеLLAт UM $L$. = Comandra umbellata. 
XII. THESIDIUM Sonder in Flord 21 jun. et 14 jul. 1857, p. 364 et 405 (charact. auctis). Thesii sp. Thunb,-Thesii sect. Hagnothesium Alph. DC. esp. nouv. Thes. $\theta$ juin 1857, p. 4, et not. sur fam. Santal. in Bibl. univ. sept. 1857.

Flores dioici. Perigonii pars libera campanulata, nune subrotata, 4-vel rarius 5-fida, glabra, fasciculo tamen pilorum in fl. masc. a medio lobi cujusque ad antheram tendente, lobis 2 florum tetramerorum antice et postice sitis, lobo uno fl. pentamerorum antice (ante bracteam) sito. Discus nullus, saltem non distinctus. $F l$. masc. Stamina lobis opposita, eorum basi inserta ; filamento tenui; anthera biloculari, rimis 2 longitudinaliter dehiscente. Femin. Ovarium inferum, 1-loculare, placentâ tenui apice 3̂-ovuliferâ. Stylus brevis. Stigma obscure 3-lobum, capitulatum. Nux monosperma, ellipsoidea, lobis persistentibus coronata, nervis primariis 5 , secundariis totidem et nervulis transversis reticulatâ. - Fruticuli vel rarius plantæ annuæ, Capenses, habitu Leptomeriæ nec non Thesii crassifolii, T. humilis, etc.; foliis alternis, parvis, sæpe squamiformibus; floribus axillaribus, sessilibus aut brevissime stipitatis, sæpius solitariis, in spicas laxas dispositis; bracteâ et bracteolis 2 cujus que floris imbricatis. - Sectionem primo generis Thesii ex habitu et flore dioico constilueram, nec genus cum cl. Sonder facile dixerim, nisi nuperrime characterem optimum in situ floris tetrameri erga bracteam detexerim, de quo confer ad meam Note sur la fam. des Santalac., $p$. 4, $f$. 4 .

\section{- Strigoso-pilosula. Placenta contortuplicata.}

1. T. G L OB OSUн, radice perpendiculari superne simplici, ramis a basi pluribus mediis erectis lateralibus adscendenti-inflexis ramosis cum foliis bracteis bracteolisque striguloso-pilosis, foliis linearibus acutis dorso carinatis, floribus per majorem partem ramulorum sparsis sessilibıs solitariis, bracteâ folio simili erectâ florem multo superante, bracteolis flore duplo longioribus bracteâ duplo brevioribus, flore 4-5-n̉ero, masculo........, stigmate capitato-3-lobo, nuce ovoideâ stipite 4० lobis conniventibus $5^{\circ}$ longiore nervis 5 primariis et 5 secundariis ramosis subæqualibus nervulis obliquis etiam validis. (1) In Africâ Capensi (Ecklou et Zeyl. n. 35, 85 in h. ber.l Eckl. et Drège, n. 35, 85 in h. vind.!). Thesium globosum Alph. DC. esp. nouv. Thes. p. 4. Thesidium hirtum fem. Sond. in Florâ 1857, p. 365. Thesid. hirtulum fem. Sond. ib. p. 405. Habitus Thesii crassifolii sed dioicum et strigosopilosum. Rami similiter inflexi, globum formantes, Anastaticam simulantes, minus tamen curvati. Radix 3-5. poll. longa. Rami radice subæquales, basi teretes, secundarii valde foliosi angulosi. Folia $4-3$ lin. longa, $\frac{1}{2}$ lin. lata, juniora erecta, vetustiora semipatentia, intus glabriuscula concava. Bracteæ 3 lin. longæ, intervallis multo longiores, carinâ et margine præsertim strigosæ, intus glahræ. Strigæ facile detersæ. Flos femin. junior obovoideus, bracteolis $1 \frac{1}{2}$ lin. longis. Vestigium nullum staminum. Stylus et stigma crassa. Placenta contortuplicata, 3-ovulata. Nur cum stipite et lobis 1 $\frac{1}{4}$ lin. longa. (v. s.)

2. T. STRIGULOSUM, radice...., caule ramisve? adscendentibus ramosis cum folis bracteis bracteolisque strigoso-pilosis, foliis linearibus acutis dorso carinatis, floribus per majorem partem ramulorum sessilibus solitariis ternisve, bracteâ folio simili patenti-inflexâ florem subæquante vel duplo triplove longiore, bracteolis bracteæ subsimilibus florem tetramerum æquantibus vel paulo superantibus, flore fem. et fructu..... 万I In Africâ Capensi (Zeyher! 3815 in h. Boiss. Ecklon et Drège 3815 in h. vindob.1), prope Caledon (h. DC. ex h. Deless.). Thesium strigulosum Alph. DC. esp. nouv. Thes. 6 juin 1857, p. 4. Thesidium hirtum mas Sond. in Florâ 1857, p. 365. Thesid. hirtulum mas Sond. ibid. p. 405. Rami in specim. non validi, basi vix angulosi, superne ex foliis decurrentibus striato-angulosi, ut folia et bracteæ (in sicco) flavescentes. Pili nt in T. globoso strigosi, breves, patentes, facile cadentes. Folia 2 lin. longa, $\frac{1}{3}-\frac{3}{4}$ lin. lata. Bracteæ 1-2 lin.longæ, intervallis in basi ramorum breviores; bracteolæ $\frac{1}{2}-\frac{3}{-}$ lin. longee, omnes ut folia intus glabræ extus carinâ præsertim et margine strigoso-pilosie. Flores $\frac{\Im}{4}$ lin. longi, campanulati, centrales ebracteolati. Lobi ovati, plani, glabri.Tubus fl. masc. brevissimus, tenuis. Stylus fere abortivus. Vestigia placentes. (v. s.) 
** Caules foliaque glabra. Placenta recta.

3. T, FRAGILE (Sond. in Florâ 1857, p. 365), caulibus humilibus ramosis basi lignosis teretibús, ramis angulosis, floriferis masc. gracilibus, fem. crassis, folìis raris minimis squamiformibus carnosis patentibus ovato-acutis glabris, floribus per ramulos elongatos vel abbreviatos sparsis solitariis, bracteâ flore subbreviore bracteolisque brevioribus ovato-acutis crassis subciliatis, floribus masc...., fem. lobis ovato-oblongis,nuce subsessili ellipsoideâ perigonii lobis conniventibus bre; vissimis $5^{\circ}-6^{\circ}$ longiore nervis nervulisque transversis æqualibus reticulatis torulosâ. 5 Ad Caput B. Spei in arenosis - Thesium fragile $\beta$ herb. Thunb.! Drège ! pl. exs. in $\mathrm{h}$. vind. et Boiss. Krauss $I$ in b. Boiss. Thesium Eckl. et Zeyh. n. 29, 78, 5 in h. ber.!, Eekl. et Drège id. num. in h. vind.! Zeyh. id. num. in h. Boiss ! Fruticulus absque radice 3-6 poll. altus, habitu Salsolæe, varie diffusus aut tor tus. Folía velustiora dentiformia, $\frac{1}{2}$ lin. longa, juniora interdum lineam longa suberecta aut patentia plus minus obtusa pinguia margine ocnlo armatissimo velutina. Specimina masc. ramis gracilioribus, raro crassis, interdum pluries flexis, floribus im. perfectis vix $\frac{i}{2}$ lin. longis. Nux $1 \frac{1}{2}$ lin. longa, lobis perigonii brevissimis inflexis obtusa. Placenta brevis, recta, 3-ovulata. - Cl. Drège in Linn. 20, p. 211, numerum 29 Zeyheri ad num. 3814 (T. microcarpum) refert. An conlusa in quibusdam herbariis? (v.s.)

4. T. MIGROCARPUM, caulibus humilibus ramosis basi lignosis terètibus, ramis flo: riferis gracilibus angulosis, foliis raris minimis squamiformibus carnosis adpressis ovato-acutis'obtusisve glebris, floribus per ramulos elongatos sparsis solitariís, bracteâ flore subbreviore bracteolisque brevioribus ovato-acutis ciliatis, floribus masculis 3-4-5-fidis lobis ovato-rotundatis, femineis $4-5$-fidis lobis angustioribus, nuce ellipsoideâ minimà subsessili perigonii lobís conniventibus $4^{\circ}$ longiore nervis transversis longitudinales æquantibus. In Africà Capensi (Zeyher I 3814 in h. Boiss. ber. et vindob.). Thesium microcarpum Alph. DC. esp. nouv. p. 5. Thesidium exocarpæoides Sond. in Florâ 1857, p. 365. Fruticulus totus cum radice 3-10-pollicaris. Radix obliqua, simplex vel ramosa. Rami velust. nudi. Folia ramorum juniorum $\frac{4}{2}-\frac{5}{4}$ lin. longa, convexa. Flores masc. presertim parvi, $\frac{1}{2}$ lin. longi. Perigonium masc. lale campanulatum. 'Stamina e basi loborum, filamento gracili antheram æquante. Pili loborum pone antheras pauci. Vestigium nullum ovarii. Flores fem. lobis ovato-oblongis absque staminibus. Stigma crassum capitatum in mediâ parte floris. Placenta recta, brevis, apice 3-ovulata. Nux cum perigonio lineả subbrevior. (v.s.)

5. T. PODOCARPUK, caulibus humilibus ramosis adscendentibus basi teretibus gracilibus, ramis augulosis apice plerumque incrassatis quasi articulatis, foliis raris minimis squamiformibus carnosis ovato-acutis vel (in eâdem plantâ) oblongis tenuioribus, floribus per ramulos sparsis solitariis, bracteâ bracteolisque minimis ovato-acutis subciliatis, floribus masc..., nuce ellipsoideâ minimâ stipitatâ stipite nunc ærquali nunc duplo fere longiore lobis perigonii conniventibus $4^{\prime}$ longiore nervis transversis reticulatis longitudinales fere iequantibus. 5 In Africâ Capensi (Eckl. et Drège 31, 93, 2 in h. vind.I Eckl. et Zeyk. id. num. in h. ber.l). Thesium fragile Linn. suppl, p. 162, fide Sond. in Florâ 1857, p. 365, qui plant. Linn: vidit. Thesium fragile $\alpha$ herb. Thunb.! Thesium jodocarpum Alph. DC. esp. nouv. p. 5. Thesidium Thunbergii Sond. in Florâ 21 jun. 1857 , p. 364 (fide ips. ibid. p. 405). Radix ign. Caules 6-10 poll. longi, a medio ramosi, basi flexi. Pars inferior caulis et ramorum gracilis, extrema ramorum fere semper carnosa incrassata articulis obverse pyramidatis quasi formata; rami tamen quidam apice graciles. Folia $\frac{1}{2}-1 \frac{1}{4}$ lin. longa, subpatentia, in ramis apice incrassatis juniora adpressa convexa. Flores ign. Nus cum stípite $1 \frac{1}{2}$ lin. longa, omnino T. microcarpi sed stipite manifẹsto diversa. (v. s.)

6. Т. цертовтаснуUм, caulibus...... ramis angulosis, foliis anguste linearibus, spicis axillaribus ramosis gracilibus, floribus masc. per ramulos inflorescentiæ aqualiter sparsis solitariis, bracted̀ flore vix breviore bracteolisque minoribus ovatis obtusis concavis subciliatis, perigonio 4 -fido. 5 In Africà Capensi merid. ad Coralra (Drìgel 8173 in h. vind.). Thesiun leptostachyum Alph DC. esp. nouv. Thes. 6 juin 1857, p. 6. Species manifeste hic collucanda, sed fem. ign. Ramus 8-pollicaris, sublignosus, non crassus. Folia 2 5 lin. longa, $\frac{1}{3}$ lin. lata, patentia, acula, marinine revoluta. Spices 2 poll. longe, nume ubjique forifere, nunc spiculis 
lateralibus salum llorentibus. Flores masc. $\div$ lin. longi, subglobosi, 4 -fidi, glalıri,

lobis rotundatis, medio basi staminiferis. Vestigium nullum pistilli. (v. s.)

XIII. NANODE. Banks in Gartn. f. cap̧pol. 3, p. 251, t. 225, Gaudich. in Ann. sc. nat. 5, p. 101, t. 2, 1. 3 (mediocris) et in Voy. Freycin. p. 442, Durville R."Mal. p. 36, Endl. gen. n. 2073, Hook. f. /l. antarct. 2, p. 342 et 549. - Ballexerda Commers. in h. Juss.!

Flores hermaphroditi (nunc unisexuales). Perigonium inferne obconicum ovario adnalum, supra cupuliforme liberum, lobis 4 ovato-deltoideis, basi abrupte constrictis, intra marginem cupulæ insertis, æstivatione valvari, persistentibus. Stamina 4 , media basi loborum inserta; filamentis brevissimis; antheris ovoideis, bilocularibus, rimis longitudinaliter dehiscentibus. Pili pauci lobos cum antherâ jungentes. Discus epigynus cupulæ perigonii adnatus, inter lobos sub formâ lobulorum tarde distinctus, margine ideo undulato-5-lobus. Ovarium inferum, uniloculare. Placenta (ex ic. ined. cl. Decaisne), centralis, recta, apice ovula 2 pendentia simplicia gerens. Stylus brevis, apice bilobus. Drupa obovoidea, stylo perigonioque persistentibus coronata, putamine osseo. Semen unicum, inversum. Embryo (ex Gærtu.) in apice albuminis carnosi rectus; radiculâ fusiformi, superâ, colyledonibus multo longiore. - Herba Americæ antarctiç, minima, glabra, verisimiliter modo Thesii parasitica (Hlook. f. l. c.) ; caule plerumque simplici, inferne gracili ; foliis crebris, alternis, erectis, linearibus, acuminatis, subcarnosis; floribus pancis, apice planta inter folia insertis, violaceis; bracteis folio subbrevioribus et latioribus, bracteâ oblongâ, utrinque subacutâ, alabastro cuique intlexâ.

N. MUSG OSA (Gærtn. 1. c.). F In paludosis et humidis ins. Falkland sive Malouines (Gaudich.! Durv.) et Patagonjie circa fretum Magellan (Commers! Hook: f.). Planta 2-3-pollicaris. Folia infer. per florationem delapsa, superiora $4-8$ lin. longa, $\frac{1}{2}$ lin . lata, flores occultantia. Bractex et bractéolæ non satis cognitæ, flore paulo majo- res, folio minores et latiores. Flos in axillâ bracteæ solitarius, $1 \frac{1}{2}$ lin. longus, in pedicellum brevem angustatus. Lobi acuti, parte in tegrâ ęt superầ non lọgiores, basi latâ sed puncto solum inserti. Lobuli prioribus paulo interiores videntur et e clissco, nẹc ut in Ghoretris e cupulá perigonii oriuntur. Flores alssque placentâ interdum reperi. Drupa 2-2 $\frac{1}{2}$ lin. longa, carnosa.' (v. s.)

XIV. GHORETRUM $R$. Br.prodr. N. Holl. p. 354.

Perigonium persistens, breve, abrupte apice truncato marginalum, ibique integrum vel denticulis 5 minimis donatum; lobis $5 \mathrm{cum}$ denticulis alternantibus, intra marginem apice tubi insertis, ab co manifesle dislinctis, æstivatione valvari, interne carinâ ab apice versus antheras descendınte quasi fornicatis; sinu axim spectante. Stamina 5 , lobis perigonii opposila ; filamentis ligulatis brevibus; antheris globoso-quadrangulis, 4-locellatis, locellis superne patention dehiscentibus, unde anthera quadrivalvis ferè dicenda, potiús orè unico crenis 4 concavis cincto; connectivo centrali ante dehiscentiam umboniformi, postea evanescente. Pollẹn (in aquâ) ellipsoideo-triqquetrum, poriș 3 ruptum. Discus concavus, 5-angularis vel sub-5-lobus. Ovarinm inferum carnosum, placentam, centralem apice ovuliferam carne subadhærentem fovens. Stylus brevissitrus. Stigma 5-lobum, stellatum, lobis ante lobos perigonii. Drupa exsucca, monosperma. - Frutices vel arbusculæ; Austialasici, spartei, ramosissimi ; ramis angulatis vel strialís ; foliis alternis, minutis, acuminatis; spiculis secus ramulos ex axilla bracteæ folio subsimili pluribracteolatis, 3-1-floris ; floribus parvis, albis.

\section{\$1. Tubus perigonii apice inter lobos brevissime denticulatus.}

1. G. LA TER IFL ORU M (Br. prodr. $\times$. Holl. p. 354), frutex, foliis secus ramos ramulosyue a basi lanceolatà subulato-liliformibus, Horilous secus ramulos solitariis crehris subsessilibus, bractcolis 4 cruciatim imbricatis uvatis sulucilialis 5 ? In tuvà Hol- 
landià merid. (Br.).-Sicb.! n. 133, in h. DC., fl. mixta, n. 525, in h. vind., F. Müller! in h. Boiss. Cel. Brown ait tantum " flores solitarii axillares sessiles " unde specics vix nota. Specimen Sieberi, hisce non contrarium, ramos erectos graciles præbet, ubi folia non rara erecta $\frac{1}{2}$ lin. longa acicularia basí crassiuscula apice filiformia, fores secus ramos erectos crebri alterni, pedicelli uniflori folio breviores bracteis tecti, quarum 2 laterales et 2 cum preced. alternantes superiores, flos $\frac{1}{2}-\frac{5}{4}$ linese solum ongus, perigonium supra ovarium transverse sulcatun et sub lente marginatum, vix tamen denticulis donatum, antheræ 4-valyes, discus vix distinctus, stigma obscure 5-dentalum. Ovarium sterile in specimine. An planta Sielseri hic descripta vere Brownianæ similis? (v. s.)

2. C. G L OMERATUM (Br.! prod. N. Holl. p. 354), frutex arborescens, ramis aphyllis, foliis ad originen pelunculorum minimis lanceolatis, peduneulis brevissimis late-: ralibus 2-3-1loris, floribus sessilibus aut brevissime pedicellatis, bracteis 2-4 flori cuique adpressis imbricatis rotundatis subciliatis. 5 In Novà-Hollandiâ orientali (A. Cunn. I), e Novâ-Walliâ inter. australi (Br.! Muller!) et austro-occid. (Preiss! 2091 et ex Miq. vol. 2, a. 2116, Drummond ! coll. 3, n. 199, 200). -Endl. icon.t. 45, Miq.in Lehm. pl. Preiss. 1, p. 608. Ex specimine meo authentico cl. Brown folia rara, $\frac{1}{2}$ lin. longa, acuta; bracteæ 2 laterales (in specim. Mull. 3, unâ externâ, ex Br. 4), $\frac{1}{3}$ lin. longæ; flos $\frac{3}{4}-1$ lin. longus; - perigonii tubus inter lobos manifeste 5-dentatus ; discus epigynus concavus ; stigmata 5, stellata. Ex specim. Mull. in h. Mus. par. drupa 4 lin. longa, perigonio $4^{\circ}$ longiore terminata, obscure 10 -nervia. Ex specim. Preiss. (arbuscula 15-ped. ex auct.) drupa ellipsoidea, 2 lin. longa, 10-costulata, perigonio immutato coronata. In specimine Gunningh. denticulos non vidi, sed flores juniores. (v. s.)

§ 2. Tubus perigonii vix apice denticulatus. Fasciculus pilorume basi interna loborum perigonii ad antheras tendens ibique adhcerens (ut in Thesiis plerisque).-An prosentis generis?

3. C. PAUG IFLORUM, fruticulosum, ramis cylindricis, foliis secus ramos ramulosque raris e basi lanceolatâ subulatis, floribus secus ramulos sparsis solitariis sessilibus, bracteâ lanceolatà, bracteolis 8 ovatis a bracteâ ad florem crescentibus et obtusioribus subciliatis. 5 In Novà Hollandiâ orientali (Cunn.!Sieb.! Verreaux! a Mus. par. sub n. 123 comm.). Thesium australe A. Cunn. herb. (uon Brown). Leptomeria aphylla Sieb.! n. 131, non Br. Fruticulıs in specimine meo vix pedalis. Rami sulcati potius quam striati (an exsiccatione?), erecti, vetustiores aphylli. Folia erecta, $\div$ lin. longa. Spicula tota e bracteá bracteolis et flore $\div-\div$ lin. longa, subglobosa. Bracteolæ interiores crucialim imbricatæe bracteâ latiores, magis ac magis ab eâ versus florem discrepantes.Alabastrum obovoideum. Denticuli minimi. Lobi medium usque intus reflexi. Fasciculus pilorum aureo colore a basi lobi cujusque ad antheram tendens, ibique inter locellos juxta connectivum penetrans. (v.s.)

\section{§ 3. Tubus perigonii fere non denticulatus.-Species inter Choretrum et Leptomeriam media.}

4. C. сн П Y SА кт н М (F. Muller ! in Hook. journ. 1856, p. 205), foliis secus ramulos et pedunculos squamiformibus lanceolatis, podunculis lateralibus brevissimis 1-2floris, bracteis 3-4 ovatis subciliatis, denticulis tubi fere nullis. J In Novà Hollandia merid. - Miq. stirp. Muell. p. 7. Rami graciles, angulosi, virgati. Folia $\frac{1}{2}-\frac{1}{3}$ lin. longa, acuta, glabra. Pedunculi secus ramos alterni, $\frac{1}{2}-1 \frac{1}{2}$ lin. longi, folia minima 2-4 sæpius prebentes. Bracteæ $\frac{1}{2}$ lin. longæ, subpatentes, caducie et inde numero incertæ, verisimiliter 4 . Flos $\div$ lin. longus, ex nomine huteus, ubi vestigia dentium inter lobos fere nulla. Ovarium ovoideum. Stigma 5-lobum. Bractere, lobi perigonii reduplicati, antherse, omnia præsentis generis potius quam Leptumerie, quamvis denticuli vix adsint. (v. s.)

\section{Species exclusa.}

- Preissianum Mit. = Leptomeria Preissiana.

C. spinos u Miq. = Leptomeria spinosa. 
XV. LEPTOMERIA $B r$, prodr. Nov. Holl. p. 353 (excl. sect. II).

l'lores pentameri (rarius tetrameri). Perigonium persistens, tubo elongatoobconico ; lobis æstivatione valvari, apice intus paulo inflexis vel solum incrassatis; sinu in floribus tetrameris ut in pentameris axi opposito. Stamina lobis perigonii opposita ; filamentis filiformibus brevibus; antheris lenticulari-4- rarius-3-2-gonis, locellis tolidem superne patentim dehiscentibus; connectivo centrali ante dehiscentiam umboniformi, postea nunc evanido, nunc accreto valviformi locellos superante. Hollen rarum, ellipsoideo-trigonum. Disćus epigynus lobatus. Ovarium inferum, carnosum, placentam centralem apice ovula pauca pendentia gerentem fovens. Stylus brevissimus. Stigma 5-lobum aut obscure sublobatum, lobis 5 (ubi adsunt) ante lobos perigonii sitis. Drupa carnosa vel exsucca, monosperma. - Frutices vel suffrutices Australasici, sæpius spartei, ramosi ; ramis sæpe angulatis; foliis alternis acutis, sæpius minutis ; ramulis floriferis vel sæpius spiculis secus ramos plurifloris ; folio vel bracteâ cuique flori, bracteolis nullis (L. spinosâ exceptâ).- Dehiscentia antherarum hucusque non descripta in vivo certioranda cum flores minutissimi in sicco male observentur.

\section{Sectio I. Oxymeria Endl. gen. p. 326, ic.t. 74. - Sectio 1 Brown, l. c.}

Antheræ 4-locellatre, apertæe concavæe patentes. Stigma 5-lobum. Drupa sæpius baccata. - hami nunc spinescentes. - Spicæe bracteis caducis. - Flores interdum 4-meri.

1. BILlarderi (Br.! prodr. p. 354, non Sieb.), fere aphylla, ramis veteribus teretibus, junioribus angulosis, spicis 3-7-floris, bracteis ovato-acutis subciliatis caducis, floribus 4-5-meris, lobis perigonii interne supra staminum insertionem pilosis apice subinflexis. F In Van Diemen (Br.l Labill., Gunn, n. 29, ab Hook. fil.in h. vind.l), et in orâ merid. N. Holl. (anno.1821 a Mus. par. comm.), loco non indic. N. Holl. (Verreaux! n. 68 a Mus. par.). Thesium drupaceum Labill.l Nov. Holl. 1, p. 68, t. 93. Rami virgati, vestigiis foliorum sparsim denticulati. Ramuli floriferi 3-6 lin. longi. Bracteue $\frac{1}{3}$ lin. longæ. Flos cum tubo perigonii vix bracteâ major, sæpius pentamerus. Antheræ subquadrangulæ, 4-locellatæe, locellis 2 interioribus minoribus. Discus planus, lobatus. Stigma 4-5-lobum. Drupa ovoidea, vix carnosa, 2-3 lin. longa. (v. s.)

2. L. A croA (Br I prodr. N. Holl. p. 353), fere aphylla, ramis angulatis, spicis multifloris, bracteis lanceolatis caducis, lobis perigonii elliptico-acutis denticulo apicis inflexo. 5 Circa Port-Jackson (Br.! Sieb.!), in orà orient. (Verreanx! 204, ex h. Mus. paris.) et in orâ meridion. ad Lewin's land (Bauer in $\mathrm{l}_{\mathrm{l}}$ vind.) et King George's sound (Hugel, ibid.l).-Sieb.l exs. N. H. n. 132, ejusd. fl. mixta 524! in h. Boiss. - Endl. icon. t. 74. Rami virgati, vestigiis foliorum sparsim denticulati. Ramuli floriferi 6-9 lin. longi. Flores ex axillis bractearum et cito ex angulis ubi bractese erant, $\frac{1}{5}$ vel $\div$ lin. longi, patentes, glabri, tubo perigonii obconico pedicellum simulante. Bractex $\frac{i}{4}$ lin. long $c$, subulatie. Lobi perig. apice solum inflexi. Discus epigynus crassus, 5 -angularis potius quam lobalus (ex Br. lobis semi-adnatis). Antheræe subquadrangulares, 4-locellatæ. Stigma 5-lobum. Drupa baccata. ovoidea, 2-3 lin. longa. (v. s.)

3. L. A PHYLL A (Br.! jrodr. p. 354, non Sieb.), ramis ramulisque cylindricis aphyllis rigidis apice spinescentibus, spicis multifloris, bracteis caducissimis obovatis, lobis perigonii intus basi pilosis apice brevi inflexo non carinato. $t$ In Novæ Hollandise orâ merid. et austro-occid. (Drumm.l coll. 3, n. 197 in h. Boiss. et coll. 2, nl. 229, ibid.). L. pungens F. Muller! in h. Mus. par. et vind. Rami erecti, subteretes (exsiccat. solum? substriati), cicatricibus raris punctiformibus. Folia ramulorum nascentium (ex specim. Drumm.) lanceolata, 3-4 lin. longa, erecta. Spicæ (ex spec. $\mathrm{Br}$. hic descripto) 3 lin. longæ, rhachi subangulosà basi denudatâ superne 6-10-llorâ. Bractew (in specimine meo omnes delıpsæe etiam si tlores inaperti) ex Br. obovate, ex specim. h. vindob. ovato-acuminatie ciliolatie alalastro subæquales caducissima. Flos, ex specim. Br., minimus, quasi pedicellatus, pedicello sive 
tubo perigonii obconico gracili $\frac{1}{3}$ lin. longo. Lobi 5 perigonii $\frac{1}{4}$ lin. longi, ovato. acuti, diu inflexi, pilis supra origînem stami num paucis longis. Discus crassus 5-lobus. Filamenta tenuia. Antheræ adeo minutex $\left(1 \frac{1}{10}-\frac{1}{16}\right.$ lin. longæe) ut dehiscentia difficile observanda, juniores sursum 4-1obæe, vetustiores cujpulẩ 4-lobâ cum um;bone centrali. Stigma deatibuts 5 , erectis. (v. s. a cl. Br. comm.)

4. L. Preissiana, ramis striato-costulatis vetustioribus subteretibus, ramulis angulato-compressis, foliis caducis in ramulis nascentibus anguste lanceolatis subciliatis erectis, spicis multifloris, bracteis lanceolatis cito delapsis, lobis perigonii interne basi et margine pilosulis, carinâ interiore ab apice versus medium prominente pendente. İ In Novấ Hóllandiâ austro-occid. (Preiss I n. 2101). Choretrum Preissianum Miq. in Lehm. pl. Preiss. 1, p. 608. Frutéx 7-ped. Rami erecti, flavieantes; aphylli. Ramulf orecti, graciles, folia $\frac{1}{2}-1$ lin. longa subula la prìbentes. Spic: 4-9 lin. longæ, rhachï angúlatà, floribus a basi alternantibus, tubo pedicellum mentiente patente. Bractea (ex Mir.) videtur sub flore unica, in specinini= bus meis et herb. Boiss. omnes delapse. Flos albus cum tubo pedicellari vix $\frac{1}{2}$ lin. lopgior. Denticuli modo Choretrorum (quiquid dixerit cel. auctor) nulli. Antheræ 4-locellatæ, connectivo umbonato centrali donatæ. Discus 5-lobus. Drupa ovoidea, immatura 2 lin. longa, lævis. (v. s.)

\section{Sectio il. Acanthomeria.}

Antheræe valvâ crassâ, e connectivo ortâ, locellis patentibus superpositâ, introrsum semiapertâ superatæ. Stigma 5 -lobum vel 5 -dentatum. Drupa exsucca.-Rami sæpius aphylli; apice indurati. Bracteæ caducæ. Flores pentameri. - Habitus sectionis primæ.

5. L. SPINOSA, ramis erectis ramulisque patentibus cylindricis sulcatis aphyllis rigidis apjice spinescenti-induratis, fuliis ramulorum nascentium minutis adpressis ovatis rel lanceolatis, spicis paucifloris, bracteis caducis dentiformibus? bracteolisque cadueis ovatis subciliatis, Iobis perigonii basí intus pubescentibus, carinà interiore ab apice ad medium prominentè pendente. $๋$ In Novầ Hollandiâ austrooccid. (Preiss 12105 , Drummond! ser. 2 ; 0.230 in h. Boiss. ser. 4, n. 226 ibid.). patentes, vestigiis foliorum verruculosi, flavescentes, sub lente punctis minimis micantibus. Folia ramulorum nascentium $\frac{3}{\div}$ lin. longa, alterna vel opposita. Spicie 1-3 lin. longæ, floribus 3-4 subumbellatis. Bracteæ rarissimæ in herbariis; ex specimine meo quasdam vidi ubi bractea exterior dentiformis minima et bracceolatæ. An casus monstrosus? Rhachis angulosa. Flores albi, cum tube pedicellari fere lineam longi, absque denticulis apice tubi. Antheræ 3-4-locellatæ, umbone serius valvam apertam simulante. Stigma 5-dentatum. Drupa $\rho$ voidea, 10 -striata, junior exsucca. Habitus $L$. aphyllæ, sed flores majores, in herbario non-nigricantes, carinâ interiore decurrente supra. partem pilosam inflexâ. Quoad florém L. Preissiane proxima. (v. s.)

6. L. LeHMANN (Miq. in Lehm. pl. Preiss. 1, p. 614), ramis ramulisque cyliudricis erectis sulcatis aphyllis rigidis demum apice induratis, foliis ramulorum nascentium minutis appressis lanceolatis, spicis paucifloris, bracteis caducis dentiformi- bus, lobis perigonii intus glabris apice incrassatis non carinatis. F In Novâ Hol- landiâ austro-occident. (Preiss, n. 2097! 2106, 2107! 2121! et 2123 forma tenerior, flor. minor.). Frutex 4-ped., habitu L. spinose. Cuticula ramorum magis quam in L. spinosâ glanduloso-subvitrea; rami non patentes minus indurati. Bracteolas laterales non vidi, sed interdum bracteam ovato-acutam $\frac{1}{4}-\frac{1}{2}$ lin. Iongam. Flores Miquel) non carinâं donato, sed solum crassiore. Antheræ minimæ, lenticulares, apertæ valvà inferiore 3-4-crenatâ, valvâ superiore (e connectivo) convexâ. minore.' Drupa oblongo-obovata, subcarnosa, nec ut in L. spinosâ (v. s.)

7? L. LAXA (Miq. in Lehm. pl. Preiss. 1, p. 612), foliis remotis acerosis semi-teretibus antice canalieulatis introrsum curvatis adultis apice spinoso-induratis, spicis subpatentibus remotifloris, bracteis elliptico-lanceolatis planiusculis. $\hbar$ In Novæ Hollandiæe austro-occid. interioribus (Preiss, n. 2120). Fruticulus semipedalis, frexilis, o radice albicante fusiformi. Caules plures, erecti, striati; inferne aphylli, 
ramulis erectis sparsis telragonis. Folia forsan carnosula, fere semipollicaria, pqtula, ramulorum breviora. Bractea $\frac{1}{2}-1$ lin. longæ. Drupa subovata, $1 \frac{1}{2}$ lin. longa, circiter 16-costulata, breviter pedicellata, limbi 5 -fidi relliquiis instrueta.

8. L. CHRYSADENa (Miq. in Lehm. pl. Preiss. 1, p. 612), ramis per anthesin fere aphyllis, spicis aureo-glandulosis, foliis vetustioribus raris lanceolato-subulatis rigidis erectis glabris, spicis densifloris, bracteis ovato-acutis subciliatis caducis, flore bracteam subæquante, lobis perigonii glabris apice subinflexis non carinatis, stylo brevissimo emarginato. 5 In Novæ Hollandiæ austro-occident. turfosis humidis (Preiss! n. 2124). Fruticulus 2-3-ped. Rami angulosi, sulcali, glabri. Folia lineam longa, juniora imbricata, lanceolata, colorata, ciliata. Spicæ subpatentes, 2-4 lin. longæe, rhachi foveolatâ. Bractere $\frac{1}{2}$ lin. longæ. Flores sessiles, tubo obconico, lobis diu clausis, demum patentibus, ellipticis, intus apice subinflexis. Lobi disci breves. Antheræ initio lenticulares, apertæ valvâ inferiore subintegrâ, superiore (e connectivo?) semi-apertâ tectee. Drupa (ex Miq.) sessilis, globosa, vix rugulosa. (v. s.)

\section{Sectio III. Xeromeria Endl. gen. p. 326.-Leptomeriæ sect. 3, Brown, l. c.}

Arutheræ valvâ crassâ (e connectivo?) locellis patentibus superpositâ introrsum semí-apertâ superatæe. Stigma obscure 2-5?-lobatum. Drupa exsucca.-Bracteæe persistentes, foliis subsimiles, ideo spicæ ramulis similes. Flores pentameri.-Folia in ultimis spec. pro genere magna anomala.

9. L. GunNinghamir (Miq. in Lehm. pl. Preiss. 1, p. 611), glabra, foliis ramorum erecto-incurvis semitereti-triangularibus acutis, ramulorum bracteisque subpatulis brevioribus ovato-acutis, pedicello et perigonii tubo bractea brevioribus, lobis patentibus ovato-acutis apice intus mucronato inflexo, stylo brevissimo obtusiusculo. 5 In Novâ Hollandiâ austro-occid. (Preiss! n. 2096, Drumm.! 2 n. 228 iń h. Boiss.). Rami erecti, angulosi. Folia ramealia 2-3 lin. longa, $\frac{1}{3}$ lin. lata, crassiuseula, sparsa. Ramuli floriferi 3-4 lin. longi, 6-10 flori. Bracteæ $\frac{1}{2}$ lin. lovigæ, craśsæ, basi angustæ, apice acutæ. Flores patentes, $\frac{1}{3}$ lin. latæ, tubo perigonii obconico, lobis vix apice uncinatis. Antheræ bivalves, juniores 4?-loculares. Stigma obscure bilobum. (v. s.)

10. L. squarRul osa (Br.! prodr. N. H. p."354), glabra, ramis gracilibus, foliis æqualiter sparsis lanceolatis et superne dentiformibus rigidis crassiusculis apice acuto arcuatis persistentibus, pedicello et tubo perigonii bracteả ovato-acutâ sub́æqualibus, lobis perigonii patentibus oblongis apice acuto subinflexo, stylo brevissimo obtusiusculo. F In Novæ Hollandice orà anstro-occid. (Br.! Cunningh.! Preiss! 2109, Drumm. ! coll. 3 n. 108), L. Brownii Miq.! in Lehm. pl. Preiss. 1, p. 612 (ubi syn. Brownii non eit. sed ex specimine meo authentico Вr. e King George's sound identitas non dubia). Rami erecti, ramuli patentes vel erecti. Folia $\frac{1}{4}-1 \frac{1}{2}$ lin. longa, acula, apice semper arcuato-recurva, internodiis breviora, regulariter alterna. Spicæ ramulos terminantes, sparsifloræ. Bracteæ a foliis supremis non diversæ, $\frac{1}{4}$ lin. longæ. Flos $\frac{1}{1}$ lin. latus, glaber, rotatus. Glandulæ disci fuscææ, ovatæ, stamina subæquantes. Antheræ globosæ, medio umbonatæ, 4-locellatæ. (v. s.)

11. L. ERICOIDES (Miq. in Lehm. pl. Preiss. 1, p. 611), folijs erecto-adpressis acerosis semitereti-compressis pungenti-acutatis, bracteis folio subsimilibus patulis non pungentíbus subincurvatis, stylo brevissimo apice 2-3-sublobato. $\zeta$ In Novâ Hollandiầ austro-occident. (Preiss, h. 2117). Fruticulus pedalis, foliis L. empetriformis, floribus L. squarrulose alfinis. Rami stricti, erecti, rigidi, tetragoni, superne foliati. Folia remotiuscula, 2-3 lin. longa. Rámuli florentes 6-12 lin. longi, patentes. Flores subsessiles, tubo subcyathiformi, lobis ellipticis planiusculis. Antheræ biloculares. Discus in glandulas 5 erectas obtusas alrofuscas margine solutus. Drupse immaluræe obovate, haud striatee.

12. L. H IR TELL A (Miq. in Lelim. pl. Preiss. 1, p. 610), ramulis hirtellis, foliis patentibus introrsum curvatis olylongo-subobovatis acutis subtus hirtellis, pedicelio floreque minimis bracteâ lincari folio subsimili multu brevioribus, lobis perigonii patcntibus ovalu-acutis apice subinflexis, stylo brevissimo apice omarginato. $\zeta$ In Novâ Hollandiâ austro-occident. (Preiss! 2113). Fruticulus 1-2-pedalis, purpuras- 
cens vel viridis. Radix subfusiformis, albicans, crassa. Caules plures, ramosi, striati. Folia 1 $\frac{1}{2}$ lin. longa, $\frac{1}{1}-\frac{1}{2}$ lin. lata, diametro majore ultra mediam partem, superne glabra, basi longe angustata crassiuscula, apice breviter acuta inflexa. Flores in specimine rari, ex axillis foliorum superiorum potius quam bractearum, $\frac{1}{3}$ lin. longi. Drupa ellipsoidea, striis circiter 20-costata, $1 \frac{1}{2}$ lin. longa. (v. s. fructif.)

13. L. eм Petrif ormis (Miq. in Lehm. pl. Preiss. 1, p. 610), glabra, foliis linearitrigonis acutis, pedicello et tubo perigonii bracteâ pingui ovato-acutâ brevioribuss, lobis perigonii ovatis mucrone apice inflexo, disci crassi lobis stamina æquantibus, stylo brevissimo subemarginato, $ち$ In arenosis Novæ Hollandiæ austro-occid. (Preiss! 2094). Fruticulus ramis diffusis torulosis vel angulosis, ramulis subtiliter resinoso-glandulosis. Folia $1 \frac{1}{2}$ lin. longa $\frac{1}{3}$ lin. lata, subpatentia, ericoidea. Bracteæ $\frac{3}{4}$ lin. longæ, approximatæ. Flos $\frac{1}{2}-\frac{1}{2}$ bracteâ brevior, diu clavatus. Stamina 5 , in disco pingui nidulantia, libera ; filamento brevi ; antherâ globosâ, 2?-loculari, medio umbonatâ. (v. s.)

14. L. ово иат а (Miq. in Lehm. pl. Preiss. 1, p. 613), foliosa, glabra, foliis obovatis vel elliptico-obovatis obtusis aut submucronatis carnosulis enerviis, ramulis floriferis patenti-reflexis, bracteis folio subsimilibus angustioribus, floribus cum pedicello bracteâ multo brevioribus, tubo perigonii longe obconico, lobis ellipticis apice intus dente inflexo donatis, glandulis disci stamina subrequantibus. 万I In Novæe Hollandiæ austro-occidentalis interioribus. (Preiss! n. 2108, Drumm.! 1848 n. 254 in l. Boiss.). Rami cortice rimoso albicante. Folia $2 \frac{1}{2}-3$ lin. longa, 1-1 $\frac{1}{2}$ lin. lata, in petiolum brevissimum angustata, plana vel subconcava. Ramuli floriferi 6-12 lin. longi, bracteis foliaceis lanceolatis 1-2 liı. longis. Flores cum pedicello gracillimo $\frac{1}{3}$ lin. longi, pentameri. Antheræ valvà semiapertà tectæex margine 2?-loculares. Lobi disci obtusi, manifesti. Stylus brevissimus, apice obtuso 5-angulari. (v. s.)

\section{Species prcesentis sectionis ex ill. Brown, sed descriptionibus deficientibus, fere ignotce.}

15. L. SCROBIGULATA (Br. prodr. N. Holl. p. 354), spicis filiformibus multifloris, bracteis caducis, flosculis sessilibus scrobiculis racheos semiimmersis. - In orầ merid. Nov:e Hollandis.

16. L. PAUCIFloRA (Br. prodr. N. Holl. p. 354), spicis paucilloris, bracteis caducis, flosculis emersis. - In orà merid. Novæe Hollandiæ.

17. L. AXILLARIS (Br. ibid.), floribus axillaribus pedicellatis folio subulato duplo brevioribus, ramulis laxiusculis. - In orâ merid. Novæ Hollandiæ.

\section{Species exclusa.}

L. ACERBA Br. = Omphacomeria acerba.

L. AGERBA Sieb. exs. = Exocarpus cupressiformis.

L. $\triangle$ CERBA Cunn. = Omphacomeria psilotoides.

L. BILlARDIERI Sieb. = Omphacomeria psilotoides.

L. o DORAT A Miq. = Exocarpos odorata.

L. XIPHOCLADA (Sieb.l fl. N. Holl. exs. n. 135, Spreng. syst. 4, p. 109.= Amperea (Euphorbiacearum). Confer ad Brongn. Voy. Duperrey, t. 49 .

XVI. OMPHACOMERIA.-Leptomeriæ sect. II, Brown prodr. N. Holl. p. 354.-Leptomeriæe sect. Omphacomeria Endl. gen. p. 326, suppl. 4 p. 2, p. 58.

Flores 4-5-meri. Perigonium persistens; tubo hemisphærico-obconico, brevi; lobis æstivatione valvari, apice incrassato subinflexo ; sinu axi spiculæ opposito. Stamina lobis perigonii opposita, filamentis ligulatis, antheris bilocularibus erectis introrsis, loculis septo longitudinali divisis, locellis longitudinaliter dehiscentibus. Discus epirynus 5-lobus, lobis cum perigonio alternantibus. Ovarium inferum, carnosum, placenta Leptomeriæ? Stylus brevissimus. Stigma bilobum aut obscure capitato-lobalum. Drupa baccata, monosperma. 
- Frutices vel suffrutices spartei, Australasici, ramosissimi ; ramis angulatis vel striatis ; foliis caducis, minulis, spiculis' lateralibus maxime abbreviatis, paucifloris; floribus in alveolis hinc dentatis rachis abbreviatæ nidulantibus, puncto unico tamen insertis, a basi spiculæ ad apicem (ubi nullus vere terminalis) florentibus, bracteolis nullis. Habitus Leptomeriæ et Exocarpos; discus et ovarium inferum prioris, antheræ posterioris.

1. 0. A CERBA, ramis ramulisque aphyllis cylindricis crebre striatis, ramulis floriferis valde abbreviatis fere nullis 1 -5-floris secus ramos sparsis, tloribus. in alveolis hinc dentatis sessilibus plerumque tetrameris, lobis perigonii denticulo crassiore apice subinflexo. 5 In Novâ Hollandiâ orient. ad Port Jakson (Br.!) et in interioribus coloniæe (Leptomeriæ sp. A. Cunn.! 1817, n. 391.) Leptomeria acerba Br.! prodr. N. Holl. p. 354, non Cunn. Rami erecti, virgati, non angulosi sed regulariter striati. Denliculi sparsi vestigia aut indicia foliorum. Flores vel fasciculi florum vix lineam longi, e rhachi abbreviatâ. Materies quædam resinosa? albida rhachi et basi florum insidens. Lobi perigonii elliptico-acuti, nunc in eâdem plantâ $\mathbf{5}$, sæpius 4. Staminum filamenta ligulata brevia. Antheræ ovato-quadrangulares, apice emarginatæ, erectæ, loculis 2 longitudin. dehiscentibus. Discus parum lohatus. Drupæ solitariæ, ovoideæ, bactatæ, 3-4 lin. longæ. Tumores ovoidei striati e ramis inflatis drupas alteras sæe simulantes. (v. s.)

2. O. PSIL отоIDES, ramis teretibus, ramulis angulosis, foliis lanceolatis cito delapsis, fasciculis florum lateralibus 3-4-floris, bracteis dentiformibus rhachique abbreviatâ subvelutinis, floribus subsessilibus pentameris, lobis perigonii apice intus vix dentatis. 5 In Novâ Hollandiá orientali (Cunningh.! Hugel $I$ in h. vind., Verreaux! 187 et 213, ex h. Mus. par.) et Van Diemen (fide schedulæ specim. ex h. Mus. par. in h. Boiss. sub n. 68, Gunn, n, 5k, ab Hook. comm. in h. vind.). Leptomeria acerba A. Cunn.! (non Br.). Lept. Billardieri Sieb.! pl. exs. N. Holl. n. 134 (non $\mathrm{Br}$.). Rami erecti, virgati. Folia in extremis ramulis solum videnda, $\frac{3}{4}$ lin. longa, ceterum ex basi persistente dentiformi secus ramos agnoscenda. Fasciculi florum sparsi, $\frac{5}{4}-1$ lin. longi, e rhachi angulosà minimâ angulis pubescente, bracteis minimis ajs angulis alveolarum indistinctis. Flos pedicello brevissimo siye puncto insidens, tubo hrevissimo extis pilosulo, lobis ovato-acutis, diu inflexis, glabris. Antleræ subquadrangulæ, 4-locellate. Discus 5 -lobus, brevis. Stigma capitato-sublobatum. Drupa ovoidea, 3 lin. longa. Rami sæpe puncturâ in tumores ovoideos sulcatos inflati. Valde similis Exocarpo cupressiformi, sed fructus inferus. In herbariis frequenter cum Euphorbiaceâ generis Amperea confusa. (v. s.)

Subtribus II. SANTALEF.

Placenta fusiformis, prope basin ovulifera.

XVII. SANTALUM Linn. gen. ed. 2, n. 383 (non herb.), R. Br. prodr. Nov. Holl. p. 355, Endl. gen. p. 327. — Sirium Linn. gen. ed. 8 (Schreb.), n. 203, Lam. ill. 1, p. 304, t. 74, Roxb. Corom. p. 2, t. 2. - Fusauus Linn. (Syst. 13. 765, ex cit. Endl.), Br. prodr. Nov. Holl. p. 355 (excl. syn. Colpoon), Endl. gen. p. 326. - Mida A. Cunningh. in Ann. of nat. hist. 1, p. 376.

Perigonium campanulatum, 4-fidum (rarius 5-fidum); lobis ovatis triangularibusve, basi interne fasciculo pilorum ad antheras tendentium donatis ; sinu uno axim spectante. Stamina 4 , rarius 5 , lobis opposita ; filamento ligulato vel filiformi ; antherâ ovoideâ, biloculari, loculis profunde bilocellatis longitudinaliter rimâ unicâ dehiscentibus. Pollen subglobosum. Discus concavus, fundo perigonii adhærens, lobis cum lobis perigonii alternantibus. Ovarium initio liberum (Henfr. trans. linn. soc. 22 , t. 17, f. 1), per anthesin semi-inferum, deinde inferum, uniloculare. Stylus conicus vel cylindricus. Stigmata 2-3-4, ubi numero loborum perigonii is alterna, ubi 2 sinubus duobus opposita. Placenta centralis, ovoideo-acuta, basi ovula pendentia numero stigmatorum iisque supposita anatropa gerens. Drupa globosa vel obovoidea, cicatrice ex lobis perigonii truncato-delapsis coronata, putamine ligneo punctis rimisque plus minus ruminato. Semen inversum, endospermio carnoso, embryone cylindraceo-fu- 
siformi, radiculâ superâ cotyledonibus multo longiore. - Arbores fruticeşve ex Asiâ merid. et Australasiâ ; foliis oppositis, raro in eâdem plantâ oppositis et alternis, aut rarius omnibus alternis, integris, planis, nervis lateralibus sæpius rectis obliquis parvis ; cymis ubi folia opposita terminalibus et axillaribus pedunculis oppositis 'vel rarius alternis, ubi folia alterna lateralibus pedunculis alternis; bracteis bracteolisque caducis.

\section{Sectio 1. EUSANTALOM.}

Folia opposita. Gymæ paniculiformes terminales et axillares, pedunculis oppositis Flores sæpius tetrameri (raro pentameri). Stigmata 2-3-4.

\section{§1. Stylus longior, et ideo stigmata altitudine apicis antherarum sita.}

14. S. FREYoINETIANUM (Gaudich.! voy. Freyc. p. 442, t. 45), foliis obovatis obtusis in petiolum brevem basi angustatis venosis, paniculis terminalibus 5-7-floris simplicibus, pedicellis oppositis flore obconico brevioribus. 5 In insulis 3andwich : in Wahou alt. 350-400 hexap. (Gaudich.). Verum Santali lignum ex auct., sed botanicis adhuc vix notum. Minime quadrat phrasis brevissima Gaudichaudii cum ejus icone : folia dicit lanceolata obtusiuscula quæ in icone obverse lanceolata, vel potius obverse obovato-lanceolata, apice oblusissima, gradatim in petio- lum a limbo vix distinctum angustata. Ex eadem ic. folia 2-3 poll. longa, 6-9 lin. lata, stricte opposita, patentia, nervis lateralibus tertiarisque reticulatis perspicuis; paniculæ pollicem longæ; pedicelli 3 lin. longi, tubo supra continui ; bracteæ - nullæ (deciduæ?); flores 4-5 lin. longi, 4-fidi, intense rosei (ex Gaudich.); fascieulus pilorum ut in congen. inter lobum et stamen; stylus basi conicus, superne gracilis, antheras superne æquaus; stigma 3 -lobum; nectaria obtusa, parva. Fragmenta possideo quæ cl. Gaudich. commuuicaverat ut iconis 45 species, ubi folia obverse lanceolala, acuta vel obtusa, sæpe falcata, in petiolum 3-5 lin. longum angustata, cum petiolo bipollicaria, 4-6 lin. lata, nervis later. paucis obliquis tenuibus; flnres truncati, ab icone ut videtur non diversi. Specimina imperf. similia vidi in $h$. Mus. par. Ex hisce iconem et phrasim cel. auctoris reformandas existimo. (v. s.)

i 2. S. ELL1PTI CUM (Gaudich.! voy. Freyc. p. 442), foliis ellipticis vêl obovato-ellipti- cis obtusis basi cuneato-angnstatis petiolo quater longioribus, paniculis axillaribus folio multoties brevioribus ramis oppositis apice 3 ?-floris, bracteis caducis ovatoacutis ciliolatis, alabastro sessili obovoideo. 5 In ins. Sandwich, ubi Maoloa dicitur ex Gaudich. Rami teretes, apice subquadranguli. Folia opposita, glabra, petiolo 3 lin. longo, limbo pollicem sæpius longo, 5-7 lin. lato, non vere coriaceo ut ait cl. auctor sed opaco glaucescente, nervis lateralibus parum distinctis aut non distinctis. Bracteæ $\frac{1}{3}$ lin. long:e. Alabastra matura $2-2 \frac{1}{2}$ lin. longa. Perigonium 4 -fidum, - flavo-virescens (ex Gaudich.). Pili inter stam. et lobum ut in congeneribus. Nectaria 4, ovala. Stylus cylindricus, altitudinem antherarum attingens; stigmata 3. Ovula 3 ? basi placentæe ovoideo-acuminatæ. (Ex fragmentis a Gaudich. comm. descriptionem fere completam industriâ erui.)

3. S. Lan Gélatum (Br. prodr. fl. N. Holl. p. 356, non Schlecht,; nẹc Mueller pl. exs.). foliis longo-lanceolatis utrinque acutis glaucis eveniis coriaceis, racemis brachiatis, caule fruticoso. $J$ In Novâ Hollandiâ or. intra fropicum. Nil amplius in opere oit. - Alt. Cunningham sub hoe nomine specimen e ciovâ Walliấ austr. communicavit phrasi nimis brevi respondens, ubi seq. video : Folia $2-3 \frac{1}{2}$ poll. longa 5-8 lin. lata, in petiolum brevissimum longe angustata, acuta vel acuminata, coriacea, nervis lateralibus pancis obliquis(nec patentibus) parum distinctis ; paniculie terminales et axillares, folio broviores, ramulis oppositis extremis 3 -flopis, pedicellis subnullis ; alabastra matura 4 lin. longa, oblongo-obovata; perigonium 4 -fidum, pili longi inter stamiuum basim et antherarum apices, aliique breves patentes cirea basim stam. interne; filamenta plana triangularia unde ab aliis $\mathrm{sp}$. differt; antheræ biloc. filamento multo longiores; nectaria obovato-rotunda, filamento subuqualia. (v. s.)

4. S. овтUSIF OLIU (Br, prodr. fl. N. Holl. p. 356), foliis oblongo-ovalibus obtusis coriaceis subtus glaucis eveniis, superioribus passim alternis, racemis paucifloris. 
J In Novâ Hollandiâ arientali prope Part Jackson. - Hanc speciem in arbore colonise Swan River (Preiss, n. 210k) agnoscere judicavit cl. Miquel (in Lehm. pl. Preiss. 1, p. 616) : folia tamen sicca non glancescentia et arborem 25-ped. (nec fruticem) confitetur. Phrasis Brownii nimis abbreviata et species raro eredem in littoribus oppositis Australiæ, quapropter similitudinem vix credo. Suam plantam, verisimiliter imperfectam, non descripsit cl. Miquel. - Specimen vidi in herb. vindob. a Ferd. Bauer S. obtusifolium Br. nuncupatum, ubi folia in eodem ramo diversa, inferiora 1-2 poll. longa et 5 lin. lata, superiora 10-12 lin. longa et 6 lin. lata, omnia obtusa brevissime petiolata, nervis later. vix distinctis, flores pauci obconici, e pedunculis axill. folio multo brevioribus. Perigonium obcoLicum, 3-4 lin. longum, 4-fidum, lobis ovato-acutis. Pili interne ad originem stam. iransversi, alii inter lobos et antheras erecti. Stylus stam. attingens, apice (ex uno flore) 3-lobus.

5. S. OBLONGATUM (Br. prodr, fl. N. Holl. p. 355), foliis angusto-oblongis obtusis coriaceis glaucis supra parum venosis quadruplo longioribus quam latis ${ }_{\mathrm{n}}$ racemis brachiatis divisis simplicibusve: - Iñ Lovà Hollandiâ orient. intertropicali. - Hic verisimiliter referenda specimina Australiæe orient. a cl. Von Hügel lecta, in herb. vind. reposita, ubi folia opposita vel rarius fere alterna, oblonga, 1-2 poll. longa, 1-4 lin. lata, obtusa, nunc mucronulata, coriacea, nervo centrali subtus prominente, paginâ infer. glaucescente; cymic axillares, 4-6 lin. longæ, 3-5-florie ; flos centralis ebrạcteatus, laterales bracteolâ lanceolatâ vix́ linean longà stipati ; flos 3 lin. longus, obconicus, semi-4-fidus; lobi'ovato-acuti, pilis albis circa originem staminum, inferioribus retroflexis, aliis longissimis antheras usque extensis, sed $a b$ is distinctis; stylus stamina atlingens, lobis 4 oblusis cum perigonii partibus alternis.

6. S. ALBUM (Linn. sp. p, 497), foliis ovato-ellipticis basi acutis apice acutis vel rarius obtusis, paniculis terminalibus et lateralibus multifloris, pedicellis tubum perigonii subæcquantibus. $\delta$ In montosis peninsulæ indice (Roxb. Perrott.! Hohen.! n. 871 in h. Boiss.) et archipelagi indici (Rumph. Zoll. n. 2804!). - Roxb. fl. ind. ed. Wall, 1, p. 462, Dict. sc. nat. t. 5 (opt. pilis perig. exceptis, in Spach Hist. veg. 1.25 iter.), Hayne Arzn. Getw. 10, t. 1, Hook. bot. mag. t. 3235, Griffith Trans. linn. soc. 18, p. 59, t. 1-3 (de ovulis et fructu). Sandalum album Rumph. Amb. 2, t. 11. S. myrtifolium Wall. list, C, ex h. Madr. (in h. ber.!) F.! ex h. bot. Calc. et D. ex herb. Wight (a cl. Hook. obs.). Lignum siccum staveolens, album vel

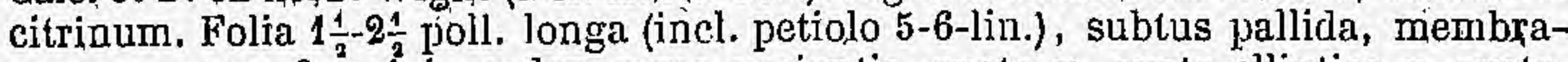
nacea, venosa, formấ in eodem ramo variantia, ovata v. ovato-elliptica v. ovatoelliptica v. ovato-lanceolata. Panicula folio brevioris ramulis trifloris, bracteis fere nullis minimis. Pedicelli $\frac{1}{3}$ lin. Iongi. Perigonium campanulatum, 4 -fidum, $1 \frac{1}{2}$ lin. longum, interne rubescens, pilis a basi ad antheram simplicibus albis. Nectaria obovato-rotunda crassa. Filamenta tenuia, nectariis subæqualia. Antheræ filamento minores. Drupa globosa, magn. cerasi parvi, demum nigra. (v. s.)

B. myrtifolium, foliis lanceolatis. 5 In montibus Circars penins. indicæ. Sirium myrtifolium Linn. manl. p. 200, Roxb. pl. Corom. 1, t. 2, in Hayne Arzn. Gew. 10, t. 2 iterata. Santalum myrtifolitim Roxb. fl. ind. ed. Wall. 1, p. 464 (non Wall. D. et F.). Ex pristinis fig. et descr. Roxb. in regione Goromandel arbusenla vel frutex, ligno mediocris valoris, foliis angustioribus et subtus pallidiuribus quam in vero Santalo, baccâ paulo minore. Lobos sive nectaria cum stam. alterna obcordata dicit et triloba nec rotundata ut in vero, sed in spetiminilus siccis Santali vulgaris obovato-rotundata sinuata video. Culturd in horto Calcutt. aut mutavit aut cum vero Santalo serius confusa fuit.

7. S. ova Tum (Br. prodr. fl. Nov. Holl. p. 355), foliis elliptico-ovatis acutis venosis petiolo quater longioribus, pedunculis indivisis trifidisve, caule arborescente. 5 In Novâ Hollandiâ orientali-septentrionali. Proxinum S. myrtifolio (S. album $\beta$ ), sed diversum, ex cel. auctore, qui nihil addit. - Specimen adest in herb. vindob. a Ferd: Bauer S. ovatum Br. vocatum, ubi folia $1 \frac{1}{9} 3$ poll. longa (incl. petiolo 3 lin.), $7-10$ tin. lata, ovata vel ovato-elliptica, obtusa vel acuta, basi acuta, nervis lateralibus tertiariisque perspicuis, modo $\mathrm{S}$. albi reticulatis sed minus distiuctis ; flores räri; fructus (segregatus) lin. longus, ellipticus, apice umbilicatus. In authenticum?

8. S, venosur (Br.! prodr. fl. Nov, Holl, p. 355), foliis ellipticis basi acutiusculis 
apice obtusis et mucronulatis glaucis parum venosis, paniculis terminalibus et lateralibus, bracteis caducis ovato-oblongis, pedicellis subnullis. 5 In Novả Hollandià or. intertropicali, ad Carpentarie (Br.! in ls. DC.). Folia in specimine $1 \frac{1}{2}$ poll. longa (incl. petiolo 2-3 lin.), 6-9 lin. lata, nervis venisque ut in S. albo, sxpius muerone acutissimo terminata. Pedunculi (ex Br.) indivisi trifidive, in specimine ramuli paniculæ folio brevioris oppositi, apice 3 -flori, bracteis $\frac{1}{2}$ lin. longis. Alabastra, obovoidea, $1 \frac{1}{3}$ lin. longa, vix pedicellata, unde a S. a!ljo differt. Nectaria obovala, minora quam in S. albo. Antheræ contra majores, filamento et nectario multo longiores. Stylus longus. Stigmata 3 , antherarum apicibus proxima. (v. s. comm. a cl. Br.)

\section{§2. Stylus abbreviatus et ideo stigmata infra antheras sita.}

9. S. Preissianum (Miq. in Lehm. pl. Preiss. 1, p. 615), foliis longe lanceolatis utrinque acuminatis petiolatis crasso-coriaceis subeveniis, paniculæ terminalis ramis oppositis patentibus ipice 3-7-floris, bracteolis caducissimis ovato-acutis flore subsessili brevioribus, putamine nuclei globoso ruminato-faveato. $\bar{F}$ In arenosis maritimis Nove Hollandiæ austro-occictentalis (Preiss!n. 2102, Drumm.l coll. 2, n. 227), in orâ austro-orientali (Behr.) et insulâ Van Diemen (h. reg. berol. ex l. Lindl. sub n. 202). S. lanceolatum Schlecht. in Linn. 20, p. 579, non Br. Ramuli foliaque flavicantia. Folia 2-3 poll. longa (incl. petiolo 3-4 lim,), 4-6 lin. lata, nervis later. paucis valde obliquis parum distinctis. Paniculie folio sæepius dimidio breviores, ramis 2-3 lin. longis ex axillâ cicatricis (bracteæ delapsæ) Bracteolæ $\frac{1}{5}$ lin. longæ. Alabastra matura lineam longa, obovoideo-quadrangula. Lobi perigonii crassi inflexi, media basi interne pilis donati. Antheræ 4, cavitatem limbi implentes, 4-locellata, filamento gracili breviore dorso adfixæ. Nectaria filamento sublongiores. Stylus brevissimus, apice bilobus. Placenta in tubo pingui abscondita, stipitata, apice conica, ovulis 2 (an semper?) e cono superiore pendentibus ideoque medio totius placentæ potius quam basi sitis. Drupa globosa $1 \frac{1}{2}$ poll. longa. (v. s.)

10. S. cogNatu (Miq. in Lelım. pl. Preiss. 1, p. 616), foliis longe sulffalcato-lanceolatis basi in petiolum brevem acuminatis apice oblique et pungenti-acuminatis coriaceis subvenosis, panicule terminalis ramis oppositis patentibus 3-5-floris, bracteolis caducissimis..... flore subsessili, putamine.... F vel 5 In arenosis sylvaticis Novæ Hollandiæ austro-occidentalis (Preiss, n. 2098, 2100), et meridionalis (S. lanceolatum Mull. exs., non Br.j. Arcte S. Preissiano affinis species, pilisque inter lobos perigonii et stamina invito cl. Niquel non destiluta. Foliorum magnitudo, color et rami simillima. Differt petiolo duplo breviore 1-2 lin. longo (ut pote limbo decurrente mensurabilis), nervis paulo frequentioribus et magis distinctis, formâ interdum subfalcatâ, paniculâ magis pyramidatâ, nempe ramis inferioribus sublongioribus, floribus paululum majoribus. Fructus magis forsan liversi ignorantur. Ex specimine Müller. in herb. vindob. folia ejusdem rami superioris nunc lineari-lanceolata pollicaria $1 \frac{1}{2}$ lin. lata, nunc obovato-spathulata $7-8$ lin. longa 2-3 lin. lata. (v. s.)

11. S. DIVERSIFOLIUM, foliis inferioribus oppositis elliptico-lanceolatis rectis, superioribus alternis liueari-lanceolatis falcatis, omnibus membranacco-coriaceis versus basin angustatis apice subuncinato-acutis venulosis. $\delta$ In limoso-arenosis coloniæ Swan River (Preiss! n. 2111). Fusanus? diversifolius Miq. in Lehm. pl. Preiss. 1, p. 617. Folia subsessilia, 2-3 poll. longa, 5-10 lin. lata (in eod. specimine herb. reg. ber.1), ideo situ et magnit. variantia, nervis later. obliquis parum distinctis. Inflorescentia ign. Drupæ ovoideo-globosæe, laterales, pedicello 4-6 lin. longo insidentes, læves, apice calvo obscure umbilicatæ, putamine (ex Miq.) leviter ruminato. (v. s. in h. meo et reg. berol.)

12. S. AсUмготим, foliis lineari-lanceolatis acumine uncinato basi in petiolum brevem angustatis crassiusculis, paniculis terminalibus et axillaribus ramulis oppositis patentibus apice paucifloris. $\bar{J}$ In Novà Hollandià merid. (Br., F. Bauer! in h. vindob.), orientali (h. Mus. par. in meo) et in siccis internis Novie Walliæ (All. Cunn.). Fusanus acuminatus Br. prodr. N. Holl. p. 355, A. Cunn.! in ll. meo,

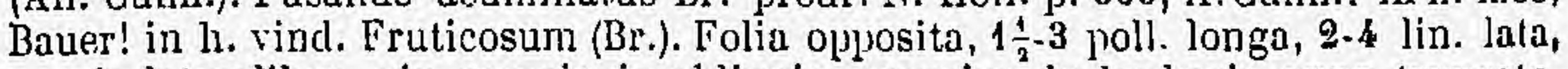
nervis lateralibus vix perspicuis obliquis, acumine in herbario sæe truncato, 
petiolo subtorso a limlo vix distincto. Inflorescentia S. cognati, cui uncinulo et formâ foliorum valde affine. Panicule $1-1 \frac{1}{2}$-pollic., ramulis inferioribus 1-3 lin. longis apice sæepius? 3-floris, superioribus minoribus. Flores nimis juniores el rari in speciminibus qua vidi; minores quam in S. cognato suspicor. Drupa (ex specim. Cunn.) globosa, 8 lin. lata, carne parca, putamine ruminato-punctato.

13. S. ANGUSTIFOLIUM, foliis linearibus subulatis basi in petiolum brevem angustatis, paniculis terminalibus ramis oppositis apice 3-5-floris, bracteis caducissirnis, foribus pedicellatis junioribus pyriformibus. $\zeta$ In Novà Hollandiâ austro-occid. (Drumm.! coll. 3, n. 218, coll. 4, n. 430). Rami 4-angu'li, erecti. Folia internodiis longiora, erecta, $1-1 \frac{1}{2}$ poll. longa, 1-2 lin. lata, acumine siepius flexo, jetiolo vix a limbo distincto, nervo centrali distincto, aliis ferc nullis. Paniculæ pollicem longæ, multifloræ, ovoidere, ramis secundariis apice florifcris. Bractere in specim. delapsee. Alabastra cum pedicello 2 lin. longa. Peilicellus a tubo non distinetus, $1 \frac{1}{2}$ lin. longus. Lobi 4, raro 5, apice vix inflexi, fasciculo lato pilorum ad originem staminum donati. Nectaria obtusissima. Stylus manifeste bilobus. Ovula 2, sub styli lobis in basi placenta sita. Materies quadam resinosa? pallida sub cuticula partium floris jacens, floribus in aquâ immersis modo lenticellarum jntus et extus manifesta. (v. s. in h. Boiss.)

14. S. CRassifoltum, fruticosum, foliis linearibus crassis obtusis, pedunculis axillaribus paucifloris, ramulis 4 -gonis. 5 In ora merid. or. Nova Hollandia. Fusanus crassifolius Br. fl. N N. Holl. 1). 355. Fusanus glaucus Gaudich. in herb. Mus. par., Mus. ber. et in meo. Specimen vidi cx herb. Bauer in l. vindol. phrasim Brownianam nimis brevem evolvens, si vere Fusanus crassifolius est ut censebat Ferd. Bauer. Rami istius teretes, ramuli 4 -goni. Folia opposita, linearia, linearilanceolata vel lineari-obovata in eodem ramo, 1-1 $\frac{1}{2}$ poll. longa, 3-4 lin. lata, in petiolulum lineam longum a limbo non vere distinctum angustata, obtusa vel rarius acuta, crassa, nervis lateralibus ideo parum distinetis obliquis. Paniculæ juniores spiciformes, folio multa breviores, axillares et terminales. $\Lambda$ lahastra obovato-globosa, ternata, bracteis et bracteolis ovato-ellipticis $\frac{1}{2}$ lin. longis inclusa, $\frac{3}{4}$ lin. longa. Perigonium 4-fidum, interne medio pilosulum. Discus concavus, lobis 4 obtusissimis liberis. Stamina 4 , filamento tenui, antherâ latâ subdiscoideâ biloculari. Stylus brevis, apice 2-lobus. Placenta ovoideo-acuta, basi ovula 2 gerens. Crescit in petrosis ad Leewins' land. Fragmenta incompleta, similia, ex sinu Chiens-marins oræ occid. attulit Gaudichaud. In hisce fructus globosus, 8 lin. latus, superne areolâ lectus 3 lin. latà perigonii vestigiis cinctâ, putamine crasso duro sparse ruminato. (v. s.)

15. S. S P I A т UM, arborescens, foliis lineari-oblongis obtusiusculis muticis, spicis axillaribus compositis. $\delta$ In orà merid. or. Novæ Hollandirc. Fusanus spicatús $\mathrm{Br}$. prodr. Nov. Holl. p. 355. Ex nomine verisimiliter affine $\mathrm{S}$. acuminato et $\mathrm{S}$. crassifolio, sed fere incognitum. Numerus Preissii 2119 idem est forsan species ex cel. Miquel (plant. Preiss. 1, p. 617), sed folia dicit alterna, cum in Fusanis Brownii opposita sint. Patria eæterum satis distans.

16. S. GYGNORU (Miq. in Lehm. pl. Preiss. 1, p. 615), foliis anguste oblongo-lanceolatis basi in petiolum brevissimum angustatis apice acutis vel obtusis mucronulatis rigide coriaceis pallidis, paniculis terminalibus et axi]laribus spicato-ramosis, floribus ternatis sessilibus, bracteis caducissimis ovato-rotundatis. 5 In lapidosis Novæ Hollandiæe austro-occid. ubi nuttree dicitur (Preiss! 2103, Drumm.! coll. 2, n. 226 in h. Boiss.). Lignum suaveolens. Rami in herb. nigricantes, quadrangulo-

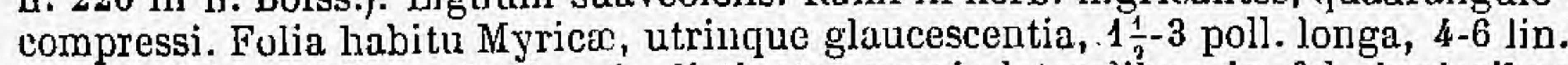
lata, petiolo 1-2 lin. a limbo vix distincto, nervis lateralibus in fol. junioribus bene distinctis obliquis ramosis. Pcdunculi folio duplo triplove breviores, basi ramosi, apice simplices. Bracter $\frac{1}{3}$ lin. longæ, concavie, flores 3 foventes, quorum centralis pracocior et 2 laterales bracteolis minoribus lateralibus donati. Perigonium in alabastro obovoideó-quadrangulum 4- nunc 5-fidum, lineam latum. Nectaria orato-rotunda. Filamenta ligulata brevia. Stylus brevissimus, subbilobus.(v.s.)

17. S. INSUzane (Bertero! mse.), foliis ellipticis coriaccis pellucide punctatis in petiolum abrupte nngustatis apicc obtusis vel sulacutis, racemis terminalibus folio multoties brevioribus, floribus ternatis vel sulitariis ajice ramulorum raceni, bractcâ flori adpressà rotundatâ cuspidatâ caducissimâ. $\delta$ In irs. Marquises diclis

XIV. 
(Navarch. du Petit-Th.1) et Taiti ubi vulgo Eai (Mœrrenhout! Bert.!). S. Freycinetianum Guillem. Zephir. Tait. p. 36 (non Gaudich.). Glabrum, ramis teretibus, ramulis angulato-compressis. Folia opposita, petiolo 4-5 liv. longo, limbo 3 poll. longo, 12-16 lin. lato, nervis lateralibus utrinque 7-8 tenuibus obliquis ad marginem evanescentibus. Racemi (in specim. rari) 6-9 longi, ramulis oppositis angulosis pauciftoris. Bracteæ ramulorum delapsæ. Bracteola alabastro adpressa, $\frac{i}{2}$ lin. longa, glabra. Alabastrum obovoideum, 4-fidum, lineam longum. Lobi apice uncinati, medio fasciculo pilorum brevi donati. Stylus brevis. Placenta congenerum. (v. s. a Mus. par. comm.)

\section{Sectio II. MidA. - Genus Mida Cunn. l. c.}

Folia alterna. Racemi axillares, simplices, pedicellis alternis. Flores sæpius pentameri (rarius tetrameri). Stigmata 2-3-4.

18. S. GUNNINGHAMII (Hook. f.l fl. N. Zel. 1, p. 223), foliis alternis laneeolatis subpunctatis, racemis axillaribus et subterminalibus folio multoties brevioribus simplicibus, bracteis ovato-acutis caducis, pedicellis bractêे et flore longioribus, flore pentamero (nunc 4-mero), fructu obovato-turbinato. 5 In Novæ Zelandiæ ins. septentrionali, ubi Maire (nec Mida) vocatur ex Colenso in Hook. f. Mida salicifolia, M. eucalyptoides et M. myrtifolia A. Cunn.! Ann. of nat. hist. 1, p. 376. Santalum Mida Hook. ic. t. 563 et $\mathbf{5 7 5}$. Rami anguloso-compressi. Folia sparsa, nunquam opposita, $1 \frac{+3}{2}$ poll longa, admoduma latitudine in div. plantis et imo in eâdem variantia, unde anguste lanceolata, late lanceolata, ovalia, imo obovata, acuta vel obtusa, petiolo vix distincto, nervis later. numerosis prope marginem arcuatoconnexis, punctis initio minimis pellucidis deinde opacis utrinque eminentibus. Racemi 5-7-flori. Pedicelli 2-3 lin. longi. Flores campanulati $1 \frac{1}{2}$ lin. longi latique, 4-5-fidi, lobis a tubo basi bene distinctis et facile segregatis. Pili mediæ basis internæe loborum e squamâ fere seu basi communi divergentes. Staminum filamenta tenuia. Discus concavus, lobis rotundatis. Stylus brevis, ideo stigmata panlo infra regionem staminum sita. Ovula 2-3, basi placentæ ovoideo-acutæ. Drupa 4-5 lin. longa, lobis demum caducis vertice umbilicata, pedicello 3-4 lin. longo, carne parcâ, putaminis rimis parvis adhærente. (v. s.)

\section{Species non satis notce.}

19. S. PAN I CUL A T U M (Hook. et Arn. bot. Beechey voy.p. 94), foliis late ellipticis venosis planis petiolo multoties longioribus, paniculis terminalibus multifloris. In insula Owhyhee Sandwicensium (Macrae). Caulis lignosus. Petioli 2 lin. longi; limbus $1 \frac{1}{9}-2$ poll. longus.-Nihil in phrasi nimis brevi ab icone S. Freycinetiani Gaudich. differt.

\section{Species dubia.}

Fusanus? emarginatus (Miq. in Lehm. plant. Preiss. 1, p. 617), foliis alternis erectis rigido-coriaceis spathulato-oblongis apice obtuso plerumque emarginatis eveniis, spicâ axillari pauciflorâ, bracteis rotiundatis concavis carnosis? In asperis

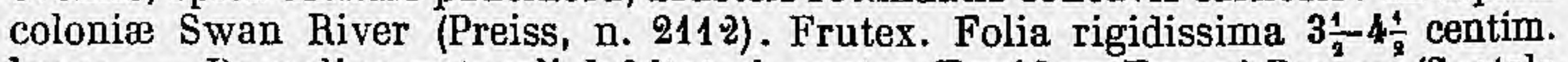
longa. - De ordine naturali dubitat cl. auctor. Equidem Fusani Brown. (Santala nob.) folia opposita nec alterna præbent.

\section{Santala vel Fusani exclusa.}

S. CAPENSE herb. germ. = Rhoiacarpos Capensis.

F USANUS PEDATUS Spreng. syst. 1, p. 490. = Lagenula pedata ,Lour. (Passifloracea?) 
Tribus III. ANTHOBOLEAE. - Genera Santalaceis affinia Brown prodr. fl. Nov. Holl.p. 356. - Anthoboleæ (ordo) Dumortier unal. fam. p. 15et 17, Meisn.gen. comm. p. 240. - Anthobolex (ad calcem Santalacearum) Endl.gen.p. 328.

\title{
Flores monochlamydei. Ovarium basi solum adhærens. Placentatio et fæcundatio fere ignotæ (1).
}

\author{
- XVIII. ANTHOBOLUS R. Brown prodr. Nov. Holl. p. 357.
}

Flores dioici. $\sigma$ Perigonium profunde 3 -fidum, lobis ovatis inflexis glabris. Stamina 3, Jobis perigonii opposita ; filamento brevissimo; antherâ oblongâ, biloculari, rimis 2 introrsum dehiscente, dorso sub medio insertâ. Discus 0 . Ovarium 0. 오 Perigonium caducum. Ovarium liberum, uniloculare. Stigma sessile, 3-lobum. Nux ovoideo-oblonga, subcarnosa, monosperma. Semen inversum (Br.). Embryo in axi albuminis carhosi rectus; radiculâ longâ, sıperâ, obtusâ, tereti, inferne attenuatâ, cotyledonibus acuminatis multo longiore. - Frutices Novæ Hollandiæ, glabri, ramosissimi, spartei, habitu Osyridis; ramis ramulisque articulatim insertis; foliis sparsis, sessilibus, cum ramulo articulatis, anguste linearibus, subfiliformibus ; pedunculis axillaribus, masculis umbellatim 3-4-floris, femineis 1-3-floris, medio dum simplices ad divisuram dum ramosi articulatis, ibique bracteis 2 caducis; floribus flavicantibus, parvis.

1. A. FI If ol ius (Br.! l. c.), foliis filiformibus ramulisque laxis. $う$ In Novæ Hollandiæ orâ orientali intra tropicum (Br.), et sept. (A. Cunn.!) A.triqueter A. Cunn.! in h. DC. Ex specimine Brownii : rami graciles, ramuli angulati ; folia 6-15 lin. longa, erecta, acuta, $\frac{1}{3}$ lin. lata ; pedunculi masc. 3 lin., pedicelli vix lin. longi; bractere 2 oppositæ, lanceolatæ, $\frac{1}{3}$ lin. longæ, apice pedunculi, patentes, caducæ; flos vix lineam longus, obovoideus ; pedunculus fructifer pollicaris, erectus ; fructus ellipsoideus, 3 lin.longus. Ex specimine simillimo Cunninghami et altero imperf. Gaudichaudii ovarium sæpe vacuum; caro fructus parca, e cellulis angulosis facile segregatis in sicco constans; putamen crustaceum ; relliquiæe endocarpii collapsæe varie ? putamini adhærentes aut semen tegentes ; semen ubi evolutum cavitatem ovarii implens; embryo albumine duplo brevior. (v. s.)

2. A. TR R UE TER (Br. l. c.), foliis subulatis semiteretibus modice patentibus, ramulis angulatis strictis. $\mathrm{J}$ In Novâ Hollandiá orient. intra tropicum.

XIX. EXOGARPOS Labill. voy. 1, p. 155, t. 14, Nov. Holl. 2, p. 123, Br. prodr. N. Holl. p. 356, gen. rem. p. 37. - Exocarpus Endl.gen. p. 328, Blume Mus. 1.p. 180, t. 36 (ubi error in fig. seminis?), Hook. f. $\mu . N$. Zeland. p. 223, t. 52. - Sarcocalyx Zippel. in Bull. Feruss. 18, p. 92, sine descr., ex diario Bat. anni 1829 memor: (non Walp.).

Flores hermaphroditi vel polygami. Perigonium 5. rarius 4-subpartitum; lobis ovato-acutis, æstivatione valvari, uno bracteam spectante. Stamina 5 , rarius 4 , lobis perigonii opposita, eorum basi inserta ; filamento ligulato brevi ; antherâ erectâ subovoideâ ; loculis 2 , sæpe bilocellatis, rimis longitudinalibús ideo 2-4 dehiscentibus, in fl. fem. vacuis ninoribus. Pollen (immersum)

(1) Flores plerumque unisexuales; feminei juniores in herbariis rari et scepe steriles. Pluribus apertis interdum (in Exocarpo Luzonensi et E. pendulâ) placentam?' filiformem sterilem vel ovulum? vel rarius ovula filiformia duo? in cavitate carnis; ovarii e basi erecta observavi, sæpius vero ovarium totum carnosum inveni. Semen. videtur nunc abortiens, carne collapsâ sporngiosâ endocarpii varie hinc inde' mesocarpio adhærens ; nunc evolutum, albumine carnoso copioso, embryone recto in apice albuminis, radiculâ superâ, carne ovarii evanescente superficie tectum, quæe omnia ut: in seminibus Santalacearum. Ovarium non vere liberum ab hoc ordine parum.differt. Attamen placentatione et sacculo embryonali incertis locus in systemate naturali adhuc dubius. 
ellipsoideum, læve. Discus epigynus vix distinctus, inter stamina plus minus margine tumefactus. Ovarium superum, carnosum, uniloculare. Stylus conicus, minimus. Stigma capitato-sublobatum. Placentatio incerta (conf. ad notam præced.), nempe : ovula plura basilaria (ex Endl. prodr. fl. Norf. p. 46 , seu potius ex ic. ined. Baueri ibi citatâ Exocarposphyllantoidis), vel 1-2 basilaria filiformia aut placenta? centralis sæpe sterilis (ex anal. meis). Nux ovoidea, parva, tubo perigonii tunc incrassato colorato insidens, basi vestigiis loborum cicatrisata. Semen unicum, materie interiori exsiccatâ collapsâ pericarpii tectum, ab ipsius parte durâ plus mirus segregatum, nunc basi, nunç lateraliter, nunc apice ex materie collapsâ endocarpii mesocarpio connexum. Albumen carnosum vel sebaceum. Embryo minimus, rectus, in vertice albuminis ; radiculâ super'â, cylindricâ, cotyledonibus minimis vix divergentibus multo Iongiore. - Arbusculæ, frutices vel suffrutices Australasici, sæpius habitu Leptomeriæ; foliis alternis, sæpe minimis aut nullis, ramulis nunc in phyllodia mutatis; spicis axillaribus ; floribus minimis ; bracteis caducis vel nullis.

\section{Sectio I. Sarcocalyx. - Genus Sarcocalyx $Z$ ippel. l. c. - Exocarpos sp. Blume l. $c$.}

Folia ampla, palminervia, petiolata, nervis basi et apice confluentibus secus ramum teretem non decurrentibus. Spicæ plerum divisce. Pubes stellata minima in novellis frequens. Albumen sebaceum. - Genus distinctum forsan, propter habitum, nam characteres seminis in ic. Blumei erronei videntur quoad funiculum superiorem. (Conf. ad E. latifoliam).

1. E. LA TIF OLIA (Br.! prodr. N. Holl. p. 356), arborescens, ramis foliis junioribus spicisque pube stellatâ brevi canescentibus, ramis teretibus, foliis ovalibus petiolatis 7-nerviis, spicis folio duplo triplove brevioribus basi excèptâ multifloris, bracteis minimis ovato-acutis, perigonio utrinque puberulo. 5 In Novâ Hollandiâ or. tropic. versus Carpentarie (Br.!). Rami foliaque demum glabrata. Folia alterna, 10-15 lin. longa (incl. petiolo 2 lin.), 5-7 lin. lata, membranacea, obtusa vel mucronulata, nervis ntrinque parum eminentíbus, centrali non majore, in folio jun. pubescente non perspicuis. Spicæe graciles, 5-7 lin. longæ, nunc subramosæ. Bractex $\frac{1}{4}$ lin. longæe, demum evanescentes. Flores in foveolâ rhachis nidulantes, $\frac{4}{3}$ lin. longi latique.Lobi perigonii 5 , ovato-acuti, patentes. Stamina omnino congenerum. Discus ad angulos 5 inter lobos perig. tumefactus. Ovarium superum, conicum. Stigma capitellatum. Fructus subglobosus, lævis, glabriusculus, 3 lin. longus, basi perigonii obconicâ $2 \frac{1}{2}$ lin. longâ insidens. Albumen sebaceum. Embryo in sup. parte, minimus, radiculâ cylindricâ superâ, cotyledonibus brevissimis. (v. s. a cel. Br. comm.)

2. E. м г м г т A (Zippel, 1. c.), frutescens, ramis petiolis foliis junioribus et rachi tomento denso subtili incanescentibus, foliis ovatis petiolatis nervulis basi et apice confluentibus, spicis folio duplo brevioribus basi exceptâ multifloris, bracteis minimis, rachi tomentosâ, perigonio papilloso-scabrido. $\bar{J}$ In petrosis littoreis Novæ Guineæ. Exocarpos ovata Blume 1. c. t. 36 . Vix differt, ex cl. Blume, ab Exocarpo latifoliâa

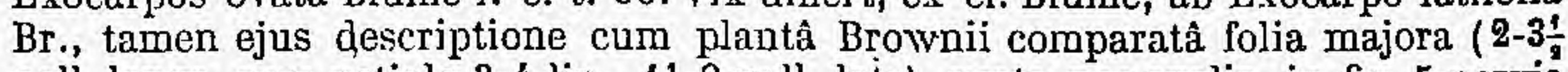
poll. longa, cum petiolo $3-4$ lin., 1,-2 poll. lata), ovata nec ovalia, in fig. 5-nervia (an errore pictoris?) nec 7-nervia. Spicæ ex Blume solitariæe vel 2 -3 aggregatæ; in E. latifoliâ interdum supra basin ramosæ. De char. seminis in fig. verisim. erroneis, confer ad char. gener.

3. E. L u z ON ENS Is (Presl epimeliæ, p. 248), ramis teretibus, novellis foliisque junioribus et rachi pube minutissimâ incano-velutinis, foliis lanceolatis rarius ellipticis petiolatis 5 -nerviis, spicis folio $3^{\circ}-6^{\circ}$ brevioribus basi exceptâ multifloris, bracteis mini$\mathrm{mis}$, lobis perigonii subvelutinis. $亏$ vel 5 . In insula Luzon Philippinensium (Cuming 1195!). Folia sparsa, integerrima, coriacea, glabrescentia, $1 \frac{1}{2}-3$ poll. longa, 8-10 lin. lata, obtusa, nervis tenuibus venulisque paucis, in petiolum 2-3 lin. basi angustatis. Spicæ $\frac{1}{2}-1 \frac{1}{2}$ poll. longæ, solitariæ vel rarissime gemine aut ternæ, simplices, rarius ramulo uno versus basin instruclæ, parte non floriferâ inferiore 1-3 lin. longî. Bractea cujusque floris minima, caduca, squamiformis, flore brevior. 
Perigonium $\frac{2}{3}$ lin. longum, $\mathbf{5}$ :lobum, patens. Drupa obovoidea, 3 lin. longa et lata, in sicco fusoo-nigricans, glabra, cupulø 2 lin. longæ cano-velutinæ concavæ in.' serta (1). (v, s.)

\section{Sectio II. EuEXocarpos.}

Folia minora vel minima, sessilia, nervis 3 secus ramum angulosım, striatum vel sulcatum decurrentibus. Pili rarissimi, sparsi, nec stellati.

"Folia elongata.

4. E. O DORA T A, frutescens? dense foliosa, ramis teretibus, ramulis angulato-striatis, foliis linearibus acutiusculis elongatis medium usque trinerviis, spicis axillaribus folio subbrevioribus plurifloris, rhachi subvelutinâ, bracteis minimis e basi squamæformi adhærente mucronatis, perigonio grabriusculo. $\hbar$ ? In Novà Hollandiå austro-occident. (Preiss | n. 2093). Leptomeria? (an Exocarpus?) odorata Miq. in Lehm. pl. Preiss, 1, p. 613. Glabra. Rami e nervis 3 sub folio decurrentibus lineati. Folia internodiis longiora, $8-10$ lin. longa, $\frac{3}{4}-1$ lin. lata, erecta, sæpe versus ramum falcata. Spicæ 4-8 lin. longæ, $a b \frac{1}{3}$ vel $\frac{1}{2}$ longitudinis floriferæ, floribus dispositione $\frac{1}{3}$, non proximis. Bractese dentiformes. Flores $\frac{1}{1}$ lin. longi latique, tamen bracteâ majores, diu globosi. Lobi perigonii elliptico-acuti, oculo armatissimo margine subvelutini, extus glabri. Discus sub-5-angularis. Ex cl. Miquel stigma 5-angulare, sublobulatum; ego subtrilobum aut obtusum vidi. Fructus ign. Infloresc. et antheræe omnino Exocarpos. (v. s.)

\section{** Folia abbreviata, scepius dentiformia.}

5. E. C U PRESSIFORMI S (Labill.! 1. c.), arborescens, ramis teretiusculis vel angulosis striatis, foliis raris dentiformibus minutis ramulorum juniorum lanceolatis adpressis, spicis plurifloris, rhachi perigonioque extus subvelutinis, bracteis ovato-acutis minimis, pedunculo fructu submajore. 5. In Van Diemen (Labill. D'Urv.! Br. Verreaux! in h. Deless. 139, 135, 154), Novâ Hollandiâ merid. (Br., h. DG.l et Mus. par. I) et orientali imo intra tropicum (Br. gen.rem. p. 37). Leptomeria acerba Sieb.I pl. N.Holl. n. 136 (non Br.). Rami erecti vel penduli, in eodem specimine sicco angulosi vel teretes. Folia ramulorum lineam longa, basi subciliata, acuminata; ramorum florentium breviora, ovato-acuta vel rlentiformia, patentia. Spicæ 2-4 lin. longee. Flores in eadem planta herm. masc. et fem., $\frac{1}{2}$ lin. longi et lati. Antheræ bi? -loculares. Nux ovoidea, nigricans (Lab.), in herb. 2 lin. longa, pedunculo rubro (Lab.) submajore. Sine fructu facile cum Omphacomeriâ psilotoide confunditur. (v. s.)

6. E. SPIC А TA, ramis teretibus striatis, foliis lineari-subulatis caducis, spicis validis multifloris, rhachi tomentosâ, bracteis e basi glabrâ scutiformi obcordatâ rhachi adhærente dẻntatis, perigonio extus basi pilosiusculo. $b$ In Novâ Hollandiâ orient. (Mus. par, in h. meo). Rami validi, striis 3 sub origine folii nitidioribus. Ramuli erecti, subangulati. Folia apice ramulorım non rara, 2 lin. longa, erecta, apice sæpius patente. Spicæ femineæ 4-6 lin. longæ, fere a basi floriferæ. Bracteæ cum basi adhærente $\frac{1}{3}-\frac{1}{4}$ lin. longø. Flos fem. $\frac{3}{4}$ lin. latus, in foveolis nidulans. Ovarium ovoideo-trigonum. Stigma capitellatum. Fructus ign. An satis ab E. cupressiformi diversa? (v. s.)

7. E. GLANDULAGEA (Miq. in Lehm. pl. Preiss 1, p. 619), ramis teretiusculis vel angulosis striatis, foliis raris lineari-subulatis caducis, spicis plnrifloris, rhachi tomentosâ, bracteis ovato-acutis minimis, perigonio extus basi piloso, pedunculo fructı nitido substriato minore. b. In Novâ Hollandiâ austro-occidentali (Preiss, n. 2122 et 2125) et austro-orientali secus fl. Murray (Stuart et Mull.! exs., Miq. stirp. Mull. p. 8). E. spartea gracilis Miq. in pl. Preiss. p. 618, ex eod. in stirp. Mull. p. 8. Rami penduli ut in E. cupressiformi sæpe adsunt. Folia in sup. parte ramorum florif. $1 \frac{1}{2}-2$ lin. longa, erecta, angusta, glabriuscula. Spicæ 3 lin. longæ. Bractexe dorso glabræ, inde a rhachi distinctæ. Flores formâ E. cupressifor . mis, sed antheræ ex analysi manifeste 4-locellatæ, locellis longitudinaliter dehis . centibus. Ovarium ovoideo-trigonum. Stigma 3-gonum. Nux matura 2 lin. longa,

(1) Char. gen. post impressionem mutavit auctor in cxemplare meo, verisimiliter ex opere Blumei nam Epimeliæ anno 1852 solum divulgatæ fuerunt, monente Wal pers Ann. 2, p. 618, nec anno 1849 ut præstat titulus. 
ellipsoidea, in herb. pallida. Pedunculus siccus nuce minor. Descripsi specimen optimum Mulleri, identitatem cum E. glandulaceâ Miq. in pl. Preiss. admittens fide ipsius auctoris. (v. s.)

8. E. S T R I T A (Br. prodr. N. Holl. p. 357, non Sieb), caule fruticoso erecto, ramulis angulatis strictis, foliis minutis denticuliformibus triangularibus, spiculis glomeruliformibus sessilibus. $\bar{\zeta}$ In Novâ Hollandiâ orient. merid. et Van Diemen. An folia jam delapsa basi tantum persistente in specimine cel. auctoris ?

9. E. S P A R T A (Br. jrodr. N. Holl. p. 356, non Miq.), caule fruticoso, ramulis erectis striato-angulatis, teneris foliosis, foliis minutis subulatis apice recurvis, spicis subpyramidatis breviter pedunculatis. $尹$ In orâ merid. Novæ Hollandiie. - Species dubia ex phrasi nimis lirevi cel. auctoris. Cl. Miquel in Lehm. pl. Preiss. 1, p. 618, errore quodam phrasim Exoc, humifusæ sub nomine E. sparteæ transcripsit. Ad E. sparteam Br., non sine dubio, retulit plantas Preissii e Swan River, sub num. 2115 ! (2114 quorumdam) et 2092 ! quæ forsan differunt quamvis nihil phrasi brevissimæ contrarium. Numerus 2125 Preissii est E. glandulacea, ex Miq. recentius in stirp. Mull. p. 8. Rami teneri, graciles, erecti, inferne teretes, superne angulosi ubique striati. Folia in ramulis obvia lanceolato-subulata, 2 lin. longa, apice recurva. Spicæ numerosæ, ex axillis foliorum delapsorum, 2-6 lin. longæ, graciles, erectæ, basi exceptâ multifloræ. Rhachis tomentosa, foveolata. Bracteæ a basi obovatå adhærente cuspidatæ, minimœ. Flores in foveolis nidulantes, $\frac{1}{4}$ lin. longi latique. Perigonium glabrum, sub-5-partitum. Sti。ma subtrilobum. Nux (in 2115) ovoidea, 2 lin. longa, pallida, basi pyriformi major. Similem florentem sine nomine a Cunn. ex orâ bor. occid. et fructiferam e Swan River a Drummond sine num. possideo, et florif. in h. Boiss. et Deless. sub num. 728 anni 1843, ques 768 anni 1844 in h. vindob., vidi. (v. s.)

10. E. DAs X т A GHY S (Schlecht. in Linn. $20, p .580$ ), ramis teretibus, ramulís subangulatis impresso-lineatis, foliis squamiformibus anguste triangularibus acutis patulis dorso carinatis, spiculis plurimis breviter pedunculatis tenuiter pubescentibus. 5 In Novà Hollandiâ meridionali ad 11. Murray (Behr). Arbor. Folia $\frac{1}{a}$ lin. longa, decidua. Spicæe creberrimæ, ex omnibus super. axillis, 2-3 lin. longæ, axi scrobiculato. Bracteæ brevissimæ. Perigonium 5-partitum, rotatum, lobis extus pubescentibus, acutis.

11. E. Lept one r o Ides (F. Müll. exs. et Miq. stirp. Mull. p. 7), ramis ramulisque crassis subdivaricatis rigidis cylindricis striatis, foliis exilibus adpressissimis caducis ovatis dorso convexis, spiculis sessilibus brevibus cylindricis puberis, perigonii 5-6idi lobis ellipticis, stigmate obtuso, fructu ellipsoideo. 5 In Novâ Hollandiâ merid. ad n. Murray (Stuart), montem Brown (Behr). E. aphylla Behr, non Br., fide cl. Miq. et Müll., num vero a plantâ Brownii diversa sit ignoro. E. aphylla Br.? ex Cunn. in h. DC. specimen e Nov. Holl. inter. Ex specim. Müll. in h. imp. vindol. rami validi, votustiores apice truncato-subspinescentes; folia dentiformia, vix $\frac{1}{2}$ lin. longa, glomerulis florum adpressa, alibi delapsa; spiculæ seu glomeruli bracteis minimis ovatis puberulis initio tecti, deinde nudi, foveolati, 2 lin. longi. Perigonium extus glabrum. Antheræ (ex Miq.) cordatæ. Cupula (ex eod.) fructus primum 5-dentata, deinde truncata. Habitus et infloresc. omnino 0mphacomeriæ, sed fructus forsan superus, ex descr. Miq. (v. s. specim. imperf. in h. vindob.)

12. E. A PH YLL A (Browil prodr. N. Holl. p. 357), caule fruticoso erecto, ramis ramulisque teretibus striatis strictis aphyllis, spiculis glomeruliformibus, floribus 5 -fidis hermaphroditis, stigmate 3-lobo. 5 In orầ merid. Novæ Hollandiæ.

13. E. GAUDICHAUDIr, ramulis cylindraceis striatis, foliis minimis triangularibus, squamæformibus, spicutlis brevibus crassis glabriuseulis basi nudis a medio 5-7loris, floribus pentameris. $\zeta$ In ins. Sandwich (Gaudich.l in h. Mus. par. et DC.). Rami lignosi, validi, ramosi, recti. Folia dentiformia $\frac{1}{4}-\frac{1}{2}$ lin. longa, patentia, rara. Spicæe 2-4 lin. longæ, juniores ovoideæ, pedunculatæ, id est basi non floriferæ. Bractere foliis subsimiles, ovato-acutse, minimæ, persistentes. Rhachis et perigonium oculo armatissimo vix puberula. Flores $\frac{1}{2}$ lin. longi latique. Antheræ ex formà biloculares, forsan 4-locellatæ. Stigma obtusum. Fructus junior ovoideus, basi perigonii incrassatâ obovoideâ insidens. Habitus omnino E. Bidwillii in Fl. Nov. Zel. figurati. (v. s.) 
14. E. Bidwiluir (Hook. f. Fl. N. Zeland. p. 223, t. 52), fruticulus jrocumbens, ramulis teretibus sulcatis, foliis minimis triangularibus squamæformibus, spiculis brevibus crassis puberulis a basi 6-8-floris, tloribus pentameris. 5 In montibus ins. mediee Novæ Zelandise. Suffrutex 6-8 poll. longus, repens inter saxa. Rami ex icone potius erecti, crassi, foliis remotis purpurascentibus $1 \frac{1}{2}-2$ lin. longis. Spica ovoideæ, 2-3 lin. longæ. Bracteঞ folio subsimiles persistentes. Perigonium glabrum, 5-partitum. Antheræex ic. biloculares, loculis rimâ longit. dehiscentibus. Nux ovoidea nigricans, 3 lin. longa, basi perigonii incrassatâ carnosâ, obovoided rubrâ 4 lin. longâ insidens. Valde affinis, ait cl. auctor, E. humifusæ, nec diversa nisi perigonio pentamero.

15. E. нuMIPUSA (Brown l. c.), caule fruticoso procumbente, ramis ramulisque teretibus sulcatis, foliis minutis denticuliformibus triangularibus marcescentibus, spiculis sessilibus glomeruliformibus, floribus 4 -fidis. 5 In Van Diemen. Frustulum e Van Diemen, sub hoc nomine, ab All. Cunningh. accepi. In eo rami robusti, cylindrici, sub quoque folio delapso 3-sulcati ; folia ramulorum lanceolato-subulata, $\frac{1}{2}$ lin. longa, erecta; spiculæ ex axillis fol. delapsorum maxime abbreviatæ glomeriformes, 1-3-floræ; bracteæ triangulari-ovatæ, minimæ; perigonium profunde 4 -fidum, lobis ovalo-lanceolatis, apice vix incrassato-uncinatis; stamina, discus et ovarium videntur congenerum sed in specimine non authentico et pessimo analysi non sıbjeci. Similis videtur Leplomeriæ n. 320, Gunn !'ab Hook. fil. ad herb. vind. missâ, ubi tamen bracteæe flori proximse (non bractea communis) ovato-acutæe potius quam obtusæ. Istius flos 4 -fidus, stigmata lobis perigonii alterna.

16. E. NANA (Hook. f. in Hook. Journ. bot. 1847, p. 281), suffrutescens, caule procumbente, ramis teretibus sulcatis, ramulis compressis, internodiis brevissimis superne in folia 2 subulata divaricata dilatatis, spiculis sessilibus, perigonio 5-partito, nucibus parvis. 5 In Van Diemun ad cacumina montium. Habitus E. humifusæ, sed minor, ramis ramulisque brevioribus angulatim flexuosis superioribus præcipue compressis.

\section{Sectio III. Phyllodanthos.}

Folia nulla. Rami floriferi in phyllodia mutati. Spicæ raræ in angulis phyllodiorum sæpius geminæ, nunc simplices. Pili nulli.

17. E. PнYLLANтноге (Endl. prodr. fl. Norfoll. p. 46), ramis inferne teretibus superne compressis, phyllodiis basi articulatis lanceolatis basi præsertim angustatis nervulis crebris longitudinalibus margine repando-crenatis, spicæ e crenis remotis simplices geminæ ternatæve angulosæ 5-6-floræ, lobis 5 perigonii papilloso-ciliatis interne puberulis. 3 In insulâ Norfolk maris Pacifici (Bauer, All. Cunning.!). Rami validi, lignosi. Phyllodia $3-5$ poll. longa et $1-1 \frac{1}{2}$ poll. lata in speci-

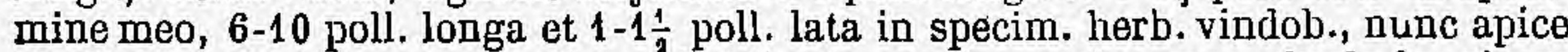
phyllodia minora gerentia. Spicæ 3-6 lin. longæ in specim. meo, duplo longiores in specim. Endl., basi nudæ, medio et apice flores sparsos subdistichos ex angulis gerentes. Bracteæ nullæ. Tubus perigonii obconicus, lobis $\mathbf{5}$ subrotatis. Discus indistinctus. Filamenta ligulata. Antheræ erectæ, biloculares, loculis oblique appositis, apice discretis. Ovarium liberum, uniloculare. Ovula plura basilaria (ex Endl.), mihi ign. Stigma discoideum. Nux (ex Endl.) pedunculo carnoșo imposita. (v. s.)

18. E. Geramica, ramis inferne teretibus superne compresso-angulosis, phyllodiis basi articulatis longe linearibus basi angustatis apice acuminatis nervo centrali donatis grosse crenatis, floribus ..... fructibus in crenis solitariis. 5 In editioribus saxosis ins. Ceramæ Moluccarum. Xylophyllos Ceramica Rumph. Amb. auct. p. 19, t. 12. Xylophylla longifolia Linn. mant. p. 221. Cel. Brown gen. rem. p. 37, primus affinitatem detexit, non vero speciem similem dixit cum plantâ Baueri ex ins. Norfolk. Gl. Blume, Mus. 1, p. 182, qui speciem præced, non viderat species miscuit. Arbuscula Ceramica. Exocarpos est propter fructum, sed ab omnibus distincta species. Phyllodia ex icone 6-12 poll. longa, tantum 2-3 lin. lata. Fructus in crenis solitarii, e spiculis paucifloris forsan proveniunt; eorum pars inferior obconica rubra, superior ovoidea basi sublongior. 


\section{Species exclusa.}

E. Stricta Sieb.! pl, exs. N. Holl. n. 137. non Br. = Casuarina.

\section{Genus dubium.}

XX. ? GERVANTESIA Ruiz et Pav. prodr. p. 31, $t .7$ (anal. mala, ubi stamina errore cum lobis perigonii alternant), syst.p. 71, Cav.! ic. $5, p .49, t .475$, Kunth in H. et B. nov. gen. 7, p. 189, Endl. gen. suppl. 1, n. 2084.

Perigonium globos $\sigma$-campanulatum, profunde 5 -fidum, æstiv. valvari, in fructu persistens et valde auclum, lobis tunc basi disjunctis medio solum inter se et cum ovario cohærentibus. Stamina 5 , lobis perigonii opposita; filamento tenui ; antherâ obovatâ biloculari basi emarginatâ, loculis 2 subintrorsum longiludinaliter dehiscentibus apicc crassioribus. Pili pauci inter lobum quemque et antheram. Discus e lobis 5 , planis, obluse subtrilobis, staminibus paulo brevioribus, is alternantibus, in æstivatione imbricatis, ut stamina per'sistentibus. Ovarium subliberum, uniloculare (sine vestigio parietum); placentâ funiculari contortuplicatâ, fundo insertâ, apice 2 ovula pendentia gerente. Stylus conico-cylindraceus. Stigma depresso-subpeltatum, margine obscure 2-3-lobum. liructus subglobosus, perigonio accreto tectus eique sub medio cohærens, pericarpio crustaceo basi pleno fungoso. Semen unum, carnosum. Embryo, ex Cavanilles, filiformis longitudine fere albuminis; ex Kunth. in parte superiore albuminis locatus radiculâ superâ. - Arbor peruviana, foliis alternis ellipticis integris, racemis axillaribus, floribus apice ramorum inflorescentiæ recurvatis brevissime pedicellatis, novellis, racemis perigonio extus et paginâ inferiore foliorum ferrugineo furlvoque tomentosis, pilis sæpe stellatis lanuginosis. - Num lobi erga stamina alterni exteriores sint, vel ejusdem verticilli, vel interiores, quæstio : ejusdem verticilli sæpius in autopsî̀ floris dixerim, sed eorum evolutio stamina sequitur et in fructu (ubi filamenta diIatata) filamentis interiores videntur. In præfloratione lobi cum staminibus alternatim imbricati, margine uno interiọre altero exteriore, unde valde approximati videntur et naturâ similes. An lobos disci Santalacearum, staminibus interiores, repræsentant? an potius stamina?. Ex eo affinitas cum Santalaceis vel Olacaceis pendere videtur. Habitus, pubescentia præsertim, et ovarium superum foliis perigonii manifeste a basi involutum, a veris Santalaceis differunt.

G. Tomentosa (Ruiz et Pav. 1. c.). 5 In sylvis montanis Peruviæ. C. bicolor Cav. 1. c. Elceodendron tomentosum Willd. mss. in Rœem. et Sch. syst. 5, p. 345 (fide Kunth. l. c.). Rami teretes, demum glabrati. Folia oblongo-elliptica, coriacea, 2-4 poll. longa, 8-10 lin. lata, utrinque obtusa, petiolo 3 lin. longo, superne glabra

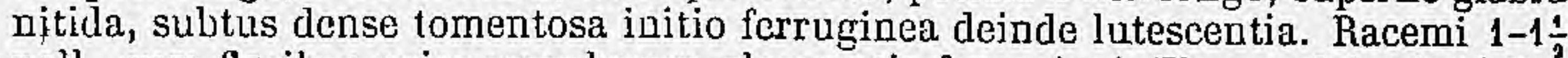
poll., cum floribus apice ramulorum glomeratis ferruginei. Flores globosi, $1 \frac{1}{9} \operatorname{lin}$. longi, bracteis et bracteolis ovato-acutis intus glabris longiores. Fructus nondum maturus semipollicaris, lobis perigonii ellipticis glabrescentibus tectus. (v. s. ex h. Cav. et a Mus. par. specim. Dombey. sub n. 990). 


\section{ADDENDA ET CORRIGENDA}

\section{IN TOTO VOLUMINE QUATUORDECIMO.}

\section{POLYGONACEE. --SUBORDO ERIOGONEÆ.}

P. 15. Eriogonum Wrightir. Numeri $620,621,622$ Wright. pl. exsicc. ad præsentem spec. pertinent (Benth. in litt. dec. 1855).

P. 15. E. o R THOGL A DON. Synonymis adde: Torr, in Rep. exped. Sitgreaves, in Florâ bot. Zeit. 1855, p. 361 ,

P. 22. E. PHARnaceordes, Syn, adde: Torr. in Rep. exped. Sitgreaves, in Florâ bot. Zeit. 1855, p. 361 .

$P$, 23. OXYTHECA DENDR OLDEA, adde: 0 . spiculata Miers trans. linn, soc. 21, p. 144, t. 17 (an err. typ. pro apiculatâ ?)

\section{POLYGONACEE. - Subordo POLYGONEA (auctore Meisner).}

P. 2, lin. 16, pro capillata, lege : capitata.

P. 32, lin. 28, pro universalem admissum, lege : universalem usum admissum.

P. 35. Rheum Ribes Gron, adde : Jaub. et Spach ill. pl. Or. t. 470.

$P .41$, lin. 14, pro Wall., lege : Wallr.

P. 44 , lin. 9 , post $368^{*}$, adde : non Kunth.

P. 44 , lin. 41 , pro $10 \beta$, lege : $14 \beta$.

P. 44, n. 14, adde : Rumex rupestris (Le Gall fl. Morbih. p. 501, Godr. et Gren. fl. de Fr. 3 , p. 37), in rupibus maritimis Galliæ boreali-occidentalis crescens, a R. crispo vix differre videtur nisi valvis anguste oblongis.

P. 45, n. 15. Rumex elongatus Guss. est R. crispus $\beta$ Bertol. 1l. ital. 4, p. 236, a plantâ vulgari solummodo recedens foliis omnibus angustioribus planioribus, valvæ unius callo perfecto, reliquarum obsoleto.

P. 46, lin. 43, pro accessit, lege : accedit.

$P .47$, post $\mathrm{n} .23$, adde :

23*. R. ALTISSIMUS (Woods in proceed. Amer. assos. for 1853, j. 177), erectus, glaber, foliis petiolatis anguste lanceolatis integris utrinque angustatis, racemis gracilibus paniculatis nudis, verticillis contiguis, floribus omnibus hermaphroditis, valvis late cordatis aculis venosis, unâ vel duabus calliferis, interiore semper nudâ. $\mathscr{F}$ In palustribus vallis Wabash, Amer. sept. Planta 3-6-pedalis, læevis. Caulis striatus, supcrne subramosus. Ochrese breves. Folia 3-5 poll. longa, $\frac{1}{4}-1$ poll. lata, sibacuminata, in petiolum pollicarem angustata. Panicula $6-10$ poll. longa; aphylla. Pedicelli filiformes. demum recurvi, 2-3 lia. longi. Sepala tenuia, integra, venosa, pallida, interiore latiore et semper nudo, altero tuberculo magno notato, tertio tuberculo parvo vel nullo. Fructus quoad colorem et formam omnino Fagi. Affinis R. Britannicæ.

P. 49 , lin. 18, pro Campd. p. 145, lege: Campd. p. 88 .

P. 49, n. 33, $\beta$. Synonymis, adde : R. campestris Savi Pis. 1 , p. 372. R. verticillatus Ucria hort. Pan. p. 164. R. glomeratus Ten. 11. Nap. 5, p. 6, Guss. suppl. 1, p. 109, ex Bertol. fl. ital. 4, p. 238.

P. 51, п. 42, adde : Bertol. 1. it. 4, p. 235.

p. 54, n. 52. Synonymis, adde : R. acutus All. ped. 2, p. 202. R. sylvestris Ten. Nap. 3, p. 390, ex Bertol. fl. ital. 4, p. 239. R. Friesii Godr. et Gren. fl. de Fr. 3, p. 36*.

P. 55, n. 57 (inter synon.) et n. 58 , pro R. ramulosus, lege : R. hamulosus.

P. 58 , n. $69 \beta$, adde : R. suffocatus Moris, Bertol. fl. ital. 4 , p. 442.

P. 59, ฉ. 77. Synonymis, adde : R. uliginosus Guss. pl. rar. p. 151, t. 20 . R. maritimus Ten. fl. Nap. 3, p. 390, fide Bertol. fl, ital. 4, p. 244.

P. 60, ․, 79, est R. palustris Smill, ficle Bertol. 1. ital, 4, p. 244. 


\section{ADDENDA ET CORRIGENDA (AdCTOR MEISNER).}

P. 63, lin. 3, pro Sect. I, lege : Sect. II.

P. 64 , n. 95,. . Synonymis, adde : R. amplexicaulis fl. Ten. Nap. 3, p. 394. Acetosa pratensis Zannich. ist. 4, t. 233, fide Bertol. fl. ital. 4, p. 252.

P. 65, adde : R. montanus Desf., Bertol. fl. it. 4, p. 255.

P. 66. n. 98, adde synon. : R. pseudo-acetosa $\beta$ Bertol. l. c. p. 252. R. thyrsoides Godr. et Gren. fl. fr. 3, p. 44 ? excl. syn. DC. R. multifidus All. ped. 2, p. 205.

P. 66 , n. 100, adde : R. thyrsoides Bertol. I. c. p. 257, excl. syn. DG. et All. Cfr. R. intermedius.

P. 67, n. 104, adde: Caules basi sublignosi? Folia interdum acutiuscula, ex Bourgeau, pl. Canar. exsicc. n. 1527!

P. 69 , lin. 11, pro non Jacq., lege : non Ait.

P. 70, lin. 37, pro vulcanis, lege : vulcanicis.

P. 70, n. 115, adde synon. : R. psendo-acetosa . Bertol. fl. ital. 4, p. 253.

P. 71, n. 116, adde $: \alpha$ in Teneriffâ, Bourgeau, 11. 1528! $\beta$ Kralik. pl. Tunetanæ, n. 327 !

P. 71 , n. 119, adde : In alpinis Tauri etiam legit Balansa! Folia infima $2 \frac{1}{2}-5$ poll. longa, 4-10 lin. lata. Valvæ basi æque latæ ac longæ, interdum leviter cordatæ.

P. 73, n. 66, adde : In Teneriffâ leg. Bourgeau, n. 1526!

P. 74, lin. 24, pro nebrioides, lege : nebroides.

$P .75$, lin. 32, deleatur signum interrog.

P. 82. POLYGONUM, adde synon : Pleuropterus Turcz. (in pag. 136 memor.).

P. 85, n. 3, adde : Ferd. Müll. in Hook. journ. 1856, p. 203. Suffruticosum, glaberrimum, multiramosum. Flores virescentes, cernui, imbricato-bracteolati.

P. 85 , n. $4, \beta$, adde :'Bertol. fl. ital. 4 , p. 384. - In muris antiquis prope Saïda, Blanche herb. Syr. n. 36! (Forma insignis achænio sæpius calyeem superante angustato, faciebus lanceolatis), Kralik pl. Tunet. n. $326 !$ in Giciliâ, Balansa, pl. or. n. 777!. - P. Venantianum Clementi sert. Olymp. (in Mem. Ac. delle science di Torino, ser. 2, vol. 16), p. 83, t. 3, f. 2 ?

P. 86, н. 5, adde : P. equisetiforme Godr. et Gren. fl. fr. 3, p. 52*.

P. 86, n. 9, adde : P. flagellare Bertol. fl. ital. 4, p. $382^{*}$ non? Godr. et Gren. fl. fr. 3 , p. 52 (cfr. P. Bellardi $\delta$ effusum, supra p. 99). Syn. P. controversum excludendim et ad P. Bellardi All. referendum videtur.

$P .88$, lin. 48 , pro calyce, lege : calyci.

P. 88, n. 17, adde : P. Roberti Lois., Godr. et Gren. fl. fr. 3, p. $52^{*}$, cum synon. P. intermedium Rob. in litt. - P. littorale Godr. et Gren. 1. c. p. $51^{*}$ ? (non Link) et (ex cit. Babingt.) certe ejus var. $\beta$ Jatifol. Godr. et Gren. 1. c.

$P .89$, lin. 1, pro caudicantibus, lege : candicantibus.

$P .92$, u. 35, adde : In alpinis Tauri legit Balansa!

P. 92, n. 37. Synonymis adde: P. micranthum Boiss.l in herb. Nö̈, n. 59! Boiss. diagn. n. 1097; ex sched. Noë. Crescit etiam circa Bagdad. Caules interdum in angulis minute papilloso-asperuli.

P. 94, n. 24, adde : Godr. et Gren. fl. fr. 3, p. 51? cum syn. : P. alpestre Heldr. pl. exsicc. Pisidiæ, quod synon. nobis dubium propter achænia " opaca, obscure granulata. " P. aviculare b. Guss. fl. Sic. prodr. 1, p. 470, suppl. 1, p.115, fide Bertol. fl. ital. 4, p. 381, ubi planta suffruticosa dicitur.

P. 95, n. 49, adde synon. : P. avicnlare $\delta$ polycnemiforme Lec. et Lamb., Godr. et Gren. fl. fr. 3, p. 53, ex cit. Wierzb. Reichenb. exsicc. n. 1738.

P. 97, n. 58, adde : Cfr. Godr. et Gren. fl. fr. 3, p. 53, excl. $\delta$.

$P .98$, lin. 46, pro strictis, lege : striatis.

P. 98, n. 62, adde : Godr. et Gren. fl. fr. 3, p. 54*, eum syn. P. Monspeliense Guss. prodr. 1, p. 470.- Huc spectare nobis videtur P. controversum Guss. 1. c. 1, p. 471, suppl. 1, p. 45, Bertol. fl. ital. 4, p. 383* . Ad nostram var. $\alpha$ procul dubio spectat P. aviculare $\beta$ Bertol. l. c. p. 379 .

P. 99, n, 62, $\delta$, adde : P. arenarium Godr. et Gren. fl. fr. $3, \mathrm{p} .53^{k}$ (non W. et Kit.)

P. 100 , n. 97 , adde ; Bertol, fl. ital. 4, p. $385^{*}$. 
P. 101, lin. 48, pro hydrophytæ, lege : hydrophilæ.

P. 103, n. 79, adde : Philippi pl. Chilens. exsicc. 11.341.

$P .104, \mathrm{n} .84, \alpha$, adde : P. stoloniferum? Blanco I mss. in herb. DC., ex ins. Philippinis.

P. 106, lin. 16, pro Biscaticlium, lege : Biscatalium.

P. 109 , n. 103 , adde : Bertol. fl. ital. 4, p. $373^{\star}$.

P. 110, n. 107, adde : P. minus Ten. fl. Nap. 4, p. 181. P. Iaxiflorum Bertol. fl. ital. 4, p. 374 *.

P. 110, n. 109, adde: Bertol. fl. ital. 4, p. 376*, Godr. et Gren. fl. fr. 3, p. 48*. Persicaria serrulata Webb et Moq.-Tand. Phyt. Canar. 3, p. 219. - In Teneriffá Bourgeau, n. 15291 Circa Saïda, Blanche, herb. Syr. n. 91!

P. 111, n. 110, $\alpha$, adde :In Chinå (Park, u. 4 !).

P. 112,n. 115, P. JA PONICUM, adde: $\beta$ grandiflorum, calyce duplo majore, oblongo, fere 2 lin. lougo. - Forma valde similis P. macrantho (p. 107, n. 98), sed distincta calyce eglanduloso et achænio biconvexo nec triquetro.- In Chinâ, circa Canton, Park, n. 149! (v. s. in herb. DC.)

P. 113, lin. 3, pro 250 , lege : 150 .

P. 113, n. 118, adde : Circa Montgomery, Africæ orient. legil Martin! (hb. DC.).

P. 117, n. 134, adde : Bertol. fl. ital. 4, p. 370 , excl. syn. P. laxi Rchb. Formæ hybridæ 5 describuntur in Godr. et Gren. fl. de Fr. 3, p. 49, sq. Cfr. etiam F. Schultz in Archiv. de Flore, p. 138.

P. 118, n. 135, adde synon. : P. tenuiflorum Bertol. fl. ital. 4, p. $375^{\star}$.

P. 119, n. 137, adde : Bertol. fl. ital. 4, p. 369, excl. syn. P. nodosi.

P. 125 , n. $161, \beta$, adde : P. bistortoides Boiss.! in Balansa pl. Or. $1855, \mathrm{n} .7781$ ex alpibus Tauri.

P. 131, n. $179, \delta$, adde : Zolling. Yl. Jav. exsicc. n. 819 !

P. 133, n. 189 , adde : Cuming, pl. Philippin. u. 484 !

P. 139, n. $213, \alpha$, adde : in Apennino, Bertol. fl. ital. 4, p. $386^{\star}$. - P. a L PINum var. olympicum Clementi sert. Olymp. (in Mem. Ac. sc. Taurin., ser. 2, t. 16) p. 83, insigne videtur " radice oblongâ incrassatâ fere tuberiformi et foliis utrinque glabratis.

P. 142. Specielous excludendis, adde: PoLYGONUM GIRRHOSUM Moc. et Sesse. = Antigonon leptopus Hook. et Arn.

P. 145, lin. 4, lege : Vent. Cels. t. 88.

$P .149$, н. $14, \beta$, adde :(v. s. in herb. Lindl.).

$P .149$, n. $15, \delta$, adde : Jameson pl. Quit. exsicc. n. 313 !

P. 153, lin. 3, pro herb., lege : hort. Kew.

P. 165, n. 62, $\gamma$, adde : in Guianâ Gallicâ, circa Acarouany, 1855, legit P. Sagot, n. 887 ! (herb. DC.).

$\delta$, macrostachya, racemis solitariis folia longe superantibus (8-9 poll. longis) sinplicibus gracilibus laxiusculis, foliis ut in var. $\alpha$. Ibidem legit Sagot, sine numero (herb. DG.).

P. 173, lin. antepenultima, lege : calycisque tubum non superantes.

$P, 181$, lin. 4 , lege : videtur species R. laurifoliæ affinis, nisi, etc.

P. 182, \& 2, lege : TRISE PALA.

\section{LAURACEÆ.}

P. 186. Ordo in futuro volumine Prodromi inserendus.

\section{MYRISTICACEE (auctore Alph. DC.).}

P. 188, lin. 12. De arillodio iterum scripsit cl. Planchon, in Bull. soc. bot. Fr. 1855, p. 677.

$P$. 192. Sectio Gal one URA.....Omnes asiaticæ, lege : omnes asiaticæ, exceptâ M. platyspermá hic descriptâ.

P. 192* M. PLATXSPERMa (Spruce! herb. n. 2491 et 2842), foliis obovatis 


\section{ADDENDA ET CORRIGENDA (AUCT. ALPH. DC.).}

obtusis basi acutis pellucide punctulatis glaluris nervis lateralibus utrinque 7-9, pedunculis axillaribas et supra-axillaribus, perlicellis (masc.) apice ramorum in- florescentiæ subumbellatis, bracteis minimis, bracteolâ cujusque floris late rotundatâ brevissimâ, flore (juniore) ovoideo pedicello vix longiore intus glabro extus ut tota inflorescentia pulverulento-velutino, antheris 6-7 stipite multo longioribus apiculo communi terminatis, fructu globoso. 5 Prope Panure, ad rio Uaupes, in rio Negro Brasiliæ sept. defluentem. Rami teretes, juniores ut folia juniora et inflorescentia rufo-pulverulenti, deinde glabri. Folia 4-6 poll. longa (incl. petiolo

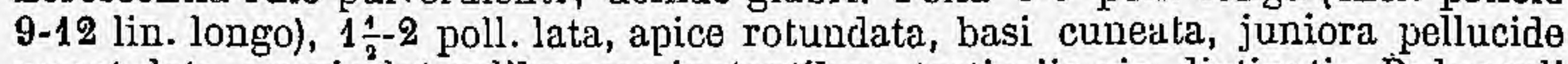
punctulata, nervis lateralibus semipatentibus, tertiariis vix distinctis. Pedunculi masc. 12-18 lin. longi, nunc gemini, ramis lateralibus abbreviatis apice 5-6-floris. Bracteæ adspectu callnrum basi pedunculorum. Bracteolæ $\frac{1}{4}$ lin. longæ, sessiles, basin floris uno latere cingentes. Alabastra 2 lin. longa, obtusa. Fructus pauci, globoso-depressi, 10-12 lin lati, hinc sulcati, pedicello duplo longiores. - Unica est species Americana ad sect. Asiaticam pertinens. (v. s.)

$P .194$ et seq. Species Americanas itorum perlustravi, cum speciminibus nonnullis herb. Mus. imp. vindob., Mus. reg. berol., herb. Mart. et novissimis a Spruce collectis, unde sequentia addenda. Descriptiones extensas ad Floram brasiliensem cel. Martii misi.

P. 195, lin. 2, bracteis atque bracteolis sub flore destitutse, lege : bracteis nullis aut rarius ad rudimentum reductis, bracteolis sub flore nullis. Adde : A piculi antherarum non connati.

P. 195. Myris tica Sebife ra. Dele: In Maynas (Pœppig), nam specimina hujus originis videntur omnia ad M. Mocoam tribuenda.

P. 195. M. THEIODORA. Hic verisimiliter referenda sunt specimina herb. vindob. et herb. Mart. sub num. 1952 et 1534 a Pohl, e Villa Boa, olim allata, quæ folia minus coriacea quam in M. sebiferâ, magis acuminata, subtus parum tomentosa et pallidiora, nervis lateralibus utrinque circiter 18, fructu magis globoso; arillodio magis laciniato. (v. s.)

P. 195. M. G us P i a t A. Phrasis servanda, sed plantæ Sprucei solum tribuenda. Varseq. addenda quoad specim. Mart. et Pav.

$\beta$. rufula, foliis oblongo-acuminatis subtus pallidis vix tomentosulis, peliolo sublongiore, floribus masc. paulo majoribus. M. rufula Mart. herb.I Rio Negro. Myristica Pav. in h. Boiss.! e Peruvià. (v. s.)

P. 196. Species $\mathrm{nl} .33$ et 35 ad sect. Iv transferendæ propter numerum nervorum M. punctatæe et ejus affinitatem cum M. Uaupensi hic descriptâ.

P. 196. M. Penuviana. E Pozuzo Peruvire (ex sched. Pav. in h. reg ber.). Perigonium intus pilosulum (nec glabrum). Antheræe stipite multo longiores.

P. 196, n. $35^{*}$. M. Mollissima (Pœpp.! in leerb. reg. Jer. et imp. vind.), ramis petiolis foliis subtus et inflorescentiâ dense fulvo-tomentosis, foliis amplis ellipticis acutis basi cordatis nervis lateralibus utrinque 20-30, paniculis (masc.) axillaribus et terminalibus folio duplo triplove brevioribus, bracteis ovato-acutis caducis, perigonio obovoiden extus fulvo-tomentoso intus glabriusculo, antheris stipite triplo longioribus apiculo brevissimo. 5 In Maynas alto (Pœppig! 1. c.). Tomentum copiosum, colore tabacino, magis quam in aliis spp. persistens. Folia 8-15 poll. longa, 4-5 poll. lata, superne glabra, subtus omnino tomentosa, nervis subpatentibus inferioribus approximatis curvatis; tertiariis distinetis, petiolo 3-6 lin. longo. Panicula multiflora. Fasciculi florum bracteả 2 lin. longâ initio amplexi. Perigonium diu obovoideum, serius infundibuliforme, semitrifidum, pedicello incluso lineam longum. Antheræ 2-3-4, in acumen minimum unicum (e pluribus vix connatis?) desinentes. Ad sect. Iv pertinet. (v. s.)

P. 196, n. $35^{* *}$. M. UAUPENSIS (Spruce! exs.), ramis junioribus petiolis paginâ inferiore foliorum et inflorescentia ferrugineo-tomentosis, foliis longe lanceolatis acuminatis basi rotundato-truncatis pellucide punctulatis, nervis lateralibus utrinque $16-18$, paniculis masc. folio $4^{\circ}-6^{\circ}$ brevioribus compositis multifloris, bracteis ovato-acutis caducissimis, floribus minimis extus ferrugineo-tomentosis intus subtomentosis, antheris 3 stipite multo longioribus apiculis punctiformibus. 5 Prope Panures, ad rio Uaupes, in rio Negro Brasil. fluentem. M. Uaupensis, an M. cuspidata var.? globifera Spruce! exs. 11. 2512, in h. DC. Tomentum ramorum petiolo- 
rum et inflorescontiæe fulvum, intensius coloratum quam in M. punclatâ. Folia brevioru, petiolo 3 lin., limbo 6 poll. longo, 15-20 lin. lato. Bracteæ 1 $\frac{1}{2}$ lin. longæ. Flores $\frac{1}{2}$ lin. longi, pedicello longiores. Antheræ apiculis vix distinctis. An mas M. punctatæ? Ad sect. Iv pertinet. (v. s.)

$P$. 196, sect. SYCHNONEURA. Antheris nunc apiculatis, lege : antheris sæpius apiculo unico terminatis.

P. 197. M. offic INALIs. Foliis acutis vel acuminatis, lege: foliis obtusis, acutis vel rarius acuminatis.

P. 198. M. venosa. Specimina e Chicoplaya ad M. Pavonis, hic descriptam, referenda. - In plantà Sprucei attente observatâ folia punctata, sed punctis raro pellucidis, nervulis tertiariis contra sæpius pellucidis.

45*. M. PAvonis, novellis ferrugineo-tomentosis, foliis ellipticis vel obovato-ellipticis obtusis vel hreviter acuminatis basi obtusis superne glabris subtus glabrescentibus nervis lateralibus utrinque 16-22 subjatentibus, racemais masc. folio sub. brevioribus vel duplo brevioribus, bracteis ovato-acutis fugacibus fasciculos florum amplectentibus, perigonio triplo infundibuliformi extus fulvo-tomentoso intus glabro, antheris 3 stipite longioribus, fructu ovoideo. 5 Prope Chicoplaya (Pavonl in h. Boiss. et reg. ber. f, forsanque in Maynas alto (Poppig ! 2048 in h. reg. ber. spec. sine fl. nec fr.). Folia 3-5 poll. longa (incl. petiolo 2-4 lin.), 1-1 $\frac{1}{2}$ poll. lata, juniora pellucide punctulata; cotera opaca (nisi in spec. minus certis Popp.), acumine (ubi adest) acuto nec obtuso ut in M. venosâ, nervis later. patentibus nec semipatentibus. Fasciculi 3-7-flori. Bractea 2 lin. Fructus 12-15 lin. longi, pedicello reclo crasso $\mathbf{3}-4$ lin. fulti. (v. s.)

$P .198$. Sectio OTOBA. Loculis disjunctis, lege : loculis sulco disjunctis.

P. 199, lin. 1. M. о т о в A. Specimina Pœppigii diferunt foliis subtus glauceseentibus, floribus masc. minoribus (ut pote ex alabastris dijudic). Varietas $\beta$ glaucescens dicenda.

P. 199. Sectio COMPSONEURA. Charact. adde : Bractere interdum fugaces minimæ circa basin pedicellorum. Bracteolæ sub flore ipso nullæ. Nervi tertiarii foliorúm inter primarium et secundarios nec solum inter secundarios extensi.

P. 200, lin. T. Delendum quæ de num. 1791 Poppig. Confer infra.

P. 200, lin. 10, adde:

48*. M. D в в I Is (Spruce! herb. n. 2468), glabra, foliis obovato-ellipticis utrinque obtusis membranaceis pellucide subpunctatis, nervis lateralibus utrinque $\mathbf{7 - 9}$, tertiarijs crebris, racemis masc. petiolo brevioribus, floribus minimis. 6 Prope Panure, ad rio Uaupes, in fl. Nigrum Brasiliæe sept. defluentem (Spruce, n. 2468l). Folia 5-6 poll. longa (incl. petiolo 5 lin.), $1 \frac{3}{4}-2$ poll. lata, utrinque (in eod. ramo) obtusissima, oblusa vel suluacuta, nervis semipatentibus margine extremo curvatis et convexis, tertiariis valde distinctis. Pedunculi (masc.) axillares, 2-3 lin. longi, simplices vel semel ramosi. Pedicelli apice pedunculi vel ejus ramorum umbellati, lineam longi. Bracteæ fugaces, $:$ lin. longæ, ovatæ, circa originem pedicellorum. Bracteolæ nullæ. Alabastra fere matura $\frac{1}{4}$ lin. longa, ovoidea, obtusa. Antherce M. Sprucei. Folia simillima, sed obtusa. (v. s.)

18**. M. c A P I telL A t a (Pœyp. exs.), ramis foliisque glabris, foliis oblongis vel obovato-oblongis obtuse acuminatis basi aculis membranaceis pellucide punctulatis, nervis lateralibus utrinque 10-11, tertiarijs crebris, racemis (masc.) compositis, petiolo $3^{\circ}-4^{\circ}$ ve longioribus lloreque extus puberulis, ramulis inflorescentiæ alternis brevissimis flores umbellatos gerentibus, lloribus parvis pedicello sublongioribus. 5 Ad Maynas alto (Pœppig! 1791, in herb. reg. ber.). Folia 7 poll. longa (incl. petiolo 6-9 lin. longo), 20-26 lin. Jata, formâ et nervatione fol. M. Sprucei, sed nervis lateralibus paulo numerosioribus. Racemi masculi nunc gemini, bipollicares, ramulis lateralibus numerosis alternis 1-2 lin. longis, apice 3-5 flores gerentibus. Indicia bractearum minimarum circa pedicellos. Bracteola sub flore nulla. Pedicelli $\frac{1}{2}$ lin. longi. Flores profunde 3 -fidi (nec ut in M. Sprucei semitrifidi), $\frac{3}{4}$ lin. longi. (nec $1 \frac{1}{3}$ lin.), infundibuliformes (nec campanulati), extus et tota inflorescentia pilis minimis adpressis puboruli (nec glabri, ut in hâc specie). Specimen sub eod. numero Poppigii scmel et cursorie in herb. Musei paris. vidi, quod femineum imperfectum erat, et mihi videbatur M. Sprucei (supra, p. 200), sed masculo nuuc viso certe species diversa. (v.s, in h, reg. ber.) 


\section{ADDENDA ET CORRIGENDA (AUCTOR MEISNER).}

\section{PROTEACEE (auctore Meisner).}

P. 216, n. 13, adde synon. : Protea densa Willd. enum. suppl. p. 7, teste Link, ex DG., adnot. mss.

P. 218 \& 3, adde : R. Br. in Linn. Trans. 10, p. 58.

P. 223, u. 35, adde synon. : Protea diversifolia Willd. enum. p. 139.

P. 228, 11. 261, adde synon. : Protea linifolia Willd. enum. p. 138.

P. 229, adde :67. LEU CADENDR ON GAUDATU M (Link enum. h. berol. 1, p. 115, n. 1056) " Nondum floruit. Rami purpurascentes hirti. Folia 2 poll. longa, 6 lin. lata, sescilia, lanceolata, apice callosa, molliter hirsuta, verticalia. - Hort. Angl. n - Certe non est P. caudata Thunb., quæ Spatalla caudata et Thunbergii, supra, p. 310.

P. 247, n. 66. Citatis adde: Spreng. neue Entd. 1, p. 100.

$P$ 250, adde : P. densa Willd. = Leucadendron tortum R. Br.

$P$. 257, lin. 2, lege : 5-8-dentatis.

P. 258, n. 14, $\delta$, lin. 2, pro lævissime, lege : levissime.

$P$. 261, lin. 9, pro Ange, lege : Auge.

$P$. 276, lin. 14, pro sectionis, lege : sectioni.

P. 278, 11. 10, lin. 6, pro Adenanthæ sericeæ, lege : Adenantho sericeo.

P. 284, lin. 8, pro Capilulæ, lege : Capiluli.

P. 284, n. 2, adde synon. Protea plumigera Thunb. in Mem. Ac. Petersb. 1818, t. 19. Spreng. neue Endt. 1, p. 100, ex DG., adnot. mss.

P. 286, n. 7, adde synon. : Protea coarctata Thunb. 1. c. Spreng. l. c. t. 15, p.100, ex DC., not. mss.

P. 293, \& 2, adde : R. Br. 1. c. p. 126.

P. 295, \& 3, adde : R. Br. I. c. p. 130.

P. 298, lin. 1, pro vidi, lege : non vidi.

P. 300,8 2, adde: R. Br. 1.c. p. 136.

P. 319 , n. 15 , lin. 3 , pro laxifolii, lege : taxifolii.

P. 320, n. 20, adde synon. : C. Dallachii Ferd. Müll.? teste ipso in Hook. Journ. 1856. p. 15.

P. 345 , lin. 10, lege : Nux vel drupa exsucca, ete.

P. 347. GuEviNa synonymis adde : Gevuina Mol. Chil. 159, 184. - Gevina Lam. dict. 2, p. 712.

P. 348. Trib. V, lin. 3, lege : Grevillece Hakecece Endl.

P. 348. XXVIII. M OL LOYA, adde : Meisn. in Hook. Journ. 1855, p. 382.

$P .352$, 1. 13, adde : Ferd. Müll. in Hook. Journ. 1856, p. 206, n. 157*.

P. 353, n. $14, a d d e^{*}:$ F. Müll. l. c. p. 205, n. $155^{*}$. Frutex in montibus humilis, foliis brevioribus fere ovatis, in vallibus ad staturam 12-pedalem excrescens (Müll. l.c.).

P. 353, n. 15. Ferd. Müll. l. Ł. p. 206, «. 156*.

P. 354, 1. 18, adde : Reichenb. ic. exot. 2, t. 105.

P. 355, ч. 22, adde synon. : G. hinearis alba Lodd.1.c.

P. 361, n. 44, adde : Bot. mag. t. 5007. Flores miniati apice lutei.

P. 368, n. 73, adde : Ferd. Müll. in Hook. Journ. 1856, p. 207, «. 158*.

P. 379, ㄲ. 118, adde : F. Müll. l. c. p. 207, n. $159^{*}$.

P. 382 , n. $130^{*}$. Grevillea p ol y в отrya (Ferd. Müll. in Hook. Journ. 1857, p. 23), ramulis teretibus adpresse puberulis, foliis indivisis vel 2-3-fidis vel pinnatim 5 -fidis subsessilibus supra glabris subtus sericeis prominulo-3-nerviis margine recurvis, segmentis elongato-linearibus acutis sphacelato-mucronulatis integerrimis, racemis elongatis dense multifloris, calycibus extus cum rhachi pedicellis ovario styloque glabris intus infra medium tenuissime puberulis pedicello triplo longioribus, stylo longe exserto, ovario stipitato, stigmate oblique terminali longe umbonato, folliculo subrotundo leviter compresso lignescente lævi, 
ADDENDA ET CORRIGENDA (AUCTOR MEISNER).

seminibus orbiculari-ovatis, alâ nucleo concolore eoque triplo angustiore. $\delta$ Ad basin mont. M'Adam's Range (Ferd. Müller). Arborescens. Folia 6-9 poll. longa. Racemi conferti, paucipollicares, basiflori, albidi. Glandula hypogyna conspicua. Fructus unciâ brevior, parum lignosus. Semina sordide cano-fusca. G. ceratophyllæ propinqua.

P. 384, u. 138, adde : F. Müll. l. c. p. 208, n. 160*.

p. 384, n. 141*? G. A L PHON S IANA (Ferd. Müll. 1. c. p. 22), ramulis teretibus velutinis, foliis lineari-ensiformibus planis crasse coriaceis sensim in petiolum brevem angustatis sphacelato-acuminatis 1 -nerviis eveniis utrinque puberulis, racemis subpaniculatis spiciformibus elongatis velutino-tomentosis, calycibus pedicello duplo longioribus intus cum pistillo sessili semipollicari glabris, stigmate oblique terminali late ovato centro elevato. 5 Ad rivum Sturt's Creek alibique in deserto Australiæ centralis (Müll.). Arbuscula habitu fere Hakeæ arborescentis. Folia pleraque 4-5 poll. longa, 2⿺辶-3 lin. lata, indivisa, plus minus curvata, dilute viridia ; cicatrices ovato-cordatæ, punctis vascularibus æequidistantibus. Racemi inferne ramosi, basiflori, undique cano-tomentosi, nunquam ferruginei. Calyx circ. 4 lin. longus, intus flavus. Glandula hypog. conspicua, nigrescens. Frucl. ignot. Affinis G. polystachyæ et Sturtii.

P. 394, n. 2'. HAKEA CH ORDOPHYLLA (F. Müll. 1. c. p. 23), glabra, ramulis teretibus lævibus pruinosis, foliis prælongis teretibus indivisis exsulcis acutis, cicatricibus late ovatis punctis vascularibus æquidistantibus uno centrali, racemis exinvolucratis patentibus, bracteis caducissimis, calycibus pedicello glabro parum longioribus utrinque glabris, stylo longe exserto, stigmate oblique terminali late ovato umbonato, glandulâ hypog. crassâ ovato-hippocrepicâ, capsulâ..... 5 In collibus arenosis, ad fl. Sturt's Creek Australiæe centralis (Müll.). Folia pleraque pedalia. Racemi pedunculati, multiflori, flore cum pedicello fere triplo longiores. Calyx vix semipollicaris. Pistillum circ. 10 lin. longum. Habitus H. Cunninghamii.

P. 396, n. 16. Synon. Müll. excludendum et verisim. ad n. 23 referendum.

P. 398, n. 23, adde synon. : H. flexilis Ferd. Müll.? Cfr. supra p. 396, n. 16.

P. 405, n. 57, adde synon. : Banksia florida hort.

P. 408, «. 70, adde : Drumm. coll. 3, u. 280, fide specim. steril. in herb. DG.

P. 416, u. 103, adde synon. : Embothrium salicifolium Willd. enum. p. 142.

$P .423$, lin. 14, lege : terminalibusque.

P. 423, n. 1, $\beta$, adde : Ferd. Müll. in Hook. Journ. 1856, p. 208, n. 261*. Spice terminales et axillares subsolitaria, ex Müll. l. c.

P. 428, ц. 12, adde : in prov. Minas Geraës, Claussen, sine num. in herb. DC.

P. 429, n. 14, $\gamma$, adde : Circa Tejuco, prov. Minas Geraës, Vauthier, n. 128 ! in hb. DG.

P. 434, n. 33, $\alpha$, adde : Rhopala diversifolia Schott neue Bras. Pfl. 1, p. 3, n. $3^{*}$, ex DG., not. miss.

P. 439, n. 7*. Helicia A ustralas ica (F. Müll. l. c. p. 22), glabra, foliis tenuicoriaceis lanceolato-ovatis integerrimis vel obscure paucidentatis planis, racemis spiciformibus elongatis cernuis dein nutantibus (aureis), glandulis hypogynis liberis, ovario sessili tomentoso, stigmate apice truncato. $\delta$ Ad rivulos prope moutes

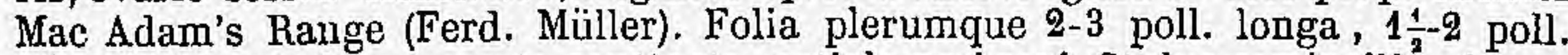
lata, basi sæpissime cuneato-contracta, petiolo perbrevi. Stylus semipollicaris.

P. 439, n. 8, adde : Zolling. pl. Jap. exsicc. n. 502 ! (v. s. a. 1857, in herb. DC.)

P. 440, n. 13, adde: In mont. Sikkim et Khasya, region. subtrop., alt. 3,000-6,000 ped., leg. Hook. fil. et Thomson!

P. 442, lin. 35, pro Novæ Hollandiæ, lege : Novæ Zeelandiæ.

$P .446$, lin. 22, lege : Semina apice alata, alâ apice truncatà vel rotundatâ, hinc, etc.

$P .451$, lin. 1, adde : Linn. fil. suppl. p. 128.

$P .453$, n. 7 , lin. ultima, pro herb., lege : hort. Kew.

$P .464$, u. 52. Cit. Bot. reg. t. 1728, excludenda Gfr. lin. seq.

P. 464, n. 53, adde : Bot. mag. t. 4906. B. speciosa Lindl. in Bot. reg. t. 1728 (non R. Br.), ex Hook. 1. c. Flores pallide citrini.

P. 466. Speciebus nondum descriptis, adde : B, то MEN T os a Ferd. Müll. (non Forst.) in Hook. Journal 1856, p. 327. 


\section{ADDENDA ET CORRIGENDA (AUCTOR MEISNER).}

$P$. 460. Speciebus exclusis, adde : B. FL orid A hort. = Hakea florida R. Br.

$P .480$, lin. 42, pro extus aucta, membranâ, etc., lege : extus aucta membranâ, etc.

$P .481$. Ad calcem generis DRYANDR 2 , adde :

\section{Species exclusce.}

D. con D A T Thunb. = Elæococca verrucosa Juss. (Euphorbiac.)

D. VE R I G I A Correa. = Elæococca Vernicia Juss.

\section{THYMELEACEE (auctore Meisner).}

P. 496, lin. 20, deleatur' : vel.

P. 496, lin. 40, pro Carpentarie, lege : Carpentaria.

P. 497, 1. 6, lin. 7, pro auctore, lege : Labill.!

$F .498$, n. 10 , lin. ultima, pro articulata, lege : apiculata.

P. 507, n. 49, lin. penultima, pro præcedentis, lege : imbricatæ,

$P .515$, lin. 5, pro affinitatibus, lege : affinitatis.

P. 517, n. 91, pro P. Arenaria, lege : P. arenaria.

P. 518. CANSJERA (1).

P. 519, lin. 9, lege : a verâ Cansjerâ Juss. differt, etc.

P. 519. Ad calcem generis Cansjeræ, adde: Species exclusa: C. M A DAG A S CARIRns Is Spreng., est Potameia Thouarsii Roem. et Schultz (Proteacea? v. supra, p. 329).

P. 523, n. 14, lin. 5, pro D. Linifolia, lege : D. tinifolia.

P. 524, n. 1, lin. 7, pro Fraro-voqui, lege : Traro-voqui; et ad calcem speciei adde : (v. s.)

P. 528, lin. 14, lege: PsiL os OLENA.

$P .528$, n. 2, ad finem, adde: (v. s.)

P. 531, n. 3 , lin. ultima, lege : v. s. sp. et c., etc.

P. 532, n. 7, adde: D. alpina Bertol, fl. ital. $4, \mathrm{p} .336^{*}$.

P. 532, n. 8, adde: D. Cneorum Bertol. 1. c. p. $338^{*}$ (excl. $\beta$ ). $\beta$, D. Verloti Godr. et Gren. Verlot cat. jard. Grenoble 1857, p. 73.

P. 535, n. 17, lin. 6, pro D. Blagayana lege : Delayana hortul. Caulis erectus. Folia coriacea, circ. pollicaria, 4-5 lin. lata, summa lloribus breviora. Flores albo-rosei, suaveolentes.

$P$. 342, ante Edgeworthiam, adde: Obs. Laureola hypericoides Plum. Descourtilz fl. méd. des Antilles 7, p. 253, t. 512. Planta obscura, facie quidein (ex ic.) Daphni similis, sed propter folia pellucido-punt:tata, 1ores diplochlamydeos et corollam bilabiatam certe alieni ordinis.

p. 600 , n. 1, adde : Meisn. in Mart. Il. bras, 14, p. 72*, t. 30.

P. 601, lin. 8, pro placentis 3 , lege : placentis 2.

P. 601, lin. 13, pro coronati, lege : connatie.

P. 601, n. 1, adde : A. Agallocha Hook. ic. $t .6$.

P. 602. GYRINOPS WALLA Gærtn. adde: Thwaites, n. 1828! Ramuli graciles, glabri. Folia 2-3 poll. longa, 8-12 lin. lata, subcoriacea, plus minus acumínata, glaberrima, densissime (Galophylli more) transverse venoso-lineata, venulis tenerrimis parallelis subtus subprominulis, supra immersis vel obliteratis. Pedicelli 2 lin. longi, cum pedunculo communi vix longiore articulati, puberuli. Drupa stipitata (stipite tenui $2 \frac{1}{2}$ lin. longo), ovali-oblonga vel obovata breviter apiculata, compressa ?, leviter rugulosa, glabra, 6-8 lin. longa. (v. s. in herb. DG.)

(1) Synon. adde : Miers in Ann. of nat. hist. sept. 1851, p. 172. Charact. gen. adde : Ovarium (ex Miers) basi 4-loculare. Radicula supera, nec infera. Gl. Miers hocce genus ad Thymelieaceas retulit. (Alph. DC.). 


\section{INDEX NOMINUM ET SYNONYMORUM}

\section{PARTIS QUATUORDECIME.}

Obs. Nomina admissa lilteris romanis, synonyma jlalicis traduntur, nempe in utrâque classe :

Ordinalia najoribus,

Tribualia majusculis,

Generica vulgaribus,

Sectionalia minoribus.

Acanthomeria..............668 67

Acelosa Meisn................ 64

Acetosa Tournef............. 41

Acelosella Meisn.............. 63

ACLITRHOPHYTA Neck......493

Aconogonon Meisn. .......... 136

Adenanthos Labill........... 310

Adenostephanus $K$ lotzsch ..... 436

Atheolhesium A. DC...........660 66

Aextoxicon Ruiz et Pav.......6616

Aetoxicum Endl............610

Agallochum Rumph..........601

Agastachys $R$. $B r \ldots \ldots \ldots \ldots \ldots . \ldots 328$

Agnostus A. Cunn...........450

Alclimilla Tournef. .........6.637

Amalobotrya Kunth.......... 185

Amblygonon Meisn........... 123

Ampelygonum Lindl.......... 83

Amphiderris $R$. Br........... 424

Amphiloma Endl. . . . . . . . . 449

Anaclissa Endl. ............ 487

Anadenia R. Br......... 340, 385

Andinia Wedd............... 147

Andriapetalum Pohl.......... 345

Andripetalum Schott...... 345, 698

Antennron Rafin..........83, 101

ANTHOBOLE $A$ A. DC........6.687

ANTHOBOLE AE Dumort. . . . . 687

Anthobolus $R$. $B r \ldots \ldots \ldots \ldots, 687$

Anligonon Endl............ 183

Aphanoptera Meisn. . . ......... 351

Aphragma $R . B r \ldots \ldots \ldots \ldots \ldots \ldots \ldots .480$

APTEROCARP $A$ Meisn . . . . . . . 39

Aquilaria $\operatorname{Lam} . \ldots \ldots \ldots \ldots 601,700$

AQUILARIACE E Lind l. . . . . . 493

AOUILAKINEA. ........ 601, 700

AOUILARINE $A$ R. Br. . . . . . 493

AQUILARIN $A$ E. Br. . . . . . . 601

Aroyrodendros Comm......... 212

ARISTOLOCHIAE, C., Reichb.... 187

Arjona Cav ................6 626

Arjoona Endl............... 626

Arthrosolen $C$. A. Mey ........ 559

Arthrostigma Endl. . . . . . . . 267

Aschenfeldtia $F$. Mull........ 515

Atraphaxis $L \ldots \ldots \ldots \ldots \ldots \ldots \ldots \ldots 74$

Xiv.
Atylus Salisb.......... 267, 276

Aulax Berg............... 211

Avicularia Meisn............. 85

Ballexerda Commers.........6 675

Banlisia Forst............... 444 Banksia L............. 451, 699 BANKSIE $A$ Meisn.............4 $45 t$

Bellendena $R . B r \ldots \ldots \ldots \ldots \ldots .347$

Bellendenia Endl............ 347

Belvala Adans............. 560

Bilderdykia Dumort......... 135

Bistorta Tournef............ 83

Bistorta Tournef............. 124

Blochmannia Weig........... 171

Boscia Well............... 525

Brabejum L................ 344

Brabyla L................. 344

Brachysiphon A. Juss.........487

Brisegnoa Remy............ 23

Britannica.............. 47

BRUNIACE Ex Desne........6617

Brunnichia Banks........... 185

BRUNNICHIE $A$ E $C, A, M e y \ldots \ldots 183$

Buckleya Torr...............623

BUCKLEYE $A$ E Alph. $D C \ldots \ldots \ldots \ldots \ldots 623$

CALLIGONE $A$ C. A. Mey.......... 28

Calligonum Lamn........... 29

Calligonum $L \ldots \ldots \ldots \ldots \ldots \ldots \ldots \ldots \ldots . \quad 28$

Calliphysa Endl.............. $\mathbf{3 0}$

Calliphysa Fisch. et Mey........ 30

Caloneura A. DC. . . . . . . . 192, 695

Calothyrsus R. Br............. 371

Calyptrostegia C. A. Mej...... 496

Calysericos Eckl. et Zeyh... 573, $\mathbf{5 8 0}$

Campderia Benth........... 170

Canalia F. V. Schmidt....... 580

Candjera Desne............. 518

Cansjera Juss........... 518, 700

CAPRIFOLIA Adans......... 619

Capura Adans. ............ 543

Cardjocaryon Endl............. 304

Casia Cam...............639

Castronia Nor..............438

Cenarrhenes Labill........... 328 
Centinodia J. Bauh........... 85

Centropodium Burch.......... 40

Centrostegia A. Gray......... 27

Cephalophilon Meisn............ 127

GERATOGONE $\notin$ Meisn........... 39

Ceratogonum Meisn.......... 39

Cervantesia Ruiz et Pav........ 692

Cestrum E. Mey............ 528

Cevallia Lag............... 622

Chamojasme Amman......... 548

Chamrestellera C. A. Mey......... 548

Chasme Salisb.............. 212

Chilurus R. Br............... 324

Chlamydanthus Meisn.......... 552

Chlamydanthus C. A. Mey...... 551

Choretrum R. Br..........6.675

Choristachys Endl............. 514

Chorizanthe $R . B r \ldots \ldots \ldots \ldots \ldots, 24$

Chrysodendron Vaill.......... 230

Chrysothesium Jaub. et Spach....... 638

Chylocalyx Hassk......... 83, 131

Ghymococca Meisn.......... 565

Cneoroides Spach............. 532

Coccoloba Jacq. ........ 150, 695

COCCOLOBE AE C. A. Mey.......... 144

Coilostigma Endl.............. 306

Coleophora Miers............ 548

Colpoon Alph. DC........... 634

Colpoon Berg...........632, 034

Comandra Nutt............ 635

Compsoneura A. DG. ........... 199

Conchium Sm............. 393

Conocarpodendron Boerh... 212, 253

Conocarpodendron Boerh......... 253

Conucarpus Adans............ 212

Conoclinium Meisn........... 577

Conogyne Br., Meisn............ 385

Conophorus Petiv.........211, 262

CONOSPERME E Endl. .. . ....... 314

Conospermum Sm........ 316, 698

Conuleum Rich . . . . . . . . . 608

Cookia Gmel.............. 496

Corymbocephalon Meisn........... 130

Cryptadenia Meisn.......... 573

Cyathodiscus Hochst........... 528

Cybele Knight et Salisb......... 450

Cycloptera $\mathrm{R} . \mathrm{Br} . \ldots \ldots \ldots \ldots \ldots \ldots . \mathbf{3 7 9}$

Cylindria Lour............. 482

Gylindrostrobus Endl............275

Cyrtostigma Endl.............. 309

Dais auct............. 593, 603

Dais $L \ldots \ldots \ldots \ldots \ldots \ldots \ldots \ldots, 523$

DAPHNACE A C. A. Mey...... 493

Daphnanthes C. A. Mey......... 532

Daphne auct.......... 551, 593

Daphne Kunth.............. 524

Daphne $L . \ldots \ldots \ldots \ldots \ldots \ldots, 530,700$

Daphne C. A. Mey........... 530

Daphne Sw................ 526

Daphne Wall............... 542

DAPHNE $A$ E................ 496
DAPHNE E Reichb.......... 493

Daphnobryon............... 566

DAPHNOIDE AE Vent......... 493

Daphnopsis Mart. et Zucc. . 520, 700

Daxbya Alph. DC............637

Darbya A. Gray..........635, 637

Dendrostellera $G$. A. Mey......... 549

Dendrotrophe Miq...........6 630

Dessenia Adans............... 580

Diarthron Turcz............. 558

Diastella Salisb............. 253

Diastella Salisb. ................, 259

Dickneckeria $\mathbf{F l}$. flum......... 436

Dicranolepis Planch.......... 599

Dictyoneura A. DC............. 201

Didymanthus Klotzsch......... 436

Didymocephalon Meisn........... 127

Dingia Gardn............... 593

Diplomorpha C. A. Mey........ 547

Diplonıorpha Meisn . ............ 546

Diplophragma $R . B r . \ldots \ldots \ldots \ldots \ldots$. 480

Dirca $L \ldots \ldots \ldots \ldots \ldots \ldots \ldots \ldots \ldots, 527$

Discothesium A. DG............ 631

Dofia Adans.................. 527

Donia R. Br.............. 37

Drapetes Hook.......... 565, 566

Drapetes Lam. ............. 518

Dryandra $R$. Br. ........ 467, 700

DRYMTSPERME E Meisn..........603

Drymispermum Reinw. ........ 603

Echinocaulon Meisn............. 131 Echinocaulos Hassk........ 83, 131

Edgeworthia Meisn.......... 542

ELAEAGNACE E Lindl . .......606 606

ELPAGNE $A$ R. Br.......... 606

EL 2 EAGNI Juss............. 606

ELAEAGNI Adans. ........... 619

ELAEAGNIDE E Dumort....... 606 ELAEAGNOIDE $A E$ Vent........606 606

Elæagnus $L \ldots \ldots \ldots \ldots \ldots \ldots \ldots, 608$

EMBOTHRIE $E$ Meisn. ............ 443

Embothrium Forst. .......... 443

Embothrium div. auct. . 340,393, 494

Emex Neck................ 40

Encycla Nutt................ 5

Endonema A. Juss............ 490

ENDONEMEA A. DC........... 490

Enkleia Griff. .............. 593

Epallage Endl............... 511

Epichroxantha Eckl. et Zeyh.... 580

ERIOGONE $A \mathrm{E}$ Benth............. 5

ERIOGONE E Meisn.......... 5,693

Eriogonum Mich. .......... 5, 693

Eriosolena B1....... 530, 540, 700

Eriosolena Meisn............... 540

Eriostylis R. Br................ 369

Erodendron Salisb............. 230

Espinosa Lag................ 5

Euatraphaxis Jaub. et Spach. ........ 75

Eubanksia Endl................. 458

Eucalligonum Endl............. 28 
Eucarpha $R . B r \ldots \ldots \ldots \ldots \ldots \ldots \ldots 443$

Euclissa Endl................. 487

Euconandra Alph. DC.......... 636

Euconospermum Endl........... 316

Eudaphne C. A. Mey. ........... 538

Eudryandra Meisn. . . ......... 467

Euexocarpos Alph. DC. .......... 689

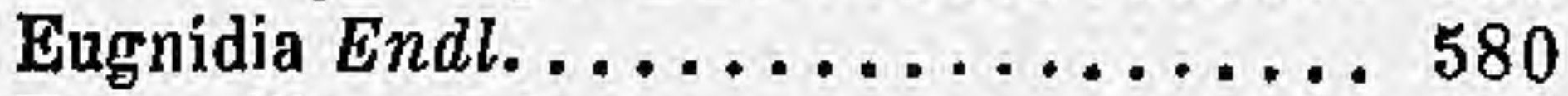

Eugrevillea Meisn............. 349

Euknightia Endl. ............. 442

Eulinostoma Meisn. ........... 599

Eulomatia Endl.............. 447

Eumimetes Endl. ........... 262

Eumdhlenbeckia Endl.......... 148

Eumyristica A. DC . . . . . . . . . . . 189

Eumyristica Hook. el Thoms. ... 189, 200

Euorites Endl............... 423

Euosyris Alph. DC...........6 633

Eupenat Endl..............484

Eupimelea Meisn............... 497

Euplassa Salisb.............456

EUPOLYGONEAE C. A. Mey....... 82

Eupolygonella Endl............ 80

Euruprechtia Meisn............ 179

Euryspermum Salisb.......... 212

Ensantalum Alph. DC.......... 681

Eusarcocolla Endl............. 488

Euthesium A. DC. . . . . . . . . . 639

Euwikstromia Meisn........... 543

Exocarpos Labill............ 687

Exocarpus Endl........... 687

Fagopyrum Meisn. mon........... 143

Fagopyrum Tourn........... 143

Fagotriticum J. Bauh......... 143

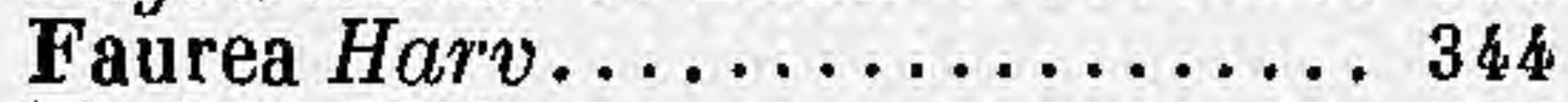

Fitchia Meisn.............. 348

Franklandia $R . B r \ldots \ldots \ldots \ldots \ldots 327$

FRANKLANDIE E Meisn.......... 327

Frisea $R . B r \ldots \ldots \ldots \ldots \ldots \ldots \ldots 662$

Funifera Leand. . . . . . . . . . . 525

Fusanus L............... 681

Gagnedi Bruce............. 230

Geissoloma Lindl. . . . . . . . . . . 492

GEISSOLOM ACE $A \mathrm{C}$ Sond. . . . . 491

GEISSOLOME $A E$ Endl......... 491

Gevina Lam.................. 698

Gevuina Mol. .............698

Gissonia Salisb............. 212

Glischrocaryon Endl......... 622

Gischrocolla Endl.............490

Glischrocolla $A$. $D C \ldots \ldots \ldots \ldots \ldots 490$

Gnidia auct............ 574, 593

Gnidia $L \ldots \ldots \ldots \ldots \ldots \ldots \ldots \ldots \ldots \ldots .580$

GNIDIE $A$ Meisn. ........... 565

Gnidium Spach.............. 538

Gomphotheca Nutt............. 23

Gonophylla Eckl. et Zeyh...... 574

Gonopyrum Fisch. et Mey......... 81

Gonopyrum C. A. Mey........ 79

Goodallia Benth........... 527
Grevillea $R . B r \ldots \ldots \ldots \ldots$ 349, 698

GREVILLE $A$ Meisn............. 348

Grubbia Berg. ............. 618

GRUBBI ACE $A$ E $n d l \ldots \ldots \ldots \ldots 617$

Guajabara Plum............ 150

Guevirıa Molina. ........ 347, 698

Gymnacranthera $A . D C . \ldots \ldots \ldots \ldots \ldots 200$

Gymnococca Meisn.............. 514

Gymnococca Fisch. el Mey....... 496

GYRINOPE $\&$ Meisn. ....... 601, 700

Gyrinops Gaertn. . .......6.602, 700

Gyrinopsis Dcsne.......... 602

Hagnothesium A. DC.............6673

Hakea Cels................ 450

Hakea Schrad. . . . . . . . 393, 699

HAKE $A$ E Endl. . . . . . . . . 348, 698

HAMAMELIDACE $A$ Gardn . . . . $\$ 17$

Hamiltonia Harv............634

Hamiltonia Muhlenb. ......... 628

Hamiltonia Spreng. . . . . . . . . 635

Hargasseria Schiede et Deppe... 520

Harveya Plant. . . . . . . . . . . 528

Helicia Lour. . . . . . . . . . 438, 699

Helittophyllum Blum........438

Helsine R. Br............... 131

Helxine L.............. 135, 143

Helwingia Willd. ...........622

Femiclidia $R . B r \ldots \ldots \ldots \ldots \ldots \ldots 481$

Henslowia $B l \ldots \ldots \ldots \ldots \ldots \ldots \ldots, 630$

Heterolona Endl. .............497

Hetarolena Fisch. et Mey....... 496

Hippophae auct. ..........607

Hippophae $L \ldots \ldots \ldots \ldots \ldots \ldots \ldots .6607$

Holderlinia Neck........... 283

HOLORACE $\not E$ L . . . . . . 1

Horsfieldia $A . D C \ldots \ldots \ldots \ldots \ldots \ldots \ldots 200$

Horsfieldia Willd............ 200

Hylogyne Kn. et Salisb........ 446

Hypophyllocarpodendron Boerh.. 262

Irya Hook. et Th............. 202

Iryarthera $A . D C \ldots \ldots \ldots \ldots \ldots \ldots .201$

Lsomerium $R . B r \ldots \ldots \ldots \ldots \ldots \ldots \ldots . \ldots \ldots$

Isopogon $R . B r \ldots \ldots \ldots \ldots \ldots \ldots 276$

Isostylis $R . B r . \ldots \ldots \ldots \ldots \ldots \ldots .466$

Jenkinsia Griff. . . . . . . . . 495 Josephia Knight et Salisb....... 467

Kelleria $E n d l \ldots \ldots \ldots \ldots \ldots \ldots \ldots 565$

Knema $B l . \ldots \ldots \ldots \ldots \ldots \ldots \ldots .204$

Knema Lour.............. 204

Knightia $R$. $B r . \ldots \ldots \ldots \ldots 442,699$

Koenigia $L \ldots \ldots \ldots \ldots \ldots \ldots \ldots \ldots \ldots$. 82

Komakon Theoph.? Adans....... 189

Lachnoea auct. ............ 574

Lachnaa $v$. Royen. .......... 574

Lachnaa v. Royen. .......... 574

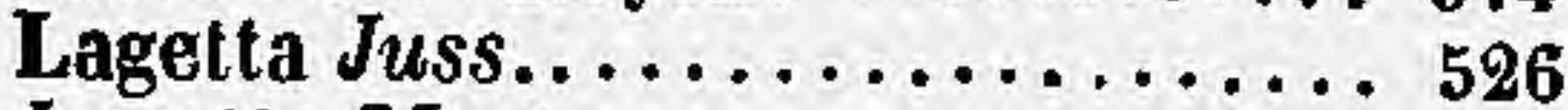

Lagetta Mart. . . . . . . . . . 525 
Lagunea Lour. . . . . . . . . 83, 123

Lambertia $S m . \ldots \ldots \ldots \ldots \ldots \ldots .420$

Lapathum Tourn. ........ 37, 41

Lapathum Meisn ............. 42

Lasiadenia Benth. ........... 527

Lasiosiphon Fresen......... 593

Lastarrixa Remy............ 186

I.AURACEA. . . . . . . 186, 695

Laureola Meisn............... 538

Laureola Spach............. 538

Laurcola Plum..............700

Laureoloides Spach............. 538

Leinkeria Scop............. 424

Lepidocarpodendran Boerh...... 911 $230,262$.

Lepiducarpus L. ........... 211

Leptargyreia Raf............ 607

Leptomerja $R$. Br.............6 677

Leplostylis Meisn.............. 331

Leucadendron Herm....... 112,698

Leucadendron L...... 211, 230, 253 $262,283$.

Leucadendros Herm. cat........ 212

Ieucosmia Benth............ 603

Leucospermum R. Br..... 253, 698

Linkia Cav................ 329

Linostoma Wall......... 599, 700

Lissostylis R. Br............. 352

Lomatia $B r . \ldots \ldots \ldots \ldots \ldots \ldots$ 447

Lophostoma Meisn..........6 600

Lygia Meisn................ 551

Lygia Fasano............. 551

Lyonia Rafin............... 79

Lyssanthe Knight el Salisb...... 349

Macrostegia Turcz.......... 496

Magunia Vell.............. 178

Malistachys Endl............. 513

Manglesia Endl.......... 349, 391

Manglesia Endl............... 391

Mezereum C. A. Mey........ 530

Mezereum Spach............. 530

Microclinium Meisn............ 578

Mida Alph. DC.............. 686

Mida A. Cunningh.......661, 686

Mimetes Salisb.............. 262

Mischocaryon Endl............. 303

Molloya Meisn. ........ 348, 698

Moschokaruon Diosc......... 189

Mucronea Benth............ 27

Mühlenbeckia Meisn...... 145, 695

Myoschylos Ruiz. et Pav.......627

Myristica $L \ldots \ldots \ldots \ldots \ldots \ldots$ 189,695

Myristica B1.............. 189

MYRISTICACE Horan.. 187, 695

MYRISTICEA Br.......... 187

Myzodendron............... 020

Nanodea Banks............6 675

Nebu Feuill............... 347

Nectandra Berg. ........ 566, 580

Nectandra Roxb........... 599
Neesia Mart. ............... 525

Nemacaulis $N u t t . . \ldots \ldots \ldots \ldots \ldots, 23$

Nivenia $R . B r . \ldots \ldots \ldots \ldots .299,698$

Nordmannia Fisch. et Mey..... 520

Nyssa L................. 622

Octarillum $L o u r . \ldots \ldots \ldots \ldots \ldots 615$

OLAC ACE $\approx \ldots \ldots \ldots \ldots, 620,623$

Omphacomeria $A . D C \ldots \ldots \ldots \ldots 680$

Omphacomeria Endl............. 680

Ophira Alph. DC...............6.618

Ophira Burm............... 618

Ophira Lam................ 618

OPHIRE E Reichb............... 617

OPHIRIACE E Arn...........617

Ophispermum Lour........... 601

Oreocallis $R . B r ., \ldots \ldots \ldots \ldots .445$

Orites $R$. $R r \ldots \ldots \ldots \ldots \ldots .423,699$

Oritina R. Br............ 423, 424

Orothamnus Meisn.............. 264

Orthocarya Jaub. et Spach.......... 31

Osyridicarpos A. DC.......... 635

Osyris $L \ldots \ldots \ldots \ldots \ldots \ldots \ldots \ldots, 632$

Osyris Scop................6 607

Otoba A. DC................. 198

Ovidia Meisn............... 524

Ovidia Raf................. 524

Owenia Hilsenb............. 39

Oxygonum Burch............ 38

Oxymeria Endl............... 677

Oxyria Hill................. 37

Oxy theca Nutt.............23, 693

Pallasia L. f.............. 29

Panopsis Salisb.............. 345

Paranomus Salisb........... 299

Passerina auct. 548, 551, 559, 561 $566,573,574,593$.

Passerina Forst............. 496

Passerina $L \ldots \ldots \ldots \ldots \ldots \ldots \ldots \ldots, 561$

PASSERIN.E Rüling............ 493

Peddiea Harvey.......... 528, 700

Penæa L.................... 484

PEN EACE E $R . B r . \ldots \ldots \ldots \ldots .483$

PENE.E $A . D C . \ldots \ldots \ldots \ldots \ldots \ldots, 484$

Pentadactylon Gærtn. ......... 329

Persicaria Meisn................. 101

Persicaria Tourn.......... 83, 101

PERSICARI E Adans. ......... 1

Per'soonia $S m \ldots . . \ldots \ldots \ldots \ldots \ldots . . .329$

PERSOONIEA Endl............. 327

Pelrophila $R$. Br.............. 267

Petrophile Endl............... 269

Petrophile Knight et Salisb..... 267

Phaleria Jack............... 603

Phidia Endl................ 590

Phyllodanthos $A, D C . \ldots \ldots \ldots \ldots \ldots \ldots, 691$

Phyllolena Endl. ................ 506

Pimelea Banks. el Sol. ..... 496, 700

Piptoclilamys Meisn............. 557

Piptorhlam!ls C. A. Mey........ 551

PISTACIE Adans............. 187 
Plagiopoda $R . B r \ldots \ldots \ldots \ldots \ldots \ldots 349$

Pleuranthe Salisb........... 230

Pleuropterus Turcz........... 136

Podocentrum Burch. ......... 40

Podoplerus Humb. et Bonpl...... 171

POLYGONACEA Lindl....... 1

POLYGONACE $A$ Meisn. gen.... 28

POLYGONE $\mathscr{E}$ Juss. ........ 1, 693

POLYGONE E Juss.............. 28

Polygonella, $b$, Meisn.......... 77

Polygonella C. A. Mey......... 80

Polygonella Mich............ 79

Polygonoides Tournef......... 28

Polygonum Flor. flum......... 150

Polygonum $L .$, Meisn. . . . . . 83, 694

Polygonum Tourn........... 85

Potameia $D u$ Pet. Th......... 328

Prolea $L \ldots \ldots \ldots \ldots \ldots \ldots$ 230, 262, 698

PRO'TEACE $R$ E $R \cdot r^{*} \ldots \ldots$ 209, 698

PROTE $\Psi$ Juss... . . . . . . . . . . . . 209

PROTEA Meisn............... 211

Pseudais Dcsne . . . . . . . . . . 603

Pseudanthus Endl. ........... 622

Pseudomimites Endl............ 264

Psilosolena Presl......... 528, 700

Psilothesium A. DC........... 670

PSYDOMORPHYTA Neck........ 209

Pterococcus Endl.............. 29

Pterococcus Pall. ............ 29

Pteropyrum Jaub. et Spach...... 30

Pterostegia Fisch. et Mey....... 27

PTERYGOGARP Aeisn.......... 28

Ptychocarpa R. Br............ 352

Pycnostylis Meisn............. 329

Pyrrlısa Blume................ 202

Pyrrhosia Blume.............. 200

Pyrularia Mich............. 628

Quadria Ruiz el Pav. ........ 347

Quinchamala Willd...........624

Quinchamali Feuill...........6.624

Quinchamalium Molin......... 624

Radojitskya Turcz. .........574

Rayania Walt............. 185

RHABARBARE $A$ E Meisn.......... 30

Rhabarbarum Tourn.......... 32

Rhamnoides Tournef.........607

Rheum $L \ldots \ldots \ldots \ldots \ldots \ldots \ldots \ldots$ 32, 693

Rhinostegia Turcz. ........6637

Rhoiacarpos A. DC.......... 634

Rhopala Schreb......... 424, 699

RHOPALEAE Meisn. gen......... 348

Rochetia Meisn............... 861

Ropala Rudge............. 424

Roumea Wall............. 530

Roupala $\mathbf{A}$ ubl............... 424

Rumex $L \ldots \ldots \ldots \ldots \ldots \ldots \ldots \ldots \& 4,693$

RUMICE $A$ C C. A. Mey.......... 41

Rupala Wall.............. 424

Ruprechtia Endl. ............ 179

Ruprechlia C. A. Mey...... 178, 181
SANTALACE $B$ E $B \ldots \ldots \ldots \ldots .619$

SANTALE $A$ A. DC.........6 624, 681

SANTALE $A$ Reichb........... 619

Santalum $L \ldots \ldots \ldots \ldots \ldots \ldots \ldots \ldots .681$

Santalum Spreng.............634

Sarcucalyx A. DC..............688

Sarcocalux Zipp...........688

Sarcocolla Kunth. .......... 488

Sarcogonella Meisn........... 147

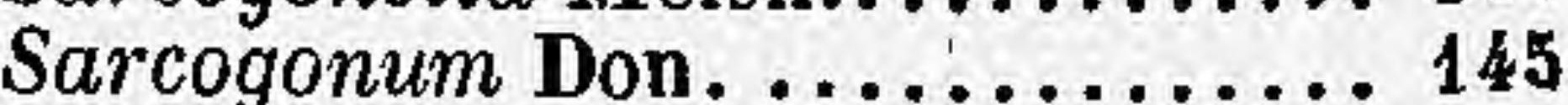

Sarcogonum Endl............. 145

Schœnobiblus Mart. et Zucc..... 519

Schopfia Schreb............. 622

Scleropyrum Arn............ 628

Scolymocephalus Herm. 211, 212, 230 262.

Scopolia L. f...........530,540

Sebophora Neck.............. 194

Serraria Burm............. 283

Serruria Salisb. ......... 283, 698

Shepherdia Nutt. ...........607 607

Simsia R. Br............... 925

Sirium L.................681

Soranthe Salisb............ 903

Sorocephalus $R . B r \ldots \ldots \ldots \ldots, 303$

Spatalla Salisb............. 306

Sphcerocarya Wall...........628

Sphæroclinium Meisn........... 574

Stellera auct..............551

Stellera Gartn............. 551

Stellera Gmel............... 548

Stenocarpus $R . B r . \ldots \ldots \ldots \ldots 450,699$

Stenogonum Nutt........... 5

Stirlingia $E n d l \ldots \ldots \ldots \ldots \ldots \ldots, 325$

Stopinaca Ral.............. 79

Strangea Meisn............. 348

Streptocarya Jaub. et Spach........ 31

Strobilocarpus A. DC..........6 618

Strobilocarpus Klotzsch........6 618

Struthia V. Royen.......... 580

Struthiola $L \ldots \ldots \ldots \ldots \ldots \ldots \ldots \ldots . \ldots \ldots 6$

Stylapterus Endl.............. $\$ 86$

Stylapterus A. Juss. . .......... 486

Stylur'us Knight et Salisb........ 349

Sychnoneura A.DC........... 196

Symmeria Benth............. 185

SYMMERIE $\not$ E Meisn. ......... 185

Symphyolepis Endl.............. 274

Syinphyonema $R . B r \ldots \ldots \ldots \ldots \ldots 327$

Synaphea $R . B r \ldots \ldots \ldots \ldots \ldots \ldots .314$

Telopea $R . B r . \ldots \ldots \ldots \ldots$ 446,699

Tephis Adans.............. 84

Tephis Meisn ............... 84

Tetraraphis Miers............ 23

Thecanthes Meisn. ..........496

Thecanthes Wikstr.......... 496

Thesidium Sond. ............673

THESIE $A$ A $A C . \ldots \ldots \ldots \ldots \ldots \ldots .624$

Thesiosyris Reichb......... 635, 639

Thesium auct............. 635

Thesium $L \ldots \ldots \ldots \ldots \ldots \ldots \ldots \ldots \ldots .637$ 
Thesium Thunb.............672

Thurnheyssera Mart.......... 185

THYMELACE E Lindl. . . . . . . 493

Thymelæa Tournef........... 551

Thymelaea Scop............ 530

THYMEL $\boldsymbol{E A C E}$ E Meisn. .. 493, 700

THYMEL $A E A$ Adans. ...... 209, 493

THYMELEA Juss. . . . . . . . . . 496

Thymelina Hoffmanns.......... 580

THYMELINE E Dumort. . . . . . 493

Thysanella A. Gray............. 82

Tiniaria Meisn. ................. 135

Tovara Adans. . . . . . . . 83, $\mathbf{8 0 1}$

Trachytheca Nutl............ 7

Thagatraphaxis Jaub: et Spach........ 76

Tragopyrum Jaub. et Spach........ 77

Tragopyrum M. Bieb....... 74, 77

Tricondylus Knight et Salisb..... 447

Trigonocarpus Bert.......... 24

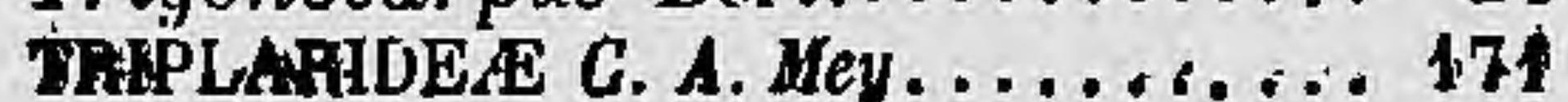

Triplaris auct............. 178

Triplaris Loefl........... 171, 695

Tropocarpa Don.............. 483

Tupeia Korth...............630

VAGINALES L............. 1

Velasquezia Bertot............. 171

VEPRECUL $A \mathrm{~L} . \ldots \ldots \ldots \ldots \ldots .493$

$\forall i b o$ Moench................. 40

Vioncea Neck................ 230

Virola $A . D C . . \ldots \ldots \ldots \ldots \ldots \ldots \ldots, 194$

Virola Aubl................ 194

Viscum BI. ................630

Wíkstrœmia Endl.......... $5 \mathbf{5 4 3}$

Xeromeria Endl.............. 678

Xerostöle Endl................ 272

Xylomelum Smith............. 
